

\title{
Bildung auf einen Blick 2014 OECD-INDIKATOREN
}



(3) $O E C D$ 


\section{Bildung auf einen Blick 2014 OECD-Indikatoren}


Das vorliegende Dokument wird unter der Verantwortung des Generalsekretärs der OECD veröffentlicht. Die darin zum Ausdruck gebrachten Meinungen und Argumente spiegeln nicht zwangsläufig die offizielle Einstellung der Organisation oder der Regierungen ihrer Mitgliedstaaten wider.

Die englische und die französische Originalfassung wurden von der OECD veröffentlicht unter dem Titel: Education at a Glance 2014: OECD Indicators

Regards sur l'éducation 2014: Les indicateurs de l'OCDE

(C) 2014 OECD

Alle Rechte vorbehalten

(C) 2014 Bundesministerium für Bildung und Forschung, Deutschland für die deutsche Übersetzung

(C) 2014 W. Bertelsmann Verlag für diese deutsche Ausgabe

Veröffentlicht in Absprache mit der OECD, Paris

Diese Publikation ist frei verfügbar zum Download unter wbv-open-access.de.

(c) $\$ \cong$ Diese Publikation ist unter folgender Creative-Commons-Lizenz veröffentlicht: BY NC ND http://creativecommons.org/licenses/by-nc-nd/3.0/de/.

Für die Qualität der deutschen Version und die Übereinstimmung mit dem Originaltext übernimmt das Bundesministerium für Bildung und Forschung die Verantwortung.

\section{Fotos:}

Banque d'images Stocklib (C) Cathy Yeulet

Fotolia.com (c) Feng Yu

Getty Images (c) blue jean images

Korrigenda zu OECD-Veröffentlichungen sind verfügbar unter: www.oecd.org/publishing/corrigenda. 


\section{Vorwort}

Bei der Suche nach einer effektiven Bildungspolitik, die auf wirksame Art und Weise die sozialen und wirtschaftlichen Aussichten des Einzelnen verbessert, die Anreize für eine größere Effizienz bei der Bildungsvermittlung bietet und die dazu beiträgt, Ressourcen zur Bewältigung der steigenden Bildungsnachfrage zu mobilisieren, lenken die Regierungen ihre Aufmerksamkeit in verstärktem Maße auf internationale Vergleiche sowohl der zur Verfügung gestellten Bildungsmöglichkeiten als auch deren Ergebnisse. Als Teil der Bemühungen in diesem Bereich sieht die OECD-Direktion Bildungswesen eine ihrer Hauptaufgaben in der Entwicklung und Analyse international vergleichbarer, quantitativer Indikatoren, die dann jährlich in Bildung auf einen Blick veröffentlicht werden. $\mathrm{Zu}-$ sammen mit den länderspezifischen Untersuchungen der OECD sind sie darauf ausgelegt, die Regierungen in ihren Bemühungen zu unterstützen, die Bildungssysteme effektiver zu machen und so $\mathrm{zu}$ gestalten, dass sie allen offenstehen.

Bildung auf einen Blick zielt ab auf die Bedürfnisse einer breit gestreuten Leserschaft - von den Regierungen, die von den bildungspolitischen Erfahrungen anderer Länder lernen wollen, über Wissenschaftler, die Daten für weiter gehende Analysen benötigen, bis zur allgemeinen Öffentlichkeit, die einen Überblick darüber gewinnen möchte, welche Fortschritte das Bildungssystem des eigenen Landes dabei macht, Schüler und Studierende von Weltklasseformat auszubilden. Die Veröffentlichung untersucht die Qualität der Lernergebnisse, die politischen Ansatzpunkte und Bedingungen, die die Bildungserfolge beeinflussen, und die - im weitesten Sinne - individuellen und gesellschaftlichen Erträge von Investitionen in Bildung.

Bildung auf einen Blick ist das Ergebnis langjähriger gemeinsamer Bemühungen der Regierungen der OECD-Länder, der Experten und Institutionen, die im Rahmen des OECD-Programms Indicators of Education Systems (INES) zusammenarbeiten, sowie des Sekretariats der OECD. Die Veröffentlichung wurde erstellt von der Abteilung „Innovation and Measuring Progress" der OECD-Direktion
Bildung und Kompetenzen unter der Leitung von Dirk Van Damme und Corinne Heckmann, mitgewirkt haben Étienne Albiser, Rodrigo CastañedaValle, Éric Charbonnier, Estelle Herbaut, Karinne Logez, Koji Miyamoto, Joris Ranchin, Cuauhtémoc Rebolledo-Gómez, Gara Rojas González, Ignacio Marín, Wida Rogh, David Valenciano und Jean Yip. Rhodia Diallo und Laetitia Dehelle waren unterstützend im Bereich Verwaltung tätig; Camila de Moraes, Adrien Régnier-Laurent und Vaishali Zambre haben die Arbeiten fachlich unterstützt sowie bei Analysen mitgewirkt. Die Autoren wurden unterstützt durch die analytischen Arbeiten von José Luis Álvarez-Galván, Francesco Avvisati, Rose Bolognini, Veronica Borg, Vanessa Denis, Alfonso Echazarra, Carlos González-Sancho, Sonia Guerriero, Maria Huerta, Hiroko Ikesako, Marco Kools, Kelly Makowiecki, Patricia Mangeol, Simon Normandeau, Giannina Rech, Michele Rimini, Simone Stelten, William Thorn, Karine Tremblay, Sophie Vayssettes, Elisabeth Villoutreix und Juliana Zapata. Marilyn Achiron, Louise Binns, Marika Boiron, Célia Braga-Schich, Cassandra Davis und Sophie Limoges leisteten wertvolle Beiträge zu Lektorat und Produktion. Die Entwicklung der Veröffentlichung wurde von den Mitgliedsländern durch die INES-Arbeitsgruppe gesteuert und durch die INES-Netzwerke unterstützt. Eine Liste der Mitglieder der verschiedenen Organe sowie der einzelnen Fachleute, die an diesem Bericht und der OECD/INES-Arbeit generell mitgewirkt haben, findet sich am Ende dieser Veröffentlichung.

In den letzten Jahren ist zwar viel erreicht worden, aber die Mitgliedsländer und die OECD setzen ihre Bemühungen fort, spezifische bildungspolitische Fragestellungen noch genauer mit den besten verfügbaren international vergleichbaren Daten zu verknüpfen. Hierbei stellen sich verschiedene Herausforderungen, und es gilt, unterschiedliche Aspekte abzuwägen. Erstens müssen die Indikatoren die Fragen ansprechen, die in den einzelnen Ländern von großer bildungspolitischer Bedeutung sind und bei denen eine international vergleichende Perspektive gegenüber nationalen Analysen und Bewertungen tatsächlich einen Informations- 
gewinn liefert. Zweitens müssen die Indikatoren zwar so vergleichbar wie möglich sein, gleichzeitig aber auch länderspezifisch genug, um historische, systembedingte und kulturelle Unterschiede zwischen den einzelnen Ländern berücksichtigen zu können. Drittens muss die Darstellung in den Indikatoren so klar wie möglich sein, gleichzeitig aber auch der facettenreichen Realität von Bildungssystemen in der heutigen Welt gerecht werden. Viertens besteht der allgemeine Wunsch, die Zahl der Indikatoren so niedrig wie möglich zu halten, während gleichzeitig ihre Zahl aber groß genug sein muss, um den politischen Entscheidungsträgern in den einzelnen Ländern, die sich teilweise ganz unterschiedlichen bildungspolitischen Herausforderungen gegenüber sehen, wirklich von Nutzen zu sein.

Die OECD wird diese Herausforderungen auch weiterhin entschieden angehen und die Entwicklung von Indikatoren nicht nur in den Bereichen vorantreiben, in denen dies möglich und vielversprechend ist, sondern auch in jene Bereiche vordringen, in denen noch sehr viel grundlegende konzeptionelle Arbeit vonnöten ist. Die Internationale Schulleistungsstudie PISA und deren Erweiterung durch die internationale OECD-Erhebung zu den grundlegenden Kompetenzen Erwachsener im Rahmen des OECD Programme for the International Assessment of Adult Competencies (PIAAC) sowie die internationale Erhebung der OECD zu Lehren und Lernen (OECD Teaching and Learning International Survey - TALIS) sind wichtige Schritte auf dem Weg zur Erreichung dieses Zieles. 
Einleitung .20

Hinweise für den Leser ...................................... 24

\section{Kapitel A}

Indikator A1

Tabelle Ar.Ia

Tabelle Ar.2a

Tabelle Ar.3a

Tabelle Ar.4a

Tabelle Ar.5a

Tabelle Ar.6a (L)

Tabelle Ar.7a (L)

Tabelle Ar.8 (L)

\section{Indikator A2}

Tabelle Ar.ga (L)

Tabelle A2.Ia

Tabelle A2.Ib

Tabelle A2.2a

Tabelle A2.3a

Tabelle A2.4

Tabelle A2.5

\section{Indikator A3}

Tabelle A3.Ia Tabelle A3.Ib

Tabelle A3.2a

\section{Bildungsergebnisse und Bildungserträge} 35

Über welche Bildungsabschlüsse verfügen Erwachsene? . . . . . 37


Anteil der Erwachsenen mit mindestens einem Abschluss im Sekundarbereich II (in \%), nach Altersgruppe (2012) . . . . . . . . . . . 56 Anteil der Erwachsenen mit einem Abschluss im Tertiärbereich (in \%), nach Tertiärbereich und Altersgruppe (20I2) . . . . . . . . . . . 5 57 Entwicklungstendenzen bei Bildungsabschlüssen, nach Altersgruppe sowie durchschnittlicher jährlicher Anstieg (2000, 2005-2012) . . . . . . 58 Erwachsene mit einem Abschluss im Sekundarbereich II, nach Ausrichtung des Bildungsgangs und Geschlecht (2012)............ 6r Bildungsstand 25- bis 64-Jähriger, nach Lesekompetenzstufe (2012) . . . . 62 Verteilung der Lesekompetenzstufen, nach Alter (20I2) . . . . . . . . . 64 Anteil 25- bis 64-Jähriger (in \%) mit einem Abschluss im berufsbildenden oder allgemeinbildenden Sekundarbereich II bzw. postsekundaren, nicht tertiären Bereich, nach Lesekompetenzstufe und Mittelwert der Lesekompetenz (2012) . . . . . . . . . . . . . . . . . . 65 Mittelwert der Lesekompetenz, nach Bildungsstand und Alter (2012). . . . . 66

Wie viele Schüler werden den Sekundarbereich II erfolgreich abschließen?............................67 Abschlussquoten im Sekundarbereich II und durchschnittliches Abschlussalter (20I2) ......................... 88 Abschlussquoten im Sekundarbereich II von Schülern, die jünger als 25 Jahre sind (2012) . . . . . . . . . . . . . . . . . . . . Entwicklung der Erstabschlussquoten im Sekundarbereich II


Verteilung der Absolventen von berufsbildenden Bildungsgängen des Sekundarbereichs II, nach Fächergruppe und Geschlecht (20I2) . . . . . 9 I Erfolgsquoten im Sekundarbereich II, nach Geschlecht und Ausrichtung


Erfolgsquoten im Sekundarbereich II, nach Ausrichtung des Bildungsgangs und Ausbildungsdauer

\section{Wie viele Studierende werden ein Studium im Tertiärbereich}


Abschlussquoten und durchschnittliches Alter im Tertiärbereich (2012) . . I05 Abschlussquoten im Tertiärbereich von Studierenden, die jünger als das


Entwicklung der Abschlussquoten im Tertiärbereich (I995-20I2) . . . . . . I07
AI 
Indikator A4 Inwieweit beeinflusst der Bildungsstand der Eltern

die Bildungsbeteiligung im Tertiärbereich?.............. Iog

Tabelle A4.ra Bildungsbeteiligung 20-bis 34-Jähriger im Tertiärbereich, nach



Tabelle A4.Ib

Wahrscheinlichkeit der Bildungsteilnahme im Tertiärbereich, nach



Tabelle A4.2

Bildungsstand von Nichtschülern/Nichtstudierenden, nach Alters-

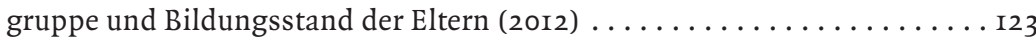

Tabelle A4.3 (L) Lesekompetenz von Nichtschülern/Nichtstudierenden, nach Alters-

gruppe, Geschlecht und Bildungsstand der Eltern (2012) . . . . . . . I27

Tabelle A4.4

Bildungsmobilität bei Nichtschülern/Nichtstudierenden, nach Alters-

gruppe und Bildungsstand der Eltern (2012) ............... I29

Indikator A5

Tabelle A5.ra

Tabelle A5.Ib

Tabelle A5.2a

Tabelle A5.2b

Tabelle A5.3a

Tabelle A5.4a

Tabelle A5.5a

Tabelle A5.6

Tabelle A5.7a (L) Erwerbsstatus, nach Bildungsstand und Lesekompetenz (2012) . . . . . . . I64

Tabelle A5.8 (L) Mittelwert der Lesekompetenz bei Erwachsenen mit einem Abschluss

im Sekundarbereich II bzw. postsekundaren, nicht tertiären Bereich,

nach Erwerbsstatus und Ausrichtung des Bildungsgangs (2012) . . . . . I66

Tabelle A5.9a (L) Erwachsenenbevölkerung nach Lesekompetenz und Erwerbsstatus



Tabelle A5.roa (L) Vollzeit- und Teilzeitbeschäftigte nach Lesekompetenz und Alters-



Indikator A6 Welche Einkommenszuschläge lassen sich durch Bildung

erzielen? .............................. 69

Tabelle A6.ra Relative Einkommen von Erwerbstätigen, nach Bildungsstand und



Tabelle A6.2a Entwicklung der relativen Einkommen von Erwerbstätigen, nach

Bildungsstand und Geschlecht (2000, 2005, 2010, 20II, 2012) . . . . . . . I85

Tabelle A6.3a Einkommensunterschiede zwischen erwerbstätigen Frauen und Männern, nach Bildungsstand und Altersgruppe (2012) . . . . . . . I87

Tabelle A6.3b Entwicklung der Einkommensunterschiede zwischen erwerbstätigen Frauen und Männern, nach Bildungsstand (2000, 2005, 2010, 20II,

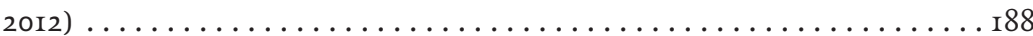

Tabelle A6.5a Relative Einkommen von I5- bis 24-jährigen Schülern/Studierenden mit Erwerbseinkommen, nach Bildungsstand und Geschlecht (2012). . . . . . . I89 Anteil I5- bis 29-Jähriger mit Erwerbseinkommen an allen I5- bis 29-Jährigen, nach Altersgruppe und Ausbildungsstatus (2012) . . . . . . I90

Tabelle A6.6a (L) Mittlere Monatseinkommen von Erwerbstätigen, nach Bildungsstand



Tabelle A6.5b
A5

A6 
Indikator A7

Tabelle A7.Ia

Tabelle A7.Ib

Tabelle A7.2a

Tabelle A7.2b

Tabelle A7.3a

Tabelle A7.3b

Tabelle A7.4a

Tabelle A7.4b

Indikator A8

Tabelle A8.Ia

Tabelle A8.2a

Tabelle A8.3a (

Tabelle A8.4a

A8.4a (L)

Welche Anreize bestehen für Investitionen in Bildung? .

Private Kosten und privater Nutzen für einen Mann, der einen Abschluss im Sekundarbereich II bzw. postsekundaren, nicht tertiären Bereich


Private Kosten und privater Nutzen für eine Frau, die einen Abschluss im Sekundarbereich II bzw. postsekundaren, nicht tertiären Bereich



Staatliche Kosten und staatlicher Nutzen bei einem Mann, der einen Abschluss im Sekundarbereich II bzw. postsekundaren, nicht tertiären


Staatliche Kosten und staatlicher Nutzen bei einer Frau, die einen Abschluss im Sekundarbereich II bzw. postsekundaren, nicht tertiären Bereich erwirbt (2010) . . . . . . . . . . . . . . . . 217 Private Kosten und privater Nutzen für einen Mann, der einen Abschluss


Private Kosten und privater Nutzen für eine Frau, die einen Abschluss im Tertiärbereich erwirbt (2010) . . . . . . . . . . . . . . 219 Staatliche Kosten und staatlicher Nutzen bei einem Mann, der einen Abschluss im Tertiärbereich erwirbt (20I0) . . . . . . . . . . . . 220 Staatliche Kosten und staatlicher Nutzen bei einer Frau, die einen Abschluss im Tertiärbereich erwirbt (2010) . . . . . . . . . . . 22I

\section{Was sind die gesamtgesellschaftlichen Auswirkungen} von Bildung?

Anteil Erwachsener (in \%), die angeben, bei guter Gesundheit zu sein, nach Bildungsstand und Lesekompetenz (2012) . . . . . . . . . . 2236

Anteil Erwachsener (in \%), die angeben, mindestens einmal im Monat eine ehrenamtliche Tätigkeit auszuüben, nach Bildungsstand und



Anteil Erwachsener (in \%), die angeben, anderen vertrauen zu können, nach Bildungsstand und Lesekompetenz (2012) . . . . . . . . . . . 240 Anteil Erwachsener (in \%), die angeben, dass sie glauben, einen Einfluss auf das zu haben, was die Regierung macht, nach Bildungsstand und Lesekompetenz (2012) ......................... 242

\section{Indikator A9 Wie hängen Schülerleistungen und Chancengerechtigkeit}

zusammen? ............................... 245

Tabelle Ag.ra Schülerleistungen im Bereich Mathematik, PISA 2012 . . . . . . . . . . 259

Tabelle Ag.Ic Veränderungen der Schülerleistungen im Bereich Mathematik zwischen



Tabelle Ag.2 Zusammenhang zwischen Schülerleistungen im Bereich Mathematik



\section{Kapitel B Die in Bildung investierten Finanz- und Human-}

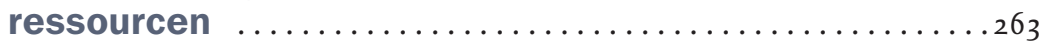

Indikator B1

Wie hoch sind die Ausgaben pro Schüler/Studierenden? . . . . . . . . 267 Jährliche Ausgaben von Bildungseinrichtungen pro Schüler/Studierenden für alle Leistungsbereiche (20II) . . . . . . . . . . . . . . . . 284

Tabelle BI.2
Jährliche Ausgaben von Bildungseinrichtungen pro Schüler/Studierenden für eigentliche Bildungsdienstleistungen, zusätzliche Dienstleis-




Tabelle Br.3a Kumulierte Ausgaben von Bildungseinrichtungen pro Studierenden für alle Leistungsbereiche während der durchschnittlichen Dauer von

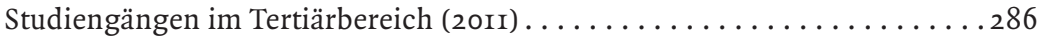

Tabelle BI.4 Jährliche Ausgaben von Bildungseinrichtungen pro Schüler/Studierenden für alle Leistungsbereiche im Verhältnis zum BIP pro Kopf (20II) . . . . 287

Tabelle Br.5a Veränderung der Ausgaben von Bildungseinrichtungen pro Schüler im Primar-, Sekundar- und postsekundaren, nicht tertiären Bildungsbereich für alle Leistungsbereiche aufgrund verschiedener Faktoren (I995, 2000, 2005, 2008, 2009, 2010, 201I) ............... 288

Tabelle BI.5b Veränderung der Ausgaben von Bildungseinrichtungen pro Studierenden im Tertiärbereich für alle Leistungsbereiche aufgrund verschiedener Faktoren (I995, 2000, 2005, 2008, 2009, 2010, 2011)............. . 289

Tabelle Bı.6 Jährliche Ausgaben von Bildungseinrichtungen pro Schüler im Sekundarbereich für alle Leistungsbereiche, nach Art des Bildungsgangs (20II) . . 290

Indikator B2 Welcher Teil des Bruttoinlandsprodukts wird für Bildung ausgegeben?.......................... 291

Tabelle B2.I Ausgaben für Bildungseinrichtungen als Prozentsatz des BIP, nach Bildungsbereich (20II) .....................

Tabelle B2.2 Entwicklung der Ausgaben für Bildungseinrichtungen als Prozentsatz des BIP, nach Bildungsbereich (I995, 2000, 2005, 2008, 2009, 2010,



Tabelle B2.3 Ausgaben für Bildungseinrichtungen als Prozentsatz des BIP, nach Herkunft der Mittel und Bildungsbereich (20II) . . . . . . . . . 303

Tabelle B2.4 Ausgaben für Bildungseinrichtungen als Prozentsatz des BIP, nach



Tabelle B2.5 Veränderung der öffentlichen Ausgaben für Bildungseinrichtungen als Prozentsatz des BIP $(2008,2009,2010,2011) \ldots \ldots \ldots \ldots \ldots \ldots \ldots 5$

Indikator B3 Wie groß ist der Anteil der öffentlichen und der privaten Ausgaben im Bildungswesen? . . . . . . . . . . . . . . . . . . 307

Tabelle B3.I

Tabelle $\mathrm{B}_{3} \cdot 2 \mathrm{a}$

Relative Anteile öffentlicher und privater Ausgaben für Bildungseinrichtungen, nach Bildungsbereich (20II) . . . . . . . . . . . 320 Entwicklung der relativen Anteile öffentlicher Ausgaben für Bildungseinrichtungen aller Bildungsbereiche und Index der Veränderung der öffentlichen und privaten Ausgaben (I995, 2000, 2005, 2008-20II) . . . . 32I

Tabelle $\mathrm{B}_{3} \cdot 2 \mathrm{~b}$ Entwicklung der relativen Anteile öffentlicher Ausgaben für Bildungseinrichtungen und Index der Veränderung der öffentlichen und privaten Ausgaben, Primar-, Sekundar- und postsekundarer, nicht tertiärer


Tabelle B3.2c Entwicklung der relativen Anteile öffentlicher Ausgaben für Bildungseinrichtungen im Tertiärbereich und Index der Veränderung der öffentlichen und privaten Ausgaben (I995, 2000, 2005, 2008-20II) . . . . 323 Tabelle B3.3 Jährliche öffentliche Ausgaben für Bildungseinrichtungen pro Schüler/ Studierenden, nach Art der Bildungseinrichtung (20II) . . . . . . . 324

Indikator B4 Tabelle B4.I Tabelle B4.2

Tabelle $\mathrm{B} 4 \cdot 3$
Wie hoch sind die öffentlichen Gesamtausgaben für Bildung? . . . 325

Öffentliche Gesamtausgaben für Bildung (20II) . . . . . . . . . 336 Entwicklung der öffentlichen Gesamtausgaben für Bildung (I995,


Herkunft der Mittel für öffentliche Bildungsausgaben im Primar-, Sekundar- und postsekundaren, nicht tertiären Bereich (20II) . . . . . 338 




Indikator B6

Tabelle B6.I

Tabelle B6.2

Indikator B7

Tabelle B7.I

Tabelle B7.2a

Tabelle B7.2b

Tabelle B7.3

Tabelle B7.4

Tabelle B7.5

\section{Kapitel C Bildungszugang, Bildungsbeteiligung und}

Indikator C1

Tabelle Cr.ra

Tabelle Cr.2

Tabelle Cr.3

Tabelle CI.4

Tabelle Cr.6

Indikator C2

Tabelle C2.I

Tabelle C2.2

Tabelle C2.3 Bildungsverlauf

Wofür werden Finanzmittel im Bereich der Bildung ausgegeben? . . 365 Ausgaben von Bildungseinrichtungen des Primar- und Sekundarbereichs, nach Ausgabenkategorie (20II) . . . . . . . . . . . 372 Ausgaben von Bildungseinrichtungen, nach Ausgabenkategorie und Bildungsbereich (20II) . . . . . . . . . . . . . . . . . 373

Welche Faktoren beeinflussen die Höhe der Bildungsausgaben? . . 375 Gehaltskosten der Lehrkräfte pro Schüler, nach Bildungsbereich (2012) . . 389 Faktoren zur Berechnung der Gehaltskosten der Lehrkräfte pro Schüler im Primarbereich $(2000,2005,2008$ und 2012) . . . . . . . . . . . 390 Faktoren zur Berechnung der Gehaltskosten der Lehrkräfte pro Schüler im Sekundarbereich I (2000, 2005, 2008 und 20I2) . . . . . . . . . . . 392 Beitrag verschiedener Faktoren zu den Gehaltskosten der Lehrkräfte pro Schüler im Primarbereich (2000, 2005, 2008 und 2012) . . . . . . . 394 Beitrag verschiedener Faktoren zu den Gehaltskosten der Lehrkräfte pro Schüler im Sekundarbereich I (2000, 2005, 2008 und 20I2) . . . . . . . 395 Beitrag verschiedener Faktoren zu den Gehaltskosten der Lehrkräfte pro Schüler im Sekundarbereich II (20I2) . . . . . . . . . . . 396

Wer nimmt an Bildung teil? . . . . . . . . . . . . . . . . . . 399

Bildungsbeteiligung, nach Altersgruppe (20I2) ............

Entwicklung der Bildungsbeteiligung (I995-20I2) .......... 4I2 Bildungsbeteiligung im Sekundarbereich II und im postsekundaren,

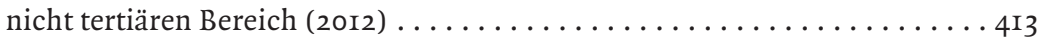
Verteilung der Schüler und Studierenden im Primar-, Sekundarund Tertiärbereich (in \%), nach Voll- und Teilzeitausbildung sowie Geschlecht (20I2) ....................... 4I4 $\mathrm{Zu}$ erwartende Jahre in Ausbildung für 5- bis 39-Jährige (20I2) $\ldots \ldots \ldots$ 4I5

Welche Systeme zur frühkindlichen Bildung gibt es weltweit? . . . . 4I7 Bildungsbeteiligung im Elementar- und Primarbereich, nach Alter (2005, 2012).............................. 430 Merkmale von Bildungsangeboten im Bereich frühkindliche Bildung


Merkmale von reinen Bildungsangeboten und integrierten Angeboten im Elementarbereich (20I2) . . . . . . . . . . . . . 432 
Indikator $\mathrm{C}_{3}$ Wie viele junge Erwachsene werden ein Studium im Tertiärbereich aufnehmen? ....................... 433

Tabelle $\mathrm{C}_{3}$. Ia

Studienanfängerquoten im Tertiärbereich und durchschnittliches Alter der Studienanfänger, nach Geschlecht und Ziel des Studiengangs (2012) . . 446

Table $\mathrm{C}_{3} \cdot \mathrm{Ib}$ Studienanfängerquoten von jungen Menschen unterhalb des typischen Eintrittsalters (2012) . . . . . . . . . . . . . . . . . . 447

Tabelle $\mathrm{C}_{3} \cdot 2 \mathrm{a}$

Tabelle $\mathrm{C}_{3} \cdot 3 \mathrm{a}$ Entwicklung der Studienanfängerquoten im Tertiärbereich (I995-20I2) . . 448 Studienanfänger im Tertiärbereich, nach Fächergruppe (20I2) . . . . . . 449

Indikator C4

Wer studiert im Ausland und wo?

$\mathrm{C}_{4}$

Tabelle $\mathrm{C}_{4}$. I

Die Mobilität internationaler Studierender und ausländische Studieren-

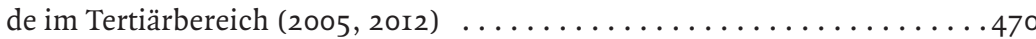

Tabelle $\mathrm{C}_{4.2}$

Verteilung internationaler und ausländischer Studierender im Tertiär-

bereich, nach Fächergruppe (20I2) ............... 47 I

Tabelle $\mathrm{C} 4 \cdot 3$

Verteilung internationaler und ausländischer Studierender im Tertiär-

bereich, nach Herkunftsland (2012) . . . . . . . . . . . . . . 472

Tabelle $\mathrm{C}_{4} \cdot 4$

Tabelle $\mathrm{C} 4.5$

Studierende, die in einem Land studieren, dessen Staatsbürger sie nicht

sind, nach Zielland (2012) . . . . . . . . . . . . . . . . . . 474

Mobilität ausländischer und internationaler Studierender (2012) . . . . . 476

Tabelle $\mathrm{C}_{4} .6$

Entwicklung der Zahl der eingeschriebenen ausländischen Studierenden im Tertiärbereich, nach Zielregion und Herkunftsland (2010 bis 2012). . . 477

Indikator C5 Der Übergang vom (Aus-)Bildungssystem zum Erwerbsleben:

Wo sind die 15- bis 29-Jährigen? . . . . . . . . . . . . . . . . . . . 479

Tabelle $\mathrm{C}_{5}$.ra $\quad \mathrm{Zu}$ erwartende Jahre in Ausbildung und nicht in Ausbildung für I5- bis 29-Jährige, nach Erwerbsstatus (20I2) . . . . . . . . . . . 49 I

Tabelle $\mathrm{C}_{5} \cdot 2 \mathrm{a}$ Anteil I5- bis 29-Jähriger (in \%), die sich in Ausbildung bzw. nicht in Ausbildung befinden, nach Altersgruppe und Erwerbsstatus (2012) . . . . 492

Tabelle $\mathrm{C}_{5} \cdot 3 \mathrm{a}$ Entwicklung des Anteils I5- bis 29-Jähriger (in \%), die sich in Ausbildung bzw. nicht in Ausbildung befinden (beschäftigt bzw. nicht beschäftigt), nach Altersgruppe (I997-2012) . . . . . . . . . 498

Tabelle $\mathrm{C}_{5} \cdot 4$ Anteil 15- bis 29-Jähriger (in \%), die sich in Ausbildung bzw. nicht in Ausbildung befinden, nach Bildungsstand und Erwerbsstatus (2012) ... . 50 I Tabelle $\mathrm{C}_{5} \cdot 5$ Entwicklung des Anteils I5- bis 29-Jähriger (in \%), die Vollzeit bzw. Teilzeit arbeiten und sich in Ausbildung bzw. nicht in Ausbildung befinden

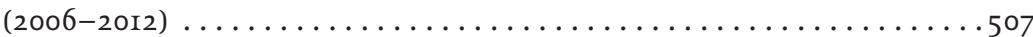

Indikator C6 Wie viele Erwachsene nehmen an formaler und nicht formaler Fort- und Weiterbildung teil? . . . . . . . . . . . . . . . . 509

Tabelle C6.I (L) Teilnahme an formaler und/oder nicht formaler Fort- und Weiterbildung, nach Lesekompetenz (2012) . . . . . . . . . . . 522

Tabelle C6.2a (L) Teilnahme an formaler und/oder nicht formaler Fort- und Weiterbildung, nach Lesekompetenz und Bildungsstand (2012) . . . . . . 523

Tabelle C6.3 Teilnahme an formaler und/oder nicht formaler Fort- und Weiterbildung, nach Geschlecht (20I2) . . . . . . . . . . . . . . . 525

Tabelle C6.4 Teilnahme an formaler und/oder nicht formaler Fort- und Weiterbildung und Wunsch nach Lernaktivitäten (20I2) . . . . . . . . . . 526

Tabelle C6.5 Für die Nichtteilnahme an weiteren/jeglichen Lernaktivitäten angegebene Gründe, nach Teilnehmer bzw. Nichtteilnehmer an formaler und/ oder nicht formaler Fort- und Weiterbildung (2012) . . . . . . . 527 




Kapitel D Das Lernumfeld und die Organisation von Schulen ...555

Indikator D1 Wie viel Zeit verbringen Schüler im Klassenzimmer? . . . . . . 557

Tabelle Di.I

Tabelle Di.2

Tabelle Di.za

Tabelle Di.3b

Indikator D2

Tabelle D2.I

Tabelle D2.2

Tabelle D2.3

Indikator D3

Tabelle D3.I

Tabelle D3.2

Tabelle D3.3

Tabelle D3.4

Tabelle D $3 \cdot 5$

Indikator D4

Tabelle D4. I

Tabelle D4.2

Indikator D5

Tabelle D5.I

Tabelle $\mathrm{D}_{5.2}$

Tabelle D5.3

Indikator D6

Tabelle D6.Ia

Tabelle D6.Ib
Unterrichtszeit während der allgemeinen Schulpflicht (2014) . . . . . . . . 569

Organisation der allgemeinen Schulpflicht (2014) . . . . . . . . . . . . . . . .

Unterrichtszeit pro Fach im Primarbereich (2014) . . . . . . . . . . 572

Unterrichtszeit pro Fach im Sekundarbereich I (2014) . . . . . . . . . . 573

Wie ist die Schüler-Lehrkräfte-Relation und wie groß sind die

Durchschnittliche Klassengröße, nach Art der Bildungseinrichtung und

Bildungsbereich (20I2) . . . . . . . . . . . . . . . . . 586

Lernende-Lehrende-Relation in Bildungseinrichtungen (2012) . . . . . . 587

Schüler-Lehrkräfte-Relation nach Art der Bildungseinrichtung (2012) . . . 588

Wie hoch sind die Gehälter der Lehrkräfte? . . . . . . . . . . . . 589

Gesetzliche bzw. vertraglich vereinbarte Gehälter von Lehrkräften zu

unterschiedlichen Zeitpunkten der beruflichen Laufbahn (2012) . . . . . 608

Gesetzliche bzw. vertraglich vereinbarte Gehälter von Lehrkräften im

Verhältnis zu Gehältern von ganzjährig Vollzeitbeschäftigten mit einem

Abschluss im Tertiärbereich (20I2) ...............6 6ro

Vergleich der gesetzlichen bzw. vertraglich vereinbarten Gehälter von

Lehrkräften (20I2) . . . . . . . . . . . . . . . . . . 6 6II

Durchschnittliche tatsächliche Gehälter von Lehrkräften (20I2). . . . . . 6 6 2

Entwicklung der Gehälter von Lehrkräften zwischen 2000 und 2012 . . . . 6 613

Wie viel Zeit unterrichten Lehrkräfte? . . . . . . . . . . 6 6 I5

Aufteilung der Arbeitszeit von Lehrern (2012) . . . . . . . . . . . . 6 629

Zahl der zu unterrichtenden Zeitstunden pro Jahr (2000, 2005, 2010



Wie ist die Zusammensetzung der Lehrerschaft? .........6 6 I

Altersstruktur der Lehrerschaft (20I2) . . . . . . . . . . . . 6 6 4 I



Geschlechterstruktur der Lehrerschaft (20I2) . . . . . . . . . . . 643

\section{Welche Anforderungen und Ausbildungsvoraussetzungen gelten}

für den Lehrerberuf? . . . . . . . . . . . . . . . . . . . . . . . 645

Lehrererstausbildung und Berufseintritt, Elementarbereich (2013) . . . . 66 I

Lehrererstausbildung und Berufseintritt, Primarbereich (2013) . . . . .662

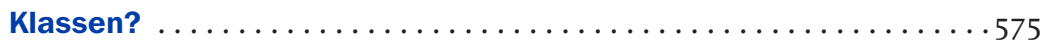

DI

D2

D3

D4

D5 
Tabelle D6.Ic

Tabelle D6.Id

Tabelle D6.2C

Tabelle D6.3C

Tabelle D6.5C

Indikator D7

Tabelle7.Ic

Tabelle D7.2c

Tabelle D7.3c

Anhang 1

Tabelle XI.ra

Tabelle XI.Ib

Tabelle XI.Ic

Tabelle XI.Id

Tabelle XI.2a

Tabelle XI.2b

Anhang 2

Tabelle X2.I

Tabelle X2.2

Tabelle X2.3

Tabelle X2.4a

Tabelle X2.4b

Tabelle X2.4C
Lehrererstausbildung und Berufseintritt, Sekundarbereich I (2013) . . . . 663

Lehrererstausbildung und Berufseintritt, Sekundarbereich II (2013) . . . . 664

Voraussetzungen für Zugang zu und Fortsetzung der Lehrererst-

ausbildung, Sekundarbereich I (2013) . . . . . . . . . . . . . . 665

Inhalt der Lehrererstausbildung, Sekundarbereich I (2013) . . . . . . 666

Einstieg in den Lehrerberuf, Sekundarbereich I (2013) . . . . . . . . . 668

Wie umfassend sind die Maßnahmen zur beruflichen Fortbildung

für Lehrkräfte? .............................669

Berufliche Fortbildungsverpflichtungen für Lehrkräfte, Sekundar-



Inhalt der obligatorischen beruflichen Fortbildungsmaßnahmen für

Lehrkräfte, Sekundarbereich I (2013) . . . . . . . . . . . . . . 688

Nicht obligatorische berufliche Fortbildung für Lehrkräfte, Sekundar-

bereich I (2013) . . . . . . . . . . . . . . . . . . . . . . 690

Merkmale der Bildungssysteme .................693

Abschlussquoten im Sekundarbereich II: Typisches Abschlussalter und Art der Abschlussquote (Brutto- bzw. Nettoabschlussquote) (2012) . . . . . 694 Abschlussquoten im postsekundaren, nicht tertiären Bereich: Typisches Abschlussalter und Art der Abschlussquote (Brutto- bzw. Netto-

abschlussquote) (2012) ......................... 696

Abschlussquoten im Tertiärbereich: Typisches Abschlussalter und Art

der Abschlussquote (Brutto- bzw. Nettoabschlussquote) (2012) . . . . . . . 697

Studienanfängerquoten: Typisches Eintrittsalter und Art der Studien-

anfängerquote (Brutto- bzw. Nettoanfängerquote) (2012) . . . . . . . . . . 6999

Für die Berechnung der Finanzindikatoren verwendete Haushalts- und

Schuljahre, OECD-Länder . . . . . . . . . . . . . . . . . . . 700

Für die Berechnung der Finanzindikatoren verwendete Haushalts- und

Schuljahre, Partnerländer ....................

Statistische Bezugsdaten

.703

Überblick über das wirtschaftliche Umfeld anhand grundlegender

Kennzahlen (Referenzzeitraum: Kalenderjahr 20II, zu konstanten

Preisen von 20II) . . . . . . . . . . . . . . . . . . . . . . 704

Grundlegende statistische Bezugsdaten (Referenzzeitraum: Kalender-

jahr 20II, zu konstanten Preisen von 20II) . . . . . . . . . . . . 705

Grundlegende statistische Bezugsdaten (Referenzzeitraum: Kalender-

jahr I995, 2000, 2005, 2008, 2009 und 2010) . . . . . . . . . . . 706

Gesetzliche bzw. vertraglich vereinbarte Gehälter von Lehrkräften zu

unterschiedlichen Zeitpunkten in ihrer beruflichen Laufbahn (2012) . . . . 709

Entwicklung der Gehälter von Lehrkräften zwischen 2000 und 2012 . . . . . 7II

Statistische Bezugsdaten zur Berechnung der Gehälter von Lehrkräften



Anhang 3 Quellen, Methoden und technische Hinweise.........715

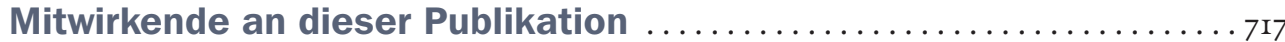

Weiterführende OECD-Publikationen .........................723 


\section{Editorial}

\section{Bildung und Kompetenzen - Schüssel zu einem Wachstum, von dem alle profitieren}

Langsam überwindet die Welt die schlimmste Wirtschaftskrise, die wir je erlebt haben. Noch sind Produktivität, Innovation, Investitionen und Handel nicht wieder völlig in Schwung gekommen, und die Überwindung der Krise ist durchaus noch mit Risiken verbunden. Darüber hinaus wird deutlich, dass wirtschaftliches Wachstum alleine nicht zu sozialem Fortschritt führt, vor allem wenn nicht alle an den Vorteilen des Wachstums teilhaben. Die Gesellschaft trägt immer noch schwer an den Kosten der Krise: In den OECD-Ländern sind mehr als 46 Millionen Menschen erwerbslos und viele weitere Millionen Menschen von relativer Armut betroffen. In vielen Ländern wächst die Kluft zwischen den Reichsten und den Ärmsten, verharrt die Jugenderwerbslosigkeit auf einem hohen Niveau, und vielen ist der Zugang zu Sozialleistungen verwehrt. Die Welt sucht nach Wegen zu einem wirtschaftlichen Wachstum, das allen zugutekommt. Die OECD unterstützt diese Bemühungen, indem sie Daten und Werkzeuge entwickelt, damit politische Entscheidungsträger neue Strategien und Maßnahmen zur Erreichung dieses Ziels entwickeln können.

Die diesjährige Ausgabe von Bildung auf einen Blick zeigt deutlich, wie wichtig Bildung und Kompetenzen für den sozialen Fortschritt sind. Zusätzlich zu den üblichen Datenquellen für die OECD-Bildungsindikatoren wird in dieser Ausgabe auch auf die umfassenden Daten der Erhebung zu den grundlegenden Kompetenzen Erwachsener (OECD Programme for the International Assessment of Adult Competencies - PIAAC), die im Oktober 2013 veröffentlicht wurde (OECD, 2013a), zurückgegriffen. Zusammen mit den Daten aus dem Jahr 2012 zu den Lernergebnissen I5-jähriger Schüler aus der Internationalen Schulleistungsstudie PISA (PISA 2012), die 2013 und 2014 veröffentlicht wurden (OECD, 2013b und 2014a), und den Daten aus $2013 \mathrm{zu}$ den Lehrkräften des Sekundarbereichs I aus der Internationalen Erhebung zu Lehren und Lernen der OECD (OECD Teaching and Learning International Survey - TALIS 2013), die im Juni 2014 veröffentlicht wurde (OECD, 20I4), verfügen wir jetzt über die umfassendste internationale Datensammlung zu Bildung und Kompetenzen, die jemals erhoben wurde. Und mit dem neu entwickelten, webbasierten Recherchewerkzeug Education GPS stehen alle diese Forschungsergebnisse mit nur einem Mausklick zur Verfügung.

Zunächst zeigt sich, dass in den OECD-Ländern der Zugang zur Bildung weiterhin zunimmt. Die Folgen des gesellschaftlichen Wandels, der innerhalb weniger Generationen dazu geführt hat, dass Bildung nicht länger einer Elite vorbehalten ist, sondern dass drei Viertel der Bevölkerung mindestens einen Abschluss im Sekundarbereich II erwerben, sind weiterhin wirksam. Fast 40 Prozent der 25- bis 34-Jährigen haben jetzt 
einen Abschluss im Tertiärbereich, das sind I5 Prozentpunkte mehr als bei den $55^{\text {- bis }}$ 64-Jährigen, und in vielen Ländern beträgt der Unterschied sogar mehr als 20 Prozentpunkte. Entscheidend ist, dass sich die Zunahme der Bildungsbeteiligung durch die Krise nicht verlangsamt hat. Ganz im Gegenteil, wo Arbeitsmärkte mit nur geringer Nachfrage keine adäquate Alternative boten, haben viele die geringen Opportunitätskosten genutzt und in ihre Bildung investiert, um damit ihre Chancen auf ein besseres Leben zu vergrößern. Und in Schwellenländern werden die Bildungssysteme, zwar von einem niedrigen Ausgangspunkt aus, mit einer Geschwindigkeit ausgebaut, die diejenige in den Industrienationen weit übertrifft.

Daher ist es nicht überraschend, dass das Kompetenzniveau der Bevölkerung ebenfalls beachtlich angestiegen ist. Die Daten zu den Kompetenzen zeigen, dass in den 24 OECD-Ländern und subnationalen Einheiten, die an der Erhebung zu den grundlegenden Kompetenzen Erwachsener teilnahmen, im Durchschnitt der Anteil der jüngeren Erwachsenen, die die höchste Lesekompetenzstufe erreichen, um ${ }_{3} 3$ Prozentpunkte höher ist als bei den älteren Erwachsenen. In einigen Ländern übersteigt der Anteil der jüngeren Erwachsenen auf dieser Kompetenzstufe denjenigen der älteren Erwachsenen sogar um 20 Prozentpunkte. Die Daten zeigen jedoch auch, dass Bildungsabschluss und Kompetenzen einander nicht immer entsprechen. Ferner gehören nicht alle Länder, die den stärksten Anstieg bei den erworbenen Bildungsabschlüssen haben, gleichzeitig auch zu denjenigen mit den größten Steigerungen beim Anteil der Erwachsenen mit den höchsten Kompetenzen. Im Gegenteil, in allen Ländern können Erwachsene mit ähnlichem Bildungsstand durchaus über sehr unterschiedliche Kompetenzniveaus verfügen - was Anlass dazu geben sollte, darüber nachzudenken, wie wir Bildungsqualifikationen definieren.

Man könnte annehmen, dass die Bildungsexpansion und der allgemeine Anstieg des in der Bevölkerung vorhandenen Kompetenzniveaus auf mehr und immer besser ausgebildete Erwerbstätige schließen lassen. Jedoch zeigt sich eine Vertiefung der sozioökonomischen Kluft, denn das Ausbildungs- und das Kompetenzniveau wirken sich in immer stärkerem Maße auf die Lebenschancen der einzelnen Menschen aus. Als Beispiel soll die Beschäftigungssituation dienen: Im Durchschnitt sind mehr als 8o Prozent der Erwachsenen mit einem Abschluss im Tertiärbereich in Beschäftigung, verglichen mit weniger als 60 Prozent der Erwachsenen mit einer Ausbildung unterhalb des Sekundarbereichs II. In einigen Ländern liegt diese Differenz zwischen den beiden Gruppen sogar bei 30 Prozentpunkten oder darüber. Dennoch sind auch Menschen mit einem Abschluss im Tertiärbereich, und vor allem die Jüngeren, nicht gegen Erwerbslosigkeit gefeit, und in vielen Ländern herrscht Besorgnis angesichts der steigenden Erwerbslosigkeit unter Hochschulabsolventen. Im Durchschnitt der OECD-Länder lag die Erwerbslosenquote von Erwachsenen mit einem Abschluss im Tertiärbereich 2012 bei 5,o Prozent (nach 3,3 Prozent 2008), aber bei den 25- bis 34-Jährigen waren es 7,4 Prozent (nach 4,6 Prozent 2008). Im Vergleich hierzu stieg die Erwerbslosenquote für 25- bis 34-Jährige ohne einen Abschluss im Sekundarbereich II von I3,6 Prozent im Jahr 2008 auf I9,8 Prozent im Jahr 2012 (und lag in vielen Ländern noch darüber). Somit bestätigen die vorliegenden Daten erneut, dass schlecht ausgebildete junge Erwachsene am stärksten von der Wirtschaftskrise betroffen sind. 
Mangelnde Kompetenzen steigern das Risiko der Erwerbslosigkeit - selbst bei Menschen mit ähnlichem Bildungsstand. So sind beispielsweise im Durchschnitt der Länder, die an der Erhebung zu den grundlegenden Kompetenzen Erwachsener teilnahmen, 5,8 Prozent der Erwachsenen mit einer Ausbildung unterhalb des Sekundarbereichs II, aber mit mittlerer Lesekompetenz erwerbslos, verglichen mit 8,o Prozent der Erwachsenen mit einem ähnlichen Bildungsstand, aber niedrigerer Lesekompetenz. Ähnliches gilt für Erwachsene mit einem Abschluss im Tertiärbereich: 3,9 Prozent derjenigen mit niedrigerer Lesekompetenz waren erwerbslos, verglichen mit 2,5 Prozent derjenigen mit der höchsten Lesekompetenz.

Auch die Daten zu den Einkommen lassen eine größer werdende Kluft zwischen gut und schlecht ausgebildeten Menschen erkennen. Die Einkommensunterschiede zwischen denjenigen ohne einen Abschluss im Sekundarbereich II und denjenigen mit einem Abschluss im Tertiärbereich nehmen in allen OECD-Ländern weiter zu. Setzt man das durchschnittliche Einkommen von 25- bis 64-Jährigen mit einem Abschluss im Sekundarbereich II auf einem Index gleich roo, so lag das Einkommen von Erwachsenen ohne einen Abschluss im Sekundarbereich II im Jahr 2000 bei 80 und ging bis 2012 auf 76 zurück, während das durchschnittliche Einkommen von Erwachsenen mit einem Abschluss im Tertiärbereich von I5I im Jahr 2000 auf 159 im Jahr 2012 anstieg. Die Daten zeigen außerdem, dass die relative Einkommenslücke zwischen Erwachsenen mit einem mittleren Bildungsabschluss und denen mit einem hohen Bildungsabschluss doppelt so stark zugenommen hat wie diejenige zwischen Erwachsenen mit einem mittleren Bildungsabschluss und mit einem niedrigen Bildungsabschluss. Das bedeutet, dass sich - relativ gesehen - das Einkommen von Erwachsenen mit einem mittleren Bildungsabschluss eher dem Einkommen von Erwachsenen mit einem niedrigen Bildungsabschluss angenähert hat - was der These der „Aushöhlung der Mitte“ entspricht.

Die Veränderungen zu größerer Ungleichheit bei der Einkommensverteilung sind zunehmend bestimmt durch die Verteilung der Bildungsabschlüsse und der Kompetenzen in den Gesellschaften. In den OECD-Ländern haben 73 Prozent der Personen ohne einen Abschluss des Sekundarbereichs II ein Erwerbseinkommen auf oder unterhalb des Medians, während das nur für 27 Prozent der Hochschulabsolventen zutrifft. Der Bildungsstand entscheidet letztendlich darüber, ob man in Armut oder in relativem Wohlstand lebt, und die Verteilung der Kompetenzen innerhalb einer Gesellschaft d. h., ob sie ausgewogen verteilt sind oder nicht - manifestiert sich im Grad der Einkommensungleichheit innerhalb einer Gesellschaft. Länder mit einem großen Anteil von Erwachsenen mit niedrigem Kompetenzniveau weisen eine starke, im Gini-Koeffizienten erfasste Einkommensungleichheit auf, was ebenso für Länder mit einem sehr polarisierten Kompetenzprofil gilt (d.h. mit vielen Menschen mit niedrigen Kompetenzen und vielen Menschen mit hohen Kompetenzen sowie einer Kompetenzverteilung, die üblicherweise mit dem sozioökonomischen Hintergrund zusammenhängt).

Die mit einem niedrigen Bildungsabschluss und niedrigen Kompetenzen einhergehenden Risiken - und die in vielen Fällen auch damit verbundenen Nachteile - betreffen nicht allein Einkommen und Beschäftigung, sondern haben zahlreiche andere gesamtgesellschaftliche Auswirkungen. So besteht beispielsweise eine Differenz von 23 Prozentpunkten zwischen dem Anteil der Erwachsenen mit hohem Bildungsstand, die 
ihren Gesundheitszustand als gut einschätzen, und dem Anteil derer mit einem niedrigen Bildungsstand, die diese Einschätzung teilen. Die Überzeugung, anderen vertrauen zu können, die Bereitschaft zu ehrenamtlichen Tätigkeiten sowie die Überzeugung, als Einzelner politischen Einfluss ausüben zu können, hängen eng mit dem Bildungsstand und dem Kompetenzniveau zusammen. Somit riskieren Gesellschaften mit einem hohen Anteil von Menschen mit niedrigen Kompetenzen eine Verschlechterung des sozialen Zusammenhalts und des allgemeinen Wohlergehens. Wenn viele Menschen nicht an den Vorteilen teilhaben, die höher qualifizierten Teilen der Bevölkerung erwachsen, können die langfristigen Kosten für die Gesellschaft - im Gesundheitswesen, durch Arbeitslosigkeit und in Fragen der Sicherheit, um nur einige zu nennen - bedrohliche Ausmaße annehmen.

Die größer werdende soziale Kluft zwischen gut und schlecht ausgebildeten Menschen - und die Gefahr, dass Letztere von den gesamtgesellschaftlichen Vorteilen der weiteren Bildungsexpansion ausgeschlossen werden - bedrohen die Gesellschaft als Ganzes. In der Vergangenheit befassten sich Länder überwiegend damit, das durchschnittliche Niveau des Humankapitals anzuheben, ohne besonders darauf zu achten, wie Bildung und Kompetenzen in der Bevölkerung verteilt sind. Selbstverständlich ist eine Verbesserung des allgemeinen Bildungs- und Kompetenzniveaus der Bevölkerung für wirtschaftliches Wachstum und sozialen Fortschritt erforderlich. Da aber immer mehr Industrienationen einen höheren Bildungsstand und höhere Kompetenzniveaus erreichen, scheinen aggregierte Kenngrößen des Humankapitals immer weniger geeignet zu sein, die zwischen den Ländern auftretenden Unterschiede bei der wirtschaftlichen Leistung zu erklären. Die Analyse der Daten aus der Erhebung zu den grundlegenden Kompetenzen Erwachsener zeigt, dass - wenn Menschen aller Kompetenzniveaus von einem besseren Zugang zu Bildung profitieren - dies auch dem wirtschaftlichen Wachstum und der sozialen Integration nützt. Länder mit einem geringen Anteil von Menschen mit niedrigen Kompetenzen und einem hohen Anteil von Menschen mit hohem Kompetenzniveau - d. h. Länder mit geringeren Unterschieden bei den Kompetenzniveaus - schneiden im Hinblick auf wirtschaftliche Leistung (BIP pro Kopf) und die Einkommensverteilung (Gini-Koeffizient) besser ab als Länder mit einem ähnlich hohen durchschnittlichen Kompetenzniveau, aber mit größeren Unterschieden bei den Kompetenzniveaus innerhalb der Bevölkerung (Van Damme, 20I4).

Bildungsstand und Kompetenzniveau sind daher immer wichtigere Faktoren der sozialen Ungleichheit geworden, gleichwohl sind sie auch unverzichtbar für die Lösung dieses Problems. Bildung kann Menschen einen Weg aus Armut und sozialer Ausgrenzung ermöglichen, damit dies geschehen kann, muss jedoch der erreichte Bildungsstand zu sozialer Mobilität führen. Die größte Bedrohung für ein Wachstum, das allen zugutekommt, liegt vielleicht in der Gefahr, dass die soziale Mobilität zum Erliegen kommen könnte. Ein Vergleich der Querschnittsdaten über verschiedene Altersgruppen hinweg scheint zu bestätigen, dass dieses Risiko in den OECD-Ländern tatsächlich besteht. In den Ländern, die an der Erhebung zu den grundlegenden Kompetenzen Erwachsener im Jahr 2012 teilgenommen haben, hatten im Durchschnitt 39 Prozent der 35- bis 44-Jährigen einen Abschluss im Tertiärbereich. Die Wahrscheinlichkeit, einen Abschluss im Tertiärbereich zu erwerben, hing stark vom elterlichen Bildungsstand ab: 68 Prozent der Erwachsenen mit wenigstens einem Elternteil mit einem Abschluss im Tertiärbereich erwarben ebenfalls einen derartigen Abschluss, während nur 24 Pro- 
zent der Erwachsenen, deren Eltern keinen Abschluss im Sekundarbereich II hatten, einen Abschluss im Tertiärbereich erwarben. In der jüngeren Altersgruppe der 25-bis 34-Jährigen, bei denen der Anteil derjenigen mit einem Abschluss im Tertiärbereich auf 43 Prozent gestiegen war, war jedoch der Einfluss des Bildungsstands der Eltern ebenso stark: Von den Erwachsenen mit wenigstens einem Elternteil mit einem Abschluss im Tertiärbereich erwarben $6_{5}$ Prozent ebenfalls einen Abschluss im Tertiärbereich, bei den Erwachsenen aus einer Familie mit einem niedrigen Bildungsstand lag der Anteil bei lediglich 23 Prozent. Anders ausgedrückt, die Vorteile der Bildungsexpansion erreichten zwar die Mittelschicht, aber nicht die weniger begünstigten Familien. Relativ gesehen wurden die Kinder aus Familien mit einem niedrigen Bildungsstand zunehmend von den möglichen Vorteilen ausgeschlossen, die die Bildungsexpansion dem Großteil der Bevölkerung brachte. Und selbst wenn ihnen der Zugang zu Bildung offenstand, führte das Zusammenspiel von sozioökonomisch ungünstigem Hintergrund und der geringeren Qualität der Ausbildung, die diese Schüler überproportional häufig erfahren müssen, zu Bildungsergebnissen, die ihrem sozialen Aufstieg nicht förderlich waren.

Eine Gesellschaft, die allen offensteht, benötigt ein Bildungssystem, welches das Lernen und den Kompetenzerwerb aller fördert, das dafür Sorge trägt, dass Leistung belohnt wird, und das soziale Mobilität unterstützt. Wenn die soziale Mobilität nachlässt, werden Gesellschaften weniger offen für alle. Selbst in Zeiten expandierender Bildungsbeteiligung sind zu viele Familien der Gefahr ausgesetzt, von der Bildungsmobilität zwischen den Generationen ausgeschlossen zu bleiben. Im Durchschnitt der Länder, die an der Erhebung zu den grundlegenden Kompetenzen Erwachsener teilgenommen haben, wird die Aufwärtsmobilität (der Prozentsatz der Bevölkerung, deren Bildungsstand über dem der Eltern liegt) bei den 55- bis 64-Jährigen auf 42 Prozent und bei den 45 - bis 54-Jährigen auf 43 Prozent geschätzt, fällt dann aber auf 38 Prozent bei den 35- bis 44-Jährigen und auf 32 Prozent bei den 25- bis 34-Jährigen. Die Abwärtsmobilität steigt von 9 Prozent bei den 55- bis 64-Jährigen und ro Prozent bei den 45 - bis 54-Jährigen auf I 2 Prozent bei den 35- bis 44-Jährigen und I6 Prozent bei den 25 - bis 34-Jährigen. Diese Daten legen die Vermutung nahe, dass die Bildungsexpansion noch nicht zu einer stärker sozial integrierten Gesellschaft geführt hat und dass hier dringender Handlungsbedarf besteht.

OECD-Durchschnittswerte können zu Fehlinterpretationen Anlass geben, da sie große Unterschiede zwischen den einzelnen Ländern verbergen. Die interessantesten Ergebnisse der diesjährigen Ausgabe von Bildung aufeinen Blick sind möglicherweise nicht die Durchschnittswerte über alle OECD-Länder hinweg, sondern die Art, in der die Indikatoren die Unterschiede zwischen den einzelnen Ländern aufzeigen. Diese Unterschiede spiegeln unterschiedliche historische und kulturelle Zusammenhänge wider, sie zeigen jedoch auch, welche Wirkung politische Maßnahmen haben können. Unterschiedliche politische Strategien und Maßnahmen führen zu unterschiedlichen Ergebnissen, dies gilt natürlich auch für Bildungsstand und Kompetenzen. Einigen Ländern gelingt es besser als anderen, den Kreislauf der sozialen Ungleichheit, der zu Ungleichheiten beim Bildungsstand führt, zu unterbrechen, das Risiko der Ausgrenzung aufgrund von Bildungsstand und Kompetenzen einzudämmen und den Anteil der Erwachsenen mit niedrigen Kompetenzen niedrig zu halten und gleichzeitig so vielen Erwachsenen wie möglich die Chancen zu bieten, ihr Kompetenzniveau zu steigern. 
Bildung und Kompetenzen sind der Schlüssel zu zukünftigem Wohlergehen. Sie sind unerlässlich, um wieder langfristiges Wachstum zu erreichen, die Erwerbslosigkeit zu bekämpfen, die Wettbewerbsfähigkeit zu stärken und eine Gesellschaft mit starkem Zusammenhalt, die allen offensteht, zu fördern. Die vorliegenden umfassenden Daten zu Bildung und Kompetenzen unterstützen die Länder darin, sich mit anderen zu vergleichen, und helfen den Ländern dabei zu erkennen, welche bildungspolitischen Maßnahmen wirklich Erfolg versprechen.

ANGEL Gurría

OECD-Generalsekretär 


\section{Weiterführende Literatur}

Education GPS: The World of Education at your Fingertips, http:|/gpseducation.oecd.org.

OECD Initiative on Inclusive Growth, www.oecd.org/inclusive-growth.

OECD (2014a):

PISA 2012 Ergebnisse: Was Schülerinnen und Schüler wissen und können (Band I, überarbeitete Ausgabe, Februar 2014): Schülerleistungen in Lesekompetenz, Mathematik und Naturwissenschaften, W. Bertelsmann Verlag, Bielefeld, http:/ldx.doi.org/10.1787/9789264208858-de.

PISA 2012 Results: Creative Problem Solving (Volume V): Students' Skills in Tackling Real-Life Problem, PISA, OECD Publishing, Paris, http://dx.doi.org/10.1787/9789264208070-en.

PISA 2012 Results: Students and Money (Volume VI): Financial Literacy Skills for the 21st Century, PISA, OECD Publishing, Paris, http:/ldx.doi.org/10.1787/9789264208094-en.

OECD (2014b), TALIS 2013 Results: An International Perspective on Teaching and Learning, TALIS, OECD Publishing, Paris, http:/|dx.doi.org/10.1787/9789264196261-en.

OECD (2013a), OECD Skills Outlook 2013: First Results from the Survey of Adult Skills, OECD Publishing, Paris, http:||dx.doi.org/ 10.1787/9789264204256-en.

$\operatorname{OECD}(2013 \mathrm{~b})$ :

PISA 2012 Results: Excellence through Equity (Volume II): Giving Every Student the Chance to Succeed, PISA, OECD Publishing, Paris, http://dx.doi.org/10.1787/9789264201132-en.

PISA 2012 Results: Ready to Learn (Volume III): Students' Engagement, Drive and Self-Beliefs, PISA, OECD Publishing, Paris, http://dx.doi.org/10.1787/9789264201170-en.

PISA 2012 Results: What Makes Schools Successful? (Volume IV): Resources, Policies and Practices, PISA, OECD Publishing, Paris, http://dx.doi.org/10.1787/9789264201156-en.

Van Damme, D. (2014), „How closely is the distribution of skills related to countries' overall level of social inequality and economic prosperity?", EDU NAEC Paper Series, No. I, www.oecd.org/edu/skills-beyond-school/EDUNAEC1.pdf. 


\section{Die Indikatoren und ihr konzeptioneller Rahmen}

\section{Das zugrunde liegende Referenzsystem}

Bildung auf einen Blick 2014 - OECD-Indikatoren bietet ein umfangreiches aktuelles Spektrum an vergleichbaren Indikatoren, die auf dem Konsens der Fachwelt beruhen, wie der gegenwärtige Stand der Bildung im internationalen Vergleich zu bewerten ist. Die Indikatoren enthalten Informationen zu den in Bildung investierten personellen und finanziellen Ressourcen, zur Funktionsweise und Weiterentwicklung von Bildungssystemen sowie zu den Erträgen der Investitionen in die Bildung. Die Indikatoren sind thematisch gegliedert und jeweils von Informationen zum politischen Kontext und zur Interpretation der Daten begleitet. Die OECD-Indikatoren sind in einen konzeptionellen Rahmen eingestellt,

der zwischen den Akteuren im Bildungssystem unterscheidet - einzelne Schüler und Lehrkräfte, Arten des Unterrichts und Lernumgebungen, Anbieter von Bildungsleistungen sowie das Bildungssystem als Ganzes;

der die Indikatoren in Gruppen zusammenfasst, je nachdem, womit sie sich beschäftigen: die Lernergebnisse von Einzelnen oder ganzen Ländern, die politischen Ansatzpunkte oder Zusammenhänge, die diese Ergebnisse beeinflussen, oder die Gegebenheiten und Bedingungen, die bei politischen Entscheidungen zu berücksichtigen sind; und

der die politischen Fragen identifiziert, auf die sich die Indikatoren beziehen und die in drei Kategorien eingeteilt sind - die Qualität der Bildungserfolge und des Bildungsangebots, Fragen der Chancengerechtigkeit beim Bildungsangebot und den Bildungsergebnissen sowie die Angemessenheit und Effektivität des Ressourcenmanagements.

Die folgende Matrix veranschaulicht die ersten beiden Dimensionen: 


\begin{tabular}{l|l|l|l} 
& $\begin{array}{l}\text { 1. } \\
\text { Bildungs- und } \\
\text { Lernergebnisse }\end{array}$ & $\begin{array}{l}2 . \\
\text { Politische Ansatzpunkte } \\
\text { und Zusammenhänge, } \\
\text { die die Bildungserfolge } \\
\text { beeinflussen }\end{array}$ & $\begin{array}{l}\text { 3. } \\
\text { Gegebenheiten und } \\
\text { Bedingungen, die von } \\
\text { der Politik zu berück- } \\
\text { sichtigen sind }\end{array}$ \\
$\begin{array}{l}\text { I. } \\
\begin{array}{l}\text { Einzelne Teilnehmer } \\
\text { am Bildungssystem }\end{array}\end{array}$ & $\begin{array}{l}\text { 1.I } \\
\text { Qualität und Verteilung } \\
\text { der individuellen } \\
\text { Bildungsergebnisse }\end{array}$ & $\begin{array}{l}\text { Einstellungen, Engage- } \\
\text { ment und Verhalten } \\
\text { des Einzelnen in Bezug } \\
\text { auf Lehren und Lernen }\end{array}$ & $\begin{array}{l}\text { 3.I } \\
\text { Persönlicher Hintergrund } \\
\text { des einzelnen Lernenden } \\
\text { und Lehrenden }\end{array}$ \\
$\begin{array}{l}\text { II. } \\
\text { Der Unterricht }\end{array}$ & $\begin{array}{l}\text { 1.II } \\
\text { Qualität des Unterrichts } \\
\text { Pädagogische Methoden } \\
\text { und Lernstrategien sowie } \\
\text { das Unterrichtsklima }\end{array}$ & $\begin{array}{l}\text { Unterrichts- und Lern- } \\
\text { bedingungen der Lernen- } \\
\text { den und Arbeitsbedin- } \\
\text { gungen der Lehrenden }\end{array}$ \\
$\begin{array}{l}\text { III. } \\
\text { Anbieter von Bildungs- } \\
\text { dienstleistungen }\end{array}$ & $\begin{array}{l}\text { 1.III } \\
\text { Abschlussquoten } \\
\text { und Leistungen der } \\
\text { Bildungseinrichtungen }\end{array}$ & $\begin{array}{l}\text { 2.III } \\
\text { Organisation und } \\
\text { Ausstattung der } \\
\text { Bildungseinrichtungen }\end{array}$ & $\begin{array}{l}\text { 3.III } \\
\text { Merkmale der Anbieter } \\
\text { von Bildungsdienst- } \\
\text { leistungen und ihres } \\
\text { Umfelds }\end{array}$ \\
$\begin{array}{l}\text { IV. } \\
\text { Das Bildungssystem } \\
\text { als Ganzes }\end{array}$ & $\begin{array}{l}\text { 1.IV } \\
\text { Gesamtleistung des } \\
\text { Bildungssystems }\end{array}$ & $\begin{array}{l}\text { 2.IV } \\
\text { Systemweite institutio- } \\
\text { nelle Struktur, Zuweisung } \\
\text { von Mitteln und politi- } \\
\text { sche Maßnahmenn }\end{array}$ & $\begin{array}{l}\text { J.IV } \\
\text { Jeweiliger nationaler, } \\
\text { sozialer, wirtschaftlicher } \\
\text { und demografischer } \\
\text { Kontext }\end{array}$ \\
\hline
\end{tabular}

\section{Die Akteure im Bildungssystem}

Das Bildungsindikatoren-System der OECD (INES) zielt auf eine Beurteilung der Leistungen der nationalen Bildungssysteme als Ganzes und nicht einzelner Bildungseinrichtungen oder anderer subnationaler Einheiten. Dennoch wird zunehmend anerkannt, dass viele wichtige Aspekte der Entwicklung, der Funktionsweise und der Auswirkungen der Bildungssysteme nur beurteilt werden können, wenn man die Lernergebnisse mit einbezieht und versteht, wie diese mit dem „Input“ und den Prozessen auf der Ebene des Einzelnen und der Institutionen zusammenhängen. Um dies zu berücksichtigen, unterscheidet der konzeptionelle Rahmen der Indikatoren zwischen der Makroebene, zwei Mesoebenen und der Mikroebene der Bildungssysteme. Diese beziehen sich auf

das Bildungssystem als Ganzes,

die Bildungseinrichtungen und Anbieter von Bildungsdienstleistungen,

den Unterricht und die Lernumgebung innerhalb der Bildungseinrichtungen und

die einzelnen Teilnehmer am Bildungssystem.

In gewisser Weise entsprechen diese Ebenen den Einheiten bzw. Gruppen, von denen Daten erhoben werden, aber sie sind deshalb so wichtig, weil sich viele Merkmale des Bildungssystems je nach Ebene ganz unterschiedlich auswirken, was bei der Interpretation der Indikatoren zu berücksichtigen ist. So kann zum Beispiel auf Ebene der Schüler einer Klasse das Verhältnis zwischen Schülerleistungen und Klassengröße negativ sein, wenn Schüler in kleinen Klassen von einer besseren Betreuung durch die Lehrkraft profitieren. Auf Klassen- oder Schulebene werden jedoch oft gezielt schwächere oder benachteiligte Schüler in kleineren Klassen zusammengefasst, damit den Schülern mehr Aufmerksamkeit zuteilwird. Auf Schulebene ist daher dann das beobachtete 
Verhältnis zwischen Klassengröße und Schülerleistung oft positiv (was den Schluss nahelegen würde, dass Schüler in größeren Klassen besser abschneiden als Schüler in kleineren Klassen). Auf den übergeordneten Ebenen der Bildungssysteme wird der Zusammenhang zwischen Schülerleistung und Klassengröße oft durch weitere Aspekte beeinflusst, z. B. durch die sozioökonomische Zusammensetzung der Schülerschaft oder durch Faktoren im Zusammenhang mit der Lernkultur in den einzelnen Ländern. Daher haben Analysen in der Vergangenheit, die sich allein auf Daten der Makroebene konzentrierten, gelegentlich zu Schlussfolgerungen geführt, die nicht in die richtige Richtung wiesen.

\section{Ergebnisse, politische Ansatzpunkte und Gegebenheiten}

Die zweite Dimension des zugrunde liegenden Referenzsystems fasst die Indikatoren auf jeder der genannten Ebenen weiter zusammen.

Die Indikatoren der beobachteten Bildungsergebnisse sowie die Indikatoren zu den Auswirkungen von Kenntnissen und Fähigkeiten auf den Einzelnen, die Gesellschaft und die Wirtschaft werden unter Bildungs- und Lernergebnisse zusammengefasst.

- Unter Politische Ansatzpunkte und Zusammenhänge, die die Bildungserfolge beeinflussen, werden Informationen zu den politischen Ansatzpunkten und Bedingungen, die die Erfolge und Ergebnisse auf jeder Ebene beeinflussen, zusammengefasst.

Diese politischen Ansatzpunkte und Zusammenhänge werden typischerweise von Gegebenheiten bestimmt - Faktoren, die die Politik bedingen oder einschränken. Sie werden unter Gegebenheiten und Bedingungen dargestellt. Die Gegebenheiten oder Bedingungen gelten normalerweise jeweils für eine bestimmte Ebene des Bildungssystems, Gegebenheiten auf einer der unteren Ebenen des Systems können durchaus auf einer höheren Ebene politische Ansatzpunkte sein. So sind zum Beispiel für die Schüler und Lehrkräfte einer Schule die Qualifikationen der Lehrkräfte eine gegebene Bedingung, dagegen ist die berufliche Weiterbildung der Lehrkräfte auf Ebene des Bildungssystems ein entscheidender bildungspolitischer Ansatzpunkt.

\section{Bildungspolitische Fragen}

Jede der sich so ergebenen Zellen des Referenzsystems kann dann genutzt werden, um eine Reihe von Fragen aus unterschiedlichen bildungspolitischen Perspektiven zu betrachten. Die bildungspolitischen Perspektiven wurden für dieses Referenzsystem in drei Klassen zusammengefasst, die die dritte Dimension des zugrunde liegenden Referenzsystems von INES bilden:

die Qualität der Bildungsergebnisse und des Bildungsangebots,

Gleichwertigkeit der Bildungsergebnisse und Chancengleichheit beim Bildungsangebot sowie

Angemessenheit, Effektivität und Effizienz des Ressourcenmanagements.

Zusätzlich zu den oben erwähnten Dimensionen erlaubt die zeitliche Perspektive, als weitere Dimension des konzeptionellen Rahmens auch dynamische Aspekte der Entwicklung der Bildungssysteme abzubilden. 
Die in Bildung aufeinen Blick 2014 veröffentlichten Indikatoren fügen sich in dieses Referenzsystem ein, beziehen sich aber häufig auf mehr als eine Zelle der Referenzmatrix.

Die meisten Indikatoren in Kapitel A: Bildungsergebnisse und Bildungserträge beziehen sich auf die erste Spalte der Matrix, in der die Bildungs- und Lernergebnisse erfasst sind. Dennoch bieten beispielsweise die Indikatoren in Kapitel A, die den Bildungsstand verschiedener Generationen messen, nicht nur eine Kennzahl für die Ergebnisse der Bildungssysteme (des „Outputs“), sondern darüber hinaus auch den Kontext für die laufende Bildungspolitik und beeinflussen zum Beispiel die Politik im Bereich lebenslanges Lernen.

Kapitel B: Die in Bildung investierten Finanz- und Humanressourcen liefert Kennzahlen, die entweder politische Ansatzpunkte oder Gegebenheiten darstellen, die von der Politik zu berücksichtigen sind, bzw. gelegentlich beides zusammen. Die Ausgaben pro Schüler/Studierenden sind eine entscheidende bildungspolitische Kennzahl, die sich direkt auf den einzelnen Lernenden auswirkt, denn diese Ausgaben beeinflussen die Lernumgebung in den Schulen sowie die Lernbedingungen im Klassenzimmer.

Kapitel C: Bildungszugang, Bildungsbeteiligung und Bildungsverlauf enthält Indikatoren, die eine Mischung aus Kennzahlen zu Erfolgen, politischen Ansatzpunkten und Zusammenhängen sind. Die Internationalisierung der Bildung und die Übergangsquoten sind beispielsweise insofern Erfolgskennzahlen, als sie die Ergebnisse der bildungspolitischen Maßnahmen und Praktiken auf Ebene des Klassenzimmers, der Schule und des Bildungssystems erfassen. Aber sie können auch den Kontext für bildungspolitische Entscheidungen bieten, indem sie die Bereiche erkennen lassen, in denen ein politisches Eingreifen erforderlich ist, um beispielsweise die Chancengerechtigkeit zu verbessern.

Kapitel D: Das Lernumfeld und die Organisation von Schulen enthält Indikatoren zur Unterrichtszeit, der Arbeitszeit der Lehrkräfte und ihren Gehältern, die nicht nur politische Ansatzpunkte darstellen, die beeinflusst werden können, sondern die auch den Kontext für die Unterrichtsqualität, die Formen des Unterrichts und die Lernerfolge der einzelnen Schüler liefern. In diesem Kapitel werden außerdem Daten zu der Alters- und Geschlechterverteilung der Lehrkräfte, der staatlichen Ebene, auf der Entscheidungen in Bildungssystemen getroffen werden, sowie zu den Möglichkeiten für den Übergang und die Zulassung zum Sekundar- und Tertiärbereich dargestellt.

Es sei darauf hingewiesen, dass Bildung auf einen Blick 2014 auch umfangreiche Daten aus Partnerländern enthält (Einzelheiten s. Hinweise für den Leser). 


\section{Hinweise für den Leser}

\section{Statistische Erfassung}

Zwar ist der Geltungsbereich der Indikatoren in vielen Ländern nach wie vor durch unvollständige Daten eingeschränkt, prinzipiell wird jedoch jeweils das gesamte nationale Bildungssystem (innerhalb der nationalen Grenzen) erfasst, unabhängig davon, wer Eigentümer oder Geldgeber der betreffenden Bildungseinrichtungen ist und wie das Bildungsangebot vermittelt wird. Abgesehen von einer Ausnahme (s. u.) sind sämtliche Schüler und Studierende sowie alle Altersgruppen berücksichtigt: Kinder (einschließlich derjenigen, die als Kinder mit besonderen Lernbedürfnissen eingestuft sind), Erwachsene, Inländer, Ausländer sowie Schüler und Studierende, die an Fernkursen, an Sonderschulmaßnahmen oder an Ausbildungsgängen teilnehmen, die von anderen Ministerien als dem Bildungsministerium angeboten werden, sofern das Hauptziel ist, das Wissen des Einzelnen zu erweitern oder zu vertiefen. Kinder, die jünger als 3 Jahre sind, sind jedoch nur erfasst, wenn sie an Bildungsmaßnahmen teilnehmen, für deren Besuch die Kinder in der Regel mindestens 3 Jahre alt sein sollen. Die berufliche und fachliche Ausbildung am Arbeitsplatz bleibt bei den grundlegenden Angaben zu den Ausgaben für die Ausbildung und zur Bildungsbeteiligung unberücksichtigt, mit Ausnahme der kombinierten schulischen und betrieblichen Ausbildungen, die ausdrücklich als Bestandteil des Bildungssystems gelten.

Bildungsaktivitäten, die als „Erwachsenenbildung“ oder „nicht reguläre Bildung“ eingestuft sind, werden berücksichtigt, sofern diese Aktivitäten fachliche Inhalte vermitteln, die denen „regulärer“ Bildungsgänge entsprechen oder ihnen vergleichbar sind, bzw. sofern die zugrunde liegenden Bildungsgänge zu ähnlichen Abschlüssen führen wie die entsprechenden regulären Bildungsgänge.
Kurse für Erwachsene, die in erster Linie aus allgemeinem Interesse, zur persönlichen Entwicklung, als Freizeitvergnügen oder zur Erholung belegt werden, sind hierbei ausgeschlossen.

\section{Länderabdeckung}

Die Veröffentlichung enthält Bildungsdaten aus den 34 OECD-Ländern, aus 2 Partnerländern, die am OECD-Programm Indicators of Education Systems (INES) teilnehmen (Brasilien und die Russische Föderation), sowie aus den anderen Partnerländern, die nicht an INES teilnehmen (Argentinien, China, Indien, Indonesien, Kolumbien, Lettland, Saudi-Arabien und Südafrika). Die Quellen für die Daten dieser letztgenannten 8 Länder sind jeweils unter den Tabellen angegeben.

Die statistischen Daten für Israel wurden von den zuständigen israelischen Stellen bereitgestellt, die für sie verantwortlich zeichnen. Die Verwendung dieser Daten durch die OECD erfolgt unbeschadet des völkerrechtlichen Status der Golanhöhen, von Ost-Jerusalem und der israelischen Siedlungen im Westjordanland.

\section{Berechnung von internationalen Mittelwerten}

Der Wert für den OECD-Durchschnitt wird als der ungewichtete Mittelwert der Datenwerte aller OECD-Länder berechnet, für die entsprechende Daten vorliegen oder geschätzt werden können. Der OECD-Durchschnitt bezieht sich somit auf einen Durchschnitt von Datenwerten auf Ebene der nationalen Bildungssysteme und kann als Antwort auf die Frage dienen, wie ein Indikatorwert für ein bestimmtes Land im Vergleich zum Wert eines typischen Landes bzw. eines Landes mit durchschnittlichen Werten abschneidet. Dabei bleibt die absolute Größe des jeweiligen Bildungssystems unberücksichtigt. 
OECD insgesamt wird als der gewichtete Mittelwert der Datenwerte aller Länder berechnet, für die entsprechende Daten vorliegen oder geschätzt werden können. Er spiegelt den Wert eines bestimmten Indikators für die OECD-Länder in ihrer Gesamtheit wider. Dieser Wert dient zu Vergleichszwecken, wenn beispielsweise die Ausgabenzahlen für einzelne Länder mit denen aller OECD-Länder insgesamt verglichen werden sollen, für die jeweils relevante Daten vorliegen, wobei diese OECD-Länder als eine Einheit betrachtet werden.

Sowohl der OECD-Durchschnitt als auch OECD insgesamt können durch fehlende Daten für einzelne Länder erheblich beeinflusst werden. Aufgrund der relativ kleinen Zahl der untersuchten Länder wird dies jedoch nicht durch statistische Verfahren ausgeglichen. In den Fällen, in denen eine Kategorie für ein Land nicht zutrifft (gekennzeichnet durch ein „a“) oder der Datenwert für die entsprechende Berechnung vernachlässigbar gering ist (gekennzeichnet durch ein „n“), wird zur Berechnung des OECD-Durchschnitts der Wert null angesetzt. In den Fällen, in denen ein Datenpunkt das Verhältnis von zwei Werten angibt, die beide auf ein bestimmtes Land nicht zutreffen (gekennzeichnet durch ein „a“), wird das betreffende Land bei der Berechnung des OECD-Durchschnitts nicht berücksichtigt.

In den Tabellen zur Finanzstatistik, die Zeitserien von I995 bis 20 II berücksichtigen, wurden sowohl der OECD-Durchschnitt als auch der Wert OECD insgesamt für die Länder berechnet, die Daten für alle Referenzjahre zur Verfügung stellten. Dies erlaubt einen Vergleich des OECD-Durchschnitts und des Wertes OECD insgesamt im Zeitablauf, der nicht durch fehlende Daten bestimmter Länder für eines der Jahre beeinträchtigt wird.

Bei vielen Indikatoren wird auch ein EU21-Durchschnitt angegeben. Er wird als der ungewichtete Mittelwert der Datenwerte der 2I OECD-Länder berechnet, die sowohl Mitglied der Europäischen Union als auch der OECD sind und für die entsprechende Daten vorliegen oder geschätzt werden können (Belgien, Dänemark, Deutschland, Estland, Finnland, Frankreich, Griechenland, Irland, Italien, Luxemburg, die Niederlande, Österreich,
Polen, Portugal, Schweden, die Slowakei, Slowenien, Spanien, Tschechien, Ungarn und das Vereinigte Königreich).

Bei einigen Indikatoren ist auch ein G20-Durchschnitt angegeben. Der G20-Durchschnitt wird als der ungewichtete Mittelwert der Datenwerte aller G20-Länder berechnet, für die entsprechende $\mathrm{Da}$ ten vorliegen oder geschätzt werden können (Argentinien, Australien, Brasilien, China, Deutschland, Frankreich, Indien, Indonesien, Italien, Japan, Kanada, Korea, Mexiko, die Russische Föderation, Saudi-Arabien, Südafrika, die Türkei, das Vereinigte Königreich und die Vereinigten Staaten; die Europäische Kommission ist das 20. Mitglied der G20-Länder, ist aber bei der Berechnung nicht berücksichtigt). Der G20-Durchschnitt wird nicht berechnet, wenn für China oder Indien keine Daten vorliegen.

Bei einigen Indikatoren ist ein Durchschnitt angegeben. Dieser Durchschnitt ist in den Tabellen mit Daten aus der Erhebung zu den grundlegenden Kompetenzen Erwachsener im Rahmen des OECD Programme for the International Assessment of Adult Competencies (PIAAC) angegeben. Der Durchschnitt entspricht dem arithmetischen Mittel der in der Tabelle oder Abbildung enthaltenen Schätzwerte sowohl der nationalen als auch subnationalen Einheiten (einschließlich Flandern [Belgien] und England/Nordirland [VK]). Partnerländer sind in dem in Tabellen oder Abbildungen angegebenen Durchschnitt nicht enthalten.

\section{Standardfehler (S. F.)}

Die in diesem Bericht dargestellten statistischen Schätzungen basieren auf Stichproben von Erwachsenen statt auf Werten, die man erhalten würde, wenn jede Person in der Zielpopulation jedes Landes jede Frage beantwortet hätte. Jede Schätzung ist daher mit einem bestimmten Grad an Unsicherheit behaftet, der mit Stichproben- und Messfehlern zusammenhängt und der als Standardfehler ausgedrückt werden kann. Konfidenzintervalle erlauben Rückschlüsse auf Mittelwerte und Mengenverhältnisse in der Population, indem sie die von den Schätzwerten aus der Stichprobe stammende Unsicherheit spezifizieren. In diesem Bericht ist 
das Konfidenzniveau auf $95 \%$ festgelegt. Anders ausgedrückt, das Ergebnis für die entsprechende Population liegt in 95 von roo Messwiederholungen mit verschiedenen Stichproben aus derselben Population innerhalb des Konfidenzintervalls.

In den Tabellen, in denen Standardfehler aufgeführt sind, gibt es eine Spalte mit der Bezeichnung „\%“, in der der durchschnittliche Prozentsatz dargestellt ist, und eine Spalte mit der Bezeichnung „S.F.“, in der der Standardfehler dargestellt ist. Aufgrund der Erhebungsmethode besteht bei den Prozentsätzen (\%) eine Stichprobenunsicherheit vom zweifachen Standardfehler (S. F.). Das heißt zum Beispiel, bei den Werten $\%=$ Io und S. F. $=2,6$ besteht für die Angabe ro \% und einem Fehlerrisiko von $5 \%$ ein Unsicherheitsbereich vom zweifachen $(I, 96)$ Standardfehler von 2,6. Daher läge der tatsächliche Prozentsatz wahrscheinlich (Fehlerrisiko $5 \%$ ) ungefähr zwischen $5 \%$ und I $5 \%$ („Konfidenzintervall"). Das Konfidenzintervall berechnet sich wie folgt: $\% \pm 1,96 \times$ S. F., d. h. beim obigen Beispiel: $5 \%=$ Io $\%-\mathrm{I}, 96 \times 2,6$ und I $5 \%=$ Io $\%+$ I, 96 $\times 2,6$.

\section{Klassifizierung der Bildungsbereiche}

Die Klassifizierung der einzelnen Bildungsbereiche beruht auf der Internationalen Standardklassifikation des Bildungswesens (ISCED I997). ISCED I997 ist ein Instrument zur Erstellung von internationalen Bildungsstatistiken und unterscheidet zwischen sechs Bildungsbereichen. ISCED 1997 wurde kürzlich überarbeitet, und die neue Internationale Standardklassifikation des Bildungswesens (ISCED 20II) wurde im November 20II offiziell verabschiedet. Diese neue Klassifikation wird in Bildung auf einen Blick 2015 umgesetzt.

Im (englischen) Glossar unter www.oecd.org/edu/ eaghtm werden die ISCED-Stufen ebenfalls ausführlich erläutert, und in Anhang I ist das typische Abschlussalter für die wichtigsten Bildungsgänge nach ISCED-Bereichen aufgeführt.

\section{Symbole für fehlende Daten und Abkürzungen}

In Tabellen und Abbildungen werden folgende Symbole und Abkürzungen verwendet:

a Daten nicht zutreffend, da die Kategorie nicht zutrifft.

c $\quad \mathrm{Zu}$ wenige Beobachtungen, um verlässliche Werte anzugeben (z. B. bei PISA: eine Zelle ist mit weniger als 30 Schülern oder weniger als fünf Schulen besetzt; in der Erhebung zu den grundlegenden Kompetenzen Erwachsener: eine Zelle ist mit weniger als 30 Personen besetzt). Diese Daten wurden jedoch bei der Berechnung der länderübergreifenden Durchschnittswerte berücksichtigt.

ESCS PISA-Index des wirtschaftlichen, sozialen und kulturellen Status.

m Keine Daten verfügbar.

n Die Größenordnung ist entweder vernachlässigbar oder null.

$r \quad$ Werte sind unterhalb einer gewissen Zuverlässigkeitsschwelle und sollten mit Vorsicht interpretiert werden (länderspezifische Definitionen s. Anhang 3).

S. F. Standardfehler.

$w$ Die Daten wurden aufWunsch des betreffenden Landes zurückgezogen.

$x \quad$ Die Daten sind in einer anderen Kategorie oder Spalte der Tabelle enthalten - z. B. bedeutet $\mathrm{x}(2)$, dass die Daten in Spalte (2) der Tabelle enthalten sind.

$\sim \quad$ Der Durchschnitt ist nicht mit anderen Bildungsbereichen vergleichbar.

\section{Weitere Quellen}

Im Internet finden sich unter www.oecd.org/eduleag. $\mathrm{htm}$ umfangreiche Informationen $\mathrm{zu}$ den bei den Indikatoren verwendeten Berechnungsmethoden, der Interpretation der Indikatoren im jeweiligen nationalen Kontext und den benutzten Datenquellen. Die Website bietet auch Zugang zu den Daten, die den Indikatoren zugrunde liegen, sowie zu einem umfangreichen (englischen) Glossar der Fachbegriffe, die in dieser Publikation verwendet werden.

Alle Änderungen, die nach Drucklegung dieser Veröffentlichung erfolgten, sind unter www.oecd.orgl eduleag.htm aufgeführt. 


\section{Klassifizierung der Bildungsbereiche}

\section{Elementarbereich}

Die erste Stufe organisierten Unterrichts, die sehr kleine Kinder an eine schulähnliche Umgebung heranführen soll. Das Mindestalter beträgt 3 Jahre.

\section{Primarbereich}

Er soll eine solide Grundbildung im Lesen, Schreiben, Rechnen sowie ein grundlegendes Verständnis einiger anderer Fächer vermitteln. Eintrittsalter: zwischen 5 und 7 Jahren. Dauer: 6 Jahre.

\section{Sekundarbereich I}

Schließt die Vermittlung der Grundbildung ab, normalerweise stärker fachorientiert mit stärker spezialisierten Lehrkräften. Eintritt erfolgt nach 6 Jahren Besuch des Primarbereichs, Dauer 3 Jahre. In einigen Ländern ist am Ende des Sekundarbereichs I die Schulpflicht erfüllt.

\section{Sekundarbereich II}

Der Unterricht ist fächerspezifischer als im Sekundarbereich I, und die Lehrkräfte sind in der Regel höher qualifiziert. Schüler sollten typischerweise bereits 9 Jahre die Schule besucht haben bzw. den Sekundarbereich I abgeschlossen haben. Das Eintrittsalter liegt im Allgemeinen bei 15 oder 16 Jahren.

\section{Postsekundarer, nicht tertiärer Bereich}

Dieser Bildungsbereich befindet sich aus internationaler Sicht im Grenzbereich zwischen dem Sekundarbereich II und dem postsekundaren Bereich, auch wenn die Bildungsgänge im nationalen Zusammenhang eindeutig als zum Sekundarbereich II oder zum postsekundaren Bereich gehörig angesehen werden können. Der Inhalt dieser Bildungsgänge ist möglicherweise nicht wesentlich anspruchsvoller als der des Sekundarbereichs II, aber nicht so anspruchsvoll wie im Tertiärbereich. Die Dauer des Besuchs beträgt normalerweise zwischen 6 Monaten und 2 Jahren (Vollzeitteilnahme). Die Teilnehmer dieser Bildungsgänge sind in der Rege älter als solche des Sekundarbereichs II.

\section{Tertiärbereich}

\section{Tertiärbereich A}

Weitgehend theoretisch orientierte Studiengänge, die hinreichende Qualifikationen für den Zugang zu weiterführenden forschungsorientierten Studiengängen und Berufen mit hohem Qualifikationsniveau, wie Medizin, Zahnmedizin oder Architektur, vermitteln sollen. Dauer mindestens 3 Jahre (Vollzeitteilnahme), obwohl normalerweise 4 oder mehr Jahre. Derartige Studiengänge werden nicht ausschließlich an Hochschulen angeboten; und umgekehrt erfüllen nicht alle Studiengänge, die national als Hochschulstudium anerkannt werden, die Kriterien für die Einstufung im Tertiärbereich A. Der Tertiärbereich A schließt zweite Abschlüsse wie den "Master“ mit ein.

\section{Tertiärbereich B}

Die Studiengänge sind typischerweise kürzer als im Tertiärbereich A und konzentrieren sich auf praktische/technische/berufsbezogene Fähigkeite für den direkten Eintritt in den Arbeitsmarkt, obwohl in diesen Studien gängen auch einige theoretische Grundlagen vermittelt werden können. Sie dauern im Tertiärbereich mindestens 2 Jahre (Vollzeitteilnahme).

\section{Weiterführende forschungsorientierte Studiengänge}

Sie führen direkt zu einem Abschluss in einem weiterführenden forschungsorientierten Studiengang, z. B. einer Promotion. Die reguläre Vollzeitstudiendauer eines solchen Programms beträgt in den meisten Ländern 3 Jahre (bei einer Vollzeitausbildungsdauer insgesamt von mindestens 7 Jahren im Tertiärbereich), obwohl die Studierenden häufig länger eingeschrieben sind. Die Studiengänge widmen sich fortgeschrittenen Studien und originären Forschungsarbeiten.
ISCED 0

ISCED 1

\section{ISCED 2}

Unterkategorien: ISCED 2A bereitet Schüler auf eine weiter gehende allgemeinbildende Ausbildung vor, führt zu ISCED 3A; ISCED 2B ist stärker beruflich orientiert, führt zu ISCED 3B; ISCED $2 \mathrm{C}$ bereitet auf den Eintritt in den Arbeitsmarkt vor.

\section{ISCED 3}

Unterkategorien: ISCED $3 A$ bereitet Schüler auf ein Studium auf Universitätsniveau (ISCED 5A) vor; ISCED 3B bereitet Schüler auf den Besuch beruflich orientierter Studiengänge im Tertiärbereich B (ISCED 5B) vor; ISCED 3 C bereitet Schüler auf den Eintritt in den Arbeitsmarkt oder den Besuch des postsekundaren, nicht tertiären Bildungsbereichs (ISCED 4) vor.

\section{ISCED 4}

Unterkategorien: ISCED 4A bereitet Schüler auf den möglichen Besuch des Tertiärbereichs vor, sowohl auf Universitätsniveau als auch mehr be ruflich orientierte Studiengänge; ISCED $4 B$ bereitet Schüler normalerweise auf den Eintritt in den Arbeitsmarkt vor.

ISCED 5

Unterkategorien: ISCED 5A und 5B, s.u.

ISCED 5A

ISCED 5B

ISCED 6 
Bildung aufeinen Blick nutzt den StatLink-Service der OECD. Unter jeder Abbildung und jeder Tabelle von Bildung aufeinen Blick 2014 findet sich eine URL, die zu einer Excel-Arbeitsmappe mit den entsprechenden zugrunde liegenden Daten führt. Diese URL sind dauerhaft eingerichtet und werden langfristig bestehen bleiben. Außerdem können Benutzer der E-Book-Ausgabe von Bildung auf einen Blick direkt auf diese Links klicken. Die entsprechende Arbeitsmappe öffnet sich dann in einem separaten Fenster.

\section{Layout der Tabellen}

In allen Tabellen werden die Zahlen in Klammern unter dem Spaltenkopf nur als Referenz benutzt. Sofern eine fortlaufende Nummer nicht aufgeführt ist, ist die entsprechende Spalte im Internet verfügbar.

\section{Ländercodes}

Diese Codes werden in einigen Abbildungen verwendet. Im Text der Indikatoren werden die Ländernamen bzw. Bezeichnungen der territorialen Einheiten verwendet. Es ist $\mathrm{zu}$ beachten, dass im Text die flämische Gemeinschaft von Belgien als „Belgien (fläm.)“ oder als „Flandern (Belgien)“ bezeichnet wird und die französische als „Belgien (frz.)“.

\begin{tabular}{|c|c|c|c|}
\hline ARG & Argentinien & ISL & Island \\
\hline AUS & Australien & ISR & Israel \\
\hline AUT & Österreich & ITA & Italien \\
\hline BEL & Belgien & JPN & Japan \\
\hline BFL & Belgien (fläm.) & KOR & Korea \\
\hline BFR & Belgien (frz.) & LUX & Luxemburg \\
\hline BRA & Brasilien & LVA & Lettland \\
\hline CAN & Kanada & NZL & Neuseeland \\
\hline CHE & Schweiz & MEX & Mexiko \\
\hline CHL & Chile & NLD & Niederlande \\
\hline $\mathrm{CHN}$ & China & NOR & Norwegen \\
\hline $\mathrm{COL}$ & Kolumbien & POL & Polen \\
\hline CZE & Tschechien & PRT & Portugal \\
\hline DEU & Deutschland & RUS & Russische \\
\hline DNK & Dänemark & & Föderation \\
\hline ENG & England & SAU & Saudi-Arabien \\
\hline ESP & Spanien & SCO & Schottland \\
\hline EST & Estland & SVK & Slowakei \\
\hline FIN & Finnland & SVN & Slowenien \\
\hline FRA & Frankreich & SWE & Schweden \\
\hline GRC & Griechenland & TUR & Türkei \\
\hline HUN & Ungarn & UKM & Vereinigtes \\
\hline IDN & Indonesien & & Königreich \\
\hline IND & Indien & USA & Vereinigte Staaten \\
\hline IRL & Irland & $\mathrm{ZAF}$ & Südafrika \\
\hline
\end{tabular}




\section{Erhebung zu den grundlegenden Kompetenzen Erwachsener}

\section{Anlage der Studie und angewandte Methodik}

Bei der Erhebung zu den grundlegenden Kompetenzen Erwachsener im Rahmen des OECD Programme for the International Assessment of Adult Competencies (PIAAC) wurden die Lesekompetenz, die alltagsmathematische Kompetenz und die technologiebasierte Problemlösekompetenz von I6- bis 65-jährigen Erwachsenen untersucht. Dies sind Schlüsselkompetenzen zur Informationsverarbeitung, die in vielen gesellschaftlichen Kontexten und Arbeitssituationen für Erwachsene von Bedeutung sind und die notwendig sind, um sich vollständig zu integrieren und am Arbeitsmarkt, an Bildung und Ausbildung sowie am sozialen und zivilgesellschaftlichen Leben teilzuhaben.

Ferner wurden Informationen zum Hintergrund der Befragten, ihrem Bildungsstand und ihren Erfahrungen auf dem Arbeitsmarkt sowie weiteren Aspekten, wie ihrem Gesundheitszustand, erhoben. Erhoben wurde darüber hinaus eine Reihe von Daten über die Aktivitäten der Befragten im Bereich der Lese- und alltagsmathematischen Kompetenz, über die Nutzung von Informations- und Kommunikationstechnologien am Arbeitsplatz und im Alltag sowie zu verschiedenen allgemeinen Kompetenzen, die dem Einzelnen im Rahmen seiner beruflichen Tätigkeit abverlangt werden, z. B. die Zusammenarbeit mit anderen und die Einteilung der eigenen Zeit. Die Erhebungsteilnehmer wurden außerdem gefragt, ob ihre Kompetenzen und Qualifikationen ihren beruflichen Anforderungen entsprechen und ob sie über wichtige Aspekte ihrer Arbeit autonom entscheiden können.

Die Erhebung zu den grundlegenden Kompetenzen Erwachsener war hauptsächlich als computergestützte Erhebung angelegt. Bei den meisten Befragten wurde die Erhebung auch in dieser Form durchgeführt, bei Befragten ohne Computererfahrung oder mit sehr geringen Computerkenntnissen erfolgte die Erhebung jedoch papierbasiert. Die Befragung wurde in der Amtssprache bzw. einer der Amtssprachen des betreffenden Teilnehmerlandes durchgeführt, in einigen Ländern auch in einer weitverbreiteten Minderheitensprache.

24 Länder ${ }^{1}$ nahmen an der ersten Erhebungsrunde ${ }^{2}$ teil. Die Datenerhebung erfolgte in den meisten Ländern zwischen August 201 I und März 20I2. Die Erhebung zur Messung der Lese- und alltagsmathematischen Kompetenz wurde in allen teilnehmenden Ländern durchgeführt. In vier Ländern (Frankreich, Italien, Spanien und Zypern ${ }^{3}$ ) wurde keine Erhebung zur Messung der technologiebasierten Problemlösekompetenz durchgeführt.

$\mathrm{Zu}$ beachten ist, dass die Bevölkerung des Stadtgebiets Moskau in der Stichprobe für die Russische Föderation nicht berücksichtigt wurde. Die veröffentlichten Daten repräsentieren daher nicht die gesamte Wohnbevölkerung im Alter von I6 bis 65 Jahren 
in Russland, sondern nur die Wohnbevölkerung Russlands ohne die im Stadtgebiet Moskau lebende Bevölkerung. Weitere Informationen zu den Daten aus der Russischen Föderation sowie anderer Länder finden sich im Technical Report of the Survey of Adult Skills (OECD, 2013, i. E.).

Weitere Informationen zur Anlage der Erhebung und der angewandten Methodik finden sich in:

OECD (2013), OECD Skills Outlook 2013: First Results from the Survey of Adult Skills, OECD Publishing, Paris, http:||dx.doi.org/10.1787/9789264204256-en.

OECD (2013), The Survey of Adult Skills: Reader's Companion, OECD Publishing, Paris, http://dx.doi.org/10.1787/9789264204027-en.

Bei der Erhebung zu den grundlegenden Kompetenzen Erwachsener wurden die folgenden Definitionen für Lese-, alltagsmathematische und technologiebasierte Problemlösekompetenz zugrunde gelegt:

\section{Lesekompetenz}

Lesekompetenz wird definiert als die Fähigkeit, geschriebene Texte zu verstehen, zu bewerten, zu nutzen und sich mit diesen nachhaltig zu beschäftigen, um sich am Leben in der Gesellschaft zu beteiligen, die eigenen Ziele zu erreichen, sein Wissen weiterzuentwickeln und das eigene Potenzial zu entfalten. Sie umfasst weder das Verstehen gesprochener Sprache noch ihre Produktion oder die Textproduktion (Schreiben). Die Lesekompetenz wird als Fähigkeit begriffen, Inhalte aus dem Gelesenen zu erschließen sowie Texte zu bewerten und zu nutzen, um verschiedene mögliche Ziele in unterschiedlichen Kontexten zu erreichen. Damit geht sie weit über die Fähigkeit, Texte zu erfassen oder zu verstehen, hinaus und umfasst die Fähigkeit, auf Texte - dem jeweiligen Kontext entsprechend - angemessen zu reagieren.

\section{Alltagsmathematische Kompetenz}

Alltagsmathematische Kompetenz wird definiert als die Fähigkeit, sich mathematische Informationen und Ideen zugänglich zu machen, diese anzuwenden, zu interpretieren und zu kommunizieren, um so mit mathematischen Anforderungen in unterschiedlichen Alltagssituationen Erwachsener umzugehen. Als alltagsmathematisch kompetent gelten Erwachsene, die angemessen auf unterschiedlich dargestellte mathematische Inhalte, Informationen und Ideen reagieren, um konkrete, reale Situationen zu bewältigen und Probleme zu lösen. Obwohl die Lösung alltagsmathematischer Aufgaben teilweise von der Fähigkeit, Texte zu lesen und zu verstehen, abhängt, umfasst die alltagsmathematische Kompetenz mehr als die Anwendung arithmetischer Fähigkeiten auf in Text eingebettete Informationen.

\section{Technologiebasiertes Problemlösen}

Technologiebasiertes Problemlösen wird definiert als die Verwendung von digitalen Technologien, Kommunikationswerkzeugen und Netzwerken, mit dem Ziel, Informationen zu beschaffen und zu bewerten, mit anderen zu kommunizieren sowie alltagsbezogene Aufgaben zu bewältigen. Der Schwerpunkt liegt auf der Fähigkeit, lösungsbezogene Ziele zu formulieren, Pläne zur Zielerreichung zu entwerfen sowie Informationen mithilfe von Computern und Computernetzwerken zu beschaffen und zu bewerten, um in den privaten Alltag, den beruflichen Bereich und auch den gesellschaftlichen 
Kontext eingebettete konkrete Probleme zu lösen (OECD Skills Outlook 2013: First Results from the Survey of Adult Skills, http://dx.doi.org/10.1787/9789264204256-en).

Das technologiebasierte Problemlösen ist die Schnittstelle zwischen den gelegentlich als „grundlegende Computerkenntnisse“ bezeichneten Fähigkeiten (d.h. die Fähigkeit, Werkzeuge und Anwendungen im Bereich Informations- und Kommunikationstechnologien zu nutzen) und den für das Problemlösen benötigten kognitiven Fähigkeiten. Ziel war jedoch nicht, die Kompetenz bei der Nutzung von IKT-Werkzeugen und -Anwendungen isoliert zu testen, sondern die Fähigkeit Erwachsener zu messen, diese Werkzeuge zielgerichtet für die Beschaffung, Verarbeitung, Auswertung und Analyse von Informationen einzusetzen.

\section{Präsentation der Ergebnisse}

In jeder der drei untersuchten Domänen ist unter Kompetenz ein Fähigkeitskontinuum zu verstehen, Aufgaben der Informationsverarbeitung mit steigendem Schwierigkeitsgrad zu meistern. Die Ergebnisse sind auf einer 500-Punkte-Skala abgebildet.

Um die Interpretation der Ergebnisse zu erleichtern, wurden die Skalen in „Kompetenzstufen“ eingeteilt, die jeweils einen bestimmten Bereich an erzielten Punkten umfassen. Für die Lesekompetenz und die alltagsmathematische Kompetenz wurden 6 Kompetenzstufen definiert (Stufe I bis 5 plus unterhalb Stufe I) und für die technologiebasierte Problemlösekompetenz 4 Stufen (Stufe I bis 3 plus unterhalb Stufe I). Jede Kompetenzstufe wird anhand der Charakteristika der Aufgabentypen beschrieben, die von Erwachsenen erfolgreich gelöst werden können, deren erzielte Punktzahl innerhalb des für eine Kompetenzstufe definierten Bereichs liegt. Die für die einzelnen Skalenbereiche jeder Lesekompetenzstufe verwendeten Aufgabentypen sind nachstehend beschrieben.

\section{Kompetenzstufe 5 (mindestens 376 Punkte)}

Stufe 5 ist die höchste Stufe auf der Kompetenzskala. Erwachsene, die diese Stufe erreichen, können Aufgaben lösen, die es erfordern, Informationen aus mehreren thematisch dichten Texten mit hoher Informationsdichte zu suchen und zu kombinieren, Synthesen ähnlicher und gegensätzlicher Ideen oder Ansichten zu erstellen oder evidenzbasierte Argumente zu bewerten. Sie sind in der Lage, logische und konzeptuelle Modelle heranzuziehen und zu bewerten sowie die Glaubwürdigkeit von Quellen einzuschätzen und Schlüsselinformationen auszuwählen. Sie erfassen subtile rhetorische Hinweise und können komplexe Schlussfolgerungen ziehen oder spezielles Hintergrundwissen einsetzen.

\section{Kompetenzstufe 4 ( 326 bis weniger als 376 Punkte)}

Erwachsene auf Kompetenzstufe 4 können mehrstufige Operationen durchführen, um Informationen aus komplexen oder langen kontinuierlichen, nicht kontinuierlichen, gemischten oder multiplen Texten mit Informationen, die Beleg- oder Behauptungscharakter haben, zu kombinieren, zu interpretieren oder zusammenzufassen.

\section{Kompetenzstufe 3 (276 bis weniger als 326 Punkte)}

Erwachsene auf Kompetenzstufe 3 können lange Texte oder Texte mit hoher Informationsdichte, einschließlich kontinuierlicher, nicht kontinuierlicher, gemischter oder 
multipler, mehrseitiger Texte verstehen und angemessen auf diese reagieren. Sie erfassen Textstrukturen und rhetorische Mittel und können eine oder mehrere Informationen identifizieren, interpretieren oder bewerten und entsprechende Schlussfolgerungen ziehen. Außerdem sind sie in der Lage, mehrstufige Operationen durchzuführen und aus konkurrierenden Informationen relevante Daten auszuwählen, um Antworten zu identifizieren und zu formulieren.

\section{Kompetenzstufe 2 (226 bis weniger als 276 Punkte)}

Auf Stufe 2 können Erwachsene zwei oder mehr Informationen nach Kriterien kombinieren, vergleichen, gegenüberstellen oder erörtern und einfache Schlussfolgerungen ziehen. Sie können in digitalen Texten navigieren, um Informationen an verschiedenen Stellen eines Dokuments zu identifizieren und darauf zuzugreifen.

\section{Kompetenzstufe I ( 176 bis weniger als 226 Punkte)}

Auf Stufe I können Erwachsene verhältnismäßig kurze digitale oder gedruckte kontinuierliche, nicht kontinuierliche oder gemischte Texte lesen, um eine einzige, spezifische Information zu lokalisieren, die mit der in der Fragestellung oder Anweisung enthaltenen Information identisch oder synonym ist. Diese Texte enthalten nur wenige konkurrierende Informationen. Erwachsene auf dieser Stufe können einfache Formulare ausfüllen, grundlegendes Vokabular verstehen, die Bedeutung von Sätzen bestimmen und kontinuierliche Texte einigermaßen flüssig lesen.

\section{Unterhalb Stufe I (maximal 175 Punkte)}

Personen auf dieser Stufe können kurze Texte zu vertrauten Themen lesen und eine einzige, spezifische Information lokalisieren, die mit der in der Fragestellung oder Anweisung enthaltenen Information identisch oder synonym. Es wird von ihnen nicht verlangt, die Struktur von Sätzen oder Abschnitten zu verstehen, und es wird nur grundlegendes Vokabular vorausgesetzt. In Aufgaben unterhalb Stufe I kommen keine für digitale Texte spezifischen Merkmale vor.

Weitere Informationen zur Erhebung zu den grundlegenden Kompetenzen Erwachsener (PIAAC) s. http://skills.oecd.org und http:/|www.oecd.org/site/piaac. 


\section{Anmerkungen:}

I. Australien, Belgien (Flandern), Dänemark, Deutschland, Estland, Finnland, Frankreich, Irland, Italien, Japan, Kanada, Korea, die Niederlande, Norwegen, Österreich, Polen, die Russische Föderation, Schweden, die Slowakei, Spanien, Tschechien, das Vereinigte Königreich (England und Nordirland), die Vereinigten Staaten und Zypern.

2. 2014 werden neun weitere Länder Daten erheben.

3. Folgende Information der Türkei und der in der OECD vertretenen EU-Mitgliedstaaten der OECD sowie der Europäischen Union zum Status Zyperns ist zu beachten:

\section{Anmerkung der Türkei}

Die Informationen in dieser Publikation unter der Überschrift „Zypern“ beziehen sich auf den südlichen Teil der Insel. Es existiert keine den türkischen und den griechischen Bevölkerungsteil der Insel gemeinsam vertretende Instanz. Die Türkei erkennt die Türkische Republik Nordzypern (TRNZ) an. Bis im Rahmen der Vereinten Nationen eine dauerhafte und gerechte Lösung gefunden ist, wird sich die Türkei ihre Stellungnahme zur „Zypernfrage“ vorbehalten.

Anmerkung aller in der OECD vertretenen EU-Mitgliedstaaten und der Europäischen Union

Die Republik Zypern wird von allen Mitgliedern der Vereinten Nationen mit Ausnahme der Türkei anerkannt. Die Informationen in diesem Bericht beziehen sich auf das Gebiet, das sich de facto unter der Kontrolle der Regierung der Republik Zypern befindet. 



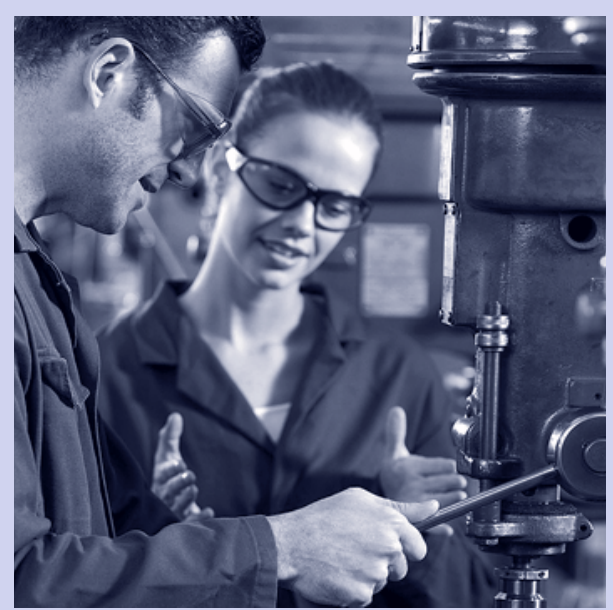

\section{Bildungsergebnisse und Bildungserträge}

Indikator AI

Über welche Bildungsabschlüsse verfügen

Erwachsene?

StatLink: http:/|dx.doi.org/10.1787/888933114761

Indikator $\mathrm{A} 2$

Wie viele Schüler werden den Sekundarbereich II erfolgreich abschließen?

StatLink: http:||dx.doi.org/10.1787/888933115122

Indikator $\mathrm{A}_{3}$

Wie viele Studierende werden ein Studium im Tertiärbereich abschließen?

StatLink: http://dx.doi.org/10.1787/888933115388

Indikator $\mathrm{A}_{4}$

Inwieweit beeinflusst der Bildungsstand der Eltern die Bildungsbeteiligung im Tertiärbereich? StatLink: http://dx.doi.org/10.1787/888933115521

Indikator $\mathrm{A}_{5}$

Wie beeinflusst der Bildungsstand die Erwerbsbeteiligung?

StatLink: http://dx.doi.org/10.1787/888933115711
Indikator A6

Welche Einkommenszuschläge lassen sich durch Bildung erzielen?

StatLink: http:||dx.doi.org/10.1787/888933116053

Indikator A7

Welche Anreize bestehen für Investitionen in Bildung?

StatLink: http://dx.doi.org/10.1787/888933116281

Indikator $\mathrm{A} 8$

Was sind die gesamtgesellschaftlichen Auswirkungen von Bildung?

StatLink: http://dx.doi.org/10.1787/888933116547

Indikator A9

Wie hängen Schülerleistungen und Chancengerechtigkeit zusammen?

StatLink: http://dx.doi.org/10.1787/888933116737 



\section{Über welche Bildungsabschlüsse verfügen Erwachsene?}

Über alle Länder hinweg verfügen rund 75 Prozent der 25- bis 64-Jährigen mindestens über einen Abschluss des Sekundarbereichs II, bei den 25- bis 34-Jährigen sind es 80 Prozent.

Im Durchschnitt haben 25- bis 34-jährige Frauen höhere Abschlussquoten sowohl im Sekundarbereich II als auch im Tertiärbereich als gleichaltrige Männer.

Über alle an der Erhebung zu den grundlegenden Kompetenzen Erwachsener (PIAAC) beteiligten Länder hinweg finden sich unter den Absolventen des Tertiärbereichs die meisten Erwachsenen mit den höchsten Lesekompetenzstufen.

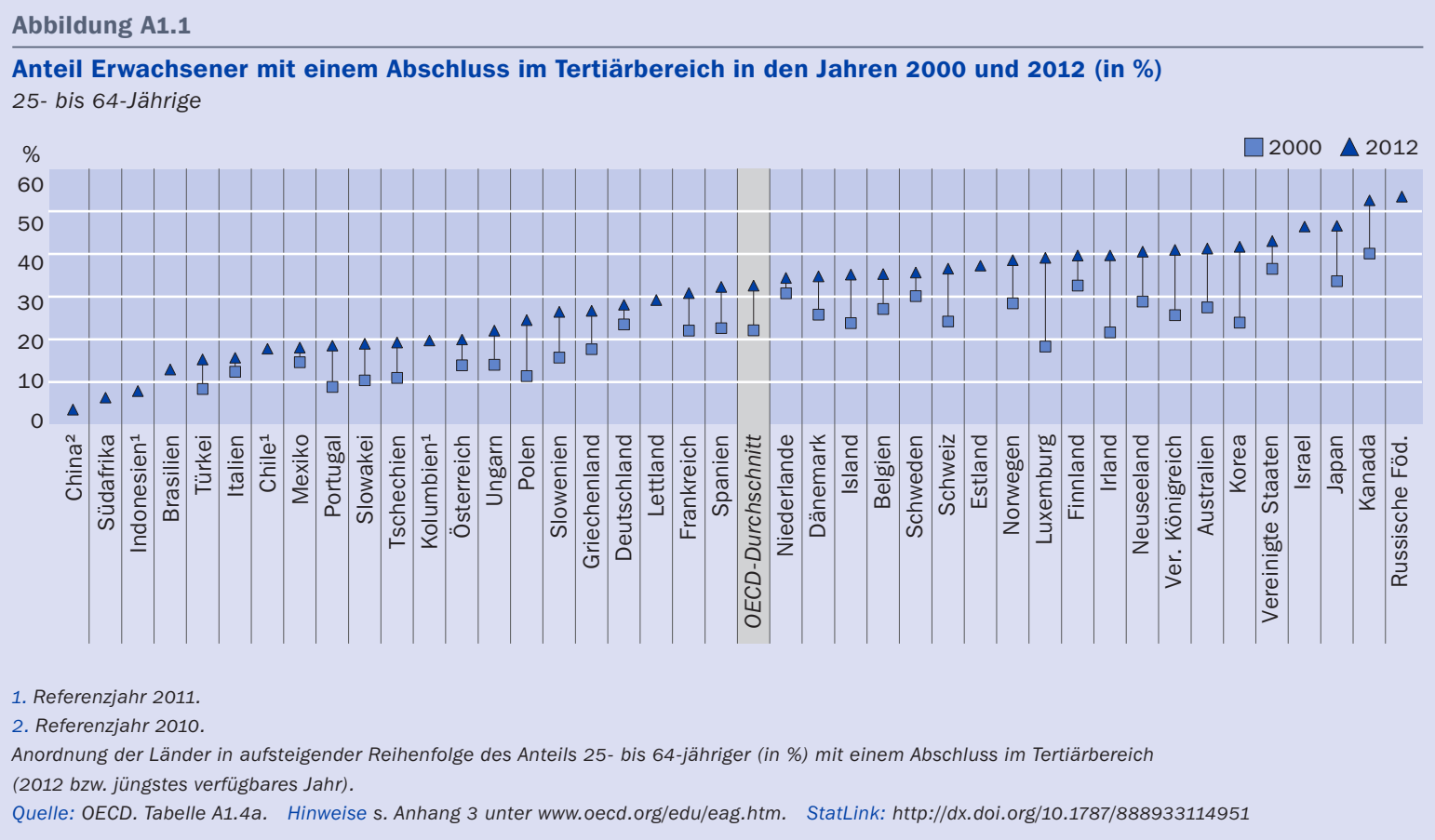

\section{Kontext}

Der Bildungsstand einer Bevölkerung bezeichnet den prozentualen Anteil einer Bevölkerung mit einem bestimmten Bildungsabschluss. Ein höherer Bildungsstand steht im Zusammenhang mit einer besseren Gesundheit, einem stärkeren sozialen Engagement und einer höheren Beschäftigungsquote - er gilt als Tor zu besseren Beschäftigungsmöglichkeiten und höheren relativen Einkommen. Grundlegende Kompetenzen, wie Lese- und alltagsmathematische Kompetenz, werden ebenfalls stark mit besseren Ergebnissen am Arbeitsmarkt und mit einem besseren und gesünderen Leben assoziiert. Für den Einzelnen bestehen starke Anreize zu einer weiteren Bildungsteilnahme, und die Regierungen sind daran interessiert, durch Aus- und Weiterbildung die Kompetenzen der Bevölkerung zu erweitern. 
Der Bildungsstand wird häufig als indirekte Kennzahl für das Humankapital und das Niveau der Kompetenzen des Einzelnen verwendet, mit anderen Worten für die in der Bevölkerung und Erwerbsbevölkerung zur Verfügung stehenden Kenntnisse und Fähigkeiten. Qualifikationen bestätigen und informieren über die von Absolventen im formalen Bildungssystem erworbene Art von Wissen und Kompetenzen.

Die Bedeutung formaler Bildung und Weiterbildung für die Entwicklung von Kompetenzen, wie Lese- und alltagsmathematische Kompetenz, ist heute mehr denn je ersichtlich. Die Ergebnisse der Erhebung zu den grundlegenden Kompetenzen Erwachsener (OECD, 2013a) im Rahmen des Programme for the International Assessment of Adult Competencies der OECD (PIAAC) ergänzt die jährlichen Daten zum Bildungsstand durch neue Daten zur Verteilung der Lese-, alltagsmathematischen und technologiebasierten Problemlösekompetenz in der Erwachsenenbevölkerung.

In den vergangenen Jahrzehnten war in fast allen OECD-Ländern eine deutliche Steigerung des Bildungsstands der Bevölkerung zu beobachten. Die Zahl der Abschlüsse im Tertiärbereich hat deutlich zugenommen, und in den meisten OECD-Ländern verfügt inzwischen eine große Mehrheit der Erwachsenen über einen Abschluss im Sekundarbereich II.

Dieser Indikator bietet Informationen zum Bildungsstand und zum ersten Mal eine Momentaufnahme der Kompetenzen Erwachsener nach Bildungsabschluss und -ausrichtung, Alter und Geschlecht.

\section{Weitere wichtige Ergebnisse}

In einigen OECD-Ländern ist der Anteil der Absolventen des Tertiärbereichs unter den jüngeren Erwachsenen höher als unter den älteren Erwachsenen - im Durchschnitt um 20 Prozentpunkte.

In den meisten OECD- und Partnerländern verfügen mehr als 40 Prozent der 25- bis 34-Jährigen über einen Abschluss im Tertiärbereich, jedoch wird dieser Anteil bei den 55- bis 64-Jährigen nur in Israel, Kanada, der Russischen Föderation und den Vereinigten Staaten erreicht.

In Australien, Finnland, Japan, den Niederlanden und Schweden weisen mehr als 30 Prozent der Erwachsenen mit einem Abschluss im Tertiärbereich eine Lesekompetenz der Stufe 4 oder 5 - den höchsten Stufen - in der Erhebung zu den grundlegenden Kompetenzen Erwachsener auf.

\section{Entwicklungstendenzen}

Zwischen 2000 und 2012 ist der Anteil der Personen ohne einen Abschluss im Sekundarbereich II bzw. postsekundaren, nicht tertiären Bereich jährlich um etwa 3 Prozent gesunken. Gleichzeitig hat die Zahl der Abschlüsse im Tertiärbereich in demselben Zeitraum mit einer Steigerung von jährlich mehr als 3 Prozent weiter zugenommen. 2012 verfügte zum ersten Mal etwa jeder dritte Erwachsene in den OECD-Ländern über einen Abschluss im Tertiärbereich. 
Im Laufe der Jahre haben sich die geschlechtsspezifischen Unterschiede im Bildungsstand umgekehrt. Im Jahr 2000 war der Anteil der erwachsenen Männer mit einem Abschluss im Tertiärbereich höher als der der erwachsenen Frauen. 2012 hatte sich die Situation umgekehrt: 34 Prozent der Frauen verfügten über einen Abschluss im Tertiärbereich im Vergleich zu 3I Prozent der Männer.

\section{Hinweise}

In dieser Publikation wird in unterschiedlichen Indikatoren der Bildungsstand von Einzelnen aufgezeigt. In Indikator AI ist der Bildungsstand, d. h. der prozentuale Anteil einer Bevölkerung, der einen bestimmten Bildungsbereich erfolgreich abgeschlossen hat, Gegenstand der Untersuchung sowie die Beziehung zwischen dem Bildungsstand und dem Erwerb von grundlegenden Kompetenzen. Die Abschlussquoten in Indikator A2 und A3 geben den voraussichtlichen prozentualen Anteil jüngerer Erwachsener an, die wahrscheinlich im Laufe ihres Lebens einen bestimmten Bildungsabschluss erwerben werden. Die Erfolgsquoten im Sekundarbereich II in Indikator A2 beziehen sich auf den Anteil der Schüler, die in den Sekundarbereich II eintreten und ihn innerhalb eines bestimmten Zeitraums erfolgreich abschließen.

\section{Analyse und Interpretationen}

\section{In den OECD-Ländern erreichte Bildungsabschlüsse}

Anteil der Bevölkerung mit einem Abschluss im Sekundarbereich II und Bedeutung der beruflichen Ausbildung

In den meisten OECD-Ländern ist ein Abschluss im Sekundarbereich II der am häufigsten erreichte Bildungsstand: Mehr Erwachsene (25- bis 64-Jährige) verfügen über einen Abschluss im Sekundarbereich II/postsekundaren, nicht tertiären Bereich (d.h. einen Abschluss auf den ISCED-Stufen 3 und 4; s. den Abschnitt Definitionen am Ende dieses Indikators) als höchsten Abschluss als über einen Abschluss irgendeines anderen Bildungsbereichs. Im Durchschnitt verfügen etwa 45 Prozent der Erwachsenen in den OECD-Ländern über einen Abschluss im Sekundarbereich II als höchsten Abschluss. In Österreich, Lettland, Polen, der Slowakei, Tschechien und Ungarn haben mehr als 6o Prozent der Erwachsenen diesen Bildungsstand erreicht (Tab. AI.4a).

Die Steigerung bei den Abschlussquoten zeigt, dass die Menschen länger in Ausbildung verbleiben und dass die Politik bei der Bekämpfung von Problemen wie Abbruch der Ausbildung und fehlender Chancengerechtigkeit in der Bildung Erfolge erzielt hat. Tatsächlich zeigen die Ergebnisse der letzten Erhebungswelle der Internationalen Schulleistungsstudie PISA der OECD, dass die Chancengerechtigkeit in der Bildung in den meisten Ländern, die seit 2003 Leistungsverbesserungen aufweisen, entweder aufrechterhalten oder verbessert wurde, sodass für alle ein grundlegender Mindestbildungsstandard verfügbar ist (OECD, 2013b).

Abbildung Ar.2 zeigt den Anteil der Bevölkerung mit einem Abschluss im Sekundarbereich II bzw. postsekundaren, nicht tertiären Bereich als höchstem Bildungsstand und ob 
Anteil der Bevölkerung, deren höchster Bildungsabschluss ein Abschluss im Sekundarbereich II bzw. im postsekundaren, nicht tertiären Bereich ist (in \%), nach Ausrichtung des Bildungsgangs (2012) 25- bis 64-Jährige

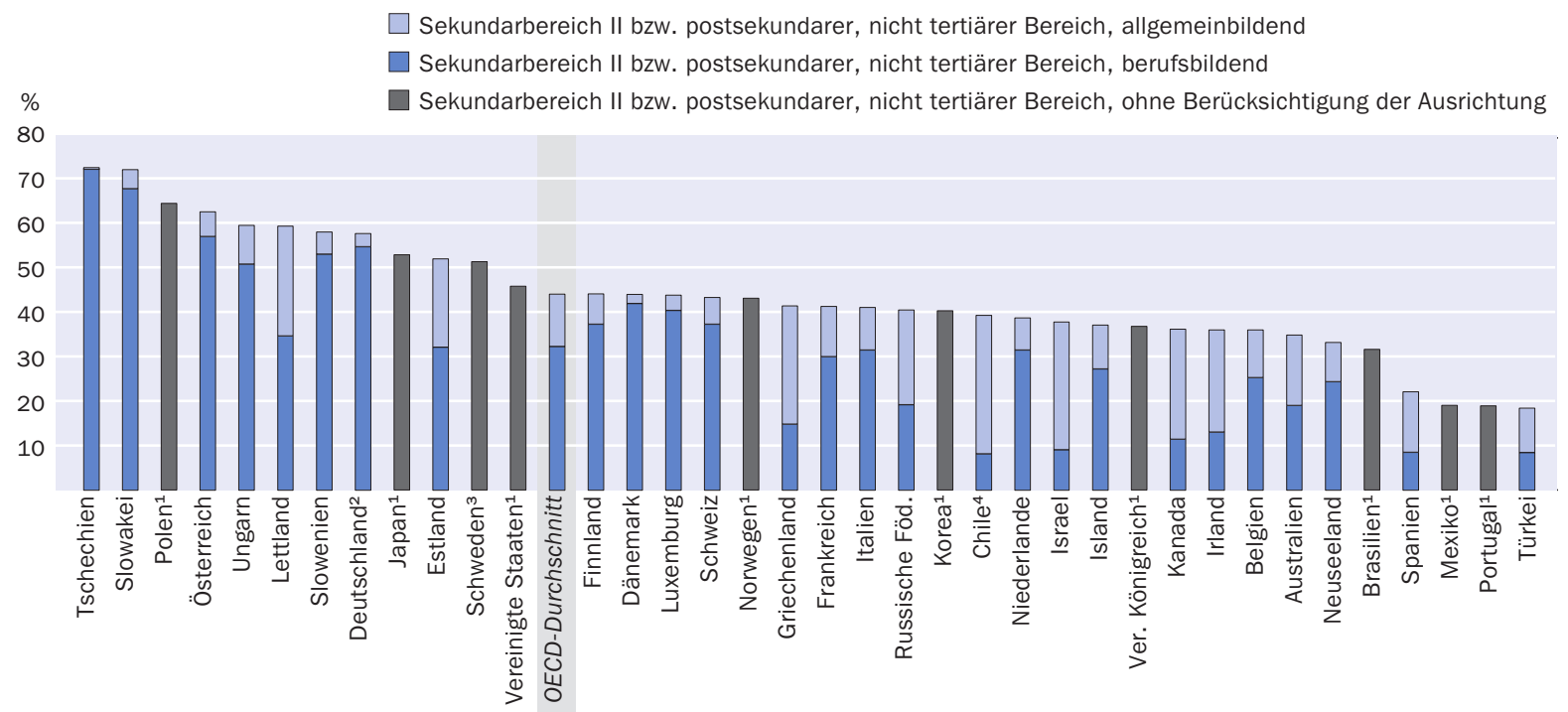

1. Länder, für die keine Daten zur Ausrichtung des Bildungsgangs vorliegen. 2. In Deutschland entspricht ein Abschluss auf ISCED-Stufe $4 A$ einem Abschluss sowohl eines allgemeinbildenden als auch eines berufsbildenden Bildungsgangs. Absolventen mit einem derartigen Abschluss wurden in dieser Abbildung den berufsbildenden Bildungsgängen zugeordnet. 3. Die Zahlen für Schweden enthalten etwa 10 Prozent 25- bis 64-Jährige, die einen Abschluss auf ISCED-Stufe 3 oder 4 in Bildungsgängen erworben haben, deren Ausrichtung nicht zugeordnet werden kann. 4. Referenzjahr 2011.

Anordnung der Länder in absteigender Reihenfolge des Anteils 25- bis 64-Jähriger, deren höchster Bildungsabschluss ein Abschluss im Sekundarbereich II bzw. postsekundaren, nicht tertiären Bereich (ISCED 3/4) ist, unabhängig von der Ausrichtung des Bildungsgangs.

Quelle: OECD. Tabelle A1.5a. Hinweise s. Anhang 3 unter www.oecd.org/edu/eag.htm. StatLink: http://dx.doi.org/10.1787/888933114970

diese Qualifikation in einem allgemeinbildenden oder berufsbildenden Bildungsgang erworben wurde. Dies zeigt die unterschiedliche Bedeutung von berufsbildenden Bildungsgängen des Sekundarbereichs II in verschiedenen Ländern. Mindestens jeder zweite Erwachsene in Deutschland, Österreich, der Slowakei, Slowenien, Tschechien und Ungarn verfügt über einen berufsbildenden Abschluss im Sekundarbereich II als höchsten Bildungsabschluss, während dieser Anteil in Chile, Israel, Spanien und der Türkei bei unter Io Prozent liegt. Je nach Ausrichtung des Bildungsgangs bestehen, wie bei den Abschlüssen im Sekundarbereich II insgesamt, große Unterschiede zwischen den einzelnen Ländern (Tab. Ar.5a).

Die Länder mit einem niedrigen Bevölkerungsanteil mit einem Abschluss im Sekundarbereich II als höchstem Abschluss lassen sich in zwei Kategorien einteilen: Entweder verlassen die meisten Schüler die Ausbildung vor Erreichen eines Abschlusses im Sekundarbereich II (d.h., sie verfügen über eine Ausbildung unterhalb des Sekundarbereichs II), oder sie setzen ihre Ausbildung über diesen Bildungsstand hinaus bis zum Erreichen eines höheren Abschlusses fort (d. h., sie haben einen Abschluss im Tertiärbereich erworben). In Australien, Irland, Israel, Kanada, Korea, Neuseeland, Spanien, der Russischen Föderation und dem Vereinigten Königreich ist der Anteil der Bevölkerung mit einem Abschluss im Tertiärbereich als höchstem Bildungsabschluss höher als der Anteil der Bevölkerung mit einem Abschluss im Sekundarbereich II als höchstem Abschluss. In Luxemburg und Portugal sind die beiden Anteile nahezu gleich (Tab. Ar.4a). 
Der geschlechtsspezifische Unterschied beim Bildungsstand hat sich bei den jüngeren Erwachsenen umgekehrt. Im Durchschnitt sind die Abschlussquoten 25-bis 34-jähriger Frauen im Tertiärbereich höher als die gleichaltriger Männer. Im Durchschnitt verfügen rund 84 Prozent der jüngeren Frauen mindestens über einen Abschluss im Sekundarbereich II, während bei den jüngeren Männern dieser Prozentsatz im Durchschnitt bei 8r Prozent liegt (Tab. Ar.2b und Ar.4b im Internet).

\section{Anteil der Bevölkerung mit einem Abschluss im Tertiärbereich}

Abbildung Ar.I zeigt, dass seit 2000 der Anteil der Bevölkerung mit einem Abschluss im Tertiärbereich (einschließlich weiterführender forschungsorientierter Studiengänge, d. h. der ISCED-Stufen 5A, 5B und 6) in den OECD-Ländern um ro Prozentpunkte gestiegen ist. Im Durchschnitt haben 34 Prozent der erwachsenen Frauen und 3I Prozent der erwachsenen Männer einen Abschluss im Tertiärbereich erworben. Diese Zunahme ist hauptsächlich auf die jüngeren Erwachsenen zurückzuführen, bei den Frauen sind die Veränderungen sogar noch größer: In allen OECD-Ländern weisen jüngere Frauen um durchschnittlich mehr als 20 Prozentpunkte höhere Abschlussquoten für den Tertiärbereich auf als ältere Frauen (Tab. Ar.3b im Internet).

Abbildung Ar.3 zeigt, dass in einigen Ländern signifikante Unterschiede zwischen den Generationen bestehen: Sie belaufen sich in Frankreich, Irland, Japan, Luxemburg, Polen und Spanien auf mehr als 20 Prozentpunkte. In Korea besteht bei den Abschlussquoten für den Tertiärbereich zwischen diesen beiden Altersgruppen ein Unterschied von 52 Prozentpunkten. Im Gegensatz hierzu beträgt der Abstand zwischen den beiden Altersgruppen bei

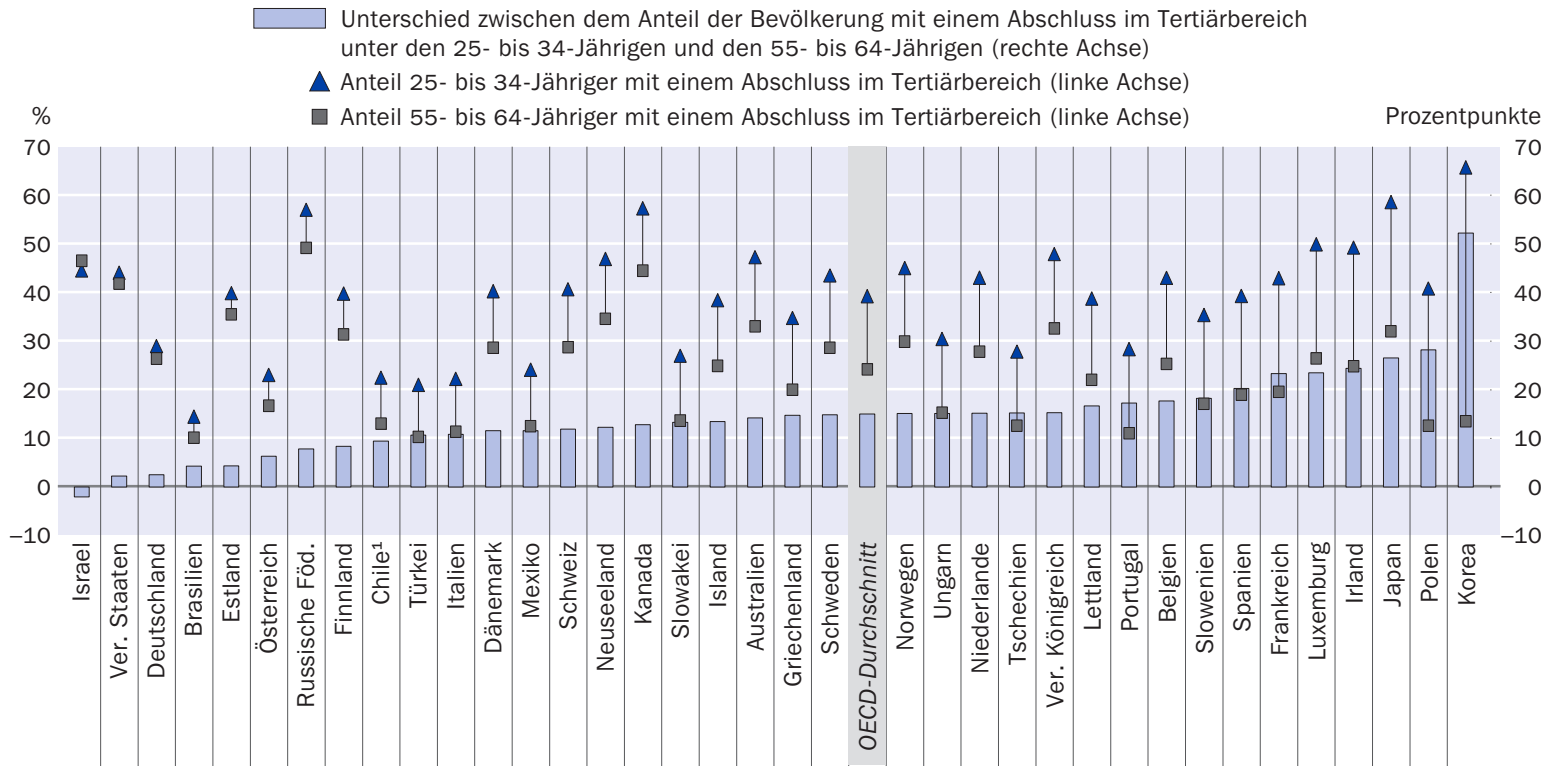




\section{Politische Relevanz subnationaler Vergleiche}

Der wesentliche Zweck von Bildung auf einen Blick besteht darin, eine verlässliche Zusammenstellung von zentralen statistischen Bildungsparametern im internationalen Vergleich zur Verfügung zu stellen. Auch wenn die einzelnen Länder in diesen Vergleichen spezifische Werte erreichen, sollte nicht davon ausgegangen werden, dass die Länder selbst homogen sind. So wie der OECD-Durchschnitt eine Vielzahl unterschiedlicher nationaler Ergebnisse umfasst, beinhalten die Länderdurchschnitte signifikante Unterschiede zwischen den subnationalen Jurisdiktionen.

In den meisten OECD-Ländern werden zumindest einige bildungspolitische Entscheidungen von subnationalen Regierungsbehörden getroffen, während nationale Entscheidungen subnationale Einrichtungen unterschiedlich beeinflussen können. In einigen Ländern können die Struktur des Bildungssystems und die relativ geringe geografische Ausdehnung die politische Relevanz subnationaler Vergleiche einschränken. In Ländern mit föderalen Bildungssystemen fällt den subnationalen Regierungen hauptsächlich die Rolle der Verwaltung von Bildungsgängen zu, selbst in Ländern mit stärker zentralisierten Bildungssystemen können subnationale Bildungsbehörden über spezifische Entscheidungsbefugnisse im Verwaltungsbereich verfügen. Es ist daher nicht überraschend, dass große föderal organisierte Länder wie Deutschland, Kanada und die Vereinigten Staaten, in denen die Bildung im Wesentlichen durch regionale Behörden gesteuert wird, große Unterschiede innerhalb des jeweiligen Landes bei den Bildungsmaßnahmen aufweisen können. Jedoch gibt es auch in vielen anderen Ländern mit zentralisierten Bildungssystemen, wie Frankreich und Italien, wesentliche Unterschiede innerhalb des Landes. Der Anteil 25- bis 34-Jähriger mit einem Abschluss im Tertiärbereich reichte $201 \mathrm{I}$ in den Vereinigten Staaten von niedrigen 29 Prozent im Staat Nevada bis zu einem Höchstwert von 7I Prozent im District of Columbia (für statistische Zwecke von den Vereinigten Staaten als Staat behandelt). In Kanada lag der Anteil der 25- bis 34-Jährigen mit einem Abschluss im Tertiärbereich 2010 zwischen 28 Prozent in Nunavut und 64 Prozent in Ontario. In Deutschland reichte der Anteil der 25- bis 34-Jährigen mit einem Abschluss im Tertiärbereich von 20 Prozent in Sachsen-Anhalt bis zu 38 Prozent in Berlin.

Obwohl Frankreich über ein nationales Bildungssystem verfügt, bestehen dennoch zwischen den einzelnen Regionen wesentliche Unterschiede bei dem Anteil der erreichten Abschlüsse im Tertiärbereich. Der Anteil 25- bis 34-Jähriger mit einem Abschluss im Tertiärbereich reichte von I9 Prozent in Französisch-Guayana als niedrigstem Prozentsatz bis zu 55 Prozent in der Île-de-France. Der Anteil der Bevölkerung mit einem Abschluss im Tertiärbereich lag in Italien 20 I für die 30- bis 34-Jährigen zwischen 15 Prozent in Campania und dem mit 27 Prozent höchsten Anteil in Apulien, basierend auf von Eurostat für die Europäische Union zusammengestellten Daten. Der Anteil der 30- bis 34-Jährigen im Vereinigten Königreich, die über einen Abschluss im Tertiärbereich verfügen, reicht von 32 Prozent in Merseyside bis zu 69 Prozent in Inner London. Zu den Ländern mit großen Unterschieden in subnationalen Regionen bei den Abschlussquoten im Tertiärbereich (d. h. mehr als das Doppelte) bei den 30- bis 34-Jährigen gehören zum Beispiel Griechenland, Portugal, die Slowakei, Spanien, die Türkei und Ungarn. Finnland, Irland, Norwegen, Österreich, 
Polen, Schweden, die Schweiz und Slowenien gehören zu den OECD-Ländern mit geringeren Unterschieden.

Andere Bildungsstatistiken zeigen ebenfalls große subnationale Unterschiede, auch in den Bildungsbereichen unterhalb des Tertiärbereichs. In einigen Ländern variierte 20 II der Anteil I5- bis I9-Jähriger, die eine Bildungseinrichtung im Sekundar- oder Tertiärbereich besuchten, stark zwischen den einzelnen subnationalen Einheiten. Zum Beispiel reichten die Beteiligungsquoten I5- bis I9-Jähriger in subnationalen Gebieten in Italien von 58 Prozent bis zu 87 Prozent, in Spanien von 70 bis 95 Prozent und in Portugal von 7I bis 95 Prozent. In anderen Ländern waren die Unterschiede immer noch signifikant, aber geringer, hierzu zählten Frankreich (69 Prozent bis 88 Prozent), das Vereinigte Königreich (7I Prozent bis 88 Prozent) und die Vereinigten Staaten ( 82 Prozent bis 9I Prozent) . Einige Länder wiesen nur geringe subnationale Unterscheide bei den Beteiligungsquoten I5- bis I9-Jähriger auf, u.a. Norwegen (84 Prozent bis 92 Prozent) und Schweden (87 Prozent bis 88 Prozent).

Auch wenn umfassendere Informationen erforderlich sind, um den geografischen Kontext dieser Daten und ihre lokalen Auswirkungen zu verstehen, zeigt sich anhand dieser Daten, dass auf Länderebene berechnete Durchschnittswerte manchmal wichtige Unterschiede innerhalb der einzelnen Länder verbergen, die für nationale und lokale Politiker von großem Interesse sind. Zusätzlich zu den Verwaltungsgrenzen können auch andere subnationale Abgrenzungen für Länder relevant sein, wie geografische Grenzen oder Unterschiede zwischen Städten und dem ländlichen Raum. Einige Länder mit relativ hohen Gesamtdurchschnittsquoten können lokale Bereiche haben, die deutlich unter den nationalen Durchschnittswerten liegen, einige Länder mit niedrigen Gesamtdurchschnittsquoten hingegen lokale Bereiche mit hohem Leistungsstand. Subnationale Daten können auch dazu beitragen, den Erfolg der Länder bei der Sicherstellung der Chancengerechtigkeit in der Bildung über alle Regionen hinweg aufzuzeigen.

den Abschlussquoten im Tertiärbereich in Deutschland, Israel und den Vereinigten Staaten weniger als 3 Prozentpunkte (Tab. Ar.3a).

Der Anteil 25- bis 34-Jähriger mit einem Abschluss im Tertiärbereich beträgt in den meisten OECD- und Partnerländern mehr als 40 Prozent (bei einem OECD-Durchschnitt von 39 Prozent), wohingegen dies bei den 55- bis 64-Jährigen nur in Israel, Kanada, der Russischen Föderation und den Vereinigten Staaten der Fall ist. Die Daten zeigen außerdem, dass nur I4 Prozent der 25- bis 34-Jährigen in Brasilien über einen Abschluss im Tertiärbereich verfügen und weniger als I4 Prozent der 55- bis 64-Jährigen in Brasilien, Chile, Italien, Mexiko, Polen, Portugal, Tschechien und der Türkei.

Obwohl bei den 55- bis 64-Jährigen die Wahrscheinlichkeit eines Abschlusses im Tertiärbereich bei Männern (25 Prozent) höher ist als bei Frauen (23 Prozent), ist die Wahrscheinlichkeit eines Abschlusses im Tertiärbereich in den meisten OECD-Ländern bei den Frauen - insbesondere jungen Frauen - höher als bei den Männern. Die Abschlussquoten für den Tertiärbereich bei jungen Frauen (25- bis 34-Jährige) sind in Australien, Belgien, Dänemark, Estland, Irland, Israel, Japan, Kanada, Korea, Lettland, Luxemburg, Neusee- 
land, Norwegen, Polen, der Russischen Föderation, Schweden und dem Vereinigten Königreich am höchsten. In diesen Ländern verfügt mindestens jede zweite junge Frau über einen Abschluss im Tertiärbereich (Tab. Ar.3b im Internet).

\section{Bildungsstand und Lese- und alltagsmathematische Kompetenz}

Die Erhebung zu den grundlegenden Kompetenzen Erwachsener diente der Erfassung der Lese- und alltagsmathematischen Kompetenz Erwachsener. Diese Kompetenzen gelten insoweit als grundlegende Kompetenzen, als sie für andere Arten des Lernens von zentraler Bedeutung sind, zum Beispiel lernen Menschen erst Lesen, und anschließend lernen sie, indem sie lesen. Da diese Kompetenzen vor allem durch formale Bildung erworben und entwickelt werden, kann eine Messung der Lese- und alltagsmathematischen Kompetenz für Regierungen und politische Entscheidungsträger ein Indiz für die Wirksamkeit ihrer Bildungssysteme sein.

Obwohl sie eng miteinander zusammenhängen, wird mit der Lese- und alltagsmathematischen Kompetenz einerseits und dem Bildungsstand andererseits Unterschiedliches gemessen. Durch formale Bildung erworbene Qualifikationen spiegeln nicht immer den Grad der Lese- oder alltagsmathematischen Kompetenz einer Person wider - selbst zu dem Zeitpunkt, an dem diese Qualifikationen erworben werden. Darüber hinaus bilden diese Qualifikationen auch andere Kompetenzen ab, die nicht mit der Lese- und alltagsmathematischen Kompetenz dargestellt werden können, wie Fach- oder praktisches Wissen und arbeitsspezifische Kompetenzen.

Abbildung Ar.4 vermittelt Einblicke in diese komplexe Beziehung und zeigt die Verteilung des Mittelwerts für Lesekompetenz in der Erhebung zu den grundlegenden Kompetenzen

Abbildung A1.4

Mittelwert der Lesekompetenz, nach Bildungsstand (2012)

Erhebung zu den grundlegenden Kompetenzen Erwachsener, 25- bis 64-Jährige

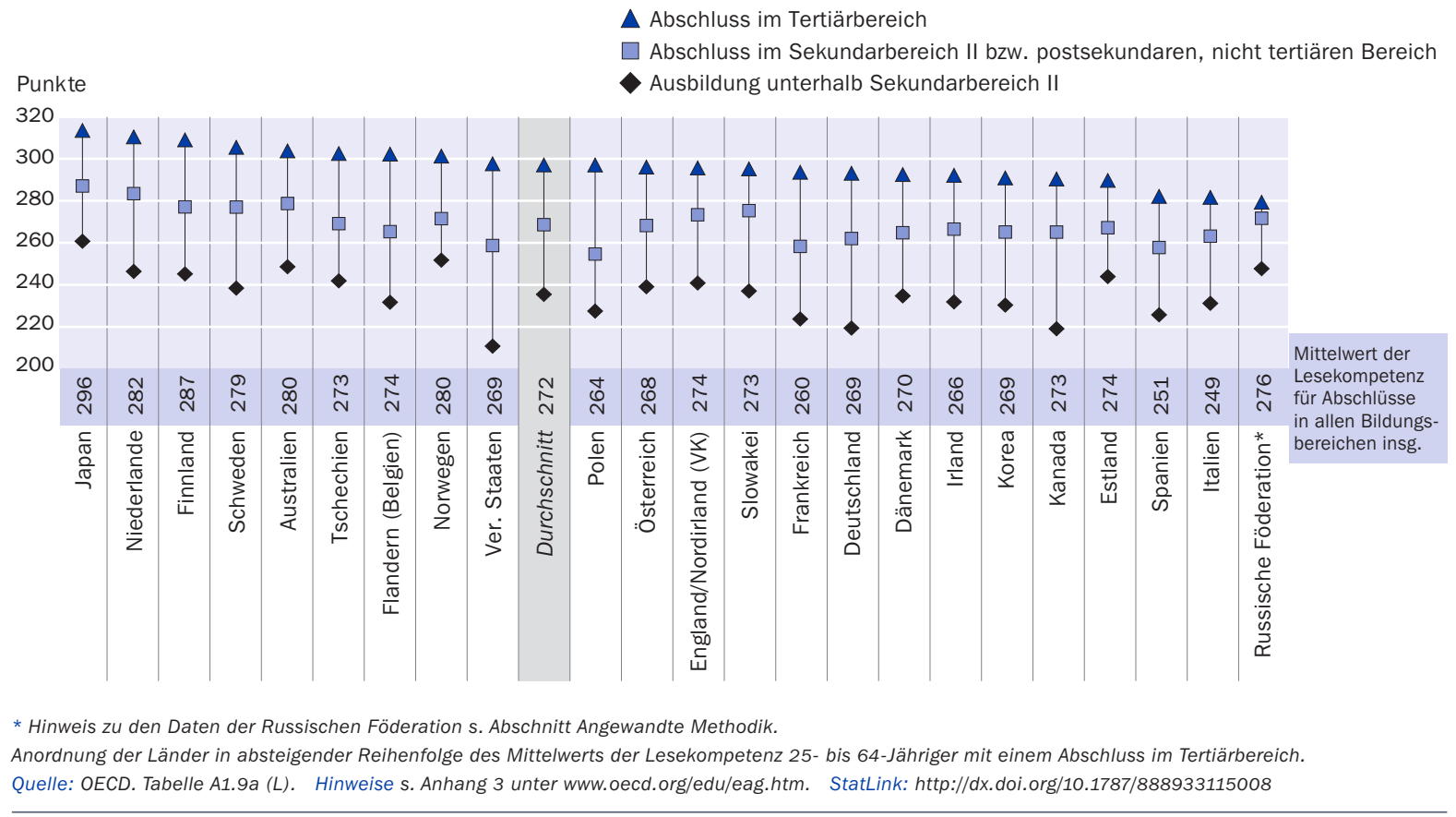




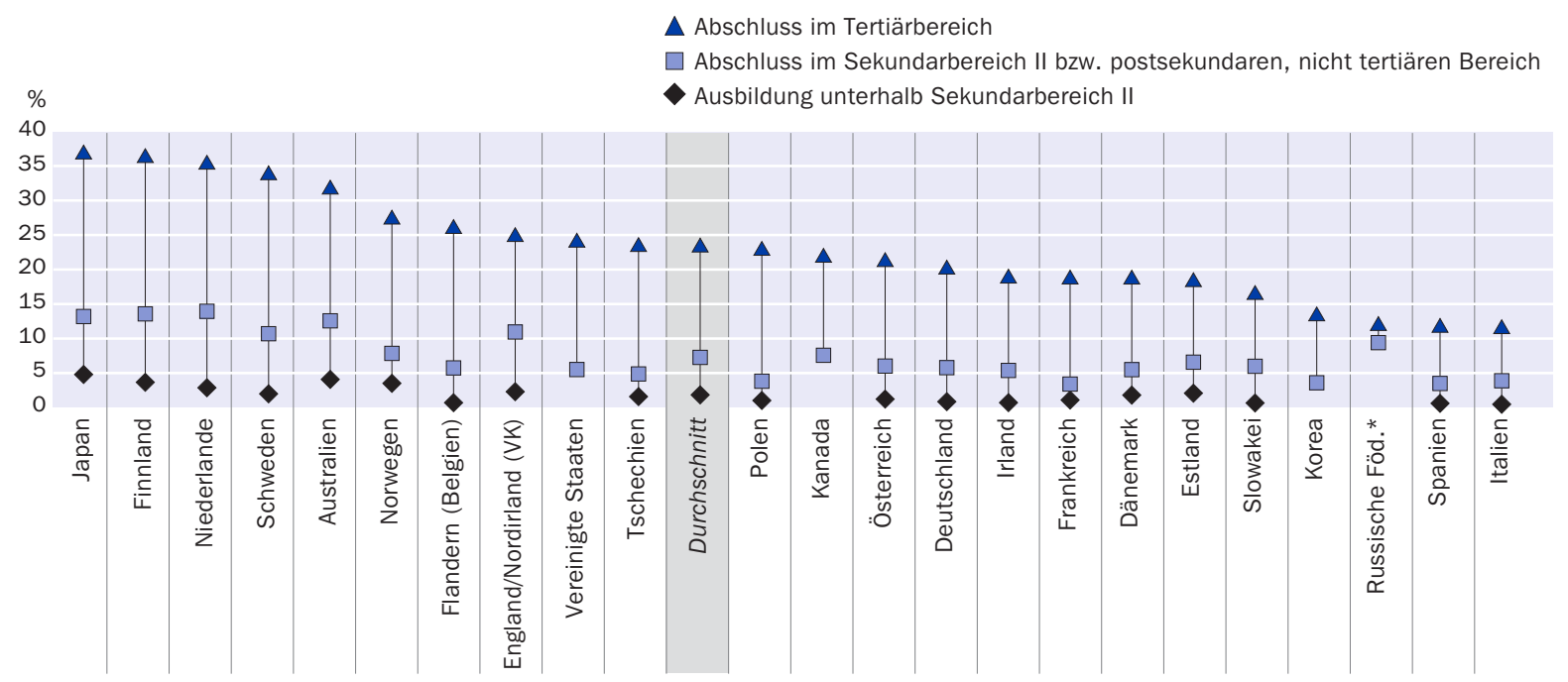

* Hinweis zu den Daten der Russischen Föderation s. Abschnitt Angewandte Methodik.

Anordnung der Länder in absteigender Reihenfolge des Anteils 25- bis 64-Jähriger mit einem Abschluss im Tertiärbereich auf Lesekompetenzstufe 4 oder 5. Quelle: OECD. Tabelle A1.6a (L). Hinweise s. Anhang 3 unter www.oecd.org/edu/eag.htm. StatLink: http://dx.doi.org/10.1787/888933115027

Erwachsener für alle Bildungsbereiche zusammen. Der durchschnittliche Mittelwert der Lesekompetenz liegt bei mehr als 270 Punkten. In allen Ländern ist der Mittelwert bei den Erwachsenen mit einem Abschluss im Tertiärbereich am höchsten und bei Erwachsenen mit einer Ausbildung unterhalb des Sekundarbereichs II am niedrigsten. Erwachsene mit einem Abschluss im Tertiärbereich weisen in allen Ländern, mit Ausnahme der Russischen Föderation, einen Mittelwert von mehr als 28o Punkten auf. Über alle Länder hinweg beträgt der durchschnittliche Punktunterschied zwischen Erwachsenen mit einem Abschluss im Tertiärbereich und Erwachsenen mit einer Ausbildung unterhalb des Sekundarbereichs II etwa 6o Punkte, von etwa 30 Punkten in der Russischen Föderation bis zu mehr als 70 Punkten in, Deutschland, Flandern (Belgien), Kanada und den Vereinigten Staaten (Tab. Ar.ga [L]).

Abbildung Ar.5 zeigt, dass Erwachsene mit einem Abschluss im Tertiärbereich in allen Ländern den größten Anteil der Erwachsenen mit den höchsten Kompetenzstufen in der Erhebung zu den grundlegenden Kompetenzen Erwachsener (d. h. Stufe 4 oder 5) stellen. Australien, Finnland, Japan, die Niederlande und Schweden weisen den höchsten Anteil an Erwachsenen mit Lesekompetenzstufe 4 oder 5 auf: Mehr als 30 Prozent der Bevölkerung mit einem Abschluss im Tertiärbereich erreichen eine dieser Stufen. In diesen Ländern ist auch der Unterschied zwischen den Punktzahlen von Erwachsenen mit einem Abschluss im Tertiärbereich und denen mit einer Ausbildung unterhalb des Sekundarbereichs II mit mehr als 25 Prozentpunkten am höchsten. Die Daten zeigen außerdem, dass in allen Ländern Erwachsene mit einem höheren Bildungsstand einen höheren Anteil an den Erwachsenen mit Lesekompetenzstufe 4 oder 5 stellen. Der Unterschied bei den Lesekompetenzstufen ist zwischen Erwachsenen mit einem Abschluss im Tertiärbereich und denjenigen mit einem Abschluss im Sekundarbereich II höher als zwischen Erwachsenen mit einem Abschluss im Sekundarbereich II und denjenigen mit einer Ausbildung unterhalb des Sekundarbereichs II (Tab. Ar.6a [L]). 


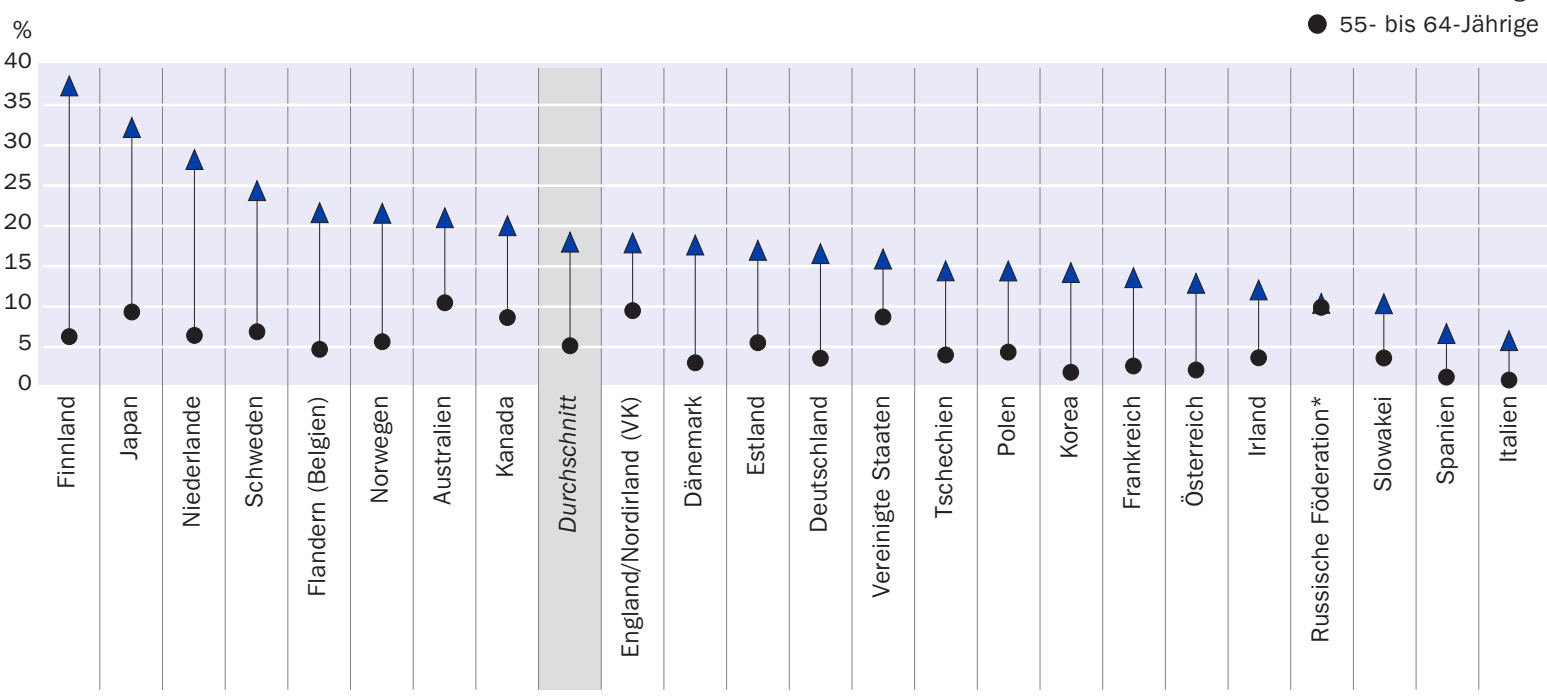

* Hinweis zu den Daten der Russischen Föderation s. Angewandte Methodik.

Anordnung der Länder in absteigender Reihenfolge des Anteils 25- bis 34-Jähriger (in \%) auf Lesekompetenzstufe 4 oder 5.

Quelle: OECD. Tabelle A1.7a (L). Hinweise s. Anhang 3 unter www.oecd.org/edu/eag.htm. StatLink: http://dx.doi.org/10.1787/888933115046

Abbildung Ar.6 zeigt, dass in allen Ländern der Anteil der Erwachsenen auf Lesekompetenzstufe 4 oder 5 in der Erhebung zu den grundlegenden Kompetenzen Erwachsener bei jungen Erwachsenen im Durchschnitt etwa Io Prozent höher ist als bei älteren Erwachsenen. In Finnland, Japan und den Niederlanden beträgt dieser Unterschied mehr als 20 Prozentpunkte. In allen Ländern erreichen mehr als 5 Prozent der jüngeren Erwachsenen diese hohen Kompetenzstufen, in Dänemark, Deutschland, Frankreich, Irland, Italien, Korea, Österreich, Polen, der Slowakei, Spanien und Tschechien jedoch nur weniger als 5 Prozent der älteren Erwachsenen.

Kasten A1.2

\section{Die Kompetenzen Erwachsener und ihre Bereitschaft, Informations- und Kommunikationstechnologien (IKT) zum Problemlösen einzusetzen}

Während auf der einen Seite im Kontext sich ständig weiterentwickelnder Arbeitsmärkte neue und bessere Kompetenzen benötigt werden, werden einige Kompetenzen durch die schnelle Entwicklung neuer Technologien überflüssig. Wie Frank Levy (2010) feststellte, kann die Technik die Art der Arbeit schneller verändern, als Menschen ihre Kompetenzen ändern können. Daher ist es von entscheidender Bedeutung, über die Kompetenz zur Verwendung von Technologien für die Lösung von Aufgaben zu verfügen, die keine Routinetätigkeiten sind und bei denen der Mensch (noch) nicht durch Technik ersetzt werden kann. IKT-Kompetenzen sind heute für die meisten Beschäftigten der Schlüssel zu einem Arbeitsplatz und/oder besserem Gehalt; für die Volkswirtschaften sind sie ausschlaggebend, um auf den globalen Märkten wettbewerbsfähig zu bleiben. In den OECD-Ländern wird davon ausgegangen, dass moderne Technologien ein wesentlicher Faktor für die Entstehung von Arbeitsplätzen bleiben werden, die Entwicklung 
von IKT-Kompetenzen wird als wichtigste politische Strategie für eine wirtschaftliche Erholung angesehen (Chinien und Boutin, 20II; OECD, 20I0).

Die Erhebung zu den grundlegenden Kompetenzen Erwachsener hat außer der Leseund alltagsmathematischen Kompetenz auch die technologiebasierte Problemlösekompetenz gemessen und abgeschätzt, wie häufig die einzelnen Kompetenzen, einschließlich IKT-Kompetenzen, am Arbeitsplatz und im privaten Bereich eingesetzt werden. Die Erhebung zum technologiebasierten Problemlösen wurde als computergestützte Erhebung durchgeführt. Befragte mussten bereits über Computererfahrung verfügen, eine gewisse Bereitschaft haben, Aufgaben mit dem vom Befrager angebotenen Laptop zu lösen, sowie über minimale Computerkenntnisse verfügen, die in einem als „IT-Übung“ bezeichneten, einfachen, aus 6 Aufgaben bestehenden Test getestet wurden. Im Durchschnitt der an der Erhebung teilnehmenden Länder haben 74 Prozent der Befragten die IT-Übung bestanden und an der computergestützten Erhebung teilgenommen (OECD, 2013a). Die Erhebung zum technologiebasierten Problemlösen konzentrierte sich unter anderem auf das Verständnis für die Art des Problems, die Festlegung von Zwischenzielen und Schritten, mit deren Hilfe das Problem gelöst werden konnte, sowie das Ergreifen der zum Erreichen dieser Zwischenziele erforderlichen Maßnahmen. Jedoch bestand bei den in der Erhebung vorgestellten Problemen ein direkter Zusammenhang zur Computertechnologie, und die Lösung der Probleme erforderte den Einsatz von Technologie. Höhere Kompetenzstufen beim technologiebasierten Problemlösen spiegeln somit sowohl eine höhere Problemlösekompetenz als auch eine bessere Kompetenz bei der Verwendung von digitaler Technik, Kommunikationsmitteln und Netzwerken zur Beschaffung und Bewertung von Informationen, zur Kommunikation mit anderen und zur Durchführung praktischer Aufgaben wider (PIAAC Expert Group in Problem Solving in Technology-Rich Environments, 2009)

Mit den durch die Erhebung zu den grundlegenden Kompetenzen Erwachsener zur Verfügung stehenden Informationen war es möglich, einen Indikator zu entwickeln, der die Kompetenzen und die Bereitschaft zur Verwendung von IKT beim Problemlösen misst. Dieser Indikator verknüpft die Informationen zur Leistung bei der Erhebung zum Problemlösen (4 Gruppen, von unter Stufe I bis Stufe 3) mit Informationen zu den Gründen für eine nicht erfolgte Teilnahme an der computergestützten Erhebung und damit einer fehlenden Bewertung des Problemlösens (3 Gruppen). Eine Selbsteinschätzung zur Häufigkeit der IKT-Nutzung diente zur Validierung der Gruppeneinteilung. Die Verwendung von IKT (die Häufigkeit verschiedener mit dem Computer und dem Internet zusammenhängender Aktivitäten) steht in Zusammenhang mit der Kompetenzstufe und der Bereitschaft zur Verwendung von IKT zum Problemlösen (s. nachstehende Abb. A.Ib). Die vorstehend aufgeführten Gruppen werden wie folgt definiert:

Gruppe o - keine IKT-Nutzung, keine Kompetenz. Personen ohne Computererfahrung. In den I9 an der Erhebung zum technologiebasierten Problemlösen beteiligten Ländern gehören 9 Prozent der 16- bis 65-Jährigen zu dieser Gruppe.

Gruppe 1 - fehlende Bereitschaft zur Verwendung neuer Geräte und Systeme, minimale Verwendung von IKT. Diese Gruppe hat sich gegen die Teilnahme an der computergestützten Erhebung entschieden. Obwohl es für die Entscheidung gegen die Teilnahme an der 
Abbildung Kasten A1.a

Die Verteilung der Kompetenzen Erwachsener und ihre Bereitschaft, Informations- und Kommunikationstechnologien (IKT) zum Problemlösen (PL) einzusetzen 25- bis 64-Jährige

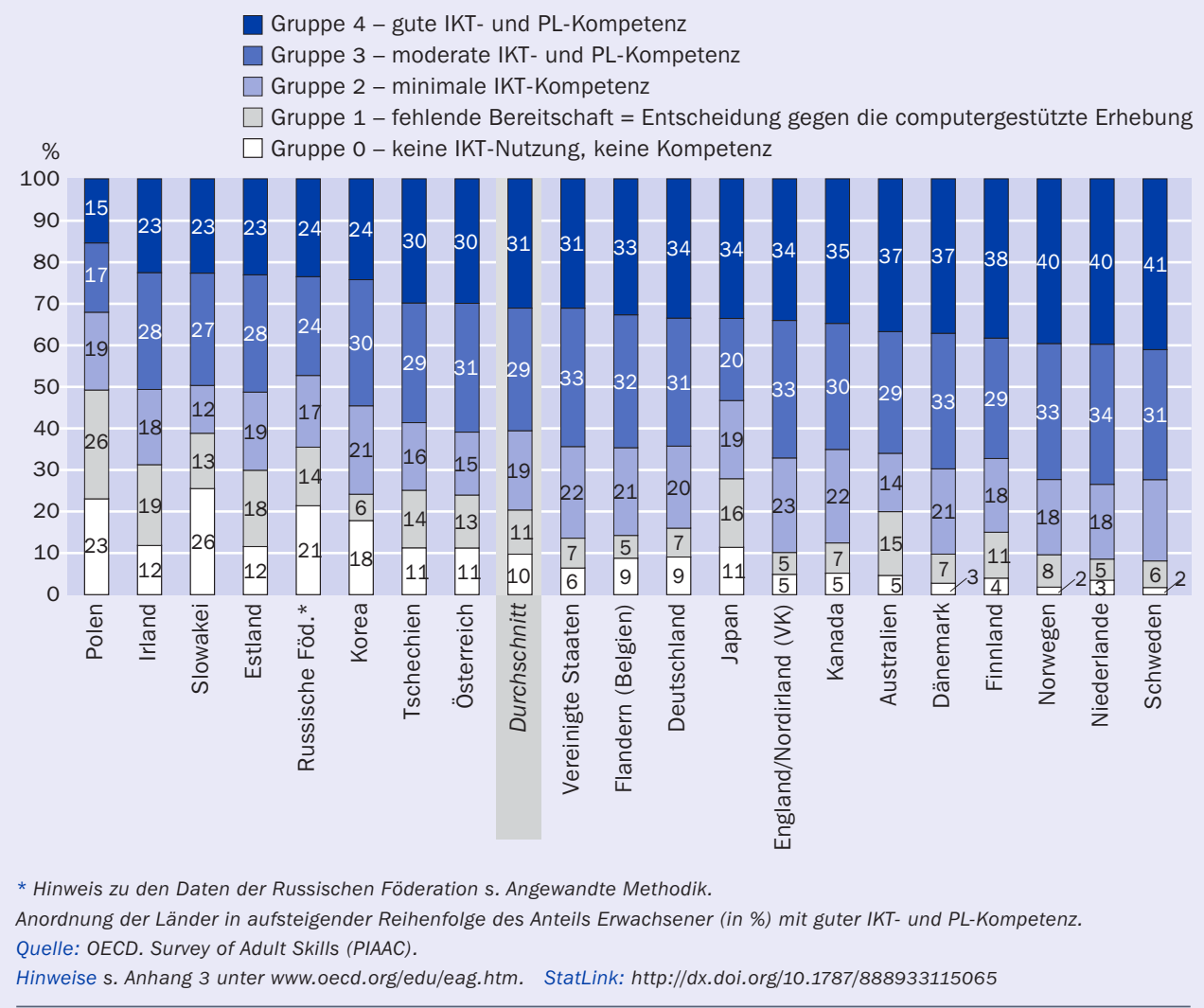

computergestützten Erhebung viele unterschiedliche Gründe gegeben haben mag, sind die Häufigkeit der Computernutzung im privaten Bereich sowie das nach Eigenangaben am Arbeitsplatz benötigte Computerkompetenzniveau geringer als bei der nächsten Gruppe; damit verfügt diese Gruppe wahrscheinlich auch bei der IKT-Nutzung über eine geringere Kompetenz. Dieser Gruppe gehören etwa 10 Prozent der Bevölkerung an.

Gruppe 2 - minimale IKT-Kompetenz, moderate IKT-Nutzung. Hierbei handelt es sich um Personen mit geringer IKT-Kompetenz, die jedoch genug Selbstvertrauen haben, um IKT einzusetzen. Sie sind in der Lage, nur eine einzige Funktion in einer generischen Schnittstelle zu nutzen (OECD, 2013c), und beherrschen unter Umständen sehr grundlegende IKT-Aufgaben, wie Scrollen oder das Markieren von Text, nicht (IT-Übung). $\mathrm{Zu}$ dieser Gruppe gehören Personen, die bei der Erhebung zum technologiebasierten Problemlösen eine unter Stufe I liegende Punktzahl erreicht haben, sowie Personen, die die IT-Übung nicht bestanden haben. Diese beiden Gruppen wurden zu einer zusammengefasst, da ihre Erfahrungen bei der Nutzung von Computern über alle Länder hinweg ähnlich sind: Sie verwenden Computer häufiger im privaten Bereich als Gruppe I, jedoch weniger häufig als Gruppe 3. Außerdem unterscheiden sie sich durch ihre Lese- und alltagsmathematische Kompetenz von den anderen Gruppen, die allgemein besser als die von Personen in Gruppe o, jedoch nicht so gut wie die von Personen in Gruppe I und 3 sind. Zu dieser Gruppe gehören etwa 17 Prozent der Bevölkerung. 
Gruppe 3-moderate IKT- und Problemlösekompetenz (Stufe I). Diese Personen können auf breiter Basis verfügbare und bekannte technologische Anwendungen, wie E-Mail-Programme oder Internetbrowser, nutzen (OECD, 2013c). Häufig sind ihnen spezifische Tools und Funktionen nicht bekannt, oder sie wissen nicht, wie diese genutzt werden (z. B. Sortierfunktion). Die von ihnen erfolgreich gelösten Aufgaben erfordern nur geringe oder keine Navigation. Dieser Gruppe gehören etwa 29 Prozent der Bevölkerung an.

Gruppe 4 - gute IKT- und Problemlösekompetenz (Stufe 2 und 3). Hierbei handelt es sich um Personen mit hoher IKT-Kompetenz, die komplizierte Probleme mithilfe technologischer Anwendungen lösen können. Auf dieser Stufe verlangen die Aufgaben in der Regel den Einsatz sowohl allgemeiner als auch spezifischerer technologischer Anwendungen. Zur Lösung des betreffenden Problems muss etwas zwischen Seiten und Anwendungen navigiert werden. Die Verwendung von Tools (z. B. zum Sortieren) erleichtert die Lösung des Problems (OECD, 2013c). Dieser Gruppe gehören etwa 33 Prozent der Bevölkerung an.

Obwohl ein klarer Zusammenhang zwischen der Häufigkeit der Computernutzung im privaten Bereich und der Kompetenz und Bereitschaft, IKT einzusetzen, besteht (Abb. Ar.b), wird der Begriff „Gruppe“ anstelle von „Stufe“ verwendet, da sich diese Gruppierungen in ihrer Art von den die Lese- und alltagsmathematische Kompetenz betreffenden Gruppen unterscheiden und auf anderen Informationsarten basieren. Gruppe o und I werden aus den Informationen über Vorkenntnisse und die

Abbildung Kasten A1.b

Häufigkeit der Nutzung von IKT im privaten Bereich (Index 1-5) bei Personen mit unterschiedlicher Kompetenz und Bereitschaft, Informations- und Kommunikationstechnologien (IKT) zur Problemlösung $(\mathrm{PL})$ einzusetzen

25- bis 64-Jährige

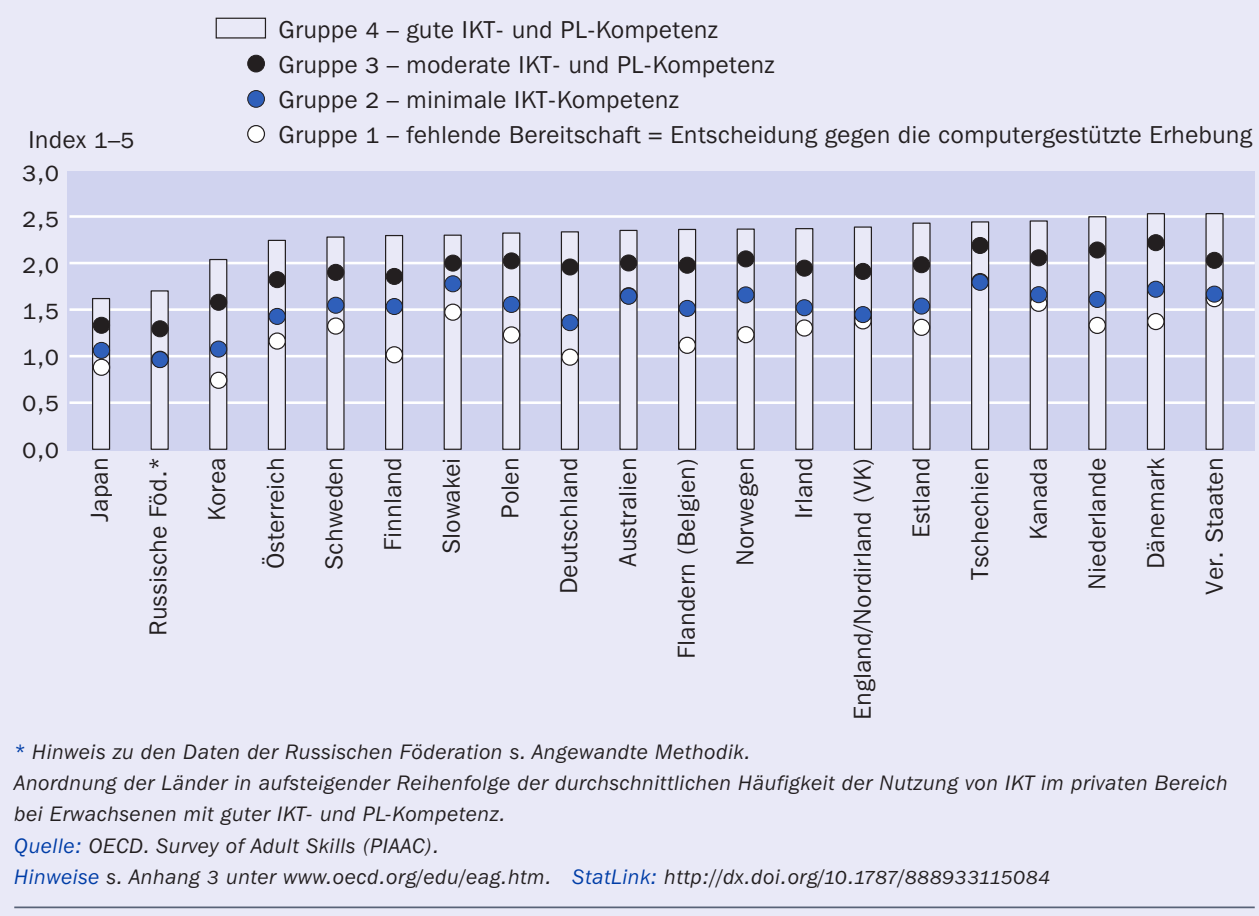


Bereitschaft zur Verwendung von Computern in Testsituationen abgeleitet; die Gruppen 2 bis 4 basieren auf einer Bewertung der IKT- und Problemlösekompetenz.

Die Verteilung der Bevölkerung auf diese 5 Gruppen in jedem an der Erhebung zu den grundlegenden Kompetenzen Erwachsener teilnehmenden Land ist in Abbildung Ar.a dargestellt.

Abbildung Ar.c zeigt, dass eine höhere IKT-Kompetenz und die Bereitschaft, IKT zur Lösung von Problemen zu verwenden, in allen Ländern mit signifikanten Unterschieden bei den Einkommen Erwachsener zusammenhängen. Weitere Zusammenhänge zwischen der IKT-Kompetenz und der Bereitschaft, IKT zur Lösung von Problemen einzusetzen, werden in einem separaten Kapitel in Bildung aufeinen Blick 2015 untersucht werden.

\section{Abbildung Kasten A1.c}

Gehaltsunterschiede (in \%) im Vergleich zur Gruppe 0 (keine IKT-Nutzung, keine Kompetenz), bereinigt um Alter und Bildungsstand 25- bis 64-Jährige

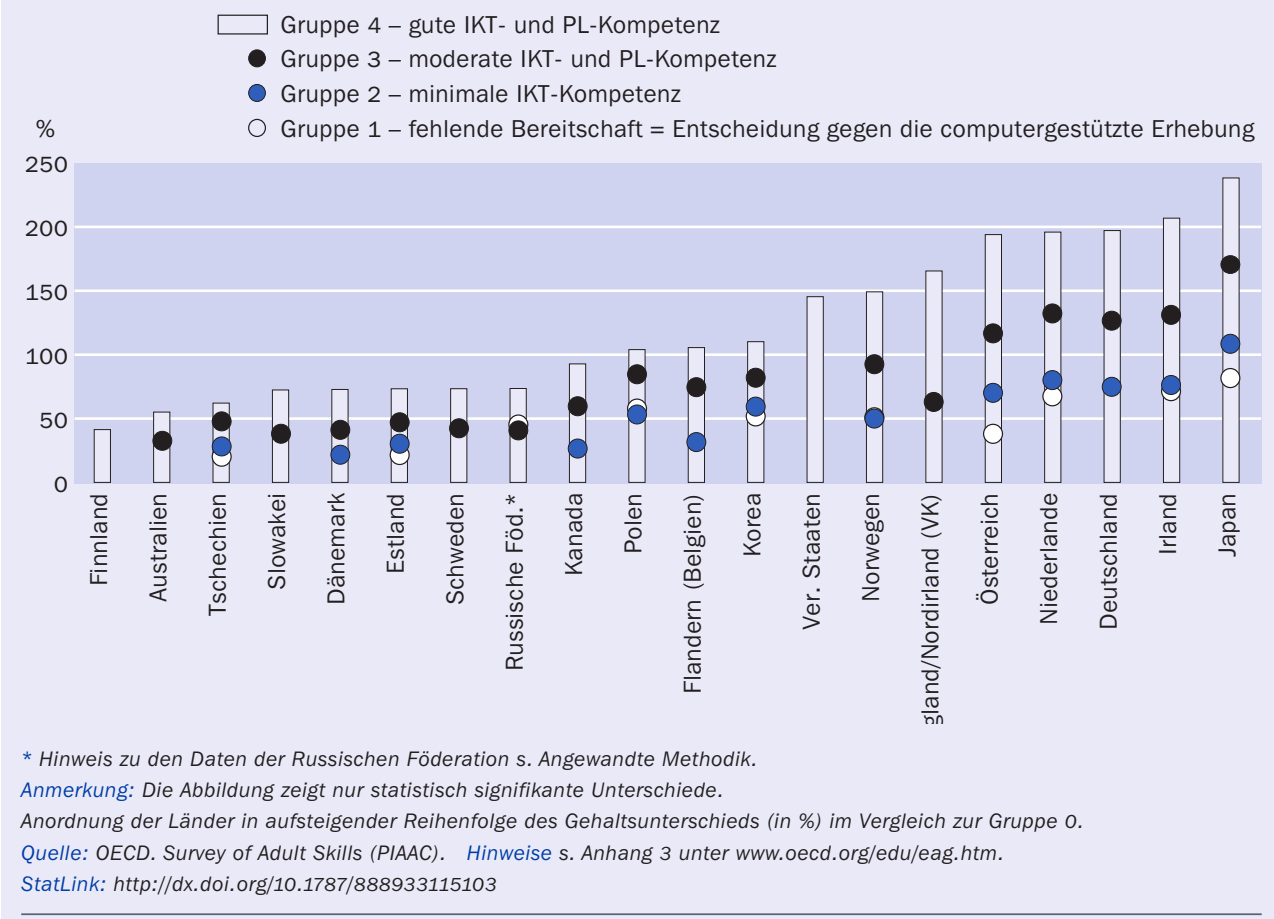

\section{Definitionen}

Altersgruppen: Erwachsene bezieht sich auf 25- bis 64-Jährige, jüngere Erwachsene auf 25- bis 34-Jährige, ältere Erwachsene auf 55- bis 64-Jährige.

Bildungsbereiche: Unterhalb Sekundarbereich II entspricht Bildungsgängen auf den ISCEDStufen o, I, 2 und ${ }_{3} \mathrm{C}$ (kurz), Sekundarbereich II bzw. postsekundarer, nicht tertiärer Bereich Bildungsgängen auf den ISCED-Stufen ${ }_{3} \mathrm{C}$ (lang), 3B, $3 \mathrm{~A}$ und 4 und Tertiärbereich Studiengän- 
gen auf den ISCED-Stufen 5 B, 5 A und 6. Erläuterungen zu allen Bildungsbereichen gemäß ISCED-Klassifizierung s. Hinweise für den Leser im vorderen Teil der Publikation.

\section{Angewandte Methodik}

Die Daten zu Bevölkerung und Bildungsstand stammen für die meisten Länder aus Datenbanken der OECD und Eurostat, die vom OECD-Netzwerk zu den Arbeitsmarktergebnissen sowie den wirtschaftlichen und sozialen Auswirkungen des Lernens (LSO) aus nationalen Arbeitskräfteerhebungen zusammengetragen sind. Bildungsstanddaten für Argentinien, China, Indonesien, Kolumbien, Saudi-Arabien und Südafrika stammen aus der Datenbank des Statistikinstituts der UNESCO zum Bildungsstand 25-Jähriger und Älterer. Daten zu den Kompetenzstufen und Mittelwerten basieren auf der Erhebung zu den grundlegenden Kompetenzen Erwachsener (PIAAC) 2012 im Rahmen des OECD Programme for the International Assessment of Adult Competencies. Weitere Informationen siehe „Erhebung zu den grundlegenden Kompetenzen Erwachsener" im vorderen Teil dieser Publikation sowie in Anhang 3 unter www.oecd.orgledu/eag.htm. Kasten Ar.I basiert bei den subnationalen Daten auf der INES-Erhebung.

Der Bildungsstand der Bevölkerung bezieht sich auf den Prozentsatz der Bevölkerung im Alter von 25 bis 64 Jahren, der einen bestimmten Bildungsbereich erfolgreich abgeschlossen hat.

Die meisten OECD-Länder ordnen Personen ohne einen Bildungsabschluss (d. h. Analphabeten oder Personen, deren Bildungsstand sich nicht in nationale Klassifizierungen einstufen lässt) der ISCED-Stufe o zu, daher sind die Durchschnittswerte für die ISCED-Stufen o/I (d. h. den Elementar- und Primarbereich) vermutlich hierdurch beeinflusst.

Anmerkung zu den Daten aus Israel

Die statistischen Daten für Israel wurden von den zuständigen israelischen Stellen bereitgestellt, die für sie verantwortlich zeichnen. Die Verwendung dieser Daten durch die OECD erfolgt unbeschadet des völkerrechtlichen Status der Golanhöhen, von Ost-Jerusalem und der israelischen Siedlungen im Westjordanland.

Hinweis zu den Daten aus der Russischen Föderation in der Erhebung zu den grundlegenden Kompetenzen Erwachsener (PIAAC)

Zu beachten ist, dass die Bevölkerung des Stadtgebiets Moskau in der Stichprobe für die Russische Föderation nicht berücksichtigt wurde. Die veröffentlichten Daten repräsentieren daher nicht die gesamte Wohnbevölkerung im Alter von I 6 bis 65 Jahren in Russland, sondern nur die Wohnbevölkerung Russlands ohne die im Stadtgebiet Moskau lebende Bevölkerung. Weitere Informationen zu den Daten aus der Russischen Föderation sowie anderer Länder finden sich im Technical Report of the Survey of Adult Skills (OECD, i. E.). 


\section{Weiterführende Informationen}

Chinien, C. and F. Boutin (20II), Defining Essential Digital Skills in the Canadian Workplace: Final Report, WDM-Consultants.

Levy, F. (2010), How Technology Changes Demands for Human Skills, OECD Education Working Papers, No. 45, OECD Publishing, Paris, http://dx.doi.org/10.1787/5kmhds6czqzq-en.

OECD (2013a), OECD Skills Outlook 2013: First Results from the Survey of Adult Skills, OECD Publishing, Paris, http:||dx.doi.org/10.1787/9789264204256-en.

OECD (2013b), PISA 2012 Results: Excellence through Equity (Volume II): Giving Every Student the Chance to Succeed, PISA, OECD Publishing, http://dx.doi.org/10.1787/9789264201132-en.

OECD (2013c), The Survey of Adult Skills: Reader's Companion, OECD Publishing, Paris, http:/| dx.doi.org/10.1787/978g264204027-en.

OECD (2010), OECD Information Technology Outlook 2010: Highlights, OECD Publishing, Paris, www.oecd.org/dataoecd/60/21/46444955.pdf.

PIAAC Expert Group in Problem Solving in Technology-Rich Environments (2009), PIAAC Problem Solving in Technology-Rich Environments: A Conceptual Framework, OECD Education Working Papers, No. 36, OECD Publishing, Paris, http:/|dx.doi.org/10.1787/220262483674.

\section{Tabellen Indikator A1}

StatLink: http://dx.doi.org/10.1787/888933114761

Tabelle Ar.ra: Bildungsstand 25- bis 64-Jähriger (20I2)

WEB Table Ar.rb: Educational attainment of 25-64 year-olds, by gender (Bildungsstand 25-bis 64-Jähriger, nach Geschlecht) (20I2)

- Tabelle Ar.2a: Anteil der Bevölkerung mit mindestens einem Abschluss im Sekundarbereich II (in \%), nach Altersgruppe (20I2)

WEB Table Ar.2b: Proportion of the population that has attained at least upper secondary education, by age group and gender (Anteil der Bevölkerung mit mindestens einem Abschluss im Sekundarbereich II [in \%], nach Altersgruppe und Geschlecht) (2012)

Tabelle Ar.3a: Anteil der Bevölkerung mit einem Abschluss im Tertiärbereich (in \%), nach Tertiärbereich und Altersgruppe (2012)

WEB Table AI.3b: Proportion of the population that has attained tertiary education, by type of programme, age group and gender (Anteil der Bevölkerung mit einem Abschluss im Tertiärbereich [in \%], nach Art des Studiengangs, Altersgruppe und Geschlecht) (2012) 
Tabelle Ar.4a: Entwicklungstendenzen bei Bildungsabschlüssen, nach Altersgruppe, sowie durchschnittlicher jährlicher Anstieg (2000, 2005-20I2)

WEB Table AI.4b: Trends in educational attainment, by gender and age group, and average annual growth rate (Entwicklungstendenzen bei Bildungsabschlüssen, nach Geschlecht und Altersgruppe, sowie durchschnittlicher jährlicher Anstieg) (2000, 2005-2012)

Tabelle Ar.5a: Erwachsene mit einem Abschluss im Sekundarbereich II, nach Ausrichtung des Bildungsgangs und Geschlecht (2012)

WEB Table Ar.5b: Educational attainment, by programme orientation, age group and gender (Bildungsstand, nach Ausrichtung des Bildungsgangs, Altersgruppe und Geschlecht) (20I2)

Tabelle Ar.6a (L): Bildungsstand 25- bis 64-Jähriger, nach Lesekompetenzstufe (2012)

WEB Table Ar.6a (N): Educational attainment of 25-64 year-olds, by numeracy proficiency level (Bildungsstand 25- bis 64-Jähriger, nach alltagsmathematischer Kompetenzstufe) (20I2)

WEB Table Ar.6b (L): Educational attainment of 25-64 year-olds, by literacy proficiency level and gender (Bildungsstand 25- bis 64-Jähriger, nach Lesekompetenzstufe und Geschlecht) (2012)

WEB Table Ar.6b (N): Educational attainment of 25-64 year-olds, by numeracy proficiency level and gender (Bildungsstand 25- bis 64-Jähriger, nach alltagsmathematischer Kompetenzstufe und Geschlecht) (2012)

Tabelle Ar.7a (L): Verteilung der Lesekompetenzstufen, nach Alter (2012)

WEB Table Ar.7a (N): Distribution of numeracy proficiency levels, by age (Verteilung der alltagsmathematischen Kompetenzstufen, nach Alter) (2012)

WEB Table Ar.7b (L): Distribution of literacy proficiency levels, by age and gender (Verteilung der Lesekompetenzstufen, nach Alter und Geschlecht) (2012)

WEB Table Ar.7b (N): Distribution of numeracy proficiency levels, by age and gender (Verteilung der alltagsmathematischen Kompetenzstufen, nach Alter und Geschlecht) (2012)

Tabelle Ar.8 (L): Anteil 25- bis 64-Jähriger (in \%) mit einem Abschluss im berufsbildenden oder allgemeinbildenden Sekundarbereich II bzw. postsekundaren, nicht tertiären Bereich, nach Lesekompetenzstufe und Mittelwert der Lesekompetenz (20I2) 
WEB Table Ar.8 (N): Proportion of 25-64 year-olds with upper secondary or post-secondary non-tertiary education, by programme orientation, numeracy proficiency level and mean numeracy score (Anteil 25-bis 64-Jähriger mit einem Abschluss im Sekundarbereich II bzw. postsekundaren, nicht tertiären Bereich, nach Ausrichtung des Bildungsgangs, alltagsmathematischer Kompetenzstufe und Mittelwert der alltagsmathematischen Kompetenz) (20I2)

Tabelle Ar.ga (L): Mittelwert der Lesekompetenz, nach Bildungsstand und Alter (2012)

WEB Table Ar.ga (N): Mean numeracy score, by educational attainment and age (Mittelwert der alltagsmathematischen Kompetenz, nach Bildungsstand und Alter) (2012)

WEB Table Ar.gb (L): Distribution of mean literacy scores, 25-64 year-olds (Verteilung der Mittelwerte der Lesekompetenz, 25- bis 64-Jährige) (2012)

WEB Table Ar.gb (N): Distribution of mean numeracy scores, 25-64 year-olds (Verteilung der Mittelwerte der alltagsmathematischen Kompetenz, 25- bis 64-Jährige) (2012) 
Bildungsstand 25- bis 64-Jähriger (2012)

\begin{tabular}{|c|c|c|c|c|c|c|c|c|c|c|}
\hline & \multirow{2}{*}{$\begin{array}{l}\text { Elemen- } \\
\text { tar- und } \\
\text { Primar- } \\
\text { bereich }\end{array}$} & \multirow{2}{*}{$\begin{array}{c}\text { Sekundar- } \\
\text { bereich I }\end{array}$} & \multirow{2}{*}{$\begin{array}{c}\text { ISCED 3C } \\
\text { (kurz) }\end{array}$} & \multicolumn{2}{|c|}{ Sekundarbereich II } & \multirow{2}{*}{$\begin{array}{c}\text { Postse- } \\
\text { kundarer, } \\
\text { nicht } \\
\text { tertiärer } \\
\text { Bereich }\end{array}$} & \multicolumn{3}{|c|}{ Tertiärbereich } & \multirow{2}{*}{\begin{tabular}{|c} 
Alle \\
Bildungs- \\
bereiche \\
zusammer
\end{tabular}} \\
\hline & & & & $\begin{array}{l}\text { ISCED 3C } \\
\text { (lang)/3B }\end{array}$ & ISCED $3 \mathrm{~A}$ & & $\begin{array}{c}\text { Tertiär- } \\
\text { bereich B }\end{array}$ & $\begin{array}{c}\text { Tertiär- } \\
\text { bereich A }\end{array}$ & \begin{tabular}{|c|} 
Weiterführende \\
forschungsorientierte \\
Studiengänge
\end{tabular} & \\
\hline & (1) & (2) & (3) & (4) & (5) & (6) & (7) & (8) & (9) & (10) \\
\hline \multicolumn{11}{|l|}{ OECD-Länder } \\
\hline Australien & 6 & 18 & $a$ & 14 & 16 & 5 & 11 & 29 & 1 & 100 \\
\hline Österreich & $x(2)$ & 16 & 1 & 47 & 6 & 10 & 7 & 13 & $x(8)$ & 100 \\
\hline Belgien & 12 & 16 & $a$ & 10 & 24 & 3 & 17 & 18 & 1 & 100 \\
\hline Kanada & 3 & 8 & a & $x(5)$ & 25 & 12 & 25 & 28 & $x(8)$ & 100 \\
\hline Chile $^{1}$ & 18 & 25 & a & $x(5)$ & 40 & a & 6 & 11 & 1 & 100 \\
\hline Tschechien & $\mathrm{n}$ & 7 & a & 38 & 35 & $x(5)$ & $x(8)$ & 19 & $x(8)$ & 100 \\
\hline Dänemark & 1 & 20 & 1 & 37 & 6 & c & 6 & 28 & 1 & 100 \\
\hline Estland & 1 & 10 & a & 14 & 32 & 7 & 13 & 24 & $\mathrm{n}$ & 100 \\
\hline Finnland & 6 & 10 & a & a & 44 & 1 & 13 & 25 & 1 & 100 \\
\hline Frankreich & 10 & 18 & a & 30 & 11 & $\mathrm{n}$ & 12 & 18 & 1 & 100 \\
\hline Deutschland & 3 & 10 & a & 47 & 3 & 8 & 11 & 16 & 1 & 100 \\
\hline Griechenland & 21 & 11 & $x(4)$ & 7 & 27 & 8 & 9 & 17 & $\mathrm{n}$ & 100 \\
\hline Ungarn & 1 & 17 & a & 29 & 29 & 2 & 1 & 21 & 1 & 100 \\
\hline Island & 21 & 7 & 2 & 19 & 10 & 6 & 4 & 30 & 1 & 100 \\
\hline Irland & 10 & 14 & 1 & $x(5)$ & 21 & 13 & 15 & 24 & 1 & 100 \\
\hline Israel & 10 & 6 & a & 7 & 31 & a & 14 & 31 & 1 & 100 \\
\hline Italien & 10 & 32 & 1 & 8 & 33 & 1 & $n$ & 15 & $\mathrm{n}$ & 100 \\
\hline Japan & $x(5)$ & $x(5)$ & $x(5)$ & $x(5)$ & 53 & a & 20 & 26 & $x(8)$ & 100 \\
\hline Korea & 8 & 10 & a & $x(5)$ & 41 & a & 13 & 28 & $x(8)$ & 100 \\
\hline Luxemburg & 8 & 9 & 5 & 16 & 20 & 4 & 13 & 25 & 1 & 100 \\
\hline Mexiko & 39 & 23 & a & 5 & 14 & a & 1 & 17 & $x(8)$ & 100 \\
\hline Niederlande & 8 & 19 & $x(4)$ & 14 & 22 & 3 & 3 & 31 & 1 & 100 \\
\hline Neuseeland & $x(2)$ & 19 & 7 & 14 & 9 & 11 & 15 & 25 & $x(8)$ & 100 \\
\hline Norwegen & $\mathrm{n}$ & 18 & a & 27 & 13 & 4 & 2 & 36 & 1 & 100 \\
\hline Polen & $x(2)$ & 10 & a & 31 & 31 & 4 & $x(8)$ & 25 & $x(8)$ & 100 \\
\hline Portugal & 42 & 21 & $x(5)$ & $x(5)$ & 19 & $\mathrm{n}$ & $x(8)$ & 16 & 3 & 100 \\
\hline Slowakei & $\mathrm{n}$ & 8 & $x(4)$ & 35 & 38 & $x(5)$ & 1 & 17 & $\mathrm{n}$ & 100 \\
\hline Slowenien & 1 & 14 & a & 27 & 32 & a & 12 & 12 & 2 & 100 \\
\hline Spanien & 17 & 29 & a & 9 & 14 & $\mathrm{n}$ & 10 & 22 & 1 & 100 \\
\hline Schweden & 4 & 9 & a & $x(5)$ & 45 & 7 & 9 & 25 & 1 & 100 \\
\hline Schweiz & 3 & 9 & 2 & 39 & 5 & 6 & 11 & 23 & 3 & 100 \\
\hline Türkei & 55 & 12 & a & 9 & 10 & a & $x(8)$ & 15 & $x(8)$ & 100 \\
\hline Ver. Königreich & $n$ & 9 & 13 & 30 & 7 & a & 10 & 30 & 1 & 100 \\
\hline Vereinigte Staaten & 4 & 7 & $x(5)$ & $x(5)$ & 46 & $x(5)$ & 10 & 31 & 1 & 100 \\
\hline & \multicolumn{3}{|c|}{ Unterhalb Sekundarbereich II } & \multicolumn{3}{|c|}{ Sekundarbereich II } & \multicolumn{3}{|c|}{ Tertiärbereich } & \\
\hline OECD-Durchschnitt & \multirow{2}{*}{\multicolumn{3}{|c|}{$\begin{array}{l}24 \\
23\end{array}$}} & \multirow{2}{*}{\multicolumn{3}{|c|}{$\begin{array}{l}44 \\
48\end{array}$}} & \multirow{2}{*}{\multicolumn{3}{|c|}{$\begin{array}{l}33 \\
29\end{array}$}} & \\
\hline EU21-Durchschnitt & & & & & & & & & & \\
\hline \multicolumn{11}{|l|}{ Partnerländer } \\
\hline Argentinien $^{2}$ & 44 & 14 & a & $x(5)$ & 28 & a & $x(8)$ & 14 & $x(8)$ & 100 \\
\hline Brasilien & 40 & 15 & $x(5)$ & $x(5)$ & 32 & a & $x(8)$ & 13 & $x(8)$ & 100 \\
\hline China $^{3}$ & 35 & 43 & $\mathrm{~m}$ & $x(5)$ & 14 & 5 & $x(8)$ & 4 & $x(8)$ & 100 \\
\hline Kolumbien ${ }^{1}$ & 44 & 14 & a & $x(5)$ & 22 & a & $x(8)$ & 20 & $x(8)$ & 100 \\
\hline Indien & $\mathrm{m}$ & $\mathrm{m}$ & $\mathrm{m}$ & $\mathrm{m}$ & $\mathrm{m}$ & $\mathrm{m}$ & $\mathrm{m}$ & $\mathrm{m}$ & $\mathrm{m}$ & $\mathrm{m}$ \\
\hline Indonesien ${ }^{1}$ & 56 & 16 & a & $x(5)$ & 21 & a & $x(8)$ & 8 & $x(8)$ & 100 \\
\hline Lettland & 1 & 10 & $\mathrm{~m}$ & 3 & 48 & 8 & 1 & 27 & $\mathrm{n}$ & 100 \\
\hline Russische Föd. & 1 & 5 & $x(4)$ & 19 & 21 & $x(4)$ & 26 & 28 & $\mathrm{n}$ & 100 \\
\hline Saudi-Arabien ${ }^{4}$ & 33 & 18 & a & $x(5)$ & 23 & 5 & $x(8)$ & 21 & $x(8)$ & 100 \\
\hline Südafrika & 26 & 14 & a & $x(5)$ & 47 & 7 & $x(8)$ & 6 & $x(8)$ & 100 \\
\hline G20-Durchschnitt & & 36 & & & 36 & & & 27 & & \\
\hline
\end{tabular}

Anmerkung: Aufgrund von Abweichungen in den Daten wurden der OECD- und EU21-Durchschnitt nicht für jede einzelne Spalte separat berechnet. 1. Referenzjahr 2011. 2. Referenzjahr 2003. 3. Referenzjahr 2010. 4. Referenzjahr 2013.

Quelle: OECD. Argentinien, China, Indien, Indonesien, Kolumbien, Saudi-Arabien, Südafrika: Statistikinstitut der UNESCO. Lettland: Eurostat. Hinweise s. Anhang 3 unter www.oecd.org/edu/eag.htm. StatLink: http://dx.doi.org/10.1787/888933114780

Erläuterung der Kennzeichnung fehlender Daten s. Hinweise für den Leser. 
Tabelle A1.2a

Anteil der Erwachsenen mit mindestens einem Abschluss im Sekundarbereich II (in \%), nach Altersgruppe (2012)

\begin{tabular}{|c|c|c|c|c|c|c|}
\hline & \multicolumn{6}{|c|}{ Altersgruppe } \\
\hline & $25-64$ & $30-34$ & $25-34$ & $35-44$ & $45-54$ & $55-64$ \\
\hline & (1) & (2) & (3) & (4) & (5) & (6) \\
\hline \multicolumn{7}{|l|}{ OECD-Länder } \\
\hline Australien & 76 & 86 & 87 & 81 & 71 & 64 \\
\hline Österreich & 83 & 89 & 89 & 86 & 83 & 74 \\
\hline Belgien & 72 & 82 & 82 & 79 & 69 & 56 \\
\hline Kanada & 89 & 93 & 92 & 92 & 88 & 84 \\
\hline Chile $^{1}$ & 57 & 72 & 77 & 61 & 50 & 38 \\
\hline Tschechien & 92 & 93 & 94 & 95 & 93 & 87 \\
\hline Dänemark & 78 & 83 & 82 & 82 & 77 & 71 \\
\hline Estland & 90 & 86 & 86 & 90 & 94 & 88 \\
\hline Finnland & 85 & 91 & 90 & 90 & 87 & 74 \\
\hline Frankreich & 73 & 83 & 83 & 79 & 69 & 59 \\
\hline Deutschland & 86 & 87 & 87 & 87 & 87 & 84 \\
\hline Griechenland & 68 & 81 & 83 & 74 & 65 & 50 \\
\hline Ungarn & 82 & 87 & 88 & 84 & 82 & 75 \\
\hline Island & 71 & 77 & 75 & 75 & 71 & 61 \\
\hline Irland & 75 & 86 & 86 & 80 & 70 & 55 \\
\hline Israel & 85 & 89 & 90 & 86 & 81 & 77 \\
\hline Italien & 57 & 70 & 72 & 62 & 53 & 42 \\
\hline Japan & $\mathrm{m}$ & $\mathrm{m}$ & $\mathrm{m}$ & $\mathrm{m}$ & $\mathrm{m}$ & $\mathrm{m}$ \\
\hline Korea & 82 & 98 & 98 & 96 & 78 & 48 \\
\hline Luxemburg & 78 & 86 & 86 & 80 & 76 & 69 \\
\hline Mexiko & 37 & 42 & 46 & 37 & 35 & 25 \\
\hline Niederlande & 73 & 83 & 83 & 78 & 72 & 61 \\
\hline Neuseeland & 74 & 81 & 80 & 78 & 73 & 64 \\
\hline Norwegen & 82 & 84 & 82 & 86 & 79 & 82 \\
\hline Polen & 90 & 94 & 94 & 92 & 90 & 81 \\
\hline Portugal & 38 & 55 & 58 & 43 & 27 & 20 \\
\hline Slowakei & 92 & 94 & 94 & 94 & 92 & 86 \\
\hline Slowenien & 85 & 94 & 94 & 89 & 83 & 74 \\
\hline Spanien & 55 & 65 & 64 & 62 & 51 & 35 \\
\hline Schweden & 88 & 90 & 91 & 92 & 88 & 79 \\
\hline Schweiz & 86 & 89 & 89 & 88 & 86 & 82 \\
\hline Türkei & 34 & 43 & 46 & 32 & 25 & 21 \\
\hline Vereinigtes Königreich & 78 & 85 & 85 & 81 & 76 & 69 \\
\hline Vereinigte Staaten & 89 & 89 & 89 & 89 & 89 & 90 \\
\hline OECD-Durchschnitt & 75 & 82 & 82 & 79 & 73 & 64 \\
\hline EU21-Durchschnitt & 77 & 84 & 84 & 81 & 75 & 66 \\
\hline \multicolumn{7}{|l|}{ Partnerländer } \\
\hline Argentinien ${ }^{2}$ & 42 & $\mathrm{~m}$ & $\mathrm{~m}$ & $\mathrm{~m}$ & $\mathrm{~m}$ & $\mathrm{~m}$ \\
\hline Brasilien & 45 & 56 & 59 & 45 & 38 & 27 \\
\hline China $^{3}$ & 22 & $\mathrm{~m}$ & m & m & $\mathrm{m}$ & $\mathrm{m}$ \\
\hline Kolumbien ${ }^{1}$ & 42 & $\mathrm{~m}$ & $\mathrm{~m}$ & $\mathrm{~m}$ & $\mathrm{~m}$ & $\mathrm{~m}$ \\
\hline Indien & $\mathrm{m}$ & $\mathrm{m}$ & $\mathrm{m}$ & $\mathrm{m}$ & $\mathrm{m}$ & $\mathrm{m}$ \\
\hline Indonesien ${ }^{1}$ & 29 & $\mathrm{~m}$ & $\mathrm{~m}$ & $\mathrm{~m}$ & $\mathrm{~m}$ & $\mathrm{~m}$ \\
\hline Lettland & 89 & 84 & 85 & 89 & 94 & 87 \\
\hline Russische Föderation & 94 & 94 & 94 & 95 & 96 & 92 \\
\hline Saudi-Arabien ${ }^{4}$ & 49 & $\mathrm{~m}$ & $\mathrm{~m}$ & $m$ & $\mathrm{~m}$ & $\mathrm{~m}$ \\
\hline Südafrika & 61 & $\mathrm{~m}$ & $\mathrm{~m}$ & $\mathrm{~m}$ & $\mathrm{~m}$ & $\mathrm{~m}$ \\
\hline G20-Durchschnitt & 61 & m & m & m & m & $\mathbf{m}$ \\
\hline
\end{tabular}

Anmerkung: Bildungsgänge ISCED 3 C (kurz) sind in den Berechnungen nicht enthalten.

1. Referenzjahr 2011. 2. Referenzjahr 2003. 3. Referenzjahr 2010. 4. Referenzjahr 2013.

Quelle: OECD. Argentinien, China, Indien, Indonesien, Kolumbien, Saudi-Arabien, Südafrika: Statistikinstitut der UNESCO. Lettland: Eurostat.

Hinweise s. Anhang 3 unter www.oecd.org/edu/eag.htm. StatLink: http://dx.doi.org/10.1787/888933114799

Erläuterung der Kennzeichnung fehlender Daten s. Hinweise für den Leser. 


\begin{tabular}{|c|c|c|c|c|c|c|c|c|c|c|c|c|c|c|c|c|c|c|c|}
\hline & \multicolumn{6}{|c|}{ Tertiärbereich B } & \multicolumn{6}{|c|}{\begin{tabular}{|c|} 
Tertiärbereich A oder weiterführende \\
forschungsorientierte Studiengänge
\end{tabular}} & \multicolumn{7}{|c|}{ Tertiärbereich insgesamt } \\
\hline & \begin{tabular}{l}
\multirow{O}{0}{} \\
1 \\
$\stackrel{N}{N}$
\end{tabular} & $\begin{array}{l}\text { + } \\
\text { 1 } \\
0 \\
0\end{array}$ & $\begin{array}{l}\stackrel{+}{m} \\
1 \\
\stackrel{N}{N}\end{array}$ & $\begin{array}{l}\text { J } \\
⿱ \\
\text { L } \\
\text { m }\end{array}$ & 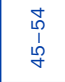 & 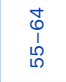 & $\begin{array}{l}\text { ț } \\
1 \\
\stackrel{1}{N}\end{array}$ & 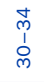 & $\begin{array}{l}\stackrel{+}{D} \\
\stackrel{1}{N}\end{array}$ & $\begin{array}{l}\text { J } \\
⿱ \\
1 \\
\text { D }\end{array}$ & 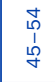 & $\begin{array}{l}\text { t } \\
1 \\
1 \\
\llcorner \\
\llcorner\end{array}$ & $\begin{array}{l}\stackrel{+}{0} \\
1 \\
\stackrel{n}{N}\end{array}$ & $\begin{array}{l}+ \\
0 \\
1 \\
0\end{array}$ & $\begin{array}{l}\stackrel{+}{D} \\
\stackrel{1}{N}\end{array}$ & 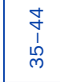 & $\begin{array}{l}1 \\
1 \\
1 \\
b\end{array}$ & $\begin{array}{l}\text { t } \\
1 \\
1 \\
\llcorner \\
\llcorner\end{array}$ & $\begin{array}{c}\text { 25-bis } \\
\text { 64-Jährige } \\
\text { (in Tsd.) }\end{array}$ \\
\hline & (1) & (2) & (3) & (4) & (5) & (6) & (7) & (8) & (9) & $(10)$ & (11) & $(12)$ & (13) & (14) & (15) & (16) & $(17)$ & $(18)$ & (19) \\
\hline \multicolumn{20}{|l|}{ OECD-Länder } \\
\hline Australien & 11 & 11 & 10 & 13 & 12 & 10 & 30 & 38 & 37 & 32 & 25 & 23 & 41 & 49 & 47 & 45 & 37 & 33 & 4846 \\
\hline Österreich & 7 & 6 & 5 & 7 & 8 & 8 & 13 & 20 & 18 & 14 & 10 & 8 & 20 & 26 & 23 & 22 & 19 & 17 & 934 \\
\hline Belgien & 17 & 20 & 18 & 20 & 16 & 13 & 18 & 24 & 25 & 21 & 16 & 12 & 35 & 44 & 43 & 40 & 32 & 25 & 2089 \\
\hline Kanada & 25 & 26 & 25 & 27 & 25 & 22 & 28 & 32 & 32 & 32 & 24 & 22 & 53 & 58 & 57 & 59 & 50 & 44 & 9981 \\
\hline Chile $^{1}$ & 6 & 6 & 6 & 7 & 6 & 4 & 12 & 17 & 16 & 12 & 9 & 9 & 18 & 23 & 22 & 19 & 16 & 13 & 1492 \\
\hline Tschechien & $x(7)$ & $x(8)$ & $x(9)$ & $x(10)$ & $x(11)$ & $x(12)$ & 19 & 26 & 28 & 19 & 18 & 13 & 19 & 26 & 28 & 19 & 18 & 13 & 1164 \\
\hline Dänemark & 6 & 6 & 5 & 6 & 6 & 5 & 29 & 37 & 35 & 32 & 27 & 24 & 35 & 43 & 40 & 39 & 32 & 29 & 817 \\
\hline Estland & 13 & 12 & 13 & 12 & 13 & 12 & 25 & 27 & 27 & 24 & 24 & 23 & 37 & 39 & 40 & 36 & 37 & 35 & 272 \\
\hline Finnland & 13 & 2 & 1 & 15 & 21 & 17 & 26 & 44 & 39 & 33 & 21 & 15 & 40 & 46 & 40 & 47 & 41 & 31 & 1136 \\
\hline Frankreich & 12 & 17 & 16 & 16 & 10 & 7 & 19 & 27 & 27 & 22 & 14 & 13 & 31 & 44 & 43 & 38 & 24 & 20 & 10049 \\
\hline Deutschland & 11 & 10 & 9 & 11 & 12 & 11 & 17 & 22 & 19 & 19 & 15 & 15 & 28 & 32 & 29 & 30 & 28 & 26 & 12612 \\
\hline Griechenland & 9 & 11 & 13 & 8 & 8 & 5 & 18 & 20 & 21 & 19 & 16 & 15 & 27 & 31 & 35 & 27 & 24 & 20 & 1641 \\
\hline Ungarn & 1 & 1 & 1 & 1 & c & c & 21 & 29 & 29 & 22 & 19 & 15 & 22 & 30 & 30 & 22 & 19 & 15 & 1225 \\
\hline Island & 4 & c & 3 & 5 & 5 & 5 & 31 & 40 & 36 & 37 & 30 & 20 & 35 & 40 & 38 & 42 & 34 & 25 & 56 \\
\hline Irland & 15 & 18 & 16 & 18 & 13 & 10 & 25 & 33 & 33 & 28 & 19 & 15 & 40 & 51 & 49 & 46 & 32 & 25 & 965 \\
\hline Israel & 14 & 13 & 12 & 14 & 14 & 16 & 33 & 38 & 33 & 36 & 30 & 30 & 46 & 51 & 44 & 50 & 45 & 47 & 1691 \\
\hline Italien & $\mathrm{n}$ & $\mathrm{n}$ & $\mathrm{n}$ & $\mathrm{n}$ & $\mathrm{n}$ & $\mathrm{n}$ & 15 & 21 & 22 & 17 & 12 & 11 & 16 & 22 & 22 & 17 & 12 & 11 & 5272 \\
\hline Japan & 20 & $\mathrm{~m}$ & 23 & 25 & 20 & 13 & 26 & $\mathrm{~m}$ & 35 & 27 & 26 & 19 & 47 & $\mathrm{~m}$ & 59 & 52 & 46 & 32 & 30890 \\
\hline Korea & 13 & 25 & 26 & 17 & 6 & 2 & 28 & 40 & 40 & 36 & 23 & 11 & 42 & 66 & 66 & 52 & 29 & 14 & 12331 \\
\hline Luxemburg & 13 & 12 & 14 & 15 & 12 & 10 & 26 & 38 & 36 & 30 & 20 & 17 & 39 & 50 & 50 & 45 & 32 & 26 & 114 \\
\hline Mexiko & 1 & 1 & 1 & 1 & 1 & 1 & 17 & 20 & 23 & 15 & 15 & 12 & 18 & 21 & 24 & 16 & 17 & 13 & 9661 \\
\hline Niederlande & 3 & 3 & 3 & 3 & 3 & 2 & 32 & 41 & 40 & 34 & 28 & 25 & 34 & 44 & 43 & 37 & 31 & 28 & 2922 \\
\hline Neuseeland & 15 & 14 & 14 & 15 & 16 & 17 & 25 & 34 & 33 & 28 & 22 & 18 & 41 & 48 & 47 & 42 & 38 & 35 & 882 \\
\hline Norwegen & 2 & c & $1^{r}$ & 2 & 3 & 3 & 36 & 47 & 44 & 41 & 32 & 27 & 39 & 47 & 45 & 44 & 35 & 30 & 1017 \\
\hline Polen & $x(7)$ & $x(8)$ & $x(9)$ & $x(10)$ & $x(11)$ & $x(12)$ & 25 & 39 & 41 & 26 & 16 & 13 & 25 & 39 & 41 & 26 & 16 & 13 & 5157 \\
\hline Portugal & $x(7)$ & $x(8)$ & $x(9)$ & $x(10)$ & $x(11)$ & $x(12)$ & 19 & 27 & 28 & 20 & 14 & 11 & 19 & 27 & 28 & 20 & 14 & 11 & 1095 \\
\hline Slowakei & 1 & 1 & 1 & 1 & 1 & 1 & 18 & 22 & 26 & 16 & 15 & 12 & 19 & 24 & 27 & 17 & 16 & 14 & 598 \\
\hline Slowenien & 12 & 15 & 14 & 13 & 11 & 9 & 15 & 24 & 22 & 18 & 12 & 8 & 26 & 39 & 35 & 30 & 23 & 17 & 315 \\
\hline Spanien & 10 & 13 & 13 & 12 & 8 & 4 & 23 & 27 & 27 & 27 & 20 & 15 & 32 & 40 & 39 & 39 & 28 & 19 & 8508 \\
\hline Schweden & 9 & 9 & 9 & 8 & 9 & 10 & 27 & 39 & 34 & 32 & 21 & 19 & 36 & 48 & 43 & 40 & 30 & 29 & 1736 \\
\hline Schweiz & 11 & 10 & 9 & 12 & 12 & 10 & 26 & 34 & 32 & 29 & 23 & 19 & 37 & 44 & 41 & 41 & 35 & 29 & 1619 \\
\hline Türkei & $x(7)$ & $x(8)$ & $x(9)$ & $x(10)$ & $x(11)$ & $x(12)$ & 15 & 19 & 21 & 15 & 10 & 10 & 15 & 19 & 21 & 15 & 10 & 10 & 5271 \\
\hline Ver. Königreich & 10 & 9 & 8 & 11 & 11 & 10 & 31 & 42 & 40 & 35 & 26 & 22 & 41 & 50 & 48 & 45 & 37 & 33 & 13508 \\
\hline Vereinigte Staaten & 10 & 11 & 10 & 11 & 10 & 11 & 33 & 35 & 34 & 35 & 31 & 31 & 43 & 45 & 44 & 46 & 41 & 42 & 70207 \\
\hline OECD-Durchschnitt & 10 & 10 & 10 & 11 & 10 & 9 & 24 & 31 & 30 & 26 & 20 & 17 & 32 & 40 & 39 & 35 & 29 & 24 & \\
\hline OECD insg. (in Tsd.) & & & & & & & & & & & & & & & & & & & 222074 \\
\hline EU21-Durchschnitt & 9 & 9 & 9 & 10 & 10 & 8 & 22 & 30 & 29 & 24 & 18 & 15 & 30 & 38 & 37 & 33 & 26 & 22 & \\
\hline
\end{tabular}

Partnerländer Argentinien² Brasilien

China $^{3}$

Kolumbien ${ }^{1}$ Indien Indonesien ${ }^{1}$ Lettland

Russische Föd. Saudi-Arabien ${ }^{4}$

Südafrika

\begin{tabular}{|r|}
$\mathbf{x}(13)$ \\
$\mathbf{x}(7)$ \\
$\mathbf{x}(13)$ \\
$\mathbf{x}(13)$ \\
$\mathrm{m}$ \\
$\mathbf{x}(13)$ \\
1 \\
26 \\
$\mathbf{x}(13)$ \\
$\mathbf{x}(13)$ \\
$\mathbf{x}(13)$
\end{tabular}

\begin{tabular}{r|r|r} 
& & \\
$m$ & $m$ & $m$ \\
$m$ & $x(9)$ & $x(10)$ \\
$m$ & $m$ & $m$ \\
$m$ & $m$ & $m$ \\
$m$ & $m$ & $m$ \\
2 & $m$ & $m$ \\
2 & 3 & 2 \\
$m$ & $m$ & 26 \\
$m$ & $m$ & $m$
\end{tabular}

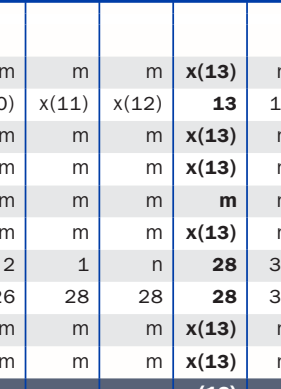

\begin{tabular}{|r|r} 
& \\
$m$ & $m$ \\
14 & 13 \\
$m$ & $m$ \\
$m$ & $m$ \\
$m$ & $m$ \\
$m$ & $m$ \\
36 & 27 \\
35 & 29 \\
$m$ & $m$ \\
$m$ & $m$ \\
$m$ & $m$
\end{tabular}

\begin{tabular}{|r|r|r} 
& & \\
$\mathrm{m}$ & $\mathrm{m}$ & $\mathbf{1 4}$ \\
$\mathrm{13}$ & 10 & $\mathbf{1 3}$ \\
$\mathrm{m}$ & $\mathrm{m}$ & $\mathbf{4}$ \\
$\mathrm{m}$ & $\mathrm{m}$ & $\mathbf{2 0}$ \\
$\mathrm{m}$ & $\mathrm{m}$ & $\mathbf{m}$ \\
$\mathrm{m}$ & $\mathrm{m}$ & $\mathbf{8}$ \\
$\mathrm{26}$ & 22 & $\mathbf{2 9}$ \\
$\mathrm{2}$ & 21 & $\mathbf{5 3}$ \\
$\mathrm{m}$ & $\mathrm{m}$ & $\mathbf{2 1}$ \\
$\mathrm{m}$ & $\mathrm{m}$ & $\mathbf{6}$ \\
$\mathrm{m}$ & $\mathrm{m}$ & $\mathbf{2 7}$
\end{tabular}

G20 insg. (in Tsd.)

1. Referenzjahr 2011. 2. Referenzjahr 2003. 3. Referenzjahr 2010. 4. Referenzjahr 2013.

Quelle: OECD. Argentinien, China, Indien, Indonesien, Kolumbien, Saudi-Arabien, Südafrika: Statistikinstitut der UNESCO. Lettland: Eurostat.

Hinweise s. Anhang 3 unter www.oecd.org/edu/eag.htm. StatLink: http://dx.doi.org/10.1787/888933114818

Erläuterung der Kennzeichnung fehlender Daten sowie der Kennzeichnung „ $r$ “ neben einigen Zahlen s. Hinweise für den Leser. 

(2000, 2005-2012)

\begin{tabular}{|c|c|c|c|c|c|c|c|c|c|c|c|c|c|}
\hline & \multirow[t]{3}{*}{ Bildungsstand } & \multicolumn{4}{|c|}{ 25- bis 64-Jährige } & \multicolumn{4}{|c|}{ 25- bis 34-Jährige } & \multicolumn{4}{|c|}{ 55- bis 64-Jährige } \\
\hline & & 2000 & 2005 & 2010 & 2012 & 2000 & 2005 & 2010 & 2012 & 2000 & 2005 & 2010 & 2012 \\
\hline & & (1) & (2) & (7) & (9) & (11) & $(12)$ & $(17)$ & (19) & $(21)$ & $(22)$ & $(27)$ & (29) \\
\hline \multicolumn{14}{|l|}{ OECD-Länder } \\
\hline Australien & $\begin{array}{l}\text { Unterhalb Sekundarbereich II } \\
\text { Sekundarbereich II bzw. postse- } \\
\text { kundarer, nicht tertiärer Bereich } \\
\text { Tertiärbereich }\end{array}$ & $\begin{array}{l}41 \\
31 \\
27\end{array}$ & $\begin{array}{l}35 \\
33 \\
32\end{array}$ & $\begin{array}{l}27 \\
36 \\
38\end{array}$ & $\begin{array}{l}24 \\
35 \\
41\end{array}$ & $\begin{array}{l}32 \\
37 \\
31\end{array}$ & $\begin{array}{l}21 \\
41 \\
38\end{array}$ & $\begin{array}{l}15 \\
40 \\
44\end{array}$ & $\begin{array}{l}13 \\
39 \\
47\end{array}$ & $\begin{array}{l}54 \\
27 \\
19\end{array}$ & $\begin{array}{l}50 \\
26 \\
24\end{array}$ & $\begin{array}{l}42 \\
29 \\
30\end{array}$ & $\begin{array}{l}36 \\
30 \\
33\end{array}$ \\
\hline Österreich & $\begin{array}{l}\text { Unterhalb Sekundarbereich II } \\
\text { Sekundarbereich II bzw. postse- } \\
\text { kundarer, nicht tertiärer Bereich } \\
\text { Tertiärbereich }\end{array}$ & $\begin{array}{l}24 \\
62 \\
14\end{array}$ & $\begin{array}{l}19 \\
63 \\
18\end{array}$ & $\begin{array}{l}18 \\
63 \\
19\end{array}$ & $\begin{array}{l}17 \\
63 \\
20\end{array}$ & $\begin{array}{l}16 \\
69 \\
14\end{array}$ & $\begin{array}{l}13 \\
68 \\
20\end{array}$ & $\begin{array}{l}12 \\
67 \\
21\end{array}$ & $\begin{array}{l}11 \\
66 \\
23\end{array}$ & $\begin{array}{l}37 \\
53 \\
10\end{array}$ & $\begin{array}{l}30 \\
56 \\
14\end{array}$ & $\begin{array}{l}27 \\
56 \\
16\end{array}$ & $\begin{array}{l}26 \\
57 \\
17\end{array}$ \\
\hline Belgien & $\begin{array}{l}\text { Unterhalb Sekundarbereich II } \\
\text { Sekundarbereich II bzw. postse- } \\
\text { kundarer, nicht tertiärer Bereich } \\
\text { Tertiärbereich }\end{array}$ & $\begin{array}{l}41 \\
31 \\
27\end{array}$ & $\begin{array}{l}34 \\
35 \\
31\end{array}$ & $\begin{array}{l}30 \\
36 \\
35\end{array}$ & $\begin{array}{l}28 \\
36 \\
35\end{array}$ & $\begin{array}{l}25 \\
39 \\
36\end{array}$ & $\begin{array}{l}19 \\
40 \\
41\end{array}$ & $\begin{array}{l}18 \\
38 \\
44\end{array}$ & $\begin{array}{l}18 \\
39 \\
43\end{array}$ & $\begin{array}{l}62 \\
22 \\
17\end{array}$ & $\begin{array}{l}52 \\
26 \\
22\end{array}$ & $\begin{array}{l}46 \\
29 \\
26\end{array}$ & $\begin{array}{l}44 \\
31 \\
25\end{array}$ \\
\hline Kanada & $\begin{array}{l}\text { Unterhalb Sekundarbereich II } \\
\text { Sekundarbereich II bzw. postse- } \\
\text { kundarer, nicht tertiärer Bereich } \\
\text { Tertiärbereich }\end{array}$ & $\begin{array}{l}19 \\
41 \\
40\end{array}$ & $\begin{array}{l}15 \\
39 \\
46\end{array}$ & $\begin{array}{l}12 \\
38 \\
51\end{array}$ & $\begin{array}{l}11 \\
36 \\
53\end{array}$ & $\begin{array}{l}12 \\
40 \\
48\end{array}$ & $\begin{array}{r}9 \\
37 \\
54\end{array}$ & $\begin{array}{r}8 \\
36 \\
56\end{array}$ & $\begin{array}{r}8 \\
35 \\
57\end{array}$ & $\begin{array}{l}36 \\
36 \\
28\end{array}$ & $\begin{array}{l}25 \\
39 \\
36\end{array}$ & $\begin{array}{l}18 \\
40 \\
42\end{array}$ & $\begin{array}{l}16 \\
39 \\
44\end{array}$ \\
\hline Chile $^{1}$ & $\begin{array}{l}\text { Unterhalb Sekundarbereich II } \\
\text { Sekundarbereich II bzw. postse- } \\
\text { kundarer, nicht tertiärer Bereich } \\
\text { Tertiärbereich }\end{array}$ & $\begin{array}{l}\mathrm{m} \\
\mathrm{m} \\
\mathrm{m}\end{array}$ & $\begin{array}{l}\mathrm{m} \\
\mathrm{m} \\
\mathrm{m}\end{array}$ & $\begin{array}{l}29 \\
45 \\
27\end{array}$ & $\begin{array}{l}\mathrm{m} \\
\mathrm{m} \\
\mathrm{m}\end{array}$ & $\begin{array}{l}\mathrm{m} \\
\mathrm{m} \\
\mathrm{m}\end{array}$ & $\begin{array}{l}\mathrm{m} \\
\mathrm{m} \\
\mathrm{m}\end{array}$ & $\begin{array}{l}13 \\
48 \\
38\end{array}$ & $\begin{array}{l}\mathrm{m} \\
\mathrm{m} \\
\mathrm{m}\end{array}$ & $\begin{array}{l}\mathrm{m} \\
\mathrm{m} \\
\mathrm{m}\end{array}$ & $\begin{array}{l}\mathrm{m} \\
\mathrm{m} \\
\mathrm{m}\end{array}$ & $\begin{array}{l}47 \\
34 \\
19\end{array}$ & $\begin{array}{l}m \\
m \\
m\end{array}$ \\
\hline Tschechien & $\begin{array}{l}\text { Unterhalb Sekundarbereich II } \\
\text { Sekundarbereich II bzw. postse- } \\
\text { kundarer, nicht tertiärer Bereich } \\
\text { Tertiärbereich }\end{array}$ & $\begin{array}{l}14 \\
75 \\
11\end{array}$ & $\begin{array}{l}10 \\
77 \\
13\end{array}$ & $\begin{array}{r}8 \\
75 \\
17\end{array}$ & $\begin{array}{r}8 \\
73 \\
19\end{array}$ & $\begin{array}{r}8 \\
81 \\
11\end{array}$ & $\begin{array}{r}6 \\
80 \\
14\end{array}$ & $\begin{array}{r}6 \\
72 \\
23\end{array}$ & $\begin{array}{r}6 \\
66 \\
28\end{array}$ & $\begin{array}{r}24 \\
67 \\
9\end{array}$ & $\begin{array}{l}17 \\
73 \\
11\end{array}$ & $\begin{array}{l}14 \\
75 \\
12\end{array}$ & $\begin{array}{l}13 \\
74 \\
13\end{array}$ \\
\hline Dänemark & $\begin{array}{l}\text { Unterhalb Sekundarbereich II } \\
\text { Sekundarbereich II bzw. postse- } \\
\text { kundarer, nicht tertiärer Bereich } \\
\text { Tertiärbereich }\end{array}$ & $\begin{array}{l}20 \\
54 \\
26\end{array}$ & $\begin{array}{l}19 \\
47 \\
34\end{array}$ & $\begin{array}{l}24 \\
42 \\
33\end{array}$ & $\begin{array}{l}22 \\
43 \\
35\end{array}$ & $\begin{array}{l}13 \\
58 \\
29\end{array}$ & $\begin{array}{l}13 \\
48 \\
40\end{array}$ & $\begin{array}{l}20 \\
42 \\
38\end{array}$ & $\begin{array}{l}18 \\
42 \\
40\end{array}$ & $\begin{array}{l}31 \\
51 \\
18\end{array}$ & $\begin{array}{l}25 \\
48 \\
27\end{array}$ & $\begin{array}{l}32 \\
41 \\
28\end{array}$ & $\begin{array}{l}29 \\
42 \\
29\end{array}$ \\
\hline Estland $^{2}$ & $\begin{array}{l}\text { Unterhalb Sekundarbereich II } \\
\text { Sekundarbereich II bzw. postse- } \\
\text { kundarer, nicht tertiärer Bereich } \\
\text { Tertiärbereich }\end{array}$ & $\begin{array}{l}15 \\
56 \\
29\end{array}$ & $\begin{array}{l}11 \\
56 \\
33\end{array}$ & $\begin{array}{l}11 \\
54 \\
35\end{array}$ & $\begin{array}{l}10 \\
53 \\
37\end{array}$ & $\begin{array}{r}9 \\
60 \\
31\end{array}$ & $\begin{array}{l}13 \\
55 \\
33\end{array}$ & $\begin{array}{l}13 \\
49 \\
38\end{array}$ & $\begin{array}{l}14 \\
47 \\
40\end{array}$ & $\begin{array}{l}33 \\
39 \\
27\end{array}$ & $\begin{array}{l}20 \\
51 \\
29\end{array}$ & $\begin{array}{l}15 \\
54 \\
31\end{array}$ & $\begin{array}{l}12 \\
53 \\
36\end{array}$ \\
\hline Finnland & $\begin{array}{l}\text { Unterhalb Sekundarbereich II } \\
\text { Sekundarbereich II bzw. postse- } \\
\text { kundarer, nicht tertiärer Bereich } \\
\text { Tertiärbereich }\end{array}$ & $\begin{array}{l}27 \\
41 \\
33\end{array}$ & $\begin{array}{l}21 \\
44 \\
35\end{array}$ & $\begin{array}{l}17 \\
45 \\
38\end{array}$ & $\begin{array}{l}15 \\
45 \\
40\end{array}$ & $\begin{array}{l}14 \\
48 \\
39\end{array}$ & $\begin{array}{l}11 \\
52 \\
38\end{array}$ & $\begin{array}{r}9 \\
52 \\
39\end{array}$ & $\begin{array}{l}10 \\
50 \\
40\end{array}$ & $\begin{array}{l}50 \\
27 \\
23\end{array}$ & $\begin{array}{l}39 \\
34 \\
27\end{array}$ & $\begin{array}{l}30 \\
40 \\
30\end{array}$ & $\begin{array}{l}26 \\
43 \\
31\end{array}$ \\
\hline Frankreich & $\begin{array}{l}\text { Unterhalb Sekundarbereich II } \\
\text { Sekundarbereich II bzw. postse- } \\
\text { kundarer, nicht tertiärer Bereich } \\
\text { Tertiärbereich }\end{array}$ & $\begin{array}{l}38 \\
41 \\
22\end{array}$ & $\begin{array}{l}33 \\
41 \\
25\end{array}$ & $\begin{array}{l}29 \\
42 \\
29\end{array}$ & $\begin{array}{l}27 \\
42 \\
31\end{array}$ & $\begin{array}{l}24 \\
45 \\
31\end{array}$ & $\begin{array}{l}19 \\
42 \\
40\end{array}$ & $\begin{array}{l}16 \\
41 \\
43\end{array}$ & $\begin{array}{l}17 \\
40 \\
43\end{array}$ & $\begin{array}{l}56 \\
31 \\
13\end{array}$ & $\begin{array}{l}49 \\
35 \\
16\end{array}$ & $\begin{array}{l}44 \\
37 \\
18\end{array}$ & $\begin{array}{l}41 \\
39 \\
20\end{array}$ \\
\hline Deutschland & $\begin{array}{l}\text { Unterhalb Sekundarbereich II } \\
\text { Sekundarbereich II bzw. postse- } \\
\text { kundarer, nicht tertiärer Bereich } \\
\text { Tertiärbereich }\end{array}$ & $\begin{array}{l}18 \\
58 \\
23\end{array}$ & $\begin{array}{l}17 \\
59 \\
25\end{array}$ & $\begin{array}{l}14 \\
59 \\
27\end{array}$ & $\begin{array}{l}14 \\
58 \\
28\end{array}$ & $\begin{array}{l}15 \\
63 \\
22\end{array}$ & $\begin{array}{l}16 \\
62 \\
22\end{array}$ & $\begin{array}{l}14 \\
60 \\
26\end{array}$ & $\begin{array}{l}13 \\
58 \\
29\end{array}$ & $\begin{array}{l}26 \\
54 \\
20\end{array}$ & $\begin{array}{l}21 \\
56 \\
23\end{array}$ & $\begin{array}{l}17 \\
58 \\
25\end{array}$ & $\begin{array}{l}16 \\
58 \\
26\end{array}$ \\
\hline Griechenland & $\begin{array}{l}\text { Unterhalb Sekundarbereich II } \\
\text { Sekundarbereich II bzw. postse- } \\
\text { kundarer, nicht tertiärer Bereich } \\
\text { Tertiärbereich }\end{array}$ & $\begin{array}{l}51 \\
32 \\
18\end{array}$ & $\begin{array}{l}43 \\
36 \\
21\end{array}$ & $\begin{array}{l}35 \\
41 \\
25\end{array}$ & $\begin{array}{l}32 \\
42 \\
27\end{array}$ & $\begin{array}{l}31 \\
45 \\
24\end{array}$ & $\begin{array}{l}26 \\
49 \\
26\end{array}$ & $\begin{array}{l}21 \\
48 \\
31\end{array}$ & $\begin{array}{l}17 \\
48 \\
35\end{array}$ & $\begin{array}{r}75 \\
17 \\
8\end{array}$ & $\begin{array}{l}68 \\
20 \\
12\end{array}$ & $\begin{array}{l}56 \\
27 \\
17\end{array}$ & $\begin{array}{l}50 \\
30 \\
20\end{array}$ \\
\hline Ungarn & $\begin{array}{l}\text { Unterhalb Sekundarbereich II } \\
\text { Sekundarbereich II bzw. postse- } \\
\text { kundarer, nicht tertiärer Bereich } \\
\text { Tertiärbereich }\end{array}$ & $\begin{array}{l}31 \\
55 \\
14\end{array}$ & $\begin{array}{l}24 \\
59 \\
17\end{array}$ & $\begin{array}{l}19 \\
61 \\
20\end{array}$ & $\begin{array}{l}18 \\
60 \\
22\end{array}$ & $\begin{array}{l}19 \\
67 \\
15\end{array}$ & $\begin{array}{l}15 \\
65 \\
20\end{array}$ & $\begin{array}{l}14 \\
60 \\
26\end{array}$ & $\begin{array}{l}12 \\
57 \\
30\end{array}$ & $\begin{array}{l}60 \\
28 \\
12\end{array}$ & $\begin{array}{l}39 \\
46 \\
15\end{array}$ & $\begin{array}{l}26 \\
58 \\
16\end{array}$ & $\begin{array}{l}25 \\
59 \\
15\end{array}$ \\
\hline Island & $\begin{array}{l}\text { Unterhalb Sekundarbereich II } \\
\text { Sekundarbereich II bzw. postse- } \\
\text { kundarer, nicht tertiärer Bereich } \\
\text { Tertiärbereich }\end{array}$ & $\begin{array}{l}44 \\
32 \\
24\end{array}$ & $\begin{array}{l}37 \\
32 \\
31\end{array}$ & $\begin{array}{l}33 \\
34 \\
33\end{array}$ & $\begin{array}{l}29 \\
36 \\
35\end{array}$ & $\begin{array}{l}37 \\
33 \\
30\end{array}$ & $\begin{array}{l}31 \\
33 \\
36\end{array}$ & $\begin{array}{l}28 \\
36 \\
36\end{array}$ & $\begin{array}{l}25 \\
37 \\
38\end{array}$ & $\begin{array}{l}60 \\
27 \\
13\end{array}$ & $\begin{array}{l}51 \\
28 \\
21\end{array}$ & $\begin{array}{l}45 \\
32 \\
23\end{array}$ & $\begin{array}{l}39 \\
36 \\
25\end{array}$ \\
\hline Irland & $\begin{array}{l}\text { Unterhalb Sekundarbereich II } \\
\text { Sekundarbereich II bzw. postse- } \\
\text { kundarer, nicht tertiärer Bereich } \\
\text { Tertiärbereich }\end{array}$ & $\begin{array}{l}43 \\
36 \\
22\end{array}$ & $\begin{array}{l}35 \\
35 \\
29\end{array}$ & $\begin{array}{l}27 \\
35 \\
38\end{array}$ & $\begin{array}{l}25 \\
35 \\
40\end{array}$ & $\begin{array}{l}27 \\
43 \\
30\end{array}$ & $\begin{array}{l}19 \\
40 \\
41\end{array}$ & $\begin{array}{l}14 \\
37 \\
48\end{array}$ & $\begin{array}{l}14 \\
37 \\
49\end{array}$ & $\begin{array}{l}64 \\
22 \\
13\end{array}$ & $\begin{array}{l}60 \\
23 \\
17\end{array}$ & $\begin{array}{l}50 \\
29 \\
22\end{array}$ & $\begin{array}{l}45 \\
30 \\
25\end{array}$ \\
\hline
\end{tabular}

Anmerkung: Die Spalten mit den Daten für die Jahre 2006, 2007, 2008, 2009 und 2011 und dem durchschnittlichen jährlichen Anstieg sind im Internet verfügbar (s. StatLink unten).

1. Unterbrechung der Zeitreihe zwischen 2010 und 2011, daher sind die Daten für 2011 nicht mit den vorhergehenden Jahren vergleichbar. 2. Die Zahlen für das Jahr 2012 für Estland und Slowenien in dieser Tabelle können aufgrund unterschiedlicher Datenquellen von anderen Tabellen in Indikator A1 abweichen. Die Zahlen in dieser Tabelle basieren für alle Jahre auf der EU-LFS. 3. Die Zahlen für das Jahr 2000 können nicht mit neueren Zahlen verglichen werden, da 2000 noch die frühere Klassifikation der Bildungsabschlüsse verwendet wurde.

Quelle: OECD. Argentinien, China, Indien, Indonesien, Kolumbien, Saudi-Arabien, Südafrika: Statistikinstitut der UNESCO. Lettland: Eurostat. Hinweise s. Anhang 3 unter www.oecd.org/edu/eag.htm. StatLink: http://dx.doi.org/10.1787/888933114837

Erläuterung der Kennzeichnung fehlender Daten s. Hinweise für den Leser. 


\begin{tabular}{|c|c|c|c|c|c|c|c|c|c|c|c|c|c|}
\hline & \multirow[t]{3}{*}{ Bildungsstand } & \multicolumn{4}{|c|}{ 25- bis 64-Jährige } & \multicolumn{4}{|c|}{ 25- bis 34-Jährige } & \multicolumn{4}{|c|}{ 55- bis 64-Jährige } \\
\hline & & 2000 & 2005 & 2010 & 2012 & 2000 & 2005 & 2010 & 2012 & 2000 & 2005 & 2010 & 2012 \\
\hline & & (1) & (2) & (7) & (9) & (11) & (12) & (17) & (19) & (21) & (22) & $(27)$ & (29) \\
\hline \multicolumn{14}{|c|}{ OECD-Länder } \\
\hline \multirow[t]{3}{*}{ Israel } & Unterhalb Sekundarbereich II & $\mathrm{m}$ & 21 & 18 & 15 & $\mathrm{~m}$ & 14 & 12 & 10 & $\mathrm{~m}$ & 31 & 26 & 23 \\
\hline & $\begin{array}{l}\text { Sekundarbereich II bzw. postse- } \\
\text { kundarer, nicht tertiärer Bereich }\end{array}$ & $\mathrm{m}$ & 33 & 37 & 38 & $\mathrm{~m}$ & 36 & 44 & 46 & $\mathrm{~m}$ & 26 & 29 & 31 \\
\hline & Tertiärbereich & $\mathrm{m}$ & 46 & 46 & 46 & $\mathrm{~m}$ & 50 & 44 & 44 & $\mathrm{~m}$ & 43 & 45 & 47 \\
\hline \multirow[t]{3}{*}{ Italien } & Unterhalb Sekundarbereich II & 55 & 50 & 45 & 43 & 41 & 34 & 29 & 28 & 76 & 70 & 62 & 58 \\
\hline & $\begin{array}{l}\text { Sekundarbereich II bzW. postse- } \\
\text { kundarer, nicht tertiärer Bereich }\end{array}$ & 36 & 38 & 40 & 42 & 49 & 50 & 50 & 50 & 18 & 22 & 28 & 31 \\
\hline & Tertiärbereich & 10 & 12 & 15 & 16 & 11 & 16 & 21 & 22 & 6 & 8 & 11 & 11 \\
\hline \multirow[t]{3}{*}{ Japan } & Unterhalb Sekundarbereich II & 17 & $\mathrm{~m}$ & $\mathrm{~m}$ & $\mathrm{~m}$ & 6 & $\mathrm{~m}$ & $\mathrm{~m}$ & $\mathrm{~m}$ & 37 & $\mathrm{~m}$ & $\mathrm{~m}$ & $\mathrm{~m}$ \\
\hline & $\begin{array}{l}\text { Sekundarbereich II bzw. postse- } \\
\text { kundarer, nicht tertiärer Bereich }\end{array}$ & 49 & 60 & 55 & 53 & 46 & 47 & 43 & 41 & 48 & 78 & 71 & 68 \\
\hline & Tertiärbereich & 34 & 40 & 45 & 47 & 48 & 53 & 57 & 59 & 15 & 22 & 29 & 32 \\
\hline \multirow[t]{3}{*}{ Korea } & Unterhalb Sekundarbereich II & 32 & 24 & 20 & 18 & 7 & 3 & 2 & 2 & 71 & 65 & 57 & 52 \\
\hline & $\begin{array}{l}\text { Sekundarbereich II bzw. postse- } \\
\text { kundarer, nicht tertiärer Bereich }\end{array}$ & 44 & 44 & 41 & 41 & 56 & 46 & 33 & 33 & 20 & 25 & 30 & 34 \\
\hline & Tertiärbereich & 24 & 32 & 40 & 42 & 37 & 51 & 65 & 66 & 9 & 10 & 13 & 14 \\
\hline \multirow[t]{3}{*}{ Luxemburg } & Unterhalb Sekundarbereich II & 39 & 34 & 22 & 22 & 32 & 23 & 16 & 14 & 51 & 45 & 31 & 31 \\
\hline & $\begin{array}{l}\text { Sekundarbereich II bzw. postse- } \\
\text { kundarer, nicht tertiärer Bereich }\end{array}$ & 43 & 39 & 42 & 39 & 45 & 40 & 40 & 36 & 36 & 37 & 44 & 42 \\
\hline & Tertiärbereich & 18 & 27 & 35 & 39 & 23 & 37 & 44 & 50 & 13 & 19 & 25 & 26 \\
\hline \multirow[t]{3}{*}{ Mexiko } & Unterhalb Sekundarbereich II & 71 & 68 & 65 & 63 & 63 & 62 & 57 & 54 & 87 & 84 & 78 & 75 \\
\hline & $\begin{array}{l}\text { Sekundarbereich II bzw. postse- } \\
\text { kundarer, nicht tertiärer Bereich }\end{array}$ & 14 & 17 & 18 & 19 & 20 & 20 & 21 & 22 & 6 & 8 & 10 & 12 \\
\hline & Tertiärbereich & 15 & 15 & 17 & 18 & 17 & 18 & 21 & 24 & 7 & 8 & 12 & 13 \\
\hline \multirow[t]{3}{*}{ Niederlande } & Unterhalb Sekundarbereich II & 34 & 28 & 28 & 27 & 25 & 19 & 18 & 17 & 46 & 41 & 40 & 39 \\
\hline & $\begin{array}{l}\text { Sekundarbereich II bzw. postse- } \\
\text { kundarer, nicht tertiärer Bereich }\end{array}$ & 42 & 42 & 40 & 40 & 48 & 46 & 42 & 42 & 35 & 35 & 34 & 35 \\
\hline & Tertiärbereich & 24 & 30 & 32 & 33 & 27 & 35 & 40 & 41 & 19 & 24 & 26 & 27 \\
\hline \multirow[t]{3}{*}{ Neuseeland } & Unterhalb Sekundarbereich II & 37 & 32 & 27 & 26 & 31 & 24 & 21 & 20 & 49 & 44 & 38 & 36 \\
\hline & $\begin{array}{l}\text { Sekundarbereich II bzw. postse- } \\
\text { kundarer, nicht tertiärer Bereich }\end{array}$ & 34 & 29 & 32 & 33 & 40 & 33 & 33 & 33 & 28 & 24 & 29 & 29 \\
\hline & Tertiärbereich & 29 & 39 & 41 & 41 & 29 & 43 & 46 & 47 & 23 & 32 & 34 & 35 \\
\hline \multirow[t]{3}{*}{ Norwegen $^{3}$} & Unterhalb Sekundarbereich II & 15 & 23 & 19 & 18 & 7 & 17 & 17 & 18 & 30 & 27 & 21 & 18 \\
\hline & $\begin{array}{l}\text { Sekundarbereich II bzw. postse- } \\
\text { kundarer, nicht tertiärer Bereich }\end{array}$ & 57 & 45 & 43 & 43 & 59 & 43 & 36 & 37 & 50 & 49 & 51 & 52 \\
\hline & Tertiärbereich & 28 & 33 & 37 & 39 & 35 & 41 & 47 & 45 & 20 & 24 & 27 & 30 \\
\hline \multirow[t]{3}{*}{ Polen } & Unterhalb Sekundarbereich II & 20 & 15 & 11 & 10 & 11 & 8 & 6 & 6 & 43 & 30 & 21 & 19 \\
\hline & $\begin{array}{l}\text { Sekundarbereich II bzw. postse- } \\
\text { kundarer, nicht tertiärer Bereich }\end{array}$ & 69 & 68 & 66 & 65 & 75 & 66 & 57 & 54 & 47 & 58 & 66 & 69 \\
\hline & Tertiärbereich & 11 & 17 & 22 & 25 & 14 & 26 & 37 & 41 & 10 & 13 & 13 & 13 \\
\hline \multirow[t]{3}{*}{ Portugal } & Unterhalb Sekundarbereich II & 81 & 74 & 68 & 62 & 68 & 57 & 48 & 42 & 92 & 87 & 84 & 80 \\
\hline & $\begin{array}{l}\text { Sekundarbereich II bzw. postse- } \\
\text { kundarer, nicht tertiärer Bereich }\end{array}$ & 11 & 14 & 16 & 19 & 19 & 24 & 27 & 30 & 3 & 5 & 7 & 9 \\
\hline & Tertiärbereich & 9 & 13 & 15 & 19 & 13 & 19 & 25 & 28 & 5 & 7 & 9 & 11 \\
\hline \multirow[t]{3}{*}{ Slowakei } & Unterhalb Sekundarbereich II & 16 & 12 & 9 & 8 & 6 & 7 & 6 & 6 & 38 & 23 & 17 & 14 \\
\hline & $\begin{array}{l}\text { Sekundarbereich II bzw. postse- } \\
\text { kundarer, nicht tertiärer Bereich }\end{array}$ & 73 & 74 & 74 & 73 & 82 & 77 & 70 & 67 & 54 & 65 & 71 & 72 \\
\hline & Tertiärbereich & 10 & 14 & 17 & 19 & 11 & 16 & 24 & 27 & 8 & 12 & 13 & 14 \\
\hline Slowenien ${ }^{2}$ & Unterhalb Sekundarbereich II & 25 & 20 & 17 & 15 & 15 & 9 & 7 & 6 & 39 & 31 & 28 & 26 \\
\hline & $\begin{array}{l}\text { Sekundarbereich II bzW. postse- } \\
\text { kundarer, nicht tertiärer Bereich }\end{array}$ & 59 & 60 & 60 & 59 & 66 & 67 & 62 & 59 & 49 & 53 & 56 & 57 \\
\hline & Tertiärbereich & 16 & 20 & 24 & 26 & 19 & 25 & 31 & 35 & 12 & 16 & 16 & 17 \\
\hline Spanien & Unterhalb Sekundarbereich II & 62 & 51 & 47 & 45 & 45 & 36 & 35 & 36 & 85 & 74 & 68 & 65 \\
\hline & $\begin{array}{l}\text { Sekundarbereich II bzw. postse- } \\
\text { kundarer, nicht tertiärer Bereich }\end{array}$ & 16 & 21 & 22 & 22 & 21 & 24 & 26 & 25 & 6 & 11 & 14 & 16 \\
\hline & Tertiärbereich & 23 & 28 & 31 & 32 & 34 & 40 & 39 & 39 & 10 & 14 & 18 & 19 \\
\hline Schweden & Unterhalb Sekundarbereich II & 22 & 16 & 14 & 12 & 13 & 9 & 9 & 9 & 37 & 28 & 23 & 21 \\
\hline & $\begin{array}{l}\text { Sekundarbereich II bzw. postse- } \\
\text { kundarer, nicht tertiärer Bereich }\end{array}$ & 47 & 54 & 52 & 52 & 54 & 53 & 49 & 47 & 40 & 47 & 50 & 51 \\
\hline & Tertiärbereich & 30 & 30 & 34 & 36 & 34 & 37 & 42 & 43 & 23 & 25 & 27 & 29 \\
\hline
\end{tabular}

Anmerkung: Die Spalten mit den Daten für die Jahre 2006, 2007, 2008, 2009 und 2011 und dem durchschnittlichen jährlichen Anstieg sind im Internet verfügbar (s. StatLink unten).

1. Unterbrechung der Zeitreihe zwischen 2010 und 2011, daher sind die Daten für 2011 nicht mit den vorhergehenden Jahren vergleichbar. 2. Die Zahlen für das Jahr 2012 für Estland und Slowenien in dieser Tabelle können aufgrund unterschiedlicher Datenquellen von anderen Tabellen in Indikator A1 abweichen. Die Zahlen in dieser Tabelle basieren für alle Jahre auf der EU-LFS. 3. Die Zahlen für das Jahr 2000 können nicht mit neueren Zahlen verglichen werden, da 2000 noch die frühere Klassifikation der Bildungsabschlüsse verwendet wurde.

Quelle: OECD. Argentinien, China, Indien, Indonesien, Kolumbien, Saudi-Arabien, Südafrika: Statistikinstitut der UNESCO. Lettland: Eurostat. Hinweise s. Anhang 3 unter www.oecd.org/edu/eag.htm. StatLink: http://dx.doi.org/10.1787/888933114837

Erläuterung der Kennzeichnung fehlender Daten s. Hinweise für den Leser. 


\begin{tabular}{|c|c|c|c|c|c|c|c|c|c|c|c|c|c|}
\hline & \multirow[t]{3}{*}{ Bildungsstand } & \multicolumn{4}{|c|}{ 25- bis 64-Jährige } & \multicolumn{4}{|c|}{ 25- bis 34-Jährige } & \multicolumn{4}{|c|}{ 55- bis 64-Jährige } \\
\hline & & 2000 & 2005 & 2010 & 2012 & 2000 & 2005 & 2010 & 2012 & 2000 & 2005 & 2010 & 2012 \\
\hline & & (1) & (2) & (7) & (9) & (11) & (12) & (17) & (19) & (21) & (22) & $(27)$ & (29) \\
\hline \multicolumn{14}{|l|}{ OECD-Länder } \\
\hline \multirow[t]{3}{*}{ Schweiz } & Unterhalb Sekundarbereich II & 16 & 15 & 14 & 14 & 10 & 10 & 11 & 11 & 26 & 21 & 19 & 18 \\
\hline & $\begin{array}{l}\text { Sekundarbereich II bzw. postse- } \\
\text { kundarer, nicht tertiärer Bereich }\end{array}$ & 60 & 56 & 51 & 50 & 64 & 59 & 49 & 49 & 55 & 57 & 53 & 53 \\
\hline & Tertiärbereich & 24 & 29 & 35 & 37 & 26 & 31 & 40 & 41 & 18 & 22 & 28 & 29 \\
\hline \multirow[t]{3}{*}{ Türkei } & Unterhalb Sekundarbereich II & 77 & 72 & 69 & 66 & 72 & 63 & 58 & 54 & 87 & 84 & 81 & 79 \\
\hline & $\begin{array}{l}\text { Sekundarbereich II bzw. postse- } \\
\text { kundarer, nicht tertiärer Bereich }\end{array}$ & 15 & 18 & 18 & 19 & 19 & 24 & 25 & 25 & 7 & 8 & 9 & 10 \\
\hline & Tertiärbereich & 8 & 10 & 13 & 15 & 9 & 13 & 17 & 21 & 6 & 8 & 9 & 10 \\
\hline \multirow{3}{*}{$\begin{array}{l}\text { Vereinigtes } \\
\text { Königreich }\end{array}$} & Unterhalb Sekundarbereich II & 37 & 33 & 25 & 22 & 33 & 27 & 17 & 15 & 45 & 40 & 35 & 31 \\
\hline & $\begin{array}{l}\text { Sekundarbereich II bzw. postse- } \\
\text { kundarer, nicht tertiärer Bereich }\end{array}$ & 37 & 37 & 37 & 37 & 38 & 38 & 37 & 37 & 37 & 36 & 35 & 36 \\
\hline & Tertiärbereich & 26 & 30 & 38 & 41 & 29 & 35 & 46 & 48 & 19 & 24 & 30 & 33 \\
\hline \multirow[t]{3}{*}{ Vereinigte Staaten } & Unterhalb Sekundarbereich II & 13 & 12 & 11 & 11 & 12 & 13 & 12 & 11 & 18 & 14 & 10 & 10 \\
\hline & $\begin{array}{l}\text { Sekundarbereich II bzw. postse- } \\
\text { kundarer, nicht tertiärer Bereich }\end{array}$ & 51 & 49 & 47 & 46 & 50 & 47 & 46 & 45 & 52 & 49 & 49 & 48 \\
\hline & Tertiärbereich & 36 & 39 & 42 & 43 & 38 & 39 & 42 & 44 & 30 & 37 & 41 & 42 \\
\hline \multirow[t]{3}{*}{ OECD-Durchschnitt } & Unterhalb Sekundarbereich II & 34 & 30 & 26 & 24 & 24 & 21 & 18 & 17 & 51 & 43 & 38 & 35 \\
\hline & $\begin{array}{l}\text { Sekundarbereich II bzw. postse- } \\
\text { kundarer, nicht tertiärer Bereich }\end{array}$ & 44 & 44 & 44 & 44 & 49 & 47 & 45 & 44 & 34 & 38 & 40 & 42 \\
\hline & Tertiärbereich & 22 & 27 & 31 & 33 & 26 & 33 & 38 & 40 & 15 & 20 & 23 & 25 \\
\hline \multirow{3}{*}{$\begin{array}{l}\text { OECD-Durchschnitt } \\
\text { für Länder mit ver- } \\
\text { fügbaren Daten für } \\
\text { alle Referenzjahre }\end{array}$} & Unterhalb Sekundarbereich II & 35 & 30 & 26 & 25 & 25 & 21 & 19 & 18 & 51 & 44 & 38 & 35 \\
\hline & $\begin{array}{l}\text { Sekundarbereich II bzw. postse- } \\
\text { kundarer, nicht tertiärer Bereich }\end{array}$ & 44 & 44 & 44 & 44 & 49 & 47 & 45 & 44 & 34 & 37 & 40 & 41 \\
\hline & Tertiärbereich & 22 & 26 & 30 & 32 & 26 & 32 & 37 & 39 & 15 & 19 & 22 & 24 \\
\hline \multirow[t]{3}{*}{ EU21-Durchschnitt } & Unterhalb Sekundarbereich II & 34 & 29 & 25 & 23 & 23 & 19 & 17 & 16 & 51 & 42 & 36 & 34 \\
\hline & $\begin{array}{l}\text { Sekundarbereich II bzw. postse- } \\
\text { kundarer, nicht tertiärer Bereich }\end{array}$ & 46 & 48 & 48 & 48 & 53 & 52 & 49 & 47 & 35 & 40 & 43 & 44 \\
\hline & Tertiärbereich & 20 & 24 & 28 & 29 & 24 & 29 & 35 & 37 & 14 & 18 & 20 & 22 \\
\hline \multicolumn{14}{|l|}{ Partnerländer } \\
\hline Argentinien & & $\mathrm{m}$ & $\mathrm{m}$ & $\mathrm{m}$ & $\mathrm{m}$ & $\mathrm{m}$ & $\mathrm{m}$ & $\mathrm{m}$ & $\mathrm{m}$ & $\mathrm{m}$ & $\mathrm{m}$ & $\mathrm{m}$ & $\mathrm{m}$ \\
\hline \multirow[t]{3}{*}{ Brasilien } & Unterhalb Sekundarbereich II & $\mathrm{m}$ & $\mathrm{m}$ & $\mathrm{m}$ & 55 & $\mathrm{~m}$ & $\mathrm{~m}$ & $\mathrm{~m}$ & 41 & $\mathrm{~m}$ & $\mathrm{~m}$ & $\mathrm{~m}$ & 73 \\
\hline & $\begin{array}{l}\text { Sekundarbereich II bzw. postse- } \\
\text { kundarer, nicht tertiärer Bereich }\end{array}$ & $\mathrm{m}$ & m & $\mathrm{m}$ & 32 & m & m & $\mathrm{m}$ & 44 & m & $\mathrm{m}$ & $\mathrm{m}$ & 17 \\
\hline & Tertiärbereich & $\mathrm{m}$ & $\mathrm{m}$ & $\mathrm{m}$ & 13 & $\mathrm{~m}$ & $\mathrm{~m}$ & $\mathrm{~m}$ & 14 & $\mathrm{~m}$ & $\mathrm{~m}$ & $\mathrm{~m}$ & 10 \\
\hline \multirow[t]{3}{*}{ China } & Unterhalb Sekundarbereich II & $\mathrm{m}$ & $\mathrm{m}$ & 78 & $\mathrm{~m}$ & $\mathrm{~m}$ & $\mathrm{~m}$ & $\mathrm{~m}$ & $\mathrm{~m}$ & $\mathrm{~m}$ & $\mathrm{~m}$ & $\mathrm{~m}$ & $\mathrm{~m}$ \\
\hline & $\begin{array}{l}\text { Sekundarbereich II bzw. postse- } \\
\text { kundarer, nicht tertiärer Bereich }\end{array}$ & $\mathrm{m}$ & m & 19 & $\mathrm{~m}$ & m & m & m & m & m & $\mathrm{m}$ & m & $\mathrm{m}$ \\
\hline & Tertiärbereich & $\mathrm{m}$ & $\mathrm{m}$ & 4 & $\mathrm{~m}$ & $\mathrm{~m}$ & $\mathrm{~m}$ & $\mathrm{~m}$ & $\mathrm{~m}$ & $\mathrm{~m}$ & $\mathrm{~m}$ & $\mathrm{~m}$ & $\mathrm{~m}$ \\
\hline Kolumbien & & $\mathrm{m}$ & $\mathrm{m}$ & $\mathrm{m}$ & $\mathrm{m}$ & $\mathrm{m}$ & $\mathrm{m}$ & $\mathrm{m}$ & $\mathrm{m}$ & $\mathrm{m}$ & $\mathrm{m}$ & $\mathrm{m}$ & $\mathrm{m}$ \\
\hline Indien & & $\mathrm{m}$ & $\mathrm{m}$ & $\mathrm{m}$ & $\mathrm{m}$ & $\mathrm{m}$ & $\mathrm{m}$ & $\mathrm{m}$ & $\mathrm{m}$ & $\mathrm{m}$ & $\mathrm{m}$ & $\mathrm{m}$ & $\mathrm{m}$ \\
\hline Indonesien & & $\mathrm{m}$ & $\mathrm{m}$ & $\mathrm{m}$ & $\mathrm{m}$ & $\mathrm{m}$ & $\mathrm{m}$ & $\mathrm{m}$ & $\mathrm{m}$ & $\mathrm{m}$ & $\mathrm{m}$ & $\mathrm{m}$ & $\mathrm{m}$ \\
\hline \multirow[t]{3}{*}{ Lettland } & Unterhalb Sekundarbereich II & $\mathrm{m}$ & $\mathrm{m}$ & $\mathrm{m}$ & 11 & $\mathrm{~m}$ & $\mathrm{~m}$ & $\mathrm{~m}$ & 15 & $\mathrm{~m}$ & $\mathrm{~m}$ & $\mathrm{~m}$ & 13 \\
\hline & $\begin{array}{l}\text { Sekundarbereich II bzw. postse- } \\
\text { kundarer, nicht tertiärer Bereich }\end{array}$ & $\mathrm{m}$ & $\mathrm{m}$ & $\mathrm{m}$ & 60 & $\mathrm{~m}$ & $\mathrm{~m}$ & $\mathrm{~m}$ & 47 & $\mathrm{~m}$ & $\mathrm{~m}$ & $\mathrm{~m}$ & 65 \\
\hline & Tertiärbereich & $\mathrm{m}$ & $\mathrm{m}$ & $\mathrm{m}$ & 29 & $\mathrm{~m}$ & $\mathrm{~m}$ & $\mathrm{~m}$ & 39 & $\mathrm{~m}$ & $\mathrm{~m}$ & $\mathrm{~m}$ & 22 \\
\hline \multirow{3}{*}{$\begin{array}{l}\text { Russische } \\
\text { Föderation }\end{array}$} & Unterhalb Sekundarbereich II & $\mathrm{m}$ & $\mathrm{m}$ & $\mathrm{m}$ & 6 & $\mathrm{~m}$ & $\mathrm{~m}$ & $\mathrm{~m}$ & 6 & $\mathrm{~m}$ & $\mathrm{~m}$ & $\mathrm{~m}$ & 8 \\
\hline & $\begin{array}{l}\text { Sekundarbereich II bzw. postse- } \\
\text { kundarer, nicht tertiärer Bereich }\end{array}$ & $\mathrm{m}$ & $\mathrm{m}$ & $\mathrm{m}$ & 41 & $\mathrm{~m}$ & $\mathrm{~m}$ & $\mathrm{~m}$ & 37 & $\mathrm{~m}$ & $\mathrm{~m}$ & $\mathrm{~m}$ & 42 \\
\hline & Tertiärbereich & $\mathrm{m}$ & $\mathrm{m}$ & $\mathrm{m}$ & 53 & $\mathrm{~m}$ & $\mathrm{~m}$ & $\mathrm{~m}$ & 57 & $\mathrm{~m}$ & $\mathrm{~m}$ & $\mathrm{~m}$ & 49 \\
\hline Saudi-Arabien & & $\mathrm{m}$ & $\mathrm{m}$ & $\mathrm{m}$ & $\mathrm{m}$ & $\mathrm{m}$ & $\mathrm{m}$ & $\mathrm{m}$ & $\mathrm{m}$ & $\mathrm{m}$ & $\mathrm{m}$ & $\mathrm{m}$ & $\mathrm{m}$ \\
\hline \multirow[t]{3}{*}{ Südafrika } & Unterhalb Sekundarbereich II & $\mathrm{m}$ & $\mathrm{m}$ & $\mathrm{m}$ & 39 & $\mathrm{~m}$ & $\mathrm{~m}$ & $\mathrm{~m}$ & $\mathrm{~m}$ & $\mathrm{~m}$ & $\mathrm{~m}$ & $\mathrm{~m}$ & $\mathrm{~m}$ \\
\hline & $\begin{array}{l}\text { Sekundarbereich II bzw. postse- } \\
\text { kundarer, nicht tertiärer Bereich }\end{array}$ & $\mathrm{m}$ & $\mathrm{m}$ & $\mathrm{m}$ & 54 & $\mathrm{~m}$ & $\mathrm{~m}$ & $\mathrm{~m}$ & m & m & $\mathrm{m}$ & m & $\mathrm{m}$ \\
\hline & Tertiärbereich & $\mathrm{m}$ & $\mathrm{m}$ & $\mathrm{m}$ & 6 & $\mathrm{~m}$ & $\mathrm{~m}$ & $\mathrm{~m}$ & $\mathrm{~m}$ & $\mathrm{~m}$ & $\mathrm{~m}$ & $\mathrm{~m}$ & $\mathrm{~m}$ \\
\hline G20-Durchschnitt & & $\mathbf{m}$ & $\mathbf{m}$ & $\mathbf{m}$ & $\mathbf{m}$ & $\mathbf{m}$ & m & m & $\mathbf{m}$ & m & $\mathbf{m}$ & $\mathbf{m}$ & $\mathbf{m}$ \\
\hline
\end{tabular}

Anmerkung: Die Spalten mit den Daten für die Jahre 2006, 2007, 2008, 2009 und 2011 und dem durchschnittlichen jährlichen Anstieg sind im Internet verfügbar (s. StatLink unten).

1. Unterbrechung der Zeitreihe zwischen 2010 und 2011, daher sind die Daten für 2011 nicht mit den vorhergehenden Jahren vergleichbar. 2. Die Zahlen für das Jahr 2012 für Estland und Slowenien in dieser Tabelle können aufgrund unterschiedlicher Datenquellen von anderen Tabellen in Indikator A1 abweichen. Die Zahlen in dieser Tabelle basieren für alle Jahre auf der EU-LFS. 3. Die Zahlen für das Jahr 2000 können nicht mit neueren Zahlen verglichen werden, da 2000 noch die frühere Klassifikation der Bildungsabschlüsse verwendet wurde.

Quelle: OECD. Argentinien, China, Indien, Indonesien, Kolumbien, Saudi-Arabien, Südafrika: Statistikinstitut der UNESCO. Lettland: Eurostat. Hinweise s. Anhang 3 unter www.oecd.org/edu/eag.htm. StatLink: http://dx.doi.org/10.1787/888933114837

Erläuterung der Kennzeichnung fehlender Daten s. Hinweise für den Leser. 
Erwachsene mit einem Abschluss im Sekundarbereich II, nach Ausrichtung des Bildungsgangs und Geschlecht (2012)

Abschluss im Sekundarbereich II bzw. postsekundaren, nicht tertiären Bereich, 25- bis 64-Jährige

\begin{tabular}{|c|c|c|c|c|c|c|c|c|c|}
\hline & \multicolumn{9}{|c|}{ Sekundarbereich II bzw. postsekundarer, nicht tertiärer Bereich } \\
\hline & \multicolumn{3}{|c|}{ Berufsbildend } & \multicolumn{3}{|c|}{ Allgemeinbildend } & \multicolumn{3}{|c|}{${\text { Gesamt }{ }^{1}}$} \\
\hline & $\mathrm{M}+\mathrm{F}$ & Männer & Frauen & $\mathrm{M}+\mathrm{F}$ & Männer & Frauen & $\mathrm{M}+\mathrm{F}$ & Männer & Frauen \\
\hline & (1) & (2) & (3) & (4) & (5) & (6) & (7) & (8) & (9) \\
\hline \multicolumn{10}{|l|}{ OECD-Länder } \\
\hline Australien & 19 & 25 & 13 & 16 & 15 & 17 & 35 & 40 & 30 \\
\hline Österreich & 58 & 61 & 54 & 6 & 5 & 6 & 63 & 66 & 60 \\
\hline Belgien & 26 & 28 & 23 & 11 & 10 & 12 & 36 & 38 & 35 \\
\hline Kanada & 12 & 15 & 8 & 25 & 25 & 24 & 36 & 41 & 32 \\
\hline Chile $^{2}$ & 8 & 8 & 8 & 31 & 32 & 31 & 40 & 40 & 39 \\
\hline Tschechien & 73 & 76 & 70 & $\mathrm{n}$ & $\mathrm{n}$ & $\mathrm{n}$ & 73 & 76 & 70 \\
\hline Dänemark & 42 & 47 & 38 & 2 & 2 & 2 & 43 & 48 & 38 \\
\hline Estland & 32 & 38 & 28 & 20 & 21 & 19 & 53 & 59 & 47 \\
\hline Finnland & 38 & 41 & 34 & 7 & 8 & 6 & 45 & 49 & 41 \\
\hline Frankreich & 30 & 35 & 26 & 11 & 9 & 13 & 42 & 44 & 39 \\
\hline Deutschland ${ }^{3}$ & 55 & 55 & 56 & 3 & 3 & 3 & 58 & 58 & 58 \\
\hline Griechenland & 15 & 18 & 12 & 27 & 24 & 29 & 42 & 42 & 42 \\
\hline Ungarn & 51 & 60 & 43 & 9 & 6 & 11 & 60 & 66 & 55 \\
\hline Island & 28 & 36 & 19 & 10 & 8 & 11 & 36 & 44 & 28 \\
\hline Irland & 13 & 14 & 12 & 23 & 23 & 23 & 35 & 36 & 34 \\
\hline Israel & 9 & 11 & 7 & 29 & 31 & 27 & 38 & 42 & 35 \\
\hline Italien & 32 & 36 & 28 & 10 & 6 & 13 & 42 & 42 & 41 \\
\hline Japan & $x(7)$ & $x(8)$ & $x(9)$ & $x(7)$ & $x(8)$ & $x(9)$ & 53 & 53 & 54 \\
\hline Korea & $x(7)$ & $x(8)$ & $x(9)$ & $x(7)$ & $x(8)$ & $x(9)$ & 41 & 41 & 41 \\
\hline Luxemburg & 41 & 40 & 42 & 3 & 3 & 4 & 39 & 38 & 40 \\
\hline Mexiko & $x(7)$ & $x(8)$ & $x(9)$ & $x(7)$ & $x(8)$ & $x(9)$ & 19 & 19 & 20 \\
\hline Niederlande & 32 & 32 & 32 & 7 & 7 & 7 & 40 & 41 & 40 \\
\hline Neuseeland & 25 & 31 & 19 & 9 & 8 & 9 & 33 & 39 & 28 \\
\hline Norwegen & $x(7)$ & $x(8)$ & $x(9)$ & $x(7)$ & $x(8)$ & $x(9)$ & 43 & 48 & 39 \\
\hline Polen & $x(7)$ & $x(8)$ & $x(9)$ & $x(7)$ & $x(8)$ & $x(9)$ & 65 & 69 & 61 \\
\hline Portugal & $x(7)$ & $x(8)$ & $x(9)$ & $x(7)$ & $x(8)$ & $x(9)$ & 19 & 19 & 20 \\
\hline Slowakei & 68 & 74 & 63 & 4 & 3 & 6 & 73 & 77 & 69 \\
\hline Slowenien & 54 & 61 & 46 & 5 & 4 & 6 & 59 & 65 & 52 \\
\hline Spanien & 9 & 8 & 9 & 14 & 14 & 13 & 22 & 22 & 22 \\
\hline Schweden & 33 & 37 & 28 & 10 & 10 & 10 & 52 & 56 & 48 \\
\hline Schweiz ${ }^{4}$ & 38 & 36 & 40 & 6 & 5 & 7 & 50 & 46 & 53 \\
\hline Türkei & 9 & 10 & 6 & 10 & 11 & 9 & 19 & 21 & 15 \\
\hline Vereinigtes Königreich & $x(7)$ & $x(8)$ & $\mathrm{x}(9)$ & $x(7)$ & $x(8)$ & $x(9)$ & 37 & 39 & 35 \\
\hline Vereinigte Staaten & $x(7)$ & $x(8)$ & $\mathrm{x}(9)$ & $x(7)$ & $x(8)$ & $x(9)$ & 46 & 48 & 45 \\
\hline OECD-Durchschnitt & 33 & 36 & 29 & 12 & 11 & 12 & 44 & 46 & 41 \\
\hline EU21-Durchschnitt & 39 & 42 & 36 & 10 & 9 & 10 & 48 & 50 & 45 \\
\hline \multicolumn{10}{|l|}{ Partnerländer } \\
\hline Argentinien & $\mathrm{m}$ & $\mathrm{m}$ & $\mathrm{m}$ & $\mathrm{m}$ & $\mathrm{m}$ & $\mathrm{m}$ & $\mathrm{m}$ & $\mathrm{m}$ & $\mathrm{m}$ \\
\hline Brasilien & $x(7)$ & $x(8)$ & $x(9)$ & $x(7)$ & & & 32 & 31 & 33 \\
\hline China & $\mathrm{m}$ & $\mathrm{m}$ & $\mathrm{m}$ & $\mathrm{m}$ & $\mathrm{m}$ & $\mathrm{m}$ & $\mathrm{m}$ & $\mathrm{m}$ & $\mathrm{m}$ \\
\hline Kolumbien & $\mathrm{m}$ & $\mathrm{m}$ & $\mathrm{m}$ & $\mathrm{m}$ & $\mathrm{m}$ & $\mathrm{m}$ & $\mathrm{m}$ & $\mathrm{m}$ & $\mathrm{m}$ \\
\hline Indien & $\mathrm{m}$ & $\mathrm{m}$ & $\mathrm{m}$ & $\mathrm{m}$ & $\mathrm{m}$ & $\mathrm{m}$ & $\mathrm{m}$ & $\mathrm{m}$ & $\mathrm{m}$ \\
\hline Indonesien & $\mathrm{m}$ & $\mathrm{m}$ & $\mathrm{m}$ & $\mathrm{m}$ & $\mathrm{m}$ & $\mathrm{m}$ & $\mathrm{m}$ & $\mathrm{m}$ & $\mathrm{m}$ \\
\hline Lettland & 35 & 39 & 31 & 25 & 25 & 24 & 60 & 64 & 56 \\
\hline Russische Föderation & 19 & 24 & 15 & 21 & 24 & 20 & 41 & 48 & 35 \\
\hline Saudi-Arabien & $\mathrm{m}$ & $\mathrm{m}$ & $\mathrm{m}$ & $\mathrm{m}$ & $\mathrm{m}$ & $\mathrm{m}$ & $\mathrm{m}$ & $\mathrm{m}$ & $\mathrm{m}$ \\
\hline Südafrika & $\mathrm{m}$ & $\mathrm{m}$ & $\mathrm{m}$ & $\mathrm{m}$ & $\mathrm{m}$ & $\mathrm{m}$ & $\mathrm{m}$ & $\mathrm{m}$ & $\mathrm{m}$ \\
\hline G20-Durchschnitt & m & m & m & m & $\mathbf{m}$ & m & m & m & $\mathbf{m}$ \\
\hline
\end{tabular}

1. Die Zahlen stehen für einen der folgenden Anteile: die kombinierten Anteile von Absolventen berufsbildender und allgemeinbildender Bildungsgänge, die kombinierten Anteile von Absolventen beider Arten von Bildungsgängen und von Bildungsgängen, für die keine Ausrichtung angegeben ist, oder den Anteil von Absolventen von Bildungsgängen, für die keine Ausrichtung angegeben ist. Die Zahlen in diesen Spalten entsprechen denjenigen für Absolventen des Sekundarbereichs II bzw. postsekundaren, nicht tertiären Bereichs in Tabelle A1.4a und A1.4b. 2. Referenzjahr 2011. 3. In Deutschland entspricht ein Abschluss auf ISCED-Stufe $4 A$ einem Abschluss sowohl eines allgemeinbildenden als auch eines berufsbildenden Bildungsgangs. Absolventen mit einem derartigen Abschluss wurden in dieser Tabelle den berufsbildenden Bildungsgängen zugeordnet. 4. Absolventen, die in der Schweiz einen Abschluss auf ISCED-Stufe 4 erworben haben, sind nur in der Gesamtzahl enthalten, da für Abschlüsse auf dieser ISCED-Stufe keine Aufgliederung nach Ausrichtung vorliegt.

Quelle: OECD. Argentinien, China, Indien, Indonesien, Kolumbien, Saudi-Arabien, Südafrika: Statistikinstitut der UNESCO. Lettland: Eurostat.

Hinweise s. Anhang 3 unter www.oecd.org/edu/eag.htm. StatLink: http://dx.doi.org/10.1787/888933114856

Erläuterung der Kennzeichnung fehlender Daten s. Hinweise für den Leser. 
Tabelle A1.6a (L)

Bildungsstand 25- bis 64-Jähriger, nach Lesekompetenzstufe (2012)

1 Lesekompetenz in der Erhebung zu den grundlegenden Kompetenzen Erwachsener

\begin{tabular}{|c|c|c|c|c|c|c|c|c|c|}
\hline & \multirow[t]{3}{*}{$\begin{array}{l}\text { Lese- } \\
\text { kompetenz- } \\
\text { stufe }\end{array}$} & \multicolumn{2}{|c|}{$\begin{array}{c}\text { Unterhalb } \\
\text { Sekundarbereich II }\end{array}$} & \multicolumn{2}{|c|}{$\begin{array}{l}\text { Sekundarbereich II } \\
\text { bzw. postsekundarer, } \\
\text { nicht tertiärer Bereich }\end{array}$} & \multicolumn{2}{|c|}{ Tertiärbereich } & \multicolumn{2}{|c|}{$\begin{array}{c}\text { Alle Bildungsbereiche } \\
\text { zusammen }\end{array}$} \\
\hline & & $\%$ & S.F. & $\%$ & S.F. & $\%$ & S.F. & $\%$ & S.F. \\
\hline & & (1) & (2) & (3) & (4) & (5) & (6) & (7) & (8) \\
\hline $\begin{array}{l}\text { OECD } \\
\text { Nationale Ein }\end{array}$ & & & & & & & & & \\
\hline Australien & $\begin{array}{r}0 / 1 \\
2 \\
3 \\
4 / 5\end{array}$ & $\begin{array}{r}28 \\
40 \\
28 \\
4\end{array}$ & $\begin{array}{l}(1,6) \\
(1,9) \\
(1,7) \\
(0,7)\end{array}$ & $\begin{array}{l}11 \\
33 \\
44 \\
13\end{array}$ & $\begin{array}{l}(1,0) \\
(1,7) \\
(1,8) \\
(1,4)\end{array}$ & $\begin{array}{r}5 \\
19 \\
45 \\
32\end{array}$ & $\begin{array}{l}(0,5) \\
(1,4) \\
(1,8) \\
(1,5)\end{array}$ & $\begin{array}{l}13 \\
29 \\
40 \\
18\end{array}$ & $\begin{array}{l}(0,6) \\
(0,8) \\
(1,1) \\
(0,8)\end{array}$ \\
\hline Österreich & $\begin{array}{r}0 / 1 \\
2 \\
3 \\
4 / 5\end{array}$ & $\begin{array}{r}35 \\
45 \\
19 \\
1\end{array}$ & $\begin{array}{l}(2,2) \\
(2,5) \\
(2,3) \\
(0,6)\end{array}$ & $\begin{array}{r}14 \\
42 \\
38 \\
6\end{array}$ & $\begin{array}{l}(0,8) \\
(1,4) \\
(1,4) \\
(0,6)\end{array}$ & $\begin{array}{r}4 \\
24 \\
51 \\
21\end{array}$ & $\begin{array}{l}(0,9) \\
(1,8) \\
(2,0) \\
(1,5)\end{array}$ & $\begin{array}{r}16 \\
39 \\
37 \\
8\end{array}$ & $\begin{array}{l}(0,7) \\
(1,0) \\
(1,0) \\
(0,5)\end{array}$ \\
\hline Kanada & $\begin{array}{r}0 / 1 \\
2 \\
3 \\
4 / 5\end{array}$ & $\begin{array}{r}53 \\
35 \\
12 \\
1\end{array}$ & $\begin{array}{l}(2,4) \\
(2,4) \\
(1,3) \\
(0,4)\end{array}$ & $\begin{array}{r}18 \\
39 \\
35 \\
8\end{array}$ & $\begin{array}{l}(0,9) \\
(1,1) \\
(1,1) \\
(0,8)\end{array}$ & $\begin{array}{r}9 \\
26 \\
43 \\
22\end{array}$ & $\begin{array}{l}(0,5) \\
(0,7) \\
(1,0) \\
(0,9)\end{array}$ & $\begin{array}{l}17 \\
32 \\
37 \\
14\end{array}$ & $\begin{array}{l}(0,5) \\
(0,7) \\
(0,7) \\
(0,6)\end{array}$ \\
\hline Tschechien & $\begin{array}{r}0 / 1 \\
2 \\
3 \\
4 / 5\end{array}$ & $\begin{array}{r}33 \\
46 \\
19 \\
2\end{array}$ & $\begin{array}{l}(4,6) \\
(6,0) \\
(4,4) \\
(1,3)\end{array}$ & $\begin{array}{r}12 \\
43 \\
40 \\
5\end{array}$ & $\begin{array}{l}(1,1) \\
(2,4) \\
(2,0) \\
(0,7)\end{array}$ & $\begin{array}{r}2 \\
18 \\
57 \\
24\end{array}$ & $\begin{array}{l}(0,9) \\
(2,9) \\
(3,8) \\
(3,0)\end{array}$ & $\begin{array}{r}12 \\
38 \\
41 \\
8\end{array}$ & $\begin{array}{l}(0,9) \\
(1,9) \\
(1,8) \\
(0,8)\end{array}$ \\
\hline Dänemark & $\begin{array}{r}0 / 1 \\
2 \\
3 \\
4 / 5\end{array}$ & $\begin{array}{r}39 \\
40 \\
20 \\
2\end{array}$ & $\begin{array}{l}(2,3) \\
(2,2) \\
(1,9) \\
(0,7)\end{array}$ & $\begin{array}{r}16 \\
42 \\
37 \\
5\end{array}$ & $\begin{array}{l}(1,0) \\
(1,5) \\
(1,5) \\
(0,7)\end{array}$ & $\begin{array}{r}6 \\
23 \\
52 \\
19\end{array}$ & $\begin{array}{l}(0,5) \\
(1,2) \\
(1,4) \\
(1,3)\end{array}$ & $\begin{array}{l}16 \\
34 \\
40 \\
10\end{array}$ & $\begin{array}{l}(0,6) \\
(0,9) \\
(0,8) \\
(0,6)\end{array}$ \\
\hline Estland & $\begin{array}{r}0 / 1 \\
2 \\
3 \\
4 / 5\end{array}$ & $\begin{array}{r}33 \\
42 \\
23 \\
2\end{array}$ & $\begin{array}{l}(2,1) \\
(2,7) \\
(2,2) \\
(0,8)\end{array}$ & $\begin{array}{r}16 \\
40 \\
38 \\
7\end{array}$ & $\begin{array}{l}(1,0) \\
(1,1) \\
(1,1) \\
(0,7)\end{array}$ & $\begin{array}{r}7 \\
28 \\
47 \\
19\end{array}$ & $\begin{array}{l}(0,6) \\
(1,1) \\
(1,6) \\
(1,2)\end{array}$ & $\begin{array}{l}14 \\
35 \\
40 \\
11\end{array}$ & $\begin{array}{l}(0,6) \\
(0,7) \\
(1,0) \\
(0,7)\end{array}$ \\
\hline Finnland & $\begin{array}{r}0 / 1 \\
2 \\
3 \\
4 / 5\end{array}$ & $\begin{array}{r}31 \\
41 \\
25 \\
4\end{array}$ & $\begin{array}{l}(2,5) \\
(2,6) \\
(2,3) \\
(1,1)\end{array}$ & $\begin{array}{l}13 \\
33 \\
40 \\
14\end{array}$ & $\begin{array}{l}(0,9) \\
(1,6) \\
(1,6) \\
(1,0)\end{array}$ & $\begin{array}{r}4 \\
16 \\
44 \\
37\end{array}$ & $\begin{array}{l}(0,5) \\
(1,1) \\
(1,4) \\
(1,2)\end{array}$ & $\begin{array}{l}11 \\
27 \\
40 \\
22\end{array}$ & $\begin{array}{l}(0,5) \\
(0,9) \\
(0,9) \\
(0,6)\end{array}$ \\
\hline Frankreich & $\begin{array}{r}0 / 1 \\
2 \\
3 \\
4 / 5\end{array}$ & $\begin{array}{r}49 \\
37 \\
13 \\
1\end{array}$ & $\begin{array}{l}(1,3) \\
(1,5) \\
(1,1) \\
(0,3)\end{array}$ & $\begin{array}{r}20 \\
45 \\
31 \\
3\end{array}$ & $\begin{array}{l}(1,0) \\
(1,1) \\
(1,0) \\
(0,4)\end{array}$ & $\begin{array}{r}5 \\
24 \\
52 \\
19\end{array}$ & $\begin{array}{l}(0,6) \\
(1,3) \\
(1,3) \\
(1,1)\end{array}$ & $\begin{array}{r}23 \\
37 \\
33 \\
7\end{array}$ & $\begin{array}{l}(0,6) \\
(0,8) \\
(0,7) \\
(0,4)\end{array}$ \\
\hline Deutschland & $\begin{array}{r}0 / 1 \\
2 \\
3 \\
4 / 5\end{array}$ & $\begin{array}{r}55 \\
35 \\
9 \\
1\end{array}$ & $\begin{array}{l}(3,7) \\
(3,8) \\
(2,0) \\
(0,5)\end{array}$ & $\begin{array}{r}20 \\
42 \\
33 \\
6\end{array}$ & $\begin{array}{l}(1,1) \\
(1,6) \\
(1,3) \\
(0,7)\end{array}$ & $\begin{array}{r}6 \\
25 \\
49 \\
20\end{array}$ & $\begin{array}{l}(0,8) \\
(1,6) \\
(1,6) \\
(1,3)\end{array}$ & $\begin{array}{l}18 \\
35 \\
36 \\
10\end{array}$ & $\begin{array}{l}(0,8) \\
(1,1) \\
(1,0) \\
(0,7)\end{array}$ \\
\hline Irland & $\begin{array}{r}0 / 1 \\
2 \\
3 \\
4 / 5\end{array}$ & $\begin{array}{r}40 \\
43 \\
16 \\
1\end{array}$ & $\begin{array}{l}(2,3) \\
(2,4) \\
(1,5) \\
(0,4)\end{array}$ & $\begin{array}{r}14 \\
42 \\
38 \\
5\end{array}$ & $\begin{array}{l}(1,2) \\
(1,6) \\
(1,8) \\
(0,9)\end{array}$ & $\begin{array}{r}5 \\
27 \\
49 \\
19\end{array}$ & $\begin{array}{l}(0,7) \\
(1,5) \\
(1,5) \\
(1,4)\end{array}$ & $\begin{array}{r}18 \\
37 \\
36 \\
9\end{array}$ & $\begin{array}{l}(0,9) \\
(0,9) \\
(0,9) \\
(0,6)\end{array}$ \\
\hline Italien & $\begin{array}{r}0 / 1 \\
2 \\
3 \\
4 / 5\end{array}$ & $\begin{array}{r}42 \\
44 \\
13 \\
n\end{array}$ & $\begin{array}{l}(2,0) \\
(1,7) \\
(1,2) \\
(0,3)\end{array}$ & $\begin{array}{r}17 \\
45 \\
35 \\
4\end{array}$ & $\begin{array}{l}(1,3) \\
(1,6) \\
(1,8) \\
(0,7)\end{array}$ & $\begin{array}{r}9 \\
31 \\
48 \\
12\end{array}$ & $\begin{array}{l}(1,3) \\
(2,3) \\
(2,6) \\
(1,7)\end{array}$ & $\begin{array}{r}29 \\
43 \\
25 \\
3\end{array}$ & $\begin{array}{l}(1,2) \\
(1,0) \\
(1,0) \\
(0,3)\end{array}$ \\
\hline Japan & $\begin{array}{r}0 / 1 \\
2 \\
3 \\
4 / 5\end{array}$ & $\begin{array}{r}19 \\
42 \\
34 \\
5\end{array}$ & $\begin{array}{l}(2,2) \\
(3,1) \\
(2,7) \\
(1,4)\end{array}$ & $\begin{array}{r}6 \\
30 \\
51 \\
13\end{array}$ & $\begin{array}{l}(0,8) \\
(1,4) \\
(1,5) \\
(1,0)\end{array}$ & $\begin{array}{r}1 \\
12 \\
50 \\
37\end{array}$ & $\begin{array}{l}(0,3) \\
(0,9) \\
(1,5) \\
(1,3)\end{array}$ & $\begin{array}{r}5 \\
23 \\
49 \\
23\end{array}$ & $\begin{array}{l}(0,4) \\
(0,9) \\
(1,1) \\
(0,8)\end{array}$ \\
\hline Korea & $\begin{array}{r}0 / 1 \\
2 \\
3 \\
4 / 5\end{array}$ & $\begin{array}{r}43 \\
44 \\
12 \\
C\end{array}$ & $\begin{array}{r}(2,2) \\
(2,1) \\
(1,3) \\
\mathrm{C}\end{array}$ & $\begin{array}{r}13 \\
48 \\
35 \\
4\end{array}$ & $\begin{array}{l}(0,9) \\
(1,7) \\
(1,7) \\
(0,5)\end{array}$ & $\begin{array}{r}3 \\
29 \\
55 \\
14\end{array}$ & $\begin{array}{l}(0,4) \\
(1,3) \\
(1,3) \\
(0,9)\end{array}$ & $\begin{array}{r}14 \\
40 \\
39 \\
7\end{array}$ & $\begin{array}{l}(0,6) \\
(0,9) \\
(1,0) \\
(0,4)\end{array}$ \\
\hline Niederlande & $\begin{array}{r}0 / 1 \\
2 \\
3 \\
4 / 5\end{array}$ & $\begin{array}{r}32 \\
39 \\
26 \\
3\end{array}$ & $\begin{array}{l}(1,7) \\
(1,9) \\
(1,7) \\
(0,7)\end{array}$ & $\begin{array}{r}9 \\
31 \\
47 \\
14\end{array}$ & $\begin{array}{l}(1,0) \\
(1,5) \\
(1,6) \\
(1,1)\end{array}$ & $\begin{array}{r}3 \\
14 \\
48 \\
36\end{array}$ & $\begin{array}{l}(0,6) \\
(1,1) \\
(1,5) \\
(1,5)\end{array}$ & $\begin{array}{l}13 \\
27 \\
41 \\
18\end{array}$ & $\begin{array}{l}(0,6) \\
(0,8) \\
(0,8) \\
(0,8)\end{array}$ \\
\hline
\end{tabular}

* Hinweis zu den Daten der Russischen Föderation s. Abschnitt Angewandte Methodik.

Anmerkung: Die Zeilen mit den Informationen für alle Lesekompetenzstufen zusammen sind im Internet verfügbar (s.StatLink unten).

Quelle: OECD. Survey of Adult Skills (PIAAC) (2012). PIAAC steht für das OECD Programme for the International Assessment of Adult Competencies. Hinweise s. Anhang 3 unter www.oecd.org/edu/eag.htm. StatLink: http://dx.doi.org/10.1787/888933114875

Erläuterung der Kennzeichnung fehlender Daten s. Hinweise für den Leser. 
Tabelle A1.6a (L) (Forts.)

Bildungsstand 25- bis 64-Jähriger, nach Lesekompetenzstufe (2012)

Lesekompetenz in der Erhebung zu den grundlegenden Kompetenzen Erwachsener

\begin{tabular}{|c|c|c|c|c|c|c|c|c|c|}
\hline & \multirow[t]{3}{*}{$\begin{array}{l}\text { Lese- } \\
\text { kompetenz- } \\
\text { stufe }\end{array}$} & \multicolumn{2}{|c|}{$\begin{array}{c}\text { Unterhalb } \\
\text { Sekundarbereich II }\end{array}$} & \multicolumn{2}{|c|}{$\begin{array}{c}\text { Sekundarbereich II } \\
\text { bzw. postsekundarer, } \\
\text { nicht tertiärer Bereich }\end{array}$} & \multicolumn{2}{|c|}{ Tertiärbereich } & \multicolumn{2}{|c|}{$\begin{array}{c}\text { Alle Bildungsbereiche } \\
\text { zusammen }\end{array}$} \\
\hline & & $\%$ & S.F. & $\%$ & S.F. & $\%$ & S.F. & $\%$ & S.F. \\
\hline & & (1) & (2) & (3) & (4) & (5) & (6) & (7) & (8) \\
\hline \multicolumn{10}{|l|}{$\begin{array}{l}\text { OECD } \\
\text { Nationale Einheiten }\end{array}$} \\
\hline Norwegen & $\begin{array}{r}0 / 1 \\
2 \\
3 \\
4 / 5\end{array}$ & $\begin{array}{r}26 \\
41 \\
30 \\
4\end{array}$ & $\begin{array}{l}(2,0) \\
(2,4) \\
(2,0) \\
(1,1)\end{array}$ & $\begin{array}{r}13 \\
37 \\
42 \\
8\end{array}$ & $\begin{array}{l}(1,3) \\
(1,6) \\
(1,5) \\
(1,0)\end{array}$ & $\begin{array}{r}5 \\
17 \\
51 \\
28\end{array}$ & $\begin{array}{l}(0,6) \\
(1,1) \\
(1,4) \\
(1,2)\end{array}$ & $\begin{array}{l}12 \\
30 \\
43 \\
15\end{array}$ & $\begin{array}{l}(0,7) \\
(0,9) \\
(0,9) \\
(0,7)\end{array}$ \\
\hline Polen & $\begin{array}{r}0 / 1 \\
2 \\
3 \\
4 / 5\end{array}$ & $\begin{array}{r}45 \\
39 \\
15 \\
1\end{array}$ & $\begin{array}{l}(3,1) \\
(3,2) \\
(2,1) \\
(0,7)\end{array}$ & $\begin{array}{r}24 \\
44 \\
29 \\
4\end{array}$ & $\begin{array}{l}(1,1) \\
(1,4) \\
(1,2) \\
(0,5)\end{array}$ & $\begin{array}{r}4 \\
24 \\
48 \\
23\end{array}$ & $\begin{array}{l}(0,8) \\
(1,5) \\
(2,0) \\
(1,7)\end{array}$ & $\begin{array}{r}20 \\
38 \\
33 \\
9\end{array}$ & $\begin{array}{l}(0,7) \\
(1,1) \\
(1,1) \\
(0,6)\end{array}$ \\
\hline Slowakei & $\begin{array}{r}0 / 1 \\
2 \\
3 \\
4 / 5\end{array}$ & $\begin{array}{r}37 \\
44 \\
18 \\
1\end{array}$ & $\begin{array}{l}(2,6) \\
(3,2) \\
(2,2) \\
(0,5)\end{array}$ & $\begin{array}{r}9 \\
39 \\
46 \\
6\end{array}$ & $\begin{array}{l}(0,7) \\
(1,6) \\
(1,5) \\
(0,6)\end{array}$ & $\begin{array}{r}3 \\
23 \\
57 \\
17\end{array}$ & $\begin{array}{l}(0,8) \\
(2,1) \\
(2,1) \\
(1,9)\end{array}$ & $\begin{array}{r}12 \\
37 \\
44 \\
7\end{array}$ & $\begin{array}{l}(0,7) \\
(1,2) \\
(1,1) \\
(0,5)\end{array}$ \\
\hline Spanien & $\begin{array}{r}0 / 1 \\
2 \\
3 \\
4 / 5\end{array}$ & $\begin{array}{r}47 \\
41 \\
12 \\
1\end{array}$ & $\begin{array}{l}(1,5) \\
(1,4) \\
(1,1) \\
(0,2)\end{array}$ & $\begin{array}{r}21 \\
46 \\
30 \\
3\end{array}$ & $\begin{array}{l}(1,4) \\
(2,0) \\
(1,8) \\
(0,8)\end{array}$ & $\begin{array}{r}8 \\
32 \\
48 \\
12\end{array}$ & $\begin{array}{l}(1,0) \\
(1,5) \\
(1,8) \\
(1,1)\end{array}$ & $\begin{array}{r}29 \\
39 \\
27 \\
5\end{array}$ & $\begin{array}{l}(0,8) \\
(0,9) \\
(0,8) \\
(0,4)\end{array}$ \\
\hline Schweden & $\begin{array}{r}0 / 1 \\
2 \\
3 \\
4 / 5\end{array}$ & $\begin{array}{r}34 \\
43 \\
21 \\
2\end{array}$ & $\begin{array}{l}(2,7) \\
(3,5) \\
(2,2) \\
(0,8)\end{array}$ & $\begin{array}{l}12 \\
32 \\
45 \\
11\end{array}$ & $\begin{array}{l}(1,0) \\
(1,8) \\
(1,9) \\
(0,9)\end{array}$ & $\begin{array}{r}5 \\
15 \\
46 \\
34\end{array}$ & $\begin{array}{l}(0,6) \\
(1,3) \\
(1,5) \\
(1,6)\end{array}$ & $\begin{array}{l}14 \\
28 \\
41 \\
17\end{array}$ & $\begin{array}{l}(0,7) \\
(1,2) \\
(1,0) \\
(0,6)\end{array}$ \\
\hline Vereinigte Staaten & $\begin{array}{r}0 / 1 \\
2 \\
3 \\
4 / 5\end{array}$ & $\begin{array}{r}62 \\
31 \\
7 \\
\mathrm{C}\end{array}$ & $\begin{array}{r}(2,8) \\
(2,8) \\
(1,5) \\
\mathrm{C}\end{array}$ & $\begin{array}{r}22 \\
42 \\
31 \\
6\end{array}$ & $\begin{array}{l}(1,4) \\
(1,8) \\
(1,4) \\
(0,8)\end{array}$ & $\begin{array}{r}5 \\
23 \\
49 \\
24\end{array}$ & $\begin{array}{l}(0,7) \\
(1,3) \\
(1,7) \\
(1,7)\end{array}$ & $\begin{array}{l}19 \\
33 \\
36 \\
12\end{array}$ & $\begin{array}{l}(0,9) \\
(1,2) \\
(1,1) \\
(0,8)\end{array}$ \\
\hline Subnationale Einheiten & & & & & & & & & \\
\hline Flandern (Belgien) & $\begin{array}{r}0 / 1 \\
2 \\
3 \\
4 / 5\end{array}$ & $\begin{array}{r}42 \\
41 \\
17 \\
1\end{array}$ & $\begin{array}{l}(2,3) \\
(2,4) \\
(1,8) \\
(0,4)\end{array}$ & $\begin{array}{r}16 \\
41 \\
36 \\
6\end{array}$ & $\begin{array}{l}(1,1) \\
(1,5) \\
(1,8) \\
(0,7)\end{array}$ & $\begin{array}{r}3 \\
17 \\
53 \\
26\end{array}$ & $\begin{array}{l}(0,5) \\
(1,3) \\
(1,7) \\
(1,6)\end{array}$ & $\begin{array}{l}16 \\
32 \\
40 \\
13\end{array}$ & $\begin{array}{l}(0,6) \\
(0,9) \\
(1,1) \\
(0,7)\end{array}$ \\
\hline England (VK) & $\begin{array}{r}0 / 1 \\
2 \\
3 \\
4 / 5\end{array}$ & $\begin{array}{r}34 \\
45 \\
20 \\
2\end{array}$ & $\begin{array}{l}(1,7) \\
(2,2) \\
(1,6) \\
(0,7)\end{array}$ & $\begin{array}{l}14 \\
35 \\
39 \\
11\end{array}$ & $\begin{array}{l}(1,4) \\
(1,8) \\
(1,6) \\
(1,1)\end{array}$ & $\begin{array}{r}7 \\
23 \\
45 \\
25\end{array}$ & $\begin{array}{l}(0,9) \\
(1,4) \\
(1,8) \\
(1,8)\end{array}$ & $\begin{array}{l}16 \\
33 \\
37 \\
15\end{array}$ & $\begin{array}{l}(0,8) \\
(1,0) \\
(1,1) \\
(0,9)\end{array}$ \\
\hline Nordirland (VK) & $\begin{array}{r}0 / 1 \\
2 \\
3 \\
4 / 5\end{array}$ & $\begin{array}{r}35 \\
46 \\
17 \\
1\end{array}$ & $\begin{array}{l}(2,5) \\
(2,6) \\
(2,0) \\
(0,4)\end{array}$ & $\begin{array}{r}14 \\
41 \\
38 \\
8\end{array}$ & $\begin{array}{l}(2,0) \\
(2,9) \\
(3,6) \\
(1,2)\end{array}$ & $\begin{array}{r}5 \\
23 \\
50 \\
22\end{array}$ & $\begin{array}{l}(1,0) \\
(2,1) \\
(2,1) \\
(2,1)\end{array}$ & $\begin{array}{l}18 \\
37 \\
35 \\
10\end{array}$ & $\begin{array}{l}(1,3) \\
(1,8) \\
(1,8) \\
(0,8)\end{array}$ \\
\hline England/Nordirland (VK) & $\begin{array}{r}0 / 1 \\
2 \\
3 \\
4 / 5\end{array}$ & $\begin{array}{r}34 \\
45 \\
19 \\
2\end{array}$ & $\begin{array}{l}(1,7) \\
(2,1) \\
(1,5) \\
(0,7)\end{array}$ & $\begin{array}{l}14 \\
35 \\
39 \\
11\end{array}$ & $\begin{array}{l}(1,3) \\
(1,8) \\
(1,6) \\
(1,1)\end{array}$ & $\begin{array}{r}7 \\
23 \\
45 \\
25\end{array}$ & $\begin{array}{l}(0,9) \\
(1,4) \\
(1,8) \\
(1,7)\end{array}$ & $\begin{array}{l}16 \\
33 \\
37 \\
14\end{array}$ & $\begin{array}{l}(0,8) \\
(1,0) \\
(1,0) \\
(0,9)\end{array}$ \\
\hline Durchschnitt & $0 / 1$ & 39 & $(0,5)$ & 15 & $(0,2)$ & 5 & $(0,2)$ & 16 & $(0,2)$ \\
\hline & $\begin{array}{l}2 \\
3\end{array}$ & $\begin{array}{l}41 \\
19\end{array}$ & $\begin{array}{l}(0,6) \\
(0,4)\end{array}$ & $\begin{array}{l}40 \\
38\end{array}$ & $\begin{array}{l}(0,3) \\
(0,3)\end{array}$ & $\begin{array}{l}22 \\
49\end{array}$ & $\begin{array}{l}(0,3) \\
(0,4)\end{array}$ & $\begin{array}{l}34 \\
38\end{array}$ & $\begin{array}{l}(0,2) \\
(0,2)\end{array}$ \\
\hline & $4 / 5$ & 2 & $(0,2)$ & 7 & $(0,2)$ & 24 & $(0,3)$ & 12 & $(0,1)$ \\
\hline Partnerländer & & & & & & & & & \\
\hline Russische Föderation* & $\begin{array}{r}0 / 1 \\
2 \\
3 \\
4 / 5\end{array}$ & $\begin{array}{l}\mathrm{C} \\
\mathrm{C} \\
\mathrm{c} \\
\mathrm{c}\end{array}$ & $\begin{array}{l}\mathrm{C} \\
\mathrm{C} \\
\mathrm{c} \\
\mathrm{c}\end{array}$ & $\begin{array}{r}15 \\
36 \\
40 \\
9\end{array}$ & $\begin{array}{l}(2,5) \\
(2,7) \\
(3,8) \\
(2,9)\end{array}$ & $\begin{array}{l}11 \\
34 \\
44 \\
12\end{array}$ & $\begin{array}{l}(1,6) \\
(2,5) \\
(2,2) \\
(2,1)\end{array}$ & $\begin{array}{l}13 \\
35 \\
42 \\
11\end{array}$ & $\begin{array}{l}(1,7) \\
(2,0) \\
(2,2) \\
(2,0)\end{array}$ \\
\hline
\end{tabular}

* Hinweis zu den Daten der Russischen Föderation s. Abschnitt Angewandte Methodik.

Anmerkung: Die Zeilen mit den Informationen für alle Lesekompetenzstufen zusammen sind im Internet verfügbar (s.StatLink unten).

Quelle: OECD. Survey of Adult Skills (PIAAC) (2012). PIAAC steht für das OECD Programme for the International Assessment of Adult Competencies.

Hinweise s. Anhang 3 unter www.oecd.org/edu/eag.htm. StatLink: http://dx.doi.org/10.1787/888933114875

Erläuterung der Kennzeichnung fehlender Daten s. Hinweise für den Leser. 
Tabelle A1.7a (L)

Verteilung der Lesekompetenzstufen, nach Alter (2012)

1 Lesekompetenz in der Erhebung zu den grundlegenden Kompetenzen Erwachsener

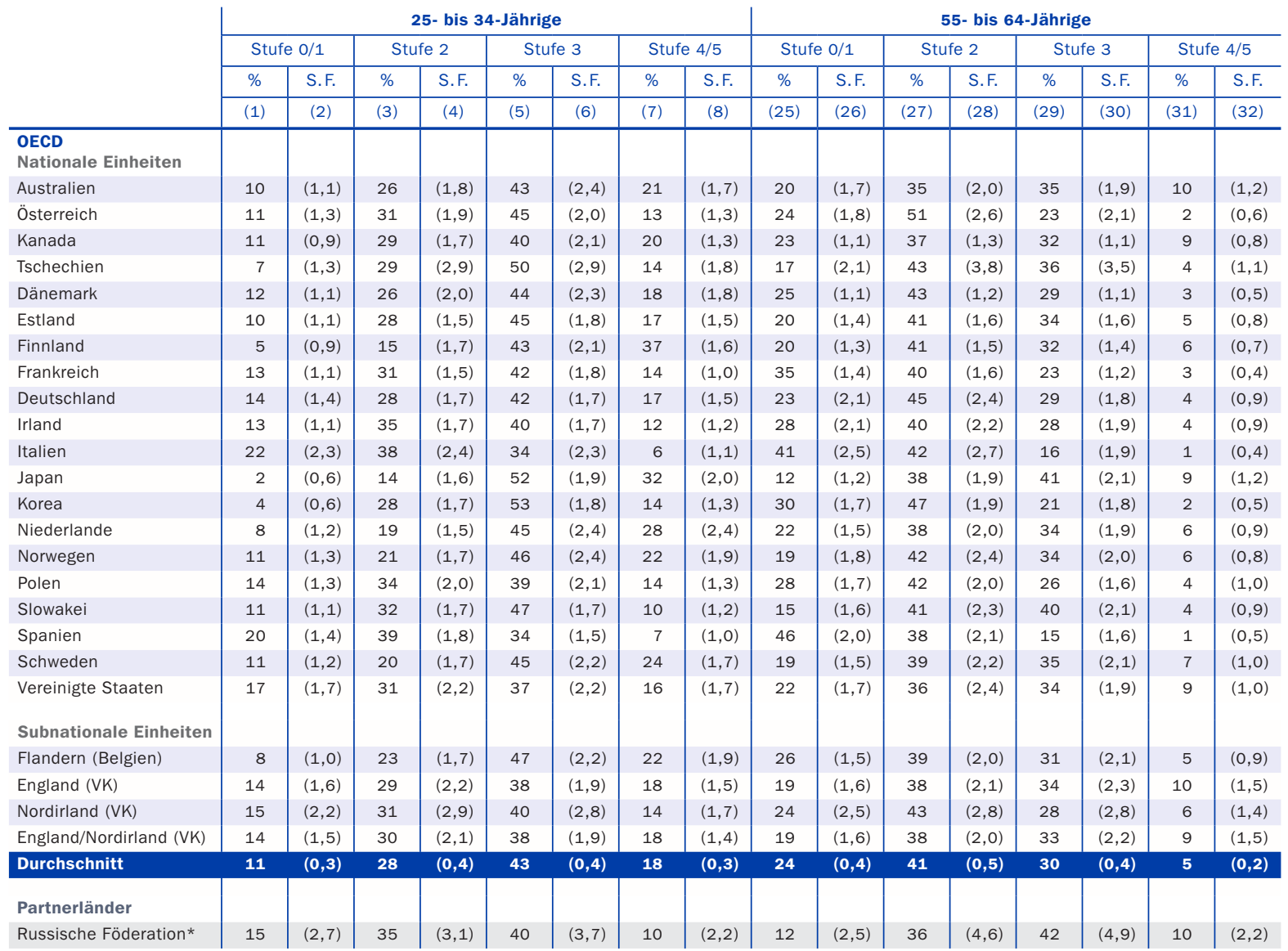

* Hinweis zu den Daten der Russischen Föderation s. Abschnitt Angewandte Methodik.

Anmerkung: Die Spalten mit den Daten für andere Altersgruppen (d.h. 35- bis 44-Jährige, 45- bis 54-Jährige und 25- bis 64-Jährige) sind im Internet verfügbar (s. StatLink unten).

Quelle: OECD. Survey of Adult Skills (PIAAC) (2012). PIAAC steht für das OECD Programme for the International Assessment of Adult Competencies.

Hinweise s. Anhang 3 unter www.oecd.org/edu/eag.htm. StatLink: http://dx.doi.org/10.1787/888933114894

Erläuterung der Kennzeichnung fehlender Daten s. Hinweise für den Leser. 
Anteil 25- bis 64-Jähriger mit einem Abschluss im berufsbildenden oder allgemeinbildenden Sekundarbereich II bzW. postsekundaren, nicht tertiären Bereich, nach Lesekompetenzstufe und Mittelwert der Lesekompetenz (2012) Lesekompetenz in der Erhebung zu den grundlegenden Kompetenzen Erwachsener

\begin{tabular}{|c|c|c|c|c|c|c|c|c|c|c|c|c|c|c|c|c|}
\hline & \multicolumn{8}{|c|}{ Berufsbildend } & \multicolumn{8}{|c|}{ Allgemeinbildend } \\
\hline & \multicolumn{2}{|c|}{ Stufe $0 / 1$} & \multicolumn{2}{|c|}{ Stufe 2} & \multicolumn{2}{|c|}{ Stufe 3} & \multicolumn{2}{|c|}{ Stufe $4 / 5$} & \multicolumn{2}{|c|}{ Stufe $0 / 1$} & \multicolumn{2}{|c|}{ Stufe 2} & \multicolumn{2}{|c|}{ Stufe 3} & \multicolumn{2}{|c|}{ Stufe $4 / 5$} \\
\hline & $\%$ & S.F. & $\%$ & S.F. & $\%$ & S.F. & $\%$ & S.F. & $\%$ & S.F. & $\%$ & S.F. & $\%$ & S.F. & $\%$ & S.F. \\
\hline & (1) & (2) & (3) & (4) & (5) & (6) & (7) & (8) & (9) & $(10)$ & (11) & $(12)$ & (13) & (14) & (15) & $(16)$ \\
\hline \multicolumn{17}{|l|}{$\begin{array}{l}\text { OECD } \\
\text { Nationale Einheiten }\end{array}$} \\
\hline Australien & 11 & $(1,2)$ & 36 & $(1,9)$ & 43 & $(2,3)$ & 11 & $(1,3)$ & 12 & $(1,5)$ & 28 & $(2,8)$ & 45 & $(2,8)$ & 15 & $(2,4)$ \\
\hline Österreich & 15 & $(1,0)$ & 44 & $(1,5)$ & 36 & $(1,4)$ & 5 & $(0,5)$ & 9 & $(2,4)$ & 25 & $(4,1)$ & 52 & $(5,1)$ & 14 & $(3,6)$ \\
\hline Kanada & 15 & $(1,2)$ & 38 & $(1,6)$ & 38 & $(1,8)$ & 8 & $(1,1)$ & 20 & $(1,2)$ & 39 & $(1,4)$ & 34 & $(1,4)$ & 7 & $(0,9)$ \\
\hline Tschechien & 13 & $(1,2)$ & 44 & $(2,4)$ & 38 & $(2,0)$ & 4 & $(0,7)$ & 2 & $(1,5)$ & 27 & $(5,9)$ & 56 & $(7,1)$ & 14 & $(5,3)$ \\
\hline Dänemark & 19 & $(1,1)$ & 45 & $(1,6)$ & 34 & $(1,5)$ & 3 & $(0,7)$ & 10 & $(1,8)$ & 27 & $(3,5)$ & 46 & $(4,8)$ & 17 & $(3,2)$ \\
\hline Estland & 17 & $(1,2)$ & 41 & $(1,7)$ & 37 & $(1,5)$ & 5 & $(0,8)$ & 15 & $(1,4)$ & 38 & $(1,6)$ & 38 & $(1,7)$ & 8 & $(1,1)$ \\
\hline Finnland & 14 & $(1,1)$ & 37 & $(1,8)$ & 39 & $(1,7)$ & 9 & $(1,0)$ & 6 & $(1,9)$ & 13 & $(2,6)$ & 46 & $(3,4)$ & 35 & $(3,5)$ \\
\hline Frankreich & 23 & $(1,1)$ & 48 & $(1,3)$ & 27 & $(1,1)$ & 2 & $(0,4)$ & 11 & $(1,4)$ & 38 & $(2,1)$ & 44 & $(2,1)$ & 8 & $(1,3)$ \\
\hline Deutschland & 20 & $(1,2)$ & 42 & $(1,6)$ & 33 & $(1,4)$ & 5 & $(0,7)$ & c & c & c & c & c & c & c & c \\
\hline Irland & 15 & $(1,6)$ & 42 & $(2,0)$ & 37 & $(2,2)$ & 6 & $(1,3)$ & 14 & $(1,7)$ & 43 & $(2,5)$ & 38 & $(2,4)$ & 5 & $(1,1)$ \\
\hline Italien & 23 & $(2,8)$ & 49 & $(3,2)$ & 25 & $(2,6)$ & 2 & $(0,9)$ & c & c & $c$ & c & c & c & c & c \\
\hline Japan & 5 & $(1,1)$ & 30 & $(2,8)$ & 53 & $(3,1)$ & 12 & $(1,9)$ & 6 & $(1,1)$ & 30 & $(1,8)$ & 50 & $(1,7)$ & 13 & $(1,5)$ \\
\hline Korea & 11 & $(1,4)$ & 47 & $(2,3)$ & 39 & $(2,3)$ & 3 & $(0,7)$ & 14 & $(1,3)$ & 49 & $(2,1)$ & 33 & $(2,1)$ & 4 & $(0,7)$ \\
\hline Niederlande & 10 & $(1,2)$ & 35 & $(1,8)$ & 45 & $(2,0)$ & 10 & $(1,1)$ & 5 & $(1,5)$ & 17 & $(2,6)$ & 52 & $(3,5)$ & 26 & $(3,3)$ \\
\hline Norwegen & 15 & $(1,3)$ & 41 & $(1,5)$ & 39 & $(1,4)$ & 5 & $(1,0)$ & 10 & $(1,9)$ & 28 & $(2,7)$ & 48 & $(3,2)$ & 14 & $(2,1)$ \\
\hline Polen & 25 & $(1,3)$ & 44 & $(1,6)$ & 27 & $(1,2)$ & 4 & $(0,6)$ & 14 & $(2,6)$ & 42 & $(3,8)$ & 38 & $(3,5)$ & 6 & $(1,6)$ \\
\hline Slowakei & 15 & $(1,1)$ & 45 & $(1,8)$ & 37 & $(1,8)$ & 3 & $(0,5)$ & 5 & $(0,8)$ & 35 & $(2,0)$ & 52 & $(1,9)$ & 8 & $(1,0)$ \\
\hline Spanien & 27 & $(5,0)$ & 52 & $(5,5)$ & 20 & $(4,1)$ & c & c & 20 & $(1,6)$ & 46 & $(2,1)$ & 31 & $(1,9)$ & 4 & $(0,9)$ \\
\hline Schweden & 12 & $(1,6)$ & 37 & $(2,2)$ & 43 & $(2,1)$ & 7 & $(1,1)$ & 13 & $(1,6)$ & 27 & $(2,7)$ & 46 & $(3,0)$ & 14 & $(1,7)$ \\
\hline $\begin{array}{l}\text { Vereinigte Staaten } \\
\text { Subnationale Einheiten }\end{array}$ & 16 & $(3,1)$ & 42 & $(3,9)$ & 35 & $(3,1)$ & 7 & $(1,7)$ & 28 & $(2,3)$ & 45 & $(2,6)$ & 24 & $(1,8)$ & 3 & $(0,7)$ \\
\hline Flandern (Belgien) & 27 & $(2,6)$ & 48 & $(2,9)$ & 23 & $(2,5)$ & 1 & $(0,7)$ & c & c & c & c & c & $\mathrm{c}$ & c & c \\
\hline England (VK) & 19 & $(2,8)$ & 41 & $(3,9)$ & 35 & $(3,5)$ & 5 & $(2,0)$ & 14 & $(1,5)$ & 37 & $(2,0)$ & 38 & $(2,3)$ & 11 & $(1,6)$ \\
\hline Nordirland (VK) & 13 & $(2,8)$ & 47 & $(4,6)$ & 35 & $(4,7)$ & 5 & $(2,1)$ & 14 & $(2,3)$ & 43 & $(3,0)$ & 37 & $(3,6)$ & 6 & $(1,3)$ \\
\hline England/Nordirland (VK) & 18 & $(2,6)$ & 41 & $(3,7)$ & 35 & $(3,3)$ & 5 & $(1,9)$ & 14 & $(1,4)$ & 37 & $(1,9)$ & 38 & $(2,2)$ & 11 & $(1,5)$ \\
\hline Durchschnitt & 17 & $(0,4)$ & 42 & $(0,5)$ & 36 & $(0,5)$ & 6 & $(0,2)$ & 12 & $(0,4)$ & 33 & $(0,7)$ & 43 & $(0,7)$ & 12 & $(0,5)$ \\
\hline \multicolumn{17}{|l|}{ Partnerländer } \\
\hline Russische Föderation* & 14 & $(2,5)$ & 36 & $(3,7)$ & 39 & $(4,0)$ & 11 & $(3,2)$ & 16 & $(3,7)$ & 35 & $(3,8)$ & 41 & $(5,7)$ & 8 & $(3,5)$ \\
\hline
\end{tabular}

* Hinweis zu den Daten der Russischen Föderation s. Abschnitt Angewandte Methodik.

Anmerkung: Die Spalten mit den Kompetenzstufen für alle Bildungsgänge (d.h. allgemeinbildend plus berufsbildend) zusammen und die Mittelwerte nach Ausrichtung des Bildungsgangs sind im Internet verfügbar (s. StatLink unten).

Quelle: OECD. Survey of Adult Skills (PIAAC) (2012). PIAAC steht für das OECD Programme for the International Assessment of Adult Competencies.

Hinweise s. Anhang 3 unter www.oecd.org/edu/eag.htm. StatLink: http://dx.doi.org/10.1787/888933114913

Erläuterung der Kennzeichnung fehlender Daten s. Hinweise für den Leser. 
Tabelle A1.9a (L)

Mittelwert der Lesekompetenz, nach Bildungsstand und Alter (2012)

1 Lesekompetenz in der Erhebung zu den grundlegenden Kompetenzen Erwachsener

\begin{tabular}{|c|c|c|c|c|c|c|c|c|c|c|c|c|c|c|c|c|}
\hline & \multicolumn{4}{|c|}{ | Unterhalb Sekundarbereich II } & \multicolumn{4}{|c|}{$\begin{array}{c}\text { Sekundarbereich II bzw. } \\
\text { postsekundarer, } \\
\text { nicht tertiärer Bereich }\end{array}$} & \multicolumn{4}{|c|}{ Tertiärbereich } & \multicolumn{4}{|c|}{$\begin{array}{l}\text { Alle Bildungsbereiche } \\
\text { zusammen }\end{array}$} \\
\hline & \multicolumn{2}{|c|}{$25-34$} & \multicolumn{2}{|c|}{$55-64$} & \multicolumn{2}{|c|}{$25-34$} & \multicolumn{2}{|c|}{$55-64$} & \multicolumn{2}{|c|}{$25-34$} & \multicolumn{2}{|c|}{$55-64$} & \multicolumn{2}{|c|}{$25-34$} & \multicolumn{2}{|c|}{$55-64$} \\
\hline & Punkte & S.F. & Punkte & S.F. & Punkte & S.F. & Punkte & S.F. & Punkte & S.F. & Punkte & S.F. & Punkte & S.F. & Punkte & S.F. \\
\hline & (1) & (2) & (7) & (8) & (11) & (12) & (17) & (18) & (21) & $(22)$ & $(27)$ & $(28)$ & (31) & (32) & (37) & (38) \\
\hline \multicolumn{17}{|l|}{$\begin{array}{l}\text { OECD } \\
\text { Nationale Einheiten }\end{array}$} \\
\hline Australien & 250 & $(5,4)$ & 242 & $(2,9)$ & 282 & $(2,6)$ & 265 & $(3,2)$ & 306 & $(2,5)$ & 292 & $(2,7)$ & 287 & $(1,7)$ & 264 & $(1,9)$ \\
\hline Österreich & 238 & $(5,4)$ & 235 & $(3,5)$ & 279 & $(1,8)$ & 251 & $(1,8)$ & 308 & $(2,9)$ & 276 & $(3,6)$ & 280 & $(1,5)$ & 250 & $(1,6)$ \\
\hline Kanada & 230 & $(5,0)$ & 220 & $(2,7)$ & 274 & $(2,0)$ & 258 & $(1,9)$ & 299 & $(1,6)$ & 279 & $(1,7)$ & 285 & $(1,3)$ & 261 & $(1,2)$ \\
\hline Tschechien & 257 & $(6,6)$ & 242 & $(5,8)$ & 278 & $(2,4)$ & 263 & $(2,0)$ & 311 & $(2,9)$ & 289 & $(4,0)$ & 287 & $(1,8)$ & 262 & $(2,1)$ \\
\hline Dänemark & 242 & $(6,8)$ & 228 & $(2,5)$ & 275 & $(2,6)$ & 250 & $(1,5)$ & 298 & $(2,4)$ & 277 & $(1,7)$ & 282 & $(1,7)$ & 253 & $(1,1)$ \\
\hline Estland & 250 & $(4,0)$ & 240 & $(3,5)$ & 279 & $(2,0)$ & 258 & $(2,0)$ & 304 & $(1,9)$ & 275 & $(2,1)$ & 286 & $(1,7)$ & 261 & $(1,5)$ \\
\hline Finnland & 264 & $(8,0)$ & 237 & $(3,5)$ & 298 & $(2,5)$ & 256 & $(2,3)$ & 328 & $(2,0)$ & 285 & $(2,0)$ & 309 & $(1,7)$ & 261 & $(1,5)$ \\
\hline Frankreich & 231 & $(3,9)$ & 220 & $(2,2)$ & 269 & $(1,7)$ & 250 & $(1,8)$ & 305 & $(1,5)$ & 278 & $(2,2)$ & 278 & $(1,4)$ & 242 & $(1,3)$ \\
\hline Deutschland & 224 & $(6,0)$ & 217 & $(7,2)$ & 276 & $(2,3)$ & 248 & $(2,1)$ & 306 & $(2,3)$ & 275 & $(2,7)$ & 281 & $(1,8)$ & 255 & $(1,7)$ \\
\hline Irland & 235 & $(4,1)$ & 230 & $(2,9)$ & 267 & $(2,5)$ & 264 & $(2,6)$ & 295 & $(2,0)$ & 284 & $(3,3)$ & 276 & $(1,5)$ & 251 & $(1,9)$ \\
\hline Italien & 231 & $(4,0)$ & 224 & $(2,6)$ & 263 & $(2,7)$ & 256 & $(3,2)$ & 290 & $(2,9)$ & 262 & $(4,8)$ & 260 & $(2,2)$ & 234 & $(2,3)$ \\
\hline Japan & 280 & $(5,0)$ & 247 & $(3,2)$ & 299 & $(2,6)$ & 271 & $(2,1)$ & 319 & $(1,8)$ & 299 & $(2,4)$ & 309 & $(1,7)$ & 274 & $(1,6)$ \\
\hline Korea & c & c & 227 & $(1,9)$ & 278 & $(2,4)$ & 258 & $(2,3)$ & 298 & $(1,4)$ & 279 & $(3,5)$ & 290 & $(1,2)$ & 245 & $(1,4)$ \\
\hline Niederlande & 255 & $(5,1)$ & 240 & $(2,4)$ & 291 & $(2,6)$ & 264 & $(2,5)$ & 323 & $(2,8)$ & 292 & $(2,6)$ & 298 & $(2,0)$ & 261 & $(1,7)$ \\
\hline Norwegen & 253 & $(5,3)$ & 245 & $(3,2)$ & 280 & $(3,0)$ & 256 & $(2,4)$ & 308 & $(2,5)$ & 283 & $(2,4)$ & 289 & $(1,8)$ & 262 & $(1,6)$ \\
\hline Polen & 236 & $(7,2)$ & 223 & $(3,8)$ & 260 & $(2,2)$ & 250 & $(2,1)$ & 300 & $(2,1)$ & 283 & $(4,0)$ & 277 & $(1,5)$ & 250 & $(1,7)$ \\
\hline Slowakei & 230 & $(4,6)$ & 242 & $(2,6)$ & 278 & $(1,7)$ & 272 & $(1,7)$ & 300 & $(2,1)$ & 284 & $(3,4)$ & 278 & $(1,4)$ & 266 & $(1,4)$ \\
\hline Spanien & 235 & $(2,7)$ & 211 & $(2,2)$ & 263 & $(2,5)$ & 247 & $(3,7)$ & 286 & $(2,0)$ & 265 & $(3,6)$ & 263 & $(1,5)$ & 228 & $(1,9)$ \\
\hline Schweden & 245 & $(7,2)$ & 239 & $(3,0)$ & 284 & $(2,7)$ & 267 & $(2,3)$ & 313 & $(2,6)$ & 286 & $(2,8)$ & 290 & $(1,9)$ & 264 & $(1,4)$ \\
\hline $\begin{array}{l}\text { Vereinigte Staaten } \\
\text { Subnationale Einheiten }\end{array}$ & 221 & $(5,7)$ & 203 & $(5,1)$ & 261 & $(2,7)$ & 256 & $(2,2)$ & 304 & $(2,5)$ & 289 & $(2,7)$ & 275 & $(2,0)$ & 262 & $(1,6)$ \\
\hline Flandern (Belgien) & 236 & $(6,2)$ & 230 & $(2,8)$ & 275 & $(2,3)$ & 255 & $(2,7)$ & 314 & $(2,2)$ & 284 & $(2,4)$ & 291 & $(1,8)$ & 255 & $(1,6)$ \\
\hline England (VK) & 240 & $(4,3)$ & 241 & $(3,3)$ & 277 & $(3,3)$ & 269 & $(3,2)$ & 296 & $(2,8)$ & 288 & $(3,2)$ & 280 & $(2,1)$ & 265 & $(2,1)$ \\
\hline Nordirland (VK) & 234 & $(5,0)$ & 238 & $(3,6)$ & 273 & $(4,3)$ & 269 & $(4,7)$ & 301 & $(3,5)$ & 282 & $(4,8)$ & 278 & $(2,9)$ & 257 & $(3,2)$ \\
\hline England/Nordirland (VK) & 240 & $(4,2)$ & 241 & $(3,2)$ & 277 & $(3,2)$ & 269 & $(3,2)$ & 296 & $(2,7)$ & 288 & $(3,1)$ & 280 & $(2,1)$ & 265 & $(2,0)$ \\
\hline Durchschnitt & 242 & $(1,2)$ & 231 & $(0,7)$ & 277 & $(0,5)$ & 258 & $(0,5)$ & 305 & $(0,5)$ & 282 & $(0,6)$ & 284 & $(0,4)$ & 256 & $(0,4)$ \\
\hline \multicolumn{17}{|l|}{ Partnerländer } \\
\hline Russische Föderation* & c & c & 257 & $(12,2)$ & 266 & $(6,3)$ & 274 & $(5,7)$ & 278 & $(3,7)$ & 278 & $(3,7)$ & 273 & $(4,1)$ & 275 & $(4,2)$ \\
\hline
\end{tabular}

* Hinweis zu den Daten der Russischen Föderation s. Abschnitt Angewandte Methodik.

Anmerkung: Die Spalten mit den Daten für andere Altersgruppen (d.h. 35- bis 44-Jährige, 45- bis 54-Jährige und 25-bis 64-Jährige) sind im Internet verfügbar (s. StatLink unten).

Quelle: OECD. Survey of Adult Skills (PIAAC) (2012). PIAAC steht für das OECD Programme for the International Assessment of Adult Competencies. Hinweise s. Anhang 3 unter www.oecd.org/edu/eag.htm. StatLink: http://dx.doi.org/10.1787/888933114932

Erläuterung der Kennzeichnung fehlender Daten s. Hinweise für den Leser. 


\section{Wie viele Schüler werden den Sekundar- bereich II erfolgreich abschließen?}

Ausgehend von den aktuellen Abschlussquoten wird geschätzt, dass im Durchschnitt 84 Prozent der gegenwärtig in den OECD-Ländern lebenden jungen Menschen im Laufe ihres Lebens einen Abschluss im Sekundarbereich II erwerben werden; in den G20-Ländern wird dies auf etwa 8o Prozent der jungen Menschen zutreffen.

Heute machen in fast allen OECD-Ländern eher junge Frauen als junge Männer einen Abschluss im Sekundarbereich II, eine Umkehr der früher üblichen Situation.

In Dänemark, Finnland, den Niederlanden und Norwegen sind mehr als Io Prozent der Absolventen des Sekundarbereichs II mindestens 25 Jahre alt, während der entsprechende Anteil in Island fast 20 Prozent beträgt.

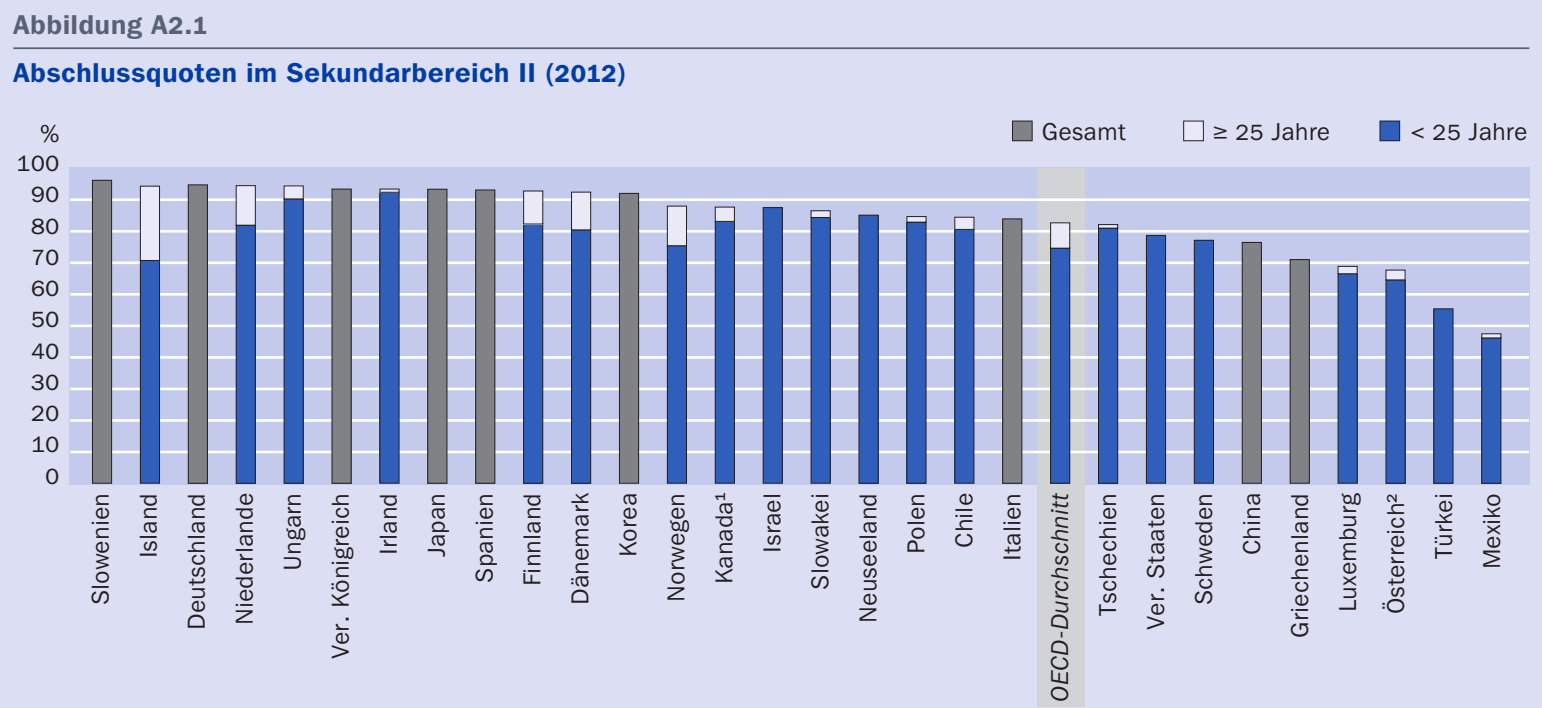

Anmerkung: Diese Abbildung enthält nur Absolventen mit einem Erstabschluss im Sekundarbereich II.

1. Referenzjahr 2011. 2. Bildungsgänge, die die ISCED-Stufen 3 und 4 umfassen (Höhere berufsbildende Schule), sind nicht erfasst.

Anordnung der Länder in absteigender Reihenfolge der Abschlussquoten im Sekundarbereich II im Jahr 2012.

Quelle: OECD. Tabellen A2.1a und A2.1b. Hinweise s. Anhang 3 unter www.oecd.org/edu/eag.htm. StatLink: http://dx.doi.org/10.1787/888933115255

\section{Kontext}

Der Sekundarbereich II festigt durch allgemeinbildende oder berufsbildende Bildungsgänge das notwendige Wissen und die grundlegenden Fertigkeiten und Fähigkeiten der Schüler. Er soll sie auf den Eintritt in den Tertiärbereich oder den Arbeitsmarkt vorbereiten und darüber hinaus die Grundlage dafür legen, dass die Schüler zu engagierten Bürgern werden. In vielen Ländern ist dieser Bildungsbereich nicht Teil der Pflichtschulzeit und kann zwischen zwei und fünf Jahren dauern. Von entscheidender Bedeutung jedoch ist, dass diese beiden Ausrichtungen der Bildungsgänge von gleicher Qualität sind und beide gewährleisten, dass den Schülern der entsprechende Übergang erfolgreich gelingen kann. 
Ein Abschluss im Sekundarbereich II ist in allen Ländern immer wichtiger geworden, da die auf dem Arbeitsmarkt benötigten Kompetenzen in zunehmendem Ausmaß wissensbasiert sind und von den Beschäftigten mehr und mehr verlangt wird, sich den Unsicherheiten einer sich schnell wandelnden Weltwirtschaft anzupassen. Abschlussquoten sind ein Hinweis darauf, inwieweit es den Bildungssystemen gelingt, die Schüler darauf vorzubereiten, den Mindestanforderungen des Arbeitsmarktes zu entsprechen, sie erfassen jedoch nicht die Qualität der Bildungsergebnisse.

In vielen OECD-Ländern können Schüler gegen Ende des Sekundarbereichs I das Bildungssystem ganz verlassen, was bedeutet, dass sie die Schulzeit ohne einen Abschluss im Sekundarbereich II beenden können. Diese jungen Menschen treffen in der Regel auf große Schwierigkeiten bei ihrem Eintritt in den Arbeitsmarkt sowie bei ihrem Verbleib dort. Ein frühzeitiges Verlassen der Schule ist sowohl für den Einzelnen als auch für die Gesellschaft problematisch. Die Politik sucht nach Möglichkeiten, die Anzahl der frühzeitigen Schulabgänger, definiert als derjenigen, die die Schule bereits vor Abschluss des Sekundarbereichs II verlassen, zu verringern. International vergleichbare Kenngrößen zur Anzahl der Absolventen des Sekundarbereichs II - aus denen somit implizit auch hervorgeht, wie viele Schüler keinen Abschluss in diesem Bereich erwerben - können hierbei hilfreich sein.

\section{Weitere wichtige Ergebnisse}

In 25 von 31 Ländern mit verfügbaren Daten liegen die Abschlussquoten für einen Erstabschluss im Sekundarbereich II bei mindestens 75 Prozent. In Dänemark, Deutschland, Finnland, Irland, Island, Japan, Korea, Lettland, den Niederlanden, Slowenien, Spanien, Ungarn und dem Vereinigten Königreich liegen die Abschlussquoten bei mindestens 9o Prozent.

Im Durchschnitt der OECD-Länder erlangen Schüler ihren Erstabschluss im Sekundarbereich II im Alter von 19 Jahren, wobei dieser Durchschnitt von 17 Jahren in Israel, Neuseeland, der Türkei und den Vereinigten Staaten bis zu mindestens 22 Jahren in Island und Norwegen reicht.

Mehr junge Frauen als je zuvor erlangen einen Abschluss in einem berufsbildenden Bildungsgang. Ihre Abschlussquoten nähern sich inzwischen in diesen Bildungsgängen denen der jungen Männer an.

Der überwiegende Teil der jungen Männer in einem berufsbildenden Bildungsgang im Sekundarbereich II wählt eine Ausbildung in den Fächergruppen Ingenieurwissenschaften, Fertigung und Bauwesen, während sich junge Frauen in diesen Bildungsgängen für andere Fächergruppen, insbesondere Wirtschafts-, Rechts- und Sozialwissenschaften, Gesundheit und Soziales sowie Dienstleistungen, entscheiden.

Zum dritten Mal werden in Bildung aufeinen Blick vergleichbare Daten für 29 Länder veröffentlicht, die sich an einer speziellen Erhebung zu den Erfolgsquoten im Sekundarbereich II beteiligt haben. Aus diesen Daten geht hervor, dass 72 Prozent der Schüler, die einen Bildungsgang im Sekundarbereich II beginnen, den von ihnen gewählten Bildungsgang innerhalb der regulären Ausbildungsdauer abschließen. Die Abschlussquoten variieren jedoch stark nach Geschlecht und Bildungsgang. 


\section{Entwicklungstendenzen}

Seit 2000 sind die Abschlussquoten im Sekundarbereich II im Durchschnitt der OECD-Länder mit vergleichbaren Daten um 8 Prozentpunkte gestiegen. Den stärksten Anstieg gab es in Mexiko, wo die jährliche Wachstumsrate zwischen 2000 und 2012 bei 3 Prozent lag.

\section{Hinweise}

Abschlussquoten zeigen den geschätzten prozentualen Anteil einer spezifischen Altersgruppe, der im Laufe des Lebens einen Abschluss im Sekundarbereich II erwerben wird. Diese Schätzung basiert auf der Zahl der Absolventen im Jahr 2012 sowie der Altersverteilung in dieser Gruppe. Die angegebenen Zahlen basieren sowohl auf einer bestimmten Population (der Altersgruppe) als auch auf den aktuellen Abschlussquoten, sie werden somit von jeder Änderung des Bildungssystems beeinflusst, wie beispielsweise der Einführung neuer Bildungsgänge und Änderungen der Dauer der Bildungsgänge. Abschlussquoten können sehr hoch sein und in einem Zeitraum, in dem unerwartet viele Personen in die Ausbildung zurückkehren, sogar mehr als Ioo Prozent betragen. Dies ist zum Beispiel in Portugal geschehen, als das Programm „Neue Chancen“ eingeführt wurde, um denjenigen, die die Schule ohne einen Abschluss im Sekundarbereich frühzeitig verlassen hatten, eine zweite Chance zu geben.

In diesem Indikator bezieht sich die Angabe „Alter“ auf das Alter von Schülern zu Beginn des Kalenderjahres, sie könnten jedoch schon ein Jahr älter als angegeben sein, wenn der Abschluss gegen Ende des Schuljahres erfolgt. Der 25. Geburtstag wird als die obere Altersgrenze für den Abschluss der Erstausbildung angesehen. 2012 waren in den OECD-Ländern mehr als 90 Prozent der Absolventen mit einem Erstabschluss im Sekundarbereich II jünger als 25 Jahre. Absolventen dieses Bereichs, die bei Erreichen ihres Abschlusses 25 Jahre oder älter sind, besuchen in der Regel spezielle Bildungsgänge, z. B. des zweiten Bildungswegs. 


\section{Analyse und Interpretationen}

\section{Abschlüsse im Sekundarbereich II \\ Überblick über die Abschlussquoten im Sekundarbereich II}

Seit 2000 sind die Abschlussquoten für einen Erstabschluss im Sekundarbereich II um 8 Prozentpunkte gestiegen. Aktuelle Schätzungen gehen davon aus, dass 84 Prozent der gegenwärtig in den OECD-Ländern lebenden jungen Menschen im Laufe ihres Lebens einen Abschluss im Sekundarbereich II erwerben werden (Tab. A2.Ia). Ein Abschluss im Sekundarbereich II wird häufig als Mindestvoraussetzung für einen erfolgreichen Einstieg in den Arbeitsmarkt und Grundvoraussetzung für den Einstieg in die weitere Ausbildung erachtet. Die Kosten, die sowohl für den Einzelnen als auch für die Gesellschaft entstehen, wenn dieser Bildungsbereich nicht rechtzeitig abgeschlossen wird, können beträchtlich sein (s. Indikatoren A6 und A7).

Abschlussquoten bieten einen Hinweis darauf, ob bildungspolitische Initiativen tatsächlich dazu geführt haben, dass mehr Menschen einen Abschluss im Sekundarbereich II erwerben. Die großen Unterschiede zwischen den Abschlussquoten spiegeln die große Vielfalt der Bildungssysteme und -programme wider.

Es wird geschätzt, dass in Dänemark, Deutschland, Finnland, Island, Irland, Japan, Korea, Lettland, den Niederlanden, Slowenien, Spanien, Ungarn und dem Vereinigten Königreich mehr als 90 Prozent der Menschen im Laufe ihres Lebens einen Abschluss im Sekundarbereich II erwerben werden, in Mexiko und der Türkei dagegen weniger als 6o Prozent (Tab. A2.ra). Dennoch weisen Mexiko, Spanien und die Türkei die höchsten durchschnittlichen jährlichen Steigerungsraten (von I995 bzw. 2000 bis 20I2) bei den Abschlussquoten im Sekundarbereich II auf - deutlich oberhalb des OECD-Durchschnitts von o,8 Prozent. Die jährliche Steigerungsrate liegt in Spanien und der Türkei bei über 2 Prozent, in Mexiko sogar bei über 3 Prozent (Tab. A2.2a). In einigen Ländern ist die jährliche Steigerungsrate deshalb relativ niedrig, weil sie bereits zuvor bildungspolitische Maßnahmen darauf ausgerichtet hatten, den Zugang zum Sekundarbereich II zu steigern. Daher beliefen sich die Abschlussquoten in Japan, Korea und Norwegen bereits im Jahr 2000 auf 90 Prozent und sind seitdem auf diesem Niveau verblieben.

Die berufliche Bildung ist in vielen OECD-Ländern ein wesentlicher Bestandteil der Ausbildung im Sekundarbereich II (s. Indikator AI). Zwischen 2005 und 2012 haben sich die Abschlussquoten für berufsvorbereitende und berufsbildende Bildungsgänge im Sekundarbereich II mit einem durchschnittlichen Anstieg von 3 Prozentpunkten ähnlich entwickelt wie die Abschlussquoten im Sekundarbereich II insgesamt. Zwischen den einzelnen Ländern bestehen jedoch deutliche Unterschiede bei diesen Entwicklungstendenzen. In Deutschland beispielsweise gingen die Abschlussquoten bei berufsbildenden Bildungsgängen in diesem Zeitraum um 15 Prozentpunkte zurück, während sie in Portugal um 37 Prozentpunkte stiegen (Tab. A2.2b im Internet).

Außerdem bedeuten diese Abschlussquoten nicht, dass alle Absolventen anschließend entweder ein Studium im Tertiärbereich aufnehmen oder direkt in den Arbeitsmarkt eintreten werden. Die Zahl der Absolventen, die weder in Beschäftigung noch in einer Form der Ausbildung sind, hat in allen OECD-Ländern sogar zugenommen (s. Indika- 
tor $\mathrm{C}_{5}$ ). Daher ist es wichtig, qualitativ hochwertige Bildungsgänge im Sekundarbereich II anzubieten, die dem Einzelnen die richtige Mischung an Anregung und Bildungsmöglichkeiten bereitstellen um sicherzustellen, dass sich den Schülern nach Erwerb eines Abschlusses ausreichend Perspektiven eröffnen.

\section{Abschlussquoten im Sekundarbereich II nach Alter}

Die Abschlussquoten unterscheiden sich auch hinsichtlich des Alters der Absolventen. Wie bereits bei den Hinweisen weiter oben erwähnt, kann das Abschlussalter mit Änderungen im Bildungssystem zusammenhängen. So können Möglichkeiten, später im Leben einen Abschluss im Sekundarbereich II zu erwerben, und die reguläre Ausbildungsdauer von allgemeinbildenden und berufsbildenden Bildungsgängen zu Unterschieden beim typischen Abschlussalter führen.

Das durchschnittliche Alter eines Absolventen des Sekundarbereichs II (Erstabschluss) beträgt in den OECD-Ländern I9 Jahre, mehr als go Prozent der Absolventen mit einem Erstabschluss sind 25 Jahre alt oder jünger. Das Alter, in dem ein Abschluss im Sekundarbereich II erworben wird, variiert jedoch zwischen den einzelnen Ländern, in einigen Fällen sogar erheblich. In Israel, Neuseeland, der Türkei und den Vereinigten Staaten liegt das durchschnittliche Alter eines Erstabsolventen bei I7 Jahren - dem niedrigsten Alter in allen OECD-Ländern. Island und Norwegen liegen am anderen Ende der Bandbreite und weisen mit mindestens 22 Jahren das höchste durchschnittliche Alter auf (Tab. A2.ra und A2.rb).

Unterschiede beim Alter der Absolventen lassen sich auch innerhalb einzelner Länder beobachten. Wie Abbildung A2.2 zeigt, bestehen innerhalb eines Landes deutliche Unterschiede zwischen dem Alter der Absolventen von allgemeinbildenden und berufsbildenden Bildungsgängen. Im Durchschnitt ist das Alter der Absolventen von berufsbildenden Bildungsgängen höher als das der Absolventen von allgemeinbildenden Bildungsgängen (22 Jahre gegenüber I9 Jahren). In Belgien, Brasilien, Dänemark, Finnland, Island, Irland, den Niederlanden und Norwegen liegt das durchschnittliche Alter der Absolventen von berufsbildenden Bildungsgängen bei mindestens 25 Jahren, in Australien sogar bei 3I Jahren (Abb. A2.2).

Das durchschnittliche Abschlussalter von Erstabsolventen spiegelt auch spezielle nationale Gegebenheiten wider. In einigen Ländern sind die Bildungssysteme flexibel genug, dass Schüler aus dem Bildungssystem aus- und zu einem späteren Zeitpunkt wieder eintreten können. Daher sind die Abschlussquoten für Absolventen, die 25 Jahre oder älter sind, in Dänemark, Finnland, den Niederlanden und Norwegen relativ hoch - mindestens ro Prozent der Absolventen sind älter als 25 Jahre, während der entsprechende Anteil in Island sogar 20 Prozent beträgt. Die Tatsache, dass der Anteil der Absolventen, die jenseits des typischen Abschlussalters einen Abschluss erwerben, zwischen den Ländern und Bildungsgängen variiert, kann auch damit zusammenhängen, ob Abschlüsse über den sogenannten zweiten Bildungsweg erworben werden können. Diese Bildungsgänge verbessern die für den Arbeitsmarkt erforderlichen Kompetenzen. In Portugal wurde beispielsweise 2005 das Programm „Neue Chancen“ eingeführt, um denjenigen, die die Schule früh verlassen haben oder bei denen dieses Risiko bestand, eine zweite Chance zu geben und um diejenigen Arbeitnehmer zu unterstützen, die weitere Qualifikationen erwerben möchten. Infolge dieses Programmes 


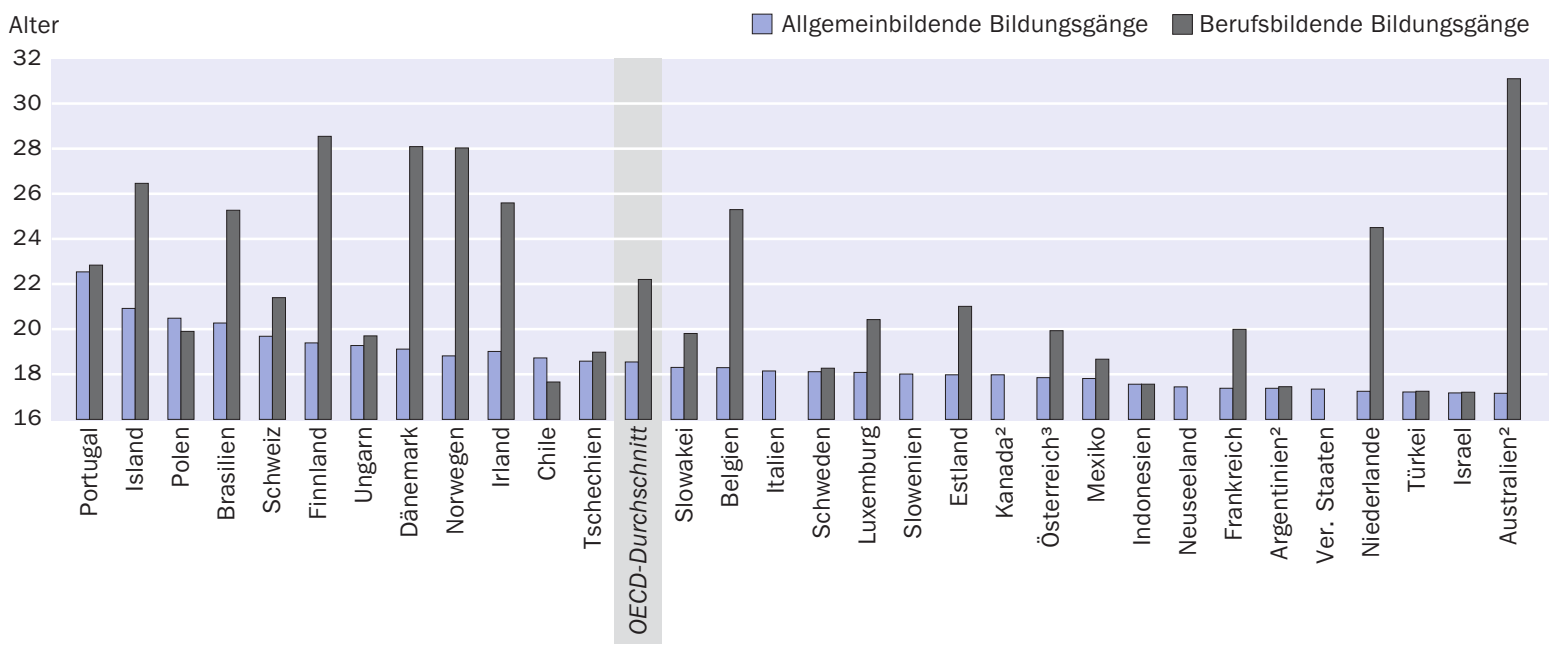

1. Das „durchschnittliche Abschlussalter“ bezieht sich in der Regel auf das Alter von Schülern zu Beginn des Kalenderjahres, sie könnten jedoch schon ein Jahr älter als angegeben sein, wenn der Abschluss gegen Ende des Schuljahres erfolgt. 2. Referenzjahr 2011. 3. Bildungsgänge, die die ISCED-Stufen 3 und 4 umfassen (Höhere berufsbildende Schule), sind nicht erfasst.

Anordnung der Länder in absteigender Reihenfolge des durchschnittlichen Abschlussalters im Sekundarbereich II (allgemeinbildende Bildungsgänge) im Jahr 2012. Quelle: OECD. Tabelle A2.1a. Hinweise s. Anhang 3 unter www.oecd.org/edu/eag.htm. StatLink: http://dx.doi.org/10.1787/888933115274

sind die Abschlussquoten zwischen 2008 und 2010 um mehr als 40 Prozentpunkte angestiegen. 2010 waren mehr als 40 Prozent der betreffenden Absolventen über 25 Jahre alt.

\section{Abschlussquoten im Sekundarbereich II nach Geschlecht}

In den meisten OECD-Ländern gibt es auch erhebliche geschlechtsspezifische Unterschiede bei den Abschlussquoten für einen Erstabschluss im Sekundarbereich II. Im Durchschnitt sind die Abschlussquoten bei den Frauen (mit 87 Prozent) höher als diejenigen der Männer (8I Prozent). In Dänemark, Griechenland, Island, Israel und Norwegen liegen die Abschlussquoten für Frauen um mindestens ro Prozentpunkte über denjenigen der Männer. Nur in Deutschland und Österreich ist der Anteil der männlichen Absolventen größer als derjenige der Frauen (Tab. A2.Ia).

Dieser Trend ist bei den unter 25-jährigen Absolventen von allgemeinbildenden Bildungsgängen sogar noch ausgeprägter. Im Jahr 2012 beliefen sich im Durchschnitt aller OECD-Länder im Sekundarbereich II die Abschlussquoten der Frauen auf 54 Prozent und die der Männer auf 43 Prozent. In Italien, Österreich, Polen, der Slowakei, Slowenien und Tschechien kommen auf zwei männliche Absolventen mindestens drei weibliche Absolventinnen (Tab. A2.Ib).

Traditionell waren die Abschlussquoten der Männer in den berufsvorbereitenden und berufsbildenden Bildungsgängen höher als diejenigen der Frauen, obwohl dies nicht auf alle Länder zutrifft. Im Durchschnitt liegen die Abschlussquoten in diesen Bildungsgängen für Männer um 4 Prozentpunkte über denen der Frauen (50 Prozent gegenüber 46 Prozent). Dieser tendenzielle Unterschied hat sich in vielen Ländern verändert, u.a. in Belgien, Dänemark, Finnland, Irland, den Niederlanden und 
Spanien, wo die Abschlussquoten bei den Frauen mindestens 5 Prozentpunkte über denen der Männer liegen. Berufsbildende Bildungsgänge werden jedoch nicht in allen Ländern in gleichem Maße angeboten, daher können die Abschlussquoten zwischen den einzelnen Ländern erheblich variieren. In Finnland, Frankreich, Irland, den Niederlanden, Österreich, der Schweiz und Slowenien betragen die Abschlussquoten in berufsvorbereitenden und berufsbildenden Bildungsgängen mehr als 70 Prozent; während sie in Argentinien, Brasilien, Estland, Indonesien, Japan, Kanada, Korea, Lettland, Mexiko, der Türkei und Ungarn bei unter 30 Prozent liegen (Tab. A2.Ia).

\section{Abschlüsse im Sekundarbereich II nach Fächergruppen}

Auch bei den berufsbildenden Bildungsgängen zeigen sich bei der Wahl der Fächergruppe geschlechtsspezifische Unterschiede. Diese Unterschiede können dem traditionellen Verständnis von Geschlechterrollen und Identitäten sowie den manchmal mit speziellen Fächergruppen assoziierten kulturellen Werten zugeschrieben werden. Im Durchschnitt der OECD-Länder erwerben die meisten Absolventen von berufsbildenden Bildungsgängen des Sekundarbereichs II einen Abschluss in den Fächergruppen Ingenieurwissenschaften, Fertigung und Bauwesen (34 Prozent), und die Mehrheit der Absolventen dieses Bereichs sind Männer (Tab. A2.3a und A2.3b im Internet). So sind in Norwegen, Tschechien und Ungarn mindestens 70 Prozent der Absolventen dieser Fächergruppe Männer. Junge Frauen finden sich dagegen eher bei den Absolventen der Sozial-, Rechts- und Wirtschaftswissenschaften (24 Prozent), Gesundheit und Soziales (ig Prozent) und Dienstleistungen (ig Prozent) (Tab. A2.3a).

\section{Abschlussquoten bei postsekundaren, nicht tertiären Bildungsgängen}

In den OECD-Ländern werden ganz unterschiedliche Bildungsgänge im postsekundaren, nicht tertiären Bereich angeboten. Unter dem Gesichtspunkt internationaler Vergleichbarkeit liegen sie im Grenzbereich zwischen Sekundarbereich II und postsekundarem Bereich und können im spezifischen nationalen Zusammenhang möglicherweise eindeutig als zum Sekundarbereich II oder zum postsekundaren Bereich gehörig angesehen werden. Auch wenn der Inhalt dieser Bildungsgänge vielleicht nicht wesentlich über den von Bildungsgängen des Sekundarbereichs II hinausgeht, erweitern diese postsekundaren, nicht tertiären Bildungsgänge doch die Kenntnisse derjenigen, die schon einen Abschluss im Sekundarbereich II erworben haben.

Die Teilnehmer der betreffenden Bildungsgänge sind in der Regel älter als diejenigen des Sekundarbereichs II. Diese Bildungsgänge bieten normalerweise Berufsbildungsabschlüsse an und umfassen u. a. die Erzieherausbildung in Österreich und die Berufsausbildung der Auszubildenden im dualen System in Deutschland, die bereits einen allgemeinbildenden Abschluss des Sekundarbereichs erlangt haben. Auch die Bildungsgänge der dualen Berufsausbildung, die nur für Schüler angeboten werden, die bereits einen Abschluss im Sekundarbereich II erzielt haben, werden bei diesen Bildungsgängen erfasst (Tab. A2.Ic im Internet).

Die Erstabschlussquoten bei postsekundaren, nicht tertiären Bildungsgängen sind niedrig im Vergleich zu denjenigen des Sekundarbereichs II. Es wird geschätzt, dass im Durchschnitt 9 Prozent der gegenwärtig in den OECD-Ländern lebenden jungen Menschen im Laufe ihres Lebens einen Abschluss im Sekundarbereich II erwerben werden. Der Anteil der Frauen liegt mit 9 Prozent leicht über dem der Männer (8 Pro- 
zent). Die höchsten Abschlussquoten in diesen Bildungsgängen erreichen Neuseeland (33 Prozent), Österreich (26 Prozent) und Tschechien (28 Prozent), und in diesen drei Ländern liegen die Abschlussquoten der Frauen (mit 39 Prozent, 32 Prozent bzw. 32 Prozent) über denjenigen der Männer (27 Prozent, 20 Prozent bzw. 24 Prozent) (Tab. A2.Ic im Internet).

\section{Übergang nach dem Sekundarbereich II bzw. dem postsekundaren, nicht tertiären Bereich}

Der überwiegende Teil der Schüler erwirbt einen Abschluss in einem Bildungsgang des Sekundarbereichs II, der Zugang zu einer weiteren Ausbildung im Tertiärbereich gewähren soll (ISCED-Stufen $3 \mathrm{~A}$ und ${ }_{3} \mathrm{~B}$ ). Schüler aller Länder präferieren Bildungsgänge, die den direkten Zugang zum Tertiärbereich A (ISCED-Stufe ${ }_{3} \mathrm{~A}$ ) ermöglichen - mit Ausnahme von Österreich, der Schweiz und Slowenien, wo die Bildungssysteme stärker auf berufsbildende Bildungsgänge ausgerichtet sind und daher mehr Schüler Bildungsgänge des Sekundarbereichs II absolvieren, die zu Studiengängen des Tertiärbereichs B führen. 2012 lag die Abschlussquote bei langen Bildungsgängen des Sekundarbereichs II, die auf einen Eintritt in den Arbeitsmarkt oder die Aufnahme eines Bildungsgangs im postsekundaren, nicht tertiären Bereich vorbereiten (ISCED ${ }_{3} \mathrm{C}$ [lang]), im Durchschnitt der OECD-Länder bei I8 Prozent (Tab. A2.Ia).

Abbildung A2.3 zeigt die Unterschiede zwischen den einzelnen Ländern auf, wenn man den Anteil der Schüler, die einen Abschluss erwerben, der den Zugang zum Tertiärbereich A ermöglicht (ISCED-Stufen 3A und 4A), mit dem Anteil der Schüler, die tatsächlich vor ihrem 25. Geburtstag ein derartiges Studium aufnehmen, vergleicht. In Belgien, Chile, Finnland, Irland, Israel und Schweden beträgt die Differenz zwischen diesen

Abbildung A2.3

Zugang zum Tertiärbereich A für Absolventen des Sekundarbereichs II und des postsekundaren, nicht tertiären Bereichs, die jünger als 25 Jahre sind (2012)

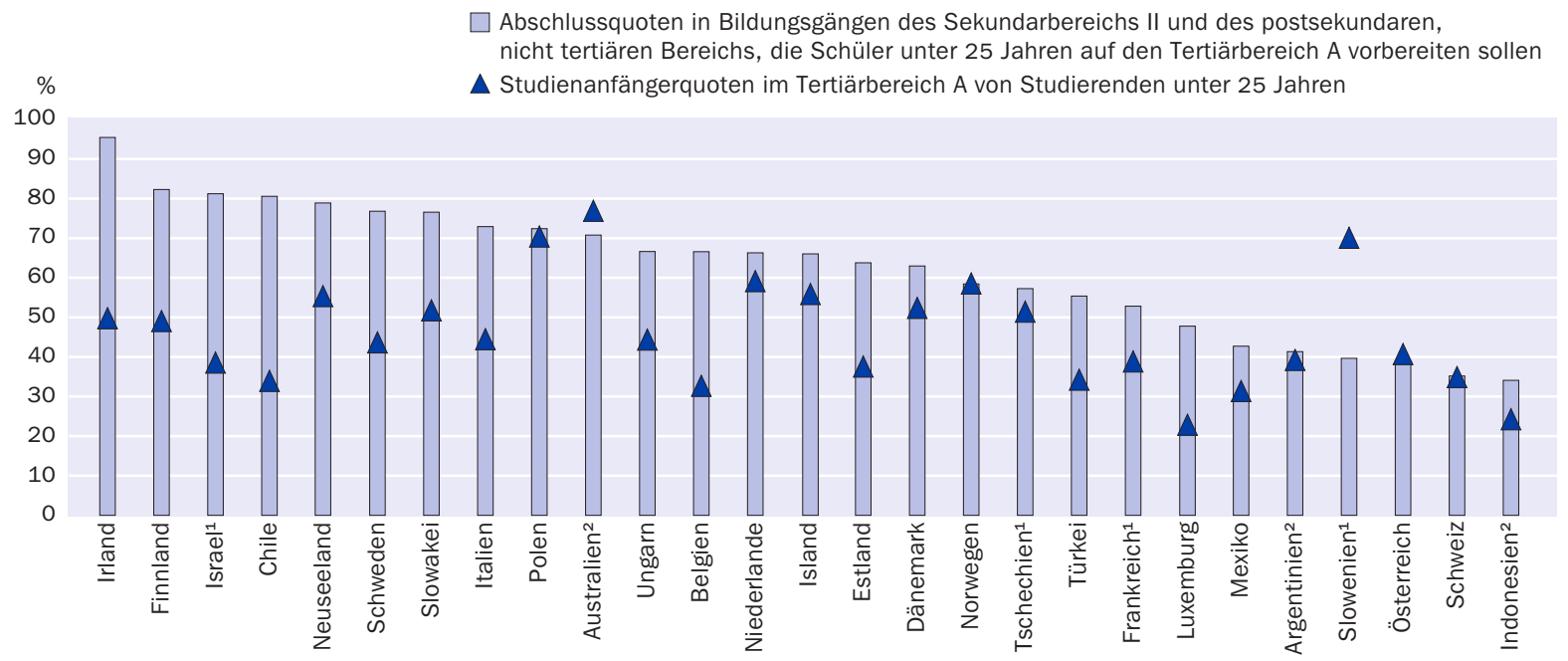

1. Es liegen keine Angaben zu Absolventen von Bildungsgängen des postsekundaren, nicht tertiären Bereichs vor. 2. Referenzjahr für Abschlussquoten 2011. Anordnung der Länder in absteigender Reihenfolge der Abschlussquoten im Jahr 2012 von Bildungsgängen im Sekundarbereich II und dem postsekundaren, nicht tertiären Bereich, die Schüler unter 25 Jahren auf den Tertiärbereich A vorbereiten sollen.

Quelle: OECD. Tabelle A2.1b, Tabelle A2.1c im Internet und Tabelle C3.1b. Hinweise s. Anhang 3 unter www.oecd.org/edu/eag.htm.

StatLink: http://dx.doi.org/10.1787/888933115293 


\section{Erfolgs- und Abschlussquoten - zwei unterschiedliche Kenngrößen}

Wie wird die Erfolgsquote in einem Bildungs-/Studiengang in Bildung aufeinen Blick ermittelt? Die „Erfolgsquote“ beschreibt den Prozentsatz der Schüler, die zum ersten Mal einen Bildungsgang im Sekundarbereich II beginnen und ihn erfolgreich innerhalb eines bestimmten Zeitraums abschließen. Sie dient dazu festzustellen, wie effizient Schüler den Sekundarbereich II durchlaufen. Bei dieser Quote handelt es sich um das Verhältnis zwischen den Absolventen und den Anfängern im gleichen Bildungsbereich. Die Berechnung erfolgt zum einen mittels der für den Bildungsgang vorgesehenen regulären Ausbildungsdauer, zum anderen mittels dieser Dauer plus zwei Jahre (für Schüler, die eine Klassenstufe oder einzelne Fächer wiederholen mussten, ihre Ausbildung in Teilzeit absolviert haben etc.). Diese Kenngröße enthält auch den Anteil Schüler, die keinen Abschluss in einem Bildungsgang des Sekundarbereichs II erwerben, sich jedoch weiterhin in Ausbildung befinden. Hierzu können Teilzeitlernende gehören, die für den Abschluss ihrer Ausbildung mehr Zeit benötigen, sowie Erwachsene, die beschließen, erneut die Schule zu besuchen, möglicherweise während sie berufstätig sind. Dieser Indikator bezieht sich nur auf Erstausbildungen.

Diese Kennzahl sollte nicht mit den Abschlussquoten im Sekundarbereich II verwechselt werden. Abschlussquoten zeigen den geschätzten prozentualen Anteil einer spezifischen Altersgruppe, der wahrscheinlich im Laufe des Lebens einen Abschluss im Sekundarbereich II erwerben wird. Sie messen den Anteil der Absolventen des Sekundarbereichs II im Verhältnis zur Bevölkerung des Landes und zeigen das Verhältnis zwischen allen Absolventen eines Jahres und einer bestimmten Bevölkerungsgruppe. Die Zahl der Absolventen eines Jahres wird für jedes Land nach Altersgruppen aufgegliedert. So wird beispielsweise die Anzahl der 15-jährigen Absolventen durch die Gesamtzahl der I5-Jährigen in diesem Land dividiert; die Anzahl der I6-jährigen Absolventen wird durch die Gesamtzahl der I6-Jährigen in diesem Land dividiert usw. Bei der Abschlussquote handelt es sich um die Summe über alle diese Altersgruppen.

Eine dritte Kenngröße in Bildung auf einen Blick verwendet das Konzept des Bildungsstands (s. Indikator AI). Mit dem Bildungsstand wird der Prozentsatz einer Bevölkerung angegeben, der einen Abschluss in einem bestimmten Bildungsbereich erreicht hat - in diesem Fall einen Abschluss im Sekundarbereich II. Er entspricht dem Verhältnis zwischen allen Absolventen (des entsprechenden Jahres und der Vorjahre) und der Gesamtbevölkerung.

beiden Gruppen mindestens 30 Prozentpunkte. Das deutet darauf hin, dass zahlreiche Schüler mit einem Abschluss, der ihnen den Zugang zu Studiengängen im Tertiärbereich A ermöglicht, kein derartiges Studium aufnehmen, wobei Bildungsgänge im Sekundarbereich II in Belgien und Israel Schüler auch auf Studiengänge im Tertiärbereich B vorbereiten. Ebenso wie die Entscheidung, den Sekundarbereich II zu besuchen, kann auch die Entscheidung, die Ausbildung im Tertiärbereich fortzusetzen, von verschiedenen Faktoren abhängen, u. a. den Opportunitätskosten einer Ausbildung im 
Tertiärbereich verglichen mit dem unmittelbaren Eintritt in den Arbeitsmarkt (Zapata, i. E.) (s. Indikator A7).

In Finnland findet im Sekundarbereich II auch eine berufliche Ausbildung statt, sodass viele Absolventen nach dem Schulabschluss direkt in den Arbeitsmarkt eintreten, ohne ihre Ausbildung im Tertiärbereich fortzusetzen. An den finnischen Hochschulen gibt es auch ein Numerus-clausus-System, d. h., die Zahl der Studienplätze für Studienanfänger ist begrenzt. Daher müssen Absolventen des Sekundarbereichs II (allgemeinbildend) ihre Ausbildung eventuell für zwei bis drei Jahre unterbrechen, ehe sie einen Studienplatz an einer Universität oder polytechnischen Einrichtung bekommen. In Irland legt die Mehrheit der Schüler im Sekundarbereich die Prüfung für das „Leaving Certificate“ (ISCED 3A) ab. Obwohl dieser Bildungsgang den Übergang in den Tertiärbereich ermöglicht, beabsichtigen nicht alle Schüler, die die Prüfung ablegen, dies auch zu tun. Bis zum Einsetzen der globalen Wirtschaftskrise konnten Schulabgänger in Irland noch von einem nachfragestarken Arbeitsmarkt profitieren, was vielleicht auch eine solche Entscheidung beeinflusst haben mag.

Im Gegensatz hierzu liegen in Slowenien die Abschlussquoten im Sekundarbereich II und postsekundaren, nicht tertiären Bereich deutlich (30 Prozentpunkte) unter den Studienanfängerquoten im Tertiärbereich A. Obwohl viele Schüler in Slowenien eher einen Abschluss im Sekundarbereich II erwerben, der den Zugang zum Tertiärbereich B eröffnet, entscheidet sich aber vielleicht später doch ein Teil von ihnen für ein Studium an einer Universität, was dort dank der flexiblen Übergangsmöglichkeiten zwischen diesen beiden Tertiärbereichen möglich ist.

\section{Erfolgsquoten im Sekundarbereich II}

In dieser Ausgabe stellt Bildung auf einen Blick zum dritten Mal einen Indikator vor, der sich mit der Ermittlung der Erfolgsquoten bei Bildungsgängen im Sekundarbereich II und damit den Übergangsmöglichkeiten zwischen den unterschiedlich ausgerichteten Bildungsgängen befasst. Dieser Indikator behandelt die zur Absolvierung dieser Bildungsgänge erforderliche Zeit sowie den Prozentsatz der Schüler, die sich auch nach Ende der regulären Ausbildungsdauer weiterhin in Ausbildung befinden. Er ermöglicht eine Schätzung der Zahl derjenigen, die die Schule frühzeitig verlassen, und einen Vergleich der Erfolgsquoten nach Geschlecht und Ausrichtung des Bildungsgangs. Daher erlaubt die Erfolgsquote - ebenso wie die Abschlussquote - keinerlei Rückschlüsse auf die Qualität der Ausbildung im Sekundarbereich II, sie weist jedoch in gewissem Umfang auf die Fähigkeit dieses Bildungsbereichs hin, die Schüler zu einem Abschluss dieses Bildungsbereichs innerhalb eines bestimmten Zeitraums zu motivieren.

Der überwiegende Teil der Schüler, die eine Ausbildung im Sekundarbereich II aufnehmen, schließt diese auch ab. Man geht davon aus, dass 72 Prozent der jungen Männer und Frauen, die eine Ausbildung im Sekundarbereich II aufnehmen, diese innerhalb der regulären Ausbildungsdauer erfolgreich abschließen. In einigen Ländern ist es jedoch für Schüler und Auszubildende relativ üblich, die Ausbildung irgendwann zu unterbrechen und das Bildungssystem vorübergehend zu verlassen. Einige nehmen ihre Ausbildung schnell wieder auf, während andere die Ausbildung für längere Zeit unterbrechen, was das Risiko erhöhen kann, überhaupt keinen Abschluss im Sekundarbereich II zu erwerben. In anderen Ländern ist es auch üblich, eine Klassenstufe zu 
wiederholen oder den Bildungsgang zu wechseln; dies führt zur einer Verzögerung bei der Erlangung des Abschlusses. Bildungspolitische Rahmenbedingungen, wie die Regelungen zur Wiederholung einer Klasse, können die Chancengerechtigkeit in einem Bildungssystem einschränken (OECD, 2012).

Der Anteil der Schüler, die ihre Ausbildung im vorgegebenen Zeitrahmen abschließen, variiert erheblich zwischen den einzelnen Ländern, wobei Korea mit 95 Prozent den höchsten und Luxemburg mit 40 Prozent den niedrigsten Anteil hat. In Griechenland, Irland, Israel, Japan, Korea, der Slowakei, Ungarn und den Vereinigten Staaten schlieBen mehr als 8o Prozent der Schüler ihre Ausbildung innerhalb des vorgesehenen Zeitraums ab. Nimmt man die reguläre Ausbildungsdauer im Sekundarbereich II plus zwei Jahre als Zeitdauer für die Erreichung des Abschlusses, haben dann im Durchschnitt der OECD-Länder etwa 87 Prozent der Schüler ihren Bildungsgang erfolgreich abgeschlossen. Das sind 15 Prozentpunkte mehr erfolgreiche Abschlüsse als nach der regulären Ausbildungsdauer (Tab. A2.4). Betrachtet man die Situation nach diesen weiteren zwei Jahren, erreichen 8 weitere Länder eine Erfolgsquote von mindestens 8o Prozent - Belgien (fläm.), Estland, Finnland, Frankreich, Italien, die Niederlande, Spanien und das Vereinigte Königreich. In Island ist der Anteil der Schüler, die den Sekundarbereich II nach zusätzlichen 2 Jahren erfolgreich abschließen, mit 58 Prozent am niedrigsten.

Innerhalb der einzelnen Länder ist der Unterschied zwischen den Erfolgsquoten innerhalb der vorgesehen regulären Ausbildungsdauer und innerhalb dieses Zeitraum plus 2 Jahre zum Teil darauf zurückzuführen, dass in den meisten OECD-Ländern Schüler die regulären Bildungseinrichtungen über die reguläre Ausbildungsdauer hinaus besuchen können, um einen Abschluss im Sekundarbereich II zu erwerben, wohingegen in einigen Ländern Schüler oberhalb dieses Alters speziell für sie eingerichtete Bil-



Anmerkung: Weiterführende Informationen zum vorliegenden Indikator, u.a. den verwendeten Methoden, den erfassten/nicht erfassten Bildungsgängen, dem Alter bei Aufnahme der Ausbildung etc., s. Anhang 3.

1. Keine Angaben zu $n+2$ vorhanden.

Anordnung der Länder in absteigender Reihenfolge der Erfolgsquoten bei Bildungsgängen im Sekundarbereich II.

Quelle: OECD. Tabelle A2.4. Hinweise s. Anhang 3 unter www.oecd.org/edu/eag.htm. StatLink: http://dx.doi.org/10.1787/888933115312 
dungsgänge besuchen müssen. Der Unterschied zwischen dem Prozentsatz der Schüler, die den Bildungsgang innerhalb der vorgesehenen regulären Ausbildungsdauer absolviert haben, und dem der Schüler, die ihren Abschluss erst nach weiteren zwei Jahren erworben haben, liegt in Luxemburg, wo es üblich ist, dass Schüler ein oder mehrere Schuljahre wiederholen, bei 32 Prozentpunkten. Im Gegensatz hierzu ist unter den Ländern mit verfügbaren Daten der Unterschied in Neuseeland und den Vereinigten Staaten mit 5 bzw. 3 Prozentpunkten sehr niedrig (Abb. A2.4). In den Vereinigten Staaten ist es sehr ungewöhnlich, dass Schüler, die älter als 20 Jahre sind, noch eine normale High School besuchen; Schüler, die innerhalb des vorgesehenen Zeitraums keinen High-School-Abschluss erwerben, können durch erfolgreiches Ablegen der General Educational Development (GED)-Prüfung einen gleichwertigen Abschluss erlangen.

Die Erfolgsquoten im Sekundarbereich II hängen auch von den Zugangsmöglichkeiten zu diesen Bildungsgängen ab. In allen Ländern mit verfügbaren Daten (mit Ausnahme Mexikos und der Türkei) sind mindestens rund 9o Prozent der Anfänger im Sekundarbereich II jünger als 20 Jahre. Die Annahme, dass Schüler in Ländern mit beschränktem Zugang zum Sekundarbereich II höhere Erfolgsquoten aufweisen als Schüler in Ländern mit nahezu universellem Zugang zu einer Ausbildung im Sekundarbereich II, ist berechtigt. Mit anderen Worten, in Ländern, deren Schüler eine Prüfung bestehen müssen oder aufgrund ihrer schulischen Leistungen in den Sekundarbereich II aufgenommen werden, kann der Anteil an Schülern mit guten Lernleistungen in diesen Bildungsgängen höher sein, was zu einer höheren Erfolgsquote führen könnte (Tab. A2.4). Die Selektivität der Bildungsgänge kann sich negativ auf die Chancengerechtigkeit im Bildungssystem auswirken, da der Zugang zu bestimmten Bildungsgängen beschränkt sein kann.

\section{Erfolgsquoten nach Geschlecht}

In allen Ländern mit verfügbaren Daten ist die Wahrscheinlichkeit, dass junge Männer die Ausbildung im Sekundarbereich II nicht im vorgesehenen Zeitraum abschließen, größer als bei jungen Frauen. Im Durchschnitt schließen 76 Prozent der jungen Frauen ihre Ausbildung im Sekundarbereich II innerhalb des vorgesehenen Zeitraums ab, im Vergleich zu 68 Prozent der Jungen. Nur in Finnland, Griechenland, Irland, Japan, Korea, Schweden und der Slowakei unterscheidet sich der Prozentsatz junger Männer und junger Frauen, die den Sekundarbereich II nicht abschließen, um weniger als 5 Prozentpunkte. In Island, Italien, Norwegen und der Türkei liegt der Prozentsatz von jungen Frauen mit einem erfolgreichen Abschluss des Sekundarbereichs II um mehr als I4 Prozentpunkte über dem der jungen Männer (Abb. A2.5). Die in Norwegen erkennbaren Unterschiede zwischen den Geschlechtern sind wahrscheinlich darauf zurückzuführen, dass junge Frauen im Sekundarbereich I tendenziell bessere Leistungen erzielen als junge Männer. Nach Kontrolle für die Leistungen im Sekundarbereich I zeigt sich kein Unterschied zwischen den Geschlechtern bzw. nur ein geringer Vorteil für junge Männer (Falch et al., 20ro).

Der geschlechtsspezifische Unterschied verringerte sich geringfügig auf durchschnittlich 5 Prozentpunkte, wenn der Abschluss erst zwei Jahre nach Ende der regulären Ausbildungsdauer erworben wurde. Der Unterschied zwischen den Erfolgsquoten, wenn man die reguläre Ausbildungsdauer oder diese plus 2 Jahre als Bezugspunkt zugrunde 


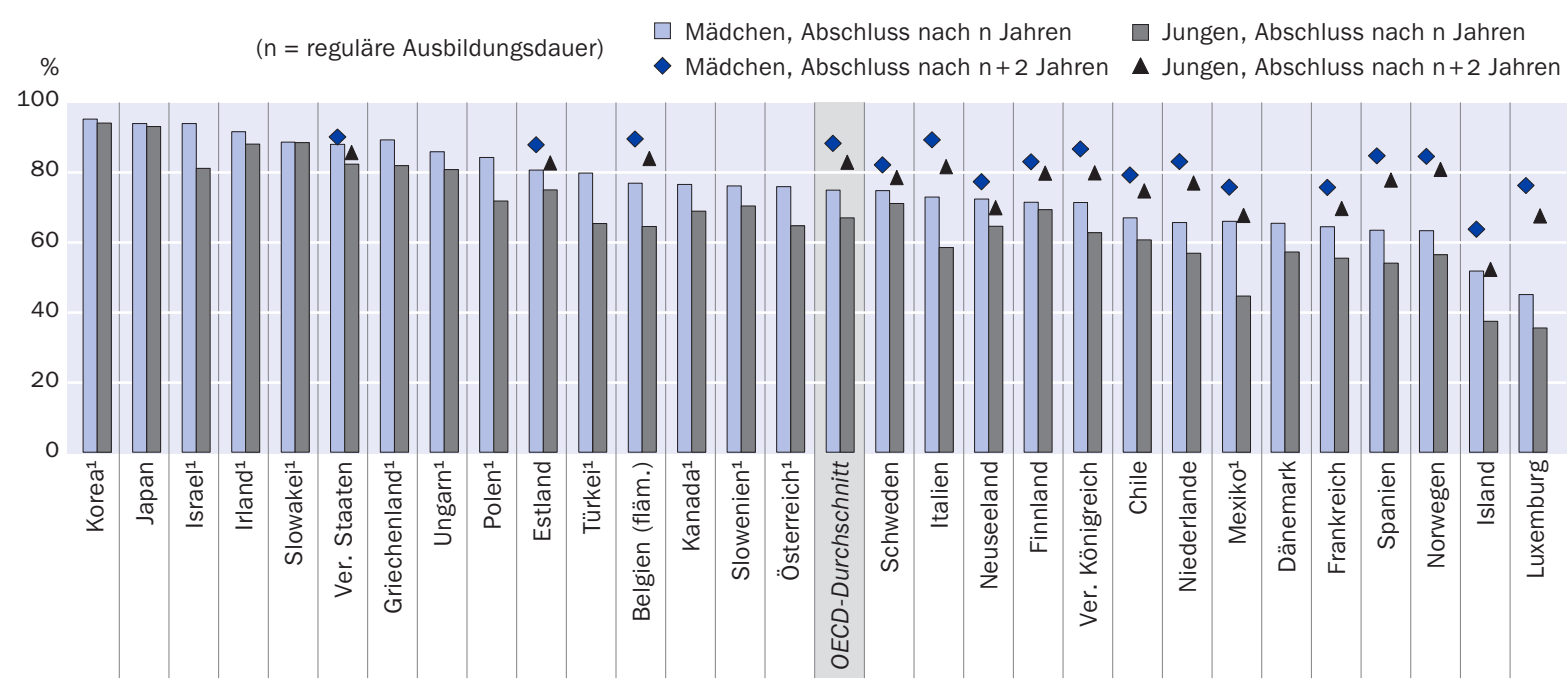

1. Keine Angaben zu $n+2$ vorhanden.

Anordnung der Länder in absteigender Reihenfolge der Erfolgsquoten von Mädchen bei Bildungsgängen im Sekundarbereich II (nach $n$ Jahren).

Quelle: OECD. Tabelle A2.4. Hinweise s. Anhang 3 unter www.oecd.org/edu/eag.htm. StatLink: http://dx.doi.org/10.1787/888933115331

legt, ist bei den jungen Männern mit I6 Prozentpunkten größer als bei den jungen Frauen, wo er I3 Prozentpunkte beträgt. Die Annäherung bei den geschlechtsspezifischen Unterschieden könnte mit dem verstärkten Vorkommen von Klassenwiederholungen oder einem Wechsel zu einem anderen Bildungsgang zusammenhängen sowie mit wirtschaftlichen und soziokulturellen Unterschieden, wodurch junge Männern länger als die reguläre Ausbildungsdauer für einen Abschluss benötigen (OECD, 2013).

Der geschlechtsspezifische Unterschied variiert außerdem je nach Bildungsgang: 8o Prozent der jungen Frauen erwerben einen Abschluss in einem allgemeinbildenden Bildungsgang im Vergleich zu 73 Prozent der jungen Männer; 67 Prozent der jungen Frauen erwerben einen Abschluss in einem berufsbildenden Bildungsgang im Vergleich zu 6r Prozent der jungen Männer. In Island beläuft sich dieser geschlechtsspezifische Unterschied in berufsbildenden Bildungsgängen auf mehr als I6 Prozentpunkte zugunsten der jungen Frauen. Nur in Estland, Griechenland und der Slowakei ist die Zahl der jungen Männer, die in berufsbildenden Bildungsgängen einen Abschluss im Sekundarbereich II innerhalb der regulären Ausbildungsdauer erwerben, höher als die der jungen Frauen (Tab. A2.5).

Vielen Untersuchungen, einschließlich der internationalen Schulleistungsstudie PISA der OECD, ist zu entnehmen, dass in den OECD-Ländern junge Frauen eher bessere Leistungen als junge Männer erbringen und eher weniger häufig die Schule frühzeitig verlassen (OECD, 2012; OECD, 2013; OECD, 2014). Abgesehen davon stehen jedoch die jungen Frauen, die die Schule frühzeitig verlassen haben, trotz des höheren durchschnittlichen Bildungsstands tendenziell eher schlechter da als gleichaltrige junge Männer (s. Indikatoren AI und C5). Die Erfolgsquote im Sekundarbereich II und die Bildungsteilnahme junger Menschen hängen auch von zahlreichen weiteren Faktoren ab, z. B. dem sozialen Druck durch Eltern und Freunde, vorherigen schulischen Erfah- 
rungen und Veränderungen der eigenen psychischen und physischen Situation (OECD, 2012; Zapata, i. E.) sowie dem Bildungsstand der Eltern und dem Migrationshintergrund (Kasten A2.2).

\section{Erfolgsquoten nach Ausrichtung des Bildungsgangs}

Die Wahl zwischen allgemein- und berufsbildenden Bildungsgängen erfolgt, je nach Land, zu unterschiedlichen Zeitpunkten im schulischen Bildungsverlauf. In Ländern mit einem Gesamtschulsystem ist der Kernlehrplan für alle Schüler bis zum Beginn des Sekundarbereichs II im Alter von I6 Jahren einheitlich (z. B. in den nordischen Ländern), während in Ländern mit einem stark gegliederten Schulsystem die Wahl von Fachrichtung oder Schultyp unter Umständen bereits im Sekundarbereich I ab einem Alter von Io bis $\mathrm{I}_{3}$ Jahren erfolgt (z. B. in Luxemburg).

In mehreren Ländern sind allgemeinbildende und berufsbildende Bildungsgänge klar voneinander abgegrenzt, die Schüler müssen sich für eine Ausrichtung entscheiden. Dies ist beispielsweise in Deutschland und Frankreich der Fall, wo sich die Bildungsgänge im Sekundarbereich II je nach Ausrichtung ganz klar unterscheiden. In anderen Ländern ist die Ausbildung im Sekundarbereich II in Gesamtschulen organisiert, und es gibt weniger Unterschiede zwischen allgemein- und berufsbildenden Bildungsgängen, wie beispielsweise in Schweden. Trotz der Aufgliederung der verschiedenen Bildungsgänge im Sekundarbereich II bieten die Länder den Schülern die Möglichkeit, zwischen den Bildungsgängen zu wechseln, wie beispielsweise in Finnland und den Niederlanden. Flexible Übergänge zwischen allgemeinbildenden und berufsbildenden

Abbildung A2.6

Erfolgsquoten bei Bildungsgängen im Sekundarbereich II, nach Ausrichtung des Bildungsgangs und Ausbildungsdauer




Bildungsgängen sind positiv für Schüler, die die Ausrichtung des Bildungsgangs wechseln und einen anderen Bildungsgang im Sekundarbereich II belegen möchten (OECD, 20I2).

Die Wahrscheinlichkeit eines erfolgreichen Abschlusses ist bei Schülern in allgemeinbildenden Bildungsgängen größer als bei Schülern in berufsbildenden Bildungsgängen. In den 26 Ländern mit verfügbaren Daten haben 76 Prozent der Schüler ihren allgemeinbildenden Bildungsgang innerhalb der regulären Ausbildungsdauer absolviert, und zwei Jahre nach Ende der regulären Ausbildungsdauer steigt dieser Anteil um weitere I5 Prozentpunkte.

Im Gegensatz dazu haben nur 64 Prozent der Schüler eines berufsbildenden Bildungsgangs diesen innerhalb der regulären Ausbildungsdauer absolviert, und dieser Anteil stieg zwei Jahre nach Ende der regulären Ausbildungsdauer um I5 Prozentpunkte. Der Unterschied zwischen den Abschlussquoten bei allgemeinbildenden und berufsbildenden Bildungsgängen des Sekundarbereichs II beträgt im Durchschnitt I 3 Prozentpunkte, reicht jedoch von mehr als 40 Prozentpunkten in Dänemark bis zu höchstens 5 Prozentpunkten in Chile, Israel und Japan (Tab. A2.5).

Der große Unterschied zwischen den Erfolgsquoten in allgemein- und berufsbildenden Bildungsgängen des Sekundarbereichs II der einzelnen Länder lässt sich dadurch erklären, dass in einigen Ländern schwache Schüler in berufsbildende Bildungsgänge gelenkt (oder umorientiert) werden können, wohingegen Schüler mit guten Lernleistungen allgemeinbildende Bildungsgänge besuchen. Einige Schüler haben möglicherweise auch Schwierigkeiten herauszufinden, welcher berufsbildende Bildungsgang am besten für sie geeignet ist, und müssen daher vielleicht in einem Bildungsbereich eine oder mehrere Klassenstufen wiederholen. Auch mag es Schwierigkeiten geben, einen Arbeitgeber zu finden, der bereit wäre, eine Stelle für eine duale Ausbildung anzubieten, es mag nicht sofort eine entsprechende Stelle frei sein, oder die Schüler geben zwischenzeitlich auf.

In einigen Ländern bestehen gut ausgebildete Übergänge zwischen diesen beiden Ausrichtungen der Bildungsgänge. Zum Beispiel erlangen in Norwegen von den 40 Prozent der Schüler, die eine berufliche Ausbildung gewählt und innerhalb des vorgesehenen Zeitraums einen Abschluss erworben haben, 45 Prozent einen Abschluss in einem berufsbildenden Bildungsgang, während 55 Prozent den Bildungsgang wechseln und einen Abschluss in einem allgemeinbildenden Bildungsgang erwerben. Andererseits erlangten in Chile von den 66 Prozent der Schüler, die einen allgemeinbildenden Bildungsgang begonnen und ihren Abschluss innerhalb des vorgesehenen Zeitraums erworben haben, 79 Prozent einen Abschluss in einem allgemeinbildenden Bildungsgang, während 2I Prozent den Bildungsgang wechselten und einen Abschluss in einem berufsbildenden Bildungsgang erwarben (Tab. A2.5).

Einige Schüler, die eine berufliche Ausbildung beginnen, verlassen möglicherweise das Bildungssystem, um direkt in den Arbeitsmarkt einzutreten. Die Attraktivität möglicher Beschäftigungen kann eine Rolle bei der Entscheidung spielen, das Bildungssystem zu verlassen, insbesondere in den höheren Klassenstufen des Sekundarbereichs II (Stearns et al., 2006 in Zapata, i. E.). Die Zugangsmöglichkeiten zum Arbeitsmarkt für 
Erfolgsquoten im Sekundarbereich II, nach Bildungsstand der Eltern bzw. Migrationshintergrund

Verhältnis von Absolventen zu Anfängern (nach Alterskohorten)

\begin{tabular}{|c|c|c|c|c|c|c|}
\hline & & \multicolumn{3}{|c|}{$\begin{array}{l}\text { ISCED-Stufe } 3 \text { nach } \\
\text { Bildungsstand der Eltern }\end{array}$} & \multicolumn{2}{|c|}{\begin{tabular}{|c} 
ISCED-Stufe 3 mit Migrationshintergrund \\
(erste oder zweite Generation)
\end{tabular}} \\
\hline & $\begin{array}{c}n=\text { reguläre } \\
\text { Ausbildungsdauer }\end{array}$ & ISCED 0-2 & ISCED 3 & ISCED $5 / 6$ & Erste Generation & Zweite Generation \\
\hline Belgien (fläm.) & $\begin{array}{l}\text { innerhalb } n \\
2 \text { Jahre nach } n\end{array}$ & $\begin{array}{l}58 \\
75\end{array}$ & $\begin{array}{l}71 \\
89\end{array}$ & $\begin{array}{l}80 \\
94\end{array}$ & $\mathrm{~m}$ & $\begin{array}{l}m \\
m\end{array}$ \\
\hline Chile & $\begin{array}{l}\text { innerhalb } n \\
2 \text { Jahre nach } n\end{array}$ & $\begin{array}{l}78 \\
87\end{array}$ & $\begin{array}{l}82 \\
90\end{array}$ & $\begin{array}{l}86 \\
92\end{array}$ & $\begin{array}{l}m \\
m\end{array}$ & $\begin{array}{l}m \\
m\end{array}$ \\
\hline Dänemark & $\begin{array}{l}\text { innerhalb } n \\
2 \text { Jahre nach } n\end{array}$ & $\begin{array}{l}44 \\
54\end{array}$ & $\begin{array}{l}56 \\
72\end{array}$ & $\begin{array}{l}73 \\
84\end{array}$ & $\begin{array}{l}46 \\
57\end{array}$ & $\begin{array}{l}50 \\
64\end{array}$ \\
\hline Finnland & $\begin{array}{l}\text { innerhalb } n \\
2 \text { Jahre nach } n\end{array}$ & $\begin{array}{l}57 \\
67\end{array}$ & $\begin{array}{l}68 \\
78\end{array}$ & $\begin{array}{l}76 \\
88\end{array}$ & $\begin{array}{l}56 \\
70\end{array}$ & $\begin{array}{l}62 \\
78\end{array}$ \\
\hline Frankreich & $\begin{array}{l}\text { innerhalb } n \\
2 \text { Jahre nach } n\end{array}$ & $\begin{array}{l}50 \\
70\end{array}$ & $\begin{array}{l}59 \\
83\end{array}$ & $\begin{array}{l}68 \\
92\end{array}$ & $\begin{array}{l}46 \\
68\end{array}$ & $\begin{array}{l}49 \\
71\end{array}$ \\
\hline Ungarn & $\begin{array}{l}\text { innerhalb } n \\
2 \text { Jahre nach } n\end{array}$ & $\begin{array}{l}\mathrm{m} \\
\mathrm{m}\end{array}$ & $\begin{array}{l}\mathrm{m} \\
\mathrm{m}\end{array}$ & $\begin{array}{l}\mathrm{m} \\
\mathrm{m}\end{array}$ & $\begin{array}{r}32 \\
m\end{array}$ & $\begin{array}{l}\mathrm{m} \\
\mathrm{m}\end{array}$ \\
\hline Island & $\begin{array}{l}\text { innerhalb } n \\
2 \text { Jahre nach } n\end{array}$ & $\begin{array}{l}\mathrm{m} \\
\mathrm{m}\end{array}$ & $\begin{array}{l}m \\
m\end{array}$ & $\begin{array}{l}m \\
m\end{array}$ & $\begin{array}{l}26 \\
31\end{array}$ & $\begin{array}{l}20 \\
20\end{array}$ \\
\hline Israel & $\begin{array}{l}\text { innerhalb } n \\
2 \text { Jahre nach } n\end{array}$ & $\begin{array}{r}78 \\
m\end{array}$ & $\begin{array}{r}92 \\
m\end{array}$ & $\begin{array}{r}95 \\
m\end{array}$ & $\begin{array}{r}85 \\
m\end{array}$ & $\begin{array}{l}\mathrm{m} \\
\mathrm{m}\end{array}$ \\
\hline Niederlande & $\begin{array}{l}\text { innerhalb } n \\
2 \text { Jahre nach } n\end{array}$ & $\begin{array}{l}\mathrm{m} \\
\mathrm{m}\end{array}$ & $\begin{array}{l}\mathrm{m} \\
\mathrm{m}\end{array}$ & $\begin{array}{l}m \\
m\end{array}$ & $\begin{array}{l}51 \\
67\end{array}$ & $\begin{array}{l}53 \\
73\end{array}$ \\
\hline Norwegen & $\begin{array}{l}\text { innerhalb } n \\
2 \text { Jahre nach } n\end{array}$ & $\begin{array}{l}36 \\
49\end{array}$ & $\begin{array}{l}52 \\
69\end{array}$ & $\begin{array}{l}70 \\
83\end{array}$ & $\begin{array}{l}39 \\
52\end{array}$ & $\begin{array}{l}55 \\
68\end{array}$ \\
\hline Schweden & $\begin{array}{l}\text { innerhalb } n \\
2 \text { Jahre nach } n\end{array}$ & $\begin{array}{l}59 \\
67\end{array}$ & $\begin{array}{l}73 \\
80\end{array}$ & $\begin{array}{l}80 \\
88\end{array}$ & $\begin{array}{l}65 \\
74\end{array}$ & $\begin{array}{l}68 \\
76\end{array}$ \\
\hline Ver. Königreich & $\begin{array}{l}\text { innerhalb } n \\
2 \text { Jahre nach } n\end{array}$ & $\begin{array}{l}49 \\
69\end{array}$ & $\begin{array}{l}69 \\
84\end{array}$ & $\begin{array}{l}85 \\
93\end{array}$ & $\begin{array}{l}\mathrm{m} \\
\mathrm{m}\end{array}$ & $\begin{array}{l}\mathrm{m} \\
\mathrm{m}\end{array}$ \\
\hline Vereinigte Staaten & $\begin{array}{l}\text { innerhalb } n \\
2 \text { Jahre nach } n\end{array}$ & $\begin{array}{l}68 \\
74\end{array}$ & $\begin{array}{l}83 \\
86\end{array}$ & $\begin{array}{l}91 \\
92\end{array}$ & $\begin{array}{l}80 \\
85\end{array}$ & $\begin{array}{l}84 \\
89\end{array}$ \\
\hline
\end{tabular}

Anmerkung: Weiterführende Informationen zum vorliegenden Indikator, u. a. den verwendeten Methoden, den eingeschlossenen/ nicht eingeschlossenen Bildungsgängen, dem Alter bei Aufnahme der Ausbildung etc. s. Anhang 3 unter www.oecd.org/edu/eag. htm. StatLink: http://dx.doi.org/10.1787/888933115369

Von den 29 Ländern, die an der Erhebung zu den Erfolgsquoten im Sekundarbereich II teilgenommen haben, haben I3 Länder Erfolgsquoten nach sozioökonomischen Gruppen aufgegliedert angegeben. Diese Quoten können nicht direkt mit den vorstehend aufgeführten Gesamtquoten verglichen werden, da zu ihrer Ermittlung unterschiedliche Kohorten verwendet wurden. Eine umfassende Beschreibung der für jedes Land verwendeten Kohorte ist in Anhang 3 enthalten. Die nachstehende Analyse konzentriert sich nur auf den Vergleich der Erfolgsquoten bei Bildungsgängen des Sekundarbereichs II in Verbindung mit dem Bildungsstand der Eltern bzw. einem Migrationshintergrund.

Zehn Länder haben die Erfolgsquoten für Schüler mit Migrationshintergrund angegeben. Die Unterschiede bei den Erfolgsquoten von Schülern mit Migrationshintergrund der ersten und der zweiten Generation betragen in Dänemark, Frankreich, den Niederlanden, Schweden und den Vereinigten Staaten weniger als 5 Prozentpunkte. Norwegen ist eine Ausnahme, dort liegen die Erfolgsquoten bei Schülern aus der zweiten Generation I7 Prozentpunkte über den Erfolgsquoten von Schülern der ersten Generation. Um festzustellen, ob Schüler mit Migrationshintergrund in Norwegen besser integriert sind als in anderen Ländern, die kaum Unterschiede zwischen den Erfolgsquoten von Schülern der ersten und zweiten Generation aufweisen, werden weitere Daten benötigt. 
Zehn Länder haben die Erfolgsquoten nach Bildungsstand der Eltern gemeldet. Der Unterschied bei den Erfolgsquoten im Sekundarbereich II zwischen Schülern aus Familien, deren Eltern über einen Abschluss im Tertiärbereich verfügen, und Schülern aus Familien, deren Eltern maximal über eine Ausbildung unterhalb des Sekundarbereichs II verfügen, reicht von 7 Prozentpunkten in Chile bis zu mehr als 30 Prozentpunkten in Norwegen und dem Vereinigten Königreich. In Norwegen erwerben nur 36 Prozent der Schüler aus Familien mit einem niedrigen Bildungsstand innerhalb der vorgesehenen regulären Ausbildungsdauer einen Abschluss im Sekundarbereich II, verglichen mit 70 Prozent der Schüler aus Familien mit einem hohen Bildungsstand.

Die politischen Entscheidungsträger sollten einen Schwerpunkt ihrer Bemühungen auf die Bildungsergebnisse von Schülern mit Migrationshintergrund bzw. aus Familien mit geringem Bildungsstand legen, insbesondere in den Ländern, in denen diese Schüler deutlich niedrigere Erfolgsquoten aufweisen als Gleichaltrige aus anderen sozioökonomischen Gruppen.

Menschen mit einem niedrigen Bildungsabschluss könnten ebenfalls Einfluss auf die Erfolgs- und Abbruchquoten haben.

Unter den Schülern, die ihren Abschluss nicht innerhalb des vorgesehenen Zeitraums erwerben, befinden sich 56 Prozent derjenigen, die einen allgemeinbildenden Bildungsgang absolvieren, weiterhin in Ausbildung gegenüber nur 43 Prozent der Schüler, die einen berufsbildenden Bildungsgang absolvieren. Zwischen den einzelnen Ländern bestehen große Unterschiede: In Belgien (fläm.), Finnland, Frankreich und Luxemburg befinden sich mindestens 8o Prozent der Schüler, die ihren Abschluss in einem allgemeinbildenden Bildungsgang nicht innerhalb des vorgesehenen Zeitraums erworben haben, weiterhin in Ausbildung, während es in Israel ro Prozent und in Korea nur 7 Prozent sind (Tab. A2.5).

Bei den Erfolgsquoten im Sekundarbereich II (allgemeinbildende und berufsbildende Bildungsgänge) nach Dauer der Bildungsgänge ergibt sich ein etwas anderes Bild. Die Ausbildungsdauer der Bildungsgänge im Sekundarbereich II unterscheidet sich in den einzelnen Ländern: von zwei Jahren in den Niederlanden und Spanien bei allgemeinbildenden Bildungsgängen bis zu fünf Jahren bei berufsbildenden Bildungsgängen in Luxemburg (Tab. A2.5). Man würde davon ausgehen, dass die Erfolgsquoten bei Bildungsgängen mit längerer Dauer geringer als bei Bildungsgängen mit kürzerer Dauer sind. Abbildung A2.6 zeigt jedoch, dass diese Annahme nicht zutrifft. So beträgt beispielsweise die Ausbildungsdauer von allgemeinbildenden Bildungsgängen des Sekundarbereichs II in Spanien zwei Jahre, während sie in anderen OECD-Ländern zwischen drei und vier Jahre beträgt. Mit einer Erfolgsquote von 6o Prozent nach n Jahren hat Spanien eine niedrige Erfolgsquote (die nach zwei zusätzlichen Jahren mit 83 Prozent wesentlich höher ist). Im Gegensatz hierzu beläuft sich die Dauer entsprechender Bildungsgänge in Ungarn auf vier Jahre, die Erfolgsquote ist jedoch mit 87 Prozent eine der höchsten. Wie bereits erwähnt können der Zugang zu den einzelnen Bildungsgängen und ihre Selektivität in Bezug auf die für ihren Besuch notwendigen Leistungen die hohen Erfolgsquoten bei Bildungsgängen mit längerer Ausbildungsdauer erklären. 
Auch das Engagement der Schüler und die Qualität der Lehr- und Lernbedingungen im Sekundarbereich II können von zentraler Bedeutung für die Erfolgsquoten sein.

\section{Definitionen}

Schüler der ersten Generation sind Schüler, die - ebenso wie ihre Eltern - in einem anderen Land als dem Erhebungsland geboren sind.

Bei Absolventen im Referenzzeitraum kann es sich sowohl um Absolventen mit einem Erstabschluss als auch Absolventen, die einen zusätzlichen Abschluss erworben haben, handeln. Ein Absolvent mit Erstabschluss ist ein Schüler, der innerhalb des Referenzzeitraums in einem bestimmten Bildungsbereich zum ersten Mal einen Abschluss erworben hat. Wenn ein Schüler im Laufe der Jahre mehrere Abschlüsse erwirbt, so wird er oder sie zwar jedes Jahr als Absolvent gezählt, als Absolvent mit Erstabschluss jedoch nur einmal.

Netto-Abschlussquoten zeigen den geschätzten prozentualen Anteil einer Altersgruppe, der einen Abschluss im Sekundarbereich II erwirbt (ausgehend von den aktuellen Abschlussquoten).

Schüler der zweiten Generation sind Schüler, die im Erhebungsland geboren wurden, deren Eltern jedoch im Ausland geboren wurden. Weiterführende Informationen zu den von den Ländern in Kasten A2.2 verwendeten Definitionen s. Anhang 3.

Die Erfolgsquote von allgemeinbildenden Bildungsgängen im Sekundarbereich II zeigt den Anteil von Anfängern in allgemeinbildenden Bildungsgängen des Sekundarbereichs II, die eine bestimmte Anzahl von Jahren später den Sekundarbereich II erfolgreich abgeschlossen haben (nach Alterskohorten).

Die Erfolgsquote von Bildungsgängen im Sekundarbereich II zeigt den Anteil von Anfängern in Bildungsgängen des Sekundarbereichs II, die eine bestimmte Anzahl von Jahren später den Sekundarbereich II erfolgreich abgeschlossen haben (nach Alterskohorten).

Die Erfolgsquote von berufsbildenden Bildungsgängen im Sekundarbereich II zeigt den Anteil von Anfängern in berufsbildenden Bildungsgängen des Sekundarbereichs II, die eine bestimmte Anzahl von Jahren später den Sekundarbereich II erfolgreich abgeschlossen haben (nach Alterskohorten). 


\section{Angewandte Methodik}

Die Daten beziehen sich auf das Schuljahr 20II/20I2 und beruhen auf der von der OECD im Jahre 2012 durchgeführten UOE-Datenerhebung zur Bildungsstatistik (weitere Informationen s. Anhang 3 unter www.oecd.org/edu/eag.htm).

Die Daten zur Entwicklung der Abschlussquoten im Sekundarbereich II basieren für die Jahre 1995 und 2000 bis 2004 auf einer im Januar 2007 durchgeführten speziellen Erhebung.

Außer es ist etwas anderes angegeben, wurden die Abschlussquoten als Netto-Abschlussquoten (d. h. die Summe der altersspezifischen Abschlussquoten) berechnet. Für diejenigen Länder, die keine derart ausführlichen Daten bereitstellen konnten, werden die Brutto-Abschlussquoten dargestellt. Zur Berechnung der Brutto-Abschlussquoten gab jedes Land das typische Abschlussalter an (s. Anhang I). Die Zahl der Absolventen wurde (ohne Berücksichtigung ihres jeweiligen Alters) durch die Bevölkerung im üblichen Abschlussalter geteilt. In vielen Ländern ist es jedoch schwierig, ein typisches Abschlussalter festzulegen, da die Altersspanne der Absolventen sehr groß ist.

Absolventen von Bildungsgängen auf den ISCED-Stufen $3 \mathrm{~A},{ }_{3} \mathrm{~B}$ und ${ }_{3} \mathrm{C}$ (bzw. $4 \mathrm{~A}, 4 \mathrm{~B}$, ${ }_{4 C}$ ) werden nicht als Absolventen mit einem Erstabschluss gezählt. Daher können die Abschlussquoten auch nicht einfach aufaddiert werden, da einige Schüler in mehr als einem Bildungsgang im Sekundarbereich II einen Abschluss erlangen und somit doppelt gezählt würden. Das Gleiche gilt für Abschlussquoten nach Ausrichtung des Bildungsgangs, d.h. allgemeinbildend oder berufsbildend. Zudem ist das typische Abschlussalter für die unterschiedlichen Bildungsgänge nicht zwangsläufig gleich (s. Anhang I). Berufsvorbereitende und berufsbildende Bildungsgänge umfassen sowohl schulische als auch kombinierte schulische und betriebliche Ausbildungen, die als Bestandteil des Bildungssystems gelten. Ausschließlich in Betrieben durchgeführte Ausbildungen und solche, die keiner formellen Aufsicht durch eine Bildungsbehörde unterstehen, bleiben unberücksichtigt.

Die Daten in den Tabellen A2.4 und A2.5 sowie Kasten A2.2 basieren auf einer im Dezember 2013 durchgeführten speziellen Erhebung. Die Erfolgsquote im Sekundarbereich II wird berechnet als das Verhältnis der Anzahl der Schüler, die im Referenzjahr einen Abschluss im Sekundarbereich II erwerben, zur Anzahl der Anfänger im entsprechenden Bildungsbereich vor $n$ Jahren (oder $n+2$ ), wobei $n$ der regulären Dauer des Bildungsgangs entspricht. Die Berechnung der Erfolgsquoten erfolgt in drei Viertel der in Tabelle A2.4 aufgeführten Länder anhand einer Kohortenanalyse (echte Kohortenmethode und Längsschnitterhebung). Die Schätzung für die anderen Länder ohne echtes Kohortenverfolgungssystem geht von einem kontinuierlichen Fortschreiten der Studierenden im Sekundarbereich II aus, da zwischen der Kohorte der Absolventen im Referenzjahr und der Kohorte der Anfänger n Jahre zuvor Konsistenz erforderlich ist (approximierte Kohortendaten). Diese Annahme könnte die Realität in den Ländern jedoch zu stark vereinfachen. Eine umfassende Beschreibung der für jedes Land verwendeten Methode (Referenzjahr für Anfänger, Referenzjahr für Absolventen, berücksichtigte Bildungsgänge etc.) findet sich in Anhang 3 . 
Die statistischen Daten für Israel wurden von den zuständigen israelischen Stellen bereitgestellt, die für sie verantwortlich zeichnen. Die Verwendung dieser Daten durch die OECD erfolgt unbeschadet des völkerrechtlichen Status der Golanhöhen, von Ost-Jerusalem und der israelischen Siedlungen im Westjordanland.

\section{Weiterführende Informationen}

Falch T. et al. (2010), Completion and Dropout in Upper Secondary Education in Norway: Causes and Consequences, Centre for Economic Research at NTNU, Trondheim, October 2010.

OECD (20I4), PISA 2012 Ergebnisse: Was Schülerinnen und Schüler wissen und können (Band I, Überarbeitete Ausgabe, Februar 2014): Schülerleistungen in Lesekompetenz, Mathematik und Naturwissenschaften, W. Bertelsmann Verlag, Germany, http://dx.doi.org/10.1787/9789264208858-de.

OECD (2013), Gleichstellung der Geschlechter: Zeit zu handeln, OECD, Paris, http:||dx.doi.org/ 10.1787/9789264190344-de.

OECD (2012), Equity and Quality in Education: Supporting Disadvantaged Students and Schools, OECD Publishing, http://dx.doi.org/10.1787/9789264130852-en.

OECD (2010), Lernen für die Arbeitswelt, ISBN: 978-92-64-08783-5, www.oecd.org/berlin/ publikationen/oecd-studiezurberufsbildunglernenfurdiearbeitswelt.htm.

Zapata, J. (i. E.), „Upper Secondary Education: a Literature Review on Provision“, OECD Publishing, Paris.

\section{Tabellen Indikator A2}

StatLink: http://dx.doi.org/10.1787/888933115122

Tabelle A2.ra Abschlussquoten im Sekundarbereich II und durchschnittliches Abschlussalter (2012)

Tabelle A2.Ib: Abschlussquoten im Sekundarbereich II von Schülern, die jünger als 25 Jahre sind (2012)

WEB Table A2.Ic: Post-secondary non-tertiary graduation rates (Abschlussquoten im postsekundaren, nicht tertiären Bereich) (2012)

Tabelle A2.2a: Entwicklung der Erstabschlussquoten im Sekundarbereich II (I995-2012) 
WEB Table A2.2b: Trends in graduation rates (general and pre-vocational/vocational programmes) at upper secondary level (Entwicklung der Abschlussquoten im Sekundarbereich II [allgemeinbildend und berufsvorbereitend/berufsbildend]) (2005-2012)

Tabelle A2.3a: Verteilung der Absolventen von berufsbildenden Bildungsgängen des Sekundarbereichs II, nach Fächergruppe und Geschlecht (20I2)

WEB Table A2.3b: Distribution of upper secondary vocational graduates, by field of education (Verteilung der Absolventen von berufsbildenden Bildungsgängen des Sekundarbereichs II, nach Fächergruppe) (20I2)

Tabelle A2.4: Erfolgsquoten im Sekundarbereich II, nach Geschlecht und Ausrichtung des Bildungsgangs

Tabelle A2.5: Erfolgsquoten im Sekundarbereich II, nach Ausrichtung des Bildungsgangs und Ausbildungsdauer 
Tabelle A2.1a

Abschlussquoten im Sekundarbereich II und durchschnittliches Abschlussalter (2012)

Summe der Abschlussquoten der einzelnen Altersjahrgänge, nach Ausrichtung und Ziel des Bildungsgangs und Geschlecht

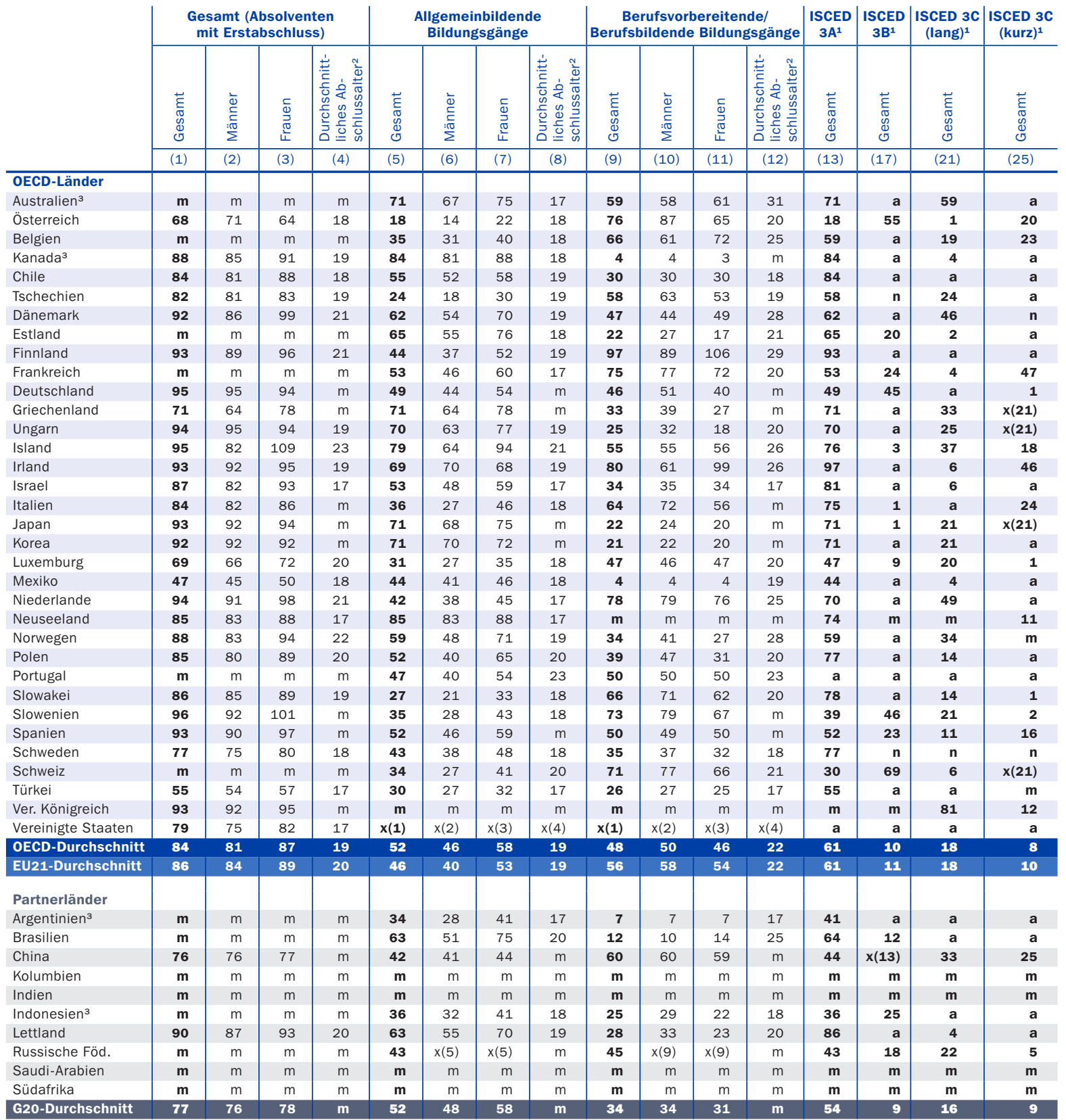

Anmerkung: Die Spalten für die separaten Abschlussquoten von Männern und Frauen und das durchschnittliche Abschlussalter im Sekundarbereich II nach Ausrichtung des Bildungsgangs, d.h. die Spalten (14) bis (16), (18) bis (20), (22) bis (24) und (26) bis (28), sind im Internet verfügbar (s. StatLink unten). Weiterführende Informationen zu den zur Berechnung der (Brutto-/Netto-)Abschlussquoten verwendeten Methoden und den entsprechenden typischen Altersjahrgängen s. Anhang 1. Unterschiede im Erhebungsbereich der Bevölkerungsdaten und der Absolventendaten bedeuten, dass die Abschlussquoten von Ländern mit einem Nettoabgang von Schülern (z. B. Luxemburg) wohl zu niedrig angesetzt und von Ländern mit einem Nettozugang von Schülern wohl zu hoch angesetzt sind.

1. ISCED 3A: Bildungsgänge sollen unmittelbaren Zugang zum Tertiärbereich A eröffnen.

ISCED 3B: Bildungsgänge sollen unmittelbaren Zugang zum Tertiärbereich B eröffnen.

ISCED 3C (lang): Ähnlich lang wie typische 3A- oder 3B-Bildungsgänge.

ISCED 3 C (kurz): Kürzer als typische 3A- oder 3B-Bildungsgänge.

2. Das „durchschnittliche Abschlussalter“ bezieht sich in der Regel auf das Alter von Schülern zu Beginn des Kalenderjahres, sie könnten jedoch schon ein Jahr älter als angegeben sein, wenn der Abschluss gegen Ende des Schuljahres erfolgt. Es bezieht sich auf ein gewichtetes Durchschnittsalter. Informationen zur Berechnung des durchschnittlichen Alters s. Anhang 3. 3. Referenzjahr 2011.

Quellen: OECD. Argentinien, China, Indien, Indonesien, Kolumbien, Saudi-Arabien und Südafrika: Statistikinstitut der UNESCO. Lettland: Eurostat. Hinweise s. Anhang 3 unter www.oecd.org/edu/eag.htm. StatLink: http://dx.doi.org/10.1787/888933115141

Erläuterung der Kennzeichnung fehlender Daten s. Hinweise für den Leser. 
Abschlussquoten im Sekundarbereich II von Schülern, die jünger als 25 Jahre sind (2012)

Summe der Abschlussquoten der einzelnen Altersjahrgänge, nach Ausrichtung und Ziel des Bildungsgangs und Geschlecht



Anmerkung: Die Spalten für die separaten Abschlussquoten von Männern und Frauen im Sekundarbereich II nach Ausrichtung des Bildungsgangs, d.h. die Spalten (14)/(15), (17)/(18), (20)/(21) und (23)/(24), sind im Internet verfügbar (s. StatLink unten). Weiterführende Informationen zu den zur Berechnung der (Brutto-/ Netto-)Abschlussquoten verwendeten Methoden und den entsprechenden typischen Altersjahrgängen s. Anhang 1. Unterschiede im Erhebungsbereich der Bevölkerungsdaten und der Absolventendaten bedeuten, dass die Abschlussquoten von Ländern mit einem Nettoabgang von Schülern (z. B. Luxemburg) wohl zu niedrig angesetzt und von Ländern mit einem Nettozugang von Schülern wohl zu hoch angesetzt sind.

1. ISCED 3A: Bildungsgänge sollen unmittelbaren Zugang zum Tertiärbereich A eröffnen.

ISCED 3B: Bildungsgänge sollen unmittelbaren Zugang zum Tertiärbereich B eröffnen.

ISCED 3C (lang): Ähnlich lang wie typische 3A- oder 3B-Bildungsgänge.

ISCED 3C (kurz): Kürzer als typische 3A- oder 3B-Bildungsgänge.

2. Anteil der Absolventen unter 25 Jahren an allen Absolventen. 3. Referenzjahr 2011.

Quellen: OECD. Argentinien, China, Indien, Indonesien, Kolumbien, Saudi-Arabien und Südafrika: Statistikinstitut der UNESCO. Lettland: Eurostat. Hinweise s. Anhang 3 unter www.oecd.org/edu/eag.htm. StatLink: http://dx.doi.org/10.1787/888933115160

Erläuterung der Kennzeichnung fehlender Daten s. Hinweise für den Leser. 
Tabelle A2.2a

Entwicklung der Erstabschlussquoten im Sekundarbereich II (1995-2012)

\begin{tabular}{|c|c|c|c|c|c|c|c|c|c|c|c|c|c|c|c|}
\hline & 1995 & 2000 & 2001 & 2002 & 2003 & 2004 & 2005 & 2006 & 2007 & 2008 & 2009 & 2010 & 2011 & 2012 & $\begin{array}{c}\text { Durchschnittl. } \\
\text { jährlicher Anstieg } \\
\text { 1995-2012 }^{1}\end{array}$ \\
\hline \multicolumn{16}{|l|}{ OECD-Länder } \\
\hline Australien & $\mathrm{m}$ & $\mathrm{m}$ & $\mathrm{m}$ & m & m & $\mathrm{m}$ & $\mathrm{m}$ & $\mathrm{m}$ & $m$ & $m$ & $\mathrm{~m}$ & $m$ & $\mathrm{~m}$ & m & $\mathrm{m}$ \\
\hline Österreich² & $\mathrm{m}$ & $\mathrm{m}$ & $\mathrm{m}$ & $\mathrm{m}$ & $\mathrm{m}$ & $\mathrm{m}$ & $\mathrm{m}$ & $\mathrm{m}$ & $\mathrm{m}$ & $\mathrm{m}$ & $\mathrm{m}$ & $\mathrm{m}$ & 66 & 68 & $\mathrm{~m}$ \\
\hline Belgien & $\mathrm{m}$ & $\mathrm{m}$ & $\mathrm{m}$ & $\mathrm{m}$ & $\mathrm{m}$ & $\mathrm{m}$ & $\mathrm{m}$ & $\mathrm{m}$ & $m$ & m & $m$ & $m$ & $\mathrm{~m}$ & m & $m$ \\
\hline Kanada & $\mathrm{m}$ & $\mathrm{m}$ & 77 & 79 & 83 & 79 & 80 & 81 & 77 & 81 & 81 & 85 & 88 & m & $m$ \\
\hline Chile & $\mathrm{m}$ & $m$ & $\mathrm{~m}$ & $m$ & $m$ & 79 & 85 & 82 & 82 & 83 & 85 & 83 & 83 & 84 & $m$ \\
\hline Tschechien & 78 & $\mathrm{~m}$ & 84 & 83 & 88 & 87 & 89 & 89 & 88 & 85 & 83 & 80 & 78 & 82 & $0,3 \%$ \\
\hline Dänemark & 83 & 95 & 95 & 94 & 88 & 88 & 82 & 84 & 85 & 83 & 85 & 86 & 90 & 92 & $0,7 \%$ \\
\hline Estland & $\mathrm{m}$ & $\mathrm{m}$ & $\mathrm{m}$ & $\mathrm{m}$ & $\mathrm{m}$ & $\mathrm{m}$ & $\mathrm{m}$ & $\mathrm{m}$ & $\mathrm{m}$ & $\mathrm{m}$ & $\mathrm{m}$ & $\mathrm{m}$ & $\mathrm{m}$ & m & $\mathrm{m}$ \\
\hline Finnland & 91 & 91 & 85 & 84 & 90 & 95 & 94 & 94 & 97 & 93 & 95 & 93 & 96 & 93 & $0,1 \%$ \\
\hline Frankreich & $\mathrm{m}$ & $\mathrm{m}$ & $\mathrm{m}$ & $\mathrm{m}$ & $\mathrm{m}$ & $\mathrm{m}$ & $\mathrm{m}$ & $\mathrm{m}$ & $\mathrm{m}$ & $\mathrm{m}$ & $\mathrm{m}$ & $\mathrm{m}$ & $\mathrm{m}$ & m & $\mathrm{m}$ \\
\hline Deutschland ${ }^{3}$ & 100 & 92 & 92 & 94 & 97 & 99 & 99 & 100 & 100 & 97 & 84 & 87 & 92 & 95 & $\mathrm{~m}$ \\
\hline Griechenland & 80 & 54 & 76 & 85 & 96 & 93 & 100 & 98 & 96 & 91 & $\mathrm{~m}$ & $\mathrm{~m}$ & $\mathrm{~m}$ & 71 & $-0,7 \%$ \\
\hline Ungarn & $\mathrm{m}$ & $\mathrm{m}$ & 83 & 82 & 87 & 86 & 84 & 87 & 84 & 78 & 86 & 86 & 86 & 94 & m \\
\hline Island & 80 & 67 & 70 & 79 & 81 & 87 & 79 & 87 & 86 & 89 & 89 & 88 & 90 & 95 & $1,1 \%$ \\
\hline Irland & m & 74 & 77 & 78 & 91 & 92 & 91 & 87 & 90 & 88 & 91 & 94 & 89 & 93 & $1,9 \%$ \\
\hline Israel & $\mathrm{m}$ & $\mathrm{m}$ & $\mathrm{m}$ & 90 & 89 & 93 & 90 & 90 & 92 & 90 & 89 & 92 & 85 & 87 & $\mathrm{~m}$ \\
\hline Italien & $m$ & 78 & 81 & 78 & $\mathrm{~m}$ & 82 & 85 & 86 & 84 & 86 & 81 & 83 & 79 & 84 & $0,6 \%$ \\
\hline Japan & 96 & 95 & 93 & 94 & 95 & 96 & 95 & 96 & 96 & 95 & 95 & 96 & 96 & 93 & $-0,2 \%$ \\
\hline Korea & 88 & 96 & 100 & 99 & 92 & 94 & 94 & 93 & 91 & 93 & 89 & 94 & 93 & 92 & $0,3 \%$ \\
\hline Luxemburg & $\mathrm{m}$ & $\mathrm{m}$ & $\mathrm{m}$ & 69 & 71 & 69 & 75 & 71 & 75 & 73 & 69 & 70 & 70 & 69 & $\mathrm{~m}$ \\
\hline Mexiko & $\mathrm{m}$ & 33 & 34 & 35 & 37 & 39 & 40 & 42 & 43 & 44 & 45 & 47 & 49 & 47 & $3,1 \%$ \\
\hline Niederlande & $\mathrm{m}$ & $\mathrm{m}$ & $\mathrm{m}$ & $\mathrm{m}$ & $\mathrm{m}$ & $\mathrm{m}$ & $\mathrm{m}$ & $\mathrm{m}$ & $\mathrm{m}$ & $\mathrm{m}$ & $\mathrm{m}$ & $\mathrm{m}$ & 92 & 94 & $\mathrm{~m}$ \\
\hline Neuseeland & $\mathrm{m}$ & $\mathrm{m}$ & $\mathrm{m}$ & $\mathrm{m}$ & $\mathrm{m}$ & $m$ & $\mathrm{~m}$ & $\mathrm{~m}$ & $\mathrm{~m}$ & $\mathrm{~m}$ & $\mathrm{~m}$ & $\mathrm{~m}$ & $m$ & m & $\mathrm{m}$ \\
\hline Norwegen & 77 & 99 & 105 & 97 & 92 & 100 & 89 & 88 & 92 & 91 & 91 & 87 & 90 & 88 & $0,8 \%$ \\
\hline Polen & $\mathrm{m}$ & 90 & 93 & 91 & 86 & 79 & 85 & 81 & 84 & 83 & 85 & 84 & 84 & 85 & $-0,5 \%$ \\
\hline Portugal ${ }^{4}$ & 52 & 52 & 48 & 50 & 60 & 53 & 51 & 54 & 65 & 63 & 96 & 104 & 89 & m & $\mathrm{m}$ \\
\hline Slowakei & 85 & 87 & 72 & 60 & 56 & 83 & 85 & 86 & 86 & 82 & 82 & 86 & 85 & 86 & $0,1 \%$ \\
\hline Slowenien & $\mathrm{m}$ & $\mathrm{m}$ & $\mathrm{m}$ & $\mathrm{m}$ & $\mathrm{m}$ & $\mathrm{m}$ & 85 & 97 & 91 & 85 & 96 & 94 & 99 & 96 & $\mathrm{~m}$ \\
\hline Spanien & 62 & 60 & 66 & 66 & 67 & 66 & 72 & 72 & 74 & 73 & 74 & 80 & 88 & 93 & $2,4 \%$ \\
\hline Schweden & $\mathrm{m}$ & 75 & 71 & 72 & 76 & 78 & 76 & 75 & 74 & 74 & 74 & 75 & 75 & 77 & $0,2 \%$ \\
\hline Schweiz & 86 & 88 & 91 & 91 & 88 & 87 & 87 & 88 & 88 & 88 & 92 & 94 & $\mathrm{~m}$ & m & $\mathrm{m}$ \\
\hline Türkei & 37 & 37 & 37 & 37 & 41 & 55 & 48 & 52 & 58 & 26 & 45 & 54 & 56 & 55 & $2,4 \%$ \\
\hline Vereinigtes Königreich & $\mathrm{m}$ & $\mathrm{m}$ & $\mathrm{m}$ & $\mathrm{m}$ & $\mathrm{m}$ & $m$ & 86 & 88 & 89 & 91 & 92 & 93 & 93 & 93 & $\mathrm{~m}$ \\
\hline Vereinigte Staaten & 69 & 70 & 71 & 73 & 74 & 75 & 76 & 75 & 75 & 76 & 76 & 77 & 77 & 79 & $0,7 \%$ \\
\hline OECD-Durchschnitt & 78 & 76 & 77 & 78 & 79 & 81 & 82 & 82 & 83 & 81 & 83 & 84 & 82 & 82 & $\mathbf{m}$ \\
\hline $\begin{array}{l}\text { OECD-Durchschnitt } \\
\text { für Länder mit verfüg- } \\
\text { baren Daten für die } \\
\text { Jahre } 2000 \text { bis } 2012\end{array}$ & & 76 & 76 & 75 & 76 & 80 & 79 & 79 & 81 & 79 & 81 & 83 & 83 & 84 & $0,8 \%$ \\
\hline EU21-Durchschnitt & 79 & 77 & 79 & 77 & 79 & 78 & 81 & 82 & 84 & 84 & 85 & 85 & 83 & 83 & m \\
\hline \multicolumn{16}{|l|}{ Partnerländer } \\
\hline Argentinien & $m$ & $\mathrm{~m}$ & $\mathrm{~m}$ & $\mathrm{~m}$ & $\mathrm{~m}$ & $\mathrm{~m}$ & $\mathrm{~m}$ & $\mathrm{~m}$ & $\mathrm{~m}$ & $m$ & $\mathrm{~m}$ & $m$ & $m$ & m & $m$ \\
\hline Brasilien & $\mathrm{m}$ & $\mathrm{m}$ & $\mathrm{m}$ & $\mathrm{m}$ & $\mathrm{m}$ & $\mathrm{m}$ & $\mathrm{m}$ & $\mathrm{m}$ & $\mathrm{m}$ & $\mathrm{m}$ & $\mathrm{m}$ & $\mathrm{m}$ & $\mathrm{m}$ & m & $\mathrm{m}$ \\
\hline Kolumbien & $\mathrm{m}$ & $\mathrm{m}$ & $\mathrm{m}$ & $\mathrm{m}$ & $\mathrm{m}$ & $\mathrm{m}$ & $\mathrm{m}$ & $m$ & $\mathrm{~m}$ & $\mathrm{~m}$ & $\mathrm{~m}$ & $\mathrm{~m}$ & $\mathrm{~m}$ & m & $\mathrm{m}$ \\
\hline China & $\mathrm{m}$ & $m$ & $\mathrm{~m}$ & $\mathrm{~m}$ & $\mathrm{~m}$ & $\mathrm{~m}$ & $\mathrm{~m}$ & $\mathrm{~m}$ & $\mathrm{~m}$ & $\mathrm{~m}$ & $\mathrm{~m}$ & 69 & 73 & 76 & $\mathrm{~m}$ \\
\hline Indien & $\mathrm{m}$ & $\mathrm{m}$ & $\mathrm{m}$ & $\mathrm{m}$ & $\mathrm{m}$ & $\mathrm{m}$ & $\mathrm{m}$ & $\mathrm{m}$ & $\mathrm{m}$ & $\mathrm{m}$ & $\mathrm{m}$ & $\mathrm{m}$ & $\mathrm{m}$ & m & $\mathrm{m}$ \\
\hline Lettland & $\mathrm{m}$ & $\mathrm{m}$ & $\mathrm{m}$ & $\mathrm{m}$ & $\mathrm{m}$ & $\mathrm{m}$ & $\mathrm{m}$ & $\mathrm{m}$ & $\mathrm{m}$ & $\mathrm{m}$ & $\mathrm{m}$ & $\mathrm{m}$ & $\mathrm{m}$ & 90 & $\mathrm{~m}$ \\
\hline Indonesien & $\mathrm{m}$ & $\mathrm{m}$ & $\mathrm{m}$ & $\mathrm{m}$ & $\mathrm{m}$ & $\mathrm{m}$ & $\mathrm{m}$ & $m$ & $\mathrm{~m}$ & $\mathrm{~m}$ & $m$ & $m$ & $\mathrm{~m}$ & m & $\mathrm{m}$ \\
\hline Russische Föderation & $\mathrm{m}$ & $\mathrm{m}$ & $\mathrm{m}$ & $\mathrm{m}$ & $\mathrm{m}$ & $\mathrm{m}$ & $\mathrm{m}$ & $\mathrm{m}$ & $\mathrm{m}$ & $\mathrm{m}$ & $\mathrm{m}$ & $\mathrm{m}$ & $\mathrm{m}$ & m & $\mathrm{m}$ \\
\hline Saudi-Arabien & $\mathrm{m}$ & $\mathrm{m}$ & $\mathrm{m}$ & $\mathrm{m}$ & $\mathrm{m}$ & $\mathrm{m}$ & $\mathrm{m}$ & $\mathrm{m}$ & $\mathrm{m}$ & $\mathrm{m}$ & $\mathrm{m}$ & $\mathrm{m}$ & $\mathrm{m}$ & m & $\mathrm{m}$ \\
\hline Südafrika & $\mathrm{m}$ & $\mathrm{m}$ & $\mathrm{m}$ & $\mathrm{m}$ & $\mathrm{m}$ & $\mathrm{m}$ & $\mathrm{m}$ & $\mathrm{m}$ & $\mathrm{m}$ & $\mathrm{m}$ & $\mathrm{m}$ & $\mathrm{m}$ & $\mathrm{m}$ & $\mathbf{m}$ & $\mathrm{m}$ \\
\hline G20-Durchschnitt & $\mathbf{m}$ & $\mathbf{m}$ & $\mathbf{m}$ & $\mathbf{m}$ & $\mathbf{m}$ & $\mathbf{m}$ & m & $\mathbf{m}$ & $\mathbf{m}$ & $\mathbf{m}$ & $\mathbf{m}$ & 71 & 75 & 76 & $\mathbf{m}$ \\
\hline
\end{tabular}

Anmerkung: Bis 2004 wurden Abschlussquoten im Sekundarbereich II als Brutto-Abschlussquoten berechnet. Ab 2005 und für Länder mit verfügbaren Daten wurden Abschlussquoten als Netto-Abschlussquoten (d.h. als Summe der altersspezifischen Abschlussquoten) berechnet. Weiterführende Informationen zu den zur Berechnung der (Brutto-/Netto-)Abschlussquoten verwendeten Methoden und den entsprechenden typischen Altersjahrgängen s. Anhang 1.

1. Für Länder, die keine Daten für 1995 angeben konnten, ist der durchschnittliche jährliche Anstieg für 2000-2012 kursiv angegeben. 2. Bildungsgänge, die die ISCED-Stufen 3 und 4 umfassen (Höhere berufsbildende Schule), sind nicht erfasst. 3. Unterbrechung der Zeitreihe zwischen 2008 und 2009 in Deutschland aufgrund einer teilweisen Neueinstufung berufsbildender Bildungsgänge in ISCED 2 und ISCED 5B. 4. Referenzjahr 1997 anstelle 1995. Quellen: OECD. Argentinien, China, Indien, Indonesien, Kolumbien, Saudi-Arabien und Südafrika: Statistikinstitut der UNESCO. Lettland: Eurostat. Hinweise s. Anhang 3 unter www.oecd.org/edu/eag.htm. StatLink: http://dx.doi.org/10.1787/888933115179 Erläuterung der Kennzeichnung fehlender Daten s. Hinweise für den Leser. 


\begin{tabular}{|c|c|c|c|c|c|c|c|c|c|c|c|c|c|c|c|c|c|c|}
\hline & \multicolumn{9}{|c|}{ Männer } & \multicolumn{9}{|c|}{ Frauen } \\
\hline &  & 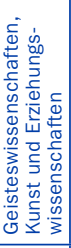 &  &  &  &  &  &  & 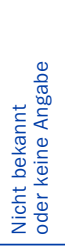 &  & 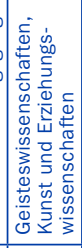 &  &  &  &  &  &  & 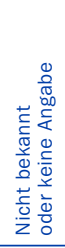 \\
\hline & (1) & (2) & (5) & (6) & (7) & (8) & (9) & (14) & (15) & (16) & (17) & (20) & (21) & (22) & (23) & (24) & (29) & (30) \\
\hline \multicolumn{19}{|l|}{ OECD-Länder } \\
\hline Australien ${ }^{1}$ & 58 & 2 & 5 & 13 & 12 & 59 & 2 & 6 & 1 & 61 & 6 & 37 & 30 & 16 & 5 & 1 & 2 & 4 \\
\hline Österreich² & 87 & 1 & 1 & 11 & 8 & 46 & 2 & 8 & 23 & 65 & 2 & 9 & 35 & 21 & 7 & $\mathrm{n}$ & 8 & 19 \\
\hline Belgien & 61 & 15 & 6 & 11 & 7 & 32 & 3 & 2 & 23 & 72 & 23 & 23 & 12 & 13 & 2 & $n$ & 1 & 26 \\
\hline Kanada $^{1}$ & 4 & $\mathrm{~m}$ & $\mathrm{~m}$ & $\mathrm{~m}$ & $\mathrm{~m}$ & $\mathrm{~m}$ & $\mathrm{~m}$ & $\mathrm{~m}$ & $\mathrm{~m}$ & 3 & $\mathrm{~m}$ & $\mathrm{~m}$ & $\mathrm{~m}$ & $\mathrm{~m}$ & $\mathrm{~m}$ & $\mathrm{~m}$ & $\mathrm{~m}$ & m \\
\hline Chile & 30 & 1 & 2 & 24 & 7 & 59 & $\mathrm{n}$ & 6 & $n$ & 30 & 13 & 8 & 48 & 16 & 12 & $n$ & 4 & $\mathrm{n}$ \\
\hline Tschechien & 63 & 3 & 1 & 10 & 12 & 70 & $\mathrm{n}$ & 3 & $\mathrm{n}$ & 53 & 8 & 13 & 33 & 30 & 9 & $\mathrm{n}$ & 5 & $\mathrm{n}$ \\
\hline Dänemark & 44 & 3 & 7 & 17 & 15 & 49 & $n$ & 8 & $\mathrm{n}$ & 49 & 1 & 50 & 31 & 10 & 5 & $\mathrm{n}$ & 4 & $\mathrm{n}$ \\
\hline Estland & 27 & 1 & $\mathrm{n}$ & $\mathrm{n}$ & 15 & 68 & 9 & 7 & $n$ & 17 & 6 & 4 & 8 & 52 & 19 & 5 & 6 & $\mathrm{n}$ \\
\hline Finnland & 89 & 4 & 5 & 10 & 16 & 55 & 4 & 5 & $n$ & 106 & 7 & 31 & 20 & 26 & 10 & 1 & 6 & $\mathrm{n}$ \\
\hline Frankreich & 77 & 2 & 3 & 14 & 12 & 62 & $\mathrm{n}$ & 7 & $\mathrm{n}$ & 72 & 2 & 29 & 32 & 26 & 7 & $\mathrm{n}$ & 3 & $\mathrm{n}$ \\
\hline Deutschland & 51 & 2 & 3 & 27 & 9 & 53 & 4 & 3 & $n$ & 40 & 3 & 16 & 54 & 17 & 7 & 1 & 1 & $\mathrm{n}$ \\
\hline Griechenland & $\mathrm{m}$ & $\mathrm{m}$ & $\mathrm{m}$ & $\mathrm{m}$ & $\mathrm{m}$ & $\mathrm{m}$ & $\mathrm{m}$ & $\mathrm{m}$ & $\mathrm{m}$ & $\mathrm{m}$ & $\mathrm{m}$ & $\mathrm{m}$ & $\mathrm{m}$ & $\mathrm{m}$ & $\mathrm{m}$ & $\mathrm{m}$ & $\mathrm{m}$ & $\mathrm{m}$ \\
\hline Ungarn & 32 & 1 & $n$ & 4 & 21 & 73 & $\mathrm{n}$ & 2 & $\mathrm{n}$ & 18 & 3 & 8 & 23 & 52 & 11 & $\mathrm{n}$ & 3 & $\mathrm{n}$ \\
\hline Island & 55 & 14 & 1 & 11 & 16 & 54 & 2 & 2 & $\mathrm{n}$ & 56 & 24 & 21 & 21 & 26 & 6 & $\mathrm{n}$ & $\mathrm{n}$ & 2 \\
\hline Irland & 61 & $\mathrm{~m}$ & $\mathrm{~m}$ & $\mathrm{~m}$ & $\mathrm{~m}$ & $\mathrm{~m}$ & $\mathrm{~m}$ & $\mathrm{~m}$ & $\mathrm{~m}$ & 99 & $\mathrm{~m}$ & $\mathrm{~m}$ & $\mathrm{~m}$ & $\mathrm{~m}$ & $\mathrm{~m}$ & $\mathrm{~m}$ & $\mathrm{~m}$ & $\mathrm{~m}$ \\
\hline Israel & 35 & $\mathrm{~m}$ & $\mathrm{~m}$ & $\mathrm{~m}$ & $\mathrm{~m}$ & $\mathrm{~m}$ & $\mathrm{~m}$ & $\mathrm{~m}$ & $\mathrm{~m}$ & 34 & $\mathrm{~m}$ & $\mathrm{~m}$ & $\mathrm{~m}$ & $\mathrm{~m}$ & $\mathrm{~m}$ & $\mathrm{~m}$ & $\mathrm{~m}$ & $\mathrm{~m}$ \\
\hline Italien & 72 & $\mathrm{~m}$ & $\mathrm{~m}$ & $\mathrm{~m}$ & $\mathrm{~m}$ & $\mathrm{~m}$ & $\mathrm{~m}$ & $\mathrm{~m}$ & $\mathrm{~m}$ & 56 & $\mathrm{~m}$ & $\mathrm{~m}$ & $\mathrm{~m}$ & $\mathrm{~m}$ & $\mathrm{~m}$ & $\mathrm{~m}$ & $\mathrm{~m}$ & $\mathrm{~m}$ \\
\hline Japan & 24 & $n$ & 1 & 17 & 2 & 56 & $n$ & 11 & 12 & 20 & $\mathrm{n}$ & 10 & 40 & 12 & 8 & $\mathrm{n}$ & 12 & 17 \\
\hline Korea & 22 & 18 & $\mathrm{n}$ & 7 & 4 & 58 & 11 & 2 & $\mathrm{n}$ & 20 & 34 & 1 & 26 & 5 & 20 & 12 & 1 & $\mathrm{n}$ \\
\hline Luxemburg & 46 & $\mathrm{~m}$ & $\mathrm{~m}$ & $\mathrm{~m}$ & $\mathrm{~m}$ & $\mathrm{~m}$ & $\mathrm{~m}$ & $\mathrm{~m}$ & $\mathrm{~m}$ & 47 & $\mathrm{~m}$ & $\mathrm{~m}$ & $\mathrm{~m}$ & $\mathrm{~m}$ & $\mathrm{~m}$ & $\mathrm{~m}$ & $\mathrm{~m}$ & $\mathrm{~m}$ \\
\hline Mexiko & 4 & $\mathrm{~m}$ & $\mathrm{~m}$ & $\mathrm{~m}$ & $\mathrm{~m}$ & $\mathrm{~m}$ & $\mathrm{~m}$ & $\mathrm{~m}$ & $\mathrm{~m}$ & 4 & $\mathrm{~m}$ & $\mathrm{~m}$ & $\mathrm{~m}$ & $\mathrm{~m}$ & $\mathrm{~m}$ & $\mathrm{~m}$ & $\mathrm{~m}$ & $\mathrm{~m}$ \\
\hline Niederlande & 79 & 4 & 8 & 18 & 25 & 34 & 7 & 4 & $\mathrm{n}$ & 76 & 7 & 45 & 23 & 19 & 3 & $\mathrm{n}$ & 3 & $\mathrm{n}$ \\
\hline Neuseeland & $\mathrm{m}$ & $\mathrm{m}$ & $\mathrm{m}$ & $\mathrm{m}$ & $\mathrm{m}$ & $\mathrm{m}$ & $\mathrm{m}$ & $\mathrm{m}$ & $\mathrm{m}$ & $\mathrm{m}$ & $\mathrm{m}$ & $\mathrm{m}$ & $\mathrm{m}$ & $\mathrm{m}$ & $\mathrm{m}$ & $\mathrm{m}$ & $\mathrm{m}$ & $\mathrm{m}$ \\
\hline Norwegen & 41 & 1 & 4 & 2 & 15 & 72 & 3 & 3 & $n$ & 27 & 4 & 48 & 12 & 24 & 9 & $n$ & 3 & $\mathrm{n}$ \\
\hline Polen & 47 & 1 & $\mathrm{n}$ & 8 & 13 & 62 & 13 & 4 & $n$ & 31 & 3 & $\mathrm{n}$ & 31 & 47 & 13 & 2 & 3 & $\mathrm{n}$ \\
\hline Portugal & 50 & $\mathrm{~m}$ & $\mathrm{~m}$ & $\mathrm{~m}$ & $\mathrm{~m}$ & $\mathrm{~m}$ & $\mathrm{~m}$ & $\mathrm{~m}$ & $\mathrm{~m}$ & 50 & $\mathrm{~m}$ & $\mathrm{~m}$ & $\mathrm{~m}$ & $\mathrm{~m}$ & $\mathrm{~m}$ & $\mathrm{~m}$ & $\mathrm{~m}$ & $\mathrm{~m}$ \\
\hline Slowakei & 71 & 4 & 2 & 11 & 19 & 61 & $n$ & 3 & $\mathrm{n}$ & 62 & 8 & 13 & 35 & 33 & 8 & $n$ & 3 & $\mathrm{n}$ \\
\hline Slowenien & 79 & 3 & 5 & 13 & 13 & 54 & 7 & 5 & $\mathrm{n}$ & 67 & 14 & 21 & 33 & 21 & 6 & $\mathrm{n}$ & 5 & $\mathrm{n}$ \\
\hline Spanien & 49 & 17 & 5 & 10 & 10 & 42 & 9 & 4 & 3 & 50 & 29 & 24 & 25 & 15 & 3 & 2 & 1 & 1 \\
\hline Schweden & 37 & 8 & 7 & 6 & 10 & 65 & $\mathrm{n}$ & 4 & $\mathrm{n}$ & 32 & 24 & 27 & 13 & 18 & 8 & $\mathrm{n}$ & 10 & $\mathrm{n}$ \\
\hline Schweiz & 77 & 2 & 2 & 24 & 6 & 54 & 4 & 6 & 2 & 66 & 4 & 23 & 48 & 12 & 9 & $\mathrm{n}$ & 3 & 1 \\
\hline Türkei & 27 & 1 & 2 & 11 & 4 & 52 & 13 & $\mathrm{n}$ & 17 & 25 & 4 & 26 & 17 & 8 & 11 & 10 & $\mathrm{n}$ & 24 \\
\hline Ver. Königreich & $\mathrm{m}$ & $\mathrm{m}$ & $\mathrm{m}$ & $\mathrm{m}$ & $\mathrm{m}$ & $\mathrm{m}$ & $\mathrm{m}$ & $\mathrm{m}$ & $\mathrm{m}$ & $\mathrm{m}$ & $\mathrm{m}$ & $\mathrm{m}$ & $\mathrm{m}$ & $\mathrm{m}$ & $\mathrm{m}$ & $\mathrm{m}$ & $\mathrm{m}$ & $\mathrm{m}$ \\
\hline Vereinigte Staaten & m & $\mathrm{m}$ & $\mathrm{m}$ & $\mathrm{m}$ & $\mathrm{m}$ & $\mathrm{m}$ & $\mathrm{m}$ & $\mathrm{m}$ & $\mathrm{m}$ & $\mathrm{m}$ & $\mathrm{m}$ & $\mathrm{m}$ & $\mathrm{m}$ & $\mathrm{m}$ & $\mathrm{m}$ & $\mathrm{m}$ & $\mathrm{m}$ & $\mathrm{m}$ \\
\hline OECD-Durchschnitt & 50 & 4 & 3 & 11 & 10 & 48 & 4 & 4 & 17 & 47 & 9 & 19 & 24 & 19 & 7 & 2 & $\mathbf{3}$ & 17 \\
\hline EU21-Durchschnitt & 59 & 4 & 3 & 11 & 12 & 50 & 5 & 4 & 12 & 56 & 8 & 20 & 25 & 23 & 7 & 1 & 3 & 12 \\
\hline
\end{tabular}

\begin{tabular}{|c|c|c|c|c|c|c|c|c|c|c|c|c|c|c|c|c|c|c|}
\hline \multicolumn{19}{|l|}{ Partnerländer } \\
\hline Argentinien $^{1}$ & 7 & $\mathrm{~m}$ & $\mathrm{~m}$ & $\mathrm{~m}$ & $\mathrm{~m}$ & $\mathrm{~m}$ & $\mathrm{~m}$ & $\mathrm{~m}$ & $\mathrm{~m}$ & 7 & $\mathrm{~m}$ & $\mathrm{~m}$ & $\mathrm{~m}$ & $\mathrm{~m}$ & $\mathrm{~m}$ & $\mathrm{~m}$ & $\mathrm{~m}$ & $\mathrm{~m}$ \\
\hline Brasilien & 10 & $\mathrm{~m}$ & $\mathrm{~m}$ & $\mathrm{~m}$ & $\mathrm{~m}$ & $\mathrm{~m}$ & $\mathrm{~m}$ & $\mathrm{~m}$ & $\mathrm{~m}$ & 14 & $\mathrm{~m}$ & $\mathrm{~m}$ & $\mathrm{~m}$ & $\mathrm{~m}$ & $\mathrm{~m}$ & $\mathrm{~m}$ & $\mathrm{~m}$ & $\mathrm{~m}$ \\
\hline China & 60 & $\mathrm{~m}$ & $\mathrm{~m}$ & $\mathrm{~m}$ & $\mathrm{~m}$ & $\mathrm{~m}$ & $\mathrm{~m}$ & $\mathrm{~m}$ & $\mathrm{~m}$ & 59 & $\mathrm{~m}$ & $\mathrm{~m}$ & $\mathrm{~m}$ & $\mathrm{~m}$ & $\mathrm{~m}$ & $\mathrm{~m}$ & $\mathrm{~m}$ & $\mathrm{~m}$ \\
\hline Kolumbien & $\mathrm{m}$ & $\mathrm{m}$ & $\mathrm{m}$ & $\mathrm{m}$ & $\mathrm{m}$ & $\mathrm{m}$ & $\mathrm{m}$ & $\mathrm{m}$ & $\mathrm{m}$ & 60 & $\mathrm{~m}$ & $\mathrm{~m}$ & $\mathrm{~m}$ & $\mathrm{~m}$ & $\mathrm{~m}$ & $\mathrm{~m}$ & $\mathrm{~m}$ & $\mathrm{~m}$ \\
\hline Indien & $\mathrm{m}$ & $\mathrm{m}$ & $\mathrm{m}$ & $\mathrm{m}$ & $\mathrm{m}$ & $\mathrm{m}$ & $\mathrm{m}$ & $\mathrm{m}$ & $\mathrm{m}$ & $\mathrm{m}$ & $\mathrm{m}$ & $\mathrm{m}$ & $\mathrm{m}$ & $\mathrm{m}$ & $\mathrm{m}$ & $\mathrm{m}$ & $\mathrm{m}$ & $\mathrm{m}$ \\
\hline Indonesien ${ }^{1}$ & 29 & 2 & 2 & 49 & $\mathrm{n}$ & 39 & $\mathrm{n}$ & $\mathrm{n}$ & 8 & 22 & 2 & 6 & 49 & $\mathrm{n}$ & 29 & $\mathrm{n}$ & 4 & 10 \\
\hline Lettland & 33 & 4 & $\mathrm{n}$ & 6 & 12 & 67 & 10 & 2 & $\mathrm{n}$ & 23 & 15 & 3 & 34 & 34 & 9 & 2 & 2 & $n$ \\
\hline Russische Föd. & $\mathrm{m}$ & $\mathrm{m}$ & $\mathrm{m}$ & $\mathrm{m}$ & $\mathrm{m}$ & $\mathrm{m}$ & $\mathrm{m}$ & $\mathrm{m}$ & $\mathrm{m}$ & $\mathrm{m}$ & $\mathrm{m}$ & $\mathrm{m}$ & $\mathrm{m}$ & $\mathrm{m}$ & $\mathrm{m}$ & $\mathrm{m}$ & $\mathrm{m}$ & $\mathrm{m}$ \\
\hline Saudi-Arabien & $\mathrm{m}$ & $\mathrm{m}$ & $\mathrm{m}$ & $\mathrm{m}$ & $\mathrm{m}$ & $\mathrm{m}$ & $\mathrm{m}$ & $\mathrm{m}$ & $\mathrm{m}$ & $\mathrm{m}$ & $\mathrm{m}$ & $\mathrm{m}$ & $\mathrm{m}$ & $\mathrm{m}$ & $\mathrm{m}$ & $\mathrm{m}$ & $\mathrm{m}$ & $\mathrm{m}$ \\
\hline Südafrika & $\mathrm{m}$ & $\mathrm{m}$ & $\mathrm{m}$ & $\mathrm{m}$ & $\mathrm{m}$ & $\mathrm{m}$ & $\mathrm{m}$ & $\mathrm{m}$ & $\mathrm{m}$ & $\mathrm{m}$ & $\mathrm{m}$ & $\mathrm{m}$ & $\mathrm{m}$ & $\mathrm{m}$ & $\mathrm{m}$ & $\mathrm{m}$ & $\mathrm{m}$ & $\mathrm{m}$ \\
\hline G20-Durchschnitt & 33 & m & m & m & $\mathbf{m}$ & $\mathbf{m}$ & m & $\mathbf{m}$ & m & 30 & m & m & m & m & m & m & m & m \\
\hline
\end{tabular}

Anmerkung: Die Spalten mit getrennten Angaben zu „Erziehungswissenschaften“ und „Geisteswissenschaften und Kunst“, d.h. die Spalten (3)/(4) und (18)/(19), sowie zu den einzelnen Naturwissenschaften, d.h. die Spalten (10) bis (13) und (25) bis (28), sind im Internet verfügbar (s. StatLink unten). Die Durchschnitte wurden an 100 Prozent angepasst und entsprechen nicht genau dem Durchschnitt jeder einzelnen Spalte. Die Spalten (1) und (16) zeigen den relativen Anteil der Absolventen von berufsvorbereitenden/berufsbildenden Bildungsgängen an der Gesamtzahl aller Absolventen. Zahlen der Fächergruppe mit dem größten Anteil an Absolventen in dem jeweiligen Land sind in Fettdruck.

1. Referenzjahr 2011. 2. Bildungsgänge, die die ISCED-Stufen 3 und 4 umfassen (Höhere berufsbildende Schule) sind nicht erfasst.

Quellen: OECD. Argentinien, China, Indien, Indonesien, Kolumbien, Saudi-Arabien und Südafrika: Statistikinstitut der UNESCO. Lettland: Eurostat. Hinweise s. Anhang 3 unter www.oecd.org/edu/eag.htm. StatLink: http://dx.doi.org/10.1787/888933115198

Erläuterung der Kennzeichnung fehlender Daten s. Hinweise für den Leser. 
Tabelle A2.4

Erfolgsquoten im Sekundarbereich II, nach Geschlecht und Ausrichtung des Bildungsgangs

Verhältnis von Absolventen zu Anfängern (nach Alterskohorten)



Anmerkung: Die Daten in dieser Tabelle stammen aus einer speziellen Erhebung, an der 29 Länder teilnahmen, und beziehen sich nur auf Bildungsgänge in der Erstausbildung. Weiterführende Informationen zum vorliegenden Indikator, u. a. den verwendeten Methoden, den eingeschlossenen/nicht eingeschlossenen Bildungsgängen, dem Alter bei Aufnahme der Ausbildung etc., s. Anhang 3.

1. Anfänger in einem allgemeinbildenden Bildungsgang auf ISCED-Stufe 3, die entweder einen allgemeinbildenden oder berufsbildenden Bildungsgang abgeschlossen haben. 2. Anfänger in einem berufsbildenden Bildungsgang auf ISCED-Stufe 3, die entweder einen allgemeinbildenden oder berufsbildenden Bildungsgang abgeschlossen haben. 3. Anfänger in einem allgemeinbildenden Bildungsgang auf ISCED-Stufe 3, die einen berufsbildenden Bildungsgang abgeschlossen haben. 4. Anfänger in einem berufsbildenden Bildungsgang auf ISCED-Stufe 3, die einen allgemeinbildenden Bildungsgang abgeschlossen haben. 5. Ohne Schüler, die ihre Ausbildung im Rahmen der Erwachsenenbildung fortgesetzt haben. 6. Der OECD-Durchschnitt für $n+2$ entspricht dem OECD-Durchschnitt für $n+$ dem Unterschied (in Prozentpunkten) des Durchschnitts für Länder mit Daten für $n$ und für $n+2$.

Quelle: OECD. Hinweise s. Anhang 3 unter www.oecd.org/edu/eag.htm. StatLink: http://dx.doi.org/10.1787/888933115217 Erläuterung der Kennzeichnung fehlender Daten s. Hinweise für den Leser. 
Erfolgsquoten im Sekundarbereich II, nach Geschlecht und Ausrichtung des Bildungsgangs

Verhältnis von Absolventen zu Anfängern (nach Alterskohorten)

\begin{tabular}{|c|c|c|c|c|c|c|c|c|c|c|}
\hline & \multirow[b]{2}{*}{ Methode } & \multirow[b]{2}{*}{$\begin{array}{l}\text { Referenzjahre } \\
\text { für Anfänger } \\
\text { Dauer des } \\
\text { Bildungsgangs } \\
\text { (A: allgemeinbildend, } \\
\text { B: berufsbildend) }\end{array}$} & \multirow[b]{2}{*}{$\begin{array}{l}\text { n: reguläre } \\
\text { Ausbil- } \\
\text { dungs- } \\
\text { dauer }\end{array}$} & \multicolumn{3}{|c|}{$\begin{array}{l}\text { Anteil der Schüler, die sich } \\
\text { immer noch in Ausbildung } \\
\text { befinden, unter den Schülern } \\
\text { ohne Abschluss (allgemein- } \\
\text { bildende Bildungsgänge) }\end{array}$} & \multicolumn{3}{|c|}{$\begin{array}{l}\text { Anteil der Schüler, die sich } \\
\text { immer noch in Ausbildung } \\
\text { befinden, unter den Schülern } \\
\text { ohne Abschluss (berufs- } \\
\text { bildende Bildungsgänge) }\end{array}$} & \multirow{2}{*}{\begin{tabular}{|c} 
Nettoan- \\
fänger- \\
quote im \\
Sekun- \\
darbe- \\
reich \\
II von \\
Schülern \\
unter \\
20 Jahren \\
$(2012)^{5}$
\end{tabular}} \\
\hline & & & & Gesamt & Männer & Frauen & Gesamt & Männer & Frauen & \\
\hline \multicolumn{11}{|l|}{ OECD-Länder } \\
\hline Österreich & $\begin{array}{l}\text { Echte } \\
\text { Kohortendaten }\end{array}$ & $\begin{array}{l}\text { 2007/2008 } \\
4 \text { Jahre A u. B }\end{array}$ & $\begin{array}{l}\text { innerhalb } n \\
n+2 \text { Jahre }\end{array}$ & $\begin{array}{r}76 \\
m\end{array}$ & $\begin{array}{r}78 \\
m\end{array}$ & $\begin{array}{r}74 \\
m\end{array}$ & $\begin{array}{l}\mathrm{m} \\
\mathrm{m}\end{array}$ & $\begin{array}{l}\mathrm{m} \\
\mathrm{m}\end{array}$ & $\begin{array}{l}\mathrm{m} \\
\mathrm{m}\end{array}$ & 100 \\
\hline Belgien (fläm.) & $\begin{array}{l}\text { Echte } \\
\text { Kohortendaten }\end{array}$ & $\begin{array}{l}\text { 2007/2008 } \\
4 \text { Jahre A u. B }\end{array}$ & $\begin{array}{l}\text { innerhalb } n \\
n+2 \text { Jahre }\end{array}$ & $\begin{array}{r}88 \\
8\end{array}$ & $\begin{array}{l}89 \\
10\end{array}$ & $\begin{array}{r}86 \\
6\end{array}$ & $\begin{array}{r}67 \\
6\end{array}$ & $\begin{array}{r}68 \\
6\end{array}$ & $\begin{array}{r}65 \\
5\end{array}$ & $\mathrm{~m}$ \\
\hline Kanada & $\begin{array}{l}\text { Approximierte } \\
\text { Kohortendaten }\end{array}$ & $\begin{array}{l}2008 / 2009 \\
3 \text { Jahre }\end{array}$ & $\begin{array}{l}\text { innerhalb } n \\
n+2 \text { Jahre }\end{array}$ & $\begin{array}{l}\mathrm{m} \\
\mathrm{m}\end{array}$ & $\begin{array}{l}\mathrm{m} \\
\mathrm{m}\end{array}$ & $\begin{array}{l}\mathrm{m} \\
\mathrm{m}\end{array}$ & $\begin{array}{l}\mathrm{m} \\
\mathrm{m}\end{array}$ & $\begin{array}{l}\mathrm{m} \\
\mathrm{m}\end{array}$ & $\begin{array}{l}\mathrm{m} \\
\mathrm{m}\end{array}$ & m \\
\hline Chile & $\begin{array}{l}\text { Echte } \\
\text { Kohortendaten }\end{array}$ & $\begin{array}{l}2007 \\
4 \text { Jahre A u. B }\end{array}$ & $\begin{array}{l}\text { innerhalb } n \\
n+2 \text { Jahre }\end{array}$ & $\begin{array}{l}57 \\
34\end{array}$ & $\begin{array}{l}58 \\
35\end{array}$ & $\begin{array}{l}57 \\
33\end{array}$ & $\begin{array}{l}57 \\
37\end{array}$ & $\begin{array}{l}58 \\
39\end{array}$ & $\begin{array}{l}56 \\
35\end{array}$ & 90 \\
\hline Dänemark & $\begin{array}{l}\text { Echte } \\
\text { Kohortendaten }\end{array}$ & $\begin{array}{l}2004-2005 \\
3-4 \text { J. A/2-5 J. B }\end{array}$ & $\begin{array}{l}\text { innerhalb } n \\
n+2 \text { Jahre }\end{array}$ & $\begin{array}{l}73 \\
41\end{array}$ & $\begin{array}{l}75 \\
44\end{array}$ & $\begin{array}{l}70 \\
39\end{array}$ & $\begin{array}{l}65 \\
42\end{array}$ & $\begin{array}{l}66 \\
42\end{array}$ & $\begin{array}{l}65 \\
42\end{array}$ & 95 \\
\hline Estland & $\begin{array}{l}\text { Echte } \\
\text { Kohortendaten }\end{array}$ & $\begin{array}{l}2005 \\
3 \mathrm{~J} . \mathrm{A} / 3-4 \mathrm{~J} . \mathrm{B}\end{array}$ & $\begin{array}{l}\text { innerhalb } n \\
n+2 \text { Jahre }\end{array}$ & $\begin{array}{l}58 \\
27\end{array}$ & $\begin{array}{l}54 \\
24\end{array}$ & $\begin{array}{l}60 \\
30\end{array}$ & $\begin{array}{l}34 \\
16\end{array}$ & $\begin{array}{l}31 \\
16\end{array}$ & $\begin{array}{l}39 \\
24\end{array}$ & 100 \\
\hline Finnland & $\begin{array}{l}\text { Echte } \\
\text { Kohortendaten }\end{array}$ & $\begin{array}{l}2006 \\
3 \text { Jahre A u. B }\end{array}$ & $\begin{array}{l}\text { innerhalb } n \\
n+2 \text { Jahre }\end{array}$ & $\begin{array}{l}82 \\
52\end{array}$ & $\begin{array}{l}81 \\
54\end{array}$ & $\begin{array}{l}83 \\
50\end{array}$ & $\begin{array}{l}50 \\
28\end{array}$ & $\begin{array}{l}49 \\
26\end{array}$ & $\begin{array}{l}52 \\
31\end{array}$ & $\mathrm{~m}$ \\
\hline Frankreich & $\begin{array}{l}\text { Längsschnitt- } \\
\text { erhebung }\end{array}$ & $\begin{array}{l}1999-2005 \\
3 \mathrm{~J} . \mathrm{A} / 2 \mathrm{~J} . \mathrm{B}\end{array}$ & $\begin{array}{l}\text { innerhalb } n \\
n+2 \text { Jahre }\end{array}$ & $\begin{array}{l}93 \\
21\end{array}$ & $\begin{array}{l}93 \\
24\end{array}$ & $\begin{array}{l}94 \\
19\end{array}$ & $\begin{array}{l}80 \\
13\end{array}$ & $\begin{array}{l}81 \\
12\end{array}$ & $\begin{array}{l}79 \\
15\end{array}$ & $\mathrm{~m}$ \\
\hline Griechenland & $\begin{array}{l}\text { Querschnitt- } \\
\text { erhebung }\end{array}$ & $\begin{array}{l}2008-2011 \\
3-4 \text { J. A } / 2-4 \text { J. B }\end{array}$ & $\begin{array}{l}\text { innerhalb } n \\
n+2 \text { Jahre }\end{array}$ & $\mathrm{m}$ & $\mathrm{m}$ & $\mathrm{m}$ & $\mathrm{m}$ & $\mathrm{m}$ & $\mathrm{m}$ & 100 \\
\hline Ungarn & $\begin{array}{l}\text { Querschnitt- } \\
\text { erhebung }\end{array}$ & $\begin{array}{l}2009 / 2010 \\
4 \text { Jahre }\end{array}$ & $\begin{array}{l}\text { innerhalb } n \\
n+2 \text { Jahre }\end{array}$ & $\begin{array}{l}\mathrm{m} \\
\mathrm{m}\end{array}$ & $\begin{array}{l}\mathrm{m} \\
\mathrm{m}\end{array}$ & $\begin{array}{l}\mathrm{m} \\
\mathrm{m}\end{array}$ & $\begin{array}{l}\mathrm{m} \\
\mathrm{m}\end{array}$ & $\begin{array}{l}\mathrm{m} \\
\mathrm{m}\end{array}$ & $\begin{array}{l}\mathrm{m} \\
\mathrm{m}\end{array}$ & 100 \\
\hline Island & $\begin{array}{l}\text { Echte } \\
\text { Kohortendaten }\end{array}$ & $\begin{array}{l}2002 \\
4 \text { Jahre A u. B }\end{array}$ & $\begin{array}{l}\text { innerhalb } n \\
n+2 \text { Jahre }\end{array}$ & $\begin{array}{l}54 \\
32\end{array}$ & $\begin{array}{l}55 \\
32\end{array}$ & $\begin{array}{l}53 \\
33\end{array}$ & $\begin{array}{l}39 \\
21\end{array}$ & $\begin{array}{l}38 \\
20\end{array}$ & $\begin{array}{l}41 \\
24\end{array}$ & 98 \\
\hline Irland & $\begin{array}{l}\text { Echte } \\
\text { Kohortendaten }\end{array}$ & $\begin{array}{l}2007 \\
2-3 \text { Jahre A u. B }\end{array}$ & $\begin{array}{l}\text { innerhalb } n \\
n+2 \text { Jahre }\end{array}$ & $\begin{array}{l}\mathrm{m} \\
\mathrm{m}\end{array}$ & $\begin{array}{l}\mathrm{m} \\
\mathrm{m}\end{array}$ & $\begin{array}{l}\mathrm{m} \\
\mathrm{m}\end{array}$ & $\begin{array}{l}\mathrm{m} \\
\mathrm{m}\end{array}$ & $\begin{array}{l}\mathrm{m} \\
\mathrm{m}\end{array}$ & $\begin{array}{l}\mathrm{m} \\
\mathrm{m}\end{array}$ & 100 \\
\hline Israel & $\begin{array}{l}\text { Echte } \\
\text { Kohortendaten }\end{array}$ & $\begin{array}{l}2009 \\
3 \text { Jahre A u. B }\end{array}$ & $\begin{array}{l}\text { innerhalb } n \\
n+2 \text { Jahre }\end{array}$ & $\begin{array}{r}10 \\
m\end{array}$ & $\begin{array}{c}9 \\
\mathrm{~m}\end{array}$ & $\begin{array}{r}12 \\
m\end{array}$ & $\begin{array}{c}2 \\
m\end{array}$ & $\begin{array}{c}2 \\
m\end{array}$ & $\begin{array}{c}4 \\
m\end{array}$ & 98 \\
\hline Italien & $\begin{array}{l}\text { Querschnitt- } \\
\text { erhebung }\end{array}$ & $\begin{array}{l}2005 / 2006 \\
5 \text { Jahre A u. B }\end{array}$ & $\begin{array}{l}\text { innerhalb } n \\
n+2 \text { Jahre }\end{array}$ & $\begin{array}{l}\mathrm{m} \\
\mathrm{m}\end{array}$ & $\begin{array}{l}\mathrm{m} \\
\mathrm{m}\end{array}$ & $\begin{array}{l}\mathrm{m} \\
\mathrm{m}\end{array}$ & $\begin{array}{l}\mathrm{m} \\
\mathrm{m}\end{array}$ & $\begin{array}{l}\mathrm{m} \\
\mathrm{m}\end{array}$ & $\begin{array}{l}m \\
m\end{array}$ & $\mathrm{~m}$ \\
\hline Japan & $\begin{array}{l}\text { Echte } \\
\text { Kohortendaten }\end{array}$ & $\begin{array}{l}2009 \\
3 \text { Jahre A u. B }\end{array}$ & $\begin{array}{l}\text { innerhalb } n \\
n+2 \text { Jahre }\end{array}$ & $\begin{array}{l}\mathrm{m} \\
\mathrm{m}\end{array}$ & $\begin{array}{l}\mathrm{m} \\
\mathrm{m}\end{array}$ & $\begin{array}{l}\mathrm{m} \\
\mathrm{m}\end{array}$ & $\begin{array}{l}\mathrm{m} \\
\mathrm{m}\end{array}$ & $\begin{array}{l}\mathrm{m} \\
\mathrm{m}\end{array}$ & $\begin{array}{l}\mathrm{m} \\
\mathrm{m}\end{array}$ & 100 \\
\hline Korea & $\begin{array}{l}\text { Querschnitt- } \\
\text { erhebung }\end{array}$ & $\begin{array}{l}2009 \\
3 \text { Jahre A u. B }\end{array}$ & $\begin{array}{l}\text { innerhalb } n \\
n+2 \text { Jahre }\end{array}$ & $\begin{array}{c}7 \\
\mathrm{~m}\end{array}$ & $\begin{array}{r}11 \\
\mathrm{~m}\end{array}$ & $\begin{array}{l}\mathrm{n} \\
\mathrm{m}\end{array}$ & $\begin{array}{c}7 \\
\mathrm{~m}\end{array}$ & $\begin{array}{l}3 \\
\mathrm{~m}\end{array}$ & $\begin{array}{r}12 \\
\mathrm{~m}\end{array}$ & $\mathrm{~m}$ \\
\hline Luxemburg & $\begin{array}{l}\text { Echte } \\
\text { Kohortendaten }\end{array}$ & $\begin{array}{l}2006 / 2007 \\
4 \text { J. A/ } 2-5 \text { J. B }\end{array}$ & $\begin{array}{l}\text { innerhalb } n \\
n+2 \text { Jahre }\end{array}$ & $\begin{array}{l}82 \\
27\end{array}$ & $\begin{array}{l}84 \\
35\end{array}$ & $\begin{array}{l}81 \\
17\end{array}$ & $\begin{array}{l}62 \\
19\end{array}$ & $\begin{array}{l}63 \\
21\end{array}$ & $\begin{array}{l}62 \\
17\end{array}$ & 90 \\
\hline Mexiko & $\begin{array}{l}\text { Echte } \\
\text { Kohortendaten }\end{array}$ & $\begin{array}{l}2009 / 2010 \\
\text { 3 J.A U. B }\end{array}$ & $\begin{array}{l}\text { innerhalb } n \\
n+2 \text { Jahre }\end{array}$ & $\mathrm{m}$ & $\mathrm{m}$ & $\mathrm{m}$ & $\mathrm{m}$ & $\mathrm{m}$ & $\mathrm{m}$ & 77 \\
\hline Niederlande & $\begin{array}{l}\text { Echte } \\
\text { Kohortendaten }\end{array}$ & $\begin{array}{l}2007 \\
2-3 \text { J. A/ } 2-4 \text { J. B }\end{array}$ & $\begin{array}{l}\text { innerhalb } n \\
n+2 \text { Jahre }\end{array}$ & $\begin{array}{l}77 \\
43\end{array}$ & $\begin{array}{l}75 \\
43\end{array}$ & $\begin{array}{l}79 \\
44\end{array}$ & $\begin{array}{l}35 \\
20\end{array}$ & $\begin{array}{l}35 \\
21\end{array}$ & $\begin{array}{l}35 \\
19\end{array}$ & $\mathrm{~m}$ \\
\hline Neuseeland & $\begin{array}{l}\text { Echte } \\
\text { Kohortendaten }\end{array}$ & $\begin{array}{l}2008 \\
3 \text { Jahre A }\end{array}$ & $\begin{array}{l}\text { innerhalb } n \\
n+2 \text { Jahre }\end{array}$ & $\begin{array}{l}46 \\
15\end{array}$ & $\begin{array}{l}45 \\
14\end{array}$ & $\begin{array}{l}48 \\
16\end{array}$ & $\begin{array}{l}\mathrm{m} \\
\mathrm{m}\end{array}$ & $\begin{array}{l}\mathrm{m} \\
\mathrm{m}\end{array}$ & $\begin{array}{l}m \\
m\end{array}$ & 100 \\
\hline Norwegen & $\begin{array}{l}\text { Echte } \\
\text { Kohortendaten }\end{array}$ & $\begin{array}{l}2006 \\
3 \mathrm{~J} . \mathrm{A} / 4 \mathrm{~J} . \mathrm{B}\end{array}$ & $\begin{array}{l}\text { innerhalb } n \\
n+2 \text { Jahre }\end{array}$ & $\begin{array}{l}37 \\
14\end{array}$ & $\begin{array}{l}36 \\
14\end{array}$ & $\begin{array}{l}38 \\
15\end{array}$ & $\begin{array}{l}37 \\
13\end{array}$ & $\begin{array}{l}40 \\
13\end{array}$ & $\begin{array}{l}31 \\
14\end{array}$ & 99 \\
\hline Polen & $\begin{array}{l}\text { Echte } \\
\text { Kohortendaten }\end{array}$ & $\begin{array}{l}2008 / 2009 \\
3 \text { J. A/3-4 J. B }\end{array}$ & $\begin{array}{l}\text { innerhalb } n \\
n+2 \text { Jahre }\end{array}$ & $\begin{array}{l}\mathrm{m} \\
\mathrm{m}\end{array}$ & $\mathrm{m}$ & $\begin{array}{l}\mathrm{m} \\
\mathrm{m}\end{array}$ & $\begin{array}{l}\mathrm{m} \\
\mathrm{m}\end{array}$ & $\begin{array}{l}\mathrm{m} \\
\mathrm{m}\end{array}$ & $\begin{array}{l}\mathrm{m} \\
\mathrm{m}\end{array}$ & 88 \\
\hline Slowakei & $\begin{array}{l}\text { Querschnitt- } \\
\text { erhebung }\end{array}$ & $\begin{array}{l}2006 \\
4 \text { J. A/2-4 J. B }\end{array}$ & $\begin{array}{l}\text { innerhalb } n \\
n+2 \text { Jahre }\end{array}$ & $\begin{array}{l}m \\
m\end{array}$ & $\begin{array}{l}\mathrm{m} \\
\mathrm{m}\end{array}$ & $\begin{array}{l}\mathrm{m} \\
\mathrm{m}\end{array}$ & $\begin{array}{l}\mathrm{m} \\
\mathrm{m}\end{array}$ & $\begin{array}{l}m \\
m\end{array}$ & $\begin{array}{l}\mathrm{m} \\
\mathrm{m}\end{array}$ & 92 \\
\hline Slowenien & $\begin{array}{l}\text { Querschnitt- } \\
\text { erhebung }\end{array}$ & $\begin{array}{l}2009-2011 \\
4 \text { J. A/3-4 J. B }\end{array}$ & $\begin{array}{l}\text { innerhalb } n \\
n+2 \text { Jahre }\end{array}$ & $\begin{array}{l}\mathrm{m} \\
\mathrm{m}\end{array}$ & $\begin{array}{l}\mathrm{m} \\
\mathrm{m}\end{array}$ & $\begin{array}{l}\mathrm{m} \\
\mathrm{m}\end{array}$ & $\begin{array}{l}\mathrm{m} \\
\mathrm{m}\end{array}$ & $\begin{array}{l}\mathrm{m} \\
\mathrm{m}\end{array}$ & $\begin{array}{l}\mathrm{m} \\
\mathrm{m}\end{array}$ & 100 \\
\hline Spanien & $\begin{array}{l}\text { Querschnitt- } \\
\text { erhebung }\end{array}$ & $\begin{array}{l}2008 / 2009 \\
2 \text { Jahre A u. B }\end{array}$ & $\begin{array}{l}\text { innerhalb } n \\
n+2 \text { Jahre }\end{array}$ & $\begin{array}{l}\mathrm{m} \\
\mathrm{m}\end{array}$ & $\begin{array}{l}\mathrm{m} \\
\mathrm{m}\end{array}$ & $\begin{array}{l}\mathrm{m} \\
\mathrm{m}\end{array}$ & $\begin{array}{l}\mathrm{m} \\
\mathrm{m}\end{array}$ & $\begin{array}{l}\mathrm{m} \\
\mathrm{m}\end{array}$ & $\begin{array}{l}\mathrm{m} \\
\mathrm{m}\end{array}$ & $\mathrm{m}$ \\
\hline Schweden 5 & $\begin{array}{l}\text { Echte } \\
\text { Kohortendaten }\end{array}$ & $\begin{array}{l}2007 \\
3 \text { Jahre A u. B }\end{array}$ & $\begin{array}{l}\text { innerhalb } n \\
n+2 \text { Jahre }\end{array}$ & $\begin{array}{r}50 \\
1\end{array}$ & $\begin{array}{r}49 \\
1\end{array}$ & $\begin{array}{r}50 \\
2\end{array}$ & $\begin{array}{r}37 \\
1\end{array}$ & $\begin{array}{r}36 \\
1\end{array}$ & $\begin{array}{r}38 \\
1\end{array}$ & 100 \\
\hline Türkei & $\begin{array}{l}\text { Echte } \\
\text { Kohortendaten }\end{array}$ & $\begin{array}{l}2008 / 2009 \\
4-5 \text { J. A } 4 \text { J. B }\end{array}$ & $\begin{array}{l}\text { innerhalb } n \\
n+2 \text { Jahre }\end{array}$ & $\begin{array}{r}22 \\
m\end{array}$ & $\begin{array}{r}20 \\
m\end{array}$ & $\begin{array}{r}25 \\
m\end{array}$ & $\begin{array}{r}23 \\
m\end{array}$ & $\begin{array}{r}22 \\
m\end{array}$ & $\begin{array}{r}26 \\
m\end{array}$ & 79 \\
\hline Ver. Königreich & $\begin{array}{l}\text { Echte } \\
\text { Kohortendaten }\end{array}$ & $\begin{array}{l}2006 \\
2 \text { Jahre }\end{array}$ & $\begin{array}{l}\text { innerhalb } n \\
n+2 \text { Jahre }\end{array}$ & $\begin{array}{r}50 \\
m\end{array}$ & $\begin{array}{r}46 \\
m\end{array}$ & $\begin{array}{r}54 \\
m\end{array}$ & $\mathrm{~m}$ & $\mathrm{~m}$ & $\mathrm{~m}$ & $\mathrm{~m}$ \\
\hline Vereinigte Staaten & $\begin{array}{l}\text { Längsschnitt- } \\
\text { erhebung }\end{array}$ & $\begin{array}{l}2002 \\
3 \text { Jahre A u. B }\end{array}$ & $\begin{array}{l}\text { innerhalb } n \\
n+2 \text { Jahre }\end{array}$ & $\begin{array}{l}\mathrm{m} \\
\mathrm{m}\end{array}$ & $\begin{array}{l}\mathrm{m} \\
\mathrm{m}\end{array}$ & $\begin{array}{l}\mathrm{m} \\
\mathrm{m}\end{array}$ & $\begin{array}{l}\mathrm{m} \\
\mathrm{m}\end{array}$ & $\begin{array}{l}\mathrm{m} \\
\mathrm{m}\end{array}$ & $\begin{array}{l}\mathrm{m} \\
\mathrm{m}\end{array}$ & 98 \\
\hline $\begin{array}{l}\text { OECD- } \\
\text { Durchschnitt }\end{array}$ & & & $\begin{array}{l}\text { innerhalb } n \\
n+2 \text { Jahre }\end{array}$ & $\begin{array}{r}56 \\
\mathrm{~m}\end{array}$ & $\begin{array}{r}56 \\
\mathrm{~m}\end{array}$ & $\begin{array}{r}60 \\
\mathrm{~m}\end{array}$ & $\begin{array}{r}43 \\
m\end{array}$ & $\begin{array}{r}42 \\
m\end{array}$ & $\begin{array}{r}43 \\
m\end{array}$ & m \\
\hline
\end{tabular}

Anmerkung: Die Daten in dieser Tabelle stammen aus einer speziellen Erhebung, an der 29 Länder teilnahmen, und beziehen sich nur auf Bildungsgänge in der Erstausbildung. Weiterführende Informationen zum vorliegenden Indikator, u.a. den verwendeten Methoden, den eingeschlossenen/nicht eingeschlossenen Bildungsgängen, dem Alter bei Aufnahme der Ausbildung etc., s. Anhang 3.

1. Anfänger in einem allgemeinbildenden Bildungsgang auf ISCED-Stufe 3, die entweder einen allgemeinbildenden oder berufsbildenden Bildungsgang abgeschlossen haben. 2. Anfänger in einem berufsbildenden Bildungsgang auf ISCED-Stufe 3, die entweder einen allgemeinbildenden oder berufsbildenden Bildungsgang abgeschlossen haben. 3. Anfänger in einem allgemeinbildenden Bildungsgang auf ISCED-Stufe 3, die einen berufsbildenden Bildungsgang abgeschlossen haben. 4. Anfänger in einem berufsbildenden Bildungsgang auf ISCED-Stufe 3, die einen allgemeinbildenden Bildungsgang abgeschlossen haben. 5. Ohne Schüler, die ihre Ausbildung im Rahmen der Erwachsenenbildung fortgesetzt haben. 6. Der OECD-Durchschnitt für $n+2$ entspricht dem OECD-Durchschnitt für $n+$ dem Unterschied (in Prozentpunkten) des Durchschnitts für Länder mit Daten für $n$ und für $n+2$.

Quelle: OECD. Hinweise s. Anhang 3 unter www.oecd.org/edu/eag.htm. StatLink: http://dx.doi.org/10.1787/888933115217

Erläuterung der Kennzeichnung fehlender Daten s. Hinweise für den Leser. 
Tabelle A2.5

Erfolgsquoten im Sekundarbereich II, nach Ausrichtung des Bildungsgangs und Ausbildungsdauer

Verhältnis von Absolventen zu Anfängern (nach Alterskohorten)

\begin{tabular}{|c|c|c|c|c|c|c|c|c|c|c|}
\hline & \multirow[b]{2}{*}{$\begin{array}{c}\mathrm{n}=\text { reguläre } \\
\text { Ausbildungs- } \\
\text { dauer }\end{array}$} & \multicolumn{4}{|c|}{ Erfolgsquoten bei allgemeinbildenden Bildungsgängen ${ }^{1}$} & \multicolumn{5}{|c|}{ Erfolgsquoten bei berufsbildenden Bildungsgängen ${ }^{2}$} \\
\hline & & Gesamt & 2 Jahre & 3 Jahre & 4 Jahre & Gesamt & 2 Jahre & 3 Jahre & 4 Jahre & 5 Jahre \\
\hline OECD-Länder & & & & & & & & & & \\
\hline Österreich & $\begin{array}{l}\text { innerhalb } n \\
n+2\end{array}$ & $\begin{array}{r}71 \\
m\end{array}$ & $\begin{array}{l}\mathrm{a} \\
\mathrm{a}\end{array}$ & $\begin{array}{l}\mathrm{a} \\
\mathrm{a}\end{array}$ & $\begin{array}{r}71 \\
m\end{array}$ & $\begin{array}{l}\mathrm{m} \\
\mathrm{m}\end{array}$ & $\begin{array}{l}\mathrm{m} \\
\mathrm{m}\end{array}$ & $\begin{array}{l}\mathrm{m} \\
\mathrm{m}\end{array}$ & $\begin{array}{l}\mathrm{m} \\
\mathrm{m}\end{array}$ & $\begin{array}{l}\mathrm{m} \\
\mathrm{m}\end{array}$ \\
\hline $\begin{array}{l}\text { Belgien } \\
\text { (fläm.) }\end{array}$ & $\begin{array}{l}\text { innerhalb } n \\
n+2\end{array}$ & $\begin{array}{l}81 \\
95\end{array}$ & $\begin{array}{l}a \\
a\end{array}$ & $\begin{array}{l}\mathrm{m} \\
\mathrm{m}\end{array}$ & $\begin{array}{l}81 \\
95\end{array}$ & $\begin{array}{l}62 \\
80\end{array}$ & $\begin{array}{l}\mathrm{m} \\
\mathrm{m}\end{array}$ & $\begin{array}{l}\mathrm{m} \\
\mathrm{m}\end{array}$ & $\begin{array}{l}62 \\
80\end{array}$ & $\begin{array}{l}\mathrm{m} \\
\mathrm{m}\end{array}$ \\
\hline Kanada & $\begin{array}{l}\text { innerhalb } n \\
n+2\end{array}$ & $\begin{array}{l}\mathrm{m} \\
\mathrm{m}\end{array}$ & $\begin{array}{l}\mathrm{a} \\
\mathrm{a}\end{array}$ & $\begin{array}{l}\mathrm{m} \\
\mathrm{m}\end{array}$ & $\begin{array}{l}\mathrm{m} \\
\mathrm{m}\end{array}$ & $\begin{array}{l}\mathrm{m} \\
\mathrm{m}\end{array}$ & $\begin{array}{l}\mathrm{m} \\
\mathrm{m}\end{array}$ & $\begin{array}{l}\mathrm{m} \\
\mathrm{m}\end{array}$ & $\begin{array}{l}\mathrm{m} \\
\mathrm{m}\end{array}$ & $\begin{array}{l}\mathrm{m} \\
\mathrm{m}\end{array}$ \\
\hline Chile & $\begin{array}{l}\text { innerhalb } n \\
n+2\end{array}$ & $\begin{array}{l}66 \\
79\end{array}$ & $\begin{array}{l}a \\
a\end{array}$ & $\begin{array}{l}a \\
a\end{array}$ & $\begin{array}{l}66 \\
79\end{array}$ & $\begin{array}{l}60 \\
74\end{array}$ & $\begin{array}{l}\mathrm{a} \\
\mathrm{a}\end{array}$ & $\begin{array}{l}a \\
a\end{array}$ & $\begin{array}{l}60 \\
74\end{array}$ & $\begin{array}{l}a \\
a\end{array}$ \\
\hline Dänemark & $\begin{array}{l}\text { innerhalb } n \\
n+2\end{array}$ & $\begin{array}{l}81 \\
89\end{array}$ & $\begin{array}{l}\mathrm{a} \\
\mathrm{a}\end{array}$ & $\begin{array}{l}81 \\
89\end{array}$ & $\begin{array}{l}\mathrm{m} \\
\mathrm{m}\end{array}$ & $\begin{array}{l}35 \\
53\end{array}$ & $\begin{array}{l}53 \\
69\end{array}$ & $\begin{array}{l}\mathrm{m} \\
\mathrm{m}\end{array}$ & $\begin{array}{l}30 \\
49\end{array}$ & $\begin{array}{l}80 \\
97\end{array}$ \\
\hline Estland & $\begin{array}{l}\text { innerhalb } n \\
n+2\end{array}$ & $\begin{array}{l}84 \\
91\end{array}$ & $\begin{array}{l}a \\
a\end{array}$ & $\begin{array}{l}84 \\
91\end{array}$ & $\begin{array}{l}a \\
a\end{array}$ & $\begin{array}{l}60 \\
66\end{array}$ & $\begin{array}{l}a \\
a\end{array}$ & $\begin{array}{l}60 \\
66\end{array}$ & $\begin{array}{l}60 \\
66\end{array}$ & $\begin{array}{l}\mathrm{a} \\
\mathrm{a}\end{array}$ \\
\hline Finnland & $\begin{array}{l}\text { innerhalb } n \\
n+2\end{array}$ & $\begin{array}{l}80 \\
92\end{array}$ & $\begin{array}{l}a \\
a\end{array}$ & $\begin{array}{l}80 \\
92\end{array}$ & $\begin{array}{l}n \\
n\end{array}$ & $\begin{array}{l}64 \\
74\end{array}$ & $\begin{array}{l}n \\
n\end{array}$ & $\begin{array}{l}64 \\
74\end{array}$ & $\begin{array}{l}n \\
n\end{array}$ & $\begin{array}{l}n \\
n\end{array}$ \\
\hline Frankreich & $\begin{array}{l}\text { innerhalb } n \\
n+2\end{array}$ & $\begin{array}{l}61 \\
90\end{array}$ & $\begin{array}{l}\mathrm{a} \\
\mathrm{a}\end{array}$ & $\begin{array}{l}61 \\
90\end{array}$ & $\begin{array}{l}\mathrm{a} \\
\mathrm{a}\end{array}$ & $\begin{array}{l}55 \\
69\end{array}$ & $\begin{array}{l}55 \\
69\end{array}$ & $\begin{array}{l}a \\
a\end{array}$ & $\begin{array}{l}a \\
a\end{array}$ & $\begin{array}{l}a \\
a\end{array}$ \\
\hline Griechenland & $\begin{array}{l}\text { innerhalb } n \\
n+2\end{array}$ & $\begin{array}{r}89 \\
m\end{array}$ & $\begin{array}{l}a \\
a\end{array}$ & $\begin{array}{r}89 \\
m\end{array}$ & $\begin{array}{r}78 \\
m\end{array}$ & $\begin{array}{r}76 \\
m\end{array}$ & $\begin{array}{r}70 \\
m\end{array}$ & $\begin{array}{r}82 \\
m\end{array}$ & $\begin{array}{r}69 \\
m\end{array}$ & $\begin{array}{l}a \\
a\end{array}$ \\
\hline Ungarn & $\begin{array}{l}\text { innerhalb } n \\
n+2\end{array}$ & $\begin{array}{r}87 \\
m\end{array}$ & $\begin{array}{l}\mathrm{a} \\
\mathrm{a}\end{array}$ & $\begin{array}{l}a \\
a\end{array}$ & $\begin{array}{r}87 \\
m\end{array}$ & $\begin{array}{r}74 \\
\mathrm{~m}\end{array}$ & $\begin{array}{l}a \\
a\end{array}$ & $\begin{array}{r}74 \\
m\end{array}$ & $\begin{array}{l}a \\
a\end{array}$ & $\begin{array}{l}a \\
a\end{array}$ \\
\hline Island & $\begin{array}{l}\text { innerhalb } n \\
n+2\end{array}$ & $\begin{array}{l}47 \\
61\end{array}$ & $\begin{array}{l}\mathrm{a} \\
\mathrm{a}\end{array}$ & $\begin{array}{l}\mathrm{m} \\
\mathrm{m}\end{array}$ & $\begin{array}{l}\mathrm{m} \\
\mathrm{m}\end{array}$ & $\begin{array}{l}37 \\
49\end{array}$ & $\begin{array}{l}\mathrm{m} \\
\mathrm{m}\end{array}$ & $\begin{array}{l}\mathrm{m} \\
\mathrm{m}\end{array}$ & $\begin{array}{l}\mathrm{m} \\
\mathrm{m}\end{array}$ & $\begin{array}{l}\mathrm{m} \\
\mathrm{m}\end{array}$ \\
\hline Irland & $\begin{array}{l}\text { innerhalb } n \\
n+2\end{array}$ & $\begin{array}{l}\mathrm{m} \\
\mathrm{m}\end{array}$ & $\begin{array}{l}a \\
a\end{array}$ & $\begin{array}{l}\mathrm{m} \\
\mathrm{m}\end{array}$ & $\begin{array}{l}\mathrm{m} \\
\mathrm{m}\end{array}$ & $\begin{array}{l}\mathrm{m} \\
\mathrm{m}\end{array}$ & $\begin{array}{l}\mathrm{m} \\
\mathrm{m}\end{array}$ & $\begin{array}{l}\mathrm{m} \\
\mathrm{m}\end{array}$ & $\begin{array}{l}\mathrm{m} \\
\mathrm{m}\end{array}$ & $\begin{array}{l}\mathrm{m} \\
\mathrm{m}\end{array}$ \\
\hline Israel & $\begin{array}{l}\text { innerhalb } n \\
n+2\end{array}$ & $\begin{array}{r}89 \\
m\end{array}$ & $\begin{array}{l}a \\
a\end{array}$ & $\begin{array}{r}89 \\
m\end{array}$ & $\begin{array}{l}a \\
a\end{array}$ & $\begin{array}{r}85 \\
m\end{array}$ & $\begin{array}{l}a \\
a\end{array}$ & $\begin{array}{r}85 \\
m\end{array}$ & $\begin{array}{l}m \\
m\end{array}$ & $\begin{array}{l}\mathrm{a} \\
\mathrm{a}\end{array}$ \\
\hline Italien & $\begin{array}{l}\text { innerhalb } n \\
n+2\end{array}$ & $\begin{array}{r}79 \\
m\end{array}$ & $\begin{array}{l}a \\
a\end{array}$ & $\begin{array}{l}\mathrm{m} \\
\mathrm{m}\end{array}$ & $\begin{array}{l}\mathrm{m} \\
\mathrm{m}\end{array}$ & $\begin{array}{r}61 \\
m\end{array}$ & $\begin{array}{l}\mathrm{m} \\
\mathrm{m}\end{array}$ & $\begin{array}{l}\mathrm{m} \\
\mathrm{m}\end{array}$ & $\begin{array}{l}\mathrm{m} \\
\mathrm{m}\end{array}$ & $\begin{array}{l}\mathrm{m} \\
\mathrm{m}\end{array}$ \\
\hline Japan & $\begin{array}{l}\text { innerhalb } n \\
n+2\end{array}$ & $\begin{array}{r}94 \\
m\end{array}$ & $\begin{array}{l}a \\
a\end{array}$ & $\begin{array}{r}94 \\
m\end{array}$ & $\begin{array}{l}\mathrm{m} \\
\mathrm{m}\end{array}$ & $\begin{array}{r}92 \\
m\end{array}$ & $\begin{array}{l}\mathrm{m} \\
\mathrm{m}\end{array}$ & $\begin{array}{r}92 \\
m\end{array}$ & $\begin{array}{l}\mathrm{m} \\
\mathrm{m}\end{array}$ & $\begin{array}{l}a \\
a\end{array}$ \\
\hline Korea & $\begin{array}{l}\text { innerhalb } n \\
n+2\end{array}$ & $\begin{array}{r}97 \\
\mathrm{~m}\end{array}$ & $\begin{array}{l}a \\
a\end{array}$ & $\begin{array}{l}\mathrm{m} \\
\mathrm{m}\end{array}$ & $\begin{array}{l}\mathrm{m} \\
\mathrm{m}\end{array}$ & $\begin{array}{r}90 \\
\mathrm{~m}\end{array}$ & $\begin{array}{l}\mathrm{m} \\
\mathrm{m}\end{array}$ & $\begin{array}{l}\mathrm{m} \\
\mathrm{m}\end{array}$ & $\begin{array}{l}\mathrm{m} \\
\mathrm{m}\end{array}$ & $\begin{array}{l}\mathrm{m} \\
\mathrm{m}\end{array}$ \\
\hline Luxemburg & $\begin{array}{l}\text { innerhalb } n \\
n+2\end{array}$ & $\begin{array}{l}64 \\
90\end{array}$ & $\begin{array}{l}\mathrm{a} \\
\mathrm{a}\end{array}$ & $\begin{array}{l}a \\
a\end{array}$ & $\begin{array}{l}64 \\
90\end{array}$ & $\begin{array}{l}29 \\
64\end{array}$ & $\begin{array}{l}41 \\
55\end{array}$ & $\begin{array}{l}30 \\
56\end{array}$ & $\begin{array}{l}27 \\
70\end{array}$ & $\begin{array}{l}29 \\
69\end{array}$ \\
\hline Mexiko & $\begin{array}{l}\text { innerhalb } n \\
n+2\end{array}$ & $\begin{array}{r}64 \\
\mathrm{~m}\end{array}$ & $\begin{array}{l}a \\
a\end{array}$ & $\begin{array}{r}64 \\
\mathrm{~m}\end{array}$ & $\begin{array}{l}\mathrm{m} \\
\mathrm{m}\end{array}$ & $\begin{array}{r}57 \\
\mathrm{~m}\end{array}$ & $\begin{array}{c}\mathrm{a} \\
\mathrm{m}\end{array}$ & $\begin{array}{r}57 \\
\mathrm{~m}\end{array}$ & $\begin{array}{l}\mathrm{m} \\
\mathrm{m}\end{array}$ & $\begin{array}{l}\mathrm{m} \\
\mathrm{m}\end{array}$ \\
\hline Niederlande & $\begin{array}{l}\text { innerhalb } n \\
n+2\end{array}$ & $\begin{array}{l}69 \\
94\end{array}$ & $\begin{array}{l}67 \\
92\end{array}$ & $\begin{array}{l}72 \\
97\end{array}$ & $\begin{array}{l}\mathrm{a} \\
\mathrm{a}\end{array}$ & $\begin{array}{l}57 \\
73\end{array}$ & $\begin{array}{l}51 \\
66\end{array}$ & $\begin{array}{l}61 \\
75\end{array}$ & $\begin{array}{l}62 \\
78\end{array}$ & $\begin{array}{l}a \\
a\end{array}$ \\
\hline Neuseeland & $\begin{array}{l}\text { innerhalb } n \\
n+2\end{array}$ & $\begin{array}{l}69 \\
74\end{array}$ & $\begin{array}{l}a \\
a\end{array}$ & $\begin{array}{l}69 \\
74\end{array}$ & $\begin{array}{l}n \\
n\end{array}$ & $\begin{array}{l}\mathrm{m} \\
\mathrm{m}\end{array}$ & $\begin{array}{l}\mathrm{m} \\
\mathrm{m}\end{array}$ & $\begin{array}{l}\mathrm{m} \\
\mathrm{m}\end{array}$ & $\begin{array}{l}\mathrm{m} \\
\mathrm{m}\end{array}$ & $\begin{array}{l}\mathrm{m} \\
\mathrm{m}\end{array}$ \\
\hline Norwegen & $\begin{array}{l}\text { innerhalb } n \\
n+2\end{array}$ & $\begin{array}{l}73 \\
83\end{array}$ & $\begin{array}{l}\mathrm{a} \\
\mathrm{a}\end{array}$ & $\begin{array}{l}73 \\
83\end{array}$ & $\begin{array}{l}n \\
n\end{array}$ & $\begin{array}{l}40 \\
60\end{array}$ & $\begin{array}{l}a \\
a\end{array}$ & $\begin{array}{l}\mathrm{m} \\
\mathrm{m}\end{array}$ & $\begin{array}{l}40 \\
60\end{array}$ & $\begin{array}{l}\mathrm{m} \\
\mathrm{m}\end{array}$ \\
\hline Polen & $\begin{array}{l}\text { innerhalb } n \\
n+2\end{array}$ & $\begin{array}{r}83 \\
m\end{array}$ & $\begin{array}{l}a \\
a\end{array}$ & $\begin{array}{r}83 \\
m\end{array}$ & $\begin{array}{l}a \\
a\end{array}$ & $\begin{array}{r}72 \\
m\end{array}$ & $\begin{array}{l}a \\
a\end{array}$ & $\begin{array}{r}71 \\
m\end{array}$ & $\begin{array}{r}73 \\
m\end{array}$ & $\begin{array}{l}a \\
a\end{array}$ \\
\hline Slowakei & $\begin{array}{l}\text { innerhalb } n \\
n+2\end{array}$ & $\begin{array}{r}97 \\
m\end{array}$ & $\begin{array}{l}a \\
a\end{array}$ & $\begin{array}{l}a \\
a\end{array}$ & $\begin{array}{r}97 \\
m\end{array}$ & $\begin{array}{r}85 \\
m\end{array}$ & $\begin{array}{c}63 \\
m\end{array}$ & $\begin{array}{r}74 \\
m\end{array}$ & $\begin{array}{r}90 \\
m\end{array}$ & $\begin{array}{l}a \\
a\end{array}$ \\
\hline Slowenien & $\begin{array}{l}\text { innerhalb } n \\
n+2\end{array}$ & $\begin{array}{r}82 \\
m\end{array}$ & $\begin{array}{l}a \\
a\end{array}$ & $\begin{array}{l}a \\
a\end{array}$ & $\begin{array}{r}82 \\
m\end{array}$ & $\begin{array}{r}66 \\
m\end{array}$ & $\begin{array}{l}a \\
a\end{array}$ & $\begin{array}{r}78 \\
m\end{array}$ & $\begin{array}{r}63 \\
m\end{array}$ & $\begin{array}{l}a \\
a\end{array}$ \\
\hline Spanien & $\begin{array}{l}\text { innerhalb } n \\
n+2\end{array}$ & $\begin{array}{l}60 \\
83\end{array}$ & $\begin{array}{l}60 \\
83\end{array}$ & $\begin{array}{l}a \\
a\end{array}$ & $\begin{array}{l}\mathrm{a} \\
\mathrm{a}\end{array}$ & $\begin{array}{l}\mathrm{m} \\
\mathrm{m}\end{array}$ & $\begin{array}{l}\mathrm{m} \\
\mathrm{m}\end{array}$ & $\begin{array}{l}\mathrm{m} \\
\mathrm{m}\end{array}$ & $\begin{array}{l}\mathrm{m} \\
\mathrm{m}\end{array}$ & $\begin{array}{l}\mathrm{m} \\
\mathrm{m}\end{array}$ \\
\hline Schweden ${ }^{3}$ & $\begin{array}{l}\text { innerhalb } n \\
n+2\end{array}$ & $\begin{array}{l}76 \\
84\end{array}$ & $\begin{array}{l}\mathrm{a} \\
\mathrm{a}\end{array}$ & $\begin{array}{l}76 \\
84\end{array}$ & $\begin{array}{l}\mathrm{a} \\
\mathrm{a}\end{array}$ & $\begin{array}{l}68 \\
75\end{array}$ & $\begin{array}{l}\mathrm{a} \\
\mathrm{a}\end{array}$ & $\begin{array}{l}68 \\
75\end{array}$ & $\begin{array}{l}\mathrm{a} \\
\mathrm{a}\end{array}$ & $\begin{array}{l}\mathrm{a} \\
\mathrm{a}\end{array}$ \\
\hline Türkei & $\begin{array}{l}\text { innerhalb } n \\
n+2\end{array}$ & $\begin{array}{r}75 \\
m\end{array}$ & $\begin{array}{l}a \\
a\end{array}$ & $\begin{array}{l}\mathrm{a} \\
\mathrm{a}\end{array}$ & $\begin{array}{r}75 \\
m\end{array}$ & $\begin{array}{r}69 \\
m\end{array}$ & $\begin{array}{l}a \\
a\end{array}$ & $\begin{array}{l}a \\
a\end{array}$ & $\begin{array}{r}69 \\
m\end{array}$ & $\begin{array}{l}a \\
a\end{array}$ \\
\hline $\begin{array}{l}\text { Vereinigtes } \\
\text { Königreich }\end{array}$ & $\begin{array}{l}\text { innerhalb } n \\
n+2\end{array}$ & $\begin{array}{r}67 \\
\mathrm{~m}\end{array}$ & $\begin{array}{l}\mathrm{a} \\
\mathrm{a}\end{array}$ & $\begin{array}{l}\mathrm{m} \\
\mathrm{m}\end{array}$ & $\begin{array}{l}\mathrm{m} \\
\mathrm{m}\end{array}$ & $\begin{array}{l}\mathrm{m} \\
\mathrm{m}\end{array}$ & $\begin{array}{l}\mathrm{m} \\
\mathrm{m}\end{array}$ & $\begin{array}{l}\mathrm{m} \\
\mathrm{m}\end{array}$ & $\begin{array}{l}\mathrm{m} \\
\mathrm{m}\end{array}$ & $\begin{array}{l}\mathrm{m} \\
\mathrm{m}\end{array}$ \\
\hline $\begin{array}{l}\text { Vereinigte } \\
\text { Staaten }\end{array}$ & $\begin{array}{l}\text { innerhalb } n \\
n+2\end{array}$ & $\begin{array}{l}\mathrm{m} \\
\mathrm{m}\end{array}$ & $\begin{array}{l}\mathrm{a} \\
\mathrm{a}\end{array}$ & $\begin{array}{l}\mathrm{m} \\
\mathrm{m}\end{array}$ & $\begin{array}{l}\mathrm{m} \\
\mathrm{m}\end{array}$ & $\begin{array}{l}\mathrm{m} \\
\mathrm{m}\end{array}$ & $\begin{array}{l}\mathrm{m} \\
\mathrm{m}\end{array}$ & $\begin{array}{l}\mathrm{m} \\
\mathrm{m}\end{array}$ & $\begin{array}{l}\mathrm{m} \\
\mathrm{m}\end{array}$ & $\begin{array}{l}\mathrm{m} \\
\mathrm{m}\end{array}$ \\
\hline $\begin{array}{l}\text { OECD- } \\
\text { Durchschnitt }\end{array}$ & $\begin{array}{l}\text { innerhalb } n \\
n+2\end{array}$ & $\begin{array}{l}76 \\
91\end{array}$ & $\begin{array}{l}\mathbf{m} \\
\mathbf{m}\end{array}$ & $\begin{array}{l}79 \\
92\end{array}$ & $\begin{array}{l}78 \\
95\end{array}$ & $\begin{array}{l}64 \\
79\end{array}$ & $\begin{array}{l}\mathbf{m} \\
\mathbf{m}\end{array}$ & $\begin{array}{l}69 \\
82\end{array}$ & $\begin{array}{l}59 \\
78\end{array}$ & $\begin{array}{l}\mathbf{m} \\
\mathbf{m}\end{array}$ \\
\hline
\end{tabular}

Anmerkung: Weiterführende Informationen zum vorliegenden Indikator, u.a. den verwendeten Methoden, den eingeschlossenen/nicht eingeschlossenen Bildungsgängen, dem Alter bei Aufnahme der Ausbildung etc., s. Anhang 3.

1. Anfänger in einem allgemeinbildenden Bildungsgang auf ISCED-Stufe 3, die entweder einen allgemeinbildenden oder berufsbildenden Bildungsgang abgeschlossen haben. 2. Anfänger in einem berufsbildenden Bildungsgang auf ISCED-Stufe 3, die entweder einen allgemeinbildenden oder berufsbildenden Bildungsgang abgeschlossen haben. 3. Ohne Schüler, die ihre Ausbildung im Rahmen der Erwachsenenbildung fortgesetzt haben. 4. Der OECD-Durchschnitt für $n+2$ entspricht dem OECD-Durchschnitt für $n+d e m$ Unterschied (in Prozentpunkten) des Durchschnitts für Länder mit Daten für $n$ und für $n+2$. Quelle: OECD. Hinweise s. Anhang 3 unter www.oecd.org/edu/eag.htm. StatLink: http://dx.doi.org/10.1787/888933115236 Erläuterung der Kennzeichnung fehlender Daten s. Hinweise für den Leser. 


\section{Wie viele Studierende werden ein Studium im Tertiärbereich abschließen?}

Ausgehend von den gegenwärtigen Abschlussquoten werden im Durchschnitt der OECD-Länder 39 Prozent der heutigen Jugendlichen im Laufe ihres Lebens ein Studium im Tertiärbereich A an einer Hochschule abschließen.

Im Durchschnitt werden wahrscheinlich rund II Prozent der heutigen jungen Erwachsenen in den OECD-Ländern im Laufe ihres Lebens einen Abschluss im (beruflich ausgerichteten) Tertiärbereich B erwerben.

Studierende erwerben im Durchschnitt der OECD-Länder ihren ersten akademischen Abschluss im Alter von 27 Jahren, wobei dieser Durchschnitt von unter 25 Jahren in Belgien, Luxemburg, Mexiko, den Niederlanden und dem Vereinigten Königreich bis zu 29 Jahren oder älter in Brasilien, Finnland, Island, Israel und Schweden reicht.

Abbildung A3.1



1. Das „durchschnittliche Abschlussalter“ bezieht sich auf ein gewichtetes durchschnittliches Alter, in der Regel das Alter von Studierenden zu Beginn des Kalenderjahres. Die Studierenden können jedoch schon ein Jahr älter als das angegebene durchschnittliche Alter sein, wenn sie ihren Abschluss am Ende des Studienjahres erwerben. Zu Berechnung des durchschnittlichen Abschlussalters s. Anhang 3. 2. Referenzjahr 2011.

Anordnung der Länder in absteigender Reihenfolge des durchschnittlichen Alters von Absolventen des Tertiärbereichs A im Jahr 2012.

Quelle: OECD. Tabelle A3.1a. Hinweise s. Anhang 3 unter www.oecd.org/edu/eag.htm. StatLink: http://dx.doi.org/10.1787/888933115464

\section{Kontext}

Abschlussquoten im Tertiärbereich veranschaulichen, in welchem Ausmaß ein Land in der Lage ist, die Beschäftigten der Zukunft mit speziellen Kenntnissen und Kompetenzen auszustatten. In den OECD-Ländern gibt es auch weiterhin große Anreize, einen Abschluss im Tertiärbereich zu erwerben - sie reichen von höheren Einkommen bis zu besseren Beschäftigungsaussichten (weiter gehende Informationen s. Indikatoren A5 und A6). Struktur und Umfang des Tertiärbereichs unterscheiden sich 
erheblich in den einzelnen Ländern, und die Abschlussquoten werden anscheinend davon beeinflusst, wie leicht der Zugang zu den Studiengängen ist, wie viel Flexibilität bei ihrem Abschluss gewährt wird sowie welche Nachfrage nach höherwertigen Kompetenzen auf dem Arbeitsmarkt besteht. Den Zugang zum Tertiärbereich zu erweitern und den Tertiärbereich stärker mit den Arbeitsmärkten und ihren Anforderungen zu vernetzen ist für wissensbasierte Volkswirtschaften von zentraler Bedeutung, aber angesichts knapper Budgets sind diese Ziele schwieriger denn je zu erreichen.

In den letzten Jahrzehnten wurde der Zugang zum Tertiärbereich deutlich erweitert, es entstanden neue Arten von Bildungseinrichtungen, die eine größere Auswahl bieten, sowie neue Formen der Vermittlung (OECD, 2008). Gleichzeitig wird die Gruppe der Studierenden zunehmend heterogener, weil jetzt Gruppen studieren, denen traditionell der Zugang zur Hochschulbildung verwehrt war, wie beispielsweise ältere Menschen, die danach streben, ihre Qualifikationen zu verbessern, um in einem zunehmend wettbewerbsorientierten Arbeitsmarkt zu bestehen, oder weil Absolventen mit einem ersten Abschluss einen zweiten Abschluss erwerben wollen.

\section{Weitere wichtige Ergebnisse}

Die Mehrheit der Absolventen der Tertiärbereiche ist weiblich - mit Ausnahme der Absolventen von Promotionsstudiengängen. Aufgrund der aktuellen Abschlussquoten wird geschätzt, dass in den OECD-Ländern im Durchschnitt 15 Prozentpunkte mehr Frauen als Männer im Lauf ihres Lebens einen Abschluss im Tertiärbereich A erwerben werden (47 Prozent gegenüber 31 Prozent).

Es wird davon ausgegangen, dass im Durchschnitt der OECD-Länder 1,6 Prozent der jungen Erwachsenen einen weiterführenden forschungsorientierten Studiengang abschließen werden.

Internationale Studierende stellen in einer Reihe von Ländern einen signifikanten Anteil der Absolventen des Tertiärbereichs, in Australien beispielsweise I 8 Prozent und in Neuseeland II Prozent.

\section{Entwicklungstendenzen}

Im Durchschnitt der OECD-Länder mit verfügbaren Daten sind die Abschlussquoten im Tertiärbereich A in den letzten 17 Jahren um 22 Prozentpunkte gestiegen, während die Abschlussquoten im Tertiärbereich B gleich geblieben sind. Promotionsstudiengänge stellen zwar nur einen geringen Teil der Studiengänge im Tertiärbereich dar, aber die Abschlussquoten in diesem Bereich haben sich im gleichen Zeitraum verdoppelt, von o,8 Prozent auf I, 6 Prozent.

\section{Hinweise}

Abschlussquoten zeigen den geschätzten prozentualen Anteil einer Altersgruppe, der wahrscheinlich im Laufe des Lebens einen Abschluss erwerben wird. Diese Schätzung basiert auf der Gesamtzahl der Absolventen im Jahr 2012 sowie der Altersverteilung 
in dieser Gruppe. Daher basieren die angegebenen Zahlen auf den aktuellen Abschlussquoten. Das aber wiederum bedeutet, dass sie von jeder Änderung des Bildungssystems beeinflusst werden, wie beispielsweise der Einführung neuer Studiengänge oder Änderungen der Dauer von Studiengängen, wie sie sich in den letzten Jahren in vielen EU-Ländern durch die Umsetzung des Bologna-Prozesses ergeben haben.

Im vorliegenden Indikator wird der 30. Geburtstag als die Obergrenze für das typische Alter für einen Erstabschluss im Tertiärbereich A oder B angesehen. Die Obergrenze für das typische Alter von Absolventen eines weiterführenden forschungsorientierten Studiengangs wurde bei 35 Jahren festgelegt.

In vielen Ländern wird klar zwischen erstem und zweitem akademischem Abschluss, d. h. dem Abschluss von Undergraduate- und Postgraduate-Studiengängen, unterschieden. In einigen Ländern wird jedoch ein Abschluss, der international vom Niveau her mit einem Masterabschlusses vergleichbar ist, am Ende eines einzigen langen Studiengangs erworben. Zur genaueren Vergleichbarkeit beziehen sich die in diesem Indikator vorgestellten Daten, soweit nicht anders angegeben, auf Erstabschlüsse.

\section{Analyse und Interpretationen}

Aufgrund der gegenwärtigen Abschlussquoten wird davon ausgegangen, dass 38 Prozent der jungen Menschen im Durchschnitt der 26 OECD-Länder mit vergleichbaren Daten für 2012 während ihres Lebens einen ersten Abschluss im Tertiärbereich A erwerben werden. Dieser Anteil reicht von weniger als 25 Prozent in Chile, Luxemburg, Mexiko und Ungarn bis zu mindestens 50 Prozent in Australien, Island, Neuseeland und Polen (Abb. A3.2).

Diese Studiengänge, die typischerweise an Universitäten angeboten werden, sind weitgehend theoretisch orientiert und sollen hinreichende Qualifikationen für den Zugang zu weiterführenden forschungsorientierten Studiengängen und Berufen mit hohen Qualifikationsanforderungen vermitteln.

Im Durchschnitt der OECD-Länder werden 39 Prozent der jungen Menschen einen ersten Abschluss im Tertiärbereich A erwerben (häufig als Bachelorabschluss bezeichnet) und I8 Prozent auch einen zweiten Abschluss (häufig als Masterabschluss bezeichnet). Für Studiengänge, die zu einem ersten Abschluss führen, liegt die Abschlussquote in Australien, Finnland, Island, Neuseeland, Polen und der Russischen Föderation bei mindestens 50 Prozent, während es in Argentinien, Belgien, Chile, China, Estland, Griechenland, Indonesien, Luxemburg, Mexiko, Saudi-Arabien und Südafrika höchstens 25 Prozent sind. Die niedrigen Abschlussquoten in Belgien und China werden durch höhere Abschlussquoten bei Studiengängen, die zu einem ersten Abschluss im (beruflich ausgerichteten) Tertiärbereich B führen, kompensiert. In China werden etwa I5 Prozent der heute dort lebenden jungen Menschen im Laufe ihres Lebens einen Abschluss in einem Studiengang im Tertiärbereich A erwerben und I 8 Prozent in einem Studiengang im Tertiärbereich B. Die Abschlussquote bei Studiengängen, die zu einem zweiten Abschluss führen, liegt in Polen, Portugal und der Slowakei bei mindestens 


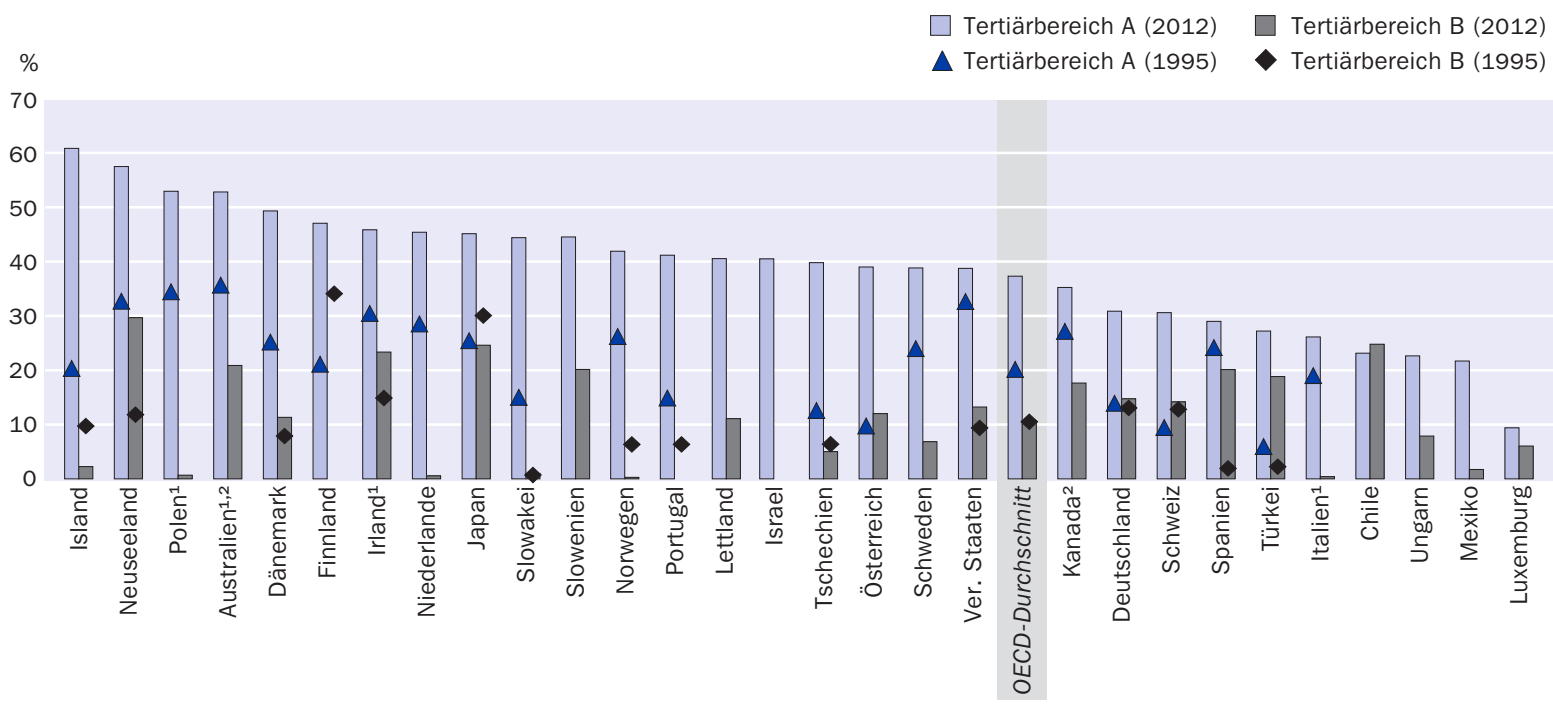

1. Referenzjahr 2000 anstelle 1995. 2. Referenzjahr 2011 anstelle 2012.

Anordnung der Länder in absteigender Reihenfolge der Abschlussquoten (Erstabschluss) im Tertiärbereich A im Jahr 2012.

Quelle: OECD. Tabelle A3.2a. Hinweise s. Anhang 3 unter www.oecd.org/edu/eag.htm. StatLink: http://dx.doi.org/10.1787/888933115483

30 Prozent. Mit der Umsetzung des Bologna-Prozesses hat in vielen EU-Mitgliedstaaten die Zahl dieser Studiengänge im Tertiärbereich deutlich zugenommen (Tab. A3.Ia).

In den letzten Jahrzehnten ist die Nachfrage nach Bildungsgängen mit berufsbildender Ausrichtung nicht so stark gestiegen wie die nach universitären Studiengängen. 2012 lagen in den 27 OECD-Ländern mit vergleichbaren Daten die Abschlussquoten im Tertiärbereich B im Durchschnitt bei II Prozent; I2 Prozent der Frauen und Io Prozent der Männer erwarben einen Abschluss in einem solchen Studiengang. Vom Niveau her werden diese Studiengänge genauso wie die stärker theoretisch orientierten Studiengänge eingeordnet, sie sind jedoch häufig von kürzerer Dauer (in der Regel zwei bis drei Jahre). Sie sind im Allgemeinen nicht auf den Zugang zu einem weiterführenden universitären Abschluss orientiert, sondern sollen den Absolventen Kompetenzen vermitteln, die direkt auf dem Arbeitsmarkt verwendet werden können und die auch dem Bedarf der Arbeitgeber an speziellen Kompetenzen entsprechen (Tab. A3.Ia).

\section{Trenddaten}

In allen Ländern mit vergleichbaren Daten stiegen die Abschlussquoten im Tertiärbereich A zwischen 1995 und 2012. In den meisten war der Anstieg zwischen 1995 und 2005 besonders signifikant (von 20 Prozent auf 36 Prozent) und flachte danach wieder ab. In den letzten 5 Jahren waren die Abschlussquoten im Tertiärbereich A mit unverändert rund 38 Prozent relativ stabil. Seit 1995 bzw. dem Jahr, für das erstmalig Daten vorliegen, sind die geschätzten Abschlussquoten im Tertiärbereich in Dänemark, Finnland, Japan, Neuseeland, Österreich, Polen, Portugal, der Schweiz, der Slowakei, Slowenien, Tschechien und der Türkei um mindestens 20 Prozentpunkte gestiegen (Tab. A3.2a). 

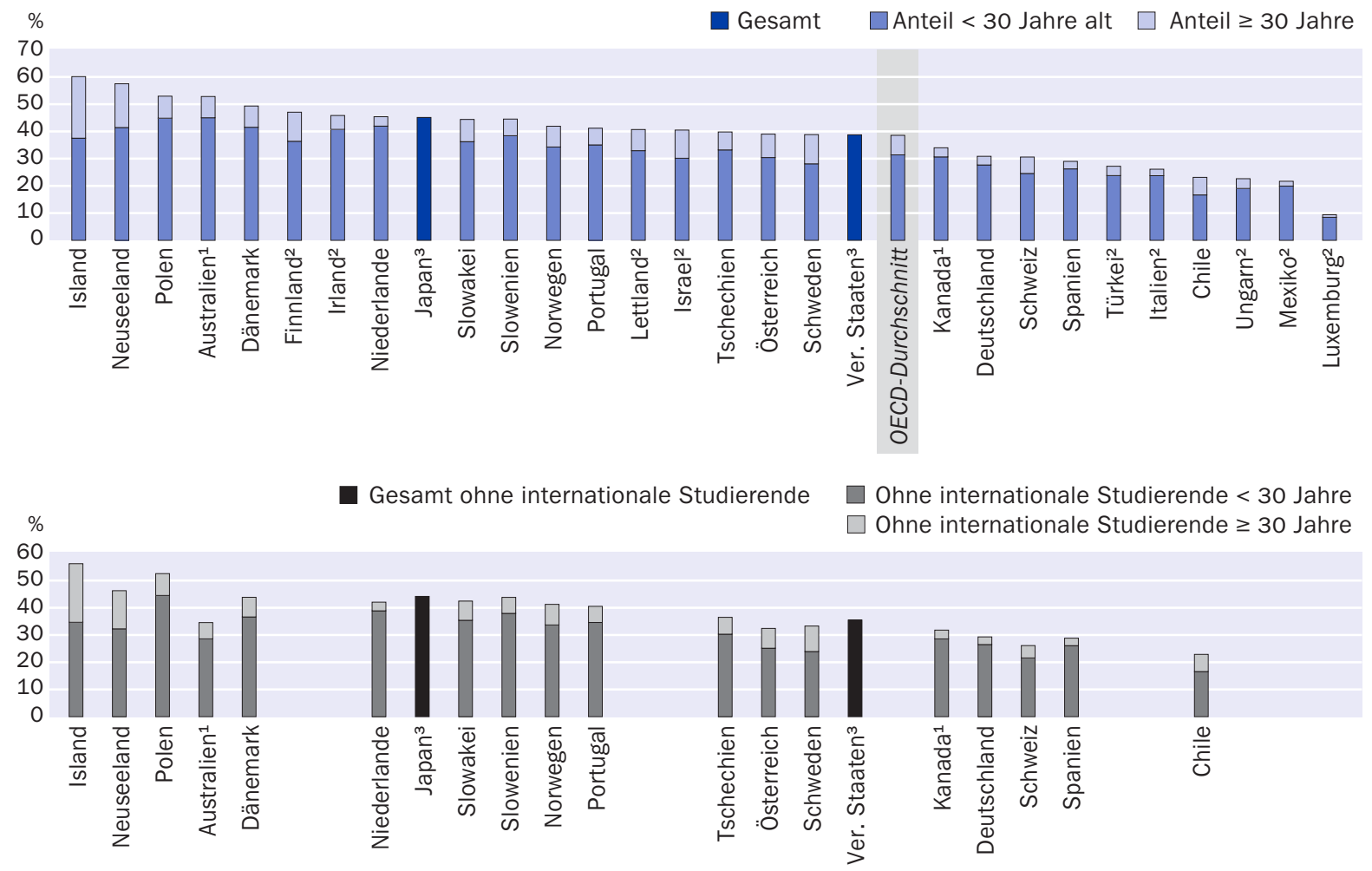

1. Referenzjahr 2011. 2. Es liegen keine Abschlussquoten für internationale Studierende vor. 3. Es liegen keine nach Altersgruppe aufgeschlüsselten Abschlussquoten vor.

Anordnung der Länder in absteigender Reihenfolge der Gesamtabschlussquoten im Tertiärbereich A im Jahr 2012.

Quelle: OECD. Tabellen A3.1a and A3.1b. Hinweise s. Anhang 3 unter www.oecd.org/edu/eag.htm. StatLink: http://dx.doi.org/10.1787/888933115502

Der Bologna-Prozess hat zu einer stärkeren Harmonisierung der Hochschulbildung geführt, indem es zu einer allgemeinen Abkehr von längeren Studiengängen zugunsten von Studiengängen mit einer Dauer von 3 Jahren kam. Als Ergebnis hiervon war in einigen Ländern ein deutlicher Anstieg der Abschlussquoten festzustellen, so in Tschechien zwischen 2004 und 2007 sowie in Finnland und der Slowakei von 2007 auf 2008.

Im Tertiärbereich B gab es zwischen 1995 und 2012 unterschiedliche Entwicklungen in einigen Ländern, auch wenn sich der OECD-Durchschnitt kaum verändert hat. In Spanien beispielsweise lässt sich der starke Anstieg der Abschlussquoten im Tertiärbereich B von 2 Prozent auf 20 Prozent auf die Einführung neuer, höherwertiger berufsbildender Studiengänge/Ausbildungsgänge zurückführen; auch in Neuseeland und der Türkei stiegen die Abschlussquoten im Tertiärbereich B während dieses Zeitraums um mehr als 15 Prozentpunkte. In Finnland hingegen laufen gegenwärtig die Studiengänge des Tertiärbereichs B aus, daher sind dort die Abschlussquoten für diese Studiengänge stark gesunken, während die Abschlussquoten stärker theoretisch orientierter Studiengänge gestiegen sind (Abb. A3.2).

Geschlechtsspezifische Trenddaten zeigen, dass der Anstieg der Abschlussquoten im Tertiärbereich A bei den Frauen in einigen OECD-Ländern wie Österreich, der Slowakei 
und Tschechien mit mehr als 20 Prozentpunkten besonders groß war. In Slowenien betrug er zwischen 2005 und 2012 sogar fast 40 Prozentpunkte. In diesen Ländern stiegen zwar auch die Abschlussquoten der Männer, jedoch in weit geringerem Maße (Tab. A3.2b im Internet).

\section{Abschlussquoten von Studierenden, die jünger als das typische Abschlussalter sind}

Im Durchschnitt der OECD-Länder erwerben Studierende ihren ersten Abschluss im Tertiärbereich im Alter von 27 Jahren, aber dieses Alter variiert sehr stark zwischen den einzelnen Ländern. Studierende in Belgien, Luxemburg, Mexiko, den Niederlanden und dem Vereinigten Königreich schließen ihr Studium vor ihrem 25. Geburtstag ab, in Brasilien, Finnland, Island, Israel und Schweden erwerben Studierende ihren ersten Abschluss im Tertiärbereich dagegen erst nach dem 29. Geburtstag (Abb. A3.I).

Altersunterschiede zwischen den Absolventen können mit strukturellen Faktoren, wie dem Abschluss des Sekundarbereichs II, der Dauer der Studiengänge oder einer eventuell bestehenden Wehrpflicht zusammenhängen. Altersunterschiede zwischen den Absolventen können auch auf wirtschaftlichen Faktoren begründet sein, wie dem Fehlen von Stipendien und der Flexibilität, Studium und Berufstätigkeit miteinander zu verbinden, oder bildungspolitischen Maßnahmen, die Erwachsene mit Berufserfahrung dazu ermutigen sollen, noch ein Studium im Tertiärbereich aufzunehmen, um so vorhandene Kompetenzen zu vertiefen oder ganz neue Kompetenzen zu erlangen. Angesichts der aktuellen schwierigen Wirtschaftslage weltweit können sich junge Menschen auch dafür entschieden haben, ihre Ausbildung im Tertiärbereich fortzusetzen, da die Opportunitätskosten eines Eintritts in einen instabilen Arbeitsmarkt in einigen OECD-Ländern hoch sind. Die Tatsache, dass diese Männer und Frauen später ins Berufsleben eintreten, hat wirtschaftliche Konsequenzen, die bei bildungspolitischen Entscheidungen zu berücksichtigen sind. Hierzu zählen höhere Ausgaben pro Studierenden und entgangene Steuereinnahmen aufgrund ihres kürzeren Arbeitslebens.

Es wird davon ausgegangen, dass weniger als ein Drittel der jungen Menschen den Abschluss im Tertiärbereich A vor Erreichen des 30. Lebensjahrs erwerben wird - wobei ihr Anteil von mehr als 40 Prozent in Australien, Dänemark, Irland, Neuseeland, den Niederlanden und Polen bis zu höchstens 20 Prozent in Chile, Luxemburg, Mexiko und Ungarn reicht (Abb. A3.3).

\section{Abschlussquoten ohne internationale Studierende}

Bei „internationalen Studierenden“ handelt es sich um Studierende, die ausdrücklich zum Studium in ein anderes Land gekommen sind. Internationale Studierende haben aus verschiedenen Gründen einen wesentlichen Einfluss auf die geschätzten Abschlussquoten. Per Definition gelten sie als Absolventen mit einem Erstabschluss, unabhängig von ihren zuvor in anderen Ländern erworbenen Abschlüssen (d. h. ein internationaler Studierender, der ein zu einem zweiten Abschluss führendes Studium aufnimmt und abschließt, gilt als Absolvent mit einem Erstabschluss in dem Land seines Auslandsstudiums). Darüber hinaus kann durch sie die absolute Zahl der Absolventen unter der Bevölkerung steigen, da sie mit der Absicht zu studieren in das Land gekommen sind und nicht unbedingt, um dort zu arbeiten und auf Dauer zu bleiben. Die Abschlussquoten in Ländern mit einem großen Anteil internationaler Studierender wie Austra- 
lien und Neuseeland sind dadurch künstlich überhöht. Rechnet man zum Beispiel die internationalen Studierenden heraus, so fallen die Abschlussquoten (Erstabschluss) im Tertiärbereich A von Studierenden in Australien und Neuseeland um I8 bzw. II Prozentpunkte geringer aus und die Abschlussquoten (Erstabschluss) im Tertiärbereich B in Neuseeland um 8 Prozentpunkte (Tab. A3.ra).

\section{Abschlussquoten bei weiterführenden forschungsorientierten Studiengängen}

Bei Promovierten handelt es sich um Absolventen, die einen Abschluss auf der höchsten Ebene des formalen Bildungssystems erworben haben, zu ihnen gehören normalerweise auch Forscher, die einen Doktorgrad erworben haben. Aufgrund der Abschlussquoten von 2012 wird davon ausgegangen, dass im Durchschnitt der OECD-Länder I, 6 Prozent der jungen Menschen einen Abschluss in einem weiterführenden forschungsorientierten Studiengang erwerben werden, verglichen mit I,o Prozent im Jahr 2000. Zu den Ländern mit dem größten Anstieg der Abschlussquoten in weiterführenden forschungsorientierten Studiengängen gehören Dänemark, Irland, Italien, Neuseeland, Norwegen, die Slowakei, Tschechien und das Vereinigte Königreich, wo diese zwischen 2000 und 2012 um mindestens I Prozentpunkt angestiegen sind (Tab. A3.2c im Internet).

Obwohl die Abschlussquoten für Frauen auf diesem Bildungsniveau mit I,5 Prozent niedriger sind als die der Männer mit I,7 Prozent, ist in einigen Ländern der geschätzte Anteil an Frauen, die einen Abschluss in einem weiterführenden forschungsorientierten Studiengang erwerben werden, höher als derjenige der Männer. In Finnland, Italien, Lettland, Portugal und den Vereinigten Staaten liegen die entsprechenden Abschlussquoten für Frauen mindestens 0,2 Prozent über denjenigen der Männer (Tab. A3.Ia).

Einige Länder wollen internationale Studierende für Promotionsstudiengänge gewinnen. So sind beispielsweise die hohen Abschlussquoten, die in Deutschland, Finnland, Schweden und der Schweiz in diesem Bereich zu beobachten sind (mehr als 2,5 Prozent), teilweise auf den hohen Anteil internationaler Studierender bei den Promotionsstudiengängen zurückzuführen (Tab. A3.ra). Werden internationale Studierende bei der Berechnung nicht berücksichtigt, reduzieren sich die Abschlussquoten für diese Länder von 0,3 Prozentpunkten in Finnland bis zu I,6 Prozentpunkten in der Schweiz, wo ungefähr die Hälfte der Absolventen von Promotionsstudiengängen internationale Studierende sind.

Im Durchschnitt der OECD-Länder sind Absolventen von weiterführenden forschungsorientierten Studiengängen 35 Jahre alt, das durchschnittliche Abschlussalter reicht jedoch von höchstens 32 Jahren in Deutschland, den Niederlanden und der Slowakei bis zu mindestens 38 Jahren in Brasilien, Finnland, Israel, Korea, Lettland, Norwegen und Portugal (Tab. A3.ra).

\section{Geschlechtsspezifische Unterschiede bei der Wahl der Studienfächer}

Die Verteilung der erworbenen Abschlüsse auf die einzelnen Fächergruppen richtet sich nach deren relativer Beliebtheit bei den Studierenden, der relativen Anzahl der in den betreffenden Fächergruppen an den Hochschulen und entsprechenden Einrichtungen angebotenen Stellen und der Struktur der für diese Studienfächer möglichen Abschlüsse in dem jeweiligen Land. 
Bei den meisten Fächergruppen stellen Frauen den Großteil der Absolventen, dies gilt besonders für die Fächergruppen Erziehungswissenschaften sowie Gesundheit und Soziales, in denen sie fast 78 Prozent bzw. 75 Prozent aller Studierenden des Tertiärbereichs (Tertiärbereich A und weiterführende forschungsorientierte Studiengänge) stellen, die 2012 in diesen Fächergruppen ihren Abschluss erwarben. Im Gegensatz hierzu erwarben Frauen nur einen geringen Teil der Abschlüsse bei den Fächergruppen Ingenieurwissenschaften, Fertigung und Bauwesen (28 Prozent) und Informatik (20 Prozent) (Tab. A3·3 im Internet). Nur in Argentinien, Estland, Island, Italien, Kolumbien, Luxemburg und Polen erwarben Frauen 2012 mindestens ein Drittel der Abschlüsse in der Fächergruppe Ingenieurwissenschaften, Fertigung und Bauwesen.

Diese Situation hat sich seit 2000 nur geringfügig verändert, trotz zahlreicher Initiativen der OECD-Länder und der EU zur Verringerung geschlechtsspezifischer Unterschiede. So hat beispielsweise die Europäische Union 2000 als Ziel festgelegt, die Zahl der Absolventen in den Studiengängen Mathematik, Naturwissenschaften und Technik bis 2010 um mindestens I5 Prozent zu steigern sowie eine Verringerung des in diesen Studiengängen bestehenden Ungleichgewichts zwischen den Geschlechtern zu erreichen. Bislang wurden jedoch nur sehr geringe Fortschritte in dieser Hinsicht erzielt. Deutschland, Portugal, die Schweiz, die Slowakei und Tschechien waren die einzigen fünfLänder, in denen der Anteil der Frauen in den Naturwissenschaften (hierzu gehören die Biowissenschaften, Physik, Mathematik und Statistik sowie Informatik) zwischen 2000 und 2012 um mindestens Io Prozentpunkte gestiegen ist. Damit haben sich diese Länder in dieser Hinsicht dem OECD-Durchschnitt angenähert bzw. liegen sogar über ihm. In den OECD-Ländern ist der Anteil der Frauen in diesen Fächergruppen geringfügig von 40 Prozent im Jahr 2000 auf 4I Prozent im Jahr 2012 gestiegen - obwohl der Anteil der weiblichen Absolventen über alle Fächergruppen hinweg in diesem Zeitraum von 54 Prozent auf 58 Prozent gestiegen ist. Obwohl der Anteil der Frauen in der Fächergruppe Ingenieurwissenschaften, Fertigung und Bauwesen ebenfalls niedrig ist, ist auch er in der letzten Dekade leicht von 23 auf 28 Prozent angestiegen (Tab. A3.3 im Internet).

\section{Definitionen}

Ein erster Abschluss im Tertiärbereich A erfolgt nach einem Studiengang mit einer kumulierten regulären Gesamtdauer von mindestens drei Jahren (vollzeitäquivalent), z. B. der Bachelorabschluss in vielen englischsprachigen Ländern, das Diplom in vielen deutschsprachigen Ländern und die licence in vielen französischsprachigen Ländern.

Ein Erstabsolvent ist ein Studierender, der innerhalb des Referenzzeitraums zum ersten Mal in einem bestimmten Bildungsbereich bzw. im Fall von ISCED 5 in einem Studiengang des Tertiärbereichs A oder B einen Abschluss erwirbt. Wenn also ein Studierender im Laufe der Jahre mehrere Abschlüsse erwirbt, so wird er oder sie zwar jedes Jahr als Absolvent gezählt, als Erstabsolvent jedoch nur einmal.

Studierende werden als internationale Studierende bezeichnet, wenn sie aus ihrem Herkunftsland zwecks Studium in ein anderes Land gekommen sind. Per Definition gelten sie als Absolventen mit einem Erstabschluss, unabhängig von ihren früher in anderen Ländern erworbenen Abschlüssen. 
Netto-Abschlussquoten zeigen den geschätzten prozentualen Anteil einer spezifischen Altersgruppe, der im Laufe des Lebens einen Abschluss im Tertiärbereich erwerben wird (ausgehend von den aktuellen Abschlussquoten).

$\mathrm{Zu}$ einem zweiten Abschluss führende und stärker theoretisch orientierte Studiengänge (z. B. der Masterabschluss in vielen Ländern) werden getrennt von weiterführenden forschungsorientierten Studiengängen (ISCED 6) in den Tertiärbereich A eingeordnet.

Als Absolventen im Tertiärbereich gelten alle Studierenden, die einen Universitätsabschluss, Fachhochschulabschluss oder Abschluss in einem weiterführenden forschungsorientierten Studiengang auf Ebene der Promotion erwerben.

\section{Angewandte Methodik}

Die Daten beziehen sich auf das Schuljahr 20II/20I2 und beruhen auf der von der OECD im Jahre 2012 durchgeführten UOE-Datenerhebung zur Bildungsstatistik (weitere Informationen s. Anhang 3 unter www.oecd.org/edu/eag.htm).

Die Daten zu den Auswirkungen internationaler Studierender auf die Abschlussquoten im Tertiärbereich basieren auf einer im Dezember 20I3 von der OECD durchgeführten speziellen Erhebung.

Die Daten zur Entwicklung der Abschlussquoten im Tertiärbereich für die Jahre 1995 und 2000 bis 2004 basieren auf einer speziellen Erhebung, die im Januar 2007 durchgeführt wurde.

Um einen von den unterschiedlichen nationalen Abschlussstrukturen unabhängigen Vergleich zu ermöglichen, werden die Abschlüsse in universitären Studiengängen entsprechend ihrer regulären Gesamtdauer untergliedert, mit anderen Worten entsprechend der (gesetzlich oder anders) festgelegten Zahl von Jahren, in denen ein Studiengang abgeschlossen werden kann. Abschlüsse, die nach Studiengängen mit einer Dauer von weniger als drei Jahren erworben werden, gelten hier nicht als gleichwertig mit einem Abschluss dieses Bildungsbereichs und werden somit bei diesem Indikator nicht berücksichtigt. $\mathrm{Zu}$ einem zweiten Abschluss führende Studiengänge werden nach der kumulierten Dauer des zum ersten und zum zweiten Abschluss führenden Studiengangs klassifiziert, wobei Absolventen, die bereits über einen ersten Abschluss verfügen, bei der Zählung der Absolventen mit einem Erstabschluss nicht berücksichtigt werden.

Außer es ist etwas anderes angegeben, wurden die Abschlussquoten als Netto-Abschlussquoten (d.h. als Summe der Abschlussquoten der einzelnen Altersjahrgänge) berechnet. Für diejenigen Länder, die keine derart ausführlichen Daten bereitstellen konnten, werden die Brutto-Abschlussquoten dargestellt. Zur Berechnung der BruttoAbschlussquoten gab jedes Land das typische Abschlussalter an (s. Anhang I). Die Zahl der Absolventen wurde (ohne Berücksichtigung ihres jeweiligen Alters) durch die Bevölkerung im üblichen Abschlussalter geteilt. In vielen Ländern ist es jedoch schwierig, ein typisches Abschlussalter festzulegen, da die Altersspanne der Absolventen sehr groß ist. 


\section{Tabellen Indikator A3}

StatLink: http://dx.doi.org/10.1787/888933115388

Tabelle A3.Ia: Abschlussquoten und durchschnittliches Abschlussalter im Tertiärbereich (2012)

Tabelle A3.Ib: Abschlussquoten im Tertiärbereich von Studierenden, die jünger als das typische Abschlussalter sind (2012)

Tabelle A3.2a: Entwicklung der Abschlussquoten im Tertiärbereich (I995-2012)

WEB Table A3.2b: Trends in tertiary graduation rates, by gender (Entwicklung der Abschlussquoten im Tertiärbereich, nach Geschlecht) (2005-20I2)

WEB Table A3.2c: Trends in net graduation rates at advanced research level (Entwicklung der Netto-Abschlussquoten bei weiterführenden forschungsorientierten Studiengängen) (I995-20I2)

WEB Table A3.3: Percentage of tertiary qualifications awarded to women in tertiary-type A and advanced research programmes, by field of education (Anteil der von Frauen erworbenen Abschlüsse im Tertiärbereich A und in weiterführenden forschungsorientierten Studiengängen [in \%], nach Fächergruppe)

(2000, 2012) 
Abschlussquoten und durchschnittliches Abschlussalter im Tertiärbereich (2012)

Summe der Abschlussquoten der einzelnen Altersjahrgänge, nach Geschlecht und Art des Studiengangs

\begin{tabular}{|c|c|c|c|c|c|c|c|c|c|c|c|c|c|c|c|c|c|c|}
\hline & \multicolumn{3}{|c|}{$\begin{array}{l}\text { Studiengänge im } \\
\text { Tertiärbereich B } \\
\text { (Absolventen mit } \\
\text { Erstabschluss) }\end{array}$} & \multicolumn{3}{|c|}{$\begin{array}{l}\text { Studiengänge im } \\
\text { Tertiärbereich B } \\
\text { (erster Abschluss) }\end{array}$} & \multicolumn{3}{|c|}{$\begin{array}{l}\text { Studiengänge im } \\
\text { Tertiärbereich A } \\
\text { (Erstabschluss) }\end{array}$} & \multicolumn{3}{|c|}{$\begin{array}{l}\text { Studiengänge im } \\
\text { Teriärbereich A } \\
\text { (erster Abschluss) }\end{array}$} & \multicolumn{3}{|c|}{$\begin{array}{c}\text { Studiengänge im } \\
\text { Tertiärbereich A } \\
\text { (zweiter und weitere } \\
\text { Abschlüsse) }\end{array}$} & \multicolumn{3}{|c|}{$\begin{array}{l}\text { Weiterführende } \\
\text { forschungs- } \\
\text { orientierte } \\
\text { Studiengänge }\end{array}$} \\
\hline &  & 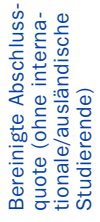 & 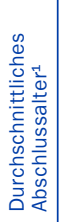 & $\begin{array}{l}\stackrel{+}{E} \\
\mathbb{D} \\
\mathscr{D} \\
心\end{array}$ & 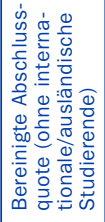 & 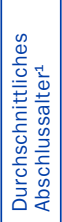 & $\begin{array}{l}\stackrel{+}{E} \\
\mathbb{D} \\
\mathscr{D} \\
0\end{array}$ & 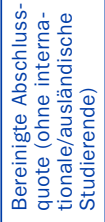 & 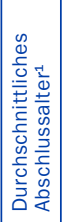 & $\begin{array}{l}\stackrel{\amalg}{E} \\
\mathbb{D} \\
\stackrel{D}{0} \\
心\end{array}$ & 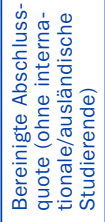 & 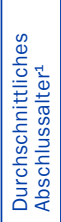 & $\begin{array}{l}\stackrel{+}{E} \\
\mathbb{D} \\
\mathbb{D} \\
心\end{array}$ &  &  & 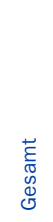 &  & 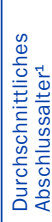 \\
\hline & (1) & (4) & (5) & (6) & (9) & (10) & (11) & (14) & (15) & (16) & (19) & $(20)$ & $(21)$ & (24) & (25) & $(26)$ & (29) & (30) \\
\hline \multicolumn{19}{|l|}{ OECD-Länder } \\
\hline Australien² & 21 & 18 & 31 & 31 & 25 & 33 & 53 & 35 & 25 & 64 & 46 & 27 & 21 & 9 & 31 & 2,0 & 1,4 & 37 \\
\hline Österreich & 12 & 12 & 30 & 14 & 14 & 32 & 39 & 32 & 28 & 36 & 31 & 27 & 12 & 10 & 32 & 2,2 & 1,6 & 34 \\
\hline Belgien & m & $m$ & $m$ & 32 & 30 & 25 & m & $m$ & $\mathrm{~m}$ & 18 & 17 & 22 & 26 & 22 & $\mathrm{~m}$ & 1,7 & 1,2 & 33 \\
\hline Kanada $^{2}$ & 18 & 17 & 26 & 21 & 19 & 27 & 34 & 32 & 25 & 35 & 33 & 26 & 12 & 11 & 32 & 1,3 & 1,1 & 36 \\
\hline Chile & 25 & 25 & 28 & 26 & 26 & 28 & 23 & 23 & 29 & 21 & 20 & 28 & 7 & 7 & 37 & 0,2 & 0,2 & 37 \\
\hline Tschechien & 5 & 5 & 25 & 5 & 5 & 25 & 40 & 36 & 27 & 42 & 38 & 27 & 25 & 23 & 29 & 1,6 & 1,4 & 35 \\
\hline Dänemark & 11 & 10 & 27 & 12 & 11 & 27 & 49 & 44 & 27 & 48 & 45 & 28 & 25 & 21 & 29 & 2,2 & 1,7 & 35 \\
\hline Estland & $\mathbf{m}$ & $\mathrm{m}$ & $\mathrm{m}$ & 19 & 19 & 29 & $\mathbf{m}$ & $\mathrm{m}$ & $\mathrm{m}$ & 23 & 22 & 26 & 13 & 13 & 30 & 1,0 & 0,9 & 36 \\
\hline Finnland & $\mathbf{n}$ & $n$ & $\mathrm{~m}$ & $\mathbf{n}$ & $n$ & $\mathrm{~m}$ & 47 & $\mathrm{~m}$ & 28 & 50 & 48 & 29 & 24 & 22 & 32 & 2,8 & 2,5 & 39 \\
\hline Frankreich ${ }^{2}$ & $\mathbf{m}$ & $\mathrm{m}$ & $\mathrm{m}$ & 27 & 26 & $\mathrm{~m}$ & m & $\mathrm{m}$ & $\mathrm{m}$ & 38 & 34 & $\mathrm{~m}$ & 18 & 15 & $\mathrm{~m}$ & 1,7 & 1,0 & $\mathrm{~m}$ \\
\hline Deutschland & 15 & $\mathrm{~m}$ & $\mathrm{~m}$ & 15 & $\mathrm{~m}$ & $m$ & 31 & 29 & 25 & 31 & 29 & 25 & 7 & 6 & 27 & 2,7 & 2,3 & 31 \\
\hline Griechenland & m & $\mathrm{m}$ & $\mathrm{m}$ & 15 & $\mathrm{~m}$ & 26 & m & $\mathrm{m}$ & $\mathrm{m}$ & 25 & $\mathrm{~m}$ & 26 & 9 & $\mathrm{~m}$ & $\mathrm{~m}$ & 1,0 & $\mathrm{~m}$ & $\mathrm{~m}$ \\
\hline Ungarn & 8 & $\mathrm{~m}$ & 23 & 9 & 9 & 23 & 23 & $\mathrm{~m}$ & 26 & 29 & 27 & 26 & 13 & 13 & 33 & 0,8 & 0,7 & 35 \\
\hline Island & 2 & $\mathrm{~m}$ & 38 & 2 & 2 & 37 & 60 & 56 & 31 & 62 & 60 & 31 & 26 & 23 & 35 & 0,9 & 0,5 & 35 \\
\hline Irland & 23 & $\mathrm{~m}$ & 30 & 23 & 22 & 30 & 46 & $\mathrm{~m}$ & 25 & 46 & 44 & 25 & 24 & 22 & 31 & 2,0 & 1,6 & 34 \\
\hline Israel & m & $\mathrm{m}$ & $\mathrm{m}$ & m & $\mathrm{m}$ & $\mathrm{m}$ & 40 & $\mathrm{~m}$ & 29 & 42 & 42 & 29 & 19 & 18 & 35 & 1,5 & 1,5 & 38 \\
\hline Italien & $\mathbf{n}$ & $\mathrm{m}$ & $\mathrm{m}$ & $\mathbf{n}$ & $n$ & $\mathrm{~m}$ & 26 & $\mathrm{~m}$ & 26 & 32 & 31 & 26 & 24 & $\mathrm{~m}$ & $\mathrm{~m}$ & 1,4 & $\mathrm{~m}$ & 34 \\
\hline Japan & 25 & 24 & $\mathrm{~m}$ & 25 & 24 & $\mathrm{~m}$ & 45 & 44 & $\mathrm{~m}$ & 45 & 44 & $\mathrm{~m}$ & 7 & 6 & $\mathrm{~m}$ & 1,1 & 0,9 & $\mathrm{~m}$ \\
\hline Korea & $\mathbf{m}$ & $\mathrm{m}$ & $\mathrm{m}$ & 29 & $\mathrm{~m}$ & 25 & $\mathbf{m}$ & $\mathrm{m}$ & $\mathrm{m}$ & 49 & $\mathrm{~m}$ & 25 & 11 & $\mathrm{~m}$ & 34 & 1,5 & $\mathrm{~m}$ & 40 \\
\hline Luxemburg & 6 & $\mathrm{~m}$ & 26 & 6 & 4 & 26 & 9 & $\mathrm{~m}$ & 25 & 9 & 6 & 25 & 2 & 2 & $\mathrm{~m}$ & 0,7 & $\mathrm{n}$ & 33 \\
\hline Mexiko & 2 & $\mathrm{~m}$ & 22 & 2 & $\mathrm{~m}$ & 22 & 22 & $\mathrm{~m}$ & 25 & 22 & $\mathrm{~m}$ & 25 & 3 & $\mathrm{~m}$ & $\mathrm{~m}$ & 0,3 & $\mathrm{~m}$ & $\mathrm{~m}$ \\
\hline Niederlande & 1 & 1 & $\mathrm{~m}$ & 1 & 1 & $\mathrm{~m}$ & 45 & 42 & 24 & 49 & 45 & 25 & 22 & 18 & 27 & 2,0 & 1,2 & 32 \\
\hline Neuseeland & 30 & 22 & 29 & 36 & 27 & 29 & 57 & 46 & 28 & 60 & 51 & 27 & 19 & 15 & 34 & 1,9 & 1,1 & 37 \\
\hline Norwegen & $\mathbf{n}$ & $\mathrm{m}$ & $\mathrm{m}$ & $\mathbf{n}$ & $\mathrm{n}$ & $\mathrm{m}$ & 42 & 41 & 27 & 46 & 45 & 27 & 13 & 12 & 32 & 2,1 & 1,9 & 38 \\
\hline Polen & 1 & $\mathrm{~m}$ & $\mathrm{~m}$ & 1 & $\mathrm{~m}$ & $\mathrm{~m}$ & 53 & 53 & 26 & 53 & 53 & 26 & 52 & 52 & $\mathrm{~m}$ & 0,6 & 0,6 & 33 \\
\hline Portugal & $\mathbf{n}$ & $\mathrm{n}$ & $\mathrm{m}$ & $\mathbf{n}$ & $\mathrm{n}$ & $\mathrm{m}$ & 41 & 41 & 26 & 41 & 41 & 26 & 30 & 29 & 31 & 1,9 & 1,7 & 38 \\
\hline Slowakei & 1 & $\mathrm{~m}$ & 26 & 1 & $\mathrm{~m}$ & 26 & 44 & 42 & 26 & 44 & 42 & 26 & 39 & 39 & 28 & 2,5 & 2,3 & 32 \\
\hline Slowenien & 20 & 20 & 31 & 21 & $\mathrm{~m}$ & 31 & 45 & 44 & 26 & 45 & 45 & 26 & 7 & $\mathrm{~m}$ & 34 & 1,9 & 1,7 & 35 \\
\hline Spanien & 20 & $\mathrm{~m}$ & 24 & 20 & $\mathrm{~m}$ & 24 & 29 & 29 & 25 & 37 & 36 & 27 & 10 & 9 & 30 & 1,2 & 0,9 & 37 \\
\hline Schweden & 7 & $\mathrm{~m}$ & 29 & 7 & 7 & 29 & 39 & 33 & 29 & 35 & 34 & 29 & 12 & 6 & 32 & 2,8 & 2,0 & 37 \\
\hline Schweiz & 14 & $\mathrm{~m}$ & $\mathrm{~m}$ & 21 & $\mathrm{~m}$ & 31 & 31 & 26 & 28 & 28 & 25 & 26 & 19 & 14 & 31 & 3,3 & 1,7 & 33 \\
\hline Türkei & 19 & $\mathrm{~m}$ & 25 & 19 & 19 & 25 & 27 & $\mathrm{~m}$ & 26 & 27 & 27 & 26 & 2 & 2 & 30 & 0,4 & 0,4 & 34 \\
\hline Ver. Königreich & m & $\mathrm{m}$ & $\mathrm{m}$ & 15 & $\mathrm{~m}$ & 31 & m & $\mathrm{m}$ & $\mathrm{m}$ & 45 & 38 & 24 & 28 & 15 & 30 & 2,4 & 1,3 & 34 \\
\hline Vereinigte Staaten & 13 & 13 & $\mathrm{~m}$ & 13 & 13 & $\mathrm{~m}$ & 39 & 35 & $\mathrm{~m}$ & 39 & 37 & $\mathrm{~m}$ & 19 & 17 & $\mathrm{~m}$ & 1,8 & 1,4 & $\mathrm{~m}$ \\
\hline OECD-Durchschnitt & 11 & m & 28 & 14 & $\mathbf{m}$ & 28 & 39 & $\mathbf{m}$ & 27 & 39 & $\mathbf{m}$ & 26 & 18 & $\mathbf{m}$ & 31 & 1,6 & m & 35 \\
\hline EU21-Durchschnitt & 8 & m & 27 & 12 & m & 28 & 38 & m & 26 & 37 & m & 26 & 20 & m & 30 & 1,8 & m & 35 \\
\hline \multicolumn{19}{|l|}{ Partnerländer } \\
\hline Argentinien ${ }^{2}$ & m & $\mathrm{m}$ & $\mathrm{m}$ & 15 & $\mathrm{~m}$ & $\mathrm{~m}$ & m & $\mathrm{m}$ & $\mathrm{m}$ & 12 & $\mathrm{~m}$ & $\mathrm{~m}$ & 1 & $\mathrm{~m}$ & $\mathrm{~m}$ & 0,3 & $\mathrm{~m}$ & $\mathrm{~m}$ \\
\hline Brasilien & m & $\mathrm{m}$ & $\mathrm{m}$ & 6 & 6 & 32 & m & $\mathrm{m}$ & $\mathrm{m}$ & 28 & 28 & 30 & 2 & 2 & 33 & 0,5 & 0,5 & 38 \\
\hline China & m & $\mathrm{m}$ & $\mathrm{m}$ & 18 & $\mathrm{~m}$ & $\mathrm{~m}$ & m & $\mathrm{m}$ & $\mathrm{m}$ & 15 & $\mathrm{~m}$ & $\mathrm{~m}$ & $\mathbf{n}$ & $\mathrm{m}$ & $\mathrm{m}$ & m & $\mathrm{m}$ & $\mathrm{m}$ \\
\hline Kolumbien & m & $\mathrm{m}$ & $\mathrm{m}$ & m & $\mathrm{m}$ & $\mathrm{m}$ & m & $\mathrm{m}$ & $\mathrm{m}$ & m & $\mathrm{m}$ & $\mathrm{m}$ & m & $\mathrm{m}$ & $\mathrm{m}$ & m & $\mathrm{m}$ & $\mathrm{m}$ \\
\hline Indien & m & $\mathrm{m}$ & $\mathrm{m}$ & m & $\mathrm{m}$ & $\mathrm{m}$ & m & $\mathrm{m}$ & $\mathrm{m}$ & m & $\mathrm{m}$ & $\mathrm{m}$ & m & $\mathrm{m}$ & $\mathrm{m}$ & m & $\mathrm{m}$ & $\mathrm{m}$ \\
\hline Indonesien & m & $\mathrm{m}$ & $\mathrm{m}$ & 5 & $\mathrm{~m}$ & $\mathrm{~m}$ & m & $\mathrm{m}$ & $\mathrm{m}$ & 15 & $\mathrm{~m}$ & $\mathrm{~m}$ & 1 & $\mathrm{~m}$ & $\mathrm{~m}$ & 0,1 & $\mathrm{~m}$ & $\mathrm{~m}$ \\
\hline Lettland & 12 & $\mathrm{~m}$ & 28 & 12 & $\mathrm{~m}$ & 28 & 43 & $\mathrm{~m}$ & 27 & 43 & $\mathrm{~m}$ & 27 & 17 & $\mathrm{~m}$ & 30 & 1,0 & $\mathrm{~m}$ & 38 \\
\hline Russische Föd. & m & $\mathrm{m}$ & $\mathrm{m}$ & 26 & 26 & $\mathrm{~m}$ & m & $\mathrm{m}$ & $\mathrm{m}$ & 60 & 59 & $\mathrm{~m}$ & 2 & $\mathrm{~m}$ & $\mathrm{~m}$ & m & $\mathrm{m}$ & $\mathrm{m}$ \\
\hline Saudi-Arabien & m & $\mathrm{m}$ & $\mathrm{m}$ & 8 & $\mathrm{~m}$ & $\mathrm{~m}$ & m & $\mathrm{m}$ & $\mathrm{m}$ & 19 & $\mathrm{~m}$ & $\mathrm{~m}$ & 2 & $\mathrm{~m}$ & $\mathrm{~m}$ & 0,1 & $\mathrm{~m}$ & $\mathrm{~m}$ \\
\hline Südafrika & m & $\mathrm{m}$ & $\mathrm{m}$ & 5 & $\mathrm{~m}$ & $\mathrm{~m}$ & m & $\mathrm{m}$ & $\mathrm{m}$ & 6 & $\mathrm{~m}$ & $\mathrm{~m}$ & 4 & $\mathrm{~m}$ & $\mathrm{~m}$ & 0,2 & $\mathrm{~m}$ & $\mathrm{~m}$ \\
\hline G20-Durchschnitt & m & $\mathbf{m}$ & m & 15 & m & m & m & m & m & 30 & m & $\mathbf{m}$ & 11 & $\mathbf{m}$ & $\mathbf{m}$ & 1,0 & $\mathbf{m}$ & m \\
\hline
\end{tabular}

Anmerkung: Die Spalten mit den separaten Abschlussquoten von Männern und Frauen, d.h. die Spalten (2), (3), (7), (8), (12), (13), (17), (18), (22), (23), (27) und (28), sind im Internet verfügbar (s. StatLink unten). Weiterführende Informationen zu den zur Berechnung der (Brutto-/Netto-)Abschlussquoten verwendeten Methoden und des entsprechenden typischen Abschlussalters s. Anhang 1. Unterschiede im Erhebungsbereich der Bevölkerungsdaten und der Absolventendaten bedeuten, dass die Abschlussquoten von Ländern mit einem Nettoabgang von Studierenden wohl zu niedrig angesetzt und von Ländern mit einem Nettozugang von Studierenden wohl zu hoch angesetzt sind. Bei den bereinigten Studienanfängerquoten in den Tabellen A3.1a und A3.1b ist dies weitgehend berücksichtigt. 1. Das „durchschnittliche Abschlussalter“ bezieht sich auf ein gewichtetes durchschnittliches Alter, in der Regel das Alter von Studierenden zu Beginn des Kalenderjahres. Die Studierenden könnten jedoch schon ein Jahr älter als das angegebene durchschnittliche Alter sein, wenn der Abschluss gegen Ende des Studienjahres erfolgt. Informationen zur Berechnung des durchschnittlichen Abschlussalters s. Anhang 3. 2. Referenzjahr 2011.

Quelle: OECD. Argentinien, China, Indien, Indonesien, Kolumbien, Saudi-Arabien und Südafrika: Statistikinstitut der UNESCO. Lettland: Eurostat. Hinweise s. Anhang 3 unter www.oecd.org/edu/eag.htm. StatLink: http://dx.doi.org/10.1787/888933115407

Erläuterung der Kennzeichnung fehlender Daten s. Hinweise für den Leser. 
Tabelle A3.1b

Abschlussquoten im Tertiärbereich von Studierenden, die jünger als das typische Abschlussalter sind (2012)

Summe der Abschlussquoten der einzelnen Altersjahrgänge von bis zu 30-Jährigen im Tertiärbereich A oder B und bis zu 35-Jährigen bei weiterführenden forschungsorientierten Studiengängen, nach Geschlecht und Art des Studiengangs

\begin{tabular}{|c|c|c|c|c|c|c|c|c|c|c|c|c|}
\hline & \multicolumn{2}{|c|}{$\begin{array}{l}\text { Studiengänge im } \\
\text { Tertiärbereich B } \\
\text { (Absolventen mit } \\
\text { Erstabschluss) }\end{array}$} & \multicolumn{2}{|c|}{$\begin{array}{l}\text { Studiengänge im } \\
\text { Tertiärbereich B } \\
\text { (erster Abschluss) }\end{array}$} & \multicolumn{2}{|c|}{$\begin{array}{l}\text { Studiengänge im } \\
\text { Tertiärbereich A } \\
\text { (Erstabschluss) }\end{array}$} & \multicolumn{2}{|c|}{$\begin{array}{l}\text { Studiengänge im } \\
\text { Teriärbereich A } \\
\text { (erster Abschluss) }\end{array}$} & \multicolumn{2}{|c|}{\begin{tabular}{|c|} 
Studiengänge im \\
Tertiärbereich A \\
(zweiter und weitere \\
Abschlüsse)
\end{tabular}} & \multicolumn{2}{|c|}{$\begin{array}{l}\text { Weiterführende } \\
\text { forschungs- } \\
\text { orientierte } \\
\text { Studiengänge }\end{array}$} \\
\hline & $\begin{array}{l}\vec{E} \\
\mathbb{0} \\
\mathbb{\Xi} \\
0\end{array}$ & 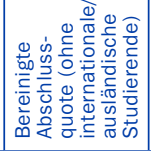 & 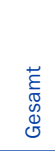 &  & $\begin{array}{l}\vec{E} \\
\text { ह } \\
0 \\
0 \\
心\end{array}$ & 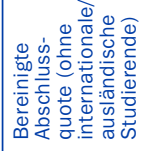 & 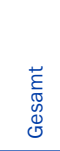 & 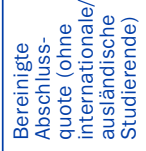 & $\begin{array}{l}\vec{\varepsilon} \\
\mathbb{W} \\
\mathbb{d} \\
心\end{array}$ & 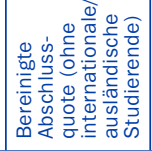 & $\begin{array}{l}\vec{E} \\
\mathbb{N} \\
\Phi \\
心 \\
心\end{array}$ & 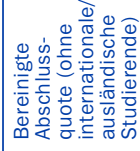 \\
\hline & (1) & (4) & (5) & (8) & (9) & (12) & (13) & (16) & (17) & (20) & (21) & (24) \\
\hline \multicolumn{13}{|l|}{ OECD-Länder } \\
\hline Australien ${ }^{1}$ & m & 9 & 16 & 11 & 45 & 29 & 51 & 34 & 13 & 4 & 1,1 & 0,7 \\
\hline Österreich & 8 & 7 & 8 & 8 & 30 & 25 & 29 & 25 & 7 & 6 & 1,6 & 1,2 \\
\hline Belgien & $\mathbf{m}$ & $\mathrm{m}$ & 28 & $\mathrm{~m}$ & m & $\mathrm{m}$ & 18 & $\mathrm{~m}$ & 24 & $\mathrm{~m}$ & 1,3 & $\mathrm{~m}$ \\
\hline Kanada $^{1}$ & 15 & 14 & 16 & 15 & 31 & 29 & 31 & 29 & 7 & 6 & 0,8 & 0,6 \\
\hline Chile & 17 & 17 & 18 & 18 & 17 & 17 & 16 & 16 & 2 & 2 & 0,2 & $n$ \\
\hline Tschechien & 4 & 4 & 4 & 4 & 33 & 30 & 35 & 32 & 20 & 19 & 0,8 & 0,6 \\
\hline Dänemark & 9 & 7 & 9 & 8 & 42 & 37 & 39 & 36 & 18 & 16 & 1,5 & 1,1 \\
\hline Estland & m & $\mathrm{m}$ & 13 & $\mathrm{~m}$ & m & $\mathrm{m}$ & 19 & $\mathrm{~m}$ & 9 & $\mathrm{~m}$ & 0,6 & $\mathrm{~m}$ \\
\hline Finnland & $\mathbf{m}$ & $\mathrm{n}$ & $\mathbf{m}$ & $\mathrm{n}$ & 36 & $\mathrm{~m}$ & 37 & 35 & 14 & 13 & 1,1 & 0,9 \\
\hline Frankreich ${ }^{1}$ & m & $\mathrm{m}$ & $\mathbf{m}$ & $\mathrm{m}$ & m & $\mathrm{m}$ & $\mathbf{m}$ & $\mathrm{m}$ & m & $\mathrm{m}$ & m & $\mathrm{m}$ \\
\hline Deutschland & m & $\mathrm{m}$ & $\mathbf{m}$ & $\mathrm{m}$ & 28 & 26 & 28 & 26 & 6 & 5 & 2,3 & 2,0 \\
\hline Griechenland & $\mathbf{m}$ & $\mathrm{m}$ & 13 & $\mathrm{~m}$ & m & $\mathrm{m}$ & 23 & $\mathrm{~m}$ & $\mathbf{m}$ & $\mathrm{m}$ & $\mathbf{m}$ & $\mathrm{m}$ \\
\hline Ungarn & 7 & $\mathrm{~m}$ & 8 & $\mathrm{~m}$ & 19 & $\mathrm{~m}$ & 24 & $\mathrm{~m}$ & 7 & $\mathrm{~m}$ & 0,5 & $\mathrm{~m}$ \\
\hline Island ${ }^{1}$ & 1 & $\mathrm{~m}$ & 1 & 1 & 37 & 35 & 39 & 38 & 10 & 8 & 0,7 & 0,4 \\
\hline Irland & 15 & $\mathrm{~m}$ & 15 & 15 & 41 & $\mathrm{~m}$ & 41 & 39 & 15 & 13 & 1,4 & 1,1 \\
\hline Israel & $\mathbf{m}$ & $\mathrm{m}$ & $\mathbf{m}$ & $\mathrm{m}$ & 30 & $\mathrm{~m}$ & 31 & $\mathrm{~m}$ & 6 & $\mathrm{~m}$ & 0,6 & $\mathrm{~m}$ \\
\hline Italien & m & $\mathrm{m}$ & $\mathbf{m}$ & $\mathrm{m}$ & 24 & $\mathrm{~m}$ & 28 & $\mathrm{~m}$ & $\mathbf{m}$ & $\mathrm{m}$ & 1,1 & $\mathrm{~m}$ \\
\hline Japan & m & $\mathrm{m}$ & $\mathbf{m}$ & $\mathrm{m}$ & m & $\mathrm{m}$ & $\mathbf{m}$ & $\mathrm{m}$ & $\mathbf{m}$ & $\mathrm{m}$ & $\mathbf{m}$ & $\mathrm{m}$ \\
\hline Korea & m & $\mathrm{m}$ & 25 & $\mathrm{~m}$ & m & $\mathrm{m}$ & 47 & $\mathrm{~m}$ & 5 & $\mathrm{~m}$ & 0,6 & $\mathrm{~m}$ \\
\hline Luxemburg & 5 & $\mathrm{~m}$ & $\mathbf{m}$ & $\mathrm{m}$ & 8 & $\mathrm{~m}$ & 8 & $\mathrm{~m}$ & 2 & $\mathrm{~m}$ & 0,6 & $\mathrm{~m}$ \\
\hline Mexiko & 2 & $\mathrm{~m}$ & 2 & $\mathrm{~m}$ & 20 & $\mathrm{~m}$ & 20 & $\mathrm{~m}$ & $\mathbf{m}$ & $\mathrm{m}$ & $\mathbf{m}$ & $\mathrm{m}$ \\
\hline Niederlande & $\mathbf{n}$ & $\mathrm{n}$ & $\mathbf{n}$ & $\mathrm{m}$ & 42 & 39 & 44 & 41 & 18 & 15 & 1,7 & 1,1 \\
\hline Neuseeland & 19 & 12 & 22 & 15 & 41 & 32 & 45 & 38 & 9 & 6 & 1,0 & 0,5 \\
\hline Norwegen & $\mathrm{n}$ & $\mathrm{m}$ & $\mathrm{n}$ & $\mathrm{m}$ & 34 & 34 & 36 & 36 & 8 & 7 & 1,1 & 1,0 \\
\hline Polen & 1 & $\mathrm{~m}$ & 1 & $\mathrm{~m}$ & 45 & 45 & 45 & 45 & $\mathbf{m}$ & $\mathrm{m}$ & 0,5 & $\mathrm{~m}$ \\
\hline Portugal & m & $\mathrm{n}$ & $\mathbf{m}$ & $\mathrm{n}$ & 35 & 35 & 35 & 35 & 20 & 20 & 1,0 & 0,9 \\
\hline Slowakei & 1 & $\mathrm{~m}$ & 1 & $\mathrm{~m}$ & 36 & 35 & 36 & 35 & 30 & 29 & 1,9 & 1,9 \\
\hline Slowenien & 12 & 12 & 12 & $\mathrm{~m}$ & 38 & 38 & 39 & 39 & 3 & $\mathrm{~m}$ & 1,2 & 1,1 \\
\hline Spanien & 18 & $\mathrm{~m}$ & 18 & $\mathrm{~m}$ & 26 & 26 & 31 & 31 & 7 & 6 & 0,7 & $\mathrm{~m}$ \\
\hline Schweden & 5 & $\mathrm{~m}$ & 5 & 5 & 28 & 24 & 24 & 24 & 7 & 3 & 1,7 & 1,1 \\
\hline Schweiz & $\mathbf{m}$ & $\mathrm{m}$ & 13 & $\mathrm{~m}$ & 25 & 22 & 24 & 22 & 12 & 9 & 2,6 & 1,3 \\
\hline Türkei & 16 & $\mathrm{~m}$ & 16 & $\mathrm{~m}$ & 24 & $\mathrm{~m}$ & 24 & $\mathrm{~m}$ & 1 & $\mathrm{~m}$ & 0,2 & $\mathrm{~m}$ \\
\hline Ver. Königreich & m & $\mathrm{m}$ & 8 & 7 & m & $\mathrm{m}$ & 40 & 33 & 18 & 8 & 1,6 & 0,9 \\
\hline Vereinigte Staaten & $\mathbf{m}$ & $\mathrm{m}$ & $\mathbf{m}$ & $\mathrm{m}$ & m & $\mathrm{m}$ & $\mathbf{m}$ & $\mathrm{m}$ & $\mathbf{m}$ & $\mathrm{m}$ & $\mathbf{m}$ & $\mathrm{m}$ \\
\hline OECD-Durchschnitt & 8 & m & 10 & m & 31 & m & 32 & m & 11 & m & 1,1 & $\mathbf{m}$ \\
\hline EU21-Durchschnitt & 6 & m & 9 & m & 32 & m & 31 & m & 13 & $\mathrm{~m}$ & 1,2 & m \\
\hline \multicolumn{13}{|l|}{ Partnerländer } \\
\hline Argentinien $^{1}$ & $\mathbf{m}$ & $\mathrm{m}$ & $\mathbf{m}$ & $\mathrm{m}$ & m & $\mathrm{m}$ & $\mathbf{m}$ & $\mathrm{m}$ & $\mathbf{m}$ & $\mathrm{m}$ & m & $\mathrm{m}$ \\
\hline Brasilien & $\mathbf{m}$ & $\mathrm{m}$ & 3 & $\mathrm{~m}$ & m & $\mathrm{m}$ & 18 & $\mathrm{~m}$ & 1 & $\mathrm{~m}$ & 0,2 & $\mathrm{~m}$ \\
\hline China & $\mathbf{m}$ & $\mathrm{m}$ & $\mathbf{m}$ & $\mathrm{m}$ & m & $\mathrm{m}$ & $\mathbf{m}$ & $\mathrm{m}$ & $\mathbf{m}$ & $\mathrm{m}$ & $\mathbf{m}$ & $\mathrm{m}$ \\
\hline Kolumbien & $\mathbf{m}$ & $\mathrm{m}$ & $\mathbf{m}$ & $\mathrm{m}$ & m & $\mathrm{m}$ & $\mathbf{m}$ & $\mathrm{m}$ & $\mathbf{m}$ & $\mathrm{m}$ & $\mathbf{m}$ & $\mathrm{m}$ \\
\hline Indien & $\mathbf{m}$ & $\mathrm{m}$ & $\mathbf{m}$ & $\mathrm{m}$ & m & $\mathrm{m}$ & $\mathbf{m}$ & $\mathrm{m}$ & $\mathbf{m}$ & $\mathrm{m}$ & $\mathbf{m}$ & $\mathrm{m}$ \\
\hline Indonesien & $\mathbf{m}$ & $\mathrm{m}$ & 1 & $\mathrm{~m}$ & m & $\mathrm{m}$ & 13 & $\mathrm{~m}$ & 1 & $\mathrm{~m}$ & 0,1 & $\mathrm{~m}$ \\
\hline Lettland & 9 & $\mathrm{~m}$ & 9 & $\mathrm{~m}$ & 35 & $\mathrm{~m}$ & 35 & $\mathrm{~m}$ & 11 & $\mathrm{~m}$ & 0,5 & $\mathrm{~m}$ \\
\hline Russische Föd. & $\mathbf{m}$ & $\mathrm{m}$ & $\mathbf{m}$ & $\mathrm{m}$ & m & $\mathrm{m}$ & $\mathbf{m}$ & $\mathrm{m}$ & $\mathbf{m}$ & $\mathrm{m}$ & $\mathbf{m}$ & $\mathrm{m}$ \\
\hline Saudi-Arabien & $\mathbf{m}$ & $\mathrm{m}$ & $\mathbf{m}$ & $\mathrm{m}$ & m & $\mathrm{m}$ & $\mathbf{m}$ & $\mathrm{m}$ & $\mathbf{m}$ & $\mathrm{m}$ & $\mathbf{m}$ & $\mathrm{m}$ \\
\hline Südafrika & m & $\mathrm{m}$ & $\mathbf{m}$ & $\mathrm{m}$ & m & $\mathrm{m}$ & $\mathbf{m}$ & $\mathrm{m}$ & $\mathbf{m}$ & $\mathrm{m}$ & $\mathbf{m}$ & $\mathrm{m}$ \\
\hline G20-Durchschnitt & $\mathbf{m}$ & $\mathbf{m}$ & $\mathbf{m}$ & $\mathbf{m}$ & $\mathbf{m}$ & $\mathbf{m}$ & $\mathbf{m}$ & $\mathbf{m}$ & $\mathbf{m}$ & $\mathbf{m}$ & $\mathbf{m}$ & $\mathbf{m}$ \\
\hline
\end{tabular}

Anmerkung: Die Spalten mit den separaten Abschlussquoten von Männern und Frauen, d.h. die Spalten (2), (3), (6), (7), (10), (11), (14), (15), (18), (19), (22) und (23), sind im Internet verfügbar (s. StatLink unten). Weiterführende Informationen zu den zur Berechnung der (Brutto-/Netto-)Abschlussquoten verwendeten Methoden und den entsprechenden typischen Altersjahrgängen s. Anhang 1. Unterschiede im Erhebungsbereich der Bevölkerungsdaten und der Absolventendaten bedeuten, dass die Abschlussquoten von Ländern mit einem Nettoabgang von Studierenden wohl zu niedrig angesetzt und von Ländern mit einem Nettozugang von Studierenden wohl zu hoch angesetzt sind. Bei den bereinigten Studienanfängerquoten in den Tabellen A3.1a und A3.1b ist dies weitgehend berücksichtigt.Die Durchschnitte wurden auf 100 Prozent angepasst und entsprechen nicht genau dem Durchschnitt jeder einzelnen Spalte.

1. Referenzjahr 2011.

Quelle: OECD. Argentinien, China, Indien, Indonesien, Kolumbien, Saudi-Arabien und Südafrika: Statistikinstitut der UNESCO. Lettland: Eurostat. Hinweise s. Anhang 3 unter www.oecd.org/edu/eag.htm. StatLink: http://dx.doi.org/10.1787/888933115426 Erläuterung der Kennzeichnung fehlender Daten s. Hinweise für den Leser. 
Entwicklung der Abschlussquoten im Tertiärbereich (1995-2012)

Summe der Abschlussquoten der einzelnen Altersjahrgänge, nach Art des Studiengangs

\begin{tabular}{|c|c|c|c|c|c|c|c|c|c|c|c|c|}
\hline & \multicolumn{6}{|c|}{ Studiengänge Tertiärbereich A (Erstabschluss) } & \multicolumn{6}{|c|}{ Studiengänge Tertiärbereich B (Erstabschluss) } \\
\hline & 1995 & 2000 & 2005 & 2010 & 2011 & 2012 & 1995 & 2000 & 2005 & 2010 & 2011 & 2012 \\
\hline & (1) & (2) & (7) & (12) & (13) & (14) & (15) & (16) & (21) & (26) & (27) & (28) \\
\hline \multicolumn{13}{|l|}{ OECD-Länder } \\
\hline Australien & $\mathrm{m}$ & 36 & 50 & 50 & 53 & m & $\mathrm{m}$ & $\mathrm{m}$ & $\mathrm{m}$ & 17 & 21 & m \\
\hline Österreich & 10 & 15 & 20 & 30 & 35 & 39 & $\mathrm{~m}$ & $\mathrm{~m}$ & 8 & 12 & 12 & 12 \\
\hline Belgien & $\mathrm{m}$ & $\mathrm{m}$ & $\mathrm{m}$ & $\mathrm{m}$ & $\mathrm{m}$ & m & $\mathrm{m}$ & $\mathrm{m}$ & $\mathrm{m}$ & $\mathrm{m}$ & $\mathrm{m}$ & m \\
\hline Kanada & 27 & 27 & 32 & 35 & 35 & m & $\mathrm{m}$ & $\mathrm{m}$ & 20 & 21 & 18 & m \\
\hline Chile & $\mathrm{m}$ & $\mathrm{m}$ & $\mathrm{m}$ & $\mathrm{m}$ & $\mathrm{m}$ & 23 & $\mathrm{~m}$ & $\mathrm{~m}$ & $\mathrm{~m}$ & $\mathrm{~m}$ & $\mathrm{~m}$ & 25 \\
\hline Tschechien & 13 & 14 & 23 & 38 & 41 & 40 & 6 & 5 & 6 & 5 & 5 & 5 \\
\hline Dänemark & 25 & 37 & 46 & 50 & 50 & 49 & 8 & 10 & 10 & 9 & 11 & 11 \\
\hline Estland & $\mathrm{m}$ & $\mathrm{m}$ & $\mathrm{m}$ & $\mathrm{m}$ & $\mathrm{m}$ & m & $\mathrm{m}$ & $\mathrm{m}$ & $\mathrm{m}$ & m & $\mathrm{m}$ & m \\
\hline Finnland & 21 & 40 & 47 & 49 & 47 & 47 & 34 & 7 & $\mathrm{n}$ & $\mathrm{n}$ & $\mathrm{n}$ & $\mathbf{n}$ \\
\hline Frankreich & $\mathrm{m}$ & $\mathrm{m}$ & $\mathrm{m}$ & $\mathrm{m}$ & $\mathrm{m}$ & m & $\mathrm{m}$ & $\mathrm{m}$ & $\mathrm{m}$ & $\mathrm{m}$ & $\mathrm{m}$ & m \\
\hline Deutschland ${ }^{1}$ & 14 & 18 & 20 & 30 & 31 & 31 & 13 & 11 & 11 & 14 & 14 & 15 \\
\hline Griechenland & 14 & 15 & 25 & $\mathrm{~m}$ & $\mathrm{~m}$ & m & 5 & 6 & 11 & $\mathrm{~m}$ & $\mathrm{~m}$ & m \\
\hline Ungarn & $\mathrm{m}$ & $\mathrm{m}$ & 33 & 31 & 27 & 23 & $\mathrm{~m}$ & $\mathrm{~m}$ & 4 & 6 & 7 & 8 \\
\hline Island & 20 & 33 & 56 & 60 & 61 & 60 & 10 & 5 & 4 & 2 & 2 & 2 \\
\hline Irland & $\mathrm{m}$ & 30 & 38 & 47 & 43 & 46 & $\mathrm{~m}$ & 15 & 24 & 26 & 24 & 23 \\
\hline Israel & $\mathrm{m}$ & $\mathrm{m}$ & 35 & 37 & 40 & 40 & $\mathrm{~m}$ & $\mathrm{~m}$ & $\mathrm{~m}$ & $\mathrm{~m}$ & $\mathrm{~m}$ & $\mathrm{~m}$ \\
\hline Italien & $\mathrm{m}$ & 19 & 41 & 32 & 32 & 26 & $\mathrm{~m}$ & $\mathrm{n}$ & 1 & 1 & $\mathrm{~m}$ & m \\
\hline Japan & 25 & 29 & 37 & 40 & 44 & 45 & 30 & 30 & 28 & 25 & 25 & 25 \\
\hline Korea & $\mathrm{m}$ & $\mathrm{m}$ & $\mathrm{m}$ & $\mathrm{m}$ & $\mathrm{m}$ & m & $\mathrm{m}$ & $\mathrm{m}$ & $\mathrm{m}$ & $\mathrm{m}$ & $\mathrm{m}$ & m \\
\hline Luxemburg & $\mathrm{m}$ & $\mathrm{m}$ & $\mathrm{m}$ & $\mathrm{m}$ & $\mathrm{m}$ & 9 & $\mathrm{~m}$ & $\mathrm{~m}$ & $\mathrm{~m}$ & $\mathrm{~m}$ & $\mathrm{~m}$ & 6 \\
\hline Mexiko & $\mathrm{m}$ & $\mathrm{m}$ & 17 & 20 & 21 & 22 & $\mathrm{~m}$ & $\mathrm{~m}$ & 1 & 1 & 2 & 2 \\
\hline Niederlande & 29 & 35 & 42 & 42 & 42 & 45 & $\mathrm{~m}$ & $\mathrm{~m}$ & $\mathrm{n}$ & $\mathrm{n}$ & $\mathrm{n}$ & 1 \\
\hline Neuseeland & 33 & 50 & 51 & 49 & 53 & 57 & 12 & 17 & 23 & 27 & 30 & 30 \\
\hline Norwegen & 26 & 37 & 41 & 42 & 43 & 42 & 6 & 6 & 2 & $\mathrm{n}$ & $n$ & $\mathbf{n}$ \\
\hline Polen & $\mathrm{m}$ & 34 & 47 & 55 & 58 & 53 & $\mathrm{~m}$ & $\mathrm{~m}$ & $\mathrm{n}$ & 1 & 1 & 1 \\
\hline Portugal & 15 & 23 & 32 & 40 & 39 & 41 & 6 & 8 & 9 & $\mathrm{n}$ & $\mathrm{n}$ & $\mathrm{n}$ \\
\hline Slowakei & 15 & $\mathrm{~m}$ & 30 & 49 & 46 & 44 & 1 & 2 & 2 & 1 & 1 & 1 \\
\hline Slowenien & $\mathrm{m}$ & $\mathrm{m}$ & 18 & 29 & 37 & 45 & $\mathrm{~m}$ & $\mathrm{~m}$ & 24 & 26 & 27 & 20 \\
\hline Spanien² & 24 & 29 & 30 & 30 & 32 & 29 & 2 & 8 & 15 & 16 & 18 & 20 \\
\hline Schweden & 24 & 28 & 38 & 37 & 41 & 39 & $\mathrm{~m}$ & 4 & 5 & 6 & 7 & 7 \\
\hline Schweiz & 9 & 12 & 27 & 31 & 32 & 31 & 13 & 14 & 8 & 16 & 15 & 14 \\
\hline Türkei & 6 & 9 & 12 & 23 & 23 & 27 & 2 & $\mathrm{~m}$ & $\mathrm{~m}$ & 19 & 17 & 19 \\
\hline Vereinigtes Königreich & $\mathrm{m}$ & 42 & 48 & 50 & 54 & m & $\mathrm{m}$ & 7 & 11 & 12 & 13 & m \\
\hline Vereinigte Staaten & 33 & 34 & 34 & 38 & 39 & 39 & 9 & 8 & 10 & 11 & 12 & 13 \\
\hline OECD-Durchschnitt & 20 & 28 & 36 & 39 & 41 & 38 & 11 & 9 & 9 & 11 & 11 & 10 \\
\hline $\begin{array}{l}\text { OECD-Durchschnitt für } \\
\text { Länder mit Daten für } \\
\text { 1995, } 2005 \text { und } 2012\end{array}$ & 20 & & 35 & & & 42 & 11 & & & & & 11 \\
\hline EU21-Durchschnitt & 18 & 27 & 34 & 40 & 41 & 38 & 9 & 7 & 8 & 8 & 9 & 8 \\
\hline
\end{tabular}

\begin{tabular}{|c|c|c|c|c|c|c|c|c|c|c|c|c|}
\hline EU21-Durchschnitt & 18 & 27 & 34 & 40 & 41 & 38 & 9 & 7 & 8 & 8 & 9 & 8 \\
\hline \multicolumn{13}{|l|}{ Partnerländer } \\
\hline Argentinien & $\mathrm{m}$ & $\mathrm{m}$ & $\mathrm{m}$ & $\mathrm{m}$ & $\mathrm{m}$ & m & $\mathrm{m}$ & $\mathrm{m}$ & $\mathrm{m}$ & $\mathrm{m}$ & $\mathrm{m}$ & m \\
\hline Brasilien & $\mathrm{m}$ & 10 & $\mathrm{~m}$ & $\mathrm{~m}$ & $\mathrm{~m}$ & $\mathbf{m}$ & $\mathrm{m}$ & $\mathrm{m}$ & $\mathrm{m}$ & $\mathrm{m}$ & $\mathrm{m}$ & m \\
\hline China & $\mathrm{m}$ & $\mathrm{m}$ & $\mathrm{m}$ & $\mathrm{m}$ & $\mathrm{m}$ & m & $\mathrm{m}$ & $\mathrm{m}$ & $\mathrm{m}$ & $\mathrm{m}$ & $\mathrm{m}$ & m \\
\hline Kolumbien & $\mathrm{m}$ & $\mathrm{m}$ & $\mathrm{m}$ & $\mathrm{m}$ & $\mathrm{m}$ & m & $\mathrm{m}$ & $\mathrm{m}$ & $\mathrm{m}$ & $\mathrm{m}$ & $\mathrm{m}$ & m \\
\hline Indien & $\mathrm{m}$ & $\mathrm{m}$ & $\mathrm{m}$ & $\mathrm{m}$ & $\mathrm{m}$ & m & $\mathrm{m}$ & $\mathrm{m}$ & $\mathrm{m}$ & $\mathrm{m}$ & $\mathrm{m}$ & m \\
\hline Indonesien & $\mathrm{m}$ & $\mathrm{m}$ & $\mathrm{m}$ & $\mathrm{m}$ & $\mathrm{m}$ & $\mathbf{m}$ & $\mathrm{m}$ & $\mathrm{m}$ & $\mathrm{m}$ & $\mathrm{m}$ & $\mathrm{m}$ & m \\
\hline Lettland & $\mathrm{m}$ & $\mathrm{m}$ & $\mathrm{m}$ & $\mathrm{m}$ & $\mathrm{m}$ & 43 & $\mathrm{~m}$ & $\mathrm{~m}$ & $\mathrm{~m}$ & $\mathrm{~m}$ & $\mathrm{~m}$ & 12 \\
\hline Russische Föderation & $\mathrm{m}$ & $\mathrm{m}$ & $\mathrm{m}$ & $\mathrm{m}$ & $\mathrm{m}$ & m & $\mathrm{m}$ & $\mathrm{m}$ & $\mathrm{m}$ & $\mathrm{m}$ & $\mathrm{m}$ & m \\
\hline Saudi-Arabien & $\mathrm{m}$ & 13 & 18 & 20 & 20 & m & $\mathrm{n}$ & 3 & 5 & 8 & 8 & m \\
\hline Südafrika & $\mathrm{m}$ & $\mathrm{m}$ & $\mathrm{m}$ & $\mathrm{m}$ & $\mathrm{m}$ & m & $\mathrm{m}$ & $\mathrm{m}$ & $\mathrm{m}$ & $\mathrm{m}$ & $\mathrm{m}$ & $\mathrm{m}$ \\
\hline G20-Durchschnitt & m & m & m & m & $\mathbf{m}$ & $\mathbf{m}$ & m & $\mathbf{m}$ & $\mathbf{m}$ & m & $\mathbf{m}$ & m \\
\hline
\end{tabular}

Anmerkung: Die Spalten mit den Angaben für die Jahre 2001, 2002, 2003, 2004, 2006 und 2007 sind im Internet verfügbar (s. StatLink unten). Bis zum Jahr 2004 wurden Abschlussquoten im Tertiärbereich A und B auf Bruttobasis berechnet. Ab 2005 und für Länder mit verfügbaren Daten wurden die Abschlussquoten als Netto-Abschlussquoten (d.h. als Summe der Abschlussquoten der einzelnen Altersjahrgänge) berechnet. Weiterführende Informationen zu den zur Berechnung der (Brutto-/Netto-)Abschlussquoten verwendeten Methoden und des entsprechenden typischen Abschlussalters s. Anhang 1.

1. Unterbrechung der Zeitreihe zwischen 2008 und 2009 aufgrund einer teilweisen Neueinstufung berufsbildender Bildungsgänge in ISCED 2 und ISCED 5B. 2. Unterbrechung der Zeitreihe für ISCED 5A im Jahr 2008 aufgrund von Veränderungen in der Methodik.

Quelle: OECD. Argentinien, China, Indien, Indonesien, Kolumbien, Saudi-Arabien und Südafrika: Statistikinstitut der UNESCO. Lettland: Eurostat. Hinweise s. Anhang 3 unter www.oecd.org/edu/eag.htm. StatLink: http://dx.doi.org/10.1787/888933115445 Erläuterung der Kennzeichnung fehlender Daten s. Hinweise für den Leser. 



\section{Inwieweit beeinflusst der Bildungsstand der Eltern die Bildungsbeteiligung im Tertiärbereich?}

Im Durchschnitt aller Länder ist der Bildungsstand von rund 40 Prozent der erwachsenen Nichtschüler/Nichtstudierenden (25- bis 64-Jährige) höher als der ihrer Eltern. Die Bildungsmobilität zwischen den Generationen ist in Finnland, Flandern (Belgien), Korea und der Russischen Föderation am höchsten, dort verfügen mehr als 55 Prozent der jungen Menschen über einen höheren Bildungsstand als ihre Eltern.

Mehr als 30 Prozent der erwachsenen Nichtschüler/Nichtstudierenden, deren Eltern keinen Abschluss im Sekundarbereich II erworben haben, haben den Schulbesuch ebenfalls vor Abschluss des Sekundarbereichs II beendet. Mehr als 45 Prozent dieser Erwachsenen verfügen jedoch über einen Abschluss im Sekundarbereich II bzw. postsekundaren, nicht tertiären Bereich und 20 Prozent über einen Abschluss im Tertiärbereich.

- Im Durchschnitt der teilnehmenden Länder erreichten 25 Prozent der Erwachsenen mit Eltern mit einer Ausbildung unterhalb des Sekundarbereichs II maximal die Lesekompetenzstufe I, die niedrigste Stufe in der Erhebung zu den grundlegenden Kompetenzen Erwachsener, während nur etwa 5 Prozent die Lesekompetenzstufe 4 oder 5 erreichten. Bei Erwachsenen, deren Eltern über einen Abschluss im Tertiärbereich verfügen, erzielten mehr als 20 Prozent Lesekompetenzstufe 4 oder 5.

Abbildung A4.1

20- bis 34-jährige Studierende im Tertiärbereich, nach dem Bildungsstand der Eltern (2012)

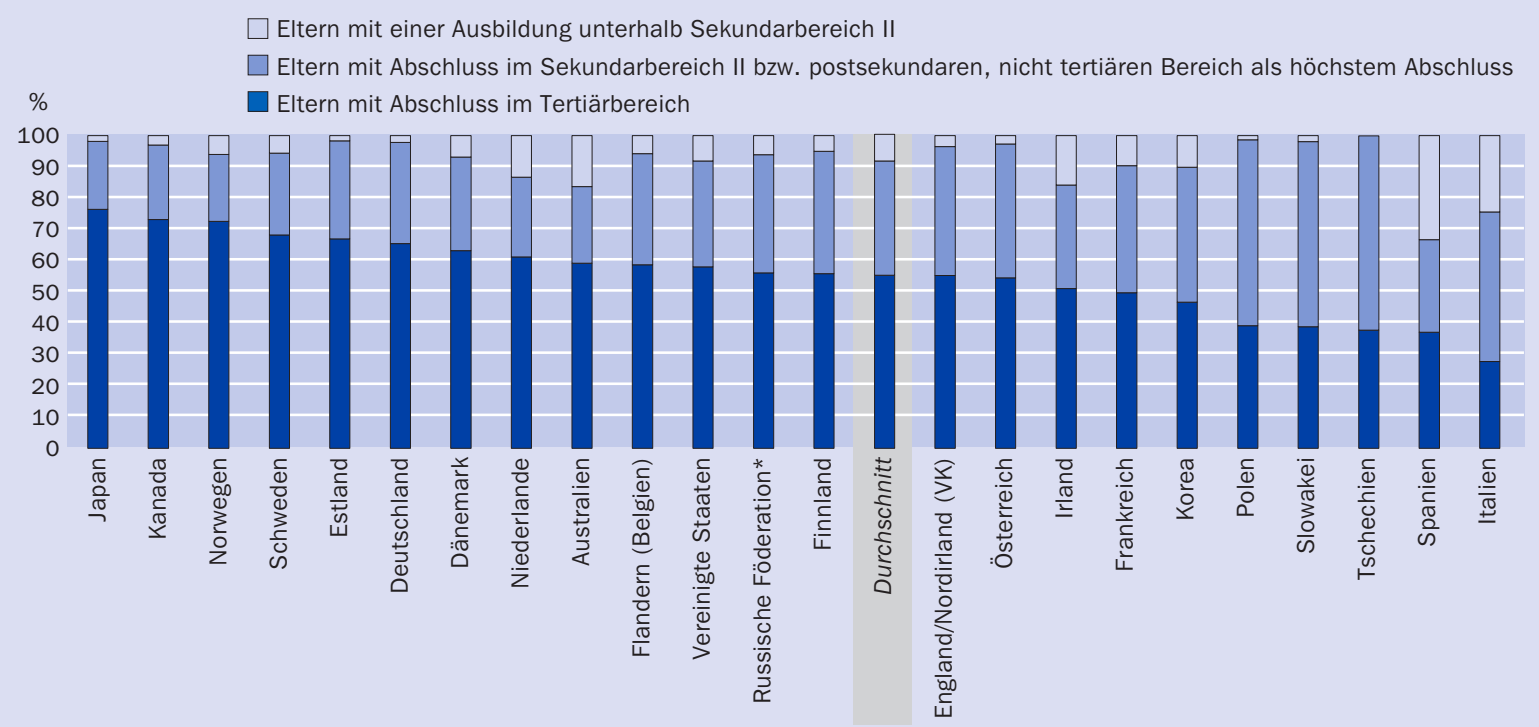

* Hinweis zu den Daten der Russischen Föderation s. Abschnitt Angewandte Methodik.

Anordnung der Länder in absteigender Reihenfolge der Bildungsbeteiligung 20- bis 34-Jähriger im Tertiärbereich, deren Eltern über einen Abschluss im Tertiärbereich verfügen.

Quelle: OECD. Tabelle A4.1a. Hinweise s. Anhang 3 unter www.oecd.org/edu/eag.htm. StatLink: http://dx.doi.org/10.1787/888933115635 


\section{Kontext}

Aufgrund des engen Zusammenhangs zwischen Bildung einerseits und Einkommen, Beschäftigung, Wohlstand insgesamt und Wohlergehen jedes Einzelnen andererseits kann Bildung Ungleichheiten in der Gesellschaft verringern, sie aber auch reproduzieren. Allen jungen Menschen eine faire Chance auf eine gute (Aus-)Bildung zu geben ist grundlegender Bestandteil des Gesellschaftsvertrags. Ungleichheiten bei Bildungsmöglichkeiten in Angriff zu nehmen ist von entscheidender Bedeutung, um die soziale Mobilität aufrechtzuerhalten und die Zahl möglicher Kandidaten für den Tertiärbereich und hoch qualifizierte Arbeitsplätze zu steigern. Dieser Indikator enthält zum ersten Mal Daten aus der Erhebung zu den grundlegenden Kompetenzen Erwachsener, hervorgegangen aus dem OECD Programme for the International Assessment of Adult Competencies (PIAAC), um den Einfluss des Bildungsstands der Eltern auf die Bildungsbeteiligung ihrer Kinder im Tertiärbereich zu untersuchen.

Gut ausgebildete und qualifizierte Arbeitskräfte sind unerlässlich für die Länder, wenn sie zukünftiges Wachstum fördern wollen. Auf den sich schnell ändernden Arbeitsmärkten von heute vergrößert sich der Abstand der Erträge von gering und hoch qualifizierten Arbeitskräften. Menschen mit niedrigeren Bildungsabschlüssen haben im Durchschnitt die höchsten Erwerbslosigkeits- und Nichterwerbsquoten sowie die niedrigsten Gehälter, die darüber hinaus im Laufe ihres Erwerbslebens auch noch schneller sinken (s. Indikatoren A5 und A6). Ein großer Anteil von Geringqualifizierten in der Bevölkerung kann somit zu einer größeren sozialen Belastung führen und bestehende Ungleichheiten weiter verstärken, beides ist nach Abschluss der Erstausbildung nur schwer und mit großem finanziellem Aufwand zu ändern.

Die Ergebnisse der internationalen Schulleistungsstudie PISA 2012 zeigen, dass sich die Leistungen von Schülern mit sozioökonomisch ungünstigem Hintergrund in mehreren Ländern, in denen stärker aufChancengerechtigkeit ausgerichtete Maßnahmen entwickelt und umgesetzt wurden, verbessert haben. Eine signifikante Anzahl von Ländern, die 2003 schlechte Ergebnisse aufwiesen, erzielten in der PISA-Studie 2012 deutlich bessere Leistungen. In mehreren dieser Länder ließen sich die Verbesserungen vor allem darauf zurückführen, dass mehr Schülern eine qualitativ höherwertige Bildung zuteilwurde (OECD, 2013).

Daher ist es wichtig, faire Voraussetzungen für alle jungen Menschen zu schaffen, auch für solche aus Familien mit einem niedrigen Bildungsstand. Verschiedene bildungspolitische Maßnahmen, wie z. B. die Begrenzung der Kosten für eine Hochschulbildung und eine finanzielle Unterstützung für Studierende, können diesen jungen Menschen helfen. Der Zugang zum und Erfolg im Tertiärbereich sollten für alle gleichermaßen möglich sein, aber ebenso wichtig ist es, Ungleichheiten schon zu Beginn der Schullaufbahn zu vermeiden.

\section{Weitere wichtige Ergebnisse}

In Deutschland, Italien, Österreich, Polen, der Slowakei, Spanien, Tschechien und den Vereinigten Staaten haben mehr als 50 Prozent der erwachsenen Nichtschüler/Nichtstudierenden denselben Bildungsstand wie ihre Eltern. 
In allen Ländern haben mindestens 35 Prozent der 20- bis 34-jährigen Studierenden im Tertiärbereich mindestens einen Elternteil, der auch über einen Abschluss in diesem Bildungsbereich verfügt. In Deutschland, Estland, Kanada, Norwegen und Schweden gilt dies für mindestens $6_{5}$ Prozent dieser Studierenden.

Im Durchschnitt haben 12 Prozent der erwachsenen Nichtschüler/Nichtstudierenden einen niedrigeren Bildungsstand als ihre Eltern. In Dänemark, Deutschland, Estland, Norwegen, Österreich, Schweden und den Vereinigten Staaten gilt dies für mehr als 15 Prozent dieser Bevölkerungsgruppe.

\section{Entwicklungstendenzen}

Der Ausbau der Bildungssysteme in vielen OECD-Ländern sowohl im Sekundarbereich II bzw. postsekundaren, nicht tertiären Bereich als auch im Tertiärbereich hat es jungen Menschen (25- bis 34-Jährigen) ermöglicht, einen höheren Bildungsstand als ihre Eltern zu erreichen. Im Durchschnitt der OECD-Länder, die an der Erhebung zu den grundlegenden Kompetenzen Erwachsener teilgenommen haben, erreichten 32 Prozent der jungen Menschen einen höheren Bildungsstand als ihre Eltern, und lediglich 16 Prozent erreichten den Bildungsstand ihrer Eltern nicht. In allen Ländern mit Ausnahme von Deutschland, Estland, Norwegen und Schweden ist häufiger eine absolute Aufwärtsmobilität zu beobachten als eine absolute Abwärtsmobilität, ein klarer Hinweis auf den Ausbau der Bildungssysteme in den meisten OECD-Ländern. Dieser Ausbau war in Frankreich, Irland, Italien, Korea, Spanien und der Russischen Föderation besonders ausgeprägt, hier liegt die Differenz zwischen Aufwärts- und Abwärtsmobilität in Bezug auf den Bildungsstand bei mindestens 30 Prozentpunkten.

\section{Analyse und Interpretationen}

\section{Mobilitätsindikatoren und Terminologie}

Die Literatur zur Mobilität unterscheidet in der Regel zwischen absoluten und relativen Kennzahlen für Mobilität. Im Bereich Bildung bezieht sich die absolute Mobilität auf den Anteil derjenigen, deren Bildungsstand von dem der Eltern abweicht: eine Abweichung nach oben bei Aufwärtsmobilität bzw. nach unten bei Abwärtsmobilität zwischen den einzelnen Generationen. Kennzahlen zur absoluten Mobilität werden beeinflusst von der Anzahl der für den Vergleich zwischen den Generationen festgelegten Bildungsstufen (die Mobilität nimmt mit der steigenden Anzahl von zur Verfügung stehenden Kategorien tendenziell zu) sowie, in noch stärkerem Maß, von Veränderungen der Struktur des Bildungssystems, insbesondere dem Ausbau bestimmter Bildungsbereiche. Mobilitätsmuster können darüber hinaus in Mobilität zwischen benachbarten Kategorien und Mobilität zwischen weiter auseinanderliegenden Kategorien unterteilt werden, da diese unterschiedliche Auswirkungen für den Einzelnen haben können. Im Gegensatz dazu bezieht sich die Bezeichnung „gleicher Bildungsstand" auf eine Situation, in der Kinder den gleichen Bildungsstand erreichen wie ihre Eltern. 
Die Analyse der Bildungsmobilität beruht außerdem auf Kennzahlen der relativen Mobilität, die die Größenordnung des Unterschieds bei der Wahrscheinlichkeit berücksichtigt, dass Personen mit Eltern mit unterschiedlichem Bildungsstand einen bestimmten Bildungsstand anstelle eines anderen erreichen. Ein extremer Fall relativer Mobilität wäre das Fehlen jeden Unterschieds zwischen Personen mit unterschiedlichem Bildungshintergrund bei der Wahrscheinlichkeit, einen bestimmten Bildungsstand anstelle eines anderen zu erreichen.

Kennzahlen zur absoluten und relativen Mobilität beeinflussen sich in der Regel gegenseitig, erfassen jedoch unterschiedliche Sachverhalte. Die Tatsache, dass ein Land eine höhere oder niedrigere absolute Mobilität als ein anderes aufweist, bedeutet nicht unbedingt, dass die Möglichkeiten, Zugang zu einem bestimmten Bildungsbereich zu erhalten, für Menschen mit unterschiedlichem Hintergrund in einem Land größer oder geringer sind als in einem anderen.

Dieser Indikator untersucht die Chancen von Personen, deren Eltern über einen unterschiedlichen Bildungsstand verfügen, Zugang zum Tertiärbereich zu erhalten, anstatt das Bildungssystem mit einem niedrigeren Bildungsstand zu verlassen. Der Indikator bietet damit Informationen über die Vor- und Nachteile in Bezug auf Eltern mit unterschiedlichem Bildungsstand.

\section{Ungleichheiten bei der Bildungsbeteiligung im Tertiärbereich in den einzelnen Ländern}

Für manche Menschen ist ein Hochschulbesuch nicht realisierbar. Einige junge Erwachsene müssen unter Umständen früher als andere in den Arbeitsmarkt eintreten, um sich und ihre Familien zu unterstützen. Das Aufwachsen in einer benachteiligten Familie, in der die Eltern über einen geringen Bildungsstand verfügen, bedeutet häufig, dass weniger finanzielle Unterstützung für eine Fortsetzung der Ausbildung zur Verfügung steht. Diese Situation wird weiter verschärft, wenn das Bildungssystem keine Unterstützung für Schüler/Studierende mit sozioökonomisch ungünstigem Hintergrund bietet. Kurzfristig kann die Fortsetzung der Ausbildung zu entgangenem Erwerbseinkommen führen. In diesen Fällen ist es nicht überraschend zu sehen, in welchem Ausmaß der Bildungsstand von Schülern/Studierenden durch den Bildungsstand der Eltern und den sozioökonomischen Hintergrund beeinflusst wird.

Mehr als die Hälfte der 20- bis 34-jährigen Studierenden im Tertiärbereich hat mindestens einen Elternteil mit einem Abschluss im Tertiärbereich (56 Prozent) und etwas mehr als ein Drittel ( 36 Prozent) mindestens einen Elternteil mit einem Abschluss im Sekundarbereich II als höchstem Bildungsstand. Im Gegensatz dazu ist der Anteil der 20- bis 34-jährigen Studierenden, deren Eltern nicht über einen Abschluss im Sekundarbereich II verfügen gering: Etwa jeder zehnte Studierende hat Eltern mit einer Ausbildung unterhalb des Sekundarbereichs II (9 Prozent).

Wie in der einleitenden Abbildung (Abb. A4.I) gezeigt, haben in allen Ländern mindestens rund 35 Prozent der 20- bis 34-jährigen Studierenden im Tertiärbereich mindestens einen Elternteil mit einem Abschluss in diesem Bildungsbereich. In Deutschland, Estland, Kanada, Norwegen und Schweden gilt dies für mindestens $6_{5}$ Prozent dieser Studierenden. Da sich die Daten auf immatrikulierte Studierende beziehen, sollte 
berücksichtigt werden, dass in einigen Ländern, u. a. Schweden, Studierende (z. B. mit einem akademisch gebildeten familiären Hintergrund) längere Studiengänge belegen, und das kann die Studierendenzahlen heraufsetzen. In allen Ländern mit verfügbaren Daten, mit Ausnahme von Spanien, ist der Anteil der Studierenden im Tertiärbereich mit Eltern mit einem Abschluss im Sekundarbereich II höher als der Anteil der Studierenden mit Eltern mit einer Ausbildung unterhalb des Sekundarbereichs II.

Die Erfassung von Ungleichheiten beim Zugang zum Hochschulstudium ist ein entscheidender erster Schritt bei der Entwicklung von Maßnahmen zur Reduzierung dieser Ungleichheiten. Die Basiskennzahl für die relative Mobilität ist die Odds Ratio (s. Abschnitt Definitionen am Ende des Indikators). Im Durchschnitt der Länder mit verfügbaren Daten ist die Wahrscheinlichkeit, dass jemand ein Studium im Tertiärbereich aufnimmt, in Abhängigkeitvom Bildungsstand der Eltern, im Vergleich zur Wahrscheinlichkeit von jemandem, dessen Eltern eine Ausbildung unterhalb des Sekundarbereichs II haben, doppelt so hoch, wenn mindestens ein Elternteil über einen Abschluss im Sekundarbereich II bzw. postsekundaren, nicht tertiären Bereich verfügt, und 4,5-mal so hoch, wenn die Eltern über einen Abschluss im Tertiärbereich verfügen (Tab. A4.Ib).

Im Durchschnitt haben 9 Prozent aller Studierenden im Tertiärbereich Eltern mit einem niedrigen Bildungsstand, während I9 Prozent der Gesamtpopulation der Eltern (Eltern von Schülern/Studierenden und Nichtschülern/Nichtstudierenden) einen niedrigen Bildungsstand aufweisen. Der höchste Anteil 20- bis 34-jähriger Studierender im Tertiärbereich, deren Eltern eine Ausbildung unterhalb des Sekundarbereichs II haben, findet sich (unter den Ländern mit verfügbaren Daten) in Australien, Irland, Italien, den

Abbildung A4.2

Bildungsbeteiligung im Tertiärbereich von 20- bis 34-jährigen Studierenden, deren Eltern eine Ausbildung unterhalb des Sekundarbereichs II haben (2012)

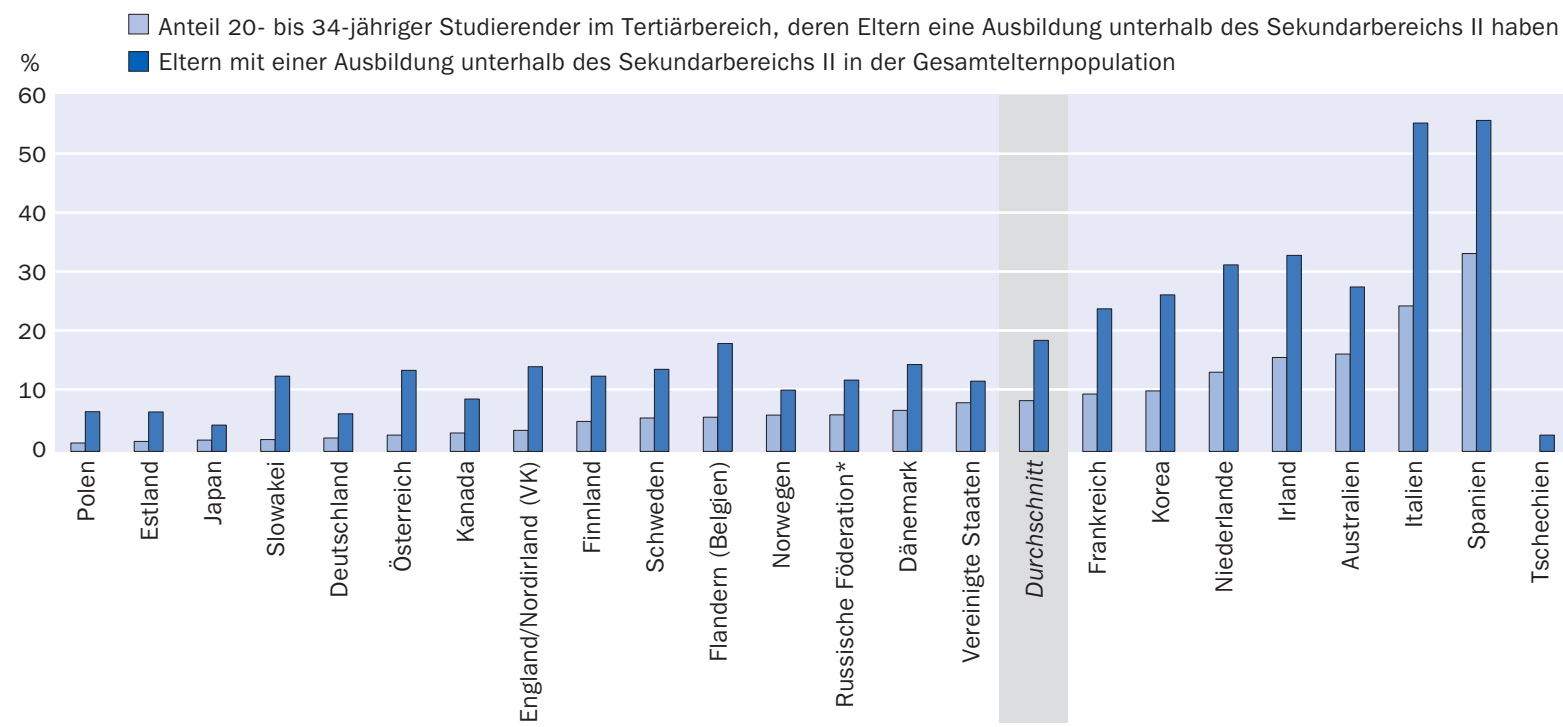

* Hinweis zu den Daten der Russischen Föderation s. Abschnitt Angewandte Methodik.

Anordnung der Länder in aufsteigender Reihenfolge des Anteils 20- bis 34-jähriger Studierender im Tertiärbereich, deren Eltern eine Ausbildung unterhalb des Sekundarbereichs II haben.

Quelle: OECD. Tabelle A4.1a. Hinweise s. Anhang 3 unter www.oecd.org/edu/eag.htm. StatLink: http://dx.doi.org/10.1787/888933115654 
Abbildung A4.3

Absolute Bildungsmobilität (2012)

Anteil 26- bis 64-jähriger Nichtschüler/Nichtstudierender, die einen höheren (Aufwärtsmobilität), niedrigeren (Abwärtsmobilität) oder den gleichen Bildungsstand wie ihre Eltern haben

Gleicher Bildungsstand:

Ausbildung unterhalb Sekundarbereich II

$\square$ Gleicher Bildungsstand: Abschluss im Sekundarbereich II bzw. postsekundaren, nicht tertiären Bereich

Gleicher Bildungsstand: Abschluss im Tertiärbereich

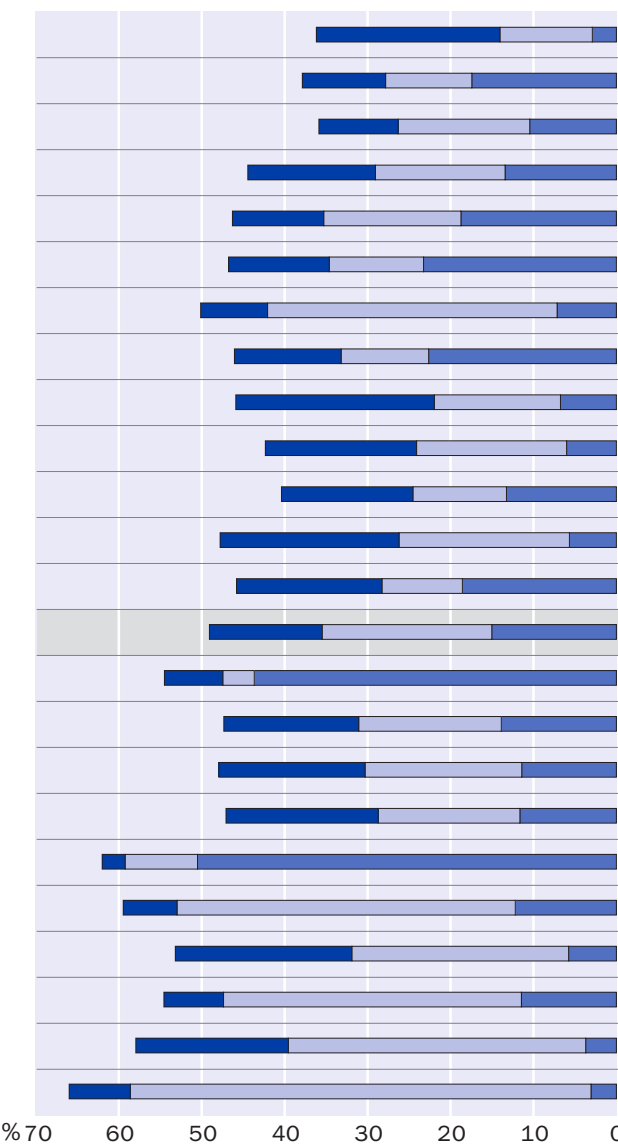

\begin{tabular}{c} 
Russische Föderation* \\
Korea \\
Finnland \\
Flandern (Belgien) \\
Frankreich \\
\hline Irland \\
Polen \\
\hline Niederlande \\
Kanada \\
Estland \\
\hline Schweden \\
\hline Japan \\
\hline Australien \\
\hline Durchschnitt \\
\hline Spanien \\
\hline Deusterreich \\
\hline Ischechien \\
\hline Englandien \\
\hline Nordirland (VK)
\end{tabular}

Aufwärtsmobilität

Abwärtsmobilität

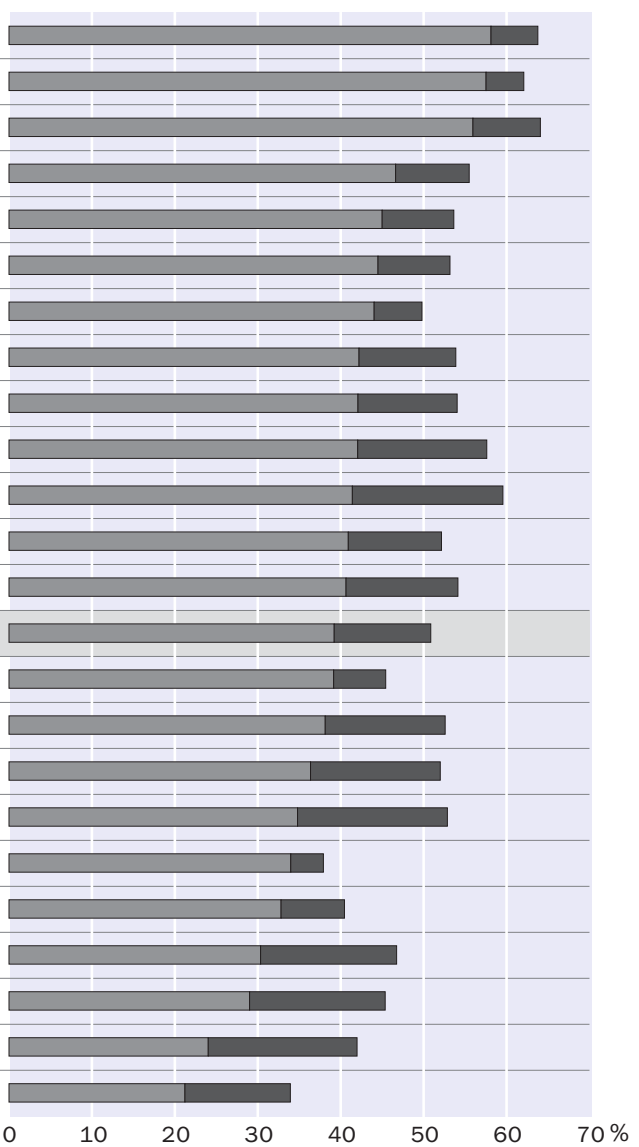

* Hinweis zu den Daten der Russischen Föderation s. Abschnitt Angewandte Methodik.

Anordnung der Länder in absteigender Reihenfolge des Anteils Erwachsener mit Aufwärtsmobilität im Vergleich zum Bildungsstand ihrer Eltern.

Quelle: OECD. Tabelle A4.4. Hinweise s. Anhang 3 unter www.oecd.org/edu/eag.htm. StatLink: http://dx.doi.org/10.1787/888933115673

Niederlanden und Spanien (mehr als ıo Prozent). Diese Länder gehören jedoch auch zu den Ländern mit dem höchsten Anteil an Eltern mit einer Ausbildung unterhalb des Sekundarbereichs II an der Gesamtelternpopulation (mehr als 20 Prozent) (Abb. A4.2).

\section{Bildungsmobilität zwischen den Generationen}

Wie in Indikator Ar gezeigt, sind die Abschlussquoten im Tertiärbereich in den letzten Jahren im Durchschnitt gestiegen, insbesondere bei den jüngeren Generationen. So haben die 25-bis 34-Jährigen sowohl die höchsten Abschlussquoten im Tertiärbereich (rund 40 Prozent) als auch den niedrigsten Anteil an Personen ohne einen Abschluss zumindest im Sekundarbereich II (weniger als 20 Prozent). Darüber hinaus hat 2012 der Anteil der 55- bis 64-Jährigen mit einem Abschluss im Tertiärbereich den seit 2000 
höchsten Wert von 25 Prozent erreicht. Zwischen 2000 und 2012 war die durchschnittliche jährliche Steigerung des Anteils der Bevölkerung mit einem Abschluss im Tertiärbereich im Vergleich aller Generationen bei den 55- bis 64-Jährigen mit 4 Prozent am höchsten (s. Indikator AI, Tab. AI.4a).

Dies lässt darauf schließen, dass in den meisten Ländern mit verfügbaren Daten eine positive Entwicklung des Zugangs zum Bildungssystem stattgefunden hat. Im Durchschnitt verfügen etwa 40 Prozent der 25- bis 64-Jährigen über einen höheren Bildungsstand als ihre Eltern (Aufwärtsmobilität). Jedoch haben in den meisten Ländern 40 bis 50 Prozent der erwachsenen Nichtschüler/Nichtstudierenden den gleichen Bildungsstand wie ihre Eltern. Dieser Anteil ist in Deutschland, Italien, Österreich, der Slowakei, Spanien, Tschechien und den Vereinigten Staaten sogar noch höher (Tab. A4.4).

Abbildung A4.3 zeigt, dass im Durchschnitt der Länder etwa die Hälfte der Erwachsenen denselben Bildungsstand wie ihre Eltern erreicht hat, der Bildungsstand der anderen Hälfte ist entweder höher oder niedriger als derjenige der Eltern. In allen Ländern findet sich wesentlich häufiger eine Aufwärtsmobilität (d. h. Erwachsene, deren Bildungsstand höher als der ihrer Eltern ist) als eine Abwärtsmobilität. Die Bildungsmobilität zwischen den Generationen ist in Finnland, Flandern (Belgien), Korea und der Russischen Föderation besonders hoch: Mehr als 55 Prozent der Erwachsenen in diesen Ländern haben entweder einen höheren oder einen niedrigeren Bildungsstand als ihre Eltern. In diesen Ländern verfügen mehr als 45 Prozent der Erwachsenen über einen höheren Bildungsstand als ihre Eltern (absolute Aufwärtsmobilität) - der höchste Anteil bei allen Ländern; in Finnland und Flandern (Belgien) ist der Bildungsstand eines relativ hohen Anteils der Erwachsenen - etwa 8 Prozent - jedoch niedriger als der ihrer Eltern (Abwärtsmobilität).

In Deutschland, Italien, Österreich, der Slowakei und Tschechien verfügen mehr als 55 Prozent der Erwachsenen über denselben Bildungsstand wie ihre Eltern. In Italien und Spanien liegt der Anteil der Erwachsenen mit einer Ausbildung unterhalb des Sekundarbereichs II, deren Eltern über denselben Bildungsstand verfügen, bei mehr als 40 Prozent. In Deutschland, Österreich, der Slowakei und Tschechien haben mehr als 35 Prozent der Erwachsenen mit einem Abschluss im Sekundarbereich II bzw. im postsekundaren, nicht tertiären Bereich Eltern, die ebenfalls über diesen Bildungsstand verfügen. Diese Länder sind zusammen mit Polen, Slowenien und Ungarn die OECD-Länder mit dem höchsten Anteil Erwachsener mit diesem Bildungsstand (in jedem Land mehr als 55 Prozent, s. Tab. Ar.5a in Indikator Ar). In Japan, Kanada, der Russischen Föderation und den Vereinigten Staaten haben mehr als 20 Prozent der Erwachsenen mit Eltern, die über einen Abschluss im Tertiärbereich verfügen, ebenfalls diesen Abschluss erworben(Tab. A4.4).

Im Durchschnitt ist die absolute Aufwärtsmobilität bei Frauen mit 40 Prozent etwas höher als bei Männern ( 38 Prozent). Jedoch ist in einigen Ländern bei Männern wesentlich häufiger eine Aufwärtsmobilität beim Bildungsstand zu beobachten als bei Frauen: in Deutschland (2I Prozent bei Frauen gegenüber 27 Prozent bei Männern), Korea (53 Prozent bzw. 62 Prozent), die Niederlande (4o Prozent bzw. 45 Prozent) und Österreich (25 Prozent bzw. 33 Prozent) (Tab. A4.4). 
Die Bildungsmobilität zwischen den Generationen variiert je nach Bildungsstand und Kontext. Mehr als 30 Prozent der erwachsenen Nichtschüler/Nichtstudierenden mit Eltern ohne einen Abschluss im Sekundarbereich II haben die Schule ebenfalls vor einem Abschluss im Sekundarbereich II verlassen. Mehr als 45 Prozent dieser Erwachsenen verfügen jedoch über einen Abschluss im Sekundarbereich II bzw. postsekundaren, nicht tertiären Bereich und etwa 20 Prozent über einen Abschluss im Tertiärbereich. In Finnland, Kanada und der Russischen Föderation haben mehr als 30 Prozent dieser Erwachsenengruppe einen Abschluss im Tertiärbereich erreicht. Im Gegensatz dazu verfügen in Deutschland, Italien, Österreich, Polen, der Slowakei, Tschechien und den Vereinigten Staaten höchstens I5 Prozent der erwachsenen Nichtschüler/Nichtstudierenden mit Eltern mit einer Ausbildung unterhalb des Sekundarbereichs II über einen Abschluss im Tertiärbereich (Tab. A4.2).

Gleichermaßen haben im Durchschnitt der Länder mehr als $6_{5}$ Prozent der Nichtschüler/Nichtstudierenden mit Eltern mit einem Abschluss im Tertiärbereich denselben Bildungsstand erreicht, etwa 30 Prozent verfügen über einen Abschluss im Sekundarbereich II bzw. postsekundaren, nicht tertiären Bereich als höchste Qualifikation, und nur 5 Prozent haben die Schule vor einem Abschluss im Sekundarbereich II verlassen. In allen Ländern mit Ausnahme von Österreich, das zu den Ländern mit einem der höchsten Anteile an Erwachsenen mit einem Abschluss im Sekundarbereich II bzw. postsekundaren, nicht tertiären Bereich gehört, verfügen mehr als 50 Prozent der Erwachsenen mit Eltern mit einem Abschluss im Tertiärbereich ebenfalls über einen Abschluss im Tertiärbereich (Tab. A4.2).

Der Zugang zum Tertiärbereich wird auch durch Ungleichheiten in vorgelagerten Bildungsbereichen beeinflusst. Eine wesentliche Voraussetzung für das Erreichen eines höheren Bildungsstands ist der Erwerb der zur Fortsetzung der Ausbildung notwendigen Kompetenzen und Kenntnisse. Die Bildungsmobilität zwischen den Generationen kann durch die frühe Schullaufbahn stark beeinflusst werden, da Schulen die sozioökonomischen Vor- oder Nachteile verstärken könnten. Seit der ersten Erhebung zeigt sich in den PISA-Studien, dass in vielen Ländern ein Zusammenhang zwischen dem sozioökonomischen Hintergrund der Schüler und ihren schulischen Leistungen besteht. Schüler mit sozioökonomisch ungünstigem Hintergrund haben sehr häufig nur begrenzt Zugang zu qualitativ hochwertiger Bildung. Im Durchschnitt erzielt ein Schüler mit günstigerem sozioökonomischem Hintergrund 39 Punkte mehr in Mathematik als ein weniger begünstigter Schüler. Dieser Unterschied entspricht fast einem Jahr Schulunterricht (OECD, 2013). Zugang zu qualitativ hochwertiger Bildung im Elementar-, Primar- und Sekundarbereich ist von essenzieller Bedeutung, um allen Schülern, unabhängig vom Bildungsstand ihrer Eltern, deren Beruf oder Erwerbsstatus, die Chance auf einen Zugang zum Tertiärbereich zu eröffnen.

\section{Kompetenzen Erwachsener im Verhältnis zum Bildungsstand ihrer Eltern}

Der Bildungsstand der Eltern scheint sich auch auf die Lese- und alltagsmathematische Kompetenz des Einzelnen auszuwirken. Im Durchschnitt stammen die leistungsstärksten Personen im Bereich Lesekompetenz bei der Erhebung zu den grundlegenden Kompetenzen Erwachsener im Rahmen des OECD Programme for the International Assessment of Adult Competencies (PIAAC) aus Familien, in denen mindestens ein Elternteil über einen Abschluss im Tertiärbereich verfügt. Ebenso haben die meisten 
Erhebung zu den grundlegenden Kompetenzen Erwachsener, Anteil 25- bis 64-jähriger Nichtschüler/Nichtstudierender auf den einzelnen

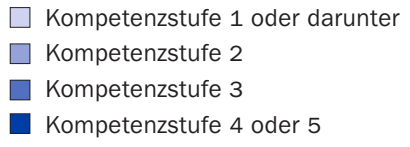

Eltern mit einer Ausbildung unterhalb Sekundarbereich II

Eltern mit einem Abschluss im Tertiärbereich

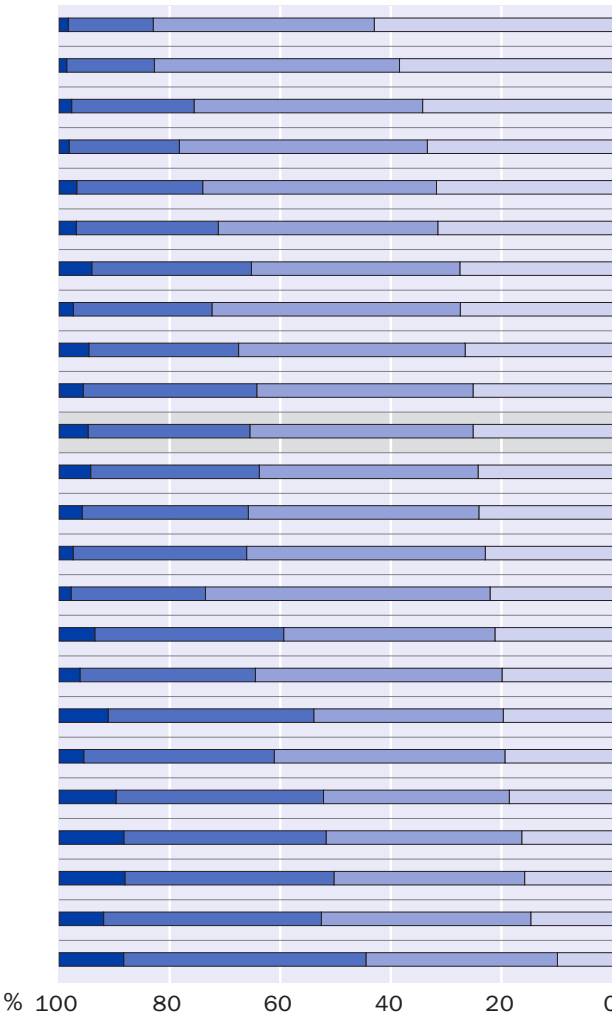

Vereinigte Staaten
Deutschland
Spanien
Italien
Polen
Frankreich
Kanada
Österreich

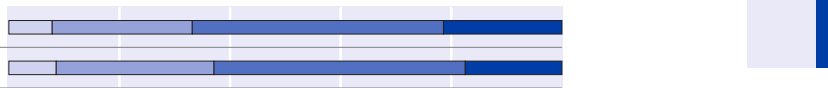

England/Nordirland (VK) Dänemark Durchschnitt

Flandern (Belgien) Irland

Slowakei

Tschechien

Norwegen

Korea

Schweden

Estland

Niederlande

Finnland

Australien

Russische Föderation*

Japan

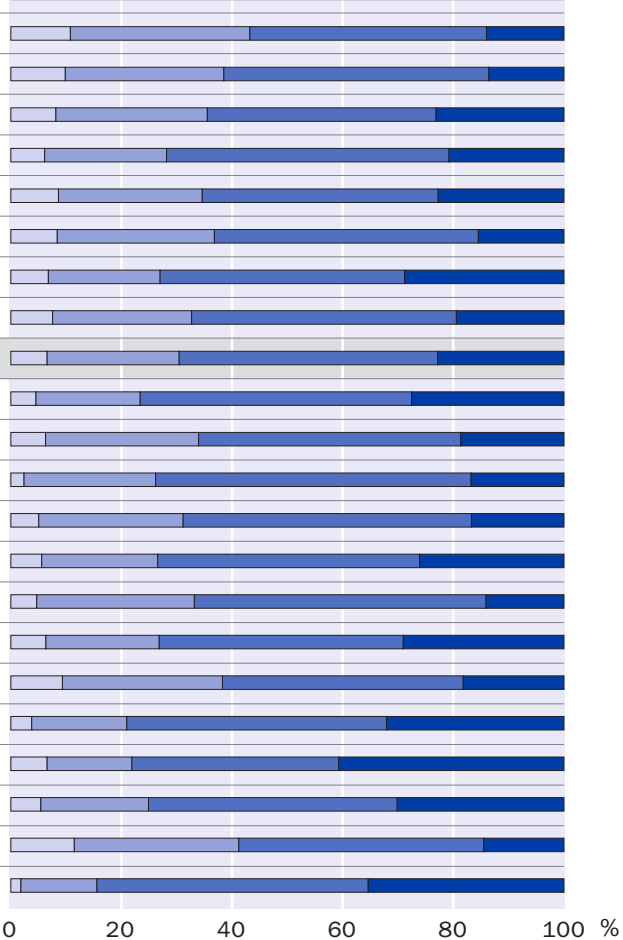

* Hinweis zu den Daten der Russischen Föderation s. Abschnitt Angewandte Methodik.

Anordnung der Länder in absteigender Reihenfolge der Erwachsenen auf Lesekompetenzstufe 1 oder darunter, deren Eltern eine Ausbildung unterhalb des Sekundarbereichs II haben.

Quelle: OECD. Tabelle A4.3 (L). Hinweise s. Anhang 3 unter www.oecd.org/edu/eag.htm. StatLink: http://dx.doi.org/10.1787/888933115692

leistungsschwächsten Erwachsenen im Bereich Lesekompetenz Eltern mit höchstens einer Ausbildung unterhalb des Sekundarbereichs II (Tab. A4.3 [L]).

Abbildung A4.4 zeigt die Lesekompetenz Erwachsener im Verhältnis zum Bildungsstand ihrer Eltern. Im Durchschnitt der teilnehmenden Länder erreichen 25 Prozent der Erwachsenen, deren Eltern eine Ausbildung unterhalb des Sekundarbereichs II haben, bei der Lesekompetenz maximal Stufe I, 40 Prozent Stufe 2, weniger als 30 Prozent Stufe 3 und nur etwa 5 Prozent die Stufe 4 oder 5. In Deutschland, Frankreich, Italien, Polen, Spanien und den Vereinigten Staaten entspricht bei mehr als 30 Prozent dieser Erwachsenen die Lesekompetenz maximal Stufe I, während höchstens 3 Prozent der Stufe 4 oder 5 zuzuordnen sind. Der Anteil der leistungsstärksten Erwachsenen im Bereich Lesekompetenz ist in Österreich, der Slowakei und Tschechien vergleichbar niedrig. 
Das Bild ändert sich signifikant bei Erwachsenen, deren Eltern über einen Abschluss im Tertiärbereich verfügen. Im Durchschnitt der Länder entspricht bei 7 Prozent dieser Erwachsenen die Lesekompetenz in der Erhebung zu den grundlegenden Kompetenzen Erwachsener maximal Stufe I, weniger als 25 Prozent sind der Stufe 2, mehr als 45 Prozent der Stufe 3 und mehr als 20 Prozent der Stufe 4 oder 5 zuzuordnen. In den meisten Ländern erzielen mehr als 20 Prozent der Erwachsenen, deren Eltern über einen Abschluss im Tertiärbereich verfügen, Lesekompetenzstufe 4 oder 5 , und in Australien, Finnland, Japan und den Niederlanden sind es mindestens 30 Prozent.

Bei Erwachsenen mit Eltern ohne einen Abschluss im Sekundarbereich II hat etwa jeder Dritte diesen Abschluss ebenfalls nicht erreicht, der Rest hat mindestens einen Abschluss im Sekundarbereich II erworben. Jeder Vierte dieser Erwachsenen ist maximal der Lesekompetenzstufe I zuzuordnen (Tab. A4.2 und A4.3 [L]).

Um die Bildungsmobilität zwischen den Generationen zu erhöhen, bedarf es vielfältiger politischer Maßnahmen. In einigen Ländern haben sich Langzeitstrategien, einschließlich der gleichmäßigen Verteilung von Ressourcen und Möglichkeiten über das gesamte Schulsystem, sowie der Einsatz von sehr guten Lehrkräften und Schulleitern an leistungsschwachen Schulen ausgezahlt - dort werden gute Leistungen erzielt, und die Chancengerechtigkeit ist überdurchschnittlich hoch. Dies ist insbesondere in Finnland, Japan, Kanada und Korea der Fall (OECD, 20I2). Zusammengefasst lässt sich sagen, dass alle Schüler, unabhängig von ihrem sozioökonomischen Hintergrund, die gleichen Chancen auf Erfolg haben sollten.

\section{Definitionen}

Erwachsene bezieht sich auf 25- bis 64-Jährige.

Bildungsbereiche: Unterhalb Sekundarbereich II entspricht Bildungsgängen auf den ISCEDStufen o, I, 2 und ${ }_{3} \mathrm{C}$ (kurz). Sekundarbereich II bzw. postsekundarer, nicht tertiärer Bereich entspricht Bildungsgängen auf den ISCED-Stufen ${ }_{3} \mathrm{C}$ (lang), ${ }_{3} \mathrm{~B}, 3_{3} \mathrm{~A}$ und 4 , und Tertiärbereich entspricht Studiengängen auf den ISCED-Stufen $5 \mathrm{~A},{ }_{5} \mathrm{~B}$ und 6 . Erläuterungen zu allen Bildungsbereichen gemäß ISCED-Klassifizierung s. Hinweise für den Leser im vorderen Teil der Publikation.

Eine Odds Ratio vergleicht die Wahrscheinlichkeit, mit der ein bestimmtes Ereignis in einer Gruppe in Relation zu einer Referenzgruppe auftritt. Eine Odds Ratio von I bedeutet, dass in beiden Gruppen die gleichen Chancen bestehen, dass ein bestimmtes Ereignis eintreten wird. Koeffizienten mit einem Wert unter I zeigen, dass die Chance, dass ein Ereignis eintreten wird, für eine spezielle Gruppe geringer ist als für ihre Referenzgruppe, bei einem Koeffizienten größer I ist die Chance größer.

Bildungsstand der Eltern: Eine Ausbildung unterhalb Sekundarbereich II/Kein Abschluss im Sekundarbereich II bedeutet, dass beide Eltern Bildungsgänge auf den ISCED-Stufen o, I, 2 und ${ }_{3} \mathrm{C}$ (kurz) besucht haben; Sekundarbereich II bzw. postsekundarer, nicht tertiärer Bereich bedeutet, dass mindestens ein Elternteil (Mutter oder Vater) einen Abschluss auf ISCED-Stufe $3 \mathrm{~A}, 3 \mathrm{~B}, 3 \mathrm{C}$ (lang) oder 4 erworben hat; und Tertiärbereich bedeutet, dass mindestens 
ein Elternteil (Mutter oder Vater) einen Abschluss auf ISCED-Stufe 5 A, 5 B oder 6 erworben hat. Erläuterungen zu allen Bildungsbereichen gemäß ISCED-Klassifizierung s. Hinweise für den Leser im vorderen Teil des Buches.

\section{Angewandte Methodik}

Alle Daten basieren auf der Erhebung Survey of Adult Skills (PIAAC) (20I2). PIAAC ist das OECD Programme for the International Assessment of Adult Competencies. Weitere Informationen siehe „Erhebung zu den grundlegenden Kompetenzen Erwachsener" im vorderen Teil dieser Publikation sowie in Anhang 3 (www.oecd.org/edu/eag.htm).

Hinweis zu den Daten aus der Russischen Föderation in der Erhebung zu den grundlegenden Kompetenzen Erwachsener (PIAAC)

$\mathrm{Zu}$ beachten ist, dass die Bevölkerung des Stadtgebiets Moskau in der Stichprobe für die Russische Föderation nicht berücksichtigt wurde. Die veröffentlichten Daten repräsentieren daher nicht die gesamte Wohnbevölkerung im Alter von I 6 bis 65 Jahren in Russland, sondern nur die Wohnbevölkerung Russlands ohne die im Stadtgebiet Moskau lebende Bevölkerung. Weitere Informationen zu den Daten aus der Russischen Föderation sowie anderer Länder finden sich im Technical Report of the Survey of Adult Skills (OECD, i. E.).

\section{Weiterführende Informationen}

OECD (2013), PISA 2012 Results: Excellence through Equity (Volume II): Giving Every Student the Chance to Succeed, PISA, OECD Publishing, http://dx.doi.org/10.1787/9789264201132-en.

OECD (2012), „How pronounced is income inequality around the world - and how can education help reduce it?", Education Indicators in Focus, OECD Publishing, Paris, http:|/www.oecd.org/edu/50204168.pdf.

\section{Tabellen Indikator A4}

StatLink: http://dx.doi.org/10.1787/888933115521

Tabelle A4.ra: Bildungsbeteiligung 20- bis 34-Jähriger im Tertiärbereich, nach

Geschlecht und Bildungsstand der Eltern (2012)

Tabelle A4.Ib: Wahrscheinlichkeit der Bildungsteilnahme im Tertiärbereich, nach Bildungsstand der Eltern und Geschlecht (2012)

Tabelle A4.2: Bildungsstand von Nichtschülern/Nichtstudierenden, nach Altersgruppe und Bildungsstand der Eltern (2012)

Tabelle A4.3 (L): Lesekompetenz von Nichtschülern/Nichtstudierenden, nach Altersgruppe, Geschlecht und Bildungsstand der Eltern (2012) 
WEB Table A4.3 (N): Numeracy proficiency level among non-students, by age group, gender and parents' educational attainment (Alltagsmathematische Kompetenz von Nichtschülern/Nichtstudierenden, nach Altersgruppe, Geschlecht und Bildungsstand der Eltern) (2012)

Tabelle A4.4: Bildungsmobilität bei Nichtschülern/Nichtstudierenden, nach Altersgruppe und Bildungsstand der Eltern (2012) 
Bildungsbeteiligung 20- bis 34-Jähriger im Tertiärbereich, nach Geschlecht und Bildungsstand der Eltern (2012)

20- bis 34-jährige Studierende im Tertiärbereich, nach dem Bildungsstand der Eltern, und Bildungsstand der Eltern von 20- bis 34-Jährigen (Schülern/Studierenden und Nichtschülern/Nichtstudierenden), nach Geschlecht

Bedeutung der ersten Zeile in Spalte (1): In Australien sind 16 Prozent der 20- bis 34-Jährigen, deren Eltern eine Ausbildung unterhalb des Sekundarbereichs II haben, Studierende im Teriärbereich. Bei der Erhebungsmethode besteht eine Stichprobenunsicherheit bei den Prozentangaben (\%) in Höhe des doppelten Standardfehlers. Weitere Informationen s. Hinweise für den Leser.

\begin{tabular}{|c|c|c|c|c|c|c|c|c|c|c|c|c|c|c|}
\hline & \multicolumn{7}{|c|}{$\begin{array}{c}\text { Studierende im Tertiärbereich nach dem Bildungsstand } \\
\text { der Eltern }\end{array}$} & \multicolumn{7}{|c|}{$\begin{array}{l}\text { Bildungsstand der Eltern in der Gesamtpopulation (Schüler/ } \\
\text { Studierende und Nichtschüler/Nichtstudierende) }\end{array}$} \\
\hline & \multicolumn{2}{|c|}{$\begin{array}{l}\text { Ausbildung } \\
\text { unterhalb } \\
\text { Sekundar- } \\
\text { bereich II }\end{array}$} & \multicolumn{2}{|c|}{$\begin{array}{l}\text { Abschluss im } \\
\text { Sekundar- } \\
\text { bereich II bzw. } \\
\text { postsekundaren, } \\
\text { nicht tertiären } \\
\text { Bereich }\end{array}$} & \multicolumn{2}{|c|}{$\begin{array}{l}\text { Abschluss im } \\
\text { Tertiärbereich }\end{array}$} & \multirow{2}{*}{$\begin{array}{c}\text { Gesamt } \\
\\
\\
\%\end{array}$} & \multicolumn{2}{|c|}{$\begin{array}{l}\text { Ausbildung } \\
\text { unterhalb } \\
\text { Sekundar- } \\
\text { bereich II }\end{array}$} & \multicolumn{2}{|c|}{$\begin{array}{l}\text { Abschluss im } \\
\text { Sekundar- } \\
\text { bereich II bzw. } \\
\text { postsekundaren, } \\
\text { nicht tertiären } \\
\text { Bereich }\end{array}$} & \multicolumn{2}{|c|}{$\begin{array}{l}\text { Abschluss im } \\
\text { Tertiärbereich }\end{array}$} & \multirow{2}{*}{$\begin{array}{c}\text { Gesamt } \\
\\
\\
\%\end{array}$} \\
\hline & $\%$ & S. F. & $\%$ & S. F. & $\%$ & S. F. & & $\%$ & S. F. & $\%$ & S. F. & $\%$ & S. F. & \\
\hline & (1) & (2) & (3) & (4) & (5) & (6) & (7) & (8) & (9) & (10) & (11) & (12) & (13) & (14) \\
\hline \multicolumn{15}{|l|}{$\begin{array}{l}\text { OECD } \\
\text { Nationale Einheiten }\end{array}$} \\
\hline Australien & 16 & $(2,7)$ & 24 & $(3,7)$ & 59 & $(3,6)$ & 100 & 28 & $(1,4)$ & 30 & $(1,5)$ & 42 & $(1,4)$ & 100 \\
\hline Österreich & 3 & $(1,1)$ & 43 & $(2,8)$ & 55 & $(3,0)$ & 100 & 14 & $(0,9)$ & 59 & $(1,4)$ & 28 & $(1,2)$ & 100 \\
\hline Kanada & 3 & $(0,6)$ & 24 & $(1,7)$ & 73 & $(1,7)$ & 100 & 9 & $(0,5)$ & 35 & $(1,0)$ & 56 & $(1,1)$ & 100 \\
\hline Tschechien & c & c & 62 & $(2,7)$ & 38 & $(2,6)$ & 100 & 3 & $(0,5)$ & 75 & $(1,4)$ & 22 & $(1,4)$ & 100 \\
\hline Dänemark & 7 & $(1,3)$ & 30 & $(2,4)$ & 63 & $(2,5)$ & 100 & 15 & $(0,9)$ & 38 & $(1,3)$ & 47 & $(1,4)$ & 100 \\
\hline Estland & 2 & $(0,6)$ & 31 & $(2,3)$ & 67 & $(2,3)$ & 100 & 7 & $(0,5)$ & 44 & $(0,9)$ & 50 & $(0,9)$ & 100 \\
\hline Finnland & 5 & $(1,1)$ & 39 & $(2,4)$ & 56 & $(2,5)$ & 100 & 13 & $(0,9)$ & 51 & $(1,2)$ & 36 & $(1,2)$ & 100 \\
\hline Frankreich & 10 & $(1,8)$ & 41 & $(2,7)$ & 50 & $(2,5)$ & 100 & 24 & $(1,0)$ & 48 & $(1,4)$ & 28 & $(1,1)$ & 100 \\
\hline Deutschland & 2 & $(0,9)$ & 32 & $(2,8)$ & 65 & $(2,8)$ & 100 & 6 & $(0,8)$ & 48 & $(1,7)$ & 46 & $(1,7)$ & 100 \\
\hline Irland & 16 & $(2,6)$ & 33 & $(3,5)$ & 51 & $(3,7)$ & 100 & 33 & $(1,3)$ & 35 & $(1,4)$ & 32 & $(1,2)$ & 100 \\
\hline Italien & 24 & $(3,7)$ & 48 & $(4,3)$ & 28 & $(3,6)$ & 100 & 55 & $(1,8)$ & 35 & $(1,7)$ & 10 & $(1,0)$ & 100 \\
\hline Japan & 2 & $(1,1)$ & 22 & $(3,1)$ & 76 & $(3,2)$ & 100 & 4 & $(0,7)$ & 44 & $(1,6)$ & 51 & $(1,5)$ & 100 \\
\hline Korea & 10 & $(1,7)$ & 43 & $(3,3)$ & 47 & $(3,6)$ & 100 & 26 & $(1,0)$ & 46 & $(1,4)$ & 28 & $(1,2)$ & 100 \\
\hline Niederlande & 13 & $(2,0)$ & 25 & $(2,3)$ & 61 & $(2,7)$ & 100 & 31 & $(1,4)$ & 31 & $(1,3)$ & 38 & $(1,6)$ & 100 \\
\hline Norwegen & 6 & $(1,2)$ & 21 & $(2,3)$ & 73 & $(2,4)$ & 100 & 10 & $(0,9)$ & 38 & $(1,4)$ & 51 & $(1,4)$ & 100 \\
\hline Polen & 1 & $(0,3)$ & 59 & $(1,7)$ & 39 & $(1,7)$ & 100 & 7 & $(0,7)$ & 72 & $(0,9)$ & 21 & $(0,8)$ & 100 \\
\hline Slowakei & 2 & $(1,0)$ & 59 & $(2,5)$ & 39 & $(2,6)$ & 100 & 13 & $(1,0)$ & 69 & $(1,2)$ & 19 & $(1,1)$ & 100 \\
\hline Spanien & 33 & $(3,0)$ & 30 & $(3,1)$ & 37 & $(2,8)$ & 100 & 56 & $(1,3)$ & 25 & $(1,2)$ & 19 & $(1,0)$ & 100 \\
\hline Schweden & 6 & $(1,4)$ & 26 & $(3,0)$ & 68 & $(3,2)$ & 100 & 14 & $(0,9)$ & 34 & $(1,5)$ & 53 & $(1,7)$ & 100 \\
\hline $\begin{array}{l}\text { Vereinigte Staaten } \\
\text { Subnationale Einheiten }\end{array}$ & 8 & $(1,9)$ & 34 & $(3,0)$ & 58 & $(3,1)$ & 100 & 12 & $(0,9)$ & 40 & $(1,4)$ & 48 & $(1,5)$ & 100 \\
\hline Flandern (Belgien) & 6 & $(1,4)$ & 36 & $(2,9)$ & 59 & $(3,0)$ & 100 & 18 & $(1,0)$ & 42 & $(1,3)$ & 40 & $(1,2)$ & 100 \\
\hline England (VK) & 3 & $(1,6)$ & 41 & $(5,0)$ & 56 & $(5,0)$ & 100 & 14 & $(1,2)$ & 49 & $(1,7)$ & 37 & $(1,8)$ & 100 \\
\hline Nordirland (VK) & 13 & $(3,4)$ & 42 & $(5,3)$ & 46 & $(5,0)$ & 100 & 22 & $(1,4)$ & 52 & $(1,8)$ & 26 & $(1,7)$ & 100 \\
\hline England/Nordirland (VK) & 4 & $(1,5)$ & 41 & $(4,9)$ & 55 & $(4,9)$ & 100 & 14 & $(1,2)$ & 49 & $(1,6)$ & 37 & $(1,7)$ & 100 \\
\hline Durchschnitt & 9 & $(0,4)$ & 37 & $(0,6)$ & 55 & $(0,6)$ & 100 & 19 & $(0,2)$ & 45 & $(0,3)$ & 36 & $(0,3)$ & 100 \\
\hline \multicolumn{15}{|l|}{ Partnerländer } \\
\hline Russische Föderation* & 6 & $(1,7)$ & 38 & $(3,3)$ & 56 & $(2,9)$ & 100 & 12 & $(2,5)$ & 44 & $(2,3)$ & 44 & $(2,8)$ & 100 \\
\hline
\end{tabular}

* Hinweis zu den Daten der Russischen Föderation s. Abschnitt Angewandte Methodik.

Anmerkung: Die Zeilen mit getrennten Angaben zu Männern und Frauen sind im Internet verfügbar (s. StatLink).

Quelle: OECD. Survey of Adult Skills (PIAAC) (2012). PIAAC steht für das OECD Programme for the International Assessment of Adult Competencies.

Hinweise s. Anhang 3 unter www.oecd.org/edu/eag.htm. StatLink: http://dx.doi.org/10.1787/888933115540

Erläuterung der Kennzeichnung fehlender Daten s. Hinweise für den Leser. 
Eine Odds Ratio vergleicht die relative Wahrscheinlichkeit der Bildungsteilnahme im Tertiärbereich von Personen, deren Eltern über einen Abschluss im Sekundarbereich II/postsekundaren, nicht tertiären Bereich verfügen, gegenüber der Wahrscheinlichkeit derjenigen, deren Eltern nur über eine Ausbildun unterhalb des Sekundarbereichs II verfügen. Letztere werden als Referenzgruppe für die Interpretation der relativen Wahrscheinlichkeit genommen, daher wird ihre Odds Ratio auf 1 festgelegt. Unterschiede zwischen den Gruppen gelten bei 95 Prozent als statistisch signifikant, wenn der mit der Odds Ratio verbundene $p$-Wert unter 0,5 ist.

Bedeutung der Zeile (1): In Australien hat eine Person mit Eltern, die über einen Abschluss im Sekundarbereich II als höchsten Bildungsabschluss verfügen, eine fast doppelt so hohe Wahrscheinlichkeit $(1,8)$ der Bildungsteilnahme im Tertiärbereich als eine Person, deren Eltern nur über einer Ausbildung unterhalb des Sekundarbereichs II verfügen. Eine Person mit Eltern, die über einen Abschluss im Tertiärbereich verfügen, hat eine rund 4-mal so große Wahrscheinlichkeit $(4,3)$ der Bildungsteilnahme im Tertiärbereich als eine Person, deren Eltern nur über eine Ausbildung unterhalb des Sekundarbereichs II verfügen.

\begin{tabular}{|c|c|c|c|c|c|c|}
\hline & \multicolumn{2}{|c|}{ Ausbildung unterhalb Sekundarbereich II } & \multicolumn{2}{|c|}{$\begin{array}{c}\text { Abschluss im Sekundarbereich II } \\
\text { bzw. postsekundaren, } \\
\text { nicht tertiären Bereich }\end{array}$} & \multicolumn{2}{|c|}{$\begin{array}{l}\text { Abschluss im Tertiärbereich/ } \\
\text { einem weiterführenden forschungs- } \\
\text { orientierten Studiengang }\end{array}$} \\
\hline & Odds Ratio & $\mathrm{p}$-Wert & Odds Ratio & $\mathrm{p}$-Wert & Odds Ratio & $\mathrm{p}$-Wert \\
\hline & (1) & (2) & (3) & (4) & (5) & (6) \\
\hline \multicolumn{7}{|l|}{$\begin{array}{l}\text { OECD } \\
\text { Nationale Einheiten }\end{array}$} \\
\hline Australien & 1 & $(0,0)$ & 1,8 & $(0,0)$ & 4,3 & $(0,0)$ \\
\hline Österreich & 1 & $(0,0)$ & 2,1 & $(0,0)$ & 5,1 & $(0,0)$ \\
\hline Kanada & 1 & $(0,0)$ & 1,6 & $(0,0)$ & 2,6 & $(0,0)$ \\
\hline Tschechien & c & c & c & c & c & c \\
\hline Dänemark & 1 & $(0,0)$ & 1,6 & $(0,0)$ & 3,0 & $(0,0)$ \\
\hline Estland & 1 & $(0,0)$ & 2,7 & $(0,0)$ & 4,7 & $(0,0)$ \\
\hline Finnland & 1 & $(0,0)$ & 1,2 & $(0,4)$ & 1,4 & $(0,0)$ \\
\hline Frankreich & 1 & $(0,0)$ & 1,8 & $(0,0)$ & 6,0 & $(0,0)$ \\
\hline Deutschland & 1 & $(0,0)$ & 2,4 & $(0,0)$ & 5,1 & $(0,0)$ \\
\hline Irland & 1 & $(0,0)$ & 2,0 & $(0,0)$ & 3,3 & $(0,0)$ \\
\hline Italien & 1 & $(0,0)$ & 4,6 & $(0,0)$ & 9,5 & $(0,0)$ \\
\hline Japan & 1 & $(0,0)$ & 2,0 & $(0,1)$ & 5,1 & $(0,0)$ \\
\hline Korea & 1 & $(0,0)$ & 1,0 & $(1,0)$ & 1,1 & $(0,7)$ \\
\hline Niederlande & 1 & $(0,0)$ & 1,3 & $(0,1)$ & 2,8 & $(0,0)$ \\
\hline Norwegen & 1 & $(0,0)$ & 1,0 & $(0,9)$ & 2,0 & $(0,0)$ \\
\hline Polen & 1 & $(0,0)$ & 3,1 & $(0,0)$ & 9,5 & $(0,0)$ \\
\hline Slowakei & c & c & c & c & c & $(0,0)$ \\
\hline Spanien & 1 & $(0,0)$ & 2,0 & $(0,0)$ & 3,9 & $(0,0)$ \\
\hline Schweden & 1 & $(0,0)$ & 1,0 & $(1,0)$ & 2,3 & $(0,0)$ \\
\hline $\begin{array}{l}\text { Vereinigte Staaten } \\
\text { Subnationale Einheiten }\end{array}$ & 1 & $(0,0)$ & 2,9 & $(0,0)$ & 6,8 & $(0,0)$ \\
\hline Flandern (Belgien) & 1 & $(0,0)$ & 2,1 & $(0,0)$ & 5,7 & $(0,0)$ \\
\hline England (VK) & 1 & $(0,0)$ & 2,1 & $(0,0)$ & 6,3 & $(0,0)$ \\
\hline Nordirland (VK) & 1 & $(0,0)$ & 2,9 & $(0,0)$ & 6,1 & $(0,0)$ \\
\hline England/Nordirland (VK) & 1 & $(0,0)$ & 2,2 & $(0,0)$ & 6,4 & $(0,0)$ \\
\hline Durchschnitt & 1 & $(0,0)$ & 2,0 & $(0,1)$ & 4,5 & $(0,0)$ \\
\hline \multicolumn{7}{|l|}{ Partnerländer } \\
\hline Russische Föderation* & 1 & $(0,0)$ & 1,6 & $(0,1)$ & 2,6 & $(0,0)$ \\
\hline
\end{tabular}

* Hinweis zu den Daten der Russischen Föderation s. Abschnitt Angewandte Methodik.

Anmerkung: Die Zeilen mit getrennten Angaben zu Männern und Frauen sind im Internet verfügbar (s. StatLink).

Quelle: OECD. Survey of Adult Skills (PIAAC) (2012). PIAAC steht für das OECD Programme for the International Assessment of Adult Competencies.

Hinweise s. Anhang 3 unter www.oecd.org/edu/eag.htm. StatLink: http://dx.doi.org/10.1787/888933115559

Erläuterung der Kennzeichnung fehlender Daten s. Hinweise für den Leser. 
Diese Tabelle zeigt für jedes einzelne Land den höchsten Bildungsabschluss von 25- bis 34-jährigen Nichtschülern/Nichtstudierenden im Vergleich zum höchsten Bildungsabschluss der Eltern. So verfügen von den 25- bis 34-jährigen Kanadierinnen, die sich nicht in Ausbildung befinden und bei denen mindestens ein Elternteil über einen Abschluss im Tertiärbereich verfügt, 3 Prozent über eine Ausbildung unterhalb Sekundarbereich II, 25 Prozent über einen Abschluss im Sekundarbereich II/postsekundaren, nicht tertiären Bereich und 73 Prozent über einen Abschluss im Tertiärbereich.

\begin{tabular}{|c|c|c|c|c|c|c|c|c|c|c|c|c|c|}
\hline & \multirow[t]{4}{*}{ Bildungsstand } & \multicolumn{6}{|c|}{$\begin{array}{l}\text { Eltern mit einer Ausbildung unterhalb } \\
\text { des Sekundarbereichs II }\end{array}$} & \multicolumn{6}{|c|}{$\begin{array}{l}\text { Eltern mit einem Abschluss im Sekundarbe- } \\
\text { reich II bzw. postsekundaren, nicht tertiären } \\
\text { Bereich als höchstem Bildungsabschluss }\end{array}$} \\
\hline & & \multicolumn{2}{|c|}{ Männer } & \multicolumn{2}{|c|}{ Frauen } & \multicolumn{2}{|c|}{$M+F$} & \multicolumn{2}{|c|}{ Männer } & \multicolumn{2}{|c|}{ Frauen } & \multicolumn{2}{|c|}{$M+F$} \\
\hline & & $\%$ & S.F. & $\%$ & S.F. & $\%$ & S.F. & $\%$ & S.F. & $\%$ & S.F. & $\%$ & S.F. \\
\hline & & (25) & $(26)$ & (27) & (28) & (29) & (30) & (31) & (32) & (33) & (34) & (35) & (36) \\
\hline $\begin{array}{l}\text { OECD } \\
\text { Nationale Ein }\end{array}$ & & & & & & & & & & & & & \\
\hline Australien & $\begin{array}{l}\text { Ausbildung unterhalb Sekundarbereich II } \\
\text { Abschluss im Sekundarbereich II/ } \\
\text { postsekundaren, nicht tertiären Bereich } \\
\text { Abschluss im Tertiärbereich }\end{array}$ & $\begin{array}{l}27 \\
52 \\
21\end{array}$ & $\begin{array}{l}(4,8) \\
(5,7) \\
(3,5)\end{array}$ & $\begin{array}{l}20 \\
47 \\
33\end{array}$ & $\begin{array}{l}(3,6) \\
(5,8) \\
(5,3)\end{array}$ & $\begin{array}{l}23 \\
50 \\
27\end{array}$ & $\begin{array}{l}(2,8) \\
(3,8) \\
(2,8)\end{array}$ & $\begin{array}{l}17 \\
55 \\
28\end{array}$ & $\begin{array}{l}(4,1) \\
(4,6) \\
(4,3)\end{array}$ & $\begin{array}{l}14 \\
38 \\
48\end{array}$ & $\begin{array}{l}(3,9) \\
(5,0) \\
(5,4)\end{array}$ & $\begin{array}{l}16 \\
47 \\
38\end{array}$ & $\begin{array}{l}(2,8) \\
(3,3) \\
(3,4)\end{array}$ \\
\hline Österreich & $\begin{array}{l}\text { Ausbildung unterhalb Sekundarbereich II } \\
\text { Abschluss im Sekundarbereich II/ } \\
\text { postsekundaren, nicht tertiären Bereich } \\
\text { Abschluss im Tertiärbereich }\end{array}$ & $\begin{array}{l}\mathrm{c} \\
\mathrm{c} \\
\mathrm{c}\end{array}$ & $\begin{array}{l}\mathrm{c} \\
\mathrm{c} \\
\mathrm{c}\end{array}$ & $\begin{array}{l}\mathrm{c} \\
\mathrm{c} \\
\mathrm{c}\end{array}$ & $\begin{array}{l}\mathrm{c} \\
\mathrm{c} \\
\mathrm{c}\end{array}$ & $\begin{array}{r}34 \\
58 \\
8\end{array}$ & $\begin{array}{l}(3,5) \\
(3,9) \\
(2,2)\end{array}$ & $\begin{array}{r}9 \\
75 \\
16\end{array}$ & $\begin{array}{l}(1,6) \\
(2,4) \\
(2,0)\end{array}$ & $\begin{array}{l}11 \\
73 \\
16\end{array}$ & $\begin{array}{l}(2,0) \\
(2,5) \\
(1,8)\end{array}$ & $\begin{array}{l}10 \\
74 \\
16\end{array}$ & $\begin{array}{l}(1,3) \\
(1,8) \\
(1,4)\end{array}$ \\
\hline Kanada & $\begin{array}{l}\text { Ausbildung unterhalb Sekundarbereich II } \\
\text { Abschluss im Sekundarbereich II/ } \\
\text { postsekundaren, nicht tertiären Bereich } \\
\text { Abschluss im Tertiärbereich }\end{array}$ & $\begin{array}{l}21 \\
48 \\
31\end{array}$ & $\begin{array}{l}(5,0) \\
(6,5) \\
(5,8)\end{array}$ & $\begin{array}{l}26 \\
34 \\
40\end{array}$ & $\begin{array}{l}(4,7) \\
(4,9) \\
(5,3)\end{array}$ & $\begin{array}{l}24 \\
40 \\
36\end{array}$ & $\begin{array}{l}(3,3) \\
(3,9) \\
(3,9)\end{array}$ & $\begin{array}{l}12 \\
46 \\
42\end{array}$ & $\begin{array}{l}(2,3) \\
(3,6) \\
(3,3)\end{array}$ & $\begin{array}{r}5 \\
39 \\
56\end{array}$ & $\begin{array}{l}(1,1) \\
(2,9) \\
(2,8)\end{array}$ & $\begin{array}{r}9 \\
43 \\
49\end{array}$ & $\begin{array}{l}(1,3) \\
(2,4) \\
(2,2)\end{array}$ \\
\hline Tschechien & $\begin{array}{l}\text { Ausbildung unterhalb Sekundarbereich II } \\
\text { Abschluss im Sekundarbereich II/ } \\
\text { postsekundaren, nicht tertiären Bereich } \\
\text { Abschluss im Tertiärbereich }\end{array}$ & $\begin{array}{l}\mathrm{c} \\
\mathrm{c} \\
\mathrm{c}\end{array}$ & $\begin{array}{l}\mathrm{c} \\
\mathrm{c} \\
\mathrm{c}\end{array}$ & $\begin{array}{l}\mathrm{c} \\
\mathrm{c} \\
\mathrm{c}\end{array}$ & $\begin{array}{l}\mathrm{c} \\
\mathrm{c} \\
\mathrm{c}\end{array}$ & $\begin{array}{l}\mathrm{c} \\
\mathrm{c} \\
\mathrm{c}\end{array}$ & $\begin{array}{l}\mathrm{c} \\
\mathrm{c} \\
\mathrm{c}\end{array}$ & $\begin{array}{r}8 \\
80 \\
12\end{array}$ & $\begin{array}{l}(1,7) \\
(2,2) \\
(1,7)\end{array}$ & $\begin{array}{r}6 \\
65 \\
28\end{array}$ & $\begin{array}{l}(1,8) \\
(3,0) \\
(2,4)\end{array}$ & $\begin{array}{r}7 \\
73 \\
19\end{array}$ & $\begin{array}{l}(1,2) \\
(1,8) \\
(1,3)\end{array}$ \\
\hline Dänemark & $\begin{array}{l}\text { Ausbildung unterhalb Sekundarbereich II } \\
\text { Abschluss im Sekundarbereich II/ } \\
\text { postsekundaren, nicht tertiären Bereich } \\
\text { Abschluss im Tertiärbereich }\end{array}$ & $\begin{array}{l}\mathrm{c} \\
\mathrm{c} \\
\mathrm{c}\end{array}$ & $\begin{array}{l}\text { c } \\
\text { c } \\
\text { c }\end{array}$ & $\begin{array}{l}\mathrm{c} \\
\mathrm{c} \\
\mathrm{c}\end{array}$ & $\begin{array}{l}\mathrm{c} \\
\mathrm{c} \\
\mathrm{c}\end{array}$ & $\begin{array}{l}33 \\
43 \\
25\end{array}$ & $\begin{array}{l}(4,6) \\
(4,7) \\
(3,7)\end{array}$ & $\begin{array}{l}12 \\
59 \\
30\end{array}$ & $\begin{array}{l}(3,1) \\
(4,6) \\
(3,5)\end{array}$ & $\begin{array}{l}12 \\
33 \\
56\end{array}$ & $\begin{array}{l}(3,0) \\
(3,7) \\
(4,1)\end{array}$ & $\begin{array}{l}12 \\
48 \\
41\end{array}$ & $\begin{array}{l}(2,3) \\
(3,1) \\
(2,5)\end{array}$ \\
\hline Estland & $\begin{array}{l}\text { Ausbildung unterhalb Sekundarbereich II } \\
\text { Abschluss im Sekundarbereich II/ } \\
\text { postsekundaren, nicht tertiären Bereich } \\
\text { Abschluss im Tertiärbereich }\end{array}$ & $\begin{array}{l}\mathrm{c} \\
\mathrm{c} \\
\mathrm{c}\end{array}$ & $\begin{array}{l}\text { c } \\
\text { c } \\
\text { c }\end{array}$ & $\begin{array}{l}\mathrm{c} \\
\mathrm{c} \\
\mathrm{c}\end{array}$ & $\begin{array}{l}\text { c } \\
\text { c } \\
\text { c }\end{array}$ & $\begin{array}{l}38 \\
44 \\
18\end{array}$ & $\begin{array}{l}(5,8) \\
(4,8) \\
(4,0)\end{array}$ & $\begin{array}{l}19 \\
52 \\
29\end{array}$ & $\begin{array}{l}(2,5) \\
(3,4) \\
(3,0)\end{array}$ & $\begin{array}{l}12 \\
39 \\
49\end{array}$ & $\begin{array}{l}(2,2) \\
(3,0) \\
(2,7)\end{array}$ & $\begin{array}{l}15 \\
46 \\
39\end{array}$ & $\begin{array}{l}(1,7) \\
(2,2) \\
(2,1)\end{array}$ \\
\hline Finnland & $\begin{array}{l}\text { Ausbildung unterhalb Sekundarbereich II } \\
\text { Abschluss im Sekundarbereich II/ } \\
\text { postsekundaren, nicht tertiären Bereich } \\
\text { Abschluss im Tertiärbereich }\end{array}$ & $\begin{array}{l}\mathrm{c} \\
\mathrm{c} \\
\mathrm{c}\end{array}$ & $\begin{array}{l}\text { c } \\
\text { c } \\
\text { c }\end{array}$ & $\begin{array}{l}\mathrm{c} \\
\mathrm{c} \\
\mathrm{c}\end{array}$ & $\begin{array}{l}\mathrm{C} \\
\mathrm{C} \\
\mathrm{c}\end{array}$ & $\begin{array}{r}7 \\
58 \\
34\end{array}$ & $\begin{array}{l}(2,8) \\
(4,4) \\
(4,5)\end{array}$ & $\begin{array}{l}12 \\
56 \\
32\end{array}$ & $\begin{array}{l}(2,7) \\
(3,4) \\
(3,1)\end{array}$ & $\begin{array}{r}7 \\
38 \\
55\end{array}$ & $\begin{array}{l}(1,9) \\
(3,2) \\
(3,2)\end{array}$ & $\begin{array}{r}9 \\
47 \\
43\end{array}$ & $\begin{array}{l}(1,6) \\
(2,2) \\
(2,2)\end{array}$ \\
\hline Frankreich & $\begin{array}{l}\text { Ausbildung unterhalb Sekundarbereich II } \\
\text { Abschluss im Sekundarbereich II/ } \\
\text { postsekundaren, nicht tertiären Bereich } \\
\text { Abschluss im Tertiärbereich }\end{array}$ & $\begin{array}{l}28 \\
48 \\
24\end{array}$ & $\begin{array}{l}(3,7) \\
(3,9) \\
(3,8)\end{array}$ & $\begin{array}{l}25 \\
49 \\
26\end{array}$ & $\begin{array}{l}(3,3) \\
(4,2) \\
(3,5)\end{array}$ & $\begin{array}{l}26 \\
48 \\
25\end{array}$ & $\begin{array}{l}(2,4) \\
(2,5) \\
(2,3)\end{array}$ & $\begin{array}{l}12 \\
55 \\
33\end{array}$ & $\begin{array}{l}(2,2) \\
(3,4) \\
(3,3)\end{array}$ & $\begin{array}{r}6 \\
45 \\
48\end{array}$ & $\begin{array}{l}(1,5) \\
(3,2) \\
(3,3)\end{array}$ & $\begin{array}{r}9 \\
50 \\
41\end{array}$ & $\begin{array}{l}(1,3) \\
(2,2) \\
(2,2)\end{array}$ \\
\hline Deutschland & $\begin{array}{l}\text { Ausbildung unterhalb Sekundarbereich II } \\
\text { Abschluss im Sekundarbereich II/ } \\
\text { postsekundaren, nicht tertiären Bereich } \\
\text { Abschluss im Tertiärbereich }\end{array}$ & $\begin{array}{l}\mathrm{c} \\
\mathrm{c} \\
\mathrm{c}\end{array}$ & $\begin{array}{l}\mathrm{c} \\
\mathrm{c} \\
\mathrm{c}\end{array}$ & $\begin{array}{l}\mathrm{c} \\
\mathrm{c} \\
\mathrm{c}\end{array}$ & $\begin{array}{l}\mathrm{c} \\
\mathrm{c} \\
\mathrm{c}\end{array}$ & $\begin{array}{l}\mathrm{c} \\
\mathrm{c} \\
\mathrm{c}\end{array}$ & $\begin{array}{l}\mathrm{c} \\
\mathrm{c} \\
\mathrm{c}\end{array}$ & $\begin{array}{r}7 \\
66 \\
27\end{array}$ & $\begin{array}{l}(2,0) \\
(4,3) \\
(3,9)\end{array}$ & $\begin{array}{l}10 \\
65 \\
25\end{array}$ & $\begin{array}{l}(2,4) \\
(3,7) \\
(3,1)\end{array}$ & $\begin{array}{r}8 \\
66 \\
26\end{array}$ & $\begin{array}{l}(1,6) \\
(2,9) \\
(2,6)\end{array}$ \\
\hline Irland & $\begin{array}{l}\text { Ausbildung unterhalb Sekundarbereich II } \\
\text { Abschluss im Sekundarbereich II/ } \\
\text { postsekundaren, nicht tertiären Bereich } \\
\text { Abschluss im Tertiärbereich }\end{array}$ & $\begin{array}{l}25 \\
44 \\
31\end{array}$ & $\begin{array}{l}(3,0) \\
(3,7) \\
(3,3)\end{array}$ & $\begin{array}{l}22 \\
48 \\
29\end{array}$ & $\begin{array}{l}(2,7) \\
(3,0) \\
(2,5)\end{array}$ & $\begin{array}{l}24 \\
46 \\
30\end{array}$ & $\begin{array}{l}(1,9) \\
(2,1) \\
(1,7)\end{array}$ & $\begin{array}{l}11 \\
51 \\
38\end{array}$ & $\begin{array}{l}(2,3) \\
(4,6) \\
(4,5)\end{array}$ & $\begin{array}{r}5 \\
41 \\
54\end{array}$ & $\begin{array}{l}(1,4) \\
(3,7) \\
(3,7)\end{array}$ & $\begin{array}{r}8 \\
46 \\
46\end{array}$ & $\begin{array}{l}(1,3) \\
(2,7) \\
(2,8)\end{array}$ \\
\hline Italien & $\begin{array}{l}\text { Ausbildung unterhalb Sekundarbereich II } \\
\text { Abschluss im Sekundarbereich II/ } \\
\text { postsekundaren, nicht tertiären Bereich } \\
\text { Abschluss im Tertiärbereich }\end{array}$ & $\begin{array}{r}49 \\
44 \\
8\end{array}$ & $\begin{array}{l}(3,9) \\
(4,0) \\
(2,1)\end{array}$ & $\begin{array}{l}40 \\
49 \\
11\end{array}$ & $\begin{array}{l}(3,7) \\
(3,7) \\
(2,1)\end{array}$ & $\begin{array}{r}45 \\
46 \\
9\end{array}$ & $\begin{array}{l}(2,6) \\
(2,7) \\
(1,5)\end{array}$ & $\begin{array}{l}\mathrm{c} \\
\mathrm{c} \\
\mathrm{c}\end{array}$ & $\begin{array}{l}\mathrm{c} \\
\mathrm{c} \\
\mathrm{c}\end{array}$ & $\begin{array}{r}6 \\
52 \\
42\end{array}$ & $\begin{array}{l}(2,6) \\
(5,4) \\
(4,8)\end{array}$ & $\begin{array}{l}10 \\
54 \\
36\end{array}$ & $\begin{array}{l}(2,7) \\
(3,5) \\
(3,3)\end{array}$ \\
\hline Japan & $\begin{array}{l}\text { Ausbildung unterhalb Sekundarbereich II } \\
\text { Abschluss im Sekundarbereich II/ } \\
\text { postsekundaren, nicht tertiären Bereich } \\
\text { Abschluss im Tertiärbereich }\end{array}$ & $\begin{array}{l}\mathrm{c} \\
\mathrm{c} \\
\mathrm{c}\end{array}$ & $\begin{array}{l}\mathrm{c} \\
\mathrm{c} \\
\mathrm{c}\end{array}$ & $\begin{array}{l}\mathrm{c} \\
\mathrm{c} \\
\mathrm{c}\end{array}$ & $\begin{array}{l}\mathrm{c} \\
\mathrm{c} \\
\mathrm{c}\end{array}$ & $\begin{array}{l}\mathrm{c} \\
\mathrm{c} \\
\mathrm{c}\end{array}$ & $\begin{array}{l}\mathrm{c} \\
\mathrm{c} \\
\mathrm{c}\end{array}$ & $\begin{array}{r}9 \\
47 \\
44\end{array}$ & $\begin{array}{l}(2,2) \\
(3,4) \\
(3,7)\end{array}$ & $\begin{array}{r}9 \\
43 \\
47\end{array}$ & $\begin{array}{l}(2,8) \\
(3,6) \\
(3,5)\end{array}$ & $\begin{array}{r}9 \\
45 \\
45\end{array}$ & $\begin{array}{l}(1,6) \\
(2,4) \\
(2,6)\end{array}$ \\
\hline Korea & $\begin{array}{l}\text { Ausbildung unterhalb Sekundarbereich II } \\
\text { Abschluss im Sekundarbereich II/ } \\
\text { postsekundaren, nicht tertiären Bereich } \\
\text { Abschluss im Tertiärbereich }\end{array}$ & $\begin{array}{r}6 \\
42 \\
52\end{array}$ & $\begin{array}{l}(1,7) \\
(3,0) \\
(3,2)\end{array}$ & $\begin{array}{r}6 \\
40 \\
54\end{array}$ & $\begin{array}{l}(1,9) \\
(3,7) \\
(3,4)\end{array}$ & $\begin{array}{r}6 \\
41 \\
53\end{array}$ & $\begin{array}{l}(1,2) \\
(2,1) \\
(2,0)\end{array}$ & $\begin{array}{r}1 \\
40 \\
59\end{array}$ & $\begin{array}{l}(0,8) \\
(3,0) \\
(2,9)\end{array}$ & $\begin{array}{r}c \\
31 \\
68\end{array}$ & $\begin{array}{r}c \\
(2,8) \\
(2,9)\end{array}$ & $\begin{array}{r}1 \\
35 \\
64\end{array}$ & $\begin{array}{l}(0,5) \\
(1,9) \\
(1,9)\end{array}$ \\
\hline Niederlande & $\begin{array}{l}\text { Ausbildung unterhalb Sekundarbereich II } \\
\text { Abschluss im Sekundarbereich II/ } \\
\text { postsekundaren, nicht tertiären Bereich } \\
\text { Abschluss im Tertiärbereich }\end{array}$ & $\begin{array}{l}36 \\
41 \\
23\end{array}$ & $\begin{array}{l}(5,3) \\
(5,1) \\
(4,7)\end{array}$ & $\begin{array}{l}19 \\
47 \\
34\end{array}$ & $\begin{array}{l}(3,3) \\
(4,4) \\
(4,1)\end{array}$ & $\begin{array}{l}27 \\
44 \\
29\end{array}$ & $\begin{array}{l}(3,2) \\
(3,3) \\
(3,0)\end{array}$ & $\begin{array}{l}15 \\
49 \\
36\end{array}$ & $\begin{array}{l}(2,6) \\
(5,3) \\
(5,7)\end{array}$ & $\begin{array}{l}14 \\
47 \\
39\end{array}$ & $\begin{array}{l}(3,3) \\
(4,8) \\
(4,4)\end{array}$ & $\begin{array}{l}14 \\
48 \\
37\end{array}$ & $\begin{array}{l}(2,0) \\
(3,2) \\
(3,3)\end{array}$ \\
\hline
\end{tabular}

* Hinweis zu den Daten der Russischen Föderation s. Abschnitt Angewandte Methodik.

Anmerkung: Spalten mit getrennten Angaben zu anderen Altergruppen und für alle Bildungsstände von Eltern zusammen sind im Internet verfügbar (s. StatLink unten). Quelle: OECD. Survey of Adult Skills (PIAAC) (2012). PIAAC steht für das OECD Programme for the International Assessment of Adult Competencies. Hinweise s. Anhang 3 unter www.oecd.org/edu/eag.htm. StatLink: http://dx.doi.org/10.1787/888933115578 Erläuterung der Kennzeichnung fehlender Daten s. Hinweise für den Leser. 
Tabelle A4.2 (Forts. 1)

\section{Bildungsstand von Nichtschülern/Nichtstudierenden, nach Altersgruppe und Bildungsstand der Eltern (2012)}

\section{5- bis 34-Jährige}

Diese Tabelle zeigt für jedes einzelne Land den höchsten Bildungsabschluss von 25- bis 34-jährigen Nichtschülern/Nichtstudierenden im Vergleich zum höchsten Bildungsabschluss der Eltern. So verfügen von den 25-bis 34-jährigen Kanadierinnen, die sich nicht in Ausbildung befinden und bei denen mindestens ein Elternteil über einen Abschluss im Tertiärbereich verfügt, 3 Prozent über eine Ausbildung unterhalb Sekundarbereich II, 25 Prozent über einen Abschluss im Sekundarbereich II/postsekundaren, nicht tertiären Bereich und 73 Prozent über einen Abschluss im Tertiärbereich.

\begin{tabular}{|c|c|c|c|c|c|c|c|c|c|c|c|c|c|}
\hline & \multirow[t]{4}{*}{ Bildungsstand } & \multicolumn{6}{|c|}{$\begin{array}{l}\text { Eltern mit einer Ausbildung unterhalb } \\
\text { des Sekundarbereichs II }\end{array}$} & \multicolumn{6}{|c|}{$\begin{array}{l}\text { Eltern mit einem Abschluss im Sekundarbe } \\
\text { reich II bzw. postsekundaren, nicht tertiärer } \\
\text { Bereich als höchstem Bildungsabschluss }\end{array}$} \\
\hline & & \multicolumn{2}{|c|}{ Männer } & \multicolumn{2}{|c|}{ Frauen } & \multicolumn{2}{|c|}{$M+F$} & \multicolumn{2}{|c|}{ Männer } & \multicolumn{2}{|c|}{ Frauen } & \multicolumn{2}{|c|}{$M+F$} \\
\hline & & $\%$ & S.F. & $\%$ & S.F. & $\%$ & S.F. & $\%$ & S.F. & $\%$ & S.F. & $\%$ & S.F. \\
\hline & & (25) & (26) & (27) & (28) & (29) & (30) & (31) & (32) & (33) & (34) & (35) & (36) \\
\hline $\begin{array}{l}\text { OECD } \\
\text { Nationale Einheiten }\end{array}$ & & & & & & & & & & & & & \\
\hline Norwegen & $\begin{array}{l}\text { Ausbildung unterhalb Sekundarbereich II } \\
\text { Abschluss im Sekundarbereich II/ } \\
\text { postsekundaren, nicht tertiären Bereich } \\
\text { Abschluss im Tertiärbereich }\end{array}$ & $\begin{array}{l}\mathrm{c} \\
\mathrm{c} \\
\mathrm{c}\end{array}$ & $\begin{array}{l}\mathrm{c} \\
\mathrm{c} \\
\mathrm{c}\end{array}$ & $\begin{array}{l}\text { c } \\
\text { c } \\
\text { c }\end{array}$ & $\begin{array}{l}\mathrm{c} \\
\mathrm{c} \\
\mathrm{c}\end{array}$ & $\begin{array}{l}\text { c } \\
\text { c } \\
\text { c }\end{array}$ & $\begin{array}{l}\mathrm{c} \\
\mathrm{c} \\
\mathrm{c}\end{array}$ & $\begin{array}{l}24 \\
50 \\
26\end{array}$ & $\begin{array}{l}(3,5) \\
(3,7) \\
(3,5)\end{array}$ & $\begin{array}{l}17 \\
40 \\
43\end{array}$ & $\begin{array}{l}(3,1) \\
(4,8) \\
(4,1)\end{array}$ & $\begin{array}{l}21 \\
45 \\
34\end{array}$ & $\begin{array}{l}(2,4) \\
(2,8) \\
(2,6)\end{array}$ \\
\hline Polen & $\begin{array}{l}\text { Ausbildung unterhalb Sekundarbereich II } \\
\text { Abschluss im Sekundarbereich II/ } \\
\text { postsekundaren, nicht tertiären Bereich } \\
\text { Abschluss im Tertiärbereich }\end{array}$ & $\begin{array}{l}\mathrm{c} \\
\mathrm{c} \\
\mathrm{c}\end{array}$ & $\begin{array}{l}\mathrm{c} \\
\mathrm{c}\end{array}$ & $\begin{array}{l}\text { c } \\
\text { c } \\
\text { c }\end{array}$ & $\begin{array}{l}\mathrm{c} \\
\mathrm{c} \\
\mathrm{c}\end{array}$ & $\begin{array}{l}18 \\
67 \\
16\end{array}$ & $\begin{array}{l}(4,3) \\
(5,2) \\
(4,7)\end{array}$ & $\begin{array}{r}6 \\
63 \\
32\end{array}$ & $\begin{array}{l}(1,3) \\
(2,6) \\
(2,6)\end{array}$ & $\begin{array}{r}4 \\
49 \\
47\end{array}$ & $\begin{array}{l}(1,2) \\
(2,7) \\
(2,8)\end{array}$ & $\begin{array}{r}5 \\
56 \\
39\end{array}$ & $\begin{array}{l}(0,9) \\
(2,0) \\
(1,9)\end{array}$ \\
\hline Slowakei & $\begin{array}{l}\text { Ausbildung unterhalb Sekundarbereich II } \\
\text { Abschluss im Sekundarbereich II/ } \\
\text { postsekundaren, nicht tertiären Bereich } \\
\text { Abschluss im Tertiärbereich }\end{array}$ & $\begin{array}{r}60 \\
40 \\
c\end{array}$ & $\begin{array}{r}(5,8) \\
(5,8) \\
\mathrm{C}\end{array}$ & $\begin{array}{r}57 \\
39 \\
4\end{array}$ & $\begin{array}{l}(5,8) \\
(5,7) \\
(2,3)\end{array}$ & $\begin{array}{r}58 \\
40 \\
2\end{array}$ & $\begin{array}{l}(4,6) \\
(4,4) \\
(1,2)\end{array}$ & $\begin{array}{r}7 \\
73 \\
20\end{array}$ & $\begin{array}{l}(1,2) \\
(2,5) \\
(2,6)\end{array}$ & $\begin{array}{r}5 \\
67 \\
28\end{array}$ & $\begin{array}{l}(0,9) \\
(2,9) \\
(2,7)\end{array}$ & $\begin{array}{r}6 \\
70 \\
24\end{array}$ & $\begin{array}{l}(0,7) \\
(2,1) \\
(2,0)\end{array}$ \\
\hline Spanien & $\begin{array}{l}\text { Ausbildung unterhalb Sekundarbereich II } \\
\text { Abschluss im Sekundarbereich II/ } \\
\text { postsekundaren, nicht tertiären Bereich } \\
\text { Abschluss im Tertiärbereich }\end{array}$ & $\begin{array}{l}56 \\
25 \\
19\end{array}$ & $\begin{array}{l}(3,1) \\
(2,6) \\
(2,2)\end{array}$ & $\begin{array}{l}45 \\
23 \\
32\end{array}$ & $\begin{array}{l}(3,2) \\
(2,8) \\
(2,9)\end{array}$ & $\begin{array}{l}51 \\
24 \\
25\end{array}$ & $\begin{array}{l}(2,2) \\
(1,7) \\
(1,9)\end{array}$ & $\begin{array}{l}30 \\
37 \\
33\end{array}$ & $\begin{array}{l}(4,5) \\
(5,3) \\
(4,2)\end{array}$ & $\begin{array}{l}14 \\
28 \\
58\end{array}$ & $\begin{array}{l}(3,1) \\
(4,7) \\
(5,1)\end{array}$ & $\begin{array}{l}22 \\
32 \\
46\end{array}$ & $\begin{array}{l}(2,9) \\
(3,7) \\
(3,6)\end{array}$ \\
\hline Schweden & $\begin{array}{l}\text { Ausbildung unterhalb Sekundarbereich II } \\
\text { Abschluss im Sekundarbereich II/ } \\
\text { postsekundaren, nicht tertiären Bereich } \\
\text { Abschluss im Tertiärbereich }\end{array}$ & $\begin{array}{l}\mathrm{c} \\
\mathrm{c} \\
\mathrm{c}\end{array}$ & $\begin{array}{l}\mathrm{c} \\
\mathrm{c} \\
\mathrm{c}\end{array}$ & $\begin{array}{l}\mathrm{c} \\
\mathrm{c} \\
\mathrm{c}\end{array}$ & $\begin{array}{l}\mathrm{c} \\
\mathrm{c} \\
\mathrm{c}\end{array}$ & $\begin{array}{l}25 \\
48 \\
27\end{array}$ & $\begin{array}{l}(4,5) \\
(4,2) \\
(3,7)\end{array}$ & $\begin{array}{l}19 \\
57 \\
23\end{array}$ & $\begin{array}{l}(4,4) \\
(5,4) \\
(3,7)\end{array}$ & $\begin{array}{l}11 \\
51 \\
38\end{array}$ & $\begin{array}{l}(3,2) \\
(4,8) \\
(4,6)\end{array}$ & $\begin{array}{l}15 \\
54 \\
31\end{array}$ & $\begin{array}{l}(2,8) \\
(3,9) \\
(3,2)\end{array}$ \\
\hline Vereinigte Staaten & $\begin{array}{l}\text { Ausbildung unterhalb Sekundarbereich II } \\
\text { Abschluss im Sekundarbereich II/ } \\
\text { postsekundaren, nicht tertiären Bereich } \\
\text { Abschluss im Tertiärbereich }\end{array}$ & $\begin{array}{l}\mathrm{c} \\
\mathrm{c} \\
\mathrm{c}\end{array}$ & $\begin{array}{l}\mathrm{c} \\
\mathrm{c} \\
\mathrm{c}\end{array}$ & $\begin{array}{l}\text { c } \\
\text { c } \\
\text { c }\end{array}$ & $\begin{array}{l}\mathrm{c} \\
\mathrm{c} \\
\mathrm{c}\end{array}$ & $\begin{array}{r}35 \\
61 \\
5\end{array}$ & $\begin{array}{l}(4,6) \\
(4,7) \\
(1,4)\end{array}$ & $\begin{array}{l}11 \\
59 \\
30\end{array}$ & $\begin{array}{l}(2,7) \\
(4,2) \\
(4,1)\end{array}$ & $\begin{array}{r}5 \\
52 \\
43\end{array}$ & $\begin{array}{l}(1,5) \\
(3,7) \\
(3,5)\end{array}$ & $\begin{array}{r}8 \\
56 \\
36\end{array}$ & $\begin{array}{l}(1,7) \\
(2,7) \\
(2,9)\end{array}$ \\
\hline Subnationale Einh & & & & & & & & & & & & & \\
\hline Flandern (Belgien) & $\begin{array}{l}\text { Ausbildung unterhalb Sekundarbereich II } \\
\text { Abschluss im Sekundarbereich II/ } \\
\text { postsekundaren, nicht tertiären Bereich } \\
\text { Abschluss im Tertiärbereich }\end{array}$ & $\begin{array}{l}\mathrm{c} \\
\mathrm{c} \\
\mathrm{c}\end{array}$ & $\begin{array}{l}\text { c } \\
\text { c } \\
\text { c }\end{array}$ & $\begin{array}{l}17 \\
54 \\
29\end{array}$ & $\begin{array}{l}(4,0) \\
(5,6) \\
(4,9)\end{array}$ & $\begin{array}{l}17 \\
61 \\
22\end{array}$ & $\begin{array}{l}(3,3) \\
(4,2) \\
(3,6)\end{array}$ & $\begin{array}{r}8 \\
59 \\
33\end{array}$ & $\begin{array}{l}(2,1) \\
(3,9) \\
(3,5)\end{array}$ & $\begin{array}{r}6 \\
47 \\
47\end{array}$ & $\begin{array}{l}(2,0) \\
(3,8) \\
(3,7)\end{array}$ & $\begin{array}{r}7 \\
53 \\
40\end{array}$ & $\begin{array}{l}(1,4) \\
(2,5) \\
(2,3)\end{array}$ \\
\hline England (VK) & $\begin{array}{l}\text { Ausbildung unterhalb Sekundarbereich II } \\
\text { Abschluss im Sekundarbereich II/ } \\
\text { postsekundaren, nicht tertiären Bereich } \\
\text { Abschluss im Tertiärbereich }\end{array}$ & $\begin{array}{l}\mathrm{c} \\
\mathrm{c} \\
\mathrm{c}\end{array}$ & $\begin{array}{l}\mathrm{c} \\
\mathrm{c} \\
\mathrm{c}\end{array}$ & $\begin{array}{l}\text { c } \\
\text { c } \\
\text { c }\end{array}$ & $\begin{array}{l}\mathrm{c} \\
\mathrm{c} \\
\mathrm{c}\end{array}$ & $\begin{array}{l}36 \\
40 \\
24\end{array}$ & $\begin{array}{l}(4,6) \\
(4,9) \\
(4,8)\end{array}$ & $\begin{array}{l}16 \\
39 \\
45\end{array}$ & $\begin{array}{l}(3,1) \\
(4,7) \\
(4,2)\end{array}$ & $\begin{array}{l}12 \\
41 \\
47\end{array}$ & $\begin{array}{l}(2,4) \\
(3,6) \\
(3,5)\end{array}$ & $\begin{array}{l}14 \\
40 \\
46\end{array}$ & $\begin{array}{l}(1,8) \\
(3,1) \\
(2,7)\end{array}$ \\
\hline Nordirland (VK) & $\begin{array}{l}\text { Ausbildung unterhalb Sekundarbereich II } \\
\text { Abschluss im Sekundarbereich II/postse- } \\
\text { kundaren, nicht tertiären Bereich } \\
\text { Abschluss im Tertiärbereich }\end{array}$ & $\begin{array}{l}\mathrm{c} \\
\mathrm{c} \\
\mathrm{c}\end{array}$ & $\begin{array}{l}\mathrm{c} \\
\mathrm{c} \\
\mathrm{c}\end{array}$ & $\begin{array}{l}40 \\
34 \\
26\end{array}$ & $\begin{array}{l}(6,8) \\
(5,1) \\
(5,0)\end{array}$ & $\begin{array}{l}44 \\
36 \\
20\end{array}$ & $\begin{array}{l}(4,6) \\
(4,2) \\
(3,2)\end{array}$ & $\begin{array}{l}17 \\
42 \\
40\end{array}$ & $\begin{array}{l}(4,4) \\
(4,6) \\
(5,4)\end{array}$ & $\begin{array}{l}12 \\
45 \\
43\end{array}$ & $\begin{array}{l}(3,0) \\
(3,9) \\
(4,3)\end{array}$ & $\begin{array}{l}15 \\
44 \\
42\end{array}$ & $\begin{array}{l}(2,6) \\
(2,8) \\
(2,8)\end{array}$ \\
\hline England/Nordirland (VK) & $\begin{array}{l}\text { Ausbildung unterhalb Sekundarbereich II } \\
\text { Abschluss im Sekundarbereich II/ } \\
\text { postsekundaren, nicht tertiären Bereich } \\
\text { Abschluss im Tertiärbereich }\end{array}$ & $\begin{array}{l}37 \\
38 \\
25\end{array}$ & $\begin{array}{l}(7,3) \\
(6,7) \\
(7,5)\end{array}$ & $\begin{array}{l}36 \\
41 \\
22\end{array}$ & $\begin{array}{l}(5,3) \\
(5,8) \\
(5,2)\end{array}$ & $\begin{array}{l}36 \\
40 \\
24\end{array}$ & $\begin{array}{l}(4,3) \\
(4,6) \\
(4,5)\end{array}$ & $\begin{array}{l}16 \\
39 \\
44\end{array}$ & $\begin{array}{l}(3,0) \\
(4,5) \\
(4,1)\end{array}$ & $\begin{array}{l}12 \\
41 \\
47\end{array}$ & $\begin{array}{l}(2,3) \\
(3,4) \\
(3,4)\end{array}$ & $\begin{array}{l}14 \\
40 \\
46\end{array}$ & $\begin{array}{l}(1,7) \\
(2,9) \\
(2,6)\end{array}$ \\
\hline Durchschnitt & $\begin{array}{l}\text { Ausbildung unterhalb Sekundarbereich II } \\
\text { Abschluss im Sekundarbereich II/ } \\
\text { postsekundaren, nicht tertiären Bereich } \\
\text { Abschluss im Tertiärbereich }\end{array}$ & $\begin{array}{l}35 \\
42 \\
26\end{array}$ & $\begin{array}{l}(1,5) \\
(1,5) \\
(1,4)\end{array}$ & $\begin{array}{l}29 \\
43 \\
29\end{array}$ & $\begin{array}{l}(1,2) \\
(1,4) \\
(1,2)\end{array}$ & $\begin{array}{l}29 \\
48 \\
23\end{array}$ & $\begin{array}{l}(0,9) \\
(0,9) \\
(0,7)\end{array}$ & $\begin{array}{l}13 \\
56 \\
32\end{array}$ & $\begin{array}{l}(0,6) \\
(0,9) \\
(0,8)\end{array}$ & $\begin{array}{r}9 \\
47 \\
45\end{array}$ & $\begin{array}{l}(0,5) \\
(0,8) \\
(0,8)\end{array}$ & $\begin{array}{l}11 \\
51 \\
38\end{array}$ & $\begin{array}{l}(0,4) \\
(0,6) \\
(0,5)\end{array}$ \\
\hline Partnerländer & & & & & & & & & & & & & \\
\hline Russische Föderation* & $\begin{array}{l}\text { Ausbildung unterhalb Sekundarbereich II } \\
\text { Abschluss im Sekundarbereich II/ } \\
\text { postsekundaren, nicht tertiären Bereich } \\
\text { Abschluss im Tertiärbereich }\end{array}$ & $\begin{array}{l}\mathrm{c} \\
\mathrm{c} \\
\mathrm{c}\end{array}$ & c & $\begin{array}{l}\mathrm{c} \\
\mathrm{c} \\
\mathrm{c}\end{array}$ & $\begin{array}{l}\mathrm{c} \\
\mathrm{c} \\
\mathrm{c}\end{array}$ & $\begin{array}{l}\mathrm{c} \\
\mathrm{c} \\
\mathrm{c}\end{array}$ & $\begin{array}{l}\mathrm{c} \\
\mathrm{c} \\
\mathrm{c}\end{array}$ & $\begin{array}{l}14 \\
22 \\
64\end{array}$ & $\begin{array}{l}(3,2) \\
(4,2) \\
(5,2)\end{array}$ & $\begin{array}{r}2 \\
32 \\
65\end{array}$ & $\begin{array}{l}(1,2) \\
(2,6) \\
(3,0)\end{array}$ & $\begin{array}{r}8 \\
27 \\
65\end{array}$ & $\begin{array}{l}(1,5) \\
(2,9) \\
(2,9)\end{array}$ \\
\hline
\end{tabular}

* Hinweis zu den Daten der Russischen Föderation s. Abschnitt Angewandte Methodik.

Anmerkung: Spalten mit getrennten Angaben zu anderen Altergruppen und für alle Bildungsstände von Eltern zusammen sind im Internet verfügbar (s. StatLink unten). Quelle: OECD. Survey of Adult Skills (PIAAC) (2012). PIAAC steht für das OECD Programme for the International Assessment of Adult Competencies. Hinweise s. Anhang 3 unter www.oecd.org/edu/eag.htm. StatLink: http://dx.doi.org/10.1787/888933115578 Erläuterung der Kennzeichnung fehlender Daten s. Hinweise für den Leser. 
Diese Tabelle zeigt für jedes einzelne Land den höchsten Bildungsabschluss von 25- bis 34-jährigen Nichtschülern/Nichtstudierenden im Vergleich zum höchsten Bildungsabschluss der Eltern. So verfügen von den 25-bis 34-jährigen Kanadierinnen, die sich nicht in Ausbildung befinden und bei denen mindestens ein Elternteil über einen Abschluss im Tertiärbereich verfügt, 3 Prozent über eine Ausbildung unterhalb Sekundarbereich II, 25 Prozent über einen Abschluss im Sekundarbereich II/postsekundaren, nicht tertiären Bereich und 73 Prozent über einen Abschluss im Tertiärbereich.

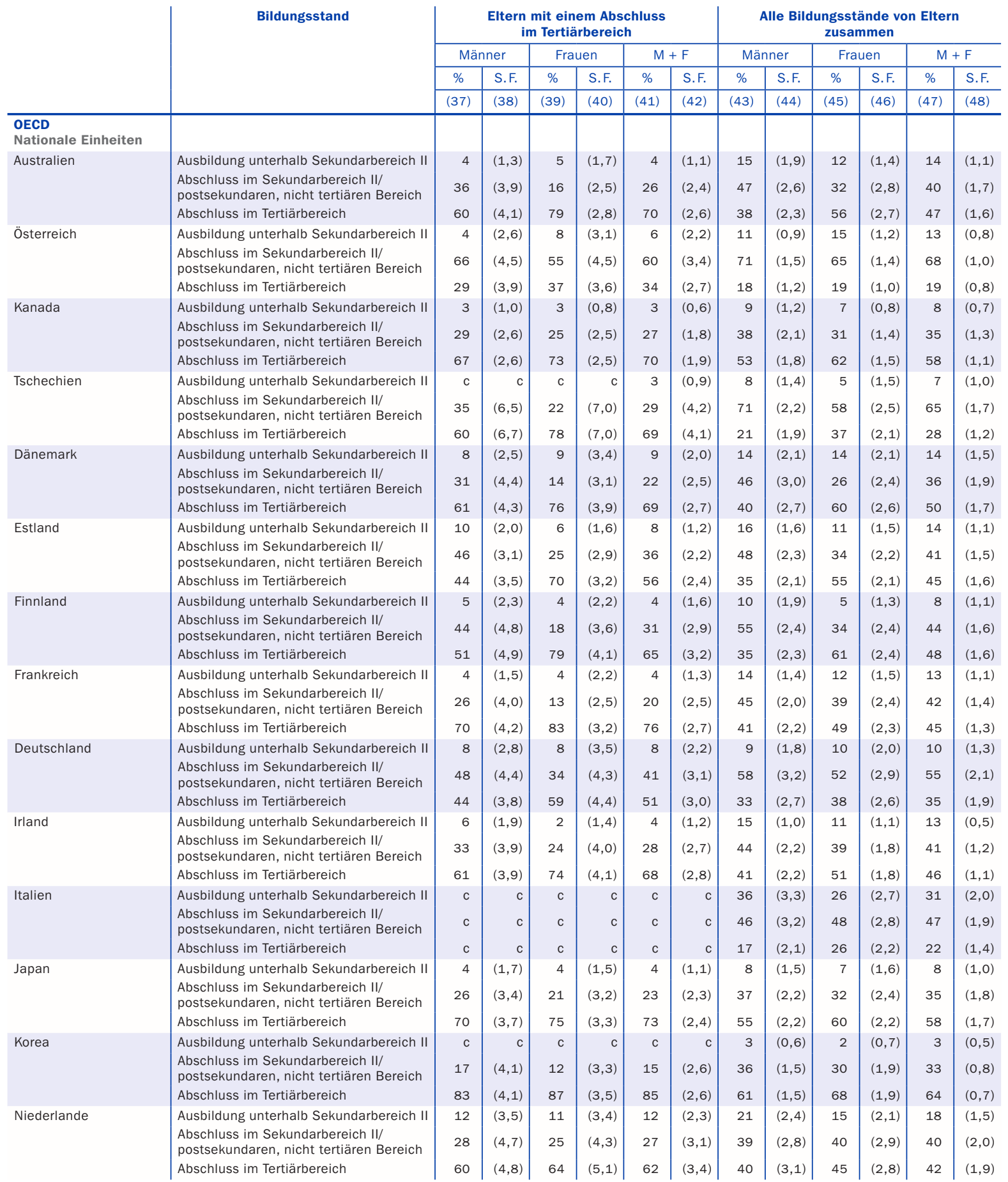

* Hinweis zu den Daten der Russischen Föderation s. Abschnitt Angewandte Methodik.

Anmerkung: Spalten mit getrennten Angaben zu anderen Altergruppen und für alle Bildungsstände von Eltern zusammen sind im Internet verfügbar (s. StatLink unten). Quelle: OECD. Survey of Adult Skills (PIAAC) (2012). PIAAC steht für das OECD Programme for the International Assessment of Adult Competencies. Hinweise s. Anhang 3 unter www.oecd.org/edu/eag.htm. StatLink: http://dx.doi.org/10.1787/888933115578 Erläuterung der Kennzeichnung fehlender Daten s. Hinweise für den Leser. 
Tabelle A4.2 (Forts. 3)

\section{Bildungsstand von Nichtschülern/Nichtstudierenden, nach Altersgruppe und Bildungsstand der Eltern (2012)}

\section{5- bis 34-Jährige}

Diese Tabelle zeigt für jedes einzelne Land den höchsten Bildungsabschluss von 25- bis 34-jährigen Nichtschülern/Nichtstudierenden im Vergleich zum höchsten Bildungsabschluss der Eltern. So verfügen von den 25- bis 34-jährigen Kanadierinnen, die sich nicht in Ausbildung befinden und bei denen mindestens ein Elternteil über einen Abschluss im Tertiärbereich verfügt, 3 Prozent über eine Ausbildung unterhalb Sekundarbereich II, 25 Prozent über einen Abschluss im Sekundarbereich II/postsekundaren, nicht tertiären Bereich und 73 Prozent über einen Abschluss im Tertiärbereich.

\begin{tabular}{|c|c|c|c|c|c|c|c|c|c|c|c|c|c|}
\hline & \multirow[t]{4}{*}{ Bildungsstand } & \multicolumn{6}{|c|}{$\begin{array}{l}\text { Eltern mit einem Abschluss } \\
\text { im Tertiärbereich }\end{array}$} & \multicolumn{6}{|c|}{$\begin{array}{l}\text { Alle Bildungsstände von Eltern } \\
\text { zusammen }\end{array}$} \\
\hline & & \multicolumn{2}{|c|}{ Männer } & \multicolumn{2}{|c|}{ Frauen } & \multicolumn{2}{|c|}{$M+F$} & \multicolumn{2}{|c|}{ Männer } & \multicolumn{2}{|c|}{ Frauen } & \multicolumn{2}{|c|}{$M+F$} \\
\hline & & $\%$ & S.F. & $\%$ & S.F. & $\%$ & S.F. & $\%$ & S.F. & $\%$ & S.F. & $\%$ & S.F. \\
\hline & & (37) & (38) & (39) & (40) & (41) & (42) & (43) & (44) & (45) & (46) & (47) & (48) \\
\hline \multicolumn{14}{|l|}{$\begin{array}{l}\text { OECD } \\
\text { Nationale Einheiten }\end{array}$} \\
\hline \multirow[t]{3}{*}{ Norwegen } & Ausbildung unterhalb Sekundarbereich II & 14 & $(3,3)$ & 4 & $(1,7)$ & 9 & $(1,9)$ & 20 & $(2,2)$ & 13 & $(1,7)$ & 17 & $(1,4)$ \\
\hline & $\begin{array}{l}\text { Abschluss im Sekundarbereich II/ } \\
\text { postsekundaren, nicht tertiären Bereich }\end{array}$ & 36 & $(3,9)$ & 25 & $(3,6)$ & 30 & $(3,0)$ & 43 & $(2,5)$ & 31 & $(2,5)$ & 37 & $(1,8)$ \\
\hline & Abschluss im Tertiärbereich & 50 & $(4,3)$ & 71 & $(3,7)$ & 61 & $(3,1)$ & 37 & $(2,4)$ & 55 & $(2,2)$ & 46 & $(1,6)$ \\
\hline \multirow[t]{3}{*}{ Polen } & Ausbildung unterhalb Sekundarbereich II & 2 & $(1,5)$ & c & c & 1 & $(0,8)$ & 7 & $(1,3)$ & 4 & $(1,0)$ & 5 & $(0,8)$ \\
\hline & $\begin{array}{l}\text { Abschluss im Sekundarbereich II/ } \\
\text { postsekundaren, nicht tertiären Bereich }\end{array}$ & 19 & $(3,8)$ & 16 & $(4,6)$ & 18 & $(3,3)$ & 54 & $(2,0)$ & 46 & $(2,4)$ & 50 & $(1,7)$ \\
\hline & Abschluss im Tertiärbereich & 79 & $(4,0)$ & 83 & $(4,6)$ & 81 & $(3,3)$ & 39 & $(2,2)$ & 51 & $(2,5)$ & 45 & $(1,7)$ \\
\hline \multirow[t]{3}{*}{ Slowakei } & Ausbildung unterhalb Sekundarbereich II & c & c & c & c & c & c & 13 & $(1,2)$ & 12 & $(1,5)$ & 13 & $(1,0)$ \\
\hline & $\begin{array}{l}\text { Abschluss im Sekundarbereich II/ } \\
\text { postsekundaren, nicht tertiären Bereich }\end{array}$ & c & c & c & c & 37 & $(3,7)$ & 64 & $(2,0)$ & 57 & $(2,3)$ & 60 & $(1,6)$ \\
\hline & Abschluss im Tertiärbereich & c & c & c & c & 63 & $(3,7)$ & 23 & $(1,8)$ & 31 & $(2,2)$ & 27 & $(1,6)$ \\
\hline \multirow[t]{3}{*}{ Spanien } & Ausbildung unterhalb Sekundarbereich II & c & c & c & c & 11 & $(2,3)$ & 43 & $(2,2)$ & 32 & $(2,1)$ & 38 & $(1,5)$ \\
\hline & \begin{tabular}{|l|} 
Abschluss im Sekundarbereich II/ \\
postsekundaren, nicht tertiären Bereich
\end{tabular} & c & c & c & c & 22 & $(3,4)$ & 27 & $(2,3)$ & 25 & $(2,0)$ & 26 & $(1,4)$ \\
\hline & Abschluss im Tertiärbereich & c & c & c & c & 67 & $(3,6)$ & 30 & $(1,8)$ & 43 & $(2,1)$ & 36 & $(1,2)$ \\
\hline \multirow[t]{3}{*}{ Schweden } & Ausbildung unterhalb Sekundarbereich II & 10 & $(2,8)$ & 4 & $(1,9)$ & 7 & $(1,7)$ & 15 & $(2,2)$ & 12 & $(2,1)$ & 13 & $(1,5)$ \\
\hline & $\begin{array}{l}\text { Abschluss im Sekundarbereich II/ } \\
\text { postsekundaren, nicht tertiären Bereich }\end{array}$ & 48 & $(3,5)$ & 33 & $(3,8)$ & 41 & $(2,5)$ & 51 & $(2,6)$ & 42 & $(2,3)$ & 47 & $(1,6)$ \\
\hline & Abschluss im Tertiärbereich & 42 & $(2,7)$ & 63 & $(3,9)$ & 51 & $(2,4)$ & 34 & $(1,7)$ & 46 & $(2,2)$ & 40 & $(1,4)$ \\
\hline \multirow[t]{3}{*}{ Vereinigte Staaten } & Ausbildung unterhalb Sekundarbereich II & 8 & $(2,7)$ & 2 & $(0,9)$ & 5 & $(1,4)$ & 12 & $(2,1)$ & 8 & $(1,2)$ & 10 & $(1,1)$ \\
\hline & $\begin{array}{l}\text { Abschluss im Sekundarbereich II/ } \\
\text { postsekundaren, nicht tertiären Bereich }\end{array}$ & 45 & $(3,1)$ & 31 & $(4,6)$ & 38 & $(2,8)$ & 53 & $(2,4)$ & 44 & $(2,5)$ & 48 & $(1,5)$ \\
\hline & Abschluss im Tertiärbereich & 47 & $(3,7)$ & 67 & $(4,7)$ & 57 & $(3,1)$ & 35 & $(2,3)$ & 48 & $(2,3)$ & 42 & $(1,6)$ \\
\hline \multicolumn{14}{|l|}{ Subnationale Einheiten } \\
\hline \multirow[t]{3}{*}{ Flandern (Belgien) } & Ausbildung unterhalb Sekundarbereich II & 2 & $(1,4)$ & 2 & $(1,1)$ & 2 & $(0,9)$ & 7 & $(1,4)$ & 7 & $(1,3)$ & 7 & $(1,0)$ \\
\hline & $\begin{array}{l}\text { Abschluss im Sekundarbereich II/ } \\
\text { postsekundaren, nicht tertiären Bereich }\end{array}$ & 36 & $(4,6)$ & 16 & $(3,1)$ & 26 & $(2,8)$ & 53 & $(2,8)$ & 37 & $(2,6)$ & 45 & $(1,8)$ \\
\hline & Abschluss im Tertiärbereich & 62 & $(4,8)$ & 82 & $(3,3)$ & 72 & $(2,9)$ & 40 & $(2,6)$ & 55 & $(2,6)$ & 48 & $(1,8)$ \\
\hline \multirow[t]{3}{*}{ England (VK) } & Ausbildung unterhalb Sekundarbereich II & 4 & $(2,4)$ & 6 & $(2,4)$ & 5 & $(1,7)$ & 15 & $(2,2)$ & 14 & $(1,8)$ & 14 & $(1,3)$ \\
\hline & $\begin{array}{l}\text { Abschluss im Sekundarbereich II/ } \\
\text { postsekundaren, nicht tertiären Bereich }\end{array}$ & 20 & $(3,8)$ & 20 & $(3,9)$ & 20 & $(2,5)$ & 32 & $(2,8)$ & 34 & $(2,5)$ & 33 & $(1,8)$ \\
\hline & Abschluss im Tertiärbereich & 76 & $(4,5)$ & 74 & $(4,7)$ & 75 & $(3,0)$ & 53 & $(2,7)$ & 52 & $(2,4)$ & 53 & $(1,5)$ \\
\hline \multirow[t]{3}{*}{ Nordirland (VK) } & Ausbildung unterhalb Sekundarbereich II & c & c & c & c & c & c & 22 & $(3,1)$ & 16 & $(2,3)$ & 19 & $(1,9)$ \\
\hline & $\begin{array}{l}\text { Abschluss im Sekundarbereich II/postse- } \\
\text { kundaren, nicht tertiären Bereich }\end{array}$ & c & c & c & c & 22 & $5,2)$ & 37 & $(3,4)$ & 37 & $(2,7)$ & 37 & $(2,0)$ \\
\hline & Abschluss im Tertiärbereich & c & c & c & c & 76 & $(5,3)$ & 41 & $(3,3)$ & 48 & $(2,9)$ & 44 & $(1,9)$ \\
\hline \multirow[t]{3}{*}{ England/Nordirland (VK) } & Ausbildung unterhalb Sekundarbereich II & 4 & $(2,3)$ & 6 & $(2,3)$ & 5 & $(1,7)$ & 15 & $(2,2)$ & 14 & $(1,7)$ & 15 & $(1,3)$ \\
\hline & $\begin{array}{l}\text { Abschluss im Sekundarbereich II/ } \\
\text { postsekundaren, nicht tertiären Bereich }\end{array}$ & 20 & $(3,7)$ & 20 & $(3,8)$ & 20 & $(2,4)$ & 32 & $(2,7)$ & 34 & $(2,3)$ & 33 & $(1,7)$ \\
\hline & Abschluss im Tertiärbereich & 76 & $(4,3)$ & 74 & $(4,6)$ & 75 & $(3,0)$ & 53 & $(2,6)$ & 52 & $(2,3)$ & 52 & $(1,4)$ \\
\hline Durchschnitt & Ausbildung unterhalb Sekundarbereich II & 6 & $(0,6)$ & 5 & $(0,6)$ & 6 & $(0,4)$ & 15 & $(0,4)$ & 12 & $(0,3)$ & 13 & $(0,3)$ \\
\hline & $\begin{array}{l}\text { Abschluss im Sekundarbereich II/ } \\
\text { postsekundaren, nicht tertiären Bereich }\end{array}$ & 35 & $(0,9)$ & 23 & $(0,9)$ & 29 & $(0,6)$ & 48 & $(0,5)$ & 40 & $(0,5)$ & 44 & $(0,3)$ \\
\hline & Abschluss im Tertiärbereich & 59 & $(\mathbf{1}, \mathbf{0})$ & 72 & $(0,9)$ & 65 & $(0,7)$ & 37 & $(0,5)$ & 49 & $(0,5)$ & 43 & $(0,3)$ \\
\hline Partnerländer & & & & & & & & & & & & & \\
\hline Russische Föderation* & Ausbildung unterhalb Sekundarbereich II & $n$ & $n$ & 3 & $(2,6)$ & 2 & $(1,3)$ & 9 & $(2,4)$ & 4 & $(1,3)$ & 7 & $(1,0)$ \\
\hline & $\begin{array}{l}\text { Abschluss im Sekundarbereich II/ } \\
\text { postsekundaren, nicht tertiären Bereich }\end{array}$ & 26 & $(6,5)$ & 6 & $(2,6)$ & 16 & 7) & 24 & ,3) & 25 & $(2,1)$ & 25 & $(1,5)$ \\
\hline & Abschluss im Tertiärbereich & 74 & $(6,5)$ & 90 & $(4,0)$ & 82 & $(4,6)$ & 67 & $(4,5)$ & 71 & $(2,2)$ & 69 & $(2,3)$ \\
\hline
\end{tabular}

\footnotetext{
* Hinweis zu den Daten der Russischen Föderation s. Abschnitt Angewandte Methodik.
}

Anmerkung: Spalten mit getrennten Angaben zu anderen Altergruppen und für alle Bildungsstände von Eltern zusammen sind im Internet verfügbar (s. StatLink unten). Quelle: OECD. Survey of Adult Skills (PIAAC) (2012). PIAAC steht für das OECD Programme for the International Assessment of Adult Competencies. Hinweise s. Anhang 3 unter www.oecd.org/edu/eag.htm. StatLink: http://dx.doi.org/10.1787/888933115578 Erläuterung der Kennzeichnung fehlender Daten s. Hinweise für den Leser. 
Tabelle A4.3 (L)

Lesekompetenz von Nichtschülern/Nichtstudierenden, nach Altersgruppe, Geschlecht und Bildungsstand der Eltern (2012) Lesekompetenz in der Erhebung zu den grundlegenden Kompetenzen Erwachsener, 25- bis 34-Jährige

\begin{tabular}{|c|c|c|c|c|c|c|c|c|c|c|c|c|c|c|c|c|c|c|c|c|c|c|c|c|c|}
\hline & \multirow[t]{4}{*}{$\begin{array}{l}\text { Kom- } \\
\text { pe- } \\
\text { tenz- } \\
\text { stufe }\end{array}$} & \multicolumn{6}{|c|}{$\begin{array}{c}\text { Eltern mit einer Ausbildung } \\
\text { unterhalb des } \\
\text { Sekundarbereichs II }\end{array}$} & \multicolumn{6}{|c|}{$\begin{array}{c}\text { Eltern mit einem Abschluss im } \\
\text { Sekundarbereich II bzw. postse- } \\
\text { kundaren, nicht tertiären Bereich } \\
\text { als höchstem Bildungsabschluss }\end{array}$} & \multicolumn{6}{|c|}{$\begin{array}{l}\text { Eltern mit einem Abschluss } \\
\text { im Tertiärbereich }\end{array}$} & \multicolumn{6}{|c|}{$\begin{array}{l}\text { Alle Bildungsstände } \\
\text { von Eltern zusammen }\end{array}$} \\
\hline & & \multicolumn{2}{|c|}{ Männer } & Fra & uen & & $+\mathrm{F}$ & Mä & nner & & uen & & $+F$ & Mär & nner & Fra & uen & & $+F$ & $\mathrm{Mä}$ & nner & Fra & auen & & $+F$ \\
\hline & & $\%$ & S.F. & $\%$ & S.F. & $\%$ & S.F. & $\%$ & S.F. & $\%$ & S.F. & $\%$ & S.F. & $\%$ & S.F. & $\%$ & S.F. & $\%$ & S.F. & $\%$ & S.F. & $\%$ & S.F. & $\%$ & S.F. \\
\hline & & (25) & (26) & $(27)$ & (28) & (29) & (30) & (31) & (32) & (33) & (34) & (35) & (36) & (37) & (38) & (39) & (40) & (41) & (42) & (43) & (44) & $(45)$ & (46) & $(47)$ & $(48)$ \\
\hline $\begin{array}{l}\text { OECD } \\
\text { Nationale } \\
\text { Einheiten }\end{array}$ & & & & & & & & & & & & & & & & & & & & & & & & & \\
\hline Australien & $0 / 1$ & 18 & $(4,8)$ & 14 & $(3,9)$ & 16 & $(3,0)$ & 11 & $(3,0)$ & 12 & $(4,2)$ & 11 & $(2,7)$ & 3 & $(1,9)$ & 4 & $(1,8)$ & 4 & $(1,3)$ & 10 & $(1,8)$ & 9 & $(1,7)$ & 10 & $(1,2)$ \\
\hline & 2 & 32 & $(5,6)$ & 35 & $(5,9)$ & 34 & $(4,2)$ & 28 & $(5,0)$ & 24 & $(5,5)$ & 26 & $(3,9)$ & 19 & $(4,5)$ & 18 & $(3,7)$ & 18 & $(2,8)$ & 26 & $(2,8)$ & 25 & $(2,9)$ & 26 & $(2,2)$ \\
\hline & 3 & 39 & $(5,9)$ & 37 & $(6,2)$ & 38 & $(4,6)$ & 44 & $(5,8)$ & 47 & $(6,5)$ & 45 & $(4,7)$ & 48 & $(5,9)$ & 43 & $(4,0)$ & 45 & $(3,4)$ & 44 & $(3,7)$ & 42 & $(3,5)$ & 43 & $(2,8)$ \\
\hline & $4 / 5$ & 10 & $(2,8)$ & 14 & $(3,5)$ & 12 & $(2,2)$ & 17 & $(4,6)$ & 18 & $(5,7)$ & 18 & $(4,1)$ & 29 & $(4,4)$ & 35 & $(3,9)$ & 32 & $(2,9)$ & 19 & $(2,3)$ & 23 & $(2,7)$ & 21 & $(1,9)$ \\
\hline Österreich & $0 / 1$ & c & c & $\mathrm{c}$ & c & 29 & $(4,5)$ & 8 & $(2,8)$ & 9 & $(2,6)$ & 9 & $(2,1)$ & $\mathrm{c}$ & c & $\mathrm{c}$ & c & 7 & $(2,7)$ & 11 & $(2,4)$ & 12 & $(2,1)$ & 12 & $(1,5)$ \\
\hline & 2 & c & c & c & c & 44 & $(5,6)$ & 35 & $(4,8)$ & 37 & $(4,2)$ & 36 & $(3,2)$ & c & c & c & c & 19 & $(4,0)$ & 33 & $(3,5)$ & 33 & $(3,1)$ & 33 & $(2,2)$ \\
\hline & 3 & $c$ & c & c & c & 23 & $(5,1)$ & 46 & $(4,0)$ & 46 & $(4,5)$ & 46 & $(3,0)$ & c & c & $c$ & c & 54 & $(5,2)$ & 44 & $(3,2)$ & 44 & $(3,1)$ & 44 & $(2,2)$ \\
\hline & $4 / 5$ & c & c & c & c & 4 & $(2,0)$ & 10 & $(2,2)$ & 9 & $(2,2)$ & 9 & $(1,6)$ & c & c & c & c & 20 & $(3,4)$ & 12 & $(1,8)$ & 10 & $(1,7)$ & 11 & $(1,2)$ \\
\hline Kanada & $0 / 1$ & 24 & $(4,5)$ & 28 & $(5,6)$ & 26 & $(3,7)$ & 14 & $(2,9)$ & 14 & $(2,4)$ & 14 & $(1,8)$ & 7 & $(1,8)$ & 6 & $(1,3)$ & 7 & $(1,1)$ & 12 & $(1,5)$ & 12 & $(1,4)$ & 12 & $(1,0)$ \\
\hline & 2 & 40 & $(7,0)$ & 31 & $(6,2)$ & 35 & $(4,8)$ & 33 & $(4,5)$ & 31 & $(3,5)$ & 32 & $(2,9)$ & 24 & $(3,3)$ & 27 & $(3,3)$ & 26 & $(2,3)$ & 29 & $(2,3)$ & 29 & $(2,5)$ & 29 & 8) \\
\hline & 3 & 32 & $(7,9)$ & 32 & $(6,4)$ & 32 & $(5,0)$ & 36 & $(4,7)$ & 40 & $(3,3)$ & 38 & $(3,1)$ & 42 & $(3,5)$ & 43 & $(4,2)$ & 42 & $(3,1)$ & 39 & $(3,0)$ & 40 & $(2,7)$ & 39 & $(2,3)$ \\
\hline & $4 / 5$ & 4 & $(4,0)$ & 9 & $(3,5)$ & 7 & $(2,6)$ & 17 & $(3,1)$ & 15 & $(2,4)$ & 16 & $(2,0)$ & 27 & $(3,4)$ & 24 & $(2,7)$ & 25 & $(2,3)$ & 20 & $(2,2)$ & 19 & $(1,6)$ & 20 & $(1,5)$ \\
\hline Tschechien & $0 / 1$ & c & c & c & c & c & c & 9 & $(2,8)$ & 8 & $(2,3)$ & 8 & $(1,8)$ & $\mathrm{c}$ & $\mathrm{c}$ & $\mathrm{c}$ & c & 2 & $(1,9)$ & 8 & $(2,2)$ & 7 & $(1,8)$ & 7 & $(1,4)$ \\
\hline & 2 & c & c & c & c & c & c & 33 & $(4,3)$ & 31 & $(4,4)$ & 32 & $(3,4)$ & c & c & 13 & $(7,3)$ & 16 & $(5,2)$ & 30 & $(3,8)$ & 29 & $(3,6)$ & 30 & $(3,0)$ \\
\hline & 3 & $c$ & c & $c$ & c & $c$ & c & 47 & $(4,3)$ & 49 & $(5,2)$ & 48 & $(3,3)$ & $c$ & c & 56 & $(9,9)$ & 57 & $(6,6)$ & 49 & $(4,1)$ & 49 & $(4,5)$ & 49 & $(3,0)$ \\
\hline & $4 / 5$ & c & c & c & c & c & c & 11 & $(2,7)$ & 12 & $(3,1)$ & 12 & $(2,1)$ & c & c & 29 & $(9,4)$ & 26 & $(5,7)$ & 13 & $(2,5)$ & 15 & $(3,0)$ & 14 & $(1,8)$ \\
\hline Dänemark & $0 / 1$ & c & c & c & c & 29 & $(4,8)$ & 12 & $(3,3)$ & 11 & $(3,0)$ & 12 & $(2,3)$ & 8 & $(2,3)$ & 7 & $(2,3)$ & 8 & $(1,7)$ & 14 & $(2,1)$ & 13 & $(2,0)$ & 13 & $(1,4)$ \\
\hline & 2 & c & c & c & c & 37 & $(6,2)$ & 30 & $(4,5)$ & 32 & $(6,0)$ & 31 & $(3,9)$ & 19 & $(3,8)$ & 23 & $(4,6)$ & 21 & $(3,1)$ & 26 & $(2,8)$ & 29 & $(3,6)$ & 28 & $(2,3)$ \\
\hline & 3 & c & c & c & c & 27 & $(4,9)$ & 47 & $(5,0)$ & 47 & $(6,6)$ & 47 & $(4,2)$ & 47 & $(4,7)$ & 47 & $(4,9)$ & 47 & $(3,5)$ & 43 & $(3,3)$ & 44 & $(3,5)$ & 43 & $(2,5)$ \\
\hline & $4 / 5$ & c & c & c & c & 7 & $(2,7)$ & 11 & $(3,1)$ & 10 & $(3,8)$ & 11 & $(2,5)$ & 27 & $(4,4)$ & 22 & $(4,2)$ & 24 & $(2,9)$ & 17 & $(2,3)$ & 15 & $(2,8)$ & 16 & $(1,9)$ \\
\hline Estland & $0 / 1$ & c & c & c & c & c & c & 10 & $(2,3)$ & 12 & $(2,4)$ & 11 & $(1,7)$ & 8 & $(2,4)$ & 7 & $(2,0)$ & 8 & $(1,5)$ & 10 & $(1,7)$ & 10 & $(1,5)$ & 10 & $(1,2)$ \\
\hline & 2 & $c$ & c & $\mathrm{c}$ & c & c & c & 35 & $(3,8)$ & 33 & $(4,3)$ & 34 & $(3,0)$ & 26 & $(3,2)$ & 20 & $(3,8)$ & 24 & $(2,4)$ & 31 & $(2,5)$ & 29 & $(2,9)$ & 30 & $(1,8)$ \\
\hline & 3 & c & c & c & c & c & c & 46 & $(3,7)$ & 46 & $(4,5)$ & 46 & $(2,9)$ & 43 & $(4,0)$ & 48 & $(4,7)$ & 45 & $(3,2)$ & 44 & $(2,5)$ & 46 & $(3,3)$ & 45 & $(2,1)$ \\
\hline & $4 / 5$ & c & c & c & c & c & c & 10 & $(2,7)$ & 9 & $(3,1)$ & 10 & $(2,3)$ & 23 & $(3,0)$ & 24 & $(3,3)$ & 23 & $(2,4)$ & 15 & $(2,1)$ & 15 & $(2,2)$ & 15 & $(1,7)$ \\
\hline Finnland & $0 / 1$ & c & c & c & c & 9 & $(3,3)$ & 5 & $(2,1)$ & 2 & $(1,1)$ & 3 & $(1,2)$ & c & c & c & c & 4 & $(1,9)$ & 7 & $(1,8)$ & 2 & $(1,1)$ & 5 & $(1,1)$ \\
\hline & 2 & c & c & $\mathrm{c}$ & c & 21 & $(5,1)$ & 24 & $(3,6)$ & 14 & $(3,2)$ & 19 & $(2,6)$ & $\mathrm{c}$ & c & c & c & 9 & $(2,8)$ & 20 & $(2,7)$ & 13 & $(2,6)$ & 17 & $(2,0)$ \\
\hline & 3 & c & c & c & c & 44 & $(5,3)$ & 43 & $(4,5)$ & 49 & $(4,6)$ & 46 & $(3,4)$ & c & c & c & c & 38 & $(4,4)$ & 40 & $(3,0)$ & 47 & $(3,3)$ & 43 & $(2,3)$ \\
\hline & $4 / 5$ & c & c & c & c & 26 & $(4,7)$ & 27 & $(3,7)$ & 35 & $(4,2)$ & 31 & $(3,0)$ & c & c & c & c & 49 & $(4,0)$ & 33 & $(2,6)$ & 37 & $(2,9)$ & 35 & $(2,0)$ \\
\hline Frankreich & $0 / 1$ & c & c & 21 & $(3,6)$ & 21 & $(2,5)$ & 10 & $(2,3)$ & 6 & $(1,7)$ & 8 & $(1,5)$ & 5 & $(1,9)$ & c & c & 5 & $(1,6)$ & 11 & $(1,6)$ & 11 & $(1,6)$ & 11 & $(1,2)$ \\
\hline & 2 & c & c & 39 & $(4,3)$ & 39 & $(3,8)$ & 34 & $(3,9)$ & 33 & $(3,8)$ & 34 & $(2,9)$ & 14 & $(3,7)$ & $c$ & c & 15 & $(2,9)$ & 30 & $(2,5)$ & 31 & $(2,2)$ & 30 & $(1,8)$ \\
\hline & 3 & c & c & 34 & $(4,2)$ & 34 & $(4,3)$ & 44 & $(4,2)$ & 48 & $(4,0)$ & 46 & $(2,8)$ & 50 & $(5,2)$ & c & c & 52 & $(3,9)$ & 43 & $(3,3)$ & 45 & $(2,6)$ & 44 & $(2,2)$ \\
\hline & $4 / 5$ & c & c & 5 & $(2,0)$ & 6 & $(1,8)$ & 12 & $(3,1)$ & 12 & $(2,6)$ & 12 & $(1,7)$ & 32 & $(4,7)$ & c & c & 28 & $(3,5)$ & 16 & $(2,1)$ & 13 & $(1,8)$ & 14 & $(1,2)$ \\
\hline Deutschland & $0 / 1$ & c & c & c & c & c & c & 14 & $(3,9)$ & 17 & $(3,6)$ & 15 & $(2,5)$ & 8 & $(2,9)$ & 7 & $(2,9)$ & 7 & $(1,9)$ & 13 & $(2,5)$ & 14 & $(2,3)$ & 14 & $(1,6)$ \\
\hline & 2 & c & c & $\mathrm{c}$ & c & c & c & 32 & $(4,9)$ & 30 & $(4,8)$ & 31 & $(3,5)$ & 24 & $(4,3)$ & 20 & $(3,9)$ & 22 & $(2,7)$ & 30 & $(2,9)$ & 28 & $(2,8)$ & 29 & $(2,0)$ \\
\hline & 3 & c & c & c & c & c & c & 42 & $(5,1)$ & 43 & $(4,7)$ & 42 & $(3,3)$ & 45 & $(5,3)$ & 51 & $(5,3)$ & 48 & $(3,5)$ & 41 & $(3,7)$ & 44 & $(3,3)$ & 42 & $(2,3)$ \\
\hline & $4 / 5$ & c & c & c & c & c & c & 12 & $(3,3)$ & 9 & $(2,9)$ & 11 & $(1,9)$ & 23 & $(4,6)$ & 22 & $(4,2)$ & 23 & $(3,2)$ & 16 & $(2,7)$ & 14 & $(2,3)$ & 15 & $(1,7)$ \\
\hline Irland & $0 / 1$ & 20 & $(3,8)$ & 17 & $(2,8)$ & 18 & $(2,5)$ & 10 & $(3,5)$ & 10 & $(2,4)$ & 10 & $(2,2)$ & 8 & $(3,0)$ & 6 & $(2,9)$ & 7 & $(2,1)$ & 13 & $(2,0)$ & 11 & ,5) & 12 & $(1,3)$ \\
\hline & 12 & 36 & $(4,5)$ & 46 & $(4,7)$ & 41 & $(3,3)$ & 35 & $(5,2)$ & 39 & $(4,9)$ & 37 & $(3,4)$ & 29 & $(5,1)$ & 30 & $(4,3)$ & 29 & $(3,1)$ & 34 & $(2,6)$ & 39 & $(2,4)$ & 36 & $(1,7)$ \\
\hline & 3 & 35 & $(4,6)$ & 33 & $(5,2)$ & 34 & $(3,2)$ & 39 & $(4,8)$ & 41 & $(4,3)$ & 40 & $(3,0)$ & 44 & $(5,3)$ & 47 & $(5,4)$ & 46 & $(3,8)$ & 39 & $(3,0)$ & 40 & $(3,0)$ & 39 & $(2,0)$ \\
\hline & $4 / 5$ & 10 & $(3,3)$ & 4 & $(1,7)$ & 7 & $(1,5)$ & 15 & $(3,6)$ & 10 & $(3,0)$ & 13 & $(2,6)$ & 19 & $(4,6)$ & 17 & $(4,2)$ & 18 & $(3,3)$ & 14 & $(2,5)$ & 10 & $(2,0)$ & 12 & $(1,5)$ \\
\hline Italien & $0 / 1$ & 30 & $(3,8)$ & 30 & $(4,6)$ & 30 & $(3,1)$ & c & $c$ & c & c & 16 & $(3,4)$ & c & c & c & c & c & c & 25 & $(2,9)$ & 24 & $(3,7)$ & 24 & $(2,5)$ \\
\hline & 2 & 45 & $(4,9)$ & 40 & $(4,9)$ & 42 & $(3,4)$ & c & c & c & c & 35 & $(4,2)$ & $\mathrm{c}$ & c & $c$ & c & c & c & 38 & $(3,5)$ & 40 & $(3,6)$ & 39 & $(2,6)$ \\
\hline & 3 & 22 & $(4,2)$ & 27 & $(4,1)$ & 24 & $(3,1)$ & c & $c$ & c & $c$ & 42 & $(4,5)$ & $\mathrm{c}$ & $c$ & $c$ & $c$ & c & $c$ & 31 & $(3,5)$ & 33 & $(3,4)$ & 32 & $(2,5)$ \\
\hline & $4 / 5$ & 3 & $(1,5)$ & 3 & $(1,7)$ & 3 & $(1,1)$ & c & c & c & c & 7 & $(3,1)$ & c & c & c & c & c & c & 6 & $(2,1)$ & 4 & $(1,5)$ & 5 & $(1,2)$ \\
\hline Japan & $0 / 1$ & c & c & c & c & c & c & 3 & $(1,4)$ & 2 & $(1,5)$ & 3 & $(1,0)$ & c & c & c & c & 1 & $(0,6)$ & 2 & $(0,9)$ & 2 & $(0,8)$ & 2 & $(0,6)$ \\
\hline & 2 & $c$ & c & c & c & c & c & 13 & $(3,1)$ & 17 & $(3,4)$ & 15 & $(2,5)$ & 10 & $(2,7)$ & 11 & $(2,6)$ & 10 & $(1,9)$ & 12 & $(1,9)$ & 14 & $(2,3)$ & 13 & $(1,7)$ \\
\hline & 3 & c & c & c & c & c & c & 55 & $(4,9)$ & 53 & $(4,7)$ & 54 & $(3,3)$ & 48 & $(5,0)$ & 52 & $(4,2)$ & 50 & $(3,2)$ & 52 & $(3,0)$ & 52 & $(3,3)$ & 52 & $(1,9)$ \\
\hline & $4 / 5$ & c & c & c & c & c & c & 29 & $(4,2)$ & 28 & $(4,5)$ & 29 & $(2,9)$ & 40 & $(5,0)$ & 36 & $(3,8)$ & 38 & $(3,3)$ & 33 & $(3,1)$ & 32 & $(3,2)$ & 33 & $(1,9)$ \\
\hline Korea & $0 / 1$ & 9 & $(2,6)$ & 7 & $(2,3)$ & 8 & $(1,7)$ & 3 & $(1,5)$ & 3 & $(1,2)$ & 3 & $(0,9)$ & c & c & $c$ & c & c & c & 5 & $(1,2)$ & 4 & $(0,9)$ & 4 & $(0,7)$ \\
\hline & 2 & 35 & $(4,8)$ & 36 & $(5,4)$ & 36 & $(3,4)$ & 28 & $(3,9)$ & 29 & $(4,6)$ & 29 & $(2,8)$ & c & c & 19 & $(3,9)$ & 17 & $(2,7)$ & 28 & $(2,5)$ & 29 & $(3,0)$ & 29 & $(1,8)$ \\
\hline & 3 & 48 & $(5,2)$ & 50 & $(5,5)$ & 49 & $(3,8)$ & 53 & $(4,6)$ & 55 & $(4,3)$ & 54 & $(3,1)$ & c & c & 62 & $(5,6)$ & 60 & $(4,3)$ & 52 & $(2,9)$ & 55 & $(3,0)$ & 53 & $(1,9)$ \\
\hline & $4 / 5$ & 8 & $(2,8)$ & 7 & $(2,3)$ & 7 & $(1,9)$ & 16 & $(3,0)$ & 13 & $(2,7)$ & 14 & $(2,2)$ & c & c & 17 & $(4,4)$ & 22 & $(3,6)$ & 15 & $(1,9)$ & 12 & $(1,7)$ & 13 & $(1,4)$ \\
\hline Niederlande & $0 / 1$ & $c$ & c & 14 & $(4,0)$ & 16 & $(3,3)$ & c & c & c & c & 4 & $(1,7)$ & c & c & C & c & 4 & $(1,8)$ & 8 & $(2,0)$ & 8 & $(1,9)$ & 8 & $(1,4)$ \\
\hline & 2 & $c$ & c & 24 & $(5,3)$ & 24 & $(3,4)$ & c & c & c & c & 24 & $(3,2)$ & c & c & $c$ & c & 12 & $(2,8)$ & 19 & $(2,8)$ & 21 & $(3,1)$ & 20 & $(1,7)$ \\
\hline & 3 & c & c & 46 & $(5,7)$ & 44 & $(4,2)$ & c & c & c & c & 45 & $(4,6)$ & C & c & C & c & 47 & $(4,6)$ & 45 & $(3,4)$ & 46 & $(3,8)$ & 45 & $(2,5)$ \\
\hline & $4 / 5$ & c & $c$ & 15 & $(4,0)$ & 16 & $(3,0)$ & c & c & c & c & 27 & $(3,7)$ & c & c & c & c & 37 & $(4,5)$ & 28 & $(3,1)$ & 25 & $(3,2)$ & 26 & $(2,3)$ \\
\hline
\end{tabular}

* Hinweis zu den Daten der Russischen Föderation s. Abschnitt Angewandte Methodik

Anmerkung: Spalten mit getrennten Angaben zu anderen Altersgruppen sind im Internet verfügbar (s. Statlink unten).

Quelle: OECD. Survey of Adult Skills (PIAAC) (2012). PIAAC steht für das OECD Programme for the International Assessment of Adult Competencies. Hinweise s. Anhang 3 unter www.oecd.org/edu/eag.htm. StatLink: http://dx.doi.org/10.1787/888933115597

Erläuterung der Kennzeichnung fehlender Daten s. Hinweise für den Leser. 
Tabelle A4.3 (L) (Forts.)

Lesekompetenz von Nichtschülern/Nichtstudierenden, nach Altersgruppe, Geschlecht und Bildungsstand der Eltern (2012)

Lesekompetenz in der Erhebung zu den grundlegenden Kompetenzen Erwachsener, 25- bis 34-Jährige

\begin{tabular}{|c|c|c|c|c|c|c|c|c|c|c|c|c|c|c|c|c|c|c|c|c|c|c|c|c|c|}
\hline \multirow[t]{4}{*}{ 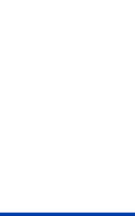 } & \multirow[t]{4}{*}{\begin{tabular}{|c|} 
Kom- \\
pe- \\
tenz- \\
stufe
\end{tabular}} & \multicolumn{6}{|c|}{$\begin{array}{l}\text { Eltern mit einer Ausbildung } \\
\text { unterhalb des } \\
\text { Sekundarbereichs II }\end{array}$} & \multicolumn{6}{|c|}{\begin{tabular}{|c|} 
Eltern mit einem Abschluss im \\
Sekundarbereich II bzw. postse- \\
kundaren, nicht tertiären Bereich \\
als höchstem Bildungsabschluss
\end{tabular}} & \multicolumn{6}{|c|}{$\begin{array}{l}\text { Eltern mit einem Abschluss } \\
\text { im Tertiärbereich }\end{array}$} & \multicolumn{6}{|c|}{$\begin{array}{l}\text { Alle Bildungsstände } \\
\text { von Eltern zusammen }\end{array}$} \\
\hline & & \multicolumn{2}{|c|}{ Männer } & \multicolumn{2}{|c|}{ Frauen } & \multicolumn{2}{|c|}{$M+F$} & \multicolumn{2}{|c|}{ Männer } & \multicolumn{2}{|c|}{ Frauen } & M & $+\mathrm{F}$ & Mär & nner & & auen & $M$ & $1+F$ & Mär & nner & Fra & uen & $M$ & $+F$ \\
\hline & & $\%$ & S.F. & $\%$ & S.F. & $\%$ & S.F. & $\%$ & \begin{tabular}{|l|} 
S.F. \\
\end{tabular} & $\%$ & S.F. & $\%$ & \begin{tabular}{|l|} 
S.F. \\
\end{tabular} & $\%$ & S.F. & $\%$ & S.F. & $\%$ & S.F. & $\%$ & S.F. & $\%$ & S.F. & $\%$ & S.F. \\
\hline & & (25) & (26) & (27) & (28) & (29) & (30) & (31) & (32) & (33) & (34) & (35) & (36) & (37) & (38) & (39) & (40) & (41) & (42) & (43) & (44) & (45) & (46) & (47) & (48) \\
\hline & & & & & & & & & & & & & & & & & & & & & & & & & \\
\hline Norwegen & o/1 & c & c & c & c) & c & c & 10 & $(2,9)$ & 11 & $(3,2)$ & 10 & $(2,2)$ & 7 & $(2,3)$ & 5 & $(2,0)$ & 6 & $(1,5)$ & 13 & $(1,8)$ & 10 & $(2,0)$ & 11 & $(1,4)$ \\
\hline & & c & c & c & c) & c & c & 25 & $(4,5)$ & 28 & $(4,3)$ & 27 & $(3,0)$ & 17 & $(3,5)$ & 16 & $(3,3)$ & 17 & $(2,4)$ & 21 & $(2,6)$ & 22 & $(2,6)$ & 22 & $(1,9)$ \\
\hline & 3 & c & c & c & c & c & c & 47 & $(5,3)$ & 49 & $(4,9)$ & 48 & $(3,6)$ & 45 & $(4,8)$ & 51 & $(5,2)$ & 48 & $(3,9)$ & 44 & $(3,3)$ & 48 & $(3,4)$ & 46 & $(2,6)$ \\
\hline & $4 / 5$ & c & c & c & c & c & c & 19 & $(4,0)$ & 12 & $(3,1)$ & 15 & $(2,7)$ & 31 & $(4,1)$ & 28 & $(3,8)$ & 29 & $(2,9)$ & 23 & $(2,8)$ & 20 & $(2,5)$ & 21 & $(2,0)$ \\
\hline Polen & $0 / 1$ & c & c & c & c & c & c & 17 & $(2,4)$ & 13 & $(2,4)$ & 15 & $(1,8)$ & 3 & $(1,9)$ & 7 & $(4,3)$ & 5 & $(2,2)$ & 15 & $(2,0)$ & 13 & $(1,9)$ & 14 & $(1,5)$ \\
\hline & 2 & c & c & c & c & c & c & 39 & $(3,9)$ & 34 & $(3,2)$ & 37 & $(2,6)$ & 21 & $(5,1)$ & 24 & $(6,7)$ & 22 & $(3,9)$ & 37 & $(3,6)$ & 33 & $(2,3)$ & 35 & $(2,2)$ \\
\hline & 3 & c & c & c & c & c & c & 37 & $(3,8)$ & 39 & $(3,2)$ & 38 & $(2,6)$ & 45 & $(7,3)$ & 44 & $(6,2)$ & 44 & $(4,8)$ & 37 & $(3,3)$ & 39 & $(2,7)$ & 38 & $(2,2)$ \\
\hline & $4 / 5$ & c & c & c & c & c & c & 7 & $(2,0)$ & 14 & $(2,4)$ & 11 & $(1,5)$ & 32 & $(6,8)$ & 25 & $(5,9)$ & 29 & $(4,4)$ & 12 & $(1,9)$ & 15 & $(2,1)$ & 13 & $(1,4)$ \\
\hline Slowakei & $0 / 1$ & c & c & c & c & 40 & $(5,0)$ & 7 & $(1,7)$ & 8 & $(1,7)$ & 7 & $(1,2)$ & c & c & c & c & c & & 12 & $(1,4)$ & 11 & $|(1,8)|$ & 11 & $(1,2)$ \\
\hline & 2 & c & c & c & c & 40 & $(4,7)$ & 35 & $(3,4)$ & 32 & $(2,6)$ & 34 & $(2,1)$ & c & c & c & c & 20 & $(4,7)$ & 34 & $(2,6)$ & 31 & $(2,2)$ & 33 & $(1,7)$ \\
\hline & 3 & c & c & c & c) & 18 & $(3,2)$ & 49 & $(3,6)$ & 50 & $(2,9)$ & 49 & $(2,4)$ & c & c & c & c & 59 & $(5,6)$ & 44 & $(2,6)$ & 48 & $(2,5)$ & 46 & $(1,8)$ \\
\hline & $4 / 5$ & c & c & c & c & c & & 9 & $(2,2)$ & 10 & $(1,9)$ & 10 & $(1,5)$ & c & c & c & c & 19 & $(4,3)$ & 10 & $(1,7)$ & 10 & $(1,8)$ & 10 & $(1,2)$ \\
\hline Spanien & $0 / 1$ & 26 & $(3,0)$ & 29 & $(3,5)$ & 28 & $(2,4)$ & c & 5 & 14 & $(4,4)$ & 14 & $(3,3)$ & c & c & c & c & 9 & $(3,3)$ & 21 & $(2,3)$ & 22 & $(2,6)$ & 22 & $(1,8)$ \\
\hline & $I^{2}$ & 47 & $(3,9)$ & 44 & $(4,1)$ & 46 & $(2,9)$ & c & c & 44 & $(6,6)$ & 43 & $(4,3)$ & c & c & c & c & 34 & $(5,7)$ & 43 & $(3,1)$ & 43 & $(3,6)$ & 43 & $(2,2)$ \\
\hline & 3 & 25 & $(3,1)$ & 24 & $(3,1)$ & 25 & $(2,1)$ & c & c & 37 & $(5,1)$ & 37 & $(4,2)$ & c & c & c & c & 47 & $(4,7)$ & 31 & $(2,9)$ & 31 & $(2,8)$ & 31 & $(1,9)$ \\
\hline & $4 / 5$ & 2 & $(1,2)$ & 2 & $(1,3)$ & 2 & $(1,0)$ & c & c & 5 & $(2,5)$ & 6 & $(1,9)$ & c & c & c & c & 10 & $(3,4)$ & 5 & $(1,4)$ & 4 & $(1,0)$ & 4 & $(0,9)$ \\
\hline Schweden & o/1 & c & c & c & c & c & c & c & c & c & c & 8 & $(2,3)$ & 6 & $(2,0)$ & 5 & $(2,1)$ & 6 & $(1,5)$ & 8 & $(1,8)$ & 12 & $(1,9)$ & 10 & $(1,3)$ \\
\hline & 2 & c & c & c & c & c & c & c & ${ }^{6}$ & c & c & 22 & $(3,7)$ & 17 & $(4,0)$ & 17 & $(4,0)$ & 17 & $(2,7)$ & 20 & $(2,9)$ & 19 & L) & 20 & $(2,0)$ \\
\hline & 3 & $c$ & c & c & . & c & . & c & s & c & c & 48 & $(3,9)$ & 46 & $(4,9)$ & 46 & $(5,3)$ & 46 & $(3,6)$ & 46 & $(3,7)$ & 45 & $(3,3)$ & 46 & $(2,4)$ \\
\hline & $4 / 5$ & c & c & c & c & c & c & c & c & c & c & 22 & $(3,3)$ & 32 & $(4,5)$ & 32 & $(4,7)$ & 32 & $(3,3)$ & 26 & $(2,7)$ & 24 & $(2,8)$ & 25 & $(2,0)$ \\
\hline & $0 / 1$ & c & c & c & c) & c & & 22 & $(5,1)$ & 11 & ,7) & 17 & $(3,0)$ & 10 & $(3,5)$ & 4 & (,9) & 7 & $2,0)$ & 21 & $(2,9)$ & 13 & ,3) & 17 & $1,8)$ \\
\hline & 2 & c & c & c & c & c & c & 36 & $(5,3)$ & 41 & $(5,9)$ & 38 & $(3,7)$ & 26 & $(5,3)$ & 26 & $(3,7)$ & 26 & $(3,4)$ & 30 & $(3,5)$ & 34 & ,1) & 32 & $2,3)$ \\
\hline & 3 & c & c & c & c & c & & 33 & $(4,8)$ & 35 & $(6,0)$ & 34 & $(3,6)$ & 41 & $(5,7)$ & 49 & $(4,7)$ & 45 & $(3,7)$ & 35 & $(2,9)$ & 38 & $(3,1)$ & 37 & $(2,2)$ \\
\hline & $4 / 5$ & c & c & c & c & c & & 10 & $(3,2)$ & 13 & $(3,2)$ & 11 & $(2,5)$ & 23 & $|(4,3)|$ & 21 & $(4,1)$ & 22 & $(2,9)$ & 15 & $(2,2)$ & 14 & $(2,2)$ & 15 & $(1,6)$ \\
\hline $\begin{array}{l}\text { Subnation } \\
\text { Einheiten }\end{array}$ & & & & & & & & & & & & & & & & & & & & & & & & & \\
\hline & 0 & c & c & c & c & 22 & $(3,9)$ & 4 & $(1,6)$ & 6 & $(1,9)$ & 5 & $(1,3)$ & 4 & $(1,9)$ & 3 & $(1,8)$ & 3 & $(1,3)$ & 8 & $(1,7)$ & 8 & $(1,5)$ & 8 & $(1,1)$ \\
\hline & & c & c & c & c) & 36 & $(5,1)$ & 28 & $(4,3)$ & 27 & $(4,6)$ & 27 & $(2,8)$ & 12 & $(3,9)$ & 13 & $(3,9)$ & 13 & $(2,4)$ & 24 & $(2,9)$ & 23 & $(3$ & 24 & $(1,9)$ \\
\hline & 3 & , & c & c & c) & 32 & $(5,5)$ & 49 & $(5,1)$ & 53 & $(4,6)$ & 51 & $(3,4)$ & 48 & $(7,0)$ & 53 & $(6,6)$ & 51 & $(4,1)$ & 44 & $(4,1)$ & 50 & $(3,5)$ & 47 & $(2$ \\
\hline & $4 / 5$ & c & c & c & c & 11 & $(3,7)$ & 19 & $(3,8)$ & 14 & $(3,7)$ & 17 & $(2,6)$ & 36 & $(5,9)$ & 31 & $(5,8)$ & 33 & $(4,2)$ & 24 & $(2,9)$ & 20 & $(2,9)$ & 22 & $(2,1)$ \\
\hline England (VK) & $0 / 1$ & c & c & c & c & 34 & $(5,9)$ & 10 & $(3,0)$ & 10 & $(2,7)$ & 10 & $(2,2)$ & c & 4 & 6 & $(2,8)$ & 6 & $(2,3)$ & 12 & $(2,5)$ & 13 & $\mid(2,3)$ & 13 & $(1,7)$ \\
\hline & 2 & c & c & c & c & 42 & $\mid(8,2)$ & 32 & $(4,9)$ & 25 & $(4,0)$ & 28 & $13=$ & c & - & 21 & $(5,0)$ & 19 & $(3,6)$ & 28 & & 27 & & 27 & $(2,4)$ \\
\hline & 3 & 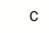 & c & c & c & 21 & $(5,1)$ & 42 & $(5,4)$ & 46 & $(4,9)$ & 44 & $(3,8)$ & c & c & 48 & $(5,6)$ & 44 & $(4,1)$ & 39 & $(3,6)$ & 42 & $(3,4)$ & 40 & $(2,4)$ \\
\hline & $4 / 5$ & c & c & c & c & 3 & $(2,0)$ & 16 & $(4,1)$ & 19 & $(3,6)$ & 18 & $(2,8)$ & c & c & 25 & $(5,3)$ & 31 & $(3,6)$ & 21 & $(3,0)$ & 18 & $(2,7)$ & 20 & $(1,9)$ \\
\hline & $0 / 1$ & c & c & c & c & 32 & $(5,5)$ & c & 4 & 12 & $(3,6)$ & 11 & $(2,9)$ & c & 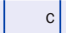 & c & c & 4 & $(3,4)$ & 13 & $(3,4)$ & 15 & $(2,8)$ & 14 & $(2,2)$ \\
\hline & 2 & . & c & c & c & 35 & (6) & c & 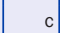 & 34 & $(4,9)$ & 31 & $(4,5)$ & c & . & c & & 24 & $(6,6)$ & 29 & $(5,1)$ & 32 & & 31 & 130 \\
\hline & 3 & . & c & c & c) & 27 & $(5,8)$ & c & c & 42 & $(5,2)$ & 43 & $(4,4)$ & c & 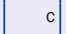 & c & c & 50 & $(6,7)$ & 41 & $(5,1)$ & 40 & $(3,5)$ & 41 & $(3,4)$ \\
\hline & $4 / 5$ & c & c & c & c & 5 & $(3,3)$ & c & c & 12 & $(3,3)$ & 15 & $(3,0)$ & c & c) & c & c & 21 & $(4,2)$ & 16 & $(3,6)$ & 12 & $(2,1)$ & 14 & $(2,0)$ \\
\hline & $0 / 1$ & c & c & 34 & $(6,6)$ & 34 & $(5,6)$ & 10 & $(2,9)$ & 10 & $(2,6)$ & 10 & $(2,1)$ & 6 & $(3,3)$ & 6 & $(2,8)$ & 6 & $|(2,3)|$ & 12 & $(2,4)$ & 13 & $(2,2)$ & 13 & $(1,7)$ \\
\hline & 2 & 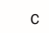 & 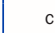 & 42 & $(6,5)$ & 41 & & 31 & $(4,7)$ & 25 & (3, & 28 & $(3,2)$ & 17 & $(5,0)$ & 21 & $(4,8)$ & 19 & 1 & 28 & $(3,5)$ & 27 & $(2$ & 27 & $\theta_{2}$ \\
\hline & 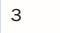 & c & c & 20 & $(5,6)$ & 22 & $(4,8)$ & 42 & $(5,2)$ & 46 & $(4,7)$ & 44 & $(3,7)$ & 41 & $(7,0)$ & 48 & $(5,5)$ & 44 & $(4,0)$ & 39 & $(3,5)$ & 42 & $(3,3)$ & 40 & $(2,4)$ \\
\hline & $4 /$ & c & c & 4 & $(2,4)$ & 3 & $(1,9)$ & 16 & $(4,0)$ & 19 & $(3,4)$ & 18 & $(2,7)$ & 36 & $(5,8)$ & 25 & $(5,2)$ & 31 & $(3,6)$ & 21 & $(2,9)$ & 18 & $(2,6)$ & 20 & $(1,9)$ \\
\hline & $0 / 1$ & c & c & c & c & 23 & $(1,0)$ & 10 & $(0,7)$ & 9 & $(0,6)$ & 10 & $(0,5)$ & 6 & $(0,7)$ & 6 & $(0,7)$ & 5 & $(0,4)$ & 12 & $(0,4)$ & 11 & $(0,4)$ & 11 & $(0,3)$ \\
\hline & 2 & 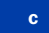 & c & c & c & 37 & $(\mathbf{1}, \mathbf{3})$ & 31 & $(1,0)$ & 31 & $(1,0)$ & 30 & $(0,7)$ & 20 & $(\mathbf{1}, \mathbf{1})$ & 20 & $(\mathbf{1}, \mathbf{1})$ & 19 & $(0,7)$ & 28 & $0,6)$ & 28 & $(0,6)$ & 28 & $(0,4)$ \\
\hline & 3 & 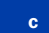 & $\mathbf{c}$ & c & c & 32 & (1, & 44 & $(\mathbf{1}, \mathbf{1})$ & 46 & $(\mathbf{1}, \mathbf{1})$ & 45 & $(0,8)$ & 45 & $(1,5)$ & 49 & $(\mathbf{1 , 5})$ & 48 & $(0,9)$ & 42 & $(0,7)$ & 44 & $(0,7)$ & 43 & $(0,5)$ \\
\hline & $4 /$ & c & c & c & c & 8 & $(0,7)$ & 15 & $(0,8)$ & 14 & $(0,8)$ & 15 & $(0,5)$ & 29 & $(1,3)$ & 26 & $(1,3)$ & 27 & $(0,8)$ & 18 & $(0,5)$ & 17 & $(0,5)$ & 17 & $(0,4)$ \\
\hline
\end{tabular}

Partnerländer Russische Föderation*
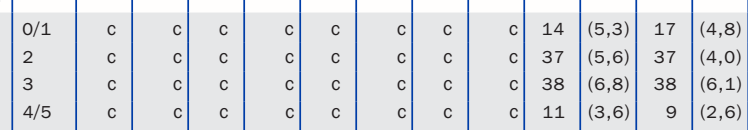

c $\begin{array}{lllllllllllll}10 & (2,7) & 11 & (2,4) & 19 & (3,8) & 11 & (3,1) & 15 & (2,7)\end{array}$ c \begin{tabular}{ll|l|l|l|l|l|l|l|l|l}
27 & $(5,3)$ & 32 & $(4,6)$ & 36 & $(4,5)$ & 34 & $(3,8)$ & 35 & $(3,3)$
\end{tabular}

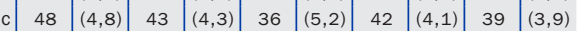

* Hinweis zu den Daten der Russischen Föderation s. Abschnitt Angewandte Methodik.

Anmerkung: Spalten mit getrennten Angaben zu anderen Altersgruppen sind im Internet verfügbar (s. Statlink unten).

Quelle: OECD. Survey of Adult Skills (PIAAC) (2012). PIAAC steht für das OECD Programme for the International Assessment of Adult Competencies.

Hinweise s. Anhang 3 unter www.oecd.org/edu/eag.htm. StatLink: http://dx.doi.org/10.1787/888933115597

Erläuterung der Kennzeichnung fehlender Daten s. Hinweise für den Leser. 
Tabelle A4.4

Bildungsmobilität bei Nichtschülern/Nichtstudierenden, nach Altersgruppe und Bildungsstand der Eltern (2012)

25- bis 34-jährige Nichtschüler/Nichtstudierende, die einen niedrigeren (Abwärtsmobilität), einen höheren (Aufwärtsmobilität) oder den gleichen Bildungsstand wie ihre Eltern aufweisen

Bedeutung der Zeilen zu 25- bis 34-jährigen Frauen, die Nichtschüler/Nichtstudierende sind: In Dänemark haben 15 Prozent dieser Frauen einen niedrigeren Bildungsstand als ihre Eltern, 33 Prozent verfügen über einen höheren Bildungsstand als die Eltern, und der Rest verfügt über den gleichen Bildungsstand wie die Eltern - 5 Prozent haben wie ihre Eltern eine Ausbildung unterhalb des Sekundarbereichs II, 11 Prozent wie ihre Eltern einen Abschluss im Sekundarbereich II/postsekundaren, nicht tertiären Bereich und 35 Prozent wie ihre Eltern einen Abschluss im Tertiärbereich.

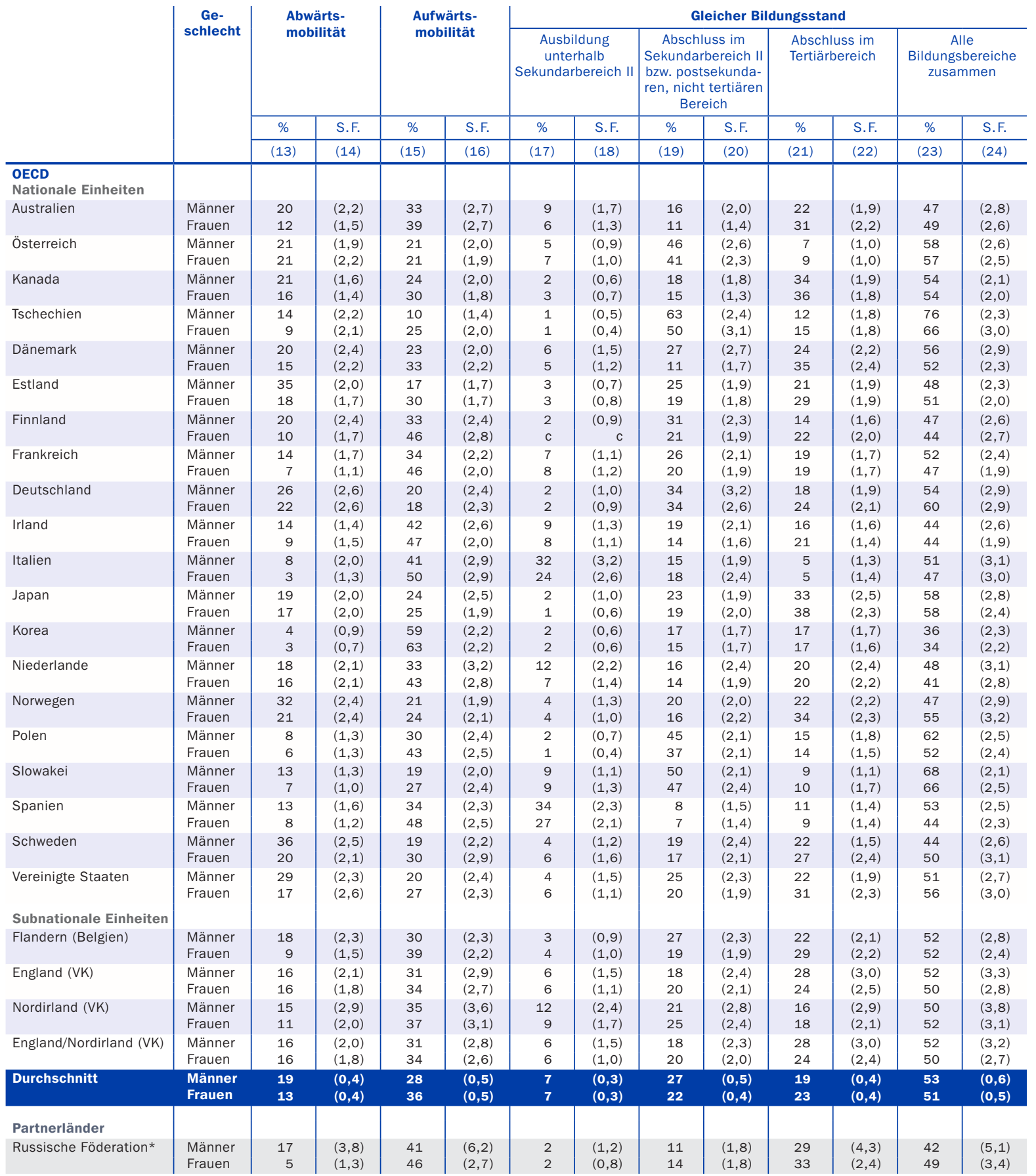

* Hinweis zu den Daten der Russischen Föderation s. Abschnitt Angewandte Methodik.

Anmerkung: Zeilen mit Angaben zu Männern und Frauen zusammen (d.h. Männer plus Frauen) und Spalten mit Angaben zu anderen Altersgruppen sind im Internet verfügbar (s. StatLink).

Quelle: OECD. Survey of Adult Skills (PIAAC) (2012). PIAAC steht für das OECD Programme for the International Assessment of Adult Competencies. Hinweise s. Anhang 3 unter www.oecd.org/edu/eag.htm. StatLink: http://dx.doi.org/10.1787/888933115616

Erläuterung der Kennzeichnung fehlender Daten s. Hinweise für den Leser. 



\section{Wie beeinflusst der Bildungsstand die Erwerbsbeteiligung?}

In den OECD-Ländern sind über 8o Prozent der Absolventen des Tertiärbereichs beschäftigt, gegenüber 70 Prozent der Absolventen des Sekundarbereichs II und weniger als 6o Prozent derjenigen mit einer Ausbildung unterhalb des Sekundarbereichs II.

Die Erwerbslosenquoten von jüngeren Erwachsenen mit einem Abschluss im Tertiärbereich sind höher als die von älteren Erwachsenen mit dem gleichen Bildungsstand: rund 7 Prozent gegenüber 4 Prozent.

Bei den beschäftigten Erwachsenen sind 74 Prozent der Absolventen des Tertiärbereichs in Vollzeitbeschäftigung gegenüber 7I Prozent der Absolventen des Sekundarbereichs II. Rund 64 Prozent der beschäftigten Erwachsenen mit einer Ausbildung unterhalb des Sekundarbereichs II arbeiten Vollzeit.

\section{Abbildung A5.1}

Beschäftigungsquoten 25- bis 64-Jähriger, nach Bildungsstand (2012)

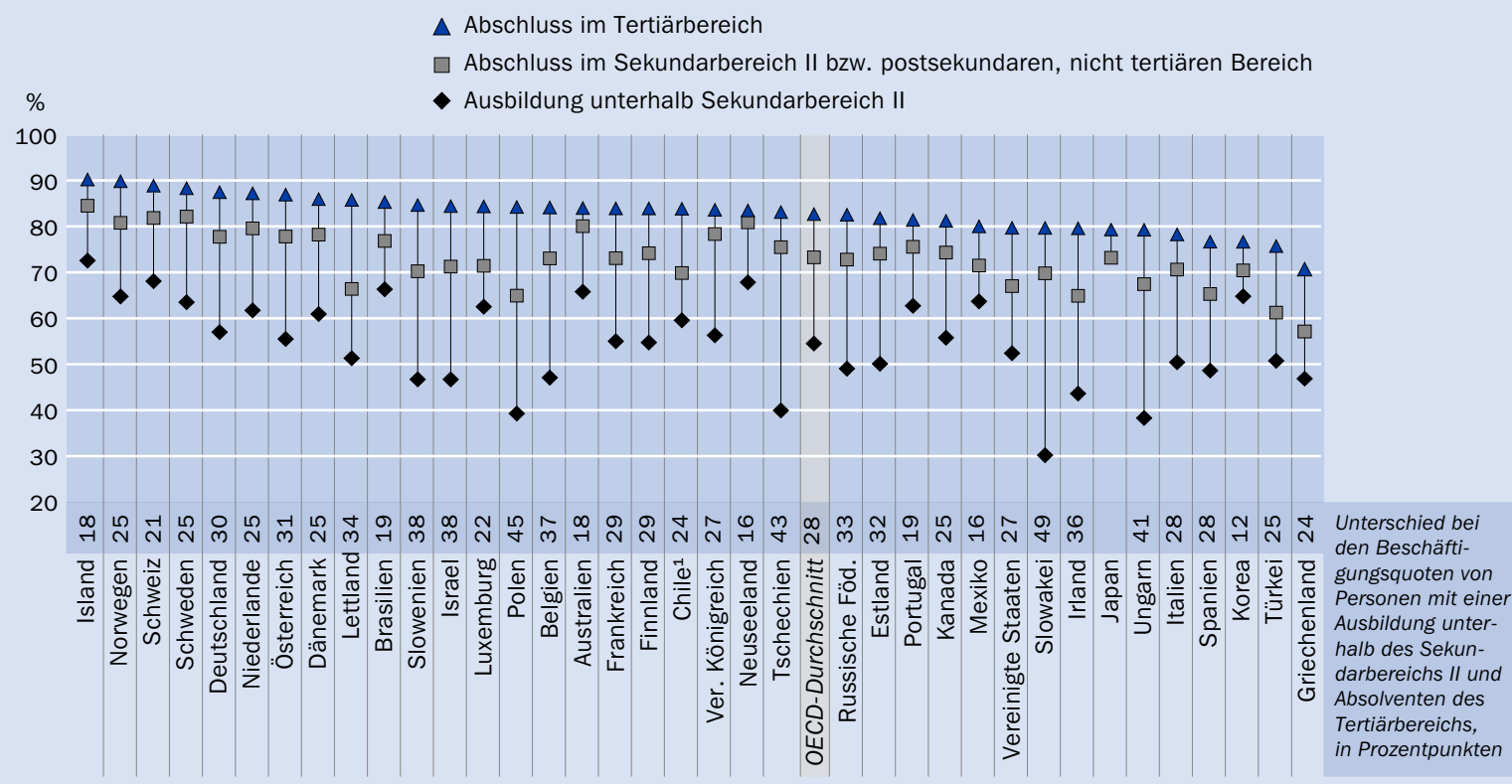

1. Referenzjahr 2011.

Anordnung der Länder in absteigender Reihenfolge der Beschäftigungsquote 25- bis 64-Jähriger mit einem Abschluss im Tertiärbereich

Quelle: OECD. Tabelle A5.3a. Hinweise s. Anhang 3 unter www.oecd.org/edu/eag.htm. StatLink: http://dx.doi.org/10.1787/888933115958

\section{Kontext}

Die Volkswirtschaften der OECD-Länder sind auf eine ausreichende Versorgung mit hoch qualifizierten Arbeitskräften angewiesen. Bildungsabschlüsse und der damit verbundene Bildungsstand werden häufig als indirekte Kennzahl für das „Humankapital“ und das Niveau der Kompetenzen des Einzelnen verwendet. In den meisten 
OECD-Ländern haben Personen mit einem hohen Bildungsstand die höchsten Beschäftigungsquoten. Gleichzeitig sehen sich Menschen mit einem nur niedrigen Bildungsstand einem größeren Risiko der Erwerbslosigkeit gegenüber. Der schnelle technische Fortschritt hat auch die Nachfrage auf dem globalen Arbeitsmarkt verändert - Beschäftigte mit hohen bzw. speziellen Kompetenzen sind sehr gefragt.

Dieser Indikator enthält zum ersten Mal Daten aus der Erhebung zu den grundlegenden Kompetenzen Erwachsener im Rahmen des OECD Programme for the International Assessment of Adult Competencies (PIAAC) sowie den OECD-Datensammlungen, um zu zeigen, inwieweit die Arbeitskräfte mit ihren Bildungsqualifikationen und grundlegenden Kompetenzen den Anforderungen des Arbeitsmarkts entsprechen. Während die Qualifikationen als Näherungsgröße für bestimmte, von Arbeitskräften erwartete Kompetenzen verwendet werden, wurden die grundlegenden Kompetenzen, wie die Lesekompetenz und die alltagsmathematische Kompetenz, separat gemessen.

Diese grundlegenden Kompetenzen werden in der Regel durch Schulbildung erworben, sie werden jedoch nicht durch formale Bildung allein entwickelt. Tatsächlich werden grundlegende Kompetenzen nur dann in der Bildung gut entwickelt und im Laufe des Lebens aufrechterhalten, wenn sie genutzt werden, insbesondere am Arbeitsplatz.

Wie in Indikator AI gezeigt, hat die Schulbildung dennoch signifikante Auswirkungen auf die beim Einzelnen vorhandenen grundlegenden Kompetenzen: Bei der Erhebung zu den grundlegenden Kompetenzen Erwachsener wiesen Personen mit einem niedrigen Bildungsstand eher niedrigere Punktzahlen bei der Lese- und alltagsmathematischen Kompetenz auf als Menschen mit einem hohen Bildungsstand. Daher werden die Bildungsqualifikationen und das Vorliegen bestimmter grundlegender Kompetenzen bei der Analyse der Arbeitsmarktergebnisse gemeinsam berücksichtigt.

\section{Weitere wichtige Ergebnisse}

Über alle Länder hinweg sind 87 Prozent der Personen mit der höchsten Lesekompetenz (Stufe 4 oder 5) in der Erhebung zu den grundlegenden Kompetenzen Erwachsener in Beschäftigung, 3,5 Prozent sind erwerbslos, und ro Prozent sind nicht im Arbeitsmarkt. In Deutschland, Estland, Flandern (Belgien), den Niederlanden, Norwegen und Schweden sind mindestens go Prozent der Hochqualifizierten in Beschäftigung.

In Belgien, Deutschland, Estland, Irland, Israel, Österreich, Polen, der Russischen Föderation, der Slowakei, Slowenien, Tschechien und Ungarn sind die Beschäftigungsquoten bei Erwachsenen mit einem Abschluss im Tertiärbereich mindestens 30 Prozentpunkte höher als bei Erwachsenen mit nur einer Ausbildung unterhalb des Sekundarbereichs II.

Die Erwerbslosenquoten von Absolventen eines berufsbildenden Abschlusses im Sekundarbereich II bzw. postsekundaren, nicht tertiären Bereich sind in der Regel niedriger (8 Prozent) als die von Absolventen eines allgemeinbildenden Bildungsgangs des Sekundarbereichs II (9 Prozent). 


\section{Entwicklungstendenzen}

Eine Langzeitbetrachtung der Daten zu Erwerbslosen- und Beschäftigungsquoten ist eine gute Grundlage zur Bewertung der langfristigen Entwicklungstendenzen und unterschiedlichen Beschäftigungsrisiken für Männer und Frauen unterschiedlichen Alters und Bildungsstands. Während der letzten I5 Jahre waren in allen OECD-Ländern die Beschäftigungsquoten von Absolventen des Tertiärbereichs stets höher als die von Arbeitsmarktteilnehmern ohne einen Abschluss im Tertiärbereich. Umgekehrt waren die Erwerbslosenquoten von Männern und Frauen mit einem niedrigeren Bildungsstand höher als diejenigen von Absolventen des Tertiärbereichs. Insgesamt sehen sich jüngere Erwachsene den größten Schwierigkeiten gegenüber, und die Erwerbslosenquoten sind unter denjenigen mit einer Ausbildung nur unterhalb des Sekundarbereichs II am höchsten. 2012 waren rund 20 Prozent der jungen Erwachsenen in den OECD-Ländern erwerbslos, das ist die höchste Erwerbslosenquote seit mehr als Io Jahren.

\section{Analyse und Interpretationen}

\section{Arbeitsmarktergebnisse nach Bildungsstand, Altersgruppe und Geschlecht \\ Erwerbsstatus nach Bildungsstand und Altersgruppe}

Kompetenzen gehören zu den Grundvoraussetzungen für wirtschaftliches Wachstum, und die Arbeitsmärkte belohnen sehr gut ausgebildete Arbeitskräfte (s. Indikator A6). Daher verbessert ein Abschluss im Tertiärbereich die Beschäftigungschancen. Wie Abbildung A5.I zeigt, gilt diese Feststellung für alle OECD- und G20-Länder, für die Daten vorliegen. Im Durchschnitt sind mehr als 8o Prozent der Absolventen des Tertiärbereichs beschäftigt - gegenüber mehr als 7o Prozent der Absolventen des Sekundarbereichs II bzw. des postsekundaren, nicht tertiären Bereichs und weniger als 6o Prozent derjenigen mit einer Ausbildung unterhalb des Sekundarbereichs II. In einigen Ländern besteht ein großer Unterschied zwischen den Beschäftigungsquoten von Absolventen des Tertiärbereichs und Personen mit einer Ausbildung unterhalb des Sekundarbereichs II. In Belgien, Deutschland, Estland, Irland, Israel, Österreich, Polen, der Russischen Föderation, der Slowakei, Slowenien, Tschechien und Ungarn beispielsweise beträgt der Unterschied bei den Beschäftigungsquoten zwischen diesen beiden Gruppen mindestens 30 Prozentpunkte (Tab. A5·3a).

Außerdem bestehen signifikante Unterschiede zwischen den Beschäftigungsquoten jüngerer und älterer Erwachsener. Jüngere Erwachsene verfügen nicht nur über einen höheren Bildungsstand als ältere Erwachsene (s. Indikator AI), sondern bei ihnen ist auch die Wahrscheinlichkeit größer, dass sie in Beschäftigung sind. Der Anteil der beschäftigten 25- bis 34-Jährigen mit einem Abschluss im Sekundarbereich II bzw. postsekundaren, nicht tertiären Bereich ist im Durchschnitt mehr als 20 Prozentpunkte höher als der Anteil der beschäftigten 55- bis 64-Jährigen mit demselben Bildungsabschluss (75 Prozent gegenüber 55 Prozent). Rund 6o Prozent der jüngeren Erwachsenen mit einer Ausbildung unterhalb des Sekundarbereichs II sind beschäftigt, jedoch 
nur etwa 40 Prozent der älteren Arbeitnehmer mit diesem Bildungsstand, während bei den Absolventen des Tertiärbereichs mehr als 8o Prozent der jüngeren Erwachsenen gegenüber weniger als 70 Prozent der älteren beschäftigt sind (Tab. A5·3a).

Am stärksten ausgeprägt ist dieser Unterschied zwischen den Altersgruppen und den verschiedenen Bildungsständen in Luxemburg, Österreich, der Russischen Föderation, Slowenien und der Türkei. So sind beispielsweise in Slowenien 80 Prozent der jüngeren Erwachsenen mit einem Abschluss im Sekundarbereich II bzw. dem postsekundaren, nicht tertiären Bereich beschäftigt, jedoch nur 30 Prozent der älteren Arbeitnehmer mit dem gleichen Bildungsstand (Tabelle A5·3a).

\section{Erwerbsstatus nach Geschlecht}

In allen OECD-Ländern und in allen Bildungsbereichen bestehen weiterhin geschlechtsspezifische Unterschiede bei der Beschäftigung. Nur $6_{5}$ Prozent der Frauen sind beschäftigt - gegenüber 8o Prozent der Männer. Der geschlechtsspezifische Unterschied bei den Beschäftigungsquoten ist unter den Erwachsenen mit dem niedrigsten Bildungsstand am größten: Zwischen Männern und Frauen mit einem Abschluss im Sekundarbereich I beträgt der Abstand rund 20 Prozentpunkte (68 Prozent bei den Männern gegenüber 48 Prozent bei den Frauen), bei den Absolventen des Sekundarbereichs II sind es I 5 Prozentpunkte ( 80 Prozent für Männer und 64 Prozent für Frauen bei einem Abschluss der ISCED-Stufe $3 \mathrm{C}$ [lang]/3B sowie 80 Prozent für Männer und 65 Prozent für Frauen bei einem Abschluss der ISCED-Stufe 3A) und weniger als Io Prozentpunkte zwischen Männern und Frauen mit einem Abschluss im Tertiärbereich (86 Prozent für Männer und 76 Prozent für Frauen mit einem Abschluss im Tertiärbereich B und 89 Prozent für Männer und 8o Prozent für Frauen mit einem Abschluss auf ISCEDStufe $5 \mathrm{~A} / 6$ ). Obwohl der Unterschied zwischen den Beschäftigungsquoten von Männern und Frauen mit höherem Bildungsstand abnimmt, liegen die Quoten der Frauen mit einem Abschluss im Tertiärbereich im OECD-Durchschnitt doch immer noch deutlich unter denen der Männer - trotz der Tatsache, dass 2012 der Anteil der Frauen mit einem Abschluss im Tertiärbereich in den OECD-Ländern etwas höher als der der Männer war (34 Prozent gegenüber 3 I Prozent) (Tab. A5.rb und Tab. Ar.Ib im Internet).

Der Unterschied zwischen den Beschäftigungsquoten von Männern und Frauen mit einem Abschluss im Tertiärbereich A bzw. eines weiterführenden forschungsorientierten Studiengangs ist in Japan, Korea, Mexiko, Tschechien und der Türkei mit mehr als I5 Prozentpunkten besonders groß. In Island, Norwegen, Portugal und Schweden beträgt der geschlechtsspezifische Unterschied zwischen den Beschäftigungsquoten weniger als 3 Prozentpunkte (Tab. A5.Ib).

\section{Erwerbslosenquoten, nach Bildungsstand und Altersgruppe}

Auch das Risiko der Erwerbslosigkeit steht in einem engen Zusammenhang mit dem Bildungsstand: Die Wahrscheinlichkeit einer Erwerbslosigkeit ist für Menschen mit einem höheren Bildungsstand niedriger. Wie in Abbildung A5.2 dargestellt, waren 2012 im Durchschnitt der OECD-Länder I4 Prozent der Erwachsenen mit einer Ausbildung unterhalb des Sekundarbereichs II erwerbslos. Dieser Anteil hat sich zwischen 2005 und 2012 kaum verändert (II Prozent im Jahr 2005 und I4 Prozent im Jahr 2012). In einigen Ländern waren jedoch signifikante Änderungen zu beobachten. In Griechenland, Irland, Spanien und Ungarn sind die Erwerbslosenquoten für Menschen 
Abbildung A5.2

Erwerbslosenquoten 25- bis 64-Jähriger, nach Bildungsstand (2005, 2010 und 2012)

$\checkmark 2005 \Delta 2010 \square 2012$

Ausbildung unterhalb Sekundarbereich II

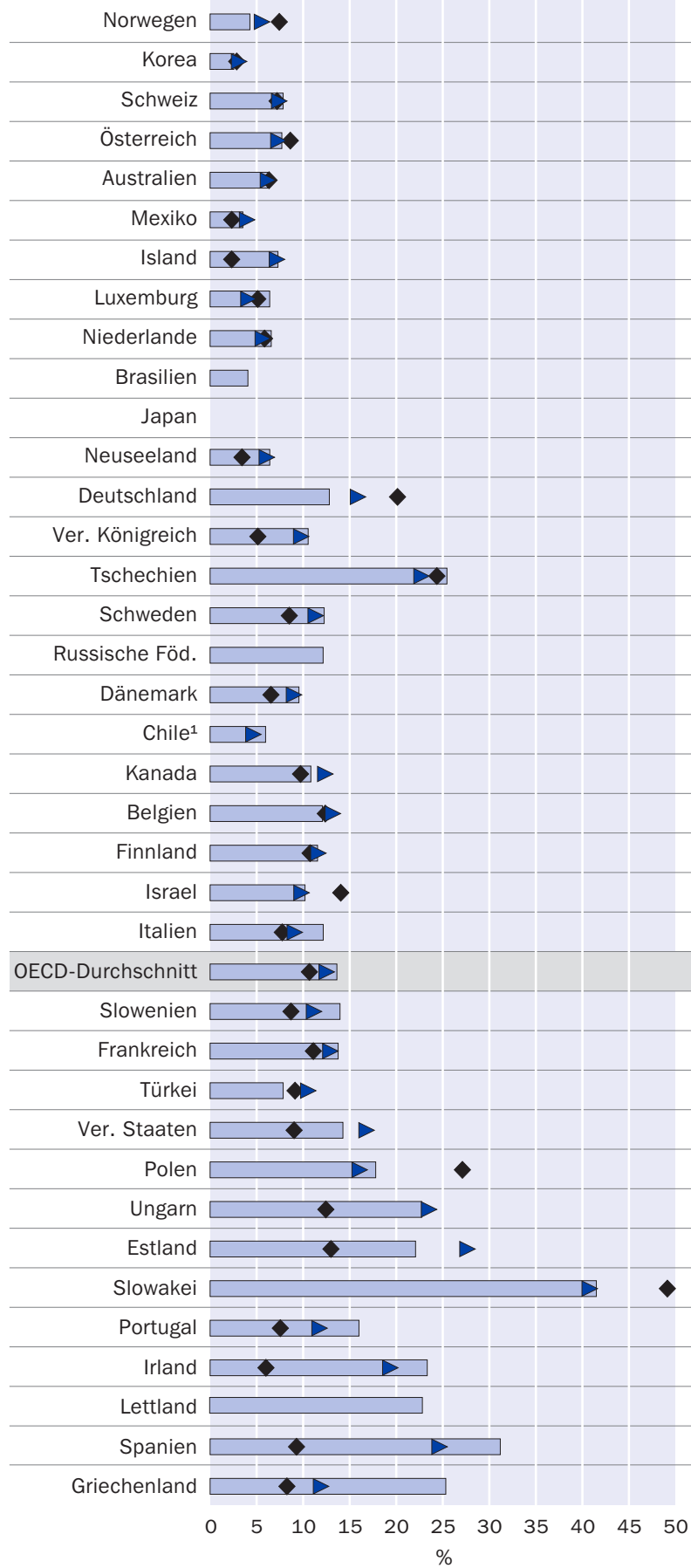

Abschluss im

Sekundarbereich II bzw. postsekundaren, nicht tertiären Bereich

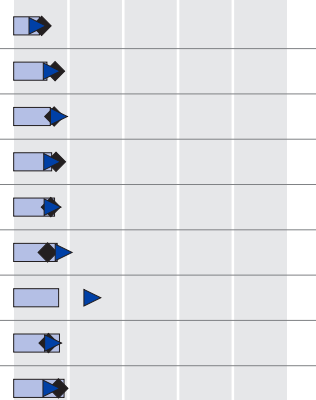

प

$\square$
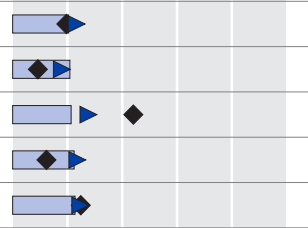

$\square$

$\square$

$\longrightarrow$
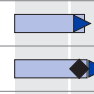

$\square$

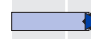

$\square$
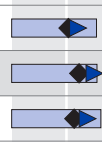

$\longrightarrow$
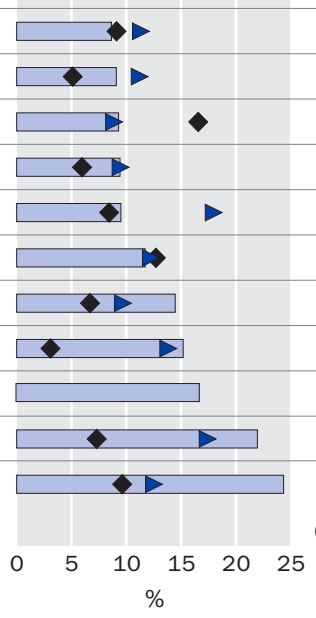

Abschluss im Tertiärbereich

\begin{tabular}{|l|l|}
\hline & Norwegen \\
\hline & Korea \\
\hline & Schweiz \\
\hline & Österreich \\
\hline & Australien \\
\hline
\end{tabular}

Australien

Mexiko

Island

Luxemburg

Niederlande

Brasilien

Japan

Neuseeland

Deutschland

Ver. Königreich

Tschechien

Schweden

Russische Föd.

Dänemark

Chile $^{1}$

Kanada

Belgien

Finnland

Israel

Italien

OECD-Durchschnitt

Slowenien

Frankreich

Türkei

Ver. Staaten

Polen

Ungarn

Estland

Slowakei

Portugal

Irland

Lettland

Spanien

Griechenland

$\begin{array}{llll}5 & 10 & 15 & 20\end{array}$

1. Referenzjahr 2011.

Anordnung der Länder in aufsteigender Reihenfolge der Erwerbslosenquoten von 25- bis 64-jährigen Absolventen des Sekundarbereichs II bzw. postsekundaren, nicht tertiären Bereichs im Jahr 2012.

Quelle: OECD. Tabelle A5.4a. Hinweise s. Anhang 3 unter www.oecd.org/edu/eag.htm. StatLink: http://dx.doi.org/10.1787/888933115977 
mit niedrigem Bildungsstand in diesem Zeitraum erheblich gestiegen - um mehr als Io Prozentpunkte. Zwischen 2010 und 2012 ist diese Quote in Deutschland, Estland, Kanada, der Türkei und den Vereinigten Staaten signifikant gesunken (Tab. A5.4a).

Im Durchschnitt der OECD-Länder waren 2012 etwa 8 Prozent der Erwachsenen mit einem Abschluss im Sekundarbereich II bzw. postsekundaren, nicht tertiären Bereich erwerbslos. Die Erwerbslosenquote bei Erwachsenen mit diesem Bildungsstand variiert je nach Land erheblich, von nur 2 Prozent in Norwegen bis zu etwa 24 Prozent in Griechenland. Im Durchschnitt der OECD-Länder waren 5 Prozent der Erwachsenen mit einem Abschluss im Tertiärbereich erwerbslos; nur in Griechenland, Portugal und Spanien lag die Erwerbslosenquote bei Absolventen des Tertiärbereichs bei mehr als Io Prozent (Abb. A5.2).

In einigen Ländern sind die Unterschiede zwischen den Erwerbslosenquoten von Erwachsenen mit einem hohen und einem niedrigen Bildungsstand sehr klein oder sogar umgekehrt. In Brasilien, Korea, Mexiko und der Türkei beispielsweise ist die Erwerbslosenquote von Absolventen des Sekundarbereichs II und des postsekundaren, nicht tertiären Bereichs höher als die von Personen mit einer Ausbildung unterhalb des Sekundarbereichs II. In Mexiko haben Erwachsene ohne einen Abschluss im Sekundarbereich II bzw. im postsekundaren, nicht tertiären Bereich sogar eine geringere Erwerbslosenquote als Absolventen des Tertiärbereichs (Tab. A5.4a).

Die jüngeren Generationen scheinen von der Erwerbslosigkeit am härtesten getroffen zu werden. Für alle Bildungsbereiche gilt, dass jüngere Erwachsene stärker von Erwerbslosigkeit betroffen sind als ältere. Im OECD-Durchschnitt sind rund Io Prozent der älteren Erwachsenen mit einer Ausbildung unterhalb des Sekundarbereichs II erwerbslos gegenüber 20 Prozent der jüngeren Erwachsenen mit vergleichbarem Bildungsstand. So sind auch to Prozent der jüngeren Erwachsenen mit einem Abschluss im Sekundarbereich II bzw. postsekundaren, nicht tertiären Bereich erwerbslos im Vergleich zu 7 Prozent der älteren Erwachsenen mit ähnlichem Bildungsstand. Bei den Absolventen des Tertiärbereichs ist der Abstand zwischen den beiden Altersgruppen am geringsten: 7 Prozent der jüngeren Erwachsenen sind erwerbslos, bei den älteren Erwachsenen sind es 4 Prozent. Dies unterstreicht die zunehmende Bedeutung des Erwerbs eines Abschlusses im Tertiärbereich. Die Tatsache, dass bei den jüngeren Erwachsenen sowohl die Erwerbslosenquoten als auch die Beschäftigungsquoten höher sind als bei den älteren Erwachsenen, hängt eng mit der höheren Nichterwerbsquote älterer Erwachsener zusammen (Tab. A5.4a).

\section{Erwerbslosigkeit nach Geschlecht}

Im Durchschnitt sind die geschlechtsspezifischen Unterschiede bei den Erwerbslosenquoten weniger ausgeprägt als bei den Beschäftigungsquoten. Unter den Erwachsenen mit einer Ausbildung unterhalb des Sekundarbereichs II sind die Erwerbslosenquoten von Frauen und Männern sehr ähnlich (I3 Prozent der Frauen gegenüber I4 Prozent der Männer). Bei Erwachsenen, die über einen Abschluss im Sekundarbereich II bzw. im postsekundaren, nicht tertiären Bereich verfügen, sind die Erwerbslosenquoten für Frauen höher als für Männer ( 9 Prozent gegenüber 7 Prozent). Dies trifft auch für die Absolventen des Tertiärbereichs zu, hier sind um 5 Prozent der Männer und auch der Frauen erwerbslos (Tab. A5.4b und A5.4c im Internet). 
Die geschlechtsspezifischen Unterschiede bei den Erwerbslosenquoten sind in Griechenland und der Türkei besonders groß. So waren beispielsweise 2012 in der Türkei II Prozent der Frauen mit einem Abschluss im Tertiärbereich erwerbslos, jedoch nur 6 Prozent der Männer mit diesem Bildungsstand (in Griechenland waren es 20 Prozent gegenüber I4 Prozent). Noch ausgeprägter war dieser Unterschied bei den Erwachsenen mit einem Abschluss im Sekundarbereich II: I7 Prozent der Frauen waren erwerbslos, aber nur 7 Prozent der Männer (in Griechenland waren es 30 Prozent gegenüber 2I Prozent) (Tab. A5.4b und A5.4c im Internet).

\section{Erwerbslosigkeit nach Fächergruppe im Tertiärbereich}

Selbst wenn Absolventen des Tertiärbereichs niedrigere Erwerbslosenquoten aufweisen als Absolventen niedrigerer Bildungsbereiche, bedeutet dies nicht, dass dieser Vorteil gleichermaßen für alle Absolventen des Tertiärbereichs bzw. durchgängig für alle Studiengänge des Tertiärbereichs gilt. In den Vereinigten Staaten und anderen Ländern hat man festgestellt, dass sich für die Beschäftigungsquoten der Arbeitnehmer mit einem ersten Abschluss im Tertiärbereich A je nach Studiengang eine erhebliche Bandbreite ergibt. Die Einkommensdaten von 25- bis 29-Jährigen in den Vereinigten Staaten zeigen beispielsweise relative hohe Erwerbseinkommen für Absolventen der Fächergruppen Ingenieurwesen und Informatik, jedoch relativ geringe Erwerbseinkommen für Absolventen der Erziehungs- oder Sozialwissenschaften.

Andererseits ergab sich aus den US-amerikanischen Daten zur Erwerbslosigkeit auch keine durchgängig niedrige Erwerbslosenquote für bestimmte stark nachgefragte Fächer mit hohem Gehaltsniveau. So übertraf beispielsweise die Erwerbslosenquote der Absolventen der mit guten Einkommensaussichten verbundenen Informatikfächer (5 Prozent) die der Absolventen der mit relativ niedrigen Einkommensaussichten verbundenen Studiengänge für die Lehrerausbildung im Sekundarbereich (2 Prozent), den Studiengängen mit einer der niedrigsten Erwerbslosenquoten. Eine Untersuchung unter Absolventen des Tertiärbereichs des Jahres 2005 in Kanada ergab außerdem, dass in 2007 die Erwerbslosenquoten von Absolventen des Tertiärbereichs A von 3 Prozent bei Absolventen von Studiengängen in den Bereichen Agrarwissenschaften, Gesundheitswesen und Ingenieurwissenschaften bis zu 8 Prozent für die Absolventen von Studiengängen im Bereich Erziehungswissenschaften reichten. Diese Ergebnisse belegen, wie komplex und unterschiedlich die Ergebnisse für Absolventen von Studiengängen des Tertiärbereichs beim Eintritt in den Arbeitsmarkt sein können (s. Kasten A5.I in OECD, 2013a).

\section{Erwerbsstatus nach berufs- und allgemeinbildenden Ausbildungsgängen} Die Internationale Standardklassifikation des Bildungswesens (ISCED-97) definiert berufliche Ausbildung (Vocational Education and Training [VET]) als „Bildung, die den Teilnehmern in erster Linie praktische Fertigkeiten, Kenntnisse und ein umfassendes Verständnis vermittelt, die sie für die Arbeit in einem bestimmten Beruf oder Berufsfeld benötigen. Der erfolgreiche Abschluss eines solchen Bildungsgangs führt zu einer für den Arbeitsmarkt relevanten beruflichen Qualifikation, die von den zuständigen Stellen in dem Land, in dem sie erworben wurde, anerkannt wird“ (UNESCO, I997).

Eine berufliche Ausbildung richtet sich zumeist an Absolventen mit einem Abschluss im Sekundarbereich II bzw. postsekundaren, nicht tertiären Bereich. In einigen Län- 
dern wurde Absolventen von berufsbildenden Ausbildungsgängen durch Reformen der direkte Zugang zum Tertiärbereich erleichtert, in anderen werden berufliche Ausbildungsgänge auch im Tertiärbereich angeboten.

In einigen Systemen ist die schulische Ausbildung umfassend mit einer Ausbildung am Arbeitsplatz kombiniert. Beispiele für diese Art von „dualem System“ finden sich in Deutschland, Luxemburg, den Niederlanden, Österreich und der Schweiz. Zu den Stärken dieses Systems gehört, dass dadurch eine Reihe öffentlich-privater Partnerschaften entsteht, durch die sich Sozialpartner und Arbeitgeber an der Entwicklung berufsbildender Bildungsgänge beteiligen können, häufig bis zur Festlegung der Rahmenrichtlinien für Lehrpläne. In vielen dieser Systeme investieren die Arbeitgeber durch die Finanzierung von Ausbildungsstellen erheblich in die berufliche Ausbildung, sie übernehmen die Kosten für Ausbilder, Material und/oder Ausrüstung.

Abgesehen von anderen positiven Auswirkungen unterstützt die Kombination aus Lernen in der Schule und am Arbeitsplatz in einer integrierten formalen Ausbildung die Eingliederung von Absolventen berufsbildender Bildungsgänge in den Arbeitsmarkt. Untersuchungen haben gezeigt, dass berufsbildende Ausbildungsgänge gute Erträge für staatliche Investitionen erbringen können, und einige Länder mit gut ausgebauten Berufsbildungssystemen, wie Deutschland, waren bei der Bekämpfung der Jugenderwerbslosigkeit relativ erfolgreich (CEDEFOP, 20II).

In den OECD-Ländern mit verfügbaren Daten sind 75 Prozent der Absolventen von berufsbildenden Ausbildungsgängen im Sekundarbereich II bzw. postsekundaren, nicht tertiären Bereich beschäftigt, damit liegt ihre Beschäftigungsquote 5 Prozentpunkte über der derjenigen, die als höchste Qualifikation einen Abschluss in einem allgemeinbildenden Ausbildungsgang im Sekundarbereich II erworben haben.

Die Erwerbslosenquoten der Absolventen von berufsbildenden Ausbildungsgängen im Sekundarbereich II bzw. im postsekundaren, nicht tertiären Bereich sind in der Regel niedriger: durchschnittlich 8 Prozent gegenüber 9 Prozent der Erwachsenen mit einem allgemeinbildenden Abschluss im Sekundarbereich II. In Dänemark und Slowenien liegen die Erwerbslosenquoten für Erwachsene mit einem berufsbildenden Abschluss im Sekundarbereich II bzw. postsekundaren, nicht tertiären Bereich mindestens 3 Prozentpunkte unter denen der Absolventen von allgemeinbildenden Ausbildungsgängen im gleichen Bildungsbereich. In Griechenland und Irland ist die Situation genau umgekehrt (Tab. A5·5a).

Ein möglicher Nachteil ist, dass die von den Ausbildungsteilnehmern in berufsbildenden Ausbildungsgängen erworbenen Kompetenzen auf sich schnell ändernden Arbeitsmärkten möglicherweise nur von begrenzter Relevanz sind. Außerdem bestehen für Absolventen berufsbildender Bildungsgänge in der Regel andere Nachteile. Wie in Indikator Ar gezeigt, verfügen Absolventen von berufsbildenden Bildungsgängen des Sekundarbereichs II in der Regel über eine niedrigere Lesekompetenz (gemäß Erhebung zu den grundlegenden Kompetenzen Erwachsener) als Personen mit einem allgemeinbildenden Abschluss im Sekundarbereich II. Das überrascht nicht, da die Erhebung Kompetenzen misst, die eher in allgemeinbildenden als in berufsbildenden Bildungsgängen betont werden, während Kompetenzen, die für berufsbildende Bil- 
dungsgänge spezifisch sind, nicht gemessen werden. Doch zeigt dieses Ergebnis, wie wichtig die Förderung der Kompetenzen im Bereich der Informationsverarbeitung, wie Lese- und alltagsmathematische Kompetenz, ist, um die Anpassungsfähigkeit von Absolventen berufsbildender Bildungsgänge im Arbeitsmarkt zu steigern (OECD, 2013 b).

\section{Vollzeitbeschäftigte unter den Absolventen des Tertiärbereichs}

Mit dem Bildungsstand steigen nicht nur die Chancen auf eine Beschäftigung, sondern auch auf eine Vollzeitbeschäftigung. In den OECD-Ländern sind 70 Prozent der Erwerbspersonen unabhängig von ihrem Bildungsstand vollzeitbeschäftigt. Unter den beschäftigten Erwachsenen sind 7I Prozent der Absolventen des Sekundarbereichs II vollzeitbeschäftigt gegenüber 74 Prozent der Absolventen des Tertiärbereichs. Von den Beschäftigten mit einer Ausbildung unterhalb des Sekundarbereichs II sind rund 64 Prozent vollzeitbeschäftigt (Tab. A5.6). Die Definition von Vollzeitbeschäftigung unterscheidet sich zwischen den einzelnen Ländern: In einigen Ländern definieren die Befragten den Begriff selbst, in anderen gibt es offizielle Vorgaben hinsichtlich einer Mindeststundenzahl. Diese Mindestanzahl an Stunden reicht von 30 Stunden pro Woche in Griechenland, Neuseeland und Tschechien bis zu 44 Stunden in Chile. Weitere Informationen zu den länderspezifischen Definitionen finden sich im Abschnitt Definitionen von Indikator A6 und in Anhang 3 unter www.oecd.org/edu/eag.htm.

In den meisten OECD-Ländern ist der Anteil der 35- bis 44-jährigen Männer in Vollzeitbeschäftigung beträchtlich größer als der der 55- bis 64-Jährigen. Ein derartiges Verhältnis lässt sich bei den Frauen nicht erkennen. In vielen Ländern ist der Anteil der

\section{Abbildung A5.3}

Beschäftigte mit einem Abschluss im Tertiärbereich, nach Geschlecht und Altersgruppe (2012) Anteil der ganzjährig Vollzeitbeschäftigten

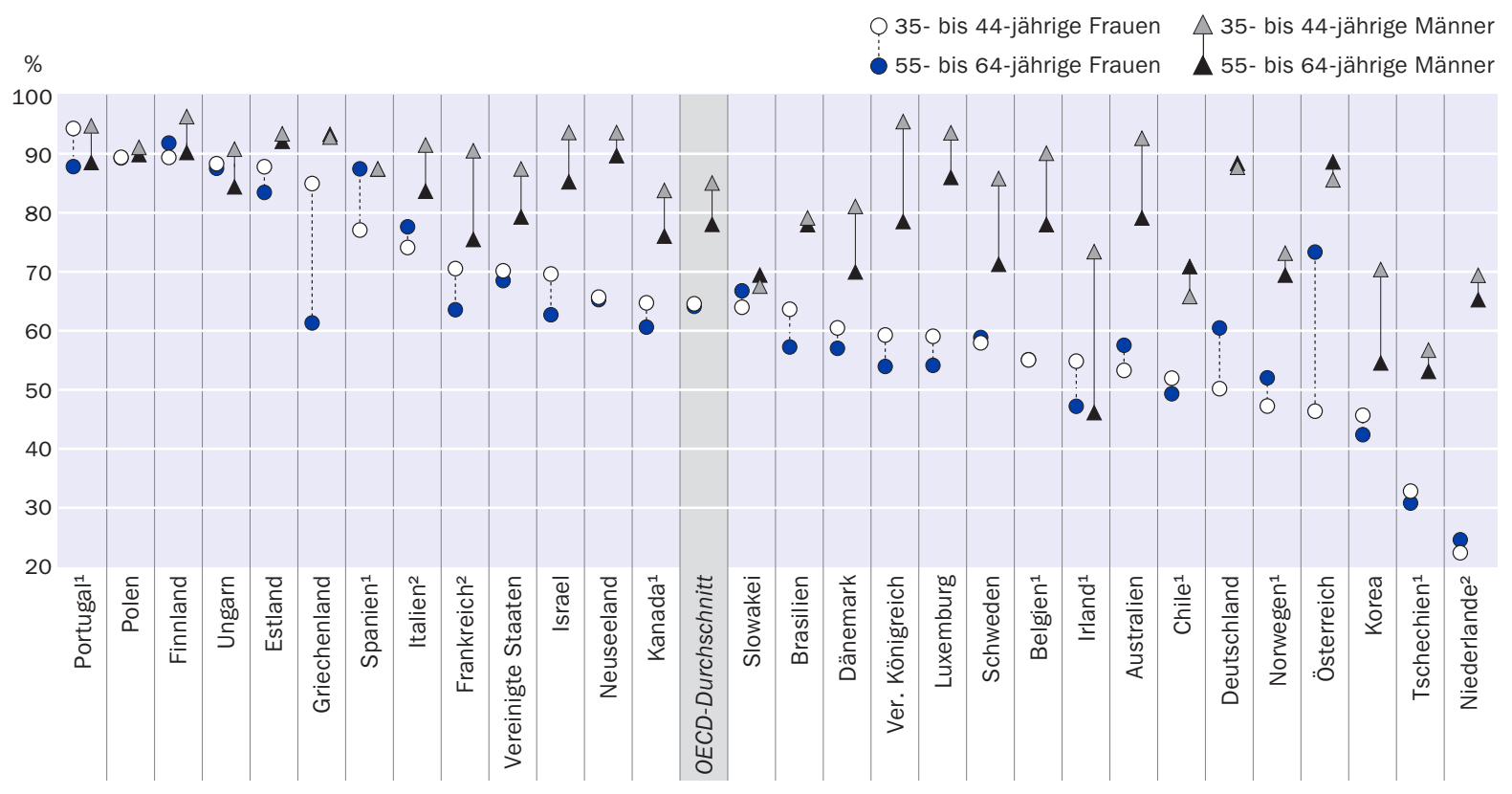

1. Referenzjahr 2011. 2. Referenzjahr 2010.

Anordnung der Länder in absteigender Reihenfolge des Anteils vollzeitbeschäftigter 35- bis 44-jähriger Frauen mit einem Abschluss im Tertiärbereich.

Quelle: OECD. Tabelle A5.6. Hinweise s. Anhang 3 unter www.oecd.org/edu/eag.htm. StatLink: http://dx.doi.org/10.1787/888933115996 
vollzeitbeschäftigten $55^{-}$bis 64 -jährigen Frauen ähnlich hoch wie der der 35 - bis 44-Jährigen mit dem gleichen Bildungsstand (Tab. A5.6).

Abbildung A5.3 zeigt den Anteil der vollzeitbeschäftigten Erwerbspersonen mit einem Abschluss im Tertiärbereich in den Altersgruppen der 35-bis 44-jährigen Männer und Frauen sowie der 55- bis 64-jährigen Männer und Frauen. Die Länge der schwarzen Linien verdeutlicht die Differenz zwischen den Anteilen der vollzeitbeschäftigten Männer in den beiden Altersgruppen, die Länge der gestrichelten Linien die Differenz zwischen den Anteilen der vollzeitbeschäftigten Frauen in den beiden Altersgruppen.

Viele 35- bis 44-jährige Frauen haben kleine Kinder und arbeiten daher häufig Teilzeit. So ist zum Beispiel in Deutschland, Österreich und Spanien der Anteil der Vollzeitbeschäftigten bei den älteren Absolventinnen des Tertiärbereichs signifikant höher als bei den jüngeren. In anderen Ländern, wie beispielsweise in Frankreich, Griechenland, Irland, Israel, Luxemburg, Portugal und dem Vereinigten Königreich, sind mehr jüngere Frauen vollzeitbeschäftigt als ältere. In Belgien, Finnland, Neuseeland, den Niederlanden, Polen, Schweden, Tschechien, Ungarn und den Vereinigten Staaten besteht nur ein minimaler Unterschied zwischen der Vollzeitbeschäftigung älterer und jüngerer Frauen. Dennoch liegt der Anteil der vollzeitbeschäftigten Absolventinnen des Tertiärbereichs in allen OECD-Ländern zusammengenommen deutlich unter dem der Männer mit dem gleichen Bildungsstand, obwohl in Estland, Finnland, Polen, Portugal und Ungarn mehr als 8o Prozent der Absolventinnen und Absolventen des Tertiärbereichs beider Altersgruppen vollzeitbeschäftigt sind (Tab. A5.6).

Außerdem müssen sich Studierende und Eltern kleiner Kinder in der Regel entscheiden, ob sie Teilzeit oder überhaupt nicht arbeiten wollen. Wie in Indikator A6 gezeigt, sind im Durchschnitt Io Prozent der Erwachsenen mit einem Abschluss im Tertiärbereich (Tertiärbereich A bzw. weiterführender forschungsorientierter Studiengang) ohne Erwerbseinkommen, und dieser Anteil ist bei den Frauen mit 12 Prozent höher als bei Männern mit 7 Prozent (s. Indikator A6, Tab. A6.4 im Internet).

\section{Arbeitsmarktergebnisse und Lese- bzw. alltagsmathematische Kompetenz}

$\mathrm{Zu}$ den zentralen Zielen der Erhebung zu den grundlegenden Kompetenzen Erwachsener gehört die Ermittlung des Zusammenhangs zwischen den Kompetenzen Einzelner und ihrem jeweiligen Erwerbsstatus (OECD, 2013c). Auch wenn Lese-, alltagsmathematische und technologiebasierte Problemlösekompetenz - die in der Erhebung explizit getesteten Kompetenzen - wichtige Elemente der Gesamtkompetenz einer Person sind, stellen sie nur einige der Fähigkeiten dar, die Beschäftigte am Arbeitsplatz zum Tragen bringen (OECD, 2013b).

Im Durchschnitt aller Länder sind 87 Prozent der Personen mit einer Lesekompetenz auf Stufe 4 oder 5 , den höchsten Kompetenzstufen in der Erhebung zu den grundlegenden Kompetenzen Erwachsener, beschäftigt, 3,5 Prozent sind erwerbslos und Io Prozent nicht im Arbeitsmarkt. In Deutschland, Estland, Flandern (Belgien), den Niederlanden, Norwegen und Schweden sind 9o Prozent derjenigen mit hohem Kompetenzniveau in Beschäftigung (Tab. A5.9a [L]). 
Beschäftigte Erwachsene auf Lesekompetenzstufe 2 bzw. 4 oder 5, nach Bildungsstand (2012)

Erhebung zu den grundlegenden Kompetenzen Erwachsener, Anteil 25- bis 64-Jähriger

Lesekompetenzstufe 2

Lesekompetenzstufe $4 / 5$

Abschluss im Sekundarbereich II

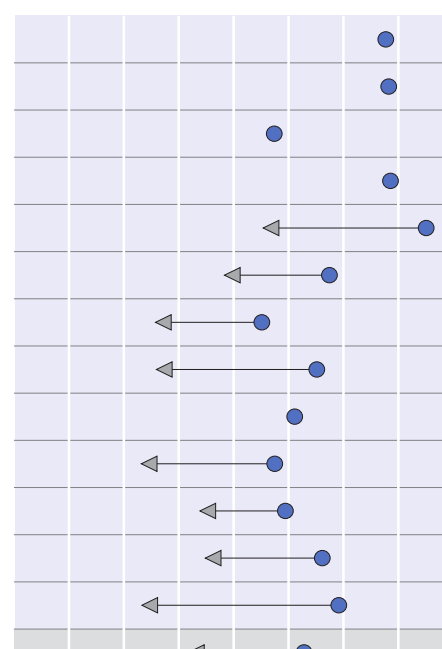

$4-1$

40

$\triangleleft-0$

40

4

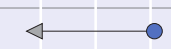

4

40

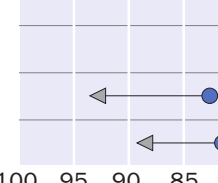

\% $100 \quad 95 \quad 90 \quad 85 \quad 80$

* Hinweis zu den Daten der Russischen Föderation s. Abschnitt Angewandte Methodik.

Anordnung der Länder in aufsteigender Reihenfolge des Anteils beschäftigter Erwachsener mit einem Abschluss im Tertiärbereich auf Lesekompetenzstufe 2. Quelle: OECD. Tabelle A5.7a (L). Hinweise s. Anhang 3 unter www.oecd.org/edu/eag.htm. StatLink: http://dx.doi.org/10.1787/888933116015
Abschluss im Tertiärbereich

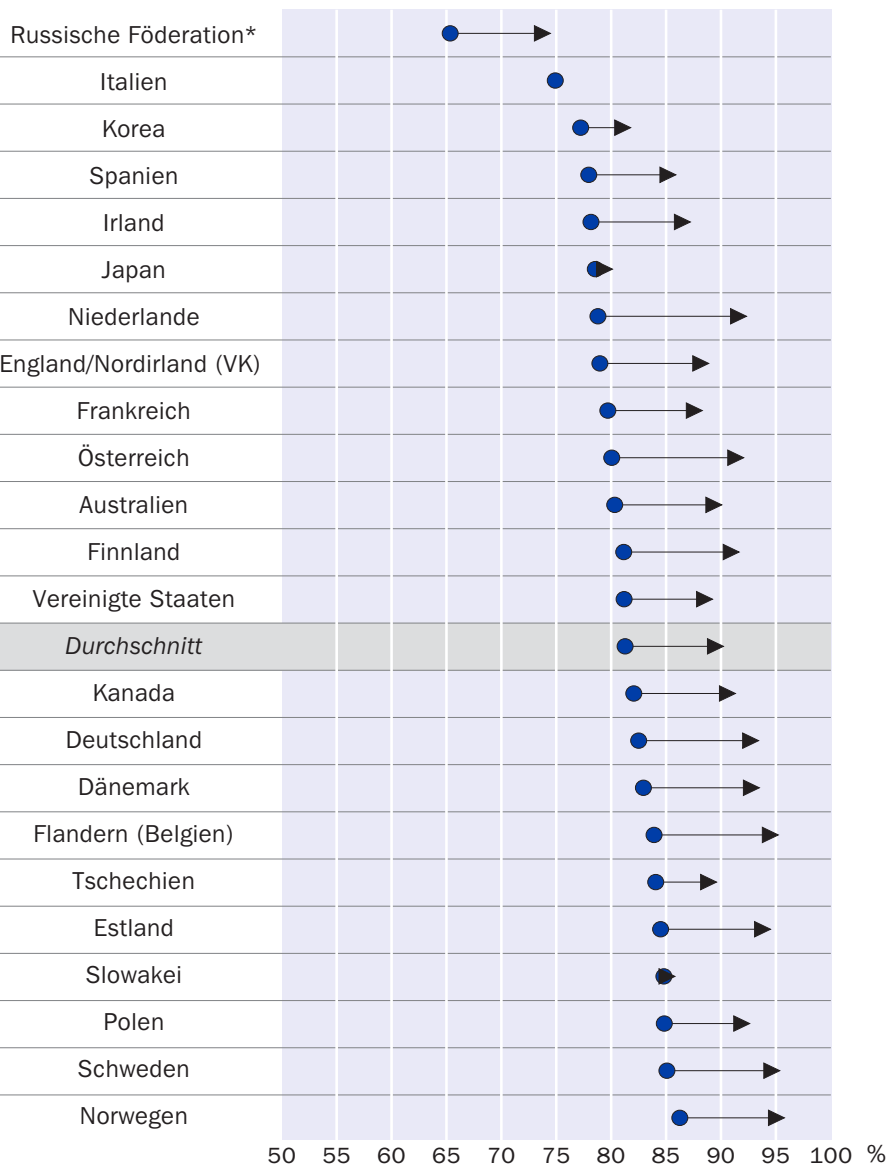


belohnt - selbst in Ländern wie Australien, Finnland, Japan, den Niederlanden und Schweden, wo etwa jeder dritte erwachsene Absolvent des Tertiärbereichs Lesekompetenzstufe 4 oder 5 erreicht (s. Tab. Ar.6a [L]).

Abbildung A5.4 zeigt außerdem, dass die Beschäftigungsquoten von Personen auf Lesekompetenzstufe 4 oder 5 bei der Erhebung zu den grundlegenden Kompetenzen Erwachsener in Finnland, Flandern (Belgien), Österreich und Schweden unabhängig von ihrem Bildungsstand mehr als Io Prozentpunkte höher liegen als die von Personen auf Kompetenzstufe 2. Jedoch scheinen die Arbeitsmärkte der einzelnen Länder Qualifikationen und Kompetenzen unterschiedlich zu gewichten, in einigen Umfeldern haben Bildungsqualifikationen einen stärkeren Einfluss auf die Beschäftigungslage als vorhandene Kompetenzen. So sind beispielsweise bei Absolventen des Tertiärbereichs in Japan, Korea und der Slowakei oder bei Absolventen des Sekundarbereichs II bzw. postsekundaren, nicht tertiären Bereichs (einschließlich Absolventen von berufsbildenden Bildungsgängen) in Dänemark und Polen die mit der Lesekompetenz zusammenhängenden Unterschiede bei den Beschäftigungsquoten sehr gering (Tab. A5.7a [L]).

\section{Erwerbslosigkeit sowie Nichtteilnahme am Arbeitsmarkt und Lesekompetenz}

Insgesamt gibt es relativ viele qualifizierte Personen, die entweder erwerbslos sind oder nicht am Arbeitsmarkt teilnehmen. Hierfür kann es eine Reihe von Gründen geben. Einige Erwerbslose verfügen, obwohl ihre Punktzahlen bei der Lese-, alltagsmathematischen und technologiebasierten Problemlösekompetenz denen von Beschäftigten entsprechen, unter Umständen nicht über andere für einen Arbeitsplatz erforderliche Schlüsselkompetenzen, wie z. B. arbeitsplatzspezifische Kompetenzen oder häufig an einem Arbeitsplatz benötigte allgemeine Kompetenzen.

Die Nichtteilnahme am Arbeitsmarkt kann teilweise freiwillig und/oder vorübergehend sein, wie bei jungen Menschen, die sich noch in Vollzeitausbildung/-studium befinden, oder bei Personen, die Familienangehörige versorgen. Gleichzeitig ist in dem Ausmaß, in dem die Lesekompetenz eine Näherungsgröße für umfassendere Kompetenzen darstellt, die bei Erwerbslosen festgestellte relativ hohe Kompetenz wichtig für die Arbeitsmarktpolitik. Zusätzlich zu verschiedenen institutionellen Einschränkungen ist wahrscheinlich die fehlende Überstimmung der tatsächlich vorhandenen Kompetenzen mit den für Arbeitsplätze erforderlichen Kompetenzen ein Grund dafür, dass Personen mit einem an sich hohen Kompetenzniveau nicht einer Beschäftigung nachgehen oder nach Arbeit suchen (OECD, 2013b).

2012 waren im Durchschnitt der OECD-Länder 20 Prozent der Erwachsenen mit einem Abschluss im Sekundarbereich bzw. postsekundaren, nicht tertiären Bereich als höchstem Abschluss, unabhängig von der Ausrichtung des Bildungsgangs, nicht im Arbeitsmarkt und etwa 8 Prozent erwerbslos (Tab. A5.5a). Die Daten zeigen, dass die Erwerbslosigkeits- und Nichterwerbsquoten mit sinkendem Bildungsstand steigen. Jedoch gibt es in den meisten Ländern, wie in Abbildung A5.5 gezeigt, eine große ungenutzte Reserve von qualifizierten Erwachsenen. Das zeigt sich an dem hohen Anteil nicht im Arbeitsmarkt befindlicher Personen mit hohem Kompetenzniveau, insbesondere Personen, die die Schulpflicht erfüllt haben und einen Abschluss im Sekundarbereich II bzw. postsekundaren, nicht tertiären Bereich erworben haben. In Dänemark, Irland, 


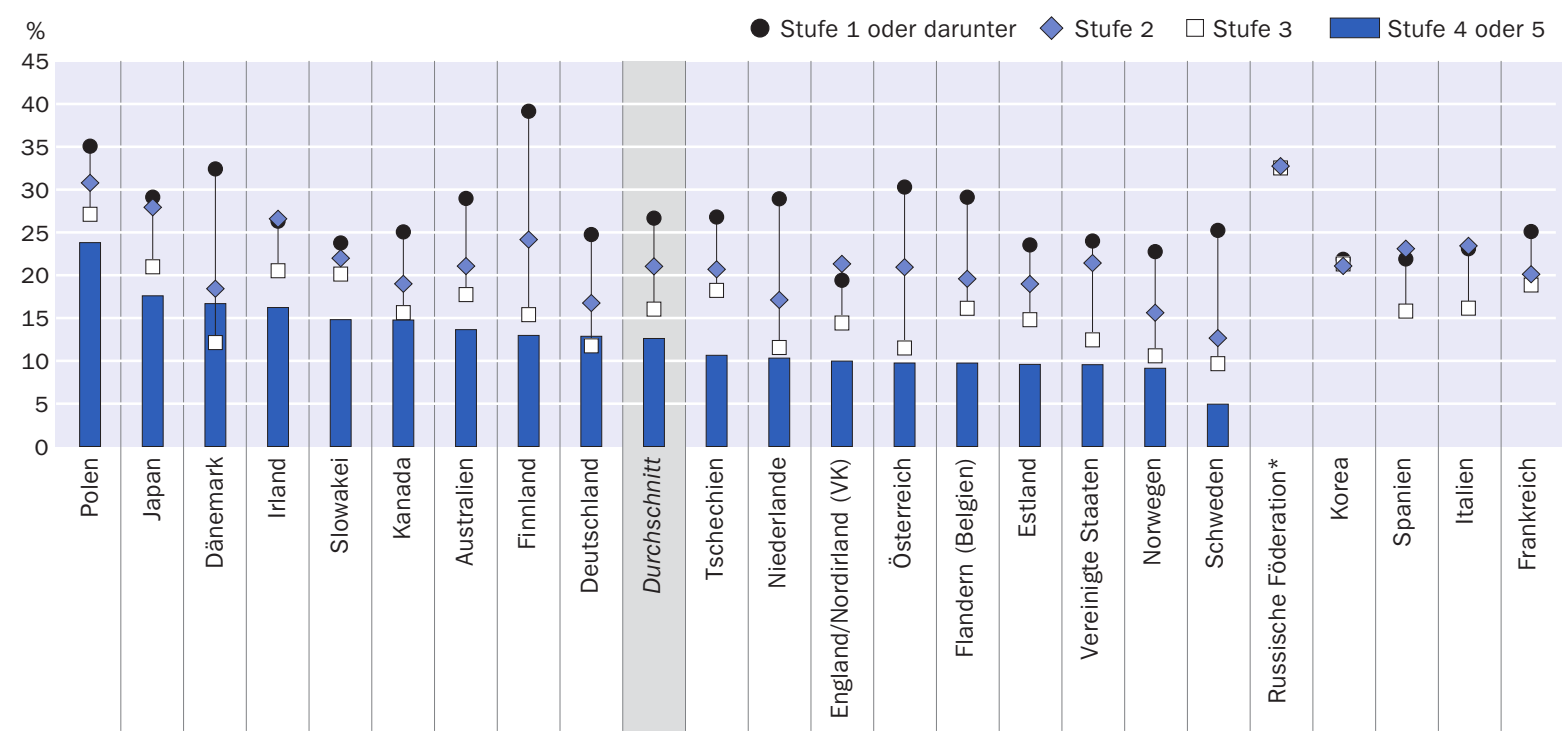

* Hinweis zu den Daten der Russischen Föderation s. Abschnitt Angewandte Methodik.

Anordnung der Länder in absteigender Reihenfolge des Anteils nicht im Arbeitsmarkt befindlicher Erwachsener mit einem Abschluss im Sekundarbereich II auf Lesekompetenzstufe 4 oder 5.

Quelle: OECD. Tabelle A5.7a (L). Hinweise s. Anhang 3 unter www.oecd.org/edu/eag.htm. StatLink: http://dx.doi.org/10.1787/888933116034

Japan und Polen sind mehr als 15 Prozent der Erwachsenen mit einem Abschluss im Sekundarbereich II und einer Lesekompetenz auf Stufe 4 oder 5 nicht im Arbeitsmarkt (Tab. A5.7a [L]).

\section{Definitionen}

Erwerbsbevölkerung ist die Summe der Erwerbstätigen und der Erwerbslosen entsprechend der Definition der Arbeitskräfteerhebung.

Altersgruppen: Erwachsene bezieht sich auf 25- bis 64-Jährige, jüngere Erwachsene bezieht sich auf 25- bis 34-Jährige, und ältere Erwachsene auf 55- bis 64-Jährige. Die Bevölkerung im erwerbsfähigen Alter umfasst die Gesamtbevölkerung im Alter von 25 bis 64 Jahren.

Beschäftigte werden definiert als diejenigen, die während der untersuchten Referenzwoche I. mindestens eine Stunde für ein Gehalt (Arbeitnehmer) oder für einen Gewinn (Selbstständige und unentgeltlich mithelfende Familienangehörige) arbeiten oder 2. einen Arbeitsplatz haben, aber vorübergehend nicht zur Arbeit gehen (aufgrund von Verletzung, Krankheit, Urlaub, Streik oder Aussperrung, Bildungs- oder Schulungsurlaub, Mutterschafts- oder Erziehungsurlaub usw.).

Die Beschäftigungsquote bezieht sich auf die Zahl der beschäftigten Personen in Relation zur Bevölkerung im erwerbsfähigen Alter, ausgedrückt in Prozent (die Zahl der 
Beschäftigten wird durch die Gesamtzahl aller Personen im erwerbsfähigen Alter dividiert). Die Beschäftigtenquoten nach Geschlecht, Alter, Bildungsstand, Ausrichtung des Ausbildungsgangs und Altersgruppe werden jeweils innerhalb der entsprechenden Kategorie berechnet. So wird beispielsweise die Beschäftigungsquote der Frauen errechnet, indem man die Zahl der beschäftigten Frauen durch die Gesamtzahl der Frauen im erwerbsfähigen Alter teilt.

Vollzeitbeschäftigung bezieht sich auf Beschäftigte mit einer ganzjährigen Beschäftigung von mindestens 30 Wochenarbeitsstunden. Die Länge des Referenzzeitraums variiert zwischen einer Woche und einem Jahr. In einigen Ländern sind hierbei Selbstständige nicht berücksichtigt. Die Daten für Tabelle A5.Io stammen aus der Erhebung zu den grundlegenden Kompetenzen Erwachsener. Personen gelten als vollzeitbeschäftigt, wenn die wöchentliche Arbeitszeit mindestens 30 Stunden beträgt. Die landesspezifischen Definitionen von Vollzeitbeschäftigung sind im Abschnitt Angewandte Methodik im Indikator A6 sowie in Anhang 3 enthalten (www.oecd.org/edu/eag.htm).

Nicht im Arbeitsmarkt umfasst diejenigen, die während der Erhebungswoche weder beschäftigt noch erwerbslos, d. h. diejenigen, die nicht arbeitssuchend sind. Die Zahl der Personen, die nicht im Arbeitsmarkt sind, errechnet sich durch den Abzug der Zahl der Erwerbspersonen von der Gesamtzahl der Personen im erwerbsfähigen Alter.

Die Nichterwerbsquote beschreibt den Anteil der Personen, die nicht im Arbeitsmarkt sind, an der Bevölkerung im erwerbsfähigen Alter, ausgedrückt in Prozent (d.h., die Zahl der nicht im Arbeitsmarkt befindlichen Personen wird durch die Zahl der Personen im erwerbsfähigen Alter dividiert). Die Nichterwerbsquoten nach Geschlecht, Alter, Bildungsstand, Ausrichtung des Ausbildungsgangs und Altersgruppe werden jeweils innerhalb der entsprechenden Kategorie berechnet. So wird beispielsweise die Nichterwerbsquote unter den Absolventen des Tertiärbereichs berechnet, indem man die Zahl der nicht im Arbeitsmarkt befindlichen Absolventen des Tertiärbereichs durch die Gesamtzahl aller Absolventen des Tertiärbereichs im erwerbsfähigen Alter dividiert.

Bildungsbereiche: Unterhalb Sekundarbereich II entspricht Bildungsgängen auf den ISCEDStufen o, I, 2 und ${ }_{3} \mathrm{C}$ (kurz), Sekundarbereich II bzw. postsekundarer, nicht tertiärer Bereich Bildungsgängen auf den ISCED-Stufen ${ }_{3} \mathrm{C}$ (lang), $3 \mathrm{~B}, 3 \mathrm{~A}$ und 4 und Tertiärbereich Studiengängen auf den ISCED-Stufen $5 \mathrm{~B}, 5 \mathrm{~A}$ und 6. Erläuterungen zu allen Bildungsbereichen gemäß ISCED-Klassifizierung s. Hinweise für den Leser im vorderen Teil der Publikation.

Die Erwerbslosenquote bezieht sich auf die Zahl der Erwerbslosen in Relation zur Erwerbsbevölkerung, ausgedrückt in Prozent (d. h. die Zahl der Erwerbslosen wird durch die Summe der Beschäftigten und Erwerbslosen dividiert). Die Erwerbslosenquoten nach Geschlecht, Alter, Bildungsstand, Ausrichtung des Ausbildungsgangs und Altersgruppe werden jeweils innerhalb der entsprechenden Kategorie berechnet. So wird beispielsweise die Erwerbslosenquote der Frauen berechnet, indem man die Zahl der erwerbslosen Frauen durch die Anzahl aller weiblichen Erwerbspersonen dividiert. 
Erwerbslose werden definiert als Personen, die während der Erhebungswoche nicht erwerbstätig waren (d. h., die weder eine Arbeit hatten noch wenigstens eine Stunde oder mehr abhängig beschäftigt oder selbstständig tätig waren), aktiv Arbeit suchten (d. h., die in den vier Wochen vor der Erhebungswoche gezielte Schritte unternommen hatten, um eine bezahlte Arbeitsstelle zu finden bzw. sich selbstständig zu machen) und dem Arbeitsmarkt zur Verfügung standen (d.h. spätestens zwei Wochen nach der Erhebungswoche für eine entgeltliche abhängige oder selbstständige Tätigkeit verfügbar waren).

\section{Angewandte Methodik}

Die Daten zu Bevölkerung und Bildungsstand stammen für die meisten Länder aus Datenbanken der OECD und Eurostat, die vom OECD-Netzwerk zu den Arbeitsmarktergebnissen sowie den wirtschaftlichen und sozialen Auswirkungen des Lernens (LSO) aus nationalen Arbeitskräfteerhebungen zusammengetragen sind. Daten zum erzielten Bildungsstand für Argentinien, China, Indonesien, Kolumbien, Saudi-Arabien und Südafrika stammen aus der Datenbank des Statistikinstituts der UNESCO zum Bildungsstand 25-Jähriger und Älterer. Die Daten zu den Einkommen stammen aus einer speziellen Erhebung zu den Einkommen von ganzjährig Vollzeitbeschäftigten des OECD-Netzwerks zu den Arbeitsmarktergebnissen sowie den wirtschaftlichen und sozialen Auswirkungen des Lernens (LSO). Die landesspezifischen Definitionen von Vollzeitbeschäftigung sind im Abschnitt Angewandte Methodik im Indikator A6 enthalten. Die Daten zu den Kompetenzstufen und durchschnittlichen Punktzahlen basieren auf der Erhebung zu den grundlegenden Kompetenzen Erwachsener (PIAAC) (2012). PIAAC steht für das OECD Programme for the International Assessment of Adult Competencies. Weitere Informationen siehe „Erhebung zu den grundlegenden Kompetenzen Erwachsener" im vorderen Teil dieser Publikation sowie in Anhang 3 unter www. oecd.org/eduleag.htm.

\section{Anmerkung zu den Daten aus Israel}

Die statistischen Daten für Israel wurden von den zuständigen israelischen Stellen bereitgestellt, die für sie verantwortlich zeichnen. Die Verwendung dieser Daten durch die OECD erfolgt unbeschadet des völkerrechtlichen Status der Golanhöhen, von Ost-Jerusalem und der israelischen Siedlungen im Westjordanland.

Hinweis zu den Daten aus der Russischen Föderation in der Erhebung zu den grundlegenden Kompetenzen Erwachsener (PIAAC)

$\mathrm{Zu}$ beachten ist, dass die Bevölkerung des Stadtgebiets Moskau in der Stichprobe für die Russische Föderation nicht berücksichtigt wurde. Die veröffentlichten Daten repräsentieren daher nicht die gesamte Wohnbevölkerung im Alter von 16 bis 65 Jahren in Russland, sondern nur die Wohnbevölkerung Russlands ohne die im Stadtgebiet Moskau lebende Bevölkerung. Weitere Informationen zu den Daten aus der Russischen Föderation sowie anderer Länder finden sich im Technical Report of the Survey of Adult Skills (OECD, i. E.). 


\section{Weiterführende Informationen}

European Centre for the Development of Vocational Training (CEDEFOP) (20II), The Benefits of Vocational Education and Training, Publications Office of the European Union, Luxembourg.

OECD (2013a), Bildung auf einen Blick 2013 - OECD-Indikatoren, W. Bertelsmann Verlag, Bielefeld.

OECD (2013b), OECD Skills Outlook 2013: First Results from the Survey of Adult Skills, OECD Publishing, Paris, http://dx.doi.org/10.1787/9789264204256-en.

OECD (2013c), The Survey of Adult Skills: Reader's Companion, OECD Publishing, Paris, http://dx.doi.org/10.1787/9789264204027-en.

UNESCO (1997), „International Standard Classification of Education: ISCED 1997“, www.unesco.org/education/information/nfsunesco/doc/isced_1997.htm.

\section{Tabellen Indikator A5}

StatLink: http:||dx.doi.org/10.1787/888933115711

Tabelle A5.ra: Beschäftigungsquoten, nach Bildungsstand (2012)

Tabelle A5.Ib: Beschäftigungsquoten, nach Bildungsstand und Geschlecht (2012)

Tabelle A5.2a: Erwerbslosenquoten, nach Bildungsstand (2012)

Tabelle A5.2b: Erwerbslosenquoten, nach Bildungsstand und Geschlecht (2012)

Tabelle A5·3a: Entwicklung der Beschäftigungsquoten, nach Bildungsstand und Altersgruppe (2000, 2005-2012)

WEB Table A5.3b: Trends in employment rates among men, by educational attainment and age group (Entwicklung der Beschäftigungsquoten von Männern, nach Bildungsstand und Altersgruppe) (2000, 2005-2012)

WEB Table A5.3c: Trends in employment rates among women, by educational attainment and age group (Entwicklung der Beschäftigungsquoten von Frauen, nach Bildungsstand und Altersgruppe) (2000, 2005-2012)

Tabelle A5.4a: Entwicklung der Erwerbslosenquoten, nach Bildungsstand und Altersgruppe (2000, 2005-2012)

WEB Table A5.4b: Trends in unemployment rates among men, by educational attainment and age group (Entwicklung der Erwerbslosenquoten von Männern, nach Bildungsstand und Altersgruppe) (2000, 2005-2012) 
WEB Table A5.4c: Trends in unemployment rates among women, by educational attainment and age group (Entwicklung der Erwerbslosenquoten von Frauen, nach Bildungsstand und Altersgruppe) (2000, 2005-2012)

Tabelle A5.5a: Erwachsene mit einem Abschluss im Sekundarbereich II bzw. postsekundaren, nicht tertiären Bereich, nach Erwerbsstatus und Ausrichtung des Bildungsgangs (2012)

WEB Table A5.5b: Distribution of adults by labour market status, educational attainment, programme orientation and gender (Erwachsene nach Erwerbsstatus, Bildungsstand, Ausrichtung des Bildungsgangs und Geschlecht) (2012)

WEB Table A5.5c: Distribution of adults by labour market status, educational attainment, programme orientation and age (Erwachsene nach Erwerbsstatus, Bildungsstand, Ausrichtung des Bildungsgangs und Alter) (2012)

Tabelle A5.6: Anteil der ganzjährig Vollzeitbeschäftigten an allen Personen mit Erwerbseinkommen, nach Bildungsstand und Altersgruppe (20I2)

Tabelle A5.7a (L): Erwerbsstatus, nach Bildungsstand und Lesekompetenz (2012)

WEB Table A5.7a (N): Labour market status, by educational attainment and numeracy proficiency level (Erwerbsstatus, nach Bildungsstand und alltagsmathematischer Kompetenz) (2012)

WEB Table A5.7b (L): Labour market status, by educational attainment, literacy proficiency level and gender (Erwerbsstatus, nach Bildungsstand, Lesekompetenz und Geschlecht) (2012)

WEB Table A5.7b (N): Labour market status, by educational attainment, numeracy proficiency level and gender (Erwerbsstatus, nach Bildungsstand, alltagsmathematischer Kompetenz und Geschlecht) (2012)

WEB Table A5.7c (L): Labour market status, by educational attainment, literacy proficiency level and age group (Erwerbsstatus, nach Bildungsstand, Lesekompetenz und Altersgruppe) (2012)

WEB Table A5.7c (N): Labour market status, by educational attainment, numeracy proficiency level and age group (Erwerbsstatus, nach Bildungsstand, alltagsmathematischer Kompetenz und Altersgruppe) (2012)

Tabelle A5.8 (L): Mittelwert der Lesekompetenz bei Erwachsenen mit einem Abschluss im Sekundarbereich II bzw. postsekundaren, nicht tertiären Bereich, nach Erwerbsstatus und Ausrichtung des Bildungsgangs (20I2) 
WEB Table A5.8 (N): Mean numeracy score among adults with upper secondary or post-secondary non-tertiary education, by labour market status and programme orientation (Mittelwert der alltagsmathematischen Kompetenz bei Erwachsenen mit einem Abschluss im Sekundarbereich II bzw. postsekundaren, nicht tertiären Bereich, nach Erwerbsstatus und Ausrichtung des Bildungsgangs) (2012)

Tabelle A5.9a (L): Erwachsenenbevölkerung nach Lesekompetenz und Erwerbsstatus (2012)

WEB Table A5.9a (N): Distribution of the adult population by numeracy proficiency levels and labour market status (Erwachsenenbevölkerung nach alltagsmathematischer Kompetenz und Erwerbsstatus) (2012)

WEB Table A5.9b (L): Mean literacy score, by educational attainment and labour market status (Mittelwert der Lesekompetenz, nach Bildungsstand und Erwerbsstatus) (2012)

WEB Table A5.9b (N): Mean numeracy score, by educational attainment and labour market status (Mittelwert der alltagsmathematischen Kompetenz, nach Bildungsstand und Erwerbsstatus) (2012)

Tabelle A5.Ioa (L): Vollzeit- und Teilzeitbeschäftigte nach Lesekompetenz und Altersgruppe (2012)

WEB Table A5.IOa (N): Distribution of people working full time/part time by numeracy proficiency level and age group (Vollzeit- und Teilzeitbeschäftigte, nach alltagsmathematischer Kompetenz und Altersgruppe) (2012)

WEB Table A5.Iob (L): Distribution of people working full time/part time by literacy proficiency level, age group and gender (Vollzeit- und Teilzeitbeschäftigte nach Lesekompetenz, Altersgruppe und Geschlecht (2012)

WEB Table A5.Iob (N): Distribution of people working full time/part time by numeracy proficiency level, age group and gender (Vollzeit- und Teilzeitbeschäftigte nach alltagsmathematischer Kompetenz, Altersgruppe und Geschlecht) (2012) 
Tabelle A5.1a

Beschäftigungsquoten, nach Bildungsstand (2012)

Anteil 25- bis 64-jähriger Beschäftigter (in \%) an allen 25-bis 64-Jährigen

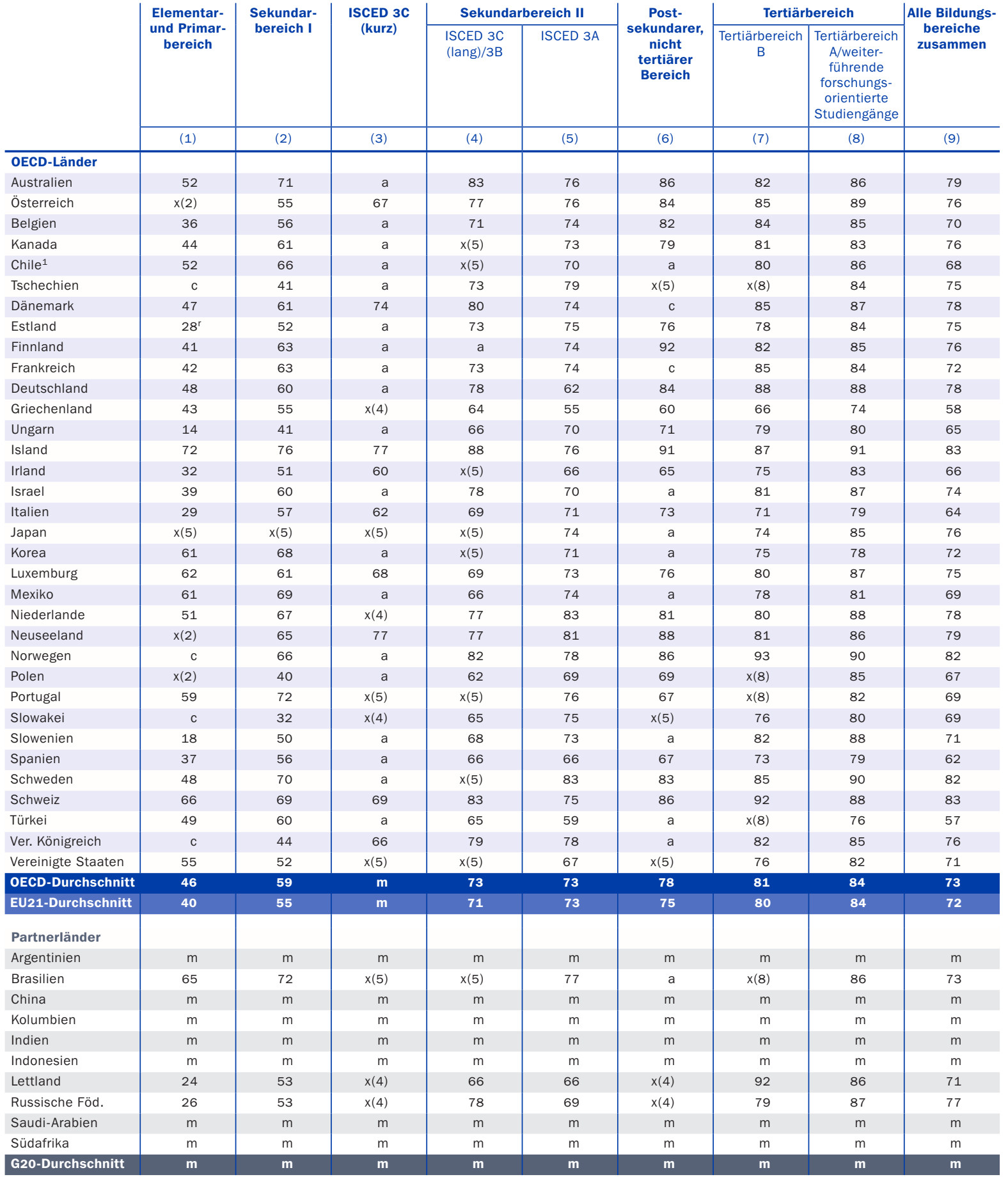

1. Referenzjahr 2011.

Quelle: OECD. Argentinien, China, Indien, Indonesien, Kolumbien, Saudi-Arabien und Südafrika: Statistikinstitut der UNESCO. Lettland: Eurostat.

Hinweise s. Anhang 3 unter www.oecd.org/edu/eag.htm. StatLink: http://dx.doi.org/10.1787/888933115730

Erläuterung der Kennzeichnung fehlender Daten sowie der Kennzeichnung " ${ }^{*}$ neben einigen Zahlen s. Hinweise für den Leser. 
Beschäftigungsquoten, nach Bildungsstand und Geschlecht (2012)

Anteil 25- bis 64-jähriger Beschäftigter an allen 25- bis 64-Jährigen

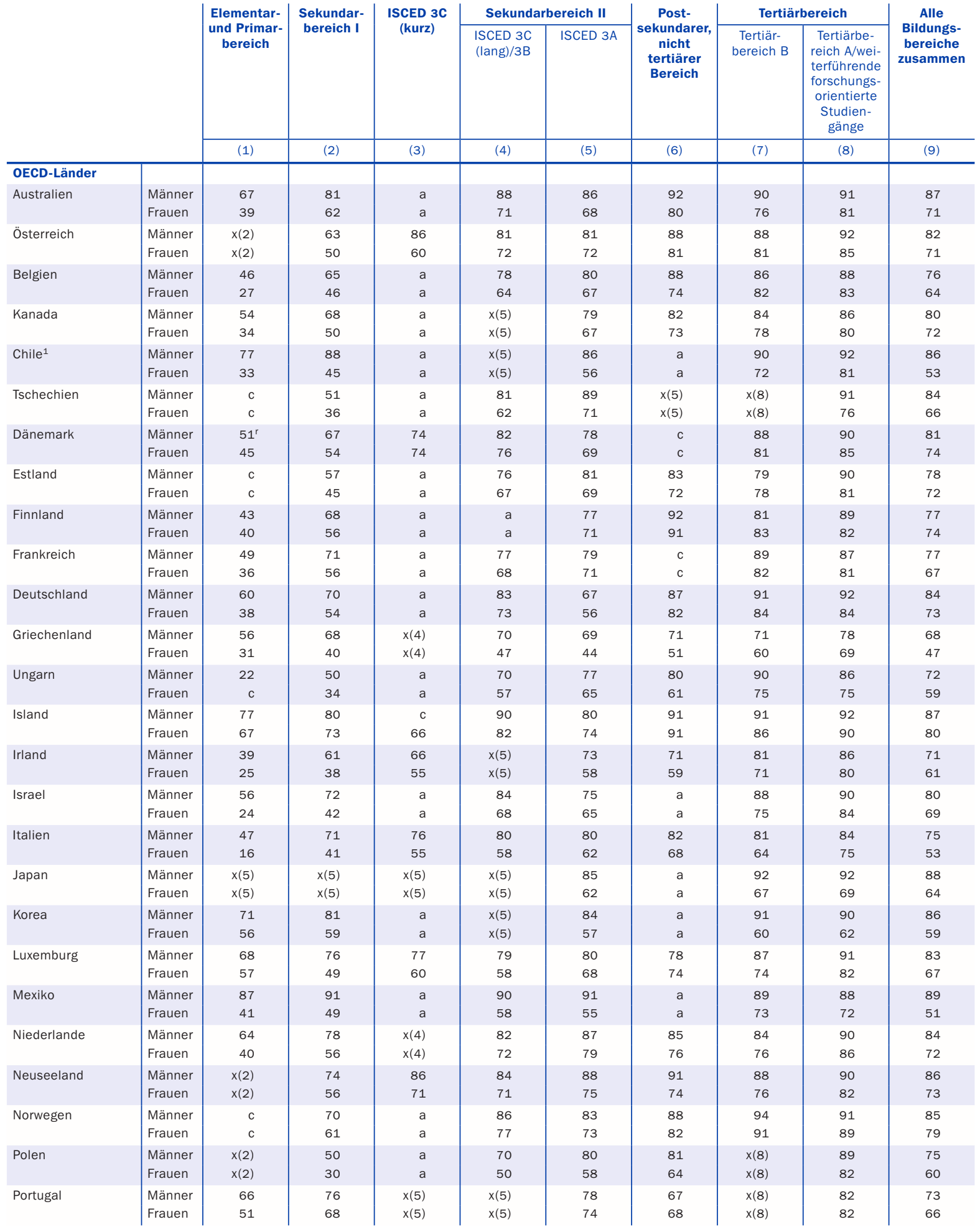

1. Referenzjahr 2011

Quelle: OECD. Argentinien, China, Indien, Indonesien, Kolumbien, Saudi-Arabien und Südafrika: Statistikinstitut der UNESCO. Lettland: Eurostat.

Hinweise s. Anhang 3 unter www.oecd.org/edu/eag.htm. StatLink: http://dx.doi.org/10.1787/888933115749

Erläuterung der Kennzeichnung fehlender Daten sowie der Kennzeichnung „ $r^{“}$ neben einigen Zahlen s. Hinweise für den Leser. 
Tabelle A5.1b (Forts.)

Beschäftigungsquoten, nach Bildungsstand und Geschlecht (2012)

Anteil 25- bis 64-jähriger Beschäftigter an allen 25- bis 64-Jährigen

\begin{tabular}{|c|c|c|c|c|c|c|c|c|c|c|}
\hline & & \multirow{2}{*}{$\begin{array}{c}\text { Elementar- } \\
\text { und Primar- } \\
\text { bereich }\end{array}$} & \multirow{2}{*}{$\begin{array}{l}\text { Sekundar- } \\
\text { bereich I }\end{array}$} & \multirow{2}{*}{$\begin{array}{c}\text { ISCED 3C } \\
\text { (kurz) }\end{array}$} & \multicolumn{2}{|c|}{ Sekundarbereich II } & \multirow{2}{*}{\begin{tabular}{|c|} 
Post- \\
sekundarer, \\
nicht \\
tertiärer \\
Bereich
\end{tabular}} & \multicolumn{2}{|c|}{ Tertiärbereich } & \multirow{2}{*}{$\begin{array}{c}\text { Alle } \\
\text { Bildungs- } \\
\text { bereiche } \\
\text { zusammen }\end{array}$} \\
\hline & & & & & $\begin{array}{l}\text { ISCED 3C } \\
\text { (lang)/3B }\end{array}$ & ISCED $3 A$ & & $\begin{array}{c}\text { Tertiär- } \\
\text { bereich B }\end{array}$ & $\begin{array}{l}\text { Tertiärbe- } \\
\text { reich A/wei- } \\
\text { terführende } \\
\text { forschungs- } \\
\text { orientierte } \\
\text { Studien- } \\
\text { gänge }\end{array}$ & \\
\hline & & (1) & (2) & (3) & (4) & (5) & (6) & (7) & (8) & (9) \\
\hline \multicolumn{11}{|l|}{ OECD-Länder } \\
\hline Slowakei & $\begin{array}{l}\text { Männer } \\
\text { Frauen }\end{array}$ & $\begin{array}{l}\mathrm{c} \\
\mathrm{c}\end{array}$ & $\begin{array}{l}38 \\
28\end{array}$ & $\begin{array}{l}x(4) \\
x(4)\end{array}$ & $\begin{array}{l}73 \\
54\end{array}$ & $\begin{array}{l}85 \\
67\end{array}$ & $\begin{array}{l}x(5) \\
x(5)\end{array}$ & $\begin{array}{l}79 \\
75\end{array}$ & $\begin{array}{l}86 \\
76\end{array}$ & $\begin{array}{l}77 \\
61\end{array}$ \\
\hline Slowenien & $\begin{array}{l}\text { Männer } \\
\text { Frauen }\end{array}$ & $\begin{array}{l}22 \\
14\end{array}$ & $\begin{array}{l}59 \\
41\end{array}$ & $\begin{array}{l}a \\
a\end{array}$ & $\begin{array}{l}72 \\
61\end{array}$ & $\begin{array}{l}77 \\
69\end{array}$ & $\begin{array}{l}a \\
a\end{array}$ & $\begin{array}{l}84 \\
80\end{array}$ & $\begin{array}{l}90 \\
86\end{array}$ & $\begin{array}{l}75 \\
67\end{array}$ \\
\hline Spanien & $\begin{array}{l}\text { Männer } \\
\text { Frauen }\end{array}$ & $\begin{array}{l}45 \\
29\end{array}$ & $\begin{array}{l}63 \\
48\end{array}$ & $\begin{array}{l}\mathrm{a} \\
\mathrm{a}\end{array}$ & $\begin{array}{l}72 \\
60\end{array}$ & $\begin{array}{l}71 \\
60\end{array}$ & $\begin{array}{l}\mathrm{c} \\
\mathrm{c}\end{array}$ & $\begin{array}{l}78 \\
67\end{array}$ & $\begin{array}{l}82 \\
76\end{array}$ & $\begin{array}{l}68 \\
56\end{array}$ \\
\hline Schweden & $\begin{array}{l}\text { Männer } \\
\text { Frauen }\end{array}$ & $\begin{array}{l}58 \\
38\end{array}$ & $\begin{array}{l}77 \\
60\end{array}$ & $\begin{array}{l}a \\
a\end{array}$ & $\begin{array}{l}x(5) \\
x(5)\end{array}$ & $\begin{array}{l}86 \\
79\end{array}$ & $\begin{array}{l}86 \\
78\end{array}$ & $\begin{array}{l}86 \\
83\end{array}$ & $\begin{array}{l}91 \\
90\end{array}$ & $\begin{array}{l}85 \\
80\end{array}$ \\
\hline Schweiz & $\begin{array}{l}\text { Männer } \\
\text { Frauen }\end{array}$ & $\begin{array}{l}76 \\
58\end{array}$ & $\begin{array}{l}78 \\
62\end{array}$ & $\begin{array}{l}77 \\
67\end{array}$ & $\begin{array}{l}90 \\
76\end{array}$ & $\begin{array}{l}78 \\
73\end{array}$ & $\begin{array}{l}90 \\
83\end{array}$ & $\begin{array}{l}95 \\
87\end{array}$ & $\begin{array}{l}93 \\
82\end{array}$ & $\begin{array}{l}90 \\
76\end{array}$ \\
\hline Türkei & $\begin{array}{l}\text { Männer } \\
\text { Frauen }\end{array}$ & $\begin{array}{l}74 \\
27\end{array}$ & $\begin{array}{l}79 \\
25\end{array}$ & $\begin{array}{l}a \\
a\end{array}$ & $\begin{array}{l}83 \\
32\end{array}$ & $\begin{array}{l}79 \\
30\end{array}$ & $\begin{array}{l}\mathrm{a} \\
\mathrm{a}\end{array}$ & $\begin{array}{l}x(8) \\
x(8)\end{array}$ & $\begin{array}{l}84 \\
65\end{array}$ & $\begin{array}{l}78 \\
33\end{array}$ \\
\hline $\begin{array}{l}\text { Vereinigtes } \\
\text { Königreich }\end{array}$ & $\begin{array}{l}\text { Männer } \\
\text { Frauen }\end{array}$ & $\begin{array}{l}\mathrm{c} \\
\mathrm{c}\end{array}$ & $\begin{array}{l}54 \\
35\end{array}$ & $\begin{array}{l}76 \\
59\end{array}$ & $\begin{array}{l}84 \\
73\end{array}$ & $\begin{array}{l}83 \\
73\end{array}$ & $\begin{array}{l}\mathrm{a} \\
\mathrm{a}\end{array}$ & $\begin{array}{l}88 \\
76\end{array}$ & $\begin{array}{l}89 \\
80\end{array}$ & $\begin{array}{l}82 \\
70\end{array}$ \\
\hline Vereinigte Staaten & $\begin{array}{l}\text { Männer } \\
\text { Frauen }\end{array}$ & $\begin{array}{l}68 \\
40\end{array}$ & $\begin{array}{l}60 \\
42\end{array}$ & $\begin{array}{l}x(5) \\
x(5)\end{array}$ & $\begin{array}{l}x(5) \\
x(5)\end{array}$ & $\begin{array}{l}73 \\
62\end{array}$ & $\begin{array}{l}x(5) \\
x(5)\end{array}$ & $\begin{array}{l}79 \\
73\end{array}$ & $\begin{array}{l}87 \\
77\end{array}$ & $\begin{array}{l}77 \\
66\end{array}$ \\
\hline OECD-Durchschnitt & $\begin{array}{l}\text { Männer } \\
\text { Frauen }\end{array}$ & $\begin{array}{l}58 \\
38\end{array}$ & $\begin{array}{l}68 \\
48\end{array}$ & $\begin{array}{l}\mathrm{m} \\
\mathrm{m}\end{array}$ & $\begin{array}{l}80 \\
64\end{array}$ & $\begin{array}{l}80 \\
65\end{array}$ & $\begin{array}{l}84 \\
74\end{array}$ & $\begin{array}{l}86 \\
76\end{array}$ & $\begin{array}{l}89 \\
80\end{array}$ & $\begin{array}{l}80 \\
65\end{array}$ \\
\hline EU21-Durchschnitt & $\begin{array}{l}\text { Männer } \\
\text { Frauen }\end{array}$ & $\begin{array}{l}51 \\
36\end{array}$ & $\begin{array}{l}64 \\
47\end{array}$ & $\begin{array}{l}m \\
m\end{array}$ & $\begin{array}{l}78 \\
64\end{array}$ & $\begin{array}{l}79 \\
67\end{array}$ & $\begin{array}{l}82 \\
72\end{array}$ & $\begin{array}{l}85 \\
77\end{array}$ & $\begin{array}{l}88 \\
81\end{array}$ & $\begin{array}{l}78 \\
66\end{array}$ \\
\hline Partnerländer & & & & & & & & & & \\
\hline Argentinien & & $\mathrm{m}$ & $\mathrm{m}$ & $\mathrm{m}$ & m & $\mathrm{m}$ & $\mathrm{m}$ & $\mathrm{m}$ & $m$ & $m$ \\
\hline Brasilien & $\begin{array}{l}\text { Männer } \\
\text { Frauen }\end{array}$ & $\begin{array}{l}82 \\
48\end{array}$ & $\begin{array}{l}87 \\
57\end{array}$ & $\begin{array}{l}x(5) \\
x(5)\end{array}$ & $\begin{array}{l}x(5) \\
x(5)\end{array}$ & $\begin{array}{l}89 \\
67\end{array}$ & $\begin{array}{l}a \\
a\end{array}$ & $\begin{array}{l}x(8) \\
x(8)\end{array}$ & $\begin{array}{l}92 \\
81\end{array}$ & $\begin{array}{l}86 \\
60\end{array}$ \\
\hline China & & $\mathrm{m}$ & $\mathrm{m}$ & $m$ & $m$ & $\mathrm{~m}$ & $\mathrm{~m}$ & $\mathrm{~m}$ & $m$ & $\mathrm{~m}$ \\
\hline Kolumbien & & $\mathrm{m}$ & $\mathrm{m}$ & $\mathrm{m}$ & $\mathrm{m}$ & $\mathrm{m}$ & $\mathrm{m}$ & $\mathrm{m}$ & $\mathrm{m}$ & $\mathrm{m}$ \\
\hline Indien & & $\mathrm{m}$ & $\mathrm{m}$ & $\mathrm{m}$ & $\mathrm{m}$ & $\mathrm{m}$ & $\mathrm{m}$ & $\mathrm{m}$ & $m$ & $\mathrm{~m}$ \\
\hline Indonesien & & $\mathrm{m}$ & $\mathrm{m}$ & $\mathrm{m}$ & $\mathrm{m}$ & $\mathrm{m}$ & $\mathrm{m}$ & $\mathrm{m}$ & $\mathrm{m}$ & $\mathrm{m}$ \\
\hline Lettland & $\begin{array}{l}\text { Männer } \\
\text { Frauen }\end{array}$ & $\begin{array}{r}34 \\
\mathrm{C}\end{array}$ & $\begin{array}{l}60 \\
42\end{array}$ & $\begin{array}{l}x(4) \\
x(4)\end{array}$ & $\begin{array}{l}63 \\
72\end{array}$ & $\begin{array}{l}71 \\
61\end{array}$ & $\begin{array}{l}x(4) \\
x(4)\end{array}$ & $\begin{array}{l}94 \\
91\end{array}$ & $\begin{array}{l}87 \\
85\end{array}$ & $\begin{array}{l}73 \\
69\end{array}$ \\
\hline $\begin{array}{l}\text { Russische } \\
\text { Föderation }\end{array}$ & $\begin{array}{l}\text { Männer } \\
\text { Frauen }\end{array}$ & $\begin{array}{l}\mathrm{c} \\
\mathrm{c}\end{array}$ & $\begin{array}{l}61 \\
43\end{array}$ & $\begin{array}{l}x(4) \\
x(4)\end{array}$ & $\begin{array}{l}83 \\
71\end{array}$ & $\begin{array}{l}77 \\
60\end{array}$ & $\begin{array}{l}x(4) \\
x(4)\end{array}$ & $\begin{array}{l}86 \\
75\end{array}$ & $\begin{array}{l}91 \\
83\end{array}$ & $\begin{array}{l}83 \\
72\end{array}$ \\
\hline Saudi-Arabien & & $\mathrm{m}$ & $\mathrm{m}$ & $\mathrm{m}$ & $\mathrm{m}$ & $\mathrm{m}$ & $\mathrm{m}$ & $\mathrm{m}$ & $\mathrm{m}$ & $\mathrm{m}$ \\
\hline Südafrika & & $\mathrm{m}$ & $\mathrm{m}$ & $\mathrm{m}$ & $\mathrm{m}$ & $\mathrm{m}$ & $\mathrm{m}$ & $\mathrm{m}$ & $\mathrm{m}$ & $\mathrm{m}$ \\
\hline G20-Durchschnitt & & m & $\mathbf{m}$ & m & m & $\mathrm{m}$ & m & m & m & $\mathrm{m}$ \\
\hline
\end{tabular}

1. Referenzjahr 2011.

Quelle: OECD. Argentinien, China, Indien, Indonesien, Kolumbien, Saudi-Arabien und Südafrika: Statistikinstitut der UNESCO. Lettland: Eurostat.

Hinweise s. Anhang 3 unter www.oecd.org/edu/eag.htm. StatLink: http://dx.doi.org/10.1787/888933115749

Erläuterung der Kennzeichnung fehlender Daten sowie der Kennzeichnung „ ${ }^{“}$ neben einigen Zahlen s. Hinweise für den Leser. 
Tabelle A5.2a

Erwerbslosenquoten, nach Bildungsstand (2012)

Anteil 25- bis 64-jähriger Erwerbsloser (in \%) an allen 25- bis 64-jährigen Erwerbspersonen

\begin{tabular}{|c|c|c|c|c|c|c|c|c|c|}
\hline & \multirow{2}{*}{$\begin{array}{l}\text { Elementar- } \\
\text { und Primar- } \\
\text { bereich }\end{array}$} & \multirow{2}{*}{$\begin{array}{l}\text { Sekundar- } \\
\text { bereich I }\end{array}$} & \multirow{2}{*}{$\begin{array}{c}\text { ISCED 3C } \\
\quad \text { (kurz) }\end{array}$} & \multicolumn{2}{|c|}{ Sekundarbereich II } & \multirow{2}{*}{$\begin{array}{c}\text { Post- } \\
\text { sekundarer, } \\
\text { nicht } \\
\text { tertiärer } \\
\text { Bereich }\end{array}$} & \multicolumn{2}{|c|}{ Tertiärbereich } & \multirow{2}{*}{$\begin{array}{c}\text { Alle } \\
\text { Bildungs- } \\
\text { bereiche } \\
\text { zusammen }\end{array}$} \\
\hline & & & & $\begin{array}{l}\text { ISCED 3C } \\
\text { (lang)/3B }\end{array}$ & ISCED $3 A$ & & $\begin{array}{c}\text { Tertiär- } \\
\text { bereich B }\end{array}$ & $\begin{array}{l}\text { Tertiärbereich } \\
\text { A oder wei- } \\
\text { terführende } \\
\text { forschungs- } \\
\text { orientierte } \\
\text { Studiengänge }\end{array}$ & \\
\hline & (1) & (2) & (3) & (4) & (5) & (6) & (7) & (8) & (9) \\
\hline \multicolumn{10}{|l|}{ OECD-Länder } \\
\hline Australien & 8,5 & 5,7 & a & 3,7 & 3,9 & 3,3 & 3,3 & 2,7 & 3,9 \\
\hline Österreich & $x(2)$ & 8,2 & c & 3,4 & 4,7 & 3,1 & c & 2,6 & 3,7 \\
\hline Belgien & 14,6 & 10,8 & a & 7,7 & 6,4 & $5,7^{r}$ & 3,0 & 3,8 & 6,5 \\
\hline Kanada & 12,6 & 10,4 & a & $x(5)$ & 6,7 & 6,3 & 5,2 & 4,8 & 6,1 \\
\hline Chile $^{1}$ & 5,9 & 6,0 & a & $x(5)$ & 6,4 & a & 4,6 & 4,2 & 5,8 \\
\hline Tschechien & c & 25,5 & a & 7,3 & 4,0 & $x(5)$ & $x(8)$ & 2,6 & 6,1 \\
\hline Dänemark & c & 9,8 & c & 5,8 & 8,4 & c & 5,1 & 4,6 & 6,2 \\
\hline Estland & c & 21,6 & a & 11,9 & 8,6 & 8,9 & 8,6 & 4,8 & 9,1 \\
\hline Finnland & 10,9 & 11,8 & a & a & 7,2 & c & 3,8 & 4,0 & 6,2 \\
\hline Frankreich & 14,6 & 13,4 & a & 8,3 & 8,2 & c & 4,8 & 5,2 & 8,4 \\
\hline Deutschland & 16,7 & 11,8 & a & 5,5 & 7,0 & 3,7 & 2,0 & 2,6 & 5,2 \\
\hline Griechenland & 24,9 & 26,0 & $x(4)$ & 25,9 & 23,0 & 26,9 & 21,1 & 15,1 & 22,4 \\
\hline Ungarn & 44,5 & 21,9 & a & 11,3 & 7,6 & 9,6 & c & 3,9 & 9,7 \\
\hline Island & 8,0 & c & c & 4,4 & c & c & c & 2,9 & 4,5 \\
\hline Irland & 26,4 & 22,4 & 19,1 & $x(5)$ & 13,5 & 17,8 & 9,1 & 5,8 & 13,1 \\
\hline Israel & 11,0 & 9,3 & a & 6,6 & 7,2 & a & 4,9 & 3,9 & 5,9 \\
\hline Italien & 16,2 & 11,5 & 14,4 & 7,6 & 7,7 & 10,9 & 9,2 & 6,3 & 9,0 \\
\hline Japan & $x(5)$ & $x(5)$ & $x(5)$ & $x(5)$ & 5,1 & a & 3,7 & 2,8 & 4,2 \\
\hline Korea & 2,4 & 2,7 & a & $x(5)$ & 3,0 & a & 3,2 & 2,7 & 2,9 \\
\hline Luxemburg & $7,5^{r}$ & $4,9^{r}$ & $7,1^{r}$ & 5,1 & 3,8 & c & $3,4^{r}$ & 3,4 & 4,2 \\
\hline Mexiko & 3,3 & 3,8 & a & 2,8 & 4,4 & a & 3,7 & 4,6 & 3,8 \\
\hline Niederlande & 7,7 & 6,2 & $x(4)$ & 4,8 & 4,3 & 3,7 & 5,0 & 2,9 & 4,4 \\
\hline Neuseeland & $\mathrm{m}$ & 7,2 & 4,5 & 7,6 & 4,3 & 3,2 & 6,0 & 3,1 & 5,0 \\
\hline Norwegen & c & 4,1 & a & 2,0 & 2,9 & c & c & 1,7 & 2,3 \\
\hline Polen & $\mathrm{m}$ & 17,8 & a & 10,9 & 7,8 & 9,5 & $x(8)$ & 4,9 & 8,6 \\
\hline Portugal & 16,1 & 15,8 & $x(5)$ & $x(5)$ & 14,2 & 24,4 & $x(8)$ & 10,5 & 14,5 \\
\hline Slowakei & 2,0 & 40,9 & $x(4)$ & 15,2 & 8,8 & a & c & 6,1 & 12,2 \\
\hline Slowenien & $30,5^{r}$ & 13,4 & a & 8,5 & 7,9 & a & 6,4 & 5,3 & 8,1 \\
\hline Spanien & 35,8 & 29,3 & a & 22,8 & 21,5 & c & 17,6 & 12,5 & 22,8 \\
\hline Schweden & 19,8 & 10,0 & a & $\mathrm{m}$ & 5,6 & 6,3 & 5,0 & 3,7 & 5,8 \\
\hline Schweiz & 7,2 & 8,1 & $7,5^{r}$ & 3,2 & 5,4 & 2,7 & 2,0 & 3,0 & 3,6 \\
\hline Türkei & 7,3 & 9,8 & a & 7,6 & 9,6 & a & $x(8)$ & 7,5 & 7,9 \\
\hline Ver. Königreich & c & 13,7 & 8,9 & 5,7 & 5,1 & a & 3,6 & 3,6 & 5,6 \\
\hline Vereinigte Staaten & 11,2 & 16,2 & $x(5)$ & $x(5)$ & 9,1 & $x(5)$ & 6,5 & 4,1 & 7,4 \\
\hline OECD-Durchschnitt & 14,6 & 13,4 & m & 8,2 & $\mathbf{7 , 7}$ & 9,1 & 6,0 & 4,8 & 7,5 \\
\hline EU21-Durchschnitt & 19,2 & 16,5 & m & 9,9 & 8,8 & 10,9 & 7,2 & 5,4 & 9,1 \\
\hline \multicolumn{10}{|l|}{ Partnerländer } \\
\hline Argentinien & $\mathrm{m}$ & $\mathrm{m}$ & $\mathrm{m}$ & $\mathrm{m}$ & $\mathrm{m}$ & $\mathrm{m}$ & $\mathrm{m}$ & $\mathrm{m}$ & $\mathrm{m}$ \\
\hline Brasilien & 3,7 & 4,9 & $x(5)$ & $x(5)$ & 5,1 & a & $x(8)$ & 2,9 & 4,2 \\
\hline China & $\mathrm{m}$ & $\mathrm{m}$ & $\mathrm{m}$ & $m$ & $\mathrm{~m}$ & $\mathrm{~m}$ & $m$ & $\mathrm{~m}$ & $\mathrm{~m}$ \\
\hline Kolumbien & $\mathrm{m}$ & $\mathrm{m}$ & $\mathrm{m}$ & $\mathrm{m}$ & $\mathrm{m}$ & $\mathrm{m}$ & $\mathrm{m}$ & $\mathrm{m}$ & $\mathrm{m}$ \\
\hline Indien & $\mathrm{m}$ & $\mathrm{m}$ & $\mathrm{m}$ & $\mathrm{m}$ & $\mathrm{m}$ & $\mathrm{m}$ & $\mathrm{m}$ & $\mathrm{m}$ & $\mathrm{m}$ \\
\hline Indonesien & $\mathrm{m}$ & $\mathrm{m}$ & $\mathrm{m}$ & $\mathrm{m}$ & $\mathrm{m}$ & $\mathrm{m}$ & $\mathrm{m}$ & $\mathrm{m}$ & $\mathrm{m}$ \\
\hline Lettland & 42,1 & 22,2 & $x(4)$ & 14,9 & 17,5 & $x(4)$ & c & 6,4 & 13,9 \\
\hline Russische Föd. & c & 11,7 & $x(4)$ & 5,1 & 6,8 & $x(4)$ & 3,4 & 2,3 & 4,4 \\
\hline Saudi-Arabien & $\mathrm{m}$ & $\mathrm{m}$ & $\mathrm{m}$ & $\mathrm{m}$ & $\mathrm{m}$ & $\mathrm{m}$ & $\mathrm{m}$ & $\mathrm{m}$ & $\mathrm{m}$ \\
\hline Südafrika & $\mathrm{m}$ & $\mathrm{m}$ & $\mathrm{m}$ & $\mathrm{m}$ & $\mathrm{m}$ & $\mathrm{m}$ & $\mathrm{m}$ & $\mathrm{m}$ & $\mathrm{m}$ \\
\hline G20-Durchschnitt & m & m & $\mathbf{m}$ & $\mathbf{m}$ & m & $\mathbf{m}$ & m & m & $\mathbf{m}$ \\
\hline
\end{tabular}

1. Referenzjahr 2011.

Quelle: OECD. Argentinien, China, Indien, Indonesien, Kolumbien, Saudi-Arabien und Südafrika: Statistikinstitut der UNESCO. Lettland: Eurostat.

Hinweise s. Anhang 3 unter www.oecd.org/edu/eag.htm. StatLink: http://dx.doi.org/10.1787/888933115768

Erläuterung der Kennzeichnung fehlender Daten sowie der Kennzeichnung „r“ neben einigen Zahlen s. Hinweise für den Leser. 
Erwerbslosenquoten, nach Bildungsstand und Geschlecht (2012)

Anteil 25- bis 64-jähriger Erwerbsloser (in \%) an 25- bis 64-jährigen Erwerbspersonen

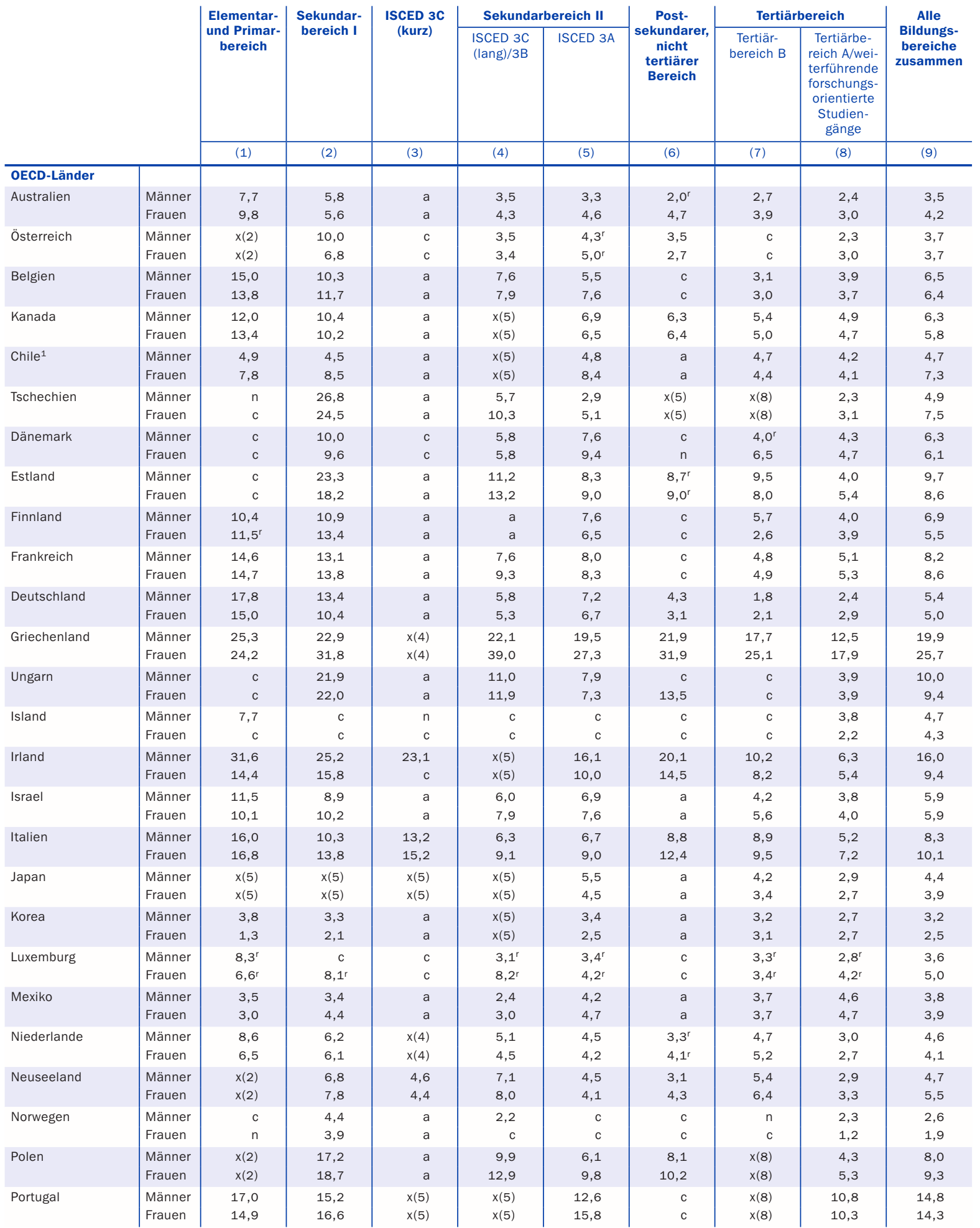

1. Referenzjahr 2011.

Quelle: OECD. Argentinien, China, Indien, Indonesien, Kolumbien, Saudi-Arabien und Südafrika: Statistikinstitut der UNESCO. Lettland: Eurostat.

Hinweise s. Anhang 3 unter www.oecd.org/edu/eag.htm. StatLink: http://dx.doi.org/10.1787/888933115787

Erläuterung der Kennzeichnung fehlender Daten sowie der Kennzeichnung „ ${ }^{“}$ neben einigen Zahlen s. Hinweise für den Leser. 
Tabelle A5.2b (Forts.)

Erwerbslosenquoten, nach Bildungsstand und Geschlecht (2012)

Anteil 25- bis 64-jähriger Erwerbsloser (in \%) an 25- bis 64-jährigen Erwerbspersonen

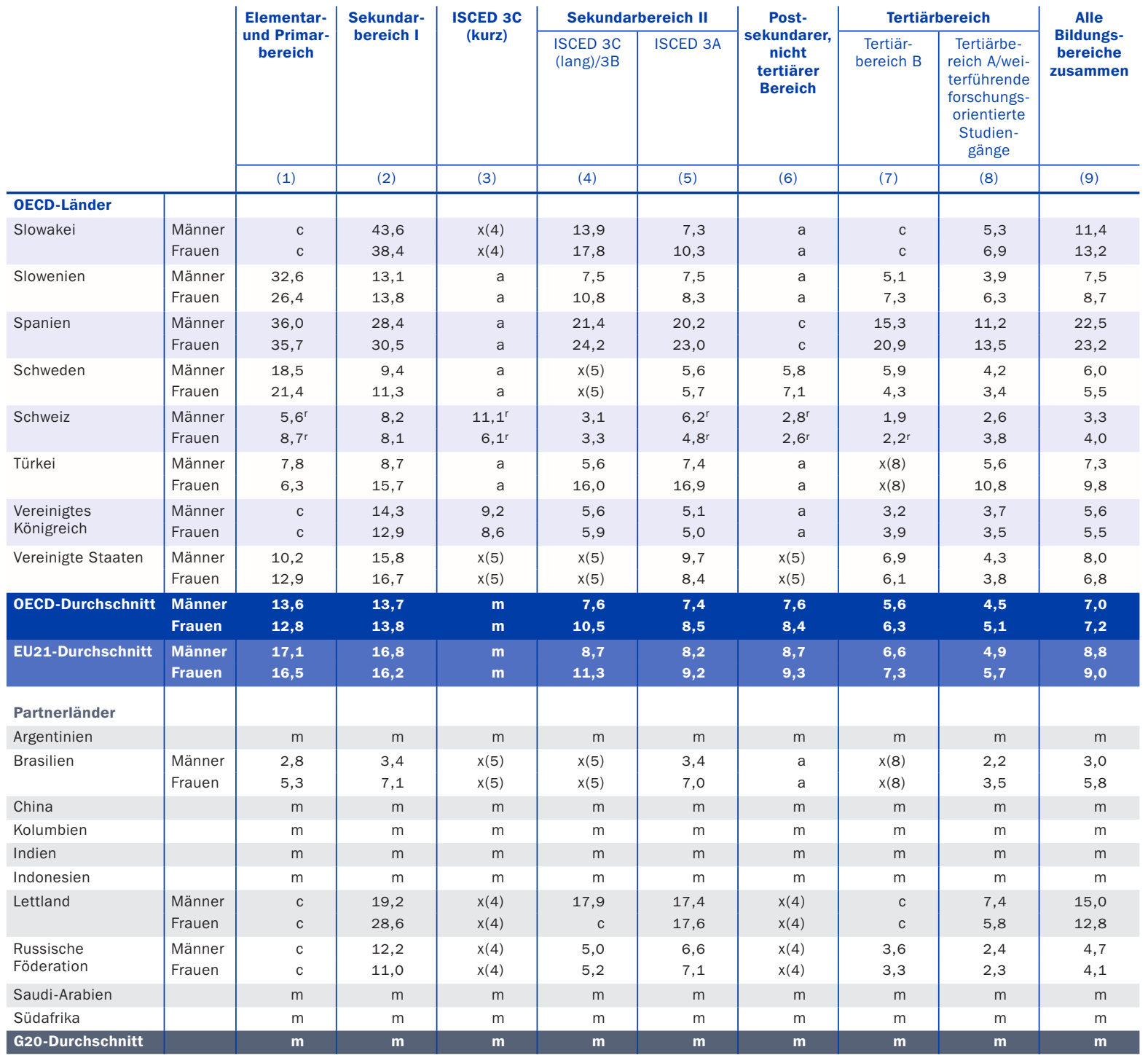

1. Referenzjahr 2011.

Quelle: OECD. Argentinien, China, Indien, Indonesien, Kolumbien, Saudi-Arabien und Südafrika: Statistikinstitut der UNESCO. Lettland: Eurostat.

Hinweise s. Anhang 3 unter www.oecd.org/edu/eag.htm. StatLink: http://dx.doi.org/10.1787/888933115787

Erläuterung der Kennzeichnung fehlender Daten sowie der Kennzeichnung „r“ neben einigen Zahlen s. Hinweise für den Leser. 
Entwicklung der Beschäftigungsquoten, nach Bildungsstand und Altersgruppe (2000, 2005-2012)

Anteil 25- bis 64-jähriger/25- bis 34-jähriger/55- bis 64-jähriger Beschäftigter (in \%) an allen 25- bis 64-Jährigen/25- bis 34-Jährigen/ 55- bis 64-Jährigen

\begin{tabular}{|c|c|c|c|c|c|c|c|c|c|c|c|c|c|}
\hline & \multirow[t]{3}{*}{ Bildungsstand } & \multicolumn{4}{|c|}{$\begin{array}{l}\text { Beschäftigungsquoten } \\
\text { 25- bis 64-Jähriger }\end{array}$} & \multicolumn{4}{|c|}{$\begin{array}{l}\text { Beschäftigungsquoten } \\
\text { 25- bis 34-Jähriger }\end{array}$} & \multicolumn{4}{|c|}{$\begin{array}{l}\text { Beschäftigungsquoten } \\
\text { 55- bis 64-Jähriger }\end{array}$} \\
\hline & & 2000 & 2005 & 2010 & 2012 & 2000 & 2005 & 2010 & 2012 & 2000 & 2005 & 2010 & 2012 \\
\hline & & (1) & (2) & (7) & (9) & $(11)$ & (12) & (17) & (19) & (41) & $(42)$ & $(47)$ & (49) \\
\hline \multicolumn{14}{|l|}{ OECD-Länder } \\
\hline Australien & $\begin{array}{l}\text { Ausbildung unterhalb Sekundarbereich II } \\
\text { Abschluss im Sekundarbereich II/ } \\
\text { postsekundaren, nicht tertiären Bereich } \\
\text { Abschluss im Tertiärbereich }\end{array}$ & $\begin{array}{l}61 \\
77 \\
83\end{array}$ & $\begin{array}{l}63 \\
80 \\
84\end{array}$ & $\begin{array}{l}65 \\
80 \\
84\end{array}$ & $\begin{array}{l}66 \\
80 \\
84\end{array}$ & $\begin{array}{l}64 \\
80 \\
84\end{array}$ & $\begin{array}{l}64 \\
81 \\
85\end{array}$ & $\begin{array}{l}61 \\
78 \\
85\end{array}$ & $\begin{array}{l}62 \\
81 \\
84\end{array}$ & $\begin{array}{l}39 \\
53 \\
65\end{array}$ & $\begin{array}{l}46 \\
62 \\
69\end{array}$ & $\begin{array}{l}53 \\
71 \\
75\end{array}$ & $\begin{array}{l}56 \\
72 \\
76\end{array}$ \\
\hline Österreich & $\begin{array}{l}\text { Ausbildung unterhalb Sekundarbereich II } \\
\text { Abschluss im Sekundarbereich II/ } \\
\text { postsekundaren, nicht tertiären Bereich } \\
\text { Abschluss im Tertiärbereich }\end{array}$ & $\begin{array}{l}54 \\
75 \\
87\end{array}$ & $\begin{array}{l}53 \\
74 \\
85\end{array}$ & $\begin{array}{l}56 \\
78 \\
86\end{array}$ & $\begin{array}{l}56 \\
78 \\
87\end{array}$ & $\begin{array}{l}70 \\
84 \\
92\end{array}$ & $\begin{array}{l}61 \\
84 \\
87\end{array}$ & $\begin{array}{l}61 \\
84 \\
87\end{array}$ & $\begin{array}{l}65 \\
86 \\
89\end{array}$ & $\begin{array}{l}19 \\
29 \\
59\end{array}$ & $\begin{array}{l}24 \\
31 \\
54\end{array}$ & $\begin{array}{l}31 \\
41 \\
64\end{array}$ & $\begin{array}{l}30 \\
42 \\
67\end{array}$ \\
\hline Belgien & $\begin{array}{l}\text { Ausbildung unterhalb Sekundarbereich II } \\
\text { Abschluss im Sekundarbereich II/ } \\
\text { postsekundaren, nicht tertiären Bereich } \\
\text { Abschluss im Tertiärbereich }\end{array}$ & $\begin{array}{l}51 \\
75 \\
85\end{array}$ & $\begin{array}{l}49 \\
74 \\
84\end{array}$ & $\begin{array}{l}49 \\
74 \\
84\end{array}$ & $\begin{array}{l}48 \\
73 \\
85\end{array}$ & $\begin{array}{l}64 \\
84 \\
92\end{array}$ & $\begin{array}{l}57 \\
81 \\
90\end{array}$ & $\begin{array}{l}56 \\
80 \\
89\end{array}$ & $\begin{array}{l}54 \\
78 \\
89\end{array}$ & $\begin{array}{l}19 \\
31 \\
46\end{array}$ & $\begin{array}{l}21 \\
38 \\
49\end{array}$ & $\begin{array}{l}26 \\
41 \\
53\end{array}$ & $\begin{array}{l}26 \\
44 \\
57\end{array}$ \\
\hline Kanada & $\begin{array}{l}\text { Ausbildung unterhalb Sekundarbereich II } \\
\text { Abschluss im Sekundarbereich II/ } \\
\text { postsekundaren, nicht tertiären Bereich } \\
\text { Abschluss im Tertiärbereich }\end{array}$ & $\begin{array}{l}55 \\
76 \\
83\end{array}$ & $\begin{array}{l}56 \\
76 \\
82\end{array}$ & $\begin{array}{l}55 \\
74 \\
81\end{array}$ & $\begin{array}{l}56 \\
75 \\
82\end{array}$ & $\begin{array}{l}60 \\
79 \\
86\end{array}$ & $\begin{array}{l}62 \\
80 \\
85\end{array}$ & $\begin{array}{l}58 \\
77 \\
84\end{array}$ & $\begin{array}{l}59 \\
79 \\
84\end{array}$ & $\begin{array}{l}37 \\
52 \\
57\end{array}$ & $\begin{array}{l}41 \\
57 \\
62\end{array}$ & $\begin{array}{l}43 \\
58 \\
65\end{array}$ & $\begin{array}{l}44 \\
60 \\
65\end{array}$ \\
\hline Chile & $\begin{array}{l}\text { Ausbildung unterhalb Sekundarbereich II } \\
\text { Abschluss im Sekundarbereich II/ } \\
\text { postsekundaren, nicht tertiären Bereich } \\
\text { Abschluss im Tertiärbereich }\end{array}$ & $\begin{array}{l}\mathrm{m} \\
\mathrm{m} \\
\mathrm{m}\end{array}$ & $\begin{array}{l}\mathrm{m} \\
\mathrm{m} \\
\mathrm{m}\end{array}$ & $\begin{array}{l}62 \\
72 \\
79\end{array}$ & $\begin{array}{l}\mathbf{m} \\
\mathbf{m} \\
\mathbf{m}\end{array}$ & $\begin{array}{l}\mathrm{m} \\
\mathrm{m} \\
\mathrm{m}\end{array}$ & $\begin{array}{l}\mathrm{m} \\
\mathrm{m} \\
\mathrm{m}\end{array}$ & $\begin{array}{l}59 \\
74 \\
75\end{array}$ & $\begin{array}{l}\mathbf{m} \\
\mathbf{m} \\
\mathbf{m}\end{array}$ & $\begin{array}{l}\mathrm{m} \\
\mathrm{m} \\
\mathrm{m}\end{array}$ & $\begin{array}{l}\mathrm{m} \\
\mathrm{m} \\
\mathrm{m}\end{array}$ & $\begin{array}{l}55 \\
59 \\
74\end{array}$ & $\begin{array}{l}\mathbf{m} \\
\mathbf{m} \\
\mathbf{m}\end{array}$ \\
\hline Tschechien & $\begin{array}{l}\text { Ausbildung unterhalb Sekundarbereich II } \\
\text { Abschluss im Sekundarbereich II/ } \\
\text { postsekundaren, nicht tertiären Bereich } \\
\text { Abschluss im Tertiärbereich }\end{array}$ & $\begin{array}{l}47 \\
76 \\
87\end{array}$ & $\begin{array}{l}41 \\
75 \\
86\end{array}$ & $\begin{array}{l}43 \\
74 \\
83\end{array}$ & $\begin{array}{l}40 \\
76 \\
84\end{array}$ & $\begin{array}{l}51 \\
77 \\
83\end{array}$ & $\begin{array}{l}43 \\
78 \\
81\end{array}$ & $\begin{array}{l}47 \\
76 \\
77\end{array}$ & $\begin{array}{l}43 \\
77 \\
75\end{array}$ & $\begin{array}{l}17 \\
39 \\
66\end{array}$ & $\begin{array}{l}20 \\
47 \\
69\end{array}$ & $\begin{array}{l}26 \\
46 \\
71\end{array}$ & $\begin{array}{l}27 \\
49 \\
76\end{array}$ \\
\hline Dänemark & $\begin{array}{l}\text { Ausbildung unterhalb Sekundarbereich II } \\
\text { Abschluss im Sekundarbereich II/ } \\
\text { postsekundaren, nicht tertiären Bereich } \\
\text { Abschluss im Tertiärbereich }\end{array}$ & $\begin{array}{l}62 \\
81 \\
88\end{array}$ & $\begin{array}{l}62 \\
80 \\
86\end{array}$ & $\begin{array}{l}63 \\
79 \\
86\end{array}$ & $\begin{array}{l}61 \\
79 \\
86\end{array}$ & $\begin{array}{l}70 \\
85 \\
88\end{array}$ & $\begin{array}{l}64 \\
83 \\
87\end{array}$ & $\begin{array}{l}65 \\
82 \\
86\end{array}$ & $\begin{array}{l}62 \\
79 \\
85\end{array}$ & $\begin{array}{l}41 \\
57 \\
73\end{array}$ & $\begin{array}{l}42 \\
61 \\
73\end{array}$ & $\begin{array}{l}46 \\
59 \\
71\end{array}$ & $\begin{array}{l}47 \\
63 \\
73\end{array}$ \\
\hline Estland $^{1}$ & $\begin{array}{l}\text { Ausbildung unterhalb Sekundarbereich II } \\
\text { Abschluss im Sekundarbereich II/ } \\
\text { postsekundaren, nicht tertiären Bereich } \\
\text { Abschluss im Tertiärbereich }\end{array}$ & $\begin{array}{l}42 \\
70 \\
83\end{array}$ & $\begin{array}{l}50 \\
74 \\
84\end{array}$ & $\begin{array}{l}45 \\
69 \\
80\end{array}$ & $\begin{array}{l}51 \\
75 \\
82\end{array}$ & $\begin{array}{l}53 \\
74 \\
85\end{array}$ & $\begin{array}{l}60 \\
77 \\
84\end{array}$ & $\begin{array}{l}51 \\
70 \\
81\end{array}$ & $\begin{array}{l}57 \\
77 \\
79\end{array}$ & $\begin{array}{l}24 \\
46 \\
62\end{array}$ & $\begin{array}{l}36 \\
53 \\
74\end{array}$ & $\begin{array}{l}30 \\
54 \\
66\end{array}$ & $\begin{array}{l}34 \\
58 \\
73\end{array}$ \\
\hline Finnland & $\begin{array}{l}\text { Ausbildung unterhalb Sekundarbereich II } \\
\text { Abschluss im Sekundarbereich II/ } \\
\text { postsekundaren, nicht tertiären Bereich } \\
\text { Abschluss im Tertiärbereich }\end{array}$ & $\begin{array}{l}60 \\
75 \\
84\end{array}$ & $\begin{array}{l}58 \\
75 \\
84\end{array}$ & $\begin{array}{l}55 \\
74 \\
84\end{array}$ & $\begin{array}{l}55 \\
75 \\
84\end{array}$ & $\begin{array}{l}69 \\
76 \\
84\end{array}$ & $\begin{array}{l}63 \\
77 \\
86\end{array}$ & $\begin{array}{l}59 \\
76 \\
84\end{array}$ & $\begin{array}{l}56 \\
76 \\
83\end{array}$ & $\begin{array}{l}33 \\
42 \\
60\end{array}$ & $\begin{array}{l}43 \\
53 \\
66\end{array}$ & $\begin{array}{l}44 \\
55 \\
70\end{array}$ & $\begin{array}{l}44 \\
58 \\
70\end{array}$ \\
\hline Frankreich & $\begin{array}{l}\text { Ausbildung unterhalb Sekundarbereich II } \\
\text { Abschluss im Sekundarbereich II/ } \\
\text { postsekundaren, nicht tertiären Bereich } \\
\text { Abschluss im Tertiärbereich }\end{array}$ & $\begin{array}{l}56 \\
75 \\
83\end{array}$ & $\begin{array}{l}59 \\
76 \\
83\end{array}$ & $\begin{array}{l}55 \\
74 \\
84\end{array}$ & $\begin{array}{l}55 \\
74 \\
84\end{array}$ & $\begin{array}{l}61 \\
80 \\
85\end{array}$ & $\begin{array}{l}63 \\
80 \\
86\end{array}$ & $\begin{array}{l}57 \\
79 \\
87\end{array}$ & $\begin{array}{l}56 \\
77 \\
86\end{array}$ & $\begin{array}{l}24 \\
31 \\
50\end{array}$ & $\begin{array}{l}32 \\
40 \\
56\end{array}$ & $\begin{array}{l}32 \\
41 \\
55\end{array}$ & $\begin{array}{l}36 \\
45 \\
61\end{array}$ \\
\hline Deutschland & $\begin{array}{l}\text { Ausbildung unterhalb Sekundarbereich II } \\
\text { Abschluss im Sekundarbereich II/ } \\
\text { postsekundaren, nicht tertiären Bereich } \\
\text { Abschluss im Tertiärbereich }\end{array}$ & $\begin{array}{l}51 \\
70 \\
83\end{array}$ & $\begin{array}{l}52 \\
71 \\
83\end{array}$ & $\begin{array}{l}55 \\
76 \\
87\end{array}$ & $\begin{array}{l}57 \\
78 \\
88\end{array}$ & $\begin{array}{l}60 \\
79 \\
89\end{array}$ & $\begin{array}{l}52 \\
74 \\
85\end{array}$ & $\begin{array}{l}55 \\
78 \\
88\end{array}$ & $\begin{array}{l}56 \\
81 \\
89\end{array}$ & $\begin{array}{l}26 \\
37 \\
58\end{array}$ & $\begin{array}{l}32 \\
43 \\
63\end{array}$ & $\begin{array}{l}40 \\
56 \\
73\end{array}$ & $\begin{array}{l}44 \\
60 \\
75\end{array}$ \\
\hline Griechenland & $\begin{array}{l}\text { Ausbildung unterhalb Sekundarbereich II } \\
\text { Abschluss im Sekundarbereich II/ } \\
\text { postsekundaren, nicht tertiären Bereich } \\
\text { Abschluss im Tertiärbereich }\end{array}$ & $\begin{array}{l}58 \\
65 \\
81\end{array}$ & $\begin{array}{l}59 \\
69 \\
82\end{array}$ & $\begin{array}{l}57 \\
67 \\
80\end{array}$ & $\begin{array}{l}47 \\
58 \\
71\end{array}$ & $\begin{array}{l}67 \\
69 \\
79\end{array}$ & $\begin{array}{l}72 \\
73 \\
79\end{array}$ & $\begin{array}{l}64 \\
71 \\
77\end{array}$ & $\begin{array}{l}51 \\
58 \\
65\end{array}$ & $\begin{array}{l}39 \\
31 \\
50\end{array}$ & $\begin{array}{l}39 \\
38 \\
59\end{array}$ & $\begin{array}{l}40 \\
37 \\
57\end{array}$ & $\begin{array}{l}33 \\
33 \\
50\end{array}$ \\
\hline Ungarn & $\begin{array}{l}\text { Ausbildung unterhalb Sekundarbereich II } \\
\text { Abschluss im Sekundarbereich II/ } \\
\text { postsekundaren, nicht tertiären Bereich } \\
\text { Abschluss im Tertiärbereich }\end{array}$ & $\begin{array}{l}36 \\
72 \\
82\end{array}$ & $\begin{array}{l}38 \\
70 \\
83\end{array}$ & $\begin{array}{l}38 \\
66 \\
79\end{array}$ & $\begin{array}{l}39 \\
68 \\
80\end{array}$ & $\begin{array}{l}50 \\
75 \\
83\end{array}$ & $\begin{array}{l}49 \\
75 \\
83\end{array}$ & $\begin{array}{l}40 \\
71 \\
79\end{array}$ & $\begin{array}{l}43 \\
72 \\
79\end{array}$ & $\begin{array}{l}12 \\
29 \\
52\end{array}$ & $\begin{array}{l}16 \\
39 \\
60\end{array}$ & $\begin{array}{l}20 \\
35 \\
54\end{array}$ & $\begin{array}{l}21 \\
38 \\
57\end{array}$ \\
\hline Island & $\begin{array}{l}\text { Ausbildung unterhalb Sekundarbereich II } \\
\text { Abschluss im Sekundarbereich II/ } \\
\text { postsekundaren, nicht tertiären Bereich } \\
\text { Abschluss im Tertiärbereich }\end{array}$ & $\begin{array}{l}89 \\
89 \\
97\end{array}$ & $\begin{array}{l}83 \\
88 \\
92\end{array}$ & $\begin{array}{l}76 \\
82 \\
89\end{array}$ & $\begin{array}{l}73 \\
85 \\
91\end{array}$ & $\begin{array}{l}89 \\
82 \\
96\end{array}$ & $\begin{array}{l}81 \\
81 \\
92\end{array}$ & $\begin{array}{l}68 \\
71 \\
86\end{array}$ & $\begin{array}{l}72 \\
77 \\
87\end{array}$ & $\begin{array}{l}83 \\
89 \\
92\end{array}$ & $\begin{array}{l}82 \\
86 \\
89\end{array}$ & $\begin{array}{l}75 \\
82 \\
88\end{array}$ & $\begin{array}{l}70 \\
84 \\
89\end{array}$ \\
\hline Irland & $\begin{array}{l}\text { Ausbildung unterhalb Sekundarbereich II } \\
\text { Abschluss im Sekundarbereich II/ } \\
\text { postsekundaren, nicht tertiären Bereich } \\
\text { Abschluss im Tertiärbereich }\end{array}$ & $\begin{array}{l}56 \\
77 \\
88\end{array}$ & $\begin{array}{l}58 \\
77 \\
87\end{array}$ & $\begin{array}{l}48 \\
66 \\
81\end{array}$ & $\begin{array}{l}44 \\
65 \\
80\end{array}$ & $\begin{array}{l}68 \\
85 \\
91\end{array}$ & $\begin{array}{l}64 \\
83 \\
89\end{array}$ & $\begin{array}{l}44 \\
67 \\
83\end{array}$ & $\begin{array}{l}40 \\
65 \\
83\end{array}$ & $\begin{array}{l}39 \\
48 \\
67\end{array}$ & $\begin{array}{l}45 \\
56 \\
70\end{array}$ & $\begin{array}{l}41 \\
55 \\
66\end{array}$ & $\begin{array}{l}38 \\
56 \\
61\end{array}$ \\
\hline
\end{tabular}

Anmerkung: Die Spalten mit den Angaben für weitere Jahre und Altersgruppen sind im Internet verfügbar (s. StatLink unten).

1. Die Zahlen für 2012 für Estland und Slowenien in dieser Tabelle können von Zahlen in anderen Tabellen in Indikator A5 abweichen, da unterschiedliche Datenquellen zugrunde liegen. Die Zahlen in dieser Tabelle basieren für alle Jahre auf der EU-Arbeitskräfteerhebung. 2. Die Zahlen für das Jahr 200o können nicht mit neueren Zahlen verglichen werden, da 2000 noch die frühere Klassifikation des Bildungswesens verwendet wurde.

Quelle: OECD. Argentinien, China, Indien, Indonesien, Kolumbien, Saudi-Arabien und Südafrika: Statistikinstitut der UNESCO. Lettland: Eurostat. Hinweise s. Anhang 3 unter www.oecd.org/edu/eag.htm. StatLink: http://dx.doi.org/10.1787/888933115806

Erläuterung der Kennzeichnung fehlender Daten s. Hinweise für den Leser. 
Entwicklung der Beschäftigungsquoten, nach Bildungsstand und Altersgruppe (2000, 2005-2012)

Anteil 25- bis 64-jähriger/25- bis 34-jähriger/55- bis 64-jähriger Beschäftigter (in \%) an allen 25- bis 64-Jährigen/25- bis 34-Jährigen/ 55- bis 64-Jährigen

\begin{tabular}{|c|c|c|c|c|c|c|c|c|c|c|c|c|c|}
\hline & \multirow[t]{3}{*}{ Bildungsstand } & \multicolumn{4}{|c|}{$\begin{array}{l}\text { Beschäftigungsquoten } \\
\text { 25- bis 64-Jähriger }\end{array}$} & \multicolumn{4}{|c|}{$\begin{array}{l}\text { Beschäftigungsquoten } \\
25 \text { - bis 34-Jähriger }\end{array}$} & \multicolumn{4}{|c|}{$\begin{array}{l}\text { Beschäftigungsquoten } \\
55-\text { bis 64-Jähriger }\end{array}$} \\
\hline & & 2000 & 2005 & 2010 & 2012 & 2000 & 2005 & 2010 & 2012 & 2000 & 2005 & 2010 & 2012 \\
\hline & & (1) & (2) & (7) & (9) & (11) & (12) & (17) & (19) & $(41)$ & $(42)$ & $(47)$ & (49) \\
\hline \multicolumn{14}{|l|}{ OECD-Länder } \\
\hline Israel & $\begin{array}{l}\text { Ausbildung unterhalb Sekundarbereich II } \\
\text { Abschluss im Sekundarbereich II/ } \\
\text { postsekundaren, nicht tertiären Bereich } \\
\text { Abschluss im Tertiärbereich }\end{array}$ & $\begin{array}{l}\mathrm{m} \\
\mathrm{m} \\
\mathrm{m}\end{array}$ & $\begin{array}{l}41 \\
67 \\
80\end{array}$ & $\begin{array}{l}45 \\
70 \\
82\end{array}$ & $\begin{array}{l}47 \\
72 \\
85\end{array}$ & $\begin{array}{l}m \\
m \\
m\end{array}$ & $\begin{array}{l}43 \\
65 \\
80\end{array}$ & $\begin{array}{l}45 \\
68 \\
82\end{array}$ & $\begin{array}{l}50 \\
70 \\
86\end{array}$ & $\begin{array}{l}m \\
m \\
m\end{array}$ & $\begin{array}{l}32 \\
52 \\
68\end{array}$ & $\begin{array}{l}38 \\
62 \\
71\end{array}$ & $\begin{array}{l}41 \\
65 \\
73\end{array}$ \\
\hline Italien & $\begin{array}{l}\text { Ausbildung unterhalb Sekundarbereich II } \\
\text { Abschluss im Sekundarbereich II/ } \\
\text { postsekundaren, nicht tertiären Bereich } \\
\text { Abschluss im Tertiärbereich }\end{array}$ & $\begin{array}{l}49 \\
71 \\
82\end{array}$ & $\begin{array}{l}52 \\
74 \\
80\end{array}$ & $\begin{array}{l}50 \\
73 \\
78\end{array}$ & $\begin{array}{l}51 \\
71 \\
79\end{array}$ & $\begin{array}{l}60 \\
68 \\
73\end{array}$ & $\begin{array}{l}65 \\
72 \\
69\end{array}$ & $\begin{array}{l}57 \\
69 \\
67\end{array}$ & $\begin{array}{l}56 \\
67 \\
67\end{array}$ & $\begin{array}{l}23 \\
40 \\
58\end{array}$ & $\begin{array}{l}24 \\
44 \\
67\end{array}$ & $\begin{array}{l}26 \\
48 \\
67\end{array}$ & $\begin{array}{l}29 \\
51 \\
70\end{array}$ \\
\hline Japan & $\begin{array}{l}\text { Ausbildung unterhalb Sekundarbereich II } \\
\text { Abschluss im Sekundarbereich II/ } \\
\text { postsekundaren, nicht tertiären Bereich } \\
\text { Abschluss im Tertiärbereich }\end{array}$ & $\begin{array}{l}67 \\
74 \\
79\end{array}$ & $\begin{array}{l}m \\
72 \\
79\end{array}$ & $\begin{array}{l}m \\
73 \\
80\end{array}$ & $\begin{array}{l}m \\
74 \\
80\end{array}$ & $\begin{array}{l}70 \\
74 \\
78\end{array}$ & $\begin{array}{l}m \\
76 \\
78\end{array}$ & $\begin{array}{l}m \\
76 \\
81\end{array}$ & $\begin{array}{l}m \\
76 \\
81\end{array}$ & $\begin{array}{l}59 \\
61 \\
72\end{array}$ & $\begin{array}{l}m \\
62 \\
72\end{array}$ & $\begin{array}{l}m \\
64 \\
70\end{array}$ & $\begin{array}{l}m \\
63 \\
70\end{array}$ \\
\hline Korea & $\begin{array}{l}\text { Ausbildung unterhalb Sekundarbereich II } \\
\text { Abschluss im Sekundarbereich II/ } \\
\text { postsekundaren, nicht tertiären Bereich } \\
\text { Abschluss im Tertiärbereich }\end{array}$ & $\begin{array}{l}68 \\
69 \\
75\end{array}$ & $\begin{array}{l}66 \\
70 \\
77\end{array}$ & $\begin{array}{l}65 \\
71 \\
76\end{array}$ & $\begin{array}{l}65 \\
71 \\
77\end{array}$ & $\begin{array}{l}65 \\
64 \\
74\end{array}$ & $\begin{array}{l}62 \\
64 \\
74\end{array}$ & $\begin{array}{l}57 \\
64 \\
74\end{array}$ & $\begin{array}{l}59 \\
63 \\
75\end{array}$ & $\begin{array}{l}59 \\
53 \\
57\end{array}$ & $\begin{array}{l}58 \\
59 \\
61\end{array}$ & $\begin{array}{l}59 \\
62 \\
64\end{array}$ & $\begin{array}{l}61 \\
64 \\
68\end{array}$ \\
\hline Luxemburg & $\begin{array}{l}\text { Ausbildung unterhalb Sekundarbereich II } \\
\text { Abschluss im Sekundarbereich II/ } \\
\text { postsekundaren, nicht tertiären Bereich } \\
\text { Abschluss im Tertiärbereich }\end{array}$ & $\begin{array}{l}58 \\
73 \\
84\end{array}$ & $\begin{array}{l}62 \\
72 \\
84\end{array}$ & $\begin{array}{l}62 \\
72 \\
85\end{array}$ & $\begin{array}{l}63 \\
72 \\
85\end{array}$ & $\begin{array}{l}78 \\
85 \\
83\end{array}$ & $\begin{array}{l}79 \\
82 \\
87\end{array}$ & $\begin{array}{l}78 \\
83 \\
87\end{array}$ & $\begin{array}{l}78 \\
80 \\
87\end{array}$ & $\begin{array}{l}15 \\
32 \\
65\end{array}$ & $\begin{array}{l}22 \\
30 \\
60\end{array}$ & $\begin{array}{l}25 \\
35 \\
67\end{array}$ & $\begin{array}{l}29 \\
35 \\
65\end{array}$ \\
\hline Mexiko & $\begin{array}{l}\text { Ausbildung unterhalb Sekundarbereich II } \\
\text { Abschluss im Sekundarbereich II/ } \\
\text { postsekundaren, nicht tertiären Bereich } \\
\text { Abschluss im Tertiärbereich }\end{array}$ & $\begin{array}{l}61 \\
71 \\
82\end{array}$ & $\begin{array}{l}62 \\
71 \\
82\end{array}$ & $\begin{array}{l}63 \\
72 \\
81\end{array}$ & $\begin{array}{l}64 \\
72 \\
80\end{array}$ & $\begin{array}{l}63 \\
71 \\
80\end{array}$ & $\begin{array}{l}63 \\
71 \\
79\end{array}$ & $\begin{array}{l}63 \\
73 \\
80\end{array}$ & $\begin{array}{l}65 \\
72 \\
79\end{array}$ & $\begin{array}{l}51 \\
48 \\
69\end{array}$ & $\begin{array}{l}52 \\
46 \\
68\end{array}$ & $\begin{array}{l}53 \\
50 \\
67\end{array}$ & $\begin{array}{l}54 \\
53 \\
66\end{array}$ \\
\hline Niederlande & $\begin{array}{l}\text { Ausbildung unterhalb Sekundarbereich II } \\
\text { Abschluss im Sekundarbereich II/ } \\
\text { postsekundaren, nicht tertiären Bereich } \\
\text { Abschluss im Tertiärbereich }\end{array}$ & $\begin{array}{l}58 \\
79 \\
86\end{array}$ & $\begin{array}{l}60 \\
78 \\
86\end{array}$ & $\begin{array}{l}61 \\
80 \\
87\end{array}$ & $\begin{array}{l}62 \\
80 \\
88\end{array}$ & $\begin{array}{l}73 \\
88 \\
94\end{array}$ & $\begin{array}{l}70 \\
86 \\
92\end{array}$ & $\begin{array}{l}70 \\
87 \\
92\end{array}$ & $\begin{array}{l}69 \\
85 \\
91\end{array}$ & $\begin{array}{l}27 \\
43 \\
54\end{array}$ & $\begin{array}{l}35 \\
49 \\
62\end{array}$ & $\begin{array}{l}42 \\
57 \\
68\end{array}$ & $\begin{array}{l}47 \\
60 \\
73\end{array}$ \\
\hline Neuseeland & $\begin{array}{l}\text { Ausbildung unterhalb Sekundarbereich II } \\
\text { Abschluss im Sekundarbereich II/ } \\
\text { postsekundaren, nicht tertiären Bereich } \\
\text { Abschluss im Tertiärbereich }\end{array}$ & $\begin{array}{l}65 \\
80 \\
82\end{array}$ & $\begin{array}{l}70 \\
84 \\
84\end{array}$ & $\begin{array}{l}68 \\
82 \\
84\end{array}$ & $\begin{array}{l}68 \\
81 \\
84\end{array}$ & $\begin{array}{l}63 \\
78 \\
82\end{array}$ & $\begin{array}{l}68 \\
82 \\
81\end{array}$ & $\begin{array}{l}64 \\
77 \\
81\end{array}$ & $\begin{array}{l}63 \\
77 \\
82\end{array}$ & $\begin{array}{l}49 \\
65 \\
67\end{array}$ & $\begin{array}{l}61 \\
75 \\
78\end{array}$ & $\begin{array}{l}64 \\
78 \\
82\end{array}$ & $\begin{array}{l}65 \\
80 \\
81\end{array}$ \\
\hline Norwegen ${ }^{2}$ & $\begin{array}{l}\text { Ausbildung unterhalb Sekundarbereich II } \\
\text { Abschluss im Sekundarbereich II/ } \\
\text { postsekundaren, nicht tertiären Bereich } \\
\text { Abschluss im Tertiärbereich }\end{array}$ & $\begin{array}{l}65 \\
83 \\
90\end{array}$ & $\begin{array}{l}64 \\
82 \\
89\end{array}$ & $\begin{array}{l}64 \\
82 \\
90\end{array}$ & $\begin{array}{l}65 \\
81 \\
90\end{array}$ & $\begin{array}{l}67 \\
84 \\
87\end{array}$ & $\begin{array}{l}66 \\
84 \\
86\end{array}$ & $\begin{array}{l}64 \\
85 \\
89\end{array}$ & $\begin{array}{l}67 \\
82 \\
89\end{array}$ & $\begin{array}{l}53 \\
68 \\
86\end{array}$ & $\begin{array}{l}48 \\
70 \\
85\end{array}$ & $\begin{array}{l}51 \\
68 \\
84\end{array}$ & $\begin{array}{l}53 \\
69 \\
85\end{array}$ \\
\hline Polen & $\begin{array}{l}\text { Ausbildung unterhalb Sekundarbereich II } \\
\text { Abschluss im Sekundarbereich II/ } \\
\text { postsekundaren, nicht tertiären Bereich } \\
\text { Abschluss im Tertiärbereich }\end{array}$ & $\begin{array}{l}43 \\
67 \\
85\end{array}$ & $\begin{array}{l}38 \\
62 \\
83\end{array}$ & $\begin{array}{l}40 \\
65 \\
85\end{array}$ & $\begin{array}{l}40 \\
65 \\
85\end{array}$ & $\begin{array}{l}50 \\
71 \\
87\end{array}$ & $\begin{array}{l}45 \\
68 \\
83\end{array}$ & $\begin{array}{l}49 \\
74 \\
86\end{array}$ & $\begin{array}{l}47 \\
73 \\
84\end{array}$ & $\begin{array}{l}24 \\
28 \\
51\end{array}$ & $\begin{array}{l}21 \\
28 \\
55\end{array}$ & $\begin{array}{l}22 \\
34 \\
56\end{array}$ & $\begin{array}{l}24 \\
38 \\
62\end{array}$ \\
\hline Portugal & $\begin{array}{l}\text { Ausbildung unterhalb Sekundarbereich II } \\
\text { Abschluss im Sekundarbereich II/ } \\
\text { postsekundaren, nicht tertiären Bereich } \\
\text { Abschluss im Tertiärbereich }\end{array}$ & $\begin{array}{l}73 \\
83 \\
91\end{array}$ & $\begin{array}{l}71 \\
79 \\
87\end{array}$ & $\begin{array}{l}68 \\
80 \\
85\end{array}$ & $\begin{array}{l}63 \\
76 \\
82\end{array}$ & $\begin{array}{l}83 \\
83 \\
91\end{array}$ & $\begin{array}{l}81 \\
78 \\
87\end{array}$ & $\begin{array}{l}75 \\
80 \\
85\end{array}$ & $\begin{array}{l}71 \\
75 \\
78\end{array}$ & $\begin{array}{l}50 \\
51 \\
69\end{array}$ & $\begin{array}{l}50 \\
48 \\
61\end{array}$ & $\begin{array}{l}48 \\
51 \\
58\end{array}$ & $\begin{array}{l}44 \\
52 \\
62\end{array}$ \\
\hline Slowakei & $\begin{array}{l}\text { Ausbildung unterhalb Sekundarbereich II } \\
\text { Abschluss im Sekundarbereich II/ } \\
\text { postsekundaren, nicht tertiären Bereich } \\
\text { Abschluss im Tertiärbereich }\end{array}$ & $\begin{array}{l}31 \\
71 \\
86\end{array}$ & $\begin{array}{l}26 \\
71 \\
84\end{array}$ & $\begin{array}{l}30 \\
70 \\
82\end{array}$ & $\begin{array}{l}31 \\
70 \\
80\end{array}$ & $\begin{array}{l}29 \\
72 \\
83\end{array}$ & $\begin{array}{l}16 \\
73 \\
84\end{array}$ & $\begin{array}{l}21 \\
72 \\
78\end{array}$ & $\begin{array}{l}30 \\
72 \\
75\end{array}$ & $\begin{array}{r}7 \\
27 \\
54\end{array}$ & $\begin{array}{r}9 \\
34 \\
54\end{array}$ & $\begin{array}{l}21 \\
41 \\
66\end{array}$ & $\begin{array}{l}20 \\
43 \\
65\end{array}$ \\
\hline Slowenien ${ }^{1}$ & $\begin{array}{l}\text { Ausbildung unterhalb Sekundarbereich II } \\
\text { Abschluss im Sekundarbereich II/ } \\
\text { postsekundaren, nicht tertiären Bereich } \\
\text { Abschluss im Tertiärbereich }\end{array}$ & $\begin{array}{l}53 \\
74 \\
86\end{array}$ & $\begin{array}{l}56 \\
75 \\
87\end{array}$ & $\begin{array}{l}51 \\
73 \\
87\end{array}$ & $\begin{array}{l}47 \\
71 \\
85\end{array}$ & $\begin{array}{l}75 \\
86 \\
92\end{array}$ & $\begin{array}{l}70 \\
84 \\
91\end{array}$ & $\begin{array}{l}60 \\
81 \\
88\end{array}$ & $\begin{array}{l}52 \\
80 \\
84\end{array}$ & $\begin{array}{l}20 \\
18 \\
48\end{array}$ & $\begin{array}{l}27 \\
27 \\
51\end{array}$ & $\begin{array}{l}28 \\
32 \\
57\end{array}$ & $\begin{array}{l}25 \\
30 \\
55\end{array}$ \\
\hline Spanien & $\begin{array}{l}\text { Ausbildung unterhalb Sekundarbereich II } \\
\text { Abschluss im Sekundarbereich II/ } \\
\text { postsekundaren, nicht tertiären Bereich } \\
\text { Abschluss im Tertiärbereich }\end{array}$ & $\begin{array}{l}54 \\
72 \\
80\end{array}$ & $\begin{array}{l}59 \\
75 \\
82\end{array}$ & $\begin{array}{l}53 \\
69 \\
80\end{array}$ & $\begin{array}{l}49 \\
66 \\
77\end{array}$ & $\begin{array}{l}65 \\
73 \\
75\end{array}$ & $\begin{array}{l}71 \\
77 \\
81\end{array}$ & $\begin{array}{l}58 \\
68 \\
78\end{array}$ & $\begin{array}{l}53 \\
63 \\
73\end{array}$ & $\begin{array}{l}33 \\
51 \\
64\end{array}$ & $\begin{array}{l}38 \\
51 \\
65\end{array}$ & $\begin{array}{l}36 \\
53 \\
64\end{array}$ & $\begin{array}{l}36 \\
53 \\
65\end{array}$ \\
\hline Schweden & $\begin{array}{l}\text { Ausbildung unterhalb Sekundarbereich II } \\
\text { Abschluss im Sekundarbereich II/ } \\
\text { postsekundaren, nicht tertiären Bereich } \\
\text { Abschluss im Tertiärbereich }\end{array}$ & $\begin{array}{l}68 \\
82 \\
87\end{array}$ & $\begin{array}{l}66 \\
81 \\
87\end{array}$ & $\begin{array}{l}63 \\
81 \\
88\end{array}$ & $\begin{array}{l}64 \\
83 \\
89\end{array}$ & $\begin{array}{l}67 \\
83 \\
82\end{array}$ & $\begin{array}{l}65 \\
81 \\
84\end{array}$ & $\begin{array}{l}60 \\
80 \\
85\end{array}$ & $\begin{array}{l}59 \\
80 \\
86\end{array}$ & $\begin{array}{l}56 \\
66 \\
79\end{array}$ & $\begin{array}{l}59 \\
69 \\
83\end{array}$ & $\begin{array}{l}60 \\
70 \\
81\end{array}$ & $\begin{array}{l}61 \\
73 \\
83\end{array}$ \\
\hline
\end{tabular}

Anmerkung: Die Spalten mit den Angaben für weitere Jahre und Altersgruppen sind im Internet verfügbar (s. StatLink unten).

1. Die Zahlen für 2012 für Estland und Slowenien in dieser Tabelle können von Zahlen in anderen Tabellen in Indikator A5 abweichen, da unterschiedliche Datenquellen zugrunde liegen. Die Zahlen in dieser Tabelle basieren für alle Jahre auf der EU-Arbeitskräfteerhebung. 2. Die Zahlen für das Jahr 200o können nicht mit neueren Zahlen verglichen werden, da 2000 noch die frühere Klassifikation des Bildungswesens verwendet wurde.

Quelle: OECD. Argentinien, China, Indien, Indonesien, Kolumbien, Saudi-Arabien und Südafrika: Statistikinstitut der UNESCO. Lettland: Eurostat. Hinweise s. Anhang 3 unter www.oecd.org/edu/eag.htm. StatLink: http://dx.doi.org/10.1787/888933115806

Erläuterung der Kennzeichnung fehlender Daten s. Hinweise für den Leser. 
Entwicklung der Beschäftigungsquoten, nach Bildungsstand und Altersgruppe (2000, 2005-2012)

Anteil 25- bis 64-jähriger/25- bis 34-jähriger/55- bis 64-jähriger Beschäftigter (in \%) an allen 25- bis 64-Jährigen/25- bis 34-Jährigen/ 55- bis 64-Jährigen

\begin{tabular}{|c|c|c|c|c|c|c|c|c|c|c|c|c|c|}
\hline & \multirow[t]{3}{*}{ Bildungsstand } & \multicolumn{4}{|c|}{$\begin{array}{l}\text { Beschäftigungsquoten } \\
25-\text { bis 64-Jähriger }\end{array}$} & \multicolumn{4}{|c|}{$\begin{array}{l}\text { Beschäftigungsquoten } \\
25 \text { - bis 34-Jähriger }\end{array}$} & \multicolumn{4}{|c|}{$\begin{array}{l}\text { Beschäftigungsquoten } \\
55-\text { bis 64-Jähriger }\end{array}$} \\
\hline & & 2000 & 2005 & 2010 & 2012 & 2000 & 2005 & 2010 & 2012 & 2000 & 2005 & 2010 & 2012 \\
\hline & & (1) & (2) & (7) & (9) & (11) & $(12)$ & (17) & (19) & $(41)$ & $(42)$ & $(47)$ & (49) \\
\hline \multicolumn{14}{|l|}{ OECD-Länder } \\
\hline Schweiz & $\begin{array}{l}\text { Ausbildung unterhalb Sekundarbereich II } \\
\text { Abschluss im Sekundarbereich II/ } \\
\text { postsekundaren, nicht tertiären Bereich } \\
\text { Abschluss im Tertiärbereich }\end{array}$ & $\begin{array}{l}64 \\
81 \\
90\end{array}$ & $\begin{array}{l}65 \\
80 \\
90\end{array}$ & $\begin{array}{l}69 \\
81 \\
88\end{array}$ & $\begin{array}{l}69 \\
82 \\
89\end{array}$ & $\begin{array}{l}68 \\
84 \\
91\end{array}$ & $\begin{array}{l}68 \\
83 \\
91\end{array}$ & $\begin{array}{l}70 \\
84 \\
87\end{array}$ & $\begin{array}{l}69 \\
84 \\
89\end{array}$ & $\begin{array}{l}47 \\
66 \\
78\end{array}$ & $\begin{array}{l}51 \\
65 \\
79\end{array}$ & $\begin{array}{l}54 \\
67 \\
79\end{array}$ & $\begin{array}{l}54 \\
70 \\
81\end{array}$ \\
\hline Türkei & $\begin{array}{l}\text { Ausbildung unterhalb Sekundarbereich II } \\
\text { Abschluss im Sekundarbereich II/ } \\
\text { postsekundaren, nicht tertiären Bereich } \\
\text { Abschluss im Tertiärbereich }\end{array}$ & $\begin{array}{l}53 \\
64 \\
78\end{array}$ & $\begin{array}{l}47 \\
62 \\
75\end{array}$ & $\begin{array}{l}49 \\
60 \\
76\end{array}$ & $\begin{array}{l}51 \\
62 \\
76\end{array}$ & $\begin{array}{l}55 \\
67 \\
83\end{array}$ & $\begin{array}{l}49 \\
64 \\
79\end{array}$ & $\begin{array}{l}51 \\
64 \\
77\end{array}$ & $\begin{array}{l}54 \\
65 \\
77\end{array}$ & $\begin{array}{l}38 \\
20 \\
37\end{array}$ & $\begin{array}{l}30 \\
24 \\
34\end{array}$ & $\begin{array}{l}31 \\
24 \\
38\end{array}$ & $\begin{array}{l}34 \\
27 \\
40\end{array}$ \\
\hline $\begin{array}{l}\text { Vereinigtes } \\
\text { Königreich }\end{array}$ & $\begin{array}{l}\text { Ausbildung unterhalb Sekundarbereich II } \\
\text { Abschluss im Sekundarbereich II/ } \\
\text { postsekundaren, nicht tertiären Bereich } \\
\text { Abschluss im Tertiärbereich }\end{array}$ & $\begin{array}{l}65 \\
81 \\
88\end{array}$ & $\begin{array}{l}65 \\
82 \\
88\end{array}$ & $\begin{array}{l}56 \\
78 \\
84\end{array}$ & $\begin{array}{l}57 \\
79 \\
84\end{array}$ & $\begin{array}{l}66 \\
83 \\
91\end{array}$ & $\begin{array}{l}64 \\
81 \\
90\end{array}$ & $\begin{array}{l}56 \\
79 \\
87\end{array}$ & $\begin{array}{l}56 \\
80 \\
86\end{array}$ & $\begin{array}{l}51 \\
65 \\
66\end{array}$ & $\begin{array}{l}56 \\
69 \\
72\end{array}$ & $\begin{array}{l}44 \\
63 \\
65\end{array}$ & $\begin{array}{l}44 \\
65 \\
66\end{array}$ \\
\hline Vereinigte Staaten & $\begin{array}{l}\text { Ausbildung unterhalb Sekundarbereich II } \\
\text { Abschluss im Sekundarbereich II/ } \\
\text { postsekundaren, nicht tertiären Bereich } \\
\text { Abschluss im Tertiärbereich }\end{array}$ & $\begin{array}{l}58 \\
77 \\
85\end{array}$ & $\begin{array}{l}57 \\
73 \\
82\end{array}$ & $\begin{array}{l}52 \\
68 \\
80\end{array}$ & $\begin{array}{l}53 \\
67 \\
80\end{array}$ & $\begin{array}{l}64 \\
80 \\
87\end{array}$ & $\begin{array}{l}62 \\
74 \\
83\end{array}$ & $\begin{array}{l}55 \\
68 \\
82\end{array}$ & $\begin{array}{l}56 \\
68 \\
82\end{array}$ & $\begin{array}{l}40 \\
58 \\
70\end{array}$ & $\begin{array}{l}39 \\
58 \\
72\end{array}$ & $\begin{array}{l}40 \\
57 \\
70\end{array}$ & $\begin{array}{l}39 \\
57 \\
71\end{array}$ \\
\hline OECD-Durchschnitt & $\begin{array}{l}\text { Ausbildung unterhalb Sekundarbereich II } \\
\text { Abschluss im Sekundarbereich II/ } \\
\text { postsekundaren, nicht tertiären Bereich }\end{array}$ & $\begin{array}{l}57 \\
75\end{array}$ & $\begin{array}{l}57 \\
75\end{array}$ & $\begin{array}{l}56 \\
74\end{array}$ & $\begin{array}{l}55 \\
74\end{array}$ & $\begin{array}{l}64 \\
78\end{array}$ & $\begin{array}{l}61 \\
77\end{array}$ & $\begin{array}{r}58 \\
75\end{array}$ & $\begin{array}{l}57 \\
75\end{array}$ & $\begin{array}{l}36 \\
46\end{array}$ & $\begin{array}{l}38 \\
50\end{array}$ & $\begin{array}{l}41 \\
53 \\
67\end{array}$ & $\begin{array}{l}41 \\
55 \\
68\end{array}$ \\
\hline $\begin{array}{l}\text { OECD-Durchschnitt } \\
\text { für Länder mit ver- } \\
\text { fügbaren Daten für } \\
\text { alle Referenzjahre }\end{array}$ & $\begin{array}{l}\text { Ausbildung unterhalb Sekundarbereich II } \\
\text { Abschluss im Sekundarbereich II/ } \\
\text { postsekundaren, nicht tertiären Bereich } \\
\text { Abschluss im Tertiärbereich }\end{array}$ & $\begin{array}{l}57 \\
75 \\
85\end{array}$ & $\begin{array}{l}57 \\
75 \\
84\end{array}$ & $\begin{array}{l}56 \\
74 \\
83\end{array}$ & $\begin{array}{l}55 \\
74 \\
83\end{array}$ & $\begin{array}{l}64 \\
78 \\
86\end{array}$ & $\begin{array}{l}62 \\
78 \\
85\end{array}$ & $\begin{array}{l}58 \\
76 \\
83\end{array}$ & $\begin{array}{l}57 \\
75 \\
82\end{array}$ & $\begin{array}{l}35 \\
46 \\
62\end{array}$ & $\begin{array}{l}39 \\
50 \\
65\end{array}$ & $\begin{array}{l}40 \\
52 \\
67\end{array}$ & $\begin{array}{l}41 \\
54 \\
68\end{array}$ \\
\hline EU21-Durchschnitt & $\begin{array}{l}\text { Ausbildung unterhalb Sekundarbereich II } \\
\text { Abschluss im Sekundarbereich II/ } \\
\text { postsekundaren, nicht tertiären Bereich } \\
\text { Abschluss im Tertiärbereich }\end{array}$ & $\begin{array}{l}53 \\
74 \\
85\end{array}$ & $\begin{array}{l}54 \\
74 \\
85\end{array}$ & $\begin{array}{l}52 \\
73 \\
84\end{array}$ & $\begin{array}{l}51 \\
73 \\
83\end{array}$ & $\begin{array}{l}63 \\
79 \\
86\end{array}$ & $\begin{array}{l}61 \\
78 \\
85\end{array}$ & $\begin{array}{l}56 \\
77 \\
83\end{array}$ & $\begin{array}{l}55 \\
75 \\
82\end{array}$ & $\begin{array}{l}29 \\
40 \\
60\end{array}$ & $\begin{array}{l}33 \\
45 \\
63\end{array}$ & $\begin{array}{l}35 \\
48 \\
64\end{array}$ & $\begin{array}{l}35 \\
50 \\
66\end{array}$ \\
\hline Partnerländer & & & & & & & & & & & & & \\
\hline Argentinien & & $\mathrm{m}$ & $\mathrm{m}$ & $\mathrm{m}$ & m & $\mathrm{m}$ & $\mathrm{m}$ & $\mathrm{m}$ & m & $\mathrm{m}$ & $\mathrm{m}$ & $\mathrm{m}$ & m \\
\hline Brasilien & $\begin{array}{l}\text { Ausbildung unterhalb Sekundarbereich II } \\
\text { Abschluss im Sekundarbereich II/ } \\
\text { postsekundaren, nicht tertiären Bereich } \\
\text { Abschluss im Tertiärbereich }\end{array}$ & $\begin{array}{l}\mathrm{m} \\
\mathrm{m} \\
\mathrm{m}\end{array}$ & $\begin{array}{l}\mathrm{m} \\
\mathrm{m} \\
\mathrm{m}\end{array}$ & $\begin{array}{l}\mathrm{m} \\
\mathrm{m} \\
\mathrm{m}\end{array}$ & $\begin{array}{l}67 \\
77 \\
86\end{array}$ & $\begin{array}{l}\mathrm{m} \\
\mathrm{m} \\
\mathrm{m}\end{array}$ & $\begin{array}{l}\mathrm{m} \\
\mathrm{m} \\
\mathrm{m}\end{array}$ & $\begin{array}{l}\mathrm{m} \\
\mathrm{m} \\
\mathrm{m}\end{array}$ & $\begin{array}{l}71 \\
79 \\
89\end{array}$ & $\begin{array}{l}\mathrm{m} \\
\mathrm{m} \\
\mathrm{m}\end{array}$ & $\begin{array}{l}\mathrm{m} \\
\mathrm{m} \\
\mathrm{m}\end{array}$ & $\begin{array}{l}\mathrm{m} \\
\mathrm{m} \\
\mathrm{m}\end{array}$ & $\begin{array}{l}50 \\
55 \\
65\end{array}$ \\
\hline China & & $\mathrm{m}$ & $\mathrm{m}$ & $\mathrm{m}$ & m & $\mathrm{m}$ & $\mathrm{m}$ & $\mathrm{m}$ & m & $\mathrm{m}$ & $\mathrm{m}$ & $\mathrm{m}$ & m \\
\hline Kolumbien & & $\mathrm{m}$ & $\mathrm{m}$ & $\mathrm{m}$ & m & $\mathrm{m}$ & $\mathrm{m}$ & $\mathrm{m}$ & m & $\mathrm{m}$ & $\mathrm{m}$ & $\mathrm{m}$ & m \\
\hline Indien & & $\mathrm{m}$ & $\mathrm{m}$ & $\mathrm{m}$ & m & $\mathrm{m}$ & $\mathrm{m}$ & $\mathrm{m}$ & m & $\mathrm{m}$ & $\mathrm{m}$ & $\mathrm{m}$ & m \\
\hline Indonesien & & $\mathrm{m}$ & $\mathrm{m}$ & $\mathrm{m}$ & m & $\mathrm{m}$ & $\mathrm{m}$ & $\mathrm{m}$ & m & $\mathrm{m}$ & $\mathrm{m}$ & $\mathrm{m}$ & m \\
\hline Lettland & $\begin{array}{l}\text { Ausbildung unterhalb Sekundarbereich II } \\
\text { Abschluss im Sekundarbereich II/ } \\
\text { postsekundaren, nicht tertiären Bereich } \\
\text { Abschluss im Tertiärbereich }\end{array}$ & $\begin{array}{l}\mathrm{m} \\
\mathrm{m} \\
\mathrm{m}\end{array}$ & $\begin{array}{l}\mathrm{m} \\
\mathrm{m} \\
\mathrm{m}\end{array}$ & $\begin{array}{l}\mathrm{m} \\
\mathrm{m} \\
\mathrm{m}\end{array}$ & $\begin{array}{l}52 \\
67 \\
86\end{array}$ & $\begin{array}{l}\mathrm{m} \\
\mathrm{m} \\
\mathrm{m}\end{array}$ & $\begin{array}{l}\mathrm{m} \\
\mathrm{m} \\
\mathrm{m}\end{array}$ & $\begin{array}{l}\mathrm{m} \\
\mathrm{m} \\
\mathrm{m}\end{array}$ & $\begin{array}{l}56 \\
72 \\
87\end{array}$ & $\begin{array}{l}\mathrm{m} \\
\mathrm{m} \\
\mathrm{m}\end{array}$ & $\begin{array}{l}\mathrm{m} \\
\mathrm{m} \\
\mathrm{m}\end{array}$ & $\begin{array}{l}\mathrm{m} \\
\mathrm{m} \\
\mathrm{m}\end{array}$ & $\begin{array}{l}33 \\
50 \\
73\end{array}$ \\
\hline $\begin{array}{l}\text { Russische } \\
\text { Föderation }\end{array}$ & $\begin{array}{l}\text { Ausbildung unterhalb Sekundarbereich II } \\
\text { Abschluss im Sekundarbereich II/ } \\
\text { postsekundaren, nicht tertiären Bereich } \\
\text { Abschluss im Tertiärbereich }\end{array}$ & $\begin{array}{l}\mathrm{m} \\
\mathrm{m} \\
\mathrm{m}\end{array}$ & $\begin{array}{l}\mathrm{m} \\
\mathrm{m} \\
\mathrm{m}\end{array}$ & $\begin{array}{l}\mathrm{m} \\
\mathrm{m} \\
\mathrm{m}\end{array}$ & $\begin{array}{l}50 \\
73 \\
83\end{array}$ & $\begin{array}{l}\mathrm{m} \\
\mathrm{m} \\
\mathrm{m}\end{array}$ & $\begin{array}{l}\mathrm{m} \\
\mathrm{m} \\
\mathrm{m}\end{array}$ & $\begin{array}{l}\mathrm{m} \\
\mathrm{m} \\
\mathrm{m}\end{array}$ & $\begin{array}{l}59 \\
80 \\
89\end{array}$ & $\begin{array}{l}\mathrm{m} \\
\mathrm{m} \\
\mathrm{m}\end{array}$ & $\begin{array}{l}\mathrm{m} \\
\mathrm{m} \\
\mathrm{m}\end{array}$ & $\begin{array}{l}\mathrm{m} \\
\mathrm{m} \\
\mathrm{m}\end{array}$ & $\begin{array}{l}28 \\
44 \\
53\end{array}$ \\
\hline Saudi-Arabien & & $\mathrm{m}$ & $\mathrm{m}$ & $\mathrm{m}$ & m & $\mathrm{m}$ & $\mathrm{m}$ & $\mathrm{m}$ & m & $\mathrm{m}$ & $\mathrm{m}$ & $\mathrm{m}$ & m \\
\hline Südafrika & & $\mathrm{m}$ & $\mathrm{m}$ & $\mathrm{m}$ & m & $\mathrm{m}$ & $\mathrm{m}$ & $\mathrm{m}$ & m & $\mathrm{m}$ & $\mathrm{m}$ & $\mathrm{m}$ & m \\
\hline G20-Durchschnitt & & $\mathbf{m}$ & $\mathbf{m}$ & $\mathbf{m}$ & $\mathbf{m}$ & $\mathbf{m}$ & m & $\mathbf{m}$ & $\mathbf{m}$ & m & $\mathbf{m}$ & $\mathbf{m}$ & m \\
\hline
\end{tabular}

Anmerkung: Die Spalten mit den Angaben für weitere Jahre und Altersgruppen sind im Internet verfügbar (s. StatLink unten).

1. Die Zahlen für 2012 für Estland und Slowenien in dieser Tabelle können von Zahlen in anderen Tabellen in Indikator A5 abweichen, da unterschiedliche Datenquellen zugrunde liegen. Die Zahlen in dieser Tabelle basieren für alle Jahre auf der EU-Arbeitskräfteerhebung. 2. Die Zahlen für das Jahr 200o können nicht mit neueren Zahlen verglichen werden, da 2000 noch die frühere Klassifikation des Bildungswesens verwendet wurde.

Quelle: OECD. Argentinien, China, Indien, Indonesien, Kolumbien, Saudi-Arabien und Südafrika: Statistikinstitut der UNESCO. Lettland: Eurostat. Hinweise s. Anhang 3 unter www.oecd.org/edu/eag.htm. StatLink: http://dx.doi.org/10.1787/888933115806

Erläuterung der Kennzeichnung fehlender Daten s. Hinweise für den Leser. 
Entwicklung der Erwerbslosenquoten, nach Bildungsstand und Altersgruppe (2000, 2005-2012)

Zahl der 25- bis 64-jährigen/25- bis 34-jährigen/55- bis 64-jährigen Erwerbslosen als Prozentsatz aller 25- bis 64-jährigen/ 25- bis 34-jährigen/55- bis 64-jährigen Erwerbspersonen

\begin{tabular}{|c|c|c|c|c|c|c|c|c|c|c|c|c|c|}
\hline & \multirow[t]{3}{*}{ Bildungsstand } & \multicolumn{4}{|c|}{$\begin{array}{l}\text { Erwerbslosenquoten } \\
\text { der 25- bis } 64-J a ̈ h r i g e n\end{array}$} & \multicolumn{4}{|c|}{$\begin{array}{l}\text { Erwerbslosenquoten } \\
\text { der 25- bis 34-Jährigen }\end{array}$} & \multicolumn{4}{|c|}{$\begin{array}{l}\text { Erwerbslosenquoten } \\
\text { der 55- bis 64-Jährigen }\end{array}$} \\
\hline & & 2000 & 2005 & 2010 & 2012 & 2000 & 2005 & 2010 & 2012 & 2000 & 2005 & 2010 & 2012 \\
\hline & & (1) & (2) & (7) & (9) & (11) & (12) & (17) & (19) & $(41)$ & (42) & $(47)$ & (49) \\
\hline \multicolumn{14}{|l|}{ OECD-Länder } \\
\hline Australien & $\begin{array}{l}\text { Ausbildung unterhalb Sekundarbereich II } \\
\text { Abschluss im Sekundarbereich II/ } \\
\text { postsekundaren, nicht tertiären Bereich } \\
\text { Abschluss im Tertiärbereich }\end{array}$ & $\begin{array}{l}7,5 \\
4,5 \\
3,6\end{array}$ & $\begin{array}{l}6,3 \\
3,4 \\
2,5\end{array}$ & $\begin{array}{l}6,2 \\
3,6 \\
2,8\end{array}$ & $\begin{array}{l}6,2 \\
3,7 \\
2,8\end{array}$ & $\begin{array}{r}11,4 \\
5,3 \\
3,8\end{array}$ & $\begin{array}{r}12,3 \\
4,0 \\
2,8\end{array}$ & $\begin{array}{r}14,3 \\
5,0 \\
3,1\end{array}$ & $\begin{array}{r}10,6 \\
4,1 \\
3,7\end{array}$ & $\begin{array}{l}4,9 \\
4,1 \\
3,5\end{array}$ & $\begin{array}{l}3,7 \\
3,4 \\
2,6\end{array}$ & $\begin{array}{l}3,8 \\
2,5 \\
1,8\end{array}$ & $\begin{array}{l}3,9 \\
3,3 \\
2,1\end{array}$ \\
\hline Österreich & $\begin{array}{l}\text { Ausbildung unterhalb Sekundarbereich II } \\
\text { Abschluss im Sekundarbereich II/ } \\
\text { postsekundaren, nicht tertiären Bereich } \\
\text { Abschluss im Tertiärbereich }\end{array}$ & $\begin{array}{l}6,2 \\
2,9 \\
1,5\end{array}$ & $\begin{array}{l}8,6 \\
3,9 \\
2,6\end{array}$ & $\begin{array}{l}7,3 \\
3,5 \\
2,3\end{array}$ & $\begin{array}{l}7,7 \\
3,5 \\
2,1\end{array}$ & $\begin{array}{r}8,1 \\
2,7 \\
C\end{array}$ & $\begin{array}{r}14,9 \\
4,5 \\
3,9\end{array}$ & $\begin{array}{r}14,1 \\
5,0 \\
3,4\end{array}$ & $\begin{array}{r}14,0 \\
4,3 \\
2,7\end{array}$ & $\begin{array}{r}6,4 \\
6,0 \\
c\end{array}$ & $\begin{array}{r}5,0 \\
3,8 \\
C\end{array}$ & $\begin{array}{l}2,7^{r} \\
2,5 \\
c\end{array}$ & $\begin{array}{r}\text { c } \\
3,4 \\
\text { c }\end{array}$ \\
\hline Belgien & $\begin{array}{l}\text { Ausbildung unterhalb Sekundarbereich II } \\
\text { Abschluss im Sekundarbereich II/ } \\
\text { postsekundaren, nicht tertiären Bereich } \\
\text { Abschluss im Tertiärbereich }\end{array}$ & $\begin{array}{l}9,8 \\
5,3 \\
2,7\end{array}$ & $\begin{array}{r}12,4 \\
6,9 \\
3,7\end{array}$ & $\begin{array}{r}13,2 \\
6,6 \\
4,0\end{array}$ & $\begin{array}{r}12,1 \\
6,7 \\
3,4\end{array}$ & $\begin{array}{r}17,5 \\
6,7 \\
3,3\end{array}$ & $\begin{array}{r}23,0 \\
9,4 \\
4,9\end{array}$ & $\begin{array}{r}23,4 \\
10,2 \\
5,1\end{array}$ & $\begin{array}{r}22,1 \\
10,9 \\
4,3\end{array}$ & $\begin{array}{r}3,8^{r} \\
3,5^{r} \\
c\end{array}$ & $\begin{array}{l}6,1 \\
4,1 \\
2,8\end{array}$ & $\begin{array}{l}6,4 \\
4,1 \\
3,5\end{array}$ & $\begin{array}{l}6,6 \\
4,0^{r} \\
3,2^{r}\end{array}$ \\
\hline Kanada & $\begin{array}{l}\text { Ausbildung unterhalb Sekundarbereich II } \\
\text { Abschluss im Sekundarbereich II/ } \\
\text { postsekundaren, nicht tertiären Bereich } \\
\text { Abschluss im Tertiärbereich }\end{array}$ & $\begin{array}{r}10,2 \\
5,9 \\
4,1\end{array}$ & $\begin{array}{l}9,7 \\
5,9 \\
4,6\end{array}$ & $\begin{array}{r}12,4 \\
7,5 \\
5,4\end{array}$ & $\begin{array}{r}10,8 \\
6,6 \\
5,0\end{array}$ & $\begin{array}{r}15,0 \\
6,8 \\
4,5\end{array}$ & $\begin{array}{r}13,3 \\
6,7 \\
5,2\end{array}$ & $\begin{array}{r}17,5 \\
9,1 \\
5,9\end{array}$ & $\begin{array}{r}15,4 \\
7,7 \\
5,5\end{array}$ & $\begin{array}{l}7,2 \\
5,5 \\
4,0\end{array}$ & $\begin{array}{l}7,9 \\
5,3 \\
4,2\end{array}$ & $\begin{array}{r}10,1 \\
7,1 \\
5,3\end{array}$ & $\begin{array}{l}8,7 \\
6,7 \\
5,3\end{array}$ \\
\hline Chile & $\begin{array}{l}\text { Ausbildung unterhalb Sekundarbereich II } \\
\text { Abschluss im Sekundarbereich II/ } \\
\text { postsekundaren, nicht tertiären Bereich } \\
\text { Abschluss im Tertiärbereich }\end{array}$ & $\begin{array}{l}m \\
m \\
m\end{array}$ & $\begin{array}{l}m \\
m \\
m\end{array}$ & $\begin{array}{l}4,6 \\
6,2 \\
5,6\end{array}$ & $\begin{array}{l}\mathbf{m} \\
\mathbf{m} \\
\mathbf{m}\end{array}$ & $\begin{array}{l}\mathrm{m} \\
\mathrm{m} \\
\mathrm{m}\end{array}$ & $\begin{array}{l}\mathrm{m} \\
\mathrm{m} \\
\mathrm{m}\end{array}$ & $\begin{array}{l}8,0 \\
8,1 \\
9,5\end{array}$ & $\begin{array}{l}\mathbf{m} \\
\mathbf{m} \\
\mathbf{m}\end{array}$ & $\begin{array}{l}m \\
m \\
m\end{array}$ & $\begin{array}{l}m \\
m \\
m\end{array}$ & $\begin{array}{l}3,5 \\
4,3 \\
3,1\end{array}$ & $\begin{array}{l}\mathbf{m} \\
\mathbf{m} \\
\mathbf{m}\end{array}$ \\
\hline Tschechien & $\begin{array}{l}\text { Ausbildung unterhalb Sekundarbereich II } \\
\text { Abschluss im Sekundarbereich II/ } \\
\text { postsekundaren, nicht tertiären Bereich } \\
\text { Abschluss im Tertiärbereich }\end{array}$ & $\begin{array}{r}19,3 \\
6,7 \\
2,5\end{array}$ & $\begin{array}{r}24,4 \\
6,2 \\
2,0\end{array}$ & $\begin{array}{r}22,7 \\
6,2 \\
2,5\end{array}$ & $\begin{array}{r}25,5 \\
5,7 \\
2,6\end{array}$ & $\begin{array}{r}28,3 \\
8,7 \\
3,4\end{array}$ & $\begin{array}{r}35,5 \\
7,0 \\
2,4\end{array}$ & $\begin{array}{r}28,9 \\
7,4 \\
3,9\end{array}$ & $\begin{array}{r}32,8 \\
7,2 \\
4,0\end{array}$ & $\begin{array}{l}8,1 \\
5,3 \\
2,2\end{array}$ & $\begin{array}{r}13,7 \\
4,9 \\
2,3\end{array}$ & $\begin{array}{r}14,7 \\
6,5 \\
2,3\end{array}$ & $\begin{array}{r}14,7 \\
5,7 \\
2,5\end{array}$ \\
\hline Dänemark & $\begin{array}{l}\text { Ausbildung unterhalb Sekundarbereich II } \\
\text { Abschluss im Sekundarbereich II/ } \\
\text { postsekundaren, nicht tertiären Bereich } \\
\text { Abschluss im Tertiärbereich }\end{array}$ & $\begin{array}{l}6,3 \\
3,9 \\
2,6\end{array}$ & $\begin{array}{l}6,5 \\
4,0 \\
3,7\end{array}$ & $\begin{array}{l}9,0 \\
6,1 \\
4,6\end{array}$ & $\begin{array}{l}9,6 \\
6,2 \\
4,7\end{array}$ & $\begin{array}{r}10,6 \\
3,9 \\
4,2\end{array}$ & $\begin{array}{l}9,7 \\
4,3 \\
5,0\end{array}$ & $\begin{array}{r}14,0 \\
7,6 \\
7,2\end{array}$ & $\begin{array}{r}14,8 \\
8,7 \\
7,7\end{array}$ & $\begin{array}{l}3,1 \\
4,9 \\
2,9\end{array}$ & $\begin{array}{l}6,5 \\
5,7 \\
3,6\end{array}$ & $\begin{array}{l}6,5 \\
6,3 \\
3,5\end{array}$ & $\begin{array}{l}8,1 \\
4,8 \\
4,3\end{array}$ \\
\hline Estland $^{1}$ & $\begin{array}{l}\text { Ausbildung unterhalb Sekundarbereich II } \\
\text { Abschluss im Sekundarbereich II/ } \\
\text { postsekundaren, nicht tertiären Bereich } \\
\text { Abschluss im Tertiärbereich }\end{array}$ & $\begin{array}{r}21,8 \\
14,5 \\
4,6\end{array}$ & $\begin{array}{r}13,0 \\
8,4 \\
3,8\end{array}$ & $\begin{array}{r}27,7 \\
18,0 \\
9,1\end{array}$ & $\begin{array}{r}22,1 \\
9,5 \\
6,1\end{array}$ & $\begin{array}{r}29,0 \\
15,4 \\
4,1^{\mathrm{r}}\end{array}$ & $\begin{array}{r}17,0 \\
7,2 \\
3,1^{r}\end{array}$ & $\begin{array}{r}33,6 \\
19,4 \\
5,3\end{array}$ & $\begin{array}{r}25,8 \\
10,6 \\
6,6\end{array}$ & $\begin{array}{r}23,4 \\
3,9^{r} \\
3,7\end{array}$ & $\begin{array}{r}\mathrm{C} \\
5,9 \\
\mathrm{C}\end{array}$ & $\begin{array}{l}17,5^{r} \\
17,3 \\
14,4\end{array}$ & $\begin{array}{r}\text { C } \\
7,8 \\
5,3^{r}\end{array}$ \\
\hline Finnland & $\begin{array}{l}\text { Ausbildung unterhalb Sekundarbereich II } \\
\text { Abschluss im Sekundarbereich II/ } \\
\text { postsekundaren, nicht tertiären Bereich } \\
\text { Abschluss im Tertiärbereich }\end{array}$ & $\begin{array}{r}11,9 \\
8,8 \\
4,9\end{array}$ & $\begin{array}{r}10,7 \\
7,4 \\
4,4\end{array}$ & $\begin{array}{r}11,6 \\
7,5 \\
4,4\end{array}$ & $\begin{array}{r}11,6 \\
7,1 \\
3,9\end{array}$ & $\begin{array}{r}16,4 \\
10,4 \\
6,7\end{array}$ & $\begin{array}{r}17,4 \\
8,0 \\
4,8\end{array}$ & $\begin{array}{r}16,4 \\
8,1 \\
5,6\end{array}$ & $\begin{array}{r}16,6 \\
8,7 \\
4,5\end{array}$ & $\begin{array}{r}11,5 \\
9,7 \\
6,5\end{array}$ & $\begin{array}{l}9,0 \\
7,0 \\
4,6\end{array}$ & $\begin{array}{l}8,5 \\
7,5 \\
4,1\end{array}$ & $\begin{array}{l}9,2 \\
7,0 \\
4,8\end{array}$ \\
\hline Frankreich & $\begin{array}{l}\text { Ausbildung unterhalb Sekundarbereich II } \\
\text { Abschluss im Sekundarbereich II/ } \\
\text { postsekundaren, nicht tertiären Bereich } \\
\text { Abschluss im Tertiärbereich }\end{array}$ & $\begin{array}{r}13,8 \\
8,0 \\
5,1\end{array}$ & $\begin{array}{r}11,1 \\
6,6 \\
5,4\end{array}$ & $\begin{array}{r}12,9 \\
7,2 \\
4,9\end{array}$ & $\begin{array}{r}13,8 \\
8,3 \\
5,1\end{array}$ & $\begin{array}{r}21,7 \\
10,3 \\
6,6\end{array}$ & $\begin{array}{r}18,8 \\
9,3 \\
6,4\end{array}$ & $\begin{array}{r}23,8 \\
10,8 \\
6,3\end{array}$ & $\begin{array}{r}23,2 \\
12,4 \\
6,8\end{array}$ & $\begin{array}{l}8,5 \\
7,7 \\
4,3\end{array}$ & $\begin{array}{l}6,3 \\
4,6 \\
4,3\end{array}$ & $\begin{array}{l}8,3 \\
6,4 \\
4,5\end{array}$ & $\begin{array}{l}9,5 \\
7,0 \\
4,1\end{array}$ \\
\hline Deutschland & $\begin{array}{l}\text { Ausbildung unterhalb Sekundarbereich II } \\
\text { Abschluss im Sekundarbereich II/ } \\
\text { postsekundaren, nicht tertiären Bereich } \\
\text { Abschluss im Tertiärbereich }\end{array}$ & $\begin{array}{r}13,7 \\
7,8 \\
4,0\end{array}$ & $\begin{array}{r}20,1 \\
11,0 \\
5,6\end{array}$ & $\begin{array}{r}15,9 \\
6,9 \\
3,1\end{array}$ & $\begin{array}{r}12,8 \\
5,3 \\
2,4\end{array}$ & $\begin{array}{r}14,6 \\
6,2 \\
2,7\end{array}$ & $\begin{array}{r}25,6 \\
10,9 \\
5,9\end{array}$ & $\begin{array}{r}21,7 \\
7,4 \\
3,5\end{array}$ & $\begin{array}{r}18,8 \\
5,4 \\
2,8\end{array}$ & $\begin{array}{r}15,8 \\
13,7 \\
7,5\end{array}$ & $\begin{array}{r}18,3 \\
13,9 \\
7,8\end{array}$ & $\begin{array}{r}13,4 \\
8,4 \\
4,3\end{array}$ & $\begin{array}{r}10,2 \\
6,6 \\
3,1\end{array}$ \\
\hline Griechenland & $\begin{array}{l}\text { Ausbildung unterhalb Sekundarbereich II } \\
\text { Abschluss im Sekundarbereich II/ } \\
\text { postsekundaren, nicht tertiären Bereich } \\
\text { Abschluss im Tertiärbereich }\end{array}$ & $\begin{array}{r}8,2 \\
11,2 \\
7,5\end{array}$ & $\begin{array}{l}8,3 \\
9,6 \\
7,1\end{array}$ & $\begin{array}{r}11,9 \\
12,5 \\
8,7\end{array}$ & $\begin{array}{l}25,3 \\
24,4 \\
17,0\end{array}$ & $\begin{array}{l}14,0 \\
15,6 \\
13,7\end{array}$ & $\begin{array}{l}11,1 \\
13,1 \\
13,3\end{array}$ & $\begin{array}{l}17,2 \\
16,3 \\
16,9\end{array}$ & $\begin{array}{l}35,7 \\
32,4 \\
30,0\end{array}$ & $\begin{array}{r}4,0 \\
5,0 \\
C\end{array}$ & $\begin{array}{r}4,5 \\
c \\
c\end{array}$ & $\begin{array}{r}7,0 \\
7,5 \\
\mathrm{C}\end{array}$ & $\begin{array}{r}16,6 \\
14,9 \\
6,7\end{array}$ \\
\hline Ungarn & $\begin{array}{l}\text { Ausbildung unterhalb Sekundarbereich II } \\
\text { Abschluss im Sekundarbereich II/ } \\
\text { postsekundaren, nicht tertiären Bereich } \\
\text { Abschluss im Tertiärbereich }\end{array}$ & $\begin{array}{l}9,9 \\
5,3 \\
1,3\end{array}$ & $\begin{array}{r}12,4 \\
6,0 \\
2,3\end{array}$ & $\begin{array}{r}23,5 \\
9,5 \\
4,1\end{array}$ & $\begin{array}{r}22,8 \\
9,4 \\
4,0\end{array}$ & $\begin{array}{r}14,1 \\
6,8 \\
1,6\end{array}$ & $\begin{array}{r}16,7 \\
7,3 \\
3,1\end{array}$ & $\begin{array}{r}32,6 \\
11,4 \\
6,3\end{array}$ & $\begin{array}{r}27,9 \\
12,7 \\
5,7\end{array}$ & $\begin{array}{r}3,9 \\
3,6 \\
C\end{array}$ & $\begin{array}{l}6,4 \\
4,0 \\
1,8\end{array}$ & $\begin{array}{r}16,2 \\
7,9 \\
2,0\end{array}$ & $\begin{array}{r}15,2 \\
7,4 \\
4,1\end{array}$ \\
\hline Island & $\begin{array}{l}\text { Ausbildung unterhalb Sekundarbereich II } \\
\text { Abschluss im Sekundarbereich II/ } \\
\text { postsekundaren, nicht tertiären Bereich } \\
\text { Abschluss im Tertiärbereich }\end{array}$ & $\begin{array}{r}2,0 \\
c \\
c\end{array}$ & $\begin{array}{r}2,3 \\
\mathrm{c} \\
\mathrm{c}\end{array}$ & $\begin{array}{l}7,2 \\
7,2 \\
3,5\end{array}$ & $\begin{array}{l}7,3 \\
4,1 \\
2,9\end{array}$ & $\begin{array}{l}\mathrm{c} \\
\mathrm{c} \\
\mathrm{c}\end{array}$ & $\begin{array}{l}\mathrm{c} \\
\mathrm{c} \\
\mathrm{c}\end{array}$ & $\begin{array}{r}15,6 \\
12,5 \\
C\end{array}$ & $\begin{array}{l}\text { c } \\
\text { c } \\
\text { c }\end{array}$ & $\begin{array}{r}c \\
c \\
0,0\end{array}$ & $\begin{array}{l}\mathrm{c} \\
\mathrm{c} \\
\mathrm{c}\end{array}$ & $\begin{array}{l}\mathrm{c} \\
\mathrm{c} \\
\mathrm{c}\end{array}$ & $\begin{array}{l}\text { c } \\
\text { c } \\
\text { c }\end{array}$ \\
\hline Irland & $\begin{array}{l}\text { Ausbildung unterhalb Sekundarbereich II } \\
\text { Abschluss im Sekundarbereich II/ } \\
\text { postsekundaren, nicht tertiären Bereich } \\
\text { Abschluss im Tertiärbereich }\end{array}$ & $\begin{array}{l}7,1 \\
2,6 \\
1,6\end{array}$ & $\begin{array}{l}6,0 \\
3,1 \\
2,0\end{array}$ & $\begin{array}{r}19,4 \\
13,8 \\
7,0\end{array}$ & $\begin{array}{r}23,3 \\
15,2 \\
7,0\end{array}$ & $\begin{array}{l}9,8 \\
2,7 \\
2,0\end{array}$ & $\begin{array}{r}10,4 \\
3,7 \\
2,4\end{array}$ & $\begin{array}{r}32,0 \\
18,7 \\
8,2\end{array}$ & $\begin{array}{r}37,3 \\
20,4 \\
7,9\end{array}$ & $\begin{array}{r}3,0 \\
\mathrm{C} \\
\mathrm{C}\end{array}$ & $\begin{array}{r}3,1 \\
\mathrm{C} \\
\mathrm{C}\end{array}$ & $\begin{array}{r}11,4 \\
8,6 \\
4,5\end{array}$ & $\begin{array}{r}14,7 \\
9,4 \\
6,3\end{array}$ \\
\hline
\end{tabular}

Anmerkung: Spalten mit weiteren Jahren und Altersgruppen sind im Internet verfügbar (s. StatLink).

1. Die Zahlen für 2012 für Estland und Slowenien in dieser Tabelle können von Zahlen in anderen Tabellen in Indikator A5 abweichen, da unterschiedliche Datenquellen zugrunde liegen. Die Zahlen in dieser Tabelle basieren für alle Jahre auf der EU-Arbeitskräfteerhebung. 2. Die Zahlen für das Jahr 20oo können nicht mit neueren Zahlen verglichen werden, da 2000 noch die frühere Klassifikation des Bildungswesens verwendet wurde.

Quelle: OECD. Argentinien, China, Indien, Indonesien, Kolumbien, Saudi-Arabien und Südafrika: Statistikinstitut der UNESCO. Lettland: Eurostat. Hinweise s. Anhang 3 unter www.oecd.org/edu/eag.htm. StatLink: http://dx.doi.org/10.1787/888933115825

Erläuterung der Kennzeichnung fehlender Daten sowie der Kennzeichnung "r“ neben einigen Zahlen s. Hinweise für den Leser. 
Entwicklung der Erwerbslosenquoten, nach Bildungsstand und Altersgruppe (2000, 2005-2012)

Zahl der 25- bis 64-jährigen/25- bis 34-jährigen/55- bis 64-jährigen Erwerbslosen als Prozentsatz aller 25- bis 64-jährigen/ 25- bis 34-jährigen/55- bis 64-jährigen Erwerbspersonen

\begin{tabular}{|c|c|c|c|c|c|c|c|c|c|c|c|c|c|}
\hline & \multirow[t]{3}{*}{ Bildungsstand } & \multicolumn{4}{|c|}{$\begin{array}{l}\text { Erwerbslosenquoten } \\
\text { der 25- bis 64-Jährigen }\end{array}$} & \multicolumn{4}{|c|}{$\begin{array}{l}\text { Erwerbslosenquoten } \\
\text { der 25- bis 34-Jährigen }\end{array}$} & \multicolumn{4}{|c|}{$\begin{array}{l}\text { Erwerbslosenquoten } \\
\text { der 55- bis 64-Jährigen }\end{array}$} \\
\hline & & 2000 & 2005 & 2010 & 2012 & 2000 & 2005 & 2010 & 2012 & 2000 & 2005 & 2010 & 2012 \\
\hline & & (1) & (2) & (7) & (9) & (11) & (12) & (17) & (19) & (41) & $(42)$ & $(47)$ & (49) \\
\hline \multicolumn{14}{|l|}{ OECD-Länder } \\
\hline Israel & $\begin{array}{l}\text { Ausbildung unterhalb Sekundarbereich II } \\
\text { Abschluss im Sekundarbereich II/ } \\
\text { postsekundaren, nicht tertiären Bereich } \\
\text { Abschluss im Tertiärbereich }\end{array}$ & $\begin{array}{l}m \\
m \\
m\end{array}$ & $\begin{array}{r}14,0 \\
9,5 \\
5,1\end{array}$ & $\begin{array}{l}9,8 \\
6,8 \\
4,2\end{array}$ & $\begin{array}{r}10,2 \\
7,1 \\
4,2\end{array}$ & $\begin{array}{l}\mathrm{m} \\
\mathrm{m} \\
\mathrm{m}\end{array}$ & $\begin{array}{r}14,2 \\
10,9 \\
5,7\end{array}$ & $\begin{array}{r}12,2 \\
8,0 \\
5,6\end{array}$ & $\begin{array}{r}13,8 \\
9,0 \\
5,5\end{array}$ & $\begin{array}{l}m \\
m \\
m\end{array}$ & $\begin{array}{r}10,3 \\
10,0 \\
5,1\end{array}$ & $\begin{array}{l}8,0 \\
5,2 \\
3,6\end{array}$ & $\begin{array}{l}8,4 \\
5,5 \\
3,4\end{array}$ \\
\hline Italien & $\begin{array}{l}\text { Ausbildung unterhalb Sekundarbereich II } \\
\text { Abschluss im Sekundarbereich II/ } \\
\text { postsekundaren, nicht tertiären Bereich } \\
\text { Abschluss im Tertiärbereich }\end{array}$ & $\begin{array}{l}9,8 \\
7,4 \\
5,9\end{array}$ & $\begin{array}{l}7,8 \\
5,2 \\
5,7\end{array}$ & $\begin{array}{l}9,1 \\
6,1 \\
5,6\end{array}$ & $\begin{array}{r}12,2 \\
7,7 \\
6,4\end{array}$ & $\begin{array}{l}15,1 \\
12,3 \\
15,5\end{array}$ & $\begin{array}{r}11,8 \\
8,1 \\
13,8\end{array}$ & $\begin{array}{l}15,0 \\
10,1 \\
12,8\end{array}$ & $\begin{array}{l}19,0 \\
13,3 \\
13,7\end{array}$ & $\begin{array}{l}5,8 \\
1,8 \\
0,7\end{array}$ & $\begin{array}{l}4,8 \\
2,4 \\
1,0\end{array}$ & $\begin{array}{l}5,6 \\
2,5 \\
0,8\end{array}$ & $\begin{array}{l}8,5 \\
3,7 \\
1,2\end{array}$ \\
\hline Japan & $\begin{array}{l}\text { Ausbildung unterhalb Sekundarbereich II } \\
\text { Abschluss im Sekundarbereich II/ } \\
\text { postsekundaren, nicht tertiären Bereich } \\
\text { Abschluss im Tertiärbereich }\end{array}$ & $\begin{array}{l}6,0 \\
4,7 \\
3,5\end{array}$ & $\begin{array}{r}m \\
4,9 \\
3,1\end{array}$ & $\begin{array}{r}m \\
5,8 \\
3,8\end{array}$ & $\begin{array}{r}\mathrm{m} \\
5,1 \\
3,2\end{array}$ & $\begin{array}{l}9,6 \\
6,6 \\
4,4\end{array}$ & $\begin{array}{l}m \\
7,0 \\
4,6\end{array}$ & $\begin{array}{r}m \\
7,8 \\
5,0\end{array}$ & $\begin{array}{r}m \\
7,4 \\
4,1\end{array}$ & $\begin{array}{l}6,5 \\
5,5 \\
4,8\end{array}$ & $\begin{array}{r}m \\
4,5 \\
2,4\end{array}$ & $\begin{array}{r}m \\
5,5 \\
3,9\end{array}$ & $\begin{array}{r}m \\
4,5 \\
3,2\end{array}$ \\
\hline Korea & $\begin{array}{l}\text { Ausbildung unterhalb Sekundarbereich II } \\
\text { Abschluss im Sekundarbereich II/ } \\
\text { postsekundaren, nicht tertiären Bereich } \\
\text { Abschluss im Tertiärbereich }\end{array}$ & $\begin{array}{l}3,7 \\
4,1 \\
3,6\end{array}$ & $\begin{array}{l}2,9 \\
3,8 \\
2,9\end{array}$ & $\begin{array}{l}3,1 \\
3,5 \\
3,3\end{array}$ & $\begin{array}{l}2,6 \\
3,0 \\
2,9\end{array}$ & $\begin{array}{l}7,3 \\
5,0 \\
4,6\end{array}$ & $\begin{array}{l}8,1 \\
5,7 \\
4,2\end{array}$ & $\begin{array}{l}9,4 \\
6,2 \\
5,0\end{array}$ & $\begin{array}{l}6,5 \\
5,4 \\
4,4\end{array}$ & $\begin{array}{l}2,7 \\
3,7 \\
3,1\end{array}$ & $\begin{array}{l}2,3 \\
3,3 \\
1,8\end{array}$ & $\begin{array}{l}3,2 \\
2,7 \\
2,2\end{array}$ & $\begin{array}{l}2,5 \\
2,6 \\
2,3\end{array}$ \\
\hline Luxemburg & $\begin{array}{l}\text { Ausbildung unterhalb Sekundarbereich II } \\
\text { Abschluss im Sekundarbereich II/ } \\
\text { postsekundaren, nicht tertiären Bereich } \\
\text { Abschluss im Tertiärbereich }\end{array}$ & $\begin{array}{r}3,1 \\
1,6^{r} \\
c\end{array}$ & $\begin{array}{l}5,1 \\
3,2 \\
3,2\end{array}$ & $\begin{array}{l}4,1 \\
3,6 \\
3,6\end{array}$ & $\begin{array}{l}6,4 \\
4,2 \\
3,4\end{array}$ & $\begin{array}{r}5,4^{r} \\
2,2^{r} \\
c\end{array}$ & $\begin{array}{l}8,1^{r} \\
4,0^{r} \\
2,7^{r}\end{array}$ & $\begin{array}{l}7,6^{r} \\
4,8^{r} \\
4,1^{r}\end{array}$ & $\begin{array}{r}11,3^{r} \\
6,4^{r} \\
4,5\end{array}$ & $\begin{array}{l}\mathrm{c} \\
\mathrm{c} \\
\mathrm{c}\end{array}$ & $\begin{array}{l}\mathrm{c} \\
\mathrm{c} \\
\mathrm{c}\end{array}$ & $\begin{array}{l}\mathrm{c} \\
\mathrm{c} \\
\mathrm{c}\end{array}$ & $\begin{array}{l}\text { c } \\
\text { c } \\
\text { c }\end{array}$ \\
\hline Mexiko & $\begin{array}{l}\text { Ausbildung unterhalb Sekundarbereich II } \\
\text { Abschluss im Sekundarbereich II/ } \\
\text { postsekundaren, nicht tertiären Bereich } \\
\text { Abschluss im Tertiärbereich }\end{array}$ & $\begin{array}{l}1,5 \\
2,2 \\
2,4\end{array}$ & $\begin{array}{l}2,3 \\
3,1 \\
3,7\end{array}$ & $\begin{array}{l}4,0 \\
4,6 \\
4,9\end{array}$ & $\begin{array}{l}3,5 \\
4,0 \\
4,6\end{array}$ & $\begin{array}{l}1,8 \\
2,5 \\
3,5\end{array}$ & $\begin{array}{l}2,8 \\
4,1 \\
5,5\end{array}$ & $\begin{array}{l}5,5 \\
5,8 \\
6,7\end{array}$ & $\begin{array}{l}4,5 \\
5,6 \\
6,7\end{array}$ & $\begin{array}{l}1,2 \\
2,6 \\
2,2\end{array}$ & $\begin{array}{l}1,9 \\
2,4 \\
3,1\end{array}$ & $\begin{array}{l}2,8 \\
4,0 \\
4,4\end{array}$ & $\begin{array}{l}2,7 \\
2,7 \\
2,9\end{array}$ \\
\hline Niederlande & $\begin{array}{l}\text { Ausbildung unterhalb Sekundarbereich II } \\
\text { Abschluss im Sekundarbereich II/ } \\
\text { postsekundaren, nicht tertiären Bereich } \\
\text { Abschluss im Tertiärbereich }\end{array}$ & $\begin{array}{l}3,4 \\
1,9 \\
1,7\end{array}$ & $\begin{array}{l}5,8 \\
4,1 \\
2,8\end{array}$ & $\begin{array}{l}5,7 \\
3,4 \\
2,7\end{array}$ & $\begin{array}{l}6,6 \\
4,6 \\
3,0\end{array}$ & $\begin{array}{l}4,5 \\
1,6 \\
1,5\end{array}$ & $\begin{array}{l}8,7 \\
3,9 \\
2,6\end{array}$ & $\begin{array}{l}9,1 \\
3,7 \\
2,5\end{array}$ & $\begin{array}{l}9,4 \\
5,1 \\
3,3\end{array}$ & $\begin{array}{r}c \\
1,9 \\
C\end{array}$ & $\begin{array}{l}4,5 \\
4,6 \\
3,1\end{array}$ & $\begin{array}{l}4,6 \\
4,0 \\
3,6\end{array}$ & $\begin{array}{l}5,1 \\
5,6 \\
3,5\end{array}$ \\
\hline Neuseeland & $\begin{array}{l}\text { Ausbildung unterhalb Sekundarbereich II } \\
\text { Abschluss im Sekundarbereich II/ } \\
\text { postsekundaren, nicht tertiären Bereich } \\
\text { Abschluss im Tertiärbereich }\end{array}$ & $\begin{array}{l}6,6 \\
3,9 \\
3,3\end{array}$ & $\begin{array}{l}3,4 \\
2,3 \\
2,3\end{array}$ & $\begin{array}{l}6,1 \\
4,5 \\
3,8\end{array}$ & $\begin{array}{l}6,4 \\
5,2 \\
4,2\end{array}$ & $\begin{array}{l}9,0 \\
4,7 \\
3,6\end{array}$ & $\begin{array}{l}5,5 \\
3,0 \\
3,3\end{array}$ & $\begin{array}{l}8,9 \\
7,2 \\
5,5\end{array}$ & $\begin{array}{r}10,7 \\
7,5 \\
4,8\end{array}$ & $\begin{array}{l}5,4 \\
3,8 \\
3,9\end{array}$ & $\begin{array}{l}1,8 \\
1,7 \\
1,9\end{array}$ & $\begin{array}{l}4,0 \\
3,4 \\
2,7\end{array}$ & $\begin{array}{l}4,5 \\
3,6 \\
3,6\end{array}$ \\
\hline Norwegen ${ }^{2}$ & $\begin{array}{l}\text { Ausbildung unterhalb Sekundarbereich II } \\
\text { Abschluss im Sekundarbereich II/ } \\
\text { postsekundaren, nicht tertiären Bereich } \\
\text { Abschluss im Tertiärbereich }\end{array}$ & $\begin{array}{l}2,2 \\
2,6 \\
1,9\end{array}$ & $\begin{array}{l}7,4 \\
2,6 \\
2,1\end{array}$ & $\begin{array}{l}5,6 \\
2,2 \\
1,6\end{array}$ & $\begin{array}{l}4,3 \\
2,3 \\
1,6\end{array}$ & $\begin{array}{r}c \\
3,7 \\
2,7\end{array}$ & $\begin{array}{r}14,4 \\
4,1 \\
3,1\end{array}$ & $\begin{array}{r}12,3 \\
3,8 \\
2,3\end{array}$ & $\begin{array}{l}6,7 r \\
3,2 \\
2,6\end{array}$ & $\begin{array}{l}\mathrm{c} \\
\mathrm{c} \\
\mathrm{c}\end{array}$ & $\begin{array}{l}\mathrm{c} \\
\mathrm{c} \\
\mathrm{c}\end{array}$ & $\begin{array}{l}\mathrm{c} \\
\mathrm{c} \\
\mathrm{c}\end{array}$ & $\begin{array}{l}\text { c } \\
\text { c } \\
\text { c }\end{array}$ \\
\hline Polen & $\begin{array}{l}\text { Ausbildung unterhalb Sekundarbereich II } \\
\text { Abschluss im Sekundarbereich II/ } \\
\text { postsekundaren, nicht tertiären Bereich } \\
\text { Abschluss im Tertiärbereich }\end{array}$ & $\begin{array}{r}20,6 \\
13,9 \\
4,3\end{array}$ & $\begin{array}{r}27,1 \\
16,6 \\
6,2\end{array}$ & $\begin{array}{r}16,1 \\
8,9 \\
4,2\end{array}$ & $\begin{array}{r}17,8 \\
9,3 \\
4,9\end{array}$ & $\begin{array}{r}32,4 \\
16,8 \\
7,4\end{array}$ & $\begin{array}{r}38,3 \\
19,9 \\
9,8\end{array}$ & $\begin{array}{r}22,6 \\
11,5 \\
6,5\end{array}$ & $\begin{array}{r}25,4 \\
12,2 \\
7,6\end{array}$ & $\begin{array}{r}7,7 \\
11,6 \\
6,7\end{array}$ & $\begin{array}{r}13,6 \\
13,0 \\
4,5\end{array}$ & $\begin{array}{r}11,4 \\
7,8 \\
2,0^{r}\end{array}$ & $\begin{array}{r}12,2 \\
8,0 \\
2,4^{r}\end{array}$ \\
\hline Portugal & $\begin{array}{l}\text { Ausbildung unterhalb Sekundarbereich II } \\
\text { Abschluss im Sekundarbereich II/ } \\
\text { postsekundaren, nicht tertiären Bereich } \\
\text { Abschluss im Tertiärbereich }\end{array}$ & $\begin{array}{l}3,6 \\
3,5 \\
2,7\end{array}$ & $\begin{array}{l}7,5 \\
6,7 \\
5,4\end{array}$ & $\begin{array}{r}11,8 \\
9,7 \\
6,3\end{array}$ & $\begin{array}{l}16,0 \\
14,5 \\
10,5\end{array}$ & $\begin{array}{l}4,2 \\
3,5 \\
4,3\end{array}$ & $\begin{array}{l}9,0 \\
8,3 \\
9,2\end{array}$ & $\begin{array}{r}15,3 \\
11,5 \\
9,4\end{array}$ & $\begin{array}{l}19,9 \\
16,8 \\
17,1\end{array}$ & $\begin{array}{r}3,3 \\
\mathrm{c} \\
\mathrm{c}\end{array}$ & $\begin{array}{r}6,4 \\
\mathrm{c} \\
\mathrm{c}\end{array}$ & $\begin{array}{l}9,7 \\
7,1 \\
3,4\end{array}$ & $\begin{array}{r}14,2 \\
13,6 \\
\text { c }\end{array}$ \\
\hline Slowakei & $\begin{array}{l}\text { Ausbildung unterhalb Sekundarbereich II } \\
\text { Abschluss im Sekundarbereich II/ } \\
\text { postsekundaren, nicht tertiären Bereich } \\
\text { Abschluss im Tertiärbereich }\end{array}$ & $\begin{array}{r}36,3 \\
14,3 \\
4,6\end{array}$ & $\begin{array}{r}49,2 \\
12,7 \\
4,4\end{array}$ & $\begin{array}{r}40,8 \\
12,3 \\
4,8\end{array}$ & $\begin{array}{r}41,5 \\
11,7 \\
6,0\end{array}$ & $\begin{array}{r}55,7 \\
17,7 \\
7,0\end{array}$ & $\begin{array}{r}73,8 \\
13,8 \\
5,3\end{array}$ & $\begin{array}{r}63,8 \\
14,6 \\
6,3\end{array}$ & $\begin{array}{r}53,3 \\
15,4 \\
9,5\end{array}$ & $\begin{array}{r}30,6 \\
10,1 \\
6,2\end{array}$ & $\begin{array}{r}36,5 \\
11,6 \\
7,7\end{array}$ & $\begin{array}{r}22,8 \\
9,9 \\
4,3\end{array}$ & $\begin{array}{r}30,8 \\
11,0 \\
3,2\end{array}$ \\
\hline Slowenien ${ }^{1}$ & $\begin{array}{l}\text { Ausbildung unterhalb Sekundarbereich II } \\
\text { Abschluss im Sekundarbereich II/ } \\
\text { postsekundaren, nicht tertiären Bereich } \\
\text { Abschluss im Tertiärbereich }\end{array}$ & $\begin{array}{l}9,8 \\
5,7 \\
2,1\end{array}$ & $\begin{array}{l}8,7 \\
5,7 \\
3,0\end{array}$ & $\begin{array}{r}11,2 \\
6,9 \\
4,1\end{array}$ & $\begin{array}{r}14,0 \\
8,1 \\
5,8\end{array}$ & $\begin{array}{r}11,3 \\
5,8 \\
3,8\end{array}$ & $\begin{array}{r}16,1 \\
6,7 \\
5,1\end{array}$ & $\begin{array}{r}18,9 \\
10,2 \\
7,9\end{array}$ & $\begin{array}{r}c \\
10,8 \\
11,0\end{array}$ & $\begin{array}{r}\text { C } \\
10,9 \\
C\end{array}$ & $\begin{array}{r}2,9 \\
6,3 \\
c\end{array}$ & $\begin{array}{r}4,2 \\
5,0 \\
c\end{array}$ & $\begin{array}{l}5,6 \\
7,3 \\
4,3\end{array}$ \\
\hline Spanien & $\begin{array}{l}\text { Ausbildung unterhalb Sekundarbereich II } \\
\text { Abschluss im Sekundarbereich II/ } \\
\text { postsekundaren, nicht tertiären Bereich } \\
\text { Abschluss im Tertiärbereich }\end{array}$ & $\begin{array}{r}13,7 \\
10,9 \\
9,5\end{array}$ & $\begin{array}{l}9,3 \\
7,3 \\
6,1\end{array}$ & $\begin{array}{l}24,7 \\
17,4 \\
10,4\end{array}$ & $\begin{array}{l}31,2 \\
22,0 \\
14,0\end{array}$ & $\begin{array}{l}17,8 \\
12,9 \\
14,5\end{array}$ & $\begin{array}{r}11,4 \\
9,0 \\
8,5\end{array}$ & $\begin{array}{l}31,7 \\
22,0 \\
14,2\end{array}$ & $\begin{array}{l}38,4 \\
27,9 \\
19,8\end{array}$ & $\begin{array}{r}10,8 \\
6,4 \\
4,1\end{array}$ & $\begin{array}{l}6,9 \\
6,6 \\
3,5\end{array}$ & $\begin{array}{r}18,3 \\
11,5 \\
5,4\end{array}$ & $\begin{array}{r}23,2 \\
14,8 \\
8,1\end{array}$ \\
\hline Schweden & $\begin{array}{l}\text { Ausbildung unterhalb Sekundarbereich II } \\
\text { Abschluss im Sekundarbereich II/ } \\
\text { postsekundaren, nicht tertiären Bereich } \\
\text { Abschluss im Tertiärbereich }\end{array}$ & $\begin{array}{l}8,0 \\
5,3 \\
3,0\end{array}$ & $\begin{array}{l}8,5 \\
6,0 \\
4,5\end{array}$ & $\begin{array}{r}11,3 \\
6,4 \\
4,5\end{array}$ & $\begin{array}{r}12,3 \\
5,7 \\
4,0\end{array}$ & $\begin{array}{r}13,1 \\
5,6 \\
3,2\end{array}$ & $\begin{array}{r}17,8 \\
8,5 \\
7,1\end{array}$ & $\begin{array}{r}19,6 \\
8,4 \\
5,8\end{array}$ & $\begin{array}{r}21,4 \\
8,1 \\
5,4\end{array}$ & $\begin{array}{l}8,1 \\
6,6 \\
2,9\end{array}$ & $\begin{array}{l}5,2 \\
5,4 \\
2,3\end{array}$ & $\begin{array}{l}7,7 \\
6,3 \\
3,5\end{array}$ & $\begin{array}{l}7,8 \\
5,6 \\
3,2\end{array}$ \\
\hline
\end{tabular}

Anmerkung: Spalten mit weiteren Jahren und Altersgruppen sind im Internet verfügbar (s. StatLink).

1. Die Zahlen für 2012 für Estland und Slowenien in dieser Tabelle können von Zahlen in anderen Tabellen in Indikator A5 abweichen, da unterschiedliche Datenquellen zugrunde liegen. Die Zahlen in dieser Tabelle basieren für alle Jahre auf der EU-Arbeitskräfteerhebung. 2. Die Zahlen für das Jahr 200o können nicht mit neueren Zahlen verglichen werden, da 2000 noch die frühere Klassifikation des Bildungswesens verwendet wurde.

Quelle: OECD. Argentinien, China, Indien, Indonesien, Kolumbien, Saudi-Arabien und Südafrika: Statistikinstitut der UNESCO. Lettland: Eurostat. Hinweise s. Anhang 3 unter www.oecd.org/edu/eag.htm. StatLink: http://dx.doi.org/10.1787/888933115825

Erläuterung der Kennzeichnung fehlender Daten sowie der Kennzeichnung " $r^{“}$ neben einigen Zahlen s. Hinweise für den Leser. 
Tabelle A5.4a (Forts. 2)

Entwicklung der Erwerbslosenquoten, nach Bildungsstand und Altersgruppe (2000, 2005-2012)

Zahl der 25- bis 64-jährigen/25- bis 34-jährigen/55- bis 64-jährigen Erwerbslosen als Prozentsatz aller 25- bis 64-jährigen/ 25- bis 34-jährigen/55- bis 64-jährigen Erwerbspersonen

\begin{tabular}{|c|c|c|c|c|c|c|c|c|c|c|c|c|c|}
\hline & \multirow[t]{3}{*}{ Bildungsstand } & \multicolumn{4}{|c|}{$\begin{array}{l}\text { Erwerbslosenquoten } \\
\text { der 25- bis 64-Jährigen }\end{array}$} & \multicolumn{4}{|c|}{$\begin{array}{l}\text { Erwerbslosenquoten } \\
\text { der 25- bis 34-Jährigen }\end{array}$} & \multicolumn{4}{|c|}{$\begin{array}{l}\text { Erwerbslosenquoten } \\
\text { der 55- bis 64-Jährigen }\end{array}$} \\
\hline & & 2000 & 2005 & 2010 & 2012 & 2000 & 2005 & 2010 & 2012 & 2000 & 2005 & 2010 & 2012 \\
\hline & & (1) & (2) & (7) & (9) & $(11)$ & $(12)$ & $(17)$ & (19) & $(41)$ & $(42)$ & $(47)$ & (49) \\
\hline \multicolumn{14}{|l|}{ OECD-Länder } \\
\hline \multirow[t]{3}{*}{ Schweiz } & Ausbildung unterhalb Sekundarbereich II & 4,8 & 7,2 & 7,4 & 7,9 & c & 11,8 & 13,3 & 14,4 & 7,0 & 6,0 & 5,4 & 5,8 \\
\hline & $\begin{array}{l}\text { Abschluss im Sekundarbereich II/ } \\
\text { postsekundaren, nicht tertiären Bereich }\end{array}$ & 2,2 & 3,7 & 4,1 & 3,3 & 2,8 & 4,7 & 5,4 & 4,3 & 1,8 & 3,7 & 3,6 & 2,9 \\
\hline & Abschluss im Tertiärbereich & 1,4 & 2,7 & 2,9 & 2,7 & $c$ & 3,4 & 4,0 & 3,7 & $c$ & 2,3 & 2,4 & $2,1^{r}$ \\
\hline \multirow[t]{3}{*}{ Türkei } & Ausbildung unterhalb Sekundarbereich II & 4,6 & 9,1 & 10,6 & 7,9 & 5,7 & 11,3 & 12,6 & 9,7 & 2,4 & 4,2 & 6,4 & 4,9 \\
\hline & $\begin{array}{l}\text { Abschluss im Sekundarbereich II/ } \\
\text { postsekundaren, nicht tertiären Bereich }\end{array}$ & 5,5 & 9,1 & 11,3 & 8,6 & 7,1 & 11,9 & 13,3 & 10,3 & 0,0 & 4,5 & 10,7 & 7,1 \\
\hline & Abschluss im Tertiärbereich & 3,9 & 6,9 & 7,9 & 7,5 & 6,5 & 10,9 & 11,9 & 11,1 & 3,3 & 4,3 & 3,8 & 4,5 \\
\hline \multirow{3}{*}{$\begin{array}{l}\text { Vereinigtes } \\
\text { Königreich }\end{array}$} & Ausbildung unterhalb Sekundarbereich II & 6,6 & 5,1 & 9,8 & 10,5 & 9,1 & 7,8 & 15,5 & 17,2 & 5,6 & 3,2 & 5,0 & 6,9 \\
\hline & $\begin{array}{l}\text { Abschluss im Sekundarbereich II/ } \\
\text { postsekundaren, nicht tertiären Bereich }\end{array}$ & 4,0 & 3,1 & 5,9 & 5,6 & 4,7 & 4,1 & 8,1 & 7,8 & 4,0 & 2,4 & 5,0 & 4,8 \\
\hline & Abschluss im Tertiärbereich & 2,1 & 2,1 & 3,5 & 3,6 & 2,0 & 2,4 & 4,1 & 4,2 & 3,7 & 2,8 & 3,8 & 3,4 \\
\hline \multirow[t]{3}{*}{ Vereinigte Staaten } & Ausbildung unterhalb Sekundarbereich II & 7,9 & 9,0 & 16,8 & 14,3 & 10,3 & 11,7 & 20,3 & 16,8 & 5,2 & 7,5 & 10,1 & 11,5 \\
\hline & $\begin{array}{l}\text { Abschluss im Sekundarbereich II/ } \\
\text { postsekundaren, nicht tertiären Bereich }\end{array}$ & 3,6 & 5,1 & 11,2 & 9,1 & 4,4 & 6,9 & 14,3 & 12,2 & 3,1 & 4,2 & 8,8 & 7,3 \\
\hline & Abschluss im Tertiärbereich & 1,8 & 2,6 & 5,3 & 4,6 & 2,0 & 3,0 & 5,3 & 4,9 & 1,5 & 2,3 & 5,5 & 5,1 \\
\hline \multirow[t]{3}{*}{ OECD-Durchschnitt } & Ausbildung unterhalb Sekundarbereich II & 9,4 & 10,7 & 12,5 & 13,6 & 14,6 & 16,4 & 19,0 & 19,8 & 7,6 & $\mathbf{7 , 5}$ & 8,6 & 10,1 \\
\hline & $\begin{array}{l}\text { Abschluss im Sekundarbereich II/ } \\
\text { postsekundaren, nicht tertiären Bereich }\end{array}$ & 5,9 & 6,2 & 7,6 & 7,8 & 7,1 & 7,5 & 9,8 & 10,4 & 5,4 & 5,5 & 6,4 & 6,6 \\
\hline & Abschluss im Tertiärbereich & 3,5 & 3,9 & 4,7 & 5,0 & 5,1 & 5,4 & 6,5 & 7,4 & 3,7 & 3,4 & 3,9 & 3,9 \\
\hline \multirow{3}{*}{$\begin{array}{l}\text { OECD-Durchschnitt } \\
\text { für Länder mit ver- } \\
\text { fügbaren Daten für } \\
\text { alle Referenzjahre }\end{array}$} & Ausbildung unterhalb Sekundarbereich II & 9,5 & 10,6 & 12,9 & 13,7 & 14,7 & 16,5 & 19,6 & 20,0 & 7,7 & 7,3 & 8,8 & 10,1 \\
\hline & & 6,0 & 6,1 & 7,7 & 7,9 & 7,2 & 7,4 & 10,0 & 10,6 & 5,4 & 5,4 & 6,6 & 6,7 \\
\hline & Abschluss im Tertiärbereich & 3,4 & 3,9 & 4,7 & 5,1 & 5,1 & 5,4 & 6,5 & 7,5 & 3,6 & 3,4 & 3,9 & 3,9 \\
\hline \multirow[t]{3}{*}{ EU21-Durchschnitt } & Ausbildung unterhalb Sekundarbereich II & 11,6 & 12,8 & 15,2 & 16,9 & 16,8 & 19,2 & 22,7 & 24,2 & 9,1 & 8,6 & 10,1 & 12,2 \\
\hline & $\begin{array}{l}\text { Abschluss im Sekundarbereich II/ } \\
\text { postsekundaren, nicht tertiären Bereich }\end{array}$ & 6,9 & 6,8 & 8,5 & 9,3 & 8,2 & 8,1 & 10,8 & 12,3 & 6,5 & 6,3 & 7,1 & 7,6 \\
\hline & Abschluss im Tertiärbereich & 3,7 & 4,1 & 5,0 & 5,7 & 5,7 & 5,8 & 6,9 & 8,5 & 4,3 & 3,7 & 4,1 & 4,1 \\
\hline \multicolumn{14}{|l|}{ Partnerländer } \\
\hline Argentinien & & $\mathrm{m}$ & $\mathrm{m}$ & $\mathrm{m}$ & $\mathbf{m}$ & $\mathrm{m}$ & $\mathrm{m}$ & $\mathrm{m}$ & m & $\mathrm{m}$ & $\mathrm{m}$ & $\mathrm{m}$ & m \\
\hline \multirow[t]{3}{*}{ Brasilien } & Ausbildung unterhalb Sekundarbereich II & $\mathrm{m}$ & $\mathrm{m}$ & $\mathrm{m}$ & 4,1 & $\mathrm{~m}$ & $\mathrm{~m}$ & $\mathrm{~m}$ & 6,5 & $\mathrm{~m}$ & $\mathrm{~m}$ & $\mathrm{~m}$ & 2,3 \\
\hline & & $\mathrm{m}$ & $\mathrm{m}$ & $\mathrm{m}$ & 5,1 & $\mathrm{~m}$ & $\mathrm{~m}$ & $\mathrm{~m}$ & 6,9 & $\mathrm{~m}$ & $\mathrm{~m}$ & $\mathrm{~m}$ & 2,8 \\
\hline & Abschluss im Tertiärbereich & $\mathrm{m}$ & $\mathrm{m}$ & $\mathrm{m}$ & 2,9 & $\mathrm{~m}$ & $\mathrm{~m}$ & $\mathrm{~m}$ & 4,0 & $\mathrm{~m}$ & $\mathrm{~m}$ & $\mathrm{~m}$ & 1,7 \\
\hline China & & $\mathrm{m}$ & $\mathrm{m}$ & $\mathrm{m}$ & $\mathbf{m}$ & $\mathrm{m}$ & $\mathrm{m}$ & $\mathrm{m}$ & m & $\mathrm{m}$ & $\mathrm{m}$ & $\mathrm{m}$ & m \\
\hline Kolumbien & & $\mathrm{m}$ & $\mathrm{m}$ & $\mathrm{m}$ & $\mathbf{m}$ & $\mathrm{m}$ & $\mathrm{m}$ & $\mathrm{m}$ & m & $\mathrm{m}$ & $\mathrm{m}$ & $\mathrm{m}$ & m \\
\hline Indien & & $\mathrm{m}$ & $\mathrm{m}$ & $\mathrm{m}$ & m & $\mathrm{m}$ & $\mathrm{m}$ & $\mathrm{m}$ & m & $\mathrm{m}$ & $\mathrm{m}$ & $\mathrm{m}$ & m \\
\hline Indonesien & & $\mathrm{m}$ & $\mathrm{m}$ & $\mathrm{m}$ & m & $\mathrm{m}$ & $\mathrm{m}$ & $\mathrm{m}$ & m & $\mathrm{m}$ & $\mathrm{m}$ & $\mathrm{m}$ & m \\
\hline \multirow[t]{3}{*}{ Lettland } & Ausbildung unterhalb Sekundarbereich II & m & $\mathrm{m}$ & $\mathrm{m}$ & 23 & $\mathrm{~m}$ & $\mathrm{~m}$ & m & 24 & $\mathrm{~m}$ & m & $\mathrm{m}$ & 23 \\
\hline & $\begin{array}{l}\text { Abschluss im Sekundarbereich II/ } \\
\text { postsekundaren, nicht tertiären Bereich }\end{array}$ & m & $\mathrm{m}$ & $\mathrm{m}$ & 12,2 & $\mathrm{~m}$ & $\mathrm{~m}$ & $\mathrm{~m}$ & 15,5 & $\mathrm{~m}$ & $\mathrm{~m}$ & $\mathrm{~m}$ & c \\
\hline & Abschluss im Tertiärbereich & $\mathrm{m}$ & $\mathrm{m}$ & $\mathrm{m}$ & 5,9 & $\mathrm{~m}$ & $\mathrm{~m}$ & $\mathrm{~m}$ & 7,4 & $\mathrm{~m}$ & $\mathrm{~m}$ & $\mathrm{~m}$ & 4,0 \\
\hline \multirow{3}{*}{$\begin{array}{l}\text { Russische } \\
\text { Föderation }\end{array}$} & Ausbildung unterhalb Sekundarbereich II & $\mathrm{m}$ & $\mathrm{m}$ & $\mathrm{m}$ & 2,8 & $\mathrm{~m}$ & $\mathrm{~m}$ & $\mathrm{~m}$ & 3,5 & $\mathrm{~m}$ & $\mathrm{~m}$ & $\mathrm{~m}$ & 2,6 \\
\hline & $\begin{array}{l}\text { Abschluss im Sekundarbereich II/ } \\
\text { postsekundaren, nicht tertiären Bereich }\end{array}$ & $\mathrm{m}$ & $\mathrm{m}$ & $\mathrm{m}$ & $\mathbf{m}$ & $\mathrm{m}$ & $\mathrm{m}$ & $\mathrm{m}$ & $\mathbf{m}$ & $\mathrm{m}$ & $\mathrm{m}$ & $\mathrm{m}$ & m \\
\hline & Abschluss im Tertiärbereich & $\mathrm{m}$ & $\mathrm{m}$ & $\mathrm{m}$ & m & $\mathrm{m}$ & $\mathrm{m}$ & $\mathrm{m}$ & m & $\mathrm{m}$ & $\mathrm{m}$ & $\mathrm{m}$ & m \\
\hline Saudi-Arabien & & $\mathrm{m}$ & $\mathrm{m}$ & $\mathrm{m}$ & m & $\mathrm{m}$ & $\mathrm{m}$ & $\mathrm{m}$ & m & $\mathrm{m}$ & $\mathrm{m}$ & $\mathrm{m}$ & m \\
\hline Südafrika & & $\mathrm{m}$ & $\mathrm{m}$ & $\mathrm{m}$ & m & $\mathrm{m}$ & $\mathrm{m}$ & $\mathrm{m}$ & m & $\mathrm{m}$ & $\mathrm{m}$ & $\mathrm{m}$ & m \\
\hline G20-Durchschnitt & & m & m & $\mathbf{m}$ & m & m & $\mathbf{m}$ & m & m & m & $\mathbf{m}$ & m & m \\
\hline
\end{tabular}

Anmerkung: Spalten mit weiteren Jahren und Altersgruppen sind im Internet verfügbar (s. StatLink).

1. Die Zahlen für 2012 für Estland und Slowenien in dieser Tabelle können von Zahlen in anderen Tabellen in Indikator A5 abweichen, da unterschiedliche Datenquellen zugrunde liegen. Die Zahlen in dieser Tabelle basieren für alle Jahre auf der EU-Arbeitskräfteerhebung. 2. Die Zahlen für das Jahr 200o können nicht mit neueren Zahlen verglichen werden, da 2000 noch die frühere Klassifikation des Bildungswesens verwendet wurde.

Quelle: OECD. Argentinien, China, Indien, Indonesien, Kolumbien, Saudi-Arabien und Südafrika: Statistikinstitut der UNESCO. Lettland: Eurostat. Hinweise s. Anhang 3 unter www.oecd.org/edu/eag.htm. StatLink: http://dx.doi.org/10.1787/888933115825

Erläuterung der Kennzeichnung fehlender Daten sowie der Kennzeichnung „ $r^{“}$ neben einigen Zahlen s. Hinweise für den Leser. 
Erwachsene mit einem Abschluss im Sekundarbereich II bzw. postsekundaren, nicht tertiären Bereich, nach Erwerbsstatus und Ausrichtung des Bildungsgangs (2012)

25- bis 64-Jährige mit einem Abschluss im Sekundarbereich II bzw. postsekundaren, nicht tertiären Bereich als höchstem Bildungsabschluss

$$
\text { Beschäftigungsquote } \quad \text { Erwerbslosenquote } \quad \text { Nichterwerbsquote }
$$
Nichterwerbsquote

\begin{tabular}{|c|c|c|c|c|c|c|c|c|c|}
\hline & \multicolumn{3}{|c|}{ Beschäftigungsquote } & \multicolumn{3}{|c|}{ Erwerbslosenquote } & \multicolumn{3}{|c|}{ Nichterwerbsquote } \\
\hline & Berufsbildend & $\begin{array}{l}\text { Allgemein- } \\
\text { bildend }\end{array}$ & Gesamt $^{1}$ & Berufsbildend & $\begin{array}{l}\text { Allgemein- } \\
\text { bildend }\end{array}$ & Gesamt $^{1}$ & Berufsbildend & $\begin{array}{l}\text { Allgemein- } \\
\text { bildend }\end{array}$ & Gesamt $^{1}$ \\
\hline & (1) & (2) & (3) & (4) & (5) & (6) & (7) & (8) & (9) \\
\hline \multicolumn{10}{|l|}{ OECD-Länder } \\
\hline Australien & 84 & 76 & 80 & 3,6 & 3,9 & 3,7 & 13 & 20 & 16 \\
\hline Österreich & 78 & 76 & 78 & 3,4 & 4,7 & 3,5 & 19 & 20 & 19 \\
\hline Belgien & 76 & 69 & 73 & 5,9 & 8,7 & 6,7 & 20 & 25 & 21 \\
\hline Kanada & 79 & 73 & 75 & 6,3 & 6,7 & 6,6 & 16 & 22 & 20 \\
\hline Chile $^{2}$ & 74 & 69 & 70 & 6,9 & 6,2 & 6,4 & 20 & 26 & 25 \\
\hline Tschechien & 76 & 72 & 76 & 5,7 & $\mathrm{c}$ & 5,7 & 19 & c & 19 \\
\hline Dänemark & 79 & 61 & 79 & 5,9 & 12,5 & 6,2 & 16 & 30 & 16 \\
\hline Estland & 76 & 72 & 75 & 9,1 & 10,1 & 9,5 & 17 & 19 & 18 \\
\hline Finnland & 75 & 73 & 75 & 6,8 & 8,2 & 7,1 & 20 & 21 & 20 \\
\hline Frankreich & 73 & 74 & 74 & 8,3 & 8,3 & 8,3 & 20 & 19 & 20 \\
\hline Deutschland & 79 & 62 & 78 & 5,3 & 7,0 & 5,3 & 17 & 34 & 17 \\
\hline Griechenland & 62 & 55 & 58 & 26,4 & 23,0 & 24,4 & 16 & 28 & 24 \\
\hline Ungarn & 69 & 63 & 68 & 9,4 & 9,4 & 9,4 & 24 & 30 & 25 \\
\hline Island & 88 & 76 & 85 & 3,7 & c & 4,1 & 9 & 19 & 11 \\
\hline Irland & 66 & 65 & 65 & 17,8 & 13,9 & 15,2 & 20 & 25 & 23 \\
\hline Israel & 79 & 69 & 72 & 6,2 & 7,4 & 7,1 & 16 & 25 & 23 \\
\hline Italien & 74 & 63 & 71 & 7,4 & 8,9 & 7,7 & 21 & 31 & 23 \\
\hline Japan & $x(3)$ & $x(3)$ & 74 & $x(6)$ & $x(6)$ & 5,1 & $x(9)$ & $x(9)$ & 22 \\
\hline Korea & $x(3)$ & $x(3)$ & 71 & $x(6)$ & $x(6)$ & 3,0 & $x(9)$ & $x(9)$ & 27 \\
\hline Luxemburg & 72 & 67 & 72 & 4,5 & c & 4,2 & 25 & 30 & 25 \\
\hline Mexiko & $x(3)$ & $x(3)$ & 72 & $x(6)$ & $x(6)$ & 4,0 & $x(9)$ & $x(9)$ & 25 \\
\hline Niederlande & 81 & 77 & 80 & 4,3 & 5,3 & 4,6 & 15 & 18 & 16 \\
\hline Neuseeland & 82 & 81 & 81 & 5,5 & 4,3 & 5,2 & 14 & 16 & 14 \\
\hline Norwegen & $x(3)$ & $x(3)$ & 81 & $x(6)$ & $x(6)$ & 2,3 & $x(9)$ & $x(9)$ & 17 \\
\hline Polen & $x(3)$ & $x(3)$ & 65 & $x(6)$ & $x(6)$ & 9,3 & $x(9)$ & $x(9)$ & 28 \\
\hline Portugal & $x(3)$ & $x(3)$ & 76 & $x(6)$ & $x(6)$ & 14,5 & $x(9)$ & $x(9)$ & 11 \\
\hline Slowakei & 71 & 66 & 70 & 11,6 & 13,9 & 11,7 & 20 & 24 & 20 \\
\hline Slowenien & 71 & 66 & 71 & 7,9 & 11,0 & 8,1 & 23 & 25 & 23 \\
\hline Spanien & 66 & 66 & 66 & 22,8 & 21,5 & 22,0 & 15 & 16 & 16 \\
\hline Schweden & 84 & 87 & 83 & 5,1 & 3,5 & 5,7 & 11 & 9 & 12 \\
\hline Schweiz & 83 & 76 & 82 & 3,2 & 5,1 & 3,3 & 15 & 20 & 15 \\
\hline Türkei & 65 & 59 & 62 & 7,6 & 9,6 & 8,6 & 29 & 35 & 32 \\
\hline Ver. Königreich & $x(3)$ & $x(3)$ & 79 & $x(6)$ & $x(6)$ & 5,6 & $x(9)$ & $x(9)$ & 17 \\
\hline Vereinigte Staaten & $x(3)$ & $x(3)$ & 67 & $x(6)$ & $x(6)$ & 9,1 & $x(9)$ & $x(9)$ & 26 \\
\hline OECD-Durchschnitt & 75 & 70 & 74 & 8,1 & 9,3 & 7,7 & 18 & 24 & 20 \\
\hline EU21-Durchschnitt & 76 & 70 & 74 & 8,8 & 10,0 & 8,7 & 17 & 23 & 19 \\
\hline \multicolumn{10}{|l|}{ Partnerländer } \\
\hline Argentinien & $\mathrm{m}$ & $\mathrm{m}$ & $\mathrm{m}$ & $\mathrm{m}$ & $\mathrm{m}$ & $\mathrm{m}$ & $\mathrm{m}$ & $\mathrm{m}$ & $\mathrm{m}$ \\
\hline Brasilien & $x(3)$ & $x(3)$ & 77 & $x(6)$ & $x(6)$ & 5,1 & $x(9)$ & $x(9)$ & 19 \\
\hline China & $\mathrm{m}$ & $\mathrm{m}$ & $\mathrm{m}$ & $\mathrm{m}$ & $\mathrm{m}$ & $\mathrm{m}$ & $\mathrm{m}$ & $\mathrm{m}$ & $\mathrm{m}$ \\
\hline Kolumbien & $\mathrm{m}$ & $\mathrm{m}$ & $\mathrm{m}$ & $\mathrm{m}$ & $\mathrm{m}$ & $\mathrm{m}$ & $\mathrm{m}$ & $\mathrm{m}$ & $\mathrm{m}$ \\
\hline Indien & $\mathrm{m}$ & $\mathrm{m}$ & $\mathrm{m}$ & $\mathrm{m}$ & $\mathrm{m}$ & $\mathrm{m}$ & $\mathrm{m}$ & $\mathrm{m}$ & $\mathrm{m}$ \\
\hline Indonesien & $\mathrm{m}$ & $\mathrm{m}$ & $\mathrm{m}$ & $\mathrm{m}$ & $\mathrm{m}$ & $\mathrm{m}$ & $\mathrm{m}$ & $\mathrm{m}$ & $\mathrm{m}$ \\
\hline Lettland & 69 & 64 & 67 & 15,0 & 19,3 & 16,7 & 19 & 21 & 20 \\
\hline Russische Föd. & 78 & 69 & 73 & 5,1 & 6,8 & 5,9 & 18 & 26 & 22 \\
\hline Saudi-Arabien & $\mathrm{m}$ & $\mathrm{m}$ & $\mathrm{m}$ & $\mathrm{m}$ & $\mathrm{m}$ & $\mathrm{m}$ & $\mathrm{m}$ & $\mathrm{m}$ & $\mathrm{m}$ \\
\hline Südafrika & $\mathrm{m}$ & $\mathrm{m}$ & $\mathrm{m}$ & $\mathrm{m}$ & $\mathrm{m}$ & $\mathrm{m}$ & $\mathrm{m}$ & $\mathrm{m}$ & $\mathrm{m}$ \\
\hline G20-Durchschnitt & $\mathbf{m}$ & $\mathbf{m}$ & $\mathbf{m}$ & $\mathbf{m}$ & m & $\mathbf{m}$ & $\mathbf{m}$ & $\mathbf{m}$ & $\mathbf{m}$ \\
\hline
\end{tabular}

1. „Gesamt“ bezieht sich jeweils auf den gewichteten Durchschnitt der Beschäftigungs-/Erwerbs/osen-/Nichterwerbsquote von Personen mit einem Abschluss auf ISCED-Stufe 3/4. 2. Referenzjahr 2011.

Quelle: OECD. Hinweise s. Anhang 3 unter www.oecd.org/edu/eag.htm. StatLink: http://dx.doi.org/10.1787/888933115844

Erläuterung der Kennzeichnung fehlender Daten s. Hinweise für den Leser. 
Tabelle A5.6

Anteil der ganzjährig Vollzeitbeschäftigten an allen Personen mit Erwerbseinkommen, nach Bildungsstand und Altersgruppe (2012) ${ }^{1}$

Erläuterung der Tabelle: In Australien erzielen 86 Prozent der 25- bis 64-jährigen Männer mit einer Ausbildung unterhalb des Sekundarbereichs II Erwerbseinkommen aus einer Vollzeitbeschäftigung. Bei den 25- bis 64-jährigen Frauen erzielen 46 Prozent der beschäftigten Frauen ein Erwerbseinkommen aus einer Vollzeitbeschäftigung.

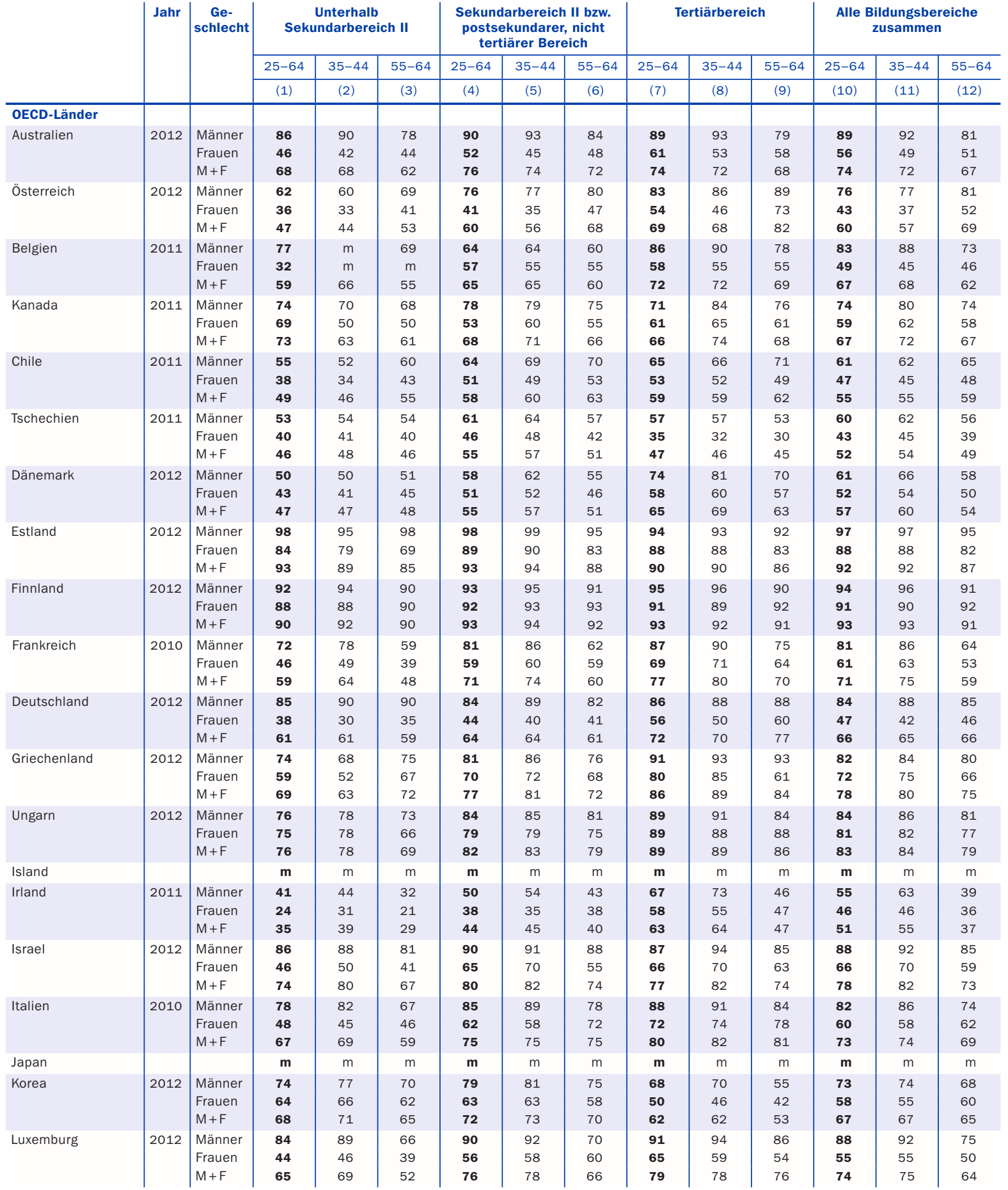

Anmerkung: Die Länge des Referenzzeitraums variiert zwischen einer Woche und einem Jahr. In einigen Ländern ohne Selbstständige.

1. Vollzeitbeschäftigung bezieht sich auf Beschäftigte mit einer ganzjährigen Beschäftigung von mindestens 30 Wochenarbeitsstunden. Einzelheiten s. Indikator A6 und Anhang 3.

Quelle: OECD. Hinweise s. Anhang 3 unter www.oecd.org/edu/eag.htm. StatLink: http://dx.doi.org/10.1787/888933115863

Erläuterung der Kennzeichnung fehlender Daten s. Hinweise für den Leser. 
Tabelle A5.6 (Forts.)

Anteil der ganzjährig Vollzeitbeschäftigten an allen Personen mit Erwerbseinkommen, nach Bildungsstand und Altersgruppe (2012) ${ }^{1}$

Erläuterung der Tabelle: In Australien erzielen 86 Prozent der 25- bis 64-jährigen Männer mit einer Ausbildung unterhalb des Sekundarbereichs II Erwerbseinkommen aus einer Vollzeitbeschäftigung. Bei den 25- bis 64-jährigen Frauen erzielen 46 Prozent der beschäftigten Frauen ein Erwerbseinkommen aus einer Vollzeitbeschäftigung.

\begin{tabular}{|c|c|c|c|c|c|c|c|c|c|c|c|c|c|c|}
\hline & \multirow[t]{3}{*}{ Jahr } & \multirow[t]{3}{*}{$\left|\begin{array}{c}\text { Ge- } \\
\text { schlecht }\end{array}\right|$} & \multicolumn{3}{|c|}{$\begin{array}{c}\text { Unterhalb } \\
\text { Sekundarbereich II }\end{array}$} & \multicolumn{3}{|c|}{$\begin{array}{l}\text { Sekundarbereich II bzw. } \\
\text { postsekundarer, nicht } \\
\text { tertiärer Bereich }\end{array}$} & \multicolumn{3}{|c|}{ Tertiärbereich } & \multicolumn{3}{|c|}{$\begin{array}{c}\text { Alle Bildungsbereiche } \\
\text { zusammen }\end{array}$} \\
\hline & & & $25-64$ & $35-44$ & $55-64$ & $25-64$ & $35-44$ & $55-64$ & $25-64$ & $35-44$ & $55-64$ & $25-64$ & $35-44$ & $55-64$ \\
\hline & & & (1) & (2) & (3) & (4) & (5) & (6) & (7) & (8) & (9) & (10) & (11) & $(12)$ \\
\hline \multicolumn{15}{|l|}{ OECD-Länder } \\
\hline Mexiko & & & $\mathbf{m}$ & $\mathrm{m}$ & $\mathrm{m}$ & $\mathbf{m}$ & $\mathrm{m}$ & $\mathrm{m}$ & $\mathbf{m}$ & $\mathrm{m}$ & $\mathrm{m}$ & $\mathbf{m}$ & $\mathrm{m}$ & $\mathrm{m}$ \\
\hline Niederlande & 2010 & $\begin{array}{l}\text { Männer } \\
\text { Frauen } \\
M+F\end{array}$ & $\begin{array}{l}71 \\
15 \\
46\end{array}$ & $\begin{array}{l}72 \\
14 \\
46\end{array}$ & $\begin{array}{l}70 \\
11 \\
42\end{array}$ & $\begin{array}{l}70 \\
19 \\
45\end{array}$ & $\begin{array}{l}73 \\
15 \\
43\end{array}$ & $\begin{array}{l}69 \\
17 \\
48\end{array}$ & $\begin{array}{l}68 \\
29 \\
49\end{array}$ & $\begin{array}{l}69 \\
22 \\
46\end{array}$ & $\begin{array}{l}65 \\
25 \\
50\end{array}$ & $\begin{array}{l}70 \\
22 \\
47\end{array}$ & $\begin{array}{l}71 \\
17 \\
45\end{array}$ & $\begin{array}{l}68 \\
17 \\
47\end{array}$ \\
\hline Neuseeland & 2012 & $\begin{array}{l}\text { Männer } \\
\text { Frauen } \\
M+F\end{array}$ & $\begin{array}{l}90 \\
63 \\
77\end{array}$ & $\begin{array}{l}92 \\
64 \\
80\end{array}$ & $\begin{array}{l}86 \\
58 \\
72\end{array}$ & $\begin{array}{l}93 \\
64 \\
82\end{array}$ & $\begin{array}{l}94 \\
57 \\
79\end{array}$ & $\begin{array}{l}89 \\
63 \\
80\end{array}$ & $\begin{array}{l}92 \\
71 \\
81\end{array}$ & $\begin{array}{l}94 \\
66 \\
79\end{array}$ & $\begin{array}{l}90 \\
65 \\
76\end{array}$ & $\begin{array}{l}92 \\
67 \\
80\end{array}$ & $\begin{array}{l}94 \\
63 \\
79\end{array}$ & $\begin{array}{l}88 \\
63 \\
76\end{array}$ \\
\hline Norwegen & 2011 & $\begin{array}{l}\text { Männer } \\
\text { Frauen } \\
\text { M+F }\end{array}$ & $\begin{array}{l}52 \\
28 \\
41\end{array}$ & $\begin{array}{l}53 \\
28 \\
42\end{array}$ & $\begin{array}{l}49 \\
26 \\
38\end{array}$ & $\begin{array}{l}66 \\
37 \\
53\end{array}$ & $\begin{array}{l}69 \\
37 \\
56\end{array}$ & $\begin{array}{l}60 \\
34 \\
48\end{array}$ & $\begin{array}{l}69 \\
47 \\
56\end{array}$ & $\begin{array}{l}73 \\
47 \\
59\end{array}$ & $\begin{array}{l}69 \\
52 \\
61\end{array}$ & $\begin{array}{l}63 \\
39 \\
52\end{array}$ & $\begin{array}{l}67 \\
41 \\
55\end{array}$ & $\begin{array}{l}61 \\
39 \\
51\end{array}$ \\
\hline Polen & 2012 & $\begin{array}{l}\text { Männer } \\
\text { Frauen } \\
M+F\end{array}$ & $\begin{array}{l}96 \\
89 \\
93\end{array}$ & $\begin{array}{l}97 \\
90 \\
94\end{array}$ & $\begin{array}{l}94 \\
88 \\
92\end{array}$ & $\begin{array}{l}97 \\
92 \\
95\end{array}$ & $\begin{array}{l}98 \\
92 \\
95\end{array}$ & $\begin{array}{l}95 \\
91 \\
93\end{array}$ & $\begin{array}{l}91 \\
89 \\
90\end{array}$ & $\begin{array}{l}91 \\
89 \\
90\end{array}$ & $\begin{array}{l}90 \\
89 \\
90\end{array}$ & $\begin{array}{l}95 \\
91 \\
93\end{array}$ & $\begin{array}{l}95 \\
91 \\
93\end{array}$ & $\begin{array}{l}93 \\
90 \\
92\end{array}$ \\
\hline Portugal & 2011 & $\begin{array}{l}\text { Männer } \\
\text { Frauen } \\
M+F\end{array}$ & $\begin{array}{l}98 \\
90 \\
95\end{array}$ & $\begin{array}{l}98 \\
92 \\
95\end{array}$ & $\begin{array}{l}98 \\
86 \\
93\end{array}$ & $\begin{array}{l}96 \\
93 \\
95\end{array}$ & $\begin{array}{l}98 \\
95 \\
96\end{array}$ & $\begin{array}{l}96 \\
93 \\
95\end{array}$ & $\begin{array}{l}94 \\
93 \\
94\end{array}$ & $\begin{array}{l}95 \\
94 \\
94\end{array}$ & $\begin{array}{l}88 \\
88 \\
88\end{array}$ & $\begin{array}{l}97 \\
92 \\
94\end{array}$ & $\begin{array}{l}97 \\
93 \\
95\end{array}$ & $\begin{array}{l}97 \\
86 \\
93\end{array}$ \\
\hline Slowakei & 2012 & $\begin{array}{l}\text { Männer } \\
\text { Frauen } \\
M+F\end{array}$ & $\begin{array}{l}52 \\
49 \\
50\end{array}$ & $\begin{array}{l}51 \\
46 \\
48\end{array}$ & $\begin{array}{l}58 \\
51 \\
53\end{array}$ & $\begin{array}{l}64 \\
59 \\
62\end{array}$ & $\begin{array}{l}66 \\
59 \\
63\end{array}$ & $\begin{array}{l}65 \\
61 \\
63\end{array}$ & $\begin{array}{l}66 \\
62 \\
64\end{array}$ & $\begin{array}{l}68 \\
64 \\
66\end{array}$ & $\begin{array}{l}69 \\
67 \\
68\end{array}$ & $\begin{array}{l}63 \\
58 \\
60\end{array}$ & $\begin{array}{l}64 \\
59 \\
62\end{array}$ & $\begin{array}{l}64 \\
60 \\
62\end{array}$ \\
\hline Slowenien & & & m & $\mathrm{m}$ & $\mathrm{m}$ & m & $\mathrm{m}$ & $\mathrm{m}$ & m & $\mathrm{m}$ & $\mathrm{m}$ & m & $\mathrm{m}$ & $\mathrm{m}$ \\
\hline Spanien & 2011 & $\begin{array}{l}\text { Männer } \\
\text { Frauen } \\
M+F\end{array}$ & $\begin{array}{l}75 \\
51 \\
66\end{array}$ & $\begin{array}{l}73 \\
43 \\
62\end{array}$ & $\begin{array}{l}77 \\
61 \\
71\end{array}$ & $\begin{array}{l}78 \\
63 \\
72\end{array}$ & $\begin{array}{l}77 \\
64 \\
71\end{array}$ & $\begin{array}{l}83 \\
76 \\
80\end{array}$ & $\begin{array}{l}84 \\
75 \\
79\end{array}$ & $\begin{array}{l}87 \\
77 \\
82\end{array}$ & $\begin{array}{l}87 \\
87 \\
87\end{array}$ & $\begin{array}{l}79 \\
65 \\
72\end{array}$ & $\begin{array}{l}79 \\
64 \\
73\end{array}$ & $\begin{array}{l}81 \\
72 \\
78\end{array}$ \\
\hline Schweden & 2010 & $\begin{array}{l}\text { Männer } \\
\text { Frauen } \\
M+F\end{array}$ & $\begin{array}{l}74 \\
37 \\
60\end{array}$ & $\begin{array}{l}77 \\
46 \\
65\end{array}$ & $\begin{array}{l}69 \\
30 \\
55\end{array}$ & $\begin{array}{l}79 \\
48 \\
65\end{array}$ & $\begin{array}{l}84 \\
49 \\
69\end{array}$ & $\begin{array}{l}63 \\
43 \\
53\end{array}$ & $\begin{array}{l}79 \\
60 \\
68\end{array}$ & $\begin{array}{l}86 \\
58 \\
70\end{array}$ & $\begin{array}{l}71 \\
59 \\
64\end{array}$ & $\begin{array}{l}78 \\
52 \\
66\end{array}$ & $\begin{array}{l}84 \\
53 \\
69\end{array}$ & $\begin{array}{l}67 \\
47 \\
57\end{array}$ \\
\hline Schweiz & & & m & $\mathrm{m}$ & $\mathrm{m}$ & m & $\mathrm{m}$ & $\mathrm{m}$ & m & $\mathrm{m}$ & $\mathrm{m}$ & m & $\mathrm{m}$ & $\mathrm{m}$ \\
\hline Türkei & 2012 & $\begin{array}{l}\text { Männer } \\
\text { Frauen } \\
M+F\end{array}$ & $\begin{array}{l}61 \\
47 \\
58\end{array}$ & $\begin{array}{l}64 \\
46 \\
60\end{array}$ & $\begin{array}{l}58 \\
59 \\
58\end{array}$ & $\begin{array}{l}75 \\
70 \\
74\end{array}$ & $\begin{array}{l}79 \\
74 \\
78\end{array}$ & $\begin{array}{l}71 \\
63 \\
70\end{array}$ & $\begin{array}{l}82 \\
76 \\
80\end{array}$ & $\begin{array}{l}91 \\
86 \\
90\end{array}$ & $\begin{array}{l}80 \\
90 \\
80\end{array}$ & $\begin{array}{l}69 \\
62 \\
67\end{array}$ & $\begin{array}{l}73 \\
63 \\
71\end{array}$ & $\begin{array}{l}64 \\
62 \\
63\end{array}$ \\
\hline $\begin{array}{l}\text { Vereinigtes } \\
\text { Königreich }\end{array}$ & 2012 & $\begin{array}{l}\text { Männer } \\
\text { Frauen } \\
M+F\end{array}$ & $\begin{array}{l}83 \\
43 \\
66\end{array}$ & $\begin{array}{l}82 \\
40 \\
67\end{array}$ & $\begin{array}{l}84 \\
41 \\
62\end{array}$ & $\begin{array}{l}92 \\
54 \\
74\end{array}$ & $\begin{array}{l}95 \\
50 \\
73\end{array}$ & $\begin{array}{l}83 \\
50 \\
68\end{array}$ & $\begin{array}{l}92 \\
65 \\
79\end{array}$ & $\begin{array}{l}95 \\
59 \\
78\end{array}$ & $\begin{array}{l}78 \\
54 \\
67\end{array}$ & $\begin{array}{l}91 \\
59 \\
76\end{array}$ & $\begin{array}{l}94 \\
54 \\
76\end{array}$ & $\begin{array}{l}82 \\
50 \\
68\end{array}$ \\
\hline Vereinigte Staaten & 2012 & $\begin{array}{l}\text { Männer } \\
\text { Frauen } \\
M+F\end{array}$ & $\begin{array}{l}66 \\
52 \\
61\end{array}$ & $\begin{array}{l}68 \\
55 \\
64\end{array}$ & $\begin{array}{l}66 \\
55 \\
61\end{array}$ & $\begin{array}{l}76 \\
64 \\
71\end{array}$ & $\begin{array}{l}78 \\
65 \\
73\end{array}$ & $\begin{array}{l}75 \\
65 \\
70\end{array}$ & $\begin{array}{l}84 \\
70 \\
77\end{array}$ & $\begin{array}{l}87 \\
70 \\
79\end{array}$ & $\begin{array}{l}79 \\
68 \\
74\end{array}$ & $\begin{array}{l}79 \\
66 \\
73\end{array}$ & $\begin{array}{l}81 \\
67 \\
75\end{array}$ & $\begin{array}{l}76 \\
66 \\
71\end{array}$ \\
\hline OECD-Durchschnitt & & $\begin{array}{l}\text { Männer } \\
\text { Frauen } \\
\mathbf{M}+\mathbf{F}\end{array}$ & $\begin{array}{l}74 \\
51 \\
64\end{array}$ & $\begin{array}{l}75 \\
51 \\
65\end{array}$ & $\begin{array}{l}71 \\
50 \\
61\end{array}$ & $\begin{array}{l}79 \\
60 \\
71\end{array}$ & $\begin{array}{l}82 \\
59 \\
72\end{array}$ & $\begin{array}{l}75 \\
59 \\
68\end{array}$ & $\begin{array}{l}82 \\
66 \\
74\end{array}$ & $\begin{array}{l}85 \\
65 \\
75\end{array}$ & $\begin{array}{l}78 \\
64 \\
72\end{array}$ & $\begin{array}{l}79 \\
60 \\
70\end{array}$ & $\begin{array}{l}82 \\
60 \\
71\end{array}$ & $\begin{array}{l}75 \\
58 \\
67\end{array}$ \\
\hline EU21-Durchschnitt & & \begin{tabular}{|l|} 
Männer \\
Frauen \\
$M+F$
\end{tabular} & $\begin{array}{l}74 \\
52 \\
65\end{array}$ & $\begin{array}{l}75 \\
52 \\
65\end{array}$ & $\begin{array}{l}72 \\
51 \\
62\end{array}$ & $\begin{array}{l}79 \\
61 \\
71\end{array}$ & $\begin{array}{l}82 \\
60 \\
72\end{array}$ & $\begin{array}{l}74 \\
60 \\
68\end{array}$ & $\begin{array}{l}83 \\
67 \\
75\end{array}$ & $\begin{array}{l}86 \\
66 \\
76\end{array}$ & $\begin{array}{l}79 \\
66 \\
74\end{array}$ & $\begin{array}{l}80 \\
61 \\
71\end{array}$ & $\begin{array}{l}83 \\
61 \\
72\end{array}$ & $\begin{array}{l}75 \\
59 \\
68\end{array}$ \\
\hline Partnerländer & & & & & & & & & & & & & & \\
\hline Argentinien & & & m & $\mathrm{m}$ & $\mathrm{m}$ & m & $\mathrm{m}$ & $\mathrm{m}$ & m & $\mathrm{m}$ & $\mathrm{m}$ & m & $\mathrm{m}$ & $\mathrm{m}$ \\
\hline Brasilien & 2012 & $\begin{array}{l}\text { Männer } \\
\text { Frauen } \\
M+F\end{array}$ & $\begin{array}{l}73 \\
48 \\
64\end{array}$ & $\begin{array}{l}75 \\
50 \\
65\end{array}$ & $\begin{array}{l}74 \\
44 \\
63\end{array}$ & $\begin{array}{l}79 \\
64 \\
72\end{array}$ & $\begin{array}{l}82 \\
65 \\
74\end{array}$ & $\begin{array}{l}80 \\
60 \\
72\end{array}$ & $\begin{array}{l}78 \\
63 \\
70\end{array}$ & $\begin{array}{l}79 \\
64 \\
70\end{array}$ & $\begin{array}{l}78 \\
57 \\
68\end{array}$ & $\begin{array}{l}76 \\
57 \\
67\end{array}$ & $\begin{array}{l}77 \\
58 \\
69\end{array}$ & $\begin{array}{l}76 \\
49 \\
65\end{array}$ \\
\hline China & & & m & $\mathrm{m}$ & $\mathrm{m}$ & m & $\mathrm{m}$ & $\mathrm{m}$ & m & $\mathrm{m}$ & $\mathrm{m}$ & m & $\mathrm{m}$ & $\mathrm{m}$ \\
\hline Kolumbien & & & m & $\mathrm{m}$ & $\mathrm{m}$ & m & $\mathrm{m}$ & $\mathrm{m}$ & m & $\mathrm{m}$ & $\mathrm{m}$ & m & $\mathrm{m}$ & $\mathrm{m}$ \\
\hline Indien & & & m & $\mathrm{m}$ & $\mathrm{m}$ & m & $\mathrm{m}$ & $\mathrm{m}$ & m & $\mathrm{m}$ & $\mathrm{m}$ & m & $\mathrm{m}$ & $\mathrm{m}$ \\
\hline Indonesien & & & m & $\mathrm{m}$ & $\mathrm{m}$ & m & $\mathrm{m}$ & $\mathrm{m}$ & m & $\mathrm{m}$ & $\mathrm{m}$ & m & $\mathrm{m}$ & $\mathrm{m}$ \\
\hline Lettland & & & m & $\mathrm{m}$ & $\mathrm{m}$ & m & $\mathrm{m}$ & $\mathrm{m}$ & m & $\mathrm{m}$ & $\mathrm{m}$ & m & $\mathrm{m}$ & $\mathrm{m}$ \\
\hline Russische Föd. & & & m & $\mathrm{m}$ & $\mathrm{m}$ & m & $\mathrm{m}$ & $\mathrm{m}$ & m & $\mathrm{m}$ & $\mathrm{m}$ & m & $\mathrm{m}$ & $\mathrm{m}$ \\
\hline Saudi-Arabien & & & m & $\mathrm{m}$ & $\mathrm{m}$ & m & $\mathrm{m}$ & $\mathrm{m}$ & m & $\mathrm{m}$ & $\mathrm{m}$ & m & $\mathrm{m}$ & $\mathrm{m}$ \\
\hline Südafrika & & & m & $\mathrm{m}$ & $\mathrm{m}$ & m & $\mathrm{m}$ & $\mathrm{m}$ & m & $\mathrm{m}$ & $\mathrm{m}$ & m & $\mathrm{m}$ & $\mathrm{m}$ \\
\hline G20-Durchschnitt & & & $\mathbf{m}$ & $\mathbf{m}$ & m & $\mathbf{m}$ & m & m & $\mathbf{m}$ & m & m & $\mathrm{m}$ & $\mathrm{m}$ & m \\
\hline
\end{tabular}

Anmerkung: Die Länge des Referenzzeitraums variiert zwischen einer Woche und einem Jahr. In einigen Ländern ohne Selbstständige.

1. Vollzeitbeschäftigung bezieht sich auf Beschäftigte mit einer ganzjährigen Beschäftigung von mindestens 30 Wochenarbeitsstunden. Einzelheiten s. Indikator A6 und Anhang 3.

Quelle: OECD. Hinweise s. Anhang 3 unter www.oecd.org/edu/eag.htm. StatLink: http://dx.doi.org/10.1787/888933115863

Erläuterung der Kennzeichnung fehlender Daten s. Hinweise für den Leser. 
Tabelle A5.7a (L)

Erwerbsstatus, nach Bildungsstand und Lesekompetenz (2012)

Lesekompetenz in der Erhebung zu den grundlegenden Kompetenzen Erwachsener, Anteil 25- bis 64-Jähriger (in \%)

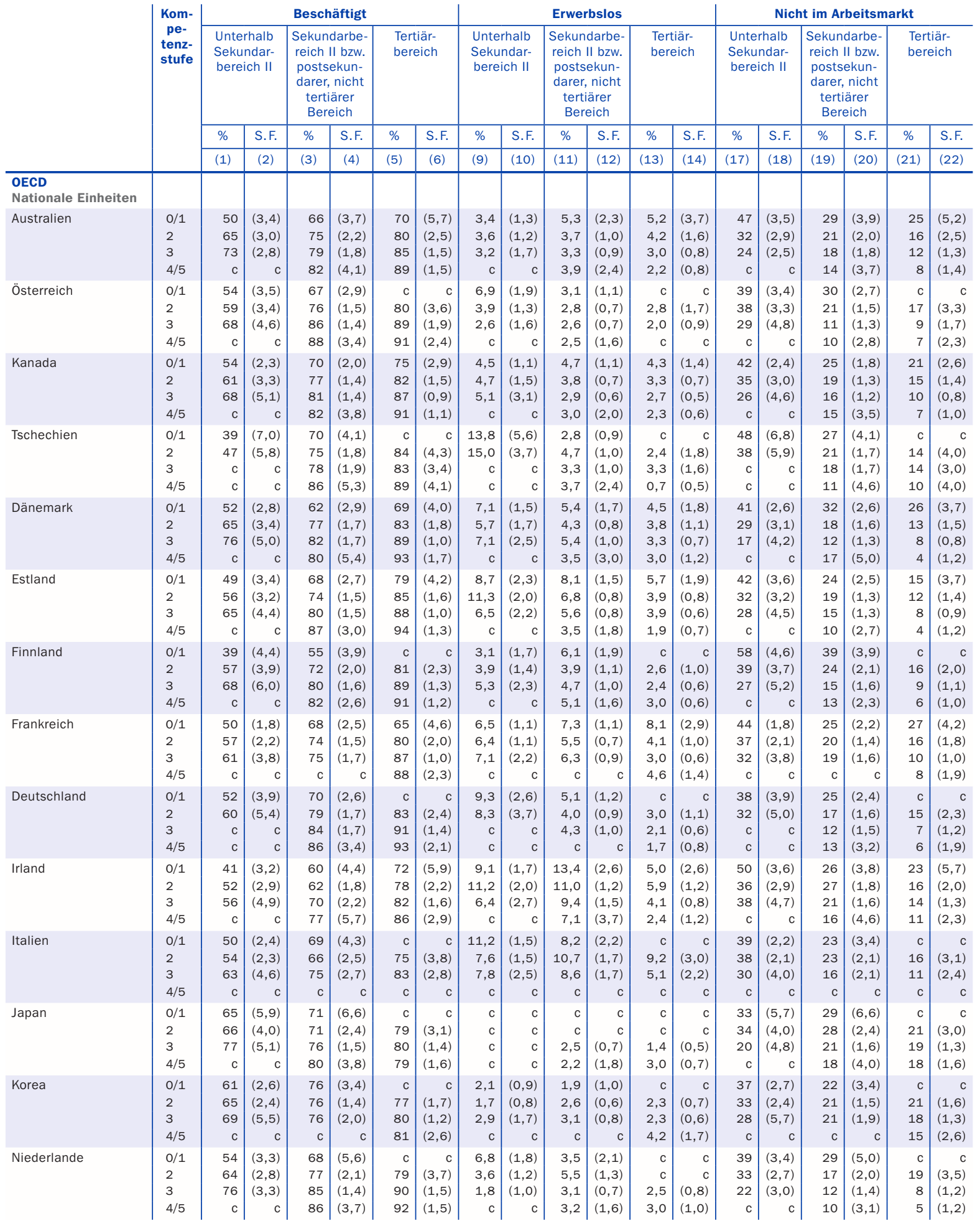

* Hinweis zu den Daten der Russischen Föderation s. Abschnitt Angewandte Methodik.

Anmerkung: Die Spalten mit den Angaben für alle Bildungsbereiche zusammen sind im Internet verfügbar (s. StatLink unten).

Quelle: OECD. Survey of Adult Skills (PIAAC) (2012). PIAAC steht für das OECD Programme for the International Assessment of Adult Competencies. Hinweise s. Anhang 3 unter www.oecd.org/edu/eag.htm. StatLink: http://dx.doi.org/10.1787/888933115882

Erläuterung der Kennzeichnung fehlender Daten s. Hinweise für den Leser. 
Tabelle A5.7a (L) (Forts.)

Erwerbsstatus, nach Bildungsstand und Lesekompetenz (2012)

Lesekompetenz in der Erhebung zu den grundlegenden Kompetenzen Erwachsener, Anteil 25- bis 64-Jähriger (in \%)

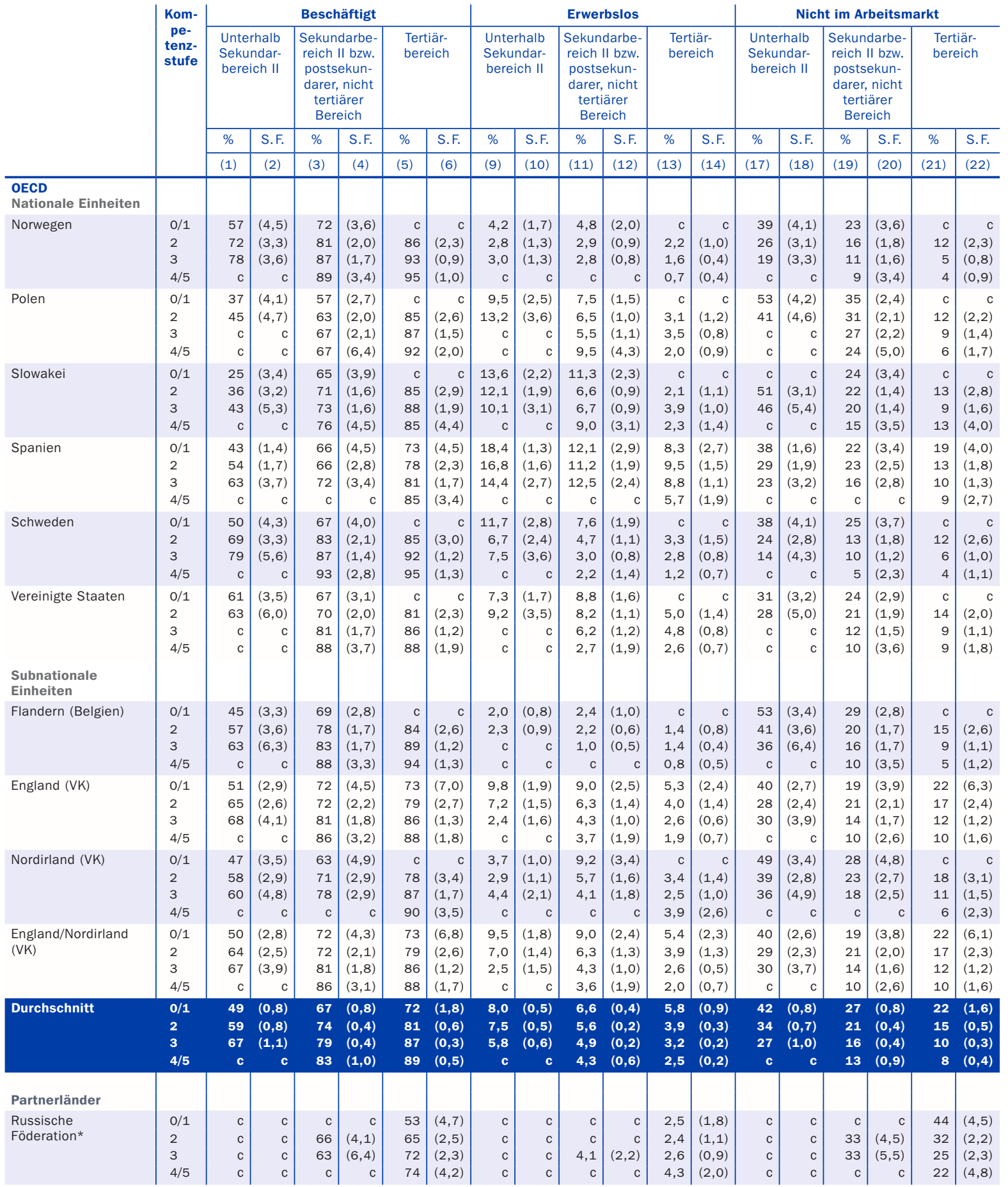

\footnotetext{
* Hinweis zu den Daten der Russischen Föderation s. Abschnitt Angewandte Methodik.

Anmerkung: Die Spalten mit den Angaben für alle Bildungsbereiche zusammen sind im Internet verfügbar (s. StatLink unten).

Quelle: OECD. Survey of Adult Skills (PIAAC) (2012). PIAAC steht für das OECD Programme for the International Assessment of Adult Competencies. Hinweise s. Anhang 3 unter www.oecd.org/edu/eag.htm. StatLink: http://dx.doi.org/10.1787/888933115882

Erläuterung der Kennzeichnung fehlender Daten s. Hinweise für den Leser.
} 
Tabelle A5.8 (L)

Mittelwert der Lesekompetenz bei Erwachsenen mit einem Abschluss im Sekundarbereich II bzw. postsekundaren, nicht tertiären Bereich, nach Erwerbsstatus und Ausrichtung des Bildungsgangs (2012)

Mittelwert der Lesekompetenz in der Erhebung zu den grundlegenden Kompetenzen Erwachsener, 25- bis 64-Jährige

\begin{tabular}{|c|c|c|c|c|c|c|c|c|c|c|c|c|c|c|c|c|c|c|}
\hline & \multicolumn{6}{|c|}{ Beschäftigt } & \multicolumn{6}{|c|}{ Erwerbslos } & \multicolumn{6}{|c|}{ Nicht im Arbeitsmarkt } \\
\hline & \multicolumn{2}{|c|}{ Berufsbildend } & \multicolumn{2}{|c|}{$\begin{array}{l}\text { Allgemein- } \\
\text { bildend }\end{array}$} & \multicolumn{2}{|c|}{ Gesamt } & \multicolumn{2}{|c|}{ Berufsbildend } & \multicolumn{2}{|c|}{$\begin{array}{l}\text { Allgemein- } \\
\text { bildend }\end{array}$} & \multicolumn{2}{|c|}{ Gesamt } & \multicolumn{2}{|c|}{ Berufsbildend } & \multicolumn{2}{|c|}{$\begin{array}{l}\text { Allgemein- } \\
\text { bildend }\end{array}$} & \multicolumn{2}{|c|}{ Gesamt } \\
\hline & \begin{tabular}{|c|} 
Punk- \\
te
\end{tabular} & S.F. & $\begin{array}{l}\text { Punk- } \\
\text { te }\end{array}$ & S.F. & $\begin{array}{l}\text { Punk- } \\
\text { te }\end{array}$ & S.F. & $\begin{array}{l}\text { Punk- } \\
\text { te }\end{array}$ & S.F. & $\begin{array}{l}\text { Punk- } \\
\text { te }\end{array}$ & S.F. & $\begin{array}{l}\text { Punk- } \\
\text { te }\end{array}$ & S.F. & $\begin{array}{c}\text { Punk- } \\
\text { te }\end{array}$ & S.F. & $\begin{array}{l}\text { Punk- } \\
\text { te }\end{array}$ & S.F. & $\begin{array}{l}\text { Punk- } \\
\text { te }\end{array}$ & S.F. \\
\hline & (1) & (2) & (3) & (4) & (5) & (6) & (7) & (8) & (9) & $(10)$ & (11) & $(12)$ & (13) & (14) & (15) & $(16)$ & (17) & (18) \\
\hline \multicolumn{19}{|l|}{$\begin{array}{l}\text { OECD } \\
\text { Nationale Einheiten }\end{array}$} \\
\hline Australien & 279 & $(1,7)$ & 285 & $(2,8)$ & 282 & $(1,7)$ & 265 & $(10,5)$ & $\mathrm{c}$ & c & 272 & $(9,7)$ & 268 & $(4,7)$ & 269 & $(4,9)$ & 269 & $(3,8)$ \\
\hline Österreich & 269 & $(1,1)$ & 290 & $(3,6)$ & 272 & $(1,1)$ & 258 & $(6,0)$ & $\mathrm{c}$ & c & 263 & $(6,0)$ & 251 & $(2,2)$ & 274 & $(9,0)$ & 253 & $(2,2)$ \\
\hline Kanada & 272 & $(1,6)$ & 265 & $(1,6)$ & 268 & $(1,2)$ & 273 & $(9,9)$ & 249 & $(6,6)$ & 258 & $(5,4)$ & 255 & $(4,0)$ & 255 & $(3,5)$ & 255 & $(2,6)$ \\
\hline Tschechien & 269 & $(1,2)$ & 291 & $(5,0)$ & 271 & $(1,1)$ & 266 & $(4,4)$ & c & $\mathrm{c}$ & 270 & $(4,6)$ & 258 & $(2,8)$ & 294 & $(5,7)$ & 263 & $(2,7)$ \\
\hline Dänemark & 264 & $(1,3)$ & 286 & $(3,2)$ & 268 & $(1,2)$ & 258 & $(6,2)$ & $\mathrm{c}$ & c & 264 & $(5,5)$ & 243 & $(3,1)$ & 277 & $(7,1)$ & 250 & $(2,8)$ \\
\hline Estland & 266 & $(1,3)$ & 274 & $(1,8)$ & 270 & $(1,1)$ & 257 & $(4,4)$ & 262 & $(5,0)$ & 259 & $(3,7)$ & 257 & $(3,1)$ & 255 & $(3,3)$ & 257 & $(2,5)$ \\
\hline Finnland & 278 & $(1,5)$ & 308 & $(4,0)$ & 282 & $(1,5)$ & 271 & $(6,3)$ & c & c & 275 & $(6,9)$ & 250 & $(3,4)$ & 303 & $(7,5)$ & 259 & $(3,3)$ \\
\hline Frankreich & 254 & $(1,1)$ & 278 & $(1,7)$ & 260 & $(1,0)$ & 254 & $(4,4)$ & 259 & $(7,6)$ & 256 & $(4,0)$ & 250 & $(2,0)$ & 269 & $(3,7)$ & 254 & $(1,9)$ \\
\hline Deutschland & 264 & $(1,2)$ & 295 & $(6,7)$ & 265 & $(1,2)$ & 255 & $(4,7)$ & c & c & 256 & $(4,5)$ & 247 & $(2,6)$ & 273 & $(17,7)$ & 249 & $(2,4)$ \\
\hline Irland & 269 & $(2,5)$ & 270 & $(2,0)$ & 269 & $(1,7)$ & 255 & $(5,4)$ & 267 & $(5,5)$ & 261 & $(4,2)$ & 264 & $(2,9)$ & 260 & $(4,1)$ & 262 & $(2,6)$ \\
\hline Italien & 253 & $(3,0)$ & c & c & 266 & $(1,6)$ & 251 & $(5,1)$ & c & c & 261 & $(3,7)$ & 251 & $(4,5)$ & c & c & 256 & $(2,6)$ \\
\hline Japan & 287 & $(2,1)$ & 288 & $(1,6)$ & 289 & $(1,2)$ & c & c & c & c & c & c & 280 & $(3,6)$ & 279 & $(2,9)$ & 281 & $(2,3)$ \\
\hline Korea & 267 & $(1,4)$ & 263 & $(1,5)$ & 265 & $(1,0)$ & c & c & 269 & $(7,3)$ & 270 & $(6,1)$ & 268 & $(3,2)$ & 265 & $(2,9)$ & 266 & $(2,4)$ \\
\hline Niederlande & 281 & $(1,4)$ & 305 & $(2,7)$ & 286 & $(1,3)$ & 271 & $(6,9)$ & c & c & 277 & $(6,3)$ & 259 & $(3,3)$ & 288 & $(7,7)$ & 269 & $(3,8)$ \\
\hline Norwegen & 269 & $(1,4)$ & 286 & $(2,5)$ & 274 & $(1,5)$ & 259 & $(10,0)$ & $\mathrm{c}$ & c & 265 & $(7,6)$ & 255 & $(3,9)$ & 273 & $(6,4)$ & 259 & $(3,7)$ \\
\hline Polen & 256 & $(1,3)$ & 272 & $(3,5)$ & 258 & $(1,2)$ & 248 & $(5,2)$ & 272 & $(8,3)$ & 252 & $(4,6)$ & 248 & $(1,9)$ & 259 & $(4,6)$ & 249 & $(1,8)$ \\
\hline Slowakei & 267 & $(1,4)$ & 283 & $(1,4)$ & 277 & $(1,0)$ & 265 & $(4,6)$ & 279 & $(6,0)$ & 273 & $(3,8)$ & 260 & $(2,2)$ & 281 & $(2,4)$ & 272 & $(1,9)$ \\
\hline Spanien & 246 & $(4,9)$ & 261 & $(1,9)$ & 259 & $(1,8)$ & c & c & 260 & $(5,2)$ & 258 & $(4,8)$ & c & c & 254 & $(3,5)$ & 254 & $(3,2)$ \\
\hline Schweden & 276 & $(1,9)$ & 284 & $(2,2)$ & 281 & $(1,3)$ & c & c & $\mathrm{c}$ & $\mathrm{c}$ & 256 & $(6,3)$ & 249 & $(6,1)$ & 260 & $(6,3)$ & 256 & $(3,8)$ \\
\hline \multicolumn{19}{|l|}{$\begin{array}{l}\text { Subnationale } \\
\text { Einheiten }\end{array}$} \\
\hline Flandern (Belgien) & 251 & $(2,2)$ & c & c & 268 & $(1,3)$ & c & c & c & c & 257 & $(8,9)$ & 239 & $(3,5)$ & c & c & 255 & $(2,7)$ \\
\hline England (VK) & 267 & $(3,7)$ & 278 & $(2,1)$ & 277 & $(1,7)$ & c & $\mathrm{C}$ & 256 & $(7,0)$ & 259 & $(6,0)$ & 254 & $(6,4)$ & 264 & $(3,5)$ & 265 & $(3,5)$ \\
\hline Nordirland (VK) & 269 & $(4,3)$ & 271 & $(2,9)$ & 273 & $(2,9)$ & c & c & c & c & 257 & $(8,1)$ & 258 & $(5,5)$ & 263 & $(3,9)$ & 262 & $(3,7)$ \\
\hline England/Nordirland (VK) & 267 & $(3,6)$ & 278 & $(2,0)$ & 276 & $(1,7)$ & 251 & $(9,8)$ & 257 & $(6,9)$ & 259 & $(5,9)$ & 254 & $(6,1)$ & 264 & $(3,3)$ & 265 & $(3,3)$ \\
\hline Durchschnitt & 267 & $(0,5)$ & 281 & $(0,7)$ & 271 & $(0,3)$ & 260 & $(1,7)$ & 262 & $(2,0)$ & 262 & $(1,3)$ & 255 & $(0,8)$ & 270 & $(1,4)$ & 259 & $(0,6)$ \\
\hline \multicolumn{19}{|l|}{ Partnerländer } \\
\hline Russische Föderation* & 274 & $(3,4)$ & 264 & $(5,7)$ & 270 & $(3,5)$ & c & c & c & c & c & C & 271 & $(11,2)$ & 273 & $(8,3)$ & 272 & $(7,6)$ \\
\hline
\end{tabular}

* Hinweis zu den Daten der Russischen Föderation s. Abschnitt Angewandte Methodik.

Quelle: OECD. Survey of Adult Skills (PIAAC) (2012). PIAAC steht für das OECD Programme for the International Assessment of Adult Competencies.

Hinweise s. Anhang 3 unter www.oecd.org/edu/eag.htm. StatLink: http://dx.doi.org/10.1787/888933115901

Erläuterung der Kennzeichnung fehlender Daten s. Hinweise für den Leser. 
Erwachsenenbevölkerung nach Lesekompetenz und Erwerbsstatus (2012)

Lesekompetenzstufe in der Erhebung zu den grundlegenden Kompetenzen Erwachsener, Anteil der 25-bis 64-Jährigen (in \%)

\begin{tabular}{|c|c|c|c|c|c|c|c|c|c|c|c|c|c|c|c|c|}
\hline & \multicolumn{8}{|c|}{ Beschäftigt } & \multicolumn{8}{|c|}{ Erwerbslos } \\
\hline & \multicolumn{2}{|c|}{ Stufe $0 / 1$} & \multicolumn{2}{|c|}{ Stufe 2} & \multicolumn{2}{|c|}{ Stufe 3} & \multicolumn{2}{|c|}{ Stufe $4 / 5$} & \multicolumn{2}{|c|}{ Stufe $0 / 1$} & \multicolumn{2}{|c|}{ Stufe 2} & \multicolumn{2}{|c|}{ Stufe 3} & \multicolumn{2}{|c|}{ Stufe $4 / 5$} \\
\hline & $\%$ & S.F. & $\%$ & S.F. & $\%$ & S.F. & $\%$ & S.F. & $\%$ & S.F. & $\%$ & S.F. & $\%$ & S.F. & $\%$ & S.F. \\
\hline & (1) & (2) & (3) & (4) & (5) & (6) & $(7)$ & (8) & (11) & $(12)$ & (13) & (14) & (15) & (16) & (17) & (18) \\
\hline \multicolumn{17}{|l|}{$\begin{array}{l}\text { OECD } \\
\text { Nationale Einheiten }\end{array}$} \\
\hline Australien & 57 & $(2,2)$ & 73 & $(1,4)$ & 80 & $(1,0)$ & 86 & $(1,6)$ & 4,2 & $(1,0)$ & 3,8 & $(0,7)$ & 3,1 & $(0,6)$ & 2,9 & $(0,9)$ \\
\hline Österreich & 61 & $(2,2)$ & 73 & $(1,4)$ & 85 & $(1,3)$ & 89 & $(1,9)$ & c & c & c & $c$ & c & c & c & c \\
\hline Kanada & 66 & $(1,3)$ & 77 & $(0,9)$ & 84 & $(0,7)$ & 89 & $(1,1)$ & 4,5 & $(0,7)$ & 3,7 & $(0,4)$ & 2,9 & $(0,4)$ & 2,5 & $(0,6)$ \\
\hline Tschechien & 62 & $(3,7)$ & 72 & $(1,6)$ & 78 & $(1,8)$ & 87 & $(3,3)$ & 5,9 & $(1,9)$ & 5,7 & $(0,8)$ & 3,6 & $(0,7)$ & 2,1 & $(1,2)$ \\
\hline Dänemark & 58 & $(1,8)$ & 76 & $(1,2)$ & 85 & $(0,9)$ & 90 & $(1,8)$ & 6,1 & $(1,0)$ & 4,5 & $(0,6)$ & 4,5 & $(0,6)$ & 3,4 & $(1,3)$ \\
\hline Estland & 65 & $(2,1)$ & 75 & $(1,2)$ & 83 & $(0,9)$ & 92 & $(1,2)$ & 7,8 & $(1,1)$ & 6,5 & $(0,6)$ & 4,8 & $(0,5)$ & 2,5 & $(0,7)$ \\
\hline Finnland & 50 & $(2,7)$ & 71 & $(1,5)$ & 83 & $(1,0)$ & 88 & $(1,1)$ & 4,2 & $(1,2)$ & 3,6 & $(0,6)$ & 3,6 & $(0,5)$ & 3,6 & $(0,6)$ \\
\hline Frankreich & 58 & $(1,4)$ & 71 & $(1,0)$ & 79 & $(0,8)$ & 84 & $(1,8)$ & 6,9 & $(0,7)$ & 5,4 & $(0,5)$ & 4,8 & $(0,6)$ & 4,5 & $(1,2)$ \\
\hline Deutschland & 65 & $(2,1)$ & 78 & $(1,3)$ & 87 & $(1,0)$ & 90 & $(1,7)$ & 6,4 & $(1,1)$ & 4,1 & $(0,7)$ & 3,4 & $(0,6)$ & 1,6 & $(0,7)$ \\
\hline Irland & 50 & $(2,3)$ & 63 & $(1,2)$ & 74 & $(1,4)$ & 84 & $(2,5)$ & 9,9 & $(1,2)$ & 9,8 & $(0,9)$ & 6,5 & $(0,8)$ & 3,7 & $(1,2)$ \\
\hline Italien & 55 & $(2,0)$ & 61 & $(1,4)$ & 74 & $(1,8)$ & 86 & $(4,7)$ & 10,4 & $(1,3)$ & 8,9 & $(0,9)$ & 7,5 & $(1,1)$ & 5,9 & $(3,1)$ \\
\hline Japan & 69 & $(4,3)$ & 72 & $(1,7)$ & 78 & $(0,9)$ & 79 & $(1,6)$ & c & c & c & $c$ & c & c & c & c \\
\hline Korea & 69 & $(2,2)$ & 74 & $(0,9)$ & 78 & $(1,1)$ & 78 & $(2,8)$ & 1,9 & $(0,6)$ & 2,3 & $(0,4)$ & 2,6 & $(0,5)$ & 3,7 & $(1,4)$ \\
\hline Niederlande & 59 & $(2,6)$ & 72 & $(1,6)$ & 85 & $(0,9)$ & 90 & $(1,4)$ & 5,6 & $(1,4)$ & 4,1 & $(0,7)$ & 2,7 & $(0,5)$ & 3,0 & $(0,8)$ \\
\hline Norwegen & 66 & $(2,7)$ & 80 & $(1,4)$ & 89 & $(0,9)$ & 93 & $(1,2)$ & c & $c$ & $c$ & $c$ & c & c & $c$ & c \\
\hline Polen & 55 & $(2,2)$ & 65 & $(1,7)$ & 75 & $(1,3)$ & 85 & $(2,2)$ & 7,5 & $(1,1)$ & 6,6 & $(0,8)$ & 4,9 & $(0,7)$ & 4,0 & $(1,4)$ \\
\hline Slowakei & 46 & $(3,0)$ & 66 & $(1,4)$ & 75 & $(1,2)$ & 80 & $(3,4)$ & 11,8 & $(1,5)$ & 7,0 & $(0,8)$ & 6,1 & $(0,7)$ & 5,7 & $(1,8)$ \\
\hline Spanien & 50 & $(1,4)$ & 63 & $(1,4)$ & 75 & $(1,5)$ & 83 & $(3,3)$ & 16,5 & $(1,1)$ & 13,5 & $(1,1)$ & 10,8 & $(1,0)$ & 7,2 & $(2,1)$ \\
\hline Schweden & 58 & $(2,5)$ & 79 & $(1,3)$ & 88 & $(1,0)$ & 94 & $(1,3)$ & 10,1 & $(1,5)$ & 5,0 & $(0,9)$ & 3,4 & $(0,6)$ & 1,5 & $(0,7)$ \\
\hline $\begin{array}{l}\text { Vereinigte Staaten } \\
\text { Subnationale Einheiten }\end{array}$ & 66 & $(2,4)$ & 73 & $(1,6)$ & 83 & $(1,1)$ & 88 & $(1,6)$ & 8,1 & $(1,1)$ & 7,4 & $(0,9)$ & 5,6 & $(0,8)$ & 2,6 & $(0,7)$ \\
\hline Flandern (Belgien) & 58 & $(2,0)$ & 75 & $(1,2)$ & 85 & $(1,0)$ & 93 & $(1,2)$ & c & c & c & c & c & c & c & c \\
\hline England (VK) & 61 & $(2,2)$ & 72 & $(1,6)$ & 82 & $(1,1)$ & 87 & $(1,7)$ & 8,8 & $(1,2)$ & 5,9 & $(0,7)$ & 3,2 & $(0,5)$ & 2,5 & $(0,7)$ \\
\hline Nordirland (VK) & 53 & $(2,9)$ & 67 & $(1,6)$ & 79 & $(1,3)$ & 88 & $(2,7)$ & 5,5 & $(1,2)$ & 4,0 & $(0,7)$ & 3,4 & $(0,8)$ & 3,7 & $(2,0)$ \\
\hline England/Nordirland (VK) & 61 & $(2,1)$ & 72 & $(1,5)$ & 82 & $(1,1)$ & 87 & $(1,6)$ & 8,7 & $(1,1)$ & 5,8 & $(0,7)$ & 3,2 & $(0,5)$ & 2,5 & $(0,7)$ \\
\hline Durchschnitt & 59 & $(0,5)$ & 72 & $(0,3)$ & 81 & $(0,2)$ & 87 & $(0,5)$ & 7,6 & $(0,3)$ & 6,0 & $(0,2)$ & 4,7 & $(0,2)$ & 3,5 & $(0,3)$ \\
\hline \multicolumn{17}{|l|}{ Partnerländer } \\
\hline Russische Föderation* & 55 & $(3,8)$ & 64 & $(2,3)$ & 68 & $(2,6)$ & 69 & $(5,6)$ & c & c & $\mathrm{c}$ & $c$ & c & c & c & c \\
\hline
\end{tabular}

* Hinweis zu den Daten der Russischen Föderation s. Abschnitt Angewandte Methodik.

Anmerkung: Spalten mit Daten für alle Lesekompetenzstufen zusammen und für Nichterwerbsqoten nach Lesekompetenz sind im Internet verfügbar (s. StatLink unten).

Quelle: OECD. Survey of Adult Skills (PIAAC) (2012). PIAAC steht für das OECD Programme for the International Assessment of Adult Competencies. Hinweise s. Anhang 3 unter www.oecd.org/edu/eag.htm. StatLink: http://dx.doi.org/10.1787/888933115920

Erläuterung der Kennzeichnung fehlender Daten s. Hinweise für den Leser. 
Tabelle A5.10a (L)

Vollzeit- und Teilzeitbeschäftigte nach Lesekompetenz und Altersgruppe (2012)

Lesekompetenzstufe in der Erhebung zu den grundlegenden Kompetenzen Erwachsener

\begin{tabular}{|c|c|c|c|c|c|c|c|c|c|c|c|c|c|c|c|c|c|}
\hline & \multirow{4}{*}{$\begin{array}{c}\text { Voll- } \\
\text { zeit/ } \\
\text { Teilzeit }\end{array}$} & \multicolumn{8}{|c|}{ 25- bis 34-Jährige } & \multicolumn{8}{|c|}{ 55- bis 64-Jährige } \\
\hline & & \multicolumn{2}{|c|}{ Stufe $0 / 1$} & \multicolumn{2}{|c|}{ Stufe 2} & \multicolumn{2}{|c|}{ Stufe 3} & \multicolumn{2}{|c|}{ Stufe $4 / 5$} & \multicolumn{2}{|c|}{ Stufe $0 / 1$} & \multicolumn{2}{|c|}{ Stufe 2} & \multicolumn{2}{|c|}{ Stufe 3} & \multicolumn{2}{|c|}{ Stufe $4 / 5$} \\
\hline & & $\%$ & S.F. & $\%$ & S.F. & $\%$ & S.F. & $\%$ & S.F. & $\%$ & S.F. & $\%$ & S.F. & $\%$ & S.F. & $\%$ & S.F. \\
\hline & & (1) & (2) & (3) & (4) & (5) & (6) & (7) & (8) & (25) & (26) & $(27)$ & $(28)$ & (29) & (30) & (31) & (32) \\
\hline \multicolumn{18}{|l|}{$\begin{array}{l}\text { OECD } \\
\text { Nationale Einheiten }\end{array}$} \\
\hline Australien & $\begin{array}{l}\text { Teilzeit } \\
\text { Vollzeit }\end{array}$ & $\begin{array}{r}13 \\
7\end{array}$ & $\begin{array}{l}(3,1) \\
(1,3)\end{array}$ & $\begin{array}{l}26 \\
23\end{array}$ & $\begin{array}{l}(4,0) \\
(1,8)\end{array}$ & $\begin{array}{l}39 \\
45\end{array}$ & $\begin{array}{l}(4,4) \\
(3,0)\end{array}$ & $\begin{array}{l}23 \\
24\end{array}$ & $\begin{array}{l}(3,7) \\
(2,3)\end{array}$ & $\begin{array}{l}16 \\
15\end{array}$ & $\begin{array}{l}(3,1) \\
(1,8)\end{array}$ & $\begin{array}{l}35 \\
33\end{array}$ & $\begin{array}{l}(4,1) \\
(3,0)\end{array}$ & $\begin{array}{l}40 \\
39\end{array}$ & $\begin{array}{l}(4,5) \\
(2,7)\end{array}$ & $\begin{array}{r}9 \\
13\end{array}$ & $\begin{array}{l}(2,1) \\
(2,2)\end{array}$ \\
\hline Österreich & $\begin{array}{l}\text { Teilzeit } \\
\text { Vollzeit }\end{array}$ & $\begin{array}{r}13 \\
8\end{array}$ & $\begin{array}{l}(3,8) \\
(1,6)\end{array}$ & $\begin{array}{l}28 \\
31\end{array}$ & $\begin{array}{l}(5,0) \\
(2,6)\end{array}$ & $\begin{array}{l}46 \\
47\end{array}$ & $\begin{array}{l}(5,8) \\
(2,8)\end{array}$ & $\begin{array}{l}13 \\
14\end{array}$ & $\begin{array}{l}(3,7) \\
(1,8)\end{array}$ & $\begin{array}{r}c \\
17\end{array}$ & $\begin{array}{r}\text { C } \\
(2,8)\end{array}$ & $\begin{array}{r}c \\
50\end{array}$ & $\begin{array}{r}\text { C } \\
(4,1)\end{array}$ & $\begin{array}{r}c \\
30\end{array}$ & $\begin{array}{r}\text { c } \\
(3,4)\end{array}$ & $\begin{array}{l}\mathrm{C} \\
4\end{array}$ & $\begin{array}{r}c \\
(1,4)\end{array}$ \\
\hline Kanada & $\begin{array}{l}\text { Teilzeit } \\
\text { Vollzeit }\end{array}$ & $\begin{array}{l}7 \\
9\end{array}$ & $\begin{array}{l}(2,2) \\
(1,1)\end{array}$ & $\begin{array}{l}29 \\
27\end{array}$ & $\begin{array}{l}(4,0) \\
(2,0)\end{array}$ & $\begin{array}{l}41 \\
42\end{array}$ & $\begin{array}{l}(4,4) \\
(2,6)\end{array}$ & $\begin{array}{l}23 \\
22\end{array}$ & $\begin{array}{l}(3,4) \\
(1,6)\end{array}$ & $\begin{array}{l}15 \\
21\end{array}$ & $\begin{array}{l}(2,5) \\
(1,4)\end{array}$ & $\begin{array}{l}39 \\
35\end{array}$ & $\begin{array}{l}(3,7) \\
(1,7)\end{array}$ & $\begin{array}{l}35 \\
33\end{array}$ & $\begin{array}{l}(3,5) \\
(1,6)\end{array}$ & $\begin{array}{l}10 \\
10\end{array}$ & $\begin{array}{l}(2,4) \\
(1,1)\end{array}$ \\
\hline Tschechien & $\begin{array}{l}\text { Teilzeit } \\
\text { Vollzeit }\end{array}$ & $\begin{array}{l}c \\
6\end{array}$ & $\begin{array}{r}\text { C } \\
(1,4)\end{array}$ & $\begin{array}{r}c \\
26\end{array}$ & $\begin{array}{r}\text { C } \\
(3,2)\end{array}$ & $\begin{array}{r}c \\
51\end{array}$ & $\begin{array}{r}c \\
(3,4)\end{array}$ & $\begin{array}{r}c \\
16\end{array}$ & $\begin{array}{r}c \\
(2,4)\end{array}$ & $\begin{array}{r}c \\
15\end{array}$ & $\begin{array}{r}\mathrm{C} \\
(2,7)\end{array}$ & $\begin{array}{r}c \\
42\end{array}$ & $\begin{array}{r}c \\
(5,3)\end{array}$ & $\begin{array}{r}c \\
37\end{array}$ & $\begin{array}{r}c \\
(4,4)\end{array}$ & $\begin{array}{l}c \\
6\end{array}$ & $\begin{array}{r}c \\
(2,4)\end{array}$ \\
\hline Dänemark & $\begin{array}{l}\text { Teilzeit } \\
\text { Vollzeit }\end{array}$ & $\begin{array}{l}c \\
9\end{array}$ & $\begin{array}{r}c \\
(1,2)\end{array}$ & $\begin{array}{r}c \\
27\end{array}$ & $\begin{array}{r}c \\
(2,5)\end{array}$ & $\begin{array}{r}c \\
46\end{array}$ & $\begin{array}{r}\mathrm{C} \\
(2,8)\end{array}$ & $\begin{array}{r}c \\
18\end{array}$ & $\begin{array}{r}\text { C } \\
(2,2)\end{array}$ & $\begin{array}{l}25 \\
17\end{array}$ & $\begin{array}{l}(3,5) \\
(1,3)\end{array}$ & $\begin{array}{l}45 \\
43\end{array}$ & $\begin{array}{l}(4,5) \\
(1,7)\end{array}$ & $\begin{array}{l}27 \\
36\end{array}$ & $\begin{array}{l}(3,6) \\
(1,8)\end{array}$ & $\begin{array}{l}3 \\
4\end{array}$ & $\begin{array}{l}(1,2) \\
(0,8)\end{array}$ \\
\hline Estland & $\begin{array}{l}\text { Teilzeit } \\
\text { Vollzeit }\end{array}$ & $\begin{array}{l}c \\
8\end{array}$ & $\begin{array}{r}\text { C } \\
(1,2)\end{array}$ & $\begin{array}{r}c \\
28\end{array}$ & $\begin{array}{r}\text { C } \\
(1,7)\end{array}$ & $\begin{array}{r}C \\
46\end{array}$ & $\begin{array}{r}c \\
(2,0)\end{array}$ & $\begin{array}{r}C \\
18\end{array}$ & $\begin{array}{r}\text { C } \\
(1,8)\end{array}$ & $\begin{array}{r}c \\
15\end{array}$ & $\begin{array}{r}c \\
(1,5)\end{array}$ & $\begin{array}{r}c \\
40\end{array}$ & $\begin{array}{r}\text { C } \\
(2,3)\end{array}$ & $\begin{array}{r}c \\
37\end{array}$ & $\begin{array}{r}\text { C } \\
(2,3)\end{array}$ & $\begin{array}{l}\mathrm{C} \\
7\end{array}$ & $\begin{array}{r}\mathrm{C} \\
(1,2)\end{array}$ \\
\hline Finnland & $\begin{array}{l}\text { Teilzeit } \\
\text { Vollzeit }\end{array}$ & $\begin{array}{l}c \\
4\end{array}$ & $\begin{array}{r}\text { C } \\
(1,0)\end{array}$ & $\begin{array}{r}c \\
15\end{array}$ & $\begin{array}{r}\mathrm{C} \\
(2,1)\end{array}$ & $\begin{array}{r}c \\
42\end{array}$ & $\begin{array}{r}\text { C } \\
(2,3)\end{array}$ & $\begin{array}{r}c \\
39\end{array}$ & $\begin{array}{r}\mathrm{C} \\
(1,9)\end{array}$ & $\begin{array}{r}9 \\
14\end{array}$ & $\begin{array}{l}(3,3) \\
(1,6)\end{array}$ & $\begin{array}{l}51 \\
38\end{array}$ & $\begin{array}{l}(6,3) \\
(2,2)\end{array}$ & $\begin{array}{l}32 \\
40\end{array}$ & $\begin{array}{l}(5,8) \\
(2,1)\end{array}$ & $\begin{array}{l}8 \\
8\end{array}$ & $\begin{array}{l}(3,2) \\
(1,1)\end{array}$ \\
\hline Frankreich & $\begin{array}{l}\text { Teilzeit } \\
\text { Vollzeit }\end{array}$ & $\begin{array}{l}c \\
9\end{array}$ & $\begin{array}{r}\mathrm{C} \\
(1,2)\end{array}$ & $\begin{array}{r}c \\
31\end{array}$ & $\begin{array}{r}c \\
(1,9)\end{array}$ & $\begin{array}{r}c \\
45\end{array}$ & $\begin{array}{r}c \\
(2,3)\end{array}$ & $\begin{array}{r}c \\
15\end{array}$ & $\begin{array}{r}c \\
(1,2)\end{array}$ & $\begin{array}{l}36 \\
30\end{array}$ & $\begin{array}{l}(4,0) \\
(1,9)\end{array}$ & $\begin{array}{l}38 \\
42\end{array}$ & $\begin{array}{l}(4,5) \\
(2,1)\end{array}$ & $\begin{array}{l}25 \\
25\end{array}$ & $\begin{array}{l}(3,9) \\
(1,7)\end{array}$ & $\begin{array}{l}2 \\
3\end{array}$ & $\begin{array}{l}(1,1) \\
(0,8)\end{array}$ \\
\hline Deutschland & $\begin{array}{l}\text { Teilzeit } \\
\text { Vollzeit }\end{array}$ & $\begin{array}{l}12 \\
12\end{array}$ & $\begin{array}{l}(3,5) \\
(1,8)\end{array}$ & $\begin{array}{l}25 \\
29\end{array}$ & $\begin{array}{l}(3,9) \\
(2,3)\end{array}$ & $\begin{array}{l}44 \\
43\end{array}$ & $\begin{array}{l}(6,2) \\
(2,5)\end{array}$ & $\begin{array}{l}20 \\
16\end{array}$ & $\begin{array}{l}(4,8) \\
(1,8)\end{array}$ & $\begin{array}{l}23 \\
16\end{array}$ & $\begin{array}{l}(4,6) \\
(2,9)\end{array}$ & $\begin{array}{l}45 \\
44\end{array}$ & $\begin{array}{l}(6,8) \\
(3,5)\end{array}$ & $\begin{array}{l}29 \\
35\end{array}$ & $\begin{array}{l}(4,8) \\
(2,8)\end{array}$ & $\begin{array}{l}3 \\
5\end{array}$ & $\begin{array}{l}(1,7) \\
(1,4)\end{array}$ \\
\hline Irland & $\begin{array}{l}\text { Teilzeit } \\
\text { Vollzeit }\end{array}$ & $\begin{array}{r}12 \\
8\end{array}$ & $\begin{array}{l}(3,3) \\
(1,2)\end{array}$ & $\begin{array}{l}41 \\
31\end{array}$ & $\begin{array}{l}(4,6) \\
(2,2)\end{array}$ & $\begin{array}{l}38 \\
45\end{array}$ & $\begin{array}{l}(4,5) \\
(2,4)\end{array}$ & $\begin{array}{r}9 \\
16\end{array}$ & $\begin{array}{l}(3,0) \\
(2,1)\end{array}$ & $\begin{array}{l}22 \\
24\end{array}$ & $\begin{array}{l}(3,9) \\
(3,6)\end{array}$ & $\begin{array}{l}43 \\
41\end{array}$ & $\begin{array}{l}(5,2) \\
(4,3)\end{array}$ & $\begin{array}{l}31 \\
31\end{array}$ & $\begin{array}{l}(5,1) \\
(3,1)\end{array}$ & $\begin{array}{l}3 \\
4\end{array}$ & $\begin{array}{l}(1,5) \\
(1,9)\end{array}$ \\
\hline Italien & $\begin{array}{l}\text { Teilzeit } \\
\text { Vollzeit }\end{array}$ & $\begin{array}{r}c \\
20\end{array}$ & $\begin{array}{r}\text { C } \\
(2,8)\end{array}$ & $\begin{array}{r}c \\
35\end{array}$ & $\begin{array}{r}\text { C } \\
(3,3)\end{array}$ & $\begin{array}{r}C \\
38\end{array}$ & $\begin{array}{r}\text { C } \\
(3,3)\end{array}$ & $\begin{array}{l}\mathrm{c} \\
7\end{array}$ & $\begin{array}{r}\text { C } \\
(1,6)\end{array}$ & $\begin{array}{r}c \\
35\end{array}$ & $\begin{array}{r}\text { C } \\
(4,8)\end{array}$ & $\begin{array}{r}c \\
43\end{array}$ & $\begin{array}{r}\text { C } \\
(5,3)\end{array}$ & $\begin{array}{r}c \\
21\end{array}$ & $\begin{array}{r}\text { C } \\
(3,8)\end{array}$ & $\begin{array}{l}\mathrm{C} \\
2\end{array}$ & $\begin{array}{r}\mathrm{C} \\
(1,1)\end{array}$ \\
\hline Japan & $\begin{array}{l}\text { Teilzeit } \\
\text { Vollzeit }\end{array}$ & $\begin{array}{l}\mathrm{c} \\
2\end{array}$ & $\begin{array}{r}\text { c } \\
(0,7)\end{array}$ & $\begin{array}{r}c \\
12\end{array}$ & $\begin{array}{r}\mathrm{C} \\
(1,7)\end{array}$ & $\begin{array}{r}c \\
53\end{array}$ & $\begin{array}{r}\text { C } \\
(2,3)\end{array}$ & $\begin{array}{r}c \\
33\end{array}$ & $\begin{array}{r}\text { C } \\
(2,4)\end{array}$ & $\begin{array}{l}15 \\
11\end{array}$ & $\begin{array}{l}(3,1) \\
(1,7)\end{array}$ & $\begin{array}{l}36 \\
36\end{array}$ & $\begin{array}{l}(4,0) \\
(2,8)\end{array}$ & $\begin{array}{l}40 \\
43\end{array}$ & $\begin{array}{l}(4,2) \\
(2,8)\end{array}$ & $\begin{array}{r}9 \\
10\end{array}$ & $\begin{array}{l}(2,3) \\
(1,7)\end{array}$ \\
\hline Korea & $\begin{array}{l}\text { Teilzeit } \\
\text { Vollzeit }\end{array}$ & $\begin{array}{l}c \\
4\end{array}$ & $\begin{array}{r}c \\
(0,9)\end{array}$ & $\begin{array}{r}c \\
28\end{array}$ & $\begin{array}{r}\text { C } \\
(2,2)\end{array}$ & $\begin{array}{r}C \\
54\end{array}$ & $\begin{array}{r}c \\
(2,3)\end{array}$ & $\begin{array}{r}c \\
14\end{array}$ & $\begin{array}{r}\mathrm{C} \\
(1,7)\end{array}$ & $\begin{array}{l}36 \\
28\end{array}$ & $\begin{array}{l}(4,5) \\
(2,3)\end{array}$ & $\begin{array}{l}45 \\
47\end{array}$ & $\begin{array}{l}(5,5) \\
(2,9)\end{array}$ & $\begin{array}{l}18 \\
23\end{array}$ & $\begin{array}{l}(4,3) \\
(2,6)\end{array}$ & $\begin{array}{l}\mathrm{c} \\
2\end{array}$ & $\begin{array}{r}\text { C } \\
(0,9)\end{array}$ \\
\hline Niederlande & $\begin{array}{l}\text { Teilzeit } \\
\text { Vollzeit }\end{array}$ & $\begin{array}{l}8 \\
5\end{array}$ & $\begin{array}{l}(2,4) \\
(1,2)\end{array}$ & $\begin{array}{l}21 \\
17\end{array}$ & $\begin{array}{l}(3,8) \\
(2,0)\end{array}$ & $\begin{array}{l}46 \\
47\end{array}$ & $\begin{array}{l}(4,8) \\
(3,1)\end{array}$ & $\begin{array}{l}25 \\
32\end{array}$ & $\begin{array}{l}(3,6) \\
(3,3)\end{array}$ & $\begin{array}{l}19 \\
16\end{array}$ & $\begin{array}{l}(2,9) \\
(2,7)\end{array}$ & $\begin{array}{l}39 \\
34\end{array}$ & $\begin{array}{l}(3,8) \\
(3,6)\end{array}$ & $\begin{array}{l}36 \\
40\end{array}$ & $\begin{array}{l}(4,0) \\
(3,0)\end{array}$ & $\begin{array}{r}5 \\
10\end{array}$ & $\begin{array}{l}(2,0) \\
(2,1)\end{array}$ \\
\hline Norwegen & $\begin{array}{l}\text { Teilzeit } \\
\text { Vollzeit }\end{array}$ & $\begin{array}{r}18 \\
9\end{array}$ & $\begin{array}{l}(4,2) \\
(1,3)\end{array}$ & $\begin{array}{l}20 \\
20\end{array}$ & $\begin{array}{l}(4,7) \\
(2,0)\end{array}$ & $\begin{array}{l}43 \\
48\end{array}$ & $\begin{array}{l}(5,6) \\
(2,6)\end{array}$ & $\begin{array}{l}19 \\
24\end{array}$ & $\begin{array}{l}(4,1) \\
(2,1)\end{array}$ & $\begin{array}{l}24 \\
12\end{array}$ & $\begin{array}{l}(4,7) \\
(1,9)\end{array}$ & $\begin{array}{l}46 \\
40\end{array}$ & $\begin{array}{l}(5,4) \\
(3,1)\end{array}$ & $\begin{array}{l}27 \\
41\end{array}$ & $\begin{array}{l}(5,2) \\
(2,7)\end{array}$ & $\begin{array}{l}3 \\
7\end{array}$ & $\begin{array}{l}(2,0) \\
(1,4)\end{array}$ \\
\hline Polen & $\begin{array}{l}\text { Teilzeit } \\
\text { Vollzeit }\end{array}$ & $\begin{array}{r}6 \\
12\end{array}$ & $\begin{array}{l}(3,5) \\
(1,5)\end{array}$ & $\begin{array}{l}30 \\
33\end{array}$ & $\begin{array}{l}(5,7) \\
(2,8)\end{array}$ & $\begin{array}{l}48 \\
38\end{array}$ & $\begin{array}{l}(7,5) \\
(2,7)\end{array}$ & $\begin{array}{l}16 \\
16\end{array}$ & $\begin{array}{l}(5,3) \\
(1,6)\end{array}$ & $\begin{array}{r}c \\
20\end{array}$ & $\begin{array}{r}c \\
(2,5)\end{array}$ & $\begin{array}{r}C \\
42\end{array}$ & $\begin{array}{r}c \\
(3,9)\end{array}$ & $\begin{array}{r}c \\
32\end{array}$ & $\begin{array}{r}c \\
(3,5)\end{array}$ & $\begin{array}{l}c \\
6\end{array}$ & $\begin{array}{r}\mathrm{C} \\
(2,1)\end{array}$ \\
\hline Slowakei & $\begin{array}{l}\text { Teilzeit } \\
\text { Vollzeit }\end{array}$ & $\begin{array}{l}c \\
6\end{array}$ & $\begin{array}{r}\text { C } \\
(1,1)\end{array}$ & $\begin{array}{r}\text { C } \\
30\end{array}$ & $\begin{array}{r}\text { C } \\
(2,1)\end{array}$ & $\begin{array}{r}C \\
52\end{array}$ & $\begin{array}{r}c \\
(2,3)\end{array}$ & $\begin{array}{r}C \\
12\end{array}$ & $\begin{array}{r}\mathrm{C} \\
(1,7)\end{array}$ & $\begin{array}{r}c \\
11\end{array}$ & $\begin{array}{r}c \\
(2,1)\end{array}$ & $\begin{array}{r}c \\
41\end{array}$ & $\begin{array}{r}\text { C } \\
(3,4)\end{array}$ & $\begin{array}{r}c \\
44\end{array}$ & $\begin{array}{r}\text { C } \\
(2,9)\end{array}$ & $\begin{array}{l}c \\
4\end{array}$ & $\begin{array}{r}\mathrm{C} \\
(1,2)\end{array}$ \\
\hline Spanien & $\begin{array}{l}\text { Teilzeit } \\
\text { Vollzeit }\end{array}$ & $\begin{array}{l}12 \\
18\end{array}$ & $\begin{array}{l}(3,4) \\
(2,1)\end{array}$ & $\begin{array}{l}33 \\
42\end{array}$ & $\begin{array}{l}(4,7) \\
(2,6)\end{array}$ & $\begin{array}{l}45 \\
34\end{array}$ & $\begin{array}{l}(4,9) \\
(2,2)\end{array}$ & $\begin{array}{r}10 \\
7\end{array}$ & $\begin{array}{l}(3,8) \\
(1,3)\end{array}$ & $\begin{array}{r}c \\
39\end{array}$ & $\begin{array}{r}\text { c } \\
(3,0)\end{array}$ & $\begin{array}{r}c \\
38\end{array}$ & $\begin{array}{r}\text { C } \\
(3,1)\end{array}$ & $\begin{array}{r}c \\
21\end{array}$ & $\begin{array}{r}\text { C } \\
(3,0)\end{array}$ & $\begin{array}{l}\mathrm{c} \\
2\end{array}$ & $\begin{array}{r}\mathrm{C} \\
(1,1)\end{array}$ \\
\hline Schweden & $\begin{array}{l}\text { Teilzeit } \\
\text { Vollzeit }\end{array}$ & $\begin{array}{l}c \\
6\end{array}$ & $\begin{array}{r}c \\
(1,2)\end{array}$ & $\begin{array}{r}c \\
20\end{array}$ & $\begin{array}{r}\text { C } \\
(2,1)\end{array}$ & $\begin{array}{r}C \\
45\end{array}$ & $\begin{array}{r}c \\
(2,6)\end{array}$ & $\begin{array}{r}C \\
28\end{array}$ & $\begin{array}{r}\text { C } \\
(2,2)\end{array}$ & $\begin{array}{r}c \\
13\end{array}$ & $\begin{array}{r}\text { C } \\
(1,5)\end{array}$ & $\begin{array}{r}c \\
36\end{array}$ & $\begin{array}{r}\text { C } \\
(2,8)\end{array}$ & $\begin{array}{r}C \\
41\end{array}$ & $\begin{array}{r}c \\
(2,9)\end{array}$ & $\begin{array}{l}c \\
9\end{array}$ & $\begin{array}{r}\mathrm{C} \\
(1,5)\end{array}$ \\
\hline Vereinigte Staaten & $\begin{array}{l}\text { Teilzeit } \\
\text { Vollzeit }\end{array}$ & $\begin{array}{r}c \\
16\end{array}$ & $\begin{array}{r}c \\
(1,8)\end{array}$ & $\begin{array}{r}c \\
29\end{array}$ & $\begin{array}{r}\mathrm{C} \\
(2,8)\end{array}$ & $\begin{array}{r}c \\
37\end{array}$ & $\begin{array}{r}\mathrm{c} \\
(2,5)\end{array}$ & $\begin{array}{r}c \\
18\end{array}$ & $\begin{array}{r}c \\
(2,2)\end{array}$ & $\begin{array}{r}c \\
18\end{array}$ & $\begin{array}{r}c \\
(2,4)\end{array}$ & $\begin{array}{r}c \\
34\end{array}$ & $\begin{array}{r}c \\
(3,0)\end{array}$ & $\begin{array}{r}c \\
38\end{array}$ & $\begin{array}{r}c \\
(2,6)\end{array}$ & $\begin{array}{r}c \\
10\end{array}$ & $\begin{array}{r}\mathrm{C} \\
(1,4)\end{array}$ \\
\hline Subnationale Einheiten & & & & & & & & & & & & & & & & & \\
\hline Flandern (Belgien) & $\begin{array}{l}\text { Teilzeit } \\
\text { Vollzeit }\end{array}$ & $\begin{array}{l}c \\
5\end{array}$ & $\begin{array}{r}c \\
(1,0)\end{array}$ & $\begin{array}{r}c \\
22\end{array}$ & $\begin{array}{r}\mathrm{C} \\
(2,1)\end{array}$ & $\begin{array}{r}c \\
49\end{array}$ & $\begin{array}{r}\mathrm{C} \\
(2,8)\end{array}$ & $\begin{array}{r}c \\
24\end{array}$ & $\begin{array}{r}\text { C } \\
(2,3)\end{array}$ & $\begin{array}{l}20 \\
18\end{array}$ & $\begin{array}{l}(4,7) \\
(2,7)\end{array}$ & $\begin{array}{l}46 \\
37\end{array}$ & $\begin{array}{l}(6,3) \\
(3,4)\end{array}$ & $\begin{array}{l}28 \\
37\end{array}$ & $\begin{array}{l}(5,4) \\
(3,6)\end{array}$ & $\begin{array}{l}5 \\
8\end{array}$ & $\begin{array}{l}(3,2) \\
(1,9)\end{array}$ \\
\hline England (VK) & $\begin{array}{l}\text { Teilzeit } \\
\text { Vollzeit }\end{array}$ & $\begin{array}{r}17 \\
8\end{array}$ & $\begin{array}{l}(4,3) \\
(1,6)\end{array}$ & $\begin{array}{l}29 \\
28\end{array}$ & $\begin{array}{l}(4,7) \\
(2,4)\end{array}$ & $\begin{array}{l}38 \\
42\end{array}$ & $\begin{array}{l}(5,0) \\
(2,7)\end{array}$ & $\begin{array}{l}16 \\
21\end{array}$ & $\begin{array}{l}(4,2) \\
(2,1)\end{array}$ & $\begin{array}{l}16 \\
17\end{array}$ & $\begin{array}{l}(3,6) \\
(3,2)\end{array}$ & $\begin{array}{l}36 \\
38\end{array}$ & $\begin{array}{l}(5,9) \\
(3,4)\end{array}$ & $\begin{array}{l}39 \\
33\end{array}$ & $\begin{array}{l}(4,8) \\
(3,6)\end{array}$ & $\begin{array}{r}9 \\
12\end{array}$ & $\begin{array}{l}(3,4) \\
(2,4)\end{array}$ \\
\hline Nordirland (VK) & $\begin{array}{l}\text { Teilzeit } \\
\text { Vollzeit }\end{array}$ & $\begin{array}{l}c \\
9\end{array}$ & $\begin{array}{r}c \\
(2,5)\end{array}$ & $\begin{array}{r}c \\
28\end{array}$ & $\begin{array}{r}c \\
(3,8)\end{array}$ & $\begin{array}{r}c \\
46\end{array}$ & $\begin{array}{r}c \\
(3,7)\end{array}$ & $\begin{array}{r}C \\
17\end{array}$ & $\begin{array}{r}c \\
(2,2)\end{array}$ & $\begin{array}{r}c \\
20\end{array}$ & $\begin{array}{r}c \\
(4,7)\end{array}$ & $\begin{array}{r}c \\
38\end{array}$ & $\begin{array}{r}c \\
(5,0)\end{array}$ & $\begin{array}{r}c \\
32\end{array}$ & $\begin{array}{r}c \\
(4,5)\end{array}$ & $\begin{array}{l}\mathrm{c} \\
9\end{array}$ & $\begin{array}{r}c \\
(2,7)\end{array}$ \\
\hline England/Nordirland (VK) & $\begin{array}{l}\text { Teilzeit } \\
\text { Vollzeit }\end{array}$ & $\begin{array}{r}17 \\
8\end{array}$ & $\begin{array}{l}(4,1) \\
(1,5)\end{array}$ & $\begin{array}{l}29 \\
28\end{array}$ & $\begin{array}{l}(4,7) \\
(2,4)\end{array}$ & $\begin{array}{l}38 \\
43\end{array}$ & $\begin{array}{l}(4,9) \\
(2,6)\end{array}$ & $\begin{array}{l}16 \\
21\end{array}$ & $\begin{array}{l}(4,1) \\
(2,1)\end{array}$ & $\begin{array}{l}16 \\
17\end{array}$ & $\begin{array}{l}(3,5) \\
(3,2)\end{array}$ & $\begin{array}{l}37 \\
38\end{array}$ & $\begin{array}{l}(5,8) \\
(3,3)\end{array}$ & $\begin{array}{l}39 \\
33\end{array}$ & $\begin{array}{l}(4,7) \\
(3,5)\end{array}$ & $\begin{array}{r}9 \\
12\end{array}$ & $\begin{array}{l}(3,4) \\
(2,3)\end{array}$ \\
\hline Durchschnitt & $\begin{array}{l}\text { Teilzeit } \\
\text { Vollzeit }\end{array}$ & $\begin{array}{r}12 \\
9\end{array}$ & $\begin{array}{l}(1,1) \\
(0,3)\end{array}$ & $\begin{array}{l}28 \\
26\end{array}$ & $\begin{array}{l}(1,4) \\
(0,5)\end{array}$ & $\begin{array}{l}43 \\
45\end{array}$ & $\begin{array}{l}(1,7) \\
(0,6)\end{array}$ & $\begin{array}{l}17 \\
20\end{array}$ & $\begin{array}{l}(1,3) \\
(0,4)\end{array}$ & $\begin{array}{l}21 \\
19\end{array}$ & $\begin{array}{l}(1,1) \\
(0,5)\end{array}$ & $\begin{array}{l}42 \\
40\end{array}$ & $\begin{array}{l}(1,5) \\
(0,7)\end{array}$ & $\begin{array}{l}32 \\
34\end{array}$ & $\begin{array}{l}(1,3) \\
(0,6)\end{array}$ & $\begin{array}{l}6 \\
7\end{array}$ & $\begin{array}{l}(0,7) \\
(0,3)\end{array}$ \\
\hline Partnerländer & & & & & & & & & & & & & & & & & \\
\hline Russische Föderation* & $\begin{array}{l}\text { Teilzeit } \\
\text { Vollzeit }\end{array}$ & $\begin{array}{r}c \\
12\end{array}$ & $\begin{array}{r}\text { C } \\
(2,2)\end{array}$ & $\begin{array}{r}c \\
34\end{array}$ & $\begin{array}{r}\text { C } \\
(3,9)\end{array}$ & $\begin{array}{r}c \\
44\end{array}$ & $\begin{array}{r}\mathrm{C} \\
(3,8)\end{array}$ & $\begin{array}{r}c \\
10\end{array}$ & $\begin{array}{r}c \\
(2,4)\end{array}$ & $\begin{array}{l}c \\
8\end{array}$ & $\begin{array}{r}c \\
(3,2)\end{array}$ & $\begin{array}{r}c \\
34\end{array}$ & $\begin{array}{r}c \\
(6,8)\end{array}$ & $\begin{array}{r}c \\
44\end{array}$ & $\begin{array}{r}\text { C } \\
(7,2)\end{array}$ & $\begin{array}{r}c \\
13\end{array}$ & $\begin{array}{r}\text { C } \\
(4,1)\end{array}$ \\
\hline
\end{tabular}

* Hinweis zu den Daten der Russischen Föderation s. Abschnitt Angewandte Methodik.

Anmerkung: Die Spalten mit den Daten für andere Altersgruppen (d.h. 35- bis 44-Jährige, 45- bis 54- Jährige und 25- bis 64-Jährige) sind im Internet verfügbar (s. StatLink unten).

Quelle: OECD. Survey of Adult Skills (PIAAC) (2012). PIAAC steht für das OECD Programme for the International Assessment of Adult Competencies. Hinweise s. Anhang 3 unter www.oecd.org/edu/eag.htm. StatLink: http://dx.doi.org/10.1787/888933115939

Erläuterung der Kennzeichnung fehlender Daten s. Hinweise für den Leser. 


\section{Indilkatior AE}

\section{Welche Einkommenszuschläge lassen sich durch Bildung erzielen?}

In allen OECD-Ländern verdienen Erwachsene mit einem Abschluss im Tertiärbereich mehr als Erwachsene mit einem Abschluss im Sekundarbereich II bzw. postsekundaren, nicht tertiären Bereich, die wiederum mehr verdienen als Erwachsene mit einer Ausbildung unterhalb des Sekundarbereichs II.

- Nimmt man Erwachsene mit Erwerbseinkommen mit einem Abschluss im Sekundarbereich II als Vergleichsmaßstab, so verdienen im Durchschnitt der OECDLänder diejenigen ohne diesen Abschluss rund 20 Prozent weniger, diejenigen mit einem Abschluss im postsekundaren, nicht tertiären Bereich rund ro Prozent mehr, diejenigen mit einem Abschluss im (berufsorientierten) Tertiärbereich B rund 30 Prozent mehr und diejenigen mit einem Abschluss im (theoretisch ausgerichteten) Tertiärbereich A bzw. einem weiterführenden forschungsorientierten Studiengang rund 70 Prozent mehr.

Im Durchschnitt der OECD-Länder erreicht eine Frau mit einem Abschluss im Tertiärbereich ungefähr 75 Prozent des Einkommens eines Mannes mit dem gleichen Bildungsstand. Nur in Belgien, Slowenien, Spanien und der Türkei erzielen die Absolventinnen des Tertiärbereichs mindestens 8o Prozent der Einkommen der Männer. In Brasilien, Chile und Ungarn erreichen Absolventinnen des Tertiärbereichs höchstens $6_{5}$ Prozent der Einkommen von Männern mit gleichem Bildungsstand.

Ein Absolvent des Tertiärbereichs mit einer Lesekompetenz auf Stufe 4 oder 5 bei der Erhebung zu den grundlegenden Kompetenzen Erwachsener (PIAAC) verdient durchschnittlich rund 45 Prozent mehr als ein Erwachsener mit vergleichbarer Ausbildung, dessen Lesekompetenz auf oder unterhalb der Stufe I liegt. Bei Erwachsenen mit einem Abschluss im Sekundarbereich II beträgt die Einkommensspanne zwischen denjenigen mit hoher und denen mit niedriger Lesekompetenz rund 30 Prozent. 


\section{Abbildung A6.1}

Relative Einkommen von Erwerbstätigen, nach Bildungsstand und Geschlecht (2012)

25- bis 64-Jährige mit Erwerbseinkommen, Abschluss im Sekundarbereich $/ I=100$

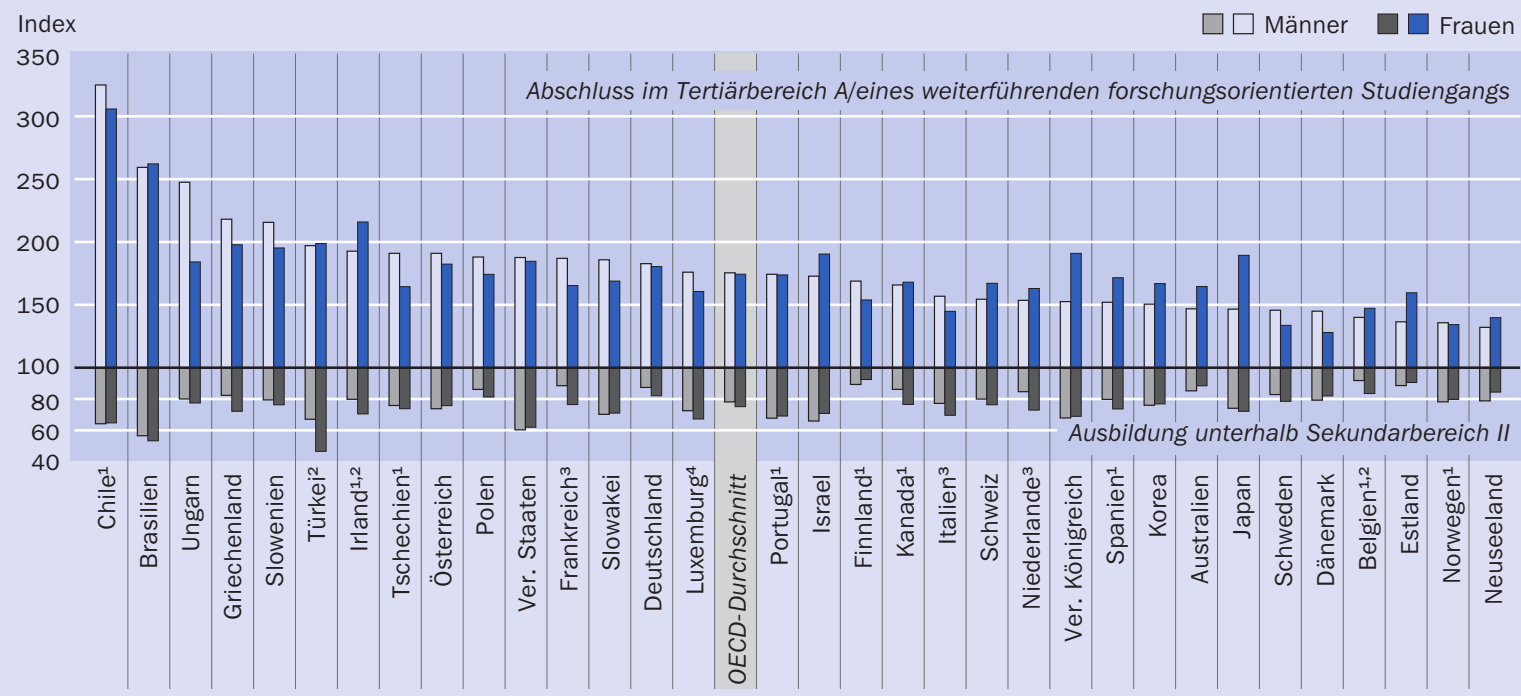

1. Referenzjahr 2011. 2. Einkommen nach Abzug der Einkommensteuer. 3. Referenzjahr 2010. 4. Daten beziehen sich auf Abschlüsse im gesamten Tertiärbereich.

Anordnung der Länder in absteigender Reihenfolge der relativen Einkommen von 25- bis 64-jährigen Männern mit einem Abschluss im Tertiärbereich A bzw. einem weiterführenden forschungsorientierten Studiengang.

Quelle: OECD. Tabelle A6.1b im Internet. Hinweise s. Anhang 3 unter www.oecd.org/edu/eag.htm. StatLink: http://dx.doi.org/10.1787/888933116205

\section{Kontext}

Auch wenn die Aussicht auf einen besseren Arbeitsplatz nur einer von vielen gesellschaftlichen und persönlichen Vorteilen ist, die ein höherer Bildungsabschluss mit sich bringt, geht aus den Daten hervor, dass ein höherer Bildungsstand in der Regel zu besseren Beschäftigungschancen (s. Indikator A5) und höheren Einkommen führt. Für alle OECD-Länder mit verfügbaren Daten gilt in der Tat, je höher der Bildungsstand, desto höher das relative Einkommen. Gleiches gilt anscheinend auch für die verschiedenen Kompetenzniveaus: Personen mit einer hohen Lesekompetenz nach der Erhebung zu den grundlegenden Kompetenzen Erwachsener im Rahmen des OECD Programme for the International Assessment of Adult Competencies (PIAAC) berichten die höchsten Einkommen, während diejenigen mit einer niedrigen Kompetenz im Allgemeinen die niedrigsten Einkommen angeben.

Die Chance auf ein höheres Einkommen und Steigerungen dieses Einkommens im Verlaufe der Zeit zusammen mit weiteren gesellschaftlichen Vorteilen stellen für den Einzelnen einen Anreiz dar, auf einen höheren Bildungsstand hinzuarbeiten, auch wenn die wirtschaftlichen Vorteile je nach gewählter Fächergruppe unterschiedlich groß sein können (s. Kasten A6.I in Bildung aufeinen Blick 2013 [OECD, 2013]). Während die relativen Einkommen von Personen mit einem höheren Bildungsstand tendenziell mit zunehmendem Alter steigen, sinken die relativen Einkommen von Personen mit einer Ausbildung unterhalb des Sekundarbereichs II eher tendenziell mit zunehmendem Alter. Das „relative Einkommen“ ist, in Prozenten ausgedrückt, das Einkommen Erwachsener mit anderen Bildungsabschlüssen als einem Abschluss im Sekundarbereich II im Verhältnis zu den Einkommen der Absolventen des Sekundarbereichs II. 
Die länderspezifischen Unterschiede bei den relativen Einkommen (vor Steuern) spiegeln verschiedene Einflussfaktoren wider, u. a. die Arbeitsmarktnachfrage nach bestimmten Kompetenzen, das Arbeitskräfteangebot mit einem bestimmten Bildungsstand, die Gesetzgebung zu den Mindestlöhnen, die Stärke der Gewerkschaften, die mehr oder weniger flächendeckende Geltung von Tarifverträgen, die relative Verbreitung von saisonaler und Teilzeitbeschäftigung und die Altersstruktur der Erwerbsbevölkerung.

Die Daten in diesem Indikator zeigen, dass die Einkommensvorteile je nach Bildungsstand, Alter, Geschlecht und Kompetenzniveau zu- oder abnehmen. Jeder dieser Faktoren scheint sich unterschiedlich stark auf die Einkommensvorteile des Einzelnen auszuwirken. Je höher die erworbene Qualifikation ist, umso günstiger ist die Ausgangsposition für die Erreichung eines höheren Einkommens und dessen Steigerung im Laufe der Zeit. Ferner scheint sich ein hohes Kompetenzniveau auf dem Arbeitsmarkt nicht nur in den Beschäftigungsquoten, sondern auch beim mittleren Einkommen bezahlt zu machen. In vielen Ländern gibt es jedoch immer noch geschlechtsspezifische Unterschiede, unabhängig von Bildungsstand und Kompetenzniveau.

\section{Weitere wichtige Ergebnisse}

Nur rund 10 Prozent der Absolventen des Tertiärbereichs befinden sich in der unteren Einkommenskategorie, im Allgemeinen verdienen sie mit hoher Wahrscheinlichkeit doppelt so viel wie ein Erwerbstätiger am Einkommensmedian. Rund 30 Prozent der Absolventen des Tertiärbereichs verdienen das Doppelte des Medians, und gleichzeitig ist die Wahrscheinlichkeit, dass sie in der niedrigen Einkommenskategorie sind, wesentlich geringer als für diejenigen mit einer Ausbildung unterhalb des Sekundarbereichs II (von denen 3 Prozent mehr als das Doppelte des Medians verdienen und rund 30 Prozent höchstens die Hälfte des Medians).

In Brasilien, der Türkei und den Vereinigten Staaten erleiden Erwachsene ohne einen Abschluss im Sekundarbereich II die größten Einkommenseinbußen aufgrund ihres Bildungsstands, sie verdienen im günstigsten Fall 35 Prozent weniger als die Absolventen des Sekundarbereichs II. In Chile, Brasilien und Ungarn profitieren die Absolventen des Tertiärbereichs vom vergleichsweise größten Bonus, denn sie verdienen mehr als das Doppelte eines Absolventen des Sekundarbereichs II.

Ungefähr 65 Prozent der 15- bis 24-Jährigen, die sich nicht in Ausbildung befinden, haben Erwerbseinkommen, wohingegen dies auf weniger als die Hälfte der Schüler/Studierenden (rund 40 Prozent) zutrifft. In den OECD-Ländern haben rund 50 Prozent der I5- bis 24-Jährigen ein Erwerbseinkommen.

55- bis 64-jährige Frauen mit einem Abschluss entweder im Tertiärbereich oder einer Ausbildung unterhalb des Sekundarbereichs II können davon ausgehen, rund 75 Prozent des Einkommens von Männern in der gleichen Altersgruppe und mit dem gleichen Bildungsstand zu verdienen, wohingegen Frauen in dieser Altersgruppe mit einem Abschluss im Sekundarbereich II davon ausgehen können, rund 8o Prozent der Einkommen von Männern in der gleichen Altersgruppe und mit dem gleichen Bildungsstand zu verdienen. 


\section{Entwicklungstendenzen}

In allen OECD-Ländern verdienen Erwachsene mit einem Abschluss im Tertiärbereich deutlich mehr als Erwachsene mit einer Ausbildung unterhalb des Sekundarbereichs II. Zwischen 2005 und 2012 sind in den Ländern mit verfügbaren Daten für beide Jahre die relativen Einkommen von Erwachsenen mit einer Ausbildung unterhalb des Sekundarbereichs II im Vergleich zu den Einkommen von Erwachsenen mit einem Abschluss im Sekundarbereich II entweder stabil geblieben oder in begrenztem Umfang gesunken. Außerdem sind in den meisten dieser Länder (mit Ausnahme von Ungarn und den Vereinigten Staaten) die Einkommen von Erwerbstätigen mit einem Abschluss im Tertiärbereich in Relation zu den Einkommen von Erwerbstätigen mit einem Abschluss im Sekundarbereich II bzw. dem postsekundaren, nicht tertiären Bereich während des gleichen Zeitraums gestiegen bzw. mindestens stabil geblieben.

Diese Unterschiede deuten darauf hin, dass die Nachfrage nach speziellen Kompetenzen, die auf dem neuesten Stand sind, gestiegen ist - und dass sich Personen mit weniger speziellen Kompetenzen heute in einer noch schwächeren Position befinden.

\section{Analyse und Interpretationen}

\section{Bildungsstand und relative Einkommen}

Je höher der Bildungsstand, desto höher das relative Einkommen. Das „relative Einkommen“ ist, in Prozenten ausgedrückt, das Einkommen Erwachsener mit anderen Bildungsabschlüssen als einem Abschluss im Sekundarbereich II im Verhältnis zu den Einkommen der Absolventen des Sekundarbereichs II.

In allen OECD-Ländern verdienen Erwachsene mit einem Abschluss im Tertiärbereich mehr als Erwachsene mit einem Abschuss im Sekundarbereich II, die wiederum mehr verdienen als Erwachsene mit einer Ausbildung unterhalb des Sekundarbereichs II. Ein Abschluss des Sekundarbereichs II stellt in vielen Ländern den Bildungsstand dar, ab dem eine weitere Ausbildung hohe relative Einkommen mit sich bringt. So könnte man einen Abschluss im Sekundarbereich II als die Bezugsgröße sehen, anhand derer das Einkommen in Relation zum Bildungsstand gemessen werden kann. Da die privaten Investitionskosten für Bildung oberhalb des Sekundarbereichs II in den meisten Ländern deutlich höher sind, stellt ein hoher Einkommenszuschlag einen wichtigen Anreiz dar, um Zeit und Geld in die weitere Ausbildung zu investieren (Tab. A6.Ia).

Die Einkommensunterschiede zwischen Absolventen des Tertiärbereichs und Absolventen des Sekundarbereichs II sind im Allgemeinen ausgeprägter als die Einkommensunterschiede zwischen Absolventen des Sekundarbereichs II und Personen mit einer Ausbildung unterhalb des Sekundarbereichs II. Nimmt man Erwachsene mit Erwerbseinkommen mit einem Abschluss im Sekundarbereich II als Vergleichsmaßstab, so verdienen im Durchschnitt der OECD-Länder diejenigen ohne diesen Abschluss rund 20 Prozent weniger, diejenigen mit einem Abschluss im postsekundaren, nicht tertiären Bereich rund so Prozent mehr, diejenigen mit einem Abschluss im Tertiärbereich B rund 30 Prozent mehr und diejenigen mit einem Abschluss im Tertiärbe- 
reich A bzw. einem weiterführenden forschungsorientierten Studiengang rund 70 Prozent mehr.

In Chile, Brasilien, der Türkei, Ungarn und den Vereinigten Staaten sind die Unterschiede zwischen den Einkommen je nach Bildungsstand am ausgeprägtesten. In Brasilien, der Türkei und den Vereinigten Staaten müssen Erwachsene ohne einen Abschluss im Sekundarbereich II die größten Einkommenseinbußen hinnehmen, da sie im günstigsten Fall 35 Prozent weniger als die Absolventen des Sekundarbereichs II verdienen. In Chile, Brasilien und Ungarn, erhalten die Absolventen des Tertiärbereichs den größten Bonus gegenüber den niedrigeren Bildungsabschlüssen, denn sie verdienen mehr als das Doppelte eines Absolventen des Sekundarbereichs II (Tab. A6.ra).

\section{Relative Einkommen - nach Geschlecht}

In den OECD-Ländern wirkt sich der Bildungsstand in unterschiedlichem Ausmaß auf die relativen Einkommen aus. Aus Abbildung A6.I ergibt sich, dass im Durchschnitt der OECD-Länder bezogen auf den Bildungsstand keine großen geschlechtsspezifischen Unterschiede bei den relativen Einkommen der Erwachsenen mit Erwerbseinkommen bestehen. Sowohl Absolventen als auch Absolventinnen des Tertiärbereichs (nur von Studiengängen auf ISCED-Stufe 5 A oder 6 in Abbildung A6.I) verdienen rund 70 Prozent mehr als ein Absolvent bzw. eine Absolventin des Sekundarbereichs II. Es bestehen jedoch große Unterschiede zwischen den einzelnen Ländern. In einigen Ländern verdienen Erwachsene mit einem Abschluss des Tertiärbereichs mehr als doppelt so viel wie Erwachsene mit einem Abschluss des Sekundarbereichs II: in Chile und Brasilien (Männer und Frauen), in Griechenland, Slowenien und Ungarn (Männer) und in Irland (Frauen) (Tab. A6.Ib im Internet).

Die geschlechtsspezifischen Unterschiede der relativen Einkommen von Absolventen und Absolventinnen des Tertiärbereichs (d. h. im Vergleich zu den Einkommen erwachsener Absolventen bzw. Absolventinnen des Sekundarbereichs II) variieren zwischen den Ländern. In Australien, Estland, Irland, Israel, Japan, Korea, der Schweiz, Spanien und dem Vereinigten Königreich liegen die relativen Einkommen der Frauen mehr als Io Prozentpunkte über den relativen Einkommen der Männer. In Chile, Dänemark, Finnland, Frankreich, Griechenland, Italien, Luxemburg, Polen, der Slowakei, Slowenien, Schweden, Tschechien und Ungarn hingegen liegen die relativen Einkommen der Männer mehr als ıo Prozentpunkte über denen der Frauen. In beiden Fällen handelt es sich um Unterschiede in Relation zu den Einkommen von Erwerbstätigen des gleichen Geschlechts mit einem Abschluss im Sekundarbereich II, die über ein Erwerbseinkommen verfügen. Beim Vergleich der Werte für beide Geschlechter ist zu berücksichtigen, dass zwischen ihnen große Unterschiede hinsichtlich des Anteils der Personen mit Erwerbseinkommen bestehen können (Tab. A6.rb im Internet).

\section{Relative Einkommen - nach Alter}

Ein höherer Bildungsstand steht im Zusammenhang mit höheren Einkommen während des gesamten Erwerbslebens. Im Durchschnitt der OECD-Länder steigen die Einkommen mit einem höheren Bildungsstand, wobei dieser Anstieg für ältere Erwerbstätige besonders groß ist. Personen mit einem höheren Bildungsstand haben eine größere Wahrscheinlichkeit, einen Arbeitsplatz zu finden und auch zu behalten, und damit auch größere Chancen, Berufserfahrung zu gewinnen. 
Unterschiede in den relativen Einkommen älterer und jüngerer Erwerbstätiger, nach Bildungsstand (2012)

55- bis 64-jährige und 25- bis 34-jährige Erwerbstätige mit Erwerbseinkommen, Unterschied in Prozentpunkten, Einkommen in Relation zu den Einkommen von Erwerbstätigen mit einem Abschluss im Sekundarbereich II

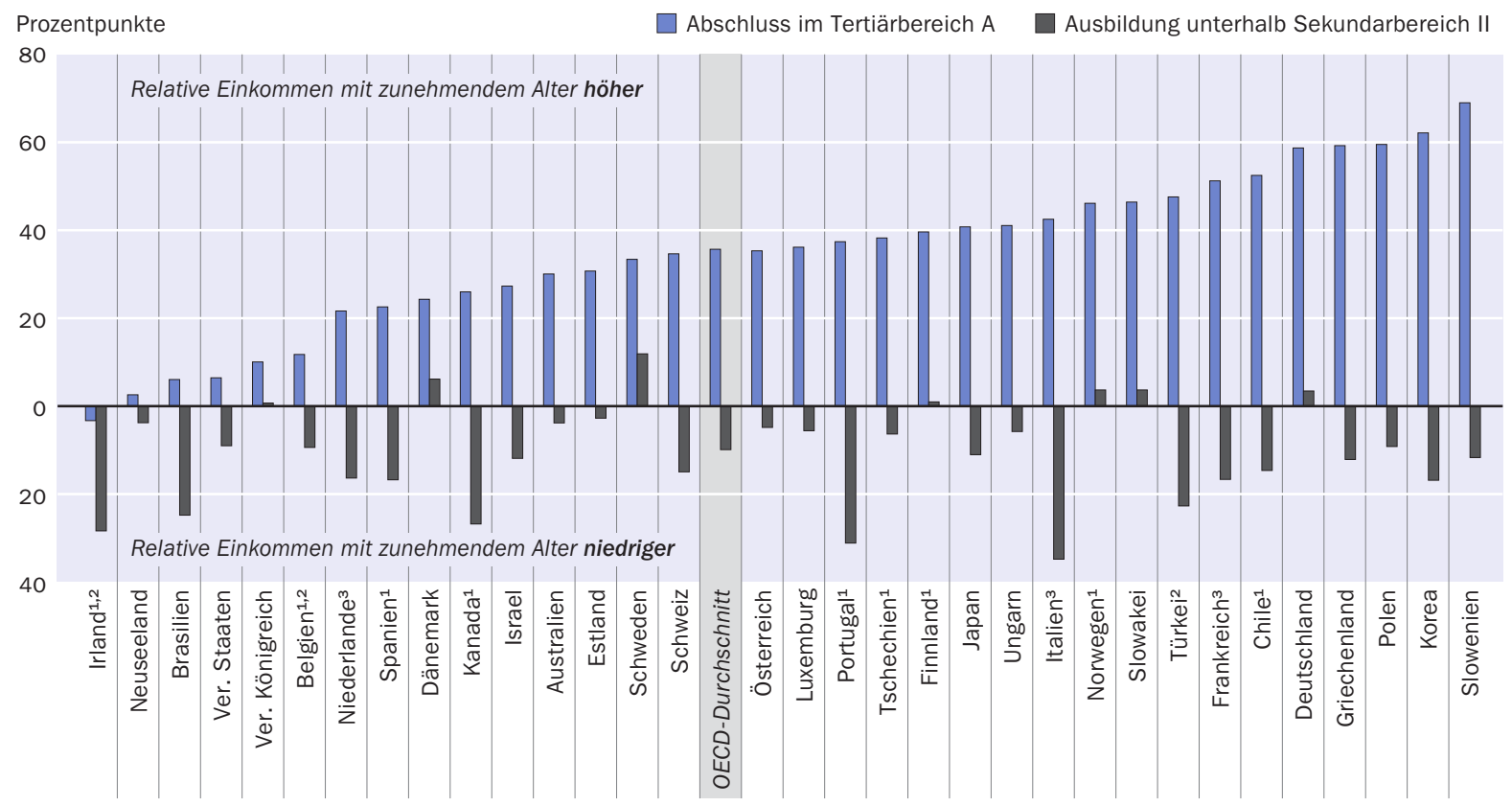

1. Referenzjahr 2011. 2. Einkommen nach Abzug der Einkommensteuer. 3. Referenzjahr 2010.

Anordnung der Länder in aufsteigender Reihenfolge des Unterschieds in den relativen Einkommen von 55- bis 64-jährigen und 25- bis 34-jährigen Erwerbstätigen mit einem Abschluss im Tertiärbereich.

Quelle: OECD. Tabelle A6.1a. Hinweise s. Anhang 3 unter www.oecd.org/edu/eag.htm. StatLink: http://dx.doi.org/10.1787/888933116224

In Abbildung A6.2 wird von dem Unterschied der relativen Einkommen der älteren Erwerbstätigen (d.h. der 55- bis 64-Jährigen) der Unterschied der relativen Einkommen der jüngeren Erwerbstätigen (d. h. der 25- bis 34-Jährigen) abgezogen. In beiden Fällen handelt es sich um Unterschiede in Relation zu den Einkommen von gleichaltrigen Erwerbstätigen mit einem Abschluss im Sekundarbereich II. Das Ergebnis ist der Unterschied der relativen Einkommen zwischen den beiden Altersgruppen, angegeben in Prozentpunkten. Legt man beispielsweise den OECD-Durchschnitt zugrunde, so verdienen junge Erwachsene mit einer Ausbildung unterhalb des Sekundarbereichs II ungefähr 8o Prozent des Entgelts junger Erwachsener mit einem Abschluss im Sekundarbereich II. Bei älteren Erwachsenen sind es 70 Prozent (Tab. A6.Ia). Abbildung A6.2 verdeutlicht den Unterschied zwischen diesen beiden Altersgruppen, der ungefähr Io Prozentpunkte beträgt. Für Beschäftigte mit einem Abschluss im Tertiärbereich bzw. in einem weiterführenden forschungsorientierten Studiengang (d. h. auf ISCED-Stufe 5A oder 6) wird der Unterschied zwischen den beiden Altersgruppen bei den relativen Einkommen auf die gleiche Art und Weise berechnet - er beläuft sich auf durchschnittlich rund 35 Prozentpunkte.

In den meisten OECD- und G20-Ländern mit Ausnahme von Irland liegen die relativen Einkommen von älteren Absolventen des Tertiärbereichs über denen von jüngeren Absolventen. Der Unterschied zwischen den beiden Altersgruppen beläuft sich im Durchschnitt auf bis zu 35 Prozentpunkte. In allen Ländern mit Ausnahme von Däne- 
mark, Deutschland, Finnland, Norwegen, Schweden, der Slowakei und dem Vereinigten Königreich vergrößern sich für diejenigen mit einer Ausbildung unterhalb des Sekundarbereichs II die Nachteile bei den relativen Einkommen mit zunehmendem Alter. Dieser zunehmende Nachteil ist nicht so ausgeprägt wie der Anstieg des Einkommensvorteils für Absolventen des Tertiärbereichs, was darauf hindeutet, dass ein Abschluss im Tertiärbereich der entscheidende Faktor für ein höheres Einkommen mit zunehmendem Alter ist (Tab. A6.ra).

\section{Entwicklung der relativen Einkommen - nach Bildungsstand}

Zwischen 2005 und 2012 sind in den Ländern mit verfügbaren Daten für beide Jahre die relativen Einkommen von Erwachsenen mit einer Ausbildung unterhalb des Sekundarbereichs II und Erwerbseinkommen im Vergleich zu den Einkommen von Erwachsenen mit einem Abschluss im Sekundarbereich II entweder stabil geblieben oder in begrenztem Umfang gesunken. In den meisten Ländern, mit Ausnahme von Ungarn und den Vereinigten Staaten, sind die relativen Einkommen von Erwerbstätigen mit einem Abschluss im Tertiärbereich zwischen 2005 und 2012 gestiegen. Dennoch waren die relativen Einkommen in einigen Ländern starken Schwankungen unterworfen. Ferner stehen die Daten zur Entwicklung der Einkommen jeweils in Relation zu den Veränderungen der Einkommen von Erwerbstätigen mit einem Abschluss im Sekundarbereich II. Daher ist es schwierig, die durchschnittliche Entwicklung der relativen Einkommen der Erwerbstätigen mit unterschiedlichem Bildungsstand über die Jahre hinweg zu beurteilen (weitere Informationen s. Abschnitt Angewandte Methodik) (Tab. A6.2a).

\section{Unterschiede im Einkommen zwischen weiblichen und männlichen Erwerbstätigen - nach Bildungsstand}

Geschlechtsspezifische Einkommensunterschiede bestehen unabhängig vom Bildungsstand weiter. Die zur Verfügung stehenden Daten zu ganzjährig Vollzeiterwerbstätigen zeigen, dass der größte Einkommensunterschied zwischen Männern und Frauen bei Erwerbstätigen mit einem Abschluss im Tertiärbereich besteht. Im Durchschnitt der OECD-Länder erreicht eine Frau mit einem Abschluss im Tertiärbereich ungefähr 75 Prozent des Einkommens eines Mannes mit gleichem Bildungsstand. Nur in Belgien, Slowenien, Spanien und der Türkei erzielen die Absolventinnen des Tertiärbereichs mindestens 8o Prozent der Einkommen der Männer. In Brasilien, Chile und Ungarn erreichen Absolventinnen des Tertiärbereichs höchstens $6_{5}$ Prozent der Einkommen von Männern mit gleichem Bildungsstand (Tab. A6.3a).

Im Durchschnitt erreichen nur vollzeiterwerbstätige Absolventinnen des Sekundarbereichs II bzw. des postsekundaren, nicht tertiären Bildungsbereichs in Relation zu den Männern mit zunehmendem Alter Einkommenssteigerungen. Frauen mit einem Abschluss im Tertiärbereich sowie Frauen mit einer Ausbildung unterhalb des Sekundarbereichs II haben mit zunehmendem Alter keine Einkommenssteigerungen im Verhältnis zu den Einkommen der Männer. 55- bis 64-jährige Absolventinnen des Tertiärbereichs bzw. mit einer Ausbildung unterhalb des Sekundarbereichs II können damit rechnen, rund 75 Prozent des Einkommens von Männern in der gleichen Altersgruppe und mit dem gleichen Bildungsstand zu verdienen, wohingegen Frauen in dieser Altersgruppe mit einem Abschluss des Sekundarbereichs II rund 8o Prozent der Einkommen von Männern in der gleichen Altersgruppe und mit dem gleichen Bildungsstand verdienen können (Tab. A6.3a). 


\section{Einkommensverteilung innerhalb des jeweiligen Bildungsstands}

Anhand der Daten zur Verteilung der Einkommen in den verschiedenen Bildungsgruppen lässt sich ersehen, wie eng die Einkommen um den Median für ein Land verteilt sind. Dies zeigt nicht nur, in welchem Ausmaß die gleiche Einkommenshöhe erzielt wird, sondern weist auch auf die mit einer Investition in Bildung verbundenen Risiken hin, da das Risiko normalerweise anhand der Unterschiede hinsichtlich der Einkommenshöhe gemessen wird. Die Daten zur Einkommensverteilung (Tab. A6.4 im Internet) umfassen die Einkommen aller Erwerbstätigen, was deren Analyse gewissen Einschränkungen unterwirft, da sich die Anzahl der Arbeitsstunden auf die Einkommen im Allgemeinen und auf die Verteilung der Einkommen im Besonderen auswirkt (weitere Informationen s. Abschnitt Angewandte Methodik).

Für Erwerbstätige mit einem Erwerbseinkommen sind fünf Einkommenskategorien von „Hälfte oder weniger als die Hälfte des Medians“ bis „Mehr als das Doppelte des Medians" angegeben. In einer separaten Spalte ist der Anteil der Personen ohne Erwerbseinkommen aufgeführt. In Abbildung A6.3 werden die Ergebnisse für Personen mit einer Ausbildung unterhalb des Sekundarbereichs II und für die Absolventen des Tertiärbereichs A bzw. weiterführender forschungsorientierter Studiengänge (also der ISCED-Stufen $5 \mathrm{~A}$ oder 6) gegenübergestellt, indem der Anteil der Erwerbstätigen, deren Einkommen in die Kategorie „Hälfte oder weniger als die Hälfte des Medians“ fällt, mit dem Anteil der Erwerbstätigen verglichen wird, deren Einkommen „Mehr als das Doppelte des Medians“ beträgt. Wie erwartet ergibt sich zwischen diesen beiden Qualifikationsniveaus ein großer Unterschied: Im Durchschnitt haben die Absolventen des Tertiärbereichs eine wesentlich höhere Wahrscheinlichkeit, das Doppelte des Medians zu verdienen (bei rund 30 Prozent ist dies der Fall), und gleichzeitig ist die Wahrscheinlichkeit, dass sie in der niedrigsten Einkommenskategorie sind (trifft auf rund Io Prozent zu), wesentlich geringer als bei denjenigen mit einer Ausbildung unterhalb des Sekundarbereichs II (von denen 3 Prozent mehr als das Doppelte des Medians verdienen und rund 30 Prozent die Hälfte oder weniger als die Hälfte des Medians) (Tab. A6.4 im Internet).

Es gibt einige bemerkenswerte Unterschiede in der Situation von Absolventen des Tertiärbereichs zwischen den einzelnen Ländern. In Brasilien und Chile verdienen mindestens $6_{5}$ Prozent derjenigen, die den Tertiärbereich A bzw. einen weiterführenden forschungsorientierten Studiengang abgeschlossen haben, das Doppelte des Medians, während in Griechenland, Kanada und Österreich mindestens I5 Prozent dieser Absolventengruppe in die niedrigste Einkommenskategorie (Hälfte oder weniger als die Hälfte des Medians) fallen und in Dänemark und Norwegen Erwerbstätige mit einer solchen Qualifikation ungefähr gleich häufig in der niedrigsten und der höchsten Einkommenskategorie anzutreffen sind (Abb. A6.3).

In allen Ländern haben Personen, die während des gesamten Erwerbslebens nur über niedrige Qualifikationen verfügen (Ausbildung unterhalb des Sekundarbereichs II), in der Regel große Einkommensnachteile. Im Durchschnitt der OECD-Länder verdienen weniger als 5 Prozent derjenigen mit einer Ausbildung unterhalb des Sekundarbereichs II das Doppelte des nationalen Medians. Nur in Brasilien, Estland, Kanada und Portugal liegt ihr Anteil bei über 5 Prozent. Im Durchschnitt verdienen mehr als 25 Prozent der Erwerbstätigen mit einer Ausbildung unterhalb des Sekundarbereichs II 
Unterschiede in den relativen Einkommen von Erwerbstätigen, nach Bildungsstand (2012)

25- bis 64-Jährige mit Erwerbseinkommen

$\square$ Hälfte oder weniger als die Hälfte des Medians

Ausbildung unterhalb Sekundarbereich II

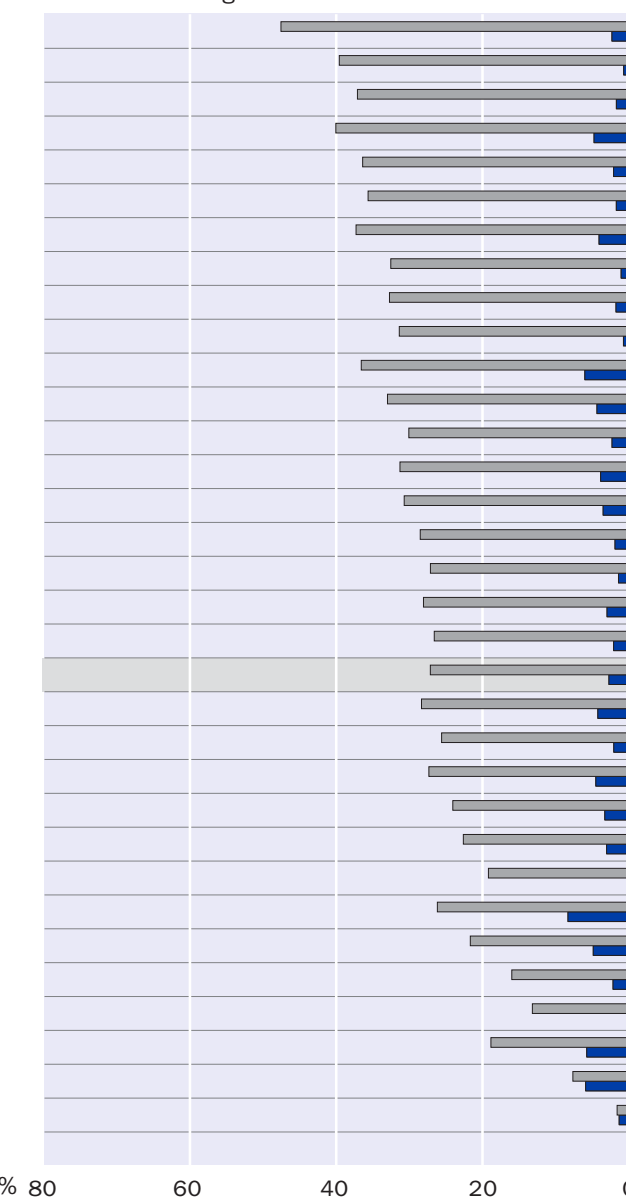

Mehr als das Doppelte des Medians

Abschluss im Tertiärbereich A/eines weiterführenden forschungsorientierten Studiengangs

Vereinigte Staaten Korea Österreich Irland $^{1,2}$ Vereinigtes Königreich Deutschland Japan Slowakei Niederlande $^{3}$ Schweiz Kanada $^{1}$ Frankreich $^{3}$ Norwegen ${ }^{1}$ Spanien $^{1}$ Griechenland Luxemburg $^{3,4}$ Schweden Finnland $^{1}$ Israel OECD-Durchschnitt Italien $^{3}$ Dänemark Australien Türkei ${ }^{2,4}$ Neuseeland Tschechien $^{1}$ Brasilien Chile $^{1}$ Polen Belgien $^{1,2}$ Estland $^{1,4}$ Portugal $^{1}$ Ungarn Slowenien

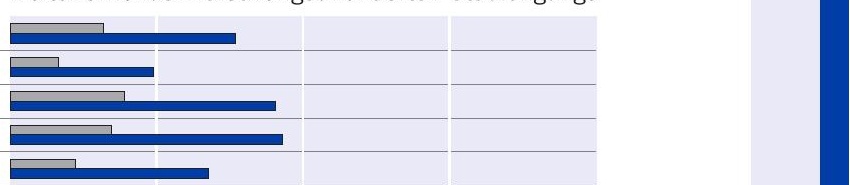

1. Referenzjahr 2011. 2. Einkommen nach Abzug der Einkommensteuer. 3. Referenzjahr 2010. . Daten beziehen sich auf Abschlüsse im gesamten Tertiärbereich.

Anordnung der Länder in absteigender Reihenfolge des Unterschieds zwischen dem Anteil der 25- bis 64jährigen Erwerbstätigen in der Einkommenskategorie „Hälfte oder weniger als die Hälfte des Medians“ und in der Einkommenskategorie „Mehr als das Doppelte des Medians“ bei einer Ausbildung unterhalb des Sekundarbereichs II.

Quelle: OECD. Tabelle A6.4 im Internet. Hinweise s. Anhang 3 unter www.oecd.org/edu/eag.htm. StatLink: http://dx.doi.org/10.1787/888933116243

weniger als die Hälfte des nationalen Medians, in den Vereinigten Staaten sind es mehr als 45 Prozent (Abb. A6.3).

\section{Relative Einkommen von Schülern/Studierenden}

In den OECD-Ländern beziehen rund 50 Prozent der 15- bis 24-Jährigen ein Erwerbseinkommen. In dieser Altersgruppe hat die Mehrheit der Nichtschüler/Nichtstudierenden (rund 65 Prozent) ein Erwerbseinkommen, wohingegen dies auf weniger als die Hälfte der Schüler/Studierenden zutrifft (rund 40 Prozent). In Belgien, Chile, Griechenland und Spanien erzielen weniger als Io Prozent der I5- bis 24-jährigen Schüler/ Studierenden ein Erwerbseinkommen. Hierbei ist zu berücksichtigen, dass in einigen 
Ländern wie beispielsweise der Schweiz ein Teil der Schüler im Sekundarbereich II aufgrund eines Ausbildungsvertrags mit einem Betrieb über Einkommen verfügt, diese Schüler jedoch in den Berechnungen nicht berücksichtigt werden. Die Daten zum Einkommen von Schülern/Studierenden zeigen, dass Schülerinnen/Studentinnen dieser Altersgruppe eine um 5 Prozentpunkte höhere Wahrscheinlichkeit haben, beschäftigt zu sein, als ihre männlichen Altersgenossen (Tab. A6.5b und Tab. A6.5c im Internet).

Im Durchschnitt erzielen in Relation zu den Nichtschülern/Nichtstudierenden von den Schülern/Studierenden mit Erwerbseinkommen diejenigen mit einem Abschluss im Sekundarbereich II bzw. postsekundaren, nicht tertiären Bereich höhere Erwerbseinkommen als Schüler mit einer Ausbildung unterhalb des Sekundarbereichs II (Tab. A6.5a).

Diese Ergebnisse unterstützen die weitverbreitete Ansicht, dass eine Fortsetzung der Ausbildung über die Schulpflicht hinaus entgangenes Einkommen während der Ausbildung mit sich bringt (selbst bei gleichzeitiger Erwerbstätigkeit). Entgangene Einkommen zusammen mit den Schul-/Studiengebühren und der notwendigen Tilgung von Darlehen könnten Einzelne davon abhalten, die Ausbildung fortzusetzen, während sie im Arbeitsmarkt aktiv sind.

\section{Mittlere Monatseinkommen und Lesekompetenz in der Erhebung zu den grundlegenden Kompetenzen Erwachsener}

Je höher die Lesekompetenz nach der Erhebung zu den grundlegenden Kompetenzen Erwachsener, umso höher das Monatseinkommen. Umgekehrt gehören die Monatseinkommen derjenigen mit niedriger Lesekompetenz im Allgemeinen zu den niedrigsten. Abbildung A6.4 zeigt, dass in allen Ländern mit steigendem Bildungsstand und höherer Lesekompetenzstufe höhere mittlere Monatseinkommen einhergehen (rechte Seite der Abbildung). In allen Ländern mit verfügbaren Daten weisen diejenigen, deren Lesekompetenz auf oder unterhalb Stufe I liegt, die niedrigsten mittleren Monatseinkommen auf und diejenigen mit einer Lesekompetenz auf Stufe 4 bzw. 5 die höchsten (linke Seite der Abbildung). Im Durchschnitt aller Länder verdient eine Person auf Lesekompetenzstufe 4 bzw. 5 rund 65 Prozent mehr als eine Person auf Kompetenzstufe I oder darunter.

Nichtsdestotrotz variiert der Unterschied zwischen den mittleren Monatsverdiensten von Erwerbstätigen auf den einzelnen Lesekompetenzstufen zwischen den einzelnen Ländern erheblich. Mit steigender Kompetenzstufe reichen die Unterschiede zwischen den Erträgen von weniger als 50 Prozent in Dänemark, Finnland, Italien, der Russischen Föderation und Schweden bis zu über Ioo Prozent in den Vereinigten Staaten.

Der rechte Teil der Abbildung zeigt außerdem die durchschnittlichen Auswirkungen von Kompetenzen und Bildungsstand auf die mittleren Monatseinkommen auf. Betrachtet man alle Bildungsbereiche zusammen, so ergeben sich bei den höheren Kompetenzstufen größere Einkommensvorteile. Ein Absolvent des Tertiärbereichs auf Lesekompetenzstufe 4 oder 5 der Erhebung zu den grundlegenden Kompetenzen Erwachsener verdient durchschnittlich rund 45 Prozent mehr als ein Erwachsener mit vergleichbarer Ausbildung, dessen Lesekompetenz auf oder unterhalb Stufe I liegt. Bei Erwachsenen mit einem Abschluss im Sekundarbereich II beträgt die Einkommensspanne zwischen denjenigen mit hoher und denen mit niedriger Lesekompetenz ungefähr 30 Prozent. 
Erhebung zu den grundlegenden Kompetenzen Erwachsener, 25- bis 64-Jährige mit Erwerbseinkommen, die Vollzeit erwerbstätig sind (d.h. mindestens 30 Stunden pro Woche)

In US-Dollar, kaufkraftbereinigt

6.000

5.500

5.000

4.500

4.000

3.500

3.000

2.500

2.000

1.500

1.000 㝵

500

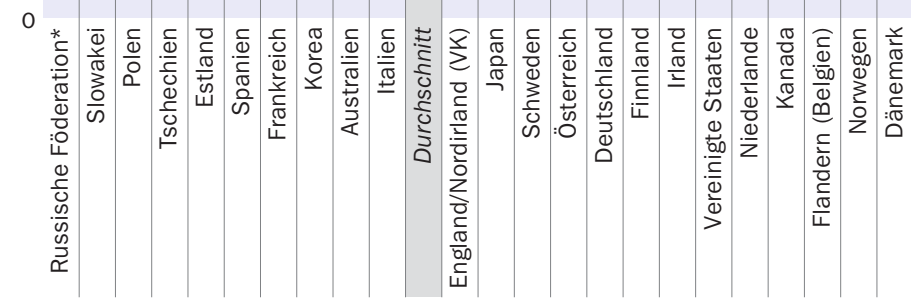

In US-Dollar, kaufkraftbereinigt
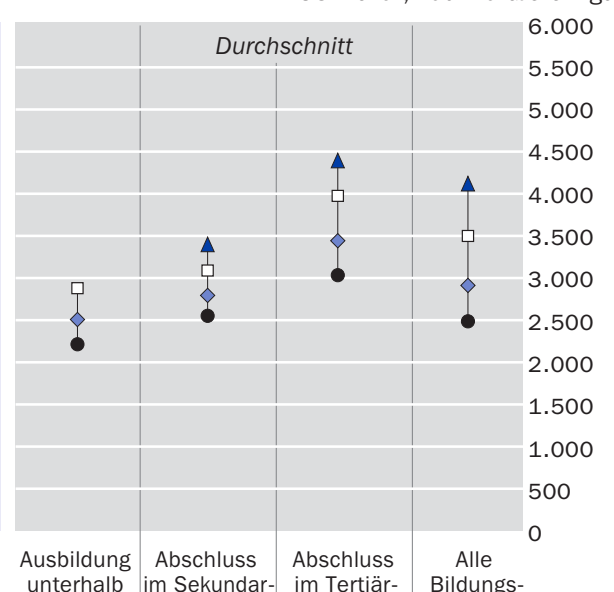

unterhalb im Sekundar- im Tertiär- Bildungs-

Sekundar- bereich/

bereich II postsekunbereich

* Hinweis zu den Daten der Russischen Föderation s. Abschnitt Angewandte Methodik.

Anordnung der Länder in aufsteigender Reihenfolge der mittleren Monatseinkommen bei Lesekompetenzstufe 1 oder darunter.

Quelle: OECD. Tabelle A6.6a (L). Hinweise s. Anhang 3 unter www.oecd.org/edu/eag.htm. StatLink: http://dx.doi.org/10.1787/888933116262

\section{Definitionen}

Altersgruppen: Erwachsene bezieht sich auf 25- bis 64-Jährige, jüngere Erwachsene auf 25- bis 34-Jährige und ältere Erwachsene auf 55- bis 64-Jährige. Die Bevölkerung im erwerbsfähigen Alter umfasst die Gesamtbevölkerung im Alter von 25 bis 64 Jahren.

Bildungsbereiche: Unterhalb Sekundarbereich II entspricht Bildungsgängen auf den ISCEDStufen o, I, 2 und ${ }_{3} \mathrm{C}$ (kurz), Sekundarbereich II bzw. postsekundarer, nicht tertiärer Bereich Bildungsgängen auf den ISCED-Stufen $3 \mathrm{~A},{ }_{3} \mathrm{~B},{ }_{3} \mathrm{C}$ (lang) und 4 und Tertiärbereich den ISCED-Stufen $5 \mathrm{~A}, 5 \mathrm{~B}$ und 6 . Erläuterungen zu allen Bildungsbereichen gemäß ISCEDKlassifizierung s. Hinweise für den Leser im vorderen Teil der Publikation.

\section{Angewandte Methodik}

Der Indikator basiert auf zwei verschiedenen Datenerhebungen. Zum einen auf der regulären Datenerhebung des OECD-Netzwerks zu den Arbeitsmarktergebnissen sowie den wirtschaftlichen und sozialen Auswirkungen des Lernens (LSO) zu den Erwerbseinkommen aller Personen während des Erhebungszeitraums, einschließlich Teilzeitoder saisonaler Erwerbstätigkeit; diese Datenbank enthält Daten zu den Einkommen von Schülern/Studierenden im Vergleich zu Nichtschülern/Nichtstudierenden. Hierbei 
werden auch die Angaben zu den Einkommen von ganzjährig Vollzeiterwerbstätigen erfasst, die in Tabelle A6.3a dargestellt sind. Die zweite Datenerhebung ist die Erhebung zu den grundlegenden Kompetenzen Erwachsener für die Tabellen A6.6a, A6.6b und A6.6c sowie A6.7. Die Angaben zu den Kompetenzstufen basieren auf der Erhebung zu den grundlegenden Kompetenzen Erwachsener (PIAAC) (20I2). PIAAC steht für das OECD Programme for the International Assessment of Adult Competencies. Weitere Informationen s. Erhebung zu den grundlegenden Kompetenzen Erwachsener im vorderen Teil der Publikation sowie im Anhang 3 unter www.oed.org/eduleag.htm.

\section{Datensammlung zu den regulären Einkommen}

Die Datensammlung zu den regulären Einkommen (die allen Tabellen außer den Tabellen A6.6 und A6.7 zugrunde liegt) liefert je nach Land Informationen zu Jahres-, Monats- oder Wocheneinkommen. Auch die Bezugszeiträume für die Einkommen unterschieden sich. Australien, Neuseeland und das Vereinigte Königreich berichteten wöchentliche Einkommen, Belgien, Brasilien, Chile, Estland, Finnland, Israel (3 Monate), Korea, Portugal und die Schweiz Monatseinkommen und alle anderen Länder Jahreseinkommen. Frankreich gab bis einschließlich 2007 monatliche Einkommen an, ab 2008 dann Jahreseinkommen. Die Einkommen sind vor Abzug der Einkommensteuer angegeben, außer für Belgien, Korea und die Türkei, dort handelt es sich um Einkommen nach Abzug der Einkommensteuer. Für Portugal, Slowenien, Tschechien und Ungarn enthalten die regulären Zahlen keine Einkommensdaten für Teilzeiterwerbstätige, und die Daten aus Portugal, Tschechien und Ungarn enthalten keine Einkommen, die nur während eines Teils des Jahres erwirtschaftet wurden. In vielen Ländern bleiben die Einkommen Selbstständiger unberücksichtigt, und es ist generell festzustellen, dass es keine einfache und vergleichbare Methode zur Abgrenzung des Erwerbseinkommens von den Erträgen aus investiertem Kapital gibt.

Da sich die Einkommensdaten für die einzelnen Länder in mehrfacher Hinsicht unterscheiden, sollten die Ergebnisse mit Vorsicht interpretiert werden. So beeinflussen beispielsweise bei Ländern, die Daten von Jahreseinkommen vorgelegt haben, Unterschiede in der Häufigkeit von saisonal beschränkter Erwerbstätigkeit bei Personen mit unterschiedlichem Bildungsstand das relative Einkommen, was sich in den Daten der Länder, die wöchentliche oder monatliche Einkommensangaben vorgelegt haben, nicht in gleichem Maße niederschlägt. Außerdem ist zu berücksichtigen, dass sich die verfügbaren Daten in den Tabellen A6.2a und A6.2b auf relative Einkommen beziehen und daher bei der Interpretation der Entwicklung der relativen Einkommen von Erwerbstätigen mit unterschiedlichem Bildungsstand mit Vorsicht zu interpretieren sind. Schließlich könnten in den Tabellen A6.5a und A6.5b Unterschiede zwischen den einzelnen Ländern auf Unterschiede bei den Datenquellen und in der Länge des Referenzzeitraums zurückzuführen sein. Weitere Einzelheiten s. Anhang 3 .

Der durchschnittliche Wert Gesamt (Männer und Frauen, d. h. M +F) bei den Erwerbseinkommen stellt nicht den einfachen, ungewichteten Durchschnitt der Einkommensdaten für Männer und Frauen dar, sondern ist als Durchschnitt der Einkommen der Gesamtpopulation errechnet. Für die Berechnung dieses Werts werden die Durchschnittswerte der Einkommen von Männern bzw. Frauen getrennt, entsprechend deren jeweiligen Anteilen an den Abschlüssen in den verschiedenen Bildungsbereichen, gewichtet. 


\section{Datensammlung zu ganzjährig Vollzeiterwerbstätigen}

Die Daten in den Tabellen A6.3a (Geschlechtsspezifische Unterschiede bei Einkommen aus Vollzeiterwerbstätigkeit) und A5.6 (Unterschiede bei Einkommen aus Vollzeiterwerbstätigkeit nach Bildungsstand) stammen aus der Datensammlung zu ganzjährig Vollzeiterwerbstätigen.

Zur Definition von Vollzeiteinkommen (in den Tab. A6.3a und A5.6) sollten die Länder angeben, ob sie einen selbst definierten Vollzeitstatus oder eine bestimmte Anzahl für in der Regel geleistete Arbeitsstunden pro Woche anwenden. Belgien, Frankreich, Italien, Luxemburg, Portugal, Schweden, Spanien und das Vereinigte Königreich verwendeten einen selbst definierten Vollzeitstatus; die übrigen Länder definierten den Vollzeitstatus über die Arbeitsstunden pro Woche. In Chile lag die Grenze bei 44/45 Wochenstunden, in der Slowakei bei 37 Wochenstunden, in Slowenien und Ungarn bei 36 Wochenstunden, in Australien, Deutschland, Estland, Israel, Kanada, Korea, Norwegen und den Vereinigten Staaten bei 35 Wochenstunden und in Griechenland, Neuseeland und Tschechien bei 30 Wochenstunden. Die übrigen teilnehmenden Länder gaben keine reguläre Mindestwochenarbeitszeit für den Vollzeitstatus an. Für einige Länder stammen die Daten zu Einkommen von ganzjährig Vollzeiterwerbstätigen aus der europäischen Gemeinschaftsstatistik über Einkommen und Lebensbedingungen (EU-SILC), die einen eigenen Ansatz zur Definition des Vollzeitstatus verwendet.

\section{Erhebung zu den grundlegenden Kompetenzen Erwachsener}

Die Daten der Tabellen A6.6 und A6.7 stammen aus der Erhebung zu den grundlegenden Kompetenzen Erwachsener im Rahmen des OECD Programme for the International Assessment of Adult Competencies (PIAAC).

Monatseinkommen beinhaltet auch Prämien für abhängig Beschäftigte sowie Selbstständige, jeweils kaufkraftbereinigt in US-Dollar. Das I. und das 99. Perzentil wurden aus der Entgeltverteilung entfernt.

Es werden lediglich Vollzeitbeschäftigte berücksichtigt, wobei als Vollzeitbeschäftigter gilt, wer mindestens 30 Stunden pro Woche arbeitet.

Anmerkung zu den Daten aus Israel

Die statistischen Daten für Israel wurden von den zuständigen israelischen Stellen bereitgestellt, die für sie verantwortlich zeichnen. Die Verwendung dieser Daten durch die OECD erfolgt unbeschadet des völkerrechtlichen Status der Golanhöhen, von Ost-Jerusalem und der israelischen Siedlungen im Westjordanland.

Hinweis zu den Daten aus der Russischen Föderation in der Erhebung zu den grundlegenden Kompetenzen Erwachsener (PIAAC)

$\mathrm{Zu}$ beachten ist, dass die Bevölkerung des Stadtgebiets Moskau in der Stichprobe für die Russische Föderation nicht berücksichtigt wurde. Die veröffentlichten Daten repräsentieren daher nicht die gesamte Wohnbevölkerung im Alter von I 6 bis 65 Jahren in Russland, sondern nur die Wohnbevölkerung Russlands ohne die im Stadtgebiet Moskau lebende Bevölkerung. Weitere Informationen zu den Daten aus der Russischen Föderation sowie anderer Länder finden sich im Technical Report of the Survey of Adult Skills (OECD, i. E.). 


\section{Weiterführende Informationen}

OECD (2013), Bildung auf einen Blick 2013 - OECD-Indikatoren, W. Bertelsmann Verlag, Bielefeld.

\section{Tabellen Indikator A6}

StatLink: http://dx.doi.org/10.1787/888933116053

Tabelle A6.ra: Relative Einkommen von Erwerbstätigen, nach Bildungsstand und Altersgruppe (2012)

WEB Table A6.Ib: Relative earnings of workers, by educational attainment, age group and gender (Relative Einkommen von Erwerbstätigen, nach Bildungsstand, Altersgruppe und Geschlecht) (2012)

Tabelle A6.2a: Entwicklung der relativen Einkommen von Erwerbstätigen, nach Bildungsstand und Geschlecht (2000, 2005, 2010, 2011, 2012)

WEB Table A6.2b: Trends in relative earnings of workers, by educational attainment and gender (Entwicklung der relativen Einkommen von Erwerbstätigen, nach Bildungsstand und Geschlecht) (2000-2012)

Tabelle A6.3a: Einkommensunterschiede zwischen erwerbstätigen Frauen und Männern, nach Bildungsstand und Altersgruppe (2012)

Tabelle A6.3b: Entwicklung der Einkommensunterschiede zwischen erwerbstätigen Frauen und Männern, nach Bildungsstand (2000, 2005, 2010, 2011, 2012)

WEB Table A6.3c: Trends in the differences in earnings between female and male workers, by educational attainment (Entwicklung der Einkommensunterschiede zwischen erwerbstätigen Frauen und Männern, nach Bildungsstand) (2000-2012)

WEB Table A6.4: Distribution of 25-64 year-olds, by gender, educational attainment and level of earnings relative to median earnings (Verteilung 25- bis 64-Jähriger nach Geschlecht, Bildungsstand und Höhe der Einkommen in Relation zum Median) (2012)

Tabelle A6.5a: Relative Einkommen von I5- bis 24-jährigen Schülern/Studierenden mit Erwerbseinkommen, nach Bildungsstand und Geschlecht (2012)

Tabelle A6.5b: Anteil I5- bis 29-Jähriger mit Erwerbseinkommen an allen I5- bis 29-Jährigen, nach Altersgruppe und Ausbildungsstatus (2012)

WEB Table A6.5c: Proportion of I5-29 year-olds with income from employment among all 15-29 year-olds, by age group, student status and gender (Anteil I5-bis 29-Jähriger mit Erwerbseinkommen an allen I5- bis 29-Jährigen, nach Altersgruppe, Ausbildungsstatus und Geschlecht) (2012) 
Tabelle A6.6a (L): Mittlere Monatseinkommen von Erwerbstätigen, nach Bildungsstand und Lesekompetenz (2012)

WEB Table A6.6a (N): Mean monthly earnings of workers, by educational attainment and numeracy proficiency level (Mittlere Monatseinkommen von Erwerbstätigen, nach Bildungsstand und alltagsmathematischer Kompetenz) (20I2)

WEB Table A6.6b (L): Mean monthly earnings of workers, by educational attainment, literacy proficiency level and gender (Mittlere Monatseinkommen von Erwerbstätigen, nach Bildungsstand, Lesekompetenz und Geschlecht) (20I2)

WEB Table A6.6b (N): Mean monthly earnings of workers, by educational attainment, numeracy proficiency level and gender (Mittlere Monatseinkommen von Erwerbstätigen, nach Bildungsstand, alltagsmathematischer Kompetenz und Geschlecht) (20I2)

WEB Table A6.6c (L): Mean monthly earnings of workers, by educational attainment, literacy proficiency level and age (Mittlere Monatseinkommen von Erwerbstätigen, nach Bildungsstand, Lesekompetenz und Alter) (2012)

WEB Table A6.6c (N): Mean monthly earnings of workers, by educational attainment, numeracy proficiency level and age (Mittlere Monatseinkommen von Erwerbstätigen, nach Bildungsstand, alltagsmathematischer Kompetenz und Alter) (2012)

WEB Table A6.7 (L): Mean monthly earnings of workers, by educational attainment, literacy proficiency level and years since obtained most recent qualification (Mittlere Monatseinkommen von Erwerbstätigen, nach Bildungsstand, Lesekompetenz und Dauer des Zurückliegens des Erwerbs der letzten Qualifikation [in Jahren]) (2012)

WEB Table A6.7 (N): Mean monthly earnings of workers, by educational attainment, numeracy proficiency level and years since obtained most recent qualification (Mittlere Monatseinkommen von Erwerbstätigen, nach Bildungsstand, alltagsmathematischer Kompetenz und Dauer des Zurückliegens des Erwerbs der letzten Qualifikation [in Jahren]) (2012) 
Relative Einkommen von Erwerbstätigen, nach Bildungsstand und Altersgruppe (2012)

Erwachsene mit Erwerbseinkommen, Abschluss im Sekundarbereich II = 100

\begin{tabular}{|c|c|c|c|c|c|c|c|c|c|c|c|c|c|c|c|c|}
\hline & \multirow[t]{3}{*}{ Jahr } & \multicolumn{3}{|c|}{$\begin{array}{l}\text { Ausbildung unterhalb } \\
\text { Sekundarbereich II }\end{array}$} & \multicolumn{3}{|c|}{$\begin{array}{c}\text { Abschluss im } \\
\text { postsekundaren, nicht } \\
\text { tertiären Bereich }\end{array}$} & \multicolumn{3}{|c|}{$\begin{array}{l}\text { Abschluss im } \\
\text { Tertiärbereich B }\end{array}$} & \multicolumn{3}{|c|}{$\begin{array}{c}\text { Abschluss im } \\
\text { Tertiärbereich A/ } \\
\text { eines weiterführenden } \\
\text { forschungsorientierten } \\
\text { Studienangs }\end{array}$} & \multicolumn{3}{|c|}{$\begin{array}{l}\text { Abschlüsse } \\
\text { im Tertiärbereich } \\
\text { insgesamt }\end{array}$} \\
\hline & & $25-64$ & $25-34$ & $55-64$ & $25-64$ & $25-34$ & $55-64$ & $25-64$ & $25-34$ & $55-64$ & $25-64$ & $25-34$ & $55-64$ & $25-64$ & $25-34$ & $55-64$ \\
\hline & & (1) & (2) & (3) & (4) & (5) & (6) & (7) & (8) & (9) & (10) & (11) & (12) & (13) & (14) & (15) \\
\hline \multicolumn{17}{|l|}{ OECD-Länder } \\
\hline Australien & 2012 & 83 & 88 & 84 & 99 & 95 & 108 & 114 & 111 & 129 & 142 & 121 & 159 & 134 & 119 & 149 \\
\hline Österreich & 2012 & 70 & 70 & 66 & 127 & 112 & 162 & 143 & 120 & 144 & 185 & 143 & 194 & 171 & 138 & 173 \\
\hline Belgien $^{1}$ & 2011 & 90 & 92 & 83 & 95 & 101 & 89 & 116 & 113 & 117 & 142 & 132 & 153 & 128 & 123 & 135 \\
\hline Kanada & 2011 & 87 & 103 & 76 & 111 & 125 & 105 & 113 & 110 & 111 & 163 & 133 & 185 & 139 & 123 & 149 \\
\hline Chile & 2011 & 66 & 70 & 56 & $\mathrm{~m}$ & $\mathrm{~m}$ & $\mathrm{~m}$ & 151 & 133 & 143 & 309 & 261 & 323 & 260 & 227 & 279 \\
\hline Tschechien & 2011 & 73 & 78 & 71 & $\mathrm{~m}$ & $\mathrm{~m}$ & $\mathrm{~m}$ & 117 & 114 & 118 & 181 & 154 & 190 & 176 & 149 & 187 \\
\hline Dänemark & 2012 & 81 & 78 & 84 & 61 & 42 & 104 & 117 & 116 & 113 & 130 & 112 & 142 & 128 & 112 & 137 \\
\hline Estland & 2012 & 94 & 93 & 91 & $\mathrm{~m}$ & $\mathrm{~m}$ & $\mathrm{~m}$ & $\mathrm{~m}$ & $\mathrm{~m}$ & $\mathrm{~m}$ & 134 & 116 & 147 & 134 & 116 & 147 \\
\hline Finnland & 2011 & 92 & 92 & 93 & $\mathrm{~m}$ & $\mathrm{~m}$ & $\mathrm{~m}$ & 128 & 118 & 127 & 157 & 127 & 205 & 147 & 126 & 166 \\
\hline Frankreich & 2010 & 82 & 89 & 72 & $\mathrm{~m}$ & $\mathrm{~m}$ & $\mathrm{~m}$ & 127 & 126 & 136 & 170 & 145 & 212 & 154 & 138 & 189 \\
\hline Deutschland & 2012 & 84 & 84 & 87 & 114 & 118 & 114 & 146 & 145 & 141 & 183 & 149 & 227 & 174 & 148 & 207 \\
\hline Griechenland & 2012 & 79 & 94 & 82 & 99 & 111 & 77 & 151 & 127 & 185 & 198 & 140 & 267 & 152 & 127 & 187 \\
\hline Ungarn & 2012 & 78 & 81 & 76 & 122 & 116 & 127 & 127 & 121 & 157 & 209 & 182 & 223 & 208 & 181 & 222 \\
\hline Island & & $\mathrm{m}$ & $m$ & $\mathrm{~m}$ & $\mathrm{~m}$ & $\mathrm{~m}$ & $\mathrm{~m}$ & $\mathrm{~m}$ & $\mathrm{~m}$ & $\mathrm{~m}$ & $\mathrm{~m}$ & $\mathrm{~m}$ & $\mathrm{~m}$ & $\mathrm{~m}$ & $\mathrm{~m}$ & $\mathrm{~m}$ \\
\hline Irland ${ }^{1}$ & 2011 & 84 & 104 & 76 & 99 & 99 & 108 & 131 & 123 & 109 & 201 & 186 & 185 & 175 & 165 & 162 \\
\hline Israel & 2012 & 71 & 76 & 64 & 109 & 91 & 94 & 112 & 96 & 109 & 170 & 133 & 174 & 152 & 123 & 151 \\
\hline Italien & 2010 & 77 & 94 & 59 & $\mathrm{~m}$ & $m$ & $m$ & $\mathrm{~m}$ & $\mathrm{~m}$ & $\mathrm{~m}$ & 147 & 125 & 167 & 147 & 125 & 167 \\
\hline Japan & 2012 & 78 & 87 & 76 & $\mathrm{~m}$ & $\mathrm{~m}$ & $\mathrm{~m}$ & 91 & 99 & 99 & 172 & 144 & 203 & 152 & 136 & 177 \\
\hline Korea & 2012 & 71 & 82 & 65 & $\mathrm{~m}$ & $m$ & $m$ & 116 & 113 & 144 & 161 & 133 & 196 & 147 & 126 & 188 \\
\hline Luxemburg & 2012 & 70 & 68 & 63 & 119 & 86 & 71 & $\mathrm{~m}$ & $\mathrm{~m}$ & $\mathrm{~m}$ & $\mathrm{~m}$ & $\mathrm{~m}$ & $\mathrm{~m}$ & 168 & 148 & 184 \\
\hline Mexiko & & $\mathrm{m}$ & $\mathrm{m}$ & $\mathrm{m}$ & $\mathrm{m}$ & $\mathrm{m}$ & $\mathrm{m}$ & $\mathrm{m}$ & $\mathrm{m}$ & $m$ & $\mathrm{~m}$ & $\mathrm{~m}$ & $\mathrm{~m}$ & $\mathrm{~m}$ & $\mathrm{~m}$ & $\mathrm{~m}$ \\
\hline Niederlande & 2010 & 83 & 90 & 74 & $\mathrm{~m}$ & $\mathrm{~m}$ & $\mathrm{~m}$ & 145 & 134 & 145 & 157 & 137 & 160 & 156 & 137 & 159 \\
\hline Neuseeland & 2012 & 82 & 85 & 82 & 110 & 115 & 101 & 105 & 107 & 100 & 134 & 126 & 146 & 123 & 121 & 123 \\
\hline Norwegen & 2011 & 78 & 76 & 80 & 128 & 125 & 137 & 155 & 136 & 169 & 128 & 107 & 152 & 130 & 108 & 154 \\
\hline Polen & 2012 & 85 & 89 & 80 & 107 & 99 & 112 & $\mathrm{~m}$ & $\mathrm{~m}$ & m & 172 & 146 & 205 & 172 & 146 & 205 \\
\hline Portugal & 2011 & 70 & 82 & 51 & 104 & 109 & 96 & 161 & 141 & 154 & 171 & 157 & 204 & 170 & 156 & 193 \\
\hline Slowakei & 2012 & 67 & 66 & 70 & $\mathrm{~m}$ & $\mathrm{~m}$ & $\mathrm{~m}$ & 126 & 116 & 134 & 175 & 145 & 193 & 173 & 144 & 190 \\
\hline Slowenien & 2012 & 78 & 85 & 73 & $\mathrm{~m}$ & $\mathrm{~m}$ & $\mathrm{~m}$ & 152 & 130 & 165 & 200 & 150 & 240 & 180 & 142 & 211 \\
\hline Spanien & 2011 & 80 & 87 & 70 & c & c & c & 106 & 105 & 103 & 156 & 139 & 160 & 141 & 127 & 150 \\
\hline Schweden & 2012 & 82 & 76 & 88 & 121 & 79 & 138 & 107 & 92 & 115 & 135 & 115 & 158 & 128 & 110 & 143 \\
\hline Schweiz & 2012 & 77 & 84 & 70 & 107 & 102 & 117 & 141 & 131 & 143 & 165 & 135 & 182 & 158 & 134 & 169 \\
\hline Türkei ${ }^{1}$ & 2012 & 63 & 68 & 46 & a & a & a & $\mathrm{m}$ & $\mathrm{m}$ & $\mathrm{m}$ & 191 & 186 & 234 & 191 & 186 & 234 \\
\hline Ver. Königreich & 2012 & 70 & 68 & 69 & $\mathrm{~m}$ & $\mathrm{~m}$ & $\mathrm{~m}$ & 130 & 127 & 136 & 164 & 153 & 170 & 156 & 149 & 159 \\
\hline Vereinigte Staaten & 2012 & 63 & 70 & 61 & $\mathrm{~m}$ & $\mathrm{~m}$ & $\mathrm{~m}$ & 109 & 112 & 100 & 182 & 170 & 180 & 174 & 165 & 172 \\
\hline OECD-Durchschnitt & & 78 & 83 & 73 & 108 & 102 & 110 & 127 & 119 & 131 & 170 & 145 & 191 & 159 & 140 & 176 \\
\hline EU21-Durchschnitt & & 79 & 84 & 75 & 106 & 98 & 109 & 131 & 122 & 135 & 168 & 143 & 190 & 159 & 138 & 175 \\
\hline \multicolumn{17}{|l|}{ Partnerländer } \\
\hline Argentinien & & $\mathrm{m}$ & $\mathrm{m}$ & $\mathrm{m}$ & $\mathrm{m}$ & $\mathrm{m}$ & $\mathrm{m}$ & $\mathrm{m}$ & $\mathrm{m}$ & m & $\mathrm{m}$ & $\mathrm{m}$ & $\mathrm{m}$ & $\mathrm{m}$ & $\mathrm{m}$ & $\mathrm{m}$ \\
\hline Brasilien & 2012 & 58 & 65 & 41 & $\mathrm{~m}$ & $\mathrm{~m}$ & $\mathrm{~m}$ & $\mathrm{~m}$ & $\mathrm{~m}$ & $\mathrm{~m}$ & 247 & 235 & 241 & 247 & 235 & 241 \\
\hline China & & $\mathrm{m}$ & $\mathrm{m}$ & $\mathrm{m}$ & $\mathrm{m}$ & $\mathrm{m}$ & $\mathrm{m}$ & $\mathrm{m}$ & $\mathrm{m}$ & $\mathrm{m}$ & $\mathrm{m}$ & $\mathrm{m}$ & $\mathrm{m}$ & $\mathrm{m}$ & $\mathrm{m}$ & $\mathrm{m}$ \\
\hline Kolumbien & & $\mathrm{m}$ & $\mathrm{m}$ & $\mathrm{m}$ & $\mathrm{m}$ & $\mathrm{m}$ & $\mathrm{m}$ & $\mathrm{m}$ & $\mathrm{m}$ & $\mathrm{m}$ & $\mathrm{m}$ & $\mathrm{m}$ & $\mathrm{m}$ & $\mathrm{m}$ & $\mathrm{m}$ & $\mathrm{m}$ \\
\hline Indien & & $\mathrm{m}$ & $\mathrm{m}$ & $\mathrm{m}$ & $\mathrm{m}$ & $\mathrm{m}$ & $\mathrm{m}$ & $\mathrm{m}$ & $\mathrm{m}$ & $\mathrm{m}$ & $\mathrm{m}$ & $\mathrm{m}$ & $\mathrm{m}$ & $\mathrm{m}$ & $\mathrm{m}$ & $\mathrm{m}$ \\
\hline Indonesien & & $\mathrm{m}$ & $\mathrm{m}$ & $\mathrm{m}$ & $\mathrm{m}$ & $\mathrm{m}$ & $\mathrm{m}$ & $\mathrm{m}$ & $\mathrm{m}$ & $\mathrm{m}$ & $\mathrm{m}$ & $\mathrm{m}$ & $\mathrm{m}$ & $\mathrm{m}$ & $\mathrm{m}$ & $\mathrm{m}$ \\
\hline Lettland & & $\mathrm{m}$ & $\mathrm{m}$ & $\mathrm{m}$ & $\mathrm{m}$ & $\mathrm{m}$ & $\mathrm{m}$ & $\mathrm{m}$ & $\mathrm{m}$ & $\mathrm{m}$ & $\mathrm{m}$ & $\mathrm{m}$ & $\mathrm{m}$ & $\mathrm{m}$ & m & $\mathrm{m}$ \\
\hline Russische Föd. & & $\mathrm{m}$ & $\mathrm{m}$ & $\mathrm{m}$ & $\mathrm{m}$ & $\mathrm{m}$ & $\mathrm{m}$ & $\mathrm{m}$ & $\mathrm{m}$ & $\mathrm{m}$ & $\mathrm{m}$ & $\mathrm{m}$ & $\mathrm{m}$ & $\mathrm{m}$ & $\mathrm{m}$ & $\mathrm{m}$ \\
\hline Saudi-Arabien & & $\mathrm{m}$ & $\mathrm{m}$ & $\mathrm{m}$ & $\mathrm{m}$ & $\mathrm{m}$ & $\mathrm{m}$ & $\mathrm{m}$ & $\mathrm{m}$ & $\mathrm{m}$ & $\mathrm{m}$ & $\mathrm{m}$ & $\mathrm{m}$ & $\mathrm{m}$ & $\mathrm{m}$ & $\mathrm{m}$ \\
\hline Südafrika & & $\mathrm{m}$ & $\mathrm{m}$ & $\mathrm{m}$ & $\mathrm{m}$ & $\mathrm{m}$ & $\mathrm{m}$ & $\mathrm{m}$ & $\mathrm{m}$ & $\mathrm{m}$ & $\mathrm{m}$ & $\mathrm{m}$ & m & $\mathrm{m}$ & $\mathrm{m}$ & $\mathrm{m}$ \\
\hline G20-Durchschnitt & & $\mathbf{m}$ & m & $\mathbf{m}$ & $\mathbf{m}$ & $\mathbf{m}$ & $\mathbf{m}$ & m & $\mathbf{m}$ & m & m & $\mathbf{m}$ & $\mathbf{m}$ & m & m & $\mathbf{m}$ \\
\hline
\end{tabular}

1. Einkommen nach Abzug der Einkommensteuer.

Quelle: OECD. Hinweise s. Anhang 3 unter www.oecd.org/edu/eag.htm. StatLink: http://dx.doi.org/10.1787/888933116072

Erläuterung der Kennzeichnung fehlender Daten s. Hinweise für den Leser. 
Entwicklung der relativen Einkommen von Erwerbstätigen, nach Bildungsstand und Geschlecht

(2000, 2005, 2010, 2011, 2012)

25- bis 64-Jährige mit Erwerbseinkommen, Abschluss im Sekundarbereich II = 100

Bildungsstand

\begin{tabular}{|c|c|c|c|c|c|c|c|c|c|c|c|c|c|c|}
\hline \multicolumn{3}{|c|}{2000} & \multicolumn{3}{|c|}{2005} & \multicolumn{3}{|c|}{2010} & \multicolumn{3}{|c|}{2011} & \multicolumn{3}{|c|}{2012} \\
\hline $\begin{array}{l}\text { Män- } \\
\text { ner }\end{array}$ & $\begin{array}{c}\text { Frau- } \\
\text { en }\end{array}$ & $M+F$ & $\begin{array}{c}\text { Män- } \\
\text { ner }\end{array}$ & \begin{tabular}{|c|}
$\begin{array}{c}\text { Frau- } \\
\text { en }\end{array}$ \\
\end{tabular} & $M+F$ & $\begin{array}{c}\text { Män- } \\
\text { ner }\end{array}$ & \begin{tabular}{|c|} 
Frau- \\
en
\end{tabular} & $M+F$ & $\begin{array}{c}\text { Män- } \\
\text { ner }\end{array}$ & $\begin{array}{c}\text { Frau- } \\
\text { en }\end{array}$ & $M+F$ & $\begin{array}{c}\text { Män- } \\
\text { ner }\end{array}$ & $\begin{array}{c}\text { Frau- } \\
\text { en }\end{array}$ & $M+F$ \\
\hline (1) & (2) & (3) & (4) & (5) & (6) & (7) & (8) & (9) & (10) & (11) & $(12)$ & (13) & (14) & (15) \\
\hline
\end{tabular}

\begin{tabular}{|c|c|c|c|c|c|c|c|c|c|c|c|c|c|c|c|c|}
\hline \multirow{2}{*}{\multicolumn{17}{|c|}{ OECD-Länder }} \\
\hline & & & & & & & & & & & & & & & & \\
\hline \multirow[t]{2}{*}{ Australien } & Ausbildung unterhalb Sekundarbereich II & $\mathrm{m}$ & $\mathrm{m}$ & $\mathrm{m}$ & 88 & 88 & 81 & $\mathrm{~m}$ & $\mathrm{~m}$ & $\mathrm{~m}$ & $\mathrm{~m}$ & $\mathrm{~m}$ & $\mathrm{~m}$ & 85 & 88 & 83 \\
\hline & Abschluss im Tertiärbereich & $\mathrm{m}$ & $\mathrm{m}$ & $\mathrm{m}$ & 141 & 148 & 134 & $\mathrm{~m}$ & $\mathrm{~m}$ & $\mathrm{~m}$ & $\mathrm{~m}$ & $\mathrm{~m}$ & $\mathrm{~m}$ & 141 & 153 & 134 \\
\hline \multirow[t]{2}{*}{ Österreich } & Ausbildung unterhalb Sekundarbereich II & $\mathrm{m}$ & $\mathrm{m}$ & $\mathrm{m}$ & 80 & 78 & 74 & 73 & 75 & 69 & 71 & 78 & 69 & 74 & 76 & 70 \\
\hline & Abschluss im Tertiärbereich & $\mathrm{m}$ & $\mathrm{m}$ & $\mathrm{m}$ & 157 & 165 & 158 & 163 & 173 & 165 & 164 & 174 & 166 & 171 & 174 & 171 \\
\hline \multirow[t]{2}{*}{ Belgien $^{1}$} & Ausbildung unterhalb Sekundarbereich II & 93 & 83 & 92 & 91 & 82 & 89 & 92 & 86 & 91 & 92 & 84 & 90 & $\mathrm{~m}$ & $\mathrm{~m}$ & $\mathrm{~m}$ \\
\hline & Abschluss im Tertiärbereich & 128 & 133 & 128 & 137 & 134 & 133 & 132 & 135 & 131 & 129 & 134 & 128 & $\mathrm{~m}$ & $\mathrm{~m}$ & $\mathrm{~m}$ \\
\hline \multirow[t]{2}{*}{ Kanada } & Ausbildung unterhalb Sekundarbereich II & 84 & 72 & 83 & 80 & 70 & 80 & 81 & 79 & 83 & 86 & 77 & 87 & $\mathrm{~m}$ & $\mathrm{~m}$ & $\mathrm{~m}$ \\
\hline & Abschluss im Tertiärbereich & 149 & 139 & 143 & 140 & 140 & 138 & 146 & 154 & 145 & 144 & 142 & 139 & $\mathrm{~m}$ & $\mathrm{~m}$ & $\mathrm{~m}$ \\
\hline \multirow[t]{2}{*}{ Chile } & Ausbildung unterhalb Sekundarbereich II & $\mathrm{m}$ & $\mathrm{m}$ & $\mathrm{m}$ & $\mathrm{m}$ & $\mathrm{m}$ & $\mathrm{m}$ & $\mathrm{m}$ & $\mathrm{m}$ & $\mathrm{m}$ & 64 & 65 & 66 & $\mathrm{~m}$ & $\mathrm{~m}$ & $\mathrm{~m}$ \\
\hline & Abschluss im Tertiärbereich & $\mathrm{m}$ & $\mathrm{m}$ & $\mathrm{m}$ & $\mathrm{m}$ & $\mathrm{m}$ & $\mathrm{m}$ & $\mathrm{m}$ & $\mathrm{m}$ & $\mathrm{m}$ & 271 & 262 & 260 & $\mathrm{~m}$ & $\mathrm{~m}$ & $\mathrm{~m}$ \\
\hline \multirow[t]{2}{*}{ Tschechien } & Ausbildung unterhalb Sekundarbereich II & $\mathrm{m}$ & $\mathrm{m}$ & $\mathrm{m}$ & 79 & 72 & 72 & 76 & 74 & 73 & 76 & 74 & 73 & $\mathrm{~m}$ & $\mathrm{~m}$ & $\mathrm{~m}$ \\
\hline & Abschluss im Tertiärbereich & $\mathrm{m}$ & $\mathrm{m}$ & $\mathrm{m}$ & 190 & 161 & 181 & 195 & 163 & 182 & 187 & 160 & 176 & $\mathrm{~m}$ & $\mathrm{~m}$ & $\mathrm{~m}$ \\
\hline \multirow[t]{2}{*}{ Dänemark } & Ausbildung unterhalb Sekundarbereich II & $\mathrm{m}$ & $\mathrm{m}$ & $\mathrm{m}$ & 82 & 84 & 82 & 80 & 83 & 81 & 79 & 83 & 81 & 79 & 82 & 81 \\
\hline & Abschluss im Tertiärbereich & $\mathrm{m}$ & $\mathrm{m}$ & $\mathrm{m}$ & 133 & 126 & 125 & 141 & 126 & 129 & 138 & 126 & 128 & 138 & 126 & 128 \\
\hline \multirow[t]{2}{*}{ Estland } & Ausbildung unterhalb Sekundarbereich II & $\mathrm{m}$ & $\mathrm{m}$ & $\mathrm{m}$ & $\mathrm{m}$ & $\mathrm{m}$ & $\mathrm{m}$ & $\mathrm{m}$ & $\mathrm{m}$ & $\mathrm{m}$ & 81 & 81 & 87 & 89 & 91 & 94 \\
\hline & Abschluss im Tertiärbereich & $\mathrm{m}$ & $\mathrm{m}$ & $\mathrm{m}$ & $\mathrm{m}$ & $\mathrm{m}$ & $\mathrm{m}$ & $\mathrm{m}$ & $\mathrm{m}$ & $\mathrm{m}$ & 146 & 148 & 135 & 137 & 160 & 134 \\
\hline \multirow[t]{2}{*}{ Finnland } & Ausbildung unterhalb Sekundarbereich II & 92 & 99 & 95 & 91 & 98 & 94 & 90 & 93 & 92 & 89 & 92 & 92 & $\mathrm{~m}$ & $\mathrm{~m}$ & $\mathrm{~m}$ \\
\hline & Abschluss im Tertiärbereich & 169 & 146 & 153 & 162 & 145 & 149 & 160 & 147 & 148 & 159 & 147 & 147 & $\mathrm{~m}$ & $\mathrm{~m}$ & $\mathrm{~m}$ \\
\hline \multirow[t]{2}{*}{ Frankreich $^{2}$} & Ausbildung unterhalb Sekundarbereich II & $\mathrm{m}$ & $\mathrm{m}$ & $\mathrm{m}$ & 90 & 81 & 86 & 89 & 76 & 82 & $\mathrm{~m}$ & $\mathrm{~m}$ & $\mathrm{~m}$ & $\mathrm{~m}$ & $\mathrm{~m}$ & $\mathrm{~m}$ \\
\hline & Abschluss im Tertiärbereich & $\mathrm{m}$ & $\mathrm{m}$ & $\mathrm{m}$ & 152 & 142 & 144 & 162 & 155 & 154 & $\mathrm{~m}$ & $\mathrm{~m}$ & $\mathrm{~m}$ & $\mathrm{~m}$ & $\mathrm{~m}$ & $\mathrm{~m}$ \\
\hline \multirow[t]{2}{*}{ Deutschland } & Ausbildung unterhalb Sekundarbereich II & 81 & 74 & 76 & 95 & 80 & 89 & 97 & 77 & 88 & 91 & 85 & 88 & 87 & 82 & 84 \\
\hline & Abschluss im Tertiärbereich & 143 & 141 & 145 & 153 & 156 & 159 & 176 & 159 & 172 & 166 & 163 & 169 & 171 & 172 & 174 \\
\hline \multirow[t]{2}{*}{ Griechenland } & Ausbildung unterhalb Sekundarbereich II & $\mathrm{m}$ & $\mathrm{m}$ & $\mathrm{m}$ & $\mathrm{m}$ & $\mathrm{m}$ & $\mathrm{m}$ & $\mathrm{m}$ & $\mathrm{m}$ & $\mathrm{m}$ & 69 & 52 & 62 & 82 & 72 & 79 \\
\hline & Abschluss im Tertiärbereich & $\mathrm{m}$ & $\mathrm{m}$ & $\mathrm{m}$ & $\mathrm{m}$ & $\mathrm{m}$ & $\mathrm{m}$ & $\mathrm{m}$ & $\mathrm{m}$ & $\mathrm{m}$ & 151 & 231 & 171 & 169 & 140 & 152 \\
\hline Ungarn & Ausbildung unterhalb Sekundarbereich II & 81 & 77 & 77 & 80 & 77 & 78 & 80 & 75 & 77 & 79 & 75 & 76 & 80 & 77 & 78 \\
\hline & Abschluss im Tertiärbereich & 252 & 179 & 210 & 269 & 202 & 229 & 259 & 198 & 221 & 256 & 193 & 217 & 246 & 184 & 208 \\
\hline Island & & $\mathrm{m}$ & $\mathrm{m}$ & $\mathrm{m}$ & $\mathrm{m}$ & $\mathrm{m}$ & $\mathrm{m}$ & $\mathrm{m}$ & $\mathrm{m}$ & $\mathrm{m}$ & $\mathrm{m}$ & $\mathrm{m}$ & $\mathrm{m}$ & $\mathrm{m}$ & $\mathrm{m}$ & $\mathrm{m}$ \\
\hline Irland $^{1}$ & Ausbildung unterhalb Sekundarbereich II & 82 & 64 & 87 & 83 & 67 & 84 & 76 & 78 & 81 & 80 & 70 & 84 & $\mathrm{~m}$ & m & m \\
\hline & Abschluss im Tertiärbereich & 135 & 161 & 149 & 187 & 190 & 192 & 168 & 177 & 165 & 169 & 190 & 175 & $\mathrm{~m}$ & $\mathrm{~m}$ & $\mathrm{~m}$ \\
\hline Israel & Ausbildung unterhalb Sekundarbereich II & $\mathrm{m}$ & $\mathrm{m}$ & $\mathrm{m}$ & 74 & 72 & 79 & 68 & 63 & 72 & 69 & 66 & 72 & 66 & 71 & 71 \\
\hline & Abschluss im Tertiärbereich & $\mathrm{m}$ & $\mathrm{m}$ & $\mathrm{m}$ & 160 & 158 & 151 & 164 & 150 & 152 & 159 & 152 & 151 & 153 & 171 & 152 \\
\hline Italien & Ausbildung unterhalb Sekundarbereich II & 71 & 84 & 78 & $\mathrm{~m}$ & $\mathrm{~m}$ & $\mathrm{~m}$ & 77 & 70 & 77 & $\mathrm{~m}$ & $\mathrm{~m}$ & $\mathrm{~m}$ & $\mathrm{~m}$ & $\mathrm{~m}$ & $\mathrm{~m}$ \\
\hline & Abschluss im Tertiärbereich & 143 & 137 & 138 & $\mathrm{~m}$ & $\mathrm{~m}$ & $\mathrm{~m}$ & 157 & 145 & 147 & $\mathrm{~m}$ & $\mathrm{~m}$ & $\mathrm{~m}$ & $\mathrm{~m}$ & $\mathrm{~m}$ & $\mathrm{~m}$ \\
\hline Japan & Ausbildung unterhalb Sekundarbereich II & $\mathrm{m}$ & $\mathrm{m}$ & $\mathrm{m}$ & $\mathrm{m}$ & $\mathrm{m}$ & $\mathrm{m}$ & $\mathrm{m}$ & $\mathrm{m}$ & $\mathrm{m}$ & $\mathrm{m}$ & $\mathrm{m}$ & $\mathrm{m}$ & 74 & 72 & 78 \\
\hline & Abschluss im Tertiärbereich & $\mathrm{m}$ & $\mathrm{m}$ & $\mathrm{m}$ & $\mathrm{m}$ & $\mathrm{m}$ & $\mathrm{m}$ & $\mathrm{m}$ & $\mathrm{m}$ & $\mathrm{m}$ & $\mathrm{m}$ & $\mathrm{m}$ & $\mathrm{m}$ & 144 & 160 & 152 \\
\hline Korea & Ausbildung unterhalb Sekundarbereich II & $\mathrm{m}$ & $\mathrm{m}$ & $\mathrm{m}$ & 73 & 76 & 68 & 71 & 77 & 69 & 72 & 78 & 71 & 76 & 77 & 71 \\
\hline & Abschluss im Tertiärbereich & $\mathrm{m}$ & $\mathrm{m}$ & $\mathrm{m}$ & 139 & 160 & 149 & 143 & 155 & 151 & 137 & 153 & 147 & 140 & 152 & 147 \\
\hline Luxemburg & Ausbildung unterhalb Sekundarbereich II & $\mathrm{m}$ & $\mathrm{m}$ & $\mathrm{m}$ & $\mathrm{m}$ & $\mathrm{m}$ & $\mathrm{m}$ & 69 & 68 & 67 & $\mathrm{~m}$ & $\mathrm{~m}$ & $\mathrm{~m}$ & 73 & 67 & 70 \\
\hline & Abschluss im Tertiärbereich & $\mathrm{m}$ & $\mathrm{m}$ & $\mathrm{m}$ & $\mathrm{m}$ & $\mathrm{m}$ & $\mathrm{m}$ & 166 & 166 & 161 & $\mathrm{~m}$ & $\mathrm{~m}$ & $\mathrm{~m}$ & 176 & 161 & 168 \\
\hline Mexiko & & $\mathrm{m}$ & $\mathrm{m}$ & $\mathrm{m}$ & $\mathrm{m}$ & $\mathrm{m}$ & $\mathrm{m}$ & $\mathrm{m}$ & $\mathrm{m}$ & $\mathrm{m}$ & $\mathrm{m}$ & $\mathrm{m}$ & $\mathrm{m}$ & $\mathrm{m}$ & $\mathrm{m}$ & $\mathrm{m}$ \\
\hline Niederlande & Ausbildung unterhalb Sekundarbereich II & $\mathrm{m}$ & $\mathrm{m}$ & $\mathrm{m}$ & $\mathrm{m}$ & $\mathrm{m}$ & $\mathrm{m}$ & 85 & 73 & 83 & $\mathrm{~m}$ & $\mathrm{~m}$ & $\mathrm{~m}$ & $\mathrm{~m}$ & $\mathrm{~m}$ & $\mathrm{~m}$ \\
\hline & Abschluss im Tertiärbereich & $\mathrm{m}$ & $\mathrm{m}$ & $\mathrm{m}$ & $\mathrm{m}$ & $\mathrm{m}$ & $\mathrm{m}$ & 153 & 162 & 156 & $\mathrm{~m}$ & $\mathrm{~m}$ & $\mathrm{~m}$ & $\mathrm{~m}$ & $\mathrm{~m}$ & $\mathrm{~m}$ \\
\hline Neuseeland & Ausbildung unterhalb Sekundarbereich II & 79 & 86 & 82 & 79 & 78 & 81 & 81 & 83 & 83 & 80 & 85 & 83 & 79 & 84 & 82 \\
\hline & Abschluss im Tertiärbereich & 128 & 126 & 127 & 122 & 121 & 125 & 130 & 132 & 131 & 124 & 129 & 125 & 122 & 127 & 123 \\
\hline Norwegen & Ausbildung unterhalb Sekundarbereich II & 81 & 82 & 80 & 79 & 81 & 79 & 78 & 79 & 78 & 78 & 80 & 78 & $\mathrm{~m}$ & $\mathrm{~m}$ & $\mathrm{~m}$ \\
\hline & Abschluss im Tertiärbereich & 134 & 134 & 131 & 136 & 136 & 131 & 137 & 136 & 131 & 137 & 135 & 130 & $\mathrm{~m}$ & $\mathrm{~m}$ & $\mathrm{~m}$ \\
\hline Polen & Ausbildung unterhalb Sekundarbereich II & $\mathrm{m}$ & $\mathrm{m}$ & $\mathrm{m}$ & $\mathrm{m}$ & $\mathrm{m}$ & $\mathrm{m}$ & 87 & 79 & 83 & $\mathrm{~m}$ & $\mathrm{~m}$ & $\mathrm{~m}$ & 86 & 81 & 85 \\
\hline & Abschluss im Tertiärbereich & $\mathrm{m}$ & $\mathrm{m}$ & $\mathrm{m}$ & $\mathrm{m}$ & $\mathrm{m}$ & $\mathrm{m}$ & 187 & 172 & 171 & $\mathrm{~m}$ & $\mathrm{~m}$ & $\mathrm{~m}$ & 188 & 174 & 172 \\
\hline Portugal & Ausbildung unterhalb Sekundarbereich II & $\mathrm{m}$ & $\mathrm{m}$ & $\mathrm{m}$ & 64 & 66 & 67 & 67 & 68 & 69 & 68 & 69 & 70 & $\mathrm{~m}$ & $\mathrm{~m}$ & $\mathrm{~m}$ \\
\hline & Abschluss im Tertiärbereich & $\mathrm{m}$ & $\mathrm{m}$ & $\mathrm{m}$ & 183 & 173 & 177 & 173 & 172 & 170 & 173 & 172 & 170 & $\mathrm{~m}$ & $\mathrm{~m}$ & $\mathrm{~m}$ \\
\hline Slowakei & Ausbildung unterhalb Sekundarbereich II & $\mathrm{m}$ & $\mathrm{m}$ & $\mathrm{m}$ & $\mathrm{m}$ & $\mathrm{m}$ & $\mathrm{m}$ & 70 & 71 & 67 & 69 & 71 & 67 & 70 & 71 & 67 \\
\hline & Abschluss im Tertiärbereich & $\mathrm{m}$ & $\mathrm{m}$ & $\mathrm{m}$ & $\mathrm{m}$ & $\mathrm{m}$ & $\mathrm{m}$ & 188 & 172 & 179 & 185 & 169 & 175 & 185 & 167 & 173 \\
\hline Slowenien & Ausbildung unterhalb Sekundarbereich II & $\mathrm{m}$ & $\mathrm{m}$ & $\mathrm{m}$ & $\mathrm{m}$ & $\mathrm{m}$ & $\mathrm{m}$ & 75 & 74 & 75 & 77 & 76 & 76 & 79 & 76 & 78 \\
\hline & Abschluss im Tertiärbereich & $\mathrm{m}$ & $\mathrm{m}$ & $\mathrm{m}$ & $\mathrm{m}$ & $\mathrm{m}$ & $\mathrm{m}$ & 201 & 181 & 186 & 197 & 180 & 183 & 192 & 177 & 180 \\
\hline
\end{tabular}

1. Einkommen nach Abzug der Einkommensteuer. 2. Unterbrechung der Zeitreihe zwischen 2007 und 2008 aufgrund einer Veränderung der Datenquelle.

3. Die Durchschnittswerte können nicht über die Jahre verglichen werden, da die Zahl der Länder zur Berechnung dieser Werte jedes Jahr differiert.

Quelle: OECD. Hinweise s. Anhang 3 unter www.oecd.org/edu/eag.htm. StatLink: http://dx.doi.org/10.1787/888933116091

Erläuterung der Kennzeichnung fehlender Daten s. Hinweise für den Leser. 
Tabelle A6.2a (Forts.)

Entwicklung der relativen Einkommen von Erwerbstätigen, nach Bildungsstand und Geschlecht (2000, 2005, 2010, 2011, 2012)

25- bis 64-Jährige mit Erwerbseinkommen, Abschluss im Sekundarbereich II = 100

\begin{tabular}{|c|c|c|c|c|c|c|c|c|c|c|c|c|c|c|c|c|}
\hline & \multirow[t]{3}{*}{ Bildungsstand } & \multicolumn{3}{|c|}{2000} & \multicolumn{3}{|c|}{2005} & \multicolumn{3}{|c|}{2010} & \multicolumn{3}{|c|}{2011} & \multicolumn{3}{|c|}{2012} \\
\hline & & $\begin{array}{c}\text { Män- } \\
\text { ner }\end{array}$ & $\begin{array}{c}\text { Frau- } \\
\text { en }\end{array}$ & $M+F$ & $\begin{array}{c}\text { Män- } \\
\text { ner }\end{array}$ & $\begin{array}{c}\text { Frau- } \\
\text { en }\end{array}$ & $M+F$ & $\begin{array}{c}\text { Män- } \\
\text { ner }\end{array}$ & $\begin{array}{c}\text { Frau- } \\
\text { en }\end{array}$ & $M+F$ & $\begin{array}{c}\text { Män- } \\
\text { ner }\end{array}$ & $\begin{array}{c}\text { Frau- } \\
\text { en }\end{array}$ & $M+F$ & $\begin{array}{c}\text { Män- } \\
\text { ner }\end{array}$ & $\begin{array}{c}\text { Frau- } \\
\text { en }\end{array}$ & $M+F$ \\
\hline & & (1) & (2) & (3) & (4) & (5) & (6) & (7) & (8) & (9) & (10) & (11) & (12) & (13) & (14) & (15) \\
\hline OECD-Länder & & & & & & & & & & & & & & & & \\
\hline Spanien & $\begin{array}{l}\text { Ausbildung unterhalb Sekundarbereich II } \\
\text { Abschluss im Tertiärbereich }\end{array}$ & $\begin{array}{l}\mathrm{m} \\
\mathrm{m}\end{array}$ & $\begin{array}{l}\mathrm{m} \\
\mathrm{m}\end{array}$ & $\begin{array}{l}\mathrm{m} \\
\mathrm{m}\end{array}$ & $\begin{array}{r}79 \\
132\end{array}$ & $\begin{array}{r}72 \\
155\end{array}$ & $\begin{array}{r}80 \\
137\end{array}$ & $\begin{array}{r}81 \\
134\end{array}$ & $\begin{array}{r}74 \\
157\end{array}$ & $\begin{array}{r}80 \\
140\end{array}$ & $\begin{array}{r}80 \\
136\end{array}$ & $\begin{array}{r}74 \\
155\end{array}$ & $\begin{array}{r}80 \\
141\end{array}$ & $\begin{array}{l}m \\
m\end{array}$ & $\begin{array}{l}m \\
m\end{array}$ & $\begin{array}{l}m \\
m\end{array}$ \\
\hline Schweden & $\begin{array}{l}\text { Ausbildung unterhalb Sekundarbereich II } \\
\text { Abschluss im Tertiärbereich }\end{array}$ & $\begin{array}{l}\mathrm{m} \\
\mathrm{m}\end{array}$ & $\begin{array}{l}\mathrm{m} \\
\mathrm{m}\end{array}$ & $\begin{array}{l}\mathrm{m} \\
\mathrm{m}\end{array}$ & $\begin{array}{r}87 \\
140\end{array}$ & $\begin{array}{r}87 \\
127\end{array}$ & $\begin{array}{r}88 \\
130\end{array}$ & $\begin{array}{r}84 \\
138\end{array}$ & $\begin{array}{r}81 \\
128\end{array}$ & $\begin{array}{r}84 \\
129\end{array}$ & $\begin{array}{r}83 \\
137\end{array}$ & $\begin{array}{r}80 \\
128\end{array}$ & $\begin{array}{r}83 \\
128\end{array}$ & $\begin{array}{r}83 \\
136\end{array}$ & $\begin{array}{r}79 \\
129\end{array}$ & $\begin{array}{r}82 \\
128\end{array}$ \\
\hline Schweiz & $\begin{array}{l}\text { Ausbildung unterhalb Sekundarbereich II } \\
\text { Abschluss im Tertiärbereich }\end{array}$ & $\begin{array}{r}79 \\
135\end{array}$ & $\begin{array}{r}72 \\
144\end{array}$ & $\begin{array}{r}75 \\
152\end{array}$ & $\begin{array}{r}81 \\
142\end{array}$ & $\begin{array}{r}77 \\
150\end{array}$ & $\begin{array}{r}76 \\
157\end{array}$ & $\begin{array}{r}78 \\
144\end{array}$ & $\begin{array}{r}78 \\
151\end{array}$ & $\begin{array}{r}76 \\
155\end{array}$ & $\begin{array}{r}80 \\
144\end{array}$ & $\begin{array}{r}77 \\
159\end{array}$ & $\begin{array}{r}77 \\
157\end{array}$ & $\begin{array}{r}80 \\
145\end{array}$ & $\begin{array}{r}76 \\
159\end{array}$ & $\begin{array}{r}77 \\
158\end{array}$ \\
\hline Türkei $^{1}$ & $\begin{array}{l}\text { Ausbildung unterhalb Sekundarbereich II } \\
\text { Abschluss im Tertiärbereich }\end{array}$ & $\begin{array}{l}\mathrm{m} \\
\mathrm{m}\end{array}$ & $\begin{array}{l}m \\
m\end{array}$ & $\begin{array}{l}\mathrm{m} \\
\mathrm{m}\end{array}$ & $\begin{array}{r}72 \\
153\end{array}$ & $\begin{array}{r}43 \\
154\end{array}$ & $\begin{array}{r}69 \\
149\end{array}$ & $\begin{array}{l}\mathrm{m} \\
\mathrm{m}\end{array}$ & $\begin{array}{l}\mathrm{m} \\
\mathrm{m}\end{array}$ & $\begin{array}{l}m \\
m\end{array}$ & $\begin{array}{l}\mathrm{m} \\
\mathrm{m}\end{array}$ & $\begin{array}{l}m \\
m\end{array}$ & $\begin{array}{l}m \\
m\end{array}$ & $\begin{array}{r}67 \\
197\end{array}$ & $\begin{array}{r}47 \\
199\end{array}$ & $\begin{array}{r}63 \\
191\end{array}$ \\
\hline $\begin{array}{l}\text { Vereinigtes } \\
\text { Königreich }\end{array}$ & $\begin{array}{l}\text { Ausbildung unterhalb Sekundarbereich II } \\
\text { Abschluss im Tertiärbereich }\end{array}$ & $\begin{array}{r}74 \\
152\end{array}$ & $\begin{array}{r}69 \\
176\end{array}$ & $\begin{array}{r}69 \\
160\end{array}$ & $\begin{array}{r}72 \\
146\end{array}$ & $\begin{array}{r}71 \\
181\end{array}$ & $\begin{array}{r}71 \\
158\end{array}$ & $\begin{array}{r}64 \\
162\end{array}$ & $\begin{array}{r}69 \\
177\end{array}$ & $\begin{array}{r}67 \\
165\end{array}$ & $\begin{array}{r}67 \\
151\end{array}$ & $\begin{array}{r}69 \\
182\end{array}$ & $\begin{array}{r}69 \\
157\end{array}$ & $\begin{array}{r}68 \\
147\end{array}$ & $\begin{array}{r}69 \\
178\end{array}$ & $\begin{array}{r}70 \\
156\end{array}$ \\
\hline $\begin{array}{l}\text { Vereinigte } \\
\text { Staaten }\end{array}$ & $\begin{array}{l}\text { Ausbildung unterhalb Sekundarbereich II } \\
\text { Abschluss im Tertiärbereich }\end{array}$ & $\begin{array}{r}65 \\
181\end{array}$ & $\begin{array}{r}66 \\
169\end{array}$ & $\begin{array}{r}68 \\
176\end{array}$ & $\begin{array}{r}69 \\
196\end{array}$ & $\begin{array}{r}67 \\
178\end{array}$ & $\begin{array}{r}71 \\
186\end{array}$ & $\begin{array}{r}64 \\
184\end{array}$ & $\begin{array}{r}61 \\
175\end{array}$ & $\begin{array}{r}66 \\
177\end{array}$ & $\begin{array}{r}64 \\
182\end{array}$ & $\begin{array}{r}58 \\
181\end{array}$ & $\begin{array}{r}64 \\
177\end{array}$ & $\begin{array}{r}60 \\
180\end{array}$ & $\begin{array}{r}62 \\
177\end{array}$ & $\begin{array}{r}63 \\
174\end{array}$ \\
\hline $\begin{array}{l}\text { OECD- } \\
\text { Durchschnitt }{ }^{3}\end{array}$ & $\begin{array}{l}\text { Ausbildung unterhalb Sekundarbereich II } \\
\text { Abschluss im Tertiärbereich }\end{array}$ & $\begin{array}{r}80 \\
154\end{array}$ & $\begin{array}{r}77 \\
149\end{array}$ & $\begin{array}{r}80 \\
151\end{array}$ & $\begin{array}{r}80 \\
158\end{array}$ & $\begin{array}{r}76 \\
155\end{array}$ & $\begin{array}{r}79 \\
154\end{array}$ & $\begin{array}{r}78 \\
164\end{array}$ & $\begin{array}{r}76 \\
158\end{array}$ & $\begin{array}{r}77 \\
158\end{array}$ & $\begin{array}{r}77 \\
164\end{array}$ & $\begin{array}{r}75 \\
165\end{array}$ & $\begin{array}{r}77 \\
161\end{array}$ & $\begin{array}{r}77 \\
164\end{array}$ & $\begin{array}{r}75 \\
162\end{array}$ & $\begin{array}{r}76 \\
159\end{array}$ \\
\hline $\begin{array}{l}\text { EU21- } \\
\text { Durchschnitt }{ }^{3}\end{array}$ & $\begin{array}{l}\text { Ausbildung unterhalb Sekundarbereich II } \\
\text { Abschluss im Tertiärbereich }\end{array}$ & $\begin{array}{r}82 \\
160\end{array}$ & $\begin{array}{r}78 \\
153\end{array}$ & $\begin{array}{r}82 \\
155\end{array}$ & $\begin{array}{r}82 \\
165\end{array}$ & $\begin{array}{r}78 \\
158\end{array}$ & $\begin{array}{r}81 \\
159\end{array}$ & $\begin{array}{r}80 \\
169\end{array}$ & $\begin{array}{r}76 \\
161\end{array}$ & $\begin{array}{r}78 \\
162\end{array}$ & $\begin{array}{r}78 \\
165\end{array}$ & $\begin{array}{r}76 \\
166\end{array}$ & $\begin{array}{r}78 \\
160\end{array}$ & $\begin{array}{r}79 \\
171\end{array}$ & $\begin{array}{r}77 \\
162\end{array}$ & $\begin{array}{r}78 \\
162\end{array}$ \\
\hline Partnerländer & & & & & & & & & & & & & & & & \\
\hline Argentinien & & $\mathrm{m}$ & $\mathrm{m}$ & $\mathrm{m}$ & $\mathrm{m}$ & $\mathrm{m}$ & $\mathrm{m}$ & $\mathrm{m}$ & $\mathrm{m}$ & $\mathrm{m}$ & $\mathrm{m}$ & $\mathrm{m}$ & $\mathrm{m}$ & $\mathrm{m}$ & $\mathrm{m}$ & $\mathrm{m}$ \\
\hline Brasilien & $\begin{array}{l}\text { Ausbildung unterhalb Sekundarbereich II } \\
\text { Abschluss im Tertiärbereich }\end{array}$ & $\begin{array}{l}m \\
m\end{array}$ & $\begin{array}{l}m \\
m\end{array}$ & $\begin{array}{l}\mathrm{m} \\
\mathrm{m}\end{array}$ & $\begin{array}{l}m \\
m\end{array}$ & $\begin{array}{l}\mathrm{m} \\
\mathrm{m}\end{array}$ & $\begin{array}{l}m \\
m\end{array}$ & $\begin{array}{l}m \\
m\end{array}$ & $\begin{array}{l}m \\
m\end{array}$ & $\begin{array}{l}m \\
m\end{array}$ & $\begin{array}{r}57 \\
273\end{array}$ & $\begin{array}{r}50 \\
269\end{array}$ & $\begin{array}{r}58 \\
257\end{array}$ & $\begin{array}{r}57 \\
259\end{array}$ & $\begin{array}{r}53 \\
262\end{array}$ & $\begin{array}{r}58 \\
247\end{array}$ \\
\hline China & & $\mathrm{m}$ & $\mathrm{m}$ & $\mathrm{m}$ & $\mathrm{m}$ & $\mathrm{m}$ & $\mathrm{m}$ & $\mathrm{m}$ & $\mathrm{m}$ & $\mathrm{m}$ & $\mathrm{m}$ & $\mathrm{m}$ & $\mathrm{m}$ & $\mathrm{m}$ & $\mathrm{m}$ & $\mathrm{m}$ \\
\hline Kolumbien & & $\mathrm{m}$ & $\mathrm{m}$ & $\mathrm{m}$ & $\mathrm{m}$ & $\mathrm{m}$ & $\mathrm{m}$ & $\mathrm{m}$ & $\mathrm{m}$ & $\mathrm{m}$ & $\mathrm{m}$ & $\mathrm{m}$ & $\mathrm{m}$ & $\mathrm{m}$ & $\mathrm{m}$ & $\mathrm{m}$ \\
\hline Indien & & $\mathrm{m}$ & $\mathrm{m}$ & $\mathrm{m}$ & $\mathrm{m}$ & $\mathrm{m}$ & m & $\mathrm{m}$ & $\mathrm{m}$ & $\mathrm{m}$ & $\mathrm{m}$ & $\mathrm{m}$ & $\mathrm{m}$ & $\mathrm{m}$ & m & $\mathrm{m}$ \\
\hline Indonesien & & $\mathrm{m}$ & $\mathrm{m}$ & $\mathrm{m}$ & $\mathrm{m}$ & $\mathrm{m}$ & $\mathrm{m}$ & $\mathrm{m}$ & $\mathrm{m}$ & $\mathrm{m}$ & $\mathrm{m}$ & $\mathrm{m}$ & $\mathrm{m}$ & $\mathrm{m}$ & $\mathrm{m}$ & $\mathrm{m}$ \\
\hline Lettland & & $\mathrm{m}$ & $\mathrm{m}$ & $\mathrm{m}$ & $\mathrm{m}$ & $m$ & $\mathrm{~m}$ & $m$ & $\mathrm{~m}$ & $\mathrm{~m}$ & $\mathrm{~m}$ & $\mathrm{~m}$ & $\mathrm{~m}$ & $\mathrm{~m}$ & $\mathrm{~m}$ & $\mathrm{~m}$ \\
\hline Russische Föd. & & $\mathrm{m}$ & $\mathrm{m}$ & $\mathrm{m}$ & $\mathrm{m}$ & $\mathrm{m}$ & $\mathrm{m}$ & $\mathrm{m}$ & $\mathrm{m}$ & $\mathrm{m}$ & $\mathrm{m}$ & $\mathrm{m}$ & $\mathrm{m}$ & $\mathrm{m}$ & $\mathrm{m}$ & $\mathrm{m}$ \\
\hline Saudi-Arabien & & $\mathrm{m}$ & $\mathrm{m}$ & $\mathrm{m}$ & $\mathrm{m}$ & $\mathrm{m}$ & $\mathrm{m}$ & $\mathrm{m}$ & $\mathrm{m}$ & $\mathrm{m}$ & $\mathrm{m}$ & $\mathrm{m}$ & $\mathrm{m}$ & $\mathrm{m}$ & $\mathrm{m}$ & $\mathrm{m}$ \\
\hline Südafrika & & $\mathrm{m}$ & $\mathrm{m}$ & $\mathrm{m}$ & $\mathrm{m}$ & $\mathrm{m}$ & $\mathrm{m}$ & $\mathrm{m}$ & $\mathrm{m}$ & $\mathrm{m}$ & $\mathrm{m}$ & $\mathrm{m}$ & $\mathrm{m}$ & $\mathrm{m}$ & $\mathrm{m}$ & $\mathrm{m}$ \\
\hline G20-Durchschnitt & & $\mathbf{m}$ & $\mathbf{m}$ & $\mathbf{m}$ & $\mathbf{m}$ & $\mathbf{m}$ & $\mathbf{m}$ & $\mathbf{m}$ & $\mathbf{m}$ & $\mathbf{m}$ & $\mathbf{m}$ & $\mathbf{m}$ & $\mathbf{m}$ & m & $\mathbf{m}$ & $\mathbf{m}$ \\
\hline
\end{tabular}

1. Einkommen nach Abzug der Einkommensteuer. 2. Unterbrechung der Zeitreihe zwischen 2007 und 2008 aufgrund einer Veränderung der Datenquelle.

3. Die Durchschnittswerte können nicht über die Jahre verglichen werden, da die Zahl der Länder zur Berechnung dieser Werte jedes Jahr differiert.

Quelle: OECD. Hinweise s. Anhang 3 unter www.oecd.org/edu/eag.htm. StatLink: http://dx.doi.org/10.1787/888933116091

Erläuterung der Kennzeichnung fehlender Daten s. Hinweise für den Leser. 
Einkommensunterschiede zwischen erwerbstätigen Frauen und Männern, nach Bildungsstand und Altersgruppe (2012) Erwachsene mit Erwerbseinkommen, durchschnittliche Jahreseinkommen von ganzjährig vollzeiterwerbstätigen Frauen als Prozentsatz derjenigen von Männern

\begin{tabular}{|c|c|c|c|c|c|c|c|c|c|c|}
\hline & \multirow[t]{3}{*}{ | Jahr } & \multicolumn{3}{|c|}{$\begin{array}{l}\text { Ausbildung unterhalb } \\
\text { Sekundarbereich II }\end{array}$} & \multicolumn{3}{|c|}{$\begin{array}{l}\text { Abschluss im Sekundarbereich II/post- } \\
\text { sekundaren, nicht tertiären Bereich }\end{array}$} & \multicolumn{3}{|c|}{ Abschluss im Tertiärbereich } \\
\hline & & $25-64$ & $35-44$ & $55-64$ & $25-64$ & $35-44$ & $55-64$ & $25-64$ & $35-44$ & $55-64$ \\
\hline & & (1) & (2) & (3) & (4) & (5) & (6) & (7) & (8) & (9) \\
\hline \multicolumn{11}{|l|}{ OECD-Länder } \\
\hline Australien & 2012 & 79 & 80 & 81 & 75 & 74 & 78 & 75 & 75 & 69 \\
\hline Österreich & 2012 & 76 & 74 & 77 & 76 & 76 & 80 & 76 & 80 & 79 \\
\hline Belgien ${ }^{1}$ & 2011 & 80 & $\mathrm{~m}$ & $\mathrm{~m}$ & 98 & 96 & 99 & 86 & 86 & 81 \\
\hline Kanada & 2011 & 65 & 70 & 73 & 70 & 71 & 70 & 69 & 68 & 70 \\
\hline Chile & 2011 & 76 & 79 & 70 & 69 & 68 & 71 & 62 & 70 & 53 \\
\hline Tschechien & 2011 & 79 & 78 & 80 & 80 & 74 & 87 & 70 & 64 & 85 \\
\hline Dänemark & 2012 & 83 & 80 & 82 & 80 & 78 & 83 & 75 & 76 & 73 \\
\hline Estland & 2012 & 64 & 60 & 88 & 59 & 59 & 66 & 68 & 64 & 69 \\
\hline Finnland & 2012 & 79 & 75 & 79 & 79 & 76 & 79 & 76 & 75 & 74 \\
\hline Frankreich & 2010 & 74 & 69 & 76 & 79 & 75 & 75 & 73 & 77 & 70 \\
\hline Deutschland & 2012 & 82 & 79 & 92 & 82 & 83 & 86 & 72 & 73 & 73 \\
\hline Griechenland & 2012 & 76 & 75 & 65 & 84 & 86 & 69 & 70 & 75 & 66 \\
\hline Ungarn & 2012 & 81 & 81 & 78 & 84 & 81 & 90 & 63 & 57 & 70 \\
\hline Island & & $\mathrm{m}$ & $\mathrm{m}$ & $\mathrm{m}$ & $\mathrm{m}$ & $\mathrm{m}$ & $\mathrm{m}$ & $\mathrm{m}$ & $\mathrm{m}$ & $\mathrm{m}$ \\
\hline Irland ${ }^{1}$ & 2011 & 73 & 84 & 71 & 77 & 76 & 75 & 76 & 86 & 80 \\
\hline Israel & 2012 & 77 & 57 & 87 & 66 & 68 & 60 & 72 & 70 & 80 \\
\hline Italien & 2010 & 78 & 79 & 72 & 78 & 78 & 77 & 69 & 77 & 68 \\
\hline Japan & 2012 & $\mathrm{~m}$ & $\mathrm{~m}$ & $\mathrm{~m}$ & $\mathrm{~m}$ & $\mathrm{~m}$ & $\mathrm{~m}$ & $\mathrm{~m}$ & $\mathrm{~m}$ & $\mathrm{~m}$ \\
\hline Korea & 2012 & 65 & 67 & 63 & 64 & 62 & 67 & 68 & 67 & 69 \\
\hline Luxemburg & 2012 & 82 & 85 & 71 & 83 & 88 & 66 & 72 & 89 & 65 \\
\hline Mexiko & & $\mathrm{m}$ & $\mathrm{m}$ & $\mathrm{m}$ & $\mathrm{m}$ & $\mathrm{m}$ & $\mathrm{m}$ & $\mathrm{m}$ & $\mathrm{m}$ & $\mathrm{m}$ \\
\hline Niederlande & 2010 & 77 & 79 & 76 & 79 & 85 & 79 & 74 & 83 & 74 \\
\hline Neuseeland & 2012 & 84 & 90 & 78 & 83 & 85 & 83 & 79 & 76 & 80 \\
\hline Norwegen & 2011 & 82 & 80 & 82 & 79 & 78 & 78 & 74 & 75 & 72 \\
\hline Polen & 2012 & 73 & 69 & 74 & 79 & 72 & 89 & 71 & 66 & 76 \\
\hline Portugal & 2011 & 75 & 75 & 74 & 72 & 72 & 69 & 70 & 74 & 68 \\
\hline Slowakei & 2012 & 73 & 74 & 72 & 75 & 71 & 83 & 67 & 59 & 73 \\
\hline Slowenien & 2012 & 85 & 84 & 85 & 88 & 84 & 99 & 82 & 80 & 87 \\
\hline Spanien & 2011 & 78 & 86 & 75 & 79 & 78 & 90 & 86 & 83 & 92 \\
\hline Schweden & & $\mathrm{m}$ & $\mathrm{m}$ & $\mathrm{m}$ & $\mathrm{m}$ & $\mathrm{m}$ & $\mathrm{m}$ & $\mathrm{m}$ & $\mathrm{m}$ & $\mathrm{m}$ \\
\hline Schweiz & & $\mathrm{m}$ & $\mathrm{m}$ & $\mathrm{m}$ & $\mathrm{m}$ & $\mathrm{m}$ & $\mathrm{m}$ & $\mathrm{m}$ & $\mathrm{m}$ & $\mathrm{m}$ \\
\hline${\text { Türkei }{ }^{1}}$ & 2012 & 67 & 64 & 59 & 83 & 74 & 148 & 82 & 85 & 69 \\
\hline Vereinigtes Königreich & 2012 & 75 & 73 & 79 & 72 & 71 & 66 & 80 & 82 & 76 \\
\hline Vereinigte Staaten & 2012 & 75 & 90 & 72 & 70 & 69 & 67 & 69 & 70 & 69 \\
\hline OECD-Durchschnitt & & 76 & 76 & 76 & 77 & 76 & 80 & 73 & 75 & 73 \\
\hline EU21-Durchschnitt & & 77 & 77 & 77 & 79 & 78 & 80 & 74 & 75 & 75 \\
\hline \multicolumn{11}{|l|}{ Partnerländer } \\
\hline Argentinien & & $\mathrm{m}$ & $\mathrm{m}$ & $\mathrm{m}$ & $\mathrm{m}$ & $\mathrm{m}$ & $\mathrm{m}$ & $\mathrm{m}$ & $\mathrm{m}$ & $\mathrm{m}$ \\
\hline Brasilien & 2012 & 68 & 69 & 64 & 62 & 60 & 58 & 63 & 63 & 66 \\
\hline China & & $\mathrm{m}$ & $\mathrm{m}$ & $\mathrm{m}$ & $\mathrm{m}$ & $\mathrm{m}$ & $\mathrm{m}$ & $\mathrm{m}$ & $\mathrm{m}$ & $\mathrm{m}$ \\
\hline Kolumbien & & $\mathrm{m}$ & $\mathrm{m}$ & $\mathrm{m}$ & $\mathrm{m}$ & $\mathrm{m}$ & $\mathrm{m}$ & $\mathrm{m}$ & $\mathrm{m}$ & $\mathrm{m}$ \\
\hline Indien & & $\mathrm{m}$ & $\mathrm{m}$ & $\mathrm{m}$ & $\mathrm{m}$ & $\mathrm{m}$ & $\mathrm{m}$ & $\mathrm{m}$ & $\mathrm{m}$ & $\mathrm{m}$ \\
\hline Indonesien & & $\mathrm{m}$ & $\mathrm{m}$ & $\mathrm{m}$ & $\mathrm{m}$ & $\mathrm{m}$ & $\mathrm{m}$ & $\mathrm{m}$ & $\mathrm{m}$ & $\mathrm{m}$ \\
\hline Lettland & & $\mathrm{m}$ & $\mathrm{m}$ & $\mathrm{m}$ & $\mathrm{m}$ & $\mathrm{m}$ & $\mathrm{m}$ & $\mathrm{m}$ & $\mathrm{m}$ & $\mathrm{m}$ \\
\hline Russische Föderation & & $\mathrm{m}$ & $\mathrm{m}$ & $\mathrm{m}$ & $\mathrm{m}$ & $\mathrm{m}$ & $\mathrm{m}$ & $\mathrm{m}$ & $\mathrm{m}$ & $\mathrm{m}$ \\
\hline Saudi-Arabien & & $\mathrm{m}$ & $\mathrm{m}$ & $\mathrm{m}$ & $\mathrm{m}$ & $\mathrm{m}$ & $\mathrm{m}$ & $\mathrm{m}$ & $\mathrm{m}$ & $\mathrm{m}$ \\
\hline Südafrika & & $\mathrm{m}$ & $\mathrm{m}$ & $\mathrm{m}$ & $\mathrm{m}$ & $\mathrm{m}$ & $\mathrm{m}$ & $\mathrm{m}$ & $\mathrm{m}$ & $\mathrm{m}$ \\
\hline G20-Durchschnitt & & $\mathbf{m}$ & $\mathbf{m}$ & $\mathbf{m}$ & $\mathbf{m}$ & $\mathbf{m}$ & $\mathbf{m}$ & m & $\mathbf{m}$ & $\mathbf{m}$ \\
\hline
\end{tabular}

Anmerkung: Die Spalten mit den relativen Einkommen für alle Bildungsbereiche zusammen sind im Internet verfügbar (s. StatLink).

1. Einkommen nach Abzug der Einkommensteuer.

Quelle: OECD. Hinweise s. Anhang 3 unter www.oecd.org/edu/eag.htm. StatLink: http://dx.doi.org/10.1787/888933116110

Erläuterung der Kennzeichnung fehlender Daten s. Hinweise für den Leser. 
Tabelle A6.3b

Entwicklung der Einkommensunterschiede zwischen erwerbstätigen Frauen und Männern, nach Bildungsstand (2000, 2005, 2010, 2011, 2012)

25- bis 64-Jährige mit Erwerbseinkommen, durchschnittliche Jahreseinkommen von Frauen als Prozentsatz derjenigen von Männern

\begin{tabular}{|c|c|c|c|c|c|c|c|c|c|c|c|c|c|c|c|}
\hline & \multicolumn{5}{|c|}{ Ausbildung unterhalb Sekundarbereich II } & \multicolumn{5}{|c|}{$\begin{array}{c}\text { Abschluss im Sekundarbereich II/ } \\
\text { postsekundaren, nicht tertiären Bereich }\end{array}$} & \multicolumn{5}{|c|}{ Abschluss im Tertiärbereich } \\
\hline & 2000 & 2005 & 2010 & 2011 & 2012 & 2000 & 2005 & 2010 & 2011 & 2012 & 2000 & 2005 & 2010 & 2011 & 2012 \\
\hline & (1) & (2) & (3) & (4) & (5) & (6) & (7) & (8) & (9) & (10) & $(11)$ & $(12)$ & $(13)$ & $(14)$ & (15) \\
\hline \multicolumn{16}{|l|}{ OECD-Länder } \\
\hline Australien & $\mathrm{m}$ & 61 & $\mathrm{~m}$ & m & 62 & m & 61 & $\mathrm{~m}$ & $\mathrm{~m}$ & 61 & $\mathrm{~m}$ & 64 & $m$ & $m$ & 65 \\
\hline Österreich & $\mathrm{m}$ & 57 & 61 & 65 & 62 & $\mathrm{~m}$ & 60 & 60 & 59 & 60 & $\mathrm{~m}$ & 62 & 63 & 63 & 62 \\
\hline Belgien $^{1}$ & 64 & 67 & 72 & 70 & $\mathrm{~m}$ & 72 & 75 & 77 & 77 & $\mathrm{~m}$ & 74 & 73 & 79 & 80 & $\mathrm{~m}$ \\
\hline Kanada & 53 & 55 & 61 & 57 & $\mathrm{~m}$ & 61 & 61 & 62 & 61 & $\mathrm{~m}$ & 57 & 62 & 67 & 64 & $\mathrm{~m}$ \\
\hline Chile & $\mathrm{m}$ & $\mathrm{m}$ & $\mathrm{m}$ & 66 & $\mathrm{~m}$ & $\mathrm{~m}$ & $\mathrm{~m}$ & $\mathrm{~m}$ & 65 & $\mathrm{~m}$ & $\mathrm{~m}$ & $\mathrm{~m}$ & $\mathrm{~m}$ & 63 & $\mathrm{~m}$ \\
\hline Tschechien & $\mathrm{m}$ & 74 & 79 & 79 & $\mathrm{~m}$ & $\mathrm{~m}$ & 80 & 82 & 81 & $\mathrm{~m}$ & $\mathrm{~m}$ & 68 & 68 & 69 & $\mathrm{~m}$ \\
\hline Dänemark & $m$ & 73 & 80 & 78 & 77 & $m$ & 71 & 76 & 75 & 74 & $\mathrm{~m}$ & 67 & 68 & 68 & 68 \\
\hline Estland & $\mathrm{m}$ & $\mathrm{m}$ & 59 & 62 & 58 & $\mathrm{~m}$ & $m$ & 60 & 62 & 56 & $\mathrm{~m}$ & $\mathrm{~m}$ & 62 & 63 & 66 \\
\hline Finnland & 76 & 78 & 77 & 76 & $\mathrm{~m}$ & 71 & 73 & 74 & 74 & $\mathrm{~m}$ & 61 & 65 & 68 & 68 & $m$ \\
\hline Frankreich ${ }^{2}$ & $\mathrm{~m}$ & 68 & 61 & $\mathrm{~m}$ & $\mathrm{~m}$ & $\mathrm{~m}$ & 75 & 71 & $\mathrm{~m}$ & $\mathrm{~m}$ & $\mathrm{~m}$ & 70 & 68 & $\mathrm{~m}$ & $\mathrm{~m}$ \\
\hline Deutschland & 56 & 52 & 49 & 56 & 56 & 63 & 62 & 62 & 61 & 62 & 61 & 62 & 56 & 59 & 60 \\
\hline Griechenland & $\mathrm{m}$ & $\mathrm{m}$ & $\mathrm{m}$ & 32 & 70 & $\mathrm{~m}$ & $\mathrm{~m}$ & $\mathrm{~m}$ & 44 & 79 & $\mathrm{~m}$ & $\mathrm{~m}$ & $\mathrm{~m}$ & 65 & 66 \\
\hline Ungarn & 83 & 88 & 83 & 84 & 84 & 88 & 93 & 89 & 88 & 85 & 62 & 69 & 68 & 67 & 64 \\
\hline Island & $\mathrm{m}$ & $\mathrm{m}$ & $\mathrm{m}$ & $\mathrm{m}$ & $\mathrm{m}$ & $\mathrm{m}$ & $\mathrm{m}$ & $\mathrm{m}$ & $\mathrm{m}$ & $\mathrm{m}$ & $\mathrm{m}$ & $\mathrm{m}$ & $\mathrm{m}$ & $\mathrm{m}$ & $\mathrm{m}$ \\
\hline Irland $^{1}$ & 46 & 49 & 60 & 56 & $\mathrm{~m}$ & 60 & 63 & 64 & 65 & $\mathrm{~m}$ & 71 & 62 & 63 & 71 & $\mathrm{~m}$ \\
\hline Israel & $\mathrm{m}$ & 57 & 60 & 62 & 61 & $\mathrm{~m}$ & 59 & 65 & 66 & 58 & $\mathrm{~m}$ & 58 & 60 & 63 & 63 \\
\hline Italien & 76 & $\mathrm{~m}$ & 62 & $\mathrm{~m}$ & $\mathrm{~m}$ & 65 & $\mathrm{~m}$ & 69 & $\mathrm{~m}$ & $\mathrm{~m}$ & 62 & $\mathrm{~m}$ & 64 & $\mathrm{~m}$ & $\mathrm{~m}$ \\
\hline Japan & $\mathrm{m}$ & $\mathrm{m}$ & $\mathrm{m}$ & $\mathrm{m}$ & 42 & $\mathrm{~m}$ & $\mathrm{~m}$ & $\mathrm{~m}$ & $\mathrm{~m}$ & 43 & $\mathrm{~m}$ & $\mathrm{~m}$ & $\mathrm{~m}$ & $\mathrm{~m}$ & 48 \\
\hline Korea & $m$ & 61 & 64 & 63 & 60 & $\mathrm{~m}$ & 59 & 59 & 58 & 60 & $\mathrm{~m}$ & 67 & 64 & 65 & 65 \\
\hline Luxemburg & $\mathrm{m}$ & $\mathrm{m}$ & 63 & $\mathrm{~m}$ & 66 & $\mathrm{~m}$ & $\mathrm{~m}$ & 64 & $\mathrm{~m}$ & 71 & $\mathrm{~m}$ & $\mathrm{~m}$ & 64 & $\mathrm{~m}$ & 65 \\
\hline Mexiko & $m$ & $\mathrm{~m}$ & $\mathrm{~m}$ & $m$ & $\mathrm{~m}$ & $\mathrm{~m}$ & $m$ & $m$ & $\mathrm{~m}$ & $m$ & $\mathrm{~m}$ & $\mathrm{~m}$ & $m$ & $m$ & $m$ \\
\hline Niederlande & $\mathrm{m}$ & $\mathrm{m}$ & 49 & $\mathrm{~m}$ & $\mathrm{~m}$ & $\mathrm{~m}$ & $\mathrm{~m}$ & 57 & $\mathrm{~m}$ & $\mathrm{~m}$ & $\mathrm{~m}$ & $\mathrm{~m}$ & 60 & $\mathrm{~m}$ & $\mathrm{~m}$ \\
\hline Neuseeland & 67 & 61 & 69 & 70 & 70 & 64 & 64 & 65 & 64 & 67 & 61 & 61 & 68 & 68 & 69 \\
\hline Norwegen & 63 & 65 & 68 & 68 & $\mathrm{~m}$ & 62 & 63 & 66 & 66 & $\mathrm{~m}$ & 62 & 63 & 65 & 66 & $\mathrm{~m}$ \\
\hline Polen & $\mathrm{m}$ & $\mathrm{m}$ & 72 & $m$ & 73 & m & m & 81 & $\mathrm{~m}$ & 79 & $\mathrm{~m}$ & $\mathrm{~m}$ & 72 & $\mathrm{~m}$ & 72 \\
\hline Portugal & $\mathrm{m}$ & 73 & 71 & 72 & $m$ & $\mathrm{~m}$ & 71 & 71 & 71 & $m$ & $\mathrm{~m}$ & 67 & 70 & 70 & $\mathrm{~m}$ \\
\hline Slowakei & $\mathrm{m}$ & $\mathrm{m}$ & 73 & 75 & 73 & $\mathrm{~m}$ & $\mathrm{~m}$ & 73 & 72 & 72 & $\mathrm{~m}$ & $m$ & 67 & 66 & 65 \\
\hline Slowenien & $\mathrm{m}$ & $\mathrm{m}$ & 85 & 85 & 85 & $\mathrm{~m}$ & $m$ & 87 & 86 & 88 & $\mathrm{~m}$ & $\mathrm{~m}$ & 79 & 79 & 82 \\
\hline Spanien & $m$ & 58 & 66 & 67 & $m$ & $\mathrm{~m}$ & 64 & 71 & 72 & $\mathrm{~m}$ & $\mathrm{~m}$ & 75 & 84 & 82 & $\mathrm{~m}$ \\
\hline Schweden & $\mathrm{m}$ & 74 & 73 & 72 & 72 & $\mathrm{~m}$ & 73 & 74 & 74 & 75 & $\mathrm{~m}$ & 68 & 71 & 71 & 72 \\
\hline Schweiz & 53 & 54 & 58 & 55 & 55 & 58 & 57 & 59 & 58 & 58 & 62 & 60 & 61 & 63 & 63 \\
\hline Türkei $^{1}$ & $\mathrm{~m}$ & 47 & $\mathrm{~m}$ & $\mathrm{~m}$ & 55 & $\mathrm{~m}$ & 78 & $\mathrm{~m}$ & $\mathrm{~m}$ & 79 & $\mathrm{~m}$ & 78 & $\mathrm{~m}$ & $\mathrm{~m}$ & 80 \\
\hline Vereinigtes Königreich & 50 & 55 & 70 & 50 & 58 & 54 & 56 & 65 & 48 & 57 & 63 & 69 & 71 & 58 & 69 \\
\hline Vereinigte Staaten & 60 & 63 & 63 & 58 & 66 & 60 & 65 & 66 & 64 & 64 & 56 & 59 & 63 & 63 & 63 \\
\hline OECD-Durchschnitt ${ }^{3}$ & 62 & 63 & 67 & 66 & 65 & 65 & 67 & 69 & 67 & 67 & 63 & 66 & 67 & 67 & 66 \\
\hline EU21-Durchschnitt ${ }^{3}$ & 65 & 67 & 68 & 67 & 69 & 68 & 70 & 71 & 69 & 72 & 65 & 68 & 68 & 69 & 68 \\
\hline \multicolumn{16}{|l|}{ Partnerländer } \\
\hline Argentinien & $\mathrm{m}$ & $\mathrm{m}$ & $\mathrm{m}$ & $\mathrm{m}$ & $\mathrm{m}$ & $\mathrm{m}$ & $\mathrm{m}$ & $\mathrm{m}$ & $\mathrm{m}$ & $\mathrm{m}$ & $\mathrm{m}$ & $\mathrm{m}$ & $\mathrm{m}$ & $\mathrm{m}$ & $\mathrm{m}$ \\
\hline Brasilien & $\mathrm{m}$ & $\mathrm{m}$ & $\mathrm{m}$ & 51 & 55 & $\mathrm{~m}$ & $\mathrm{~m}$ & $\mathrm{~m}$ & 59 & 58 & $\mathrm{~m}$ & $\mathrm{~m}$ & $\mathrm{~m}$ & 58 & 59 \\
\hline China & $\mathrm{m}$ & $\mathrm{m}$ & $\mathrm{m}$ & $m$ & $\mathrm{~m}$ & $m$ & $m$ & $\mathrm{~m}$ & $m$ & $\mathrm{~m}$ & $\mathrm{~m}$ & $\mathrm{~m}$ & $\mathrm{~m}$ & $m$ & $\mathrm{~m}$ \\
\hline Kolumbien & $\mathrm{m}$ & $\mathrm{m}$ & $\mathrm{m}$ & $\mathrm{m}$ & $\mathrm{m}$ & $\mathrm{m}$ & $\mathrm{m}$ & $\mathrm{m}$ & $\mathrm{m}$ & $\mathrm{m}$ & $\mathrm{m}$ & $\mathrm{m}$ & $\mathrm{m}$ & $\mathrm{m}$ & $\mathrm{m}$ \\
\hline Indien & $\mathrm{m}$ & $\mathrm{m}$ & $\mathrm{m}$ & $\mathrm{m}$ & $\mathrm{m}$ & $\mathrm{m}$ & $\mathrm{m}$ & $\mathrm{m}$ & $\mathrm{m}$ & $\mathrm{m}$ & $\mathrm{m}$ & $\mathrm{m}$ & $\mathrm{m}$ & $m$ & $\mathrm{~m}$ \\
\hline Indonesien & $\mathrm{m}$ & $\mathrm{m}$ & $\mathrm{m}$ & $\mathrm{m}$ & $\mathrm{m}$ & $\mathrm{m}$ & $\mathrm{m}$ & $\mathrm{m}$ & $\mathrm{m}$ & $\mathrm{m}$ & $\mathrm{m}$ & $\mathrm{m}$ & $\mathrm{m}$ & $\mathrm{m}$ & $\mathrm{m}$ \\
\hline Lettland & $\mathrm{m}$ & $\mathrm{m}$ & $\mathrm{m}$ & $\mathrm{m}$ & $m$ & $\mathrm{~m}$ & $\mathrm{~m}$ & $\mathrm{~m}$ & $\mathrm{~m}$ & $\mathrm{~m}$ & $\mathrm{~m}$ & $\mathrm{~m}$ & $\mathrm{~m}$ & $\mathrm{~m}$ & $m$ \\
\hline Russische Föderation & $\mathrm{m}$ & $\mathrm{m}$ & $\mathrm{m}$ & $\mathrm{m}$ & $\mathrm{m}$ & $\mathrm{m}$ & $\mathrm{m}$ & $\mathrm{m}$ & $\mathrm{m}$ & $\mathrm{m}$ & $\mathrm{m}$ & $\mathrm{m}$ & $\mathrm{m}$ & $\mathrm{m}$ & $\mathrm{m}$ \\
\hline Saudi-Arabien & $\mathrm{m}$ & $\mathrm{m}$ & $\mathrm{m}$ & $\mathrm{m}$ & $\mathrm{m}$ & $\mathrm{m}$ & $\mathrm{m}$ & $\mathrm{m}$ & $\mathrm{m}$ & $\mathrm{m}$ & $\mathrm{m}$ & $\mathrm{m}$ & $\mathrm{m}$ & $\mathrm{m}$ & $\mathrm{m}$ \\
\hline Südafrika & $\mathrm{m}$ & $\mathrm{m}$ & $\mathrm{m}$ & $\mathrm{m}$ & $\mathrm{m}$ & $\mathrm{m}$ & $\mathrm{m}$ & $\mathrm{m}$ & $\mathrm{m}$ & $\mathrm{m}$ & m & $\mathrm{m}$ & $\mathrm{m}$ & $\mathrm{m}$ & $\mathrm{m}$ \\
\hline G20-Durchschnitt & $\mathbf{m}$ & m & $\mathbf{m}$ & $\mathbf{m}$ & m & $\mathbf{m}$ & $\mathbf{m}$ & m & $\mathbf{m}$ & $\mathbf{m}$ & $\mathbf{m}$ & $\mathbf{m}$ & m & $\mathbf{m}$ & $\mathbf{m}$ \\
\hline
\end{tabular}

1. Einkommen nach Abzug der Einkommensteuer. 2. Unterbrechung der Zeitreihe zwischen 2007 und 2008 aufgrund einer Veränderung der Datenquelle.

3. Die Durchschnittswerte können nicht über die Jahre verglichen werden, da die Zahl der Länder zur Berechnung dieser Werte jedes Jahr differiert.

Quelle: OECD. Hinweise s. Anhang 3 unter www.oecd.org/edu/eag.htm. StatLink: http://dx.doi.org/10.1787/888933116129

Erläuterung der Kennzeichnung fehlender Daten s. Hinweise für den Leser. 
Relative Einkommen von 15- bis 24-jährigen Schülern/Studierenden mit Erwerbseinkommen, nach Bildungsstand und Geschlecht (2012) 1

Einkommen von 15- bis 24-jährigen Schülern/Studierenden mit Erwerbseinkommen im Vergleich zu den Einkommen von 15- bis 24-jährigen Nichtschülern/Nichtstudierenden mit Erwerbseinkommen, Nichtschüler/Nichtstudierende mit Erwerbseinkommen $=100$

\begin{tabular}{|c|c|c|c|c|c|c|c|c|c|c|}
\hline & \multirow[t]{3}{*}{ Jahr } & \multicolumn{3}{|c|}{$\begin{array}{l}\text { Ausbildung unterhalb } \\
\text { Sekundarbereich II }\end{array}$} & \multicolumn{3}{|c|}{$\begin{array}{l}\text { Abschluss im Sekundarbereich II/post- } \\
\text { sekundaren, nicht tertiären Bereich }\end{array}$} & \multicolumn{3}{|c|}{ Abschluss im Tertiärbereich } \\
\hline & & Männer & Frauen & $M+F$ & Männer & Frauen & $M+F$ & Männer & Frauen & $M+F$ \\
\hline & & (1) & (2) & (3) & (4) & (5) & (6) & (7) & (8) & (9) \\
\hline \multicolumn{11}{|l|}{ OECD-Länder } \\
\hline Australien & 2012 & c & c & 29 & 51 & 57 & 52 & c & c & 68 \\
\hline Österreich & 2012 & 57 & 54 & 55 & 37 & 32 & 33 & c & c & c \\
\hline Belgien & 2010 & 56 & 57 & 54 & 78 & 63 & 67 & 79 & 83 & 82 \\
\hline Kanada & 2011 & 34 & 47 & 37 & 47 & 57 & 49 & 51 & 55 & 53 \\
\hline Chile & 2011 & 123 & 78 & 112 & 121 & 93 & 111 & $\mathrm{c}$ & c & c \\
\hline Tschechien & & $\mathrm{m}$ & $\mathrm{m}$ & $\mathrm{m}$ & $\mathrm{m}$ & $\mathrm{m}$ & $\mathrm{m}$ & $\mathrm{m}$ & $\mathrm{m}$ & $\mathrm{m}$ \\
\hline Dänemark & 2012 & 45 & 46 & 44 & 42 & 55 & 47 & c & $\mathrm{c}$ & c \\
\hline Estland & 2012 & c & c & c & c & c & c & c & c & c \\
\hline Finnland & 2011 & 33 & 48 & $\mathrm{c}$ & 55 & 58 & $\mathrm{c}$ & c & c & c \\
\hline Frankreich & 2010 & 53 & 46 & 50 & 46 & 47 & 45 & $\mathrm{c}$ & c & c \\
\hline Deutschland & 2012 & 38 & 48 & 41 & 34 & 48 & 40 & c & c & c \\
\hline Griechenland & 2012 & $\mathrm{c}$ & c & c & 58 & 121 & 92 & c & c & c \\
\hline Ungarn & & $\mathrm{m}$ & $\mathrm{m}$ & $\mathrm{m}$ & $\mathrm{m}$ & $\mathrm{m}$ & $\mathrm{m}$ & $\mathrm{m}$ & $\mathrm{m}$ & $\mathrm{m}$ \\
\hline Island & & $\mathrm{m}$ & $\mathrm{m}$ & $\mathrm{m}$ & $\mathrm{m}$ & $\mathrm{m}$ & $\mathrm{m}$ & $\mathrm{m}$ & $\mathrm{m}$ & $\mathrm{m}$ \\
\hline Irland & 2011 & 21 & c & 17 & 57 & 60 & 57 & c & c & c \\
\hline Israel & 2012 & $\mathrm{c}$ & c & $\mathrm{c}$ & 63 & 22 & 44 & c & c & c \\
\hline Italien & 2010 & 45 & 45 & 43 & 45 & 79 & 59 & c & c & c \\
\hline Japan & & $\mathrm{m}$ & $\mathrm{m}$ & $\mathrm{m}$ & $\mathrm{m}$ & $\mathrm{m}$ & $\mathrm{m}$ & $\mathrm{m}$ & $\mathrm{m}$ & $\mathrm{m}$ \\
\hline Korea & 2012 & 41 & 40 & 40 & 64 & 53 & 57 & c & c & c \\
\hline Luxemburg & & $\mathrm{m}$ & $\mathrm{m}$ & $\mathrm{m}$ & $\mathrm{m}$ & $\mathrm{m}$ & $\mathrm{m}$ & $\mathrm{m}$ & $\mathrm{m}$ & $\mathrm{m}$ \\
\hline Mexiko & & $\mathrm{m}$ & $\mathrm{m}$ & $\mathrm{m}$ & $\mathrm{m}$ & $\mathrm{m}$ & $\mathrm{m}$ & $\mathrm{m}$ & $\mathrm{m}$ & $\mathrm{m}$ \\
\hline Niederlande & & $\mathrm{m}$ & $\mathrm{m}$ & $\mathrm{m}$ & $\mathrm{m}$ & $\mathrm{m}$ & $\mathrm{m}$ & $\mathrm{m}$ & $\mathrm{m}$ & $\mathrm{m}$ \\
\hline Neuseeland & 2010 & 42 & 29 & 35 & 62 & 47 & 53 & c & c & c \\
\hline Norwegen & 2011 & 38 & 34 & 36 & 38 & 46 & 40 & c & c & c \\
\hline Polen & & $\mathrm{m}$ & $\mathrm{m}$ & $\mathrm{m}$ & $\mathrm{m}$ & $\mathrm{m}$ & $\mathrm{m}$ & $\mathrm{m}$ & $\mathrm{m}$ & $\mathrm{m}$ \\
\hline Portugal & & $\mathrm{m}$ & $\mathrm{m}$ & $\mathrm{m}$ & $\mathrm{m}$ & $\mathrm{m}$ & $\mathrm{m}$ & $\mathrm{m}$ & $\mathrm{m}$ & $\mathrm{m}$ \\
\hline Slowakei & & $\mathrm{m}$ & $\mathrm{m}$ & $\mathrm{m}$ & $\mathrm{m}$ & $\mathrm{m}$ & $\mathrm{m}$ & $\mathrm{m}$ & $\mathrm{m}$ & $\mathrm{m}$ \\
\hline Slowenien & & $\mathrm{m}$ & $\mathrm{m}$ & $\mathrm{m}$ & $\mathrm{m}$ & $\mathrm{m}$ & $\mathrm{m}$ & $\mathrm{m}$ & $\mathrm{m}$ & $\mathrm{m}$ \\
\hline Spanien & 2011 & 49 & 71 & 56 & 45 & 32 & 39 & c & c & c \\
\hline Schweden & 2009 & 11 & 12 & 11 & 46 & 58 & 50 & 30 & 44 & 38 \\
\hline Schweiz & 2012 & 36 & 47 & 43 & 63 & 50 & 56 & c & c & c \\
\hline Türkei & 2012 & 81 & 99 & 83 & 100 & 64 & 84 & c & c & c \\
\hline Vereinigtes Königreich & 2012 & 31 & 57 & 48 & 51 & 51 & 49 & 79 & 76 & 78 \\
\hline Vereinigte Staaten & 2012 & 24 & 34 & 26 & 50 & 66 & 56 & 64 & 73 & 68 \\
\hline OECD-Durchschnitt & & 45 & 50 & 45 & $\mathbf{5 7}$ & 57 & 56 & c & c & c \\
\hline EU21-Durchschnitt & & 40 & 48 & 42 & 49 & 59 & 53 & c & c & c \\
\hline \multicolumn{11}{|l|}{ Partnerländer } \\
\hline Argentinien & & $\mathrm{m}$ & $\mathrm{m}$ & $\mathrm{m}$ & $\mathrm{m}$ & $\mathrm{m}$ & $\mathrm{m}$ & $\mathrm{m}$ & $\mathrm{m}$ & $\mathrm{m}$ \\
\hline Brasilien & 2012 & 59 & 74 & 62 & 114 & 115 & 112 & $\mathrm{~m}$ & $\mathrm{~m}$ & $\mathrm{~m}$ \\
\hline China & & $\mathrm{m}$ & $\mathrm{m}$ & $\mathrm{m}$ & $\mathrm{m}$ & $\mathrm{m}$ & $\mathrm{m}$ & $\mathrm{m}$ & $\mathrm{m}$ & $\mathrm{m}$ \\
\hline Kolumbien & & $\mathrm{m}$ & $\mathrm{m}$ & $\mathrm{m}$ & $\mathrm{m}$ & $\mathrm{m}$ & $\mathrm{m}$ & $\mathrm{m}$ & $\mathrm{m}$ & $\mathrm{m}$ \\
\hline Indien & & $\mathrm{m}$ & $\mathrm{m}$ & $\mathrm{m}$ & $\mathrm{m}$ & $\mathrm{m}$ & $\mathrm{m}$ & $\mathrm{m}$ & $\mathrm{m}$ & $\mathrm{m}$ \\
\hline Indonesien & & $\mathrm{m}$ & $\mathrm{m}$ & $\mathrm{m}$ & $\mathrm{m}$ & $\mathrm{m}$ & $\mathrm{m}$ & $\mathrm{m}$ & $\mathrm{m}$ & $\mathrm{m}$ \\
\hline Lettland & & $\mathrm{m}$ & $\mathrm{m}$ & $\mathrm{m}$ & $\mathrm{m}$ & $\mathrm{m}$ & $\mathrm{m}$ & $\mathrm{m}$ & $\mathrm{m}$ & $\mathrm{m}$ \\
\hline Russische Föderation & & $\mathrm{m}$ & $\mathrm{m}$ & $\mathrm{m}$ & $\mathrm{m}$ & $\mathrm{m}$ & $\mathrm{m}$ & $\mathrm{m}$ & $\mathrm{m}$ & $\mathrm{m}$ \\
\hline Saudi-Arabien & & $\mathrm{m}$ & $\mathrm{m}$ & $\mathrm{m}$ & $\mathrm{m}$ & $\mathrm{m}$ & $\mathrm{m}$ & $\mathrm{m}$ & $\mathrm{m}$ & $\mathrm{m}$ \\
\hline Südafrika & & $\mathrm{m}$ & $\mathrm{m}$ & $\mathrm{m}$ & $\mathrm{m}$ & $\mathrm{m}$ & $\mathrm{m}$ & $\mathrm{m}$ & $\mathrm{m}$ & $\mathrm{m}$ \\
\hline G20-Durchschnitt & & $\mathbf{m}$ & $\mathbf{m}$ & $\mathbf{m}$ & $\mathbf{m}$ & $\mathbf{m}$ & $\mathbf{m}$ & $\mathbf{m}$ & $\mathbf{m}$ & $\mathbf{m}$ \\
\hline
\end{tabular}

Anmerkung: Die Spalten mit den relativen Einkommen für „Abschlüsse alle Bildungsbereiche zusammen“ sind im Internet verfügbar (s. StatLink).

1. Bei einigen Ländern in dieser Tabelle umfasst diese Altersgruppe 16- bis 24-Jährige.

Quelle: OECD. Hinweise s. Anhang 3 unter www.oecd.org/edu/eag.htm. StatLink: http://dx.doi.org/10.1787/888933116148

Erläuterung der Kennzeichnung fehlender Daten s. Hinweise für den Leser. 
Tabelle A6.5b

Anteil 15- bis 29-Jähriger mit Erwerbseinkommen an allen 15- bis 29-Jährigen, nach Altersgruppe und Ausbildungsstatus (2012)

Erläuterung der Tabelle: In Australien verfügen 70 Prozent aller 15- bis 24-jährigen Nichtschüler/Nichtstudierenden über Erwerbseinkommen und 47 Prozent aller 15- bis 24-jährigen Schüler/Studierenden. Von allen 15- bis 24-Jährigen verfügen 56 Prozent über Erwerbseinkommen.

\begin{tabular}{|c|c|c|c|c|c|c|c|}
\hline & \multirow[t]{3}{*}{ Jahr } & \multicolumn{3}{|c|}{ 15- bis 24-Jährige ${ }^{1}$} & \multicolumn{3}{|c|}{ 25- bis 29-Jährige } \\
\hline & & $\begin{array}{c}\text { Nichtschüler/ } \\
\text { Nichtstudierende }\end{array}$ & $\begin{array}{c}\text { Schüler/ } \\
\text { Studierende }\end{array}$ & Gesamt & $\begin{array}{c}\text { Nichtschüler/ } \\
\text { Nichtstudierende }\end{array}$ & $\begin{array}{c}\text { Schüler/ } \\
\text { Studierende }\end{array}$ & Gesamt \\
\hline & & (1) & (2) & (3) & (4) & (5) & (6) \\
\hline \multicolumn{8}{|l|}{ OECD-Länder } \\
\hline Australien & 2012 & 70 & 47 & 56 & 79 & 71 & 77 \\
\hline Österreich & 2012 & 87 & 64 & 73 & 91 & 81 & 89 \\
\hline Belgien & 2010 & 60 & 6 & 24 & 73 & 41 & 71 \\
\hline Kanada & 2011 & 86 & 68 & 75 & 89 & 77 & 87 \\
\hline Chile & 2011 & 50 & 10 & 27 & 70 & 45 & 66 \\
\hline Tschechien & & $\mathrm{m}$ & $\mathrm{m}$ & $\mathrm{m}$ & $\mathrm{m}$ & $\mathrm{m}$ & $\mathrm{m}$ \\
\hline Dänemark & 2012 & 71 & 71 & 71 & 81 & 82 & 82 \\
\hline Estland & 2012 & c & 13 & 22 & c & c & 49 \\
\hline Finnland & 2011 & c & c & c & c & c & c \\
\hline Frankreich & 2010 & 78 & 35 & 56 & 91 & 79 & 90 \\
\hline Deutschland & 2012 & 66 & 37 & 46 & 70 & 62 & 68 \\
\hline Griechenland & 2012 & 32 & 5 & 15 & 58 & 30 & 55 \\
\hline Ungarn & & $\mathrm{m}$ & $\mathrm{m}$ & $\mathrm{m}$ & $\mathrm{m}$ & $\mathrm{m}$ & $\mathrm{m}$ \\
\hline Island & & $\mathrm{m}$ & $\mathrm{m}$ & $\mathrm{m}$ & $\mathrm{m}$ & $\mathrm{m}$ & $\mathrm{m}$ \\
\hline Irland & 2011 & 35 & 26 & 30 & 69 & 36 & 65 \\
\hline Israel & 2012 & 63 & 18 & 42 & 76 & 68 & 74 \\
\hline Italien & 2010 & 56 & 12 & 33 & 79 & 38 & 74 \\
\hline Japan & & $\mathrm{m}$ & $\mathrm{m}$ & $\mathrm{m}$ & $\mathrm{m}$ & $\mathrm{m}$ & $\mathrm{m}$ \\
\hline Korea & 2012 & 54 & 10 & 24 & 71 & 32 & 68 \\
\hline Luxemburg & & $\mathrm{m}$ & $\mathrm{m}$ & $\mathrm{m}$ & $\mathrm{m}$ & $\mathrm{m}$ & $\mathrm{m}$ \\
\hline Mexiko & & $\mathrm{m}$ & $\mathrm{m}$ & $\mathrm{m}$ & $\mathrm{m}$ & $\mathrm{m}$ & $\mathrm{m}$ \\
\hline Niederlande & & $\mathrm{m}$ & $\mathrm{m}$ & $\mathrm{m}$ & $\mathrm{m}$ & $\mathrm{m}$ & $\mathrm{m}$ \\
\hline Neuseeland & 2010 & 69 & 33 & 48 & 75 & 61 & 73 \\
\hline Norwegen & 2011 & 71 & 76 & 74 & 89 & 90 & 90 \\
\hline Polen & & $\mathrm{m}$ & $\mathrm{m}$ & $\mathrm{m}$ & $\mathrm{m}$ & $\mathrm{m}$ & $\mathrm{m}$ \\
\hline Portugal & & $\mathrm{m}$ & $\mathrm{m}$ & $\mathrm{m}$ & $\mathrm{m}$ & $\mathrm{m}$ & $\mathrm{m}$ \\
\hline Slowakei & & $\mathrm{m}$ & $\mathrm{m}$ & $\mathrm{m}$ & $\mathrm{m}$ & $\mathrm{m}$ & $\mathrm{m}$ \\
\hline Slowenien & & $\mathrm{m}$ & $\mathrm{m}$ & $\mathrm{m}$ & $\mathrm{m}$ & $\mathrm{m}$ & $\mathrm{m}$ \\
\hline Spanien & 2011 & 53 & 10 & 26 & 73 & 54 & 70 \\
\hline Schweden & 2009 & 100 & 100 & 100 & 99 & 100 & 99 \\
\hline Schweiz & 2012 & 70 & 17 & 36 & 82 & 60 & 78 \\
\hline Türkei & 2012 & 76 & 77 & 76 & 86 & 88 & 86 \\
\hline Vereinigtes Königreich & 2012 & 65 & 33 & 51 & 79 & 62 & 77 \\
\hline Vereinigte Staaten & 2012 & 72 & 41 & 54 & c & c & c \\
\hline \multicolumn{2}{|l|}{ OECD-Durchschnitt } & 66 & 37 & 48 & 79 & 63 & 76 \\
\hline EU21-Durchschnitt & & 64 & 34 & 46 & 79 & 60 & 74 \\
\hline \multicolumn{8}{|l|}{ Partnerländer } \\
\hline Argentinien & & $\mathrm{m}$ & $\mathrm{m}$ & $\mathrm{m}$ & $\mathrm{m}$ & $\mathrm{m}$ & $\mathrm{m}$ \\
\hline Brasilien & 2012 & 64 & 34 & 50 & 76 & 73 & 75 \\
\hline China & & $\mathrm{m}$ & $\mathrm{m}$ & $\mathrm{m}$ & $\mathrm{m}$ & $\mathrm{m}$ & $\mathrm{m}$ \\
\hline Kolumbien & & $\mathrm{m}$ & $\mathrm{m}$ & $\mathrm{m}$ & $\mathrm{m}$ & $\mathrm{m}$ & $\mathrm{m}$ \\
\hline Indien & & $\mathrm{m}$ & $\mathrm{m}$ & $\mathrm{m}$ & $\mathrm{m}$ & $\mathrm{m}$ & $\mathrm{m}$ \\
\hline Indonesien & & $\mathrm{m}$ & $\mathrm{m}$ & $\mathrm{m}$ & $\mathrm{m}$ & $\mathrm{m}$ & $\mathrm{m}$ \\
\hline Lettland & & $\mathrm{m}$ & $\mathrm{m}$ & $\mathrm{m}$ & $\mathrm{m}$ & $\mathrm{m}$ & $\mathrm{m}$ \\
\hline Russische Föderation & & $\mathrm{m}$ & $\mathrm{m}$ & $\mathrm{m}$ & $\mathrm{m}$ & $\mathrm{m}$ & $\mathrm{m}$ \\
\hline Saudi-Arabien & & $\mathrm{m}$ & $\mathrm{m}$ & $\mathrm{m}$ & $\mathrm{m}$ & $\mathrm{m}$ & $\mathrm{m}$ \\
\hline Südafrika & & $\mathrm{m}$ & $\mathrm{m}$ & $\mathrm{m}$ & $\mathrm{m}$ & $\mathrm{m}$ & $\mathrm{m}$ \\
\hline G20-Durchschnitt & & m & $\mathbf{m}$ & m & $\mathbf{m}$ & m & m \\
\hline
\end{tabular}

1. Bei einigen Ländern in dieser Tabelle umfasst diese Altersgruppe 16- bis 24-Jährige.

Quelle: OECD. Hinweise s. Anhang 3 unter www.oecd.org/edu/eag.htm. StatLink: http://dx.doi.org/10.1787/888933116167 Erläuterung der Kennzeichnung fehlender Daten s. Hinweise für den Leser. 
Mittlere Monatseinkommen von Erwerbstätigen nach Bildungsstand und Lesekompetenz (2012)

25- bis 64-Jährige mit Erwerbseinkommen, die Vollzeit erwerbstätig sind (d.h. mindestens 30 Stunden pro Woche), in US-Dollar, kaufkraftbereinigt mittels KKP für den privaten Verbrauch

\begin{tabular}{|c|c|c|c|c|c|c|c|c|c|c|c|c|c|c|}
\hline & \multicolumn{6}{|c|}{ Ausbildung unterhalb Sekundarbereich II } & \multicolumn{8}{|c|}{$\begin{array}{c}\text { Abschluss im Sekundarbereich II/ } \\
\text { postsekundaren, nicht tertiären Bereich }\end{array}$} \\
\hline & \multicolumn{2}{|c|}{ Stufe $0 / 1$} & \multicolumn{2}{|c|}{ Stufe 2} & \multicolumn{2}{|c|}{ Stufe 3} & \multicolumn{2}{|c|}{ Stufe $0 / 1$} & \multicolumn{2}{|c|}{ Stufe 2} & \multicolumn{2}{|c|}{ Stufe 3} & \multicolumn{2}{|c|}{ Stufe $4 / 5$} \\
\hline & $\begin{array}{c}\text { Mittel- } \\
\text { wert }\end{array}$ & S.F. & $\begin{array}{c}\text { Mittel- } \\
\text { wert }\end{array}$ & S.F. & $\begin{array}{l}\text { Mittel- } \\
\text { wert }\end{array}$ & S.F. & $\begin{array}{c}\text { Mittel- } \\
\text { wert }\end{array}$ & S.F. & $\begin{array}{c}\text { Mittel- } \\
\text { wert }\end{array}$ & S.F. & $\begin{array}{c}\text { Mittel- } \\
\text { wert }\end{array}$ & S.F. & $\begin{array}{c}\text { Mittel- } \\
\text { wert }\end{array}$ & S.F. \\
\hline & (1) & (2) & (3) & (4) & (5) & (6) & (9) & (10) & (11) & (12) & (13) & (14) & (15) & (16) \\
\hline \multicolumn{15}{|l|}{$\begin{array}{l}\text { OECD } \\
\text { Nationale Einheiten }\end{array}$} \\
\hline Australien & 2160 & (125) & 2570 & (155) & 2790 & $(179)$ & 2680 & (157) & 2870 & (127) & 3140 & (105) & 3710 & (259) \\
\hline Österreich & 2170 & (106) & 2400 & (105) & 2860 & $(224)$ & 2910 & (121) & 3310 & (83) & 3810 & (91) & 4310 & (313) \\
\hline Kanada & 2790 & (148) & 3170 & (196) & 3720 & $(417)$ & 3040 & (155) & 3410 & (99) & 3740 & (116) & 3970 & (224) \\
\hline Tschechien & 950 & (78) & 1230 & (49) & c & $c$ & 1440 & (72) & 1500 & (44) & 1600 & (45) & 1740 & (138) \\
\hline Dänemark & 3020 & (126) & 3480 & (110) & 3840 & $(175)$ & 3770 & (145) & 3880 & (72) & 4160 & (84) & 4420 & (248) \\
\hline Estland & 1490 & (213) & 1620 & (153) & 1720 & $(166)$ & 1510 & (100) & 1530 & (63) & 1710 & (65) & 1940 & (173) \\
\hline Finnland & 2630 & (132) & 2900 & (154) & 2920 & (169) & 2810 & $(136)$ & 2910 & (62) & 3110 & (59) & 3360 & (133) \\
\hline Frankreich & 1960 & (52) & 2250 & (80) & 2570 & $(122)$ & 2270 & (62) & 2390 & (41) & 2490 & (52) & 2520 & (179) \\
\hline Deutschland & 2290 & $(178)$ & 2590 & $(218)$ & c & $\mathrm{c}$ & 2820 & $(130)$ & 3170 & (87) & 3500 & (99) & 3990 & $(346)$ \\
\hline Irland & 2820 & $(240)$ & 3290 & $(223)$ & 3330 & (303) & 2650 & $(143)$ & 3230 & (119) & 3680 & (167) & 4180 & $(410)$ \\
\hline Italien & 2470 & (135) & 2300 & (112) & 2640 & (191) & 2310 & (127) & 2630 & (84) & 2850 & (87) & 3200 & $(294)$ \\
\hline Japan & 2140 & $(216)$ & 2410 & (150) & 3000 & $(238)$ & 2870 & (333) & 2870 & (131) & 3010 & (94) & 3050 & (178) \\
\hline Korea & 2060 & (120) & 2330 & (130) & 2460 & $(264)$ & 2470 & (156) & 2750 & (81) & 2950 & $(105)$ & 2960 & (319) \\
\hline Niederlande & 2830 & (155) & 3420 & (138) & 3590 & (159) & 2990 & $(220)$ & 3480 & (138) & 3800 & (94) & 4070 & (192) \\
\hline Norwegen & 3160 & (181) & 3670 & (125) & 3920 & $(170)$ & 3440 & $(180)$ & 3950 & (98) & 4350 & (93) & 4630 & $(277)$ \\
\hline Polen & 1210 & (171) & 1180 & $(172)$ & c & c & 1260 & (62) & 1350 & (49) & 1530 & (57) & 1620 & $(147)$ \\
\hline Slowakei & 960 & (75) & 990 & (55) & 1130 & $(92)$ & 1170 & (85) & 1390 & (49) & 1520 & (51) & 1630 & $(147)$ \\
\hline Spanien & 1870 & (64) & 1980 & (69) & 2200 & $(122)$ & 2200 & (143) & 2250 & (106) & 2510 & (131) & c & c \\
\hline Schweden & 2550 & (127) & 2870 & (87) & 2970 & $(160)$ & 2660 & (110) & 3000 & (57) & 3270 & (57) & 3440 & (125) \\
\hline $\begin{array}{l}\text { Vereinigte Staaten } \\
\text { Subnationale Einheiten }\end{array}$ & 1990 & (71) & 2500 & (208) & c & c & 3200 & (223) & з з3о & (130) & 4150 & $(182)$ & 4770 & $(472)$ \\
\hline Belgien (fläm.) & 2790 & (135) & 3330 & (152) & 3320 & $(195)$ & 3130 & (161) & 3410 & (80) & 3600 & (77) & 3740 & $(250)$ \\
\hline England (VK) & 2420 & $(176)$ & 2710 & (108) & 2850 & $(229)$ & 2550 & (135) & 2880 & (128) & 3490 & $(146)$ & 4150 & (331) \\
\hline Nordirland (VK) & 2020 & (107) & 2230 & (107) & 2550 & $(259)$ & 2210 & (198) & 2560 & (178) & 3260 & $(227)$ & 3660 & $(455)$ \\
\hline England/Nordirland (VK) & 2400 & (168) & 2690 & (103) & 2840 & $(218)$ & 2540 & $(132)$ & 2870 & (124) & 3480 & $(142)$ & 4140 & (323) \\
\hline Durchschnitt & 2210 & (31) & 2510 & (30) & 2880 & (50) & 2550 & (33) & 2790 & (20) & 3090 & (21) & 3400 & (57) \\
\hline \multicolumn{15}{|l|}{ Partnerländer } \\
\hline Russische Föderation* & c & c & c & c & c & c & c & c & 690 & $(72)$ & 880 & $(105)$ & c & c \\
\hline
\end{tabular}

* Hinweis zu den Daten der Russischen Föderation s. Abschnitt Angewandte Methodik.

Anmerkung: Für die Spalten zu der Ausbildung unterhalb Sekundarbereich II sind die Werte für die Lesekompetenzstufe 4 bzw. 5 nur im Internet verfügbar, da bei vielen Ländern zu wenige Daten zur Verfügung stehen, um verlässliche Schätzungen vorzunehmen. Die Mittelwerte in dieser Tabelle sind auf den nächsten Zehnerwert gerundet. Die nicht gerundeten Werte sind im Internet verfügbar.

Quelle: OECD. Survey of Adult Skills (PIAAC) (2012). PIAAC steht für das OECD Programme for the International Assessment of Adult Competencies. Hinweise s. Anhang 3 unter www. oecd.org/edu/eag.htm. StatLink: http://dx.doi.org/10.1787/888933116186

Erläuterung der Kennzeichnung fehlender Daten s. Hinweise für den Leser. 
Tabelle A6.6a (L) (Forts.)

Mittlere Monatseinkommen von Erwerbstätigen nach Bildungsstand und Lesekompetenz (2012)

25- bis 64-Jährige mit Erwerbseinkommen, die Vollzeit erwerbstätig sind (d.h. mindestens 30 Stunden pro Woche), in US-Dollar, kaufkraftbereinigt mittels KKP für den privaten Verbrauch

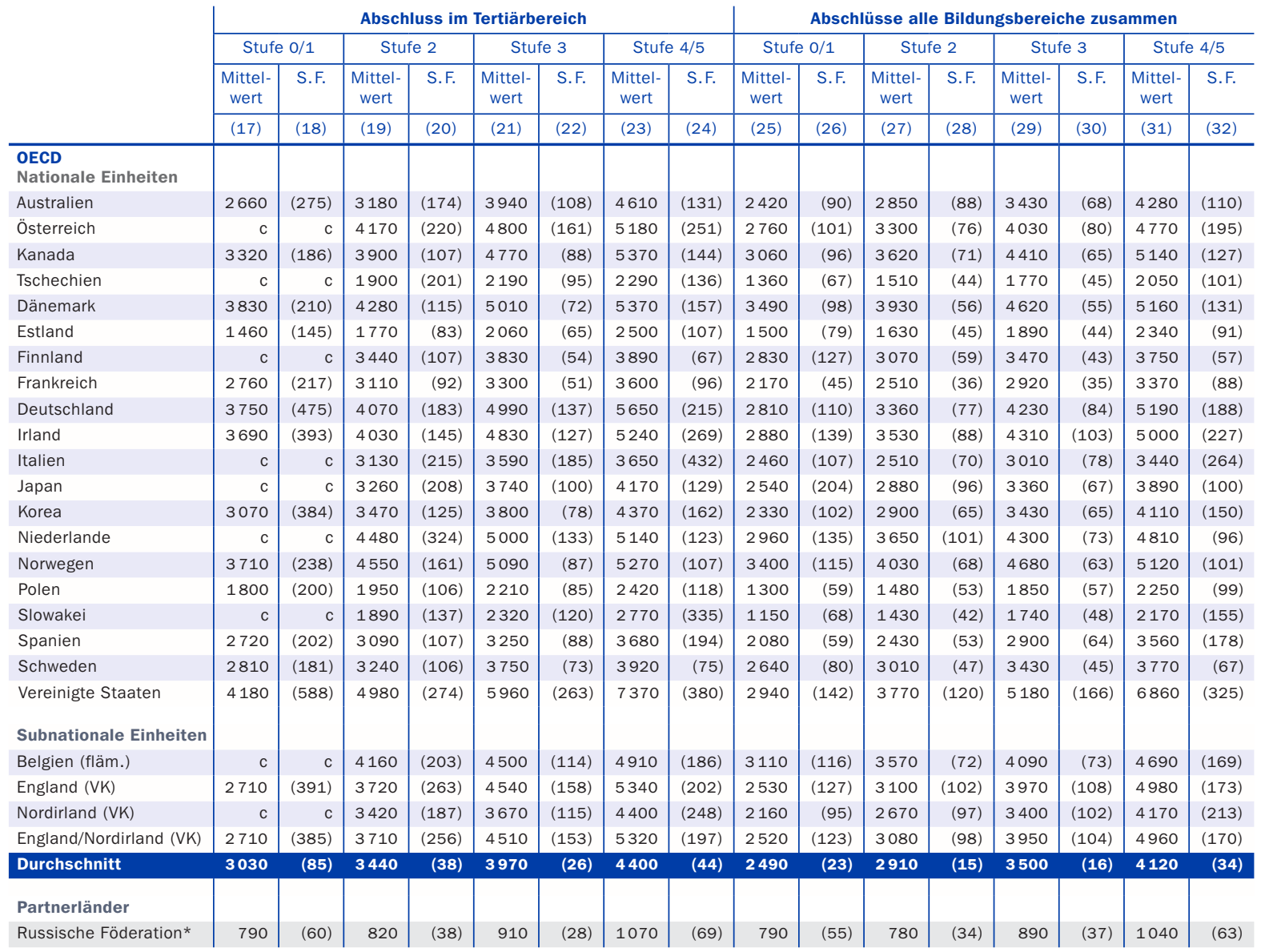

* Hinweis zu den Daten der Russischen Föderation s. Abschnitt Angewandte Methodik.

Anmerkung: Für die Spalten zu der Ausbildung unterhalb Sekundarbereich II sind die Werte für die Lesekompetenzstufe 4 bzw. 5 nur im Internet verfügbar, da bei vielen Ländern zu wenige Daten zur Verfügung stehen, um verlässliche Schätzungen vorzunehmen. Die Mittelwerte in dieser Tabelle sind auf den nächsten Zehnerwert gerundet. Die nicht gerundeten Werte sind im Internet verfügbar.

Quelle: OECD. Survey of Adult Skills (PIAAC) (2012). PIAAC steht für das OECD Programme for the International Assessment of Adult Competencies. Hinweise s. Anhang 3 unter www. oecd.org/edu/eag.htm. StatLink: http://dx.doi.org/10.1787/888933116186

Erläuterung der Kennzeichnung fehlender Daten s. Hinweise für den Leser. 


\section{Welche Anreize bestehen für Investitionen in Bildung?}

Für Erwachsene führt die Bildungsinvestition in einem Abschluss im Tertiärbereich zu erheblichen Erträgen: Sie finden eher einen Arbeitsplatz und verdienen im Durchschnitt besser als Erwachsene ohne einen Abschluss im Tertiärbereich.

Im Durchschnitt der OECD-Länder ist der finanzielle Ertrag für Absolventen des Tertiärbereichs rund doppelt so hoch wie für Absolventen des Sekundarbereichs II bzw. des postsekundaren, nicht tertiären Bereichs.

Ein höherer Bildungsstand zahlt sich nicht nur für den Einzelnen aus, sondern auch für den Staat, dem aufgrund eines hohen Anteils von Absolventen des Tertiärbereichs höhere Steuereinnahmen und Sozialversicherungsbeiträge zufließen.

Der staatliche Nettoertrag aus einer Bildungsinvestition im Tertiärbereich bei einem Mann beläuft sich in den OECD-Ländern auf mehr als I05.00o US-Dollar - fast das Dreifache der staatlichen Investitionssumme für diese Ausbildung. Bei einer Frau beläuft sich der staatliche Nettoertrag auf mehr als 60.000 US-Dollar - fast das Doppelte der staatlichen Investitionssumme.

Abbildung A7.1

Privater und staatlicher Nettoertrag bei einem Mann, der einen Abschluss im Tertiärbereich erwirbt (2010) Im Vergleich zu den Erträgen eines Abschlusses im Sekundarbereich II/postsekundaren, nicht tertiären Bereich

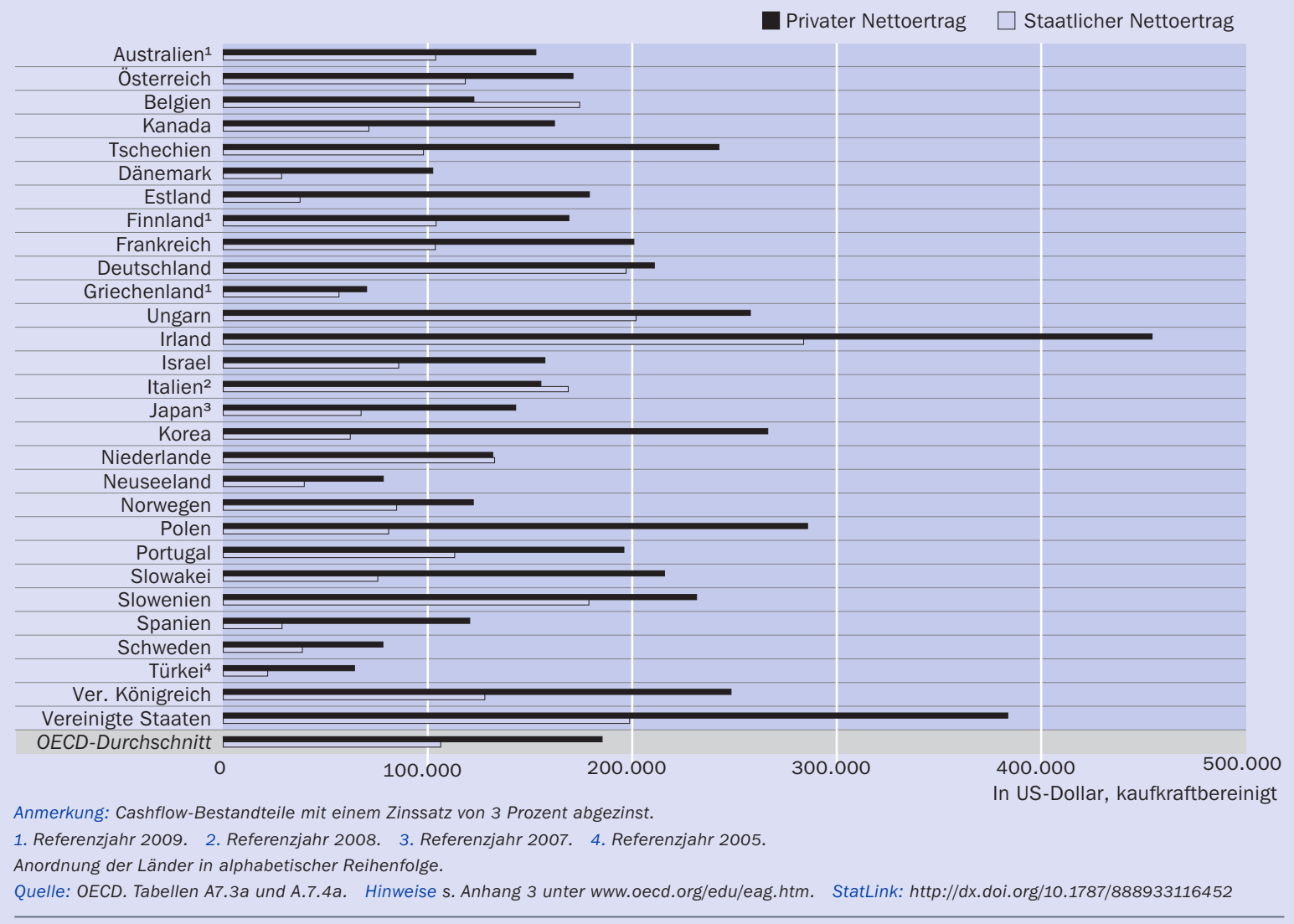




\section{Kontext}

Der Erwerb eines höheren Bildungsabschlusses ist sowohl für den Einzelnen als auch die Gesellschaft als Ganzes von Vorteil, nicht nur finanziell, sondern auch wegen der Lebensqualität, die damit einhergeht, wie beispielsweise ein besserer Gesundheitszustand der Bürger und mehr bürgerschaftliches Engagement. Für den Einzelnen verbessert ein höherer Bildungsstand die Beschäftigungschancen und mindert das Risiko der Erwerbslosigkeit. Die besseren Arbeitsmarktchancen (s. Indikator A5) und die Aussichten auf ein höheres Erwerbseinkommen (s. Indikator A6) sind ein starker Anreiz für den Einzelnen, in Bildung zu investieren und im Hinblick auf zukünftige Erträge in der Gegenwart Konsum- und Einkommensverzicht zu leisten. Die Gesellschaft ihrerseits gewinnt durch geringere öffentliche Ausgaben für Sozialleistungen und höhere Steuereinnahmen, wenn diese Bildungsteilnehmer dann in den Arbeitsmarkt eintreten.

Für politische Entscheidungsträger ist es von entscheidender Bedeutung, genau zu verstehen, welche wirtschaftlichen Anreize den Einzelnen zu einer Bildungsinvestition motivieren. So kann ein starker Anstieg der Arbeitsmarktnachfrage nach höher qualifizierten Arbeitskräften die Einkommen und die Erträge erheblich steigern, bevor sich das Angebot entsprechend anpasst. Dies signalisiert einen Bedarf an weiteren Bildungsinvestitionen. In Ländern mit rigidem Arbeitsrecht und starren Strukturen, die Entgeltunterschiede eher generell einschränken, wird ein solches Signal schwächer ausfallen.

Die Erträge genau zu kennen ist auch für die Entwicklung von politischen Maßnahmen für den Zugang zu Bildung, die Besteuerung und die Weiterbildungskosten für den Einzelnen wichtig. Daher sollte die Ausgewogenheit von privaten und staatlichen Erträgen zusammen mit den Informationen aus den anderen Indikatoren in dieser Veröffentlichung betrachtet werden. Um zu entscheiden, welches der optimale Betrag ist, den ein Staat in die Bildung investieren sollte, genügt nicht allein die Betrachtung der staatlichen Ertragsrate (s. Kasten A7.I in Bildung aufeinen Blick 2013 [OECD, 2013a]).

In Ländern mit lang dauernden Studiengängen im Tertiärbereich und relativ hohen Einkommen bei einem Abschluss im Sekundarbereich II bzw. dem postsekundaren, nicht tertiären Bereich sind die Auswirkungen des entgangenen Einkommens recht hoch. Wie stark der Effekt tatsächlich ist, hängt auch vom zu erwartenden Entgeltniveau und der Beschäftigungswahrscheinlichkeit mit oder ohne einen Abschluss im Tertiärbereich ab. Mit zunehmender Verschlechterung der Arbeitsmarktlage für junge Erwachsene (s. Indikator $\mathrm{C}_{5}$ ) sinkt der Effekt des entgangenen Einkommens, wodurch die Kosten einer Ausbildung im Tertiärbereich ebenfalls sinken. Da Besserqualifizierte bei schlechter Konjunktur auf dem Arbeitsmarkt tendenziell besser dastehen (s. Indikator A5), steigt der Nutzen sowohl für den Einzelnen als auch die Gesellschaft durch die größeren Einkommensunterschiede noch weiter. Aus den hier zugrunde gelegten Daten für 2010, als die Auswirkungen der globalen Wirtschaftskrise schon recht deutlich zu spüren waren, ergibt sich, dass sowohl die privaten als auch die staatlichen Erträge für Absolventen des Tertiärbereichs höher waren als für die Absolventen des Sekundarbereichs II und des postsekundaren, nicht tertiären Bereichs. 
Hierbei ist jedoch zu berücksichtigen, dass sich auch eine Vielzahl von in diesem Indikator unberücksichtigten bildungsspezifischen und situationsbedingten Faktoren auf die Bildungserträge auswirken. Dazu gehören u. a. der gewählte Studiengang, die landesspezifische Konjunkturlage, Arbeitsmarkt- und institutionelle Bedingungen sowie soziale und kulturelle Faktoren.

\section{Weitere wichtige Ergebnisse}

Die Bruttoeinkommensvorteile aus einem Abschluss im Tertiärbereich gegenüber einem Abschluss im Sekundarbereich II bzw. im postsekundaren, nicht tertiären Bereich belaufen sich im OECD-Durchschnitt für Männer auf 350.000 US-Dollar und für Frauen auf 250.000 US-Dollar.

Der Bruttoeinkommensvorteil für Absolventen des Sekundarbereichs II bzw. des postsekundaren, nicht tertiären Bereichs gegenüber Erwerbspersonen ohne diesen Abschluss ist in den Niederlanden (für eine Frau), Norwegen, Österreich und den Vereinigten Staaten besonders ausgeprägt. In diesen Ländern beläuft er sich auf mindestens 260.00o US-Dollar für einen Mann und r6o.00o US-Dollar für eine Frau.

Im Durchschnitt der 28 OECD-Länder mit verfügbaren Daten liegt der staatliche Ertrag (der Kapitalwert) bei einem Mann, der einen Abschluss im Sekundarbereich II bzw. dem postsekundaren, nicht tertiären Bereich erworben hat, bei rund 39.000 US-Dollar im Vergleich zu einem Mann ohne einen solchen Abschluss. Bei einer Frau beträgt der staatliche Ertrag 24.000 US-Dollar.

Mit wenigen Ausnahmen ist der private Nettoertrag einer Investition in einen Abschluss im Tertiärbereich größer als der in einen Abschluss im Sekundarbereich II oder im postsekundaren, nicht tertiären Bereich. Nur in Norwegen und Schweden erzielen Männer mit einem Abschluss im Sekundarbereich II oder im postsekundaren, nicht tertiären Bereich höhere Erträge.

In den OECD-Ländern bringt ein Bildungsteilnehmer rund 50.000 US-Dollar für einen Abschluss im Tertiärbereich auf. In Japan, den Niederlanden und den Vereinigten Staaten sind es im Durchschnitt - unter Berücksichtigung der direkten und indirekten Kosten - mehr als 100.00o US-Dollar. 


\section{Analyse und Interpretationen}

\section{Finanzielle Erträge aus Bildungsinvestitionen}

In diesem Indikator werden die Kosten und der Nutzen von Bildung und die Anreize für eine Investition in Bildung untersucht. Der wirtschaftliche Nutzen von Bildung für den Einzelnen wird mittels einer Schätzung des Einkommenszuschlags für einen höheren Bildungsstand unter Berücksichtigung der direkten und indirekten Kosten und des Nutzens des Erwerbs eines solchen Bildungsabschlusses bewertet. Zur Nutzenseite gehören nicht nur höhere Einkommen im Vergleich zu den Absolventen niedrigerer Bildungsabschlüsse, sondern auch die Beschäftigungswahrscheinlichkeit, hier als geldwerter Vorteil mittels der als „Effekt der Erwerbslosigkeit“ bezeichneten Variablen ausgedrückt (s. Abschnitt Definitionen weiter unten).

Zu den Kosten gehören zum einen die direkten Kosten, insbesondere Schul-/Studiengebühren, und zum anderen indirekte Kosten wie höhere Einkommensteuern und Sozialversicherungsbeiträge sowie Einkommensausfälle durch den späteren Eintritt in den Arbeitsmarkt und ein niedrigerer Anspruch auf soziale Transferleistungen, wie Wohngeld, Familienbeihilfen oder ergänzende Sozialhilfeleistungen. Ferner werden Sozialversicherungsbeiträge und Einkommensteuern als Prozentsatz des Einkommens berechnet und sind für die Bessergebildeten meist höher, da sie eher zu den Besserverdienenden gehören.

Der wirtschaftliche Nutzen und die Kosten eines Abschlusses im Tertiärbereich werden mit denen eines Abschlusses im Sekundarbereich II bzw. im postsekundaren, nicht tertiären Bereich verglichen, der Bezugspunkt für den Sekundarbereich II bzw. den postsekundaren, nicht tertiären Bereich ist eine Ausbildung unterhalb des Sekundarbereichs II. Bei den Berechnungen werden jeweils die Ergebnisse für Frauen untereinander und die für Männer untereinander verglichen. Die Berechnungen werden getrennt für Männer und Frauen durchgeführt, und es wird kein Durschnitt berechnet, um den geschlechtsspezifischen Einkommensunterschieden und Erwerbslosenquoten Rechnung zu tragen.

Die Darstellung von Kosten und Nutzen der Bildung und den Anreizen für eine Investition in Bildung ist ein recht komplexes Unterfangen, das gewisse methodische und analytische Überlegungen voraussetzt. Eine Bildungsinvestition, sowohl seitens des Einzelnen als auch seitens des Staates, umfasst ein komplexes Zusammenspiel von Faktoren und Wirkungen, die weit über die hier berücksichtigten Aspekte hinausgehen. Zum besseren Verständnis der getroffenen Aussagen sollte daher der vorliegende Indikator im Zusammenhang mit anderen in dieser Publikation (und in Bildung aufeinen Blick 2013 [OECD, 2013a]) behandelten Indikatoren interpretiert werden. Die Grenzen der Berechnungen sowie die zugrundeliegenden Konzepte und Annahmen werden im Abschnitt Angewandte Methodik am Ende dieses Indikators erläutert.

\section{Anreize zur Investition in Bildung für den Einzelnen}

Abschluss im Sekundarbereich II bzw. postsekundaren, nicht tertiären Bereich In den OECD-Ländern kann ein Mann, der in einen Abschluss des Sekundarbereichs II bzw. des postsekundaren, nicht tertiären Bereichs investiert, damit rechnen, in seinem Erwerbsleben netto rund Ioo.00o US-Dollar mehr zu verdienen als ein Mann ohne ei- 
nen solchen Abschluss. Dieser Betrag variiert jedoch erheblich zwischen den einzelnen Ländern: In Irland, der Slowakei und den Vereinigten Staaten generiert ein Abschluss dieses Bildungsbereichs im Laufe des Berufslebens eines Mannes mindestens I60.000 US-Dollar zusätzlich (Tab. A7.ra).

Der Nutzen für den Einzelnen ergibt sich im Allgemeinen aus dem Bruttoerwerbseinkommen und dem geringeren Risiko der Erwerbslosigkeit. In allen Ländern haben Männer mit einem Abschluss im Sekundarbereich II bzw. postsekundaren, nicht tertiären Bereich einen deutlichen Einkommensvorteil gegenüber geringer Qualifizierten. Auch das geringere Risiko der Erwerbslosigkeit kann einen großen Wert darstellen. Die besseren Beschäftigungsaussichten von Männern mit einem Abschluss in diesem Bereich werden in Deutschland, Irland, der Slowakei und Tschechien mit mindestens 80.000 US-Dollar bewertet (Tab. A7.ra).

Als Kosten der Bildung gelten sämtliche Faktoren wie direkte Kosten, entgangenes Einkommen, der Einkommensteuereffekt, die Effekte sozialer Transferleistungen und der Sozialversicherungsbeiträge (s. Abschnitt Definitionen). Die direkten Bildungskosten sind für Frauen und Männer gleich hoch. Die direkten Investitionskosten, die einer Person für den Erwerb eines Abschlusses im Sekundarbereich II bzw. im postsekundaren, nicht tertiären Bereich entstehen, sind in allen Ländern zu vernachlässigen, sie belaufen sich im Durchschnitt auf weniger als 2 Prozent und höchstens auf 6 Prozent des Ertrags. Der Investitionsaufwand besteht also im Wesentlichen aus dem entgangenen Einkommen, das man potenziell verdienen könnte, wenn man nicht in Ausbildung wäre. Die Höhe des entgangenen Einkommens ist in den einzelnen Ländern sehr unterschiedlich, je nach Länge der Ausbildung, Einkommensniveaus und den Einkommensunterschieden zwischen denjenigen mit einem Abschluss des Sekundarbereichs II bzw. postsekundaren, nicht tertiären Bereichs und denjenigen ohne einen solchen (Tab. A7.ra und A7.rb).

Gute Arbeitsmarktchancen sowohl für männliche als auch weibliche Jugendliche ohne einen Abschluss im Sekundarbereich II bzw. postsekundaren, nicht tertiären Bereich erhöhen die Kosten für weitere Investitionen in einen höheren Bildungsabschluss, Gleiches gilt für geringere Einkommensunterschiede und eine längere Ausbildungsdauer von Bildungsgängen im Sekundarbereich II bzw. dem postsekundaren, nicht tertiären Bereich. In Estland, der Slowakei, Spanien, der Türkei und Ungarn beläuft sich das entgangene Einkommen schätzungsweise auf weniger als 13.000 US-Dollar für den Einzelnen (Männer und Frauen), während es in Dänemark, den Niederlanden, Norwegen und Österreich (sowohl für Frauen als auch Männer) mehr als 42.00o USDollar sind (Tab. A7.ra und A7.Ib).

Die Daten für einen Mann, der einen Abschluss im Sekundarbereich II bzw. im postsekundaren, nicht tertiären Bereich erwirbt, zeigen, dass Dänemark, Irland, Norwegen, Österreich und die Vereinigten Staaten zu den Ländern mit relativ starken Einkommensteuereffekten (schätzungsweise über 65.000 US-Dollar) gehören. Auch in Estland ergibt sich ein Einkommensteuereffekt von fast 40 Prozent des Einkommenszuschlags für einen Mann, der einen Abschluss im Sekundarbereich II bzw. postsekundaren, nicht tertiären Bereich erwirbt. In Griechenland, Korea, Polen und der Türkei sind die Einkommensteuereffekte geringer (schätzungsweise weniger als 20.000 US-Dollar). 
Deutschland, die Niederlande, Österreich, die Slowakei und Slowenien sind die Länder mit den höchsten Anteilen an Sozialversicherungsbeiträgen (schätzungsweise mehr als 22.00o US-Dollar sowohl für Männer als auch für Frauen) (Tab. A7.ra und A7.rb). In Dänemark, Frankreich, Griechenland, Österreich, Schweden und dem Vereinigten Königreich summieren sich die indirekten Kosten durch niedrigere Ansprüche auf Sozialleistungen (Transferleistungen) für einen Mann auf mehr als Io.ooo US-Dollar (Tab. A7.ra).

Männer erzielen meist höhere finanzielle Erträge aus einem Abschluss im Sekundarbereich II bzw. postsekundaren, nicht tertiären Bereich als Frauen. Ausnahmen sind hier Griechenland, Italien und Polen. In diesen Ländern ist der private Kapitalwert für einen Abschluss im Sekundarbereich II bzw. postsekundaren, nicht tertiären Bereich für Frauen höher als für Männer. Im Durchschnitt der OECD-Länder liegt der Nettoertrag für Frauen im Laufe ihres Erwerbslebens bei 63.000 US-Dollar, rund 34.000 US-Dollar weniger als für Männer. Der geschlechtsspezifische Unterschied bei den privaten Nettoerträgen ist in Estland, Irland, Korea, Norwegen, Österreich und dem Vereinigten Königreich besonders ausgeprägt. Das größte Gefälle besteht in Irland, wo ein Mann beim Erwerb eines Abschlusses im Sekundarbereich II bzw. postsekundaren, nicht tertiären Bereich einen Nettonutzen von rund 195.000 US-Dollar erzielt, eine Frau jedoch lediglich von I03.000 US-Dollar, rund die Hälfte. Im Wesentlichen ergibt sich dieser Abstand bei den privaten Nettoerträgen aus den unterschiedlichen Effekten der Erwerbslosigkeit, dieser ist für Männer durchschnittlich günstiger als für Frauen. Das bedeutet, dass die Beschäftigungsaussichten für Männer durch einen Abschluss im Sekundarbereich II bzw. im postsekundaren, nicht tertiären Bereich gegenüber den Arbeitsmarktteilnehmern ohne einen solchen Abschluss stärker positiv beeinflusst werden als für Frauen (Abb. A7.2).

\section{Abschluss im Tertiärbereich}

Absolventen des Tertiärbereichs können mit noch höheren Nettoerträgen rechnen als diejenigen, die nur in einen Abschluss im Sekundarbereich II investiert haben. Im Durchschnitt der OECD-Länder beläuft sich der Ertrag von Absolventen des Tertiärbereichs im Vergleich zu Absolventinnen und Absolventen des Sekundarbereichs II bzw. postsekundaren, nicht tertiären Bereichs auf I85.000 mehr US-Dollar für einen Mann und I30.000 US-Dollar mehr für eine Frau. Von einigen wenigen Ausnahmen abgesehen führt eine Investition in einen Abschluss im Tertiärbereich zu einem höheren privaten Nettoertrag als die Investition in einen Abschluss im Sekundarbereich II bzw. postsekundaren, nicht tertiären Bereich.

Der private Nettoertrag einer Bildungsinvestition im Tertiärbereich ist für Männer in der Regel höher als für Frauen. In Griechenland, Neuseeland, Spanien und der Türkei erzielen die Frauen höhere Erträge (Tab. A7.3a und A7.3b).

Der Bruttoeinkommensvorteil aus einem Abschluss im Tertiärbereich stellt für Frauen und Männer einen beachtlichen Wert dar: durchschnittlich 350.00o US-Dollar für Männer und 250.000 US-Dollar für Frauen, allerdings bestehen auch hierbei zwischen den einzelnen Ländern signifikante Unterschiede.

Polen, Slowenien, Tschechien und Ungarn gehören zu den Ländern mit Einkommenszuschlägen über dem OECD-Durchschnitt, obwohl dort die Gesamtkosten und das 
Private Kosten und privater Nutzen eines Abschlusses im Sekundarbereich II bzw. postsekundaren, nicht tertiären Bereich für Männer und Frauen (2010)

Im Vergleich zu den Erträgen einer Ausbildung unterhalb des Sekundarbereichs II

Direkte Kosten

Effekt Transferleistungen

$\square$ Effekt Vorteile Bruttoeinkommen $\square$ Effekt Einkommensteuer

Effekt Erwerbslosigkeit

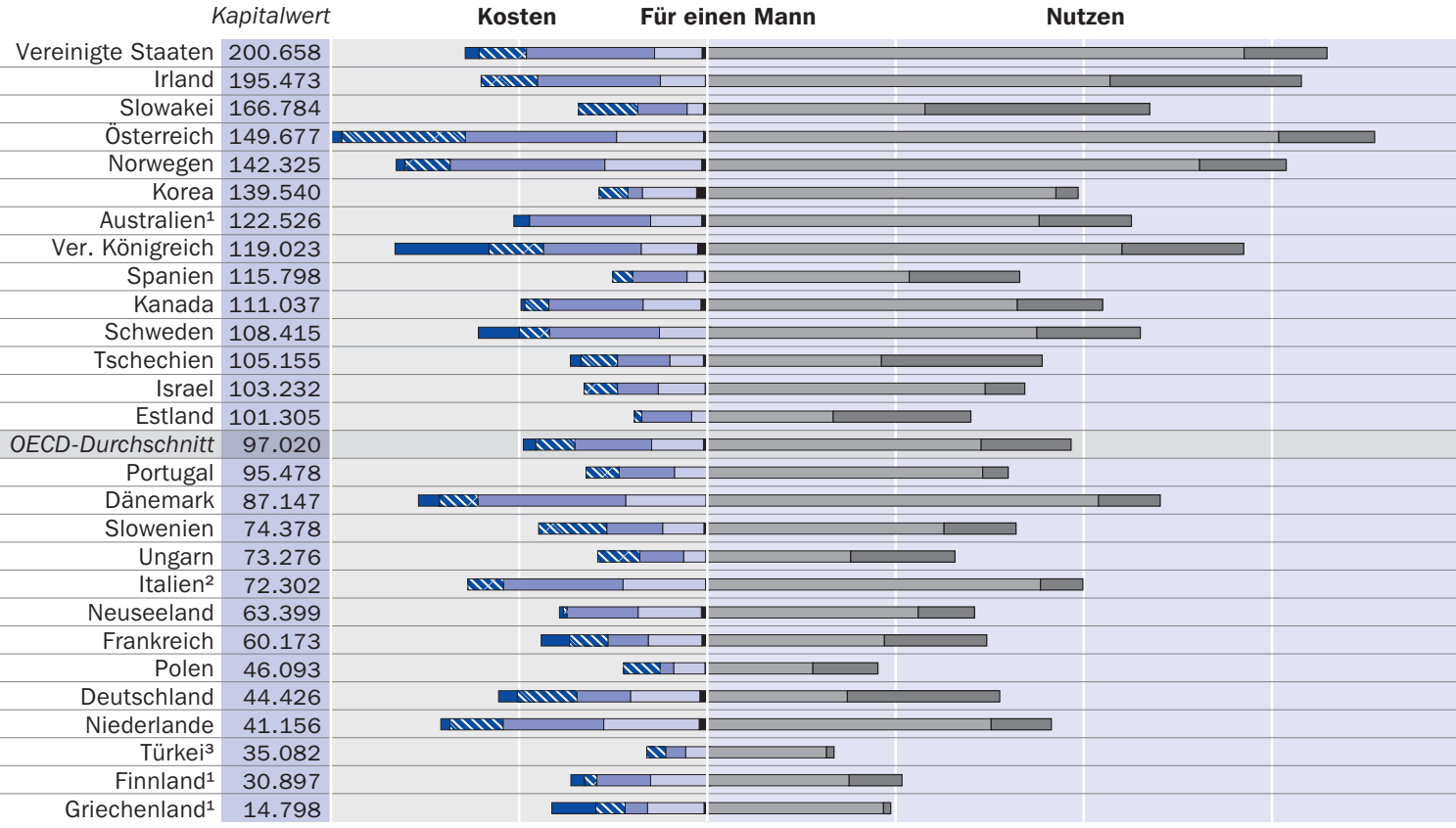

200.000

100.000

0

100.000

200.000

300.000

400.000 In US-Dollar, kaufkraftbereinigt

Kapitalwert

Vereinigte Staaten 142.886

Slowakei 124.017

Irland 103.176

Israel 84.692

Tschechien $\quad 81.634$

Spanien 80.159

Schweden 78.473

Österreich 75.251

Portugal 74.838

Italien ${ }^{2} \quad 74.010$

Korea 71.013

Ungarn 65.834

OECD-Durchschnitt $\quad 62.820$

Dänemark 60.818

Australien $^{1} \quad 60.094$

Griechenland $^{1} \quad 53.481$

Polen 52.682

Norwegen 52.631

Slowenien $\quad 51.510$

Kanada 46.187

Frankreich 44.093

Ver. Königreich 38.230

Neuseeland 34.428

Deutschland 33.618

Türkei $^{3} \quad 33.223$

Estland 32.074

Niederlande 31.082

Finnland $^{1} \quad 16.009$

(⿸丆口

Kosten

Für eine Frau

Nutzen

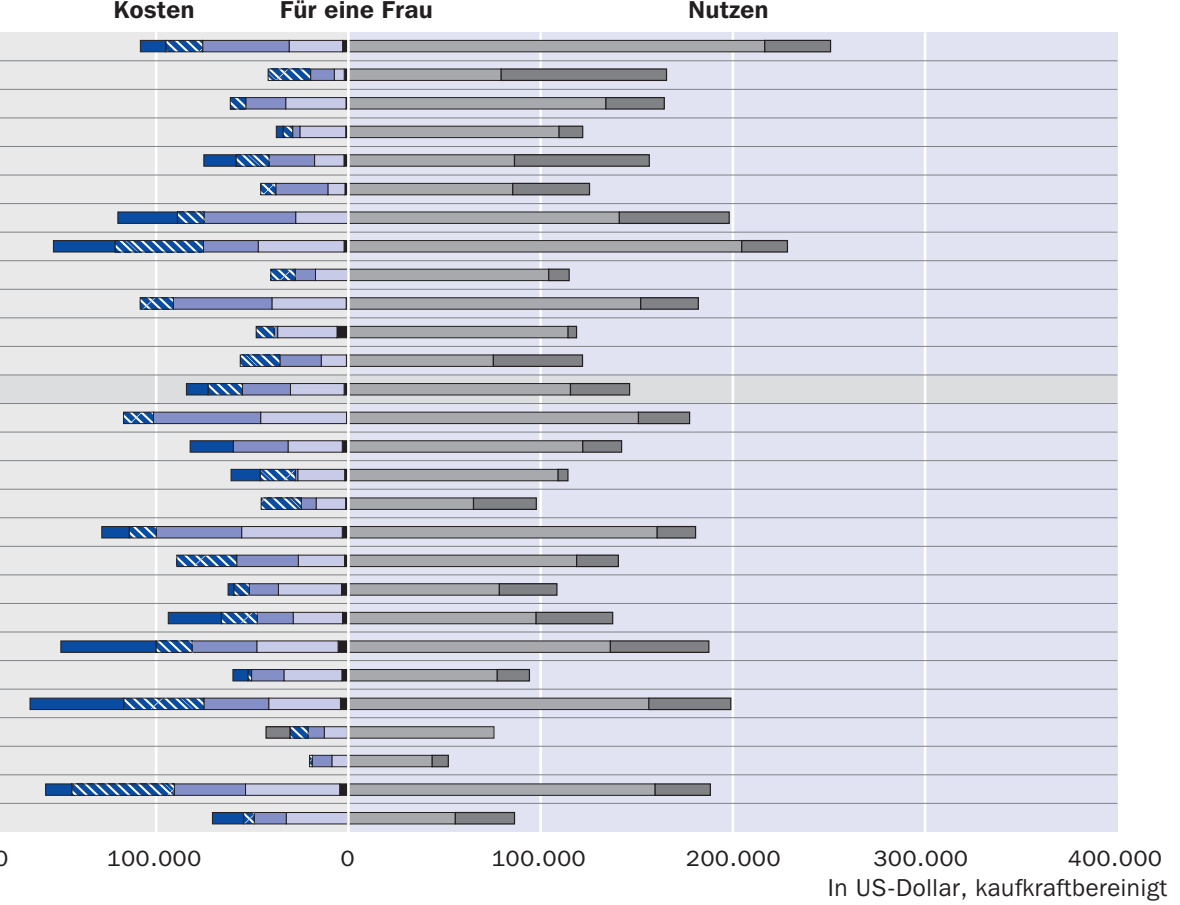

Anmerkung: Cashflow-Bestandteile mit einem Zinssatz von 3 Prozent abgezinst.

1. Referenzjahr 2009. 2. Referenzjahr 2008. 3. Referenzjahr 2005.

Anordnung der Länder in absteigender Reihenfolge des privaten Kapitalwerts.

Quelle: OECD. Tabellen A7.1a und A7.1b. Hinweise s. Anhang 3 unter www.oecd.org/edu/eag.htm. StatLink: http://dx.doi.org/10.1787/888933116471 
Einkommensniveau im Vergleich zu anderen OECD-Ländern relativ niedrig sind. Eine mögliche Erklärung könnte der immer noch relativ niedrige Anteil von Absolventen des Tertiärbereichs in der Bevölkerung im erwerbsfähigen Alter sein, was wiederum auf ein knappes Angebot an Hochschulabsolventen hindeutet. Dies könnte im Laufe der Jahre zu einer Steigerung der Einkommen und der Entgeltunterschiede zwischen Absolventen des Tertiärbereichs und der Bildungsbereiche darunter geführt haben.

Im Durchschnitt der OECD-Länder wirkt sich der Effekt der Erwerbslosenunterstützung gegenüber einem Abschluss im Sekundarbereich II bzw. postsekundaren, nicht tertiären Bereich weniger deutlich aus als der Einkommensunterschied, wohingegen sich die Effekte von Steuern, Sozialversicherungsbeiträgen und sozialen Transferleistungen sowie die direkten Kosten wesentlich stärker auswirken. Insbesondere für einen Abschluss im Tertiärbereich ist ein längerer Verbleib im Bildungssystem erforderlich, wodurch den Absolventen Einkommen in erheblichem Umfang entgeht (entgangenes Einkommen), das sie bei einem früheren Eintritt in den Arbeitsmarkt hätten verdienen können.

Der private Investitionsaufwand einschließlich direkter und indirekter Kosten für einen Abschluss im Tertiärbereich ist in einigen Ländern sehr hoch. Im Durchschnitt aller OECD-Länder bringt ein Bildungsteilnehmer rund 50.000 US-Dollar für einen Abschluss im Tertiärbereich auf. In Japan sind es sogar durchschnittlich mehr als I00.000 US-Dollar für einen Mann und sowohl für Männer als auch für Frauen in den Niederlanden und den Vereinigten Staaten. Im OECD-Durchschnitt machen die direkten Kosten wie Studiengebühren ungefähr ein Fünftel der privaten Gesamtinvestition für einen Abschluss im Tertiärbereich aus (geschätzte I0.000 US-Dollar pro Person, unabhängig vom Geschlecht) (Tab. A7.3a und A7.3b).

Schwache Arbeitsmarkterträge können zum Beispiel durch die Senkung der privaten Kosten für den Besuch des Tertiärbereichs verbessert werden. Eine Reihe von Ländern subventioniert nicht nur die direkten Bildungskosten, sondern gewährt auch Studiendarlehen oder Zuschüsse, um den Tertiärbereich attraktiver und leichter zugänglich zu machen. Studienzuschüsse in Form von Geld, Sach- oder Dienstleistungen sind Transferleistungen, die - anders als Darlehen - nicht zurückgezahlt werden müssen. Im vorliegenden Indikator werden lediglich die Studienzuschüsse, nicht jedoch die Darlehen berücksichtigt (s. Kasten A7.I zu den Auswirkungen von Darlehen in einigen Ländern).

Der Effekt der Studienzuschüsse ist besonders in Dänemark und den Vereinigten Staaten von Bedeutung, wo sie rund 35 Prozent (29.000 US-Dollar) bzw. 26 Prozent (27.000 US-Dollar) der Gesamtkosten eines Abschlusses im Tertiärbereich abdecken. In Finnland, den Niederlanden, Österreich und Schweden werden die Zuschüsse auf mindestens 8.00o US-Dollar, d. h. rund I5 Prozent der Gesamtkosten, geschätzt (Tab. A7·3a und $\mathrm{A} 7 \cdot 3 \mathrm{~b})$.

Aus den Daten geht jedoch hervor, dass es in den Ländern mit den höchsten direkten Kosten für die Teilnahme am Tertiärbereich, insbesondere in Australien, Kanada, dem Vereinigten Königreich und den Vereinigten Staaten, angesichts der Höhe der direkten Kosten nur verhältnismäßig geringe Studienzuschüsse gibt. In Australien und Kanada 
tragen Zuschüsse weniger als 5 Prozent zu den direkten Kosten für einen Abschluss im Tertiärbereich bei. Auch Japan und Korea gehören zu den Ländern mit den höchsten direkten Kosten einer Ausbildung im Tertiärbereich, aus diesen Ländern liegen jedoch keine Daten über Studienzuschüsse vor. Andererseits bieten viele Länder, u. a. auch diejenigen mit nur niedrigen Zuschüssen, Studiendarlehen an, die nach dem Studienabschluss zurückgezahlt werden müssen. Die Konditionen für diese Darlehen, insbesondere der Beginn der Tilgung (z.B. sobald das Einkommen eine bestimmte Höhe erreicht oder direkt nach dem Abschluss etc.) sowie die Zinssätze, unterscheiden sich stark von Land zu Land. Bei den meisten Studiendarlehen hängen jedoch der zu tilgende Betrag und die Tilgungsrate vom Beschäftigungsstatus und dem tatsächlichen Einkommen nach dem Abschluss ab. Das Angebot von Studiendarlehen verbunden mit hinreichender Aufklärung und Hilfestellung zu deren Nutzung kann Bildungsteilnehmer, insbesondere aus sozioökonomisch benachteiligten Bevölkerungsschichten, ermutigen, einen Abschluss anzustreben. Da die Darlehen jedoch nach Abschluss des Studiums zurückgezahlt werden müssen - und somit von den Einkommensvorteilen abzuziehen sind -, mindern sie den finanziellen Nutzen der Bildung.

\section{Staatliche Ertragsraten von Bildungsinvestitionen}

\section{Abschluss im Sekundarbereich II bzw. postsekundaren, nicht tertiären Bereich}

Wie schon oben ausgeführt, führt ein höherer Bildungsstand tendenziell im Durchschnitt zu einem höheren Einkommensniveau (s. Indikator A6). So gesehen generieren Bildungsinvestitionen auch staatliche Erträge, da Absolventen des Tertiärbereichs (aufgrund ihres höheren Einkommens) höhere Einkommensteuern und Sozialversicherungsbeiträge zahlen und geringere sozialstaatliche Transferleistungen in Anspruch nehmen. In den meisten Ländern sind die staatlichen Erträge bei der Investition in einen Abschluss im Sekundarbereich II bzw. im postsekundaren, nicht tertiären Bereich von männlichen und weiblichen Bildungsteilnehmern positiv. Im Durchschnitt aller OECD-Länder generiert ein Abschluss in diesem Bildungsbereich einen staatlichen Nettoertrag von 39.000 US-Dollar bei einem Mann und von 24.000 US-Dollar bei einer Frau (Tab. A7.2a und A7.2b).

Im Durchschnitt ist der staatliche Nutzen doppelt so hoch wie der staatliche Gesamtaufwand für eine Ausbildung im Sekundarbereich II bzw. postsekundaren, nicht tertiären Bereich, sowohl bei Frauen als auch bei Männern. Im Vereinigten Königreich ist der staatliche Nutzen neunmal höher als der staatliche Aufwand bei einem Mann mit diesem Bildungsstand und bei einer Frau fast zehnmal höher (Tab. A7.2a und A7.2b).

\footnotetext{
Abschluss im Tertiärbereich

Im Durchschnitt der OECD-Länder sind die staatlichen Investitionen für einen Bildungsabschluss im Tertiärbereich (unter Berücksichtigung des direkten staatlichen Aufwands und der indirekten Kosten) pro Absolvent 38.000 US-Dollar höher als für einen Abschluss im Sekundarbereich II bzw. im postsekundaren, nicht tertiären Bereich. Der staatliche Aufwand für einen Absolventen im Tertiärbereich ist in Dänemark, Deutschland, Finnland, den Niederlanden, Österreich, Schweden und den Vereinigten Staaten am höchsten (über 50000 US-Dollar mehr als für einen Absolventen im Sekundarbereich II bzw. postsekundaren, nicht tertiären Bereich) (Abb. A7.3).
} 
Staatliche Kosten und staatlicher Nutzen bei einer Frau, die einen Abschluss im Tertiärbereich erwirbt (2010)

Im Vergleich zu den Kosten und dem Nutzen eines Abschlusses im Sekundarbereich II/postsekundaren, nicht tertiären Bereich.

Direkte Kosten

$\square$ Effekt Einkommensteuer

\section{$\square$ Entgangene Einkommensteuer}

$\square$ Effekt Sozialversicherungsbeiträge
Effekt Zuschüsse

Effekt Transferleistungen

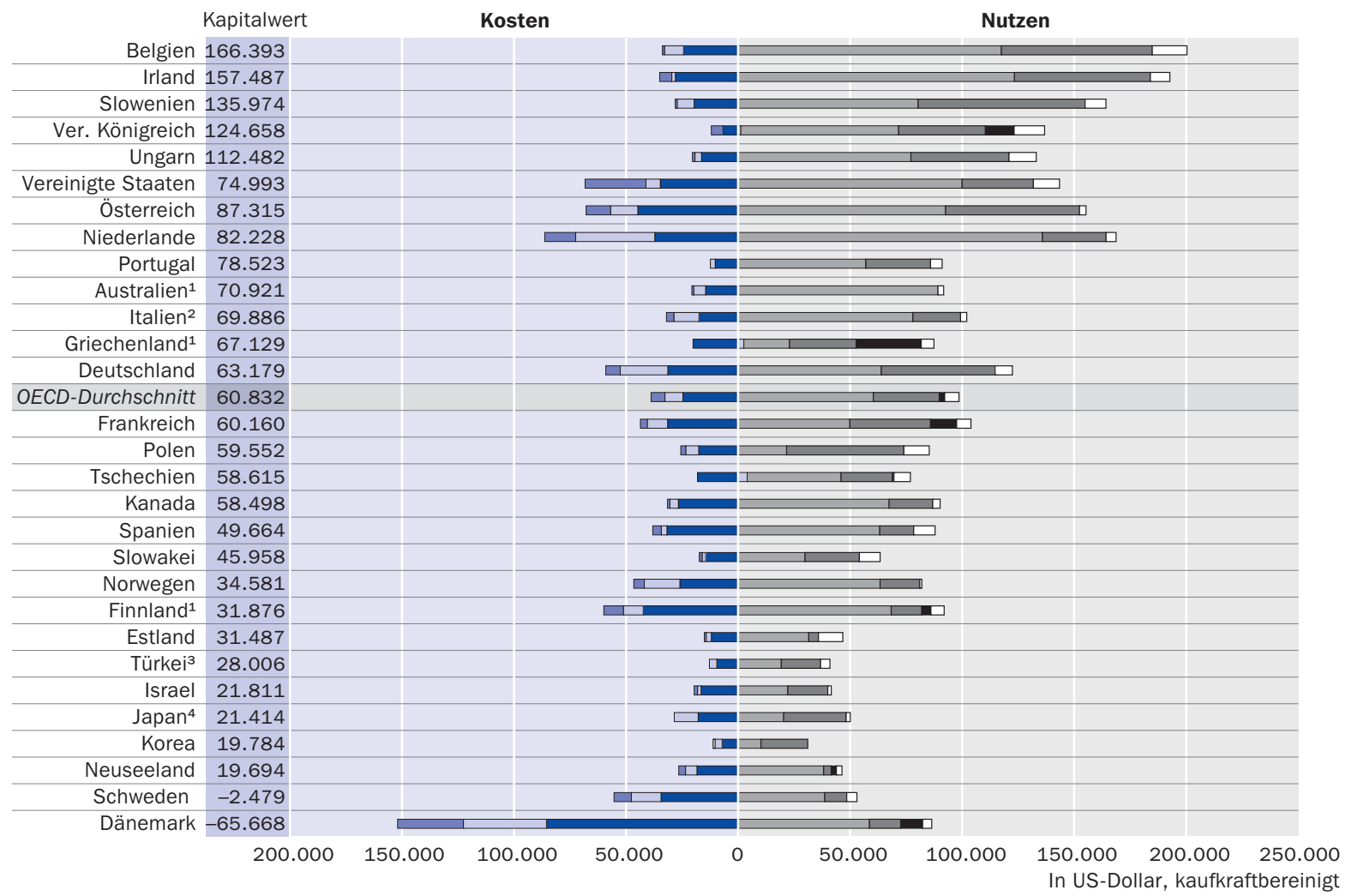

Anmerkung: Cashflow-Bestandteile mit einem Zinssatz von 3 Prozent abgezinst.

1. Referenzjahr 2009. 2. Referenzjahr 2008. 3. Referenzjahr 2005. 4. Referenzjahr 2007.

Anordnung der Länder in absteigender Reihenfolge des staatlichen Kapitalwerts.

Quelle: OECD. Tabelle A7.4b. Hinweise s. Anhang 3 unter www.oecd.org/edu/eag.htm. StatLink: http://dx.doi.org/10.1787/888933116490

In den meisten Ländern sind die staatlichen Erträge für einen Abschluss im Tertiärbereich wesentlich höher als für einen Abschluss im Sekundarbereich II bzw. im postsekundaren, nicht tertiären Bildungsbereich. Grund hierfür sind die durch das bessere Einkommensniveau der Absolventen des Tertiärbereichs veranlassten höheren Steuereinnahmen und Sozialversicherungsbeitragszahlungen. Im Durchschnitt der OECD-Länder beläuft sich der staatliche Nettoertrag aus einer Investition in einen Abschluss im Tertiärbereich bei einem Mann auf mehr als I05.000 US-Dollar und bei einer Frau auf mehr als 60.00o US-Dollar. Unter Berücksichtigung der direkten Kosten, des entgangenen Einkommens und der öffentlichen Zuschüsse übertrifft der staatliche Nutzen bei einem männlichen Absolventen des Tertiärbereichs den staatlichen Aufwand um das 4-Fache, bei einer Absolventin um das 2,5-Fache (Tab. A7.4a und A7.4b).

Die unterschiedlichen Erträge sowohl auf privater als auch auf staatlicher Seite werden weitgehend durch die unterschiedlichen Einkommen bestimmt. Wenn die Einkommensunterschiede geringer sind, ist auch der wirtschaftliche Ertrag eines Abschlusses im Tertiärbereich geringer. Dies trifft besonders in Dänemark, Neuseeland, Norwegen 
und Schweden zu. In den nordischen Ländern werden die Effekte dieser geringen Einkommensdifferenzen im Allgemeinen dadurch aufgewogen, dass die Ausbildung im Tertiärbereich fast kostenlos angeboten wird und großzügige Studienzuschüsse gewährt werden (s. Indikator B5).

Aufgrund der erheblichen Unterschiede bei den Einkommenszuschlägen in den einzelnen OECD-Ländern ergeben sich auch Unterschiede bei den Steuer- und anderen staatlichen Einnahmen in einer Art und Weise, die nicht ganz den allgemeinen Erwartungen entspricht. Wegen des geringen Einkommenszuschlags in den nordischen Ländern erreichen die durchschnittlichen Einkommen von Absolventen des Tertiärbereichs normalerweise nicht den Bereich mit hohen Grenzsteuersätzen. Der Staat profitiert bei den Steuern und Sozialabgaben von Hochschulabsolventen in den Ländern am stärksten, in denen die Einkommensunterschiede groß sind bzw. in denen das durchschnittliche Einkommensniveau einem hohen Einkommensteuersatz unterliegt. In Belgien, Dänemark, Deutschland, Irland, Italien, den Niederlanden, Österreich, Slowenien, Ungarn und den Vereinigten Staaten zahlen Absolventen des Tertiärbereichs erheblich mehr Steuern und Sozialabgaben. Der Einkommenszuschlag liegt in jedem dieser Länder über dem OECD-Durchschnitt, und daher sind auch die abgeführten Sozialabgaben höher.

In einigen Ländern gibt es steuerpolitische Maßnahmen zur effektiven Senkung der tatsächlich abgeführten privaten Einkommensteuern, insbesondere in den oberen Einkommensklassen. Zur Förderung des Eigenheimbesitzes haben viele OECD-Länder Steuererleichterungen für Hypothekenzinsen eingeführt. Derartige Vergünstigungen kommen hauptsächlich den Absolventen des Tertiärbereichs und den Zahlern hoher Grenzsteuersätze zugute. Besonders hohe Steuererleichterungen für ein Eigenheim werden in Dänemark, Finnland, Griechenland, den Niederlanden, Norwegen, Schweden, Tschechien und den Vereinigten Staaten gewährt (Andrews et al., 20II).

\section{Die Verteilung der Bildungskosten zwischen dem staatlichen und dem privaten Sektor}

Die direkten Kosten der Bildung werden größtenteils vom staatlichen Sektor getragen. So betragen beispielsweise im Durchschnitt aller OECD-Länder die direkten Kosten für einen Mann, der einen Abschluss im Tertiärbereich erwirbt, 30 Prozent der gesamten direkten privaten und staatlichen Investitionskosten. Nur in wenigen Ländern, insbesondere in Australien, Japan, Korea, dem Vereinigten Königreich und den Vereinigten Staaten, machen die direkten privaten Kosten wie Studiengebühren mehr als 55 Prozent der gesamten direkten öffentlichen und privaten Kosten für eine Ausbildung im Tertiärbereich aus. Einige Länder gewähren den Bildungsteilnehmern Studienzuschüsse und Darlehen zur Erleichterung der finanziellen Belastung, die der angestrebte Erwerb eines Abschlusses im Tertiärbereich mit sich bringt. Die Studienzuschüsse werden nach verschiedenen Kriterien gewährt, z. B. aufgrund von herausragenden Leistungen oder sozioökonomischer Herkunft, um auch junge Menschen aus weniger wohlhabenden Familien zu einer Fortsetzung ihrer Ausbildung zu ermutigen. Besonders hohe Zuschüsse werden in den nordischen Ländern wie Dänemark (29.000 USDollar), Finnland (9.000 US-Dollar) und Schweden (8.00o US-Dollar) gewährt sowie in den Niederlanden (I4.00o US-Dollar), Österreich (II.00o US-Dollar) und den Vereinigten Staaten (27.000 US-Dollar). Interessanterweise lassen die verfügbaren Daten 
Staatliche gegenüber privaten Kosten für einen Abschluss im Tertiärbereich bei einem Mann (2010)

Im Vergleich zu den Kosten eines Abschlusses im Sekundarbereich II/postsekundaren, nicht tertiären Bereich.

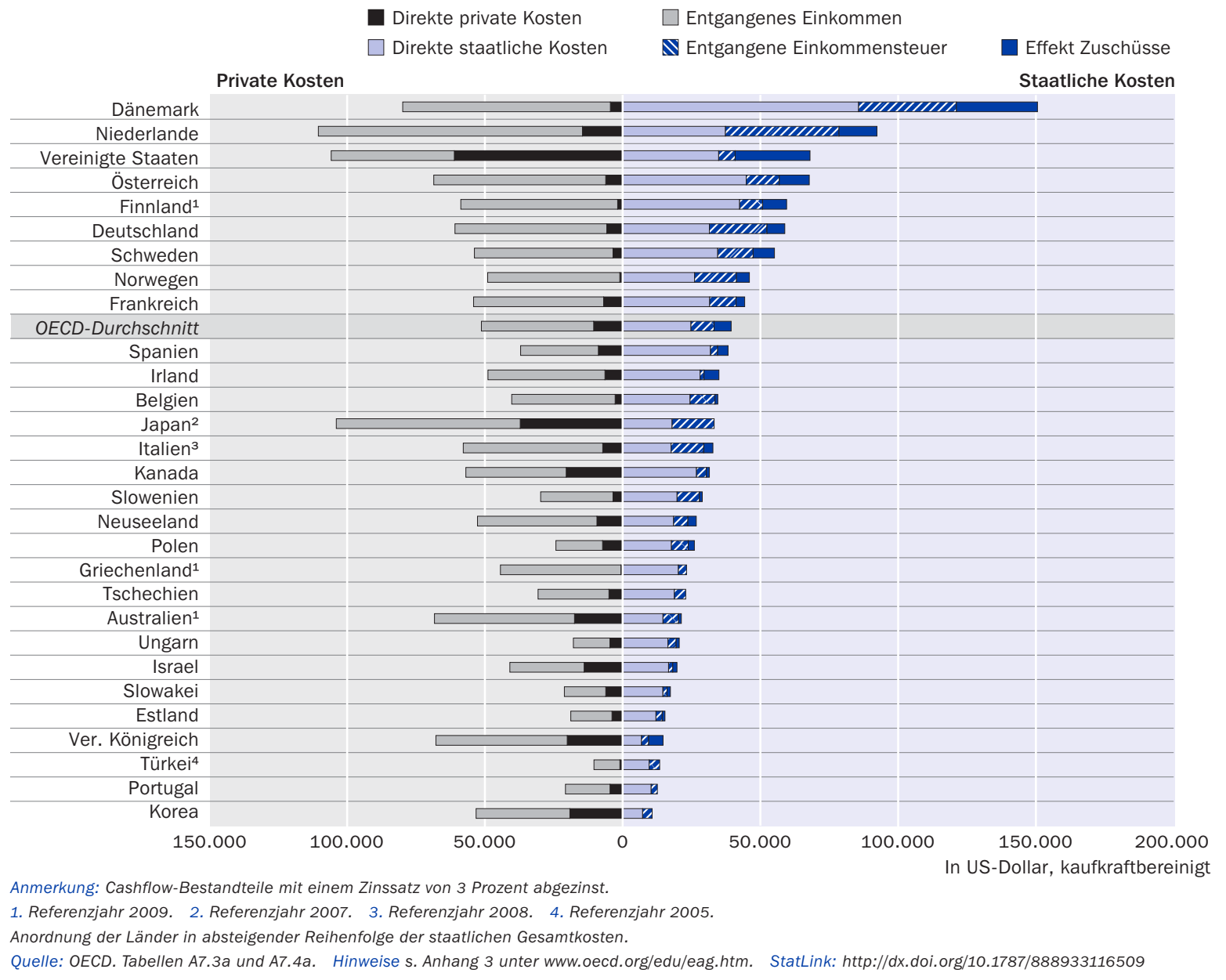

keine Beziehung zwischen den direkten Kosten und den Studienzuschüssen erkennen. Die Länder mit den höheren Studienzuschüssen sind nicht immer diejenigen mit den höchsten direkten privaten Kosten. Umgekehrt gewähren unter den fünf Ländern mit den höchsten direkten Kosten (mindestens rund 20.000 US-Dollar) nur das Vereinigte Königreich und die Vereinigten Staaten Studienzuschüsse in nennenswerter Höhe (5.000 US-Dollar im Vereinigten Königreich). Außer Zuschüssen gibt es jedoch auch noch andere staatliche Förderinstrumente, z. B. subventionierte Studiendarlehen (Kasten A7.I), sowie reduzierte Studiengebühren für wirtschaftlich benachteiligte Studierende, die die privaten Kosten des Besuchs des Tertiärbereichs mindern können (Tabelle A7.3a und A7.4a). 


\section{Weiter gehende Analyse der Erträge aus Bildung}

Abgesehen von den arbeitsmarktbedingten Einkommensunterschieden werden die Erträge aus Bildung im Wesentlichen durch politische Entscheidungen über den Zugang zur Bildung, Steuern und die Kosten der Bildung für den Einzelnen bestimmt. Soweit entsprechende Daten vorliegen, lässt sich die Analyse des Kapitalwerts um eine Reihe von Aspekten erweitern. So berücksichtigt die Untersuchung im vorliegenden Kapitel beispielsweise Studienzuschüsse in den einzelnen Ländern, während Darlehenssysteme nicht berücksichtigt werden.

Die Analyse in diesem Kasten geht einen Schritt weiter und versucht erstmals, den Effekt von Studiendarlehen für Studierende des Tertiärbereichs auf die Erträge aus Bildung zu quantifizieren. Grundlage sind Informationen zu den Darlehen, die für die 14 in der nachstehenden Abbildung dargestellten Länder in einer Ad-hoc-Erhebung des OECD-Netzwerks zu den Arbeitsmarktergebnissen sowie den wirtschaftlichen und sozialen Auswirkungen des Lernens (LSO) erhoben wurden (die entsprechenden Tabellen sind im Internet verfügbar).

In diesem Kasten variieren die Auswirkungen von Studiendarlehen auf den Kapitelwert eines Abschlusses im Tertiärbereich aufgrund folgender Faktoren:

die Zugangsmöglichkeiten zu den Darlehen bzw. der Anteil der Darlehensbezieher unter den Studierenden,

- die durchschnittliche Höhe eines regulären Studiendarlehens,

die Kosten bzw. der berechnete Zinssatz und

der Schuldenerlass und Zahlungsausfälle, d. h., welcher Prozentsatz eines durchschnittlichen Darlehens insgesamt als uneinbringbar eingestuft wird, d. h. abzuschreiben ist.

Im Prinzip gibt es zwei Arten von Studiendarlehen: Darlehen mit fester Tilgung (auch als hypothekenähnliche Darlehen bezeichnet) und einkommensabhängige Darlehen. Beide Arten von Darlehen implizieren in gewissem Umfang Kosten für den Staat, der die Darlehensrückzahlung garantiert oder/und die Zinsen subventioniert. Rein theoretisch sollte es sich auf die Nettoerträge von Bildung auswirken, ob hauptsächlich einkommensabhängige Darlehen oder solche mit fester Tilgung gewährt werden, da es bei einkommensabhängigen Darlehen häufiger zu einem Schuldenerlass kommt (was höhere Kosten für den Staat bei gleichzeitig größerem Nutzen für den Studierenden bedeutet) (s. Kasten B5.I)

Bei einem Ansatz zur Schätzung der finanziellen Erträge aus Bildung nach der Investitionsrechnung aus dem Bereich der Finanzwissenschaften werden sowohl die durchschnittliche Darlehenshöhe pro Studierenden pro Jahr (ausgehend vom Anteil der Darlehensempfänger unter den Studierenden und dem durchschnittlichen Darlehensbetrag) als auch der durchschnittliche Darlehenszinssatz berücksichtigt. Der Darlehenszinssatz wird einbezogen, weil zu berücksichtigen ist, dass es mehr als eine Finanzierungsquelle gibt, die jeweils anteilig nach ihrem Marktwert zu gewichten ist. Daraus resultiert der gewichtete Durchschnitt der Kapitalkosten (Weighted Average Cost of Capital - WACC), eine gewichtete Kombination des Darlehenszins- 
satzes und des Diskontsatzes (d. h. des Zinssatzes, zu dem die Banken von der Zentralbank Kredite aufnehmen können). Diese Kenngröße WACC ermöglicht es, einen Kapitalwert zu berechnen und die Erträge in monetären Einheiten auszudrücken. Ein Schuldenerlass für den Studienabschluss in der Regelstudienzeit (oder andere leistungsbezogene Anreize) sowie Zahlungsausfälle bei staatlich garantierten Darlehen wurden in die Berechnung der Auswirkungen von Darlehen auf den Kapitalwert einbezogen - sie wirken sich positiv auf diesen aus. Daher ist der in diesem Kasten dargestellte Darlehenseffekt eine Kombination aus den genannten Elementen.

Die Ergebnisse der Erhebung zeigen, dass von den I4 Ländern mit verfügbaren Daten die Auswirkungen der Darlehen auf den Indikator Kapitalwert in Neuseeland, Norwegen, Schweden, dem Vereinigten Königreich und den Vereinigten Staaten größer als in Kanada und den Niederlanden sind, obwohl alle diese Länder gut ausgebaute Systeme zur finanziellen Unterstützung der Studierenden haben.

Die Abbildung zeigt ferner, dass zwischen den Ländern erhebliche Unterschiede bei der durchschnittlichen Höhe der Studiengebühren, die von öffentlichen Bildungseinrichtungen des Tertiärbereichs A von inländischen Vollzeitstudierenden für das Studium zur Erlangung des ersten Abschlusses verlangt werden, sowie bei der finanziellen Unterstützung dieser Studierenden bestehen. Australien, Kanada, Neuseeland, die Niederlande, das Vereinigte Königreich und die Vereinigten Staaten sind Länder mit relativ hohen Studiengebühren und gut entwickelten Darlehenssystemen für die Studierenden. Dänemark, Finnland, Norwegen und Schweden sind Länder mit vergleichsweise niedrigen Studiengebühren und gut ausgebauten Unterstützungsmöglichkeiten für Studierende (s. Indikator B5).

\section{Abbildung A7.a}

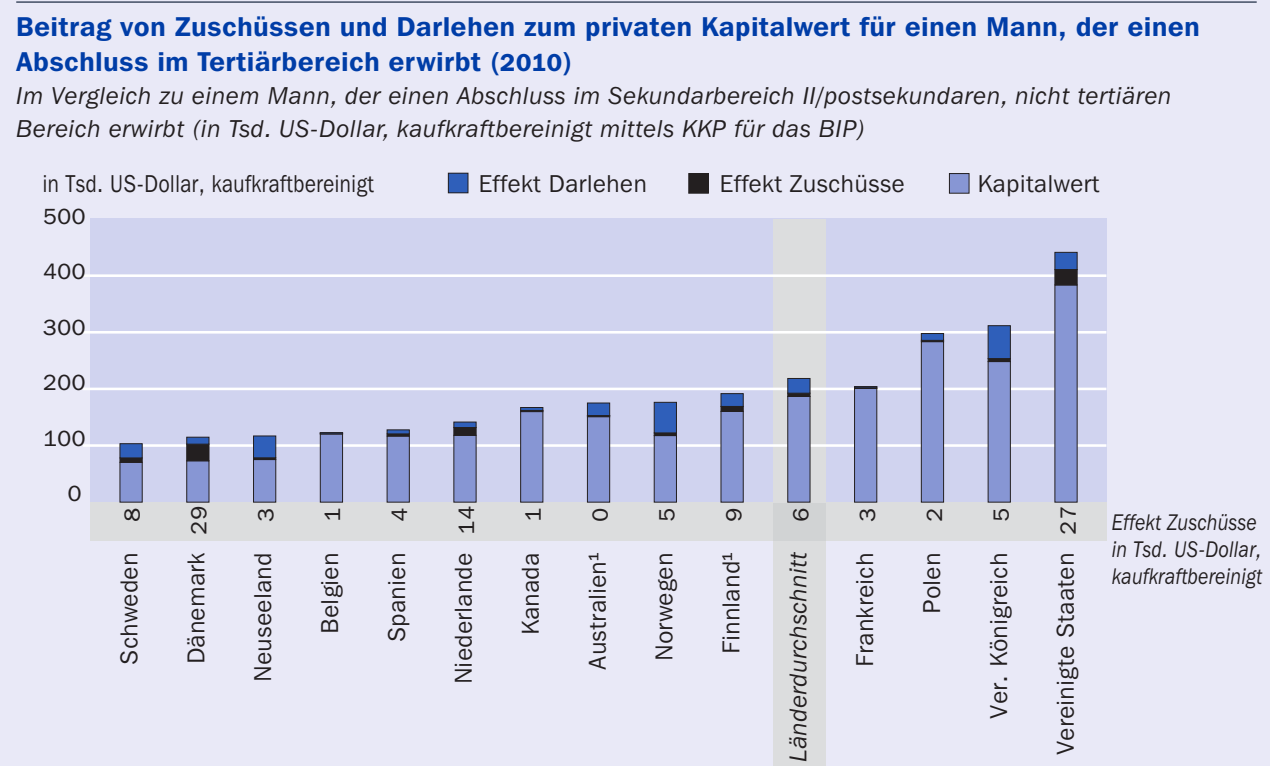

Anmerkung: Cashflow-Bestandteile mit einem Zinssatz von 3 Prozent abgezinst. 1. Referenzjahr 2009.

Anordnung der Länder in aufsteigender Reihenfolge des privaten Kapitalwerts.

Quelle: OECD. Tabelle A7.5a im Internet. Hinweise s. Anhang 3 unter www.oecd.org/edu/eag.htm.

StatLink: http://dx.doi.org/10.1787/888933116528 
In den Niederlanden wirken sich Zuschüsse bzw. Stipendien stärker auf den Kapitalwert aus als Darlehen, da Zuschüsse besser zugänglich sind als Darlehen - mehr als zwei Drittel der Studierenden erhalten Zuschüsse (gegenüber einem Drittel der Studierenden, die in den Genuss eines Darlehens kommen), ferner sind die Zuschüsse im Durchschnitt höher als die durchschnittlichen Darlehen. Die durchschnittlichen Darlehenskosten sind in den Niederlanden höher als in anderen Ländern, allerdings bleiben bei dieser Schätzung spezielle finanzielle Regelungen unberücksichtigt, wie z. B. die steuerliche Absetzbarkeit bestimmter Bildungsausgaben usw.

In Kanada kommen die Studierenden in den Genuss relativ hoher Schuldenerlasse, d. h., man geht davon aus, dass ein Großteil des Durchschnittsdarlehens beim Studienabschluss abgeschrieben wird. Dennoch wird der Gesamtnutzen der Darlehen durch deren relativ hohe Durchschnittskosten aufgewogen (d. h. den hohen Zinssatz, der nach dem Studienabschluss für das Darlehen berechnet wird).

Es überrascht nicht, dass die Auswirkungen von Darlehen in Belgien, Frankreich und Spanien zu vernachlässigen sind, da die Studiengebühren dort relativ niedrig sind und die Unterstützung weniger gut ausgebaut ist.

\section{Definitionen}

Erwachsene bezieht sich auf 25- bis 64-Jährige.

Direkte Kosten stehen für die Ausgaben, die jährlich für Bildungsteilnehmer mit Mitteln aus allen Quellen (öffentlichen, privaten Haushalten und anderen private Einheiten) getätigt werden. Sie stehen im Verhältnis zur Länge der Ausbildungsdauer.

Die Höhe des entgangenen Einkommens während der Dauer der Ausbildung/des Studiums hängt hauptsächlich vom Einkommensniveau ab, das jemand, der nicht in Ausbildung ist, zu erwarten hätte, sowie von der Ausbildungsdauer. Das entgangene Einkommen eines Bildungsteilnehmers ist der Nettobetrag nach Steuern, Sozialversicherungsbeiträgen und sozialen Transferleistungen.

Entgangene Einkommensteuern umfassen die Steuern, Sozialversicherungsbeiträge und sozialen Transferleistungen, die die Staatskasse nicht vereinnahmt.

Die Bruttoeinkommensvorteile sind eine Schätzung des Erwerbseinkommens, das der Einzelne nach dem Ausbildungsabschluss auf dem Arbeitsmarkt erzielen kann.

Der Einkommensteuereffekt ist der Betrag, der dem staatlichen Sektor schätzungsweise durch die Steuern zufließt. In der Regel ist dies die Hauptquelle der staatlichen Erträge aus den getätigten Bildungsinvestitionen. Aufgrund der Steuerprogression ist der Effekt bei den Absolventen des Tertiärbereichs ausgeprägter.

Die Ertragsrate gibt an, bei welchem realen Zinssatz die Investition die Gewinnschwelle erreicht. 
Bildungsbereiche: Unterhalb Sekundarbereich II umfasst Bildungsgänge auf den ISCED-Stufen 0, I, 2 und ${ }_{3} \mathrm{C}$ (kurz), Sekundarbereich II oder postsekundarer, nicht tertiärer Bereich auf den ISCED-Stufen $3 \mathrm{~A}, 3 \mathrm{~B}$ und ${ }_{3} \mathrm{C}$ (lang) sowie 4 und Tertiärbereich auf den ISCED-Stufen $5 \mathrm{~A}$, $5^{B}$ und 6. Erläuterungen zu allen Bildungsbereichen gemäß ISCED-Klassifizierung s. Hinweise für den Leser im vorderen Teil der Publikation.

Der Kapitalwert steht für den Unterschied zwischen dem abgezinsten Nutzen und den abgezinsten Investitionskosten und bildet den Mehrwert ab, den die Bildung über den realen Zinssatz von 3 Prozent hinaus erwirtschaftet, der für derartige Kapitalflüsse angesetzt wird.

Der Effekt der Sozialversicherungsbeiträge in den vorliegenden Berechnungen umfasst nur die vom Arbeitnehmer geleisteten Beiträge, die Arbeitgeberbeiträge bleiben unberücksichtigt, denn diese sind eine weitere Quelle staatlicher Erträge. In den meisten OECDLändern zahlen die Arbeitnehmer pauschale Sozialversicherungsbeiträge, daher sind die Unterschiede zwischen den Bildungsbereichen geringer und proportional zum Einkommensniveau.

Der Effekt der Transferleistungen betrifft die sozialen Transferleistungen für ein bestimmtes Einkommensniveau.

Der Effekt der Erwerbslosigkeit wird anhand des Einkommensniveaus für die verschiedenen Bildungsbereiche im Laufe des Erwerbslebens in geldwerte Vorteile umgerechnet.

\section{Angewandte Methodik}

Dieser Indikator baut auf Informationen auf, die in anderen Kapiteln von Bildung aufeinen Blick 2013 (OECD, 2013a) dargestellt wurden, mit einer Ausnahme: Zur Berechnung der staatlichen Erträge und der Untersuchung des Nettonutzens für den Einzelnen wurden Daten aus der OECD-Datenbank „Taxing Wages“ herangezogen. Als Einkommensdaten werden die Angaben aus den Erhebungen des Netzwerks zu den Arbeitsmarktergebnissen sowie den wirtschaftlichen und sozialen Auswirkungen des Lernens (LSO) verwendet (in Bildung auf einen Blick 2013 sind diese in Indikator A6 als relative Einkommen dargestellt). Die Angaben zu den direkten Kosten der Bildung wurden den Indikatoren BI und B3 entnommen. Die Daten zur Beschäftigungswahrscheinlichkeit (Erwerbslosenquote für die verschiedenen Bildungsstände und Altersgruppen) sind Indikator A5 entnommen. Die Mindestlöhne werden als Näherungswert für das potenzielle Entgelt eines Bildungsteilnehmers verwendet, das er verdienen könnte, wenn er sich nicht in Ausbildung befände, um das entgangene Einkommen eines Absolventen des Sekundarbereichs II bzw. postsekundaren, nicht tertiären Bereichs zu berechnen. Weitere Informationen s. Anhang 3 unter www.oed.org/edu/eag.htm.

In diesem Indikator werden die Erträge aus Bildung mittels des Kapitalwerts (net present value - NPV) der Investition berechnet. Hierbei werden Kosten und Nutzen während des gesamten Lebens auf den Zeitpunkt zurückgerechnet, an dem mit der Investition begonnen wurde. Dies geschieht, indem alle Mittelflüsse mit einem bestimmten Zinssatz (dem Abzinsungssatz) auf den Investitionsbeginn abgezinst werden. Die 
Festlegung des Zinssatzes ist recht schwierig, da er nicht nur den gesamten Zeithorizont der Investitionsdauer erfassen sollte, sondern auch die Kreditkosten bzw. das empfundene Investitionsrisiko. Zur Vereinfachung und leichteren Interpretation der Ergebnisse wird der gleiche Abzinsungssatz für alle OECD-Länder angewendet.

Um einen angemessenen Abzinsungssatz zu bestimmen, wurden langfristige Staatsanleihen als Bezugspunkt gewählt. 201o betrug der durchschnittliche langfristige Zinssatz in den OECD-Ländern ungefähr 4,4 Prozent (OECD-Finanzdatenbank [OECD, 20I3b]). Unter der Annahme, dass die nationalen Zentralbanken die erwartete Inflation bei maximal 2 Prozent pro Jahr halten konnten, bedeutet dies einen Realzinssatz zwischen 2 Prozent und 3 Prozent. Der hier verwendete reale Abzinsungssatz von 3 Prozent spiegelt die Tatsache wider, dass die Berechnungen zu konstanten Preisen durchgeführt wurden. Die Veränderung des Abzinsungssatzes hat wesentliche Auswirkungen auf den Kapitalwert von Bildungsinvestitionen.

Die Abzinsung von Kosten und Nutzen mittels dieses Zinssatzes auf den Gegenwartsoder Barwert macht den wirtschaftlichen Nutzen der Gesamtinvestition und die Höhe ihrer einzelnen Bestandteile über die Zeit und alle Länder vergleichbar. Durch Verwendung der gleichen Betrachtungsgröße können auch einzelne Bestandteile in den einzelnen Bildungsbereichen oder zwischen privater und staatlicher Seite hinzugezählt oder abgezogen werden, um die Wechselwirkungen einzelner Faktoren zu untersuchen. Die Berechnungen nach der Kapitalwertmethode basieren auf dem gleichen Prinzip wie die Berechnungen der Ertragsrate nach der internen Zinsfußmethode (internal rate of return - IRR), der wesentliche Unterschied zwischen beiden Methoden liegt in der Festlegung des Zinssatzes. Bei den Berechnungen im Rahmen der internen Zinsfußmethode wird der Zinssatz so weit angehoben, bis sich der wirtschaftliche Nutzen und die Investitionskosten die Waage halten. Dies ergibt den Zinssatz, bei dem die Investition die Gewinnschwelle erreicht.

Bei der Berechnung des Kapitalwerts beinhaltet der private Investitionsaufwand das entgangene Nettoeinkommen, bereinigt um die Beschäftigungswahrscheinlichkeit (Erwerbslosenquote) und den direkten privaten Aufwand für die Bildungsteilnahme. Beide Investitionsflüsse berücksichtigen die Dauer der Bildungsteilnahme. Auf der Nutzenseite gehen die altersabhängigen Einkommensprofile in die Berechnung der Einkommensunterschiede zwischen den verschiedenen Absolventengruppen ein. Aus diesen Unterschieden bei den Bruttoeinkommen ergeben sich nach Bereinigung um die Unterschiede bei den Einkommensteuern, Sozialabgaben und Transferleistungen (u. a. Wohngeld und einkommensabhängige Sozialleistungen) die Nettoeinkommensunterschiede. Ferner wird der Cashflow um die Beschäftigungswahrscheinlichkeit bereinigt. Die Berechnungen werden getrennt für Männer und Frauen durchgeführt, um den geschlechtsspezifischen Einkommensunterschieden und Erwerbslosenquoten Rechnung zu tragen.

Zur Berechnung des Kapitalwerts einer staatlichen Investition gehen in den staatlichen Aufwand die entgangenen staatlichen Einnahmen während der Ausbildung (Einkommensteuern und Sozialabgaben) ein sowie die staatlichen Ausgaben (unter Berücksichtigung der Ausbildungsdauer). In einigen Ländern sind die Steuerausfälle gering, da junge Menschen weniger verdienen. Die Kosten der Bildung bestehen für 
den staatlichen Sektor aus den direkten Bildungsausgaben (wie dem direkten Aufwand für Gehälter der Lehrkräfte, den Bau von Schulgebäuden, den Kauf von Schulbüchern usw.) sowie aus den öffentlich-privaten Transferleistungen (wie Stipendien und Studienzuschüssen an private Haushalte und andere Zuschüsse für Ausbildungsangebote am Arbeitsplatz an andere private Einheiten). Auf der Nutzenseite stehen für den öffentlichen Sektor die Mehreinnahmen von Steuern und Sozialabgaben aus höheren Einkommen sowie Einsparungen bei den Transferzahlungen, d. h. bei Wohngeld und Sozialleistungen, die der Staat oberhalb eines bestimmten Einkommensniveaus nicht mehr aufbringen muss.

Für die hier vorgenommenen Ermittlungen der finanziellen Erträge sind einige generelle konzeptionelle Einschränkungen zu berücksichtigen, u. a.:

- Für die Berechnung der Gesamterträge während des Erwerbslebens wird für alle Länder einheitlich das Alter von 64 Jahren als Obergrenze angesetzt. Das Renteneintrittsalter variiert jedoch stark von Land zu Land. Einige Jahre aktiver Arbeitsmarktteilnahme mehr oder weniger können für den Einzelnen und den Staat einen großen Unterschied bei dem Ertrag aus Bildung bedeuten. Daher sind die Ertragsraten in den Ländern, in denen das Renteneintrittsalter deutlich von der Altersgrenze 64 Jahre abweicht, mit großer Wahrscheinlichkeit entweder zu hoch oder zu niedrig angesetzt.

Da das Einkommen üblicherweise mit dem Bildungsstand steigt, konsumieren Bessergebildete normalerweise auch mehr Waren und Dienstleistungen und zahlen so zusätzlich Mehrwertsteuer auf ihren Konsum. Daher sind in diesem Indikator die staatlichen Ertragsraten wohl zu niedrig angesetzt.

Besserverdienende zahlen tendenziell auch mehr für ihre Altersvorsorge ein und verfügen somit auch nach dem Ausscheiden aus dem Erwerbsleben noch über weitere Einkommensvorteile, die in den Berechnungen in diesem Indikator unberücksichtigt bleiben. Bessergebildete haben außerdem tendenziell eine höhere Lebenserwartung, was zusätzliche staatliche Kosten mit sich bringt, die hier ebenfalls unberücksichtigt bleiben. Zudem werden in Ländern, in denen ein Großteil des Rentensystems durch die Arbeitgeber mittels zusätzlich zum Entgelt zu entrichtender Arbeitgeberbeiträge finanziert wird, die Erträge einer Hochschulausbildung eher zu niedrig angesetzt sein im Vergleich zu Ländern, in denen die Erwerbstätigen selbst die Rentenbeiträge erbringen.

Viele Staaten gewähren Bildungsteilnehmern Darlehen zu niedrigen Zinssätzen. Darlehen können für den Einzelnen einen starken Anreiz zur Fortsetzung der Bildungsteilnahme darstellen, deren Kosten hierdurch gesenkt werden. Allerdings müssen Darlehen später zurückgezahlt werden und vermindern daher auch den finanziellen Nutzen der Bildungsteilnahme. Solche Beihilfen können den Ertrag aus Bildung für den Einzelnen häufig erheblich beeinflussen, sie werden jedoch in diesem Indikator nicht berücksichtigt.

- In einigen Ländern ist die Erwerbslosenunterstützung recht großzügig, während Erwerbslose in anderen Ländern auf Sozialhilfe angewiesen sind.

- Bei den direkten Kosten handelt es sich vorrangig um die Schul-/Studiengebühren, aber auch um die Kosten für Lernmaterialien oder die Lebenshaltungskosten, die durch den Wohnungswechsel an einen Ort veranlasst werden, an dem ein bestimmtes Bildungsangebot wahrgenommen wird. Sie werden hier nicht berücksichtigt. 
Die angegebenen Daten stellen rein rechnerische Werte dar. Zweifellos unterscheiden sich diese Ergebnisse von ökonometrischen Schätzungen, die eher die gleichen Daten auf der Mikroebene (z. B. Daten aus Haushalts- oder Einzelerhebungen) anwenden würden und nicht das lebenslange Einkommen errechnet auf Basis von Durchschnittseinkommen.

Bei der Interpretation der entgangenen Einkommen bei einem Abschluss im Sekundarbereich II bzw. postsekundaren, nicht tertiären Bereich ist Vorsicht angebracht, da die Mindestlöhne als Näherungswert verwendet werden.

Vor diesem Hintergrund sollten die Zahlen zu den Bildungserträgen in den einzelnen Ländern mit Vorsicht interpretiert werden.

Der hier gewählte Ansatz schätzt das künftige Einkommen von Personen mit unterschiedlichem Bildungsstand auf Grundlage der Erkenntnisse über die aktuellen Unterschiede bei den durchschnittlichen Bruttoeinkommen nach Bildungsstand und Alter. Die Beziehungen zwischen den unterschiedlichen Abschlüssen und Einkommen müssen in der Zukunft jedoch nicht unbedingt die gleichen sein wie in der Gegenwart, denn der technologische, wirtschaftliche und soziale Wandel können das mit einem bestimmten Bildungsstand assoziierte Einkommensniveau verändern.

In den Unterschieden bei den Erträgen zwischen den einzelnen Ländern kommen zum Teil auch unterschiedliche institutionelle und vom Markt unabhängige, einkommenswirksame Bedingungen zum Tragen, wie institutionelle Bedingungen, die die Flexibilität der relativen Einkommen einschränken.

Die Beurteilung des Nutzens berücksichtigt auch den Beitrag von Bildung zu einer höheren Beschäftigungswahrscheinlichkeit, wenn eine Beschäftigung angestrebt wird. Das macht die Ergebnisse jedoch auch abhängig von der Konjunkturphase, in der die Daten erhoben wurden. Da Besserausgebildete normalerweise auch in schwierigeren ökonomischen Zeiten eher im Arbeitsmarkt verbleiben, steigt im Allgemeinen der Wert des erworbenen Bildungsstandes in Zeiten schwachen wirtschaftlichen Wachstums.

Ferner erfordern die Berechnungen eine Reihe restriktiver Annahmen zur Wahrung der internationalen Vergleichbarkeit. Zur Berechnung der Bildungsinvestition wurde das entgangene Einkommen auf der Höhe des gesetzlichen Mindestlohnes bzw. einer Entsprechung hierfür für die Länder, in denen die Einkommensdaten auch Teilzeitarbeitsverhältnisse enthalten, standardisiert. Wenn kein nationaler Mindestlohn verfügbar war, wurde eine Einkommensstufe aus den Tarifverträgen gewählt. Durch diese Annahme wird versucht, die angegebenen sehr niedrigen Einkommen für I5bis 24-Jährige auszugleichen, die in früheren Ausgaben von Bildung auf einen Blick zu außergewöhnlich hohen Schätzwerten führten. Bei Japan, den Niederlanden, Portugal, Tschechien, Ungarn und dem Vereinigten Königreich werden die tatsächlichen Einkommen zur Berechnung der entgangenen Einkommen verwendet, da dort in den Erhebungen zu den Einkommensdaten keine Teilzeitbeschäftigungen enthalten sind.

Kosten und Nutzen eines Abschlusses im Sekundarbereich II bzw. im postsekundaren, nicht tertiären Bereich lassen sich für Belgien nicht berechnen, da dort der Besuch des Sekundarbereichs II bzw. des postsekundaren, nicht tertiären Bereichs Pflicht ist. Im 
Falle einer verpflichtenden Bildungsteilnahme kann die Methodik dieses Indikators, die den Investitionsansatz verfolgt, nicht konsequent angewendet werden. Der Investitionsansatz unterstellt, dass eine Investitionsentscheidung über den Erwerb eines Abschlusses auf einem bestimmten Niveau getroffen wird, um in den Genuss des damit verbundenen Nutzens zu gelangen. In den Ländern, in denen die Teilnahme an einem bestimmten Bildungsbereich Pflicht ist, steht eine solche Entscheidung nicht an, und daher greift diese Methodik in diesen Fällen nicht.

Weiterführende Informationen zur angewandten Methodik siehe OECD (20II) und Anhang 3 unter www.oecd.orgleduleag.htm.

\section{Anmerkung zu den Daten aus Israel}

Die statistischen Daten für Israel wurden von den zuständigen israelischen Stellen bereitgestellt, die für sie verantwortlich zeichnen. Die Verwendung dieser Daten durch die OECD erfolgt unbeschadet des völkerrechtlichen Status der Golanhöhen, von Ost-Jerusalem und der israelischen Siedlungen im Westjordanland.

\section{Weiterführende Informationen}

Andrews, D., A. Caldera Sánchez and Å. Johansson (20II), „Housing Markets and Structural Policies in OECD Countries“, OECD Economics Department Working Papers, No. 836, OECD Publishing, Paris, http://dx.doi.org/10.1787/5kgk8t2 kguf3-en.

OECD (2013a), Bildung auf einen Blick - OECD-Indikatoren, W, Bertelsmann Verlag, Bielefeld.

OECD (2013b), „Exchange Rates (USD monthly averages)“, Monthly Monetary and Financial Statistics (MEI) (database), http://stats.oecd.org/Index.aspx?QueryId=I69.

OECD (20II), „A User's Guide to Indicator A9: Incentives to Invest in Education“ (verfügbar unter www.oecd.org/edu/eag2011).

\section{Tabellen Indikator A7}

StatLink: http://dx.doi.org/10.1787/888933116281

Tabelle A7.ra: Private Kosten und privater Nutzen für einen Mann, der einen Abschluss im Sekundarbereich II bzw. postsekundaren, nicht tertiären Bereich erwirbt (2010)

Tabelle A7.Ib: Private Kosten und privater Nutzen für eine Frau, die einen Abschluss im Sekundarbereich II bzw. postsekundaren, nicht tertiären Bereich erwirbt (20I0) 
Tabelle A7.2a: Staatliche Kosten und staatlicher Nutzen bei einem Mann, der einen Abschluss im Sekundarbereich II bzw. postsekundaren, nicht tertiären Bereich erwirbt (2010)

Tabelle A7.2b: Staatliche Kosten und staatlicher Nutzen bei einer Frau, die einen Abschluss im Sekundarbereich II bzw. postsekundaren, nicht tertiären Bereich erwirbt (2010)

Tabelle A7.3a: Private Kosten und privater Nutzen für einen Mann, der einen Abschluss im Tertiärbereich erwirbt (2010)

Tabelle A7.3b: Private Kosten und privater Nutzen für eine Frau, die einen Abschluss im Tertiärbereich erwirbt (2010)

Tabelle A7.4a: Staatliche Kosten und staatlicher Nutzen bei einem Mann, der einen Abschluss im Tertiärbereich erwirbt (2010)

Tabelle A7.4b: Staatliche Kosten und staatlicher Nutzen bei einer Frau, die einen Abschluss im Tertiärbereich erwirbt (2010)

WEB Table A7.5a: Private net present value including grants and loans for a man attaining tertiary education (Privater Kapitalwert einschließlich Zuschüssen und Darlehen für einen Mann, der einen Abschluss im Tertiärbereich erwirbt) (20I0)

Web Table A7.5b: Private net present value including grants and loans for a woman attaining tertiary education (Privater Kapitalwert einschließlich Zuschüssen und Darlehen für eine Frau, die einen Abschluss im Tertiärbereich erwirbt) (2010)

WEB Table A7.6a: Public net present value including grants and loans for a man attaining tertiary education (Staatlicher Kapitalwert einschließlich Zuschüssen und Darlehen bei einem Mann, der einen Abschluss im Tertiärbereich erwirbt) (2010)

WEB Table A7.6b: Public net present value including grants and loans for a woman attaining tertiary education (Staatlicher Kapitalwert einschließlich Zuschüssen und Darlehen bei einer Frau, die einen Abschluss im Tertiärbereich erwirbt) (2010) 
Tabelle A7.1a

Private Kosten und privater Nutzen für einen Mann, der einen Abschluss im Sekundarbereich II bzw. postsekundaren, nicht tertiären Bereich erwirbt (2010)

Im Vergleich zu einem Mann, der einen Abschluss im Sekundarbereich I erwirbt (in US-Dollar, kaufkraftbereinigt mittels KKP für das BIP)

\begin{tabular}{|c|c|c|c|c|c|c|c|c|c|c|c|c|}
\hline & Jahr & $\begin{array}{l}\text { Direkte } \\
\text { Kosten }\end{array}$ & $\begin{array}{c}\text { Entgan- } \\
\text { genes } \\
\text { Einkom- } \\
\text { men }\end{array}$ & $\begin{array}{c}\text { Gesamt- } \\
\text { kosten }\end{array}$ & $\begin{array}{c}\text { Bruttoein- } \\
\text { kommens- } \\
\text { vorteile }\end{array}$ & $\begin{array}{c}\text { Effekt } \\
\text { Einkom- } \\
\text { men- } \\
\text { steuer }\end{array}$ & $\begin{array}{c}\text { Effekt } \\
\text { Sozial- } \\
\text { versiche- } \\
\text { rungs- } \\
\text { beiträge }\end{array}$ & $\begin{array}{l}\text { Effekt } \\
\text { Trans- } \\
\text { ferleis- } \\
\text { tungen }\end{array}$ & \begin{tabular}{|c|} 
Effekt \\
Erwerbs- \\
losigkeit
\end{tabular} & $\begin{array}{c}\text { Gesamt- } \\
\text { nutzen }\end{array}$ & $\begin{array}{c}\text { Kapital- } \\
\text { wert }\end{array}$ & $\begin{array}{c}\text { Ertrags- } \\
\text { rate }\end{array}$ \\
\hline & & (1) & (2) & (3) & (4) & (5) & (6) & (7) & (8) & (9) & (10) & (11) \\
\hline \multicolumn{13}{|l|}{ OECD-Länder } \\
\hline Australien & 2009 & -3019 & -27156 & -30175 & 176400 & -64407 & 0 & -8303 & 49011 & 152701 & 122526 & $19,9 \%$ \\
\hline Österreich & 2010 & -2084 & -46210 & -48294 & 303737 & -80357 & -65732 & -10652 & 50975 & 197971 & 149677 & $12,1 \%$ \\
\hline Belgien ${ }^{1}$ & & $\mathrm{~m}$ & $\mathrm{~m}$ & m & $\mathrm{m}$ & $\mathrm{m}$ & $\mathrm{m}$ & $\mathrm{m}$ & $\mathrm{m}$ & m & $\mathbf{m}$ & $\mathrm{m}$ \\
\hline Kanada & 2010 & -3424 & -30793 & -34217 & 164771 & -50060 & -13432 & -1362 & 45338 & 145254 & 111037 & $13,3 \%$ \\
\hline Chile & & $\mathrm{m}$ & $\mathrm{m}$ & m & $\mathrm{m}$ & $\mathrm{m}$ & $\mathrm{m}$ & $\mathrm{m}$ & $\mathrm{m}$ & $\mathbf{m}$ & $\mathbf{m}$ & $\mathrm{m}$ \\
\hline Tschechien & 2010 & -2130 & -17846 & -19976 & 92549 & -27793 & -19496 & -5574 & 85445 & 125131 & 105155 & $18,2 \%$ \\
\hline Dänemark & 2010 & -797 & -42671 & -43468 & 207899 & -78437 & -20515 & -11164 & 32831 & 130615 & 87147 & $11,7 \%$ \\
\hline Estland & 2010 & -249 & -8196 & -8445 & 66894 & -26383 & -3919 & 0 & 73157 & 109750 & 101305 & $39,5 \%$ \\
\hline Finnland & 2009 & -178 & -30022 & -30201 & 75381 & -28532 & -6632 & -7202 & 28082 & 61097 & 30897 & $7,8 \%$ \\
\hline Frankreich & 2010 & -2904 & -28503 & -31407 & 94133 & -21451 & -20444 & -15050 & 54391 & 91579 & 60173 & $10,6 \%$ \\
\hline Deutschland & 2010 & -3973 & -36901 & -40874 & 74406 & -28450 & -31726 & -9942 & 81012 & 85299 & 44426 & $7,5 \%$ \\
\hline Griechenland & 2009 & -1780 & -30044 & -31824 & 93624 & -11870 & -15658 & -23320 & 3845 & 46622 & 14798 & $4,1 \%$ \\
\hline Ungarn & 2010 & -878 & -11766 & -12644 & 76171 & -23298 & -22368 & 0 & 55414 & 85919 & 73276 & $19,3 \%$ \\
\hline Island & & $\mathrm{m}$ & $\mathrm{m}$ & m & $\mathrm{m}$ & $\mathrm{m}$ & $\mathrm{m}$ & $\mathrm{m}$ & $\mathrm{m}$ & $\mathbf{m}$ & $\mathbf{m}$ & $\mathrm{m}$ \\
\hline Irland & 2010 & -1084 & -23927 & -25011 & 214036 & -65316 & -29965 & 0 & 101729 & 220484 & 195473 & $30,3 \%$ \\
\hline Israel & 2010 & -1215 & -24905 & -26120 & 147712 & -21659 & -17721 & 0 & 21021 & 129352 & 103232 & $12,6 \%$ \\
\hline Italien & 2008 & -986 & -43886 & -44872 & 177073 & -63514 & -18903 & 0 & 22519 & 117174 & 72302 & $8,1 \%$ \\
\hline$J^{\prime} a n^{2}$ & & $\mathrm{~m}$ & $\mathrm{~m}$ & m & $\mathrm{m}$ & $\mathrm{m}$ & $\mathrm{m}$ & $\mathrm{m}$ & $\mathrm{m}$ & m & m & $\mathrm{m}$ \\
\hline Korea & 2010 & -5756 & -28830 & -34587 & 185305 & -7688 & -15277 & 0 & 11785 & 174126 & 139540 & $13,1 \%$ \\
\hline Luxemburg & & $\mathrm{m}$ & $\mathrm{m}$ & m & $\mathrm{m}$ & $\mathrm{m}$ & $\mathrm{m}$ & $\mathrm{m}$ & $\mathrm{m}$ & $\mathbf{m}$ & m & $\mathrm{m}$ \\
\hline Mexiko & & $\mathrm{m}$ & $\mathrm{m}$ & m & $\mathrm{m}$ & $\mathrm{m}$ & $\mathrm{m}$ & $\mathrm{m}$ & $\mathrm{m}$ & $\mathbf{m}$ & $\mathbf{m}$ & $\mathrm{m}$ \\
\hline Niederlande & 2010 & -4358 & -50747 & -55105 & 150870 & -53510 & -28296 & -4801 & 31999 & 96261 & 41156 & $5,7 \%$ \\
\hline Neuseeland & 2010 & -3213 & -33613 & -36827 & 112064 & -37790 & -2839 & -1172 & 29961 & 100226 & 63399 & $8,7 \%$ \\
\hline Norwegen & 2010 & -3023 & -51519 & -54543 & 261645 & -82184 & -23995 & -4680 & 46082 & 196868 & 142325 & $13,0 \%$ \\
\hline Polen & 2010 & -1276 & -16640 & -17916 & 56062 & -7234 & -19415 & 0 & 34594 & 64008 & 46093 & $11,6 \%$ \\
\hline Portugal & 2010 & 0 & -17510 & -17510 & 146361 & -29407 & -17538 & 0 & 13572 & 112987 & 95478 & $12,0 \%$ \\
\hline Slowakei & 2010 & -2007 & -8802 & -10809 & 115675 & -26205 & -31402 & 0 & 119524 & 177592 & 166784 & $35,1 \%$ \\
\hline Slowenien & 2010 & -1833 & -21943 & -23776 & 125817 & -29689 & -36241 & 0 & 38266 & 98153 & 74378 & $12,8 \%$ \\
\hline Spanien & 2010 & -1613 & -9225 & -10838 & 107297 & -28928 & -10463 & 0 & 58730 & 126636 & 115798 & $35,3 \%$ \\
\hline Schweden & 2010 & -16 & -25456 & -25473 & 175142 & -58469 & -16085 & -21705 & 55004 & 133887 & 108415 & $16,5 \%$ \\
\hline Schweiz & & $\mathrm{m}$ & $\mathrm{m}$ & m & $\mathrm{m}$ & $\mathrm{m}$ & $\mathrm{m}$ & $\mathrm{m}$ & $\mathrm{m}$ & $\mathbf{m}$ & $\mathbf{m}$ & $\mathrm{m}$ \\
\hline Türkei & 2005 & -336 & -11218 & -11554 & 63318 & -10584 & -10115 & 0 & 4017 & 46637 & 35082 & $9,5 \%$ \\
\hline Ver. Königreich & 2010 & -5195 & -30014 & -35209 & 220438 & -51976 & -28912 & -49957 & 64640 & 154232 & 119023 & $18,2 \%$ \\
\hline Vereinigte Staaten & 2010 & -2853 & -25225 & -28078 & 285333 & -68131 & -25197 & -7344 & 44074 & 228736 & 200658 & $19,4 \%$ \\
\hline \multicolumn{2}{|l|}{ OECD-Durchschnitt } & -2081 & -27169 & -29250 & 147041 & -40123 & -20455 & -6749 & 46556 & 126270 & 97020 & $15,8 \%$ \\
\hline EU21-Durchschnitt & & -1755 & -26332 & -28087 & 135451 & -38990 & -23353 & -8388 & 52933 & 117653 & 89566 & $16,7 \%$ \\
\hline
\end{tabular}

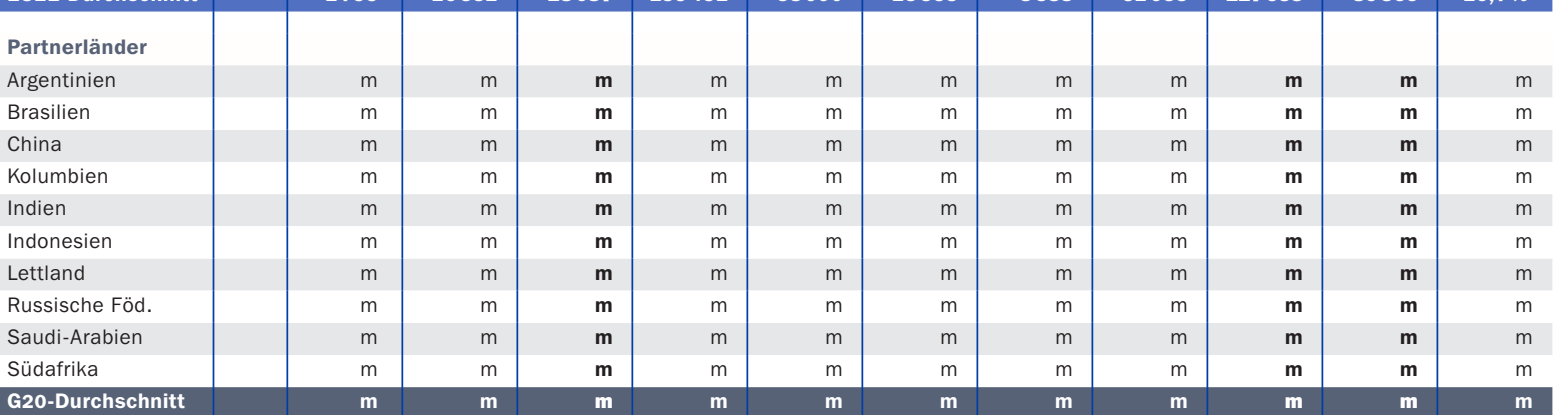

Anmerkung: Die Zahlen basieren auf dem Unterschied zwischen Männern, die einen Abschluss im Sekundarbereich II/postsekundaren, nicht tertiären Bereich erworben haben, und Männern, die keinen derartigen Abschluss erworben haben.

1. Für Belgien keine Datenangabe in der Tabelle, da der Sekundarbereich II dort Pflicht ist. 2. Daten sind nicht aufgegliedert nach Abschluss im Sekundarbereich I und Sekundarbereich II.

Quelle: OECD. Hinweise s. Anhang 3 unter www.oecd.org/edu/eag.htm. StatLink: http://dx.doi.org/10.1787/888933116300

Erläuterung der Kennzeichnung fehlender Daten s. Hinweise für den Leser. 
Private Kosten und privater Nutzen für eine Frau, die einen Abschluss im Sekundarbereich II bzw. postsekundaren, nicht tertiären Bereich erwirbt (2010)

Im Vergleich zu einer Frau, die einen Abschluss im Sekundarbereich I erwirbt (in US-Dollar, kaufkraftbereinigt mittels KKP für das BIP)

\begin{tabular}{|c|c|c|c|c|c|c|c|c|c|c|c|c|}
\hline & Jahr & $\begin{array}{l}\text { Direkte } \\
\text { Kosten }\end{array}$ & $\begin{array}{l}\text { Entgan- } \\
\text { genes } \\
\text { Einkom- } \\
\text { men }\end{array}$ & $\begin{array}{l}\text { Gesamt- } \\
\text { kosten }\end{array}$ & $\begin{array}{c}\text { Bruttoein- } \\
\text { kommens- } \\
\text { vorteile }\end{array}$ & $\begin{array}{c}\text { Effekt } \\
\text { Einkom- } \\
\text { men- } \\
\text { steuer }\end{array}$ & $\begin{array}{c}\text { Effekt } \\
\text { Sozial- } \\
\text { versiche- } \\
\text { rungs- } \\
\text { beiträge }\end{array}$ & $\begin{array}{l}\text { Effekt } \\
\text { Trans- } \\
\text { ferleis- } \\
\text { tungen }\end{array}$ & $\begin{array}{l}\text { Effekt } \\
\text { Erwerbs- } \\
\text { losigkeit }\end{array}$ & $\begin{array}{c}\text { Gesamt- } \\
\text { nutzen }\end{array}$ & $\begin{array}{c}\text { Kapital- } \\
\text { wert }\end{array}$ & $\begin{array}{c}\text { Ertrags- } \\
\text { rate }\end{array}$ \\
\hline & & (1) & (2) & (3) & (4) & (5) & (6) & (7) & (8) & (9) & (10) & (11) \\
\hline \multicolumn{13}{|l|}{ OECD-Länder } \\
\hline Australien & 2009 & -3019 & -28198 & -31217 & 122044 & -28457 & 0 & -22467 & 20190 & 91311 & 60094 & $12,7 \%$ \\
\hline Österreich & 2010 & -2084 & -44642 & -46726 & 204709 & -28457 & -46030 & -32029 & 23784 & 121977 & 75251 & $9,0 \%$ \\
\hline Belgien ${ }^{1}$ & & $\mathrm{~m}$ & $\mathrm{~m}$ & $\mathbf{m}$ & $\mathrm{m}$ & $\mathrm{m}$ & $\mathrm{m}$ & $\mathrm{m}$ & $\mathrm{m}$ & m & m & $\mathrm{m}$ \\
\hline Kanada & 2010 & -3424 & -32817 & -36241 & 78654 & -15117 & -8057 & -3002 & 29950 & 82428 & 46187 & $7,1 \%$ \\
\hline Chile & & $\mathrm{m}$ & $\mathrm{m}$ & m & $\mathrm{m}$ & $\mathrm{m}$ & $\mathrm{m}$ & $\mathrm{m}$ & $\mathrm{m}$ & m & m & $\mathrm{m}$ \\
\hline Tschechien & 2010 & -2130 & -15299 & -17429 & 86525 & -23652 & -17196 & -16740 & 70127 & 99064 & 81634 & $19,3 \%$ \\
\hline Dänemark & 2010 & -797 & -44663 & -45460 & 151000 & -55719 & -15607 & 0 & 26604 & 106278 & 60818 & $9,1 \%$ \\
\hline Estland & 2010 & -249 & -8187 & -8436 & 43751 & -10151 & -1455 & 0 & 8365 & 40510 & 32074 & $31,6 \%$ \\
\hline Finnland & 2009 & -178 & -31990 & -32168 & 55774 & -16608 & -5546 & -16226 & 30783 & 48177 & 16009 & $5,5 \%$ \\
\hline Frankreich & 2010 & -2904 & -25642 & -28546 & 97781 & -18674 & -18682 & -27615 & 39828 & 72639 & 44093 & $8,1 \%$ \\
\hline Deutschland & 2010 & -3973 & -37300 & -41272 & 156387 & -33692 & -41680 & -48767 & 42644 & 74891 & 33618 & $6,4 \%$ \\
\hline Griechenland & 2009 & -1780 & -24381 & -26160 & 109244 & -1304 & -18230 & -15164 & 5096 & 79641 & 53481 & $7,8 \%$ \\
\hline Ungarn & 2010 & -878 & -13082 & -13960 & 75548 & -21486 & -20637 & 0 & 46369 & 79794 & 65834 & $15,8 \%$ \\
\hline Island & & $\mathrm{m}$ & $\mathrm{m}$ & $\mathbf{m}$ & $\mathrm{m}$ & $\mathrm{m}$ & $\mathrm{m}$ & $\mathrm{m}$ & $\mathrm{m}$ & m & m & $\mathrm{m}$ \\
\hline Irland & 2010 & -1084 & -31344 & -32428 & 134069 & -20768 & -8056 & 0 & 30359 & 135604 & 103176 & $15,0 \%$ \\
\hline Israel & 2010 & -1215 & -23860 & -25076 & 109731 & -3747 & -5003 & -3505 & 12291 & 109768 & 84692 & $13,0 \%$ \\
\hline Italien & 2008 & -986 & -38624 & -39610 & 152167 & -51238 & -17293 & 0 & 29983 & 113620 & 74010 & $8,4 \%$ \\
\hline Japan $^{2}$ & & $\mathrm{~m}$ & $\mathrm{~m}$ & $\mathbf{m}$ & $\mathrm{m}$ & $\mathrm{m}$ & $\mathrm{m}$ & $\mathrm{m}$ & $\mathrm{m}$ & m & m & $\mathrm{m}$ \\
\hline Korea & 2010 & -5756 & -30875 & -36631 & 114418 & -1830 & -9342 & 0 & 4399 & 107644 & 71013 & $11,3 \%$ \\
\hline Luxemburg & & $\mathrm{m}$ & $\mathrm{m}$ & $\mathbf{m}$ & $\mathrm{m}$ & $\mathrm{m}$ & $\mathrm{m}$ & $\mathrm{m}$ & $\mathrm{m}$ & m & m & $\mathrm{m}$ \\
\hline Mexiko & & $\mathrm{m}$ & $\mathrm{m}$ & $\mathbf{m}$ & $\mathrm{m}$ & $\mathrm{m}$ & $\mathrm{m}$ & $\mathrm{m}$ & $m$ & m & m & $\mathrm{m}$ \\
\hline Niederlande & 2010 & -4358 & -48974 & -53332 & 159683 & -36998 & -53343 & -13638 & 28711 & 84414 & 31082 & $5,1 \%$ \\
\hline Neuseeland & 2010 & -3213 & -30148 & -33362 & 77579 & -16827 & -1872 & -7825 & 16735 & 67790 & 34428 & $7,7 \%$ \\
\hline Norwegen & 2010 & -3023 & -52322 & -55345 & 160744 & -44395 & -14122 & -14220 & 19969 & 107976 & 52631 & $6,9 \%$ \\
\hline Polen & 2010 & -1276 & -15341 & -16618 & 65215 & -7681 & -20906 & 0 & 32672 & 69299 & 52682 & $11,7 \%$ \\
\hline Portugal & 2010 & 0 & -16952 & -16952 & 104322 & -10554 & -12633 & 0 & 10654 & 91790 & 74838 & $11,3 \%$ \\
\hline Slowakei & 2010 & -2007 & -5179 & -7187 & 79613 & -12302 & -22099 & 0 & 85991 & 131204 & 124017 & $43,8 \%$ \\
\hline Slowenien & 2010 & -1833 & -24045 & -25877 & 118868 & -32045 & -31131 & 0 & 21694 & 77387 & 51510 & $8,8 \%$ \\
\hline Spanien & 2010 & -1613 & -8881 & -10494 & 85625 & -27101 & -7802 & 0 & 39931 & 90653 & 80159 & $16,5 \%$ \\
\hline Schweden & 2010 & -16 & -27231 & -27247 & 141055 & -47672 & -13857 & -30949 & 57144 & 105720 & 78473 & $11,5 \%$ \\
\hline Schweiz & & $\mathrm{m}$ & $\mathrm{m}$ & $\mathbf{m}$ & $\mathrm{m}$ & m & $\mathrm{m}$ & $\mathrm{m}$ & m & m & m & m \\
\hline Türkei & 2005 & -336 & -12058 & -12394 & 75879 & -8395 & -9432 & 0 & -12434 & 45618 & 33223 & $9,2 \%$ \\
\hline Ver. Königreich & 2010 & -5195 & -42268 & -47464 & 136400 & -33662 & -18761 & -49494 & 51211 & 85693 & 38230 & $6,7 \%$ \\
\hline Vereinigte Staaten & 2010 & -2853 & -27807 & -30659 & 216685 & -44957 & -19154 & -13250 & 34220 & 173546 & 142886 & $16,7 \%$ \\
\hline \multicolumn{2}{|l|}{ OECD-Durchschnitt } & -2081 & -27486 & -29566 & 115314 & -24203 & -16960 & -11663 & 29899 & 92386 & 62820 & $12,5 \%$ \\
\hline EU21-Durchschnitt & & -1755 & -26528 & -28282 & 113565 & -25777 & -20576 & -13191 & 35892 & 89913 & 61631 & $13,2 \%$ \\
\hline
\end{tabular}

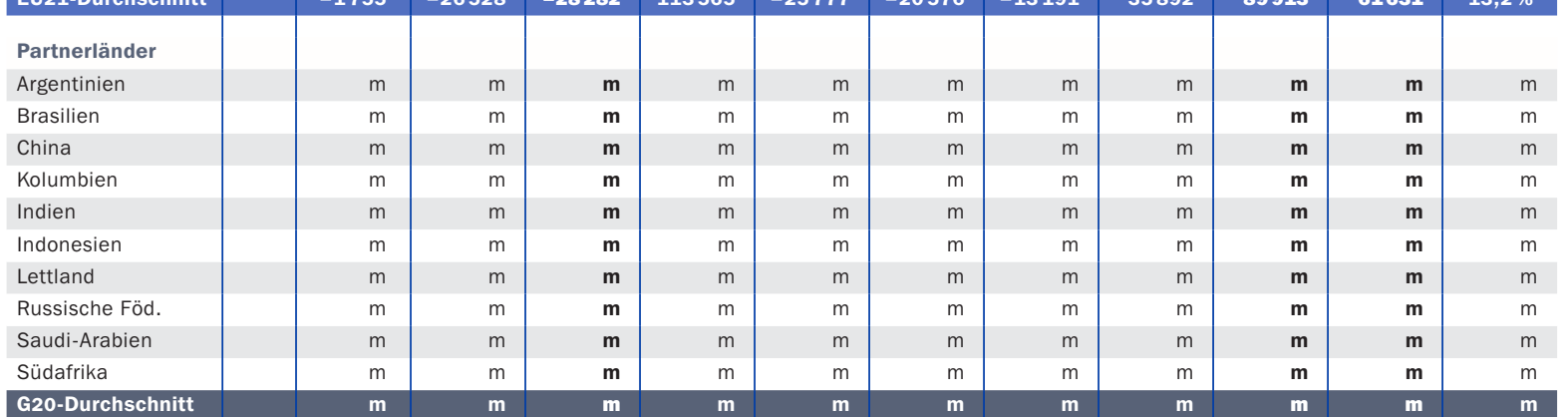

Anmerkung: Die Zahlen basieren auf dem Unterschied zwischen Frauen, die einen Abschluss im Sekundarbereich II/postsekundaren, nicht tertiären Bereich erworben haben, und Frauen, die keinen derartigen Abschluss erworben haben

1. Für Belgien keine Datenangabe in der Tabelle, da der Sekundarbereich II dort Pflicht ist. 2. Daten sind nicht aufgegliedert nach Abschluss im Sekundarbereich I und Sekundarbereich II.

Quelle: OECD. Hinweise s. Anhang 3 unter www.oecd.org/edu/eag.htm. StatLink: http://dx.doi.org/10.1787/888933116319

Erläuterung der Kennzeichnung fehlender Daten s. Hinweise für den Leser. 
Tabelle A7.2a

Staatliche Kosten und staatlicher Nutzen bei einem Mann, der einen Abschluss im Sekundarbereich II bzw. postsekundaren, nicht tertiären Bereich erwirbt (2010)

Im Vergleich zu einem Mann mit einem Abschluss im Sekundarbereich I (in US-Dollar, kaufkraftbereinigt mittels KKP für das BIP)

\begin{tabular}{|c|c|c|c|c|c|c|c|c|c|c|c|}
\hline & Jahr & $\begin{array}{l}\text { Direkte } \\
\text { Kosten }\end{array}$ & \begin{tabular}{|c|} 
Entgan- \\
gene \\
Einkom- \\
mensteuer
\end{tabular} & $\begin{array}{l}\text { Gesamt- } \\
\text { kosten }\end{array}$ & $\begin{array}{c}\text { Effekt } \\
\text { Einkom- } \\
\text { mensteuer }\end{array}$ & $\begin{array}{c}\text { Effekt } \\
\text { Sozial- } \\
\text { versiche- } \\
\text { rungs- } \\
\text { beiträge }\end{array}$ & \begin{tabular}{|c|} 
Effekt \\
Transfer- \\
leistungen
\end{tabular} & $\begin{array}{c}\text { Effekt } \\
\text { Erwerbs- } \\
\text { losigkeit }\end{array}$ & $\begin{array}{c}\text { Gesamt- } \\
\text { nutzen }\end{array}$ & $\begin{array}{l}\text { Kapital- } \\
\text { wert }\end{array}$ & $\begin{array}{l}\text { Ertrags- } \\
\text { rate }\end{array}$ \\
\hline & & (1) & (2) & (3) & (4) & (5) & (6) & (7) & (8) & (9) & (10) \\
\hline \multicolumn{12}{|l|}{ OECD-Länder } \\
\hline Australien & 2009 & -15955 & -3020 & -18975 & 55053 & 0 & 8303 & 9355 & 72710 & 53735 & $17,1 \%$ \\
\hline Österreich & 2010 & -43971 & -8869 & -52840 & 73918 & 56580 & 10652 & 15590 & 156741 & 103901 & $9,5 \%$ \\
\hline  & & $m$ & $\mathrm{~m}$ & m & $\mathrm{m}$ & $\mathrm{m}$ & $\mathrm{m}$ & $\mathrm{m}$ & m & $\mathbf{m}$ & $\mathrm{m}$ \\
\hline Kanada & 2010 & -27754 & -2945 & -30700 & 43075 & 10028 & 1322 & 8540 & 62965 & 32266 & $6,4 \%$ \\
\hline Chile & & $\mathrm{m}$ & $\mathrm{m}$ & $\mathbf{m}$ & $\mathrm{m}$ & $m$ & $\mathrm{~m}$ & $\mathrm{~m}$ & m & $\mathbf{m}$ & $\mathrm{m}$ \\
\hline Tschechien & 2010 & -21080 & 2849 & -18231 & 18550 & 10152 & 5574 & 18586 & 52862 & 34631 & $10,2 \%$ \\
\hline Dänemark & 2010 & -32430 & -20100 & -52530 & 69942 & 16687 & 11164 & 12323 & 110115 & 57585 & $7,6 \%$ \\
\hline Estland & 2010 & -19081 & -1241 & -20323 & 13696 & 1879 & 0 & 14726 & 30301 & 9978 & $5,5 \%$ \\
\hline Finnland & 2009 & -21711 & -4391 & -26103 & 23424 & 4855 & 7202 & 6884 & 42366 & 16263 & $6,5 \%$ \\
\hline Frankreich & 2010 & -33511 & -5799 & -39310 & 15415 & 13033 & 15050 & 13446 & 56945 & 17635 & $5,9 \%$ \\
\hline Deutschland & 2010 & -27953 & -13996 & -41949 & 17205 & 15268 & 9942 & 27703 & 70119 & 28170 & $6,8 \%$ \\
\hline Griechenland & 2009 & -22045 & 2032 & -20013 & 11723 & 15045 & 23320 & 760 & 50848 & 30835 & $6,0 \%$ \\
\hline Ungarn & 2010 & -15696 & -2625 & -18321 & 16503 & 12994 & 0 & 16168 & 45666 & 27345 & $8,5 \%$ \\
\hline Island & & $\mathrm{m}$ & $\mathrm{m}$ & m & $\mathrm{m}$ & $\mathrm{m}$ & $\mathrm{m}$ & $\mathrm{m}$ & m & m & $\mathrm{m}$ \\
\hline Irland & 2010 & -25625 & -794 & -26419 & 55056 & 23939 & 0 & 16285 & 95281 & 68862 & $10,8 \%$ \\
\hline Israel & 2010 & -14670 & -1409 & -16079 & 20681 & 16468 & 0 & 2231 & 39380 & 23301 & $6,7 \%$ \\
\hline Italien & 2008 & -32919 & -10264 & -43183 & 59003 & 16776 & 0 & 6638 & 82418 & 39235 & $6,0 \%$ \\
\hline$J^{J a p a n}{ }^{2}$ & & $\mathrm{~m}$ & $\mathrm{~m}$ & $\mathbf{m}$ & $\mathrm{m}$ & $\mathrm{m}$ & $\mathrm{m}$ & $\mathrm{m}$ & m & $\mathbf{m}$ & $\mathrm{m}$ \\
\hline Korea & 2010 & -21051 & -2923 & -23974 & 7529 & 14366 & 0 & 1069 & 22965 & -1009 & $2,8 \%$ \\
\hline Luxemburg & & $\mathrm{m}$ & $\mathrm{m}$ & $\mathbf{m}$ & $\mathrm{m}$ & $\mathrm{m}$ & $\mathrm{m}$ & $\mathrm{m}$ & m & m & $\mathrm{m}$ \\
\hline Mexiko & & $\mathrm{m}$ & $\mathrm{m}$ & m & $\mathrm{m}$ & $\mathrm{m}$ & $\mathrm{m}$ & $\mathrm{m}$ & m & $\mathbf{m}$ & $\mathrm{m}$ \\
\hline Niederlande & 2010 & -28879 & -2153 & -31032 & 50757 & 20313 & 4801 & 10736 & 86607 & 55575 & $9,8 \%$ \\
\hline Neuseeland & 2010 & -22264 & -4017 & -26281 & 32780 & 2243 & 1172 & 5605 & 41800 & 15519 & $5,1 \%$ \\
\hline Norwegen & 2010 & -38967 & -16326 & -55292 & 73242 & 20424 & 4680 & 12512 & 110859 & 55566 & $7,6 \%$ \\
\hline Polen & 2010 & -19278 & -5994 & -25272 & 4952 & 12024 & 0 & 9673 & 26648 & 1377 & $3,3 \%$ \\
\hline Portugal & 2010 & -26371 & -2429 & -28800 & 28325 & 16055 & 0 & 2565 & 46945 & 18145 & $4,7 \%$ \\
\hline Slowakei & 2010 & -14722 & -874 & -15596 & 17620 & 15479 & 0 & 24507 & 57606 & 42011 & $12,3 \%$ \\
\hline Slowenien & 2010 & -19303 & -6815 & -26119 & 25987 & 27826 & 0 & 12116 & 65930 & 39811 & $9,0 \%$ \\
\hline Spanien & 2010 & -18107 & -843 & -18950 & 23289 & 6766 & 0 & 9336 & 39391 & 20441 & $6,1 \%$ \\
\hline Schweden & 2010 & -29675 & -6505 & -36180 & 46649 & 12257 & 21705 & 15648 & 96259 & 60079 & $14,3 \%$ \\
\hline Schweiz & & $m$ & $m$ & m & $\mathrm{m}$ & m & $\mathrm{m}$ & $\mathrm{m}$ & m & m & $\mathrm{m}$ \\
\hline Türkei & 2005 & -4776 & -4551 & -9327 & 9997 & 9514 & 0 & 1188 & 20699 & 11371 & $6,4 \%$ \\
\hline Ver. Königreich & 2010 & -19434 & 4949 & -14485 & 44222 & 24322 & 49957 & 12344 & 130846 & 116361 & $27,1 \%$ \\
\hline Vereinigte Staaten & 2010 & -34048 & -3381 & -37429 & 61984 & 21854 & 7344 & 9490 & 100671 & 63242 & $9,1 \%$ \\
\hline OECD-Durchschnitt & & -24121 & -4535 & -28656 & 34095 & 15450 & 6748 & 10964 & 67257 & 38601 & $8,6 \%$ \\
\hline EU21-Durchschnitt & & -24831 & -4414 & -29245 & 32433 & 16961 & 8388 & 12949 & 70731 & 41486 & $8,9 \%$ \\
\hline \multicolumn{12}{|l|}{ Partnerländer } \\
\hline Argentinien & & $\mathrm{m}$ & $\mathrm{m}$ & $\mathbf{m}$ & $\mathrm{m}$ & $\mathrm{m}$ & $\mathrm{m}$ & $\mathrm{m}$ & m & $\mathbf{m}$ & $\mathrm{m}$ \\
\hline Brasilien & & $\mathrm{m}$ & $\mathrm{m}$ & $\mathbf{m}$ & $\mathrm{m}$ & $\mathrm{m}$ & $\mathrm{m}$ & $\mathrm{m}$ & $\mathbf{m}$ & $\mathbf{m}$ & $\mathrm{m}$ \\
\hline China & & $\mathrm{m}$ & $\mathrm{m}$ & $\mathbf{m}$ & $\mathrm{m}$ & $\mathrm{m}$ & $\mathrm{m}$ & $\mathrm{m}$ & m & m & $\mathrm{m}$ \\
\hline Kolumbien & & $\mathrm{m}$ & $\mathrm{m}$ & m & $\mathrm{m}$ & $\mathrm{m}$ & $\mathrm{m}$ & $\mathrm{m}$ & m & $\mathbf{m}$ & $\mathrm{m}$ \\
\hline Indien & & $\mathrm{m}$ & $\mathrm{m}$ & $\mathbf{m}$ & $\mathrm{m}$ & $\mathrm{m}$ & $\mathrm{m}$ & $\mathrm{m}$ & $\mathbf{m}$ & $\mathbf{m}$ & $\mathrm{m}$ \\
\hline Indonesien & & $\mathrm{m}$ & $\mathrm{m}$ & m & $\mathrm{m}$ & $\mathrm{m}$ & $\mathrm{m}$ & $\mathrm{m}$ & m & m & $\mathrm{m}$ \\
\hline Lettland & & m & $m$ & m & $\mathrm{m}$ & m & $\mathrm{m}$ & $\mathrm{m}$ & m & m & $\mathrm{m}$ \\
\hline Russische Föd. & & $\mathrm{m}$ & $\mathrm{m}$ & $\mathbf{m}$ & $\mathrm{m}$ & $\mathrm{m}$ & $\mathrm{m}$ & $\mathrm{m}$ & $\mathbf{m}$ & $\mathbf{m}$ & $\mathrm{m}$ \\
\hline Saudi-Arabien & & m & $m$ & $\mathbf{m}$ & $\mathrm{m}$ & $\mathrm{m}$ & $\mathrm{m}$ & $\mathrm{m}$ & $\mathbf{m}$ & $\mathbf{m}$ & m \\
\hline Südafrika & & $\mathrm{m}$ & $\mathrm{m}$ & $\mathbf{m}$ & $\mathrm{m}$ & $\mathrm{m}$ & $\mathrm{m}$ & $\mathrm{m}$ & $\mathbf{m}$ & $\mathbf{m}$ & $\mathrm{m}$ \\
\hline G20-Durchschnitt & & m & $\mathbf{m}$ & m & $\mathbf{m}$ & $\mathbf{m}$ & $\mathbf{m}$ & m & m & $\mathbf{m}$ & $\mathbf{m}$ \\
\hline
\end{tabular}

Anmerkung: Die Zahlen basieren auf dem Unterschied zwischen Männern, die einen Abschluss im Sekundarbereich II/postsekundaren, nicht tertiären Bereich erworben haben, und Männern, die keinen derartigen Abschluss erworben haben.

1. Für Belgien keine Datenangabe in der Tabelle, da der Sekundarbereich II dort Pflicht ist. 2. Daten sind nicht aufgegliedert nach Abschluss im Sekundarbereich I und Sekundarbereich II.

Quelle: OECD. Hinweise s. Anhang 3 unter www.oecd.org/edu/eag.htm. StatLink: http://dx.doi.org/10.1787/888933116338 Erläuterung der Kennzeichnung fehlender Daten s. Hinweise für den Leser. 
Staatliche Kosten und staatlicher Nutzen bei einer Frau, die einen Abschluss im Sekundarbereich II bzw. postsekundaren, nicht tertiären Bereich erwirbt (2010)

Im Vergleich zu einer Frau mit einem Abschluss im Sekundarbereich I (in US-Dollar, kaufkraftbereinigt mittels KKP für das BIP)

\begin{tabular}{|c|c|c|c|c|c|c|c|c|c|c|c|}
\hline & Jahr & $\begin{array}{l}\text { Direkte } \\
\text { Kosten }\end{array}$ & \begin{tabular}{|c|} 
Entgan- \\
gene \\
Einkom- \\
mensteuer
\end{tabular} & $\begin{array}{l}\text { Gesamt- } \\
\text { kosten }\end{array}$ & $\begin{array}{c}\text { Effekt } \\
\text { Einkom- } \\
\text { mensteuer }\end{array}$ & $\begin{array}{c}\text { Effekt } \\
\text { Sozial- } \\
\text { versiche- } \\
\text { rungs- } \\
\text { beiträge }\end{array}$ & \begin{tabular}{|c|} 
Effekt \\
Transfer- \\
leistungen
\end{tabular} & $\begin{array}{c}\text { Effekt } \\
\text { Erwerbs- } \\
\text { losigkeit }\end{array}$ & $\begin{array}{c}\text { Gesamt- } \\
\text { nutzen }\end{array}$ & $\begin{array}{l}\text { Kapital- } \\
\text { wert }\end{array}$ & $\begin{array}{c}\text { Ertrags- } \\
\text { rate }\end{array}$ \\
\hline & & (1) & (2) & (3) & (4) & (5) & (6) & (7) & (8) & (9) & (10) \\
\hline \multicolumn{12}{|l|}{ OECD-Länder } \\
\hline Australien & 2009 & -15955 & -3136 & -19091 & 26218 & 0 & 22467 & 2239 & 50924 & 31833 & $18,4 \%$ \\
\hline Österreich & 2010 & -43971 & -8568 & -52539 & 28045 & 41879 & 32029 & 4562 & 106516 & 53977 & $8,2 \%$ \\
\hline Belgien ${ }^{1}$ & & $\mathrm{~m}$ & $\mathrm{~m}$ & m & $\mathrm{m}$ & $\mathrm{m}$ & $\mathrm{m}$ & $\mathrm{m}$ & m & m & $\mathrm{m}$ \\
\hline Kanada & 2010 & -28587 & -3233 & -31820 & 13613 & 6115 & 3002 & 3447 & 26176 & -5644 & $2,3 \%$ \\
\hline Chile & & $\mathrm{m}$ & $\mathrm{m}$ & m & $\mathrm{m}$ & $\mathrm{m}$ & $\mathrm{m}$ & $\mathrm{m}$ & m & m & $\mathrm{m}$ \\
\hline Tschechien & 2010 & -21080 & 2442 & -18638 & 17417 & 9532 & 16740 & 13901 & 57589 & 38951 & $10,5 \%$ \\
\hline Dänemark & 2010 & -32430 & -21038 & -53468 & 49505 & 12177 & 0 & 9644 & 71326 & 17858 & $4,8 \%$ \\
\hline Estland & 2010 & -19081 & -1240 & -20321 & 8914 & 1223 & 0 & 1469 & 11606 & -8715 & $0,2 \%$ \\
\hline Finnland & 2009 & -21711 & -4679 & -26390 & 12075 & 3607 & 16226 & 6472 & 38380 & 11989 & $6,6 \%$ \\
\hline Frankreich & 2010 & -33511 & -5217 & -38728 & 15257 & 13296 & 27615 & 8802 & 64970 & 26243 & $5,6 \%$ \\
\hline Deutschland & 2010 & -27953 & -14147 & -42100 & 30323 & 33057 & 48767 & 11993 & 124140 & 82040 & $13,7 \%$ \\
\hline Griechenland & 2009 & -22045 & 1649 & -20396 & 1347 & 17423 & 15164 & 764 & 34699 & 14303 & $4,8 \%$ \\
\hline Ungarn & 2010 & -15696 & -2918 & -18614 & 16259 & 12802 & 0 & 13062 & 42123 & 23509 & $7,5 \%$ \\
\hline Island & & $\mathrm{m}$ & $\mathrm{m}$ & $\mathbf{m}$ & $\mathrm{m}$ & $\mathrm{m}$ & $\mathrm{m}$ & $\mathrm{m}$ & m & m & $\mathrm{m}$ \\
\hline Irland & 2010 & -25625 & -1040 & -26665 & 19850 & 7690 & 0 & 1284 & 28824 & 2159 & $3,3 \%$ \\
\hline Israel & 2010 & -14670 & -1350 & -16020 & 3668 & 4543 & 3505 & 539 & 12254 & -3766 & $1,8 \%$ \\
\hline Italien & 2008 & -32919 & -9033 & -41952 & 47153 & 14467 & 0 & 6910 & 68530 & 26578 & $5,2 \%$ \\
\hline Japan $^{2}$ & & $\mathrm{~m}$ & $\mathrm{~m}$ & m & $\mathrm{m}$ & $\mathrm{m}$ & $\mathrm{m}$ & $\mathrm{m}$ & m & m & $\mathrm{m}$ \\
\hline Korea & 2010 & -21051 & -3130 & -24181 & 1797 & 9001 & 0 & 374 & 11172 & -13009 & $-1,0 \%$ \\
\hline Luxemburg & & $\mathrm{m}$ & $\mathrm{m}$ & $\mathbf{m}$ & $\mathrm{m}$ & $\mathrm{m}$ & $\mathrm{m}$ & $\mathrm{m}$ & m & m & $\mathrm{m}$ \\
\hline Mexiko & & $\mathrm{m}$ & $\mathrm{m}$ & m & $\mathrm{m}$ & $\mathrm{m}$ & $\mathrm{m}$ & $\mathrm{m}$ & m & m & $\mathrm{m}$ \\
\hline Niederlande & 2010 & -28879 & 1113 & -27766 & 35228 & 46047 & 13638 & 9066 & m & 76213 & $14,6 \%$ \\
\hline Neuseeland & 2010 & -22264 & -3603 & -25867 & 14529 & 1540 & 7825 & 2630 & 26524 & 657 & $3,1 \%$ \\
\hline Norwegen & 2010 & -38967 & -16580 & -55547 & 41576 & 12582 & 14220 & 4360 & 72737 & 17190 & $4,8 \%$ \\
\hline Polen & 2010 & -19278 & -5526 & -24804 & 5740 & 13937 & 0 & 8910 & 28588 & 3784 & $3,6 \%$ \\
\hline Portugal & 2010 & -26371 & -2352 & -28722 & 10290 & 11473 & 0 & 1424 & 23187 & -5536 & $2,3 \%$ \\
\hline Slowakei & 2010 & -14722 & -514 & -15236 & 9428 & 10668 & 0 & 14305 & 34401 & 19165 & $7,8 \%$ \\
\hline Slowenien & 2010 & -19303 & -7468 & -26771 & 30404 & 26364 & 0 & 6407 & 63175 & 36404 & $7,4 \%$ \\
\hline Spanien & 2010 & -18107 & -811 & -18919 & 25096 & 5301 & 0 & 4506 & 34904 & 15985 & $5,2 \%$ \\
\hline Schweden & 2010 & -29675 & -6959 & -36633 & 36329 & 9895 & 30949 & 15306 & 92478 & 55845 & $13,6 \%$ \\
\hline Schweiz & & $\mathrm{m}$ & $\mathrm{m}$ & m & $\mathrm{m}$ & $\mathrm{m}$ & m & $\mathrm{m}$ & m & m & $\mathrm{m}$ \\
\hline Türkei & 2005 & -4776 & -4892 & -9668 & 10025 & 11264 & 0 & -3463 & 17827 & 8159 & $5,8 \%$ \\
\hline Ver. Königreich & 2010 & -19434 & 8961 & -10473 & 27379 & 15059 & 49494 & 9985 & 101917 & 91444 & $19,3 \%$ \\
\hline Vereinigte Staaten & 2010 & -34048 & -3727 & -37775 & 41313 & 16564 & 13250 & 6233 & 77360 & 39585 & $7,5 \%$ \\
\hline \multicolumn{2}{|l|}{ OECD-Durchschnitt } & -24152 & -4333 & -28485 & 21436 & 13611 & 11663 & 6116 & 50859 & 24341 & $6,9 \%$ \\
\hline EU21-Durchschnitt & & -24831 & -4071 & -28902 & 22423 & 16100 & 13191 & 7830 & 57075 & 30642 & $7,6 \%$ \\
\hline
\end{tabular}

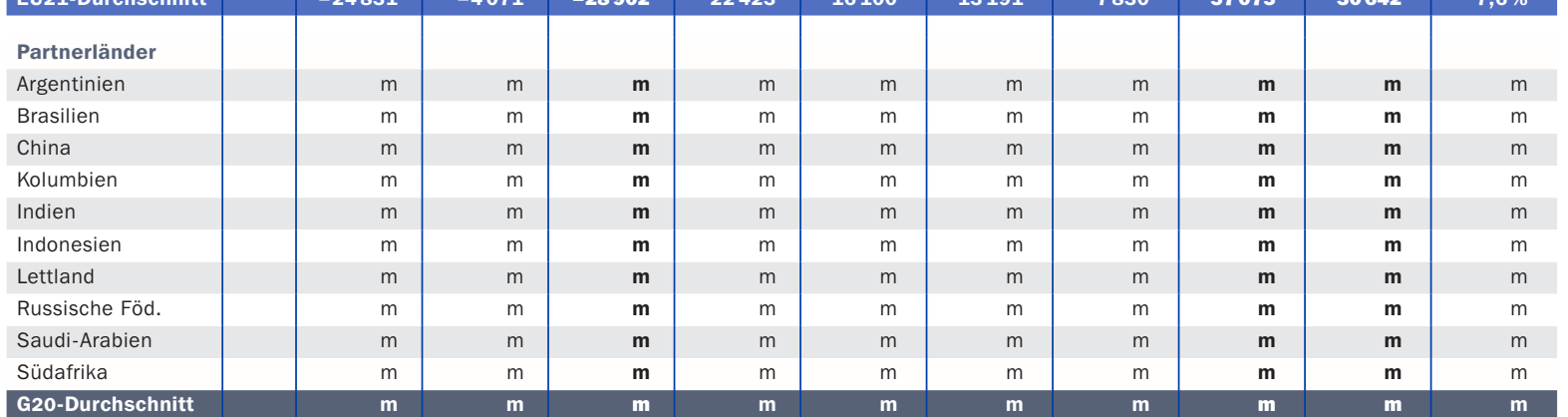

Anmerkung: Die Zahlen basieren auf dem Unterschied zwischen Frauen, die einen Abschluss im Sekundarbereich II/postsekundaren, nicht tertiären Bereich erworben haben, und Frauen, die keinen derartigen Abschluss erworben haben.

1. Für Belgien keine Datenangabe in der Tabelle, da der Sekundarbereich II dort Pflicht ist. 2. Daten sind nicht aufgegliedert nach Abschluss im Sekundarbereich I und Sekundarbereich II.

Quelle: OECD. Hinweise s. Anhang 3 unter www.oecd.org/edu/eag.htm. StatLink: http://dx.doi.org/10.1787/888933116357

Erläuterung der Kennzeichnung fehlender Daten s. Hinweise für den Leser. 
Tabelle A7.3a

Private Kosten und privater Nutzen für einen Mann, der einen Abschluss im Tertiärbereich erwirbt (2010)

Im Vergleich zu einem Mann, der einen Abschluss im Sekundarbereich II/postsekundaren, nicht tertiären Bereich erwirbt

(in US-Dollar, kaufkraftbereinigt mittels KKP für das BIP)

\begin{tabular}{|c|c|c|c|c|c|c|c|c|c|c|c|c|c|}
\hline & Jahr & $\begin{array}{l}\text { Direkte } \\
\text { Kosten }\end{array}$ & $\begin{array}{c}\text { Entgan- } \\
\text { genes } \\
\text { Einkom- } \\
\text { men }\end{array}$ & $\begin{array}{c}\text { Gesamt- } \\
\text { kosten }\end{array}$ & $\begin{array}{c}\text { Vorteile } \\
\text { Brutto- } \\
\text { einkom- } \\
\text { men }\end{array}$ & \begin{tabular}{|c|} 
Effekt \\
Einkom- \\
men- \\
steuer
\end{tabular} & \begin{tabular}{|c|} 
Effekt \\
Sozial- \\
versiche- \\
rungs- \\
beiträge
\end{tabular} & $\begin{array}{l}\text { Effekt } \\
\text { Trans- } \\
\text { ferleis- } \\
\text { tungen }\end{array}$ & $\begin{array}{c}\text { Effekt } \\
\text { Erwerbs- } \\
\text { losigkeit }\end{array}$ & $\begin{array}{c}\text { Effekt } \\
\text { Zu- } \\
\text { schüsse }\end{array}$ & $\begin{array}{c}\text { Gesamt- } \\
\text { nutzen }\end{array}$ & $\begin{array}{c}\text { Kapital- } \\
\text { wert }\end{array}$ & $\begin{array}{l}\text { Ertrags- } \\
\text { rate }\end{array}$ \\
\hline & & (1) & (2) & (3) & (4) & (5) & (6) & (7) & (8) & (9) & (10) & (11) & (12) \\
\hline \multicolumn{14}{|l|}{ OECD-Länder } \\
\hline Australien & 2009 & -17528 & -50814 & -68342 & 339977 & -124441 & 0 & 0 & 5363 & 335 & 221234 & 152892 & $9,0 \%$ \\
\hline Österreich & 2010 & -6199 & -62401 & -68600 & 396272 & -132408 & -53634 & 0 & 18521 & 10877 & 239629 & 171029 & $10,1 \%$ \\
\hline Belgien & 2010 & -2780 & -37528 & -40307 & 348982 & -155156 & -53464 & 0 & 21666 & 862 & 162891 & 122584 & $11,9 \%$ \\
\hline Kanada & 2010 & -20529 & -36423 & -56952 & 293058 & -96272 & -6355 & 0 & 27401 & 1103 & 218935 & 161982 & $10,2 \%$ \\
\hline Chile & & $\mathrm{m}$ & $\mathrm{m}$ & $\mathbf{m}$ & $\mathrm{m}$ & $\mathrm{m}$ & $\mathrm{m}$ & $\mathrm{m}$ & $\mathrm{m}$ & $\mathrm{m}$ & $\mathbf{m}$ & $\mathrm{m}$ & $\mathrm{m}$ \\
\hline Tschechien & 2010 & -5029 & -25719 & -30748 & 365437 & -70726 & -41771 & 0 & 20181 & $\mathrm{~m}$ & 273121 & 242373 & $18,6 \%$ \\
\hline Dänemark & 2010 & -4509 & -75357 & -79866 & 314158 & -143348 & -26897 & -8763 & 17765 & 29411 & 182326 & 102460 & $8,4 \%$ \\
\hline Estland & 2010 & -3924 & -14951 & -18875 & 207579 & -46145 & -6453 & 0 & 42224 & 730 & 197934 & 179059 & $20,6 \%$ \\
\hline Finnland & 2009 & -1873 & -56911 & -58784 & 343119 & -138956 & -24568 & 0 & 39479 & 8730 & 227803 & 169020 & $11,9 \%$ \\
\hline Frankreich & 2010 & -6963 & -47182 & -54145 & 380704 & -95841 & -51427 & -691 & 19109 & 103 & 254957 & 00812 & $11,4 \%$ \\
\hline Deutschland & 2010 & -5813 & -55093 & -60906 & 462289 & -166502 & -89273 & 0 & 58741 & 472 & 71727 & 210821 & $13,4 \%$ \\
\hline Griechenland & 2009 & -690 & -43715 & -44405 & 182193 & -35679 & -29437 & -8700 & 6156 & $\mathrm{~m}$ & 14533 & 70128 & $7,5 \%$ \\
\hline Ungarn & 2010 & -4664 & -13268 & -17932 & 459159 & -147118 & -75232 & 0 & 37773 & 1135 & 275718 & 257785 & $28,5 \%$ \\
\hline Island & & $\mathrm{m}$ & $\mathrm{m}$ & $\mathbf{m}$ & $\mathrm{m}$ & $\mathrm{m}$ & $\mathrm{m}$ & $\mathrm{m}$ & $\mathrm{m}$ & $\mathrm{m}$ & $\mathbf{m}$ & m & $\mathrm{m}$ \\
\hline Irland & 2010 & -6478 & -42453 & -48931 & 684820 & -259751 & -58952 & 0 & 131625 & 5412 & 503154 & 454224 & $29,9 \%$ \\
\hline Israel & 2010 & -14023 & -26963 & -40987 & 285448 & -69772 & -35702 & 0 & 16788 & 1528 & 98291 & 57304 & $11,8 \%$ \\
\hline Italien & 2008 & -7285 & -50608 & -57893 & 408011 & -159562 & -41835 & 0 & 3295 & 3330 & 213239 & 55346 & $8,1 \%$ \\
\hline Japan & 2007 & -37215 & -66750 & -103965 & 326614 & -64523 & -36039 & 0 & 20931 & $\mathrm{~m}$ & 246983 & 43018 & 7,4\% \\
\hline Korea & 2010 & -19211 & -34019 & -53231 & 379884 & -47160 & -25602 & 0 & 12407 & $\mathrm{~m}$ & 319528 & 266298 & $12,8 \%$ \\
\hline Luxemburg & & $\mathrm{m}$ & $\mathrm{m}$ & $\mathbf{m}$ & $\mathrm{m}$ & $\mathrm{m}$ & $\mathrm{m}$ & $\mathrm{m}$ & $\mathrm{m}$ & $\mathrm{m}$ & $\mathbf{m}$ & m & $\mathrm{m}$ \\
\hline Mexiko & & $\mathrm{m}$ & $\mathrm{m}$ & $\mathbf{m}$ & $\mathrm{m}$ & $\mathrm{m}$ & m & $\mathrm{m}$ & $\mathrm{m}$ & $\mathrm{m}$ & $\mathbf{m}$ & $\mathrm{m}$ & $\mathrm{m}$ \\
\hline Niederlande & 2010 & -14646 & -95834 & -110480 & 442661 & -197999 & -26901 & 0 & 10736 & 13770 & 242267 & 131787 & $7,2 \%$ \\
\hline Neuseeland & 2010 & -9384 & -43347 & -52731 & 193910 & -62325 & -3875 & -86 & 358 & 3039 & 131021 & 78290 & $7,3 \%$ \\
\hline Norwegen & 2010 & -1086 & -47946 & -49032 & 274357 & -107528 & -23197 & 0 & 23000 & 4690 & 171321 & 122289 & $8,2 \%$ \\
\hline Polen & 2010 & -7343 & -16928 & -24270 & 376155 & -30873 & -75986 & 0 & 38492 & 2228 & 310015 & 285745 & $24,6 \%$ \\
\hline Portugal & 2010 & -4627 & -16181 & -20808 & 324887 & -89461 & -36243 & 0 & 17564 & $\mathrm{~m}$ & 216746 & 195937 & $18,3 \%$ \\
\hline Slowakei & 2010 & -6183 & -15019 & -21202 & 290121 & -51866 & -40961 & 0 & 38465 & 1226 & 236985 & 215783 & $21,4 \%$ \\
\hline Slowenien & 2010 & -3564 & -26242 & -29806 & 447946 & -110866 & -96037 & 0 & 19992 & 259 & 261294 & 231488 & $17,1 \%$ \\
\hline Spanien & 2010 & -8864 & -28219 & -37083 & 178900 & -52903 & -14033 & 0 & 41874 & 3791 & 157629 & 120546 & $11,2 \%$ \\
\hline Schweden & 2010 & -3560 & -50291 & -53851 & 209467 & -84430 & -9281 & 0 & 8454 & 7735 & 131945 & 78094 & $7,4 \%$ \\
\hline Schweiz & & $\mathrm{m}$ & $\mathrm{m}$ & m & $\mathrm{m}$ & $\mathrm{m}$ & $\mathrm{m}$ & $\mathrm{m}$ & $\mathrm{m}$ & $\mathrm{m}$ & $\mathbf{m}$ & m & $\mathrm{m}$ \\
\hline Türkei & 2005 & -1061 & -9402 & -10463 & 106985 & -18682 & -16424 & 0 & 2761 & $\mathrm{~m}$ & 74640 & 64177 & $19,3 \%$ \\
\hline Ver. Königreich & 2010 & -20162 & -47655 & -67817 & 413163 & -89124 & -49107 & -4303 & 40284 & 5225 & 316138 & 248322 & $14,3 \%$ \\
\hline Vereinigte Staa & 2010 & -61135 & -44678 & -105813 & 628922 & -210898 & -55768 & 0 & 100046 & 27162 & 489463 & 383649 & $15,4 \%$ \\
\hline \multirow{2}{*}{\multicolumn{2}{|c|}{ OECD-Durchschnitt }} & 63 & -40755 & -51318 & 347075 & 05528 & -38085 & 77 & 29016 & 6181 & 236602 & 185284 & $3,9 \%$ \\
\hline & & -6258 & -41078 & -47335 & 361801 & -112936 & -45075 & -1123 & 31620 & 6135 & 239503 & 192167 & $15,1 \%$ \\
\hline
\end{tabular}

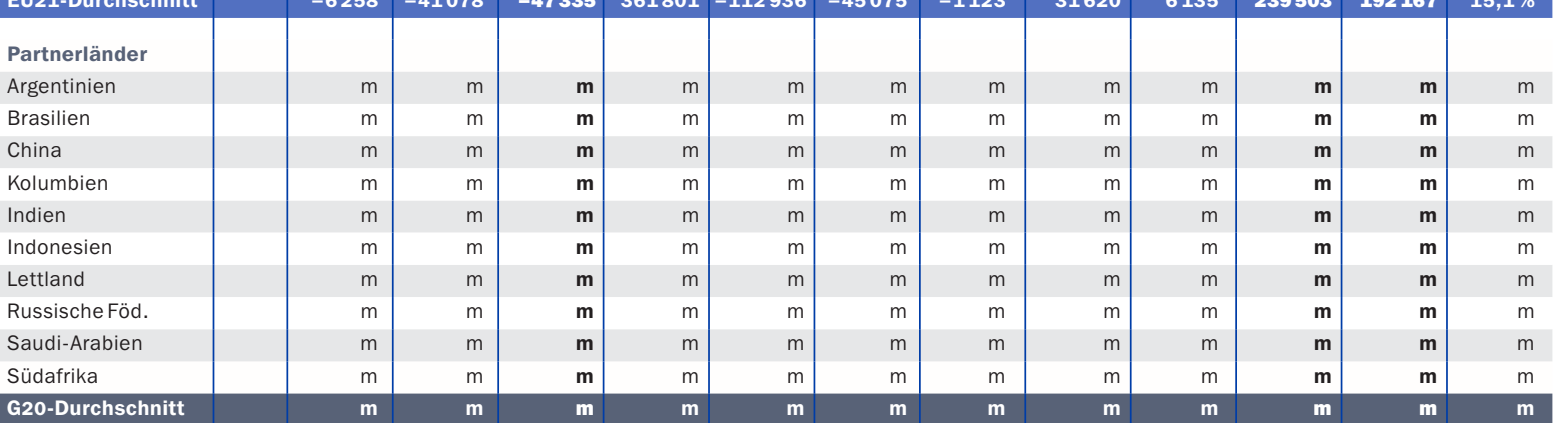

Anmerkung: Die Zahlen basieren auf dem Unterschied zwischen Männern, die einen Abschluss im Tertiärbereich erworben haben, und Männern, die einen Abschluss im Sekundarbereich II/postsekundaren, nicht tertiären Bereich erworben haben.

Quelle: OECD. Hinweise s. Anhang 3 unter www.oecd.org/edu/eag.htm. StatLink: http://dx.doi.org/10.1787/888933116376

Erläuterung der Kennzeichnung fehlender Daten s. Hinweise für den Leser. 
Private Kosten und privater Nutzen für eine Frau, die einen Abschluss im Tertiärbereich erwirbt (2010)

Im Vergleich zu einer Frau, die einen Abschluss im Sekundarbereich II/postsekundaren, nicht tertiären Bereich erwirbt (in US-Dollar, kaufkraftbereinigt mittels KKP für das BIP)

\begin{tabular}{|c|c|c|c|c|c|c|c|c|c|c|c|c|c|}
\hline & Jahr & $\begin{array}{l}\text { Direkte } \\
\text { Kosten }\end{array}$ & $\begin{array}{l}\text { Entgan- } \\
\text { genes } \\
\text { Einkom- } \\
\text { men }\end{array}$ & $\begin{array}{c}\text { Gesamt- } \\
\text { kosten }\end{array}$ & $\begin{array}{l}\text { Vorteile } \\
\text { Brutto- } \\
\text { einkom- } \\
\text { men }\end{array}$ & \begin{tabular}{|c|} 
Effekt \\
Einkom- \\
men- \\
steuer
\end{tabular} & \begin{tabular}{|c|} 
Effekt \\
Sozial- \\
versiche- \\
rungs- \\
beiträge
\end{tabular} & $\begin{array}{l}\text { Effekt } \\
\text { Trans- } \\
\text { ferleis- } \\
\text { tungen }\end{array}$ & \begin{tabular}{|c|} 
Effekt \\
Erwerbs- \\
losigkeit
\end{tabular} & $\begin{array}{l}\text { Effekt } \\
\text { Zu- } \\
\text { schüsse }\end{array}$ & $\begin{array}{c}\text { Gesamt- } \\
\text { nutzen }\end{array} \mid$ & $\begin{array}{c}\text { Kapital- } \\
\text { wert }\end{array}$ & $\begin{array}{c}\text { Ertrags- } \\
\text { rate }\end{array}$ \\
\hline & & (1) & (2) & (3) & (4) & (5) & (6) & (7) & (8) & (9) & (10) & (11) & (12) \\
\hline \multicolumn{14}{|l|}{ OECD-Länder } \\
\hline Australien & 2009 & -17528 & -52120 & -69648 & 253308 & -91641 & 0 & 0 & 13021 & 335 & 175023 & 105374 & $8,9 \%$ \\
\hline Österreich & 2010 & -6199 & -63316 & -69515 & 331700 & -93938 & -61225 & 0 & 8104 & 10877 & 195518 & 126003 & $9,0 \%$ \\
\hline Belgien & 2010 & -2780 & -35428 & -38207 & 310555 & -127305 & -72908 & 0 & 40296 & 862 & 151500 & 113293 & $13,7 \%$ \\
\hline Kanada & 2010 & -20529 & -37837 & -58366 & 261335 & -69368 & -20695 & 0 & 16627 & 1103 & 189002 & 130636 & $11,4 \%$ \\
\hline Chile & & $\mathrm{m}$ & $\mathrm{m}$ & $\mathbf{m}$ & $\mathrm{m}$ & $\mathrm{m}$ & $\mathrm{m}$ & $\mathrm{m}$ & $\mathrm{m}$ & $\mathrm{m}$ & $\mathbf{m}$ & m & $\mathrm{m}$ \\
\hline Tschechien & 2010 & -4882 & -24979 & -29862 & 208439 & -45919 & -26193 & -688 & 29891 & $\mathrm{~m}$ & 165530 & 135668 & $15,3 \%$ \\
\hline Dänemark & 2010 & -4509 & -78578 & -83087 & 175082 & -61404 & -15158 & -9772 & 10710 & 29411 & 128869 & 45782 & $6,5 \%$ \\
\hline Estland & 2010 & -3924 & -15754 & -19678 & 153829 & -40802 & -5839 & 0 & 54649 & 730 & 162567 & 142889 & $29,7 \%$ \\
\hline Finnland & 2009 & -1873 & -60589 & -62461 & 211875 & -72749 & -15039 & -4079 & 21742 & 8730 & 150480 & 88019 & $8,8 \%$ \\
\hline Frankreich & 2010 & -6963 & -44369 & -51332 & 263248 & -52801 & -39383 & -11640 & 24882 & 3103 & 187409 & 136077 & $10,9 \%$ \\
\hline Deutschland & 2010 & -5813 & -55984 & -61797 & 247459 & -67041 & -55248 & -17 & 22124 & 6472 & 153749 & 91952 & $8,5 \%$ \\
\hline Griechenland & 2009 & -690 & -36674 & -37363 & 186037 & -21786 & -33976 & -29066 & 26865 & $\mathrm{~m}$ & 128074 & 90710 & $9,6 \%$ \\
\hline Ungarn & 2010 & -4664 & -13164 & -17828 & 257527 & -83602 & -49345 & 0 & 32818 & 1135 & 158533 & 140705 & $24,6 \%$ \\
\hline Island & & $\mathrm{m}$ & $\mathrm{m}$ & $\mathbf{m}$ & $\mathrm{m}$ & $\mathrm{m}$ & $\mathrm{m}$ & $\mathrm{m}$ & $\mathrm{m}$ & $\mathrm{m}$ & $\mathbf{m}$ & $\mathbf{m}$ & $\mathrm{m}$ \\
\hline Irland & 2010 & -6478 & -48135 & -54612 & 456714 & -129055 & -63508 & 0 & 39212 & 5412 & 308775 & 254163 & $21,0 \%$ \\
\hline Israel & 2010 & -14023 & -27428 & -41451 & 151423 & -22840 & -18663 & 0 & 12245 & 1528 & 123692 & 82240 & $8,6 \%$ \\
\hline Italien & 2008 & -7285 & -47826 & -55111 & 223811 & -79954 & -21986 & 0 & 7563 & 3330 & 132764 & 77652 & $6,9 \%$ \\
\hline Japan & 2007 & -37215 & -49265 & -86481 & 231306 & -20848 & -29117 & 0 & 9951 & $\mathrm{~m}$ & 191293 & 104812 & $7,8 \%$ \\
\hline Korea & 2010 & -19211 & -35087 & -54298 & 268211 & -10077 & -20463 & 0 & -5570 & $\mathrm{~m}$ & 232101 & 177802 & $11,0 \%$ \\
\hline Luxemburg & & $\mathrm{m}$ & $\mathrm{m}$ & $\mathbf{m}$ & $\mathrm{m}$ & $\mathrm{m}$ & $\mathrm{m}$ & $\mathrm{m}$ & $\mathrm{m}$ & $\mathrm{m}$ & $\mathbf{m}$ & $\mathbf{m}$ & $\mathrm{m}$ \\
\hline Mexiko & & $\mathrm{m}$ & $\mathrm{m}$ & $\mathbf{m}$ & $\mathrm{m}$ & $\mathrm{m}$ & $\mathrm{m}$ & $\mathrm{m}$ & $\mathrm{m}$ & $\mathrm{m}$ & $\mathbf{m}$ & m & $\mathrm{m}$ \\
\hline Niederlande & 2010 & -14646 & -90283 & -104929 & 353759 & -137587 & -30982 & 0 & 11955 & 13770 & 210915 & 105985 & $7,0 \%$ \\
\hline Neuseeland & 2010 & -9384 & -42595 & -51980 & 167699 & -40316 & -3622 & -2329 & 13769 & 3039 & 138239 & 86260 & $10,3 \%$ \\
\hline Norwegen & 2010 & -1086 & -50062 & -51148 & 227688 & -63403 & -17791 & 0 & 785 & 4690 & 151970 & 100822 & $9,6 \%$ \\
\hline Polen & 2010 & -7343 & -16014 & -23356 & 243941 & -24419 & -60782 & 0 & 39454 & 2228 & 200423 & 177066 & $21,6 \%$ \\
\hline Portugal & 2010 & -4627 & -15481 & -20108 & 262280 & -59602 & -31363 & 0 & 22688 & $\mathrm{~m}$ & 194001 & 173893 & $22,0 \%$ \\
\hline Slowakei & 2010 & -6183 & -15551 & -21734 & 181063 & -33609 & -29678 & 0 & 40616 & 1226 & 159618 & 137884 & $18,5 \%$ \\
\hline Slowenien & 2010 & -3564 & -26170 & -29734 & 343115 & -84277 & -79783 & 0 & 24076 & 259 & 203390 & 173657 & $15,3 \%$ \\
\hline Spanien & 2010 & -8864 & -27626 & -36490 & 237736 & -69735 & -18075 & 0 & 46399 & 3791 & 200115 & 163625 & $14,5 \%$ \\
\hline Schweden & 2010 & -3560 & -51796 & -55356 & 140237 & -42057 & -10883 & 0 & 15631 & 7735 & 110663 & 55306 & $7,1 \%$ \\
\hline Schweiz & & $\mathrm{m}$ & $\mathrm{m}$ & $\mathbf{m}$ & $\mathrm{m}$ & $\mathrm{m}$ & $\mathrm{m}$ & $\mathrm{m}$ & $\mathrm{m}$ & $\mathrm{m}$ & $\mathbf{m}$ & m & $\mathrm{m}$ \\
\hline Türkei & 2005 & -1061 & -8185 & -9246 & 116530 & -21267 & -19627 & 0 & 14075 & $\mathrm{~m}$ & 89711 & 80466 & $19,2 \%$ \\
\hline Ver. Königreich & 2010 & -20162 & -47080 & -67241 & 351526 & -79076 & -43645 & -12831 & 55550 & 5225 & 276748 & 209506 & $12,3 \%$ \\
\hline Vereinigte Staaten & 2010 & -61135 & -47732 & -108867 & 416147 & -107923 & -35416 & 0 & 47389 & 27162 & 347358 & 238491 & $12,9 \%$ \\
\hline \multicolumn{2}{|l|}{ OECD-Durchschnitt } & -10558 & -40176 & -50734 & 249434 & -63945 & -32082 & -2428 & 24052 & 6181 & 179932 & 129198 & $13,2 \%$ \\
\hline$=021-1$ & & -6250 & 40 & 46990 & 256997 & 336 & -38250 & & 8761 & 135 & 178982 & 131992 & $14,1 \%$ \\
\hline
\end{tabular}

\begin{tabular}{|c|c|c|c|c|c|c|c|c|c|c|c|c|}
\hline \multicolumn{13}{|l|}{ Partnerländer } \\
\hline Argentinien & $\mathrm{m}$ & $\mathrm{m}$ & $\mathbf{m}$ & $\mathrm{m}$ & $\mathrm{m}$ & $\mathrm{m}$ & $\mathrm{m}$ & $\mathrm{m}$ & $\mathrm{m}$ & m & $\mathbf{m}$ & $\mathrm{m}$ \\
\hline Brasilien & $\mathrm{m}$ & $\mathrm{m}$ & $\mathbf{m}$ & $\mathrm{m}$ & $\mathrm{m}$ & $\mathrm{m}$ & $\mathrm{m}$ & $\mathrm{m}$ & $\mathrm{m}$ & $\mathbf{m}$ & $\mathbf{m}$ & $\mathrm{m}$ \\
\hline China & $\mathrm{m}$ & $\mathrm{m}$ & $\mathbf{m}$ & $\mathrm{m}$ & $\mathrm{m}$ & $\mathrm{m}$ & $\mathrm{m}$ & $\mathrm{m}$ & $\mathrm{m}$ & m & $\mathbf{m}$ & $\mathrm{m}$ \\
\hline Kolumbien & $\mathrm{m}$ & $\mathrm{m}$ & $\mathbf{m}$ & $\mathrm{m}$ & $\mathrm{m}$ & $\mathrm{m}$ & $\mathrm{m}$ & $\mathrm{m}$ & $\mathrm{m}$ & m & $\mathbf{m}$ & $\mathrm{m}$ \\
\hline Indien & $\mathrm{m}$ & $\mathrm{m}$ & $\mathbf{m}$ & $\mathrm{m}$ & $\mathrm{m}$ & $\mathrm{m}$ & $\mathrm{m}$ & $\mathrm{m}$ & $\mathrm{m}$ & m & $\mathbf{m}$ & $\mathrm{m}$ \\
\hline Indonesien & $\mathrm{m}$ & $\mathrm{m}$ & $\mathbf{m}$ & $\mathrm{m}$ & $\mathrm{m}$ & $\mathrm{m}$ & $\mathrm{m}$ & $\mathrm{m}$ & $\mathrm{m}$ & m & $\mathbf{m}$ & $\mathrm{m}$ \\
\hline Lettland & $\mathrm{m}$ & $\mathrm{m}$ & $\mathbf{m}$ & $\mathrm{m}$ & $\mathrm{m}$ & $\mathrm{m}$ & $\mathrm{m}$ & $\mathrm{m}$ & $\mathrm{m}$ & m & $\mathbf{m}$ & $\mathrm{m}$ \\
\hline Russische Föd. & $\mathrm{m}$ & $\mathrm{m}$ & $\mathbf{m}$ & $\mathrm{m}$ & $\mathrm{m}$ & $\mathrm{m}$ & $\mathrm{m}$ & $\mathrm{m}$ & $\mathrm{m}$ & m & $\mathbf{m}$ & $\mathrm{m}$ \\
\hline Saudi-Arabien & $\mathrm{m}$ & $\mathrm{m}$ & $\mathbf{m}$ & $\mathrm{m}$ & $\mathrm{m}$ & $\mathrm{m}$ & $\mathrm{m}$ & $\mathrm{m}$ & $\mathrm{m}$ & m & $\mathbf{m}$ & $\mathrm{m}$ \\
\hline Südafrika & $\mathrm{m}$ & $\mathrm{m}$ & $\mathbf{m}$ & $\mathrm{m}$ & $\mathrm{m}$ & $\mathrm{m}$ & $\mathrm{m}$ & $\mathrm{m}$ & $\mathrm{m}$ & m & $\mathbf{m}$ & $\mathrm{m}$ \\
\hline G20-Durchschnitt & $\mathbf{m}$ & $\mathbf{m}$ & m & m & $\mathbf{m}$ & $\mathbf{m}$ & m & $\mathbf{m}$ & m & $\mathbf{m}$ & $\mathbf{m}$ & $\mathbf{m}$ \\
\hline
\end{tabular}

Anmerkung: Die Zahlen basieren auf dem Unterschied zwischen Frauen, die einen Abschluss im Tertiärbereich erworben haben, und Frauen, die einen Abschluss im Sekundarbereich II/postsekundaren, nicht tertiären Bereich erworben haben.

Quelle: OECD. Hinweise s. Anhang 3 unter www.oecd.org/edu/eag.htm. StatLink: http://dx.doi.org/10.1787/888933116395

Erläuterung der Kennzeichnung fehlender Daten s. Hinweise für den Leser. 
Tabelle A7.4a

Staatliche Kosten und staatlicher Nutzen bei einem Mann, der einen Abschluss im Tertiärbereich erwirbt (2010)

Im Vergleich zu einem Mann, der einen Abschluss im Sekundarbereich II/postsekundaren, nicht tertiären Bereich erwirbt

(in US-Dollar, kaufkraftbereinigt mittels KKP für das BIP)

\begin{tabular}{|c|c|c|c|c|c|c|c|c|c|c|c|c|}
\hline & Jahr & $\begin{array}{l}\text { Direkte } \\
\text { Kosten }\end{array}$ & $\begin{array}{l}\text { Entgan- } \\
\text { gene } \\
\text { Einkom- } \\
\text { men- } \\
\text { steuer }\end{array}$ & $\begin{array}{c}\text { Effekt } \\
\text { Zu- } \\
\text { schüsse }\end{array}$ & $\begin{array}{c}\text { Gesamt- } \\
\text { kosten }\end{array}$ & $\begin{array}{c}\text { Effekt } \\
\text { Einkom- } \\
\text { men- } \\
\text { steuer }\end{array}$ & \begin{tabular}{|c|} 
Effekt \\
Sozial- \\
versiche- \\
rungs- \\
beiträge
\end{tabular} & $\begin{array}{c}\text { Effekt } \\
\text { Trans- } \\
\text { ferleis- } \\
\text { tungen }\end{array}$ & $\begin{array}{c}\text { Effekt } \\
\text { Erwerbs- } \\
\text { losigkeit }\end{array}$ & $\begin{array}{l}\text { Gesamt- } \\
\text { nutzen }\end{array}$ & $\begin{array}{c}\text { Kapital- } \\
\text { wert }\end{array}$ & $\begin{array}{l}\text { Ertrags- } \\
\text { rate }\end{array}$ \\
\hline & & (1) & (2) & (3) & (4) & (5) & (6) & (7) & (8) & (9) & (10) & (11) \\
\hline \multicolumn{13}{|l|}{ OECD-Länder } \\
\hline Australien & 2009 & -14588 & -5652 & -335 & -20575 & 123233 & 0 & 0 & 1208 & 124441 & 103866 & $12,9 \%$ \\
\hline Österreich & 2010 & -44819 & -11977 & -10877 & -67673 & 128843 & 50561 & 0 & 6637 & 186041 & 118368 & $8,0 \%$ \\
\hline Belgien & 2010 & -24413 & -9051 & -862 & -34326 & 149431 & 50456 & 0 & 8733 & 208619 & 174293 & $15,1 \%$ \\
\hline Kanada & 2010 & -26735 & -3589 & -1103 & -31427 & 91254 & 4772 & 0 & 6602 & 102627 & 71201 & $8,9 \%$ \\
\hline Chile & & $\mathrm{m}$ & $\mathrm{m}$ & $\mathrm{m}$ & m & $\mathrm{m}$ & $\mathrm{m}$ & $\mathrm{m}$ & $\mathrm{m}$ & $\mathbf{m}$ & m & $\mathrm{m}$ \\
\hline Tschechien & 2010 & -18717 & 4105 & $\mathrm{~m}$ & -14612 & 67727 & 39580 & 0 & 5191 & 112497 & 97885 & $17,6 \%$ \\
\hline Dänemark & 2010 & -85578 & -35496 & -29411 & -150485 & 137397 & 25140 & 8763 & 7708 & 179007 & 28522 & $3,8 \%$ \\
\hline Estland & 2010 & -12037 & -2264 & -730 & -15032 & 38729 & 5313 & 0 & 8557 & 52599 & 37567 & $10,5 \%$ \\
\hline Finnland & 2009 & -42400 & -8324 & -8730 & -59454 & 128733 & 22053 & 0 & 12738 & 163525 & 104071 & $8,3 \%$ \\
\hline Frankreich & 2010 & -31533 & -9599 & -3103 & -44236 & 92737 & 48871 & 691 & 5660 & 147960 & 103724 & $8,7 \%$ \\
\hline Deutschland & 2010 & -31421 & -20896 & -6472 & -58789 & 153573 & 78113 & 0 & 24090 & 255776 & 196987 & $11,9 \%$ \\
\hline Griechenland & 2009 & -20179 & 2956 & $\mathrm{~m}$ & -17223 & 34885 & 28464 & 8700 & 1766 & 73816 & 56593 & $11,6 \%$ \\
\hline Ungarn & 2010 & -16393 & -2960 & -1135 & -20489 & 138343 & 69279 & 0 & 14727 & 222349 & 201861 & $23,0 \%$ \\
\hline Island & & $\mathrm{m}$ & $\mathrm{m}$ & $\mathrm{m}$ & m & $\mathrm{m}$ & $\mathrm{m}$ & $\mathrm{m}$ & $\mathrm{m}$ & $\mathbf{m}$ & m & $\mathrm{m}$ \\
\hline Irland & 2010 & -28066 & -1409 & -5412 & -34887 & 231031 & 49600 & 0 & 38072 & 318703 & 283816 & $26,9 \%$ \\
\hline Israel & 2010 & -16613 & -1526 & -1528 & -19666 & 67496 & 34209 & 0 & 3768 & 105474 & 85807 & $11,4 \%$ \\
\hline Italien & 2008 & -17538 & -11836 & -3330 & -32704 & 157696 & 41484 & 0 & 2217 & 201397 & 168693 & $10,1 \%$ \\
\hline Japan & 2007 & -17897 & -15254 & $\mathrm{~m}$ & -33151 & 62285 & 33612 & 0 & 4665 & 100562 & 67411 & $8,4 \%$ \\
\hline Korea & 2010 & -7198 & -3449 & $\mathrm{~m}$ & -10648 & 46494 & 24687 & 0 & 1581 & 72762 & 62115 & $12,3 \%$ \\
\hline Luxemburg & & $\mathrm{m}$ & $\mathrm{m}$ & $\mathrm{m}$ & m & $\mathrm{m}$ & $\mathrm{m}$ & $\mathrm{m}$ & $\mathrm{m}$ & $\mathbf{m}$ & m & $\mathrm{m}$ \\
\hline Mexiko & & $\mathrm{m}$ & $\mathrm{m}$ & $\mathrm{m}$ & m & $\mathrm{m}$ & $\mathrm{m}$ & $\mathrm{m}$ & $\mathrm{m}$ & m & m & $\mathrm{m}$ \\
\hline Niederlande & 2010 & -37254 & -41204 & -13770 & -92227 & 195349 & 25117 & 0 & 4433 & 224900 & 132673 & $7,2 \%$ \\
\hline Neuseeland & 2010 & -18444 & -5180 & -3039 & -26663 & 61879 & 3868 & 86 & 453 & 66286 & 39623 & $7,0 \%$ \\
\hline Norwegen & 2010 & -26059 & -15194 & -4690 & -45942 & 102100 & 21412 & 0 & 7213 & 130725 & 84783 & $7,1 \%$ \\
\hline Polen & 2010 & -17653 & -6097 & -2228 & -25978 & 28162 & 68381 & 0 & 10316 & 106860 & 80882 & $12,4 \%$ \\
\hline Portugal & 2010 & -10295 & -2245 & $\mathrm{~m}$ & -12540 & 85300 & 34368 & 0 & 6036 & 125705 & 113164 & $16,1 \%$ \\
\hline Slowakei & 2010 & -14559 & -1492 & -1226 & -17276 & 47313 & 36008 & 0 & 9505 & 92826 & 75550 & $13,8 \%$ \\
\hline Slowenien & 2010 & -19698 & -8151 & -259 & -28108 & 107113 & 91799 & 0 & 7991 & 206903 & 178795 & $15,4 \%$ \\
\hline Spanien & 2010 & -31833 & -2577 & -3791 & -38201 & 46168 & 11387 & 0 & 9381 & 66936 & 28735 & $5,6 \%$ \\
\hline Schweden & 2010 & -34448 & -12852 & -7735 & -55035 & 82130 & 8756 & 0 & 2826 & 93711 & 38676 & $5,2 \%$ \\
\hline Schweiz & & $\mathrm{m}$ & $\mathrm{m}$ & $\mathrm{m}$ & m & $\mathrm{m}$ & $\mathrm{m}$ & $\mathrm{m}$ & $\mathrm{m}$ & m & m & $m$ \\
\hline Türkei & 2005 & -9567 & -3814 & $\mathrm{~m}$ & -13381 & 18209 & 16010 & 0 & 886 & 35106 & 21724 & $9,3 \%$ \\
\hline Ver. Königreich & 2010 & -6798 & -2591 & -5225 & -14615 & 82483 & 45366 & 4303 & 10381 & 142534 & 127919 & $26,1 \%$ \\
\hline Vereinigte Staaten & 2010 & -34787 & -5989 & -27162 & -67937 & 189603 & 48143 & 0 & 28922 & 266667 & 198730 & $10,8 \%$ \\
\hline \multicolumn{2}{|l|}{ OECD-Durchschnitt } & -24742 & -8400 & -6181 & -38044 & 99852 & 35062 & 777 & 8699 & 144390 & 106346 & $11,9 \%$ \\
\hline EU21-Durchschnitt & & -27282 & -9198 & -6135 & -41694 & 106657 & 41505 & 1123 & 9848 & 159133 & 117439 & $12,9 \%$ \\
\hline
\end{tabular}

\begin{tabular}{|c|c|c|c|c|c|c|c|c|c|c|c|}
\hline \multicolumn{12}{|l|}{ Partnerländer } \\
\hline Argentinien & $\mathrm{m}$ & $\mathrm{m}$ & $\mathrm{m}$ & $\mathbf{m}$ & $\mathrm{m}$ & $\mathrm{m}$ & $\mathrm{m}$ & $\mathrm{m}$ & m & $\mathbf{m}$ & $\mathrm{m}$ \\
\hline Brasilien & $\mathrm{m}$ & $\mathrm{m}$ & $\mathrm{m}$ & m & $\mathrm{m}$ & $\mathrm{m}$ & $\mathrm{m}$ & $\mathrm{m}$ & m & $\mathbf{m}$ & $\mathrm{m}$ \\
\hline China & $\mathrm{m}$ & $\mathrm{m}$ & $\mathrm{m}$ & $\mathbf{m}$ & $\mathrm{m}$ & $\mathrm{m}$ & $\mathrm{m}$ & $\mathrm{m}$ & m & $\mathbf{m}$ & $\mathrm{m}$ \\
\hline Kolumbien & $\mathrm{m}$ & $\mathrm{m}$ & $\mathrm{m}$ & $\mathbf{m}$ & $\mathrm{m}$ & $\mathrm{m}$ & $\mathrm{m}$ & $\mathrm{m}$ & m & $\mathbf{m}$ & $\mathrm{m}$ \\
\hline Indien & $\mathrm{m}$ & $\mathrm{m}$ & $\mathrm{m}$ & $\mathbf{m}$ & $\mathrm{m}$ & $\mathrm{m}$ & $\mathrm{m}$ & $\mathrm{m}$ & m & $\mathbf{m}$ & $\mathrm{m}$ \\
\hline Indonesien & $\mathrm{m}$ & $\mathrm{m}$ & $\mathrm{m}$ & m & $\mathrm{m}$ & $\mathrm{m}$ & $\mathrm{m}$ & $\mathrm{m}$ & m & $\mathbf{m}$ & $\mathrm{m}$ \\
\hline Lettland & $\mathrm{m}$ & $\mathrm{m}$ & $\mathrm{m}$ & m & $\mathrm{m}$ & $\mathrm{m}$ & $\mathrm{m}$ & $\mathrm{m}$ & m & m & $\mathrm{m}$ \\
\hline Russische Föd. & $\mathrm{m}$ & $\mathrm{m}$ & $\mathrm{m}$ & m & $\mathrm{m}$ & $\mathrm{m}$ & $\mathrm{m}$ & $\mathrm{m}$ & m & m & $\mathrm{m}$ \\
\hline Saudi-Arabien & $\mathrm{m}$ & $m$ & $m$ & m & $\mathrm{m}$ & $\mathrm{m}$ & $\mathrm{m}$ & $\mathrm{m}$ & m & m & $\mathrm{m}$ \\
\hline Südafrika & $\mathrm{m}$ & $\mathrm{m}$ & $\mathrm{m}$ & $\mathbf{m}$ & $\mathrm{m}$ & $\mathrm{m}$ & $\mathrm{m}$ & $\mathrm{m}$ & m & $\mathbf{m}$ & $\mathrm{m}$ \\
\hline G20-Durchschnitt & $\mathbf{m}$ & m & $\mathbf{m}$ & m & $\mathbf{m}$ & $\mathbf{m}$ & m & m & m & $\mathbf{m}$ & m \\
\hline
\end{tabular}

Anmerkung: Die Zahlen basieren auf dem Unterschied zwischen Männern, die einen Abschluss im Tertiärbereich erworben haben, und Männern, die einen Abschluss im Sekundarbereich II/postsekundaren, nicht tertiären Bereich erworben haben.

Quelle: OECD. Hinweise s. Anhang 3 unter www.oecd.org/edu/eag.htm. StatLink: http://dx.doi.org/10.1787/888933116414

Erläuterung der Kennzeichnung fehlender Daten s. Hinweise für den Leser. 


\begin{tabular}{|c|c|c|c|c|c|c|c|c|c|c|c|c|}
\hline & Jahr & $\begin{array}{l}\text { Direkte } \\
\text { Kosten }\end{array}$ & $\begin{array}{l}\text { Entgan- } \\
\text { gene } \\
\text { Einkom- } \\
\text { men- } \\
\text { steuer }\end{array}$ & $\begin{array}{c}\text { Effekt } \\
\text { Zu- } \\
\text { schüsse }\end{array}$ & \begin{tabular}{|c} 
Gesamt- \\
kosten
\end{tabular} & $\begin{array}{c}\text { Effekt } \\
\text { Einkom- } \\
\text { men- } \\
\text { steuer }\end{array}$ & $\begin{array}{c}\text { Effekt } \\
\text { Sozial- } \\
\text { versiche- } \\
\text { rungs- } \\
\text { beiträge }\end{array}$ & $\begin{array}{l}\text { Effekt } \\
\text { Trans- } \\
\text { ferleis- } \\
\text { tungen }\end{array}$ & $\begin{array}{l}\text { Effekt } \\
\text { Erwerbs- } \\
\text { losigkeit }\end{array}$ & $\begin{array}{c}\text { Gesamt- } \\
\text { nutzen }\end{array}$ & $\begin{array}{c}\text { Kapital- } \\
\text { wert }\end{array}$ & $\begin{array}{c}\text { Ertrags- } \\
\text { rate }\end{array}$ \\
\hline & & (1) & (2) & (3) & (4) & (5) & (6) & (7) & (8) & (9) & (10) & (11) \\
\hline \multicolumn{13}{|l|}{ OECD-Länder } \\
\hline Australien & 2009 & -14588 & -5797 & -335 & -20720 & 89111 & 0 & 0 & 2530 & 91641 & 70921 & $13,5 \%$ \\
\hline Österreich & 2010 & -44819 & -12152 & -10877 & -67849 & 92488 & 59772 & 0 & 2903 & 155164 & 87315 & $7,0 \%$ \\
\hline Belgien & 2010 & -24413 & -8544 & -862 & -33820 & 117399 & 67323 & 0 & 15490 & 200212 & 166393 & $19,0 \%$ \\
\hline Kanada & 2010 & -26735 & -3728 & -1103 & -31566 & 67254 & 19517 & 0 & 3293 & 90064 & 58498 & $9,5 \%$ \\
\hline Chile & & $\mathrm{m}$ & $\mathrm{m}$ & $\mathrm{m}$ & m & $\mathrm{m}$ & $\mathrm{m}$ & $\mathrm{m}$ & $\mathrm{m}$ & m & m & $\mathrm{m}$ \\
\hline Tschechien & 2010 & -18172 & 3987 & $\mathrm{~m}$ & -14185 & 41879 & 22919 & 688 & 7315 & 72800 & 58615 & $14,6 \%$ \\
\hline Dänemark & 2010 & -85578 & -37013 & -29411 & -152002 & 58528 & 13964 & 9772 & 4069 & 86334 & -65668 & $0,4 \%$ \\
\hline Estland & 2010 & -12037 & -2386 & -730 & -15153 & 31454 & 4315 & 0 & 10872 & 46641 & 31487 & $12,9 \%$ \\
\hline Finnland & 2009 & -42400 & -8862 & -8730 & -59992 & 68219 & 13657 & 4079 & 5912 & 91868 & 31876 & $5,2 \%$ \\
\hline Frankreich & 2010 & -31533 & -9027 & -3103 & -43664 & 49775 & 35999 & 11640 & 6409 & 103824 & 60160 & $8,4 \%$ \\
\hline Deutschland & 2010 & -31421 & -21234 & -6472 & -59127 & 63819 & 50751 & 17 & 7718 & 122306 & 63179 & $6,9 \%$ \\
\hline Griechenland & 2009 & -20179 & 2480 & $\mathrm{~m}$ & -17699 & 20386 & 29703 & 29066 & 5673 & 84828 & 67129 & $11,7 \%$ \\
\hline Ungarn & 2010 & -16393 & -2937 & -1135 & -20465 & 77014 & 43784 & 0 & 12149 & 132947 & 112482 & $17,3 \%$ \\
\hline Island & & $\mathrm{m}$ & $\mathrm{m}$ & $\mathrm{m}$ & m & $\mathrm{m}$ & $\mathrm{m}$ & $\mathrm{m}$ & $\mathrm{m}$ & m & m & $\mathrm{m}$ \\
\hline Irland & 2010 & -28066 & -1598 & -5412 & -35076 & 123230 & 60647 & 0 & 8686 & 192563 & 157487 & $17,5 \%$ \\
\hline Israel & 2010 & -16613 & -1552 & -1528 & -19692 & 22108 & 17839 & 0 & 1557 & 41503 & 21811 & $6,4 \%$ \\
\hline Italien & 2008 & -17538 & -11185 & -3330 & -32053 & 77919 & 21270 & 0 & 2750 & 101940 & 69886 & $8,0 \%$ \\
\hline Japan & 2007 & -17897 & -10654 & $\mathrm{~m}$ & -28551 & 20218 & 27924 & 0 & 1822 & 49965 & 21414 & $6,2 \%$ \\
\hline Korea & 2010 & -7198 & -3557 & $\mathrm{~m}$ & -10756 & 10123 & 20892 & 0 & -474 & 30540 & 19784 & $8,0 \%$ \\
\hline Luxemburg & & $\mathrm{m}$ & $\mathrm{m}$ & $\mathrm{m}$ & m & $\mathrm{m}$ & $\mathrm{m}$ & $\mathrm{m}$ & $\mathrm{m}$ & m & m & $\mathrm{m}$ \\
\hline Mexiko & & $\mathrm{m}$ & $\mathrm{m}$ & $\mathrm{m}$ & m & $\mathrm{m}$ & $\mathrm{m}$ & $\mathrm{m}$ & $\mathrm{m}$ & m & m & $\mathrm{m}$ \\
\hline Niederlande & 2010 & -37254 & -35318 & -13770 & -86341 & 135724 & 28393 & 0 & 4453 & 168569 & 82228 & $6,5 \%$ \\
\hline Neuseeland & 2010 & -18444 & -5090 & -3039 & -26573 & 38104 & 3348 & 2329 & 2486 & 46267 & 19694 & $6,5 \%$ \\
\hline Norwegen & 2010 & -26059 & -15864 & -4690 & -46613 & 63264 & 17730 & 0 & 199 & 81193 & 34581 & $5,8 \%$ \\
\hline Polen & 2010 & -17653 & -5768 & -2228 & -25648 & 21556 & 52341 & 0 & 11304 & 85200 & 59552 & $10,5 \%$ \\
\hline Portugal & 2010 & -10295 & -2148 & $\mathrm{~m}$ & -12443 & 56914 & 28879 & 0 & 5172 & 90966 & 78523 & $14,9 \%$ \\
\hline Slowakei & 2010 & -14559 & -1544 & -1226 & -17329 & 29789 & 24260 & 0 & 9238 & 63287 & 45958 & $11,1 \%$ \\
\hline Slowenien & 2010 & -19698 & -8128 & -259 & -28085 & 80209 & 74531 & 0 & 9320 & 164060 & 135974 & $13,1 \%$ \\
\hline Spanien & 2010 & -31833 & -2523 & -3791 & -38147 & 63118 & 15146 & 0 & 9546 & 87811 & 49664 & $7,5 \%$ \\
\hline Schweden & 2010 & -34448 & -13236 & -7735 & -55420 & 38592 & 9798 & 0 & 4551 & 52940 & -2479 & $2,8 \%$ \\
\hline Schweiz & & $\mathrm{m}$ & $\mathrm{m}$ & $\mathrm{m}$ & m & $\mathrm{m}$ & $\mathrm{m}$ & $\mathrm{m}$ & $\mathrm{m}$ & m & m & $\mathrm{m}$ \\
\hline Türkei & 2005 & -9567 & -3320 & $\mathrm{~m}$ & -12887 & 19194 & 17528 & 0 & 4171 & 40894 & 28006 & $9,1 \%$ \\
\hline Ver. Königreich & 2010 & -6798 & 1128 & -5225 & -10895 & 70396 & 38718 & 12831 & 13607 & 135553 & 124658 & $36,4 \%$ \\
\hline Vereinigte Staaten & 2010 & -34787 & -6398 & -27162 & -68347 & 99860 & 31811 & 0 & 11668 & 143339 & 74993 & $7,4 \%$ \\
\hline \multicolumn{2}{|l|}{ CD-Durchschnitt } & -24723 & -7999 & -6181 & -37624 & 60264 & 29405 & 2428 & 6358 & 98456 & 60832 & $10,5 \%$ \\
\hline EU21-Durchschnitt & & -27254 & -8800 & -6135 & -41270 & 65920 & 34809 & 3405 & 7857 & 111991 & 70721 & $11,6 \%$ \\
\hline
\end{tabular}

\begin{tabular}{|c|c|c|c|c|c|c|c|c|c|c|c|}
\hline \multicolumn{12}{|l|}{ Partnerländer } \\
\hline Argentinien & $\mathrm{m}$ & $\mathrm{m}$ & $\mathrm{m}$ & m & $\mathrm{m}$ & $\mathrm{m}$ & $\mathrm{m}$ & $\mathrm{m}$ & $\mathbf{m}$ & m & $\mathrm{m}$ \\
\hline Brasilien & $\mathrm{m}$ & $\mathrm{m}$ & $\mathrm{m}$ & m & $\mathrm{m}$ & $\mathrm{m}$ & $\mathrm{m}$ & $\mathrm{m}$ & $\mathbf{m}$ & m & $\mathrm{m}$ \\
\hline China & $\mathrm{m}$ & $\mathrm{m}$ & $\mathrm{m}$ & m & $\mathrm{m}$ & $\mathrm{m}$ & $\mathrm{m}$ & $\mathrm{m}$ & $\mathbf{m}$ & m & $\mathrm{m}$ \\
\hline Kolumbien & $\mathrm{m}$ & $\mathrm{m}$ & $\mathrm{m}$ & m & $\mathrm{m}$ & $\mathrm{m}$ & $\mathrm{m}$ & $\mathrm{m}$ & m & m & $\mathrm{m}$ \\
\hline Indien & $\mathrm{m}$ & $\mathrm{m}$ & $\mathrm{m}$ & m & $\mathrm{m}$ & $\mathrm{m}$ & $\mathrm{m}$ & $\mathrm{m}$ & m & m & $\mathrm{m}$ \\
\hline Indonesien & $\mathrm{m}$ & $\mathrm{m}$ & $\mathrm{m}$ & m & $\mathrm{m}$ & $\mathrm{m}$ & $\mathrm{m}$ & $\mathrm{m}$ & m & m & $\mathrm{m}$ \\
\hline Lettland & $\mathrm{m}$ & $\mathrm{m}$ & $\mathrm{m}$ & m & $\mathrm{m}$ & $\mathrm{m}$ & $\mathrm{m}$ & $\mathrm{m}$ & $\mathbf{m}$ & m & $\mathrm{m}$ \\
\hline Russische Föd. & $\mathrm{m}$ & $\mathrm{m}$ & $\mathrm{m}$ & m & $\mathrm{m}$ & $\mathrm{m}$ & $\mathrm{m}$ & $\mathrm{m}$ & $\mathbf{m}$ & m & $\mathrm{m}$ \\
\hline Saudi-Arabien & $\mathrm{m}$ & $\mathrm{m}$ & $\mathrm{m}$ & m & $\mathrm{m}$ & $\mathrm{m}$ & $\mathrm{m}$ & $\mathrm{m}$ & $\mathbf{m}$ & m & $\mathrm{m}$ \\
\hline Südafrika & $\mathrm{m}$ & $\mathrm{m}$ & $\mathrm{m}$ & m & $\mathrm{m}$ & $\mathrm{m}$ & $\mathrm{m}$ & $\mathrm{m}$ & $\mathbf{m}$ & m & $\mathrm{m}$ \\
\hline G20-Durchschnitt & $\mathbf{m}$ & $\mathbf{m}$ & m & m & $\mathbf{m}$ & $\mathbf{m}$ & $\mathbf{m}$ & m & $\mathbf{m}$ & m & m \\
\hline
\end{tabular}

Anmerkung: Die Zahlen basieren auf dem Unterschied zwischen Frauen, die einen Abschluss im Tertiärbereich erworben haben, und Frauen, die einen Abschluss im Sekundarbereich II/postsekundaren, nicht tertiären Bereich erworben haben.

Quelle: OECD. Hinweise s. Anhang 3 unter www.oecd.org/edu/eag.htm. StatLink: http://dx.doi.org/10.1787/888933116433

Erläuterung der Kennzeichnung fehlender Daten s. Hinweise für den Leser. 



\section{Was sind die gesamtgesellschaftlichen Auswirkungen von Bildung?}

Sowohl der Bildungsstand als auch die Lesekompetenz stehen mit besseren Ergebnissen bei gesamtgesellschaftlichen Auswirkungen wie dem Gesundheitszustand, ehrenamtlicher Tätigkeit, zwischenmenschlichem Vertrauen und politischer Wirksamkeit (jeweils nach Selbstangabe) in Zusammenhang. Bei Menschen mit demselben Bildungsstand schneiden diejenigen mit besserer Lesekompetenz bei den gesamtgesellschaftlichen Auswirkungen besser ab.

Ein besonders deutlicher Zusammenhang besteht zwischen der Lesekompetenz und der politischen Wirksamkeit bei Absolventen des Tertiärbereichs. Im Durchschnitt von 20 OECD-Ländern gibt es bei der Frage, ob man glaubt, einen Einfluss auf das zu haben, was die Regierung macht, einen Unterschied von 2I Prozentpunkten zwischen Absolventen des Tertiärbereichs mit der höchsten und denen mit der niedrigsten Lesekompetenz.

- Bei Personen ohne einen Abschluss im Sekundarbereich II gibt es einen deutlichen Zusammenhang zwischen der Lesekompetenz und ehrenamtlicher Tätigkeit. Im Durchschnitt von 2I OECD-Ländern besteht bei Personen mit niedrigem Bildungsstand, die angeben, dass sie mindestens einmal im Monat einer ehrenamtlichen Tätigkeit nachgehen, zwischen dem Anteil mit hoher Lesekompetenz und dem Anteil mit niedriger Lesekompetenz, ein Unterschied von 8 Prozentpunkten. 


\section{Abbildung A8.1}

Gesamtgesellschaftliche Auswirkungen von Bildung in den OECD-Ländern (2012)

Erhebung zu den grundlegenden Kompetenzen Erwachsener, Durchschnitt, 25 bis 64-Jährige

\section{- Stufe 1 oder darunter $\diamond$ Stufe $2 \square$ Stufe $3 \Delta$ Stufe 4 oder 5}

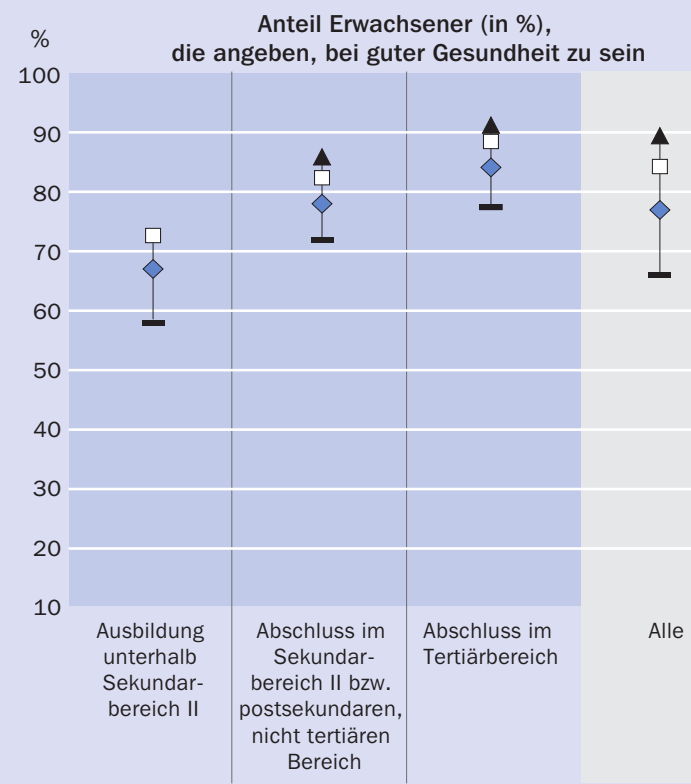

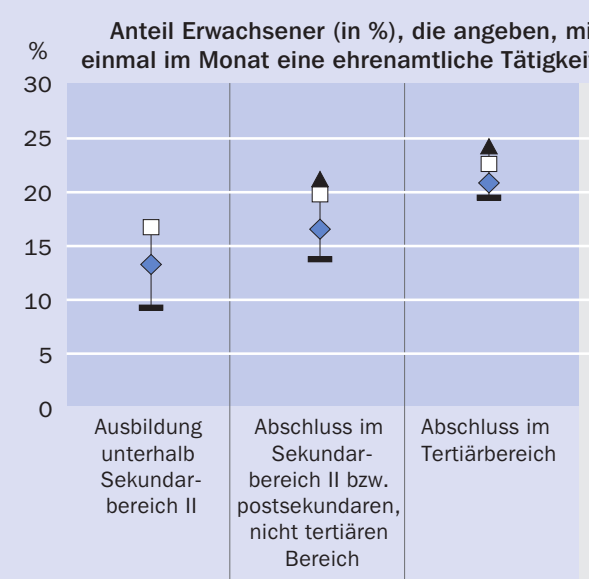

estens

Quelle: OECD. Tabelle A8.1a (L), A8.2a (L), A8.3a (L) und A8.4a (L). Hinweise s. Anhang 3 unter www.oecd.org/edu/eag.htm. StatLink: http://dx.doi.org/10.1787/888933116642

\section{Kontext}

Den Gesundheitszustand der Bevölkerung zu verbessern gehört in allen OECD-Ländern zu den wichtigsten politischen Zielen. Dies wird aus den hohen Ausgaben für das Gesundheitswesen ersichtlich, die sich in den OECD-Ländern 2009 auf 6,9 Prozent des BIP beliefen (OECD, 20Ira). Dieser Betrag liegt deutlich über den öffentlichen Ausgaben für Bildung von 5,o Prozent im gleichen Jahr (OECD, 20Irb). Obwohl die in das Gesundheitswesen geflossenen beträchtlichen Mittel in der Regel das Leben der Menschen zu verlängern geholfen haben, hat sich doch die Art der Gesundheits- 
probleme verändert; schwerwiegende chronische Erkrankungen wie Herzerkrankungen, Diabetes und Depressionen haben in jüngster Zeit zugenommen. Bei den Bemühungen zur Bekämpfung dieser Entwicklungen kommt es zum Teil darauf an, dass die Betroffenen ihren individuellen Lebensstil ändern. Die hierzu notwendigen Entscheidungen könnten durch eine Steigerung der kognitiven und psychosozialen Kompetenzen mittels Bildung entsprechend beeinflusst werden (OECD, 2013а).

Dem sozialen Zusammenhalt, der sich häufig im Grad des bürgerschaftlichen und sozialen Engagements widerspiegelt, wird in den OECD-Ländern ebenfalls große Bedeutung beigemessen. Die Regierungen sind ganz allgemein der Auffassung, dass das Maß an bürgerschaftlicher Beteiligung, politischer Wirksamkeit sowie zwischenmenschlichem Vertrauen unzureichend sei, wodurch sich die Aufrechterhaltung gut funktionierender demokratischer Institutionen und politischer Prozesse schwierig gestaltet. Bildung kann eine wichtige Rolle in der Sicherung des sozialen Zusammenhalts spielen, indem sie die Lesekompetenz, die Selbstwirksamkeit und Belastbarkeit fördert, die gesellschaftlichen und politischen Interaktionen zugrunde liegen.

\section{Weitere wichtige Ergebnisse}

Das unterschiedliche Abschneiden bei gesamtgesellschaftlichen Auswirkungen zwischen Personen mit der höchsten und mit der niedrigsten Lesekompetenzstufe ist im Allgemeinen vergleichbar mit den diesbezüglichen Unterschieden zwischen Personen ohne einen Abschluss im Sekundarbereich II und Personen mit einem Abschluss im Tertiärbereich. So beträgt beispielsweise der Unterschied zwischen Erwachsenen mit einem hohen und mit einem niedrigen Bildungsstand, die angeben, bei guter Gesundheit zu sein, 23 Prozentpunkte. Der Unterschied zwischen Erwachsenen mit der höchsten Lesekompetenzstufe und mit der niedrigsten Lesekompetenzstufe, die angeben, bei guter Gesundheit zu sein, beträgt ebenfalls 23 Prozentpunkte.

Frauen scheinen im Hinblick auf einen besseren Gesundheitszustand und mehr zwischenmenschlichem Vertrauen mehr von einer Verbesserung ihrer Kompetenzen zu profitieren. So beträgt z. B. der Unterschied zwischen Frauen mit der höchsten Lesekompetenzstufe und mit der niedrigsten Lesekompetenzstufe, die angeben, anderen vertrauen zu können, Ig Prozentpunkte, während es bei den Männern I5 Prozentpunkte sind.

\section{Analyse und Interpretationen}

Der diesjährige Indikator zu den gesamtgesellschaftlichen Auswirkungen von Bildung (und Kompetenzen) enthält Informationen über den Gesundheitszustand (nach Selbstangabe), ehrenamtliche Tätigkeit, zwischenmenschliches Vertrauen und politische Wirksamkeit, die in der Erhebung zu den grundlegenden Kompetenzen Erwachsener im Rahmen des OECD Programme for the International Assessment of Adult Competencies (PIACC) erhoben wurden. Diese vier Aspekte gesamtgesellschaftlicher Auswirkungen werden als Schlüsselindikatoren für die Lebensqualität des Einzelnen und der Gesellschaft betrachtet (OECD, 2013a). 
Anteil Erwachsener (in \%), die angeben, bei guter Gesundheit zu sein, nach Bildungsstand und Lesekompetenz (2012) Erhebung zu den grundlegenden Kompetenzen Erwachsener, 25- bis 64-Jährige

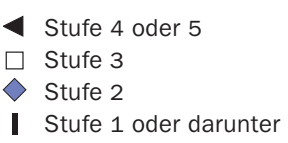

Nach Lesekompetenz
Abschluss im Tertiärbereich

Abschluss im Sekundarbereich II bzw. postsekundaren, nicht tertiären Bereich

| Ausbildung unterhalb Sekundarbereich II

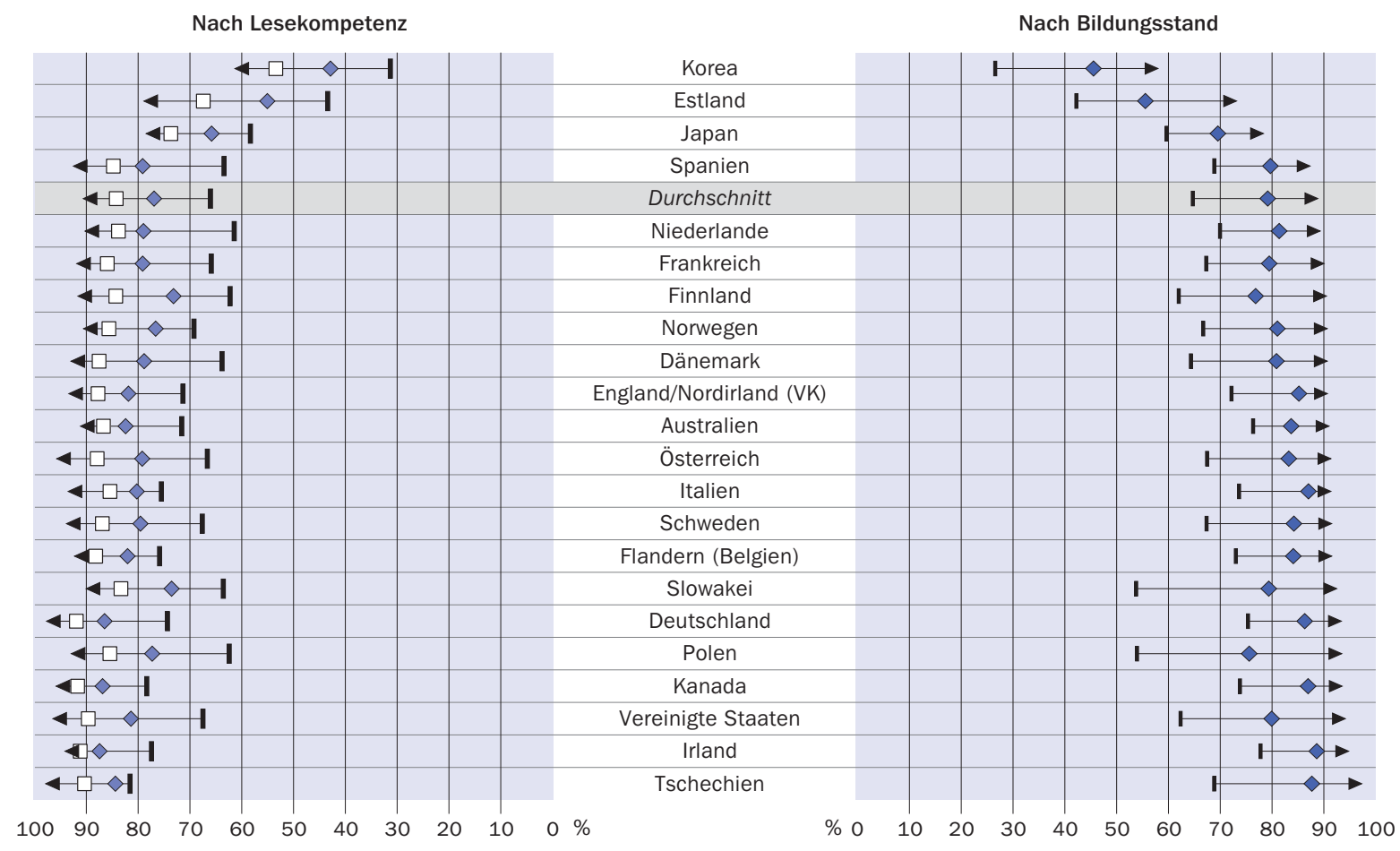

Anordnung der Länder in aufsteigender Reihenfolge des Anteils Erwachsener mit einem Abschluss im Tertiärbereich, die angeben, bei guter Gesundheit zu sein. Quelle: OECD. Tabelle A8.1a (L). Hinweise s. Anhang 3 unter www.oecd.org/edu/eag.htm. StatLink: http://dx.doi.org/10.1787/888933116661

Sowohl der Bildungsstand als auch die Lesekompetenz korrelieren positiv mit den Ergebnissen im Hinblick auf die gesamtgesellschaftlichen Auswirkungen (Abb. A8.2, A8.3, A8.4 und A8.5, Tab. A8.I, A8.2, A8.3 und A8.4). Die Unterschiede zwischen Personen mit unterschiedlicher Lesekompetenz oder unterschiedlichem Bildungsstand sind mitunter erheblich. Auch wenn sich das Bild in den einzelnen Ländern möglicherweise unterscheidet, so sind doch das Gesamtergebnis und die Stärke der Korrelationen ähnlich, wenn man die alltagsmathematische Kompetenz betrachtet (Tab. A8.ra [N], A8.2a [N], A8.3a [N], A8.4a [N] im Internet).

\section{Gesundheit (nach Selbstangabe)}

Der Unterschied zwischen dem Anteil der Personen mit einem hohen Bildungsstand (d. h. mit einem Abschluss im Tertiärbereich) und dem Anteil der Personen mit niedrigem Bildungsstand (d. h. einer Ausbildung unterhalb des Sekundarbereichs II), die angeben, bei guter Gesundheit zu sein, beträgt im Durchschnitt von 22 OECD-Ländern 23 Prozentpunkte (Abb. A8.2, Tab. A8.ra [L]). Sowohl in Polen als auch in der Slowakei war der Unterschied mit 38 bzw. 37 Prozentpunkten besonders ausgeprägt. Der Unterschied zwischen Personen mit der höchsten und mit der niedrigsten Lesekompetenz in der Erhebung zu den grundlegenden Kompetenzen Erwachsener die angeben, bei 
guter Gesundheit zu sein, beträgt in diesen Ländern im Durchschnitt ebenfalls 23 Prozentpunkte (Abb. A8.2 und Tab. A8.ra [L]). Estland wies hier einen großen Unterschied von 34 Prozentpunkten auf.

\section{Ehrenamtliche Tätigkeit}

Der Unterschied zwischen dem Anteil Erwachsener mit einem hohen Bildungsstand und mit einem niedrigen Bildungsstand, die angeben, ehrenamtlich tätig zu sein, beträgt im Durchschnitt von 2I OECD-Ländern ro Prozentpunkte (Abb. A8.3 und Tab. A8.2a [L]). Besonders große Unterschiede sind in den Vereinigten Staaten (26 Prozentpunkte) und Deutschland (I7 Prozentpunkte) zu beobachten. Entsprechend beträgt der Unterschied zwischen Personen mit der höchsten und der niedrigsten Lesekompetenz, die angeben, ehrenamtlich tätig zu sein, im Durchschnitt dieser Länder II Prozentpunkte (Abb. A8.3 und Tab. A8.2a [L]). Besonders große Unterschiede sind in den Vereinigten Staaten mit 2I Prozentpunkten und in Kanada mit 20 Prozentpunkten zu beobachten.

Abbildung A8.3

Anteil Erwachsener (in \%), die angeben, mindestens einmal im Monat ehrenamtlich tätig zu sein, nach Bildungsstand und Lesekompetenz (2012)

Erhebung zu den grundlegenden Kompetenzen Erwachsener, 25- bis 64-Jährige

Stufe 4 oder 5

$\square$ Stufe 3

Stufe 2

I Stufe 1 oder darunter
Abschluss im Tertiärbereich

Abschluss im Sekundarbereich II bzw. postsekundaren, nicht tertiären Bereich

- Ausbildung unterhalb Sekundarbereich II

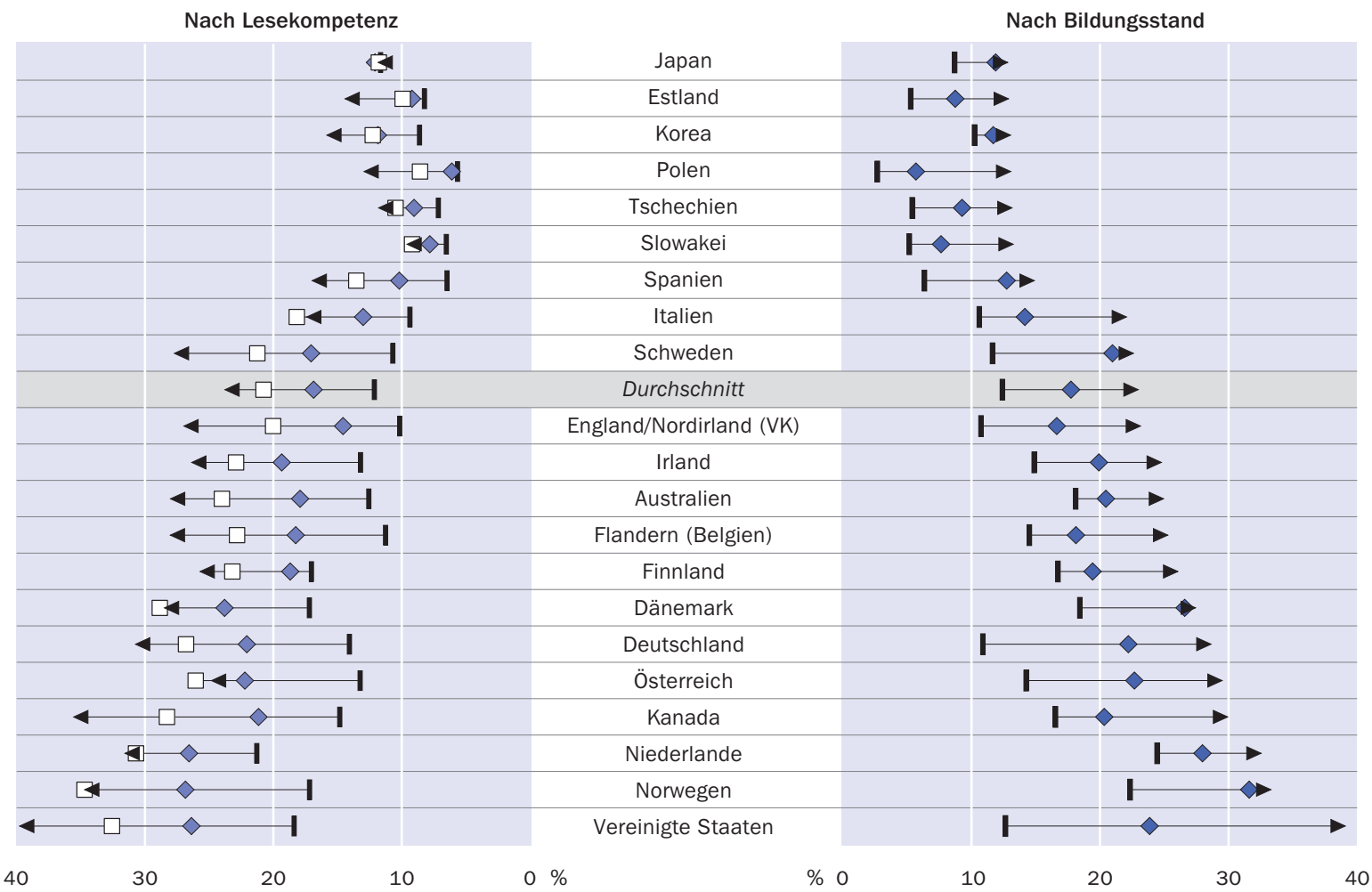

Anordnung der Länder in aufsteigender Reihenfolge des Anteils Erwachsener mit einem Abschluss im Tertiärbereich, die angeben, mindestens einmal im Monat ehrenamtlich tätig zu sein.

Quelle: OECD. Tabelle A8.2a (L). Hinweise s. Anhang 3 unter www.oecd.org/edu/eag.htm. StatLink: http://dx.doi.org/10.1787/888933116680 
Anteil Erwachsener (in \%), die angeben, anderen vertrauen zu können, nach Bildungsstand und Lesekompetenz (2012) Erhebung zu den grundlegenden Kompetenzen Erwachsener, 25- bis 64-Jährige

Stufe 4 oder 5

$\square$ Stufe 3

$\checkmark$ Stufe 2

I Stufe 1 oder darunter
- Abschluss im Tertiärbereich

Abschluss im Sekundarbereich II bzw. postsekundaren, nicht tertiären Bereich

| Ausbildung unterhalb Sekundarbereich II

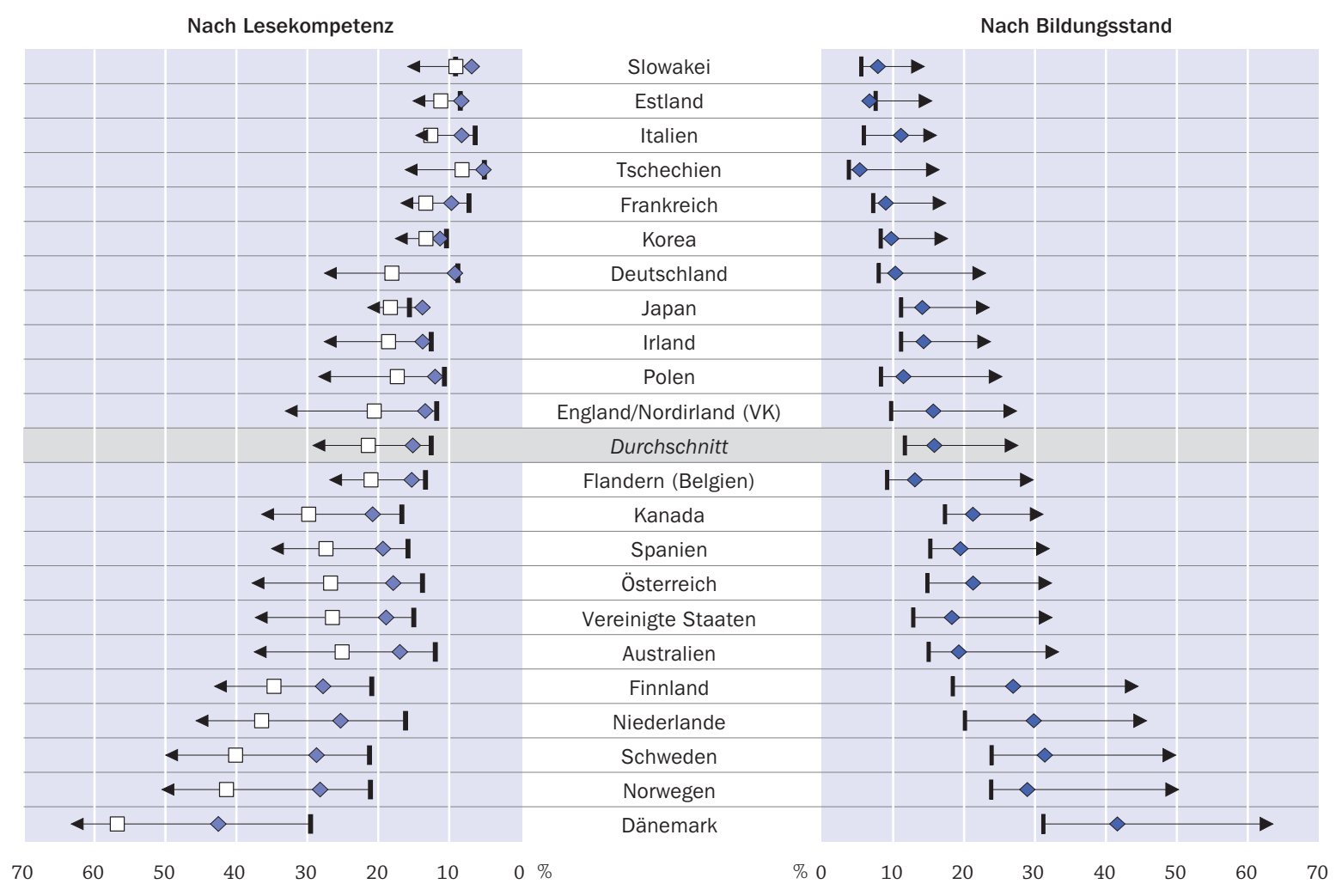

Anordnung der Länder in aufsteigender Reihenfolge des Anteils Erwachsener mit einem Abschluss im Tertiärbereich, die angeben, anderen vertrauen zu können. Quelle: OECD. Tabelle A8.3a (L). Hinweise s. Anhang 3 unter www.oecd.org/edu/eag.htm. StatLink: http://dx.doi.org/10.1787/888933116699

\section{Zwischenmenschliches Vertrauen}

Die Unterschiede im Anteil der Erwachsenen, die angeben, anderen vertrauen zu können, zwischen Erwachsenen mit einem hohen und mit einem niedrigen Bildungsstand betragen im Durchschnitt von 22 OECD-Ländern I6 Prozentpunkte (Abb. A8.4 und Tab. A8.3C [L] im Internet). Besonders groß sind diese Unterschiede in Dänemark (3I Prozentpunkte) und in den Niederlanden (25 Prozentpunkte). Entsprechend betragen die Unterschiede zwischen Personen mit der höchsten und der niedrigsten Lesekompetenz hinsichtlich des zwischenmenschlichen Vertrauens (nach eigener Angabe) im Durchschnitt dieser Länder 17 Prozentpunkte (Abb. A8.4 und Tab. A8.3c [L] im Internet). Besonders groß sind die Unterschiede in Dänemark (33 Prozentpunkte) und Norwegen (29 Prozentpunkte).

\section{Politische Wirksamkeit}

Im Durchschnitt von 20 OECD-Ländern beträgt der Unterschied zwischen dem Anteil von Personen mit einem hohen und mit einem niedrigen Bildungsstand, die angeben, dass sie glauben, einen Einfluss darauf zu haben, was die Regierung macht, 20 Prozent- 
Anteil Erwachsener (in \%), die angeben, dass sie glauben, einen Einfluss auf das zu haben, was die Regierung macht, nach Bildungsstand und Lesekompetenz (2012)

Erhebung zu den grundlegenden Kompetenzen Erwachsener, 25- bis 64-Jährige

4 Stufe 4 oder 5

$\square$ Stufe 3

$>$ Stufe 2

I Stufe 1 oder darunter
Abschluss im Tertiärbereich

Abschluss im Sekundarbereich II bzw. postsekundaren, nicht tertiären Bereich

- Ausbildung unterhalb Sekundarbereich II

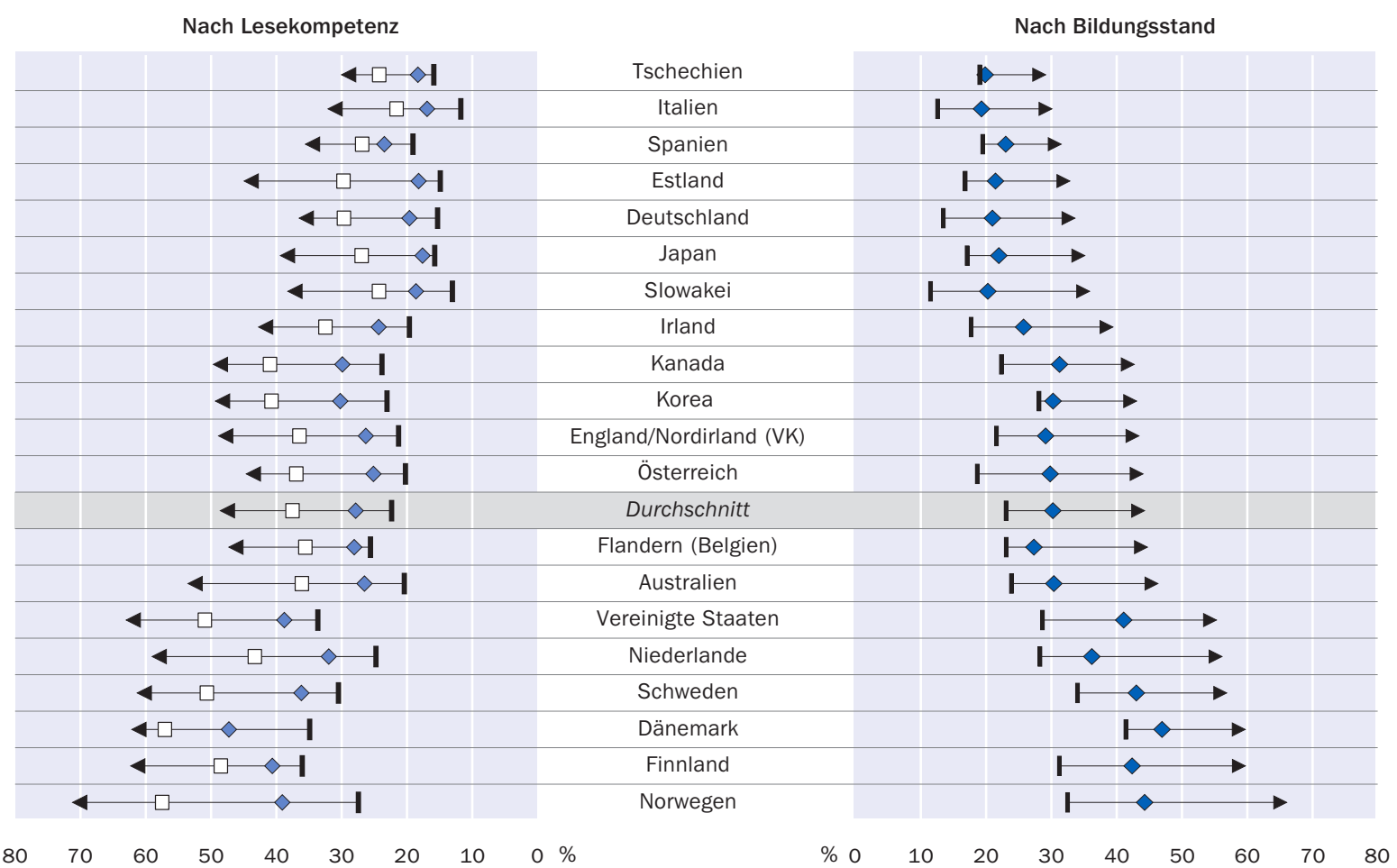

Anordnung der Länder in aufsteigender Reihenfolge des Anteils Erwachsener mit einem Abschluss im Tertiärbereich, die angeben, dass sie glauben, einen Einfluss auf das zu haben, was die Regierung macht.

Quelle: OECD. Tabelle A8.4a (L). Hinweise s. Anhang 3 unter www.oecd.org/edu/eag.htm. StatLink: http://dx.doi.org/10.1787/888933116718

punkte (Abb. A8.5 und Tab. A8.4a [L]). Besonders große Unterschiede sind in Norwegen (33 Prozentpunkte) und den Niederlanden (27 Prozentpunkte) zu beobachten. Im Durchschnitt dieser Länder beträgt der Unterschied zwischen Menschen mit der höchsten und mit der niedrigsten Lesekompetenz im Hinblick auf die politische Wirksamkeit (nach eigener Angabe) im Durchschnitt 25 Prozentpunkte (Abb. A8.5 und Tab. A8.4a [L]). Besonders groß ist der Unterschied mit 43 Prozentpunkten in Norwegen.

Die Unterschiede im Abschneiden bei gesamtgesellschaftlichen Auswirkungen zwischen Personen mit der höchsten und mit der niedrigsten Lesekompetenzstufe sind im Allgemeinen vergleichbar mit den Unterschieden im Abschneiden bei gesamtgesellschaftlichen Auswirkungen zwischen Menschen, die nicht über einen Abschluss im Sekundarbereich II verfügen, und jenen, die über einen Abschluss im Tertiärbereich verfügen (Abb. A8.I, A8.2, A8.3, A8.4 und A8.5 und Tab. A8.I, A8.2, A8.3 und A8.4). Hierbei ist zu beachten, dass der Anteil der Erwachsenen mit der niedrigsten Lesekompetenzstufe bzw. der höchsten Lesekompetenzstufe I 2 Prozent bzw. I6 Prozent beträgt (OECD, 2013b). Dagegen beträgt der Anteil der Erwachsenen ohne einen Abschluss im 
Abschluss im Sekundarbereich II und jener mit einem Abschluss im Tertiärbereich 24 Prozent bzw. 33 Prozent. Dies könnte darauf hindeuten, dass zwischen dem Bildungsstand und dem Abschneiden bei gesamtgesellschaftlichen Auswirkungen ein stärkerer Zusammenhang besteht als zwischen der Lesekompetenz und dem Abschneiden bei diesen Auswirkungen. Gleichermaßen deuten OECD-Ergebnisse (2013b, S. 232) darauf hin, dass der Zusammenhang zwischen der Lesekompetenz und dem Einkommen viel stärker ist als der zwischen der Anzahl der Jahre, die man in Ausbildung verbracht hat, und dem Einkommen.

\section{Kausale Zusammenhänge}

Andere Studien, die auf Längsschnittdaten basieren, deuten darauf hin, dass die in den Abbildungen A8.I, A8.2, A8.3, A8.4 und A8.5 dargestellten Beziehungen möglicherweise kausale Zusammenhänge zwischen Bildung und Kompetenzen einerseits und dem Abschneiden bei gesamtgesellschaftlichen Auswirkungen andererseits widerspiegeln. Conti, Heckman und Urzua (20I0) zeigen zum Beispiel anhand der British Cohort Study (BSC - Britische Kohortenstudie) von I970, dass ein beträchtlicher Anteil der Korrelation zwischen Bildungsstand und Gesundheitszustand auf einen kausalen Zusammenhang zurückzuführen ist. Heckmann et al. (20I4) zeigen ferner anhand der National Longitudinal Study of Youth (NLSY - Nationale Längsschnittstudie junger Menschen), dass kognitive und sozioemotionale Fähigkeiten in kausalem Zusammenhang mit verschiedenen Arbeitsmarktergebnissen und gesamtgesellschaftlichen Auswirkungen stehen. Heckmann und Kautz (2013) führen außerdem mittels Ergebnissen experimenteller Studien an, dass eine Reihe von Bildungsangeboten im Bereich frühkindlicher Bildung sowie verschiedene schulbasierte Bildungsgänge aufgrund einer Verbesserung der kognitiven und sozioemotionalen Fähigkeiten die Bildungs- und Arbeitsmarktergebnisse sowie das Abschneiden bei gesamtgesellschaftlichen Auswirkungen verbessern.

\section{Zusammenhang zwischen Lesekompetenz und dem Abschneiden bei gesamtgesellschaftlichen Auswirkungen nach Bildungsstand}

Abbildung A8.r zeigt für drei verschiedene Bildungsniveaus (Ausbildung unterhalb des Sekundarbereichs II, Abschluss im Sekundarbereich II/einem postsekundaren, nicht tertiären Bildungsgang und Abschluss im Tertiärbereich) den Zusammenhang zwischen der Lesekompetenz und jeweils vier Aspekten gesamtgesellschaftlicher Auswirkungen. Diese Abbildung legt nahe, dass die Korrelationen je nach Bildungsstand unterschiedlich stark ausgeprägt sind. So besteht beispielsweise ein starker Zusammenhang zwischen der Lesekompetenz und der politischen Wirksamkeit, insbesondere bei Absolventen des Tertiärbereichs. Eine Ausbildung im Tertiärbereich verleiht Studierenden möglicherweise besseren Zugang zu öffentlichen Entscheidungsprozessen und zur Politik, und eine gute Lesekompetenz verbessert möglicherweise die Fähigkeit des Einzelnen, einen Beitrag zu diesem Prozess zu leisten. Der Einfluss der Lesekompetenz steigt, je mehr Gelegenheit der Einzelne hat, entsprechende Kompetenzen unter Beweis zu stellen. Ferner besteht ein starker Zusammenhang zwischen Lesekompetenz und ehrenamtlicher Tätigkeit, insbesondere bei denjenigen, die nicht über einen Abschluss im Sekundarbereich II verfügen. Wer ein niedriges Bildungsniveau hat, hat möglicherweise auch relativ wenig Zugang zu ehrenamtlichen Tätigkeiten; die Daten unterstützen jedoch das Argument, dass eine hohe Lesekompetenz diesen eingeschränkten Zugang mehr als kompensieren kann, indem sie die Fähigkeit 
stärkt, den Nutzen ehrenamtlicher Tätigkeit für sich selbst und für die Gesellschaft zu erkennen und sich Zugang zu den geeignetsten Aktivitäten zu verschaffen. Die obige Analyse deutet ferner darauf hin, dass Bildung über ihren indirekten Einfluss hinaus aufgrund der Erhöhung der Lesekompetenz auch einen direkten (d. h. unabhängigen) Einfluss auf die gesamtgesellschaftlichen Auswirkungen hat.

\section{Geschlechtsspezifische Unterschiede}

Frauen profitieren in Bezug auf einen besseren Gesundheitszustand und mehr zwischenmenschliches Vertrauen eher von einer Verbesserung ihrer Kompetenzen. Der Unterschied zwischen Frauen mit der höchsten und der niedrigsten Lesekompetenz, die angeben, bei guter Gesundheit zu sein, beträgt im Durchschnitt von 22 OECDLändern 25 Prozentpunkte (Tab. A8.rb im Internet). Bei Männern beträgt dieser Unterschied 22 Prozentpunkte. Ferner beträgt der Unterschied zwischen Frauen mit der höchsten und mit der niedrigsten Lesekompetenz, die angeben, in der Lage zu sein, anderen vertrauen zu können, I9 Prozentpunkte (Tab. 8.3 b im Internet). Bei Männern beträgt dieser Unterschied I5 Prozentpunkte. Im Gegensatz hierzu profitieren Frauen eher weniger als Männer durch eine Steigerung ihres Bildungsstands in Bezug auf eine bessere Gesundheit, ehrenamtliche Aktivitäten und ihren Glauben, dass sie Einfluss darauf haben, was die Regierung macht.

\section{Definitionen}

Altersgruppen: Erwachsene bezieht sich auf 25- bis 64-Jährige.

Über zwischenmenschliches Vertrauen (d. h. die Fähigkeit, anderen zu vertrauen) verfügen all jene, die der Aussage, dass es nur wenige Menschen gibt, denen man voll vertrauen kann, nicht oder überhaupt nicht zustimmen.

Bildungsbereiche: Unterhalb Sekundarbereich II entspricht Bildungsgängen auf den ISCEDStufen o, I, 2 und 3 C (kurz), Sekundarbereich II bzw. postsekundarer, nicht tertiärer Bereich Bildungsgängen auf den ISCED-Stufen ${ }_{3} \mathrm{C}$ (lang), $3 \mathrm{~B}$, 3A und 4 und Tertiärbereich Studiengängen auf den ISCED-Stufen $5 \mathrm{~B}, 5 \mathrm{~A}$ und 6 . Erläuterungen zu allen Bildungsbereichen gemäß ISCED-Klassifizierung s. Hinweise für den Leser im vorderen Teil der Publikation.

Politische Wirksamkeit (d.h., ob man glaubt, einen Einfluss auf das zu haben, was die Regierung macht) wird daran gemessen, ob man der Aussage nicht oder überhaupt nicht zustimmt: „Menschen wie ich haben keinerlei Einfluss darauf, was die Regierung macht."

Gesundheit (nach eigener Angabe) (d. h. eine gute Gesundheit) liegt bei all denen vor, die angaben, dass ihre Gesundheit sehr gut, gut oder zufriedenstellend ist.

Unter ehrenamtlich tätig fallen all jene, die angeben, mindestens einmal im Monat eine ehrenamtliche Tätigkeit auszuüben. 


\section{Angewandte Methodik}

Alle Daten basieren auf der Erhebung zu den grundlegenden Kompetenzen Erwachsener (PIAAC) 20I2. PIAAC steht für das OECD Programme for the International Assessment of Adult Competencies. Weitere Informationen s. Erhebung zu den grundlegenden Kompetenzen Erwachsener im vorderen Teil der Publikation sowie Anhang 3 unter www.oecd.org/ edu/eag.htm.

Hinweis zu den Daten der Russischen Föderation in der PIAAC-Erhebung Es ist zu beachten, dass die Bevölkerung des Stadtgebiets Moskau in der Stichprobe für die Russische Föderation nicht berücksichtigt wurde. Die veröffentlichten Daten repräsentieren daher nicht die gesamte Wohnbevölkerung im Alter von I 6 bis 65 Jahren in Russland, sondern nur die Wohnbevölkerung Russlands ohne die im Stadtgebiet Moskau lebende Bevölkerung. Nähere Informationen zu den Daten aus der Russischen Föderation sowie anderer Länder finden sich im Technical Report of the Survey of Adult Skills (OECD, i. E.).

\section{Weiterführende Informationen}

Conti, G., J. J. Heckman and S. Urzúa (20ro), „The Education-Health Gradient“, American Economic Review: Papers \& Proceedings 100, May 2010, pp. 234-248.

Heckman, J. J., J. E. Humphries, G. Veramendi and S. Urzúa (2014), „Education, Health and Wages“, NBER Working Paper, No. I997I, National Bureau of Economic Research, March 2014.

Heckman, J. J. and T. Kautz (2013), „Fostering and Measuring Skills: Interventions that Improve Character and Cognition “, NBER Working Paper, No. 19656, National Bureau of Economic Research, November 2013.

OECD (20I0), Improving Health and Social Cohesion through Education, OECD Publishing, Paris, http://dx.doi.org/10.1787/9789264086319-en.

OECD (201ra), Health at a Glance 2011: OECD Indicators, OECD Publishing, Paris, http://dx.doi.org/10.1787/health_glance-2013-en.

OECD (20IIb), Bildung auf einen Blick 2011 - OECD-Indikatoren, W. Bertelsmann Verlag, Bielefeld.

OECD (2013a), How's Life? 2013: Measuring Well-being, OECD Publishing, Paris, http://dx.doi.org/10.1787/9789264201392-en.

OECD (2013b), OECD Skills Outlook 2013: First Results from the Survey of Adult Skills, OECD Publishing, Paris, http:||dx.doi.org/10.1787/9789264204256-en. 


\section{Tabellen Indikator A8}

StatLink: http://dx.doi.org/10.1787/888933116547

Tabelle A8.ra (L): Anteil Erwachsener (in \%), die angeben, bei guter Gesundheit zu sein, nach Bildungsstand und Lesekompetenz (2012)

WEB Table A8.ra (N): Percentage of adults reporting that they are in good health, by educational attainment and numeracy proficiency level (Anteil Erwachsener [ in $\%$, die angeben, bei guter Gesundheit zu sein, nach Bildungsstand und alltagsmathematischer Kompetenz) (20I2)

WEB Table A8.Ib (L): Percentage of adults reporting that they are in good health, by educational attainment, literacy proficiency level and gender (Anteil Erwachsener [ in \%], die angeben, bei guter Gesundheit zu sein, nach Bildungsstand, Lesekompetenz und Geschlecht) (20I2)

WEB Table A8.Ib (N): Percentage of adults reporting that they are in good health, by educational attainment, numeracy proficiency level and gender (Anteil Erwachsener [ in \%], die angeben, bei guter Gesundheit zu sein, nach Bildungsstand, alltagsmathematischer Kompetenz und Geschlecht) (2012)

Tabelle A8.2a (L): Anteil Erwachsener (in \%), die angeben, mindestens einmal im Monat eine ehrenamtliche Tätigkeit auszuüben, nach Bildungsstand und Lesekompetenz (2012)

WEB Table A8.2a (N): Percentage of adults reporting that they volunteer at least once a month, by educational attainment and numeracy proficiency level (Anteil Erwachsener [ in \%], die angeben, mindestens einmal im Monat eine ehrenamtliche Tätigkeit auszuüben, nach Bildungsstand und alltagsmathematischer Kompetenz) (2012)

WEB Table A8.2b (L): Percentage of adults reporting that they volunteer at least once a month, by educational attainment, literacy proficiency level and gender (Anteil Erwachsener [ in \%], die angeben, mindestens einmal im Monat eine ehrenamtliche Tätigkeit auszuüben, nach Bildungsstand, Lesekompetenz und Geschlecht) (2012)

WEB Table A8.2b (N): Percentage of adults reporting that they volunteer at least once a month, by educational attainment, numeracy proficiency level and gender (Anteil Erwachsener [in \%], die angeben, mindestens einmal im Monat eine ehrenamtliche Tätigkeit auszuüben, nach Bildungsstand, alltagsmathematischer Kompetenz und Geschlecht) (2012)

Tabelle A8.3a (L): Anteil Erwachsener (in \%), die angeben, anderen vertrauen zu können, nach Bildungsstand und Lesekompetenz (2012) 
WEB Table A8.3a (N): Percentage of adults reporting that they trust others, by educational attainment and numeracy proficiency level (Anteil Erwachsener [ in $\%$, die angeben, anderen vertrauen zu können, nach Bildungsstand und alltagsmathematischer Kompetenz) (2012)

WEB Table A8.3b (L): Percentage of adults reporting that they trust others, by educational attainment, literacy proficiency level and gender (Anteil Erwachsener [ in \%], die angeben, anderen vertrauen zu können, nach Bildungsstand, Lesekompetenz und Geschlecht) (2012)

WEB Table A8.3b (N): Percentage of adults reporting that they trust others, by educational attainment, numeracy proficiency level and gender (Anteil Erwachsener [ in \%], die angeben, anderen zu vertrauen, nach Bildungsstand, alltagsmathematischer Kompetenz und Geschlecht) (20I2)

WEB Table A8.3c (L): Percentage of adults reporting that others do not take advantage of them, by educational attainment and literacy proficiency level (Anteil Erwachsener [ in \%], die angeben, dass sie nicht von anderen ausgenutzt werden, nach Bildungsstand und Lesekompetenz) (2012)

WEB Table A8.3c (N): Percentage of adults reporting that others do not take advantage of them, by educational attainment and numeracy proficiency level (Anteil Erwachsener [ in \%], die angeben, dass sie nicht von anderen ausgenutzt werden, nach Bildungsstand und alltagsmathematischer Kompetenz) (2012)

WEB Table A8.3d (L): Percentage of adults reporting that others do not take advantage of them, by educational attainment, literacy proficiency level and gender (Anteil Erwachsener [ in \%], die angeben, dass sie nicht von anderen ausgenutzt werden, nach Bildungsstand, Lesekompetenz und Geschlecht) (2012)

WEB Table A8.3d (N): Percentage of adults reporting that others do not take advantage of them, by educational attainment, numeracy proficiency level and gender (Anteil Erwachsener [ in \%], die angeben, dass sie nicht von anderen ausgenutzt werden, nach Bildungsstand, alltagsmathematischer Kompetenz und Geschlecht) (2012)

Tabelle A8.4a (L): Anteil Erwachsener (in \%), die angeben, dass sie glauben, einen Einfluss auf das zu haben, was die Regierung macht, nach Bildungsstand und Lesekompetenz (2012)

WEB Table A8.4a (N): Percentage of adults reporting that they believe they have a say in government, by educational attainment and numeracy proficiency level (Anteil Erwachsener [ in \%], die angeben, dass sie glauben, einen Einfluss auf das zu haben, was die Regierung macht, nach Bildungsstand und alltagsmathematischer Kompetenz) (2012) 
WEB Table A8.4b (L): Percentage of adults reporting that they believe they have a say in government, by educational attainment, literacy proficiency level and gender (Anteil Erwachsener [ in \%], die angeben, dass sie glauben, einen Einfluss auf das zu haben, was die Regierung macht, nach Bildungsstand, Lesekompetenz und Geschlecht) (2012)

WEB Table A8.4b (N): Percentage of adults reporting that they believe they have a say in government, by educational attainment, numeracy proficiency level and gender (Anteil Erwachsener [ in \%], die angeben, dass sie glauben, einen Einfluss auf das zu haben, was die Regierung macht, nach Bildungsstand, alltagsmathematischer Kompetenz und Geschlecht) (2012) 
Tabelle A8.1a (L)

Anteil Erwachsener (in \%), die angeben, bei guter Gesundheit zu sein, nach Bildungsstand und Lesekompetenz (2012)

Lesekompetenzstufe in der Erhebung zu den grundlegenden Kompetenzen Erwachsener, 25- bis 64-Jährige

\begin{tabular}{|c|c|c|c|c|c|c|c|c|c|c|c|c|c|c|c|c|c|c|}
\hline & \multicolumn{8}{|c|}{ Ausbildung unterhalb Sekundarbereich II } & \multicolumn{10}{|c|}{$\begin{array}{c}\text { Abschluss im Sekundarbereich II } \\
\text { bzw. postsekundaren, nicht tertiären Bereich }\end{array}$} \\
\hline & \multicolumn{2}{|c|}{ Stufe 0/1 } & \multicolumn{2}{|c|}{ Stufe 2} & \multicolumn{2}{|c|}{ Stufe 3} & \multicolumn{2}{|c|}{ Gesamt } & \multicolumn{2}{|c|}{ Stufe 0/1 } & \multicolumn{2}{|c|}{ Stufe 2} & \multicolumn{2}{|c|}{ Stufe 3} & \multicolumn{2}{|c|}{ Stufe $4 / 5$} & \multicolumn{2}{|c|}{ Gesamt } \\
\hline & $\%$ & S.F. & $\%$ & S.F. & $\%$ & S.F. & $\%$ & S.F. & $\%$ & S.F. & $\%$ & S.F. & $\%$ & S.F. & $\%$ & S.F. & $\%$ & S.F. \\
\hline & (1) & (2) & (3) & (4) & (5) & (6) & (9) & (10) & (11) & (12) & (13) & (14) & (15) & (16) & (17) & (18) & (19) & (20) \\
\hline \multicolumn{19}{|l|}{$\begin{array}{l}\text { OECD } \\
\text { Nationale Einheiten }\end{array}$} \\
\hline Australien & 67 & $(3,2)$ & 79 & $(2,7)$ & 82 & $(3,0)$ & 76 & $(1,2)$ & 77 & $(3,5)$ & 82 & $(1,9)$ & 86 & $(1,6)$ & 85 & $(2,5)$ & 84 & $(1,1)$ \\
\hline Österreich & 60 & $(3,5)$ & 69 & $(3,2)$ & 75 & $(5,3)$ & 68 & $(1,7)$ & 71 & $(2,8)$ & 81 & $(1,4)$ & 88 & $(1,2)$ & 93 & $(2,8)$ & 83 & $(0,6)$ \\
\hline Kanada & 69 & $(2,2)$ & 76 & $(2,6)$ & 87 & $(3,6)$ & 74 & $(1,7)$ & 82 & $(1,8)$ & 87 & $(1,2)$ & 89 & $(1,1)$ & 91 & $(3,3)$ & 87 & $(0,6)$ \\
\hline Tschechien & 73 & $(7,0)$ & 66 & $(6,7)$ & 68 & $(9,3)$ & 69 & $(3,6)$ & 84 & $(3,5)$ & 86 & $(1,9)$ & 90 & $(1,9)$ & 95 & $(3,7)$ & 88 & $(0,9)$ \\
\hline Dänemark & 54 & $(2,9)$ & 68 & $(3,1)$ & 78 & $(3,9)$ & 64 & $(1,5)$ & 69 & $(3,0)$ & 80 & $(1,8)$ & 85 & $(1,7)$ & 89 & $(4,7)$ & 81 & $(0,9)$ \\
\hline Estland & 37 & $(3,6)$ & 42 & $(3,4)$ & 47 & $(5,3)$ & 42 & $(1,8)$ & 43 & $(3,3)$ & 52 & $(1,7)$ & 62 & $(1,8)$ & 69 & $(4,7)$ & 56 & $(0,9)$ \\
\hline Finnland & 58 & $(4,2)$ & 60 & $(4,2)$ & 70 & $(5,6)$ & 62 & $(1,8)$ & 62 & $(4,5)$ & 74 & $(2,1)$ & 81 & $(1,5)$ & 84 & $(3,2)$ & 77 & $(1,0)$ \\
\hline Frankreich & 61 & $(2,1)$ & 72 & $(2,2)$ & 78 & $(3,9)$ & 67 & $(1,0)$ & 71 & $(2,7)$ & 80 & $(1,5)$ & 83 & $(1,9)$ & 85 & $(4,7)$ & 80 & $(0,8)$ \\
\hline Deutschland & 71 & $(4,3)$ & 80 & $(4,7)$ & 82 & $(8,2)$ & 75 & $(2,5)$ & 76 & $(2,3)$ & 87 & $(1,4)$ & 90 & $(1,4)$ & 96 & $(2,6)$ & 86 & $(0,8)$ \\
\hline Irland & 71 & $(2,4)$ & 82 & $(2,4)$ & 85 & $(4,0)$ & 78 & $(1,3)$ & 88 & $(2,7)$ & 89 & $(1,5)$ & 89 & $(1,6)$ & 88 & $(5,3)$ & 89 & $(0,8)$ \\
\hline Italien & 72 & $(2,2)$ & 75 & $(2,2)$ & 75 & $(4,1)$ & 74 & $(1,3)$ & 87 & $(2,7)$ & 86 & $(1,8)$ & 88 & $(1,9)$ & 91 & $(5,0)$ & 87 & $(1,1)$ \\
\hline Japan & 53 & $(6,2)$ & 55 & $(4,8)$ & 68 & $(5,4)$ & 60 & $(2,5)$ & 63 & $(6,2)$ & 67 & $(2,5)$ & 72 & $(1,9)$ & 70 & $(4,5)$ & 70 & $(1,3)$ \\
\hline Korea & 22 & $(2,6)$ & 28 & $(2,7)$ & 35 & $(5,2)$ & 27 & $(1,4)$ & 41 & $(3,8)$ & 44 & $(2,0)$ & 49 & $(2,5)$ & 52 & $(9,5)$ & 46 & $(1,3)$ \\
\hline Niederlande & 59 & $(3,2)$ & 77 & $(2,6)$ & 72 & $(3,4)$ & 70 & $(1,3)$ & 64 & $(5,6)$ & 81 & $(2,0)$ & 84 & $(1,6)$ & 85 & $(3,5)$ & 81 & $(1,0)$ \\
\hline Norwegen & 61 & $(4,4)$ & 65 & $(3,4)$ & 75 & $(3,3)$ & 67 & $(1,9)$ & 73 & $(4,1)$ & 79 & $(2,2)$ & 84 & $(1,8)$ & 88 & $(4,0)$ & 81 & $(1,0)$ \\
\hline Polen & 45 & $(4,1)$ & 59 & $(4,1)$ & 66 & $(7,9)$ & 54 & $(2,3)$ & 66 & $(2,4)$ & 76 & $(1,5)$ & 82 & $(2,1)$ & 86 & $(6,0)$ & 76 & $(0,9)$ \\
\hline Slowakei & 51 & $(3,6)$ & 52 & $(4,1)$ & 62 & $(5,9)$ & 54 & $(2,2)$ & 75 & $(3,5)$ & 77 & $(1,5)$ & 82 & $(1,2)$ & 86 & $(4,2)$ & 79 & $(0,7)$ \\
\hline Spanien & 60 & $(1,7)$ & 76 & $(1,7)$ & 81 & $(3,3)$ & 69 & $(1,2)$ & 73 & $(3,9)$ & 81 & $(2,6)$ & 81 & $(3,1)$ & 92 & $(6,1)$ & 80 & $(1,4)$ \\
\hline Schweden & 59 & $(4,1)$ & 71 & $(3,9)$ & 75 & $(5,9)$ & 67 & $(2,3)$ & 75 & $(3,9)$ & 82 & $(2,3)$ & 86 & $(1,5)$ & 92 & $(2,6)$ & 84 & $(0,9)$ \\
\hline $\begin{array}{l}\text { Vereinigte Staaten } \\
\text { Subnationale Einheiten }\end{array}$ & 57 & $(4,2)$ & 70 & $(6,3)$ & 78 & $(10,1)$ & 62 & $(2,7)$ & 71 & $(2,6)$ & 79 & $(2,1)$ & 85 & $(2,1)$ & 90 & $(4,2)$ & 80 & $(1,4)$ \\
\hline Flandern (Belgien) & 68 & $(2,6)$ & 77 & $(2,5)$ & 76 & $(4,6)$ & 73 & $(1,6)$ & 83 & $(2,5)$ & 82 & $(1,6)$ & 87 & $(1,8)$ & 90 & $(4,1)$ & 84 & $(0,8)$ \\
\hline England (VK) & 60 & $(2,8)$ & 76 & $(2,5)$ & 83 & $(3,9)$ & 72 & $(1,4)$ & 82 & $(3,4)$ & 83 & $(2,0)$ & 87 & $(1,8)$ & 92 & $(2,7)$ & 85 & $(1,0)$ \\
\hline Nordirland (VK) & 62 & $(3,5)$ & 70 & $(3,0)$ & 73 & $(4,4)$ & 68 & $(1,8)$ & 77 & $(4,4)$ & 82 & $(2,6)$ & 85 & $(2,5)$ & 89 & $(5,1)$ & 83 & $(1,4)$ \\
\hline England/Nordirland (VK) & 60 & $(2,7)$ & 76 & $(2,4)$ & 83 & $(3,8)$ & 72 & $(1,3)$ & 82 & $(3,3)$ & 83 & $(2,0)$ & 87 & $(1,8)$ & 92 & $(2,7)$ & 85 & $(1,0)$ \\
\hline Durchschnitt & 59 & $(0,8)$ & 67 & $(0,8)$ & 73 & $(1,2)$ & 65 & $(0,4)$ & 72 & $(0,8)$ & 78 & $(0,4)$ & 82 & $(0,4)$ & 86 & $(1,0)$ & 79 & $(0,2)$ \\
\hline \multicolumn{19}{|l|}{ Partnerländer } \\
\hline Russische Föderation* & w & w & w & w & w & $\mathrm{w}$ & w & w & w & w & w & w & w & w & w & w & w & w \\
\hline
\end{tabular}

* Hinweis zu den Daten der Russischen Föderation s. Abschnitt Angewandte Methodik.

Anmerkung: Die Spalten mit getrennten Angaben zu Lesekompetenzstufe 4 oder 5 sowie für eine Ausbildung unterhalb Sekundarbereich II, d.h. die Spalten (7) und (8), sind im Internet verfügbar (s. StatLink unten).

Quelle: OECD. Survey of Adult Skills (PIAAC) (2012). PIAAC steht für das OECD Programme for the International Assessment of Adult Competencies.

Hinweise s. Anhang 3 unter www.oecd.org/edu/eag.htm. StatLink: http://dx.doi.org/10.1787/888933116566

Erläuterung der Kennzeichnung fehlender Daten s. Hinweise für den Leser. 
Tabelle A8.1a (L) (Forts.)

Anteil Erwachsener (in \%), die angeben, bei guter Gesundheit zu sein, nach Bildungsstand und Lesekompetenz (2012) Lesekompetenzstufe in der Erhebung zu den grundlegenden Kompetenzen Erwachsener, 25- bis 64-Jährige

\begin{tabular}{|c|c|c|c|c|c|c|c|c|c|c|c|c|c|c|c|c|c|c|c|c|}
\hline & \multicolumn{10}{|c|}{ Abschluss im Tertiärbereich } & \multicolumn{10}{|c|}{ Alle Bildungsbereiche zusammen } \\
\hline & \multicolumn{2}{|c|}{ Stufe $0 / 1$} & \multicolumn{2}{|c|}{ Stufe 2} & \multicolumn{2}{|c|}{ Stufe 3} & \multicolumn{2}{|c|}{ Stufe $4 / 5$} & \multicolumn{2}{|c|}{ Gesamt } & \multicolumn{2}{|c|}{ Stufe $0 / 1$} & \multicolumn{2}{|c|}{ Stufe 2} & \multicolumn{2}{|c|}{ Stufe 3} & \multicolumn{2}{|c|}{ Stufe $4 / 5$} & \multicolumn{2}{|c|}{ Gesamt } \\
\hline & $\%$ & S.F. & $\%$ & S.F. & $\%$ & S.F. & $\%$ & S.F. & $\%$ & S.F. & $\%$ & S.F. & $\%$ & S.F. & $\%$ & S.F. & $\%$ & S.F. & $\%$ & S.F. \\
\hline & (21) & $(22)$ & (23) & $(24)$ & $(25)$ & $(26)$ & $(27)$ & $(28)$ & (29) & (30) & (31) & $(32)$ & $(33)$ & $(34)$ & (35) & $(36)$ & $(37)$ & $(38)$ & (39) & $(40)$ \\
\hline \multicolumn{21}{|l|}{$\begin{array}{l}\text { OECD } \\
\text { Nationale Einheiten }\end{array}$} \\
\hline Australien & 80 & $(5,4)$ & 89 & $(2,3)$ & 89 & $(1,3)$ & 92 & $(1,3)$ & 90 & $(0,8)$ & 72 & $(2,2)$ & 82 & $(1,4)$ & 87 & $(0,9)$ & 90 & $(1,1)$ & 84 & $(0,5)$ \\
\hline Österreich & 77 & $(8,8)$ & 85 & $(2,8)$ & 91 & $(1,4)$ & 96 & $(1,7)$ & 90 & $(1,0)$ & 67 & $(2,2)$ & 79 & $(1,3)$ & 88 & $(1,1)$ & 95 & $(1,7)$ & 82 & $(0,6)$ \\
\hline Kanada & 85 & $(2,3)$ & 90 & $(1,2)$ & 93 & $(0,7)$ & 96 & $(0,8)$ & 92 & $(0,4)$ & 78 & $(1,2)$ & 87 & $(0,8)$ & 92 & $(0,5)$ & 95 & $(0,9)$ & 88 & $(0,3)$ \\
\hline Tschechien & c & c & 95 & $(2,8)$ & 96 & $(1,6)$ & 98 & $(1,2)$ & 96 & $(0,9)$ & 82 & $(3,1)$ & 84 & $(1,9)$ & 90 & $(1,5)$ & 97 & $(1,8)$ & 88 & $(0,7)$ \\
\hline Dänemark & 79 & $(4,1)$ & 85 & $(2,0)$ & 91 & $(0,9)$ & 94 & $(1,6)$ & 89 & $(0,6)$ & 64 & $(1,7)$ & 79 & $(1,1)$ & 88 & $(0,9)$ & 92 & $(1,8)$ & 81 & $(0,6)$ \\
\hline Estland & 52 & $(4,9)$ & 65 & $(2,0)$ & 75 & $(1,4)$ & 82 & $(2,3)$ & 72 & $(0,8)$ & 43 & $(2,1)$ & 55 & $(1,2)$ & 67 & $(1,1)$ & 78 & $(2,2)$ & 61 & $(0,5)$ \\
\hline Finnland & 77 & $(6,7)$ & 82 & $(2,2)$ & 90 & $(1,2)$ & 93 & $(1,0)$ & 89 & $(0,7)$ & 62 & $(2,7)$ & 73 & $(1,4)$ & 84 & $(1,1)$ & 90 & $(1,2)$ & 80 & $(0,6)$ \\
\hline Frankreich & 74 & $(5,0)$ & 85 & $(1,8)$ & 90 & $(0,9)$ & 93 & $(1,7)$ & 89 & $(0,6)$ & 66 & $(1,6)$ & 79 & $(1,0)$ & 86 & $(1,0)$ & 91 & $(1,7)$ & 79 & $(0,5)$ \\
\hline Deutschland & 77 & $(5,8)$ & 88 & $(2,1)$ & 94 & $(1,0)$ & 97 & $(1,4)$ & 92 & $(0,7)$ & 74 & $(1,9)$ & 86 & $(1,1)$ & 92 & $(1,0)$ & 97 & $(1,4)$ & 87 & $(0,6)$ \\
\hline Irland & 87 & $(5,0)$ & 93 & $(1,5)$ & 94 & $(0,9)$ & 94 & $(1,4)$ & 94 & $(0,6)$ & 77 & $(1,9)$ & 87 & $(1,0)$ & 91 & $(0,9)$ & 93 & $(1,6)$ & 87 & $(0,5)$ \\
\hline Italien & 88 & $(4,9)$ & 88 & $(3,1)$ & 91 & $(2,2)$ & 94 & $(2,9)$ & 90 & $(1,3)$ & 76 & $(1,8)$ & 80 & $(1,4)$ & 85 & $(1,7)$ & 92 & $(3,1)$ & 81 & $(0,9)$ \\
\hline Japan & c & c & 74 & $(3,6)$ & 76 & $(1,4)$ & 80 & $(1,8)$ & 77 & $(0,9)$ & 58 & $(4,4)$ & 66 & $(1,9)$ & 74 & $(1,2)$ & 77 & $(1,6)$ & 72 & $(0,8)$ \\
\hline Korea & 53 & $(9,4)$ & 52 & $(2,4)$ & 58 & $(1,8)$ & 62 & $(3,8)$ & 57 & $(1,1)$ & 31 & $(2,0)$ & 43 & $(1,2)$ & 53 & $(1,3)$ & 60 & $(3,4)$ & 47 & $(0,7)$ \\
\hline Niederlande & 76 & $(8,3)$ & 80 & $(3,6)$ & 89 & $(1,2)$ & 91 & $(1,6)$ & 88 & $(0,8)$ & 61 & $(2,5)$ & 79 & $(1,5)$ & 84 & $(1,1)$ & 89 & $(1,5)$ & 81 & $(0,6)$ \\
\hline Norwegen & 84 & $(4,7)$ & 86 & $(2,2)$ & 90 & $(1,1)$ & 91 & $(1,5)$ & 89 & $(0,7)$ & 69 & $(2,6)$ & 77 & $(1,5)$ & 86 & $(1,0)$ & 89 & $(1,8)$ & 82 & $(0,7)$ \\
\hline Polen & 88 & $(5,3)$ & 91 & $(2,2)$ & 92 & $(1,6)$ & 94 & $(1,9)$ & 92 & $(0,8)$ & 62 & $(1,9)$ & 77 & $(1,2)$ & 85 & $(1,2)$ & 92 & $(2,2)$ & 78 & $(0,6)$ \\
\hline Slowakei & c & c & 89 & $(2,6)$ & 92 & $(1,3)$ & 92 & $(3,0)$ & 91 & $(1,0)$ & 64 & $(2,8)$ & 74 & $(1,4)$ & 83 & $(0,9)$ & 89 & $(2,6)$ & 78 & $(0,6)$ \\
\hline Spanien & 79 & $(4,2)$ & 83 & $(2,4)$ & 88 & $(1,6)$ & 91 & $(2,6)$ & 86 & $(1,1)$ & 63 & $(1,5)$ & 79 & $(1,2)$ & 85 & $(1,3)$ & 91 & $(2,4)$ & 77 & $(0,7)$ \\
\hline Schweden & 77 & $(5,9)$ & 85 & $(3,0)$ & 91 & $(1,3)$ & 94 & $(1,3)$ & 90 & $(0,7)$ & 68 & $(2,5)$ & 80 & $(1,7)$ & 87 & $(1,1)$ & 93 & $(1,4)$ & 83 & $(0,7)$ \\
\hline $\begin{array}{l}\text { Vereinigte Staaten } \\
\text { Subnationale Einheiten }\end{array}$ & 81 & $(5,0)$ & 90 & $(1,6)$ & 94 & $(1,0)$ & 97 & $(1,1)$ & 93 & $(0,6)$ & 68 & $(1,9)$ & 81 & $(1,6)$ & 90 & $(1,0)$ & 95 & $(1,2)$ & 83 & $(0,8)$ \\
\hline Flandern (Belgien) & 80 & $(5,6)$ & 88 & $(2,5)$ & 91 & $(1,2)$ & 92 & $(1,6)$ & 90 & $(0,8)$ & 76 & $(1,7)$ & 82 & $(1,2)$ & 88 & $(0,9)$ & 91 & $(1,5)$ & 85 & $(0,5)$ \\
\hline England (VK) & 82 & $(5,7)$ & 87 & $(2,3)$ & 90 & $(1,3)$ & 93 & $(1,6)$ & 89 & $(0,8)$ & 71 & $(2,1)$ & 82 & $(1,3)$ & 88 & $(1,2)$ & 92 & $(1,4)$ & 84 & $(0,6)$ \\
\hline Nordirland (VK) & 86 & $(5,4)$ & 84 & $(3,2)$ & 91 & $(1,5)$ & 95 & $(1,5)$ & 90 & $(0,9)$ & 68 & $(2,7)$ & 77 & $(1,7)$ & 86 & $(1,4)$ & 93 & $(1,7)$ & 80 & $(0,9)$ \\
\hline England/Nordirland (VK) & 82 & $(5,6)$ & 87 & $(2,2)$ & 90 & $(1,3)$ & 93 & $(1,6)$ & 89 & $(0,8)$ & 71 & $(2,0)$ & 82 & $(1,2)$ & 88 & $(1,1)$ & 92 & $(1,4)$ & 84 & $(0,6)$ \\
\hline Durchschnitt & 78 & $(1,3)$ & 84 & $(0,5)$ & 88 & $(0,3)$ & 91 & $(0,4)$ & 88 & $(0,2)$ & 66 & $(0,5)$ & 77 & $(0,3)$ & 84 & $(0,2)$ & 89 & $(0,4)$ & 79 & $(0,1)$ \\
\hline \multicolumn{21}{|l|}{ Partnerländer } \\
\hline Russische Föderation* & w & w & w & w & w & w & w & w & w & w & w & w & w & w & w & w & w & w & w & w \\
\hline
\end{tabular}

* Hinweis zu den Daten der Russischen Föderation s. Abschnitt Angewandte Methodik.

Anmerkung: Die Spalten mit getrennten Angaben zu Lesekompetenzstufe 4 oder 5 sowie für eine Ausbildung unterhalb Sekundarbereich II, d.h. die Spalten (7) und (8), sind im Internet verfügbar (s. StatLink unten).

Quelle: OECD. Survey of Adult Skills (PIAAC) (2012). PIAAC steht für das OECD Programme for the International Assessment of Adult Competencies.

Hinweise s. Anhang 3 unter www.oecd.org/edu/eag.htm. StatLink: http://dx.doi.org/10.1787/888933116566

Erläuterung der Kennzeichnung fehlender Daten s. Hinweise für den Leser. 
Tabelle A8.2a (L)

Anteil Erwachsener (in \%), die angeben, mindestens einmal im Monat eine ehrenamtliche Tätigkeit auszuüben, nach Bildungsstand und Lesekompetenz (2012)

Lesekompetenzstufe in der Erhebung zu den grundlegenden Kompetenzen Erwachsener, 25- bis 64-Jährige

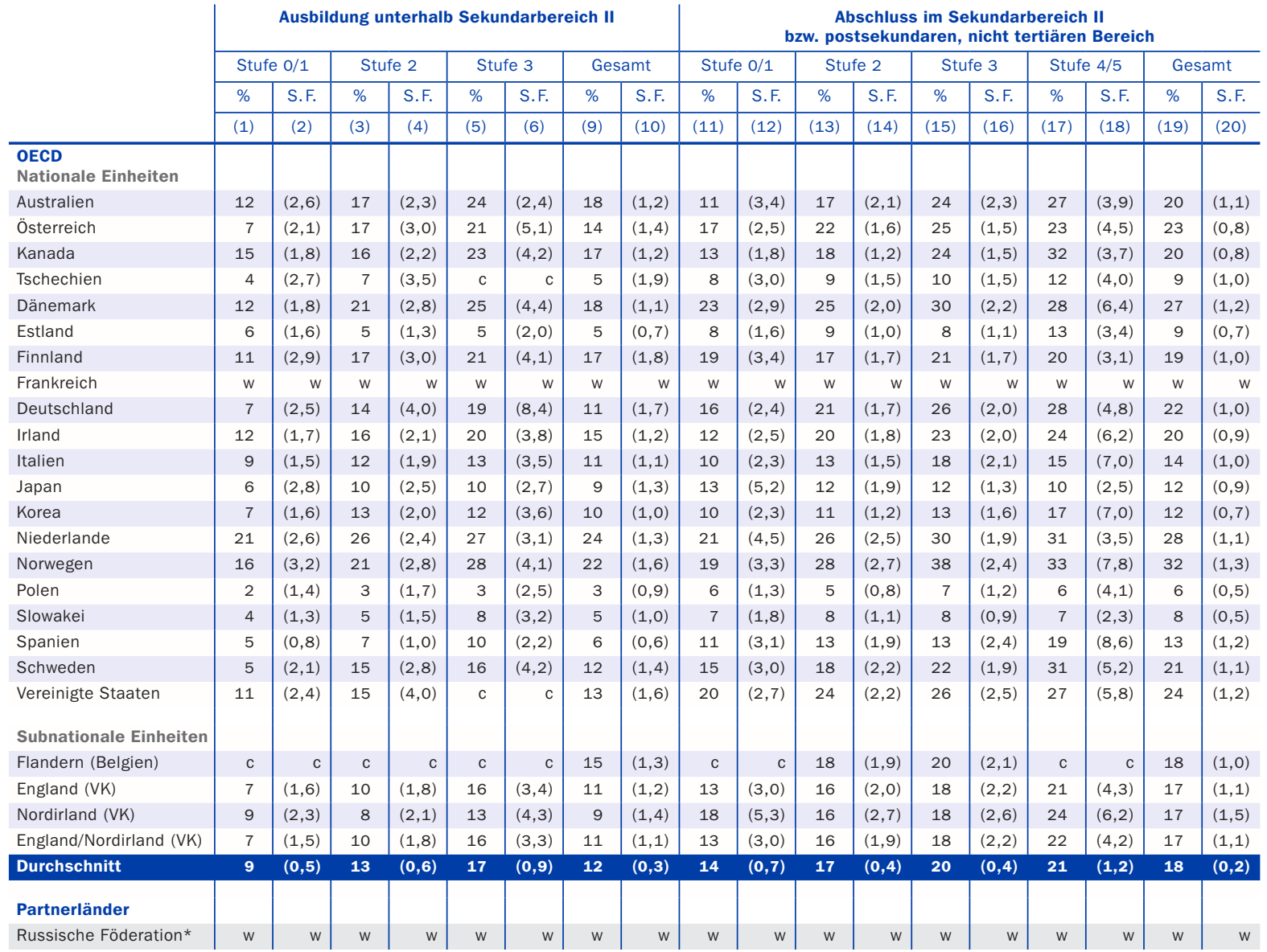

* Hinweis zu den Daten der Russischen Föderation s. Abschnitt Angewandte Methodik.

Anmerkung: Die Spalten mit getrennten Angaben zu Lesekompetenzstufe 4 oder 5 sowie für eine Ausbildung unterhalb Sekundarbereich II, d. h. die Spalten (7) und (8), sind im Internet verfügbar (s. StatLink unten).

Quelle: OECD. Survey of Adult Skills (PIAAC) (2012). PIAAC steht für das OECD Programme for the International Assessment of Adult Competencies.

Hinweise s. Anhang 3 unter www.oecd.org/edu/eag.htm. StatLink: http://dx.doi.org/10.1787/888933116585

Erläuterung der Kennzeichnung fehlender Daten s. Hinweise für den Leser. 
Tabelle A8.2a (L) (Forts.)

Anteil Erwachsener (in \%), die angeben, mindestens einmal im Monat eine ehrenamtliche Tätigkeit auszuüben, nach Bildungsstand und Lesekompetenz (2012)

Lesekompetenzstufe in der Erhebung zu den grundlegenden Kompetenzen Erwachsener, 25- bis 64-Jährige

\begin{tabular}{|c|c|c|c|c|c|c|c|c|c|c|c|c|c|c|c|c|c|c|c|c|}
\hline & \multicolumn{10}{|c|}{ Abschluss im Tertiärbereich } & \multicolumn{10}{|c|}{ Alle Bildungsbereiche zusammen } \\
\hline & \multicolumn{2}{|c|}{ Stufe $0 / 1$} & \multicolumn{2}{|c|}{ Stufe 2} & \multicolumn{2}{|c|}{ Stufe 3} & \multicolumn{2}{|c|}{ Stufe $4 / 5$} & \multicolumn{2}{|c|}{ Gesamt } & \multicolumn{2}{|c|}{ Stufe $0 / 1$} & \multicolumn{2}{|c|}{ Stufe 2} & \multicolumn{2}{|c|}{ Stufe 3} & \multicolumn{2}{|c|}{ Stufe $4 / 5$} & \multicolumn{2}{|c|}{ Gesamt } \\
\hline & $\%$ & S.F. & $\%$ & S.F. & $\%$ & S.F. & $\%$ & S.F. & $\%$ & S.F. & $\%$ & S.F. & $\%$ & S.F. & $\%$ & S.F. & $\%$ & S.F. & $\%$ & S.F. \\
\hline & $(21)$ & (22) & (23) & $(24)$ & $(25)$ & $(26)$ & $(27)$ & $(28)$ & $(29)$ & (30) & (31) & (32) & (33) & (34) & (35) & $(36)$ & (37) & (38) & (39) & $(40)$ \\
\hline \multicolumn{21}{|l|}{$\begin{array}{l}\text { OECD } \\
\text { Nationale Einheiten }\end{array}$} \\
\hline Australien & 17 & $(4,7)$ & 21 & $(2,8)$ & 24 & $(2,0)$ & 28 & $(2,2)$ & 24 & $(1,2)$ & 13 & $(2,0)$ & 18 & $(1,3)$ & 24 & $(1,3)$ & 27 & $(1,7)$ & 21 & $(0,6)$ \\
\hline Österreich & 21 & $(8,3)$ & 32 & $(3,6)$ & 30 & $(2,6)$ & 26 & $(3,5)$ & 29 & $(1,6)$ & 13 & $(1,6)$ & 22 & $(1,4)$ & 26 & $(1,3)$ & 24 & $(2,7)$ & 22 & $(0,7)$ \\
\hline Kanada & 17 & $(2,4)$ & 26 & $(1,6)$ & 31 & $(1,2)$ & 36 & $(2,1)$ & 29 & $(0,7)$ & 15 & $(1,1)$ & 21 & $(0,9)$ & 28 & $(0,9)$ & 35 & $(1,8)$ & 25 & $(0,5)$ \\
\hline Tschechien & c & c & 11 & $(6,0)$ & 14 & $(3,0)$ & 11 & $(4,3)$ & 13 & $(2,0)$ & 7 & $(2,3)$ & 9 & $(1,5)$ & 10 & $(1,3)$ & 11 & $(3,0)$ & 10 & $(0,8)$ \\
\hline Dänemark & 19 & $(4,0)$ & 24 & $(2,1)$ & 29 & $(1,6)$ & 28 & $(2,7)$ & 27 & $(0,9)$ & 17 & $(1,5)$ & 24 & $(1,4)$ & 29 & $(1,3)$ & 28 & $(2,5)$ & 25 & $(0,6)$ \\
\hline Estland & 13 & $(3,6)$ & 12 & $(1,6)$ & 12 & $(1,2)$ & 14 & $(2,1)$ & 12 & $(0,6)$ & 8 & $(1,1)$ & 9 & $(0,7)$ & 10 & $(0,8)$ & 14 & $(1,8)$ & 10 & $(0,4)$ \\
\hline Finnland & 26 & $(5,4)$ & 22 & $(2,7)$ & 25 & $(1,7)$ & 27 & $(1,9)$ & 26 & $(1,0)$ & 17 & $(2,2)$ & 19 & $(1,5)$ & 23 & $(1,2)$ & 25 & $(1,6)$ & 22 & $(0,6)$ \\
\hline Frankreich & w & $w$ & w & w & w & w & w & w & w & w & w & w & w & w & w & w & w & w & w & w \\
\hline Deutschland & 20 & $(5,9)$ & 27 & $(2,7)$ & 28 & $(2,1)$ & 31 & $(3,1)$ & 28 & $(1,2)$ & 14 & $(1,7)$ & 22 & $(1,3)$ & 27 & $(1,5)$ & 30 & $(2,8)$ & 23 & $(0,8)$ \\
\hline Irland & 24 & $(6,5)$ & 23 & $(2,6)$ & 24 & $(2,0)$ & 27 & $(3,4)$ & 24 & $(1,0)$ & 13 & $(1,4)$ & 19 & $(1,3)$ & 23 & $(1,4)$ & 26 & $(2,9)$ & 20 & $(0,7)$ \\
\hline Italien & 17 & $(6,1)$ & 21 & $(4,0)$ & 23 & $(3,1)$ & 20 & $(6,5)$ & 22 & $(2,0)$ & 9 & $(1,2)$ & 13 & $(1,2)$ & 18 & $(1,7)$ & 17 & $(4,5)$ & 13 & $(0,8)$ \\
\hline Japan & 27 & $(12,2)$ & 14 & $(2,9)$ & 12 & $(1,2)$ & 12 & $(1,4)$ & 12 & $(0,7)$ & 12 & $(3,0)$ & 12 & $(1,5)$ & 12 & $(0,8)$ & 11 & $(1,2)$ & 12 & $(0,5)$ \\
\hline Korea & 15 & $(6,5)$ & 13 & $(1,6)$ & 12 & $(1,2)$ & 15 & $(2,5)$ & 12 & $(0,7)$ & 9 & $(1,5)$ & 12 & $(0,9)$ & 12 & $(0,9)$ & 15 & $(2,4)$ & 12 & $(0,5)$ \\
\hline Niederlande & 26 & $(8,8)$ & 29 & $(4,2)$ & 33 & $(2,1)$ & 32 & $(2,5)$ & 32 & $(1,2)$ & 21 & $(2,2)$ & 27 & $(1,5)$ & 31 & $(1,2)$ & 31 & $(2,1)$ & 28 & $(0,6)$ \\
\hline Norwegen & c & $\mathrm{c}$ & 31 & $(3,4)$ & 34 & $(1,9)$ & 34 & $(2,6)$ & 33 & $(1,2)$ & 17 & $(2,0)$ & 27 & $(1,8)$ & 35 & $(1,5)$ & 34 & $(2,7)$ & 30 & $(0,8)$ \\
\hline Polen & 15 & $(7,7)$ & 12 & $(2,5)$ & 12 & $(1,6)$ & 15 & $(3,0)$ & 12 & $(1,0)$ & 6 & $(1,1)$ & 6 & $(0,7)$ & 9 & $(0,9)$ & 12 & $(2,4)$ & 7 & $(0,4)$ \\
\hline Slowakei & 24 & $(11,5)$ & 12 & $(2,9)$ & 13 & $(1,8)$ & 12 & $(4,2)$ & 13 & $(1,2)$ & 6 & $(1,2)$ & 8 & $(1,0)$ & 9 & $(0,8)$ & 9 & $(2,4)$ & 8 & $(0,5)$ \\
\hline Spanien & 9 & $(2,8)$ & 14 & $(1,9)$ & 15 & $(1,7)$ & 16 & $(3,3)$ & 14 & $(1,0)$ & 6 & $(0,8)$ & 10 & $(0,8)$ & 13 & $(1,2)$ & 16 & $(2,9)$ & 10 & $(0,4)$ \\
\hline Schweden & 16 & $(5,0)$ & 19 & $(3,0)$ & 21 & $(2,0)$ & 26 & $(2,4)$ & 22 & $(1,2)$ & 11 & $(1,6)$ & 17 & $(1,5)$ & 21 & $(1,3)$ & 27 & $(2,2)$ & 20 & $(0,7)$ \\
\hline $\begin{array}{l}\text { Vereinigte Staaten } \\
\text { Subnationale Einheiten }\end{array}$ & 31 & $(5,8)$ & 37 & $(3,1)$ & 38 & $(2,0)$ & 43 & $(3,0)$ & 39 & $(1,0)$ & 18 & $(2,0)$ & 26 & $(1,8)$ & 33 & $(1,5)$ & 39 & $(2,7)$ & 29 & $(0,7)$ \\
\hline Flandern (Belgien) & 20 & $(6,9)$ & 21 & $(2,9)$ & 24 & $(1,6)$ & 29 & $(2,8)$ & 25 & $(1,1)$ & 11 & $(1,6)$ & 18 & $(1,4)$ & 23 & $(1,3)$ & 28 & $(2,6)$ & 20 & $(0,8)$ \\
\hline England (VK) & c & $c$ & 18 & $(2,2)$ & 23 & $(1,7)$ & 29 & $(2,8)$ & 22 & $(1,0)$ & 10 & $(1,5)$ & 15 & $(1,1)$ & 20 & $(1,2)$ & 26 & $(2,3)$ & 18 & $(0,6)$ \\
\hline Nordirland (VK) & 16 & $(6,9)$ & 23 & $(4,1)$ & 29 & $(2,7)$ & 30 & $(3,8)$ & 27 & $(1,5)$ & 12 & $(2,0)$ & 14 & $(1,4)$ & 22 & $(1,7)$ & 28 & $(3,3)$ & 18 & $(0,8)$ \\
\hline England/Nordirland (VK) & 14 & $(4,2)$ & 18 & $(2,2)$ & 23 & $(1,7)$ & 29 & $(2,7)$ & 23 & $(1,0)$ & 10 & $(1,5)$ & 15 & $(1,1)$ & 20 & $(1,2)$ & 26 & $(2,3)$ & 18 & $(0,6)$ \\
\hline Durchschnitt & 19 & $(1,5)$ & 21 & $(0,7)$ & 23 & $(0,4)$ & 24 & $(0,7)$ & 22 & $(0,3)$ & 12 & $(0,4)$ & 17 & $(0,3)$ & 21 & $(0,3)$ & 23 & $(0,6)$ & 18 & $(0,1)$ \\
\hline
\end{tabular}

Partnerländer

Russische Föderation*

* Hinweis zu den Daten der Russischen Föderation s. Abschnitt Angewandte Methodik.

Anmerkung: Die Spalten mit getrennten Angaben zu Lesekompetenzstufe 4 oder 5 sowie für eine Ausbildung unterhalb Sekundarbereich II, d. $h$. die Spalten (7) und (8), sind im Internet verfügbar (s. StatLink unten).

Quelle: OECD. Survey of Adult Skills (PIAAC) (2012). PIAAC steht für das OECD Programme for the International Assessment of Adult Competencies.

Hinweise s. Anhang 3 unter www.oecd.org/edu/eag.htm. StatLink: http://dx.doi.org/10.1787/888933116585

Erläuterung der Kennzeichnung fehlender Daten s. Hinweise für den Leser. 
Tabelle A8.3a (L)

Anteil Erwachsener (in \%), die angeben, anderen vertrauen zu können, nach Bildungsstand und Lesekompetenz (2012)

Lesekompetenzstufe in der Erhebung zu den grundlegenden Kompetenzen Erwachsener, 25- bis 64-Jährige

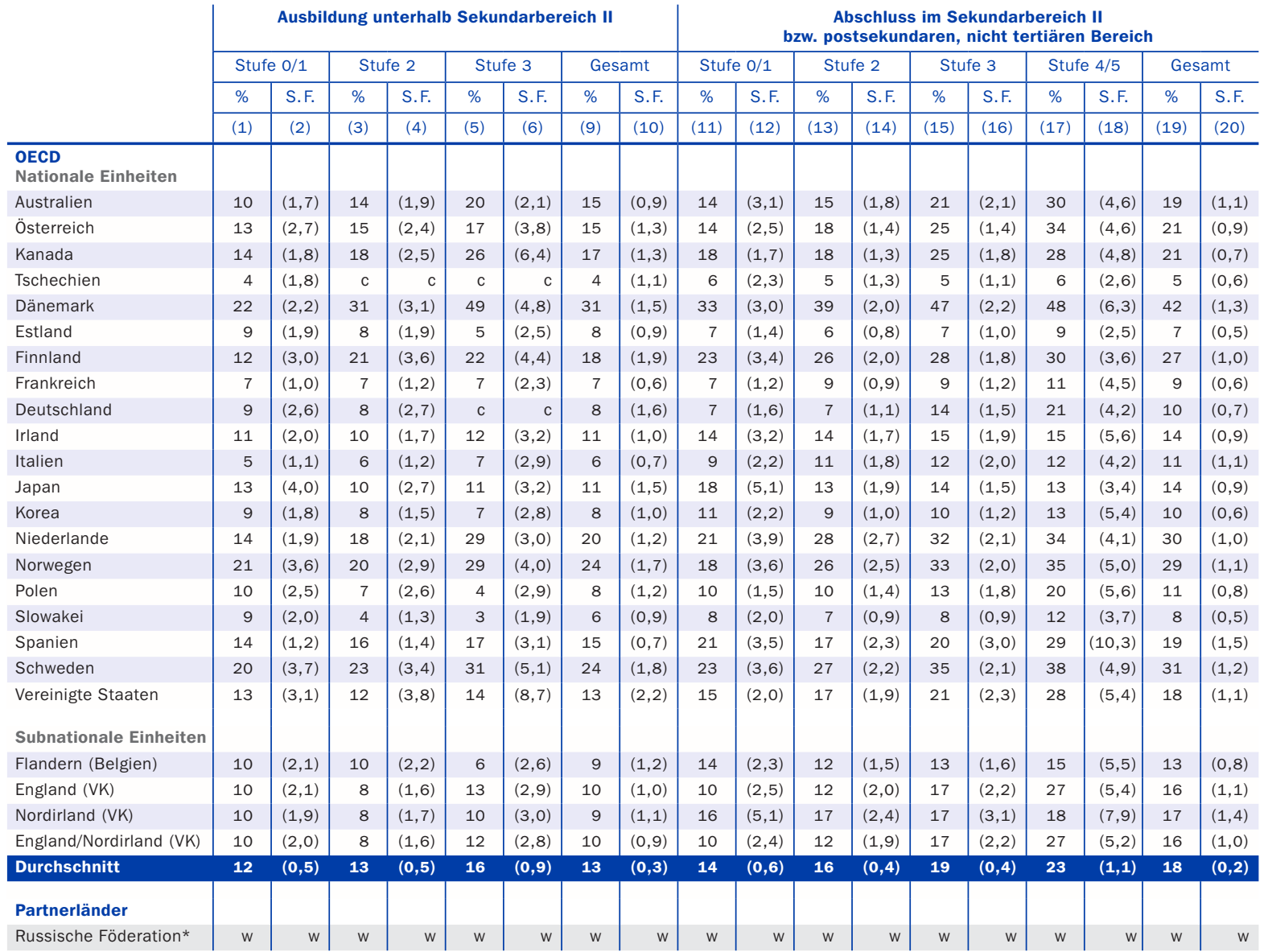

* Hinweis zu den Daten der Russischen Föderation s. Abschnitt Angewandte Methodik.

Anmerkung: Die Spalten mit getrennten Angaben zu Lesekompetenzstufe 4 oder 5 sowie für eine Ausbildung unterhalb Sekundarbereich II, d.h. die Spalten (7) und (8), sind im Internet verfügbar (s. StatLink unten).

Quelle: OECD. Survey of Adult Skills (PIAAC) (2012). PIAAC steht für das OECD Programme for the International Assessment of Adult Competencies. Hinweise s. Anhang 3 unter www.oecd.org/edu/eag.htm. StatLink: http://dx.doi.org/10.1787/888933116604

Erläuterung der Kennzeichnung fehlender Daten s. Hinweise für den Leser. 
Tabelle A8.3a (L) (Forts.)

Anteil Erwachsener (in \%), die angeben, anderen vertrauen zu können, nach Bildungsstand und Lesekompetenz (2012) Lesekompetenzstufe in der Erhebung zu den grundlegenden Kompetenzen Erwachsener, 25- bis 64-Jährige

\begin{tabular}{|c|c|c|c|c|c|c|c|c|c|c|c|c|c|c|c|c|c|c|c|c|}
\hline & \multicolumn{10}{|c|}{ Abschluss im Tertiärbereich } & \multicolumn{10}{|c|}{ Alle Bildungsbereiche zusammen } \\
\hline & \multicolumn{2}{|c|}{ Stufe $0 / 1$} & \multicolumn{2}{|c|}{ Stufe 2} & \multicolumn{2}{|c|}{ Stufe 3} & \multicolumn{2}{|c|}{ Stufe $4 / 5$} & \multicolumn{2}{|c|}{ Gesamt } & \multicolumn{2}{|c|}{ Stufe $0 / 1$} & \multicolumn{2}{|c|}{ Stufe 2} & \multicolumn{2}{|c|}{ Stufe 3} & \multicolumn{2}{|c|}{ Stufe $4 / 5$} & \multicolumn{2}{|c|}{ Gesamt } \\
\hline & $\%$ & S.F. & $\%$ & S.F. & $\%$ & S.F. & $\%$ & S.F. & $\%$ & S.F. & $\%$ & S.F. & $\%$ & S.F. & $\%$ & S.F. & $\%$ & S.F. & $\%$ & S.F. \\
\hline & $(21)$ & $(22)$ & (23) & $(24)$ & $(25)$ & $(26)$ & $(27)$ & $(28)$ & (29) & (30) & (31) & $(32)$ & $(33)$ & $(34)$ & (35) & $(36)$ & $(37)$ & $(38)$ & (39) & $(40)$ \\
\hline \multicolumn{21}{|l|}{$\begin{array}{l}\text { OECD } \\
\text { Nationale Einheiten }\end{array}$} \\
\hline Australien & 17 & $(5,3)$ & 23 & $(2,8)$ & 32 & $(2,0)$ & 41 & $(2,1)$ & 32 & $(1,0)$ & 12 & $(1,5)$ & 17 & $(1,2)$ & 25 & $(1,3)$ & 37 & $(1,8)$ & 23 & $(0,7)$ \\
\hline Österreich & 18 & $(7,3)$ & 21 & $(3,3)$ & 34 & $(2,9)$ & 40 & $(4,5)$ & 31 & $(1,6)$ & 14 & $(1,7)$ & 18 & $(1,1)$ & 27 & $(1,3)$ & 37 & $(3,5)$ & 22 & $(0,7)$ \\
\hline Kanada & 18 & $(2,5)$ & 24 & $(1,4)$ & 33 & $(1,2)$ & 37 & $(2,1)$ & 30 & $(0,7)$ & 17 & $(1,1)$ & 21 & $(0,9)$ & 30 & $(1,0)$ & 36 & $(2,1)$ & 26 & $(0,5)$ \\
\hline Tschechien & c & c & 7 & $(4,4)$ & 16 & $(3,6)$ & 22 & $(5,1)$ & 16 & $(2,2)$ & 5 & $(1,6)$ & 5 & $(1,1)$ & 8 & $(1,4)$ & 15 & $(3,7)$ & 7 & $(0,7)$ \\
\hline Dänemark & 46 & $(4,5)$ & 58 & $(2,3)$ & 65 & $(1,5)$ & 67 & $(2,9)$ & 63 & $(1,0)$ & 30 & $(1,7)$ & 43 & $(1,2)$ & 57 & $(1,2)$ & 63 & $(2,6)$ & 48 & $(0,7)$ \\
\hline Estland & 11 & $(2,7)$ & 12 & $(1,6)$ & 16 & $(1,4)$ & 17 & $(2,1)$ & 15 & $(0,7)$ & 8 & $(1,1)$ & 8 & $(0,7)$ & 11 & $(0,8)$ & 14 & $(1,5)$ & 10 & $(0,4)$ \\
\hline Finnland & 40 & $(7,6)$ & 37 & $(3,0)$ & 43 & $(1,8)$ & 47 & $(2,1)$ & 44 & $(1,1)$ & 21 & $(2,3)$ & 28 & $(1,5)$ & 35 & $(1,3)$ & 42 & $(1,9)$ & 33 & $(0,7)$ \\
\hline Frankreich & 7 & $(2,6)$ & 14 & $(1,8)$ & 18 & $(1,3)$ & 18 & $(2,2)$ & 17 & $(0,8)$ & 7 & $(0,7)$ & 10 & $(0,7)$ & 13 & $(0,8)$ & 16 & $(1,9)$ & 11 & $(0,4)$ \\
\hline Deutschland & 18 & $(5,5)$ & 14 & $(2,3)$ & 23 & $(1,9)$ & 30 & $(2,7)$ & 22 & $(1,0)$ & 9 & $(1,4)$ & 9 & $(1,0)$ & 18 & $(1,2)$ & 27 & $(2,3)$ & 14 & $(0,6)$ \\
\hline Irland & 18 & $(5,5)$ & 18 & $(2,1)$ & 23 & $(1,7)$ & 30 & $(2,7)$ & 23 & $(1,0)$ & 13 & $(1,7)$ & 14 & $(0,9)$ & 19 & $(1,1)$ & 27 & $(2,6)$ & 16 & $(0,6)$ \\
\hline Italien & 13 & $(5,5)$ & 12 & $(3,2)$ & 18 & $(2,6)$ & 16 & $(5,6)$ & 15 & $(1,4)$ & 6 & $(0,9)$ & 8 & $(0,9)$ & 13 & $(1,3)$ & 14 & $(3,7)$ & 9 & $(0,6)$ \\
\hline Japan & c & c & 17 & $(2,8)$ & 23 & $(1,4)$ & 24 & $(1,7)$ & 23 & $(0,9)$ & 16 & $(3,1)$ & 14 & $(1,4)$ & 18 & $(1,0)$ & 21 & $(1,4)$ & 18 & $(0,6)$ \\
\hline Korea & 21 & $(6,6)$ & 17 & $(1,6)$ & 16 & $(1,1)$ & 18 & $(2,9)$ & 17 & $(0,7)$ & 10 & $(1,3)$ & 11 & $(0,7)$ & 13 & $(0,8)$ & 17 & $(2,6)$ & 12 & $(0,4)$ \\
\hline Niederlande & 19 & $(8,8)$ & 38 & $(4,1)$ & 45 & $(2,2)$ & 50 & $(2,6)$ & 45 & $(1,3)$ & 16 & $(1,7)$ & 25 & $(1,7)$ & 36 & $(1,3)$ & 45 & $(2,2)$ & 32 & $(0,6)$ \\
\hline Norwegen & 28 & $(5,6)$ & 42 & $(3,8)$ & 51 & $(2,0)$ & 54 & $(2,7)$ & 49 & $(1,2)$ & 21 & $(2,3)$ & 28 & $(1,9)$ & 41 & $(1,3)$ & 50 & $(2,4)$ & 36 & $(0,8)$ \\
\hline Polen & 17 & $(6,3)$ & 21 & $(3,3)$ & 24 & $(2,4)$ & 30 & $(3,6)$ & 24 & $(1,3)$ & 11 & $(1,3)$ & 12 & $(1,1)$ & 17 & $(1,3)$ & 28 & $(3,1)$ & 15 & $(0,6)$ \\
\hline Slowakei & c & c & 11 & $(2,7)$ & 12 & $(1,5)$ & 19 & $(4,1)$ & 13 & $(1,1)$ & 9 & $(1,6)$ & 7 & $(0,8)$ & 9 & $(0,8)$ & 15 & $(3,0)$ & 9 & $(0,4)$ \\
\hline Spanien & 23 & $(4,8)$ & 27 & $(2,3)$ & 34 & $(2,0)$ & 36 & $(4,6)$ & 31 & $(1,2)$ & 16 & $(1,2)$ & 19 & $(1,1)$ & 27 & $(1,5)$ & 34 & $(4,2)$ & 21 & $(0,6)$ \\
\hline Schweden & 22 & $(5,6)$ & 41 & $(4,1)$ & 50 & $(2,1)$ & 55 & $(2,4)$ & 49 & $(1,3)$ & 21 & $(2,3)$ & 29 & $(1,6)$ & 40 & $(1,5)$ & 49 & $(2,3)$ & 36 & $(0,8)$ \\
\hline $\begin{array}{l}\text { Vereinigte Staaten } \\
\text { Subnationale Einheiten }\end{array}$ & 20 & $(6,4)$ & 26 & $(2,8)$ & 32 & $(1,7)$ & 39 & $(2,9)$ & 31 & $(1,2)$ & 15 & $(2,1)$ & 19 & $(1,5)$ & 26 & $(1,5)$ & 37 & $(2,7)$ & 23 & $(0,8)$ \\
\hline Flandern (Belgien) & 30 & $(7,9)$ & 29 & $(4,2)$ & 29 & $(2,1)$ & 29 & $(2,7)$ & 29 & $(1,2)$ & 13 & $(1,7)$ & 15 & $(1,3)$ & 21 & $(1,2)$ & 26 & $(2,5)$ & 19 & $(0,6)$ \\
\hline England (VK) & 21 & $(5,6)$ & 21 & $(2,8)$ & 25 & $(2,0)$ & 36 & $(3,1)$ & 27 & $(1,2)$ & 12 & $(1,6)$ & 13 & $(1,3)$ & 21 & $(1,4)$ & 32 & $(2,8)$ & 19 & $(0,7)$ \\
\hline Nordirland (VK) & 10 & $(6,3)$ & 18 & $(3,4)$ & 24 & $(2,4)$ & 30 & $(4,1)$ & 23 & $(1,6)$ & 11 & $(1,9)$ & 14 & $(1,5)$ & 19 & $(1,8)$ & 26 & $(4,0)$ & 16 & $(0,8)$ \\
\hline England/Nordirland (VK) & 20 & $(5,5)$ & 21 & $(2,7)$ & 25 & $(1,9)$ & 36 & $(3,1)$ & 26 & $(1,2)$ & 12 & $(1,6)$ & 13 & $(1,3)$ & 21 & $(1,4)$ & 32 & $(2,8)$ & 18 & $(0,7)$ \\
\hline Durchschnitt & 21 & $(1,3)$ & 24 & $(0,6)$ & 30 & $(0,4)$ & 34 & $(0,7)$ & 29 & $(0,3)$ & 14 & $(0,4)$ & 17 & $(0,3)$ & 24 & $(0,3)$ & 31 & $(0,6)$ & 21 & $(0,1)$ \\
\hline \multicolumn{21}{|l|}{ Partnerländer } \\
\hline Russische Föderation* & w & w & w & w & w & w & w & w & w & w & w & w & w & w & w & w & w & w & w & w \\
\hline
\end{tabular}

* Hinweis zu den Daten der Russischen Föderation s. Abschnitt Angewandte Methodik.

Anmerkung: Die Spalten mit getrennten Angaben zu Lesekompetenzstufe 4 oder 5 sowie für eine Ausbildung unterhalb Sekundarbereich II, d.h. die Spalten (7) und (8), sind im Internet verfügbar (s. StatLink unten).

Quelle: OECD. Survey of Adult Skills (PIAAC) (2012). PIAAC steht für das OECD Programme for the International Assessment of Adult Competencies.

Hinweise s. Anhang 3 unter www.oecd.org/edu/eag.htm. StatLink: http://dx.doi.org/10.1787/888933116604

Erläuterung der Kennzeichnung fehlender Daten s. Hinweise für den Leser. 
Tabelle A8.4a (L)

Anteil Erwachsener (in \%), die angeben, dass sie glauben, einen Einfluss auf das zu haben, was die Regierung macht, nach Bildungsstand und Lesekompetenz (2012)

Lesekompetenzstufe in der Erhebung zu den grundlegenden Kompetenzen Erwachsener, 25- bis 64-Jährige

\begin{tabular}{|c|c|c|c|c|c|c|c|c|c|c|c|c|c|c|c|c|c|c|}
\hline & \multicolumn{8}{|c|}{ Ausbildung unterhalb Sekundarbereich II } & \multicolumn{10}{|c|}{$\begin{array}{l}\text { Abschluss im Sekundarbereich II } \\
\text { bzw. postsekundaren, nicht tertiären Bereich }\end{array}$} \\
\hline & \multicolumn{2}{|c|}{ Stufe $0 / 1$} & \multicolumn{2}{|c|}{ Stufe 2} & \multicolumn{2}{|c|}{ Stufe 3} & \multicolumn{2}{|c|}{ Gesamt } & \multicolumn{2}{|c|}{ Stufe 0/1 } & \multicolumn{2}{|c|}{ Stufe 2} & \multicolumn{2}{|c|}{ Stufe 3} & \multicolumn{2}{|c|}{ Stufe $4 / 5$} & \multicolumn{2}{|c|}{ Gesamt } \\
\hline & $\%$ & S.F. & $\%$ & S.F. & $\%$ & S.F. & $\%$ & S.F. & $\%$ & S.F. & $\%$ & S.F. & $\%$ & S.F. & $\%$ & S.F. & $\%$ & S.F. \\
\hline & (1) & (2) & (3) & (4) & (5) & (6) & (9) & (10) & (11) & (12) & (13) & (14) & (15) & (16) & (17) & (18) & (19) & (20) \\
\hline \multicolumn{19}{|l|}{$\begin{array}{l}\text { OECD } \\
\text { Nationale Einheiten }\end{array}$} \\
\hline Australien & 18 & $(2,6)$ & 21 & $(2,3)$ & 30 & $(3,1)$ & 24 & $(1,3)$ & 23 & $(3,5)$ & 26 & $(2,3)$ & 32 & $(2,3)$ & 43 & $(4,3)$ & 30 & $(1,1)$ \\
\hline Österreich & 15 & $(3,0)$ & 18 & $(2,5)$ & 25 & $(4,2)$ & 19 & $(1,6)$ & 23 & $(2,6)$ & 26 & $(1,6)$ & 35 & $(1,9)$ & 40 & $(4,9)$ & 30 & $(1,0)$ \\
\hline Kanada & 20 & $(2,1)$ & 21 & $(2,5)$ & 35 & $(6,0)$ & 22 & $(1,4)$ & 24 & $(2,1)$ & 28 & $(1,5)$ & 37 & $(1,7)$ & 37 & $(4,9)$ & 31 & $(0,9)$ \\
\hline Tschechien & 19 & $(6,3)$ & 19 & $(5,3)$ & 17 & $(6,9)$ & 19 & $(3,0)$ & 15 & $(3,8)$ & 17 & $(2,0)$ & 24 & $(2,4)$ & 22 & $(7,6)$ & 20 & $(1,2)$ \\
\hline Dänemark & 33 & $(3,1)$ & 42 & $(3,3)$ & 55 & $(4,9)$ & 41 & $(1,6)$ & 37 & $(2,8)$ & 46 & $(2,3)$ & 51 & $(2,8)$ & 54 & $(8,0)$ & 47 & $(1,2)$ \\
\hline Estland & 17 & $(2,4)$ & 16 & $(2,2)$ & 17 & $(3,0)$ & 17 & $(1,2)$ & 12 & $(1,8)$ & 17 & $(1,2)$ & 27 & $(1,6)$ & 38 & $(4,0)$ & 21 & $(0,8)$ \\
\hline Finnland & 27 & $(4,4)$ & 32 & $(3,6)$ & 33 & $(4,9)$ & 31 & $(2,4)$ & 42 & $(3,8)$ & 39 & $(2,7)$ & 42 & $(2,3)$ & 51 & $(4,3)$ & 42 & $(1,2)$ \\
\hline Frankreich & w & w & w & w & w & w & w & w & w & w & w & w & w & w & w & w & w & w \\
\hline Deutschland & 12 & $(2,9)$ & 15 & $(3,9)$ & 13 & $(8,2)$ & 13 & $(2,1)$ & 17 & $(2,3)$ & 18 & $(1,5)$ & 26 & $(1,9)$ & 31 & $(5,0)$ & 21 & $(0,8)$ \\
\hline Irland & 18 & $(2,3)$ & 16 & $(2,3)$ & 19 & $(4,3)$ & 18 & $(1,4)$ & 16 & $(2,9)$ & 25 & $(1,8)$ & 28 & $(2,2)$ & 37 & $(7,0)$ & 26 & $(1,2)$ \\
\hline Italien & 11 & $(1,7)$ & 13 & $(2,0)$ & 16 & $(4,0)$ & 12 & $(1,3)$ & 13 & $(2,5)$ & 19 & $(1,8)$ & 22 & $(2,2)$ & 26 & $(7,1)$ & 19 & $(1,1)$ \\
\hline Japan & 14 & $(4,2)$ & 14 & $(3,4)$ & 22 & $(4,0)$ & 17 & $(1,8)$ & 14 & $(4,4)$ & 16 & $(1,9)$ & 23 & $(1,6)$ & 34 & $(3,7)$ & 22 & $(1,0)$ \\
\hline Korea & 21 & $(2,4)$ & 31 & $(2,7)$ & 39 & $(5,6)$ & 28 & $(1,5)$ & 24 & $(3,4)$ & 27 & $(1,7)$ & 35 & $(2,1)$ & 40 & $(7,8)$ & 30 & $(1,2)$ \\
\hline Niederlande & 22 & $(2,6)$ & 28 & $(2,2)$ & 35 & $(3,0)$ & 28 & $(1,5)$ & 33 & $(4,6)$ & 30 & $(2,4)$ & 36 & $(2,2)$ & 50 & $(4,3)$ & 36 & $(1,3)$ \\
\hline Norwegen & 24 & $(4,0)$ & 28 & $(3,1)$ & 43 & $(4,2)$ & 32 & $(1,8)$ & 29 & $(4,0)$ & 39 & $(2,8)$ & 50 & $(2,6)$ & 59 & $(5,9)$ & 44 & $(1,6)$ \\
\hline Polen & w & w & w & w & w & w & w & w & w & w & w & w & w & w & w & w & w & w \\
\hline Slowakei & 9 & $(2,1)$ & 12 & $(2,3)$ & 14 & $(3,6)$ & 11 & $(1,1)$ & 16 & $(2,8)$ & 20 & $(1,5)$ & 20 & $(1,5)$ & 27 & $(4,5)$ & 20 & $(0,8)$ \\
\hline Spanien & 18 & $(1,6)$ & 21 & $(1,8)$ & 20 & $(2,7)$ & 19 & $(0,9)$ & 21 & $(3,8)$ & 23 & $(2,7)$ & 23 & $(2,8)$ & 29 & $(12,2)$ & 23 & $(1,4)$ \\
\hline Schweden & 27 & $(4,0)$ & 34 & $(4,2)$ & 41 & $(5,7)$ & 34 & $(2,5)$ & 30 & $(4,7)$ & 34 & $(2,4)$ & 49 & $(2,2)$ & 56 & $(4,8)$ & 43 & $(1,2)$ \\
\hline $\begin{array}{l}\text { Vereinigte Staaten } \\
\text { Subnationale Einheiten }\end{array}$ & 29 & $(3,2)$ & 28 & $(6,6)$ & 28 & $(12,7)$ & 29 & $(2,4)$ & 37 & $(2,5)$ & 37 & $(2,1)$ & 47 & $(2,9)$ & 58 & $(6,1)$ & 41 & $(1,2)$ \\
\hline Flandern (Belgien) & 22 & $(2,7)$ & 22 & $(2,6)$ & 27 & $(4,4)$ & 23 & $(1,4)$ & 28 & $(3,2)$ & 26 & $(2,0)$ & 27 & $(2,2)$ & 32 & $(5,8)$ & 27 & $(1,0)$ \\
\hline England (VK) & 18 & $(2,8)$ & 20 & $(2,5)$ & 29 & $(4,3)$ & 22 & $(1,5)$ & 21 & $(3,9)$ & 27 & $(2,6)$ & 31 & $(2,4)$ & 41 & $(5,3)$ & 29 & $(1,4)$ \\
\hline Nordirland (VK) & 14 & $(2,1)$ & 15 & $(2,1)$ & 14 & $(3,8)$ & 15 & $(1,0)$ & 17 & $(4,8)$ & 19 & $(2,7)$ & 23 & $(3,0)$ & 32 & $(7,0)$ & 21 & $(1,5)$ \\
\hline England/Nordirland (VK) & 18 & $(2,6)$ & 20 & $(2,4)$ & 29 & $(4,1)$ & 21 & $(1,5)$ & 20 & $(3,8)$ & 27 & $(2,6)$ & 31 & $(2,3)$ & 40 & $(5,2)$ & 29 & $(1,3)$ \\
\hline Durchschnitt & 20 & $(0,7)$ & 23 & $(0,7)$ & 28 & $(1,2)$ & 23 & $(0,4)$ & 24 & $(0,8)$ & 27 & $(0,5)$ & 33 & $(0,5)$ & 40 & $(1,4)$ & 30 & $(0,3)$ \\
\hline \multicolumn{19}{|l|}{ Partnerländer } \\
\hline Russische Föderation* & w & w & w & w & w & w & w & w & w & w & w & w & w & w & w & w & w & w \\
\hline
\end{tabular}

* Hinweis zu den Daten der Russischen Föderation s. Abschnitt Angewandte Methodik.

Anmerkung: Die Spalten mit getrennten Angaben zu Lesekompetenzstufe 4 oder 5 sowie für eine Ausbildung unterhalb Sekundarbereich II, d. $h$. die Spalten (7) und (8), sind im Internet verfügbar (s. StatLink unten).

Quelle: OECD. Survey of Adult Skills (PIAAC) (2012). PIAAC steht für das OECD Programme for the International Assessment of Adult Competencies.

Hinweise s. Anhang 3 unter www.oecd.org/edu/eag.htm. StatLink: http://dx.doi.org/10.1787/888933116623

Erläuterung der Kennzeichnung fehlender Daten s. Hinweise für den Leser. 
Tabelle A8.4a (L) (Forts.)

Anteil Erwachsener (in \%), die angeben, dass sie glauben, einen Einfluss auf das zu haben, was die Regierung macht, nach Bildungsstand und Lesekompetenz (2012)

Lesekompetenzstufe in der Erhebung zu den grundlegenden Kompetenzen Erwachsener, 25- bis 64-Jährige

\begin{tabular}{|c|c|c|c|c|c|c|c|c|c|c|c|c|c|c|c|c|c|c|c|c|}
\hline & \multicolumn{10}{|c|}{ Abschluss im Tertiärbereich } & \multicolumn{10}{|c|}{ Alle Bildungsbereiche zusammen } \\
\hline & \multicolumn{2}{|c|}{ Stufe $0 / 1$} & \multicolumn{2}{|c|}{ Stufe 2} & \multicolumn{2}{|c|}{ Stufe 3} & \multicolumn{2}{|c|}{ Stufe $4 / 5$} & \multicolumn{2}{|c|}{ Gesamt } & \multicolumn{2}{|c|}{ Stufe $0 / 1$} & \multicolumn{2}{|c|}{ Stufe 2} & \multicolumn{2}{|c|}{ Stufe 3} & \multicolumn{2}{|c|}{ Stufe $4 / 5$} & \multicolumn{2}{|c|}{ Gesamt } \\
\hline & $\%$ & S.F. & $\%$ & S.F. & $\%$ & S.F. & $\%$ & S.F. & $\%$ & S.F. & $\%$ & S.F. & $\%$ & S.F. & $\%$ & S.F. & $\%$ & S.F. & $\%$ & S.F. \\
\hline & $(21)$ & (22) & (23) & $(24)$ & $(25)$ & $(26)$ & $(27)$ & $(28)$ & $(29)$ & (30) & (31) & (32) & (33) & (34) & (35) & $(36)$ & (37) & (38) & (39) & $(40)$ \\
\hline \multicolumn{21}{|l|}{$\begin{array}{l}\text { OECD } \\
\text { Nationale Einheiten }\end{array}$} \\
\hline Australien & 24 & $(6,9)$ & 36 & $(2,9)$ & 43 & $(2,2)$ & 57 & $(2,6)$ & 45 & $(1,2)$ & 20 & $(1,9)$ & 27 & $(1,5)$ & 36 & $(1,4)$ & 53 & $(2,0)$ & 34 & $(0,6)$ \\
\hline Österreich & 32 & $(10,4)$ & 35 & $(3,9)$ & 46 & $(2,6)$ & 47 & $(4,4)$ & 43 & $(1,6)$ & 20 & $(2,0)$ & 25 & $(1,3)$ & 37 & $(1,5)$ & 44 & $(2,9)$ & 30 & $(0,8)$ \\
\hline Kanada & 29 & $(2,6)$ & 35 & $(1,7)$ & 43 & $(1,4)$ & 51 & $(2,1)$ & 42 & $(0,8)$ & 24 & $(1,3)$ & 30 & $(1,0)$ & 41 & $(1,1)$ & 49 & $(1,9)$ & 36 & $(0,5)$ \\
\hline Tschechien & c & c & 25 & $(6,4)$ & 27 & $(4,0)$ & 34 & $(4,9)$ & 28 & $(2,4)$ & 16 & $(3,2)$ & 18 & $(2,0)$ & 24 & $(2,2)$ & 29 & $(3,9)$ & 21 & $(1,1)$ \\
\hline Dänemark & 36 & $(4,8)$ & 54 & $(2,6)$ & 61 & $(1,8)$ & 63 & $(3,1)$ & 59 & $(1,1)$ & 35 & $(1,9)$ & 47 & $(1,5)$ & 57 & $(1,6)$ & 61 & $(3,1)$ & 51 & $(0,8)$ \\
\hline Estland & 18 & $(3,5)$ & 21 & $(1,9)$ & 34 & $(1,6)$ & 47 & $(2,8)$ & 32 & $(1,0)$ & 15 & $(1,4)$ & 18 & $(1,0)$ & 30 & $(1,0)$ & 44 & $(2,4)$ & 25 & $(0,5)$ \\
\hline Finnland & 41 & $(7,4)$ & 51 & $(3,6)$ & 57 & $(2,2)$ & 66 & $(2,0)$ & 59 & $(1,1)$ & 36 & $(2,8)$ & 41 & $(1,9)$ & 49 & $(1,5)$ & 61 & $(2,0)$ & 48 & $(0,8)$ \\
\hline Frankreich & w & $w$ & w & w & w & w & w & w & w & w & w & w & w & w & w & w & w & w & w & w \\
\hline Deutschland & 17 & $(5,1)$ & 27 & $(2,9)$ & 35 & $(2,0)$ & 38 & $(3,1)$ & 33 & $(1,3)$ & 15 & $(1,8)$ & 20 & $(1,2)$ & 30 & $(1,3)$ & 35 & $(2,5)$ & 24 & $(0,7)$ \\
\hline Irland & 35 & $(6,6)$ & 34 & $(2,9)$ & 39 & $(1,9)$ & 44 & $(3,5)$ & 38 & $(1,2)$ & 20 & $(1,8)$ & 24 & $(1,2)$ & 32 & $(1,4)$ & 42 & $(3,3)$ & 28 & $(0,7)$ \\
\hline Italien & 26 & $(7,4)$ & 31 & $(4,5)$ & 26 & $(3,3)$ & 37 & $(8,3)$ & 29 & $(2,2)$ & 12 & $(1,4)$ & 17 & $(1,4)$ & 22 & $(1,8)$ & 31 & $(5,4)$ & 17 & $(0,9)$ \\
\hline Japan & c & & 24 & $(3,3)$ & 32 & $(1,5)$ & 41 & $(2,0)$ & 34 & $(1,0)$ & 16 & $(3,2)$ & 18 & $(1,6)$ & 27 & $(1,1)$ & 38 & $(1,8)$ & 27 & $(0,6)$ \\
\hline Korea & 30 & $(8,0)$ & 34 & $(2,2)$ & 44 & $(1,8)$ & 51 & $(3,9)$ & 42 & $(1,3)$ & 23 & $(2,0)$ & 30 & $(1,2)$ & 41 & $(1,4)$ & 48 & $(3,6)$ & 35 & $(0,8)$ \\
\hline Niederlande & 28 & $(10,0)$ & 46 & $(4,5)$ & 54 & $(2,2)$ & 62 & $(2,6)$ & 55 & $(1,5)$ & 25 & $(2,4)$ & 32 & $(1,6)$ & 43 & $(1,5)$ & 58 & $(2,3)$ & 41 & $(0,9)$ \\
\hline Norwegen & 36 & $(5,6)$ & 52 & $(3,5)$ & 67 & $(2,0)$ & 74 & $(2,5)$ & 65 & $(1,1)$ & 27 & $(2,5)$ & 39 & $(1,8)$ & 57 & $(1,5)$ & 70 & $(2,3)$ & 50 & $(0,8)$ \\
\hline Polen & w & w & w & w & w & w & w & w & w & w & w & w & w & w & w & w & w & w & w & w \\
\hline Slowakei & c & $c$ & 23 & $(3,8)$ & 36 & $(2,8)$ & 48 & $(6,4)$ & 35 & $(2,0)$ & 13 & $(2,0)$ & 19 & $(1,2)$ & 24 & $(1,4)$ & 37 & $(3,6)$ & 22 & $(0,7)$ \\
\hline Spanien & 24 & $(5,3)$ & 28 & $(2,7)$ & 31 & $(2,2)$ & 37 & $(4,3)$ & 30 & $(1,2)$ & 19 & $(1,6)$ & 23 & $(1,2)$ & 27 & $(1,6)$ & 35 & $(3,9)$ & 24 & $(0,6)$ \\
\hline Schweden & 44 & $(6,5)$ & 45 & $(4,2)$ & 56 & $(2,3)$ & 62 & $(2,4)$ & 56 & $(1,4)$ & 30 & $(2,9)$ & 36 & $(1,8)$ & 51 & $(1,5)$ & 60 & $(2,1)$ & 46 & $(0,9)$ \\
\hline $\begin{array}{l}\text { Vereinigte Staaten } \\
\text { Subnationale Einheiten }\end{array}$ & 32 & $(6,3)$ & 47 & $(2,8)$ & 55 & $(2,0)$ & 63 & $(3,2)$ & 54 & $(1,5)$ & 34 & $(1,8)$ & 39 & $(1,7)$ & 51 & $(1,7)$ & 62 & $(3,0)$ & 45 & $(1,0)$ \\
\hline Flandern (Belgien) & 33 & $(9,3)$ & 39 & $(3,9)$ & 43 & $(2,1)$ & 50 & $(2,8)$ & 44 & $(1,3)$ & 26 & $(1,9)$ & 28 & $(1,4)$ & 36 & $(1,4)$ & 46 & $(2,5)$ & 33 & $(0,8)$ \\
\hline England (VK) & 33 & $(6,7)$ & 33 & $(3,2)$ & 43 & $(2,4)$ & 52 & $(3,2)$ & 42 & $(1,4)$ & 21 & $(2,3)$ & 27 & $(1,8)$ & 37 & $(1,6)$ & 48 & $(2,7)$ & 33 & $(0,9)$ \\
\hline Nordirland (VK) & 23 & $(8,2)$ & 31 & $(4,6)$ & 35 & $(2,9)$ & 47 & $(4,5)$ & 36 & $(1,9)$ & 16 & $(2,0)$ & 20 & $(1,8)$ & 27 & $(1,8)$ & 42 & $(3,8)$ & 24 & $(0,8)$ \\
\hline England/Nordirland (VK) & 33 & $(6,6)$ & 33 & $(3,1)$ & 43 & $(2,3)$ & 52 & $(3,1)$ & 42 & $(1,4)$ & 21 & $(2,2)$ & 26 & $(1,7)$ & 36 & $(1,5)$ & 48 & $(2,6)$ & 32 & $(0,9)$ \\
\hline Durchschnitt & 30 & $(1,7)$ & 36 & $(0,8)$ & 44 & $(0,5)$ & 51 & $(0,9)$ & 43 & $(0,3)$ & 22 & $(0,5)$ & 28 & $(0,3)$ & 38 & $(0,3)$ & 48 & $(0,7)$ & 33 & $(0,2)$ \\
\hline
\end{tabular}

Partnerländer

Russische Föderation*

* Hinweis zu den Daten der Russischen Föderation s. Abschnitt Angewandte Methodik.

Anmerkung: Die Spalten mit getrennten Angaben zu Lesekompetenzstufe 4 oder 5 sowie für eine Ausbildung unterhalb Sekundarbereich II, d. $h$. die Spalten (7) und (8), sind im Internet verfügbar (s. StatLink unten).

Quelle: OECD. Survey of Adult Skills (PIAAC) (2012). PIAAC steht für das OECD Programme for the International Assessment of Adult Competencies.

Hinweise s. Anhang 3 unter www.oecd.org/edu/eag.htm. StatLink: http://dx.doi.org/10.1787/888933116623

Erläuterung der Kennzeichnung fehlender Daten s. Hinweise für den Leser. 



\section{indikatior A}

\section{Wie hängen Schülerleistungen und Chancengerechtigkeit zusammen?}

- Von allen Ländern und Volkswirtschaften, die an PISA 2012 teilnahmen, schneidet Shanghai (VR China) im Bereich Mathematik mit einer mittleren Punktzahl von 6I3 Punkten am besten ab, es liegt damit II9 Punkte über dem OECD-Durchschnitt, was nahezu drei Jahren formaler Bildung entspricht. Singapur, Hongkong (VR China), Taipeh (Republik China), Korea, Macau (VR China), Japan, Liechtenstein, Schweiz und die Niederlande folgen nach erzielten Punkten und schließen die Liste der Io leistungsstärksten Länder in Mathematik ab.

In 37 der 64 Länder, die an PISA 2012 teilnahmen, schnitten Jungen besser ab als Mädchen, in 5 Ländern dagegen erzielten Mädchen bessere Ergebnisse als Jungen.

Wie PISA 2012 erkennen lässt, gelingt es Australien, Estland, Finnland, Hongkong (VR China), Japan, Kanada, Korea, Liechtenstein, den Niederlanden und Macau (VR China), gleichzeitig hohe Leistungen und Chancengerechtigkeit bei den Bildungsangeboten zu erreichen.

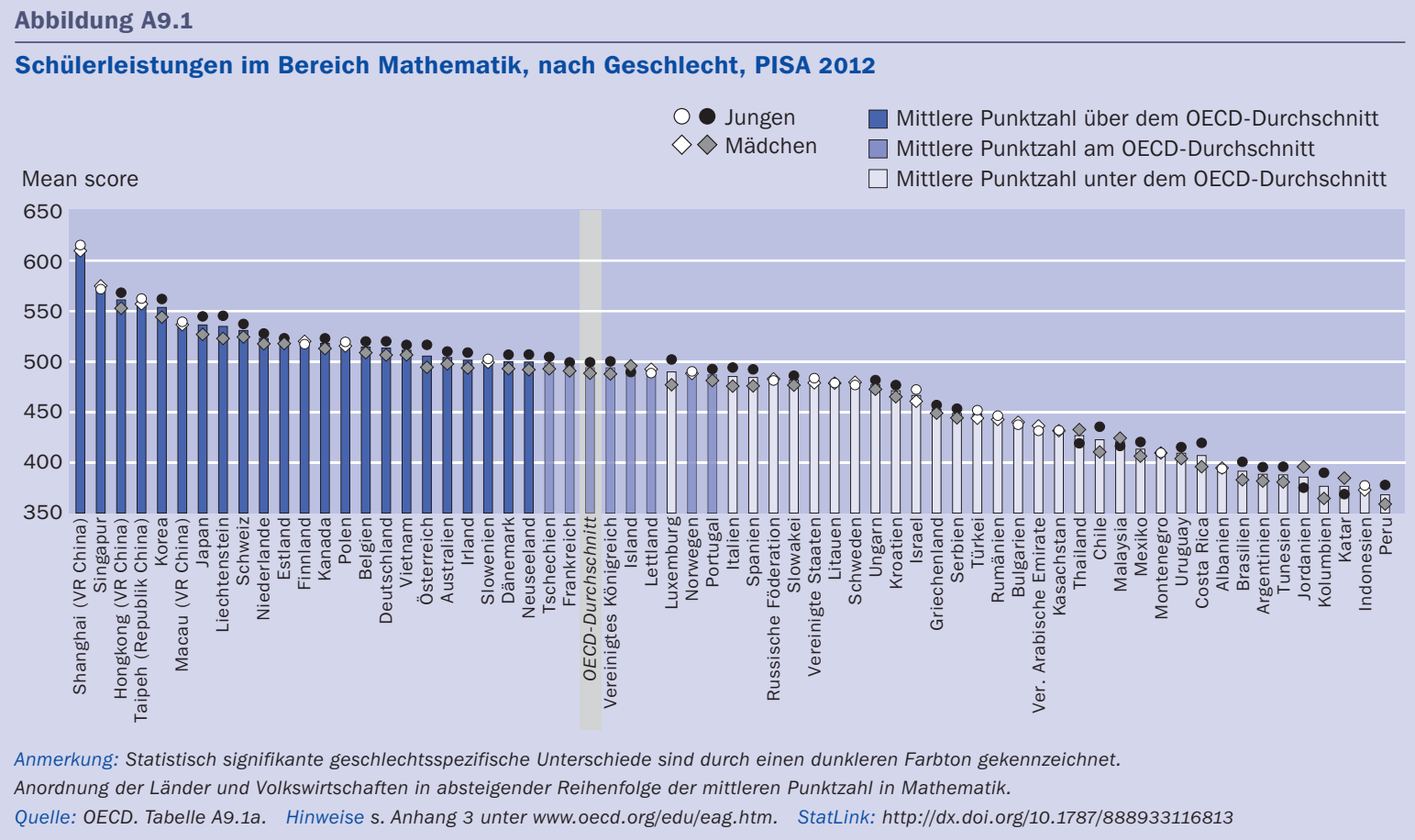

\section{Kontext}

Mit ihrem Schwerpunkt auf Mathematik untersuchte die Internationale Schulleistungsstudie PISA 2012 das mathematische Denken 15-jähriger Schüler und ihren Einsatz mathematischer Konzepte, Verfahren, Fakten und Instrumente, um Phänomene zu beschreiben, zu erklären und vorherzusagen. Die Erhebung, die im Dreijahresturnus durchgeführt wird, untersucht Schülerleistungen in den Bereichen Lesen, 
Mathematik, Naturwissenschaften und Problemlösen. Geprüft wird jedoch nicht nur, ob die Schüler Gelerntes wiedergeben können, sondern es wird auch untersucht, wie gut sie aus dem Gelernten extrapolieren und ihr Wissen in ungewohnten Situationen - sowohl im schulischen als auch im außerschulischen Kontext - anwenden können. Dieser Ansatz basiert auf der Tatsache, dass für den Einzelnen in modernen Volkswirtschaften nicht das Wissen entscheidend ist, sondern die Fähigkeit, dieses Wissen anzuwenden.

Die PISA-Ergebnisse verdeutlichen, was im Bildungsbereich möglich ist, indem sie aufzeigen, was die Schüler in den Bildungssystemen, die am besten abschneiden und die am schnellsten Verbesserungen erzielen, leisten können. Die Ergebnisse ermöglichen es den politischen Entscheidungsträgern in aller Welt, die Kenntnisse und Fähigkeiten der Schüler des eigenen Landes im Vergleich zu denen anderer Länder zu beurteilen, politische Vorgaben festzulegen, die sich an in anderen Bildungssystemen erreichten messbaren Zielen orientieren, und von in anderen Ländern angewandten Grundsätzen und Verfahren zu lernen.

Analysiert man die Ergebnisse der PISA-Studie mit Blick auf verschiedene demografische und soziale Merkmale der Schüler und Schulen, wie z. B. Geschlecht, sozioökonomischen Status und Migrationshintergrund, zeigt die Studie auch, wie gut es den teilnehmenden Ländern gelingt, Chancengerechtigkeit in der Bildung und bei den Bildungsergebnissen zu erzielen - ein klarer Hinweis auf die Chancengerechtigkeit in der Gesellschaft insgesamt.

\section{Weitere wichtige Ergebnisse}

Im Durchschnitt der OECD-Länder erreichen 13 Prozent der Schüler Spitzenleistungen im Bereich Mathematik (Stufe 5 oder 6). Gleichzeitig gehören 23 Prozent der Schüler in den OECD-Ländern und 32 Prozent der Schüler in allen teilnehmenden Ländern zu den leistungsschwächsten Schülern in Mathematik (d. h., sie bleiben unterhalb der Grundkompetenzstufe 2).

Nur in sechs Ländern entspricht der Leistungsabstand bei Mathematik zwischen Jungen und Mädchen - zugunsten der Jungen - mehr als einem halben Jahr formaler Bildung.

Im Durchschnitt aller OECD-Länder lassen sich 15 Prozent des Leistungsunterschiedes zwischen den Schülern durch Unterschiede im sozioökonomischen Status der Schüler erklären. In Ländern, in denen dieser Zusammenhang stark ausgeprägt ist, ist die Wahrscheinlichkeit geringer, dass Schüler aus benachteiligten Familien Spitzenleistungen erzielen. Noch aufschlussreicher ist die Tatsache, dass sich die Mathematikleistungen der Schüler mit einem günstigen sozioökonomischen Hintergrund und derjenigen Schüler, deren sozioökonomischer Status eher dem OECD-Durchschnitt entspricht, um rund 39 Ergebnispunkte unterscheiden - was ungefähr einem Jahr formaler Bildung entspricht. 


\section{Entwicklungstendenzen}

Von den 64 Ländern und Volkswirtschaften mit Trenddaten von 2003 bis 2012 weisen 25 eine Verbesserung der Mathematikleistungen auf, in 25 ist keine Veränderung zu erkennen, und in I4 ist eine Leistungsverschlechterung zu beobachten.

Von den Ländern, die zwischen 2003 und 2012 ihre Leistungen verbesserten, gelang es Italien, Polen und Portugal, den Anteil der leistungsschwachen Schüler zu verringern und den Anteil der leistungsstarken Schüler zu vergrößern.

- Von den 39 Ländern und Volkswirtschaften, die sowohl an PISA 2003 und PISA 2012 teilnahmen, erzielten Mexiko, die Türkei und Deutschland in diesem Zeitraum sowohl eine Verbesserung der Leistungen in Mathematik als auch eine Anhebung der Chancengerechtigkeit in der Bildung.

\section{Analyse und Interpretationen}

\section{Ergebnisse aus PISA 2012}

Wie Abbildung A9.I zeigt, lassen sich die Länder und Volkswirtschaften, die an PISA teilnehmen, in drei große Gruppen einteilen: diejenigen, deren mittlere Punktzahl statistisch um den OECD-Durchschnitt herum liegt (in Mittelblau), diejenigen, deren mittlere Punktzahl oberhalb des OECD-Durchschnitts liegt (in Dunkelblau), und diejenigen, deren mittlere Punktzahl unterhalb des OECD-Durchschnitts liegt (in Hellblau). Bei PISA 2012 beträgt das Durchschnittsergebnis im Bereich Mathematik für den OECD-Raum insgesamt 494 Punkte.

Von den 64 teilnehmenden Ländern und Volkswirtschaften lagen 23 oberhalb des OECD-Durchschnitts, 7 in etwa auf diesem Wert und 34 darunter.

Zwischen dem besten und dem schlechtesten Durchschnittsergebnis der Länder/ Volkswirtschaften liegen 245 Punkte. Bei den OECD-Ländern liegt diese Differenz bei I40 Punkten. Zur Beurteilung des Umfangs der Punktzahldifferenzen sei angeführt, dass 4I Punkte einem Jahr formaler Bildung entsprechen (s. Tabelle AI. 2 in Band I von PISA 2012 Ergebnisse).

\section{Geschlechtsspezifische Leistungsunterschiede in Mathematik}

Im OECD-Durchschnitt haben die Jungen im Bereich Mathematik einen Leistungsvorsprung von II Punkten gegenüber den Mädchen. Trotz der stereotypen Vorstellung, dass Jungen in Mathematik besser sind als Mädchen, haben die Jungen nur in 37 der 64 Länder und Volkswirtschaften, die an PISA 2012 teilgenommen haben, einen Vorsprung, und dieser Vorsprung entspricht nur in 6 Ländern mehr als einem halben Schuljahr.

Bei den 23 Ländern/Volkswirtschaften mit den besten Ergebnissen schneiden nur in Shanghai (VR China), Singapur, Taipeh (Republik China), Macau (VR China), Finnland, Polen und Slowenien im Bereich Mathematik die Jungen genauso gut ab wie die 
Mädchen, in den anderen Ländern/Volkswirtschaften dieser Gruppe schneiden die Jungen besser $\mathrm{ab}$ als die Mädchen.

Die größte Punktzahldifferenz zwischen Jungen und Mädchen mit einem Unterschied von rund 25 Punkten ist in Chile, Kolumbien und Luxemburg zu beobachten. In Costa Rica, Liechtenstein und Österreich liegt die Differenz zwischen 22 und 24 Punkten.

Dagegen schneiden nur in 5 Ländern Mädchen besser ab in Mathematik als Jungen. Hierbei ist der größte Unterschied in Jordanien zu beobachten, wo die Mädchen rund 2I Punkte mehr erreichen als Jungen. Auch in Island, Malaysia, Katar und Thailand schneiden die Mädchen besser ab als die Jungen.

\section{Entwicklungstendenzen der durchschnittlichen Mathematikleistungen}

Die Entwicklung der durchschnittlichen Schülerleistungen liefert einen Indikator dafür, ob und wie sich die Schulsysteme verbessern. Daten zu den Leistungstrends in Mathematik stehen für die 64 Länder und Volkswirtschaften zur Verfügung, die an PISA 2012 teilnahmen. Für 38 dieser Länder und Volkswirtschaften liegen Mathematikergebnisse aus PISA 2012 und den drei früheren PISA-Erhebungen vor (2003, 2006 und 2009), I7 Länder und Volkswirtschaften verfügen über Ergebnisse aus der Erhebung 2012 und zwei weiteren Erhebungen und 9 Länder und Volkswirtschaften über Resultate aus dem Jahr 2012 und einer früheren Erhebung. Um die Entwicklung der Schülerleistungen eines Landes/einer Volkswirtschaft besser nachvollziehen zu können und die Zahl der Länder in den Vergleichen zu erhöhen, richtet sich das Augenmerk in diesem Indikator auf die annualisierte Veränderung der Schülerleistungen (s. die Abschnitte Definitionen und Angewandte Methodik am Ende dieses Indikators). Für Länder und Volkswirtschaften, die an allen vier PISA-Erhebungen teilgenommen haben, werden in der annualisierten Veränderung alle vier Zeitpunkte berücksichtigt, während bei Ländern mit validen Daten für weniger Erhebungen nur die validen und verfügbaren Informationen zugrunde gelegt werden.

Wie Abbildung A9.2 zeigt, blieben die Leistungen insgesamt weitgehend unverändert, doch gibt es mehr Länder, in denen sich die Mathematikleistungen verbessert haben, als Länder, in denen sie sich verschlechtert haben. Von den 64 Ländern und Volkswirtschaften mit Trenddaten bis 2012 weisen 25 durchschnittliche jährliche Verbesserungen der Mathematikleistungen auf, und in I4 ist eine durchschnittliche Leistungsverschlechterung zwischen 2003 und $2012 \mathrm{zu}$ beobachten. In den verbleibenden 25 Ländern und Volkswirtschaften veränderten sich die Mathematikergebnisse in diesem Zeitraum nicht. Albanien, Kasachstan, Katar, Malaysia und die Vereinigten Arabischen Emirate (ohne Dubai) weisen im Durchschnitt pro Jahr eine Steigerung der Mathematikleistungen um mehr als 5 Ergebnispunkte auf. Im OECD-Raum wurden Leistungssteigerungen im Bereich Mathematik in Israel (mit einer durchschnittlichen Verbesserung um mehr als 4 Punkte pro Jahr), Mexiko, der Türkei (mehr als 3 Punkte pro Jahr), Italien, Polen, Portugal (mehr als 2 Punkte pro Jahr) sowie Chile, Deutschland und Griechenland (mehr als I Punkt pro Jahr) beobachtet. Von den Ländern, die seit 2003 an allen PISA-Erhebungen teilgenommen haben, weisen Brasilien, Italien, Mexiko, Polen, Portugal, Tunesien und die Türkei eine durchschnittliche Verbesserung der Mathematikleistungen um mehr als 2,5 Punkte pro Jahr auf (Tab. A9.Ic). 
Annualisierte Veränderung der Ergebnisse im Bereich Mathematik im Verlauf der PISA-Teilnahme

Mit einem Kalenderjahr assoziierte Punktzahldifferenz im Bereich Mathematik

Zahl der vergleichbaren Ergebnisse

im Bereich Mathematik, die zur

Berechnung der annualisierten Veränderungen herangezogen wurden

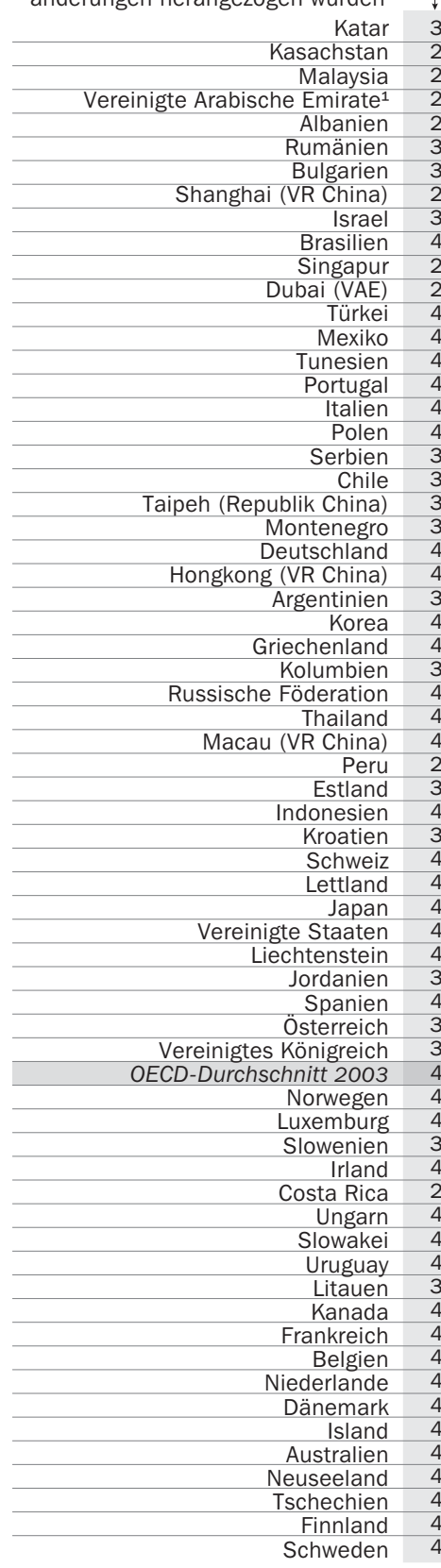

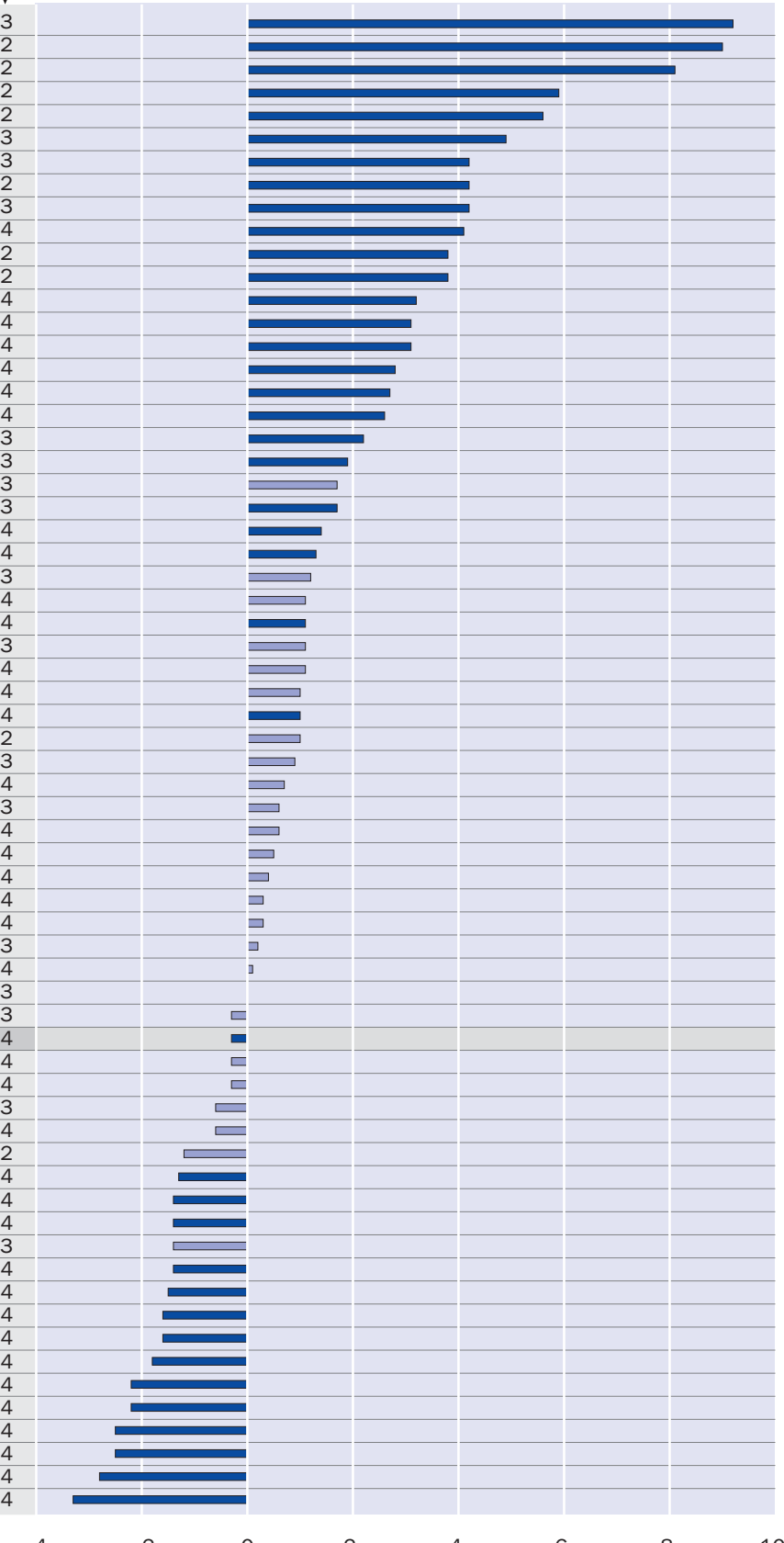

$-4$

$-2$

0

2

4

6

8
Annualisierte Veränderung der Ergebnisse im

Anmerkung: Statistisch signifikante Punktzahlveränderungen sind durch einen dunkleren Farbton gekennzeichnet. Die annualisierte Veränderung entspricht der jahresdurchschnittlichen Veränderung der PISA-Punktzahl von der ersten PISA-Teilnahme eines Landes/einer Volkswirtschaft bis zur Teilnahme an PISA 2012. Dabei wird jede PISA-Teilnahme eines Landes/einer Volkswirtschaft berücksichtigt. Der OECD-Durchschnitt 2003 umfasst nur die OECD-Länder, deren Ergebnisse im Bereich Mathematik seit dem Jahr 2003 vergleichbar sind.

1. Von den Vereinigten Arabischen Emiraten nahm nur Dubai im Jahr 2009 an der PISA-Erhebung 2009 teil, der Rest der Vereinigten Arabischen Emirate nahm 2010 im Rahmen von PISA 2009+ teil. Die Ergebnisse sind daher getrennt ausgewiesen.

Anordnung der Länder/Volkswirtschaften in absteigender Reihenfolge der annualisierten Veränderung der Ergebnisse im Bereich Mathematik. Quelle: OECD. Tabelle A9.1c. Hinweise s. Anhang 3 unter www.oecd.org/edu/eag.htm. StatLink: http://dx.doi.org/10.1787/888933116832 
Besonders leistungsstarke und besonders leistungsschwache Schüler in PISA 2012 Die Ergebnisse der PISA-Erhebung 2012 zeigen, dass die Förderung von Spitzenleistungen und die Bekämpfung von Leistungsschwächen nicht unvereinbar sein müssen. Einige Länder, die in PISA 2012 sehr gut abgeschnitten haben, wie Estland und Finnland, haben zugleich auch eine geringe Varianz der Schülerleistungen.

Fast jeder dritte Schüler in Korea ist besonders leistungsstark in Mathematik und erreicht Kompetenzstufe 5 oder 6 (eine Beschreibung der Kompetenzstufen, die die leistungsschwächsten und die leistungsstärksten Schüler erreichen, s. die Abschnitte Definitionen und Angewandte Methodik am Ende dieses Indikators). Dies ist der höchste Anteil aller OECD-Länder. Korea liegt zwar deutlich über dem OECD-Durchschnitt von I3 Prozent, dennoch bleibt dieser Anteil hinter dem in Shanghai (VR China) beobachteten Anteil zurück, wo über 50 Prozent der Schüler besonders leistungsstark sind (Tab. Ag.ra).

Bei den Ländern mit ähnlichen Mittelwerten in PISA gibt es beim Prozentsatz der besonders leistungsstarken Schülerinnen und Schüler bemerkenswerte Unterschiede. Beispielsweise weist Dänemark im Bereich Mathematik in PISA 2012 eine mittlere Punktzahl von 500 auf, und ro Prozent der Schüler erreichten dort in Mathematik die höchste Kompetenzstufe, weniger als im OECD-Durchschnitt von rund I3 Prozent. Neuseeland hat mit 500 Punkten einen ähnlichen Mittelwert bei den Mathematikleistungen, doch erreichen dort I5 Prozent der Schüler die höchste Kompetenzstufe.

In 2I Ländern und Volkswirtschaften, einschließlich der OECD-Länder Chile und Mexiko, erreichen mehr als 40 Prozent der Schüler nicht die Grundkompetenzstufe in Mathematik (Stufe 2). Im besten Falle können die Schüler einer einzelnen Quelle relevante Informationen entnehmen und elementare Algorithmen, Formeln, Verfahren oder Regeln anwenden, um Probleme mit ganzen Zahlen zu lösen. Der Anteil der I5-Jährigen, die sich in dieser Situation befinden, ist in den einzelnen Ländern sehr unterschiedlich und reicht von weniger als einem von zehn Schülern in 4 Ländern und Volkswirtschaften bis zur Mehrzahl der Schüler in I5 Ländern. Bei den meisten Schülern, deren Mathematikleistungen unter Kompetenzstufe 2 liegen, besteht nur eine geringe Wahrscheinlichkeit, über die Schulpflicht hinaus eine Schule zu besuchen, daher besteht das Risiko, dass sie ihr ganzes Leben lang Schwierigkeiten damit haben werden, mathematische Konzepte anzuwenden.

Um den Anteil der besonders leistungsstarken Schüler zu erhöhen, müssen Länder und Volkswirtschaften betrachten, inwiefern der sozioökonomische Hintergrund (s. Band II von PISA 2012 Results), der Zusammenhang zwischen den Leistungen und der Einstellung der Schüler zum Lernen (s. Band III von PISA 2012 Results) und die Organisation der Schulen, ihre Ressourcen und die Lernumgebungen (s. Band IV von PISA 2012 Results) mögliche Erfolge behindern.

\section{Entwicklungstendenzen beim Anteil der leistungsstärksten und leistungs- schwächsten Schüler}

Betrachtet man die Veränderungen beim Anteil der leistungsstärksten und leistungsschwächsten Schüler zwischen PISA 2003 und PISA 20I2, so lassen sich generelle Entwicklungen erkennen. Die einzelnen Länder und Volkswirtschaften lassen sich 
nach den Veränderungen dieser beiden Gruppen in unterschiedliche Kategorien einteilen.

- Generelle Verbesserung: Verringerung des Anteils der besonders leistungsschwachen und Erhöhung des Anteils der besonders leistungsstarken Schüler

Jene Länder und Volkswirtschaften, denen es gelungen ist, den Anteil der Schüler unter Kompetenzstufe 2 zu senken und den Anteil der Schüler über Kompetenzstufe 5 zu erhöhen, waren in der Lage, die Verbesserungen ihres Bildungssystems dem gesamten Leistungsspektrum zugutekommen zu lassen. Dies war zwischen 2003 und 2012 in Italien, Polen und Portugal zu beobachten (Abb. A9.3).

Abbau von Leistungsschwächen: Senkung des Anteils der besonders leistungsschwachen ohne Veränderung des Anteils der besonders leistungsstarken Schüler

In anderen Ländern und Volkswirtschaften konzentrierten sich die Veränderungen auf die Gruppe der Schüler, die die Grundkompetenzstufe nicht erreicht hatten. In diesen Ländern und Volkswirtschaften haben sich die Leistungen der Schüler deut-

Abbildung A9.3

Anteil der besonders leistungsstarken und der besonders leistungsschwachen Schüler in Mathematik (in \%), PISA 2003 und 2012

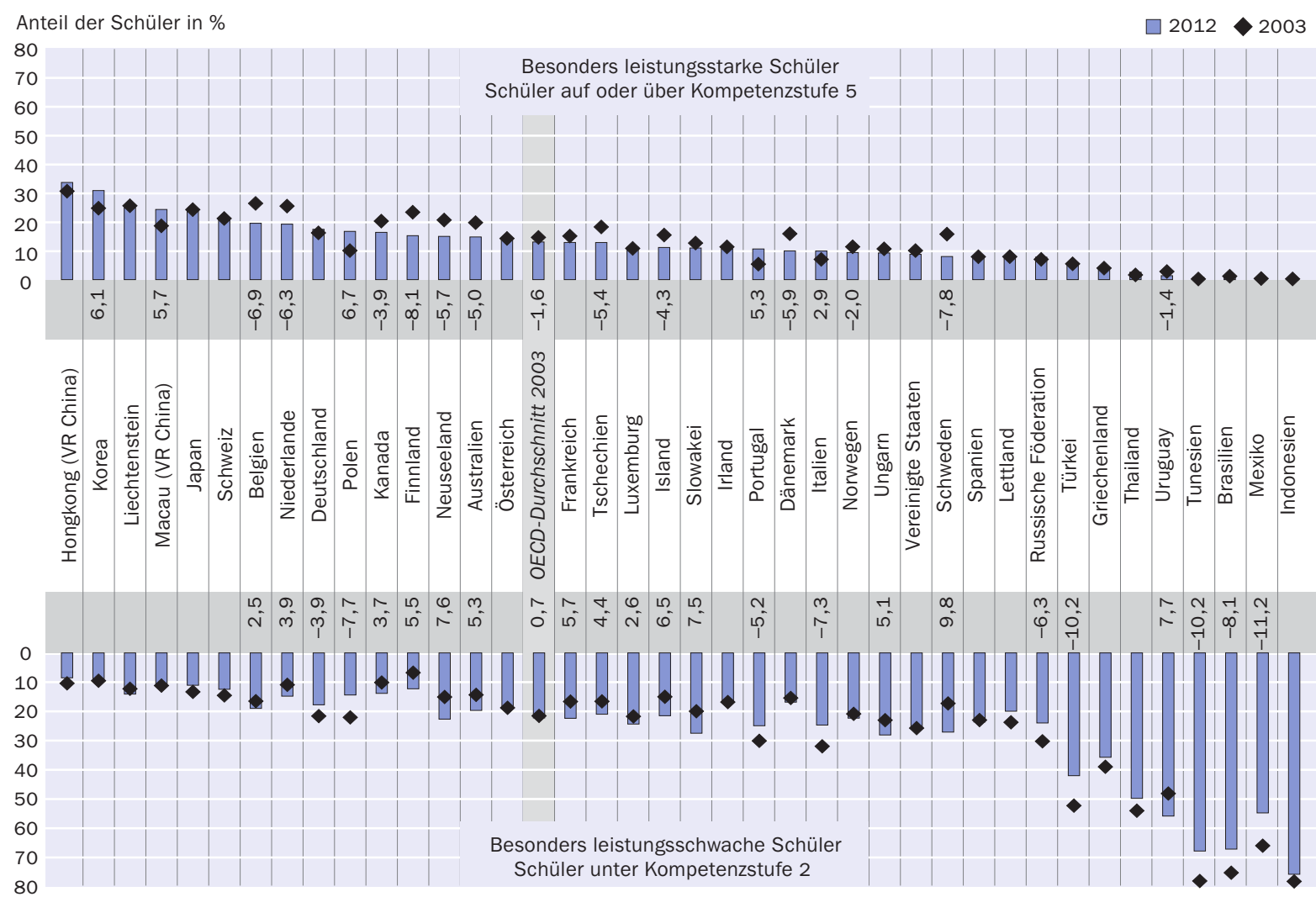

Anteil der Schüler in \%

Anmerkung: In der Abbildung sind nur die Länder/Volkswirtschaften aufgeführt, die sowohl an PISA 2003 als auch an PISA 2012 teilgenommen haben. Die Veränderung zwischen PISA 2003 und PISA 2012 beim Anteil der Schüler, deren Leistungen im Bereich Mathematik unter Stufe 2 lagen, ist unter den Namen der Länder/Volkswirtschaften angegeben. Die Veränderung zwischen PISA 2003 und PISA 2012 beim Anteil der Schüler, deren Leistungen im Bereich Mathematik auf oder über Stufe 5 lagen, ist über den Namen der Länder/Volkswirtschaften angegeben. Nur statistisch signifikante Veränderungen sind angegeben. Der OECDDurchschnitt 2003 umfasst nur die OECD-Länder, deren Ergebnisse im Bereich Mathematik seit dem Jahr 2003 vergleichbar sind.

Anordnung der Länder/Volkswirtschaften in absteigender Reihenfolge des Anteils der Schüler (in \%), die 2012 im Bereich Mathematik auf oder über Stufe 5 lagen. Quelle: OECD. Tabellen A9.1a, A9.1b und A9.1c. Hinweise s. Anhang 3 unter www.oecd.org/edu/eag.htm. StatLink: http://dx.doi.org/10.1787/888933116851 
lich verbessert, die eine Verbesserung am nötigsten hatten und die inzwischen über Grundkompetenzen verfügen, die ihnen die volle Teilhabe am Leben der Gesellschaft ermöglichen. Zwischen 2003 und 2012 verringerte sich der Anteil der Schüler, die in Mathematik unter Kompetenzstufe 2 lagen, in Brasilien, Deutschland, Mexiko, der Russischen Föderation, Tunesien und der Türkei (Abb. A9.3).

Förderung von Spitzenleistungen: Vergrößerung des Anteils der besonders leistungsstarken ohne Veränderung des Anteils der besonders leistungsschwachen Schüler

In einigen Ländern erhöhte sich der Anteil der Schüler auf oder über Kompetenzstufe 5. Hierbei handelt es sich um Schüler, die mit komplexen mathematischen Inhalten und Prozessen umgehen können. Zwischen 2003 und 2012 war in Korea und Macau (VR China) ein Anstieg des Anteils der auf dieser Stufe liegenden Schüler um etwa 6 Prozentpunkte zu beobachten (Abb. A9.3).

- Vergrößerung des Anteils der besonders leistungsschwachen oder Verringerung des Anteils der besonders leistungsstarken Schüler

In I6 Ländern ist der Anteil der Schüler, die das Grundkompetenzniveau nicht erreichten, in PISA 2012 im Vergleich zu PISA 2003 indessen gestiegen bzw. der Anteil der Schüler, die die höchste Kompetenzstufe erreichten, gesunken (Abb. A9.3).

\section{Leistungen und Chancengerechtigkeit}

Chancengerechtigkeit in der Bildung bedeutet, allen Schülern, unabhängig von ihrem sozioökonomischen Status, die Möglichkeiten zu geben, von Bildung zu profitieren. Nach dieser Definition bedeutet Chancengerechtigkeit nicht, dass jeder die gleichen Bildungsergebnisse erreichen wird. Chancengerechtigkeit bedeutet vielmehr, dass der sozioökonomische Status der Schüler sich kaum oder gar nicht auf ihre Leistungen auswirkt und dass allen Schülern, unabhängig von ihrem Hintergrund, der Zugang zu guten Bildungsressourcen und Lernangeboten offensteht.

Obwohl schlechte schulische Leistungen nicht automatisch durch einen ungünstigen sozioökonomischen Hintergrund begründet sind, scheint der sozioökonomische Hintergrund der Schüler und der Schulen die Leistungen doch stark zu beeinflussen. Sei es, weil Familien aus privilegierten Verhältnissen eher in der Lage sind, den Effekt der Schulen zu verstärken und zu verbessern, weil Schüler aus privilegierten Verhältnissen bessere Schulen besuchen oder weil es den Schulen besser gelingt, junge Menschen zu fördern und ihre Weiterentwicklung zu unterstützen, die aus privilegierten Verhältnissen kommen, in vielen Ländern reproduzieren die Schulen tendenziell die bereits existierenden Privilegien, anstatt allen eine gerechtere Verteilung der Möglichkeiten zu bieten und damit auch eine gerechtere Verteilung der Bildungsergebnisse zu erreichen.

Der sozioökonomische Hintergrund der Schüler wird erfasst durch den PISA-Index des wirtschaftlichen, sozialen und kulturellen Status, der auf den Angaben der Schüler zum Bildungsstand und der beruflichen Stellung der Eltern, zur Ausstattung des Elternhauses mit Dingen wie beispielsweise einem Schreibtisch zum Lernen und zur Zahl der Bücher basiert (s. die Abschnitte Definitionen und Angewandte Methodik am Ende dieses Indikators).

PISA legt zwei Kenngrößen für die Chancengerechtigkeit der Bildungsergebnisse fest: der Anteil der mit dem sozioökonomischen Status zusammenhängenden Leistungsvarianz (die Stärke des sozioökonomischen Gradienten) und der durchschnittliche Leis- 


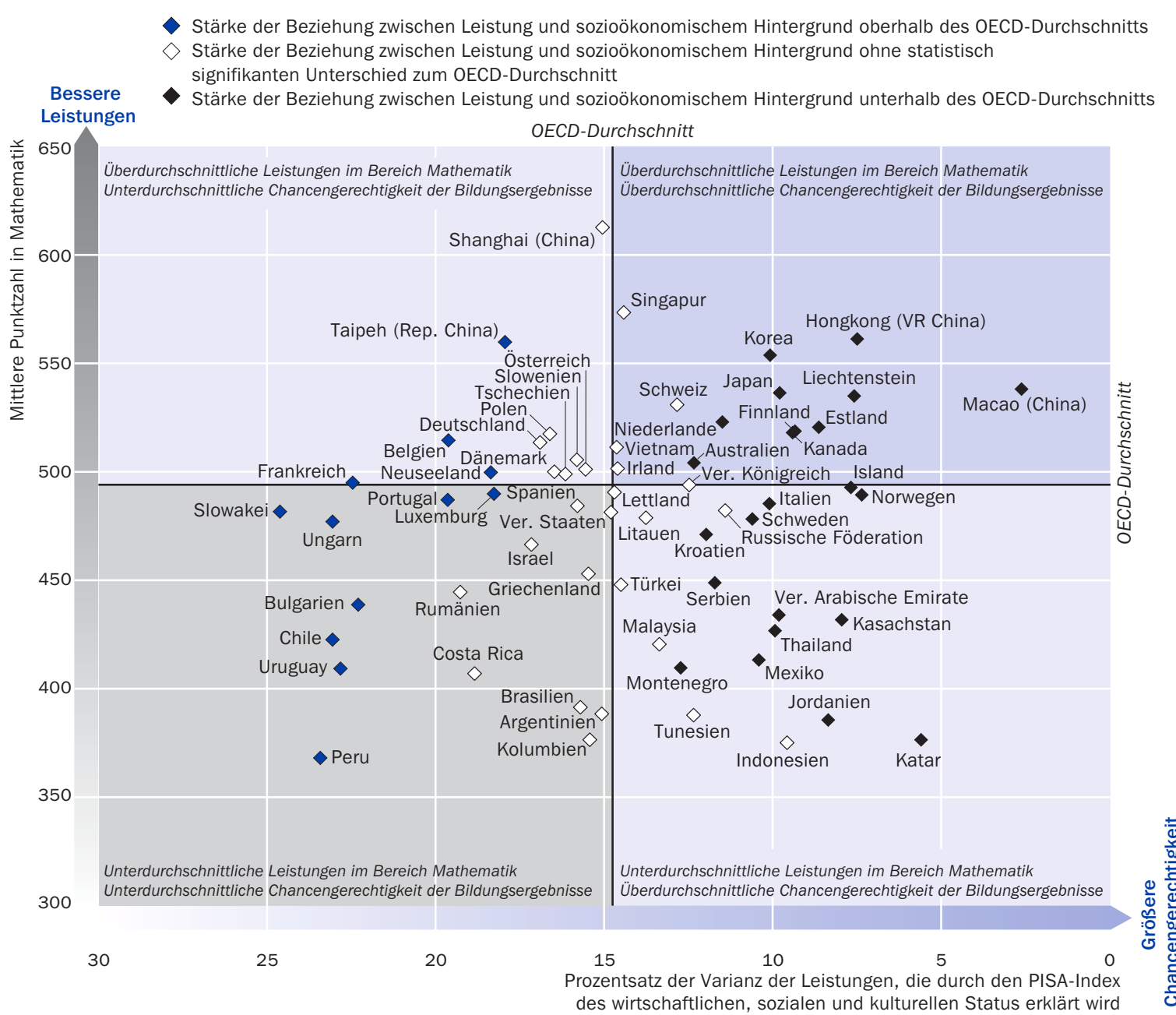

Quelle: OECD. Tabellen A9.1a and A9.2. Hinweise s. Anhang 3 unter www.oecd.org/edu/eag.htm. StatLink: http://dx.doi.org/10.1787/888933116870

tungsabstand zwischen verschiedenen sozioökonomischen Gruppen (die Steigung des sozioökonomischen Gradienten).

Der Anteil der durch den sozioökonomischen Status erklärten Leistungsvarianz dient gemeinsam mit den Leistungsunterschieden über das sozioökonomische Spektrum hinweg als hilfreicher Indikator, um zu entscheiden, ob die Bemühungen, die Schülerleistungen zu verbessern, hauptsächlich auf diejenigen Schüler zu konzentrieren sind, die schlecht abschneiden, oder eher auf Schüler aus sozioökonomisch benachteiligten Bevölkerungsschichten. Es besteht somit ein grundlegender Unterschied zwischen der Stärke des sozialen Gradienten, die darauf basiert, wie genau Schüler den auf ihrem sozioökonomischen Status basierenden Leistungsprognosen entsprechen, und der Steigung dieses Gradienten, die auf den durchschnittlichen Leistungsabstand zwischen Schülern mit unterschiedlichem sozioökonomischem Hintergrund verweist. 


\section{Sozioökonomischer Status der Schüler}

In den OECD-Ländern sind I5 Prozent der Varianz der Schülerleistungen in Mathematik auf Unterschiede beim sozioökonomischen Hintergrund der Schüler zurückzuführen. Unter den besonders leistungsstarken Ländern und Volkswirtschaften reicht dieser Anteil von 3 Prozent in Macau (VR China) bis zu 20 Prozent in Belgien. In Bulgarien, Chile, Frankreich, Peru, der Slowakei, Ungarn und Uruguay dagegen erklären sich mehr als 20 Prozent der Varianz der Schülerleistungen aus dem sozioökonomischen Hintergrund der Schüler. In den Ländern, in denen dieser Anteil groß ist, ist die Wahrscheinlichkeit, dass Schüler aus benachteiligten Familien hohe Leistungen erzielen, geringer.

Wie Abbildung A9.4 zeigt, ist die Stärke des Zusammenhangs zwischen den Leistungen und dem sozioökonomischen Status in ro der 23 Länder und Volkswirtschaften, die in PISA 2012 oberhalb des OECD-Durchschnitts liegen, schwächer ausgeprägt als im Durchschnitt. Diese ro Länder sind Australien, Estland, Finnland, Hongkong (VR China), Japan, Kanada, Korea, Liechtenstein, Macau (VR China) und die Niederlande. In weiteren Io Ländern (Dänemark, Deutschland, Irland, Österreich, Polen, Shanghai [VR China], der Schweiz, Singapur, Slowenien und Vietnam) entspricht die Stärke dieses Zusammenhangs in etwa dem Durchschnitt. Nur in 3 der leistungsstärksten Länder und Volkswirtschaften, Belgien, Neuseeland und Taipeh (Republik China), liegt die Stärke des Zusammenhangs zwischen Leistung und sozioökonomischem Status oberhalb des Durchschnitts.

Im Durchschnitt der OECD-Länder beträgt die Steigung des sozioökonomischen Gradienten 39 Punkte, was bedeutet, dass eine Veränderung um eine Indexeinheit auf dem PISA-Index des wirtschaftlichen, sozialen und kulturellen Status mit einem Unterschied von 39 erzielten Punkten in Mathematik einhergeht. Schüler mit einem sozioökonomisch günstigen Hintergrund (d. h. mit einem Wert von I auf dem Index) werden wahrscheinlich im Durchschnitt 39 Punkte mehr erreichen als Schüler, deren sozioökonomischer Status dem Mittelwert entspricht (Wert von o auf dem Index) und 78 Punkte mehr als sozioökonomisch benachteiligte Schüler (Wert von - I auf dem Index).

Von den 23 leistungsstärksten Länder und Volkswirtschaften weisen Estland, Finnland, Hongkong (VR China), Kanada, Macau (VR China) und Vietnam geringere mit dem sozioökonomischen Status zusammenhängende Leistungsunterschiede als der Durchschnitt auf, in I2 Ländern und Volkswirtschaften entsprechen diese Unterschiede in etwa dem Durchschnitt, und in 5 sind sie größer als der Durchschnitt.

In Ländern mit einem relativ flachen Gradienten, d. h., in denen die auf den sozioökonomischen Status zurückzuführenden Leistungsunterschiede gering sind, würden bildungspolitische Maßnahmen, die speziell auf Schüler mit sozioökonomisch ungünstigem Hintergrund ausgelegt sind, nicht zwangsläufig den Bedürfnissen vieler der leistungsschwächeren Schüler gerecht werden. In diesem Fall könnte es sich als effektiver erweisen, den Fokus eher auf die leistungsschwachen als auf die benachteiligten Schüler zu richten. 
Veränderung der Schülerleistungen und der Chancengerechtigkeit zwischen 2003 und 2012

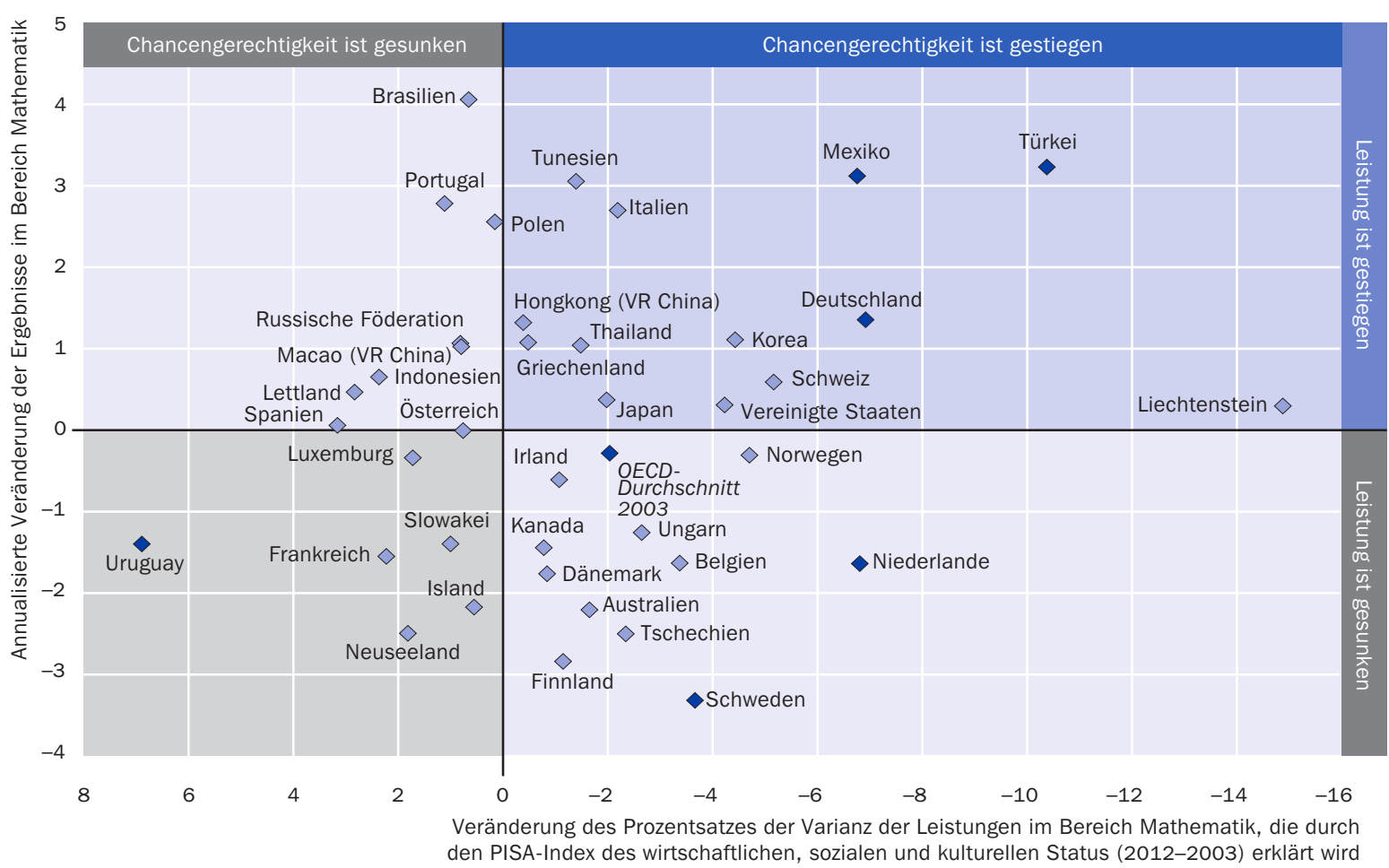

Anmerkung: Statistisch signifikante Veränderungen sowohl der Chancengerechtigkeit als auch der Leistungen zwischen 2003 und 2012 sind durch einen dunkleren Farbton gekennzeichnet. Die annualisierte Veränderung entspricht der jahresdurchschnittlichen Veränderung der PISA-Punktzahl von der ersten PISATeilnahme eines Landes/einer Volkswirtschaft bis zur Teilnahme an PISA 2012. Dabei wird jede PISA-Teilnahme eines Landes/einer Volkswirtschaft berücksichtigt. Diese Abbildung enthält nur Länder/Volkswirtschaften mit vergleichbaren Daten für PISA 2003 und PISA 2012. Um die Vergleichbarkeit über die Zeit zu erhalten, wurden die Werte des PISA-Index des wirtschaftlichen, sozialen und kulturellen Status (ESCS) aus PISA 2003 auf die Skala des Index in PISA 2012 umskaliert. Daher können sich die Ergebnisse aus PISA 2003, die in dieser Abbildung angegeben werden, von denen in Lernen für die Welt von morgen - Erste Ergebnisse von PISA 2003 (OECD, 2004) unterscheiden. Der OECD-Durchschnitt 2003 umfasst nur die OECD-Länder, deren Ergebnisse im Bereich Mathematik und Werte auf dem PISA-Index des wirtschaftlichen, sozialen und kulturellen Status seit dem Jahr 2003 vergleichbar sind.

Quelle: OECD. Tabellen A9.1c and A9.2. Hinweise s. Anhang 3 unter www.oecd.org/edu/eag.htm. StatLink: http://dx.doi.org/10.1787/888933116889

\section{Entwicklungstendenzen bei der Chancengerechtigkeit in PISA 2003 und PISA 2012}

Vergleicht man die Daten der verschiedenen PISA-Erhebungen, so kann man erkennen, welchen Ländern es gelungen ist, mehr Chancengerechtigkeit im Schulsystem zu erreichen.

Zwischen 2003 und 2012 blieb die durchschnittliche Differenz der Mathematikleistungen, die mit einer Veränderung um eine Indexeinheit auf dem PISA-Index des wirtschaftlichen, sozialen und kulturellen Status einhergeht, unverändert bei 39 Ergebnispunkten, aber das Maß, in dem der sozioökonomische Status der Schüler als Prädiktor der Mathematikleistungen diente, ging von 17 auf I5 $_{5}$ Prozent zurück. Anders ausgedrückt, 2012 war es für Schüler etwas einfacher als 2003, bessere Leistungen zu erzielen, als die Prognosen aufgrund ihres sozioökonomischen Status würden erwarten lassen.

Die Türkei und Mexiko haben sowohl die Steigung als auch die Stärke des sozioökonomischen Gradienten verringert und dadurch mehr Chancengerechtigkeit erreicht, während sie gleichzeitig auch die Gesamtleistung des Bildungssystems verbessert haben. Das heißt, dass es in diesen beiden Ländern für Schüler 2012 leichter als 2003 
war, die aufgrund ihres sozioökonomischen Status bestehenden Leistungserwartungen zu übertreffen, und dass der durchschnittliche Leistungsunterschied zwischen begünstigten und benachteiligten Schülern zurückging. In Deutschland blieb die Leistungslücke zwischen sozialökonomisch begünstigten und sozialökonomisch benachteiligten Schülern unverändert, jedoch erreichte ein größerer Anteil Schüler bessere Leistungen, als aufgrund ihres sozioökonomischen Status zu erwarten war. Entscheidend ist jedoch, dass in diesen drei Ländern die Verbesserung der Chancengerechtigkeit mit einer Verbesserung der Leistungen in Mathematik einherging (Abb. A9.5 und Tab. A9.2).

In anderen Länder und Volkswirtschaften, denen es gelungen ist, die Leistungen in Mathematik zu verbessern (Brasilien, Griechenland, Hongkong [VR China], Italien, Macau [VR China], Polen und Tunesien), blieb die Chancengerechtigkeit unverändert, nur in Portugal ging die Verbesserung der Leistung mit einem Rückgang der Chancengerechtigkeit einher (Tab. A9.2). Diese Ergebnisse zeigen, dass in den meisten Ländern und Volkswirtschaften eine Verbesserung der Leistungen nicht auf Kosten der Chancengerechtigkeit erfolgen muss (s. Band II der PISA 2012 Results).

\section{Definitionen}

Die annualisierte Veränderung entspricht der durchschnittlichen Rate, mit der sich die Durchschnittsergebnisse eines Landes/einer Volkswirtschaft in Mathematik im Verlauf der Teilnahme an den PISA-Erhebungen verändert haben. So deutet eine positive annualisierte Veränderung von x Punkten darauf hin, dass das Land/die Volkswirtschaft seine/ihre Leistungen seit der ersten PISA-Erhebung, aus der vergleichbare Ergebnisse vorliegen, um x Punkte pro Jahr verbessert hat. Bei Ländern/Volkswirtschaften, die nur an zwei PISA-Erhebungen teilgenommen haben, entspricht die annualisierte Veränderung der Differenz zwischen den beiden Erhebungen, dividiert durch die Zahl der Jahre, die zwischen den Erhebungen verstrichen sind.

Besonders leistungsschwache Schüler in Mathematik bleiben unterhalb der Grundkompetenzstufe 2 der PISA-Erhebung. Auf Stufe 2 können Schüler Situationen in Kontexten interpretieren und erkennen, die einen direkten Zugriff gestatten; sie können relevante Informationen einer einzigen Quelle entnehmen und eine einzige Darstellungsform benutzen; Schüler auf dieser Stufe können elementare Algorithmen, Formeln, Verfahren oder Regeln anwenden, um Probleme mit ganzen Zahlen zu lösen, und wörtliche Interpretationen vornehmen.

Besonders leistungsstarke Schüler in Mathematik erreichen Kompetenzstufe 5 oder 6 der PISA-Skala. Sie können Modelle für komplexe Situationen konzipieren und mit ihnen arbeiten, einschränkende Bedingungen identifizieren und Annahmen spezifizieren; sie können im Zusammenhang mit diesen Modellen geeignete Strategien für die Lösung komplexer Probleme auswählen, sie miteinander vergleichen und bewerten; sie können strategisch vorgehen, indem sie sich auf breit gefächerte, gut entwickelte Denk- und Argumentationsfähigkeiten, passende Darstellungen, symbolische und formale Beschreibungen und für diese Situationen relevante Einsichten stützen; sie sind imstande, über ihr Tun zu reflektieren und ihre Interpretationen und Überlegungen zu formulieren und zu kommunizieren. 


\section{Angewandte Methodik}

Die annualisierte Veränderung ist eine robuste Kenngröße zur Messung der Fortschritte, die ein Land/eine Volkswirtschaft bei der Verbesserung der Bildungsergebnisse erzielt hat, da sie auf Informationen aus allen Erhebungen basiert. Sie reagiert dementsprechend weniger auf anormale Messungen, die die PISA-Trends eines Landes/einer Volkswirtschaft verändern könnten, wenn die Ergebnisse nur zwischen zwei Erhebungen verglichen werden. Berechnet wird die annualisierte Veränderung als die Linie, die die Leistungsveränderungen eines Landes/einer Volkswirtschaft im Lauf der PISA-Teilnahme am besten darstellt. Die annualisierte Veränderung ergibt sich aus der Regression des Jahres der Teilnahme der einzelnen Schülerinnen und Schüler an PISA auf ihre PISA-Ergebnisse. Die annualisierte Veränderung trägt auch der Tatsache Rechnung, dass der Zeitraum zwischen zwei PISA-Erhebungen in einigen Ländern und Volkswirtschaften weniger als drei Jahre beträgt (weitere Informationen s. PISA 2012 Ergebnisse, Band I).

Der PISA-Index des wirtschaftlichen, sozialen und kulturellen Status (ESCS) wurde aus den folgenden drei Indizes abgeleitet: dem Index der höchsten beruflichen Stellung der Eltern (HISEI), dem Index des höchsten Bildungsabschlusses der Eltern in Ausbildungsjahren gemäß ISCED (PARED) und dem Index der Ausstattung des Elternhauses (HOMEPOS). In PISA 2012 machten die Schüler Angaben zum Vorhandensein von I4 bestimmten Objekten in ihrem Elternhaus. Ergänzt wurden diese durch 3 länderspezifische Objekte, die in den jeweiligen Ländern als angemessene Kenngrößen des Wohlstands der Familie angesehen werden. Der Index der Ausstattung des Elternhauses (HOMEPOS) wurde aus diesen Objekten abgeleitet und enthält darüber hinaus die Variable für die Zahl der Bücher im Elternhaus. Um eine Trendstudie zu ermöglichen, wurde jedoch die Skala der Ausstattung des Elternhauses bei PISA 2012 anders berechnet als in früheren Erhebungen. Weitere Informationen finden sich im Abschnitt zu Trends beim ESCS in PISA 2012 Technical Report (OECD, i. E.).

Der PISA-Index des wirtschaftlichen, sozialen und kulturellen Status (ESCS) wurde aus einer Hauptkomponentenanalyse standardisierter Variablen (in der jede Variable einen OECD-Mittelwert von o und eine Standardabweichung von I hat) abgeleitet. Für Partnerländer wurden die Berechnungen wie folgt durchgeführt:

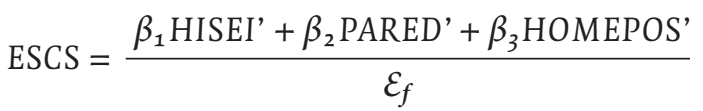

Dabei sind $\beta_{1}, \beta_{2}$ und $\beta_{3}$ die OECD-Faktorwerte, HISEI', PARED' und HOMEPOS' die „OECD-standardisierten"-Variablen und $\mathcal{E}_{f}$ der Eigenwert der ersten Hauptkomponente. Weitere Informationen zu ESCS s. PISA 2012 Technical Report (OECD, i. E.).

Anmerkung zu den Daten aus Israel

Die statistischen Daten für Israel wurden von den zuständigen israelischen Stellen bereitgestellt, die für sie verantwortlich zeichnen. Die Verwendung dieser Daten durch die OECD erfolgt unbeschadet des völkerrechtlichen Status der Golanhöhen, von Ost-Jerusalem und der israelischen Siedlungen im Westjordanland. 


\section{Weiterführende Informationen}

OECD (2014), PISA 2012 Ergebnisse: Was Schülerinnen und Schüler wissen und können: Schülerleistungen in Lesekompetenz, Mathematik und Naturwissenschaften (Band I), W. Bertelsmann Verlag, Bielefeld.

OECD (2013), PISA 2012 Results: Excellence Through Equity: Giving Every Student the Chance to Succeed (Volume II), PISA, OECD Publishing, Paris, http://dx.doi.org/10.1797/9789264201132-en.

\section{Tabellen Indikator A9}

StatLink: http://dx.doi.org/10.1787/888933116737

Tabelle A9.Ia: Schülerleistungen im Bereich Mathematik, PISA 2012

WEB Table A9.Ib: Student performance in mathematics (Schülerleistungen im Bereich Mathematik), PISA 2003

Tabelle A9.Ic: Veränderungen der Schülerleistungen im Bereich Mathematik zwischen 2003 und 2012

Tabelle A9.2: Zusammenhang zwischen Schülerleistungen im Bereich Mathematik und sozioökonomischem Status 
PISA 2012

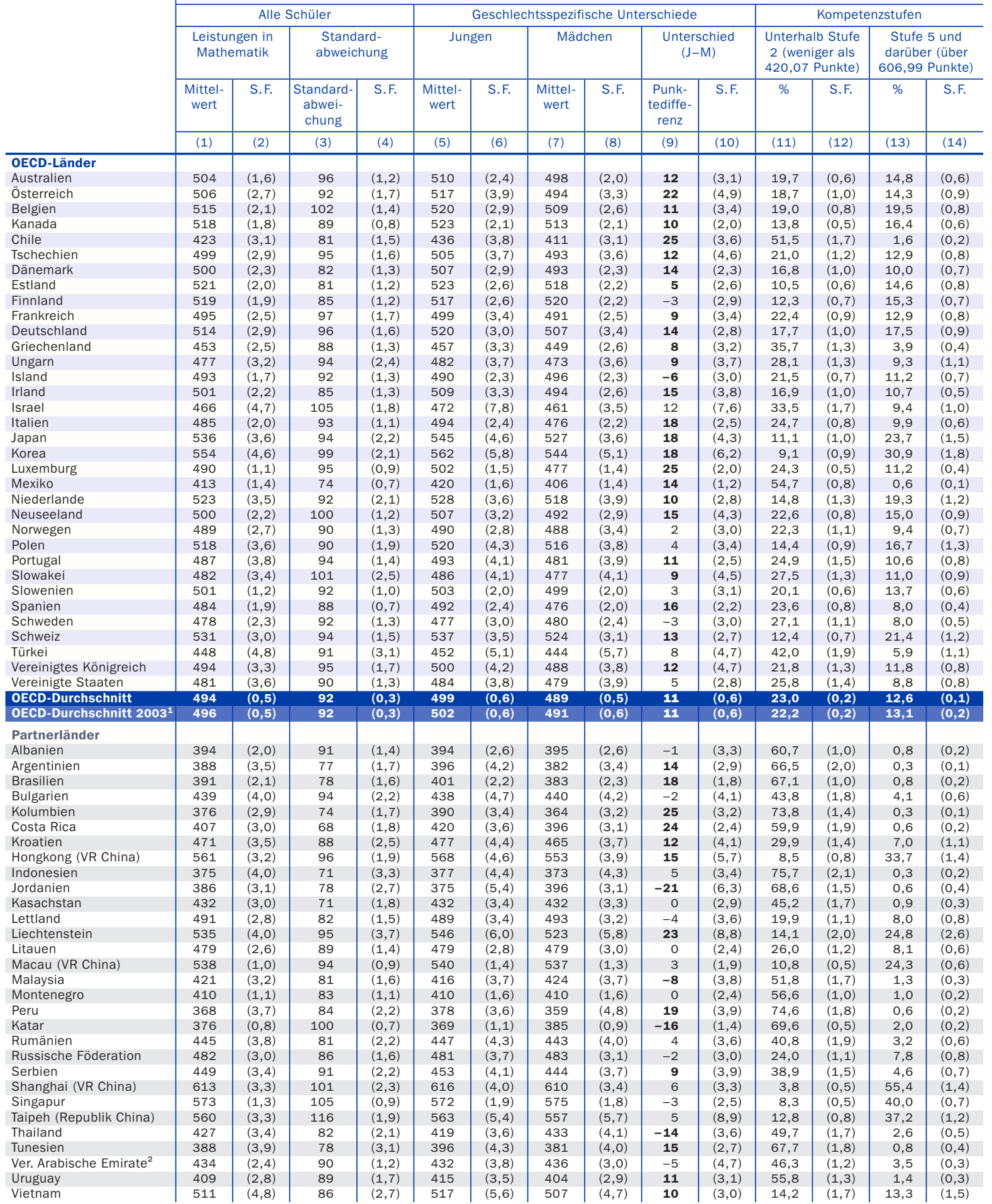

Anmerkung: Statistisch signifikante Differenzen sind in Fettdruck.

1. Der OECD-Durchschnitt 2003 umfasst nur die OECD-Länder, deren Ergebnisse im Bereich Mathematik seit dem Jahr 2003 vergleichbar sind. 2. Von den Vereinigten Arabischen Emiraten nahm nur Dubai im Jahr 2009 an der PISA-Erhebung 2009 teil, der Rest der Vereinigten Arabischen Emirate nahm 2010 im Rahmen von PISA 2009+ teil. Die Ergebnisse sind daher getrennt ausgewiesen. Die Leistungen in Mathematik des Jahres 2012 für Dubai und den Rest der Vereinigten Arabischen Emirate sind 464 (1,2) bzw. 423 (3,2).

Quelle: OECD. PISA-2012-Datenbank. StatLink: http://dx.doi.org/10.1787/888933116756 
Tabelle A9.1c

Veränderungen der Schülerleistungen im Bereich Mathematik zwischen 2003 und 2012

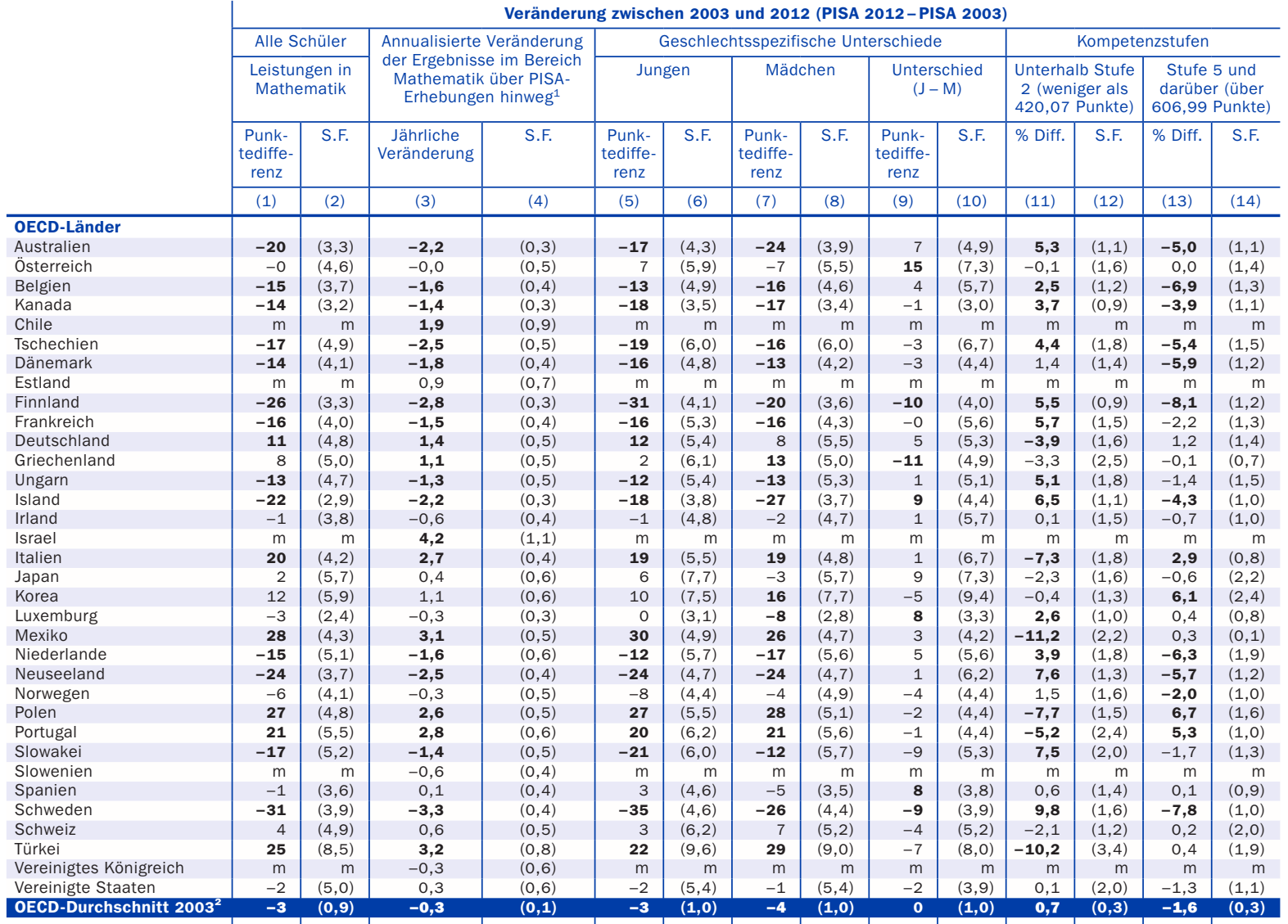

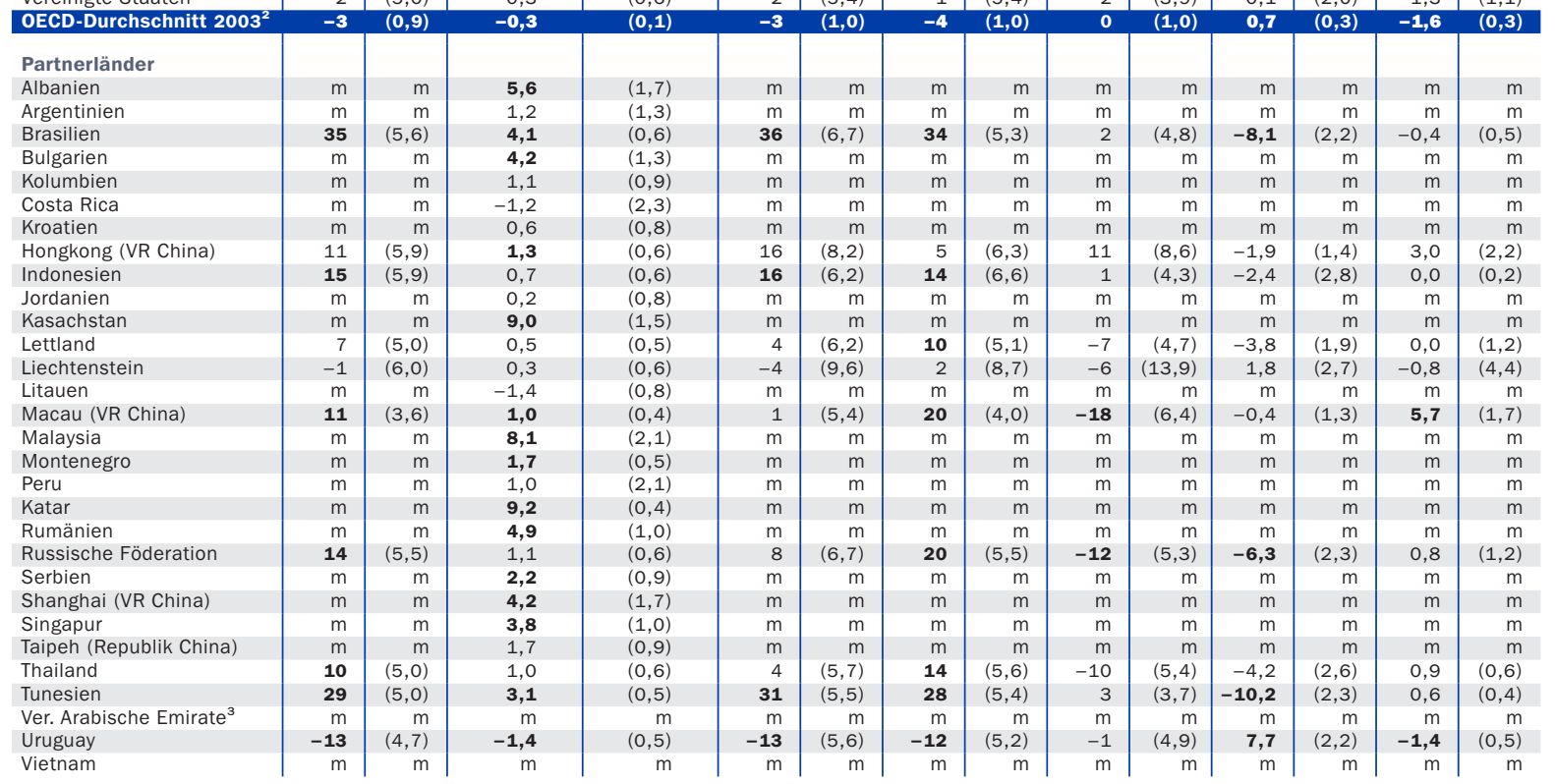

Anmerkung: Statistisch signifikante Veränderungen sind in Fettdruck.

1. Die annualisierte Veränderung entspricht der jahresdurchschnittlichen Veränderung der PISA-Punktzahl von der ersten PISA-Teilnahme eines Landes/einer Volkswirtschaft bis zur Teilnahme an PISA 2012. Bei Ländern mit mehr als einer verfügbaren Messung wurde die annualisierte Veränderung mittels eines linearen Regressionsmodells berechnet. Bei diesem Modell wird berücksichtigt, dass Costa Rica, Malaysia und die Vereinigten Arabischen Emirate (mit Ausnahme Dubais) die Leistungsmessung von PISA 2009 im Jahr 2010 als Teil von PISA 2009+ durchführten. 2. Der OECD-Durchschnitt 2003 umfasst nur die OECD-Länder, deren Ergebnisse im Bereich Mathematik seit dem Jahr 2003 vergleichbar sind. 3. Von den Vereinigten Arabischen Emiraten nahm nur Dubai im Jahr 2009 an der PISA-Erhebung 2009 teil, der Rest der Vereinigten Arabischen Emirate nahm 2010 im Rahmen von PISA 2009+ teil. Die Ergebnisse sind daher getrennt ausgewiesen. Die annualisierten Veränderungen für Dubai und die restlichen Vereinigten Arabischen Emirate sind signifikant und belaufen sich auf 3,8 (0,9) bzw. 5,9 (2,6).

Quelle: OECD. PISA-2012-Datenbank. StatLink: http://dx.doi.org/10.1787/888933116775

Erläuterung der Kennzeichnung fehlender Daten s. Hinweise für den Leser. 


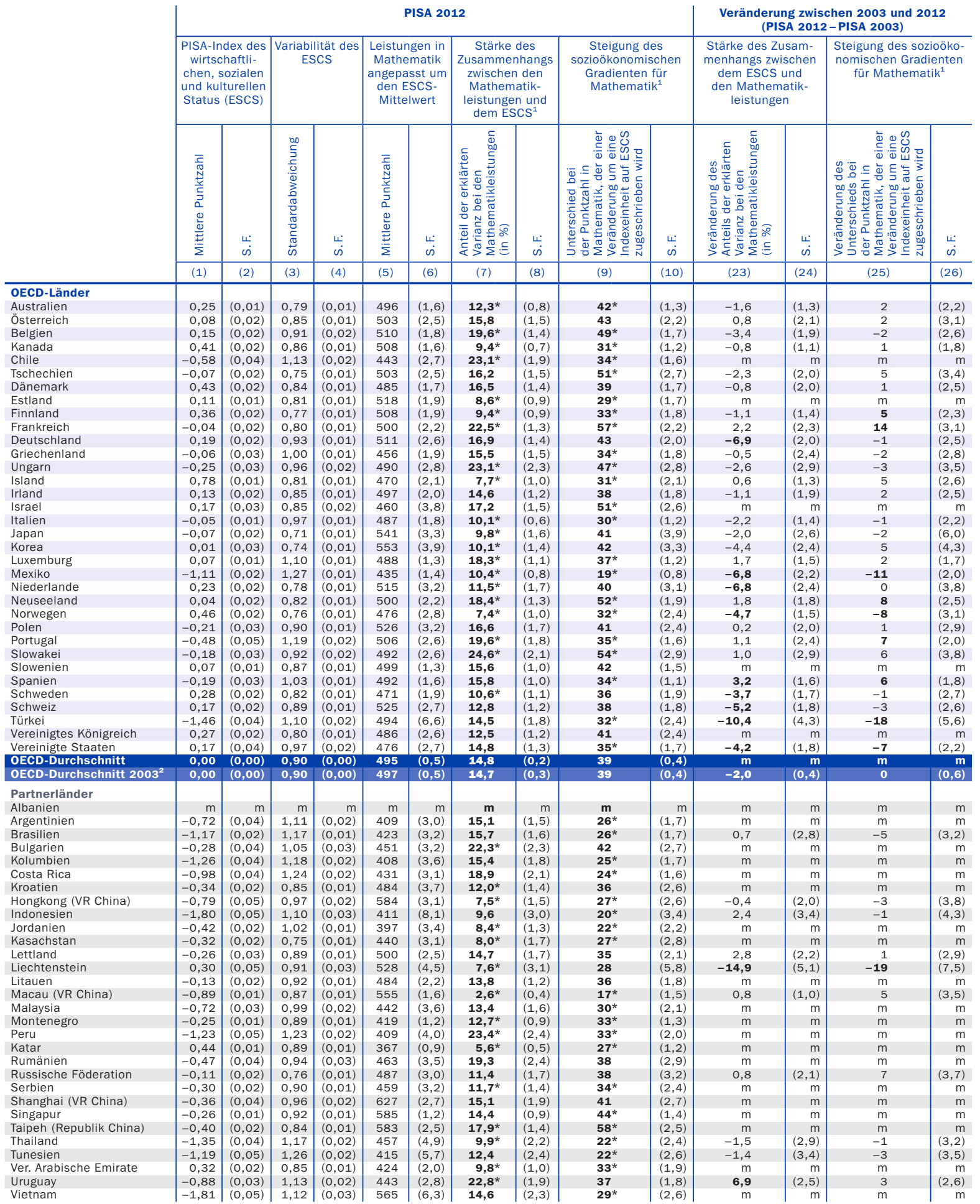

Anmerkung: Statistisch signifikante Werte und Veränderungen sind in Fettdruck. Werte, die sich statistisch signifikant vom OECD-Durchschnitt unterscheiden, sind durch einen Stern gekennzeichnet. Die Spalten (11) bis (22) sind im Internet verfügbar (s. StatLink).

1. Einstufige bivariate Regression der Leistungen auf dem ESCS. Die Steigung ist der Regressionskoeffizient für den ESCS und die Stärke des Zusammenhangs $r^{2} \times 100$. 2. Der OECD-Durchschnitt 2003 vergleicht ausschließlich OECD-Länder/Volkswirtschaften mit vergleichbaren Daten seit PISA 2003.

Quelle: OECD. PISA-2012-Datenbank. StatLink: http://dx.doi.org/10.1787/888933116794

Erläuterung der Kennzeichnung fehlender Daten s. Hinweise für den Leser. 



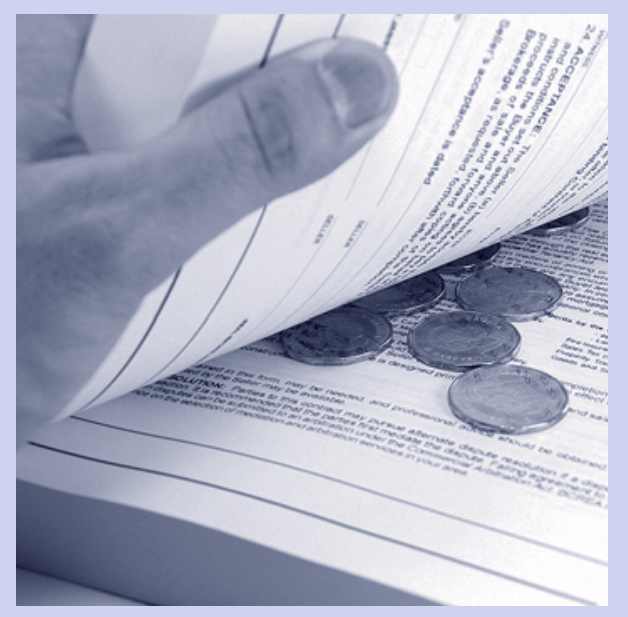

\section{Die in Bildung investierten Finanz- und Humanressourcen}

Indikator $\mathrm{BI}$

Wie hoch sind die Ausgaben pro Schüler/

Studierenden?

StatLink: http://dx.doi.org/10.1787/888933116908

Indikator B2

Welcher Teil des Bruttoinlandsprodukts wird für Bildung ausgegeben?

StatLink: http://dx.doi.org/10.1787/888933117174

Indikator $\mathrm{B}_{3}$

Wie groß ist der Anteil der öffentlichen und der privaten Ausgaben im Bildungswesen?

StatLink: http://dx.doi.org/10.1787/888933117364

Indikator $\mathrm{B} 4$

Wie hoch sind die öffentlichen Gesamtausgaben für Bildung?

StatLink: http://dx.doi.org/10.1787/888933117554
Indikator $\mathrm{B}_{5}$

Wie hoch sind die Studiengebühren und welche öffentlichen Unterstützungsleistungen erhalten Studierende?

StatLink: http://dx.doi.org/10.1787/888933117706

Indikator B6

Wofür werden Finanzmittel im Bereich der Bildung ausgegeben?

StatLink: http:/|dx.doi.org/10.1787/888933117858

Indikator $\mathrm{B} 7$

Welche Faktoren beeinflussen die Höhe der Bildungsausgaben?

StatLink: http://dx.doi.org/10.1787/888933117953 


\section{Klassifizierung der Bildungsausgaben}

In diesem Kapitel werden die Bildungsausgaben anhand von drei Dimensionen klassifiziert:

Die erste Dimension ist im nachstehenden Diagramm durch die horizontale Achse dargestellt und bezieht sich auf den Ort, an dem Ausgaben anfallen. Die eine Komponente dieser Dimension sind Ausgaben in den Schulen und Hochschulen sowie in den Bildungsministerien und anderen Einrichtungen, die direkt an der Bereitstellung und Unterstützung von Bildung beteiligt sind. Ausgaben für Bildung außerhalb von Bildungseinrichtungen sind eine weitere Komponente.

Die zweite Dimension ist im nachstehenden Diagramm durch die vertikale Achse dargestellt und kennzeichnet die für Bildungszwecke erworbenen Sach- und Dienstleistungen. Nicht alle Ausgaben für Bildungseinrichtungen sind als unmittelbare Ausgaben für Bildung oder Unterricht einzustufen. In vielen OECD-Ländern bieten die Bildungseinrichtungen zusätzlich zum Unterricht auch noch verschiedene zusätzliche Dienstleistungen zur Unterstützung der Schüler/Studierenden und ihrer Familien an, wie z. B. Mahlzeiten, Transport, Unterbringung etc. Im Tertiärbereich können die Ausgaben für Forschung und Entwicklung einen nicht unerheblichen Anteil darstellen. Nicht alle Ausgaben für Sach- und Dienstleistungen im Bildungsbereich finden in Bildungseinrichtungen statt. So können beispielsweise Familien die erforderlichen Schulbücher und Unterrichtsmaterialien selbst kaufen oder ihren Kindern Privatunterricht erteilen lassen.

Die dritte Dimension - im nachstehenden Diagramm durch die farbliche Kennzeichnung dargestellt - nimmt eine Einteilung der Mittel nach ihrer Herkunft vor. $\mathrm{Zu}$ diesen Quellen zählen die öffentliche Hand und internationale Organisationen (hellgrau) sowie die privaten Haushalte und andere private Einheiten (hellblau). Wo private Bildungsausgaben durch öffentliche Mittel subventioniert werden, ist dies im Diagramm graublau gekennzeichnet.

Ausgaben für eigentliche Bildungsdienstleistungen

Ausgaben für Forschung und Entwicklung

Ausgaben für nicht unterrichtsbezogene Dienstleistungen im Bildungsbereich
Ausgaben für Bildungseinrichtungen

(z. B. Schulen, Hochschulen, Einrichtungen der Bildungs-

verwaltung und soziale Dienste für Schüler/Studierende)

Bildungsausgaben außerhalb von Bildungseinrichtungen

(z.B. der private Erwerb von Gütern und Dienstleistungen

für Bildungszwecke, inkl. Privatunterricht)

\begin{tabular}{|c|c|}
\hline $\begin{array}{l}\text { z. B. öffentliche Ausgaben für Bildungsangebote in } \\
\text { Bildungseinrichtungen }\end{array}$ & z.B. subventionierte private Ausgaben für Bücher \\
\hline $\begin{array}{l}\text { z. B. subventionierte private Ausgaben für Unterrichtszwecke } \\
\text { in Bildungseinrichtungen }\end{array}$ & $\begin{array}{l}\text { z. B. private Ausgaben für Bücher und anderes Unterrichts- } \\
\text { material oder Privatunterricht }\end{array}$ \\
\hline \multicolumn{2}{|l|}{ z. B. private Ausgaben für Schul- bzw. Studiengebühren } \\
\hline \multicolumn{2}{|l|}{ z. B. öffentliche Ausgaben für Forschung an Hochschulen } \\
\hline \multicolumn{2}{|l|}{$\begin{array}{l}\text { z. B. Mittel der Privatwirtschaft für Forschung und Entwick- } \\
\text { lung an Bildungseinrichtungen }\end{array}$} \\
\hline $\begin{array}{l}\text { z.B. öffentliche Ausgaben für zusätzliche Dienstleistungen } \\
\text { wie Mahlzeiten, Transport zur Schule, Unterbringung auf } \\
\text { dem Campus }\end{array}$ & $\begin{array}{l}\text { z. B. subventionierte private Ausgaben für den Lebens- } \\
\text { unterhalt der Schüler/Studierenden bzw. reduzierte Tarife } \\
\text { im ÖPNV }\end{array}$ \\
\hline z.B. private Ausgaben für zusätzliche Dienstleistungen & $\begin{array}{l}\text { z. B. private Ausgaben für den Lebensunterhalt der Schüler/ } \\
\text { Studierenden bzw. reduzierte Tarife im ÖPNV }\end{array}$ \\
\hline
\end{tabular}




\section{Erfasste Daten}

Indikator B1, B2, B3 und B6

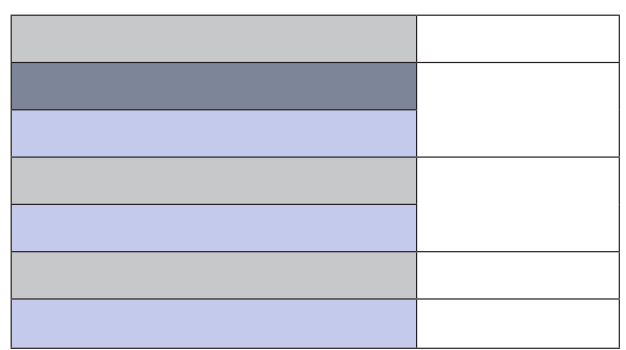

Indikator B4 und B5

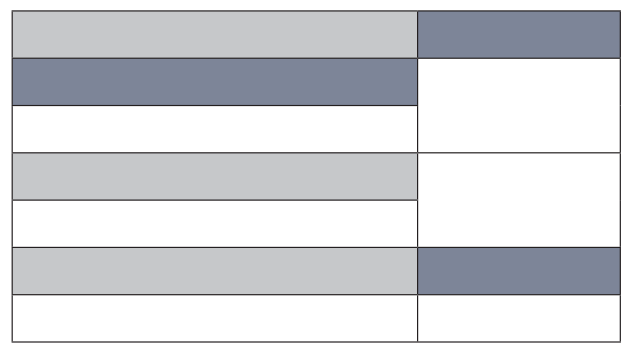





\section{Wie hoch sind die Ausgaben pro Schüler/ Studierenden?}

Die OECD-Länder geben vom Primar- bis zum Tertiärbereich jährlich im Durchschnitt 9.487 US-Dollar pro Schüler/Studierenden aus: 8.296 US-Dollar pro Schüler im Primarbereich, 9.280 US-Dollar pro Schüler im Sekundarbereich und I3.958 US-Dollar pro Studierenden im Tertiärbereich.

- Im Primar-, Sekundar- und postsekundaren, nicht tertiären Bereich entfallen 94 Prozent der Gesamtausgaben pro Schüler auf die Ausgaben für eigentliche Bildungsdienstleistungen. Größere Unterschiede treten im Tertiärbereich auf, u.a. weil dort die Ausgaben für Forschung und Entwicklung (F\&E) im Durchschnitt 32 Prozent der Gesamtausgaben pro Studierenden ausmachen.

Zwischen 2005 und 20II stiegen die Ausgaben in Bildungseinrichtungen des Primar-, Sekundar- und postsekundaren, nicht tertiären Bereichs pro Schüler im Durchschnitt der OECD-Länder um I7 Prozentpunkte. Von 2009 bis $201 \mathrm{I}$ jedoch sanken als Folge der Wirtschaftskrise die Bildungsausgaben in rund einem Drittel der OECD-Länder, was in einigen Ländern zu einem Rückgang der Ausgaben pro Schüler führte.

\section{Abbildung B1.1}

Jährliche Ausgaben von Bildungseinrichtungen pro Schüler/Studierenden, nach Leistungsbereich (2011) In US-Dollar, kaufkraftbereinigt, basierend auf Vollzeitäquivalenten, für Primar- bis Tertiärbereich

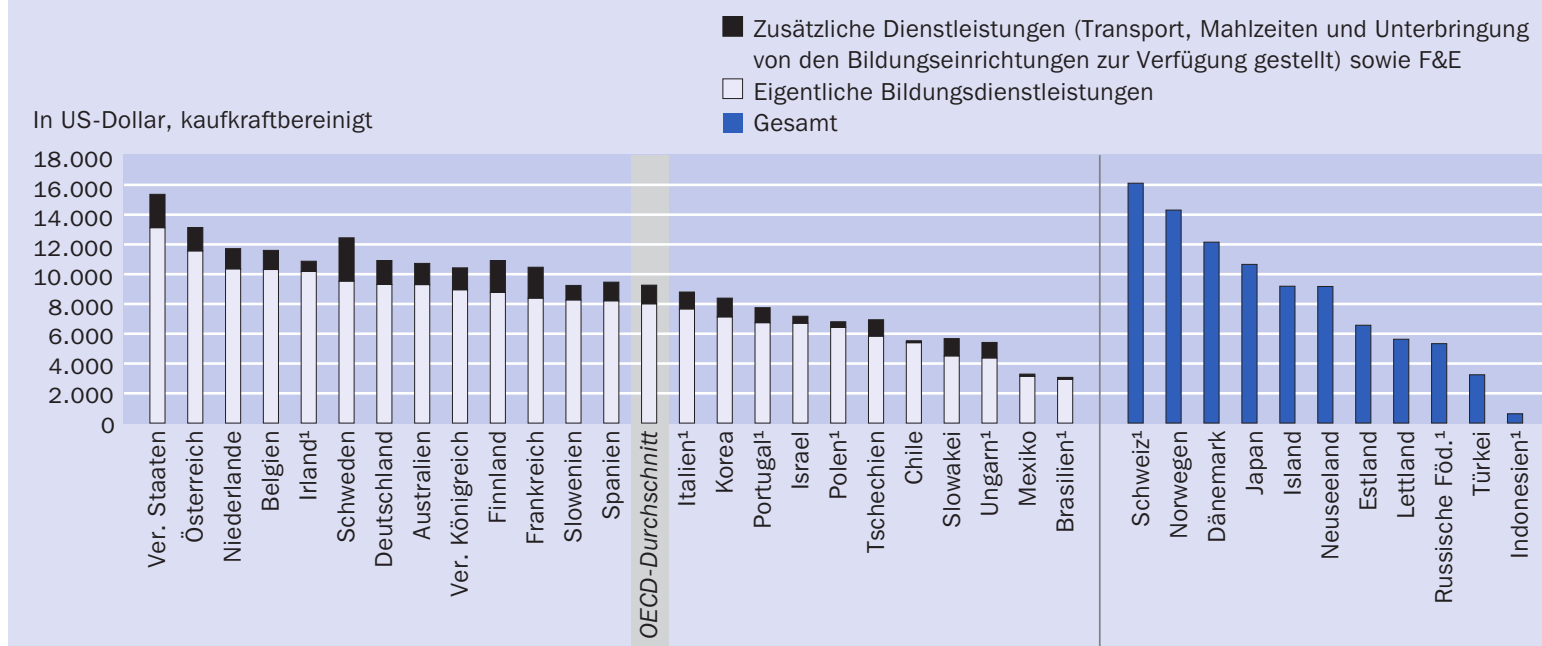




\section{Kontext}

Zwischen der Nachfrage nach qualitativ hochwertiger Bildung, die sich in höheren Kosten pro Schüler/Studierenden niederschlagen kann, einerseits und dem Bedarfan öffentlichen Ausgaben für andere Bereiche und der Gesamtbelastung für den Steuerzahler andererseits muss ein ausgewogenes Verhältnis gefunden werden. Die Politik muss auch die Notwendigkeit, die Qualität des Bildungsangebots zu verbessern, mit dem Wunsch, den Zugang zur Bildung, insbesondere im Tertiärbereich, zu erweitern, in Einklang bringen. Eine vergleichende Übersicht der Entwicklung der Ausgaben von Bildungseinrichtungen pro Schüler/Studierenden zeigt, dass in vielen OECD-Ländern mit dem Anstieg der Schüler-/Studierendenzahlen keine entsprechende Steigerung der dem Bildungsbereich zur Verfügung stehenden Mittel einhergegangen ist. Außerdem legen einige OECD-Länder besonderen Wert auf eine hohe Bildungsbeteiligung im Tertiärbereich, während andere stärker in eine möglichst umfassende Bildungsbeteiligung schon kleiner Kinder im Alter von drei oder vier Jahren investieren. Finanzkrisen können sich sowohl auf die Höhe der Bildungsinvestitionen als auch auf die Zahl der Schüler/Studierenden auswirken. Die aktuelle globale Wirtschaftskrise wird daher wahrscheinlich zu Änderungen bei der Höhe der Ausgaben pro Schüler/ Studierenden geführt haben. Das volle Ausmaß der Auswirkungen ist jedoch anhand der verfügbaren Daten bis zum Jahr 20 I noch nicht erkennbar, da die Krise erst Ende 2008 einsetzte.

Die Ausgaben von Bildungseinrichtungen pro Schüler/Studierenden werden in hohem Maße von den Gehältern der Lehrkräfte (s. Indikatoren $\mathrm{B}_{7}$ und $\mathrm{D}_{3}$ ) beeinflusst, den Ruhestandsregelungen, den Unterrichtsstunden der Schüler sowie den von den Lehrkräften zu unterrichtenden Stunden (s. Indikator B7), den Kosten von Lehrmaterialien und -einrichtungen, der Ausrichtung der angebotenen Bildungs- bzw. Studiengänge (z. B. allgemeinbildend oder berufsbildend) und der Zahl der Schüler/ Studierenden in einem Bildungssystem (s. Indikator CI). Maßnahmen zur Anwerbung neuer Lehrkräfte, zur Verringerung der durchschnittlichen Klassengröße oder zur Änderung der Zusammensetzung der Beschäftigten im Bildungswesen (s. Indikator D2) haben ebenfalls im Lauf der Zeit zu Veränderungen bei den Ausgaben von Bildungseinrichtungen pro Schüler/Studierenden geführt. Außerdem können sich auch Ausgaben für zusätzliche Dienstleistungen sowie für Forschung und Entwicklung auf die Höhe der Ausgaben pro Schüler/Studierenden auswirken.

\section{Weitere wichtige Ergebnisse}

In den ro Ländern mit den höchsten Ausgaben von Bildungseinrichtungen pro Schüler im Sekundarbereich sind häufig hohe Gehälter der Lehrkräfte sowie eine niedrige Schüler-Lehrkräfte-Relation die wesentlichsten Faktoren für die Höhe der Ausgaben.

Im Primar- und Sekundarbereich gibt es eine eindeutig positive Korrelation zwischen den Ausgaben von Bildungseinrichtungen pro Schüler und dem BIP pro Kopf. Im Tertiärbereich ist diese schwächer ausgeprägt, da in diesem Bereich größere Unterschiede bei den Finanzierungsmechanismen und der Bildungsbeteiligung bestehen. 
Werden nicht unterrichtsbezogene Tätigkeiten (Forschung und Entwicklung sowie zusätzliche Dienstleistungen, z. B. soziale Dienstleistungen für Schüler/Studierende) nicht berücksichtigt, geben die OECD-Länder pro Schüler/Studierenden durchschnittlich vom Primar- bis zum Tertiärbereich 8.002 US-Dollar pro Jahr aus. Im Vergleich mit den durchschnittlichen Gesamtausgaben ergibt sich dieser niedrigere Wert hauptsächlich aus den wesentlich niedrigeren Ausgaben pro Studierenden im Tertiärbereich, wenn nicht unterrichtsbezogene Tätigkeiten unberücksichtigt bleiben.

Im Durchschnitt sind die Bildungsausgaben der OECD-Länder pro Studierenden im Tertiärbereich um zwei Drittel höher als im Primarbereich. Im Tertiärbereich können jedoch Leistungen im Zusammenhang mit Forschung und Entwicklung bzw. zusätzliche Dienstleistungen einen wesentlichen Teil der Kosten ausmachen. Ohne diese beiden Leistungsbereiche sind die Ausgaben pro Studierenden für eigentliche Bildungsdienstleistungen im Tertiärbereich immer noch um durchschnittlich II Prozent höher als im Primar-, Sekundar- und postsekundaren, nicht tertiären Bereich.

Die Schülern im Sekundarbereich angebotenen Ausrichtungen von Bildungsgängen beeinflussen das Ausgabenniveau pro Schüler/Studierenden in den meisten Ländern. Die 19 OECD-Länder, aus denen separate Daten zu den Ausgaben für allgemeinbildende und berufsbildende Bildungsgänge im Sekundarbereich II vorliegen, geben durchschnittlich 694 US-Dollar mehr pro Bildungsteilnehmer in berufsbildenden Bildungsgängen aus als für diejenigen in allgemeinbildenden Bildungsgängen.

\section{Entwicklungstendenzen}

In allen Ländern mit verfügbaren Daten, mit Ausnahme von Italien, stiegen die Ausgaben von Bildungseinrichtungen pro Schüler im Primar-, Sekundar- und postsekundaren, nicht tertiären Bereich zwischen 1995 und $201 \mathrm{I}$ im Durchschnitt um mehr als 6o Prozent, während die Schülerzahlen in diesem Zeitraum in den meisten Ländern relativ stabil blieben. Im Durchschnitt aller OECD-Länder fiel der Anstieg im Zeitraum I995-2005 im Verhältnis höher aus als im Zeitraum 2005-20Ir. Den größten Anstieg der Kosten pro Schüler/Studierenden erlebten Länder, die auch 20 II immer noch zu den Ländern mit den niedrigsten Ausgaben pro Schüler/Studierenden gehörten. Seit Beginn der Wirtschaftskrise 2008 sind die Ausgaben pro Schüler im Primar-, Sekundar- und postsekundaren, nicht tertiären Bereich weiter gestiegen, mit Ausnahme von Dänemark, Estland, Island, Italien, der Russischen Föderation, Spanien und Ungarn.

Im Tertiärbereich stiegen die Ausgaben pro Studierenden von 1995 bis $201 \mathrm{I}$ in den meisten Ländern, mit Ausnahme von Australien, Brasilien, Israel, der Schweiz, Tschechien und Ungarn. Im Zeitraum von 1995 bis 2000 blieben die Ausgaben von Bildungseinrichtungen pro Studierenden im Tertiärbereich im Durchschnitt der OECDLänder konstant, stiegen dann aber von 2000 bis 2005 sowie von 2005 bis $201 \mathrm{I}$ ähnlich schnell an. Seit Beginn der Wirtschaftskrise 2008 sanken die Ausgaben pro Studierenden im Tertiärbereich in mehr als einem Drittel der Länder, hauptsächlich weil die Studierendenzahlen schneller stiegen als die Ausgaben. In Irland, Island, Polen und der Russischen Föderation hingegen kam es zu einer tatsächlichen Senkung der Ausgaben. 


\section{Analyse und Interpretationen}

\section{Ausgaben von Bildungseinrichtungen pro Schüler/Studierenden}

Die jährlichen Ausgaben pro Schüler/Studierenden vom Primar- bis zum Tertiärbereich reichten 20 II von höchstens 4.000 US-Dollar pro Schüler/Studierenden in Brasilien, Indonesien, Mexiko und der Türkei über mehr als ı. 000 US-Dollar pro Schüler/Studierenden in Australien, Belgien, Dänemark, Deutschland, Finnland, Frankreich, Irland, Japan, den Niederlanden, Norwegen, Österreich, Schweden und dem Vereinigten Königreich bis zu mehr als 15.000 US-Dollar in der Schweiz und den Vereinigten Staaten. In mehr als einem Viertel der Länder mit verfügbaren Daten (in 9 von 35 Ländern) lagen die Ausgaben pro Schüler/Studierenden vom Primar- bis zum Tertiärbereich zwischen I0.000 US-Dollar und weniger als I2.00o US-Dollar (Abb. BI.I und Tab. BI.ra).

Die einzelnen Länder verteilen ihre Mittel nach unterschiedlichen Prioritäten (s. Indikator B7). So gehören beispielsweise bei den zehn Ländern mit den höchsten Ausgaben der Bildungseinrichtungen pro Schüler im Sekundarbereich I (Tab. BI.ıa) Dänemark, Irland, Luxemburg, die Niederlande, die Schweiz und die Vereinigten Staaten zu den Ländern mit den höchsten Gehältern von Lehrkräften nach I5 Jahren Berufserfahrung im Sekundarbereich I und Finnland, Luxemburg, Norwegen und Österreich zu den Ländern mit der niedrigsten Schüler-Lehrkräfte-Relation in diesem Bildungsbereich (s. Tab. B7.2b).

Auch wenn die Gesamtausgaben pro Schüler/Studierenden vom Primar- bis zum Tertiärbereich in einigen OECD-Ländern ähnlich hoch sind, sind die Unterschiede bei der Verteilung der Mittel auf die einzelnen Bildungsbereiche beträchtlich. Die Ausgaben von Bildungseinrichtungen pro Schüler/Studierenden in einem typischen OECD-Land (ausgedrückt durch das arithmetische Mittel aller OECD-Länder) belaufen sich auf 8.296 US-Dollar im Primarbereich, 9.280 US-Dollar im Sekundarbereich und 13.958 USDollar im Tertiärbereich (Tab. Br.ra und Abb. BI.2). Die durchschnittlichen Ausgaben pro Studierenden im Tertiärbereich werden sehr stark durch das hohe Ausgabenniveau (mehr als 20.00o US-Dollar) in einigen wenigen OECD-Ländern, insbesondere Dänemark, Kanada, Schweden, der Schweiz und den Vereinigten Staaten, beeinflusst.

Hinter diesen Durchschnittswerten verbergen sich sehr unterschiedlich hohe Ausgaben von Bildungseinrichtungen in den OECD-Ländern pro Schüler/Studierenden, die sich im Primarbereich um den Faktor II und im Sekundarbereich um den Faktor 6 unterscheiden. Im Primarbereich reichen die Ausgaben von höchstens 2.700 US-Dollar pro Schüler in Argentinien, Brasilien, Indonesien, Kolumbien, Mexiko und der Türkei bis zu mehr als 23.000 US-Dollar in Luxemburg, im Sekundarbereich reichen die Ausgaben von höchstens 3.000 US-Dollar pro Schüler in Brasilien, Indonesien, Kolumbien, Mexiko und der Türkei bis zu mehr als I6.00o US-Dollar in Luxemburg (Tab. BI.ra und Abb. Bi.2).

Diese Vergleiche beruhen auf kaufkraftbereinigten Zahlen, die mittels Kaufkraftparitäten für das BIP und nicht mittels Devisenmarktkurs berechnet wurden. Damit entsprechen sie dem Betrag in Landeswährung, der erforderlich wäre, um dieselben Waren und Dienstleistungen eines Warenkorbs in einem bestimmten Land zu erhalten wie mit dem angegebenen Betrag in US-Dollar in den Vereinigten Staaten. 
Abbildung B1.2a

Jährliche Ausgaben von Bildungseinrichtungen pro Schüler/Studierenden für alle Leistungsbereiche, nach Bildungsbereich (2011)

In US-Dollar, kaufkraftbereinigt, basierend auf Vollzeitäquivalenten

Ausgaben pro Schüler

(in US-Dollar, kaufkraftbereinigt)

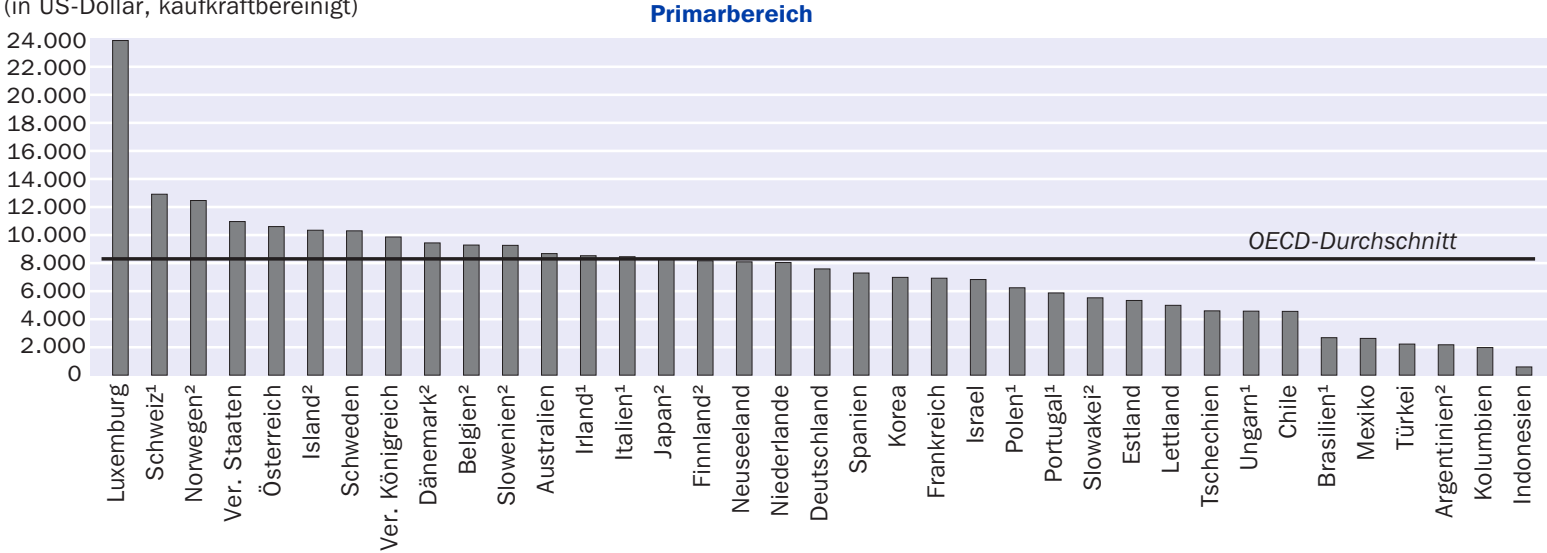

Ausgaben pro Schüler

Sekundarbereich

(in US-Dollar, kaufkraftbereinigt)

$\square$ Sekundarbereich

$\triangle$ Sekundarbereich I

Sekundarbereich II

20.000

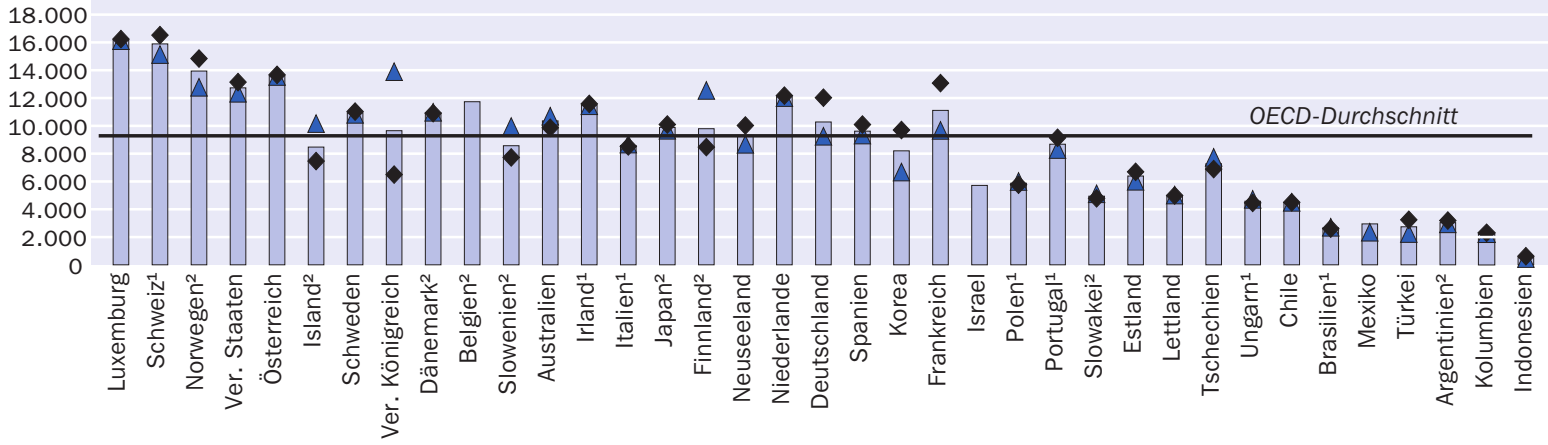

Ausgaben pro Studierenden

(in US-Dollar, kaufkraftbereinigt)

28.000

26.000

24.000

22.000

20.000

18.000

16.000

14.000

12.000

10.000

8.000

6.000

4.000

2.000

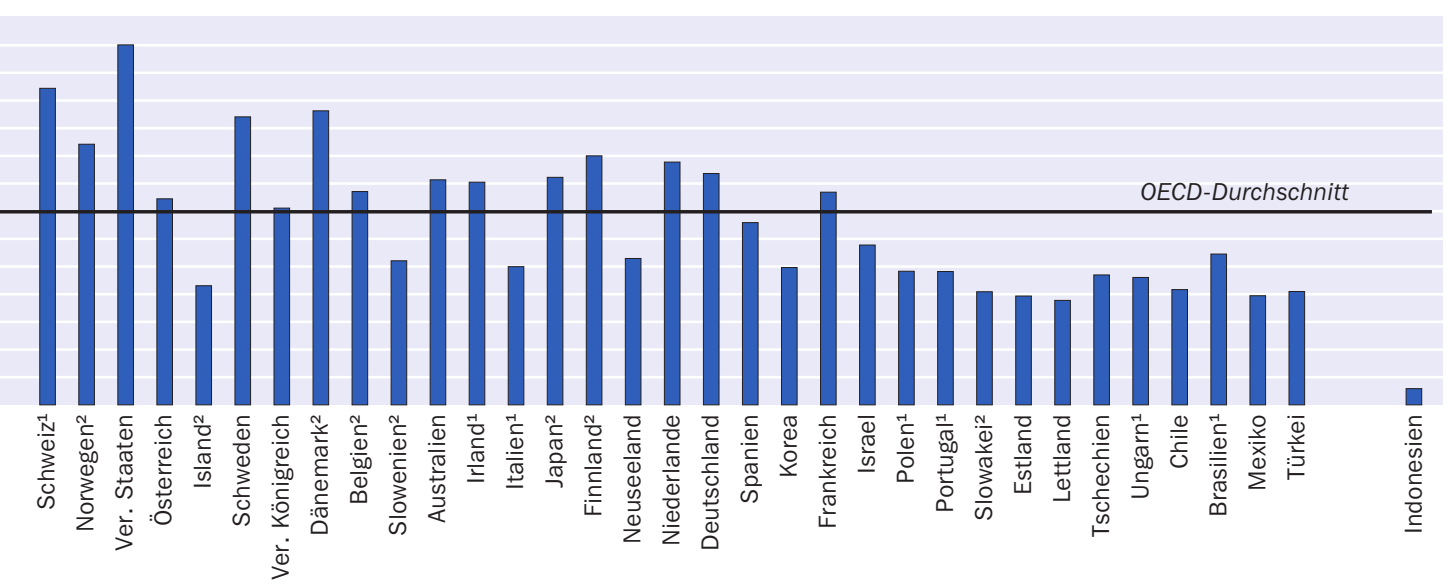

1. Nur öffentliche Bildungseinrichtungen (Italien: außer im Tertiärbereich). 2. Einige Bildungsbereiche sind in anderen Bildungseinrichtungen enthalten. Einzelheiten s. Erläuterung von „x“ in Hinweise für den Leser.

Anordnung der Länder in absteigender Reihenfolge der Ausgaben von Bildungseinrichtungen pro Schüler im Primarbereich.

Quelle: OECD. Tabelle B1.1a. Hinweise s. Anhang 3 unter www.oecd.org/edu/eag.htm. StatLink: http://dx.doi.org/10.1787/888933117079 


\section{Ausgaben pro Schüler/Studierenden für eigentliche Bildungs- dienstleistungen}

Im Durchschnitt aller OECD-Länder machen die Ausgaben für eigentliche Bildungsdienstleistungen vom Primar- bis zum Tertiärbereich 84 Prozent der Gesamtausgaben pro Schüler/Studierenden aus, in Brasilien, Chile, Mexiko und Polen sogar mehr als 94 Prozent. In 2 der 24 Länder mit verfügbaren Daten (Schweden und der Slowakei) entfallen weniger als 80 Prozent der Gesamtausgaben pro Schüler/Studierenden auf eigentliche Bildungsdienstleistungen. Die jährlichen Ausgaben für Forschung und Entwicklung sowie zusätzliche Dienstleistungen beeinflussen die Rangfolge der Länder, wenn alle Leistungsbereiche zusammen betrachtet werden. Hinter diesen Durchschnittswerten verbergen sich jedoch große Unterschiede zwischen den einzelnen Bildungsbereichen (Tab. BI.2).

Im Primar- und Sekundarbereich spielen die Ausgaben für eigentliche Bildungsdienstleistungen die wichtigste Rolle bei den Bildungsausgaben. Im Durchschnitt der OECDLänder, für die Daten vorliegen, entfallen 94 Prozent der Gesamtausgaben der Bildungseinrichtungen (bzw. 8.297 US-Dollar) pro Schüler im Primar-, Sekundar- und postsekundaren, nicht tertiären Bereich auf eigentliche Bildungsdienstleistungen. In II der 26 Länder mit verfügbaren Daten entfallen auf zusätzliche Dienstleistungen der Bildungseinrichtungen weniger als 5 Prozent der Gesamtausgaben pro Schüler. Andererseits liegt dieser Anteil in Finnland, Frankreich, Korea, Schweden, der Slowakei und Ungarn bei mehr als io Prozent (Tab. BI.2).

Größere Unterschiede ergeben sich im Tertiärbereich, was unter anderem darauf zurückzuführen ist, dass Ausgaben für Forschung und Entwicklung hier einen wesentlichen Teil der Bildungsausgaben ausmachen können. Die OECD-Länder, in denen Forschung und Entwicklung hauptsächlich in Bildungseinrichtungen des Tertiärbereichs stattfinden (z. B. Portugal und die Schweiz sowie Schweden bei öffentlich finanzierter F\&E), haben in der Regel höhere Ausgaben für Bildungseinrichtungen pro Studierenden als Länder, in denen ein Großteil der Forschungs- und Entwicklungsaktivitäten in anderen öffentlichen Einrichtungen oder in Unternehmen angesiedelt ist.

Ohne die Ausgaben für Forschung und Entwicklung sowie zusätzliche Dienstleistungen (nicht unterrichtsbezogene Dienstleistungen wie zum Beispiel soziale Dienstleistungen für Studierende) belaufen sich die Ausgaben für die eigentlichen Bildungsdienstleistungen an Bildungseinrichtungen des Tertiärbereichs im Durchschnitt der OECD-Länder auf 9.262 US-Dollar pro Studierenden. Sie reichen von höchstens 5.000 US-Dollar in Estland bis zu mehr als I0.000 US-Dollar in Brasilien, Finnland, Irland, Israel, Kanada, den Niederlanden, Norwegen, Österreich und der Schweiz und mehr als I9.000 US-Dollar in den Vereinigten Staaten (Tab. BI.2).

Im Durchschnitt der OECD-Länder machen die Ausgaben für Forschung und Entwicklung (F\&E) sowie zusätzliche Dienstleistungen im Tertiärbereich 32 Prozent bzw. 4 Prozent der Gesamtausgaben von Bildungseinrichtungen im Tertiärbereich pro Studierenden aus. In einigen der 28 OECD-Länder, für die Daten zu den Ausgaben für Forschung und Entwicklung sowie für zusätzliche Dienstleistungen getrennt von den Gesamtausgaben vorliegen (Australien, Deutschland, Norwegen, Portugal, Schweden und die Schweiz), entfallen mindestens 40 Prozent der Gesamtausgaben von Bildungs- 
einrichtungen pro Studierenden im Tertiärbereich auf F\&E und zusätzliche Dienstleistungen. Dies kann erhebliche Beträge ergeben: In Australien, Deutschland, Norwegen, Schweden und der Schweiz belaufen sich die Ausgaben für F\&E sowie für zusätzliche Dienstleistungen auf mehr als 6.00o US-Dollar pro Studierenden, dies gilt auch für Finnland, Kanada, die Niederlande und die Vereinigten Staaten (Tab. BI.2).

\section{Ausgaben von Bildungseinrichtungen pro Schüler/Studierenden in den verschiedenen Bildungsbereichen}

In fast allen Ländern steigen die Ausgaben von Bildungseinrichtungen pro Schüler/ Studierenden mit der Höhe des Bildungsbereichs, das Ausmaß der Steigerung variiert jedoch erheblich zwischen den einzelnen Ländern (Tab. Bı.ıa und Abb. BI.3). Die Ausgaben im Sekundarbereich sind im Durchschnitt I,I-mal höher als im Primarbereich. In Frankreich, den Niederlanden und Tschechien liegt der Faktor sogar bei mehr als I,5. Dies ist vor allem auf die im Sekundar- gegenüber dem Primarbereich höhere Zahl der Unterrichtsstunden für Schüler bei einer gleichzeitig signifikant niedrigeren Zahl der von den Lehrkräften zu erteilenden Unterrichtszeitstunden im Vergleich zum OECD-Durchschnitt zurückzuführen. In diesen Ländern sind auch die Gehälter der Lehrkräfte im Primarbereich im Vergleich zu denen im Sekundarbereich I niedriger (s. Indikatoren B7, Di und D4).

In der OECD geben die Bildungseinrichtungen im Tertiärbereich im Durchschnitt pro Studierenden das I,7-Fache an Mitteln aus wie die Bildungseinrichtungen pro Schüler im Primarbereich; es gibt jedoch große Unterschiede in den Ausgabenstrukturen, hauptsächlich aufgrund der Tatsache, dass sich der bildungspolitische Rahmen im Tertiärbereich stärker unterscheidet (s. Indikator B5). Während beispielsweise Estland, Island, Italien, Korea, Neuseeland, Österreich, die Slowakei, Slowenien und das Vereinigte Königreich für einen Studierenden im Tertiärbereich weniger als das I,5-Fache an Mitteln aufwenden als für einen Schüler im Primarbereich, geben Mexiko und die Türkei das 3-Fache und Brasilien das 4-Fache aus (Tab. Br.ra und Abb. BI.3).

\section{Unterschiede in den Bildungsausgaben pro Schüler/Studierenden zwischen allgemein- und berufsbildenden Bildungsgängen}

Die I9 OECD-Länder mit verfügbaren Daten geben durchschnittlich 694 US-Dollar mehr pro Bildungsteilnehmer in berufsbildenden Bildungsgängen des Sekundarbereichs II aus als für Teilnehmer an allgemeinbildenden Bildungsgängen. Die Länder mit einer hohen Beteiligung an dualen Berufsbildungssystemen im Sekundarbereich II (z.B. Deutschland, Finnland, Frankreich, Luxemburg, die Niederlande, Österreich, die Schweiz und Ungarn) weisen in der Regel auch die größten Unterschiede bei den Ausgaben pro Bildungsteilnehmer zwischen allgemeinbildenden und berufsbildenden Bildungsgängen (im Vergleich zum OECD-Durchschnitt) auf. So wendet Finnland beispielsweise I.480 US-Dollar mehr für einen Teilnehmer in einem berufsbildenden Bildungsgang des Sekundarbereichs II auf als in einem allgemeinbildenden Bildungsgang, in Deutschland sind es 4.020 US-Dollar mehr, in den Niederlanden 3.139 USDollar mehr und in Neuseeland I.286 US-Dollar mehr. Frankreich, die Slowakei und Tschechien geben ebenfalls mehr für einen Teilnehmer an berufsbildenden Bildungsgängen aus (852 US-Dollar, I.442 US-Dollar bzw. I.397 US-Dollar mehr) als für einen Teilnehmer an allgemeinbildenden Bildungsgängen, auch wenn die Unterschiede hier kleiner sind. Ausnahmen sind hier Australien und Ungarn, wo die Ausgaben pro Teil- 
Abbildung B1.3

Ausgaben von Bildungseinrichtungen pro Schüler/Studierenden in den einzelnen Bildungsbereichen im Vergleich zum Primarbereich, für alle Leistungsbereiche (2011)

Primarbereich $=100$

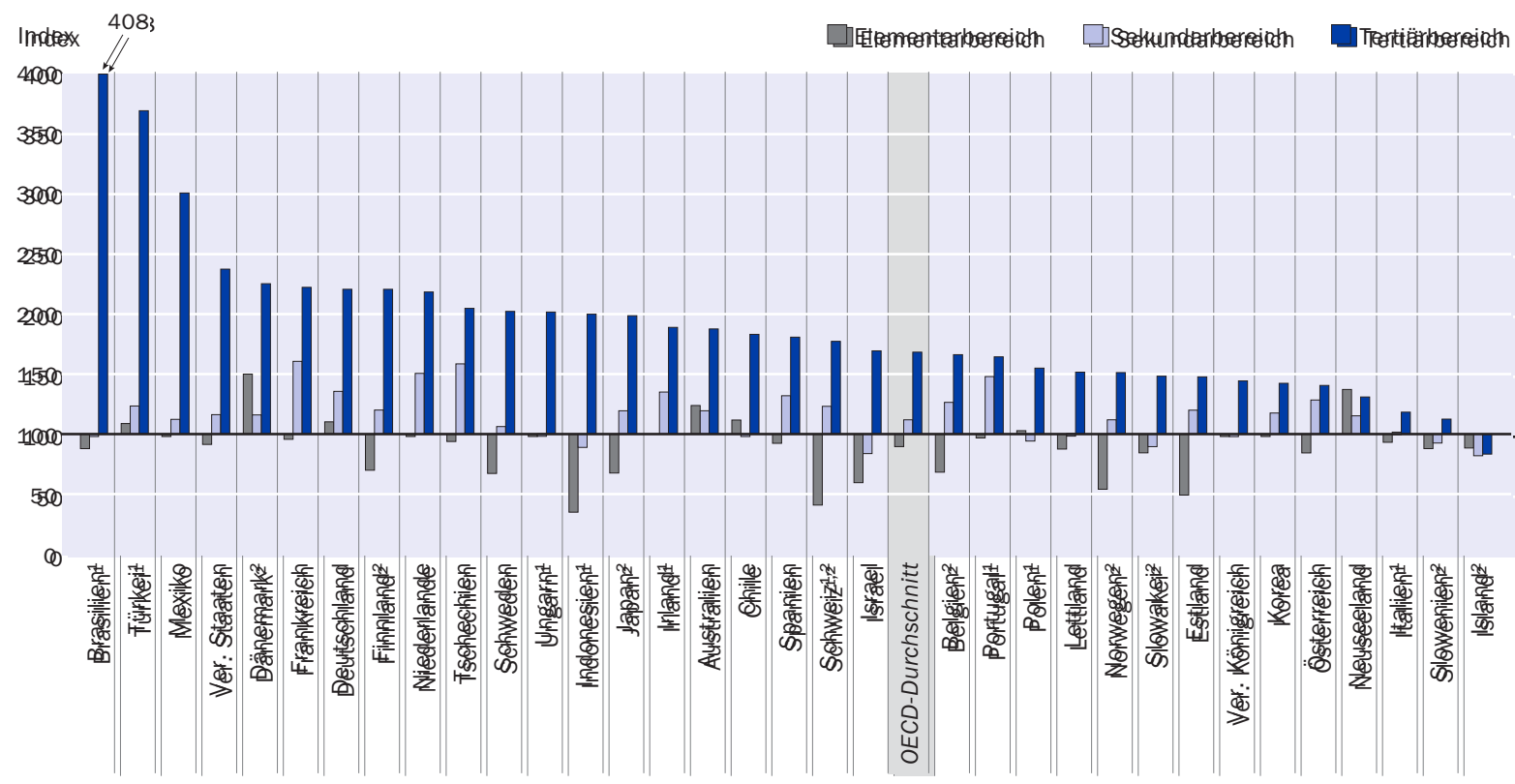

Anmerkung: Ein Index vom 300 für den Tertiärbereich bedeutet, dass die Ausgaben von Bildungseinrichtungen pro Studierenden dreimal so hoch sind wie die Ausgaben von Bildungseinrichtungen pro Schüler im Primarbereich. Ein Index vom 50 für den Elementarbereich bedeutet, dass die Ausgaben von Bildungseinrichtungen pro Kind im Elementarbereich halb so hoch sind wie die Ausgaben von Bildungseinrichtungen pro Schüler im Primarbereich.

1. Nur öffentliche Bildungseinrichtungen. 2. Einige Bildungsbereiche sind in anderen Bildungsbereichen enthalten. Einzelheiten s. Erläuterung von „ $x^{\prime \prime}$ in Hinweise für den Leser.

Anordnung der Länder in absteigender Reihenfolge der Ausgaben von Bildungseinrichtungen pro Studierenden im Tertiärbereich im Verhältnis zu den Bildungsausgaben pro Schüler im Primarbereich.

Quelle: OECD. Tabelle B1.1a. Hinweise s. Anhang 3 unter www.oecd.org/edu/eag.htm. StatLink: http://dx.doi.org/10.1787/888933117098

Abbildung B1.4

Kumulierte Ausgaben von Bildungseinrichtungen pro Studierenden während der durchschnittlichen Dauer von Studiengängen im Tertiärbereich (2011)

Jährliche Ausgaben von Bildungseinrichtungen pro Studierenden multipliziert mit der durchschnittlichen Dauer von Studiengängen im Tertiärbereich, in US-Dollar (kaufkraftbereinigt)

In US-Dollar, kaufkraftbereinigt

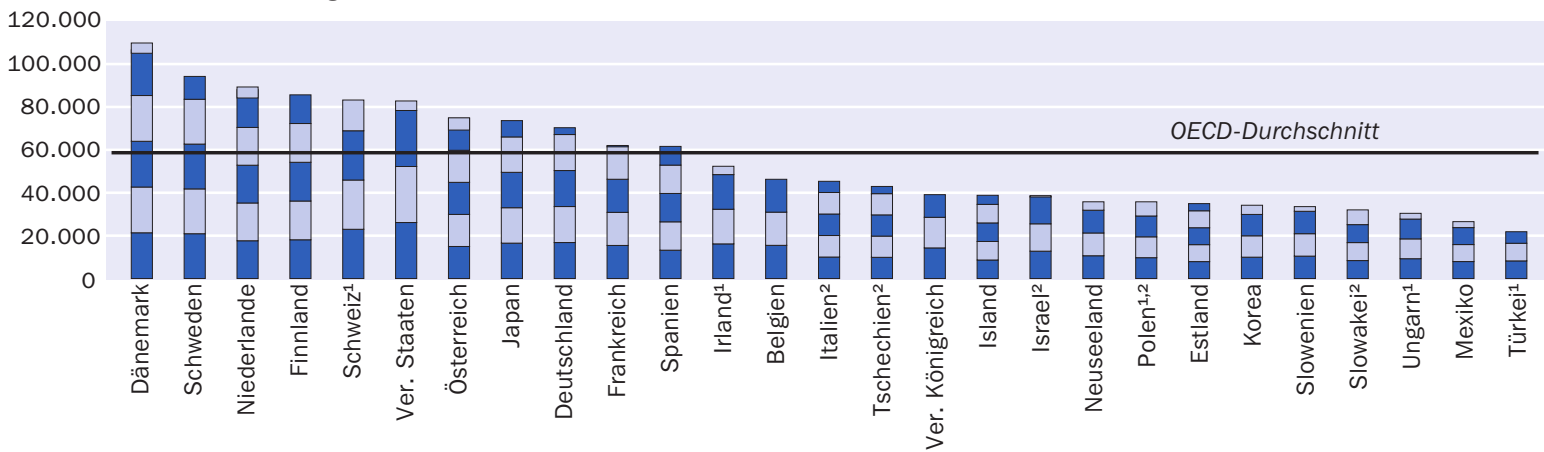

Anmerkung: Jeder Abschnitt eines Balkens steht für die jährlichen Ausgaben von Bildungseinrichtungen pro Studierenden. Die Zahl der Abschnitte steht für die Zahl an Jahren, die ein Studierender im Durchschnitt im Tertiärbereich verbringt.

1. Nur öffentliche Bildungseinrichtungen. 2. Nur Tertiärbereich A und weiterführende forschungsorientierte Studiengänge.

Anordnung der Länder in absteigender Reihenfolge der Gesamtausgaben von Bildungseinrichtungen pro Studierenden während der durchschnittlichen Dauer von Studiengängen im Tertiärbereich.

Quelle: OECD. Tabelle B1.3a. Hinweise s. Anhang 3 unter www.oecd.org/edu/eag.htm. StatLink: http://dx.doi.org/10.1787/888933117117 
nehmer an einem allgemeinbildenden Bildungsgang die Ausgaben pro Teilnehmer an einem dualen Ausbildungsgang übersteigen. Die geringen Unterschiede in Frankreich, Österreich und Ungarn lassen sich zum Teil aus den zu niedrig angesetzten Ausgaben privater Unternehmen im Rahmen dualer Ausbildungsgänge erklären (Tab. Br.6, s. außerdem Tab. CI.3 in Indikator CI sowie Kasten B3.I in Bildung aufeinen Blick 2011).

\section{Ausgaben von Bildungseinrichtungen pro Studierenden während der durchschnittlichen Dauer der Studiengänge im Tertiärbereich}

Angesichts der Tatsache, dass sowohl die Dauer von Studiengängen im Tertiärbereich als auch die Intensität der Teilnahme (Anteil der Vollzeit-/Teilzeitstudierenden) zwischen den einzelnen Ländern variieren, geben die Unterschiede zwischen den einzelnen Ländern bei den jährlichen Ausgaben pro Studierenden für Bildungsdienstleistungen (Abb. Br.2) nicht unbedingt die Unterschiede in den Gesamtkosten für die Ausbildung eines typischen Studierenden im Tertiärbereich wider. Beispielsweise können vergleichsweise niedrige jährliche Ausgaben von Bildungseinrichtungen pro Studierenden zu vergleichsweise hohen Gesamtkosten im Tertiärbereich führen, wenn die übliche Dauer der Studiengänge im Tertiärbereich lang ist. Abbildung BI.4 gibt einen Überblick über die durchschnittlichen Ausgaben pro Studierenden im Laufe des gesamten Studiums. Die Zahlen beziehen sich auf alle Studierenden, für die Ausgaben anfallen, unabhängig davon, ob sie einen Abschluss erwerben oder nicht. Obwohl die Berechnungen auf einer Reihe vereinfachter Annahmen beruhen und daher mit Vorsicht zu interpretieren sind (s. Anhang 3 unter www.oecd.org/edu/eag.htm), gibt es einige bemerkenswerte Unterschiede in der Rangfolge der Länder, je nachdem ob sie auf den jährlichen oder kumulierten Ausgaben basiert.

So sind beispielsweise die jährlichen Bildungsausgaben pro Studierenden im Tertiärbereich in Japan mit 16.446 US-Dollar ungefähr genauso hoch wie in Irland mit I6.095 US-Dollar (Tab. Br.Ia). Jedoch ist die durchschnittliche Studiendauer in Japan über ein Jahr länger als in Irland (4,5 gegenüber 3,2 Jahren). Daher sind in Irland die kumulierten Ausgaben für jeden Studierenden im Tertiärbereich 20.000 US-Dollar niedriger als in Japan (52.I48 US-Dollar gegenüber 73.364 US-Dollar) (Abb. BI.4 und Tab. BI.3a).

Die Gesamtkosten eines Studiengangs im Tertiärbereich A sind in der Schweiz (mit I32.433 US-Dollar) mehr als doppelt so hoch wie in der Hälfte der Länder mit Ausnahme von Deutschland, Finnland, Frankreich, Japan, den Niederlanden, Österreich, Schweden und Spanien (Tab. BI.3a). Diese Zahlen müssen natürlich im Zusammenhang mit den Unterschieden in den nationalen Abschlussstrukturen sowie möglichen Unterschieden bei den Hochschulabschlüssen gesehen werden. Die (kürzeren und beruflich ausgerichteten) Studiengänge im Tertiärbereich B sind in der Regel kostengünstiger als Studiengänge des Tertiärbereichs A, hauptsächlich aufgrund der kürzeren Dauer.

\section{Ausgaben von Bildungseinrichtungen pro Schüler/Studierenden im Verhältnis zum BIP pro Kopf}

$\mathrm{Da}$ in den meisten OECD-Ländern in den unteren Bildungsbereichen eine universelle Bildungsbeteiligung gegeben ist (und dort in der Regel Schulpflicht besteht), können die Ausgaben von Bildungseinrichtungen pro Schüler im Verhältnis zum BIP pro Kopf in diesen Bildungsbereichen auch als die Ressourcen ausgelegt werden, die für junge 
Menschen im schulpflichtigen Alter in Relation zur Finanzkraft eines Landes ausgegeben werden. In den höheren Bildungsbereichen sind die aus dieser Kenngröße abzuleitenden Schlussfolgerungen aufgrund der sehr unterschiedlichen Bildungsbeteiligung in den einzelnen Ländern weniger eindeutig. So können beispielsweise OECD-Länder im Tertiärbereich bei dieser Kennzahl einen vorderen Rang belegen, wenn ein großer Anteil ihres BIP für eine relativ niedrige Zahl von Studierenden aufgewendet wird.

In den OECD-Ländern belaufen sich die Ausgaben von Bildungseinrichtungen pro Schüler im Primarbereich auf durchschnittlich 23 Prozent des BIP pro Kopf, pro Schüler im Sekundarbereich auf 26 Prozent und pro Studierenden im Tertiärbereich auf 4I Prozent. Insgesamt belaufen sich die Ausgaben pro Schüler/Studierenden vom Primar- bis zum Tertiärbereich in den OECD-Ländern auf durchschnittlich 27 Prozent des BIP pro Kopf (Tab. BI.4). Länder mit einem niedrigen Ausgabenniveau können dennoch eine Höhe der Ausgaben im Verhältnis zum BIP pro Kopf aufweisen, die ähnlich hoch ist wie in Ländern mit einem hohen Ausgabenniveau pro Schüler/Studierenden. So werden beispielsweise in Korea und Portugal, wo sowohl die Ausgaben von Bildungseinrichtungen pro Schüler im Sekundarbereich als auch das BIP pro Kopf unter dem OECD-Durchschnitt liegen, im Verhältnis zum BIP pro Kopf mehr Mittel pro Schüler aufgewendet als im OECD-Durchschnitt.

Das Verhältnis zwischen BIP pro Kopf und Ausgaben von Bildungseinrichtungen pro Schüler/Studierenden ist nicht eindeutig. Jedoch gibt es sowohl im Primar-als auch im Sekundarbereich eine eindeutig positive Korrelation zwischen den Ausgaben von Bildungseinrichtungen pro Schüler und dem BIP pro Kopf - ärmere Länder geben in der Regel weniger pro Schüler aus als reichere. Obwohl in diesen Bildungsbereichen die Korrelation im Allgemeinen positiv ist, gibt es selbst zwischen Ländern mit ähnlichem BIP pro Kopf Unterschiede, insbesondere wenn das BIP pro Kopf mehr als 30.000 USDollar beträgt. Israel und Neuseeland sind beispielsweise Länder mit einem ähnlich hohen BIP pro Kopf (s. Tab. X2.I in Anhang 2), geben aber im Primar- und Sekundarbereich völlig unterschiedliche Anteile ihres BIP pro Kopf aus. In Israel liegt dieser Anteil im Primarbereich bei 23 Prozent und im Sekundarbereich bei ig Prozent (und somit auf bzw. unter dem OECD-Durchschnitt von 23 Prozent bzw. 26 Prozent), während sich die entsprechenden Anteile in Neuseeland auf 26 Prozent bzw. 30 Prozent belaufen und somit zu den höchsten Werten überhaupt gehören (Tab. BI.4 und Abb. BI.2b im Internet).

Bei den Ausgaben im Tertiärbereich sind die Unterschiede größer, und auch das Verhältnis zwischen dem relativen Wohlstand eines Landes und dem Ausgabenniveau unterscheidet sich. Dänemark, Kanada, Schweden und die Vereinigten Staaten geben pro Studierenden im Tertiärbereich mehr als 49 Prozent ihres BIP pro Kopf aus, mit die größten Anteile nach Brasilien (Tab. BI.4 und Abb. BI.5). Brasilien wendet den Gegenwert von 93 Prozent des BIP pro Kopf für jeden Studierenden im Tertiärbereich auf, hierbei ist jedoch zu berücksichtigen, dass nur 4 Prozent der Schüler/Studierenden aller Bildungsbereiche im Tertiärbereich eingeschrieben sind (Tab. BI.7 im Internet). 


\section{Abbildung B1.5}

Korrelation zwischen den jährlichen Ausgaben pro Schüler/Studierenden im Jahr 2011 und den Veränderungen der Ausgaben pro Schüler/Studierenden zwischen 2005 und 2011

In US-Dollar, kaufkraftbereinigt, basierend auf Vollzeitäquivalenten

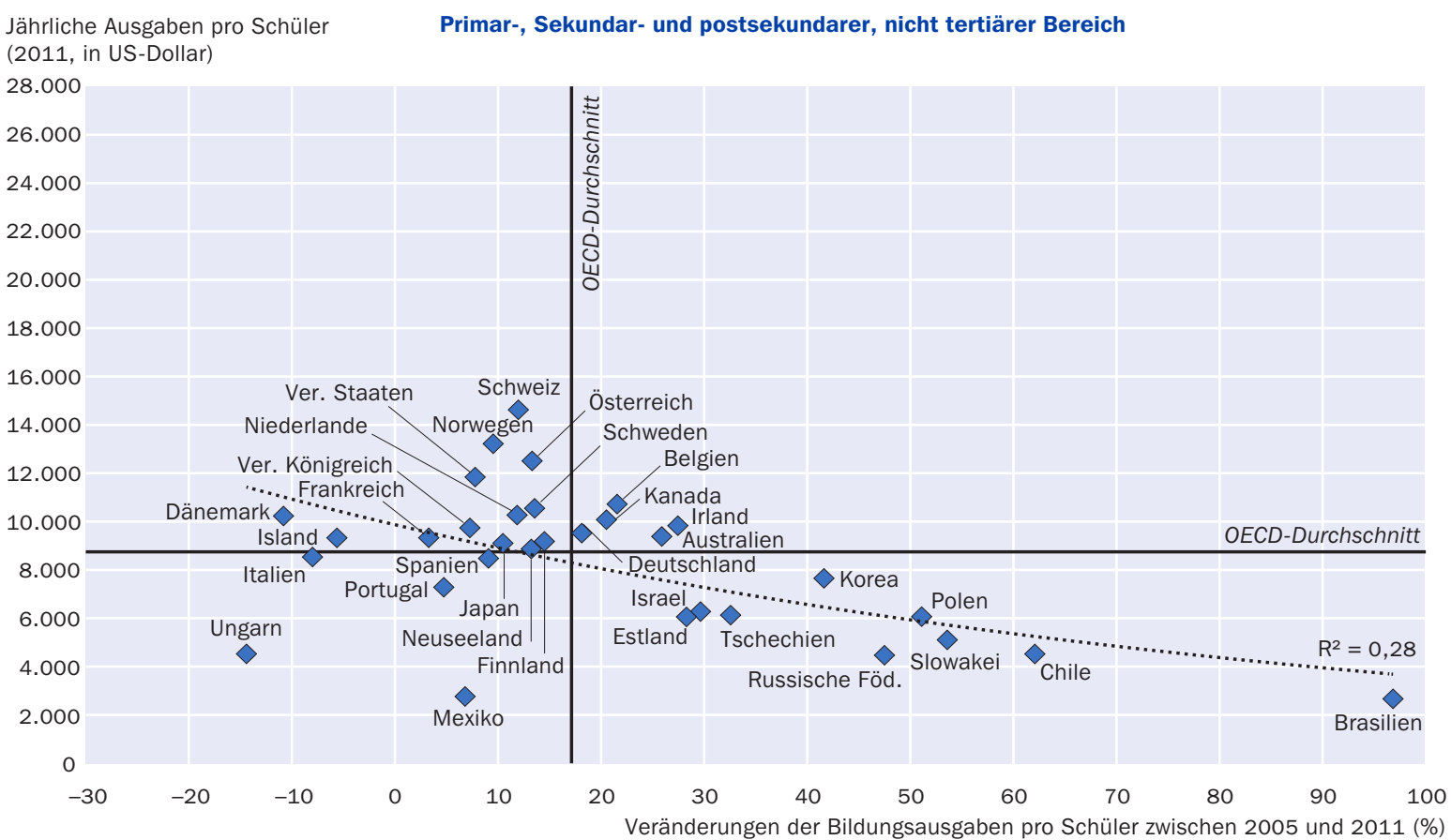

Jährliche Ausgaben pro Studierenden (2011, in US-Dollar)

Tertiärbereich

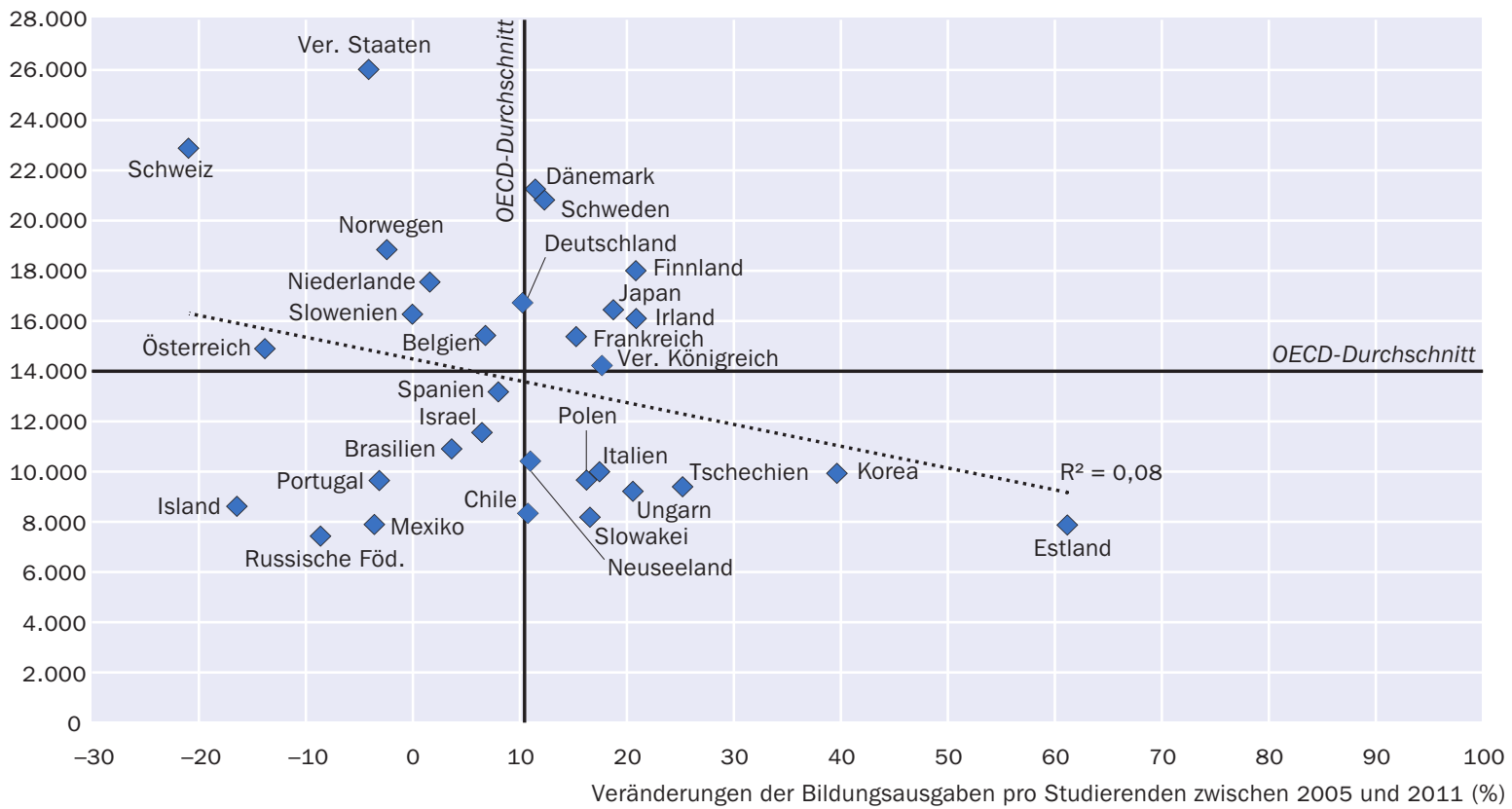




\section{Veränderungen der Ausgaben von Bildungseinrichtungen pro Schüler/ Studierenden zwischen 1995 und 2011}

Veränderungen bei den Ausgaben von Bildungseinrichtungen spiegeln hauptsächlich Veränderungen in der Zahl junger Menschen im schulpflichtigen Alter sowie bei den Gehältern der Lehrkräfte wider. Diese steigen tendenziell im Laufe der Zeit real: Die Gehälter der Lehrkräfte (der Hauptkostenfaktor) sind in den meisten Ländern in den letzten Io Jahren gestiegen (s. Indikator D3). Die Zahl junger Menschen im üblichen Schulalter beeinflusst sowohl die Zahl der Schüler/Studierenden als auch den organisatorischen Aufwand und den Umfang der Mittel, die ein Land in sein Bildungssystem investieren muss. Je größer diese Bevölkerungsgruppe ist, desto höher ist die potenzielle Nachfrage nach Bildungsdienstleistungen. Veränderungen der Ausgaben pro Schüler/Studierenden können sich im Laufe der Jahre innerhalb der Länder in den einzelnen Bildungsbereichen unterscheiden, da es in den verschiedenen Bildungsbereichen unterschiedliche Entwicklungen bei den Schüler-/Studierendenzahlen und den Ausgaben geben kann. Zwischen 2005 und 20II sanken in viel mehr Ländern die Bildungsausgaben pro Studierenden im Tertiärbereich als die Bildungsausgaben pro Schüler in den anderen Bildungsbereichen (Tab. BI.5a und BI.5b sowie Abb. Br.5).

In allen Ländern stiegen die Ausgaben von Bildungseinrichtungen pro Schüler im Primar-, Sekundar- und postsekundaren, nicht tertiären Bereich zwischen 1995 und 20 II im Durchschnitt um mehr als 6o Prozent, während die Schülerzahlen in diesen Bildungsbereichen in diesem Zeitraum relativ stabil blieben. Infolge eines stärkeren Anstiegs der Ausgaben zwischen 1995 und 2005 als zwischen 2005 und 2011 war der Anstieg in den meisten Ländern im früheren Zeitraum vergleichsweise höher als im späteren Zeitraum.

Zwischen 2005 und 201 I stiegen in 23 der 34 Länder mit verfügbaren Daten die Ausgaben von Bildungseinrichtungen pro Schüler im Primar-, Sekundar- und postsekundaren, nicht tertiären Bereich um mindestens ro Prozent. In Brasilien, Chile, Polen und der Slowakei belief sich der Anstieg auf mehr als 50 Prozent. In Frankreich und Portugal hingegen nahmen diese Ausgaben um höchstens 5 Prozent zu. Nur in Dänemark, Island, Italien und Ungarn gab es im genannten Zeitraum einen Rückgang der Ausgaben pro Schüler im Primar-, Sekundar- und postsekundaren, nicht tertiären Bereich (Tab. Br.5a).

Brasilien, Chile, Polen, die Russische Föderation und die Slowakei gehörten zu den Ländern mit dem höchsten Anstieg der Ausgaben pro Schüler/Studierenden zwischen 2005 und 20II, dennoch waren ihre Ausgaben pro Schüler/Studierenden im Jahr $201 \mathrm{I}$ immer noch mit am niedrigsten. Es besteht nur eine schwache Korrelation zwischen dem Ausgabenniveau pro Schüler/Studierenden und seiner Varianz im Zeitverlauf. Ungarn und Mexiko hatten beispielsweise im Jahr 20 I ungefähr gleich hohe Ausgaben pro Schüler/Studierenden, die Ausgaben pro Schüler/Studierenden stiegen jedoch nicht im gleichen Maß. Im genannten Zeitraum gingen in Ungarn die Ausgaben pro Schüler/ Studierenden infolge eines Rückgangs sowohl der Ausgaben als auch der Schüler-l Studierendenzahlen zurück. Sinkende Schüler-/Studierendenzahlen waren in Ungarn offensichtlich nicht der ausschlaggebende Faktor für die Veränderungen bei den Ausgaben pro Schüler/Studierenden (Tab. BI.5a und Abb. BI.5). 


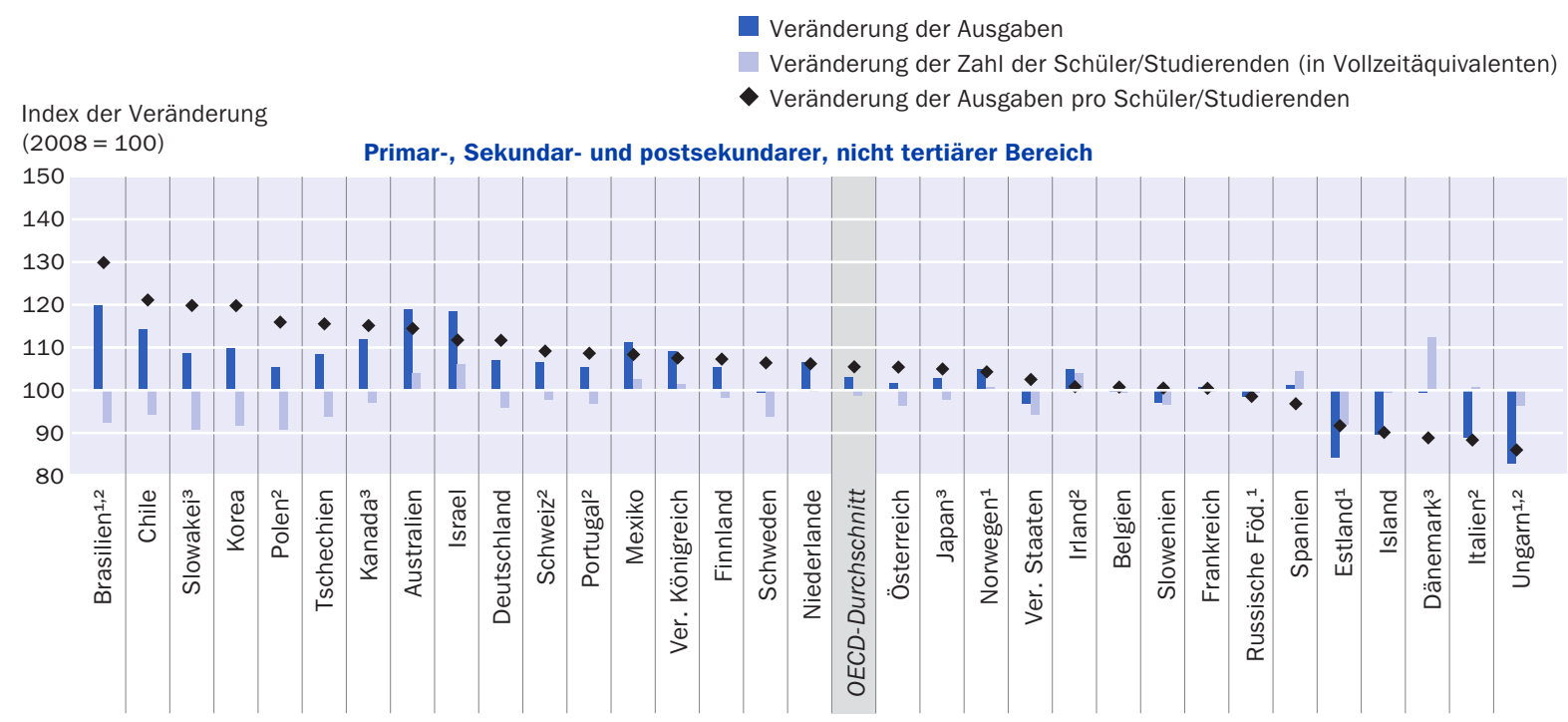

Index der Veränderung

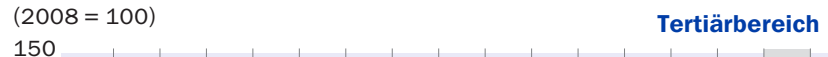

1. Nur öffentliche Ausgaben. 2. Nur öffentliche Bildungseinrichtungen. 3. Einige Bildungsbereiche sind in anderen Bildungsbereichen enthalten. Einzelheiten s. Erläuterung von „x“ in Hinweise für den Leser.

Anordnung der Länder in absteigender Reihenfolge der Veränderung der Ausgaben von Bildungseinrichtungen pro Schüler/Studierenden.

Quelle: OECD. Tabellen B1.5a and B1.5b. Hinweise s. Anhang 3 unter www.oecd.org/edu/eag.htm. StatLink: http://dx.doi.org/10.1787/888933117155

Seit Beginn der Wirtschaftskrise 2008 gingen die Ausgaben pro Schüler im Primar-, Sekundar- und postsekundaren, nicht tertiären Bereich jedoch in einigen Ländern wie z. B. Dänemark, Estland, Island, Italien, der Russischen Föderation, Spanien und Ungarn zurück. Mit Ausnahme von Spanien war der Rückgang das Ergebnis niedrigerer Ausgaben (in Dänemark in Kombination mit einer Zunahme der Schüler-/Studierendenzahlen). In den meisten anderen Ländern (mit Ausnahme von Australien und Israel) stiegen die Ausgaben selbst bei fallenden Schüler-/Studierendenzahlen weiter, d.h., die Ausgaben pro Schüler/Studierenden nahmen zu. Dies zeigt, dass sich die globale Wirtschaftskrise in der Mehrzahl der Länder noch nicht auf die Bildungsausgaben ausgewirkt hatte (Abb. Br.6). 
Im Tertiärbereich ergibt sich ein anderes Bild. Zwischen 1995 und 20 II stiegen die Ausgaben im Tertiärbereich pro Studierenden in den meisten Ländern mit verfügbaren Daten mit Ausnahme von Australien, Brasilien, Israel, der Schweiz, Tschechien und Ungarn, wo die Bildungsausgaben nicht mit den steigenden Studierendenzahlen Schritt hielten. Im Zeitraum von 1995 bis 2000 blieben die Ausgaben von Bildungseinrichtungen pro Studierenden im Tertiärbereich im Durchschnitt der OECD-Länder gleich, stiegen dann aber in ähnlichem Umfang (5 Prozent bis Io Prozent) sowohl zwischen 2000 und 2005 als auch zwischen 2005 und 201 I.

Zwischen 2005 und 20II stiegen die Ausgaben pro Studierenden in den meisten Ländern, dabei lag der Durchschnitt für die OECD-Länder mit verfügbaren Daten bei Io Prozent. Infolge einer Ausgabenerhöhung in Kombination mit konstanten Studierendenzahlen stiegen die Ausgaben in Estland und Korea um mindestens 40 Prozent. Im Gegensatz dazu sanken im gleichen Zeitraum die Ausgaben pro Studierenden in einem Viertel der Länder (in 8 der 32 Länder mit verfügbaren Daten), insbesondere in Island, Österreich und der Schweiz (um mindestens I4 Prozent). In all diesen Ländern ist der Rückgang größtenteils auf einen schnellen Anstieg der Studierendenzahlen im Tertiärbereich zurückzuführen (Tab. BI.5b und Abb. BI.5).

Seit Beginn der Wirtschaftskrise 2008 sanken die Ausgaben für Bildungseinrichtungen im Tertiärbereich in 4 der 32 Länder mit verfügbaren Daten: in Irland, Island, Polen und der Russischen Föderation. Dadurch fielen die Ausgaben pro Studierenden in all diesen Ländern mit Ausnahme von Polen und der Russischen Föderation, wo die Studierendenzahlen im Tertiärbereich noch schneller zurückgingen. Weltweit sanken die Ausgaben pro Studierenden zwischen 2008 und $201 \mathrm{I}$ in mehr als einem Drittel der Länder, hauptsächlich weil die Zahl der Studierenden schneller stieg als die Ausgaben (Abb. Br.6).

\section{Definitionen}

Zusätzliche Dienstleistungen sind Dienstleistungen, die von den Bildungseinrichtungen neben dem eigentlichen Bildungsauftrag erbracht werden. Soziale Dienstleistungen für Schüler/Studierende stellen den wichtigsten Bereich zusätzlicher Dienstleistungen dar. Im Primar-, Sekundar- und postsekundaren, nicht tertiären Bereich umfassen die sozialen Dienstleistungen die Bereitstellung von Mahlzeiten, die Gesundheitsdienste der Schulen sowie Schultransporte. Im Tertiärbereich zählen u. a. Wohnheime, Mensen und Gesundheitsdienste dazu.

Eigentliche Bildungsdienstleistungen stehen in direktem Zusammenhang mit Unterricht und Bildung an Bildungseinrichtungen. Hierzu gehören die Vergütungen der Lehrkräfte, der Bau und die Instandhaltung von Schulgebäuden, Unterrichtsmaterial, Bücher und die Verwaltung der Schulen.

Forschung und Entwicklung (F\&E) umfasst Forschung an Hochschulen und anderen Bildungseinrichtungen des Tertiärbereichs, unabhängig davon, ob diese aus dem allgemeinen Etat der Einrichtungen, über separate Zuschüsse oder über Verträge mit öffentlichen oder privaten Geldgebern finanziert werden. 


\section{Angewandte Methodik}

Die Daten beziehen sich auf das Haushaltsjahr $201 \mathrm{I}$ und beruhen auf der von der OECD im Jahre 2013 durchgeführten UOE-Datenerhebung zur Bildungsstatistik (weitere Informationen s. Anhang 3 unter www.oecd.org/edu/eag.htm).

Die Tabellen Br.5a und Br.5b zeigen die Veränderungen der Ausgaben von Bildungseinrichtungen pro Schüler/Studierenden zwischen den Haushaltsjahren I995, 2000, 2005, 2008, 2009, 2010 und 20II. Die OECD-Länder wurden gebeten, die Daten für I995, 2000, 2005, 2008, 2009 und 2010 entsprechend den Definitionen und dem Erhebungsbereich der UOE-Datenerhebung von 2013 zu erfassen. Alle Daten zu den Ausgaben sowie die Angaben zum BIP der Jahre I995, 2000, 2005, 2008, 2009 und 2010 wurden mittels des BIP-Preisdeflators an das Preisniveau von $201 \mathrm{I}$ angepasst.

Dieser Indikator gibt Auskunft über die Ausgaben von Bildungseinrichtungen aus öffentlichen und privaten Quellen im Verhältnis zur Zahl der Schüler bzw. Studierenden (in Vollzeitäquivalenten) an diesen Einrichtungen. Im Interesse einer besseren internationalen Vergleichbarkeit sind öffentliche Zuwendungen zum Lebensunterhalt der Schüler/Studierenden außerhalb von Bildungseinrichtungen nicht enthalten.

Die Ausgaben für eigentliche Bildungsdienstleistungen werden als der Restbetrag sämtlicher Ausgaben ermittelt, d.h., sie ergeben sich aus den Gesamtausgaben für Bildungseinrichtungen abzüglich der Ausgaben für F\&E und zusätzliche Dienstleistungen. Ausgaben für Forschung und Entwicklung werden anhand der Angaben der forschenden Institutionen und nicht der betreffenden Geldgeber klassifiziert.

Die Ausgaben von Bildungseinrichtungen pro Schüler/Studierenden in einem bestimmten Bildungsbereich werden mittels Division der Gesamtausgaben von Bildungseinrichtungen in diesem Bereich durch die entsprechende Schüler-/Studierendenzahl (in Vollzeitäquivalenten) ermittelt. Dabei wurden nur jene Bildungseinrichtungen und Bildungsgänge berücksichtigt, für die sowohl Daten über die Zahl der Schüler/Studierenden als auch Zahlen über die Ausgaben vorlagen. Die Ausgaben in Landeswährung werden in US-Dollar umgerechnet, indem der betreffende Betrag in Landeswährung durch den Kaufkraftparitätsindex (KKP-Index) für das BIP geteilt wird. Dieser Umrechnungskurs wird verwendet, weil der Devisenmarktkurs von einer Vielzahl von Faktoren beeinflusst wird (Zinssätze, Handelspolitik, Konjunkturerwartungen etc.), die wenig mit der aktuellen relativen inländischen Kaufkraft in den einzelnen OECD-Ländern zu tun haben (weitere Informationen s. Anhang 2).

Für einige Länder sind keine Zahlen zu den Ausgaben für Schüler/Studierende an privaten Bildungseinrichtungen verfügbar, für andere Länder sind die Angaben zu unabhängigen privaten Bildungseinrichtungen nicht vollständig. In diesen Fällen wurden nur die Ausgaben für öffentliche sowie staatlich subventionierte private Einrichtungen berücksichtigt.

Die Ausgaben von Bildungseinrichtungen pro Schüler/Studierenden im Verhältnis zum BIP pro Kopf werden berechnet, indem die Ausgaben von Bildungseinrichtungen pro Schüler/ Studierenden in Landeswährung als prozentualer Anteil des ebenfalls in Landeswäh- 
rung ausgedrückten BIP pro Kopf angegeben werden. Wenn die Referenzzeiträume für Daten zu den Bildungsausgaben und für das BIP unterschiedlich sind, werden unter Verwendung der für das betreffende OECD-Land geltenden Inflationsraten die Ausgabendaten auf den Bezugszeitraum der BIP-Daten umgerechnet (s. Anhang 2).

Die kumulierten Ausgaben während der durchschnittlichen Dauer von Studiengängen im Tertiärbereich (Tab. BI.3a) werden durch Multiplikation der aktuellen jährlichen Ausgaben mit der typischen Dauer der betreffenden Studiengänge berechnet. Die Vorgehensweise zur Ermittlung der typischen Dauer von Studiengängen im Tertiärbereich ist (auf Englisch) in Anhang 3 unter www.oecd.org/edu/eag.htm beschrieben. Die Studiendauer im Tertiärbereich wird anhand von Daten ermittelt, die aus einer 2013 in den OECD-Ländern durchgeführten Erhebung stammen.

Vollzeitäquivalente Schüler/Studierende: Die Erstellung einer Rangfolge der OECD-Länder nach den jährlichen Ausgaben von Bildungseinrichtungen pro Schüler/Studierenden wird durch unterschiedliche Definitionen der einzelnen Länder für Vollzeit-, Teilzeitund vollzeitäquivalente Bildungsteilnahme erschwert. In einigen OECD-Ländern gelten alle Bildungsteilnehmer im Tertiärbereich als Vollzeitstudierende, während in anderen Ländern die Beteiligung aufgrund der innerhalb eines vorgegebenen Referenzzeitraums für die erfolgreiche Absolvierung bestimmter Module erworbenen Credits (Leistungspunkte) beurteilt wird. Bei OECD-Ländern, die genaue Angaben über Teilzeitstudierende machen können, werden sich höhere Ausgaben der Bildungseinrichtungen pro vollzeitäquivalenten Studierenden ergeben als bei denjenigen OECD-Ländern, die nicht zwischen den verschiedenen Teilnahmemöglichkeiten differenzieren können.

Hinweis zu den Daten aus Israel

Die statistischen Daten für Israel wurden von den zuständigen israelischen Stellen bereitgestellt, die für sie verantwortlich zeichnen. Die Verwendung dieser Daten durch die OECD erfolgt unbeschadet des völkerrechtlichen Status der Golanhöhen, von Ost-Jerusalem und der israelischen Siedlungen im Westjordanland.

\section{Tabellen Indikator B1}

StatLink: http://dx.doi.org/10.1787/888933116908

Tabelle BI.ra: Jährliche Ausgaben von Bildungseinrichtungen pro Schüler/ Studierenden für alle Leistungsbereiche (20II)

WEB Table BI.Ib: Annual expenditure per student by educational institutions for core services (Jährliche Ausgaben von Bildungseinrichtungen pro Schüler/ Studierenden für eigentliche Bildungsdienstleistungen) (20II)

Tabelle Br.2: Jährliche Ausgaben von Bildungseinrichtungen pro Schüler/Studierenden für eigentliche Bildungsdienstleistungen, zusätzliche Dienstleistungen und F\&E (20II) 
- Tabelle Br.za: Kumulierte Ausgaben von Bildungseinrichtungen pro Studierenden für alle Leistungsbereiche während der durchschnittlichen Dauer von Studiengängen im Tertiärbereich (20II)

WEB Table Br.3b: Cumulative expenditure per student by educational institutions for all services over the theoretical duration of primary and secondary studies (Kumulierte Ausgaben von Bildungseinrichtungen pro Schüler für alle Leistungsbereiche während der regulären Ausbildungsdauer im Primar- und Sekundarbereich) (20II)

Tabelle BI.4: Jährliche Ausgaben von Bildungseinrichtungen pro Schüler/Studierenden für alle Leistungsbereiche im Verhältnis zum BIP pro Kopf (20II)

Tabelle Br.5a: Veränderung der Ausgaben von Bildungseinrichtungen pro Schüler im Primar-, Sekundar- und postsekundaren, nicht tertiären Bildungsbereich für alle Leistungsbereiche aufgrund verschiedener Faktoren (I995, 2000, 2005, 2008, 2009, 2010, 201I)

Tabelle BI.5b: Veränderung der Ausgaben von Bildungseinrichtungen pro Studierenden im Tertiärbereich für alle Leistungsbereiche aufgrund verschiedener Faktoren (I995, 2000, 2005, 2008, 2009, 2010, 201I)

Tabelle Br.6: Jährliche Ausgaben von Bildungseinrichtungen pro Schüler im Sekundarbereich für alle Leistungsbereiche, nach Art des Bildungsgangs (20II)

WEB Table BI.7: Percentage of expenditure by educational institutions compared to the proportion of students enrolled at each level of education (Anteil der Ausgaben von Bildungseinrichtungen [in \%] im Vergleich zum Anteil der Schüler/ Studierenden pro jeweiligen Bildungsbereich) (20II) 
Jährliche Ausgaben von Bildungseinrichtungen pro Schüler/Studierenden für alle Leistungsbereiche (2011)

In US-Dollar, kaufkraftbereinigt mittels KKP für das BIP, nach Bildungsbereich, basierend auf Vollzeitäquivalenten

\begin{tabular}{|c|c|c|c|c|c|c|c|c|c|c|c|}
\hline & \multirow{2}{*}{$\mid \begin{array}{c}\text { Elemen- } \\
\text { tarbereich } \\
\text { (für 3-Jäh- } \\
\text { rige und } \\
\text { Ältere) }\end{array}$} & \multirow[t]{2}{*}{$\begin{array}{l}\text { Primar- } \\
\text { bereich }\end{array}$} & \multicolumn{3}{|c|}{ Sekundarbereich } & \multirow{2}{*}{$\mid \begin{array}{c}\text { Postse- } \\
\text { kundarer, } \\
\text { nicht } \\
\text { tertiärer } \\
\text { Bereich }\end{array}$} & \multicolumn{3}{|c|}{$\begin{array}{c}\text { Tertiärbereich } \\
\text { (einschl. F\&E-Aktivitäten) }\end{array}$} & \multirow{2}{*}{\begin{tabular}{|c|} 
Tertiär- \\
bereich \\
insgesamt \\
(ohne \\
F\&E-Akti- \\
vitäten)
\end{tabular}} & \multirow{2}{*}{\begin{tabular}{|c} 
Primar- \\
bis Terti- \\
ärbereich \\
(einschl. \\
F\&E-Akti- \\
vitäten)
\end{tabular}} \\
\hline & & & $\begin{array}{l}\text { Sekundar- } \\
\text { bereich I }\end{array}$ & $\begin{array}{l}\text { Sekundar- } \\
\text { bereich II }\end{array}$ & $\begin{array}{l}\text { Sekundar- } \\
\text { bereich } \\
\text { insgesamt }\end{array}$ & & $\begin{array}{c}\text { Tertiär- } \\
\text { bereich B }\end{array}$ & $\begin{array}{c}\text { Tertiärbereich A } \\
\text { und weiter- } \\
\text { führende for- } \\
\text { schungsorientier- } \\
\text { te Studiengänge }\end{array}$ & $\begin{array}{c}\text { Tertiär- } \\
\text { bereich } \\
\text { insgesamt }\end{array}$ & & \\
\hline & (1) & (2) & (3) & (4) & (5) & (6) & (7) & (8) & (9) & (10) & (11) \\
\hline \multicolumn{12}{|l|}{ OECD-Länder } \\
\hline Australien & 10734 & 8671 & 10689 & 9859 & 10354 & 6728 & 8495 & 18038 & 16267 & 10068 & 10711 \\
\hline Österreich & 8933 & 10600 & 13547 & 13666 & 13607 & 5917 & 6944 & 14967 & 14895 & 10487 & 13116 \\
\hline Belgien & 6333 & 9281 & $x(5)$ & $x(5)$ & 11732 & $x(5)$ & $x(9)$ & $x(9)$ & 15420 & 10075 & 11585 \\
\hline Kanada $^{1,2}$ & $x(2)$ & 9232 & $x(2)$ & 11607 & $\mathrm{~m}$ & $\mathrm{~m}$ & 15729 & 27373 & 23226 & 17006 & $\mathbf{m}$ \\
\hline Chile $^{3}$ & 5083 & 4551 & 4494 & 4496 & 4495 & a & 5045 & 11082 & 8333 & 7897 & 5522 \\
\hline Tschechien & 4302 & 4587 & 7730 & 6886 & 7270 & 2205 & 3350 & 9856 & 9392 & 6320 & 6931 \\
\hline Dänemark & 14148 & 9434 & 10971 & 10908 & 10937 & $x(4,9)$ & $x(9)$ & $x(9)$ & 21254 & 4827 & 12136 \\
\hline Estland & 2618 & 5328 & 6009 & 6688 & 6389 & 8333 & 6628 & 8450 & 7868 & 4827 & 6563 \\
\hline Finnland & 5700 & 8159 & 12545 & 8467 & 9792 & $x(5)$ & $\mathrm{n}$ & 18002 & 18002 & 10973 & 10905 \\
\hline Frankreich & 6615 & 6917 & 9668 & 13071 & 11109 & $\mathrm{~m}$ & 12554 & 16328 & 15375 & 10470 & 10454 \\
\hline Deutschland & 8351 & 7579 & 9247 & 12022 & 10275 & 9694 & 8891 & 18348 & 16723 & 10164 & 10904 \\
\hline Griechenland & $\mathrm{m}$ & $\mathrm{m}$ & $\mathrm{m}$ & $\mathrm{m}$ & $\mathrm{m}$ & $\mathrm{m}$ & $\mathrm{m}$ & $\mathrm{m}$ & $\mathrm{m}$ & $\mathrm{m}$ & $\mathbf{m}$ \\
\hline Ungarn ${ }^{2}$ & 4564 & 4566 & 4709 & 4455 & 4574 & 3165 & 5213 & 9521 & 9210 & 7153 & 5410 \\
\hline Island & 9138 & 10339 & 10160 & 7461 & 8470 & $x(5)$ & $x(9)$ & $x(9)$ & 8612 & $\mathrm{~m}$ & 9180 \\
\hline Irland ${ }^{2}$ & $\mathrm{~m}$ & 8520 & 11442 & 11576 & 11502 & 11636 & $x(9)$ & $x(9)$ & 16095 & 11938 & 10857 \\
\hline Israel & 4058 & 6823 & $x(5)$ & $x(5)$ & 5712 & 2834 & 6474 & 12711 & 11554 & $\mathrm{~m}$ & 7167 \\
\hline Italien² & 7868 & 8448 & 8686 & 8519 & 8585 & $\mathrm{~m}$ & 9134 & 9993 & 9990 & 6482 & 8790 \\
\hline Japan & 5591 & 8280 & 9677 & 10093 & 9886 & $x(4,9)$ & 10181 & 18110 & 16446 & $\mathrm{~m}$ & 10646 \\
\hline Korea & 6861 & 6976 & 6674 & 9698 & 8199 & a & 5692 & 11230 & 9927 & 8168 & 8382 \\
\hline Luxemburg ${ }^{4}$ & 25074 & 23871 & 16125 & 16238 & 16182 & $\mathrm{~m}$ & $\mathrm{~m}$ & $\mathrm{~m}$ & $\mathrm{~m}$ & $\mathrm{~m}$ & m \\
\hline Mexiko & 2568 & 2622 & 2344 & 4034 & 2943 & a & $x(9)$ & $x(9)$ & 7889 & 6476 & 3286 \\
\hline Niederlande & 8020 & 8036 & 12031 & 12171 & 12100 & 11532 & 10208 & 17561 & 17549 & 10665 & 11701 \\
\hline Neuseeland & 11088 & 8084 & 8670 & 10023 & 9312 & 9898 & 8863 & 10995 & 10582 & 9039 & 9163 \\
\hline Norwegen & 6730 & 12459 & 12769 & 14838 & 13939 & $x(5)$ & $x(9)$ & $x(9)$ & 18840 & 11036 & 14288 \\
\hline Polen ${ }^{2}$ & 6409 & 6233 & 5995 & 5764 & 5870 & 10620 & 6851 & 9686 & 9659 & 7916 & 6796 \\
\hline Portugal $^{2}$ & 5674 & 5865 & 8294 & 9139 & 8676 & $\mathrm{~m}$ & $x(9)$ & $x(9)$ & 9640 & 5219 & 7741 \\
\hline Slowakei & 4653 & 5517 & 5109 & 4783 & 4938 & $x(4)$ & $x(4)$ & 8177 & 8177 & 6436 & 5667 \\
\hline Slowenien & 8136 & 9260 & 9947 & 7724 & 8568 & $x(4)$ & $x(9)$ & $x(9)$ & 10413 & 8279 & 9233 \\
\hline Spanien & 6725 & 7288 & 9335 & 10090 & 9615 & $a$ & 10042 & 13933 & 13173 & 9436 & 9454 \\
\hline Schweden & 6915 & 10295 & 10823 & 11022 & 10938 & 4029 & 6604 & 22090 & 20818 & 9922 & 12426 \\
\hline Schweiz ${ }^{2}$ & 5267 & 12907 & 15124 & 16521 & 15891 & $x(4)$ & 6371 & 24287 & 22882 & 10017 & 16090 \\
\hline Türkei & 2412 & 2218 & 2250 & 3239 & 2736 & a & $x(9)$ & $x(9)$ & 8193 & $\mathrm{~m}$ & 3240 \\
\hline Ver. Königreich & 9692 & 9857 & 13894 & 6491 & 9649 & a & $x(9)$ & $x(9)$ & 14223 & 10570 & 10412 \\
\hline Vereinigte Staaten & 10010 & 10958 & 12338 & 13143 & 12731 & $\mathrm{~m}$ & $x(9)$ & $x(9)$ & 26021 & 23094 & 15345 \\
\hline OECD-Durchschnitt & 7428 & 8296 & 9377 & 9506 & 9280 & 4811 & $\sim$ & $\sim$ & 13958 & 9635 & 9487 \\
\hline OECD insgesamt & 7044 & 7900 & 9111 & 9953 & 9505 & $\sim$ & $\sim$ & $\sim$ & 17929 & 14596 & 10561 \\
\hline EU21-Durchschnitt & 7933 & 8482 & 9795 & 9457 & 9615 & 6103 & $\sim$ & $\sim$ & 13572 & 8741 & 9531 \\
\hline
\end{tabular}

\begin{tabular}{|c|c|c|c|c|c|c|c|c|c|c|c|}
\hline \multicolumn{12}{|l|}{ Partnerländer } \\
\hline Argentinien ${ }^{2}$ & 1979 & 2167 & 2947 & 3184 & 3034 & a & 2255 & $\mathrm{~m}$ & $\mathrm{~m}$ & $\mathrm{~m}$ & $\mathbf{m}$ \\
\hline Brasilien² $^{2}$ & 2349 & 2673 & 2700 & 2605 & 2662 & a & $x(9)$ & $x(9)$ & 10902 & 10140 & 3066 \\
\hline China & $\mathrm{m}$ & $\mathrm{m}$ & $\mathrm{m}$ & $\mathrm{m}$ & $\mathrm{m}$ & $\mathrm{m}$ & $\mathrm{m}$ & $\mathrm{m}$ & $\mathrm{m}$ & $\mathrm{m}$ & $\mathbf{m}$ \\
\hline Kolumbien ${ }^{3}$ & 3491 & 2041 & 2164 & 2326 & 2207 & a & $\mathrm{m}$ & $\mathrm{m}$ & 6882 & $\mathrm{~m}$ & m \\
\hline Indien & $\mathrm{m}$ & $\mathrm{m}$ & $\mathrm{m}$ & $\mathrm{m}$ & $\mathrm{m}$ & $\mathrm{m}$ & $\mathrm{m}$ & $\mathrm{m}$ & $\mathrm{m}$ & $\mathrm{m}$ & m \\
\hline Indonesien ${ }^{3}$ & 205 & 587 & 449 & 617 & 522 & a & 1888 & 1012 & 1173 & $\mathrm{~m}$ & 625 \\
\hline Lettland & 4359 & 4982 & 5019 & 4983 & 4998 & 5452 & 7389 & 7578 & 7552 & 5832 & 5624 \\
\hline Russische Föd. & $\mathrm{m}$ & $x(5)$ & $x(5)$ & $x(5)$ & 4470 & $x(5)$ & 4446 & 8095 & 7424 & 6898 & 5328 \\
\hline Saudi-Arabien & $\mathrm{m}$ & $\mathrm{m}$ & $\mathrm{m}$ & $\mathrm{m}$ & $\mathrm{m}$ & $\mathrm{m}$ & $\mathrm{m}$ & $\mathrm{m}$ & $\mathrm{m}$ & $\mathrm{m}$ & m \\
\hline Südafrika & $\mathrm{m}$ & $\mathrm{m}$ & $\mathrm{m}$ & $\mathrm{m}$ & $\mathrm{m}$ & $\mathrm{m}$ & $\mathrm{m}$ & $\mathrm{m}$ & $\mathrm{m}$ & $\mathrm{m}$ & m \\
\hline G20-Durchschnitt & m & m & m & m & $\mathbf{m}$ & $\mathbf{m}$ & m & m & m & m & m \\
\hline
\end{tabular}

1. Referenzjahr 2010. 2. Nur öffentliche Ausgaben (Kanada: nur im Tertiärbereich, Italien: außer im Tertiärbereich). 3. Referenzjahr 2012. 4. Angaben für den Elementar- und Primarbereich enthalten Erstattungen lokaler Behörden für frühere Jahre.

Quelle: OECD. Argentinien, China, Indien, Indonesien, Kolumbien, Saudi-Arabien und Südafrika: Statistikinstitut der UNESCO. Lettland: Eurostat.

Hinweise s. Anhang 3 unter www.oecd.org/edu/eag.htm. StatLink: http://dx.doi.org/10.1787/888933116927

Erläuterung der Kennzeichnung fehlender Daten s. Hinweise für den Leser. 
Jährliche Ausgaben von Bildungseinrichtungen pro Schüler/Studierenden für eigentliche Bildungsdienstleistungen, zusätzliche Dienstleistungen und F\&E (2011)

In US-Dollar, kaufkraftbereinigt mittels KKP für das BIP, nach Bildungsbereich und Leistungsbereich, basierend auf Vollzeitäquivalenten

\begin{tabular}{|c|c|c|c|c|c|c|c|c|c|c|}
\hline & \multicolumn{3}{|c|}{$\begin{array}{l}\text { Primar-, Sekundar- und post- } \\
\text { sekundarer, nicht tertiärer Bereich }\end{array}$} & \multicolumn{4}{|c|}{ Tertiärbereich } & \multicolumn{3}{|c|}{ Primar- bis Tertiärbereich } \\
\hline & \begin{tabular}{|c|} 
Eigent- \\
liche \\
Bildungs- \\
dienst- \\
leistun- \\
gen
\end{tabular} & \begin{tabular}{|c|} 
Zusätzliche Dienst- \\
leistungen (Trans- \\
port, Mahlzeiten \\
und Unterbringung, \\
von den Bildungs- \\
einrichtungen zur \\
Verfügung gestellt)
\end{tabular} & Gesamt & $\begin{array}{l}\text { Eigent- } \\
\text { liche } \\
\text { Bildungs- } \\
\text { dienst- } \\
\text { leistun- } \\
\text { gen }\end{array}$ & \begin{tabular}{|c|} 
Zusätzliche Dienst- \\
leistungen (Trans- \\
port, Mahlzeiten \\
und Unterbringung, \\
von den Bildungs- \\
einrichtungen zur \\
Verfügung gestellt)
\end{tabular} & $\mathrm{F} \& \mathrm{E}$ & Gesamt & $\begin{array}{l}\text { Eigent- } \\
\text { liche } \\
\text { Bildungs- } \\
\text { dienst- } \\
\text { leistun- } \\
\text { gen }\end{array}$ & \begin{tabular}{|c|} 
Zusätzliche Dienst- \\
leistungen (Trans- \\
port, Mahlzeiten \\
und Unterbringung, \\
von den Bildungs- \\
einrichtungen zur \\
Verfügung gestellt) \\
sowie F\&E
\end{tabular} & Gesamt \\
\hline & (1) & (2) & (3) & (4) & (5) & (6) & (7) & (8) & (9) & (10) \\
\hline \multicolumn{11}{|l|}{ OECD-Länder } \\
\hline Australien & 9221 & 162 & 9383 & 9571 & 496 & 6200 & 16267 & 9288 & 1422 & 10711 \\
\hline Österreich & 11956 & 552 & 12509 & 10368 & 119 & 4408 & 14895 & 11552 & 1565 & 13116 \\
\hline Belgien & 10430 & 293 & 10722 & 9726 & 350 & 5345 & 15420 & 10300 & 1284 & 11585 \\
\hline Kanada $^{1,2,3}$ & 9586 & 492 & 10078 & 17006 & 1187 & 6219 & 23226 & $\mathrm{~m}$ & $\mathrm{~m}$ & m \\
\hline Chile $^{4}$ & 4522 & a & 4522 & 7897 & $x(4)$ & 436 & 8333 & 5407 & 114 & 5522 \\
\hline Tschechien & 5699 & 430 & 6128 & 6241 & 79 & 3072 & 9392 & 5832 & 1099 & 6931 \\
\hline Dänemark ${ }^{1}$ & 10230 & a & 10230 & $x(7)$ & a & $x(7)$ & 21254 & $x(10)$ & $x(10)$ & 12136 \\
\hline Estland & $x(3)$ & $x(3)$ & 6055 & 4827 & $x(4)$ & 3041 & 7868 & $x(10)$ & $x(10)$ & 6563 \\
\hline Finnland & 8222 & 958 & 9180 & 10973 & $\mathrm{n}$ & 7029 & 18002 & 8759 & 2145 & 10905 \\
\hline Frankreich & 8091 & 1238 & 9329 & 9662 & 808 & 4905 & 15375 & 8384 & 2071 & 10454 \\
\hline Deutschland & 9260 & 260 & 9521 & 9457 & 707 & 6559 & 16723 & 9298 & 1606 & 10904 \\
\hline Griechenland & $\mathrm{m}$ & $\mathrm{m}$ & $\mathbf{m}$ & $\mathrm{m}$ & $\mathrm{m}$ & $\mathrm{m}$ & $\mathbf{m}$ & $\mathrm{m}$ & $\mathrm{m}$ & m \\
\hline Ungarn ${ }^{3}$ & 4002 & 525 & 4527 & 5959 & 1194 & 2056 & 9210 & 4371 & 1039 & 5410 \\
\hline Island & $x(3)$ & $x(3)$ & 9326 & $x(7)$ & $x(7)$ & $x(7)$ & 8612 & $x(10)$ & $x(10)$ & 9180 \\
\hline Irland ${ }^{3}$ & 9830 & $\mathrm{~m}$ & 9830 & 11938 & $\mathrm{~m}$ & 4157 & 16095 & 10175 & 681 & 10857 \\
\hline Israel & 5969 & 308 & 6277 & 10296 & 1258 & $\mathrm{~m}$ & 11554 & 6699 & 468 & 7167 \\
\hline Italien ${ }^{3,5}$ & 8133 & 401 & 8534 & 6114 & 368 & 3509 & 9990 & 7659 & 1131 & 8790 \\
\hline Japan $^{1}$ & $x(3)$ & $x(3)$ & 9102 & $x(7)$ & $x(7)$ & $x(7)$ & 16446 & $x(10)$ & $x(10)$ & 10646 \\
\hline Korea & 6668 & 984 & 7652 & 8093 & 75 & 1758 & 9927 & 7125 & 1257 & 8382 \\
\hline Luxemburg & 18160 & 1237 & 19600 & $\mathrm{~m}$ & $\mathrm{~m}$ & $\mathrm{~m}$ & $\mathbf{m}$ & $\mathrm{m}$ & $\mathrm{m}$ & m \\
\hline Mexiko & $x(3)$ & $x(3)$ & 2765 & 6476 & $\mathrm{~m}$ & 1413 & 7889 & 3142 & 144 & 3286 \\
\hline Niederlande & 10268 & $\mathrm{n}$ & 10268 & 10665 & $\mathrm{n}$ & 6884 & 17549 & 10346 & 1355 & 11701 \\
\hline Neuseeland & $x(3)$ & $x(3)$ & 8831 & 9039 & $x(4)$ & 1543 & 10582 & $x(10)$ & $x(10)$ & 9163 \\
\hline Norwegen & $x(3)$ & $x(3)$ & 13219 & 10850 & 187 & 7804 & 18840 & $x(10)$ & $x(10)$ & 14288 \\
\hline Polen ${ }^{3}$ & 6038 & 28 & 6066 & 7916 & $\mathrm{n}$ & 1743 & 9659 & 6420 & 376 & 6796 \\
\hline Portugal $^{3}$ & 7102 & 180 & 7282 & 5219 & $x(4)$ & 4421 & 9640 & 6735 & 1006 & 7741 \\
\hline Slowakei ${ }^{1}$ & 4390 & 715 & 5105 & 5036 & 1401 & 1741 & 8177 & 4508 & 1159 & 5667 \\
\hline Slowenien & 8267 & 600 & 8867 & 8248 & 31 & 2134 & 10413 & 8262 & 971 & 9233 \\
\hline Spanien & 8010 & 466 & 8476 & 8939 & 496 & 3737 & 13173 & 8203 & 1250 & 9454 \\
\hline Schweden & 9435 & 1113 & 10548 & 9922 & $\mathrm{n}$ & 10896 & 20818 & 9524 & 2902 & 12426 \\
\hline Schweiz ${ }^{3}$ & $x(3)$ & $x(3)$ & 14623 & 10017 & $x(4)$ & 12864 & 22882 & $x(10)$ & $x(10)$ & 16090 \\
\hline Türkei & 2423 & 78 & 2501 & $x(7)$ & $x(7)$ & $\mathrm{m}$ & 8193 & $x(10)$ & $x(10)$ & 3240 \\
\hline Ver. Königreich & 8938 & 800 & 9738 & 8975 & 1595 & 3653 & 14223 & 8944 & 1469 & 10412 \\
\hline Vereinigte Staaten & 10879 & 961 & 11841 & 19896 & 3198 & 2928 & 26021 & 13107 & 2237 & 15345 \\
\hline OECD-Durchschnitt & 8297 & 511 & 8868 & 9262 & 616 & 4461 & 13958 & 8002 & 1250 & 9487 \\
\hline EU21-Durchschnitt & 8761 & 544 & 9126 & 8344 & 447 & 4405 & 13572 & 8193 & 1359 & 9531 \\
\hline \multicolumn{11}{|l|}{ Partnerländer } \\
\hline Argentinien ${ }^{3}$ & $x(3)$ & $x(3)$ & 2578 & $x(7)$ & $x(7)$ & $x(7)$ & m & $x(10)$ & $x(10)$ & m \\
\hline Brasilien $^{3}$ & $x(3)$ & $x(3)$ & 2667 & 10140 & $x(4)$ & 762 & 10902 & 3029 & 37 & 3066 \\
\hline China & $\mathrm{m}$ & $\mathrm{m}$ & m & $\mathrm{m}$ & $\mathrm{m}$ & $\mathrm{m}$ & m & $\mathrm{m}$ & $\mathrm{m}$ & m \\
\hline Kolumbien ${ }^{4}$ & $x(3)$ & $x(3)$ & 2122 & $\mathrm{~m}$ & $\mathrm{~m}$ & $\mathrm{~m}$ & m & $\mathrm{m}$ & $\mathrm{m}$ & m \\
\hline Indien & $\mathrm{m}$ & $\mathrm{m}$ & $\mathbf{m}$ & $\mathrm{m}$ & $\mathrm{m}$ & $\mathrm{m}$ & $\mathbf{m}$ & $\mathrm{m}$ & $\mathrm{m}$ & m \\
\hline Indonesien & $x(3)$ & $x(3)$ & 560 & $x(7)$ & $x(7)$ & $x(7)$ & 1173 & $x(10)$ & $x(10)$ & 625 \\
\hline Lettland & $x(3)$ & $x(3)$ & 4995 & 5832 & $x(4)$ & 1720 & 7552 & $x(10)$ & $x(10)$ & 5624 \\
\hline Russische Föd. & $x(3)$ & $x(3)$ & 4470 & $x(7)$ & $x(7)$ & 526 & 7424 & $x(10)$ & $x(10)$ & 5328 \\
\hline Saudi-Arabien & $m$ & $\mathrm{~m}$ & m & $\mathrm{m}$ & $\mathrm{m}$ & $\mathrm{m}$ & m & $\mathrm{m}$ & $\mathrm{m}$ & m \\
\hline Südafrika & $\mathrm{m}$ & $\mathrm{m}$ & $\mathbf{m}$ & $\mathrm{m}$ & $\mathrm{m}$ & $\mathrm{m}$ & $\mathbf{m}$ & $\mathrm{m}$ & $\mathrm{m}$ & m \\
\hline G20-Durchschnitt & $\mathbf{m}$ & $\mathbf{m}$ & $\mathbf{m}$ & $\mathbf{m}$ & $\mathbf{m}$ & $\mathbf{m}$ & $\mathbf{m}$ & $\mathbf{m}$ & $\mathbf{m}$ & $\mathbf{m}$ \\
\hline
\end{tabular}

1. Einige Bildungsbereiche sind in anderen Bildungsbereichen enthalten. Einzelheiten s. Erläuterung von "x“ in Hinweise für den Leser. 2. Referenzjahr 2010.

3. Nur öffentliche Bildungseinrichtungen (Kanada: nur im Tertiärbereich, Italien: außer im Tertiärbereich). 4. Referenzjahr 2012. 5. Ohne postsekundaren, nicht tertiären Bereich.

Quelle: OECD. Argentinien, China, Indien, Indonesien, Kolumbien, Saudi-Arabien und Südafrika: Statistikinstitut der UNESCO. Lettland: Eurostat. Hinweise s. Anhang 3 unter www.oecd.org/edu/eag.htm. StatLink: http://dx.doi.org/10.1787/888933116946

Erläuterung der Kennzeichnung fehlender Daten s. Hinweise für den Leser. 
Kumulierte Ausgaben von Bildungseinrichtungen pro Studierenden für alle Leistungsbereiche während der durchschnittlichen Dauer von Studiengängen im Tertiärbereich (2011)

In US-Dollar, kaufkraftbereinigt mittels KKP für das BIP, nach Art des Studiengangs

\begin{tabular}{|c|c|c|c|c|c|c|c|}
\hline & \multirow[t]{3}{*}{$\mid$ Methode $^{1} \mid$} & \multicolumn{3}{|c|}{$\begin{array}{l}\text { Durchschnittliche Dauer von Studiengängen } \\
\text { im Tertiärbereich in } 2011 \text { (in Jahren) }\end{array}$} & \multicolumn{3}{|c|}{$\begin{array}{l}\text { Kumulierte Ausgaben pro Studierenden während der durch- } \\
\text { schnittlichen Dauer tertiärer Studiengänge (in US-Dollar) }\end{array}$} \\
\hline & & Tertiärbereich B & \begin{tabular}{|c|} 
Tertiärbereich A \\
und weiterführende \\
forschungsorien- \\
tierte Studiengänge
\end{tabular} & $\begin{array}{c}\text { Tertiärbereich } \\
\text { insgesamt }\end{array}$ & Tertiärbereich B & \begin{tabular}{|c|} 
Tertiärbereich A \\
und weiterführende \\
forschungsorien- \\
tierte Studiengänge
\end{tabular} & $\begin{array}{c}\text { Tertiärbereich } \\
\text { insgesamt }\end{array}$ \\
\hline & & (1) & (2) & (3) & (4) & (5) & (6) \\
\hline \multicolumn{8}{|l|}{ OECD-Länder } \\
\hline Australien & & $\mathrm{m}$ & $\mathrm{m}$ & m & $\mathrm{m}$ & $\mathrm{m}$ & m \\
\hline Österreich & VM & 2,34 & 6,10 & 5,34 & 16248 & 91300 & 79539 \\
\hline Belgien ${ }^{2}$ & VM & 2,41 & 3,67 & 2,99 & $x(6)$ & $x(6)$ & 46107 \\
\hline Kanada & & $\mathrm{m}$ & $\mathrm{m}$ & m & $\mathrm{m}$ & $\mathrm{m}$ & m \\
\hline Chile & & $\mathrm{m}$ & $\mathrm{m}$ & m & $\mathrm{m}$ & $\mathrm{m}$ & m \\
\hline Tschechien $^{3}$ & VM & 2,36 & 4,34 & 4,10 & $\mathrm{~m}$ & 42777 & m \\
\hline Dänemark & NF & 2,74 & 5,49 & 5,20 & $x(6)$ & $x(6)$ & 110520 \\
\hline Estland & VM & 3,29 & 4,97 & 4,42 & 21808 & 41978 & 34810 \\
\hline Finnland & VM & a & 4,74 & 4,74 & a & 85328 & 85328 \\
\hline Frankreich $^{3}$ & VM & 3,00 & 4,74 & 4,02 & 37662 & 77397 & 61807 \\
\hline Deutschland & VM & 2,41 & 4,95 & 4,19 & 21427 & 90821 & 70069 \\
\hline Griechenland & & $\mathrm{m}$ & $\mathrm{m}$ & m & $\mathrm{m}$ & $\mathrm{m}$ & m \\
\hline Ungarn ${ }^{4}$ & NF & 1,85 & 3,71 & 3,29 & 9664 & 35335 & 30292 \\
\hline Island & VM & $x(3)$ & $x(3)$ & 4,49 & $x(6)$ & $x(6)$ & 38668 \\
\hline Irland ${ }^{4}$ & VM & 2,21 & 4,02 & 3,24 & $x(6)$ & $x(6)$ & 52148 \\
\hline Israel & VM & $\mathrm{m}$ & 3,03 & m & $\mathrm{m}$ & 38513 & m \\
\hline Italien & NF & $\mathrm{m}$ & 4,52 & m & $\mathrm{m}$ & 45168 & m \\
\hline Japan & VM & 2,09 & 4,63 & 4,46 & 21312 & 83893 & 73364 \\
\hline Korea & VM & 2,07 & 4,22 & 3,43 & 11782 & 47392 & 34048 \\
\hline Luxemburg & & $\mathrm{m}$ & $\mathrm{m}$ & m & $\mathrm{m}$ & $\mathrm{m}$ & m \\
\hline Mexiko & $\mathrm{NF}$ & 1,72 & 3,49 & 3,35 & $x(6)$ & $x(6)$ & 26428 \\
\hline Niederlande & VM & $\mathrm{m}$ & 5,26 & 5,26 & $\mathrm{~m}$ & 92373 & 92310 \\
\hline Neuseeland & VM & 1,93 & 4,06 & 3,37 & 17137 & 44584 & 35655 \\
\hline Norwegen & & $\mathrm{m}$ & $\mathrm{m}$ & m & $\mathrm{m}$ & $\mathrm{m}$ & m \\
\hline Polen ${ }^{4}$ & VM & $\mathrm{m}$ & 3,68 & m & $\mathrm{m}$ & 35644 & m \\
\hline Portugal & & $\mathrm{m}$ & $\mathrm{m}$ & m & $\mathrm{m}$ & $\mathrm{m}$ & m \\
\hline Slowakei & NF & 2,47 & 3,90 & 3,82 & $\mathrm{~m}$ & 31892 & m \\
\hline Slowenien & $\mathrm{NF}$ & 2,63 & 3,64 & 3,21 & $x(6)$ & $x(6)$ & 33409 \\
\hline Spanien & VM & 2,15 & 5,54 & 4,66 & 21590 & 77190 & 61386 \\
\hline Schweden & VM & 2,44 & 4,70 & 4,51 & 16095 & 103827 & 93890 \\
\hline Schweiz ${ }^{4}$ & VM & 2,19 & 5,45 & 3,62 & 13932 & 132433 & 82929 \\
\hline Türkei & VM & 1,94 & 2,73 & 2,65 & $x(6)$ & $x(6)$ & 21746 \\
\hline Ver. Königreich ${ }^{3}$ & VM & $x(3)$ & $x(3)$ & 2,74 & $x(6)$ & $x(6)$ & 38971 \\
\hline Vereinigte Staaten & $\mathrm{NF}$ & $x(3)$ & $x(3)$ & 3,17 & $x(6)$ & $x(6)$ & 82488 \\
\hline \multicolumn{2}{|l|}{ OECD-Durchschnitt } & 2,21 & 4,40 & $\mathbf{3 , 9 3}$ & $\sim$ & $\sim$ & 58450 \\
\hline EU21-Durchschnitt & & 2,31 & 4,59 & 4,11 & $\sim$ & $\sim$ & 63613 \\
\hline
\end{tabular}

\begin{tabular}{|c|c|c|c|c|c|c|}
\hline \multicolumn{7}{|l|}{ Partnerländer } \\
\hline Argentinien & $\mathrm{m}$ & $\mathrm{m}$ & m & $\mathrm{m}$ & $\mathrm{m}$ & m \\
\hline Brasilien & $\mathrm{m}$ & $\mathrm{m}$ & m & $\mathrm{m}$ & $\mathrm{m}$ & m \\
\hline China & $\mathrm{m}$ & $\mathrm{m}$ & m & $\mathrm{m}$ & $\mathrm{m}$ & m \\
\hline Kolumbien & $\mathrm{m}$ & $\mathrm{m}$ & m & $\mathrm{m}$ & $\mathrm{m}$ & m \\
\hline Indien & $\mathrm{m}$ & $\mathrm{m}$ & m & $\mathrm{m}$ & $\mathrm{m}$ & m \\
\hline Indonesien & $\mathrm{m}$ & $\mathrm{m}$ & m & $\mathrm{m}$ & $\mathrm{m}$ & m \\
\hline Lettland & $\mathrm{m}$ & $\mathrm{m}$ & m & $\mathrm{m}$ & $\mathrm{m}$ & m \\
\hline Russische Föd. & $\mathrm{m}$ & $\mathrm{m}$ & $\mathbf{m}$ & $\mathrm{m}$ & $\mathrm{m}$ & m \\
\hline Saudi-Arabien & $\mathrm{m}$ & $\mathrm{m}$ & m & $\mathrm{m}$ & $\mathrm{m}$ & m \\
\hline Südafrika & $\mathrm{m}$ & $\mathrm{m}$ & m & $\mathrm{m}$ & $\mathrm{m}$ & m \\
\hline G20-Durchschnitt & $\mathbf{m}$ & m & $\mathbf{m}$ & m & m & m \\
\hline
\end{tabular}

1. Zur Ermittlung der Dauer von Studiengängen im Tertiärbereich wurde entweder die Verkettungsmethode (VM) oder eine Näherungsformel (NF) verwendet.

2. Referenzjahr 2008. 3. Die durchschnittliche Dauer von Studiengängen im Tertiärbereich wurde auf Grundlage nationaler Daten ermittelt. 4. Nur öffentliche Bildungseinrichtungen (Ungarn: durchschnittliche Dauer für öffentliche und private Bildungseinrichtungen).

Quelle: OECD. Argentinien, China, Indien, Indonesien, Kolumbien, Saudi-Arabien und Südafrika: Statistikinstitut der UNESCO. Lettland: Eurostat. Hinweise s. Anhang 3 unter www.oecd.org/edu/eag.htm. StatLink: http://dx.doi.org/10.1787/888933116965

Erläuterung der Kennzeichnung fehlender Daten s. Hinweise für den Leser. 
Jährliche Ausgaben von Bildungseinrichtungen pro Schüler/Studierenden für alle Leistungsbereiche im Verhältnis zum BIP pro Kopf (2011)

Nach Bildungsbereich, basierend auf Vollzeitäquivalenten

\begin{tabular}{|c|c|c|c|c|c|c|c|c|c|c|c|}
\hline & \multirow{2}{*}{\begin{tabular}{|} 
Elemen- \\
tarbereich \\
(für 3 -Jäh- \\
rige und \\
Ältere)
\end{tabular}} & \multirow[t]{2}{*}{$\begin{array}{l}\text { Primar- } \\
\text { bereich }\end{array}$} & \multicolumn{3}{|c|}{ Sekundarbereich } & \multirow{2}{*}{\begin{tabular}{|} 
Postse- \\
kundarer, \\
nicht \\
tertiärer \\
Bereich
\end{tabular}} & \multicolumn{3}{|c|}{$\begin{array}{c}\text { Tertiärbereich } \\
\text { (einschl. F\&E-Aktivitäten) }\end{array}$} & \multirow{2}{*}{\begin{tabular}{|c|} 
Tertiär- \\
bereich \\
insgesamt \\
ohne \\
F\&E-Akti- \\
vitäten
\end{tabular}} & \multirow{2}{*}{\begin{tabular}{|} 
Primar- \\
bis Terti- \\
ärbereich \\
(einschl. \\
F\&E-Akti- \\
vitäten)
\end{tabular}} \\
\hline & & & $\begin{array}{l}\text { Sekundar- } \\
\text { bereich I }\end{array}$ & \begin{tabular}{|l|} 
Sekundar- \\
bereich II
\end{tabular} & \begin{tabular}{|c|}
$\begin{array}{c}\text { Sekundar- } \\
\text { bereich } \\
\text { insgesamt }\end{array}$ \\
\end{tabular} & & $\begin{array}{c}\text { Tertiär- } \\
\text { bereich B }\end{array}$ & \begin{tabular}{|c|} 
Tertiärbereich A \\
und weiter- \\
führende for- \\
schungsorientier- \\
te Studiengänge
\end{tabular} & $\begin{array}{c}\text { Tertiär- } \\
\text { bereich } \\
\text { insgesamt }\end{array}$ & & \\
\hline & (1) & (2) & (3) & (4) & (5) & (6) & (7) & (8) & (9) & (10) & (11) \\
\hline \multicolumn{12}{|l|}{ OECD-Länder } \\
\hline Australien & 25 & 20 & 25 & 23 & 24 & 16 & 20 & 42 & 38 & 23 & 25 \\
\hline Österreich & 21 & 25 & 32 & 32 & 32 & 14 & 16 & 35 & 35 & 24 & 31 \\
\hline Belgien & 16 & 23 & $x(5)$ & $x(5)$ & 29 & $x(5)$ & $x(9)$ & $x(9)$ & 38 & 25 & 29 \\
\hline Kanada $^{1,2}$ & $x(2)$ & 25 & $x(2)$ & 31 & $\mathrm{~m}$ & $\mathrm{~m}$ & 42 & 73 & 62 & 45 & m \\
\hline Chile $^{3}$ & 24 & 21 & 21 & 21 & 21 & a & 23 & 52 & 39 & 37 & 26 \\
\hline Tschechien & 16 & 17 & 29 & 25 & 27 & 8 & 12 & 36 & 35 & 23 & 26 \\
\hline Dänemark & 34 & 23 & 26 & 26 & 26 & $x(4,9)$ & $x(9)$ & $x(9)$ & 51 & $\mathrm{~m}$ & 29 \\
\hline Estland & 11 & 23 & 26 & 29 & 28 & 36 & 29 & 37 & 34 & 21 & 28 \\
\hline Finnland & 15 & 21 & 32 & 22 & 25 & $x(5)$ & $n$ & 47 & 47 & 28 & 28 \\
\hline Frankreich & 18 & 19 & 27 & 36 & 31 & $\mathrm{~m}$ & 34 & 45 & 42 & 29 & 29 \\
\hline Deutschland & 20 & 18 & 23 & 29 & 25 & 24 & 22 & 45 & 41 & 25 & 27 \\
\hline Griechenland & $\mathrm{m}$ & $\mathrm{m}$ & $\mathrm{m}$ & $\mathrm{m}$ & $\mathrm{m}$ & $\mathrm{m}$ & $\mathrm{m}$ & $\mathrm{m}$ & $\mathrm{m}$ & $\mathrm{m}$ & m \\
\hline Ungarn² & 20 & 20 & 21 & 20 & 20 & 14 & 23 & 42 & 41 & 32 & 24 \\
\hline Island & 24 & 27 & 27 & 20 & 22 & $x(5)$ & $x(9)$ & $\mathrm{x}(9)$ & 23 & $\mathrm{~m}$ & 24 \\
\hline Irland ${ }^{2}$ & $\mathrm{~m}$ & 20 & 27 & 27 & 27 & 27 & $x(9)$ & $x(9)$ & 37 & 28 & 25 \\
\hline Israel & 13 & 23 & $x(5)$ & $x(5)$ & 19 & 9 & 21 & 42 & 38 & $\mathrm{~m}$ & 24 \\
\hline Italien ${ }^{2}$ & 23 & 25 & 26 & 25 & 25 & $\mathrm{~m}$ & 27 & 30 & 29 & 19 & 26 \\
\hline Japan & 16 & 24 & 28 & 29 & 28 & $x(4,9)$ & 29 & 52 & 47 & $\mathrm{~m}$ & 30 \\
\hline Korea & 24 & 24 & 23 & 33 & 28 & a & 20 & 39 & 34 & 28 & 29 \\
\hline Luxemburg & 28 & 27 & 18 & 18 & 18 & $\mathrm{~m}$ & $\mathrm{~m}$ & $\mathrm{~m}$ & $\mathrm{~m}$ & $\mathrm{~m}$ & m \\
\hline Mexiko & 15 & 15 & 14 & 24 & 17 & a & $x(9)$ & $x(9)$ & 46 & 38 & 19 \\
\hline Niederlande & 19 & 19 & 28 & 28 & 28 & 27 & 24 & 41 & 41 & 25 & 27 \\
\hline Neuseeland & 35 & 26 & 28 & 32 & 30 & 31 & 28 & 35 & 34 & 29 & 29 \\
\hline Norwegen & 14 & 27 & 27 & 32 & 30 & $x(5)$ & $x(9)$ & $x(9)$ & 40 & 24 & 31 \\
\hline Polen ${ }^{2}$ & 29 & 29 & 28 & 26 & 27 & 49 & 31 & 45 & 44 & 36 & 31 \\
\hline Portugal ${ }^{2}$ & 22 & 23 & 32 & 36 & 34 & $\mathrm{~m}$ & $x(9)$ & $x(9)$ & 38 & 20 & 30 \\
\hline Slowakei & 19 & 22 & 20 & 19 & 20 & $x(4)$ & $x(4)$ & 33 & 33 & 26 & 23 \\
\hline Slowenien & 29 & 33 & 35 & 27 & 30 & $x(4)$ & $x(9)$ & $x(9)$ & 37 & 29 & 33 \\
\hline Spanien & 21 & 23 & 29 & 31 & 30 & a & 31 & 43 & 41 & 29 & 29 \\
\hline Schweden & 17 & 25 & 26 & 26 & 26 & 10 & 16 & 53 & 50 & 24 & 30 \\
\hline Schweiz ${ }^{2}$ & 10 & 25 & 29 & 32 & 31 & $x(4)$ & 12 & 47 & 44 & 19 & 31 \\
\hline Türkei & 14 & 12 & 13 & 18 & 15 & a & $x(9)$ & $x(9)$ & 46 & $\mathrm{~m}$ & 18 \\
\hline Ver. Königreich & 29 & 29 & 41 & 19 & 28 & a & $x(9)$ & $x(9)$ & 42 & 31 & 31 \\
\hline Vereinigte Staaten & 20 & 22 & 25 & 27 & 26 & $\mathrm{~m}$ & $x(9)$ & $x(9)$ & 53 & 47 & 31 \\
\hline OECD-Durchschnitt & 21 & 23 & 26 & 27 & 26 & 15 & 23 & 43 & 41 & 28 & 27 \\
\hline EU21-Durchschnitt & 20 & 22 & 26 & 27 & 26 & 13 & 22 & 41 & 39 & 28 & 27 \\
\hline \multicolumn{12}{|l|}{ Partnerländer } \\
\hline Argentinien ${ }^{2}$ & 18 & 20 & 27 & 29 & 28 & a & 21 & $\mathrm{~m}$ & $\mathrm{~m}$ & $\mathrm{~m}$ & m \\
\hline Brasilien ${ }^{2}$ & 20 & 23 & 23 & 22 & 23 & a & $x(9)$ & $\mathrm{x}(9)$ & 93 & 86 & 26 \\
\hline China & $\mathrm{m}$ & $\mathrm{m}$ & $\mathrm{m}$ & $\mathrm{m}$ & $\mathrm{m}$ & $\mathrm{m}$ & $\mathrm{m}$ & $\mathrm{m}$ & $\mathrm{m}$ & $\mathrm{m}$ & m \\
\hline Kolumbien ${ }^{3}$ & 34 & 20 & 21 & 23 & 21 & a & $\mathrm{m}$ & $\mathrm{m}$ & 67 & $\mathrm{~m}$ & m \\
\hline Indien & $\mathrm{m}$ & $\mathrm{m}$ & $\mathrm{m}$ & $\mathrm{m}$ & $\mathrm{m}$ & $\mathrm{m}$ & $\mathrm{m}$ & $\mathrm{m}$ & $\mathrm{m}$ & $\mathrm{m}$ & m \\
\hline Indonesien & $\mathrm{m}$ & $\mathrm{m}$ & $\mathrm{m}$ & $\mathrm{m}$ & $\mathrm{m}$ & $\mathrm{m}$ & $\mathrm{m}$ & $\mathrm{m}$ & $\mathrm{m}$ & $\mathrm{m}$ & m \\
\hline Lettland & 22 & 25 & 25 & 25 & 25 & 27 & 37 & 38 & 38 & 29 & 28 \\
\hline Russische Föd. & $\mathrm{m}$ & $x(5)$ & $x(5)$ & $x(5)$ & 20 & a & 20 & 36 & 33 & 31 & 24 \\
\hline Saudi-Arabien & $\mathrm{m}$ & $\mathrm{m}$ & $\mathrm{m}$ & $\mathrm{m}$ & $\mathrm{m}$ & $\mathrm{m}$ & $\mathrm{m}$ & $\mathrm{m}$ & $\mathrm{m}$ & $\mathrm{m}$ & m \\
\hline Südafrika & $\mathrm{m}$ & $\mathrm{m}$ & $\mathrm{m}$ & $\mathrm{m}$ & $\mathrm{m}$ & $\mathrm{m}$ & $\mathrm{m}$ & $\mathrm{m}$ & $\mathrm{m}$ & $\mathrm{m}$ & m \\
\hline G20-Durchschnitt & $\mathbf{m}$ & m & $\mathbf{m}$ & $\mathbf{m}$ & m & $\mathbf{m}$ & m & m & $\mathbf{m}$ & m & $\mathbf{m}$ \\
\hline
\end{tabular}

1. Referenzjahr 2010. 2. Nur öffentliche Bildungseinrichtungen (Kanada: nur im Tertiärbereich, Italien: außer im Tertiärbereich). 3. Referenzjahr 2012. Quelle: OECD. Argentinien, China, Indien, Indonesien, Kolumbien, Saudi-Arabien und Südafrika: Statistikinstitut der UNESCO. Lettland: Eurostat. Hinweise s. Anhang 3 unter www.oecd.org/edu/eag.htm. StatLink: http://dx.doi.org/10.1787/888933116984 Erläuterung der Kennzeichnung fehlender Daten s. Hinweise für den Leser. 
Veränderung der Ausgaben von Bildungseinrichtungen pro Schüler im Primar-, Sekundar- und postsekundaren, nicht tertiären Bildungsbereich für alle Leistungsbereiche aufgrund verschiedener Faktoren (1995, 2000, 2005, 2008, 2009, 2010, 2011)

Index der Veränderung (BIP-Deflator $2005=100$, zu konstanten Preisen)

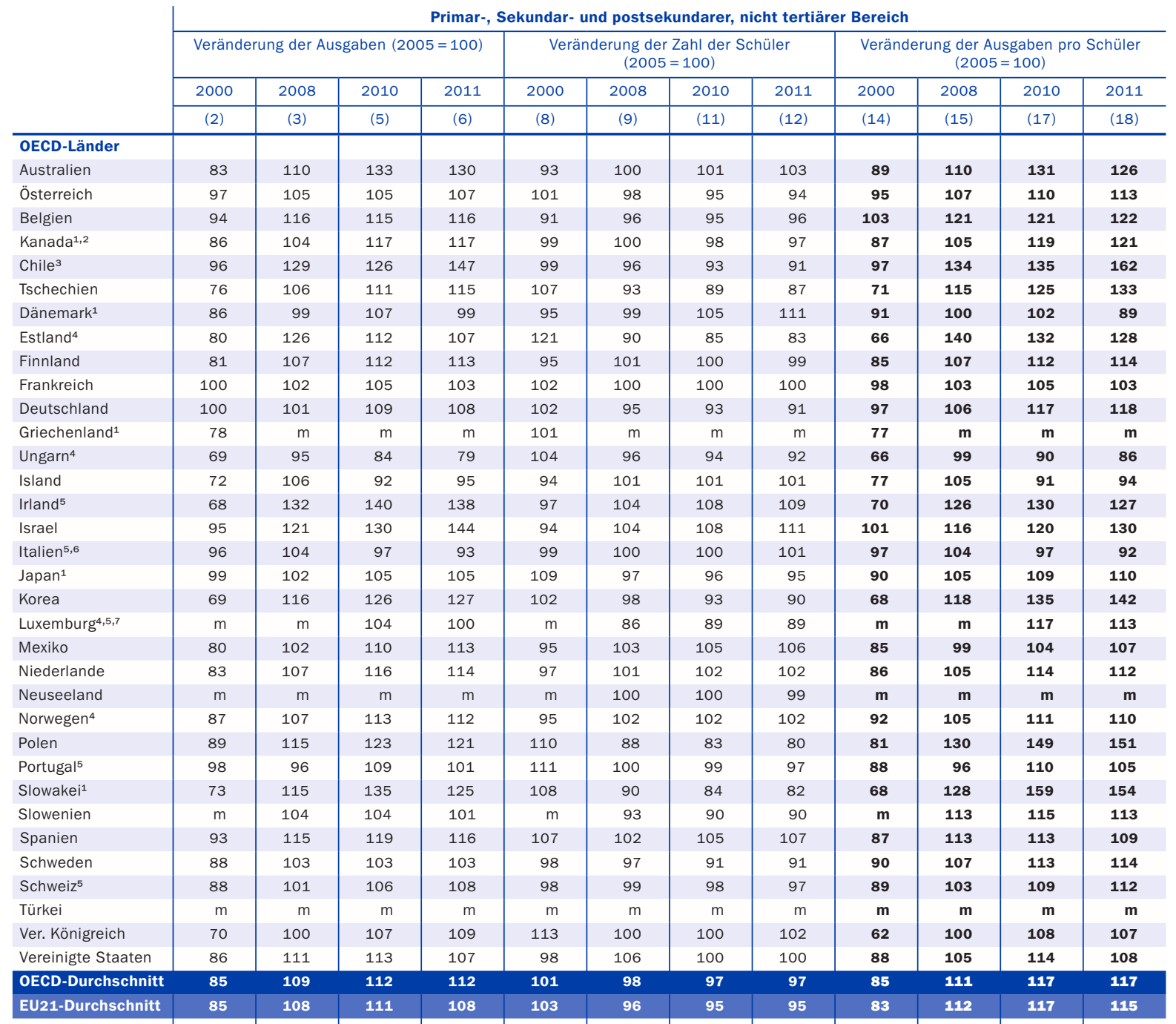

\begin{tabular}{|c|c|c|c|c|c|c|c|c|c|c|c|c|}
\hline \multicolumn{13}{|l|}{ Partnerländer } \\
\hline Argentinien & $\mathrm{m}$ & $\mathrm{m}$ & $\mathrm{m}$ & $\mathrm{m}$ & $\mathrm{m}$ & $\mathrm{m}$ & $\mathrm{m}$ & $\mathrm{m}$ & m & $\mathbf{m}$ & m & m \\
\hline Brasilien 4,5 & 66 & 146 & 170 & 175 & 98 & 96 & 91 & 89 & 67 & 152 & 187 & 197 \\
\hline China & $\mathrm{m}$ & $\mathrm{m}$ & $\mathrm{m}$ & $\mathrm{m}$ & $\mathrm{m}$ & $\mathrm{m}$ & $\mathrm{m}$ & $\mathrm{m}$ & m & m & m & m \\
\hline Kolumbien & $\mathrm{m}$ & $\mathrm{m}$ & $\mathrm{m}$ & $\mathrm{m}$ & $\mathrm{m}$ & $\mathrm{m}$ & $\mathrm{m}$ & $\mathrm{m}$ & m & $\mathbf{m}$ & m & m \\
\hline Indien & $\mathrm{m}$ & $\mathrm{m}$ & $\mathrm{m}$ & $\mathrm{m}$ & $\mathrm{m}$ & $\mathrm{m}$ & $\mathrm{m}$ & $\mathrm{m}$ & m & $\mathbf{m}$ & m & m \\
\hline Indonesien & $\mathrm{m}$ & $\mathrm{m}$ & $\mathrm{m}$ & $\mathrm{m}$ & $\mathrm{m}$ & $\mathrm{m}$ & $\mathrm{m}$ & $\mathrm{m}$ & $\mathbf{m}$ & $\mathbf{m}$ & m & m \\
\hline Lettland & $\mathrm{m}$ & $\mathrm{m}$ & $\mathrm{m}$ & $\mathrm{m}$ & $\mathrm{m}$ & $\mathrm{m}$ & $\mathrm{m}$ & $\mathrm{m}$ & $\mathbf{m}$ & $\mathbf{m}$ & $\mathbf{m}$ & m \\
\hline Russische Föd. & 66 & 132 & 126 & 130 & $\mathrm{~m}$ & 88 & 87 & 88 & $\mathbf{m}$ & 150 & 144 & 147 \\
\hline Saudi-Arabien & $\mathrm{m}$ & $\mathrm{m}$ & $\mathrm{m}$ & $\mathrm{m}$ & $\mathrm{m}$ & $\mathrm{m}$ & $\mathrm{m}$ & $\mathrm{m}$ & m & $\mathbf{m}$ & m & m \\
\hline Südafrika & $\mathrm{m}$ & $\mathrm{m}$ & $\mathrm{m}$ & $\mathrm{m}$ & $\mathrm{m}$ & $\mathrm{m}$ & $\mathrm{m}$ & $\mathrm{m}$ & m & m & m & m \\
\hline G20-Durchschnitt & m & $\mathbf{m}$ & $\mathbf{m}$ & m & m & m & m & m & m & m & m & m \\
\hline
\end{tabular}

Anmerkung: Die Spalten mit den Angaben für die Jahre 1995 und 2009, d.h. die Spalten (1), (4), (7), (10), (13) und (16), sind im Internet verfügbar (s. StatLink unten). 1. Einige Bildungsbereiche sind in anderen Bildungsbereichen enthalten. Einzelheiten s. Erläuterung von „x“ in Hinweise für den Leser. 2. Referenzjahr 2010 anstelle 2011. 3. Referenzjahr 2012 anstelle 2011 sowie 2006 anstelle 2005. 4. Nur öffentliche Ausgaben. 5. Nur öffentliche Bildungseinrichtungen. 6. Ohne postsekundaren, nicht tertiären Bereich. 7. Einschließlich Elementarbereich.

Quelle: OECD. Argentinien, China, Indien, Indonesien, Kolumbien, Saudi-Arabien und Südafrika: Statistikinstitut der UNESCO. Lettland: Eurostat. Hinweise s. Anhang 3 unter www.oecd.org/edu/eag.htm. StatLink: http://dx.doi.org/10.1787/888933117003

Erläuterung der Kennzeichnung fehlender Daten s. Hinweise für den Leser. 
Veränderung der Ausgaben von Bildungseinrichtungen pro Studierenden im Tertiärbereich für alle Leistungsbereiche aufgrund verschiedener Faktoren $(1995,2000,2005,2008,2009,2010,2011)$

Index der Veränderung (BIP-Deflator $2005=100$, zu konstanten Preisen)

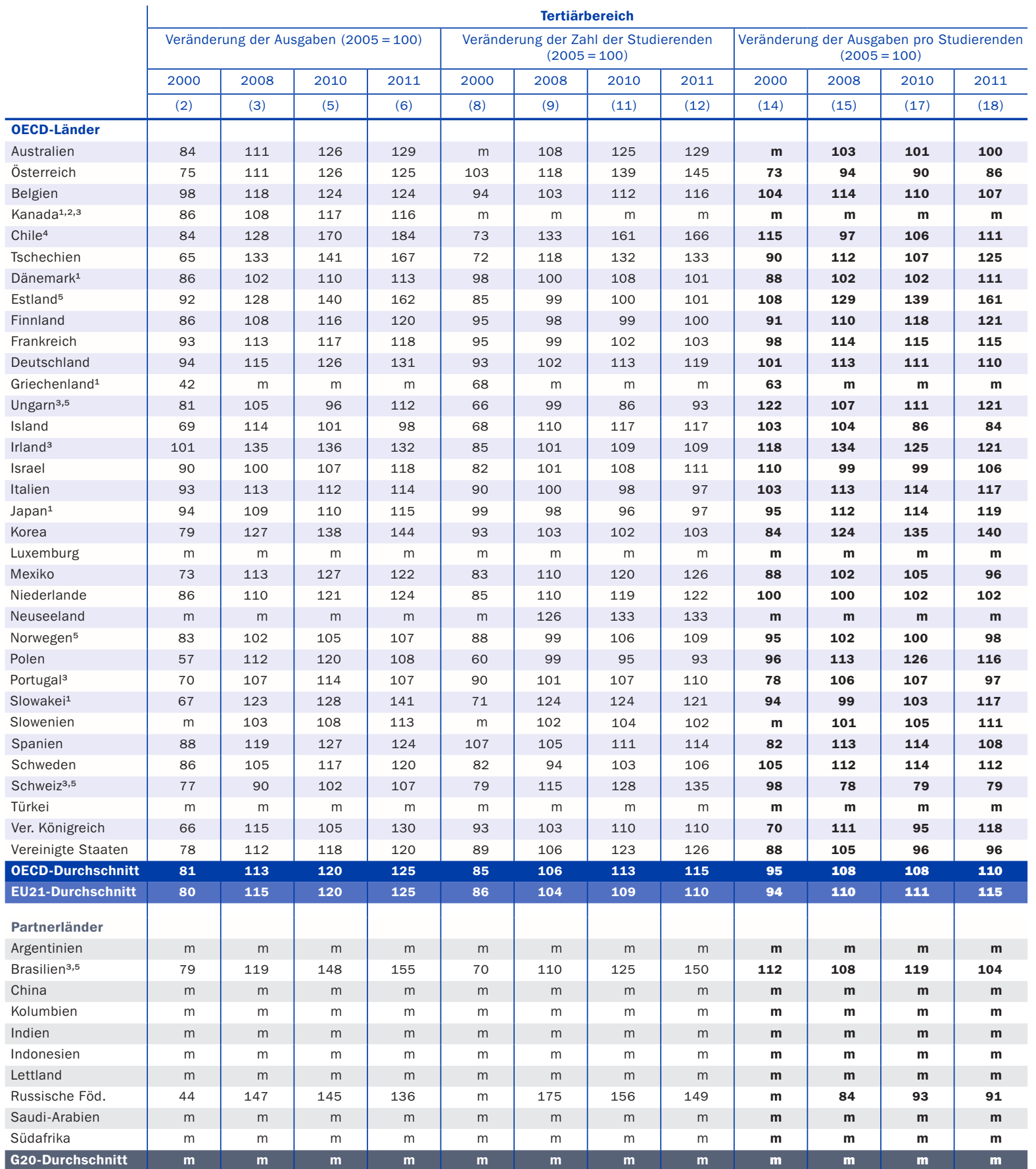

Anmerkung: Die Spalten mit den Angaben für die Jahre 1995 und 2009, d. h. die Spalten (1), (4), (7), (10), (13) und (16), sind im Internet verfügbar (s. StatLink unten). 1. Einige Bildungsbereiche sind in anderen Bildungsbereichen enthalten. Einzelheiten s. Erläuterung von „X“ in Hinweise für den Leser. 2. Referenzjahr 2010 anstelle 2011. 3. Nur öffentliche Bildungseinrichtungen. 4. Referenzjahr 2012 anstelle 2011 sowie 2006 anstelle 2005. 5. Nur öffentliche Ausgaben. Quelle: OECD. Argentinien, China, Indien, Indonesien, Kolumbien, Saudi-Arabien und Südafrika: Statistikinstitut der UNESCO. Lettland: Eurostat. Hinweise s. Anhang 3 unter www.oecd.org/edu/eag.htm. StatLink: http://dx.doi.org/10.1787/888933117022 Erläuterung der Kennzeichnung fehlender Daten s. Hinweise für den Leser. 
Tabelle B1.6

Jährliche Ausgaben von Bildungseinrichtungen pro Schüler im Sekundarbereich für alle Leistungsbereiche, nach Art des Bildungsgangs (2011)

In US-Dollar, kaufkraftbereinigt mittels KKP für das BIP, nach Bildungsbereich (basierend auf Vollzeitäquivalenten)

\begin{tabular}{|c|c|c|c|c|c|c|c|c|c|}
\hline & \multicolumn{9}{|c|}{ Sekundarbereich } \\
\hline & \multicolumn{3}{|c|}{ Sekundarbereich I } & \multicolumn{3}{|c|}{ Sekundarbereich II } & \multicolumn{3}{|c|}{ Sekundarbereich insgesamt } \\
\hline & \begin{tabular}{|c|}
$\begin{array}{c}\text { Alle Bildungs- } \\
\text { gänge }\end{array}$ \\
\end{tabular} & $\begin{array}{l}\text { Allgemein- } \\
\text { bildende } \\
\text { Bildungs- } \\
\text { gänge }\end{array}$ & \begin{tabular}{|c|} 
Berufsvor- \\
bereitende/ \\
Berufsbilden- \\
de Bildungs- \\
gänge
\end{tabular} & $\begin{array}{c}\text { Alle Bildungs- } \\
\text { gänge }\end{array}$ & $\begin{array}{l}\text { Allgemein- } \\
\text { bildende } \\
\text { Bildungs- } \\
\text { gänge }\end{array}$ & \begin{tabular}{|c|} 
Berufsvor- \\
bereitende/ \\
Berufsbilden- \\
de Bildungs- \\
gänge
\end{tabular} & $\begin{array}{c}\text { Alle Bildungs- } \\
\text { gänge }\end{array}$ & $\begin{array}{l}\text { Allgemein- } \\
\text { bildende } \\
\text { Bildungs- } \\
\text { gänge }\end{array}$ & $\begin{array}{l}\text { Berufsvor- } \\
\text { bereitende/ } \\
\text { Berufsbilden- } \\
\text { de Bildungs- } \\
\text { gänge }\end{array}$ \\
\hline & (1) & (2) & (3) & (4) & (5) & (6) & (7) & (8) & (9) \\
\hline \multicolumn{10}{|l|}{ OECD-Länder } \\
\hline Australien & 10689 & 11068 & 6728 & 9859 & 11337 & 6727 & 10354 & 11158 & 6727 \\
\hline Österreich & 13547 & 13547 & a & 13666 & 12668 & 14022 & 13607 & 13362 & 14022 \\
\hline Belgien ${ }^{1}$ & $x(7)$ & $x(7)$ & $x(7)$ & $x(7)$ & $x(7)$ & $x(7)$ & 11732 & $x(7)$ & $x(7)$ \\
\hline Kanada ${ }^{1,2}$ & m & $\mathrm{m}$ & $\mathrm{m}$ & 11607 & $x(4)$ & $x(4)$ & m & $\mathrm{m}$ & $\mathrm{m}$ \\
\hline Chile $^{3}$ & 4494 & 4494 & a & 4496 & 3840 & 5900 & 4495 & 4113 & 5900 \\
\hline Tschechien & 7730 & 7699 & $x(1)$ & 6886 & 5867 & 7264 & 7270 & 7249 & 7302 \\
\hline Dänemark & 10971 & 10971 & a & 10908 & $x(4)$ & $x(4)$ & 10937 & $x(7)$ & $x(7)$ \\
\hline Estland & 6009 & $x(1)$ & $x(1)$ & 6688 & 6153 & 7651 & 6389 & 6074 & 7651 \\
\hline Finnland $^{1}$ & 12545 & 12545 & a & 8467 & 7407 & 8887 & 9792 & 10639 & 8887 \\
\hline Frankreich & 9668 & 9668 & a & 13071 & 12735 & 13587 & 11109 & 10612 & 13587 \\
\hline Deutschland & 9247 & 9247 & a & 12022 & 9975 & 13995 & 10275 & 9410 & 13995 \\
\hline Griechenland & m & $\mathrm{m}$ & $\mathrm{m}$ & $\mathbf{m}$ & $\mathrm{m}$ & $\mathrm{m}$ & $\mathbf{m}$ & $\mathrm{m}$ & $\mathrm{m}$ \\
\hline Ungarn ${ }^{4}$ & 4709 & 4733 & 1931 & 4455 & 4989 & 3094 & 4574 & 4848 & 3064 \\
\hline Island ${ }^{1}$ & 10160 & 10160 & a & 7461 & $x(4)$ & $x(4)$ & 8470 & $x(7)$ & $x(7)$ \\
\hline Irland ${ }^{4}$ & 11442 & $x(1)$ & $x(1)$ & 11576 & $x(4)$ & $x(4)$ & 11502 & $x(7)$ & $x(7)$ \\
\hline Israel & $x(7)$ & $x(8)$ & $x(9)$ & $x(7)$ & $x(8)$ & $x(9)$ & 5712 & 4128 & 13905 \\
\hline Italien ${ }^{4}$ & 8686 & 8681 & 9646 & 8519 & $x(4)$ & $x(4)$ & 8585 & $x(7)$ & $x(7)$ \\
\hline$J^{\prime a p a n}{ }^{1}$ & 9677 & 9677 & a & 10093 & $x(4)$ & $x(4)$ & 9886 & $x(7)$ & $x(7)$ \\
\hline Korea & 6674 & 6674 & a & 9698 & $x(4)$ & $x(4)$ & 8199 & $x(7)$ & $x(7)$ \\
\hline Luxemburg & 16125 & 16125 & a & 16238 & 16701 & 15942 & 16182 & 16289 & 15942 \\
\hline Mexiko & 2344 & 2805 & 516 & 4034 & 3986 & 4522 & 2943 & 3260 & 1302 \\
\hline Niederlande & 12031 & 10646 & 15632 & 12171 & 10028 & 13167 & 12100 & 10460 & 13890 \\
\hline Neuseeland & 8670 & 8670 & a & 10023 & 9747 & 11033 & 9312 & 9117 & 11033 \\
\hline Norwegen $^{1}$ & 12769 & 12769 & a & 14838 & $x(4)$ & $x(4)$ & 13939 & $x(7)$ & $x(7)$ \\
\hline Polen ${ }^{4}$ & 5995 & $x(1)$ & $x(1)$ & 5764 & 5709 & 5376 & 5870 & $x(7)$ & $x(7)$ \\
\hline Portugal ${ }^{4}$ & 8294 & $x(1)$ & $x(1)$ & 9139 & $x(4)$ & $x(4)$ & 8676 & $x(7)$ & $x(7)$ \\
\hline Slowakei ${ }^{1}$ & 5109 & 5109 & $x(6)$ & 4783 & 3803 & 5245 & 4938 & 4769 & 5245 \\
\hline Slowenien ${ }^{1}$ & 9947 & 9947 & a & 7724 & $x(4)$ & $x(4)$ & 8568 & $x(7)$ & $x(7)$ \\
\hline Spanien & 9335 & $x(1)$ & $x(1)$ & 10090 & $x(4)$ & $x(4)$ & 9615 & $x(7)$ & $x(7)$ \\
\hline Schweden & 10823 & 10894 & $\mathrm{~m}$ & 11022 & 10771 & 11208 & 10938 & 10848 & 11208 \\
\hline Schweiz & 15124 & 15124 & a & 16521 & 16035 & 16730 & 15891 & 15368 & 16730 \\
\hline Türkei & 2250 & $x(1)$ & a & 3239 & 3292 & 3181 & 2736 & 2599 & 3181 \\
\hline Ver. Königreich ${ }^{1}$ & $x(7)$ & $x(7)$ & $x(7)$ & $x(7)$ & $x(7)$ & $x(7)$ & 9649 & $x(7)$ & $x(7)$ \\
\hline Vereinigte Staaten & 12338 & 12338 & a & 13143 & 13143 & a & 12731 & 12731 & a \\
\hline OECD-Durchschnitt & 9377 & $\sim$ & $\sim$ & 9506 & 8613 & 9307 & 9280 & 8572 & 9643 \\
\hline EU21-Durchschnitt & 9568 & $\sim$ & $\sim$ & 9622 & 8900 & 9953 & 9615 & 9506 & 10436 \\
\hline \multicolumn{10}{|l|}{ Partnerländer } \\
\hline Argentinien ${ }^{4}$ & 2947 & 2947 & a & 3184 & $x(4)$ & $x(4)$ & 3034 & $x(7)$ & $x(7)$ \\
\hline Brasilien $^{4}$ & 2700 & 2700 & a & 2605 & $x(4)$ & $x(4)$ & 2662 & $x(7)$ & $x(7)$ \\
\hline China & m & $\mathrm{m}$ & $\mathrm{m}$ & $\mathbf{m}$ & $\mathrm{m}$ & $\mathrm{m}$ & $\mathbf{m}$ & $\mathrm{m}$ & $\mathrm{m}$ \\
\hline Kolumbien ${ }^{3}$ & 2164 & $x(1)$ & $x(1)$ & 2326 & $x(4)$ & $x(4)$ & 2207 & $x(7)$ & $x(7)$ \\
\hline Indien & m & $\mathrm{m}$ & $\mathrm{m}$ & $\mathbf{m}$ & $\mathrm{m}$ & $\mathrm{m}$ & $\mathbf{m}$ & $\mathrm{m}$ & $\mathrm{m}$ \\
\hline Indonesien ${ }^{3}$ & 449 & 449 & a & 617 & 853 & 307 & 522 & 571 & 307 \\
\hline Lettland & 5019 & 5025 & 4226 & 4983 & 5241 & 4599 & 4998 & 5123 & 4594 \\
\hline Russische Föd. ${ }^{1}$ & $x(7)$ & $x(8)$ & a & $x(7)$ & $x(8)$ & $x(9)$ & 4470 & 4492 & 4299 \\
\hline Saudi-Arabien & m & $\mathrm{m}$ & $\mathrm{m}$ & m & $\mathrm{m}$ & $\mathrm{m}$ & m & $\mathrm{m}$ & $\mathrm{m}$ \\
\hline Südafrika & m & $\mathrm{m}$ & $\mathrm{m}$ & $\mathbf{m}$ & $\mathrm{m}$ & $\mathrm{m}$ & $\mathbf{m}$ & $\mathrm{m}$ & $\mathrm{m}$ \\
\hline G20-Durchschnitt & $\mathbf{m}$ & m & m & $\mathbf{m}$ & m & $\mathbf{m}$ & $\mathbf{m}$ & m & m \\
\hline
\end{tabular}

1. Einige Bildungsbereiche sind in anderen Bildungsbereichen enthalten. Einzelheiten s. Erläuterung von „x“ in Hinweise für den Leser. 2. Referenzjahr 2010.

3. Referenzjahr 2012. 4. Nur öffentliche Bildungseinrichtungen.

Quelle: OECD. Argentinien, China, Indien, Indonesien, Kolumbien, Saudi-Arabien und Südafrika: Statistikinstitut der UNESCO. Lettland: Eurostat.

Hinweise s. Anhang 3 unter www.oecd.org/edu/eag.htm. StatLink: http://dx.doi.org/10.1787/888933117041

Erläuterung der Kennzeichnung fehlender Daten s. Hinweise für den Leser. 


\section{Welcher Teil des Bruttoinlandsprodukts wird für Bildung ausgegeben?}

$20 I$ I gaben die OECD-Länder im Durchschnitt 6, I Prozent ihres BIP für Bildungseinrichtungen aus. In sieben Ländern - Argentinien, Dänemark, Island, Israel, Korea, Neuseeland und Norwegen - waren es mehr als 7 Prozent.

Zwischen 2000 und 20 II stiegen in fast allen Ländern mit verfügbaren Daten die Gesamtausgaben für alle Bildungsbereiche zusammen stärker als das Bruttoinlandsprodukt.

Seit dem Beginn der Wirtschaftskrise 2008 stieg das BIP in der Hälfte der Länder mit verfügbaren Daten (real) bis 20II, während die öffentlichen Ausgaben für Bildungseinrichtungen in diesem Zeitraum nur in sechs Ländern zurückgingen. In dem kürzeren Zeitraum zwischen 2009 und 2011 stieg das BIP in den meisten Ländern (real), und die öffentlichen Ausgaben für Bildungseinrichtungen sanken in diesem Zeitraum in einem Drittel der OECD-Länder, wahrscheinlich aufgrund fiskalischer Konsolidierungsmaßnahmen.

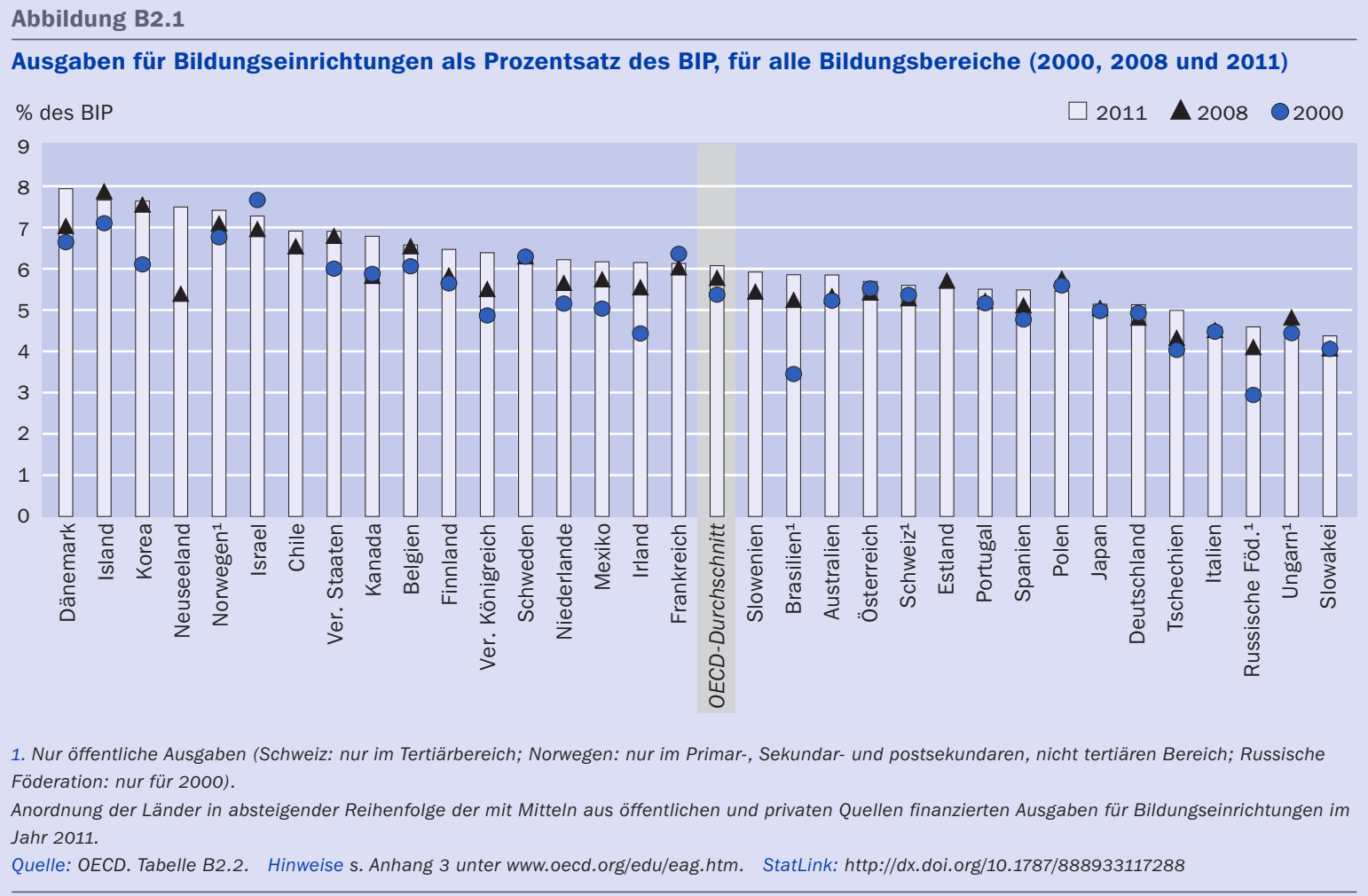

\section{Kontext}

Dieser Indikator zeigt die Ausgaben für Bildungseinrichtungen der einzelnen Länder in Relation zum jeweiligen nationalen Wohlstand auf. Der nationale Wohlstand wird basierend auf dem Bruttoinlandsprodukt (BIP) geschätzt, die Bildungsausgaben um- 
fassen dabei die Ausgaben der öffentlichen Haushalte, von Unternehmen, einzelnen Schülern/Studierenden und ihren Familien.

Ausgaben für Bildungseinrichtungen stellen eine Investition dar, die unter anderem dazu beitragen soll, das Wirtschaftswachstum zu stärken, die Produktivität zu steigern, die persönliche und gesellschaftliche Entwicklung zu fördern sowie soziale Ungleichheiten zu verringern. Welcher Anteil des BIP für das Bildungswesen bereitgestellt wird, hängt von den unterschiedlichen Präferenzen verschiedener öffentlicher und privater Akteure ab. Die Mittel für Bildung stammen jedoch hauptsächlich aus den öffentlichen Haushalten, daher stehen diese Ausgaben ständig auf dem Prüfstand. Während einer Finanzkrise können selbst zentrale staatliche Aufgaben wie das Bildungswesen von Haushaltskürzungen betroffen sein.

Die Höhe der Ausgaben eines Landes für Bildungseinrichtungen wird bestimmt durch die Zahl junger Menschen im schulpflichtigen Alter, die Bildungsbeteiligung, die Gehälter der Lehrkräfte sowie die Unterrichtsorganisation und die Art und Weise der Vermittlung von Lerninhalten. Im Primar- und Sekundarbereich I (d. h. grob bei den 5- bis I4-Jährigen) liegt die Bildungsbeteiligung in den OECD-Ländern bei nahezu Ioo Prozent, und Veränderungen bei der Zahl der Schüler hängen eng mit der demografischen Entwicklung zusammen. Im Sekundarbereich II und dem Tertiärbereich ist dies jedoch weniger der Fall, da Teile der entsprechenden Altersgruppen das Bildungssystem bereits verlassen haben (s. Indikator $\mathrm{CI}$ ).

\section{Weitere wichtige Ergebnisse}

Auf den Elementarbereich entfallen im Durchschnitt der OECD-Länder fast 10 Prozent der Ausgaben für Bildungseinrichtungen bzw. o,6 Prozent des BIP. Es bestehen jedoch große Unterschiede zwischen den einzelnen Ländern. So liegen beispielsweise die Ausgaben für den Elementarbereich in Australien und der Schweiz bei unter 0,2 Prozent des BIP, in Dänemark und Island dagegen bei rund I Prozent oder mehr.

Auf den Primar-, Sekundar- und postsekundaren, nicht tertiären Bereich entfallen im Durchschnitt der OECD-Länder fast zwei Drittel der Gesamtausgaben für Bildungseinrichtungen bzw. 3,8 Prozent des Bruttoinlandsprodukts. Argentinien und Neuseeland geben unter den OECD- und Partnerländern mit mindestens 5 Prozent des BIP den größten Anteil für diese Bildungsbereiche aus, Japan, Lettland, die Russische Föderation, die Slowakei, Tschechien, die Türkei und Ungarn dagegen höchstens 3 Prozent.

Auf den Tertiärbereich entfällt im Durchschnitt der OECD-Länder ein Viertel der Ausgaben für Bildungseinrichtungen bzw. I, 6 Prozent des BIP. Chile, Kanada, Korea und die Vereinigten Staaten investieren zwischen 2,4 Prozent und 2,8 Prozent ihres BIP in Bildungseinrichtungen des Tertiärbereichs.

Die privaten Ausgaben für Bildungseinrichtungen als Prozentsatz des BIP sind im Durchschnitt der OECD-Länder im Tertiärbereich am höchsten. In Chile, Korea und den Vereinigten Staaten ist ihr Anteil mit I,7 Prozent bis I,9 Prozent des BIP am höchsten. 


\section{Entwicklungstendenzen}

Die öffentlichen Ausgaben für Bildung (alle Bildungsbereiche zusammen) sind in den OECD-Ländern zwischen 2008 und 20II durchschnittlich um 7 Prozent gestiegen. Dennoch verlangsamte sich der jährliche Anstieg der öffentlichen Ausgaben für Bildungseinrichtungen während dieses Zeitraums im Durchschnitt der OECD-Länder von 4 Prozent in 2008/2009 auf I Prozent in 2009/2010 und 2010/201r.

Während des gesamten Zeitraums 2008 bis 20 II kürzten nur Estland, Island, Italien, die Russische Föderation, Ungarn und die Vereinigten Staaten die öffentlichen Ausgaben für Bildungseinrichtungen (real), aber nur in 5 Ländern sanken die öffentlichen Ausgaben von 2008 auf 2009 und in ro Ländern zwischen 2009 und 20II. In Island, Italien, Portugal, der Russischen Föderation und Ungarn sanken die öffentlichen Ausgaben zwischen 2009 und 201 I um mindestens 5 Prozent.

\section{Analyse und Interpretationen}

\section{Gesamtausgaben im Verhältnis zum BIP}

In allen OECD- und Partnerländern mit verfügbaren Daten wird ein bedeutender Teil des BIP für Bildungseinrichtungen ausgegeben. 20II gaben die OECD-Länder im Durchschnitt 6,I Prozent ihres jeweiligen BIP für Bildungseinrichtungen aus. Berücksichtigt man öffentliche und private Quellen, so gaben die OECD-Länder insgesamt auch 6, I Prozent der Gesamtsumme ihrer Bruttoinlandsprodukte für Bildungseinrichtungen aus.

$20 I$ lagen die Ausgaben für Bildungseinrichtungen (alle Bildungsbereiche zusammen) als Prozentsatz des BIP in der Hälfte der OECD- und Partnerländer bei über 6 Prozent und in den folgenden sieben Ländern sogar bei über 7 Prozent: Argentinien, Dänemark, Island, Israel, Korea, Neuseeland und Norwegen. Am anderen Ende des Spektrums wendeten Italien, die Russische Föderation, die Slowakei, die Türkei und Ungarn weniger als 5 Prozent ihres BIP für den Bildungsbereich auf (Tab. B2.I).

\section{Ausgaben für Bildungseinrichtungen aufgegliedert nach Bildungs- bereichen}

Fast zwei Drittel der Bildungsausgaben aller OECD-Länder entfallen im Durchschnitt auf den Primar-, Sekundar- und postsekundaren, nicht tertiären Bereich, ein Viertel auf den Tertiärbereich und fast ein Zehntel auf den Elementarbereich. Auf den Primarund Sekundarbereich I entfallen im Durchschnitt der OECD-Länder 42 Prozent der Bildungsausgaben. Die Ausgaben für Bildungseinrichtungen sind abhängig von der Altersstruktur der Bevölkerung. Länder mit überdurchschnittlich hohen Ausgaben für Bildungseinrichtungen als Prozentsatz des BIP sind in der Regel Länder mit einem überdurchschnittlich hohen Anteil der Bevölkerung in dem für den Primar- und Sekundarbereich I typischen Alter (Tab. B2.2 und Indikator CI).

In allen OECD- und Partnerländern mit verfügbaren Daten entfällt der größte Teil der insgesamt für Bildungseinrichtungen aufgewendeten Mittel auf den Primar-, Sekun- 
Ausgaben für Bildungseinrichtungen als Prozentsatz des BIP (2011)

Finanziert mit Mitteln aus öffentlichen und privaten Quellen, nach Bildungsbereich und Herkunft der Mittel

$\square$ Öffentliche Ausgaben für Bildungseinrichtungen

Private Ausgaben für Bildungseinrichtungen

$\%$ des BIP

Primar-, Sekundar- und postsekundarer, nicht tertiärer Bereich
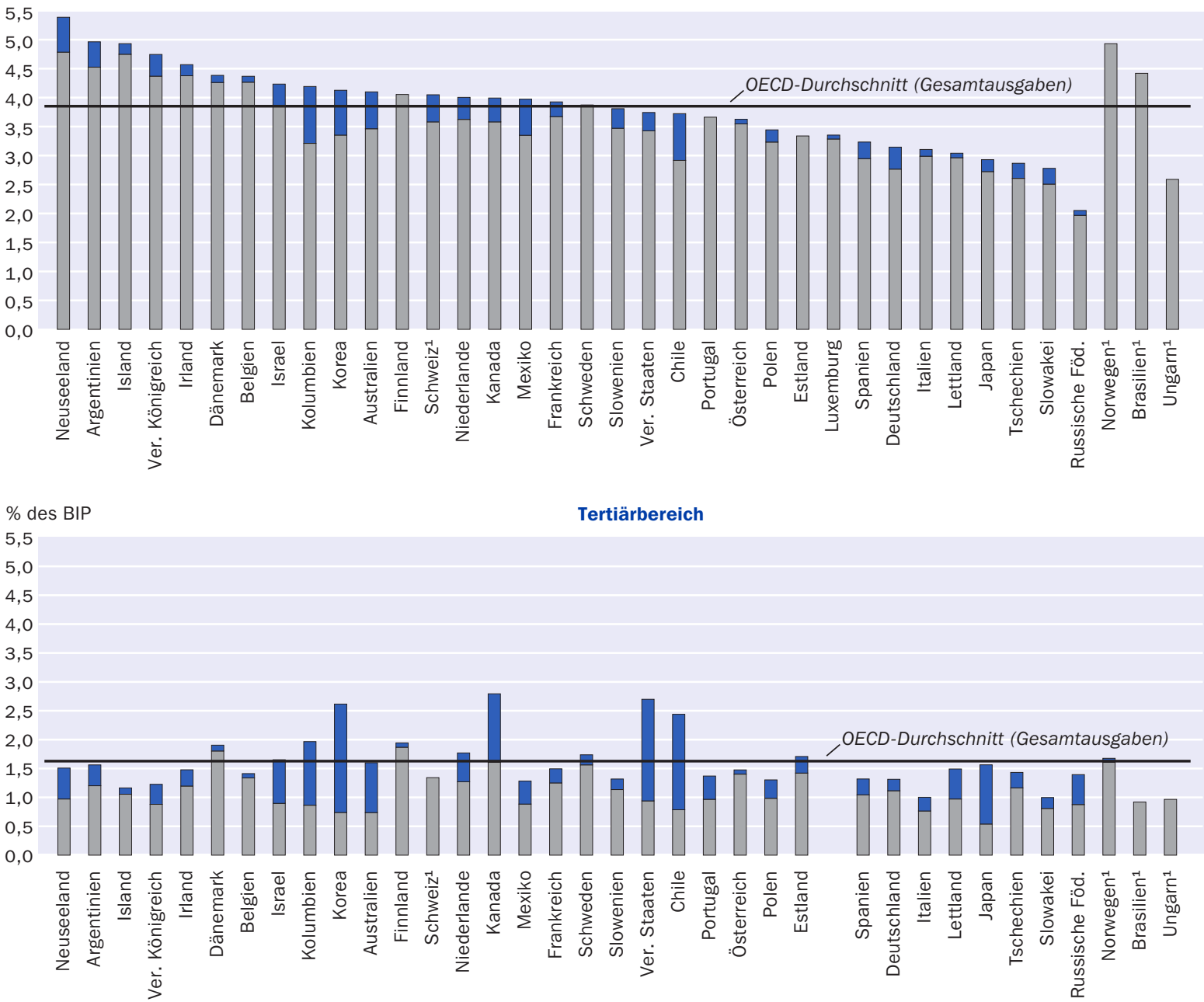

1. Nur öffentliche Ausgaben (Schweiz: nur im Tertiärbereich; Norwegen: nur im Primar-, Sekundar- und postsekundaren, nicht tertiären Bereich).

Anordnung der Länder in absteigender Reihenfolge der mit Mitteln aus öffentlichen und privaten Quellen finanzierten Ausgaben für Bildungseinrichtungen im Primar-, Sekundar- und postsekundaren, nicht tertiären Bereich.

Quelle: OECD. Tabelle B2.3. Hinweise s. Anhang 3 unter www.oecd.org/edu/eag.htm. StatLink: http://dx.doi.org/10.1787/888933117307

dar- und postsekundaren, nicht tertiären Bereich (verglichen mit den auf den Elementar- und den Tertiärbereich entfallenden Mitteln). Dieser Anteil liegt in fast allen Ländern bei über 50 Prozent, eine Ausnahme bildet hier nur die Russische Föderation mit 45 Prozent. Für den Primar-, Sekundar- und postsekundaren, nicht tertiären Bereich reichen die Ausgaben als Prozentsatz des BIP von höchstens 3 Prozent in Japan, Lettland, der Russischen Föderation, der Slowakei, Tschechien, der Türkei und Ungarn bis zu mindestens 5 Prozent in Argentinien und Neuseeland.

Für den Primar- und Sekundarbereich I belaufen sich die Ausgaben als Prozentsatz des BIP in allen Ländern auf mindestens I, 5 Prozent und auf mindestens 3 Prozent in Ar- 
gentinien, Australien, Brasilien, Dänemark, Irland, Island, Kolumbien, Mexiko, Neuseeland, Norwegen und dem Vereinigten Königreich (Tab. B2.I).

Mit Ausnahme von Dänemark und Island geben alle Länder weniger als I Prozent des BIP für den Elementarbereich aus. Die Daten zum Elementarbereich sind jedoch mit Vorsicht zu betrachten, weil zwischen den Ländern große Unterschiede bei der Bildungsbeteiligung, dem Eintrittsalter in den Elementarbereich und der Erfassung privat finanzierter Bildungseinrichtungen im Elementarbereich bestehen (s. Indikator $\mathrm{CI}_{\mathrm{I}}$ ).

In mehr als der Hälfte der Länder machen die Ausgaben für den Tertiärbereich mindestens I, 5 Prozent des BIP aus, in Chile, Kanada, Korea und den Vereinigten Staaten belaufen sie sich sogar auf mehr als 2,4 Prozent. Vier Länder wenden höchstens I Prozent des BIP für den Tertiärbereich auf - Brasilien, Italien, die Slowakei und Ungarn (Tab. B2.I und Abb. B2.2).

\section{Veränderungen der Gesamtausgaben für Bildungseinrichtungen zwischen 2000 und 2011}

Der Anstieg der Schüler-/Studierendenzahlen im Sekundarbereich II und Tertiärbereich zwischen 2000 und $201 \mathrm{I}$ ging in den meisten Ländern mit einem Anstieg der finanziellen Ausgaben für diese Bereiche einher.

Im Zeitraum 2000 bis 20 II stiegen in den Ländern mit vergleichbaren Daten sowohl die Ausgaben für Bildungseinrichtungen (alle Bildungsbereiche zusammen) als auch das BIP (s. Tab. X2.3, Anhang 2). In Frankreich, Israel und Polen stiegen die Bildungsausgaben langsamer als das BIP, sodass die Ausgaben als Prozentsatz des BIP um bis zu o,4 Prozentpunkte sanken. In allen anderen Ländern mit vergleichbaren Daten stiegen die öffentlichen Ausgaben für Bildungseinrichtungen (alle Bildungsbereiche zusammen) stärker als das BIP, was zu einem Anstieg der Ausgaben für Bildungseinrichtungen als Prozentsatz des BIP führte (Abb. B2.I). Einen Anstieg von über I Prozentpunkt war in Brasilien zu beobachten (von 3,5 Prozent auf 5,9 Prozent), Dänemark (von 6,6 Prozent auf 7,9 Prozent), Irland (von 4,4 Prozent auf 6,2 Prozent), Korea (von 6, I Prozent auf 7,6 Prozent), Mexiko (von 5,o Prozent auf 6,2 Prozent), den Niederlanden (von 5,2 Prozent auf 6,2 Prozent), der Russischen Föderation (von 2,9 Prozent auf 4,6 Prozent), der Türkei (von 2,5 Prozent auf 4,2 Prozent) und dem Vereinigten Königreich (von 4,9 auf 6,4 Prozent) (Tab. B2.2).

Ähnliche Veränderungen der Ausgaben waren für den Primar-, Sekundar- und den postsekundaren, nicht tertiären Bereich zusammen sowie für den Tertiärbereich zu beobachten.

\section{Die Auswirkungen der Finanzkrise auf die öffentlichen Ausgaben für Bildungseinrichtungen zwischen 2008 und 2011}

Die im Jahr 2008 einsetzende globale Wirtschaftskrise hatte und hat noch immer sehr negative Auswirkungen auf die unterschiedlichen Bereiche der Wirtschaft. Auf der Basis von Daten für die Jahre 2008 und 20 II allein ist eine Bewertung der umfassenden Auswirkungen dieser Krise auf die Finanzierung von Bildungseinrichtungen verfrüht, erste Auswirkungen auf die Wirtschaft insgesamt lassen sich jedoch bereits jetzt beobachten. 


\section{Abbildung B2.3}

\section{Auswirkungen der Wirtschaftskrise auf die öffentlichen Bildungsausgaben}

Index der Veränderung der öffentlichen Ausgaben für Bildungseinrichtungen als Prozentsatz des BIP zwischen 2008 und 2011, für alle Bildungsbereiche $(2008=100$, zu konstanten Preisen des Jahres 2011)
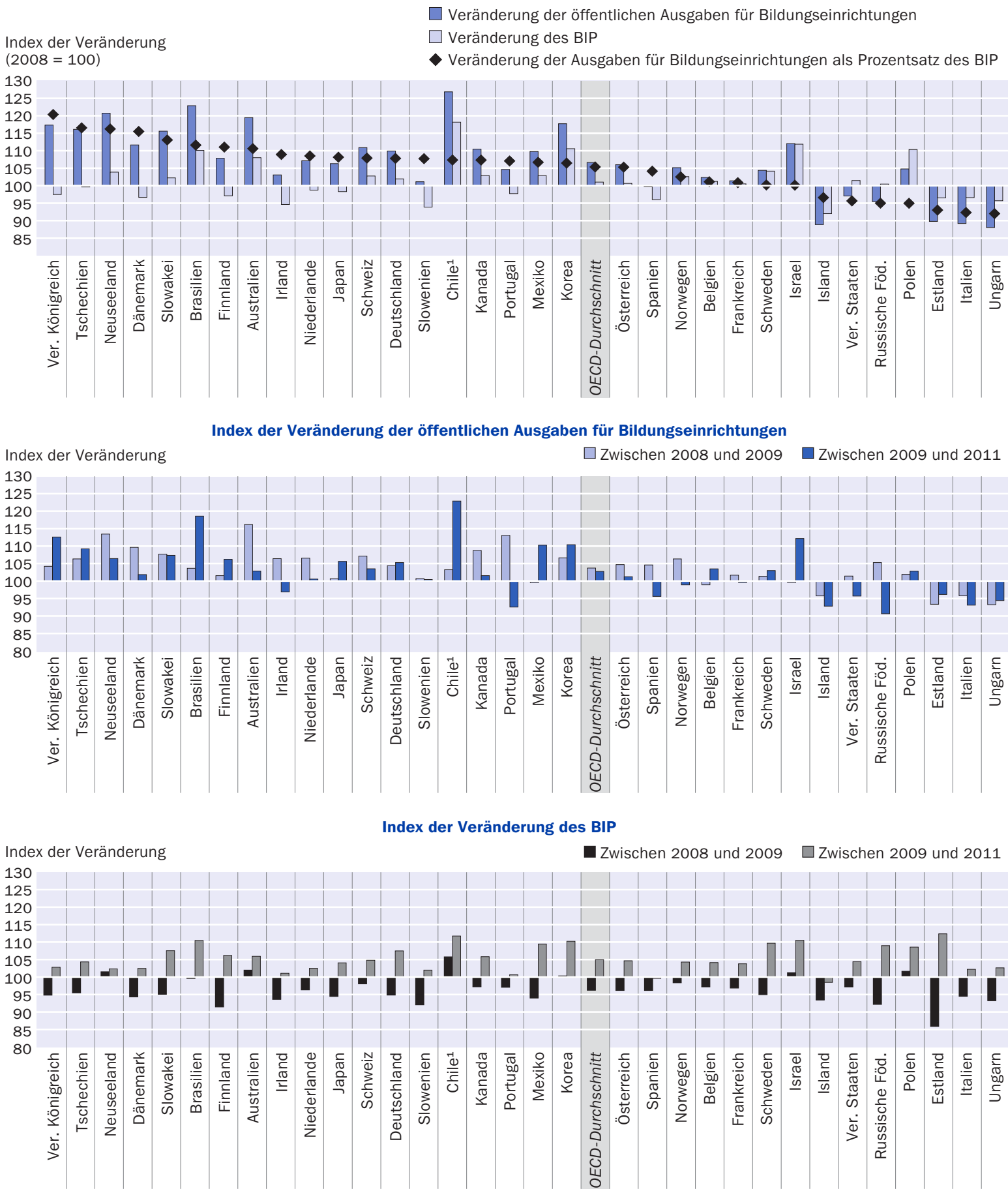
Zwischen 2008 und 20II sank das BIP (zu konstanten Preisen) in mehr als einem Drittel der Länder mit verfügbaren Daten ( ${ }_{5}$ von ${ }_{3} 6$ ), in vier Ländern sogar um mindestens 5 Prozent - in Griechenland, Island, Irland und Slowenien. Da in den meisten Ländern mehr als drei Viertel der Bildungsausgaben mit Mitteln aus öffentlichen Quellen finanziert werden, ergibt sich die Frage, wie sich der Rückgang des BIP-Wachstums auf die öffentlichen Bildungsausgaben ausgewirkt hat. Verfügbare Zahlen zeigen, dass der Bildungssektor von den Haushaltskürzungen am Anfang kaum berührt war.

Da in den meisten Ländern der öffentliche Haushalt, lange bevor die Mittel tatsächlich fließen, verabschiedet wird, wirken sich aktuelle Entwicklungen nur in gewissem Umfang unmittelbar auf die Bildungsfinanzierung aus. Außerdem versuchen die meisten Staaten, den Bildungsbereich vor starken finanziellen Einschnitten zu schützen.

Von den 34 Ländern mit verfügbaren Daten für den Zeitraum 2008 bis 20 Ir kürzten nur 6 Länder die öffentlichen Ausgaben für Bildungseinrichtungen real: Estland (um Io Prozent), Island (um II Prozent), Italien (um II Prozent), die Russische Föderation (um 5 Prozent), Ungarn (um I2 Prozent) und die Vereinigten Staaten (um 3 Prozent). Dies führte in diesen Ländern zu einer Senkung der Ausgaben für Bildungseinrichtungen als Prozentsatz des BIP (da die Ausgabensenkung höher war als der Rückgang des BIP bzw. das BIP im gleichen Zeitraum stieg). In allen anderen Ländern stiegen die öffentlichen Ausgaben für Bildungseinrichtungen, während das BIP in einigen sank. Daher stieg der für Bildung bereitgestellte Anteil des BIP zwischen 2008 und $201 \mathrm{I}$ weiter. Eine Ausnahme ist hier Polen, wo auch das BIP stieg, und zwar schneller als die öffentlichen Ausgaben für Bildungseinrichtungen, was zu einer Senkung der öffentlichen Ausgaben für Bildungseinrichtungen als Prozentsatz des BIP führte (Abb. B2.3).

Hinter den Gesamtänderungen der Jahre 2008 bis 201 I stehen unterschiedliche Änderungen der Jahre 2008 auf 2009 und 2009 bis 201 I.

Während in den meisten der 30 Länder mit verfügbaren Daten das BIP von 2008 auf 2009 sank (mit Ausnahme von Australien, Chile, Israel, Korea, Neuseeland und Polen), stieg es in den meisten Ländern 2010 und/oder 201 I wieder, sodass das BIP zwischen 2009 und $201 \mathrm{I}$ bis auf Ausnahme von zwei Ländern insgesamt anstieg: Griechenland, wo das BIP in beiden Jahren sank (zwischen 2009 und 201 I um I2 Prozent), und Island, wo der Anstieg des BIP von 2010 auf 201 I nicht den Rückgang von 2009 auf 2010 kompensierte (ein Rückgang von 2 Prozent zwischen 2009 und 20II).

Währenddessen fingen die öffentlichen Ausgaben für Bildungseinrichtungen mit einer gewissen Verzögerung im Vergleich zum BIP an zu sinken, was auf die unvermeidliche zeitliche Verzögerung zwischen dem Eintritt der Krise und der Anpassung der öffentlichen Haushalte zurückzuführen ist. Zwar sank das BIP von 2008 auf 2009 in den meisten Ländern, doch die öffentlichen Ausgaben für Bildungseinrichtungen stiegen in diesem Zeitraum in den meisten Ländern, im Durchschnitt der OECD-Länder um 4 Prozent. Trotzdem gingen die öffentlichen Ausgaben in Estland, Island, Italien und Ungarn um mindestens 4 Prozent zurück. Während das BIP in diesen Ländern noch weiter sank, stiegen in den meisten Ländern die öffentlichen Ausgaben als Prozentsatz des BIP. Nur in Chile und Israel sank dieser Anteil leicht um weniger als 2 Prozent. 
Im Zeitraum 2009 bis 2011 sanken die öffentlichen Ausgaben von 2009 auf 2010 oder von 2010 auf 2011 oder kontinuierlich über den ganzen 2-Jahres-Zeitraum, und zwar in mehr Ländern als von 2008 auf 2009. Über den gesamten Zeitraum 2009 bis $201 \mathrm{I}$ sanken die öffentlichen Ausgaben in ro Ländern (in Island, Italien, Portugal, der Russischen Föderation und Ungarn um mehr als 5 Prozent), während das BIP in den meisten Ländern stieg. Zusammen mit dem Anstieg des BIP führte dies zu einem Rückgang der öffentlichen Ausgaben für Bildung als Prozentsatz des BIP in all diesen Ländern, am stärksten ausgeprägt in Estland mit I4 Prozent und in der Russischen Föderation mit I7 Prozent. In I2 anderen Ländern jedoch fiel der Anstieg der öffentlichen Ausgaben für Bildung zwischen 2009 und 20II nicht so groß aus wie der Anstieg des BIP, daher sanken auch die öffentlichen Ausgaben für Bildung als Prozentsatz des BIP, in Polen und Schweden um mehr als 5 Prozent.

\section{Ausgaben für Unterricht, Forschung und Entwicklung sowie zusätzliche Dienstleistungen}

Im Durchschnitt der OECD-Länder entfallen rund go Prozent aller Ausgaben für den Primar-, Sekundar- und postsekundaren, nicht tertiären Bereich zusammen auf eigentliche Bildungsdienstleistungen. Dieser Anteil ist im Tertiärbereich deutlich niedriger (im Durchschnitt der OECD 7o Prozent), da dort andere Leistungen, insbesondere im Zusammenhang mit Forschung und Entwicklung (F\&E), einen wesentlichen Teil der Bildungsausgaben ausmachen können.

Im Tertiärbereich reichen die Ausgaben für Forschung und Entwicklung (F\&E) als Prozentsatz des BIP von weniger als 0,2 Prozent in Brasilien und Chile bis zu mehr als o,6 Prozent in Australien, Estland, Finnland, Kanada, den Niederlanden, Norwegen und der Schweiz und mehr als 0,9 Prozent in Schweden. Diese Unterschiede erklären einen Teil der Unterschiede zwischen den einzelnen Ländern bei den Gesamtausgaben pro Studierenden im Tertiärbereich (Tab. B2.4 und Abb. B2.4). So deuten zum Beispiel hohe F\&E-Ausgaben in den oben angeführten Ländern darauf hin, dass die Ausgaben für Bildungseinrichtungen pro Studierenden in diesen Ländern nach einer Bereinigung um den F\&E-Anteil wesentlich niedriger wären (s. Tab. BI.2).

In vielen OECD-Ländern bieten Schulen und Hochschulen soziale Dienste für Schüler und Studierende ebenso wie in einigen Fällen auch Dienstleistungen für die Allgemeinheit an. Die Finanzierung dieser zusätzlichen Dienstleistungen erfolgt durch öffentliche Mittel und Gebühren, die von den Schülern/Studierenden und ihren Familien erhoben werden. Die Ausgaben für zusätzliche Dienstleistungen im Primar-, Sekundarund postsekundaren, nicht tertiären Bereich zusammen als Prozentsatz des BIP liegen im Durchschnitt der OECD-Länder bei ungefähr 0,22 Prozent (Tab. B2.4). In Finnland, Frankreich, Korea und Schweden sind es mehr als o,4 Prozent.

Im Tertiärbereich werden diese zusätzlichen Dienstleistungen häufiger als in jedem anderen Bildungsbereich durch die privaten Nutzer bezahlt. Im Durchschnitt der OECD-Länder belaufen sich die Ausgaben für zusätzliche Dienstleistungen im Tertiärbereich auf o,o6 Prozent des BIP. In Israel, Kanada, der Slowakei und Ungarn liegt dieser Anteil bei über o, I Prozent und erreicht in den Vereinigten Staaten o, 33 Prozent. 
Ausgaben für Bildungseinrichtungen für eigentliche Bildungsdienstleistungen, Forschung und Entwicklung (F\&E) sowie zusätzliche Dienstleistungen als Prozentsatz des BIP, Tertiärbereich (2011)

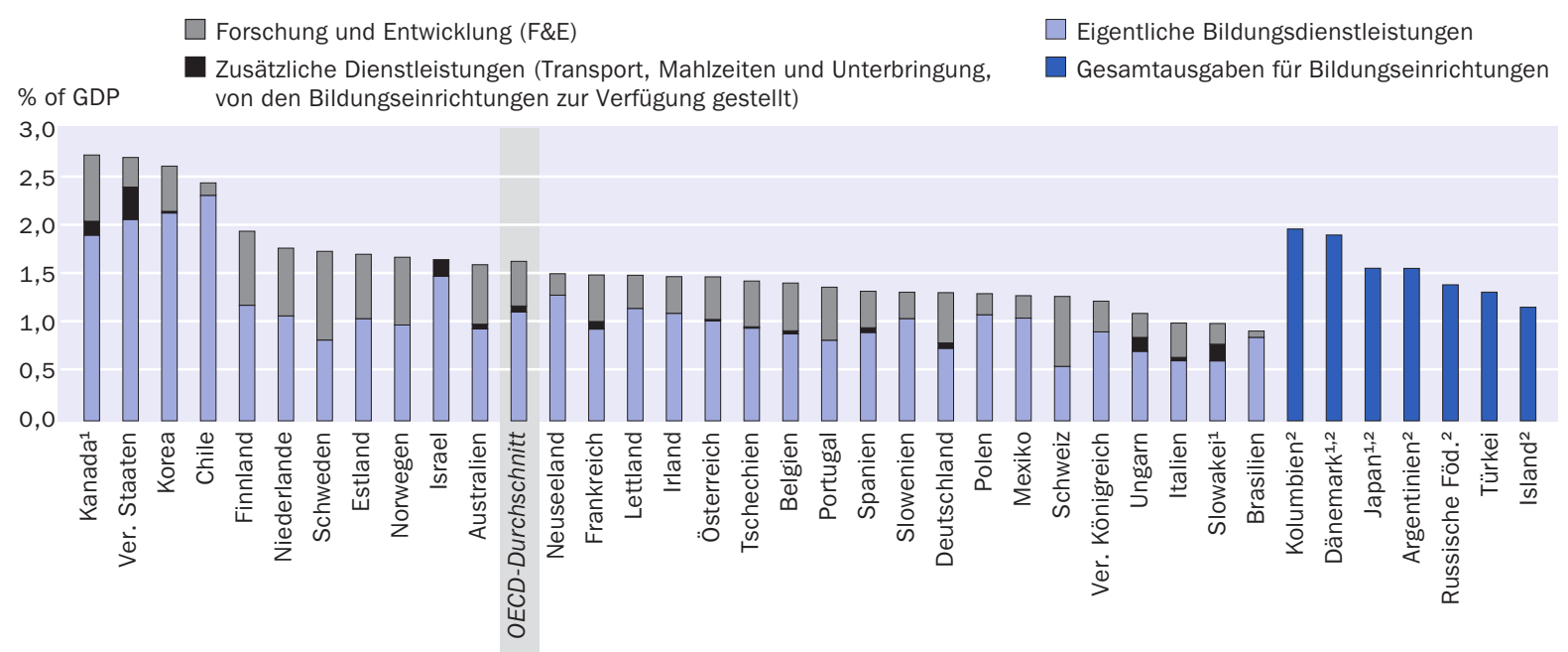

1. Einige Bildungsbereiche sind in anderen Bildungsbereichen enthalten. Einzelheiten s. Erläuterung von „x“ in Hinweise für den Leser. 2. Gesamtausgaben im Tertiärbereich einschließlich Ausgaben für Forschung und Entwicklung (F\&E).

Anordnung der Länder in absteigender Reihenfolge der Gesamtausgaben für Bildungseinrichtungen im Tertiärbereich.

Quelle: OECD. Tabelle B2.4. Hinweise s. Anhang 3 unter www.oecd.org/edu/eag.htm. StatLink: http://dx.doi.org/10.1787/888933117345

\section{Ausgaben für Bildungseinrichtungen nach Herkunft der Mittel}

Bildung wird mit Mitteln sowohl aus öffentlichen als auch privaten Quellen finanziert. Höhere Ausgaben für Bildungseinrichtungen infolge höherer Schüler-/Studierendenzahlen und aufgrund anderer Faktoren bedeuten eine größere finanzielle Belastung für die Gesellschaft insgesamt, wobei diese Belastung jedoch nicht nur die öffentliche Hand betrifft (s. Indikator A7). Im Durchschnitt stammen von den 6, I Prozent der Gesamtsumme der Bruttoinlandsprodukte in der OECD, die für Bildung bereitgestellt werden, drei Viertel der Ausgaben für alle Bildungsbereiche zusammen (5,3 Prozent der Gesamtsumme der Bruttoinlandsprodukte in der OECD) aus öffentlichen Quellen (Tab. B2.3). Sie sind in allen Ländern die wichtigste Finanzierungsquelle und stellen zwischen mindestens 62 Prozent (Chile) bis zu fast 98 Prozent (Finnland) aller für Bildung bereitgestellten Mittel dar. Die Aufschlüsselung der Bildungsausgaben nach Herkunft der Mittel und Bildungsbereichen macht jedoch größere Unterschiede zwischen den einzelnen Ländern deutlich (s. Indikator B3).

\section{Definitionen}

Zusätzliche Dienstleistungen sind Dienstleistungen, die von den Bildungseinrichtungen neben dem eigentlichen Bildungsauftrag erbracht werden. Soziale Dienstleistungen für Schüler/Studierende stellen den wichtigsten Bereich zusätzlicher Dienstleistungen dar. Im Primar-, Sekundar- und postsekundaren, nicht tertiären Bereich umfassen die sozialen Dienstleistungen die Bereitstellung von Mahlzeiten, die Gesundheitsdienste der Schulen sowie Schultransporte. Im Tertiärbereich sind es u. a. Wohnheime, Mensen und Gesundheitsdienste. 
Eigentliche Bildungsdienstleistungen umfassen alle Dienstleistungen, die direkt mit dem Unterricht an Bildungseinrichtungen in Zusammenhang stehen, einschließlich der Lehrkräfte, des Baus und der Instandhaltung von Schulgebäuden, des Unterrichtsmaterials, der Bücher und der Verwaltung der Schulen.

Ausgaben für Forschung und Entwicklung (F\&E) beinhalten sämtliche Ausgaben für Forschung an Hochschulen und anderen Bildungseinrichtungen des Tertiärbereichs, unabhängig davon, ob diese aus dem allgemeinen Etat der Einrichtungen, über separate Zuschüsse oder über Verträge mit öffentlichen oder privaten Geldgebern finanziert werden. Ausgaben für Forschung und Entwicklung werden anhand der Angaben der forschenden Institutionen und nicht der betreffenden Geldgeber klassifiziert.

Private Zahlungen für Unterrichtsleistungen/Bildungsgüter außerhalb von Bildungseinrichtungen umfassen alle Bildungsgüter und Dienstleistungen, die außerhalb von Bildungseinrichtungen erworben werden. So können beispielsweise Familien Schulbücher und Unterrichtsmaterialien selbst kaufen oder ihren Kindern Privatunterricht erteilen lassen.

\section{Angewandte Methodik}

Die Daten beziehen sich auf das Haushaltsjahr 201 I und beruhen auf der von der OECD im Jahre 2013 durchgeführten UOE-Datenerhebung zur Bildungsstatistik (weitere Informationen s. Anhang 3 unter www.oecd.org/edu/eag.htm).

\section{Anmerkung zu den Daten aus Israel}

Die statistischen Daten für Israel wurden von den zuständigen israelischen Stellen bereitgestellt, die für sie verantwortlich zeichnen. Die Verwendung dieser Daten durch die OECD erfolgt unbeschadet des völkerrechtlichen Status der Golanhöhen, von Ost-Jerusalem und der israelischen Siedlungen im Westjordanland.

\section{Tabellen Indikator B2}

StatLink: http://dx.doi.org/10.1787/888933117174

Tabelle B2.I: Ausgaben für Bildungseinrichtungen als Prozentsatz des BIP, nach Bildungsbereich (20II)

Tabelle B2.2: Entwicklung der Ausgaben für Bildungseinrichtungen als Prozentsatz des BIP, nach Bildungsbereich (I995, 2000, 2005, 2008, 2009, 2010, 20II)

Tabelle B2.3: Ausgaben für Bildungseinrichtungen als Prozentsatz des BIP, nach Herkunft der Mittel und Bildungsbereich (20II)

Tabelle B2.4: Ausgaben für Bildungseinrichtungen als Prozentsatz des BIP, nach Leistungsbereich (20II)

Tabelle B2.5: Veränderung der öffentlichen Ausgaben für Bildungseinrichtungen als Prozentsatz des BIP (2008, 2009, 2010, 20II) 
Ausgaben für Bildungseinrichtungen als Prozentsatz des BIP, nach Bildungsbereich (2011)

Finanziert mit Mitteln aus öffentlichen und privaten Quellen ${ }^{1}$

\begin{tabular}{|c|c|c|c|c|c|c|c|c|c|}
\hline & \multirow{2}{*}{$\begin{array}{l}\text { Elementar- } \\
\text { bereich } \\
\text { (3-Jährige } \\
\text { und Ältere) }\end{array}$} & \multicolumn{4}{|c|}{$\begin{array}{l}\text { Primar-, Sekundar- und postsekundarer, } \\
\text { nicht tertiärer Bereich }\end{array}$} & \multicolumn{3}{|c|}{ Tertiärbereich } & \multirow{2}{*}{\begin{tabular}{|c} 
Alle Bildungs- \\
bereiche \\
zusammen \\
(einschl. \\
nicht zuge- \\
ordneter \\
Bildungs- \\
gänge)
\end{tabular}} \\
\hline & & \begin{tabular}{c|} 
Primar-, Se- \\
kundar- und \\
postsekunda- \\
rer, nicht ter- \\
tiärer Bereich \\
insgesamt
\end{tabular} & $\begin{array}{l}\text { Primar- und } \\
\text { Sekundar- } \\
\text { bereich I }\end{array}$ & $\begin{array}{l}\text { Sekundar- } \\
\text { bereich II }\end{array}$ & \begin{tabular}{|c|} 
Post- \\
sekundarer, \\
nicht tertiärer \\
Bereich
\end{tabular} & $\begin{array}{c}\text { Tertiärbereich } \\
\text { insgesamt }\end{array}$ & $\begin{array}{c}\text { Tertiär- } \\
\text { bereich B }\end{array}$ & \begin{tabular}{|c|} 
Tertiärbereich \\
A und weiter- \\
führende \\
forschungs- \\
orientierte \\
Studiengänge
\end{tabular} & \\
\hline & (1) & (2) & (3) & (4) & (5) & (6) & (7) & (8) & (9) \\
\hline \multicolumn{10}{|l|}{ OECD-Länder } \\
\hline Australien & 0,1 & 4,1 & 3,2 & 0,8 & 0,1 & 1,6 & 0,2 & 1,4 & 5,8 \\
\hline Österreich & 0,6 & 3,6 & 2,3 & 1,3 & $\mathrm{n}$ & 1,5 & $\mathrm{n}$ & 1,5 & 5,7 \\
\hline Belgien ${ }^{2}$ & 0,6 & 4,4 & 1,6 & 2,8 & $x(4)$ & 1,4 & $x(6)$ & $x(6)$ & 6,6 \\
\hline Kanada $^{3}$ & $x(3)$ & 4,0 & 2,4 & 1,6 & $x(7)$ & 2,8 & 0,9 & 1,9 & 6,8 \\
\hline Chile $^{4}$ & 0,8 & 3,7 & 2,5 & 1,3 & a & 2,4 & 0,7 & 1,8 & 6,9 \\
\hline Tschechien & 0,5 & 2,9 & 1,8 & 1,1 & $\mathrm{n}$ & 1,4 & $\mathrm{n}$ & 1,4 & 5,0 \\
\hline Dänemark & 1,4 & 4,4 & 3,1 & 1,3 & $x(4,6)$ & 1,9 & $x(6)$ & $x(6)$ & 7,9 \\
\hline Estland & 0,4 & 3,4 & 2,0 & 1,1 & 0,3 & 1,7 & 0,5 & 1,2 & 5,5 \\
\hline Finnland & 0,4 & 4,1 & 2,5 & 1,6 & $x(4)$ & 1,9 & $\mathrm{n}$ & 1,9 & 6,5 \\
\hline Frankreich & 0,7 & 3,9 & 2,6 & 1,3 & $\mathrm{n}$ & 1,5 & 0,3 & 1,2 & 6,1 \\
\hline Deutschland & 0,6 & 3,1 & 2,0 & 1,0 & 0,2 & 1,3 & 0,1 & 1,2 & 5,1 \\
\hline Griechenland & $\mathrm{m}$ & $\mathrm{m}$ & $\mathrm{m}$ & $\mathrm{m}$ & $\mathrm{m}$ & $\mathrm{m}$ & $\mathrm{m}$ & $\mathrm{m}$ & m \\
\hline Ungarn ${ }^{5}$ & 0,6 & 2,6 & 1,5 & 1,0 & 0,1 & 1,0 & $n$ & 0,9 & 4,4 \\
\hline Island & 1,0 & 4,9 & 3,6 & 1,3 & $x(4)$ & 1,2 & $x(6)$ & 1,2 & 7,7 \\
\hline Irland & $x(9)$ & 4,6 & 3,3 & 0,9 & 0,4 & 1,5 & $x(6)$ & $x(6)$ & 6,2 \\
\hline Israel & 0,7 & 4,2 & 2,4 & 1,8 & $\mathrm{n}$ & 1,7 & 0,3 & 1,4 & 7,3 \\
\hline Italien & 0,5 & 3,1 & 1,9 & 1,2 & 0,1 & 1,0 & $\mathrm{n}$ & 1,0 & 4,6 \\
\hline Japan & 0,2 & 2,9 & 2,1 & 0,9 & $x(4,6)$ & 1,6 & 0,2 & 1,3 & 5,1 \\
\hline Korea & 0,3 & 4,1 & 2,7 & 1,5 & a & 2,6 & 0,3 & 2,3 & 7,6 \\
\hline Luxemburg & 0,8 & 3,4 & 2,5 & 0,8 & $\mathrm{n}$ & $\mathrm{m}$ & $\mathrm{m}$ & $\mathrm{m}$ & m \\
\hline Mexiko & 0,6 & 4,0 & 3,1 & 0,9 & a & 1,3 & $x(6)$ & $x(6)$ & 6,2 \\
\hline Niederlande & 0,4 & 4,0 & 2,7 & 1,3 & $\mathrm{n}$ & 1,8 & $\mathrm{n}$ & 1,8 & 6,2 \\
\hline Neuseeland & 0,6 & 5,4 & 3,6 & 1,6 & 0,2 & 1,5 & 0,2 & 1,3 & 7,5 \\
\hline Norwegen ${ }^{5}$ & 0,5 & 4,9 & 3,3 & 1,6 & $x(4)$ & 1,7 & $x(6)$ & $x(6)$ & 7,4 \\
\hline Polen & 0,7 & 3,4 & 2,4 & 1,0 & $\mathrm{n}$ & 1,3 & $\mathrm{n}$ & 1,3 & 5,5 \\
\hline Portugal & 0,4 & 3,7 & 2,6 & 1,1 & $\mathrm{~m}$ & 1,4 & $x(6)$ & $x(6)$ & 5,5 \\
\hline Slowakei & 0,5 & 2,8 & 1,8 & 1,0 & $x(4)$ & 1,0 & $x(4)$ & 1,0 & 4,4 \\
\hline Slowenien & 0,8 & 3,8 & 2,7 & 1,1 & $x(4)$ & 1,3 & $x(6)$ & $x(6)$ & 5,9 \\
\hline Spanien & 0,9 & 3,2 & 2,5 & 0,7 & a & 1,3 & 0,2 & 1,1 & 5,5 \\
\hline Schweden & 0,7 & 3,9 & 2,6 & 1,3 & $\mathrm{n}$ & 1,7 & $x(6)$ & $x(6)$ & 6,3 \\
\hline Schweiz ${ }^{5}$ & 0,2 & 4,0 & 2,6 & 1,4 & $x(4)$ & 1,3 & $\mathrm{n}$ & 1,2 & 5,6 \\
\hline Türkei ${ }^{5}$ & 0,2 & 2,7 & 1,8 & 0,9 & a & 1,3 & $x(6)$ & $x(6)$ & 4,2 \\
\hline Ver. Königreich & 0,4 & 4,7 & 3,7 & 1,0 & a & 1,2 & $x(6)$ & $x(6)$ & 6,4 \\
\hline Vereinigte Staaten & 0,5 & 3,7 & 2,7 & 1,0 & $\mathrm{~m}$ & 2,7 & $x(6)$ & $x(6)$ & 6,9 \\
\hline OECD-Durchschnitt & 0,6 & 3,8 & 2,5 & 1,2 & $\mathrm{n}$ & 1,6 & 0,2 & 1,4 & 6,1 \\
\hline OECD insgesamt & 0,5 & 3,6 & 2,5 & 1,1 & $\mathrm{n}$ & 1,9 & 0,2 & 1,4 & 6,1 \\
\hline EU21-Durchschnitt & 0,6 & 3,6 & 2,4 & 1,2 & $\mathbf{n}$ & 1,4 & 0,1 & 1,3 & $\mathbf{5 , 8}$ \\
\hline \multicolumn{10}{|l|}{ Partnerländer } \\
\hline Argentinien & 0,7 & 5,0 & 3,8 & 1,1 & a & 1,6 & 0,5 & 1,1 & 7,2 \\
\hline Brasilien $^{5}$ & 0,5 & 4,4 & 3,4 & 1,0 & a & 0,9 & $x(6)$ & $x(6)$ & 5,9 \\
\hline China & $\mathrm{m}$ & $\mathrm{m}$ & $\mathrm{m}$ & $\mathrm{m}$ & $\mathrm{m}$ & $\mathrm{m}$ & $\mathrm{m}$ & $\mathrm{m}$ & $\mathbf{m}$ \\
\hline Kolumbien ${ }^{4}$ & 0,5 & 4,2 & 3,6 & 0,6 & a & 2,0 & $x(6)$ & $x(6)$ & 6,7 \\
\hline Indien & $\mathrm{m}$ & $\mathrm{m}$ & $\mathrm{m}$ & $\mathrm{m}$ & $\mathrm{m}$ & $\mathrm{m}$ & $\mathrm{m}$ & $\mathrm{m}$ & m \\
\hline Indonesien & $\mathrm{m}$ & $\mathrm{m}$ & $\mathrm{m}$ & $\mathrm{m}$ & $\mathrm{m}$ & $\mathrm{m}$ & $\mathrm{m}$ & $\mathrm{m}$ & $\mathbf{m}$ \\
\hline Lettland & 0,8 & 3,0 & 2,1 & 0,9 & $\mathrm{n}$ & 1,5 & 0,2 & 1,3 & 5,4 \\
\hline Russische Föd. & 0,8 & 2,1 & $x(2)$ & $x(2)$ & $x(2)$ & 1,4 & 0,2 & 1,2 & 4,6 \\
\hline Saudi-Arabien & $\mathrm{m}$ & $\mathrm{m}$ & $\mathrm{m}$ & $\mathrm{m}$ & $\mathrm{m}$ & $\mathrm{m}$ & $\mathrm{m}$ & $\mathrm{m}$ & m \\
\hline Südafrika & $\mathrm{m}$ & $\mathrm{m}$ & $\mathrm{m}$ & $\mathrm{m}$ & $\mathrm{m}$ & $\mathrm{m}$ & $\mathrm{m}$ & $\mathrm{m}$ & m \\
\hline G20-Durchschnitt & m & m & $\mathbf{m}$ & m & $\mathbf{m}$ & m & m & m & $\mathbf{m}$ \\
\hline
\end{tabular}

1. Einschließlich Mitteln aus internationalen Quellen. 2. Spalte (3) bezieht sich nur auf den Primarbereich und Spalte (4) auf den gesamten Sekundarbereich. 3. Referenzjahr 2010. 4. Referenzjahr 2012. 5. Nur öffentliche Ausgaben (Schweiz: nur im Tertiärbereich; Norwegen: nur im Primar-, Sekundar- und postsekundaren, nicht tertiären Bereich).

Quelle: OECD. Argentinien, China, Indien, Indonesien, Kolumbien, Saudi-Arabien und Südafrika: Statistikinstitut der UNESCO. Lettland: Eurostat. Hinweise s. Anhang 3 unter www.oecd.org/edu/eag.htm. StatLink: http://dx.doi.org/10.1787/888933117193 Erläuterung der Kennzeichnung fehlender Daten s. Hinweise für den Leser. 
Entwicklung der Ausgaben für Bildungseinrichtungen als Prozentsatz des BIP, nach Bildungsbereich (1995, 2000, 2005, 2008, 2009, 2010, 2011)

Finanziert mit Mitteln aus öffentlichen und privaten Quellen, nach Jahr

\begin{tabular}{|c|c|c|c|c|c|c|c|c|c|c|c|c|c|c|c|}
\hline & \multicolumn{5}{|c|}{$\begin{array}{l}\text { Primar-, Sekundar- und postsekundarer, } \\
\text { nicht tertiärer Bereich }\end{array}$} & \multicolumn{5}{|c|}{ Tertiärbereich } & \multicolumn{5}{|c|}{ Alle Bildungsbereiche zusammen } \\
\hline & 2000 & 2005 & 2008 & 2010 & 2011 & 2000 & 2005 & 2008 & 2010 & 2011 & 2000 & 2005 & 2008 & 2010 & 2011 \\
\hline & (2) & (3) & (4) & (6) & (7) & (9) & (10) & (11) & (13) & (14) & (16) & (17) & (18) & (20) & (21) \\
\hline \multicolumn{16}{|l|}{ OECD-Länder } \\
\hline Australien & 3,6 & 3,7 & 3,7 & 4,3 & 4,1 & 1,4 & 1,5 & 1,5 & 1,6 & 1,6 & 5,2 & 5,3 & 5,3 & 6,1 & 5,8 \\
\hline Österreich & 3,9 & 3,7 & 3,6 & 3,7 & 3,6 & 1,1 & 1,3 & 1,3 & 1,5 & 1,5 & 5,5 & 5,5 & 5,4 & 5,8 & 5,7 \\
\hline Belgien & 4,1 & 4,1 & 4,4 & 4,4 & 4,4 & 1,3 & 1,2 & 1,4 & 1,4 & 1,4 & 6,1 & 6,0 & 6,5 & 6,6 & 6,6 \\
\hline Kanada ${ }^{1,2}$ & 3,3 & 3,4 & 3,4 & 3,7 & 4,0 & 2,3 & 2,4 & 2,5 & 2,6 & 2,8 & 5,9 & 5,8 & 5,8 & 6,4 & 6,8 \\
\hline Chile $^{3}$ & 4,2 & 3,2 & 3,9 & 3,4 & 3,7 & 2,0 & 1,7 & 2,0 & 2,4 & 2,4 & 6,5 & 5,4 & 6,5 & 6,4 & 6,9 \\
\hline Tschechien & 2,7 & 2,9 & 2,6 & 2,8 & 2,9 & 0,8 & 1,0 & 1,1 & 1,2 & 1,4 & 4,0 & 4,5 & 4,3 & 4,7 & 5,0 \\
\hline Dänemark ${ }^{2}$ & 4,1 & 4,5 & 4,2 & 4,8 & 4,4 & 1,6 & 1,7 & 1,7 & 1,9 & 1,9 & 6,6 & $\mathbf{7 , 4}$ & 7,0 & 8,0 & 7,9 \\
\hline Estland & $\mathrm{m}$ & 3,5 & 3,9 & 3,9 & 3,4 & $\mathrm{~m}$ & 1,2 & 1,3 & 1,6 & 1,7 & $\mathbf{m}$ & 5,0 & 5,7 & 6,0 & 5,5 \\
\hline Finnland & 3,6 & 3,9 & 3,8 & 4,1 & 4,1 & 1,7 & 1,7 & 1,7 & 1,9 & 1,9 & 5,6 & 6,0 & 5,8 & 6,5 & 6,5 \\
\hline Frankreich & 4,3 & 4,0 & 3,9 & 4,1 & 3,9 & 1,3 & 1,3 & 1,4 & 1,5 & 1,5 & 6,4 & 6,0 & 6,0 & 6,3 & 6,1 \\
\hline Deutschland & 3,3 & 3,2 & 3,0 & 3,3 & 3,1 & 1,1 & 1,1 & 1,2 & 1,3 & 1,3 & 4,9 & 5,0 & 4,8 & 5,3 & 5,1 \\
\hline Griechenland ${ }^{2}$ & 2,7 & 2,8 & $\mathrm{~m}$ & $\mathrm{~m}$ & $\mathrm{~m}$ & 0,8 & 1,5 & $\mathrm{~m}$ & $\mathrm{~m}$ & $\mathrm{~m}$ & 3,6 & 4,3 & $\mathbf{m}$ & m & $\mathbf{m}$ \\
\hline Ungarn ${ }^{4}$ & 2,8 & 3,3 & 3,0 & 2,8 & 2,6 & 0,9 & 0,9 & 0,9 & 0,8 & 1,0 & 4,4 & 5,1 & 4,8 & 4,6 & 4,4 \\
\hline Island & 4,8 & 5,4 & 5,1 & 4,9 & 4,9 & 1,1 & 1,2 & 1,3 & 1,2 & 1,2 & 7,1 & 8,0 & 7,9 & 7,8 & 7,7 \\
\hline Irland & 2,9 & 3,4 & 4,1 & 4,7 & 4,6 & 1,5 & 1,1 & 1,4 & 1,6 & 1,5 & 4,4 & 4,5 & 5,5 & 6,4 & 6,2 \\
\hline Israel & 4,3 & 4,1 & 4,0 & 4,0 & 4,2 & 1,9 & 1,9 & 1,5 & 1,6 & 1,7 & 7,7 & 7,5 & 7,0 & 7,0 & 7,3 \\
\hline Italien & 3,1 & 3,1 & 3,2 & 3,1 & 3,1 & 0,9 & 0,9 & 1,0 & 1,0 & 1,0 & 4,5 & 4,4 & 4,5 & 4,4 & 4,6 \\
\hline$J^{\prime} a n^{2}$ & 3,0 & 2,9 & 2,8 & 2,9 & 2,9 & 1,4 & 1,4 & 1,5 & 1,5 & 1,6 & 5,0 & 4,9 & 5,0 & 5,1 & 5,1 \\
\hline Korea & 3,5 & 4,1 & 4,2 & 4,2 & 4,1 & 2,2 & 2,3 & 2,6 & 2,6 & 2,6 & 6,1 & 6,7 & 7,6 & 7,6 & 7,6 \\
\hline Luxemburg & $\mathrm{m}$ & 3,7 & $\mathrm{~m}$ & 3,6 & 3,4 & $\mathrm{~m}$ & $\mathrm{~m}$ & $\mathrm{~m}$ & $\mathrm{~m}$ & $\mathrm{~m}$ & $\mathbf{m}$ & m & $\mathbf{m}$ & $\mathbf{m}$ & $\mathbf{m}$ \\
\hline Mexiko & 3,5 & 4,0 & 3,7 & 4,0 & 4,0 & 1,0 & 1,2 & 1,2 & 1,4 & 1,3 & 5,0 & 5,9 & 5,7 & 6,2 & 6,2 \\
\hline Niederlande & 3,4 & 3,8 & 3,7 & 4,1 & 4,0 & 1,4 & 1,5 & 1,6 & 1,7 & 1,8 & 5,2 & 5,8 & 5,7 & 6,3 & 6,2 \\
\hline Neuseeland & $\mathrm{m}$ & 3,9 & 3,8 & 4,4 & 5,4 & $\mathrm{~m}$ & 0,9 & 1,1 & 1,0 & 1,5 & $\mathbf{m}$ & 5,1 & 5,4 & 5,9 & 7,5 \\
\hline Norwegen ${ }^{4}$ & 5,0 & 5,1 & 4,8 & 5,1 & 4,9 & 1,6 & 1,7 & 1,6 & 1,6 & 1,7 & 6,8 & 7,5 & 7,1 & 7,4 & 7,4 \\
\hline Polen & 3,9 & 3,7 & 3,6 & 3,7 & 3,4 & 1,1 & 1,6 & 1,5 & 1,5 & 1,3 & 5,6 & 5,9 & 5,8 & 5,8 & 5,5 \\
\hline Portugal & 3,7 & 3,7 & 3,4 & 3,9 & 3,7 & 1,0 & 1,3 & 1,3 & 1,5 & 1,4 & 5,2 & $\mathbf{5 , 5}$ & 5,2 & 5,8 & 5,5 \\
\hline Slowakei ${ }^{2}$ & 2,7 & 2,9 & 2,6 & 3,1 & 2,8 & 0,8 & 0,9 & 0,9 & 0,9 & 1,0 & 4,1 & 4,4 & 4,1 & 4,6 & 4,4 \\
\hline Slowenien & $\mathrm{m}$ & 4,1 & 3,7 & 3,9 & 3,8 & $\mathrm{~m}$ & 1,3 & 1,1 & 1,3 & 1,3 & $\mathbf{m}$ & 6,0 & 5,4 & 5,9 & 5,9 \\
\hline Spanien & 3,2 & 2,9 & 3,1 & 3,3 & 3,2 & 1,1 & 1,1 & 1,2 & 1,4 & 1,3 & 4,8 & 4,6 & 5,1 & 5,6 & 5,5 \\
\hline Schweden & 4,2 & 4,2 & 4,0 & 4,0 & 3,9 & 1,6 & 1,6 & 1,6 & 1,8 & 1,7 & 6,3 & 6,4 & 6,3 & 6,5 & 6,3 \\
\hline Schweiz ${ }^{4}$ & 4,0 & 4,2 & 3,9 & 4,0 & 4,0 & 1,1 & 1,4 & 1,1 & 1,2 & 1,3 & 5,4 & 5,9 & 5,3 & 5,6 & 5,6 \\
\hline Türkei $^{4}$ & 1,8 & $\mathrm{~m}$ & $\mathrm{~m}$ & 2,5 & 2,7 & 0,7 & $\mathrm{~m}$ & $\mathrm{~m}$ & $\mathrm{~m}$ & 1,3 & 2,5 & $\mathbf{m}$ & $\mathbf{m}$ & $\mathbf{m}$ & 4,2 \\
\hline Vereinigtes Königreich & 3,5 & 4,3 & 4,1 & 4,5 & 4,7 & 1,0 & 1,3 & 1,4 & 1,3 & 1,2 & 4,9 & 5,9 & 5,5 & 6,2 & 6,4 \\
\hline Vereinigte Staaten & 3,6 & 3,6 & 3,9 & 4,0 & 3,7 & 2,1 & 2,3 & 2,5 & 2,7 & 2,7 & 6,0 & 6,4 & 6,8 & 7,0 & 6,9 \\
\hline OECD-Durchschnitt & 3,6 & 3,7 & 3,7 & 3,9 & 3,8 & 1,3 & 1,4 & 1,5 & 1,6 & 1,6 & 5,4 & $\mathbf{5 , 7}$ & 5,8 & 6,1 & 6,1 \\
\hline OECD insgesamt & 3,5 & 3,6 & 3,6 & 3,7 & 3,6 & 1,6 & 1,7 & 1,8 & 1,9 & 1,9 & 5,5 & 5,8 & 6,0 & 6,2 & 6,1 \\
\hline EU21-Durchschnitt & 3,5 & 3,6 & 3,6 & 3,8 & 3,6 & 1,1 & 1,3 & 1,3 & 1,4 & 1,4 & 5,1 & 5,4 & 5,5 & 5,9 & 5,8 \\
\hline $\begin{array}{l}\text { OECD-Durchschnitt } \\
\text { für } 25 \text { Länder mit } \\
\text { verfügbaren Daten für } \\
\text { alle Referenzjahre }\end{array}$ & 3,6 & 3,7 & 3,6 & 3,8 & 3,7 & 1,3 & 1,4 & 1,5 & 1,6 & 1,6 & 5,4 & $\mathbf{5 , 7}$ & 5,6 & 6,0 & 6,0 \\
\hline \multicolumn{16}{|l|}{ Partnerländer } \\
\hline Argentinien & $\mathrm{m}$ & $\mathrm{m}$ & $\mathrm{m}$ & $\mathrm{m}$ & 5,0 & $\mathrm{~m}$ & $\mathrm{~m}$ & $\mathrm{~m}$ & $\mathrm{~m}$ & 1,6 & $\mathbf{m}$ & $\mathbf{m}$ & $\mathbf{m}$ & $\mathbf{m}$ & 7,2 \\
\hline Brasilien $^{4}$ & 2,4 & 3,2 & 4,1 & 4,3 & 4,4 & 0,7 & 0,8 & 0,8 & 0,9 & 0,9 & 3,5 & 4,4 & 5,2 & 5,6 & 5,9 \\
\hline China & $\mathrm{m}$ & $\mathrm{m}$ & $\mathrm{m}$ & $\mathrm{m}$ & $\mathrm{m}$ & $\mathrm{m}$ & $\mathrm{m}$ & $\mathrm{m}$ & $\mathrm{m}$ & $\mathrm{m}$ & $\mathbf{m}$ & m & $\mathbf{m}$ & $\mathbf{m}$ & $\mathbf{m}$ \\
\hline Kolumbien ${ }^{3}$ & $\mathrm{~m}$ & $\mathrm{~m}$ & $\mathrm{~m}$ & $\mathrm{~m}$ & 4,2 & $\mathrm{~m}$ & $\mathrm{~m}$ & $\mathrm{~m}$ & $\mathrm{~m}$ & 2,0 & $\mathbf{m}$ & m & $\mathbf{m}$ & $\mathbf{m}$ & 6,7 \\
\hline Indien & $\mathrm{m}$ & $\mathrm{m}$ & $\mathrm{m}$ & $\mathrm{m}$ & $\mathrm{m}$ & $\mathrm{m}$ & $\mathrm{m}$ & $\mathrm{m}$ & $\mathrm{m}$ & $\mathrm{m}$ & $\mathbf{m}$ & m & $\mathbf{m}$ & $\mathbf{m}$ & m \\
\hline Indonesien & $\mathrm{m}$ & $\mathrm{m}$ & $\mathrm{m}$ & $\mathrm{m}$ & $\mathrm{m}$ & $\mathrm{m}$ & $\mathrm{m}$ & $\mathrm{m}$ & $\mathrm{m}$ & $\mathrm{m}$ & m & m & m & m & m \\
\hline Lettland & $\mathrm{m}$ & $\mathrm{m}$ & $\mathrm{m}$ & $\mathrm{m}$ & 3,0 & $\mathrm{~m}$ & $\mathrm{~m}$ & $\mathrm{~m}$ & $\mathrm{~m}$ & 1,5 & $\mathbf{m}$ & $\mathbf{m}$ & $\mathbf{m}$ & $\mathbf{m}$ & 5,4 \\
\hline Russische Föderation ${ }^{4}$ & 1,7 & 1,9 & 2,0 & 2,0 & 2,1 & 0,5 & 0,8 & 0,9 & 1,0 & 1,4 & 2,9 & 3,8 & 4,1 & 4,0 & 4,6 \\
\hline Saudi-Arabien & $\mathrm{m}$ & $\mathrm{m}$ & $\mathrm{m}$ & $\mathrm{m}$ & $\mathrm{m}$ & $\mathrm{m}$ & $\mathrm{m}$ & $\mathrm{m}$ & $\mathrm{m}$ & $\mathrm{m}$ & $\mathbf{m}$ & $\mathbf{m}$ & $\mathbf{m}$ & $\mathbf{m}$ & m \\
\hline Südafrika & $\mathrm{m}$ & $\mathrm{m}$ & $\mathrm{m}$ & $\mathrm{m}$ & $\mathrm{m}$ & $\mathrm{m}$ & $\mathrm{m}$ & $\mathrm{m}$ & $\mathrm{m}$ & $\mathrm{m}$ & m & m & m & m & m \\
\hline G20-Durchschnitt & m & m & $\mathbf{m}$ & m & m & $\mathbf{m}$ & m & m & m & $\mathbf{m}$ & $\mathbf{m}$ & m & m & $\mathbf{m}$ & m \\
\hline
\end{tabular}

Anmerkung: Die Spalten mit den Angaben für die Jahre 1995 und 2009, d.h. die Spalten (1), (5), (8), (12), (15) und (19), sind im Internet verfügbar (s. StatLink unten). Die Spalten „Alle Bildungsbereiche zusammen“ umfasst auch den Elementarbereich, der in dieser Tabelle nicht in separaten Spalten aufgeführt ist. 1. Referenzjahr 2010 anstelle 2011. 2. Einige Bildungsbereiche sind in anderen Bildungsbereichen enthalten. Einzelheiten s. Erläuterung von „x“ in Hinweise für den Leser. 3. Referenzjahr 2012 anstelle 2011. Referenzjahr 2006 anstelle 2005. 4. Nur öffentliche Ausgaben (Schweiz: nur im Tertiärbereich; Norwegen: nur im Primar-, Sekundar- und postsekundaren, nicht tertiären Bereich; Russische Föderation: nur Daten für 1995 und 2000 verfügbar).

Quelle: OECD. Argentinien, China, Indien, Indonesien, Kolumbien, Saudi-Arabien und Südafrika: Statistikinstitut der UNESCO. Lettland: Eurostat. Hinweise s. Anhang 3 unter www.oecd.org/edu/eag.htm. StatLink: http://dx.doi.org/10.1787/888933117212 Erläuterung der Kennzeichnung fehlender Daten s. Hinweise für den Leser. 
Ausgaben für Bildungseinrichtungen als Prozentsatz des BIP, nach Herkunft der Mittel und Bildungsbereich (2011) Finanziert mit Mitteln aus öffentlichen und privaten Quellen

\begin{tabular}{|c|c|c|c|c|c|c|c|c|c|c|c|c|}
\hline & \multicolumn{3}{|c|}{ Elementarbereich } & \multicolumn{3}{|c|}{$\begin{array}{l}\text { Primar-, Sekundar- } \\
\text { und Postsekundarer, } \\
\text { nicht tertiärer Bereich }\end{array}$} & \multicolumn{3}{|c|}{ Tertiärbereich } & \multicolumn{3}{|c|}{$\begin{array}{c}\text { Alle Bildungsbereiche } \\
\text { zusammen }\end{array}$} \\
\hline & Öffentlich ${ }^{1}$ & Privat $^{2}$ & Gesamt & Öffentlich ${ }^{1}$ & Privat $^{2}$ & Gesamt & Öffentlich ${ }^{1}$ & Privat $^{2}$ & Gesamt & Öffentlich ${ }^{1}$ & Privat $^{2}$ & Gesamt \\
\hline & (1) & (2) & (3) & (4) & (5) & (6) & (7) & (8) & (9) & (10) & (11) & (12) \\
\hline \multicolumn{13}{|l|}{ OECD-Länder } \\
\hline Australien & 0,11 & 0,04 & 0,15 & 3,5 & 0,6 & 4,1 & 0,7 & 0,9 & 1,6 & 4,3 & 1,5 & 5,8 \\
\hline Österreich & 0,59 & $\mathrm{n}$ & 0,59 & 3,5 & 0,1 & 3,6 & 1,4 & 0,1 & 1,5 & 5,5 & 0,2 & 5,7 \\
\hline Belgien & 0,63 & 0,02 & 0,64 & 4,3 & 0,1 & 4,4 & 1,3 & 0,1 & 1,4 & 6,4 & 0,2 & 6,6 \\
\hline$K^{K a n a d a}{ }^{3,4}$ & $x(4)$ & $x(5)$ & $x(6)$ & 3,6 & 0,4 & 4,0 & 1,6 & 1,2 & 2,8 & 5,2 & 1,6 & 6,8 \\
\hline Chile $^{5}$ & 0,63 & 0,12 & 0,75 & 2,9 & 0,8 & 3,7 & 0,8 & 1,7 & 2,4 & 4,3 & 2,6 & 6,9 \\
\hline Tschechien & 0,47 & 0,04 & 0,51 & 2,6 & 0,3 & 2,9 & 1,2 & 0,3 & 1,4 & 4,4 & 0,6 & 5,0 \\
\hline Dänemark ${ }^{4}$ & 1,30 & 0,11 & 1,41 & 4,3 & 0,1 & 4,4 & 1,8 & 0,1 & 1,9 & 7,5 & 0,4 & 7,9 \\
\hline Estland & 0,42 & 0,01 & 0,42 & 3,3 & $\mathrm{n}$ & 3,4 & 1,4 & 0,3 & 1,7 & 5,2 & 0,3 & 5,5 \\
\hline Finnland & 0,40 & 0,04 & 0,45 & 4,1 & $n$ & 4,1 & 1,9 & 0,1 & 1,9 & 6,3 & 0,1 & 6,5 \\
\hline Frankreich & 0,66 & 0,04 & 0,71 & 3,7 & 0,3 & 3,9 & 1,3 & 0,2 & 1,5 & 5,6 & 0,5 & 6,1 \\
\hline Deutschland & 0,47 & 0,12 & 0,59 & 2,8 & 0,4 & 3,1 & 1,1 & 0,2 & 1,3 & 4,4 & 0,7 & 5,1 \\
\hline Griechenland & $\mathrm{m}$ & $\mathrm{m}$ & m & $\mathrm{m}$ & $\mathrm{m}$ & m & $\mathrm{m}$ & $\mathrm{m}$ & m & $\mathrm{m}$ & $\mathrm{m}$ & m \\
\hline Ungarn & 0,63 & $\mathrm{~m}$ & m & 2,6 & $\mathrm{~m}$ & m & 1,0 & $\mathrm{~m}$ & m & 4,4 & $\mathrm{~m}$ & m \\
\hline Island & 0,73 & 0,23 & 0,96 & 4,7 & 0,2 & 4,9 & 1,1 & 0,1 & 1,2 & 6,9 & 0,7 & 7,7 \\
\hline Irland & $\mathrm{m}$ & $\mathrm{m}$ & m & 4,4 & 0,2 & 4,6 & 1,2 & 0,3 & 1,5 & 5,7 & 0,5 & 6,2 \\
\hline Israel & 0,60 & 0,11 & 0,71 & 3,8 & 0,4 & 4,2 & 0,9 & 0,8 & 1,7 & 5,6 & 1,7 & 7,3 \\
\hline Italien & 0,44 & 0,05 & 0,49 & 3,0 & 0,1 & 3,1 & 0,8 & 0,2 & 1,0 & 4,2 & 0,4 & 4,6 \\
\hline$J^{\prime a p a n}{ }^{4}$ & 0,10 & 0,12 & 0,22 & 2,7 & 0,2 & 2,9 & 0,5 & 1,0 & 1,6 & 3,6 & 1,6 & 5,1 \\
\hline Korea & 0,16 & 0,13 & 0,29 & 3,4 & 0,8 & 4,1 & 0,7 & 1,9 & 2,6 & 4,9 & 2,8 & 7,6 \\
\hline Luxemburg & 0,76 & 0,01 & 0,76 & 3,3 & 0,1 & 3,4 & $\mathrm{~m}$ & $\mathrm{~m}$ & m & $\mathrm{m}$ & $\mathrm{m}$ & m \\
\hline Mexiko & 0,54 & 0,10 & 0,64 & 3,3 & 0,6 & 4,0 & 0,9 & 0,4 & 1,3 & 5,0 & 1,1 & 6,2 \\
\hline Niederlande & 0,41 & 0,03 & 0,44 & 3,6 & 0,4 & 4,0 & 1,3 & 0,5 & 1,8 & 5,3 & 0,9 & 6,2 \\
\hline Neuseeland & 0,51 & 0,09 & 0,60 & 4,8 & 0,6 & 5,4 & 1,0 & 0,5 & 1,5 & 6,3 & 1,2 & 7,5 \\
\hline Norwegen & 0,48 & 0,03 & 0,51 & 4,9 & $\mathrm{~m}$ & m & 1,6 & 0,1 & 1,7 & 7,3 & $\mathrm{~m}$ & m \\
\hline Polen & 0,54 & 0,17 & 0,71 & 3,2 & 0,2 & 3,4 & 1,0 & 0,3 & 1,3 & 4,8 & 0,7 & 5,5 \\
\hline Portugal & 0,39 & $\mathrm{n}$ & 0,39 & 3,7 & $\mathrm{n}$ & 3,7 & 1,0 & 0,4 & 1,4 & 5,1 & 0,4 & 5,5 \\
\hline Slowakei ${ }^{4}$ & 0,41 & 0,08 & 0,49 & 2,5 & 0,3 & 2,8 & 0,8 & 0,2 & 1,0 & 3,8 & 0,5 & 4,4 \\
\hline Slowenien & 0,64 & 0,15 & 0,79 & 3,5 & 0,3 & 3,8 & 1,1 & 0,2 & 1,3 & 5,3 & 0,7 & 5,9 \\
\hline Spanien & 0,67 & 0,27 & 0,93 & 2,9 & 0,3 & 3,2 & 1,0 & 0,3 & 1,3 & 4,7 & 0,8 & 5,5 \\
\hline Schweden & 0,72 & $\mathrm{n}$ & 0,72 & 3,9 & $\mathrm{n}$ & 3,9 & 1,6 & 0,2 & 1,7 & 6,2 & 0,2 & 6,3 \\
\hline Schweiz & 0,19 & $\mathrm{~m}$ & m & 3,6 & 0,5 & 4,0 & 1,3 & $\mathrm{~m}$ & m & 5,2 & 0,4 & 5,6 \\
\hline Türkei & $\mathrm{m}$ & $\mathrm{m}$ & m & $\mathrm{m}$ & $\mathrm{m}$ & m & $\mathrm{m}$ & $\mathrm{m}$ & m & $\mathrm{m}$ & $\mathrm{m}$ & m \\
\hline Ver. Königreich & 0,34 & 0,08 & 0,42 & 4,4 & 0,4 & 4,7 & 0,9 & 0,3 & 1,2 & 5,6 & 0,8 & 6,4 \\
\hline Vereinigte Staaten & 0,33 & 0,14 & 0,47 & 3,4 & 0,3 & 3,7 & 0,9 & 1,8 & 2,7 & 4,7 & 2,2 & 6,9 \\
\hline OECD-Durchschnitt & 0,51 & 0,08 & 0,60 & 3,6 & 0,3 & 3,9 & 1,1 & 0,5 & 1,6 & 5,3 & 0,9 & 6,1 \\
\hline OECD insgesamt & 0,38 & 0,11 & 0,49 & 3,3 & 0,3 & 3,7 & 1,0 & 1,0 & 2,0 & 4,8 & 1,5 & 6,2 \\
\hline EU21-Durchschnitt & 0,57 & 0,07 & 0,64 & 3,5 & 0,2 & $\mathbf{3 , 7}$ & 1,2 & 0,2 & 1,5 & 5,3 & 0,5 & 5,8 \\
\hline \multicolumn{13}{|l|}{ Partnerländer } \\
\hline Argentinien & 0,51 & 0,18 & 0,68 & 4,5 & 0,4 & 5,0 & 1,2 & 0,4 & 1,6 & 6,2 & 1,0 & 7,2 \\
\hline Brasilien & 0,52 & $\mathrm{~m}$ & m & 4,4 & $\mathrm{~m}$ & m & 0,9 & $\mathrm{~m}$ & m & 5,9 & $\mathrm{~m}$ & m \\
\hline China & $\mathrm{m}$ & $\mathrm{m}$ & m & $\mathrm{m}$ & $\mathrm{m}$ & m & $\mathrm{m}$ & $\mathrm{m}$ & m & $\mathrm{m}$ & $\mathrm{m}$ & m \\
\hline Kolumbien 5 & 0,27 & 0,23 & 0,50 & 3,2 & 1,0 & 4,2 & 0,9 & 1,1 & 2,0 & 4,3 & 2,3 & 6,7 \\
\hline Indien & $\mathrm{m}$ & $\mathrm{m}$ & m & $\mathrm{m}$ & $\mathrm{m}$ & m & $\mathrm{m}$ & $\mathrm{m}$ & m & $\mathrm{m}$ & $\mathrm{m}$ & m \\
\hline Indonesien & $\mathrm{m}$ & $\mathrm{m}$ & $\mathbf{m}$ & $\mathrm{m}$ & $\mathrm{m}$ & m & $\mathrm{m}$ & $\mathrm{m}$ & m & $\mathrm{m}$ & $\mathrm{m}$ & m \\
\hline Lettland & 0,81 & 0,02 & 0,83 & 3,0 & 0,1 & 3,0 & 1,0 & 0,5 & 1,5 & 4,7 & 0,6 & 5,4 \\
\hline Russische Föd. & 0,71 & 0,09 & 0,80 & 2,0 & 0,1 & 2,1 & 0,9 & 0,5 & 1,4 & 3,9 & 0,7 & 4,6 \\
\hline Saudi-Arabien & $\mathrm{m}$ & $\mathrm{m}$ & m & $\mathrm{m}$ & $\mathrm{m}$ & m & $\mathrm{m}$ & $\mathrm{m}$ & m & $\mathrm{m}$ & $\mathrm{m}$ & m \\
\hline Südafrika & $\mathrm{m}$ & $\mathrm{m}$ & m & $\mathrm{m}$ & $\mathrm{m}$ & m & $\mathrm{m}$ & $\mathrm{m}$ & m & $\mathrm{m}$ & $\mathrm{m}$ & m \\
\hline G20-Durchschnitt & $\mathbf{m}$ & $\mathbf{m}$ & m & $\mathbf{m}$ & $\mathbf{m}$ & $\mathbf{m}$ & $\mathbf{m}$ & $\mathbf{m}$ & $\mathbf{m}$ & $\mathbf{m}$ & $\mathbf{m}$ & $\mathbf{m}$ \\
\hline
\end{tabular}

1. Einschließlich öffentlicher Subventionen an private Haushalte, die Bildungseinrichtungen zuzurechnen sind, sowie direkter mit Mitteln aus internationalen Quellen finanzierter Ausgaben für Bildungseinrichtungen. 2. Abzüglich öffentlicher Subventionen, die Bildungseinrichtungen zuzurechnen sind.

3. Referenzjahr 2010. 4. Einige Bildungsbereiche sind in anderen Bildungsbereichen enthalten. Einzelheiten s. Erläuterung von „ ${ }^{“}$ in Hinweise für den Leser. 5. Referenzjahr 2012.

Quelle: OECD. Argentinien, China, Indien, Indonesien, Kolumbien, Saudi-Arabien und Südafrika: Statistikinstitut der UNESCO. Lettland: Eurostat. Hinweise s. Anhang 3 unter www.oecd.org/edu/eag.htm. StatLink: http://dx.doi.org/10.1787/888933117231

Erläuterung der Kennzeichnung fehlender Daten s. Hinweise für den Leser. 
Tabelle B2.4

Ausgaben für Bildungseinrichtungen als Prozentsatz des BIP, nach Leistungsbereich (2011)

Ausgaben für Unterricht, Forschung und Entwicklung und zusätzliche Dienstleistungen in Bildungseinrichtungen sowie private Ausgaben für außerhalb von Bildungseinrichtungen erworbene Bildungsgüter

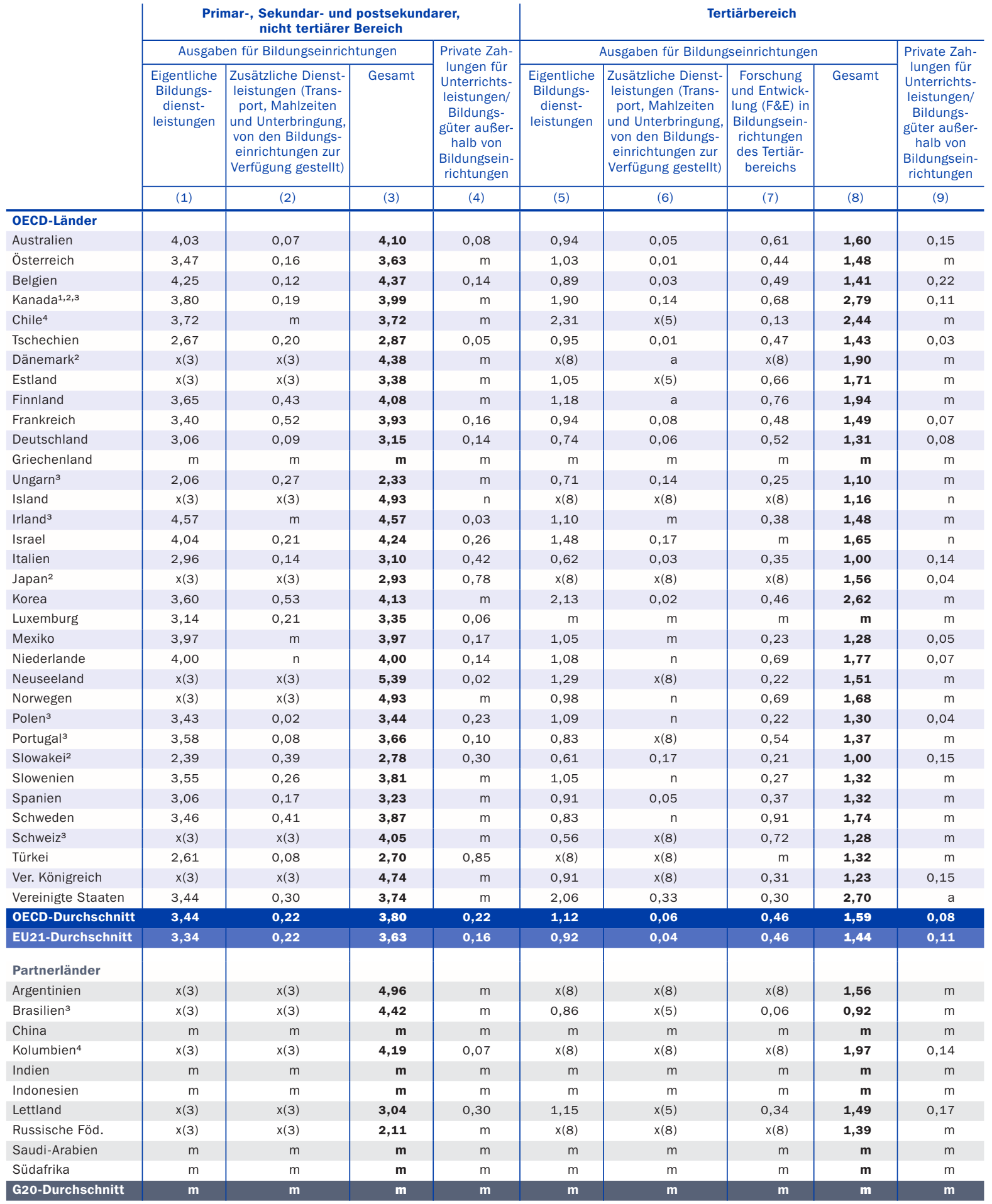

1. Referenzjahr 2010. 2. Einige Bildungsbereiche sind in anderen Bildungsbereichen enthalten. Einzelheiten s. Erläuterung von „x“ in Hinweise für den Leser. 3. Nur öffentliche Ausgaben (Kanada: nur im Tertiärbereich, Italien: außer im Tertiärbereich). 4. Referenzjahr 2012.

Quelle: OECD. Argentinien, China, Indien, Indonesien, Kolumbien, Saudi-Arabien und Südafrika: Statistikinstitut der UNESCO. Lettland: Eurostat. Hinweise s. Anhang 3 unter www.oecd.org/edu/eag.htm. StatLink: http://dx.doi.org/10.1787/888933117250 Erläuterung der Kennzeichnung fehlender Daten s. Hinweise für den Leser. 
Veränderung der öffentlichen Ausgaben für Bildungseinrichtungen als Prozentsatz des BIP (2008, 2009, 2010, 2011) Index der Veränderung der öffentlichen Ausgaben für Bildungseinrichtungen als Prozentsatz des BIP zwischen 2008 und 2011, für alle Bildungsbereiche (zu konstanten Preisen des Jahres 2011)

\begin{tabular}{|c|c|c|c|c|c|c|c|c|c|c|c|c|c|c|c|}
\hline & \multicolumn{5}{|c|}{$\begin{array}{l}\text { Veränderung der öffentlichen }{ }^{1} \\
\text { Ausgaben für Bildungseinrichtungen, } \\
\text { für alle Bildungsbereiche zusammen }\end{array}$} & \multicolumn{5}{|c|}{ Veränderung des BIP } & \multicolumn{5}{|c|}{$\begin{array}{l}\text { Veränderung der öffentlichen }{ }^{1} \\
\text { Ausgaben für Bildungseinrichtungen } \\
\text { als Prozentsatz des BIP }\end{array}$} \\
\hline & \multirow[b]{2}{*}{ 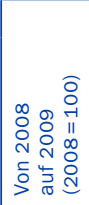 } & \multicolumn{3}{|c|}{ Zwischen 2009 und 2011} & \multirow[b]{2}{*}{ 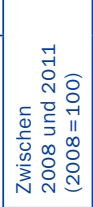 } & \multirow[b]{2}{*}{ 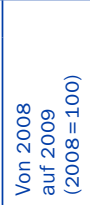 } & \multicolumn{3}{|c|}{ Zwischen 2009 und 2011} & \multirow[b]{2}{*}{ 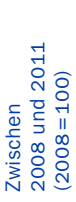 } & \multirow[b]{2}{*}{ 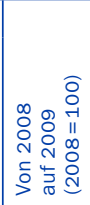 } & \multicolumn{3}{|c|}{ Zwischen 2009 und 2011} & \multirow[b]{2}{*}{ 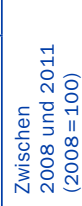 } \\
\hline & & 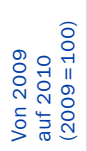 & 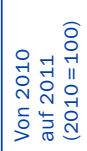 & 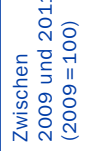 & & & 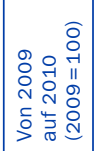 & 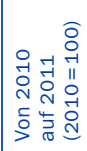 & 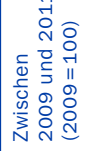 & & & 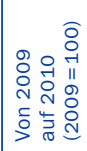 & 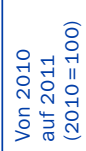 & 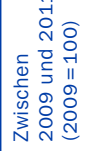 & \\
\hline & (1) & (2) & (3) & (4) & (5) & (6) & (7) & (8) & (9) & (10) & (11) & (12) & (13) & (14) & (15) \\
\hline \multicolumn{16}{|l|}{ OECD-Länder } \\
\hline Australien & 116 & 106 & 97 & 103 & 119 & 102 & 102 & 104 & 106 & 108 & 114 & 104 & 93 & 97 & 111 \\
\hline Österreich & 105 & 100 & 101 & 101 & 106 & 96 & 102 & 103 & 105 & 101 & 109 & 98 & 98 & 97 & 105 \\
\hline Belgien & 99 & 102 & 101 & 103 & 102 & 97 & 102 & 102 & 104 & 101 & 102 & 100 & 99 & 99 & 101 \\
\hline Kanada & 109 & 101 & 101 & 102 & 110 & 97 & 103 & 103 & 106 & 103 & 112 & 98 & 98 & 96 & 107 \\
\hline Chile $^{2}$ & 103 & 104 & 119 & 123 & 127 & 106 & 106 & 106 & 112 & 118 & 98 & 98 & 112 & 110 & 107 \\
\hline Tschechien & 106 & 101 & 109 & 109 & 116 & 95 & 102 & 102 & 104 & 100 & 111 & 98 & 107 & 105 & 117 \\
\hline Dänemark & 110 & 102 & 100 & 102 & 112 & 94 & 101 & 101 & 102 & 97 & 116 & 100 & 99 & 99 & 116 \\
\hline Estland & 93 & 96 & 101 & 96 & 90 & 86 & 103 & 110 & 112 & 97 & 109 & 93 & 92 & 86 & 93 \\
\hline Finnland & 102 & 104 & 102 & 106 & 108 & 91 & 103 & 103 & 106 & 97 & 111 & 101 & 99 & 100 & 111 \\
\hline Frankreich & 102 & 101 & 99 & 100 & 101 & 97 & 102 & 102 & 104 & 101 & 105 & 99 & 97 & 96 & 101 \\
\hline Deutschland & 104 & 104 & 101 & 105 & 110 & 95 & 104 & 103 & 107 & 102 & 110 & 100 & 98 & 98 & 108 \\
\hline Griechenland & $\mathrm{m}$ & $\mathrm{m}$ & $\mathrm{m}$ & $\mathbf{m}$ & m & 97 & 95 & 93 & 88 & 86 & $\mathrm{~m}$ & $\mathrm{~m}$ & $\mathrm{~m}$ & $\mathbf{m}$ & $\mathbf{m}$ \\
\hline Ungarn & 93 & 97 & 98 & 94 & 88 & 93 & 101 & 102 & 103 & 96 & 100 & 96 & 96 & 92 & 92 \\
\hline Island & 96 & 92 & 101 & 93 & 89 & 93 & 96 & 103 & 98 & 92 & 102 & 95 & 99 & 94 & 97 \\
\hline Irland & 106 & 99 & 98 & 97 & 103 & 94 & 99 & 102 & 101 & 95 & 114 & 100 & 96 & 96 & 109 \\
\hline Israel & 100 & 107 & 105 & 112 & 112 & 101 & 106 & 105 & 110 & 112 & 99 & 101 & 100 & 102 & 100 \\
\hline Italien & 96 & 97 & 96 & 93 & 89 & 95 & 102 & 100 & 102 & 97 & 101 & 95 & 96 & 91 & 92 \\
\hline Japan & 101 & 104 & 101 & 106 & 106 & 94 & 105 & 99 & 104 & 98 & 107 & 100 & 102 & 101 & 108 \\
\hline Korea & 107 & 104 & 106 & 110 & 118 & 100 & 106 & 104 & 110 & 111 & 106 & 98 & 102 & 100 & 106 \\
\hline Luxemburg & $\mathrm{m}$ & $\mathrm{m}$ & $\mathrm{m}$ & m & m & 94 & 103 & 102 & 105 & 99 & $\mathrm{~m}$ & $\mathrm{~m}$ & $\mathrm{~m}$ & m & m \\
\hline Mexiko & 100 & 107 & 103 & 110 & 110 & 94 & 105 & 104 & 109 & 103 & 106 & 102 & 99 & 101 & 107 \\
\hline Niederlande & 107 & 102 & 99 & 101 & 107 & 96 & 102 & 101 & 102 & 99 & 111 & 100 & 98 & 98 & 109 \\
\hline Neuseeland & 113 & 99 & 108 & 106 & 121 & 101 & 100 & 102 & 102 & 104 & 112 & 99 & 105 & 104 & 116 \\
\hline Norwegen & 106 & 99 & 100 & 99 & 105 & 98 & 102 & 103 & 104 & 103 & 108 & 97 & 98 & 95 & 103 \\
\hline Polen & 102 & 103 & 100 & 103 & 105 & 102 & 104 & 105 & 109 & 110 & 100 & 99 & 96 & 95 & 95 \\
\hline Portugal & 113 & 100 & 93 & 93 & 105 & 97 & 102 & 99 & 101 & 98 & 116 & 98 & 94 & 92 & 107 \\
\hline Slowakei & 108 & 108 & 99 & 107 & 116 & 95 & 104 & 103 & 108 & 102 & 113 & 104 & 96 & 100 & 113 \\
\hline Slowenien & 101 & 101 & 100 & 100 & 101 & 92 & 101 & 101 & 102 & 94 & 109 & 99 & 99 & 98 & 108 \\
\hline Spanien & 105 & 99 & 97 & 96 & 100 & 96 & 100 & 100 & 100 & 96 & 109 & 99 & 97 & 96 & 104 \\
\hline Schweden & 101 & 102 & 101 & 103 & 104 & 95 & 107 & 103 & 110 & 104 & 107 & 96 & 98 & 94 & 100 \\
\hline Schweiz & 107 & 101 & 102 & 104 & 111 & 98 & 103 & 102 & 105 & 103 & 109 & 98 & 101 & 99 & 108 \\
\hline Türkei & $\mathrm{m}$ & $\mathrm{m}$ & $\mathrm{m}$ & m & $\mathbf{m}$ & 95 & 109 & 109 & 119 & 113 & $\mathrm{~m}$ & $\mathrm{~m}$ & $\mathrm{~m}$ & m & $\mathbf{m}$ \\
\hline Ver. Königreich & 104 & 102 & 110 & 113 & 117 & 95 & 102 & 101 & 103 & 97 & 110 & 100 & 109 & 110 & 120 \\
\hline Vereinigte Staaten & 101 & 98 & 98 & 96 & 97 & 97 & 103 & 102 & 104 & 101 & 104 & 96 & 96 & 92 & 96 \\
\hline OECD-Durchschnitt & 104 & 101 & 101 & 103 & 107 & 96 & 103 & 102 & 105 & 101 & 108 & 99 & 99 & 98 & 105 \\
\hline EU21-Durchschnitt & 103 & 101 & 100 & 101 & 104 & 95 & 102 & 102 & 104 & 98 & 109 & 99 & 98 & 97 & 105 \\
\hline \multicolumn{16}{|l|}{ Partnerländer } \\
\hline Argentinien & $\mathrm{m}$ & $\mathrm{m}$ & $\mathrm{m}$ & m & m & $\mathrm{m}$ & $\mathrm{m}$ & $\mathrm{m}$ & m & m & $\mathrm{m}$ & $\mathrm{m}$ & $\mathrm{m}$ & m & $\mathbf{m}$ \\
\hline Brasilien & 104 & 114 & 104 & 119 & 123 & 100 & 110 & 101 & 110 & 110 & 104 & 104 & 104 & 107 & 112 \\
\hline China & $\mathrm{m}$ & $\mathrm{m}$ & $\mathrm{m}$ & $\mathbf{m}$ & $\mathbf{m}$ & $\mathrm{m}$ & $\mathrm{m}$ & $\mathrm{m}$ & $\mathbf{m}$ & $\mathbf{m}$ & $\mathrm{m}$ & $\mathrm{m}$ & $\mathrm{m}$ & m & m \\
\hline Kolumbien & $\mathrm{m}$ & $\mathrm{m}$ & $\mathrm{m}$ & m & $\mathbf{m}$ & $\mathrm{m}$ & $\mathrm{m}$ & $\mathrm{m}$ & m & $\mathbf{m}$ & $\mathrm{m}$ & $\mathrm{m}$ & $\mathrm{m}$ & $\mathbf{m}$ & m \\
\hline Indien & $\mathrm{m}$ & $\mathrm{m}$ & $\mathrm{m}$ & m & $\mathbf{m}$ & $\mathrm{m}$ & $\mathrm{m}$ & $\mathrm{m}$ & m & m & $\mathrm{m}$ & $\mathrm{m}$ & $\mathrm{m}$ & m & m \\
\hline Indonesien & $\mathrm{m}$ & $\mathrm{m}$ & $\mathrm{m}$ & m & m & $\mathrm{m}$ & $\mathrm{m}$ & $\mathrm{m}$ & m & $\mathbf{m}$ & $\mathrm{m}$ & $\mathrm{m}$ & $\mathrm{m}$ & m & m \\
\hline Lettland & $\mathrm{m}$ & $\mathrm{m}$ & $\mathrm{m}$ & m & m & $\mathrm{m}$ & $\mathrm{m}$ & $\mathrm{m}$ & m & m & $\mathrm{m}$ & $\mathrm{m}$ & $\mathrm{m}$ & m & m \\
\hline Russische Föd. & 105 & 89 & 102 & 91 & 95 & 92 & 105 & 104 & 109 & 100 & 114 & 85 & 98 & 83 & 95 \\
\hline Saudi-Arabien & $\mathrm{m}$ & $\mathrm{m}$ & $\mathrm{m}$ & m & m & $\mathrm{m}$ & $\mathrm{m}$ & $\mathrm{m}$ & m & $\mathbf{m}$ & $\mathrm{m}$ & $\mathrm{m}$ & $\mathrm{m}$ & m & m \\
\hline Südafrika & $\mathrm{m}$ & $\mathrm{m}$ & $\mathrm{m}$ & $\mathbf{m}$ & $\mathbf{m}$ & $\mathrm{m}$ & $\mathrm{m}$ & $\mathrm{m}$ & m & $\mathbf{m}$ & $\mathrm{m}$ & $\mathrm{m}$ & $\mathrm{m}$ & $\mathbf{m}$ & $\mathbf{m}$ \\
\hline G20-Durchschnitt & m & m & m & m & m & m & m & m & m & m & m & m & m & m & $\mathbf{m}$ \\
\hline
\end{tabular}





\section{Wie groß ist der Anteil der öffentlichen und der privaten Ausgaben im Bildungswesen?}

Im Durchschnitt der OECD-Länder stammen 84 Prozent aller Mittel für Bildungseinrichtungen aus öffentlichen Quellen.

Fast 92 Prozent der Mittel für Bildungseinrichtungen im Primar-, Sekundar- und postsekundaren, nicht tertiären Bereich stammen in den OECD-Ländern im Durchschnitt aus öffentlichen Quellen, und nur in Chile und Kolumbien liegt dieser Anteil bei unter 80 Prozent.

Die Bildungseinrichtungen des Tertiärbereichs und in geringerem Ausmaß die des Elementarbereichs werden am stärksten aus privaten Mitteln finanziert: mit 3I Prozent bzw. I9 Prozent. In allen Ländern mit vergleichbaren Daten, mit Ausnahme Italiens, stieg zwischen 2000 und 201 I der Anteil der öffentlichen Ausgaben für Bildungseinrichtungen aller Bildungsbereiche zusammen. Da jedoch immer mehr private Haushalte einen Teil der Bildungskosten übernehmen, nahm die private Finanzierung in mehr als drei Viertel der Länder sogar noch stärker zu.

Abbildung B3.1

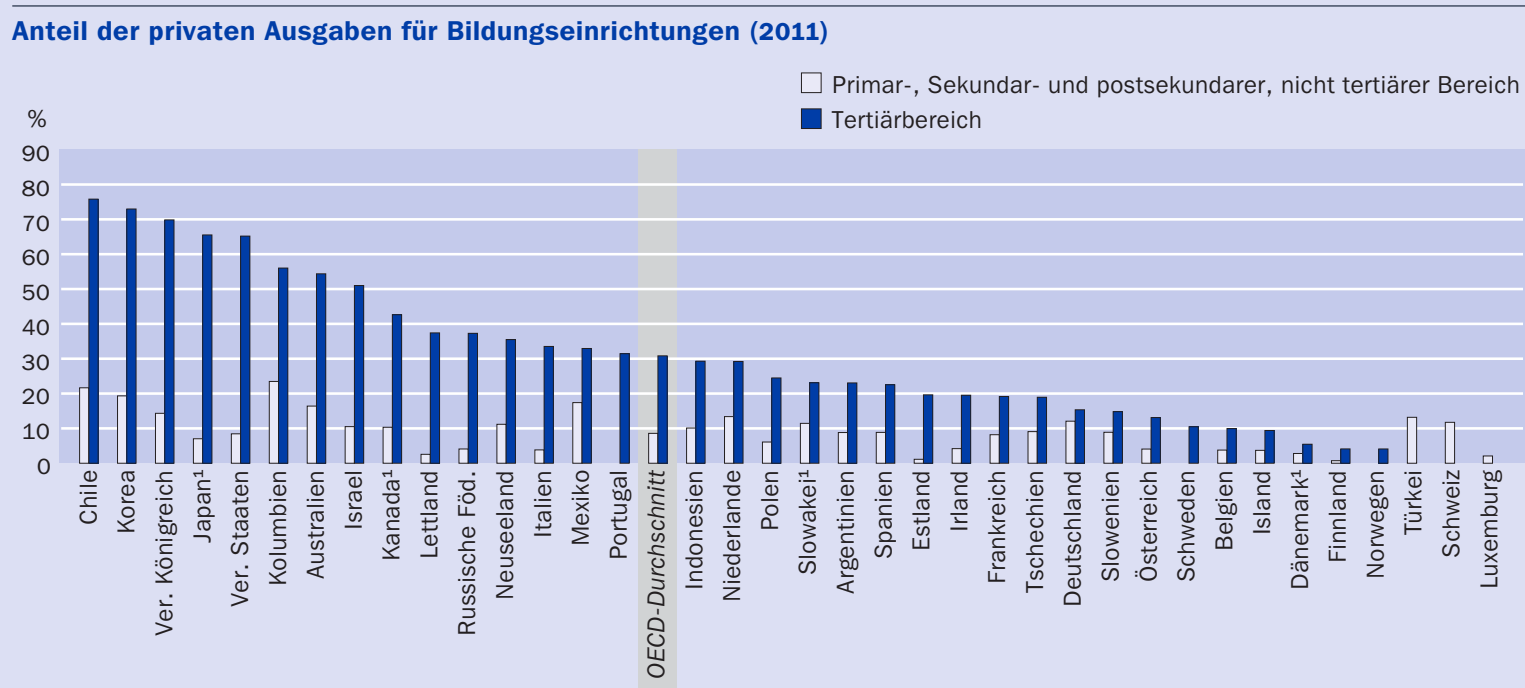

1. Einige Bildungsbereiche sind in anderen Bildungsbereichen enthalten. Einzelheiten s. Erläuterung von "x" in Hinweise für den Leser. Anordnung der Länder in absteigender Reihenfolge des Anteils privater Ausgaben für Bildungseinrichtungen im Tertiärbereich.

Quelle: OECD. Tabelle B3.1. Hinweise s. Anhang 3 unter www.oecd.org/edu/eag.htm. StatLink: http://dx.doi.org/10.1787/888933117478

Erläuterung der Abbildung: Die Abbildung zeigt die privaten Ausgaben für Bildungseinrichtungen als Prozentsatz der Gesamtausgaben für Bildungseinrichtungen. Darin enthalten sind sämtliche Beträge, die über private Quellen an Bildungseinrichtungen fließen, einschließlich staatlich subventionierter Zahlungen privater Haushalte, von privaten Haushalten bezahlter Schul-/Studiengebühren sowie anderer privater Ausgaben (z. B. für Internatsunterbringung), die den Bildungseinrichtungen zukommen. 


\section{Kontext}

Heute nehmen mehr Menschen an einer größeren Vielfalt von Bildungsgängen als je zuvor teil, die von immer mehr Anbietern angeboten werden. Deshalb wird die Antwort auf die Frage, wer das Streben des Einzelnen nach besserer Bildung unterstützen soll, der Staat oder die Bildungsteilnehmer selbst, immer wichtiger. In der gegenwärtigen wirtschaftlichen Situation sehen sich viele Länder Schwierigkeiten gegenüber, die nötigen Mittel für eine Finanzierung der gestiegenen Nachfrage nach Bildung durch die öffentliche Hand alleine aufzubringen. Zudem fordern manche Politiker, dass diejenigen, die am stärksten von Bildung profitieren, nämlich diejenigen, die Bildungsangebote wahrnehmen, auch zumindest einen Teil der Kosten tragen sollten. Zwar stellt die Finanzierung durch öffentliche Mittel noch immer einen großen Teil der Bildungsfinanzierung dar, aber private Mittel rücken zunehmend in den Vordergrund.

In vielen OECD-Ländern ist das Verhältnis von öffentlichen und privaten Mitteln bei der Bildungsfinanzierung ein wichtiges politisches Thema, insbesondere in Bezug auf den Elementar- und Tertiärbereich, wo eine vollständige oder fast vollständige Finanzierung durch öffentliche Mittel weniger üblich ist. In diesen Bildungsbereichen stammt die private Finanzierung vor allem von den privaten Haushalten, was Befürchtungen hinsichtlich eines gerechten Zugangs zu Bildung aufwirft. Besonders intensiv wird diese Debatte im Hinblick auf die Finanzierung des Tertiärbereichs geführt. Einige Akteure haben Bedenken, dass sich das Verhältnis zwischen öffentlicher und privater Finanzierung so stark verschieben könnte, dass dadurch potenzielle Studierende von der Aufnahme eines Studiums im Tertiärbereich abgehalten werden. Andere meinen, die Länder sollten die öffentlichen Unterstützungsleistungen für Studierende signifikant erhöhen, während sich wiederum andere dafür einsetzen, dass mehr Mittel von privaten Unternehmen zur Finanzierung des Tertiärbereichs genutzt werden. Im Gegensatz dazu gilt der Besuch des Primar-, Sekundar- und postsekundaren, nicht tertiären Bildungsbereichs, für den größtenteils Schulpflicht besteht, normalerweise als öffentliches Gut, und er wird daher hauptsächlich von der öffentlichen Hand finanziert.

\section{Weitere wichtige Ergebnisse}

Mit öffentlichen Mitteln werden hauptsächlich öffentliche Bildungseinrichtungen finanziert, aber auch private Bildungseinrichtungen, jedoch in unterschiedlichem Ausmaß. Im Durchschnitt aller OECD-Länder sind für alle Bildungsbereiche zusammen die öffentlichen Ausgaben für öffentliche Bildungseinrichtungen pro Schüler/Studierenden fast doppelt so hoch wie die öffentlichen Ausgaben für private Bildungseinrichtungen. Das Verhältnis reicht jedoch von weniger als dem Doppelten im Primar-, Sekundar- und postsekundaren, nicht tertiären Bereich (Faktor I,8) sowie dem Elementarbereich (Faktor $\mathrm{I}, 8$ ) bis zu fast dem Dreifachen (Faktor 2,9) im Tertiärbereich.

Die Länder mit den niedrigsten öffentlichen Ausgaben pro Studierenden an öffentlichen und privaten Bildungseinrichtungen des Tertiärbereichs haben auch die geringste Anzahl an Studierenden an öffentlichen Bildungseinrichtungen im Tertiärbereich, mit Ausnahme von Kolumbien, Mexiko und Polen. 
In den meisten Ländern mit verfügbaren Daten wird der größte Teil der privaten Ausgaben für den Tertiärbereich von den privaten Haushalten getragen. Ausnahmen sind hier Argentinien, Belgien, Kanada, Österreich, Schweden und Tschechien, wo die Ausgaben anderer privater Einheiten (z. B. privater Unternehmen und gemeinnütziger Organisationen) höher als die Ausgaben privater Haushalte sind, hauptsächlich weil die hier von den Bildungseinrichtungen des Tertiärbereichs erhobenen Studiengebühren niedrig oder vernachlässigbar sind (mit Ausnahme Kanadas).

\section{Entwicklungstendenzen}

Zwischen 2000 und 201 I ging im Durchschnitt der 20 OECD-Länder, für die Trenddaten für alle Jahre verfügbar sind, der Anteil der öffentlichen Finanzierung von Bildungseinrichtungen im Tertiärbereich von 73,7 Prozent im Jahr 2000 auf 69, I Prozent im Jahr 2005 und dann geringfügig auf 68, 3 Prozent im Jahr 20II zurück (Tab. B3.2c). Diese Entwicklung wurde hauptsächlich durch einige europäische Länder beeinflusst, in denen die Studiengebühren signifikant geändert wurden und Unternehmen durch die Gewährung von Zuschüssen stärker in die Finanzierung von Bildungseinrichtungen des Tertiärbereichs eingebunden sind.

Zwischen 2000 und 20II ließ sich in mehr als drei Viertel der Länder mit vergleichbaren Daten (2I von 26 Ländern) eine Steigerung des Anteils der privaten Finanzierung im Tertiärbereich beobachten. Im Durchschnitt der OECD-Länder stieg dieser Anteil um 6 Prozentpunkte und in Israel, Italien, Mexiko, Portugal, Österreich, der Slowakei und dem Vereinigten Königreich um mehr als 9 Prozentpunkte (Tab. B3.2c). In diesen Ländern stieg - mit Ausnahme Italiens - der private Anteil der Finanzierung am stärksten zwischen 2000 und 2008, was auf einen wesentlich stärkeren Anstieg der privaten als der öffentlichen Finanzierung zurückzuführen ist.

Zwischen 2000 und 201 I stieg im Durchschnitt der OECD-Länder auch im Primar-, Sekundar- und postsekundaren, nicht tertiären Bereich sowie in allen Bildungsbereichen zusammen der Anteil der privaten Finanzierung, am stärksten in der Slowakei und dem Vereinigten Königreich (in allen Bildungsbereichen zusammen) (Tab. B3.2a und $\left.\mathrm{B}_{3} .2 \mathrm{~b}\right)$. 


\section{Analyse und Interpretationen}

Die Anteile öffentlicher und privater Ausgaben für Bildungseinrichtungen

In den OECD-Ländern werden Bildungseinrichtungen immer noch überwiegend aus öffentlichen Mitteln finanziert, obwohl es im Tertiärbereich einen erheblichen und zunehmenden Anteil privater Finanzierung gibt. Im Durchschnitt aller OECD-Länder stammen 84 Prozent aller Mittel für Bildungseinrichtungen direkt aus öffentlichen Quellen, I6 Prozent aus privaten Quellen (Tab. B3.I).

Die Anteile der öffentlichen und der privaten Finanzierung variieren jedoch erheblich zwischen den einzelnen Ländern. Bei einem Vergleich der Ausgaben über alle Bildungsbereiche hinweg liegt der Anteil der privaten Finanzierung in Israel, Kanada und Mexiko bei mehr als I9 Prozent, in Australien, Japan, Kolumbien, dem Vereinigten Königreich und den Vereinigten Staaten bei mehr als 25 Prozent und in Chile und Korea bei mehr als 35 Prozent. Im Gegensatz hierzu werden in Finnland und Schweden weniger als 3 Prozent der Ausgaben für Bildungseinrichtungen aus privaten Mitteln finanziert (Tab. B3.I).

Nimmt man alle Bildungsbereiche zusammen, sind die privaten Ausgaben für Bildung zwischen 2000 und 201 I im Durchschnitt der OECD-Länder mit verfügbaren Daten für alle Jahre gestiegen, und in den meisten Ländern stiegen auch die privaten Ausgaben als Prozentsatz der Gesamtausgaben für Bildungseinrichtungen. Hierdurch verringerte sich der Anteil öffentlicher Mittel für Bildungseinrichtungen in fast einem Viertel der OECD-Länder (Israel, Italien, Kanada, Mexiko, Portugal und den Vereinigten Staaten) um mindestens 3 Prozentpunkte und in der Slowakei und dem Vereinigten Königreich um mehr als ro Prozentpunkte. Dieser Rückgang ist hauptsächlich auf einen signifikanten Anstieg der privaten Ausgaben im gleichen Zeitraum zurückzuführen. In Portugal und dem Vereinigten Königreich beispielsweise stiegen die von Bildungseinrichtungen des Tertiärbereichs erhobenen Studiengebühren beträchtlich (Tab. B3.2a und B3.2c).

Der Rückgang des Anteils der öffentlichen Ausgaben an den Gesamtausgaben für Bildungseinrichtungen (und daraus resultierende Erhöhungen des Anteils der privaten Ausgaben) wurde jedoch nicht durch eine (reale) Kürzung der öffentlichen Ausgaben für Bildungseinrichtungen begleitet, nur in Italien kam es zu einem Rückgang der öffentlichen Ausgaben zwischen 2000 und 20II (Tab. B3.2a). Tatsächlich war sogar in vielen OECD-Ländern mit dem höchsten Anstieg der privaten Finanzierung auch der höchste Anstieg der öffentlichen Finanzierung zu beobachten. Dies deutet darauf hin, dass eine verstärkte private Finanzierung tendenziell die öffentlichen Mittel nicht ersetzt, sondern eher ergänzt. Allerdings fiel der Anstieg der privaten Finanzierung gegenüber dem Anstieg der öffentlichen Finanzierung in den meisten Ländern zwischen 2000 und 2005 wesentlich stärker aus als zwischen 2005 und 20II. Daher sank der durchschnittliche Anteil der öffentlichen Finanzierung in Ländern mit verfügbaren Daten für alle Jahre von 86,o Prozent im Jahr 2000 auf 83,5 Prozent im Jahr 2005 und blieb dann bis 20II stabil (bei 83,2 Prozent).

Die Anteile der öffentlichen und der privaten Ausgaben für Bildungseinrichtungen variieren jedoch je nach Land und Bildungsbereich. 
Die Anteile öffentlicher und privater Ausgaben für Bildungseinrichtungen im Primar-, Sekundar- und postsekundaren, nicht tertiären Bereich

Die öffentlichen Haushalte sind in allen Ländern im Primar-, Sekundar- und postsekundaren, nicht tertiären Bildungsbereich die wichtigste Finanzquelle. Mit Ausnahme von Australien, Chile, Deutschland, Indonesien, Israel, Kanada, Kolumbien, Korea, Mexiko, Neuseeland, den Niederlanden, der Schweiz, der Slowakei, der Türkei und dem Vereinigten Königreich stammen weniger als ıo Prozent der Mittel für diese Bildungsbereiche aus privaten Quellen (Tab. B3.2b und Abb. B3.2). In den meisten Ländern wird in diesen Bereichen der größte Teil der privaten Ausgaben von den privaten Haushalten getätigt und betrifft hauptsächlich Schul-/Studiengebühren. In den Niederlanden und der Schweiz hingegen machen Beiträge privater Unternehmen zur dualen Berufsausbildung den Großteil der privaten Ausgaben im Sekundarbereich II und im postsekundaren, nicht tertiären Bereich aus (s. Kasten B3.I in Bildung aufeinen Blick 2011).

Zwischen 2000 und 201 I sank der Anteil der öffentlichen Finanzierung für den Primar-, Sekundar- und postsekundaren, nicht tertiären Bereich in den 20 Ländern mit verfügbaren Daten für alle Jahre leicht von 9I,6 Prozent im Jahr 2000 auf 9I, o Prozent im Jahr 20II. In Israel, Kanada, Mexiko und dem Vereinigten Königreich sank dieser Anteil um mindestens 2 Prozentpunkte und in der Slowakei um bis zu 9 Prozentpunkte. In den anderen Ländern betrug die Verlagerung in die entgegengesetzte Richtung, also hin zur öffentlichen Finanzierung, zwischen 2000 und $201 \mathrm{I}$ in Chile und Japan mehr als 3 Prozentpunkte (von 68, 4 Prozent auf 78, 3 Prozent bzw. von 89,8 Prozent auf 93 Prozent) (Tab. B3.2b).

\section{Die Anteile öffentlicher und privater Ausgaben für Bildungseinrichtungen im Tertiärbereich}

Im Tertiärbereich deuten die hohen privaten Erträge (s. Indikator A7) darauf hin, dass eine stärkere Beteiligung des Einzelnen und anderer privater Einheiten an den Kosten der (Aus-)Bildung gerechtfertigt sein könnte, solange gewährleistet wird, dass Studierenden unabhängig von ihren wirtschaftlichen Verhältnissen Finanzierungsmöglichkeiten zur Verfügung stehen (s. Indikator B5). In allen Ländern ist der Anteil privater Mittel an der Bildungsfinanzierung im Tertiärbereich weitaus höher (durchschnittlich 3I Prozent der Gesamtausgaben in diesem Bildungsbereich) als im Primar-, Sekundarund postsekundaren, nicht tertiären Bereich (Tab. B3.I).

Der Anteil der Ausgaben für Bildungseinrichtungen im Tertiärbereich, der von Einzelnen, Unternehmen und anderen privaten Einheiten getragen wird, einschließlich staatlich subventionierter privater Zahlungen, reicht von weniger als 6 Prozent in Dänemark, Finnland und Norwegen (wo die von den Bildungseinrichtungen im Tertiärbereich erhobenen Studiengebühren niedrig oder vernachlässigbar sind) über mehr als 40 Prozent in Australien, Israel, Japan, Kanada, Kolumbien und den Vereinigten Staaten bis zu mindestens fast 70 Prozent in Chile, Korea und dem Vereinigten Königreich (Abb. B3.2 und Tab. B3.I). Von diesen Ländern sind in Korea und dem Vereinigten Königreich die meisten Studierenden an privaten Bildungseinrichtungen eingeschrieben (rund 8o Prozent an privaten Hochschulen in Korea, roo Prozent an staatlich subventionierten privaten Einrichtungen im Vereinigten Königreich). In Korea stammen 40 Prozent der Mittel für das Bildungswesen aus Studiengebühren. Im Vereinigten Königreich 
wird der Tertiärbereich mittels einer Kombination verschiedener Quellen finanziert: Studiengebühren, die von den Studierenden direkt an die Bildungseinrichtung beglichen werden, und Zuschüsse der Zentralregierung, die indirekt durch eine Higher Education Funding Agency gezahlt werden (s. Indikatoren $\mathrm{B}_{5}$ und $\mathrm{C}_{7}$ ).

Die Beiträge anderer privater Einheiten als der privaten Haushalte zur Finanzierung von Bildungseinrichtungen sind im Durchschnitt aller OECD-Länder im Tertiärbereich höher als in anderen Bildungsbereichen. In mehr als einem Drittel der OECD-Länder mit verfügbaren Daten (Australien, Israel, Japan, Kanada, Korea, den Niederlanden, Österreich, Schweden, Tschechien und den Vereinigten Staaten) sowie in Argentinien und der Russischen Föderation werden mindestens ıo Prozent der Ausgaben für Bildungseinrichtungen im Tertiärbereich von anderen privaten Einheiten als den privaten Haushalten aufgebracht. In Schweden fließen diese Beiträge größtenteils in die finanzielle Förderung von Forschung und Entwicklung.

In vielen OECD-Ländern spiegeln die steigenden Studierendenzahlen im Tertiärbereich (s. Indikator $\mathrm{CI}_{\text {I }}$ eine starke individuelle und gesellschaftliche Nachfrage wider. Diese höheren Studierendenzahlen gingen Hand in Hand mit einer Erhöhung der Investitionen, sowohl mit Mitteln aus öffentlichen als auch aus privaten Quellen, und einer Verschiebung des Verhältnisses von öffentlicher und privater Finanzierung. Im Durchschnitt der 20 OECD-Länder, für die Trenddaten für alle Referenzjahre verfügbar sind, ging der Anteil der öffentlichen Finanzierung von Bildungseinrichtungen im Tertiärbereich von 73,3 Prozent im Jahr 2000 auf 69, I Prozent im Jahr 2005 zurück und sank dann langsam im Laufe der folgenden Jahre auf 68,3 Prozent im Jahr 20 Ir. Der Rückgang dieses Anteils war in einigen - vor allem europäischen - Ländern besonders groß, in denen die private Finanzierung mittels Studiengebühren und/oder einer aktiveren Teilnahme von Unternehmen, größtenteils durch Zuschüsse an Einrichtungen des Tertiärbereichs, stark zugenommen hatte. In den meisten Ländern mit Daten für die verschiedenen Jahre war die Veränderung des Anteils der öffentlichen/ privaten Finanzierung nach 2008 weniger ausgeprägt. In einigen Ländern, insbesondere Chile, Österreich, Portugal, der Slowakei und Tschechien, sank der Anteil der öffentlichen Finanzierung zwischen 2000 und 2008 und stieg dann zwischen 2008 und 201 I (Tab. B3.2c, Abb. B3.3 und Indikator B5).

In 2I der 26 Länder mit vergleichbaren Daten für 2000 und 20 I s stieg der Anteil der privaten Finanzierung im Tertiärbereich. Dieser Anstieg betrug in Israel, Italien, Mexiko, Österreich, Portugal und der Slowakei mehr als 9 Prozentpunkte und im Vereinigten Königreich mehr als 37 Prozentpunkte. In Australien war dieser Anstieg zwischen I 995 und 2000 aufgrund von Änderungen des Higher Education Contribution Scheme/ Higher Education Loan Programme (HECS/HELP) im Jahr 1997 besonders ausgeprägt. Im Vereinigten Königreich ist dieser sehr starke Anstieg das Ergebnis schrittweiser Erhöhungen der Studiengebühren im Verlauf des letzten Jahrzehnts (weitere Informationen s. Indikator $B_{5}$ und Anhang 3). Im Gegensatz hierzu kam es in Chile, Irland, Korea, Polen und Spanien zwischen 2000 und $201 \mathrm{I}$ zu einem signifikanten Rückgang des Anteils der privaten Ausgaben für Bildungseinrichtungen im Tertiärbereich. In Irland wurden während des letzten Jahrzehnts die Studiengebühren in Studiengängen, die zu einem ersten Abschluss im Tertiärbereich führen, schrittweise abgeschafft, was zu einem Rückgang der privaten Ausgaben in diesem Bereich führte. 
Anteile öffentlicher und privater Ausgaben für Bildungseinrichtungen (2011)

Nach Bildungsbereich

Alle privaten Quellen, einschließlich Subventionen, die aus öffentlichen

Quellen finanzierten Zahlungen an Bildungseinrichtungen zuzurechnen sind

- Ausgaben anderer privater Einheiten

$\square$ Ausgaben privater Haushalte

$\square$ Öffentliche Ausgaben für Bildungseinrichtungen

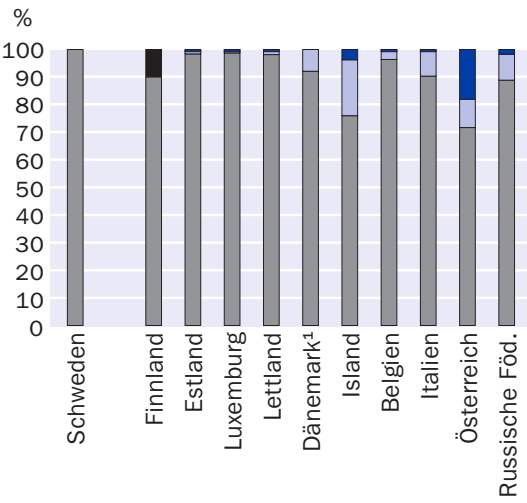

Elementarbereich
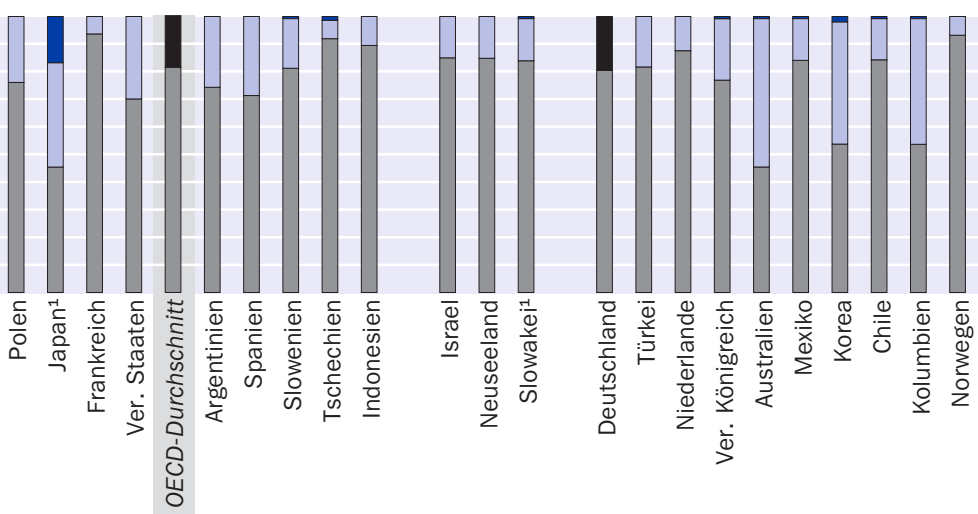

Primar-, Sekundar- und postsekundarer, nicht tertiärer Bereich
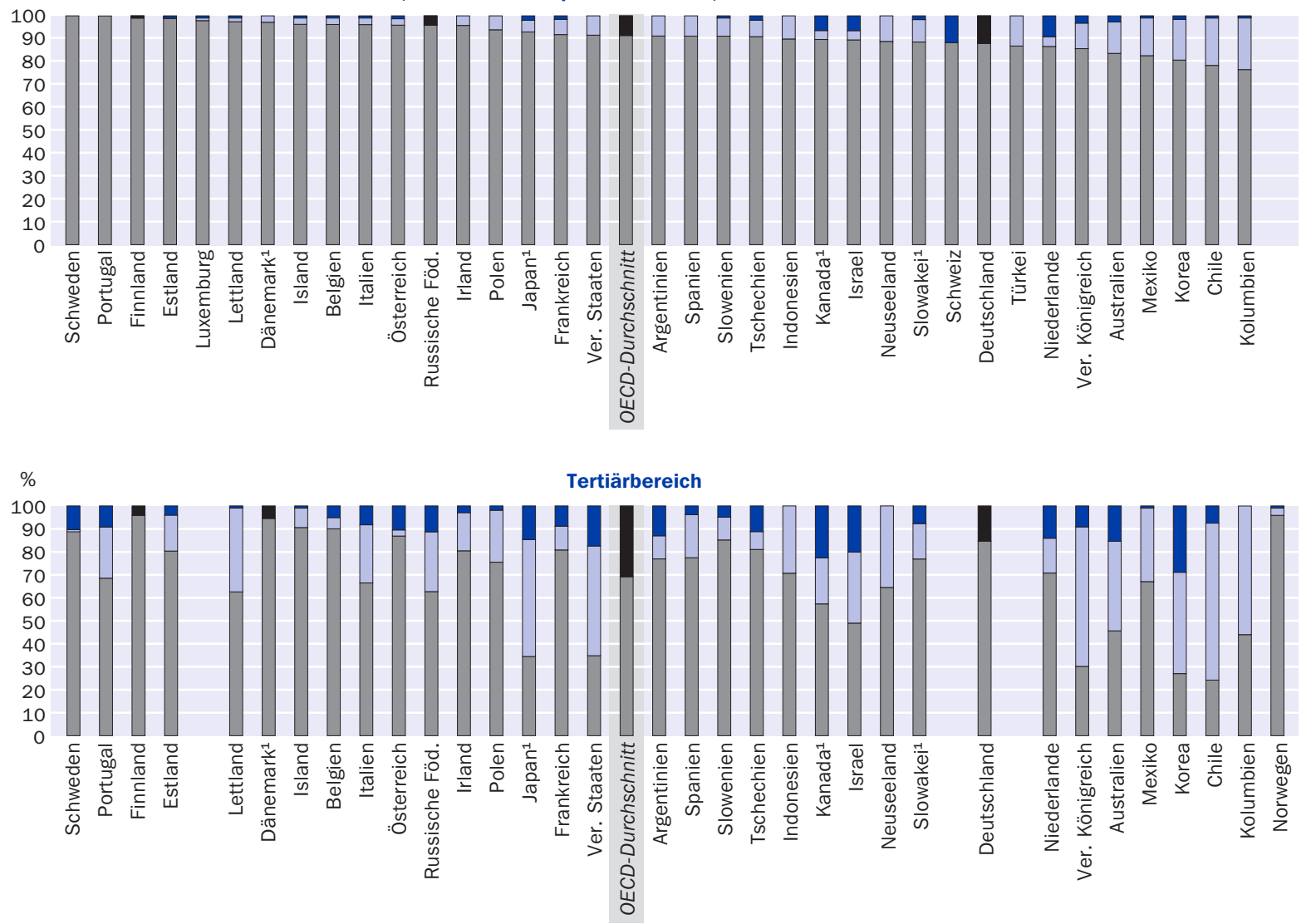

1. Einige Bildungsbereiche sind in anderen Bildungsbereichen enthalten. Einzelheiten s. Erläuterung von „ $x^{\prime}$ in Hinweise für den Leser.

Anordnung der Länder in absteigender Reihenfolge des Anteils der öffentlichen Ausgaben für Bildungseinrichtungen im Primar, Sekundar- und postsekundaren, nicht tertiären Bereich.

Quelle: OECD. Tabelle B3.1. Hinweise s. Anhang 3 unter www.oecd.org/edu/eag.htm. StatLink: http://dx.doi.org/10.1787/888933117497 
In einigen Ländern verlief die Veränderung der Anteile der öffentlichen/privaten Finanzierung vor und nach 2008 in entgegengesetzter Richtung. In Irland, Spanien und den Vereinigten Staaten beispielsweise sank der Anteil der privaten Finanzierung zwischen 2000 und 2008 und stieg dann - in geringerem Ausmaß - zwischen 2008 und 20II, mit Ausnahme der Vereinigten Staaten. Im Gegensatz hierzu stieg der Anteil der privaten Finanzierung in Australien, Chile, Japan, Korea, Österreich, Portugal, der Slowakei und Tschechien (sowie in geringerem Ausmaß in Belgien, Finnland und Schweden) zwischen 2000 und 2008, um dann zwischen 2008 und 201 I zu sinken. Insgesamt jedoch ist der Anteil der privaten Finanzierung in all diesen Ländern, mit Ausnahme von Chile und Korea, zwischen 2000 und 201 I gestiegen. Polen ist das einzige Land, in dem der Anteil der privaten Finanzierung sowohl im Zeitraum 2000-2008 und 2008-20II sank (Abb. B3.3).

Die privaten Ausgaben für Bildungseinrichtungen stiegen zwischen 2000 und $201 \mathrm{I}$ im Allgemeinen stärker als die öffentlichen Ausgaben. Dennoch stiegen auch die öffentlichen Ausgaben im Tertiärbereich in allen Ländern mit verfügbaren Daten für 2000 und 20II, und zwar unabhängig von den Veränderungen bei den privaten Ausgaben. 4 der Io Länder, in denen die privaten Ausgaben während dieses Zeitraums am stärksten anstiegen (Chile, Österreich, die Slowakei und Tschechien), gehören auch zu den ıo Ländern, in denen die öffentlichen Ausgaben am stärksten anstiegen (Tab. B3.2c).

\section{Öffentliche Ausgaben für Bildungseinrichtungen pro Schüler/ Studierenden nach Art der Bildungseinrichtung}

Die Höhe der öffentlichen Ausgaben zeigt teilweise den Stellenwert, den einzelne Länder der Bildung zuweisen (s. Indikatoren B2 und B4). Öffentliche Mittel fließen selbstverständlich in erster Linie in öffentliche Bildungseinrichtungen, aber in einigen Fällen fließt auch ein signifikanter Anteil der öffentlichen Mittel in private Bildungseinrichtungen.

Tabelle B3.3 zeigt die öffentlichen Mittel für Bildungseinrichtungen im Verhältnis zur Größe des jeweiligen Bildungssystems, mit dem Schwerpunkt auf den öffentlichen Ausgaben pro Schüler/Studierenden für öffentliche und private Bildungseinrichtungen (private Mittel werden in Tabelle B3.3 nicht berücksichtigt, obwohl sie in einigen Ländern einen signifikanten Anteil der Finanzmittel für Bildungseinrichtungen, besonders im Tertiärbereich, darstellen). Dies kann somit als ergänzende Information zu den öffentlichen Ausgaben im Verhältnis zum Volkseinkommen betrachtet werden (s. Indikator B2).

Im Durchschnitt aller OECD-Länder sind für alle Bildungsbereiche zusammen die öffentlichen Ausgaben für öffentliche Bildungseinrichtungen pro Schüler/Studierenden fast doppelt so hoch wie die öffentlichen Ausgaben für private Bildungseinrichtungen pro Schüler/Studierenden (8.952 US-Dollar gegenüber 4.6I4 US-Dollar). Die Unterschiede variieren jedoch in den einzelnen Bildungsbereichen. Im Elementarbereich sind die öffentlichen Ausgaben für öffentliche Bildungseinrichtungen pro Kind rund I, 8-mal so hoch wie für private Bildungseinrichtungen (6.502 US-Dollar gegenüber 3.6I8 US-Dollar), ebenso wie im Primar-, Sekundar- und postsekundaren, nicht tertiären Bereich (8.762 US-Dollar gegenüber 4.9I8 US-Dollar). Im Tertiärbereich sind die öffentlichen Ausgaben pro Studierenden für öffentliche Bildungseinrichtungen fast 
Anteil der privaten Ausgaben für Bildungseinrichtungen im Tertiärbereich (2000, 2008 und 2011) und Veränderung des Anteils der privaten Ausgaben zwischen 2000 und 2011 (in Prozentpunkten)
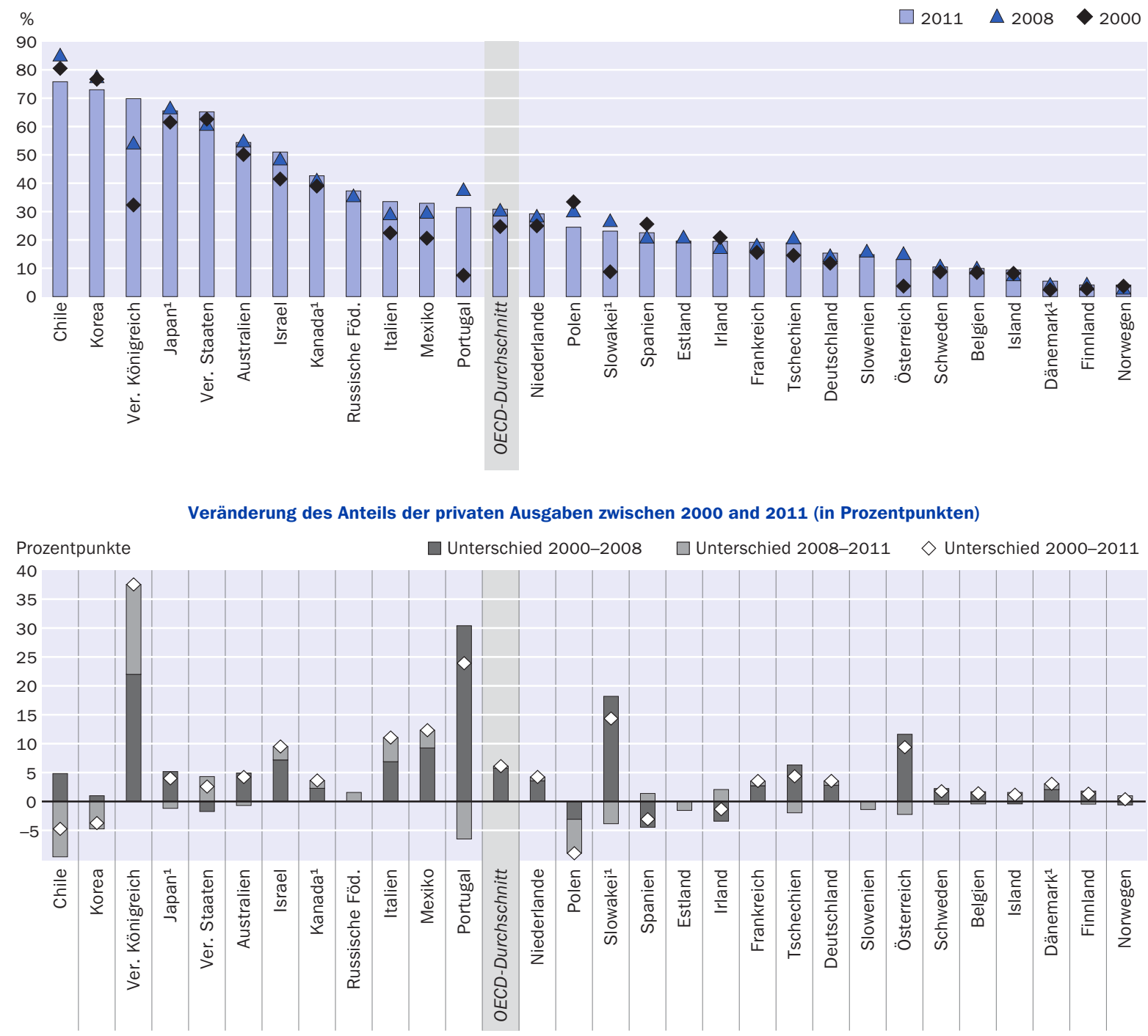

1. Einige Bildungsbereiche sind in anderen Bildungsbereichen enthalten. Einzelheiten s. Erläuterung von "X“ in Hinweise für den Leser. Anordnung der Länder in absteigender Reihenfolge des Anteils der privaten Ausgaben für Bildungseinrichtungen im Jahr 2011.

Quelle: OECD. Tabelle B3.2c. Hinweise s. Anhang 3 unter www.oecd.org/edu/eag.htm. StatLink: http://dx.doi.org/10.1787/888933117516

dreimal so hoch wie für private Bildungseinrichtungen (II.877 US-Dollar gegenüber 4.06I US-Dollar).

Im Elementarbereich liegen in den OECD-Ländern die öffentlichen Ausgaben pro Schüler sowohl für öffentliche als auch für private Bildungseinrichtungen bei durchschnittlich 6.043 US-Dollar, reichen jedoch von weniger als 2.00o US-Dollar in der Türkei und dem Partnerland Kolumbien bis zu mehr als 22.000 US-Dollar in Luxemburg. Die öffentlichen Ausgaben pro Schüler sind in der Regel bei öffentlichen Bildungseinrichtungen höher als bei privaten Bildungseinrichtungen, aber in der Regel besuchen weniger Schüler private Bildungseinrichtungen. So sind beispielsweise in Mexiko die öffentlichen Ausgaben pro Schüler für private Bildungseinrichtungen verschwindend 
niedrig, und ein verhältnismäßig kleiner Teil der Schüler besucht private Bildungseinrichtungen. Im Gegensatz dazu besuchen fast alle Schüler in Neuseeland private Einrichtungen, und die öffentlichen Ausgaben pro Schüler in privaten Einrichtungen liegen über dem Durchschnitt (9.526 US-Dollar) (Tab. B3.3 und C2.2).

Im Primar-, Sekundar- und postsekundaren, nicht tertiären Bereich (den Bereichen mit dem höchsten Anteil öffentlicher Mittel bei der Finanzierung, Tab. B3.2b) liegen die öffentlichen Ausgaben pro Schüler sowohl für öffentliche als auch private Bildungseinrichtungen im Durchschnitt der OECD-Länder bei 7.966 US-Dollar, variieren aber von weniger als 2.300 US-Dollar in Mexiko, der Türkei und dem Partnerland Kolumbien bis zu mehr als I0.00o US-Dollar in Belgien, Luxemburg, Norwegen, Österreich, Schweden und den Vereinigten Staaten. Die meisten Schüler in diesen Bereichen besuchen öffentliche Bildungseinrichtungen, und die öffentlichen Ausgaben pro Schüler sind in der Regel für öffentliche Bildungseinrichtungen höher als für private Bildungseinrichtungen, mit Ausnahme von Finnland, Israel, Kolumbien und Norwegen (Tab. B3.3). In den drei OECD-Ländern besuchen zwischen 7 Prozent und 25 Prozent der Schüler private Bildungseinrichtungen. In Mexiko und den Niederlanden sind die öffentlichen Ausgaben für private Bildungseinrichtungen pro Schüler niedrig oder zu vernachlässigen, da der private Bildungssektor nur schwach ausgebildet ist und keine oder nur sehr geringe öffentliche Finanzmittel erhält (s. Tab. Cr.4).

Abbildung B3.4

Jährliche öffentliche Ausgaben für Bildungseinrichtungen pro Studierenden im Tertiärbereich, nach Art der Bildungseinrichtung (2011)

In US-Dollar, kaufkraftbereinigt

Öffentliche Bildungseinrichtungen

$\square$ Private Bildungseinrichtungen

25.000

- Öffentliche und private Bildungseinrichtungen zusammen

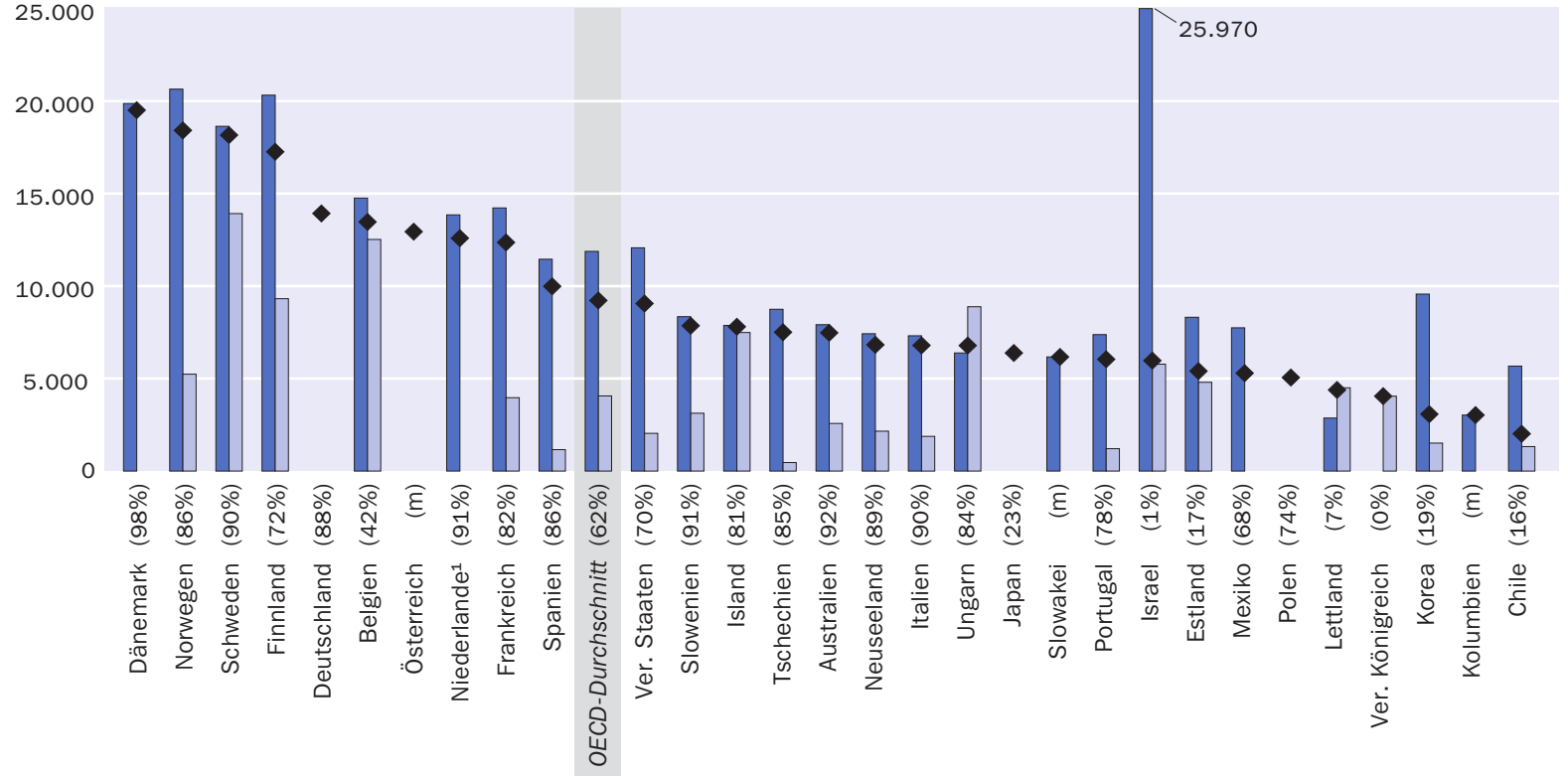

Anmerkung: Die Zahlen in Klammern stehen für den Prozentsatz von Studierenden, die öffentliche Bildungseinrichtungen des Tertiärbereichs besuchen (basierend auf Vollzeitäquivalenten).

1. Staatlich subventionierte private Bildungseinrichtungen sind in den öffentlichen Bildungseinrichtungen enthalten.

Anordnung der Länder in absteigender Reihenfolge der öffentlichen Ausgaben für öffentliche und private Bildungseinrichtungen pro Studierenden.

Quelle: OECD. Tabelle B3.3. Hinweise s. Anhang 3 unter www.oecd.org/edu/eag.htm. StatLink: http://dx.doi.org/10.1787/888933117535 
Im Tertiärbereich belaufen sich die öffentlichen Ausgaben pro Studierenden sowohl für öffentliche als auch private Bildungseinrichtungen im Durchschnitt der OECDLänder auf 9.22I US-Dollar, variieren aber von rund 2.000 US-Dollar in Chile bis zu mehr als 17.00o US-Dollar in Dänemark, Finnland, Norwegen und Schweden, vier Länder, in denen die Höhe privater Ausgaben in diesem Bildungsbereich niedrig oder zu vernachlässigen ist. In allen Ländern mit verfügbaren Daten (mit Ausnahme von Lettland und Ungarn) sind die öffentlichen Ausgaben pro Studierenden für öffentliche Bildungseinrichtungen höher als für private (Tab. B3.3 und Abb. B3.4).

In diesem Bildungsbereich ist die Zuteilung öffentlicher Mittel an öffentliche und private Bildungseinrichtungen in den einzelnen Ländern unterschiedlich. In Dänemark und den Niederlanden besuchen mindestens go Prozent der Studierenden öffentliche Bildungseinrichtungen, und der größte Teil der öffentlichen Mittel fließt in diese Einrichtungen. Die öffentlichen Ausgaben pro Studierenden für öffentliche Bildungseinrichtungen liegen über dem OECD-Durchschnitt, und die öffentlichen Ausgaben pro Studierenden für private Bildungseinrichtungen sind zu vernachlässigen. In diesen Ländern ergänzen die privaten Mittel die öffentlichen in ganz unterschiedlichem Ausmaß: In Dänemark liegt der Anteil privater Ausgaben an den Ausgaben für öffentliche und private Bildungseinrichtungen bei unter 6 Prozent, in den Niederlanden bei mehr als 28 Prozent (Abb. B3.4 und Tab. B3.I).

In Belgien, Estland, Island, Schweden und Ungarn fließen öffentliche Mittel sowohl in öffentliche als auch private Bildungseinrichtungen, und die öffentlichen Ausgaben pro Studierenden für private Bildungseinrichtungen belaufen sich auf mindestens 58 Prozent (und bis zu mehr als Ioo Prozent) der öffentlichen Ausgaben pro Studierenden für öffentliche Bildungseinrichtungen (Tab. B3.3). Allerdings ist die Bildungsbeteiligung in diesen Ländern sehr unterschiedlich. In Island, Schweden und Ungarn besuchen mindestens 80 Prozent der Studierenden öffentliche Bildungseinrichtungen, während Studierende in Belgien und Estland hauptsächlich staatlich subventionierte private Bildungseinrichtungen besuchen. In all diesen Ländern liegt der Anteil der privaten Ausgaben für Bildungseinrichtungen im Tertiärbereich unter dem OECDDurchschnitt. In den übrigen Ländern fließen öffentliche Mittel hauptsächlich in öffentliche Bildungseinrichtungen (Abb. B3.4 und Tab. B3.3).

\section{Definitionen}

Andere private Einheiten umfasst private Unternehmen und gemeinnützige Organisationen, wie beispielsweise kirchliche Organisationen, Wohltätigkeitseinrichtungen, Unternehmerverbände und Arbeitnehmervereinigungen.

Private Ausgaben umfassen alle direkten Ausgaben für Bildungseinrichtungen, unabhängig davon, ob diese teilweise durch öffentliche Mittel subventioniert werden oder nicht. Ausgaben von privaten Unternehmen für den betrieblichen Teil der dualen Ausbildung von Auszubildenden und Schülern gelten ebenfalls als Ausgaben anderer privater Einheiten. Die in den privaten Mitteln enthaltenen öffentlichen Subventionen an die privaten Haushalte werden getrennt ausgewiesen. 
Die Anteile der öffentlichen und der privaten Ausgaben für Bildungseinrichtungen sind angegeben in Prozent der gesamten Bildungsausgaben, die im öffentlichen und privaten Sektor entstehen bzw. anfallen.

Öffentliche Ausgaben beziehen sich auf alle Schüler/Studierenden in öffentlichen und privaten Bildungseinrichtungen, unabhängig davon, ob diese Einrichtungen öffentliche Mittel erhalten oder nicht.

\section{Angewandte Methodik}

Die Daten beziehen sich auf das Haushaltsjahr 20II und beruhen auf der von der OECD im Jahre 2013 durchgeführten UOE-Datenerhebung zur Bildungsstatistik (weitere Informationen s. Anhang 3 unter www.oecd.org/edu/eag.htm).

Nicht alle Ausgaben für bildungsbezogene Sach- und Dienstleistungen fallen in Bildungseinrichtungen an. Familien erwerben beispielsweise Schul-/Lehrbücher oder Unterrichtsmaterial im Handel oder finanzieren private Nachhilfestunden für ihre Kinder außerhalb von Bildungseinrichtungen. Im Tertiärbereich können auch die Kosten für den Lebensunterhalt sowie entgangene Einkommen einen signifikanten Anteil der Bildungskosten ausmachen. Diese außerhalb von Bildungseinrichtungen anfallenden Ausgaben sind, selbst wenn sie öffentlich subventioniert werden, bei diesem Indikator nicht berücksichtigt. Öffentliche Subventionen für Bildungsausgaben außerhalb von Bildungseinrichtungen werden in den Indikatoren $\mathrm{B}_{4}$ und $\mathrm{B}_{5}$ behandelt.

Ein Teil der Haushaltsmittel von Bildungseinrichtungen bezieht sich auf zusätzliche Dienstleistungen für Schüler/Studierende, u. a. soziale Dienste für Schüler/Studierende (Unterkunft, Verpflegung und Transport). Die Kosten für diese Leistungen werden teilweise über Beiträge der Schüler/Studierenden gedeckt und in diesem Indikator mit erfasst.

Die Daten für die Ausgaben der Jahre 1995 und 2000 wurden im Rahmen einer 2012 aktualisierten speziellen Erhebung ermittelt, in der die Ausgaben für 1995 und 2000 entsprechend den Definitionen und den Methoden der aktuellen UOE-Datenerhebung angepasst wurden.

\section{Anmerkung zu den Daten aus Israel}

Die statistischen Daten für Israel wurden von den zuständigen israelischen Stellen bereitgestellt, die für sie verantwortlich zeichnen. Die Verwendung dieser Daten durch die OECD erfolgt unbeschadet des völkerrechtlichen Status der Golanhöhen, von Ost-Jerusalem und der israelischen Siedlungen im Westjordanland. 


\section{Tabellen Indikator B3}

StatLink: http:/|dx.doi.org/10.1787/888933117364

Tabelle B3.I: Relative Anteile öffentlicher und privater Ausgaben für Bildungseinrichtungen, nach Bildungsbereich (20II)

Tabelle B3.2a: Entwicklung der relativen Anteile öffentlicher Ausgaben für Bildungseinrichtungen aller Bildungsbereiche und Index der Veränderung der öffentlichen und privaten Ausgaben (I995, 2000, 2005, 2008-20II)

Tabelle B3.2b: Entwicklung der relativen Anteile öffentlicher Ausgaben für Bildungseinrichtungen und Index der Veränderung der öffentlichen und privaten Ausgaben, Primar-, Sekundar- und postsekundarer, nicht tertiärer Bereich (I995, 2000, 2005, 2008-20II)

Tabelle B3.2c: Entwicklung der relativen Anteile öffentlicher Ausgaben für Bildungseinrichtungen im Tertiärbereich und Index der Veränderung der öffentlichen und privaten Ausgaben (I995, 2000, 2005, 2008-20II)

Tabelle B3.3: Jährliche öffentliche Ausgaben für Bildungseinrichtungen pro Schüler/Studierenden, nach Art der Bildungseinrichtung (20II) 
Tabelle B3.1

Relative Anteile öffentlicher und privater Ausgaben für Bildungseinrichtungen, nach Bildungsbereich (2011)

Aufteilung der Mittel für Bildungseinrichtungen aus öffentlichen und privaten Quellen nach Transferzahlungen aus öffentlichen Quellen

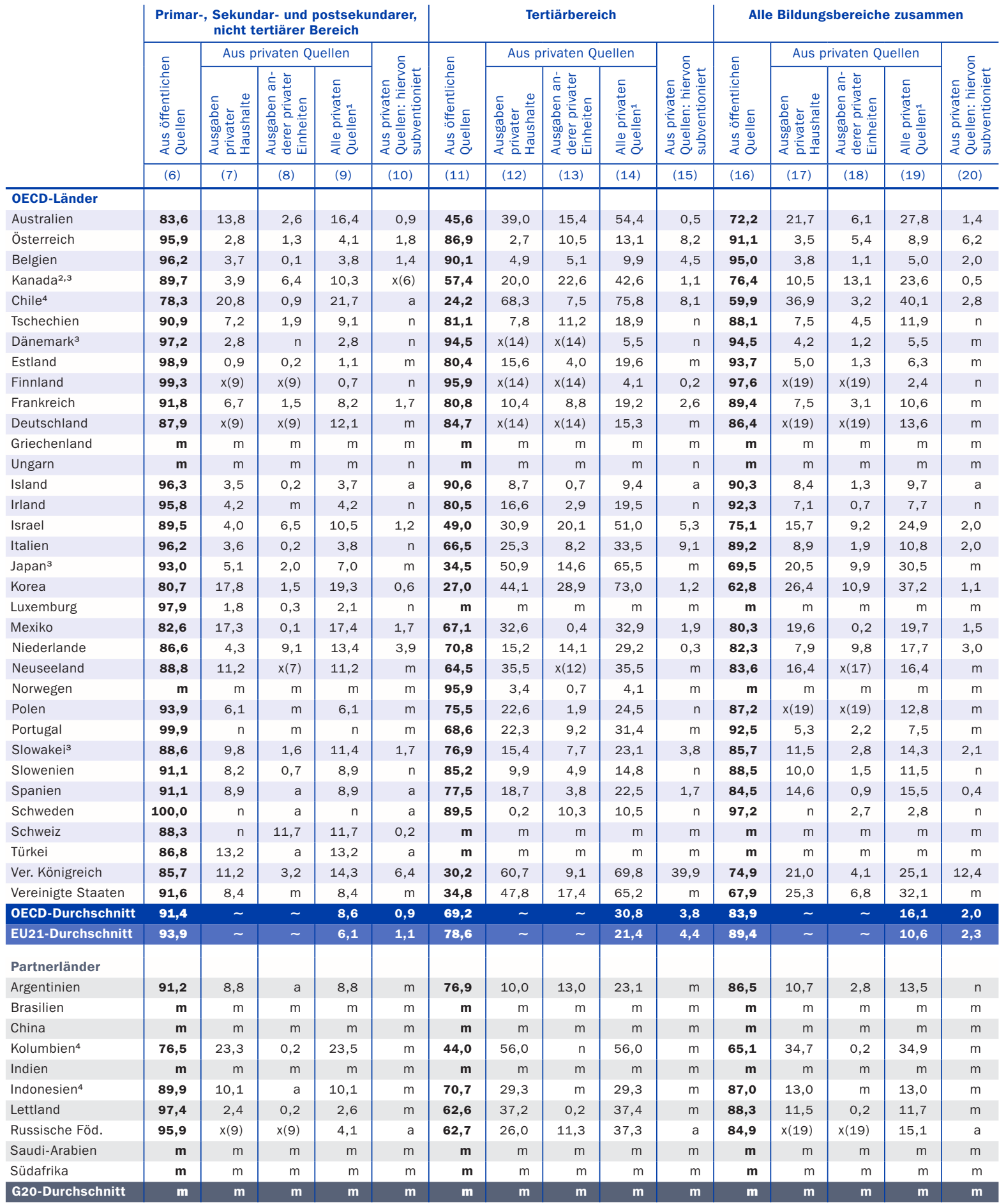

Anmerkung: Die Spalten mit den Angaben für den Elementarbereich, d. h. die Spalten (1), (2), (3), (4) und (5), stehen im Internet zur Verfügung (s. StatLink unten). 1. Einschließlich Subventionen, die mit Mitteln aus öffentlichen Quellen finanzierten Zahlungen an Bildungseinrichtungen zuzurechnen sind. 2. Referenzjahr 2010 anstelle 2011. 3. Einige Bildungsbereiche sind in anderen Bildungsbereichen enthalten. Einzelheiten s. Erläuterung von "x“ in Hinweise für den Leser. 4. Referenzjahr 2012 anstelle 2011.

Quelle: OECD. Argentinien, China, Indien, Indonesien, Kolumbien, Saudi-Arabien und Südafrika: Statistikinstitut der UNESCO. Lettland: Eurostat. Hinweise s. Anhang 3 unter www.oecd.org/edu/eag.htm. StatLink: http://dx.doi.org/10.1787/888933117383

Erläuterung der Kennzeichnung fehlender Daten s. Hinweise für den Leser. 
Entwicklung der relativen Anteile öffentlicher Ausgaben ${ }^{1}$ für Bildungseinrichtungen aller Bildungsbereiche und Index der Veränderung der öffentlichen und privaten Ausgaben (1995, 2000, 2005, 2008-2011)

Index der Veränderung der Mittel für Bildungseinrichtungen aus öffentlichen Quellen nach Transferzahlungen aus öffentlichen Quellen, nach Jahr

\begin{tabular}{|c|c|c|c|c|c|c|c|c|c|c|c|c|c|}
\hline & \multirow{2}{*}{\multicolumn{5}{|c|}{$\begin{array}{l}\text { Anteil der öffentlichen Ausgaben } \\
\text { für Bildungseinrichtungen (\%) }\end{array}$}} & \multicolumn{8}{|c|}{$\begin{array}{l}\text { Index der Veränderung der Ausgaben für Bildungseinrichtungen } \\
\text { zwischen } 1995 \text { und } 2011(2005=100 \text {, zu konstanten Preisen) }\end{array}$} \\
\hline & & & & & & \multicolumn{4}{|c|}{ Aus öffentlichen Quellen } & \multicolumn{4}{|c|}{ Aus privaten Quellen ${ }^{2}$} \\
\hline & 2000 & 2005 & 2008 & 2010 & 2011 & 2000 & 2008 & 2010 & 2011 & 2000 & 2008 & 2010 & 2011 \\
\hline & (2) & (3) & (4) & (6) & (7) & (9) & $(10)$ & (12) & (13) & $(15)$ & $(16)$ & (18) & (19) \\
\hline \multicolumn{14}{|l|}{ OECD-Länder } \\
\hline Australien & 74,1 & 72,7 & 71,6 & 74,1 & 72,2 & 85 & 109 & 134 & 130 & 79 & 115 & 125 & 133 \\
\hline Österreich & 94,0 & 91,4 & 90,8 & 91,0 & 91,1 & 95 & 107 & 112 & 113 & 64 & 116 & 118 & 118 \\
\hline Belgien & 94,3 & 94,2 & 94,3 & 94,8 & 95,0 & 93 & 116 & 118 & 119 & 92 & 113 & 104 & 100 \\
\hline Kanada ${ }^{3}$ & 79,9 & 75,5 & 76,0 & 75,8 & 76,4 & 94 & 107 & 117 & 118 & 73 & 104 & 115 & 112 \\
\hline Chile $^{4}$ & 55,2 & 52,8 & 58,9 & 57,9 & 59,9 & 92 & 146 & 157 & 186 & 83 & 114 & 127 & 139 \\
\hline Tschechien & 89,9 & 87,6 & 87,3 & 87,7 & 88,1 & 76 & 112 & 120 & 131 & 60 & 116 & 119 & 125 \\
\hline Dänemark & 96,0 & 92,3 & 92,2 & 94,5 & 94,5 & 88 & 98 & 109 & 110 & 44 & 100 & 76 & 76 \\
\hline Estland & $\mathrm{m}$ & 92,4 & 94,7 & 93,0 & 93,7 & 83 & 131 & 117 & 118 & $\mathrm{~m}$ & 90 & 107 & 96 \\
\hline Finnland & 98,0 & 97,8 & 97,4 & 97,6 & 97,6 & 83 & 107 & 114 & 116 & 76 & 126 & 121 & 124 \\
\hline Frankreich & 91,2 & 90,8 & 90,0 & 89,8 & 89,4 & 98 & 104 & 107 & 105 & 94 & 115 & 120 & 124 \\
\hline Deutschland & 86,1 & 85,7 & 85,4 & 85,9 & 86,4 & 97 & 105 & 114 & 115 & 94 & 107 & 112 & 108 \\
\hline Griechenland & 93,8 & 94,0 & $\mathrm{~m}$ & $\mathrm{~m}$ & $\mathrm{~m}$ & 68 & $\mathrm{~m}$ & $\mathrm{~m}$ & $\mathrm{~m}$ & 70 & $\mathrm{~m}$ & $\mathrm{~m}$ & $\mathrm{~m}$ \\
\hline Ungarn & 88,3 & 91,3 & $\mathrm{~m}$ & $\mathrm{~m}$ & $\mathrm{~m}$ & 71 & 99 & 89 & 87 & 99 & $\mathrm{~m}$ & $\mathrm{~m}$ & $\mathrm{~m}$ \\
\hline Island & 90,0 & 89,6 & 90,9 & 90,4 & 90,3 & 72 & 112 & 98 & 99 & 69 & 96 & 90 & 92 \\
\hline Irland & 90,5 & 93,7 & 93,8 & 92,5 & 92,3 & 74 & 133 & 139 & 137 & 115 & 129 & 167 & 170 \\
\hline Israel & 79,8 & 74,9 & 78,0 & 77,6 & 75,1 & 98 & 120 & 128 & 134 & 74 & 101 & 110 & 133 \\
\hline Italien & 94,3 & 91,4 & 91,4 & 90,1 & 89,2 & 98 & 106 & 98 & 95 & 63 & 106 & 115 & 123 \\
\hline Japan & 71,0 & 68,6 & 66,4 & 70,2 & 69,5 & 99 & 103 & 108 & 109 & 89 & 114 & 100 & 105 \\
\hline Korea & 59,2 & 58,9 & 59,6 & 61,6 & 62,8 & 73 & 128 & 143 & 151 & 72 & 125 & 128 & 128 \\
\hline Luxemburg & $\mathrm{m}$ & $\mathrm{m}$ & $\mathrm{m}$ & $\mathrm{m}$ & $\mathrm{m}$ & $\mathrm{m}$ & $\mathrm{m}$ & $\mathrm{m}$ & $\mathrm{m}$ & $\mathrm{m}$ & $\mathrm{m}$ & $\mathrm{m}$ & $\mathrm{m}$ \\
\hline Mexiko & 85,3 & 80,3 & 80,8 & 80,5 & 80,3 & 82 & 107 & 114 & 118 & 57 & 104 & 113 & 118 \\
\hline Niederlande & 84,0 & 84,3 & 83,3 & 83,3 & 82,3 & 83 & 106 & 115 & 113 & 85 & 113 & 123 & 131 \\
\hline Neuseeland & $\mathrm{m}$ & 78,4 & 82,4 & 82,6 & 83,6 & 89 & 110 & 123 & 133 & $\mathrm{~m}$ & 85 & 94 & 94 \\
\hline Norwegen & 95,0 & $\mathrm{~m}$ & 98,2 & 98,1 & $\mathrm{~m}$ & 79 & 106 & 111 & 111 & $\mathrm{~m}$ & $\mathrm{~m}$ & $\mathrm{~m}$ & $\mathrm{~m}$ \\
\hline Polen & 89,0 & 90,7 & 87,1 & 86,2 & 87,2 & 80 & 111 & 117 & 116 & 96 & 160 & 182 & 167 \\
\hline Portugal & 98,6 & 92,6 & 90,5 & 92,6 & 92,5 & 96 & 96 & 108 & 100 & 18 & 126 & 108 & 101 \\
\hline Slowakei & 96,4 & 83,9 & 82,5 & 84,2 & 85,7 & 84 & 114 & 133 & 132 & 16 & 126 & 129 & 114 \\
\hline Slowenien & $\mathrm{m}$ & 87,0 & 88,4 & 88,4 & 88,5 & $\mathrm{~m}$ & 108 & 109 & 109 & $\mathrm{~m}$ & 94 & 96 & 94 \\
\hline Spanien & 87,4 & 88,6 & 87,1 & 85,4 & 84,5 & 87 & 118 & 122 & 118 & 97 & 136 & 161 & 168 \\
\hline Schweden & 97,0 & 97,0 & 97,3 & 97,5 & 97,2 & 87 & 106 & 110 & 111 & 89 & 97 & 93 & 104 \\
\hline Schweiz & $\mathrm{m}$ & $\mathrm{m}$ & $\mathrm{m}$ & $\mathrm{m}$ & $\mathrm{m}$ & 86 & 98 & 106 & 108 & 74 & 107 & 97 & 97 \\
\hline Türkei & 98,6 & $\mathrm{~m}$ & $\mathrm{~m}$ & $\mathrm{~m}$ & $\mathrm{~m}$ & $\mathrm{~m}$ & $\mathrm{~m}$ & $\mathrm{~m}$ & $\mathrm{~m}$ & $\mathrm{~m}$ & $\mathrm{~m}$ & $\mathrm{~m}$ & $\mathrm{~m}$ \\
\hline Vereinigtes Königreich & 85,2 & 80,0 & 69,5 & 68,6 & 74,9 & 76 & 85 & 91 & 100 & 53 & 150 & 167 & 134 \\
\hline Vereinigte Staaten & 72,0 & 71,8 & 71,5 & 69,4 & 67,9 & 83 & 111 & 110 & 108 & 83 & 112 & 124 & 129 \\
\hline OECD-Durchschnitt & 86,7 & 84,3 & $\mathbf{8 4 , 0}$ & 84,2 & 83,9 & 85 & 110 & 116 & 118 & 74 & 114 & 119 & 119 \\
\hline $\begin{array}{l}\text { OECD-Durchschnitt } \\
\text { für } 21 \text { Länder mit } \\
\text { verfügbaren Daten für } \\
\text { alle Referenzjahre }\end{array}$ & 86,0 & 83,5 & 82,9 & 83,2 & 83,2 & 88 & 110 & 117 & 119 & 72 & 116 & 121 & 123 \\
\hline EU21-Durchschnitt & 91,9 & 90,3 & 89,1 & 89,1 & 89,4 & 85 & 109 & 113 & 113 & 74 & 118 & 123 & 121 \\
\hline \multicolumn{14}{|l|}{ Partnerländer } \\
\hline Argentinien & $\mathrm{m}$ & $\mathrm{m}$ & $\mathrm{m}$ & $\mathrm{m}$ & 86,5 & $\mathrm{~m}$ & $\mathrm{~m}$ & $\mathrm{~m}$ & $\mathrm{~m}$ & $\mathrm{~m}$ & $\mathrm{~m}$ & $\mathrm{~m}$ & $\mathrm{~m}$ \\
\hline Brasilien & $\mathrm{m}$ & $\mathrm{m}$ & $\mathrm{m}$ & $\mathrm{m}$ & $\mathrm{m}$ & 69 & 140 & 165 & 172 & $\mathrm{~m}$ & $\mathrm{~m}$ & $\mathrm{~m}$ & $\mathrm{~m}$ \\
\hline China & $\mathrm{m}$ & $\mathrm{m}$ & $\mathrm{m}$ & $\mathrm{m}$ & $\mathrm{m}$ & $\mathrm{m}$ & $\mathrm{m}$ & $\mathrm{m}$ & $\mathrm{m}$ & $\mathrm{m}$ & $\mathrm{m}$ & $\mathrm{m}$ & $\mathrm{m}$ \\
\hline Kolumbien ${ }^{4}$ & $\mathrm{~m}$ & $\mathrm{~m}$ & $\mathrm{~m}$ & $\mathrm{~m}$ & 65,1 & $\mathrm{~m}$ & $\mathrm{~m}$ & $\mathrm{~m}$ & $\mathrm{~m}$ & $\mathrm{~m}$ & $\mathrm{~m}$ & $\mathrm{~m}$ & $\mathrm{~m}$ \\
\hline Indien & $\mathrm{m}$ & $\mathrm{m}$ & $\mathrm{m}$ & $\mathrm{m}$ & $\mathrm{m}$ & $\mathrm{m}$ & $\mathrm{m}$ & $\mathrm{m}$ & $\mathrm{m}$ & $\mathrm{m}$ & $\mathrm{m}$ & $\mathrm{m}$ & $\mathrm{m}$ \\
\hline Indonesien ${ }^{4}$ & $\mathrm{~m}$ & $\mathrm{~m}$ & $\mathrm{~m}$ & $\mathrm{~m}$ & 87,0 & $\mathrm{~m}$ & $\mathrm{~m}$ & $\mathrm{~m}$ & $\mathrm{~m}$ & $\mathrm{~m}$ & $\mathrm{~m}$ & $\mathrm{~m}$ & $\mathrm{~m}$ \\
\hline Lettland & $\mathrm{m}$ & $\mathrm{m}$ & $\mathrm{m}$ & $\mathrm{m}$ & 88,3 & $\mathrm{~m}$ & $\mathrm{~m}$ & $\mathrm{~m}$ & $\mathrm{~m}$ & $\mathrm{~m}$ & $\mathrm{~m}$ & $\mathrm{~m}$ & $\mathrm{~m}$ \\
\hline Russische Föderation & $\mathrm{m}$ & $\mathrm{m}$ & 85,8 & 84,2 & 84,9 & 58 & 134 & 126 & 128 & $\mathrm{~m}$ & $\mathrm{~m}$ & $\mathrm{~m}$ & $\mathrm{~m}$ \\
\hline Saudi-Arabien & $\mathrm{m}$ & $\mathrm{m}$ & $\mathrm{m}$ & $\mathrm{m}$ & $\mathrm{m}$ & $\mathrm{m}$ & $\mathrm{m}$ & $\mathrm{m}$ & $\mathrm{m}$ & $\mathrm{m}$ & $\mathrm{m}$ & $\mathrm{m}$ & $\mathrm{m}$ \\
\hline Südafrika & $\mathrm{m}$ & $\mathrm{m}$ & $\mathrm{m}$ & $\mathrm{m}$ & $\mathrm{m}$ & $\mathrm{m}$ & $\mathrm{m}$ & $\mathrm{m}$ & $\mathrm{m}$ & $\mathrm{m}$ & $\mathrm{m}$ & $\mathrm{m}$ & $\mathrm{m}$ \\
\hline G20-Durchschnitt & $\mathbf{m}$ & $\mathbf{m}$ & $\mathbf{m}$ & $\mathbf{m}$ & m & $\mathbf{m}$ & $\mathbf{m}$ & m & m & m & $\mathbf{m}$ & m & m \\
\hline
\end{tabular}

Anmerkung: Die Spalten mit den Angaben für die Jahre 1995 und 2009, d.h. die Spalten (1), (5), (8), (11), (14) und (17), sind im Internet verfügbar (s. StatLink unten)

1. Öffentliche Ausgaben und Gesamtausgaben für Bildungseinrichtungen ohne Mittel aus internationalen Quellen. 2. Einschließlich Subventionen, die mit Mitteln aus öffentlichen Quellen finanzierten Zahlungen an Bildungseinrichtungen zuzurechnen sind. 3. Referenzjahr 2010 anstelle 2011.4. Referenzjahr 2012 anstelle 2011.

Quelle: OECD. Argentinien, China, Indien, Indonesien, Kolumbien, Saudi-Arabien und Südafrika: Statistikinstitut der UNESCO. Lettland: Eurostat. Hinweise s. Anhang 3 unter www.oecd.org/edu/eag.htm. StatLink: http://dx.doi.org/10.1787/888933117402

Erläuterung der Kennzeichnung fehlender Daten s. Hinweise für den Leser. 
Entwicklung der relativen Anteile öffentlicher Ausgaben ${ }^{1}$ für Bildungseinrichtungen und Index der Veränderung der öffentlichen und privaten Ausgaben, Primar-, Sekundar- und postsekundarer, nicht tertiärer Bereich (1995, 2000, 2005, 2008-2011)

Index der Veränderung der Mittel für Bildungseinrichtungen aus öffentlichen Quellen nach Transferzahlungen aus öffentlichen Quellen, nach Jahr

\begin{tabular}{|c|c|c|c|c|c|c|c|c|c|c|c|c|c|}
\hline & \multirow{2}{*}{\multicolumn{5}{|c|}{$\begin{array}{l}\text { Anteil der öffentlichen Ausgaben } \\
\text { für Bildungseinrichtungen (\%) }\end{array}$}} & \multicolumn{8}{|c|}{$\begin{array}{l}\text { Index der Veränderung der Ausgaben für Bildungseinrichtungen } \\
\text { zwischen } 1995 \text { und } 2011(2005=100 \text {, zu konstanten Preisen) }\end{array}$} \\
\hline & & & & & & \multicolumn{4}{|c|}{ Aus öffentlichen Quellen } & \multicolumn{4}{|c|}{ Aus privaten Quellen ${ }^{2}$} \\
\hline & 2000 & 2005 & 2008 & 2010 & 2011 & 2000 & 2008 & 2010 & 2011 & 2000 & 2008 & 2010 & 2011 \\
\hline & (2) & (3) & (4) & (6) & (7) & (9) & (10) & (12) & (13) & (15) & (16) & (18) & (19) \\
\hline \multicolumn{14}{|l|}{ OECD-Länder } \\
\hline Australien & 83,7 & 83,5 & 82,5 & 84,7 & 83,6 & 83 & 108 & 135 & 130 & 82 & 116 & 123 & 129 \\
\hline Österreich & 95,8 & 94,3 & 95,9 & 95,5 & 95,9 & 98 & 107 & 106 & 109 & 71 & 75 & 83 & 76 \\
\hline Belgien & 94,7 & 94,7 & 95,2 & 96,0 & 96,2 & 94 & 117 & 117 & 118 & 94 & 106 & 88 & 83 \\
\hline Kanada $^{3,4}$ & 92,4 & 89,9 & 88,6 & 89,3 & 89,7 & 88 & 103 & 116 & 116 & 65 & 117 & 123 & 119 \\
\hline Chile $^{5}$ & 68,4 & 69,8 & 78,4 & 78,6 & 78,3 & 94 & 145 & 141 & 165 & 100 & 92 & 89 & 105 \\
\hline Tschechien & 91,7 & 89,9 & 90,4 & 90,8 & 90,9 & 78 & 107 & 112 & 116 & 63 & 101 & 101 & 104 \\
\hline Dänemark ${ }^{3}$ & 97,8 & 97,9 & 97,6 & 97,6 & 97,2 & 86 & 99 & 107 & 98 & 89 & 112 & 123 & 133 \\
\hline Estland & $\mathrm{m}$ & 98,9 & 99,0 & 98,7 & 98,9 & 80 & 126 & 112 & 107 & 0 & 121 & 133 & 111 \\
\hline Finnland & 99,3 & 99,2 & 99,0 & 99,2 & 99,3 & 82 & 107 & 112 & 113 & 65 & 126 & 105 & 98 \\
\hline Frankreich & 92,6 & 92,5 & 92,3 & 92,0 & 91,8 & 100 & 102 & 104 & 102 & 98 & 105 & 111 & 112 \\
\hline Deutschland & 87,1 & 87,5 & 87,1 & 87,8 & 87,9 & 99 & 100 & 109 & 108 & 103 & 104 & 106 & 104 \\
\hline Griechenland & 91,7 & 92,5 & $\mathrm{~m}$ & $\mathrm{~m}$ & $\mathrm{~m}$ & 77 & $\mathrm{~m}$ & $\mathrm{~m}$ & $\mathrm{~m}$ & 86 & $\mathrm{~m}$ & $\mathrm{~m}$ & $\mathrm{~m}$ \\
\hline Ungarn & 92,7 & 95,5 & $\mathrm{~m}$ & $\mathrm{~m}$ & $\mathrm{~m}$ & 69 & 95 & 84 & 79 & 114 & $\mathrm{~m}$ & $\mathrm{~m}$ & $\mathrm{~m}$ \\
\hline Island & 96,4 & 96,2 & 96,4 & 96,2 & 96,3 & 73 & 106 & 92 & 95 & 69 & 102 & 93 & 93 \\
\hline Irland & 96,0 & 96,8 & 97,7 & 95,9 & 95,8 & 67 & 133 & 138 & 137 & 86 & 97 & 179 & 183 \\
\hline Israel & 94,1 & 93,0 & 93,0 & 92,4 & 89,5 & 96 & 121 & 129 & 138 & 79 & 121 & 142 & 216 \\
\hline Italien & 97,8 & 96,3 & 97,1 & 96,6 & 96,2 & 94 & 105 & 98 & 93 & 55 & 81 & 89 & 96 \\
\hline$J_{a p a n^{3}}$ & 89,8 & 90,1 & 90,0 & 93,0 & 93,0 & 98 & 102 & 108 & 108 & 101 & 103 & 73 & 74 \\
\hline Korea & 80,8 & 77,0 & 77,8 & 78,5 & 80,7 & 72 & 117 & 128 & 133 & 58 & 112 & 118 & 107 \\
\hline Luxemburg & $\mathrm{m}$ & $\mathrm{m}$ & $\mathrm{m}$ & 97,9 & 97,9 & $\mathrm{~m}$ & $\mathrm{~m}$ & 104 & 100 & $\mathrm{~m}$ & $\mathrm{~m}$ & $\mathrm{~m}$ & $\mathrm{~m}$ \\
\hline Mexiko & 86,1 & 82,9 & 82,9 & 82,7 & 82,6 & 83 & 102 & 109 & 113 & 65 & 102 & 111 & 115 \\
\hline Niederlande & 86,1 & 87,1 & 86,6 & 86,9 & 86,6 & 82 & 106 & 115 & 113 & 90 & 111 & 118 & 118 \\
\hline Neuseeland & $\mathrm{m}$ & 84,9 & 85,7 & 87,4 & 88,8 & 91 & 102 & 118 & 132 & $\mathrm{~m}$ & 96 & 96 & 93 \\
\hline Norwegen & 99,0 & $\mathrm{~m}$ & $\mathrm{~m}$ & $\mathrm{~m}$ & $\mathrm{~m}$ & 87 & 107 & 113 & 112 & $\mathrm{~m}$ & $\mathrm{~m}$ & $\mathrm{~m}$ & $\mathrm{~m}$ \\
\hline Polen & 95,4 & 98,2 & 94,7 & 93,8 & 93,9 & 87 & 111 & 118 & 116 & 225 & 339 & 422 & 407 \\
\hline Portugal & 99,9 & 99,9 & 99,9 & 100,0 & 99,9 & 98 & 96 & 109 & 101 & 99 & 90 & 87 & 89 \\
\hline Slowakei ${ }^{3}$ & 97,6 & 86,2 & 84,8 & 88,0 & 88,6 & 84 & 113 & 138 & 129 & 13 & 126 & 117 & 104 \\
\hline Slowenien & $\mathrm{m}$ & 91,9 & 91,7 & 91,3 & 91,1 & $\mathrm{~m}$ & 104 & 103 & 101 & $\mathrm{~m}$ & 107 & 111 & 111 \\
\hline Spanien & 93,0 & 93,5 & 93,1 & 91,8 & 91,1 & 93 & 114 & 117 & 113 & 100 & 121 & 149 & 158 \\
\hline Schweden & 99,9 & 99,9 & 99,9 & 99,9 & 100,0 & 88 & 103 & 103 & 103 & 106 & 90 & 66 & $\mathrm{~m}$ \\
\hline Schweiz & 88,9 & 86,9 & 86,3 & 88,1 & 88,3 & 90 & 101 & 108 & 110 & 74 & 107 & 97 & 97 \\
\hline Türkei & $\mathrm{m}$ & $\mathrm{m}$ & $\mathrm{m}$ & $\mathrm{m}$ & 86,8 & $\mathrm{~m}$ & $\mathrm{~m}$ & $\mathrm{~m}$ & $\mathrm{~m}$ & $\mathrm{~m}$ & $\mathrm{~m}$ & $\mathrm{~m}$ & $\mathrm{~m}$ \\
\hline Vereinigtes Königreich & 88,7 & 83,0 & 77,9 & 78,9 & 85,7 & 75 & 94 & 102 & 113 & 47 & 130 & 133 & 92 \\
\hline Vereinigte Staaten & 91,7 & 91,8 & 91,8 & 92,5 & 91,6 & 86 & 111 & 114 & 107 & 87 & 111 & 103 & 110 \\
\hline OECD-Durchschnitt & 92,1 & 91,0 & 90,8 & 91,4 & 91,4 & 86 & 109 & 113 & 113 & 85 & 115 & 120 & 123 \\
\hline $\begin{array}{l}\text { OECD-Durchschnitt } \\
\text { für } 20 \text { Länder mit } \\
\text { verfügbaren Daten für } \\
\text { alle Referenzjahre }\end{array}$ & 91,6 & 90,4 & 90,5 & 90,9 & 91,0 & 88 & 109 & 116 & 117 & 80 & 108 & 112 & 118 \\
\hline EU21-Durchschnitt & 94,3 & 93,8 & 93,3 & 93,6 & 93,9 & 86 & 107 & 110 & 108 & 84 & 119 & 129 & 128 \\
\hline \multicolumn{14}{|l|}{ Partnerländer } \\
\hline Argentinien & $\mathrm{m}$ & $\mathrm{m}$ & $\mathrm{m}$ & $\mathrm{m}$ & 91,2 & $\mathrm{~m}$ & $\mathrm{~m}$ & $\mathrm{~m}$ & $\mathrm{~m}$ & $\mathrm{~m}$ & $\mathrm{~m}$ & $\mathrm{~m}$ & $\mathrm{~m}$ \\
\hline Brasilien & $\mathrm{m}$ & $\mathrm{m}$ & $\mathrm{m}$ & $\mathrm{m}$ & $\mathrm{m}$ & 66 & 146 & 170 & 175 & $\mathrm{~m}$ & $\mathrm{~m}$ & $\mathrm{~m}$ & $\mathrm{~m}$ \\
\hline China & $\mathrm{m}$ & $\mathrm{m}$ & $\mathrm{m}$ & $\mathrm{m}$ & $\mathrm{m}$ & $\mathrm{m}$ & $\mathrm{m}$ & $\mathrm{m}$ & $\mathrm{m}$ & $\mathrm{m}$ & $\mathrm{m}$ & $\mathrm{m}$ & $\mathrm{m}$ \\
\hline Kolumbien 5 & $\mathrm{~m}$ & $\mathrm{~m}$ & $\mathrm{~m}$ & $\mathrm{~m}$ & 76,5 & $\mathrm{~m}$ & $\mathrm{~m}$ & $\mathrm{~m}$ & $\mathrm{~m}$ & $\mathrm{~m}$ & $\mathrm{~m}$ & $\mathrm{~m}$ & $\mathrm{~m}$ \\
\hline Indien & $\mathrm{m}$ & $\mathrm{m}$ & $\mathrm{m}$ & $\mathrm{m}$ & $\mathrm{m}$ & $\mathrm{m}$ & $\mathrm{m}$ & $\mathrm{m}$ & $\mathrm{m}$ & $\mathrm{m}$ & $\mathrm{m}$ & $\mathrm{m}$ & $\mathrm{m}$ \\
\hline Indonesien 5 & $\mathrm{~m}$ & $\mathrm{~m}$ & $\mathrm{~m}$ & $\mathrm{~m}$ & 89,9 & $\mathrm{~m}$ & $\mathrm{~m}$ & $\mathrm{~m}$ & $\mathrm{~m}$ & $\mathrm{~m}$ & $\mathrm{~m}$ & $\mathrm{~m}$ & $\mathrm{~m}$ \\
\hline Lettland & $\mathrm{m}$ & $\mathrm{m}$ & $\mathrm{m}$ & $\mathrm{m}$ & 97,4 & $\mathrm{~m}$ & $\mathrm{~m}$ & $\mathrm{~m}$ & $\mathrm{~m}$ & $\mathrm{~m}$ & $\mathrm{~m}$ & $\mathrm{~m}$ & $\mathrm{~m}$ \\
\hline Russische Föderation & $\mathrm{m}$ & $\mathrm{m}$ & 96,8 & 96,9 & 95,9 & 66 & 132 & 126 & 130 & $\mathrm{~m}$ & $\mathrm{~m}$ & $\mathrm{~m}$ & $\mathrm{~m}$ \\
\hline Saudi-Arabien & $\mathrm{m}$ & $\mathrm{m}$ & $\mathrm{m}$ & $\mathrm{m}$ & $\mathrm{m}$ & $\mathrm{m}$ & $\mathrm{m}$ & $\mathrm{m}$ & $\mathrm{m}$ & $\mathrm{m}$ & $\mathrm{m}$ & $\mathrm{m}$ & $\mathrm{m}$ \\
\hline Südafrika & $\mathrm{m}$ & $\mathrm{m}$ & $\mathrm{m}$ & $\mathrm{m}$ & $\mathrm{m}$ & $\mathrm{m}$ & $\mathrm{m}$ & $\mathrm{m}$ & $\mathrm{m}$ & $\mathrm{m}$ & $\mathrm{m}$ & $\mathrm{m}$ & $\mathrm{m}$ \\
\hline G20-Durchschnitt & $\mathbf{m}$ & m & m & $\mathbf{m}$ & $\mathbf{m}$ & m & $\mathbf{m}$ & m & m & $\mathbf{m}$ & $\mathbf{m}$ & $\mathbf{m}$ & m \\
\hline
\end{tabular}

Anmerkung: Die Spalten mit den Angaben für die Jahre 1995 und 2009, d.h. die Spalten (1), (5), (8), (11), (14) und (17), sind im Internet verfügbar (s. StatLink unten).

1. Öffentliche Ausgaben und Gesamtausgaben für Bildungseinrichtungen ohne Mittel aus internationalen Quellen. 2. Einschließlich Subventionen, die mit Mitteln aus öffentlichen Quellen finanzierten Zahlungen an Bildungseinrichtungen zuzurechnen sind. 3. Einige Bildungsbereiche sind in anderen Bildungsbereichen enthalten. Einzelheiten s. Erläuterung von „x“ in Hinweise für den Leser. 4. Referenzjahr 2010 anstelle 20115. Referenzjahr 2012 anstelle 2011. Quelle: OECD. Argentinien, China, Indien, Indonesien, Kolumbien, Saudi-Arabien und Südafrika: Statistikinstitut der UNESCO. Lettland: Eurostat. Hinweise s. Anhang 3 unter www.oecd.org/edu/eag.htm. StatLink: http://dx.doi.org/10.1787/888933117421 Erläuterung der Kennzeichnung fehlender Daten s. Hinweise für den Leser. 
Entwicklung der relativen Anteile öffentlicher Ausgaben ${ }^{1}$ für Bildungseinrichtungen im Tertiärbereich und Index der Veränderung der öffentlichen und privaten Ausgaben (1995, 2000, 2005, 2008-2011)

Index der Veränderung der Mittel für Bildungseinrichtungen aus öffentlichen Quellen nach Transferzahlungen aus öffentlichen Quellen, nach Jahr

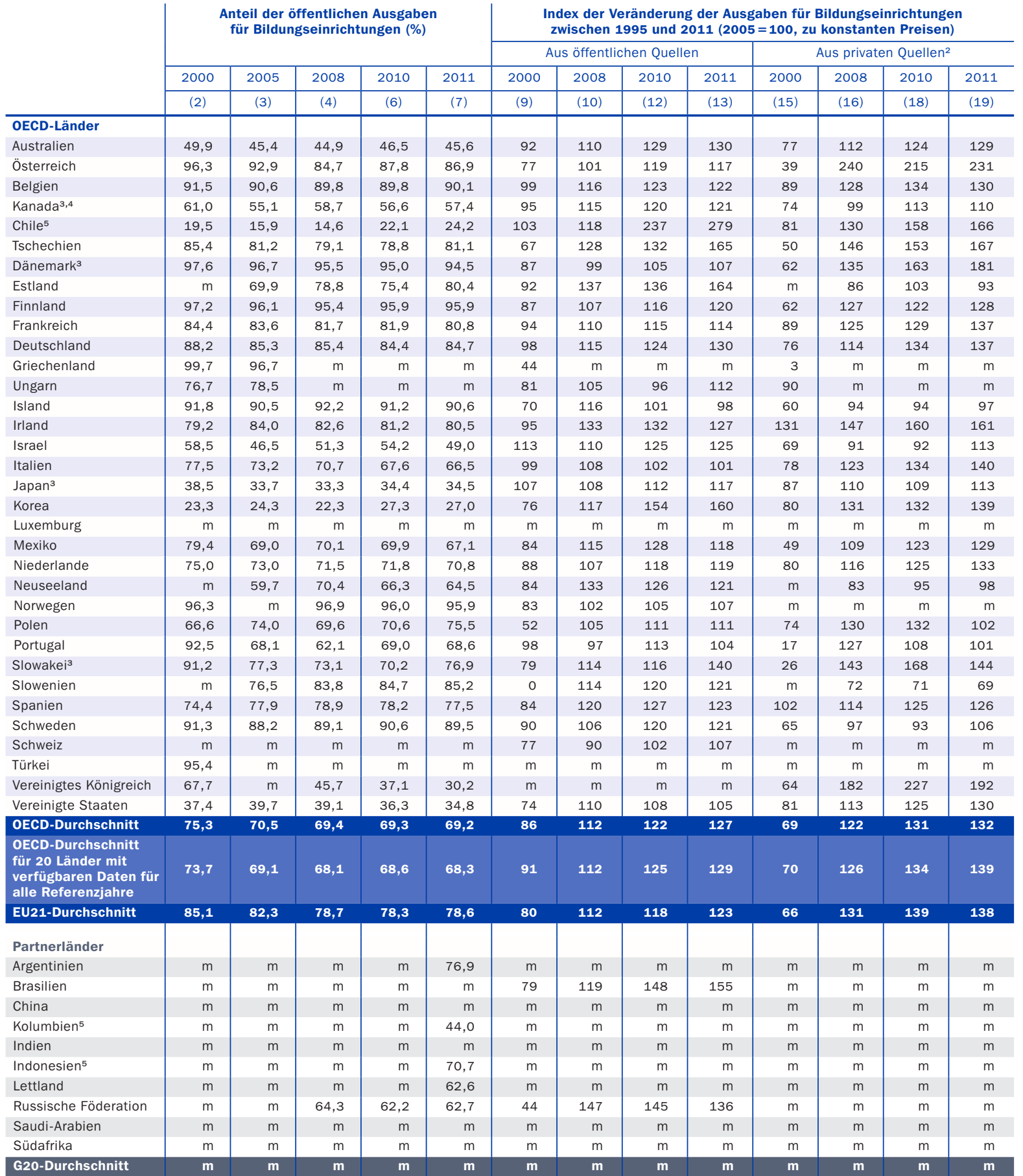

Anmerkung: Die Spalten mit den Angaben für die Jahre 1995 und 2009, d.h. die Spalten (1), (5), (8), (11), (14) und (17), sind im Internet verfügbar (s. StatLink unten).

1. Öffentliche Ausgaben und Gesamtausgaben für Bildungseinrichtungen ohne Mittel aus internationalen Quellen. 2. Einschließlich Subventionen, die mit Mitteln aus öffentlichen Quellen finanzierten Zahlungen an Bildungseinrichtungen zuzurechnen sind. 3. Einige Bildungsbereiche sind in anderen Bildungsbereichen enthalten. Einzelheiten s. Erläuterung von „x“ in Hinweise für den Leser. 4. Referenzjahr 2010 anstelle 2011.5. Referenzjahr 2012 anstelle 2011. Quelle: OECD. Argentinien, China, Indien, Indonesien, Kolumbien, Saudi-Arabien und Südafrika: Statistikinstitut der UNESCO. Lettland: Eurostat. Hinweise s. Anhang 3 unter www.oecd.org/edu/eag.htm. StatLink: http://dx.doi.org/10.1787/888933117440 Erläuterung der Kennzeichnung fehlender Daten s. Hinweise für den Leser. 
Tabelle B3.3

Jährliche öffentliche Ausgaben für Bildungseinrichtungen pro Schüler/Studierenden, nach Art der Bildungseinrichtung (2011)

In US-Dollar, kaufkraftbereinigt mittels KKP für das BIP, nach Bildungsbereich und Art der Bildungseinrichtung

\begin{tabular}{|c|c|c|c|c|c|c|c|c|c|c|c|c|c|}
\hline & \multicolumn{3}{|c|}{ Elementarbereich } & \multicolumn{3}{|c|}{$\begin{array}{l}\text { Primar-, Sekundar- und } \\
\text { postsekundarer, } \\
\text { nicht tertiärer Bereich }\end{array}$} & \multicolumn{4}{|c|}{ Tertiärbereich } & \multicolumn{3}{|c|}{$\begin{array}{l}\text { Alle Bildungsbereiche } \\
\text { zusammen }\end{array}$} \\
\hline & \begin{tabular}{|l} 
Öffent- \\
liche \\
Bildungs- \\
einrich- \\
tungen
\end{tabular} & \begin{tabular}{|c|} 
Private \\
Bildungs- \\
einrich- \\
tungen
\end{tabular} & $\begin{array}{l}\text { Insge- } \\
\text { samt: } \\
\text { offentli- } \\
\text { che und } \\
\text { private }\end{array}$ & $\begin{array}{l}\text { Öffent- } \\
\text { liche } \\
\text { Bildungs- } \\
\text { einrich- } \\
\text { tungen }\end{array}$ & \begin{tabular}{|c|} 
Private \\
Bildungs- \\
einrich- \\
tungen
\end{tabular} & \begin{tabular}{|l} 
Insge- \\
samt: \\
offentli- \\
che und \\
private
\end{tabular} & \begin{tabular}{|l} 
Öffent- \\
liche \\
Bildungs- \\
einrich- \\
tungen
\end{tabular} & \begin{tabular}{|c|} 
Private \\
Bildungs- \\
einrich- \\
tungen
\end{tabular} & $\begin{array}{l}\text { Insge- } \\
\text { samt: } \\
\text { offentli- } \\
\text { che und } \\
\text { private }\end{array}$ & \begin{tabular}{|c|} 
davon: \\
F\&E-Tä- \\
tigkeiten
\end{tabular} & \begin{tabular}{|c|} 
Öffent- \\
liche \\
Bildungs- \\
einrich- \\
tungen
\end{tabular} & $\begin{array}{l}\text { Private } \\
\text { Bildungs- } \\
\text { einrich- } \\
\text { tungen }\end{array}$ & $\begin{array}{l}\text { Insge- } \\
\text { samt: } \\
\text { offentli- } \\
\text { che und } \\
\text { private }\end{array}$ \\
\hline & (1) & (2) & (3) & (4) & (5) & (6) & (7) & (8) & (9) & (10) & (11) & (12) & (13) \\
\hline \multicolumn{14}{|l|}{ OECD-Länder } \\
\hline Australien & $x(3)$ & $x(3)$ & 4880 & 9188 & 6817 & 8387 & 7912 & 2575 & 7475 & 5718 & $x(13)$ & $x(13)$ & 8122 \\
\hline Österreich & $x(3)$ & $x(3)$ & 6406 & $x(6)$ & $x(6)$ & 11999 & $x(9)$ & $x(9)$ & 12942 & 4408 & $x(13)$ & $x(13)$ & 11395 \\
\hline Belgien & 6672 & 5595 & 6103 & 11395 & 9576 & 10315 & 14758 & 12521 & 13468 & 4149 & 11517 & 9478 & 10335 \\
\hline Kanada $^{1}$ & $x(4)$ & $\mathrm{m}$ & $\mathbf{m}$ & 9522 & $\mathrm{~m}$ & m & 14312 & $\mathrm{~m}$ & $\mathbf{m}$ & $\mathrm{m}$ & 10629 & $\mathrm{~m}$ & $\mathbf{m}$ \\
\hline Chile $^{2}$ & 5864 & 3490 & 4285 & 4970 & 2591 & 3543 & 5675 & 1324 & 2016 & 398 & 5152 & 2324 & 3276 \\
\hline Tschechien & 3984 & 2550 & 3957 & 5710 & 3714 & 5572 & 8747 & 460 & 7507 & 2999 & 6222 & 2403 & 5926 \\
\hline Dänemark & $x(3)$ & $x(3)$ & 13031 & 10513 & 6393 & 9943 & 19868 & a & 19509 & $x(9)$ & 12903 & 5436 & 12061 \\
\hline Estland & 2587 & 2131 & 2573 & 6033 & 4533 & 5974 & 8314 & 4801 & 5405 & 2358 & 5442 & 4711 & 5281 \\
\hline Finnland & 5247 & 3945 & 5135 & 9096 & 9281 & 9113 & 20321 & 9319 & 17260 & 5713 & 10179 & 8832 & 10013 \\
\hline Frankreich & 6683 & 2759 & 6199 & 9315 & 5491 & 8558 & 14225 & 3967 & 12360 & 4578 & 9588 & 4941 & 8739 \\
\hline Deutschland & $x(3)$ & $x(3)$ & 6717 & $x(6)$ & $x(6)$ & 8371 & $x(9)$ & $x(9)$ & 13927 & $x(9)$ & $x(13)$ & $x(13)$ & 9202 \\
\hline Griechenland & $\mathrm{m}$ & $\mathrm{m}$ & m & $\mathrm{m}$ & $\mathrm{m}$ & m & $\mathrm{m}$ & $\mathrm{m}$ & m & $\mathrm{m}$ & $\mathrm{m}$ & $\mathrm{m}$ & $\mathbf{m}$ \\
\hline Ungarn & $x(3)$ & $x(3)$ & 4127 & $x(6)$ & $x(6)$ & 4270 & 6385 & 8883 & 6786 & 1377 & $x(13)$ & $x(13)$ & 4928 \\
\hline Island & 7285 & 4426 & 6947 & 9207 & 6204 & 8980 & 7873 & 7491 & 7802 & $x(9)$ & 9291 & 6335 & 8994 \\
\hline Irland & $x(3)$ & $x(3)$ & 5405 & 9492 & $\mathrm{~m}$ & m & 12826 & $\mathrm{~m}$ & $\mathbf{m}$ & 4157 & 10037 & $\mathrm{~m}$ & $\mathbf{m}$ \\
\hline Israel & 3830 & 1876 & 3211 & 5589 & 6001 & 5682 & 25970 & 5779 & 5971 & $\mathrm{~m}$ & 5613 & 5025 & 5400 \\
\hline Italien ${ }^{3}$ & 7259 & 444 & 5216 & 8192 & 1423 & 7682 & 7314 & 1876 & 6795 & 3226 & 7926 & 1098 & 7158 \\
\hline Japan & $x(3)$ & $x(3)$ & 2849 & $x(6)$ & $x(6)$ & 8579 & $x(9)$ & $x(9)$ & 6384 & $x(9)$ & $x(13)$ & $x(13)$ & 8106 \\
\hline Korea & 8365 & 2652 & 3929 & 7090 & 5798 & 6856 & 9567 & 1511 & 3076 & 1281 & 8686 & 2888 & 6354 \\
\hline Luxemburg & 23958 & 3757 & 22144 & 20606 & 6722 & 18598 & $\mathrm{~m}$ & $\mathrm{~m}$ & m & $\mathrm{m}$ & $\mathrm{m}$ & $\mathrm{m}$ & $\mathbf{m}$ \\
\hline Mexiko & 2509 & 2 & 2160 & 2552 & 6 & 2284 & 7745 & a & 5291 & 1413 & 3072 & 4 & 2677 \\
\hline Niederlande $^{4}$ & 7321 & 3095 & 6983 & 8950 & $\mathrm{n}$ & 8753 & 13850 & $\mathrm{n}$ & 12590 & 5355 & 9612 & 626 & 9252 \\
\hline Neuseeland & 2450 & 9526 & 9409 & 8219 & 2537 & 7844 & 7425 & 2156 & 6826 & 1543 & 8067 & 5877 & 7769 \\
\hline Norwegen & 7228 & 5462 & 6422 & 13244 & 13630 & 13263 & 20647 & 5238 & 18417 & 7047 & 14099 & 10922 & 13714 \\
\hline Polen & $x(3)$ & $x(3)$ & 4146 & $x(6)$ & $x(6)$ & 5308 & $x(9)$ & $x(9)$ & 5056 & 996 & $x(13)$ & $x(13)$ & 5093 \\
\hline Portugal & 5674 & $\mathrm{~m}$ & m & 7278 & $\mathrm{~m}$ & $\mathbf{m}$ & 7377 & 1211 & 6043 & 3003 & 7265 & $\mathrm{~m}$ & m \\
\hline Slowakei & 3941 & 3011 & 3906 & 4536 & 4356 & 4520 & 6170 & $\mathrm{~m}$ & 6170 & 1652 & 4883 & 4256 & 4840 \\
\hline Slowenien & 6697 & 2134 & 6567 & 8060 & 5684 & 8027 & 8346 & 3127 & 7858 & 1596 & 7919 & 3715 & 7784 \\
\hline Spanien & 6956 & 2083 & 5232 & 9291 & 3689 & 7569 & 11452 & 1158 & 9987 & 2687 & 9285 & 3080 & 7488 \\
\hline Schweden & 6992 & 6528 & 6915 & 10634 & 10028 & 10548 & 18638 & 13920 & 18163 & 8359 & 11219 & 9668 & 11000 \\
\hline Schweiz & 5267 & $\mathrm{~m}$ & m & 12724 & $\mathrm{~m}$ & m & 22882 & $\mathrm{~m}$ & $\mathbf{m}$ & $\mathrm{m}$ & 13799 & $\mathrm{~m}$ & $\mathbf{m}$ \\
\hline Türkei & 2102 & $\mathrm{n}$ & 1971 & 2233 & a & 2233 & $\mathrm{~m}$ & $\mathrm{~m}$ & m & $\mathrm{m}$ & $\mathrm{m}$ & $\mathrm{m}$ & $\mathbf{m}$ \\
\hline Ver. Königreich & 6213 & 12217 & 7457 & 9936 & 2559 & 8336 & a & 4049 & 4049 & 1667 & 9631 & 3627 & 7675 \\
\hline Vereinigte Staaten & 10975 & 1909 & 7019 & 11753 & 1009 & 10840 & 12069 & 2039 & 9057 & $x(9)$ & 11760 & 1652 & 10062 \\
\hline OECD-Durchschnitt & 6502 & 3618 & 6043 & 8762 & 4918 & 7996 & 11877 & 4061 & 9221 & 3290 & 8952 & 4614 & 7876 \\
\hline EU21-Durchschnitt & 7156 & 3865 & 6748 & 9315 & 5246 & 8525 & 11162 & 4664 & 10326 & 3428 & 8909 & 4759 & 8128 \\
\hline \multicolumn{14}{|l|}{ Partnerländer } \\
\hline Argentinien & 1979 & $\mathrm{~m}$ & m & 2578 & $\mathrm{~m}$ & m & $\mathrm{m}$ & $\mathrm{m}$ & $\mathbf{m}$ & $\mathrm{m}$ & $\mathrm{m}$ & $\mathrm{m}$ & $\mathbf{m}$ \\
\hline Brasilien & 2349 & $\mathrm{~m}$ & m & 2667 & $\mathrm{~m}$ & m & 10902 & $\mathrm{~m}$ & m & 762 & 2985 & $\mathrm{~m}$ & $\mathbf{m}$ \\
\hline China & $\mathrm{m}$ & $\mathrm{m}$ & m & $\mathrm{m}$ & $\mathrm{m}$ & m & $\mathrm{m}$ & $\mathrm{m}$ & m & $\mathrm{m}$ & $\mathrm{m}$ & $\mathrm{m}$ & $\mathbf{m}$ \\
\hline Kolumbien ${ }^{2}$ & 1857 & 2111 & 1871 & 1608 & 1818 & 1619 & 3027 & $\mathrm{~m}$ & 3027 & $\mathrm{~m}$ & 1063 & 1838 & 1084 \\
\hline Indien & $\mathrm{m}$ & $\mathrm{m}$ & m & $\mathrm{m}$ & $\mathrm{m}$ & m & $\mathrm{m}$ & $\mathrm{m}$ & m & $\mathrm{m}$ & $\mathrm{m}$ & $\mathrm{m}$ & $\mathbf{m}$ \\
\hline Indonesien & $\mathrm{m}$ & $\mathrm{m}$ & m & $\mathrm{m}$ & $\mathrm{m}$ & $\mathbf{m}$ & $\mathrm{m}$ & $\mathrm{m}$ & m & $\mathrm{m}$ & $\mathrm{m}$ & $\mathrm{m}$ & $\mathbf{m}$ \\
\hline Lettland & 4407 & 1704 & 4269 & 4901 & 1885 & 4860 & 2865 & 4503 & 4384 & 1531 & 4752 & 4263 & 4653 \\
\hline Russische Föd. & $\mathrm{m}$ & $\mathrm{m}$ & $\mathbf{m}$ & 4322 & $\mathrm{~m}$ & $\mathbf{m}$ & 5221 & $\mathrm{~m}$ & m & $\mathrm{m}$ & $\mathrm{m}$ & $\mathrm{m}$ & $\mathbf{m}$ \\
\hline Saudi-Arabien & $\mathrm{m}$ & $\mathrm{m}$ & m & $\mathrm{m}$ & $\mathrm{m}$ & m & $\mathrm{m}$ & $\mathrm{m}$ & m & $\mathrm{m}$ & $\mathrm{m}$ & $\mathrm{m}$ & $\mathbf{m}$ \\
\hline Südafrika & $\mathrm{m}$ & $\mathrm{m}$ & $\mathbf{m}$ & $\mathrm{m}$ & $\mathrm{m}$ & $\mathbf{m}$ & $\mathrm{m}$ & $\mathrm{m}$ & $\mathbf{m}$ & $\mathrm{m}$ & $\mathrm{m}$ & $\mathrm{m}$ & $\mathbf{m}$ \\
\hline G20-Durchsch & m & m & m & m & m & m & m & m & m & m & m & m & m \\
\hline
\end{tabular}

1. Referenzjahr 2010. 2. Referenzjahr 2012. 3. Ohne postsekundaren, nicht tertiären Bereich. 4. Staatlich subventionierte private Bildungseinrichtungen sind in den öffentlichen Bildungseinrichtungen enthalten.

Quelle: OECD. Argentinien, China, Indien, Indonesien, Kolumbien, Saudi-Arabien und Südafrika: Statistikinstitut der UNESCO. Lettland: Eurostat. Hinweise s. Anhang 3 unter www.oecd.org/edu/eag.htm. StatLink: http://dx.doi.org/10.1787/888933117459

Erläuterung der Kennzeichnung fehlender Daten s. Hinweise für den Leser. 


\section{Wie hoch sind die öffentlichen Gesamt- ausgaben für Bildung?}

Die OECD-Länder wenden im Durchschnitt I2,9 Prozent ihrer öffentlichen Gesamtausgaben für Bildung auf, dies reicht jedoch von weniger als Io Prozent in Italien, Japan und Ungarn bis zu mehr als 20 Prozent in Indonesien, Mexiko und Neuseeland.

Zwischen 1995 und 2005 stieg der Anteil der öffentlichen Mittel, die in den Bildungsbereich flossen, in den meisten Ländern mit vergleichbaren Daten für beide Jahre. Nur in Frankreich, Israel, Japan, Kanada, Neuseeland und Portugal ergab sich ein anderes Bild.

Zwischen 2005 und 201 I nahm zwar der Anteil der öffentlichen Bildungsausgaben an den öffentlichen Gesamtausgaben in zwei Drittel der Länder ab, aber während des kürzeren Zeitraums 2008 bis 2011 - des Höhepunkts der Wirtschaftskrise stiegen in I6 der 3r Länder mit verfügbaren Daten die öffentlichen Ausgaben für Bildung schneller als die öffentlichen Ausgaben für alle sonstigen Leistungsbereiche bzw. sanken sie langsamer.

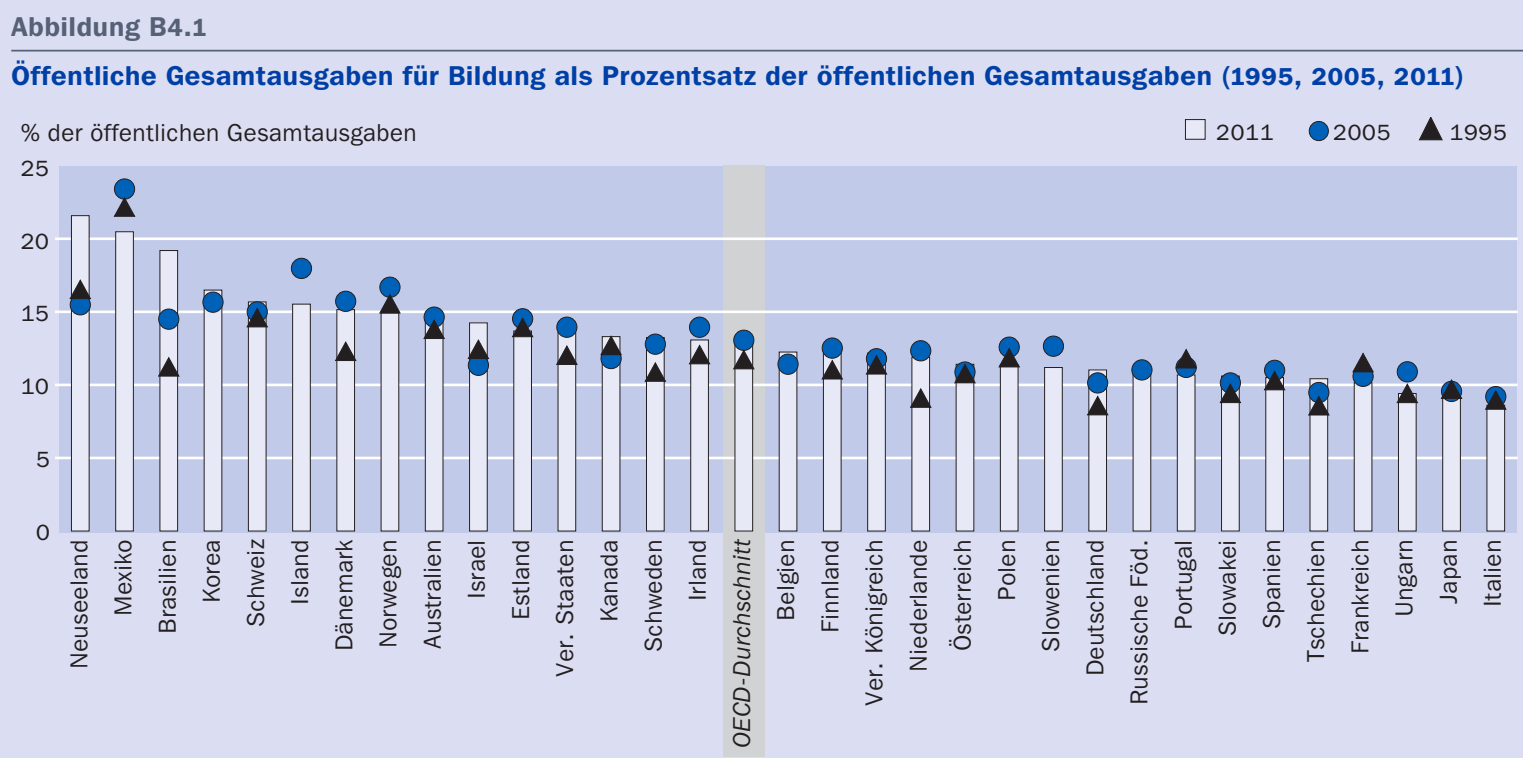

Anordnung der Länder in absteigender Reihenfolge der öffentlichen Gesamtausgaben für Bildung in allen Bildungsbereichen zusammen als Prozentsatz der öffentlichen Gesamtausgaben im Jahr 2011.

Quelle: OECD. Tabelle B4.2. Hinweise s. Anhang 3 unter www.oecd.org/edu/eag.htm. StatLink: http://dx.doi.org/10.1787/888933117630

\section{Kontext}

Die Entscheidungen der Länder über die Zuweisung von Haushaltsmitteln auf die unterschiedlichen Sektoren, wie z. B. Bildung, Gesundheit, soziale Sicherheit oder Verteidigung, hängen nicht nur von den jeweiligen Prioritäten des einzelnen Landes $a b$, sondern auch davon, ob die Märkte allein diese Dienstleistungen - insbesondere im 
Tertiärbereich - angemessen erbringen können. Die Märkte werden möglicherweise versagen, wenn der öffentliche Nutzen größer als der private Nutzen ist, daher können staatliche Mittel dazu beitragen, den Zugang zum Tertiärbereich zu erleichtern.

Die Wirtschaftskrise hat die öffentlichen Haushalte jedoch so stark belastet, dass möglicherweise weniger öffentliche Mittel für Bildung bereitgestellt werden. Dies kann wiederum den Zugang zu Bildung bzw. die Ergebnisse und die Qualität von Bildung beeinflussen. Gleichzeitig kann die Nachfrage von Menschen ohne Arbeit nach Bildung und Ausbildung steigen, wodurch höhere Bildungsausgaben notwendig werden. Doch höhere Ausgaben bedeuten nicht notwendigerweise bessere Ergebnisse oder eine höhere Qualität der Ausbildung. Außerdem werden Ausgaben durch viele Faktoren beeinflusst (s. Indikator B7), die bei einem Vergleich der einzelnen Länder zu berücksichtigen sind.

Dieser Indikator stellt die öffentlichen Gesamtausgaben für Bildung dar, und zwar sowohl im Verhältnis zu den öffentlichen Gesamtausgaben eines Landes als auch im Verhältnis zum jeweiligen Bruttoinlandsprodukt, um die relative Größe des jeweiligen öffentlichen Haushalts zu berücksichtigen. Darüber hinaus enthält er Informationen über die verschiedenen öffentlichen Finanzierungsquellen für das Bildungswesen (zentrale, regionale und lokale staatliche Ebenen) und Transferzahlungen zwischen den verschiedenen staatlichen Ebenen.

\section{Weitere wichtige Ergebnisse}

In den meisten OECD- und Partnerländern (32 der 37 Länder mit verfügbaren Daten) sind die öffentlichen Bildungsausgaben für den Primar-, Sekundar- und postsekundaren, nicht tertiären Bereich mehr als doppelt so hoch wie für den Tertiärbereich.

Im Primar-, Sekundar- und postsekundaren, nicht tertiären Bereich erfolgt die öffentliche Finanzierung dezentraler als im Tertiärbereich. Im Durchschnitt der OECD-Länder stammen mehr als 50 Prozent der originär öffentlichen Mittel für den Primar-, Sekundar- und postsekundaren, nicht tertiären Bildungsbereich von der zentralen staatlichen Ebene, während dies im Tertiärbereich auf 85 Prozent der originär öffentlichen Mittel zutrifft.

Im Primar-, Sekundar- und postsekundaren, nicht tertiären Bildungsbereich hatte nur Neuseeland eine vollkommen zentralisierte Finanzierung durch öffentliche Mittel, während der Tertiärbereich in neun Ländern (Chile, Estland, Irland, Island, Lettland, Neuseeland, den Niederlanden, Norwegen und der Slowakei) vollständig zentral finanziert wird.

\section{Entwicklungstendenzen}

Zwischen I995 und 20II stieg der für Bildung (alle Bildungsbereiche zusammen) verwendete Anteil der öffentlichen Gesamtausgaben in zwei Drittel der Länder mit verfügbaren Daten leicht an. Es war jedoch kein stetiger Zuwachs während des gesamten Zeitraums: Zwischen 2005 und 20 I gingen die öffentlichen Bildungsausgaben als Prozentsatz der öffentlichen Gesamtausgaben in mehr als der Hälfte der Länder mit verfügbaren Daten zurück. Dieser Rückgang war in Island, Mexiko, Nor- 
wegen, Polen, Slowenien und Ungarn (mit mindestens I Prozentpunkt) besonders ausgeprägt (Tab. B4.2).

Ähnliche Veränderungen waren zwischen 1995 und 20II bei den öffentlichen Ausgaben für Bildung als Prozentsatz des BIP zu beobachten, und auch hier verlief die Entwicklung während des Zeitraums 2005 bis 201 I ganz anders. Während der Anteil der öffentlichen Ausgaben für Bildung in den meisten Ländern von 2005 bis $201 \mathrm{I}$ rückläufig war, sanken die Bildungsausgaben als Prozentsatz des BIP während dieses Zeitraums in weniger als einem Drittel der Länder. Im Durchschnitt der OECD-Länder mit verfügbaren Daten für beide Jahre stieg er leicht an.

Zwischen 2008 und 20II stiegen in allen Ländern mit Ausnahme von Estland, Island, Italien, Ungarn, dem Vereinigten Königreich und den Vereinigten Staaten sowohl die Ausgaben für Bildung als auch die öffentlichen Gesamtausgaben für alle Leistungsbereiche. In I 3 von 3I Ländern stiegen dabei jedoch die öffentlichen Ausgaben für alle Leistungsbereiche schneller bzw. gingen langsamer zurück als die öffentlichen Ausgaben für Bildung (Tab. B4.2).

\section{Analyse und Interpretationen}

\section{Gesamtvolumen der in Bildung investierten öffentlichen Mittel}

20II wendeten die OECD-Länder für die öffentlichen Gesamtausgaben für Bildung im Durchschnitt I 2,9 Prozent ihrer öffentlichen Gesamtausgaben für alle Leistungsbereiche auf, wobei die Bandbreite von weniger als so Prozent in Italien (8,6 Prozent), Japan (9,I Prozent) und Ungarn (9,4 Prozent) bis zu mindestens 20 Prozent in Indonesien (20,5 Prozent), Mexiko (20,5 Prozent) und Neuseeland (2I,6 Prozent) reichte (Abb. B4.I und Tab. B4.I).

In den meisten Ländern werden rund zwei Drittel der öffentlichen Gesamtausgaben für Bildung (als Prozentsatz der öffentlichen Gesamtausgaben) für den Primar-, Sekundar- und postsekundaren, nicht tertiären Bereich aufgewendet. Dies erklärt sich hauptsächlich durch die fast universelle Bildungsbeteiligung in diesen Bildungsbereichen (s. Indikator CI) und die demografische Bevölkerungsstruktur.

Die öffentlichen Ausgaben für den Tertiärbereich belaufen sich im Durchschnitt der OECD-Länder auf fast ein Viertel (24,5 Prozent) der öffentlichen Gesamtausgaben für Bildung. In den OECD- und Partnerländern reicht dieser Anteil von weniger als 16 Prozent in Korea ( 15,6 Prozent) bis zu mehr als 30 Prozent in Finnland (32,0 Prozent), Kanada (35,6 Prozent) und der Türkei (37,8 Prozent).

Bei der Betrachtung der öffentlichen Bildungsausgaben als Teil der öffentlichen Gesamtausgaben ist die relative Größe der öffentlichen Haushalte zu berücksichtigen. Die Ergebnisse verändern sich, wenn man die öffentlichen Ausgaben für Bildung für alle Bildungsbereiche zusammen als Prozentsatz des BIP betrachtet und diese mit den öffentlichen Gesamtausgaben für Bildung als Prozentsatz der öffentlichen Gesamtausgaben vergleicht. $\mathrm{Zu}$ den OECD-Ländern mit den niedrigsten öffentlichen Ausgaben 


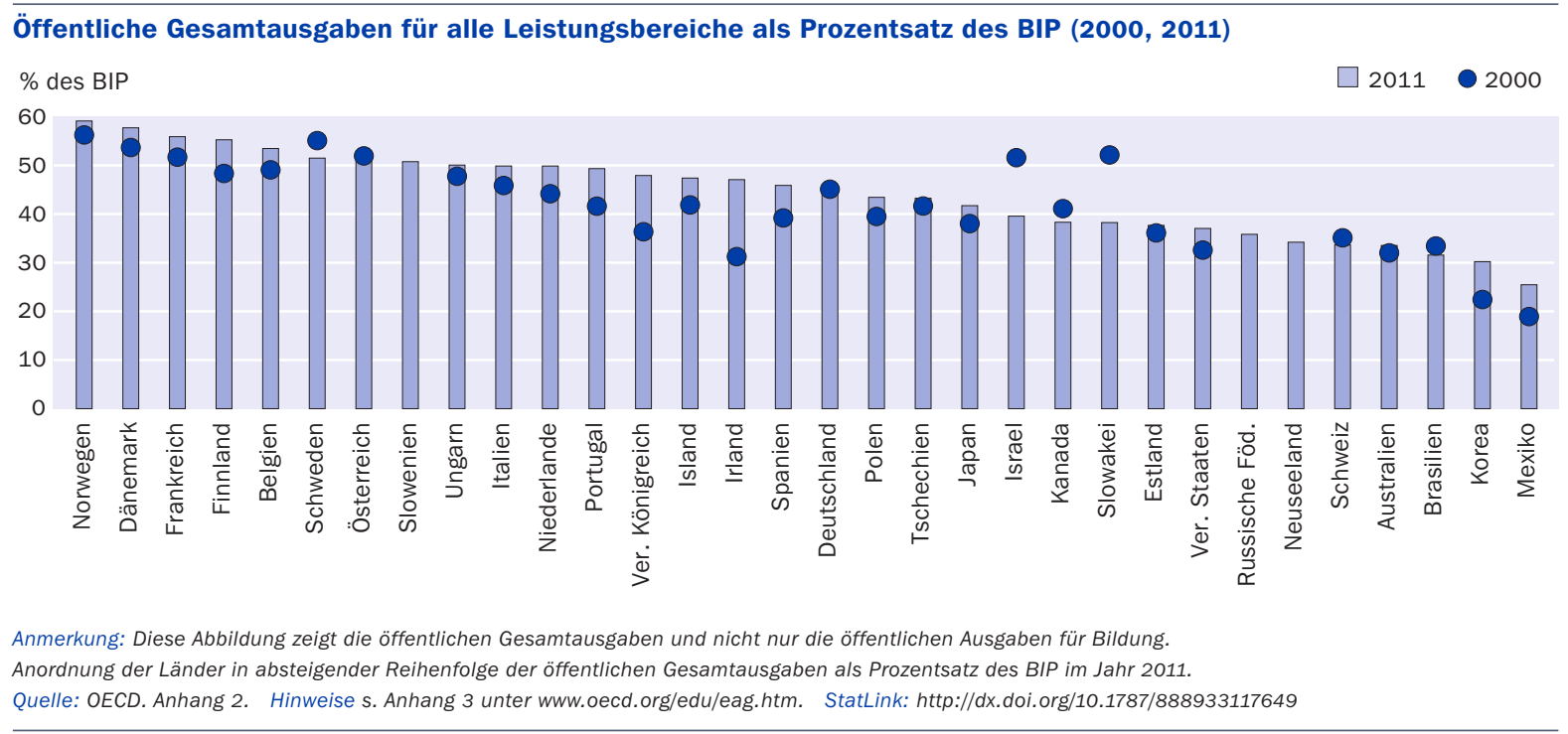

für Bildung im Verhältnis zum BIP zählten 20II Italien (mit 4,3 Prozent), Japan (mit 3,8 Prozent), die Slowakei (mit 4, I Prozent) und die Türkei (mit 4, I Prozent) sowie das Partnerland Russische Föderation (mit 3,9 Prozent). Am anderen Ende des Spektrums wendeten nur Dänemark und Norwegen mehr als 8 Prozent des BIP für Bildung auf (jeweils 8,7 Prozent), wesentlich mehr als den OECD-Durchschnitt von 5,6 Prozent (Tab. B4.I).

Entgegen den Erwartungen liegen die 5 Länder mit den höchsten öffentlichen Gesamtausgaben für Bildung als Prozentsatz der öffentlichen Gesamtausgaben im Jahr 20II Brasilien, Korea, Mexiko, Neuseeland und die Schweiz (Abb. B4.I) - ganz hinten bezüglich der öffentlichen Gesamtausgaben für alle Leistungsbereiche als Prozentsatz des BIP (Abb. B4.2). Dänemark und Norwegen sind hier die Ausnahmen, da sie bei beiden Kennzahlen hohe Werte aufweisen.

Bei der Betrachtung der öffentlichen Gesamtausgaben für alle Leistungsbereiche (u.a. Gesundheit, soziale Sicherheit, Umwelt) und nicht allein der öffentlichen Bildungsausgaben als Prozentsatz des BIP variieren die Zahlen erheblich zwischen den einzelnen Ländern. Fast ein Drittel der Länder mit verfügbaren Daten gab für 20 I an, dass die öffentlichen Gesamtausgaben für alle Leistungsbereiche als Prozentsatz des BIP mehr als 50 Prozent ausmachten, und in 4 der Länder waren es mehr als 55 Prozent (57,7 Prozent in Dänemark, 55,3 Prozent in Finnland, 55,9 Prozent in Frankreich und 59, I Prozent in Norwegen). In Korea und Mexiko, am anderen Ende der Skala, beliefen sich die öffentlichen Gesamtausgaben auf 30,2 Prozent bzw. 25,5 Prozent des BIP (Abb. B4.2 und Anhang 2).

Veränderungen der öffentlichen Gesamtausgaben für Bildung als Prozentsatz der öffentlichen Gesamtausgaben zwischen 1995 und 2011 Zwischen 1995 und 2005 wurde ein signifikanter Anstieg beobachtet ... Im Verlauf der Io Jahre von 1995 bis 2005 stiegen die öffentlichen Bildungsausgaben (für alle Bildungsbereiche zusammen) als Prozentsatz der öffentlichen Gesamtausga- 
ben in 2I der 27 OECD-Länder mit verfügbaren Daten sowohl für I995 als auch 2005 (im Durchschnitt der 27 Länder um o,9 Prozentpunkte). Nur in Frankreich, Israel, Japan, Kanada, Neuseeland und Portugal ergab sich ein anderes Bild.

Zwischen 1995 und 2005 stiegen die öffentlichen Bildungsausgaben als Prozentsatz des BIP weniger stark als die öffentlichen Bildungsausgaben als Prozentsatz der öffentlichen Gesamtausgaben. Im Durchschnitt stiegen die öffentlichen Ausgaben für Bildung als Prozentsatz des BIP zwischen 1995 und 2005 um 0,I Prozentpunkte, wohingegen die öffentlichen Ausgaben für Bildung als Prozentsatz der öffentlichen Gesamtausgaben im gleichen Zeitraum um I,4 Prozentpunkte stiegen. In Dänemark stiegen die öffentlichen Bildungsausgaben als Prozentsatz des BIP um I Prozentpunkt, während sie in Kanada um mehr als I Prozentpunkt sanken (Tab. B4.2).

\section{... dem jedoch ab 2005 ein Rückgang folgte, der mit der Finanzkrise von 2008 zusammenfiel}

Die Ausgaben änderten sich zwischen 2005 und 201 I sehr. Während dieser sechs Jahre gingen die öffentlichen Bildungsausgaben als Prozentsatz der öffentlichen Gesamtausgaben in mehr als der Hälfte der Länder mit verfügbaren Daten (in I8 von 32) im Durchschnitt um 0,2 Prozentpunkte zurück (von I3, I Prozent in 2005 auf I 2,9 Prozent in 20II). In Island und Mexiko war der Rückgang am ausgeprägtesten $(-2,4$ Prozentpunkte bzw. -2,9 Prozentpunkte), aber auch in Norwegen, Polen, Slowenien und Ungarn war er signifikant (mindestens -I Prozentpunkt). Ausnahmen waren hier Israel, Kanada und Neuseeland, wo es zwischen 2005 und $201 \mathrm{I} \mathrm{zu}$ einem Anstieg der Bildungsausgaben als Prozentsatz der öffentlichen Gesamtausgaben kam (um I,5 Prozentpunkte auf 6,I Prozentpunkte), nachdem vorher von I995 bis 2005 ein Rückgang (um 0,9 Prozentpunkte bis I,I Prozentpunkte) festzustellen war.

Bei einem Vergleich von 201 I mit 2005 ergibt sich ein anderes Bild, weil sich die Finanzkrise auch auf das BIP auswirkte. Daher stiegen die Bildungsausgaben als Prozentsatz des BIP in den meisten Ländern bzw. blieben gleich. In Island, Norwegen, Polen, der Schweiz und Ungarn sanken sie zwischen den beiden Jahren um o,2 Prozentpunkte. Im Durchschnitt der OECD-Länder mit verfügbaren Daten für alle Jahre belief sich der Anstieg auf o,3 Prozentpunkte (Tab. B4.2 und Kasten B2.I in Indikator B2).

\section{Erste Auswirkungen der Finanzkrise: In der Hälfte der Länder variierten die öffentlichen Ausgaben für Bildung weniger stark als die öffentlichen Ausgaben für alle Leistungsbereiche}

Die zwischen 2008 und 201 I beobachteten Veränderungen gehen möglicherweise auf die ersten Auswirkungen der globalen Wirtschaftskrise, die 2008 begann, zurück. Die Krise belastete die öffentlichen Haushalte insgesamt stärker und erforderte von den Regierungen eine Priorisierung bei den Mittelzuweisungen für Bildung und andere wichtige öffentliche Sektoren wie z. B. Gesundheit oder soziale Sicherheit (Tab. B4.2 und Abb. B4.3).

Im Zeitraum 2008 bis $201 \mathrm{I}$ lassen sich im Gegensatz zum Zeitraum 1995 bis 2005 keine klaren globalen Entwicklungstendenzen bei den öffentlichen Ausgaben für Bildung als Prozentsatz der öffentlichen Gesamtausgaben beobachten. Gleichwohl stiegen in 25 von 3I Ländern zwischen 2008 und 20 II sowohl die öffentlichen Ausgaben für Bil- 
Abbildung B4.3

Index der Veränderung der öffentlichen Gesamtausgaben für Bildung als Prozentsatz der öffentlichen Gesamtausgaben für alle Leistungsbereiche zusammen zwischen 2008 und 2011 (2008 =100, zu konstanten Preisen von 2011)

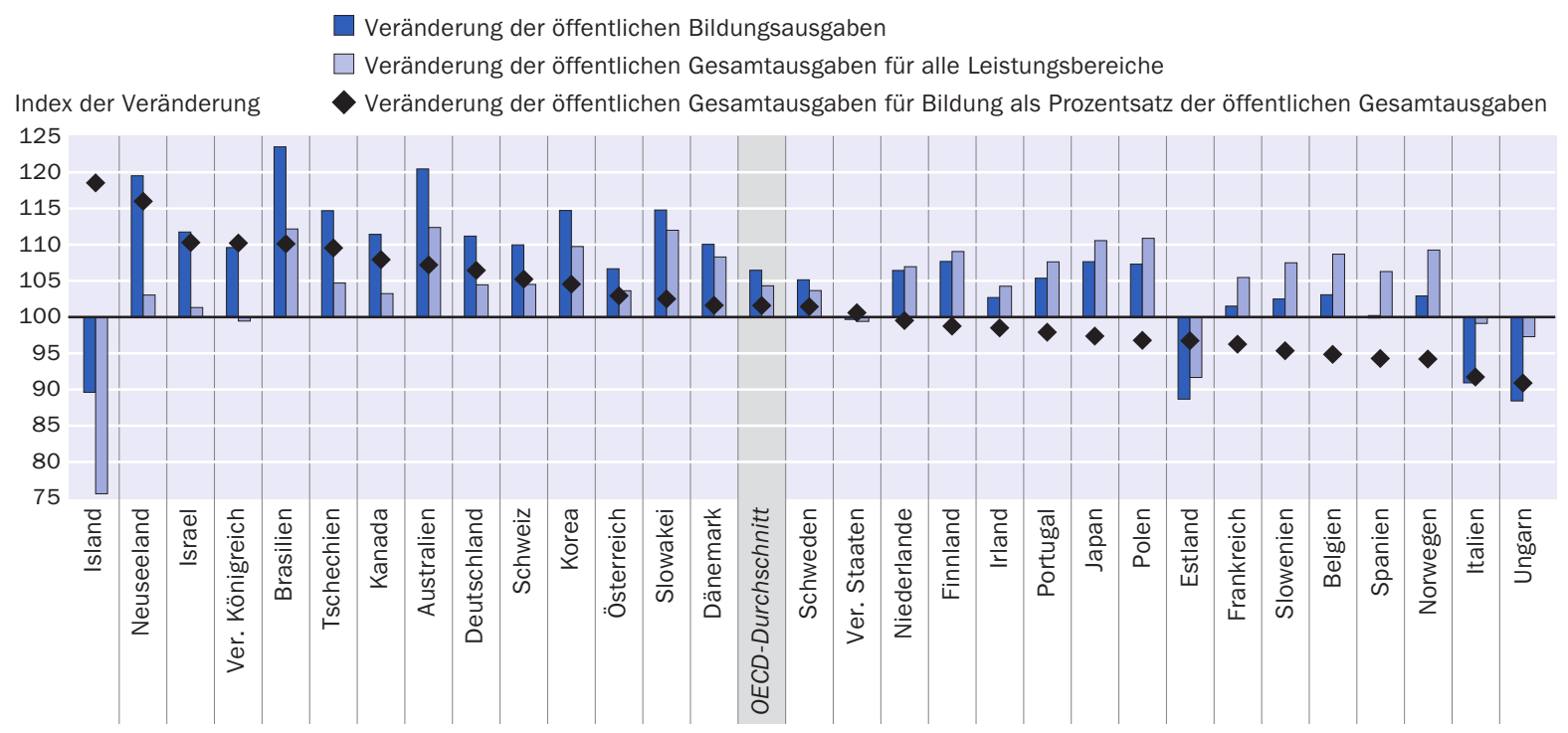

Anordnung der Länder in absteigender Reihenfolge der Veränderung der öffentlichen Gesamtausgaben für Bildung als Prozentsatz der öffentlichen Gesamtausgaben. Quelle: OECD. Tabelle B4.2. Hinweise s. Anhang 3 unter www.oecd.org/edu/eag.htm. StatLink: http://dx.doi.org/10.1787/888933117668

dung als auch die öffentlichen Gesamtausgaben für alle Leistungsbereiche. In I2 dieser 25 Länder stiegen dabei die öffentlichen Ausgaben für alle Leistungsbereiche schneller als die öffentlichen Ausgaben für Bildung (Tab. B4.2 und Abb. B4.3). Die Unterschiede waren in Belgien, Norwegen und Slowenien am größten. In den I3 anderen Ländern stiegen die öffentlichen Bildungsausgaben schneller als die öffentlichen Ausgaben für alle Leistungsbereiche. Der Anstieg der öffentlichen Gesamtausgaben für alle Leistungsbereiche in diesen Ländern variierte zwischen I Prozent in Israel und 12 Prozent in Australien, Brasilien und der Slowakei.

In den 6 übrigen Ländern (Estland, Island, Italien, Ungarn, dem Vereinigten Königreich und den Vereinigten Staaten) sanken die öffentlichen Ausgaben für alle Leistungsbereiche zwischen 2008 und 20II. In Island, wo die öffentlichen Gesamtausgaben für alle Leistungsbereiche um ganze 24 Prozent abnahmen, sanken die öffentlichen Bildungsausgaben zwar auch, jedoch weniger stark. Im Vereinigten Königreich und den Vereinigten Staaten sanken die öffentlichen Gesamtausgaben für alle Leistungsbereiche leicht, während die öffentlichen Ausgaben für Bildung stiegen (im Vereinigten Königreich) bzw. gleich blieben (in den Vereinigten Staaten). In Estland, Italien und Ungarn sanken die öffentlichen Ausgaben für Bildung stärker als die öffentlichen Gesamtausgaben für alle Leistungsbereiche (Tab. B4.2 und Abb. B4.3).

\section{Herkunft der öffentlichen Mittel, die in Bildung investiert werden}

Alle staatlichen Quellen für Mittel für Bildungsausgaben (außer den internationalen Quellen) sind einer der folgenden drei staatlichen Ebenen zugeordnet: der zentralen, der regionalen und der lokalen staatlichen Ebene. In einigen Ländern wird Bildung zentral finanziert, während in anderen die Finanzierung nach Transferzahlungen zwischen den verschiedenen staatlichen Ebenen dezentral erfolgen kann. 
In den letzten Jahren wurden viele Schulen zu autonomeren und dezentraleren Einrichtungen, die außerdem Schülern, Eltern und der Allgemeinheit gegenüber stärker rechenschaftspflichtig in Bezug auf die erzielten Ergebnisse geworden sind. Die Ergebnisse der Schulleistungsstudie PISA deuten darauf hin, dass - wenn Autonomie und Rechenschaftspflichten intelligent kombiniert werden - sie tendenziell mit besseren Leistungen der Schüler einhergehen.

Die Finanzierung mittels öffentlicher Mittel ist im Tertiärbereich stärker zentralisiert als in den anderen Bildungsbereichen. 20II stammten in den OECD-Ländern im Durchschnitt 50,3 Prozent der öffentlichen Mittel für den Primar-, Sekundar- und postsekundaren, nicht tertiären Bereich zusammen (vor Transferzahlungen) aus dem zentralen staatlichen Haushalt. Im Tertiärbereich waren dies 85 , I Prozent (Tab. B4.3 und Tab. B4.4 im Internet).

Der Anteil der originär öffentlichen Mittel von der zentralen staatlichen Ebene für den Primar-, Sekundar- und postsekundaren, nicht tertiären Bereich zusammen unterschied sich stark von Land zu Land. Drei Länder gaben einen Anteil von weniger als Io Prozent an - Kanada (3,2 Prozent), Polen (3,4 Prozent) und die Schweiz (3,3 Prozent). In Kanada wird die Finanzierung des Primar- und Sekundarbereichs von den Provinzen bzw. Territorien zur Verfügung gestellt. Eine Ausnahme sind geringe öffentliche Mittel für einige „First Nations/Aboriginal Schools“. Am anderen Ende des Spektrums stammten in Irland, Neuseeland und der Türkei die öffentlichen Mittel fast ausschließlich von der zentralen staatlichen Ebene, ebenso wie mehr als 90 Prozent der originär öffentlichen Mittel in Chile (95, I Prozent), Israel (90,8 Prozent), den Niederlanden (90,4 Prozent) und Slowenien (90,4 Prozent).

Berücksichtigt man jedoch die Transferzahlungen zwischen den einzelnen staatlichen Ebenen, ergibt sich ein anderes Bild. Nach diesen Transferzahlungen stammten in Argentinien (mit 3,7 Prozent), Australien (4,5 Prozent), Japan (I,8 Prozent), Kanada (2,7 Prozent), Korea (o,8 Prozent), Polen ( 2,4 Prozent), der Schweiz ( 0,2 Prozent) und den Vereinigten Staaten (o, 5 Prozent) weniger als 5 Prozent der öffentlichen Mittel aus zentralen staatlichen Quellen. Nur in Neuseeland erfolgt die Finanzierung (selbst nach Berücksichtigung der Transferzahlungen) ausschließlich zentral (Abb. B4.4 und Tab. B4·3).

Die Transferzahlungen von der zentralen staatlichen Ebene an regionale und lokale staatliche Ebenen im Primar-, Sekundar- und postsekundaren, nicht tertiären Bildungsbereich zusammen sind im Durchschnitt der OECD-Länder höher als im Tertiärbereich, was die Dezentralisierung auch auf diese Bildungsbereiche ausdehnt. Im Primar-, Sekundar- und postsekundaren, nicht tertiären Bereich zusammen stammen im Durchschnitt der OECD-Länder 43,4 Prozent der öffentlichen Mittel nach Transferzahlungen von der lokalen staatlichen Ebene, verglichen mit 27, o Prozent vor derartigen Transferzahlungen. Im Tertiärbereich stammen im Durchschnitt der OECD-Länder weniger als 3 Prozent der öffentlichen Mittel von der lokalen staatlichen Ebene, und zwar sowohl vor als auch nach Transferzahlungen (Tab. B4.3 und Tab. B4.4 im Internet).

Im Primar-, Sekundar- und postsekundaren, nicht tertiären Bereich zusammen gibt es zwischen den einzelnen Ländern große Unterschiede beim Umfang der Transferzah- 


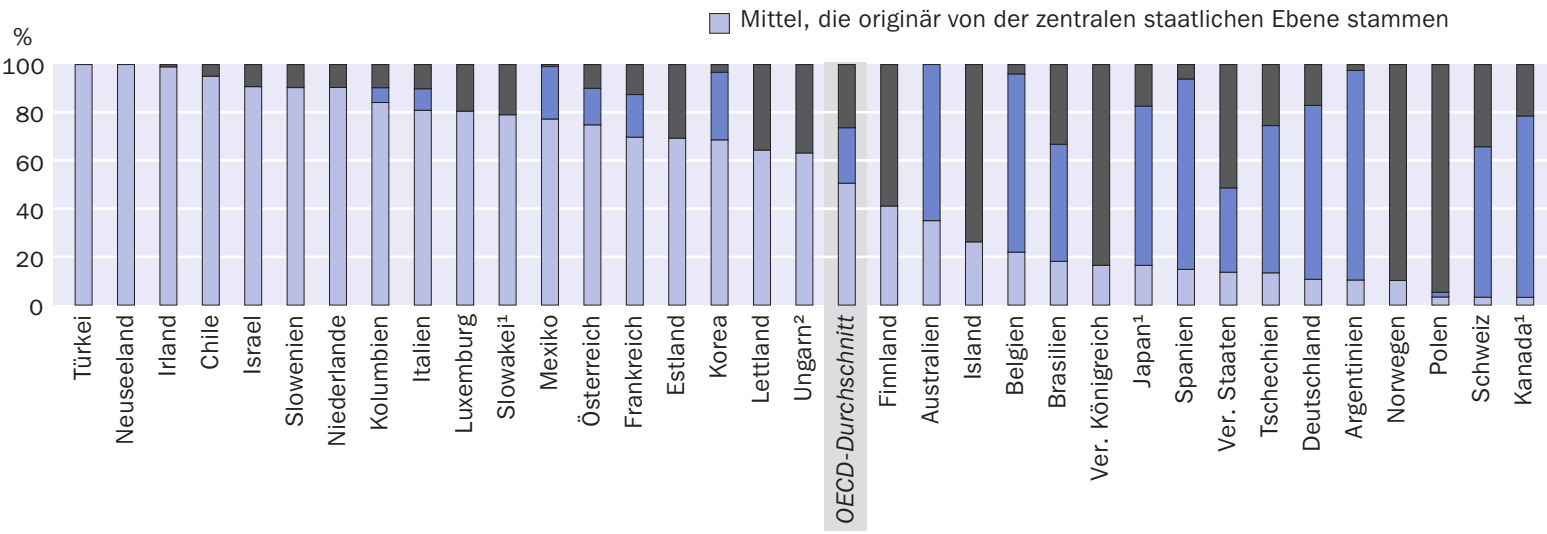

Mittel, die originär von der lokalen staatlichen Ebene stammen Mittel, die originär von der regionalen staatlichen Ebene stammen Mittel, die originär von der zentralen staatlichen Ebene stammen

Veränderung des Anteils der Mittel für Bildung im Primar-, Sekundar- und postsekundaren, nicht tertiären Bildungsbereich, die von den unterschiedlichen staatlichen Ebenen stammen, aufgegliedert nach den originären und letztendlichen Erwerbern von Bildungsressourcen (2011)

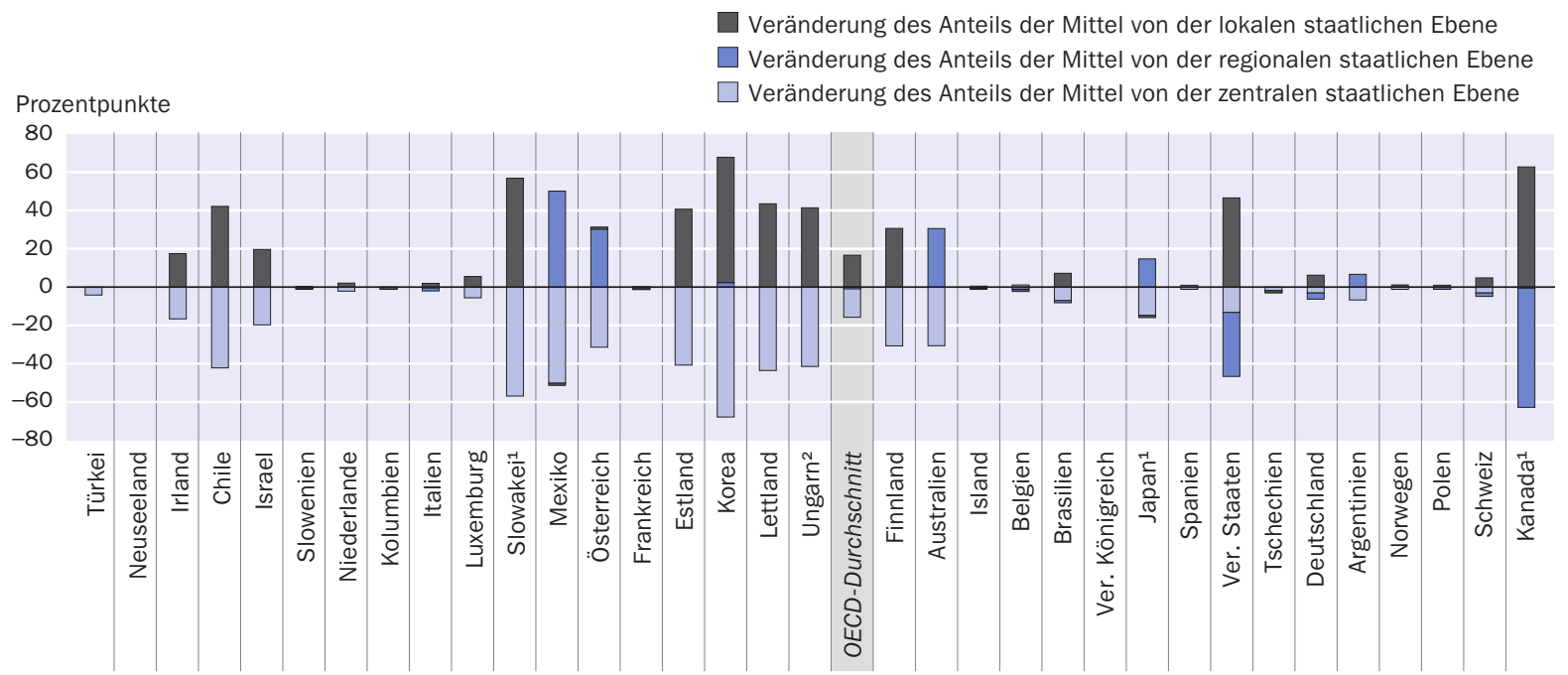

1. Einige Bildungsbereiche sind in anderen Bildungsbereichen enthalten. Einzelheiten s. Erläuterung von „x" in Hinweise für den Leser. 2. Mittel von der lokalen staatlichen Ebene enthalten Mittel von der regionalen staatlichen Ebene.

Anordnung der Länder in absteigender Reihenfolge des Anteils der Mittel, die originär von der zentralen staatlichen Ebene stammen.

Quelle: OECD. Tabelle B4.3. Hinweise s. Anhang 3 unter www.oecd.org/edu/eag.htm. StatLink: http://dx.doi.org/10.1787/888933117687

lungen von Mitteln der zentralen staatlichen Ebene an nachgeordnete staatliche Ebenen. Der Unterschied nach Transferzahlungen von der zentralen staatlichen Ebene an nachgeordnete staatliche Ebenen beträgt in Chile, Estland, Korea, Lettland, Mexiko, der Slowakei und Ungarn mehr als 40 Prozentpunkte. In Kanada und den Vereinigten Staaten beläuft sich die Differenz nach Transferzahlungen öffentlicher Mittel von der regionalen staatlichen Ebene auf die lokale staatliche Ebene auf mehr als 30 Prozentpunkte (Abb. B4.4).

Im Tertiärbereich ist der Anteil der öffentlichen Mittel von der zentralen staatlichen Ebene relativ hoch, und zwar sowohl vor als auch nach Transferzahlungen zwischen 
den verschiedenen staatlichen Ebenen. Am niedrigsten ist der Anteil der öffentlichen Mittel von der zentralen staatlichen Ebene in Belgien (27,9 Prozent vor und 26,6 Prozent nach Transferzahlungen), Deutschland (26,8 vor und 20,4 Prozent nach Transfer-

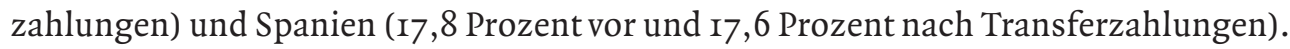
Demgegenüber liegt dieser Anteil am anderen Ende des Spektrums in II Ländern (Chile, Estland, Island, Lettland, den Niederlanden, Neuseeland, Norwegen, Portugal, der Slowakei, Ungarn und dem Vereinigten Königreich) sowohl vor als auch nach Transferzahlungen bei fast Ioo Prozent (Tab. B4.4 im Internet).

\section{Definitionen}

Öffentliche Bildungsausgaben beinhalten die Ausgaben für Bildungseinrichtungen sowie Unterstützungsleistungen für den Lebensunterhalt von Schülern/Studierenden und für andere private Ausgaben außerhalb von Bildungseinrichtungen. Darin enthalten sind die Ausgaben sämtlicher öffentlichen Einrichtungen einschließlich anderer Ministerien neben dem Bildungsministerium sowie die Ausgaben der lokalen und regionalen Verwaltungen und anderer öffentlicher Stellen. Hinsichtlich der Verwendung öffentlicher Mittel für Bildung gibt es Unterschiede zwischen den einzelnen OECD-Ländern. Öffentliche Mittel können direkt an Bildungseinrichtungen fließen oder über staatliche Programme oder die privaten Haushalte in die Bildungseinrichtungen gelenkt werden. Sie können auch auf den Erwerb von Bildungsdienstleistungen beschränkt sein oder als Unterstützung zur Bestreitung der Lebenshaltungskosten von Schülern/Studierenden gewährt werden.

Alle staatlichen Quellen für Mittel für Bildungsausgaben (außer den internationalen Quellen) können einer der folgenden drei Ebenen zugeordnet werden: zentrale (nationale) staatliche Ebene, regionale staatliche Ebene (Provinz, Bundesstaat, Bundesland etc.), lokale staatliche Ebene (Stadt, Gemeinde, Distrikt etc.). Die Begriffe „regional“ und „lokal“ beziehen sich auf staatliche Stellen, deren Zuständigkeit sich auf bestimmte geografische Untereinheiten eines Landes beschränkt. Sie beziehen sich nicht auf staatliche Stellen, deren Befugnisse nicht geografisch determiniert sind, sondern die für bestimmte Dienstleistungen, Funktionen oder Gruppen von Schülern/Studierenden zuständig sind.

Die öffentlichen Gesamtausgaben beinhalten die nicht rückzahlbaren laufenden und investiven Ausgaben aller staatlichen Verwaltungseinheiten auf zentraler, regionaler und lokaler Ebene. Darin sind die direkten öffentlichen Finanzmittel für Bildungseinrichtungen ebenso enthalten wie die öffentlichen Unterstützungsleistungen für private Haushalte (z. B. in Form von Stipendien und Studiendarlehen für Studiengebühren und die Lebenshaltungskosten von Studierenden) und andere private Einheiten für Bildungszwecke (z. B. Subventionen für Unternehmen oder Arbeitnehmerorganisationen, die Ausbildungsgänge im Rahmen der dualen Berufsausbildung durchführen). 


\section{Angewandte Methodik}

Die Daten beziehen sich auf das Haushaltsjahr 20II und beruhen auf der von der OECD im Jahre 2013 durchgeführten UOE-Datenerhebung zur Bildungsstatistik (weitere Informationen s. Anhang 3 unter www.oecd.org/eduleag.htm).

Die Daten für die öffentlichen Gesamtausgaben und das BIP stammen aus der OECDDatenbank der volkswirtschaftlichen Gesamtrechnungen (s. Anhang 2) und beruhen auf dem System of National Accounts 1993.

Bildungsausgaben werden ausgedrückt als Prozentsatz der öffentlichen Gesamtausgaben eines Landes und als Prozentsatz des BIP.

Ausgaben für den Schuldendienst (z. B. Zinszahlungen) sind zwar bei den öffentlichen Gesamtausgaben erfasst, nicht aber bei den öffentlichen Bildungsausgaben. Grund hierfür ist, dass einige Länder nicht zwischen den Zinszahlungen für den Bereich Bildung und denen für andere Bereiche differenzieren können. Das bedeutet, dass die öffentlichen Ausgaben für Bildung als Prozentsatz der öffentlichen Gesamtausgaben in denjenigen Ländern zu niedrig geschätzt sein können, in denen Zinszahlungen einen großen Teil der öffentlichen Gesamtausgaben für alle Leistungsbereiche ausmachen.

\section{Anmerkung zu den Daten aus Israel}

Die statistischen Daten für Israel wurden von den zuständigen israelischen Stellen bereitgestellt, die für sie verantwortlich zeichnen. Die Verwendung dieser Daten durch die OECD erfolgt unbeschadet des völkerrechtlichen Status der Golanhöhen, von Ost-Jerusalem und der israelischen Siedlungen im Westjordanland.

\section{Weiterführende Informationen}

OECD (2013), PISA 2012 Results: What Makes Schools Successful? (Volume IV): Resources, Policies and Practices, PISA, OECD Publishing, Paris, http://dx.doi.org/10.1787/9789264201156-en.

\section{Tabellen Indikator B4}

StatLink: http://dx.doi.org/10.1787/888933117554

Tabelle B4.I: Öffentliche Gesamtausgaben für Bildung (20II)

Tabelle B4.2: Entwicklung der öffentlichen Gesamtausgaben für Bildung (I995, 2000, 2005, 2008, 2009, 2010 und 20II)

Tabelle B4.3: Herkunft der Mittel für öffentliche Bildungsausgaben im Primar-, Sekundar- und postsekundaren, nicht tertiären Bereich (20II) 
WEB Table B4.4: Sources of public educational funds, before and after transfers, by level of government for tertiary education (Herkunft der Mittel für öffentliche Bildungsausgaben für den Tertiärbereich, vor und nach Transferzahlungen, nach staatlicher Ebene) (20II)

WEB Table B4.5: Distribution of total public expenditure on education (Öffentliche Gesamtausgaben für Bildung) (20II)

WEB Table B4.6: Public expenditure on education, by level of education (Öffentliche Ausgaben für Bildung, nach Bildungsbereich) (20II) 
Öffentliche Gesamtausgaben für Bildung (2011)

Direkte öffentliche Ausgaben für Bildungseinrichtungen plus öffentliche Subventionen an private Haushalte ${ }^{1}$ und andere private Einheiten als Prozentsatz der öffentlichen Gesamtausgaben und als Prozentsatz des BIP, nach Bildungsbereich

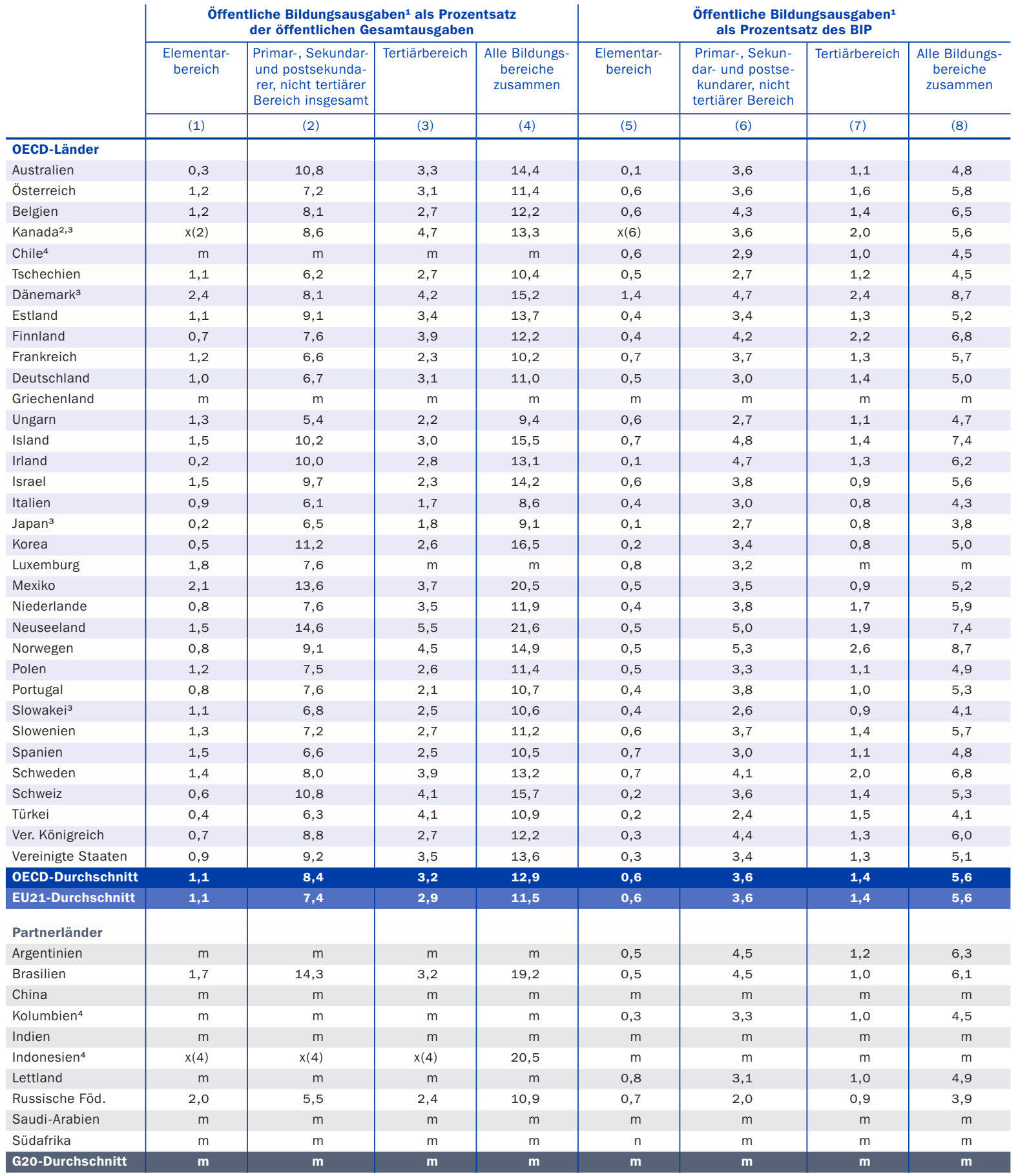

1. In dieser Tabelle enthaltene öffentliche Ausgaben beinhalten öffentliche Subventionen an private Haushalte für den Lebensunterhalt (Stipendien und Zuschüsse für Schüler bzw. Studierende/private Haushalte und Studiendarlehen), die nicht für Bildungseinrichtungen ausgegeben werden. Daher übersteigen die in dieser Tabelle angegebenen Zahlen die für öffentliche Ausgaben für Bildungseinrichtungen in Tabelle B2.4. 2. Referenzjahr 2010 anstelle $2011 . \quad 3$. Einige Bildungsbereiche sind in anderen Bildungsbereichen enthalten. Einzelheiten s. Erläuterung von „x“ in Hinweise für den Leser. 4. Referenzjahr 2012 anstelle 2011. Quelle: OECD. Argentinien, China, Indien, Indonesien, Kolumbien, Saudi-Arabien und Südafrika: Statistikinstitut der UNESCO. Lettland: Eurostat. Hinweise s. Anhang 3 unter www.oecd.org/edu/eag.htm. StatLink: http://dx.doi.org/10.1787/888933117573 Erläuterung der Kennzeichnung fehlender Daten s. Hinweise für den Leser. 
Entwicklung der öffentlichen Gesamtausgaben für Bildung (1995, 2000, 2005, 2008, 2009, 2010 und 2011)

Direkte öffentliche Ausgaben für Bildungseinrichtungen plus öffentliche Subventionen an private Haushalte ${ }^{1}$ und andere private Einheiten als Prozentsatz der öffentlichen Gesamtausgaben und als Prozentsatz des BIP, für alle Bildungsbereiche zusammen, nach Jahr

\begin{tabular}{|c|c|c|c|c|c|c|c|c|c|c|c|c|c|}
\hline & \multicolumn{5}{|c|}{$\begin{array}{l}\text { Öffentliche Bildungsausgaben }{ }^{1} \\
\text { als Prozentsatz der öffentlichen } \\
\text { Gesamtausgaben }\end{array}$} & \multicolumn{5}{|c|}{$\begin{array}{l}\text { Öffentliche Bildungsausgaben }{ }^{1} \\
\text { als Prozentsatz des BIP }\end{array}$} & \multicolumn{3}{|c|}{$\begin{array}{l}\text { Index der Veränderung zwischen } 2008 \text { und } 2011 \\
(2008=100, \text { zu konstanten Preisen von 2011) }\end{array}$} \\
\hline & 2000 & 2005 & 2008 & 2010 & 2011 & 2000 & 2005 & 2008 & 2010 & 2011 & $\begin{array}{l}\text { Öffentliche } \\
\text { Bildungsaus- } \\
\text { gaben }\end{array}$ & \begin{tabular}{|c|} 
Öffentliche \\
Gesamtaus- \\
gaben für alle \\
Leistungs- \\
bereiche \\
\end{tabular} & \begin{tabular}{|c|} 
Öffentliche Ge- \\
samtausgaben für \\
Bildung als Prozent- \\
satz der öffentlichen \\
Gesamtausgaben
\end{tabular} \\
\hline & (2) & (3) & (4) & (6) & (7) & (9) & (10) & (11) & (13) & (14) & (15) & (16) & (17) \\
\hline \multicolumn{14}{|l|}{ OECD-Länder } \\
\hline Australien & 14,3 & 14,6 & 13,5 & 15,2 & 14,4 & 4,6 & 4,5 & 4,3 & 5,1 & 4,8 & 120 & 112 & 107 \\
\hline Österreich & 10,7 & 10,9 & 11,1 & 11,2 & 11,4 & 5,6 & 5,4 & 5,5 & 5,9 & 5,8 & 107 & 104 & 103 \\
\hline Belgien & 12,0 & 11,4 & 12,9 & 12,5 & 12,2 & 5,9 & 5,9 & 6,4 & 6,6 & 6,5 & 103 & 109 & 95 \\
\hline Kanada $^{2,3}$ & 12,4 & 11,8 & 12,3 & 13,2 & 13,3 & 5,1 & 4,6 & 4,7 & 5,2 & 5,1 & 111 & 103 & 108 \\
\hline Chile $^{4}$ & 15,0 & 16,2 & 17,2 & 17,7 & $\mathrm{~m}$ & 3,8 & 3,0 & 4,2 & 4,1 & 4,5 & 126 & $\mathrm{~m}$ & $\mathrm{~m}$ \\
\hline Tschechien & 9,2 & 9,5 & 9,5 & 9,7 & 10,4 & 3,8 & 4,1 & 3,9 & 4,2 & 4,5 & 115 & 105 & 110 \\
\hline Dänemark ${ }^{3}$ & 15,4 & 15,7 & 14,9 & 15,3 & 15,2 & 8,3 & 8,3 & 7,7 & 8,8 & 8,7 & 110 & 108 & 102 \\
\hline Estland & 14,9 & 14,5 & 14,2 & 14,0 & 13,7 & 5,4 & 4,9 & 5,6 & 5,7 & 5,2 & 89 & 92 & 97 \\
\hline Finnland & 12,5 & 12,5 & 12,4 & 12,3 & 12,2 & 6,0 & 6,3 & 6,1 & 6,8 & 6,8 & 108 & 109 & 99 \\
\hline Frankreich & 11,6 & 10,6 & 10,5 & 10,4 & 10,2 & 6,0 & 5,7 & 5,6 & 5,9 & 5,7 & 102 & 105 & 96 \\
\hline Deutschland & 10,2 & 10,1 & 10,4 & 10,6 & 11,0 & 4,6 & 4,8 & 4,6 & 5,1 & 5,0 & 111 & 104 & 106 \\
\hline Griechenland & 7,2 & $\mathrm{~m}$ & $\mathrm{~m}$ & $\mathrm{~m}$ & $\mathrm{~m}$ & 3,4 & $\mathrm{~m}$ & $\mathrm{~m}$ & $\mathrm{~m}$ & $\mathrm{~m}$ & $\mathrm{~m}$ & 88 & $\mathrm{~m}$ \\
\hline Ungarn & 10,4 & 10,9 & 10,4 & 9,8 & 9,4 & 5,0 & 5,5 & 5,1 & 4,9 & 4,7 & 88 & 97 & 91 \\
\hline Island & 15,9 & 18,0 & 13,1 & 14,7 & 15,5 & 6,7 & 7,6 & 7,6 & 7,6 & 7,4 & 90 & 76 & 119 \\
\hline Irland & 13,6 & 13,9 & 13,3 & 9,8 & 13,1 & 4,2 & 4,7 & 5,7 & 6,4 & 6,2 & 103 & 104 & 99 \\
\hline Israel & 12,3 & 11,3 & 12,9 & 13,2 & 14,2 & 6,3 & 5,6 & 5,6 & 5,6 & 5,6 & 112 & 101 & 110 \\
\hline Italien & 9,9 & 9,2 & 9,4 & 8,9 & 8,6 & 4,5 & 4,4 & 4,6 & 4,5 & 4,3 & 91 & 99 & 92 \\
\hline$J^{\prime a p a n}{ }^{3}$ & 9,5 & 9,6 & 9,4 & 9,3 & 9,1 & 3,6 & 3,5 & 3,5 & 3,8 & 3,8 & 108 & 111 & 97 \\
\hline Korea & 16,6 & 15,6 & 15,8 & 16,2 & 16,5 & 3,7 & 4,1 & 4,8 & 4,9 & 5,0 & 115 & 110 & 105 \\
\hline Luxemburg & $\mathrm{m}$ & $\mathrm{m}$ & $\mathrm{m}$ & $\mathrm{m}$ & $\mathrm{m}$ & $\mathrm{m}$ & $\mathrm{m}$ & $\mathrm{m}$ & $\mathrm{m}$ & $\mathrm{m}$ & $\mathrm{m}$ & 109 & $\mathrm{~m}$ \\
\hline Mexiko & 23,4 & 23,4 & 20,6 & 20,6 & 20,5 & 4,4 & 5,0 & 4,9 & 5,3 & 5,2 & 110 & 110 & 100 \\
\hline Niederlande & 11,3 & 12,3 & 11,9 & 11,6 & 11,9 & 5,0 & 5,5 & 5,5 & 6,0 & 5,9 & 106 & 107 & 100 \\
\hline Neuseeland & $\mathrm{m}$ & 15,5 & 18,6 & 20,0 & 21,6 & 6,6 & 6,0 & 6,4 & 7,1 & 7,4 & 120 & 103 & 116 \\
\hline Norwegen & 14,0 & 16,7 & 16,1 & 15,2 & 15,2 & 7,8 & 9,3 & 8,8 & 8,8 & 8,8 & 103 & 109 & 94 \\
\hline Polen & 12,7 & 12,6 & 11,8 & 11,4 & 11,4 & 5,0 & 5,5 & 5,1 & 5,2 & 4,9 & 107 & 111 & 97 \\
\hline Portugal & 12,5 & 11,2 & 10,9 & 10,9 & 10,7 & 5,2 & 5,2 & 4,9 & 5,6 & 5,3 & 105 & 108 & 98 \\
\hline Slowakei ${ }^{3}$ & 7,5 & 10,1 & 10,3 & 10,6 & 10,6 & 3,9 & 3,8 & 3,6 & 4,2 & 4,1 & 115 & 112 & 102 \\
\hline Slowenien & $\mathrm{m}$ & 12,7 & 11,7 & 11,3 & 11,2 & $\mathrm{~m}$ & 5,7 & 5,2 & 5,7 & 5,7 & 102 & 107 & 95 \\
\hline Spanien & 10,9 & 11,0 & 11,1 & 10,7 & 10,5 & 4,3 & 4,2 & 4,6 & 5,0 & 4,8 & 100 & 106 & $\mathrm{~m}$ \\
\hline Schweden & 13,0 & 12,8 & 13,1 & 13,3 & 13,2 & 7,2 & 6,9 & 6,8 & 7,0 & 6,8 & 105 & 104 & 101 \\
\hline Schweiz & 14,4 & 15,0 & 14,9 & 15,8 & 15,7 & 5,1 & 5,5 & 4,9 & 5,2 & 5,3 & 110 & 105 & 105 \\
\hline Türkei & $\mathrm{m}$ & $\mathrm{m}$ & $\mathrm{m}$ & $\mathrm{m}$ & 10,9 & $\mathrm{~m}$ & $\mathrm{~m}$ & $\mathrm{~m}$ & $\mathrm{~m}$ & 3,8 & $\mathrm{~m}$ & 116 & $\mathrm{~m}$ \\
\hline Vereinigtes Königreich & 11,7 & 11,8 & 11,0 & 11,9 & 12,2 & 4,2 & 5,1 & 5,2 & 5,9 & 5,8 & 110 & 99 & 110 \\
\hline Vereinigte Staaten & 13,8 & 13,9 & 13,5 & 12,7 & 13,6 & 4,5 & 4,9 & 5,1 & 5,2 & 5,0 & 100 & 99 & 101 \\
\hline OECD-Durchschnitt & 12,6 & 13,1 & 12,9 & 12,9 & 12,9 & 5,2 & 5,3 & 5,4 & 5,7 & 5,6 & 106 & 104 & 102 \\
\hline EU21-Durchschnitt & 11,4 & 11,8 & 11,6 & 11,4 & 11,5 & 5,1 & 5,4 & 5,3 & 5,8 & 5,6 & 104 & 104 & 99 \\
\hline $\begin{array}{l}\text { OECD-Durchschnitt } \\
\text { (Länder mit verfügbaren } \\
\text { Daten für alle Jahre) }\end{array}$ & 12,5 & 12,6 & 12,4 & 12,3 & 12,5 & 5,2 & 5,3 & 5,3 & 5,6 & 5,6 & $\sim$ & $\sim$ & $\sim$ \\
\hline \multicolumn{14}{|l|}{ Partnerländer } \\
\hline Argentinien & $\mathrm{m}$ & $\mathrm{m}$ & $\mathrm{m}$ & m & $\mathrm{m}$ & $\mathrm{m}$ & $\mathrm{m}$ & $\mathrm{m}$ & $\mathrm{m}$ & 6,3 & $\mathrm{~m}$ & $\mathrm{~m}$ & $\mathrm{~m}$ \\
\hline Brasilien & 10,5 & 14,5 & 17,4 & 18,1 & 19,2 & 3,5 & 4,5 & 5,4 & 5,8 & 6,1 & 123 & 112 & 110 \\
\hline China & $\mathrm{m}$ & $\mathrm{m}$ & $\mathrm{m}$ & m & $\mathrm{m}$ & $\mathrm{m}$ & $\mathrm{m}$ & $\mathrm{m}$ & $\mathrm{m}$ & $\mathrm{m}$ & $\mathrm{m}$ & $\mathrm{m}$ & $\mathrm{m}$ \\
\hline Kolumbien ${ }^{4}$ & $\mathrm{~m}$ & $\mathrm{~m}$ & $\mathrm{~m}$ & $\mathrm{~m}$ & $\mathrm{~m}$ & $\mathrm{~m}$ & $\mathrm{~m}$ & $\mathrm{~m}$ & $\mathrm{~m}$ & 4,5 & $\mathrm{~m}$ & $\mathrm{~m}$ & $\mathrm{~m}$ \\
\hline Indien & $\mathrm{m}$ & $\mathrm{m}$ & $\mathrm{m}$ & $\mathrm{m}$ & $\mathrm{m}$ & $\mathrm{m}$ & $\mathrm{m}$ & $\mathrm{m}$ & $\mathrm{m}$ & $\mathrm{m}$ & $\mathrm{m}$ & $\mathrm{m}$ & $\mathrm{m}$ \\
\hline Indonesien & $\mathrm{m}$ & $\mathrm{m}$ & $\mathrm{m}$ & $\mathrm{m}$ & 20,5 & $\mathrm{~m}$ & $\mathrm{~m}$ & $\mathrm{~m}$ & $\mathrm{~m}$ & $\mathrm{~m}$ & $\mathrm{~m}$ & $\mathrm{~m}$ & $\mathrm{~m}$ \\
\hline Lettland & $\mathrm{m}$ & $\mathrm{m}$ & $\mathrm{m}$ & $\mathrm{m}$ & $\mathrm{m}$ & $\mathrm{m}$ & $\mathrm{m}$ & $\mathrm{m}$ & $\mathrm{m}$ & 4,9 & $\mathrm{~m}$ & $\mathrm{~m}$ & $\mathrm{~m}$ \\
\hline Russische Föderation & 10,6 & 11,0 & $\mathrm{~m}$ & $\mathrm{~m}$ & 10,9 & 2,9 & 3,8 & 4,1 & 4,0 & 3,9 & $\mathrm{~m}$ & $\mathrm{~m}$ & $\mathrm{~m}$ \\
\hline Saudi-Arabien & $\mathrm{m}$ & $\mathrm{m}$ & $\mathrm{m}$ & $\mathrm{m}$ & $\mathrm{m}$ & $\mathrm{m}$ & $\mathrm{m}$ & $\mathrm{m}$ & $\mathrm{m}$ & $\mathrm{m}$ & $\mathrm{m}$ & $\mathrm{m}$ & $\mathrm{m}$ \\
\hline \multicolumn{14}{|l|}{ Südafrika } \\
\hline G20-Durchschnitt & $\mathbf{m}$ & m & m & $\mathbf{m}$ & m & $\mathbf{m}$ & m & $\mathbf{m}$ & $\mathbf{m}$ & $\mathbf{m}$ & m & m & m \\
\hline
\end{tabular}

Anmerkung: Die Spalten mit den Angaben für die Jahre 1995 und 2009, d.h. die Spalten (1), (5), (8) und (12), sind im Internet verfügbar (s. StatLink unten). 1. In dieser Tabelle enthaltene öffentliche Ausgaben beinhalten öffentliche Subventionen an private Haushalte für den Lebensunterhalt (Stipendien und Zuschüsse für Schüler bzw. Studierende/private Haushalte und Studiendarlehen), die nicht für Bildungseinrichtungen ausgegeben werden. Daher übersteigen die in dieser Tabelle angegebenen Zahlen die für öffentliche Ausgaben für Bildungseinrichtungen in Tabelle B2.4. 2. Referenzjahr 2010 anstelle $2011 . \quad 3$. Einige Bildungsbereiche sind in anderen Bildungsbereichen enthalten. Einzelheiten s. Erläuterung von „x“ in Hinweise für den Leser. 4. Referenzjahr 2012 anstelle 2011. Daten beziehen sich auf 2009-2012 anstelle 2008-2011.

Quelle: OECD. Argentinien, China, Indien, Indonesien, Kolumbien, Saudi-Arabien und Südafrika: Statistikinstitut der UNESCO. Lettland: Eurostat. Hinweise s. Anhang 3 unter www. oecd.org/edu/eag.htm. StatLink: http://dx.doi.org/10.1787/888933117592

Erläuterung der Kennzeichnung fehlender Daten s. Hinweise für den Leser. 
Tabelle B4.3

Herkunft der Mittel für öffentliche Bildungsausgaben im Primar-, Sekundar- und postsekundaren, nicht tertiären Bereich (2011)

Vor und nach Transferzahlungen

\begin{tabular}{|c|c|c|c|c|c|c|c|c|}
\hline & \multicolumn{4}{|c|}{$\begin{array}{l}\text { Originäre Herkunft der Mittel (vor Transferzahlungen } \\
\text { zwischen den verschiedenen staatlichen Ebenen) }\end{array}$} & \multicolumn{4}{|c|}{$\begin{array}{l}\text { Letztendliche Herkunft der Mittel (nach Transferzahlungen } \\
\text { zwischen den verschiedenen staatlichen Ebenen) }\end{array}$} \\
\hline & $\begin{array}{l}\text { Zentrale staat- } \\
\text { liche Ebene }\end{array}$ & $\begin{array}{l}\text { Regionale } \\
\text { Ebene }\end{array}$ & Lokale Ebene & Gesamt & $\begin{array}{l}\text { Zentrale staat- } \\
\text { liche Ebene }\end{array}$ & $\begin{array}{l}\text { Regionale } \\
\text { Ebene }\end{array}$ & Lokale Ebene & Gesamt \\
\hline & (1) & (2) & (3) & (4) & (5) & (6) & (7) & (8) \\
\hline \multicolumn{9}{|l|}{ OECD-Länder } \\
\hline Australien & 35,1 & 64,9 & $\mathrm{~m}$ & 100 & 4,5 & 95,5 & $\mathrm{~m}$ & 100 \\
\hline Österreich & 74,9 & 15,2 & 9,9 & 100 & 43,5 & 46,2 & 10,3 & 100 \\
\hline Belgien & 22,0 & 74,1 & 3,9 & 100 & 23,1 & 73,0 & 3,9 & 100 \\
\hline Kanada $^{1,2}$ & 3,2 & 75,4 & 21,4 & 100 & 2,7 & 13,2 & 84,2 & 100 \\
\hline Chile $^{3}$ & 95,1 & a & 4,9 & 100 & 53,0 & a & 47,0 & 100 \\
\hline Tschechien & 13,7 & 62,3 & 25,8 & 100 & 11,9 & 62,3 & 25,8 & 100 \\
\hline Dänemark ${ }^{2}$ & $\mathrm{~m}$ & $\mathrm{~m}$ & $\mathrm{~m}$ & 100 & 44,0 & $\mathrm{n}$ & 56,0 & 100 \\
\hline Estland & 69,4 & a & 30,6 & 100 & 28,7 & a & 71,3 & 100 \\
\hline Finnland & 41,2 & a & 58,8 & 100 & 10,5 & a & 89,5 & 100 \\
\hline Frankreich & 69,8 & 17,7 & 12,5 & 100 & 69,7 & 17,6 & 12,7 & 100 \\
\hline Deutschland & 10,7 & 72,3 & 17,0 & 100 & 7,7 & 69,1 & 23,2 & 100 \\
\hline Griechenland & $\mathrm{m}$ & $\mathrm{m}$ & $\mathrm{m}$ & $\mathrm{m}$ & $\mathrm{m}$ & $\mathrm{m}$ & $\mathrm{m}$ & $\mathrm{m}$ \\
\hline Ungarn & 63,3 & $x(3)$ & 36,7 & 100 & 21,8 & $x(7)$ & 78,2 & 100 \\
\hline Island & 26,3 & $a$ & 73,7 & 100 & 25,8 & a & 74,2 & 100 \\
\hline Irland & 99,0 & a & 1,0 & 100 & 82,5 & a & 17,5 & 100 \\
\hline Israel & 90,8 & a & 9,2 & 100 & 71,1 & a & 28,9 & 100 \\
\hline Italien & 81,0 & 8,9 & 10,0 & 100 & 80,5 & 7,4 & 12,0 & 100 \\
\hline Japan $^{2}$ & 16,5 & 66,2 & 17,2 & 100 & 1,8 & 81,0 & 17,2 & 100 \\
\hline Korea & 68,7 & 28,1 & 3,2 & 100 & 0,8 & 30,5 & 68,7 & 100 \\
\hline Luxemburg & 80,6 & $a$ & 19,4 & 100 & 75,1 & a & 24,9 & 100 \\
\hline Mexiko & 77,4 & 22,4 & 0,2 & 100 & 27,2 & 72,6 & 0,2 & 100 \\
\hline Niederlande & 90,4 & $\mathrm{n}$ & 9,5 & 100 & 88,3 & $\mathrm{n}$ & 11,6 & 100 \\
\hline Neuseeland & 100,0 & $n$ & $n$ & 100 & 100,0 & $n$ & $n$ & 100 \\
\hline Norwegen & 10,2 & $n$ & 89,8 & 100 & 9,1 & $n$ & 90,9 & 100 \\
\hline Polen & 3,4 & 1,9 & 94,7 & 100 & 2,4 & 2,0 & 95,7 & 100 \\
\hline Portugal & $\mathrm{m}$ & $\mathrm{m}$ & $\mathrm{m}$ & $\mathrm{m}$ & $\mathrm{m}$ & $\mathrm{m}$ & $\mathrm{m}$ & $\mathrm{m}$ \\
\hline Slowakei ${ }^{2}$ & 79,1 & a & 20,9 & 100 & 22,2 & a & 77,8 & 100 \\
\hline Slowenien & 90,4 & a & 9,6 & 100 & 90,0 & a & 10,0 & 100 \\
\hline Spanien & 14,8 & 79,2 & 6,0 & 100 & 13,9 & 80,1 & 6,0 & 100 \\
\hline Schweden & $\mathrm{m}$ & $\mathrm{m}$ & $\mathrm{m}$ & $\mathrm{m}$ & $\mathrm{m}$ & $\mathrm{m}$ & $\mathrm{m}$ & $\mathrm{m}$ \\
\hline Schweiz & 3,3 & 62,6 & 34,2 & 100 & 0,2 & 60,8 & 39,0 & 100 \\
\hline Türkei & 100,0 & a & $\mathrm{m}$ & 100 & 96,0 & 4,0 & $\mathrm{~m}$ & 100 \\
\hline Ver. Königreich & 16,5 & a & 83,5 & 100 & 16,5 & a & 83,5 & 100 \\
\hline Vereinigte Staaten & 13,7 & 35,0 & 51,3 & 100 & 0,5 & 1,6 & 97,9 & 100 \\
\hline OECD-Durchschnitt & 52,0 & 23,7 & 27,0 & 100 & 36,3 & 23,9 & 43,4 & 100 \\
\hline EU21-Durchschnitt & 54,1 & 20,7 & 26,5 & 100 & 40,7 & 21,0 & 39,4 & 100 \\
\hline \multicolumn{9}{|l|}{ Partnerländer } \\
\hline Argentinien & 10,4 & 87,1 & 2,4 & 100 & 3,7 & 93,8 & 2,4 & 100 \\
\hline Brasilien & 18,2 & 48,7 & 33,1 & 100 & 11,2 & 48,4 & 40,4 & 100 \\
\hline China & $\mathrm{m}$ & $\mathrm{m}$ & $\mathrm{m}$ & $\mathrm{m}$ & $\mathrm{m}$ & $\mathrm{m}$ & $\mathrm{m}$ & $\mathrm{m}$ \\
\hline Kolumbien ${ }^{3}$ & 84,2 & 6,2 & 9,6 & 100 & 84,2 & 6,2 & 9,6 & 100 \\
\hline Indien & $\mathrm{m}$ & $\mathrm{m}$ & $\mathrm{m}$ & $\mathrm{m}$ & $\mathrm{m}$ & $\mathrm{m}$ & $\mathrm{m}$ & $\mathrm{m}$ \\
\hline Indonesien & $\mathrm{m}$ & $\mathrm{m}$ & $\mathrm{m}$ & $\mathrm{m}$ & $\mathrm{m}$ & $\mathrm{m}$ & $\mathrm{m}$ & $\mathrm{m}$ \\
\hline Lettland & 64,5 & a & 35,5 & 100 & 20,9 & a & 79,1 & 100 \\
\hline Russische Föd. & $\mathrm{m}$ & $\mathrm{m}$ & $\mathrm{m}$ & $\mathrm{m}$ & 6,7 & 93,3 & $\mathrm{n}$ & 100 \\
\hline Saudi-Arabien & $\mathrm{m}$ & $\mathrm{m}$ & $\mathrm{m}$ & $\mathrm{m}$ & $\mathrm{m}$ & $\mathrm{m}$ & $\mathrm{m}$ & $\mathrm{m}$ \\
\hline Südafrika & $\mathrm{m}$ & $\mathrm{m}$ & $\mathrm{m}$ & $\mathrm{m}$ & $\mathrm{m}$ & $\mathrm{m}$ & $\mathrm{m}$ & $\mathrm{m}$ \\
\hline G20-Durchschnitt & $\mathbf{m}$ & m & m & m & $\mathbf{m}$ & $\mathbf{m}$ & m & $\mathbf{m}$ \\
\hline
\end{tabular}

1. Referenzzeitraum 2010. 2. Einige Bildungsbereiche sind in anderen Bildungsbereichen enthalten. Einzelheiten s. Erläuterung von „x“ in Hinweise für den Leser. 3. Referenzjahr 2012.

Quelle: OECD. Argentinien, China, Indien, Indonesien, Kolumbien, Saudi-Arabien und Südafrika: Statistikinstitut der UNESCO. Lettland: Eurostat. Hinweise s. Anhang 3 unter www.oecd.org/edu/eag.htm. StatLink: http://dx.doi.org/10.1787/888933117611

Erläuterung der Kennzeichnung fehlender Daten s. Hinweise für den Leser. 


\section{Wie hoch sind die Studiengebühren und welche öffentlichen Unterstützungs- leistungen erhalten Studierende?}

In den OECD-Ländern gibt es signifikante Unterschiede bei der Höhe der von Bildungseinrichtungen des Tertiärbereichs erhobenen Studiengebühren. In 8 OECDLändern erheben öffentliche Bildungseinrichtungen überhaupt keine Studiengebühren, in einem Drittel der 26 OECD-Länder mit verfügbaren Daten jedoch verlangen öffentliche Bildungseinrichtungen von inländischen Studierenden jährliche Studiengebühren von mehr als I.50o US-Dollar.

In immer mehr OECD-Ländern werden für internationale Studierende höhere Studiengebühren als für inländische Studierende erhoben.

Hohe Studiengebühren werden meist in den Ländern erhoben, in denen private Einheiten (z. B. Unternehmen) am stärksten zur Finanzierung der Bildungseinrichtungen im Tertiärbereich beitragen.

Durchschnittlich fast 22 Prozent der öffentlichen Ausgaben für den Tertiärbereich betreffen finanzielle Unterstützungsleistungen an Studierende, private Haushalte und andere private Einheiten.

Abbildung B5.1

Verhältnis zwischen den durchschnittlichen Studiengebühren öffentlicher Bildungseinrichtungen und dem Anteil der Studierenden im Tertiärbereich A, die öffentliche Darlehen und/oder Stipendien/Zuschüsse erhalten (2011) Für inländische Studierende im Vollzeitstudium, in US-Dollar, kaufkraftbereinigt mittels KKP für das BIP, Studienjahr 2010/2011

Durchschnittliche Studiengebühren öffentlicher Bildungseinrichtungen für Studiengänge, die zu einem ersten Abschluss führen, in US-Dollar 7.500

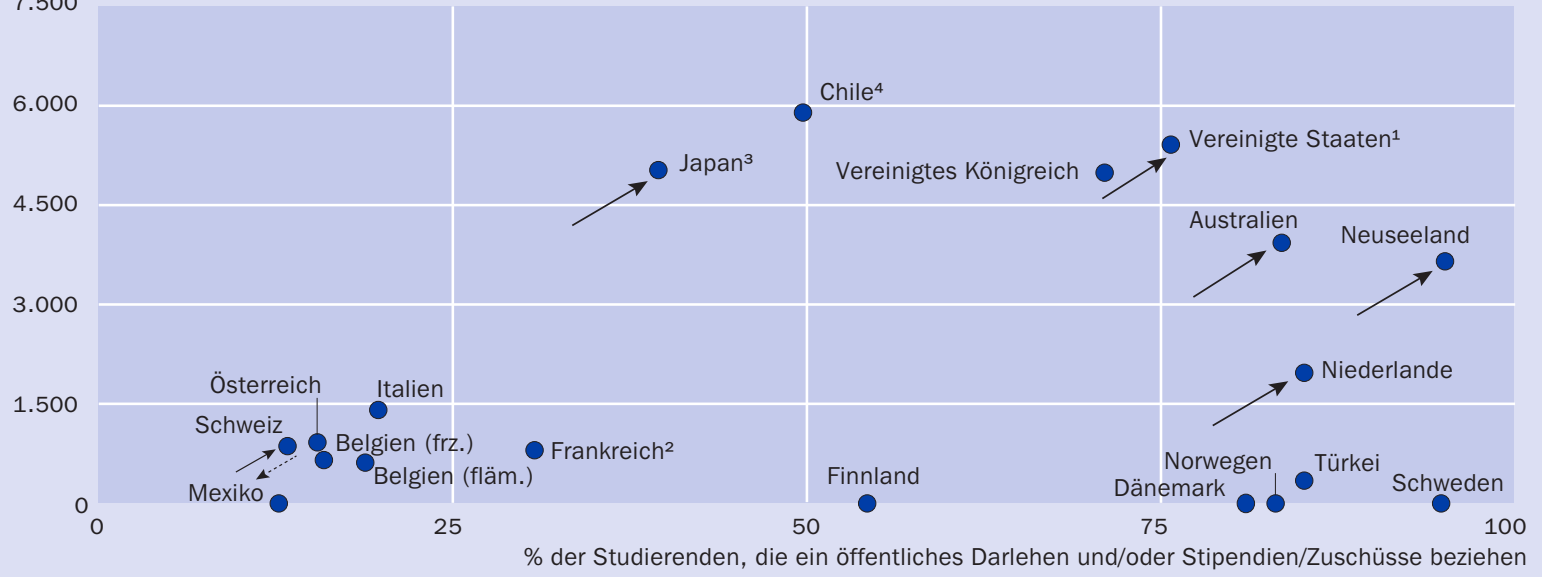

1. Die angegebenen Zahlen beziehen sich auf alle Studierenden (inländische und nicht inländische/ausländische Vollzeitstudierende). 2. Durchschnittliche Studiengebühren von 200 bis 1.402 US-Dollar für Studiengänge an Universitäten, vom Bildungsministerium abhängig. 3. Studiengebühren beziehen sich auf öffentliche Bildungseinrichtungen, aber mehr als zwei Drittel der Studierenden sind an privaten Bildungseinrichtungen eingeschrieben. 4 . Wenn nur öffentliche Bildungseinrichtungen berücksichtigt werden, sollte der Anteil der Studierenden, die in den Genuss von öffentlichen Darlehen und/oder Stipendien/ Darlehen kommen, bei rund 68 Prozent liegen.

Quelle: OECD. Tabellen B5.1 und B5.2. Hinweise s. Anhang 3 unter www.oecd.org/edu/eag.htm. StatLink: http://dx.doi.org/10.1787/888933117801

Erläuterung der Abbildung: Diese Abbildung zeigt für den Tertiärbereich A die Beziehungen zwischen den jährlich von Bildungseinrichtungen erhobenen Studiengebühren und den an private Haushalte gezahlten öffentlichen Unterstützungsleistungen für die Lebenshaltungskosten von Studierenden. Die Pfeile zeigen an, wie sich die durchschnittlichen Studiengebühren sowie der Anteil der Studierenden, die öffentliche Unterstützungsleistungen erhalten, seit 1995 aufgrund von Reformen verändert haben. 


\section{Kontext}

Politische Entscheidungen über die Höhe der Studiengebühren von Bildungseinrichtungen wirken sich sowohl auf die Kosten eines Studiums für die Studierenden aus als auch auf die Ressourcen, die den Bildungseinrichtungen im Tertiärbereich zur Verfügung stehen. Öffentliche Unterstützungsleistungen an Studierende und ihre Familien dienen den Ländern auch als Mittel zur Steigerung der Bildungsbeteiligung, insbesondere von Schülern und Studierenden aus einkommensschwachen Familien, indem ein Teil der direkten und indirekten Bildungskosten übernommen wird. Hierdurch haben die Regierungen die Möglichkeit, Probleme des Zugangs zu Bildung und der Chancengleichheit anzugehen. Die Auswirkungen dieser Unterstützungsleistungen müssen daher - zumindest teilweise - anhand einer Untersuchung von Aufnahme, Weiterverfolgung und Abschluss einer Ausbildung im Tertiärbereich beurteilt werden.

Öffentliche Unterstützungsleistungen an Studierende spielen auch bei der indirekten Finanzierung von Bildungseinrichtungen im Tertiärbereich eine Rolle. Finanzmittel für Bildungseinrichtungen über Studierende zu lenken kann auch ein Beitrag zu mehr Wettbewerb zwischen den Bildungseinrichtungen und zu einem besseren Eingehen auf die Bedürfnisse der Studierenden sein. Da Zuschüsse zu den Lebenshaltungskosten der Studierenden ein Erwerbseinkommen ersetzen können, können öffentliche Subventionen dazu beitragen, den Bildungsstand anzuheben, da die Studierenden so teilweise auf eine Erwerbstätigkeit neben dem Studium verzichten können. Diese Unterstützungsleistungen können in vielfältiger Weise bereitgestellt werden, u. a. als bedarfsabhängige Zuschüsse, als Familienbeihilfen für Studierende, als Steuerfreibeträge für Studierende oder ihre Eltern oder in Form sonstiger Transferleistungen an private Haushalte. Vor allem während einer Finanzkrise müssen die Regierungen das richtige Verhältnis zwischen diesen verschiedenen Formen der Unterstützungsleistungen finden. Bei einer festen Gesamtsumme der Subventionen können öffentliche Unterstützungsleistungen wie Steuerermäßigungen oder Familienbeihilfen für einkommensschwache Studierende eine geringere Unterstützung darstellen, als dies bei bedarfsabhängigen Zuschüssen der Fall ist, da Erstere nicht spezifisch auf einkommensschwache Studierende abzielen. Sie können jedoch auf jeden Fall dazu beitragen, finanzielle Ungleichheiten zwischen Haushalten mit und ohne Kinder in Ausbildung abzubauen.

\section{Weitere wichtige Ergebnisse}

In den OECD-Ländern sind im Allgemeinen die Studiengebühren an öffentlichen und staatlich subventionierten privaten Bildungseinrichtungen für Studiengänge, die zu einem zweiten oder weiteren Abschluss führen, nicht wesentlich höher als die für Studiengänge, die zu einem ersten Abschluss führen. Ausnahmen sind hier Australien, Chile und das Vereinigte Königreich.

Die hohen Studienanfängerquoten im Tertiärbereich in einigen der Länder ohne Studiengebühren hängen vermutlich auch damit zusammen, dass es bei ihnen sehr gut entwickelte öffentliche Unterstützungsleistungen für Studierende gibt, und nicht nur damit, dass es keine Studiengebühren gibt. 
OECD-Länder, in denen Studierende zwar Studiengebühren zahlen müssen, aber ausgesprochen hohe öffentliche Unterstützungsleistungen erhalten können, haben keine unterdurchschnittlichen Studienanfängerquoten im Tertiärbereich A.

Systeme der finanziellen Unterstützung, die für alle Studierenden Darlehen mit einkommensabhängiger Rückzahlung in Kombination mit bedarfsabhängigen Zuschüssen anbieten, können dazu beitragen, den Zugang und die Chancengerechtigkeit für Studierende zu fördern und gleichzeitig die Kosten der Hochschulausbildung zwischen Staat und Studierenden aufzuteilen.

\section{Entwicklungstendenzen}

Wie in Bildung auf einen Blick 2013 berichtet, haben I4 der 25 Länder mit verfügbaren Daten ihr System der Studiengebühren seit 1995 reformiert. In allen I4 Ländern - mit Ausnahme von Island und der Slowakei - erfolgten diese Reformen parallel zu Änderungen der Höhe der öffentlichen Unterstützungsleistungen für Studierende.

In mehreren Ländern gab es seit 2009 weitere Veränderungen bei den Studiengebühren und den öffentlichen Unterstützungsleistungen für Studierende. Im Vereinigten Königreich beispielsweise wurden die Studiengebühren 2012 als Teil eines Regierungsprogramms zur Stabilisierung der Finanzen der Universitäten verdoppelt bzw. an einigen Universitäten fast verdreifacht. Die in diesem Indikator verwendeten Daten beziehen sich jedoch auf den Zeitraum 20I0/20II und spiegeln daher diese jüngsten Entwicklungen noch nicht wider. Auch Korea führte Reformen zur Verbesserung der öffentlichen Unterstützungsleistungen für Studierende im Hochschulbereich ein (in 20II), um den Zugang zum und die Chancengerechtigkeit im Tertiärbereich A zu verbessern.

\section{Analyse und Interpretationen}

\section{Jährliche Studiengebühren für inländische Studierende an Bildungs- einrichtungen des Tertiärbereichs A}

Gegenwärtig gibt es heftige bildungspolitische Debatten über die Kosten im Hochschulwesen und die beste Möglichkeit zur Unterstützung der Studierenden bei der Finanzierung ihres Studiums. Die Höhe der von den Bildungseinrichtungen im Tertiärbereich erhobenen Studiengebühren sowie die Höhe und Art der von den einzelnen Ländern durch ihre jeweiligen Subventionssysteme für Studierende gewährten finanziellen Unterstützung können sich stark auf den Zugang zum und die Chancengerechtigkeit im Tertiärbereich auswirken.

Das richtige Verhältnis zwischen ausreichender Unterstützung der Bildungseinrichtungen durch Studiengebühren und Aufrechterhaltung des Zugangs zu Bildung und Chancengerechtigkeit zu finden ist eine große Aufgabe. Einerseits erhöhen hohe Studiengebühren die Mittel, die Bildungseinrichtungen zur Verfügung stehen, unterstützen sie in ihren Bemühungen, auch weiterhin qualitativ hochwertige Studiengänge anzubieten und neue zu entwickeln, und können den Bildungseinrichtungen dabei 
helfen, mehr Studierende aufzunehmen. Daher wirken sich mehrere Faktoren auf die Höhe der Studiengebühren aus, wie z. B. die Gehälter der Professoren im Wettbewerb um die Gewinnung der besten Professoren in einem globalen akademischen Markt, der Ausbau von nicht unterrichtsbezogenen Leistungen (Förderung der Beschäftigungsfähigkeit, Beziehungen zu Unternehmen), die Zunahme des digitalen Lernens und Investitionen in die Förderung der Internationalisierung.

Aber Studiengebühren können auch den Zugang zu Hochschulbildung für Studierende beschränken, insbesondere für Studierende aus einkommensschwachen Familien, wenn es kein ausgeprägtes System öffentlicher Unterstützungsleistungen gibt, mit dessen Hilfe die Kosten eines Studiums bezahlt bzw. erstattet werden. Daneben könnten hohe Studiengebühren manche Studierende davon abhalten, sich für Fächergruppen mit langen Studiengängen zu entscheiden, wenn es bei diesen keine ausreichenden Perspektiven auf dem Arbeitsmarkt gibt.

Andererseits können niedrige Studiengebühren Zugang und Chancengerechtigkeit insbesondere von einkommensschwachen Bevölkerungsschichten fördern. Sie könnten jedoch auch die Möglichkeiten der Bildungseinrichtungen einschränken, ein hohes Ausbildungsniveau aufrechtzuerhalten, insbesondere angesichts der deutlichen Ausweitung des Tertiärbereichs in allen OECD-Ländern in den letzten Jahren. Die Belastungen der Haushalte aufgrund der globalen Wirtschaftskrise könnten es Ländern mit niedrigeren Studiengebühren außerdem erschweren, dieses Modell auch in Zukunft weiterzuverfolgen.

Mittels unterschiedlich hoher Studiengebühren (je nach Bildungsbereich, Studienfach, Hintergrund des Studierenden oder Vollzeit- bzw. Teilzeitstudium) können Länder die Höhe der Studiengebühren unter Einbeziehung von Aspekten der Chancengerechtigkeit bei der Bildungsbeteiligung im Tertiärbereich den entstehenden Bildungskosten und den Arbeitsmarktchancen anpassen.

Bei der durchschnittlichen Höhe der Studiengebühren, die von öffentlichen Bildungseinrichtungen des Tertiärbereichs A von inländischen Studierenden für zu einem ersten Abschluss führende Studiengänge erhoben werden, bestehen große Unterschiede zwischen den einzelnen Ländern. Die öffentlichen Bildungseinrichtungen in den fünf nordischen Ländern (Dänemark, Finnland, Island, Norwegen und Schweden) sowie in Mexiko, Polen und Slowenien erheben keine Studiengebühren. Im Gegensatz dazu erhebt ein Drittel der Länder mit verfügbaren Daten an öffentlichen Bildungseinrichtungen Studiengebühren von mehr als I.500 US-Dollar, und in Chile, Japan, Korea und den Vereinigten Staaten sind es mehr als 5.000 US-Dollar. Währenddessen zahlen Studierende für ein Studium im Tertiärbereich A in Belgien, Frankreich, Italien, Österreich, der Schweiz, Spanien und der Türkei nur geringe Studiengebühren. Bei den EU2I-Ländern mit verfügbaren Daten werden nur in den Niederlanden, der Slowakei und dem Vereinigten Königreich jährliche Studiengebühren für einen inländischen Vollzeitstudierenden von mehr als I.500 US-Dollar erhoben (Tab. B5.I und Abb. B5.2).

Die Studiengebühren für inländische Studierende für Studiengänge, die zu einem zweiten oder weiteren Abschluss führen, sind im Allgemeinen nicht wesentlich höher als für Studiengänge, die zu einem ersten Abschluss führen. Die Mehrzahl der Länder mit 
Abbildung B5.2

Durchschnittliche jährliche Studiengebühren für inländische Studierende im Vollzeitstudium an öffentlichen Bildungseinrichtungen des Tertiärbereichs A (2011)

In US-Dollar, kaufkraftbereinigt mittels KKP für das BIP, Studienjahr 2010/2011

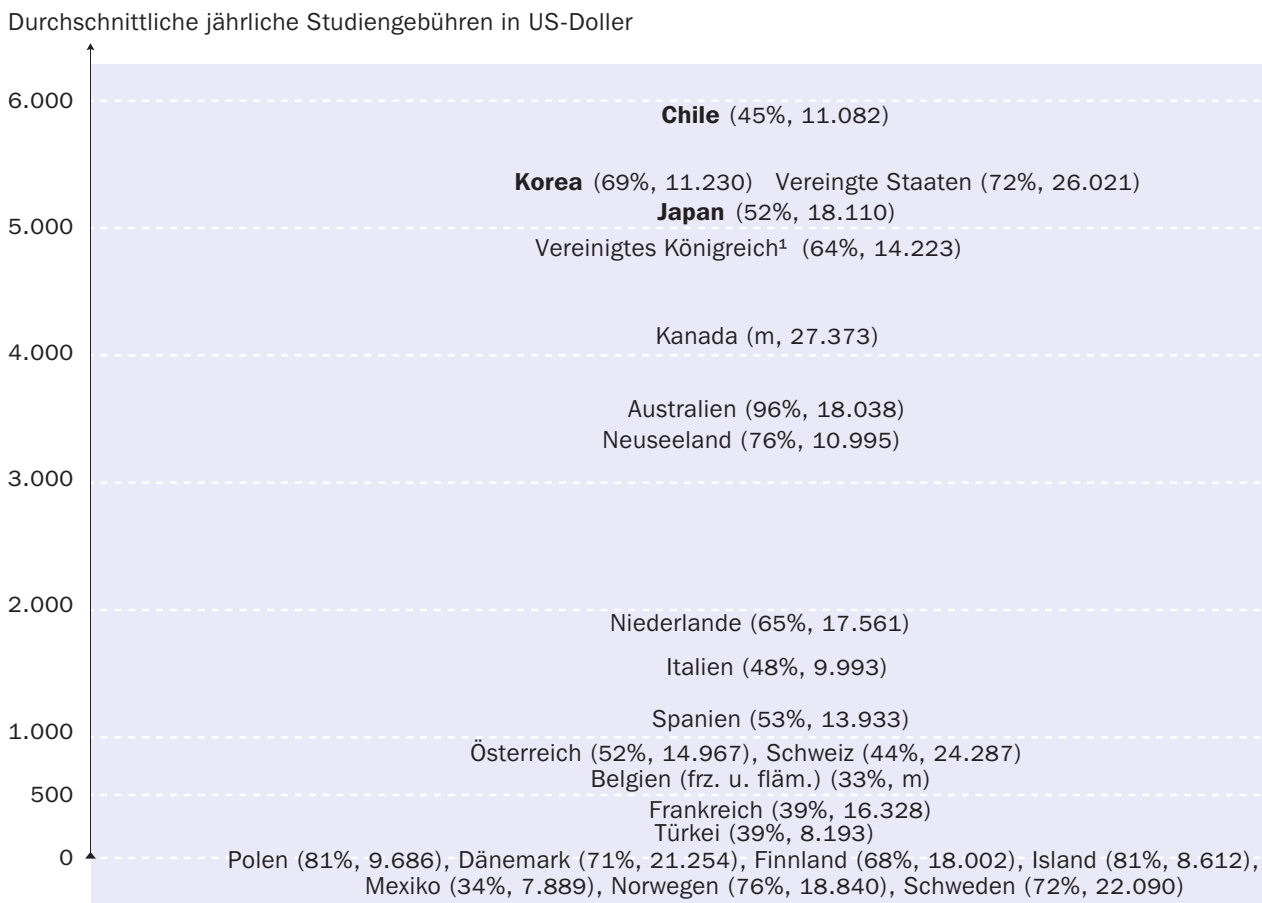

Anmerkung: Diese Abbildung zeigt die jährlichen Studiengebühren in US-Dollar, kaufkraftbereinigt mittels KKP. Fett gedruckte Ländernamen bedeuten, dass sich die Studiengebühren auf öffentliche Bildungseinrichtungen beziehen, jedoch mehr als zwei Drittel der Studierenden an privaten Bildungseinrichtungen eingeschrieben sind. Nach den Ländernamen folgen die jeweilige Netto-Studienanfängerquote und die Ausgaben pro Studierenden im Tertiärbereich A (in US-Dollar). In dieser Abbildung werden keine Zuschüsse, Subventionen oder Darlehen, die die Studiengebühren ganz oder teilweise abdecken, berücksichtigt.

1. In diesem Bildungsbereich gibt es keine öffentlichen Bildungseinrichtungen, und fast alle Studierenden sind in staatlich subventionierten privaten Bildungseinrichtungen eingeschrieben.

Quelle: OECD. Tabellen B1.1a, B5.1 und Indikator C3. Hinweise s. Anhang 3 unter www.oecd.org/edu/eag.htm. StatLink: http://dx.doi.org/10.1787/888933117820 Erläuterung der Kennzeichnung fehlender Daten s. Hinweise für den Leser.

verfügbaren Daten verlangt Studiengebühren, die denen der Studiengänge, die zu einem ersten Abschluss führen, entsprechen oder nur geringfügig höher sind. Ausnahmen bilden hier Australien, Chile, Irland und das Vereinigte Königreich. In Australien steigt die Höhe der Studiengebühren an öffentlichen Bildungseinrichtungen von Studiengängen, die zu einem ersten Abschluss führen, zu Studiengängen, die zu einem zweiten oder weiteren Abschluss führen, von 3.924 US-Dollar auf 6.099 US-Dollar, während sie an unabhängigen privaten Bildungseinrichtungen leicht sinkt. In Australien, Chile und im Vereinigten Königreich unterscheiden sich die Studiengebühren bei Studiengängen, die zu einem ersten Abschluss führen, auch nach dem Studienfach. Die Türkei dagegen ist das einzige Land, in dem die Gebühren für Studiengänge zur Erlangung eines zweiten oder weiteren Abschlusses an öffentlichen Bildungseinrichtungen niedriger sind (Tab. B5.I und B5.3).

\section{Studiengebühren für nicht inländische Studierende}

Die nationalen Bestimmungen für Studiengebühren und Finanzhilfen an Studierende gelten im Allgemeinen für alle Studierenden an den Bildungseinrichtungen des jeweiligen Landes. Bei diesen bildungspolitischen Regelungen werden auch internationale 
Studierende berücksichtigt. Wird bei der Höhe der Studiengebühren oder der finanziellen Unterstützung im Studienland zwischen inländischen und internationalen Studierenden unterschieden, kann sich dies (zusammen mit anderen Faktoren) auf die Mobilität internationaler Studierender auswirken. Diese Unterschiede machen einige Länder für Studierende attraktiver, während Studierende von einem Studium in anderen abgehalten werden können (s. Indikator $\mathrm{C}_{4}$ ), vor allem da immer mehr OECD-Länder von internationalen Studierenden höhere Studiengebühren verlangen.

In der Mehrzahl der Länder mit verfügbaren Daten können öffentliche Bildungseinrichtungen für den gleichen Studiengang unterschiedliche Studiengebühren von inländischen und internationalen Studierenden erheben. In Österreich beispielsweise betragen die durchschnittlichen Studiengebühren, die öffentliche Bildungseinrichtungen von Studierenden erheben, die nicht Bürger eines EU- oder EWR-Landes sind, das Doppelte der von Studierenden dieser Länder erhobenen Gebühren. Ähnliche Regelungen gibt es in Dänemark (seit 2006/2007), Irland, Kanada, den Niederlanden, Neuseeland (mit Ausnahme ausländischer Promotionsstudierender), Polen, Schweden (seit 20II), der Schweiz, der Slowakei, Slowenien, der Türkei, dem Vereinigten Königreich und den Vereinigten Staaten. In diesen Ländern werden je nach Staatsangehörigkeit bzw. Wohnsitz des Studierenden unterschiedlich hohe Studiengebühren erhoben (s. Indikator $\mathrm{C}_{4}$ und Kasten $\mathrm{C}_{4} \cdot 3$ ). In Australien stehen internationalen Studierenden nicht die gleichen Unterstützungen wie inländischen Studierenden zu.

\section{Zuschüsse und Studiendarlehen}

OECD-Untersuchungen (OECD, 2008) deuten darauf hin, dass ein belastungsfähiges System der finanziellen Unterstützung wichtig ist, um gute Ergebnisse der Studierenden im Tertiärbereich zu gewährleisten, und dass hierbei auch die Art der Unterstützung eine Rolle spielt. In vielen OECD-Ländern stellt sich die zentrale Frage, ob die an private Haushalte geleisteten Finanzhilfen für ein Studium im Tertiärbereich A in erster Linie als Zuschüsse oder als Darlehen gewährt werden sollten. In den einzelnen Ländern werden zur Subventionierung der Lebenshaltungs- bzw. Bildungskosten der Studierenden unterschiedliche Kombinationen dieser beiden Arten von Unterstützungsleistungen eingesetzt. Steuerermäßigungen und die steuerliche Anrechenbarkeit von Bildungsmaßnahmen werden in diesem Indikator nicht berücksichtigt. Die Befürworter von Studiendarlehen argumentieren, dass Darlehen die Reichweite der vorhandenen Mittel vergrößern. Wenn die als Zuschüsse ausgegebenen Gelder stattdessen zur Absicherung oder Subventionierung von Darlehen verwendet würden, stünden mehr Studierenden Finanzhilfen zur Verfügung, und mehr Studierende würden ein Studium aufnehmen.

Darlehen verlagern außerdem einen Teil der Bildungskosten auf diejenigen, die auch am meisten von einer abgeschlossenen Hochschulausbildung in Form eines hohen privaten Ertrags profitieren - nämlich die einzelnen Studierenden (s. Indikator A7). Die Gegner von Studiendarlehen führen dagegen an, dass Studiendarlehen weniger als Zuschüsse dazu beitragen, einkommensschwache Studierende zur Fortsetzung ihres Bildungswegs zu ermutigen. Ferner führen sie an, dass Darlehen sowohl aufgrund der verschiedenen Subventionen für Darlehensnehmer und -geber als auch der Verwaltungs- und Schuldendienstkosten weniger wirksam sein könnten als erwartet. Letztendlich könnte es negative Folgen sowohl für die Studierenden als auch den jeweiligen 
Abbildung B5.3

Öffentliche Unterstützungsleistungen für eine Ausbildung im Tertiärbereich (2011)

Öffentliche Unterstützungsleistungen für Bildung an private Haushalte und andere private Einheiten als Prozentsatz der öffentlichen Gesamtausgaben für Bildung im Tertiärbereich, nach Art der Subvention

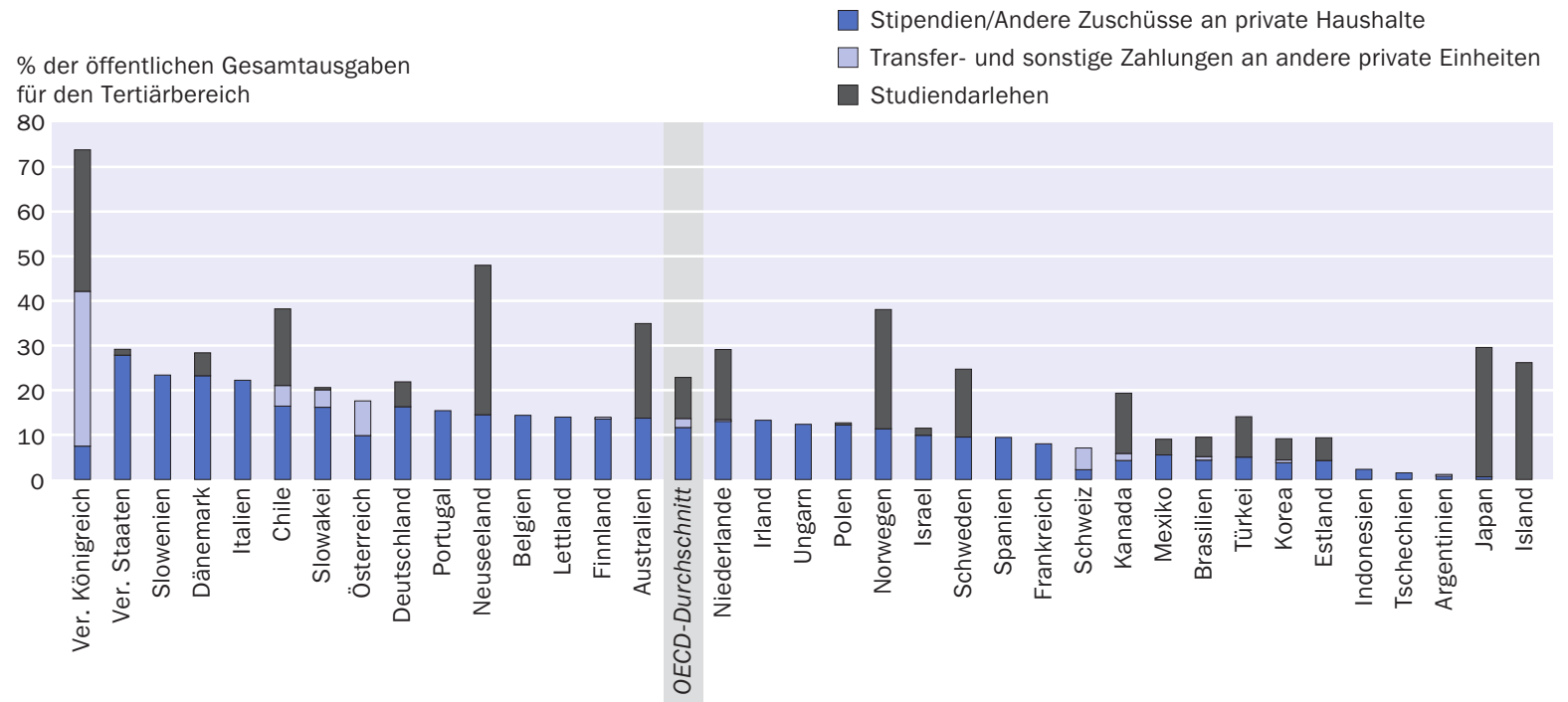

Anordnung der Länder in absteigender Reihenfolge des Anteils von „Stipendien/Andere Zuschüsse an private Haushalte“ und „Transfer- und sonstigen Zahlungen an andere private Einheiten " an den öffentlichen Gesamtausgaben für den Tertiärbereich.

Quelle: OECD. Tabelle B5.4. Hinweise s. Anhang 3 unter www.oecd.org/edu/eag.htm. StatLink: http://dx.doi.org/10.1787/888933117839

Staat haben, wenn eine hohe Zahl von Studierenden ihre Darlehen nicht zurückzahlen können (Kasten B5.I).

Unterstützungsleistungen an private Haushalte und andere private Einheiten machen in den OECD-Ländern im Durchschnitt rund 22 Prozent der öffentlichen Bildungshaushalte für den Tertiärbereich aus (Abb. B5.3). In Australien, Chile, Dänemark, Island, Japan, Neuseeland, den Niederlanden, Norwegen, dem Vereinigten Königreich und den Vereinigten Staaten machen öffentliche Unterstützungsleistungen mehr als 25 Prozent der öffentlichen Ausgaben für den Tertiärbereich aus. Nur in Argentinien, Indonesien und Tschechien machen Unterstützungsleistungen weniger als 7 Prozent der öffentlichen Gesamtausgaben für den Tertiärbereich aus. In Tschechien werden Subventionen für Studienzuschüsse jedoch direkt an die Bildungseinrichtungen überwiesen, die für deren Verteilung unter den Studierenden verantwortlich sind (Tab. B5.4).

Ein Drittel der 36 Länder mit verfügbaren Daten gewährt ausschließlich Stipendien/ Zuschüsse sowie Transfer- und sonstige Zahlungen an andere private Einheiten. Island vergibt ausschließlich Studiendarlehen, während es in anderen Ländern Kombinationen aus Studienzuschüssen und Darlehen gibt. Beide Formen der Unterstützung werden in Australien, Chile, Neuseeland, den Niederlanden, Norwegen, Schweden, dem Vereinigten Königreich und den Vereinigten Staaten in großem Umfang eingesetzt.

In der Regel sind die Länder mit Studiendarlehen auch diejenigen Länder, in denen öffentliche Unterstützungsleistungen an private Haushalte den größten Teil der öffentlichen Gesamtausgaben für den Tertiärbereich ausmachen. In den meisten Fällen ge- 
ben diese Länder auch einen überdurchschnittlich hohen Anteil ihrer Etats für den Tertiärbereich für Zuschüsse und Stipendien aus (Abb. B5.3 und Tab. B5.4).

\section{Länderspezifische Ansätze bei der Finanzierung des Tertiärbereichs}

Viele Länder verfolgen hinsichtlich des Tertiärbereichs ähnliche Ziele, z. B. eine Stärkung der wissensbasierten Wirtschaft, einen breiteren Zugang zum Tertiärbereich, die Förderung hoher Erfolgsquoten und Gewährleistung der Finanzstabilität der Hochschulsysteme. Es gibt jedoch wesentliche Unterschiede zwischen den einzelnen OECDLändern hinsichtlich der Aufteilung der Kosten für Bildung im Tertiärbereich auf den Staat, die Studierenden und ihre Familien und andere private Einheiten sowie hinsichtlich der finanziellen Unterstützung, die Studierenden staatlicherseits gewährt wird.

Wie vorstehend dargelegt unterscheiden sich die Kosten für den Tertiärbereich und die Höhe der Unterstützungsleistungen für die Studierenden in den einzelnen OECDLändern beträchtlich. Dieser Abschnitt systematisiert die in Ländern mit verfügbaren Daten verfolgten Ansätze bei der Finanzierung des Tertiärbereichs und analysiert die Auswirkungen des jeweiligen Modells auf den Zugang zum Tertiärbereich. Die Länder werden unter zwei Aspekten in vier Gruppen eingeteilt: die Höhe der Studiengebühren und die finanzielle Unterstützung, die über das System der Finanzbeihilfen für Studierende des Tertiärbereichs gewährt wird.

Es gibt kein einheitliches Finanzierungsmodell im Tertiärbereich A. Länder mit ähnlich hohen Studiengebühren im Tertiärbereich A können sich hinsichtlich des Anteils der Studierenden, die öffentliche Unterstützung erhalten, unterscheiden und/oder auch hinsichtlich der durchschnittlichen Höhe dieser Unterstützung (Tab. B5.I, B5.2, B5.3, B5.4 sowie Tab. B5.5 im Internet und Abb. B5.I). Da seit 1995 in vielen OECD-Ländern die Regelungen hinsichtlich der Studiengebühren an Bildungseinrichtungen des Tertiärbereichs reformiert wurden, haben einige Länder in diesem Zeitraum den einen Ansatz durch einen anderen ersetzt (Abb. B5.I und Kasten B5.I in Bildung aufeinen Blick 2012).

Gruppe 1: Länder ohne bzw. mit niedrigen Studiengebühren und großzügiger finanzieller Unterstützung der Studierenden

Diese Gruppe umfasst die nordischen Länder Dänemark, Finnland, Island, Norwegen und Schweden. In diesen Ländern gibt es ein progressiveres Steuersystem (OECD, 20II), die Studierenden bezahlen keine Studiengebühren und erhalten großzügige öffentliche Unterstützung für ihre Ausbildung im Tertiärbereich. Dafür sind die Einkommensteuersätze hoch. Mit 74 Prozent liegt die durchschnittliche Studienanfängerquote für den Tertiärbereich A in dieser Ländergruppe signifikant über dem OECD-Durchschnitt von 59 Prozent (s. Indikator $\mathrm{C}_{3}, \mathrm{Tab} . \mathrm{C}_{3} .2 \mathrm{2}$ ). Die hohen Studienanfängerquoten könnten auch mit der Attraktivität der guten finanziellen Unterstützung dieser Länder für Studierende zusammenhängen und nicht nur damit, dass keine Studiengebühren anfallen. So erhalten beispielsweise mehr als 55 Prozent der Studierenden in diesen Ländern öffentliche Zuschüsse, staatliche Darlehen oder eine Kombination aus beidem (Tab. B5.I und B5.2 sowie Abb. B5.I).

Diese Vorgehensweise bei der Finanzierung des Tertiärbereichs spiegelt in diesen Ländern tief verwurzelte soziale Werte wie Chancengleichheit und soziale Gerechtigkeit 
wider. Die Grundidee, dass der Staat seinen Bürgern eine kostenlose Ausbildung im Tertiärbereich ermöglichen sollte, ist eine Besonderheit der Bildungskultur dieser Länder: Die Finanzierung sowohl der Bildungseinrichtungen als auch der Studierenden in diesen Ländern basiert auf dem Grundsatz, dass der Zugang zum Tertiärbereich ein Recht und nicht ein Privileg ist. Im Verlauf der letzten Io Jahre haben sich jedoch Dänemark und Schweden (ab 20II) für die Einführung von Studiengebühren für internationale Studierende entschieden, um die für Bildungseinrichtungen im Tertiärbereich zur Verfügung stehenden Ressourcen zu erhöhen, auch Island zog dies in Betracht. Dabei besteht die Gefahr, dass einige internationale Studierende so von einem Studium in diesen Ländern abgehalten werden. Seit der Einführung der Reform ist die Zahl der internationalen Studierenden in Schweden gesunken: Zwischen Herbst 2010 und Herbst 201 I sank die Zahl der Studierenden, die nicht an einem Austauschprogramm teilnahmen und von außerhalb des Europäischen Wirtschaftsraums und der Schweiz kamen, um fast 8o Prozent (Swedish Higher Education Authority, 2013).

\section{Gruppe 2: Länder mit hohen Studiengebühren und stark ausgeprägter Unterstützung für Studierende}

Diese zweite Ländergruppe umfasst Australien, Kanada, Neuseeland, die Niederlande, das Vereinigte Königreich und die Vereinigten Staaten. In diesen Ländern sind die finanziellen Barrieren für den Zugang zu Bildungseinrichtungen des Tertiärbereichs A hoch, gleichzeitig werden jedoch Studierenden hohe öffentliche Unterstützungsleistungen gewährt. Die durchschnittliche Studienanfängerquote im Tertiärbereich A in dieser Ländergruppe liegt mit 75 Prozent signifikant über dem OECD-Durchschnitt und ist höher als in den meisten Ländern mit niedrigen Studiengebühren (mit Ausnahme der nordischen Länder). In den Ländern der Gruppe 2 tragen tendenziell private Einheiten (z. B. Privatunternehmen und gemeinnützige Organisationen) am stärksten zur Finanzierung der Bildungseinrichtungen im Tertiärbereich bei. Anders ausgedrückt werden in den Ländern der Gruppe 2 die Bildungskosten gemeinsam vom Staat, den privaten Haushalten und Privatunternehmen getragen (s. Abb. B3.2 und Tab. B3.I).

In allen Ländern dieser Gruppe liegen die von Bildungseinrichtungen des Tertiärbereichs A erhobenen Studiengebühren bei über I.500 US-Dollar, gleichzeitig aber erhalten mehr als 75 Prozent der Studierenden des Tertiärbereichs A öffentliche Unterstützungsleistungen (in Australien, Neuseeland, den Niederlanden, dem Vereinigten Königreich und den Vereinigten Staaten, den fünf Ländern mit verfügbaren Daten; Tab. B5.I und B5.2). Die Systeme zur finanziellen Unterstützung der Studierenden sind gut ausgebaut und tragen weitgehend den Bedürfnissen aller Studierenden Rechnung. Daher liegt der Anteil der Bildungsausgaben im Tertiärbereich, der in diesen Ländern in öffentliche Unterstützungsleistungen fließt, in fünf der sechs Länder über dem OECD-Durchschnitt von 22 Prozent: in Australien (35 Prozent), Neuseeland (48 Prozent), den Niederlanden (29 Prozent), dem Vereinigten Königreich (74 Prozent) und den Vereinigten Staaten (29 Prozent). In Kanada ist er mit I9 Prozent nahe am OECDDurchschnitt (Tab. B5.4). 
In den Ländern dieser Gruppe liegt die Studienanfängerquote im Tertiärbereich A über dem OECD-Durchschnitt. So gehören beispielsweise Australien mit 96 Prozent und Neuseeland mit 79 Prozent zu den Ländern mit den höchsten Studienanfängerquoten im Tertiärbereich A, wobei dies teilweise auch auf den hohen Anteil internationaler Studierender im Tertiärbereich A zurückzuführen ist. Über dem OECD-Durchschnitt der Studienanfängerquoten im Tertiärbereich A von 59 Prozent lagen 201 I auch die in den Niederlanden (65 Prozent), dem Vereinigten Königreich (64 Prozent) und den Vereinigten Staaten ( 72 Prozent). In diesen Ländern liegen die Ausgaben pro Studierenden des Tertiärbereichs für eigentliche Bildungsdienstleistungen (Dienstleistungen, die direkt mit Unterricht und Bildung an Bildungseinrichtungen in Zusammenhang stehen) über dem OECD-Durchschnitt, und ihr Einkommensteueraufkommen als Prozentsatz des BIP ist im Vergleich zum OECD-Durchschnitt relativ hoch. Bei der Höhe der Einkommensbesteuerung sind die Niederlande ein Sonderfall, denn diese liegt unter dem OECD-Durchschnitt (s. Tab. Br.Ib im Internet und Tab. C3.I).

OECD-Untersuchungen (OECD, 2008) deuten darauf hin, dass ganz allgemein gesprochen dieser Ansatz für Länder eine effektive Möglichkeit darstellen kann, die Studienanfängerquoten im Tertiärbereich zu erhöhen. Während einer Wirtschaftskrise jedoch können Studiengebühren eine beträchtliche finanzielle Belastung für Studierende und ihre Familien darstellen und einige davon abhalten, ein Studium im Tertiärbereich aufzunehmen, selbst wenn den Studierenden relativ hohe Unterstützungsleistungen zur Verfügung stehen. Dies ist in Kanada, dem Vereinigten Königreich und den Vereinigten Staaten ein viel diskutiertes Thema.

\section{Gruppe 3: Länder mit hohen Studiengebühren und einer weniger gut ausgebauten} finanziellen Unterstützung von Studierenden

In Chile, Japan und Korea entrichten die meisten Studierenden hohe Studiengebühren (an Bildungseinrichtungen im Tertiärbereich A durchschnittlich mehr als 4.500 USDollar), aber die finanzielle Unterstützung von Studierenden ist weniger gut ausgebaut als in den Ländern der Gruppen I und 2. Dieser Ansatz kann eine hohe finanzielle Belastung für Studierende und ihre Familien bedeuten. Die Studienanfängerquoten im Tertiärbereich A liegen in Chile mit 45 Prozent und Japan mit 52 Prozent unter dem OECD-Durchschnitt, in Korea mit 69 Prozent jedoch signifikant darüber. In Japan und Korea gibt es für einige Studierende mit sehr guten akademischen Leistungen, die Schwierigkeiten bei der Finanzierung ihres Studiums haben, die Möglichkeit, dass die Studien- und/oder Aufnahmegebühren verringert bzw. vollkommen erlassen werden.

Japan und Korea zählen zu den Ländern, in denen der Anteil der öffentlichen Ausgaben für den Tertiärbereich, ausgedrückt als Prozentsatz des BIP, mit am niedrigsten ist (s. Tab. B4.I). Dies erklärt zum Teil den niedrigen Anteil Studierender, die öffentliche Darlehen erhalten. Es muss jedoch angemerkt werden, dass in beiden Ländern vor Kurzem Reformen zur Verbesserung der Unterstützung von Studierenden umgesetzt wurden.

Gruppe 4: Länder mit niedrigen Studiengebühren und weniger gut ausgebauten finanziellen Unterstützungsleistungen für Studierende

Die vierte Gruppe umfasst alle anderen europäischen Länder, für die Daten vorliegen (Belgien, Frankreich, Irland, Italien, Österreich, Polen, Portugal, die Schweiz, Spanien und Tschechien), sowie Mexiko. In all diesen Ländern sind die Studiengebühren 
verglichen mit denen der Gruppe 2 und 3 verhältnismäßig niedrig, obwohl seit 1995 in einigen dieser Länder Reformen umgesetzt wurden, insbesondere in Italien und Österreich, um die von den öffentlichen Bildungseinrichtungen erhobenen Studiengebühren zu erhöhen (Abb. B5.I und Kasten B5.I). In den Ländern der Gruppe 4 sind die finanziellen Zugangsbarrieren zu einer Ausbildung im Tertiärbereich in Form von Studiengebühren relativ niedrig (oder es gibt wie in Irland und Mexiko überhaupt keine Studiengebühren), während gleichzeitig auch die finanziellen Unterstützungsleistungen für Studierende, die überwiegend auf bestimmte Gruppen von Studierenden ausgerichtet sind, relativ niedrig sind. Die seitens öffentlicher Bildungseinrichtungen erhobenen Studiengebühren übersteigen in dieser Gruppe in keinem Fall I.300 USDollar, und in den Ländern mit verfügbaren Daten liegt der Anteil der Studierenden, die öffentliche Unterstützung erhalten, bei weniger als 40 Prozent (Tab. B5.I und B5.2).

Für gewöhnlich sind die Bildungseinrichtungen in den Ländern der Gruppe 4 bei ihrer Finanzierung stark von öffentlichen Mitteln abhängig, und die Bildungsbeteiligung im Tertiärbereich liegt für gewöhnlich unter dem OECD-Durchschnitt. Die durchschnittliche Studienanfängerquote im Tertiärbereich A ist in dieser Ländergruppe mit 56 Prozent relativ niedrig. Sie wird jedoch in Belgien durch relativ hohe Studienanfängerquoten im Tertiärbereich B ausgeglichen. Die Ausgaben pro Studierenden im Tertiärbereich A sind ebenfalls vergleichsweise niedrig (Abb. B5.2 und Indikator BI). Während hohe Studiengebühren potenziell ein Hindernis bei der Aufnahme eines Studiums im Tertiärbereich sein können, deuten die Daten der Länder der Gruppe 4 darauf hin, dass niedrigere Studiengebühren, die den Zugang zu Bildung eigentlich erleichtern sollten, nicht notwendigerweise eine Garantie für höhere Studienanfängerquoten oder eine bessere Qualität der Ausbildung im Tertiärbereich A sind.

In diesen Ländern können Studierende und ihre Familien Anspruch auf Unterstützungsleistungen haben, die seitens anderer Stellen als dem Bildungsministerium zur Verfügung gestellt werden (z. B. Wohnungsbeihilfen, Steuerermäßigungen und/oder die steuerliche Anrechenbarkeit von Ausbildungskosten), die jedoch in dieser Analyse nicht berücksichtigt werden. In Frankreich beispielsweise machen bei den staatlichen Unterstützungsleistungen Wohnungsbeihilfen, die ungefähr ein Drittel der Studierenden erhalten, rund 9o Prozent der Stipendien/Zuschüsse aus. Polen stellt einen Sonderfall dar, da das Studium der meisten Studierenden an öffentlichen Einrichtungen vollständig durch die öffentliche Hand finanziert wird, während Teilzeitstudierende die Studienkosten in vollem Umfang selbst tragen müssen.

In Ländern der Gruppe 4 gibt es entweder überhaupt keine Systeme der Darlehensfinanzierung durch öffentliche Darlehen oder staatlich garantierte Darlehen, oder sie stehen nur einem kleinen Teil der Studierenden in diesen Ländern zur Verfügung (Tab. B5.2). Gleichzeitig variieren die Höhe der öffentlichen Ausgaben und das Einkommensteueraufkommen als Prozentsatz des BIP in dieser Ländergruppe signifikant stärker als in den anderen Gruppen.

\section{Öffentliche Darlehenssysteme und Höhe der öffentlichen Darlehen}

Die öffentlichen Darlehenssysteme (Einzelheiten zu den unterschiedlichen Darlehenssystemen für Studierende s. Kasten B5.I) sind in Australien, Norwegen, dem Vereinigten Königreich und den Vereinigten Staaten besonders gut entwickelt, dort erhalten 
mindestens rund 70 Prozent der Studierenden im Tertiärbereich A im Verlauf ihres Studiums ein öffentliches Darlehen. Auch in Norwegen (64 Prozent) sowie in Island und Schweden - zwei der Länder, in denen ebenso wie in Norwegen die Bildungseinrichtungen im Tertiärbereich A keine Studiengebühren für inländische Studierende erheben - sind die öffentlichen Darlehenssysteme relativ gut ausgebaut (63 bzw. 40 Prozent der Studierenden erhalten ein Darlehen). Gleichzeitig gehören die Vereinigten Staaten zu den Ländern, in denen das Niveau der Studiengebühren in öffentlichen Bildungseinrichtungen des Tertiärbereichs A mit am höchsten ist, und dort erhalten jedes Jahr 84 Prozent der ganzjährig Vollzeitstudierenden öffentliche Darlehen.

Die finanzielle Unterstützung, die Studierende während ihres Studiums durch öffentliche Darlehen erhalten, kann jedoch nicht allein anhand des Anteils der Studierenden interpretiert werden, die Darlehen erhalten. Die Unterstützung für die Studierenden hängt auch von der möglichen Höhe der öffentlichen Darlehen ab. In Ländern mit vergleichbaren Daten beträgt der durchschnittliche jährliche Bruttobetrag der öffentlichen Darlehen, die jedem Studierenden zur Verfügung stehen, in ungefähr der Hälfte der Länder mehr als 4.000 US-Dollar; er variiert zwischen weniger als 3.000 USDollar in Belgien (frz.), Finnland (eher von staatlichen Stellen garantierte Darlehen als staatliche Darlehen), den Niederlanden und der Türkei und mehr als 9.00o US-Dollar in Island, Mexiko, Norwegen, Spanien, dem Vereinigten Königreich und den Vereinigten Staaten (Tab. B5·3, Studienjahr 2010/20II).

Der Vergleich der durchschnittlichen Studiengebühren und der durchschnittlichen Darlehensbeträge sollte mit Vorsicht interpretiert werden, da in ein und demselben Studiengang die Darlehenshöhe unter den Studierenden stark variieren kann, selbst wenn die von den Studierenden zu zahlenden Studiengebühren gleich hoch sind. Trotzdem liefert ein solcher Vergleich einen ersten Eindruck davon, ob Studierende ein Darlehen zur Deckung der Studiengebühren und der Lebenshaltungskosten aufnehmen. Je höher die durchschnittlichen Studiengebühren, die seitens der Bildungseinrichtungen erhoben werden, desto höher der Bedarf der Studierenden an finanzieller Unterstützung durch öffentliche Darlehen. Mit steigenden Studiengebühren steigt der Druck auf den jeweiligen Staat, die Studierenden finanziell zu unterstützen. In allen OECD-Ländern, in denen Daten zu den jährlichen Brutto-Darlehensbeträgen vorliegen, übersteigt die durchschnittliche Höhe öffentlicher Darlehen die durchschnittlichen Studiengebühren öffentlicher Bildungseinrichtungen - mit Ausnahme Australiens. Dies deutet darauf hin, dass öffentliche Darlehen auch dazu beitragen können, einen Teil der Lebenshaltungskosten Studierender während ihres Studiums zu decken.

Bei den Ländern, in denen die durchschnittlichen Studiengebühren von öffentlichen Bildungseinrichtungen des Tertiärbereichs A mehr als I.500 US-Dollar betragen, ist der durchschnittliche Darlehensbetrag im Vereinigten Königreich (für Studierende staatlich subventionierter privater Bildungseinrichtungen) und den Vereinigten Staaten mindestens doppelt so hoch wie die durchschnittlichen Studiengebühren. Die größten Unterschiede zwischen durchschnittlichen Studiengebühren und durchschnittlicher Darlehenshöhe sind in den nordischen Ländern zu beobachten, wo die Bildungseinrichtungen keine Studiengebühren erheben und ein hoher Anteil der Studierenden jedes Jahr öffentliche Darlehen erhält, wobei der durchschnittliche Darlehensbetrag 
Kasten B5.1

\section{Studiendarlehen: Einkommensabhängige Rückzahlung im Vergleich zu fester Tilgung}

Die Investition in eine Ausbildung im Tertiärbereich verschafft dem Einzelnen im Allgemeinen bessere Chancen auf dem Arbeitsmarkt, senkt das Risiko der Erwerbslosigkeit und kann zu hohen privaten und öffentlichen Erträgen führen (s. Indikatoren $\mathrm{A}_{5}$, A6 und $\mathrm{A} 7$ ).

Studiendarlehen als Ergänzung zu Zuschüssen und Stipendien sollen den Studierenden helfen, die Kosten ihres Studiums im Tertiärbereich zu decken (Studiengebühren und/oder Lebenshaltungskosten). Öffentliche Darlehenssysteme sind noch relativ neu. Sie wurden hauptsächlich in den I96oer- bis I980er-Jahren entwickelt, als die Bildungsbeteiligung im Tertiärbereich massiv stieg, und gingen Hand in Hand mit steigenden Studiengebühren.

Aber die sich ansammelnde Schuldenbelastung der Studierenden ist ein Faktor, der sich auf ihre Entscheidung, in ein Studium im Tertiärbereich zu investieren, auswirken könnte. Die Höhe der Schuldenbelastung hängt von der Höhe der Studiengebühren und der Höhe der Lebenshaltungskosten sowie den auf die Darlehen anfallenden Zinsen ab (die eventuell subventioniert werden).

In Ländern, in denen für ein Studium im Tertiärbereich keine oder niedrige Studiengebühren erhoben werden (Gruppe I und Gruppe 4, s. oben), fällt die Schuldenbelastung der Absolventen bei Studienabschluss gewöhnlich niedriger aus als bei Absolventen in Ländern mit hohen Studiengebühren, da die Studiendarlehen hauptsächlich der Deckung der Lebenshaltungskosten der Studierenden dienen. Dennoch kann die Schuldenbelastung für Absolventen bei Studienabschluss in den nordischen Ländern, wo keine oder nur geringe Studiengebühren erhoben werden, hoch sein, da dort die Lebenshaltungskosten hoch sind. Die Schuldenbelastung für Studierende in Ländern mit hohen Studiengebühren (Gruppe 2 und Gruppe 3) kann bei Studienabschluss höher sein, und die Anreize und Risiken für eine Investition in ein Studium im Tertiärbereich können sich je nach Art des aufgenommenen Studiendarlehens unterscheiden.

Es gibt zwei grundlegende Arten von Studiendarlehen: Darlehen mit fester Tilgung (auch als hypothekenähnliche Darlehen bezeichnet) und Darlehen mit einkommensabhängiger Rückzahlung. Bei einem Darlehen mit fester Tilgung sind die Studierenden verpflichtet, das Darlehen unabhängig von ihrer finanziellen Situation nach dem Studienabschluss innerhalb eines festgelegten Zeitraums zurückzuzahlen. Dies kann eine enorme finanzielle Belastung für die Absolventen (bzw. für diejenigen, die das Studium nichtabschließen) mitniedrigen Einkommen darstellen, wie sich jüngst während der Wirtschaftskrise zeigte, als 2013 die Verschuldung von Studierenden in den Vereinigten Staaten I, I Billionen US-Dollar erreichte. Bei Darlehenssystemen mit einkommensabhängiger Rückzahlung hängt die Rückzahlung davon ab, ob der Darlehensnehmer ein Mindesteinkommen verdient. Dabei werden die Darlehensschulden nach einer bestimmten Zeit erlassen. Diese Art von Rückzahlungsvereinbarung berücksichtigt die Fähigkeit der Absolventen, ihre Darlehen zurückzuzahlen. 
Bei beiden Systemen fallen für den Staat, der die Rückzahlung der Darlehen garantiert bzw. die Zinssätze subventioniert, gewisse Kosten an. Die Rückzahlung öffentlicher Darlehen kann für Staaten eine bedeutende Einnahmequelle darstellen (durch Zinszahlungen, denn die Rückzahlung von Darlehenskapital wirkt sich in der Bilanz aus) und die Kosten der Darlehensprogramme beträchtlich senken. Die potenzielle finanzielle Belastung der Staaten ist jedoch bei einer einkommensabhängigen Rückzahlung ungewisser, da diese von der Fähigkeit der Absolventen abhängt, eine Arbeitsstelle zu finden und mehr als das für die Darlehensrückzahlung festgelegte Mindesteinkommen zu verdienen. Diese Form von Studiendarlehen wurde in den letzten Jahren in mehreren Ländern eingeführt. So wurde beispielsweise $1999 \mathrm{im}$ Vereinigten Königreich das hypothekenähnliche Darlehenssystem durch ein einkommensabhängiges Darlehenssystem abgelöst. Zwar beziehen die meisten Studierenden in Einrichtungen des Tertiärbereichs A im Vereinigten Königreich ein Darlehen, dennoch musste 20II zusätzliche öffentliche Unterstützung in Höhe von 6 Milliarden Britischen Pfund gewährt werden (mehr als 30 Prozent der öffentlichen Gesamtausgaben im Tertiärbereich, Tab. B5.4), obwohl die letztendlichen Ausgaben des Staates bei Berücksichtigung der Darlehensrückzahlungen niedriger sind. Nach dem Anstieg der Schulden von Studierenden in den Vereinigten Staaten wurden auch dort einkommensabhängige Darlehenssysteme eingeführt: 2009 das einkommensbasierte Rückzahlungsprogramm und 2012 das Pay-As-You-Earn-(PAYE-)Programm.

Sieht man Bildung als Investition an, so wirken sich Studiendarlehen auf die Nettoerträge der Bildung aus (s. Indikator A7). Abgesehen von der Möglichkeit der Bildungsbeteiligung und der damit verbundenen Vorteile hängt der persönliche Ertrag einer Ausbildung im Tertiärbereich von den mit den Darlehen verbundenen Zinsaufwendungen und den Vorteilen der Studierenden durch einen Rückzahlungserlass ab. Die staatlichen Nettoerträge sinken in dem Ausmaß der Kosten, die im Zusammenhang mit der Subventionierung niedriger Zinssätze für Studiendarlehen und dem Erlass von Darlehensrückzahlungen entstehen.

Die Verbreitung von einkommensabhängigen bzw. festen Rückzahlungssystemen wirkt sich auf die Nettoerträge von Bildung aus, da die Rückzahlung bei einkommensabhängigen Systemen häufiger ausfällt (erlassen wird), was höhere Kosten für die öffentlichen Haushalte bei gleichzeitig größerem Nutzen für die Studierenden bedeutet. Von den Ländern mit verfügbaren Daten berichten Kanada und das Vereinigte Königreich den höchsten Erlass von Darlehensschulden, sie gehören aber gleichzeitig zu den Ländern mit hohen zu bezahlenden Darlehenszinsen (Tab. B5·3).

von ungefähr 4.200 US-Dollar in Dänemark über 9.400 US-Dollar in Norwegen bis zu fast I0.400 US-Dollar in Island reicht (Tab. B5.I und B5.3).

Die öffentlichen Darlehenssysteme bieten auch durch spezielle Zinssätze für Studierende, die Rückzahlungsmodalitäten und sogar durch die Mechanismen, die im Hinblick auf den Erlass der Rückzahlung greifen, ein gewisses Maß an finanzieller Unterstützung (Tab. B5.3). 
Finanzielle Unterstützung durch verminderte Zinssätze

Die finanzielle Unterstützung durch verminderte Zinssätze bei öffentlichen bzw. privaten Darlehen ist zweifacher Natur: Die Höhe der unterstützten Zinssätze für Studierende kann sich während des Studiums und danach unterscheiden. Ein Vergleich der Zinsniveaus in den einzelnen Ländern ist schwierig, da die Struktur der (öffentlichen wie privaten) Zinssätze nicht bekannt ist und sich signifikant von Land zu Land unterscheiden kann, sodass ein bestimmter Zinssatz in einem Land als hoch und in einem anderen als niedrig angesehen werden kann. Unterschiedliche Zinssätze während des Studiums und im Anschluss daran scheinen jedoch das Ziel zu verfolgen, die finanzielle Belastung der Studierenden während des Studiums zu mindern. So erheben beispielsweise Island, Japan, Kanada, Neuseeland und Norwegen während der Dauer des Studiums keine nominalen Zinssätze auf öffentliche Darlehen, während die Studierenden/ Absolventen nach ihrem Studium eventuell Zinsen in einer Höhe zahlen müssen, die mindestens den staatlichen Fremdfinanzierungskosten entspricht. Neuseeland beispielsweise führte 2006/2007 ein, dass Studierende, die ihren ständigen Wohnsitz in Neuseeland haben, zinslose Darlehen erhalten können, trifft diese Bedingung jedoch nicht zu, fallen Zinsen an. In Belgien, Estland, den Niederlanden, Polen, Schweden, Ungarn, dem Vereinigten Königreich und den Vereinigten Staaten gibt es keinen Unterschied zwischen den während des Studiums und im Anschluss daran geltenden Zinssätzen für die Studierenden. In Australien wird kein Realzins auf Darlehen erhoben; stattdessen wird der Teil des Darlehens, der nach II Monaten und darüber hinaus noch nicht zurückgezahlt ist, indexiert, um so den Erhalt des Realwerts des Darlehens sicherzustellen (Tab. B5·3).

\section{Rückzahlung von Darlehen}

In den aktuellen Zahlen über die Bildungsausgaben der privaten Haushalte als Teil der privaten Ausgaben (s. Indikator B3) sind die Rückzahlungen öffentlicher Darlehen durch frühere Darlehensempfänger nicht enthalten. Wie aus Tabelle B5.3 ersichtlich, unterscheidet sich die Rückzahlungsdauer von Land zu Land und reicht von weniger als Io Jahren in Australien, Belgien (frz.), Finnland, Neuseeland, Spanien und der Türkei bis zu mindestens 20 Jahren in Island und Schweden. Von den I8 OECD-Ländern, für die Daten über die Rückzahlungssysteme vorliegen, machen vier englischsprachige Länder (Australien, Neuseeland, das Vereinigte Königreich und unter speziellen Bedingungen die Vereinigten Staaten) sowie Island, die Niederlande, Schweden und Ungarn die Rückzahlung der Darlehen von der Einkommenshöhe der Absolventen abhängig. Die Rückzahlungsdauer kann bis zu maximal I5 Jahre betragen, wie dies in den Niederlanden der Fall ist. Das jährliche Mindesteinkommen für die Rückzahlung der Darlehen durch die Darlehensnehmer variiert sehr stark zwischen den Ländern mit einkommensabhängigen Rückzahlungssystemen: Während es in Schweden mit weniger als 7.000 US-Dollar besonders niedrig ist, variiert es von 13.000 US-Dollar in Neuseeland bis zu mehr als 29.000 US-Dollar in Australien.

In den anglofonen Ländern liegen auch die von den Bildungseinrichtungen erhobenen durchschnittlichen Studiengebühren bei mehr als I.500 US-Dollar, und die durchschnittliche Darlehenshöhe ist im Vergleich zu anderen Ländern mit öffentlichen Darlehenssystemen mit am höchsten (Tab. B5.3). 


\section{Schulden bei Studienabschluss}

Während einer Wirtschaftskrise haben es junge Absolventen möglicherweise schwer, Arbeitsplätze zu finden, und daher können die Schulden bei Studienabschluss Anlass zur Besorgnis geben. Wenn die Chancen auf dem Arbeitsmarkt abnehmen, neigen Absolventen eventuell dazu weiterzustudieren, wodurch sie noch höhere Schulden anhäufen.

In mehreren Ländern haben die meisten Studierenden bei Studienabschluss Schulden. Die Länder, in denen die Bildungseinrichtungen des Tertiärbereichs hohe Studiengebühren erheben, sind auch die Länder, in denen die Studierenden bei Studienabschluss die höchsten Schulden haben. Im Gegensatz dazu fällt in Ländern, bei denen ein verhältnismäßig kleiner Teil der Absolventen Schulden hat, auch die Schuldenbelastung niedriger aus. So hat in der Türkei beispielsweise ein Fünftel der Absolventen bei Studienabschluss Schulden, im Durchschnitt 5.200 US-Dollar, wohingegen in den Vereinigten Staaten zwei Drittel der Absolventen durchschnittliche Darlehensschulden in Höhe von 25.400 US-Dollar haben.

Auch in Ländern ohne Studiengebühren für inländische Studierende ist eine hohe Schuldenbelastung der Studierenden zu beobachten. Dies trifft auf Studierende in Schweden zu, die bei Studienabschluss im Durchschnitt eine Schuldenbelastung von 20.000 US-Dollar haben. In Norwegen beträgt die durchschnittliche Schuldenbelastung von Studierenden 25.000 US-Dollar. Im Gegensatz zu Ländern mit hohen Studiengebühren sollen die Darlehen in diesen Ländern alle Arten von Ausgaben der Studierenden abdecken. Darüber hinaus ist in diesen Ländern das Einkommen nach Studienabschluss im Allgemeinen niedriger und die Steuerbelastung höher (s. Gruppe I).

\section{Definitionen}

Bei den durchschnittlichen Studiengebühren, die öffentliche und private Bildungseinrichtungen des Tertiärbereichs A erheben, wird nicht zwischen unterschiedlichen Studiengängen unterschieden. Der Indikator liefert einen Überblick über die Studiengebühren in diesem Bildungsbereich nach Art der Bildungseinrichtung und zeigt die Anteile der Studierenden auf, die Stipendien/Zuschüsse zur vollständigen oder teilweisen Abdeckung der Studiengebühren erhalten bzw. nicht erhalten. Die Höhe der Studiengebühren und die entsprechenden Anteile der Studierenden sollten mit Vorsicht interpretiert werden, da sie aus dem gewichteten Durchschnitt der wichtigsten Studiengänge des Tertiärbereichs A resultieren und nicht alle Bildungseinrichtungen berücksichtigt sind.

Öffentliche Bildungsausgaben, die aus Transferzahlungen an Studierende, ihre Familien und andere private Einheiten bestehen, umfassen Mittel, die indirekt an Bildungseinrichtungen fließen können, wie z. B. Unterstützungsleistungen, die für die Zahlung von Studiengebühren genutzt werden, sowie Mittel, die nicht - auch nicht indirekt - an Bildungseinrichtungen fließen, wie finanzielle Zuschüsse zu den Lebenshaltungskosten von Studierenden.

Öffentliche Subventionen an private Haushalte umfassen: Zuschüsse/Stipendien (nicht rückzahlbare Subventionen), öffentliche Studiendarlehen, die zurückzuzahlen sind, Fami- 
lienbeihilfen oder Kindergeld, die an den Status als Studierender gebunden sind, öffentliche Unterstützungsleistungen in Form von Geld- oder Sachleistungen, besonders für Unterbringung, Transport, medizinische Versorgung, Bücher und Lernmittel, soziale Zwecke, Freizeitgestaltung und sonstige Zwecke, sowie Zinssubventionen für private Darlehen.

Nicht unterschieden wird jedoch bei den öffentlichen Unterstützungsleistungen zwischen den verschiedenen Arten von Zuschüssen bzw. Darlehen, wie z. B. Stipendien, Familienbeihilfen und Subventionen in Form von Sachleistungen. Die Länder können die Studierenden und ihre Familien auch durch die Gewährung von Wohnungsbeihilfen, Steuerermäßigungen und/oder die steuerliche Anrechenbarkeit von Ausbildungskosten unterstützen. Diese Subventionen werden von diesem Indikator jedoch nicht erfasst. Daher können die in manchen Ländern den Studierenden gewährten Finanzhilfen deutlich zu niedrig geschätzt sein.

Häufig übernimmt der Staat auch gegenüber privaten Kreditgebern eine Bürgschaft für die Rückzahlung von Studiendarlehen. In einigen OECD-Ländern ist diese indirekte Form der Unterstützung ebenso bedeutend oder sogar noch bedeutender als die direkte Finanzhilfe an Studierende. Aus Gründen der besseren Vergleichbarkeit werden jedoch in diesem Indikator nur die öffentlichen Transferleistungen für private Darlehen an private Einheiten berücksichtigt und nicht das Gesamtvolumen der gewährten Darlehen. Einige der Tabellen enthalten trotzdem einige qualitative Informationen, um so auch einen Einblick in diese Art von Unterstützungsleistungen zu gewähren.

Studiendarlehen beziehen sich auf die gesamte Bandbreite an Studiendarlehen, um ein Bild der Höhe der Unterstützungsleistungen für Studierende zu vermitteln. Der Bruttobetrag der Darlehen stellt eine geeignete Kennzahl zur Ermittlung der Finanzhilfen an die gegenwärtigen Bildungsteilnehmer dar. Zins- und Tilgungszahlungen des Darlehensnehmers sollten jedoch bei der Ermittlung der durch Studiendarlehen entstehenden Nettokosten für die öffentlichen und privaten Darlehensgeber berücksichtigt werden. Diese Zahlungen werden jedoch in der Regel nicht von gegenwärtigen Studierenden, sondern von ehemaligen Studierenden geleistet und sind in diesem Indikator nicht erfasst. Außerdem fließen Darlehensrückzahlungen in den meisten Ländern nicht den Bildungsbehörden zu, sodass ihnen diese Mittel nicht zur Deckung anderer Bildungsausgaben zur Verfügung stehen. Die OECD-Indikatoren berücksichtigen bei der Diskussion der finanziellen Unterstützung für gegenwärtige Studierende die Gesamtsumme der Stipendien und Darlehen (brutto). Für einige OECD-Länder gestaltet es sich zudem schwierig, die Gesamtsumme der Darlehen an Studierende anzugeben. Zahlen zu Studiendarlehen sind daher mit Vorsicht zu interpretieren.

\section{Angewandte Methodik}

Die Daten beziehen sich auf das Haushaltsjahr $201 \mathrm{I}$ und beruhen auf der von der OECD im Jahre 2012 durchgeführten UOE-Datenerhebung zur Bildungsstatistik (weitere Informationen s. Anhang 3 unter www.oed.org/edu/eag.htm). 
Die Daten zu den Studiengebühren der Bildungseinrichtungen, den Finanzhilfen für Studierende und den seit 1995 umgesetzten Reformen wurden im Rahmen einer besonderen, 2012 durchgeführten Erhebung gewonnen und beziehen sich auf das Studienjahr 20I0/20II.

Die Angaben zu den Studiengebühren und Darlehensbeträgen in Landeswährung werden in US-Dollar umgerechnet, indem der betreffende Betrag in Landeswährung durch den Kaufkraftparitätsindex (KKP) für das BIP geteilt wird. Die Höhe der Studiengebühren und die entsprechenden Anteile der Studierenden sind mit Vorsicht zu interpretieren, da sie aus dem gewichteten Durchschnitt der wichtigsten Studiengänge des Tertiärbereichs A resultieren und nicht alle Bildungseinrichtungen einbeziehen.

Öffentliche Kosten in Verbindung mit staatlich garantierten privaten Darlehen sind in den Subventionen an andere private Einheiten enthalten. Im Unterschied zu den öffentlichen Darlehen sind hierbei nur die Nettokosten der Darlehen enthalten.

Nicht berücksichtigt ist der Geldwert von Steuerermäßigungen bzw. der steuerlichen Anrechenbarkeit von Ausgaben für private Haushalte und Studierende.

\section{Anmerkung zu den Daten aus Israel}

Die statistischen Daten für Israel wurden von den zuständigen israelischen Stellen bereitgestellt, die für sie verantwortlich zeichnen. Die Verwendung dieser Daten durch die OECD erfolgt unbeschadet des völkerrechtlichen Status der Golanhöhen, von Ost-Jerusalem und der israelischen Siedlungen im Westjordanland.

\section{Weiterführende Informationen}

OECD (2008), Tertiary Education for the Knowledge Society: Volume 1 and Volume 2, OECD Publishing, Paris, http://dx.doi.org/10.1787/9789264046535-en.

OECD (20II), Revenue Statistics 2011, OECD Publishing, Paris, http:/|dx.doi.org/10.1787| rev_stats-2011-en-fr.

Swedish Higher Education Authority (2012), „Fewer Students from Asia after the Tuition Reform“, Statistical Analysis, Stockholm.

\section{Tabellen Indikator B5}

StatLink: http://dx.doi.org/10.1787/888933117706

Tabelle B5.I: Geschätzte durchschnittliche jährliche Studiengebühren an Bildungseinrichtungen des Tertiärbereichs A (20II)

Tabelle B5.2: Finanzhilfen für Studierende und von Bildungseinrichtungen des

Tertiärbereichs A erhobene Studiengebühren (20II) 
Tabelle B5.3: Staatliche Darlehen für Studierende im Tertiärbereich A (Studienjahr 2010/20II)

Tabelle B5.4: Öffentliche Unterstützungsleistungen an private Haushalte und andere private Einheiten, für den Tertiärbereich (20II)

WEB Table B5.5: Public support for households and other private entities for primary, secondary and post-secondary non-tertiary education (Öffentliche Unterstützungsleistungen an private Haushalte und andere private Einheiten, für den Primar-, Sekundar- und postsekundaren, nicht tertiären Bereich) (20II) 
Geschätzte durchschnittliche jährliche Studiengebühren an Bildungseinrichtungen des Tertiärbereichs $A^{1}$ (2011) Inländische Studierende, in US-Dollar, kaufkraftbereinigt mittels KKP, nach Art der Bildungseinrichtung und Abschlussstruktur, basierend auf Vollzeitäquivalenten, Studienjahr 2010/2011

Anmerkung: Studiengebühren und die entsprechenden Studierendenzahlen sollten mit Vorsicht interpretiert werden, da sie aus dem gewichteten Durchschnitt der wichtigsten Studiengänge des Tertiärbereichs A resultieren und nicht alle Bildungseinrichtungen berücksichtigt sind. Die angegebenen Zahlen können jedoch als gute Näherungswerte betrachtet werden, sie zeigen den Unterschied zwischen den einzelnen Ländern bei den von der Mehrzahl der Bildungseinrichtungen von der Mehrheit der Studierenden verlangten Studiengebühren.

\begin{tabular}{|c|c|c|c|c|c|c|c|c|c|c|c|}
\hline & \multirow{3}{*}{ 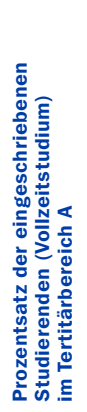 } & \multicolumn{3}{|c|}{$\begin{array}{c}\text { Prozentsatz der eingeschriebenen } \\
\text { Studierenden (Vollzeitstudium) } \\
\text { im Tertiärbereich A an: }\end{array}$} & \multicolumn{6}{|c|}{$\begin{array}{l}\text { Durchschnittliche jährliche Studiengebühren in US-Dollar } \\
\text { (für Studierende im Vollzeitstudium) an: }\end{array}$} & \multirow{3}{*}{ 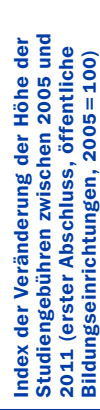 } \\
\hline & & \multirow{2}{*}{ 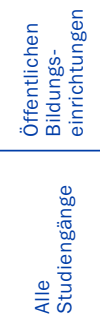 } & \multirow{2}{*}{ 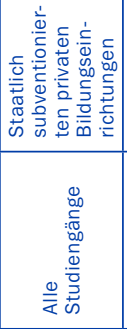 } & \multirow{2}{*}{ 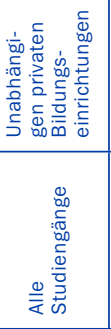 } & \multicolumn{2}{|c|}{$\begin{array}{l}\text { Öffentlichen Bildungs- } \\
\text { einrichtungen }\end{array}$} & \multicolumn{2}{|c|}{$\begin{array}{l}\text { Staatlich } \\
\text { subventionierten } \\
\text { privaten Bildungs- } \\
\text { einrichtungen }\end{array}$} & \multicolumn{2}{|c|}{$\begin{array}{l}\text { Unabhängigen } \\
\text { privaten Bildungs- } \\
\text { einrichtungen }\end{array}$} & \\
\hline & & & & & 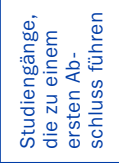 & 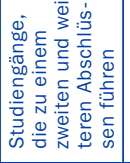 & 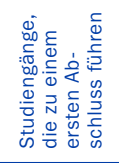 & 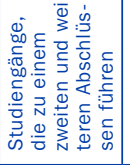 & 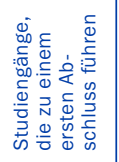 & 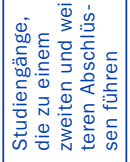 & \\
\hline & (1) & (2) & (3) & (4) & (5) & (6) & (7) & (8) & (9) & (10) & (11) \\
\hline \multicolumn{12}{|l|}{ OECD-Länder } \\
\hline Australien & 71 & 96 & a & 4 & 3924 & 6099 & a & a & 10110 & 9635 & 128 \\
\hline Österreich ${ }^{2}$ & $\mathrm{~m}$ & 84 & 13 & 3 & 860 & 860 & 860 & 860 & $\begin{array}{r}\text { Bis zu } \\
11735\end{array}$ & $\begin{array}{r}\text { Bis zu } \\
11735\end{array}$ & $\mathrm{~m}$ \\
\hline Belgien (fläm.) & 75 & 52 & 48 & $\mathrm{~m}$ & $\begin{array}{r}576 \text { bis } \\
653\end{array}$ & $\begin{array}{r}576 \text { bis } \\
653\end{array}$ & $\begin{array}{r}576 \text { bis } \\
653\end{array}$ & $\begin{array}{r}576 \text { bis } \\
653\end{array}$ & $\mathrm{~m}$ & $\mathrm{~m}$ & $\mathrm{~m}$ \\
\hline Belgien (frz.) & 84 & 33 & 67 & $\mathrm{~m}$ & 653 & 696 & 754 & 785 & $\mathrm{~m}$ & $\mathrm{~m}$ & m \\
\hline Kanada & 82 & $\mathrm{~m}$ & $\mathrm{~m}$ & $\mathrm{~m}$ & 4288 & $\mathrm{~m}$ & $x(4)$ & $\mathrm{m}$ & $x(4)$ & $\mathrm{m}$ & 124 \\
\hline Chile & $\mathrm{m}$ & 23 & 18 & 59 & 5885 & 6345 & 6924 & 8757 & 6230 & 8357 & $\mathrm{~m}$ \\
\hline Tschechien & 97 & $\mathrm{~m}$ & $\mathrm{~m}$ & $\mathrm{~m}$ & $\mathrm{~m}$ & $\mathrm{~m}$ & $\mathrm{~m}$ & $\mathrm{~m}$ & $\mathrm{~m}$ & $\mathrm{~m}$ & $\mathrm{~m}$ \\
\hline Dänemark ${ }^{3}$ & 90 & $\mathrm{~m}$ & $\mathrm{~m}$ & $\mathrm{~m}$ & $\begin{array}{l}\text { Keine } \\
\text { Studien- } \\
\text { gebühren }\end{array}$ & $\begin{array}{l}\text { Keine } \\
\text { Studien- } \\
\text { gebühren }\end{array}$ & $\mathrm{m}$ & $\mathrm{m}$ & a & a & $\mathrm{m}$ \\
\hline Estland & 87 & $\mathrm{~m}$ & 93 & 7 & $\mathrm{~m}$ & $\mathrm{~m}$ & 3527 & 3786 & 5322 & 6699 & $\mathrm{~m}$ \\
\hline Finnland & 56 & 74 & 26 & a & $\begin{array}{l}\text { Keine } \\
\text { Studien- } \\
\text { gebühren }\end{array}$ & $\begin{array}{l}\text { Keine } \\
\text { Studien- } \\
\text { gebühren }\end{array}$ & $\begin{array}{l}\text { Keine } \\
\text { Studien- } \\
\text { gebühren }\end{array}$ & $\begin{array}{l}\text { Keine } \\
\text { Studien- } \\
\text { gebühren }\end{array}$ & a & a & m \\
\hline Frankreich & $\mathrm{m}$ & 86 & 5 & 9 & $\begin{array}{r}200 \text { bis } \\
1402\end{array}$ & $\begin{array}{r}273 \text { bis } \\
1402\end{array}$ & $\begin{array}{r}1138 \text { bis } \\
8290\end{array}$ & $x(6)$ & $\mathrm{m}$ & $\mathrm{m}$ & 116 \\
\hline Deutschland & 94 & 96 & 4 & $x(3)$ & $\mathrm{m}$ & $\mathrm{m}$ & m & $\mathrm{m}$ & $\mathrm{m}$ & $\mathrm{m}$ & $\mathrm{m}$ \\
\hline Griechenland & 100 & $\mathrm{~m}$ & $\mathrm{~m}$ & $\mathrm{~m}$ & $\mathrm{~m}$ & $\mathrm{~m}$ & $\mathrm{~m}$ & $\mathrm{~m}$ & $\mathrm{~m}$ & $\mathrm{~m}$ & $\mathrm{~m}$ \\
\hline Ungarn & 65 & $\mathrm{~m}$ & $\mathrm{~m}$ & $\mathrm{~m}$ & $\mathrm{~m}$ & $\mathrm{~m}$ & $\mathrm{~m}$ & $\mathrm{~m}$ & $\mathrm{~m}$ & $\mathrm{~m}$ & $\mathrm{~m}$ \\
\hline Island & 71 & $\mathrm{~m}$ & $\mathrm{~m}$ & $\mathrm{~m}$ & $\mathrm{~m}$ & $\mathrm{~m}$ & $\mathrm{~m}$ & $\mathrm{~m}$ & $\mathrm{~m}$ & $\mathrm{~m}$ & $\mathrm{~m}$ \\
\hline Irland & 87 & $\mathrm{~m}$ & a & $\mathrm{m}$ & 6450 & 7036 & a & a & $\mathrm{m}$ & $\mathrm{m}$ & 136 \\
\hline Israel & 82 & $\mathrm{~m}$ & $\mathrm{~m}$ & $\mathrm{~m}$ & $\mathrm{~m}$ & $\mathrm{~m}$ & $\mathrm{~m}$ & $\mathrm{~m}$ & $\mathrm{~m}$ & $\mathrm{~m}$ & $\mathrm{~m}$ \\
\hline Italien & 100 & 90 & a & 10 & 1407 & $x(5)$ & a & a & 4406 & $x(9)$ & $\mathrm{m}$ \\
\hline Japan & 91 & 25 & a & 75 & 5019 & 5106 & a & a & 8039 & 7423 & 109 \\
\hline Korea & $\mathrm{m}$ & 23 & a & 77 & 5395 & $\mathrm{~m}$ & a & a & 9383 & $\mathrm{~m}$ & m \\
\hline Luxemburg & 95 & $\mathrm{~m}$ & $\mathrm{~m}$ & $\mathrm{~m}$ & $\mathrm{~m}$ & $\mathrm{~m}$ & m & $\mathrm{m}$ & $\mathrm{m}$ & $\mathrm{m}$ & m \\
\hline Mexiko & 95 & 67 & a & 33 & $\begin{array}{l}\text { Keine } \\
\text { Studien- } \\
\text { gebühren }\end{array}$ & $\begin{array}{l}\text { Keine } \\
\text { Studien- } \\
\text { gebühren }\end{array}$ & a & a & 5684 & $x(9)$ & $\mathrm{m}$ \\
\hline Niederlande & 86 & $\mathrm{~m}$ & a & $\mathrm{m}$ & 1966 & $x(4)$ & a & a & $\mathrm{m}$ & $\mathrm{m}$ & 113 \\
\hline Neuseeland & 60 & $\mathrm{~m}$ & $\mathrm{~m}$ & $\mathrm{~m}$ & 3645 & $x(4)$ & $\mathrm{m}$ & $\mathrm{m}$ & $\mathrm{m}$ & $\mathrm{m}$ & 135 \\
\hline Norwegen & 71 & 85 & 5 & 10 & $\begin{array}{l}\text { Keine } \\
\text { Studien- } \\
\text { gebühren }\end{array}$ & $\begin{array}{l}\text { Keine } \\
\text { Studien- } \\
\text { gebühren }\end{array}$ & $\mathrm{m}$ & $\mathrm{m}$ & 5868 & 7296 & $\mathrm{~m}$ \\
\hline Polen & 45 & 90 & a & 10 & $\mathrm{n}$ & $\mathrm{n}$ & a & a & 1242 & 1335 & $\mathrm{~m}$ \\
\hline Portuga| ${ }^{3}$ & $\mathrm{~m}$ & $\mathrm{~m}$ & $\mathrm{~m}$ & $\mathrm{~m}$ & $\mathrm{~m}$ & $\mathrm{~m}$ & $\mathrm{~m}$ & $\mathrm{~m}$ & $\mathrm{~m}$ & $\mathrm{~m}$ & $\mathrm{~m}$ \\
\hline Slowakei & 64 & 93 & a & 7 & $\begin{array}{r}\text { Maximal } \\
2916\end{array}$ & $x(4)$ & a & a & $\mathrm{m}$ & $\mathrm{m}$ & m \\
\hline Slowenien & 75 & 94 & 6 & 1 & $\mathrm{n}$ & $\mathrm{n}$ & $n$ & $\mathrm{n}$ & 11040 & 12144 & $\mathrm{~m}$ \\
\hline Spanien & 76 & 88 & a & 12 & 1129 & $\mathrm{~m}$ & a & a & $\mathrm{m}$ & $\mathrm{m}$ & $\mathrm{m}$ \\
\hline Schweden & 48 & 93 & 7 & $\mathrm{n}$ & $\begin{array}{l}\text { Keine } \\
\text { Studien- } \\
\text { gebühren }\end{array}$ & $\begin{array}{l}\text { Keine } \\
\text { Studien- } \\
\text { gebühren }\end{array}$ & $\begin{array}{l}\text { Keine } \\
\text { Studien- } \\
\text { gebühren }\end{array}$ & $\begin{array}{l}\text { Keine } \\
\text { Studien- } \\
\text { gebühren }\end{array}$ & $\mathrm{m}$ & $\mathrm{m}$ & $\mathrm{m}$ \\
\hline Schweiz & 89 & 95 & 3 & 2 & 863 & 863 & 863 & 863 & $\mathrm{~m}$ & $\mathrm{~m}$ & $\mathrm{~m}$ \\
\hline Türkei & 100 & 94 & a & 6 & 332 & 270 & a & a & $\mathrm{m}$ & $\mathrm{m}$ & 136 \\
\hline Ver. Königreich & 76 & a & 100 & $\mathrm{n}$ & a & a & 4980 & 7814 & $\mathrm{~m}$ & $\mathrm{~m}$ & $\mathrm{~m}$ \\
\hline Vereinigte Staaten & 66 & 70 & a & 30 & 5402 & m & a & a & 17163 & m & 116 \\
\hline \multicolumn{12}{|l|}{ Partnerländer } \\
\hline Brasilien & $\mathrm{m}$ & $\mathrm{m}$ & $\mathrm{m}$ & $\mathrm{m}$ & $\mathrm{m}$ & $\mathrm{m}$ & $\mathrm{m}$ & $\mathrm{m}$ & $\mathrm{m}$ & $\mathrm{m}$ & $\mathrm{m}$ \\
\hline Russische Föd. & 49 & $\mathrm{~m}$ & $\mathrm{~m}$ & $\mathrm{~m}$ & $\mathrm{~m}$ & $\mathrm{~m}$ & $\mathrm{~m}$ & $\mathrm{~m}$ & $\mathrm{~m}$ & $\mathrm{~m}$ & $\mathrm{~m}$ \\
\hline
\end{tabular}

1. Ohne Berücksichtigung möglicher Stipendien/Zuschüsse der Studierenden. 2. Einschließlich Studierender weiterführender forschungsorientierter Studiengänge. 3. Studiengebühren im Tertiärbereich insgesamt.

Quelle: OECD. Tabelle B5.1 in Bildung auf einen Blick 2013. Hinweise s. Anhang 3 unter www.oecd.org/edu/eag.htm. StatLink: http://dx.doi.org/10.1787/888933117725 Erläuterung der Kennzeichnung fehlender Daten s. Hinweise für den Leser. 
Tabelle B5.1 (Forts.)

Geschätzte durchschnittliche jährliche Studiengebühren an Bildungseinrichtungen des Tertiärbereichs A $^{\mathbf{1}}$ (2011) Inländische Studierende, in US-Dollar, kaufkraftbereinigt mittels KKP, nach Art der Bildungseinrichtung und Abschlussstruktur, basierend auf Vollzeitäquivalenten, Studienjahr 2010/2011

Anmerkung: Studiengebühren und die entsprechenden Studierendenzahlen sollten mit Vorsicht interpretiert werden, da sie aus dem gewichteten Durchschnitt der wichtigsten Studiengänge des Tertiärbereichs A resultieren und nicht alle Bildungseinrichtungen berücksichtigt sind. Die angegebenen Zahlen können jedoch als gute Näherungswerte betrachtet werden, sie zeigen den Unterschied zwischen den einzelnen Ländern bei den von der Mehrzahl der Bildungseinrichtungen von der Mehrheit der Studierenden verlangten Studiengebühren.

\begin{tabular}{l|l} 
& \multicolumn{1}{c}{ Kommentar } \\
\cline { 2 - 3 } $\begin{array}{l}\text { OECD-Länder } \\
\text { Australien }\end{array}$ & $\begin{array}{l}\text { 93 Prozent der inländischen Studierenden in öffentlichen Bildungseinrichtungen haben einen subventionierten Studienplatz und zahlen im } \\
\text { Durchschnitt eine Studiengebühr von 3.817 US-Dollar, einschl. HECS/HELP-Subventionen. Als Ergebnis von Regierungsreformen, die darauf } \\
\text { abzielen, die Zahl der Commonwealth-Stipendien bis 2012 zu verdoppeln, ist die Zahl der Stipendien für inländische Studierende zwischen } \\
\text { 2007 und 2009 signifikant gestiegen (ca. 50 Prozent). Die neuen Stipendien sind hauptsächlich auf Studierende ausgerichtet, die Fächer } \\
\text { belegen, für die eine nationale Priorität besteht, sowie auf Studierende, die zum Studium spezieller Fächer umziehen mussten, und auf } \\
\text { indigene Studierende. } \\
\text { Seit dem Somersemester 2009 gelten Studiengebühren für inländische Studierende und Studierende aus EU-/EWR-Ländern, wenn sie die } \\
\text { Regelstudienzeit für den Studiengang um mehr als zwei Semester überschreiten, sowie für Studierende aus Nicht-EU-/EWR-Länder (mit } \\
\text { Ausnahme von Studierenden aus den am wenigstens entwickelten Ländern). } \\
\text { Österreich² }\end{array}$ \\
$\begin{array}{l}\text { Die Studiengebühren beziehen sich auf den Höchst- und Mindestbetrag, den Bildungseinrichtungen laut Gesetz erheben dürfen (indizierte } \\
\text { Zahlen). Sie beziehen sich auf Studierende, die in Studiengängen, die zu einem ersten (Bachelor) oder zweiten (Master) Studienabschluss } \\
\text { Bühren, eingeschrieben sind. Die Angaben beziehen sich nicht auf zu weiteren akadamischen Abschlüssen führende Studiengänge (z. B. } \\
\text { "Master after Master“). Die Angaben beziehen sich auf Studierende ohne Stipendien (Studierende mit Stipendien zahlen geringere Studien- } \\
\text { gebühren, weitere Informationen s. Anhang 3). } \\
\text { Die Studiengebühren sind an öffentlichen und privaten Bildungseinrichtungen gleich, die Studierendenzahlen aber unterschiedlich, sodass } \\
\text { der gewichtete Durchschnitt ein anderer ist. }\end{array}$ \\
Belgien (frz.)
\end{tabular}

\section{Chile}

Tschechien

Dänemark ${ }^{3}$

Estland

Nur Studierende an Universitäten. Der Anteil der Studierenden,

Ländern und der Schweiz gelten als inländische Studierende.

In Estland gibt es ein zweigleisiges Studiengebührensystem. Studierende, die einen der staatlich finanzierten Studienplätze an einer Universität erhalten, zahlen keine Studiengebühren. Die Universitäten können von Studierenden, die einen der über die staatlich finanzierten Studienplätze hinausgehenden Studienplätze erhalten, Studiengebühren erheben. Die Universitäten können sowohl die Höhe der Studiengebühren als auch die Zahl der Studierenden, die Studiengebühren zahlen müssen, selbst bestimmen. Bei den weiterführenden forschungsorientierten Studiengängen beispielsweise richten die Universitäten die meisten der zusätzlichen Studienplätze ohne Studiengebühren ein. In einem gewissen Ausmaß gilt dies auch für die Studiengänge, die zu einem zweiten oder weiteren Abschluss führen.

Finnland Ohne Mitgliedsbeiträge für die Studierendenvertretung.

Frankreich

Studiengebühren an öffentlichen Bildungseinrichtungen beziehen sich bei den höchsten Studiengebühren auf universitäre Studiengänge, die vom Ministerium für Hochschulwesen abhängig sind, und bei den höchsten Studiengebühren an öffentlichen Bildungseinrichtungen auf das Staatsexamen als Psychomotricien(ne) (1.218 Euro). Bei den staatlich subventionierten privaten Bildungseinrichtungen beziehen sich die

Deutschland

Griechenland

Ungarn

Island

Irland

niedrigsten Studiengebühren in der Tabelle auf die Katholische Universität und die höchsten Studiengebühren auf Kunsthochschulen.

Israel

Italien

\begin{tabular}{|c|c|}
\hline Japan & \\
\hline Korea & \\
\hline Luxemburg & \\
\hline Mexiko & \\
\hline Niederlande & \\
\hline Neuseeland & \\
\hline Norwegen & \\
\hline Polen & \\
\hline Portugal $^{3}$ & \\
\hline Slowakei & \\
\hline Slowenien & \\
\hline Spanien & \\
\hline Schweden & \\
\hline Schweiz & \\
\hline Türkei & \\
\hline Ver. Königreich & \\
\hline Vereinigte Staaten & \\
\hline
\end{tabular}

\section{Partnerländer}

Brasilien

Russische Föd.
Die von öffentlichen Einrichtungen erhobenen Studiengebühren werden nur für in Undergraduate-Studiengänge eingeschriebene Vollzeitstudierende aus der EU direkt vom Staat übernommen. Etwa die Hälfte aller Studiengebühren wird von den privaten Haushalten getragen (vor allem für Teilzeitstudierende, Studierende in Postgraduate-Studiengängen und Studierende, die keine EU-Bürger sind). Das bedeutet, dass im Studienjahr 2010/2011 Studierende nur 1.500 Euro der angegebenen Studiengebühren gezahlt haben.

Jede Bildungseinrichtung legt ihr Gebührensystem fest, hierbei werden die wirtschaftlichen Verhältnisse der Familie des Studierenden nach Kriterien der Gerechtigkeit und Solidarität berücksichtigt, die den allgemeinen Regeln, die auf nationaler Ebene festgelegt werden, gerecht werden. Die durchschnittlichen jährlichen Studiengebühren werden auf Grundlage der tatsächlich von den einzelnen Studierenden gezahlten Gebühren berechnet. Studierende, die keine Studiengebühren zahlen müssen, werden bei der Berechnung des Durchschnitts nicht berücksichtigt.

Die durchschnittlichen jährlichen Studiengebühren enthalten nicht die von der Bildungseinrichtung verlangte Zulassungsgebühr für das erste Jahr.

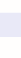

Studiengebühren sind repräsentativ für die in Norwegen überwiegend privaten Bildungseinrichtungen (ISCED-Stufe 5).

Vollzeitstudierende entrichten im Allgemeinen keine Studiengebühren. Aber Studierende, die in einem Studienjahr in zwei oder mehr

Studiengängen einer öffentlichen Universität im gleichen Tertiärbereich eingeschrieben sind, müssen für den zweiten und jeden weiteren Studiengang für dieses Studienjahr Studiengebühren entrichten. Außerdem müssen Studierende, die die Regelstudienzeit überschreiten, für jedes weitere Studienjahr eine jährliche Studiengebühr entrichten.

An öffentlichen und staatlich subventionierten privaten Einrichtungen: Vollzeitstudierende des ersten und zweiten Studienabschnitts zahlen keine Studiengebühren. Studierende des zweiten Abschnitts, die bereits über einen dem zweiten Abschnitt entsprechenden Abschluss/eine Qualifikation verfügen, zahlen jedoch Studiengebühren.

Im Herbst 2011 wurden für Studierende, die aus der Schweiz bzw. aus einem Nicht-EWR-Land kommen, Studiengebühren eingeführt.

Die Zahlen beziehen sich auf alle Studierenden (inländische und nicht inländische/ausländische Studierende im Vollzeitstudium).

1. Ohne Berücksichtigung möglicher Stipendien/Zuschüsse der Studierenden. 2. Einschließlich Studierender weiterführender forschungsorientierter Studiengänge.

3. Studiengebühren im Tertiärbereich insgesamt.

Quelle: OECD. Tabelle B5.1 in Bildung auf einen Blick 2013. Hinweise s. Anhang 3 unterwww.oecd.org/edu/eag.htm. StatLink: http://dx.doi.org/10.1787/888933117725

Erläuterung der Kennzeichnung fehlender Daten s. Hinweise für den Leser. 
Finanzhilfen für Studierende und von Bildungseinrichtungen des Tertiärbereichs A erhobene Studiengebühren (2011) Inländische Studierende und zu einem ersten Abschluss führende Studiengänge, basierend auf Vollzeitstudierenden, Studienjahr 2010/2011

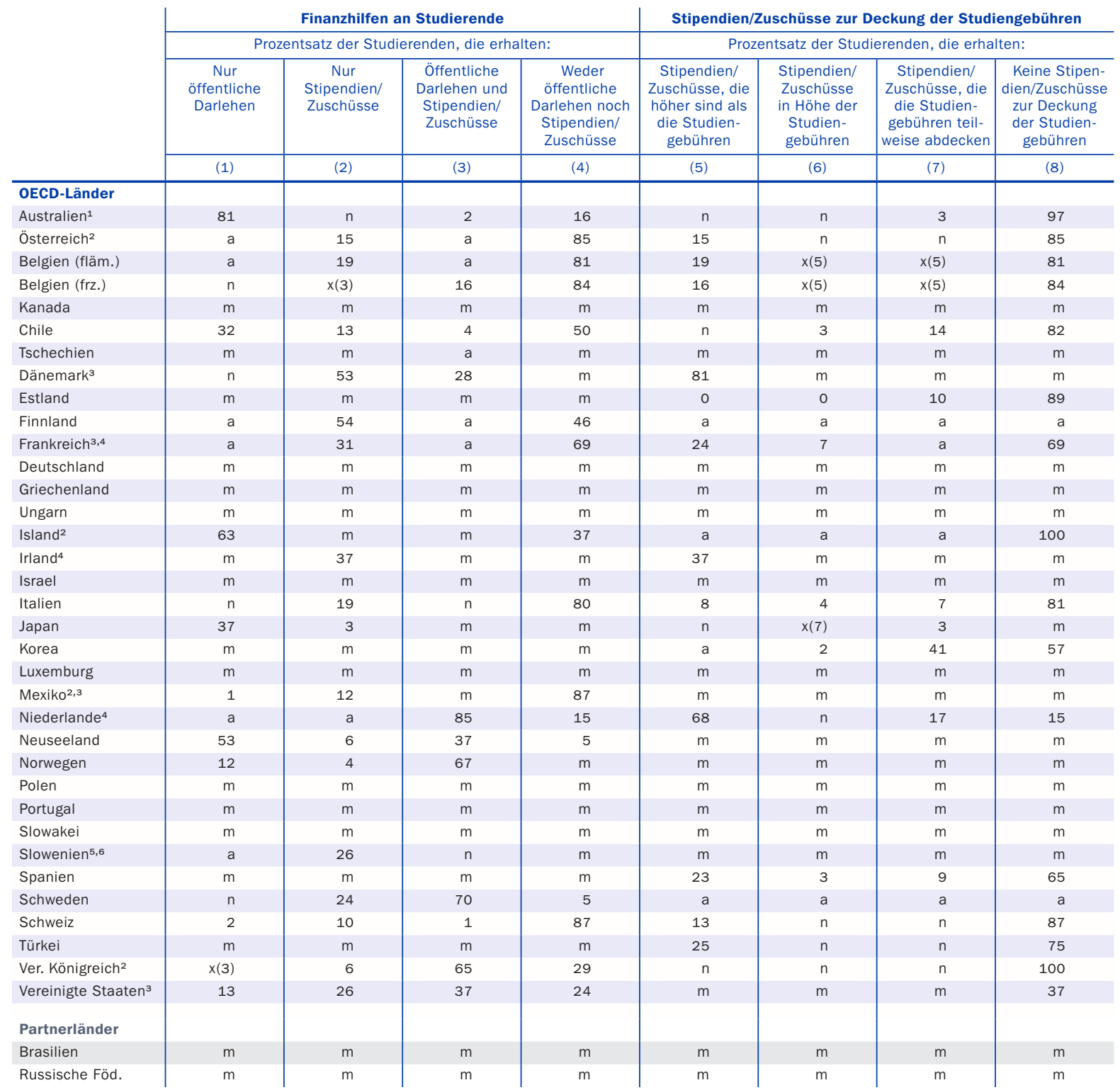

1. Ohne ausländische Studierende. 2. Daten beziehen sich auf das Studienjahr 2008/2009. 3. Studierende im gesamten Tertiärbereich (nur öffentliche Universitäten, einschließlich Tertiärbereich B in Frankreich). 4. Nur öffentliche Bildungseinrichtungen. 5. Spalte (2) enthält nur Stipendien. 6. Daten beziehen sich auf das Studienjahr 2009/2010.

Quelle: OECD. Tabelle B5.2 in Bildung auf einen Blick 2013. Hinweise s. Anhang 3 unter www.oecd.org/edu/eag.htm.

StatLink: http://dx.doi.org/10.1787/888933117744

Erläuterung der Kennzeichnung fehlender Daten s. Hinweise für den Leser. 
Tabelle B5.3

Staatliche Darlehen für Studierende im Tertiärbereich A (Studienjahr 2010/2011)

Inländische Studierende, in US-Dollar, kaufkraftbereinigt

\begin{tabular}{|c|c|c|c|c|c|}
\hline & \multirow{2}{*}{$\begin{array}{l}\text { Jahr der Einführung } \\
\text { eines öffentlichen } \\
\text { Darlehenssystems } \\
\text { in dem Land }\end{array}$} & \multirow{2}{*}{$\begin{array}{c}\text { Anteil der Studierenden } \\
\text { mit einem Darlehen } \\
\text { (in \%) (Studienjahr } \\
\text { 2010/2011) }\end{array}$} & \multirow{2}{*}{\begin{tabular}{|c} 
Durchschn. jährlicher \\
Bruttodarlehensbetrag, \\
der jedem Studierenden \\
zur Verfügung steht \\
(in US-Dollar)
\end{tabular}} & \multicolumn{2}{|c|}{ Subventionen durch verringerten Zinssatz } \\
\hline & & & & $\begin{array}{c}\text { Zinssatz } \\
\text { während des Studiums }\end{array}$ & $\begin{array}{c}\text { Zinssatz } \\
\text { nach dem Studium }\end{array}$ \\
\hline & (1) & (2) & (3) & (4) & (5) \\
\hline \multicolumn{6}{|l|}{ OECD-Länder } \\
\hline Australien ${ }^{1,2}$ & 1989 & 77,1 & 3507 & $1,9 \%$ & Verbraucherpreis indiziert \\
\hline Belgien (fläm.) & a & a & a & $a$ & $a$ \\
\hline Belgien (frz.) $)^{3}$ & 1983 & $\mathrm{~m}$ & 1525 & $4,0 \%$ & $4,0 \%$ \\
\hline Kanada ${ }^{4}$ & 1964 & $m$ & 4421 & Kein nominaler Zinssatz & $\begin{array}{l}\text { Zinszahlungen durch den } \\
\text { Studierenden }(6,7 \%)\end{array}$ \\
\hline Dänemark ${ }^{2}$ & 1970 & 28 & 4227 & $4,0 \%$ & $1,75 \%$ \\
\hline Estland $^{5}$ & 1995 & 16 & 3281 & $\begin{array}{l}5 \% \text {, Rest vom Staat } \\
\text { bezahlt }\end{array}$ & $\begin{array}{l}5 \% \text {, Rest vom Staat } \\
\text { bezahlt }\end{array}$ \\
\hline Finnland $^{5}$ & 1969 & 27,7 & 1200 & $1,0 \%$ & $\begin{array}{l}\text { Voller von privater Bank } \\
\text { gewährter Zinssatz; } \\
\text { Zinserleichterung für } \\
\text { Personen mit niedrigem } \\
\text { Einkommen }\end{array}$ \\
\hline Ungarn $^{5}$ & 2001 & 17 & Maximal 3876 & $\begin{array}{l}\text { Variabel }(8,5 \% \text { in } \\
2010 / 2011)\end{array}$ & $\begin{array}{l}\text { Variabel }(8,5 \% \text { in } \\
2010 / 2011)\end{array}$ \\
\hline Island & 1961 & 63 & 10342 & Kein nominaler Zinssatz & $1,0 \%$ \\
\hline |srae|2,6 & $\mathrm{m}$ & 11,4 & 3552 & $\mathrm{~m}$ & $m$ \\
\hline$J^{\prime a p a n}{ }^{7}$ & 1943 & 28 & 5602 & $\begin{array}{l}\text { Weder nominaler noch } \\
\text { realer Zinssatz }\end{array}$ & $\begin{array}{l}\text { Max. 3\%, Rest vom Staat } \\
\text { bezahlt }\end{array}$ \\
\hline Mexiko 8 & 1970 & $\mathrm{~m}$ & 13608 & $\mathrm{~m}$ & $\mathrm{~m}$ \\
\hline Niederlande $^{2}$ & 1986 & 33,4 & 2646 & $1,5 \%$ & $1,5 \%$ \\
\hline Neuseeland ${ }^{2}$ & 1992 & 64 & 4917 & Kein nominaler Zinssatz & $\begin{array}{l}\text { Wenn in Neuseeland } \\
\text { wohnend } 0 \% \text {, } \\
\text { sonst } 6,6 \%\end{array}$ \\
\hline Norwegen $^{2}$ & 1947 & 70,0 & 9381 & Kein nominaler Zinssatz & $\begin{array}{l}2,673 \% \text { (variabler } \\
\text { Zinssatz) }\end{array}$ \\
\hline Polen 2,5 & 1998 & $\mathrm{~m}$ & 3240 & Ca. $1,9 \%$ & Ca. $1,9 \%$ \\
\hline Spanien & 2010 & 0,1 & 10218 & $0 \%$ & $3,21 \%$ \\
\hline Schweden ${ }^{9}$ & 1965 & 43 & 8718 & $2,4 \%$ & $2,4 \%$ \\
\hline Türkei & 1961 & $\mathrm{~m}$ & 2605 & $\mathrm{~m}$ & $m$ \\
\hline Ver. Königreich2,10,11 & 1990 & 83,9 & 10070 & $\begin{array}{l}1,5 \% \text { (Basiszinssatz } \\
\text { plus } 1 \% \text { ) }\end{array}$ & $\begin{array}{l}3,3 \% \text { (Einzelhandels- } \\
\text { preisindex oder Basis- } \\
\text { zinssatz, je nachdem, } \\
\text { was niedriger ist, plus } \\
1 \%)\end{array}$ \\
\hline Vereinigte Staaten ${ }^{12}$ & 1970 er & $\begin{array}{l}71 \% \text { aller Under- } \\
\text { graduate-Studierenden, } \\
84 \% \text { der ganzjährig } \\
\text { Vollzeitstudierenden }\end{array}$ & 15510 & $\begin{array}{l}3,86 \% \text { (direkt subventio- } \\
\text { nierte und nicht subven- } \\
\text { tionierte Darlehen, ohne } \\
\text { Darlehen an Eltern) }\end{array}$ & $x(5)$ \\
\hline
\end{tabular}

1. Einschließlich Commonwealth-Länder. 2. Alle Studierenden im Tertiärbereich. 3. Darlehen an die Eltern des/der Studierenden, nur die Eltern müssen das Darlehen zurückzahlen. 4. Darlehen außerhalb von Quebec. In Quebec gibt es nur staatlich garantierte private Darlehen. 5. Eher Darlehen vom Staat garantiert als staatliche Darlehen. 6. Jährliche Darlehenssumme bezieht sich auf alle staatlichen und privaten Darlehen. 7. Referenzjahr 2004/2005. Durchschnittliche Darlehenssumme für Studierende in Studiengängen des Tertiärbereichs A, die zu einem ersten Abschluss führen. 8. Durchschnittliche Darlehenssumme für Studierende im Tertiärbereich. 9. Durchschnittliche jährliche Rückzahlung im Tertiärbereich. 10. Durchschnittliche Bruttodarlehenssumme bezieht sich auf Studierende in England. 11. Referenzjahr 2009/2011. 12. Nur Studierende in Studiengängen, die zu einem ersten Abschluss führen/Undergraduate-Studierende auf ISCED-Stufe 5. Enthält Darlehen an Eltern „Parent Loans for Undergraduate Students (PLUS)“ sowie weitere direkt von den Eltern bezogene Darlehen. Aufgenommene Gesamtsumme ohne Darlehen von Familie und Freunden. Durchschnittlicher jährlicher Bruttodarlehensbetrag, der jedem Studierenden zur Verfügung steht, bezieht sich auf ganzjährig Vollzeitstudierende. Studienjahr 2011/2012, mit Ausnahme von Spalte (4), die sich auf $2013 / 2014$ bezieht.

Quelle: OECD. Hinweise s. Anhang 3 unter www.oecd.org/edu/eag.htm. StatLink: http://dx.doi.org/10.1787/888933117763

Erläuterung der Kennzeichnung fehlender Daten s. Hinweise für den Leser. 
Tabelle B5.3 (Forts.)

Staatliche Darlehen für Studierende im Tertiärbereich A (Studienjahr 2010/11) Inländische Studierende, in US-Dollar, kaufkraftbereinigt

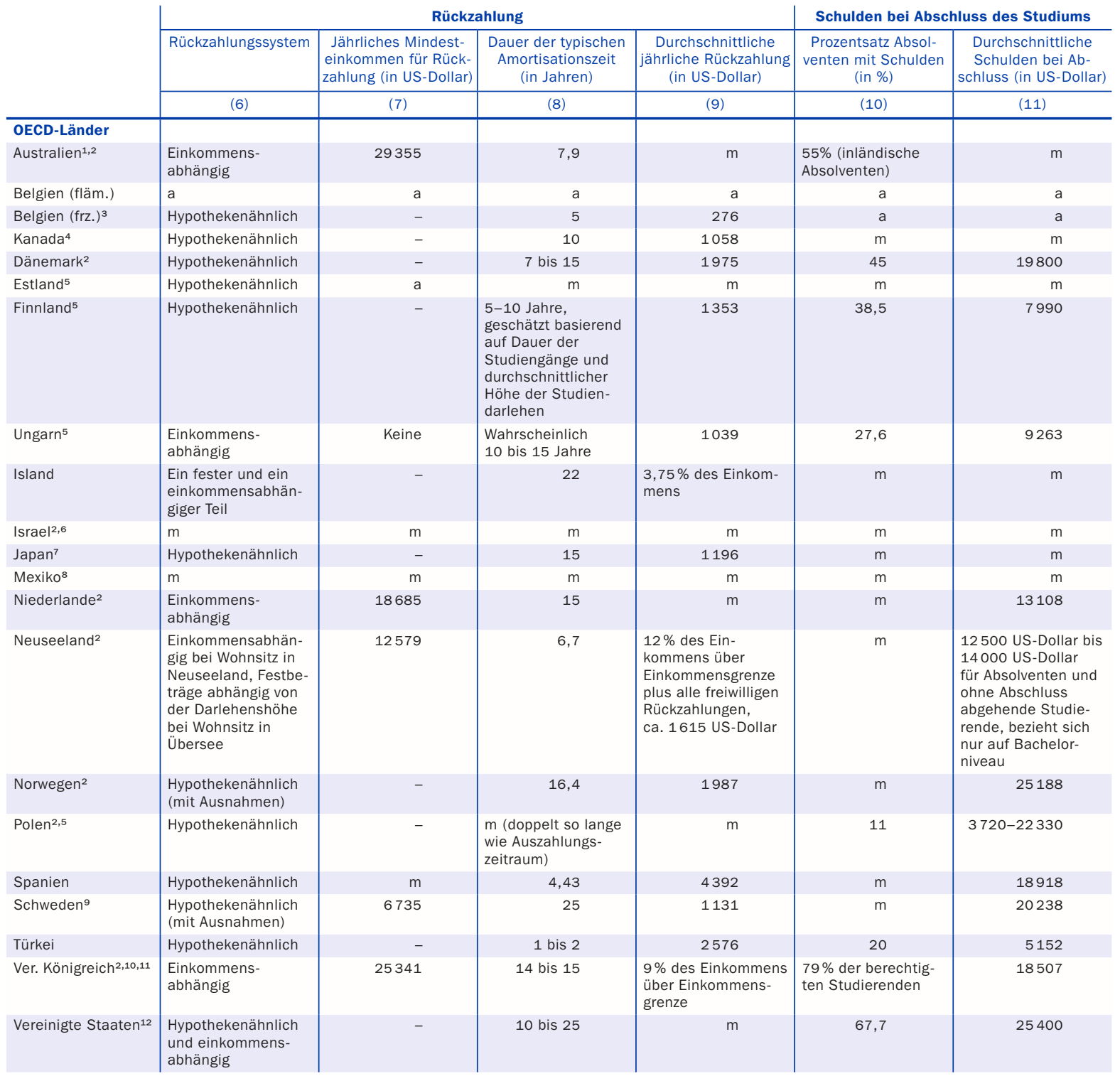

1. Einschließlich Commonwealth-Länder. 2. Alle Studierenden im Tertiärbereich. 3. Darlehen an die Eltern des/der Studierenden, nur die Eltern müssen das Darlehen zurückzahlen. 4. Darlehen außerhalb von Quebec. In Quebec gibt es nur staatlich garantierte private Darlehen. 5. Eher Darlehen vom Staat garantiert als staatliche Darlehen. 6. Jährliche Darlehenssumme bezieht sich auf alle staatlichen und privaten Darlehen. 7. Referenzjahr 2004/2005. Durchschnittliche Darlehenssumme für Studierende in Studiengängen des Tertiärbereichs A, die zu einem ersten Abschluss führen. 8. Durchschnittliche Darlehenssumme für Studierende im Tertiärbereich. 9. Durchschnittliche jährliche Rückzahlung im Tertiärbereich. 10. Durchschnittliche Bruttodarlehenssumme bezieht sich auf Studierende in England. 11. Referenzjahr 2009/2011. 12. Nur Studierende in Studiengängen, die zu einem ersten Abschluss führen/Undergraduate-Studierende auf ISCED-Stufe 5. Enthält Darlehen an Eltern „Parent Loans for Undergraduate Students (PLUS)“ sowie weitere direkt von den Eltern bezogene Darlehen. Aufgenommene Gesamtsumme ohne Darlehen von Familie und Freunden. Durchschnittlicher jährlicher Bruttodarlehensbetrag, der jedem Studierenden zur Verfügung steht, bezieht sich auf ganzjährig Vollzeitstudierende. Studienjahr 2011/2012, mit Ausnahme von Spalte (4), die sich auf 2013/2014 bezieht. Quelle: OECD. Hinweise s. Anhang 3 unter www.oecd.org/edu/eag.htm. StatLink: http://dx.doi.org/10.1787/888933117763 Erläuterung der Kennzeichnung fehlender Daten s. Hinweise für den Leser. 
Tabelle B5.4

Öffentliche Unterstützungsleistungen an private Haushalte und andere private Einheiten, für den Tertiärbereich (2011) Als Prozentsatz der öffentlichen Gesamtausgaben für Bildung und des BIP

\begin{tabular}{|c|c|c|c|c|c|c|c|c|}
\hline & \multirow{3}{*}{$\begin{array}{l}\text { Direkte öffent- } \\
\text { liche Ausgaben } \\
\text { für Bildungs- } \\
\text { einrichtungen }\end{array}$} & \multicolumn{6}{|c|}{ Öffentliche Unterstützungsleistungen für Bildung an private Einheiten } & \multirow{3}{*}{$\begin{array}{c}\text { Öffentliche } \\
\text { Unter- } \\
\text { stützungs- } \\
\text { leistungen } \\
\text { für Bildung } \\
\text { an private } \\
\text { Einheiten als } \\
\text { Prozentsatz } \\
\text { des BIP }\end{array}$} \\
\hline & & \multicolumn{5}{|c|}{ Finanzhilfen für Studierende } & \multirow[t]{2}{*}{ Gesamt } & \\
\hline & & $\begin{array}{l}\text { Stipendien/ } \\
\text { Andere } \\
\text { Zuschüsse } \\
\text { an private } \\
\text { Haushalte }\end{array}$ & $\begin{array}{l}\text { Studien- } \\
\text { darlehen }\end{array}$ & Gesamt & \begin{tabular}{|c|} 
Stipendien/ \\
Andere Zu- \\
schüsse an pri- \\
vate Haushalte, \\
die Bildungs- \\
einrichtungen \\
zuzuordnen sind
\end{tabular} & $\begin{array}{l}\text { Transfer- und } \\
\text { sonstige } \\
\text { Zahlungen an } \\
\text { andere private } \\
\text { Einheiten }\end{array}$ & & \\
\hline & (1) & (2) & (3) & (4) & (5) & (6) & (7) & (8) \\
\hline \multicolumn{9}{|l|}{ OECD-Länder } \\
\hline Australien & 65,0 & 13,7 & 21,2 & 34,9 & 0,7 & $\mathrm{n}$ & 35,0 & 0,39 \\
\hline Österreich & 82,4 & 9,8 & a & 9,8 & m & 7,8 & 17,6 & 0,27 \\
\hline Belgien & 85,6 & 14,4 & $n$ & 14,4 & 4,2 & $n$ & 14,4 & 0,21 \\
\hline Kanada $^{1}$ & 80,7 & 4,3 & 13,5 & 17,8 & $\mathrm{~m}$ & 1,6 & 19,3 & 0,38 \\
\hline Chile $^{2}$ & 61,8 & 16,4 & 17,2 & 33,6 & 16,0 & 4,6 & 38,2 & 0,36 \\
\hline Tschechien & 98,5 & 1,5 & $a$ & 1,5 & m & $n$ & 1,5 & 0,02 \\
\hline Dänemark ${ }^{3}$ & 71,6 & 23,2 & 5,1 & 28,4 & $\mathrm{n}$ & $\mathrm{n}$ & 28,4 & 0,69 \\
\hline Estland & 90,7 & 4,3 & 5,1 & 9,3 & $\mathrm{~m}$ & $\mathrm{n}$ & 9,3 & 0,12 \\
\hline Finnland & 86,0 & 13,7 & $n$ & 13,7 & $\mathrm{n}$ & 0,2 & 14,0 & 0,30 \\
\hline Frankreich & 92,0 & 8,0 & $\mathrm{~m}$ & 8,0 & $\mathrm{~m}$ & a & 8,0 & 0,10 \\
\hline Deutschland & 78,1 & 16,3 & 5,6 & 21,9 & $\mathrm{~m}$ & $\mathrm{n}$ & 21,9 & 0,31 \\
\hline Griechenland & m & $\mathrm{m}$ & $\mathrm{m}$ & $\mathrm{m}$ & $\mathrm{m}$ & $\mathrm{m}$ & $\mathbf{m}$ & $\mathrm{m}$ \\
\hline Ungarn & 87,6 & 12,4 & $\mathrm{~m}$ & 12,4 & $\mathrm{n}$ & $\mathrm{n}$ & 12,4 & 0,14 \\
\hline Island & 73,8 & $\mathrm{~m}$ & 26,2 & 26,2 & a & $\mathrm{n}$ & 26,2 & 0,37 \\
\hline Irland & 86,7 & 13,3 & $n$ & 13,3 & $\mathrm{n}$ & $\mathrm{n}$ & 13,3 & 0,18 \\
\hline Israel & 88,5 & 9,9 & 1,6 & 11,5 & 9,6 & $\mathrm{n}$ & 11,5 & 0,11 \\
\hline Italien & 77,8 & 22,2 & $n$ & 22,2 & 10,6 & $n$ & 22,2 & 0,18 \\
\hline$J^{J a p a n^{3}}$ & 70,4 & 0,6 & 29,0 & 29,6 & m & $\mathrm{n}$ & 29,6 & 0,23 \\
\hline Korea & 90,9 & 3,8 & 4,8 & 8,5 & 3,5 & 0,6 & 9,1 & 0,07 \\
\hline Luxemburg & m & $\mathrm{m}$ & $\mathrm{m}$ & $\mathrm{m}$ & $\mathrm{m}$ & $\mathrm{m}$ & m & $\mathrm{m}$ \\
\hline Mexiko & 91,0 & 5,5 & 3,5 & 9,0 & 2,5 & a & 9,0 & 0,09 \\
\hline Niederlande & 70,9 & 13,2 & 15,7 & 28,8 & $\mathrm{n}$ & 0,3 & 29,1 & 0,50 \\
\hline Neuseeland & 52,0 & 14,5 & 33,5 & 48,0 & $\mathrm{~m}$ & $\mathrm{n}$ & 48,0 & 0,90 \\
\hline Norwegen & 61,9 & 11,4 & 26,7 & 38,1 & $\mathrm{~m}$ & $\mathrm{n}$ & 38,1 & 0,99 \\
\hline Polen & 87,3 & 12,2 & 0,5 & 12,7 & $\mathrm{~m}$ & $\mathrm{n}$ & 12,7 & 0,14 \\
\hline Portugal & 84,6 & 15,4 & $\mathrm{~m}$ & 15,4 & $\mathrm{~m}$ & $\mathrm{~m}$ & 15,4 & 0,16 \\
\hline Slowakei ${ }^{3}$ & 79,4 & 16,2 & 0,5 & 16,7 & $\mathrm{~m}$ & 3,9 & 20,6 & 0,20 \\
\hline Slowenien & 76,6 & 23,4 & $\mathrm{n}$ & 23,4 & $\mathrm{~m}$ & $\mathrm{n}$ & 23,4 & 0,32 \\
\hline Spanien & 90,6 & 9,4 & $\mathrm{n}$ & 9,4 & 2,0 & $\mathrm{n}$ & 9,4 & 0,11 \\
\hline Schweden & 75,3 & 9,5 & 15,2 & 24,7 & a & a & 24,7 & 0,49 \\
\hline Schweiz & 92,9 & 2,2 & $n$ & 2,2 & $\mathrm{~m}$ & 4,9 & 7,1 & 0,10 \\
\hline Türkei & 85,9 & 5,0 & 9,1 & 14,1 & $\mathrm{n}$ & $\mathrm{m}$ & 14,1 & 0,22 \\
\hline Ver. Königreich & 26,2 & 7,5 & 31,7 & 39,2 & $x(4)$ & 34,7 & 73,8 & 0,99 \\
\hline Vereinigte Staaten & 70,8 & 27,9 & 1,3 & 29,2 & $\mathrm{~m}$ & $\mathrm{~m}$ & 29,2 & 0,39 \\
\hline OECD-Durchschnitt & 78,5 & 11,6 & 9,2 & 19,6 & 3,1 & 2,0 & 21,5 & 0,31 \\
\hline \multicolumn{9}{|l|}{ Partnerländer } \\
\hline Argentinien & 98,9 & 1,1 & $\mathrm{n}$ & 1,1 & $\mathrm{~m}$ & 0,1 & 1,1 & 0,01 \\
\hline Brasilien & 90,5 & 4,3 & 4,4 & 8,7 & $x(2)$ & 0,8 & 9,5 & 0,10 \\
\hline China & m & $\mathrm{m}$ & $\mathrm{m}$ & $\mathrm{m}$ & $\mathrm{m}$ & $\mathrm{m}$ & m & $\mathrm{m}$ \\
\hline Kolumbien ${ }^{2}$ & 86,5 & $x(4)$ & $x(4)$ & 13,5 & $x(4)$ & $\mathrm{n}$ & 13,5 & 0,14 \\
\hline Indien & m & $\mathrm{m}$ & $\mathrm{m}$ & $\mathrm{m}$ & $\mathrm{m}$ & $\mathrm{m}$ & m & $\mathrm{m}$ \\
\hline Indonesien² & 97,7 & 2,3 & $\mathrm{~m}$ & 2,3 & $\mathrm{~m}$ & $\mathrm{~m}$ & 2,3 & $\mathrm{~m}$ \\
\hline Lettland & 86,0 & 14,0 & $\mathrm{n}$ & 14,0 & $x(2)$ & $n$ & 14,0 & 0,14 \\
\hline Russische Föd. & m & $\mathrm{m}$ & a & $\mathrm{m}$ & a & $\mathrm{m}$ & m & $\mathrm{m}$ \\
\hline Saudi-Arabien & m & $\mathrm{m}$ & $\mathrm{m}$ & $\mathrm{m}$ & $\mathrm{m}$ & $\mathrm{m}$ & m & $\mathrm{m}$ \\
\hline Südafrika & m & $\mathrm{m}$ & $\mathrm{m}$ & $\mathrm{m}$ & $\mathrm{m}$ & $\mathrm{m}$ & m & $\mathrm{m}$ \\
\hline G20-Durchschnitt & m & $\mathbf{m}$ & m & $\mathbf{m}$ & $\mathbf{m}$ & $\mathbf{m}$ & $\mathbf{m}$ & m \\
\hline
\end{tabular}

1. Referenzjahr 2010. 2. Referenzjahr 2012. 3. Einige Bildungsbereiche sind in anderen Bildungsbereichen enthalten. Einzelheiten s. Erläuterung von „x“ in Hinweise für den Leser.

Quelle: OECD. Argentinien, China, Indien, Indonesien, Kolumbien, Saudi-Arabien und Südafrika: Statistikinstitut der UNESCO. Lettland: Eurostat. Hinweise s. Anhang 3 unter www.oecd.org/edu/eag.htm. StatLink: http://dx.doi.org/10.1787/888933117782

Erläuterung der Kennzeichnung fehlender Daten s. Hinweise für den Leser. 



\section{Wofür werden Finanzmittel im Bereich der Bildung ausgegeben?}

Rund 9o Prozent der Bildungsgesamtausgaben werden in den OECD-Ländern im Durchschnitt für laufende Ausgaben aufgewendet, und in den meisten OECDLändern trifft dies sowohl für den Primar-, Sekundar- und postsekundaren, nicht tertiären Bereich zusammengenommen als auch für den Tertiärbereich zu.

In 25 der 33 OECD- und Partnerländer mit verfügbaren Daten ist der Anteil der Gesamtausgaben, der auf Investitionsausgaben entfällt, im Tertiärbereich höher als im Primar-, Sekundar- und postsekundaren, nicht tertiären Bereich zusammen. Dies könnte mit dem Wachstum des Tertiärbereichs in den letzten Jahren und der daraus resultierenden Notwendigkeit des Neubaus von Gebäuden zusammenhängen.

In den OECD- und Partnerländern, für die Daten zur Verfügung stehen, entfällt der Großteil der laufenden Ausgaben auf die Vergütung der im Bildungswesen Beschäftigten (Lehrkräfte und andere).

Der auf andere Zwecke als die Vergütung von Beschäftigten entfallende Teil der laufenden Ausgaben ist im Tertiärbereich am höchsten und beläuft sich im Durchschnitt der OECD-Länder auf 33 Prozent aller laufenden Ausgaben. In 8 OECD- und Partnerländern beträgt dieser Anteil mehr als 40 Prozent. Ein wesentlicher Grund hierfür könnten die im Vergleich mit den anderen Bildungsbereichen höheren Kosten für die Einrichtung und Ausrüstung der Bildungseinrichtungen im Tertiärbereich sein.

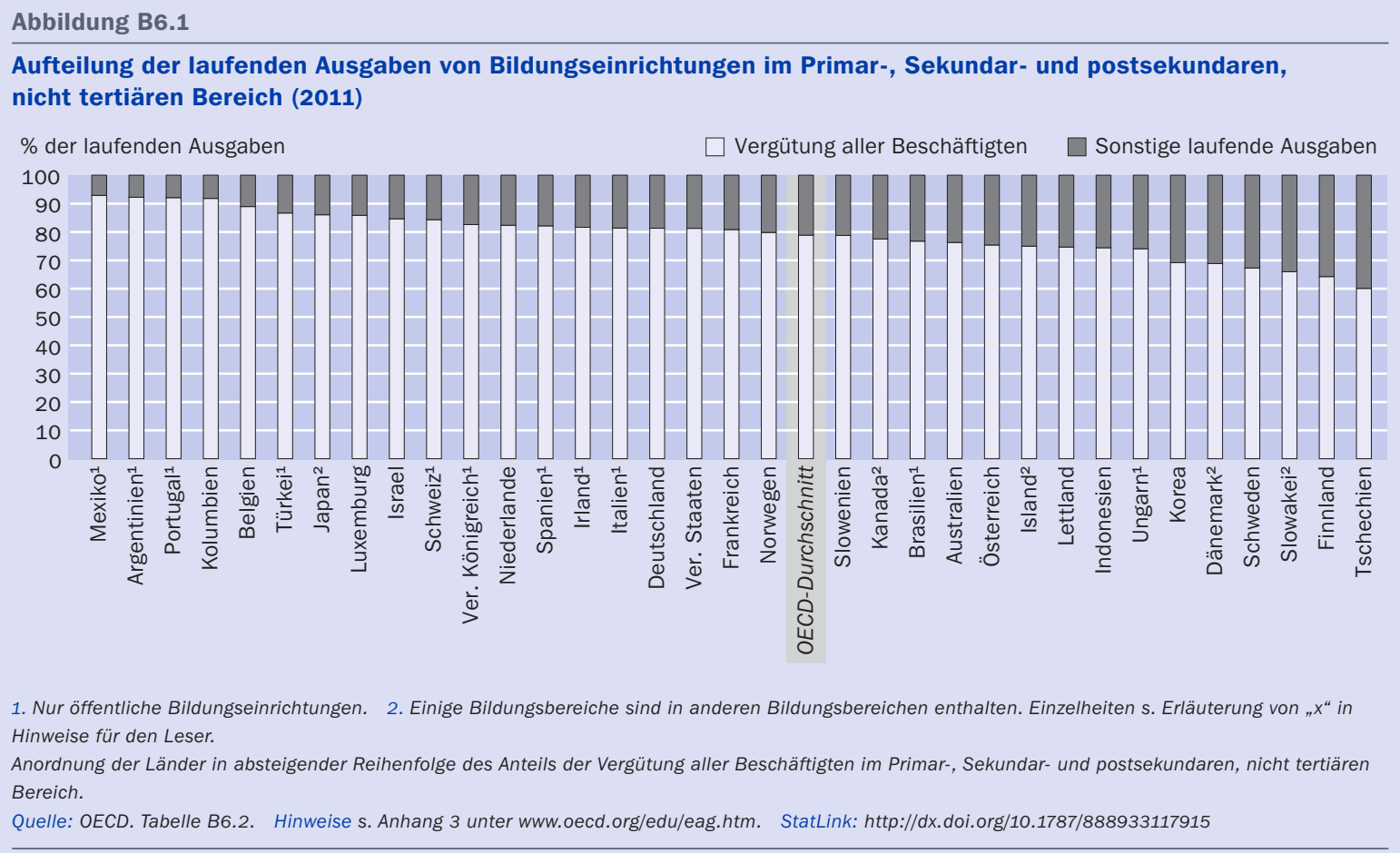




\section{Kontext}

Entscheidungen über die Zuweisung von Mitteln beeinflussen die materiellen Unterrichtsbedingungen und können sich auch auf die Art des Unterrichts auswirken.

Zwar können durch die Kürzung von Investitionsausgaben (z. B. die Streichung von Schulneubauten) und einiger laufender Ausgaben (kein Kauf bestimmter Unterrichtsmaterialien) bei zunehmendem Druck auf die Bildungshaushalte Einsparungen erzielt werden, die größten Auswirkungen auf die Gesamtausgaben haben jedoch Veränderungen der Ausgaben für Beschäftigte. Einsparungen durch die Kürzung von Gehältern und Leistungen oder eine Verringerung der Zahl an Lehrkräften und sonstigen Beschäftigten sind jedoch politisch unpopulär und möglicherweise kontraproduktiv, da so gute Lehrkräfte davon abgehalten werden, diesen Beruf zu ergreifen bzw. in diesem Beruf zu bleiben. Deshalb ist für die Verbesserung der Qualität des Bildungswesens neben einem effizienteren Management der materiellen Ressourcen von grundlegender Bedeutung, das Personalmanagement zu verbessern. Außerdem stellt die Verschiebung von Ausgaben wie die Anstellung neuer Lehrkräfte oder Gehaltserhöhungen eine weitere Möglichkeit dar, durch zeitlich begrenzte Maßnahmen auf den Druck auf die öffentlichen Haushalte zu reagieren.

Dieser Indikator beschreibt die Ressourcen und Dienstleistungen, für die im Bildungsbereich Geld ausgegeben wird. Er zeigt die Unterschiede zwischen laufenden Ausgaben und Investitionsausgaben auf. Steigende Schüler-/Studierendenzahlen können sich auf die Investitionsausgaben auswirken, da sie häufig den Bau neuer Gebäude erforderlich machen. Dieser Indikator zeigt auch auf, wofür die laufenden Ausgaben eingesetzt werden - für die Vergütung von Beschäftigten im Bildungswesen oder sonstige Zwecke. Die laufenden Ausgaben werden hauptsächlich von den Gehältern der Lehrkräfte (s. Indikator D3), aber auch von den Ruhestandsregelungen, der Altersverteilung der Lehrkräfte sowie der Zahl der nicht unterrichtenden Beschäftigten im Bildungswesen beeinflusst. Außerdem wird in Bildungseinrichtungen nicht nur unterrichtet, sondern es werden auch sonstige Dienstleistungen wie z. B. Mahlzeiten, Transport, Internatsleistungen und/oder Forschungstätigkeiten angeboten. All diese Ausgaben werden in diesem Indikator beschrieben.

\section{Weitere wichtige Ergebnisse}

Die OECD-Länder wenden im Primar-, Sekundar- und postsekundaren, nicht tertiären Bereich durchschnittlich 21 Prozent der laufenden Ausgaben für andere Zwecke als die Vergütung der im Bildungsbereich Beschäftigten auf. Zwischen Primar- und Sekundarbereich gibt es beim Anteil der laufenden Ausgaben für andere Zwecke als die Vergütung der im Bildungsbereich Beschäftigten nur geringe Unterschiede. Nur in Brasilien, Frankreich, Indonesien, Irland, und Luxemburg beläuft sich dieser Unterschied auf mehr als 5 Prozentpunkte und in Dänemark auf 20 Prozentpunkte.

In fast allen Ländern, außer in Indonesien und Tschechien im Tertiärbereich, wird der Großteil der laufenden Ausgaben für die Vergütung von Beschäftigten aufgewendet. Im Tertiärbereich entfallen nur in Brasilien, Island und Kolumbien mehr als 8o Prozent 
der laufenden Ausgaben auf die Vergütung der im Bildungsbereich Beschäftigten, im Primar-, Sekundar- und postsekundaren, nicht tertiären Bereich zusammen ist dies in I8 Ländern der Fall.

In fast allen Ländern mit Ausnahme von Brasilien, Dänemark, Island und Kolumbien ist der Anteil der laufenden Ausgaben für andere Zwecke als die Vergütung von Beschäftigten im Tertiärbereich höher als im Primar-, Sekundar- und postsekundaren, nicht tertiären Bereich zusammen.

\title{
Analyse und Interpretationen
}

\begin{abstract}
Laufende Ausgaben und Investitionsausgaben der Bildungseinrichtungen Bildungsausgaben umfassen sowohl laufende als auch Investitionsausgaben. Laufende Ausgaben von Bildungseinrichtungen beinhalten finanzielle Aufwendungen für Ressourcen der Bildungseinrichtungen, die jedes Jahr für den laufenden Betrieb der Bildungseinrichtungen erforderlich sind. Dazu gehören beispielsweise die Vergütung von Lehrkräften und anderen Beschäftigten, die Instandhaltung von Schulgebäuden, Mahlzeiten für Schüler/Studierende oder die Miete von Schulgebäuden und anderen Einrichtungen. Investitionsausgaben von Bildungseinrichtungen sind Ausgaben für Sachmittel mit einer Nutzungsdauer von mehr als einem Jahr. Hierzu gehören beispielsweise Aufwendungen für den Bau, die Renovierung und größere Instandsetzungsarbeiten von Gebäuden.
\end{abstract}

Da Bildungsvermittlung sehr arbeitskräfteintensiv ist, entfällt der Großteil der Ausgaben auf laufende Ausgaben. 20II entfielen im Durchschnitt der OECD-Länder mindestens rund 9o Prozent der Gesamtausgaben auf laufende Ausgaben: im Primar-, Sekundar- und postsekundaren, nicht tertiären Bereich zusammen 92,6 Prozent und im Tertiärbereich 89,5 Prozent. Die laufenden Ausgaben machen in allen OECD- und Partnerländern in allen Bildungsbereichen mehr als 79 Prozent der Gesamtausgaben aus, mit Ausnahme des Tertiärbereichs in Indonesien und Kolumbien. Der Anteil variiert im Primarbereich zwischen 8r Prozent in Australien und fast 99 Prozent in Portugal, im Sekundarbereich zwischen 86 Prozent in Korea und fast 99 Prozent in Australien, und im Tertiärbereich zwischen 50 Prozent in Kolumbien und 98 Prozent in Dänemark. Der OECD-Durchschnitt ist für den Primar- und Sekundarbereich ähnlich und weist einen Unterschied von 3 Prozentpunkten zwischen Primar-, Sekundar- und postsekundarem, nicht tertiärem Bildungsbereich zusammen einerseits und Tertiärbereich andererseits auf (92,6 Prozent gegenüber 89,5 Prozent) (Tab. B6.I und B6.2 sowie Abb. B6.2).

Dennoch kann es relativ große Unterschiede zwischen den laufenden Ausgaben im Primar-, Sekundar- und postsekundaren, nicht tertiären Bereich zusammen und dem Tertiärbereich geben. In den meisten Ländern ist der Anteil der laufenden Ausgaben in den erstgenannten Bildungsbereichen höher als im letztgenannten. Die drei größten Ausnahmen sind Dänemark, Finnland und Norwegen, wo der Anteil der laufenden Ausgaben im Tertiärbereich den Anteil im Primar-, Sekundar- und postsekundaren, nicht tertiären Bildungsbereich zusammen um mehr als 4 bis 6 Prozentpunkte über- 
steigt. Dagegen übersteigt der Anteil der laufenden Ausgaben im Primar-, Sekundarund postsekundaren, nicht tertiären Bereich zusammen in Indonesien, Kolumbien, Polen, der Slowakei, Spanien, Tschechien und der Türkei den entsprechenden Anteil im Tertiärbereich um mindestens io Prozentpunkte.

Die Unterschiede zwischen den einzelnen Ländern spiegeln wahrscheinlich die Organisation der einzelnen Bildungsbereiche in dem jeweiligen Land sowie das Ausmaß wider, in dem steigende Schüler- und Studierendenzahlen den Neubau von Gebäuden, insbesondere im Tertiärbereich, erfordern. Die Investitionsausgaben im Tertiärbereich liegen teilweise über I5 Prozent - sie belaufen sich in Indonesien auf 28, I Prozent, in Lettland auf 17,0 Prozent, in Polen auf 20,2 Prozent, in Kolumbien auf 49,6 Prozent, in der Slowakei auf I9,4 Prozent, in Spanien auf 17,6 Prozent und in Tschechien auf I 9,4 Prozent. Die Art und Weise, wie Länder Ausgaben im Zusammenhang mit Universitätsgebäuden verbuchen, könnte auch die Unterschiede der Anteile der laufenden und Investitionsausgaben im Tertiärbereich erklären. So können sich für Bildungsaufgaben genutzte Gebäude und Grundstücke im Eigentum der Bildungseinrichtungen befinden, kostenlos genutzt werden oder angemietet sein und die Höhe der laufenden und Investitionsausgaben somit zum Teil von der Art der Immobilienverwaltung in einem Land abhängen (s. Kasten B6.I in Bildung auf einen Blick 2012 [OECD, 2012]).

\section{Aufteilung der laufenden Ausgaben}

Die laufenden Ausgaben von Bildungseinrichtungen lassen sich in drei große, funktional definierte Kategorien unterteilen: die Vergütung der Lehrkräfte, die Vergütung der sonstigen Beschäftigten und sonstige laufende Ausgaben. Zu den sonstigen laufenden Ausgaben gehören beispielsweise die Ausgaben für Unterrichts- und Hilfsmaterial, die Instandhaltung von Bildungseinrichtungen, die Zubereitung von Mahlzeiten für Schüler/Studierende sowie Mietzahlungen für Gebäude und Ausrüstung der Bildungseinrichtungen. Die Höhe der Mittelzuteilung für jede einzelne dieser Kategorien wird in gewissem Maße durch die gegenwärtige und erwartete Entwicklung der Schüler-/Studierendenzahlen, die Gehälter der im Bildungsbereich Beschäftigten und die Kosten für die Instandhaltung und den Bau von Gebäuden und Einrichtungen der Bildungseinrichtungen beeinflusst. Auch wenn sich der Anteil der einzelnen Kategorien von Jahr zu Jahr nicht stark ändert, könnten sich die Entscheidungen der Länder nicht nur auf die Gesamtbeträge, sondern auch auf die Anteile selbst auswirken.

Im Primar-, Sekundar- und postsekundaren, nicht tertiären Bereich entfallen in den OECD-Ländern im Durchschnitt mehr als 62 Prozent der laufenden Ausgaben auf die Vergütung von Lehrkräften, I5 Prozent auf die Vergütung von sonstigen Beschäftigten und 2I Prozent auf andere Ausgaben als die Vergütung von Beschäftigten. Im Tertiärbereich entfallen in den OECD-Ländern im Durchschnitt 42 Prozent der laufenden Ausgaben auf die Vergütung von Lehrkräften und höhere Anteile auf die Vergütung der sonstigen Beschäftigten (fast 25 Prozent) und auf sonstige laufende Ausgaben (rund 32 Prozent).

Es gibt relativ große Unterschiede, wie sich die laufenden Ausgaben auf den Primar-, Sekundar- und postsekundaren, nicht tertiären Bildungsbereich zusammen und den Tertiärbereich verteilen. In allen Ländern ist beispielsweise der auf die Vergütung von Lehrkräften entfallende Anteil im Primar-, Sekundar- und postsekundaren, nicht ter- 

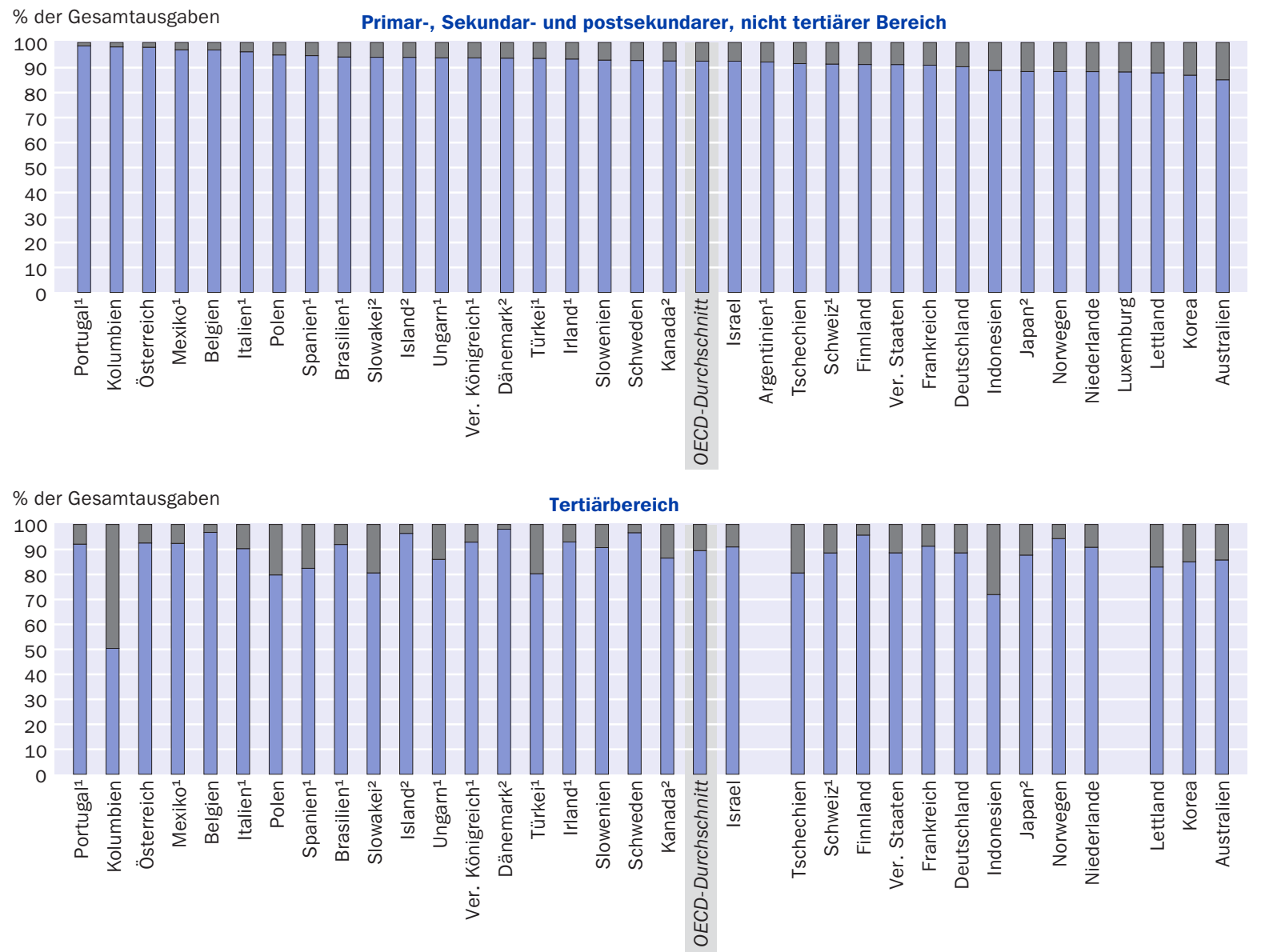

1. Nur öffentliche Bildungseinrichtungen (Italien und Vereinigtes Königreich: außer im Tertiärbereich). 2. Einige Bildungsbereiche sind in anderen Bildungsbereichen enthalten. Einzelheiten s. Erläuterung von „x“ in Hinweise für den Leser.

Anordnung der Länder in absteigender Reihenfolge des Anteils der laufenden Ausgaben im Primar-, Sekundar- und postsekundaren, nicht tertiären Bildungsbereich. Quelle: OECD. Tabelle B6.2. Hinweise s. Anhang 3 unter www.oecd.org/edu/eag.htm. StatLink: http://dx.doi.org/10.1787/888933117934

tiären Bildungsbereich zusammen höher als im Tertiärbereich. Die einzige Ausnahme ist Kolumbien, wo der Anteil im Tertiärbereich den zusammengenommenen Anteil der anderen Bereiche um 9 Prozentpunkte übersteigt. Der Prozentsatz der sonstigen laufenden Ausgaben beträgt in nur 7 Ländern für den Primar-, Sekundar- und postsekundaren, nicht tertiären Bereich zusammen mehr als 30 Prozent - in Dänemark (3I, 2 Prozent), Finnland (35,8 Prozent), Korea (30,9 Prozent), Schweden (32,8 Prozent), der Slowakei (34,0 Prozent) und Tschechien (39,9 Prozent). Im Gegensatz dazu beträgt dieser Anteil im Tertiärbereich in fast der Hälfte der OECD-Länder mehr als 30 Prozent und in nur 3 Ländern weniger als 20 Prozent - in Brasilien sind es I6, I Prozent, in Island I2,9 Prozent und in Kolumbien 7,5 Prozent.

Der Unterschied bei den nicht auf die Vergütung der Beschäftigten entfallenden laufenden Ausgaben zwischen den Bildungsbereichen spiegelt den unterschiedlichen Umfang des Verwaltungsapparats in diesen Bildungsbereichen wider (z. B. die Mitar- 
beiterzahl oder die den Verwaltungsmitarbeitern zur Verfügung stehende Ausstattung). Dass die Kosten für Einrichtungen und Ausrüstung im Tertiärbereich höher sind als in den anderen Bildungsbereichen, ist zu erwarten. Die Unterschiede zwischen den einzelnen Ländern bei der Vergütung der sonstigen Beschäftigten währenddessen spiegeln wahrscheinlich wider, inwieweit in einem bestimmten Land im Bildungsbereich Beschäftigte wie z. B. Schulleiter, Beratungslehrer, Busfahrer, Schulkrankenschwestern, Hausmeister und Handwerker der Kategorie „nicht unterrichtende Beschäftigte" zugerechnet werden (s. Indikator D2). Die Vergütung der Beschäftigten in den Bereichen Forschung und Entwicklung im Tertiärbereich könnte auch teilweise die Unterschiede - zwischen den Ländern und den Bildungsbereichen - bei den auf die Vergütung von Beschäftigten entfallenden Anteilen der laufenden Ausgaben erklären.

\section{Definitionen}

Investitionsausgaben beziehen sich auf Ausgaben für Sachwerte mit einer Lebensdauer von mehr als einem Jahr. Hierzu zählen u. a. die Ausgaben für Bau, Renovierung und größere Instandsetzungsarbeiten von Gebäuden sowie für die Neubeschaffung oder den Ersatz von Ausrüstungsgegenständen. Die hier ausgewiesenen Investitionsausgaben beziehen sich auf den Wert der in dem betreffenden Jahr erworbenen oder geschaffenen bildungsbezogenen Vermögenswerte, ausgedrückt in der Höhe der Kapitalbildung, unabhängig davon, ob die Investitionsausgaben durch laufende Einnahmen oder Kreditaufnahmen finanziert wurden. Der Schuldendienst ist weder in den laufenden Ausgaben noch in den Investitionsausgaben enthalten.

Laufende Ausgaben beziehen sich auf Ausgaben für die im laufenden Haushaltsjahr verbrauchten Güter und Dienstleistungen, die immer wieder anfallen, um die Bereitstellung von Bildungsdienstleistungen aufrechtzuerhalten. Die laufenden Ausgaben der Bildungseinrichtungen beinhalten, abgesehen von den Personalausgaben, auch Ausgaben für per Auftrag vergebene oder zugekaufte Serviceleistungen (z. B. für die Instandhaltung von Schulgebäuden), zusätzliche Dienstleistungen (z. B. für die Zubereitung von Schulmahlzeiten) und Mietzahlungen für Schulgebäude und andere Einrichtungen. Diese Dienstleistungen werden von externen Anbietern erbracht, im Unterschied zu Leistungen, die von den Bildungsbehörden oder den Bildungseinrichtungen selbst mit eigenen Beschäftigten erbracht werden.

\section{Angewandte Methodik}

Die Daten beziehen sich auf das Haushaltsjahr 201 und beruhen auf der von der OECD im Jahre 20I3 durchgeführten UOE-Datenerhebung zur Bildungsstatistik (weitere Informationen s. Anhang 3 unter www.oecd.org/edu/eag.htm).

Die Berechnungen beziehen sich auf die Ausgaben öffentlicher Bildungseinrichtungen bzw. soweit verfügbar auf die Ausgaben öffentlicher und privater Bildungseinrichtungen zusammen. 
Anmerkung zu den Daten aus Israel

Die statistischen Daten für Israel wurden von den zuständigen israelischen Stellen bereitgestellt, die für sie verantwortlich zeichnen. Die Verwendung dieser Daten durch die OECD erfolgt unbeschadet des völkerrechtlichen Status der Golanhöhen, von Ost-Jerusalem und der israelischen Siedlungen im Westjordanland.

\section{Weiterführende Informationen}

OECD (2012), Bildung auf einen Blick 2012 - OECD-Indikatoren, W. Bertelsmann Verlag, Bielefeld.

\section{Tabellen Indikator B6}

StatLink: http://dx.doi.org/10.1787/888933117858

Tabelle B6.I: Ausgaben von Bildungseinrichtungen des Primar- und Sekundarbereichs, nach Ausgabenkategorie (20II)

Tabelle B6.2: Ausgaben von Bildungseinrichtungen, nach Ausgabenkategorie und Bildungsbereich (20II) 
Tabelle B6.1

Ausgaben von Bildungseinrichtungen im Primar- und Sekundarbereich, nach Ausgabenkategorie (2011)

Verteilung der mit Mitteln aus öffentlichen und privaten Quellen finanzierten Gesamtausgaben und der laufenden Ausgaben von Bildungseinrichtungen

\begin{tabular}{|c|c|c|c|c|c|c|c|c|c|c|c|c|}
\hline & \multicolumn{6}{|c|}{ Primarbereich } & \multicolumn{6}{|c|}{ Sekundarbereich } \\
\hline & \multicolumn{2}{|c|}{$\begin{array}{l}\text { Prozentsatz der } \\
\text { Gesamtausgaben }\end{array}$} & \multicolumn{4}{|c|}{ Prozentsatz der laufenden Ausgaben } & \multicolumn{2}{|c|}{$\begin{array}{l}\text { Prozentsatz der } \\
\text { Gesamtausgaben }\end{array}$} & \multicolumn{4}{|c|}{ Prozentsatz der laufenden Ausgaben } \\
\hline & \begin{tabular}{|l|} 
Laufende \\
Ausgaben
\end{tabular} & \begin{tabular}{|c|} 
Investi- \\
tionsaus- \\
gaben
\end{tabular} & \begin{tabular}{|c|} 
Vergütung \\
der Lehr- \\
kräfte
\end{tabular} & $\begin{array}{l}\text { Vergü- } \\
\text { tung der } \\
\text { sonstigen } \\
\text { Beschäf- } \\
\text { tigten }\end{array}$ & \begin{tabular}{|c|} 
Vergütung \\
aller \\
Beschäf- \\
tigten
\end{tabular} & \begin{tabular}{|c|} 
Sonstige \\
laufende \\
Ausgaben
\end{tabular} & \begin{tabular}{|l|} 
Laufende \\
Ausgaben
\end{tabular} & $\begin{array}{c}\text { Investi- } \\
\text { tionsaus- } \\
\text { gaben }\end{array}$ & \begin{tabular}{|c|} 
Vergütung \\
der Lehr- \\
kräfte
\end{tabular} & \begin{tabular}{|c|} 
Vergü- \\
tung der \\
sonstigen \\
Beschäf- \\
tigten
\end{tabular} & $\begin{array}{l}\text { Vergütung } \\
\text { aller } \\
\text { Beschäf- } \\
\text { tigten }\end{array}$ & $\begin{array}{l}\text { Sonstige } \\
\text { laufende } \\
\text { Ausgaben }\end{array}$ \\
\hline & (1) & (2) & (3) & (4) & (5) & (6) & (7) & (8) & (9) & (10) & (11) & (12) \\
\hline \multicolumn{13}{|l|}{ OECD-Länder } \\
\hline Australien & 81,3 & 18,7 & 62,9 & 15,1 & 78,0 & 22,0 & 88,3 & 11,7 & 59,2 & 16,2 & 75,4 & 24,6 \\
\hline Österreich & 98,1 & 1,9 & 60,7 & 12,6 & 73,3 & 26,7 & 98,2 & 1,8 & 68,0 & 8,6 & 76,5 & 23,5 \\
\hline Belgien $^{1}$ & 96,2 & 3,8 & 69,7 & 19,3 & 89,0 & 11,0 & 97,5 & 2,5 & 72,4 & 16,5 & 88,9 & 11,1 \\
\hline Kanada $^{1,2}$ & 92,6 & 7,4 & 62,6 & 15,0 & 77,5 & 22,5 & 92,6 & 7,4 & 62,6 & 15,0 & 77,5 & 22,5 \\
\hline Chile & $\mathbf{m}$ & m & $\mathrm{m}$ & $\mathrm{m}$ & $\mathrm{m}$ & $\mathrm{m}$ & m & m & $\mathrm{m}$ & $\mathrm{m}$ & $\mathrm{m}$ & $\mathrm{m}$ \\
\hline Tschechien & 90,1 & 9,9 & 46,1 & 16,5 & 62,6 & 37,4 & 92,1 & 7,9 & 46,8 & 12,4 & 59,2 & 40,8 \\
\hline Dänemark ${ }^{1}$ & 94,7 & 5,3 & 63,4 & 17,0 & 80,5 & 19,5 & 93,0 & 7,0 & 39,0 & 20,7 & 59,8 & 40,2 \\
\hline Estland & $\mathbf{m}$ & m & $\mathrm{m}$ & $\mathrm{m}$ & $\mathrm{m}$ & $\mathrm{m}$ & m & m & $\mathrm{m}$ & $\mathrm{m}$ & $\mathrm{m}$ & $\mathrm{m}$ \\
\hline Finnland $^{1}$ & 91,7 & 8,3 & 55,6 & 9,5 & 65,1 & 34,9 & 91,0 & 9,0 & 51,1 & 12,7 & 63,8 & 36,2 \\
\hline Frankreich & 91,6 & 8,4 & 56,8 & 20,4 & 77,2 & 22,8 & 90,6 & 9,4 & 58,4 & 24,0 & 82,5 & 17,5 \\
\hline Deutschland & 90,8 & 9,2 & $x(5)$ & $x(5)$ & 82,1 & 17,9 & 90,2 & 9,8 & $x(11)$ & $x(11)$ & 81,5 & 18,5 \\
\hline Griechenland & $\mathbf{m}$ & m & $\mathrm{m}$ & $\mathrm{m}$ & $\mathrm{m}$ & $\mathrm{m}$ & m & m & $\mathrm{m}$ & $\mathrm{m}$ & $\mathrm{m}$ & $\mathrm{m}$ \\
\hline Ungarn ${ }^{3}$ & 94,1 & 5,9 & $x(5)$ & $x(5)$ & 72,8 & 27,2 & 93,8 & 6,2 & $x(11)$ & $x(11)$ & 74,7 & 25,3 \\
\hline Island ${ }^{1}$ & 93,0 & 7,0 & $x(5)$ & $x(5)$ & 74,5 & 25,5 & 95,2 & 4,8 & $x(11)$ & $x(11)$ & 75,4 & 24,6 \\
\hline Irland ${ }^{3}$ & 92,0 & 8,0 & 76,5 & 12,4 & 89,0 & 11,0 & 94,5 & 5,5 & 70,2 & 8,9 & 79,1 & 20,9 \\
\hline Israel & 91,5 & 8,5 & $x(5)$ & $x(5)$ & 85,2 & 14,8 & 94,0 & 6,1 & $x(11)$ & $x(11)$ & 83,9 & 16,1 \\
\hline Italien ${ }^{3}$ & 96,6 & 3,4 & 62,4 & 19,0 & 81,3 & 18,7 & 97,2 & 2,8 & 64,7 & 18,7 & 83,4 & 16,6 \\
\hline$J^{J} a^{1}$ & 88,1 & 11,9 & $x(5)$ & $x(5)$ & 85,8 & 14,2 & 88,6 & 11,4 & $x(11)$ & $x(11)$ & 86,2 & 13,8 \\
\hline Korea & 87,4 & 12,6 & 54,6 & 14,9 & 69,4 & 30,6 & 86,6 & 13,4 & 56,5 & 12,5 & 68,9 & 31,1 \\
\hline Luxemburg & 85,8 & 14,2 & 78,4 & 3,7 & 82,1 & 17,9 & 91,1 & 8,9 & 77,0 & 12,9 & 89,9 & 10,1 \\
\hline Mexiko $^{3}$ & 97,4 & 2,6 & 86,4 & 8,2 & 94,6 & 5,4 & 96,8 & 3,2 & 78,8 & 12,0 & 90,8 & 9,2 \\
\hline Niederlande & 88,0 & 12,0 & $x(5)$ & $x(5)$ & 83,6 & 16,4 & 88,6 & 11,4 & $x(11)$ & $x(11)$ & 81,6 & 18,4 \\
\hline Neuseeland & m & m & $\mathrm{m}$ & $\mathrm{m}$ & $\mathrm{m}$ & $\mathrm{m}$ & m & m & $\mathrm{m}$ & $\mathrm{m}$ & $\mathrm{m}$ & $\mathrm{m}$ \\
\hline Norwegen $^{1}$ & 89,3 & 10,7 & $x(5)$ & $x(5)$ & 79,8 & 20,2 & 87,6 & 12,4 & $x(11)$ & $x(11)$ & 79,8 & 20,2 \\
\hline Polen & 94,1 & 5,9 & $x(1)$ & $x(1)$ & $\mathrm{x}(1)$ & $\mathrm{x}(1)$ & 95,9 & 4,1 & $x(7)$ & $x(7)$ & $x(7)$ & $x(7)$ \\
\hline Portugal $^{3}$ & 98,7 & 1,3 & 80,0 & 13,9 & 93,9 & 6,1 & 98,7 & 1,3 & 80,7 & 10,2 & 90,9 & 9,1 \\
\hline Slowakei ${ }^{1}$ & 92,6 & 7,4 & 51,1 & 13,8 & 64,9 & 35,1 & 94,8 & 5,2 & 52,4 & 14,0 & 66,4 & 33,6 \\
\hline Slowenien ${ }^{1}$ & 92,4 & 7,6 & $x(5)$ & $x(5)$ & 81,2 & 18,8 & 93,5 & 6,5 & $x(11)$ & $x(11)$ & 76,8 & 23,2 \\
\hline Spanien $^{3}$ & 94,9 & 5,1 & 71,0 & 9,7 & 80,7 & 19,3 & 94,7 & 5,3 & 74,9 & 8,3 & 83,1 & 16,9 \\
\hline Schweden & 93,5 & 6,5 & 52,7 & 16,7 & 69,4 & 30,6 & 92,3 & 7,7 & 50,7 & 14,9 & 65,6 & 34,4 \\
\hline Schweiz $z^{1,3}$ & 90,5 & 9,5 & 66,6 & 16,6 & 83,2 & 16,8 & 92,0 & 8,0 & 73,0 & 12,2 & 85,2 & 14,8 \\
\hline Türkei $^{3}$ & 96,3 & 3,7 & $x(5)$ & $x(5)$ & 89,3 & 10,7 & 91,9 & 8,1 & $x(11)$ & $x(11)$ & 84,8 & 15,2 \\
\hline Ver. Königreich ${ }^{3}$ & 93,7 & 6,3 & 54,4 & 29,0 & 83,4 & 16,6 & 94,0 & 6,0 & 59,8 & 22,0 & 81,8 & 18,2 \\
\hline Vereinigte Staaten & 91,2 & 8,8 & 54,6 & 26,6 & 81,3 & 18,7 & 91,2 & 8,8 & 54,6 & 26,6 & 81,2 & 18,8 \\
\hline OECD-Durchschnitt & 92,3 & $\mathbf{7 , 7}$ & 63,3 & 15,5 & $\mathbf{7 9 , 7}$ & 20,3 & 92,9 & 7,1 & 62,5 & 15,0 & 78,4 & 21,6 \\
\hline EU21-Durchschnitt & 93,1 & 6,9 & 62,8 & 15,3 & 78,5 & 21,5 & 93,8 & 6,2 & 61,9 & 14,6 & 77,0 & 23,0 \\
\hline \multicolumn{13}{|l|}{ Partnerländer } \\
\hline Argentinien $^{3}$ & 94,7 & 5,3 & 70,7 & 20,6 & 91,3 & 8,7 & 90,2 & 9,8 & 68,2 & 24,7 & 92,9 & 7,1 \\
\hline Brasilien $^{2}$ & 94,3 & 5,7 & $x(5)$ & $x(5)$ & 72,0 & 28,0 & 94,2 & 5,8 & $x(11)$ & $x(11)$ & 79,8 & 20,2 \\
\hline China & m & m & $\mathrm{m}$ & $\mathrm{m}$ & $\mathrm{m}$ & $\mathrm{m}$ & m & m & $\mathrm{m}$ & $\mathrm{m}$ & $\mathrm{m}$ & $\mathrm{m}$ \\
\hline Kolumbien ${ }^{4}$ & 98,3 & 1,7 & 82,8 & 9,0 & 91,8 & 8,2 & 98,3 & 1,7 & 82,8 & 9,0 & 91,8 & 8,2 \\
\hline Indien & m & $\mathbf{m}$ & $\mathrm{m}$ & $\mathrm{m}$ & $\mathrm{m}$ & $\mathrm{m}$ & $\mathbf{m}$ & $\mathbf{m}$ & $\mathrm{m}$ & $\mathrm{m}$ & $\mathrm{m}$ & $\mathrm{m}$ \\
\hline Indonesien ${ }^{4}$ & 86,5 & 13,5 & $x(5)$ & $x(5)$ & 81,2 & 18,8 & 92,6 & 7,4 & $x(11)$ & $x(11)$ & 64,2 & 35,8 \\
\hline Lettland & 87,7 & 12,3 & $x(5)$ & $x(5)$ & 75,4 & 24,6 & 88,0 & 12,0 & $x(11)$ & $x(11)$ & 74,2 & 25,8 \\
\hline Russische Föd. & m & $\mathbf{m}$ & $\mathrm{m}$ & $\mathrm{m}$ & $\mathrm{m}$ & $\mathrm{m}$ & $\mathbf{m}$ & $\mathbf{m}$ & $\mathrm{m}$ & $\mathrm{m}$ & $\mathrm{m}$ & $\mathrm{m}$ \\
\hline Saudi-Arabien & m & m & $\mathrm{m}$ & $\mathrm{m}$ & $\mathrm{m}$ & $\mathrm{m}$ & m & $\mathbf{m}$ & $\mathrm{m}$ & $\mathrm{m}$ & $\mathrm{m}$ & $\mathrm{m}$ \\
\hline Südafrika & m & m & $\mathrm{m}$ & $\mathrm{m}$ & $\mathrm{m}$ & $\mathrm{m}$ & m & m & $\mathrm{m}$ & $\mathrm{m}$ & $\mathrm{m}$ & $\mathrm{m}$ \\
\hline G20-Durchschnitt & m & m & m & m & m & m & m & $\mathbf{m}$ & m & m & $\mathbf{m}$ & m \\
\hline
\end{tabular}

1. Einige Bildungsbereiche sind in anderen Bildungsbereichen enthalten. Einzelheiten s. Erläuterung von „x“ in Hinweise für den Leser. 2. Referenzjahr 2010. 3. Nur öffentliche Bildungseinrichtungen. 4. Referenzjahr 2012.

Quelle: OECD. Argentinien, China, Indien, Indonesien, Kolumbien, Saudi-Arabien und Südafrika: Statistikinstitut der UNESCO. Lettland: Eurostat.

Hinweise s. Anhang 3 unter www.oecd.org/edu/eag.htm. StatLink: http://dx.doi.org/10.1787/888933117877

Erläuterung der Kennzeichnung fehlender Daten s. Hinweise für den Leser. 
Ausgaben von Bildungseinrichtungen, nach Ausgabenkategorie und Bildungsbereich (2011)

Verteilung der mit Mitteln aus öffentlichen und privaten Quellen finanzierten Gesamtausgaben und der laufenden Ausgaben von Bildungseinrichtungen

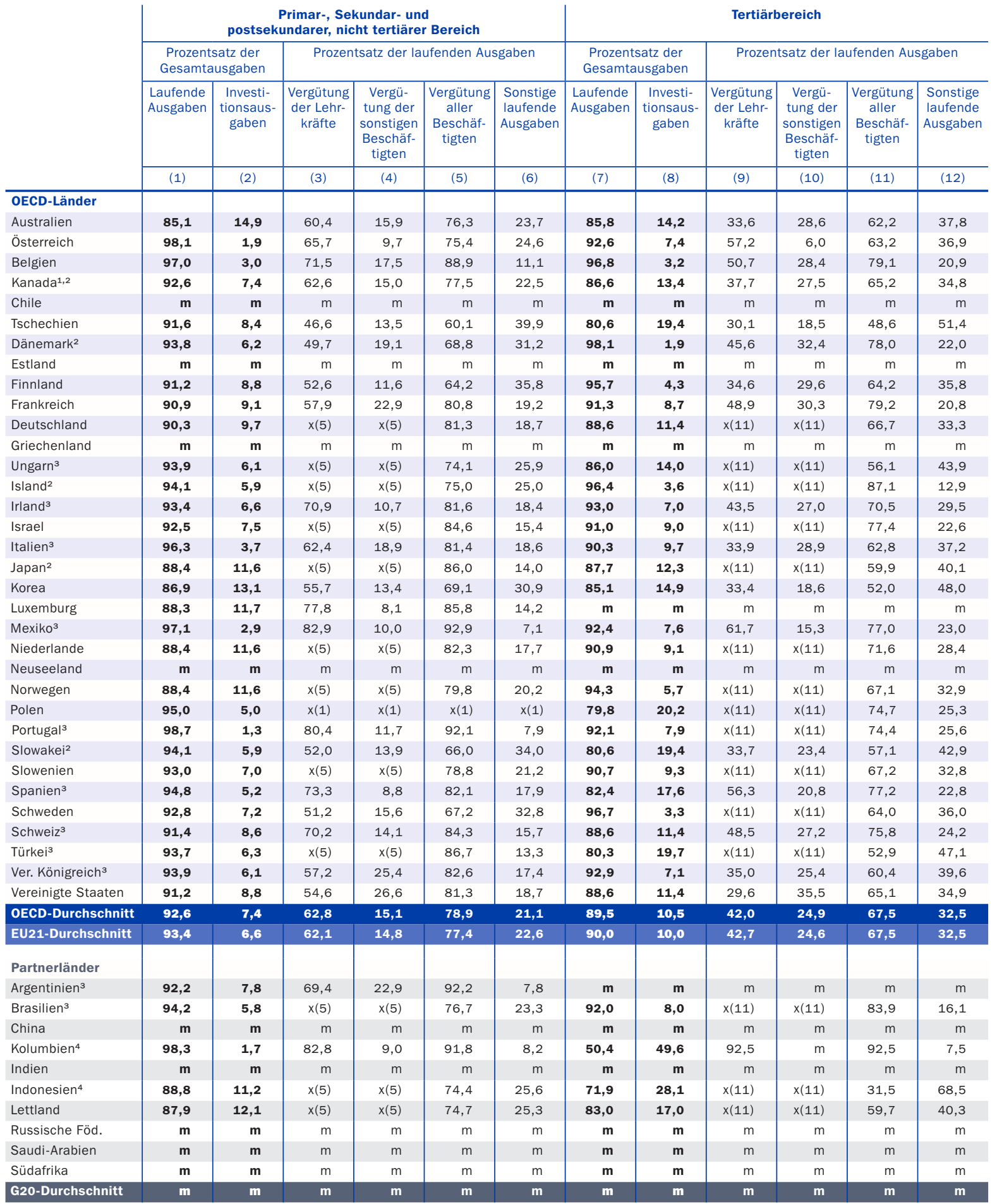

1. Referenzjahr 2010. 2. Einige Bildungsbereiche sind in anderen Bildungsbereichen enthalten. Einzelheiten s. Erläuterung von „x“ in Hinweise für den Leser. 3. Nur öffentliche Bildungseinrichtungen (Italien und Vereinigtes Königreich: außer im Tertiärbereich). 4. Referenzjahr 2012.

Quelle: OECD. Argentinien, China, Indien, Indonesien, Kolumbien, Saudi-Arabien und Südafrika: Statistikinstitut der UNESCO. Lettland: Eurostat.

Hinweise s. Anhang 3 unter www.oecd.org/edu/eag.htm. StatLink: http://dx.doi.org/10.1787/888933117896

Erläuterung der Kennzeichnung fehlender Daten s. Hinweise für den Leser. 



\section{Welche Faktoren beeinflussen die Höhe der Bildungsausgaben?}

Vier Faktoren beeinflussen die Bildungsausgaben in Bezug auf die Gehaltskosten der Lehrkräfte pro Schüler: die Unterrichtszeit der Schüler, die zu unterrichtenden Zeitstunden der Lehrkräfte, die Gehälter der Lehrkräfte und die geschätzte Klassengröße. Somit können gleiche Gehaltskosten der Lehrkräfte pro Schüler auf völlig unterschiedlichen Kombinationen dieser vier Faktoren beruhen.

Es bestehen große Unterschiede zwischen den Ländern bei den Gehaltskosten der Lehrkräfte pro Schüler; in den meisten Ländern steigen die Gehaltskosten der Lehrkräfte mit dem Bildungsbereich, in dem sie unterrichten.

Zwischen 2008 und 2012 stiegen in rund zwei Drittel der Länder die Gehaltskosten der Lehrkräfte pro Schüler im Primarbereich und in mehr als der Hälfte der Länder im Sekundarbereich I. Durchschnittlich stiegen sie im Primarbereich um 7 Prozent (von 2.454 US-Dollar auf 2.633 US-Dollar) und um 4 Prozent im Sekundarbereich I (von 3.217 US-Dollar auf 3.355 US-Dollar).

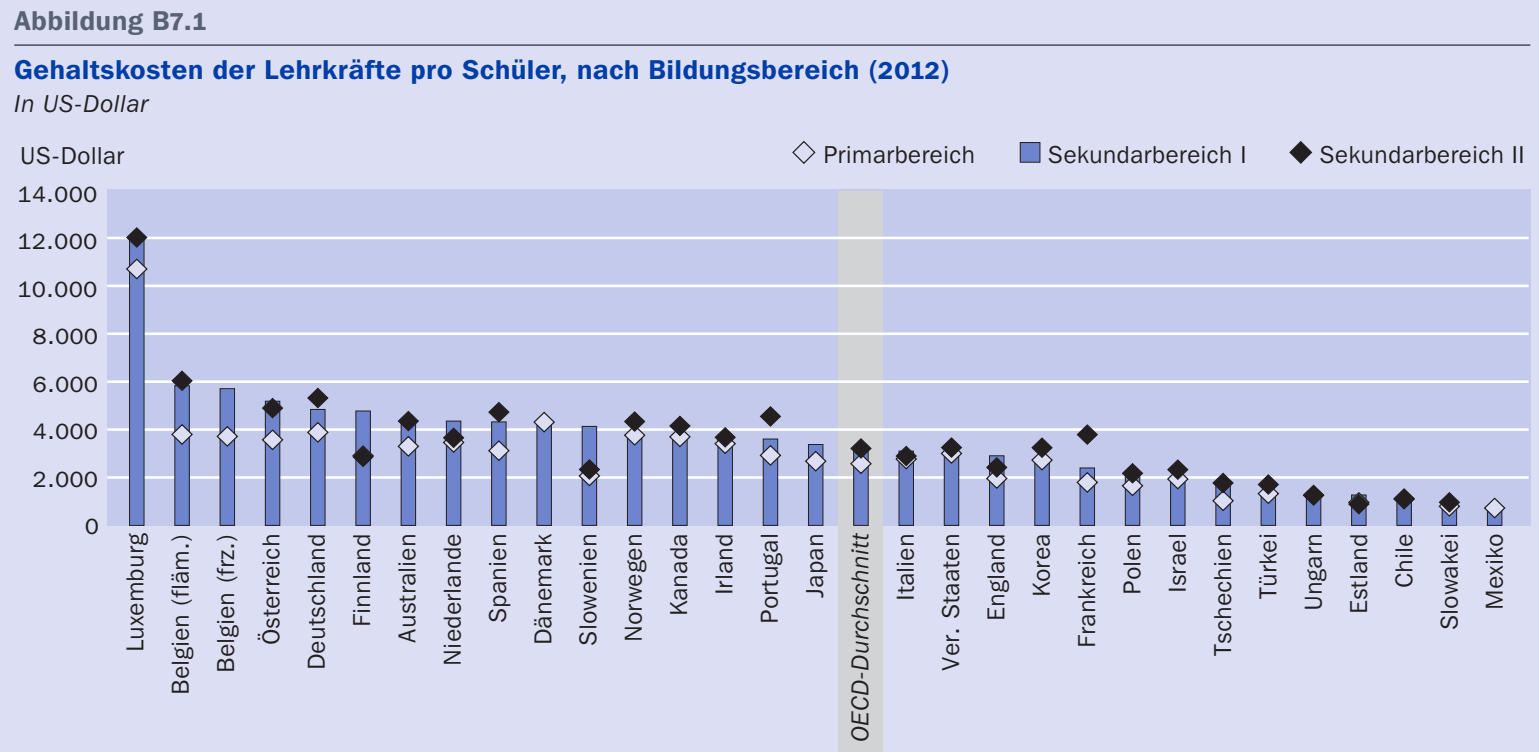

Anordnung der Länder in absteigender Reihenfolge der Gehaltskosten von Lehrkräften pro Schüler im Sekundarbereich I.

Quelle: OECD. Tabelle B7.1. Hinweise s. Anhang 3 unter www.oecd.org/edu/eag.htm. StatLink: http://dx.doi.org/10.1787/888933118105

\section{Kontext}

Die Regierungen interessieren sich inzwischen verstärkt für das Verhältnis zwischen den in Bildung investierten Ressourcen und den erzielten Lernergebnissen. Sie wollen die Bevölkerung mit mehr und besserer Bildung versorgen, während sie gleichzeitig sicherstellen müssen, dass die öffentlichen Mittel effizient eingesetzt werden, besonders in Zeiten, in denen bei den öffentlichen Haushalten immer mehr gespart werden muss. Die Vergütung der Lehrkräfte ist in der Regel der größte Ausgabenposten im 
Bildungswesen und somit auch der Ausgaben pro Schüler. Sie ist eine Funktion der Unterrichtszeit der Schüler, der Zahl der von den Lehrkräften zu unterrichtenden Zeitstunden, der Gehälter der Lehrkräfte und der Zahl der zum Unterrichten der Schüler benötigten Lehrkräfte, die von der geschätzten Klassengröße abhängt (Kasten B7.I).

Unterschiede in den einzelnen Ländern bei diesen vier Faktoren können Unterschiede im Ausgabenniveau pro Schüler erklären. Ebenso kann ein bestimmtes Ausgabenniveau das Ergebnis verschiedener Kombinationen dieser Faktoren sein. Dieser Indikator befasst sich damit, wie Länder ihre Mittel im Primar- und Sekundarbereich einsetzen, und untersucht, wie sich Veränderungen der bildungspolitischen Entscheidungen hinsichtlich dieser vier Faktoren zwischen den Jahren 2000, 2005, 2008 und 2012 auf die Höhe der Gehaltskosten der Lehrkräfte ausgewirkt haben. Manchmal sind diese Veränderungen jedoch nicht unbedingt das Ergebnis bildungspolitischer Entscheidungen, sondern ergeben sich eher aus demografischen Veränderungen, wie z. B. sinkenden Schülerzahlen. So würde sich beispielsweise in den Ländern, die in den letzten Jahren zurückgehende Schülerzahlen haben, auch die Klassengröße verringern, außer die Zahl der Lehrkräfte ginge gleichzeitig zurück.

\section{Weitere wichtige Ergebnisse}

Einem ähnlichen Ausgabenniveau verschiedener Länder können ganz unterschiedliche bildungspolitische Entscheidungen zugrunde liegen. Dies ist einer der Gründe, weshalb es keinen unmittelbaren Zusammenhang zwischen den Gesamtausgaben für Bildung und den Leistungen der Schüler gibt. So waren beispielsweise 2012 in Frankreich und Irland im Sekundarbereich II die Gehaltskosten der Lehrkräfte pro Schüler ähnlich hoch - sie lagen in beiden Ländern über dem Durchschnitt. In Frankreich war dies hauptsächlich das Ergebnis einer Kombination aus unterdurchschnittlichen Gehältern der Lehrkräfte und Klassengrößen sowie einer überdurchschnittlich hohen Zahl Unterrichtszeitstunden der Schüler, während es in Irland hauptsächlich das Ergebnis von überdurchschnittlichen Gehältern war, deren Auswirkungen durch eine überdurchschnittlich hohe Zahl der von Lehrkräften $\mathrm{zu}$ unterrichtenden Zeitstunden ausgeglichen wurde.

Die Gehälter der Lehrkräfte erweisen sich in allen Bildungsbereichen am häufigsten als wichtigster Faktor für den Unterschied zu den durchschnittlichen Gehaltskosten der Lehrkräfte pro Schüler. Die geschätzte Klassengröße ist in allen Bildungsbereichen der zweitwichtigste Faktor für den Unterschied.

Die Gehälter der Lehrkräfte erweisen sich weniger häufig als wichtigster Faktor für den Unterschied zu den durchschnittlichen Gehaltskosten der Lehrkräfte pro Schüler, wenn man den unterschiedlichen Wohlstand der einzelnen Länder berücksichtigt.

\section{Entwicklungstendenzen}

Die gestiegenen Gehaltskosten der Lehrkräfte pro Schüler zwischen 2008 und 2012 wurden hauptsächlich durch die Veränderungen zweier Faktoren beeinflusst: die Gehälter der Lehrkräfte und die geschätzte Klassengröße. Zwischen 2008 und 2012 stiegen die Gehälter der Lehrkräfte in den Ländern, für die Daten für beide Jahre zur 
Verfügung standen, im Primarbereich um durchschnittlich 3,0 Prozent und im Sekundarbereich I um durchschnittlich fast I, 5 Prozent, während die geschätzte Klassengröße im Primarbereich um durchschnittlich 2,6 Prozent zurückging und im Sekundarbereich I um durchschnittlich 6, I Prozent stieg. Die Unterschiede bei den zwei anderen Faktoren, der Unterrichtszeit der Schüler und den von den Lehrkräften zu unterrichtenden Zeitstunden, waren in den meisten Ländern geringer: Die von den Lehrkräften zu unterrichtenden Zeitstunden veränderten sich in diesem Zeitraum am stärksten, sie stiegen in den Ländern mit verfügbaren Daten für beide Jahre im Durchschnitt um 3,7 Prozent.

In den meisten Ländern wurden zwischen 2008 und 2012 im Primar- und Sekundarbereich I die Gehälter der Lehrkräfte erhöht und/oder die geschätzte Klassengröße reduziert. Diese Veränderungen führten zu einem Anstieg der Gehaltskosten pro Schüler. Die Gehaltskosten der Lehrkräfte pro Schüler sanken jedoch während dieses Zeitraums in einigen Ländern sehr stark - am stärksten mit mindestens I4 Prozent in Italien und Ungarn sowohl im Primar- als auch Sekundarbereich I, in Tschechien im Primarbereich und in Portugal im Sekundarbereich I. Einige Länder haben seit 2005 Reformen durchgeführt, die sich auf die Gehaltskosten der Lehrkräfte pro Schüler auswirkten. So wurde beispielsweise in Ungarn 2006 die Zahl der zu unterrichtenden Zeitstunden für den Sekundarbereich erhöht, was die Zahl der in diesem Bildungsbereich benötigten Lehrkräfte senkte. Das wiederum senkte die Ausgaben für die Gehälter der Lehrkräfte. In Italien gab es eine Reform der Klassengröße, bei der die Zahl der Schüler pro Klasse leicht erhöht wurde. Dies führte zu einer Senkung der Gehaltskosten der Lehrkräfte pro Schüler (s. Tab. B7.5 in Bildung auf einen Blick 2012 [OECD, 2012]).

\section{Analyse und Interpretationen}

\section{Unterschiede in den Gehaltskosten der Lehrkräfte pro Schüler in den einzelnen Bildungsbereichen}

Die Ausgaben pro Schüler spiegeln strukturelle und institutionelle Faktoren in Bezug auf die Organisation der Schulen und die Lehrpläne wider. Ausgaben lassen sich aufgliedern in die Vergütung von Lehrkräften und andere Ausgaben (definiert als alle sonstigen Ausgaben abgesehen von der Vergütung der Lehrkräfte). Die Vergütung der Lehrkräfte ist in der Regel der größte Ausgabenposten im Bildungswesen. Somit bildet die Vergütung der Lehrkräfte geteilt durch die Anzahl der Schüler (hier als „Gehaltskosten der Lehrkräfte pro Schüler“ bezeichnet) den größten Posten der Ausgaben pro Schüler.

Die Vergütung der Lehrkräfte ergibt sich aus der Unterrichtszeit der Schüler, der Zahl der von den Lehrkräften zu unterrichtenden Zeitstunden, den Gehältern der Lehrkräfte und der Zahl der zum Unterrichten der Schüler benötigten Lehrkräfte, die von der geschätzten Klassengröße abhängt (Kasten B7.I). Daher können Unterschiede in den einzelnen Ländern bei diesen vier Faktoren Unterschiede im jeweiligen Ausgabenniveau erklären. Ebenso kann ein bestimmtes Ausgabenniveau das Ergebnis verschiedener Kombinationen dieser Faktoren sein. 
Kasten B7.1

\section{Verhältnis zwischen den Gehaltskosten der Lehrkräfte pro Schüler und der Unterrichtszeit der Schüler, den zu unterrichtenden Zeitstunden der Lehrkräfte, den Gehältern der Lehrkräfte und der geschätzten Klassengröße}

Eine Möglichkeit, die Faktoren zu analysieren, die sich auf die Ausgaben pro Schüler auswirken, und das Ausmaß ihrer jeweiligen Auswirkung zu bestimmen, ist ein Vergleich der Unterschiede zwischen den nationalen Zahlen und dem OECDDurchschnitt. Bei dieser Analyse werden die Unterschiede bei den Ausgaben pro Schüler zwischen den einzelnen Ländern und dem OECD-Durchschnitt ermittelt und anschließend der Beitrag der verschiedenen Faktoren zu diesem Unterschied berechnet.

Dieses Vorgehen basiert auf einer mathematischen Korrelation zwischen den einzelnen berücksichtigten Faktoren und greift die in der kanadischen Publikation Education Statistics Bulletin (2005) vorgestellte Methode auf (s. Erläuterungen in Anhang 3). Bildungsausgaben sind mathematisch gesehen mit Faktoren verknüpft, die im Zusammenhang mit dem schulischen Umfeld eines Landes stehen (der Zahl der Unterrichtszeitstunden der Schüler, der Zahl der von den Lehrkräften zu unterrichtenden Zeitstunden, der geschätzten Klassengröße), und einem Faktor in Bezug auf die Lehrkräfte (das gesetzliche bzw. vertraglich vereinbarte Gehalt).

Die Ausgaben werden aufgegliedert in die Vergütung von Lehrkräften und sonstige Ausgaben (definiert als alle sonstigen Ausgaben abgesehen von der Vergütung der Lehrkräfte). Die „Gehaltskosten der Lehrkräfte pro Schüler“ (GKLS), d. h. die Vergütung der Lehrkräfte geteilt durch die Anzahl der Schüler, werden folgendermaßen ermittelt:

$$
\text { GKLS }=\text { GEHL } \times \text { UntZS } \times \frac{1}{\text { UntZL }} \times \frac{1}{\text { GKl }}=\frac{\text { GEHL }}{\text { SLR }}
$$

GEHL: Gehälter der Lehrkräfte (angesetzt anhand des gesetzlichen bzw. vertraglich vereinbarten Gehalts nach I5 Jahren Berufserfahrung)

UntZS: Unterrichtszeit der Schüler (angesetzt als die jährliche Zahl an Zeitstunden, die Schüler pro Jahr unterrichtet werden sollen)

UntZL: Unterrichtszeit der Lehrkräfte (angesetzt als Zahl der von Lehrkräften zu unterrichtenden Zeitstunden pro Jahr)

GKl: Größe der Klasse, eine Näherungsgröße für die Größe der Klasse

SLR: Schüler-Lehrkräfte-Relation

Mit Ausnahme der Größe der Klasse (die im Sekundarbereich II nicht berechnet wird, da sie schwer zu definieren und zu vergleichen ist, weil Schüler je nach Fach eventuell in verschiedenen Klassen unterrichtet werden) können die Werte für die verschiedenen Variablen aus den in Bildung auf einen Blick veröffentlichten Indikatoren (Kapitel D) entnommen werden. Zur Durchführung der Analyse wird jedoch ausgehend von der Schüler-Lehrkräfte-Relation und der Zahl der Unterrichtszeitstunden der Schüler und der Zahl der von den Lehrkräften zu unterrichtenden 
Zeitstunden eine „geschätzte“ Klassengröße angesetzt (s. Kasten D2.I). Da diese geschätzte Klassengröße nur eine Näherungsgröße ist, sollte sie mit Vorsicht interpretiert werden.

Mithilfe dieser mathematischen Gleichung und eines Vergleichs der Werte für diese vier Faktoren in einem bestimmten Land mit dem OECD-Durchschnitt lässt sich sowohl der direkte als auch der indirekte Beitrag jedes einzelnen dieser vier Faktoren zum Unterschied in den Gehaltskosten pro Schüler in einem bestimmten Land und dem OECD-Durchschnitt bestimmen (weitere Informationen s. Anhang 3). Wenn beispielsweise nur zwei Faktoren zusammenwirken und ein Arbeiter einen um Io Prozent höheren Stundenlohn erhält, während er gleichzeitig die Zahl seiner Arbeitsstunden um 20 Prozent erhöht, dann erhöht sich sein Lohn um 32 Prozent, und zwar aufgrund des direkten Beitrags jeder dieser beiden Variablen $(0, \mathrm{I}+0,2)$ sowie des indirekten Beitrags dieser Variablen aufgrund der Kombination dieser beiden Faktoren $(0, \mathrm{I} \times 0,2)$.

Um das Wohlstandsgefälle zwischen den einzelnen Ländern bei einem Vergleich der Gehaltskosten pro Schüler zu berücksichtigen, können die Gehaltskosten pro Schüler ebenso wie die Gehälter der Lehrkräfte durch das BIP pro Kopf dividiert werden (ausgehend von der Annahme, dass das BIP pro Kopf eine Näherungsgröße für den Wohlstand eines Landes ist). So können die „relativen“ Gehaltskosten pro Schüler einzelner Länder miteinander verglichen werden (s. Tab. von Bildung auf einen Blick 2014 im Internet).

Die Gehaltskosten der Lehrkräfte pro Schüler haben in allen OECD-Ländern eins gemeinsam: In der Regel steigen sie steil mit der Höhe des Bildungsbereichs an, in dem unterrichtet wird. Doch in manchen Ländern (insbesondere Finnland, den Niederlanden und Slowenien) sind sie im Sekundarbereich II niedriger als im Sekundarbereich I. So lagen 2012 in den OECD-Ländern mit verfügbaren Daten für die unterschiedlichen Bildungsbereiche die durchschnittlichen Gehaltskosten der Lehrkräfte pro Schüler im Primarbereich bei 2.70I US-Dollar, im Sekundarbereich I bei 3.358 US-Dollar und im Sekundarbereich II bei 3.359 US-Dollar (Abb. B7.I).

\section{Unterschiede in den Gehaltskosten der Lehrkräfte zwischen den einzelnen OECD-Ländern}

Die Unterschiede zwischen den einzelnen Bildungsbereichen bei den Gehaltskosten der Lehrkräfte pro Schüler variieren signifikant zwischen den einzelnen Ländern. 2012 lag der Unterschied zwischen den drei Bildungsbereichen in Chile und Ungarn bei weniger als 50 US-Dollar, aber in Belgien (frz.), Finnland und Frankreich bei mehr als I.800 US-Dollar und in Belgien (fläm.) und Slowenien bei mehr als 2.000 US-Dollar (Tab. B7.I und Abb. B7.I).

Die Zunahme der Gehaltskosten der Lehrkräfte pro Schüler ist, je höher der Bildungsbereich ist, zum Teil auf steigende Gehälter der Lehrkräfte und die zunehmende Zahl an Unterrichtsstunden für Schüler in den höheren Bildungsbereichen zurückzuführen. 2012 reichten die durchschnittlichen Gehälter der Lehrkräfte in der OECD von 39.642 US-Dollar im Primarbereich über 4I.382 US-Dollar im Sekundarbereich I bis zu 
43.949 US-Dollar im Sekundarbereich II, während die Bandbreite der jährlichen Zahl an Unterrichtszeitstunden im OECD-Durchschnitt von 805 Stunden im Primarbereich über 920 Stunden im Sekundarbereich I bis zu 947 Stunden im Sekundarbereich II reichte. Der Anstieg hängt auch damit zusammen, dass die Zahl der von den Lehrkräften zu unterrichtenden Zeitstunden mit steigendem Bildungsbereich im Allgemeinen abnimmt, was impliziert, dass mehr Lehrkräfte für den Unterricht für eine bestimmte Schülerzahl notwendig sind (2012 nahm der OECD-Durchschnitt der jährlich zu unterrichtenden Zeitstunden von 782 Stunden im Primarbereich auf 69I Stunden im Sekundarbereich I und 655 im Sekundarbereich II ab). Größere Klassen in den höheren Bildungsbereichen führen jedoch tendenziell zu niedrigeren Gehaltskosten pro Schüler (der OECD-Durchschnitt der geschätzten Klassengröße steigt von I5,7 Schülern im Primarbereich über I7,8 Schüler im Sekundarbereich I auf I9,6 Schüler im Sekundarbereich II) (Tab. B7.2a und B7.2b sowie Tab. B7.2c im Internet).

\section{Veränderung der Gehaltskosten der Lehrkräfte pro Schüler zwischen 2008 und 2012}

Die Gehaltskosten der Lehrkräfte pro Schüler innerhalb eines bestimmten Bildungsbereichs variieren auch im Laufe der Zeit. Diese Veränderungen der Gehaltskosten der Lehrkräfte pro Schüler werden nur für den Primarbereich und Sekundarbereich I analysiert, da für den Sekundarbereich II keine Trenddaten vorliegen. Die Analyse beschränkt sich auch auf Länder mit verfügbaren Daten sowohl für 2008 als auch 2012 (27 Länder für den Primarbereich und 25 Länder für den Sekundarbereich I), denn vergleichbare Daten für einen längeren Zeitraum (für 2000, 2005, 2008 und 2012) liegen nur für weniger Länder vor.

Die Gehaltskosten der Lehrkräfte pro Schüler stiegen zwischen 2008 und 2012 sowohl im Primar- als auch im Sekundarbereich I, jedoch in unterschiedlichem Ausmaß: im Durchschnitt der Länder mit verfügbaren Daten für beide Jahre im Primarbereich um 7 Prozent (von 2.454 US-Dollar auf 2.633 US-Dollar) und im Sekundarbereich I um 4 Prozent (von 3.217 US-Dollar auf 3.355 US-Dollar) (Abb. B7.2).

In den meisten Ländern stiegen die Gehaltskosten der Lehrkräfte pro Schüler zwischen 2008 und 2012 in beiden Bildungsbereichen. Sie stiegen um mindestens 25 Prozent im Primarbereich in Israel, Korea und der Türkei und um mehr als 45 Prozent in Luxemburg im Primarbereich sowie in Estland und Polen im Sekundarbereich I (Abb. B7.3).

In einer signifikanten Zahl von Ländern sanken jedoch die Gehaltskosten der Lehrkräfte pro Schüler zwischen 2008 und 2012, insbesondere in Ungarn (um 23 Prozent im Primarbereich und 20 Prozent im Sekundarbereich I) und Italien (um I5 Prozent im Primarbereich und um 20 Prozent im Sekundarbereich I). Ein ähnlicher Rückgang der Gehaltskosten der Lehrkräfte pro Schüler war auch im Primarbereich in Tschechien zu beobachten (-I5 Prozent) und im Sekundarbereich I in Portugal (-I9 Prozent). Der Rückgang belief sich im Primarbereich in England, Portugal, Spanien und den Vereinigten Staaten auf 8 Prozent bis II Prozent, und der Rückgang im Sekundarbereich I in Irland und Spanien war ähnlich hoch (Abb. B7.2). 
Veränderung der Gehaltskosten der Lehrkräfte pro Schüler, nach Bildungsbereich $(2005,2008,2012)$ In US-Dollar
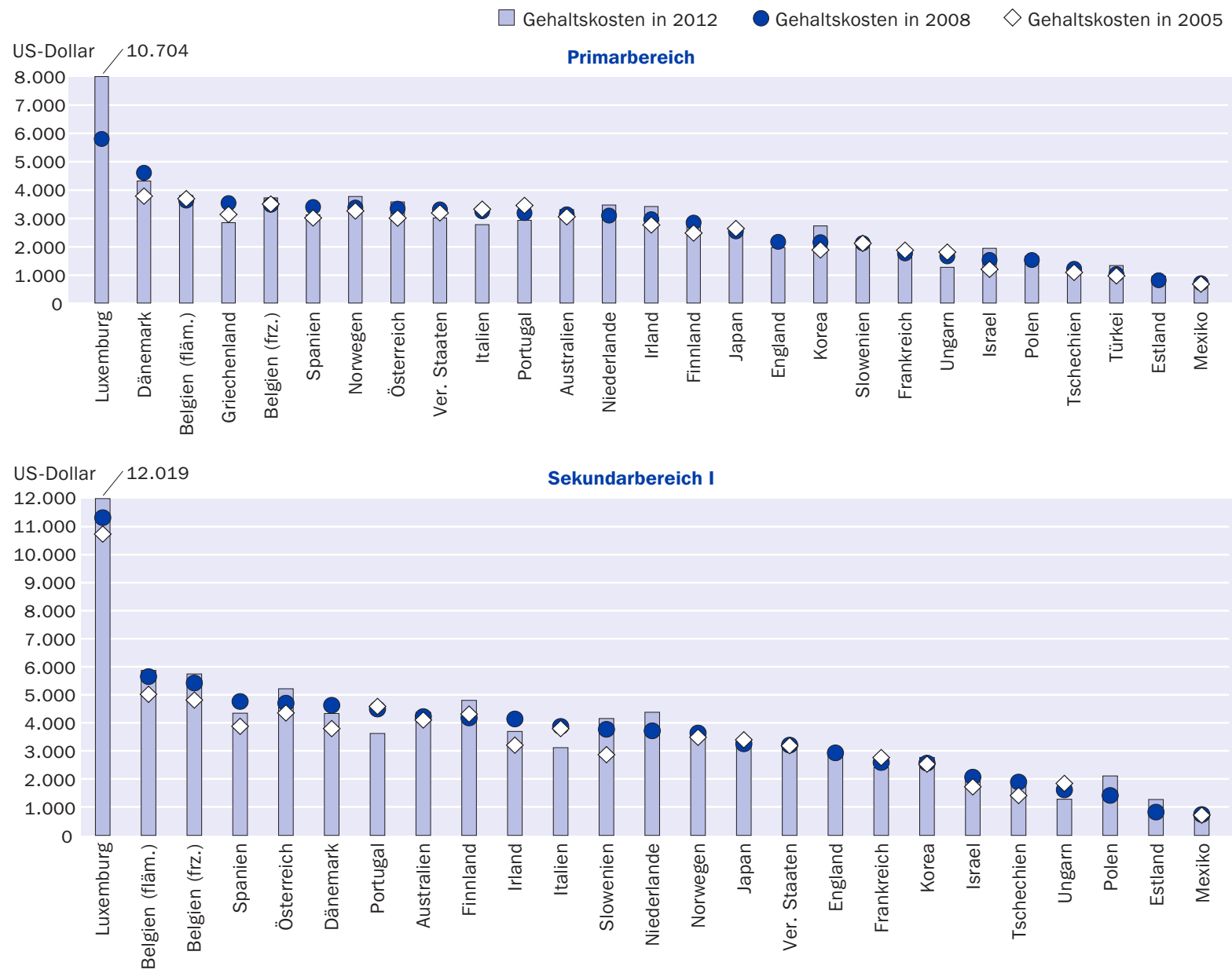

Anordnung der Länder in absteigender Reihenfolge der Gehaltskosten der Lehrkräfte pro Schüler im Jahr 2008.

Quelle: OECD. Tabellen B7.3 und B7.4. Hinweise s. Anhang 3 unter www.oecd.org/edu/eag.htm. StatLink: http://dx.doi.org/10.1787/888933118124

\section{Auswirkungen der Gehälter der Lehrkräfte und der Klassengröße auf die Gehälter der Lehrkräfte pro Schüler}

Von den vier für die Gehaltskosten der Lehrkräfte entscheidenden Faktoren sind zwei maßgeblich für die großen Unterschiede bei den Gehaltskosten verantwortlich: die Gehaltskosten der Lehrkräfte und die Klassengröße. Zwischen 2008 und 2012 stiegen in den Ländern mit verfügbaren Daten für diesen Zeitraum die durchschnittlichen Gehälter der Lehrkräfte (in konstanten Preisen ausgedrückt) im Primarbereich um 3,o Prozent und im Sekundarbereich I um I,5 Prozent, während gleichzeitig die geschätzte Klassengröße im Primarbereich um rund 2,6 Prozent sank und im Sekundarbereich I um durchschnittlich 6, I Prozent zunahm (Tab. B7.2a und B7.2b).

Zwar stiegen im Durchschnitt der OECD-Länder mit vergleichbaren Daten für 2008 und 2012 während dieses Zeitraums die Gehälter der Lehrkräfte real, sanken aber in den meisten dieser Länder während dieses Zeitraums. Im Primarbereich war dies auf den starken Anstieg der Gehälter der Lehrkräfte in Luxemburg (+4I Prozent) zurück- 
Abbildung B7.3

Veränderung der Gehaltskosten der Lehrkräfte pro Schüler, der Gehälter der Lehrkräfte und der geschätzten Klassengröße im Primar- und Sekundarbereich I $(2008,2012)$

Veränderung (in \%) zwischen 2008 und 2012
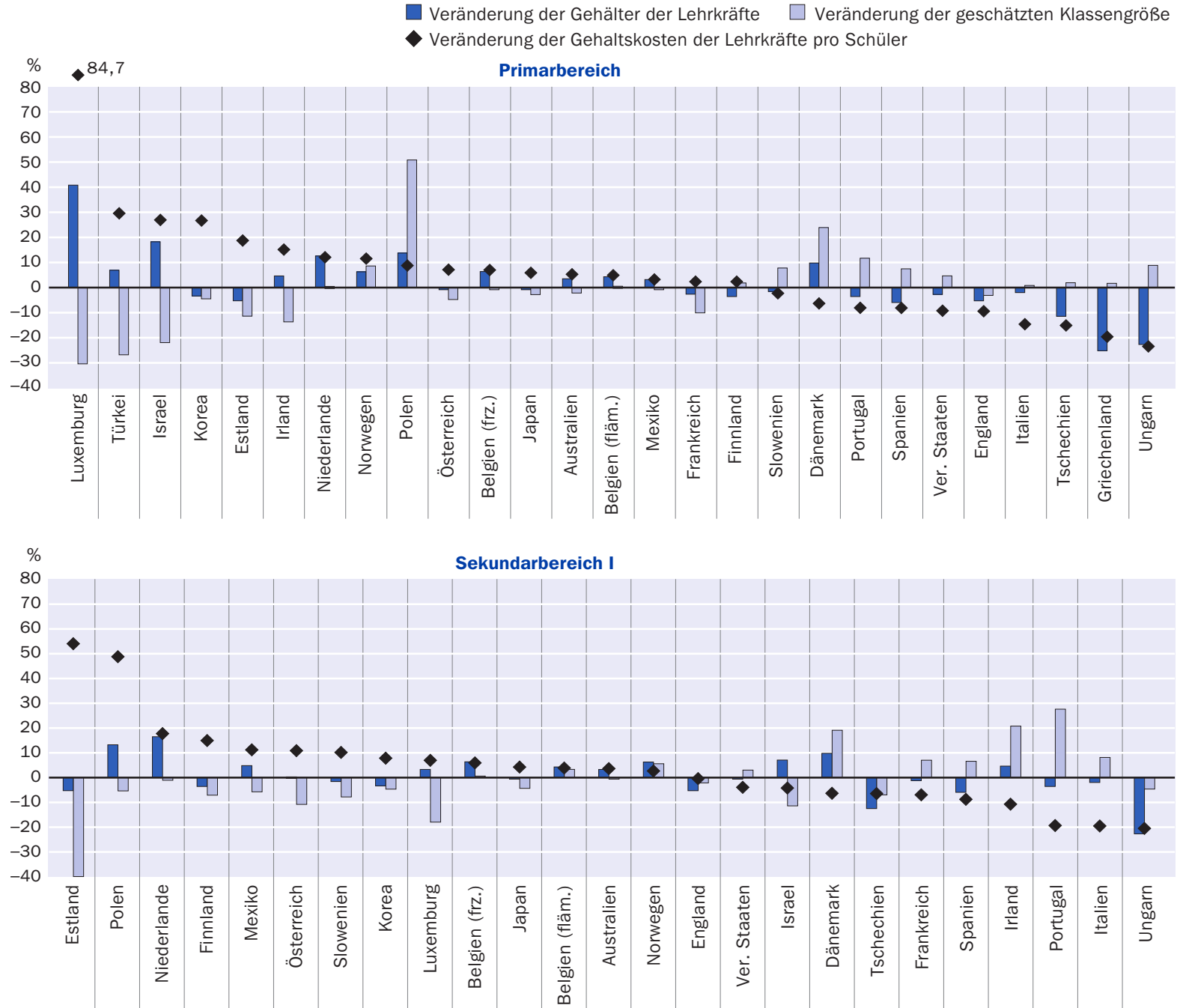

zuführen, der die sinkenden Gehälter in den anderen Ländern ausglich. Im Sekundarbereich I führten Anstiege und Rückgänge in einer ähnlichen Zahl von Ländern im Durchschnitt zu einem insgesamt leichten Anstieg. In einigen Ländern sanken die Gehälter der Lehrkräfte, insbesondere in Griechenland und Ungarn (um mehr als 22 Prozent sowohl im Primar- als auch im Sekundarbereich I), was die gesunkenen Gehaltskosten der Lehrkräfte pro Schüler in diesen Ländern zu einem großen Teil erklären könnte (Abb. B7.3).

Im Gegensatz hierzu ging in weniger als der Hälfte der Länder mit vergleichbaren Daten sowohl für 2008 als auch 2012 die geschätzte Klassengröße im Primarbereich in diesem Zeitraum tendenziell zurück und in mehr als der Hälfte der Länder auch im Sekundarbereich I, was zu einem Anstieg der Gehaltskosten der Lehrkräfte führte. 
Im Primar- und Sekundarbereich I gab es die stärksten Rückgänge in den Ländern mit relativ großen geschätzten Klassengrößen im Jahr 2008 (Israel und die Türkei im Primarbereich, Estland im Sekundarbereich I) sowie in Ländern mit einer unterdurchschnittlichen geschätzten Klassengröße im Jahr 2008 (Luxemburg sowohl im Primarals auch Sekundarbereich I). Aber die geschätzte Klassengröße stieg auch in einigen Ländern signifikant, was zu einer Verringerung der Gehaltskosten pro Schüler beigetragen hat. Dies war im Primarbereich insbesondere in Dänemark der Fall (von Io,9 auf I3,6 Schüler) und in Polen (von 8, I auf I2,2 Schüler) sowie im Sekundarbereich I in Portugal (von 9,7 auf I2,4 Schüler).

Im gleichen Zeitraum beliefen sich die Veränderungen bei der Unterrichtszeit der Schüler und der zu unterrichtenden Zeitstunden der Lehrkräfte, den beiden anderen Faktoren mit Auswirkungen auf die Gehaltskosten der Lehrkräfte, sowohl im Primarbereich als auch im Sekundarbereich I (der Länder mit verfügbaren Daten für beide Jahre) im Durchschnitt auf-2,5 Prozent bis +3,7 Prozent. Dies könnte ein Anzeichen dafür sein, wie viel politisches Feingefühl bei einer Umsetzung von bildungspolitischen Reformen in diesen Bereichen notwendig ist (s. Tab. B7.5 in Bildung auf einen Blick 2012).

Dennoch änderten sich in einigen wenigen Ländern die Unterrichtszeit der Schüler und/oder die Zahl der von Lehrkräften zu unterrichtenden Zeitstunden signifikant. So gab es kürzlich in Norwegen, Polen und Portugal Reformen, um die Unterrichtszeit der Schüler beim Lesen und in Mathematik zu erhöhen. Zwischen 2008 und 2012 hat sich die Zahl der von Lehrkräften zu unterrichtenden Zeitstunden am signifikantesten (um mehr als Ioo Zeitstunden) in folgenden drei Ländern verändert: in Israel (ein Anstieg von 73I Zeitstunden auf 838 Zeitstunden im Primarbereich), in Korea (ein Rückgang von 840 Zeitstunden auf 694 Zeitstunden im Primarbereich) und in Luxemburg (ein Anstieg von 634 Zeitstunden auf 739 Zeitstunden im Sekundarbereich I). Die Unterrichtszeitstunden der Schüler stiegen zwischen 2008 und 2012 in Island und Polen im Primar- und Sekundarbereich I um mehr als Ioo Zeitstunden und sanken um mehr als roo Zeitstunden in Israel im Sekundarbereich I. Die sinkende Zahl von Unterrichtszeitstunden für Schüler in Italien (fast roo Zeitstunden weniger zwischen 2008 und 2012 sowohl im Primar-als auch im Sekundarbereich I) ist einer der Hauptgründe für die gesunkenen Gehaltskosten der Lehrkräfte pro Schüler in diesem Land (Tab. B7.2a und B7.2b).

\section{Zusammenhang zwischen Bildungsausgaben und bildungspolitischen Entscheidungen}

Höhere Ausgabenniveaus im Bildungsbereich lassen sich nicht notwendigerweise mit einem leistungsstärkeren Bildungssystem gleichsetzen. Dies ist keineswegs überraschend, denn auch wenn einzelne Länder ähnlich hohe Finanzmittel in Bildung investieren, verfolgen sie nicht notwendigerweise die gleichen bildungspolitischen Ansätze und ergreifen die gleichen Maßnahmen. So waren beispielsweise 2012 in Portugal und Spanien die Gehaltskosten der Lehrkräfte pro Schüler im Sekundarbereich II ähnlich hoch (4.550 US-Dollar bzw. 4.727), in beiden Ländern lagen sie über dem Durchschnitt. In Portugal war dies hauptsächlich auf eine unterdurchschnittliche geschätzte Klassengröße zurückzuführen, während in Spanien eine Kombination aus unterdurchschnittlicher geschätzter Klassengröße und überdurchschnittlich hohen Gehältern der Lehrkräfte zusammen mit einer überdurchschnittlich hohen Zahl an Unterrichtszeitstunden der Schüler hierfür verantwortlich war. Auch Israel und Polen hatten ähnliche 
Beitrag verschiedener Faktoren zu den Gehaltskosten der Lehrkräfte pro Schüler im Sekundarbereich II (2012) In US-Dollar

$\begin{array}{lll} & \square \text { Beitrag der geschätzten Klassengröße } & \square \quad \text { Beitrag der Gehälter der Lehrkräfte } \\ \text { Beitrag der von den Lehrkräften zu unterrichtenden Zeitstunden } \quad \diamond \quad \text { Unterschied zum OECD-Durchschnitt } \\ \text { US-Dollar } & \square \text { Beitrag der Unterrichtszeit der Schüler }\end{array}$

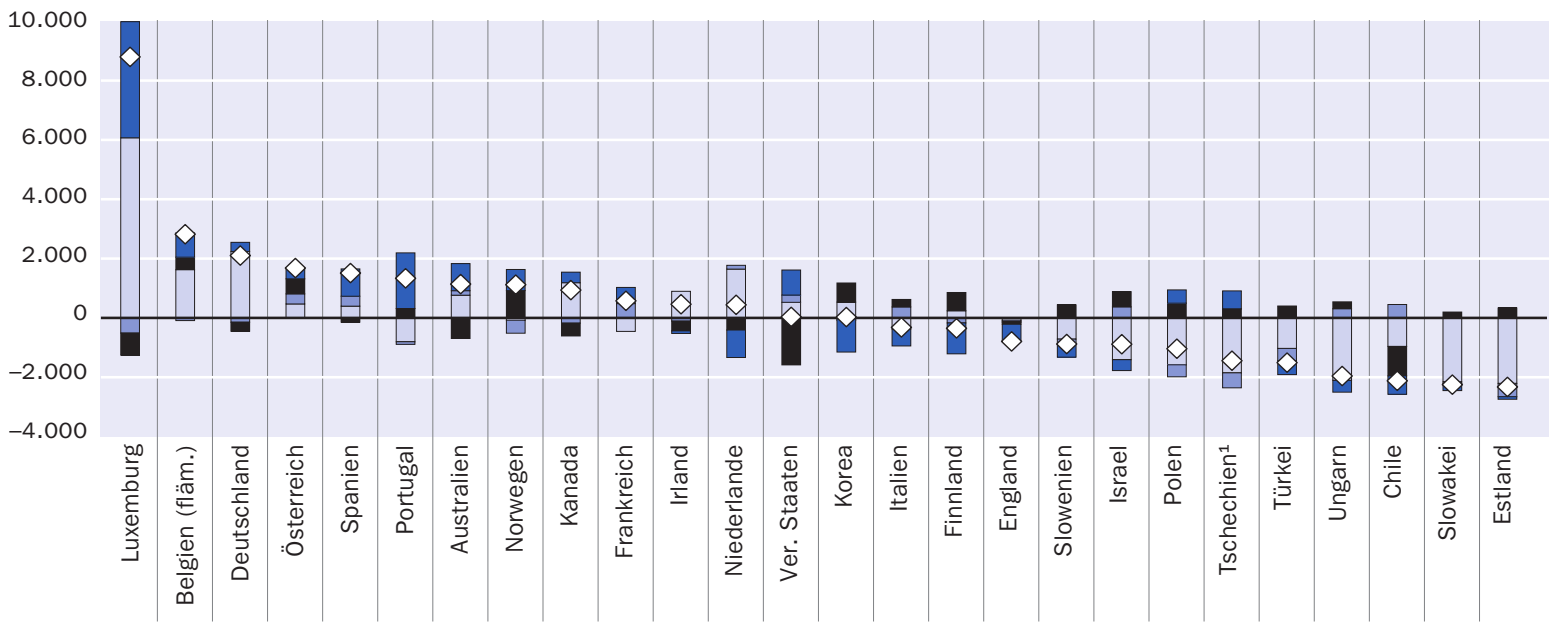

Anmerkung: Die Beiträge der verschiedenen Faktoren als Prozentsatz des BIP sind im Internet verfügbar.

1. Der Beitrag der Unterrichtszeit ist auf Grundlage der Mindestunterrichtszeit berechnet.

Anordnung der Länder in absteigender Reihenfolge des Unterschieds zwischen den Gehaltskosten der Lehrkräfte pro Schüler und dem OECD-Durchschnitt.

Quelle: OECD. Tabelle B7.5. Hinweise s. Anhang 3 unter www.oecd.org/edu/eag.htm. StatLink: http://dx.doi.org/10.1787/888933118162

Gehaltskosten der Lehrkräfte pro Schüler. Zwar sind die Gehälter der Lehrkräfte in beiden Ländern ähnlich hoch, aber die drei anderen Faktoren wirken sich in jedem der Länder unterschiedlich auf die Gehaltskosten der Lehrkräfte aus (Tab. B7.5 und Abb. B7.4).

Außerdem können ähnliche bildungspolitische Entscheidungen der Länder dennoch zu unterschiedlichen Gehaltskostenniveaus der Lehrkräfte pro Schüler führen. So ergeben sich beispielsweise in Irland, Kanada und den Vereinigten Staaten die Gehaltskosten pro Schüler im Sekundarbereich II aus dem Zusammenwirken zweier gegenläufiger Faktoren: einer im Verhältnis zum OECD-Durchschnitt überdurchschnittlich hohen Zahl an von den Lehrkräften zu unterrichtenden Zeitstunden und relativ kleinen Klassengrößen in Verbindung mit hohen Gehältern der Lehrkräfte, die zu einer Erhöhung der Gehaltskosten pro Schüler im Verhältnis zum OECD-Durchschnitt führen. Die Gehaltskosten pro Schüler, die sich aus dieser Kombination ergeben, liegen in diesen drei Ländern über dem OECD-Durchschnitt, reichen dabei jedoch von weniger als Ioo US-Dollar über dem Durchschnitt in den Vereinigten Staaten bis zu rund I.000 USDollar über dem Durchschnitt in Kanada (Tab. B7.5 und Abb. B7.4).

\section{Die wichtigsten bestimmenden Faktoren der Gehaltskosten der Lehrkräfte pro Schüler in den einzelnen Bildungsbereichen}

Ein Vergleich der Gehaltskosten der Lehrkräfte pro Schüler mit dem OECD-Durchschnitt und wie die einzelnen vier Faktoren zu diesem Unterschied beitragen, ermöglicht zu untersuchen, wie stark sich die einzelnen Faktoren auf die Gehaltskosten der Lehrkräfte pro Schüler auswirken. In allen Bildungsbereichen erweisen sich die Gehälter der Lehrkräfte am häufigsten als wichtigster Faktor für den Unterschied der durch- 


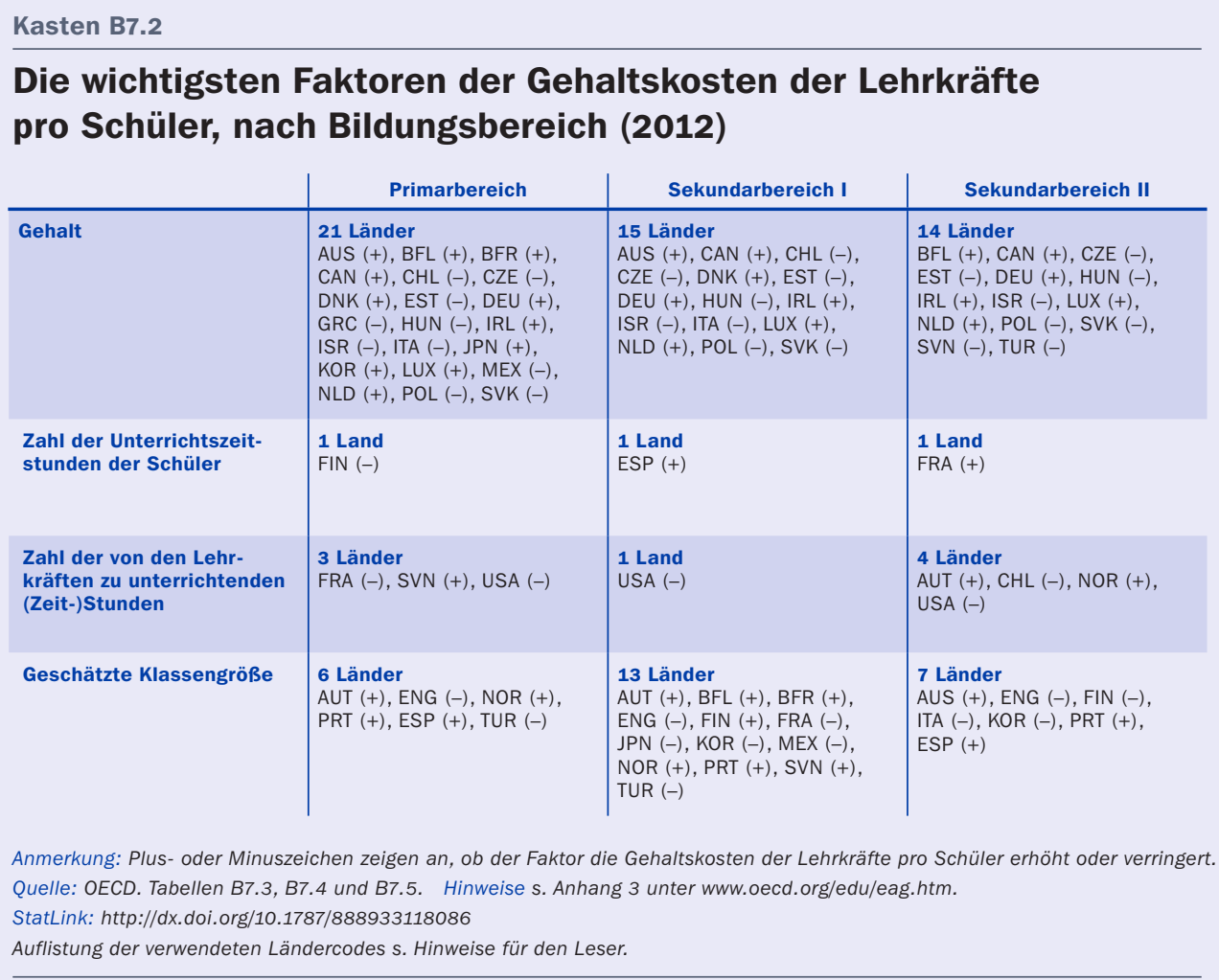

schnittlichen Gehaltskosten der Lehrkräfte pro Schüler. Sie sind in den Ländern mit verfügbaren Daten für 2012 in 2I von 3I Ländern im Primarbereich, in I5 von 30 Ländern im Sekundarbereich I und in I4 von 26 Ländern im Sekundarbereich II der wichtigste Faktor. Dies trifft sowohl für die Länder mit den höchsten Gehaltskosten der Lehrkräfte pro Schüler als auch für die Länder mit den niedrigsten Gehaltskosten der Lehrkräfte pro Schüler zu.

Im Sekundarbereich II sind beispielsweise im Land mit den höchsten Gehaltskosten der Lehrkräfte pro Schüler (Luxemburg) die überdurchschnittlichen Gehälter der Lehrkräfte der wichtigste Faktor, genauso wie in 8 der 9 Länder mit den niedrigsten Gehaltskosten der Lehrkräfte pro Schüler (Estland, Israel, Polen, der Slowakei, Slowenien, Tschechien, Türkei und Ungarn) (Abb. B7.4).

Die geschätzte Klassengröße ist in jedem der Bildungsbereiche der zweitwichtigste Faktor für die Unterschiede (in 6 Ländern im Primarbereich, I3 Ländern im Sekundarbereich I und in 7 Ländern im Sekundarbereich II). Im Sekundarbereich II ist in 2 der 6 Länder mit den höchsten Gehaltskosten der Lehrkräfte pro Schüler (Portugal und Spanien) die unterdurchschnittliche geschätzte Klassengröße der wichtigste Faktor für Abweichungen von den durchschnittlichen Gehaltskosten der Lehrkräfte pro Schüler (Kasten B7.2). 


\section{Die wichtigsten Faktoren der Gehaltskosten der Lehrkräfte pro} Schüler unter Berücksichtigung des Wohlstands der einzelnen Länder Das Gehaltsniveau der Lehrkräfte und im Gegenzug das Niveau der Gehaltskosten der Lehrkräfte pro Schüler hängen jedoch vom relativen Wohlstand eines Landes ab. Um das Wohlstandsgefälle zwischen den Ländern zu berücksichtigen, wurden die Gehälter der Lehrkräfte (und die Gehaltskosten pro Schüler) im Verhältnis zum BIP pro Kopf untersucht. Bei einem Vergleich der so ermittelten relativen Gehaltskosten der Lehrkräfte pro Schüler ergibt sich eine andere Reihenfolge der Länder (Abb. B7.4 [Forts.] im Internet). Im Vergleich zur Analyse in US-Dollar ändert sich jedoch nur die Position von einigen wenigen Ländern signifikant. Im Sekundarbereich II hat Luxemburg die höchsten Gehaltskosten der Lehrkräfte pro Schüler in US-Dollar, insbesondere infolge des hohen Gehaltsniveaus in US-Dollar, nicht jedoch als Anteil des BIP pro Kopf, auch wenn es aufgrund einer unterdurchschnittlich großen geschätzten Klassengröße immer noch über dem OECD-Durchschnitt liegt. Somit führen die Gehälter der Lehrkräfte als Prozentsatz des BIP pro Kopf nicht zu höheren Gehaltskosten der Lehrkräfte pro Schüler (Tab. B7.3 [Forts.], B7.4 [Forts.], B7.5 [Forts.] und Abb. B7.4 [Forts.] im Internet).

Selbst nach Berücksichtigung der Unterschiede im BIP der einzelnen Länder sind die Gehälter der Lehrkräfte (in Prozent des BIP pro Kopf) und die geschätzte Klassengröße in jedem der Bildungsbereiche die wichtigsten Faktoren für die Abweichungen von den durchschnittlichen Gehaltskosten der Lehrkräfte pro Schüler (Kasten B7.2 [Forts.] im Internet).

\section{Angewandte Methodik}

Die Daten für das Schuljahr 2012 beruhen auf der UOE-Datenerhebung zur Bildungsstatistik sowie der Erhebung zu Lehrkräften und Lehrplänen, die beide 2013 von der OECD durchgeführt wurden. Die Daten für die Schuljahre 2000 und 2008 beruhen auf der UOE-Datenerhebung zur Bildungsstatistik und der Erhebung zu Lehrkräften und Lehrplänen, die beide von der OECD durchgeführt und in Bildung auf einen Blick 2013 (Trenddaten zu von Lehrkräften zu unterrichtenden Zeitstunden und den Gehältern der Lehrkräfte) und in Bildung auf einen Blick 2002, 2007 und 2010 (Schüler-LehrkräfteRelation und Unterrichtszeit der Schüler) veröffentlicht wurden. Die Konsistenz der Daten für 2000, 2005, 2008 und 2012 wurde validiert (weitere Informationen s. Anhang 3 unter www.oecd.org/eduleag.htm).

Gehaltskosten der Lehrkräfte pro Schüler wurden auf Grundlage der Gehälter der Lehrkräfte, der Unterrichtszeitstunden der Schüler, der Zahl der von den Lehrkräften zu unterrichtenden Zeitstunden sowie der geschätzten Klassengröße (Näherungswert für die Klassengröße, s. Kasten D2.I) ermittelt. In den meisten Fällen wurden die Werte für diese Variablen Bildung auf einen Blick 2013 entnommen und beziehen sich auf die Schuljahre 20II/2012, 2007/2008, 2004/2005 und 1999/2000. Die Daten für die Schuljahre I999/2000, 2004/2005 und 2007/2008 wurden, wenn in der aktuellen Ausgabe nicht verfügbar, den Ausgaben von Bildung aufeinen Blick der Jahre 2002, 2007 und 2010 entnommen. Die Daten für 2000, 2005 und 2008 wurden überprüft, um die Konsistenz mit den Daten für 2012 zu gewährleisten. Die Gehälter der Lehrkräfte in Landeswäh- 
rung werden in US-Dollar umgerechnet, indem der betreffende Betrag in Landeswährung durch den Kaufkraftparitätsindex (KKP-Index) für den privaten Verbrauch geteilt wird. Dabei kommt die in Indikator $\mathrm{D}_{3}$ bei den Gehältern der Lehrkräfte verwendete Methode zur Anwendung. Das Ergebnis sind die Gehaltskosten der Lehrkräfte pro Schüler ausgedrückt in US-Dollar. Weitere Einzelheiten zur Analyse dieser Faktoren s. Anhang 3 unter www.oecd.org/edu/eag.htm.

\section{Anmerkung zu den Daten aus Israel}

Die statistischen Daten für Israel wurden von den zuständigen israelischen Stellen bereitgestellt, die für sie verantwortlich zeichnen. Die Verwendung dieser Daten durch die OECD erfolgt unbeschadet des völkerrechtlichen Status der Golanhöhen, von Ost-Jerusalem und der israelischen Siedlungen im Westjordanland.

\section{Weiterführende Informationen}

OECD (2012), Bildung auf einen Blick 2012 - OECD-Indikatoren, W. Bertelsmann Verlag, Bielefeld.

\section{Tabellen Indikator B7}

StatLink: http:/|dx.doi.org/10.1787/888933117953

Tabelle B7.I: Gehaltskosten der Lehrkräfte pro Schüler, nach Bildungsbereich (2012)

Tabelle B7.2a: Faktoren zur Berechnung der Gehaltskosten der Lehrkräfte pro Schüler im Primarbereich (2000, 2005, 2008 und 2012)

Tabelle B7.2b: Faktoren zur Berechnung der Gehaltskosten der Lehrkräfte pro Schüler im Sekundarbereich I (2000, 2005, 2008 und 20I2)

WEB Table B7.2c: Factors used to compute the salary cost of teachers per student, in upper secondary education (Faktoren zur Berechnung der Gehaltskosten der Lehrkräfte pro Schüler im Sekundarbereich II) (20I2)

Tabelle B7.3: Beitrag verschiedener Faktoren zu den Gehaltskosten der Lehrkräfte pro Schüler im Primarbereich (2000, 2005, 2008 und 2012)

WEB Table B7.3 (continued): Contribution of various factors to salary cost of teachers per student in primary education ([Forts.] Beitrag verschiedener Faktoren zu den Gehaltskosten der Lehrkräfte pro Schüler im Primarbereich) (20I2)

Tabelle B7.4: Beitrag verschiedener Faktoren zu den Gehaltskosten der Lehrkräfte pro Schüler im Sekundarbereich I (2000, 2005, 2008 und 20I2) 
WEB Table B7.4 (continued): Contribution of various factors to salary cost of teachers per student in lower secondary education ([Forts.] Beitrag verschiedener Faktoren zu den Gehaltskosten der Lehrkräfte pro Schüler im Sekundarbereich I) (20I2)

Tabelle B7.5: Beitrag verschiedener Faktoren zu den Gehaltskosten der Lehrkräfte pro Schüler im Sekundarbereich II (20I2)

WEB Table B7.5 (continued): Contribution of various factors to salary cost of teachers per student in upper secondary education ([Forts.] Beitrag verschiedener Faktoren zu den Gehaltskosten der Lehrkräfte pro Schüler im Sekundarbereich II) (20I2) 
Gehaltskosten der Lehrkräfte pro Schüler, nach Bildungsbereich (2012)

In US-Dollar, kaufkraftbereinigt mittels KKP für den privaten Verbrauch, und als Prozentsatz des BIP pro Kopf

\begin{tabular}{|c|c|c|c|c|c|c|}
\hline & \multicolumn{3}{|c|}{$\begin{array}{l}\text { Gehaltskosten der Lehrkräfte pro Schüler } \\
\text { (in US-Dollar) }\end{array}$} & \multicolumn{3}{|c|}{$\begin{array}{l}\text { Gehaltskosten der Lehrkräfte pro Schüler } \\
\text { (als Prozentsatz des BIP pro Kopf) }\end{array}$} \\
\hline & Primarbereich & Sekundarbereich I & Sekundarbereich II & Primarbereich & Sekundarbereich I & Sekundarbereich II \\
\hline & (1) & (2) & (3) & (4) & (5) & (6) \\
\hline \multicolumn{7}{|l|}{ OECD-Länder } \\
\hline Australien & 3301 & 4355 & 4355 & 7,7 & 10,1 & 10,1 \\
\hline Österreich & 3572 & 5185 & 4897 & 8,4 & 12,1 & 11,5 \\
\hline Belgien (fläm.) & 3797 & 5833 & 6037 & 10,2 & 15,6 & 16,2 \\
\hline Belgien (frz.) & 3716 & 5708 & $\mathrm{~m}$ & 10,0 & 15,3 & $\mathrm{~m}$ \\
\hline Kanada & 3696 & 3696 & 4152 & 9,1 & 9,1 & 10,2 \\
\hline Chile & 1117 & 1102 & 1093 & 5,6 & 5,5 & 5,5 \\
\hline Tschechien & 1027 & 1766 & 1771 & 4,2 & 7,2 & 7,2 \\
\hline Dänemark & 4310 & 4310 & $\mathrm{~m}$ & 11,2 & 11,2 & $\mathrm{~m}$ \\
\hline England & 1959 & 2907 & 2421 & 5,7 & 8,4 & 7,0 \\
\hline Estland & 957 & 1270 & 886 & 4,5 & 6,0 & 4,2 \\
\hline Finnland & 2909 & 4775 & 2863 & 8,1 & 13,2 & 7,9 \\
\hline Frankreich & 1795 & 2398 & 3790 & 5,1 & 6,8 & 10,7 \\
\hline Deutschland & 3884 & 4840 & 5318 & 9,8 & 12,2 & 13,4 \\
\hline Griechenland & 2839 & $\mathrm{~m}$ & $\mathrm{~m}$ & 12,5 & $\mathrm{~m}$ & $\mathrm{~m}$ \\
\hline Ungarn & 1263 & 1279 & 1255 & 6,2 & 6,3 & 6,2 \\
\hline Island & $\mathrm{m}$ & $\mathrm{m}$ & $\mathrm{m}$ & $\mathrm{m}$ & $\mathrm{m}$ & $\mathrm{m}$ \\
\hline Irland & 3410 & 3676 & 3676 & 9,1 & 9,8 & 9,8 \\
\hline Israel & 1935 & 1974 & 2327 & 6,6 & 6,7 & 7,9 \\
\hline Italien & 2769 & 3102 & 2895 & 8,9 & 10,0 & 9,3 \\
\hline Japan & 2680 & 3377 & $\mathrm{~m}$ & 8,3 & 10,4 & $\mathrm{~m}$ \\
\hline Korea & 2725 & 2757 & 3243 & 9,8 & 9,9 & 11,6 \\
\hline Luxemburg & 10704 & 12019 & 12019 & 13,1 & 14,8 & 14,8 \\
\hline Mexiko & 724 & 822 & $\mathrm{~m}$ & 4,9 & 5,6 & $m$ \\
\hline Niederlande & 3463 & 4354 & 3656 & 8,4 & 10,6 & 8,9 \\
\hline Neuseeland & $\mathrm{m}$ & $\mathrm{m}$ & $\mathrm{m}$ & $\mathrm{m}$ & $\mathrm{m}$ & $\mathrm{m}$ \\
\hline Norwegen & 3763 & 3719 & 4335 & 6,3 & 6,2 & 7,3 \\
\hline Polen & 1653 & 2101 & 2175 & 7,7 & 9,8 & 10,2 \\
\hline Portugal & 2923 & 3605 & 4550 & 13,1 & 16,2 & 20,4 \\
\hline Schottland & $\mathrm{m}$ & $\mathrm{m}$ & $\mathrm{m}$ & $\mathrm{m}$ & $\mathrm{m}$ & $\mathrm{m}$ \\
\hline Slowakei & 797 & 1044 & 964 & 3,5 & 4,5 & 4,2 \\
\hline Slowenien & 2066 & 4133 & 2334 & 8,2 & 16,3 & 9,2 \\
\hline Spanien & 3118 & 4321 & 4727 & 10,8 & 15,0 & 16,4 \\
\hline Schweden & $\mathrm{m}$ & $\mathrm{m}$ & $\mathrm{m}$ & $\mathrm{m}$ & $\mathrm{m}$ & $\mathrm{m}$ \\
\hline Schweiz & $\mathrm{m}$ & $\mathrm{m}$ & $m$ & $\mathrm{~m}$ & $\mathrm{~m}$ & $\mathrm{~m}$ \\
\hline Türkei & 1325 & 1376 & 1706 & 8,4 & 8,8 & 10,9 \\
\hline Vereinigte Staaten & 3003 & 3068 & 3249 & 5,8 & 5,9 & 6,3 \\
\hline OECD-Durchschnitt & 2575 & 3129 & 3212 & 7,7 & 9,2 & 9,4 \\
\hline
\end{tabular}

Quelle: OECD. Hinweise s. Anhang 3 unter www.oecd.org/edu/eag.htm. StatLink: http://dx.doi.org/10.1787/888933117972

Erläuterung der Kennzeichnung fehlender Daten s. Hinweise für den Leser. 
Faktoren zur Berechnung der Gehaltskosten der Lehrkräfte pro Schüler im Primarbereich (2000, 2005, 2008 und 2012)

\begin{tabular}{|c|c|c|c|c|c|c|c|c|c|c|c|c|}
\hline & \multicolumn{4}{|c|}{$\begin{array}{l}\text { Gehälter der Lehrkräfte } \\
\text { (pro Jahr in US-Dollar, zu konstanten } \\
\text { Preisen des Jahres 2012) }\end{array}$} & \multicolumn{4}{|c|}{$\begin{array}{l}\text { Zahl der Unterrichtsstunden } \\
\text { (der Schüler, Zeitstunden pro Jahr) }\end{array}$} & \multicolumn{4}{|c|}{$\begin{array}{l}\text { Zu unterrichtende Zeitstunden } \\
\text { (der Lehrkräfte, Zeitstunden pro Jahr) }\end{array}$} \\
\hline & 2005 & 2008 & 2012 & $\begin{array}{l}\text { Veränderung } \\
2008-2012 \\
\quad \text { (in \%) }\end{array}$ & 2005 & 2008 & 2012 & $\begin{array}{l}\text { Veränderung } \\
2008-2012 \\
\quad \text { (in \%) }\end{array}$ & 2005 & 2008 & 2012 & $\begin{array}{l}\text { Veränderung } \\
2008-2012 \\
\text { (in \%) }\end{array}$ \\
\hline & (2) & (3) & (4) & (5) & (7) & (8) & (9) & (10) & (12) & (13) & (14) & (15) \\
\hline \multicolumn{13}{|l|}{ OECD-Länder } \\
\hline Australien $^{1}$ & 49407 & 49544 & 51289 & 3,5 & 979 & 959 & 953 & $-0,6$ & 888 & 873 & 871 & $-0,1$ \\
\hline Österreich ${ }^{1}$ & 42404 & 42993 & 42994 & 0,0 & 812 & 735 & 750 & 2,0 & 774 & 779 & 779 & 0,0 \\
\hline Belgien (fläm.) ${ }^{1}$ & 47136 & 45664 & 47635 & 4,3 & 835 & 840 & 831 & $-1,1$ & 761 & 765 & 748 & $-2,2$ \\
\hline Belgien (frz.) ${ }^{1}$ & 44715 & 43816 & 46616 & 6,4 & 930 & 930 & 930 & 0,0 & 722 & 724 & 721 & $-0,4$ \\
\hline Kanada & $\mathrm{m}$ & $\mathrm{m}$ & 58495 & m & $\mathrm{m}$ & $\mathrm{m}$ & 919 & m & $\mathrm{m}$ & $\mathrm{m}$ & 802 & m \\
\hline Chile & $\mathrm{m}$ & $\mathrm{m}$ & 24725 & m & $\mathrm{m}$ & 1089 & 1007 & $-7,5$ & 1128 & 1101 & 1103 & 0,2 \\
\hline Tschechien ${ }^{1,2}$ & 18981 & 21863 & 19363 & $-11,4$ & 774 & 627 & 597 & $-4,8$ & 813 & 849 & 827 & $-2,6$ \\
\hline Dänemark ${ }^{1}$ & 44963 & 46551 & 51122 & 9,8 & 763 & 701 & 754 & 7,5 & 640 & 648 & 659 & 1,7 \\
\hline England $^{1}$ & 43668 & 43695 & 41393 & $-5,3$ & 900 & 893 & 861 & $-3,5$ & $\mathrm{~m}$ & 654 & 680 & 4,1 \\
\hline Estland $^{1}$ & 9587 & 13220 & 12525 & $-5,3$ & 910 & 595 & 650 & 9,2 & 630 & 630 & 619 & $-1,7$ \\
\hline Finnland $^{1}$ & 39317 & 40907 & 39445 & $-3,6$ & 673 & 608 & 654 & 7,5 & 677 & 677 & 673 & $-0,5$ \\
\hline Frankreich $^{1}$ & 36113 & 34912 & 33994 & $-2,6$ & 894 & 926 & 864 & $-6,7$ & 936 & 936 & 924 & $-1,3$ \\
\hline Deutschland & $\mathrm{m}$ & $\mathrm{m}$ & 62195 & m & 777 & 635 & 702 & 10,6 & 808 & 805 & 804 & $-0,1$ \\
\hline Griechenland $^{1}$ & 34627 & 35573 & 26617 & $-25,2$ & 928 & 720 & 756 & 5,0 & 604 & 593 & 569 & $-3,9$ \\
\hline Ungarn $^{1}$ & 19090 & 17486 & 13520 & $-22,7$ & 718 & 614 & 655 & 6,6 & 583 & 611 & 604 & $-1,1$ \\
\hline Island & 29811 & 31135 & 28742 & $-7,7$ & 792 & 720 & 857 & 19,0 & 671 & 671 & $\mathrm{~m}$ & m \\
\hline Irland $^{1}$ & 49451 & 52696 & 55148 & 4,7 & 941 & 915 & 869 & $-5,0$ & 915 & 915 & 915 & 0,0 \\
\hline Israel $^{1}$ & 20576 & 24873 & 29413 & 18,3 & 990 & 996 & 956 & $-3,9$ & 731 & 731 & 838 & 14,6 \\
\hline Italien ${ }^{1}$ & 35157 & 34252 & 33570 & $-2,0$ & 1023 & 990 & 891 & $-10,0$ & 739 & 735 & 752 & 2,4 \\
\hline$J^{J a p a n^{1}}$ & 50982 & 47604 & 47561 & $-0,1$ & 774 & 709 & 754 & 6,3 & 578 & 709 & 731 & 3,2 \\
\hline Korea $^{1}$ & 52522 & 51879 & 50145 & $-3,3$ & 703 & 612 & 632 & 3,3 & 883 & 840 & 694 & $-17,5$ \\
\hline Luxemburg $^{1}$ & 73324 & 70145 & 98788 & 40,8 & 847 & 924 & 924 & 0,0 & 774 & 739 & 810 & 9,5 \\
\hline Mexiko $^{1}$ & 18952 & 19666 & 20296 & 3,2 & 800 & 800 & 800 & 0,0 & 800 & 800 & 800 & 0,0 \\
\hline Niederlande $^{1}$ & $\mathrm{~m}$ & 48720 & 54865 & 12,6 & 1000 & 940 & 940 & 0,0 & 930 & 930 & 930 & 0,0 \\
\hline Neuseeland & 41198 & 42312 & 43050 & 1,7 & 985 & 985 & $\mathrm{~m}$ & m & $\mathrm{m}$ & 945 & $\mathrm{~m}$ & m \\
\hline Norwegen $^{1}$ & 35497 & 36475 & 38773 & 6,3 & 713 & 656 & 748 & 14,0 & 741 & 741 & 741 & 0,0 \\
\hline Polen $^{1}$ & 14793 & 15963 & 18160 & 13,8 & $\mathrm{~m}$ & 486 & 703 & 44,6 & $\mathrm{~m}$ & 632 & 633 & 0,2 \\
\hline Portugal $^{1}$ & 37224 & 35980 & 34694 & $-3,6$ & 861 & 776 & 812 & 4,6 & 855 & 770 & 756 & $-1,8$ \\
\hline Schottland & 48021 & 47593 & 44867 & $-5,7$ & a & a & a & m & 893 & 855 & 855 & 0,0 \\
\hline Slowakei & $\mathrm{m}$ & $\mathrm{m}$ & 13365 & m & $\mathrm{m}$ & 662 & 698 & 5,4 & $\mathrm{~m}$ & $\mathrm{~m}$ & 819 & m \\
\hline Slowenien ${ }^{1}$ & 31673 & 33345 & 32819 & $-1,6$ & 721 & 621 & 664 & 7,0 & 627 & 627 & 627 & 0,0 \\
\hline Spanien $^{1}$ & 43035 & 44513 & 41862 & $-6,0$ & 794 & 833 & 875 & 5,0 & 880 & 880 & 880 & 0,0 \\
\hline Schweden & 34533 & $\mathrm{~m}$ & 35115 & m & 741 & 741 & 741 & 0,0 & $\mathrm{~m}$ & $\mathrm{~m}$ & $\mathrm{~m}$ & m \\
\hline Schweiz & 60706 & 59196 & 61279 & 3,5 & $\mathrm{~m}$ & 713 & $m$ & m & $\mathrm{m}$ & $m$ & $\mathrm{~m}$ & $\mathbf{m}$ \\
\hline Türkei $^{1}$ & 24834 & 24951 & 26678 & 6,9 & 864 & 864 & 864 & 0,0 & 639 & 639 & 720 & 12,7 \\
\hline Vereinigte Staaten ${ }^{1}$ & 47441 & 47290 & 45998 & $-2,7$ & 952 & 960 & 967 & 0,7 & 1080 & 1097 & 1131 & 3,1 \\
\hline OECD-Durchschnitt & 38056 & 38865 & 39642 & 0,9 & 846 & 787 & 805 & 3,6 & 783 & 778 & 782 & 0,6 \\
\hline $\begin{array}{l}\text { Durchschnitt von } \\
27 \text { Ländern, für die } \\
\text { alle Daten für } 2008 \\
\text { und } 2012 \text { vorliegen }\end{array}$ & & 37947 & 39085 & 3,0 & & 786 & 802 & 2,0 & & 760 & 764 & 0,5 \\
\hline
\end{tabular}

Anmerkung: Die Spalten mit den Angaben für das Referenzjahr 2000, d. h. die Spalten (1), (6), (11), (16) und (21), sind im Internet verfügbar (s. StatLink unten). Die Daten in dieser Tabelle wurden entweder Kapitel D entnommen (Daten für 2000, 2005, 2008 und 2012 zu Gehältern der Lehrkräfte und zu unterrichtenden Zeitstunden, Daten für 2012 zur Schüler-Lehrkräfte-Relation) oder Bildung auf einen Blick 2002, 2007 bzw. 2010 (Daten zur Schüler-Lehrkräfte-Relation und Unterrichtszeit). Die Daten für 2012 zur Unterrichtszeit beziehen sich auf die Daten für 2011 aus Bildung auf einen Blick 2013 (für die Vereinigten Staaten beziehen sich die Daten auf 2012 und wurden für frühere Jahre überarbeitet). Einige Daten für 2000 wurden überarbeitet, um die Konsistenz mit den Daten für 2012 zu gewährleisten.

1. Länder, für die alle Daten sowohl für 2008 als auch für 2012 vorliegen. 2. Aktuelle Unterrichtszeit für 2000 und 2005 , Mindestunterrichtszeit für 2012. Quelle: OECD. Hinweise s. Anhang 3 unter www.oecd.org/edu/eag.htm. StatLink: http://dx.doi.org/10.1787/888933117991

Erläuterung der Kennzeichnung fehlender Daten s. Hinweise für den Leser. 
Faktoren zur Berechnung der Gehaltskosten der Lehrkräfte pro Schüler im Primarbereich (2000, 2005, 2008 und 2012)

\begin{tabular}{|c|c|c|c|c|c|c|c|c|}
\hline & \multicolumn{4}{|c|}{$\begin{array}{l}\text { Schüler-Lehrkräfte-Relation } \\
\text { (Zahl der Schüler pro Lehrkraft) }\end{array}$} & \multicolumn{4}{|c|}{$\begin{array}{l}\text { Geschätzte Klassengröße } \\
\text { (Zahl der Schüler pro Klasse) }\end{array}$} \\
\hline & 2005 & 2008 & 2012 & \begin{tabular}{|c|} 
Veränderung \\
$2008-2012$ \\
(in \%)
\end{tabular} & 2005 & 2008 & 2012 & $\begin{array}{l}\text { Veränderung } \\
2008-2012 \\
\text { (in \%) }\end{array}$ \\
\hline & (17) & $(18)$ & (19) & (20) & $(22)=(17) \times(7) /(12)$ & $(23)=(18) \times(8) /(13)$ & $(24)=(19) \times(9) /(14)$ & (25) \\
\hline \multicolumn{9}{|l|}{ OECD-Länder } \\
\hline Australien $^{1}$ & 16,2 & 15,8 & 15,5 & $-1,7$ & 17,9 & 17,4 & 17,0 & $-2,2$ \\
\hline Österreich ${ }^{1}$ & 14,1 & 12,9 & 12,0 & $-6,7$ & 14,8 & 12,2 & 11,6 & $-4,8$ \\
\hline Belgien (fläm.) ${ }^{1}$ & 12,8 & 12,6 & 12,5 & $-0,6$ & 14,0 & 13,9 & 13,9 & 0,5 \\
\hline Belgien (frz.) ${ }^{1}$ & 12,8 & 12,6 & 12,5 & $-0,6$ & 16,5 & 16,2 & 16,2 & $-0,2$ \\
\hline Kanada & $\mathrm{m}$ & 16,3 & 15,8 & $-3,1$ & $\mathrm{~m}$ & $\mathrm{~m}$ & 18,1 & m \\
\hline Chile & 25,9 & 24,1 & 22,1 & $-8,3$ & $\mathrm{~m}$ & 23,9 & 20,2 & $-15,3$ \\
\hline Tschechien ${ }^{1,2}$ & 17,5 & 18,1 & 18,9 & 4,3 & 16,7 & 13,3 & 13,6 & 1,9 \\
\hline Dänemark ${ }^{1}$ & 11,9 & 10,1 & 11,9 & 17,2 & 14,2 & 10,9 & 13,6 & 23,9 \\
\hline England $^{1}$ & 14,9 & 20,2 & 21,1 & 4,6 & $\mathrm{~m}$ & 27,6 & 26,7 & $-3,1$ \\
\hline Estland $^{1}$ & $\mathrm{~m}$ & 16,4 & 13,1 & $-20,2$ & $\mathrm{~m}$ & 15,5 & 13,7 & $-11,4$ \\
\hline Finnland $^{1}$ & 15,9 & 14,4 & 13,6 & $-5,8$ & 15,8 & 12,9 & 13,2 & 1,8 \\
\hline Frankreich ${ }^{1}$ & 19,4 & 19,9 & 18,9 & $-4,9$ & 18,5 & 19,7 & 17,7 & $-10,1$ \\
\hline Deutschland & 18,8 & 18,0 & 16,0 & $-10,8$ & 18,1 & 14,2 & 14,0 & $-1,4$ \\
\hline Griechenland $^{1}$ & 11,1 & 10,1 & 9,4 & $-6,9$ & 17,0 & 12,2 & 12,4 & 1,7 \\
\hline Ungarn ${ }^{1}$ & 10,6 & 10,6 & 10,7 & 1,0 & 13,1 & 10,7 & 11,6 & 8,9 \\
\hline Island & 11,3 & 10,0 & 10,2 & 2,7 & 13,4 & 10,7 & $\mathrm{~m}$ & m \\
\hline Irland $^{1}$ & 17,9 & 17,8 & 16,2 & $-9,1$ & 18,4 & 17,8 & 15,4 & $-13,7$ \\
\hline$\left.\right|_{\text {srael }} ^{1}$ & 17,3 & 16,3 & 15,2 & $-6,9$ & 23,4 & 22,2 & 17,4 & $-21,9$ \\
\hline Italien ${ }^{1}$ & 10,6 & 10,6 & 12,1 & 14,7 & 14,7 & 14,2 & 14,4 & 0,9 \\
\hline Japan $^{1}$ & 19,4 & 18,8 & 17,7 & $-5,6$ & 25,9 & 18,8 & 18,3 & $-2,8$ \\
\hline Korea $^{1}$ & 28,0 & 24,1 & 18,4 & $-23,7$ & 22,3 & 17,6 & 16,8 & $-4,5$ \\
\hline Luxemburg $^{1}$ & $\mathrm{~m}$ & 12,1 & 9,2 & $-23,8$ & $\mathrm{~m}$ & 15,1 & 10,5 & $-30,4$ \\
\hline Mexiko $^{1}$ & 28,3 & 28,0 & 28,0 & $-0,0$ & 28,3 & 28,0 & 28,0 & 0,0 \\
\hline Niederlande ${ }^{1}$ & 15,9 & 15,8 & 15,8 & 0,5 & 17,1 & 15,9 & 16,0 & 0,5 \\
\hline Neuseeland & 18,1 & 17,1 & 16,4 & $-4,2$ & $\mathrm{~m}$ & 17,8 & $\mathrm{~m}$ & m \\
\hline Norwegen $^{1}$ & 10,9 & 10,8 & 10,3 & $-4,7$ & 10,5 & 9,6 & 10,4 & 8,6 \\
\hline Polen $^{1}$ & 11,7 & 10,5 & 11,0 & 4,6 & $\mathrm{~m}$ & 8,1 & 12,2 & 50,9 \\
\hline Portugal $^{1}$ & 10,8 & 11,3 & 11,9 & 4,9 & 10,9 & 11,4 & 12,7 & 11,7 \\
\hline Schottland & 14,9 & 20,2 & 21,1 & 4,6 & $\mathrm{~m}$ & $\mathrm{~m}$ & $\mathrm{~m}$ & m \\
\hline Slowakei & 18,9 & 18,6 & 16,8 & $-9,8$ & $\mathrm{~m}$ & $\mathrm{~m}$ & 14,3 & m \\
\hline Slowenien ${ }^{1}$ & 15,0 & 15,8 & 15,9 & 0,7 & 17,3 & 15,6 & 16,8 & 7,8 \\
\hline Spanien $^{1}$ & 14,3 & 13,1 & 13,4 & 2,3 & 12,9 & 12,4 & 13,3 & 7,5 \\
\hline Schweden & 12,2 & 12,2 & 11,8 & $-3,2$ & $\mathrm{~m}$ & $\mathrm{~m}$ & $\mathrm{~m}$ & m \\
\hline Schweiz & 14,6 & 15,4 & $\mathrm{~m}$ & m & $\mathrm{m}$ & $\mathrm{m}$ & $\mathrm{m}$ & m \\
\hline Türkei ${ }^{1}$ & 25,8 & 24,4 & 20,1 & $-17,5$ & 34,9 & 33,0 & 24,2 & $-26,8$ \\
\hline Vereinigte Staaten ${ }^{1}$ & 14,9 & 14,3 & 15,3 & 7,1 & 13,1 & 12,5 & 13,1 & 4,7 \\
\hline OECD-Durchschnitt & 16,1 & 15,8 & 15,2 & $-3,1$ & 17,6 & 16,2 & 15,7 & $-0,6$ \\
\hline $\begin{array}{l}\text { Durchschnitt von } \\
27 \text { Ländern, für die } \\
\text { alle Daten für } 2008 \\
\text { und } 2012 \text { vorliegen }\end{array}$ & & 15,5 & 15,5 & 0,5 & 19,8 & 16,0 & 15,6 & $-2,6$ \\
\hline
\end{tabular}

Anmerkung: Die Spalten mit den Angaben für das Referenzjahr 2000, d. h. die Spalten (1), (6), (11), (16) und (21), sind im Internet verfügbar (s. StatLink unten). Die Daten in dieser Tabelle wurden entweder Kapitel D entnommen (Daten für 2000, 2005, 2008 und 2012 zu Gehältern der Lehrkräfte und zu unterrichtenden Zeitstunden, Daten für 2012 zur Schüler-Lehrkräfte-Relation) oder Bildung auf einen Blick 2002, 2007 bzw. 2010 (Daten zur Schüler-Lehrkräfte-Relation und Unterrichtszeit). Die Daten für 2012 zur Unterrichtszeit beziehen sich auf die Daten für 2011 aus Bildung auf einen Blick 2013 (für die Vereinigten Staaten beziehen sich die Daten auf 2012 und wurden für frühere Jahre überarbeitet). Einige Daten für 2000 wurden überarbeitet, um die Konsistenz mit den Daten für 2012 zu gewährleisten.

1. Länder, für die alle Daten sowohl für 2008 als auch für 2012 vorliegen. 2. Aktuelle Unterrichtszeit für 2000 und 2005 , Mindestunterrichtszeit für 2012. Quelle: OECD. Hinweise s. Anhang 3 unter www.oecd.org/edu/eag.htm. StatLink: http://dx.doi.org/10.1787/888933117991

Erläuterung der Kennzeichnung fehlender Daten s. Hinweise für den Leser. 
Faktoren zur Berechnung der Gehaltskosten der Lehrkräfte pro Schüler im Sekundarbereich I (2000, 2005, 2008 und 2012)

\begin{tabular}{|c|c|c|c|c|c|c|c|c|c|c|c|c|}
\hline & \multicolumn{4}{|c|}{$\begin{array}{c}\text { Gehälter der Lehrkräfte } \\
\text { (pro Jahr, in US-Dollar, zu konstanten } \\
\text { Preisen des Jahres 2012) }\end{array}$} & \multicolumn{4}{|c|}{$\begin{array}{l}\text { Zahl der Unterrichtsstunden } \\
\text { (der Schüler, Zeitstunden pro Jahr) }\end{array}$} & \multicolumn{4}{|c|}{$\begin{array}{l}\text { Zu unterrichtende Zeitstunden } \\
\text { (der Lehrkräfte, Zeitstunden pro Jahr) }\end{array}$} \\
\hline & 2005 & 2008 & 2012 & $\begin{array}{l}\text { Veränderung } \\
2008-2012 \\
\text { (in \%) }\end{array}$ & 2005 & 2008 & 2012 & $\begin{array}{l}\text { Veränderung } \\
2008-2012 \\
\text { (in \%) }\end{array}$ & 2005 & 2008 & 2012 & $\begin{array}{l}\text { Veränderung } \\
2008-2012 \\
\text { (in \%) }\end{array}$ \\
\hline & (2) & (3) & (4) & (5) & (7) & (8) & (9) & (10) & (12) & (13) & (14) & (15) \\
\hline \multicolumn{13}{|l|}{ OECD-Länder } \\
\hline Australien ${ }^{1}$ & 49521 & 50416 & 52082 & 3,3 & 1014 & 1011 & 1009 & $-0,3$ & 810 & 812 & 809 & $-0,4$ \\
\hline Österreich ${ }^{1}$ & 45935 & 46484 & 46625 & 0,3 & 958 & 958 & 945 & $-1,4$ & 607 & 607 & 607 & 0,0 \\
\hline Belgien (fläm.) ${ }^{1}$ & 47136 & 45664 & 47635 & 4,3 & 960 & 965 & 955 & $-1,1$ & 690 & 679 & 652 & $-3,9$ \\
\hline Belgien (frz.) ${ }^{1}$ & 45215 & 43816 & 46616 & 6,4 & 1020 & 1020 & 1020 & 0,0 & 724 & 662 & 661 & $-0,2$ \\
\hline Kanada & $\mathrm{m}$ & $\mathrm{m}$ & 58495 & m & $\mathrm{m}$ & $\mathrm{m}$ & 923 & m & $\mathrm{m}$ & $\mathrm{m}$ & 747 & m \\
\hline Chile & $\mathrm{m}$ & $\mathrm{m}$ & 24725 & m & $\mathrm{m}$ & 1089 & 1083 & $-0,5$ & 1128 & 1101 & 1103 & 0,2 \\
\hline Tschechien ${ }^{1,2}$ & 18981 & 22299 & 19515 & $-12,5$ & 902 & 876 & 848 & $-3,1$ & 647 & 637 & 620 & $-2,6$ \\
\hline Dänemark ${ }^{1}$ & 44963 & 46551 & 51122 & 9,8 & 880 & 900 & 930 & 3,3 & 640 & 648 & 659 & 1,7 \\
\hline England $^{1}$ & 43668 & 43695 & 41393 & $-5,3$ & 933 & 925 & 912 & $-1,4$ & $\mathrm{~m}$ & 722 & 692 & $-4,2$ \\
\hline Estland $^{1}$ & 9587 & 13220 & 12525 & $-5,3$ & 1073 & 802 & 770 & $-4,0$ & 630 & 630 & 619 & $-1,7$ \\
\hline Finnland $^{1}$ & 42799 & 44180 & 42601 & $-3,6$ & 815 & 829 & 913 & 10,2 & 592 & 592 & 589 & $-0,5$ \\
\hline Frankreich ${ }^{1}$ & 39002 & 37524 & 37065 & $-1,2$ & 1053 & 1072 & 1081 & 0,8 & 648 & 648 & 648 & 0,0 \\
\hline Deutschland & $\mathrm{m}$ & $\mathrm{m}$ & 67736 & m & 872 & 887 & 890 & 0,3 & 758 & 756 & 755 & $-0,1$ \\
\hline Griechenland & 34627 & 35573 & 26617 & $-25,2$ & 998 & 821 & 796 & $-3,1$ & 434 & 429 & 415 & $-3,2$ \\
\hline Ungarn ${ }^{1}$ & 19090 & 17486 & 13520 & $-22,7$ & 921 & 885 & 859 & $-3,0$ & 555 & 611 & 604 & $-1,1$ \\
\hline Island & 29811 & 31135 & 28742 & $-7,7$ & 872 & 872 & 987 & 13,1 & 671 & 671 & $\mathrm{~m}$ & m \\
\hline Irland $^{1}$ & 49451 & 52696 & 55148 & 4,7 & 907 & 907 & 935 & 3,1 & 735 & 735 & 735 & 0,0 \\
\hline |srael $^{1}$ & 22965 & 25129 & 26912 & 7,1 & 971 & 1139 & 981 & $-13,9$ & 579 & 579 & 629 & 8,7 \\
\hline Italien ${ }^{1}$ & 38295 & 37306 & 36577 & $-2,0$ & 1082 & 1089 & 990 & $-9,1$ & 605 & 601 & 616 & 2,4 \\
\hline$J^{J a p a n^{1}}$ & 50982 & 47604 & 47561 & $-0,1$ & 869 & 868 & 866 & $-0,2$ & 505 & 603 & 602 & $-0,1$ \\
\hline Korea $^{1}$ & 52395 & 51760 & 50040 & $-3,3$ & 867 & 867 & 850 & $-2,0$ & 621 & 616 & 568 & $-7,8$ \\
\hline Luxemburg ${ }^{1}$ & 95884 & 102386 & 105780 & 3,3 & 782 & 908 & 900 & $-0,9$ & 642 & 634 & 739 & 16,7 \\
\hline Mexiko $^{1}$ & 24104 & 25016 & 26229 & 4,8 & 1167 & 1167 & 1167 & 0,0 & 1047 & 1047 & 1047 & 0,0 \\
\hline Niederlande ${ }^{1}$ & $\mathrm{~m}$ & 58421 & 68064 & 16,5 & 1067 & 1000 & 1000 & 0,0 & 750 & 750 & 750 & 0,0 \\
\hline Neuseeland & 41198 & 42312 & 44710 & 5,7 & 962 & 985 & $\mathrm{~m}$ & m & $\mathrm{m}$ & 853 & $\mathrm{~m}$ & m \\
\hline Norwegen $^{1}$ & 35497 & 36475 & 38773 & 6,3 & 827 & 826 & 855 & 3,5 & 656 & 654 & 663 & 1,5 \\
\hline Polen $^{1}$ & 17080 & 18277 & 20700 & 13,3 & $\mathrm{~m}$ & 644 & 800 & 24,1 & $\mathrm{~m}$ & 562 & 561 & $-0,2$ \\
\hline Portugal $^{1}$ & 37224 & 35980 & 34694 & $-3,6$ & 905 & 755 & 792 & 4,9 & 564 & 627 & 616 & $-1,8$ \\
\hline Schottland & 48021 & 47593 & 44867 & $-5,7$ & a & a & a & a & 893 & 855 & 855 & 0,0 \\
\hline Slowakei & $\mathrm{m}$ & $\mathrm{m}$ & 13365 & m & $\mathrm{m}$ & 883 & 832 & $-5,8$ & $\mathrm{~m}$ & $\mathrm{~m}$ & 635 & m \\
\hline Slowenien ${ }^{1}$ & 31673 & 33345 & 32819 & $-1,6$ & 791 & 791 & 817 & 3,2 & 627 & 627 & 627 & 0,0 \\
\hline Spanien ${ }^{1}$ & 48298 & 48671 & 45783 & $-5,9$ & 956 & 1015 & 1050 & 3,4 & 713 & 713 & 713 & 0,0 \\
\hline Schweden & 35411 & $\mathrm{~m}$ & 36247 & m & 741 & 741 & 741 & 0,0 & $\mathrm{~m}$ & $\mathrm{~m}$ & $\mathrm{~m}$ & m \\
\hline Schweiz & 69129 & 67669 & 69816 & 3,2 & $\mathrm{~m}$ & 912 & $\mathrm{~m}$ & m & $\mathrm{m}$ & $\mathrm{m}$ & $\mathrm{m}$ & m \\
\hline Türkei & a & a & 27607 & m & a & a & 864 & m & a & a & 504 & m \\
\hline Vereinigte Staaten ${ }^{1}$ & 47856 & 47105 & 47046 & $-0,1$ & 996 & 1003 & 1011 & 0,8 & 1080 & 1068 & 1085 & 1,7 \\
\hline OECD-Durchschnitt & 40527 & 41860 & 41382 & $-0,6$ & 937 & 922 & 920 & 0,7 & 698 & 701 & 691 & 0,2 \\
\hline $\begin{array}{l}\text { Durchschnitt von } \\
25 \text { Ländern, für die } \\
\text { alle Daten für } 2008 \\
\text { und } 2012 \text { vorliegen }\end{array}$ & & 41260 & 41873 & 1,5 & & 929 & 930 & 0,1 & & 682 & 708 & $\mathbf{3 , 7}$ \\
\hline
\end{tabular}

Anmerkung: Die Spalten mit den Angaben für das Referenzjahr 2000, d.h. die Spalten (1), (6), (11), (16) und (21), sind im Internet verfügbar (s. StatLink unten). Die Daten in dieser Tabelle wurden entweder Kapitel D entnommen (Daten für 2000, 2005, 2008 und 2012 zu Gehältern der Lehrkräfte und zu unterrichtenden Zeitstunden, Daten für 2012 zur Schüler-Lehrkräfte-Relation) oder Bildung auf einen Blick 2002, 2007 bzw. 2010 (Daten zur Schüler-Lehrkräfte-Relation und Unterrichtszeit). Die Daten für 2012 zur Unterrichtszeit beziehen sich auf die Daten für 2011 aus Bildung auf einen Blick 2013 (für die Vereinigten Staaten beziehen sich die Daten auf 2012 und wurden für frühere Jahre überarbeitet). Einige Daten für 2000 wurden überarbeitet, um die Konsistenz mit den Daten für 2012 zu gewährleisten.

1. Länder, für die alle Daten sowohl für 2008 als auch für 2012 vorliegen. 2. Aktuelle Unterrichtszeit für 2000 und 2005 , Mindestunterrichtszeit für 2012. Quelle: OECD. Hinweise s. Anhang 3 unter www.oecd.org/edu/eag.htm. StatLink: http://dx.doi.org/10.1787/888933118010

Erläuterung der Kennzeichnung fehlender Daten s. Hinweise für den Leser. 
Faktoren zur Berechnung der Gehaltskosten der Lehrkräfte pro Schüler im Sekundarbereich I $(2000,2005,2008$ und 2012)

\begin{tabular}{|c|c|c|c|c|c|c|c|c|}
\hline & \multicolumn{4}{|c|}{$\begin{array}{l}\text { Schüler-Lehrkräfte-Relation } \\
\text { (Zahl der Schüler pro Lehrkraft) }\end{array}$} & \multicolumn{4}{|c|}{$\begin{array}{l}\text { Geschätzte Klassengröße } \\
\text { (Zahl der Schüler pro Klasse) }\end{array}$} \\
\hline & 2005 & 2008 & 2012 & \begin{tabular}{|c|} 
Veränderung \\
$2008-2012$ \\
(in \%)
\end{tabular} & 2005 & 2008 & 2012 & $\begin{array}{l}\text { Veränderung } \\
2008-2012 \\
\text { (in \%) }\end{array}$ \\
\hline & $(17)$ & $(18)$ & (19) & (20) & $(22)=(17) \times(7) /(12)$ & $(23)=(18) \times(8) /(13)$ & $(24)=(19) \times(9) /(14)$ & (25) \\
\hline \multicolumn{9}{|l|}{ OECD-Länder } \\
\hline Australien $^{1}$ & 12,1 & 12,0 & 12,0 & $-0,3$ & 15,2 & 15,0 & 14,9 & $-0,2$ \\
\hline Österreich ${ }^{1}$ & 10,6 & 9,9 & 9,0 & $-9,5$ & 16,8 & 15,7 & 14,0 & $-10,8$ \\
\hline Belgien (fläm.) ${ }^{1}$ & 9,4 & 8,1 & 8,2 & 0,4 & 13,1 & 11,6 & 12,0 & 3,3 \\
\hline Belgien (frz.) ${ }^{1}$ & 9,4 & 8,1 & 8,2 & 0,4 & 13,3 & 12,5 & 12,6 & 0,6 \\
\hline Kanada & $\mathrm{m}$ & 16,3 & 15,8 & $-3,1$ & $\mathrm{~m}$ & $\mathrm{~m}$ & 19,6 & m \\
\hline Chile & 25,9 & 24,1 & 22,4 & $-7,0$ & $\mathrm{~m}$ & 23,9 & 22,0 & $-7,6$ \\
\hline Tschechien ${ }^{1,2}$ & 13,5 & 11,8 & 11,1 & $-6,5$ & 18,8 & 16,2 & 15,1 & $-7,0$ \\
\hline Dänemark ${ }^{1}$ & 11,9 & 10,1 & 11,9 & 17,2 & 16,4 & 14,1 & 16,7 & 19,1 \\
\hline England $^{1}$ & 15,1 & 15,0 & 14,2 & $-4,9$ & $\mathrm{~m}$ & 19,2 & 18,8 & $-2,1$ \\
\hline Estland $^{1}$ & $\mathrm{~m}$ & 16,0 & 9,9 & $-38,5$ & $\mathrm{~m}$ & 20,4 & 12,3 & $-39,9$ \\
\hline Finnland $^{1}$ & 10,0 & 10,6 & 8,9 & $-16,1$ & 13,7 & 14,9 & 13,8 & $-7,1$ \\
\hline Frankreich ${ }^{1}$ & 14,2 & 14,6 & 15,5 & 6,1 & 23,0 & 24,1 & 25,8 & 7,0 \\
\hline Deutschland & 15,5 & 15,0 & 14,0 & $-6,9$ & 17,9 & 17,6 & 16,5 & $-6,4$ \\
\hline Griechenland & 7,9 & 7,7 & $\mathrm{~m}$ & m & 18,1 & 14,7 & $\mathrm{~m}$ & $\mathbf{m}$ \\
\hline Ungarn ${ }^{1}$ & 10,4 & 10,9 & 10,6 & $-2,8$ & 17,2 & 15,8 & 15,0 & $-4,6$ \\
\hline Island & 11,3 & 10,0 & 10,6 & 6,3 & 14,7 & 13,0 & $\mathrm{~m}$ & m \\
\hline Irland $^{1}$ & 15,5 & 12,8 & 15,0 & 17,2 & 19,1 & 15,8 & 19,1 & 20,8 \\
\hline |srael $^{1}$ & 13,4 & 12,2 & 13,6 & 11,8 & 22,4 & 24,0 & 21,3 & $-11,4$ \\
\hline Italien ${ }^{1}$ & 10,1 & 9,7 & 11,8 & 21,8 & 18,1 & 17,5 & 19,0 & 8,1 \\
\hline Japan $^{1}$ & 15,1 & 14,7 & 14,1 & $-4,2$ & 26,0 & 21,2 & 20,2 & $-4,3$ \\
\hline Korea $^{1}$ & 20,8 & 20,2 & 18,1 & $-10,4$ & 29,0 & 28,5 & 27,2 & $-4,6$ \\
\hline Luxemburg $^{1}$ & 9,0 & 9,1 & 8,8 & $-3,4$ & 11,0 & 13,1 & 10,7 & $-18,0$ \\
\hline Mexiko $^{1}$ & 33,7 & 33,9 & 31,9 & $-5,7$ & 37,6 & 37,7 & 35,6 & $-5,7$ \\
\hline Niederlande ${ }^{1}$ & 16,2 & 15,8 & 15,6 & $-1,1$ & 23,1 & 21,1 & 20,8 & $-1,1$ \\
\hline Neuseeland & 16,8 & 16,2 & 16,4 & 1,3 & $\mathrm{~m}$ & 18,7 & $\mathrm{~m}$ & m \\
\hline Norwegen ${ }^{1}$ & 10,2 & 10,1 & 10,4 & 3,5 & 12,9 & 12,7 & 13,4 & 5,6 \\
\hline Polen $^{1}$ & 12,7 & 12,9 & 9,9 & $-23,9$ & $\mathrm{~m}$ & 14,8 & 14,1 & $-5,4$ \\
\hline Portugal $^{1}$ & 8,2 & 8,1 & 9,6 & 19,5 & 13,1 & 9,7 & 12,4 & 27,6 \\
\hline Schottland & 15,1 & 15,0 & 14,2 & $-4,9$ & $\mathrm{~m}$ & $\mathrm{~m}$ & $\mathrm{~m}$ & m \\
\hline Slowakei & 14,1 & 14,5 & 12,8 & $-11,5$ & $\mathrm{~m}$ & $\mathrm{~m}$ & 16,8 & m \\
\hline Slowenien ${ }^{1}$ & 11,1 & 8,9 & 7,9 & $-10,7$ & 14,0 & 11,2 & 10,3 & $-7,8$ \\
\hline Spanien $^{1}$ & 12,5 & 10,3 & 10,6 & 3,1 & 16,8 & 14,6 & 15,6 & 6,6 \\
\hline Schweden & 12,0 & 11,4 & 11,3 & $-1,3$ & $\mathrm{~m}$ & $\mathrm{~m}$ & $\mathrm{~m}$ & m \\
\hline Schweiz & 11,7 & 12,1 & $\mathrm{~m}$ & m & $\mathrm{m}$ & $\mathrm{m}$ & $\mathrm{m}$ & m \\
\hline Türkei & $\mathrm{a}$ & a & 20,1 & m & a & a & 34,4 & m \\
\hline Vereinigte Staaten $^{1}$ & 15,1 & 14,8 & 15,3 & 3,9 & 13,9 & 13,9 & 14,3 & 3,0 \\
\hline OECD-Durchschnitt & 13,7 & 13,2 & 13,2 & $-1,8$ & 18,2 & 17,4 & 17,8 & $-1,6$ \\
\hline $\begin{array}{l}\text { Durchschnitt von } \\
25 \text { Ländern, für die } \\
\text { alle Daten für } 2008 \\
\text { und } 2012 \text { vorliegen }\end{array}$ & & 12,8 & 12,5 & $-2,7$ & & 16,0 & 17,0 & 6,1 \\
\hline
\end{tabular}

Anmerkung: Die Spalten mit den Angaben für das Referenzjahr 2000, d.h. die Spalten (1), (6), (11), (16) und (21), sind im Internet verfügbar (s. StatLink unten). Die Daten in dieser Tabelle wurden entweder Kapitel D entnommen (Daten für 2000, 2005, 2008 und 2012 zu Gehältern der Lehrkräfte und zu unterrichtenden Zeitstunden, Daten für 2012 zur Schüler-Lehrkräfte-Relation) oder Bildung auf einen Blick 2002, 2007 bzw. 2010 (Daten zur Schüler-Lehrkräfte-Relation und Unterrichtszeit). Die Daten für 2012 zur Unterrichtszeit beziehen sich auf die Daten für 2011 aus Bildung auf einen Blick 2013 (für die Vereinigten Staaten beziehen sich die Daten auf 2012 und wurden für frühere Jahre überarbeitet). Einige Daten für 2000 wurden überarbeitet, um die Konsistenz mit den Daten für 2012 zu gewährleisten.

1. Länder, für die alle Daten sowohl für 2008 als auch für 2012 vorliegen. 2. Aktuelle Unterrichtszeit für 2000 und 2005 , Mindestunterrichtszeit für 2012. Quelle: OECD. Hinweise s. Anhang 3 unter www.oecd.org/edu/eag.htm. StatLink: http://dx.doi.org/10.1787/888933118010

Erläuterung der Kennzeichnung fehlender Daten s. Hinweise für den Leser. 
Beitrag verschiedener Faktoren zu den Gehaltskosten der Lehrkräfte pro Schüler im Primarbereich (2000, 2005, 2008 und 2012)

In US-Dollar, kaufkraftbereinigt mittels KKP für den privaten Verbrauch

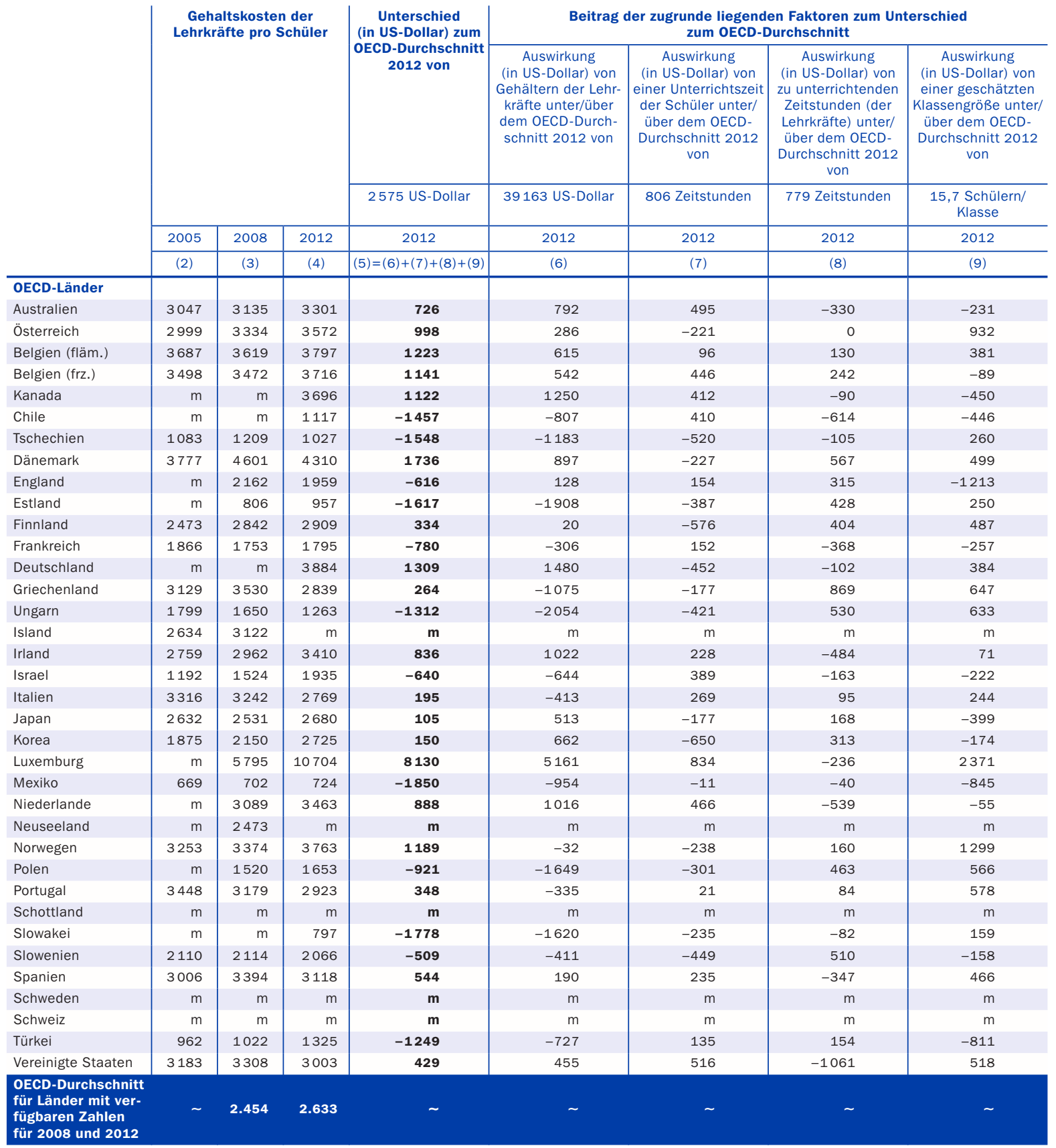

Anmerkung: Die Spalte mit den Angaben für das Referenzjahr 2000, d.h. die Spalte (1), ist im Internet verfügbar (s. StatLink unten). Quelle: OECD. Hinweise s. Anhang 3 unter www.oecd.org/edu/eag.htm. StatLink: http://dx.doi.org/10.1787/888933118029 Erläuterung der Kennzeichnung fehlender Daten s. Hinweise für den Leser. 
Beitrag verschiedener Faktoren zu den Gehaltskosten der Lehrkräfte pro Schüler im Sekundarbereich I (2000, 2005, 2008 und 2012)

In US-Dollar, kaufkraftbereinigt mittels KKP für den privaten Verbrauch

\begin{tabular}{|c|c|c|c|c|c|c|c|c|}
\hline & \multirow{3}{*}{\multicolumn{3}{|c|}{$\begin{array}{l}\text { Gehaltskosten der Lehr- } \\
\text { kräfte pro Schüler }\end{array}$}} & \multirow{2}{*}{$\mid \begin{array}{c}\text { Unterschied } \\
\text { (in US-Dollar) zum } \\
\text { OECD-Durchschnitt } \\
2012 \text { von }\end{array}$} & \multicolumn{4}{|c|}{$\begin{array}{c}\text { Beitrag der zugrunde liegenden Faktoren zum Unterschied } \\
\text { zum OECD-Durchschnitt }\end{array}$} \\
\hline & & & & & $\begin{array}{c}\text { Auswirkung } \\
\text { (in US-Dollar) von } \\
\text { Gehältern der Lehr- } \\
\text { kräfte unter/über } \\
\text { dem OECD-Durch- } \\
\text { schnitt } 2012 \text { von }\end{array}$ & \begin{tabular}{|c|} 
Auswirkung \\
(in US-Dollar) von \\
einer Unterrichtszeit \\
der Schüler unter/ \\
über dem OECD- \\
Durchschnitt 2012 \\
von
\end{tabular} & $\begin{array}{c}\text { Auswirkung } \\
\text { (in US-Dollar) von } \\
\text { zu unterrichtenden } \\
\text { Zeitstunden (der } \\
\text { Lehrkräfte) unter/ } \\
\text { über dem OECD- } \\
\text { Durchschnitt } 2012 \\
\text { von }\end{array}$ & $\begin{array}{c}\text { Auswirkung } \\
\text { (in US-Dollar) von } \\
\text { einer geschätzten } \\
\text { Klassengröße unter/ } \\
\text { über dem OECD- } \\
\text { Durchschnitt 2012 } \\
\text { von }\end{array}$ \\
\hline & & & & 3129 US-Dollar & 41382 US-Dollar & 920 Zeitstunden & 691 Zeitstunden & $\begin{array}{l}\text { 17,6 Schülern/ } \\
\text { Klasse }\end{array}$ \\
\hline & 2005 & 2008 & 2012 & 2012 & 2012 & 2012 & 2012 & 2012 \\
\hline & (2) & (3) & (4) & $(5)=(6)+(7)+(8)+(9)$ & (6) & (7) & (8) & (9) \\
\hline OECD-Länder & & & & & & & & \\
\hline Australien & 4080 & 4201 & 4355 & 1226 & 855 & 343 & -589 & 616 \\
\hline Österreich & 4330 & 4676 & 5185 & 2056 & 487 & 108 & 533 & 928 \\
\hline Belgien (fläm.) & 4988 & 5615 & 5833 & 2704 & 615 & 161 & 255 & 1672 \\
\hline Belgien (frz.) & 4785 & 5388 & 5708 & 2579 & 514 & 444 & 195 & 1427 \\
\hline Kanada & $\mathrm{m}$ & $\mathrm{m}$ & 3696 & 567 & 1186 & 11 & -265 & -365 \\
\hline Chile & $\mathrm{m}$ & $\mathrm{m}$ & 1102 & -2028 & -1002 & 335 & -913 & -447 \\
\hline Tschechien & 1409 & 1887 & 1766 & -1363 & -1817 & -203 & 273 & 385 \\
\hline Dänemark & 3777 & 4601 & 4310 & 1181 & 778 & 39 & 178 & 187 \\
\hline England & $\mathrm{m}$ & 2919 & 2907 & -222 & 1 & -27 & -1 & -194 \\
\hline Estland & $\mathrm{m}$ & 824 & 1270 & -1859 & -2573 & -412 & 260 & 866 \\
\hline Finnland & 4289 & 4153 & 4775 & 1646 & 114 & -30 & 625 & 937 \\
\hline Frankreich & 2752 & 2577 & 2398 & -731 & -307 & 451 & 181 & -1056 \\
\hline Deutschland & $\mathrm{m}$ & $\mathrm{m}$ & 4840 & 1711 & 1940 & -136 & -355 & 262 \\
\hline Griechenland & 4396 & 4639 & $\mathrm{~m}$ & m & $\mathrm{m}$ & $\mathrm{m}$ & $\mathrm{m}$ & $\mathrm{m}$ \\
\hline Ungarn & 1839 & 1609 & 1279 & -1850 & -2371 & -157 & 313 & 366 \\
\hline Island & 2634 & 3122 & $\mathrm{~m}$ & m & $\mathrm{m}$ & $\mathrm{m}$ & $\mathrm{m}$ & $\mathrm{m}$ \\
\hline Irland & 3190 & 4117 & 3676 & 547 & 979 & 55 & -208 & -279 \\
\hline Israel & 1717 & 2061 & 1974 & -1155 & -1082 & 163 & 242 & -478 \\
\hline Italien & 3776 & 3854 & 3102 & -27 & -386 & 228 & 363 & -232 \\
\hline Japan & 3381 & 3238 & 3377 & 248 & 454 & -199 & 450 & -458 \\
\hline Korea & 2519 & 2556 & 2757 & -372 & 572 & -239 & 592 & -1297 \\
\hline Luxemburg & 10654 & 11235 & 12019 & 8890 & 6136 & -162 & -486 & 3401 \\
\hline Mexiko & 714 & 739 & 822 & -2308 & -807 & 452 & -737 & -1214 \\
\hline Niederlande & $\mathrm{m}$ & 3698 & 4354 & 1225 & 1864 & 315 & -310 & -644 \\
\hline Neuseeland & $\mathrm{m}$ & 2619 & $\mathrm{~m}$ & m & $\mathrm{m}$ & $\mathrm{m}$ & $\mathrm{m}$ & $\mathrm{m}$ \\
\hline Norwegen & 3468 & 3621 & 3719 & 590 & -224 & -252 & 144 & 922 \\
\hline Polen & $\mathrm{m}$ & 1412 & 2101 & -1028 & -1836 & -380 & 572 & 616 \\
\hline Portugal & 4559 & 4468 & 3605 & 475 & -603 & -514 & 394 & 1199 \\
\hline Schottland & $\mathrm{m}$ & $\mathrm{m}$ & $\mathrm{m}$ & m & $\mathrm{m}$ & $\mathrm{m}$ & $\mathrm{m}$ & $\mathrm{m}$ \\
\hline Slowakei & $\mathrm{m}$ & $\mathrm{m}$ & 1044 & -2085 & -2157 & -210 & 181 & 101 \\
\hline Slowenien & 2853 & 3751 & 4133 & 1004 & -866 & -444 & 363 & 1952 \\
\hline Spanien & 3857 & 4735 & 4321 & 1192 & 374 & 487 & -113 & 445 \\
\hline Schweden & $\mathrm{m}$ & $m$ & $\mathrm{~m}$ & m & $\mathrm{m}$ & $\mathrm{m}$ & $\mathrm{m}$ & $\mathrm{m}$ \\
\hline Schweiz & $\mathrm{m}$ & $\mathrm{m}$ & $m$ & m & $\mathrm{m}$ & $\mathrm{m}$ & $\mathrm{m}$ & $\mathrm{m}$ \\
\hline Türkei & a & a & 1376 & a & a & a & a & a \\
\hline Vereinigte Staaten & 3172 & 3193 & 3068 & -61 & 407 & 298 & -1429 & 663 \\
\hline $\begin{array}{l}\text { OECD-Durchschnitt } \\
\text { für Länder mit ver- } \\
\text { fügbaren Zahlen } \\
\text { für } 2008 \text { und } 2012\end{array}$ & & 3217 & 3355 & $\sim$ & $\sim$ & $\sim$ & $\sim$ & $\sim$ \\
\hline
\end{tabular}

Anmerkung: Die Spalte mit den Angaben für das Referenzjahr 2000, d.h. die Spalte (1), ist im Internet verfügbar (s. StatLink unten).

Quelle: OECD. Hinweise s. Anhang 3 unter www.oecd.org/edu/eag.htm. StatLink: http://dx.doi.org/10.1787/888933118048

Erläuterung der Kennzeichnung fehlender Daten s. Hinweise für den Leser. 
Beitrag verschiedener Faktoren zu den Gehaltskosten der Lehrkräfte pro Schüler im Sekundarbereich II (2012) In US-Dollar, kaufkraftbereinigt mittels KKP für den privaten Verbrauch

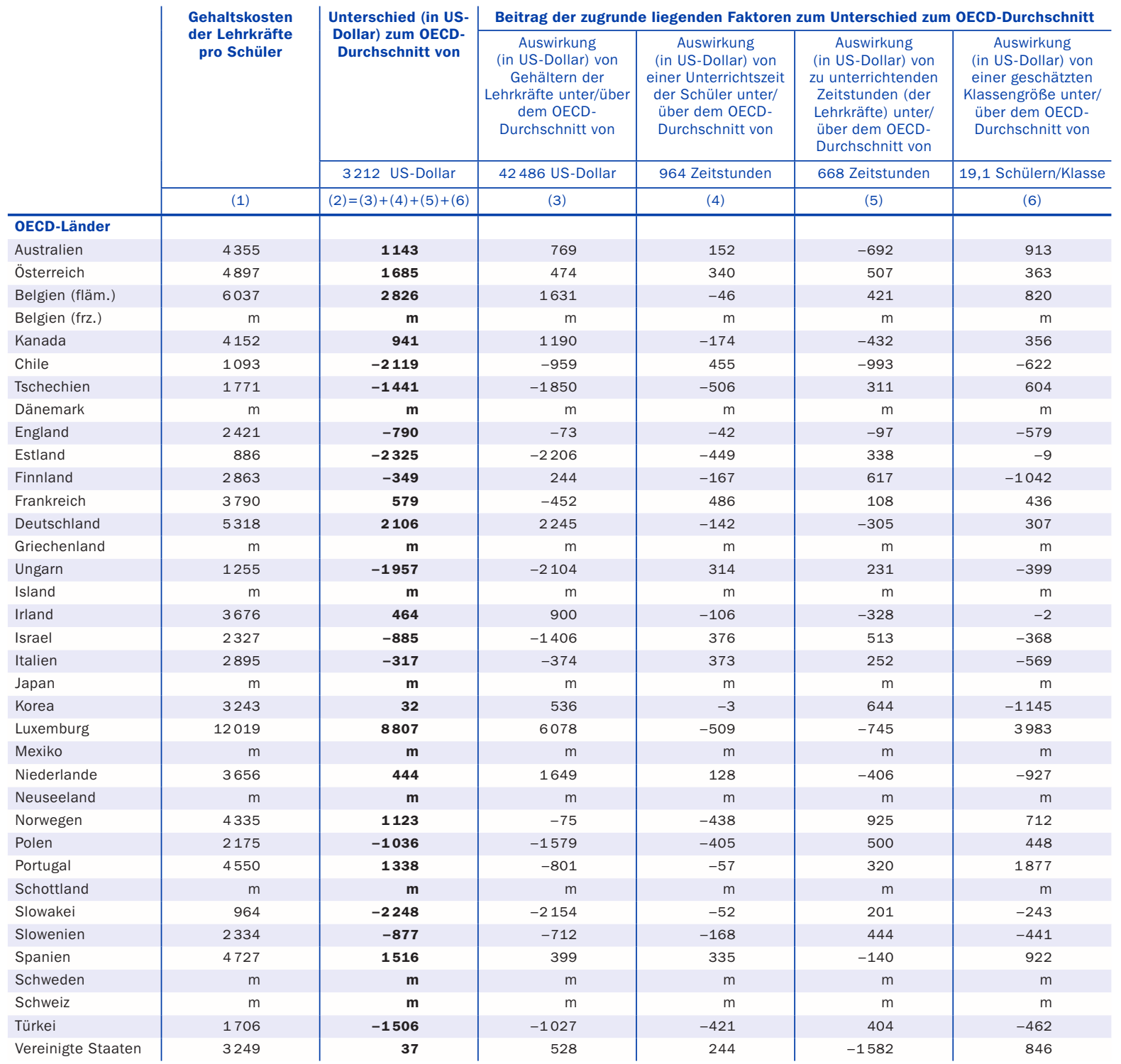

Quelle: OECD. Hinweise s. Anhang 3 unter www.oecd.org/edu/eag.htm. StatLink: http://dx.doi.org/10.1787/888933118067

Erläuterung der Kennzeichnung fehlender Daten s. Hinweise für den Leser. 


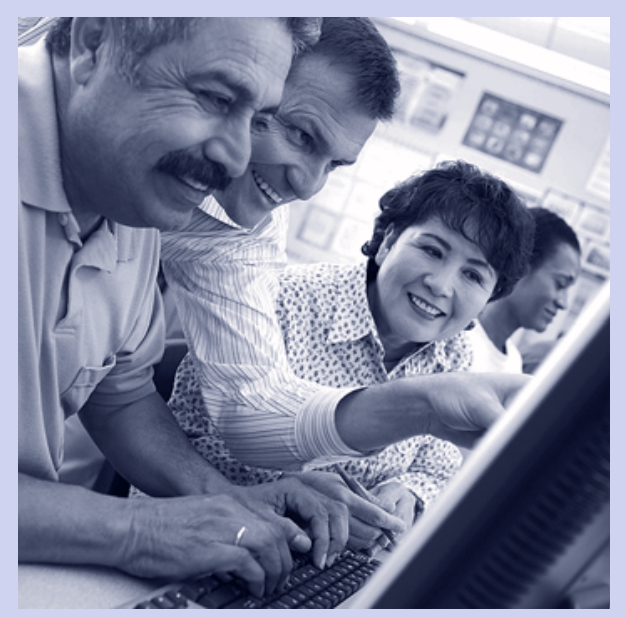

\section{Bildungszugang, Bildungsbeteiligung und Bildungsverlauf}

Indikator $\mathrm{CI}$

Wer nimmt an Bildung teil?

StatLink: http://dx.doi.org/10.1787/888933118181

Indikator $\mathrm{C}_{2}$

Welche Systeme zur frühkindlichen Bildung gibt es weltweit?

StatLink: http:/|dx.doi.org/10.1787/888933118333

Indikator $\mathrm{C}_{3}$

Wie viele junge Erwachsene werden ein Studium im Tertiärbereich aufnehmen?

StatLink: http://dx.doi.org/10.1787/888933118485

Indikator $\mathrm{C}_{4}$

Wer studiert im Ausland und wo?

StatLink: http://dx.doi.org/10.1787/888933118656
Indikator $\mathrm{C}_{5}$

Der Übergang vom (Aus-)Bildungssystem zum Erwerbsleben: Wo sind die I5- bis

29-Jährigen?

StatLink: http://dx.doi.org/10.1787/888933118903

Indikator C6

Wie viele Erwachsene nehmen an formaler und nicht formaler Fort- und Weiterbildung teil?

StatLink: http://dx.doi.org/10.1787/888933119093

Indikator $\mathrm{C}_{7}$

Worin unterscheiden sich öffentliche und private Schulen/Bildungseinrichtungen?

StatLink: http://dx.doi.org/10.1787/888933119321 



\section{Indikatior C1.}

\section{Wer nimmt an Bildung teil?}

Alle OECD- und die meisten Partnerländer mit verfügbaren Daten weisen für das Alter von 5 bis 14 Jahren eine universelle Bildungsbeteiligung aus.

2012 lag die Bildungsbeteiligung der 15- bis I9-Jährigen in 34 der 40 OECD- und Partnerländer mit verfügbaren Daten bei über 75 Prozent.

Bei den 20- bis 29-Jährigen betrug die Bildungsbeteiligung 2012 in allen OECDLändern, mit Ausnahme von Luxemburg, Mexiko und dem Vereinigten Königreich, mehr als 20 Prozent.

Zwischen 1995 und 2012 stieg die Bildungsbeteiligung der 20- bis 29-Jährigen in den OECD-Ländern mit verfügbaren Daten durchschnittlich um Io Prozentpunkte.

\section{Abbildung C1.1}

Bildungsbeteiligung 20- bis 29-Jähriger (1995, 2000, 2005 und 2012)

Voll- und Teilzeitschüler/-studierende an öffentlichen und privaten Bildungseinrichtungen

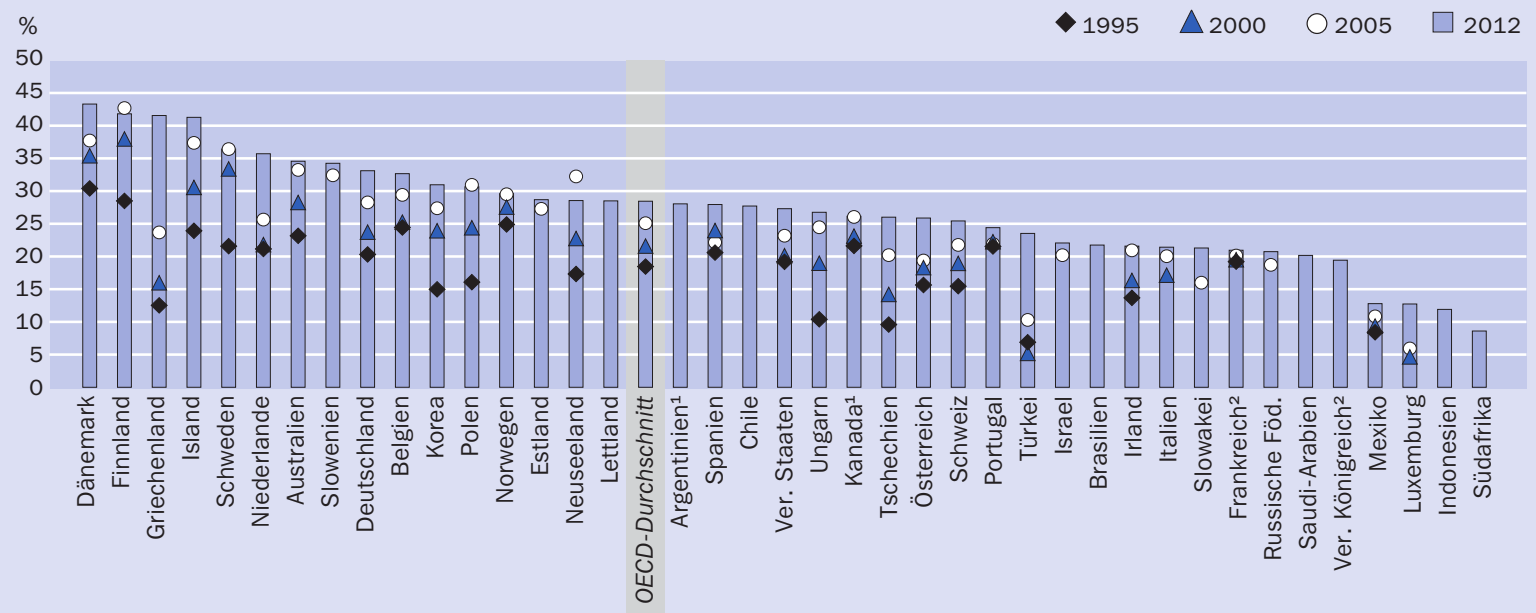

1. Referenzjahr 2011. 2. 1995 ohne Übersee-Departments. 3. Unterbrechung der Zeitreihe nach 2006 aufgrund von Veränderungen in der Methodik. Anordnung der Länder in absteigender Reihenfolge der Bildungsbeteiligung 20- bis 29-Jähriger im Jahr 2012.

Quelle: OECD. Tabelle C1.2. Hinweise s. Anhang 3 unter www.oecd.org/edu/eag.htm. StatLink: http://dx.doi.org/10.1787/888933118295

\section{Kontext}

In wirtschaftlich schwierigen Zeiten wird der Vorteil von Bildung für die Chancen auf dem Arbeitsmarkt noch deutlicher. Die Bildungssysteme in den OECD-Ländern und den meisten G20-Ländern bieten heute einen universellen Zugang zu Grundbildung, sodass inzwischen in den meisten Ländern auch zunehmend im Elementarbereich und im Sekundarbereich II eine universelle Bildungsbeteiligung gegeben ist (s. Indikator C2). Die Ausweitung des Sekundarbereichs II ist sowohl durch die steigende Nachfrage als auch bildungspolitische Veränderungen, wie flexiblere Lehrpläne, eine Umstrukturierung der berufsbildenden Bildungsgänge und Bemühungen, die Bildungsbeteiligung auf die gesamte Bevölkerung auszuweiten, vorangetrieben worden. Obwohl diese Veränderungen auch für den Tertiärbereich gelten, sind die Teilnahmequoten in diesem höheren Bildungsbereich deutlich niedriger. 
Ein Abschluss im Sekundarbereich II ist inzwischen zur Mindestanforderung für einen reibungslosen Übergang in den Arbeitsmarkt geworden und verringert das Risiko der Erwerbslosigkeit (s. Indikator A5). Hohe Erfolgsquoten im Sekundarbereich II sind ein wesentlicher Faktor für eine verbesserte Chancengerechtigkeit (OECD, 20I0a; OECD, 20II), allerdings bestehen bei den Erfolgsquoten große Unterschiede zwischen den einzelnen OECD-Ländern (s. Indikator A2). In ihrem Bemühen, diesen Bildungsbereich weiter auszubauen und dazu beizutragen, einen guten Ertrag für den Einzelnen zu sichern, müssen die Bildungssysteme den Lernenden die Fähigkeiten und Kenntnisse vermitteln, die diese benötigen, um schnell eine Beschäftigung zu finden, sowie allgemeine Kompetenzen und Kenntnisse, die es ihnen ermöglichen, über ihr gesamtes Arbeitsleben ständig weiterzulernen (OECD, 20Iob). Die in den letzten Jahrzehnten zu beobachtenden tief greifenden strukturellen Veränderungen auf dem globalen Arbeitsmarkt lassen darauf schließen, dass besser qualifizierte Menschen auch weiterhin einen Vorteil haben werden, da dieser Arbeitsmarkt immer stärker wissensbasiert ist.

\section{Weitere wichtige Ergebnisse}

Nach den Beteiligungsdaten von 2012 kann ein 5-jähriges Kind in einem OECD-Land davon ausgehen, vor Erreichen des 40. Lebensjahres im Durchschnitt mehr als 17 Jahre in Vollzeit- oder Teilzeitausbildung zu verbringen. Die zu erwartende Bildungsdauer reicht von mehr als I3 Jahren in Indien und Indonesien bis zu mehr als I9 Jahren in Australien, Dänemark, Finnland, Island, und Schweden.

2012 nahmen im Durchschnitt in den OECD-Ländern mindestens 90 Prozent der Bevölkerung im schulpflichtigen Alter 13 Jahre an formaler Bildung teil. 26 der 44 Länder mit verfügbaren Daten lagen am oder oberhalb dieses OECD-Durchschnitts und I8 der Länder darunter.

\section{Entwicklungstendenzen}

Zwischen 1995 und 2012 stiegen die Beteiligungsquoten der 15- bis I9-Jährigen in den OECD-Ländern kontinuierlich um rund to Prozentpunkte an, von durchschnittlich 74 Prozent auf 84 Prozent. Während die Quoten in diesem Zeitraum in der Türkei um fast 30 Prozentpunkte und in Griechenland, Tschechien und Ungarn um mehr als 20 Prozentpunkte anstiegen, blieben sie in Belgien (mit einer Bildungsbeteiligung für diese Altersgruppe von rund 94 Prozent) und Deutschland (mit einer Bildungsbeteiligung von knapp go Prozent) nahezu unverändert. In Frankreich fiel die Beteiligungsquote in dieser Altersgruppe in diesem Zeitraum von 89 auf 84 Prozent (Tab. Cr.2 und Abb. CI.2). 2012 betrugen die Beteiligungsquoten für I5- bis I9-Jährige in China, Israel, Kolumbien, Mexiko und der Türkei immer noch weniger als 70 Prozent. 


\section{Analyse und Interpretationen}

In I9 der 44 OECD- und Partnerländer mit verfügbaren Daten für 2012 beginnt die vollständige Bildungsbeteiligung, hier definiert als Beteiligung von über 90 Prozent der Bevölkerung einer für bestimmte Bildungsgänge typischen Altersgruppe, im Alter zwischen 3 und 4 Jahren, in den anderen 25 Ländern im Alter zwischen 5 und 6 Jahren. Ausnahmen sind hier Kolumbien und die Russische Föderation, wo sie mit 7 Jahren beginnt, Saudi-Arabien (mit 9 Jahren), Südafrika (mit Io Jahren) und China (mit I3 Jahren). In der Hälfte der OECD-Länder werden mindestens 75 Prozent der 3- bis 4-Jährigen entweder im Elementar- oder Primarbereich unterrichtet (Tab. Cr.ra und Indikator C2). In Belgien, Dänemark, Frankreich, Island, Norwegen, Spanien und dem Vereinigten Königreich lag 2012 die Bildungsbeteiligung der 3-bis 4-Jährigen bei mindestens 95 Prozent.

\section{Bildungsbeteiligung während der Schulpflicht}

Die Schulpflicht dauert in den einzelnen Ländern unterschiedlich lang. 2012 reichte das typische Alter zu Beginn der Schulpflicht von 4 Jahren in Luxemburg und Mexiko bis zu 7 Jahren in Estland, Finnland, der Russischen Föderation, Schweden und Südafrika. Im Vereinigten Königreich und den Vereinigten Staaten reichte das typische Alter zu Beginn der Schulpflicht von 4 bis 5 Jahren bzw. 4 bis 6 Jahren, in der Schweiz von 5 bis 7 Jahren. Geht man von den für die einzelnen Bildungsbereiche typischen Altersgruppen aus, gilt die Schulpflicht in allen OECD-Ländern für den Primar- und Sekundarbereich I, in den meisten auch für den Sekundarbereich II. Für die Altersgruppe der 5- bis I4-Jährigen liegen die Beteiligungsquoten bei mehr als 90 Prozent, d. h., in allen OECD- und Partnerländern - mit Ausnahme von China, Indien, Indonesien, Saudi-Arabien und Südafrika - gibt es bei der Grundbildung eine universelle Bildungsbeteiligung. 2012 hatten 35 der 44 Länder mit verfügbaren Daten eine Bildungsbeteiligung von rund 95 Prozent und darüber (Tab. Cr.Ia).

\section{Bildungsbeteiligung im Sekundarbereich II}

In den letzten Jahren haben die Länder die Vielfalt der Bildungsgänge im Sekundarbereich II erweitert. Diese Diversifizierung ist eine Folge der wachsenden Nachfrage nach Bildungsangeboten in diesem Bereich und einer Weiterentwicklung der Lehrpläne von der Vermittlung von Allgemeinwissen in allgemeinbildenden Bildungsgängen und praktischen Kompetenzen in berufsbildenden Bildungsgängen zu umfassenderen Bildungsgängen, die beide Aspekte abdecken und flexiblere Übergänge in eine weitere Ausbildung oder den Arbeitsmarkt ermöglichen.

Die Daten für 2012 zeigen, dass die Beteiligung bei den I5- bis I9-Jährigen, d. h. der Altersgruppe, die sich normalerweise im Sekundarbereich II oder im Übergang zum Tertiärbereich befindet, in 29 der 42 OECD- und Partnerländer mit verfügbaren Daten bei mindestens 80 Prozent lag und in Belgien, Deutschland, Irland, Lettland, den Niederlanden, Polen, Slowenien, Tschechien und Ungarn bei rund 9o Prozent und darüber (Tab. Ci.Ia). Im Gegensatz dazu betrug der Anteil dieser Altersgruppe, der sich nicht in Ausbildung befand, in Argentinien, Brasilien, Chile, Indonesien, Luxemburg, Österreich, Südafrika und dem Vereinten Königreich mehr als 20 Prozent. In Israel betrug aufgrund des Wehrdienstes dieser Anteil mehr als 30 Prozent und in Mexiko und 


\section{Zu erwartende Jahre in Ausbildung}

Kinder können bei Eintritt in das Bildungssystem wahrscheinlich für jedes Altersjahr, für das in ihrem Land eine vollständige Bildungsbeteiligung besteht, ein zusätzliches Jahr in Ausbildung erwarten. Die Schätzung der erwarteten Jahre in Ausbildung umfasst jegliche Beteiligung an formaler Bildung, auch eine nicht kontinuierliche Teilnahme oder eine Teilnahme ohne Erwerb der formalen Abschlussqualifikation. Nach den Beteiligungsdaten von 2012 kann ein 5-jähriges Kind in einem OECDLand davon ausgehen, vor Erreichen des 40. Lebensjahres im Durchschnitt mehr als 17 Jahre an Bildung teilzunehmen. Genauer gesagt kann dieses Kind davon ausgehen, fast 17 Jahre in Vollzeitausbildung zu verbringen: 9,4 Jahre im Primar- und Sekundarbereich I, 3,4 Jahre im Sekundarbereich II, o, 2 Jahre im postsekundaren, nicht tertiären Bereich und 2,7 Jahre im Tertiärbereich. Außerdem kann es davon ausgehen, zusätzlich über einen Zeitraum von I, 2 Jahren eine Teilzeitausbildung zu absolvieren, die größtenteils im Tertiärbereich erfolgen wird. Frauen können davon ausgehen, sich im Durchschnitt rund I7 Jahre in Vollzeitausbildung zu befinden, bei Männern sind es r6 Jahre.

In den Ländern mit verfügbaren Daten reicht die voraussichtlich in Ausbildung verbrachte Zeit von 13,4 Jahren in Indien über mehr als I9 Jahre in Australien, Dänemark und Schweden bis zu fast 20 Jahren in Finnland und Island (Tab. Cr.6).

Die Teilnahme an einem Bildungsgang ist nicht auf eine bestimmte Altersspanne beschränkt. Aufgrund der Daten für 2012 lässt sich sagen, dass sich in Australien, Belgien, Finnland, Island, Neuseeland und Schweden ein signifikanter Anteil der Erwachsenenbevölkerung in Ausbildung befindet, insbesondere 40-Jährige und Ältere. Dies lässt sich durch einen höheren Anteil an Teilzeitausbildung und/oder Bildungsgängen im Bereich des lebenslangen Lernens in diesen Ländern erklären. Zum Beispiel können Erwachsene in Schweden durch Systeme, die auf Leistungspunkten basieren, an einzelnen Teilen eines Bildungsprogramms im Rahmen der formalen Bildung teilnehmen, um ihre Kompetenzen in einem spezifischen Bereich zu erweitern.

Bei den zu erwartenden Jahren in Ausbildung handelt es sich nur um eine Schätzung der Jahre, die Menschen wahrscheinlich in Ausbildung verbringen werden. Dieser statistische Wert entspricht nicht den aktuell erzielten Bildungsabschlüssen und kann auch von den Prognosen für die in Zukunft zu erwartenden Bildungsabschlüsse abweichen, da die in einem Bildungsgang verbrachte Zeit innerhalb der Bevölkerung variieren kann.

der Türkei mehr als 40 Prozent. In China und Kolumbien waren es 66 bzw. 57 Prozent (Tab. Cr.ra und Abb. Cr.2)

Die Beteiligungsquoten der I5- bis I9-Jährigen stiegen in den OECD-Ländern zwischen 1995 und 2012 im Durchschnitt um ro Prozentpunkte. Dies ist hauptsächlich auf eine Annäherung der Beteiligungsquoten in den einzelnen OECD-Ländern im Verlauf der 


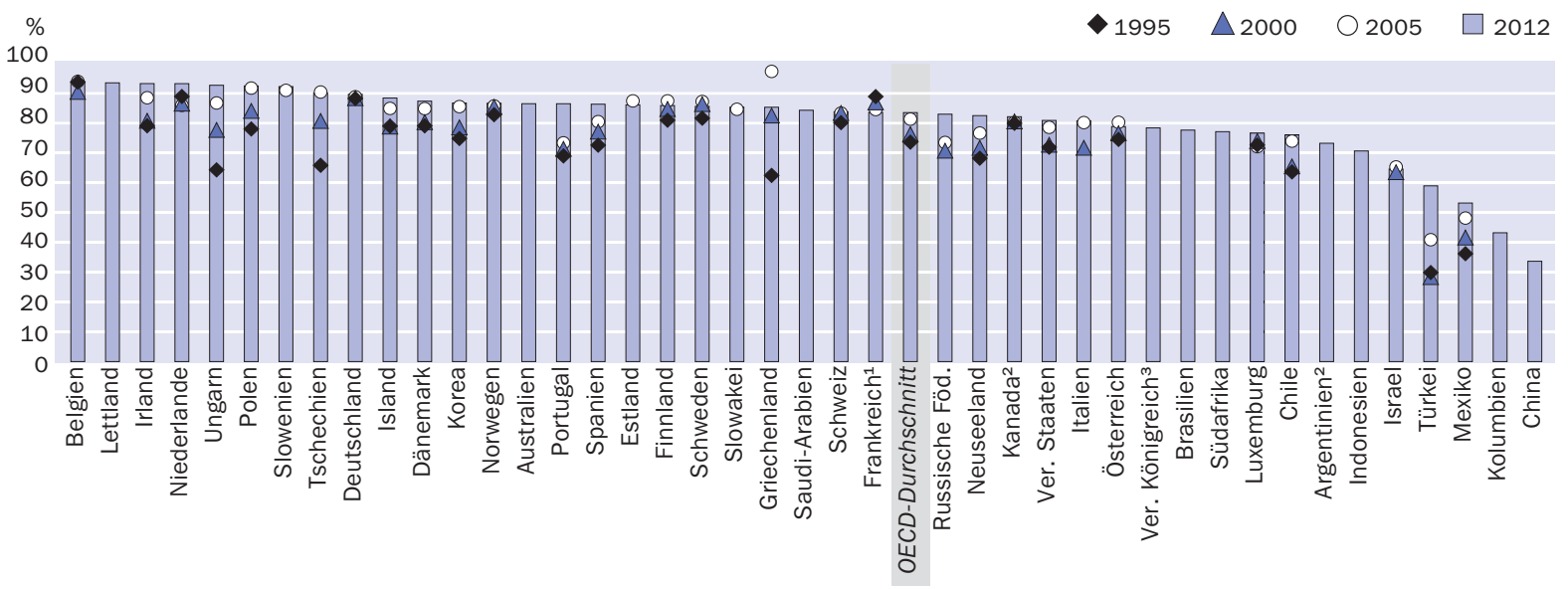

1. 1995 ohne Übersee-Departments. 2. Referenzjahr 2011. 3. Unterbrechung der Zeitreihe nach 2006 aufgrund von Veränderungen in der Methodik. Anordnung der Länder in absteigender Reihenfolge der Bildungsbeteiligung 15- bis 19-Jähriger im Jahr 2012.

Quelle: OECD. Tabelle C1.2. Hinweise s. Anhang 3 unter www.oecd.org/edu/eag.htm. StatLink: http://dx.doi.org/10.1787/888933118314

letzten I7 Jahre zurückzuführen. Während die Beteiligungsquoten in diesem Zeitraum in Griechenland, Tschechien, der Türkei und Ungarn um mehr als 20 Prozentpunkte und in Mexiko und Portugal um mehr als 17 Prozentpunkte anstiegen, blieben sie in Belgien, Deutschland und Kanada (nur Daten bis 2oII verfügbar) nahezu unverändert (Tab. Cr.2 und Abb. Cr.2). Dagegen sank in Frankreich im gleichen Zeitraum die Bildungsbeteiligung um mehr als 5 Prozentpunkte.

2012 betrug die Bildungsbeteiligung der 15- und I6-Jährigen im Sekundarbereich II in 38 der 44 Länder mit verfügbaren Daten mindestens 85 Prozent (mit Ausnahme Indonesiens und der Russischen Föderation, wo 8o Prozent bzw. 69 Prozent der I6-Jährigen an Bildung teilnahmen). In anderen Ländern gab es in diesen Altersgruppen größere Unterschiede in der Beteiligungsquote. So lag beispielsweise in Kolumbien, Südafrika und der Türkei die Beteiligungsquote bei den 15 -Jährigen bei fast 80 Prozent, während es bei den I6-Jährigen 67 Prozent, 83 Prozent bzw. 72 Prozent waren. In China und Mexiko waren es 57 Prozent bzw. 66 Prozent der 15-Jährigen und 44 Prozent bzw. 62 Prozent der I6-Jährigen (Tab. Cr.rb im Internet).

Diese unterschiedlichen Beteiligungsquoten im Sekundarbereich II spiegeln unterschiedliche Abschlussanforderungen oder Altersbegrenzungen wider. In einigen Ländern, wie Belgien, Deutschland und Portugal, können ältere Schüler den Abschluss im Sekundarbereich II in Teilzeitunterricht erwerben. In den Niederlanden können Schüler über 20 an berufsbildenden Bildungsgängen des Sekundarbereichs II teilnehmen. Diese Ansätze, zusammen mit anderen Faktoren, wie längeren (Aus-)Bildungsgängen, Klassenwiederholungen, einem späten Eintritt in den Arbeitsmarkt oder einer Berufstätigkeit parallel zur Ausbildung, haben zu einer größeren Zahl von älteren Teilnehmern im Sekundarbereich II geführt (s. Indikator A2). Daher besucht in einigen OECD-Ländern rund jeder Vierte bis zu jedem Dritten der 20-Jährigen noch den Sekundarbereich II. Hierzu gehören Dänemark (33 Prozent), Deutschland (24 Pro- 
zent), Island (37 Prozent), Luxemburg (27 Prozent), die Niederlande (3o Prozent) und die Schweiz (23 Prozent) (Tab. Cr.rb im Internet).

\section{Berufliche Bildung}

In vielen Ländern zeigt sich in der letzten Zeit wieder ein verstärktes Interesse an beruflichen Bildungsgängen, da diese als wirksames Instrument zur Entwicklung von Kompetenzen bei denjenigen eingeschätzt werden, die sonst nicht die notwendigen Qualifikationen für einen reibungslosen und erfolgreichen Übergang in den Arbeitsmarkt vorweisen könnten (OECD, 20I0a). Ländern mit einem gut entwickelten und etablierten System der beruflichen Bildung einschließlich dualer Ausbildungsgänge ist es besser gelungen, die Jugenderwerbslosigkeit in Grenzen zu halten (s. Indikator $\mathrm{C}_{5}$ ). Gleichzeitig wird manchmal eine berufliche Ausbildung als weniger attraktiv als eine stärker akademisch ausgerichtete Ausbildung angesehen, und einige Forschungsergebnisse deuten darauf hin, dass eine berufliche Ausbildung das Risiko einer Erwerbslosigkeit im späteren Verlauf des Erwerbslebens erhöht (Hanushek et al., 20II).

In den meisten Ländern führt der erfolgreiche Abschluss einer dualen Berufsausbildung normalerweise zur Anerkennung eines Abschlusses des Sekundarbereichs II oder des postsekundaren Bereichs. In einigen Ländern können auch höhere Abschlüsse erworben werden wie beispielsweise das Advanced Diploma in Australien. Die Struktur der beruflichen Bildung unterscheidet sich in den einzelnen OECD-Ländern; es gibt verschiedene Kombinationen von berufsbildenden oder berufsvorbereitenden Bildungsgängen und dualen Ausbildungsgängen. In vielen Bildungssystemen können Schüler im Sekundarbereich II berufsbildende Bildungsgänge wählen, in einigen OECD-Ländern erfolgt die berufliche Ausbildung jedoch erst nach Abschluss des Sekundarbereichs II. Während beispielsweise Österreich, Spanien und Ungarn berufsbildende Bildungsgänge als Stufe innerhalb des Sekundarbereichs II anbieten, werden sie in Kanada normalerweise im postsekundaren Bereich angeboten (s. Indikator A2).

In mehr als einem Drittel der Länder mit Daten für das Jahr 2012 nahmen mehr als 50 Prozent der Teilnehmer im Sekundarbereich II - und mindestens 70 Prozent dieser Schüler in Belgien, Finnland, den Niederlanden, Österreich, der Slowakei und Tschechien - an berufsvorbereitenden oder berufsbildenden Bildungsgängen teil. In den übrigen zwei Drittel der Länder nimmt mehr als die Hälfte der Schüler im Sekundarbereich II an allgemeinbildenden und nicht an berufsbildenden Bildungsgängen teil. In Argentinien, Brasilien, Kanada, Korea, Mexiko und Südafrika betrug dieser Anteil mehr als 8o Prozent. Nur in ungefähr 20 Prozent der Länder werden im Sekundarbereich II auch berufsvorbereitende Bildungsgänge angeboten. Unter diesen weisen Irland (mit 3I Prozent), Kolumbien (mit 24 Prozent) und die Russische Föderation (mit 24 Prozent) eine hohe Beteiligung in diesem Bildungsbereich auf (Tab. Cr.3).

In Tschechien nehmen mehr als 50 Prozent der I5- bis I9-Jährigen an einer beruflichen Ausbildung im Sekundarbereich II teil, während es in Belgien, Italien, Österreich, der Slowakei und Slowenien mehr als 40 Prozent dieser Altersgruppe sind.

In den meisten Ländern wird die berufliche Bildung im Sekundarbereich II ausschließlich in der Schule vermittelt. In einer Reihe von Ländern werden jedoch auch Bildungsgänge, in denen schulische und betriebliche Ausbildung kombiniert werden, 
angeboten. In der Schweiz entfallen rund 6o Prozent der Beteiligungsquote im Sekundarbereich II auf solche dualen Bildungsgänge, in Dänemark, Deutschland, Österreich, der Slowakei und Tschechien mehr als 30 Prozent (Tab. Cr.3).

\section{Bildungsbeteiligung junger Erwachsener}

2012 nahmen in den OECD-Ländern im Durchschnitt 28 Prozent der 20- bis 29-Jährigen an irgendeinem Bildungsgang teil. Dänemark, Finnland, Griechenland und Island sind die Länder mit der höchsten Beteiligungsquote in dieser Altersgruppe (über 40 Prozent). In Australien, Belgien, Deutschland, Korea, den Niederlanden, Polen, Slowenien und Schweden betrug die Beteiligungsquote mehr als 30 Prozent. Andererseits war in Indonesien, Kolumbien, Luxemburg, Mexiko und Südafrika eine Beteiligungsquote von unter ${ }_{5}$ Prozent bei dieser Altersgruppe zu beobachten (Tab. Cr.Ia und Abb. Cr.I).

Von 1995 bis 2012 ist die Beteiligungsquote in dieser Altersgruppe in den OECD-Ländern im Durchschnitt um ro Prozentpunkte gestiegen. In Griechenland, Island, Korea, Tschechien, der Türkei und Ungarn ist diese Quote in diesem Zeitraum um mehr als I5 Prozentpunkte gestiegen, während es in Frankreich, Kanada (nur Daten bis 20 II verfügbar), Mexiko, Norwegen und Portugal nur ein Anstieg von höchstens 5 Prozentpunkten war (Tab. CI.2 und Abb. CI.I).

In den meisten untersuchten Ländern sind die 20-Jährigen in der Regel im Tertiärbereich eingeschrieben. 2012 waren in den OECD-Ländern im Durchschnitt 38 Prozent der 20-Jährigen im Tertiärbereich eingeschrieben. In Korea betrug die Beteiligungsquote bei den 20-Jährigen in diesem Bildungsbereich 70 Prozent, während sie in Belgien, Griechenland, Irland, der Russischen Föderation, Slowenien und den Vereinigten Staaten bei mindestens 50 Prozent lag. Im Gegensatz dazu waren in Brasilien, Israel, Luxemburg, Südafrika und der Schweiz höchstens 20 Prozent der 20-Jährigen im Tertiärbereich eingeschrieben (Tab. Cr.rb im Internet).

Die Wiederaufnahme oder Fortsetzung der Ausbildung ist eine Möglichkeit für Erwachsene, die ihre Kompetenzen vertiefen und erweitern wollen, um den sich verändernden Anforderungen des Arbeitsmarktes besser gewachsen zu sein. In der aktuellen Situation hoher Erwerbslosigkeit und sich verändernder Kompetenzanforderungen auf den Arbeitsmärkten haben einige Länder, wie beispielsweise Chile, spezielle bildungspolitische Rahmenbedingungen geschaffen, um Erwachsene zur Aufnahme eines Studiums im Tertiärbereich B zu ermutigen.

\section{Geschlechtsspezifische Unterschiede}

Neuere Untersuchungen haben angesichts der Tatsache, dass die Hälfte des Wirtschaftswachstums der letzten 50 Jahre in den OECD-Ländern auf einen höheren Bildungsstand zurückzuführen ist, der wiederum hauptsächlich durch die verstärkte Beteiligung von Mädchen und Frauen in allen Bildungsbereichen erreicht wurde, die Bedeutung eines mehr auf die Gleichstellung von Mann und Frau ausgerichteten Ansatzes herausgestellt (OECD, 2013b).

2012 lag die durchschnittliche Bildungsbeteiligung bei den I5- bis I9-jährigen Jungen in den OECD-Ländern bei 82 Prozent, bei den Mädchen dieser Altersgruppe bei 85 Prozent. In den meisten OECD- und Partnerländern waren die Beteiligungsquoten in dieser 
Altersgruppe bei den Mädchen höher als bei den Jungen. Die größten geschlechtsspezifischen Unterschiede in dieser Altersgruppe gab es in Argentinien, wo 8o Prozent der Mädchen, aber nur 67 Prozent der Jungen an Bildung teilnahmen. Die Beteiligungsquoten in Irland, Israel und Neuseeland weisen einen geschlechtsspezifischen Unterschied von mehr als 5 Prozentpunkten zugunsten der Mädchen auf. In Saudi-Arabien, der Schweiz und der Türkei besteht ein geschlechtsspezifischer Unterschied bei den Beteiligungsquoten (von jeweils mehr als 2 Prozentpunkten) zugunsten der Jungen. In Dänemark, Finnland, Kolumbien, Mexiko, Schweden und Ungarn besteht, wenn überhaupt, nur ein kleiner geschlechtsspezifischer Unterschied bei dieser Altersgruppe.

Bei den 20- bis 29-Jährigen ist der geschlechtsspezifische Unterschied bei den Beteiligungsquoten ähnlich groß. Im Durchschnitt befinden sich in den OECD-Ländern 30 Prozent der Frauen und 27 Prozent der Männer dieser Altersgruppe in Ausbildung. Wie bei den I5- bis I9-Jährigen ist in den meisten OECD- und Partnerländern die Beteiligungsquote bei den Frauen höher als bei den Männern, allerdings ist dies in weniger Ländern der Fall als bei der jüngeren Altersgruppe. Auch innerhalb der Länder gibt es größere Unterschiede. In Argentinien nehmen beispielsweise 34 Prozent der Frauen, aber nur 22 Prozent der Männer an Bildungsmaßnahmen teil. In Argentinien, Schweden und Slowenien ist die Beteiligungsquote bei den Frauen mindestens um II Prozentpunkte höher als bei den Männern. Die um I5 Prozentpunkte höhere Beteiligungsquote von Männern im Vergleich zu der von Frauen im Jahr 2012 in Korea hängt damit zusammen, dass Männer aufgrund der Wehrpflicht ihren Abschluss erst später erwerben können.

In den meisten Ländern ist auch in der Altersgruppe der 30- bis 39-Jährigen die Beteiligungsquote bei Frauen höher als bei Männern. In dieser Altersgruppe haben Australien, Finnland, Island, Neuseeland und Schweden die höchste Beteiligungsquote bei den Frauen, wobei der geschlechtsspezifische Unterschied in Island und Schweden (mit mindestens 6 Prozentpunkten) am größten ist (Tab. Cr.ra).

\section{Teilzeitstudium}

Unabhängig davon, ob sie einen Studiengang im Tertiärbereich A oder B belegen, nehmen Studierende eher ein Vollzeit- als ein Teilzeitstudium auf. Gründe für eine Entscheidung zugunsten eines Teilzeitstudiums können u. a. eine gleichzeitig ausgeübte Berufstätigkeit, familiär bedingte Einschränkungen (insbesondere bei Frauen) sowie die Präferenz für verschiedene Fächer sein. Im Jahr 2012 absolvierten im Durchschnitt der OECD-Länder 74 Prozent der Studierenden im Tertiärbereich B ein Vollzeitstudium und nur 26 Prozent ein Teilzeitstudium. Im Tertiärbereich A und in weiterführenden forschungsorientierten Studiengängen beliefen sich die entsprechenden Zahlen auf 79 Prozent bzw. 2I Prozent (Tab. Cr.4 ).

In einigen Ländern studierten im Tertiärbereich B mehr Studierende Teilzeit als Vollzeit. In Australien, Neuseeland und den Vereinigten Staaten entschieden sich mehr als 50 Prozent der Studierenden in diesem Bildungsbereich für ein Teilzeitstudium, während es in der Schweiz und dem Vereinigten Königreich rund 70 Prozent waren.

In Polen, der Russischen Föderation und Schweden entschieden sich mehr als 50 Prozent der Studierenden im Tertiärbereich A und in weiterführenden forschungsorientierten Studiengängen für ein Teilzeitstudium - dies ist deutlich mehr als im OECD- 
Durchschnitt (2I Prozent). In Argentinien, Finnland, Neuseeland, der Slowakei, Spanien, Ungarn und den Vereinigten Staaten entschieden sich mehr als 30 Prozent der Studierenden in diesen Bildungsbereichen für ein Teilzeitstudium.

\section{Die relative Größe des privaten und öffentlichen Sektors}

(Ausführliche Informationen finden sich auch im neuen Indikator $\mathrm{C}_{7}$ )

In den meisten Ländern findet Bildung vom Primarbereich bis zum Tertiärbereich überwiegend in öffentlichen Bildungseinrichtungen statt. In den OECD-Ländern besuchten 2012 durchschnittlich rund 89 Prozent der Schüler im Primarbereich, 85 Prozent der Schüler im Sekundarbereich I und 8o Prozent der Schüler im Sekundarbereich II öffentliche Schulen. Rund 97 Prozent aller Schüler im Sekundarbereich I und 95 Prozent aller Schüler im Sekundarbereich II gingen entweder in eine öffentliche oder in eine staatlich subventionierte private Schule.

Der Anteil der Schüler, die unabhängige private Bildungseinrichtungen besuchen, nimmt in den höheren Bildungsbereichen zu. Im Primar- und Sekundarbereich I beispielsweise besuchen rund 3 Prozent der Schüler im Durchschnitt der OECD vollständig private Bildungseinrichtungen, während dieser Anteil im Sekundarbereich II etwas mehr als 5 Prozent beträgt. Im Tertiärbereich ist der Anteil der Studierenden, die in unabhängigen privaten Bildungseinrichtungen eingeschrieben sind, deutlich größer. Im Tertiärbereich B sind durchschnittlich rund I9 Prozent der Studierenden, im Tertiärbereich A und in weiterführenden forschungsorientierten Studiengängen I4 Prozent der Studierenden in vollständig privaten Bildungseinrichtungen eingeschrieben. Betrachtet man die vollständig privaten und staatlich subventionierten privaten Bildungseinrichtungen des Tertiärbereichs zusammen, so lässt sich feststellen, dass rund 42 Prozent der Studierenden im Tertiärbereich B und mindestens 30 Prozent im Tertiärbereich A und den weiterführenden forschungsorientierten Studiengängen eingeschrieben sind (Tab. Cr.5 im Internet).

Das Vereinigte Königreich ist das einzige Land, das angibt, dass roo Prozent aller Studierenden im Tertiärbereich $\mathrm{B}$ und im Tertiärbereich A sowie den weiterführenden forschungsorientierten Studiengängen an staatlich subventionierten privaten Bildungseinrichtungen eingeschrieben sind (Tab. CI.5 im Internet).

\section{Definitionen}

Die Bildungsgänge des Sekundarbereichs können anhand des Ausmaßes, in dem sie auf bestimmte Berufsfelder vorbereiten und zu einer auf dem Arbeitsmarkt verwertbaren Qualifikation führen, in drei Kategorien unterteilt werden:

Bei kombinierten schulischen und betrieblichen Bildungsgängen werden weniger als 75 Prozent des Lehrplans in der Bildungseinrichtung oder in einem Fernkurs behandelt. Diese Bildungsgänge können in Zusammenarbeit mit den Bildungsbehörden oder Bildungseinrichtungen angeboten werden; $z u$ ihnen zählen auch die dualen Bildungsgänge, die Ausbildung in der Schule und am Arbeitsplatz nebeneinander beinhalten, sowie Bildungsgänge, die aus abwechselnden Phasen von Ausbildung in der Schule und am Arbeitsplatz bestehen (manchmal als „Sandwich-Bildungsgänge“ bezeichnet). 
Allgemeinbildende Bildungsgänge sollen die Teilnehmer weder explizit auf bestimmte Berufsfelder noch auf den Eintritt in einen weiterführenden berufsbildenden oder fachspezifischen Bildungsgang vorbereiten (weniger als 25 Prozent des Inhalts des Bildungsgangs sind berufs- oder fachspezifisch).

Berufsvorbereitende Bildungsgänge sollen den Teilnehmern hauptsächlich als Einführung in die Arbeitswelt dienen und sie für den späteren Eintritt in einen berufsbildenden oder fachspezifischen Bildungsgang vorbereiten. Durch den erfolgreichen Abschluss dieser Bildungsgänge wird keine auf dem Arbeitsmarkt direkt verwertbare berufliche oder fachspezifische Qualifikation erworben (mindestens 25 Prozent des Inhalts des Bildungsgangs sind berufsbildend oder fachspezifisch).

Das Ausmaß der berufsbildenden bzw. allgemeinbildenden Ausrichtung des Bildungsganges ist nicht unbedingt ausschlaggebend dafür, ob die Teilnehmer eine Zugangsberechtigung für den Tertiärbereich erwerben. In mehreren OECD-Ländern haben Bildungsgänge mit berufsbildender Ausrichtung das Ziel, auf ein späteres Studium im Tertiärbereich vorzubereiten, während in anderen Ländern wiederum Bildungsgänge mit allgemeinbildender Ausrichtung nicht automatisch den direkten Zugang zur Hochschulbildung ermöglichen.

In schulischen Ausbildungsgängen erfolgt der Unterricht (entweder teilweise oder ausschließlich) in Bildungseinrichtungen. Dazu zählen u. a. spezielle Berufsausbildungszentren, die von öffentlichen oder privaten Stellen betrieben werden, und betriebliche Ausbildungszentren, sofern diese als Bildungseinrichtungen anerkannt sind. Diese Bildungsgänge können eine Komponente der Ausbildung am Arbeitsplatz umfassen, um in gewissem Umfang praktische Erfahrung am Arbeitsplatz zu gewinnen. Ausbildungen gelten als schulische Ausbildungsgänge, wenn mindestens 75 Prozent des Lehrplans in der Bildungseinrichtung behandelt werden, wobei Fernkurse eingeschlossen sein können.

Berufsvorbereitende und berufsbildende Bildungsgänge werden weiter in zwei Kategorien unterteilt - schulische Ausbildungen sowie kombinierte schulische und betriebliche Ausbildungen. Grundlage der Unterscheidung ist hierbei, inwieweit die Ausbildung einerseits in Bildungseinrichtungen und andererseits am Arbeitsplatz stattfindet.

Berufliche und fachspezifische Bildungsgänge sollen die Teilnehmer auf die direkte Aufnahme einer Beschäftigung in bestimmten Berufsfeldern, ohne weitere berufliche Qualifizierung, vorbereiten. Durch den erfolgreichen Abschluss wird eine auf dem Arbeitsmarkt direkt verwertbare berufliche oder fachspezifische Qualifikation erworben.

Viele Länder klassifizieren die Teilnahme von Schülern/Studierenden als Vollzeit bzw. Teilzeit aufgrund unterschiedlicher Merkmale der Lernbelastung der Schüler/Studierenden, z. B. der erzielten Leistungspunkte, der Zeit im Klassenzimmer/Hörsaal oder der insgesamt aufgewandten Zeit. Nimmt man den zeitlichen Aufwand als Grundlage ergeben sich folgende Definitionen:

Als Vollzeitschüler/Vollzeitstudierende gelten Schüler/Studierende, deren zeitlicher Aufwand für die Ausbildung (sowohl in der Bildungseinrichtung als auch außerhalb) mehr als 
75 Prozent einer Unterrichtswoche ausmacht, wie sie lokal in diesem Bildungsbereich gilt, und wenn davon auszugehen ist, dass sie das ganze Schuljahr/Studienjahr an der Ausbildung teilnehmen werden.

Als Teilzeitschüler/Teilzeitstudierende gelten Schüler/Studierende, deren zeitlicher Aufwand weniger als 75 Prozent einer Unterrichtswoche beträgt bzw. wenn davon auszugehen ist, dass sie nicht das ganze Schuljahr/Studienjahr an der Ausbildung teilnehmen werden.

\section{Angewandte Methodik}

Die Daten zur Bildungsbeteiligung beziehen sich auf das Schuljahr 20II/20I2 und beruhen auf der alljährlich von der OECD durchgeführten UOE-Datenerhebung zur Bildungsstatistik. Die Zahlen basieren auf Personenzahlen (außer wenn etwas anderes angegeben ist), d. h., es wird nicht zwischen Vollzeit- und Teilzeitlernenden unterschieden, da in einigen Ländern entsprechende Teilzeitkonzepte/-modelle nicht anerkannt werden. In einigen OECD-Ländern wird die Teilzeitausbildung nur teilweise in den zur Verfügung gestellten Daten erfasst. Die Berechnung der in den Tabellen Cr.ra und Cr.2 verwendeten Netto-Bildungsbeteiligung (ausgedrückt in Prozent) erfolgte, indem die Zahl der Lernenden einer bestimmten Altersgruppe in allen Bildungsbereichen durch die Gesamtzahl der Personen in der entsprechenden Altersgruppe in der Bevölkerung dividiert wurde. In Tabelle CI.Ib (im Internet) wird die Netto-Bildungsbeteiligung für Schüler/Studierende in einem bestimmten Bildungsbereich berechnet.

In Tabelle Cr.2 basieren die Daten zur Entwicklung der Bildungsbeteiligung für die Jahre I995, 2000, 2001, 2002, 2003 und 2004 auf einer speziellen Erhebung, die im Januar 2007 in den OECD-Ländern und 4 der damals 6 Partnerländer durchgeführt wurde (Brasilien, Chile, Israel und der Russischen Föderation).

Zu erwartende Jahre in Ausbildung werden als Anteil der Bevölkerung berechnet, der in einem spezifischen Alter am Bildungssystem teilnimmt, zusammengefasst für eine Altersgruppe. Hierbei wird im Wesentlichen davon ausgegangen, dass jeder Altersjahrgang mit vollständiger Bildungsbeteiligung einem vollen Jahr der erwarteten Bildungsbeteiligung für eine Person unterhalb dieses Altersjahrgangs entspricht.

Hinweis zu den Daten aus Israel

Die statistischen Daten für Israel wurden von den zuständigen israelischen Stellen bereitgestellt, die für sie verantwortlich zeichnen. Die Verwendung dieser Daten durch die OECD erfolgt unbeschadet des völkerrechtlichen Status der Golanhöhen, von Ost-Jerusalem und der israelischen Siedlungen im Westjordanland.

\section{Weiterführende Informationen}

Hanushek, E., L. Woessmann and L. Zhang (20II), „General education, vocational education, and labor-market outcomes over the life-cycle“, IZA Discussion Paper, No. 6083, Institute for the Study of Labor (IZA), Bonn, October 20 II. 
OECD (2013a), Trends Shaping Education 2013, OECD Publishing, Paris, http://dx.doi.org/ 10.1787/trends_edu-2013-en.

OECD (2013b), Gleichstellung der Geschlechter: Zeit zu handeln, OECD Paris, http://dx.doi. org/10.1787/9789264190344-de.

OECD (2012a), „How has the global economic crisis affected people with different levels of education?" Education Indicators in Focus, No. I, OECD Publishing, Paris, http:/ dx.doi.org/10.1787/5kgfgpwlc6so-en.

OECD (20I2b), „How well are countries educating young people to the level needed for a job and a living wage?" Education Indicators in Focus, No. 7, OECD Publishing, Paris, http://dx.doi.org/10.1787/5kg1d4fsqjow-en.

OECD (20II), Equity and Quality in Education: Supporting Disadvantaged Students and Schools, OECD Publishing, Paris, http:|/dx.doi.org/10.1787/9789264130852-en.

OECD (2010a), PISA 2009 Ergebnisse: Potenziale nutzen und Chancengerechtigkeit sichern-Sozialer Hintergrund und Schülerleistungen (Band II), http://dx.doi.org/10.1787/9789264095359-de.

OECD (20Iob), Learning for Jobs, OECD Reviews of Vocational Education and Training, OECD Publishing, http://dx.doi.org/10.1787/9789264087460-en.

\section{Tabellen Indikator C1}

StatLink: http://dx.doi.org/10.1787/888933118181

Tabelle Cr.Ia: Bildungsbeteiligung, nach Altersgruppe (2012)

WEB Table Cr.Ib: Transition characteristics from age 15 to 20 , by level of education (Übergangscharakteristika bei I5- bis 20-Jährigen, nach Bildungsbereich) (20I2)

Tabelle Cr.2: Entwicklung der Bildungsbeteiligung (I995-2012)

Tabelle Cr.3: Bildungsbeteiligung im Sekundarbereich II und im postsekundaren, nicht tertiären Bereich (20I2)

Tabelle Cr.4: Verteilung der Schüler und Studierenden im Primar-, Sekundar- und Tertiärbereich (in \%), nach Voll- und Teilzeitausbildung sowie Geschlecht (20I2)

WEB Table Cr.5: Students in primary, secondary and tertiary education, by percent share in type of institution (Verteilung der Schüler im Primar-, Sekundarbereich und Tertiärbereich [in \%], nach Art der Bildungseinrichtung) (20I2)

Tabelle Cr.6: Zu erwartende Jahre in Ausbildung für 5- bis 39-Jährige (20I2) 
Bildungsbeteiligung, nach Altersgruppe (2012)

Voll- und Teilzeitschüler/-studierende an öffentlichen und privaten Bildungseinrichtungen

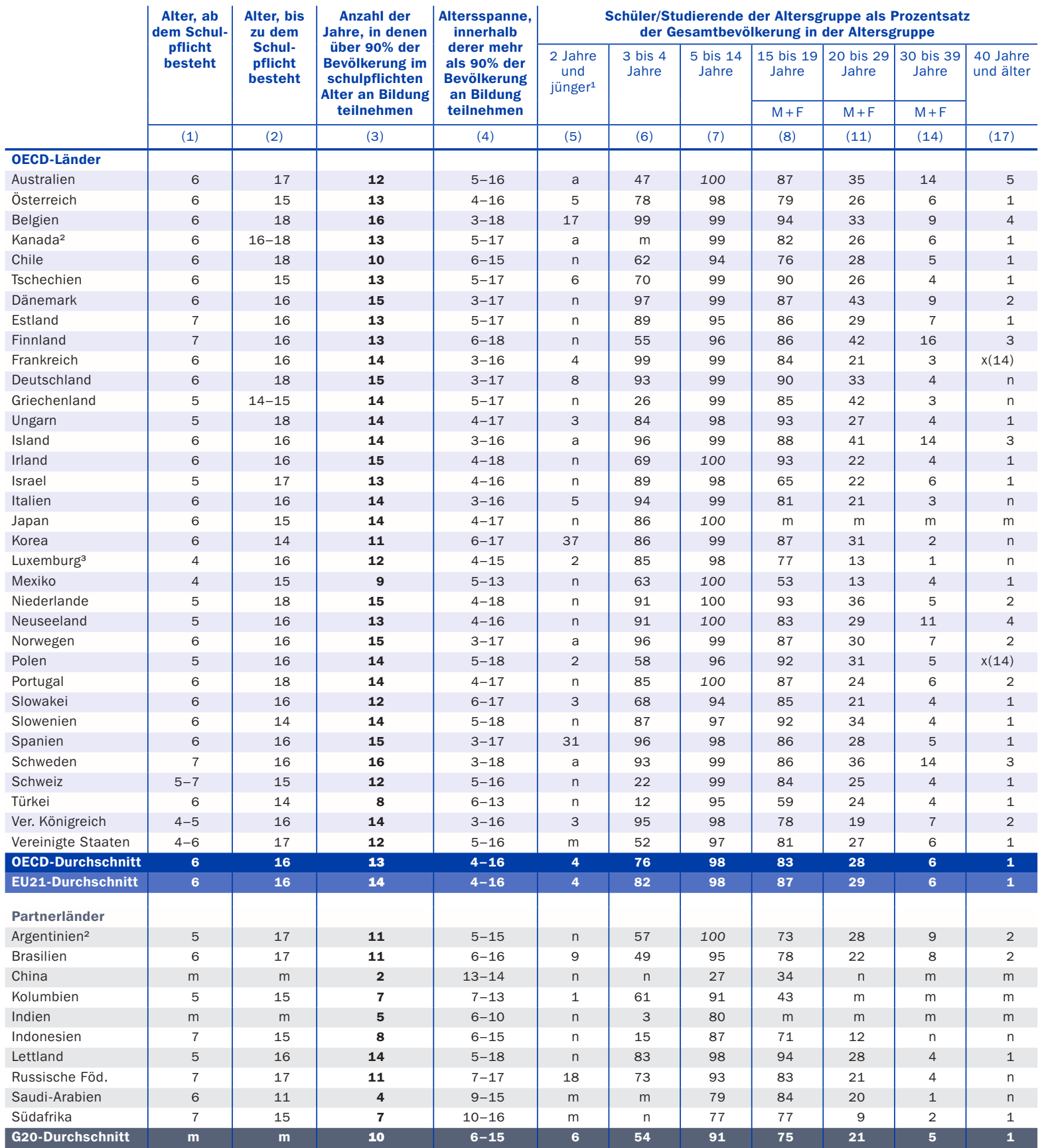

Anmerkung: Alter, bis zu dem Schulpflicht besteht, ist das Alter, in dem die Schulpflicht endet. So bedeutet eine Altersangabe von 18 (Jahren) in dieser Spalte, dass Schüler unter 18 Jahren gesetzlich zum Schulbesuch verpflichtet sind. Unterschiede im Erhebungsbereich der Bevölkerungsdaten und der Beteiligungsdaten bedeuten, dass die Teilnahmedaten von Ländern mit einem Nettoabgang von Studierenden wie z. B. Luxemburg wohl zu niedrig angesetzt und Länder mit einem Nettozugang von Studierenden wohl zu hoch angesetzt sind. Berechnete Beteiligungsquoten von über $100 \%$ sind als „100\%“ in kursiv angegeben. Die Beteiligungsquoten nach Geschlecht für die 15- bis 19-Jährigen, 20- bis 29-Jährigen und 30- bis 39-Jährigen stehen im Internet zur Verfügung (s. StatLink unten). 1. Nur institutionalisierter Elementarbereich. Dies ist aber nicht die einzige Form qualitativ hochwertiger frühkindlicher Bildung für Kinder unter 3 Jahren. Daher sollten Schlussfolgerungen hinsichtlich des Zugangs zu frühkindlicher Bildung und Betreuung und deren Qualität mit Vorsicht gezogen werden. In Ländern mit einem integrierten System aus frühkindlicher Bildung und Kinderbetreuung wird die Bildungsbeteiligung von Kindern im Alter von 2 Jahren und darunter mit „a“ (nicht anwendbar) angegeben. 2. Referenzjahr 2011. 3. Zu niedrig angesetzt, weil viele der dort wohnenden Schüler in den benachbarten Ländern zur Schule gehen. Quelle: OECD. Argentinien, China, Indien, Indonesien, Kolumbien, Saudi-Arabien und Südafrika: Statistikinstitut der UNESCO. Lettland: Eurostat. Hinweise s. Anhang 3 unter www.oecd.org/edu/eag.htm. StatLink: http://dx.doi.org/10.1787/888933118200 Erläuterung der Kennzeichnung fehlender Daten s. Hinweise für den Leser. 
Entwicklung der Bildungsbeteiligung (1995-2012)

Voll- und Teilzeitschüler/-studierende an öffentlichen und privaten Bildungseinrichtungen

\begin{tabular}{|c|c|c|c|c|c|c|c|c|c|c|c|c|}
\hline & \multicolumn{6}{|c|}{ 15- bis 19-jährige Schüler/Studierende } & \multicolumn{6}{|c|}{ 20- bis 29-jährige Schüler/Studierende } \\
\hline & \multicolumn{6}{|c|}{ als Prozentsatz der Gesamtbevölkerung in der Altersgruppe } & \multicolumn{6}{|c|}{ als Prozentsatz der Gesamtbevölkerung in der Altersgruppe } \\
\hline & 1995 & 2000 & 2005 & 2010 & 2011 & 2012 & 1995 & 2000 & 2005 & 2010 & 2011 & 2012 \\
\hline \multicolumn{13}{|l|}{ OECD-Länder } \\
\hline Australien & 81 & 82 & 82 & 81 & 84 & 87 & 23 & 28 & 33 & 32 & 33 & 35 \\
\hline Österreich & 75 & 77 & 80 & 78 & 78 & 79 & 16 & 18 & 19 & 25 & 25 & 26 \\
\hline Belgien & 94 & 91 & 94 & 93 & 94 & 94 & 24 & 25 & 29 & 30 & 32 & 33 \\
\hline Kanada & 80 & 81 & 80 & 81 & 82 & $\mathrm{~m}$ & 22 & 23 & 26 & 25 & 26 & $\mathrm{~m}$ \\
\hline Chile & 64 & 66 & 74 & 75 & 76 & 76 & $\mathrm{~m}$ & $\mathrm{~m}$ & $\mathrm{~m}$ & 25 & 27 & 28 \\
\hline Tschechien & 66 & 81 & 90 & 90 & 90 & 90 & 10 & 14 & 20 & 24 & 25 & 26 \\
\hline Dänemark & 79 & 80 & 85 & 85 & 87 & 87 & 30 & 35 & 38 & 38 & 41 & 43 \\
\hline Estland & $\mathrm{m}$ & $\mathrm{m}$ & 87 & 87 & 87 & 86 & $\mathrm{~m}$ & $\mathrm{~m}$ & 27 & 28 & 29 & 29 \\
\hline Finnland & 81 & 85 & 87 & 87 & 87 & 86 & 28 & 38 & 43 & 42 & 42 & 42 \\
\hline Frankreich & 89 & 87 & 85 & 84 & 84 & 84 & 19 & 19 & 20 & 20 & 20 & 21 \\
\hline Deutschland & 88 & 88 & 89 & 89 & 92 & 90 & 20 & 24 & 28 & 31 & 32 & 33 \\
\hline Griechenland & 62 & 82 & 97 & 83 & 84 & 85 & 13 & 16 & 24 & 40 & 40 & 42 \\
\hline Ungarn & 64 & 78 & 87 & 92 & 92 & 93 & 10 & 19 & 24 & 25 & 26 & 27 \\
\hline Island & 79 & 79 & 85 & 88 & 87 & 88 & 24 & 31 & 37 & 38 & 39 & 41 \\
\hline Irland & 79 & 81 & 89 & 96 & 93 & 93 & 14 & 16 & 21 & 21 & 21 & 22 \\
\hline Israel & $\mathrm{m}$ & 64 & 65 & 65 & 64 & 65 & $\mathrm{~m}$ & $\mathrm{~m}$ & 20 & 22 & 22 & 22 \\
\hline Italien & $\mathrm{m}$ & 72 & 80 & 83 & 81 & 81 & $\mathrm{~m}$ & 17 & 20 & 21 & 21 & 21 \\
\hline Japan & $\mathrm{m}$ & $\mathrm{m}$ & $\mathrm{m}$ & $\mathrm{m}$ & $\mathrm{m}$ & $\mathrm{m}$ & $\mathrm{m}$ & $\mathrm{m}$ & $\mathrm{m}$ & $\mathrm{m}$ & $\mathrm{m}$ & $\mathrm{m}$ \\
\hline Korea & 75 & 79 & 86 & 86 & 86 & 87 & 15 & 24 & 27 & 30 & 30 & 31 \\
\hline Luxemburg & 73 & 74 & 72 & 77 & $\mathrm{~m}$ & 77 & $\mathrm{~m}$ & 5 & 6 & 13 & $\mathrm{~m}$ & 13 \\
\hline Mexiko & 36 & 42 & 48 & 54 & 56 & 53 & 8 & 9 & 11 & 12 & 12 & 13 \\
\hline Niederlande & 89 & 87 & 86 & 91 & 93 & 93 & 21 & 22 & 26 & 30 & 35 & 36 \\
\hline Neuseeland & 68 & 72 & 77 & 81 & 81 & 83 & 17 & 23 & 32 & 30 & 29 & 29 \\
\hline Norwegen & 83 & 86 & 86 & 86 & 86 & 87 & 25 & 28 & 29 & 29 & 30 & 30 \\
\hline Polen & 78 & 84 & 92 & 93 & 93 & 92 & 16 & 24 & 31 & 30 & 30 & 31 \\
\hline Portugal & 69 & 71 & 73 & 86 & 87 & 87 & 22 & 22 & 22 & 24 & 24 & 24 \\
\hline Slowakei & $\mathrm{m}$ & $\mathrm{m}$ & 85 & 85 & 85 & 85 & $\mathrm{~m}$ & $\mathrm{~m}$ & 16 & 21 & 21 & 21 \\
\hline Slowenien & $\mathrm{m}$ & $\mathrm{m}$ & 91 & 92 & 92 & 92 & $\mathrm{~m}$ & $\mathrm{~m}$ & 32 & 34 & 34 & 34 \\
\hline Spanien & 73 & 77 & 81 & 84 & 86 & 86 & 21 & 24 & 22 & 24 & 26 & 28 \\
\hline Schweden & 82 & 86 & 87 & 86 & 86 & 86 & 22 & 33 & 36 & 36 & 37 & 36 \\
\hline Schweiz & 80 & 83 & 83 & 85 & 85 & 84 & 15 & 19 & 22 & 24 & 25 & 25 \\
\hline Türkei & 30 & 28 & 41 & 56 & 64 & 59 & 7 & 5 & 10 & 20 & 21 & 24 \\
\hline Ver. Königreich & $\mathrm{m}$ & $\mathrm{m}$ & $\mathrm{m}$ & 77 & 78 & 78 & $\mathrm{~m}$ & $\mathrm{~m}$ & $\mathrm{~m}$ & 18 & 19 & 19 \\
\hline Vereinigte Staaten & 72 & 73 & 79 & 82 & 80 & 81 & 19 & 20 & 23 & 26 & 27 & 27 \\
\hline OECD-Durchschnitt & 74 & 76 & 81 & 83 & 84 & 84 & 18 & 22 & 25 & 27 & 28 & 28 \\
\hline $\begin{array}{l}\text { OECD-Durchschnitt } \\
\text { für Länder mit ver- } \\
\text { fügbaren Daten für } \\
\text { alle Referenzjahre }\end{array}$ & 73 & 77 & 81 & 83 & 85 & 84 & 18 & 22 & 26 & 28 & 29 & 30 \\
\hline EU21-Durchschnitt & 78 & 81 & 86 & 87 & 87 & 87 & 19 & 22 & 25 & 27 & 29 & 29 \\
\hline \multicolumn{13}{|l|}{ Partnerländer } \\
\hline Argentinien & $\mathrm{m}$ & $\mathrm{m}$ & $\mathrm{m}$ & 73 & 73 & $\mathrm{~m}$ & $m$ & $\mathrm{~m}$ & $\mathrm{~m}$ & 28 & 28 & $\mathrm{~m}$ \\
\hline Brasilien & $\mathrm{m}$ & $\mathrm{m}$ & $\mathrm{m}$ & 76 & 77 & 78 & $\mathrm{~m}$ & $\mathrm{~m}$ & $\mathrm{~m}$ & 20 & 21 & 22 \\
\hline China & $\mathrm{m}$ & $\mathrm{m}$ & $\mathrm{m}$ & 33 & 34 & 34 & $\mathrm{~m}$ & $\mathrm{~m}$ & $\mathrm{~m}$ & $\mathrm{~m}$ & $\mathrm{~m}$ & $\mathrm{~m}$ \\
\hline Kolumbien & $\mathrm{m}$ & $\mathrm{m}$ & $\mathrm{m}$ & $\mathrm{m}$ & $\mathrm{m}$ & 43 & $\mathrm{~m}$ & $\mathrm{~m}$ & $\mathrm{~m}$ & $\mathrm{~m}$ & $\mathrm{~m}$ & $\mathrm{~m}$ \\
\hline Indien & $\mathrm{m}$ & $\mathrm{m}$ & $\mathrm{m}$ & $\mathrm{m}$ & $\mathrm{m}$ & $\mathrm{m}$ & $\mathrm{m}$ & $\mathrm{m}$ & $\mathrm{m}$ & $\mathrm{m}$ & $\mathrm{m}$ & $\mathrm{m}$ \\
\hline Indonesien & $\mathrm{m}$ & $\mathrm{m}$ & $\mathrm{m}$ & 60 & 67 & 71 & $\mathrm{~m}$ & $\mathrm{~m}$ & $\mathrm{~m}$ & $\mathrm{~m}$ & 10 & 12 \\
\hline Lettland & $\mathrm{m}$ & $\mathrm{m}$ & $\mathrm{m}$ & $\mathrm{m}$ & $\mathrm{m}$ & 94 & $\mathrm{~m}$ & $\mathrm{~m}$ & $\mathrm{~m}$ & $\mathrm{~m}$ & $\mathrm{~m}$ & 28 \\
\hline Russische Föderation & $\mathrm{m}$ & 71 & 74 & $\mathrm{~m}$ & 78 & 83 & $\mathrm{~m}$ & $\mathrm{~m}$ & 19 & $\mathrm{~m}$ & 22 & 21 \\
\hline Saudi-Arabien & $\mathrm{m}$ & $\mathrm{m}$ & $\mathrm{m}$ & 87 & $\mathrm{~m}$ & 84 & $\mathrm{~m}$ & $\mathrm{~m}$ & $\mathrm{~m}$ & 19 & $\mathrm{~m}$ & 20 \\
\hline Südafrika & $\mathrm{m}$ & $\mathrm{m}$ & $\mathrm{m}$ & $\mathrm{m}$ & $\mathrm{m}$ & 77 & $\mathrm{~m}$ & $\mathrm{~m}$ & $\mathrm{~m}$ & $\mathrm{~m}$ & $\mathrm{~m}$ & 9 \\
\hline G20-Durchschnitt & m & m & m & 74 & 74 & 75 & m & m & m & $\mathbf{m}$ & m & m \\
\hline
\end{tabular}

Anmerkung: Die Spalten mit den Angaben für 2001, 2002, 2003, 2004, 2006, 2007, 2008 und 2009 sind im Internet verfügbar (s. StatLink unten). Quelle: OECD. Argentinien, China, Indien, Indonesien, Kolumbien, Saudi-Arabien und Südafrika: Statistikinstitut der UNESCO. Lettland: Eurostat. Hinweise s. Anhang 3 unter www.oecd.org/edu/eag.htm. StatLink: http://dx.doi.org/10.1787/888933118219

Erläuterung der Kennzeichnung fehlender Daten s. Hinweise für den Leser. 
Bildungsbeteiligung im Sekundarbereich II und im postsekundaren, nicht tertiären Bereich (2012)

Bildungsbeteiligung an öffentlichen und privaten Bildungseinrichtungen, nach Ausrichtung des Bildungsgangs, Altersgruppe sowie Vollzeit-/Teilzeitausbildung

\begin{tabular}{|c|c|c|c|c|c|c|c|c|c|c|c|c|c|c|}
\hline & \multicolumn{7}{|c|}{ Sekundarbereich II } & \multicolumn{7}{|c|}{ Postsekundarer, nicht tertiärer Bereich } \\
\hline & \multicolumn{4}{|c|}{$\begin{array}{l}\text { Anteil der Schüler nach Ausrichtung } \\
\text { des Bildungsgangs }\end{array}$} & \multicolumn{3}{|c|}{ 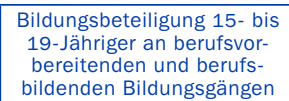 } & \multicolumn{4}{|c|}{$\begin{array}{c}\text { Anteil der Schüler nach Ausrichtung } \\
\text { des Bildungsgangs }\end{array}$} & \multicolumn{3}{|c|}{\begin{tabular}{|l} 
Bildungsbeteiligung 15 - bis \\
24 -Jähriger an berufs- \\
vorbereitenden und berufs- \\
bildenden Bildungsgängen
\end{tabular}} \\
\hline & $\begin{array}{c}\text { Allge- } \\
\text { mein- } \\
\text { bil- } \\
\text { dend }\end{array}$ & \begin{tabular}{|c|} 
Be- \\
rufs- \\
vor- \\
berei- \\
tend
\end{tabular} & $\begin{array}{c}\mathrm{Be}- \\
\text { rufsbil- } \\
\text { dend }\end{array}$ & $\begin{array}{c}\text { Hiervon: } \\
\text { Kombinierte } \\
\text { schulische } \\
\text { und betrieb- } \\
\text { liche Ausbil- } \\
\text { dungen }\end{array}$ & $\begin{array}{c}\text { Vollzeit } \\
+ \\
\text { Teilzeit }\end{array}$ & \begin{tabular}{|l|} 
Teilzeit \\
\end{tabular} & \begin{tabular}{|c|} 
Hiervon: \\
Kombinierte \\
schulische \\
und betrieb- \\
liche Aus- \\
bildungen
\end{tabular} & $\begin{array}{l}\text { Allge- } \\
\text { mein- } \\
\text { bil- } \\
\text { dend }\end{array}$ & \begin{tabular}{|c|} 
Be- \\
rufs- \\
vorbe- \\
reitend
\end{tabular} & $\begin{array}{c}\mathrm{Be}- \\
\text { rufsbil- } \\
\text { dend }\end{array}$ & $\begin{array}{l}\text { Hiervon: } \\
\text { Kombinierte } \\
\text { schulische } \\
\text { und betrieb- } \\
\text { liche Aus- } \\
\text { bildungen }\end{array}$ & $\begin{array}{c}\text { Vollzeit } \\
+ \\
\text { Teilzeit }\end{array}$ & Teilzeit & $\begin{array}{l}\text { Hiervon: } \\
\text { Kombinierte } \\
\text { schulische } \\
\text { und betrieb- } \\
\text { liche Aus- } \\
\text { bildungen }\end{array}$ \\
\hline & (1) & (2) & (3) & (4) & (5) & (6) & (7) & (11) & (12) & (13) & (14) & (15) & (16) & (17) \\
\hline \multicolumn{15}{|l|}{ OECD-Länder } \\
\hline Australien & 50 & a & 50 & $\mathrm{~m}$ & 9 & 7 & $\mathrm{~m}$ & a & a & 100 & $\mathrm{~m}$ & 2 & 2 & $\mathrm{~m}$ \\
\hline Österreich & 25 & 6 & 70 & 34 & 46 & $\mathrm{~m}$ & 21 & a & a & 100 & 19 & 6 & $\mathrm{~m}$ & 1 \\
\hline Belgien & 27 & a & 73 & 3 & 40 & 3 & 2 & 1 & a & 99 & 21 & 3 & 1 & 1 \\
\hline Kanada $^{1}$ & 94 & $x(3)$ & 6 & a & m & $\mathrm{m}$ & $\mathrm{m}$ & $\mathbf{m}$ & $\mathrm{m}$ & $\mathrm{m}$ & $\mathrm{m}$ & m & $\mathrm{m}$ & $\mathrm{m}$ \\
\hline Chile & 68 & a & 32 & $\mathrm{~m}$ & 20 & $x(5)$ & $\mathrm{m}$ & a & a & $a$ & a & $\mathbf{a}$ & $a$ & a \\
\hline Tschechien & 27 & $\mathrm{n}$ & 73 & 32 & 51 & $n$ & 22 & 44 & $\mathrm{n}$ & 56 & 8 & 2 & $\mathrm{n}$ & $\mathrm{n}$ \\
\hline Dänemark & 54 & a & 46 & 44 & 14 & $\mathrm{n}$ & 14 & 100 & a & a & a & a & a & a \\
\hline Estland & 66 & a & 34 & $n$ & 18 & $\mathrm{n}$ & $\mathrm{n}$ & a & a & 100 & 4 & 3 & $n$ & $\mathrm{n}$ \\
\hline Finnland & 30 & a & 70 & 11 & 30 & a & $\mathrm{m}$ & $\mathbf{a}$ & a & 100 & 71 & $n$ & a & $\mathrm{m}$ \\
\hline Frankreich & 56 & a & 44 & 12 & 25 & $\mathrm{n}$ & 7 & 37 & $\mathrm{n}$ & 63 & 2 & $\mathrm{n}$ & $\mathrm{m}$ & $\mathrm{n}$ \\
\hline Deutschland & 52 & a & 48 & 42 & 18 & a & $\mathrm{m}$ & 15 & a & 85 & $\mathrm{~m}$ & 5 & a & $\mathrm{m}$ \\
\hline Griechenland & 67 & a & 33 & a & 16 & 1 & a & a & a & 100 & a & 1 & $\mathrm{n}$ & $\mathrm{m}$ \\
\hline Ungarn & 73 & 8 & 19 & 19 & 20 & $n$ & 14 & $\mathbf{a}$ & a & 100 & a & 5 & 1 & a \\
\hline Island & 66 & 2 & 31 & 14 & 15 & 2 & 6 & $n$ & $\mathrm{n}$ & 100 & 16 & $\mathrm{n}$ & $n$ & $\mathrm{n}$ \\
\hline Irland & 68 & 31 & 1 & a & 15 & $\mathrm{n}$ & a & $\mathbf{a}$ & a & 100 & 14 & 7 & 1 & 1 \\
\hline Israel & 61 & a & 39 & 4 & 22 & $\mathrm{n}$ & 2 & $\mathbf{m}$ & 100 & a & a & $\mathbf{n}$ & $\mathrm{n}$ & a \\
\hline Italien & 41 & a & 59 & a & 42 & $\mathrm{n}$ & a & $\mathbf{a}$ & a & 100 & a & m & $\mathrm{m}$ & a \\
\hline Japan & 77 & 1 & 22 & a & 13 & $\mathrm{n}$ & a & a & a & a & a & m & $\mathrm{m}$ & $a$ \\
\hline Korea & 81 & a & 19 & a & 11 & $n$ & a & $\mathbf{a}$ & a & a & a & $\mathbf{a}$ & a & a \\
\hline Luxemburg & 39 & a & 61 & 14 & 35 & $n$ & 8 & a & a & 100 & 100 & 1 & $n$ & $n$ \\
\hline Mexiko & 91 & a & 9 & a & 3 & $\mathrm{n}$ & a & a & a & a & a & a & a & a \\
\hline Niederlande & 30 & a & 70 & 18 & 29 & $\mathrm{n}$ & 8 & a & a & 100 & 94 & $\mathrm{n}$ & $\mathrm{n}$ & $\mathrm{n}$ \\
\hline Neuseeland & 73 & 6 & 22 & a & 7 & 4 & a & 21 & $\mathrm{n}$ & 78 & a & 3 & 2 & a \\
\hline Norwegen & 48 & a & 52 & 15 & 30 & $\mathrm{n}$ & 9 & 13 & a & 87 & $\mathrm{n}$ & 1 & $\mathrm{n}$ & a \\
\hline Polen & 52 & a & 48 & 7 & 32 & 1 & 5 & $\mathbf{a}$ & a & 100 & $a$ & 4 & 3 & $a$ \\
\hline Portugal & 56 & 3 & 41 & a & 22 & $\mathrm{~m}$ & a & $\mathbf{a}$ & a & 100 & a & 1 & $\mathrm{~m}$ & a \\
\hline Slowakei & 30 & a & 70 & 30 & 48 & $n$ & 21 & $\mathbf{a}$ & a & 100 & a & $\mathrm{n}$ & $n$ & $a$ \\
\hline Slowenien & 34 & a & 66 & $n$ & 47 & 1 & $\mathrm{n}$ & 40 & a & 60 & $\mathrm{n}$ & $\mathrm{n}$ & $\mathrm{n}$ & $\mathrm{n}$ \\
\hline Spanien & 54 & a & 46 & 1 & 13 & 1 & $n$ & a & a & $a$ & a & $\mathbf{a}$ & $a$ & a \\
\hline Schweden & 51 & $\mathrm{n}$ & 49 & $\mathrm{~m}$ & 30 & $\mathrm{n}$ & $\mathrm{m}$ & 15 & $\mathrm{n}$ & 85 & $\mathrm{~m}$ & 1 & $\mathrm{n}$ & $\mathrm{m}$ \\
\hline Schweiz & 35 & a & 65 & 60 & 34 & $n$ & 32 & 53 & a & 47 & 1 & 1 & $n$ & $\mathrm{n}$ \\
\hline Türkei ${ }^{2}$ & 56 & a & 44 & $\mathrm{n}$ & 22 & $\mathrm{~m}$ & $\mathrm{n}$ & a & a & a & a & a & a & a \\
\hline Ver. Königreich & 61 & $n$ & 39 & 17 & 19 & 2 & 9 & a & a & $a$ & $a$ & $\mathbf{a}$ & $a$ & $a$ \\
\hline Vereinigte Staaten & m & $\mathrm{m}$ & $\mathrm{m}$ & $\mathrm{m}$ & $\mathbf{m}$ & $\mathrm{m}$ & $\mathrm{m}$ & a & a & 100 & $\mathrm{~m}$ & m & $\mathrm{m}$ & $\mathrm{m}$ \\
\hline OECD-Durchschnitt & 54 & 2 & 44 & 13 & 25 & 1 & 11 & 34 & 50 & 90 & 32 & 2 & 1 & n \\
\hline EU21-Durchschnitt & 47 & 2 & 50 & 14 & 29 & $\mathrm{n}$ & 7 & 12 & $\mathrm{n}$ & 78 & 18 & 2 & $\mathrm{n}$ & $\mathrm{n}$ \\
\hline \multicolumn{15}{|l|}{ Partnerländer } \\
\hline Argentinien $^{1}$ & 85 & a & 15 & a & 7 & $\mathrm{n}$ & a & a & a & a & a & $\mathbf{a}$ & a & a \\
\hline Brasilien & 86 & a & 14 & a & 4 & $x(5)$ & a & $\mathbf{a}$ & a & a & a & $\mathbf{a}$ & a & a \\
\hline China & 47 & $x(3)$ & 53 & a & m & $\mathrm{m}$ & a & 71 & $x(12)$ & 29 & a & m & a & a \\
\hline Kolumbien & 76 & 24 & $x(2)$ & $\mathrm{m}$ & 6 & $\mathrm{n}$ & $\mathrm{m}$ & a & a & a & a & $\mathbf{a}$ & a & a \\
\hline Indien & m & $\mathrm{m}$ & $\mathrm{m}$ & $\mathrm{m}$ & $\mathbf{m}$ & $\mathrm{m}$ & $\mathrm{m}$ & m & $\mathrm{m}$ & $\mathrm{m}$ & $\mathrm{m}$ & m & $\mathrm{m}$ & $\mathrm{m}$ \\
\hline Indonesien & 57 & a & 43 & a & 18 & a & a & $\mathbf{a}$ & a & a & a & $\mathbf{a}$ & a & a \\
\hline Lettland & 61 & a & 39 & $\mathrm{n}$ & 23 & $\mathrm{n}$ & $n$ & $\mathbf{a}$ & a & 100 & $\mathrm{n}$ & 1 & $\mathrm{n}$ & $\mathrm{n}$ \\
\hline Russische Föd. & 49 & 24 & 27 & $\mathrm{~m}$ & $\mathbf{m}$ & $\mathrm{m}$ & $\mathrm{m}$ & $\mathbf{a}$ & a & 100 & $\mathrm{~m}$ & $\mathbf{m}$ & $\mathrm{m}$ & a \\
\hline Saudi-Arabien & m & $\mathrm{m}$ & $\mathrm{m}$ & $\mathrm{m}$ & $\mathbf{m}$ & $\mathrm{m}$ & $\mathrm{m}$ & $\mathbf{a}$ & a & a & a & m & $\mathrm{m}$ & a \\
\hline Südafrika & 91 & $\mathrm{~m}$ & 9 & $\mathrm{~m}$ & $\mathbf{m}$ & $\mathrm{m}$ & $\mathrm{m}$ & m & $\mathrm{m}$ & 100 & $\mathrm{~m}$ & m & $\mathrm{m}$ & $\mathrm{m}$ \\
\hline G20-Durchschnitt & 67 & $\mathbf{m}$ & 31 & $\mathbf{m}$ & $\mathbf{m}$ & $\mathbf{m}$ & $\mathbf{m}$ & 41 & $\mathbf{m}$ & 85 & $\mathbf{m}$ & $\mathbf{m}$ & $\mathbf{m}$ & $\mathbf{m}$ \\
\hline
\end{tabular}

Anmerkung: Bei einem Vergleich der Beteiligungsquoten in diesem Bildungsbereich ist die unterschiedliche Dauer der Bildungsgänge im Sekundarbereich II in den einzelnen Ländern zu berücksichtigen. Spalten mit den Angaben zur Bildungsbeteiligung von 20- bis 24-Jährigen in berufsbildenden Bildungsgängen des Sekundarbereichs II sowie von 25- bis 29-Jährigen in berufsbildenden Bildungsgängen des postsekundaren, nicht tertiären Bereichs sind im Internet verfügbar (s. StatLink unten). Die Spalten (7) und (17) sowie (10) und (20) im Internet basieren auf der geschätzten Zahl an Schülern in kombinierten schulischen und betrieblichen Berufsausbildungen für die jeweiligen Altersgruppen.

1. Referenzjahr 2011. 2. Ohne ISCED 3C.

Quelle: OECD. Argentinien, China, Indien, Indonesien, Kolumbien, Saudi-Arabien und Südafrika: Statistikinstitut der UNESCO. Lettland: Eurostat. Hinweise s. Anhang 3 unter www.oecd.org/edu/eag.htm. StatLink: http://dx.doi.org/10.1787/888933118238

Erläuterung der Kennzeichnung fehlender Daten s. Hinweise für den Leser. 
Verteilung der Schüler und Studierenden im Primar-, Sekundar- und Tertiärbereich (in \%), nach Voll- und Teilzeitausbildung sowie Geschlecht (2012)

\begin{tabular}{|c|c|c|c|c|c|c|c|c|c|c|}
\hline & \multicolumn{2}{|c|}{$\begin{array}{c}\text { Primar- und } \\
\text { Sekundarbereich }\end{array}$} & \multicolumn{4}{|c|}{ Tertiärbereich B } & \multicolumn{4}{|c|}{$\begin{array}{l}\text { Tertiärbereich A und weiterführende } \\
\text { forschungsorientierte Studiengänge }\end{array}$} \\
\hline & Vollzeit & Teilzeit & \multirow{2}{*}{$\begin{array}{l}\text { Vollzeit } \\
\text { Männer + } \\
\text { Frauen }\end{array}$} & \multicolumn{3}{|c|}{ Teilzeit } & \multirow{3}{*}{$\begin{array}{c}\text { Vollzeit } \\
\text { Männer + } \\
\text { Frauen } \\
(7)\end{array}$} & \multicolumn{3}{|c|}{ Teilzeit } \\
\hline & \multicolumn{2}{|c|}{ Männer + Frauen } & & $M+F$ & Männer & Frauen & & $M+F$ & Männer & Frauen \\
\hline & (1) & (2) & (3) & (4) & (5) & (6) & & (8) & (9) & $(10)$ \\
\hline \multicolumn{11}{|l|}{ OECD-Länder } \\
\hline Australien & 83 & 17 & 44 & 56 & 54 & 57 & 71 & 29 & 28 & 31 \\
\hline Österreich & 100 & $\mathrm{n}$ & m & $\mathrm{m}$ & $\mathrm{m}$ & $\mathrm{m}$ & m & $\mathrm{m}$ & $\mathrm{m}$ & $\mathrm{m}$ \\
\hline Belgien & 80 & 20 & 62 & 38 & 41 & 36 & 81 & 19 & 20 & 17 \\
\hline Kanada $^{1}$ & 100 & a & 88 & 12 & 11 & 13 & 77 & 23 & 21 & 24 \\
\hline Chile & 100 & $\mathrm{~m}$ & m & $\mathrm{m}$ & $\mathrm{m}$ & $\mathrm{m}$ & m & $\mathrm{m}$ & $\mathrm{m}$ & $\mathrm{m}$ \\
\hline Tschechien & 100 & $\mathrm{n}$ & 90 & 10 & 10 & 9 & 98 & 2 & 2 & 3 \\
\hline Dänemark & 97 & 3 & 69 & 31 & 27 & 36 & 90 & 10 & 9 & 11 \\
\hline Estland & 96 & 4 & 89 & 11 & 13 & 9 & 85 & 15 & 18 & 13 \\
\hline Finnland & 100 & a & 100 & a & a & a & 56 & 44 & 49 & 41 \\
\hline Frankreich & 100 & $\mathrm{~m}$ & m & $\mathrm{m}$ & $\mathrm{m}$ & $\mathrm{m}$ & m & $\mathrm{m}$ & $\mathrm{m}$ & $\mathrm{m}$ \\
\hline Deutschland & 100 & $\mathrm{n}$ & 87 & 13 & 23 & 7 & 86 & 14 & 15 & 12 \\
\hline Griechenland & 98 & 2 & 100 & a & a & a & 100 & a & a & a \\
\hline Ungarn & 95 & 5 & 75 & 25 & 22 & 27 & 66 & 34 & 30 & 37 \\
\hline Island & 90 & 10 & 54 & 46 & 61 & 23 & 72 & 28 & 25 & 31 \\
\hline Irland & 100 & $\mathrm{n}$ & 73 & 27 & 23 & 32 & 88 & 12 & 11 & 12 \\
\hline Israel & 100 & a & 100 & a & a & a & 83 & 17 & 16 & 17 \\
\hline Italien & 99 & 1 & 100 & a & a & a & 100 & a & a & a \\
\hline Japan & 99 & 1 & 97 & 3 & 2 & 3 & 91 & 9 & 7 & 11 \\
\hline Korea & 100 & a & m & $\mathrm{m}$ & $\mathrm{m}$ & $\mathrm{m}$ & m & $\mathrm{m}$ & $\mathrm{m}$ & $\mathrm{m}$ \\
\hline Luxemburg & 100 & $\mathrm{n}$ & 75 & 25 & 31 & 20 & 94 & 6 & $\mathrm{~m}$ & $\mathrm{~m}$ \\
\hline Mexiko & 100 & a & 100 & a & a & a & 100 & a & a & a \\
\hline Niederlande & 97 & 3 & 50 & 50 & 49 & 52 & 82 & 18 & 17 & 18 \\
\hline Neuseeland & 91 & 9 & 39 & 61 & 58 & 65 & 61 & 39 & 37 & 40 \\
\hline Norwegen & 99 & 1 & 50 & 50 & 33 & 60 & 72 & 28 & 26 & 29 \\
\hline Polen & 94 & 6 & 69 & 31 & 31 & 32 & 50 & 50 & 47 & 52 \\
\hline Portugal & 100 & $\mathrm{~m}$ & m & $\mathrm{m}$ & $\mathrm{m}$ & $\mathrm{m}$ & m & $\mathrm{m}$ & $\mathrm{m}$ & $\mathrm{m}$ \\
\hline Slowakei & 99 & 1 & 80 & 20 & 16 & 22 & 67 & 33 & 29 & 37 \\
\hline Slowenien & 94 & 6 & 58 & 42 & 43 & 40 & 80 & 20 & 19 & 20 \\
\hline Spanien & 91 & 9 & 93 & 7 & 5 & 9 & 69 & 31 & 33 & 29 \\
\hline Schweden & 83 & 17 & 91 & 9 & 11 & 8 & 49 & 51 & 48 & 53 \\
\hline Schweiz & 100 & $\mathrm{n}$ & 30 & 70 & 77 & 62 & 88 & 12 & 14 & 10 \\
\hline Türkei & 100 & $\mathrm{~m}$ & 100 & $n$ & $n$ & $n$ & 100 & $n$ & $\mathrm{n}$ & $\mathrm{n}$ \\
\hline Vereinigtes Königreich & 96 & 4 & 28 & 72 & 71 & 73 & 77 & 23 & 21 & 24 \\
\hline Vereinigte Staaten & 100 & a & 48 & 52 & 52 & 53 & 66 & 34 & 32 & 36 \\
\hline OECD-Durchschnitt & 97 & 4 & 74 & 26 & 26 & 26 & 79 & 21 & 20 & 22 \\
\hline EU21-Durchschnitt & 96 & 4 & 77 & 23 & 23 & 23 & 79 & 21 & 22 & 22 \\
\hline \multicolumn{11}{|l|}{ Partnerländer } \\
\hline Argentinien ${ }^{1}$ & 100 & $n$ & 94 & 6 & 8 & 5 & 53 & 47 & 48 & 47 \\
\hline Brasilien & 100 & $\mathrm{~m}$ & m & $\mathrm{m}$ & $\mathrm{m}$ & $\mathrm{m}$ & m & $\mathrm{m}$ & $\mathrm{m}$ & $\mathrm{m}$ \\
\hline China & 97 & 3 & 71 & 29 & 30 & 27 & 79 & 21 & 21 & 20 \\
\hline Kolumbien & 100 & a & 100 & a & a & a & 100 & a & a & a \\
\hline Indien & m & $\mathrm{m}$ & m & $\mathrm{m}$ & $\mathrm{m}$ & $\mathrm{m}$ & m & $\mathrm{m}$ & $\mathrm{m}$ & $\mathrm{m}$ \\
\hline Indonesien & 100 & a & 100 & a & a & a & 100 & a & a & a \\
\hline Lettland & 95 & 5 & 52 & 48 & 50 & 46 & 75 & 25 & 23 & 26 \\
\hline Russische Föderation & 100 & $\mathrm{n}$ & 67 & 33 & 37 & 30 & 48 & 52 & 49 & 54 \\
\hline Saudi-Arabien & 100 & $\mathrm{n}$ & 100 & $n$ & $n$ & $n$ & 74 & 26 & 33 & 19 \\
\hline Südafrika ${ }^{2}$ & 59 & 41 & 100 & $\mathrm{n}$ & $\mathrm{n}$ & $\mathrm{n}$ & 100 & $\mathrm{n}$ & $\mathrm{n}$ & $\mathrm{n}$ \\
\hline G20-Durchschnitt & 96 & 4 & 82 & 18 & 19 & 18 & 82 & 18 & 18 & 18 \\
\hline
\end{tabular}

1. Referenzjahr 2011. 2. Referenzjahr für den Tertiärbereich 2011.

Quelle: OECD. Argentinien, China, Indien, Indonesien, Kolumbien, Saudi-Arabien und Südafrika: Statistikinstitut der UNESCO. Lettland: Eurostat. Hinweise s. Anhang 3 unter www.oecd.org/edu/eag.htm. StatLink: http://dx.doi.org/10.1787/888933118257

Erläuterung der Kennzeichnung fehlender Daten s. Hinweise für den Leser. 
Zu erwartende Jahre in Ausbildung für 5- bis 39-Jährige (2012)

Zu erwartende Jahre in Ausbildung unter gleichbleibenden Rahmenbedingungen des Bildungssystems im jeweiligen Land (ohne [Aus-] Bildung von Kindern, die jünger als 5 Jahre sind, und Personen, die älter als 40 Jahre sind), nach Geschlecht und Voll-/Teilzeitausbildung

\begin{tabular}{|c|c|c|c|c|c|c|c|c|c|c|c|c|c|c|c|}
\hline & \multicolumn{7}{|c|}{ Vollzeit } & \multicolumn{7}{|c|}{ Teilzeit $^{1}$} & \multirow{4}{*}{ 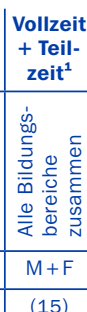 } \\
\hline & \multicolumn{3}{|c|}{ 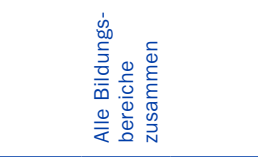 } & 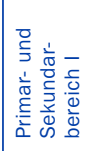 & 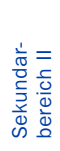 & 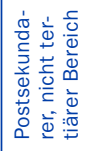 & 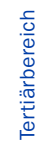 & \multicolumn{3}{|c|}{ 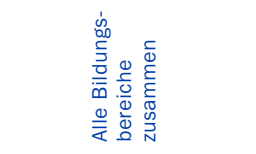 } & 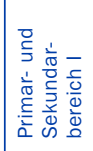 & 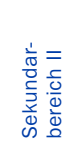 & 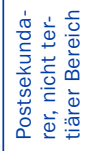 & 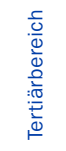 & \\
\hline & $M+F$ & Männer & Frauen & \multicolumn{4}{|c|}{ Männer + Frauen } & $M+F$ & Männer & Frauen & \multicolumn{4}{|c|}{ Männer + Frauen } & \\
\hline & (1) & (2) & (3) & (4) & (5) & (6) & (7) & (8) & (9) & (10) & (11) & (12) & (13) & (14) & \\
\hline \multicolumn{16}{|l|}{$\overline{O O E C D-L a ̈ n d e r}$} \\
\hline Australien & 16 & 16 & 16 & 11,1 & 1,9 & 0,1 & 2,7 & 3,5 & 3,5 & 3,2 & 0,6 & 1,2 & 0,4 & 1,0 & 19,4 \\
\hline Österreich & 17 & 17 & 17 & 8,0 & 3,8 & 0,6 & 3,1 & $\mathrm{n}$ & $n$ & $\mathrm{n}$ & $\mathrm{n}$ & $\mathrm{n}$ & $\mathrm{n}$ & $\mathrm{n}$ & 17,0 \\
\hline Belgien & 16 & 16 & 17 & 8,4 & 4,1 & 0,3 & 2,5 & 2,6 & 2,2 & 2,9 & 0,3 & 1,3 & 0,1 & 0,9 & 18,9 \\
\hline Kanada $^{2}$ & 16 & 15 & 16 & 12,5 & $x(4)$ & $\mathrm{m}$ & 2,4 & 1,7 & 1,6 & 1,8 & $x(4)$ & $x(4)$ & $\mathrm{m}$ & 0,5 & 17,2 \\
\hline Chile $^{3}$ & 17 & 16 & 17 & 8,0 & 3,8 & a & 3,8 & $n$ & $n$ & $n$ & $\mathrm{n}$ & $\mathrm{n}$ & a & $\mathrm{n}$ & 16,5 \\
\hline Tschechien & 18 & 17 & 18 & 9,1 & 3,8 & 0,2 & 2,9 & 0,5 & 0,4 & 0,7 & $\mathrm{n}$ & $\mathrm{n}$ & 0,3 & 0,1 & 18,1 \\
\hline Dänemark & 19 & 19 & 19 & 10,6 & 3,8 & $\mathrm{n}$ & 3,4 & 0,6 & 0,5 & 0,7 & $\mathrm{n}$ & 0,3 & $\mathrm{n}$ & 0,3 & 19,4 \\
\hline Estland & 17 & 16 & 17 & 8,8 & 2,9 & 0,5 & 2,8 & 0,8 & 0,7 & 0,9 & 0,1 & 0,3 & $n$ & 0,4 & 17,5 \\
\hline Finnland & 18 & 18 & 19 & 9,0 & 4,8 & 0,2 & 2,4 & 1,6 & 1,7 & 1,6 & $\mathrm{n}$ & $\mathrm{n}$ & $\mathrm{n}$ & 1,6 & 19,7 \\
\hline Frankreich ${ }^{3}$ & 16 & 16 & 17 & 9,2 & 3,3 & 0,1 & 2,9 & $\mathbf{m}$ & $\mathrm{m}$ & $\mathrm{m}$ & $\mathrm{m}$ & $\mathrm{m}$ & $\mathrm{m}$ & $\mathrm{m}$ & 16,4 \\
\hline Deutschland & 18 & 18 & 18 & 10,1 & 3,1 & 0,6 & 2,6 & 0,4 & 0,5 & 0,4 & $\mathrm{n}$ & $\mathrm{n}$ & $\mathrm{n}$ & 0,4 & 18,2 \\
\hline Griechenland & 18 & 18 & 19 & 9,1 & 3,2 & 0,1 & 5,0 & 0,3 & 0,4 & 0,2 & 0,1 & 0,2 & $\mathrm{n}$ & $\mathrm{n}$ & 18,6 \\
\hline Ungarn & 16 & 16 & 16 & 8,0 & 4,2 & 0,4 & 2,0 & 1,2 & 1,0 & 1,4 & $n$ & 0,4 & 0,1 & 0,7 & 17,6 \\
\hline Island & 18 & 17 & 18 & 9,9 & 4,1 & 0,1 & 2,7 & 2,1 & 1,8 & 2,3 & $\mathrm{n}$ & 1,2 & 0,1 & 0,8 & 19,8 \\
\hline Irland & 17 & 17 & 17 & 10,9 & 2,7 & 1,0 & 3,9 & 0,5 & 0,6 & 0,5 & $\mathrm{n}$ & $\mathrm{n}$ & 0,3 & 0,2 & 17,6 \\
\hline Israel & 15 & 15 & 16 & 8,8 & 2,8 & $\mathrm{n}$ & 2,7 & 0,4 & 0,3 & 0,4 & $\mathrm{n}$ & $\mathrm{n}$ & $\mathrm{n}$ & 0,4 & 15,8 \\
\hline Italien & 17 & 16 & 17 & 8,1 & 4,8 & $\mathrm{n}$ & 2,9 & 0,1 & 0,1 & 0,1 & 0,1 & $\mathrm{n}$ & $\mathrm{n}$ & $\mathrm{n}$ & 16,8 \\
\hline Japan & 16 & 15 & 15 & 9,2 & 2,9 & $\mathrm{n}$ & $\mathrm{m}$ & 0,4 & 0,4 & 0,4 & $\mathrm{n}$ & 0,1 & $\mathrm{n}$ & $\mathrm{m}$ & 16,3 \\
\hline Korea $^{3}$ & 18 & 18 & 17 & 9,0 & 2,9 & a & 4,7 & $x(1)$ & $x(2)$ & $x(3)$ & $x(4)$ & $x(5)$ & $a$ & $x(7)$ & 17,5 \\
\hline Luxemburg ${ }^{4}$ & 15 & 15 & 15 & 9,4 & 3,8 & 0,1 & 0,8 & 0,1 & 0,1 & 0,1 & $\mathrm{n}$ & $\mathrm{n}$ & $\mathrm{n}$ & 0,1 & 15,1 \\
\hline Mexiko ${ }^{3}$ & 14 & 14 & 14 & 10,1 & 2,0 & a & 1,5 & $x(1)$ & $x(2)$ & $x(3)$ & $x(4)$ & $x(5)$ & a & $x(7)$ & 14,4 \\
\hline Niederlande & 18 & 18 & 18 & 10,4 & 3,5 & $\mathrm{n}$ & 3,1 & 0,7 & 0,7 & 0,7 & $\mathrm{n}$ & 0,2 & $\mathrm{n}$ & 0,4 & 18,7 \\
\hline Neuseeland & 15 & 15 & 16 & 10,2 & 2,9 & 0,2 & 2,1 & 2,7 & 2,5 & 2,9 & $\mathrm{n}$ & 0,9 & 0,4 & 1,4 & 18,1 \\
\hline Norwegen & 17 & 17 & 17 & 10,0 & 3,6 & 0,1 & 2,3 & 1,0 & 0,8 & 1,2 & $n$ & 0,1 & 0,1 & 0,8 & 17,9 \\
\hline Polen & 16 & 15 & 16 & 8,9 & 3,0 & 0,1 & 1,9 & 2,8 & 2,3 & 3,4 & $n$ & 0,5 & 0,5 & 1,7 & 18,4 \\
\hline Portugal $^{3}$ & 18 & 18 & 18 & 10,2 & 3,4 & 0,1 & 2,9 & $x(1)$ & $x(2)$ & $x(3)$ & $x(4)$ & $x(5)$ & $x(6)$ & $x(7)$ & 17,6 \\
\hline Slowakei & 15 & 15 & 16 & 8,7 & 3,7 & $\mathrm{n}$ & 1,9 & 0,8 & 0,6 & 1,1 & $\mathrm{n}$ & 0,1 & $\mathrm{n}$ & 0,7 & 16,3 \\
\hline Slowenien & 17 & 16 & 18 & 8,8 & 3,9 & $\mathrm{n}$ & 3,2 & 1,4 & 1,3 & 1,5 & $\mathrm{n}$ & 0,6 & $\mathrm{n}$ & 0,8 & 18,4 \\
\hline Spanien & 16 & 16 & 16 & 10,2 & 2,3 & a & 2,7 & 1,4 & 1,4 & 1,5 & 0,4 & 0,3 & a & 0,7 & 17,6 \\
\hline Schweden & 16 & 16 & 17 & 9,1 & 3,2 & 0,2 & 1,8 & 3,0 & 2,4 & 3,7 & 0,7 & 1,0 & $\mathrm{n}$ & 1,3 & 19,3 \\
\hline Schweiz & 17 & 17 & 17 & 9,5 & 3,5 & 0,1 & 1,9 & 0,6 & 0,7 & 0,5 & $\mathrm{n}$ & $\mathrm{n}$ & $\mathrm{n}$ & 0,5 & 17,3 \\
\hline Türkei ${ }^{3}$ & 16 & 17 & 16 & 8,7 & 3,7 & a & 3,4 & $\mathbf{m}$ & $\mathrm{m}$ & $\mathrm{m}$ & $\mathrm{m}$ & $\mathrm{m}$ & a & $\mathrm{m}$ & 16,4 \\
\hline Ver. Königreich & 15 & 15 & 16 & 9,2 & 4,2 & a & 2,0 & 1,0 & 0,9 & 1,1 & 0,2 & 0,2 & a & 0,6 & 16,4 \\
\hline Vereinigte Staaten & 15 & 15 & 16 & 8,9 & 2,8 & $\mathrm{~m}$ & 2,8 & 1,9 & 1,6 & 2,2 & $\mathrm{n}$ & $\mathrm{n}$ & $\mathrm{m}$ & 1,5 & 17,2 \\
\hline OECD-Durchschnitt & 17 & 16 & 17 & 9,4 & 3,4 & 0,2 & 2,7 & 1,2 & 1,1 & 1,3 & 0,1 & 0,3 & 0,1 & 0,7 & 17,6 \\
\hline EU21-Durchschnitt & 17 & 17 & 17 & 9,3 & 3,6 & 0,2 & 2,7 & 1,0 & 0,9 & 1,2 & 0,1 & 0,3 & 0,1 & 0,6 & 17,8 \\
\hline \multicolumn{16}{|l|}{ Partnerländer } \\
\hline Argentinien ${ }^{2}$ & 16 & 15 & 16 & 11,0 & 2,4 & a & $\mathrm{m}$ & 2,6 & 2,2 & 3,0 & $\mathrm{n}$ & $\mathrm{n}$ & a & $\mathrm{m}$ & 18,2 \\
\hline Brasilien $^{3}$ & 16 & 16 & 17 & 9,8 & 3,1 & a & 2,1 & $\mathbf{n}$ & $\mathrm{n}$ & $n$ & $n$ & $\mathrm{n}$ & a & $\mathrm{n}$ & 16,3 \\
\hline China & 14 & 14 & 14 & 9,4 & 2,4 & $\mathrm{~m}$ & 1,1 & 1,8 & 1,7 & 1,9 & $\mathrm{n}$ & 0,3 & $\mathrm{~m}$ & $\mathrm{~m}$ & 16,0 \\
\hline Kolumbien & 14 & 13 & 14 & 9,3 & 1.4 & $\mathrm{~m}$ & $\mathrm{~m}$ & a & $a$ & $a$ & a & a & $a$ & a & 13,5 \\
\hline Indien & $\mathbf{m}$ & $\mathrm{m}$ & $\mathrm{m}$ & $\mathrm{m}$ & $\mathrm{m}$ & $\mathrm{m}$ & $\mathrm{m}$ & $\mathbf{m}$ & $\mathrm{m}$ & $\mathrm{m}$ & $\mathrm{m}$ & $\mathrm{m}$ & $\mathrm{m}$ & $\mathrm{m}$ & 13,4 \\
\hline Indonesien & 13 & 13 & 14 & 9,1 & 2,2 & a & 1,5 & $\mathbf{n}$ & $\mathrm{n}$ & $\mathrm{n}$ & $\mathrm{n}$ & $\mathrm{n}$ & a & $\mathrm{n}$ & 13,5 \\
\hline Lettland & 17 & 16 & 17 & 9,2 & 3,0 & 0,1 & 2,3 & 1,3 & 1,2 & 1,5 & 0,1 & 0,4 & $n$ & 0,8 & 17,8 \\
\hline Russische Föd. ${ }^{5}$ & 13 & 13 & 13 & 8,5 & 2,1 & $x(5)$ & 2,7 & 3,3 & 3,1 & 3,5 & a & $\mathrm{m}$ & $\mathrm{m}$ & 1,7 & $\mathbf{m}$ \\
\hline Saudi-Arabien & 14 & 14 & 14 & 9,0 & 3,0 & a & 1,9 & 0,6 & 0,7 & 0,4 & $\mathrm{~m}$ & $\mathrm{n}$ & a & 0,6 & m \\
\hline Südafrika & $\mathbf{m}$ & $\mathrm{m}$ & $\mathrm{m}$ & $\mathrm{m}$ & $\mathrm{m}$ & $\mathrm{m}$ & $\mathrm{m}$ & $\mathbf{m}$ & $\mathrm{m}$ & $\mathrm{m}$ & $\mathrm{m}$ & $\mathrm{m}$ & $\mathrm{m}$ & $\mathrm{m}$ & $\mathbf{m}$ \\
\hline G20-Durchschnitt & 15 & 15 & 16 & 9,6 & 2,9 & m & 2,5 & 1,3 & 1,2 & 1,4 & m & 0,2 & m & $\mathbf{m}$ & 16,5 \\
\hline
\end{tabular}

1. Die Angaben zu den zu erwartenden Jahren in Teilzeitausbildung sind mit Vorsicht zu interpretieren, da sie Unterschiede aufgrund unterschiedlicher Beteiligungsintensität in den einzelnen Ländern, Bildungsbereichen und Personen unterschiedlichen Alters widerspiegeln können. 2. Referenzjahr 2011. 3. Vollzeit und Teilzeit. 4. Eine hohe Zahl von Schülern/Studierenden, die ihre Ausbildung im Ausland absolvieren, und Immigration können sich auf die zu erwartenden Jahre in Ausbildung auswirken. 5. Einschreibungen auf ISCED-Stufe 3B sind im Tertiärbereich enthalten.

Quelle: OECD. Argentinien, China, Indien, Indonesien, Kolumbien, Saudi-Arabien und Südafrika: Statistikinstitut der UNESCO. Lettland: Eurostat. Hinweise s. Anhang 3 unter www.oecd.org/edu/eag.htm. StatLink: http://dx.doi.org/10.1787/888933118276 Erläuterung der Kennzeichnung fehlender Daten s. Hinweise für den Leser. 



\section{Indikatior Cen}

\section{Welche Systeme zur frühkindlichen Bildung gibt es weltweit?}

In vielen OECD-Ländern wurden die Angebote im Bereich der frühkindlichen Bildung im Zusammenhang mit der sich ändernden Erwerbsquote von Frauen ausgeweitet. Ein verbesserter Zugang zu diesen Angeboten, ohne gleichzeitig ihre Qualität zu verbessern, ist jedoch keine Garantie für ein gutes Ergebnis für den Einzelnen und für die Gesellschaft.

Frühkindliche Bildung wird mit besseren Leistungen in der späteren schulischen Laufbahn in Verbindung gebracht. Im Alter von I5 Jahren erzielen Schüler, die mindestens ein Jahr an Unterricht im Elementarbereich teilgenommen haben, selbst nach Berücksichtigung des sozioökonomischen Hintergrunds bessere Ergebnisse bei der Internationalen Schulleistungsstudie PISA der OECD als Schüler, die nicht an frühkindlicher Bildung teilnahmen.

- In der Mehrzahl der OECD-Länder beginnt inzwischen Bildung für die meisten Kinder lange vor dem fünften Lebensjahr. In den OECD-Ländern nehmen mehr als drei Viertel aller 4-Jährigen (84 Prozent) an frühkindlicher Bildung und dem Primarbereich teil, in den zur Europäischen Union gehörenden OECD-Ländern sind es 89 Prozent.

In Belgien, Dänemark, Deutschland, Frankreich, Island, Italien, Norwegen, Schweden, Spanien und dem Vereinigten Königreich nehmen mehr als 90 Prozent der 3-Jährigen an frühkindlicher Bildung teil.

Abbildung C2.1

Bildungsbeteiligung 3-Jähriger im Bereich frühkindliche Bildung (2005 und 2012)

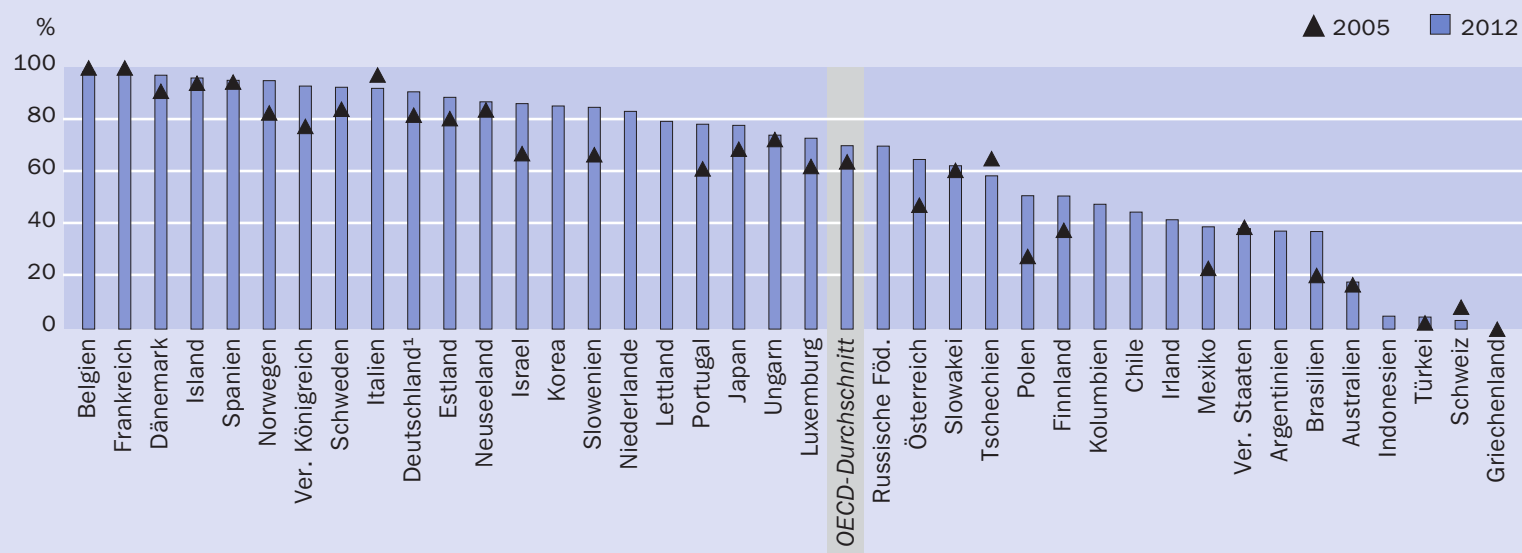

1. Referenzjahr 2006 anstelle 2005.

Anordnung der Länder in absteigender Reihenfolge der Bildungsbeteiligung 3-Jähriger im Jahr 2012.

Quelle: OECD. Tabelle C2.1. Hinweise s. Anhang 3 unter www.oecd.org/edu/eag.htm. StatLink: http://dx.doi.org/10.1787/888933118409 


\section{Kontext}

Im Zuge sich verändernder Familienstrukturen ändert sich auch das relative Alter der Eltern. Mehr Frauen und Männer verlegen die Familiengründung auf einen späteren Zeitpunkt im Leben. Dies geschieht aus verschiedenen Gründen, u. a. aus einem Streben nach finanzieller Sicherheit und emotionaler Reife heraus, aufgrund einer längeren Suche nach einer stabilen Beziehung und des Wunsches nach einer beruflichen Karriere vor der Elternschaft. Da Eltern heute auch eher erwerbstätig sind, besteht ein steigender Bedarf an frühkindlicher Betreuung. Ferner rückt die große Bedeutung der frühkindlichen Bildung für die kognitive und emotionale Entwicklung von Kindern immer stärker ins Bewusstsein. Daher hat in vielen Ländern die Gewährleistung der Qualität im Bereich der frühkindlichen Bildung, Betreuung und Erziehung (FBBE) politische Priorität erlangt.

Die Teilnahme an Angeboten zur frühkindlichen Bildung kann ferner für mehr Chancengleichheit sorgen und die schulischen Lernergebnisse insgesamt verbessern. Viele der in Bildungssystemen auftretenden Ungleichheiten sind bereits beim Eintritt der Schüler in das formale Bildungssystem offensichtlich und ziehen sich im Bildungsverlauf durch das gesamte Schulsystem hindurch (Downey et al., 2004). Da sich die Ungleichheiten tendenziell verstärken, wenn die Unterrichtsteilnahme nicht verpflichtend ist, kann ein früherer Eintritt in das Schulsystem möglicherweise für mehr Chancengleichheit sorgen. Darüber hinaus trägt der Besuch des Elementarbereichs zur Vorbereitung der Schüler auf den Eintritt in die formale Schulbildung und eine erfolgreiche schulische Laufbahn bei (Heckman, 2000).

Das Angebot im Bereich frühkindliche Bildung wird immer mehr ausgebaut; hierbei kommt es darauf an, die Bedürfnisse und Erwartungen der Eltern im Hinblick auf die Verfügbarkeit, die Kosten, die Qualität des Angebots und der Lehrkräfte sowie Rechenschaftspflichten zu berücksichtigen. Werden die Erwartungen der Eltern im Hinblick auf die Qualität des Angebots, Zugangsmöglichkeiten und Rechenschaftspflichten nicht erfüllt, kann es sein, dass einige Eltern für ihre Kinder tendenziell eher private Bildungs- und Betreuungseinrichtungen wählen oder ihre Kinder zu Zusatzangeboten außerhalb des formalen Bildungssystems schicken. Selbst bei staatlicher Förderung kann dies zu einer starken finanziellen Belastung der Eltern führen (Shin et al., 2009).

In den OECD-Ländern gibt es viele verschiedene FBBE-Systeme und -Strukturen. Entsprechend gibt es auch viele verschiedene Ansätze zur Unterscheidung zwischen Angeboten zur frühkindlichen Bildung und Angeboten zur Kinderbetreuung (s. Kasten C2.I und Abschnitt Definitionen). Diese Unterschiede sollten bei der Interpretation internationaler Vergleiche berücksichtigt werden.

\section{Weitere wichtige Ergebnisse}

Die öffentliche Finanzierung des Elementarbereichs ist in den europäischen Ländern der OECD tendenziell weiterentwickelt als in den nicht europäischen Ländern der OECD. Die private Finanzierung variiert erheblich zwischen den einzelnen Ländern und reicht von höchstens 5 Prozent in Belgien, Estland, Lettland, Luxemburg und Schweden bis zu mindestens 25 Prozent in Argentinien, Australien, Japan, Kolumbien, Korea, Österreich, Spanien und den Vereinigten Staaten. 
Als Prozentsatz des BIP ausgedrückt belaufen sich die Ausgaben für den Elementarbereich auf durchschnittlich o,6 Prozent des BIP. Zwischen den einzelnen Ländern gibt es große Unterschiede. Während beispielsweise in Australien o, I Prozent des BIP für den Elementarbereich ausgegeben werden, sind es in Chile, Dänemark, Island, Lettland, Luxemburg, Slowenien, Spanien und der Russischen Föderation mindestens o,8 Prozent.

Die Schüler-Lehrkräfte-Relation ist auch ein wichtiger Indikator für die dem Elementarbereich bereitgestellten Ressourcen. Die Schüler-Lehrkräfte-Relation ohne nicht unterrichtende Beschäftigte (z. B. Hilfslehrkräfte) beträgt zwischen mehr als 20 Schülern pro Lehrkraft in Chile, Frankreich, Indonesien, Israel, Mexiko und der Türkei und weniger als 10 in Estland, Island, Neuseeland, Schweden und Slowenien.

Einige Länder bauen im Elementarbereich in starkem Maße auf Hilfslehrkräfte. I2 Länder weisen eine niedrigere Schüler-Kontaktpersonen-Relation als Schüler-LehrkräfteRelation aus. So ist die Schüler-Kontaktpersonen-Relation in Brasilien, Chile, Deutschland, Frankreich, Indonesien, Israel, Österreich und dem Vereinigten Königreich wesentlich niedriger als die Schüler-Lehrkräfte-Relation (um mindestens zwei Schüler).

\section{Entwicklungstendenzen}

In den letzten zehn Jahren wurde das Bildungsangebot im Elementarbereich in zahlreichen Ländern ausgeweitet. Diese verstärkte Fokussierung auf die frühkindliche Bildung hat in einigen Ländern zu einer Ausweitung der Schulpflicht auf jüngere Altersgruppen geführt, zu gebührenfreier Teilnahme an frühkindlicher Bildung, einem universellen Angebot an frühkindlicher Bildung, Betreuung und Erziehung sowie zur Einführung von Angeboten, bei denen die Betreuung der Kinder in formale Bildungsmaßnahmen im Elementarbereich integriert ist.

Im Durchschnitt der OECD-Länder mit Daten für 2005 und 2012 ist die Bildungsbeteiligung 3-Jähriger an Angeboten im Bereich frühkindlicher Bildung von 64 Prozent im Jahr 2005 auf 7I Prozent im Jahr 2012 gestiegen. Für die 4-Jährigen gilt Ähnliches: Hier stieg die Beteiligung von 79 Prozent im Jahr 2005 auf 84 Prozent im Jahr 2012. In Australien, Brasilien und Polen stieg die Beteiligung der 4-Jährigen an frühkindlicher Bildung zwischen 2005 und 2012 um 20 Prozentpunkte. 


\section{Analyse und Interpretationen}

In der Mehrzahl der OECD-Länder verlief die Entwicklung der FBBE-Politik parallel zur Entwicklung der Erwerbstätigkeit von Frauen. Bedingt durch das Wachstum der auf Wissen und Dienstleistungen basierenden Wirtschaft sind seit den I970er-Jahren immer mehr Frauen erwerbstätig. Da wirtschaftlicher Wohlstand von einer dauerhaft hohen Beschäftigungsquote abhängt, hat das Bestreben, mehr Frauen zu einem Eintritt in den Arbeitsmarkt zu bewegen, zu einem verstärkten staatlichen Interesse an einer Ausweitung der FBBE-Dienstleistungen geführt. Zwischen I970 und I990 haben insbesondere die europäischen Staaten eine familienfreundliche Politik mit neuen Bestimmungen zur Kinderbetreuung etabliert, um Paare zur Elternschaft zu ermutigen und für Frauen eine Vereinbarkeit von Familie und Beruf zu gewährleisten (OECD, 20I3c; OECD, 20II).

Das Durchschnittsalter von Frauen bei der Geburt ihres ersten Kindes ist in den letzten 40 Jahren in allen OECD-Ländern, mit Ausnahme Mexikos, gestiegen. I970 lag das Durchschnittsalter von Frauen bei der Geburt ihres ersten Kindes in Island mit etwas über 2I Jahren am niedrigsten. Island war jedoch kein Sonderfall: Von den 23 Ländern mit verfügbaren Daten lag in 5 weiteren Ländern das durchschnittliche Alter bei der Geburt des ersten Kindes bei unter 23 Jahren, und der Gesamtdurchschnitt aller Länder lag bei nur etwas über 24 Jahren. Dieses Alter stieg bis zum Jahr 1995 im OECD-Durchschnitt auf mehr als 26 Jahre, bis 2012 auf 28 Jahre. Trotz dieser Tendenz bestehen immer noch große Unterschiede zwischen den einzelnen Ländern. Im Jahr 2012 war in der Schweiz, Spanien und dem Vereinigten Königreich das Durchschnittsalter bei der Geburt des ersten Kindes mit mehr als 30 Jahren am höchsten. Mexiko dagegen hatte mit etwas über 2I Jahren das jüngste Durchschnittsalter (Abb. C2.2).

Abbildung C2.2

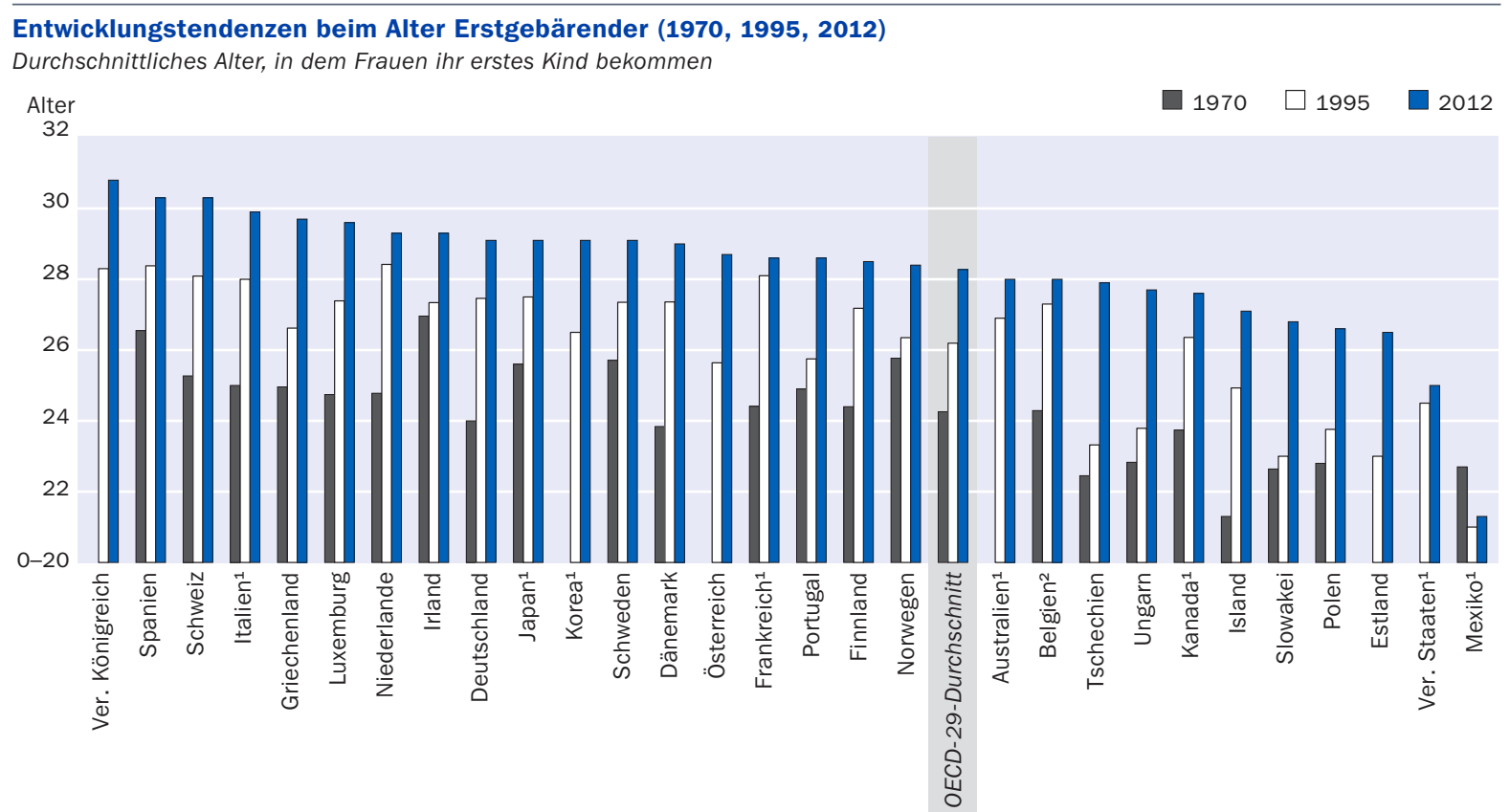

Anordnung der Länder in absteigender Reihenfolge des durchschnittlichen Alters, in dem Frauen ihr erstes Kind bekommen im Jahr 2012.

1. Referenzjahr 2009 anstelle 2012. 2. Referenzjahr 2010 anstelle 2012.

Quelle: OECD (2014), OECD-Familiendatenbank. Hinweise s. Anhang 3 unter www.oecd.org/edu/eag.htm. StatLink: http://dx.doi.org/10.1787/888933118428 


\section{Die Grenze zwischen frühkindlicher Bildung und Kinderbetreuung}

Es gibt in den OECD-Ländern viele verschiedene Systeme und Strukturen der frühkindlichen Bildung, Betreuung und Erziehung (FBBE). Entsprechend gibt es auch viele verschiedene Ansätze zur Unterscheidung zwischen Angeboten zur frühkindlichen Bildung und Angeboten zur Kinderbetreuung. Da der Bildungscharakter von Angeboten der ISCED-Stufe o nur schwer direkt zu bewerten ist, werden verschiedene Näherungskriterien angewandt, um zu einer fachlichen Definition zu gelangen. Dazu gehört die Frage danach, ob das Angebot von qualifiziertem Personal durchgeführt wird, ob es in einem institutionalisierten Kontext stattfindet und auf welche Altersgruppe es ausgerichtet ist.

Um dem Leser von Bildung aufeinen Blick die Interpretation der Ergebnisse in diesem Indikator zu erleichtern, werden nachfolgend mehrere Beispiele aus den der OECD gemeldeten Daten dafür aufgeführt, wie einzelne Länder eine Unterscheidung zwischen frühkindlichen Bildungsangeboten und Angeboten zur Kinderbetreuung treffen und praktisch umsetzen.

In Ländern, in denen FBBE-Angebote und Angebote zur Kinderbetreuung in getrennten Einrichtungen stattfinden, ist es relativ leicht, die entsprechenden Daten aufgegliedert zu melden. In Belgien beispielsweise werden die unterschiedlichen Einrichtungen von verschiedenen Ministerien finanziert, wodurch sich Schätzungen erübrigen, obwohl die internationale Vergleichbarkeit der verwendeten Definition von Bildung hierbei ungeklärt bleibt (Abb. I).

In Ländern mit kombinierten Bildungs- und Betreuungsangeboten (,integrierten“ Angeboten) stellt die Unterscheidung zwischen Bildungsangeboten und Betreuungsangeboten eine größere Herausforderung dar. OECD-Länder mit integrierten FBBE-Angeboten verfügen oft auch über reine Bildungsangebote. Mehr als die Hälfte aller OECD-Länder ist in der Praxis nicht in der Lage, bei integrierten Angeboten eine Unterscheidung zwischen der reinen Bildungskomponente und dem Betreuungsangebot zu treffen. Diese Länder, darunter Italien, Dänemark und die Vereinigten Staaten, haben sich mehrheitlich für die Erfassung aller dieser Daten unter der ISCED-Stufe o entschieden. Nur bei einer Minderheit der Länder werden die integrierten Angebote nicht der ISCED-Stufe o zugeordnet, wenn es um die Daten zur personellen Ausstattung (Australien, Norwegen), zu den Ausgaben (Korea) oder die gesamte Datenerhebung (Griechenland, die Schweiz) geht. Diese Unterschiede sollten bei der Interpretation internationaler Vergleiche berücksichtigt werden.

In Ländern, die bei ihren integrierten Angeboten den Versuch unternehmen, die Bildungskomponente separat auszuweisen, werden verschiedene Schätzverfahren eingesetzt, um die Daten zur Beteiligung, zu den Ausgaben und zum Personal zu trennen. Einige Länder, wie beispielsweise die Niederlande, Norwegen und Schweden, haben ein Schätzverfahren gewählt, bei dem einfach die Hälfte aller Werte für Beteiligung, Personal und Ausgaben der Bildungskomponente zugeschrieben wird. Andere Länder ziehen Datenerhebungen heran, wenden andere Aufteilungen in Bildung einerseits und Betreuung anderseits an oder verwenden ein komplexeres 
Schätzverfahren. Finnland gewichtet beispielsweise die Ausgaben in integrierten Angeboten nach dem Alter des Kindes, während Estland den Ausgabenanteil auf 30 Prozent ansetzt.

Die OECD-Länder arbeiten gemeinsam an einer Verbesserung der zur Verfügung gestellten Statistiken zur frühkindlichen Bildung. Diese Verbesserung, die die neue internationale Klassifizierung von ISCED-Bildungsgängen berücksichtigen wird, wird in Bildung aufeinen Blick 2015 umgesetzt werden.

In Abbildung I sind die Systeme zur frühkindlichen Bildung und die Ansätze zur Datenerfassung innerhalb der OECD- und Partnerländer dargestellt. Länderspezifische Informationen sind Anhang 3 der vorliegenden Veröffentlichung zu entnehmen.

Abbildung 1

Schematische Darstellung der verschiedenen Systeme im Elementarbereich (ISCED-Stufe 0) und der Datenerhebung innerhalb der OECD

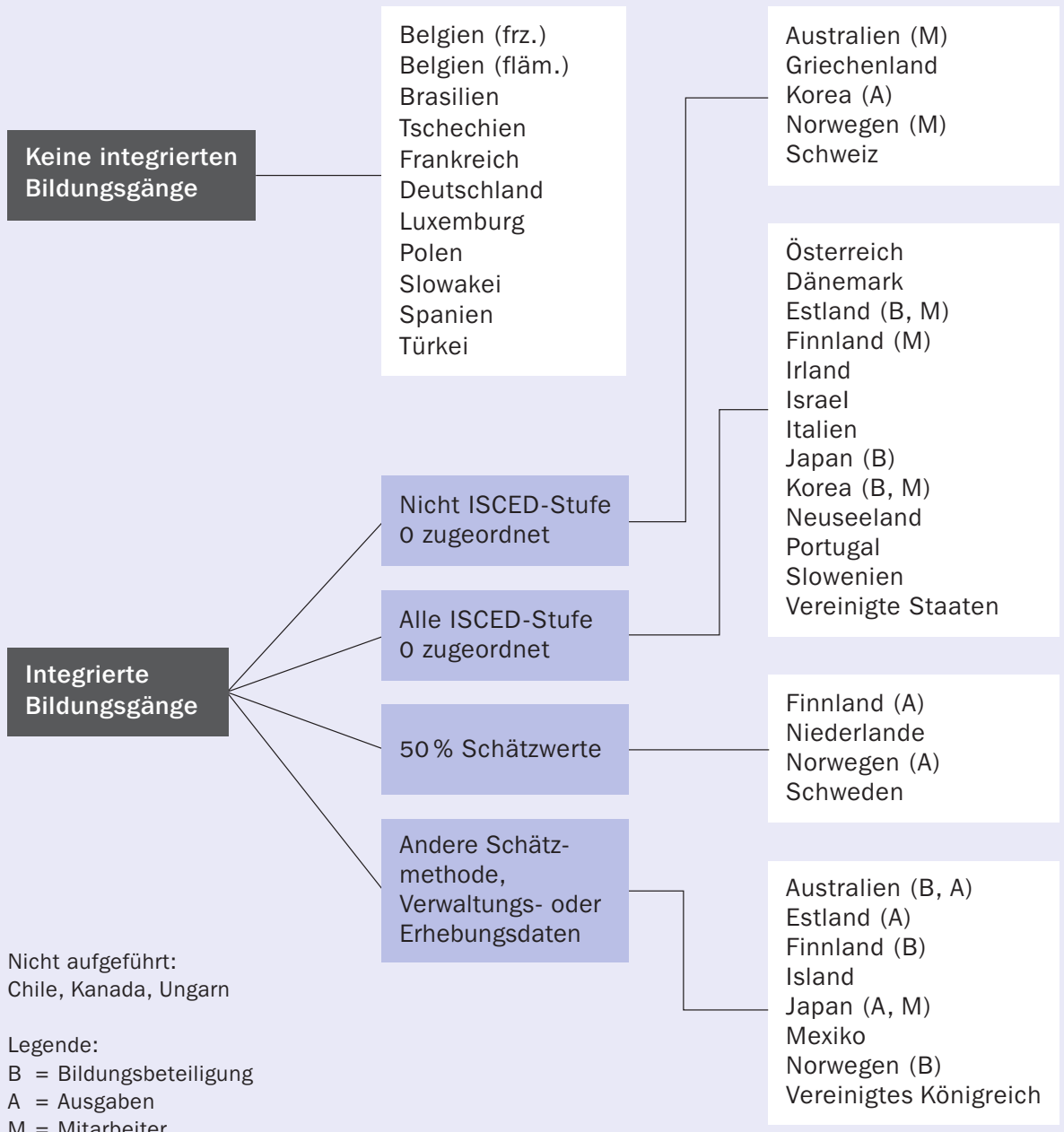




\section{Bildungsbeteiligung im Elementarbereich}

Für viele Kinder bildet die frühkindliche Bildung die Eingangsstufe in den organisierten Unterricht und kann eine wesentliche Rolle in ihrer Entwicklung spielen. Während die Bildungsbeteiligung im Primar- und Sekundarbereich I in allen OECD-Ländern relativ ähnlich ist, bestehen im Elementarbereich deutliche Unterschiede in den OECDund sonstigen G20-Ländern. Dies gilt im Hinblick auf die Gesamtbeteiligung an Bildungsangeboten, das typische Eintrittsalter der Kinder, die Finanzierung und die Dauer der Angebote.

In der Mehrzahl der OECD-Länder beginnt Bildung für die meisten Kinder inzwischen lange vor dem fünften Lebensjahr. Insgesamt nehmen in den OECD-Ländern mehr als drei Viertel aller 4-Jährigen (84 Prozent) an Bildungsangeboten des Elementarund Primarbereichs teil. In den OECD-Ländern, die zur Europäischen Union gehören, sind dies durchschnittlich sogar 89 Prozent. In diesem Alter beträgt die Beteiligung im Elementar- und Primarbereich zwischen mehr als 95 Prozent in Belgien, Dänemark, Deutschland, Frankreich, Island, Irland, Italien, Luxemburg, den Niederlanden, Norwegen, Spanien und dem Vereinigten Königreich und weniger als 6o Prozent in Finnland, Indonesien und der Türkei. Auch Griechenland und die Schweiz gehören in diese Gruppe, da aber aus diesen Ländern keine Angaben zur Bildungsbeteiligung in integrierten Bildungsgängen vorliegen, kann die spezifische Bildungsbeteiligung nicht berechnet werden und wird wahrscheinlich oberhalb der hier angegebenen liegen. In den beiden Ländern ist die Bildungsbeteiligung an frühkindlicher Bildung bei den 5-Jährigen am höchsten (Tab. C2.I)

Im Durchschnitt gaben in den OECD-Ländern 74 Prozent der 15-jährigen Teilnehmer an der Internationalen Schulleistungsstudie PISA der OECD an, dass sie mehr als ein Jahr an Angeboten aus dem Elementarbereich teilgenommen haben. Den Angaben der Schüler zufolge war vor Io Jahren in Belgien, Frankreich, Island, Japan, den Niederlanden und Ungarn die Bildungsbeteiligung im Elementarbereich für mehr als ein Jahr nahezu universell. In diesen Ländern gaben über 90 Prozent der I5-Jährigen an, dass sie länger als ein Jahr an Angeboten im Elementarbereich teilgenommen hatten. In der Türkei ist frühkindliche Bildung selten, dort hatten unabhängig von der Dauer der Teilnahme weniger als 30 Prozent der 15-Jährigen an Angeboten aus dem Elementarbereich teilgenommen. Eine Beteiligung am Elementarbereich von mehr als einem Jahr ist in Australien, Chile, Irland und Polen unüblich. In diesen Ländern hatten weniger als 52 Prozent der Schüler über eine derartige Zeitdauer an Angeboten aus dem Elementarbereich teilgenommen (s. OECD, 2013a, Tab. IV.3.33).

Bemerkenswert in diesem Zusammenhang ist, dass der PISA-Studie zufolge in den meisten Ländern Schüler, die mindestens ein Jahr an Angeboten des Elementarbereichs teilgenommen haben, tendenziell bessere Ergebnisse erzielen als Schüler, die nicht an frühkindlicher Bildung teilgenommen haben, selbst nach Berücksichtigung des sozioökonomischen Hintergrunds der Schüler. Die PISA-Untersuchungen zeigen außerdem, dass der Zusammenhang zwischen der Bildungsbeteiligung im Elementarbereich und den Leistungen in Schulsystemen mit einer längeren Beteiligungsdauer im Elementarbereich, niedrigeren Schüler-Lehrkräfte-Relationen im Elementarbereich und höheren öffentlichen Ausgaben pro Kind im Elementarbereich tendenziell stärker ausgeprägt ist (OECD, 2013, Tab. II.4.I2). 
Angebote zur frühkindlichen Bildung für noch jüngere Kinder sind nicht so weit verbreitet. In einigen Ländern ist der Bedarf an frühkindlicher Bildung für Kinder im Alter von drei Jahren und darunter deutlich größer als das Angebot, und zwar selbst in Ländern, in denen die Möglichkeit eines langen Erziehungsurlaubs besteht. Belgien, Dänemark, Frankreich, Island, Italien, Norwegen, Schweden, Spanien und das Vereinigte Königreich weisen die höchste Beteiligungsquote von 3-Jährigen an frühkindlicher Bildung auf. In Ländern, in denen Erziehungsurlaub nur begrenzt öffentlich finanziert wird, müssen viele erwerbstätige Eltern entweder Lösungen im privaten Sektor finden, wo der Zugang zu qualitativ hochwertigen Angeboten in hohem Maße von der Zahlungsfähigkeit der Eltern bestimmt wird, oder sind auf informelle Vereinbarungen mit Familienangehörigen, Freunden und Nachbarn angewiesen (Tab. C2.I und Starting Strong III [OECD, 20I3d]).

Einige Länder haben für einen nahezu universellen Zugang zum Elementarbereich ab einem Alter von drei Jahren Sorge getragen. Die Verfügbarkeit von Angeboten im Elementarbereich nimmt in den meisten Ländern schnell zu. In den OECD-Ländern mit verfügbaren Daten für 2005 und 2012 stieg die Bildungsbeteiligung im Durchschnitt bei den 3-Jährigen von 64 Prozent im Jahr 2005 auf 7 I Prozent im Jahr 2012 und bei den 4-Jährigen von 79 Prozent im Jahr 2005 auf 84 Prozent im Jahr 20I2. In Brasilien und Polen stieg die Beteiligung der 4-Jährigen in diesem Zeitraum um mindestens 20 Prozentpunkte (Tab. C2.I).

\section{Finanzierung der frühkindlichen Bildung}

Eine langfristig gesicherte öffentliche Finanzierung ist entscheidend für die Sicherung der weiteren Expansion und Qualität frühkindlicher Bildungsgänge. Eine geeignete Finanzierung trägt dazu bei, dass qualifiziertes Personal eingestellt werden kann, das in der Lage ist, die kognitive, soziale und emotionale Entwicklung der Kinder zu unterstützen. Investitionen in Einrichtungen und Materialien zur frühkindlichen Bildung leisten außerdem einen Beitrag zur Förderung der Entwicklung eines kindgerechten Lernumfelds. In Ländern, in denen nicht genügend öffentliche Mittel zur Finanzierung eines qualitativ und quantitativ ausreichenden Angebots im Elementarbereich bereitgestellt werden, kann es sein, dass einige Eltern für ihre Kinder tendenziell eher private FBBE-Einrichtungen wählen, was eine große finanzielle Belastung bedeuten kann (OECD, 2013d); andere entscheiden sich möglicherweise dafür, zu Hause zu bleiben, was sich negativ auf die Erwerbstätigkeit von Frauen auswirken kann (OECD, 20II).

Mit öffentlichen Mitteln für den Elementarbereich werden hauptsächlich öffentliche Bildungseinrichtungen finanziert, in einigen Ländern werden öffentliche Mittel aber auch in unterschiedlichem Ausmaß für private Bildungseinrichtungen eingesetzt. Die öffentlichen Ausgaben pro Schüler für öffentliche Einrichtungen im Elementarbereich sind in den OECD-Ländern im Durchschnitt mehr als doppelt so hoch wie die für private Einrichtungen (6.46o US-Dollar gegenüber 3.6I8 US-Dollar) (s. Tab. B3.4). In den OECD-Ländern betragen die (mit Mitteln aus öffentlichen und privaten Quellen finanzierten) jährlichen Ausgaben pro Schüler im Elementarbereich für öffentliche und private Einrichtungen im Durchschnitt 7.446 US-Dollar. Allerdings variieren diese Ausgaben von höchstens 2.500 US-Dollar in Argentinien, Brasilien, Indonesien und der Türkei bis zu mehr als I0.00o US-Dollar in Australien, Dänemark, Luxemburg, Neuseeland und den Vereinigten Staaten (Tab. C2.2 und Tab. B3.3 in Indikator B3). 


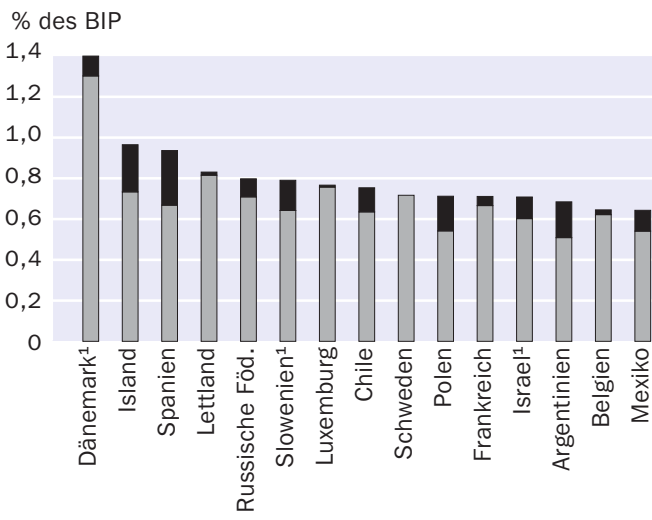

Ausgaben insgesamt

1. Einschließlich einiger Ausgaben für die Betreuung der Kinder.

Anordnung der Länder in absteigender Reihenfolge der privaten und öffentlichen Ausgaben für Bildungseinrichtungen.

Quelle: OECD. Tabelle C2.2. Hinweise s. Anhang 3 unter www.oecd.org/edu/eag.htm. StatLink: http://dx.doi.org/10.1787/888933118447

Die Ausgaben für den Elementarbereich belaufen sich im Durchschnitt auf o,6 Prozent des BIP der OECD insgesamt. Zwischen den einzelnen Ländern gibt es jedoch signifikante Unterschiede. In Australien beispielsweise werden höchstens o, I Prozent des BIP für den Elementarbereich ausgegeben, während es in Chile, Dänemark, Island, Lettland, Luxemburg, Slowenien, Spanien und der Russischen Föderation mindestens o,8 Prozent sind (Tab. C2.2 und Abb. C2.3). Diese Unterschiede erklären sich größtenteils durch die Bildungsbeteiligung, gesetzlich festgelegte Ansprüche und Kosten sowie das unterschiedliche Eintrittsalter in den Primarbereich, sie werden jedoch auch von dem Ausmaß beeinflusst, in dem private frühkindliche Bildung von diesem Indikator erfasst wird. Da für die Schweiz keine Daten über integrierte Angebote vorliegen, sind die tatsächlichen Ausgaben für den Elementarbereich und die tatsächliche Beteiligung dort wahrscheinlich zu niedrig angesetzt (Einzelheiten s. Kasten C2.I.), was die Vergleichbarkeit der Daten mit denen anderer Länder beeinflussen kann. Schlussfolgerungen hinsichtlich des Zugangs zu FBBE und deren Qualität sollten deshalb mit Vorsicht gezogen werden (Tab. C2.2 und Kasten C2.I).

Eine öffentliche Finanzierung des Elementarbereichs ist in den europäischen Ländern der OECD tendenziell stärker entwickelt als in den nicht europäischen Ländern. In Europa ist das Prinzip des universellen Bildungszugangs für 3- bis 6-Jährige allgemein anerkannt. Die meisten Länder dieser Region bieten allen Kindern vor dem Eintritt in den Primarbereich mindestens zwei Jahre gebührenfreier, öffentlich finanzierter frühkindlicher Bildung. Mit Ausnahme von Irland und den Niederlanden gibt es im Allgemeinen ab dem Alter von drei Jahren, in manchen Ländern sogar noch früher, einen gesetzlichen Anspruch auf Bildungszugang. Verglichen mit Bildungseinrichtungen im Primarbereich, Sekundarbereich und postsekundaren, nicht tertiären Bereich ist bei Einrichtungen des Elementarbereichs der Anteil an privater Finanzierung mit I9 Prozent am höchsten. Dieser Anteil variiert jedoch erheblich zwischen den einzelnen Ländern und reicht von höchstens 5 Prozent in Belgien, Estland, Lettland, Luxemburg und Schweden bis zu mindestens 25 Prozent in Argentinien, Australien, Japan, Kolum- 
bien, Korea, Österreich, Spanien und den Vereinigten Staaten (Tab. C2.2 und Starting Strong II [OECD, 2006]).

\section{Die Schüler-Lehrkräfte-Relation unterscheidet sich signifikant zwischen den einzelnen OECD-Ländern}

Untersuchungen zeigen, dass der Einsatz qualifizierterer Lehrkräfte ein vielfältiges, anregendes Umfeld und einen pädagogisch hochwertigen Unterricht fördert und dass qualitativ bessere Interaktionen zwischen den Kindern und den Mitarbeitern der Bildungseinrichtungen zu besseren Lernerfolgen führen (Heckman, 2000; Shin et al., 2009). Qualifikationen bilden zwar eines der aussagekräftigsten Kriterien für die Qualität der Mitarbeiter, aber die Höhe der Qualifikation ist nur ein Aspekt des Gesamtbilds. Qualifikationen geben einen Hinweis darauf, in welchem Umfang die Mitarbeiter in ihrer Erstausbildung sowohl fachlich als auch praktisch ausgebildet wurden, welche Möglichkeiten der beruflichen Weiterentwicklung und -bildung zur Verfügung stehen und tatsächlich in Anspruch genommen werden und über wie viele Jahre Erfahrung das Personal verfügt. Ferner können die Arbeitsbedingungen die berufliche Zufriedenheit beeinflussen, was sich höchstwahrscheinlich wiederum auf die Fähigkeit und die Bereitschaft der Mitarbeiter auswirkt, eine Beziehung zu den Kindern aufzubauen und aufmerksam mit ihnen zu interagieren (Shin et al., 2009). Eine hohe Fluktuationsrate beeinträchtigt die Kontinuität der Betreuung, behindert Anstrengungen zur beruflichen Weiterbildung, führt zu allgemeinen Qualitätseinbußen und hat negative Auswirkungen auf die Lernerfolge der Kinder.

Die Schüler-Lehrkräfte-Relation ist ebenfalls ein wichtiger Indikator für die zu Bildungszwecken zur Verfügung gestellten Ressourcen. Sie wird berechnet, indem (gemessen in Vollzeitäquivalenten) die Zahl der Schüler eines bestimmten Bildungsbe-

Abbildung $\mathbf{C 2 . 4}$

Schüler-Lehrkräfte-Relation im Bereich frühkindliche Bildung (2012)

Öffentliche und private Bildungseinrichtungen, Berechnung basierend auf Vollzeitäquivalenten

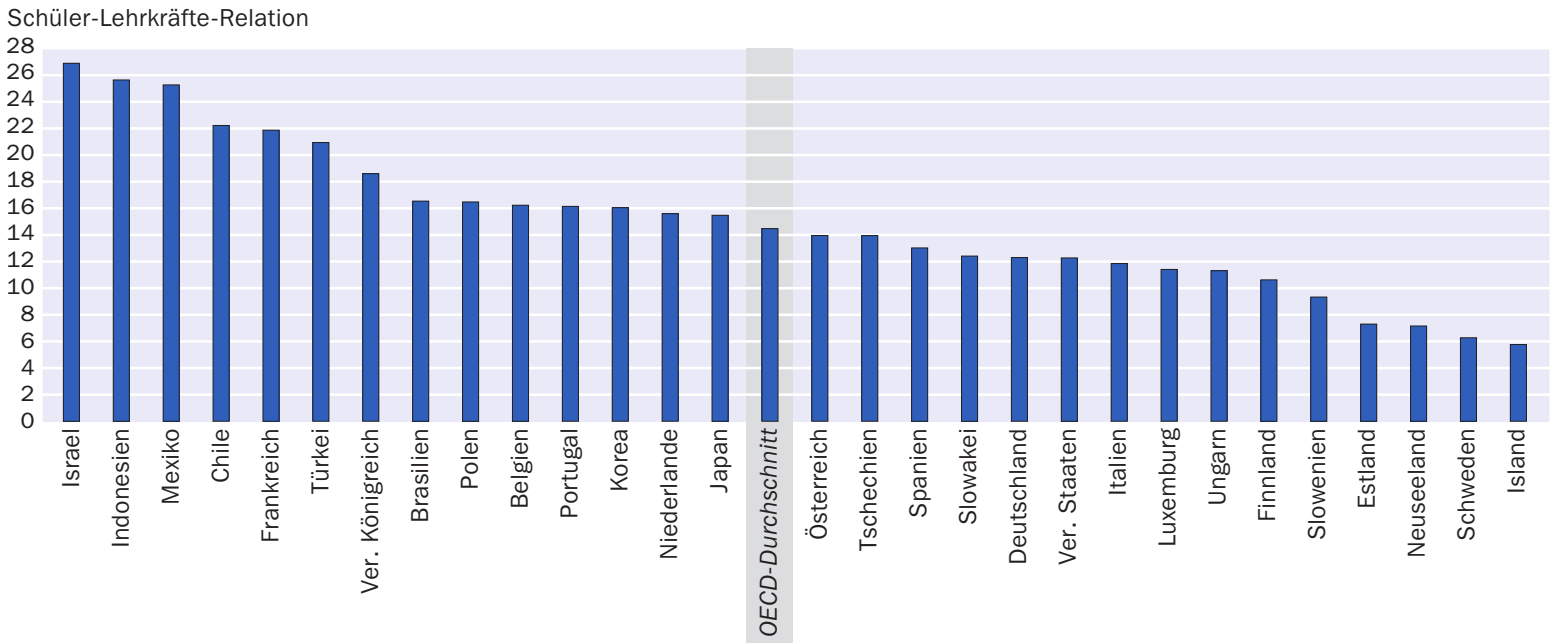

Anmerkung: Die Daten sollten mit Vorsicht interpretiert werden, da in dem Indikator die Schüler-Lehrkräfte-Relation in Ländern verglichen wird, die „reine Bildungsangebote“ und „integrierte Bildungsangebote“ haben. In einigen Ländern sind die Anforderungen hinsichtlich der personellen Ausstattung bei diesen beiden Bildungsangeboten sehr unterschiedlich.

Anordnung der Länder in absteigender Reihenfolge der Schüler-Lehrkräfte-Relation im Bereich frühkindliche Bildung.

Quelle: OECD. Tabelle C2.2. Hinweise s. Anhang 3 unter www.oecd.org/edu/eag.htm. StatLink: http://dx.doi.org/10.1787/888933118466 
reichs durch die Zahl der Lehrkräfte des gleichen Bildungsbereichs und ähnlicher Bildungseinrichtungen dividiert wird. Diese Relation berücksichtigt jedoch weder die Unterrichtszeit der Schüler im Verhältnis zur Länge des Arbeitstages einer Lehrkraft noch, wie viel Zeit eine Lehrkraft auf das Unterrichten verwendet, und kann daher nicht als Klassengröße interpretiert werden. Die Zahl der Schüler pro Klasse umfasst unterschiedliche Faktoren, eine Differenzierung dieser Faktoren erlaubt jedoch, die Qualitätsunterschiede zwischen den Bildungssystemen der einzelnen Länder herauszuarbeiten (s. Indikator D2).

Tabelle C2.2 enthält Angaben zur Schüler-Lehrkräfte-Relation sowie zur Schüler-Kontaktpersonen-Relation (Lehrkräfte und nicht voll qualifizierte Beschäftigte, z. B. Hilfslehrkräfte) im Bereich frühkindliche Bildung. Einige Länder bauen im Elementarbereich in großem Umfang aufHilfslehrkräfte. In 12 OECD- und G20-Ländern ist die gemeldete Schüler-Kontaktpersonen-Relation (Tab. C2.2, Spalte [4]) niedriger als die SchülerLehrkräfte-Relation. So ist die Schüler-Kontaktpersonen-Relation in Brasilien, Chile, Deutschland, Frankreich, Indonesien, Israel, Österreich, dem Vereinigten Königreich und den Vereinigten Staaten wesentlich niedriger. Im Durchschnitt der OECD-Länder kommen im Elementarbereich auf jede Lehrkraft I5 Schüler. Die Schüler-LehrkräfteRelation (ohne Hilfslehrkräfte) beträgt zwischen mehr als 20 Schülern pro Lehrkraft in Chile, Frankreich, Indonesien, Israel, Mexiko und der Türkei und weniger als Io in Estland, Island, Neuseeland, Schweden und Slowenien (Tab. C2.2 und Abb. C2.4).

\section{Definitionen}

Frühkindliche Bildung (Elementarbereich, ISCED-Stufe o) ist definiert als erste Stufe organisierten Unterrichts, die jüngere Kinder hauptsächlich an eine schulähnliche Umgebung heranführen soll.

Die Unterscheidung zwischen Angeboten, die ISCED-Stufe o zugerechnet werden, und Angeboten, bei denen dies nicht der Fall ist, beruht hauptsächlich auf dem Bildungscharakter des Angebots. Da der Bildungscharakter dieser Angebote nur schwer direkt zu bewerten ist, werden verschiedene Näherungskriterien angewandt. Bildungsgänge der ISCED-Stufe o umfassen Angebote zur frühkindlichen Bildung, die

in einem Zentrum oder einer Schule stattfinden,

auf die Bildungs- und Entwicklungsbedürfnisse von Kindern zugeschnitten sind,

- sich in der Regel an Kinder im Alter von mindestens 3 Jahren und höchstens 6 Jahren richten und

über angemessen ausgebildetes (d. h. qualifiziertes) Personal verfügen, um den Kindern ein Bildungsangebot zu bieten.

Sie umfassen keine Angebote der frühkindlichen Bildung, die diese Kriterien nicht erfüllen.

Reine Bildungsangebote im Bereich der frühkindlichen Bildung umfassen hauptsächlich Bildungsangebote für einen kurzen Zeitraum im Laufe des Tages. Berufstätige Eltern werden in der Regel zusätzliche Betreuungsangebote am Morgen und/oder am Nachmittag in Anspruch nehmen müssen. 
Integrierte Angebote im Bereich der frühkindlichen Bildung verbinden Bildung und Betreuung in einem Bildungsgang.

\section{Angewandte Methodik}

Zur Unterscheidung zwischen Vollzeit- und Teilzeitangeboten werden in Bildung auf einen Blick zwei Methoden verwendet:

I. basierend auf nationalen Definitionen für Angebote zur frühkindlichen Bildung und

2. ein Näherungsverfahren abgeleitet aus der Dauer der ersten Klassenstufe des Primarbereichs (ISCED-Stufe I).

Die Klassifizierungsansätze unterscheiden sich zwar von Land zu Land, dies hat jedoch keinen Einfluss auf die Bildungsbeteiligung (Tab. C2.I), da diese auf dem Gesamtumfang der Bildungsbeteiligung als Anteil an der Bevölkerung unabhängig von einer Unterscheidung in Teilzeit und Vollzeit basiert. Es ist allerdings möglich, dass sich die unterschiedlichen Klassifizierungsansätze auf die Ausgaben pro Kind und die SchülerLehrkräfte-Relation auswirken, da diese Daten auf vollzeitäquivalenten Schülerzahlen beruhen.

Daher sind die Ausgaben für die Betreuungskomponente von integrierten Angeboten in Bildung aufeinen Blick nicht berücksichtigt, da bei der ISCED-Stufe o der Schwerpunkt auf dem Bildungscharakter des Angebots liegt. Die Länder, in denen sich die Ausgaben für Kinderbetreuung nicht von den in Bildung auf einen Blick erfassten Daten trennen lassen, sind in der Fußnote zu Tabelle $\mathrm{C} 2.2$ angegeben. Es ist wahrscheinlich, dass sich der erfasste Anteil der Ausgaben für die Kinderbetreuung von Land zu Land unterscheidet, daher sollten diese Ergebnisse mit Vorsicht interpretiert werden (weitere Einzelheiten s. Kasten C2.I).

Manche Unterschiede auf der nationalen Ebene können hier nicht dargestellt werden, und in einigen Fällen wurden Informationen über den (Bildungs- bzw. Betreuungs-) Charakter von Angeboten vereinfacht. Es gibt zum Beispiel Länder, in denen sich das Eintrittsalter für Angebote zur frühkindlichen Bildung je nach Region oder rechtlicher Zuständigkeit unterscheidet. In diesen Fällen liefert der Indikator Informationen zu den am weitesten verbreiteten oder typischsten Angeboten.

Anmerkung zu den Daten aus Israel

Die statistischen Daten für Israel wurden von den zuständigen israelischen Stellen bereitgestellt, die für sie verantwortlich zeichnen. Die Verwendung dieser Daten durch die OECD erfolgt unbeschadet des völkerrechtlichen Status der Golanhöhen, von Ost-Jerusalem und der israelischen Siedlungen im Westjordanland.

\section{Weiterführende Informationen}

Downey, D. B., P. T. von Hippel and B. A. Broh (2004), „Are schools the great equalizer? Cognitive inequality during the summer months and the school year", American Sociological Review, Vol. 69, No. 5, pp. 613-635. 
Heckman, J. J. (2000), „The case for investing in disadvantaged young children“, CESifo DICE Report, Vol. 6, No. 2, Ifo Institute for Economic Research at the University of Munich, pages $3-8,07$.

OECD (2013a), PISA 2012 Results: What Makes Schools Successful? (Volume IV): Resources, Policies and Practices, PISA, OECD Publishing, Paris, http:/|dx.doi.org/10.1787| 9789264201156-en.

OECD (2013b), Trends Shaping Education 2013, OECD Publishing, Paris, http://dx.doi.org/ 10.1787/trends_edu-2013-en.

OECD (2013c), „How do early childhood education and care (ECEC) policies, systems and quality vary across OECD countries?" Education Indicators in Focus, February, http:/l dx.doi.org/10.1787/5k49czkz4bq2-en.

OECD (2013d), Starting Strong III: Eine Qualitäts-Toolbox für die Frühkindliche Bildung, Betreuung und Erziehung, Deutsches Jugendinstitut, München, http:||dx.doi.org/10.1787| 9789264202184-de.

OECD (20II), How's Life? Measuring Well-being, OECD Publishing, Paris, http:/|dx.doi.org/ 10.1787/9789264121164-en.

OECD (2010), Improving Health and Social Cohesion through Education, Educational Research and Innovation, OECD Publishing, Paris, http://dx.doi.org/10.1787/9789264086319-en.

OECD (2006), Starting Strong II: Early Childhood Education and Care, OECD Publishing, Paris, http://dx.doi.org/10.1787/9789264035461-en.

Shin, E., M. Jung and E. Park (2009), „A survey on the development of the pre-school free service model“, Research Report of the Korean Educational Development Institute, Seoul.

\section{Tabellen Indikator C2}

StatLink: http://dx.doi.org/10.1787/888933118333

Tabelle C2.I: Bildungsbeteiligung im Elementar- und Primarbereich, nach Alter (2005, 2012)

Tabelle C2.2: Merkmale von Bildungsangeboten im Bereich frühkindliche Bildung (20II, 20I2)

Tabelle C2.3: Merkmale von reinen Bildungsangeboten und integrierten Angeboten im Elementarbereich (20I2) 
Bildungsbeteiligung im Elementar- und Primarbereich, nach Alter $(2005,2012)$

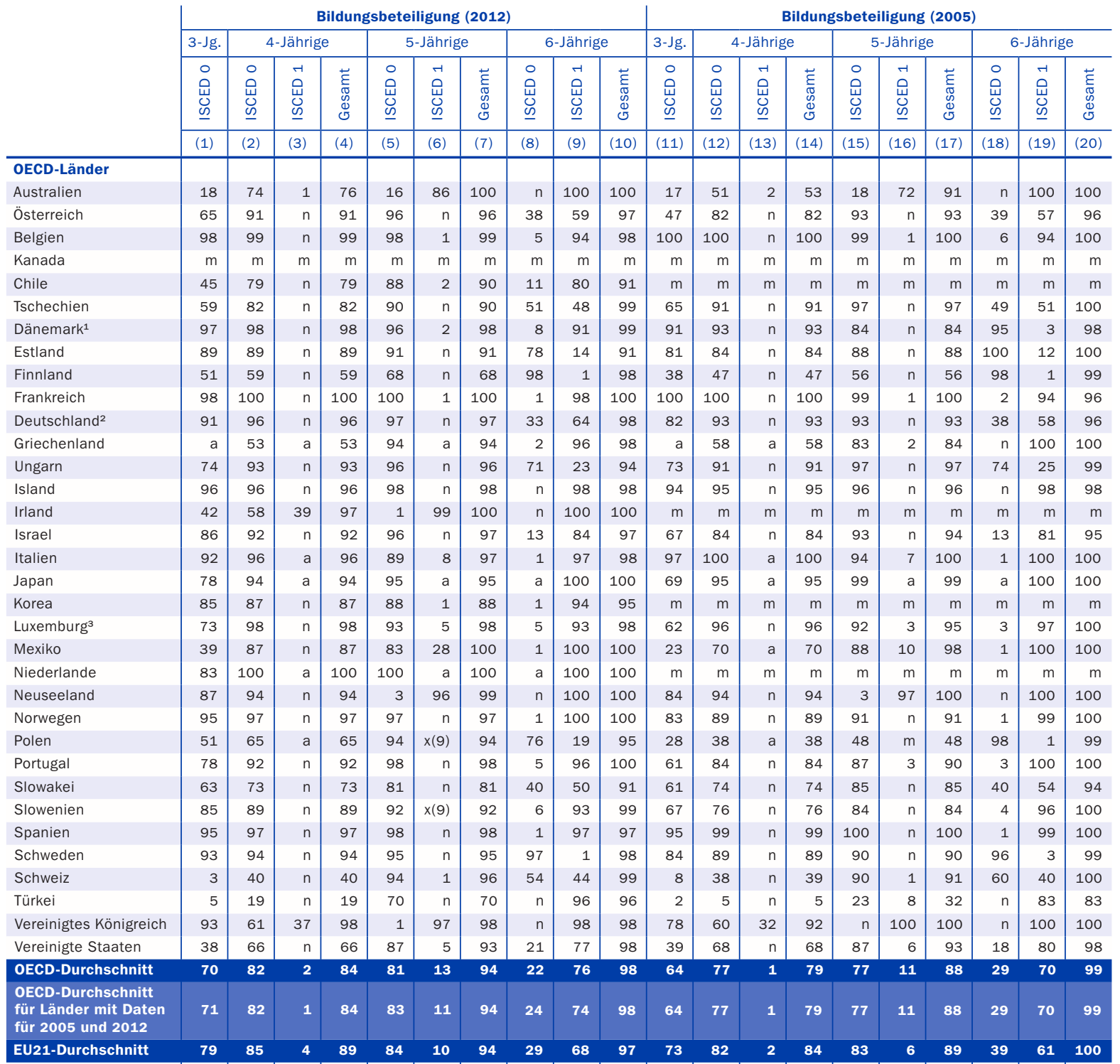

\begin{tabular}{|c|c|c|c|c|c|c|c|c|c|c|c|c|c|c|c|c|c|c|c|c|}
\hline Partnerländer & & & & & & & & & & & & & & & & & & & & \\
\hline Argentinien & 38 & 77 & $n$ & 77 & 100 & $n$ & 100 & $n$ & 100 & 100 & $\mathrm{~m}$ & $\mathrm{~m}$ & $\mathrm{~m}$ & $\mathrm{~m}$ & $\mathrm{~m}$ & $\mathrm{~m}$ & $\mathrm{~m}$ & $\mathrm{~m}$ & $\mathrm{~m}$ & $\mathrm{~m}$ \\
\hline Brasilien & 37 & 61 & $\mathrm{n}$ & 61 & 82 & $\mathrm{n}$ & 83 & 54 & 37 & 91 & 21 & 37 & $\mathrm{n}$ & 37 & 62 & 1 & 63 & 63 & 21 & 83 \\
\hline China & $\mathrm{m}$ & $\mathrm{m}$ & $\mathrm{n}$ & $\mathrm{m}$ & $\mathrm{m}$ & $\mathrm{n}$ & $\mathrm{m}$ & $\mathrm{n}$ & $\mathrm{m}$ & $\mathrm{m}$ & $\mathrm{m}$ & $\mathrm{m}$ & $\mathrm{m}$ & $\mathrm{m}$ & $\mathrm{m}$ & $\mathrm{m}$ & $\mathrm{m}$ & $\mathrm{m}$ & $\mathrm{m}$ & $\mathrm{m}$ \\
\hline Kolumbien & 48 & 75 & 1 & 75 & 65 & 14 & 79 & 8 & 65 & 73 & $\mathrm{~m}$ & $\mathrm{~m}$ & $\mathrm{~m}$ & $\mathrm{~m}$ & $\mathrm{~m}$ & $\mathrm{~m}$ & $\mathrm{~m}$ & $\mathrm{~m}$ & $\mathrm{~m}$ & $\mathrm{~m}$ \\
\hline Indien & $\mathrm{m}$ & $\mathrm{m}$ & $\mathrm{m}$ & $\mathrm{m}$ & $\mathrm{m}$ & $\mathrm{m}$ & $\mathrm{m}$ & $\mathrm{m}$ & $\mathrm{m}$ & $\mathrm{m}$ & $\mathrm{m}$ & $\mathrm{m}$ & $\mathrm{m}$ & $\mathrm{m}$ & $\mathrm{m}$ & $\mathrm{m}$ & $\mathrm{m}$ & $\mathrm{m}$ & $\mathrm{m}$ & $\mathrm{m}$ \\
\hline Indonesien & 5 & 25 & $\mathrm{n}$ & 25 & 41 & 4 & 46 & 24 & 72 & 97 & $\mathrm{~m}$ & $\mathrm{~m}$ & $\mathrm{~m}$ & $\mathrm{~m}$ & $\mathrm{~m}$ & $\mathrm{~m}$ & $\mathrm{~m}$ & $\mathrm{~m}$ & $\mathrm{~m}$ & $\mathrm{~m}$ \\
\hline Lettland & 80 & 87 & $\mathrm{n}$ & 87 & 96 & $\mathrm{n}$ & 96 & 92 & 5 & 97 & $\mathrm{~m}$ & $\mathrm{~m}$ & $\mathrm{~m}$ & $\mathrm{~m}$ & $\mathrm{~m}$ & $\mathrm{~m}$ & $\mathrm{~m}$ & $\mathrm{~m}$ & $\mathrm{~m}$ & $\mathrm{~m}$ \\
\hline Russische Föderation & 70 & 77 & a & 77 & 80 & $\mathrm{n}$ & 80 & 72 & 12 & 84 & $\mathrm{~m}$ & $\mathrm{~m}$ & a & $\mathrm{m}$ & $\mathrm{m}$ & $\mathrm{n}$ & $\mathrm{m}$ & $\mathrm{m}$ & 23 & $\mathrm{~m}$ \\
\hline Saudi-Arabien & $\mathrm{m}$ & $\mathrm{m}$ & $\mathrm{m}$ & $\mathrm{m}$ & $\mathrm{m}$ & $\mathrm{m}$ & $\mathrm{m}$ & $\mathrm{m}$ & $\mathrm{m}$ & $\mathrm{m}$ & $\mathrm{m}$ & $\mathrm{m}$ & $\mathrm{m}$ & $\mathrm{m}$ & $\mathrm{m}$ & $\mathrm{m}$ & $\mathrm{m}$ & $\mathrm{m}$ & $\mathrm{m}$ & $\mathrm{m}$ \\
\hline Südafrika & $\mathrm{m}$ & $\mathrm{m}$ & $\mathrm{m}$ & $\mathrm{m}$ & $\mathrm{m}$ & $\mathrm{m}$ & $\mathrm{m}$ & $\mathrm{m}$ & $\mathrm{m}$ & $\mathrm{m}$ & $\mathrm{m}$ & $\mathrm{m}$ & $\mathrm{m}$ & $\mathrm{m}$ & $\mathrm{m}$ & $\mathrm{m}$ & $\mathrm{m}$ & $\mathrm{m}$ & $\mathrm{m}$ & $\mathrm{m}$ \\
\hline
\end{tabular}

Anmerkung: Die Bildungsbeteiligung von kleinen Kinder sollte mit Vorsicht interpretiert werden. Unterschiede im Erhebungsbereich der Bevölkerungsdaten und der Beteiligungsdaten bedeuten, dass die Teilnahmedaten von Ländern mit einem Nettoabgang von Kindern wie z. B. Luxemburg wohl zu niedrig angesetzt und Länder mit einem Nettozugang von Kindern wohl zu hoch angesetzt sind.

1. Seit 2011 sind Pflichtklassen ISCED-Stufe 1 zugeordnet. 2. Referenzjahr 2006 anstelle 2005. 3. Zu niedrig angesetzt, weil viele der dort wohnenden Schüler in den benachbarten Ländern zur Schule gehen.

Quelle: OECD. Argentinien, China, Indien, Indonesien, Kolumbien, Saudi-Arabien und Südafrika: Statistikinstitut der UNESCO. Lettland: Eurostat.

Hinweise s. Anhang 3 unter www.oecd.org/edu/eag.htm. Stat Link: http://dx.doi.org/10.1787/888933118352

Erläuterung der Kennzeichnung fehlender Daten s. Hinweise für den Leser. 


\begin{tabular}{|c|c|c|c|c|c|c|c|c|c|c|c|c|c|c|c|c|}
\hline & \multicolumn{3}{|c|}{$\begin{array}{l}\text { Verteilung der Schüler } \\
\text { in ISCED-Stufe 0, } \\
\text { nach Art der Bildungs- } \\
\text { einrichtung (2012) }\end{array}$} & \multicolumn{2}{|c|}{$\begin{array}{c}\text { Schüler-Lehr- } \\
\text { kräfte-Relation } \\
\text { in Vollzeitäqui- } \\
\text { valenten (2012) }\end{array}$} & \multicolumn{4}{|c|}{$\begin{array}{c}\text { Ausgaben für } \\
\text { Bildungseinrichtungen (2011) }\end{array}$} & \multicolumn{7}{|c|}{$\begin{array}{l}\text { Merkmale von Bildungsangeboten } \\
\text { im Bereich frühkindliche Bildung }\end{array}$} \\
\hline & 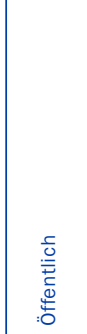 & 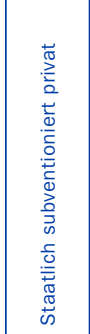 & 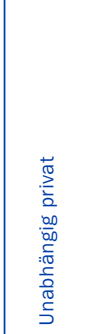 & 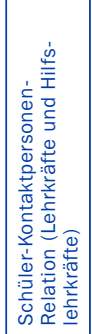 & 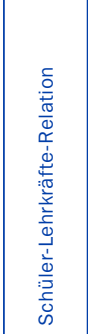 & 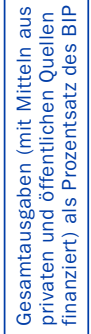 & 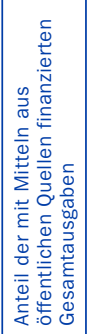 & 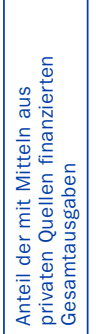 & 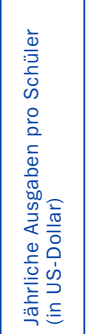 & 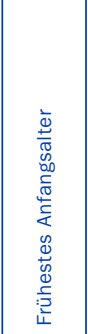 & 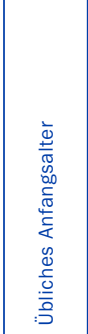 & 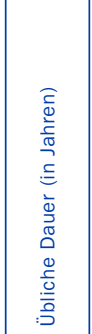 & 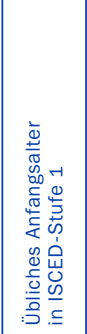 & 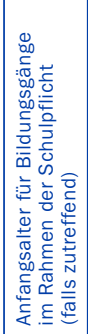 & 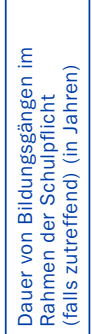 & 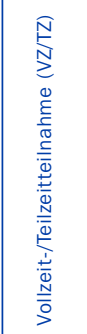 \\
\hline & ISCED 0 & ISCED O & ISCED 0 & ISCED O & ISCED O & ISCED O & ISCED O & ISCED O I & ISCED O & ISCED O & ISCED O & ISCED O & ISCED 1 & ISCED O & ISCED O & ISCED 0 \\
\hline & (1) & (2) & (3) & (4) & (5) & (6) & (7) & (8) & (9) & (10) & (11) & (12) & (13) & (14) & (15) & (16) \\
\hline \multicolumn{17}{|l|}{ OECD-Länder } \\
\hline Australien & 22,0 & 78,0 & $\mathrm{n}$ & $\mathrm{m}$ & $\mathrm{m}$ & 0,1 & 45 & 55 & 10734 & 3 & 4 & 1 & 5 & a & a & TZ \\
\hline Österreich ${ }^{1}$ & 70,3 & 29,7 & $x(2)$ & 9,6 & 13,9 & 0,6 & 72 & 28 & 8933 & 3 & 3 & 3 & 6 & 5 & 1 & VZ \\
\hline Belgien & 47,1 & 52,9 & $\mathrm{~m}$ & 16,2 & 16,2 & 0,6 & 96 & 4 & 6333 & 2,5 & 2,5 & $3-4$ & 6 & a & a & VZ \\
\hline Kanada $^{2}$ & m & m & $\mathrm{m}$ & m & m & m & $\mathrm{m}$ & $\mathrm{m}$ & $\mathrm{m}$ & $\mathrm{m}$ & $\mathrm{m}$ & m & 6 & $\mathrm{~m}$ & $\mathrm{~m}$ & $\mathrm{~m}$ \\
\hline Chile & 33,5 & 60,4 & 6,0 & 10,8 & 22,2 & 0,8 & 84 & 16 & 5083 & 0,25 & 4 & 2 & $\mathrm{~m}$ & $a$ & $a$ & VZ/TZ \\
\hline Tschechien & 97,9 & 2,1 & a & 13,6 & 13,9 & 0,5 & 92 & 8 & 4302 & 3 & 3 & 3 & 6 & a & a & VZ \\
\hline Dänemark ${ }^{1}$ & 80,7 & 19,3 & $n$ & $m$ & $\mathrm{~m}$ & 1,4 & 92 & 8 & 14148 & 0 & 1 & 5 & 6 & $\mathrm{~m}$ & $\mathrm{~m}$ & VZ \\
\hline Estland & 96,7 & a & 3,3 & $\mathrm{~m}$ & 7,3 & 0,4 & 98 & 2 & 2618 & 0 & 3 & 4 & 7 & $\mathrm{~m}$ & $\mathrm{~m}$ & VZ \\
\hline Finnland & 91,5 & 8,5 & a & $\mathrm{m}$ & 10,6 & 0,4 & 90 & 10 & 5700 & 0 & a & a & 7 & a & a & VZ \\
\hline Frankreich & 87,2 & 12,5 & 0,4 & 14,5 & 21,9 & 0,7 & 94 & 6 & 6615 & 2 & $2-3$ & 3 & 6 & a & a & VZ \\
\hline Deutschland & 34,9 & 65,1 & $x(2)$ & 9,7 & 12,3 & 0,6 & 80 & 20 & 8351 & 3 & 3 & 3 & 6 & a & a & VZ \\
\hline Griechenland & 93,1 & a & 6,9 & $\mathrm{~m}$ & m & $\mathrm{m}$ & $\mathrm{m}$ & $\mathrm{m}$ & $\mathrm{m}$ & 4 & 4 & $1-2$ & 6 & 5 & 1 & VZ \\
\hline Ungarn 1,3 & 92,6 & 7,4 & a & $\mathrm{m}$ & 11,3 & 0,6 & $\mathrm{~m}$ & $\mathrm{~m}$ & 4564 & 2,5 & 3 & 3 & 7 & 5 & 1 & VZ \\
\hline Island & 87,7 & 12,3 & $n$ & 5,8 & 5,8 & 1,0 & 76 & 24 & 9138 & 0 & 2 & 4 & 6 & a & a & $\mathrm{VZ} / \mathrm{TZ}$ \\
\hline Irland & 1,9 & a & 98,1 & $\mathrm{~m}$ & $\mathrm{~m}$ & $\mathrm{~m}$ & $\mathrm{~m}$ & m & $\mathrm{m}$ & 3 & 3 & 1 & $4-5$ & a & a & $\mathrm{VZ} / \mathrm{TZ}$ \\
\hline Israel1,4 & 90,9 & $a$ & 9,1 & 12,8 & 26,9 & 0,7 & 85 & 15 & 4058 & 3 & 3 & 3 & 6 & 3 & 3 & VZ \\
\hline Italien ${ }^{3}$ & 70,2 & a & 29,8 & 11,8 & 11,8 & 0,5 & 90 & 10 & 7868 & $\mathrm{~m}$ & $m$ & $\mathrm{~m}$ & $\mathrm{~m}$ & a & a & VZ \\
\hline Japan & 28,7 & a & 71,3 & 14,6 & 15,5 & 0,2 & 45 & 55 & 5591 & 3 & 3 & 3 & 6 & a & a & VZ \\
\hline Korea & 16,0 & 84,0 & a & 16,0 & 16,0 & 0,3 & 54 & 46 & 6861 & 3 & $3-5$ & 3 & 6 & $\mathrm{~m}$ & $\mathrm{~m}$ & VZ \\
\hline Luxemburg $^{3}$ & 90,9 & $n$ & 9,1 & $\mathrm{~m}$ & 11,4 & 0,8 & 99 & 1 & 25074 & 3 & 3 & 3 & 6 & 4 & 2 & VZ \\
\hline Mexiko & 86,1 & a & 13,9 & 25,3 & 25,3 & 0,6 & 84 & 16 & 2568 & 3 & $4-5$ & 3 & 6 & 3 & 3 & VZ \\
\hline Niederlande & 70,1 & a & 29,9 & 14,0 & 15,6 & 0,4 & 88 & 12 & 8020 & 3 & $3-4$ & $2-3$ & 6 & 5 & 1 & VZ \\
\hline Neuseeland & 1,4 & 98,6 & $n$ & m & 7,2 & 0,6 & 85 & 15 & 11088 & 0 & 3 & 2 & 5 & a & a & VZ/TZ \\
\hline Norwegen & 54,3 & 45,7 & $x(2)$ & $\mathrm{m}$ & $\mathrm{m}$ & 0,5 & 85 & 15 & 7283 & 0 & 1 & 5 & 6 & a & a & VZ/TZ \\
\hline Polen ${ }^{3}$ & 84,3 & 1,3 & 14,4 & $\mathrm{~m}$ & 16,5 & 0,7 & 76 & 24 & 6409 & 2,5 & 3 & 4 & 7 & 6 & 1 & VZ \\
\hline Portugal $^{3}$ & 53,2 & 30,4 & 16,5 & $\mathrm{~m}$ & 16,1 & 0,4 & $\mathrm{~m}$ & $\mathrm{~m}$ & 5674 & 3 & 3 & 3 & 6 & a & a & VZ \\
\hline Slowakei & 95,9 & 4,1 & $n$ & 12,3 & 12,4 & 0,5 & 84 & 16 & 4653 & 2 & 3 & 3 & 6 & a & a & VZ \\
\hline Slowenien ${ }^{1}$ & 97,1 & 2,5 & 0,4 & 9,3 & 9,3 & 0,8 & 81 & 19 & 8136 & 3 & 3 & 3 & 6 & a & a & VZ \\
\hline Spanien & 65,0 & 24,5 & 10,6 & $\mathrm{~m}$ & 13,0 & 0,9 & 71 & 29 & 6725 & 0 & $2-3$ & $3-4$ & 6 & a & a & VZ \\
\hline Schweden & 82,9 & 17,1 & $n$ & 6,2 & 6,3 & 0,7 & 100 & $\mathrm{n}$ & 6915 & 0 & $2-3$ & $4-5$ & 7 & a & a & $\mathrm{VZ} / \mathrm{TZ}$ \\
\hline Schweiz ${ }^{3,5}$ & 96,2 & 0,3 & 3,5 & $\mathrm{~m}$ & $\mathrm{~m}$ & 0,2 & m & $\mathrm{m}$ & 5267 & 4 & 5 & 2 & 6 & 5 & 1 & VZ \\
\hline Türkei & 90,5 & $a$ & 9,5 & $\mathrm{~m}$ & 20,9 & 0,2 & $\mathrm{~m}$ & $\mathrm{~m}$ & 2412 & 3 & 5 & $1-3$ & 6 & a & a & VZ \\
\hline Ver. Königreich & 62,5 & 31,2 & 6,3 & 11,6 & 18,6 & 0,4 & 77 & 23 & 9692 & 3 & 3 & 1,5 & 5 & a & a & VZ/TZ \\
\hline Vereinigte Staaten $n^{1,6}$ & 59,8 & a & 40,2 & 10,4 & 12,3 & 0,5 & 70 & 30 & 10010 & 3 & 4 & 1 & 6 & a & a & $\mathrm{VZ} / \mathrm{TZ}$ \\
\hline OECD-Durchschnitt & 68,4 & 20,4 & 11,1 & 12,5 & 14,5 & 0,6 & 81,3 & 18,7 & 7446 & & & & & & & \\
\hline OECD insgesamt & - & - & - & - & - & 0,5 & - & - & 7047 & & & & & & & \\
\hline EU21-Durchschnitt & 74,6 & 14,7 & 10,7 & 11,3 & 13,1 & 0,6 & 80,3 & 19,7 & 7933 & & & & & & & \\
\hline \multicolumn{17}{|l|}{ Partnerländer } \\
\hline Argentinien & 68,1 & 24,7 & 7,2 & $\mathrm{~m}$ & $\mathrm{~m}$ & 0,7 & 74 & 26 & 1979 & $\mathrm{~m}$ & $\mathrm{~m}$ & $\mathrm{~m}$ & $\mathrm{~m}$ & $\mathrm{~m}$ & $\mathrm{~m}$ & VZ \\
\hline Brasilien $^{1}$ & 71,0 & a & 29,0 & 12,2 & 16,5 & 0,5 & $\mathrm{~m}$ & $\mathrm{~m}$ & 2349 & 0 & 1 & 5 & 6 & 4 & 2 & VZ \\
\hline China & 50,5 & 49,5 & $x(2)$ & $\mathrm{m}$ & $\mathrm{m}$ & $\mathrm{m}$ & $\mathrm{m}$ & $\mathrm{m}$ & $\mathrm{m}$ & $\mathrm{m}$ & $\mathrm{m}$ & $\mathrm{m}$ & $\mathrm{m}$ & $\mathrm{m}$ & $\mathrm{m}$ & VZ \\
\hline Kolumbien & 78,5 & a & 21,5 & $\mathrm{~m}$ & $\mathrm{~m}$ & 0,5 & 54 & 46 & 3491 & $\mathrm{~m}$ & $\mathrm{~m}$ & $\mathrm{~m}$ & $\mathrm{~m}$ & $\mathrm{~m}$ & $\mathrm{~m}$ & $\mathrm{~m}$ \\
\hline Indien & $m$ & $\mathrm{~m}$ & $\mathrm{~m}$ & $\mathrm{~m}$ & $\mathrm{~m}$ & $\mathrm{~m}$ & $\mathrm{~m}$ & $\mathrm{~m}$ & $\mathrm{~m}$ & $\mathrm{~m}$ & $\mathrm{~m}$ & $m$ & $\mathrm{~m}$ & $\mathrm{~m}$ & $m$ & m \\
\hline Indonesien & 2,8 & a & 97,2 & 23,0 & 25,6 & $\mathrm{~m}$ & 90 & 10 & 205 & $\mathrm{~m}$ & $\mathrm{~m}$ & $\mathrm{~m}$ & $\mathrm{~m}$ & $\mathrm{~m}$ & $\mathrm{~m}$ & VZ \\
\hline Lettland & 94,9 & a & 5,1 & $\mathrm{~m}$ & $\mathrm{~m}$ & 0,8 & 98 & 2 & 4359 & $\mathrm{~m}$ & $\mathrm{~m}$ & $\mathrm{~m}$ & m & $\mathrm{m}$ & $\mathrm{m}$ & m \\
\hline Russische Föd. & 99,1 & a & 0,9 & $\mathrm{~m}$ & $\mathrm{~m}$ & 0,8 & 89 & 11 & $\mathrm{~m}$ & $\mathrm{~m}$ & $\mathrm{~m}$ & $\mathrm{~m}$ & $\mathrm{~m}$ & $\mathrm{~m}$ & $\mathrm{~m}$ & $\mathrm{~m}$ \\
\hline Saudi-Arabien & 59,3 & 40,7 & $x(2)$ & $\mathrm{m}$ & $\mathrm{m}$ & $\mathrm{m}$ & $\mathrm{m}$ & $\mathrm{m}$ & $\mathrm{m}$ & $\mathrm{m}$ & $\mathrm{m}$ & $\mathrm{m}$ & $\mathrm{m}$ & $\mathrm{m}$ & $\mathrm{m}$ & $\mathrm{m}$ \\
\hline Südafrika & 93,9 & 6,1 & $x(2)$ & $\mathrm{m}$ & $\mathrm{m}$ & $\mathrm{m}$ & $\mathrm{m}$ & $\mathrm{m}$ & $\mathrm{m}$ & $\mathrm{m}$ & $\mathrm{m}$ & $\mathrm{m}$ & $\mathrm{m}$ & $\mathrm{m}$ & $\mathrm{m}$ & $\mathrm{m}$ \\
\hline G20-Durchschnitt & 59,3 & 23,1 & 17,6 & 14,4 & 17,0 & 0,5 & 74 & 26 & 5854 & $\mathbf{m}$ & $\mathbf{m}$ & $\mathbf{m}$ & m & $\mathbf{m}$ & $\mathbf{m}$ & $\mathbf{m}$ \\
\hline
\end{tabular}

1. Einschließlich einiger Ausgaben für die Betreuung der Kinder. 2. Bildungsgänge der ISCED-Stufe 0 werden in allen 13 Provinzen/Territorien angeboten, in zweien sind sie für alle Kinder obligatorisch. Frühestes Anfangsalter, typisches Anfangsalter und Dauer von Bildungsgängen der ISCED-Stufe 0 variieren je nach Provinz/ Territorium. 3. Die Angaben zu den Bildungsausgaben beziehen sich nur auf öffentliche Bildungseinrichtungen. 4. Durch ein kürzlich in Kraft getretenes Gesetz ist die Teilnahme an Bildungsgängen der ISCED-Stufe O landesweit obligatorisch und kostenfrei. Die Umsetzung beginnt schrittweise ab $2013 . \quad 5$. Bildungsgänge der ISCED-Stufe 0 sind in einigen Kantonen für zwei Jahre obligatorisch, in anderen nur für ein Jahr. 6. Bildungsgänge der ISCED-Stufe 0 sind in rund einem Drittel der Bundesstaaten obligatorisch.

Quelle: OECD. Argentinien, China, Indien, Indonesien, Kolumbien, Saudi-Arabien und Südafrika: Statistikinstitut der UNESCO. Lettland: Eurostat. Hinweise s. Anhang 3 unter www.oecd.org/edu/eag.htm. StatLink: http://dx.doi.org/10.1787/888933118371 Erläuterung der Kennzeichnung fehlender Daten s. Hinweise für den Leser. 
Tabelle C2.3

Merkmale von reinen Bildungsangeboten und integrierten Angeboten im Elementarbereich (2012)

Existenz und Merkmale von reinen Bildungsangeboten und integrierten Angeboten im Elementarbereich

In Bildung auf einen Blick angegebene relative Anteile der Bildungsbeteiligung in reinen Bildungsangeboten und integrierten Angeboten im Bereich frühkindliche Bildung

\begin{tabular}{|c|c|c|c|c|c|c|c|c|c|}
\hline & \multicolumn{3}{|c|}{ Reine Bildungsangebote } & \multicolumn{3}{|c|}{$\begin{array}{c}\text { Integrierte Bildungsgänge } \\
\text { (umfassen Bildungsangebote } \\
\text { und Betreuungsleistung) }\end{array}$} & \multicolumn{3}{|c|}{$\begin{array}{c}\begin{array}{c}\text { Relativer Anteil der Schülerzahlen, } \\
\text { wie in Bildung auf einen Blick angegeben } \\
\text { (in \%) }\end{array} \\
\end{array}$} \\
\hline & $\begin{array}{c}\text { National } \\
\text { vorhanden }\end{array}$ & $\begin{array}{l}\text { Unterricht } \\
\text { durch } \\
\text { qualifizierte } \\
\text { Lehrkräfte }\end{array}$ & $\begin{array}{l}\text { Formaler } \\
\text { Lehrplan }\end{array}$ & $\begin{array}{c}\text { National } \\
\text { vorhanden }\end{array}$ & $\begin{array}{l}\text { Unterricht } \\
\text { durch } \\
\text { qualifizierte } \\
\text { Lehrkräfte }\end{array}$ & $\begin{array}{l}\text { Formaler } \\
\text { Lehrplan }\end{array}$ & $\begin{array}{l}\text { Reine } \\
\text { Bildungs- } \\
\text { angebote }\end{array}$ & $\begin{array}{l}\text { Integrierte } \\
\text { Bildungs- } \\
\text { gänge }\end{array}$ & Gesamt \\
\hline & (1) & (2) & (3) & (4) & (5) & (6) & (7) & (8) & (9) \\
\hline \multicolumn{10}{|l|}{ OECD-Länder } \\
\hline Australien & $\mathrm{Ja}$ & $\mathrm{Ja}$ & $\mathrm{Ja}$ & $\mathrm{Ja}$ & $\mathrm{Ja}$ & $\mathrm{Ja}$ & $x(9)$ & $x(9)$ & 100 \\
\hline Österreich & $\mathrm{Ja}$ & $\mathrm{Ja}$ & Ja & $\mathrm{Ja}$ & $\mathrm{Ja}$ & Nein & 3 & 97 & 100 \\
\hline Belgien & $\mathrm{Ja}$ & $\mathrm{Ja}$ & $\mathrm{Ja}$ & Nein & a & a & 100 & a & 100 \\
\hline Kanada & $\mathrm{Ja}$ & $\mathrm{Ja}$ & Ja & $\mathrm{Ja}$ & $\mathrm{Ja}$ & Ja & $\mathrm{m}$ & $\mathrm{m}$ & $\mathrm{m}$ \\
\hline Chile & $\mathrm{Ja}$ & $\mathrm{Ja}$ & Ja & Ja & $\mathrm{Ja}$ & $\mathrm{Ja}$ & $x(9)$ & $x(9)$ & 100 \\
\hline Tschechien & $\mathrm{Ja}$ & $\mathrm{Ja}$ & Ja & Nein & a & a & 100 & a & 100 \\
\hline Dänemark & Nein & a & a & Ja & $\mathrm{Ja}$ & $\mathrm{Ja}$ & a & 100 & 100 \\
\hline Estland & Nein & a & a & $\mathrm{Ja}$ & $\mathrm{Ja}$ & $\mathrm{Ja}$ & a & 100 & 100 \\
\hline Finnland & $\mathrm{Ja}$ & $\mathrm{Ja}$ & $\mathrm{Ja}$ & Ja & $\mathrm{Ja}$ & $\mathrm{Ja}$ & 37 & 63 & 100 \\
\hline Frankreich & $\mathrm{Ja}$ & $\mathrm{Ja}$ & Ja & Nein & a & a & 100 & a & 100 \\
\hline Deutschland & Ja & $\mathrm{Ja}$ & Ja & Nein & a & a & 100 & a & 100 \\
\hline Griechenland & $\mathrm{Ja}$ & $\mathrm{Ja}$ & Ja & Ja & $\mathrm{m}$ & $\mathrm{m}$ & 100 & $\mathrm{~m}$ & 100 \\
\hline Ungarn & Nein & a & a & $\mathrm{Ja}$ & Ja & $\mathrm{Ja}$ & a & 100 & 100 \\
\hline Island & $\mathrm{Ja}$ & $\mathrm{Ja}$ & Ja & $\mathrm{Ja}$ & $\mathrm{Ja}$ & $\mathrm{Ja}$ & 1 & 99 & 100 \\
\hline Irland & Nein & a & a & $\mathrm{Ja}$ & a & a & a & 100 & 100 \\
\hline Israel & $\mathrm{Ja}$ & $\mathrm{Ja}$ & Ja & $\mathrm{Ja}$ & Ja & $\mathrm{Ja}$ & 98 & 2 & 100 \\
\hline Italien & Nein & a & a & $\mathrm{Ja}$ & $\mathrm{m}$ & $\mathrm{m}$ & a & 100 & $\mathrm{~m}$ \\
\hline Japan & $\mathrm{Ja}$ & $\mathrm{Ja}$ & Ja & $\mathrm{Ja}$ & Variiert & Variiert & $x(9)$ & $\mathrm{x}(9)$ & 100 \\
\hline Korea & $\mathrm{Ja}$ & $\mathrm{Ja}$ & Ja & $\mathrm{Ja}$ & Ja & $\mathrm{Ja}$ & $x(9)$ & $x(9)$ & 100 \\
\hline Luxemburg & $\mathrm{Ja}$ & $\mathrm{Ja}$ & Ja & Nein & a & a & 100 & a & 100 \\
\hline Mexiko & $\mathrm{Ja}$ & $\mathrm{Ja}$ & Ja & $\mathrm{Ja}$ & Ja & $\mathrm{Ja}$ & 99 & 1 & 100 \\
\hline Niederlande & $\mathrm{Ja}$ & $\mathrm{Ja}$ & Ja & $\mathrm{Ja}$ & Nein & Variiert & 70 & 30 & 100 \\
\hline Neuseeland & Nein & a & a & $\mathrm{Ja}$ & Ja & $\mathrm{Ja}$ & a & 100 & 100 \\
\hline Norwegen & Nein & a & a & $\mathrm{Ja}$ & Ja & $\mathrm{Ja}$ & a & 100 & 100 \\
\hline Polen & $\mathrm{Ja}$ & $\mathrm{Ja}$ & Ja & Nein & a & a & 100 & $a$ & 100 \\
\hline Portugal & Nein & a & a & $\mathrm{Ja}$ & $\mathrm{Ja}$ & $\mathrm{Ja}$ & a & 100 & 100 \\
\hline Slowakei & $\mathrm{Ja}$ & $\mathrm{Ja}$ & Ja & Nein & a & a & 100 & a & 100 \\
\hline Slowenien & Nein & a & $a$ & $\mathrm{Ja}$ & $\mathrm{Ja}$ & $\mathrm{Ja}$ & a & 100 & 100 \\
\hline Spanien & $\mathrm{Ja}$ & $\mathrm{Ja}$ & Ja & Nein & a & $a$ & 100 & $a$ & 100 \\
\hline Schweden & $\mathrm{Ja}$ & $\mathrm{Ja}$ & $\mathrm{Ja}$ & $\mathrm{Ja}$ & $\mathrm{Ja}$ & $\mathrm{Ja}$ & 25 & 75 & 100 \\
\hline Schweiz & $\mathrm{Ja}$ & $\mathrm{Ja}$ & $\mathrm{Ja}$ & $\mathrm{Ja}$ & Ja & $m$ & 100 & $\mathrm{~m}$ & 100 \\
\hline Türkei & $\mathrm{Ja}$ & $\mathrm{Ja}$ & $\mathrm{Ja}$ & Nein & $a$ & a & 100 & a & 100 \\
\hline Vereinigtes Königreich & $\mathrm{Ja}$ & $\mathrm{Ja}$ & $\mathrm{Ja}$ & $\mathrm{Ja}$ & Variiert & $\mathrm{Ja}$ & $x(9)$ & $x(9)$ & 100 \\
\hline Vereinigte Staaten & Ja & Variiert & Variiert & Ja & Variiert & Variiert & $\mathrm{x}(9)$ & $x(9)$ & 100 \\
\hline \multicolumn{10}{|l|}{ OECD-Durchschnitt } \\
\hline \multicolumn{10}{|l|}{ OECD insgesamt } \\
\hline \multicolumn{10}{|l|}{ EU21-Durchschnitt } \\
\hline \multicolumn{10}{|l|}{ Partnerländer } \\
\hline Argentinien & $\mathrm{m}$ & $\mathrm{m}$ & $\mathrm{m}$ & $\mathrm{m}$ & $\mathrm{m}$ & $\mathrm{m}$ & $\mathrm{m}$ & $\mathrm{m}$ & $\mathrm{m}$ \\
\hline Brasilien & $\mathrm{Ja}$ & $\mathrm{Ja}$ & Nein & $\mathrm{Ja}$ & $\mathrm{Ja}$ & Nein & $x(9)$ & $x(9)$ & 100 \\
\hline China & $\mathrm{m}$ & $\mathrm{m}$ & $\mathrm{m}$ & $\mathrm{m}$ & $\mathrm{m}$ & $\mathrm{m}$ & $\mathrm{m}$ & $\mathrm{m}$ & $\mathrm{m}$ \\
\hline Kolumbien & $\mathrm{m}$ & $\mathrm{m}$ & $\mathrm{m}$ & $\mathrm{m}$ & $\mathrm{m}$ & $\mathrm{m}$ & $\mathrm{m}$ & $\mathrm{m}$ & $\mathrm{m}$ \\
\hline Indien & m & $\mathrm{m}$ & $\mathrm{m}$ & $\mathrm{m}$ & $\mathrm{m}$ & $\mathrm{m}$ & $\mathrm{m}$ & $\mathrm{m}$ & $\mathrm{m}$ \\
\hline Indonesien & $\mathrm{m}$ & $\mathrm{m}$ & $\mathrm{m}$ & $\mathrm{m}$ & $\mathrm{m}$ & $\mathrm{m}$ & $\mathrm{m}$ & $\mathrm{m}$ & $\mathrm{m}$ \\
\hline Lettland & $\mathrm{m}$ & $\mathrm{m}$ & $\mathrm{m}$ & $\mathrm{m}$ & $\mathrm{m}$ & $\mathrm{m}$ & $\mathrm{m}$ & $\mathrm{m}$ & $\mathrm{m}$ \\
\hline Russische Föderation & $\mathrm{m}$ & $\mathrm{m}$ & $\mathrm{m}$ & $\mathrm{m}$ & $\mathrm{m}$ & $\mathrm{m}$ & $\mathrm{m}$ & $\mathrm{m}$ & $\mathrm{m}$ \\
\hline Saudi-Arabien & $\mathrm{m}$ & $\mathrm{m}$ & $\mathrm{m}$ & $\mathrm{m}$ & $\mathrm{m}$ & $\mathrm{m}$ & $\mathrm{m}$ & $\mathrm{m}$ & $\mathrm{m}$ \\
\hline Südafrika & $\mathrm{m}$ & $\mathrm{m}$ & $\mathrm{m}$ & $\mathrm{m}$ & $\mathrm{m}$ & $\mathrm{m}$ & $\mathrm{m}$ & $\mathrm{m}$ & $\mathrm{m}$ \\
\hline
\end{tabular}

Quelle: OECD. Spezielle Datenerhebung der INES-Arbeitsgruppe zu Bildungsangeboten im Bereich frühkindliche Bildung und Betreuung. Hinweise s. Anhang 3 unter www.oecd.org/edu/eag.htm. StatLink: http://dx.doi.org/10.1787/888933118390 Erläuterung der Kennzeichnung fehlender Daten s. Hinweise für den Leser. 


\section{Wie viele junge Erwachsene werden ein Studium im Tertiärbereich aufnehmen?}

Während im Durchschnitt 58 Prozent der heute in den OECD-Ländern lebenden jungen Erwachsenen im Lauf ihres Lebens wahrscheinlich einen (weitgehend theoretisch orientierten) Studiengang im Tertiärbereich A aufnehmen werden, werden weniger als 3 Prozent ein Studium in einem weiterführenden forschungsorientierten Studiengang aufnehmen.

Die in allen OECD-Ländern am häufigsten von den Studienanfängern gewählte Fächergruppe ist die der Sozial-, Rechts- und Wirtschaftswissenschaften - mit Ausnahme von Finnland (Ingenieurwissenschaften, Fertigung und Bauwesen), Korea (Geisteswissenschaften, Kunst und Erziehungswissenschaften) und SaudiArabien (Geisteswissenschaften, Kunst und Erziehungswissenschaften).

- Im Durchschnitt aller OECD-Länder liegen die Studienanfängerquoten im Tertiärbereich A bei Frauen (mit 65 Prozent) immer noch höher als bei Männern ( 52 Prozent). Je höher der Bildungsbereich, umso geringer sind die geschlechtsspezifischen Unterschiede, bei weiterführenden forschungsorientierten Studiengängen bestehen nahezu keine geschlechtsspezifischen Unterschiede.

Abbildung C3.1

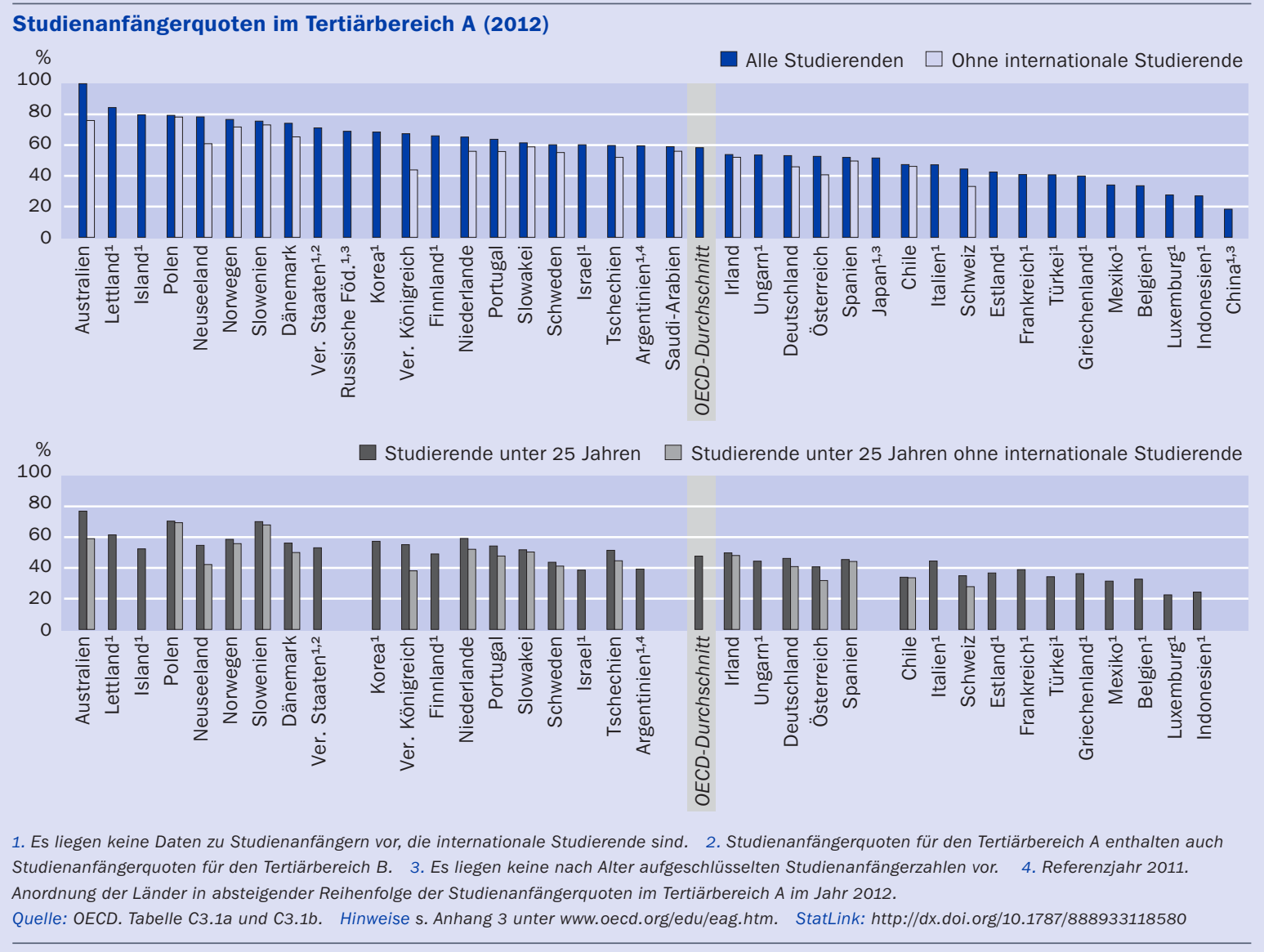




\section{Kontext}

Studienanfängerquoten stellen eine Schätzung des Anteils der Bevölkerung dar, der im Laufe des Lebens wahrscheinlich ein Studium im Tertiärbereich aufnehmen wird. Sie sind außerdem ein Hinweis auf die Zugangsmöglichkeiten zum Tertiärbereich und den Wert, der einer Ausbildung im Tertiärbereich beigemessen wird, sowie ein Anhaltspunkt dafür, in welchem Umfang die Bevölkerung die Fähigkeiten und Kenntnisse auf hohem Qualifikationsniveau erwirbt, die wissensbasierte Volkswirtschaften begründen und sie voranbringen können. Hohe Studienanfänger- und Beteiligungsquoten im Tertiärbereich lassen darauf schließen, dass eine hoch qualifizierte Erwerbsbevölkerung herangebildet und aufrechterhalten wird.

In den OECD-Ländern hat die Überzeugung, dass durch einen Hochschulabschluss erworbene Fähigkeiten und Kenntnisse einen höheren Stellenwert haben als die von Menschen mit einem niedrigeren Bildungsstand, ihre Ursache in der durchaus begründeten Befürchtung, dass „Routinetätigkeiten“ in Niedriglohnländer exportiert oder automatisiert werden können, sowie in dem wachsenden Verständnis dafür, dass Wissen und Innovation von zentraler Bedeutung für ein nachhaltiges Wirtschaftswachstum sind. Die Bildungseinrichtungen des Tertiärbereichs sehen sich nicht nur der Aufgabe gegenüber, den steigenden Bedarf durch die Erhöhung der Anzahl der angebotenen Studienplätze zu decken, sondern auch Studiengänge und Lehrmethoden an die unterschiedlichen Bedürfnisse einer neuen Generation von Studierenden anzupassen.

\section{Weitere wichtige Ergebnisse}

Während davon ausgegangen wird, dass 5 Prozent der Studierenden in Deutschland und der Schweiz im Laufe des Lebens einen weiterführenden forschungsorientierten Studiengang belegen werden, wird dies in Argentinien, Chile, Indonesien, Luxemburg und Mexiko wahrscheinlich bei weniger als I Prozent der Studierenden der Fall sein.

Basierend auf aktuellen Studienanfängerquoten wird davon ausgegangen, dass im Durchschnitt 18 Prozent der jungen Menschen von heute (20 Prozent der Frauen und 17 Prozent der Männer) im Laufe ihres Lebens einen (kürzeren und weitgehend beruflich ausgerichteten) Studiengang im Tertiärbereich B aufnehmen werden.

Werden internationale Studierende nicht berücksichtigt, sind Polen und Slowenien die beiden einzigen Länder (der 17 Länder mit verfügbaren Daten), in denen rund 70 Prozent der jungen Erwachsenen vor ihrem 25. Geburtstag ein Studium im Tertiärbereich A aufnehmen werden.

Lebenslanges Lernen ist jedoch noch nicht in allen OECD-Ländern Realität. Einerseits werden in Australien, Chile, Finnland, Island, Neuseeland und Schweden mehr als 25 Prozent der jungen Menschen, die ein Studium im Tertiärbereich A aufnehmen, älter als 25 Jahre sein. Andererseits werden in Belgien und Frankreich weniger als 5 Prozent der Studienanfänger älter als 25 Jahre sein. 


\section{Entwicklungstendenzen}

Zwischen I995 und 2012 stiegen die Studienanfängerquoten im Tertiärbereich A im Durchschnitt der OECD-Länder um fast 20 Prozentpunkte, obwohl inzwischen neue Daten einen deutlichen Rückgang von 4 Prozentpunkten seit 2010 zeigen, wahrscheinlich aufgrund der Finanzkrise. Gleichwohl war der vorherige Anstieg auf einen inzwischen in vielen Ländern erweiterten Zugang zum Tertiärbereich zurückzuführen sowie auf strukturelle Veränderungen in den Bildungssystemen einiger Länder, wie die Einrichtung neuer Studiengänge (um den Anforderungen der Arbeitsmärkte gerecht zu werden) oder kürzerer Studiengänge (im Rahmen der Umsetzung des Bologna-Prozesses). Ein weiterer Grund für die gestiegenen Anfängerquoten im Tertiärbereich ist die breitere Bewerberbasis, die inzwischen auch eine wesentlich höhere Zahl internationaler (s. Indikator $\mathrm{C}_{4}$ ) und älterer Studierender umfasst.

Währenddessen sind die Studienanfängerquoten im Tertiärbereich B zwischen 1995 und 2012 relativ gleich geblieben, ohne signifikante Veränderungen in den letzten drei Jahren während der Finanzkrise.

\section{Hinweise}

Anfängerquoten zeigen den geschätzten Prozentsatz einer Altersgruppe, der im Laufe des Lebens ein Studium im Tertiärbereich aufnehmen wird. Die Schätzung basiert auf der Zahl der Studienanfänger im Jahr 2012 und der Altersverteilung in dieser Gruppe. Daher basieren die Anfängerquoten auf der Annahme einer „synthetischen“ Kohorte, nach der die aktuellen Anfängerquoten die beste Schätzung für das Verhalten junger Erwachsener von heute im Laufe ihres Lebens darstellen. Anfängerquoten reagieren sensibel auf jede Änderung im Bildungssystem, wie die Einführung neuer Studiengänge (im Rahmen der Umsetzung des Bologna-Prozesses) oder Veränderungen der Zahl internationaler Studierender. Anfängerquoten können sehr hoch sein und in einem Zeitraum, in dem nicht in der Prognose berücksichtigte Personen beschließen, ein Studium aufzunehmen, sogar mehr als soo Prozent betragen (was eindeutig darauf hinweist, dass die Annahme einer synthetischen Kohorte nicht plausibel ist). In Australien beispielsweise sinkt die Anfängerquote im Tertiärbereich A um mehr als 25 Prozentpunkte, wenn internationale Studierende nicht berücksichtigt werden. In Portugal haben sich sehr viele Frauen über 25 dazu entschieden, ein Studium aufzunehmen, daher ist die Anfängerquote bei den Frauen von 2007 bis $201 \mathrm{I}$ um 40 Prozentpunkte gestiegen. 


\section{Analyse und Interpretationen}

\section{Zugang zum Tertiärbereich}

In den OECD-Ländern werden schätzungsweise 58 Prozent der jungen Erwachsenen von heute im Laufe ihres Lebens einen Studiengang im Tertiärbereich A aufnehmen, sofern die aktuellen Studienanfängerquoten auch für die Zukunft gelten. In mehreren Ländern werden wahrscheinlich mindestens 70 Prozent der jungen Erwachsenen ein Studium im Tertiärbereich aufnehmen, während es in Belgien, China, Indonesien, Luxemburg und Mexiko wahrscheinlich weniger als 35 Prozent sein werden (Abb. C3.I).

Der Anteil derjenigen, die ein Studium im Tertiärbereich B aufnehmen, ist im Allgemeinen vor allem deshalb niedriger, weil diese Studiengänge in den meisten OECDLändern in geringerem Umfang angeboten werden. Die Bandbreite reicht von weniger als 5 Prozent in Island, Indonesien, Mexiko, Polen und der Slowakei bis zu mehr als 35 Prozent in Belgien, Korea und Neuseeland und mehr als 50 Prozent in Argentinien und Chile (Tab. C3.ra).

Im Gegensatz hierzu wird in Belgien, Chile und China davon ausgegangen, dass die Studienanfängerquoten im Tertiärbereich B höher als im Tertiärbereich A sein werden. In diesen Ländern gleicht ein breiter Zugang zu Studiengängen im Tertiärbereich B vergleichsweise geringe Studienanfängerquoten im Tertiärbereich A aus (Abb. C3.2). Andere Länder, vor allem Argentinien, Israel und Korea, haben im Tertiärbereich A Studienanfängerquoten, die ungefähr dem OECD-Durchschnitt entsprechen, und vergleichsweise hohe Studienanfängerquoten im Tertiärbereich B. Obwohl Neuseeland zu den OECD-Ländern gehört, die für beide Tertiärbereiche mit die höchsten Studienanfängerquoten aufweisen, werden diese jedoch durch eine größere Zahl älterer und internationaler Studierender überhöht (Tab. C3.ra).

In einigen Ländern können hohe Anfängerquoten vorübergehende Phänomene widerspiegeln, wie z. B. Hochschulreformen im Rahmen der Umsetzung des Bologna-Prozesses, Auswirkungen der Wirtschaftskrise oder die Zunahme der Zahl internationaler Studierender.

Im Durchschnitt aller OECD-Länder mit vergleichbaren Daten stieg der Anteil der jungen Erwachsenen, die ein Studium im Tertiärbereich A aufnahmen, zwischen 2000 und 2012 um Io Prozentpunkte und zwischen 1995 und 2012 um fast 20 Prozentpunkte (Tab. C3.2a). Die Studienanfängerquoten bei diesen Studiengängen nahmen zwischen 2000 und 2012 in Australien, Dänemark, Deutschland, Irland, Korea, der Slowakei und Tschechien um mindestens 20 Prozentpunkte zu. In Korea war der Anstieg von 2007 auf 2008 vor allem auf eine Umklassifizierung von Studiengängen des Tertiärbereichs B in Studiengänge des Tertiärbereichs A zurückzuführen. Im Gegensatz hierzu waren Finnland, Neuseeland, Schweden und Ungarn die einzigen OECD-Länder, in denen es einen Rückgang bei den Studienanfängerquoten für diese Studiengänge gab. In Ungarn wurde dieser Rückgang im gleichen Zeitraum jedoch durch eine signifikante Steigerung der Studienanfängerquoten im Tertiärbereich B ausgeglichen. In Neuseeland spiegelten Anstieg und Rückgang der Studienanfängerquoten von 2000 auf 2012 den Anstieg und Rückgang der Zahl internationaler Studierender in diesem Zeitraum wider (Abb. C3.2). 


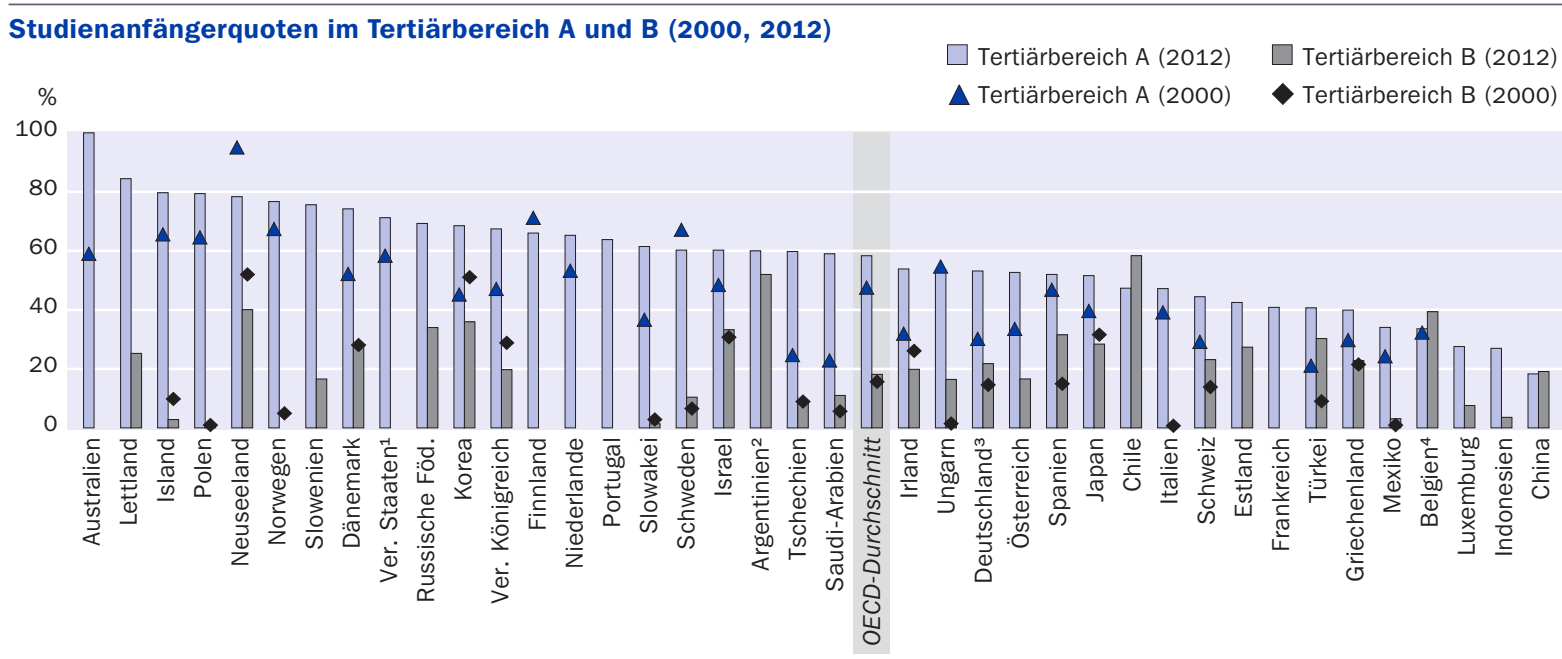

1. Studienanfängerquoten für den Tertiärbereich A enthalten auch Studienanfängerquoten für den Tertiärbereich B. 2. Referenzjahr 2011 anstelle 2012.

3. Unterbrechung der Zeitreihe zwischen 2008 und 2009 aufgrund einer teilweisen Neueinstufung berufsbildender Bildungsgänge in ISCED 2 und ISCED 5B.

4. Referenzjahr 2001 anstelle 2000.

Anordnung der Länder in absteigender Reihenfolge der Studienanfängerquoten im Tertiärbereich A im Jahr 2012.

Quelle: OECD. Tabelle C3.2a. Hinweise s. Anhang 3 unter www.oecd.org/edu/eag.htm. StatLink: http://dx.doi.org/10.1787/888933118599

In den OECD-Ländern sind die Gesamtnettostudienanfängerquoten in Studiengängen des Tertiärbereichs B zwischen 2000 und 2012 relativ stabil geblieben, mit Ausnahme von Spanien, der Türkei und Ungarn, wo sie um mehr als Io Prozentpunkte stiegen, und Korea und Neuseeland, wo sie um mehr als ro Prozentpunkte sanken (Abb. C3.2).

Rund 3 Prozent der heutigen Jugendlichen in den OECD-Ländern werden (unter Annahme der aktuellen Studienanfängerquoten) im Laufe ihres Lebens einen weiterführenden forschungsorientierten Studiengang belegen. Die Zahlen reichen in den Ländern mit vergleichbaren Daten von höchstens I Prozent in Argentinien, Chile, Indonesien, Japan, Luxemburg und Mexiko bis zu rund 5 Prozent in Deutschland und der Schweiz (Tab. C3.ra).

\section{Alter der Studienanfänger im Tertiärbereich}

2012 waren im Durchschnitt der OECD-Länder 82 Prozent der Erststudienanfänger im Tertiärbereich A und 58 Prozent im Tertiärbereich B jünger als 25 Jahre. Außerdem waren 2012 rund 57 Prozent der Studierenden, die einen weiterführenden forschungsorientierten Studiengang aufnahmen, jünger als 30 Jahre (Tab. C3.rb).

Das Alter der Studienanfänger im Tertiärbereich variiert aus unterschiedlichen Gründen zwischen den einzelnen OECD-Ländern, unter anderem aufgrund von Unterschieden im typischen Abschlussalter für den Sekundarbereich II (s. Tab. XI.ra und XI.rb), der Aufnahmekapazität von Einrichtungen (Numerus clausus bei der Zulassung, eine von zahlreichen Methoden zur Beschränkung der Zulassungszahlen für Studierende), der Opportunitätskosten des Eintritts in den Arbeitsmarkt, bevor ein Studium im Tertiärbereich aufgenommen wird, und gesellschaftlicher Erwartungen.

Während der jüngsten Wirtschaftskrise haben einige junge Erwachsene ihren Eintritt in den Arbeitsmarkt aufgeschoben und sind stattdessen im Bildungssystem verblieben. 
In einigen Ländern wurde außerdem für Menschen, die die Schule früh verlassen haben, der sogenannte zweite Bildungsweg ausgebaut, um die Qualifizierung der Arbeitskräfte zu verbessern und verstärkt Möglichkeiten zum Erwerb von praxisorientierten Kenntnissen und Fähigkeiten zu bieten. Nichtsdestotrotz verursacht ein späterer Eintritt in den Tertiärbereich höhere Kosten - sowohl für den Einzelnen als auch für den Staat. Er bedeutet, dass das produktive Potenzial dieser Menschen für einen gewissen Zeitraum nicht genutzt wird. Damit sinken die Steuereinnahmen, die staatlichen Ausgaben hingegen können steigen. Für ältere Studierende kann es schwieriger sein, Arbeit und Studium zu verbinden, was dazu führen kann, dass sie nicht in der Lage sind, ihr Studium im vorgegebenen zeitlichen Rahmen abzuschließen. Von staatlicher Seite werden inzwischen Maßnahmen zur Förderung eines rechtzeitigen Abschlusses eingeführt, da bekannt ist, dass Verzögerungen beim Erwerb eines Abschlusses zu höheren Ausbildungskosten führen. Die spätere Aufnahme eines Hochschulstudiums kann jedoch auch ein Hinweis darauf sein, dass die Studierenden dann genauer wissen, was sie studieren möchten, und höher motiviert sind.

Traditionellerweise nehmen Studierende das Studium im Tertiärbereich direkt nach dem Abschluss des Sekundarbereichs II auf, und das ist auch heute immer noch in vielen Ländern der Fall. Zum Beispiel sind in Belgien, Frankreich und Indonesien mindestens 95 Prozent der Studienanfänger im Tertiärbereich A oder B jünger als 25 Jahre. In anderen OECD-Ländern erfolgt der Übergang vom Sekundarbereich II zum Tertiärbereich unter Umständen erst später, z. B. aufgrund einer Zeit der Erwerbstätigkeit oder der Ableistung von Militärdienst. So sind beispielsweise in Israel nur zwei Drittel aller Erststudienanfänger im Tertiärbereich A jünger als 25 Jahre. In diesen Fällen gehören Erststudienanfänger im Tertiärbereich A oder B ganz unterschiedlichen Altersgruppen an (Tab. C3.Ib).

Der Anteil der älteren Studienanfänger in einem derartigen Erststudium (Tertiärbereich A und B) kann ein Anzeichen für die Flexibilität dieser Studiengänge und ihre Eignung für Studierende, die nicht der typischen Altersgruppe angehören, sein. Darüber hinaus kann er die Wertschätzung von Berufserfahrung vor der Aufnahme eines Hochschulstudiums widerspiegeln, was charakteristisch für die nordischen Länder und auch in Australien, Chile, Neuseeland, Österreich, Ungarn und den Vereinigten Staaten durchaus üblich ist, wo ein beträchtlicher Teil der Studierenden mit einem deutlich höheren Alter als dem typischen Eintrittsalter das Studium aufnimmt. Er kann auch die Reaktion auf bildungspolitische Maßnahmen sein, die darauf abzielen, das lebenslange Lernen auszuweiten und einen flexibleren Zugang zum Tertiärbereich zu schaffen. Die Gründe unterscheiden sich stark von Land zu Land. In Australien beispielsweise nehmen junge Leute in zunehmendem Maße vor Beginn des Studiums ein Jahr Auszeit: Dies war im Zeitraum 2009/2010 bei fast 25 Prozent der Schüler der Fall, und 5I Prozent von ihnen gaben „Arbeit“ als wichtigsten Grund hierfür an (Lumsden and Stanwick, 20I2). In einigen Ländern müssen junge Erwachsene Wehrdienst leisten, der die Aufnahme eines Studiums verzögert. Dies ist in Israel der Fall, wo für I8- bis 2I-jährige Männer und I8- bis 20-jährige Frauen Wehrpflicht besteht. 


\section{Auswirkungen internationaler Studierender auf die Studienanfänger- quoten im Tertiärbereich A}

Alle internationalen Studierenden, die sich zum ersten Mal in einem Land einschreiben, gelten per Definition als Studienanfänger, unabhängig von bereits absolvierten Bildungsgängen in anderen Ländern. Um die Auswirkungen internationaler Studierender auf die Studienanfängerquoten im Tertiärbereich A aufzuzeigen, enthalten die Tabellen $\mathrm{C}_{3}$.ra und $\mathrm{C}_{3}$.Ib sowohl die unbereinigten als auch die bereinigten Studienanfängerquoten, d. h. die Studienanfängerquoten nach Abzug der internationalen Studierenden.

Unter den Ländern mit vergleichbaren Daten weist Australien mit 26 Prozentpunkten den höchsten Unterschied zwischen unbereinigten und bereinigten Studienanfängerquoten auf. Dieser Unterschied ist auch im Vereinigten Königreich mit 24 Prozentpunkten sehr groß. Auch in Island, Neuseeland, Österreich und der Schweiz wirkt sich die Anwesenheit internationaler Studierender stark auf die Studienanfängerquoten aus: Es ergeben sich Unterschiede von II bis I7 Prozentpunkten (Tab. C3.ra).

Der erwartete Prozentsatz der Studienanfänger im Tertiärbereich A ändert sich deutlich, wenn ältere und internationale Studierende nicht berücksichtigt werden. Diese beiden Gruppen sind in einigen Ländern ein wesentlicher Bestandteil der studierenden Bevölkerung, sie können jedoch den zu erwartenden Anteil der jungen Erwachsenen von heute, die ein Studium aufnehmen werden, künstlich überhöhen. Werden internationale und ältere Studierende nicht berücksichtigt, sind Polen und Slowenien die beiden Länder mit dem höchsten Prozentsatz der Bevölkerung, der im Alter von unter 25 Jahren ein Studium im Tertiärbereich A aufnehmen wird. Der höhere Prozentsatz in Polen hängt mit dem Anstieg der Zahl der Absolventen des Sekundarbereichs II aufgrund der Bildungsreformen von 1999 zusammen. Diese Reformen waren darauf ausgerichtet, die Qualität der Bildung im Sekundar- und Tertiärbereich zu steigern und die Chancengleichheit zu erhöhen. Polen und Slowenien sind auch zwei der sechs Länder mit dem höchsten Anteil 25- bis 34-Jähriger, die mindestens über einen Abschluss im Sekundarbereich II verfügen (s. Indikator AI).

\section{Übergänge zwischen Tertiärbereich A und B}

In einigen Ländern werden Studiengänge im Tertiärbereich A und Tertiärbereich B von unterschiedlichen Arten von Bildungseinrichtungen angeboten. Immer häufiger jedoch bieten Universitäten oder andere Einrichtungen Studiengänge beider Bereiche an. Außerdem werden sich die beiden Bereiche im Hinblick aufCurricula, Ausrichtung und Lernergebnisse immer ähnlicher.

In einigen Ländern haben Absolventen des Tertiärbereichs B die Möglichkeit, zu Studiengängen des Tertiärbereichs A zugelassen zu werden, normalerweise zum zweiten oder dritten Studienjahr, oder sogar zu einem Masterstudiengang. Die Studienanfängerquoten für den Tertiärbereich A und den Tertiärbereich B zur Bestimmung der Gesamtstudienanfängerquoten für den Tertiärbereich einfach aufzuaddieren würde zu überhöhten Zahlen führen. Die Zulassung ist je nach Land oder Studiengang üblicherweise an bestimmte Bedingungen gebunden, wie z. B. das Bestehen einer besonderen Prüfung, vorherige persönliche oder berufliche Leistungen und/oder das Absolvieren eines „Brückenkurses“. In einigen Fällen können Studierende, die einen theoretisch 
Verteilung der Studienanfänger nach Fächergruppe (2012)

Es werden nur die Fächergruppen aufgezeigt, in denen 2012 mehr als 20 Prozent der Studierenden ein Studium aufnahmen.

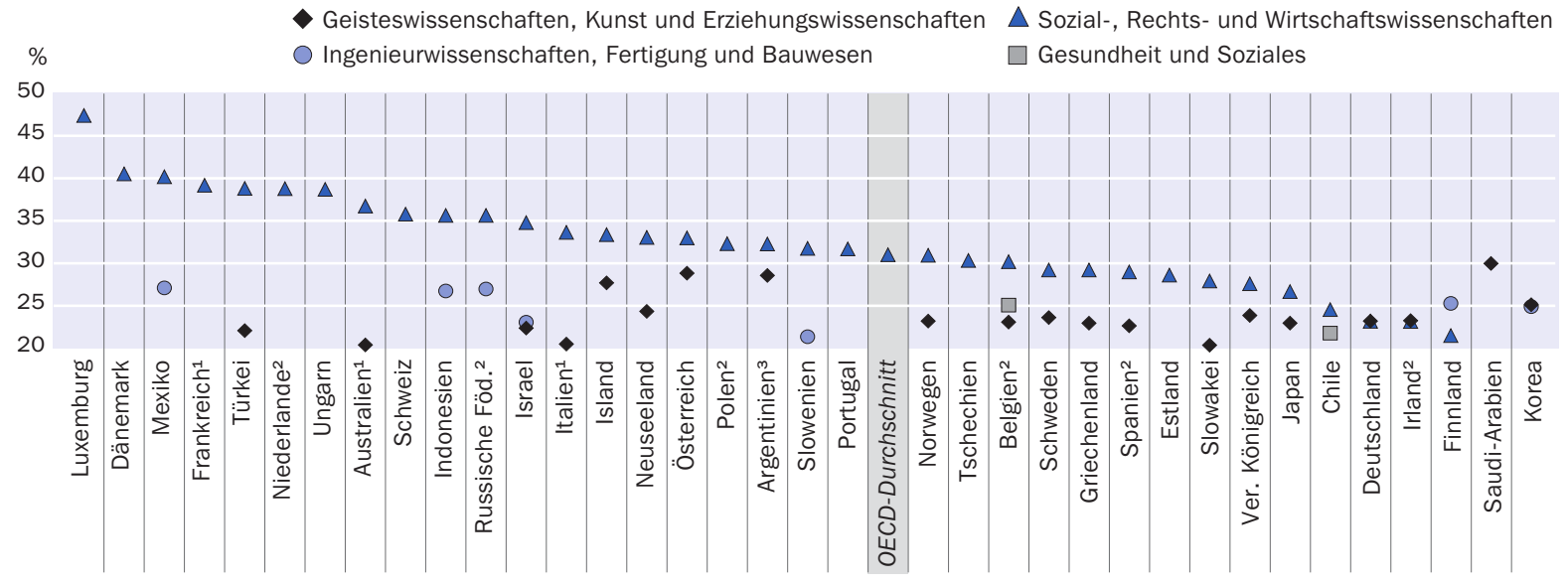

1. Ohne Studiengänge im Tertiärbereich B. 2. Ohne weiterführende forschungsorientierte Studiengänge. 3. Referenzjahr 2011.

Anordnung der Länder in absteigender Reihenfolge der Studienanfänger in „Sozial-, Rechts- und Wirtschaftswissenschaften“ im Jahr 2012.

Quelle: OECD. Tabelle C3.3а. Hinweise s. Anhang 3 unter www.oecd.org/edu/eag.htm. StatLink: http://dx.doi.org/10.1787/888933118618

orientierten Studiengang (im Tertiärbereich A) ohne Abschluss verlassen, ihr Studium im Tertiärbereich B (berufsorientiert) erfolgreich fortsetzen.

\section{Studienanfängerquoten nach Fächergruppen (Tertiärbereich A und B)}

In fast allen Ländern ist ein großer Teil der Studierenden für ein Studium in der Fächergruppe Sozial-, Rechts- und Wirtschaftswissenschaften eingeschrieben. 2012 entfiel in allen Ländern, mit Ausnahme von Finnland und Korea, der höchste Anteil der Studienanfänger auf diese Fächergruppe. In Finnland wählten die meisten Studienanfänger einen Studiengang aus der Fächergruppe Ingenieurwissenschaften, Fertigung und Bauwesen, wohingegen in Korea und Saudi-Arabien die Fächergruppe Geisteswissenschaften, Kunst und Erziehungswissenschaften den größten Zulauf erfuhr (Abb. C3.3).

Studiengänge aus naturwissenschaftlich ausgerichteten Fächergruppen, dies umfasst die Natur- und Ingenieurwissenschaften, Fertigung und Bauwesen, werden weniger häufig gewählt. Im Durchschnitt entscheidet sich nur ein Viertel aller Studierenden für die Aufnahme eines Studiums in diesen Fächergruppen (Tab. C3.3a). Dieser geringe Anteil an der Gesamtzahl der Studierenden ist teilweise darauf zurückzuführen, dass Frauen in diesen Fächergruppen unterrepräsentiert sind. 2012 haben sich im Durchschnitt nur I4 Prozent der weiblichen Studienanfänger im Tertiärbereich für einen Studiengang aus diesen Fächergruppen entschieden gegenüber 39 Prozent der männlichen Studienanfänger. Bei den Studienanfängern reicht der Anteil der Frauen in naturwissenschaftlich ausgerichteten Studiengängen von 5 bis 6 Prozent in Belgien, Japan und den Niederlanden bis zu I9 bis 20 Prozent in Griechenland, Italien und Mexiko und der Russischen Föderation, während der Anteil der Männer in diesen Studiengängen von 17 Prozent in Argentinien bis zu 58 Prozent in Finnland reicht (Tab. C3.3b im Internet).

Die Verteilung der Studienanfänger nach Fächergruppen fällt bei den weiterführenden forschungsorientierten Studiengängen ganz anders aus als für den Tertiärbereich insge- 
samt. Obwohl die Sozial-, Rechts- und Wirtschaftswissenschaften 2012 die beliebteste Fächergruppe der Studierenden im Tertiärbereich war, haben Promotionsstudierende naturwissenschaftlich ausgerichtete Studiengänge etwas stärker bevorzugt als diese Fächergruppe. Fast ein Viertel der Studierenden, die ein Promotionsstudium aufnahmen, wählte die Naturwissenschaften (24 Prozent) - dieser Anteil ist mehr als doppelt so hoch wie der der Studienanfänger in dieser Fächergruppe (Io Prozent). In Frankreich, Israel und Luxemburg entschieden sich mehr als 35 Prozent der Studierenden in einem weiterführenden forschungsorientierten Studiengang für die Naturwissenschaften.

\section{Weiterführende forschungsorientierte Studiengänge: \\ Die Wissensfabrik der Gesellschaft}

Forschung auf Promotionsniveau ist von entscheidender Bedeutung für die Förderung von Innovationen und Wirtschaftswachstum und trägt signifikant zu der nationalen und internationalen Wissensbasis bei. Für Unternehmen sind Länder, die einen leichten Zugang zu Forschungsvorhaben auf diesem Niveau bieten, von großem Interesse (Halse and Mowbray, 20II; Smith, 20I0), während Absolventen dieser Studiengänge von höheren Einkommen und besseren Beschäftigungsquoten profitieren (s. Indikatoren $\mathrm{A}_{5}$ und $\mathrm{A} 6$ ).

Viele OECD-Länder investieren stark, um Promotionsstudiengänge anbieten zu können. Abbildung $\mathrm{C}_{3} .4$ zeigt den Anteil der Studierenden in den OECD-Ländern, die ihr Studium bis zum höchsten akademischen Abschluss fortsetzen werden. In Deutschland, Österreich, der Schweiz und in Slowenien wird davon ausgegangen, dass jeder 20. Studierende einen weiterführenden forschungsorientierten Studiengang aufnehmen wird. In Argentinien, Chile, Indonesien, Luxemburg und Mexiko hingegen wird (unter Zugrundelegung der aktuellen Zahlen) erwartet, dass dies bei weniger als I Prozent der Studierenden im Lauf ihres Lebens der Fall sein wird (Tab. C3.ra). Die Studienanfängerquoten können in diesen Ländern jedoch auch zu niedrig angesetzt sein, da Studierende aus Lateinamerika sehr häufig ihr Promotionsstudium in den Vereinigten Staaten absolvieren. Gleiches gilt für Studierende aus Indonesien, die für das Promotionsstudium nach Australien, und Studierende aus Luxemburg, die hierfür in andere europäische Länder gehen.

Verschiedene Länder entwickeln zurzeit Promotionsstudiengänge oder ändern ihre Finanzierungspolitik, um für internationale Studierende, also Studierende, die aus ihrem Herkunftsland zwecks Studium in ein anderes Land gehen, interessant zu werden. Die besten Studierenden aus der ganzen Welt anzuziehen trägt dazu bei sicherzustellen, dass ein Land bei Forschung und Innovation eine führende Rolle einnimmt (Smith, 2010). So sind beispielsweise mehr als die Hälfte der Studienanfänger in Promotionsstudiengängen in der Schweiz internationale Studierende (Abb. C3.4). Außerdem stellten 2012 - wie aus Indikator $\mathrm{C}_{4}$ ersichtlich - internationale Studierende, also Studierende, die nicht Staatsbürger des Landes sind, in dem die Daten erhoben wurden, in Neuseeland (mit 4I Prozent), der Schweiz (5I Prozent) und dem Vereinigten Königreich (4I Prozent) einen Großteil der Studierenden in diesen Studiengängen.

Obwohl in den OECD-Ländern fast 6o Prozent der Studienanfänger ihr Studium in einem weiterführenden forschungsorientierten Studiengang vor ihrem 30. Geburtstag aufgenommen haben, bestehen zwischen den einzelnen Ländern signifikante Unter- 


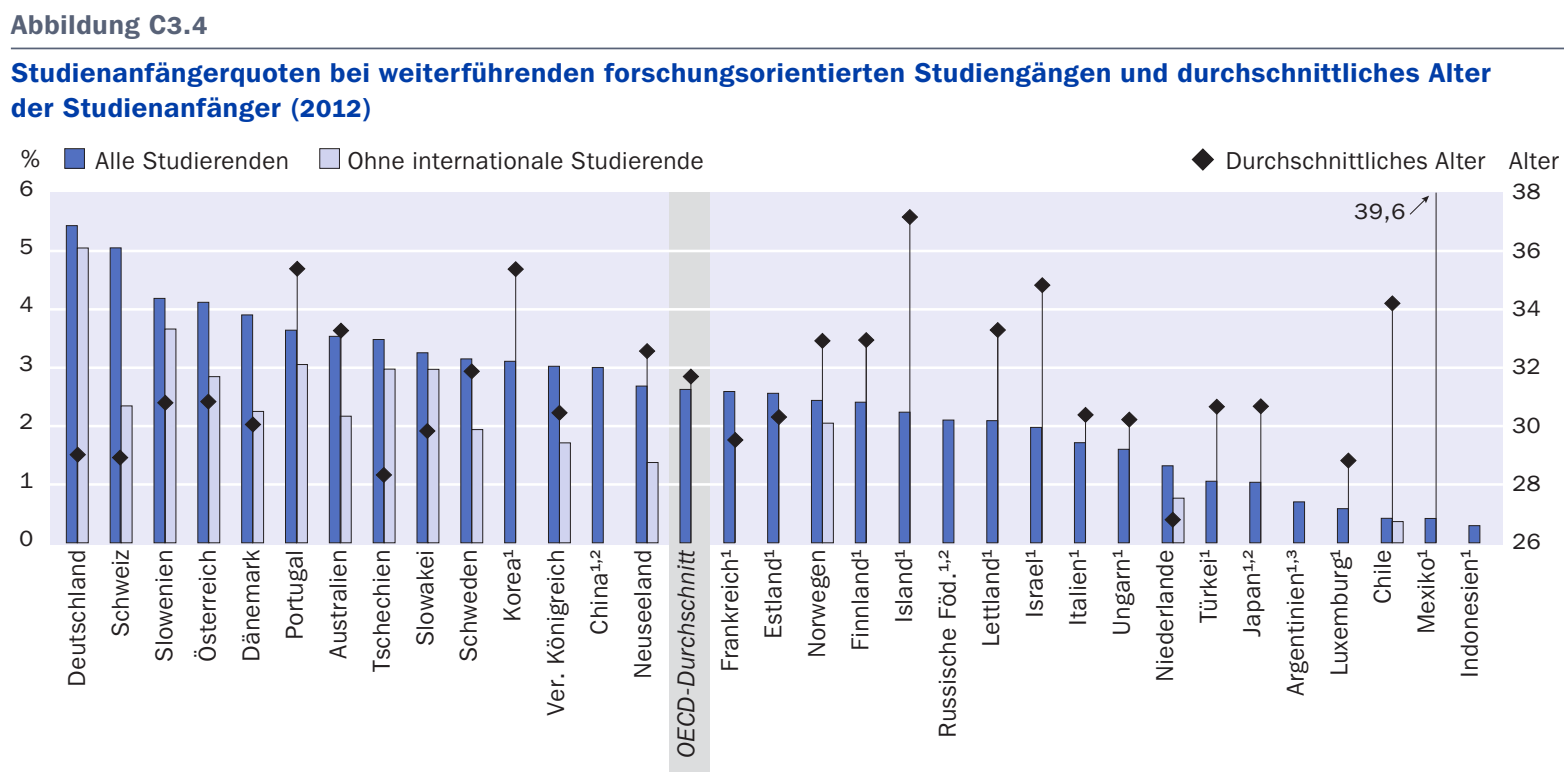

Anmerkung: Das durchschnittliche Alter bezieht sich auf ein gewichtetes durchschnittliches Alter, in der Regel das Alter von Studierenden zu Beginn des Kalenderjahres. Die Studierenden können ein Jahr älter als das angegebene durchschnittliche Alter sein, wenn sie ihren Abschluss am Ende des Studienjahres erwerben. Informationen zur Berechnung des durchschnittlichen Abschlussalters s. Anhang 3.

1. Es liegen keine Daten zu Studienanfängern vor, die internationale Studierende sind. 2. Es liegen keine Daten zu nach Alter aufgeschlüsselten Studienanfängerzahlen vor. 3. Referenzjahr 2011.

Anordnung der Länder in absteigender Reihenfolge der Studienanfänger in weiterführenden forschungsorientierten Studiengängen im Jahr 2012.

Quelle: OECD. Tabelle C3.1a. Hinweise s. Anhang 3 unter www.oecd.org/edu/eag.htm. StatLink: http://dx.doi.org/10.1787/888933118637

schiede. In Deutschland, Indonesien, den Niederlanden und Tschechien sind mehr als 75 Prozent der Studierenden bei Aufnahme eines Studiums in diesem Bildungsbereich jünger als 30 Jahre, während in Island, Israel, Korea, Mexiko und Portugal das durchschnittliche Alter bei mehr als 35 Jahren liegt (Tab. C3.ra und $\mathrm{C}_{3} \cdot \mathrm{rb}$ ).

Diese Unterschiede können auf mehrere Faktoren zurückzuführen sein. Sie könnten geringere Abbruchquoten und eine größere Bedeutung des Erwerbs spezieller Kompetenzen mit einem ersten Abschluss eines Studiums im Tertiärbereich A widerspiegeln. Einige Länder bieten spezielle Anreize, wie Studienbeihilfen, Stipendien, internationale Mobilitätsprogramme, Teilzeitbeschäftigungen und Fernstudiengänge, um Studierende zu motivieren, ihre Ausbildung direkt nach ihrem ersten Abschluss des Tertiärbereichs fortzusetzen. Andererseits könnte die späte Aufnahme des Promotionsstudiums mit unterschiedlichen Studiengebühren, der Verfügbarkeit von Stipendien und/oder gesellschaftlichen Erwartungen zusammenhängen, wenn beispielsweise erwartet wird, dass bis zu einem bestimmten Alter der Eintritt in den Arbeitsmarkt erfolgt oder vor Aufnahme eines Promotionsstudiums Berufserfahrungen gewonnen werden.

Die Promotionsstudiengänge sind der einzige Bildungsbereich, in dem nahezu keine geschlechtsspezifischen Unterschiede bestehen. Während in jedem anderen Bildungsbereich der Anteil der Frauen höher als der der Männer ist, ist dies der einzige Bildungsbereich, in dem der Anteil der Männer bei den Anfängern (und folglich bei den Absolventen) etwas höher als der der Frauen ist. Im Durchschnitt aller OECD-Länder nehmen 2,7 Prozent der Männer und 2,6 Prozent der Frauen ein Promotionsstudium auf (Tab. C3.ra). 


\section{Definitionen}

Studierende werden als internationale Studierende eingestuft, wenn sie aus ihrem Herkunftsland zwecks Studium in ein anderes Land gekommen sind. Internationale Studierende, die im Rahmen eines Studiums zum ersten Mal an dem Bildungssystem eines Landes teilnehmen, gelten als Studienanfänger im Erststudium.

Studienanfänger im Erststudium sind Studierende, die sich zum ersten Mal in dem entsprechenden Bildungsbereich einschreiben.

Studienanfängerquote ist die geschätzte Wahrscheinlichkeit, mit der ein junger Erwachsener im Laufe des Lebens ein Studium im Tertiärbereich aufnehmen wird (ausgehend von den aktuellen Studienanfängerquoten).

\section{Angewandte Methodik}

Die Daten beziehen sich auf das Schuljahr 20II/20I2 und beruhen auf der von der OECD im Jahre 2013 durchgeführten UOE-Datenerhebung zur Bildungsstatistik (weitere Informationen s. Anhang 3 unter www.oecd.org/edu/eag.htm). Die Fächergruppen, die in der UOE-Datenerhebung verwendet wurden, entsprechen der überarbeiteten ISCED97-Klassifizierung nach Fächergruppen. Diese Klassifizierung nach Fächergruppen wird auf alle Bildungsbereiche angewendet.

Die Daten zur Entwicklung der Studienanfängerquoten (Tab. C3.2a) für die Jahre I995, 2000, 2001, 2002, 2003 und 2004 basieren auf einer speziellen Erhebung, die im Januar 2007 in den OECD-Ländern durchgeführt wurde.

Die Daten zu den Auswirkungen internationaler Studierender auf die Studienanfängerquoten basieren auf einer im Dezember 2013 von der OECD durchgeführten speziellen Erhebung.

Die Tabellen C3.ra, C3.rb, C3.2a und C3.2b enthalten die Summe der Netto-Studienanfängerquoten für alle Altersgruppen.

Die Netto-Studienanfängerquote eines speziellen Altersjahrgangs wird berechnet, indem die Zahl der Erststudienanfänger des speziellen Altersjahrgangs in den einzelnen Tertiärbereichen durch die Gesamtpopulation des entsprechenden Altersjahrgangs geteilt wird. Die Summe der Netto-Studienanfängerquoten wird berechnet, indem die Studienanfängerquoten der einzelnen Altersjahrgänge aufaddiert werden. Das Ergebnis zeigt die geschätzte Wahrscheinlichkeit, mit der ein Schulabgänger im Laufe des Lebens ein Studium im Tertiärbereich aufnehmen wird, sofern die heutigen altersspezifischen Studienanfängerquoten unverändert bleiben.

Das gewichtete Durchschnittsalter bei Aufnahme des Studiums wird berechnet, indem den Altersjahrgängen ein höheres Gewicht zugewiesen wird, in denen die Zahl der Studierenden, die in einen neuen Bildungsbereich eintreten, höher ist. Diese Varia- 
ble vermittelt eine genaue Vorstellung vom durchschnittlichen Eintrittsalter. Weitere Informationen s. Anhang 3.

Nicht alle OECD-Länder unterscheiden zwischen Studierenden, die zum ersten Mal einen Studiengang des Tertiärbereichs aufnehmen, und Studierenden, die zwischen den Tertiärbereichen wechseln, einen Studiengang des Tertiärbereichs wiederholen oder nach einer gewissen Unterbrechung wieder aufnehmen. Daher können die Studienanfängerquoten für ein Erststudium im Tertiärbereich A und B aufgrund der unvermeidlichen Doppelzählung von Studienanfängern nicht einfach aufaddiert werden, um zu einer Gesamtstudienanfängerquote für den Tertiärbereich zu gelangen.

Anmerkung zu den Daten aus Israel

Die statistischen Daten für Israel wurden von den zuständigen israelischen Stellen bereitgestellt, die für sie verantwortlich zeichnen. Die Verwendung dieser Daten durch die OECD erfolgt unbeschadet des völkerrechtlichen Status der Golanhöhen, von Ost-Jerusalem und der israelischen Siedlungen im Westjordanland.

\section{Weiterführende Informationen}

Halse C. and S. Mowbray (20II), „The impact of the doctorate“, Studies in Higher Education, Vol. 5, No. 36, pp. 513-525, www.tandfonline.com/doi/abs/10.1080/03075079.2011. 594590 .

Lumsden, M. and J. Stanwick (2012), „Who takes a gap year and why?“, Longitudinal Surveys Of Australian Youth, Briefing Paper 28, National Centre for Vocational Education Research (NCVER), Adelaide.

OECD (2013), Bildung auf einen Blick 2013 - OECD-Indikatoren, W. Bertelsmann Verlag, Bielefeld.

Smith, A. (2010), „One step beyond: making the most of postgraduate education“, Report for UK Department for Business, Innovation and Skills.

\section{Tabellen Indikator $\mathbf{C 3}_{3}$}

StatLink: http://dx.doi.org/10.1787/888933118485

Tabelle C3.ra: Studienanfängerquoten im Tertiärbereich und durchschnittliches Alter der Studienanfänger, nach Geschlecht und Ziel des Studiengangs (2012)

Table $C_{3}$.Ib: Studienanfängerquoten von jungen Menschen unterhalb des typischen Eintrittsalters (2012)

Tabelle C3.2a: Entwicklung der Studienanfängerquoten im Tertiärbereich (I995-2012) 
WEB Table $\mathrm{C}_{3} .2 \mathrm{~b}$ : Trends in entry rates at tertiary level, by gender (Entwicklung der Studienanfängerquoten im Tertiärbereich, nach Geschlecht) (2005-2012)

Tabelle C3·3a: Studienanfänger im Tertiärbereich, nach Fächergruppe (2012)

WEB Table $\mathrm{C}_{3} \cdot 3 \mathrm{~b}$ : Distribution of tertiary new entrants, by field of education and gender (Studienanfänger im Tertiärbereich, nach Fächergruppe und Geschlecht) (20I2)

WEB Table C3.3c: Distribution of new entrants into advanced research programmes, by field of education (Studienanfänger in weiterführenden forschungsorientierten Studiengängen, nach Fächergruppe) (2012) 
Studienanfängerquoten im Tertiärbereich und durchschnittliches Alter der Studienanfänger, nach Geschlecht und Ziel des Studiengangs (2012)

Summe der Abschlussquoten der einzelnen Altersjahrgänge, nach Geschlecht und Ziel des Studiengangs

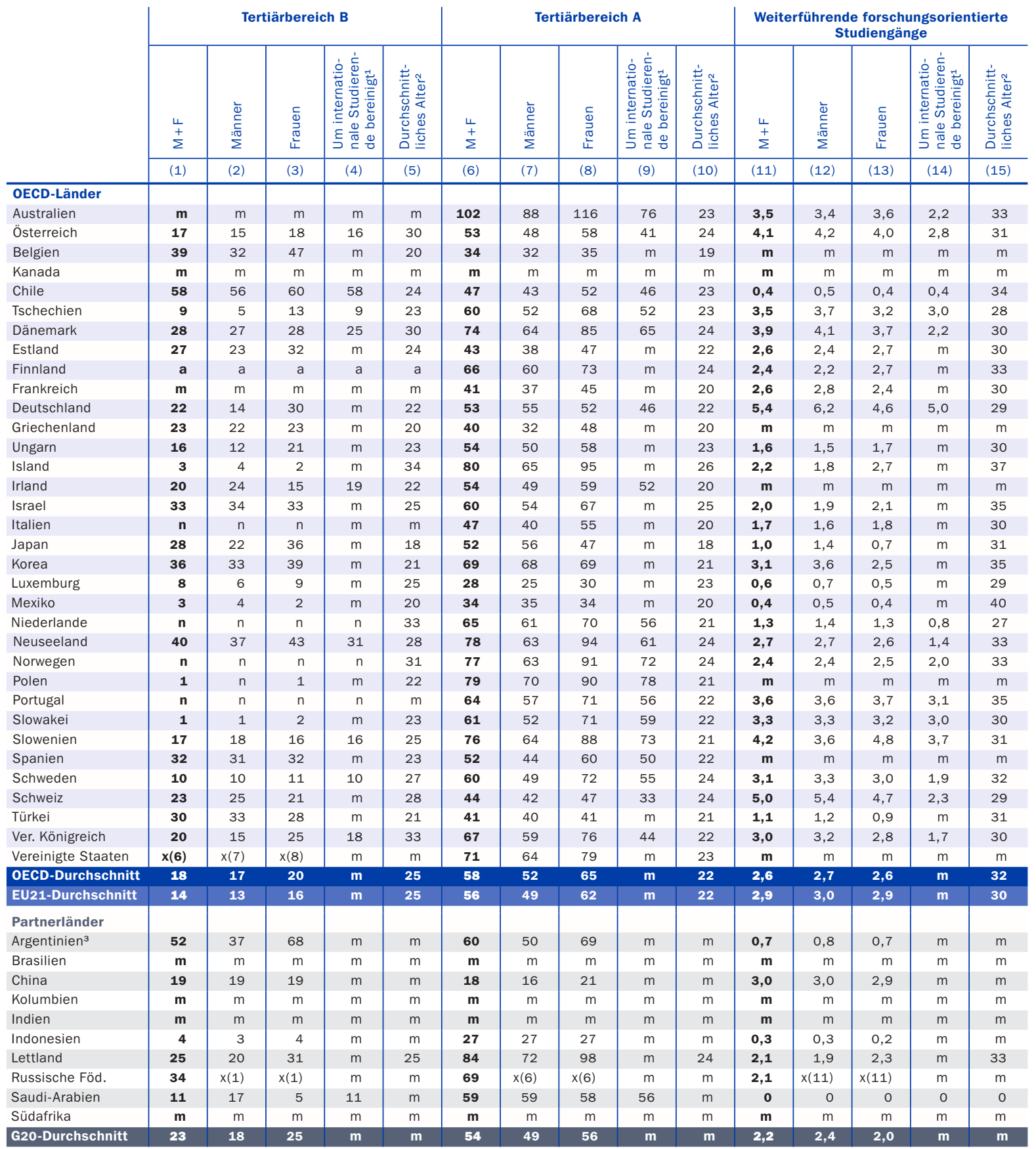

Anmerkung: Unterschiede im Erhebungsbereich der Bevölkerungsdaten und der Studienanfängerdaten bedeuten, dass die Studienanfängerquoten von Ländern mit einem Nettoabgang von Studierenden wohl zu niedrig angesetzt und Länder mit einem Nettozugang von Studierenden wohl zu hoch angesetzt sind. Bei den bereinigten Studienanfängerquoten ist dies weitgehend berücksichtigt. Länderspezifische Informationen s. Anhang 3. Weiterführende Informationen zu den zur Berechnung der (Brutto-/Netto-)Studienanfängerquoten verwendeten Methoden und dem entsprechenden Alter bei Aufnahme des Studiums s. Anhang 1.

1. Die bereinigten Studienanfängerquoten entsprechen den Studienanfängerquoten ohne Berücksichtigung internationaler Studierender. 2. Das „durchschnittliche Alter" bezieht sich auf ein gewichtetes durchschnittliches Alter, in der Regel das Alter von Studierenden zu Beginn des Kalenderjahres. Die Studierenden können ein Jahr älter als das angegebe durchschnittliche Alter sein, wenn sie ihren Abschluss gegen Ende des Studienjahres erwerben. Informationen zur Berechnung des durchschnittlichen Abschlussalters s. Anhang 3. 3. Referenzjahr 2011.

Quelle: OECD. Argentinien, China, Indien, Indonesien, Kolumbien und Südafrika: Statistikinstitut der UNESCO. Lettland: Eurostat. Saudi-Arabien: Observatory on Higher Education. Hinweise s. Anhang 3 unter www.oecd.org/edu/eag.htm. StatLink: http://dx.doi.org/10.1787/888933118504 Erläuterung der Kennzeichnung fehlender Daten s. Hinweise für den Leser. 
Studienanfängerquoten von jungen Menschen unterhalb des typischen Eintrittsalters (2012)

Summe der Netto-Studienanfängerquoten der Altersjahrgänge bis 25 Jahre für Tertiärbereich A oder B und bis 30 Jahre für weiterführende forschungsorientierte Studiengänge

\begin{tabular}{|c|c|c|c|c|c|c|c|c|c|c|c|c|c|c|c|}
\hline & \multicolumn{5}{|c|}{ Tertiärbereich B } & \multicolumn{5}{|c|}{ Tertiärbereich $\mathrm{A}$} & \multicolumn{5}{|c|}{$\begin{array}{l}\text { Weiterführende forschungsorientierte } \\
\text { Studiengänge }\end{array}$} \\
\hline & $\stackrel{L}{+}+$ & 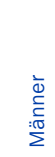 & $\begin{array}{l}\overline{\bar{\omega}} \\
\stackrel{\sigma}{\tilde{L}}\end{array}$ & 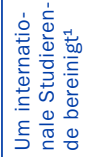 & 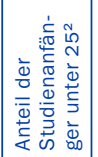 & 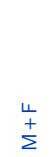 & 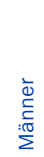 & 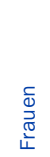 & 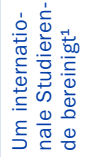 & 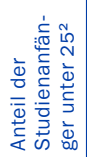 & $\begin{array}{l}u \\
\stackrel{+}{+} \\
\Sigma\end{array}$ & 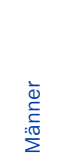 & $\begin{array}{l}\frac{c}{\mathbb{N}} \\
\frac{\mathbb{\widetilde { J }}}{\tilde{L}}\end{array}$ & 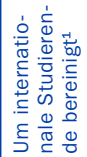 & 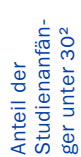 \\
\hline & (1) & (2) & (3) & (4) & (5) & (6) & (7) & (8) & (9) & (10) & (11) & (12) & (13) & (14) & (15) \\
\hline \multicolumn{16}{|l|}{ OECD-Länder } \\
\hline Australien & m & $\mathrm{m}$ & $\mathrm{m}$ & $\mathrm{m}$ & $\mathrm{m}$ & 77 & 67 & 88 & 59 & 74 & 1,7 & 1,7 & 1,7 & 0,9 & 49 \\
\hline Österreich & 8 & 7 & 8 & 8 & 44 & 41 & 35 & 47 & 32 & 76 & 2,6 & 2,6 & 2,6 & 1,8 & 63 \\
\hline Belgien & 38 & 31 & 44 & $\mathrm{~m}$ & 95 & 33 & 31 & 34 & $\mathrm{~m}$ & 97 & m & $\mathrm{m}$ & $\mathrm{m}$ & $\mathrm{m}$ & $\mathrm{m}$ \\
\hline Kanada & m & $\mathrm{m}$ & $\mathrm{m}$ & $\mathrm{m}$ & $\mathrm{m}$ & m & $\mathrm{m}$ & $\mathrm{m}$ & $\mathrm{m}$ & $\mathrm{m}$ & m & $\mathrm{m}$ & $\mathrm{m}$ & $\mathrm{m}$ & $\mathrm{m}$ \\
\hline Chile & 39 & 38 & 39 & 38 & 69 & 34 & 30 & 38 & 34 & 75 & 0,2 & 0,2 & 0,2 & 0,2 & 45 \\
\hline Tschechien & 7 & 4 & 10 & 7 & 80 & 51 & 46 & 57 & 45 & 83 & 2,9 & 3,0 & 2,7 & 2,5 & 79 \\
\hline Dänemark & 12 & 13 & 12 & 10 & 45 & 56 & 47 & 66 & 50 & 76 & 2,5 & 2,8 & 2,1 & 1,0 & 61 \\
\hline Estland & 20 & 17 & 22 & $\mathrm{~m}$ & 71 & 37 & 33 & 41 & $\mathrm{~m}$ & 85 & 1,6 & 1,4 & 1,7 & $\mathrm{~m}$ & 65 \\
\hline Finnland & a & $a$ & a & a & a & 49 & 45 & 53 & $\mathrm{~m}$ & 75 & 1,1 & 1,1 & 1,2 & $\mathrm{~m}$ & 49 \\
\hline Frankreich & m & $\mathrm{m}$ & $\mathrm{m}$ & $\mathrm{m}$ & $\mathrm{m}$ & 39 & 35 & 43 & $\mathrm{~m}$ & 95 & 1,8 & 1,9 & 1,7 & $\mathrm{~m}$ & 69 \\
\hline Deutschland & 16 & 9 & 24 & $\mathrm{~m}$ & 73 & 46 & 47 & 45 & 41 & 86 & 4,0 & 4,6 & 3,5 & 3,7 & 75 \\
\hline Griechenland & 21 & 20 & 21 & $\mathrm{~m}$ & 88 & 36 & 29 & 44 & $\mathrm{~m}$ & 87 & $\mathbf{m}$ & $\mathrm{m}$ & $\mathrm{m}$ & $\mathrm{m}$ & $\mathrm{m}$ \\
\hline Ungarn & 14 & 10 & 18 & $\mathrm{~m}$ & 82 & 44 & 41 & 48 & $\mathrm{~m}$ & 80 & 1,1 & 1,0 & 1,2 & $\mathrm{~m}$ & 66 \\
\hline Island & 1 & 1 & 1 & $\mathrm{~m}$ & 18 & 52 & 45 & 60 & $\mathrm{~m}$ & 66 & 1,1 & 1,1 & 1,1 & $\mathrm{~m}$ & 33 \\
\hline Irland & 17 & 21 & 13 & 17 & 83 & 50 & 45 & 55 & 48 & 90 & m & $\mathrm{m}$ & $\mathrm{m}$ & $\mathrm{m}$ & $\mathrm{m}$ \\
\hline Israel & 20 & 16 & 25 & $\mathrm{~m}$ & 62 & 39 & 29 & 48 & $\mathrm{~m}$ & 65 & 0,7 & 0,6 & 0,8 & $\mathrm{~m}$ & 35 \\
\hline Italien & $\mathrm{n}$ & $\mathrm{n}$ & $\mathrm{n}$ & $\mathrm{m}$ & $n$ & 44 & 37 & 52 & $\mathrm{~m}$ & 94 & 1,2 & 1,1 & 1,3 & $\mathrm{~m}$ & 64 \\
\hline Japan & m & $\mathrm{m}$ & $\mathrm{m}$ & $\mathrm{m}$ & $\mathrm{m}$ & m & $\mathrm{m}$ & $\mathrm{m}$ & $\mathrm{m}$ & $\mathrm{m}$ & $\mathbf{m}$ & $\mathrm{m}$ & $\mathrm{m}$ & $\mathrm{m}$ & $\mathrm{m}$ \\
\hline Korea & 32 & 30 & 35 & $\mathrm{~m}$ & 89 & 57 & 56 & 59 & $\mathrm{~m}$ & 83 & 1,3 & 1,4 & 1,1 & $\mathrm{~m}$ & 38 \\
\hline Luxemburg & 5 & 3 & 6 & $\mathrm{~m}$ & 57 & 22 & 21 & 24 & $\mathrm{~m}$ & 79 & 0,4 & 0,3 & 0,4 & $\mathrm{~m}$ & 63 \\
\hline Mexiko & 3 & 3 & 2 & $\mathrm{~m}$ & 93 & 31 & 32 & 31 & $\mathrm{~m}$ & 93 & 0,1 & 0,1 & 0,1 & $\mathrm{~m}$ & 26 \\
\hline Niederlande & $\mathrm{n}$ & $\mathrm{n}$ & $\mathrm{n}$ & $\mathrm{n}$ & 40 & 59 & 55 & 63 & 52 & 91 & 1,1 & 1,2 & 1,1 & 0,7 & 87 \\
\hline Neuseeland & 21 & 21 & 20 & 15 & 55 & 55 & 46 & 64 & 42 & 72 & 1,3 & 1,4 & 1,3 & 0,6 & 52 \\
\hline Norwegen & $\mathbf{n}$ & $\mathrm{n}$ & $\mathrm{n}$ & $\mathrm{n}$ & 38 & 59 & 48 & 70 & 56 & 76 & 1,2 & 1,3 & 1,2 & 1,0 & 49 \\
\hline Polen & 1 & $n$ & 1 & $\mathrm{~m}$ & 76 & 70 & 62 & 79 & 69 & 87 & m & $\mathrm{m}$ & $\mathrm{m}$ & $\mathrm{m}$ & $\mathrm{m}$ \\
\hline Portugal & $\mathbf{n}$ & $\mathrm{n}$ & $\mathrm{n}$ & $\mathrm{n}$ & $\mathrm{n}$ & 54 & 46 & 62 & 48 & 82 & 1,6 & 1,4 & 1,7 & 1,3 & 37 \\
\hline Slowakei & 1 & 1 & 2 & $\mathrm{~m}$ & 83 & 52 & 44 & 59 & 50 & 82 & 2,3 & 2,2 & 2,4 & 2,2 & 69 \\
\hline Slowenien & 11 & 13 & 10 & 11 & 64 & 70 & 60 & 81 & 68 & 90 & 2,8 & 2,3 & 3,3 & 2,4 & 64 \\
\hline Spanien & 25 & 25 & 25 & $\mathrm{~m}$ & 73 & 45 & 38 & 53 & 44 & 82 & m & $\mathrm{m}$ & $\mathrm{m}$ & $\mathrm{m}$ & $\mathrm{m}$ \\
\hline Schweden & 5 & 5 & 5 & 5 & 52 & 44 & 37 & 51 & 41 & 74 & 1,8 & 2,0 & 1,5 & 0,9 & 57 \\
\hline Schweiz & 11 & 11 & 11 & $\mathrm{~m}$ & 45 & 35 & 32 & 38 & 28 & 77 & 3,8 & 4,0 & 3,5 & 1,8 & 73 \\
\hline Türkei & 25 & 27 & 23 & $\mathrm{~m}$ & 83 & 34 & 33 & 36 & $\mathrm{~m}$ & 84 & 0,6 & 0,7 & 0,6 & $\mathrm{~m}$ & 60 \\
\hline Ver. Königreich & 7 & 6 & 7 & 5 & 34 & 55 & 50 & 61 & 38 & 82 & 1,8 & 1,9 & 1,7 & 1,0 & 62 \\
\hline Vereinigte Staaten & $x(6)$ & $x(7)$ & $x(8)$ & $\mathrm{m}$ & $\mathrm{m}$ & 53 & 51 & 56 & $\mathrm{~m}$ & 76 & m & $\mathrm{m}$ & $\mathrm{m}$ & $\mathrm{m}$ & $\mathrm{m}$ \\
\hline OECD-Durchschnitt & 12 & 12 & 13 & m & 58 & 48 & 42 & 53 & m & 82 & 1,6 & 1,7 & 1,6 & m & 57 \\
\hline EU21-Durchschnitt & 10 & 9 & 11 & m & 57 & 48 & 42 & 53 & m & 84 & 1,9 & 1,9 & 1,9 & m & 64 \\
\hline \multicolumn{16}{|l|}{ Partnerländer } \\
\hline Argentinien ${ }^{3}$ & 31 & 24 & 38 & $\mathrm{~m}$ & 60 & 39 & 34 & 45 & $\mathrm{~m}$ & 68 & m & m & $\mathrm{m}$ & $\mathrm{m}$ & $\mathrm{m}$ \\
\hline Brasilien & m & $\mathrm{m}$ & $\mathrm{m}$ & $\mathrm{m}$ & $\mathrm{m}$ & m & $\mathrm{m}$ & $\mathrm{m}$ & $\mathrm{m}$ & $\mathrm{m}$ & m & $\mathrm{m}$ & $\mathrm{m}$ & $\mathrm{m}$ & $\mathrm{m}$ \\
\hline China & $\mathbf{m}$ & $\mathrm{m}$ & $\mathrm{m}$ & $\mathrm{m}$ & $\mathrm{m}$ & m & $\mathrm{m}$ & $\mathrm{m}$ & $\mathrm{m}$ & $\mathrm{m}$ & $\mathbf{m}$ & $\mathrm{m}$ & $\mathrm{m}$ & $\mathrm{m}$ & $\mathrm{m}$ \\
\hline Kolumbien & m & $\mathrm{m}$ & $\mathrm{m}$ & $\mathrm{m}$ & $\mathrm{m}$ & m & $\mathrm{m}$ & $\mathrm{m}$ & $\mathrm{m}$ & $\mathrm{m}$ & m & $\mathrm{m}$ & $\mathrm{m}$ & $\mathrm{m}$ & $\mathrm{m}$ \\
\hline Indien & $\mathbf{m}$ & $\mathrm{m}$ & $\mathrm{m}$ & $\mathrm{m}$ & $\mathrm{m}$ & m & $\mathrm{m}$ & $\mathrm{m}$ & $\mathrm{m}$ & $\mathrm{m}$ & $\mathbf{m}$ & $\mathrm{m}$ & $\mathrm{m}$ & $\mathrm{m}$ & $\mathrm{m}$ \\
\hline Indonesien & 4 & 3 & 4 & $\mathrm{~m}$ & 100 & 24 & 25 & 24 & $\mathrm{~m}$ & 100 & 0,3 & 0,3 & 0,2 & $\mathrm{~m}$ & 92 \\
\hline Lettland & 17 & 14 & 20 & $\mathrm{~m}$ & 67 & 62 & 54 & 70 & $\mathrm{~m}$ & 73 & 0,9 & 0,8 & 1,1 & $\mathrm{~m}$ & 47 \\
\hline Russische Föd. & m & $\mathrm{m}$ & $\mathrm{m}$ & $\mathrm{m}$ & $\mathrm{m}$ & m & $\mathrm{m}$ & $\mathrm{m}$ & $\mathrm{m}$ & $\mathrm{m}$ & m & $\mathrm{m}$ & m & $\mathrm{m}$ & $\mathrm{m}$ \\
\hline Saudi-Arabien & m & $\mathrm{m}$ & $\mathrm{m}$ & $\mathrm{m}$ & $\mathrm{m}$ & m & $\mathrm{m}$ & $\mathrm{m}$ & $\mathrm{m}$ & $\mathrm{m}$ & m & $\mathrm{m}$ & $\mathrm{m}$ & $\mathrm{m}$ & $\mathrm{m}$ \\
\hline Südafrika & $\mathbf{m}$ & $\mathrm{m}$ & $\mathrm{m}$ & $\mathrm{m}$ & $\mathrm{m}$ & m & $\mathrm{m}$ & $\mathrm{m}$ & $\mathrm{m}$ & $\mathrm{m}$ & m & $\mathrm{m}$ & $\mathrm{m}$ & $\mathrm{m}$ & $\mathrm{m}$ \\
\hline G20-Durchschnitt & m & m & $\mathbf{m}$ & m & m & $\mathbf{m}$ & $\mathbf{m}$ & m & m & m & m & m & $\mathbf{m}$ & m & m \\
\hline
\end{tabular}

Anmerkung: Unterschiede im Erhebungsbereich der Bevölkerungsdaten und der Studienanfängerdaten bedeuten, dass die Studienanfängerquoten von Ländern mit einem Nettoabgang von Studierenden wohl zu niedrig angesetzt und Länder mit einem Nettozugang von Studierenden wohl zu hoch angesetzt sind. Bei den bereinigten Studienanfängerquoten ist dies weitgehend berücksichtigt. Weiterführende Informationen zu den zur Berechnung der (Brutto-/Netto-)Studienanfängerquoten verwendeten Methoden und dem entsprechenden typischen Alter bei Aufnahme des Studiums s. Anhang 1.

1. Die bereinigten Studienanfängerquoten entsprechen den Studienanfängerquoten ohne Berücksichtigung internationaler Studierender. 2. Anteil der unter 25-jährigen Studienanfänger an allen Studienanfängern. 3. Referenzjahr 2011.

Quelle: OECD. Argentinien, China, Indien, Indonesien, Kolumbien, Saudi-Arabien und Südafrika: Statistikinstitut der UNESCO. Lettland: Eurostat. Hinweise s. Anhang 3 unter www.oecd.org/edu/eag.htm. StatLink: http://dx.doi.org/10.1787/888933118523

Erläuterung der Kennzeichnung fehlender Daten s. Hinweise für den Leser. 
Entwicklung der Studienanfängerquoten im Tertiärbereich (1995-2012)

\begin{tabular}{|c|c|c|c|c|c|c|c|c|c|c|c|c|}
\hline & \multicolumn{6}{|c|}{ Tertiärbereich $5 \mathrm{~A}^{1}$} & \multicolumn{6}{|c|}{ Tertiärbereich 5B } \\
\hline & 1995 & 2000 & 2005 & 2010 & 2011 & 2012 & 1995 & 2000 & 2005 & 2010 & 2011 & 2012 \\
\hline & (1) & (2) & (7) & (12) & (13) & (14) & (15) & $(16)$ & (21) & (26) & (27) & (28) \\
\hline \multicolumn{13}{|l|}{ OECD-Länder } \\
\hline Australien & $\mathrm{m}$ & 59 & 82 & 96 & 96 & 102 & $\mathrm{~m}$ & $\mathrm{~m}$ & $\mathrm{~m}$ & $\mathrm{~m}$ & $\mathrm{~m}$ & m \\
\hline Österreich & 27 & 34 & 37 & 53 & 52 & 53 & $\mathrm{~m}$ & $\mathrm{~m}$ & 9 & 16 & 16 & 17 \\
\hline Belgien & $\mathrm{m}$ & $\mathrm{m}$ & 33 & 33 & 33 & 34 & $\mathrm{~m}$ & $\mathrm{~m}$ & 34 & 38 & 38 & 39 \\
\hline Kanada & $\mathrm{m}$ & $\mathrm{m}$ & $\mathrm{m}$ & $\mathrm{m}$ & $\mathrm{m}$ & $\mathbf{m}$ & $\mathrm{m}$ & $\mathrm{m}$ & $\mathrm{m}$ & $\mathrm{m}$ & $\mathrm{m}$ & $\mathbf{m}$ \\
\hline Chile & $\mathrm{m}$ & $\mathrm{m}$ & 46 & 47 & 45 & 47 & $\mathrm{~m}$ & $\mathrm{~m}$ & 35 & 58 & 59 & 58 \\
\hline Tschechien & $\mathrm{m}$ & 25 & 41 & 60 & 60 & 60 & $\mathrm{~m}$ & 9 & 8 & 9 & 9 & 9 \\
\hline Dänemark & 40 & 52 & 57 & 65 & 71 & 74 & 33 & 28 & 23 & 25 & 26 & 28 \\
\hline Estland & $\mathrm{m}$ & $\mathrm{m}$ & 55 & 43 & 43 & 43 & $\mathrm{~m}$ & $\mathrm{~m}$ & 33 & 29 & 28 & 27 \\
\hline Finnland & 39 & 71 & 73 & 68 & 68 & 66 & 32 & a & a & a & a & a \\
\hline Frankreich & $\mathrm{m}$ & $\mathrm{m}$ & $\mathrm{m}$ & $\mathrm{m}$ & 39 & 41 & $\mathrm{~m}$ & $\mathrm{~m}$ & $\mathrm{~m}$ & $\mathrm{~m}$ & $\mathrm{~m}$ & $\mathbf{m}$ \\
\hline Deutschland $^{2}$ & 26 & 30 & 36 & 42 & 46 & 53 & 15 & 15 & 14 & 21 & 21 & 22 \\
\hline Griechenland & 15 & 30 & 43 & $\mathrm{~m}$ & 40 & 40 & 5 & 21 & 13 & $\mathrm{~m}$ & 31 & 23 \\
\hline Ungarn & $\mathrm{m}$ & 55 & 68 & 54 & 52 & 54 & $\mathrm{~m}$ & 1 & 11 & 16 & 17 & 16 \\
\hline Island & $\mathrm{m}$ & 66 & 74 & 93 & 81 & 80 & $\mathrm{~m}$ & 10 & 7 & 4 & 4 & 3 \\
\hline Irland & $\mathrm{m}$ & 32 & 45 & 56 & 51 & 54 & $\mathrm{~m}$ & 26 & 14 & 28 & 24 & 20 \\
\hline Israel & $\mathrm{m}$ & 48 & 55 & 60 & 60 & 60 & $\mathrm{~m}$ & 31 & 25 & 29 & 27 & 33 \\
\hline Italien & $\mathrm{m}$ & 39 & 56 & 49 & 48 & 47 & $\mathrm{~m}$ & 1 & $n$ & $n$ & $\mathrm{n}$ & $\mathrm{n}$ \\
\hline Japan & 31 & 40 & 44 & 51 & 52 & 52 & 33 & 32 & 31 & 27 & 29 & 28 \\
\hline Korea & 41 & 45 & 51 & 71 & 69 & 69 & 27 & 51 & 48 & 36 & 37 & 36 \\
\hline Luxemburg & $\mathrm{m}$ & $\mathrm{m}$ & $\mathrm{m}$ & $\mathrm{m}$ & 27 & 28 & $\mathrm{~m}$ & $\mathrm{~m}$ & $\mathrm{~m}$ & $\mathrm{~m}$ & 10 & 8 \\
\hline Mexiko & $\mathrm{m}$ & 24 & 27 & 33 & 34 & 34 & $\mathrm{~m}$ & 1 & 2 & 3 & 3 & 3 \\
\hline Niederlande & 44 & 53 & 59 & 65 & 65 & 65 & a & a & a & $\mathrm{n}$ & $\mathrm{n}$ & m \\
\hline Neuseeland & 83 & 95 & 76 & 79 & 76 & 78 & 44 & 52 & 50 & 47 & 44 & 40 \\
\hline Norwegen & 59 & 67 & 73 & 76 & 76 & 77 & 5 & 5 & $\mathrm{n}$ & $\mathrm{n}$ & $\mathrm{n}$ & m \\
\hline Polen & 36 & 65 & 76 & 84 & 81 & 79 & 1 & 1 & 1 & 1 & 1 & 1 \\
\hline Portugal & $\mathrm{m}$ & $\mathrm{m}$ & $\mathrm{m}$ & 89 & 98 & 64 & $\mathrm{~m}$ & $\mathrm{~m}$ & $\mathrm{~m}$ & $\mathrm{n}$ & $\mathrm{n}$ & $\mathrm{n}$ \\
\hline Slowakei & 28 & 37 & 59 & 65 & 61 & 61 & 1 & 3 & $\mathrm{~m}$ & 1 & 1 & 1 \\
\hline Slowenien & $\mathrm{m}$ & $\mathrm{m}$ & 40 & 77 & 75 & 76 & $\mathrm{~m}$ & $\mathrm{~m}$ & 49 & 19 & 18 & 17 \\
\hline Spanien & $\mathrm{m}$ & 47 & 43 & 52 & 53 & 52 & 3 & 15 & 22 & 26 & 28 & 32 \\
\hline Schweden & 57 & 67 & 76 & 76 & 72 & 60 & $\mathrm{~m}$ & 7 & 7 & 12 & 11 & 10 \\
\hline Schweiz & 17 & 29 & 37 & 44 & 44 & 44 & 29 & 14 & 16 & 23 & 22 & 23 \\
\hline Türkei & 18 & 21 & 27 & 40 & 39 & 41 & 9 & 9 & 19 & 28 & 27 & 30 \\
\hline Vereinigtes Königreich & $\mathrm{m}$ & 47 & 51 & 63 & 64 & 67 & $\mathrm{~m}$ & 29 & 28 & 26 & 23 & 20 \\
\hline Vereinigte Staaten & 57 & 58 & 64 & 74 & 72 & 71 & $x(1)$ & $x(2)$ & $x(7)$ & $x(12)$ & $x(13)$ & $x(14)$ \\
\hline OECD-Durchschnitt & 39 & 48 & 54 & 62 & 59 & 58 & 17 & 16 & 18 & 19 & 19 & 18 \\
\hline $\begin{array}{l}\text { OECD-Durchschnitt } \\
\text { für Länder mit verfüg- } \\
\text { baren Daten für die } \\
\text { Jahre } 2000 \text { bis } 2012\end{array}$ & & 48 & 55 & 62 & 61 & 61 & & 17 & 19 & 21 & 21 & 19 \\
\hline EU21-Durchschnitt & 35 & 46 & 53 & 61 & 57 & 56 & 11 & 11 & 16 & 15 & 15 & 14 \\
\hline
\end{tabular}

\begin{tabular}{|c|c|c|c|c|c|c|c|c|c|c|c|c|}
\hline \multicolumn{13}{|l|}{ Partnerländer } \\
\hline Argentinien & $\mathrm{m}$ & $\mathrm{m}$ & $\mathrm{m}$ & 60 & 60 & m & $\mathrm{m}$ & $\mathrm{m}$ & $\mathrm{m}$ & 52 & 52 & m \\
\hline Brasilien & $\mathrm{m}$ & $\mathrm{m}$ & $\mathrm{m}$ & $\mathrm{m}$ & $\mathrm{m}$ & m & $\mathrm{m}$ & $\mathrm{m}$ & $\mathrm{m}$ & $\mathrm{m}$ & $\mathrm{m}$ & m \\
\hline China & $\mathrm{m}$ & $\mathrm{m}$ & $\mathrm{m}$ & 17 & 19 & 18 & $\mathrm{~m}$ & $\mathrm{~m}$ & $m$ & 19 & 19 & 19 \\
\hline Kolumbien & $\mathrm{m}$ & $\mathrm{m}$ & $\mathrm{m}$ & $\mathrm{m}$ & $\mathrm{m}$ & m & $\mathrm{m}$ & $\mathrm{m}$ & $\mathrm{m}$ & $\mathrm{m}$ & $\mathrm{m}$ & m \\
\hline Indien & $\mathrm{m}$ & $\mathrm{m}$ & $\mathrm{m}$ & $\mathrm{m}$ & $\mathrm{m}$ & m & $\mathrm{m}$ & $\mathrm{m}$ & $\mathrm{m}$ & $\mathrm{m}$ & $\mathrm{m}$ & m \\
\hline Indonesien & $\mathrm{m}$ & $\mathrm{m}$ & $\mathrm{m}$ & 22 & 24 & 27 & $\mathrm{~m}$ & $\mathrm{~m}$ & $\mathrm{~m}$ & 5 & 4 & 4 \\
\hline Lettland & $\mathrm{m}$ & $\mathrm{m}$ & $\mathrm{m}$ & $\mathrm{m}$ & $\mathrm{m}$ & 84 & $\mathrm{~m}$ & $\mathrm{~m}$ & $\mathrm{~m}$ & $\mathrm{~m}$ & $\mathrm{~m}$ & 25 \\
\hline Russische Föderation & $\mathrm{m}$ & $\mathrm{m}$ & 67 & 77 & 72 & 69 & $\mathrm{~m}$ & $\mathrm{~m}$ & 33 & 29 & 25 & 34 \\
\hline Saudi-Arabien & 24 & 23 & 37 & 48 & 53 & 59 & 4 & 6 & 10 & 11 & 10 & 11 \\
\hline Südafrika & $\mathrm{m}$ & $\mathrm{m}$ & $\mathrm{m}$ & $\mathrm{m}$ & $\mathrm{m}$ & m & $\mathrm{m}$ & $\mathrm{m}$ & $\mathrm{m}$ & $\mathrm{m}$ & $\mathrm{m}$ & m \\
\hline G20-Durchschnitt & $\mathbf{m}$ & m & $\mathbf{m}$ & 53 & 53 & 53 & m & m & $\mathbf{m}$ & 21 & 22 & 20 \\
\hline
\end{tabular}

Anmerkung: Die Spalten für die Studienanfängerquoten für die Jahre 2001-2004, 2006-2009, d.h. die Spalten (3) bis (6), (8) bis (11), (17) bis (20) und (22) bis (25) sind im Internet verfügbar (s. StatLink unten). Weiterführende Informationen zu den zur Berechnung der (Brutto-/Netto-)Studienanfängerquoten verwendeten Methoden und dem entsprechenden typischen Alter bei Aufnahme des Studiums s. Anhang 1.

1. Studienanfängerquoten für den Tertiärbereich A enthalten für 1995 sowie für 2000 bis 2003 (mit Ausnahme von Belgien und Deutschland) weiterführende forschungsorientierte Studiengänge. 2. Unterbrechung der Zeitreihe zwischen 2008 und 2009 aufgrund einer teilweisen Neueinstufung berufsbildender Bildungsgänge in ISCED 2 und ISCED $5 B$.

Quelle: OECD. Argentinien, China, Indien, Indonesien, Kolumbien und Südafrika: Statistikinstitut der UNESCO. Lettland: Eurostat. Saudi-Arabien: Observatory on Higher Education. Hinweise s. Anhang 3 unter www.oecd.org/edu/eag.htm. StatLink: http://dx.doi.org/10.1787/888933118542

Erläuterung der Kennzeichnung fehlender Daten s. Hinweise für den Leser. 
Studienanfänger im Tertiärbereich, nach Fächergruppe (2012)

\begin{tabular}{|c|c|c|c|c|c|c|c|c|}
\hline & \begin{tabular}{|} 
Geisteswis- \\
senschaften, \\
Kunst und \\
Erziehungswis- \\
senschaften
\end{tabular} & $\begin{array}{l}\text { Gesundheit } \\
\text { und Soziales }\end{array}$ & $\begin{array}{c}\text { Sozial-, } \\
\text { Rechts- und } \\
\text { Wirtschaftswis- } \\
\text { senschaften }\end{array}$ & $\begin{array}{c}\text { Dienst- } \\
\text { leistungen }\end{array}$ & $\begin{array}{l}\text { Ingenieurwis- } \\
\text { senschaften, } \\
\text { Fertigung und } \\
\text { Bauwesen }\end{array}$ & $\begin{array}{l}\text { Naturwissen- } \\
\text { schaften }\end{array}$ & $\begin{array}{l}\text { Agrarwissen- } \\
\text { schaften }\end{array}$ & $\begin{array}{l}\text { Nicht bekannt } \\
\text { oder keine } \\
\text { Angabe }\end{array}$ \\
\hline & (1) & (4) & (5) & (6) & (7) & (8) & (13) & (14) \\
\hline \multicolumn{9}{|l|}{ OECD-Länder } \\
\hline Australien $^{1}$ & 20 & 17 & 37 & 4 & 9 & 12 & 1 & $\mathrm{n}$ \\
\hline Österreich & 29 & 7 & 33 & 3 & 16 & 10 & 1 & $\mathrm{n}$ \\
\hline Belgien² & 23 & 25 & 30 & 2 & 10 & 5 & 3 & 1 \\
\hline Kanada & $\mathrm{m}$ & $\mathrm{m}$ & m & $\mathrm{m}$ & $\mathrm{m}$ & $\mathrm{m}$ & $\mathrm{m}$ & $\mathrm{m}$ \\
\hline Chile & 16 & 22 & 25 & 12 & 18 & 6 & 2 & $\mathrm{n}$ \\
\hline Tschechien & 17 & 13 & 30 & 6 & 15 & 13 & 4 & 2 \\
\hline Dänemark & 16 & 19 & 41 & 2 & 12 & 8 & 2 & $\mathrm{n}$ \\
\hline Estland & 18 & 12 & 29 & 9 & 16 & 14 & 2 & $\mathrm{n}$ \\
\hline Finnland & 14 & 19 & 22 & 8 & 25 & 9 & 2 & $\mathrm{n}$ \\
\hline Frankreich ${ }^{1}$ & 19 & 10 & 39 & 4 & 9 & 18 & $\mathrm{n}$ & $\mathrm{n}$ \\
\hline Deutschland & 23 & 19 & 23 & 3 & 17 & 13 & 1 & $\mathrm{n}$ \\
\hline Griechenland & 23 & 11 & 29 & 2 & 17 & 15 & 3 & $\mathrm{n}$ \\
\hline Ungarn & 14 & 10 & 39 & 12 & 14 & 9 & 2 & $\mathrm{n}$ \\
\hline Island & 28 & 11 & 33 & 3 & 10 & 13 & 1 & $\mathrm{n}$ \\
\hline Irland ${ }^{2}$ & 23 & 14 & 23 & 7 & 11 & 17 & 2 & 2 \\
\hline Israel & 22 & 7 & 35 & $\mathrm{n}$ & 23 & 8 & $\mathrm{n}$ & 4 \\
\hline Italien ${ }^{1}$ & 21 & 12 & 34 & 4 & 16 & 10 & 3 & $\mathrm{n}$ \\
\hline Japan & 23 & 16 & 27 & 9 & 14 & 2 & 2 & 7 \\
\hline Korea & 25 & 14 & 20 & 7 & 25 & 7 & 1 & $\mathrm{n}$ \\
\hline Luxemburg & $\mathrm{m}$ & 12 & 47 & $\mathrm{n}$ & 8 & 9 & $\mathrm{n}$ & $\mathrm{n}$ \\
\hline Mexiko & 14 & 9 & 40 & 1 & 27 & 6 & 2 & $\mathrm{n}$ \\
\hline Niederlande $^{2}$ & 17 & 19 & 39 & 7 & 9 & 7 & 1 & 1 \\
\hline Neuseeland & 24 & 12 & 33 & 6 & 7 & 17 & 1 & $\mathrm{n}$ \\
\hline Norwegen & 23 & 17 & 31 & 7 & 9 & 9 & 1 & 2 \\
\hline Polen ${ }^{2}$ & 19 & 9 & 32 & 10 & 18 & 10 & 2 & $\mathrm{n}$ \\
\hline Portugal & 16 & 16 & 32 & 8 & 19 & 8 & 2 & $\mathrm{n}$ \\
\hline Slowakei & 20 & 18 & 28 & 6 & 15 & 10 & 3 & $\mathrm{n}$ \\
\hline Slowenien & 14 & 10 & 32 & 10 & 21 & 9 & 3 & $\mathrm{n}$ \\
\hline Spanien ${ }^{2}$ & 23 & 13 & 29 & 8 & 16 & 9 & 1 & $\mathrm{n}$ \\
\hline Schweden & 24 & 14 & 29 & 3 & 18 & 11 & 1 & $\mathrm{n}$ \\
\hline Schweiz & 16 & 13 & 36 & 8 & 16 & 9 & 1 & 1 \\
\hline Türkei & 22 & 6 & 39 & 5 & 16 & 9 & 3 & $\mathrm{n}$ \\
\hline Ver. Königreich & 24 & 17 & 28 & 2 & 8 & 15 & 1 & 6 \\
\hline Vereinigte Staaten & $\mathrm{m}$ & $\mathrm{m}$ & $\mathbf{m}$ & $\mathrm{m}$ & $\mathrm{m}$ & $\mathrm{m}$ & $\mathrm{m}$ & $\mathrm{m}$ \\
\hline OECD-Durchschnitt & 20 & 13 & 31 & 5 & 15 & 10 & 2 & 4 \\
\hline EU21-Durchschnitt & 20 & 14 & 32 & 5 & 15 & 11 & 2 & 1 \\
\hline \multicolumn{9}{|l|}{ Partnerländer } \\
\hline Argentinien ${ }^{3}$ & 29 & 13 & 32 & 5 & 8 & 9 & 2 & 1 \\
\hline Brasilien & $\mathrm{m}$ & $\mathrm{m}$ & m & $\mathrm{m}$ & $\mathrm{m}$ & $\mathrm{m}$ & $\mathrm{m}$ & $\mathrm{m}$ \\
\hline China & $\mathrm{m}$ & $\mathrm{m}$ & m & $\mathrm{m}$ & $\mathrm{m}$ & $\mathrm{m}$ & $\mathrm{m}$ & $\mathrm{m}$ \\
\hline Kolumbien & $\mathrm{m}$ & $\mathrm{m}$ & m & $\mathrm{m}$ & $\mathrm{m}$ & $\mathrm{m}$ & $\mathrm{m}$ & $\mathrm{m}$ \\
\hline Indien & $\mathrm{m}$ & $\mathrm{m}$ & m & $\mathrm{m}$ & $\mathrm{m}$ & $\mathrm{m}$ & $\mathrm{m}$ & $\mathrm{m}$ \\
\hline Indonesien & 12 & 7 & 36 & 7 & 27 & 8 & 2 & 3 \\
\hline Lettland & $\mathrm{m}$ & $\mathrm{m}$ & $\mathbf{m}$ & $\mathrm{m}$ & $\mathrm{m}$ & $\mathrm{m}$ & $\mathrm{m}$ & $\mathrm{m}$ \\
\hline Russische Föd. ${ }^{2}$ & 12 & 7 & 36 & 7 & 27 & 8 & 2 & 3 \\
\hline Saudi-Arabien & 30 & 5 & 19 & 1 & 5 & 11 & 1 & 28 \\
\hline Südafrika & $\mathrm{m}$ & $\mathrm{m}$ & m & $\mathrm{m}$ & $\mathrm{m}$ & $\mathrm{m}$ & $\mathrm{m}$ & $\mathrm{m}$ \\
\hline G20-Durchschnitt & $\mathbf{m}$ & $\mathbf{m}$ & $\mathbf{m}$ & $\mathbf{m}$ & m & m & $\mathbf{m}$ & m \\
\hline
\end{tabular}

Anmerkung: Die Spalten mit getrennten Angaben zu „Erziehungswissenschaften“ und „Geisteswissenschaften und Kunst“, d.h. die Spalten (2) und (3), sowie zu den einzelnen Naturwissenschaften, d.h. die Spalten (9) bis (12), sind im Internet verfügbar (s. StatLink unten).

1. Ohne Studiengänge im Tertiärbereich B. 2. Ohne weiterführende forschungsorientierte Studiengänge. 3. Referenzjahr 2011.

Quelle: OECD. Argentinien, China, Indien, Indonesien, Kolumbien und Südafrika: Statistikinstitut der UNESCO. Lettland: Eurostat. Saudi-Arabien: Observatory on Higher Education. Hinweise s. Anhang 3 unter www.oecd.org/edu/eag.htm. StatLink: http://dx.doi.org/10.1787/888933118561

Erläuterung der Kennzeichnung fehlender Daten s. Hinweise für den Leser. 



\section{Wer studiert im Ausland und wo?}

2012 waren mehr als 4,5 Millionen Studierende außerhalb ihres Heimatlandes eingeschrieben. Australien, Luxemburg, Neuseeland, Österreich, die Schweiz und das Vereinigte Königreich haben die höchsten Anteile internationaler Studierender an der Gesamtzahl eingeschriebener Studierender.

Studierende aus Asien stellen weltweit 53 Prozent der eingeschriebenen ausländischen Studierenden. In absoluten Zahlen kommen die meisten ausländischen Studierenden dieses Kontinents aus China, Indien und Korea.

2012 war die Zahl der in OECD-Ländern eingeschriebenen ausländischen Studierenden im Durchschnitt dreimal so hoch wie die Zahl der Studierenden aus OECDLändern, die im Ausland studierten. Bei den 2r europäischen Ländern, die Mitglied der OECD sind, kamen im Durchschnitt auf jeden im Ausland studierenden europäischen Staatsbürger 3 ausländische Studierende.

Rund 82 Prozent aller ausländischen Studierenden sind in G20-Ländern eingeschrieben und 75 Prozent in OECD-Ländern. Diese Anteile sind in den letzten zehn Jahren stabil geblieben.

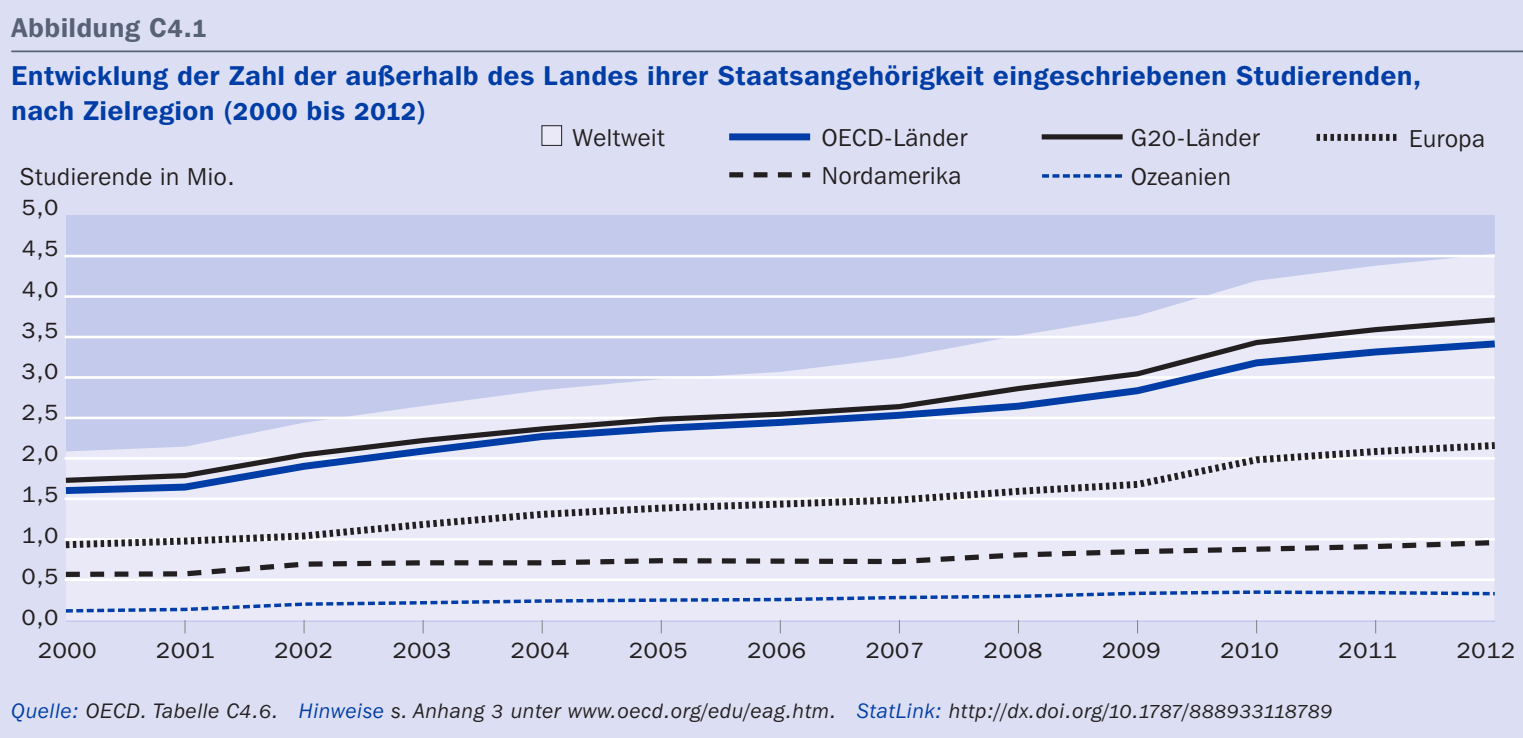

\section{Kontext}

Bedingt durch die zunehmende internationale Vernetzung der Volkswirtschaften und eine wachsende Bildungsteilnahme erwarten sowohl die Regierungen als auch die Bürger von der Ausbildung im Tertiärbereich, dass sie den Horizont der Studierenden erweitern und ihnen ein besseres Verständnis der Sprachen, Kulturen und betriebswirtschaftlichen Methoden anderer Länder ermöglicht. Eine Möglichkeit für Studierende, ihre Kenntnisse anderer Gesellschaften und Sprachen zu erweitern und so ihre Chancen in globalisierten Bereichen der Arbeitsmärkte zu verbessern, besteht darin, zum Studium ins Ausland zu gehen. 
Die zum allgemeinen Anstieg der Mobilität Studierender führenden Faktoren reichen von der weltweit außerordentlich stark steigenden Nachfrage nach einer Ausbildung im Tertiärbereich und dem Wert, der einem Studium an angesehenen ausländischen Einrichtungen im Tertiärbereich beigemessen wird, über spezielle bildungspolitische Rahmenbedingungen zur Förderung der Mobilität von Studierenden in einer geografischen Region (wie dies in Europa der Fall ist) bis zur staatlichen Unterstützung Studierender, die bestimmte, in ihrem Herkunftsland stark nachgefragte Fächergruppen studieren. Darüber hinaus betreiben einige Länder und Einrichtungen ein intensives Marketing, um Studierende aus dem Ausland zu gewinnen.

Die zunehmende Mobilität der Studierenden im Tertiärbereich kann insbesondere für kleinere und/oder weniger entwickelte Bildungssysteme eine Chance sein, ihr Bildungsangebot kosteneffizienter zu gestalten. Denn durch sie können Länder in die Lage versetzt werden, ihre begrenzten finanziellen Mittel auf diejenigen Bildungsangebote zu konzentrieren, in denen sie Größenvorteile erreichen können, bzw. die Bildungsbeteiligung im Tertiärbereich ohne die Notwendigkeit der Bereitstellung entsprechender Studienplätze im eigenen Land zu erhöhen. Für die Zielländer kann die Aufnahme internationaler Studierender nicht nur dazu beitragen, mit Bildungsangeboten im Hochschulbereich Einnahmen zu erzielen, sie kann auch Teil einer breiter angelegten Strategie zur Anwerbung hoch qualifizierter Einwanderer sein.

Ein signifikant hoher Teil der Studierenden aus G20-Ländern, die nicht Mitglied der OECD sind, gehört zu den leistungsfähigeren Studierenden, die naheliegende Kandidaten für eine öffentliche oder private Unterstützung sind, oder sie haben einen relativ günstigen sozioökonomischen Hintergrund. Damit kann die Mobilität Studierender nicht nur die Reputation der Studiengänge des Tertiärbereichs fördern, sondern den Bildungssystemen der Zielländer auch wirtschaftliche Vorteile bringen.

Angesichts der aktuellen wirtschaftlichen Situation können die sinkende Unterstützung mit Stipendien und Beihilfen sowie knappere Mittel der einzelnen Studierenden die Mobilität der Studierenden insgesamt verringern. Andererseits können begrenzte Möglichkeiten auf den Arbeitsmärkten der Herkunftsländer der Studierenden die Attraktivität eines Auslandsstudiums als Möglichkeit, im Wettbewerb einen Schritt voraus zu sein, erhöhen und so zu einer Steigerung der Mobilität Studierender beitragen.

Internationale Studierende wählen häufig andere Studiengänge als inländische Studierende (s. Indikator A4 in Bildung aufeinen Blick 2011), was entweder auf eine gewisse Spezialisierung der Länder bei den angebotenen Studiengängen, einen Mangel an entsprechenden Studiengängen im Herkunftsland und/oder bessere Beschäftigungsmöglichkeiten bei Belegung spezieller Fächergruppen schließen lässt.

In diesem Indikator handelt es sich bei „internationalen Studierenden“ bzw. „mobilen Studierenden " um Studierende, die ausdrücklich zum Studium aus ihrem Herkunftsland in ein anderes Land gekommen sind. „Ausländische Studierende“ andererseits sind Studierende, die nicht Staatsbürger des Landes sind, in dem sie eingeschrieben sind, jedoch in manchen Fällen dort bereits seit vielen Jahren ihren dauerhaften Wohnsitz haben oder sogar dort geboren wurden. Internationale Studierende sind also im Allgemeinen eine Untergruppe der ausländischen Studierenden (s. Abschnitt Definitionen am Ende des Indikators). 


\section{Weitere wichtige Ergebnisse}

In Australien, Deutschland, Frankreich, Kanada, dem Vereinigten Königreich und den Vereinigten Staaten zusammen studieren mehr als 50 Prozent aller ausländischen Studierenden weltweit.

Von den OECD-Ländern entsenden Deutschland, Frankreich, Italien, Kanada, Korea und die Vereinigten Staaten die meisten internationalen Studierenden.

Internationale Studierende stellen in Australien, Luxemburg, Neuseeland, Österreich, der Schweiz und dem Vereinigten Königreich mindestens 10 Prozent der eingeschriebenen Studierenden. In Australien, Belgien, Luxemburg, Neuseeland, den Niederlanden, der Schweiz und dem Vereinigten Königreich stellen sie auch mehr als 30 Prozent der in weiterführenden forschungsorientierten Studiengängen eingeschriebenen Studierenden.

\section{Entwicklungstendenzen}

Die Zahl der weltweit eingeschriebenen ausländischen Studierenden hat sich zwischen 2000 und 2012 mehr als verdoppelt, die durchschnittliche jährliche Steigerung betrug fast 7 Prozent. In den OECD-Ländern spiegelt die Zahl der ausländischen Studierenden im Tertiärbereich den globalen Trend wider.

Mit 48 Prozent aller Studierenden im Auslandsstudium ist Europa das bevorzugte Ziel von Studierenden, die außerhalb ihres Herkunftslandes eingeschrieben sind, gefolgt von Nordamerika mit 2I Prozent aller internationalen Studierenden und Asien mit I8 Prozent. Die Zahl der internationalen Studierenden in Ozeanien hat sich seit 2000 fast verdreifacht, obwohl weniger als ı Prozent aller ausländischen Studierenden dort studieren. Auch andere Regionen wie Afrika sowie Lateinamerika und die Karibik haben steigende Zahlen internationaler Studierender, was die Internationalisierung von Universitäten in einer wachsenden Zahl von Ländern widerspiegelt (Tab. C4.6 und Abb. C4.I). 


\section{Analyse und Interpretationen}

In den letzten 30 Jahren ist die Zahl der außerhalb ihres Heimatlandes eingeschriebenen Studierenden außerordentlich stark gestiegen, von weltweit o, 8 Millionen im Jahr I975 auf 4,5 Millionen im Jahr 2012, also auf das mehr als Fünffache (Kasten C4.I). Diese außerordentliche Steigerung ergibt sich aus dem Interesse an der Förderung akademischer, kultureller, gesellschaftlicher und politischer Bindungen zwischen Ländern, insbesondere während der Aufbauzeiten der Europäischen Union, sowie einem starken Anstieg des weltweiten Zugangs zu Bildung im Tertiärbereich und gesunkenen Reisekosten. Die wachsende Internationalisierung der Arbeitsmärkte für hoch qualifizierte Arbeitnehmer hat auch als Anreiz für die Studierenden gewirkt, im Laufe des Studiums Auslandserfahrungen zu sammeln.

Die meisten neuen ausländischen Studierenden kommen aus Ländern außerhalb des OECD-Gebiets und werden in den kommenden Jahren wahrscheinlich zu einem allmählichen Anstieg des Anteils ausländischer Studierender in weiterführenden forschungsorientierten Studiengängen in den OECD- und sonstigen G20-Ländern führen.

Die weltweite Mobilität Studierender folgt in hohem Ausmaß inter- und intraregionalen Migrationsbewegungen. Die zunehmende Internationalisierung der Einschreibungen an den Bildungseinrichtungen des Tertiärbereichs der OECD-Länder und die hohe

Kasten C4.1

\section{Langfristige Zunahme der Zahl der außerhalb des Landes ihrer Staatsangehörigkeit eingeschriebenen Studierenden}

Zunahme der Internationalisierung des Tertiärbereichs (1975-2012, in Mio.)

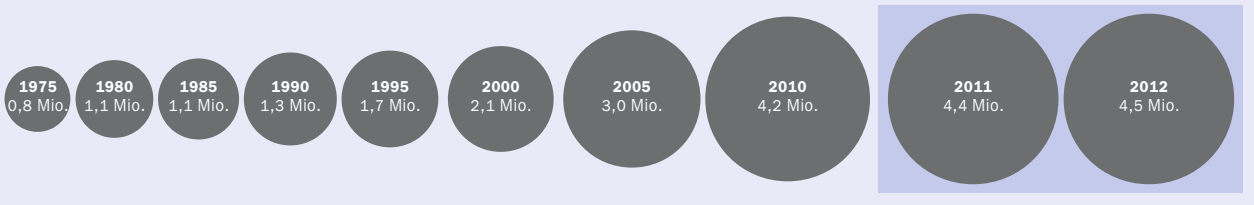

Quelle: OECD und Statistikinstitut der UNESCO.

Die Daten zu den weltweit eingeschriebenen ausländischen Studierenden stammen sowohl von der OECD als auch dem Statistikinstitut der UNESCO (UIS). Das UIS lieferte die Daten für alle Länder von 1975 bis 1995 sowie für die meisten NichtOECD-Länder für die Jahre 2000, 2005, 20I0, 20II und 20I2. Die OECD lieferte die Daten für die OECD- und die sonstigen Nicht-OECD-Länder für die Jahre 2000 und 2012. Da beide Quellen ähnliche Definitionen verwenden, können sie gemeinsam genutzt werden. Fehlende Angaben wurden auf Grundlage von Daten mit nächstliegenden Berichtszeitpunkten berechnet, um zu vermeiden, dass Lücken im Datenerhebungsbereich zu Unterbrechungen der Zeitreihen führen.

Die Datenpunkte im schattierten Bereich entsprechen einer anderen Zeitskala als die anderen Zeitreihen, werden jedoch zur Information aufgeführt, da es sich bei ihnen um die beiden letzten verfügbaren Jahre handelt und 2012 als Referenzjahr dient. 
Verteilung ausländischer Studierender im Tertiärbereich nach Zielland (2012)

Anteil aus/ändischer Studierender (in \%) in dem jeweiligen Zielland (gemäß Datenmeldung an die OECD)

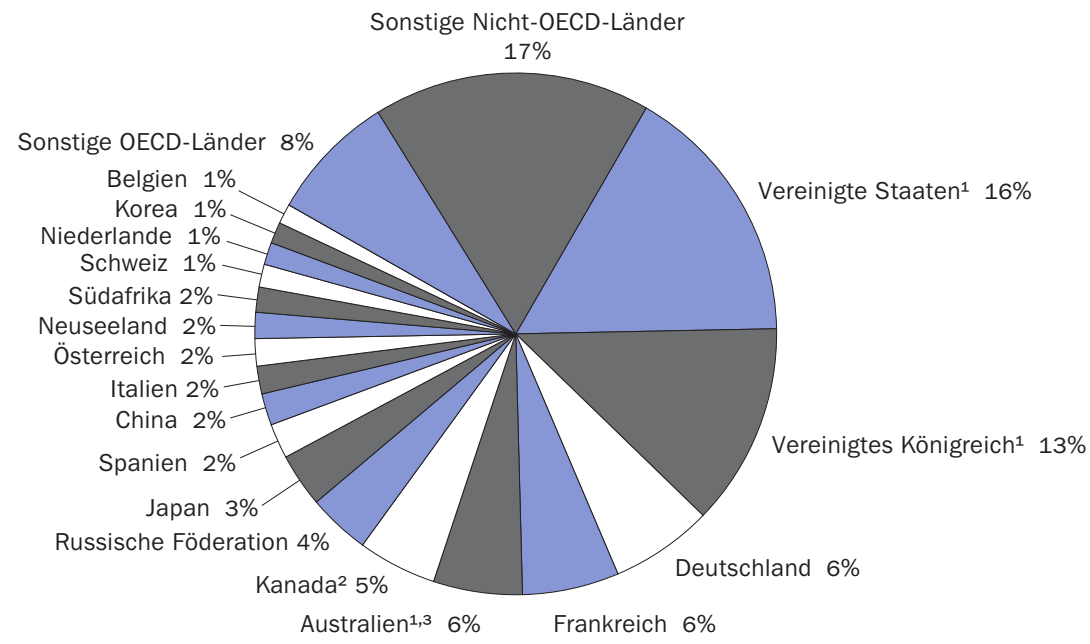

1. Die Daten beziehen sich auf internationale Studierende, die auf Grundlage ihres Wohnsitzstaates definiert sind. 2. Referenzjahr 2011. 3. Die Daten zu den Studierenden stammen aus verschiedenen Quellen und bilden daher die Verteilung nur näherungsweise ab.

Quelle: OECD. Tabelle C4.4 und Tabelle C4.7 im Internet. Hinweise s. Anhang 3 unter www.oecd.org/edu/eag.htm. StatLink: http://dx.doi.org/10.1787/888933118808

intraregionale Mobilität Studierender weisen auf die zunehmende Bedeutung regionaler Mobilität im Vergleich zur weltweiten Mobilität hin. Die Mobilitätsmuster Studierender in den europäischen Ländern sowie in Ostasien und Ozeanien spiegeln tendenziell die Entwicklung geopolitischer Großräume wider, wie engere Bindungen zwischen den Ländern im asiatisch-pazifischen Raum und die über die Europäische Union hinausgehende Zusammenarbeit unter den europäischen Ländern (UNESCO, 2009).

\section{Die wichtigsten Zielländer ausländischer Studierender}

82 Prozent der ausländischen Studierenden weltweit gehen für ein Auslandsstudium in eines der G20-Länder, während etwa 75 Prozent an Hochschulen in einem OECD-Land eingeschrieben sind. Innerhalb des OECD-Gebiets sind mit 39 Prozent die meisten ausländischen Studierenden in den EU2I-Ländern eingeschrieben. Darüber hinaus nehmen diese 2I Länder 98 Prozent der in EU-Ländern eingeschriebenen ausländischen Studierenden auf. Rund 74 Prozent der in den EU2I-Ländern eingeschriebenen ausländischen Studierenden stammen aus einem anderen EU2I-Mitgliedstaat, was zeigt, wie erfolgreich die Mobilitätspolitik der EU ist. Mit einem Anteil von 2I Prozent aller ausländischen Studierenden liegt Nordamerika bei der Attraktivität für ausländische Studierende an zweiter Stelle. Die Gruppe der internationalen Studierenden in dieser Region ist wesentlich heterogener als in der EU. Obwohl beispielsweise 53 Prozent der kanadischen Studierenden ihr Auslandsstudium in den Vereinigten Staaten absolvieren, stellen sie dort nur 4 Prozent der internationalen Studierenden. Ebenso entscheiden sich I4 Prozent der US-amerikanischen Studierenden für ein Auslandsstudium in Kanada, stellen dort aber nur 6 Prozent aller ausländischen Studierenden (Tab. $\mathrm{C}_{4} \cdot 3, \mathrm{C}_{4} \cdot 4$ und $\mathrm{C}_{4} \cdot 6$ ).

2012 waren mehr als die Hälfte der ausländischen Studierenden in Australien, Deutschland, Frankreich, Kanada, dem Vereinigten Königreich oder den Vereinigten Staaten im 
Tertiärbereich eingeschrieben. Mit I6 Prozent aller ausländischen Studierenden waren die Vereinigten Staaten das größte Aufnahmeland (in absoluten Zahlen), gefolgt vom Vereinigten Königreich (I3 Prozent), Deutschland (6 Prozent), Frankreich (6 Prozent), Australien (6 Prozent) und Kanada (5 Prozent). Obwohl diese Zielländer mehr als die Hälfte aller Studierenden, die im Ausland studieren, aufnehmen, sind in den letzten Jahren einige neue Akteure auf dem internationalen Bildungsmarkt aufgetreten (Abb. $\mathrm{C}_{4} .2$ und Tab. C4.7 im Internet). Abgesehen von den sechs wichtigsten Zielländern war 2012 eine signifikante Zahl ausländischer Studierender in der Russischen Föderation (4 Prozent), Japan (3 Prozent), Österreich (2 Prozent), Italien (2 Prozent), Neuseeland (2 Prozent) und Spanien (2 Prozent) eingeschrieben. Die Zahlen für Australien und die Vereinigten Staaten beziehen sich hierbei auf internationale Studierende (Tab. C4.4).

\section{Neue Akteure auf dem internationalen Bildungsmarkt}

Im Vergleich mit dem Jahr 2000 sank der Anteil der Vereinigten Staaten als Zielland internationaler Studierender von 23 Prozent in 2000 auf I6 Prozent in 2012, und der Anteil internationaler Studierender, die sich für Deutschland entschieden, sank im gleichen Zeitraum um fast 3 Prozentpunkte. Im Gegensatz dazu stieg der Prozentsatz internationaler Studierender, die Korea oder Neuseeland als Ziel wählten, um mindestens I Prozentpunkt, und der Anteil der Studierenden, die das Vereinigte Königreich und die Russische Föderation wählten, um etwa 2 Prozentpunkte (Abb. C4.3). Einige dieser Änderungen unterstreichen die unterschiedlichen Schwerpunkte der Internationalisierungsansätze einzelner Länder, die von einer aktiven Vermarktung im asiatischpazifischen Raum bis zu einem eher lokalen und universitätsspezifischen Ansatz in den Vereinigten Staaten reichen.

\section{Ausschlaggebende Faktoren bei der Wahl des Landes für ein Auslandsstudium \\ Die Unterrichtssprache}

Die Landessprache und die Unterrichtssprache sind manchmal bei der Auswahl des Landes für ein Auslandsstudium von entscheidender Bedeutung. Daher sind die Länder sowohl relativ als auch in absoluten Zahlen die wichtigsten Aufnahmeländer für ausländische Studierende, deren Unterrichtssprache weit verbreitet ist, wie beispielsweise Deutsch, Englisch, Französisch, Russisch und Spanisch. Japan ist eine bemerkenswerte Ausnahme: Trotz einer weltweit wenig verbreiteten Unterrichtssprache hat Japan hohe Einschreibungszahlen ausländischer Studierender, von denen 94 Prozent aus Asien kommen (Tab. C4.3 und Abb. C4.2).

Die Vorherrschaft hauptsächlich englischsprachiger Zielländer wie Australien, Kanada, Neuseeland, das Vereinigte Königreich und die Vereinigten Staaten spiegelt teilweise wider, dass das Englische zunehmend zur Weltsprache wird. Ein weiterer Grund könnte sein, dass auslandsinteressierte Studierende im Heimatland höchstwahrscheinlich Englisch gelernt haben oder ihre Englischkenntnisse durch das Leben und Studieren in einem englischsprachigen Land vertiefen wollen. Daher können rund 4I Prozent des Gesamtanstiegs der Einschreibungen ausländischer Studierender weltweit zwischen 2000 und 2012 durch einen Anstieg derartiger Einschreibungen in Australien, Irland, Kanada, Neuseeland, Südafrika, dem Vereinigten Königreich und den Vereinigten Staaten erklärt werden (Tab. C4.7 im Internet). Verstärkend kommt hinzu, dass in vielen Ländern Englisch entweder Amtssprache ist oder als Lingua franca verwendet wird. 
Ein hoher Prozentsatz ausländischer Studierender aus englischsprachigen Ländern geht für ein Auslandsstudium in ein anderes englischsprachiges Land, u. a. nach Australien (I8 Prozent), Irland (mehr als 40 Prozent), Kanada (mehr als 30 Prozent), Neuseeland (mehr als 40 Prozent), Südafrika (mehr als 80 Prozent), das Vereinigte Königreich (mehr als 30 Prozent) und die Vereinigten Staaten (25 Prozent). 2012 kam im Durchschnitt aller OECD-Länder etwa jeder vierte Studierende aus einem Land, dessen Amtssprache oder verbreitet gesprochene Sprache der Sprache des Ziellandes entsprach (Tab. C4.5).

Angesichts dieser Entwicklung bieten inzwischen immer mehr Bildungseinrichtungen in nicht englischsprachigen Ländern Studiengänge in Englisch an. Dieser Trend ist besonders in den Ländern ausgeprägt, in denen das Englische weit verbreitet ist, wie beispielsweise den nordischen Ländern (Kasten $\mathrm{C}_{4.2}$ ).

\section{Qualität der Studiengänge}

Internationale Studierende wählen ihr Zielland zunehmend nach der Qualität der angebotenen Studiengänge, wie sie anhand einer Vielzahl von Informationen und Rankings zu Studiengängen eingeschätzt wird, die inzwischen sowohl in gedruckter Form als auch im Internet zur Verfügung stehen. So lenken beispielsweise der hohe Anteil von Bildungseinrichtungen mit Spitzenrankings in den Hauptzielländern und das Aufkommen von Rankings für Institutionen, die sich in Ländern mit einem starken $\mathrm{Zu}$ wachs internationaler Studierender befinden, die Aufmerksamkeit auf die zunehmende Bedeutung von Qualität, wie sie von den Studierenden wahrgenommen wird, auch wenn es schwierig ist, einen direkten Zusammenhang zwischen den strukturellen Merkmalen der Mobilität Studierender und den Qualitätsbewertungen für einzelne Einrichtungen herzustellen. 


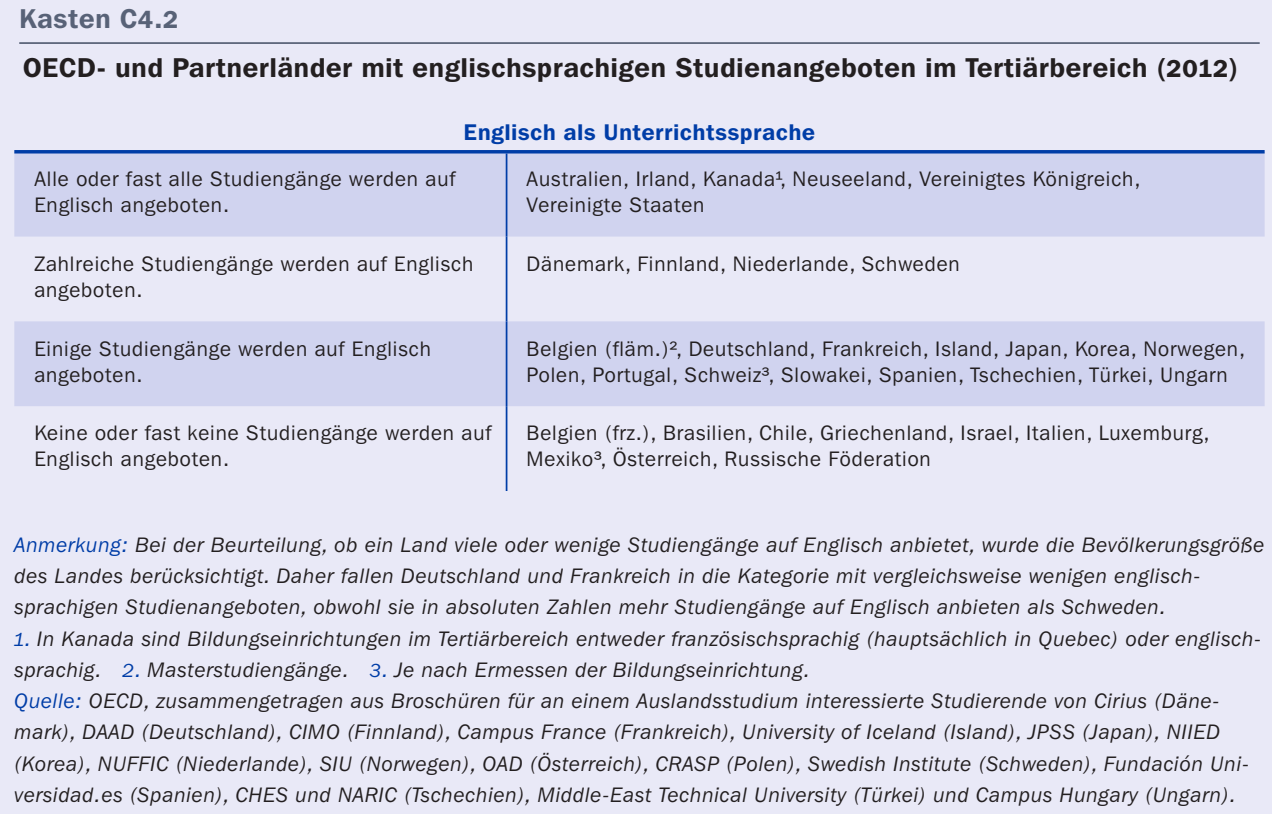

Anmerkung: Bei der Beurteilung, ob ein Land viele oder wenige Studiengänge auf Englisch anbietet, wurde die Bevölkerungsgröße des Landes berücksichtigt. Daher fallen Deutschland und Frankreich in die Kategorie mit vergleichsweise wenigen englischsprachigen Studienangeboten, obwohl sie in absoluten Zahlen mehr Studiengänge auf Englisch anbieten als Schweden.

1. In Kanada sind Bildungseinrichtungen im Tertiärbereich entweder französischsprachig (hauptsächlich in Quebec) oder englischsprachig. 2. Masterstudiengänge. 3. Je nach Ermessen der Bildungseinrichtung.

Quelle: OECD, zusammengetragen aus Broschüren für an einem Auslandsstudium interessierte Studierende von Cirius (Dänemark), DAAD (Deutschland), CIMO (Finnland), Campus France (Frankreich), University of Iceland (Island), JPSS (Japan), NIIED (Korea), NUFFIC (Niederlande), SIU (Norwegen), OAD (Österreich), CRASP (Polen), Swedish Institute (Schweden), Fundación Universidad.es (Spanien), CHES und NARIC (Tschechien), Middle-East Technical University (Türkei) und Campus Hungary (Ungarn).

\section{Studiengebühren}

In den meisten EU-Ländern, u.a. Belgien (fläm.), Dänemark, Deutschland, Estland, Finnland, Frankreich, Italien, den Niederlanden, Österreich, Polen, Schweden, der Slowakei, Spanien, Tschechien und dem Vereinigten Königreich, gelten internationale Studierende aus anderen EU-Ländern hinsichtlich der Studiengebühren als inländische Studierende. Dies ist auch in Irland der Fall, jedoch nur unter der Voraussetzung, dass Studierende aus dem EU-Ausland drei der fünf vorangegangenen Jahre in der EU, dem Europäischen Wirtschaftsraum oder der Schweiz gelebt haben. Wird diese Bedingung erfüllt, haben Studierende aus dem EU-Ausland Anspruch auf ein kostenloses Studium in dem jeweiligen Studienjahr. In Deutschland, Finnland und Italien erstreckt sich diese Regelung auch auf internationale Studierende, die nicht aus einem EU-Land kommen.

Während es in Finnland, Island und Schweden keine Studiengebühren gibt, werden in Deutschland von allen staatlich subventionierten privaten Einrichtungen und in einigen Bundesländern mittlerweile auch von öffentlichen Einrichtungen im Tertiärbereich Studiengebühren verlangt, auch wenn diese Ende 2014 vollständig abgeschafft werden. In Dänemark werden Studierende aus Norwegen und Island sowie aus EU-Ländern wie inländische Studierende behandelt und sind von Studiengebühren befreit, da ihre Ausbildung voll subventioniert wird. Die meisten internationalen Studierenden, die nicht aus einem Land der EU oder des Europäischen Wirtschaftsraums kommen, müssen jedoch Studiengebühren in voller Höhe zahlen, wenngleich eine begrenzte Anzahl begabter Studierender aus diesen Ländern Stipendien erhalten kann, die einen Teil der Studiengebühren bzw. die gesamten Studiengebühren abdecken (Kasten C4.3).

In einigen Nicht-EU-Ländern, darunter Island, Japan, Korea, Norwegen und den Vereinigten Staaten, werden bei den Studiengebühren alle inländischen und internationalen Studierenden gleich behandelt. In Norwegen werden für inländische und internatio- 
nale Studierende dieselben Studiengebühren angesetzt: An öffentlichen Bildungseinrichtungen gibt es keine Studiengebühren, während an einigen privaten Einrichtungen Gebühren erhoben werden. In Island müssen alle Studierenden Einschreibegebühren zahlen, und von Studierenden an privaten Bildungseinrichtungen werden zudem Studiengebühren verlangt. In Japan werden im Allgemeinen von inländischen und internationalen Studierenden Studiengebühren in gleicher Höhe erhoben, aber internationale Studierende mit einem Stipendium der japanischen Regierung müssen keine Studiengebühren zahlen, zudem gibt es Stipendien für internationale Studierende, die ihr Studium privat finanzieren. In den Vereinigten Staaten zahlen internationale Studierende dieselben Studiengebühren wie Studierende aus einem anderen Bundesstaat. $\mathrm{Da}$ jedoch die meisten inländischen Studierenden in ihrem jeweiligen Bundesstaat eingeschrieben sind, zahlen in der Praxis internationale Studierende höhere Studiengebühren als die meisten inländischen Studierenden. An privaten Bildungseinrichtungen sind die Studiengebühren für inländische und internationale Studierende gleich hoch.

In Korea variieren Studiengebühren und Unterstützungszahlungen für internationale Studierende in Abhängigkeit von der vertraglichen Vereinbarung zwischen der Bildungseinrichtung, von der sie kommen, und der Bildungseinrichtung, die sie in Korea besuchen. Im Allgemeinen zahlen die meisten internationalen Studierenden in Korea Studiengebühren, die etwas niedriger sind als die für inländische Studierende. In Neuseeland zahlen in der Regel internationale Studierende, mit Ausnahme von Studierenden in weiterführenden forschungsorientierten Studiengängen, höhere Studiengebühren, internationale Studierende aus Australien erhalten jedoch dieselben Unterstützungszahlungen wie inländische Studierende. In Australien (abgesehen von

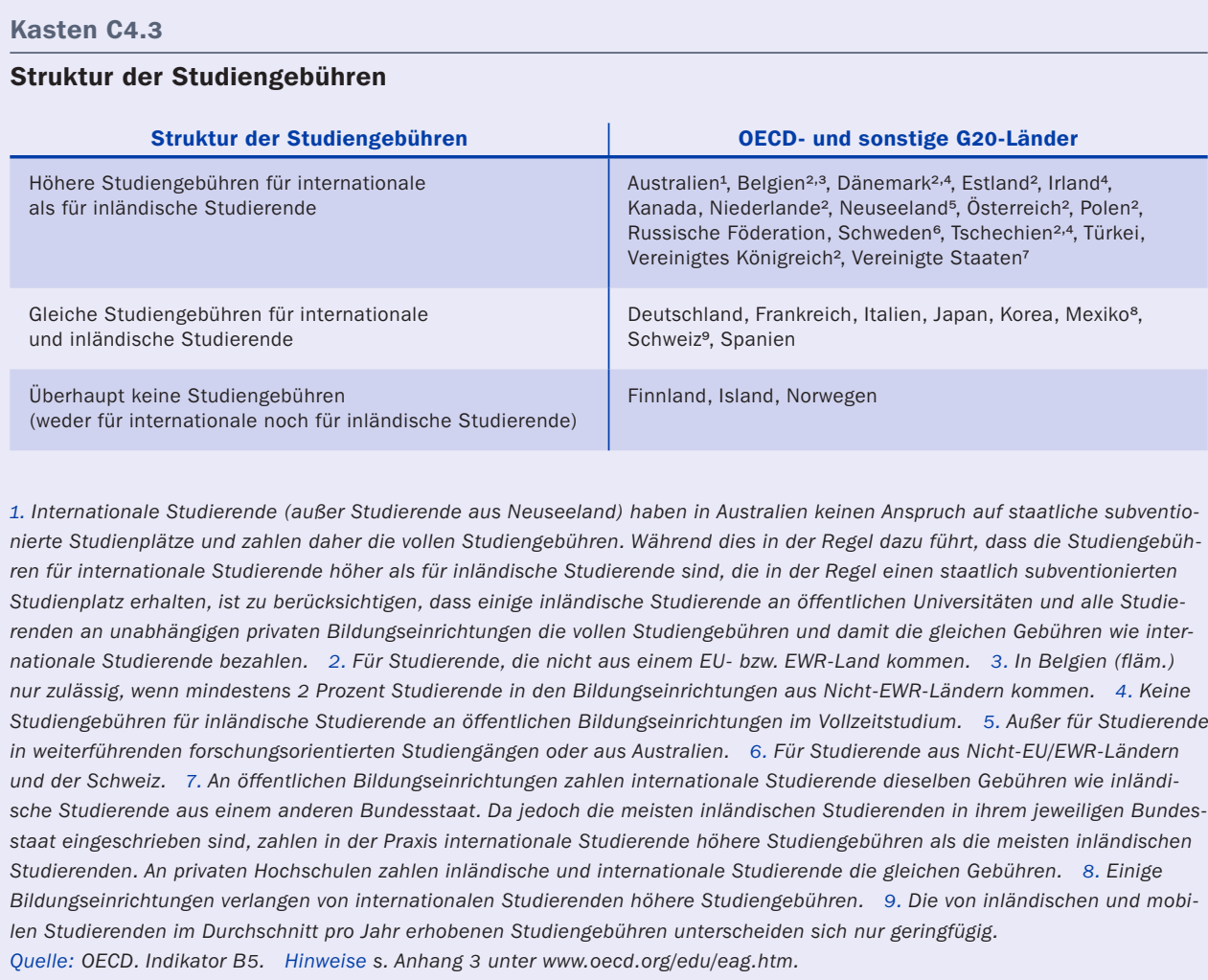


den in Kasten $\mathrm{C}_{4} \cdot 3$ aufgeführten Ausnahmen) und in Kanada zahlen in der Regel internationale Studierende höhere Studiengebühren als inländische Studierende. Dies trifft auch für die Russische Föderation zu, außer die Studierenden werden von der russischen Regierung unterstützt.

Die Tatsache, dass es in Finnland, Island und Norwegen keine Studiengebühren für internationale Studierende gibt und außerdem englischsprachige Studiengänge angeboten werden, erklärt wahrscheinlich teilweise den Anstieg der ausländischen Studierenden, der in einigen dieser Länder zwischen 2005 und $2012 \mathrm{zu}$ beobachten war (Tab. C4.I). Angesichts der hohen Kosten pro Studierenden führen internationale Studierende jedoch zu großen finanziellen Belastungen der Zielländer, wenn diese keine Studiengebühren erheben (s. Tab. BI.ra). Deshalb hat Dänemark, wo es vorher keine Studiengebühren gab, ab dem Studienjahr 2006/2007 Studiengebühren für internationale Studierende eingeführt, die nicht aus einem EU- oder EWR-Land kommen. In Finnland werden gegenwärtig ähnliche Überlegungen angestellt und ausprobiert, und Schweden hat mit Beginn des Studienjahrs 20II/20I2 für Studierende aus Nicht-EUoder Nicht-EWR-Ländern (durch Stipendien kompensierte) Studiengebühren eingeführt. Zukünftige Analysen werden sich genauer hiermit auseinandersetzen.

Länder, die die vollen Bildungskosten an die internationalen Studierenden weitergeben, haben erhebliche wirtschaftliche Vorteile. Einige Länder im asiatisch-pazifischen Raum haben in der Tat internationale Bildung als expliziten Teil ihrer sozioökonomischen Entwicklungsstrategie definiert und verfolgen eine Politik, die darauf abzielt, ihre Bildungseinrichtungen für internationale Studierende attraktiv zu machen und dabei gewinnorientiert oder zumindest kostendeckend zu arbeiten. Neuseeland hat erfolgreich differenzierte Studiengebühren für internationale Studierende eingeführt, trotzdem stieg in diesen beiden Ländern die Zahl der ausländischen Studierenden in den letzten Jahren stark an (Tab. C4.I). Dies zeigt, dass interessierte internationale Studierende nicht zwangsläufig durch Studiengebühren abgeschreckt werden, solange die Qualität der angebotenen Ausbildung hoch ist und die potenziellen Erträge die Investition als lohnend erscheinen lassen.

Wenn jedoch eine Entscheidung zwischen ähnlichen Bildungsangeboten erforderlich wird, spielen Kosten durchaus eine Rolle. In diesem Zusammenhang lässt sich der Rückgang des auf die Vereinigten Staaten entfallenden Anteils am internationalen Bildungsmarkt möglicherweise auf die im Vergleich mit anderen hauptsächlich englischsprachigen Zielländern, die ähnliche Studiengänge kostengünstiger anbieten, hohen Studiengebühren für internationale Studierende zurückführen (Abb. C4·3). Weiterführende forschungsorientierte Studiengänge in Neuseeland sind zum Beispiel seit 2005 attraktiver geworden, als die Studiengebühren für internationale Studierende auf die Höhe der Gebühren für inländische Studierende gesenkt wurden (Kasten C4·3).

Ein Anspruch auf öffentliche Mittel oder Unterstützungszahlungen für Studierende auch während eines Auslandsstudiums können die Kosten eines solchen Studiums reduzieren, wie sich in Chile, Finnland, Island, den Niederlanden, Norwegen und Schweden zeigt. 


\section{Einwanderungsbestimmungen}

In den letzten Jahren hat eine Reihe von OECD-Ländern ihre Einwanderungsbestimmungen gelockert, um die zeitlich befristete oder dauerhafte Einwanderung internationaler Studierender in ihr Land zu fördern (OECD, 2008). So werden diese Länder für Studierende attraktiver, und die Erwerbsbevölkerung des jeweiligen Landes wird verstärkt. Daher könnten für einige Studierende neben den Studiengebühren auch Erwägungen zum Thema Einwanderung bei der Wahl des ausländischen Studienlandes eine Rolle spielen (OECD, 20II).

\section{Sonstige Faktoren}

Bei der Wahl der ausländischen Hochschule spielen auch andere Faktoren eine Rolle, wie beispielsweise die wissenschaftliche Reputation bestimmter Hochschulen oder Studiengänge, die Flexibilität der Studiengänge im Heimatland hinsichtlich der Anrechnung von Auslandsaufenthalten auf die Studienzeit und die zu erbringenden Prüfungsleistungen, die Anerkennung von im Ausland erworbenen Abschlüssen, das eingeschränkte Angebot im Tertiärbereich im Heimatland, restriktive Zulassungspraktiken zum Studium an den Hochschulen im Heimatland, Handelsbeziehungen, geografische oder geschichtlich bedingte Beziehungen zwischen einzelnen Ländern, zukünftige Beschäftigungsmöglichkeiten, kulturelle Aspekte und staatliche Regelungen zur erleichterten gegenseitigen Anrechnung von erworbenen Credits (Leistungspunkten).

\section{Ausmaß der internationalen Mobilität Studierender}

Von den Ländern mit verfügbaren Daten zu internationalen Studierenden weisen - gemessen am Anteil der internationalen Studierenden an der Gesamtzahl der eingeschriebenen Studierenden in ihrem Tertiärbereich - Australien, Luxemburg, Neuseeland, Österreich, die Schweiz und das Vereinigte Königreich den höchsten Zustrom an Studierenden auf. In Australien kommen I8 Prozent der im Tertiärbereich des Landes

Anteil internationaler bzw. ausländischer Studierender an der Gesamtzahl der Studierenden im Tertiärbereich (in \%)

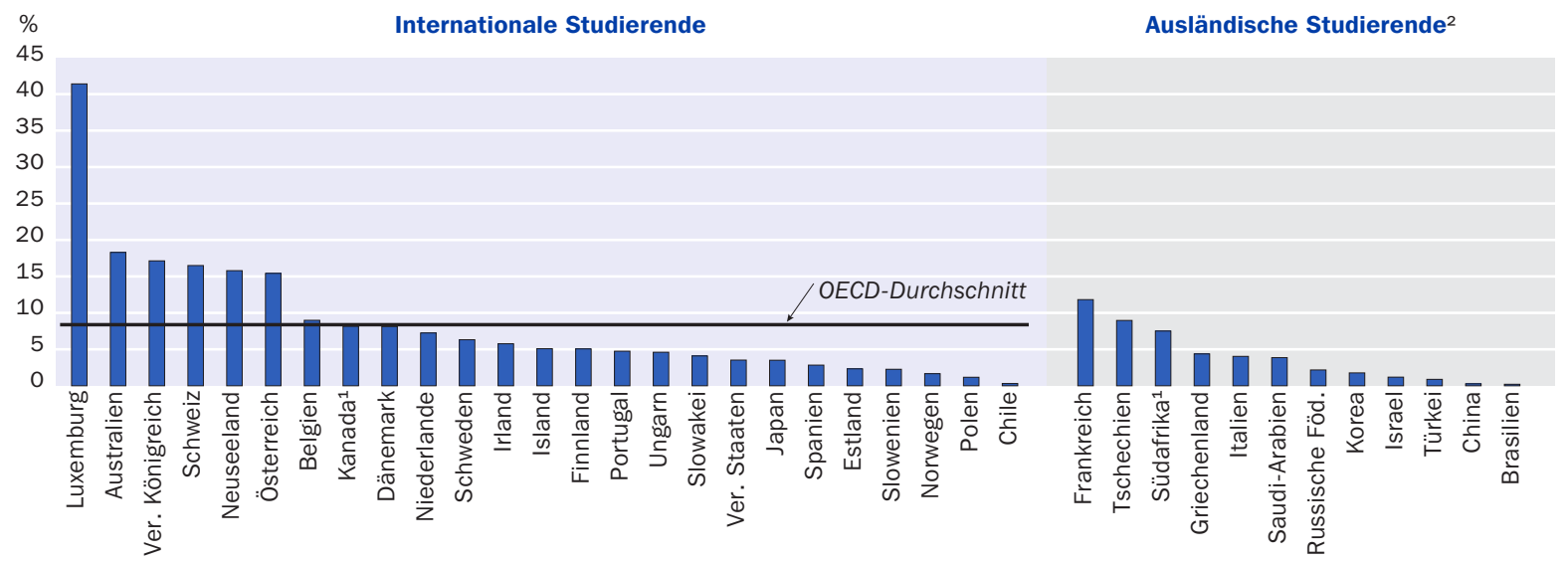

1. Referenzjahr 2011. 2. Ausländische Studierende sind auf der Grundlage des Landes, dessen Staatsbürger sie sind, definiert; diese Daten sind nicht mit den Daten zu internationalen Studierenden vergleichbar, daher werden sie in der Abbildung getrennt aufgeführt.

Anordnung der Länder in absteigender Reihenfolge des Anteils internationaler bzw. ausländischer Studierender an der Gesamtzahl der Studierenden im Tertiärbereich.

Quelle: OECD. Tabelle C4.1. Hinweise s. Anhang 3 unter www.oecd.org/edu/eag.htm. StatLink: http://dx.doi.org/10.1787/888933118846 
eingeschriebenen Studierenden aus einem anderen Land. In ähnlicher Weise entfallen auf internationale Studierende in Neuseeland 16 Prozent, in Österreich I5 Prozent, in der Schweiz I6 Prozent und im Vereinigten Königreich I7 Prozent der eingeschriebenen Studierenden im Tertiärbereich.

Andererseits machen sie in Chile, Estland, Norwegen, Polen, Slowenien und Spanien weniger als 3 Prozent aus (Tab. C4.I und Abb. $\mathrm{C}_{4 \cdot 4}$ ).

Unter den Ländern, in denen internationale Studierende auf der Grundlage des Staates definiert werden, dessen Staatsbürger sie sind, hatte Frankreich den größten Anteil ausländischer Studierender an allen Studierenden (I2 Prozent). Andererseits belief sich dieser Anteil in Brasilien, China und der Türkei auf weniger als I Prozent (Tab. C4.I und Abb. C4.4).

\section{Anteil internationaler Studierender nach Tertiärbereich}

Die Anteile internationaler Studierender an den verschiedenen Tertiärbereichen in den einzelnen Zielländern zeigen auch die der Mobilität Studierender zugrunde liegenden strukturellen Merkmale auf. 2012 machten im Durschnitt aller OECD-Länder internationale Studierende fast 6 Prozent aller Einschreibungen bei den (in der Regel kürzeren und beruflich ausgerichteten) Studiengängen des Tertiärbereichs B aus. Den größten Anteil internationaler Studierender in derartigen Studiengängen gab es in Luxemburg mit 49 Prozent, gefolgt von Neuseeland mit 2I Prozent.

Im Gegensatz hierzu machten 2012 in den (größtenteils theoretisch ausgerichteten) Studiengängen des Tertiärbereichs A internationale Studierende im Durchschnitt der OECD-Länder 8 Prozent aller Einschreibungen in diesem Bildungsbereich aus. Luxemburg hatte mit 34 Prozent aller Einschreibungen den größten Anteil internationaler Studierender in diesem Bildungsbereich, gefolgt von Australien mit ig Prozent, dem Vereinigten Königreich mit I8 Prozent und der Schweiz mit I7 Prozent (Tab. C4.I).

Alle Länder, die Daten angeben, mit Ausnahme Deutschlands, haben bei den weiterführenden forschungsorientierten Studiengängen mehr internationale Studierende als im Tertiärbereich A oder B. In Luxemburg beispielsweise sind rund 8o Prozent der in weiterführenden forschungsorientierten Studiengängen eingeschriebenen Studierenden internationale Studierende. In 13 der 26 Länder, die Daten zu internationalen Studierenden gemeldet haben, sind mehr als 20 Prozent der in weiterführenden forschungsorientierten Studiengängen eingeschriebenen Studierenden internationale Studierende. In der Schweiz stellen die internationalen Studierenden mehr als 50 Prozent aller in weiterführenden forschungsorientierten Studiengängen eingeschriebenen Studierenden, in Neuseeland und dem Vereinigten Königreich sind es mehr als 40 Prozent.

Nimmt man die Staatsbürgerschaft als entscheidendes Kriterium, weist Frankreich den größten Teil ausländischer Studierender in diesem Bildungsbereich auf: mehr als 40 Prozent (Tab. C4.I). Diese hohen Anteile internationaler bzw. ausländischer Studierender könnten ein Hinweis auf die hohe Attraktivität der weiterführenden forschungsorientierten Studiengänge in diesen Ländern oder auf eine bevorzugte Anwerbung internationaler Studierender in den höheren Bildungsbereichen sein, um von deren 
potenziellem Beitrag zur nationalen Forschung und Entwicklung zu profitieren bzw. um sie später als hoch qualifizierte Einwanderer zu gewinnen.

Die Analyse der Verteilung internationaler und ausländischer Studierender in den einzelnen Zielländern aufgeschlüsselt nach Art des Tertiärbereichs gibt deutliche Hinweise auf die von den einzelnen Ländern angebotenen Studiengänge. In einigen Ländern besucht ein relativ großer Teil der internationalen Studierenden Bildungsgänge im Tertiärbereich B. Dies gilt für Spanien, wo 35 Prozent der internationalen Studierenden in einem Studiengang des Tertiärbereichs B eingeschrieben sind, Griechenland (34 Prozent, ausländische Studierende), Neuseeland (3I Prozent), Luxemburg (27 Prozent), Chile (23 Prozent), Belgien (22 Prozent) und Japan (20 Prozent) (Tab. C4.I).

In anderen Ländern ist ein hoher Prozentsatz der internationalen Studierenden in einem weiterführenden forschungsorientierten Studiengang eingeschrieben. Dies trifft insbesondere auf die Schweiz zu, wo sich 25 Prozent aller internationalen Studierenden in einem solchen Studiengang einschreiben. Diese Präferenz lässt sich auch in Schweden beobachten, wo 22 Prozent der internationalen Studierenden in weiterführenden forschungsorientierten Studiengängen eingeschrieben sind, sowie in den Vereinigten Staaten (Ig Prozent), Irland (I8 Prozent) und Slowenien (I7 Prozent).

In den Ländern, die nur Daten zu ausländischen Studierenden melden, wie Israel, Italien, Lettland, die Russische Föderation und Tschechien, sind mindestens 9o Prozent der ausländischen Studierenden in Studiengängen des (weitgehend theoretisch orientierten) Tertiärbereichs A eingeschrieben. In China sind 27 Prozent aller ausländischen Studierenden in weiterführenden forschungsorientierten Studiengängen eingeschrieben, ebenso wie II Prozent in Frankreich und Brasilien (Tab. C4.I). Alle diese Zielländer werden vermutlich von einem entsprechenden Beitrag dieser hoch qualifizierten internationalen Studierenden zu ihren Forschungs- und Entwicklungsprogrammen profitieren.

\section{Die Zusammensetzung der internationaler Studierenden in den einzelnen Ländern}

\section{Das Ausmaß der Mobilität Studierender in den OECD-Ländern}

Die Zahl der von den OECD-Ländern aufgenommenen internationalen Studierenden ist höher als die Zahl der aus diesen Ländern ins Ausland gehenden Studierenden. 2012 waren in den OECD-Ländern pro OECD-Staatsbürger, der außerhalb des eigenen Herkunftslandes studierte, 3 ausländische Studierende eingeschrieben. In absoluten Zahlen sind dies 3,4 Millionen ausländische Studierende in OECD-Ländern verglichen mit mehr als einer Million Studierenden, die außerhalb des OECD-Landes eingeschrieben sind, dessen Staatsangehörigkeit sie besitzen (Tab. C4.7 im Internet). Während 9I Prozent der Staatsbürger von OECD-Ländern im Auslandsstudium in einem anderen OECD-Land studieren, stammen mehr als zwei Drittel der ausländischen Studierenden in OECD-Ländern aus einem Nicht-OECD-Land (Tab. C4.4 und C4.5).

Auf Ebene der einzelnen Länder variiert das Verhältnis stark. Während in Australien pro australischen Studierenden, der im Ausland studiert, I8 ausländische Studierende eingeschrieben sind, beträgt das Verhältnis in Mexiko weniger als o, I : I. Andere Länder mit einer hohen Zahl ausländischer Studierender per inländischen Studierenden im 
Auslandsstudium sind das Vereinigte Königreich (I3:I), Neuseeland (I2:I) und die Vereinigten Staaten (II : I). Argentinien, Brasilien, Estland, Island, Israel, Korea, Lettland, Luxemburg, Mexiko, die Slowakei und die Türkei geben alle weniger als einen ausländischen Studierenden pro Staatsbürger des eigenen Landes im Auslandsstudium an.

\section{Die wichtigsten Herkunftsregionen}

Studierende aus Asien bilden die größte Gruppe der internationalen Studierenden in den Ländern, die der OECD oder dem Statistikinstitut der UNESCO Daten zur Verfügung stellen: 53 Prozent aller Studierenden in allen Zielländern, die Daten gemeldet haben. Die Anteile von Studierenden aus Asien an allen internationalen und ausländischen Studierenden sind in Japan (mit 94 Prozent), Korea (93 Prozent), Australien (82 Prozent), den Vereinigten Staaten (73 Prozent) und Neuseeland (70 Prozent) besonders groß. In den OECD-Ländern kommen 26 Prozent aller internationalen und ausländischen Studierenden aus europäischen Ländern (bzw. I7 Prozent aus den EU2I-Ländern), 9 Prozent aus Afrika, 6 Prozent aus Lateinamerika und der Karibik sowie 3 Prozent aus Nordamerika. Insgesamt stammen 30 Prozent der innerhalb der OECD eingeschriebenen internationalen Studierenden aus einem anderen OECD-Land (Tab. C4.3).

\section{Die wichtigsten Herkunftsländer}

2012 stellten Studierende aus China mit 22 Prozent aller internationalen Studierenden im OECD-Gebiet den größten Anteil aus Ländern, die Daten zur Verfügung gestellt haben (Tab. C4.3). Rund 28 Prozent aller im Ausland eingeschriebenen chinesischen Studierenden sind in den Vereinigten Staaten eingeschrieben, II Prozent entschieden sich für Australien, 6 Prozent für Korea, I3 Prozent für Japan und II Prozent für das Vereinigte Königreich (Tab. C4.4). Die zweitgrößte Gruppe internationaler Studierender in OECD-Ländern kommt aus Indien (5,8 Prozent) (Tab. C4.3). Rund 45 Prozent der Studierenden aus Indien sind in den Vereinigten Staaten eingeschrieben, I7 Prozent im Vereinigten Königreich, 6 Prozent in Kanada und 5 Prozent in Australien (Tab. C4.4).

Auch bei einem Blick auf die einzelnen OECD-Länder zeigt sich, dass die Studierenden aus Asien und Europa eindeutig die größte Gruppe stellen. Studierende aus Deutschland, Frankreich und Korea stellen mit 4,2 Prozent, 2,I Prozent bzw. 4,2 Prozent die größten Gruppen internationaler, in OECD-Ländern eingeschriebener Studierender, gefolgt von Studierenden aus den Vereinigten Staaten (I,6 Prozent), Italien (I,6 Prozent), Kanada (I,5 Prozent), der Slowakei (I,2 Prozent), Japan (I,I Prozent) und der Türkei (I,I Prozent) (Tab. C4·3).

Ein großer Teil der ausländischen Studierenden in OECD-Ländern stammt aus benachbarten Ländern. 2012 kamen in allen OECD-Ländern durchschnittlich 2I Prozent aller ausländischen Studierenden aus Ländern, die eine Land- oder Seegrenze mit dem Zielland teilen. Eine verstärkte Mobilität aus Nachbarländern ergibt sich nicht nur aufgrund einer speziellen geografischen Lage, wie in Tschechien, sondern die Gründe können auch in Vorteilen bezüglich Kosten, Qualität und Zulassung zum Studium liegen, die für Studierende in benachbarten Ländern offensichtlicher sind. Auf der anderen Seite finden sich in den Ländern mit den höchsten Marktanteilen im Bereich internationaler Bildung höhere Prozentsätze ausländischer Studierender aus nicht unmittelbar benachbarten Ländern. Dies gilt auch für Länder wie beispielsweise Por- 


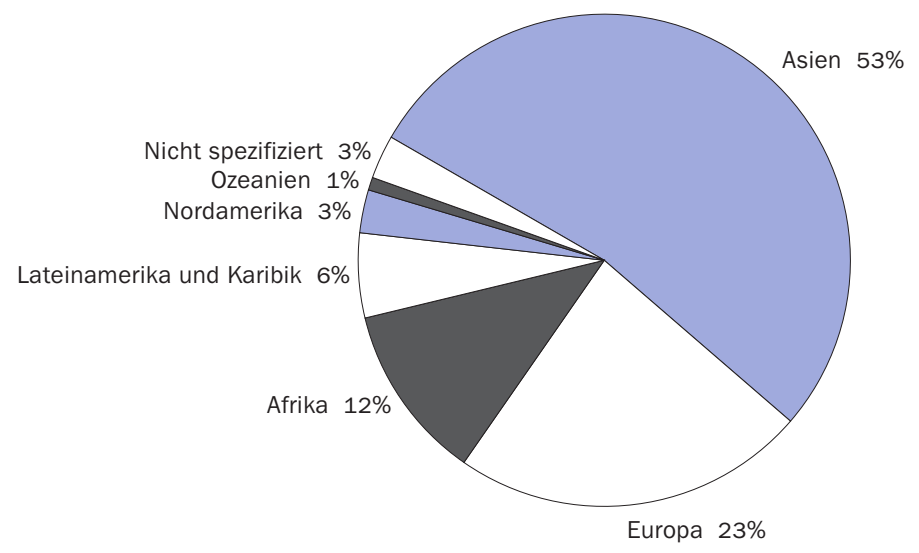

Quelle: OECD. Tabelle C4.3. Hinweise s. Anhang 3 unter www.oecd.org/edu/eag.htm. StatLink: http://dx.doi.org/10.1787/888933118865

tugal und Spanien, die enge geschichtliche und kulturelle Bindungen mit anderen, weit entfernt liegenden Ländern haben (Tab. C4.5 und Tab. C4.7 im Internet).

In den OECD-Ländern findet sich der höchste Anteil von Studierenden aus benachbarten Ländern in Japan (8I Prozent), Griechenland (76 Prozent), Korea (75 Prozent), Estland (70 Prozent), der Russischen Föderation (68 Prozent) und Tschechien (65 Prozent). Auch Belgien, Österreich, Polen, die Slowakei und Südafrika weisen hohe Anteile ausländischer Studierender aus benachbarten Ländern auf. Im Gegensatz hierzu kommen in Kanada nur 4 Prozent der ausländischen Studierenden aus den Vereinigten Staaten, und in den Vereinigten Staaten kommen nur 6 Prozent der Studierenden von den Bahamas, aus Kanada oder Mexiko (Tab. C4.5 und Tab. C.4.7 im Internet).

Sprachliche Kriterien sind hauptsächlich für Studierende, die zum Auslandsstudium nach Portugal kommen, verantwortlich: 55 Prozent der ausländischen Studierenden in Portugal kommen aus Angola, Brasilien, Guinea-Bissau, Kap Verde, Mosambik, São Tomé und Príncipe oder Timor-Leste - alles Länder, in denen Portugiesisch eine Amtssprache ist (Tab. C4.5 und Tab. C4.7 im Internet).

Überlegungen hinsichtlich der Unterrichts- und Landessprache, kulturelle Aspekte, die geografische Nähe und die Ähnlichkeit der Bildungssysteme sind alles wichtige Faktoren, die Studierende ebenfalls bei der Wahl des Studienlandes abwägen. Geografische Erwägungen und unterschiedliche Zulassungsbedingungen (wie der Numerus clausus oder intensivere Auswahlverfahren für einige Studiengänge) erklären höchstwahrscheinlich die Konzentration von Studierenden aus Deutschland in Österreich und den Niederlanden, aus Belgien in Frankreich und den Niederlanden, aus Frankreich in Belgien, aus Kanada in den Vereinigten Staaten, aus Neuseeland in Australien usw. Überlegungen im Zusammenhang mit der Sprache und akademischen Traditionen erklären auch die tendenzielle Konzentration englischsprachiger Studierender in anderen Ländern des British Commonwealth bzw. in den Vereinigten Staaten, selbstwenn diese geografisch weit entfernt sind. Dies trifft auch auf andere geschichtlich und 
geopolitisch verbundene Gebiete wie die frühere Sowjetunion, das Gebiet der Frankofonie sowie auf Lateinamerika zu. Auch Migrantennetzwerke spielen eine Rolle, wie am Beispiel der Konzentration von Studierenden mit portugiesischer Staatsangehörigkeit in Frankreich, Studierenden aus der Türkei in Deutschland oder Studierenden aus Mexiko in den Vereinigten Staaten deutlich wird.

\section{Definitionen}

Das Land der vorherigen Ausbildung ist das Land, in dem Studierende die für die Einschreibung in dem aktuellen Studiengang erforderliche Zulassungsberechtigung erhielten, d. h. bei internationalen Studierenden im Tertiärbereich A und im Tertiärbereich B das Land, in dem die Studierenden ihre Ausbildung im Sekundarbereich II oder im beruflich ausgerichteten postsekundaren, nicht tertiären Bildungsbereich erhielten, und bei internationalen Studierenden, die an weiterführenden forschungsorientierten Studiengängen teilnehmen, das Land ihres Studienabschlusses im Tertiärbereich A. Die jeweiligen landesspezifischen operationalen Definitionen der Bezeichnung „internationale Studierende" sind in den Tabellen und in Anhang 3 unter www.oecd.org/ edu/eag.htm aufgeführt.

Ausländische Studierende sind Studierende, die nicht Staatsangehörige des Landes sind, für das die Daten erhoben werden. Diese Klassifikation ist zwar pragmatisch und operational, eignet sich jedoch aufgrund der unterschiedlichen nationalen Regelungen zur Einbürgerung von Migranten für die Erfassung der Mobilität Studierender nicht. So ist Australien beispielsweise eher bereit, seinen Einwanderern eine Daueraufenthaltsgenehmigung zu erteilen, als die Schweiz. Das bedeutet, dass sogar bei einem ähnlich hohen Anteil ausländischer Studierender im Tertiärbereich beider Länder der Anteil der internationalen Studierenden in der Schweiz niedriger ist als in Australien. Daher ist bei der Interpretation von Daten, die auf dem Konzept der ausländischen Studierenden basieren, in Bezug auf die Mobilität Studierender sowie bei bilateralen Vergleichen Vorsicht angebracht.

Internationale oder mobile Studierende sind Studierende, die aus ihrem Herkunftsland zwecks Studium in ein anderes Land gekommen sind. Abhängig von den landesspezifischen Einwanderungsbestimmungen, Mobilitätsvereinbarungen, wie z. B. dem freien Personenverkehr innerhalb der EU und des EWR, und der Datenverfügbarkeit können internationale Studierende als Studierende definiert werden, bei denen es sich nicht um Personen mit dauerhaftem Wohnsitz oder gewöhnlichem Aufenthaltsort in ihrem Studienland handelt, bzw. alternativ als Studierende, die ihre vorherige Ausbildung in einem anderen Land, einschließlich einem anderen EU-Mitgliedstaat, absolviert haben.

Der dauerhafte Wohnsitz oder gewöhnliche Aufenthaltsort in dem Land, das Daten zur Verfügung gestellt hat, wird nach Maßgabe der jeweiligen nationalen Gesetze definiert. In der Praxis bedeutet dies ein für Studienzwecke erteiltes Visum oder eine Aufenthaltsgenehmigung oder die Wahl eines ausländischen Wohnsitzstaates in dem Jahr, das dem Einstieg in das Bildungssystem des Landes, das Daten zur Verfügung gestellt hat, vorausgeht. 


\section{Angewandte Methodik}

Die Daten zu den internationalen und ausländischen Studierenden beziehen sich auf das Studienjahr 20II/20I2 (außer es ist etwas anderes angegeben) und beruhen auf der von der OECD im Jahre 2012 durchgeführten UOE-Datenerhebung zur Bildungsstatistik. Die in der UOE-Datenerhebung verwendeten Fächergruppen entsprechen der überarbeiteten ISCED-Klassifikation nach Fächergruppen. Diese Klassifizierung nach Fächergruppen wird auf alle Bildungsbereiche angewendet (Einzelheiten s. Anhang 3 unter www.oecd.org/edu/eag.htm). Es wurden auch zusätzliche Daten vom Statistikinstitut der UNESCO verwendet.

Die Daten über internationale und ausländische Studierende werden von den Zielländern anhand der erfolgten Einschreibungen erhoben. Die Daten zur Zahl internationaler und ausländischer Studierender wurden daher mit der gleichen Methode gewonnen wie die zur Gesamtzahl der Studierenden, d. h., es werden die Unterlagen über die regulär in einem Studiengang eingeschriebenen Studierenden zugrunde gelegt.

Die inländischen und die internationalen Studierenden werden üblicherweise an einem bestimmten Tag oder innerhalb eines bestimmten Zeitraums während des Jahres gezählt. Damit lässt sich der Anteil der internationalen Studierenden bestimmen, die in einem Bildungssystem eingeschrieben sind, aber die tatsächliche Zahl der betreffenden Studierenden kann viel höher liegen, da viele Studierende für weniger als ein ganzes akademisches Jahr ins Ausland gehen oder an einem Austauschprogramm teilnehmen, das keine Einschreibung bei der ausländischen Bildungseinrichtung voraussetzt, wie beispielsweise bei Austauschprogrammen zwischen Universitäten oder kurzzeitigen Forschungsprojekten. Außerdem umfassen die Zahlen zu den internationalen Studierenden auch einige Studierende, die an einem Fernstudium teilnehmen, obwohl sie streng genommen keine internationalen Studierenden sind. Diese Art der Einschreibung an einer ausländischen Bildungseinrichtung des Tertiärbereichs ist in Australien, dem Vereinigten Königreich und den Vereinigten Staaten sehr verbreitet (OECD, 2004).

Da die Daten zu den internationalen und ausländischen Studierenden im Zielland erhoben werden, beziehen sie sich eher auf die Studierenden, die in das betreffende Land gekommen sind, und nicht auf diejenigen, die aus dem betreffenden Land ins Ausland gehen. Die von diesem Indikator erfassten Zielländer umfassen alle OECD-Länder und sonstigen G20-Länder mit Ausnahme von Mexiko sowie Länder, die ähnliche Daten an das Statistikinstitut der UNESCO melden. Diese Daten werden zur Ableitung weltweiter Zahlen verwendet sowie zur Analyse der Zielländer der Studierenden und der Entwicklungen der einzelnen Marktanteile.

Die Daten über Studierende im Ausland und die Trendanalysen basieren nicht auf Zahlen internationaler Studierender, sondern auf den Zahlen ausländischer Staatsbürger, für die länderübergreifend und im Zeitverlauf konsistente Daten leicht zugänglich sind. Eingeschriebene Studierende in Ländern, die weder gegenüber der OECD noch gegenüber dem Statistikinstitut der UNESCO Angaben über die Zahl der ausländischen Studierenden machten, bleiben in den Daten unberücksichtigt. Daher ist bei allen Aussagen über die Zahl der Studierenden, die ein Studium außerhalb ihres Heimatlandes absolvieren, deren Zahl wahrscheinlich zu niedrig angesetzt (Tab. C4.3); dies gilt 
vor allem für die Länder, von denen zahlreiche Bürger in Ländern studieren, die der OECD oder dem Statistikinstitut der UNESCO keine Zahlen zu ausländischen Studierenden zur Verfügung stellen wie beispielsweise China und Indien.

Die relativen Anteile der in einem Bildungssystem eingeschriebenen internationalen Studierenden wirken sich auf die Studienanfänger- und Abschlussquoten aus und können in einigen Bildungsbereichen oder Fächergruppen zu einem künstlichen Anstieg führen (s. Indikatoren A2 und A3). Sie können auch die berichtete Kombination von öffentlichen und privaten Ausgaben beeinflussen (s. Indikator B3).

In Ländern, in denen für internationale Studierende besondere Studiengebühren gelten, kann die Mobilität Studierender die finanzielle Ausstattung der Bildungseinrichtungen im Tertiärbereich verbessern und so zur Finanzierung des Bildungssystems beitragen.

Andererseits können internationale Studierende angesichts der hohen Kosten pro Studierenden für Länder, in denen keine oder nur geringe Studiengebühren erhoben werden, eine bedeutende finanzielle Belastung darstellen (s. Indikator $\mathrm{B}_{5}$ ).

Studierende, die außerhalb ihres Herkunftslands studieren, repräsentieren jedoch nur einen Teil der Internationalisierung des Tertiärbereichs. In den letzten Io Jahren sind neue Formen der grenzüberschreitenden Bildung entstanden, z. B. grenzüberschreitende Angebote von Bildungsgängen und Bildungseinrichtungen. Die grenzüberschreitende Bildung im Tertiärbereich hat sich jedoch aus verschiedenen Gründen in unterschiedlichen Regionen der Welt ganz unterschiedlich entwickelt. Eine detaillierte Analyse dieser Sachverhalte sowie der Auswirkungen der Internationalisierung des Tertiärbereichs auf Handel und Politik findet sich in OECD (2004).

\section{Anmerkung zu den Daten aus Israel}

Die statistischen Daten für Israel wurden von den zuständigen israelischen Stellen bereitgestellt, die für sie verantwortlich zeichnen. Die Verwendung dieser Daten durch die OECD erfolgt unbeschadet des völkerrechtlichen Status der Golanhöhen, von Ost-Jerusalem und der israelischen Siedlungen im Westjordanland.

\section{Weiterführende Informationen}

Kelo, M., U. Teichler and B. Wachter (eds.) (2005), EURODATA: Student Mobility in European Higher Education, Verlags- und Mediengesellschaft, Bonn.

OECD (20II), International Migration Outlook 2011, OECD Publishing, Paris, http:/|dx.doi. org/10.1787/migr_outlook-2011-en.

OECD (2008), Tertiary Education for the Knowledge Society: Volume 1 and Volume 2, OECD Publishing, Paris, http://dx.doi.org/10.1787/9789264046535-en. 
OECD (2004), Internationalisation and Trade in Higher Education: Opportunities and Challenges, OECD Publishing, Paris, http:||dx.doi.org/10.1787/978g264015067-en.

UNESCO (2009), Global Education Digest 2009: Comparing Education Statistics across the World, UNESCO Institute for Statistics, Montreal.

UNESCO Institute for Statistics (20I2), Education Database, www.uis.unesco.org, accessed I July 2012.

Varghese, N. V. (2009), Globalization, Economic Crisis and National Strategies for Higher Education Development, IIEP, UNESCO, Paris.

\section{Tabellen Indikator C4}

StatLink: http://dx.doi.org/10.1787/888933118656

Tabelle C4.I: Die Mobilität internationaler Studierender und ausländische Studierende im Tertiärbereich (2005, 2012)

Tabelle C4.2: Verteilung internationaler und ausländischer Studierender im Tertiärbereich, nach Fächergruppe (2012)

Tabelle $\mathrm{C}_{4} \cdot 3$ : Verteilung internationaler und ausländischer Studierender im Tertiärbereich, nach Herkunftsland (2012)

Tabelle C4.4: Studierende, die in einem Land studieren, dessen Staatsbürger sie nicht sind, nach Zielland (2012)

Tabelle C4.5: Mobilität ausländischer und internationaler Studierender (2012)

Tabelle C4.6: Entwicklung der Zahl der eingeschriebenen ausländischen Studierenden, nach Zielregion und Herkunftsland (20I0 bis 20I2)

WEB Table $\mathrm{C}_{4.7}$ : Number of foreign students in tertiary education, by country of origin and destination (Zahl ausländischer Studierender im Tertiärbereich, nach Herkunfts- und Zielland) (20I2) 
Tabelle C4.1

Die Mobilität internationaler Studierender und ausländische Studierende im Tertiärbereich $(2005,2012)$

Eingeschriebene internationale und ausländische Studierende als Prozentsatz aller Studierenden (internationaler und inländischer) und Verteilung der internationalen Mobilität nach Bildungsbereich

Bedeutung der Spalte (1) im oberen Teil der Tabelle (Internationale Studierende): 18 Prozent der Studierenden im Tertiärbereich in Australien sind internationale Studierende, und 16 Prozent der Studierenden im Tertiärbereich in der Schweiz sind internationale Studierende. Die in dieser Tabelle zusammengestellten Daten zur Mobilität internationaler Studierender sind die jeweils besten verfügbaren Näherungswerte für die Mobilität Studierender für jedes einzelne Land.

Bedeutung der Spalte (1) im unteren Teil der Tabelle (Ausländische Studierende): 12 Prozent der Studierenden im Tertiärbereich in Frankreich sind nicht französische Staatsbürger, und 2 Prozent der Studierenden im Tertiärbereich in Korea sind nicht koreanische Staatsbürger.

\begin{tabular}{|c|c|c|c|c|c|c|c|}
\hline & \multicolumn{4}{|c|}{$\begin{array}{l}\text { Internationale bzw. ausländische Studierende als Prozentsatz } \\
\text { aller eingeschriebenen Studierenden im Tertiärbereich }\end{array}$} & \multicolumn{3}{|c|}{$\begin{array}{l}\text { Verteilung internationaler } \\
\text { bzw. ausländischer Studierender }\end{array}$} \\
\hline & $\begin{array}{l}\text { Tertiärbereich } \\
\text { insgesamt }\end{array}$ & $\begin{array}{l}\text { Studiengänge } \\
\text { Tertiärbereich B }\end{array}$ & $\begin{array}{l}\text { Studiengänge } \\
\text { Tertiärbereich A }\end{array}$ & $\begin{array}{l}\text { Weiterführende } \\
\text { forschungs- } \\
\text { orientierte } \\
\text { Studiengänge }\end{array}$ & $\begin{array}{l}\text { Studiengänge } \\
\text { Tertiärbereich B }\end{array}$ & $\begin{array}{l}\text { Studiengänge } \\
\text { Tertiärbereich A }\end{array}$ & $\begin{array}{l}\text { Weiterführende } \\
\text { forschungs- } \\
\text { orientierte } \\
\text { Studiengänge }\end{array}$ \\
\hline & (1) & (2) & (3) & (4) & (7) & (8) & (9) \\
\hline & \multicolumn{7}{|c|}{ Internationale Studierende } \\
\hline \multicolumn{8}{|l|}{ OECD-Länder } \\
\hline Australien & 18 & 11 & 19 & 32 & 11 & 82 & 7 \\
\hline Österreich & 15 & 2 & 17 & 23 & 1 & 88 & 10 \\
\hline Belgien & 9 & 4 & 13 & 34 & 22 & 67 & 11 \\
\hline Kanada $^{1,2}$ & 8 & 8 & 8 & 24 & 20 & 70 & 9 \\
\hline Chile & $\mathbf{n}$ & $n$ & $n$ & 8 & 23 & 68 & 10 \\
\hline Dänemark & 8 & 11 & 7 & 24 & 17 & 74 & 10 \\
\hline Estland & 2 & $\mathrm{n}$ & 3 & 6 & 4 & 83 & 13 \\
\hline Finnland & 5 & $\mathrm{n}$ & 5 & 10 & $\mathrm{n}$ & 87 & 13 \\
\hline Deutschland & $\mathbf{m}$ & $\mathrm{m}$ & 8 & 7 & $\mathrm{~m}$ & $\mathrm{~m}$ & $\mathrm{~m}$ \\
\hline Ungarn & 5 & $\mathrm{n}$ & 5 & 6 & 1 & 97 & 3 \\
\hline Island & 5 & 2 & 5 & 17 & 1 & 92 & 8 \\
\hline Irland & 6 & 3 & 6 & 23 & 10 & 72 & 18 \\
\hline Japan & 4 & 4 & 3 & 19 & 20 & 69 & 11 \\
\hline Luxemburg & 41 & 49 & 34 & 83 & 27 & 60 & 13 \\
\hline Mexiko & m & $\mathrm{m}$ & $\mathrm{m}$ & $\mathrm{m}$ & $\mathrm{m}$ & $\mathrm{m}$ & $\mathrm{m}$ \\
\hline Niederlande $^{3}$ & 7 & $\mathrm{n}$ & 7 & 39 & $n$ & 91 & 9 \\
\hline Neuseeland & 16 & 21 & 13 & 41 & 31 & 61 & 8 \\
\hline Norwegen & 2 & 1 & 2 & 4 & $\mathrm{n}$ & 91 & 9 \\
\hline Polen & 1 & $\mathrm{n}$ & 1 & 1 & $\mathrm{n}$ & 97 & 3 \\
\hline Portugal & 5 & 1 & 4 & 10 & $\mathrm{n}$ & 89 & 11 \\
\hline Slowakei & 4 & $\mathrm{n}$ & 4 & 8 & $\mathrm{n}$ & 89 & 11 \\
\hline Slowenien & 2 & 1 & 2 & 10 & 6 & 77 & 17 \\
\hline Spanien & 3 & 6 & 2 & 17 & 35 & 58 & 7 \\
\hline Schweden & 6 & $\mathrm{n}$ & 6 & 29 & $\mathrm{n}$ & 78 & 22 \\
\hline Schweiz ${ }^{4}$ & 16 & $\mathrm{~m}$ & 17 & 51 & $\mathrm{~m}$ & 75 & 25 \\
\hline Ver. Königreich & 17 & 6 & 18 & 41 & 5 & 86 & 9 \\
\hline Vereinigte Staaten ${ }^{5}$ & 4 & 1 & 3 & 29 & 7 & 74 & 19 \\
\hline OECD-Durchschnitt & 8 & 6 & 8 & 23 & 10 & 79 & 11 \\
\hline \multicolumn{8}{|l|}{ Partnerländer } \\
\hline Argentinien & m & $\mathrm{m}$ & $\mathrm{m}$ & $\mathrm{m}$ & $\mathrm{m}$ & $\mathrm{m}$ & $\mathrm{m}$ \\
\hline Indien & $\mathbf{m}$ & $\mathrm{m}$ & $\mathrm{m}$ & $\mathrm{m}$ & $\mathrm{m}$ & $\mathrm{m}$ & $\mathrm{m}$ \\
\hline \multirow[t]{2}{*}{ Lettland } & 3 & 1 & 3 & 3 & 4 & 93 & 3 \\
\hline & \multicolumn{7}{|c|}{ Ausländische Studierende ${ }^{6}$} \\
\hline \multicolumn{8}{|l|}{ OECD-Länder } \\
\hline Tschechien & 9 & 2 & 9 & 12 & 1 & 91 & 8 \\
\hline Frankreich & 12 & 4 & 13 & 42 & 9 & 80 & 11 \\
\hline Griechenland ${ }^{7,8}$ & 4 & 4 & 5 & $\mathrm{~m}$ & 34 & 66 & $\mathrm{n}$ \\
\hline Israel & 1 & $\mathrm{~m}$ & 1 & 3 & $\mathrm{n}$ & 94 & 6 \\
\hline Italien & 4 & 7 & 4 & 11 & $\mathrm{n}$ & 95 & 5 \\
\hline Korea & 2 & $\mathrm{n}$ & 2 & 7 & 4 & 89 & 8 \\
\hline Türkei & 1 & $n$ & 1 & 4 & 7 & 88 & 5 \\
\hline \multicolumn{8}{|l|}{ Partnerländer } \\
\hline Brasilien & $\mathbf{n}$ & $n$ & $n$ & 2 & 8 & 81 & 11 \\
\hline China & $\mathbf{n}$ & $\mathrm{n}$ & $\mathrm{n}$ & 1 & 1 & 72 & 27 \\
\hline Kolumbien & $\mathbf{m}$ & $\mathrm{m}$ & $\mathrm{m}$ & $\mathrm{m}$ & $\mathrm{m}$ & $\mathrm{m}$ & $\mathrm{m}$ \\
\hline Indonesien & $\mathbf{m}$ & $\mathrm{m}$ & $\mathrm{m}$ & $\mathrm{m}$ & $\mathrm{m}$ & $\mathrm{m}$ & $\mathrm{m}$ \\
\hline Russische Föd. ${ }^{8}$ & 2 & 1 & 2 & $\mathrm{~m}$ & 8 & 92 & $\mathrm{n}$ \\
\hline Saudi-Arabien & 4 & 1 & 4 & 15 & 3 & 95 & 2 \\
\hline Südafrika ${ }^{1}$ & 8 & $\mathrm{~m}$ & $\mathrm{~m}$ & $\mathrm{~m}$ & $\mathrm{n}$ & $\mathrm{n}$ & $\mathrm{n}$ \\
\hline
\end{tabular}

Anmerkung: Die Spalten mit dem Index der Veränderung des Anteils mobiler/ausländischer Studierender (in \%), dem Tertiärbereich insgesamt (2005 = 100) und dem Index der Veränderung der Anzahl ausländischer Studierender im Tertiärbereich insgesamt $(2005=100)$ sind im Internet verfügbar (s. StatLink unten).

1. Referenzjahr 2011. 2. Index der Veränderung basiert auf $2004=100$ anstelle von 2005, Referenzjahr 2011. 3. Der Nenner des Prozentsatzes internationaler Studierender umfasst alle Studierenden in unabhängigen privaten Studiengängen im Tertiärbereich. Das Land, in dem diese Studierenden den vorgelagerten Bildungsbereich besucht oder ihren dauerhaften Wohnsitz haben, ist unbekannt. Das bedeutet, dass es nicht möglich ist festzustellen, ob diese Studierenden international mobil sind oder nicht. 4. Ohne internationale Studierende im Tertiärbereich B. Der Nenner des Prozentsatzes internationaler Studierender umfasst alle im Tertiärbereich eingeschriebenen Studierenden, jedoch ist die Zahl internationaler Studierender in Studiengängen im Tertiärbereich B unbekannt, sodass sie nicht in den Berechnungen enthalten sind. Damit sind die in der Tabelle aufgeführten Prozentangaben zu niedrig angesetzt. 5. Internationale Studierende in Spalte (6) im Internet. 6. Ausländische Studierende sind auf der Grundlage des Landes, dessen Staatsbürger sie sind, definiert; diese Daten sind nicht mit den Daten zu internationalen Studierenden vergleichbar, daher werden sie in der Tabelle getrennt aufgeführt. 7. Ohne private Bildungseinrichtungen. 8. Ohne weiterführende forschungsorientierte Studiengänge.

Quelle: OECD. Argentinien, China, Indien, Indonesien, Kolumbien, Saudi-Arabien und Südafrika: Statistikinstitut der UNESCO. Lettland: Eurostat. Hinweise s. Anhang 3 unter www.oecd.org/edu/eag.htm. StatLink: http://dx.doi.org/10.1787/888933118675 Erläuterung der Kennzeichnung fehlender Daten s. Hinweise für den Leser. 
Verteilung internationaler und ausländischer Studierender im Tertiärbereich, nach Fächergruppe (2012)

\begin{tabular}{|c|c|c|c|c|c|c|c|c|c|}
\hline & \begin{tabular}{|c} 
Geisteswis- \\
senschaften, \\
Kunst und \\
Erziehungs- \\
wissen- \\
schaften
\end{tabular} & \begin{tabular}{|} 
Gesundheit \\
und Soziales
\end{tabular} & $\begin{array}{l}\text { Sozial-, } \\
\text { Rechts- und } \\
\text { Wirtschafts- } \\
\text { wissen- } \\
\text { schaften }\end{array}$ & $\begin{array}{l}\text { Dienst- } \\
\text { leistungen }\end{array}$ & \begin{tabular}{|c} 
Ingenieurwis- \\
senschaften, \\
Fertigung \\
und \\
Bauwesen
\end{tabular} & $\begin{array}{c}\text { Naturwissen- } \\
\text { schaften }\end{array}$ & $\begin{array}{c}\text { Agrarwissen- } \\
\text { schaften }\end{array}$ & $\begin{array}{c}\text { Nicht } \\
\text { bekannt } \\
\text { oder keine } \\
\text { Angabe }\end{array}$ & $\begin{array}{l}\text { Alle Fächer- } \\
\text { gruppen } \\
\text { zusammen }\end{array}$ \\
\hline & (1) & (4) & (5) & (6) & (7) & (8) & (13) & (14) & (15) \\
\hline & \multicolumn{9}{|c|}{ Internationale Studierende } \\
\hline \multicolumn{10}{|l|}{ OECD-Länder } \\
\hline Australien & 9 & 10 & 54 & 2 & 13 & 12 & 1 & $\mathrm{n}$ & 100 \\
\hline Österreich ${ }^{1}$ & 23 & 9 & 39 & 1 & 14 & 12 & 2 & $\mathrm{n}$ & 100 \\
\hline Belgien & 16 & 34 & 21 & 2 & 14 & 8 & 5 & $n$ & 100 \\
\hline Kanada $^{2}$ & 8 & 5 & 41 & 2 & 17 & 15 & 1 & 10 & 100 \\
\hline Chile & 16 & 7 & 44 & 8 & 13 & 8 & 3 & $\mathrm{n}$ & 100 \\
\hline Dänemark & 12 & 11 & 41 & 1 & 21 & 11 & 4 & $\mathrm{n}$ & 100 \\
\hline Estland & 18 & 6 & 51 & 1 & 6 & 9 & 10 & $n$ & 100 \\
\hline Finnland $^{1}$ & 11 & 9 & 28 & 7 & 32 & 12 & 2 & $\mathrm{n}$ & 100 \\
\hline Deutschland $^{1}$ & 24 & 6 & 27 & 2 & 24 & 15 & 2 & 1 & 100 \\
\hline Griechenland & $\mathrm{m}$ & $\mathrm{m}$ & $\mathrm{m}$ & $\mathrm{m}$ & $\mathrm{m}$ & $\mathrm{m}$ & $\mathrm{m}$ & $\mathrm{n}$ & $\mathrm{m}$ \\
\hline Ungarn & 12 & 44 & 19 & 3 & 9 & 4 & 9 & $\mathrm{n}$ & 100 \\
\hline Island & 47 & 4 & 25 & $\mathrm{n}$ & 5 & 16 & 3 & $\mathrm{n}$ & 100 \\
\hline Irland & $\mathrm{m}$ & $\mathrm{m}$ & $\mathrm{m}$ & $\mathrm{m}$ & $\mathrm{m}$ & $\mathrm{m}$ & $\mathrm{m}$ & $\mathrm{m}$ & 100 \\
\hline Japan & 23 & 2 & 40 & 2 & 16 & 1 & 2 & 12 & 100 \\
\hline Luxemburg & 14 & 4 & 61 & $\mathrm{n}$ & 5 & 15 & 1 & $n$ & 100 \\
\hline Mexiko & $\mathrm{n}$ & $\mathrm{m}$ & $\mathrm{m}$ & $\mathrm{m}$ & $\mathrm{m}$ & $\mathrm{m}$ & $\mathrm{m}$ & $\mathrm{m}$ & $\mathrm{m}$ \\
\hline Niederlande $^{3}$ & 15 & 14 & 43 & 8 & 10 & 6 & 2 & 2 & 100 \\
\hline Neuseeland & 14 & 7 & 39 & 8 & 8 & 18 & 1 & 5 & 100 \\
\hline Norwegen & 31 & 10 & 31 & 5 & 5 & 12 & 2 & 3 & 100 \\
\hline Portugal & 19 & 8 & 37 & 6 & 18 & 10 & 1 & 2 & 100 \\
\hline Slowenien & 18 & 10 & 33 & 6 & 18 & 13 & 3 & $n$ & 100 \\
\hline Spanien & 11 & 12 & 22 & 3 & 10 & 5 & 1 & 35 & 100 \\
\hline Schweden & 12 & 11 & 24 & 2 & 31 & 20 & 1 & $n$ & 100 \\
\hline Schweiz ${ }^{1}$ & 21 & 7 & 33 & 2 & 17 & 18 & 1 & 2 & 100 \\
\hline Ver. Königreich & 16 & 9 & 46 & 2 & 14 & 13 & 1 & $n$ & 100 \\
\hline $\begin{array}{l}\text { Vereinigte Staaten } \\
\text { Partnerländer }\end{array}$ & 15 & 7 & 33 & 2 & 18 & 17 & 1 & 7 & 100 \\
\hline Argentinien & $\mathrm{m}$ & $\mathrm{m}$ & $\mathrm{m}$ & $\mathrm{m}$ & $\mathrm{m}$ & $\mathrm{m}$ & $\mathrm{m}$ & $\mathrm{m}$ & $\mathrm{m}$ \\
\hline Brasilien & $\mathrm{m}$ & $\mathrm{m}$ & $\mathrm{m}$ & $\mathrm{m}$ & $\mathrm{m}$ & $\mathrm{m}$ & $\mathrm{m}$ & $\mathrm{m}$ & $\mathrm{m}$ \\
\hline China & $\mathrm{m}$ & $\mathrm{m}$ & $\mathrm{m}$ & $\mathrm{m}$ & $\mathrm{m}$ & $\mathrm{m}$ & $\mathrm{m}$ & $\mathrm{m}$ & $\mathrm{m}$ \\
\hline Kolumbien & $\mathrm{m}$ & $\mathrm{m}$ & $\mathrm{m}$ & $\mathrm{m}$ & $\mathrm{m}$ & $\mathrm{m}$ & $\mathrm{m}$ & $\mathrm{m}$ & $\mathrm{m}$ \\
\hline Indien & $\mathrm{m}$ & $\mathrm{m}$ & $\mathrm{m}$ & $\mathrm{m}$ & $\mathrm{m}$ & $\mathrm{m}$ & $\mathrm{m}$ & $\mathrm{m}$ & $\mathrm{m}$ \\
\hline Indonesien & $\mathrm{m}$ & $\mathrm{m}$ & $\mathrm{m}$ & $\mathrm{m}$ & $\mathrm{m}$ & $\mathrm{m}$ & $\mathrm{m}$ & $\mathrm{m}$ & $\mathrm{m}$ \\
\hline Lettland & 8 & 25 & 47 & 12 & 5 & 3 & $\mathrm{n}$ & $n$ & 100 \\
\hline Russische Föd. & $\mathrm{m}$ & $\mathrm{m}$ & $\mathrm{m}$ & $\mathrm{m}$ & $\mathrm{m}$ & $\mathrm{m}$ & $\mathrm{m}$ & $\mathrm{m}$ & $\mathrm{m}$ \\
\hline Saudi-Arabien & $\mathrm{m}$ & $\mathrm{m}$ & $\mathrm{m}$ & $\mathrm{m}$ & $\mathrm{m}$ & $\mathrm{m}$ & $\mathrm{m}$ & $\mathrm{m}$ & $\mathrm{m}$ \\
\hline Südafrika & $\mathrm{m}$ & $\mathrm{m}$ & $\mathrm{m}$ & $\mathrm{m}$ & $\mathrm{m}$ & $\mathrm{m}$ & $\mathrm{m}$ & $\mathrm{m}$ & $\mathrm{m}$ \\
\hline & \multicolumn{9}{|c|}{ Ausländische Studierende ${ }^{4}$} \\
\hline \multicolumn{10}{|l|}{ OECD-Länder } \\
\hline Tschechien & 13 & 16 & 39 & 3 & 11 & 15 & 2 & $n$ & 100 \\
\hline Frankreich & 20 & 7 & 41 & 2 & 13 & 17 & $\mathrm{n}$ & $\mathrm{n}$ & 100 \\
\hline Israel & 23 & 15 & 30 & $\mathrm{n}$ & 8 & 23 & 1 & $n$ & 100 \\
\hline Italien & 21 & 16 & 32 & 2 & 21 & 6 & 2 & $\mathrm{n}$ & 100 \\
\hline Korea & 25 & 4 & 45 & 4 & 16 & 5 & 1 & $n$ & 100 \\
\hline Polen & 15 & 24 & 40 & 6 & 7 & 6 & 1 & $\mathrm{n}$ & 100 \\
\hline Slowakei & 18 & 51 & 19 & 2 & 7 & 2 & 2 & $n$ & 100 \\
\hline Türkei & 21 & 14 & 34 & 4 & 16 & 9 & 2 & $\mathrm{n}$ & 100 \\
\hline
\end{tabular}

Anmerkung: Die Spalten mit getrennten Angaben zu „Erziehungswissenschaften“ und „Geisteswissenschaften und Kunst“, d.h. die Spalten (2) und (3), sowie zu den einzelnen Naturwissenschaften, d.h. die Spalten (9) bis (12), sind im Internet verfügbar (s. StatLink unten).

1. Ohne Studiengänge im Tertiärbereich B. 2. Referenzjahr 2011. 3. Ohne Studiengänge in privaten Bildungseinrichtungen. 4. Ausländische Studierende sind auf der Grundlage des Landes, dessen Staatsbürger sie sind, definiert; diese Daten sind nicht mit den Daten zu internationalen Studierenden vergleichbar, daher werden sie in der Tabelle und der Abbildung getrennt aufgeführt.

Quelle: OECD. Argentinien, China, Indien, Indonesien, Saudi-Arabien und Südafrika: Statistikinstitut der UNESCO. Lettland: Eurostat.

Hinweise s. Anhang 3 unter www.oecd.org/edu/eag.htm. StatLink: http://dx.doi.org/10.1787/888933118694

Erläuterung der Kennzeichnung fehlender Daten s. Hinweise für den Leser. 
Tabelle C4.3

Verteilung internationaler und ausländischer Studierender im Tertiärbereich, nach Herkunftsland (2012)

Zahl der im Tertiärbereich eingeschriebenen internationalen und ausländischen Studierenden der einzelnen Herkunftsländer als Prozentsatz aller internationalen und ausländischen Studierenden im Zielland (basierend auf Personenzahlen)

Die Tabelle zeigt für jedes Land den Anteil der internationalen Studierenden im Tertiärbereich, die ihren dauerhaften Wohnsitz in einem bestimmten Herkunftsland haben bzw. dort den vorgelagerten Bildungsbereich besucht haben. Wenn Daten zur Mobilität Studierender nicht zur Verfügung stehen, ist in der Tabelle der Anteil ausländischer Studierender im Tertiärbereich angegeben, die Staatsbürger eines bestimmten Herkunftslandes sind.

Bedeutung der Spalte (2): 15,7 Prozent der internationalen Studierenden im Tertiärbereich in Belgien kommen aus Frankreich, 9,9 Prozent der internationalen Studierenden im Tertiärbereich in Belgien kommen aus den Niederlanden usw.

Bedeutung der Spalte (6): 48,2 Prozent der internationalen Studierenden im Tertiärbereich in Estland kommen aus Finnland, 1,4 Prozent der internationalen Studierenden im Tertiärbereich in Estland kommen aus Italien usw.

Bedeutung der Spalte (21): 40,5 Prozent der ausländischen Studierenden im Tertiärbereich in Österreich sind deutsche Staatsbürger, 2,4 Prozent der ausländischen Studierenden im Tertiärbereich in Österreich sind ungarische Staatsbürger usw.

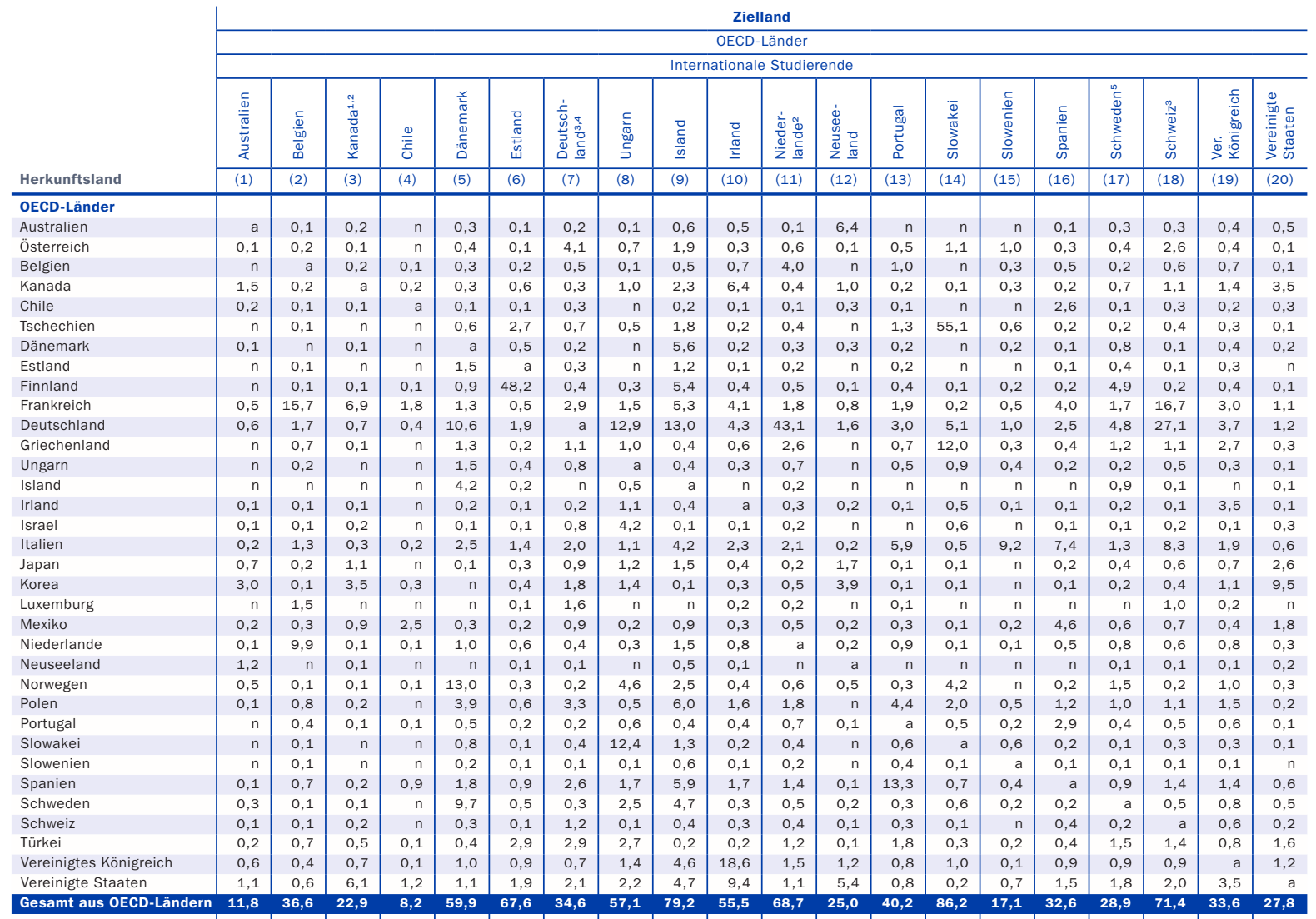

\begin{tabular}{|c|c|c|c|c|c|c|c|c|c|c|c|c|c|c|c|c|c|c|c|c|}
\hline Gesamt aus OECD-Ländern & 11,8 & 36,6 & 22,9 & $\mathbf{8 , 2}$ & 59,9 & 67,6 & 34,6 & $\mathbf{5 7 , 1}$ & 79,2 & $\mathbf{5 5 , 5}$ & 68,7 & 25,0 & 40,2 & 86,2 & 17,1 & 32,6 & 28,9 & 71,4 & 33,6 & 27,8 \\
\hline \multicolumn{21}{|l|}{ Partnerländer } \\
\hline Argentinien & $\mathrm{n}$ & 0,1 & 0,1 & 3,4 & 0,1 & $\mathrm{n}$ & 0,2 & $\mathrm{n}$ & 0,2 & $\mathrm{n}$ & 0,1 & 0,1 & 0,2 & $\mathrm{n}$ & 0,3 & 3,8 & 0,1 & 0,4 & $\mathrm{n}$ & 0,2 \\
\hline Brasilien & 0,3 & 0,3 & 0,3 & 2,2 & 0,3 & 0,6 & 1,1 & 0,1 & 0,2 & 0,3 & 0,4 & 0,4 & 27,9 & 0,1 & 0,8 & 2,8 & 0,4 & 1,2 & 0,3 & 1,2 \\
\hline China & 35,1 & 2,6 & 21,7 & 0,2 & 4,1 & 5,1 & 9,9 & 1,4 & 3,2 & 13,3 & 8,1 & 27,7 & 1,0 & $\mathrm{n}$ & 0,9 & 2,7 & 11,3 & 2,5 & 18,0 & 28,4 \\
\hline Kolumbien & 0,5 & 0,3 & 0,4 & 22,3 & 0,1 & 0,5 & 0,7 & $\mathrm{n}$ & 0,3 & 0,1 & 0,4 & 0,2 & 0,2 & $\mathrm{n}$ & $\mathrm{n}$ & 10,5 & 0,4 & 0,8 & 0,2 & 0,8 \\
\hline Indien & 4,7 & 1,3 & 6,7 & 0,1 & 0,9 & 1,1 & 2,3 & 0,2 & 1,8 & 3,2 & 1,4 & 17,7 & 0,3 & 0,1 & 0,6 & 0,4 & 5,4 & 1,4 & 6,9 & 13,1 \\
\hline Indonesien & 3,8 & 0,3 & 0,5 & $\mathrm{n}$ & 0,1 & 0,3 & 0,7 & 0,1 & 0,1 & 0,1 & 1,6 & 0,9 & 0,1 & $\mathrm{n}$ & $\mathrm{n}$ & 0,1 & 0,2 & 0,1 & 0,3 & 0,9 \\
\hline Lettland & $\mathrm{n}$ & 0,1 & $\mathrm{n}$ & $\mathrm{n}$ & 3,3 & $\mathrm{n}$ & 0,3 & $\mathrm{n}$ & 1,4 & 0,2 & 0,7 & $\mathrm{n}$ & 0,3 & $\mathrm{n}$ & $\mathrm{n}$ & 0,1 & 0,4 & 0,1 & 0,5 & $\mathrm{n}$ \\
\hline Russische Föderation & 0,4 & 0,6 & 0,5 & 0,1 & 0,5 & 8,6 & 4,9 & 0,5 & 2,3 & 0,5 & 1,0 & 0,8 & 0,6 & 0,3 & 1,6 & 1,3 & 1,8 & 2,0 & 0,8 & 0,6 \\
\hline Saudi-Arabien & 2,2 & $\mathrm{n}$ & 2,6 & $\mathrm{n}$ & $\mathrm{n}$ & $\mathrm{n}$ & 0,1 & 1,2 & $\mathrm{n}$ & 2,0 & 0,1 & 2,4 & $\mathrm{n}$ & 0,9 & $\mathrm{n}$ & 0,1 & 0,1 & 0,1 & 2,3 & 4,5 \\
\hline Südafrika & 0,3 & 0,2 & 0,1 & $\mathrm{n}$ & $\mathrm{n}$ & 0,1 & 0,1 & $\mathrm{n}$ & 0,1 & 0,3 & 0,2 & 0,3 & 0,1 & $\mathrm{n}$ & $\mathrm{n}$ & $\mathrm{n}$ & 0,1 & 0,2 & 0,3 & 0,2 \\
\hline $\begin{array}{l}\text { Gesamt aus sonstigen } \\
\text { G20-Ländern }\end{array}$ & 46,7 & 5,3 & 32,6 & 6,0 & 6,0 & 15,9 & 19,3 & 3,5 & 7,8 & 19,5 & 12,7 & 50,2 & 30,2 & 1,3 & 4,2 & 11,1 & 19,4 & 7,8 & 29,1 & 49,2 \\
\hline \multicolumn{21}{|l|}{ Geografische Großräume } \\
\hline Gesamt aus Afrika & 2,8 & 6,6 & 9,9 & 0,1 & 2,1 & 1,6 & 8,4 & 4,0 & 2,2 & 4,5 & 2,1 & 1,0 & 21,5 & 1,3 & 1,6 & 9,1 & 5,4 & 4,8 & 8,2 & 4,6 \\
\hline Gesamt aus Asien & 81,5 & 9,3 & 49,0 & 0,8 & 9,6 & 18,4 & 31,9 & 21,7 & 9,9 & 32,3 & 16,8 & 69,8 & 5,5 & 6,1 & 3,4 & 5,9 & 42,0 & 10,7 & 53,0 & 73,3 \\
\hline Gesamt aus Europa & 4,0 & 37,4 & 11,4 & 4,1 & 80,4 & 75,3 & 44,1 & 70,6 & 76,9 & 40,6 & 72,9 & 6,9 & 42,1 & 92,0 & 89,7 & 34,1 & 29,9 & 73,3 & 31,2 & 9,4 \\
\hline hierv.: aus EU21-Ländern & 2,8 & 34,0 & 9,8 & 3,8 & 39,9 & 60,3 & 23,0 & 38,7 & 65,1 & 37,2 & 63,3 & 5,3 & 36,2 & 80,5 & 15,7 & 22,2 & 20,6 & 64,2 & 23,3 & 7,0 \\
\hline Gesamt aus Nordamerika & 2,7 & 0,8 & 6,4 & 1,4 & 1,4 & 2,5 & 2,5 & 3,3 & 7,1 & 15,8 & 1,5 & 6,4 & 1,0 & 0,2 & 0,9 & 1,7 & 2,5 & 3,1 & 5,0 & 3,6 \\
\hline Gesamt aus Ozeanien & 1,9 & 0,1 & 0,4 & $\mathrm{n}$ & 0,3 & 0,2 & 0,3 & 0,1 & 1,1 & 0,7 & 0,1 & 9,0 & 0,2 & $\mathrm{n}$ & $\mathrm{n}$ & 0,1 & 0,3 & 0,4 & 0,6 & 0,7 \\
\hline $\begin{array}{l}\text { Gesamt aus Lateinamerika } \\
\text { und der Karibik }\end{array}$ & 1,7 & 1,9 & 5,9 & 88,7 & 1,1 & 2,0 & 4,8 & 0,3 & 2,5 & 1,0 & 2,9 & 1,4 & 29,8 & 0,4 & 1,4 & 49,1 & 2,3 & 4,8 & 1,9 & 8,4 \\
\hline Nicht spezifiziert & 5,4 & 43,8 & 17,0 & 5,0 & 5,2 & $\mathrm{n}$ & 8,0 & $\mathrm{n}$ & 0,3 & 5,2 & 3,6 & 5,5 & $\pi$ & $\mathrm{n}$ & 2,9 & 0,1 & 17,6 & 2,9 & 0,2 & $\mathrm{n}$ \\
\hline Gesamt aus allen Ländern & 100 & 100 & 100 & 100 & 100 & 100 & 100 & 100 & 100 & 100 & 100 & 100 & 100 & 100 & 100 & 100 & 100 & 100 & 100 & 100 \\
\hline
\end{tabular}

1. Referenzjahr 2011. 2. Ohne private Bildungseinrichtungen. 3. Ohne Studiengänge im Tertiärbereich B. 4. Ohne weiterführende forschungsorientierte Studiengänge (Deutschland: weiterführende forschungsorientierte Studiengänge sind nur in den geografischen Hauptregionen berücksichtigt). 5. Studierende, deren Herkunftsland nicht näher spezifiziert ist, kommen zum überwiegenden Teil aus den anderen nordischen Ländern. 6. Ausländische Studierende sind auf der Grundlage des Landes, dessen Staatsbürger sie sind, definiert; diese Daten sind nicht mit den Daten zu internationalen Studierenden vergleichbar, daher werden sie in der Tabelle getrennt aufgeführt.

Quelle: OECD und Statistikinstitut der UNESCO für die meisten Daten zu Nicht-OECD-Ländern. Lettland: Eurostat. Hinweise s. Anhang 3 unter www.oecd.org/edu/eag.htm. StatLink: $h$ ttp://dx.doi.org/10.1787/888933118713

Erläuterung der Kennzeichnung fehlender Daten s. Hinweise für den Leser. 
Tabelle C4.3 (Forts.)

Verteilung internationaler und ausländischer Studierender im Tertiärbereich, nach Herkunftsland (2012)

Zahl der im Tertiärbereich eingeschriebenen internationalen und ausländischen Studierenden der einzelnen Herkunftsländer als Prozentsatz aller internationalen und ausländischen Studierenden im Zielland (basierend auf Personenzahlen)

Die Tabelle zeigt für jedes Land den Anteil der internationalen Studierenden im Tertiärbereich, die ihren dauerhaften Wohnsitz in einem bestimmten Herkunftsland haben bzw. dort den vorgelagerten Bildungsbereich besucht haben. Wenn Daten zur Mobilität Studierender nicht zur Verfügung stehen, ist in der Tabelle der Anteil ausländischer Studierender im Tertiärbereich angegeben, die Staatsbürger eines bestimmten Herkunftslandes sind.

Bedeutung der Spalte (2): 15,7 Prozent der internationalen Studierenden im Tertiärbereich in Belgien kommen aus Frankreich, 9,9 Prozent der internationalen Studierenden im Tertiärbereich in Belgien kommen aus den Niederlanden usw.

Bedeutung der Spalte (6): 48,2 Prozent der internationalen Studierenden im Tertiärbereich in Estland kommen aus Finnland, 1,4 Prozent der internationalen Studierenden im Tertiärbereich in Estland kommen aus Italien usw.

Bedeutung der Spalte (21): 40,5 Prozent der ausländischen Studierenden im Tertiärbereich in Österreich sind deutsche Staatsbürger, 2, 4 Prozent der ausländischen Studierenden im Tertiärbereich in Österreich sind ungarische Staatsbürger usw.

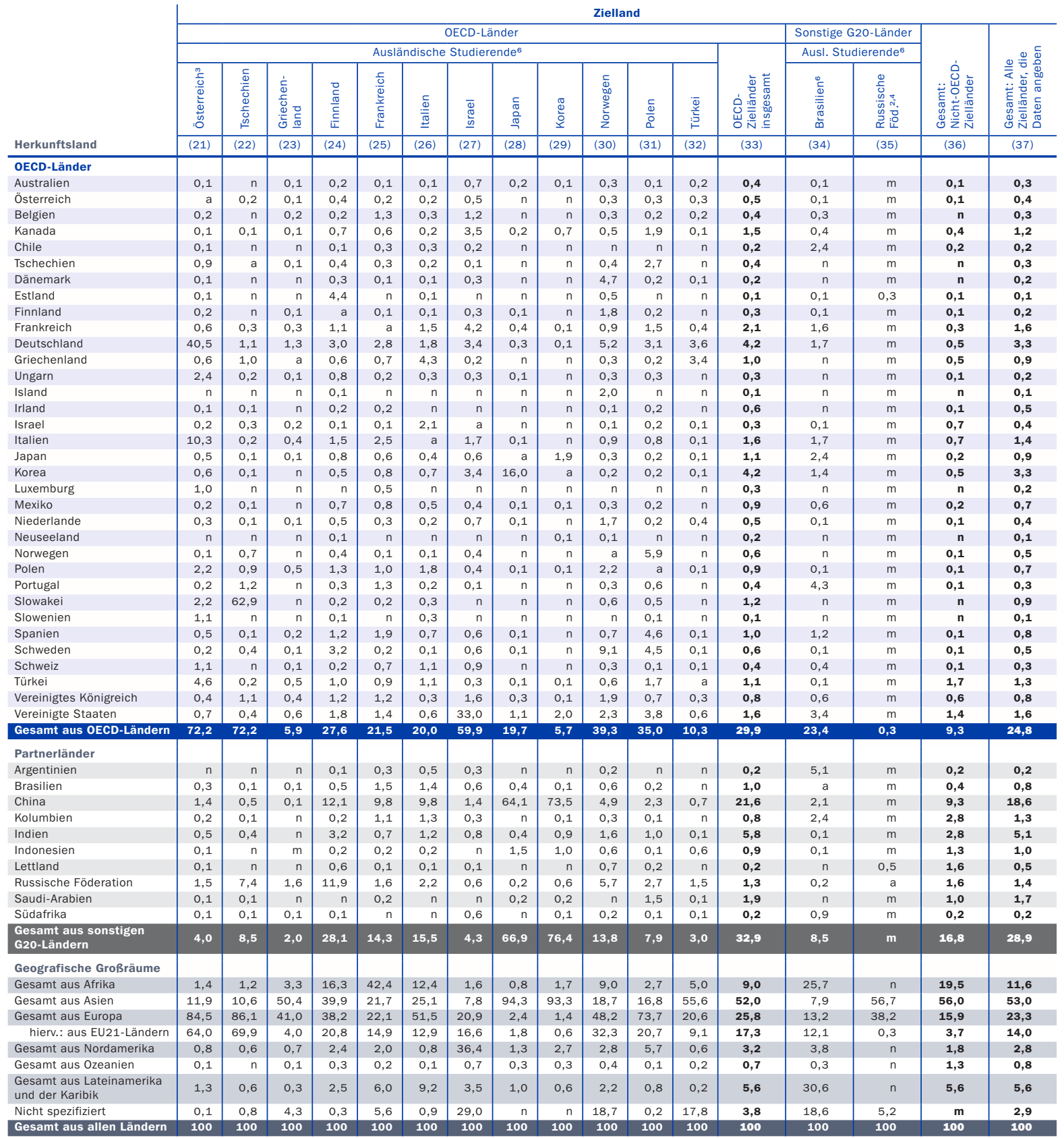

1. Referenzjahr 2011. 2. Ohne private Bildungseinrichtungen. 3. Ohne Studiengänge im Tertiärbereich B. 4. Ohne weiterführende forschungsorientierte Studiengänge (Deutschland: weiterführende forschungssorientierte Studiengänge sind nur in den geografischen Hauptregionen berücksichtigt). 5. Studierende, deren Herkunftsland nicht näher spezifiziert ist, kommen zum überwiegenden Teil aus den anderen nordischen Ländern. 6. Ausländische Studierende sind auf der Grundlage des Landes, dessen Staatsbürger sie sind, definiert; diese Daten sind nicht mit den Daten zu internationalen Studierenden vergleichbar, daher werden sie in der Tabelle getrennt aufgeführt.

Quelle: OECD und Statistikinstitut der UNESCO für die meisten Daten zu Nicht-OECD-Ländern. Lettland: Eurostat. Hinweise s. Anhang 3 unter www.oecd.org/edu/eag.htm. StatLink: $h$ ttp://dx.doi.org/10.1787/888933118713

Erläuterung der Kennzeichnung fehlender Daten s. Hinweise für den Leser 
Tabelle C4.4

Studierende, die in einem Land studieren, dessen Staatsbürger sie nicht sind, nach Zielland (2012)

Zahl der im Tertiärbereich eingeschriebenen ausländischen Studierenden in einem bestimmten Zielland als Prozentsatz aller im Ausland eingeschriebenen Studierenden in Zielländern, die Daten gemeldet haben (basierend auf Personenzahlen)

Die Tabelle zeigt den Anteil der Studierenden jedes Landes, die in einem bestimmten Zielland studieren.

Bedeutung der Spalte (2): 4,5 Prozent der tschechischen Studierenden im Auslandsstudium studieren in Österreich, 10, 8 Prozent der italienischen Studierenden im Auslandsstudium studieren in Österreich usw.

Bedeutung der Zeile (1): 2,5 Prozent der australischen Studierenden im Auslandsstudium studieren in Frankreich, 19,7 Prozent der australischen Studierenden im Auslandsstudium studieren in Neuseeland usw.

Zielland

\begin{tabular}{|c|c|c|c|c|c|c|c|c|c|c|c|c|c|c|c|c|c|c|c|c|}
\hline \multirow[b]{4}{*}{ Herkunftsland } & \multicolumn{20}{|c|}{ Zielland } \\
\hline & \multicolumn{20}{|c|}{ OECD-Länder } \\
\hline & 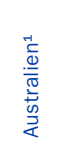 & 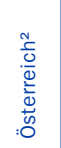 & 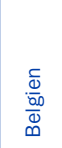 & 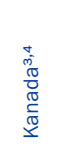 & $\frac{\frac{d}{C}}{\frac{C}{U}}$ & 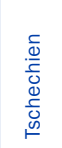 & 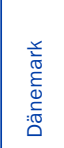 & 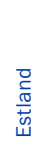 & 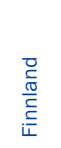 & 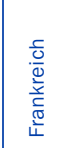 & $\begin{array}{l}n \\
0 \\
\frac{n}{c} \\
\frac{0}{c} \\
\frac{1}{0} \\
0 \\
5 \\
0 \\
0 \\
0\end{array}$ & 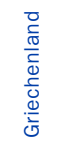 & $\begin{array}{l}5 \\
\frac{5}{5} \\
\infty \\
5 \\
5\end{array}$ & $\begin{array}{l}\bar{D} \\
\stackrel{\mathbb{C}}{\sigma} \\
\underline{\omega}\end{array}$ & 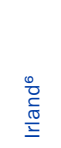 & $\begin{array}{l}\bar{\Phi} \\
\frac{\pi}{\omega} \\
\underline{\omega}\end{array}$ & $\begin{array}{l}\frac{\bar{\Phi}}{\stackrel{\Phi}{\sigma}} \\
\pm\end{array}$ & $\begin{array}{l}\frac{1}{\sqrt{0}} \\
\frac{2}{\sqrt{0}} \\
\stackrel{0}{7}\end{array}$ & 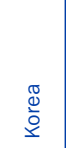 & 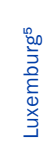 \\
\hline & (1) & (2) & (3) & (4) & (5) & (6) & (7) & (8) & (9) & (10) & (11) & (12) & (13) & (14) & (15) & $(16)$ & (17) & (18) & (19) & (20) \\
\hline \multicolumn{21}{|l|}{ OECD-Länder } \\
\hline Australien & a & 0,4 & 0,3 & 3,6 & $\mathrm{n}$ & 0,1 & 0,6 & $n$ & 0,3 & 2,5 & 3,6 & 0,2 & 0,1 & $n$ & 1,0 & 0,2 & 0,5 & 1,9 & 0,5 & $\mathrm{n}$ \\
\hline Österreich & 1,2 & a & 0,6 & 0,8 & $\mathrm{n}$ & 0,4 & 0,6 & $\mathrm{n}$ & 0,3 & 2,7 & 52,5 & 0,1 & 0,8 & 0,1 & 0,4 & 0,1 & 0,9 & 0,2 & $\mathrm{n}$ & 0,1 \\
\hline Belgien & 0,7 & 0,9 & $a$ & 3,0 & 0,1 & 0,1 & 0,5 & $n$ & 0,3 & 23,7 & 8,5 & 0,3 & 0,2 & $n$ & 0,4 & 0,4 & 1,4 & 0,4 & 0,1 & 2,3 \\
\hline Kanada & 7,8 & 0,2 & 0,3 & a & $n$ & 0,1 & 0,2 & $\mathrm{n}$ & 0,2 & 3,4 & 1,4 & 0,1 & 0,4 & 0,1 & 1,9 & 0,3 & 0,3 & 0,6 & 0,9 & $\mathrm{n}$ \\
\hline Chile & 4,9 & 0,4 & 1,1 & 3,7 & a & 0,1 & 0,4 & $n$ & 0,2 & 7,9 & 5,5 & 0,1 & 0,1 & $\mathrm{n}$ & 0,1 & 0,1 & 1,8 & 0,3 & 0,2 & $n$ \\
\hline Tschechien & 0,6 & 4,5 & 0,6 & 0,7 & $\mathrm{n}$ & a & 1,0 & 0,1 & 0,4 & 5,4 & 12,2 & 0,2 & 0,6 & 0,1 & 0,8 & $\mathrm{n}$ & 1,0 & 0,3 & 0,1 & 0,2 \\
\hline Dänemark & 2,3 & 0,9 & 0,7 & 1,3 & $\mathrm{n}$ & 0,1 & a & 0,1 & 0,6 & 2,2 & 6,9 & 0,1 & 0,1 & 1,1 & 0,6 & 0,2 & 0,6 & 0,7 & $\mathrm{n}$ & 0,1 \\
\hline Estland & 0,4 & 1,3 & 0,5 & 0,2 & $\mathrm{n}$ & 0,2 & 6,5 & a & 12,7 & 2,2 & 10,1 & 0,1 & 0,2 & 0,2 & 1,7 & $\mathrm{n}$ & 1,1 & 0,4 & $\mathrm{n}$ & 0,1 \\
\hline Finnland & 1,0 & 1,6 & 0,7 & 0,8 & 0,1 & 0,1 & 2,7 & 6,7 & a & 2,8 & 8,1 & 0,2 & 0,5 & 0,5 & 0,7 & 0,1 & 0,8 & 0,9 & 0,1 & 0,1 \\
\hline Frankreich & 1,3 & 0,5 & 22,3 & 12,4 & 0,1 & 0,1 & 0,5 & $\mathrm{n}$ & 0,2 & a & 7,8 & 0,1 & 0,4 & 0,1 & 0,8 & 0,2 & 1,4 & 0,6 & 0,1 & 1,0 \\
\hline Deutschland & 1,1 & 22,1 & 0,9 & 1,1 & $\mathrm{n}$ & 0,3 & 2,2 & $\mathrm{n}$ & 0,4 & 5,5 & a & 0,3 & 1,7 & 0,1 & 0,7 & 0,1 & 1,0 & 0,3 & 0,1 & 0,3 \\
\hline Griechenland & 0,2 & 1,1 & 1,6 & 0,3 & $\mathrm{n}$ & 1,0 & 0,9 & $\mathrm{n}$ & 0,2 & 4,9 & 15,4 & a & 0,5 & $\mathrm{n}$ & 0,2 & $\mathrm{n}$ & 8,2 & 0,1 & $\mathrm{n}$ & 0,1 \\
\hline Ungarn & 0,6 & 16,7 & 1,3 & 0,8 & $\mathrm{n}$ & 0,8 & 3,4 & $\mathrm{n}$ & 1,3 & 5,4 & 18,1 & 0,2 & a & 0,1 & 1,3 & 0,1 & 1,9 & 0,8 & 0,1 & 0,2 \\
\hline Island & 0,4 & 0,9 & 0,3 & 1,2 & $\mathrm{n}$ & 0,1 & 39,3 & 0,1 & 0,4 & 1,3 & 2,8 & $n$ & 2,3 & a & 0,2 & $\mathrm{n}$ & 0,5 & 0,6 & $\mathrm{n}$ & $n$ \\
\hline Irland & 0,9 & 0,2 & 0,3 & 0,8 & $\mathrm{n}$ & 0,2 & 0,3 & $n$ & 0,1 & 1,8 & 1,7 & $n$ & 0,7 & $\mathrm{n}$ & a & $\mathrm{n}$ & 0,1 & 0,1 & $\mathrm{n}$ & $n$ \\
\hline Israel & 0,7 & 0,7 & 0,2 & 5,3 & $\mathrm{n}$ & 0,7 & 0,2 & $\mathrm{n}$ & 0,1 & 1,5 & 9,0 & 0,4 & 4,2 & $n$ & 0,1 & a & 9,2 & 0,2 & $\mathrm{n}$ & $n$ \\
\hline Italien & 0,6 & 10,8 & 3,0 & 0,6 & $n$ & 0,1 & 0,9 & $n$ & 0,4 & 9,2 & 13,1 & 0,1 & 0,3 & 0,1 & 0,7 & 0,1 & a & 0,2 & $\mathrm{n}$ & 0,2 \\
\hline Japan & 5,1 & 1,0 & 0,4 & 4,5 & $\mathrm{n}$ & 0,1 & 0,2 & $\mathrm{n}$ & 0,4 & 4,6 & 5,4 & 0,1 & 0,6 & 0,1 & 0,2 & 0,1 & 0,9 & a & 3,0 & $\mathrm{n}$ \\
\hline Korea & 5,6 & 0,3 & 0,1 & 6,4 & $\mathrm{n}$ & $n$ & $n$ & $n$ & 0,1 & 1,7 & 3,5 & $n$ & 0,2 & $n$ & 0,1 & 0,1 & 0,4 & 18,0 & a & $\mathrm{n}$ \\
\hline Luxemburg & 0,1 & 9,1 & 20,7 & 0,4 & $\mathrm{n}$ & $\mathrm{n}$ & 0,1 & $\mathrm{n}$ & $\mathrm{n}$ & 16,6 & 38,6 & $\mathrm{n}$ & 0,1 & $\mathrm{n}$ & 0,2 & $\mathrm{n}$ & 0,2 & 0,1 & $\mathrm{n}$ & a \\
\hline Mexiko & 2,0 & 0,5 & 0,6 & 6,5 & 0,7 & 0,1 & 0,3 & $\mathrm{n}$ & 0,4 & 7,4 & 5,9 & $n$ & 0,1 & $\mathrm{n}$ & 0,2 & 0,1 & 1,3 & 0,6 & 0,1 & $\mathrm{n}$ \\
\hline Niederlande & 1,0 & 1,1 & 27,9 & 1,8 & $n$ & 0,1 & 1,7 & $n$ & 0,4 & 4,0 & 7,3 & 0,1 & 0,2 & 0,1 & 1,0 & 0,1 & 0,7 & 0,4 & $\mathrm{n}$ & 0,1 \\
\hline Neuseeland & 46,1 & 0,2 & 0,1 & 2,6 & $n$ & 0,1 & 0,2 & $n$ & 0,3 & 1,3 & 1,4 & $\mathrm{n}$ & 0,1 & 0,1 & 0,6 & $\mathrm{n}$ & 0,1 & 1,2 & 1,0 & $\mathrm{n}$ \\
\hline Norwegen & 6,8 & 0,3 & 0,2 & 1,0 & $n$ & 1,4 & 18,2 & $\mathrm{n}$ & 0,4 & 1,8 & 2,1 & $n$ & 4,2 & 0,1 & 0,3 & 0,1 & 0,4 & 0,3 & $\mathrm{n}$ & $\mathrm{n}$ \\
\hline Polen & 0,3 & 3,6 & 1,6 & 1,2 & $\mathrm{n}$ & 0,7 & 2,7 & $n$ & 0,5 & 5,5 & 21,5 & 0,3 & 0,3 & 0,1 & 3,7 & $n$ & 2,9 & 0,2 & 0,1 & 0,1 \\
\hline Portugal & 0,5 & 0,5 & 4,3 & 1,0 & $\mathrm{n}$ & 2,0 & 0,7 & $\mathrm{n}$ & 0,3 & 14,7 & 8,4 & 0,1 & 0,4 & $n$ & 0,5 & $n$ & 0,7 & 0,2 & $\mathrm{n}$ & 1,6 \\
\hline Slowakei & 0,2 & 4,7 & 0,3 & 0,3 & $n$ & 68,1 & 0,6 & $n$ & 0,1 & 1,2 & 3,0 & $n$ & 6,9 & $n$ & 0,5 & $n$ & 0,6 & 0,1 & $n$ & $\mathrm{n}$ \\
\hline Slowenien & 0,4 & 25,2 & 1,1 & 0,7 & $\mathrm{n}$ & 0,5 & 1,6 & $\mathrm{n}$ & 0,6 & 3,4 & 15,2 & 0,1 & 0,9 & 0,2 & 0,4 & 0,1 & 8,1 & 0,2 & $\mathrm{n}$ & 0,2 \\
\hline Spanien & 0,5 & 0,9 & 2,9 & 0,7 & 0,2 & 0,1 & 1,3 & $n$ & 0,6 & 13,2 & 16,1 & 0,2 & 0,9 & 0,2 & 1,1 & 0,1 & 1,5 & 0,4 & $n$ & 0,1 \\
\hline Schweden & 3,2 & 0,8 & 0,4 & 0,9 & $\mathrm{n}$ & 0,8 & 12,3 & $\mathrm{n}$ & 2,6 & 2,3 & 3,1 & 0,1 & 2,0 & 0,2 & 0,5 & 0,1 & 0,5 & 0,9 & 0,1 & $n$ \\
\hline Schweiz & 2,4 & 6,6 & 1,2 & 3,3 & 0,1 & 0,1 & 0,8 & $\mathrm{n}$ & 0,3 & 14,8 & 22,1 & 0,3 & 0,2 & $n$ & 0,4 & 0,3 & 6,6 & 0,5 & 0,1 & 0,1 \\
\hline Türkei & 0,6 & 4,2 & 0,6 & 1,2 & $\mathrm{n}$ & 0,1 & 0,8 & $\mathrm{n}$ & 0,2 & 2,9 & 41,0 & 0,2 & 0,6 & $\mathrm{n}$ & 0,1 & $\mathrm{n}$ & 1,0 & 0,2 & 0,1 & $n$ \\
\hline Ver. Königreich & 3,2 & 0,7 & 0,8 & 5,6 & $n$ & 1,0 & 1,5 & $n$ & 0,5 & 7,2 & 4,9 & 0,3 & 0,6 & 0,1 & 11,4 & 0,2 & 0,6 & 1,0 & 0,2 & n \\
\hline Vereinigte Staaten & 4,1 & 0,7 & 0,5 & 13,8 & 0,1 & 0,3 & 0,6 & $\mathrm{n}$ & 0,4 & 5,6 & 6,3 & 0,2 & 0,6 & 0,1 & 2,0 & 2,1 & 0,6 & 2,3 & 1,7 & $n$ \\
\hline $\begin{array}{l}\text { Gesamt aus } \\
\text { OECD-Ländern }\end{array}$ & 2,5 & 4,7 & 3,1 & 3,7 & 0,1 & 2,4 & 1,6 & 0,1 & 0,4 & 4,9 & 10,2 & 0,1 & 0,9 & 0,1 & 1,2 & 0,2 & 1,3 & 2,5 & 0,3 & 0,2 \\
\hline $\begin{array}{l}\text { Gesamt aus } \\
\text { EU21-Ländern }\end{array}$ & 1,0 & 7,0 & 5,1 & 2,6 & $\mathbf{n}$ & 3,9 & 1,7 & 0,1 & 0,5 & 5,8 & 9,7 & 0,2 & 1,1 & 0,1 & 1,5 & 0,1 & 1,4 & 0,4 & 0,1 & 0,3 \\
\hline \multicolumn{21}{|l|}{ Partnerländer } \\
\hline Argentinien & 0,9 & 0,3 & 0,4 & 3,9 & 4,3 & $n$ & 0,2 & $n$ & 0,2 & 6,4 & 2,9 & 0,1 & $\mathrm{n}$ & $\mathrm{n}$ & 0,1 & 0,1 & 3,3 & 0,5 & 0,2 & $\mathrm{n}$ \\
\hline Brasilien & 2,0 & 0,5 & 0,7 & 3,9 & 0,6 & 0,1 & 0,4 & $n$ & 0,2 & 10,5 & 6,5 & $\mathrm{n}$ & $\mathrm{n}$ & $\mathrm{n}$ & 0,4 & 0,1 & 2,9 & 1,5 & 0,1 & $\mathrm{n}$ \\
\hline China & 11,5 & 0,1 & 0,2 & 5,2 & $n$ & $n$ & 0,2 & $n$ & 0,3 & 3,5 & 2,9 & $n$ & $n$ & $\mathrm{n}$ & 0,3 & $n$ & 1,0 & 12,7 & 5,7 & $n$ \\
\hline Kolumbien & 3,9 & 0,6 & 0,7 & 8,1 & 4,5 & 0,1 & 0,2 & $\mathrm{n}$ & 0,1 & 9,4 & 5,0 & $\mathrm{n}$ & $n$ & $\mathrm{n}$ & $\mathrm{n}$ & $\mathrm{n}$ & 3,1 & 0,2 & 0,1 & $\mathrm{n}$ \\
\hline Indien & 5,4 & 0,2 & 0,3 & 6,5 & $n$ & 0,1 & 0,1 & $\mathrm{n}$ & 0,3 & 0,9 & 2,1 & $n$ & $n$ & $\mathrm{n}$ & 0,4 & $\mathrm{n}$ & 0,4 & 0,3 & 0,3 & $n$ \\
\hline Indonesien & 22,7 & 0,2 & 0,4 & 2,2 & $\mathrm{n}$ & $\mathrm{n}$ & 0,1 & $\mathrm{n}$ & 0,1 & 1,3 & 5,6 & $\mathrm{~m}$ & $\mathrm{n}$ & $\mathrm{n}$ & $\mathrm{n}$ & $\mathrm{n}$ & 0,4 & 5,3 & 1,5 & $n$ \\
\hline Lettland & 0,3 & 1,2 & 0,8 & 0,6 & $n$ & 0,1 & 9,3 & $n$ & 1,2 & 1,9 & 8,8 & 0,1 & 0,1 & 0,2 & 4,2 & $\mathrm{n}$ & 1,1 & 0,2 & $\mathrm{n}$ & 0,1 \\
\hline Russische Föd. & 1,3 & 1,7 & 0,8 & 2,4 & $\mathrm{n}$ & 4,3 & 0,6 & 1,7 & 3,1 & 6,4 & 20,1 & 0,7 & 0,2 & $\mathrm{n}$ & 0,3 & $\mathrm{n}$ & 2,6 & 0,5 & 0,5 & 0,1 \\
\hline Saudi-Arabien & 8,1 & 0,1 & $n$ & 4,9 & $\mathrm{n}$ & 0,1 & $n$ & $n$ & $n$ & 0,8 & 0,3 & $n$ & 0,3 & $\mathrm{n}$ & 0,7 & $n$ & 0,1 & 0,4 & 0,2 & $n$ \\
\hline Südafrika & 6,1 & 0,4 & 0,8 & 3,3 & $\mathrm{n}$ & 0,2 & 0,3 & $n$ & 0,2 & 0,9 & 1,4 & 0,3 & $\mathrm{n}$ & $\mathrm{n}$ & 1,9 & 0,2 & 0,3 & 0,1 & 0,3 & $\mathrm{n}$ \\
\hline $\begin{array}{l}\text { Gesamt aus sons- } \\
\text { tigen G20-Ländern }\end{array}$ & 9,6 & 0,2 & 0,3 & 5,1 & 0,1 & 0,3 & 0,2 & 0,1 & 0,4 & 3,2 & 3,8 & $\mathbf{n}$ & 0,1 & $\mathbf{n}$ & 0,3 & n & 1,0 & 8,3 & 3,7 & n \\
\hline $\begin{array}{l}\text { Gesamt aus allen } \\
\text { Ländern }\end{array}$ & 5,5 & 1,7 & 1,2 & 4,9 & 0,3 & 0,9 & 0,7 & 0,1 & 0,4 & 6,0 & 6,3 & 0,6 & 0,4 & $\mathbf{n}$ & 0,6 & 0,1 & 1,7 & 3,3 & 1,3 & 0,1 \\
\hline
\end{tabular}

Anmerkung: Der Anteil der im Ausland Studierenden basiert nur auf der Gesamtzahl der in Ländern eingeschriebenen Studierenden, die Daten an die OECD und das Statistikinstitut der UNESCO melden.

1. Die Daten beziehen sich auf internationale Studierende. 2. Ohne Studiengänge im Tertiärbereich B. 3. Referenzjahr $2011 . \quad 4.0 h n e$ private Bildungseinrichtungen. 5. Ohne weiterführende forschungsorientierte Studiengänge (Deutschland: weiterführende forschungsorientierte Studiengänge sind nur in den geografischen Hauptregionen berücksichtigt). 6. Ohne Teilzeitstudierende.

Quelle: OECD und Statistikinstitut der UNESCO für die meisten Daten zu Nicht-OECD-Ländern. Lettland: Eurostat.

Hinweise s. Anhang 3 unter www.oecd.org/edu/eag.htm. StatLink: http://dx.doi.org/10.1787/888933118732

Erläuterung der Kennzeichnung fehlender Daten s. Hinweise für den Leser. 
Studierende, die in einem Land studieren, dessen Staatsbürger sie nicht sind, nach Zielland (2012)

Zahl der im Tertiärbereich eingeschriebenen ausländischen Studierenden in einem bestimmten Zielland als Prozentsatz aller im Ausland eingeschriebenen Studierenden in Zielländern, die Daten gemeldet haben (basierend auf Personenzahlen)

Die Tabelle zeigt den Anteil der Studierenden jedes Landes, die in einem bestimmten Zielland studieren.

Bedeutung der Spalte (2): 4,5 Prozent der tschechischen Studierenden im Auslandsstudium studieren in Österreich, 10,8 Prozent der italienischen Studierenden im Auslandsstudium studieren in Österreich usw.

Bedeutung der Zeile (1): 2,5 Prozent der australischen Studierenden im Auslandsstudium studieren in Frankreich, 19,7 Prozent der australischen Studierenden im Auslandsstudium studieren in Neuseeland usw.

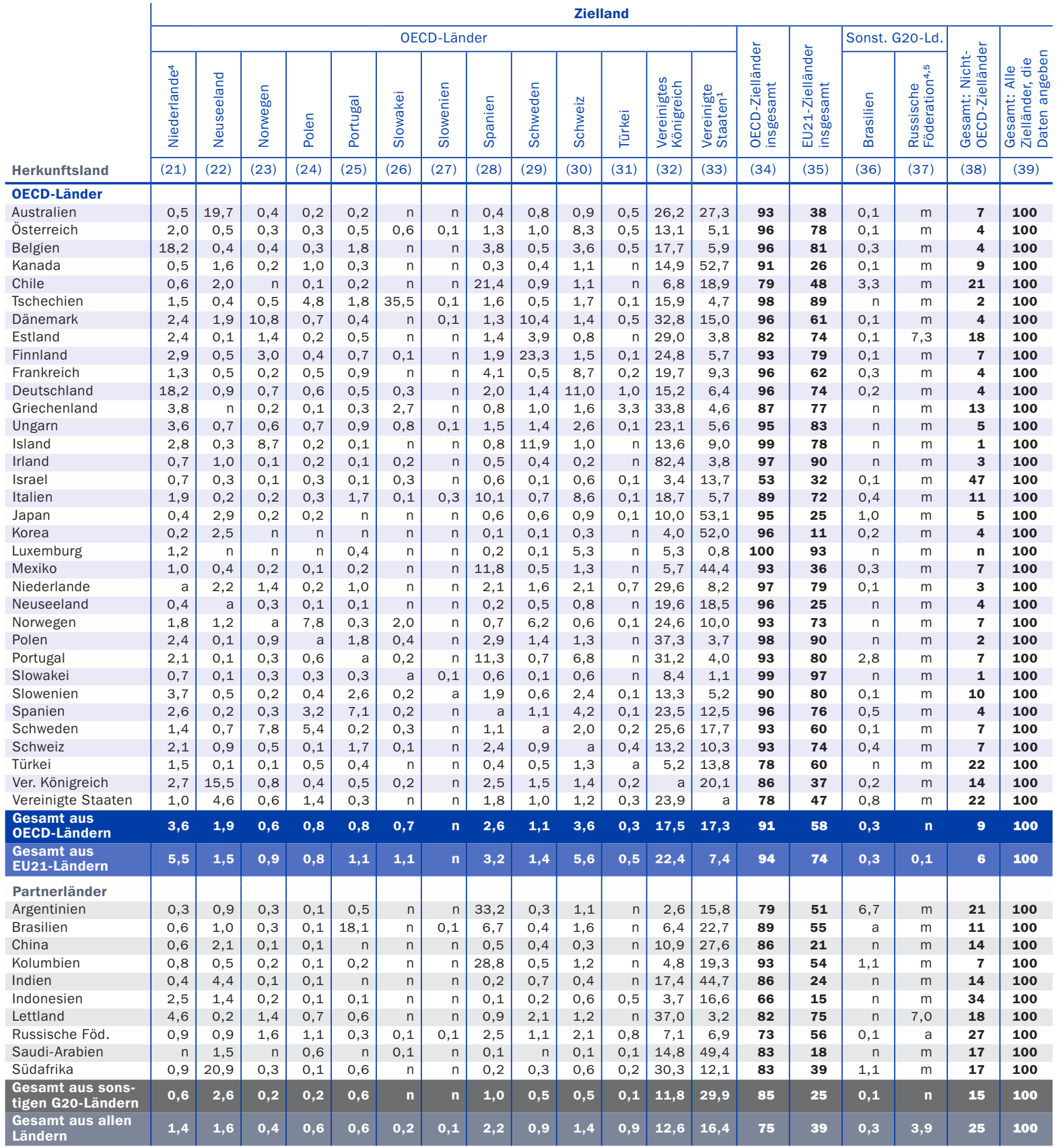

Anmerkung: Der Anteil der im Ausland Studierenden basiert nur auf der Gesamtzahl der in Ländern eingeschriebenen Studierenden, die Daten an die OECD und das Statistikinstitut der UNESCO melden.

1. Die Daten beziehen sich auf internationale Studierende. 2. Ohne Studiengänge im Tertiärbereich B. 3. Referenzjahr 2011.4 . Ohne private Bildungseinrichtungen. 5. Ohne weiterführende forschungsorientierte Studiengänge (Deutschland: weiterführende forschungsorientierte Studiengänge sind nur in den geografischen Hauptregionen berücksichtigt). 6. Ohne Teilzeitstudierende.

Quelle: OECD und Statistikinstitut der UNESCO für die meisten Daten zu Nicht-OECD-Ländern. Lettland: Eurostat.

Hinweise s. Anhang 3 unter www.oecd.org/edu/eag.htm. StatLink: http://dx.doi.org/10.1787/888933118732

Erläuterung der Kennzeichnung fehlender Daten s. Hinweise für den Leser. 
Tabelle C4.5

Mobilität ausländischer und internationaler Studierender (2012)

Regionale und grenzüberschreitende Mobilität, Ausmaß der Mobilität und Verwendung der Amtssprache des Ziellands in den Herkunftsländern

\begin{tabular}{|c|c|c|c|c|}
\hline & $\begin{array}{c}\text { Anteil inländischer } \\
\text { Studierender, die im Ausland } \\
\text { eingeschrieben sind (in \%) }\end{array}$ & $\begin{array}{c}\text { Anteil ausländischer } \\
\begin{array}{c}\text { Studierender pro im Ausland } \\
\text { eingeschriebenen inländischen } \\
\text { Studierenden }\end{array} \\
\end{array}$ & $\begin{array}{l}\text { Anteil ausländischer } \\
\text { Studierender aus benach- } \\
\text { barten Ländern (in \%) }\end{array}$ & $\begin{array}{l}\text { Anteil Studierender aus } \\
\text { Ländern mit derselben } \\
\text { Amtssprache (in \%) }\end{array}$ \\
\hline & (1) & (2) & (3) & (4) \\
\hline \multicolumn{5}{|l|}{ OECD-Länder } \\
\hline Australien & 1 & 18 & 40 & 18 \\
\hline Österreich & 6 & 4 & 59 & 53 \\
\hline Belgien & 3 & 4 & 52 & 66 \\
\hline Kanada $^{2}$ & 3 & 4 & 4 & 33 \\
\hline Chile & 1 & 1 & 33 & 59 \\
\hline Tschechien ${ }^{3}$ & 3 & 3 & 65 & $n$ \\
\hline Dänemark & 3 & 4 & 36 & $n$ \\
\hline Estland & 8 & $\mathrm{n}$ & 70 & $\mathrm{n}$ \\
\hline Finnland & 4 & 2 & 20 & 3 \\
\hline Frankreich ${ }^{3}$ & 4 & 3 & 15 & 29 \\
\hline Deutschland & 5 & 2 & 14 & 9 \\
\hline Griechenland ${ }^{3}$ & 6 & 1 & 76 & 44 \\
\hline Ungarn & 3 & 2 & 42 & $n$ \\
\hline Island & 19 & $\mathrm{n}$ & 10 & $\mathrm{n}$ \\
\hline Irland & 13 & 1 & 18 & 44 \\
\hline |srael $^{3}$ & 4 & $\mathrm{n}$ & $\mathrm{n}$ & $\mathrm{n}$ \\
\hline Italien ${ }^{3}$ & 4 & 1 & 28 & 5 \\
\hline Japan & 1 & 4 & 81 & $\mathrm{n}$ \\
\hline Korea $^{3}$ & 4 & $n$ & 75 & $\mathrm{n}$ \\
\hline Luxemburg & 70 & $\mathrm{n}$ & $\mathrm{m}$ & 29 \\
\hline Mexiko & 1 & $n$ & $\mathrm{~m}$ & $\mathrm{~m}$ \\
\hline Niederlande & 3 & 3 & 47 & 5 \\
\hline Neuseeland & 3 & 12 & 11 & 46 \\
\hline Norwegen & 8 & 1 & 25 & $n$ \\
\hline Polen & 2 & 1 & 56 & $n$ \\
\hline Portugal & 6 & 1 & 9 & 55 \\
\hline Slowakei & 15 & $n$ & 60 & $n$ \\
\hline Slowenien & 3 & 1 & 31 & 6 \\
\hline Spanien & 2 & 3 & 22 & 40 \\
\hline Schweden & 5 & 2 & 20 & 6 \\
\hline Schweiz & 5 & 5 & 49 & 53 \\
\hline Türkei ${ }^{3}$ & 2 & $\mathrm{n}$ & 28 & 11 \\
\hline Vereinigtes Königreich & 2 & 13 & 14 & 32 \\
\hline Vereinigte Staaten & $\mathrm{n}$ & 11 & 6 & 25 \\
\hline OECD insgesamt & 2 & 3 & 21 & 24 \\
\hline Gesamt EU21 & 4 & 3 & 24 & 26 \\
\hline \multicolumn{5}{|l|}{ Partnerländer } \\
\hline Argentinien & $n$ & $\mathrm{n}$ & $\mathrm{m}$ & 92 \\
\hline Brasilien $^{3}$ & 1 & $\mathrm{n}$ & 25 & 27 \\
\hline China $^{3}$ & 2 & $\mathrm{~m}$ & $\mathrm{~m}$ & $\mathrm{~m}$ \\
\hline Kolumbien & 2 & $\mathrm{~m}$ & $\mathrm{~m}$ & $\mathrm{~m}$ \\
\hline Indien & 1 & $\mathrm{~m}$ & $\mathrm{~m}$ & $\mathrm{~m}$ \\
\hline Indonesien ${ }^{3}$ & 1 & $\mathrm{~m}$ & $\mathrm{~m}$ & $\mathrm{~m}$ \\
\hline Lettland & 9 & $n$ & $\mathrm{~m}$ & $\mathrm{~m}$ \\
\hline Russische Föderation 3,4 & 1 & 3 & 68 & 37 \\
\hline Saudi-Arabien ${ }^{3}$ & 5 & 1 & 27 & 37 \\
\hline Südafrika ${ }^{3}$ & 1 & 5 & 60 & 81 \\
\hline
\end{tabular}

1. Als Nachbarländer gelten Länder, die gemeinsame Land- oder Seegrenzen mit dem Zielland haben. 2. Referenzjahr 2011. 3. Inländische Studierende im Tertiärbereich werden berechnet als Gesamtzahl der Studierenden minus ausländische Studierende, nicht als Gesamtzahl minus internationale Studierende. 4. Der Anteil ausländischer Studierender aus den Nachbarländern enthält auch die Studierenden aus den Ländern der früheren Sowietunion, vor allem aus Zentralasien. Quelle: OECD und das Statistikinstitut der UNESCO für die meisten Daten zu Nicht-OECD-Ländern. Lettland: Eurostat. CIA World Factbook 2012 für Amtssprachen in den einzelnen Ländern. Hinweise s. Anhang 3 unter www.oecd.org/edu/eag.htm. StatLink: http://dx.doi.org/10.1787/888933118751

Erläuterung der Kennzeichnung fehlender Daten s. Hinweise für den Leser. 
Tabelle C4.6

Entwicklung der Zahl der eingeschriebenen ausländischen Studierenden im Tertiärbereich, nach Zielregion und Herkunftsland (2000 bis 2012)

Zahl eingeschriebener ausländischer Studierender im Tertiärbereich (basierend auf Personenzahlen)

\begin{tabular}{|c|c|c|c|c|c|c|c|c|c|c|}
\hline \multirow[b]{2}{*}{$\begin{array}{l}\text { In folgenden Zielregionen } \\
\text { eingeschriebene } \\
\text { ausländische Studierende }\end{array}$} & \multicolumn{5}{|c|}{ Zahl ausländischer Studierender } & \multicolumn{4}{|c|}{ Index der Veränderung (2011) } & \multirow{2}{*}{\begin{tabular}{|} 
In OECD-Ländern \\
eingeschriebene auslän- \\
dische Studierende \\
aus folgenden Herkunfts- \\
regionen (2012)
\end{tabular}} \\
\hline & 2012 & 2011 & 2010 & 2005 & 2000 & $\begin{array}{r}2011 \\
=100\end{array}$ & $\begin{array}{r}2010 \\
=100\end{array}$ & $\begin{array}{r}2005 \\
=100\end{array}$ & $\begin{array}{r}2000 \\
=100\end{array}$ & \\
\hline Afrika & 196568 & 191037 & 178716 & 108765 & 100031 & 103 & 110 & 181 & 197 & 346511 \\
\hline Asien & 806281 & 772410 & 726054 & 458377 & 334562 & 104 & 111 & 176 & 241 & 1662788 \\
\hline Europa & 2160874 & 2086980 & 1984442 & 1388027 & 935879 & 104 & 109 & 156 & 231 & 969377 \\
\hline Nordamerika & 961967 & 913480 & 880427 & 738401 & 569640 & 105 & 109 & 130 & 169 & 101100 \\
\hline Lateinamerika und Karibik & 71468 & 74267 & 76041 & 37114 & 28945 & 96 & 94 & 193 & 247 & 204874 \\
\hline Ozeanien & 330886 & 343466 & 350165 & 251904 & 118646 & 96 & 94 & 131 & 279 & 26617 \\
\hline Weltweit & 4528044 & 4381639 & 4195845 & 2982588 & 2087702 & 103 & 108 & 152 & 217 & 3415975 \\
\hline OECD-Länder & 3415975 & 3316209 & 3181939 & 2373011 & 1604601 & 103 & 107 & 144 & 213 & 1085398 \\
\hline EU-Länder & 1822330 & 1769450 & 1686734 & 1201503 & 822025 & 103 & 108 & 152 & 222 & 779936 \\
\hline hiervon: in EU21-Ländern & 1779998 & 1728586 & 1647730 & 1174107 & 792411 & 103 & 108 & 152 & 225 & 657911 \\
\hline G20-Länder & 3712641 & 3591996 & 3432928 & 2485330 & 1730913 & 103 & 108 & 149 & 214 & 1721226 \\
\hline
\end{tabular}

Anmerkung: Diese Zahlen beruhen auf der Zahl ausländischer Studierender, die in OECD- und Nicht-OECD-Ländern eingeschrieben sind, die Daten an die OECD und das Statistikinstitut der UNESCO melden, um ein umfassendes Bild der weltweit eingeschriebenen ausländischen Studierenden zu vermitteln. Die Zahl der Länder, die Daten zur Verfügung stellen, hat im Laufe der Zeit zugenommen, daher wurden fehlende Zahlen gegebenenfalls berechnet, um die Vergleichbarkeit der Zeitreihen über die Jahre zu gewährleisten. Da einerseits Daten der UNESCO für Nicht-OECD-Länder berücksichtigt und andererseits fehlende Daten berechnet wurden, können die Schätzwerte der Zahl ausländischer Studierender von denen in früheren Ausgaben von Bildung auf einen Blick abweichen. Die Gesamtzahlen für die Jahre 2006 bis 2009 und 2001 bis 2004 sind im Internet verfügbar (s StatLink unten).

Quelle: OECD und das Statistikinstitut der UNESCO für die meisten Daten zu Nicht-OECD-Ländern. Hinweise s. Anhang 3 unter www.oecd.org/edu/eag.htm). StatLink: http://dx.doi.org/10.1787/888933118770

Erläuterung der Kennzeichnung fehlender Daten s. Hinweise für den Leser. 



\section{Der Übergang vom (Aus-)Bildungssystem zum Erwerbsleben: Wo sind die 15- bis 29-Jährigen?}

- Auf dem Höhepunkt der Wirtschaftskrise fiel der Anteil der 15- bis 29-Jährigen, die nicht länger in Ausbildung, aber in Beschäftigung waren, im Durchschnitt der OECD-Länder von 4I Prozent (2008) auf 36 Prozent (2012).

2012 befanden sich im Durchschnitt der OECD-Länder I5 Prozent der I5- bis 29-Jährigen weder in Beschäftigung noch in einer Form der Ausbildung (diese Gruppe wird mit der englischen Abkürzung NEET bezeichnet - Not in employment, education or training).

Im Durchschnitt der OECD-Länder wollten rund 40 Prozent der I5- bis 29-Jährigen, die 2012 Teilzeit arbeiteten, gerne mehr arbeiten.

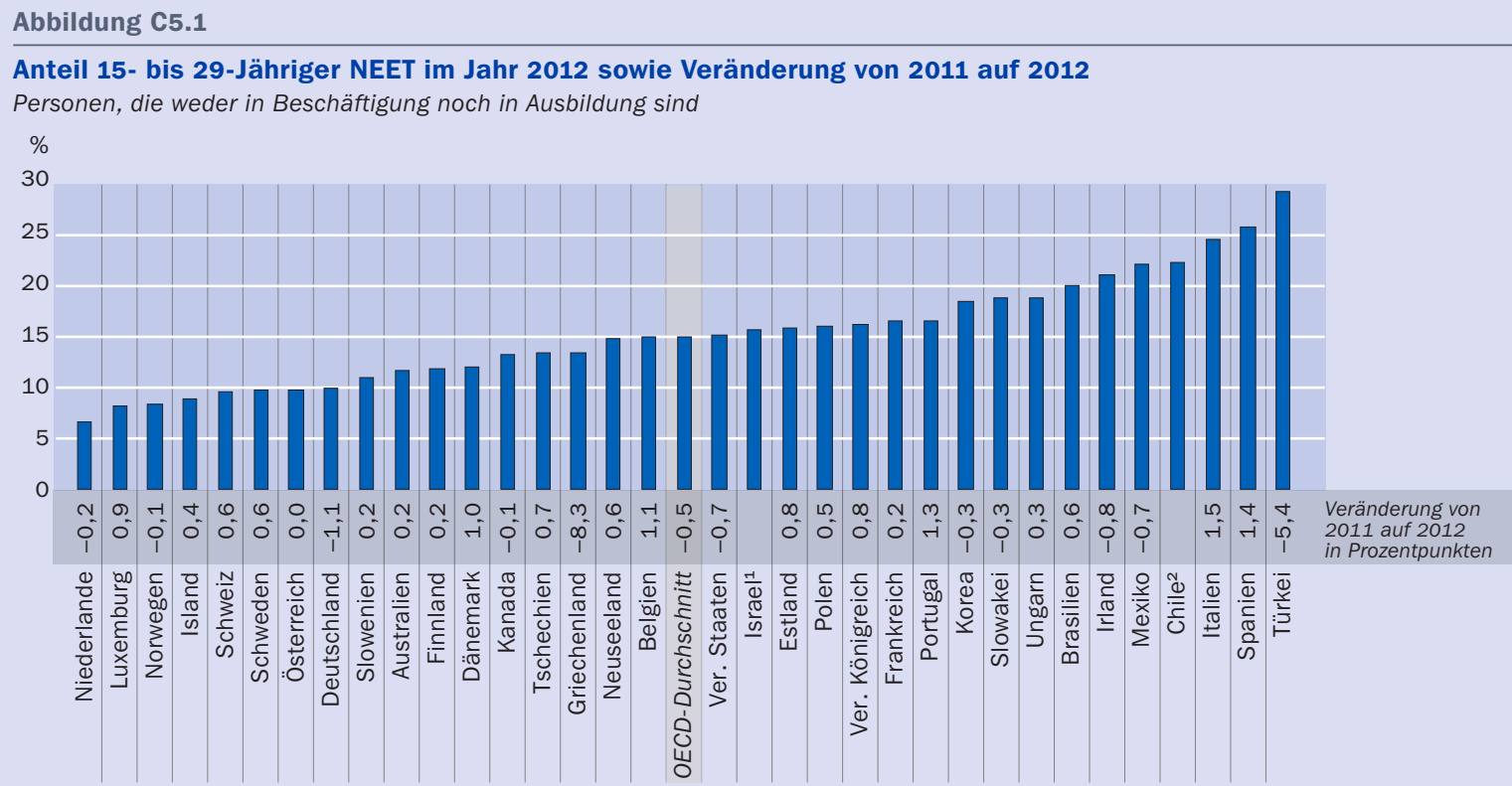

1. Die Daten von 2011 und 2012 sind nicht vergleichbar. S. Abschnitt Methodik am Ende des Indikators. 2. Referenzjahr 2011.

Anordnung der Länder in aufsteigender Reihenfolge der Größe des Anteils NEET unter den 15- bis 29-Jährigen mit einem Abschluss im Sekundarbereich II bzw. im postsekundaren, nicht tertiären Bereich im Jahr 2012.

Quelle: OECD. Tab. C5.3d im Internet. Hinweise s. Anhang 3 unter www.oecd.org/edu/eag.htm. StatLink: http://dx.doi.org/10.1787/888933119017

\section{Kontext}

Die Länge und Qualität der Schulausbildung des Einzelnen wirken sich ebenso auf den späteren Übergang von der Ausbildung in das Erwerbsleben aus wie die Arbeitsmarktbedingungen, das wirtschaftliche Umfeld und die demografischen Gegebenheiten. Auch nationale Gepflogenheiten spielen hier eine wichtige Rolle. So schließen beispielsweise junge Menschen in manchen Ländern in der Regel erst ihre Ausbildung ab und suchen sich dann einen Arbeitsplatz, während in anderen Ländern Ausbildung 
und Beschäftigung parallel stattfinden. In einigen Ländern gestaltet sich der Übergang von der (Aus-)Bildung in das Erwerbsleben bei Männern und Frauen recht ähnlich, während sich in anderen ein erheblicher Anteil der jungen Frauen nach dem Verlassen des Bildungssystems zunächst Vollzeit der Kindererziehung widmet und nicht in den Arbeitsmarkt eintritt.

Die Alterung der Bevölkerung in den OECD-Ländern sollte sich positiv auf die Beschäftigungslage junger Menschen in den OECD-Ländern auswirken, da - rein theoretisch - die Arbeitsplätze älterer Menschen, wenn diese den Arbeitsmarkt verlassen, den jungen Menschen zur Verfügung stehen. Während einer Rezession erschwert jedoch die geringere Zahl freier Stellen den Jüngeren den Übergang vom (Aus-)Bildungssystem zum Erwerbsleben erheblich, da erfahrene Arbeitskräfte den Berufsanfängern vorgezogen werden. Junge Menschen neigen bei ungünstiger Arbeitsmarktlage dazu, ihre Ausbildung zu verlängern, da hohe Erwerbslosenquoten die Opportunitätskosten der Bildung/Ausbildung senken. Gleichzeitig wird in den meisten Ländern das Ruhestandsalter angehoben. Wenn das Ruhestandsalter steigt, werden weniger Arbeitsplätze für eine Neubesetzung frei, wodurch sich die Zahl der offenen Stellen meist verringert. Das könnte den Unterschied zwischen der Anzahl junger Arbeitskräfte (Neueintritt) und der Anzahl älterer Arbeitskräfte (Abgänger aus dem Arbeitsmarkt) erklären.

Um den Übergang junger Menschen vom Bildungssystem in Beschäftigung unabhängig von der jeweiligen konjunkturellen Lage zu erleichtern, sollte das (Aus-)Bildungssystem sicherstellen, dass die Absolventen mit den auf dem Arbeitsmarkt nachgefragten Kompetenzen ausgestattet werden. Während einer Rezession können öffentliche Investitionen in das Bildungssystem eine vernünftige Maßnahme zur Vermeidung von Erwerbslosigkeit und - durch den Aufbau nachgefragter Kompetenzen - eine Investition in künftiges Wirtschaftswachstum sein. Darüber hinaus könnten öffentliche Investitionen in Richtung potenzieller Arbeitgeber gelenkt werden, um als Anreiz für die Anstellung junger Menschen zu dienen.

\section{Weitere wichtige Ergebnisse}

Im Jahr 2012 befanden sich in den OECD-Ländern im Durchschnitt 49 Prozent der 15- bis 29-Jährigen im Bildungssystem. Von den verbleibenden 51 Prozent waren 36 Prozent beschäftigt, 7 Prozent erwerbslos und 8 Prozent nicht im Arbeitsmarkt.

2012 konnten typische 15-Jährige in einem OECD-Land davon ausgehen, während der nächsten 15 Jahre ungefähr weitere 7 Jahre im formalen Bildungssystem zu verbleiben. Zusätzlich konnten sie damit rechnen, vor ihrem 30. Geburtstag mehr als 5 Jahre beschäftigt, fast I Jahr erwerbslos und mehr als I Jahr nicht auf dem Arbeitsmarkt zu sein, d. h. weder in Ausbildung noch arbeitssuchend.

Die Wahrscheinlichkeit, nicht im Arbeitsmarkt zu sein, war für 15- bis 29-jährige Frauen doppelt so hoch wie für gleichaltrige Männer. Während dieser Zeitspanne konnte eine Frau erwarten, I,7 Jahre lang nicht zur Erwerbsbevölkerung zu gehören, gegenüber o,8 Jahren für einen Mann. 


\section{Entwicklungstendenzen}

Aufgrund der staatlichen Anstrengungen zur Anhebung des Bildungsstands kam es im Laufe der Jahre zu deutlichen Veränderungen bei der Bildungsteilnahme. 2000 befanden sich in den OECD-Ländern im Durchschnitt 4I Prozent der 15- bis 29-Jährigen im Bildungssystem, 2012 war ihr Anteil auf 49 Prozent angestiegen (Tab. C5.3a).

Gleichzeitig fiel der Anteil der 15- bis 29-Jährigen, die nicht in Ausbildung, aber in Beschäftigung waren, von 44 Prozent auf 36 Prozent. Obwohl der Prozentsatz derjenigen in Ausbildung von 2000 bis 2012 ständig zunahm, gab es bei der Entwicklung der Beschäftigtenzahlen junger Erwachsener zwei große Einbrüche: das erste Mal zwischen 2000 und 2003 ( $-3,3$ Prozentpunkte) und dann noch einmal zwischen 2008 und $2012(-4,4$ Prozentpunkte). Diese Einbrüche der Beschäftigtenzahlen junger Erwachsener fielen mit der Abschwächung der Weltwirtschaft Anfang des Jahrtausends und der durch die globale Finanzkrise 2008 ausgelösten Rezession zusammen. Der Anteil der I5- bis 29-Jährigen, die sich weder in Ausbildung noch in Beschäftigung befanden (NEET), blieb zwischen 2000 und 2012 mit rund I5 Prozent unverändert (Tab. C5·3a).

\section{Analyse und Interpretationen}

\section{Junge Menschen im und außerhalb des (Aus-)Bildungssystems und ihr Arbeitsmarktstatus}

Ein höherer Bildungsstand verbessert zwar die wirtschaftlichen Chancen junger Menschen, aber die weltweite Verschlechterung der Konjunktur in den letzten Jahren hat es ihnen schwer gemacht, einen Arbeitsplatz zu finden.

Abbildung $\mathrm{C}_{5.2}$ zeigt, dass in den OECD-Ländern ungefähr die Hälfte der 15- bis 29-Jährigen an einer (Aus-)Bildungsmaßnahme teilnehmen; die Situation ist in allen Ländern ähnlich - der Anteil variiert von weniger als 40 Prozent in Brasilien und Mexiko bis zu mehr als 6o Prozent in Griechenland, Japan und Slowenien. Untersucht man den Beschäftigungsstatus dieser Bevölkerungsgruppe, ergeben sich größere Unterschiede zwischen den Ländern. In Australien, Dänemark, Island, den Niederlanden und der Schweiz arbeitet über die Hälfte der jungen Menschen, die sich im (Aus-)Bildungssystem befinden, nebenher zumindest in Teilzeit. In allen anderen Ländern ist der Anteil der jungen Erwachsenen, die gleichzeitig arbeiten und an einer (Aus-)Bildungsmaßnahme teilnehmen, geringer; in Belgien, Italien, Spanien und Ungarn sind es weniger als Io Prozent. Auch für junge Erwachsene mit abgeschlossener Ausbildung ergeben sich große Unterschiede zwischen den Ländern, in allen Ländern jedoch sind die meisten von ihnen in Beschäftigung.

Erwerbslosen- und Beschäftigungsquoten sind hilfreiche Indikatoren für die Arbeitsmarktteilnahme, aber gerade bei jungen Menschen ist die Wahrscheinlichkeit hoch, dass sie ihren Eintritt in den Arbeitsmarkt aufschieben oder aus der Erwerbsbevölkerung ausscheiden und dann außerhalb des Arbeitsmarkts stehen (d.h. nicht beschäftigt sind und auch nicht aktiv nach einer Arbeitsstelle suchen; s. Abschnitt Definitionen 
Abbildung C5.2

Anteil 15- bis 29-Jähriger, die sich in Ausbildung bzw. nicht in Ausbildung befinden, nach Erwerbsstatus (2012)

Beschäftigt (einschließlich dualer Ausbildungsgänge)

Nicht beschäftigt (nur Schüler/Studierende)

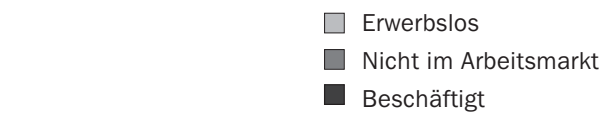

Nicht in Ausbildung

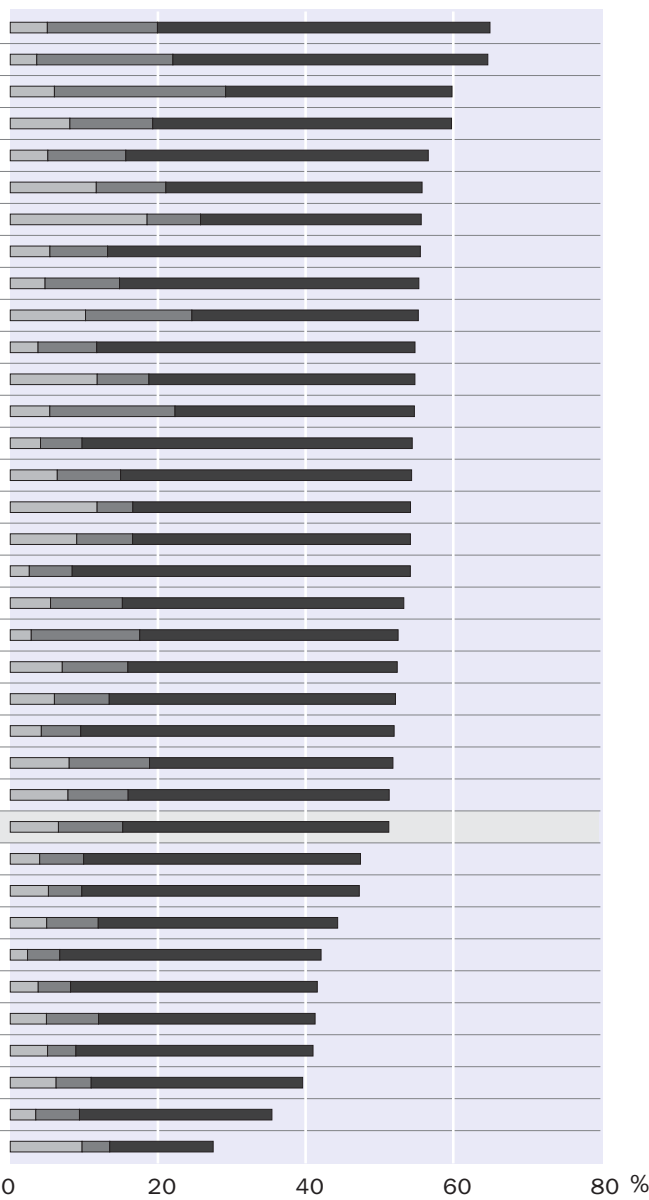

40

$80 \%$

Brasilien Mexiko

Türkei

Ver. Königreich

Israel $^{1}$

Irland

Spanien

Kanada

Neuseeland

Italien

Australien

Slowakei Chile $^{2}$

Österreich

Belgien

Portugal

Frankreich

Norwegen

Vereinigte Staaten

Korea

Estland

Tschechien

Schweiz

Ungarn

Polen

OECD-Durchschnitt

Deutschland

Schweden

Finnland

Niederlande

Luxemburg

Dänemark Island

Slowenien

Japan $^{3}$

Griechenland

1. Der geringe Anteil von Angehörigen dieser Altersgruppe, die sich in Ausbildung befinden, erklärt sich durch die Wehrpflicht für 18- bis 21-Jährige.

2. Referenzjahr 2011. 3. Daten beziehen sich auf 15- bis 24-Jährige.

Anordnung der Länder in absteigender Reihenfolge des Anteils 15- bis 29-Jähriger, die sich nicht in Ausbildung befinden.

Quelle: OECD. Tabelle C5.2a. Hinweise s. Anhang 3 unter www.oecd.org/edu/eag.htm. StatLink: http://dx.doi.org/10.1787/888933119036

am Ende des Indikators). Obwohl ein wachsender Anteil junger Menschen tendenziell über die Schulpflicht hinaus im Bildungssystem verbleibt und daher auch als „nicht im Arbeitsmarkt" erfasst wird, wäre es irreführend, diese als eine stark gefährdete Gruppe anzusehen. Daher ist der Prozentsatz junger Menschen, die sich weder in Beschäftigung noch in (Aus-)Bildung befinden, eine bessere Kennzahl für die Probleme der jungen Menschen bei der Arbeitsplatzsuche, da sie nicht nur die diejenigen erfasst, denen der Eintritt in den Arbeitsmarkt nicht gelingt, sondern auch diejenigen, die sich nicht mehr in Ausbildung befinden.

Junge Menschen, die weder beschäftigt noch in Ausbildung sind (NEET) Junge Erwachsene, die das Bildungssystem verlassen und auf eine schwierige Arbeitsmarktlage treffen, können für einen längeren Zeitraum erwerbslos sein oder völlig aus 
der Erwerbsbevölkerung ausscheiden, d. h. außerhalb des Arbeitsmarkts stehen. Der Prozentsatz junger Menschen, die sich weder in Beschäftigung noch in (Aus-)Bildung befinden, eignet sich besser, um die Probleme aufzuzeigen, auf die junge Menschen bei der Arbeitsplatzsuche treffen, als die Erwerbslosenquote, da hierbei nicht nur diejenigen erfasst werden, die keine Arbeitsstelle finden (also erwerbslos sind), sondern auch diejenigen, die entmutigt sind und nicht aktiv nach einer Beschäftigung suchen (also nicht im Arbeitsmarkt sind).

Wenn viele junge Menschen weder in Ausbildung noch in Beschäftigung sind, ist dies häufig die Folge einer Konjunkturabschwächung. Es kann aber auch ein Hinweis auf Störungen beim Übergang von der (Aus-)Bildung in das Erwerbsleben sein oder auf eine Inkongruenz zwischen den Kompetenzen, über die die jungen Menschen verfügen, und denjenigen, die auf dem Arbeitsmarkt nachfragt werden.

Angehörige der NEET-Gruppe, die nicht im Arbeitsmarkt oder langzeiterwerbslos sind, könnten wertvolle Kompetenzen verlieren, und ihre künftigen Beschäftigungsund Einkommenschancen könnten langfristig beeinträchtigt werden, was für die Volkswirtschaften möglicherweise die Chancen verringert, Humankapital zu bilden, und den Verlust von Steuereinnahmen mit sich bringt. Außerdem haben zahlreiche Studien einen Zusammenhang zwischen Erwerbslosigkeit und schlechter psychischer Gesundheit, einschließlich Depressionen, nachgewiesen, was u.a. zu weiteren von der Gesellschaft zu tragenden Kosten führen kann (OECD, 2008).

Abbildung $\mathrm{C}_{5}$.I zeigt, dass in den OECD-Ländern insgesamt der Prozentsatz I5- bis 29-Jähriger, die weder in Beschäftigung waren noch irgendeiner Ausbildung nachgingen, von 20 II auf 2012 geringfügig um 0,5 Prozentpunkte zurückgegangen ist. Allerdings ergab sich in vielen Ländern keine derartige Verbesserung. In Italien beispielsweise wuchs diese Gruppe im gleichen Zeitraum um 2,5 Prozentpunkte, während der Anstieg in Portugal bei 4 Prozentpunkten lag (Tab. $\mathrm{C}_{5} \cdot 3 \mathrm{~d}$ im Internet).

Die jüngste Kohorte: I5- bis I9-Jährige, die sich weder in Beschäftigung noch in Ausbildung befinden

Da die Bildungsteilnahme im Sekundarbereich II im Laufe der Jahre zugenommen hat, ist inzwischen die Zahl der I5- bis I9-Jährigen, die sich nicht im Bildungssystem befinden, gesunken. Unter diesen jungen Menschen sind diejenigen, die weder beschäftigt noch in Ausbildung sind, besonders gefährdet.

Wenn sich die Arbeitsmarktlage verschlechtert, treffen meist die Jüngsten, die 15- bis I9-Jährigen, die gerade vom (Aus-)Bildungssystem ins Erwerbsleben übertreten wollen, zuerst auf Schwierigkeiten. Sie sind vielleicht geringer qualifiziert, während die Arbeitgeber die wenigen vorhandenen Arbeitsplätze lieber mit erfahreneren Arbeitnehmern besetzen möchten. Abbildung $\mathrm{C}_{5} \cdot 3$ zeigt, dass es manchen Ländern besser gelingt als anderen, die I5- bis I9-Jährigen in Beschäftigung zu bringen (gekennzeichnet als „Nicht in Ausbildung, beschäftigt“). Im Durchschnitt der OECD-Länder ist ungefähr jeder zweite I5- bis I9-Jährige, der sich nicht in Ausbildung befindet, beschäftigt. In Griechenland, Italien, Slowenien und Spanien sind jedoch weniger als 20 Prozent dieser jungen Erwachsenen, die sich nicht mehr in Ausbildung befinden, in Beschäftigung. 


\section{Abbildung C5.3}

Anteil 15- bis 19-Jähriger, die sich nicht in Ausbildung befinden, nach Arbeitsmarktstatus (2012)

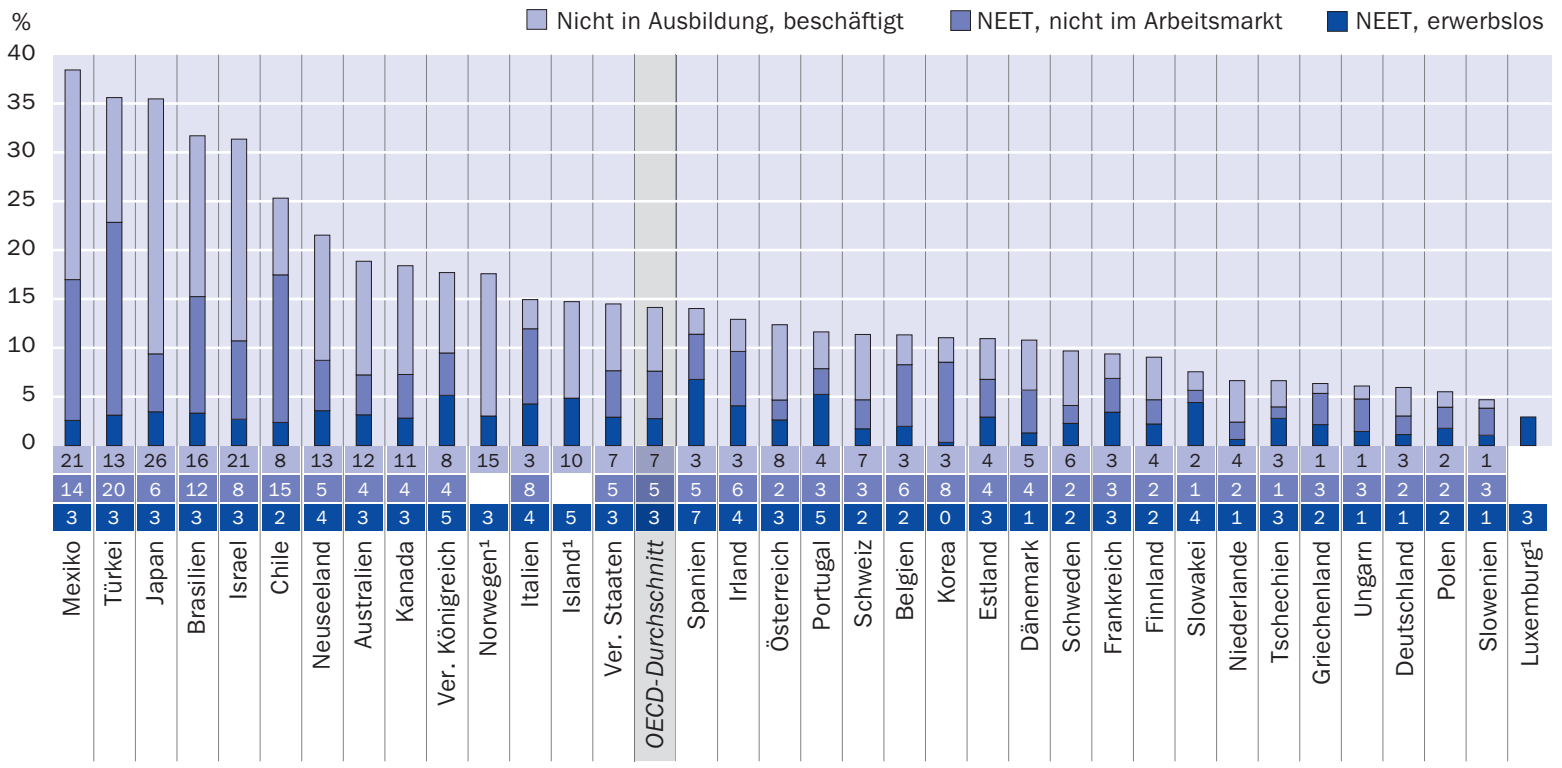

1. Gesamtzahl der NEET (erwerbslos und nicht im Arbeitsmarkt).

Anordnung der Länder in absteigender Reihenfolge des Anteils 15- bis 19-Jähriger, die sich nicht in Ausbildung befinden.

Quelle: OECD. Tabelle C5.2a. Hinweise s. Anhang 3 unter www.oecd.org/edu/eag.htm. StatLink: http://dx.doi.org/10.1787/888933119055

Im Durchschnitt der OECD-Länder gehören rund 5 Prozent der I5- bis I9-Jährigen der Gruppe der NEET an und sind nicht im Arbeitsmarkt. Sie laufen daher Gefahr, ausgegrenzt zu werden, weil sie weder weiter am Bildungssystem teilnehmen und aufgegeben haben, nach einem Arbeitsplatz zu suchen. In Brasilien, Chile, Mexiko und der Türkei befinden sich über ${ }_{5}$ Prozent der I5- bis I9-Jährigen in dieser Lage, d. h., sie sind weder in Ausbildung noch in Beschäftigung noch auf Arbeitssuche (Tab. C5.2a).

\section{Anzahl der NEET, die erwerbslos bzw. nicht im Arbeitsmarkt sind}

Die Anzahl der jungen Menschen, die weder beschäftigt sind noch einer Ausbildung nachgehen (NEET), umfasst sowohl diejenigen, die erwerbslos, als auch diejenigen, die nicht im Arbeitsmarkt sind. Bedeutsam ist hier insbesondere die letzte Gruppe, denn hierzu gehören die entmutigten jungen Menschen, die die Arbeitsplatzsuche aufgegeben haben.

Betrachtet man alle Bildungsbereiche zusammen, so gehören in Chile, Irland, Italien, Mexiko, Spanien und der Türkei mehr als 20 Prozent der 15- bis 29-Jährigen zur Gruppe der NEET. In Spanien sind ig Prozent von ihnen nicht beschäftigt und 7 Prozent nicht im Arbeitsmarkt. In Brasilien, Chile, Mexiko und der Türkei ist die Situation umgekehrt: Rund 5 Prozent der NEET sind nicht im Arbeitsmarkt, während höchstens 6 Prozent erwerbslos sind. In Deutschland, Island, Luxemburg, den Niederlanden, Norwegen, Österreich, Schweden und der Schweiz sind weniger als ro Prozent der I5bis 29-Jährigen weder in Ausbildung noch in Beschäftigung (Tab. C5.2a).

2012 zählten im Durchschnitt der OECD-Länder I7 Prozent der 15- bis 29-jährigen Frauen zu der NEET-Gruppe (6 Prozent erwerbslos und 12 Prozent nicht im Arbeits- 
markt) und I3 Prozent der I5- bis 29-jährigen Männer (7 Prozent erwerbslos und 5 Prozent nicht im Arbeitsmarkt) (Tab. C5.2b und C5.2c im Internet).

Teilzeit- und Vollzeitbeschäftigung derjenigen, die in Ausbildung, und derjenigen, die nicht in Ausbildung sind

Ungefähr jeder zweite I5- bis 29-Jährige in den OECD-Ländern ist beschäftigt. Rund 8 Prozent dieser jungen Menschen arbeiten während der Ausbildung Teilzeit, 5 Prozent sind teilzeitbeschäftigt, aber nicht mehr in Ausbildung, 6 Prozent arbeiten während der Ausbildung Vollzeit, und 30 Prozent arbeiten Vollzeit, befinden sich aber nicht mehr in Ausbildung. Betrachtet man nur die Vertreter dieser Altersgruppe, so arbeitet ungefähr ein Viertel von ihnen Teilzeit (I4 Prozent dieser 50 Prozent junger Menschen), und von diesen Teilzeitbeschäftigten würden mehr als 40 Prozent gerne mehr arbeiten, d. h., sie sind nicht freiwillig teilzeitbeschäftigt (Tab. C5.5).

Abbildung $\mathrm{C}_{5} .4$ zeigt, dass die Verbreitung der Teilzeitbeschäftigung unter jungen Menschen in den einzelnen Ländern sehr unterschiedlich ist. Im OECD-Durchschnitt sind ungefähr 25 Prozent der I5- bis 29-Jährigen teilzeitbeschäftigt, aber die Spanne reicht von weniger als 5 Prozent in Tschechien und der Slowakei bis zu 50 Prozent in Dänemark. Aus der Abbildung ergibt sich ferner, dass der Anteil der jungen Menschen, die neben der Ausbildung vollzeit- oder teilzeitbeschäftigt sind, im Durchschnitt der OECD-Länder gestiegen ist, während die Vollzeitbeschäftigung unter denjenigen, die sich nicht mehr in Ausbildung befinden, abgenommen hat. Dieser Rückgang wurde nur teilweise durch die Zunahme der Teilzeitbeschäftigung ausgeglichen.

Häufig würden Teilzeitbeschäftigte gerne mehr arbeiten, wenn sie dazu Gelegenheit hätten. Teilzeitbeschäftigung gilt nur dann als positiv, wenn sie freiwillig gewählt wurde. Im Durchschnitt der I9 OECD-Länder mit vergleichbaren Daten arbeiten weniger als die Hälfte der jungen Beschäftigten, die sich nicht in Ausbildung befinden, freiwillig Teilzeit (Tab. C5.4). Ein hoher Anteil an unfreiwillig ausgeübter Teilzeitbeschäftigung deutet darauf hin, dass diese Beschäftigten Schwierigkeiten haben, eine Vollzeitbeschäftigung zu finden, und dass diese Beschäftigungsverhältnisse als prekär einzustufen sind. Teilzeitbeschäftigte werden nur langsamer als Vollzeitbeschäftigte auf der Erfahrungs- und Gehaltsskala nach oben steigen. Dadurch wird es für die Einzelnen potenziell schwieriger, sowohl beim Gehalt als auch bei der Position im Vergleich zu gleichaltrigen Vollzeitbeschäftigten „aufzuholen“ (OECD, 2010).

Bei den I5- bis 29-Jährigen, die ihre Erstausbildung abgeschlossen haben, besteht eine positive Beziehung zwischen dem Bildungsstand und den Beschäftigungsquoten. Sowohl Teilzeit- als auch Vollzeitbeschäftigung sind häufiger bei den besser Qualifizierten anzutreffen, aber der Anteil der Teilzeitbeschäftigten unter allen Beschäftigten nimmt mit steigendem Bildungsstand ab, desgleichen auch der Anteil der unfreiwilligen Teilzeitbeschäftigung (als Anteil an Beschäftigung insgesamt). 2012 gingen ${ }_{3} 3$ Prozent der beschäftigten 15 - bis 29-Jährigen mit einem Abschluss im Tertiärbereich, die sich nicht länger in Ausbildung befanden, einer Teilzeitbeschäftigung nach (7,9 Prozent von 6I,5 Prozent, die sich nicht mehr in Ausbildung befanden und beschäftigt waren, waren teilzeitbeschäftigt), während dies bei 2I Prozent der beschäftigten I5- bis 29-Jährigen mit einer Ausbildung unterhalb des Sekundarbereichs II, die sich nicht mehr in Ausbildung befanden, der Fall war (3,2 Prozent von I5,5 Prozent insgesamt). 


\section{Abbildung C5.4}

\section{Entwicklung der Teilzeit- und Vollzeitbeschäftigung 15- bis 29-Jähriger (2006-2012)}

OECD-Durchschnitt des Anteils der 15- bis 29-Jährigen in Teilzeit- bzw. Vollzeitbeschäftigung, in Ausbildung bzw. nicht in Ausbildung (2006-2012)
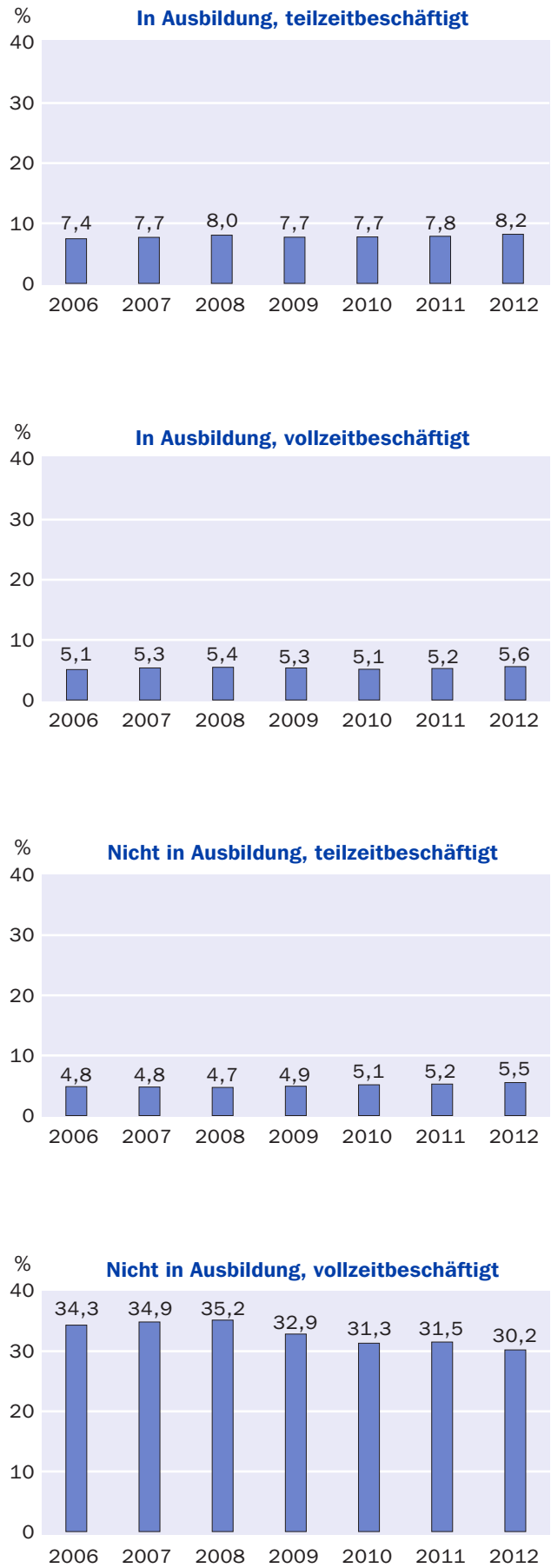

Anteil der beschäftigten 15- bis 29-Jährigen in Teilzeitbeschäftigung (2012)

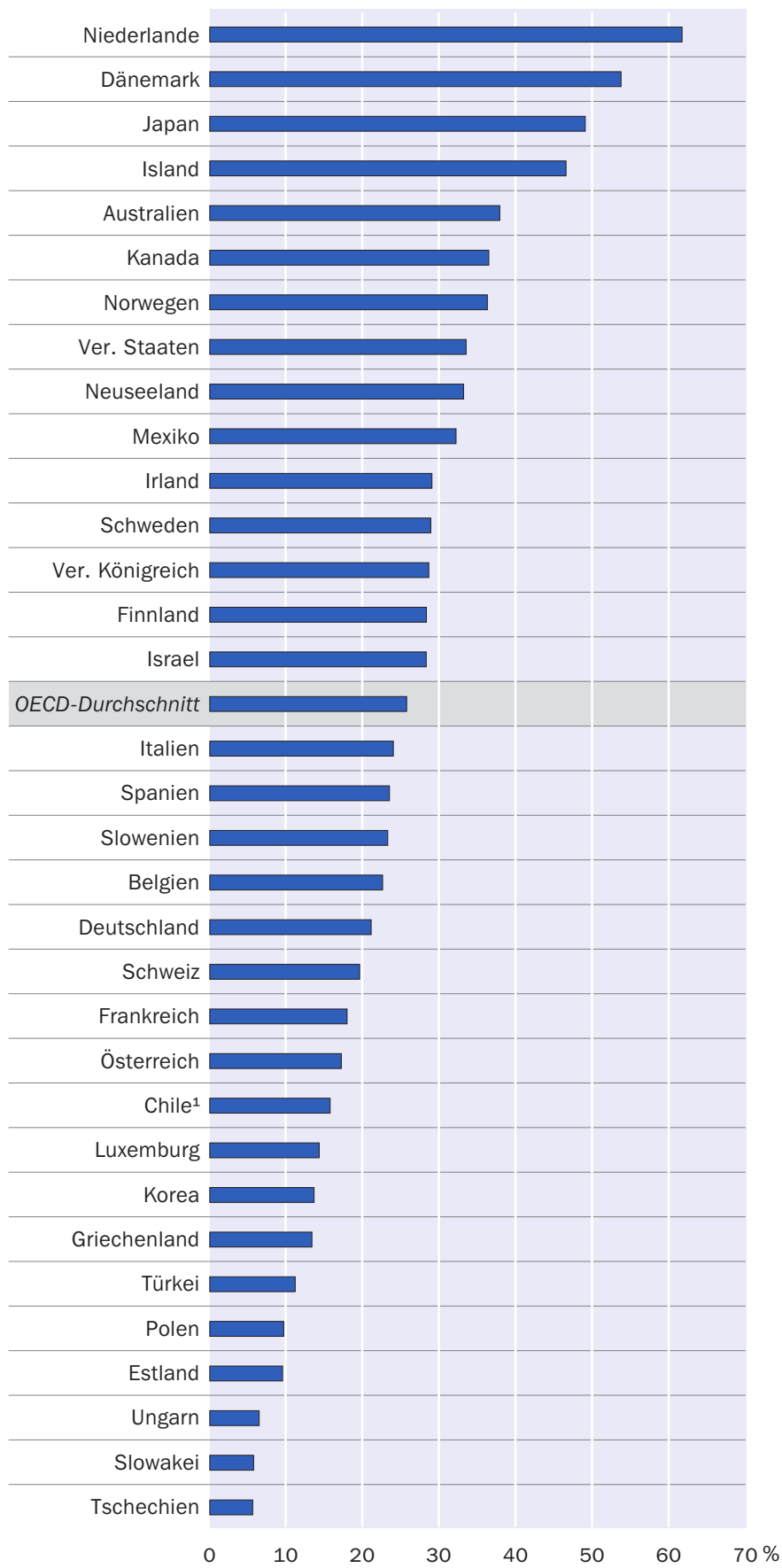


Mit steigendem Bildungsstand verringert sich auch der relative Anteil von freiwilliger Teilzeitbeschäftigung: 7 Prozent der beschäftigten I5- bis 29-Jährigen mit einem Abschluss im Tertiärbereich, die sich nicht länger in Ausbildung befinden, gehen freiwillig einer Teilzeitbeschäftigung nach (4,2 Prozent von 6I,5 Prozent insgesamt), während dies bei I2 Prozent der beschäftigten I5- bis 29-Jährigen mit einer Ausbildung unterhalb des Sekundarbereichs II, die sich nicht mehr in Ausbildung befinden, der Fall ist (I,8 Prozent von $\mathrm{I}_{5}, 5$ Prozent) (Tab. $\mathrm{C}_{5} \cdot 4$ ).

Bei jungen Teilzeitbeschäftigten, die sich nicht länger in Ausbildung befinden, findet sich ein signifikant hoher geschlechtsspezifischer Unterschied. 2012 war im Durchschnitt der OECD-Länder die Wahrscheinlichkeit, nach der Ausbildung teilzeitbeschäftigt zu sein, für I5- bis 29-jährige Frauen doppelt so hoch wie für gleichaltrige Männer (7,2 Prozent gegenüber 3,8 Prozent). In den I7 Ländern, die Daten zu unfreiwilliger Teilzeitbeschäftigung meldeten, war der Anteil der betroffenen jungen Frauen höher als der junger Männer (3,5 Prozent gegenüber 2,0 Prozent). Anteilig zur gesamten Teilzeitbeschäftigung waren jedoch mehr Männer als Frauen unfreiwillig teilzeitbeschäftigt. Männer arbeiten eher nicht Teilzeit, aber wenn sie es dennoch tun, dann meist nicht aufgrund ihrer eigenen Entscheidung (Tab. $\mathrm{C}_{5} .2 \mathrm{~b}$ und $\mathrm{C}_{5.2 \mathrm{C}}$ im Internet).

\section{Zu erwartende Jahre in Ausbildung}

Im Durchschnitt der OECD-Länder sind junge Menschen zwischen ihrem I5. und 29. Geburtstag 7 Jahre in Ausbildung (Voll- oder Teilzeit) und fast 8 Jahre nicht in Ausbildung (beschäftigt, erwerbslos oder nicht im Arbeitsmarkt). Durchschnittlich sind die jungen Menschen während fast 6 der 8 Jahre, in denen sie sich nicht in Ausbildung befinden, beschäftigt, fast I Jahr lang erwerbslos und I Jahr lang nicht im Arbeitsmarkt. Es bestehen jedoch große Unterschiede zwischen den einzelnen Ländern: In Brasilien und Mexiko verbringen diese jungen Menschen durchschnittlich 5 Jahre im Bildungssystem, in Dänemark, Island, Luxemburg, den Niederlanden und Slowenien sind es durchschnittlich 9 Jahre und in Griechenland durchschnittlich II Jahre (Tab. C5.Ia).

In den meisten Ländern steht für die I5-Jährigen das Ende der Schulpflicht unmittelbar bevor, und im letzten Jahrzehnt wurden Anstrengungen unternommen, um sie zum längeren Verbleib im Bildungssystem zu bewegen. Daraufhin ist die durchschnittliche Gesamtzahl der nach der Schulpflicht zu erwartenden Jahre in formaler Ausbildung stark gestiegen. Im Durchschnitt der OECD-Länder hat sich die formale Ausbildungsdauer seit dem Jahr 2000 um ein Jahr verlängert. Im gleichen Zeitraum verlängerte sich die Ausbildungsdauer in Luxemburg, den Niederlanden, der Slowakei, der Türkei und Tschechien um 2 Jahre und in Griechenland um 5 Jahre (Tab. C5.Ic im Internet).

In den meisten Ländern sind diese jungen Menschen während der Ausbildungsjahre nicht gleichzeitig berufstätig. Ausnahmen bilden hier lediglich Island, die Niederlande und die Schweiz, wo die jungen Menschen während der Ausbildungsdauer durchschnittlich mehr als vier Jahre berufstätig sind (unter Einbeziehung dualer Ausbildungsgänge). Im Durchschnitt der OECD-Länder sind Schüler/Studierende während 2 der 7 Jahre, die sie sich in Ausbildung befinden, gleichzeitig berufstätig (Tab. C5.Ia).

Bei den Jahren, die in Ausbildung zu erwarten sind, besteht kein großer geschlechtsspezifischer Unterschied, in einigen Ländern zeigen sich jedoch größere Unterschiede 
in der Erwerbshistorie der Abgänger des (Aus-)Bildungssystems. In Brasilien, Mexiko, Polen, der Slowakei, Tschechien und der Türkei sind Männer ungefähr 2 Jahre länger berufstätig als Frauen (Tab. C5.rb im Internet).

\section{Definitionen}

Die Kategorie Beschäftigte umfasst Personen, die entsprechend der ILO-Definition einen Arbeitsplatz hatten oder mindestens eine Stunde abhängig beschäftigt oder selbstständig tätig waren. Die hier angewendete Definition umfasst nicht die Auszubildenden in dualen Ausbildungsgängen. Weitere Erläuterungen siehe Indikator A5 und Anhang 3.

Die Kategorie Vollzeitbeschäftigte umfasst Personen, die üblicherweise mindestens 30 Wochenstunden in ihrer Hauptbeschäftigung tätig sind. In einigen Ländern gelten Grenzwerte zwischen 30 und 36 Wochenstunden, andere verwenden einen selbst definierten Vollzeitstatus. Weitere Erläuterungen siehe Indikator A6 und Anhang 3.

Die Kategorie nicht im Arbeitsmarkt umfasst die Personen, die weder beschäftigt noch erwerbslos sind, d. h. diejenigen, die nicht arbeitssuchend sind. Weitere Erläuterungen siehe Indikator $\mathrm{A}_{5}$ und Anhang 3.

NEET: Junge Menschen, die sich weder in Beschäftigung noch in Ausbildung befinden.

Teilzeitbeschäftigung ist aufgeteilt in freiwillige Teilzeitbeschäftigung, unfreiwillige Teilzeitbeschäftigung und unbekannt. Unfreiwillige Teilzeitbeschäftigung umfasst die nachfolgenden drei in Arbeitskräfteerhebungen erfassten Kategorien: Personen, die üblicherweise eine Vollzeitbeschäftigung ausüben, aber während der Erhebungswoche aus ökonomischen Gründen weniger Wochenstunden als üblich arbeiteten, unabhängig davon, wie viele Stunden sie weniger arbeiteten, bzw. Personen, die aus ökonomischen Gründen Teilzeit arbeiteten, Personen, die normalerweise Teilzeit arbeiten, weil sie keine Vollzeitstelle finden können, und Personen, die aus anderen Gründen Teilzeit arbeiten und die während der Erhebungswoche aus ökonomischen Gründen weniger als sonst üblich arbeiteten. Unfreiwillige Teilzeit umfasst alle Personen, die mehr Stunden arbeiten wollen, wenngleich nicht notwendigerweise Vollzeit.

Erwerbslose werden definiert als Personen, die während der Erhebungswoche nicht erwerbstätig waren (d. h., die weder eine Arbeit hatten noch wenigstens eine Stunde oder mehr abhängig beschäftigt oder selbstständig tätig waren), aktiv Arbeit suchten (d. h., die in den vier Wochen vor der Erhebungswoche gezielte Schritte unternommen hatten, um eine bezahlte Arbeitsstelle zu finden bzw. sich selbstständig zu machen) und dem Arbeitsmarkt zur Verfügung stehen (d. h. spätestens zwei Wochen nach der Erhebungswoche verfügbar waren, eine entgeltliche abhängige oder selbstständige Tätigkeit aufzunehmen). Weitere Erläuterungen siehe Indikator A5 und Anhang 3. 


\section{Angewandte Methodik}

Die Daten zu Bevölkerung, Bildungsstand und Arbeitsmarktstatus stammen für die meisten Länder aus Datenbanken der OECD und Eurostat, die vom OECD-Netzwerk zu den Arbeitsmarktergebnissen sowie den wirtschaftlichen und sozialen Auswirkungen des Lernens (LSO) aus nationalen Arbeitskräfteerhebungen zusammengetragen wurden. Sie beziehen sich normalerweise auf das erste Quartal oder den Durchschnitt der ersten drei Monate des Kalenderjahres. Weitere Informationen s. Anhang 3 unter www.oecd.org/edu/eag.htm.

Die erhobenen Daten können Unterschiede aufweisen. Einige Länder erfassen beispielsweise alle Beschäftigungsverhältnisse anstelle des Hauptbeschäftigungsverhältnisses, oder Teilzeitbeschäftigung bezieht sich auf weniger als 35 Wochenstunden anstelle von 30 Stunden. Einzelheiten zum Erhebungsbereich der unfreiwilligen Teilzeitbeschäftigung finden sich in Anhang 3.

Der Anteil der NEET in Israel für 2012 ist nicht vergleichbar mit dem für 20Ir. Eingezogene Wehrpflichtige gelten nunmehr als beschäftigt, im Vorjahr zählten sie nicht zur Erwerbsbevölkerung.

Anmerkung zu den Daten aus Israel

Die statistischen Daten für Israel wurden von den zuständigen israelischen Stellen bereitgestellt, die für sie verantwortlich zeichnen. Die Verwendung dieser Daten durch die OECD erfolgt unbeschadet des völkerrechtlichen Status der Golanhöhen, von Ost-Jerusalem und der israelischen Siedlungen im Westjordanland.

\section{Weiterführende Informationen}

OECD (20I0), „How Good is Part-Time Work?“, in OECD Employment Outlook 2010: Moving beyond the Jobs Crisis, OECD Publishing, Paris, http://dx.doi.org/10.1787/empl_outlook2010-5-en.

OECD (2008), „Mental Health in OECD Countries“, OECD Policy Brief, November 2008, www.oecd.org/els/health-systems/mental-health-systems.htm.

\section{Tabellen Indikator C5}

StatLink: http:/|dx.doi.org/10.1787/888933118903

Tabelle C5.ra: Zu erwartende Jahre in Ausbildung und nicht in Ausbildung für I5- bis 29-Jährige, nach Erwerbsstatus (2012)

WEB Table $\mathrm{C}_{5}$.Ib: Expected years in education and not in education for I5-29 year-olds, by work status and gender (Zu erwartende Jahre in Ausbildung und nicht in Ausbildung für 15- bis 29-Jährige, nach Erwerbsstatus und Geschlecht) (20I2) 
WEB Table C5.Ic: Trends in expected years in education and not in education for 15-29 year-olds, by gender (Entwicklung der zu erwartenden Jahre in Ausbildung und nicht in Ausbildung für I5- bis 29-Jährige, nach Geschlecht) (1999-20I2)

Tabelle C5.2a: Anteil 15- bis 29-Jähriger (in \%), die sich in Ausbildung bzw. nicht in Ausbildung befinden, nach Altersgruppe und Erwerbsstatus (20I2)

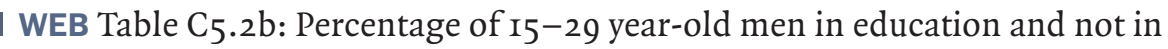
education, by age group and work status (Anteil I5- bis 29-jähriger Männer [in \%], die sich in Ausbildung bzw. nicht in Ausbildung befinden, nach Altersgruppe und Erwerbsstatus) (2012)

WEB Table C5.2c: Percentage of $15-29$ year-old women in education and not in education, by age group and work status (Anteil I5- bis 29-jähriger Frauen [in \%], die sich in Ausbildung bzw. nicht in Ausbildung befinden, nach Altersgruppe und Erwerbsstatus) (2012)

Tabelle C5.3a: Entwicklung des Anteils 15- bis 29-Jähriger (in \%), die sich in Ausbildung bzw. nicht in Ausbildung befinden (beschäftigt bzw. nicht beschäftigt), nach Altersgruppe (I997-2012)

WEB Table $\mathrm{C}_{5 \cdot 3} \mathrm{~b}$ : Trends in the percentage of ${ }_{15-29}$ year-old men in education and not in education, employed or not, by age group (Entwicklung des Anteils I5- bis 29-jähriger Männer [in \%], die sich in Ausbildung bzw. nicht in Ausbildung befinden [beschäftigt bzw. nicht beschäftigt], nach Altersgruppe)

(I997-2012)

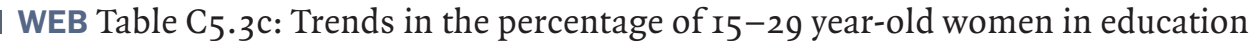
and not in education, employed or not, by age group (Entwicklung des Anteils I5- bis 29-jähriger Frauen [in \%], die sich in Ausbildung bzw. nicht in Ausbildung befinden [beschäftigt bzw. nicht beschäftigt], nach Altersgruppe) (I997-20I2)

WEB Table $\mathrm{C}_{5 \cdot 3} \mathrm{~d}$ : Trends in the percentage of $\mathrm{I}_{5-29}$ year-olds in education and not in education, employed or not, by educational attainment (Entwicklung des Anteils I5- bis 29-Jähriger [in \%], die sich in Ausbildung bzw. nicht in Ausbildung befinden [beschäftigt bzw. nicht beschäftigt], nach Bildungsstand) (2006-2012)

Tabelle $\mathrm{C}_{5.4}$ : Anteil 15- bis 29-Jähriger (in \%), die sich in Ausbildung bzw. nicht in Ausbildung befinden, nach Bildungsstand und Erwerbsstatus (20I2)

Tabelle $\mathrm{C}_{5.5}$ : Entwicklung des Anteils I5- bis 29-Jähriger (in \%), die Vollzeit bzw. Teilzeit arbeiten und sich in Ausbildung bzw. nicht in Ausbildung befinden (2006-2012) 
Zu erwartende Jahre in Ausbildung und nicht in Ausbildung für 15- bis 29-Jährige, nach Erwerbsstatus (2012)

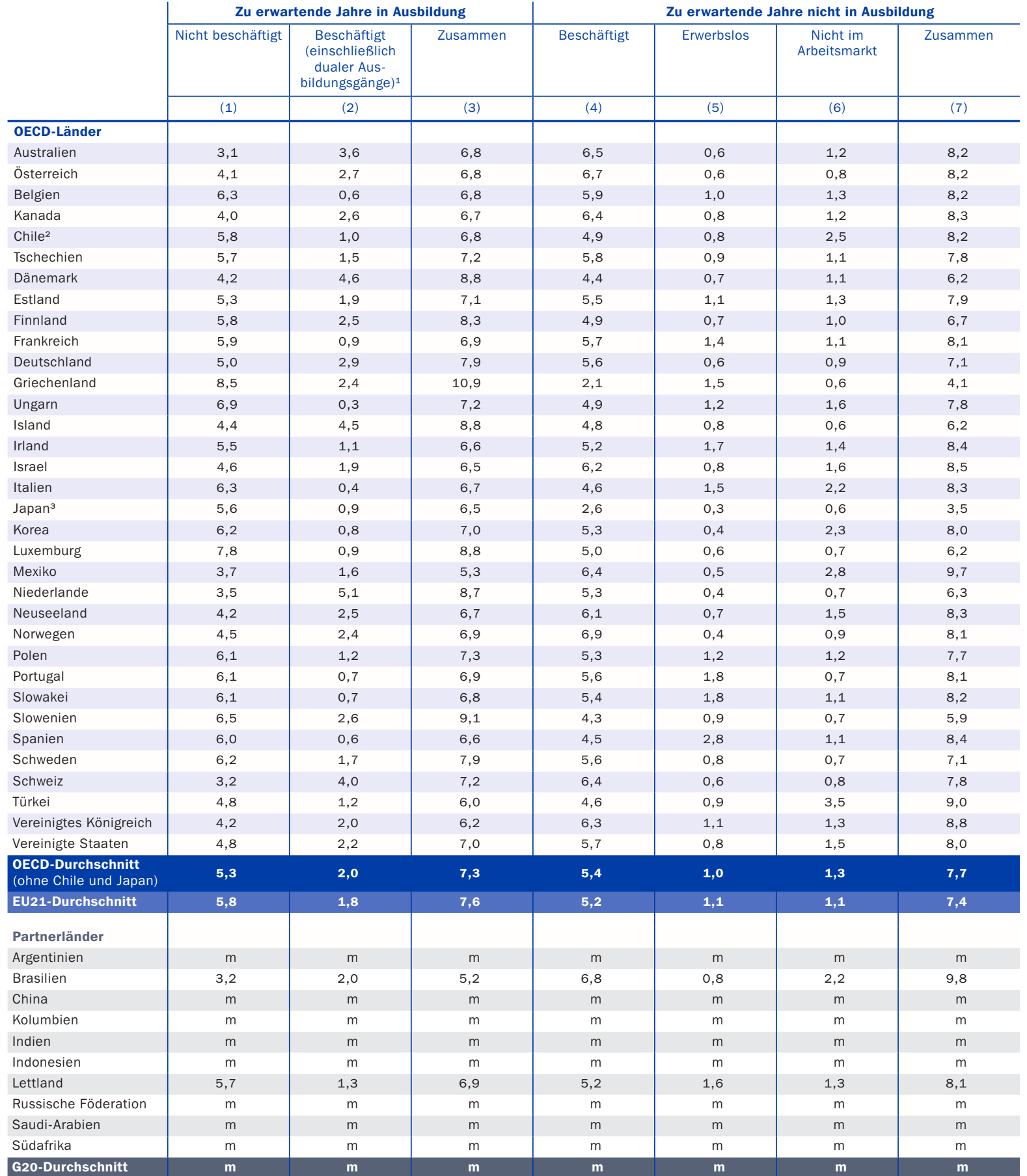

1. Teilnehmer an dualen Ausbildungsprogrammen gelten als sowohl in Ausbildung als auch beschäftigt, ohne Bezug auf ihren ILO-Erwerbsstatus. 2. Referenzjahr 2011. 3. Daten beziehen sich auf 15- bis 24-Jährige.

Quelle: OECD. Argentinien, China, Indien, Indonesien, Kolumbien, Saudi-Arabien und Südafrika: Statistikinstitut der UNESCO. Lettland: Eurostat. Hinweise s. Anhang 3 unter www.oecd.org/edu/eag.htm. StatLink: http://dx.doi.org/10.1787/888933118922

Erläuterung der Kennzeichnung fehlender Daten s. Hinweise für den Leser. 
Anteil 15- bis 29-Jähriger (in \%), die sich in Ausbildung bzw. nicht in Ausbildung befinden, nach Altersgruppe und Erwerbsstatus (2012)

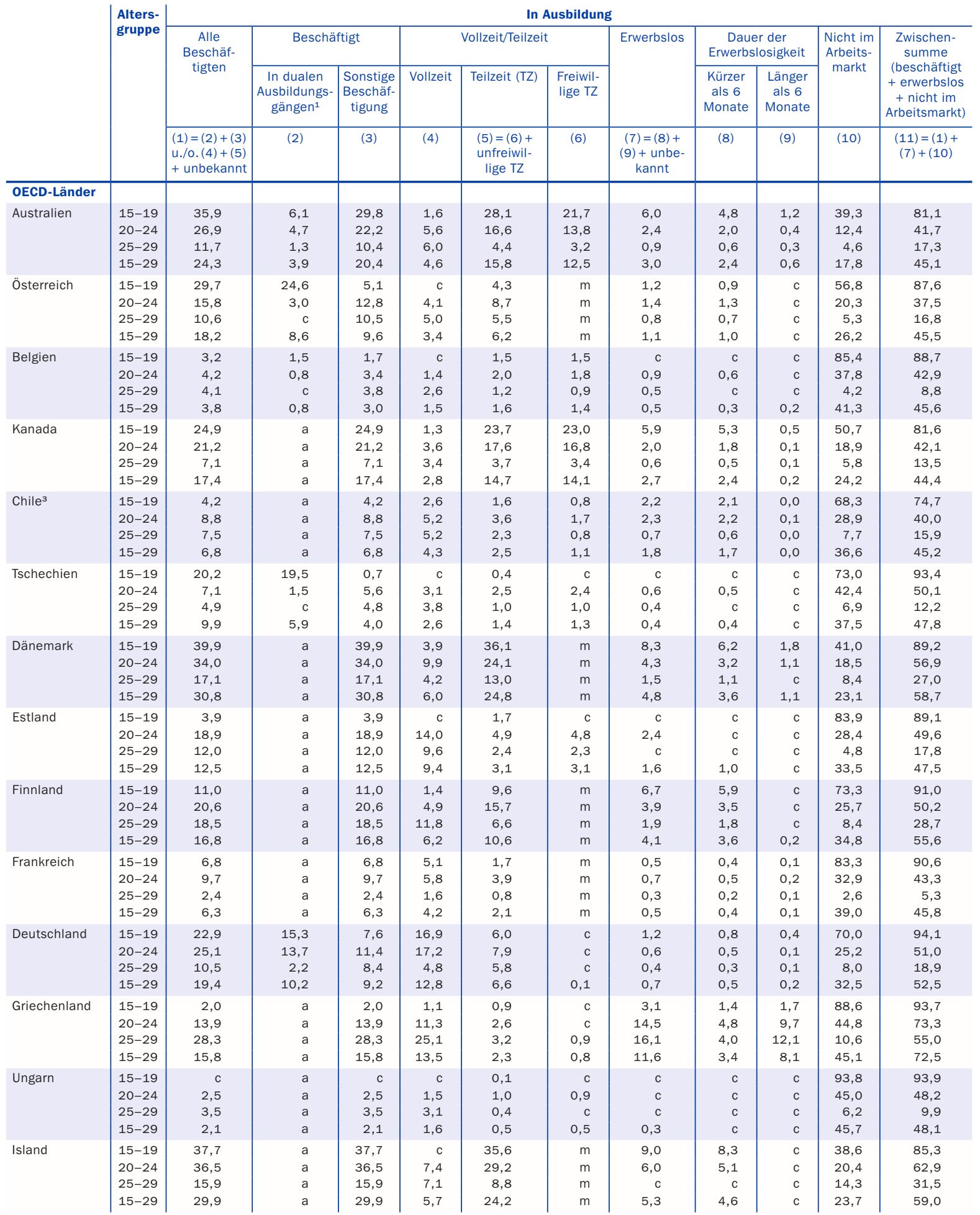

1. Teilnehmer an dualen Ausbildungsprogrammen gelten als sowohl in Ausbildung als auch beschäftigt, ohne Bezug auf ihren ILO-Erwerbsstatus. 2. Junge Menschen, die weder in Ausbildung noch in Beschäftigung sind. 3. Referenzjahr 2011.

Quelle: OECD. Argentinien, China, Indien, Indonesien, Kolumbien, Saudi-Arabien und Südafrika: Statistikinstitut der UNESCO. Lettland: Eurostat. Hinweise s. Anhang 3 unter www.oecd.org/edu/eag.htm. StatLink: http://dx.doi.org/10.1787/888933118941

Erläuterung der Kennzeichnung fehlender Daten s. Hinweise für den Leser. 
Tabelle C5.2a (Forts. 1)

Anteil 15- bis 29-Jähriger (in \%), die sich in Ausbildung bzw. nicht in Ausbildung befinden, nach Altersgruppe und Erwerbsstatus (2012)

\begin{tabular}{|c|c|c|c|c|c|c|c|c|c|c|c|c|}
\hline & \multirow{4}{*}{$\begin{array}{l}\text { Alters- } \\
\text { gruppe }\end{array}$} & \multicolumn{10}{|c|}{ Nicht in Ausbildung } & \multirow{3}{*}{$\begin{array}{c}\text { Gesamt: } \\
\text { In Aus- } \\
\text { bildung und } \\
\text { nicht in } \\
\text { Ausbildung }\end{array}$} \\
\hline & & \multirow[t]{2}{*}{$\begin{array}{c}\text { Alle Beschäf- } \\
\text { tigten }\end{array}$} & \multicolumn{3}{|c|}{ Art der Beschäftigung } & \multirow[t]{2}{*}{$\mathrm{NEET}^{2}$} & \multirow[t]{2}{*}{ Erwerbslos } & \multicolumn{2}{|c|}{$\begin{array}{c}\text { Dauer der } \\
\text { Erwerbslosigkeit }\end{array}$} & \multirow{2}{*}{$\begin{array}{c}\text { Nicht im } \\
\text { Arbeits- } \\
\text { markt }\end{array}$} & \multirow{2}{*}{$\begin{array}{l}\text { Zwischen- } \\
\text { summe } \\
\text { (beschäftigt } \\
\text { + erwerbslos } \\
\text { + nicht im } \\
\text { Arbeitsmarkt) }\end{array}$} & \\
\hline & & & Vollzeit & Teilzeit (TZ) & $\begin{array}{c}\text { Frei- } \\
\text { willige } \\
\text { TZ }\end{array}$ & & & $\begin{array}{c}\text { Kürzer } \\
\text { als } 6 \\
\text { Monate }\end{array}$ & $\begin{array}{c}\text { Länger } \\
\text { als } 6 \\
\text { Monate }\end{array}$ & & & \\
\hline & & $\begin{array}{c}(12)= \\
(13)+(14)+ \\
\text { unbekannt }\end{array}$ & (13) & $\begin{array}{c}(14)=(15)+ \\
\text { unfreiwillige } \\
\text { TZ }\end{array}$ & (15) & $\begin{array}{c}(16)= \\
(17)+(20)\end{array}$ & $\begin{array}{c}(17)= \\
(18)+(19)\end{array}$ & (18) & (19) & (20) & $\begin{array}{c}(21)=(12)+ \\
(17)+(20)\end{array}$ & $\begin{array}{c}(22)= \\
(11)+(21)\end{array}$ \\
\hline \multicolumn{13}{|l|}{ OECD-Länder } \\
\hline Australien & \begin{tabular}{|l|}
$15-19$ \\
$20-24$ \\
$25-29$ \\
$15-29$
\end{tabular} & $\begin{array}{l}11,6 \\
46,1 \\
67,6 \\
43,2\end{array}$ & $\begin{array}{r}6,0 \\
35,6 \\
56,3 \\
33,8\end{array}$ & $\begin{array}{r}5,6 \\
10,5 \\
11,3 \\
9,3\end{array}$ & $\begin{array}{l}2,4 \\
4,6 \\
7,4 \\
4,9\end{array}$ & $\begin{array}{r}7,2 \\
12,2 \\
15,1 \\
11,7\end{array}$ & $\begin{array}{l}3,1 \\
4,8 \\
3,3 \\
3,8\end{array}$ & $\begin{array}{l}2,2 \\
3,3 \\
2,5 \\
2,7\end{array}$ & $\begin{array}{l}1,0 \\
1,5 \\
0,8 \\
1,1\end{array}$ & $\begin{array}{r}4,1 \\
7,4 \\
11,8 \\
7,9\end{array}$ & $\begin{array}{l}18,9 \\
58,3 \\
82,7 \\
54,9\end{array}$ & $\begin{array}{l}100 \\
100 \\
100 \\
100\end{array}$ \\
\hline Österreich & \begin{tabular}{|l|}
$15-19$ \\
$20-24$ \\
$25-29$ \\
$15-29$
\end{tabular} & $\begin{array}{r}7,7 \\
51,3 \\
70,4 \\
44,8\end{array}$ & $\begin{array}{r}7,1 \\
47,7 \\
61,5 \\
40,2\end{array}$ & $\begin{array}{r}c \\
3,6 \\
8,9 \\
4,6\end{array}$ & $\begin{array}{l}\mathrm{m} \\
\mathrm{m} \\
\mathrm{m} \\
\mathrm{m}\end{array}$ & $\begin{array}{r}4,7 \\
11,1 \\
12,8 \\
9,7\end{array}$ & $\begin{array}{l}2,6 \\
5,1 \\
4,5 \\
4,1\end{array}$ & $\begin{array}{l}1,4 \\
3,9 \\
2,7 \\
2,7\end{array}$ & $\begin{array}{l}1,2 \\
1,2 \\
1,7 \\
1,4\end{array}$ & $\begin{array}{l}2,0 \\
6,1 \\
8,3 \\
5,6\end{array}$ & $\begin{array}{l}12,4 \\
62,5 \\
83,2 \\
54,5\end{array}$ & $\begin{array}{l}100 \\
100 \\
100 \\
100\end{array}$ \\
\hline Belgien & \begin{tabular}{|l|}
$15-19$ \\
$20-24$ \\
$25-29$ \\
$15-29$
\end{tabular} & $\begin{array}{r}3,1 \\
39,6 \\
72,7 \\
39,5\end{array}$ & $\begin{array}{r}2,4 \\
31,8 \\
58,2 \\
31,6\end{array}$ & $\begin{array}{r}0,7 \\
7,8 \\
14,5 \\
7,9\end{array}$ & $\begin{array}{r}\mathrm{C} \\
2,2 \\
7,9 \\
3,6\end{array}$ & $\begin{array}{r}8,3 \\
17,5 \\
18,5 \\
15,0\end{array}$ & $\begin{array}{l}2,0 \\
8,3 \\
8,5 \\
6,4\end{array}$ & $\begin{array}{l}0,9 \\
3,6 \\
4,1 \\
2,9\end{array}$ & $\begin{array}{l}1,1 \\
4,7 \\
4,4 \\
3,5\end{array}$ & $\begin{array}{r}6,3 \\
9,3 \\
10,0 \\
8,6\end{array}$ & $\begin{array}{l}11,3 \\
57,1 \\
91,2 \\
54,4\end{array}$ & $\begin{array}{l}100 \\
100 \\
100 \\
100\end{array}$ \\
\hline Kanada & \begin{tabular}{|l|}
$15-19$ \\
$20-24$ \\
$25-29$ \\
$15-29$
\end{tabular} & $\begin{array}{l}11,1 \\
43,0 \\
69,7 \\
42,4\end{array}$ & $\begin{array}{r}6,6 \\
34,4 \\
61,6 \\
35,3\end{array}$ & $\begin{array}{l}4,5 \\
8,6 \\
8,1 \\
7,1\end{array}$ & $\begin{array}{l}2,3 \\
3,4 \\
3,7 \\
3,2\end{array}$ & $\begin{array}{r}7,3 \\
14,8 \\
16,8 \\
13,2\end{array}$ & $\begin{array}{l}2,8 \\
6,6 \\
6,4 \\
5,4\end{array}$ & $\begin{array}{l}2,5 \\
5,6 \\
5,2 \\
4,5\end{array}$ & $\begin{array}{l}0,2 \\
0,8 \\
1,0 \\
0,7\end{array}$ & $\begin{array}{r}4,5 \\
8,2 \\
10,4 \\
7,8\end{array}$ & $\begin{array}{l}18,4 \\
57,9 \\
86,5 \\
55,6\end{array}$ & $\begin{array}{l}100 \\
100 \\
100 \\
100\end{array}$ \\
\hline Chile $^{3}$ & \begin{tabular}{|l|}
$15-19$ \\
$20-24$ \\
$25-29$ \\
$15-29$
\end{tabular} & $\begin{array}{r}7,8 \\
35,1 \\
59,1 \\
32,5\end{array}$ & $\begin{array}{r}6,6 \\
31,4 \\
52,6 \\
28,8\end{array}$ & $\begin{array}{l}1,2 \\
3,7 \\
6,6 \\
3,6\end{array}$ & $\begin{array}{l}0,7 \\
1,5 \\
2,3 \\
1,4\end{array}$ & $\begin{array}{l}17,5 \\
24,9 \\
25,0 \\
22,3\end{array}$ & $\begin{array}{l}2,4 \\
7,2 \\
6,7 \\
5,4\end{array}$ & $\begin{array}{l}2,3 \\
6,9 \\
6,3 \\
5,1\end{array}$ & $\begin{array}{l}0,1 \\
0,3 \\
0,4 \\
0,2\end{array}$ & $\begin{array}{l}15,1 \\
17,7 \\
18,3 \\
17,0\end{array}$ & $\begin{array}{l}25,3 \\
60,0 \\
84,1 \\
54,8\end{array}$ & $\begin{array}{l}100 \\
100 \\
100 \\
100\end{array}$ \\
\hline Tschechien & \begin{tabular}{|l}
$15-19$ \\
$20-24$ \\
$25-29$ \\
$15-29$
\end{tabular} & $\begin{array}{r}2,7 \\
36,5 \\
67,4 \\
38,8\end{array}$ & $\begin{array}{r}2,5 \\
35,6 \\
65,7 \\
37,8\end{array}$ & $\begin{array}{l}0,2 \\
0,9 \\
1,7 \\
1,0\end{array}$ & $\begin{array}{r}c \\
0,7 \\
1,4 \\
0,8\end{array}$ & $\begin{array}{r}4,0 \\
13,4 \\
20,4 \\
13,4\end{array}$ & $\begin{array}{l}2,8 \\
7,8 \\
6,6 \\
6,0\end{array}$ & $\begin{array}{l}1,5 \\
3,2 \\
2,7 \\
2,6\end{array}$ & $\begin{array}{l}1,3 \\
4,6 \\
3,9 \\
3,4\end{array}$ & $\begin{array}{r}1,2 \\
5,6 \\
13,7 \\
7,4\end{array}$ & $\begin{array}{r}6,6 \\
49,9 \\
87,8 \\
52,2\end{array}$ & $\begin{array}{l}100 \\
100 \\
100 \\
100\end{array}$ \\
\hline Dänemark & $\begin{array}{l}15-19 \\
20-24 \\
25-29 \\
15-29\end{array}$ & $\begin{array}{r}5,1 \\
28,7 \\
56,8 \\
29,4\end{array}$ & $\begin{array}{r}2,1 \\
19,7 \\
45,8 \\
21,8\end{array}$ & $\begin{array}{r}3,0 \\
9,0 \\
11,0 \\
7,5\end{array}$ & $\begin{array}{l}\mathrm{m} \\
\mathrm{m} \\
\mathrm{m} \\
\mathrm{m}\end{array}$ & $\begin{array}{r}5,7 \\
14,5 \\
16,2 \\
12,0\end{array}$ & $\begin{array}{l}1,3 \\
5,8 \\
7,9 \\
4,9\end{array}$ & $\begin{array}{l}1,0 \\
4,5 \\
5,5 \\
3,6\end{array}$ & $\begin{array}{r}C \\
1,2 \\
2,3 \\
1,2\end{array}$ & $\begin{array}{l}4,4 \\
8,7 \\
8,3 \\
7,1\end{array}$ & $\begin{array}{l}10,8 \\
43,1 \\
73,0 \\
41,3\end{array}$ & $\begin{array}{l}100 \\
100 \\
100 \\
100\end{array}$ \\
\hline Estland & \begin{tabular}{|l|}
$15-19$ \\
$20-24$ \\
$25-29$ \\
$15-29$
\end{tabular} & $\begin{array}{r}4,2 \\
33,3 \\
61,3 \\
36,5\end{array}$ & $\begin{array}{r}3,9 \\
32,3 \\
58,4 \\
35,0\end{array}$ & $\begin{array}{l}0,3 \\
1,1 \\
2,8 \\
1,5\end{array}$ & $\begin{array}{r}c \\
c \\
2,7 \\
1,3\end{array}$ & $\begin{array}{r}6,8 \\
17,1 \\
21,0 \\
15,9\end{array}$ & $\begin{array}{l}2,9 \\
9,1 \\
7,8 \\
7,1\end{array}$ & $\begin{array}{r}c \\
4,4 \\
2,3 \\
2,9\end{array}$ & $\begin{array}{r}c \\
4,7 \\
5,5 \\
4,2\end{array}$ & $\begin{array}{r}3,9 \\
8,0 \\
13,1 \\
8,9\end{array}$ & $\begin{array}{l}10,9 \\
50,4 \\
82,2 \\
52,5\end{array}$ & $\begin{array}{l}100 \\
100 \\
100 \\
100\end{array}$ \\
\hline Finnland & $\begin{array}{l}15-19 \\
20-24 \\
25-29 \\
15-29\end{array}$ & $\begin{array}{r}4,4 \\
34,6 \\
55,9 \\
32,5\end{array}$ & $\begin{array}{r}3,1 \\
30,6 \\
51,3 \\
29,1\end{array}$ & $\begin{array}{l}1,2 \\
4,1 \\
4,6 \\
3,4\end{array}$ & $\begin{array}{l}\mathrm{m} \\
\mathrm{m} \\
\mathrm{m} \\
\mathrm{m}\end{array}$ & $\begin{array}{r}4,7 \\
15,2 \\
15,4 \\
11,9\end{array}$ & $\begin{array}{l}2,2 \\
7,0 \\
5,5 \\
4,9\end{array}$ & $\begin{array}{l}1,7 \\
5,3 \\
3,8 \\
3,6\end{array}$ & $\begin{array}{r}C \\
1,6 \\
1,6 \\
1,2\end{array}$ & $\begin{array}{l}2,5 \\
8,2 \\
9,9 \\
7,0\end{array}$ & $\begin{array}{r}9,0 \\
49,8 \\
71,3 \\
44,4\end{array}$ & $\begin{array}{l}100 \\
100 \\
100 \\
100\end{array}$ \\
\hline Frankreich & \begin{tabular}{|l}
$15-19$ \\
$20-24$ \\
$25-29$ \\
$15-29$
\end{tabular} & $\begin{array}{r}2,5 \\
36,6 \\
72,3 \\
37,7\end{array}$ & $\begin{array}{r}1,7 \\
29,2 \\
63,5 \\
31,9\end{array}$ & $\begin{array}{l}0,8 \\
7,4 \\
8,8 \\
5,7\end{array}$ & $\begin{array}{l}\mathrm{m} \\
\mathrm{m} \\
\mathrm{m} \\
\mathrm{m}\end{array}$ & $\begin{array}{r}6,9 \\
20,1 \\
22,4 \\
16,6\end{array}$ & $\begin{array}{r}3,4 \\
12,0 \\
11,3 \\
9,0\end{array}$ & $\begin{array}{l}1,7 \\
5,4 \\
5,6 \\
4,3\end{array}$ & $\begin{array}{l}1,7 \\
6,5 \\
5,7 \\
4,7\end{array}$ & $\begin{array}{r}3,5 \\
8,0 \\
11,0 \\
7,6\end{array}$ & $\begin{array}{r}9,4 \\
56,7 \\
94,7 \\
54,2\end{array}$ & $\begin{array}{l}100 \\
100 \\
100 \\
100\end{array}$ \\
\hline Deutschland & $\begin{array}{l}15-19 \\
20-24 \\
25-29 \\
15-29\end{array}$ & $\begin{array}{r}2,9 \\
37,8 \\
66,5 \\
37,5\end{array}$ & $\begin{array}{r}2,2 \\
33,3 \\
56,4 \\
32,1\end{array}$ & $\begin{array}{r}0,8 \\
4,6 \\
10,2 \\
5,4\end{array}$ & $\begin{array}{l}0,3 \\
2,0 \\
2,4 \\
1,6\end{array}$ & $\begin{array}{r}3,0 \\
11,2 \\
14,6 \\
9,9\end{array}$ & $\begin{array}{l}1,1 \\
4,9 \\
5,5 \\
4,0\end{array}$ & $\begin{array}{l}0,7 \\
2,7 \\
2,9 \\
2,2\end{array}$ & $\begin{array}{l}0,4 \\
2,1 \\
2,6 \\
1,8\end{array}$ & $\begin{array}{l}1,9 \\
6,3 \\
9,0 \\
6,0\end{array}$ & $\begin{array}{r}5,9 \\
49,0 \\
81,1 \\
47,5\end{array}$ & $\begin{array}{l}100 \\
100 \\
100 \\
100\end{array}$ \\
\hline Griechenland & \begin{tabular}{|l}
$15-19$ \\
$20-24$ \\
$25-29$ \\
$15-29$
\end{tabular} & $\begin{array}{r}1,0 \\
11,4 \\
26,4 \\
14,0\end{array}$ & $\begin{array}{r}0,8 \\
9,7 \\
23,6 \\
12,3\end{array}$ & $\begin{array}{l}0,2 \\
1,6 \\
2,9 \\
1,7\end{array}$ & $\begin{array}{r}c \\
c \\
0,7 \\
0,4\end{array}$ & $\begin{array}{r}5,3 \\
15,4 \\
18,5 \\
13,5\end{array}$ & $\begin{array}{r}2,1 \\
11,7 \\
14,3 \\
9,7\end{array}$ & $\begin{array}{l}0,9 \\
3,5 \\
3,6 \\
2,7\end{array}$ & $\begin{array}{r}1,3 \\
8,2 \\
10,7 \\
7,0\end{array}$ & $\begin{array}{l}3,2 \\
3,7 \\
4,2 \\
3,7\end{array}$ & $\begin{array}{r}6,3 \\
26,7 \\
45,0 \\
27,5\end{array}$ & $\begin{array}{l}100 \\
100 \\
100 \\
100\end{array}$ \\
\hline Ungarn & $\begin{array}{l}15-19 \\
20-24 \\
25-29 \\
15-29\end{array}$ & $\begin{array}{r}1,3 \\
29,4 \\
62,8 \\
33,0\end{array}$ & $\begin{array}{r}1,2 \\
27,3 \\
59,9 \\
31,2\end{array}$ & $\begin{array}{l}0,1 \\
2,0 \\
2,9 \\
1,8\end{array}$ & $\begin{array}{r}\mathrm{C} \\
\mathrm{C} \\
1,1 \\
0,6\end{array}$ & $\begin{array}{r}4,8 \\
22,5 \\
27,3 \\
18,9\end{array}$ & $\begin{array}{r}1,4 \\
10,9 \\
10,8 \\
8,0\end{array}$ & $\begin{array}{r}c \\
3,9 \\
4,1 \\
3,0\end{array}$ & $\begin{array}{r}c \\
7,0 \\
6,7 \\
5,0\end{array}$ & $\begin{array}{r}3,3 \\
11,6 \\
16,5 \\
10,9\end{array}$ & $\begin{array}{r}6,1 \\
51,8 \\
90,1 \\
51,9\end{array}$ & $\begin{array}{l}100 \\
100 \\
100 \\
100\end{array}$ \\
\hline Island & \begin{tabular}{|l|}
$15-19$ \\
$20-24$ \\
$25-29$ \\
$15-29$
\end{tabular} & $\begin{array}{r}9,9 \\
28,1 \\
56,2 \\
32,2\end{array}$ & $\begin{array}{r}8,2 \\
21,6 \\
50,6 \\
27,4\end{array}$ & $\begin{array}{r}c \\
6,3 \\
5,6 \\
4,7\end{array}$ & $\begin{array}{l}\mathrm{m} \\
\mathrm{m} \\
\mathrm{m} \\
\mathrm{m}\end{array}$ & $\begin{array}{r}4,8 \\
9,0 \\
12,4 \\
8,9\end{array}$ & $\begin{array}{r}c \\
5,9 \\
6,2 \\
5,1\end{array}$ & $\begin{array}{r}C \\
4,7 \\
4,9 \\
4,0\end{array}$ & $\begin{array}{l}\mathrm{c} \\
\mathrm{c} \\
\mathrm{c} \\
\mathrm{c}\end{array}$ & $\begin{array}{r}c \\
c \\
6,1 \\
3,8\end{array}$ & $\begin{array}{l}14,7 \\
37,1 \\
68,5 \\
41,0\end{array}$ & $\begin{array}{l}100 \\
100 \\
100 \\
100\end{array}$ \\
\hline
\end{tabular}

1. Teilnehmer an dualen Ausbildungsprogrammen gelten als sowohl in Ausbildung als auch beschäftigt, ohne Bezug auf ihren ILO-Erwerbsstatus. 2. Junge Menschen, die weder in Ausbildung noch in Beschäftigung sind. 3. Referenzjahr 2011.

Quelle: OECD. Argentinien, China, Indien, Indonesien, Kolumbien, Saudi-Arabien und Südafrika: Statistikinstitut der UNESCO. Lettland: Eurostat. Hinweise s. Anhang 3 unter www.oecd.org/edu/eag.htm. StatLink: http://dx.doi.org/10.1787/888933118941

Erläuterung der Kennzeichnung fehlender Daten s. Hinweise für den Leser. 
Tabelle C5.2a (Forts. 2)

Anteil 15- bis 29-Jähriger (in \%), die sich in Ausbildung bzw. nicht in Ausbildung befinden, nach Altersgruppe und Erwerbsstatus (2012)

\begin{tabular}{|c|c|c|c|c|c|c|c|c|c|c|c|c|}
\hline & \multirow{4}{*}{$\begin{array}{l}\text { Alters- } \\
\text { gruppe }\end{array}$} & \multicolumn{11}{|c|}{ In Ausbildung } \\
\hline & & \multirow{2}{*}{$\begin{array}{c}\text { Alle } \\
\text { Beschäf- } \\
\text { tigten }\end{array}$} & \multicolumn{2}{|c|}{ Beschäftigt } & \multicolumn{3}{|c|}{ Vollzeit/Teilzeit } & \multirow[t]{2}{*}{ Erwerbslos } & \multicolumn{2}{|c|}{$\begin{array}{c}\text { Dauer der } \\
\text { Erwerbslosigkeit }\end{array}$} & \multirow{2}{*}{$\begin{array}{c}\text { Nicht im } \\
\text { Arbeits- } \\
\text { markt }\end{array}$} & \multirow{2}{*}{$\begin{array}{l}\text { Zwischen- } \\
\text { summe } \\
\text { (beschäftigt } \\
\text { + erwerbslos } \\
\text { + nicht im } \\
\text { Arbeitsmarkt) }\end{array}$} \\
\hline & & & $\begin{array}{c}\text { In dualen } \\
\text { Ausbildungs- } \\
\text { gängen }^{1}\end{array}$ & $\begin{array}{c}\text { Sonstige } \\
\text { Beschäf- } \\
\text { tigung }\end{array}$ & Vollzeit & Teilzeit (TZ) & $\begin{array}{l}\text { Freiwil- } \\
\text { lige TZ }\end{array}$ & & $\begin{array}{l}\text { Kürzer } \\
\text { als } 6 \\
\text { Monate }\end{array}$ & $\begin{array}{l}\text { Länger } \\
\text { als } 6 \\
\text { Monate }\end{array}$ & & \\
\hline & & $\begin{array}{l}(1)=(2)+(3) \\
\text { u./o. }(4)+(5) \\
+ \text { unbekannt }\end{array}$ & (2) & (3) & (4) & $\begin{array}{l}(5)=(6)+ \\
\text { unfreiwil- } \\
\text { lige TZ }\end{array}$ & (6) & $\begin{array}{c}(7)=(8)+ \\
(9)+\text { unbe- } \\
\text { kannt }\end{array}$ & (8) & (9) & (10) & $\begin{array}{c}(11)=(1)+ \\
(7)+(10)\end{array}$ \\
\hline \multicolumn{13}{|c|}{ OECD-Länder } \\
\hline Irland & $\begin{array}{l}15-19 \\
20-24 \\
25-29 \\
15-29\end{array}$ & $\begin{array}{r}6,1 \\
12,0 \\
5,4 \\
7,6\end{array}$ & $\begin{array}{l}\mathrm{a} \\
\mathrm{a} \\
\mathrm{a} \\
\mathrm{a}\end{array}$ & $\begin{array}{r}6,1 \\
12,0 \\
5,4 \\
7,6\end{array}$ & $\begin{array}{l}0,4 \\
2,8 \\
3,7 \\
2,4\end{array}$ & $\begin{array}{l}5,6 \\
9,2 \\
1,6 \\
5,2\end{array}$ & $\begin{array}{l}\mathrm{m} \\
\mathrm{m} \\
\mathrm{m} \\
\mathrm{m}\end{array}$ & $\begin{array}{l}1,4 \\
1,3 \\
0,8 \\
1,1\end{array}$ & $\begin{array}{r}0,5 \\
0,6 \\
c \\
0,4\end{array}$ & $\begin{array}{l}0,8 \\
0,7 \\
0,6 \\
0,7\end{array}$ & $\begin{array}{r}79,7 \\
28,6 \\
5,6 \\
35,4\end{array}$ & $\begin{array}{l}87,1 \\
41,8 \\
11,8 \\
44,2\end{array}$ \\
\hline Israel & $\begin{array}{l}15-19 \\
20-24 \\
25-29 \\
15-29\end{array}$ & $\begin{array}{r}5,3 \\
13,5 \\
20,4 \\
13,0\end{array}$ & $\begin{array}{l}\mathrm{a} \\
\mathrm{a} \\
\mathrm{a} \\
\mathrm{a}\end{array}$ & $\begin{array}{r}5,3 \\
13,5 \\
20,4 \\
13,0\end{array}$ & $\begin{array}{l}0,5 \\
4,9 \\
9,1 \\
4,8\end{array}$ & $\begin{array}{r}4,8 \\
8,6 \\
11,4 \\
8,2\end{array}$ & $\begin{array}{r}4,5 \\
8,1 \\
10,7 \\
7,8\end{array}$ & $\begin{array}{l}1,3 \\
1,4 \\
1,6 \\
1,4\end{array}$ & $\begin{array}{l}1,0 \\
1,2 \\
1,4 \\
1,2\end{array}$ & $\begin{array}{r}c \\
c \\
c \\
0,1\end{array}$ & $\begin{array}{r}62,0 \\
14,8 \\
8,7 \\
28,9\end{array}$ & $\begin{array}{l}68,6 \\
29,7 \\
30,7 \\
43,3\end{array}$ \\
\hline Italien & $\begin{array}{l}15-19 \\
20-24 \\
25-29 \\
15-29\end{array}$ & $\begin{array}{l}0,7 \\
2,9 \\
3,6 \\
2,5\end{array}$ & $\begin{array}{l}0,2 \\
0,2 \\
0,2 \\
0,2\end{array}$ & $\begin{array}{l}0,6 \\
2,6 \\
3,4 \\
2,3\end{array}$ & $\begin{array}{l}0,1 \\
0,8 \\
1,7 \\
0,9\end{array}$ & $\begin{array}{l}0,4 \\
1,9 \\
1,7 \\
1,4\end{array}$ & $\begin{array}{l}0,3 \\
1,3 \\
0,8 \\
0,8\end{array}$ & $\begin{array}{l}0,4 \\
1,2 \\
1,0 \\
0,9\end{array}$ & $\begin{array}{l}0,3 \\
0,6 \\
0,3 \\
0,4\end{array}$ & $\begin{array}{r}c \\
0,6 \\
0,8 \\
0,5\end{array}$ & $\begin{array}{l}83,9 \\
34,8 \\
10,9 \\
41,3\end{array}$ & $\begin{array}{l}85,1 \\
38,9 \\
15,6 \\
44,7\end{array}$ \\
\hline Japan & $15-24$ & 8,8 & a & 8,8 & 0,3 & 8,5 & $\mathrm{~m}$ & 0,2 & $\mathrm{~m}$ & $\mathrm{~m}$ & 55,6 & 64,5 \\
\hline Korea & $\begin{array}{l}15-19 \\
20-24 \\
25-29 \\
15-29\end{array}$ & $\begin{array}{l}4,5 \\
9,4 \\
2,8 \\
5,3\end{array}$ & $\begin{array}{l}a \\
a \\
a \\
a\end{array}$ & $\begin{array}{l}4,5 \\
9,4 \\
2,8 \\
5,3\end{array}$ & $\begin{array}{l}1,3 \\
3,4 \\
1,9 \\
2,2\end{array}$ & $\begin{array}{l}3,2 \\
6,0 \\
0,9 \\
3,2\end{array}$ & $\begin{array}{l}3,2 \\
5,9 \\
0,9 \\
3,1\end{array}$ & $\begin{array}{l}0,3 \\
0,7 \\
0,3 \\
0,4\end{array}$ & $\begin{array}{l}0,3 \\
0,7 \\
0,3 \\
0,4\end{array}$ & $\begin{array}{l}0,0 \\
0,0 \\
0,0 \\
0,0\end{array}$ & $\begin{array}{r}84,1 \\
32,3 \\
5,7 \\
40,7\end{array}$ & $\begin{array}{r}89,0 \\
42,4 \\
8,8 \\
46,5\end{array}$ \\
\hline Luxemburg & $\begin{array}{l}15-19 \\
20-24 \\
25-29 \\
15-29\end{array}$ & $\begin{array}{r}2,8 \\
10,5 \\
5,7 \\
6,3\end{array}$ & $\begin{array}{l}\mathrm{a} \\
\mathrm{a} \\
\mathrm{a} \\
\mathrm{a}\end{array}$ & $\begin{array}{r}2,8 \\
10,5 \\
5,7 \\
6,3\end{array}$ & $\begin{array}{r}c \\
4,3 \\
3,7 \\
3,1\end{array}$ & $\begin{array}{r}c \\
6,0 \\
2,0 \\
3,1\end{array}$ & $\begin{array}{l}\mathrm{m} \\
\mathrm{m} \\
\mathrm{m} \\
\mathrm{m}\end{array}$ & $\begin{array}{r}0,3 \\
3,8 \\
c \\
1,7\end{array}$ & $\begin{array}{r}- \\
c \\
c \\
0,6\end{array}$ & $\begin{array}{r}c \\
3,1 \\
c \\
1,1\end{array}$ & $\begin{array}{l}92,6 \\
51,5 \\
13,2 \\
50,4\end{array}$ & $\begin{array}{l}95,7 \\
65,9 \\
20,0 \\
58,4\end{array}$ \\
\hline Mexiko & $\begin{array}{l}15-19 \\
20-24 \\
25-29 \\
15-29\end{array}$ & $\begin{array}{r}14,2 \\
10,9 \\
4,9 \\
10,4\end{array}$ & $\begin{array}{l}a \\
a \\
a \\
a\end{array}$ & $\begin{array}{r}14,2 \\
10,9 \\
4,9 \\
10,4\end{array}$ & $\begin{array}{l}3,1 \\
4,8 \\
3,1 \\
3,7\end{array}$ & $\begin{array}{r}11,0 \\
6,1 \\
1,7 \\
6,7\end{array}$ & $\begin{array}{l}4,0 \\
2,4 \\
0,7 \\
2,5\end{array}$ & $\begin{array}{l}0,6 \\
0,8 \\
0,3 \\
0,6\end{array}$ & $\begin{array}{l}0,5 \\
0,7 \\
0,2 \\
0,5\end{array}$ & $\begin{array}{l}0,0 \\
0,0 \\
0,0 \\
0,0\end{array}$ & $\begin{array}{r}46,8 \\
16,8 \\
2,6 \\
24,2\end{array}$ & $\begin{array}{r}61,6 \\
28,5 \\
7,8 \\
35,3\end{array}$ \\
\hline Niederlande & $\begin{array}{l}15-19 \\
20-24 \\
25-29 \\
15-29\end{array}$ & $\begin{array}{l}47,8 \\
37,8 \\
17,2 \\
34,2\end{array}$ & $\begin{array}{l}\mathrm{a} \\
\mathrm{a} \\
\mathrm{a} \\
\mathrm{a}\end{array}$ & $\begin{array}{l}47,8 \\
37,8 \\
17,2 \\
34,2\end{array}$ & $\begin{array}{l}1,7 \\
5,6 \\
7,9 \\
5,1\end{array}$ & $\begin{array}{r}46,1 \\
32,2 \\
9,3 \\
29,2\end{array}$ & $\begin{array}{l}\mathrm{m} \\
\mathrm{m} \\
\mathrm{m} \\
\mathrm{m}\end{array}$ & $\begin{array}{l}7,1 \\
3,2 \\
0,9 \\
3,7\end{array}$ & $\begin{array}{l}5,0 \\
2,1 \\
0,6 \\
2,6\end{array}$ & $\begin{array}{l}1,8 \\
1,0 \\
0,3 \\
1,0\end{array}$ & $\begin{array}{r}38,5 \\
17,3 \\
4,1 \\
19,9\end{array}$ & $\begin{array}{l}93,4 \\
58,3 \\
22,2 \\
57,9\end{array}$ \\
\hline Neuseeland & $\begin{array}{l}15-19 \\
20-24 \\
25-29 \\
15-29\end{array}$ & $\begin{array}{l}20,8 \\
18,6 \\
11,0 \\
16,9\end{array}$ & $\begin{array}{l}\mathrm{a} \\
\mathrm{a} \\
\mathrm{a} \\
\mathrm{a}\end{array}$ & $\begin{array}{l}20,8 \\
18,6 \\
11,0 \\
16,9\end{array}$ & $\begin{array}{l}2,5 \\
6,9 \\
7,5 \\
5,6\end{array}$ & $\begin{array}{r}18,2 \\
11,8 \\
3,5 \\
11,3\end{array}$ & $\begin{array}{r}16,2 \\
10,0 \\
2,8 \\
9,8\end{array}$ & $\begin{array}{l}6,9 \\
2,8 \\
1,3 \\
3,7\end{array}$ & $\begin{array}{l}4,9 \\
1,7 \\
0,7 \\
2,5\end{array}$ & $\begin{array}{r}1,3 \\
0,5 \\
c \\
0,7\end{array}$ & $\begin{array}{r}50,8 \\
15,1 \\
5,6 \\
24,0\end{array}$ & $\begin{array}{l}78,5 \\
36,5 \\
17,9 \\
44,6\end{array}$ \\
\hline Norwegen & $\begin{array}{l}15-19 \\
20-24 \\
25-29 \\
15-29\end{array}$ & $\begin{array}{r}23,2 \\
18,3 \\
6,1 \\
15,9\end{array}$ & $\begin{array}{l}\mathrm{a} \\
\mathrm{a} \\
\mathrm{a} \\
\mathrm{a}\end{array}$ & $\begin{array}{r}23,2 \\
18,3 \\
6,1 \\
15,9\end{array}$ & $\begin{array}{l}\mathrm{c} \\
\mathrm{c} \\
\mathrm{c} \\
\mathrm{c}\end{array}$ & $\begin{array}{r}22,8 \\
17,5 \\
6,0 \\
15,4\end{array}$ & $\begin{array}{l}\mathrm{m} \\
\mathrm{m} \\
\mathrm{m} \\
\mathrm{m}\end{array}$ & $\begin{array}{r}3,7 \\
C \\
c \\
1,9\end{array}$ & $\begin{array}{r}3,1 \\
c \\
c \\
1,6\end{array}$ & $\begin{array}{l}\mathrm{c} \\
\mathrm{c} \\
\mathrm{c} \\
\mathrm{c}\end{array}$ & $\begin{array}{r}55,5 \\
20,9 \\
7,8 \\
28,0\end{array}$ & $\begin{array}{l}82,4 \\
40,6 \\
14,6 \\
45,8\end{array}$ \\
\hline Polen & $\begin{array}{l}15-19 \\
20-24 \\
25-29 \\
15-29\end{array}$ & $\begin{array}{r}2,9 \\
12,8 \\
7,0 \\
7,8\end{array}$ & $\begin{array}{l}a \\
a \\
a \\
a\end{array}$ & $\begin{array}{r}2,9 \\
12,8 \\
7,0 \\
7,8\end{array}$ & $\begin{array}{l}0,8 \\
9,5 \\
6,0 \\
5,7\end{array}$ & $\begin{array}{l}2,1 \\
3,3 \\
0,9 \\
2,1\end{array}$ & $\begin{array}{r}c \\
0,4 \\
c \\
0,2\end{array}$ & $\begin{array}{l}1,0 \\
3,6 \\
1,0 \\
1,9\end{array}$ & $\begin{array}{l}0,7 \\
1,8 \\
0,5 \\
1,0\end{array}$ & $\begin{array}{l}0,3 \\
1,8 \\
0,6 \\
0,9\end{array}$ & $\begin{array}{r}90,6 \\
35,5 \\
3,4 \\
39,0\end{array}$ & $\begin{array}{l}94,5 \\
52,0 \\
11,4 \\
48,6\end{array}$ \\
\hline Portugal & $\begin{array}{l}15-19 \\
20-24 \\
25-29 \\
15-29\end{array}$ & $\begin{array}{l}1,9 \\
5,1 \\
6,9 \\
4,8\end{array}$ & $\begin{array}{l}\mathrm{a} \\
\mathrm{a} \\
\mathrm{a} \\
\mathrm{a}\end{array}$ & $\begin{array}{l}1,9 \\
5,1 \\
6,9 \\
4,8\end{array}$ & $\begin{array}{l}\mathrm{m} \\
\mathrm{m} \\
\mathrm{m} \\
\mathrm{m}\end{array}$ & $\begin{array}{l}\mathrm{m} \\
\mathrm{m} \\
\mathrm{m} \\
\mathrm{m}\end{array}$ & $\begin{array}{l}\mathrm{m} \\
\mathrm{m} \\
\mathrm{m} \\
\mathrm{m}\end{array}$ & $\begin{array}{l}1,6 \\
3,5 \\
2,8 \\
2,6\end{array}$ & $\begin{array}{l}0,9 \\
1,6 \\
0,8 \\
1,1\end{array}$ & $\begin{array}{r}\mathrm{C} \\
1,9 \\
2,0 \\
1,6\end{array}$ & $\begin{array}{r}84,9 \\
33,0 \\
5,6 \\
38,3\end{array}$ & $\begin{array}{l}88,4 \\
41,6 \\
15,3 \\
45,7\end{array}$ \\
\hline Slowakei & $\begin{array}{l}15-19 \\
20-24 \\
25-29 \\
15-29\end{array}$ & $\begin{array}{r}11,0 \\
2,3 \\
2,3 \\
4,8\end{array}$ & $\begin{array}{r}10,8 \\
C \\
c \\
3,3\end{array}$ & $\begin{array}{l}0,1 \\
1,9 \\
2,2 \\
1,5\end{array}$ & $\begin{array}{r}C \\
1,4 \\
2,0 \\
1,2\end{array}$ & $\begin{array}{r}c \\
c \\
c \\
0,3\end{array}$ & $\begin{array}{l}\mathrm{m} \\
\mathrm{m} \\
\mathrm{m} \\
\mathrm{m}\end{array}$ & $\begin{array}{r}c \\
c \\
c \\
0,3\end{array}$ & $\begin{array}{l}\mathrm{c} \\
\mathrm{c} \\
\mathrm{c} \\
\mathrm{c}\end{array}$ & $\begin{array}{r}c \\
c \\
c \\
0,2\end{array}$ & $\begin{array}{r}81,3 \\
44,1 \\
4,9 \\
40,1\end{array}$ & $\begin{array}{r}92,4 \\
46,7 \\
7,6 \\
45,1\end{array}$ \\
\hline Slowenien & $\begin{array}{l}15-19 \\
20-24 \\
25-29 \\
15-29\end{array}$ & $\begin{array}{r}7,0 \\
24,1 \\
18,1 \\
17,1\end{array}$ & $\begin{array}{l}a \\
a \\
a \\
a\end{array}$ & $\begin{array}{r}7,0 \\
24,1 \\
18,1 \\
17,1\end{array}$ & $\begin{array}{r}1,6 \\
8,9 \\
12,6 \\
8,3\end{array}$ & $\begin{array}{r}5,4 \\
15,2 \\
5,5 \\
8,8\end{array}$ & $\begin{array}{l}\mathrm{m} \\
\mathrm{m} \\
\mathrm{m} \\
\mathrm{m}\end{array}$ & $\begin{array}{r}c \\
3,2 \\
2,2 \\
2,1\end{array}$ & $\begin{array}{r}c \\
2,3 \\
1,3 \\
1,3\end{array}$ & $\begin{array}{r}c \\
0,9 \\
0,9 \\
0,8\end{array}$ & $\begin{array}{r}87,9 \\
41,5 \\
7,0 \\
41,2\end{array}$ & $\begin{array}{l}95,3 \\
68,8 \\
27,3 \\
60,4\end{array}$ \\
\hline Spanien & $\begin{array}{l}15-19 \\
20-24 \\
25-29 \\
15-29\end{array}$ & $\begin{array}{l}1,1 \\
6,0 \\
5,2 \\
4,3\end{array}$ & $\begin{array}{l}\mathrm{a} \\
\mathrm{a} \\
\mathrm{a} \\
\mathrm{a}\end{array}$ & $\begin{array}{l}1,1 \\
6,0 \\
5,2 \\
4,3\end{array}$ & $\begin{array}{r}c \\
1,6 \\
3,2 \\
1,8\end{array}$ & $\begin{array}{l}0,9 \\
4,4 \\
2,0 \\
2,4\end{array}$ & $\begin{array}{l}0,8 \\
3,4 \\
1,3 \\
1,8\end{array}$ & $\begin{array}{l}2,7 \\
6,0 \\
3,1 \\
3,9\end{array}$ & $\begin{array}{l}1,2 \\
1,7 \\
1,0 \\
1,3\end{array}$ & $\begin{array}{l}1,4 \\
4,1 \\
2,0 \\
2,5\end{array}$ & $\begin{array}{r}82,2 \\
31,9 \\
5,0 \\
36,1\end{array}$ & $\begin{array}{l}86,0 \\
43,9 \\
13,2 \\
44,3\end{array}$ \\
\hline
\end{tabular}

1. Teilnehmer an dualen Ausbildungsprogrammen gelten als sowohl in Ausbildung als auch beschäftigt, ohne Bezug auf ihren ILO-Erwerbsstatus. 2. Junge Menschen, die weder in Ausbildung noch in Beschäftigung sind. 3. Referenzjahr 2011.

Quelle: OECD. Argentinien, China, Indien, Indonesien, Kolumbien, Saudi-Arabien und Südafrika: Statistikinstitut der UNESCO. Lettland: Eurostat. Hinweise s. Anhang 3 unter www.oecd.org/edu/eag.htm. StatLink: http://dx.doi.org/10.1787/888933118941

Erläuterung der Kennzeichnung fehlender Daten s. Hinweise für den Leser. 
Anteil 15- bis 29-Jähriger (in \%), die sich in Ausbildung bzw. nicht in Ausbildung befinden, nach Altersgruppe und Erwerbsstatus (2012)

\begin{tabular}{|c|c|c|c|c|c|c|c|c|c|c|c|c|}
\hline & \multirow{4}{*}{$\begin{array}{l}\text { Alters- } \\
\text { gruppe }\end{array}$} & \multicolumn{10}{|c|}{ Nicht in Ausbildung } & \multirow{3}{*}{\begin{tabular}{|} 
Gesamt: \\
In Aus- \\
bildung und \\
nicht in \\
Ausbildung
\end{tabular}} \\
\hline & & \multirow[t]{2}{*}{$\begin{array}{c}\text { Alle Beschäf- } \\
\text { tigten }\end{array}$} & \multicolumn{3}{|c|}{ Art der Beschäftigung } & \multirow[t]{2}{*}{$\mathrm{NEET}^{2}$} & \multirow[t]{2}{*}{ Erwerbslos } & \multicolumn{2}{|c|}{$\begin{array}{c}\text { Dauer der } \\
\text { Erwerbslosigkeit }\end{array}$} & \multirow{2}{*}{$\begin{array}{c}\text { Nicht im } \\
\text { Arbeits- } \\
\text { markt }\end{array}$} & \multirow{2}{*}{\begin{tabular}{|l} 
Zwischen- \\
summe \\
(beschäftigt \\
+ erwerbslos \\
+ nicht im \\
Arbeitsmarkt)
\end{tabular}} & \\
\hline & & & Vollzeit & Teilzeit (TZ) & $\begin{array}{c}\text { Frei- } \\
\text { willige } \\
\text { TZ }\end{array}$ & & & $\begin{array}{l}\text { Kürzer } \\
\text { als } 6 \\
\text { Monate }\end{array}$ & $\begin{array}{l}\text { Länger } \\
\text { als } 6 \\
\text { Monate }\end{array}$ & & & \\
\hline & & $\begin{array}{c}(12)= \\
(13)+(14)+ \\
\text { unbekannt }\end{array}$ & (13) & $\begin{array}{c}(14)=(15)+ \\
\text { unfreiwillige } \\
\text { TZ }\end{array}$ & (15) & $\begin{array}{c}(16)= \\
(17)+(20)\end{array}$ & $\begin{array}{c}(17)= \\
(18)+(19)\end{array}$ & (18) & (19) & (20) & $\begin{array}{c}(21)=(12)+ \\
(17)+(20)\end{array}$ & $\begin{array}{c}(22)= \\
(11)+(21)\end{array}$ \\
\hline \multicolumn{13}{|l|}{ OECD-Länder } \\
\hline Irland & $\begin{array}{l}15-19 \\
20-24 \\
25-29 \\
15-29\end{array}$ & $\begin{array}{r}3,3 \\
32,5 \\
61,7 \\
34,7\end{array}$ & $\begin{array}{r}1,6 \\
23,8 \\
51,6 \\
27,7\end{array}$ & $\begin{array}{r}1,7 \\
8,6 \\
10,1 \\
7,1\end{array}$ & $\begin{array}{l}\mathrm{m} \\
\mathrm{m} \\
\mathrm{m} \\
\mathrm{m}\end{array}$ & $\begin{array}{r}9,6 \\
25,7 \\
26,5 \\
21,1\end{array}$ & $\begin{array}{r}4,1 \\
16,0 \\
14,1 \\
11,7\end{array}$ & $\begin{array}{l}1,0 \\
4,3 \\
3,0 \\
2,8\end{array}$ & $\begin{array}{r}3,0 \\
11,6 \\
11,0 \\
8,7\end{array}$ & $\begin{array}{r}5,6 \\
9,7 \\
12,3 \\
9,4\end{array}$ & $\begin{array}{l}12,9 \\
58,2 \\
88,2 \\
55,8\end{array}$ & $\begin{array}{l}100 \\
100 \\
100 \\
100\end{array}$ \\
\hline Israel & \begin{tabular}{|l|}
$15-19$ \\
$20-24$ \\
$25-29$ \\
$15-29$
\end{tabular} & $\begin{array}{l}20,6 \\
51,5 \\
51,6 \\
41,0\end{array}$ & $\begin{array}{l}18,1 \\
42,7 \\
41,5 \\
33,9\end{array}$ & $\begin{array}{r}2,5 \\
8,7 \\
10,1 \\
7,1\end{array}$ & $\begin{array}{l}1,5 \\
5,4 \\
6,8 \\
4,5\end{array}$ & $\begin{array}{l}10,7 \\
18,7 \\
17,7 \\
15,7\end{array}$ & $\begin{array}{l}2,7 \\
6,5 \\
6,2 \\
5,1\end{array}$ & $\begin{array}{l}2,1 \\
4,6 \\
4,0 \\
3,5\end{array}$ & $\begin{array}{l}0,6 \\
1,5 \\
1,7 \\
1,2\end{array}$ & $\begin{array}{r}8,0 \\
12,3 \\
11,5 \\
10,6\end{array}$ & $\begin{array}{l}31,4 \\
70,3 \\
69,3 \\
56,7\end{array}$ & $\begin{array}{l}100 \\
100 \\
100 \\
100\end{array}$ \\
\hline Italien & \begin{tabular}{|l|}
$15-19$ \\
$20-24$ \\
$25-29$ \\
$15-29$
\end{tabular} & $\begin{array}{r}3,0 \\
29,5 \\
55,4 \\
30,7\end{array}$ & $\begin{array}{r}2,2 \\
23,0 \\
44,0 \\
24,2\end{array}$ & $\begin{array}{r}0,8 \\
6,5 \\
11,3 \\
6,5\end{array}$ & $\begin{array}{r}C \\
0,8 \\
2,4 \\
1,1\end{array}$ & $\begin{array}{l}12,0 \\
31,5 \\
29,0 \\
24,6\end{array}$ & $\begin{array}{r}4,3 \\
14,6 \\
11,2 \\
10,2\end{array}$ & $\begin{array}{l}1,3 \\
5,4 \\
4,2 \\
3,7\end{array}$ & $\begin{array}{l}3,0 \\
9,1 \\
7,1 \\
6,5\end{array}$ & $\begin{array}{r}7,7 \\
17,0 \\
17,8 \\
14,4\end{array}$ & $\begin{array}{l}14,9 \\
61,1 \\
84,4 \\
55,3\end{array}$ & $\begin{array}{l}100 \\
100 \\
100 \\
100\end{array}$ \\
\hline Japan & $15-24$ & 26,1 & 17,4 & 8,6 & $\mathrm{~m}$ & 9,4 & 3,5 & $\mathrm{~m}$ & $\mathrm{~m}$ & 5,9 & 35,5 & 100 \\
\hline Korea & \begin{tabular}{|l|}
$15-19$ \\
$20-24$ \\
$25-29$ \\
$15-29$
\end{tabular} & $\begin{array}{r}2,5 \\
35,1 \\
66,4 \\
35,0\end{array}$ & $\begin{array}{r}2,0 \\
32,2 \\
62,8 \\
32,7\end{array}$ & $\begin{array}{l}0,5 \\
3,0 \\
3,6 \\
2,3\end{array}$ & $\begin{array}{l}0,4 \\
2,6 \\
3,1 \\
2,0\end{array}$ & $\begin{array}{r}8,5 \\
22,5 \\
24,7 \\
18,5\end{array}$ & $\begin{array}{l}0,3 \\
3,7 \\
4,6 \\
2,9\end{array}$ & $\begin{array}{l}0,3 \\
3,5 \\
4,0 \\
2,6\end{array}$ & $\begin{array}{l}0,0 \\
0,2 \\
0,6 \\
0,3\end{array}$ & $\begin{array}{r}8,2 \\
18,8 \\
20,2 \\
15,6\end{array}$ & $\begin{array}{l}11,0 \\
57,6 \\
91,2 \\
53,5\end{array}$ & $\begin{array}{l}100 \\
100 \\
100 \\
100\end{array}$ \\
\hline Luxemburg & \begin{tabular}{|l|}
$15-19$ \\
$20-24$ \\
$25-29$ \\
$15-29$
\end{tabular} & $\begin{array}{r}c \\
23,8 \\
69,1 \\
33,4\end{array}$ & $\begin{array}{r}c \\
21,2 \\
64,8 \\
30,9\end{array}$ & $\begin{array}{r}c \\
2,7 \\
4,3 \\
2,6\end{array}$ & $\begin{array}{l}\mathrm{m} \\
\mathrm{m} \\
\mathrm{m} \\
\mathrm{m}\end{array}$ & $\begin{array}{r}2,9 \\
10,3 \\
10,9 \\
8,2\end{array}$ & $\begin{array}{r}c \\
6,2 \\
4,2 \\
3,8\end{array}$ & $\begin{array}{r}c \\
3,3 \\
2,8 \\
2,2\end{array}$ & $\begin{array}{r}c \\
2,9 \\
C \\
1,6\end{array}$ & $\begin{array}{l}1,9 \\
4,1 \\
6,7 \\
4,4\end{array}$ & $\begin{array}{r}4,3 \\
34,1 \\
80,0 \\
41,6\end{array}$ & $\begin{array}{l}100 \\
100 \\
100 \\
100\end{array}$ \\
\hline Mexiko & \begin{tabular}{|l|}
$15-19$ \\
$20-24$ \\
$25-29$ \\
$15-29$
\end{tabular} & $\begin{array}{l}21,5 \\
48,0 \\
65,1 \\
42,7\end{array}$ & $\begin{array}{l}14,7 \\
37,1 \\
49,6 \\
32,1\end{array}$ & $\begin{array}{r}6,7 \\
10,6 \\
15,1 \\
10,4\end{array}$ & $\begin{array}{l}1,9 \\
3,2 \\
4,8 \\
3,1\end{array}$ & $\begin{array}{l}17,0 \\
23,6 \\
27,1 \\
22,0\end{array}$ & $\begin{array}{l}2,6 \\
4,3 \\
4,2 \\
3,6\end{array}$ & $\begin{array}{l}2,3 \\
3,8 \\
3,7 \\
3,2\end{array}$ & $\begin{array}{l}0,1 \\
0,3 \\
0,3 \\
0,2\end{array}$ & $\begin{array}{l}14,4 \\
19,3 \\
22,9 \\
18,5\end{array}$ & $\begin{array}{l}38,4 \\
71,5 \\
92,2 \\
64,7\end{array}$ & $\begin{array}{l}100 \\
100 \\
100 \\
100\end{array}$ \\
\hline Niederlande & \begin{tabular}{|l|}
$15-19$ \\
$20-24$ \\
$25-29$ \\
$15-29$
\end{tabular} & $\begin{array}{r}4,2 \\
34,5 \\
67,3 \\
35,4\end{array}$ & $\begin{array}{r}1,6 \\
19,8 \\
43,3 \\
21,6\end{array}$ & $\begin{array}{r}2,7 \\
14,7 \\
23,9 \\
13,8\end{array}$ & $\begin{array}{l}\mathrm{m} \\
\mathrm{m} \\
\mathrm{m} \\
\mathrm{m}\end{array}$ & $\begin{array}{r}2,4 \\
7,1 \\
10,6 \\
6,7\end{array}$ & $\begin{array}{l}0,6 \\
2,8 \\
3,6 \\
2,3\end{array}$ & $\begin{array}{l}0,4 \\
1,8 \\
2,1 \\
1,5\end{array}$ & $\begin{array}{l}0,2 \\
0,9 \\
1,4 \\
0,8\end{array}$ & $\begin{array}{l}1,8 \\
4,3 \\
7,0 \\
4,4\end{array}$ & $\begin{array}{r}6,6 \\
41,7 \\
77,8 \\
42,1\end{array}$ & $\begin{array}{l}100 \\
100 \\
100 \\
100\end{array}$ \\
\hline Neuseeland & $\begin{array}{l}15-19 \\
20-24 \\
25-29 \\
15-29\end{array}$ & $\begin{array}{l}12,8 \\
46,6 \\
63,2 \\
40,6\end{array}$ & $\begin{array}{r}7,5 \\
37,6 \\
54,2 \\
32,8\end{array}$ & $\begin{array}{l}5,3 \\
9,0 \\
9,0 \\
7,7\end{array}$ & $\begin{array}{l}3,1 \\
5,9 \\
5,7 \\
4,9\end{array}$ & $\begin{array}{r}8,7 \\
16,9 \\
18,9 \\
14,8\end{array}$ & $\begin{array}{l}3,6 \\
6,2 \\
4,3 \\
4,7\end{array}$ & $\begin{array}{l}2,4 \\
3,9 \\
2,6 \\
3,0\end{array}$ & $\begin{array}{l}0,7 \\
1,7 \\
1,0 \\
1,1\end{array}$ & $\begin{array}{r}5,1 \\
10,7 \\
14,6 \\
10,1\end{array}$ & $\begin{array}{l}21,5 \\
63,5 \\
82,1 \\
55,4\end{array}$ & $\begin{array}{l}100 \\
100 \\
100 \\
100\end{array}$ \\
\hline Norwegen & \begin{tabular}{|l|}
$15-19$ \\
$20-24$ \\
$25-29$ \\
$15-29$
\end{tabular} & $\begin{array}{l}14,6 \\
48,8 \\
74,0 \\
45,8\end{array}$ & $\begin{array}{l}10,1 \\
38,2 \\
64,4 \\
37,6\end{array}$ & $\begin{array}{l}2,7 \\
9,3 \\
8,8 \\
7,0\end{array}$ & $\begin{array}{l}\mathrm{m} \\
\mathrm{m} \\
\mathrm{m} \\
\mathrm{m}\end{array}$ & $\begin{array}{r}3,0 \\
10,7 \\
11,4 \\
8,4\end{array}$ & $\begin{array}{r}c \\
3,9 \\
3,0 \\
2,6\end{array}$ & $\begin{array}{r}C \\
2,9 \\
2,2 \\
1,9\end{array}$ & $\begin{array}{r}c \\
c \\
c \\
0,5\end{array}$ & $\begin{array}{l}2,3 \\
6,7 \\
8,4 \\
5,8\end{array}$ & $\begin{array}{l}17,6 \\
59,4 \\
85,4 \\
54,2\end{array}$ & $\begin{array}{l}100 \\
100 \\
100 \\
100\end{array}$ \\
\hline Polen & \begin{tabular}{|l|}
$15-19$ \\
$20-24$ \\
$25-29$ \\
$15-29$
\end{tabular} & $\begin{array}{r}1,6 \\
29,1 \\
66,2 \\
35,4\end{array}$ & $\begin{array}{r}1,3 \\
26,8 \\
62,8 \\
33,3\end{array}$ & $\begin{array}{l}0,3 \\
2,3 \\
3,3 \\
2,1\end{array}$ & $\begin{array}{r}c \\
0,6 \\
0,9 \\
0,6\end{array}$ & $\begin{array}{r}3,9 \\
18,9 \\
22,4 \\
16,0\end{array}$ & $\begin{array}{r}1,8 \\
10,5 \\
10,0 \\
7,8\end{array}$ & $\begin{array}{l}1,1 \\
4,4 \\
4,1 \\
3,3\end{array}$ & $\begin{array}{l}0,7 \\
6,1 \\
5,9 \\
4,5\end{array}$ & $\begin{array}{r}2,2 \\
8,4 \\
12,4 \\
8,2\end{array}$ & $\begin{array}{r}5,5 \\
48,0 \\
88,6 \\
51,4\end{array}$ & $\begin{array}{l}100 \\
100 \\
100 \\
100\end{array}$ \\
\hline Portugal & \begin{tabular}{|l|}
$15-19$ \\
$20-24$ \\
$25-29$ \\
$15-29$
\end{tabular} & $\begin{array}{r}3,8 \\
35,7 \\
66,4 \\
37,6\end{array}$ & $\begin{array}{l}\mathrm{m} \\
\mathrm{m} \\
\mathrm{m} \\
\mathrm{m}\end{array}$ & $\begin{array}{l}\mathrm{m} \\
\mathrm{m} \\
\mathrm{m} \\
\mathrm{m}\end{array}$ & $\begin{array}{l}\mathrm{m} \\
\mathrm{m} \\
\mathrm{m} \\
\mathrm{m}\end{array}$ & $\begin{array}{r}7,9 \\
22,7 \\
18,3 \\
16,6\end{array}$ & $\begin{array}{r}5,2 \\
16,4 \\
13,0 \\
11,8\end{array}$ & $\begin{array}{l}3,2 \\
6,3 \\
4,3 \\
4,6\end{array}$ & $\begin{array}{r}2,0 \\
10,1 \\
8,7 \\
7,2\end{array}$ & $\begin{array}{l}2,6 \\
6,3 \\
5,3 \\
4,8\end{array}$ & $\begin{array}{l}11,6 \\
58,4 \\
84,7 \\
54,3\end{array}$ & $\begin{array}{l}100 \\
100 \\
100 \\
100\end{array}$ \\
\hline Slowakei & \begin{tabular}{|l|}
$15-19$ \\
$20-24$ \\
$25-29$ \\
$15-29$
\end{tabular} & $\begin{array}{r}1,9 \\
33,1 \\
64,9 \\
36,1\end{array}$ & $\begin{array}{r}1,5 \\
31,4 \\
61,7 \\
34,2\end{array}$ & $\begin{array}{r}c \\
1,7 \\
3,1 \\
1,9\end{array}$ & $\begin{array}{l}\mathrm{m} \\
\mathrm{m} \\
\mathrm{m} \\
\mathrm{m}\end{array}$ & $\begin{array}{r}5,6 \\
20,2 \\
27,5 \\
18,8\end{array}$ & $\begin{array}{r}4,4 \\
14,6 \\
14,8 \\
11,8\end{array}$ & $\begin{array}{l}0,8 \\
2,8 \\
2,2 \\
2,0\end{array}$ & $\begin{array}{r}3,6 \\
11,9 \\
12,7 \\
9,8\end{array}$ & $\begin{array}{r}1,2 \\
5,6 \\
12,7 \\
7,0\end{array}$ & $\begin{array}{r}7,6 \\
53,3 \\
92,4 \\
54,9\end{array}$ & $\begin{array}{l}100 \\
100 \\
100 \\
100\end{array}$ \\
\hline Slowenien & \begin{tabular}{|l|}
$15-19$ \\
$20-24$ \\
$25-29$ \\
$15-29$
\end{tabular} & $\begin{array}{r}0,9 \\
19,8 \\
56,9 \\
28,7\end{array}$ & $\begin{array}{r}c \\
18,2 \\
54,0 \\
26,9\end{array}$ & $\begin{array}{r}c \\
1,6 \\
3,0 \\
1,8\end{array}$ & $\begin{array}{l}\mathrm{m} \\
\mathrm{m} \\
\mathrm{m} \\
\mathrm{m}\end{array}$ & $\begin{array}{r}3,8 \\
11,4 \\
15,7 \\
11,0\end{array}$ & $\begin{array}{l}1,1 \\
7,2 \\
9,0 \\
6,2\end{array}$ & $\begin{array}{r}c \\
3,0 \\
3,6 \\
2,4\end{array}$ & $\begin{array}{l}1,1 \\
4,2 \\
5,4 \\
3,8\end{array}$ & $\begin{array}{l}2,8 \\
4,2 \\
6,7 \\
4,8\end{array}$ & $\begin{array}{r}4,7 \\
31,2 \\
72,7 \\
39,6\end{array}$ & $\begin{array}{l}100 \\
100 \\
100 \\
100\end{array}$ \\
\hline Spanien & \begin{tabular}{|l|}
$15-19$ \\
$20-24$ \\
$25-29$ \\
$15-29$
\end{tabular} & $\begin{array}{r}2,6 \\
25,2 \\
54,3 \\
29,9\end{array}$ & $\begin{array}{r}1,7 \\
19,0 \\
45,7 \\
24,3\end{array}$ & $\begin{array}{l}0,9 \\
6,2 \\
8,6 \\
5,6\end{array}$ & $\begin{array}{l}0,3 \\
1,2 \\
2,0 \\
1,2\end{array}$ & $\begin{array}{l}11,4 \\
30,9 \\
32,5 \\
25,8\end{array}$ & $\begin{array}{r}6,8 \\
23,0 \\
23,8 \\
18,6\end{array}$ & $\begin{array}{l}2,1 \\
7,3 \\
7,7 \\
5,9\end{array}$ & $\begin{array}{r}4,5 \\
14,9 \\
15,1 \\
11,9\end{array}$ & $\begin{array}{l}4,6 \\
8,0 \\
8,6 \\
7,2\end{array}$ & $\begin{array}{l}14,0 \\
56,1 \\
86,8 \\
55,7\end{array}$ & $\begin{array}{l}100 \\
100 \\
100 \\
100\end{array}$ \\
\hline
\end{tabular}

1. Teilnehmer an dualen Ausbildungsprogrammen gelten als sowohl in Ausbildung als auch beschäftigt, ohne Bezug auf ihren ILO-Erwerbsstatus. 2. Junge Menschen, die weder in Ausbildung noch in Beschäftigung sind. 3. Referenzjahr 2011.

Quelle: OECD. Argentinien, China, Indien, Indonesien, Kolumbien, Saudi-Arabien und Südafrika: Statistikinstitut der UNESCO. Lettland: Eurostat. Hinweise s. Anhang 3 unter www.oecd.org/edu/eag.htm. StatLink: http://dx.doi.org/10.1787/888933118941

Erläuterung der Kennzeichnung fehlender Daten s. Hinweise für den Leser. 
Tabelle C5.2a (Forts. 4)

Anteil 15- bis 29-Jähriger (in \%), die sich in Ausbildung bzw. nicht in Ausbildung befinden, nach Altersgruppe und Erwerbsstatus (2012)

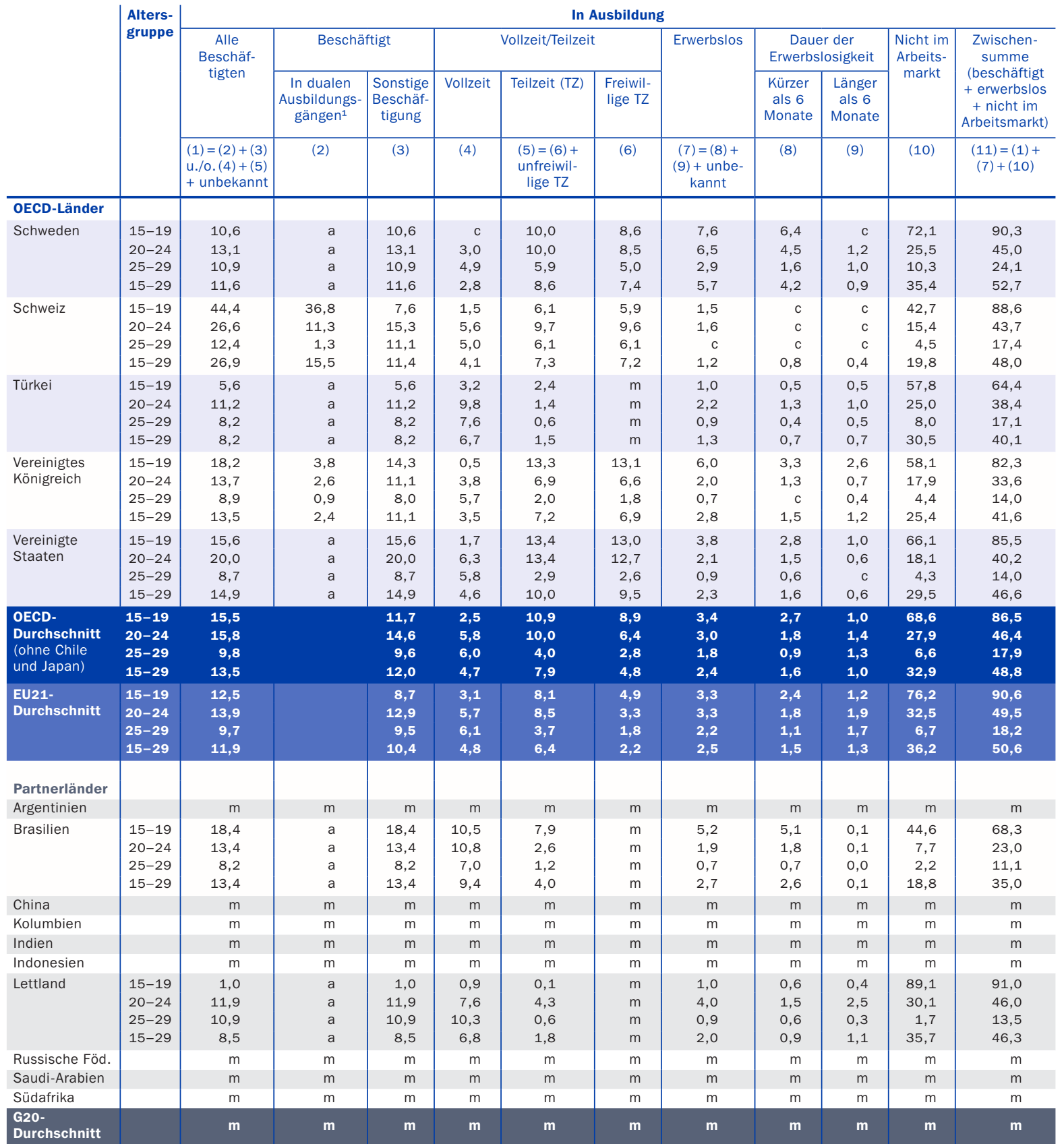

1. Teilnehmer an dualen Ausbildungsprogrammen gelten als sowohl in Ausbildung als auch beschäftigt, ohne Bezug auf ihren ILO-Erwerbsstatus. 2. Junge Menschen, die weder in Ausbildung noch in Beschäftigung sind. 3. Referenzjahr 2011.

Quelle: OECD. Argentinien, China, Indien, Indonesien, Kolumbien, Saudi-Arabien und Südafrika: Statistikinstitut der UNESCO. Lettland: Eurostat. Hinweise s. Anhang 3 unter www.oecd.org/edu/eag.htm. StatLink: http://dx.doi.org/10.1787/888933118941

Erläuterung der Kennzeichnung fehlender Daten s. Hinweise für den Leser. 
Tabelle C5.2a (Forts. 5)

Anteil 15- bis 29-Jähriger (in \%), die sich in Ausbildung bzw. nicht in Ausbildung befinden, nach Altersgruppe und Erwerbsstatus (2012)

\begin{tabular}{|c|c|c|c|c|c|c|c|c|c|c|c|c|}
\hline & \multirow{4}{*}{\begin{tabular}{|l|} 
Alters- \\
gruppe
\end{tabular}} & \multicolumn{10}{|c|}{ Nicht in Ausbildung } & \multirow{3}{*}{$\begin{array}{l}\text { Gesamt: } \\
\text { In Aus- } \\
\text { bildung und } \\
\text { nicht in } \\
\text { Ausbildung }\end{array}$} \\
\hline & & \multirow[t]{2}{*}{$\begin{array}{c}\text { Alle Beschäf- } \\
\text { tigten }\end{array}$} & \multicolumn{3}{|c|}{ Art der Beschäftigung } & \multirow[t]{2}{*}{ NEET $^{2}$} & \multirow[t]{2}{*}{ Erwerbslos } & \multicolumn{2}{|c|}{$\begin{array}{c}\text { Dauer der } \\
\text { Erwerbslosigkeit }\end{array}$} & \multirow{2}{*}{$\begin{array}{c}\text { Nicht im } \\
\text { Arbeits- } \\
\text { markt }\end{array}$} & \multirow{2}{*}{\begin{tabular}{|l} 
Zwischen- \\
summe \\
(beschäftigt \\
+ erwerbslos \\
+ nicht im \\
Arbeitsmarkt)
\end{tabular}} & \\
\hline & & & Vollzeit & Teilzeit (TZ) & $\begin{array}{c}\text { Frei- } \\
\text { willige } \\
\text { TZ }\end{array}$ & & & $\begin{array}{c}\text { Kürzer } \\
\text { als } 6 \\
\text { Monate }\end{array}$ & $\begin{array}{c}\text { Länger } \\
\text { als } 6 \\
\text { Monate }\end{array}$ & & & \\
\hline & & \begin{tabular}{|c|}
$(12)=$ \\
$(13)+(14)+$ \\
unbekannt
\end{tabular} & (13) & $\begin{array}{c}(14)=(15)+ \\
\text { unfreiwillige } \\
\text { TZ }\end{array}$ & (15) & $\begin{array}{c}(16)= \\
(17)+(20)\end{array}$ & $\begin{array}{c}(17)= \\
(18)+(19)\end{array}$ & (18) & (19) & (20) & $\begin{array}{l}(21)=(12)+ \\
(17)+(20)\end{array}$ & $\begin{array}{c}(22)= \\
(11)+(21)\end{array}$ \\
\hline \multicolumn{13}{|l|}{ OECD-Länder } \\
\hline Schweden & \begin{tabular}{|l|}
$15-19$ \\
$20-24$ \\
$25-29$ \\
$15-29$
\end{tabular} & $\begin{array}{r}5,6 \\
41,5 \\
64,8 \\
37,6\end{array}$ & $\begin{array}{r}3,6 \\
33,2 \\
58,5 \\
32,0\end{array}$ & $\begin{array}{l}2,0 \\
8,2 \\
6,2 \\
5,6\end{array}$ & $\begin{array}{r}c \\
3,3 \\
3,1 \\
2,4\end{array}$ & $\begin{array}{r}4,1 \\
13,5 \\
11,1 \\
9,7\end{array}$ & $\begin{array}{l}2,3 \\
7,5 \\
5,4 \\
5,2\end{array}$ & $\begin{array}{l}1,7 \\
5,2 \\
3,8 \\
3,6\end{array}$ & $\begin{array}{r}c \\
1,9 \\
1,5 \\
1,3\end{array}$ & $\begin{array}{l}1,8 \\
5,9 \\
5,6 \\
4,5\end{array}$ & $\begin{array}{r}9,7 \\
55,0 \\
75,9 \\
47,3\end{array}$ & $\begin{array}{l}100 \\
100 \\
100 \\
100\end{array}$ \\
\hline Schweiz & \begin{tabular}{|l|}
$15-19$ \\
$20-24$ \\
$25-29$ \\
$15-29$
\end{tabular} & $\begin{array}{r}6,7 \\
44,2 \\
71,3 \\
42,5\end{array}$ & $\begin{array}{r}5,5 \\
38,6 \\
60,5 \\
36,4\end{array}$ & $\begin{array}{r}1,2 \\
5,6 \\
10,8 \\
6,1\end{array}$ & $\begin{array}{r}1,2 \\
5,5 \\
10,7 \\
6,1\end{array}$ & $\begin{array}{r}4,7 \\
12,1 \\
11,3 \\
9,6\end{array}$ & $\begin{array}{l}1,7 \\
6,0 \\
4,7 \\
4,2\end{array}$ & $\begin{array}{r}c \\
4,0 \\
2,7 \\
2,6\end{array}$ & $\begin{array}{r}c \\
1,9 \\
1,9 \\
1,5\end{array}$ & $\begin{array}{l}3,0 \\
6,1 \\
6,6 \\
5,3\end{array}$ & $\begin{array}{l}11,4 \\
56,3 \\
82,6 \\
52,0\end{array}$ & $\begin{array}{l}100 \\
100 \\
100 \\
100\end{array}$ \\
\hline Türkei & $\begin{array}{l}15-19 \\
20-24 \\
25-29 \\
15-29\end{array}$ & $\begin{array}{l}12,8 \\
30,6 \\
48,8 \\
30,7\end{array}$ & $\begin{array}{l}10,8 \\
27,7 \\
45,1 \\
27,8\end{array}$ & $\begin{array}{l}1,9 \\
3,0 \\
3,7 \\
2,9\end{array}$ & $\begin{array}{l}\mathrm{m} \\
\mathrm{m} \\
\mathrm{m}\end{array}$ & $\begin{array}{l}22,8 \\
30,9 \\
34,1 \\
29,2\end{array}$ & $\begin{array}{l}3,1 \\
7,2 \\
7,8 \\
6,0\end{array}$ & $\begin{array}{l}2,1 \\
4,2 \\
4,4 \\
3,6\end{array}$ & $\begin{array}{l}1,0 \\
3,0 \\
3,4 \\
2,4\end{array}$ & $\begin{array}{l}19,7 \\
23,7 \\
26,3 \\
23,2\end{array}$ & $\begin{array}{l}35,6 \\
61,6 \\
82,9 \\
59,9\end{array}$ & $\begin{array}{l}100 \\
100 \\
100 \\
100\end{array}$ \\
\hline $\begin{array}{l}\text { Vereinigtes } \\
\text { Königreich }\end{array}$ & \begin{tabular}{|l|}
$15-19$ \\
$20-24$ \\
$25-29$ \\
$15-29$
\end{tabular} & $\begin{array}{r}8,2 \\
46,1 \\
67,7 \\
42,1\end{array}$ & $\begin{array}{r}4,6 \\
34,7 \\
55,1 \\
32,7\end{array}$ & $\begin{array}{r}3,3 \\
10,4 \\
10,9 \\
8,4\end{array}$ & $\begin{array}{l}1,2 \\
4,9 \\
7,6 \\
4,7\end{array}$ & $\begin{array}{r}9,5 \\
20,2 \\
18,3 \\
16,3\end{array}$ & $\begin{array}{r}5,1 \\
10,2 \\
7,0 \\
7,6\end{array}$ & $\begin{array}{l}2,5 \\
4,6 \\
3,3 \\
3,5\end{array}$ & $\begin{array}{l}2,6 \\
5,6 \\
3,7 \\
4,0\end{array}$ & $\begin{array}{r}4,3 \\
10,0 \\
11,2 \\
8,7\end{array}$ & $\begin{array}{l}17,7 \\
66,4 \\
86,0 \\
58,4\end{array}$ & $\begin{array}{l}100 \\
100 \\
100 \\
100\end{array}$ \\
\hline $\begin{array}{l}\text { Vereinigte } \\
\text { Staaten }\end{array}$ & $\begin{array}{l}15-19 \\
20-24 \\
25-29 \\
15-29\end{array}$ & $\begin{array}{r}6,8 \\
42,1 \\
65,8 \\
38,2\end{array}$ & $\begin{array}{r}3,8 \\
32,6 \\
56,0 \\
30,7\end{array}$ & $\begin{array}{l}3,0 \\
9,3 \\
9,6 \\
7,3\end{array}$ & $\begin{array}{l}1,6 \\
4,2 \\
5,2 \\
3,7\end{array}$ & $\begin{array}{r}7,7 \\
17,7 \\
20,2 \\
15,2\end{array}$ & $\begin{array}{l}2,9 \\
6,8 \\
6,6 \\
5,5\end{array}$ & $\begin{array}{l}2,1 \\
4,2 \\
3,7 \\
3,3\end{array}$ & $\begin{array}{l}0,8 \\
2,6 \\
2,9 \\
2,1\end{array}$ & $\begin{array}{r}4,8 \\
10,9 \\
13,6 \\
9,7\end{array}$ & $\begin{array}{l}14,5 \\
59,8 \\
86,0 \\
53,4\end{array}$ & $\begin{array}{l}100 \\
100 \\
100 \\
100\end{array}$ \\
\hline $\begin{array}{l}\text { OECD-Durch- } \\
\text { schnitt } \\
\text { (ohne Chile } \\
\text { und Japan) }\end{array}$ & $\begin{array}{l}15-19 \\
20-24 \\
25-29 \\
15-29\end{array}$ & $\begin{array}{r}6,5 \\
36,1 \\
62,7 \\
36,2\end{array}$ & $\begin{array}{r}4,8 \\
29,9 \\
54,5 \\
30,7\end{array}$ & $\begin{array}{l}2,0 \\
6,1 \\
8,0 \\
5,4\end{array}$ & $\begin{array}{l}1,5 \\
3,1 \\
4,2 \\
2,7\end{array}$ & $\begin{array}{r}7,2 \\
17,5 \\
19,4 \\
15,0\end{array}$ & $\begin{array}{l}2,8 \\
8,5 \\
8,0 \\
6,6\end{array}$ & $\begin{array}{l}1,5 \\
4,2 \\
3,7 \\
3,2\end{array}$ & $\begin{array}{l}1,4 \\
4,5 \\
4,5 \\
3,4\end{array}$ & $\begin{array}{r}4,6 \\
9,1 \\
11,3 \\
8,4\end{array}$ & $\begin{array}{l}13,5 \\
53,6 \\
82,1 \\
51,2\end{array}$ & $\begin{array}{l}100 \\
100 \\
100 \\
100\end{array}$ \\
\hline $\begin{array}{l}\text { EU21-Durch- } \\
\text { schnitt }\end{array}$ & \begin{tabular}{|l|}
$15-19$ \\
$20-24$ \\
$25-29$ \\
$15-29$
\end{tabular} & $\begin{array}{r}3,5 \\
32,9 \\
62,2 \\
34,5\end{array}$ & $\begin{array}{r}2,5 \\
27,4 \\
54,3 \\
29,5\end{array}$ & $\begin{array}{l}1,2 \\
5,3 \\
7,7 \\
4,8\end{array}$ & $\begin{array}{l}0,6 \\
2,0 \\
2,9 \\
1,7\end{array}$ & \begin{tabular}{r|}
6,1 \\
17,6 \\
19,5 \\
14,8
\end{tabular} & $\begin{array}{r}2,9 \\
10,1 \\
9,5 \\
7,7\end{array}$ & $\begin{array}{l}1,3 \\
4,2 \\
3,7 \\
3,1\end{array}$ & $\begin{array}{l}1,9 \\
5,8 \\
5,9 \\
4,5\end{array}$ & $\begin{array}{r}3,3 \\
7,6 \\
10,0 \\
7,2\end{array}$ & $\begin{array}{r}9,4 \\
50,5 \\
81,8 \\
49,4\end{array}$ & $\begin{array}{l}100 \\
100 \\
100 \\
100\end{array}$ \\
\hline Partnerländer & & & & & & & & & & & & \\
\hline Argentinien & & $\mathrm{m}$ & $\mathrm{m}$ & $\mathrm{m}$ & $\mathrm{m}$ & $\mathrm{m}$ & $\mathrm{m}$ & $\mathrm{m}$ & $\mathrm{m}$ & $\mathrm{m}$ & $\mathrm{m}$ & $\mathrm{m}$ \\
\hline Brasilien & \begin{tabular}{|l|}
$15-19$ \\
$20-24$ \\
$25-29$ \\
$15-29$
\end{tabular} & $\begin{array}{l}16,5 \\
53,3 \\
67,6 \\
45,1\end{array}$ & $\begin{array}{l}13,9 \\
47,7 \\
60,2 \\
40,0\end{array}$ & $\begin{array}{l}2,5 \\
5,6 \\
7,4 \\
5,1\end{array}$ & $\begin{array}{l}\mathrm{m} \\
\mathrm{m} \\
\mathrm{m} \\
\mathrm{m}\end{array}$ & $\begin{array}{l}15,2 \\
23,7 \\
21,3 \\
20,0\end{array}$ & $\begin{array}{l}3,3 \\
6,8 \\
5,1 \\
5,0\end{array}$ & $\begin{array}{l}3,2 \\
6,4 \\
4,7 \\
4,7\end{array}$ & $\begin{array}{l}0,1 \\
0,4 \\
0,4 \\
0,3\end{array}$ & $\begin{array}{l}11,9 \\
16,9 \\
16,2 \\
14,9\end{array}$ & $\begin{array}{l}31,7 \\
77,0 \\
88,9 \\
65,0\end{array}$ & $\begin{array}{l}100 \\
100 \\
100 \\
100\end{array}$ \\
\hline China & & $\mathrm{m}$ & $\mathrm{m}$ & $\mathrm{m}$ & $\mathrm{m}$ & $\mathrm{m}$ & $\mathrm{m}$ & $\mathrm{m}$ & $\mathrm{m}$ & $\mathrm{m}$ & $\mathrm{m}$ & $\mathrm{m}$ \\
\hline Kolumbien & & $\mathrm{m}$ & $\mathrm{m}$ & $\mathrm{m}$ & $\mathrm{m}$ & $\mathrm{m}$ & $\mathrm{m}$ & $\mathrm{m}$ & $\mathrm{m}$ & $\mathrm{m}$ & $\mathrm{m}$ & $\mathrm{m}$ \\
\hline Indien & & $\mathrm{m}$ & $\mathrm{m}$ & $\mathrm{m}$ & $\mathrm{m}$ & $\mathrm{m}$ & $\mathrm{m}$ & $\mathrm{m}$ & $\mathrm{m}$ & $\mathrm{m}$ & $\mathrm{m}$ & $\mathrm{m}$ \\
\hline Indonesien & & $\mathrm{m}$ & $\mathrm{m}$ & $\mathrm{m}$ & $\mathrm{m}$ & $\mathrm{m}$ & $\mathrm{m}$ & $\mathrm{m}$ & $\mathrm{m}$ & $\mathrm{m}$ & $\mathrm{m}$ & $\mathrm{m}$ \\
\hline Lettland & $\begin{array}{l}15-19 \\
20-24 \\
25-29 \\
15-29\end{array}$ & $\begin{array}{r}1,8 \\
33,7 \\
59,9 \\
34,6\end{array}$ & $\begin{array}{r}1,5 \\
30,8 \\
55,6 \\
31,9\end{array}$ & $\begin{array}{l}0,3 \\
2,9 \\
4,3 \\
2,7\end{array}$ & $\begin{array}{l}\mathrm{m} \\
\mathrm{m} \\
\mathrm{m} \\
\mathrm{m}\end{array}$ & $\begin{array}{r}7,2 \\
20,3 \\
26,7 \\
19,1\end{array}$ & $\begin{array}{r}4,0 \\
12,5 \\
13,9 \\
10,7\end{array}$ & $\begin{array}{l}2,4 \\
4,4 \\
5,7 \\
4,3\end{array}$ & $\begin{array}{l}1,6 \\
8,1 \\
8,2 \\
6,4\end{array}$ & $\begin{array}{r}3,1 \\
7,8 \\
12,8 \\
8,4\end{array}$ & $\begin{array}{r}9,0 \\
54,0 \\
86,5 \\
53,7\end{array}$ & $\begin{array}{l}100 \\
100 \\
100 \\
100\end{array}$ \\
\hline Russische Föd. & & $\mathrm{m}$ & $\mathrm{m}$ & $\mathrm{m}$ & $\mathrm{m}$ & $\mathrm{m}$ & $\mathrm{m}$ & $\mathrm{m}$ & $\mathrm{m}$ & $\mathrm{m}$ & $\mathrm{m}$ & $\mathrm{m}$ \\
\hline Saudi-Arabien & & $\mathrm{m}$ & $\mathrm{m}$ & $\mathrm{m}$ & $\mathrm{m}$ & $\mathrm{m}$ & $\mathrm{m}$ & $\mathrm{m}$ & $\mathrm{m}$ & $\mathrm{m}$ & $\mathrm{m}$ & $\mathrm{m}$ \\
\hline Südafrika & & $\mathrm{m}$ & $\mathrm{m}$ & $\mathrm{m}$ & $\mathrm{m}$ & $\mathrm{m}$ & $\mathrm{m}$ & $\mathrm{m}$ & $\mathrm{m}$ & $\mathrm{m}$ & $\mathrm{m}$ & $\mathrm{m}$ \\
\hline $\begin{array}{l}\text { G20- } \\
\text { Durchschnitt }\end{array}$ & & m & $\mathbf{m}$ & $\mathbf{m}$ & $\mathbf{m}$ & $\mathbf{m}$ & m & m & m & m & m & m \\
\hline
\end{tabular}

1. Teilnehmer an dualen Ausbildungsprogrammen gelten als sowohl in Ausbildung als auch beschäftigt, ohne Bezug auf ihren ILO-Erwerbsstatus. 2. Junge Menschen, die weder in Ausbildung noch in Beschäftigung sind. 3. Referenzjahr 2011.

Quelle: OECD. Argentinien, China, Indien, Indonesien, Kolumbien, Saudi-Arabien und Südafrika: Statistikinstitut der UNESCO. Lettland: Eurostat. Hinweise s. Anhang 3 unter www.oecd.org/edu/eag.htm. StatLink: http://dx.doi.org/10.1787/888933118941

Erläuterung der Kennzeichnung fehlender Daten s. Hinweise für den Leser. 
Entwicklung des Anteils 15- bis 29-Jähriger (in \%), die sich in Ausbildung bzw. nicht in Ausbildung befinden (beschäftigt bzw. nicht beschäftigt), nach Altersgruppe (1997-2012)

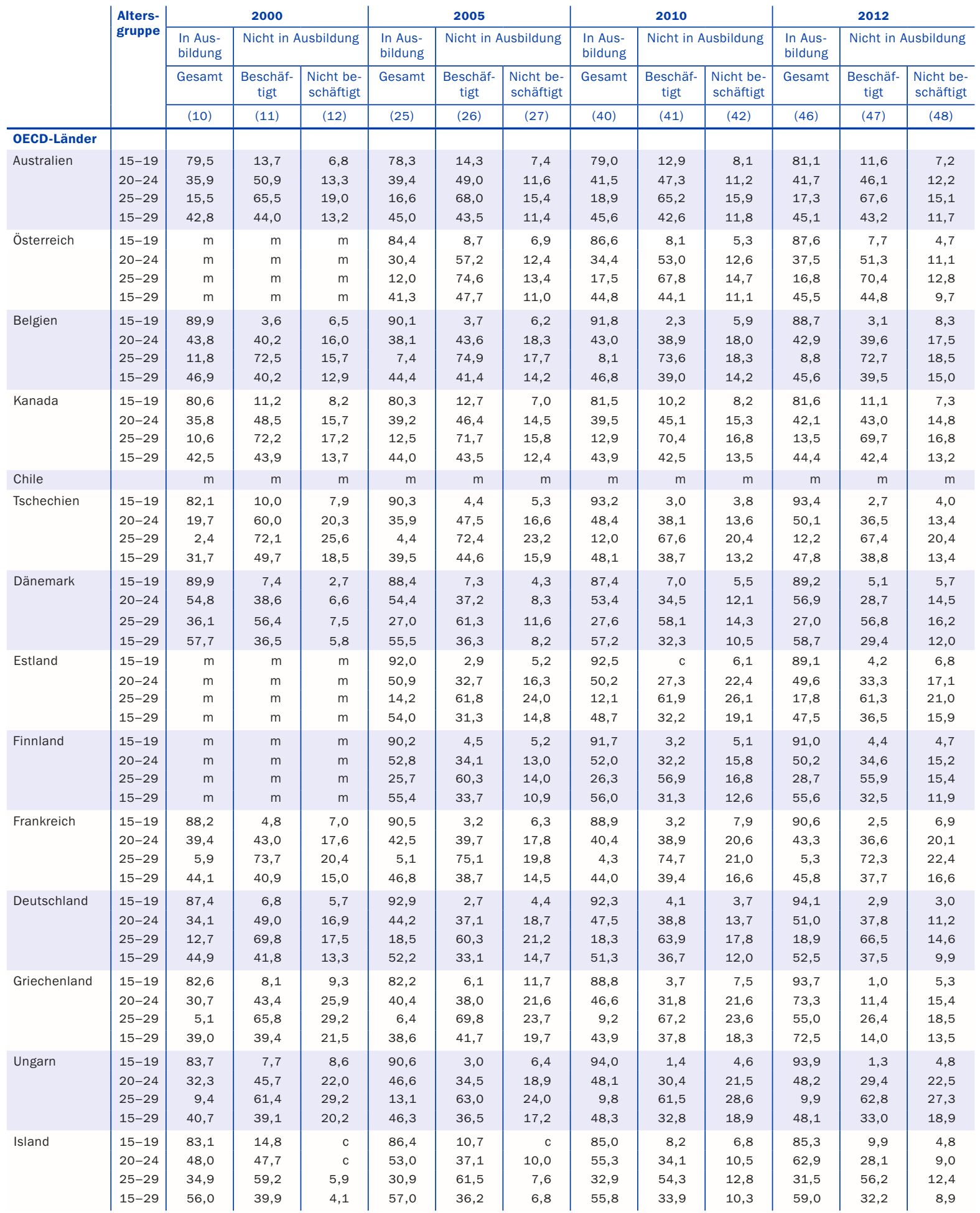

Anmerkung: Die Spalten mit Angaben zu weiteren Jahren sind im Internet verfügbar (s. StatLink unten).

Quelle: OECD. Argentinien, China, Indien, Indonesien, Kolumbien, Saudi-Arabien und Südafrika: Statistikinstitut der UNESCO. Lettland: Eurostat.

Hinweise s. Anhang 3 unter www.oecd.org/edu/eag.htm. StatLink: http://dx.doi.org/10.1787/888933118960

Erläuterung der Kennzeichnung fehlender Daten s. Hinweise für den Leser. 
Entwicklung des Anteils 15- bis 29-Jähriger (in \%), die sich in Ausbildung bzw. nicht in Ausbildung befinden (beschäftigt bzw. nicht beschäftigt), nach Altersgruppe (1997-2012)

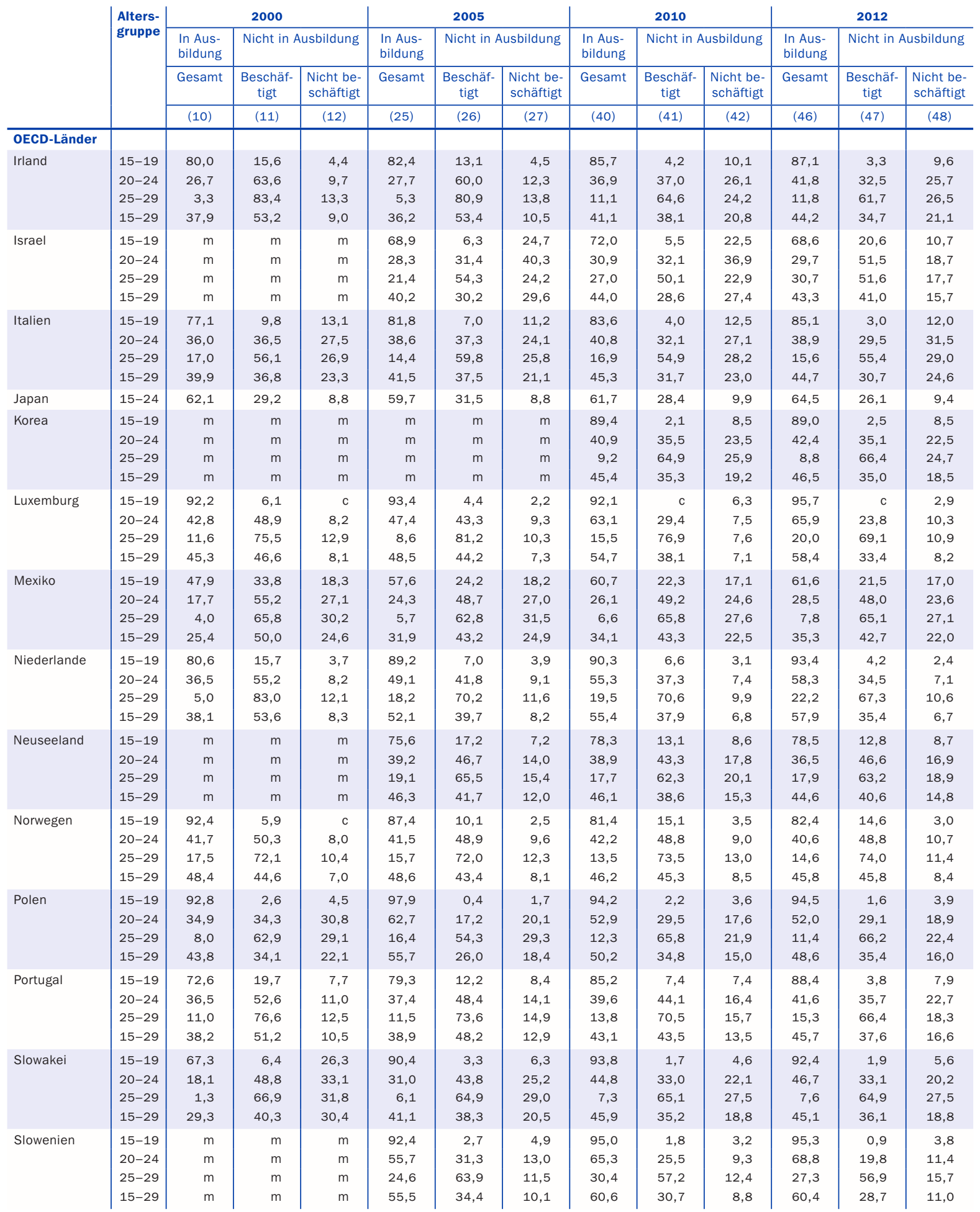

Anmerkung: Die Spalten mit Angaben zu weiteren Jahren sind im Internet verfügbar (s. StatLink unten).

Quelle: OECD. Argentinien, China, Indien, Indonesien, Kolumbien, Saudi-Arabien und Südafrika: Statistikinstitut der UNESCO. Lettland: Eurostat.

Hinweise s. Anhang 3 unter www.oecd.org/edu/eag.htm. StatLink: http://dx.doi.org/10.1787/888933118960

Erläuterung der Kennzeichnung fehlender Daten s. Hinweise für den Leser. 
Tabelle C5.3a (Forts. 2)

Entwicklung des Anteils 15- bis 29-Jähriger (in \%), die sich in Ausbildung bzw. nicht in Ausbildung befinden (beschäftigt bzw. nicht beschäftigt), nach Altersgruppe (1997-2012)

\begin{tabular}{|c|c|c|c|c|c|c|c|c|c|c|c|c|c|}
\hline & \multirow{4}{*}{\begin{tabular}{|l|} 
Alters- \\
gruppe
\end{tabular}} & \multicolumn{3}{|c|}{2000} & \multicolumn{3}{|c|}{2005} & \multicolumn{3}{|c|}{2010} & \multicolumn{3}{|c|}{2012} \\
\hline & & \multirow{2}{*}{$\begin{array}{l}\text { In Aus- } \\
\text { bildung } \\
\text { Gesamt }\end{array}$} & \multicolumn{2}{|c|}{ Nicht in Ausbildung } & \multirow{2}{*}{$\begin{array}{l}\text { In Aus- } \\
\text { bildung }\end{array}$} & \multicolumn{2}{|c|}{ Nicht in Ausbildung } & \multirow{2}{*}{$\begin{array}{l}\text { In Aus- } \\
\text { bildung } \\
\text { Gesamt }\end{array}$} & \multicolumn{2}{|c|}{ Nicht in Ausbildung } & \multirow{2}{*}{$\begin{array}{l}\text { In Aus- } \\
\text { bildung } \\
\text { Gesamt }\end{array}$} & \multicolumn{2}{|c|}{ Nicht in Ausbildung } \\
\hline & & & $\begin{array}{l}\text { Beschäf- } \\
\text { tigt }\end{array}$ & $\begin{array}{l}\text { Nicht be- } \\
\text { schäftigt }\end{array}$ & & $\begin{array}{l}\text { Beschäf- } \\
\text { tigt }\end{array}$ & $\begin{array}{l}\text { Nicht be- } \\
\text { schäftigt }\end{array}$ & & $\begin{array}{l}\text { Beschäf- } \\
\text { tigt }\end{array}$ & $\begin{array}{l}\text { Nicht be- } \\
\text { schäftigt }\end{array}$ & & $\begin{array}{l}\text { Beschäf- } \\
\text { tigt }\end{array}$ & $\begin{array}{l}\text { Nicht be- } \\
\text { schäftigt }\end{array}$ \\
\hline & & (10) & (11) & (12) & (25) & (26) & (27) & $(40)$ & (41) & $(42)$ & (46) & $(47)$ & (48) \\
\hline \multicolumn{14}{|l|}{ OECD-Länder } \\
\hline Spanien & $\begin{array}{l}15-19 \\
20-24 \\
25-29 \\
15-29\end{array}$ & $\begin{array}{l}80,6 \\
44,6 \\
16,2 \\
45,0\end{array}$ & $\begin{array}{l}11,4 \\
40,3 \\
62,4 \\
39,8\end{array}$ & $\begin{array}{r}8,0 \\
15,0 \\
21,4 \\
15,3\end{array}$ & $\begin{array}{l}78,2 \\
35,1 \\
10,9 \\
37,1\end{array}$ & $\begin{array}{l}11,0 \\
45,5 \\
69,3 \\
45,7\end{array}$ & $\begin{array}{l}10,8 \\
19,4 \\
19,8 \\
17,2\end{array}$ & $\begin{array}{l}82,6 \\
39,3 \\
11,3 \\
40,3\end{array}$ & $\begin{array}{r}4,6 \\
33,3 \\
60,1 \\
35,9\end{array}$ & $\begin{array}{l}12,8 \\
27,4 \\
28,6 \\
23,7\end{array}$ & $\begin{array}{l}86,0 \\
43,9 \\
13,2 \\
44,3\end{array}$ & $\begin{array}{r}2,6 \\
25,2 \\
54,3 \\
29,9\end{array}$ & $\begin{array}{l}11,4 \\
30,9 \\
32,5 \\
25,8\end{array}$ \\
\hline Schweden & $\begin{array}{l}15-19 \\
20-24 \\
25-29 \\
15-29\end{array}$ & $\begin{array}{l}90,6 \\
42,1 \\
21,9 \\
50,2\end{array}$ & $\begin{array}{r}5,8 \\
47,2 \\
68,9 \\
41,9\end{array}$ & $\begin{array}{r}3,6 \\
10,7 \\
9,2 \\
7,9\end{array}$ & $\begin{array}{l}89,6 \\
42,5 \\
23,6 \\
52,9\end{array}$ & $\begin{array}{r}5,8 \\
44,1 \\
66,5 \\
38,0\end{array}$ & $\begin{array}{r}4,7 \\
13,4 \\
10,0 \\
9,2\end{array}$ & $\begin{array}{l}89,5 \\
46,0 \\
24,8 \\
54,5\end{array}$ & $\begin{array}{r}5,2 \\
39,8 \\
63,6 \\
35,2\end{array}$ & $\begin{array}{r}5,3 \\
14,2 \\
11,6 \\
10,3\end{array}$ & $\begin{array}{l}90,3 \\
45,0 \\
24,1 \\
52,7\end{array}$ & $\begin{array}{r}5,6 \\
41,5 \\
64,8 \\
37,6\end{array}$ & $\begin{array}{r}4,1 \\
13,5 \\
11,1 \\
9,7\end{array}$ \\
\hline Schweiz & $\begin{array}{l}15-19 \\
20-24 \\
25-29 \\
15-29\end{array}$ & $\begin{array}{l}84,6 \\
37,4 \\
15,1 \\
45,1\end{array}$ & $\begin{array}{r}7,5 \\
56,7 \\
73,9 \\
46,6\end{array}$ & $\begin{array}{r}7,9 \\
5,9 \\
11,0 \\
8,3\end{array}$ & $\begin{array}{l}85,3 \\
37,9 \\
12,3 \\
44,4\end{array}$ & $\begin{array}{r}7,2 \\
50,3 \\
75,9 \\
45,2\end{array}$ & $\begin{array}{r}7,5 \\
11,9 \\
11,8 \\
10,4\end{array}$ & $\begin{array}{l}88,5 \\
45,8 \\
17,2 \\
49,3\end{array}$ & $\begin{array}{r}6,7 \\
43,1 \\
70,0 \\
41,1\end{array}$ & $\begin{array}{r}4,8 \\
11,1 \\
12,8 \\
9,7\end{array}$ & $\begin{array}{l}88,6 \\
43,7 \\
17,4 \\
48,0\end{array}$ & $\begin{array}{r}6,7 \\
44,2 \\
71,3 \\
42,5\end{array}$ & $\begin{array}{r}4,7 \\
12,1 \\
11,3 \\
9,6\end{array}$ \\
\hline Türkei & $\begin{array}{l}15-19 \\
20-24 \\
25-29 \\
15-29\end{array}$ & $\begin{array}{r}39,2 \\
12,7 \\
2,9 \\
18,5\end{array}$ & $\begin{array}{l}29,6 \\
43,1 \\
58,8 \\
43,7\end{array}$ & $\begin{array}{l}31,2 \\
44,2 \\
38,3 \\
37,8\end{array}$ & $\begin{array}{r}45,8 \\
15,4 \\
4,0 \\
22,4\end{array}$ & $\begin{array}{l}18,1 \\
34,9 \\
50,2 \\
34,0\end{array}$ & $\begin{array}{l}36,1 \\
49,7 \\
45,8 \\
43,6\end{array}$ & $\begin{array}{r}59,7 \\
25,2 \\
8,1 \\
31,4\end{array}$ & $\begin{array}{l}14,7 \\
31,1 \\
50,1 \\
32,0\end{array}$ & $\begin{array}{l}25,6 \\
43,7 \\
41,8 \\
36,6\end{array}$ & $\begin{array}{l}64,4 \\
38,4 \\
17,1 \\
40,1\end{array}$ & $\begin{array}{l}12,8 \\
30,6 \\
48,8 \\
30,7\end{array}$ & $\begin{array}{l}22,8 \\
30,9 \\
34,1 \\
29,2\end{array}$ \\
\hline $\begin{array}{l}\text { Vereinigtes } \\
\text { Königreich }\end{array}$ & $\begin{array}{l}15-19 \\
20-24 \\
25-29 \\
15-29\end{array}$ & $\begin{array}{l}77,0 \\
32,4 \\
13,3 \\
40,0\end{array}$ & $\begin{array}{l}15,0 \\
52,2 \\
70,3 \\
46,6\end{array}$ & $\begin{array}{r}8,0 \\
15,4 \\
16,3 \\
13,3\end{array}$ & $\begin{array}{l}76,0 \\
32,1 \\
13,3 \\
41,2\end{array}$ & $\begin{array}{l}14,6 \\
51,0 \\
70,1 \\
44,6\end{array}$ & $\begin{array}{r}9,3 \\
16,8 \\
16,6 \\
14,2\end{array}$ & $\begin{array}{l}80,6 \\
33,7 \\
14,3 \\
42,1\end{array}$ & $\begin{array}{r}9,4 \\
46,9 \\
67,6 \\
42,0\end{array}$ & $\begin{array}{l}10,0 \\
19,3 \\
18,1 \\
15,9\end{array}$ & $\begin{array}{l}82,3 \\
33,6 \\
14,0 \\
41,6\end{array}$ & $\begin{array}{r}8,2 \\
46,1 \\
67,7 \\
42,1\end{array}$ & $\begin{array}{r}9,5 \\
20,2 \\
18,3 \\
16,3\end{array}$ \\
\hline $\begin{array}{l}\text { Vereinigte } \\
\text { Staaten }\end{array}$ & $\begin{array}{l}15-19 \\
20-24 \\
25-29 \\
15-29\end{array}$ & $\begin{array}{l}81,3 \\
32,5 \\
11,4 \\
43,1\end{array}$ & $\begin{array}{l}11,7 \\
53,1 \\
72,8 \\
44,6\end{array}$ & $\begin{array}{r}7,0 \\
14,4 \\
15,8 \\
12,2\end{array}$ & $\begin{array}{l}85,6 \\
36,1 \\
11,9 \\
45,2\end{array}$ & $\begin{array}{r}8,3 \\
48,4 \\
70,0 \\
41,7\end{array}$ & $\begin{array}{r}6,1 \\
15,5 \\
18,1 \\
13,1\end{array}$ & $\begin{array}{l}85,5 \\
38,6 \\
14,6 \\
46,0\end{array}$ & $\begin{array}{r}6,8 \\
42,0 \\
64,2 \\
37,8\end{array}$ & $\begin{array}{r}7,6 \\
19,4 \\
21,2 \\
16,1\end{array}$ & $\begin{array}{l}85,5 \\
40,2 \\
14,0 \\
46,6\end{array}$ & $\begin{array}{r}6,8 \\
42,1 \\
65,8 \\
38,2\end{array}$ & $\begin{array}{r}7,7 \\
17,7 \\
20,2 \\
15,2\end{array}$ \\
\hline $\begin{array}{l}\text { OECD- } \\
\text { Durchschnitt } \\
\text { (ohne Japan) }\end{array}$ & $\begin{array}{l}15-19 \\
20-24 \\
25-29 \\
15-29\end{array}$ & $\begin{array}{l}80,1 \\
34,7 \\
12,2 \\
41,4\end{array}$ & $\begin{array}{l}11,4 \\
48,2 \\
68,7 \\
43,6\end{array}$ & $\begin{array}{r}9,4 \\
17,7 \\
19,1 \\
15,1\end{array}$ & $\begin{array}{l}83,7 \\
40,3 \\
14,1 \\
45,1\end{array}$ & $\begin{array}{r}8,3 \\
42,2 \\
67,1 \\
39,9\end{array}$ & $\begin{array}{r}8,2 \\
17,5 \\
18,8 \\
14,9\end{array}$ & $\begin{array}{l}85,6 \\
44,0 \\
15,7 \\
47,2\end{array}$ & $\begin{array}{r}6,7 \\
37,6 \\
64,4 \\
37,1\end{array}$ & $\begin{array}{r}8,0 \\
18,4 \\
19,9 \\
15,7\end{array}$ & $\begin{array}{l}86,5 \\
46,4 \\
17,9 \\
48,8\end{array}$ & $\begin{array}{r}6,5 \\
36,1 \\
62,7 \\
36,2\end{array}$ & $\begin{array}{r}7,2 \\
17,5 \\
19,4 \\
15,0\end{array}$ \\
\hline $\begin{array}{l}\text { EU21- } \\
\text { Durchschnitt }\end{array}$ & $\begin{array}{l}15-19 \\
20-24 \\
25-29 \\
15-29\end{array}$ & $\begin{array}{l}83,2 \\
35,6 \\
11,3 \\
41,9\end{array}$ & $\begin{array}{r}9,2 \\
47,0 \\
69,3 \\
43,0\end{array}$ & $\begin{array}{r}7,9 \\
17,3 \\
19,4 \\
15,0\end{array}$ & $\begin{array}{l}87,7 \\
42,6 \\
13,7 \\
46,4\end{array}$ & $\begin{array}{r}6,1 \\
41,2 \\
68,0 \\
39,8\end{array}$ & $\begin{array}{r}6,2 \\
16,1 \\
18,3 \\
13,8\end{array}$ & $\begin{array}{l}89,5 \\
46,8 \\
15,4 \\
48,7\end{array}$ & $\begin{array}{r}4,4 \\
35,8 \\
65,2 \\
36,5\end{array}$ & \begin{tabular}{r|}
6,4 \\
17,4 \\
19,4 \\
14,8
\end{tabular} & $\begin{array}{l}90,6 \\
49,5 \\
18,2 \\
50,6\end{array}$ & $\begin{array}{r}3,5 \\
32,9 \\
62,2 \\
34,5\end{array}$ & $\begin{array}{r}6,1 \\
17,6 \\
19,5 \\
14,8\end{array}$ \\
\hline Partnerländer & & & & & & & & & & & & & \\
\hline Argentinien & & $\mathrm{m}$ & $\mathrm{m}$ & $\mathrm{m}$ & $\mathrm{m}$ & $\mathrm{m}$ & $\mathrm{m}$ & $\mathrm{m}$ & $\mathrm{m}$ & $\mathrm{m}$ & $\mathrm{m}$ & $\mathrm{m}$ & $\mathrm{m}$ \\
\hline Brasilien & $\begin{array}{l}15-19 \\
20-24 \\
25-29 \\
15-29\end{array}$ & $\begin{array}{l}\mathrm{m} \\
\mathrm{m} \\
\mathrm{m} \\
\mathrm{m}\end{array}$ & $\begin{array}{l}\mathrm{m} \\
\mathrm{m} \\
\mathrm{m} \\
\mathrm{m}\end{array}$ & $\begin{array}{l}\mathrm{m} \\
\mathrm{m} \\
\mathrm{m} \\
\mathrm{m}\end{array}$ & $\begin{array}{l}\mathrm{m} \\
\mathrm{m} \\
\mathrm{m} \\
\mathrm{m}\end{array}$ & $\begin{array}{l}\mathrm{m} \\
\mathrm{m} \\
\mathrm{m} \\
\mathrm{m}\end{array}$ & $\begin{array}{l}\mathrm{m} \\
\mathrm{m} \\
\mathrm{m} \\
\mathrm{m}\end{array}$ & $\begin{array}{l}\mathrm{m} \\
\mathrm{m} \\
\mathrm{m} \\
\mathrm{m}\end{array}$ & $\begin{array}{l}\mathrm{m} \\
\mathrm{m} \\
\mathrm{m} \\
\mathrm{m}\end{array}$ & $\begin{array}{l}\mathrm{m} \\
\mathrm{m} \\
\mathrm{m} \\
\mathrm{m}\end{array}$ & $\begin{array}{l}68,3 \\
23,0 \\
11,1 \\
35,0\end{array}$ & $\begin{array}{l}16,5 \\
53,3 \\
67,6 \\
45,1\end{array}$ & $\begin{array}{l}15,2 \\
23,7 \\
21,3 \\
20,0\end{array}$ \\
\hline China & & $\mathrm{m}$ & $\mathrm{m}$ & $\mathrm{m}$ & $\mathrm{m}$ & $\mathrm{m}$ & $\mathrm{m}$ & $\mathrm{m}$ & $\mathrm{m}$ & $\mathrm{m}$ & $\mathrm{m}$ & $\mathrm{m}$ & $\mathrm{m}$ \\
\hline Kolumbien & & $\mathrm{m}$ & $\mathrm{m}$ & $\mathrm{m}$ & $\mathrm{m}$ & $\mathrm{m}$ & $\mathrm{m}$ & $\mathrm{m}$ & $\mathrm{m}$ & $\mathrm{m}$ & $\mathrm{m}$ & $\mathrm{m}$ & $\mathrm{m}$ \\
\hline Indien & & $\mathrm{m}$ & $\mathrm{m}$ & $\mathrm{m}$ & $\mathrm{m}$ & $\mathrm{m}$ & $\mathrm{m}$ & $\mathrm{m}$ & $\mathrm{m}$ & $\mathrm{m}$ & $\mathrm{m}$ & $\mathrm{m}$ & $\mathrm{m}$ \\
\hline Indonesien & & $\mathrm{m}$ & $\mathrm{m}$ & $\mathrm{m}$ & $\mathrm{m}$ & $\mathrm{m}$ & $\mathrm{m}$ & $\mathrm{m}$ & $\mathrm{m}$ & $\mathrm{m}$ & $\mathrm{m}$ & $\mathrm{m}$ & $\mathrm{m}$ \\
\hline Lettland & $\begin{array}{l}15-19 \\
20-24 \\
25-29 \\
15-29\end{array}$ & $\begin{array}{l}\mathrm{m} \\
\mathrm{m} \\
\mathrm{m} \\
\mathrm{m}\end{array}$ & $\begin{array}{l}\mathrm{m} \\
\mathrm{m} \\
\mathrm{m} \\
\mathrm{m}\end{array}$ & $\begin{array}{l}\mathrm{m} \\
\mathrm{m} \\
\mathrm{m} \\
\mathrm{m}\end{array}$ & $\begin{array}{l}m \\
m \\
m \\
m\end{array}$ & $\begin{array}{l}\mathrm{m} \\
\mathrm{m} \\
\mathrm{m} \\
\mathrm{m}\end{array}$ & $\begin{array}{l}\mathrm{m} \\
\mathrm{m} \\
\mathrm{m} \\
\mathrm{m}\end{array}$ & $\begin{array}{l}91,8 \\
39,8 \\
10,0 \\
44,5\end{array}$ & $\begin{array}{r}1,8 \\
30,3 \\
60,9 \\
32,7\end{array}$ & $\begin{array}{r}6,4 \\
29,9 \\
29,2 \\
22,9\end{array}$ & $\begin{array}{l}91,0 \\
46,0 \\
13,5 \\
46,3\end{array}$ & $\begin{array}{r}1,8 \\
33,7 \\
59,9 \\
34,6\end{array}$ & $\begin{array}{r}7,2 \\
20,3 \\
26,7 \\
19,1\end{array}$ \\
\hline Russische Föd. & & $\mathrm{m}$ & $\mathrm{m}$ & $\mathrm{m}$ & $\mathrm{m}$ & $\mathrm{m}$ & $\mathrm{m}$ & $\mathrm{m}$ & $\mathrm{m}$ & $\mathrm{m}$ & $\mathrm{m}$ & $\mathrm{m}$ & $\mathrm{m}$ \\
\hline Saudi-Arabien & & $\mathrm{m}$ & $\mathrm{m}$ & $\mathrm{m}$ & $\mathrm{m}$ & $\mathrm{m}$ & $\mathrm{m}$ & $\mathrm{m}$ & $\mathrm{m}$ & $\mathrm{m}$ & $\mathrm{m}$ & $\mathrm{m}$ & $\mathrm{m}$ \\
\hline Südafrika & & $\mathrm{m}$ & $\mathrm{m}$ & $\mathrm{m}$ & $\mathrm{m}$ & $\mathrm{m}$ & $\mathrm{m}$ & $\mathrm{m}$ & $\mathrm{m}$ & $\mathrm{m}$ & $\mathrm{m}$ & $\mathrm{m}$ & $\mathrm{m}$ \\
\hline $\begin{array}{l}\text { G20- } \\
\text { Durchschnitt }\end{array}$ & & m & m & m & m & m & m & $\mathbf{m}$ & $\mathbf{m}$ & m & $\mathbf{m}$ & $\mathbf{m}$ & $\mathbf{m}$ \\
\hline
\end{tabular}

Anmerkung: Die Spalten mit Angaben zu weiteren Jahren sind im Internet verfügbar (s. StatLink unten)

Quelle: OECD. Argentinien, China, Indien, Indonesien, Kolumbien, Saudi-Arabien und Südafrika: Statistikinstitut der UNESCO. Lettland: Eurostat. Hinweise s. Anhang 3 unter www.oecd.org/edu/eag.htm. StatLink: http://dx.doi.org/10.1787/888933118960

Erläuterung der Kennzeichnung fehlender Daten s. Hinweise für den Leser. 
Anteil 25- bis 29-Jähriger (in \%), die sich in Ausbildung bzw. nicht in Ausbildung befinden, nach Bildungsstand und Erwerbsstatus (2012)

\begin{tabular}{|c|c|c|c|c|c|c|c|c|c|c|c|c|}
\hline & \multirow{4}{*}{ 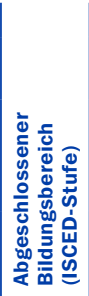 } & \multicolumn{11}{|c|}{ In Ausbildung } \\
\hline & & \multirow{2}{*}{$\begin{array}{c}\text { Alle } \\
\text { Beschäf- } \\
\text { tigten }\end{array}$} & \multicolumn{2}{|c|}{ Beschäftigt } & \multicolumn{3}{|c|}{ Vollzeit/Teilzeit } & \multirow[t]{2}{*}{ Erwerbslos } & \multicolumn{2}{|c|}{$\begin{array}{c}\text { Dauer der } \\
\text { Erwerbslosigkeit }\end{array}$} & \multirow{2}{*}{$\begin{array}{c}\text { Nicht im } \\
\text { Arbeits- } \\
\text { markt }\end{array}$} & \multirow{2}{*}{ 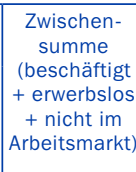 } \\
\hline & & & \begin{tabular}{|c|} 
In dualen \\
Ausbil- \\
dungs- \\
gängen ${ }^{1}$
\end{tabular} & $\begin{array}{c}\text { Sonstige } \\
\text { Beschäf- } \\
\text { tigung }\end{array}$ & Vollzeit & Teilzeit (TZ) & $\begin{array}{l}\text { Freiwil- } \\
\text { lige TZ }\end{array}$ & & $\begin{array}{l}\text { Kürzer } \\
\text { als } 6 \\
\text { Monate }\end{array}$ & $\begin{array}{l}\text { Länger } \\
\text { als } 6 \\
\text { Monate }\end{array}$ & & \\
\hline & & $\begin{array}{l}(1)=(2)+(3) \\
\text { u./o. }(4)+(5) \\
+ \text { unbekannt }\end{array}$ & (2) & (3) & (4) & \begin{tabular}{|c|}
$(5)=(6)+$ \\
unfreiwillige $T Z$ \\
\end{tabular} & (6) & $\begin{array}{c}(7)=(8)+ \\
(9)+ \\
\text { unbekannt }\end{array}$ & (8) & (9) & (10) & $\begin{array}{l}(11)=(1)+ \\
(7)+(10)\end{array}$ \\
\hline \multicolumn{13}{|l|}{ OECD-Länder } \\
\hline Australien & $\begin{array}{l}0 / 1 / 2 \\
3 / 4 \\
5 / 6\end{array}$ & $\begin{array}{l}25,0 \\
28,1 \\
16,5\end{array}$ & $\begin{array}{l}4,7 \\
5,1 \\
0,9\end{array}$ & $\begin{array}{l}20,3 \\
23,0 \\
15,6\end{array}$ & $\begin{array}{l}1,2 \\
5,4 \\
7,1\end{array}$ & $\begin{array}{r}19,1 \\
17,6 \\
8,4\end{array}$ & $\begin{array}{r}15,3 \\
13,7 \\
6,7\end{array}$ & $\begin{array}{l}4,8 \\
2,6 \\
1,4\end{array}$ & $\begin{array}{l}3,7 \\
2,3 \\
1,0\end{array}$ & $\begin{array}{l}1,2 \\
0,4 \\
0,4\end{array}$ & $\begin{array}{r}34,1 \\
12,9 \\
7,5\end{array}$ & $\begin{array}{l}63,9 \\
43,6 \\
25,3\end{array}$ \\
\hline Österreich & $\begin{array}{l}0 / 1 / 2 \\
3 / 4 \\
5 / 6\end{array}$ & $\begin{array}{l}26,4 \\
13,0 \\
19,7\end{array}$ & $\begin{array}{r}22,3 \\
1,6 \\
a\end{array}$ & $\begin{array}{r}4,1 \\
11,4 \\
19,7\end{array}$ & $\begin{array}{r}c \\
3,8 \\
11,0\end{array}$ & $\begin{array}{l}3,4 \\
7,5 \\
8,7\end{array}$ & $\begin{array}{l}\mathrm{m} \\
\mathrm{m} \\
\mathrm{m}\end{array}$ & $\begin{array}{r}1,0 \\
1,3 \\
C\end{array}$ & $\begin{array}{r}0,8 \\
1,1 \\
c\end{array}$ & $\begin{array}{l}\mathrm{C} \\
\mathrm{C} \\
\mathrm{C}\end{array}$ & $\begin{array}{l}47,5 \\
15,5 \\
10,6\end{array}$ & $\begin{array}{l}74,9 \\
29,7 \\
31,1\end{array}$ \\
\hline Belgien & $\begin{array}{l}0 / 1 / 2 \\
3 / 4 \\
5 / 6\end{array}$ & $\begin{array}{l}2,9 \\
3,8 \\
5,4\end{array}$ & $\begin{array}{l}1,3 \\
0,5 \\
0,7\end{array}$ & $\begin{array}{l}1,7 \\
3,2 \\
4,7\end{array}$ & $\begin{array}{r}c \\
1,8 \\
2,8\end{array}$ & $\begin{array}{l}1,5 \\
1,4 \\
1,9\end{array}$ & $\begin{array}{l}1,3 \\
1,3 \\
1,5\end{array}$ & $\begin{array}{r}0,5 \\
0,5 \\
c\end{array}$ & $\begin{array}{l}\mathrm{c} \\
\mathrm{c} \\
\mathrm{c}\end{array}$ & $\begin{array}{l}\mathrm{C} \\
\mathrm{C} \\
\mathrm{c}\end{array}$ & $\begin{array}{l}61,5 \\
37,4 \\
16,7\end{array}$ & $\begin{array}{l}64,9 \\
41,7 \\
22,6\end{array}$ \\
\hline Kanada & $\begin{array}{l}0 / 1 / 2 \\
3 / 4 \\
5 / 6\end{array}$ & $\begin{array}{l}19,0 \\
18,3 \\
15,1\end{array}$ & $\begin{array}{l}a \\
a \\
a\end{array}$ & $\begin{array}{l}19,0 \\
18,3 \\
15,1\end{array}$ & $\begin{array}{l}0,8 \\
2,7 \\
4,4\end{array}$ & $\begin{array}{l}18,2 \\
15,6 \\
10,6\end{array}$ & $\begin{array}{l}17,6 \\
14,9 \\
10,1\end{array}$ & $\begin{array}{l}5,6 \\
2,3 \\
1,1\end{array}$ & $\begin{array}{l}4,9 \\
2,0 \\
1,0\end{array}$ & $\begin{array}{l}0,6 \\
0,1 \\
0,1\end{array}$ & $\begin{array}{l}46,3 \\
20,8 \\
11,4\end{array}$ & $\begin{array}{l}71,0 \\
41,4 \\
27,6\end{array}$ \\
\hline Chile $^{3}$ & $\begin{array}{l}0 / 1 / 2 \\
3 / 4 \\
5 / 6\end{array}$ & $\begin{array}{r}3,7 \\
10,1 \\
1,1\end{array}$ & $\begin{array}{l}a \\
a \\
a\end{array}$ & $\begin{array}{r}3,7 \\
10,1 \\
1,1\end{array}$ & $\begin{array}{l}2,6 \\
6,2 \\
0,7\end{array}$ & $\begin{array}{l}1,1 \\
3,9 \\
0,4\end{array}$ & $\begin{array}{l}0,6 \\
1,7 \\
0,1\end{array}$ & $\begin{array}{l}1,8 \\
2,1 \\
0,0\end{array}$ & $\begin{array}{l}1,8 \\
2,0 \\
0,0\end{array}$ & $\begin{array}{l}0,0 \\
0,1 \\
0,0\end{array}$ & $\begin{array}{r}54,6 \\
28,8 \\
0,9\end{array}$ & $\begin{array}{r}60,1 \\
41,0 \\
2,1\end{array}$ \\
\hline Tschechien & $\begin{array}{l}0 / 1 / 2 \\
3 / 4 \\
5 / 6\end{array}$ & $\begin{array}{r}19,2 \\
4,9 \\
10,3\end{array}$ & $\begin{array}{r}18,4 \\
0,9 \\
a\end{array}$ & $\begin{array}{r}0,8 \\
4,0 \\
10,3\end{array}$ & $\begin{array}{r}c \\
2,6 \\
6,9\end{array}$ & $\begin{array}{l}0,3 \\
1,4 \\
3,4\end{array}$ & $\begin{array}{r}c \\
1,3 \\
3,4\end{array}$ & $\begin{array}{r}c \\
0,5 \\
c\end{array}$ & $\begin{array}{r}c \\
0,4 \\
c\end{array}$ & $\begin{array}{l}\mathrm{C} \\
\mathrm{C} \\
\mathrm{C}\end{array}$ & $\begin{array}{l}63,4 \\
27,8 \\
22,6\end{array}$ & $\begin{array}{l}82,7 \\
33,2 \\
33,8\end{array}$ \\
\hline Dänemark & $\begin{array}{l}0 / 1 / 2 \\
3 / 4 \\
5 / 6\end{array}$ & $\begin{array}{l}35,2 \\
29,2 \\
24,8\end{array}$ & $\begin{array}{l}a \\
a \\
a\end{array}$ & $\begin{array}{l}35,2 \\
29,2 \\
24,8\end{array}$ & $\begin{array}{l}6,7 \\
5,5 \\
5,9\end{array}$ & $\begin{array}{l}28,5 \\
23,8 \\
18,8\end{array}$ & $\begin{array}{l}\mathrm{m} \\
\mathrm{m} \\
\mathrm{m}\end{array}$ & $\begin{array}{l}7,2 \\
3,0 \\
2,4\end{array}$ & $\begin{array}{l}5,2 \\
2,4 \\
1,8\end{array}$ & $\begin{array}{r}1,8 \\
0,5 \\
C\end{array}$ & $\begin{array}{r}34,2 \\
14,7 \\
9,9\end{array}$ & $\begin{array}{l}76,6 \\
46,8 \\
37,1\end{array}$ \\
\hline Estland & $\begin{array}{l}0 / 1 / 2 \\
3 / 4 \\
5 / 6\end{array}$ & $\begin{array}{r}4,3 \\
16,3 \\
17,3\end{array}$ & $\begin{array}{l}a \\
a \\
a\end{array}$ & $\begin{array}{r}4,3 \\
16,3 \\
17,3\end{array}$ & $\begin{array}{r}2,8 \\
12,5 \\
12,9\end{array}$ & $\begin{array}{l}1,4 \\
3,8 \\
4,5\end{array}$ & $\begin{array}{r}c \\
3,6 \\
4,5\end{array}$ & $\begin{array}{r}\mathrm{C} \\
1,9 \\
\mathrm{C}\end{array}$ & $\begin{array}{l}\mathrm{C} \\
\mathrm{C} \\
\mathrm{C}\end{array}$ & $\begin{array}{l}\mathrm{C} \\
\mathrm{c} \\
\mathrm{C}\end{array}$ & $\begin{array}{l}62,9 \\
22,3 \\
10,7\end{array}$ & $\begin{array}{l}68,5 \\
40,5 \\
29,2\end{array}$ \\
\hline Finnland & $\begin{array}{l}0 / 1 / 2 \\
3 / 4 \\
5 / 6\end{array}$ & $\begin{array}{l}10,7 \\
19,9 \\
22,0\end{array}$ & $\begin{array}{l}a \\
a \\
a\end{array}$ & $\begin{array}{l}10,7 \\
19,9 \\
22,0\end{array}$ & $\begin{array}{r}2,2 \\
6,5 \\
15,4\end{array}$ & $\begin{array}{r}8,4 \\
13,4 \\
6,6\end{array}$ & $\begin{array}{l}\mathrm{m} \\
\mathrm{m} \\
\mathrm{m}\end{array}$ & $\begin{array}{r}5,9 \\
3,4 \\
C\end{array}$ & $\begin{array}{r}5,1 \\
3,2 \\
C\end{array}$ & $\begin{array}{l}\mathrm{c} \\
\mathrm{C} \\
\mathrm{c}\end{array}$ & $\begin{array}{r}64,3 \\
20,6 \\
6,4\end{array}$ & $\begin{array}{l}80,8 \\
44,0 \\
29,7\end{array}$ \\
\hline Frankreich & $\begin{array}{l}0 / 1 / 2 \\
3 / 4 \\
5 / 6\end{array}$ & $\begin{array}{l}4,2 \\
7,7 \\
6,7\end{array}$ & $\begin{array}{l}a \\
a \\
a\end{array}$ & $\begin{array}{l}4,2 \\
7,7 \\
6,7\end{array}$ & $\begin{array}{l}3,4 \\
4,6 \\
4,4\end{array}$ & $\begin{array}{l}0,8 \\
3,1 \\
2,3\end{array}$ & $\begin{array}{l}\mathrm{m} \\
\mathrm{m} \\
\mathrm{m}\end{array}$ & $\begin{array}{l}0,2 \\
0,8 \\
0,5\end{array}$ & $\begin{array}{l}0,1 \\
0,6 \\
0,4\end{array}$ & $\begin{array}{l}0,1 \\
0,2 \\
0,1\end{array}$ & $\begin{array}{l}60,6 \\
32,4 \\
18,7\end{array}$ & $\begin{array}{l}65,0 \\
40,9 \\
26,0\end{array}$ \\
\hline Deutschland & $\begin{array}{l}0 / 1 / 2 \\
3 / 4 \\
5 / 6\end{array}$ & $\begin{array}{l}24,1 \\
16,8 \\
12,6\end{array}$ & $\begin{array}{r}17,5 \\
6,0 \\
0,9\end{array}$ & $\begin{array}{r}6,6 \\
10,9 \\
11,7\end{array}$ & $\begin{array}{r}19,3 \\
8,8 \\
5,6\end{array}$ & $\begin{array}{l}4,8 \\
8,0 \\
6,9\end{array}$ & $\begin{array}{l}c \\
c \\
c\end{array}$ & $\begin{array}{l}1,0 \\
0,5 \\
0,8\end{array}$ & $\begin{array}{l}0,6 \\
0,4 \\
0,6\end{array}$ & $\begin{array}{r}0,3 \\
0,1 \\
c\end{array}$ & $\begin{array}{r}52,9 \\
20,6 \\
7,8\end{array}$ & $\begin{array}{l}78,0 \\
37,9 \\
21,1\end{array}$ \\
\hline Griechenland & $\begin{array}{l}0 / 1 / 2 \\
3 / 4 \\
5 / 6\end{array}$ & $\begin{array}{l}13,4 \\
18,7 \\
28,6\end{array}$ & $\begin{array}{l}a \\
a \\
a\end{array}$ & $\begin{array}{l}13,4 \\
18,7 \\
28,6\end{array}$ & $\begin{array}{l}11,5 \\
15,9 \\
25,5\end{array}$ & $\begin{array}{l}1,9 \\
2,8 \\
3,1\end{array}$ & $\begin{array}{r}c \\
0,9 \\
c\end{array}$ & $\begin{array}{r}9,3 \\
14,2 \\
19,2\end{array}$ & $\begin{array}{l}2,6 \\
4,4 \\
5,1\end{array}$ & $\begin{array}{r}6,7 \\
9,8 \\
14,1\end{array}$ & $\begin{array}{r}49,7 \\
32,3 \\
4,4\end{array}$ & $\begin{array}{l}72,3 \\
65,2 \\
52,2\end{array}$ \\
\hline Ungarn & $\begin{array}{l}0 / 1 / 2 \\
3 / 4 \\
5 / 6\end{array}$ & $\begin{array}{r}c \\
2,4 \\
6,6\end{array}$ & $\begin{array}{l}a \\
a \\
a\end{array}$ & $\begin{array}{r}C \\
2,4 \\
6,6\end{array}$ & $\begin{array}{r}C \\
1,8 \\
5,1\end{array}$ & $\begin{array}{l}0,0 \\
0,6 \\
1,4\end{array}$ & $\begin{array}{r}c \\
0,6 \\
c\end{array}$ & $\begin{array}{l}\mathrm{C} \\
\mathrm{C} \\
\mathrm{c}\end{array}$ & $\begin{array}{l}\mathrm{C} \\
\mathrm{C} \\
\mathrm{c}\end{array}$ & $\begin{array}{l}\mathrm{C} \\
\mathrm{C} \\
\mathrm{c}\end{array}$ & $\begin{array}{r}73,2 \\
36,0 \\
9,5\end{array}$ & $\begin{array}{l}73,3 \\
38,8 \\
16,4\end{array}$ \\
\hline Island & $\begin{array}{l}0 / 1 / 2 \\
3 / 4 \\
5 / 6\end{array}$ & $\begin{array}{l}31,5 \\
32,4 \\
14,4\end{array}$ & $\begin{array}{l}a \\
a \\
a\end{array}$ & $\begin{array}{l}31,5 \\
32,4 \\
14,4\end{array}$ & $\begin{array}{r}4,1 \\
7,1 \\
\mathrm{C}\end{array}$ & $\begin{array}{r}27,4 \\
25,4 \\
C\end{array}$ & $\begin{array}{l}\mathrm{m} \\
\mathrm{m} \\
\mathrm{m}\end{array}$ & $\begin{array}{r}7,4 \\
\mathrm{C} \\
\mathrm{C}\end{array}$ & $\begin{array}{r}6,3 \\
c \\
c\end{array}$ & $\begin{array}{l}\mathrm{c} \\
\mathrm{c} \\
\mathrm{c}\end{array}$ & $\begin{array}{r}27,6 \\
22,8 \\
\mathrm{C}\end{array}$ & $\begin{array}{l}66,5 \\
58,6 \\
24,5\end{array}$ \\
\hline Irland & $\begin{array}{l}0 / 1 / 2 \\
3 / 4 \\
5 / 6\end{array}$ & $\begin{array}{r}2,6 \\
10,6 \\
9,6\end{array}$ & $\begin{array}{l}a \\
a \\
a\end{array}$ & $\begin{array}{r}2,6 \\
10,6 \\
9,6\end{array}$ & $\begin{array}{l}0,3 \\
2,2 \\
5,6\end{array}$ & $\begin{array}{l}2,2 \\
8,4 \\
4,0\end{array}$ & $\begin{array}{l}m \\
m \\
m\end{array}$ & $\begin{array}{l}0,9 \\
1,6 \\
0,8\end{array}$ & $\begin{array}{r}c \\
0,6 \\
c\end{array}$ & $\begin{array}{l}0,6 \\
1,0 \\
0,5\end{array}$ & $\begin{array}{l}64,1 \\
29,1 \\
10,8\end{array}$ & $\begin{array}{l}67,5 \\
41,3 \\
21,2\end{array}$ \\
\hline Israel & $\begin{array}{l}0 / 1 / 2 \\
3 / 4 \\
5 / 6\end{array}$ & $\begin{array}{r}5,2 \\
15,7 \\
18,1\end{array}$ & $\begin{array}{l}a \\
a \\
a\end{array}$ & $\begin{array}{r}5,2 \\
15,7 \\
18,1\end{array}$ & $\begin{array}{l}0,5 \\
5,7 \\
9,4\end{array}$ & $\begin{array}{r}4,7 \\
10,0 \\
8,7\end{array}$ & $\begin{array}{l}4,4 \\
9,5 \\
7,9\end{array}$ & $\begin{array}{l}1,4 \\
1,4 \\
1,7\end{array}$ & $\begin{array}{l}1,1 \\
1,2 \\
1,4\end{array}$ & $\begin{array}{l}\mathrm{C} \\
\mathrm{C} \\
\mathrm{C}\end{array}$ & $\begin{array}{r}68,1 \\
15,2 \\
4,7\end{array}$ & $\begin{array}{l}74,7 \\
32,3 \\
24,5\end{array}$ \\
\hline
\end{tabular}

Anmerkung: Die Zeilen mit Angaben zu allen Bildungsbereichen zusammen sind im Internet verfügbar (s. StatLink unten)

1. Teilnehmer an dualen Ausbildungsprogrammen gelten als sowohl in Ausbildung als auch beschäftigt, ohne Bezug auf ihren ILO-Erwerbsstatus.

2. Junge Menschen, die weder in Beschäftigung noch in Ausbildung sind. 3. Referenzjahr 2011. 4. Daten beziehen sich auf 15- bis 24-Jährige. Quelle: OECD. Argentinien, China, Indien, Indonesien, Kolumbien, Saudi-Arabien und Südafrika: Statistikinstitut der UNESCO. Lettland: Eurostat. Hinweise s. Anhang 3 unter www.oecd.org/edu/eag.htm. StatLink: http://dx.doi.org/10.1787/888933118979

Erläuterung der Kennzeichnung fehlender Daten s. Hinweise für den Leser. 
Anteil 25- bis 29-Jähriger (in \%), die sich in Ausbildung bzw. nicht in Ausbildung befinden, nach Bildungsstand und Erwerbsstatus (2012)

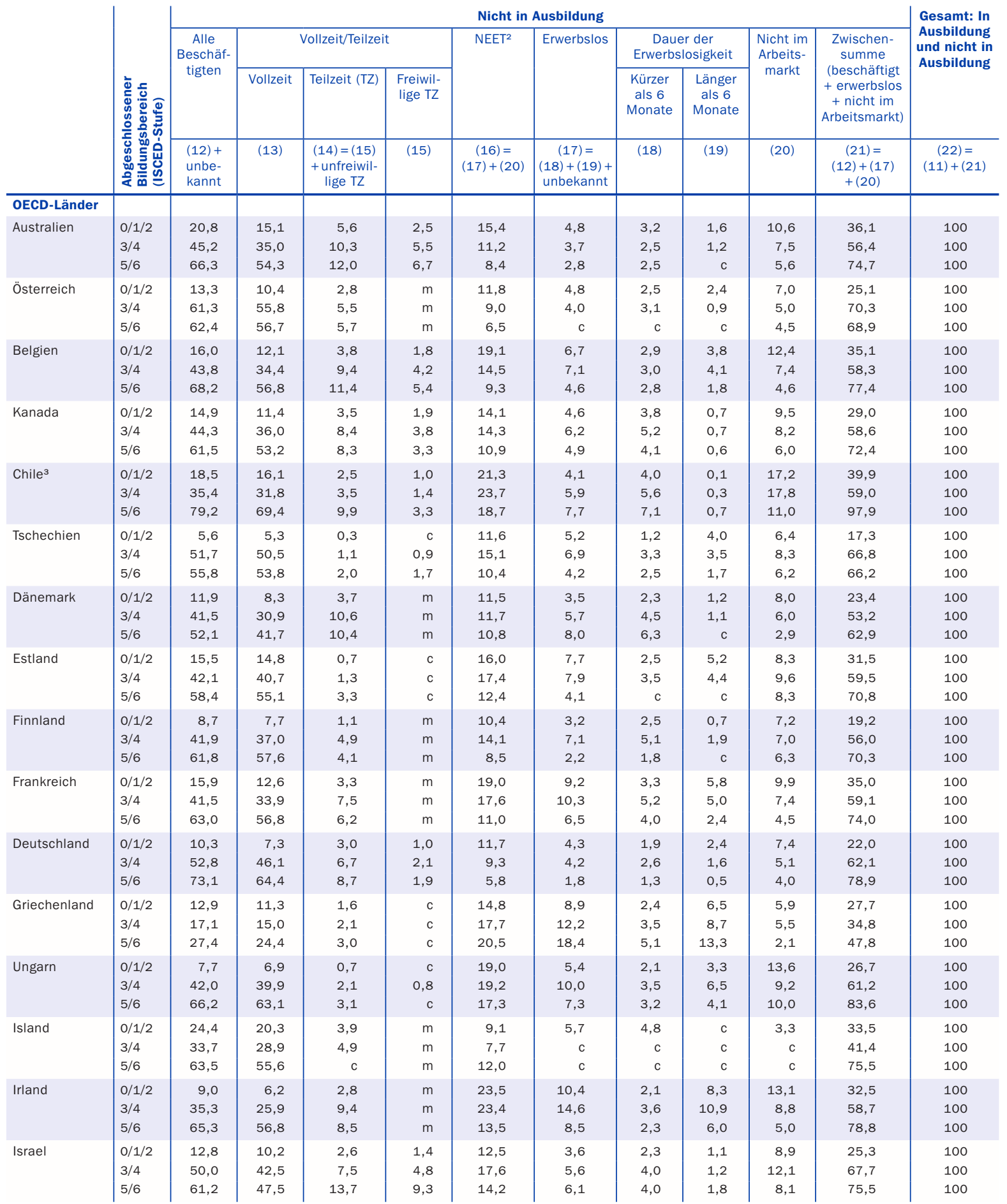

Anmerkung: Die Zeilen mit Angaben zu allen Bildungsbereichen zusammen sind im Internet verfügbar (s. StatLink unten)

1. Teilnehmer an dualen Ausbildungsprogrammen gelten als sowohl in Ausbildung als auch beschäftigt, ohne Bezug auf ihren ILO-Erwerbsstatus.

2. Junge Menschen, die weder in Beschäftigung noch in Ausbildung sind. 3. Referenzjahr 2011. 4. Daten beziehen sich auf 15- bis 24-Jährige. Quelle: OECD. Argentinien, China, Indien, Indonesien, Kolumbien, Saudi-Arabien und Südafrika: Statistikinstitut der UNESCO. Lettland: Eurostat.

Hinweise s. Anhang 3 unter www.oecd.org/edu/eag.htm. StatLink: http://dx.doi.org/10.1787/888933118979

Erläuterung der Kennzeichnung fehlender Daten s. Hinweise für den Leser. 
Anteil 25- bis 29-Jähriger (in \%), die sich in Ausbildung bzw. nicht in Ausbildung befinden, nach Bildungsstand und Erwerbsstatus (2012)

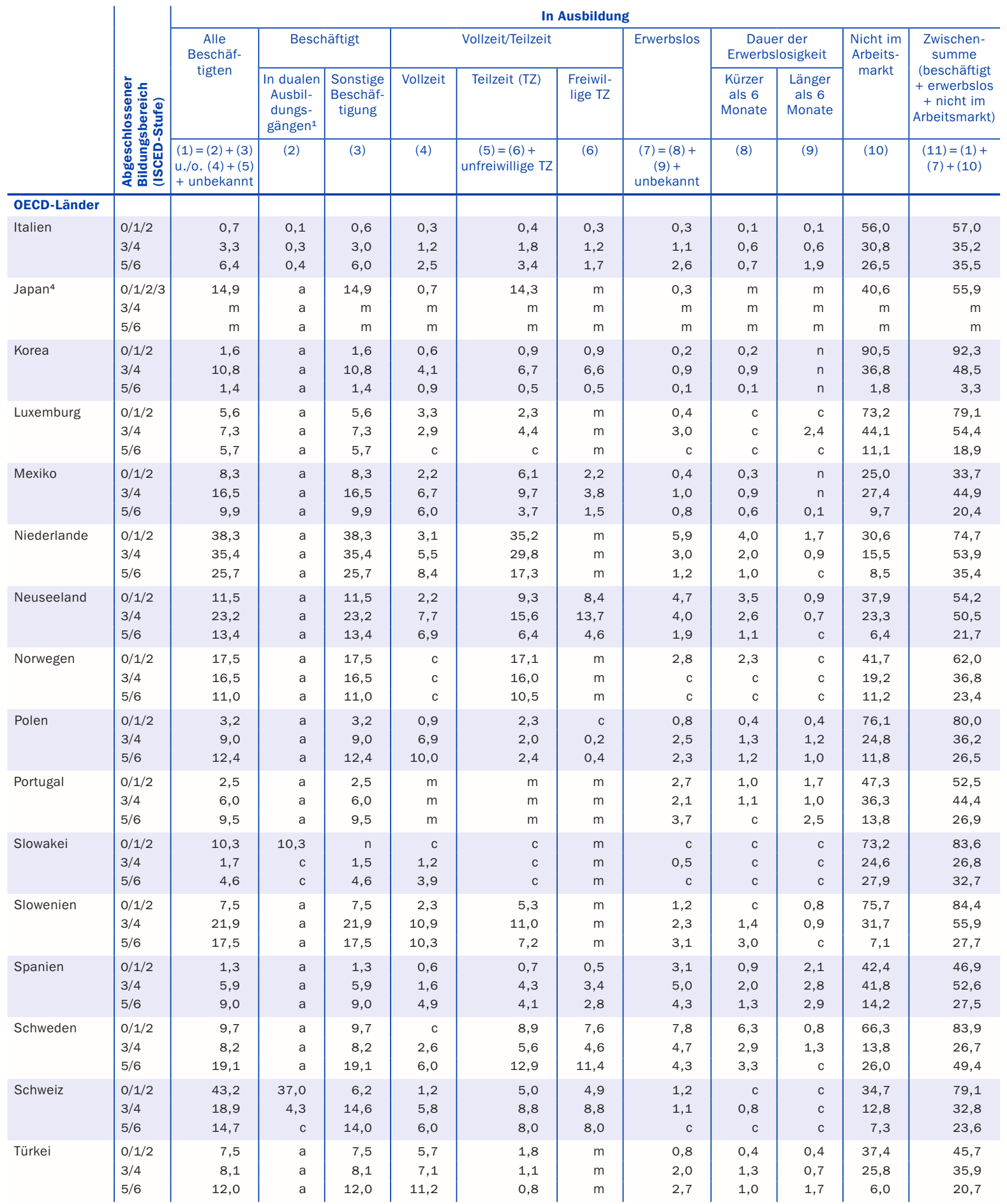

Anmerkung: Die Zeilen mit Angaben zu allen Bildungsbereichen zusammen sind im Internet verfügbar (s. StatLink unten)

1. Teilnehmer an dualen Ausbildungsprogrammen gelten als sowohl in Ausbildung als auch beschäftigt, ohne Bezug auf ihren ILO-Erwerbsstatus.

2. Junge Menschen, die weder in Beschäftigung noch in Ausbildung sind. 3. Referenzjahr 2011. 4. Daten beziehen sich auf 15- bis 24-Jährige. Quelle: OECD. Argentinien, China, Indien, Indonesien, Kolumbien, Saudi-Arabien und Südafrika: Statistikinstitut der UNESCO. Lettland: Eurostat. Hinweise s. Anhang 3 unter www.oecd.org/edu/eag.htm. StatLink: http://dx.doi.org/10.1787/888933118979

Erläuterung der Kennzeichnung fehlender Daten s. Hinweise für den Leser. 
Anteil 25- bis 29-Jähriger (in \%), die sich in Ausbildung bzw. nicht in Ausbildung befinden, nach Bildungsstand und Erwerbsstatus (2012)

\begin{tabular}{|c|c|c|c|c|c|c|c|c|c|c|c|c|}
\hline & \multirow{4}{*}{ 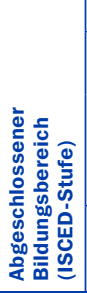 } & \multicolumn{10}{|c|}{ Nicht in Ausbildung } & \multirow{3}{*}{$\begin{array}{l}\text { Gesamt: In } \\
\text { Ausbildung } \\
\text { und nicht in } \\
\text { Ausbildung }\end{array}$} \\
\hline & & \multirow{2}{*}{\begin{tabular}{|c|} 
Alle \\
Beschäf- \\
tigten
\end{tabular}} & \multicolumn{3}{|c|}{ Vollzeit/Teilzeit } & \multirow[t]{2}{*}{$\mathrm{NEET}^{2}$} & \multirow[t]{2}{*}{ Erwerbslos } & \multicolumn{2}{|c|}{$\begin{array}{c}\text { Dauer der } \\
\text { Erwerbslosigkeit }\end{array}$} & \multirow{2}{*}{$\begin{array}{l}\text { Nicht im } \\
\text { Arbeits- } \\
\text { markt }\end{array}$} & \multirow{2}{*}{\begin{tabular}{|c} 
Zwischen- \\
summe \\
(beschäftigt \\
+ erwerbslos \\
+ nicht im \\
Arbeitsmarkt)
\end{tabular}} & \\
\hline & & & Vollzeit & Teilzeit (TZ) & $\begin{array}{l}\text { Freiwil- } \\
\text { lige TZ }\end{array}$ & & & $\begin{array}{c}\text { Kürzer } \\
\text { als } 6 \\
\text { Monate }\end{array}$ & $\begin{array}{l}\text { Länger } \\
\text { als } 6 \\
\text { Monate }\end{array}$ & & & \\
\hline & & $\begin{array}{l}(12)+ \\
\text { unbe- } \\
\text { kannt }\end{array}$ & (13) & $\begin{array}{c}(14)=(15) \\
+ \text { unfreiwil- } \\
\text { lige TZ }\end{array}$ & (15) & $\begin{array}{c}(16)= \\
(17)+(20)\end{array}$ & $\begin{array}{c}(17)= \\
(18)+(19)+ \\
\text { unbekannt }\end{array}$ & (18) & (19) & (20) & $\begin{array}{c}(21)= \\
(12)+(17) \\
+(20)\end{array}$ & $\begin{array}{c}(22)= \\
(11)+(21)\end{array}$ \\
\hline \multicolumn{13}{|l|}{ OECD-Länder } \\
\hline Italien & $\begin{array}{l}0 / 1 / 2 \\
3 / 4 \\
5 / 6\end{array}$ & $\begin{array}{l}18,7 \\
39,3 \\
42,8\end{array}$ & $\begin{array}{l}14,7 \\
30,8 \\
34,4\end{array}$ & $\begin{array}{l}4,0 \\
8,4 \\
8,4\end{array}$ & $\begin{array}{l}0,6 \\
1,5 \\
1,4\end{array}$ & $\begin{array}{l}24,3 \\
25,5 \\
21,7\end{array}$ & $\begin{array}{r}7,9 \\
12,2 \\
10,8\end{array}$ & $\begin{array}{l}2,6 \\
4,3 \\
5,8\end{array}$ & $\begin{array}{l}5,4 \\
7,9 \\
5,0\end{array}$ & $\begin{array}{l}16,4 \\
13,3 \\
10,9\end{array}$ & $\begin{array}{l}43,0 \\
64,8 \\
64,5\end{array}$ & $\begin{array}{l}100 \\
100 \\
100\end{array}$ \\
\hline$J^{J a p a n}{ }^{4}$ & $\begin{array}{l}0 / 1 / 2 / 3 \\
3 / 4 \\
5 / 6\end{array}$ & $\begin{array}{r}30,4 \\
m \\
80,7\end{array}$ & $\begin{array}{r}19,2 \\
m \\
57,9\end{array}$ & $\begin{array}{r}11,2 \\
m \\
22,8\end{array}$ & $\begin{array}{l}\mathrm{m} \\
\mathrm{m} \\
\mathrm{m}\end{array}$ & $\begin{array}{r}13,8 \\
m \\
19,3\end{array}$ & $\begin{array}{r}4,8 \\
m \\
8,2\end{array}$ & $\begin{array}{l}\mathrm{m} \\
\mathrm{m} \\
\mathrm{m}\end{array}$ & $\begin{array}{l}\mathrm{m} \\
\mathrm{m} \\
\mathrm{m}\end{array}$ & $\begin{array}{r}9,0 \\
m \\
11,1\end{array}$ & $\begin{array}{r}44,1 \\
m \\
100,0\end{array}$ & $\begin{array}{r}100 \\
m \\
100\end{array}$ \\
\hline Korea & $\begin{array}{l}0 / 1 / 2 \\
3 / 4 \\
5 / 6\end{array}$ & $\begin{array}{r}2,7 \\
28,7 \\
72,3\end{array}$ & $\begin{array}{r}2,4 \\
26,3 \\
68,2\end{array}$ & $\begin{array}{l}0,3 \\
2,3 \\
4,1\end{array}$ & $\begin{array}{l}0,2 \\
2,0 \\
3,6\end{array}$ & $\begin{array}{r}5,1 \\
22,9 \\
24,4\end{array}$ & $\begin{array}{l}0,2 \\
2,6 \\
5,6\end{array}$ & $\begin{array}{l}0,2 \\
2,4 \\
4,9\end{array}$ & $\begin{array}{l}0,0 \\
0,2 \\
0,7\end{array}$ & $\begin{array}{r}4,9 \\
20,3 \\
18,9\end{array}$ & $\begin{array}{r}7,7 \\
51,5 \\
96,7\end{array}$ & $\begin{array}{l}100 \\
100 \\
100\end{array}$ \\
\hline Luxemburg & $\begin{array}{l}0 / 1 / 2 \\
3 / 4 \\
5 / 6\end{array}$ & $\begin{array}{l}12,0 \\
38,7 \\
71,8\end{array}$ & $\begin{array}{l}11,1 \\
34,4 \\
68,8\end{array}$ & $\begin{array}{r}C \\
4,3 \\
3,0\end{array}$ & $\begin{array}{l}\mathrm{m} \\
\mathrm{m} \\
\mathrm{m}\end{array}$ & $\begin{array}{l}8,9 \\
6,9 \\
9,3\end{array}$ & $\begin{array}{l}3,5 \\
3,9 \\
4,4\end{array}$ & $\begin{array}{r}C \\
3,1 \\
2,8\end{array}$ & $\begin{array}{r}2,3 \\
\mathrm{C} \\
\mathrm{C}\end{array}$ & $\begin{array}{l}5,4 \\
3,0 \\
4,9\end{array}$ & $\begin{array}{l}20,9 \\
45,6 \\
81,1\end{array}$ & $\begin{array}{l}100 \\
100 \\
100\end{array}$ \\
\hline Mexiko & $\begin{array}{l}0 / 1 / 2 \\
3 / 4 \\
5 / 6\end{array}$ & $\begin{array}{l}41,4 \\
38,3 \\
64,8\end{array}$ & $\begin{array}{l}30,3 \\
30,5 \\
49,3\end{array}$ & $\begin{array}{r}10,8 \\
7,5 \\
15,0\end{array}$ & $\begin{array}{l}3,0 \\
2,5 \\
5,8\end{array}$ & $\begin{array}{l}24,9 \\
16,9 \\
14,8\end{array}$ & $\begin{array}{l}3,1 \\
3,7 \\
7,1\end{array}$ & $\begin{array}{l}2,8 \\
3,3 \\
5,7\end{array}$ & $\begin{array}{l}0,2 \\
0,2 \\
0,8\end{array}$ & $\begin{array}{r}21,8 \\
13,2 \\
7,7\end{array}$ & $\begin{array}{l}66,3 \\
55,1 \\
79,6\end{array}$ & $\begin{array}{l}100 \\
100 \\
100\end{array}$ \\
\hline Niederlande & $\begin{array}{l}0 / 1 / 2 \\
3 / 4 \\
5 / 6\end{array}$ & $\begin{array}{l}17,3 \\
40,2 \\
60,7\end{array}$ & $\begin{array}{l}11,0 \\
23,1 \\
39,3\end{array}$ & $\begin{array}{r}6,3 \\
17,1 \\
21,4\end{array}$ & $\begin{array}{l}\mathrm{m} \\
\mathrm{m} \\
\mathrm{m}\end{array}$ & $\begin{array}{l}8,0 \\
5,9 \\
3,9\end{array}$ & $\begin{array}{l}2,1 \\
2,6 \\
2,0\end{array}$ & $\begin{array}{l}1,1 \\
1,6 \\
1,7\end{array}$ & $\begin{array}{r}0,9 \\
1,0 \\
c\end{array}$ & $\begin{array}{l}5,9 \\
3,3 \\
1,9\end{array}$ & $\begin{array}{l}25,3 \\
46,1 \\
64,6\end{array}$ & $\begin{array}{l}100 \\
100 \\
100\end{array}$ \\
\hline Neuseeland & $\begin{array}{l}0 / 1 / 2 \\
3 / 4 \\
5 / 6\end{array}$ & $\begin{array}{l}25,1 \\
37,6 \\
66,4\end{array}$ & $\begin{array}{l}18,7 \\
29,7 \\
57,0\end{array}$ & $\begin{array}{l}6,5 \\
7,9 \\
9,3\end{array}$ & $\begin{array}{l}3,8 \\
5,2 \\
6,0\end{array}$ & $\begin{array}{l}20,7 \\
11,9 \\
12,0\end{array}$ & $\begin{array}{l}5,9 \\
4,2 \\
4,0\end{array}$ & $\begin{array}{l}3,6 \\
2,5 \\
3,0\end{array}$ & $\begin{array}{r}1,9 \\
1,1 \\
C\end{array}$ & $\begin{array}{r}14,7 \\
7,7 \\
8,0\end{array}$ & $\begin{array}{l}45,8 \\
49,5 \\
78,3\end{array}$ & $\begin{array}{l}100 \\
100 \\
100\end{array}$ \\
\hline Norwegen & $\begin{array}{l}0 / 1 / 2 \\
3 / 4 \\
5 / 6\end{array}$ & $\begin{array}{l}28,4 \\
55,8 \\
70,5\end{array}$ & $\begin{array}{l}22,1 \\
46,2 \\
60,0\end{array}$ & $\begin{array}{l}4,8 \\
8,3 \\
9,9\end{array}$ & $\begin{array}{l}\mathrm{m} \\
\mathrm{m} \\
\mathrm{m}\end{array}$ & $\begin{array}{l}9,6 \\
7,4 \\
6,0\end{array}$ & $\begin{array}{r}2,7 \\
2,6 \\
C\end{array}$ & $\begin{array}{r}1,8 \\
1,9 \\
C\end{array}$ & $\begin{array}{l}\mathrm{c} \\
\mathrm{c} \\
\mathrm{c}\end{array}$ & $\begin{array}{l}6,9 \\
4,8 \\
3,7\end{array}$ & $\begin{array}{l}38,0 \\
63,2 \\
76,6\end{array}$ & $\begin{array}{l}100 \\
100 \\
100\end{array}$ \\
\hline Polen & $\begin{array}{l}0 / 1 / 2 \\
3 / 4 \\
5 / 6\end{array}$ & $\begin{array}{r}8,0 \\
42,8 \\
59,9\end{array}$ & $\begin{array}{r}7,0 \\
40,2 \\
56,9\end{array}$ & $\begin{array}{l}0,9 \\
2,6 \\
3,0\end{array}$ & $\begin{array}{r}c \\
0,7 \\
0,8\end{array}$ & $\begin{array}{l}12,0 \\
21,0 \\
13,7\end{array}$ & $\begin{array}{r}4,4 \\
10,5 \\
7,9\end{array}$ & $\begin{array}{l}1,7 \\
4,4 \\
3,7\end{array}$ & $\begin{array}{l}2,7 \\
6,1 \\
4,2\end{array}$ & $\begin{array}{r}7,5 \\
10,5 \\
5,8\end{array}$ & $\begin{array}{l}20,0 \\
63,8 \\
73,5\end{array}$ & $\begin{array}{l}100 \\
100 \\
100\end{array}$ \\
\hline Portugal & $\begin{array}{l}0 / 1 / 2 \\
3 / 4 \\
5 / 6\end{array}$ & $\begin{array}{l}30,5 \\
40,1 \\
55,0\end{array}$ & $\begin{array}{l}\mathrm{m} \\
\mathrm{m} \\
\mathrm{m}\end{array}$ & $\begin{array}{l}\mathrm{m} \\
\mathrm{m} \\
\mathrm{m}\end{array}$ & $\begin{array}{l}\mathrm{m} \\
\mathrm{m} \\
\mathrm{m}\end{array}$ & $\begin{array}{l}17,0 \\
15,5 \\
18,1\end{array}$ & $\begin{array}{l}10,5 \\
11,9 \\
15,4\end{array}$ & $\begin{array}{l}4,0 \\
4,9 \\
6,0\end{array}$ & $\begin{array}{l}6,5 \\
7,0 \\
9,4\end{array}$ & $\begin{array}{l}6,4 \\
3,6 \\
2,6\end{array}$ & $\begin{array}{l}47,5 \\
55,6 \\
73,1\end{array}$ & $\begin{array}{l}100 \\
100 \\
100\end{array}$ \\
\hline Slowakei & $\begin{array}{l}0 / 1 / 2 \\
3 / 4 \\
5 / 6\end{array}$ & $\begin{array}{r}3,6 \\
49,8 \\
52,8\end{array}$ & $\begin{array}{r}1,6 \\
47,9 \\
51,1\end{array}$ & $\begin{array}{l}2,0 \\
1,9 \\
1,7\end{array}$ & $\begin{array}{l}\mathrm{m} \\
\mathrm{m} \\
\mathrm{m}\end{array}$ & $\begin{array}{l}12,9 \\
23,4 \\
14,5\end{array}$ & $\begin{array}{r}6,8 \\
15,5 \\
8,7\end{array}$ & $\begin{array}{l}0,7 \\
2,7 \\
1,7\end{array}$ & $\begin{array}{r}6,0 \\
12,8 \\
7,0\end{array}$ & $\begin{array}{l}6,1 \\
7,9 \\
5,8\end{array}$ & $\begin{array}{l}16,4 \\
73,2 \\
67,3\end{array}$ & $\begin{array}{l}100 \\
100 \\
100\end{array}$ \\
\hline Slowenien & $\begin{array}{l}0 / 1 / 2 \\
3 / 4 \\
5 / 6\end{array}$ & $\begin{array}{r}6,0 \\
32,9 \\
59,3\end{array}$ & $\begin{array}{r}5,3 \\
30,7 \\
56,9\end{array}$ & $\begin{array}{l}0,7 \\
2,2 \\
2,4\end{array}$ & $\begin{array}{l}\mathrm{m} \\
\mathrm{m} \\
\mathrm{m}\end{array}$ & $\begin{array}{r}9,6 \\
11,2 \\
13,1\end{array}$ & $\begin{array}{l}3,2 \\
7,0 \\
9,2\end{array}$ & $\begin{array}{l}0,5 \\
3,0 \\
4,1\end{array}$ & $\begin{array}{l}2,7 \\
4,1 \\
5,1\end{array}$ & $\begin{array}{l}6,4 \\
4,1 \\
3,9\end{array}$ & $\begin{array}{l}15,6 \\
44,1 \\
72,3\end{array}$ & $\begin{array}{l}100 \\
100 \\
100\end{array}$ \\
\hline Spanien & $\begin{array}{l}0 / 1 / 2 \\
3 / 4 \\
5 / 6\end{array}$ & $\begin{array}{l}22,5 \\
27,7 \\
49,9\end{array}$ & $\begin{array}{l}18,6 \\
22,4 \\
40,3\end{array}$ & $\begin{array}{l}4,0 \\
5,3 \\
9,6\end{array}$ & $\begin{array}{l}0,8 \\
1,4 \\
1,9\end{array}$ & $\begin{array}{l}30,6 \\
19,7 \\
22,6\end{array}$ & $\begin{array}{l}21,5 \\
14,5 \\
16,9\end{array}$ & $\begin{array}{l}6,0 \\
5,2 \\
6,7\end{array}$ & $\begin{array}{r}14,9 \\
8,8 \\
9,2\end{array}$ & $\begin{array}{l}9,1 \\
5,2 \\
5,7\end{array}$ & $\begin{array}{l}53,1 \\
47,4 \\
72,5\end{array}$ & $\begin{array}{l}100 \\
100 \\
100\end{array}$ \\
\hline Schweden & $\begin{array}{l}0 / 1 / 2 \\
3 / 4 \\
5 / 6\end{array}$ & $\begin{array}{r}8,6 \\
59,0 \\
45,4\end{array}$ & $\begin{array}{r}6,8 \\
48,5 \\
41,4\end{array}$ & $\begin{array}{r}1,7 \\
10,3 \\
3,8\end{array}$ & $\begin{array}{r}c \\
4,5 \\
1,8\end{array}$ & $\begin{array}{r}7,5 \\
14,3 \\
5,2\end{array}$ & $\begin{array}{l}3,3 \\
8,5 \\
2,9\end{array}$ & $\begin{array}{l}2,2 \\
5,8 \\
2,2\end{array}$ & $\begin{array}{r}0,9 \\
2,0 \\
c\end{array}$ & $\begin{array}{l}4,3 \\
5,8 \\
2,4\end{array}$ & $\begin{array}{l}16,1 \\
73,3 \\
50,6\end{array}$ & $\begin{array}{l}100 \\
100 \\
100\end{array}$ \\
\hline Schweiz & $\begin{array}{l}0 / 1 / 2 \\
3 / 4 \\
5 / 6\end{array}$ & $\begin{array}{l}12,4 \\
56,5 \\
68,4\end{array}$ & $\begin{array}{r}9,9 \\
48,9 \\
58,6\end{array}$ & $\begin{array}{l}2,5 \\
7,6 \\
9,7\end{array}$ & $\begin{array}{l}2,5 \\
7,5 \\
9,7\end{array}$ & $\begin{array}{r}8,5 \\
10,7 \\
8,0\end{array}$ & $\begin{array}{l}3,2 \\
4,8 \\
4,5\end{array}$ & $\begin{array}{l}1,5 \\
3,0 \\
3,9\end{array}$ & $\begin{array}{r}1,6 \\
1,7 \\
C\end{array}$ & $\begin{array}{l}5,4 \\
5,9 \\
3,5\end{array}$ & $\begin{array}{l}20,9 \\
67,2 \\
76,4\end{array}$ & $\begin{array}{l}100 \\
100 \\
100\end{array}$ \\
\hline Türkei & $\begin{array}{l}0 / 1 / 2 \\
3 / 4 \\
5 / 6\end{array}$ & $\begin{array}{l}25,0 \\
32,8 \\
54,8\end{array}$ & $\begin{array}{l}21,6 \\
31,3 \\
52,1\end{array}$ & $\begin{array}{l}3,4 \\
1,5 \\
2,8\end{array}$ & $\begin{array}{l}\mathrm{m} \\
\mathrm{m} \\
\mathrm{m}\end{array}$ & $\begin{array}{l}29,2 \\
31,3 \\
24,5\end{array}$ & $\begin{array}{r}5,0 \\
6,3 \\
10,6\end{array}$ & $\begin{array}{l}3,5 \\
3,8 \\
3,5\end{array}$ & $\begin{array}{l}1,5 \\
2,5 \\
7,0\end{array}$ & $\begin{array}{l}24,3 \\
25,0 \\
13,9\end{array}$ & $\begin{array}{l}54,3 \\
64,1 \\
79,3\end{array}$ & $\begin{array}{l}100 \\
100 \\
100\end{array}$ \\
\hline
\end{tabular}

Anmerkung: Die Zeilen mit Angaben zu allen Bildungsbereichen zusammen sind im Internet verfügbar (s. StatLink unten)

1. Teilnehmer an dualen Ausbildungsprogrammen gelten als sowohl in Ausbildung als auch beschäftigt, ohne Bezug auf ihren ILO-Erwerbsstatus.

2. Junge Menschen, die weder in Beschäftigung noch in Ausbildung sind. 3. Referenzjahr 2011. 4. Daten beziehen sich auf 15- bis 24-Jährige. Quelle: OECD. Argentinien, China, Indien, Indonesien, Kolumbien, Saudi-Arabien und Südafrika: Statistikinstitut der UNESCO. Lettland: Eurostat.

Hinweise s. Anhang 3 unter www.oecd.org/edu/eag.htm. StatLink: http://dx.doi.org/10.1787/888933118979

Erläuterung der Kennzeichnung fehlender Daten s. Hinweise für den Leser. 
Anteil 25- bis 29-Jähriger (in \%), die sich in Ausbildung bzw. nicht in Ausbildung befinden, nach Bildungsstand und Erwerbsstatus (2012)

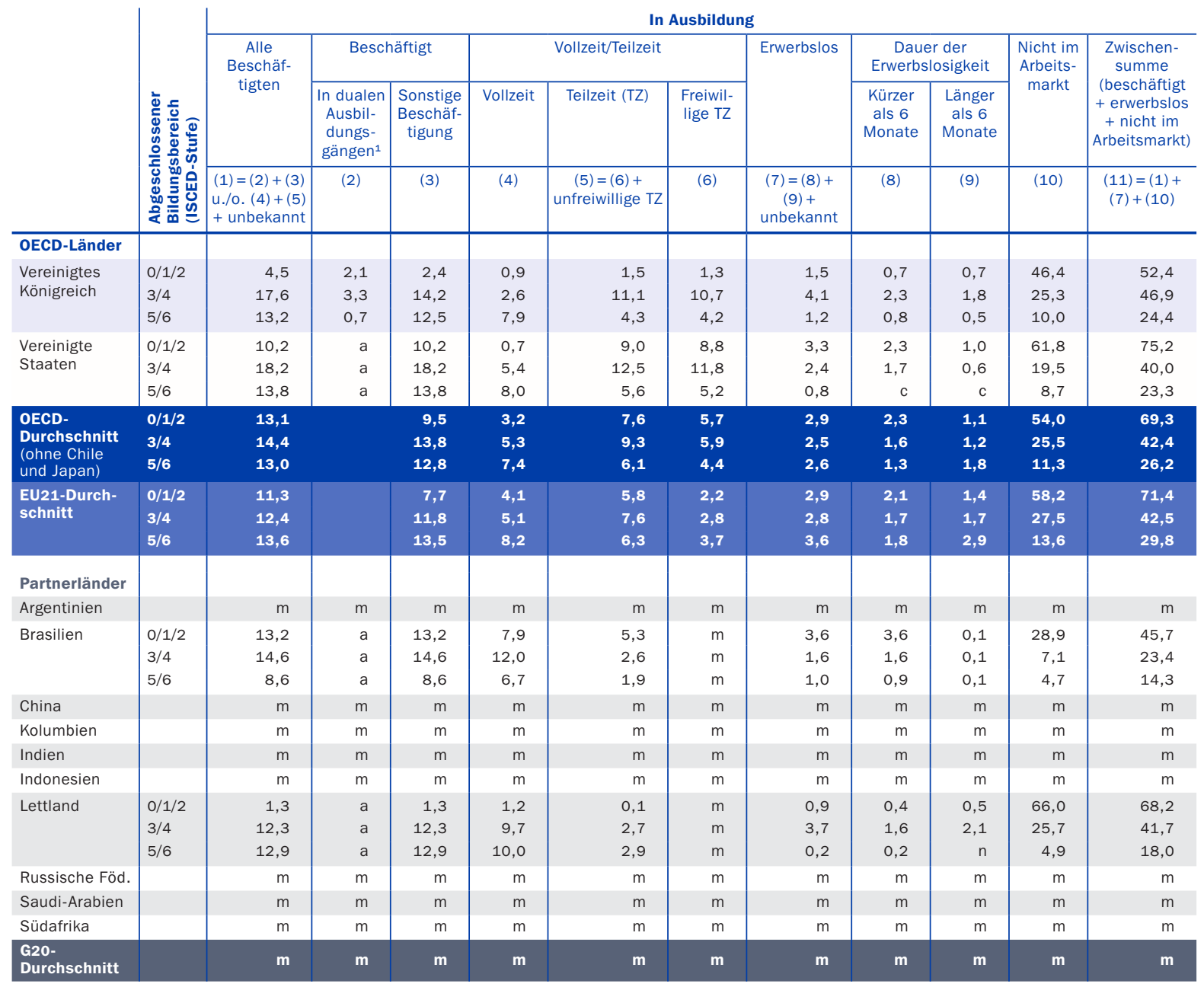

Anmerkung: Die Zeilen mit Angaben zu allen Bildungsbereichen zusammen sind im Internet verfügbar (s. StatLink unten)

1. Teilnehmer an dualen Ausbildungsprogrammen gelten als sowohl in Ausbildung als auch beschäftigt, ohne Bezug auf ihren ILO-Erwerbsstatus. 2. Junge Menschen, die weder in Beschäftigung noch in Ausbildung sind. 3. Referenzjahr 2011. 4. Daten beziehen sich auf 15- bis 24-Jährige. Quelle: OECD. Argentinien, China, Indien, Indonesien, Kolumbien, Saudi-Arabien und Südafrika: Statistikinstitut der UNESCO. Lettland: Eurostat. Hinweise s. Anhang 3 unter www.oecd.org/edu/eag.htm. StatLink: http://dx.doi.org/10.1787/888933118979 Erläuterung der Kennzeichnung fehlender Daten s. Hinweise für den Leser. 
Anteil 25- bis 29-Jähriger (in \%), die sich in Ausbildung bzw. nicht in Ausbildung befinden, nach Bildungsstand und Erwerbsstatus (2012)

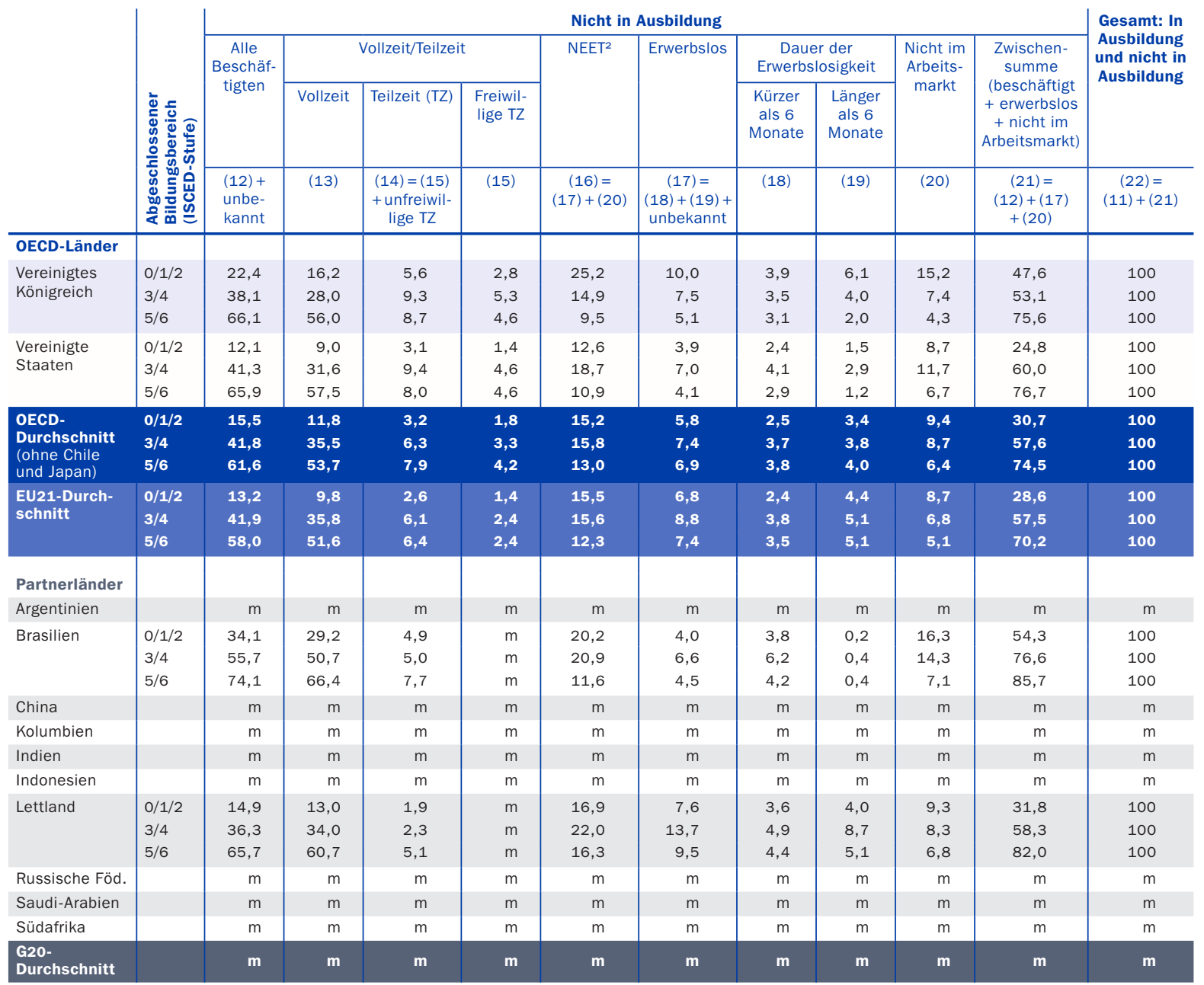

Anmerkung: Die Zeilen mit Angaben zu allen Bildungsbereichen zusammen sind im Internet verfügbar (s. StatLink unten)

1. Teilnehmer an dualen Ausbildungsprogrammen gelten als sowohl in Ausbildung als auch beschäftigt, ohne Bezug auf ihren ILO-Erwerbsstatus.

2. Junge Menschen, die weder in Beschäftigung noch in Ausbildung sind. 3. Referenzjahr 2011. 4. Daten beziehen sich auf 15- bis 24-Jährige.

Quelle: OECD. Argentinien, China, Indien, Indonesien, Kolumbien, Saudi-Arabien und Südafrika: Statistikinstitut der UNESCO. Lettland: Eurostat.

Hinweise s. Anhang 3 unter www.oecd.org/edu/eag.htm. StatLink: http://dx.doi.org/10.1787/888933118979

Erläuterung der Kennzeichnung fehlender Daten s. Hinweise für den Leser. 
Entwicklung des Anteils 15- bis 29-Jähriger (in \%), die Vollzeit bzw. Teilzeit arbeiten und sich in Ausbildung bzw. nicht in Ausbildung befinden (2006-2012)

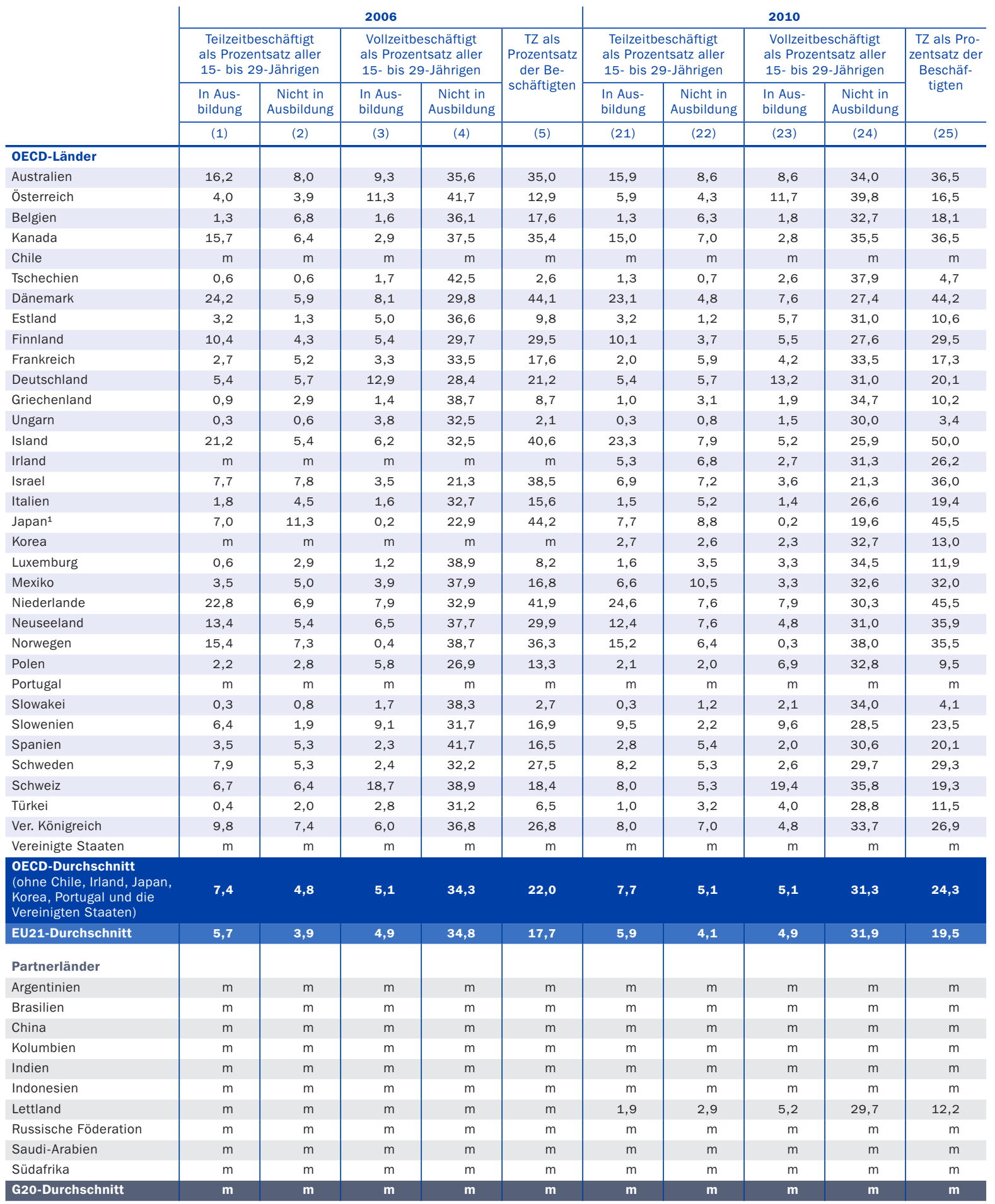

Anmerkung: Die Spalten mit Angaben für weitere Jahre sind im Internet verfügbar (s. StatLink unten) 1. Daten beziehen sich auf 15- bis 24-Jährige.

Quelle: OECD. Argentinien, China, Indien, Indonesien, Kolumbien, Saudi-Arabien und Südafrika: Statistikinstitut der UNESCO. Lettland: Eurostat. Hinweise s. Anhang 3 unter www.oecd.org/edu/eag.htm. StatLink: http://dx.doi.org/10.1787/888933118998 Erläuterung der Kennzeichnung fehlender Daten s. Hinweise für den Leser. 
Entwicklung des Anteils 15- bis 29-Jähriger (in \%), die Vollzeit bzw. Teilzeit arbeiten und sich in Ausbildung bzw. nicht in Ausbildung befinden (2006-2012)

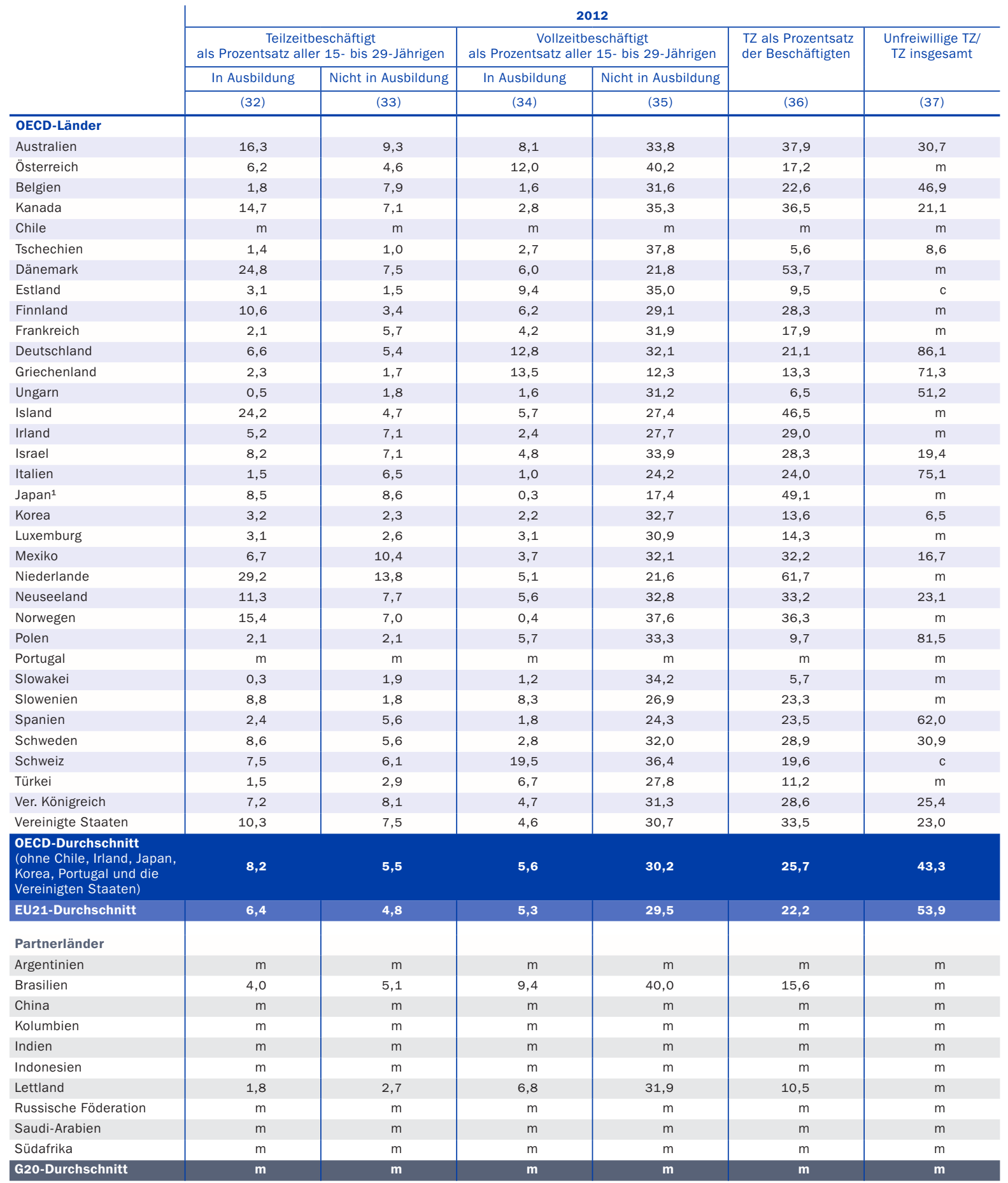

Anmerkung: Die Spalten mit Angaben für weitere Jahre sind im Internet verfügbar (s. StatLink unten)

1. Daten beziehen sich auf 15- bis 24-Jährige.

Quelle: OECD. Argentinien, China, Indien, Indonesien, Kolumbien, Saudi-Arabien und Südafrika: Statistikinstitut der UNESCO. Lettland: Eurostat. Hinweise s. Anhang 3 unter www.oecd.org/edu/eag.htm. StatLink: http://dx.doi.org/10.1787/888933118998

Erläuterung der Kennzeichnung fehlender Daten s. Hinweise für den Leser. 


\section{Wie viele Erwachsene nehmen an formaler und nicht formaler Fort- und Weiterbildung teil?}

In vielen Ländern beteiligen sich jedes Jahr mehr als 50 Prozent der Erwachsenen an formalen und/oder nicht formalen Bildungsmaßnahmen. Der Anteil reicht von mehr als zwei Drittel der Erwachsenen in Dänemark, Finnland und Schweden über ein Drittel in der Slowakei, einem Viertel in Italien bis zu einem Fünftel in der Russischen Föderation.

Die Teilnahme an formalen und/oder nicht formalen Bildungsmaßnahmen hängt eng mit der Lesekompetenz, dem Bildungsstand, der Altersgruppe und dem Erwerbsstatus des Einzelnen sowie dem Bildungsstand der Eltern zusammen.

Insgesamt wollten in den letzten I2 Monaten vor Durchführung der Erhebung zu den grundlegenden Kompetenzen Erwachsener (PIACC) 25 Prozent der Erwachsenen in den OECD-Ländern an Lernaktivitäten teilnehmen, ohne diese jedoch begonnen zu haben. Etwa 45 Prozent dieser potenziellen Teilnehmer gaben als Grund für die nicht erfolgte Aufnahme von Lernaktivitäten die Belastung durch Arbeit oder Familie an.

Im Durchschnitt der Länder nehmen ro Prozent der 25- bis 64-Jährigen an vom formalen Bildungssystem organisierten Lernaktivitäten teil. Der Prozentsatz reicht von 2 Prozent in Japan bis zu I7 Prozent in Australien.

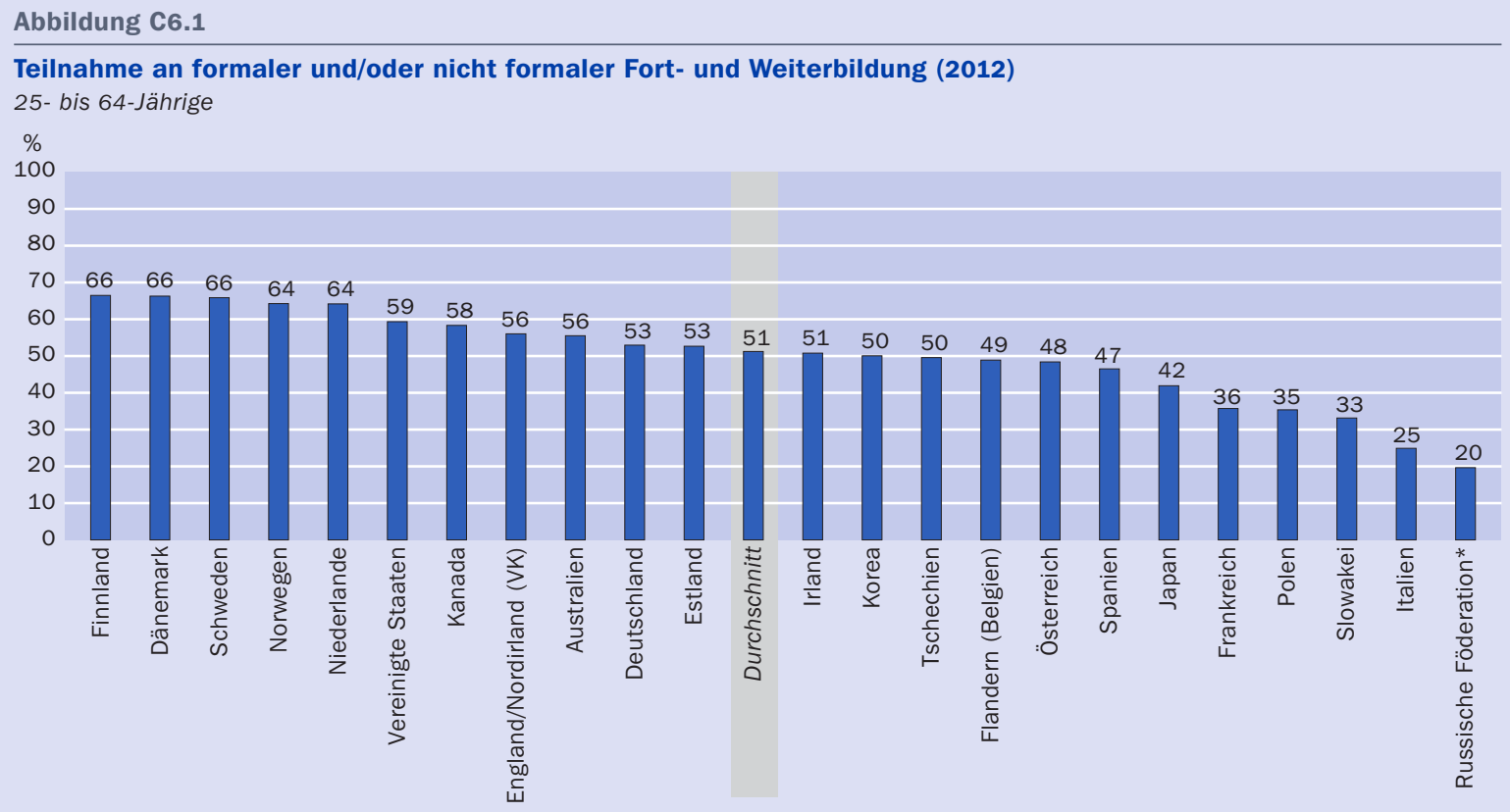

* Hinweis zu den Daten der Russischen Föderation s. Abschnitt Angewandte Methodik.

Anordnung der Länder in absteigender Reihenfolge des Anteils 25- bis 64-Jähriger (in \%), die an formalen und/oder nicht formalen Bildungsmaßnahmen teilnehmen.

Quelle: OECD. Tabelle C6.4. Hinweise s. Anhang 3 unter www.oecd.org/edu/eag.htm. StatLink: http://dx.doi.org/10.1787/888933119207 


\section{Kontext}

Erwachsenenbildung kann wesentlich dazu beitragen, dass Erwachsene lebenslang wichtige Fähigkeiten und Fertigkeiten im Bereich der Informationsverarbeitung erwerben und auf dem neuesten Stand halten sowie andere Kenntnisse, Fähigkeiten und Fertigkeiten erwerben. Es ist von entscheidender Bedeutung, über die formale Erstausbildung hinaus organisierte Lernmöglichkeiten für Erwachsene anzubieten und den Zugang zu diesen sicherzustellen, dies gilt insbesondere für Beschäftigte, die sich während ihrer gesamten beruflichen Laufbahn immer wieder an Änderungen anpassen müssen. Die Möglichkeit der Teilnahme an Fortbildungsmöglichkeiten ist inzwischen sowohl für hoch als auch für gering qualifizierte Beschäftigte von Bedeutung. In Hochtechnologiebereichen müssen die Beschäftigten ihre Kompetenzen fortlaufend auf den neuesten Stand bringen und mit sich schnell ändernden Techniken Schritt halten. Beschäftigte in Bereichen mit niedrigem technologischem Niveau sowie Beschäftigte, deren Arbeit nur eine geringe Qualifizierung erfordert, müssen lernen, anpassungsfähig zu sein, da für sie das Risiko, ihren Arbeitsplatz zu verlieren, höher ist, weil Routinearbeiten zunehmend von Maschinen ausgeführt werden und Unternehmen diese Arbeiten vielleicht in Länder mit niedrigeren Lohnkosten verlagern (OECD, 2013).

Lebenslanges Lernen kann auch zum Erreichen nicht wirtschaftlicher Ziele, wie persönliche Zufriedenheit, bessere Gesundheit, gesellschaftliche Teilhabe und soziale Integration, beitragen (siehe Indikator: „Was sind die gesamtgesellschaftlichen Auswirkungen von Bildung?" in früheren Ausgaben von Bildung auf einen Blick). Die zwischen OECD-Ländern mit ähnlichem wirtschaftlichen Entwicklungsstand bestehenden großen Unterschiede bei den Lernaktivitäten Erwachsener und den Teilnahmequoten legen die Vermutung nahe, dass zwischen den Lernkulturen, Lernmöglichkeiten am Arbeitsplatz und den Strukturen der Erwachsenenbildung der einzelnen Länder signifikante Unterschiede bestehen. Ergebnisse der Erhebung zu den grundlegenden Kompetenzen Erwachsener im Rahmen des OECD Programme for the International Assessment of Adult Competencies (PIAAC) zeigen einen eindeutigen Zusammenhang zwischen dem Maß der Teilnahme an organisierten Lernaktivitäten für Erwachsene und dem durchschnittlichen Stand der in einem Land vorhandenen Kompetenzen im Bereich der Informationsverarbeitung.

\section{Weitere wichtige Ergebnisse}

Die Teilnahme an formaler und/oder nicht formaler Fort- und Weiterbildung hängt in allen Ländern eng mit dem Grad der grundlegenden Kompetenzen sowie dem Bildungsstand zusammen. In Kombination bewirken diese eine Aufwärtsdynamik für Personen mit hohen Kompetenzen und hohem Bildungsstand, die tendenziell durch die Teilnahme an Lernaktivitäten für Erwachsene ihre Kompetenzen noch weiter ausbauen. In Kombination führen jedoch genau diese Faktoren auch zu einem Teufelskreis aus niedrigem Bildungsstand, geringen Kompetenzen und fehlendem Zugang zu formalen Lernaktivitäten, um bestehende Bildungslücken zu schließen.

Die Teilnahme an formaler und/oder nicht formaler Fort- und Weiterbildung ist bei den jüngeren Erwachsenen (25- bis 34-Jährigen) am höchsten und nimmt bei den älteren Erwachsenen (55- 
bis 64-Jährige) stetig ab. Diese Korrelation findet sich aufjeder Lesekompetenzstufe. In Ländern mit einer hohen Gesamtteilnahme an formalen und/oder nicht formalen Bildungsmaßnahmen haben Alter und Lesekompetenz einen geringeren Einfluss auf die Teilnahme an Lernaktivitäten für Erwachsene.

Erwachsene, die in benachteiligten Familien (hier definiert als Familien, in denen beide Eltern keinen Abschluss im Sekundarbereich II haben) aufgewachsen sind, nehmen seltener an formalen und/oder nicht formalen Fort- und Weiterbildungsmaßnahmen teil. Dies gilt sogar für Personen, die nach den Maßstäben der Erhebung zu den grundlegenden Kompetenzen Erwachsener eine hohe Lesekompetenz aufweisen.

Im Allgemeinen weisen Länder mit hohen Teilnahmequoten Erwachsener bei formalen Bildungsmaßnahmen auch hohe Teilnahmequoten Erwachsener bei nicht formalen Bildungsmaßnahmen auf. Durchschnittlich zwei Drittel der Teilnehmer an formalen Bildungsmaßnahmen nehmen auch an nicht formalen Bildungsmaßnahmen teil.

\section{Analyse und Interpretationen}

\section{Große Unterschiede zwischen den einzelnen Ländern}

Im Durchschnitt beteiligten sich in den Ländern 5I Prozent der Bevölkerung im Alter von 25 bis 64 Jahren im vorangegangenen Jahr an mindestens einem formalen und/ oder nicht formalen Bildungsangebot. Die an der Erhebung beteiligten Länder lassen sich in sechs Gruppen einteilen, zwischen denen signifikante Unterschiede bei den Teilnahmequoten bestehen (Tab. C6.I [L]).

Gruppe I mit Teilnahmequoten von mehr als 6o Prozent, hierzu gehören Dänemark, Finnland, die Niederlande, Norwegen und Schweden.

Gruppe 2 mit Teilnahmequoten zwischen 55 Prozent und 59 Prozent, hierzu gehören Australien, England/Nordirland (VK), Kanada und die Vereinigten Staaten.

- Gruppe 3, deren Teilnahmequoten am OECD-Durchschnitt zwischen 48 Prozent und 53 Prozent liegen, hierzu gehören Flandern (Belgien), Deutschland, Estland, Irland, Korea, Österreich und Tschechien.

- Gruppe 4 besteht aus zwei Ländern mit Teilnahmequoten zwischen 38 Prozent und 47 Prozent: Japan und Spanien.

- Gruppe 5 mit Teilnahmequoten zwischen 33 Prozent und 36 Prozent umfasst Frankreich, Polen und die Slowakei.

Gruppe 6 mit Teilnahmequoten unter 25 Prozent besteht aus Italien und der Russischen Föderation.

\section{Ausbildung führt zu Fort- und Weiterbildung}

Sowohl das Kompetenzniveau als auch der Bildungsstand einer Person haben Einfluss auf das Lernen im Erwachsenenalter. Im Durchschnitt der Länder haben 30 Prozent der Personen mit geringer Lesekompetenz (Stufe I oder darunter in der Erhebung zu den grundlegenden Kompetenzen Erwachsener) in den letzten I2 Monaten vor Durchführung der Erhebung an formaler und/oder nicht formaler Fort- und Weiterbildung teilgenommen, bei Personen mit hoher Lesekompetenz (Stufe 4 oder 5) lag der Prozentsatz bei 74 Prozent. Bei Personen mit hoher Kompetenz war die Wahrscheinlichkeit einer 
Abbildung C6.2

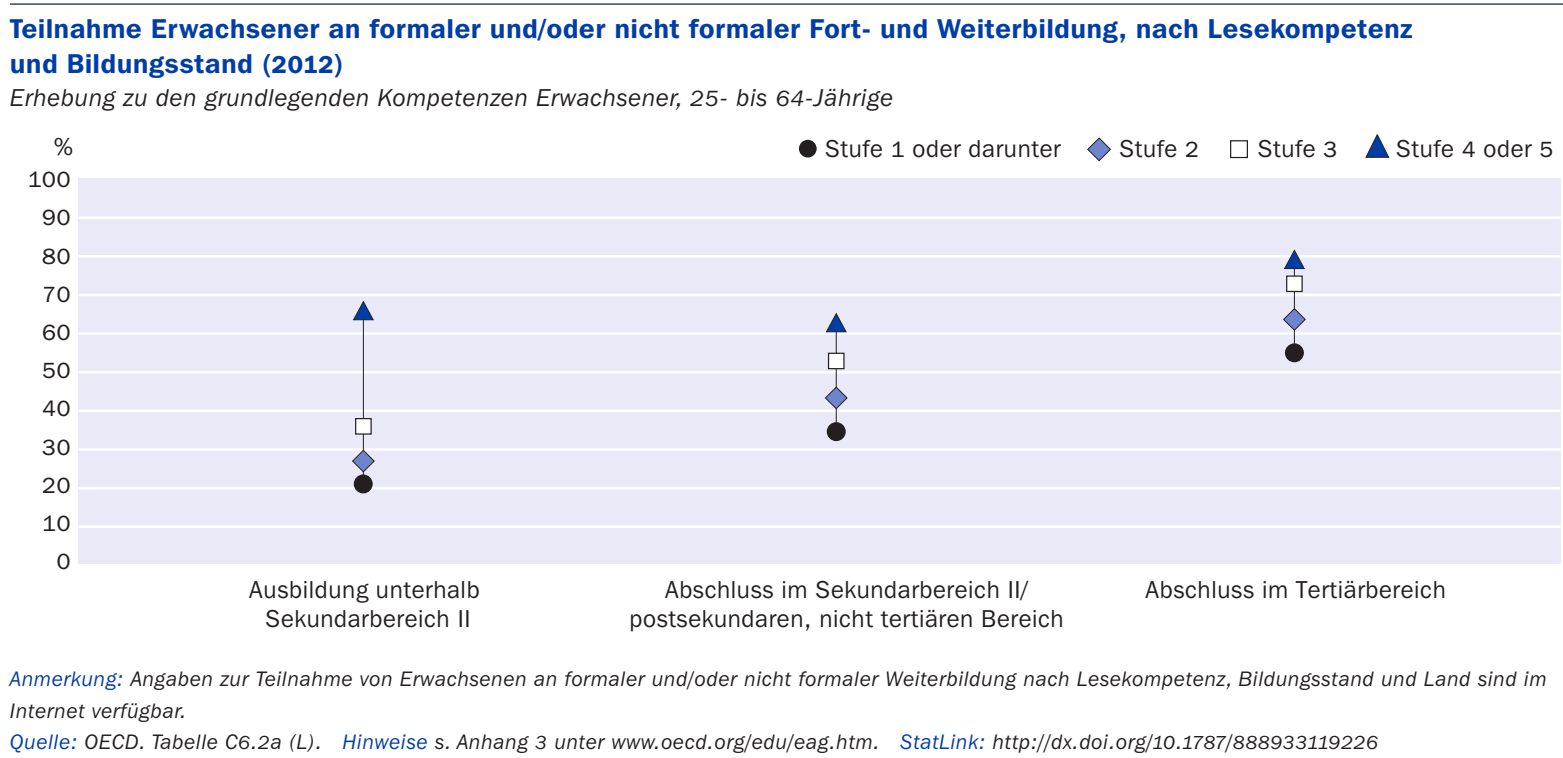

Teilnahme an formalen und/oder nicht formalen Fort- und Weiterbildungsmaßnahmen somit fast 2,5-mal so hoch wie bei Personen mit niedriger Lesekompetenz. Rund 27 Prozent der Erwachsenen ohne einen Abschluss im Sekundarbereich II haben an formalen und/oder nicht formalen Bildungsangeboten teilgenommen, bei den Erwachsenen mit einem Abschluss im Tertiärbereich waren es 7I Prozent. Bei Erwachsenen mit einem Abschluss im Tertiärbereich war die Wahrscheinlichkeit der Teilnahme an formaler und/oder nicht formaler Bildung mehr als 2,5-mal so hoch wie bei Erwachsenen ohne eine Ausbildung im Sekundarbereich II. Der starke positive Zusammenhang zwischen der Teilnahme an formalen und/oder nicht formalen Bildungsmaßnahmen, Lesekompetenz und Bildungsstand besteht länderübergreifend (Tab. C6.I [L] und C6.2a [L]).

Lesekompetenz und Bildungsstand scheinen für die Teilnahme an formaler und/oder nicht formaler Fort- und Weiterbildung einen sich gegenseitig verstärkenden Effekt zu haben. Rund 79 Prozent der Personen mit hoher Lesekompetenz und einem Abschluss im Tertiärbereich haben an formalen und/oder nicht formalen Bildungsmaßnahmen teilgenommen. Bei ihnen war die Wahrscheinlichkeit einer Teilnahme fast viermal so hoch wie bei Personen mit niedriger Lesekompetenz und ohne eine Ausbildung im Sekundarbereich II. Aus der letztgenannten Gruppe haben nur 2I Prozent teilgenommen. Diese sich gegenseitig verstärkenden Aspekte führen für Erwachsene mit hoher Kompetenz zu einer Aufwärtsdynamik und für Erwachsene mit niedriger Kompetenz in einen Teufelskreis. Im Gegensatz zu Erwachsenen mit niedrigem Kompetenzniveau ist bei Erwachsenen mit hoher Kompetenz die Wahrscheinlichkeit einer Teilnahme an Bildungsaktivitäten, die ihre Kompetenzen weiter ausbauen, größer - damit steigt die Wahrscheinlichkeit, dass diese Menschen weiterhin von Lernangeboten profitieren (Abb. C6.2).

Dänemark, die Niederlande, Norwegen und Schweden weisen die größten Erfolge dabei auf, für Erwachsene, die bei der Erhebung zu den grundlegenden Kompetenzen Erwachsener maximal Stufe I erreicht haben und keinen Abschluss im Sekundarbereich II aufweisen, Möglichkeiten zur Teilnahme an formalen und/oder nicht formalen 
Teilnahme an formaler und/oder nicht formaler Fort- und Weiterbildung, nach Erwerbsstatus (2012)

25- bis 64-Jährige

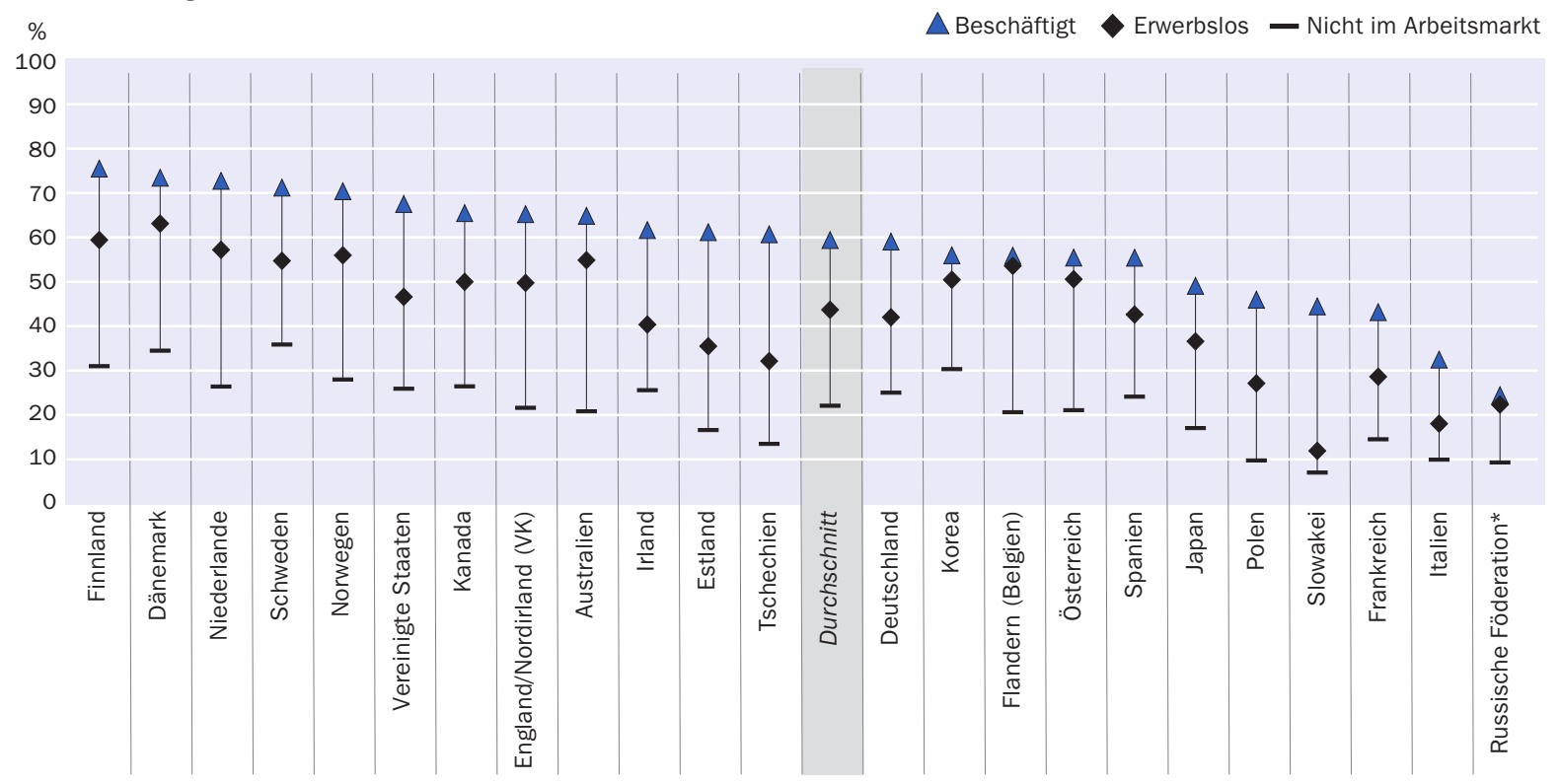

* Hinweis zu den Daten der Russischen Föderation s. Abschnitt Angewandte Methodik.

Anordnung der Länder in absteigender Reihenfolge des Anteils 25- bis 64-Jähriger in Beschäftigung, die an formaler und/oder nicht formaler Fortbildung teilnehmen. Quelle: OECD. Tabelle C6.2d (L) im Internet. Hinweise s. Anhang 3 unter www.oecd.org/edu/eag.htm. StatLink: http://dx.doi.org/10.1787/888933119245

Bildungsmaßnahmen zu bieten: In jedem dieser Länder nehmen mehr als 30 Prozent dieser Erwachsenengruppe teil (Tab. C6.2a [L]).

\section{Unterschiede bei der Teilnahme nach sozialen Gruppen}

Zwischen den einzelnen Ländern bestehen große Unterschiede bei dem Ausmaß der Teilnahme Erwachsener an formalen Lernaktivitäten. Die Teilnahmequote bei der Erwachsenenbildung wird in allen untersuchten nationalen Einheiten auf ähnliche Art und Weise durch mehrere Faktoren beeinflusst. Hierzu gehören Erwerbsstatus, Alter, Bildungsstand der Eltern und, in geringerem Umfang, das Geschlecht.

Im Durchschnitt der OECD-Länder nehmen beschäftigte Erwachsene häufiger an formaler und/oder nicht formaler Fort- und Weiterbildung teil (59 Prozent) als erwerbslose Erwachsene (44 Prozent) und nicht im Arbeitsmarkt befindliche Erwachsene (22 Prozent) (Abb. C6.3). Bei den beschäftigten Erwachsenen ist die Wahrscheinlichkeit einer Teilnahme an Bildungsmaßnahmen bei Personen mit hoher Lesekompetenz (Stufe 4 oder 5) fast doppelt so hoch wie bei Personen mit niedriger Kompetenzstufe (Stufe I oder darunter). Diese Beobachtung trifft auf die meisten Länder zu, während die Unterschiede bei den mit der Lesekompetenz zusammenhängenden Teilnahmequoten in Ländern mit einer geringen Gesamtteilnahme (Korrelation $=-0,54$ ) tendenziell eher größer sind (Tab. C6.2d [L] im Internet).

In vielen Ländern nimmt die Teilnahme an sämtlichen Arten der Erwachsenenbildung formaler, nicht formaler und informeller - bei älteren Personen tendenziell ab (OECD, 20II sowie OECD/Statistics Canada, 20II). Im Durchschnitt der untersuchten Länder ist die Beteiligung der jüngsten Altersgruppe der 25- bis 34-Jährigen an formalen und/ 
oder nicht formalen Fortbildungsangeboten mit 62 Prozent am stärksten, während die Beteiligung der ältesten Altersgruppe der 55- bis 64-Jährigen mit 34 Prozent am niedrigsten ist. Die Altersgruppen dazwischen weisen eine moderate Teilnahmequote auf (56 Prozent für 35- bis 44-Jährige, 5 I Prozent für 45- bis 54-Jährige) (Tab. C6.2b [L] im Internet).

Die mit jeder Altersgruppe sinkende Teilnahme an formaler und/oder nicht formaler Fort- und Weiterbildung gilt im Durchschnitt für jede Stufe der Lesekompetenz. Damit ist die Beteiligung der jüngsten Erwachsenen mit der höchsten Lesekompetenz (Kompetenzstufe 4 oder 5) mit 79 Prozent am höchsten, während die ältesten Erwachsenen mit niedriger Lesekompetenz (Stufe I oder darunter) mit 2I Prozent die geringste Beteiligung aufweisen. Bei jungen Erwachsenen mit hoher Lesekompetenz ist die Wahrscheinlichkeit einer Teilnahme an formaler und/oder nicht formaler Fortund Weiterbildung somit 3,8-mal so hoch wie bei älteren Erwachsenen mit niedriger Lesekompetenz (Tab. C6.2b [L] im Internet).

Alter und Lesekompetenz scheinen die Teilnahme an Erwachsenenbildung gegenseitig zu verstärken. Dieser Zusammenhang zeigt sich in jedem an der Erhebung beteiligten Land, jedoch in unterschiedlich starker Ausprägung. Die Vereinigten Staaten weisen zum Beispiel den geringsten Unterschied nach Altersgruppe und Lesekompetenz auf: Bei jungen Menschen mit hoher Lesekompetenz ist die Wahrscheinlichkeit einer Teilnahme an formalen und/oder nicht formalen Bildungsmaßnahmen 2,6-mal so hoch wie bei älteren Erwachsenen mit niedriger Kompetenz. Der größte Unterschied besteht in Polen, wo die Wahrscheinlichkeit der Teilnahme junger Personen mit hoher Lesekompetenz mehr als 9-mal so hoch ist wie die von älteren Erwachsenen mit niedriger Lesekompetenz. Je höher die Gesamtquote der Teilnehmer in einem Land ist, desto geringer ist der relative Vorteil dieser jungen Erwachsenen; je niedriger die Gesamtquote der Teilnehmer ist, umso höher ist ihr relativer Vorteil (Korrelation $=-0,86$ ) (Tab. C6.2b [L] im Internet).

Für die niedrigere Teilnahmequote bei älteren Erwachsenen gibt es mehrere mögliche Ursachen. Hierzu gehören die hohe Nichtteilnahme älterer Menschen am Arbeitsmarkt (s. Indikator A5), niedrige Investitionen der Arbeitgeber in die Kompetenzen älterer Beschäftigter und geringere Anreize für ältere Beschäftigte, ihre Kompetenzen zu verbessern.

Der Bildungsstand der Eltern kann als Näherungsgröße für den sozioökonomischen Status gesehen werden (OECD, 2013). Es besteht ein Zusammenhang zwischen dem Bildungsstand der Eltern und Bildungsstand (s. Indikator A4) und Kompetenzniveau des Einzelnen (OECD, 2013). Die Teilnahme an formaler und/oder nicht formaler Fort- und Weiterbildung als Erwachsener könnte dazu beitragen, die negativen Auswirkungen von zu einem früheren Zeitpunkt im Leben entstandenen Nachteilen zu kompensieren.

Im Durchschnitt der Länder nahmen 68 Prozent der Erwachsenen mit mindestens einem Elternteil mit einem Abschluss im Tertiärbereich an formalen und/oder nicht formalen Fort- und Weiterbildungsmaßnahmen teil. Etwa 56 Prozent der Erwachsenen mit mindestens einem Elternteil mit einem Abschluss im Sekundarbereich II nahmen teil, jedoch nur 40 Prozent der Erwachsenen, bei denen kein Elternteil über eine Ausbil- 
Teilnahme Erwachsener auf Lesekompetenzstufe 4/5 an formaler und/oder nicht formaler Fort- und Weiterbildung, nach Bildungsstand der Eltern (2012)

Erhebung zu den grundlegenden Kompetenzen Erwachsener, 25- bis 64-Jährige

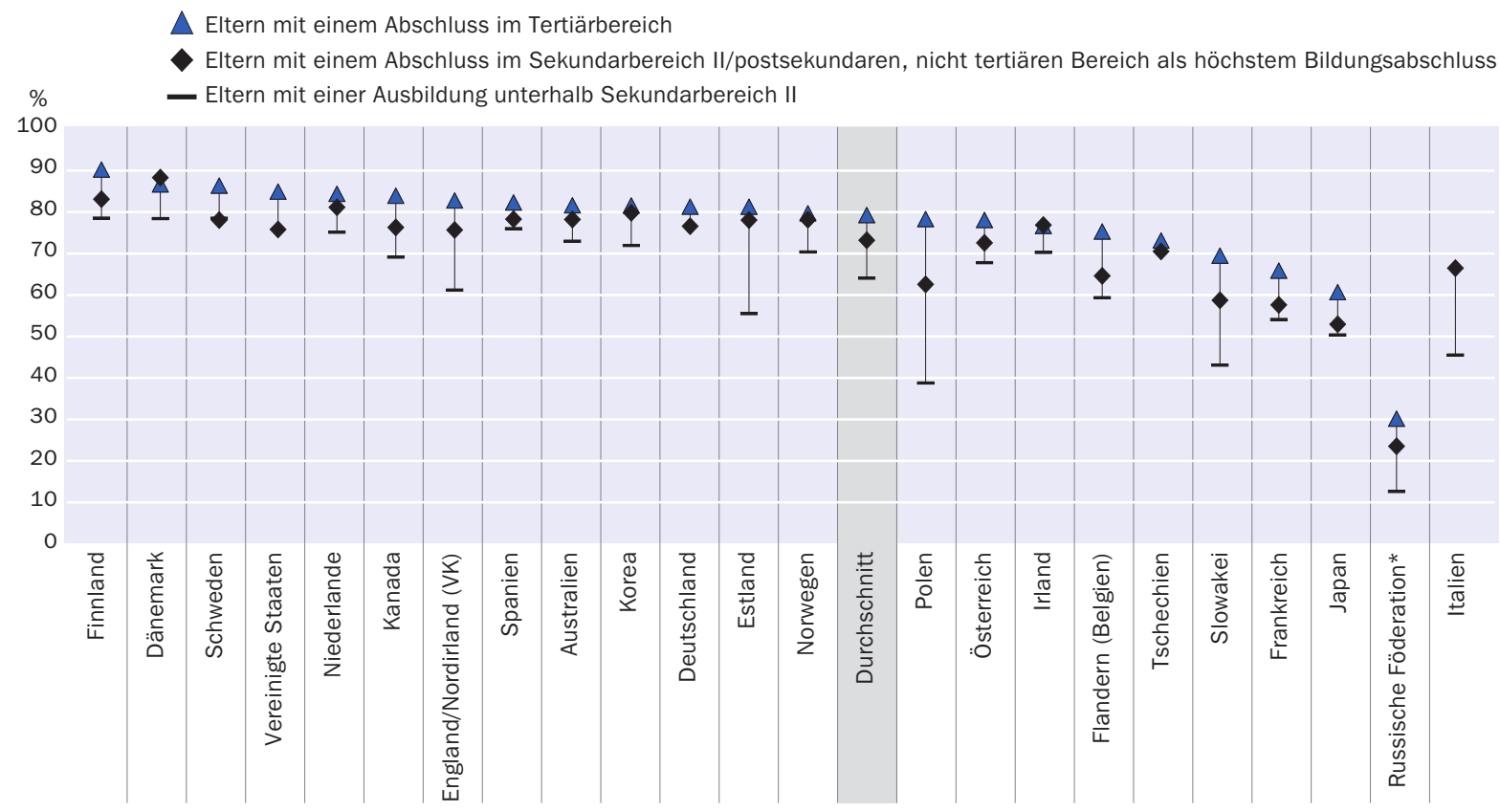

* Hinweis zu den Daten der Russischen Föderation s. Abschnitt Angewandte Methodik.

Anordnung der Länder in absteigender Reihenfolge des Anteils 25- bis 64-Jähriger, die an formalen und/oder nicht formalen Fort- und Weiterbildungsmaßnahmen teilnehmen und Lesekompetenzstufe 4/5 erreichen, deren Eltern über einen Abschluss im Tertiärbereich verfügen.

Quelle: OECD. Tabelle C6.2e (L) im Internet. Hinweise s. Anhang 3 unter www.oecd.org/edu/eag.htm. StatLink: http://dx.doi.org/10.1787/888933119264

dung im Sekundarbereich II verfügt. Bei Erwachsenen mit Eltern mit einem Abschluss im Tertiärbereich ist die Wahrscheinlichkeit einer Teilnahme an einer Bildungsmaßnahme I,7-mal so hoch wie bei Erwachsenen mit Eltern mit einer Ausbildung unterhalb des Sekundarbereichs II (Tab. C6.2e [L] im Internet). Abbildung C6.4 zeigt, dass bei den Erwachsenen, die in der Erhebung zu den grundlegenden Kompetenzen Erwachsener die Lesekompetenzstufe 4 oder 5 erzielten, 79 Prozent derjenigen mit mindestens einem Elternteil mit einem Abschluss im Tertiärbereich an formaler und/oder nicht formaler Fort- und Weiterbildung teilnehmen, 73 Prozent derjenigen mit mindestens einem Elternteil mit einem Abschluss im Sekundarbereich II und 64 Prozent derjenigen, bei denen kein Elternteil über eine Ausbildung im Sekundarbereich II verfügt.

Länder mit einer höheren Gesamtteilnehmerquote bei formaler und/oder nicht formaler Fort- und Weiterbildung weisen geringere Unterschiede bei der Teilnahme in Abhängigkeit vom Bildungsstand der Eltern auf (Korrelation $=-0,74$ ). Bei den Ländern mit dem geringsten Einfluss der Bildung der Eltern auf die Teilnahme von Erwachsenen mit hohem Kompetenzniveau handelt es sich um Australien, Dänemark, Irland, Korea, die Niederlande, Norwegen, Schweden und Spanien, während der Einfluss in Deutschland, Estland, Italien, Polen, der Russischen Föderation und der Slowakei am höchsten ist.

\section{Hindernisse für die Teilnahme an Lernaktivitäten}

Alle Erwachsenen (25- bis 64-Jährige) wurden gefragt, ob sie in den vorangegangenen I2 Monaten an (mehr) formaler oder nicht formaler Fort- und Weiterbildung teilneh- 
men wollten, jedoch damit nicht begonnen haben. Abbildung C6.5 zeigt, dass im Durchschnitt der Länder 25 Prozent aller Erwachsenen Interesse an einer Teilnahme hatten, jedoch nicht teilnehmen konnten. Drei von vier der an einer weiteren Teilnahme interessierten Erwachsenen hatten in den vorangegangenen 12 Monaten an anderen formalen und/oder nicht formalen Fort- und Weiterbildungsmaßnahmen teilgenommen (I8 Prozent aller Erwachsenen). Nur wenige der an einer Teilnahme interessierten Erwachsenen (7 Prozent) hatten in den vorangegangenen 12 Monaten an keiner Fortund Weiterbildungsmaßnahme teilgenommen und konnten so als potenzielle neue Teilnehmer angesehen werden. Der Anteil Erwachsener, die an Lernaktivitäten teilnehmen wollten, jedoch nicht teilnahmen, reicht von mehr als 33 Prozent in Dänemark, Korea und den Vereinigten Staaten bis zu weniger als I5 Prozent in Polen, der Russischen Föderation und der Slowakei. In allen an der Erhebung beteiligten Ländern war die Zahl der Teilnehmer, die an (weiteren) Lernaktivitäten teilnehmen wollten, höher als die der Nichtteilnehmer. In Frankreich, Italien und der Russischen Föderation ist der Unterschied gering. Insgesamt ist in Ländern mit höheren Teilnahmequoten bei formaler und/oder nicht formaler Fort- und Weiterbildung auch der Anteil der Personen, die Lernaktivitäten beginnen möchten, höher (Korrelation = 0,76) (Tab. C6.4).

Die Personen mit Wunsch nach einer Lernaktivität wurden gefragt, warum sie nicht mit der Teilnahme an einer solchen Aktivität begonnen hatten. Es wurden 7 alternative Antworten sowie die Kategorie „Sonstiges“ angeboten. Im Durchschnitt der OECDLänder gaben 30 Prozent der Befragten als Grund „Ich hatte beruflich zu viel zu tun“ an. Weitere 15 Prozent der Befragten nannten als Grund „Ich hatte keine Zeit, weil ich mich um Familie oder Kinder kümmern musste“. Damit schien bei 45 Prozent der Befragten die Belastung durch Arbeit oder Familie keine Zeit für (weitere) Lernaktivitäten zu lassen. Mit der Organisation der Lernaktivitäten zusammenhängende Faktoren haben ebenfalls zur Nichtteilnahme an Lernaktivitäten geführt: „Die Fort- und Weiterbildung fand zu einer ungünstigen Zeit oder an einem ungünstigen Ort statt“ (I2 Prozent), „Die Fort- und Weiterbildung war zu teuer / Ich konnte sie mir nicht leisten“ (I4 Prozent) und „Mir fehlten die Voraussetzungen dafür“ (3 Prozent) gaben insgesamt 29 Prozent der Befragten als Grund an. Etwa 8 Prozent der Befragten nannten „Fehlende Unterstützung durch den Arbeitgeber“ als Grund, warum sie an einer gewünschten Lernaktivität nicht teilgenommen haben, und etwa 4 Prozent sagten „Ein unerwartetes Ereignis hat mich davon abgehalten“ (Tab. C6.5).

Der Grund „Ich hatte beruflich zu viel zu tun“ wurde von mehr als 35 Prozent der Befragten in Italien, Japan, Korea und Tschechien angegeben, in Frankreich, Irland und Polen gaben weniger als 25 Prozent diesen Grund an. „Ich hatte keine Zeit, weil ich mich um Familie oder Kinder kümmern musste“ wurde von mindestens 20 Prozent der Befragten in Australien, Flandern (Belgien), Irland und Spanien angegeben und von höchstens ıo Prozent in Dänemark, Estland, Finnland, Frankreich und der Slowakei. „Die Fort- und Weiterbildung fand zu einer ungünstigen Zeit oder an einem ungünstigen Ort statt" gaben mehr als 17 Prozent der Befragten in Finnland, Flandern (Belgien) und Japan und weniger als 7 Prozent in Frankreich, Italien und Tschechien an. „Die Fort- und Weiterbildung war zu teuer/Ich konnte sie mir nicht leisten" wurde von mindestens 20 Prozent der Befragten in Irland, Polen, der Russischen Föderation und den Vereinigten Staaten genannt und von höchstens 9 Prozent der Befragten in Deutschland, Finnland, Flandern (Belgien), Japan und Norwegen (Tab. C6.5). 
Abbildung C6.5

Teilnahme an formaler und/oder nicht formaler Fort- und Weiterbildung und Wunsch nach Lernaktivitäten (2012) 25- bis 64-Jährige

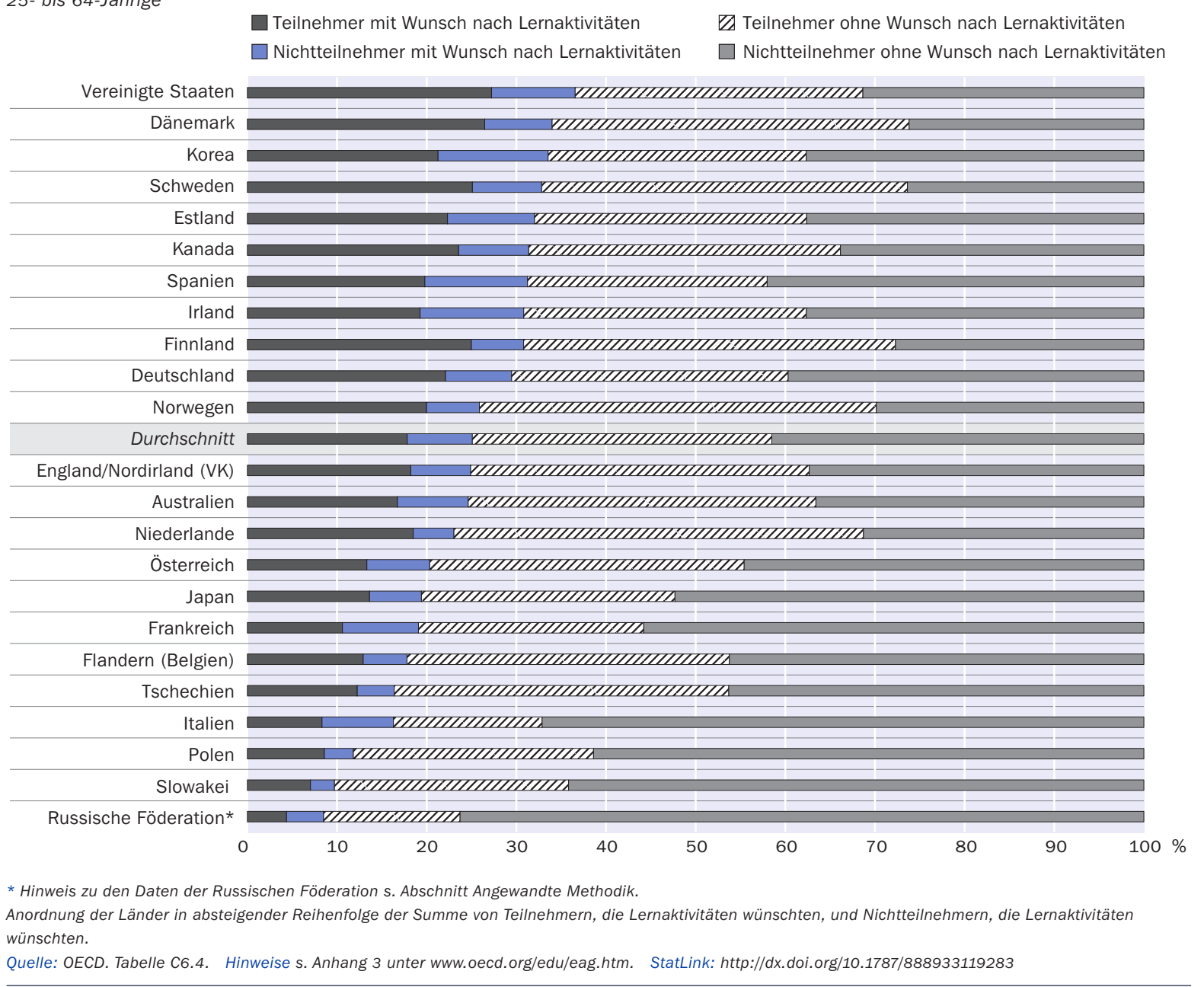

Die für eine Nichtteilnahme angegebenen Gründe unterschieden sich auch zwischen Erwachsenen, die an formaler und/oder nicht formaler Fort- und Weiterbildung teilgenommen haben, und nicht teilnehmenden Erwachsenen. Im Durchschnitt der Länder gaben 34 Prozent der Teilnehmer und 22 Prozent der Nichtteilnehmer „Ich hatte beruflich zu viel zu tun" als Grund an. In jedem Land wurde die Arbeitsbelastung häufiger von Teilnehmern als von Nichtteilnehmern genannt. Mit rund 2I Prozent fühlten sich Nichtteilnehmer häufiger durch die Verantwortung für Kinder und Familie gehindert als Teilnehmer (I2 Prozent). „Die Fort- und Weiterbildung fand zu einer

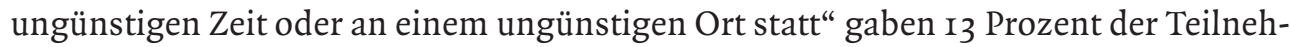
mer und 8 Prozent der Nichtteilnehmer an. In jedem an der Erhebung teilnehmenden Land nannten Teilnehmer diesen Grund häufiger als Nichtteilnehmer (Tab. C6.5).

\section{Vergleich zwischen der Teilnahme an formalen und an nicht formalen Bildungsmaßnahmen}

Die Länder unterscheiden sich in dem Ausmaß, in dem Erwachsene für ihre Fort- und Weiterbildungsbedürfnisse Zugang zum formalen Bildungssystem haben. Im Durchschnitt aller Länder beteiligen sich Io Prozent der 25- bis 64-Jährigen an formalen Bil- 
dungsmaßnahmen. Die Bandbreite reichtvon 17 Prozent in Australien bis zu 2 Prozent in Japan. In Kanada, allen angelsächsischen Ländern (d. h. Australien, England/Nordirland [VK], Irland und den Vereinigten Staaten) sowie allen nordischen Ländern (d. h. Dänemark, Finnland, Norwegen und Schweden) ist der Anteil der Erwachsenen, die formale Bildungseinrichtungen besuchen, überdurchschnittlich hoch. Abgesehen von diesen beiden Gruppen weisen nur die Niederlande und Spanien überdurchschnittlich hohe Teilnahmequoten auf. Im Gegensatz dazu nehmen in Frankreich, Japan und Korea weniger als 5 Prozent der Erwachsenen an formalen Bildungsmaßnahmen teil (Tab. C6.3).

Im Allgemeinen weisen Länder mit hohen Teilnahmequoten Erwachsener bei formaler Bildung auch hohe Teilnahmequoten Erwachsener bei nicht formalen Bildungsmaßnahmen auf. Das Verhältnis (Korrelation $=0,66$ ) ist nicht durchgehend gegeben: In Korea und Tschechien sind niedrige Teilnahmequoten bei formaler Bildung in Kombination mit durchschnittlichen Quoten bei nicht formalen Bildungsmaßnahmen zu beobachten.

Durchschnittlich zwei Drittel der Teilnehmer an formalen Bildungsmaßnahmen besuchen auch nicht formale Bildungsmaßnahmen, ein Hinweis darauf, dass diese Personen sich bemühen, verschiedenste Bildungsmöglichkeiten wahrzunehmen. Abbildung C6.6 zeigt, dass etwa die Hälfte der Erwachsenen weder an formalen noch an nicht formalen Fort- und Weiterbildungsmaßnahmen teilnimmt.

Abbildung C6.6

Teilnahme an formaler und/oder nicht formaler Fort- und Weiterbildung (2012)

25- bis 64-Jährige

$\square$ Nur formale Fort- und Weiterbildung

Nicht formale Fort- und Weiterbildung

Formale und nicht formale Fort- und Weiterbildung

Keine Teilnahme

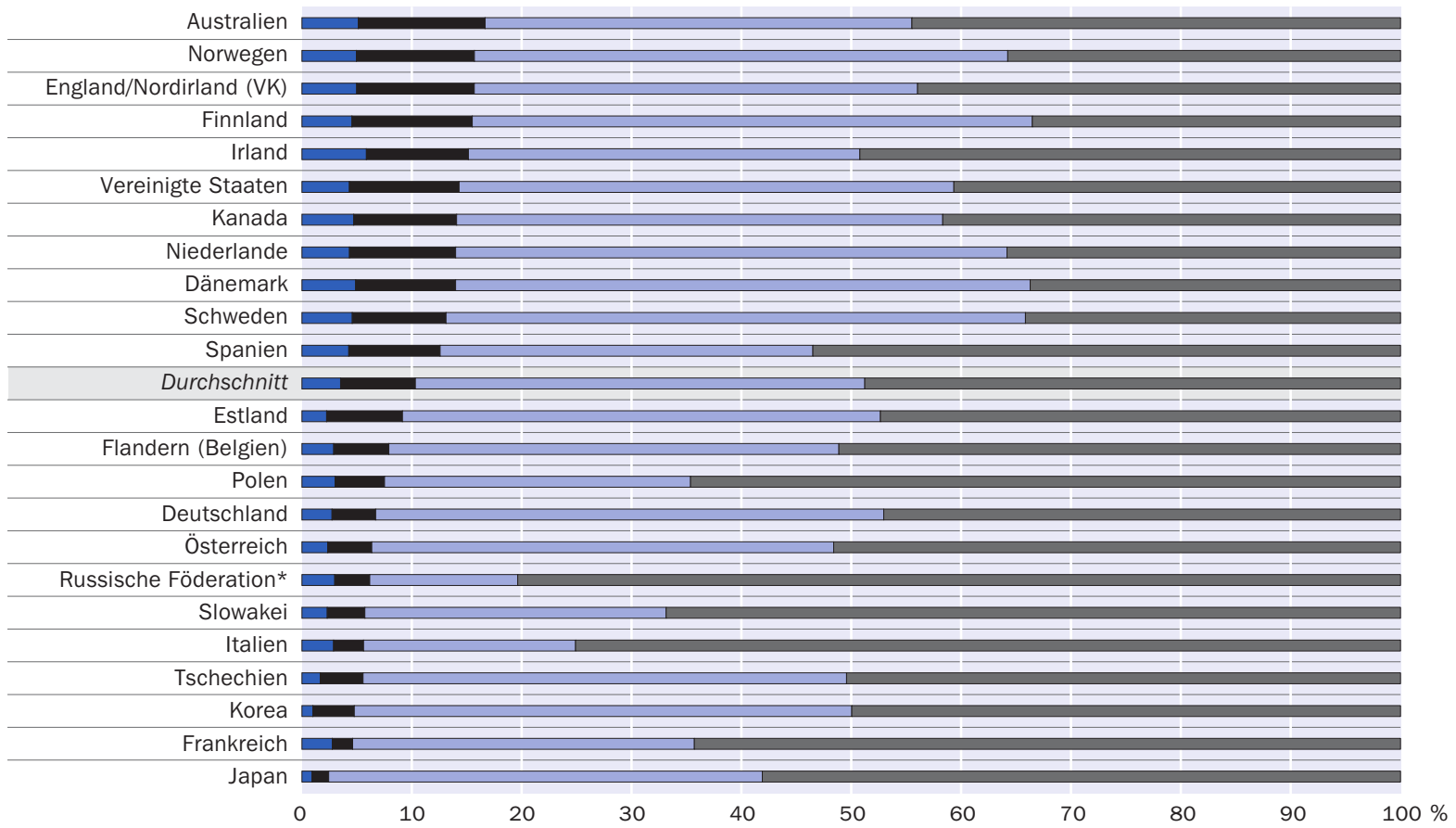

* Hinweis zu den Daten der Russischen Föderation s. Abschnitt Angewandte Methodik.

Anordnung der Länder in absteigender Reihenfolge der Summe der Teilnehmer an nur formaler sowie an formaler und nicht formaler Fort- und Weiterbildung. Quelle: OECD. Tabelle C6.3. Hinweise s. Anhang 3 unter www.oecd.org/edu/eag.htm. StatLink: http://dx.doi.org/10.1787/888933119302 


\section{Definitionen}

Altersgruppen: Erwachsene bezieht sich auf 25- bis 64-Jährige, jüngere Erwachsene auf 25- bis 34-Jährige und ältere Erwachsene auf 55- bis 64-Jährige.

Formale Fort- und Weiterbildung wird als geplante Bildung definiert, die durch das System der Schulen, Universitäten und anderen formalen Bildungseinrichtungen vermittelt wird, es ist normalerweise eine aufeinander aufbauende Abfolge von Vollzeitunterricht für Kinder bzw. junge Menschen. Bei den Anbietern kann es sich um öffentliche oder private Einrichtungen handeln.

Bildungsbereiche: Unterhalb des Sekundarbereichs II umfasst die ISCED-Stufen o, I, 2 und ${ }_{3} \mathrm{C}$ (kurz), Sekundarbereich II bzw. postsekundarer, nicht tertiärer Bereich die ISCED-Stufen ${ }_{3} \mathrm{C}$ (lang), 3B, 3A und 4 und Tertiärbereich die ISCED-Stufen 5A, 5B und 6. Erläuterungen $\mathrm{zu}$ allen Bildungsbereichen gemäß ISCED-Klassifizierung s. Hinweise für den Leser im vorderen Teil der Publikation.

Nicht formale Fort- und Weiterbildung wird definiert als fortgesetzte Bildungsmaßnahme, die nicht genau den vorstehenden Definitionen der formalen Fort- und Weiterbildung entspricht. Somit kann nicht formale Bildung sowohl innerhalb als auch außerhalb von Bildungseinrichtungen stattfinden und sich an alle Altersgruppen wenden. Je nach den landesspezifischen Gegebenheiten können hierzu Bildungsmaßnahmen gehören, die die Lesekompetenz Erwachsener fördern, Grundbildungsmaßnahmen für nicht zur Schule gehende Kinder sowie Maßnahmen, die berufliche Kompetenzen, Kompetenzen zur Lebensbewältigung oder Allgemeinbildung vermitteln. Die Erhebung zu den grundlegenden Kompetenzen Erwachsener verwendet eine Liste möglicher nicht formaler Bildungsaktivitäten einschließlich Fernstudium, Privatunterricht, organisierter Unterrichtseinheiten für eine Ausbildung am Arbeitsplatz und Workshops oder Seminare, um die Befragten zu veranlassen, sämtliche Lernaktivitäten aufzuführen, an denen sie in den vorangegangenen I2 Monaten teilgenommen haben. Dabei können diese Lernaktivitäten auch von kurzer Dauer sein.

Bildungsstand der Eltern: Ausbildung unterhalb Sekundarbereich II bedeutet, dass beide Elternteile eine Ausbildung auf ISCED-Stufe o, I, 2 oder ${ }_{3} \mathrm{C}$ (kurz) erhalten haben, Abschluss im Sekundarbereich II oder postsekundaren, nicht tertiären Bereich bedeutet, dass mindestens ein Elternteil (Vater oder Mutter) einen Abschluss auf ISCED-Stufe $3 \mathrm{~A},{ }_{3} \mathrm{~B},{ }_{3} \mathrm{C}$ (lang) oder 4 erworben hat, und Abschluss im Tertiärbereich, dass mindestens ein Elternteil (Vater oder Mutter) einen Abschluss auf ISCED-Stufe 5A, 5B oder 6 erworben hat. Eine Darstellung aller ISCED-Bereiche findet sich am Anfang dieser Publikation in den Hinweisen für den Leser.

\section{Angewandte Methodik}

Alle Daten basieren auf der Erhebung zu den grundlegenden Kompetenzen Erwachsener (Survey of Adult Skills) (PIAAC) (20I2). PIAAC steht für das OECD Programme for the International Assessment of Adult Competencies der OECD. Weitere Informationen 
s. Erhebung zu den grundlegenden Kompetenzen Erwachsener im vorderen Teil dieser Publikation sowie Anhang 3 unter www.oecd.org/edu/eag.htm.

Hinweis zu den Daten aus der Russischen Föderation in der Erhebung zu den grundlegenden Kompetenzen Erwachsener (PIAAC)

$\mathrm{Zu}$ beachten ist, dass die Bevölkerung des Stadtgebiets Moskau in der Stichprobe für die Russische Föderation nicht berücksichtigt wurde. Die veröffentlichten Daten repräsentieren daher nicht die gesamte Wohnbevölkerung im Alter von I 6 bis 65 Jahren in Russland, sondern nur die Wohnbevölkerung Russlands ohne die im Stadtgebiet Moskau lebende Bevölkerung. Weitere Informationen zu den Daten aus der Russischen Föderation sowie anderer Länder finden sich im Technical Report of the Survey of Adult Skills (OECD, i. E.).

\section{Weiterführende Informationen}

OECD (2013), OECD Skills Outlook 2013: First Results from the Survey of Adult Skills, OECD Publishing, Paris, http://dx.doi.org/10.1787/9789264204256-en.

OECD (20II), Bildung auf einen Blick 2011 - OECD-Indikatoren, W. Bertelsmann Verlag, Bielefeld.

OECD/Statistics Canada (20II), Literacy for Life: Further Results from the Adult Literacy and Life Skills Survey, OECD Publishing, Paris, www.statcan.gc.ca/pub/89-604-x/89-604x2011001-eng.pdf.

\section{Tabellen Indikator C6}

StatLink: http://dx.doi.org/10.1787/888933119093

Tabelle C6.I (L): Teilnahme an formaler und/oder nicht formaler Fort- und Weiterbildung, nach Lesekompetenz (2012)

WEB Table C6.I (N): Participation in formal and/or non-formal education, by numeracy proficiency level (Teilnahme an formaler und/oder nicht formaler Fort- und Weiterbildung, nach alltagsmathematischer Kompetenz) (2012)

Tabelle C6.2a (L): Teilnahme an formaler und/oder nicht formaler Fort- und Weiterbildung, nach Lesekompetenz und Bildungsstand (2012)

WEB Table C6.2a (N): Participation in formal and/or non-formal education, by numeracy proficiency level and educational attainment (Teilnahme an formaler und/oder nicht formaler Fort- und Weiterbildung, nach alltagsmathematischer Kompetenz und Bildungsstand) (20I2) 
WEB Table C6.2b (L): Participation in formal and/or non-formal education, by literacy proficiency level and age group (Teilnahme an formaler und/oder nicht formaler Fort- und Weiterbildung, nach Lesekompetenz und Altersgruppe) (2012)

WEB Table C6.2b (N): Participation in formal and/or non-formal education, by numeracy proficiency level and age group (Teilnahme an formaler und/oder nicht formaler Fort- und Weiterbildung, nach alltagsmathematischer Kompetenz und Altersgruppe) (2012)

WEB Table C6.2c (L): Participation in formal and/or non-formal education, by literacy proficiency level and gender (Teilnahme an formaler und/oder nicht formaler Fort- und Weiterbildung, nach Lesekompetenz und Geschlecht) (20I2)

WEB Table C6.2c (N): Participation in formal and/or non-formal education, by numeracy proficiency level and gender (Teilnahme an formaler und/oder nicht formaler Fort- und Weiterbildung, nach alltagsmathematischer Kompetenz und Geschlecht) (20I2)

WEB Table C6.2d (L): Participation in formal and/or non-formal education, by literacy proficiency level and labour market status(Teilnahme an formaler und/ oder nicht formaler Fort- und Weiterbildung, nach Lesekompetenz und Erwerbsstatus) (20I2)

WEB Table C6.2d (N): Participation in formal and/or non-formal education, by numeracy proficiency level and labour market status (Teilnahme an formaler und/oder nicht formaler Fort- und Weiterbildung, nach alltagsmathematischer Kompetenz und Erwerbsstatus) (2012)

WEB Table C6.2e (L): Participation in formal and/or non-formal education, by literacy proficiency level and parents' level of education (Teilnahme an formaler und/oder nicht formaler Fort- und Weiterbildung, nach Lesekompetenz und Bildungsstand der Eltern) (2012)

WEB Table C6.2e (N): Participation in formal and/or non-formal education, by numeracy proficiency level and parents' level of education (Teilnahme an formaler und/oder nicht formaler Fort- und Weiterbildung, nach alltagsmathematischer Kompetenz und Bildungsstand der Eltern) (2012)

Tabelle C6.3: Teilnahme an formaler und/oder nicht formaler Fort- und Weiterbildung, nach Geschlecht (2012)

Tabelle C6.4: Teilnahme an formaler und/oder nicht formaler Fort- und Weiterbildung und Wunsch nach Lernaktivitäten (2012)

Tabelle C6.5: Für die Nichtteilnahme an weiteren/jeglichen Lernaktivitäten angegebene Gründe, nach Teilnehmer bzw. Nichtteilnehmer an formaler und/oder nicht formaler Fort- und Weiterbildung (2012) 
Tabelle C6.1 (L)

Teilnahme an formaler und/oder nicht formaler Fort- und Weiterbildung, nach Lesekompetenz (2012)

Erhebung zu den grundlegenden Kompetenzen Erwachsener, 25- bis 64-Jährige

\begin{tabular}{|c|c|c|c|c|c|c|c|c|c|c|}
\hline & \multicolumn{2}{|c|}{ Stufe $0 / 1$} & \multicolumn{2}{|c|}{ Stufe 2} & \multicolumn{2}{|c|}{ Stufe 3} & \multicolumn{2}{|c|}{ Stufe $4 / 5$} & \multicolumn{2}{|c|}{ Gesamt } \\
\hline & $\%$ & S.F. & $\%$ & S.F. & $\%$ & S.F. & $\%$ & S.F. & $\%$ & S.F. \\
\hline & (1) & (2) & (3) & (4) & (5) & (6) & (7) & (8) & (9) & (10) \\
\hline \multicolumn{11}{|l|}{$\begin{array}{l}\text { OECD } \\
\text { Nationale Einheiten }\end{array}$} \\
\hline Australien & 28 & $(2,3)$ & 45 & $(1,8)$ & 63 & $(1,3)$ & 78 & $(2,0)$ & 56 & $(0,7)$ \\
\hline Österreich & 27 & $(2,6)$ & 41 & $(1,5)$ & 60 & $(1,5)$ & 74 & $(3,3)$ & 48 & $(0,7)$ \\
\hline Kanada & 34 & $(1,6)$ & 51 & $(1,1)$ & 68 & $(1,0)$ & 80 & $(1,5)$ & 58 & $(0,6)$ \\
\hline Tschechien & 32 & $(4,0)$ & 44 & $(2,1)$ & 56 & $(2,1)$ & 71 & $(4,3)$ & 50 & $(1,2)$ \\
\hline Dänemark & 42 & $(1,8)$ & 61 & $(1,4)$ & 75 & $(1,2)$ & 86 & $(2,2)$ & 66 & $(0,6)$ \\
\hline Estland & 33 & $(2,3)$ & 46 & $(1,6)$ & 59 & $(1,3)$ & 77 & $(2,3)$ & 53 & $(0,7)$ \\
\hline Finnland & 38 & $(2,6)$ & 55 & $(1,7)$ & 72 & $(1,1)$ & 84 & $(1,3)$ & 66 & $(0,7)$ \\
\hline Frankreich & 20 & $(1,2)$ & 31 & $(1,0)$ & 47 & $(1,4)$ & 60 & $(3,0)$ & 36 & $(0,6)$ \\
\hline Deutschland & 29 & $(2,2)$ & 46 & $(2,0)$ & 64 & $(1,6)$ & 79 & $(2,6)$ & 53 & $(1,0)$ \\
\hline Irland & 33 & $(2,3)$ & 46 & $(1,3)$ & 59 & $(1,5)$ & 75 & $(2,9)$ & 51 & $(0,7)$ \\
\hline Italien & 14 & $(1,5)$ & 21 & $(1,4)$ & 40 & $(2,3)$ & 57 & $(6,1)$ & 25 & $(1,0)$ \\
\hline Japan & 22 & $(3,5)$ & 30 & $(2,0)$ & 43 & $(1,3)$ & 56 & $(2,0)$ & 42 & $(0,8)$ \\
\hline Korea & 25 & $(1,9)$ & 43 & $(1,4)$ & 62 & $(1,5)$ & 77 & $(2,9)$ & 50 & $(0,8)$ \\
\hline Niederlande & 41 & $(3,1)$ & 53 & $(1,8)$ & 72 & $(1,2)$ & 81 & $(1,7)$ & 64 & $(0,6)$ \\
\hline Norwegen & 46 & $(2,9)$ & 55 & $(1,9)$ & 71 & $(1,3)$ & 78 & $(2,0)$ & 64 & $(0,7)$ \\
\hline Polen & 18 & $(2,0)$ & 29 & $(1,6)$ & 45 & $(1,7)$ & 65 & $(3,2)$ & 35 & $(0,8)$ \\
\hline Slowakei & 13 & $(2,0)$ & 26 & $(1,4)$ & 40 & $(1,4)$ & 59 & $(3,9)$ & 33 & $(0,8)$ \\
\hline Spanien & 29 & $(1,5)$ & 44 & $(1,3)$ & 63 & $(1,9)$ & 79 & $(3,9)$ & 47 & $(0,7)$ \\
\hline Schweden & 42 & $(3,0)$ & 58 & $(2,0)$ & 73 & $(1,3)$ & 83 & $(1,9)$ & 66 & $(0,8)$ \\
\hline $\begin{array}{l}\text { Vereinigte Staaten } \\
\text { Subnationale Einheiten }\end{array}$ & 37 & $(2,5)$ & 52 & $(2,1)$ & 70 & $(1,3)$ & 82 & $(2,5)$ & 59 & $(1,1)$ \\
\hline Flandern (Belgien) & 27 & $(1,9)$ & 40 & $(1,7)$ & 58 & $(1,4)$ & 68 & $(2,4)$ & 49 & $(0,8)$ \\
\hline England (VK) & 38 & $(2,6)$ & 49 & $(1,8)$ & 63 & $(1,7)$ & 76 & $(2,4)$ & 56 & $(0,9)$ \\
\hline Nordirland (VK) & 26 & $(2,5)$ & 43 & $(2,2)$ & 60 & $(2,1)$ & 74 & $(4,2)$ & 49 & $(0,9)$ \\
\hline England/Nordirland (VK) & 38 & $(2,5)$ & 48 & $(1,7)$ & 63 & $(1,6)$ & 76 & $(2,3)$ & 56 & $(0,9)$ \\
\hline Durchschnitt & 30 & $(0,5)$ & 44 & $(0,4)$ & 60 & $(0,3)$ & 74 & $(0,6)$ & 51 & $(0,2)$ \\
\hline \multicolumn{11}{|l|}{ Partnerländer } \\
\hline Russische Föderation* & 32 & $(6,8)$ & 38 & $(7,7)$ & 26 & $(6,7)$ & 4 & $(2,9)$ & 15 & $(2,5)$ \\
\hline
\end{tabular}

* Hinweis zu den Daten der Russischen Föderation s. Abschnitt Angewandte Methodik.

Quelle: OECD. Survey of Adult Skills (PIAAC) (2012). PIAAC steht für das OECD Programme for the International Assessment of Adult Competencies.

Hinweise s. Anhang 3 unter www. oecd.org/edu/eag.htm. StatLink: http://dx.doi.org/10.1787/888933119112

Erläuterung der Kennzeichnung fehlender Daten s. Hinweise für den Leser. 
Teilnahme an formaler und/oder nicht formaler Fort- und Weiterbildung, nach Lesekompetenz und Bildungsstand (2012) Erhebung zu den grundlegenden Kompetenzen Erwachsener, 25- bis 64-Jährige

\begin{tabular}{|c|c|c|c|c|c|c|c|c|c|c|c|}
\hline & \multirow[t]{3}{*}{ Bildungsstand } & \multicolumn{2}{|c|}{ Stufe $0 / 1$} & \multicolumn{2}{|c|}{ Stufe 2} & \multicolumn{2}{|c|}{ Stufe 3} & \multicolumn{2}{|c|}{ Stufe $4 / 5$} & \multicolumn{2}{|c|}{ Gesamt } \\
\hline & & $\%$ & S.F. & $\%$ & S.F. & $\%$ & S.F. & $\%$ & S.F. & $\%$ & S.F. \\
\hline & & (1) & (2) & (3) & (4) & (5) & (6) & (7) & (8) & (9) & (10) \\
\hline $\begin{array}{l}\text { OECD } \\
\text { Nationale Eir }\end{array}$ & & & & & & & & & & & \\
\hline Australien & $\begin{array}{l}\text { Ausbildung unterhalb Sekundarbereich II } \\
\text { Abschluss im Sekundarbereich II/ } \\
\text { postsekundaren, nicht tertiären Bereich } \\
\text { Abschluss im Tertiärbereich }\end{array}$ & $\begin{array}{l}19 \\
31 \\
59\end{array}$ & $\begin{array}{l}(2,9) \\
(4,7) \\
(6,1)\end{array}$ & $\begin{array}{l}31 \\
45 \\
66\end{array}$ & $\begin{array}{l}(2,6) \\
(3,2) \\
(3,3)\end{array}$ & $\begin{array}{l}44 \\
56 \\
77\end{array}$ & $\begin{array}{l}(3,3) \\
(2,4) \\
(1,8)\end{array}$ & $\begin{array}{l}60 \\
67 \\
84\end{array}$ & $\begin{array}{l}(8,9) \\
(4,7) \\
(1,9)\end{array}$ & $\begin{array}{l}32 \\
51 \\
76\end{array}$ & $\begin{array}{l}(1,5) \\
(1,1) \\
(1,1)\end{array}$ \\
\hline Österreich & $\begin{array}{l}\text { Ausbildung unterhalb Sekundarbereich II } \\
\text { Abschluss im Sekundarbereich II/ } \\
\text { postsekundaren, nicht tertiären Bereich } \\
\text { Abschluss im Tertiärbereich }\end{array}$ & $\begin{array}{l}20 \\
31 \\
53\end{array}$ & $\begin{array}{r}(3,2) \\
(3,6) \\
(10,3)\end{array}$ & $\begin{array}{l}23 \\
44 \\
58\end{array}$ & $\begin{array}{l}(2,9) \\
(1,7) \\
(4,0)\end{array}$ & $\begin{array}{l}37 \\
57 \\
74\end{array}$ & $\begin{array}{l}(5,4) \\
(1,9) \\
(2,3)\end{array}$ & $\begin{array}{r}c \\
67 \\
80\end{array}$ & $\begin{array}{r}\text { c } \\
(5,0) \\
(3,7)\end{array}$ & $\begin{array}{l}25 \\
48 \\
71\end{array}$ & $\begin{array}{l}(1,8) \\
(0,9) \\
(1,5)\end{array}$ \\
\hline Kanada & $\begin{array}{l}\text { Ausbildung unterhalb Sekundarbereich II } \\
\text { Abschluss im Sekundarbereich II/ } \\
\text { postsekundaren, nicht tertiären Bereich } \\
\text { Abschluss im Tertiärbereich }\end{array}$ & $\begin{array}{l}22 \\
33 \\
50\end{array}$ & $\begin{array}{l}(2,0) \\
(2,5) \\
(3,4)\end{array}$ & $\begin{array}{l}29 \\
47 \\
61\end{array}$ & $\begin{array}{l}(3,0) \\
(1,7) \\
(1,7)\end{array}$ & $\begin{array}{l}35 \\
59 \\
75\end{array}$ & $\begin{array}{l}(5,0) \\
(1,7) \\
(1,3)\end{array}$ & $\begin{array}{r}c \\
71 \\
82\end{array}$ & $\begin{array}{r}\text { C } \\
(3,7) \\
(1,7)\end{array}$ & $\begin{array}{l}26 \\
50 \\
70\end{array}$ & $\begin{array}{l}(1,3) \\
(1,0) \\
(0,8)\end{array}$ \\
\hline Tschechien & $\begin{array}{l}\text { Ausbildung unterhalb Sekundarbereich II } \\
\text { Abschluss im Sekundarbereich II/ } \\
\text { postsekundaren, nicht tertiären Bereich } \\
\text { Abschluss im Tertiärbereich }\end{array}$ & $\begin{array}{r}14 \\
38 \\
c\end{array}$ & $\begin{array}{r}(4,7) \\
(5,0) \\
\text { C }\end{array}$ & $\begin{array}{l}18 \\
45 \\
65\end{array}$ & $\begin{array}{l}(5,0) \\
(2,4) \\
(6,4)\end{array}$ & $\begin{array}{l}27 \\
52 \\
70\end{array}$ & $\begin{array}{r}(10,0) \\
(2,2) \\
(3,7)\end{array}$ & $\begin{array}{r}c \\
60 \\
78\end{array}$ & $\begin{array}{r}\mathrm{C} \\
(8,3) \\
(4,7)\end{array}$ & $\begin{array}{l}19 \\
48 \\
71\end{array}$ & $\begin{array}{l}(2,6) \\
(1,4) \\
(2,6)\end{array}$ \\
\hline Dänemark & $\begin{array}{l}\text { Ausbildung unterhalb Sekundarbereich II } \\
\text { Abschluss im Sekundarbereich II/ } \\
\text { postsekundaren, nicht tertiären Bereich } \\
\text { Abschluss im Tertiärbereich }\end{array}$ & $\begin{array}{l}33 \\
45 \\
64\end{array}$ & $\begin{array}{l}(2,8) \\
(3,2) \\
(4,3)\end{array}$ & $\begin{array}{l}46 \\
60 \\
77\end{array}$ & $\begin{array}{l}(3,5) \\
(2,0) \\
(2,0)\end{array}$ & $\begin{array}{l}59 \\
68 \\
83\end{array}$ & $\begin{array}{l}(5,4) \\
(1,9) \\
(1,3)\end{array}$ & $\begin{array}{r}c \\
83 \\
88\end{array}$ & $\begin{array}{r}c \\
(5,5) \\
(2,0)\end{array}$ & $\begin{array}{l}44 \\
62 \\
82\end{array}$ & $\begin{array}{l}(1,9) \\
(1,0) \\
(0,7)\end{array}$ \\
\hline Estland & $\begin{array}{l}\text { Ausbildung unterhalb Sekundarbereich II } \\
\text { Abschluss im Sekundarbereich II/ } \\
\text { postsekundaren, nicht tertiären Bereich } \\
\text { Abschluss im Tertiärbereich }\end{array}$ & $\begin{array}{l}23 \\
31 \\
51\end{array}$ & $\begin{array}{l}(2,8) \\
(3,1) \\
(4,4)\end{array}$ & $\begin{array}{l}28 \\
39 \\
64\end{array}$ & $\begin{array}{l}(3,0) \\
(2,0) \\
(2,3)\end{array}$ & $\begin{array}{l}34 \\
48 \\
72\end{array}$ & $\begin{array}{l}(4,3) \\
(1,8) \\
(1,6)\end{array}$ & $\begin{array}{r}c \\
64 \\
83\end{array}$ & $\begin{array}{r}c \\
(4,2) \\
(2,5)\end{array}$ & $\begin{array}{l}28 \\
43 \\
70\end{array}$ & $\begin{array}{l}(1,4) \\
(0,9) \\
(1,0)\end{array}$ \\
\hline Finnland & $\begin{array}{l}\text { Ausbildung unterhalb Sekundarbereich II } \\
\text { Abschluss im Sekundarbereich II/ } \\
\text { postsekundaren, nicht tertiären Bereich } \\
\text { Abschluss im Tertiärbereich }\end{array}$ & $\begin{array}{l}24 \\
40 \\
71\end{array}$ & $\begin{array}{l}(4,1) \\
(3,8) \\
(6,7)\end{array}$ & $\begin{array}{l}34 \\
56 \\
71\end{array}$ & $\begin{array}{l}(3,6) \\
(2,2) \\
(2,6)\end{array}$ & $\begin{array}{l}44 \\
68 \\
81\end{array}$ & $\begin{array}{l}(4,8) \\
(1,9) \\
(1,5)\end{array}$ & $\begin{array}{r}c \\
77 \\
88\end{array}$ & $\begin{array}{r}c \\
(3,6) \\
(1,3)\end{array}$ & $\begin{array}{l}34 \\
62 \\
81\end{array}$ & $\begin{array}{l}(2,2) \\
(1,0) \\
(0,9)\end{array}$ \\
\hline Frankreich & $\begin{array}{l}\text { Ausbildung unterhalb Sekundarbereich II } \\
\text { Abschluss im Sekundarbereich II/ } \\
\text { postsekundaren, nicht tertiären Bereich } \\
\text { Abschluss im Tertiärbereich }\end{array}$ & $\begin{array}{l}15 \\
26 \\
33\end{array}$ & $\begin{array}{l}(1,4) \\
(2,2) \\
(5,1)\end{array}$ & $\begin{array}{l}18 \\
32 \\
47\end{array}$ & $\begin{array}{l}(1,8) \\
(1,4) \\
(2,6)\end{array}$ & $\begin{array}{l}26 \\
37 \\
60\end{array}$ & $\begin{array}{l}(3,6) \\
(1,9) \\
(1,8)\end{array}$ & $\begin{array}{r}c \\
44 \\
65\end{array}$ & $\begin{array}{r}c \\
(6,9) \\
(3,3)\end{array}$ & $\begin{array}{l}17 \\
33 \\
56\end{array}$ & $\begin{array}{l}(1,0) \\
(1,0) \\
(1,1)\end{array}$ \\
\hline Deutschland & $\begin{array}{l}\text { Ausbildung unterhalb Sekundarbereich II } \\
\text { Abschluss im Sekundarbereich II/ } \\
\text { postsekundaren, nicht tertiären Bereich } \\
\text { Abschluss im Tertiärbereich }\end{array}$ & $\begin{array}{l}17 \\
31 \\
47\end{array}$ & $\begin{array}{l}(3,6) \\
(3,1) \\
(7,2)\end{array}$ & $\begin{array}{l}24 \\
44 \\
62\end{array}$ & $\begin{array}{l}(5,0) \\
(2,6) \\
(3,4)\end{array}$ & $\begin{array}{l}40 \\
57 \\
73\end{array}$ & $\begin{array}{r}(10,1) \\
(2,5) \\
(2,1)\end{array}$ & $\begin{array}{r}c \\
73 \\
82\end{array}$ & $\begin{array}{r}\text { C } \\
(4,3) \\
(2,8)\end{array}$ & $\begin{array}{l}22 \\
47 \\
71\end{array}$ & $\begin{array}{l}(2,7) \\
(1,4) \\
(1,3)\end{array}$ \\
\hline Irland & $\begin{array}{l}\text { Ausbildung unterhalb Sekundarbereich II } \\
\text { Abschluss im Sekundarbereich II/ } \\
\text { postsekundaren, nicht tertiären Bereich } \\
\text { Abschluss im Tertiärbereich }\end{array}$ & $\begin{array}{l}27 \\
35 \\
59\end{array}$ & $\begin{array}{l}(2,6) \\
(3,6) \\
(7,1)\end{array}$ & $\begin{array}{l}30 \\
46 \\
66\end{array}$ & $\begin{array}{l}(2,7) \\
(1,9) \\
(2,8)\end{array}$ & $\begin{array}{l}32 \\
50 \\
74\end{array}$ & $\begin{array}{l}(5,3) \\
(2,2) \\
(1,8)\end{array}$ & $\begin{array}{r}c \\
60 \\
82\end{array}$ & $\begin{array}{r}c \\
(7,4) \\
(2,8)\end{array}$ & $\begin{array}{l}29 \\
47 \\
72\end{array}$ & $\begin{array}{l}(1,5) \\
(1,2) \\
(1,1)\end{array}$ \\
\hline Italien & $\begin{array}{l}\text { Ausbildung unterhalb Sekundarbereich II } \\
\text { Abschluss im Sekundarbereich II/ } \\
\text { postsekundaren, nicht tertiären Bereich } \\
\text { Abschluss im Tertiärbereich }\end{array}$ & $\begin{array}{l}11 \\
19 \\
36\end{array}$ & $\begin{array}{l}(1,8) \\
(3,1) \\
(6,7)\end{array}$ & $\begin{array}{l}12 \\
26 \\
51\end{array}$ & $\begin{array}{l}(1,8) \\
(2,2) \\
(4,8)\end{array}$ & $\begin{array}{l}16 \\
40 \\
65\end{array}$ & $\begin{array}{l}(3,9) \\
(2,8) \\
(3,8)\end{array}$ & $\begin{array}{r}c \\
46 \\
70\end{array}$ & $\begin{array}{r}c \\
(9,5) \\
(8,1)\end{array}$ & $\begin{array}{l}12 \\
31 \\
59\end{array}$ & $\begin{array}{l}(1,2) \\
(1,4) \\
(2,1)\end{array}$ \\
\hline Japan & $\begin{array}{l}\text { Ausbildung unterhalb Sekundarbereich II } \\
\text { Abschluss im Sekundarbereich II/ } \\
\text { postsekundaren, nicht tertiären Bereich } \\
\text { Abschluss im Tertiärbereich }\end{array}$ & $\begin{array}{r}16 \\
24 \\
c\end{array}$ & $\begin{array}{r}(4,7) \\
(6,2) \\
\mathrm{C}\end{array}$ & $\begin{array}{l}21 \\
27 \\
46\end{array}$ & $\begin{array}{l}(4,0) \\
(3,2) \\
(3,3)\end{array}$ & $\begin{array}{l}25 \\
35 \\
54\end{array}$ & $\begin{array}{l}(4,0) \\
(2,4) \\
(2,0)\end{array}$ & $\begin{array}{r}c \\
40 \\
62\end{array}$ & $\begin{array}{r}c \\
(3,8) \\
(2,2)\end{array}$ & $\begin{array}{l}22 \\
32 \\
56\end{array}$ & $\begin{array}{l}(2,2) \\
(1,2) \\
(1,1)\end{array}$ \\
\hline Korea & $\begin{array}{l}\text { Ausbildung unterhalb Sekundarbereich II } \\
\text { Abschluss im Sekundarbereich II/ } \\
\text { postsekundaren, nicht tertiären Bereich } \\
\text { Abschluss im Tertiärbereich }\end{array}$ & $\begin{array}{l}15 \\
32 \\
65\end{array}$ & $\begin{array}{l}(2,0) \\
(3,6) \\
(8,0)\end{array}$ & $\begin{array}{l}24 \\
39 \\
62\end{array}$ & $\begin{array}{l}(2,5) \\
(2,1) \\
(2,4)\end{array}$ & $\begin{array}{l}31 \\
51 \\
73\end{array}$ & $\begin{array}{l}(6,1) \\
(2,4) \\
(1,7)\end{array}$ & $\begin{array}{r}c \\
62 \\
82\end{array}$ & $\begin{array}{r}c \\
(8,1) \\
(3,6)\end{array}$ & $\begin{array}{l}21 \\
43 \\
71\end{array}$ & $\begin{array}{l}(1,3) \\
(1,3) \\
(1,1)\end{array}$ \\
\hline Niederlande & $\begin{array}{l}\text { Ausbildung unterhalb Sekundarbereich II } \\
\text { Abschluss im Sekundarbereich II/ } \\
\text { postsekundaren, nicht tertiären Bereich } \\
\text { Abschluss im Tertiärbereich }\end{array}$ & $\begin{array}{l}36 \\
50 \\
63\end{array}$ & $\begin{array}{r}(3,4) \\
(6,0) \\
(11,0)\end{array}$ & $\begin{array}{l}38 \\
59 \\
75\end{array}$ & $\begin{array}{l}(2,7) \\
(2,6) \\
(3,7)\end{array}$ & $\begin{array}{l}51 \\
70 \\
82\end{array}$ & $\begin{array}{l}(3,3) \\
(1,9) \\
(1,6)\end{array}$ & $\begin{array}{l}70 \\
70 \\
86\end{array}$ & $\begin{array}{r}(11,2) \\
(3,8) \\
(1,9)\end{array}$ & $\begin{array}{l}42 \\
65 \\
82\end{array}$ & $\begin{array}{l}(1,3) \\
(1,3) \\
(0,9)\end{array}$ \\
\hline Norwegen & $\begin{array}{l}\text { Ausbildung unterhalb Sekundarbereich II } \\
\text { Abschluss im Sekundarbereich II/ } \\
\text { postsekundaren, nicht tertiären Bereich } \\
\text { Abschluss im Tertiärbereich }\end{array}$ & $\begin{array}{l}37 \\
51 \\
61\end{array}$ & $\begin{array}{l}(4,3) \\
(4,4) \\
(6,8)\end{array}$ & $\begin{array}{l}38 \\
57 \\
71\end{array}$ & $\begin{array}{l}(3,5) \\
(2,7) \\
(3,6)\end{array}$ & $\begin{array}{l}49 \\
67 \\
80\end{array}$ & $\begin{array}{l}(3,7) \\
(2,3) \\
(1,4)\end{array}$ & $\begin{array}{r}c \\
70 \\
82\end{array}$ & $\begin{array}{r}c \\
(5,9) \\
(2,0)\end{array}$ & $\begin{array}{l}42 \\
62 \\
78\end{array}$ & $\begin{array}{l}(1,9) \\
(1,4) \\
(0,9)\end{array}$ \\
\hline
\end{tabular}

* Hinweis zu den Daten der Russischen Föderation s. Abschnitt Angewandte Methodik.

Quelle: OECD. Survey of Adult Skills (PIAAC) (2012). PIAAC steht für das OECD Programme for the International Assessment of Adult Competencies. Hinweise s. Anhang 3 unter www.oecd.org/edu/eag.htm. StatLink: http://dx.doi.org/10.1787/888933119131

Erläuterung der Kennzeichnung fehlender Daten s. Hinweise für den Leser. 
Tabelle C6.2a (L) (Forts.)

Teilnahme an formaler und/oder nicht formaler Fort- und Weiterbildung, nach Lesekompetenz und Bildungsstand (2012) Erhebung zu den grundlegenden Kompetenzen Erwachsener, 25- bis 64-Jährige

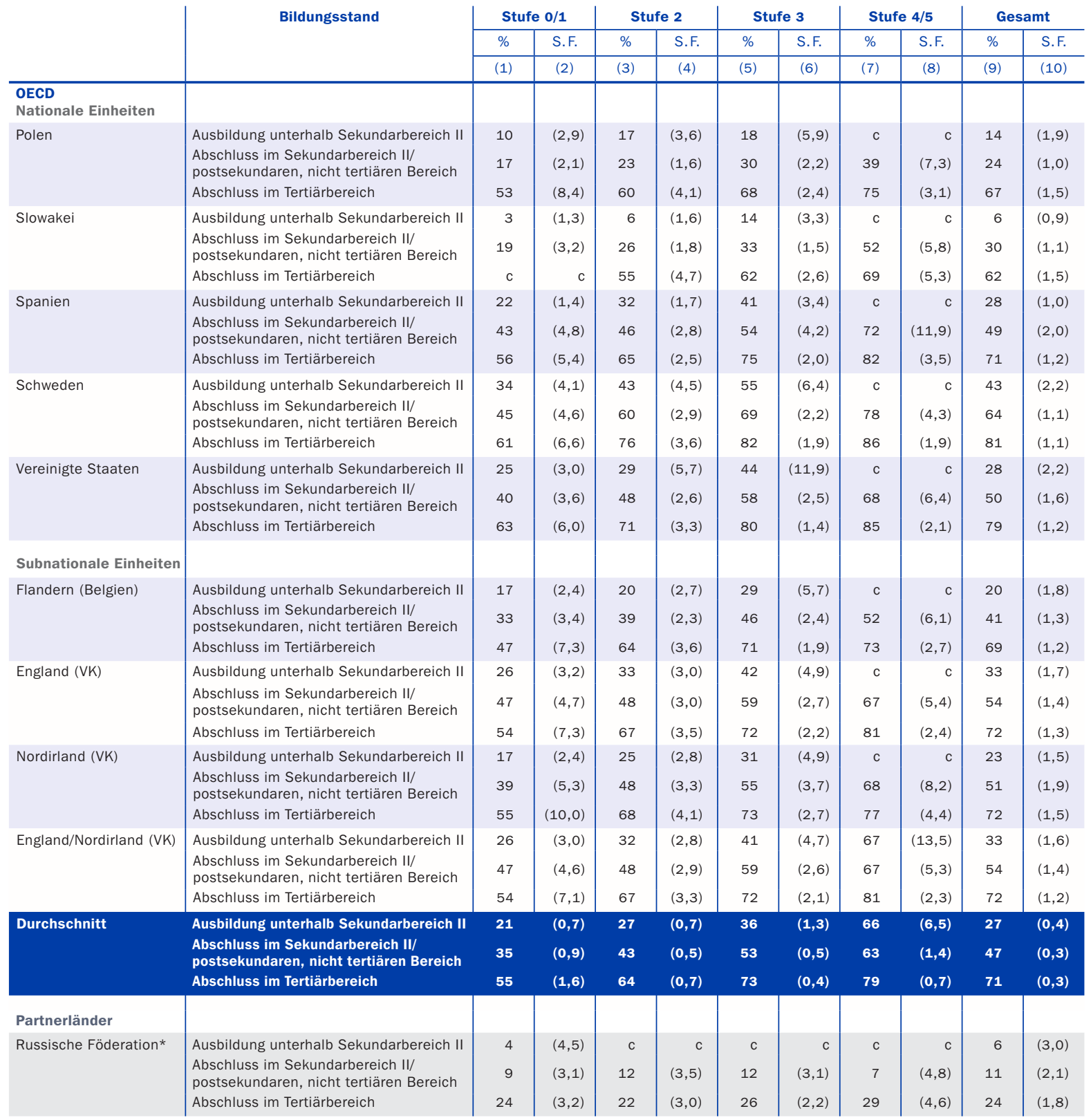

* Hinweis zu den Daten der Russischen Föderation s. Abschnitt Angewandte Methodik.

Quelle: OECD. Survey of Adult Skills (PIAAC) (2012). PIAAC steht für das OECD Programme for the International Assessment of Adult Competencies.

Hinweise s. Anhang 3 unter www.oecd.org/edu/eag.htm. StatLink: http://dx.doi.org/10.1787/888933119131

Erläuterung der Kennzeichnung fehlender Daten s. Hinweise für den Leser. 
Teilnahme an formaler und/oder nicht formaler Fort- und Weiterbildung, nach Geschlecht (2012)

25- bis 64-Jährige

\begin{tabular}{|c|c|c|c|c|c|c|c|c|c|c|c|c|}
\hline & \multicolumn{12}{|c|}{ Teilnahme an } \\
\hline & \multicolumn{2}{|c|}{$\begin{array}{l}\text { Formaler Fort- und } \\
\text { Weiterbildung }\end{array}$} & \multicolumn{2}{|c|}{$\begin{array}{l}\text { Nicht formaler Fort- } \\
\text { und Weiterbildung }\end{array}$} & \multicolumn{2}{|c|}{$\begin{array}{l}\text { Nur formaler Fort- } \\
\text { und Weiterbildung }\end{array}$} & \multicolumn{2}{|c|}{$\begin{array}{l}\text { Formaler und nicht } \\
\text { formaler Fort- und } \\
\text { Weiterbildung }\end{array}$} & \multicolumn{2}{|c|}{$\begin{array}{l}\text { Nur nicht formaler } \\
\text { Fort- und } \\
\text { Weiterbildung }\end{array}$} & \multicolumn{2}{|c|}{ Keine Teilnahme } \\
\hline & $\%$ & S.F. & $\%$ & S.F. & $\%$ & S.F. & $\%$ & S.F. & $\%$ & S.F. & $\%$ & S.F. \\
\hline & (1) & (2) & (3) & (4) & (5) & (6) & (7) & (8) & (9) & (10) & (11) & (12) \\
\hline \multicolumn{13}{|l|}{$\begin{array}{l}\text { OECD } \\
\text { Nationale Einheiten }\end{array}$} \\
\hline Australien & 17 & $(0,5)$ & 50 & $(0,7)$ & 5 & $(0,4)$ & 12 & $(0,5)$ & 39 & $(0,8)$ & 44 & $(0,7)$ \\
\hline Österreich & 6 & $(0,4)$ & 46 & $(0,8)$ & 2 & $(0,2)$ & 4 & $(0,3)$ & 42 & $(0,7)$ & 52 & $(0,7)$ \\
\hline Kanada & 14 & $(0,4)$ & 54 & $(0,6)$ & 5 & $(0,3)$ & 9 & $(0,4)$ & 44 & $(0,6)$ & 42 & $(0,6)$ \\
\hline Tschechien & 6 & $(0,5)$ & 48 & $(1,2)$ & 2 & $(0,3)$ & 4 & $(0,4)$ & 44 & $(1,2)$ & 50 & $(1,2)$ \\
\hline Dänemark & 14 & $(0,5)$ & 61 & $(0,6)$ & 5 & $(0,3)$ & 9 & $(0,4)$ & 52 & $(0,6)$ & 34 & $(0,6)$ \\
\hline Estland & 9 & $(0,4)$ & 50 & $(0,7)$ & 2 & $(0,2)$ & 7 & $(0,3)$ & 44 & $(0,7)$ & 47 & $(0,7)$ \\
\hline Finnland & 16 & $(0,5)$ & 62 & $(0,7)$ & 5 & $(0,3)$ & 11 & $(0,4)$ & 51 & $(0,7)$ & 34 & $(0,7)$ \\
\hline Frankreich & 5 & $(0,3)$ & 33 & $(0,6)$ & 3 & $(0,2)$ & 2 & $(0,2)$ & 31 & $(0,6)$ & 64 & $(0,6)$ \\
\hline Deutschland & 7 & $(0,4)$ & 50 & $(1,1)$ & 3 & $(0,3)$ & 4 & $(0,3)$ & 46 & $(1,1)$ & 47 & $(1,0)$ \\
\hline Irland & 15 & $(0,6)$ & 45 & $(0,8)$ & 6 & $(0,4)$ & 9 & $(0,4)$ & 36 & $(0,8)$ & 49 & $(0,7)$ \\
\hline Italien & 6 & $(0,4)$ & 22 & $(0,9)$ & 3 & $(0,3)$ & 3 & $(0,3)$ & 19 & $(0,8)$ & 75 & $(1,0)$ \\
\hline Japan & 2 & $(0,3)$ & 41 & $(0,8)$ & 1 & $(0,2)$ & 2 & $(0,2)$ & 39 & $(0,8)$ & 58 & $(0,8)$ \\
\hline Korea & 5 & $(0,3)$ & 49 & $(0,8)$ & 1 & $(0,1)$ & 4 & $(0,3)$ & 45 & $(0,8)$ & 50 & $(0,8)$ \\
\hline Niederlande & 14 & $(0,6)$ & 60 & $(0,6)$ & 4 & $(0,4)$ & 10 & $(0,5)$ & 50 & $(0,7)$ & 36 & $(0,6)$ \\
\hline Norwegen & 16 & $(0,5)$ & 59 & $(0,7)$ & 5 & $(0,3)$ & 11 & $(0,5)$ & 49 & $(0,7)$ & 36 & $(0,7)$ \\
\hline Polen & 8 & $(0,4)$ & 32 & $(0,8)$ & 3 & $(0,3)$ & 4 & $(0,3)$ & 28 & $(0,7)$ & 65 & $(0,8)$ \\
\hline Slowakei & 6 & $(0,4)$ & 31 & $(0,8)$ & 2 & $(0,2)$ & 3 & $(0,3)$ & 27 & $(0,8)$ & 67 & $(0,8)$ \\
\hline Spanien & 13 & $(0,5)$ & 42 & $(0,7)$ & 4 & $(0,3)$ & 8 & $(0,4)$ & 34 & $(0,7)$ & 53 & $(0,7)$ \\
\hline Schweden & 13 & $(0,5)$ & 61 & $(0,8)$ & 5 & $(0,4)$ & 9 & $(0,4)$ & 53 & $(0,8)$ & 34 & $(0,8)$ \\
\hline $\begin{array}{l}\text { Vereinigte Staaten } \\
\text { Subnationale Einheiten }\end{array}$ & 14 & $(0,6)$ & 55 & $(1,1)$ & 4 & $(0,4)$ & 10 & $(0,5)$ & 45 & $(1,1)$ & 41 & $(1,1)$ \\
\hline Flandern (Belgien) & 8 & $(0,4)$ & 46 & $(0,8)$ & 3 & $(0,2)$ & 5 & $(0,4)$ & 41 & $(0,8)$ & 51 & $(0,8)$ \\
\hline England (VK) & 16 & $(0,6)$ & 51 & $(0,8)$ & 5 & $(0,4)$ & 11 & $(0,5)$ & 40 & $(0,8)$ & 44 & $(0,9)$ \\
\hline Nordirland (VK) & 12 & $(0,8)$ & 45 & $(0,9)$ & 4 & $(0,4)$ & 8 & $(0,6)$ & 37 & $(1,0)$ & 51 & $(0,9)$ \\
\hline England/Nordirland (VK) & 16 & $(0,6)$ & 51 & $(0,8)$ & 5 & $(0,4)$ & 11 & $(0,5)$ & 40 & $(0,8)$ & 44 & $(0,9)$ \\
\hline Durchschnitt & 10 & $(0,1)$ & 48 & $(0,2)$ & 4 & $(0,1)$ & 7 & $(0,1)$ & 41 & $(0,2)$ & 49 & $(0,2)$ \\
\hline \multicolumn{13}{|l|}{ Partnerländer } \\
\hline Russische Föderation* & 6 & $(0,6)$ & 17 & $(1,4)$ & 3 & $(0,3)$ & 3 & $(0,5)$ & 13 & $(1,0)$ & 80 & $(1,6)$ \\
\hline
\end{tabular}

* Hinweis zu den Daten der Russischen Föderation s. Abschnitt Angewandte Methodik.

Anmerkung: Die Zeilen mit den getrennten Angaben zu Männern und Frauen sind im Internet verfügbar (s. StatLink unten).

Quelle: OECD. Survey of Adult Skills (PIAAC) (2012). PIAAC steht für das OECD Programme for the International Assessment of Adult Competencies.

Hinweise s. Anhang 3 unter www.oecd.org/edu/eag.htm. StatLink: http://dx.doi.org/10.1787/888933119150

Erläuterung der Kennzeichnung fehlender Daten s. Hinweise für den Leser. 
Teilnahme an formaler und/oder nicht formaler Fort- und Weiterbildung und Wunsch nach Lernaktivitäten (2012) 25- bis 64-Jährige

\begin{tabular}{|c|c|c|c|c|c|c|c|c|c|c|c|c|c|}
\hline & \multicolumn{2}{|c|}{$\begin{array}{c}\text { Teilnahme an } \\
\text { formaler und/oder } \\
\text { nicht formaler } \\
\text { Fort- und Weiter- } \\
\text { bildung }\end{array}$} & \multicolumn{2}{|c|}{$\begin{array}{c}\text { Lernaktivitä- } \\
\text { ten - Teilnahme } \\
\text { erwünscht, aber } \\
\text { nicht begonnen }\end{array}$} & \multicolumn{2}{|c|}{$\begin{array}{l}\text { Teilnehmer mit } \\
\text { Wunsch nach } \\
\text { Lernaktivitäten }\end{array}$} & \multicolumn{2}{|c|}{$\begin{array}{l}\text { Nichtteilnehmer } \\
\text { mit Wunsch nach } \\
\text { Lernaktivitäten }\end{array}$} & \multicolumn{2}{|c|}{$\begin{array}{l}\text { Teilnehmer ohne } \\
\text { Wunsch nach } \\
\text { Lernaktivitäten }\end{array}$} & \multicolumn{2}{|c|}{$\begin{array}{l}\text { Nichtteilnehmer } \\
\text { ohne Wunsch } \\
\text { nach Lern- } \\
\text { aktivitäten }\end{array}$} & \multirow[t]{2}{*}{$\begin{array}{c}\text { Gesamt } \\
\\
\%\end{array}$} \\
\hline & $\%$ & S.F. & $\%$ & S.F. & $\%$ & S.F. & $\%$ & S.F. & $\%$ & S.F. & $\%$ & S.F. & \\
\hline & $\begin{array}{c}(1)= \\
(5)+(9)\end{array}$ & (2) & $\begin{array}{c}(3)= \\
(5)+(7)\end{array}$ & (4) & (5) & (6) & (7) & (8) & (9) & (10) & (11) & (12) & $\begin{array}{c}(13)= \\
(5)+(7)+ \\
(9)+(11)\end{array}$ \\
\hline \multicolumn{14}{|l|}{$\begin{array}{l}\text { OECD } \\
\text { Nationale Einheiten }\end{array}$} \\
\hline Australien & 56 & $(0,7)$ & 25 & $(0,8)$ & 17 & $(0,6)$ & 8 & $(0,5)$ & 39 & $(0,8)$ & 37 & $(0,7)$ & 100 \\
\hline Österreich & 48 & $(0,7)$ & 20 & $(0,6)$ & 13 & $(0,5)$ & 7 & $(0,4)$ & 35 & $(0,7)$ & 45 & $(0,7)$ & 100 \\
\hline Kanada & 58 & $(0,6)$ & 31 & $(0,5)$ & 24 & $(0,5)$ & 8 & $(0,3)$ & 35 & $(0,5)$ & 34 & $(0,5)$ & 100 \\
\hline Tschechien & 50 & $(1,2)$ & 16 & $(0,9)$ & 12 & $(0,6)$ & 4 & $(0,6)$ & 37 & $(1,1)$ & 46 & $(1,3)$ & 100 \\
\hline Dänemark & 66 & $(0,6)$ & 34 & $(0,7)$ & 26 & $(0,7)$ & 8 & $(0,4)$ & 40 & $(0,7)$ & 26 & $(0,6)$ & 100 \\
\hline Estland & 53 & $(0,7)$ & 32 & $(0,6)$ & 22 & $(0,5)$ & 10 & $(0,5)$ & 30 & $(0,7)$ & 38 & $(0,6)$ & 100 \\
\hline Finnland & 66 & $(0,7)$ & 31 & $(0,8)$ & 25 & $(0,7)$ & 6 & $(0,4)$ & 41 & $(0,7)$ & 28 & $(0,7)$ & 100 \\
\hline Frankreich & 36 & $(0,6)$ & 19 & $(0,5)$ & 11 & $(0,4)$ & 8 & $(0,3)$ & 25 & $(0,5)$ & 56 & $(0,7)$ & 100 \\
\hline Deutschland & 53 & $(1,0)$ & 29 & $(0,8)$ & 22 & $(0,7)$ & 7 & $(0,5)$ & 31 & $(0,9)$ & 40 & $(1,1)$ & 100 \\
\hline Irland & 51 & $(0,7)$ & 31 & $(0,8)$ & 19 & $(0,6)$ & 12 & $(0,5)$ & 32 & $(0,7)$ & 38 & $(0,8)$ & 100 \\
\hline Italien & 25 & $(1,0)$ & 16 & $(0,9)$ & 8 & $(0,6)$ & 8 & $(0,6)$ & 17 & $(0,7)$ & 67 & $(1,1)$ & 100 \\
\hline Japan & 42 & $(0,8)$ & 19 & $(0,7)$ & 14 & $(0,6)$ & 6 & $(0,3)$ & 28 & $(0,6)$ & 52 & $(0,8)$ & 100 \\
\hline Korea & 50 & $(0,8)$ & 34 & $(0,8)$ & 21 & $(0,6)$ & 12 & $(0,5)$ & 29 & $(0,7)$ & 38 & $(0,8)$ & 100 \\
\hline Niederlande & 64 & $(0,6)$ & 23 & $(0,6)$ & 18 & $(0,5)$ & 5 & $(0,4)$ & 46 & $(0,7)$ & 31 & $(0,6)$ & 100 \\
\hline Norwegen & 64 & $(0,7)$ & 26 & $(0,8)$ & 20 & $(0,6)$ & 6 & $(0,4)$ & 44 & $(0,8)$ & 30 & $(0,7)$ & 100 \\
\hline Polen & 35 & $(0,8)$ & 12 & $(0,5)$ & 9 & $(0,5)$ & 3 & $(0,3)$ & 27 & $(0,7)$ & 61 & $(0,8)$ & 100 \\
\hline Slowakei & 33 & $(0,8)$ & 10 & $(0,5)$ & 7 & $(0,4)$ & 3 & $(0,2)$ & 26 & $(0,8)$ & 64 & $(0,8)$ & 100 \\
\hline Spanien & 47 & $(0,7)$ & 31 & $(0,6)$ & 20 & $(0,6)$ & 11 & $(0,5)$ & 27 & $(0,6)$ & 42 & $(0,6)$ & 100 \\
\hline Schweden & 66 & $(0,8)$ & 33 & $(0,8)$ & 25 & $(0,7)$ & 8 & $(0,5)$ & 41 & $(0,9)$ & 26 & $(0,7)$ & 100 \\
\hline $\begin{array}{l}\text { Vereinigte Staaten } \\
\text { Subnationale Einheiten }\end{array}$ & 59 & $(1,1)$ & 37 & $(1,0)$ & 27 & $(0,8)$ & 9 & $(0,6)$ & 32 & $(0,9)$ & 31 & $(1,1)$ & 100 \\
\hline Flandern (Belgien) & 49 & $(0,8)$ & 18 & $(0,6)$ & 13 & $(0,5)$ & 5 & $(0,4)$ & 36 & $(0,7)$ & 46 & $(0,8)$ & 100 \\
\hline England (VK) & 56 & $(0,9)$ & 25 & $(0,9)$ & 18 & $(0,8)$ & 7 & $(0,4)$ & 38 & $(0,8)$ & 37 & $(0,9)$ & 100 \\
\hline Nordirland (VK) & 49 & $(0,9)$ & 18 & $(0,8)$ & 13 & $(0,6)$ & 5 & $(0,4)$ & 36 & $(1,0)$ & 46 & $(0,9)$ & 100 \\
\hline England/Nordirland (VK) & 56 & $(0,9)$ & 25 & $(0,9)$ & 18 & $(0,7)$ & 7 & $(0,4)$ & 38 & $(0,8)$ & 37 & $(0,9)$ & 100 \\
\hline Durchschnitt & 51 & $(0,2)$ & 25 & $(0,2)$ & 18 & $(0,1)$ & 7 & $(0,1)$ & 33 & $(0,2)$ & 42 & $(0,2)$ & 100 \\
\hline \multicolumn{14}{|l|}{ Partnerländer } \\
\hline Russische Föderation* & 20 & $(1,6)$ & 8 & $(0,6)$ & 4 & $(0,4)$ & 4 & $(0,4)$ & 15 & $(1,2)$ & 76 & $(1,8)$ & 100 \\
\hline
\end{tabular}

* Hinweis zu den Daten der Russischen Föderation s. Abschnitt Angewandte Methodik.

Quelle: OECD. Survey of Adult Skills (PIAAC) (2012). PIAAC steht für das OECD Programme for the International Assessment of Adult Competencies. Hinweise s. Anhang 3 unter www.oecd.org/edu/eag.htm. StatLink: http://dx.doi.org/10.1787/888933119169

Erläuterung der Kennzeichnung fehlender Daten s. Hinweise für den Leser. 
Für die Nichtteilnahme an weiteren/jeglichen Lernaktivitäten angegebene Gründe, nach Teilnehmer bzw. Nichtteilnehmer an formaler und/oder nicht formaler Fort- und Weiterbildung (2012)

25- bis 64-Jährige

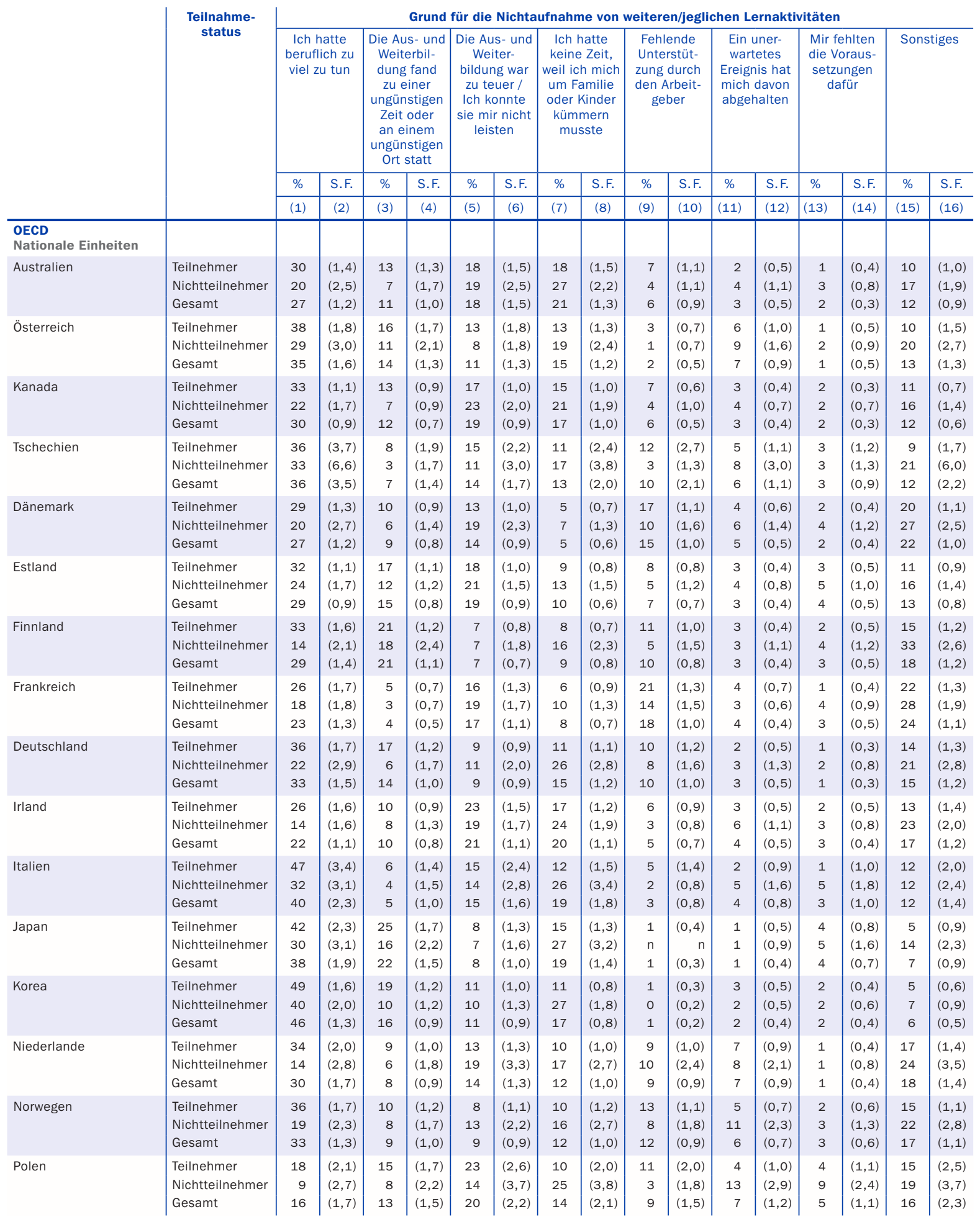

* Hinweis zu den Daten der Russischen Föderation s. Abschnitt Angewandte Methodik.

Quelle: OECD. Survey of Adult Skills (PIAAC) (2012). PIAAC steht für das OECD Programme for the International Assessment of Adult Competencies.

Hinweise s. Anhang 3 unter www.oecd.org/edu/eag.htm. StatLink: http://dx.doi.org/10.1787/888933119188

Erläuterung der Kennzeichnung fehlender Daten s. Hinweise für den Leser. 
Für die Nichtteilnahme an weiteren/jeglichen Lernaktivitäten angegebene Gründe, nach Teilnehmer bzw. Nichtteilnehmer an formaler und/oder nicht formaler Fort- und Weiterbildung (2012)

25- bis 64-Jährige

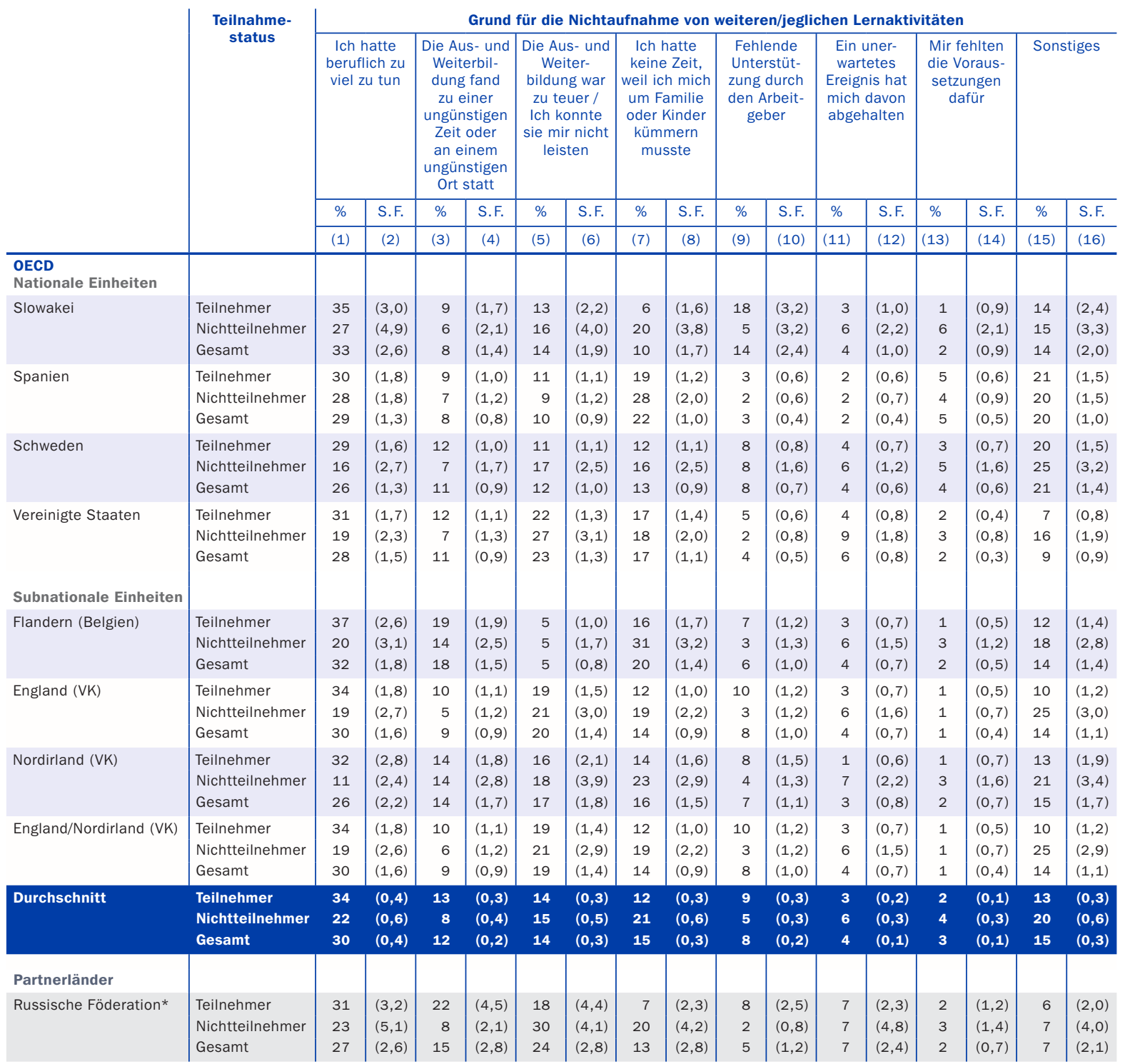

* Hinweis zu den Daten der Russischen Föderation s. Abschnitt Angewandte Methodik.

Quelle: OECD. Survey of Adult Skills (PIAAC) (2012). PIAAC steht für das OECD Programme for the International Assessment of Adult Competencies.

Hinweise s. Anhang 3 unter www.oecd.org/edu/eag.htm. StatLink: http://dx.doi.org/10.1787/888933119188

Erläuterung der Kennzeichnung fehlender Daten s. Hinweise für den Leser. 


\section{Indikatior C7}

\section{Worin unterscheiden sich öffentliche und private Schulen/Bildungseinrichtungen?}

In den meisten Ländern werden private Bildungseinrichtungen vom Primar- bis zum Sekundarbereich II von einer Minderheit der Schüler besucht - 2012 besuchten nur rund 3 Prozent aller Schüler des Primar- und Sekundarbereichs unabhängige private Bildungseinrichtungen. Im Elementarbereich ist der Anteil der Kinder, die private Einrichtungen besuchen, deutlich höher - rund II Prozent der Schüler des Elementarbereichs besuchen eine unabhängige private Bildungseinrichtung.

Schüler an privaten Bildungseinrichtungen, seien sie staatlich subventioniert oder unabhängig, schneiden in der Internationalen Schulleistungsstudie PISA der OECD tendenziell signifikant besser ab als Schüler öffentlicher Schulen. Schüler öffentlicher Schulen in einem ähnlichen sozioökonomischen Kontext wie private Bildungseinrichtungen schneiden jedoch tendenziell genauso gut ab.

Im Durchschnitt der OECD-Länder ist die Klassengröße im Primar- und Sekundarbereich an öffentlichen und privaten Schulen in etwa gleich. Dies deutet darauf hin, dass in den Ländern, in denen sich ein erheblicher Teil der Schüler und Familien für private Bildungseinrichtungen entscheidet, die Klassengröße kein ausschlaggebender Faktor für diese Entscheidung ist.

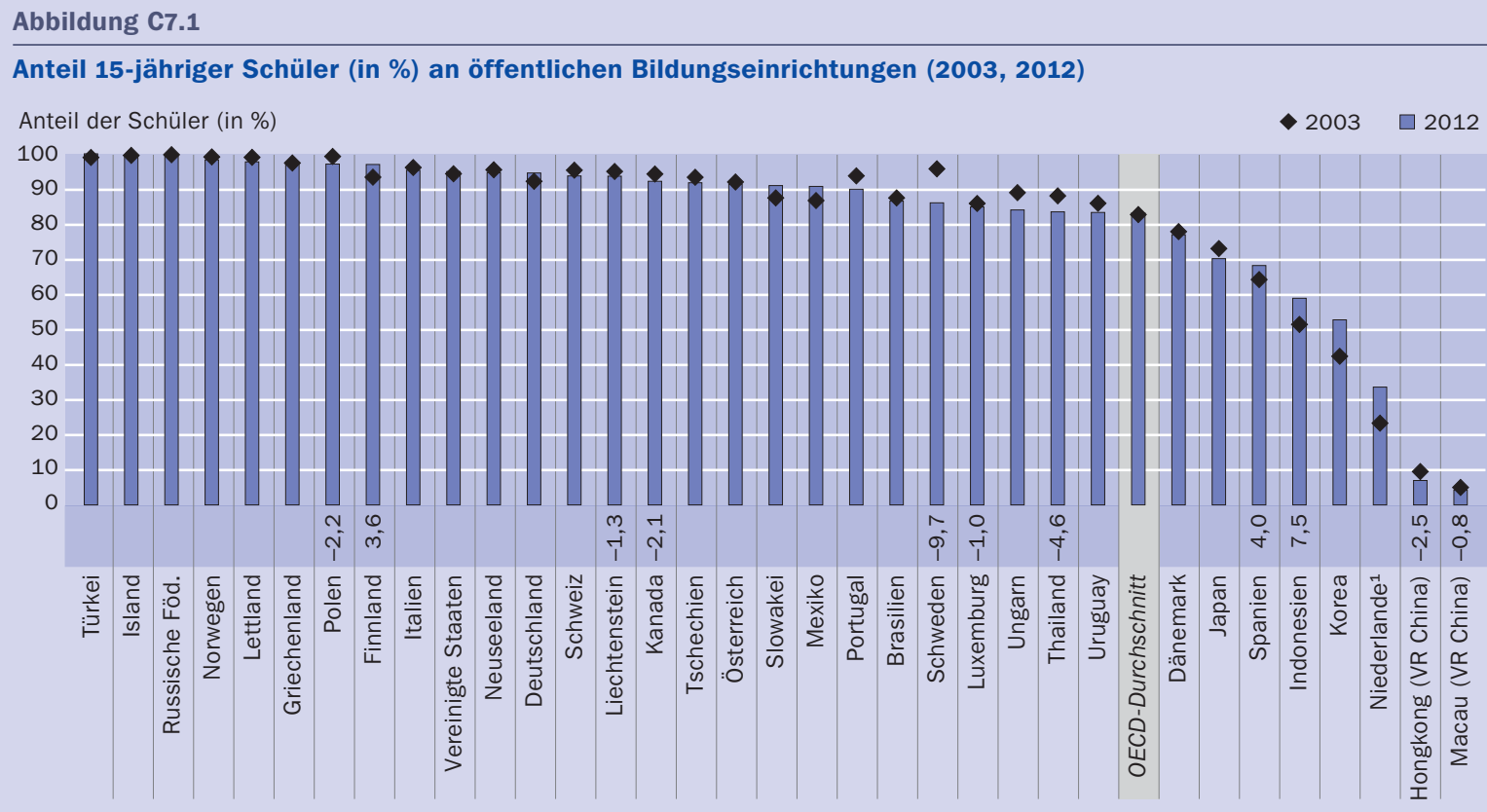

Anmerkung: Diese Abbildung enthält nur Länder mit vergleichbaren Daten aus PISA 2003 und PISA 2012. Die Differenz (in Prozentpunkten) zwischen den Anteilen der Schüler, die 2012 und 2003 private Bildungseinrichtungen besuchten, ist oberhalb des Namens des Landes/der Volkswirtschaft angegeben (2012-2003). Nur statistisch signifikante Unterschiede sind angegeben. Der OECD-Durchschnitt 2003 vergleicht ausschließlich OECD-Länder mit vergleichbaren Daten seit 2003.

1. In den Niederlanden besuchen rund 99 Prozent der 15-jährigen Schüler eine öffentlich finanzierte Schule: Ein Drittel dieser Schulen ist öffentlich verwaltet und zwei Drittel privat.

Anordnung der Länder und Volkswirtschaften in absteigender Reihenfolge des Anteils der Schüler in öffentlichen Bildungseinrichtungen im Jahr 2012. Quelle: OECD. Tabellen C7.2 und C7.3. Hinweise s. Anhang 3 unter www.oecd.org/edu/eag.htm. StatLink: http://dx.doi.org/10.1787/888933119454 


\section{Kontext}

Viele Eltern fragen sich irgendwann im Laufe der Ausbildung ihres Kindes, ob sich die Ausgaben für eine private Bildungseinrichtung lohnen könnten. Ebenso entscheiden sich mehr und mehr Studierende dafür, an einer privaten Hochschule zu studieren. Private Bildungseinrichtungen können Eltern und Schülern möglicherweise eine besondere Form des Unterrichts bieten, wie sie an öffentlichen Schulen nicht zur Verfügung steht. In einigen Bildungssystemen werden private Bildungseinrichtungen auch deshalb gefördert, weil man davon ausgeht, dass die dort mit der Autonomie einhergehende Flexibilität bei der Entwicklung der Lehrpläne und der Zuweisung von Mitteln als stimulierende Innovation für das Schulsystem dienen könne. Private Bildungseinrichtungen können jedoch durch ihre Schülerauswahl auch ausgrenzen und dadurch Ungleichheiten der Bildungschancen verstärken, insbesondere wenn sie Schulgebühren erheben. Da sie finanziell besser ausgestattet sind, können die Schulen die besten Schüler auswählen und die besten Lehrer einstellen.

Bislang gibt es jedoch noch keine eindeutigen Belege für den Zusammenhang zwischen der Zahl privater Bildungseinrichtungen in einem Bildungssystem und den in diesem System insgesamt erzielten Leistungen. Untersuchungen in Chile (Lara, Mizala and Repetto, 2009), Schweden (Sandstrom and Bergstrom, 2005), Tschechien (Filer and Munich, 2003), dem Vereinigten Königreich (Green et al., 20II) und den Vereinigten Staaten (Couch, Shugart and Williams, I993; Peterson et al., 2003) zeigen beispielsweise basierend auf Quer- oder Längsschnittdaten, dass ein größerer Anteil von Schülern an privaten Bildungseinrichtungen mit besseren Leistungen zusammenhängt. Aber diese Debatte über Schulleistungen ist bei Weitem noch nicht abgeschlossen, da andere Untersuchungen geringe, negative oder unwesentliche Effekte angeben oder aufzeigen, dass Ergebnisse oft von methodologischen Ansätzen beeinflusst werden.

So kommen beispielsweise einige Studien, die auf bundesstaatlichen Daten der Vereinigten Staaten beruhen, zu dem Schluss, dass kein signifikanter Zusammenhang zwischen einem größeren Anteil von Schülern an privaten Bildungseinrichtungen und den erzielten Leistungen bestehe (Wrinkle et al., I999; Sander, 1999; Geller, Sjoquist and Walker, 2006). Vereinzelte Studien belegen geringe negative Effekte (Smith and Meier, I995), negative Effekte für einkommensschwache Bezirke (Maranto, Milliman and Scott, 2000) oder dass der Zusammenhang davon abhängt, welche Lernerfolge gemessen werden (Greene and Kang, 2004). In den OECD-Ländern und allen Ländern und Volkswirtschaften, die an PISA 2012 teilnahmen, korreliert der Anteil der Schüler an privaten Bildungseinrichtungen nicht mit der Gesamtleistung des Bildungssystems (s. Band IV von PISA 20I2).

Bei der Betrachtung privater Bildungseinrichtungen wird je nach Abhängigkeit von staatlichen Mitteln zwischen staatlich subventionierten und unabhängigen privaten Bildungseinrichtungen unterschieden. Denn anders als oft angenommen, sind nicht alle privat geführten Schulen auch privat finanziert. 


\section{Weitere wichtige Ergebnisse}

In den meisten der an PISA teilnehmenden Ländern und Volkswirtschaften ist der sozioökonomische Hintergrund der Schüler, die eine staatlich subventionierte oder unabhängige private Bildungseinrichtung besuchen, im Durchschnitt günstiger als derjenige von Schülern an öffentlichen Schulen.

Private Bildungseinrichtungen haben tendenziell größere Autonomie bei der „Ressourcenallokation“ oder bei „Entscheidungen über Unterrichtsinhalte und Beurteilungen“ als öffentliche Schulen. Der Grad der Autonomie privater Bildungseinrichtungen variiert jedoch sowohl zwischen den einzelnen Ländern als auch zwischen staatlich subventionierten und unabhängigen privaten Bildungseinrichtungen.

- In 34 von 47 Ländern und Volkswirtschaften berichteten Schulleiter öffentlicher Schulen häufiger von Lehrermangel als Schulleiter privater Schulen.

Im Durchschnitt der OECD-Länder wenden Schüler privater Bildungseinrichtungen pro Woche eine Stunde mehr für Hausaufgaben oder sonstige von ihren Lehrern gestellte Aufgaben auf als Schüler öffentlicher Schulen (5,6 gegenüber 4,7 Stunden). In Australien, Kanada, Katar, Kolumbien, Neuseeland, Österreich, Portugal, den Vereinigten Staaten sowie den Vereinigten Arabischen Emiraten beträgt diese zusätzliche Zeit mehr als I,5 Stunden.

2012 besuchten 72 Prozent der Studierenden des Tertiärbereichs A öffentliche Bildungseinrichtungen, 14 Prozent staatlich subventionierte private Einrichtungen und 14 Prozent unabhängige private Bildungseinrichtungen. Der Besuch einer privaten Bildungseinrichtung ist für die Studierenden mit zusätzlichen Kosten verbunden, da in den meisten Ländern private Bildungseinrichtungen höhere Studiengebühren als öffentliche Bildungseinrichtungen verlangen.

\section{Entwicklungstendenzen}

Der Anteil der I5-jährigen Schüler, die eine private Schule besuchen, ist zwar zwischen 2003 und 2012 im Durchschnitt nicht angestiegen, dennoch gab es über diesen Zeitraum hinweg in einigen Ländern signifikante Veränderungen - in einigen zugunsten der öffentlichen Schulen, in anderen zugunsten der privaten Bildungseinrichtungen.

Dagegen ist in 2I der 29 OECD-Länder, für die Daten für 2003 und 2012 verfügbar sind, der Anteil der Studierenden in privaten Bildungseinrichtungen des Tertiärbereichs zwischen 2003 und 2012 signifikant angestiegen. Im Durchschnitt der OECD-Länder mit verfügbaren Daten für 2003 und 2012 stieg entsprechend die Bildungsbeteiligung in privaten Bildungseinrichtungen des (theoretisch ausgerichteten) Tertiärbereichs $\mathrm{A}$ in diesem Zeitraum um 2 Prozentpunkte von 23 Prozent auf 25 Prozent, während es im (berufsorientierten) Tertiärbereich B ein Anstieg um 4 Prozentpunkte von 33 Prozent auf 37 Prozent war. 


\section{Analyse und Interpretationen}

\section{Bildungsbeteiligung an privaten und öffentlichen Schulen}

Weltweit erfolgt Schulbildung hauptsächlich in öffentlichen Schulen, d. h. an Schulen, die direkt oder indirekt von einer staatlichen Bildungsbehörde, einer Regierungsbehörde bzw. einem Verwaltungsgremium verwaltet werden, dessen Mitglieder entweder von einer staatlichen Behörde ernannt oder mit öffentlichem Wahlrecht gewählt werden. Im Durchschnitt der OECD-Länder besuchten 2012 fast 89 Prozent der Schüler im Primarbereich, 86 Prozent der Schüler im Sekundarbereich I und 8I Prozent der Schüler im Sekundarbereich II öffentliche Schulen.

Bei der Betrachtung privater Schulen wird je nach Grad der Abhängigkeit von staatlichen Finanzmitteln zwischen staatlich subventionierten und unabhängigen privaten Bildungseinrichtungen unterschieden. Denn anders als gemeinhin angenommen, werden nicht alle privat geführten Bildungseinrichtungen auch privat finanziert (s. Abschnitt Definitionen und angewandte Methodik). In Australien, Belgien, Chile und Spanien und in geringerem Ausmaß auch in Argentinien, Dänemark, Frankreich und Israel besucht ein erheblicher Anteil der Schüler des Primar- und Sekundarbereichs I (I4 Prozent oder mehr) eine Schule, die von einer nicht staatlichen Organisation geführt, aber überwiegend durch staatliche Quellen finanziert wird (Tab. C7.I).

Dagegen besuchen im Durchschnitt der OECD-Länder nur rund 3 Prozent aller Schüler eine unabhängige private Bildungseinrichtung des Primar- oder Sekundarbereichs (d. h. Bildungseinrichtungen, die direkt oder indirekt einer nicht staatlichen Organisation unterstehen und weniger als 50 Prozent ihrer Mittel aus staatlichen Quellen erhalten). Je höher der Bildungsbereich, desto höher ist jedoch der Anteil der Schüler, die unabhängige private Bildungseinrichtungen besuchen. Im Primarbereich beispielsweise sind 2 Prozent der Schüler an unabhängigen privaten Bildungseinrichtungen, während sich dieser Anteil im Sekundarbereich I auf 3 Prozent und im Sekundarbereich II auf 5 Prozent beläuft (Tab. C7.I). In Brasilien, Indonesien, Japan, Kolumbien, Mexiko, Polen und Portugal besuchen mehr als ıo Prozent der Schüler des Sekundarbereichs II eine unabhängige private Bildungseinrichtung.

Im Elementarbereich ist der Anteil der Schüler, die eine private Bildungseinrichtung besuchen, deutlich höher als im Primar- und Sekundarbereich. Rund II Prozent der Schüler des Elementarbereichs besuchen eine unabhängige private Bildungseinrichtung. Fasst man die unabhängigen privaten und staatlich subventionierten privaten Bildungseinrichtungen zusammen, so erreichen private Einrichtungen im Elementarbereich einen Anteil von 3I Prozent. In Australien, Belgien, Chile, Deutschland, Indonesien, Irland, Japan, Korea und Neuseeland übersteigt dieser Anteil 50 Prozent (Tab. C7.I).

\section{Veränderung des Anteils der Schüler an privaten Schulen zwischen 2003 und 2012}

2003 besuchten im Durchschnitt der OECD-Länder 83 Prozent der I5-jährigen Schüler öffentliche Bildungseinrichtungen, I4 Prozent staatlich subventionierte private Bildungseinrichtungen und 4 Prozent unabhängige private Bildungseinrichtungen. Seither sind die Durchschnittszahlen unverändert geblieben, innerhalb der Länder kam es 
jedoch zu Verschiebungen. 2012 besuchten mehr als 98 Prozent der I5-jährigen Schüler in Bulgarien, Island, Israel, Kroatien, Litauen, Montenegro, Norwegen, Rumänien, der Russischen Föderation, Serbien, Tunesien und der Türkei eine öffentliche Schule. Dagegen besuchten in Chile, Hongkong (VR China), Macau (VR China) und den Niederlanden weniger als 50 Prozent der Schüler eine öffentliche Bildungseinrichtung - in diesen Ländern besucht die Mehrheit der I5-jährigen Schüler staatlich subventionierte private Bildungseinrichtungen (Tab. $\mathrm{C}_{7.2}$ und $\mathrm{C}_{7 \cdot 3}$ ).

Trenddaten zeigen hierbei unterschiedliche Verhältnisse in den einzelnen Ländern. Zwischen 2003 und 2012 stiegen in einigen Ländern und Volkswirtschaften die Schülerzahlen an öffentlichen Bildungseinrichtungen (z. B. in Finnland, Indonesien, Korea, Mexiko, der Slowakei und Spanien), in anderen Ländern wie Hongkong (VR China), Japan, Kanada, Polen, Portugal, Schweden, Thailand, Ungarn und Uruguay hingegen war eine Verlagerung hin zu privaten Bildungseinrichtungen zu beobachten. Einige der signifikantesten Veränderungen waren in Finnland, Indonesien, Mexiko und Spanien zu beobachten, hier besuchte 2012 ein größerer Anteil der 15-jährigen Schüler öffentliche Bildungseinrichtungen als im Jahr 2003. In Indonesien ging der Anteil der Schüler, die eine unabhängige private Bildungseinrichtung besuchen, um 2I Prozentpunkte zurück, entsprechend stieg der Anteil der Schüler in staatlich subventionierten privaten Schulen um I3 Prozentpunkte und in öffentlichen Bildungseinrichtungen um 7 Prozentpunkte. In Finnland, Mexiko und Spanien stieg der Anteil der Schüler in öffentlichen Bildungseinrichtungen um 4 Prozentpunkte. In Schweden ging der Anteil der Schüler, die öffentliche Bildungseinrichtungen besuchen, um ro Prozentpunkte zurück, entsprechend stieg der Anteil der Schüler in staatlich subventionierten privaten Bildungseinrichtungen. In Thailand und in geringerem Ausmaß auch in Polen war eine ähnliche Verlagerung hin zu staatlich subventionierten privaten Bildungseinrichtungen zu beobachten (Tab. $\mathrm{C}_{7.2}, \mathrm{C}_{7} .3$ und Abb. C7.I).

\section{Art der Bildungseinrichtung und Schülerleistungen}

Vergleicht man die durchschnittlichen Mathematikleistungen I5-jähriger Schüler an öffentlichen und privaten Bildungseinrichtungen ohne Berücksichtigung des sozioökonomischen Status der Schüler, so erreichen in 27 der 45 Länder und Volkswirtschaften mit verfügbaren Daten private Bildungseinrichtungen (staatlich subventionierte oder unabhängige private Bildungseinrichtungen) tendenziell statistisch signifikant bessere Leistungen als öffentliche Bildungseinrichtungen (Abb. C7.2 und Tab. C7.2). Der Leistungsunterschied reicht von 23 Punkten im Vereinigten Königreich bis zu Io8 Punkten in Katar - was nahezu 3 Jahren formaler Bildung entspricht. Das Gegenteil (statistisch signifikant bessere Leistungen an öffentlichen Bildungseinrichtungen) gilt nur in 4 dieser 45 Länder und Volkswirtschaften: In Hongkong (VR China), Luxemburg, Taipeh (Republik China) und Thailand schneiden öffentliche Bildungseinrichtungen im Durchschnitt um I3 bis 6o Punkte besser ab als private Schulen. Von 2003 bis 2012 stieg die Gesamtdifferenz der Mathematikleistungen zwischen Schülern öffentlicher und privater Bildungseinrichtungen innerhalb der OECD-Länder um 9 Punkte (und bis zu 28 Punkte zugunsten der Schüler privater Bildungseinrichtungen) (Tab. C7.3).

Ein ähnliches Bild ergibt sich, wenn man öffentliche Bildungseinrichtungen ausschließlich mit staatlich subventionierten privaten Bildungseinrichtungen vergleicht. In diesem Fall schneiden staatlich subventionierte private Bildungseinrichtungen in 6 
der 30 Länder und Volkswirtschaften mit verfügbaren Daten statistisch signifikant besser ab (Tab. C7.2). Der Leistungsunterschied reicht hierbei von 2I Punkten in Australien bis zu II2 Punkten in Taipeh (Republik China). Nur Italien und die Schweiz weisen atypische Leistungsunterschiede auf. Während in der Schweiz I5-jährige Schüler staatlich subventionierter privater Bildungseinrichtungen im Durchschnitt statistisch signifikant besser abschneiden als Schüler öffentlicher oder unabhängiger privater Bildungseinrichtungen, ist in Italien genau das Gegenteil der Fall.

Die vorliegenden Ergebnisse sind jedoch stark durch den sozioökonomischen Status der 15 -jährigen Schüler bestimmt. In 37 teilnehmenden Ländern und Volkswirtschaften sind die Schüler privater Schulen (sowohl staatlich subventionierter als auch unabhängiger privater Bildungseinrichtungen) in sozioökonomischer Hinsicht tendenziell besser gestellt als die Schüler öffentlicher Schulen. 2012 war der Unterschied zwischen öffentlichen und privaten Schulen beim durchschnittlichen sozioökonomischen Status ihrer Schüler in Brasilien, Costa Rica, Mexiko, Peru, Polen und Uruguay besonders groß. Lediglich in Taipeh (Republik China) ist der sozioökonomische Status der Schüler öffentlicher Schulen im Durchschnitt vorteilhafter als derjenige der Schüler an privaten Schulen. Im Durchschnitt erreichen Schüler öffentlicher Schulen rund o,5 Punkte weniger auf dem PISA-Index des wirtschaftlichen, sozialen und kulturellen Status als Schüler privater Bildungseinrichtungen. Ein ähnliches Bild ergibt sich beim Vergleich von öffentlichen und staatlich subventionierten privaten Bildungseinrichtungen, wenn auch die absolute Differenz geringer ist. Im Durchschnitt erreichen Schüler öffentlicher Bildungseinrichtungen rund o,3 Punkte weniger auf dem PISA-Index des wirtschaftlichen, sozialen und kulturellen Status als Schüler staatlich subventionierter privater Bildungseinrichtungen (Tab. C7.2).

Der Leistungsvorteil privater Schulen gegenüber öffentlichen Schulen ist jedoch in den meisten Ländern/Volkswirtschaften nicht länger zu beobachten, wenn der sozioökonomische Status der Schüler und der Schulen berücksichtigt wird. Nach Berücksichtigung des sozioökonomischen Hintergrunds der Schüler und der Schulen schneiden die privaten Schulen nur in 8 Ländern und Volkswirtschaften besser ab als öffentliche Schulen, und in I2 Ländern und Volkswirtschaften schneiden die öffentlichen Schulen besser $\mathrm{ab}$ als die privaten. Private Bildungseinrichtungen - und öffentliche Schulen mit Schülern mit einem sozioökonomisch günstigen Hintergrund - bringen also Vorteile für die Schüler, die sie besuchen, aber es gibt keine Belege dafür, dass private Bildungseinrichtungen dazu beitragen, das Leistungsniveau des Schulsystems insgesamt anzuheben (Tab. C7.2 und Abb. C7.2).

\section{Das Lernumfeld an öffentlichen und privaten Bildungseinrichtungen Lehrkräftemangel}

Lehrkräfte sind für den Lernerfolg entscheidend: Ein Schulsystem kann niemals besser als seine Lehrkräfte sein. Die PISA-Ergebnisse zeigen, dass Schulen, die stark unter Lehrermangel leiden, tendenziell niedrigere Punktzahlen bei PISA erreichen. Kompetente Lehrkräfte anzuwerben und zu halten hat daher für die Bildungspolitik Prioritätund da die öffentlichen Schulen in stärkerem Maße vom Lehrermangel betroffen sind als private Schulen, stellt dies für öffentliche Schulen (aber auch, allgemeiner gesehen, für benachteiligte Schulen) eine besondere Herausforderung dar. 
Art der Bildungseinrichtung und Leistungen in Mathematik ( 2012)

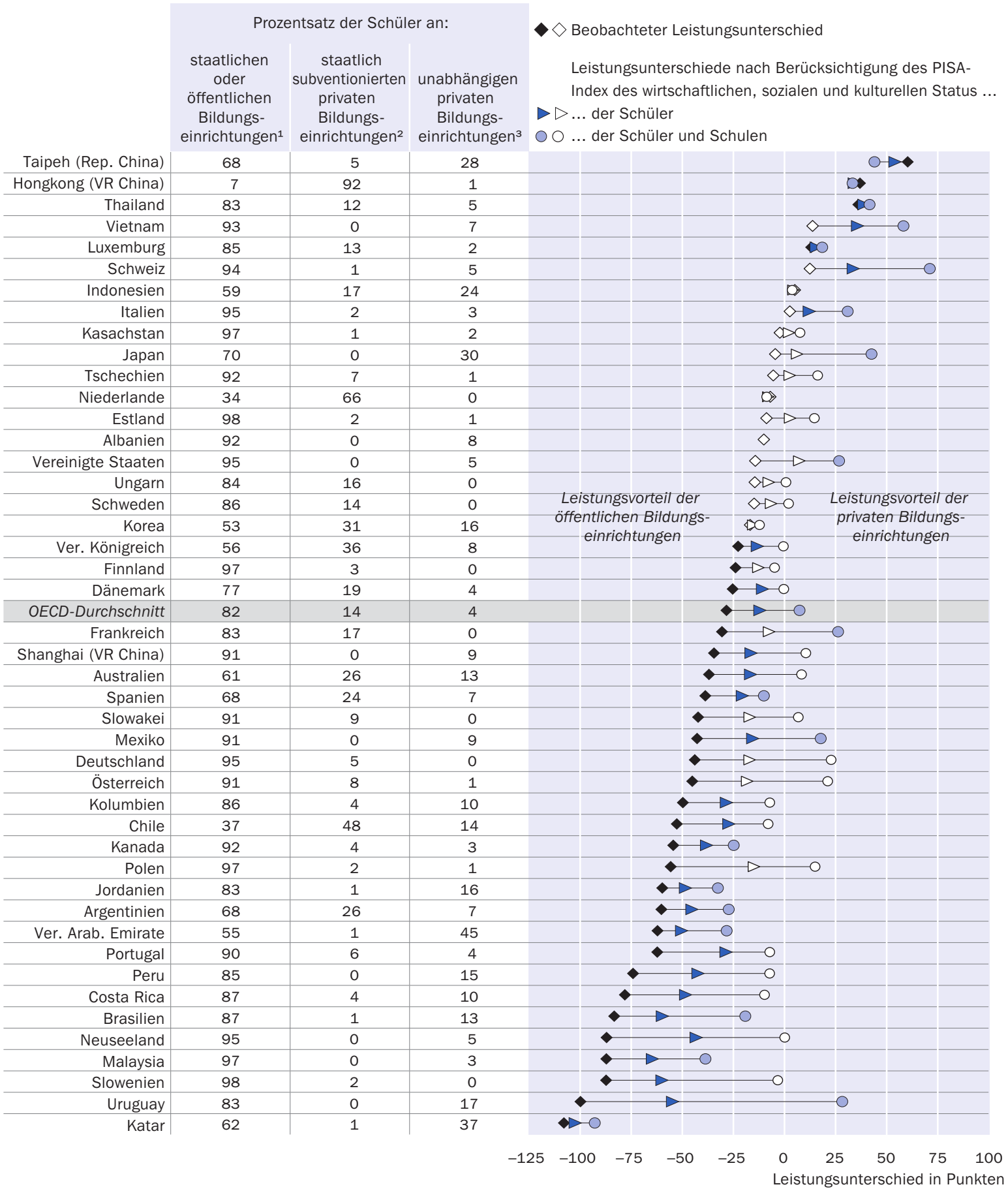

Anmerkung: Weiße Symbole kennzeichnen Unterschiede, die statistisch nicht signifikant sind.

1. Schulen, die direkt kontrolliert oder verwaltet werden von einer staatlichen Bildungsbehörde oder von einer Regierungsbehörde bzw. einem Verwaltungsgremium, dessen Mitglieder überwiegend entweder von einer staatlichen Behörde ernannt oder mit öffentlichem Wahlrecht gewählt werden. 2. Schulen, die mehr als 50 Prozent ihrer Kernfinanzierung (d.h. der Finanzierung, die die grundlegenden Bildungsdienstleistungen der Einrichtung unterstützt) von staatlichen Stellen erhalten. 3. Schulen, die weniger als 50 Prozent ihrer Kernfinanzierung (d.h. der Finanzierung, die die grundlegenden Bildungsdienstleistungen der Einrichtung unterstützt) von staatlichen Stellen erhalten.

Anordnung der Länder und Volkswirtschaften in absteigender Reihenfolge des Leistungsunterschiedes (in Punkten) in Mathematik zwischen öffentlichen und privaten Schulen (staatlich subventionierte und unabhängige private Bildungseinrichtungen).

Quelle: OECD. Tabelle C7.2. Hinweise s. Anhang 3 unter www.oecd.org/edu/eag.htm. StatLink: http://dx.doi.org/10.1787/888933119473 
PISA erfasst den Lehrermangel über die Standardabweichung des Index des Lehrermangels. Höhere Indexwerte weisen darauf hin, dass der Lehrkräftemangel nach Ansicht der Schulleitungen mehr Unterrichtsprobleme verursacht. In Israel, Jordanien, Kolumbien, Luxemburg, Shanghai (VR China), Thailand und Türkei ist der (für alle Schulen) erfasste Gesamtwert vergleichsweise hoch, in Bulgarien, Litauen, Polen, Portugal, Serbien, Slowenien und Spanien dagegen relativ niedrig (Tab. C7.4).

Tabelle $\mathrm{C}_{7.4}$ zeigt auch, dass öffentliche Bildungseinrichtungen häufiger unter Lehrermangel leiden als staatlich subventionierte oder unabhängige private Bildungseinrichtungen. In 33 von 47 Ländern und Volkswirtschaften gaben die Schulleiter öffentlicher Schulen häufiger einen Lehrermangel an als die Schulleiter privater Schulen. Besonders große Unterschiede zwischen öffentlichen und privaten Schulen werden beim Lehrermangel in Australien, Brasilien, Italien, Jordanien, Katar, Luxemburg, Mexiko, Neuseeland, Peru, Uruguay, den Vereinigten Arabischen Emiraten und Vietnam beobachtet, hier liegt die Differenz bei mehr als o,5 Indexpunkten (d. h. die Hälfte der Standardabweichung dieses Index). Vergleicht man öffentliche Schulen nur mit staatlich subventionierten privaten Schulen, so verringert sich der Abstand leicht, aber in 20 der 33 OECD-Länder mit verfügbaren Daten berichten öffentliche Schulen trotzdem häufiger von Lehrermangel als private Einrichtungen (Tab. C7.4).

\section{Zeit für Hausaufgaben oder sonstige von den Lehrern gestellte Aufgaben}

Schüler in privaten Schulen verwenden auch mehr Zeit auf Hausaufgaben oder sonstige von den Lehrkräften gestellte Aufgaben als Schüler öffentlicher Schulen. Für diese Angaben wurden I5-jährige Schüler bei PISA gefragt, wie viel Zeit sie jede Woche auf unterschiedliche Formen des Lernens außerhalb der Schule über alle Fächer hinweg verwenden.

In den OECD-Ländern gaben die Schüler an, pro Woche 4,9 Stunden auf Hausaufgaben oder sonstige von den Lehrkräften gestellte Aufgaben zu verwenden. Schüler in Italien, Kasachstan, Rumänien, der Russischen Föderation, Shanghai (VR China) und Singapur gaben an, hierfür mindestens 7 Stunden pro Woche aufzubringen. Dagegen verwenden die Schüler in Argentinien, Brasilien, Chile, Costa Rica, Japan, Liechtenstein, Portugal, Schweden, der Schweiz, der Slowakei, Slowenien, Tschechien und Tunesien weniger als 4 Stunden pro Woche darauf (Tab. C7.4).

Bei dieser Kennzahl wurden auch Unterschiede zwischen den Schülern privater und öffentlicher Bildungseinrichtungen beobachtet. Im Durchschnitt der OECD-Länder wenden Schüler privater Bildungseinrichtungen pro Woche eine Stunde mehr für Hausaufgaben oder sonstige von ihren Lehrern gestellte Aufgaben auf als Schüler öffentlicher Schulen (5,6 gegenüber 4,7 Stunden). In 38 von 47 Ländern und Volkswirtschaften verwenden Schüler privater Schulen mit verfügbaren Daten mehr Zeit auf ihre Hausaufgaben als Schüler öffentlicher Schulen, nur in 9 Ländern und Volkswirtschaften trifft das Gegenteil zu. Die zusätzliche Zeit, die Schüler privater Schulen für die Hausaufgaben verwenden, übersteigt in Australien, Kanada, Katar, Kolumbien, Neuseeland, Österreich, Portugal, den Vereinigten Staaten sowie den Vereinigten Arabischen Emiraten I, 5 Stunden (Tab. C7.4). Die Unterschiede sind auch erheblich, wenn man staatlich subventionierte und unabhängige private Bildungseinrichtungen miteinander vergleicht. Schüler unabhängiger privater Bildungseinrichtungen verwenden 
im Durchschnitt mehr Zeit auf Hausaufgaben oder sonstige von ihren Lehrern gestellte Aufgaben als Schüler an staatlich subventionierten und unabhängigen privaten Schulen (o,4 bzw. 2 Stunden) (Tab. C7.4).

\section{Klassengröße}

Für Eltern kann die Klassengröße ein wichtiger Faktor bei der Auswahl der Schule für ihre Kinder sein, und sie kann sich auf das Lernumfeld auswirken. In den OECDLändern mit verfügbaren Daten unterscheidet sich die durchschnittliche Klassengröße im Allgemeinen zwischen privaten und öffentlichen Bildungseinrichtungen sowohl im Primar- als auch im Sekundarbereich I in der Regel um nicht mehr als zwei Schüler (Abb. D7.3 und Indikator D2).

Es gibt jedoch deutliche Unterschiede zwischen den einzelnen Ländern. So ist beispielsweise in Brasilien, Island, Israel, Lettland, Polen, der Russischen Föderation, Tschechien, der Türkei, dem Vereinigten Königreich und den Vereinigten Staaten im Primarbereich die durchschnittliche Klassengröße in öffentlichen Bildungseinrichtungen um mindestens 4 Schüler pro Klasse größer als in privaten Bildungseinrichtungen. In all diesen Ländern, mit Ausnahme von Brasilien und Israel, ist jedoch der Anteil der privaten Bildungseinrichtungen mit höchstens 5 Prozent der Schüler im Primarbereich

Abbildung $\mathbf{C 7 . 3}$

Durchschnittliche Klassengröße in privaten und öffentlichen Bildungseinrichtungen, nach Bildungsbereich (2012)

Öffentliche Bildungseinrichtungen $\square$ Private Bildungseinrichtungen

Zahl der Schüler pro Klasse

Primarbereich
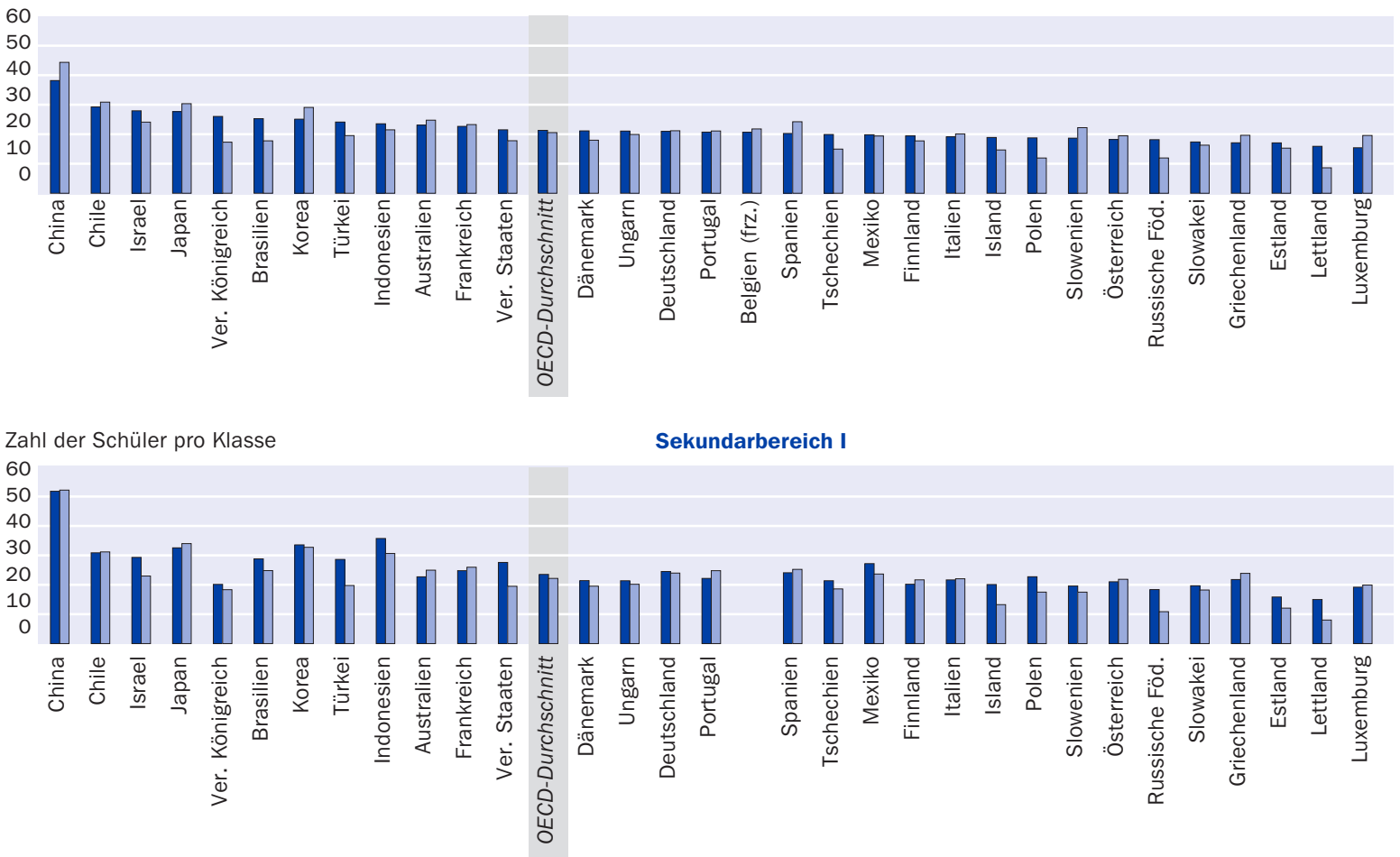

Anordnung der Länder in absteigender Reihenfolge der durchschnittlichen Klassengröße in öffentlichen Bildungseinrichtungen des Primarbereichs.

Quelle: OECD. Tabelle D2.1. Hinweise s. Anhang 3 unter www.oecd.org/edu/eag.htm. StatLink: http://dx.doi.org/10.1787/888933119492 
relativ klein (Tab. C7.I). In Spanien dagegen, wo 32 Prozent der Schüler im Primarbereich eine private Bildungseinrichtung besuchen, ist die durchschnittliche Klassengröße in privaten Bildungseinrichtungen um 4 Schüler pro Klasse größer als in öffentlichen Bildungseinrichtungen (Abb. C7.3 und Indikator D2).

Der Vergleich der Klassengröße zwischen öffentlichen und privaten Bildungseinrichtungen ergibt auch für den Sekundarbereich I, wo es mehr private Bildungseinrichtungen gibt, ein uneinheitliches Bild. In I2 Ländern ist die durchschnittliche Klassengröße im Sekundarbereich I in privaten Bildungseinrichtungen größer als in öffentlichen Einrichtungen, auch wenn die Unterschiede tendenziell kleiner als im Primarbereich sind. In Ländern mit einem größeren Anteil an privaten Bildungseinrichtungen im Primar- und Sekundarbereich I (d. h. Ländern, in denen mehr als Io Prozent der Schüler dieser Bereiche private Bildungseinrichtungen besuchen) können große Unterschiede zwischen der Klassengröße an öffentlichen und privaten Bildungseinrichtungen bestehen (Tab. C7.I und Indikator D2).

Auch die Ergebnisse von PISA zeigen, dass es im Durchschnitt der OECD-Länder keine Unterschiede bei der Klassengröße zwischen öffentlichen und privaten Schulen, die I5-jährige Schüler besuchen, gibt. Dennoch sind Unterschiede zwischen den Ländern zu beobachten: In 2I Ländern und Volkswirtschaften ist die Klassengröße beim Mathematikunterricht tendenziell an öffentlichen Bildungseinrichtungen größer, in 26 Ländern dagegen tendenziell an privaten Bildungseinrichtungen (Tab. C7.4). Dies deutet darauf hin, dass in den Ländern, in denen sich ein erheblicher Teil der Schüler und ihrer Familien für private Bildungseinrichtungen entscheidet, die Klassengröße kein ausschlaggebender Faktor für diese Entscheidung ist.

\section{Grad der Autonomie bei der Ressourcenallokation und bei der Festlegung von Lehrplänen und Schülerbeurteilungen}

Von den vielen Entscheidungen, die in Bildungssystemen und an Schulen zu treffen sind, wirken sich diejenigen zum Lehrplan und zur Verteilung und Verwendung der Mittel unmittelbar auf den Unterricht und das Lernen aus. Seit Anfang der I980er-Jahre wurden in vielen Bildungssystemen den einzelnen Schulen größere Entscheidungsbefugnisse über den Lehrplan und die Ressourcenallokation übertragen, da man davon ausging, dass die einzelnen Schulen gut einschätzen können, welche Lernbedürfnisse die Schüler haben und wie Ressourcen am wirksamsten einzusetzen sind. Ziel war es, das Leistungsniveau dadurch anzuheben, dass man die lokale Ebene dazu ermutigt, besser auf die Bedürfnisse der Schüler und der Schulen einzugehen (Whitty, I997; Carnoy, 2000; Clark, 2009; Machin and Vernoit, 20II). Hierzu gehörten gesteigerte Entscheidungsbefugnisse und Rechenschaftspflichten für Schulleiter und in manchen Fällen eine größere Leistungsverantwortung für Lehrer oder Fachbereichsleiter.

Im Rahmen von PISA 2012 wurden die Schulleitungen gebeten anzugeben, ob die Lehrkräfte, die Schulleitung, der Schulverwaltungsrat, die regionalen und lokalen Bildungsbehörden oder die nationale Bildungsbehörde in folgenden Bereichen erhebliche Verantwortung tragen: Allokation von Ressourcen an Schulen (Einstellung und Entlassung von Lehrkräften, Festlegung der Anfangsgehälter und Gehaltserhöhungen der Lehrkräfte, Festlegung des Schulbudgets, Entscheidung über die Verwendung des Budgets innerhalb der Schulen), Verantwortung für die Lehrplangestaltung und Schülerbe- 
urteilungen innerhalb der Schule (Festlegung von Kriterien für die Schülerbeurteilung, Wahl der verwendeten Schulbücher und Entscheidung über das Kursangebot und die Unterrichtsinhalte). Diese Informationen wurden kombiniert, um zwei zusammengesetzte Indizes zu erstellen: einen Index der Schulautonomie: Ressourcenallokation und einen Index der Schulautonomie: Unterrichtsinhalte und Beurteilungen, die derart beschaffen sind, dass sie in den OECD-Ländern einen Mittelwert von o und eine Standardabweichung von I aufweisen. Höhere Werte verweisen auf mehr Autonomie der Schulleitung und Lehrkräfte (Tab. C7.5).

Die Ergebnisse zeigen, dass private Bildungseinrichtungen tendenziell bei diesen beiden Indizes über ein größeres Maß an Autonomie verfügen als öffentliche Bildungseinrichtungen. Dies ist jedoch beim Index der Schulautonomie: Ressourcenallokation besonders stark ausgeprägt. Bei diesem Index haben in praktisch allen teilnehmenden Ländern und Volkswirtschaften die staatlich subventionierten und die unabhängigen privaten Bildungseinrichtungen mehr Autonomie bei der Ressourcenallokation als öffentliche Bildungseinrichtungen. Eine ähnliche Abstufung ergibt sich auch beim Vergleich der beiden Arten der privaten Bildungseinrichtungen: In den meisten Ländern haben die unabhängigen privaten Bildungseinrichtungen mehr Autonomie bei der Ressourcenallokation als staatlich subventionierte private Bildungseinrichtungen. In Brasilien, Finnland, Kolumbien, Luxemburg, Malaysia, Mexiko und Peru sind die Unterschiede beim Grad der Autonomie zwischen öffentlichen und privaten Bildungseinrichtungen am größten.

Beim Index der Schulautonomie: Unterrichtsinhalte und Beurteilungen ist der Unterschied zwischen privaten und öffentlichen Bildungseinrichtungen weniger ausgeprägt, insbesondere dann, wenn staatlich subventionierte private Bildungseinrichtungen mit öffentlichen Bildungseinrichtungen verglichen werden. In 26 Ländern und Volkswirtschaften ist die Autonomie privater Bildungseinrichtungen bei diesem Index höher, aber in Estland, Neuseeland, den Niederlanden, Österreich, der Slowakei, Slowenien und Taipeh (Republik China) trifft das Gegenteil zu (Tab. C7.5).

Die Schulsysteme unterscheiden sich auch nach dem Grad der Autonomie, der privaten Schulen zugestanden wird. Private Bildungseinrichtungen in den OECD-Ländern verfügen beispielsweise über unterschiedlich große Autonomie bei der Ressourcenallokation. Schulleiter in Belgien, Deutschland, Frankreich, Korea, Österreich und Spanien berichteten von relativ geringer Autonomie (Indexwerte von weniger als 2), während Schulleiter in Finnland, den Niederlanden, Schweden, Tschechien und dem Vereinigten Königreich das Gegenteil angaben (Indexwerte von über I,68) (Tab. C7.5).

\section{Bildungsbeteiligung und Finanzierung öffentlicher und privater Bildungseinrichtungen des Tertiärbereichs}

Der Anteil an Lernenden, die unabhängige private Bildungseinrichtungen besuchen, ist im Tertiärbereich am größten. Rund 17 Prozent der Studierenden des Tertiärbereichs B und I4 Prozent der Studierenden des Tertiärbereichs A und weiterführender forschungsorientierter Studiengänge sind an unabhängigen privaten Bildungseinrichtungen eingeschrieben. Betrachtet man die unabhängigen privaten und staatlich subventionierten privaten Bildungseinrichtungen des Tertiärbereichs zusammen, so sind dort 4I Prozent der Studierenden im Tertiärbereich B und mindestens 28 Prozent der 
Abbildung $\mathrm{C} 7.4$

Studierende des Tertiärbereichs A und weiterführender forschungsorientierter Studiengänge, nach Art der privaten Bildungseinrichtung $(2003,2012)$

Staatlich subventionierte private Bildungseinrichtungen $\square$ Unabhängige private Bildungseinrichtungen

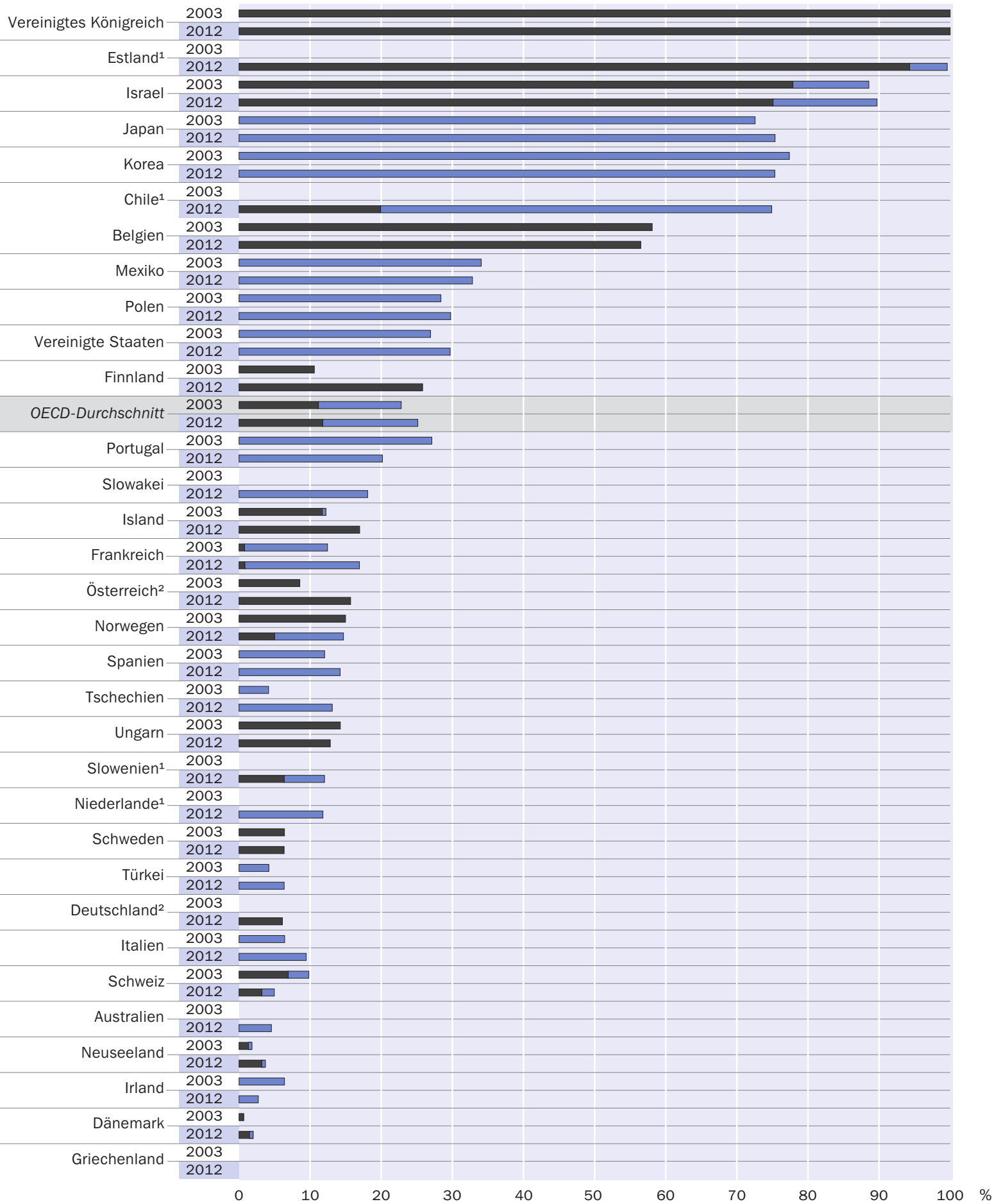

1. Keine Daten für 2003 vorhanden. 2. Einschließlich unabhängiger privater Bildungseinrichtungen.

Anordnung der Länder in absteigender Reihenfolge des Anteils Studierender im Tertiärbereich und in weiterführenden forschungsorientierten Studiengängen (ISCED 5A/6), die 2012 in privaten Bildungseinrichtungen eingeschrieben waren.

Quelle: OECD. Tabelle C7.6. Hinweise s. Anhang 3 unter www.oecd.org/edu/eag.htm. StatLink: http://dx.doi.org/10.1787/888933119511 
Studierenden im Tertiärbereich A und weiterführenden forschungsorientierten Studiengängen eingeschrieben (Tab. C7.6).

2003 besuchten im Durchschnitt der OECD-Länder 77 Prozent der im Tertiärbereich A eingeschriebenen Studierenden öffentliche Bildungseinrichtungen, II Prozent staatlich subventionierte private Bildungseinrichtungen und I2 Prozent unabhängige private Bildungseinrichtungen. Zwischen 2003 und 2012 ist der Anteil der Studierenden, die eine private Bildungseinrichtung des Tertiärbereichs besuchen, in 2I der 29 OECDLänder mit verfügbaren Daten angestiegen. Dementsprechend stieg in den OECDLändern die Bildungsbeteiligung an privaten Bildungseinrichtungen des Tertiärbereichs A zwischen 2003 und 2012 um 2 Prozentpunkte von 23 Prozent auf 25 Prozent und im Tertiärbereich B um 4 Prozentpunkte von 33 Prozent auf 37 Prozent. Der stärkste Anstieg der Studierendenzahlen in privaten Bildungseinrichtungen des Tertiärbereichs A mit über 6 Prozentpunkten war in diesem Zeitraum in Deutschland, Finnland, Österreich, der Slowakei und Tschechien zu beobachten (Tab. C7.6 und Abb. C7.4).

Die Ausweitung der privaten Bildungseinrichtungen des Tertiärbereichs ist eine Reaktion auf die signifikante Steigerung der Nachfrage nach einer Ausbildung im Tertiärbereich, die in den letzten Jahrzehnten zu beobachten ist. In den meisten Ländern bringt jedoch das Studium an einer privaten Bildungseinrichtung zusätzliche Kosten für die Studierenden mit sich. In den OECD- und G20-Ländern gibt es signifikante Unterschiede bei der Höhe der von Bildungseinrichtungen des Tertiärbereichs erhobenen Studiengebühren. In 8 OECD-Ländern erheben öffentliche Bildungseinrichtungen überhaupt keine Studiengebühren, in einem Drittel der 26 OECD-Länder mit verfügbaren Daten jedoch verlangen öffentliche Bildungseinrichtungen von inländischen Studierenden jährliche Studiengebühren von mehr als I.500 US-Dollar. In den meisten Ländern erheben private Bildungseinrichtungen höhere Studiengebühren als öffentliche. Nur in Finnland und Schweden werden weder von öffentlichen noch von privaten Bildungseinrichtungen Studiengebühren erhoben. Innerhalb eines Landes sind die Unterschiede in der Regel in den Ländern am höchsten, in denen der größte Teil der Studierenden an unabhängigen privaten Bildungseinrichtungen des Tertiärbereichs A studiert. Dagegen unterscheiden sich in den meisten Ländern die Studiengebühren von öffentlichen und staatlich subventionierten privaten Bildungseinrichtungen weniger als die von öffentlichen und unabhängigen privaten Bildungseinrichtungen. In Österreich sind sie sogar gleich (s. Indikator $\mathrm{B}_{5}$ ).

Angesichts einer wachsenden Vielfalt an Bildungsangeboten, Bildungsgängen und Anbietern im Bildungsbereich gehen die Regierungen neue Partnerschaften zur Mobilisierung von Ressourcen für den Tertiärbereich ein und verfolgen neue bildungspolitische Ansätze, die es ermöglichen, die verschiedenen Akteure stärker einzubinden und Kosten und Nutzen gerechter aufzuteilen. Entsprechend spielen auch Unternehmen eine größere Rolle bei der Finanzierung öffentlicher Bildungseinrichtungen des Tertiärbereichs. In Australien, Israel, Japan, Kanada, Korea, den Niederlanden, Österreich, Schweden, der Slowakei, Tschechien, dem Vereinigten Königreich und den Vereinigten Staaten werden mindestens 9 Prozent der Ausgaben für Bildungseinrichtungen im Tertiärbereich von anderen privaten Einheiten als den privaten Haushalten aufgebracht. In Schweden fließen diese Beiträge größtenteils in die finanzielle Förderung von Forschung und Entwicklung (s. Indikator B3). 


\section{Definitionen und angewandte Methodik}

Art der Bildungseinrichtung: Da der Indikator im Wesentlichen auf der UOE- und PISADatenerhebung beruht, entsprechen die Definitionen den in diesen Erhebungen verwendeten Definitionen. Bildungseinrichtungen werden entweder als öffentliche oder private Einrichtungen eingestuft, je nachdem, ob die letzte Entscheidungsgewalt über ihre Angelegenheiten einem privaten Träger oder einer staatlichen Behörde obliegt. Diese Angaben werden mit den Informationen über den prozentualen Anteil der Gesamtfinanzierung aus staatlichen Quellen kombiniert. In den Indikatoren werden die Bildungseinrichtungen in drei Kategorien unterteilt: unabhängige private Bildungseinrichtungen, die einer nicht staatlichen Organisation oder einem Direktorium unterstehen, dessen Mitglieder nicht von einer staatlichen Stelle ausgewählt wurden, und die weniger als 50 Prozent der Kernfinanzierung von staatlichen Stellen beziehen; staatlich subventionierte private Bildungseinrichtungen, die einer nicht staatlichen Organisation unterstehen oder deren Direktorium sich aus Mitgliedern zusammensetzt, die nicht von einer öffentlichen Stelle ausgewählt wurden, und die mehr als 50 Prozent der Kernfinanzierung von staatlichen Quellen beziehen; und öffentliche Bildungseinrichtungen, die der direkten Kontrolle und Verwaltung einer Behörde oder eines Amts für das Bildungswesen unterstehen.

Lehrermangel: Um zu bewerten, für wie angemessen Schulleiter das Angebot an Lehrkräften halten, fragte PISA 2012 die Schulleiter, inwiefern ihrer Ansicht nach der Unterricht an ihrer Schule durch den Mangel an qualifizierten Lehrkräften in bestimmten Fächern leidet. Diese Informationen wurden kombiniert, um den zusammengesetzten Index des Lehrermangels zu erhalten, der für die OECD-Länder einen Mittelwert von o und eine Standardabweichung von I aufweist. Höhere Indexwerte weisen darauf hin, dass der Lehrkräftemangel nach Ansicht der Schulleitung stärkere Unterrichtsprobleme verursacht. Bei der Interpretation dieser Ergebnisse ist jedoch Vorsicht geboten: Die Erwartungen und Leistungsstandards der Schulleiter bei der Entscheidung darüber, wann ein Mangel an qualifizierten Lehrkräften besteht, könnten sich zwischen den einzelnen Ländern und Volkswirtschaften und sogar innerhalb derselben unterscheiden. Dennoch liefern diese Berichte wichtige Informationen für die Beurteilung, ob den Schülern in Schulen oder Schulsystemen angemessene Humanressourcen zur Verfügung stehen.

\section{Anmerkung zu den Daten aus Israel}

Die statistischen Daten für Israel wurden von den zuständigen israelischen Stellen bereitgestellt, die für sie verantwortlich zeichnen. Die Verwendung dieser Daten durch die OECD erfolgt unbeschadet des völkerrechtlichen Status der Golanhöhen, von Ost-Jerusalem und der israelischen Siedlungen im Westjordanland. 


\section{Weiterführende Informationen}

Couch, J., W. Shugart and A. Williams (1993), „Private school enrolment and public school performance“, Public Choice, Vol. 76, pp. 30I-312.

Filer, R. K. and D. Munich (2003), „Public support for private schools in post-communist Europe: Czech and Hungarian experiences“, in D. N. Plank and G. Sykes (eds.), Choosing Choice: School Choice in International Perspective, Teachers College Press, New York.

Geller, C. R., D. L. Sjoquist and M. B. Walker (2006), „The effect of private school competition on public school performance in Georgia“, Public Finance Review, Vol. 34, No. I, pp. 4-32.

Green, F., et al. (20II), „The changing economic advantage from private schools“, Economica, Vol. 79, No. 316, pp. 658-678.

Greene, K.V. and B. G. Kang (2004), „The effect of public and private competition on high school outputs in New York State“, Economics of Education Review, No. 23, pp. 497-506.

Lara, B., A. Mizala and A. Repetto (2009), „The effectiveness of private voucher education: Evidence from structural school switches“, Working Paper No. 263, CEA, Universidad de Chile.

Maranto, R., S. Milliman and S. Scott (2000), „Does private school competition harm public schools? Revisiting Smith and Meier's The Case Against School Choice“, Political Research Quarterly, Vol. 53, No. I, pp. I77-I92.

Peterson, P., et al. (2003), „School vouchers: Results from randomized experiments“, in C. Hoxby (ed.), The Economics of School Choice, University of Chicago Press, Chicago, pp. I07-I44.

Sander W. (I999), „Private schools and public school achievement“, Journal of Human Resources, Vol. 34, No. 4, pp. 697-709.

Sandström, M. and F. Bergström (2005), „School vouchers in practice: Competition will not hurt you“, Journal of Public Economics, Vol. 89, No. 2-3, pp. 35I-380.

Wrinkle, R., et al. (1999), „Public school quality, private schools, and race“, American Journal of Political Science, Vol. 43, No. 4, pp. I248-I253.

\section{Tabellen Indikator $\mathbf{C 7}$}

StatLink: http://dx.doi.org/10.1787/888933119321

Tabelle C7.I: Verteilung der Schüler im Elementar-, Primar- und Sekundarbereich, nach Art der Bildungseinrichtung (20I2) 
Tabelle C7.2: Art der Bildungseinrichtung und Leistungen in Mathematik (2012)

Tabelle C7.3: Art der Bildungseinrichtung und Leistungen in Mathematik (2003)

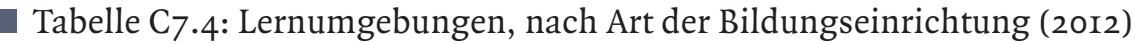

Tabelle C7.5: Autonomie der Schule bei Ressourcenallokation, Unterrichtsinhalten und Beurteilungen, nach Art der Bildungseinrichtung und Bildungsbereich (2012)

Tabelle C7.6: Verteilung der Studierenden im Tertiärbereich nach Art der Bildungseinrichtung (2003, 2012) 
Verteilung der Schüler im Elementar-, Primar- und Sekundarbereich, nach Art der Bildungseinrichtung (2012)

Verteilung der Schüler nach Art der Bildungseinrichtung

\begin{tabular}{|c|c|c|c|c|c|c|c|c|c|c|c|c|}
\hline & \multicolumn{3}{|c|}{ Elementarbereich } & \multicolumn{3}{|c|}{ Primarbereich } & \multicolumn{3}{|c|}{ Sekundarbereich I } & \multicolumn{3}{|c|}{ Sekundarbereich II } \\
\hline & Öffentlich & $\begin{array}{c}\text { Staatlich } \\
\text { subven- } \\
\text { tioniert } \\
\text { privat }\end{array}$ & $\begin{array}{c}\text { Unab- } \\
\text { hängig } \\
\text { privat }\end{array}$ & Öffentlich & $\begin{array}{c}\text { Staatlich } \\
\text { subven- } \\
\text { tioniert } \\
\text { privat }\end{array}$ & $\begin{array}{l}\text { Unab- } \\
\text { hängig } \\
\text { privat }\end{array}$ & Öffentlich & $\begin{array}{c}\text { Staatlich } \\
\text { subven- } \\
\text { tioniert } \\
\text { privat }\end{array}$ & $\begin{array}{c}\text { Unab- } \\
\text { hängig } \\
\text { privat }\end{array}$ & Öffentlich & $\begin{array}{c}\text { Staatlich } \\
\text { subven- } \\
\text { tioniert } \\
\text { privat }\end{array}$ & $\begin{array}{c}\text { Unab- } \\
\text { hängig } \\
\text { privat }\end{array}$ \\
\hline & (1) & (2) & (3) & (4) & (5) & (6) & (7) & (8) & (9) & (10) & (11) & (12) \\
\hline \multicolumn{13}{|l|}{ OECD-Länder } \\
\hline Australien $^{1}$ & 22 & 78 & $\mathrm{~m}$ & 69 & 31 & $\mathrm{~m}$ & 64 & 36 & $\mathrm{~m}$ & 63 & 36 & $\mathrm{~m}$ \\
\hline Österreich & 70 & 30 & $x(2)$ & 94 & 6 & $x(5)$ & 91 & 9 & $x(8)$ & 90 & 10 & $x(11)$ \\
\hline Belgien $^{1}$ & 47 & 53 & $\mathrm{~m}$ & 46 & 54 & $\mathrm{~m}$ & 39 & 61 & $\mathrm{~m}$ & 43 & 57 & $\mathrm{~m}$ \\
\hline Kanada ${ }^{2}$ & $\mathrm{~m}$ & $\mathrm{~m}$ & $\mathrm{~m}$ & 94 & 6 & $x(5)$ & 91 & 9 & $x(8)$ & 94 & 6 & $x(11)$ \\
\hline Chile & 34 & 60 & 6 & 40 & 53 & 7 & 45 & 48 & 7 & 38 & 55 & 7 \\
\hline Tschechien & 98 & 2 & a & 98 & 2 & a & 97 & 3 & a & 86 & 14 & a \\
\hline Dänemark & 81 & 19 & $\mathrm{n}$ & 85 & 15 & $\mathrm{n}$ & 73 & 26 & 1 & 98 & 2 & $\mathrm{n}$ \\
\hline Estland & 97 & a & 3 & 96 & a & 4 & 96 & a & 4 & 97 & a & 3 \\
\hline Finnland & 92 & 8 & a & 98 & 2 & a & 95 & 5 & a & 81 & 19 & a \\
\hline Frankreich & 87 & 12 & $\mathrm{n}$ & 85 & 14 & $\mathrm{n}$ & 78 & 22 & $\mathrm{n}$ & 69 & 31 & 1 \\
\hline Deutschland & 35 & 65 & $x(2)$ & 96 & 4 & $x(5)$ & 91 & 9 & $x(8)$ & 92 & 8 & $x(11)$ \\
\hline Griechenland & 93 & a & 7 & 93 & a & 7 & 95 & a & 5 & 96 & a & 4 \\
\hline Ungarn & 93 & 7 & a & 89 & 11 & a & 88 & 12 & a & 76 & 24 & a \\
\hline Island & 88 & 12 & $\mathrm{n}$ & 97 & 3 & $\mathrm{n}$ & 99 & 1 & $\mathrm{n}$ & 79 & 20 & 1 \\
\hline Irland & 2 & a & 98 & 99 & a & 1 & 100 & a & a & 99 & a & 1 \\
\hline Israel & 91 & a & 9 & 77 & 23 & a & 84 & 16 & a & 94 & 6 & a \\
\hline Italien & 70 & a & 30 & 93 & a & 7 & 96 & a & 4 & 91 & 4 & 5 \\
\hline Japan & 29 & a & 71 & 99 & a & 1 & 93 & a & 7 & 69 & a & 31 \\
\hline Korea & 16 & 84 & a & 98 & a & 2 & 82 & 18 & a & 56 & 44 & $\mathrm{a}$ \\
\hline Luxemburg & 91 & $\mathrm{n}$ & 9 & 91 & $\mathrm{n}$ & 9 & 81 & 10 & 9 & 84 & 7 & 9 \\
\hline Mexiko & 86 & a & 14 & 92 & a & 8 & 89 & a & 11 & 83 & a & 17 \\
\hline Niederlande & 70 & a & 30 & 100 & a & $\mathrm{n}$ & 97 & a & 3 & 91 & a & 9 \\
\hline Neuseeland & 1 & 99 & $\mathrm{n}$ & 98 & a & 2 & 95 & a & 5 & 85 & 8 & 7 \\
\hline Norwegen & 54 & 46 & $x(2)$ & 98 & 2 & $x(5)$ & 97 & 3 & $x(8)$ & 90 & 10 & $x(11)$ \\
\hline Polen & 84 & 1 & 14 & 97 & 1 & 3 & 95 & 1 & 4 & 85 & 1 & 14 \\
\hline Portugal & 53 & 30 & 16 & 88 & 4 & 8 & 85 & 7 & 8 & 78 & 5 & 17 \\
\hline Slowakei & 96 & 4 & $\mathrm{n}$ & 94 & 6 & $n$ & 93 & 7 & $n$ & 85 & 15 & $n$ \\
\hline Slowenien & 97 & 2 & $\mathrm{n}$ & 99 & 1 & $\mathrm{n}$ & 100 & $\mathrm{n}$ & a & 96 & 2 & 2 \\
\hline Spanien & 65 & 24 & 11 & 68 & 28 & 4 & 69 & 28 & 3 & 79 & 12 & 9 \\
\hline Schweden & 83 & 17 & $\mathrm{n}$ & 91 & 9 & $\mathrm{n}$ & 86 & 14 & $\mathrm{n}$ & 83 & 17 & $\mathrm{n}$ \\
\hline Schweiz & 96 & $n$ & 4 & 95 & 2 & 3 & 92 & 3 & 5 & 87 & 9 & 4 \\
\hline Türkei & 91 & a & 9 & 97 & a & 3 & 97 & $a$ & 3 & 97 & a & 3 \\
\hline Vereinigtes Königreich & 63 & 31 & 6 & 93 & 3 & 5 & 55 & 40 & 5 & 33 & 62 & 5 \\
\hline Vereinigte Staaten & 60 & a & 40 & 92 & a & 8 & 92 & a & 8 & 92 & a & 8 \\
\hline OECD-Durchschnitt & 68 & 20 & 11 & 89 & 8 & 3 & 86 & 11 & 3 & 81 & 14 & 5 \\
\hline EU21-Durchschnitt & 75 & 15 & 11 & 90 & 8 & 2 & 86 & 12 & 2 & 82 & 14 & 4 \\
\hline \multicolumn{13}{|l|}{ Partnerländer } \\
\hline Argentinien ${ }^{2}$ & 68 & 25 & 7 & 76 & 20 & 4 & 77 & 19 & 3 & 71 & 24 & 5 \\
\hline Brasilien & 71 & a & 29 & 85 & a & 15 & 88 & a & 12 & 84 & a & 16 \\
\hline Kolumbien & 64 & a & 36 & 81 & a & 19 & 81 & a & 19 & 77 & a & 23 \\
\hline China & 51 & 49 & $x(2)$ & 94 & 6 & $x(5)$ & 91 & 9 & $x(8)$ & 89 & 11 & $x(11)$ \\
\hline Indien & $\mathrm{m}$ & $\mathrm{m}$ & $\mathrm{m}$ & $\mathrm{m}$ & $\mathrm{m}$ & $\mathrm{m}$ & $\mathrm{m}$ & $\mathrm{m}$ & $\mathrm{m}$ & $\mathrm{m}$ & $\mathrm{m}$ & $\mathrm{m}$ \\
\hline Indonesien & 3 & a & 97 & 83 & a & 17 & 64 & a & 36 & 50 & a & 50 \\
\hline Lettland & 95 & a & 5 & 99 & a & 1 & 99 & a & 1 & 98 & a & 2 \\
\hline Russische Föderation & 99 & a & 1 & 99 & a & 1 & 99 & a & 1 & 98 & a & 2 \\
\hline Saudi-Arabien & 59 & 41 & $x(2)$ & 90 & 10 & $x(5)$ & 92 & 8 & $x(8)$ & 83 & 17 & $x(11)$ \\
\hline Südafrika² & 94 & 6 & $x(2)$ & 96 & 4 & $x(5)$ & 96 & 4 & $x(8)$ & 96 & 4 & $x(11)$ \\
\hline G20-Durchschnitt & 59 & 23 & 18 & 91 & 5 & 4 & 85 & 10 & 5 & 78 & 14 & 8 \\
\hline
\end{tabular}

1. Ohne unabhängige private Bildungseinrichtungen. 2. Referenzjahr 2011.

Quelle: OECD. Argentinien, China, Indonesien, Kolumbien, Saudi-Arabien, Südafrika: Statistikinstitut der UNESCO (World Education Indicators Programme).

Hinweise s. Anhang 3 unter www.oecd.org/edu/eag.htm. StatLink: http://dx.doi.org/10.1787/888933119340

Erläuterung der Kennzeichnung fehlender Daten s. Hinweise für den Leser. 
Tabelle C7.2

Art der Bildungseinrichtung und Leistungen in Mathematik (2012)

Ergebnisse basieren auf den Angaben der Schulleiter

\begin{tabular}{|c|c|c|c|c|c|c|c|c|c|c|c|c|}
\hline & \multicolumn{4}{|c|}{ Öffentliche Bildungseinrichtungen } & \multicolumn{4}{|c|}{$\begin{array}{l}\text { Staatlich subventionierte } \\
\text { private Bildungseinrichtungen }\end{array}$} & \multicolumn{4}{|c|}{$\begin{array}{l}\text { Unabhängige private } \\
\text { Bildungseinrichtungen }\end{array}$} \\
\hline & \multicolumn{2}{|c|}{$\begin{array}{l}\text { Anteil der Schüler } \\
\text { (in \%) }\end{array}$} & \multicolumn{2}{|c|}{$\begin{array}{l}\text { Leistung auf der } \\
\text { Mathematikskala }\end{array}$} & \multicolumn{2}{|c|}{$\begin{array}{l}\text { Anteil der Schüler } \\
\text { (in \%) }\end{array}$} & \multicolumn{2}{|c|}{$\begin{array}{l}\text { Leistung auf der } \\
\text { Mathematikskala }\end{array}$} & Anteil d & chüler & $\begin{array}{l}\text { Leistung } \\
\text { Mathema }\end{array}$ & $\begin{array}{l}\text { auf der } \\
\text { tikskala }\end{array}$ \\
\hline & $\%$ & S.F. & Mittelwert & S.F. & $\%$ & S.F. & Mittelwert & S.F. & $\%$ & S.F. & Mittelwert & S.F. \\
\hline & (1) & (2) & (3) & (4) & (5) & (6) & (7) & (8) & (9) & $(10)$ & (11) & (12) \\
\hline OECD-Länder & & & & & & & & & & & & \\
\hline Australien & 61,0 & $(0,7)$ & 489 & $(2,3)$ & 26,5 & $(1,0)$ & 510 & $(2,9)$ & 12,5 & $(0,9)$ & 559 & $(3,6)$ \\
\hline Österreich & 91,4 & $(2,3)$ & 502 & $(3,2)$ & 7,5 & $(2,1)$ & 546 & $(15,9)$ & 1,1 & $(0,9)$ & 559 & $(14,5)$ \\
\hline Belgien & w & w & w & w & w & w & w & w & w & w & w & w \\
\hline Kanada & 92,2 & $(0,8)$ & 514 & $(2,0)$ & 4,3 & $(0,6)$ & 570 & $(8,1)$ & 3,5 & $(0,8)$ & 566 & $(10,1)$ \\
\hline Chile & 37,5 & $(1,6)$ & 390 & $(5,0)$ & 48,1 & $(2,7)$ & 424 & $(4,9)$ & 14,5 & $(2,2)$ & 503 & $(6,6)$ \\
\hline Tschechien & 91,8 & $(1,9)$ & 498 & $(3,8)$ & 6,9 & $(1,6)$ & 493 & $(17,3)$ & 1,3 & $(0,9)$ & C & c \\
\hline Dänemark & 77,0 & $(1,8)$ & 494 & $(2,5)$ & 18,9 & $(2,0)$ & 517 & $(6,2)$ & 4,2 & $(1,5)$ & 527 & $(13,0)$ \\
\hline Estland & 97,5 & $(1,0)$ & 520 & $(2,0)$ & 1,9 & $(1,0)$ & 509 & $(36,3)$ & 0,5 & $(0,0)$ & c & C \\
\hline Finnland & 97,0 & $(0,7)$ & 518 & $(2,0)$ & 3,0 & $(0,7)$ & 542 & $(7,2)$ & 0,0 & c & c & C \\
\hline Frankreich & 82,8 & $(1,4)$ & 490 & $(3,2)$ & 17,2 & $(1,4)$ & 521 & $(6,6)$ & 0,0 & c & c & C \\
\hline Deutschland & 94,5 & $(1,6)$ & 511 & $(3,5)$ & 5,0 & $(1,6)$ & 549 & $(19,4)$ & 0,5 & $(0,4)$ & c & C \\
\hline Griechenland & 97,7 & $(0,7)$ & 450 & $(2,7)$ & 0,0 & C & c & c & 2,3 & $(0,7)$ & c & C \\
\hline Ungarn & 84,0 & $(2,9)$ & 475 & $(3,4)$ & 16,0 & $(2,9)$ & 489 & $(14,1)$ & 0,0 & C & c & C \\
\hline Island & 99,5 & $(0,1)$ & 493 & $(1,7)$ & 0,5 & $(0,1)$ & $\mathrm{C}$ & C & 0,0 & C & c & C \\
\hline Irland & w & w & w & w & w & w & w & w & w & w & w & w \\
\hline Israel & 100,0 & c & 466 & $(4,7)$ & 0,0 & c & c & c & 0,0 & c & c & c \\
\hline Italien & 95,3 & $(0,7)$ & 487 & $(2,3)$ & 1,8 & $(0,4)$ & 437 & $(7,1)$ & 2,9 & $(0,5)$ & 515 & $(8,9)$ \\
\hline Japan & 70,1 & $(1,2)$ & 535 & $(3,3)$ & 0,0 & c & c & c & 29,9 & $(1,2)$ & 540 & $(9,6)$ \\
\hline Korea & 52,7 & $(4,1)$ & 546 & $(7,1)$ & 31,4 & $(3,8)$ & 539 & $(7,2)$ & 15,9 & $(3,1)$ & 609 & $(10,5)$ \\
\hline Luxemburg & 84,9 & $(0,1)$ & 492 & $(1,3)$ & 13,4 & $(0,0)$ & 464 & $(2,4)$ & 1,8 & $(0,0)$ & c & c \\
\hline Mexiko & 90,7 & $(0,9)$ & 408 & $(1,5)$ & 0,1 & $(0,1)$ & c & c & 9,2 & $(0,8)$ & 452 & $(6,0)$ \\
\hline Niederlande $^{1}$ & 33,6 & $(4,4)$ & 516 & $(10,0)$ & 66,4 & $(4,4)$ & 523 & $(5,6)$ & 0,0 & c & c & C \\
\hline Neuseeland & 94,7 & $(1,4)$ & 496 & $(2,5)$ & 0,0 & C & c & c & 5,3 & $(1,4)$ & 583 & $(6,8)$ \\
\hline Norwegen & 98,3 & $(1,0)$ & 489 & $(2,8)$ & 1,7 & $(1,0)$ & c & c & 0,0 & C & c & c \\
\hline Polen & 97,1 & $(0,4)$ & 516 & $(3,6)$ & 1,9 & $(0,4)$ & 566 & $(22,1)$ & 1,0 & $(0,2)$ & 581 & $(14,9)$ \\
\hline Portugal & 89,9 & $(2,0)$ & 481 & $(3,8)$ & 5,8 & $(1,9)$ & 516 & $(7,3)$ & 4,2 & $(1,4)$ & 581 & $(5,2)$ \\
\hline Slowakei & 91,0 & $(2,4)$ & 478 & $(4,1)$ & 8,6 & $(2,5)$ & 520 & $(20,2)$ & 0,5 & $(0,3)$ & c & c \\
\hline Slowenien & 97,6 & $(0,1)$ & 501 & $(1,3)$ & 2,4 & $(0,1)$ & 589 & $(6,9)$ & 0,0 & c & c & c \\
\hline Spanien & 68,2 & $(0,8)$ & 471 & $(2,5)$ & 24,4 & $(1,1)$ & 506 & $(3,6)$ & 7,4 & $(1,0)$ & 523 & $(4,8)$ \\
\hline Schweden & 86,0 & $(0,7)$ & 476 & $(2,4)$ & 14,0 & $(0,7)$ & 491 & $(7,9)$ & 0,0 & c & c & $\mathrm{C}$ \\
\hline Schweiz & 93,7 & $(1,3)$ & 532 & $(3,3)$ & 1,5 & $(0,8)$ & 567 & $(18,4)$ & 4,8 & $(1,0)$ & 505 & $(13,0)$ \\
\hline Türkei & 100,0 & c & 447 & $(4,9)$ & 0,0 & c & c & c & 0,0 & c & c & c \\
\hline Vereinigtes Königreich & 56,2 & $(3,1)$ & 485 & $(3,6)$ & 36,0 & $(3,2)$ & 494 & $(7,6)$ & 7,8 & $(0,7)$ & 569 & $(12,7)$ \\
\hline Vereinigte Staaten & 94,9 & $(0,9)$ & 482 & $(4,0)$ & 0,0 & c & c & c & 5,1 & $(0,9)$ & 496 & $(10,0)$ \\
\hline OECD-Durchschnitt & $\mathbf{8 1 , 7}$ & $(0,3)$ & 489 & $(0,7)$ & 14,2 & $(0,4)$ & 517 & $(2,6)$ & 4,1 & $(0,2)$ & 542 & $(2,5)$ \\
\hline Partnerländer & & & & & & & & & & & & \\
\hline Albanien & 91,7 & $(2,1)$ & 393 & $(2,2)$ & 0,0 & $c$ & c & c & 8,3 & $(2,1)$ & 403 & $(6,4)$ \\
\hline Argentinien & 67,7 & $(2,3)$ & 368 & $(4,1)$ & 25,6 & $(2,9)$ & 428 & $(5,7)$ & 6,7 & $(2,2)$ & 428 & $(14,3)$ \\
\hline Brasilien & 86,5 & $(1,3)$ & 376 & $(2,0)$ & 0,6 & $(0,4)$ & c & C & 12,8 & $(1,3)$ & 461 & $(6,9)$ \\
\hline Bulgarien & 98,8 & $(0,9)$ & 438 & $(4,1)$ & 0,0 & C & c & c & 1,2 & $(0,9)$ & $\mathrm{C}$ & C \\
\hline Kolumbien & 85,9 & $(1,4)$ & 369 & $(2,8)$ & 4,0 & $(0,8)$ & 362 & $(8,0)$ & 10,1 & $(1,4)$ & 441 & $(12,7)$ \\
\hline Costa Rica & 86,9 & $(1,4)$ & 396 & $(3,3)$ & 3,6 & $(0,9)$ & 465 & $(17,1)$ & 9,5 & $(1,5)$ & 478 & $(9,5)$ \\
\hline Kroatien & 98,2 & $(1,1)$ & 471 & $(3,6)$ & 0,8 & $(0,8)$ & $\mathrm{C}$ & $\mathrm{C}$ & 0,9 & $(0,7)$ & c & $\mathrm{C}$ \\
\hline Hongkong (VR China) & 7,0 & $(0,2)$ & 597 & $(9,5)$ & 91,9 & $(0,8)$ & 560 & $(3,5)$ & 1,2 & $(0,7)$ & c & C \\
\hline Indonesien & 58,9 & $(2,6)$ & 377 & $(5,0)$ & 17,5 & $(2,3)$ & 342 & $(5,6)$ & 23,7 & $(2,7)$ & 395 & $(10,7)$ \\
\hline Jordanien & 83,3 & $(1,5)$ & 376 & $(3,1)$ & 0,9 & $(0,6)$ & $\mathrm{C}$ & $\mathrm{C}$ & 15,8 & $(1,2)$ & 440 & $(10,8)$ \\
\hline Kasachstan & 97,2 & $(1,0)$ & 432 & $(3,0)$ & 0,7 & $(0,5)$ & c & c & 2,1 & $(0,9)$ & 436 & $(14,7)$ \\
\hline Lettland & 97,7 & $(1,5)$ & 490 & $(2,9)$ & 0,4 & $(0,4)$ & c & c & 1,9 & $(1,3)$ & c & $\mathrm{C}$ \\
\hline Liechtenstein & 93,6 & $(0,4)$ & 541 & $(3,9)$ & 0,0 & c & c & c & 6,4 & $(0,4)$ & c & c \\
\hline Litauen & 98,6 & $(0,7)$ & 478 & $(2,7)$ & 1,1 & $(0,6)$ & c & c & 0,4 & $(0,4)$ & c & C \\
\hline Macau (VR China) & 4,2 & $(0,0)$ & c & c & 81,3 & $(0,0)$ & 537 & $(1,1)$ & 14,5 & $(0,0)$ & 559 & $(2,9)$ \\
\hline Malaysia & 96,6 & $(0,7)$ & 418 & $(3,2)$ & 0,0 & c & c & c & 3,4 & $(0,7)$ & 505 & $(27,3)$ \\
\hline Montenegro & 99,6 & $(0,0)$ & 410 & $(1,1)$ & 0,0 & c & c & c & 0,4 & $(0,0)$ & C & c \\
\hline Peru & 85,3 & $(1,8)$ & 350 & $(3,2)$ & 0,0 & c & c & c & 14,7 & $(1,8)$ & 424 & $(11,3)$ \\
\hline Katar & 61,9 & $(0,1)$ & 335 & $(1,0)$ & 0,9 & $(0,0)$ & c & c & 37,2 & $(0,1)$ & 442 & $(1,3)$ \\
\hline Rumänien & 99,4 & $(0,6)$ & 444 & $(3,7)$ & 0,0 & c & c & c & 0,6 & $(0,6)$ & c & c \\
\hline Russische Föderation & 99,4 & $(0,6)$ & 482 & $(3,0)$ & 0,0 & C & c & c & 0,6 & $(0,6)$ & c & C \\
\hline Serbien & 99,6 & $(0,4)$ & 448 & $(3,9)$ & 0,0 & $\mathrm{C}$ & c & c & 0,4 & $(0,4)$ & c & C \\
\hline Shanghai (VR China) & 90,7 & $(1,8)$ & 609 & $(3,4)$ & 0,0 & c & c & c & 9,3 & $(1,8)$ & 644 & $(9,3)$ \\
\hline Singapur & 97,6 & $(0,7)$ & 574 & $(1,2)$ & 0,0 & c & $\mathrm{C}$ & c & 2,4 & $(0,7)$ & $\mathrm{C}$ & C \\
\hline Taipeh (Republik China) & 67,6 & $(1,4)$ & 581 & $(3,7)$ & 4,6 & $(1,3)$ & 469 & $(9,5)$ & 27,9 & $(1,9)$ & 529 & $(7,9)$ \\
\hline Thailand & 83,5 & $(0,6)$ & 433 & $(3,8)$ & 11,6 & $(1,5)$ & 396 & $(5,1)$ & 4,9 & $(1,3)$ & 398 & $(23,2)$ \\
\hline Tunesien & 99,4 & $(0,4)$ & 389 & $(3,9)$ & 0,0 & c & c & c & 0,6 & $(0,4)$ & c & $\mathrm{c}$ \\
\hline Ver. Arabische Emirate & 54,5 & $(1,7)$ & 399 & $(2,6)$ & 0,6 & $(0,4)$ & c & c & 44,9 & $(1,7)$ & 461 & $(4,3)$ \\
\hline Uruguay & 83,3 & $(1,2)$ & 393 & $(2,6)$ & 0,0 & C & c & c & 16,7 & $(1,2)$ & 492 & $(6,6)$ \\
\hline Vietnam & 92,6 & $(1,1)$ & 513 & $(5,1)$ & 0,0 & c & c & c & 7,4 & $(1,1)$ & 499 & $(11,6)$ \\
\hline
\end{tabular}

Anmerkung: Statistisch signifikante Werte sind durch Fettdruck gekennzeichnet (s. Anhang A3).

1. In den Niederlanden sind staatlich subventionierte private Bildungseinrichtungen öffentlich finanziert, sie unterscheiden sich von öffentlichen Bildungseinrichtungen durch die konfessionelle Ausrichtung und/oder pädagogische Konzepte.

Quelle: OECD. PISA-2012-Datenbank. Hinweise s. Anhang 3 unter www.oecd.org/edu/eag.htm. StatLink: http://dx.doi.org/10.1787/888933119359

Erläuterung der Kennzeichnung fehlender Daten s. Hinweise für den Leser. 
Tabelle C7.2 (Forts.)

Art der Bildungseinrichtung und Leistungen in Mathematik (2012)

Ergebnisse basieren auf den Angaben der Schulleiter

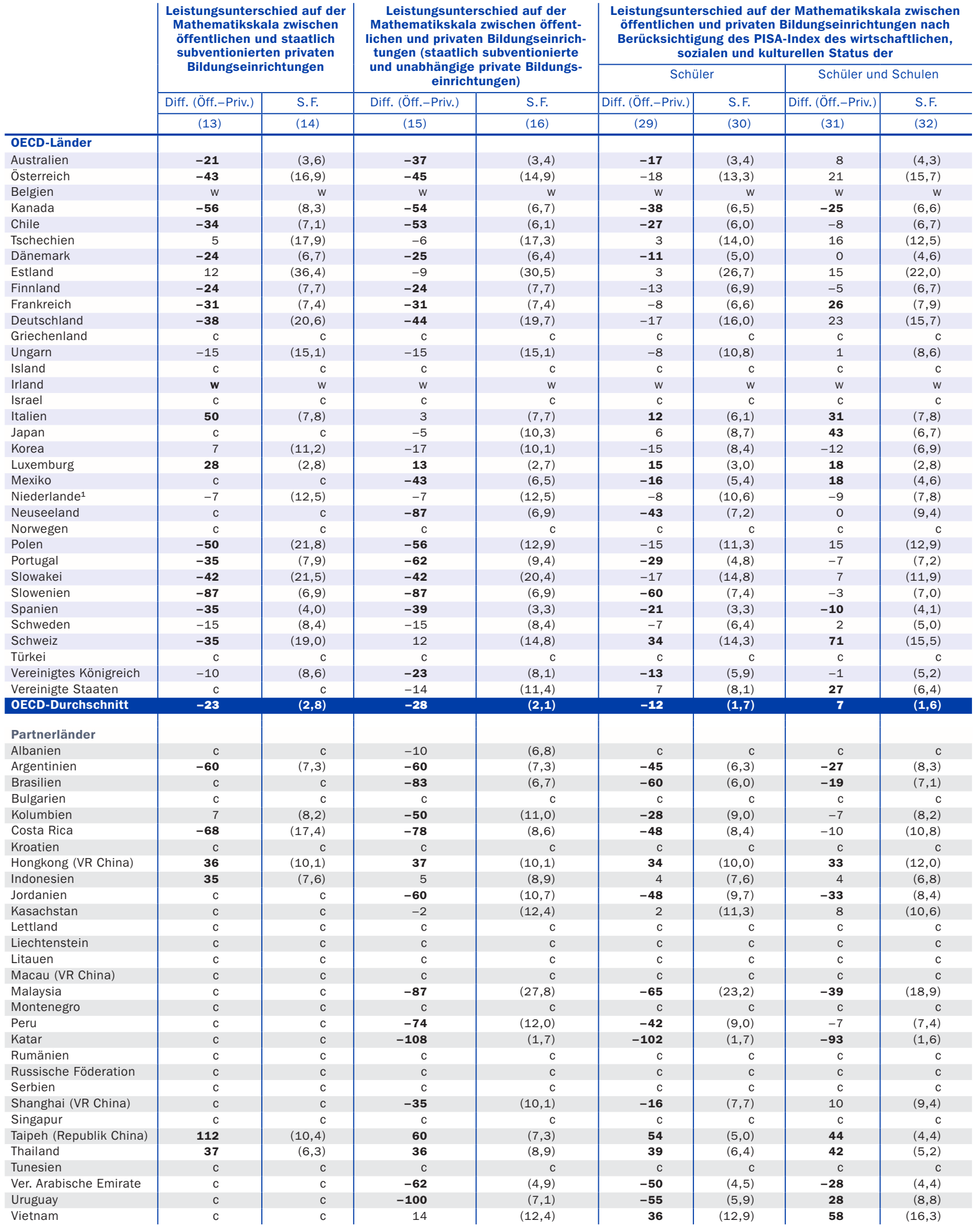

Anmerkung: Statistisch signifikante Werte sind durch Fettdruck gekennzeichnet (s. Anhang A3).

1. In den Niederlanden sind staatlich subventionierte private Bildungseinrichtungen öffentlich finanziert, sie unterscheiden sich von öffentlichen Bildungseinrichtungen durch die konfessionelle Ausrichtung und/oder pädagogische Konzepte.

Quelle: OECD. PISA-2012-Datenbank. Hinweise s. Anhang 3 unter www.oecd.org/edu/eag.htm. StatLink: http://dx.doi.org/10.1787/888933119359

Erläuterung der Kennzeichnung fehlender Daten s. Hinweise für den Leser. 
Art der Bildungseinrichtung und Leistungen in Mathematik (2003)

Ergebnisse basieren auf den Angaben der Schulleiter

\begin{tabular}{|c|c|c|c|c|c|c|c|c|c|c|c|c|}
\hline & \multicolumn{4}{|c|}{ Öffentliche Bildungseinrichtungen } & \multicolumn{4}{|c|}{$\begin{array}{c}\text { Staatlich subventionierte } \\
\text { private Bildungseinrichtungen }\end{array}$} & \multicolumn{4}{|c|}{$\begin{array}{l}\text { Unabhängige private } \\
\text { Bildungseinrichtungen }\end{array}$} \\
\hline & \multicolumn{2}{|c|}{$\begin{array}{l}\text { Anteil der Schüler } \\
\text { (in \%) }\end{array}$} & \multicolumn{2}{|c|}{$\begin{array}{l}\text { Leistung auf der } \\
\text { Mathematikskala }\end{array}$} & \multicolumn{2}{|c|}{$\begin{array}{l}\text { Anteil der Schüler } \\
\text { (in \%) }\end{array}$} & \multicolumn{2}{|c|}{$\begin{array}{l}\text { Leistung auf der } \\
\text { Mathematikskala }\end{array}$} & \multicolumn{2}{|c|}{$\begin{array}{l}\text { Anteil der Schüler } \\
\text { (in \%) }\end{array}$} & \multicolumn{2}{|c|}{$\begin{array}{l}\text { Leistung auf der } \\
\text { Mathematikskala }\end{array}$} \\
\hline & $\%$ & S.F. & Mittelwert & S.F. & $\%$ & S.F. & Mittelwert & S.F. & $\%$ & S.F. & Mittelwert & S.F. \\
\hline & (1) & (2) & (3) & (4) & (5) & (6) & (7) & (8) & (9) & (10) & (11) & (12) \\
\hline \multicolumn{13}{|l|}{ OECD-Länder } \\
\hline Australien & w & w & w & w & w & w & w & w & w & w & w & w \\
\hline Österreich & 92,0 & $(1,9)$ & 504 & $(3,4)$ & 6,7 & $(1,6)$ & 518 & $(12,6)$ & 1,3 & $(0,6)$ & c & $c$ \\
\hline Belgien & w & w & w & w & w & w & w & w & w & w & w & W \\
\hline Kanada & 94,2 & $(0,7)$ & 529 & $(1,8)$ & 3,8 & $(0,6)$ & 573 & $(10,8)$ & 1,9 & $(0,3)$ & 563 & $(11,1)$ \\
\hline Tschechien & 93,3 & $(1,7)$ & 517 & $(3,8)$ & 5,8 & $(1,6)$ & 505 & $(13,5)$ & 0,9 & $(0,5)$ & $\mathrm{c}$ & $c$ \\
\hline Dänemark & 77,8 & $(2,5)$ & 515 & $(3,1)$ & 21,7 & $(2,6)$ & 511 & $(6,3)$ & 0,5 & $(0,5)$ & c & $c$ \\
\hline Finnland & 93,3 & $(1,6)$ & 545 & $(1,8)$ & 6,7 & $(1,6)$ & 539 & $(12,2)$ & 0,0 & c & c & $c$ \\
\hline Frankreich & w & w & w & w & w & w & w & w & w & w & w & w \\
\hline Deutschland & 92,2 & $(1,7)$ & 497 & $(3,7)$ & 7,5 & $(1,8)$ & 566 & $(12,7)$ & 0,4 & $(0,4)$ & c & c \\
\hline Griechenland & 97,4 & $(1,9)$ & 442 & $(3,6)$ & 0,0 & c & $\mathrm{c}$ & c & 2,6 & $(1,9)$ & 507 & $(30,1)$ \\
\hline Ungarn & 88,9 & $(2,5)$ & 489 & $(3,6)$ & 9,8 & $(2,3)$ & 504 & $(16,8)$ & 1,2 & $(0,8)$ & c & c \\
\hline Island & 99,5 & $(0,1)$ & 515 & $(1,6)$ & 0,0 & c & c & c & 0,5 & $(0,1)$ & c & c \\
\hline Irland & $w$ & w & w & $w$ & w & w & w & w & w & w & w & w \\
\hline Italien & 96,1 & $(1,2)$ & 468 & $(3,1)$ & 0,4 & $(0,2)$ & 392 & $(61,4)$ & 3,5 & $(1,3)$ & 452 & $(35,4)$ \\
\hline Japan & 73,0 & $(1,7)$ & 544 & $(4,7)$ & 0,6 & $(0,6)$ & c & $\mathrm{c}$ & 26,4 & $(1,8)$ & 513 & $(7,5)$ \\
\hline Korea & 42,3 & $(3,7)$ & 527 & $(6,1)$ & 36,0 & $(4,1)$ & 532 & $(7,5)$ & 21,7 & $(3,4)$ & 593 & $(9,6)$ \\
\hline Luxemburg & 85,9 & $(0,1)$ & 498 & $(1,1)$ & 14,1 & $(0,1)$ & 463 & $(2,9)$ & 0,0 & $\mathrm{c}$ & c & c \\
\hline Mexiko & 86,7 & $(1,9)$ & 375 & $(3,5)$ & 0,1 & $(0,1)$ & c & c & 13,2 & $(1,9)$ & 430 & $(8,9)$ \\
\hline Niederlande $^{1}$ & 23,3 & $(4,2)$ & 516 & $(14,0)$ & 76,7 & $(4,2)$ & 541 & $(4,5)$ & 0,0 & c & c & c \\
\hline Neuseeland & 95,4 & $(0,5)$ & 522 & $(2,3)$ & 0,0 & c & c & c & 4,6 & $(0,5)$ & 579 & $(17,1)$ \\
\hline Norwegen & 99,1 & $(0,7)$ & 494 & $(2,4)$ & 0,9 & $(0,7)$ & c & c & 0,0 & c & c & c \\
\hline Polen & 99,2 & $(0,4)$ & 489 & $(2,5)$ & 0,4 & $(0,4)$ & c & $\mathrm{c}$ & 0,4 & $(0,3)$ & c & c \\
\hline Portugal & 93,7 & $(1,3)$ & 465 & $(3,6)$ & 4,2 & $(1,2)$ & 459 & $(8,5)$ & 2,1 & $(1,2)$ & c & c \\
\hline Slowakei & 87,4 & $(2,7)$ & 495 & $(3,7)$ & 12,6 & $(2,7)$ & 523 & $(9,3)$ & 0,0 & c & c & c \\
\hline Spanien & 64,2 & $(1,5)$ & 472 & $(3,4)$ & 28,1 & $(2,1)$ & 505 & $(4,2)$ & 7,7 & $(1,7)$ & 520 & $(9,7)$ \\
\hline Schweden & 95,7 & $(0,5)$ & 509 & $(2,6)$ & 4,3 & $(0,5)$ & 516 & $(11,0)$ & 0,0 & c & $\mathrm{c}$ & c \\
\hline Schweiz & 95,3 & $(1,0)$ & 528 & $(3,8)$ & 0,9 & $(0,7)$ & 546 & $(34,2)$ & 3,8 & $(0,7)$ & 497 & $(23,2)$ \\
\hline Türkei & 99,0 & $(1,0)$ & 420 & $(6,6)$ & 0,0 & $\mathrm{c}$ & c & c & 1,0 & $(1,0)$ & c & c \\
\hline Vereinigte Staaten & 94,3 & $(1,0)$ & 483 & $(3,6)$ & 0,0 & c & c & c & 5,7 & $(1,0)$ & 507 & $(9,1)$ \\
\hline $\begin{array}{l}\text { OECD-Durchschnitt } \\
\text { (für Länder mit verfüg- } \\
\text { baren Daten für } 2003 \\
\text { und 2012) }\end{array}$ & 82,7 & $(0,3)$ & 494 & $(0,9)$ & 13,6 & $(0,4)$ & 514 & $(4,5)$ & 3,7 & $(0,3)$ & 516 & $(5,9)$ \\
\hline \multicolumn{13}{|l|}{ Partnerländer } \\
\hline Brasilien & 87,4 & $(2,3)$ & 342 & $(6,2)$ & 0,0 & c & c & c & 12,6 & $(2,3)$ & 454 & $(11,3)$ \\
\hline Hongkong (VR China) & 9,5 & $(0,4)$ & 571 & $(11,4)$ & 90,1 & $(0,5)$ & 548 & $(4,8)$ & 0,4 & $(0,3)$ & c & $c$ \\
\hline Indonesien & 51,4 & $(2,3)$ & 373 & $(4,9)$ & 4,1 & $(1,5)$ & 326 & $(19,3)$ & 44,5 & $(2,6)$ & 345 & $(7,0)$ \\
\hline Lettland & 99,0 & $(0,7)$ & 485 & $(3,7)$ & 0,0 & c & c & $\mathrm{c}$ & 1,0 & $(0,7)$ & c & $c$ \\
\hline Liechtenstein & 95,0 & $(0,3)$ & 539 & $(4,1)$ & 0,0 & c & c & c & 5,0 & $(0,3)$ & c & $c$ \\
\hline Macau (VR China) & 5,0 & $(0,1)$ & c & c & 49,3 & $(0,2)$ & 528 & $(3,5)$ & 45,8 & $(0,2)$ & 529 & $(5,2)$ \\
\hline Russische Föderation & 99,7 & $(0,2)$ & 468 & $(4,3)$ & 0,0 & c & c & c & 0,3 & $(0,2)$ & c & c \\
\hline Thailand & 88,0 & $(1,2)$ & 416 & $(3,0)$ & 6,0 & $(1,1)$ & 419 & $(18,8)$ & 6,0 & $(1,6)$ & 428 & $(13,7)$ \\
\hline Tunesien & $\mathrm{m}$ & $\mathrm{m}$ & $\mathrm{m}$ & $\mathrm{m}$ & $\mathrm{m}$ & $\mathrm{m}$ & $\mathrm{m}$ & $\mathrm{m}$ & $\mathrm{m}$ & $\mathrm{m}$ & $\mathrm{m}$ & $\mathrm{m}$ \\
\hline Uruguay & 85,9 & $(0,8)$ & 409 & $(3,7)$ & 0,0 & $\mathrm{C}$ & $\mathrm{C}$ & $\mathrm{C}$ & 14,1 & $(0,8)$ & 501 & $(6,1)$ \\
\hline
\end{tabular}

Anmerkung: Statistisch signifikante Werte sind durch Fettdruck gekennzeichnet (s. Anhang A3). Diese Tabelle enthält nur Länder mit vergleichbaren Daten aus PISA 2003 und PISA 2012.

1. In den Niederlanden sind staatlich subventionierte private Bildungseinrichtungen öffentlich finanziert, sie unterscheiden sich von öffentlichen Bildungseinrichtungen durch die konfessionelle Ausrichtung und/oder pädagogische Konzepte.

Quelle: OECD. PISA-2003-Datenbank. Hinweise s. Anhang 3 unter www.oecd.org/edu/eag.htm. StatLink: http://dx.doi.org/10.1787/888933119378

Erläuterung der Kennzeichnung fehlender Daten s. Hinweise für den Leser. 
Tabelle C7.3 (Forts.)

Art der Bildungseinrichtung und Leistungen in Mathematik (2003)

Ergebnisse basieren auf den Angaben der Schulleiter

\begin{tabular}{|c|c|c|c|c|c|c|c|c|}
\hline & \multirow{2}{*}{\multicolumn{2}{|c|}{\begin{tabular}{|} 
Leistungsunterschied auf der \\
Mathematikskala zwischen \\
öfentlichen und staatlich \\
subventionierten privaten \\
Bildungseinrichtungen
\end{tabular}}} & \multirow{2}{*}{\multicolumn{2}{|c|}{$\begin{array}{l}\text { Leistungsunterschied auf der } \\
\text { Mathematikskala zwischen öffent- } \\
\text { lichen und privaten Bildungseinrich- } \\
\text { tungen (staatlich subventionierte } \\
\text { und unabhängige private Bildungs- } \\
\text { einrichtungen) }\end{array}$}} & \multicolumn{4}{|c|}{\begin{tabular}{|c|} 
Leistungsunterschied auf der Mathematikskala zwischen \\
öffentlichen und privaten Bildungseinrichtungen nach \\
Berücksichtigung des PISA-Index des wirtschaftlichen, \\
sozialen und kulturellen Status der
\end{tabular}} \\
\hline & & & & & \multicolumn{2}{|c|}{ Schüler } & \multicolumn{2}{|c|}{ Schüler und Schulen } \\
\hline & Diff. (Öff.-Priv.) & S.F. & Diff. (Öff.-Priv.) & S.F. & Diff.(Öff._Priv.) & S.F. & Diff.(Öff.-Priv.) & S.F. \\
\hline & (13) & (14) & (15) & (16) & (17) & (18) & (19) & (20) \\
\hline \multicolumn{9}{|l|}{ OECD-Länder } \\
\hline Australien & w & w & w & w & w & w & w & w \\
\hline Österreich & -14 & $(12,9)$ & -18 & $(12,0)$ & -6 & $(10,3)$ & 10 & $(11,9)$ \\
\hline Belgien & w & w & w & w & w & w & w & w \\
\hline Kanada & -44 & $(10,9)$ & -41 & $(8,3)$ & -27 & $(6,4)$ & -14 & $(6,6)$ \\
\hline Tschechien & 12 & $(14,4)$ & 3 & $(13,5)$ & 12 & $(9,8)$ & 17 & $(10,5)$ \\
\hline Dänemark & 4 & $(7,2)$ & 4 & $(7,1)$ & 5 & $(5,2)$ & 5 & $(4,8)$ \\
\hline Finnland & 5 & $(12,3)$ & 5 & $(12,3)$ & 13 & $(11,0)$ & 14 & $(11,2)$ \\
\hline Frankreich & w & w & w & w & w & w & w & w \\
\hline Deutschland & -68 & $(14,1)$ & -66 & $(13,7)$ & -29 & $(10,7)$ & 17 & $(11,7)$ \\
\hline Griechenland & c & c & -65 & $(30,4)$ & -19 & $(15,5)$ & 42 & $(9,0)$ \\
\hline Ungarn & -15 & $(18,4)$ & -17 & $(18,1)$ & -4 & $(13,1)$ & 8 & $(9,8)$ \\
\hline Island & c & c & c & c & c & c & c & c \\
\hline Irland & w & w & w & w & w & w & w & w \\
\hline Italien & 76 & $(61,2)$ & 22 & $(22,4)$ & 31 & $(22,5)$ & 46 & $(23,5)$ \\
\hline Japan & c & c & 31 & $(8,6)$ & 41 & $(6,8)$ & 62 & $(5,6)$ \\
\hline Korea & -5 & $(11,1)$ & -28 & $(10,1)$ & -14 & $(8,2)$ & 10 & $(7,1)$ \\
\hline Luxemburg & 35 & $(3,3)$ & 35 & $(3,3)$ & 27 & $(3,5)$ & 13 & $(3,4)$ \\
\hline Mexiko & c & c & -55 & $(9,8)$ & -25 & $(8,0)$ & 19 & $(8,1)$ \\
\hline Niederlande ${ }^{1}$ & -25 & $(16,4)$ & -25 & $(16,4)$ & -10 & $(10,7)$ & -2 & $(8,6)$ \\
\hline Neuseeland & c & c & -57 & $(17,3)$ & -23 & $(12,8)$ & 12 & $(9,7)$ \\
\hline Norwegen & c & c & c & c & c & c & c & c \\
\hline Polen & $\mathrm{c}$ & c & c & c & c & c & c & c \\
\hline Portugal & 6 & $(9,3)$ & -19 & $(16,9)$ & -11 & $(9,9)$ & -2 & $(10,6)$ \\
\hline Slowakei & -27 & $(10,3)$ & -27 & $(10,3)$ & -15 & $(7,8)$ & -2 & $(7,3)$ \\
\hline Spanien & -32 & $(5,7)$ & -35 & $(5,4)$ & -20 & $(4,4)$ & -6 & $(4,3)$ \\
\hline Schweden & -8 & $(11,3)$ & -8 & $(11,3)$ & 6 & $(8,2)$ & 17 & $(7,0)$ \\
\hline Schweiz & -18 & $(34,7)$ & 21 & $(22,3)$ & 40 & $(20,1)$ & 62 & $(19,6)$ \\
\hline Türkei & c & c & c & c & c & c & c & c \\
\hline Vereinigte Staaten & c & c & -24 & $(9,9)$ & -6 & $(8,3)$ & 11 & $(9,7)$ \\
\hline $\begin{array}{l}\text { OECD-Durchschnitt } \\
\text { (für Länder mit verfüg- } \\
\text { baren Daten für } 2003 \\
\text { und 2012) }\end{array}$ & -11 & $-(4,7)$ & -19 & $(3,0)$ & -4 & $(2,2)$ & 14 & $(2,1)$ \\
\hline \multicolumn{9}{|l|}{ Partnerländer } \\
\hline Brasilien & c & c & -112 & $(13,5)$ & -73 & $(14,0)$ & 12 & $(20,3)$ \\
\hline Hongkong (VR China) & 23 & $(12,3)$ & 23 & $(12,3)$ & 22 & $(10,0)$ & 20 & $(8,9)$ \\
\hline Indonesien & 47 & $(20,1)$ & 29 & $(8,1)$ & 27 & $(7,2)$ & 23 & $(6,1)$ \\
\hline Lettland & c & c & c & c & c & c & c & c \\
\hline Liechtenstein & $\mathrm{c}$ & $\mathrm{c}$ & c & $\mathrm{c}$ & c & $\mathrm{c}$ & c & c \\
\hline Macau (VR China) & c & c & $\mathrm{c}$ & c & c & c & c & c \\
\hline Russische Föderation & c & c & c & c & c & c & c & c \\
\hline Thailand & -3 & $(19,1)$ & -7 & $(12,7)$ & 3 & $(11,9)$ & 13 & $(11,5)$ \\
\hline Tunesien & c & c & $\mathrm{m}$ & $\mathrm{m}$ & $\mathrm{m}$ & $\mathrm{m}$ & $\mathrm{m}$ & $\mathrm{m}$ \\
\hline Uruguay & c & c & -92 & $(6,8)$ & -55 & $(6,7)$ & 16 & $(11,4)$ \\
\hline
\end{tabular}

Anmerkung: Statistisch signifikante Werte sind durch Fettdruck gekennzeichnet (s. Anhang A3). Diese Tabelle enthält nur Länder mit vergleichbaren Daten aus PISA 2003 und PISA 2012.

1. In den Niederlanden sind staatlich subventionierte private Bildungseinrichtungen öffentlich finanziert, sie unterscheiden sich von öffentlichen Bildungseinrichtungen durch die konfessionelle Ausrichtung und/oder pädagogische Konzepte.

Quelle: OECD. PISA-2003-Datenbank. Hinweise s. Anhang 3 unter www.oecd.org/edu/eag.htm. StatLink: http://dx.doi.org/10.1787/888933119378 Erläuterung der Kennzeichnung fehlender Daten s. Hinweise für den Leser. 
Tabelle C7.4

Lernumgebungen, nach Art der Bildungseinrichtung (2012)

Ergebnisse basieren auf den Angaben der Schulleiter und den Selbstangaben der Schüler

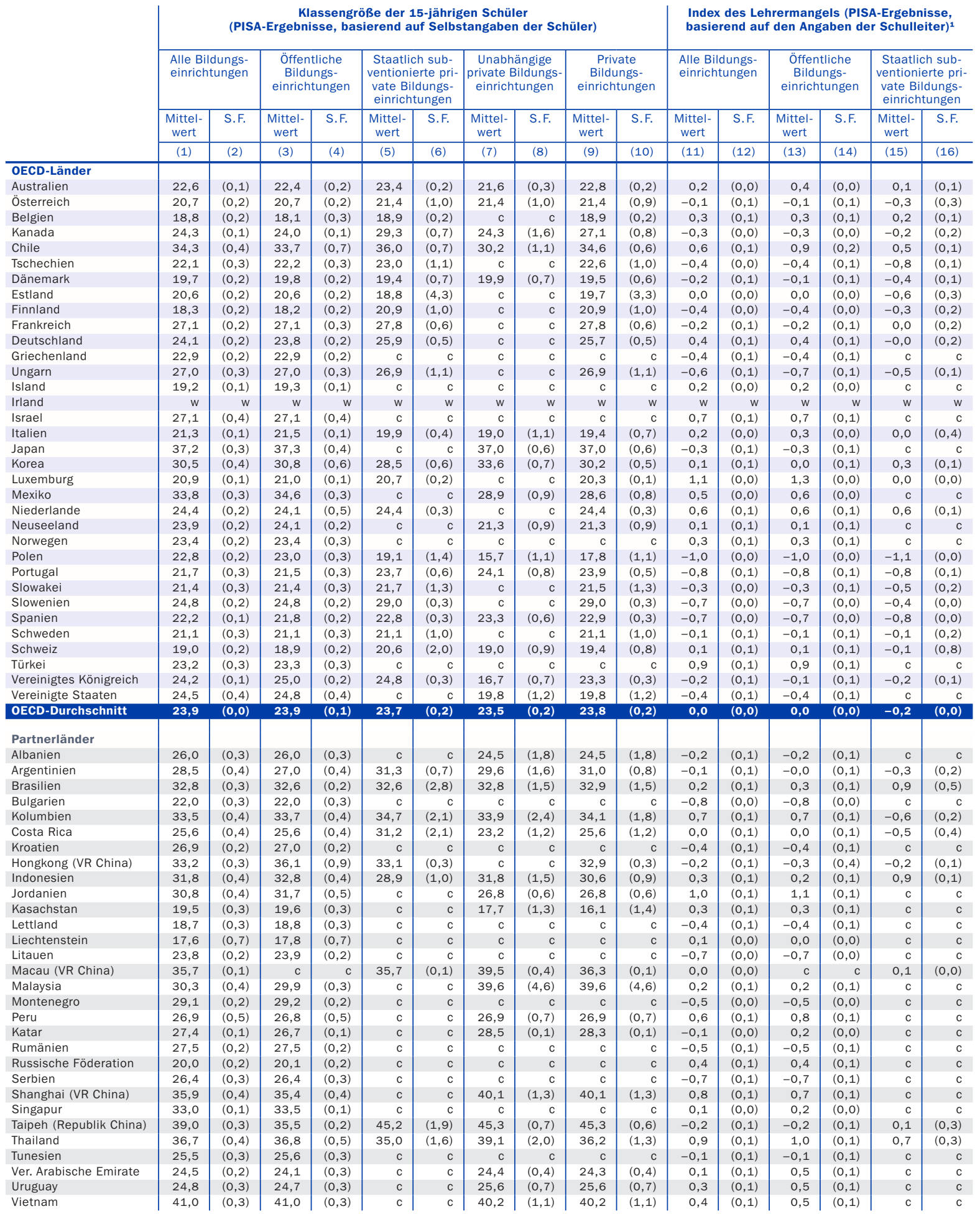

1. Bei PISA 2012 wurden Schulleiter gefragt, inwiefern ihrer Ansicht nach der Unterricht an ihrer Schule durch den Mangel an qualifizierten Lehrkräften in bestimmten Fächern leidet. Diese Informationen wurden kombiniert, um den zusammengesetzten Index des Lehrermangels zu erhalten, der für die OECD-Länder einen Mittelwert null und eine Standardabweichung von 1 aufweist. Höhere Indexwerte weisen darauf hin, dass der Lehrkräftemangel nach Ansicht der Schulleitung stärkere Unterrichtsprobleme verursacht.

Quelle: OECD. PISA-2012-Datenbank. Hinweise s. Anhang 3 unter www.oecd.org/edu/eag.htm. StatLink: http://dx.doi.org/10.1787/888933119397

Erläuterung der Kennzeichnung fehlender Daten s. Hinweise für den Leser. 
Lernumgebungen, nach Art der Bildungseinrichtung (2012)

Ergebnisse basieren auf den Angaben der Schulleiter und den Selbstangaben der Schüler

\begin{tabular}{|c|c|c|c|c|c|c|c|c|c|c|c|c|c|c|}
\hline & \multicolumn{4}{|c|}{$\begin{array}{l}\text { Index des Lehrermangels (PISA- } \\
\text { Ergebnisse, basierend auf den } \\
\text { Angaben der Schulleiter) }\end{array}$} & \multicolumn{10}{|c|}{$\begin{array}{l}\text { Zeit (in Zeitstunden), die pro Woche für Hausaufgaben oder sonstige von den Lehrern gestell- } \\
\text { te Aufgaben verwendet wird (PISA-Ergebnisse, basierend auf Selbstangaben der Schüler) }\end{array}$} \\
\hline & \multicolumn{2}{|c|}{$\begin{array}{l}\text { Unabhängige } \\
\text { private Bildungs- } \\
\text { einrichtungen }\end{array}$} & \multicolumn{2}{|c|}{$\begin{array}{l}\text { Private Bildungs- } \\
\text { einrichtungen }\end{array}$} & \multicolumn{2}{|c|}{$\begin{array}{l}\text { Alle Bildungs- } \\
\text { einrichtungen }\end{array}$} & \multicolumn{2}{|c|}{$\begin{array}{l}\text { Öffentliche } \\
\text { Bildungs- } \\
\text { einrichtungen }\end{array}$} & $\begin{array}{c}\text { Sta } \\
\text { subven } \\
\text { private } \\
\text { einric }\end{array}$ & $\begin{array}{l}\text { ich } \\
\text { nierte } \\
\text { dungs- } \\
\text { ingen }\end{array}$ & $\begin{array}{r}\text { Unab } \\
\text { private } \\
\text { einric }\end{array}$ & $\begin{array}{l}\text { ngige } \\
\text { Idungs- } \\
\text { ungen }\end{array}$ & $\begin{array}{r}\text { Private } \\
\text { einrich }\end{array}$ & $\begin{array}{l}\text { Idungs- } \\
\text { ungen }\end{array}$ \\
\hline & $\begin{array}{c}\text { Mittel- } \\
\text { wert }\end{array}$ & S.F. & $\begin{array}{c}\text { Mittel- } \\
\text { wert }\end{array}$ & S.F. & $\begin{array}{c}\text { Mittel- } \\
\text { wert }\end{array}$ & S.F. & $\begin{array}{c}\text { Mittel- } \\
\text { wert }\end{array}$ & S.F. & $\begin{array}{c}\text { Mittel- } \\
\text { wert }\end{array}$ & S.F. & $\begin{array}{c}\text { Mittel- } \\
\text { wert }\end{array}$ & S.F. & $\begin{array}{c}\text { Mittel- } \\
\text { wert }\end{array}$ & S.F. \\
\hline & (17) & (18) & (19) & (20) & (21) & (22) & (23) & (24) & (25) & (26) & $(27)$ & (28) & (29) & (30) \\
\hline OECD-Länder & & & & & & & & & & & & & & \\
\hline Australien & $-0,4$ & $(0,1)$ & $-0,1$ & $(0,1)$ & 6,0 & $(0,1)$ & 5,1 & $(0,1)$ & 6,6 & $(0,2)$ & 9,0 & $(0,3)$ & 7,4 & $(0,2)$ \\
\hline Österreich & $-0,9$ & $(0,2)$ & $-0,4$ & $(0,2)$ & 4,5 & $(0,1)$ & 4,4 & $(0,1)$ & 6,0 & $(0,5)$ & 8,5 & $(0,4)$ & 6,3 & $(0,5)$ \\
\hline Belgien & c & c & 0,2 & $(0,1)$ & 5,5 & $(0,1)$ & 4,7 & $(0,2)$ & 5,7 & $(0,1)$ & c & c & 5,8 & $(0,1)$ \\
\hline Kanada & $-0,6$ & $(0,3)$ & $-0,4$ & $(0,1)$ & 5,5 & $(0,1)$ & 5,3 & $(0,1)$ & 6,4 & $(0,4)$ & 7,8 & $(0,7)$ & 7,0 & $(0,4)$ \\
\hline Chile & 0,2 & $(0,2)$ & 0,4 & $(0,1)$ & 3,5 & $(0,1)$ & 3,2 & $(0,1)$ & 3,4 & $(0,1)$ & 4,4 & $(0,2)$ & 3,7 & $(0,1)$ \\
\hline Tschechien & c & $\mathrm{c}$ & $-0,8$ & $(0,1)$ & 3,1 & $(0,1)$ & 3,1 & $(0,1)$ & 3,1 & $(0,3)$ & c & c & 3,2 & $(0,3)$ \\
\hline Dänemark & $-0,3$ & $(0,2)$ & $-0,4$ & $(0,1)$ & 4,3 & $(0,1)$ & 4,2 & $(0,1)$ & 4,4 & $(0,2)$ & 4,6 & $(0,7)$ & 4,4 & $(0,2)$ \\
\hline Estland & c & c & $-0,4$ & $(0,3)$ & 6,9 & $(0,1)$ & 7,0 & $(0,1)$ & 4,8 & $(0,3)$ & c & c & 5,3 & $(0,3)$ \\
\hline Finnland & c & c & $-0,3$ & $(0,2)$ & 2,8 & $(0,1)$ & 2,8 & $(0,1)$ & 3,4 & $(0,3)$ & c & c & 3,4 & $(0,3)$ \\
\hline Frankreich & c & c & 0,0 & $(0,2)$ & 5,1 & $(0,1)$ & 4,8 & $(0,1)$ & 6,1 & $(0,3)$ & c & c & 6,1 & $(0,3)$ \\
\hline Deutschland & c & c & 0,0 & $(0,2)$ & 4,7 & $(0,1)$ & 4,6 & $(0,1)$ & 5,5 & $(0,3)$ & c & c & 5,0 & $(0,5)$ \\
\hline Griechenland & c & c & c & c & 5,3 & $(0,1)$ & 5,1 & $(0,1)$ & c & c & c & c & c & c \\
\hline Ungarn & c & c & $-0,5$ & $(0,1)$ & 6,2 & $(0,1)$ & 6,0 & $(0,1)$ & 7,4 & $(0,5)$ & c & c & 7,4 & $(0,5)$ \\
\hline Island & c & c & c & c & 4,1 & $(0,1)$ & 4,1 & $(0,1)$ & c & c & c & c & c & c \\
\hline Irland & w & w & w & w & w & w & w & w & w & w & w & w & w & w \\
\hline Israel & c & c & c & c & 4,6 & $(0,1)$ & 4,6 & $(0,1)$ & c & c & c & c & c & c \\
\hline Italien & $-0,4$ & $(0,2)$ & $-0,3$ & $(0,2)$ & 8,7 & $(0,1)$ & 8,9 & $(0,1)$ & 3,6 & $(0,5)$ & 9,8 & $(0,5)$ & 7,4 & $(0,6)$ \\
\hline Japan & $-0,3$ & $(0,1)$ & $-0,3$ & $(0,1)$ & 3,8 & $(0,1)$ & 3,8 & $(0,1)$ & c & c & 3,9 & $(0,3)$ & 3,9 & $(0,3)$ \\
\hline Korea & $-0,2$ & $(0,3)$ & 0,1 & $(0,1)$ & 2,9 & $(0,1)$ & 2,7 & $(0,2)$ & 2,6 & $(0,1)$ & 3,9 & $(0,4)$ & 3,1 & $(0,2)$ \\
\hline Luxemburg & c & c & $-0,1$ & $(0,0)$ & 4,6 & $(0,1)$ & 4,4 & $(0,1)$ & 5,1 & $(0,2)$ & c & c & 5,4 & $(0,2)$ \\
\hline Mexiko & $-0,1$ & $(0,1)$ & $-0,1$ & $(0,1)$ & 5,2 & $(0,1)$ & 5,2 & $(0,1)$ & c & c & 5,6 & $(0,2)$ & 5,6 & $(0,2)$ \\
\hline Niederlande & c & c & 0,6 & $(0,1)$ & 5,8 & $(0,1)$ & 5,7 & $(0,3)$ & 6,0 & $(0,2)$ & c & c & 6,0 & $(0,2)$ \\
\hline Neuseeland & $-0,4$ & $(0,3)$ & $-0,4$ & $(0,3)$ & 4,2 & $(0,1)$ & 4,1 & $(0,1)$ & c & c & 7,2 & $(0,6)$ & 7,2 & $(0,6)$ \\
\hline Norwegen & C & c & c & c & 4,7 & $(0,1)$ & 4,7 & $(0,1)$ & c & c & c & c & c & c \\
\hline Polen & $-1,0$ & $(0,1)$ & $-1,1$ & $(0,0)$ & 6,6 & $(0,1)$ & 6,6 & $(0,1)$ & 6,7 & $(0,7)$ & 7,4 & $(0,7)$ & 6,9 & $(0,5)$ \\
\hline Portugal & $-1,1$ & $(0,0)$ & $-0,9$ & $(0,1)$ & 3,8 & $(0,1)$ & 3,7 & $(0,1)$ & 4,7 & $(0,4)$ & 6,1 & $(0,6)$ & 5,3 & $(0,5)$ \\
\hline Slowakei & c & c & $-0,4$ & $(0,2)$ & 3,2 & $(0,1)$ & 3,2 & $(0,1)$ & 3,9 & $(0,4)$ & c & c & 3,9 & $(0,4)$ \\
\hline Slowenien & c & c & $-0,4$ & $(0,0)$ & 3,7 & $(0,1)$ & 3,7 & $(0,1)$ & 4,4 & $(0,4)$ & c & c & 4,4 & $(0,4)$ \\
\hline Spanien & $-0,8$ & $(0,1)$ & $-0,8$ & $(0,0)$ & 6,5 & $(0,1)$ & 6,2 & $(0,1)$ & 7,1 & $(0,2)$ & 7,5 & $(0,5)$ & 7,2 & $(0,1)$ \\
\hline Schweden & c & c & $-0,1$ & $(0,2)$ & 3,6 & $(0,1)$ & 3,4 & $(0,1)$ & 4,4 & $(0,2)$ & c & c & 4,4 & $(0,2)$ \\
\hline Schweiz & $-0,1$ & $(0,3)$ & $-0,1$ & $(0,3)$ & 4,0 & $(0,1)$ & 3,9 & $(0,1)$ & 4,9 & $(1,0)$ & 5,2 & $(0,7)$ & 5,1 & $(0,6)$ \\
\hline Türkei & c & c & c & c & 4,2 & $(0,1)$ & 4,3 & $(0,1)$ & c & c & c & c & c & c \\
\hline Vereinigtes Königreich & $-1,0$ & $(0,1)$ & $-0,3$ & $(0,1)$ & 4,9 & $(0,1)$ & 4,5 & $(0,1)$ & 4,7 & $(0,3)$ & 9,1 & $(0,6)$ & 5,4 & $(0,3)$ \\
\hline Vereinigte Staaten & $-0,2$ & $(0,2)$ & $-0,2$ & $(0,2)$ & 6,1 & $(0,2)$ & 6,0 & $(0,2)$ & c & C & 8,2 & $(1,1)$ & 8,2 & $(1,1)$ \\
\hline OECD-Durchschnitt & $-0,5$ & $(0,0)$ & $-0,3$ & $(0,0)$ & 4,9 & $(0,0)$ & 4,7 & $(0,0)$ & 5,1 & $(0,1)$ & 6,8 & $(0,1)$ & 5,6 & $(0,1)$ \\
\hline Partnerländer & & & & & & & & & & & & & & \\
\hline Albanien & $-0,4$ & $(0,3)$ & $-0,4$ & $(0,3)$ & 5,1 & $(0,1)$ & 5,1 & $(0,1)$ & c & c & 4,9 & $(0,3)$ & 4,9 & $(0,3)$ \\
\hline Argentinien & 0,0 & $(0,3)$ & $-0,2$ & $(0,1)$ & 3,7 & $(0,1)$ & 3,4 & $(0,1)$ & 4,3 & $(0,2)$ & 4,1 & $(0,3)$ & 4,3 & $(0,2)$ \\
\hline Brasilien & $-0,5$ & $(0,1)$ & $-0,4$ & $(0,2)$ & 3,3 & $(0,1)$ & 3,1 & $(0,1)$ & 4,0 & $(0,2)$ & 4,2 & $(0,2)$ & 4,2 & $(0,2)$ \\
\hline Bulgarien & c & c & c & c & 5,6 & $(0,2)$ & 5,6 & $(0,2)$ & c & c & c & c & c & c \\
\hline Kolumbien & 0,7 & $(0,7)$ & 0,4 & $(0,5)$ & 5,3 & $(0,1)$ & 5,1 & $(0,1)$ & 5,8 & $(0,5)$ & 7,0 & $(0,9)$ & 6,7 & $(0,6)$ \\
\hline Costa Rica & $-0,2$ & $(0,2)$ & $-0,3$ & $(0,2)$ & 3,5 & $(0,2)$ & 3,3 & $(0,2)$ & 4,6 & $(0,4)$ & 4,8 & $(0,7)$ & 4,8 & $(0,5)$ \\
\hline Kroatien & c & c & c & c & 5,9 & $(0,1)$ & 5,9 & $(0,1)$ & c & c & c & c & c & c \\
\hline Hongkong (VR China) & c & c & $-0,2$ & $(0,1)$ & 6,0 & $(0,2)$ & 6,0 & $(1,0)$ & 6,0 & $(0,2)$ & c & c & 6,1 & $(0,2)$ \\
\hline Indonesien & 0,1 & $(0,2)$ & 0,4 & $(0,1)$ & 4,9 & $(0,2)$ & 5,2 & $(0,2)$ & 3,7 & $(0,2)$ & 5,1 & $(0,3)$ & 4,5 & $(0,2)$ \\
\hline Jordanien & 0,4 & $(0,3)$ & 0,5 & $(0,3)$ & 4,2 & $(0,1)$ & 4,1 & $(0,1)$ & c & c & 4,8 & $(0,4)$ & 4,9 & $(0,4)$ \\
\hline Kasachstan & 0,5 & $(0,3)$ & 0,6 & $(0,2)$ & 8,8 & $(0,2)$ & 8,9 & $(0,2)$ & c & c & 6,5 & $(0,6)$ & 6,9 & $(0,6)$ \\
\hline Lettland & $\mathrm{C}$ & c & $\mathrm{c}$ & c & 6,2 & $(0,1)$ & 6,1 & $(0,2)$ & c & c & c & c & $\mathrm{C}$ & $\mathrm{C}$ \\
\hline Liechtenstein & c & c & C & c & 3,3 & $(0,2)$ & 3,2 & $(0,2)$ & c & c & c & c & c & c \\
\hline Litauen & c & c & c & c & 6,7 & $(0,1)$ & 6,7 & $(0,1)$ & c & c & c & $\mathrm{c}$ & c & c \\
\hline Macau (VR China) & $-0,3$ & $(0,0)$ & 0,0 & $(0,0)$ & 5,9 & $(0,1)$ & c & c & 5,7 & $(0,1)$ & 7,8 & $(0,3)$ & 6,0 & $(0,1)$ \\
\hline Malaysia & 0,8 & $(0,4)$ & 0,8 & $(0,4)$ & 4,8 & $(0,1)$ & 4,8 & $(0,1)$ & c & c & 5,6 & $(0,7)$ & 5,6 & $(0,7)$ \\
\hline Montenegro & c & c & c & c & 4,3 & $(0,1)$ & 4,3 & $(0,1)$ & $c$ & c & c & c & c & c \\
\hline Peru & $-0,2$ & $(0,2)$ & $-0,2$ & $(0,2)$ & 5,5 & $(0,1)$ & 5,4 & $(0,1)$ & c & c & 5,2 & $(0,3)$ & 5,2 & $(0,3)$ \\
\hline Katar & $-0,7$ & $(0,0)$ & $-0,7$ & $(0,0)$ & 4,3 & $(0,0)$ & 3,5 & $(0,1)$ & $c$ & c & 5,4 & $(0,1)$ & 5,5 & $(0,1)$ \\
\hline Rumänien & C & $\mathrm{C}$ & c & c & 7,3 & $(0,2)$ & 7,3 & $(0,2)$ & c & c & c & c & c & c \\
\hline Russische Föderation & c & c & c & $c$ & 9,7 & $(0,2)$ & 9,7 & $(0,2)$ & $c$ & c & c & c & c & c \\
\hline Serbien & c & c & c & c & 4,4 & $(0,1)$ & 4,4 & $(0,1)$ & c & c & c & c & c & c \\
\hline Shanghai (VR China) & 0,9 & $(0,4)$ & 0,9 & $(0,4)$ & 13,8 & $(0,3)$ & 13,7 & $(0,3)$ & c & c & 14,9 & $(0,9)$ & 14,9 & $(0,9)$ \\
\hline Singapur & c & c & c & c & 9,4 & $(0,2)$ & 9,4 & $(0,1)$ & c & c & c & c & c & c \\
\hline Taipeh (Republik China) & 0,0 & $(0,2)$ & 0,0 & $(0,2)$ & 5,3 & $(0,1)$ & 5,9 & $(0,2)$ & 3,4 & $(0,3)$ & 4,6 & $(0,3)$ & 4,4 & $(0,3)$ \\
\hline Thailand & 0,8 & $(0,3)$ & 0,7 & $(0,3)$ & 5,6 & $(0,1)$ & 5,8 & $(0,2)$ & 4,3 & $(0,2)$ & 4,2 & $(0,8)$ & 4,3 & $(0,3)$ \\
\hline Tunesien & c & c & c & c & 3,5 & $(0,1)$ & 3,6 & $(0,1)$ & c & c & c & c & c & c \\
\hline Ver. Arabische Emirate & $-0,3$ & $(0,1)$ & $-0,3$ & $(0,1)$ & 6,2 & $(0,1)$ & 4,9 & $(0,1)$ & c & c & 7,1 & $(0,2)$ & 7,0 & $(0,2)$ \\
\hline Uruguay & $-0,3$ & $(0,2)$ & $-0,3$ & $(0,2)$ & 4,7 & $(0,1)$ & 4,5 & $(0,1)$ & c & c & 5,4 & $(0,2)$ & 5,4 & $(0,2)$ \\
\hline Vietnam & $-0,7$ & $(0,2)$ & $-0,7$ & $(0,2)$ & 5,8 & $(0,2)$ & 5,9 & $(0,2)$ & c & c & 5,6 & $(0,7)$ & 5,6 & $(0,7)$ \\
\hline
\end{tabular}

1. Bei PISA 2012 wurden Schulleiter gefragt, inwiefern ihrer Ansicht nach der Unterricht an ihrer Schule durch den Mangel an qualifizierten Lehrkräften in bestimmten Fächern leidet. Diese Informationen wurden kombiniert, um den zusammengesetzten Index des Lehrermangels zu erhalten, der für die OECD-Länder einen Mittelwert null und eine Standardabweichung von 1 aufweist. Höhere Indexwerte weisen darauf hin, dass der Lehrkräftemangel nach Ansicht der Schulleitung stärkere Unterrichtsprobleme verursacht.

Quelle: OECD. PISA-2012-Datenbank. Hinweise s. Anhang 3 unter www.oecd.org/edu/eag.htm. StatLink: http://dx.doi.org/10.1787/888933119397 Erläuterung der Kennzeichnung fehlender Daten s. Hinweise für den Leser. 
Autonomie der Schule bei Ressourcenallokation, Unterrichtsinhalten und Beurteilungen, nach Art der Bildungseinrichtung und Bildungsbereich (2012)

Ergebnisse basierend auf den Angaben der Schulleiter

\begin{tabular}{|c|c|c|c|c|c|c|c|c|c|c|}
\hline & \multicolumn{10}{|c|}{ Index der Schulautonomie: Ressourcenallokation } \\
\hline & \multicolumn{2}{|c|}{ Alle Bildungseinrichtungen } & \multicolumn{2}{|c|}{$\begin{array}{l}\text { Öffentliche Bildungs- } \\
\text { einrichtungen }\end{array}$} & \multicolumn{2}{|c|}{$\begin{array}{l}\text { Staatlich subventionierte } \\
\text { private Bildungs- } \\
\text { einrichtungen }\end{array}$} & \multicolumn{2}{|c|}{$\begin{array}{l}\text { Unabhängige private } \\
\text { Bildungseinrichtungen }\end{array}$} & \multicolumn{2}{|c|}{$\begin{array}{l}\text { Private Bildungs- } \\
\text { einrichtungen }\end{array}$} \\
\hline & $\begin{array}{l}\text { Mittlerer } \\
\text { Index }\end{array}$ & S.F. & $\begin{array}{l}\text { Mittlerer } \\
\text { Index }\end{array}$ & S.F. & $\begin{array}{l}\text { Mittlerer } \\
\text { Index }\end{array}$ & S.F. & $\begin{array}{l}\text { Mittlerer } \\
\text { Index }\end{array}$ & S.F. & $\begin{array}{l}\text { Mittlerer } \\
\text { Index }\end{array}$ & S.F. \\
\hline & (1) & (2) & (3) & (4) & (5) & (6) & (7) & (8) & (9) & (10) \\
\hline \multicolumn{11}{|l|}{ OECD-Länder } \\
\hline Australien & 0,06 & $(0,03)$ & $-0,43$ & $(0,02)$ & 0,44 & $(0,08)$ & 1,46 & $(0,14)$ & 0,77 & $(0,06)$ \\
\hline Österreich & $-0,56$ & $(0,03)$ & $-0,57$ & $(0,03)$ & $-0,42$ & $(0,04)$ & $-0,32$ & $(0,52)$ & $-0,41$ & $(0,06)$ \\
\hline Belgien & $-0,29$ & $(0,01)$ & $-0,38$ & $(0,03)$ & $-0,23$ & $(0,01)$ & c & c & $-0,23$ & $(0,01)$ \\
\hline Kanada & $-0,35$ & $(0,03)$ & $-0,48$ & $(0,01)$ & 0,83 & $(0,26)$ & 1,46 & $(0,32)$ & 1,11 & $(0,22)$ \\
\hline Chile & 0,57 & $(0,07)$ & $-0,65$ & $(0,02)$ & 1,21 & $(0,14)$ & 1,62 & $(0,19)$ & 1,31 & $(0,11)$ \\
\hline Tschechien & 1,22 & $(0,10)$ & 1,47 & $(0,10)$ & 1,87 & $(0,30)$ & c & c & 2,01 & $(0,27)$ \\
\hline Dänemark & 0,18 & $(0,06)$ & $-0,04$ & $(0,04)$ & 1,18 & $(0,23)$ & 0,73 & $(0,40)$ & 1,10 & $(0,22)$ \\
\hline Estland & 0,14 & $(0,04)$ & 0,12 & $(0,05)$ & 0,44 & $(0,52)$ & C & c & 0,83 & $(0,47)$ \\
\hline Finnland & $-0,28$ & $(0,02)$ & $-0,34$ & $(0,02)$ & 1,68 & $(0,39)$ & c & c & 1,68 & $(0,39)$ \\
\hline Frankreich & $-0,54$ & $(0,01)$ & $-0,62$ & $(0,01)$ & $-0,26$ & $(0,08)$ & c & c & $-0,26$ & $(0,08)$ \\
\hline Deutschland & $-0,58$ & $(0,01)$ & $-0,62$ & $(0,01)$ & $-0,49$ & $(0,06)$ & c & c & $-0,49$ & $(0,05)$ \\
\hline Griechenland & $-0,70$ & $(0,01)$ & $-0,72$ & $(0,01)$ & c & c & c & c & c & c \\
\hline Ungarn & 0,46 & $(0,10)$ & 0,26 & $(0,08)$ & 1,57 & $(0,27)$ & c & c & 1,57 & $(0,27)$ \\
\hline Island & $-0,04$ & $(0,00)$ & $-0,05$ & $(0,00)$ & c & $\mathrm{c}$ & c & c & c & $\mathrm{c}$ \\
\hline Irland & w & w & w & w & w & w & w & w & w & w \\
\hline Israel & $-0,24$ & $(0,04)$ & $-0,24$ & $(0,04)$ & c & c & c & c & c & c \\
\hline Italien & $-0,59$ & $(0,02)$ & $-0,70$ & $(0,01)$ & 1,03 & $(0,39)$ & 1,08 & $(0,28)$ & 1,06 & $(0,22)$ \\
\hline Japan & $-0,27$ & $(0,04)$ & $-0,64$ & $(0,03)$ & c & c & 0,61 & $(0,11)$ & 0,61 & $(0,11)$ \\
\hline Korea & $-0,44$ & $(0,05)$ & $-0,68$ & $(0,01)$ & $-0,18$ & $(0,11)$ & $-0,14$ & $(0,20)$ & $-0,17$ & $(0,09)$ \\
\hline Luxemburg & $-0,20$ & $(0,00)$ & $-0,51$ & $(0,00)$ & 1,49 & $(0,00)$ & c & c & 1,54 & $(0,00)$ \\
\hline Mexiko & $-0,31$ & $(0,02)$ & $-0,55$ & $(0,01)$ & c & c & 1,40 & $(0,15)$ & 1,39 & $(0,15)$ \\
\hline Niederlande & 1,26 & $(0,10)$ & 1,16 & $(0,15)$ & 1,65 & $(0,12)$ & c & c & 1,65 & $(0,12)$ \\
\hline Neuseeland & 0,11 & $(0,05)$ & 0,10 & $(0,05)$ & C & c & 1,56 & $(0,42)$ & 1,56 & $(0,42)$ \\
\hline Norwegen & $-0,18$ & $(0,03)$ & $-0,21$ & $(0,03)$ & c & c & c & $\mathrm{c}$ & c & $\mathrm{c}$ \\
\hline Polen & $-0,34$ & $(0,02)$ & $-0,39$ & $(0,02)$ & 1,29 & $(0,47)$ & 1,87 & $(0,57)$ & 1,50 & $(0,36)$ \\
\hline Portugal & $-0,48$ & $(0,03)$ & $-0,58$ & $(0,02)$ & 0,07 & $(0,31)$ & 0,85 & $(0,39)$ & 0,40 & $(0,25)$ \\
\hline Slowakei & 0,78 & $(0,09)$ & 0,77 & $(0,09)$ & 0,80 & $(0,30)$ & c & c & 0,90 & $(0,28)$ \\
\hline Slowenien & $-0,11$ & $(0,02)$ & $-0,13$ & $(0,02)$ & 1,03 & $(0,08)$ & c & c & 1,03 & $(0,08)$ \\
\hline Spanien & $-0,42$ & $(0,03)$ & $-0,69$ & $(0,01)$ & 0,10 & $(0,12)$ & 0,28 & $(0,19)$ & 0,14 & $(0,10)$ \\
\hline Schweden & 0,63 & $(0,07)$ & 0,40 & $(0,08)$ & 2,06 & $(0,17)$ & c & c & 2,06 & $(0,17)$ \\
\hline Schweiz & $-0,13$ & $(0,04)$ & $-0,22$ & $(0,04)$ & 0,40 & $(0,21)$ & 1,59 & $(0,29)$ & 1,31 & $(0,24)$ \\
\hline Türkei & $-0,72$ & $(0,01)$ & $-0,73$ & $(0,01)$ & C & c & c & c & c & $\mathrm{c}$ \\
\hline Vereinigtes Königreich & 1,10 & $(0,08)$ & 0,80 & $(0,09)$ & 1,64 & $(0,14)$ & 2,18 & $(0,21)$ & 1,73 & $(0,11)$ \\
\hline Vereinigte Staaten & 0,08 & $(0,06)$ & 0,01 & $(0,06)$ & c & c & 1,26 & $(0,35)$ & 1,26 & $(0,35)$ \\
\hline OECD-Durchschnitt & $-0,05$ & $(0,01)$ & $-0,20$ & $(0,01)$ & 0,75 & $(0,05)$ & 1,09 & $(0,08)$ & 0,92 & $(0,04)$ \\
\hline \multicolumn{11}{|l|}{ Partnerländer } \\
\hline Albanien & $-0,60$ & $(0,04)$ & $-0,70$ & $(0,01)$ & c & c & 0,37 & $(0,48)$ & 0,37 & $(0,48)$ \\
\hline Argentinien & $\mathrm{m}$ & $\mathrm{m}$ & c & c & c & c & c & c & c & c \\
\hline Brasilien & $-0,32$ & $(0,04)$ & $-0,73$ & $(0,01)$ & 0,01 & $(0,45)$ & 1,82 & $(0,15)$ & 1,74 & $(0,16)$ \\
\hline Bulgarien & 0,86 & $(0,10)$ & 0,83 & $(0,09)$ & c & c & c & c & c & c \\
\hline Kolumbien & $-0,36$ & $(0,04)$ & $-0,68$ & $(0,01)$ & 1,30 & $(0,33)$ & 1,43 & $(0,40)$ & 1,39 & $(0,30)$ \\
\hline Costa Rica & $-0,36$ & $(0,04)$ & $-0,66$ & $(0,01)$ & 0,15 & $(0,39)$ & 1,62 & $(0,33)$ & 1,21 & $(0,27)$ \\
\hline Kroatien & $-0,34$ & $(0,03)$ & $-0,36$ & $(0,02)$ & c & $\mathrm{C}$ & C & c & c & c \\
\hline Hongkong (VR China) & 0,42 & $(0,09)$ & $-0,48$ & $(0,04)$ & 0,45 & $(0,10)$ & c & c & 0,48 & $(0,10)$ \\
\hline Indonesien & 0,33 & $(0,09)$ & $-0,31$ & $(0,10)$ & 1,30 & $(0,18)$ & 1,24 & $(0,21)$ & 1,27 & $(0,14)$ \\
\hline Jordanien & $-0,51$ & $(0,03)$ & $-0,67$ & $(0,02)$ & c & c & 0,32 & $(0,14)$ & 0,26 & $(0,14)$ \\
\hline Kasachstan & $-0,33$ & $(0,04)$ & $-0,38$ & $(0,04)$ & c & c & 0,91 & $(0,44)$ & 1,34 & $(0,45)$ \\
\hline Lettland & 0,60 & $(0,08)$ & 0,56 & $(0,08)$ & c & c & c & c & c & c \\
\hline Liechtenstein & $-0,08$ & $(0,02)$ & $-0,27$ & $(0,01)$ & c & c & c & c & c & c \\
\hline Litauen & 0,78 & $(0,08)$ & 0,76 & $(0,08)$ & c & c & c & c & c & $\mathrm{c}$ \\
\hline Macau (VR China) & 1,64 & $(0,00)$ & c & $\mathrm{c}$ & 1,73 & $(0,00)$ & 1,74 & $(0,00)$ & 1,73 & $(0,00)$ \\
\hline Malaysia & $-0,49$ & $(0,03)$ & $-0,58$ & $(0,01)$ & c & c & 2,09 & $(0,45)$ & 2,09 & $(0,45)$ \\
\hline Montenegro & $-0,33$ & $(0,00)$ & $-0,34$ & $(0,00)$ & c & c & $\mathrm{C}$ & C & $\mathrm{C}$ & $\mathrm{C}$ \\
\hline Peru & 0,18 & $(0,07)$ & $-0,51$ & $(0,05)$ & c & c & 2,32 & $(0,18)$ & 2,32 & $(0,18)$ \\
\hline Katar & $-0,37$ & $(0,00)$ & $-0,39$ & $(0,00)$ & c & c & $-0,33$ & $(0,00)$ & $-0,33$ & $(0,00)$ \\
\hline Rumänien & $-0,57$ & $(0,02)$ & $-0,57$ & $(0,02)$ & c & c & C & c & c & c \\
\hline Russische Föderation & 0,03 & $(0,07)$ & 0,01 & $(0,06)$ & c & c & c & c & c & c \\
\hline Serbien & $-0,39$ & $(0,02)$ & $-0,41$ & $(0,02)$ & c & c & c & $\mathrm{C}$ & c & c \\
\hline Shanghai (VR China) & $-0,28$ & $(0,05)$ & $-0,38$ & $(0,04)$ & c & c & 0,67 & $(0,30)$ & 0,67 & $(0,30)$ \\
\hline Singapur & $-0,36$ & $(0,01)$ & $-0,40$ & $(0,00)$ & $\mathrm{c}$ & c & c & c & c & $\mathrm{c}$ \\
\hline Taipeh (Republik China) & 0,07 & $(0,06)$ & $-0,41$ & $(0,03)$ & 0,52 & $(0,28)$ & 1,00 & $(0,19)$ & 0,93 & $(0,17)$ \\
\hline Thailand & 0,70 & $(0,08)$ & 0,46 & $(0,08)$ & 1,79 & $(0,22)$ & 2,29 & $(0,31)$ & 1,94 & $(0,20)$ \\
\hline Tunesien & $-0,20$ & $(0,06)$ & $-0,20$ & $(0,06)$ & c & c & c & c & c & c \\
\hline Ver. Arabische Emirate & 0,39 & $(0,05)$ & $-0,56$ & $(0,03)$ & c & c & 1,10 & $(0,10)$ & 1,09 & $(0,10)$ \\
\hline Uruguay & $-0,46$ & $(0,04)$ & $-0,73$ & $(0,01)$ & c & $\mathrm{c}$ & 0,89 & $(0,20)$ & 0,89 & $(0,20)$ \\
\hline Vietnam & $-0,43$ & $(0,06)$ & $-0,54$ & $(0,04)$ & c & c & 1,03 & $(0,58)$ & 1,03 & $(0,58)$ \\
\hline
\end{tabular}

Anmerkung: Im Rahmen von PISA 2012 wurden die Schulleitungen gebeten anzugeben, ob die Lehrkräfte, die Schulleitung, der Schulverwaltungsrat, die regionalen und lokalen Bildungsbehörden oder die nationale Bildungsbehörde erhebliche Verantwortung für die Allokation von Ressourcen an Schulen und Verantwortung für die Lehrplangestaltung und Schülerbeurteilung haben. Diese Informationen wurden zu zwei zusammengesetzten Indizes zusammengefasst: dem Index der Schulautonomie: Ressourcenallokation und dem Index der Schulautonomie: Unterrichtsinhalte und Beurteilungen, wobei beide Indizes einen Mittelwert von null und eine Standardabweichung von 1 aufweisen. Höhere Werte weisen auf mehr Autonomie der Schulleiter und Lehrkräfte hin.

Quelle: OECD. PISA-2012-Datenbank. Hinweise s. Anhang 3 unter www.oecd.org/edu/eag.htm. StatLink: http://dx.doi.org/10.1787/888933119416 Erläuterung der Kennzeichnung fehlender Daten s. Hinweise für den Leser. 
Autonomie der Schule bei Ressourcenallokation, Unterrichtsinhalten und Beurteilungen, nach Art der Bildungseinrichtung und Bildungsbereich (2012)

Ergebnisse basierend auf den Angaben der Schulleiter

\begin{tabular}{|c|c|c|c|c|c|c|c|c|c|c|}
\hline & \multicolumn{10}{|c|}{ Index der Schulautonomie: Unterrichtsinhalte und Beurteilungen } \\
\hline & \multicolumn{2}{|c|}{ Alle Bildungseinrichtungen } & \multicolumn{2}{|c|}{$\begin{array}{l}\text { Öffentliche Bildungs- } \\
\text { einrichtungen }\end{array}$} & \multicolumn{2}{|c|}{$\begin{array}{l}\text { Staatlich subventionierte } \\
\text { private Bildungs- } \\
\text { einrichtungen }\end{array}$} & \multicolumn{2}{|c|}{$\begin{array}{l}\text { Unabhängige private } \\
\text { Bildungseinrichtungen }\end{array}$} & \multicolumn{2}{|c|}{$\begin{array}{l}\text { Private Bildungs- } \\
\text { einrichtungen }\end{array}$} \\
\hline & $\begin{array}{l}\text { Mittlerer } \\
\text { Index }\end{array}$ & S.F. & $\begin{array}{l}\text { Mittlerer } \\
\text { Index }\end{array}$ & S.F. & $\begin{array}{l}\text { Mittlerer } \\
\text { Index }\end{array}$ & S.F. & $\begin{array}{l}\text { Mittlerer } \\
\text { Index }\end{array}$ & S.F. & $\begin{array}{l}\text { Mittlerer } \\
\text { Index }\end{array}$ & S.F. \\
\hline & (11) & (12) & (13) & (14) & (15) & (16) & (17) & (18) & (19) & $(20)$ \\
\hline \multicolumn{11}{|l|}{ OECD-Länder } \\
\hline Australien & 0,13 & $(0,04)$ & $-0,06$ & $(0,04)$ & 0,35 & $(0,07)$ & 0,50 & $(0,10)$ & 0,40 & $(0,06)$ \\
\hline Österreich & $-0,30$ & $(0,06)$ & $-0,29$ & $(0,07)$ & $-0,32$ & $(0,17)$ & $-0,47$ & $(0,37)$ & $-0,34$ & $(0,16)$ \\
\hline Belgien & $-0,11$ & $(0,05)$ & $-0,19$ & $(0,09)$ & $-0,04$ & $(0,06)$ & c & $\mathrm{c}$ & $-0,05$ & $(0,06)$ \\
\hline Kanada & $-0,49$ & $(0,03)$ & $-0,56$ & $(0,03)$ & 0,11 & $(0,18)$ & 0,43 & $(0,24)$ & 0,25 & $(0,14)$ \\
\hline Chile & 0,12 & $(0,07)$ & $-0,35$ & $(0,11)$ & 0,34 & $(0,12)$ & 0,54 & $(0,17)$ & 0,39 & $(0,10)$ \\
\hline Tschechien & 0,75 & $(0,06)$ & 1,03 & $(0,06)$ & 1,01 & $(0,18)$ & c & c & 1,05 & $(0,15)$ \\
\hline Dänemark & $-0,05$ & $(0,06)$ & $-0,11$ & $(0,07)$ & 0,44 & $(0,17)$ & 0,40 & $(0,32)$ & 0,43 & $(0,14)$ \\
\hline Estland & 0,49 & $(0,05)$ & 0,50 & $(0,05)$ & 0,12 & $(0,32)$ & c & $\mathrm{c}$ & $-0,08$ & $(0,24)$ \\
\hline Finnland & $-0,05$ & $(0,07)$ & $-0,06$ & $(0,07)$ & 0,72 & $(0,17)$ & c & c & 0,72 & $(0,17)$ \\
\hline Frankreich & $-0,10$ & $(0,06)$ & $-0,19$ & $(0,06)$ & 0,48 & $(0,21)$ & c & c & 0,48 & $(0,21)$ \\
\hline Deutschland & $-0,19$ & $(0,05)$ & $-0,14$ & $(0,05)$ & 0,32 & $(0,31)$ & c & c & 0,26 & $(0,29)$ \\
\hline Griechenland & $-1,15$ & $(0,02)$ & $-1,17$ & $(0,01)$ & c & c & c & c & c & c \\
\hline Ungarn & 0,02 & $(0,07)$ & $-0,07$ & $(0,07)$ & 0,53 & $(0,19)$ & c & c & 0,53 & $(0,19)$ \\
\hline Island & 0,15 & $(0,00)$ & 0,16 & $(0,00)$ & c & $\mathrm{c}$ & c & c & c & c \\
\hline Irland & w & w & w & w & w & w & w & w & w & w \\
\hline Israel & 0,00 & $(0,06)$ & 0,01 & $(0,06)$ & c & c & c & c & c & c \\
\hline Italien & 0,36 & $(0,04)$ & 0,41 & $(0,04)$ & 0,68 & $(0,19)$ & 0,47 & $(0,20)$ & 0,55 & $(0,15)$ \\
\hline Japan & 1,15 & $(0,05)$ & 1,04 & $(0,07)$ & c & c & 1,43 & $(0,01)$ & 1,43 & $(0,01)$ \\
\hline Korea & 0,71 & $(0,08)$ & 0,72 & $(0,11)$ & 0,80 & $(0,14)$ & 0,47 & $(0,23)$ & 0,69 & $(0,11)$ \\
\hline Luxemburg & $-0,84$ & $(0,00)$ & $-0,89$ & $(0,00)$ & $-0,80$ & $(0,00)$ & c & c & $-0,54$ & $(0,01)$ \\
\hline Mexiko & $-0,87$ & $(0,02)$ & $-0,94$ & $(0,01)$ & c & c & $-0,31$ & $(0,11)$ & $-0,30$ & $(0,11)$ \\
\hline Niederlande & 0,96 & $(0,08)$ & 1,30 & $(0,07)$ & 1,18 & $(0,07)$ & c & $\mathrm{c}$ & 1,18 & $(0,07)$ \\
\hline Neuseeland & 0,47 & $(0,07)$ & 0,66 & $(0,07)$ & C & c & 0,26 & $(0,31)$ & 0,26 & $(0,31)$ \\
\hline Norwegen & $-0,55$ & $(0,05)$ & $-0,55$ & $(0,05)$ & c & $\mathrm{c}$ & c & $\mathrm{c}$ & c & c \\
\hline Polen & 0,37 & $(0,07)$ & 0,36 & $(0,07)$ & 0,91 & $(0,30)$ & 0,68 & $(0,40)$ & 0,83 & $(0,25)$ \\
\hline Portugal & $-0,68$ & $(0,03)$ & $-0,72$ & $(0,03)$ & $-0,44$ & $(0,27)$ & $-0,04$ & $(0,29)$ & $-0,27$ & $(0,21)$ \\
\hline Slowakei & 0,48 & $(0,08)$ & 0,53 & $(0,08)$ & $-0,11$ & $(0,24)$ & c & $\mathrm{c}$ & $-0,03$ & $(0,20)$ \\
\hline Slowenien & $-0,35$ & $(0,01)$ & $-0,31$ & $(0,01)$ & $-0,79$ & $(0,00)$ & c & c & $-0,79$ & $(0,00)$ \\
\hline Spanien & $-0,47$ & $(0,04)$ & $-0,66$ & $(0,04)$ & $-0,03$ & $(0,12)$ & $-0,17$ & $(0,18)$ & $-0,06$ & $(0,09)$ \\
\hline Schweden & $-0,25$ & $(0,06)$ & $-0,27$ & $(0,06)$ & $-0,09$ & $(0,10)$ & c & c & $-0,09$ & $(0,10)$ \\
\hline Schweiz & $-0,60$ & $(0,04)$ & $-0,67$ & $(0,04)$ & $-0,38$ & $(0,16)$ & 0,75 & $(0,27)$ & 0,48 & $(0,25)$ \\
\hline Türkei & $-1,12$ & $(0,02)$ & $-1,14$ & $(0,02)$ & c & c & c & $\mathrm{c}$ & c & $\mathrm{c}$ \\
\hline Vereinigtes Königreich & 0,93 & $(0,05)$ & 0,93 & $(0,06)$ & 1,21 & $(0,07)$ & 1,44 & $(0,00)$ & 1,25 & $(0,06)$ \\
\hline Vereinigte Staaten & $-0,39$ & $(0,08)$ & $-0,49$ & $(0,07)$ & c & c & 0,87 & $(0,27)$ & 0,87 & $(0,27)$ \\
\hline OECD-Durchschnitt & $-0,04$ & $(0,01)$ & $-0,06$ & $(0,01)$ & 0,25 & $(0,04)$ & 0,45 & $(0,06)$ & 0,33 & $(0,03)$ \\
\hline \multicolumn{11}{|l|}{ Partnerländer } \\
\hline Albanien & $-0,27$ & $(0,07)$ & $-0,30$ & $(0,07)$ & c & c & 0,13 & $(0,36)$ & 0,13 & $(0,36)$ \\
\hline Argentinien & $-0,51$ & $(0,06)$ & $-0,57$ & $(0,05)$ & $-0,47$ & $(0,10)$ & 0,03 & $(0,40)$ & $-0,37$ & $(0,14)$ \\
\hline Brasilien & $-0,42$ & $(0,03)$ & $-0,59$ & $(0,03)$ & 0,23 & $(0,76)$ & 0,41 & $(0,14)$ & 0,39 & $(0,14)$ \\
\hline Bulgarien & $-0,84$ & $(0,03)$ & $-0,84$ & $(0,03)$ & c & c & c & $\mathrm{c}$ & c & $\mathrm{c}$ \\
\hline Kolumbien & $-0,08$ & $(0,07)$ & $-0,20$ & $(0,07)$ & 0,21 & $(0,21)$ & 0,77 & $(0,17)$ & 0,61 & $(0,14)$ \\
\hline Costa Rica & $-0,65$ & $(0,05)$ & $-0,88$ & $(0,04)$ & 0,10 & $(0,46)$ & 0,75 & $(0,20)$ & 0,57 & $(0,20)$ \\
\hline Kroatien & $-0,86$ & $(0,03)$ & $-0,85$ & $(0,03)$ & C & $\mathrm{c}$ & c & $\mathrm{c}$ & c & c \\
\hline Hongkong (VR China) & 0,96 & $(0,07)$ & 0,98 & $(0,32)$ & 0,99 & $(0,07)$ & c & c & 0,99 & $(0,07)$ \\
\hline Indonesien & 0,65 & $(0,08)$ & 0,49 & $(0,11)$ & 0,85 & $(0,14)$ & 0,87 & $(0,18)$ & 0,86 & $(0,12)$ \\
\hline Jordanien & $-1,04$ & $(0,04)$ & $-1,12$ & $(0,04)$ & c & c & $-0,58$ & $(0,13)$ & $-0,61$ & $(0,13)$ \\
\hline Kasachstan & $-0,76$ & $(0,05)$ & $-0,77$ & $(0,05)$ & c & c & $-0,73$ & $(0,16)$ & $-0,21$ & $(0,34)$ \\
\hline Lettland & $-0,19$ & $(0,06)$ & $-0,21$ & $(0,06)$ & c & c & c & c & c & c \\
\hline Liechtenstein & $-0,33$ & $(0,02)$ & $-0,45$ & $(0,02)$ & c & c & c & $c$ & c & c \\
\hline Litauen & 0,66 & $(0,05)$ & 0,65 & $(0,05)$ & c & c & c & c & c & c \\
\hline Macau (VR China) & 0,78 & $(0,00)$ & c & $\mathrm{C}$ & 0,86 & $(0,00)$ & 0,52 & $(0,00)$ & 0,81 & $(0,00)$ \\
\hline Malaysia & $-0,88$ & $(0,04)$ & $-0,95$ & $(0,04)$ & C & c & 1,07 & $(0,30)$ & 1,07 & $(0,30)$ \\
\hline Montenegro & $-0,83$ & $(0,00)$ & $-0,84$ & $(0,00)$ & c & c & $\mathrm{C}$ & $\mathrm{C}$ & $\mathrm{C}$ & $\mathrm{C}$ \\
\hline Peru & $-0,09$ & $(0,05)$ & $-0,41$ & $(0,07)$ & c & c & 0,99 & $(0,13)$ & 0,99 & $(0,13)$ \\
\hline Katar & $-0,90$ & $(0,00)$ & $-0,94$ & $(0,00)$ & c & c & $-0,84$ & $(0,00)$ & $-0,84$ & $(0,00)$ \\
\hline Rumänien & $-0,52$ & $(0,05)$ & $-0,52$ & $(0,05)$ & c & c & c & c & c & c \\
\hline Russische Föderation & $-0,22$ & $(0,05)$ & $-0,22$ & $(0,05)$ & c & c & c & c & c & c \\
\hline Serbien & $-0,86$ & $(0,02)$ & $-0,87$ & $(0,02)$ & c & c & c & c & c & c \\
\hline Shanghai (VR China) & $-0,56$ & $(0,05)$ & $-0,55$ & $(0,05)$ & c & c & $-0,57$ & $(0,23)$ & $-0,57$ & $(0,23)$ \\
\hline Singapur & $-0,25$ & $(0,01)$ & $-0,24$ & $(0,00)$ & c & $\mathrm{C}$ & C & $\mathrm{C}$ & c & c \\
\hline Taipeh (Republik China) & 0,21 & $(0,07)$ & 0,15 & $(0,09)$ & 0,12 & $(0,30)$ & 0,38 & $(0,12)$ & 0,34 & $(0,12)$ \\
\hline Thailand & 0,98 & $(0,05)$ & 0,95 & $(0,06)$ & 1,02 & $(0,16)$ & 1,44 & $(0,00)$ & 1,15 & $(0,11)$ \\
\hline Tunesien & $-0,58$ & $(0,08)$ & $-0,58$ & $(0,08)$ & C & $\mathrm{C}$ & C & c & c & $\mathrm{C}$ \\
\hline Ver. Arabische Emirate & $-0,44$ & $(0,04)$ & $-1,07$ & $(0,04)$ & c & c & 0,01 & $(0,07)$ & 0,03 & $(0,07)$ \\
\hline Uruguay & $-0,83$ & $(0,04)$ & $-1,02$ & $(0,02)$ & c & c & 0,11 & $(0,21)$ & 0,11 & $(0,21)$ \\
\hline Vietnam & $-0,98$ & $(0,03)$ & $-1,05$ & $(0,03)$ & c & c & $-0,48$ & $(0,38)$ & $-0,48$ & $(0,38)$ \\
\hline
\end{tabular}

Anmerkung: Im Rahmen von PISA 2012 wurden die Schulleitungen gebeten anzugeben, ob die Lehrkräfte, die Schulleitung, der Schulverwaltungsrat, die regionalen und lokalen Bildungsbehörden oder die nationale Bildungsbehörde erhebliche Verantwortung für die Allokation von Ressourcen an Schulen und Verantwortung für die Lehrplangestaltung und Schülerbeurteilung haben. Diese Informationen wurden zu zwei zusammengesetzten Indizes zusammengefasst: dem Index der Schulautonomie: Ressourcenallokation und dem Index der Schulautonomie: Unterrichtsinhalte und Beurteilungen, wobei beide Indizes einen Mittelwert von null und eine Standardabweichung von 1 aufweisen. Höhere Werte weisen auf mehr Autonomie der Schulleiter und Lehrkräfte hin.

Quelle: OECD. PISA-2012-Datenbank. Hinweise s. Anhang 3 unter www.oecd.org/edu/eag.htm. StatLink: http://dx.doi.org/10.1787/888933119416 Erläuterung der Kennzeichnung fehlender Daten s. Hinweise für den Leser. 
Tabelle C7.6

Verteilung der Studierenden im Tertiärbereich nach Art der Bildungseinrichtung $(2003,2012)$

Verteilung der Studierenden, nach Art der Bildungseinrichtung und Ziel des Studiengangs

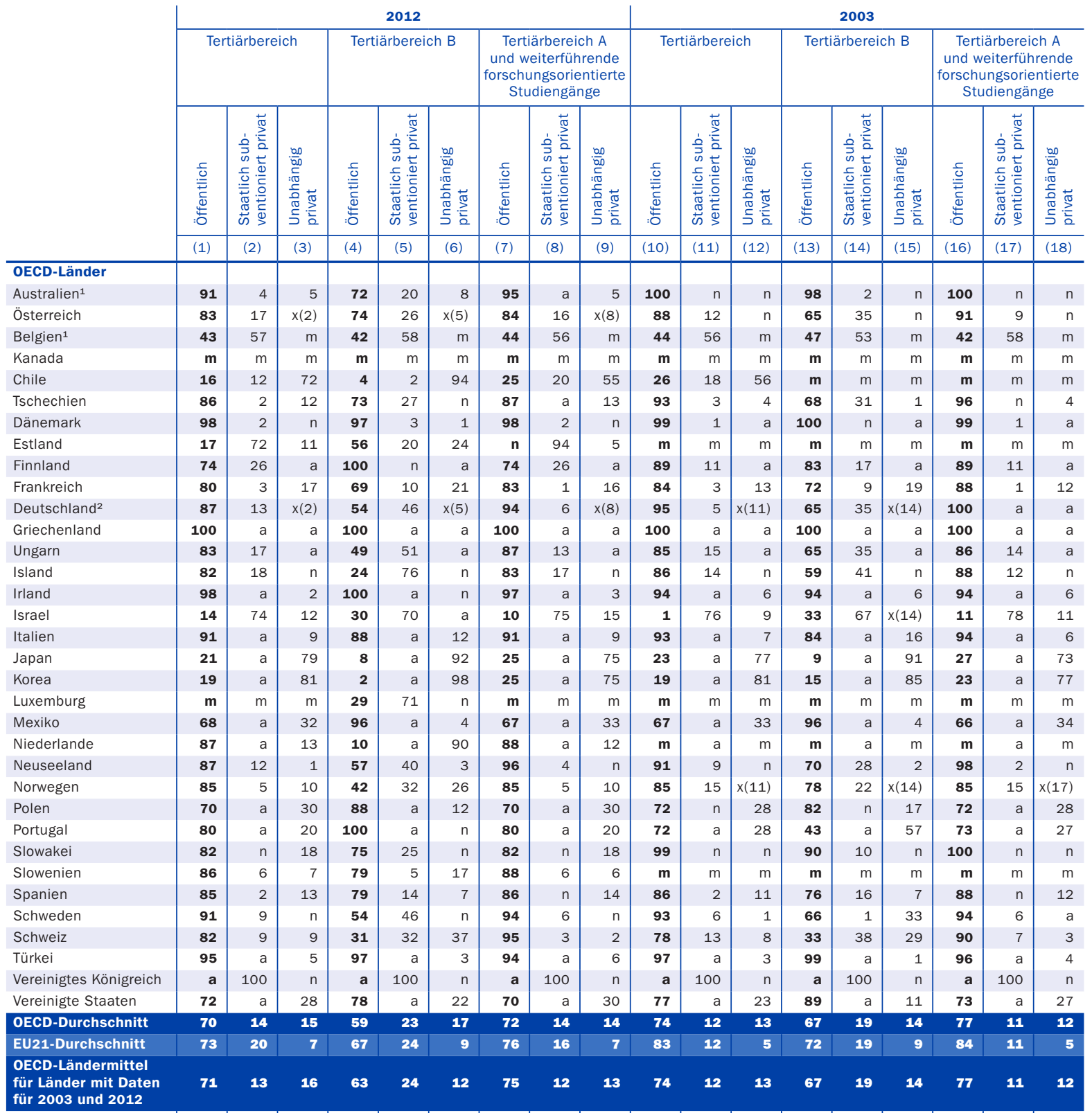

\begin{tabular}{|c|c|c|c|c|c|c|c|c|c|c|c|c|c|c|c|c|c|c|}
\hline \multicolumn{19}{|l|}{ Partnerländer } \\
\hline Argentinien $^{3}$ & 74 & 5 & 20 & 64 & 17 & 20 & 79 & $\mathbf{a}$ & 21 & 78 & 8 & 13 & m & $\mathbf{m}$ & m & m & $\mathbf{m}$ & m \\
\hline Brasilien & 29 & a & 71 & 15 & a & 85 & 31 & a & 69 & 32 & $\mathbf{a}$ & 68 & m & m & m & m & m & m \\
\hline China & m & $\mathbf{m}$ & m & m & m & m & m & m & m & m & m & m & m & $\mathbf{m}$ & m & m & $\mathbf{m}$ & m \\
\hline Kolumbien & 53 & a & 47 & m & a & m & m & a & m & m & $\mathbf{m}$ & m & m & m & $\mathbf{m}$ & m & $\mathbf{m}$ & m \\
\hline Indien & m & $\mathbf{m}$ & m & m & m & m & m & m & m & m & m & m & $\mathbf{m}$ & $\mathbf{m}$ & m & m & $\mathbf{m}$ & m \\
\hline Indonesien & 34 & a & 66 & 43 & a & 57 & 32 & a & 68 & 39 & a & 61 & $\mathbf{m}$ & m & m & m & $\mathbf{m}$ & m \\
\hline Lettland & 7 & 64 & 29 & 42 & 17 & 41 & a & 74 & 26 & $\mathbf{m}$ & $\mathbf{m}$ & m & m & m & m & m & m & $\mathbf{m}$ \\
\hline Russische Föderation² & 86 & a & 14 & 95 & a & 5 & 84 & a & 16 & 91 & $\mathbf{a}$ & 9 & $\mathbf{m}$ & $\mathbf{m}$ & $\mathbf{m}$ & m & m & m \\
\hline Saudi-Arabien & 95 & 5 & $\mathbf{a}$ & 100 & $\mathbf{n}$ & $\mathbf{n}$ & 95 & 5 & a & $\mathbf{m}$ & $\mathbf{m}$ & m & m & $\mathbf{m}$ & $\mathbf{m}$ & $\mathbf{m}$ & $\mathbf{m}$ & $\mathbf{m}$ \\
\hline Südafrika & m & $\mathbf{m}$ & m & m & m & m & m & m & m & m & m & m & m & m & $\mathbf{m}$ & $\mathbf{m}$ & $\mathbf{m}$ & $\mathbf{m}$ \\
\hline G20-Durchschnitt & $\mathbf{m}$ & m & m & m & m & m & $\mathbf{m}$ & $\mathbf{m}$ & m & m & $\mathbf{m}$ & $\mathbf{m}$ & $\mathbf{m}$ & $\mathbf{m}$ & $\mathbf{m}$ & m & m & m \\
\hline
\end{tabular}

1. Ohne unabhängige private Bildungseinrichtungen. 2. Ohne weiterführende forschungsorientierte Studiengänge. 3. Referenzjahr 2011. Quelle: OECD. Argentinien, Indonesien, Kolumbien, Saudi-Arabien: Statistikinstitut der UNESCO (World Education Indicators Programme). Hinweise s. Anhang 3 unter www.oecd.org/edu/eag.htm. StatLink: http://dx.doi.org/10.1787/888933119435 Erläuterung der Kennzeichnung fehlender Daten s. Hinweise für den Leser. 


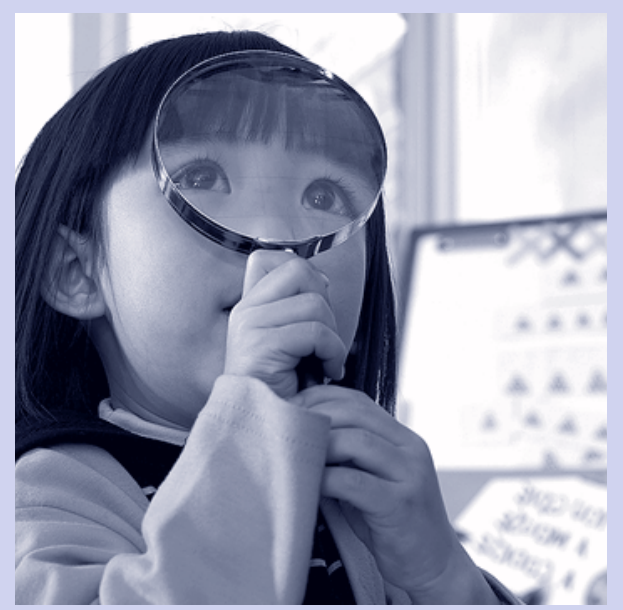

\section{Kapitiel D. \\ Das Lernumfeld und die Organisation von Schulen}

Indikator DI

Wie viel Zeit verbringen Schüler im

Klassenzimmer?

StatLink: http://dx.doi.org/10.1787/888933119530

Indikator $\mathrm{D} 2$

Wie ist die Schüler-Lehrkräfte-Relation und wie groß sind die Klassen?

StatLink: http://dx.doi.org/10.1787/888933119682

Indikator $\mathrm{D}_{3}$

Wie hoch sind die Gehälter der Lehrkräfte?

StatLink: http://dx.doi.org/10.1787/888933119815

Indikator $\mathrm{D}_{4}$

Wie viel Zeit unterrichten Lehrkräfte?

StatLink: http://dx.doi.org/10.1787/888933120005
Indikator $\mathrm{D}_{5}$

Wie ist die Zusammensetzung der Lehrerschaft?

StatLink: http://dx.doi.org/10.1787/888933120138

Indikator D6

Welche Anforderungen und Ausbildungs-

voraussetzungen gelten für den Lehrerberuf?

StatLink: http://dx.doi.org/10.1787/888933120252

Indikator $\mathrm{D} 7$

Wie umfassend sind die Maßnahmen zur

beruflichen Fortbildung für Lehrkräfte?

StatLink: http://dx.doi.org/10.1787/888933120461 



\section{Indilkatior D1}

\section{Wie viel Zeit verbringen Schüler im Klassenzimmer?}

In den OECD-Ländern erhalten Schüler im Verlauf des Besuchs des Primar- und Sekundarbereichs I zusammen 7.475 Zeitstunden Pflichtunterricht.

- Für Schüler des Primarbereichs entfallen im Durchschnitt der OECD-Länder 45 Prozent der Pflichtunterrichtszeit auf Lesen, Schreiben und Literatur, Mathematik und Kunst; für Schüler des Sekundarbereichs I entfallen 39 Prozent der Pflichtunterrichtszeit auf Lesen, Schreiben und Literatur, erste und weitere Fremdsprachen sowie Mathematik.

\section{Abbildung D1.1}

Pflichtunterrichtszeit im allgemeinbildenden Bereich (2014)

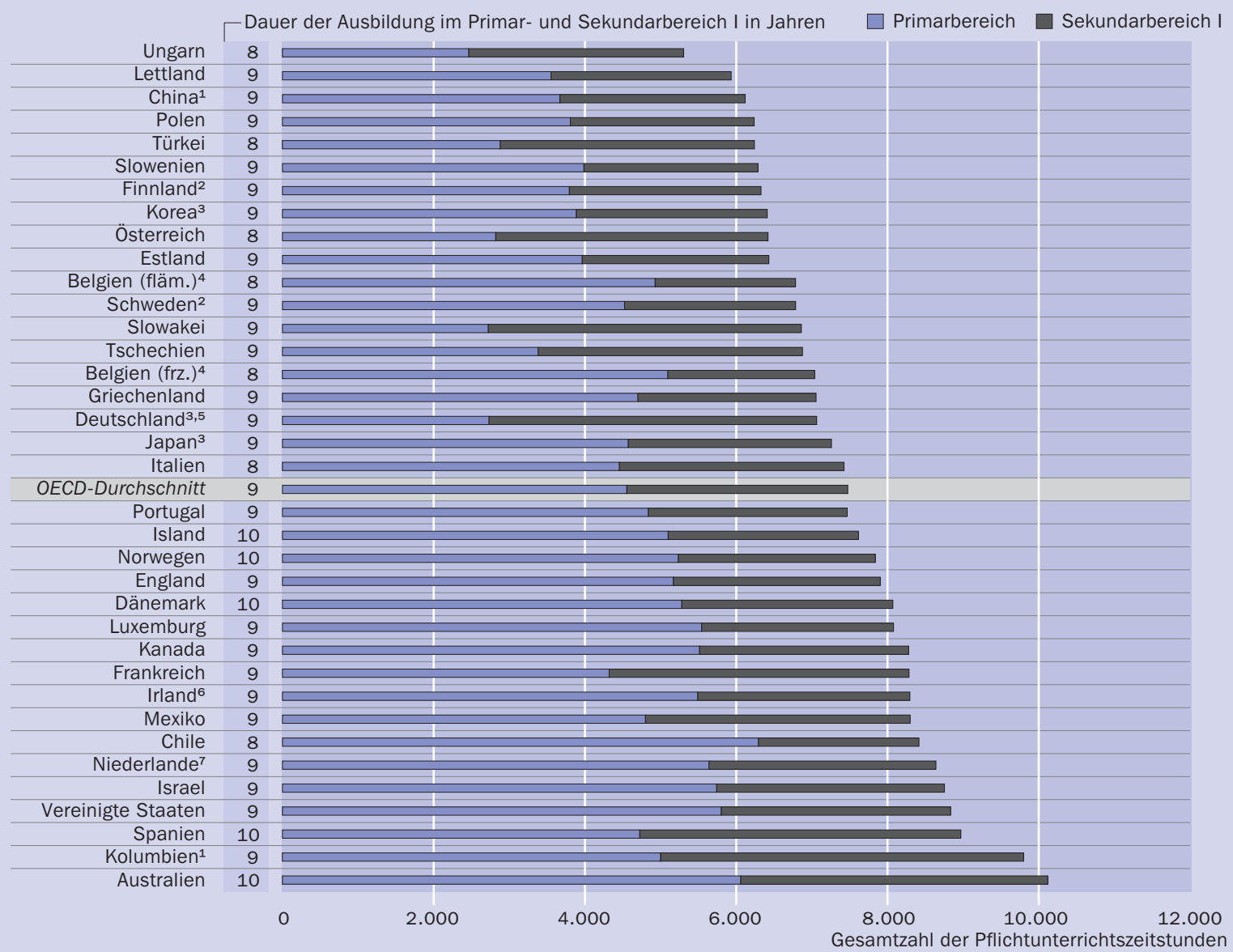

1. Referenzzeitraum 2012. 2. Geschätzte Anzahl der Zeitstunden nach Bildungsbereich, da die Unterrichtszeit über mehrere Klassenstufen hinweg flexibel aufgeteilt werden kann. 3. Referenzzeitraum 2013. 4. Schüler unterliegen bis zum 15. oder 16. Lebensjahr der Vollzeitschulpflicht. Für Schüler im allgemeinbildenden Bereich dauert diese bis zum 18. Lebensjahr 5. Ohne letztes Jahr der Schulpflicht, die entweder Sekundarbereich I oder Sekundarbereich II zugeordnet werden kann. 6. Tatsächliche Unterrichtszeit für den Sekundarbereich I. 7. Die Anzahl der Klassenstufen im Sekundarbereich I beträgt je nach Ausbildungszug 3 oder 4 Jahre.

Anordnung der Länder in aufsteigender Reihenfolge der Gesamtzahl an Pflichtunterrichtszeitstunden.

Quelle: OECD. Tabelle D1.1. Hinweise s. Anhang 3 unter www.oecd.org/edu/eag.htm. StatLink: http://dx.doi.org/10.1787/888933119625 


\section{Kontext}

Ein Großteil der öffentlichen Investitionen in das Lernen der Schüler erfolgt in Form der Bereitstellung von formalem Unterricht im Klassenzimmer. Die Länder treffen verschiedene Entscheidungen im Zusammenhang mit der insgesamt für Unterricht vorgesehenen Zeit und den von den Schülern zu belegenden Pflichtfächern. Diese Entscheidungen spiegeln nationale und/oder regionale Prioritäten und Präferenzen in Bezug darauf wider, in welchem Alter die Schüler in welchen Fächern unterrichtet werden sollten. Üblicherweise legen die Länder per Gesetz oder Vorschrift bestimmte Anforderungen hinsichtlich der Unterrichtszeit fest. Meistens handelt es sich dabei um die Mindestzahl an Unterrichtszeitstunden, die eine Schule anbieten muss, da davon ausgegangen wird, dass ein ausreichendes Angebot an Unterrichtszeit eine Grundvoraussetzung für gute Lernergebnisse ist. Es ist eine der zentralen Aufgaben der Bildungspolitik, die zur Verfügung stehenden Ressourcen auf die Bedürfnisse der Schüler abzustimmen und für eine optimale Nutzung der zur Verfügung stehenden Zeit Sorge zu tragen. Die Gehälter der Lehrkräfte, die Instandhaltung der Bildungseinrichtungen und die Bereitstellung sonstiger Bildungsressourcen sind die wichtigsten Kostenfaktoren von Bildung. Die Zeitdauer, für die den Schülern diese Bildungsressourcen zur Verfügung gestellt werden (wie zum Teil in diesem Indikator dargestellt), ist bei der Zuweisung der Mittel von großer Bedeutung (s. Indikator B7, in dem die Faktoren aufgezeigt werden, die die Gehaltskosten der Lehrkräfte pro Schüler beeinflussen).

\section{Weitere wichtige Ergebnisse}

In den OECD-Ländern erhalten Schüler des Primarbereichs im Durchschnitt pro Jahr 794 Zeitstunden Pflichtunterricht; Schüler des Sekundarbereichs I erhalten im Durchschnitt III Zeitstunden mehr Pflichtunterricht pro Jahr als Schüler des Primarbereichs.

Der Anteil des für Lesen, Schreiben und Literatur vorgesehenen Pflichtteils des Lehrplans für Schüler des Primarbereichs variiert zwischen 18 Prozent in Polen und 37 Prozent in Frankreich; für Schüler des Sekundarbereichs I reicht er von 12 Prozent in Finnland, Irland, Japan und Tschechien bis zu 33 Prozent in Italien.

In den OECD-Ländern entfallen im Durchschnitt für Schüler im Primarbereich 14 Prozent des Pflichtunterrichts auf Pflichtfächer mit flexiblem Unterrichtsplan, für Schüler im Sekundarbereich I sind es 6 Prozent. Durchschnittlich 4 Prozent der Pflichtunterrichtszeit beider Schülergruppen entfallen auf von den Schulen ausgewählte flexible Pflichtfächer.

In etwa einem Drittel der Länder mit verfügbaren Daten wird die Unterrichtszeit flexibel über mehrere Klassenstufen hinweg verteilt, d. h., die Unterrichtszeit für ein bestimmtes Fach wird für eine bestimmte Anzahl von Klassenstufen oder sogar für den gesamten Zeitraum der allgemeinen Schulpflicht definiert, ohne festzulegen, wie viel Zeit in jeder einzelnen Klassenstufe für dieses Fach vorzusehen ist. 


\title{
Analyse und Interpretationen
}

\begin{abstract}
Allgemeine Schulpflicht
Die jährliche Unterrichtszeit sollte im Zusammenhang mit der Dauer der Schulpflicht betrachtet werden. In einigen Ländern ist der Zeitraum der Schulpflicht kürzer, und das Arbeitspensum der Schüler ist in diesem Zeitraum größer, während in anderen Ländern das Arbeitspensum gleichmäßiger über mehr Jahre verteilt ist.
\end{abstract}

In rund drei Viertel der Länder mit verfügbaren Daten beginnt der Besuch des Primarbereichs mit 6 Jahren. In Estland, Finnland, Lettland, Polen und Schweden jedoch beginnen die Schüler nicht vor dem 7. Geburtstag mit dem Schulbesuch. Nur in Australien, England und Schottland beginnt der Besuch des Primarbereichs schon mit 5 Jahren. Auch bei der Dauer des Primarbereichs gibt es große Unterschiede zwischen den einzelnen Ländern. Im Durchschnitt dauert der Primarbereich sechs Jahre, dies variiert jedoch von vier Jahren in Deutschland, Österreich, der Slowakei, der Türkei und Ungarn bis zu sieben Jahren in Dänemark, Island, Norwegen und Schottland. Der Sekundarbereich I dauert im Durchschnitt drei Jahre, aber hier reicht die Bandbreite von zwei Jahren in Belgien (fläm. und frz.) und Chile bis zu fünf Jahren in der Slowakei. In etwas mehr als der Hälfte der Länder mit verfügbaren Daten fällt zumindest noch ein Jahr des Sekundarbereichs II in die Schulpflicht (Vollzeitunterricht) (Tab. Di.2).

Auch die Aufteilung der jährlichen Unterrichtszeit auf Unterrichtstage unterscheidet sich in den einzelnen Ländern. Im Durchschnitt der OECD-Länder haben Schüler des Primar- und Sekundarbereichs I I 85 bzw. I 83 Unterrichtstage pro Jahr. Es gibt jedoch auch Länder, in denen die Schüler höchstens 170 Unterrichtstage pro Jahr haben China (im Primar- und Sekundarbereich I), Frankreich (Primarbereich), Griechenland (Sekundarbereich I), Irland (Sekundarbereich I), Island (Primar- und Sekundarbereich I), Lettland (Primarbereich) und Luxemburg (Sekundarbereich I). Im Gegensatz hierzu haben Schüler im Primar- und Sekundarbereich I in Brasilien, Israel, Italien, Japan, Kolumbien und Mexiko mindestens 200 Unterrichtstage pro Jahr (Tab. Dr.2).

\section{Pflichtunterrichtszeit}

Die Pflichtunterrichtszeit bezieht sich auf den Umfang und die Aufteilung der Unterrichtsstunden, die laut staatlichen Vorgaben von fast jeder öffentlichen Schule zu unterrichten und von fast jedem Schüler einer öffentlichen Bildungseinrichtung zu besuchen sind.

In den OECD-Ländern sind für Schüler im Primarbereich im Durchschnitt 4.553 Zeitstunden Unterricht vorgesehen, für Schüler im Sekundarbereich I sind es durchschnittlich 2.922 Zeitstunden. Während sich für Schüler des Primar- und Sekundarbereichs I in den OECD-Ländern die durchschnittliche Pflichtunterrichtszeit auf 7.475 Zeitstunden beläuft, reicht die festgelegte Zahl an Unterrichtszeitstunden von 5.304 Zeitstunden in Ungarn bis zu I0.I20 Stunden in Australien (Tab. Dr.I).

Die Pflichtunterrichtszeit kann sich auch von der tatsächlich unterrichteten Zeit unterscheiden, da sie nur die Zeit erfasst, in der Schüler formalen Unterricht im Klassenzimmer erhalten. Das ist jedoch nur ein Teil der Zeit, in der Schüler insgesamt unterrichtet werden, Unterricht wird auch außerhalb des Klassenzimmers und/oder außerhalb der 
Schule erteilt. In einigen Ländern werden Schüler des Sekundarbereichs angehalten, zusätzlichen Unterricht in Fächern zu besuchen, die bereits in der Schule unterrichtet werden, um ihre Leistungen in diesen Fächern zu verbessern. Schüler können nach dem offiziellen Schulunterricht an Zusatzunterricht teilnehmen, bei dem es sich um Nachhilfeunterricht oder um Neigungskurse, angeboten durch einzelne Lehrer oder in Form von Gruppenunterricht durch Lehrer der Schule, oder um andere externe Angebote handeln kann. Dieser Unterricht kann durch staatliche Mittel finanziert oder von den Schülern und ihren Familien selbst bezahlt werden (s. Kasten Di.r in OECD, 20II).

\section{Vorgesehene Unterrichtszeit}

Die insgesamt vorgesehene Unterrichtszeit bezeichnet die Zahl der Zeitstunden, in denen die Bildungseinrichtungen Unterricht in den Pflichtfächern und (soweit zutreffend) den Wahlfächern anbieten müssen.

Die vorgesehene Unterrichtszeit ist in drei Viertel der Länder mit verfügbaren Daten im Primar- und Sekundarbereich I gleichzeitig vollständig Pflichtunterrichtszeit, d.h., die vorgesehene und die Pflichtunterrichtszeit sind gleich lang. In Finnland, Griechenland, Polen, Portugal und Slowenien jedoch übersteigt die insgesamt vorgesehene Unterrichtszeit im Primar- und Sekundarbereich I die Pflichtunterrichtszeit um mindestens 5 Prozent.

\section{Unterrichtszeit pro Fach}

Für Schüler des Primarbereichs entfallen im Durchschnitt 45 Prozent des Pflichtcurriculums auf drei Fächer: Lesen, Schreiben und Literatur (22 Prozent), Mathematik (I5 Prozent) und Kunst (9 Prozent). Zusammen mit Sport und Gesundheit (8 Prozent), Naturwissenschaften (7 Prozent) und Sozialkunde (6 Prozent) machen diese sechs Fächer in allen OECD-Ländern, in denen die Unterrichtszeit pro Fach festgelegt ist, den größten Teil des Lehrplans aus. Moderne Fremdsprachen, Religion/Ethikunterricht, Informations- und Kommunikationstechnologien (IKT), Technik, praktische und berufsbezogene Kenntnisse und Kompetenzen sowie sonstige Fächer decken die verbleibenden 16 Prozent des nicht flexiblen Teils des Pflichtteils des Lehrplans im Primarbereich ab (Tab. Dr.3a und Abb. Dr.2a).

Im Durchschnitt nehmen Lesen, Schreiben und Literatur den größten Teil des Lehrplans im Primarbereich ein, aber ihr Anteil variiert stark. In Chile, Deutschland, Irland, Island und Polen beispielsweise machen Lesen, Schreiben und Literatur höchstens 20 Prozent der Pflichtunterrichtszeit aus, während es in Frankreich und Mexiko mindestens 35 Prozent sind. Die Unterschiede zwischen den einzelnen Ländern hinsichtlich des Anteils, der auf Mathematik und Kunst entfällt, sind ebenfalls sehr groß. In Griechenland, Korea und Polen entfallen auf Mathematik höchstens I4 Prozent der Unterrichtszeit, in Mexiko und Portugal sind es mindestens 27 Prozent. In Israel und Mexiko macht Kunst 5 Prozent der Unterrichtszeit aus, während dieser Anteil in Deutschland, Estland, Island, Norwegen und Slowenien bei mindestens I5 Prozent der Pflichtunterrichtszeit liegt. In Finnland entfallen auf den Kunstunterricht mindestens I3 Prozent der Pflichtunterrichtszeit, die Schulen sind jedoch verpflichtet, auch zusätzlich flexible Zeit für Kunst, Musik und Werken vorzusehen. 


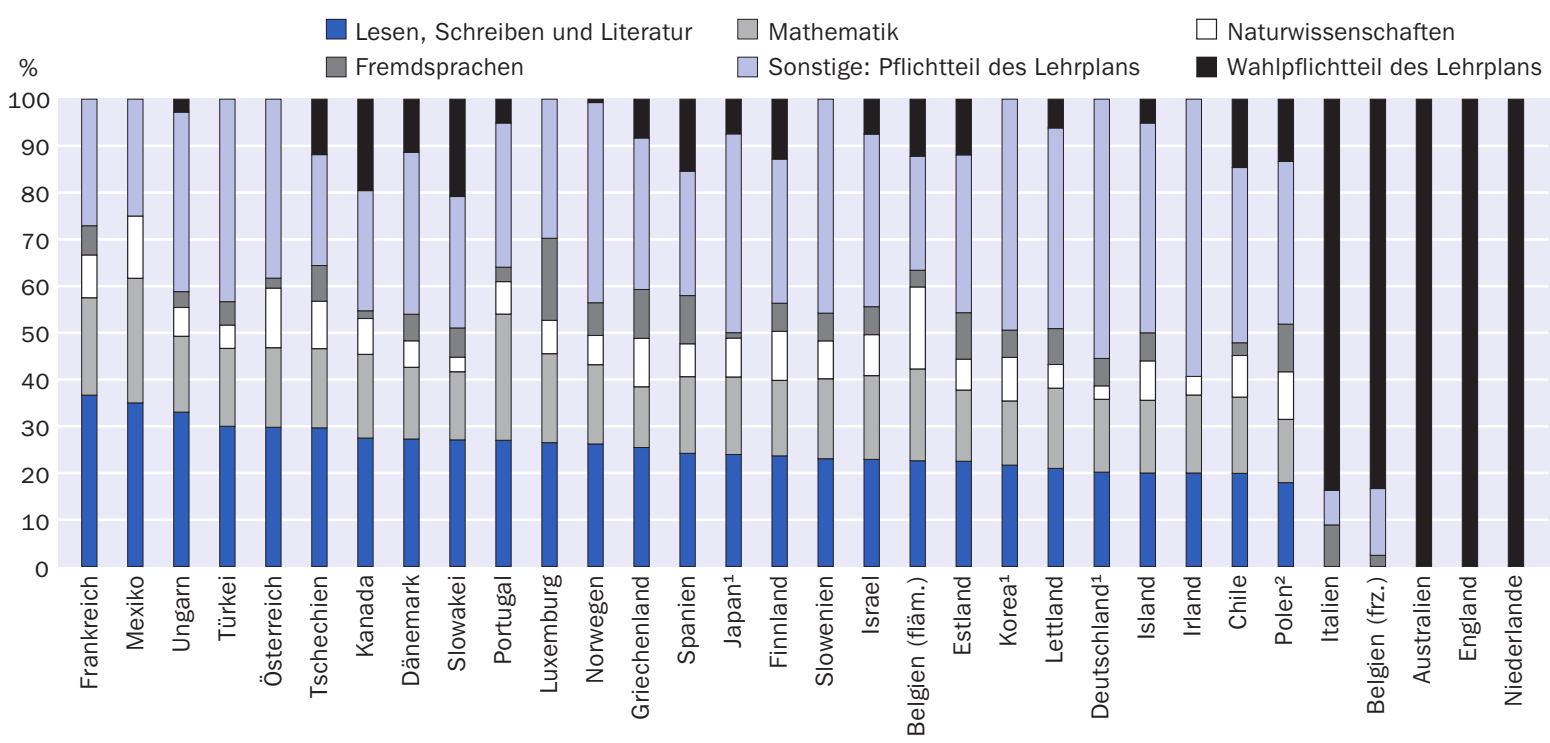

1. Referenzjahr 2013. 2. Ohne die ersten 3 Jahre des Primarbereichs, in denen ein großer Teil der den Pflichtfächern zugeordneten Zeit flexibel ist. Anordnung der Länder in absteigender Reihenfolge des Anteils der für Lesen, Schreiben und Literatur vorgesehenen Unterrichtszeitstunden. Quelle: OECD. Tabelle D1.3a. Hinweise s. Anhang 3 unter www.oecd.org/edu/eag.htm. StatLink: http://dx.doi.org/10.1787/888933119644

Im Sekundarbereich I entfallen im Durchschnitt 39 Prozent des Pflichtcurriculums auf drei Fächer: Lesen, Schreiben und Literatur (I4 Prozent), erste und weitere Fremdsprachen (I3 Prozent) und Mathematik (I2 Prozent). Außerdem sind im Durchschnitt weitere II Prozent des Pflichtcurriculums den Naturwissenschaften und so Prozent der Sozialkunde gewidmet. Zusammen mit Sport und Gesundheit (7 Prozent) und Kunst (7 Prozent) machen diese sieben Fächer in allen OECD- und Partnerländern, in denen die Unterrichtszeit pro Fach festgelegt ist, den größten Teil des Lehrplans dieser Altersgruppe aus. Religion/Ethik, IKT, Technik, praktische und berufsbezogene Kompetenzen sowie sonstige Fächer decken die verbleibenden I2 Prozent des nicht flexiblen Teils des Pflichtcurriculums für Schüler dieses Bildungsbereichs ab (Tab. Dr.3b und Abb. Di.2b).

Die Aufteilung der Unterrichtszeit ändert sich jedoch signifikant vom Primar- auf den Sekundarbereich I. Der Unterricht in Lesen, Schreiben und Literatur reduziert sich von 22 Prozent des Unterrichts im Pflichtteil des Lehrplans auf I4 Prozent. Auf den Unterricht in Mathematik entfallen statt I5 Prozent nun I2 Prozent der Pflichtunterrichtszeit. Umgekehrt nimmt der Unterricht sowohl in den Naturwissenschaften als auch in Sozialkunde von 7 Prozent bzw. 6 Prozent des Pflichtcurriculums auf iI Prozent bzw. Io Prozent zu, während der Unterricht in Fremdsprachen (erste und weitere) von 5 Prozent auf I $_{3}$ Prozent steigt. Der Unterricht in Fremdsprachen macht im Sekundarbereich in Belgien (fläm.), Deutschland, Finnland (zusammen mit Naturwissenschaften), Frankreich, Island, Israel (zusammen mit Lesen, Schreiben und Literatur), Japan, Luxemburg, Norwegen, Polen (zusammen mit Lesen, Schreiben und Literatur) und Portugal (zusammen mit Naturwissenschaften) den größten Teil des Kernpflichtteils des Lehrplans im Sekundarbereich I aus (Tab. Dr.za und Dr.3b). 
Als Prozentsatz der insgesamt vorgesehenen Pflichtunterrichtszeit

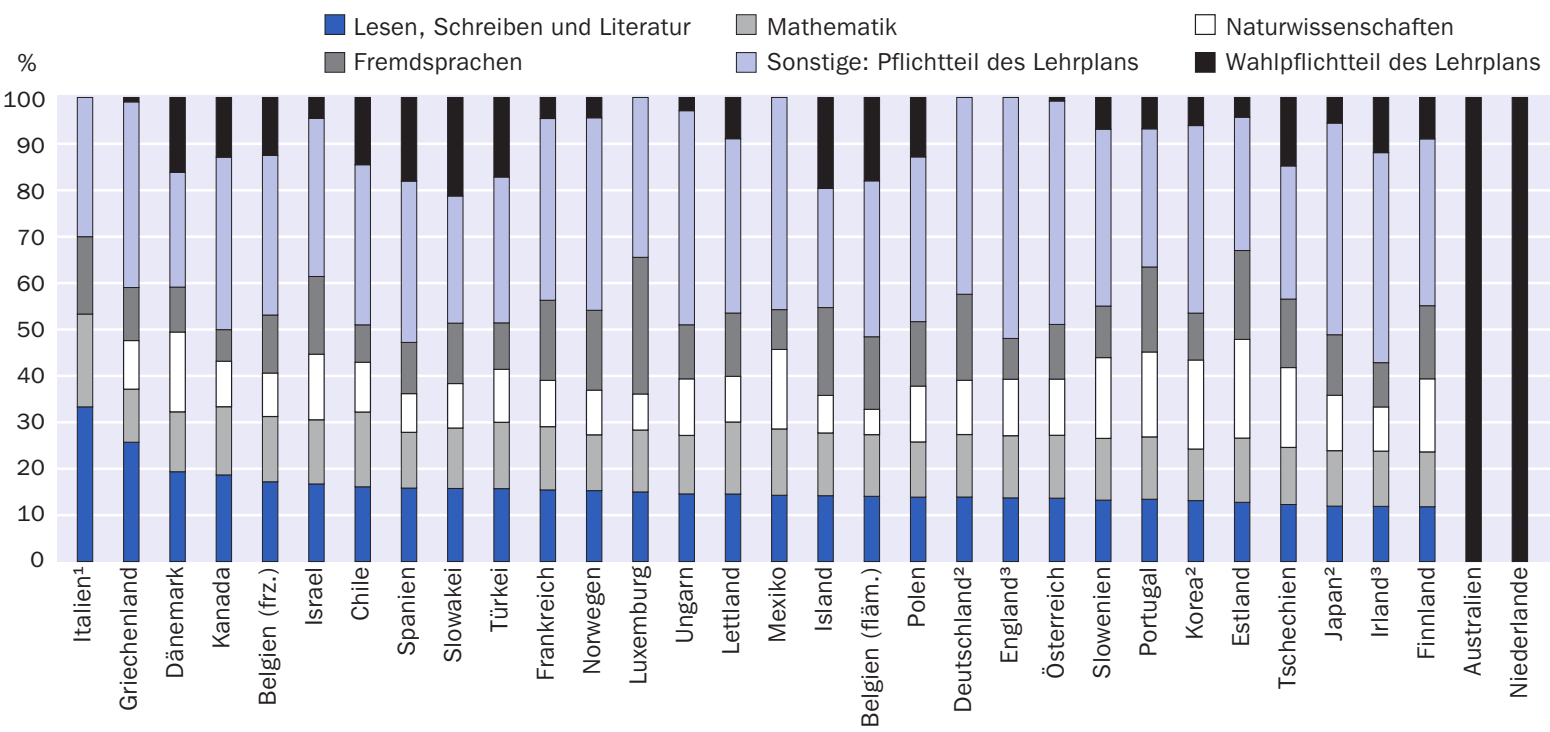

1. Naturwissenschaften in Mathematik enthalten. 2. Referenzjahr 2013. 3. Tatsächliche Unterrichtszeit.

Anordnung der Länder in absteigender Reihenfolge des Anteils der für Lesen, Schreiben und Literatur vorgesehenen Unterrichtszeitstunden.

Quelle: OECD. Tabelle D1.3b. Hinweise s. Anhang 3 unter www.oecd.org/edu/eag.htm. StatLink: http://dx.doi.org/10.1787/888933119663

Im Sekundarbereich I gibt es zwischen den einzelnen Ländern bei der Verteilung der Unterrichtszeit auf die einzelnen Fächer innerhalb des Pflichtlehrplans große Unterschiede. In Finnland, Irland, Japan und Tschechien beispielsweise machen Lesen, Schreiben und Literatur 12 Prozent der Pflichtunterrichtszeit aus, während dieser Anteil in Griechenland und Italien bei mehr als 25 Prozent liegt. In England, Griechenland und Kanada entfallen auf die erste Fremdsprache höchstens 7 Prozent der Pflichtunterrichtszeit, während es in Luxemburg I7 Prozent sind. Ferner ist in etwas weniger als der Hälfte der Länder mit verfügbaren Daten das Erlernen einer zweiten Fremdsprache für Schüler des Sekundarbereichs I Pflicht.

Im Primar- und Sekundarbereich I gibt es also große Unterschiede bei der Aufteilung der Unterrichtszeit auf die einzelnen Fächer, je älter die Schüler werden. Im Durchschnitt der OECD-Länder entfallen 25 Prozent der Unterrichtszeit für 7-Jährige auf den Unterricht in Lesen, Schreiben und Literatur, bei den II-Jährigen sind es I7 Prozent und bei den I5-Jährigen schließlich I2 Prozent. Im Gegensatz hierzu entfallen bei den 7-Jährigen im Durchschnitt 2 Prozent der Unterrichtszeit auf den Unterricht in Fremdsprachen, während bei den II-Jährigen 9 Prozent auf den Unterricht in der ersten Fremdsprache entfallen, 2 Prozent auf den Unterricht in anderen Fremdsprachen, und bei den I5-Jährigen dann ro Prozent und 4 Prozent (Tab. Di.5b, Di.5f und Di.5j im Internet).

\section{Flexibilität beim Lehrplan}

In den meisten Ländern werden die Zahl der Unterrichtszeitstunden der Schüler und der Lehrplan auf zentraler und bundesstaatlicher Ebene festgelegt bzw. werden dementsprechende Empfehlungen ausgesprochen. Jedoch können auch lokale Behörden, 
Schulen, Lehrkräfte und/oder Schüler in unterschiedlich starkem Ausmaß wählen, wie sie die Unterrichtszeit organisieren oder welche Fächer sie anbieten, unterrichten bzw. belegen möchten.

In etwa einem Drittel der Länder mit verfügbaren Daten kann die Unterrichtszeit flexibel über mehrere Klassenstufen verteilt werden, d.h., die Unterrichtszeit für ein bestimmtes Fach wird für eine bestimmte Anzahl von Klassenstufen definiert oder sogar für den gesamten Zeitraum der Schulpflicht, ohne Angaben dazu, wie viel Zeit für die einzelnen Klassenstufen vorzusehen ist. In diesen Fällen können die Schulen/lokalen Behörden frei entscheiden, wie viel Unterrichtszeit in den einzelnen Klassenstufen für dieses Fach vorzusehen ist (Tab. Dr.2).

Das Unterrichten von Pflichtfächern in einem flexiblen Unterrichtsplan findet sich häufiger im Primarbereich, wo der Anteil im Durchschnitt der OECD-Länder bei I4 Prozent der vorgesehenen Pflichtunterrichtszeit liegt. In diesem Fall werden die Pflichtfächer und die Gesamtunterrichtszeit angegeben, jedoch nicht die jedem Fach zuzuweisende Unterrichtszeit. Lokale Behörden, Schulen und/oder Lehrkräfte können frei entscheiden, wie viel Unterrichtszeit für jedes Pflichtfach vorzusehen ist. In Belgien (frz.) und Italien machen Pflichtfächer mit flexiblem Unterrichtsplan etwa 85 Prozent der Unterrichtszeit im Primarbereich aus und in Australien, England und den Niederlanden bis zu roo Prozent. Dies gilt auch für das erste Jahr des Primarbereichs in Dänemark. Im Sekundarbereich I ist auch in Australien und den Niederlanden eine vollständige Flexibilität bei der Aufteilung der Unterrichtsstunden für die Pflichtfächer gegeben. In Schottland werden sowohl im Primar- also auch im Sekundarbereich I einige Pflichtfächer festgelegt, es gibt jedoch keine Vorgaben zur Gesamtunterrichtszeit, die in der Verantwortung der lokalen Behörden liegt.

Flexibilität bei der Fächerwahl ist im Durchschnitt der OECD-Länder weniger häufig gegeben als Flexibilität bei der Aufteilung der Unterrichtszeit zwischen den Pflichtfächern. Durchschnittlich 4 Prozent der Pflichtunterrichtszeit werden im Primarbereich für von der Schule gewählte Fächer vorgesehen. Im Sekundarbereich I sind 4 Prozent der Pflichtunterrichtszeit für von der Schule und weitere 4 Prozent für von den Schülern gewählte Fächer vorgesehen. Jedoch ist in einigen Ländern ein erheblicher Teil der Pflichtunterrichtszeit für flexible Fächer vorgesehen. Zum Beispiel entfallen in Belgien (fläm., Primarbereich), Chile, Estland (Primarbereich), Irland (Sekundarbereich I), Polen und Tschechien mindestens Io Prozent der Pflichtunterrichtszeit auf von den Schulen gewählte Fächer; in der Slowakei gilt dies für bis zu 2I Prozent der Pflichtunterrichtszeit. In Island, Spanien und der Türkei sind im Sekundarbereich I mindestens I7 Prozent der Pflichtunterrichtszeit für von Schülern gewählte Fächer vorgesehen (Tab. Dr.3a und Dr.3b).

\section{Nichtpflichtunterrichtszeit}

Im Durchschnitt der OECD-Länder entfallen im Primarbereich 4 Prozent der Gesamtpflichtunterrichtszeit auf den Nichtpflichtteil des Lehrplans, im Sekundarbereich I sind es 2 Prozent. Trotzdem wird in einigen Ländern in beträchtlichem Umfang zusätzlich Unterricht angeboten, der nicht zwingend vorgeschrieben ist. Im Primarbereich belaufen sich in Griechenland zusätzliche Nichtpflichtstunden auf 36 Prozent und 23 Prozent in Portugal. Im Sekundarbereich I beläuft sich in Slowenien die Nicht- 
Kasten D1.1

\section{Aktivitäten außerhalb des Lehrplans}

Die vorgesehene Unterrichtszeit erfasst nur die Zeit, in der Schüler formalen Unterricht im Klassenzimmer erhalten. Zusätzlich zum formalen Unterricht können die Schüler außerhalb der Unterrichtszeit oder während der Schulferien an nicht im Lehrplan enthaltenen Aktivitäten auf dem Schulgelände teilnehmen.

In den OECD-und Partnerländern werden nicht im Lehrplan enthaltene Aktivitäten häufiger während des Schuljahres (vor und/oder nach dem Unterricht) als während der Schulferien angeboten. Auch wenn es den Schulen häufig frei steht, ob sie diese Aktivitäten anbieten möchten oder nicht, sind manchmal alle Schulen verpflichtet, nicht im Lehrplan enthaltene Aktivitäten anzubieten. Dies ist zum Beispiel in Frankreich, Polen und Slowenien im Primar- und/oder Sekundarbereich I der Fall. In Ungarn müssen die Schulen im Primar- und Sekundarbereich I nicht nur bis I6 Uhr extracurriculare Aktivitäten anbieten, die Teilnahme an ihnen ist auch für die Schüler Pflicht.

Diese Aktivitäten können von den Schulen organisiert werden, wie in Brasilien und Ungarn, von städtischen Behörden, wie in Israel, oder von ehrenamtlichen Schulmitarbeitern, wie in Irland. Häufig sind auch externe öffentliche Partner an der Organisation von nicht im Lehrplan enthaltenen Aktivitäten auf dem Schulgelände beteiligt, sowie private Träger, dies ist jedoch weniger häufig der Fall. In Portugal beispielsweise können diese Aktivitäten von Elternvertretungen und nicht staatlichen Organisationen organisiert werden. In I8 von 36 Ländern mit verfügbaren Daten können Lehrkräften für die Teilnahme an diesen nicht im Lehrplan enthaltenen Aktivitäten Zusatzvergütungen gezahlt werden (s. Indikator $\mathrm{D}_{3}$ ).

Zu den außerhalb der Unterrichtszeit durchgeführten Aktivitäten gehören unter anderem Betreuungsangebote (im Primarbereich), Nachhilfe oder Förderkurse, Aktivitäten in den Bereichen Sport und/oder Kunst und Kultur. In Ungarn und der Türkei umfassen diese Aktivitäten auch gemeinnützige Arbeit; in Spanien wird Unterricht in Fremdsprachen, IKT sowie Workshops zu Lesen und Schreiben angeboten.

pflichtunterrichtszeit auf I3 Prozent der Pflichtunterrichtszeit und in Frankreich auf ro Prozent (Tab. Dr.3a und Dr.3b).

\section{Definitionen}

Pflichtteil des Lehrplans bezieht sich auf den Umfang und die Aufteilung der Unterrichtsstunden, die von fast jeder öffentlichen Schule zu unterrichten und von fast jedem Schüler einer öffentlichen Bildungseinrichtung zu besuchen sind. Der Pflichtteil des Lehrplans kann flexibel gestaltet sein, da die lokalen Behörden, Schulen, Lehrkräfte und/oder Schüler in unterschiedlich starkem Ausmaß wählen können, welche Fächer sie in welchem zeitlichen Umfang in Bezug auf die Pflichtunterrichtszeit anbieten, unterrichten bzw. belegen möchten. 
Von den Schulen gewählte flexible Pflichtfächer bezieht sich auf die Gesamtzahl der von den zentralen Behörden angegebenen Pflichtunterrichtszeitstunden, die regionale und lokale Behörden, Schulen oder Lehrkräfte auf Fächer ihrer Wahl verteilen (oder Fächer, die sie aus einer von den zentralen Bildungsbehörden definierten Liste auswählen). Die Schule ist verpflichtet, eines dieser Fächer anzubieten, und der Besuch dieses Unterrichts ist für die Schüler Pflicht.

Von den Schülern gewählte Wahlpflichtfächer bezieht sich auf die Gesamtzahl der Unterrichtszeitstunden in einem oder mehreren Fächern, die die Schüler auszuwählen haben (aus einer Reihe von Fächern, die die Schule anbieten muss), um einen Teil der vorgesehenen Pflichtunterrichtszeit abzudecken.

Pflichtfächer mit flexiblem Unterrichtsplan bezieht sich auf die von den zentralen Behörden für eine bestimmte Fächergruppe festgelegte Gesamtzahl der Unterrichtszeitstunden, die regionale oder lokale Behörden, Schulen oder Lehrkräfte auf einzelne Fächer verteilen. Flexibilität besteht bei der Zeit, die mit einem Fach verbracht wird, jedoch nicht bei den zu unterrichtenden Fächern.

Flexible Aufteilung der Unterrichtszeit über mehrere Klassenstufen bezieht sich auf den Fall, dass der Lehrplan nur die Gesamtunterrichtszeit für ein bestimmtes Fach für eine bestimmte Anzahl von Klassenstufen oder sogar für den gesamten Zeitraum der Schulpflicht definiert, ohne Angaben dazu, wie viel Unterrichtszeit für jede Klassenstufe vorzusehen ist. In diesen Fällen können die Schulen/lokalen Behörden frei entscheiden, wie viel Unterrichtszeit sie für jede Klassenstufe einplanen.

Unterrichtszeit bezieht sich auf die Zahl der Zeitstunden pro Schuljahr, die von einer öffentlichen Schule für den Unterricht der Schüler in sämtlichen im Pflicht- und Nichtpflichtteil des Lehrplans enthaltenen Fächern auf dem Schulgelände bzw. als extracurriculare Aktivität außerhalb der regulären Schulzeit anzubieten sind, bei denen es sich um einen formalen Bestandteil des Pflichtteils des Lehrplans handelt. Nicht in der Unterrichtszeit enthalten sind Pausen zwischen den Unterrichtseinheiten oder andere Arten der Unterbrechung, freiwillige Aktivitäten außerhalb der regulären Schulzeit, für Hausaufgaben vorgesehene Zeit und individuelle Nachhilfe oder Selbststudium.

Die vorgesehene Unterrichtszeit bezieht sich auf die Anzahl an Zeitstunden pro Jahr, auf die Schüler an öffentlichen Bildungseinrichtungen im Pflicht- und Nichtpflichtteil des Lehrplans Anspruch haben. Der vorgesehene Lehrplan kann auf Vorschriften oder Standards der zentralen (oder obersten) Bildungsbehörden basieren oder auf regionaler Ebene als Empfehlung festgeschrieben sein.

Der Nichtpflichtteil des Lehrplans bezieht sich auf die Gesamtzahl an Unterrichtszeitstunden, auf die Schüler zusätzlich zu den Pflichtunterrichtszeitstunden Anspruch haben und die von fast jeder öffentlichen Bildungseinrichtung anzubieten sind. Die Fächer können von Schule zu Schule oder von Region zu Region variieren und werden beispielsweise als „Wahlfächer“ angeboten. Schüler sind nicht zur Belegung eines Wahlfaches verpflichtet, es wird jedoch von allen öffentlichen Bildungseinrichtungen erwartet, dass sie diese Möglichkeit anbieten. 


\section{Angewandte Methodik}

Die Daten zur Unterrichtszeit stammen aus der gemeinsamen Eurydice-OECD Datenerhebung zur Unterrichtszeit aus dem Jahr 2013 und beziehen sich auf die Unterrichtszeit während der Schulpflicht im Primar- und Sekundarbereich I und II (allgemeinbildend) mit Vollzeitunterricht für das Schuljahr 2013/20I4.

In früheren Ausgaben von Bildung auf einen Blick erfolgte die Erfassung der Daten zur Unterrichtszeit mithilfe einer anderen Erhebung, deren Umfang, Methodik und Definitionen von den in der gemeinsamen Eurydice-OECD-Datenerhebung zu Unterrichtszeiten verwendeten abweichen. Daher ist kein direkter Vergleich der Unterrichtszeit in dieser Ausgabe von Bildung auf einen Blick mit den in früheren Ausgaben präsentierten möglich.

Dieser Indikator erfasst die - offiziell vorgeschriebene - vorgesehene Unterrichtszeit als Kennzahl für die auf das formale Lernen zu verwendende Zeit im Klassenzimmer. Er zeigt aber nicht die tatsächliche Anzahl der Zeitstunden, die Schüler unterrichtet werden, und auch das Lernen außerhalb des Klassenzimmers wird nicht erfasst. In den einzelnen Ländern können Unterschiede zwischen der vorgeschriebenen Mindestanzahl an Unterrichtszeitstunden und der tatsächlichen Zahl an Stunden, die Schüler unterrichtet wurden, bestehen. Eine von Regioplan Beleidsonderzoek in den Niederlanden durchgeführte Untersuchung hat gezeigt, dass Faktoren wie Stundenpläne der Schulen, der Ausfall von Unterrichtsstunden und die Abwesenheit von Lehrern dazu führen können, dass Schulen die offiziell vorgesehene Mindestanzahl an Unterrichtsstunden nicht regelmäßig erreichen (s. Kasten DI.I in OECD, 2007).

Dieser Indikator zeigt außerdem, wie die Mindestunterrichtszeit auf verschiedene Bereiche des Lehrplans aufgeteilt wird. Er zeigt die vorgesehene Nettoanzahl an Unterrichtszeitstunden für die Klassenstufen der allgemeinen Schulpflicht mit Vollzeitunterricht. Die Daten sind zwar aufgrund der unterschiedlichen Lehrplanvorgaben schwer über die einzelnen Länder hinweg zu vergleichen, sie geben aber dennoch einen Hinweis darauf, wie viel formale Unterrichtszeit für die Schüler als notwendig erachtet wird, damit sie die angestrebten Bildungsziele erreichen.

Wenn die Aufteilung der Unterrichtszeit auf die einzelnen Klassenstufen flexibel ist, d. h., wenn die Unterrichtszeit für ein Fach für eine Reihe von Klassenstufen oder sogar nur für die gesamte Pflichtschulzeit festgelegt ist, ohne genaue Spezifizierung der Unterrichtszeit pro einzelne Klassenstufe, wurde für die Abschätzung der Unterrichtszeit pro Altersstufe oder Bildungsbereich die Gesamtzahl der Unterrichtszeitstunden durch die entsprechende Zahl an Klassenstufen geteilt.

Hinweise zu den für diesen Indikator in den einzelnen Ländern verwendeten Definitionen und der angewandten Methodik s. Anhang 3 unter www.oecd.org/edu/eag.htm. 
Hinweis zu den Daten aus Israel

Die statistischen Daten für Israel wurden von den zuständigen israelischen Stellen bereitgestellt, die für sie verantwortlich zeichnen. Die Verwendung dieser Daten durch die OECD erfolgt unbeschadet des völkerrechtlichen Status der Golanhöhen, von Ost-Jerusalem und der israelischen Siedlungen im Westjordanland.

\section{Weiterführende Informationen}

OECD (20II), Bildung auf einen Blick 2011 - OECD-Indikatoren, W. Bertelsmann Verlag, Bielefeld.

OECD (2007), Bildung auf einen Blick 2007 - OECD-Indikatoren, W. Bertelsmann Verlag, Bielefeld.

\section{Tabellen Indikator D1}

StatLink: http://dx.doi.org/10.1787/888933119530

Tabelle DI.I: Unterrichtszeit während der allgemeinen Schulpflicht (20I4)

Tabelle Di.2: Organisation der allgemeinen Schulpflicht (2014)

Tabelle Di.3a: Unterrichtszeit pro Fach im Primarbereich (2014)

Tabelle Dr.3b: Unterrichtszeit pro Fach im Sekundarbereich I (2014)

WEB Table Dr.4: Instruction time in compulsory general education, by age (Unterrichtszeit während der allgemeinen Schulpflicht, nach Alter) (2014)

WEB Table Di.5a: Instruction time per subject for 6-year-olds (Unterrichtszeit pro Fach für 6-Jährige) (2014)

WEB Table Di.5b: Instruction time per subject for 7-year-olds (Unterrichtszeit pro Fach für 7-Jährige) (2014)

WEB Table Di.5c: Instruction time per subject for 8-year-olds (Unterrichtszeit pro Fach für 8-Jährige) (2014)

WEB Table Di.5d: Instruction time per subject for 9-year-olds (Unterrichtszeit pro Fach für 9-Jährige) (2014)

WEB Table Di.5e: Instruction time per subject for Io-year-olds (Unterrichtszeit pro Fach für Io-Jährige) (20I4) 
WEB Table Dr.5f: Instruction time per subject for II-year-olds (Unterrichtszeit pro Fach für II-Jährige) (20I4)

WEB Table Di.5g: Instruction time per subject for I2-year-olds (Unterrichtszeit pro Fach für I2-Jährige) (2014)

WEB Table Di.5h: Instruction time per subject for I3-year-olds (Unterrichtszeit pro Fach für I3-Jährige) (2014)

WEB Table Dr.5i: Instruction time per subject for I4-year-olds (Unterrichtszeit pro Fach für I4-Jährige) (20I4)

WEB Table DI.5j: Instruction time per subject for 15 -year-olds (Unterrichtszeit pro Fach für I5-Jährige) (2014)

WEB Table Di.5k: Instruction time per subject for I6-year-olds (Unterrichtszeit pro Fach für I6-Jährige) (2014)

WEB Table Di.5l: Instruction time per subject for I7-year-olds (Unterrichtszeit pro Fach für I7-Jährige) (20I4) 
Unterrichtszeit während der allgemeinen Schulpflicht ${ }^{1}$ (2014)

Nach Bildungsbereich, in öffentlichen Bildungseinrichtungen

\begin{tabular}{|c|c|c|c|c|c|c|c|c|c|c|c|}
\hline & \multicolumn{7}{|c|}{ Primarbereich } & \multicolumn{4}{|c|}{ Sekundarbereich I } \\
\hline & \multirow{2}{*}{\begin{tabular}{|c|} 
Anzahl der \\
Klassen- \\
stufen \\
während \\
der Schul- \\
pflicht
\end{tabular}} & \multicolumn{3}{|c|}{$\begin{array}{l}\text { Durchschnittliche jährliche } \\
\text { Zeitstundenzahl }\end{array}$} & \multicolumn{3}{|c|}{ Zeitstunden insgesamt } & \multirow{2}{*}{$\begin{array}{l}\text { Anzahl der } \\
\text { Klassen- } \\
\text { stufen } \\
\text { während } \\
\text { der Schul- } \\
\text { pflicht }\end{array}$} & \multicolumn{3}{|c|}{$\begin{array}{c}\text { Durchschnittliche jährliche } \\
\text { Zeitstundenzahl }\end{array}$} \\
\hline & & $\begin{array}{c}\text { Pflicht- } \\
\text { unter- } \\
\text { richtszeit }\end{array}$ & $\begin{array}{c}\text { Nicht- } \\
\text { pflicht- } \\
\text { unter- } \\
\text { richtszeit }\end{array}$ & $\begin{array}{c}\text { Vor- } \\
\text { gesehene } \\
\text { Unter- } \\
\text { richtszeit }\end{array}$ & $\begin{array}{c}\text { Pflicht- } \\
\text { unter- } \\
\text { richtszeit }\end{array}$ & $\begin{array}{l}\text { Nicht- } \\
\text { pflichtun- } \\
\text { terrichts- } \\
\text { zeit }\end{array}$ & $\begin{array}{c}\text { Vor- } \\
\text { gesehene } \\
\text { Unter- } \\
\text { richtszeit }\end{array}$ & & $\begin{array}{c}\text { Pflicht- } \\
\text { unter- } \\
\text { richtszeit }\end{array}$ & $\begin{array}{c}\text { Nicht- } \\
\text { pflicht- } \\
\text { unter- } \\
\text { richtszeit }\end{array}$ & $\begin{array}{c}\text { Vorgesehene } \\
\text { Unterrichts- } \\
\text { zeit }\end{array}$ \\
\hline & (1) & (2) & (3) & $(4)=(2)+(3)$ & (5) & (6) & $(7)=(5)+(6)$ & (8) & (9) & (10) & $(11)=(9)+(10)$ \\
\hline \multicolumn{12}{|l|}{ OECD-Länder } \\
\hline Australien & 6 & 1010 & $\mathrm{~m}$ & $\mathrm{~m}$ & 6060 & $\mathrm{~m}$ & $\mathrm{~m}$ & 4 & 1015 & $\mathrm{~m}$ & $\mathrm{~m}$ \\
\hline Österreich & 4 & 705 & $\mathrm{~m}$ & $\mathrm{~m}$ & 2820 & $\mathrm{~m}$ & $\mathrm{~m}$ & 4 & 900 & $\mathrm{~m}$ & $\mathrm{~m}$ \\
\hline Belgien (fläm.)² & 6 & 821 & $\mathrm{n}$ & 821 & 4928 & $\mathrm{n}$ & 4928 & 2 & 928 & $n$ & 928 \\
\hline Belgien (frz.) $)^{2}$ & 6 & 849 & $\mathrm{~m}$ & m & 5096 & $\mathrm{~m}$ & $\mathrm{~m}$ & 2 & 971 & $\mathrm{~m}$ & $\mathrm{~m}$ \\
\hline Kanada & 6 & 919 & $n$ & 919 & 5515 & $\mathrm{n}$ & 5515 & 3 & 921 & 3 & 924 \\
\hline Chile & 6 & 1049 & a & 1049 & 6293 & a & 6293 & 2 & 1062 & a & 1062 \\
\hline Tschechien & 5 & 676 & $\mathrm{~m}$ & m & 3381 & $\mathrm{~m}$ & m & 4 & 874 & $\mathrm{~m}$ & m \\
\hline Dänemark & 7 & 754 & a & 754 & 5280 & a & 5280 & 3 & 930 & a & 930 \\
\hline England & 6 & 861 & $\mathrm{~m}$ & $\mathrm{~m}$ & 5168 & $\mathrm{~m}$ & m & 3 & 912 & $n$ & 912 \\
\hline Estland & 6 & 661 & $a$ & 661 & 3964 & $a$ & 3964 & 3 & 823 & $a$ & 823 \\
\hline Finnland $^{3}$ & 6 & 632 & 29 & 661 & 3794 & 171 & 3965 & 3 & 844 & 57 & 901 \\
\hline Frankreich & 5 & 864 & $\mathrm{n}$ & 864 & 4320 & $\mathrm{n}$ & 4320 & 4 & 991 & 99 & 1090 \\
\hline Deutschland ${ }^{4,5}$ & 4 & 683 & a & 683 & 2732 & a & 2732 & 5 & 866 & $a$ & 866 \\
\hline Griechenland & 6 & 783 & 282 & 1065 & 4699 & 1690 & 6390 & 3 & 785 & $\mathrm{n}$ & 785 \\
\hline Ungarn & 4 & 616 & $a$ & 616 & 2464 & a & 2464 & 4 & 710 & a & 710 \\
\hline Island & 7 & 729 & a & 729 & 5100 & a & 5100 & 3 & 839 & a & 839 \\
\hline Irland 6 & 6 & 915 & a & 915 & 5490 & a & 5490 & 3 & 935 & a & 935 \\
\hline Israel & 6 & 957 & $\mathrm{n}$ & 957 & 5741 & $\mathrm{n}$ & 5741 & 3 & 1004 & $\mathrm{n}$ & 1004 \\
\hline Italien & 5 & 891 & a & 891 & 4455 & a & 4455 & 3 & 990 & a & 990 \\
\hline$J^{J a p a n}{ }^{4}$ & 6 & 762 & $\mathrm{~m}$ & $\mathrm{~m}$ & 4573 & $\mathrm{~m}$ & $\mathrm{~m}$ & 3 & 895 & $\mathrm{~m}$ & $\mathrm{~m}$ \\
\hline Korea $^{4}$ & 6 & 648 & a & 648 & 3885 & a & 3885 & 3 & 842 & a & 842 \\
\hline Luxemburg & 6 & 924 & a & 924 & 5544 & a & 5544 & 3 & 845 & a & 845 \\
\hline Mexiko & 6 & 800 & a & 800 & 4800 & a & 4800 & 3 & 1167 & a & 1167 \\
\hline Niederlande ${ }^{7}$ & 6 & 940 & $\mathrm{~m}$ & $\mathrm{~m}$ & 5640 & $\mathrm{~m}$ & $\mathrm{~m}$ & 3 & 1000 & $\mathrm{~m}$ & $\mathrm{~m}$ \\
\hline Neuseeland & $\mathrm{m}$ & $\mathrm{m}$ & $\mathrm{m}$ & $\mathrm{m}$ & $\mathrm{m}$ & $\mathrm{m}$ & $\mathrm{m}$ & $\mathrm{m}$ & $\mathrm{m}$ & $\mathrm{m}$ & $\mathrm{m}$ \\
\hline Norwegen & 7 & 748 & a & 748 & 5234 & a & 5234 & 3 & 868 & a & 868 \\
\hline Polen & 6 & 635 & 58 & 693 & 3807 & 348 & 4155 & 3 & 810 & 64 & 874 \\
\hline Portugal & 6 & 806 & 189 & 995 & 4838 & 1133 & 5971 & 3 & 877 & 27 & 903 \\
\hline Schottland 8 & 7 & a & a & a & $a$ & a & $a$ & 3 & $a$ & $a$ & $a$ \\
\hline Slowakei & 4 & 680 & a & 680 & 2722 & a & 2722 & 5 & 828 & a & 828 \\
\hline Slowenien & 6 & 664 & 79 & 743 & 3986 & 473 & 4459 & 3 & 767 & 102 & 869 \\
\hline Spanien & 6 & 787 & a & 787 & 4725 & a & 4725 & 4 & 1061 & a & 1061 \\
\hline Schweden ${ }^{3}$ & 6 & 754 & $\mathrm{~m}$ & $\mathrm{~m}$ & 4523 & $\mathrm{~m}$ & m & 3 & 754 & $\mathrm{~m}$ & $\mathrm{~m}$ \\
\hline Schweiz & $\mathrm{m}$ & $\mathrm{m}$ & $\mathrm{m}$ & $\mathrm{m}$ & $\mathrm{m}$ & $\mathrm{m}$ & $\mathrm{m}$ & $\mathrm{m}$ & $\mathrm{m}$ & $\mathrm{m}$ & $\mathrm{m}$ \\
\hline Türkei & 4 & 720 & a & 720 & 2880 & a & 2880 & 4 & 840 & a & 840 \\
\hline Vereinigte Staaten ${ }^{9}$ & 6 & 967 & $\mathrm{~m}$ & $\mathrm{~m}$ & 5802 & $\mathrm{~m}$ & $\mathrm{~m}$ & 3 & 1011 & $\mathrm{~m}$ & $\mathrm{~m}$ \\
\hline OECD-Durchschnitt8 & 6 & 794 & 26 & $\sim$ & 4553 & 159 & $\sim$ & 3 & 905 & 14 & $\sim$ \\
\hline EU21-Durchschnitt ${ }^{8}$ & 6 & 768 & 40 & $\sim$ & 4290 & 238 & $\sim$ & 3 & 882 & 21 & $\sim$ \\
\hline \multicolumn{12}{|l|}{ Partnerländer } \\
\hline Argentinien & $\mathrm{m}$ & $\mathrm{m}$ & $\mathrm{m}$ & $\mathrm{m}$ & $\mathrm{m}$ & $\mathrm{m}$ & $\mathrm{m}$ & $\mathrm{m}$ & $\mathrm{m}$ & $\mathrm{m}$ & $\mathrm{m}$ \\
\hline Brasilien 8 & 5 & $\mathrm{~m}$ & $\mathrm{~m}$ & $\mathrm{~m}$ & $\mathrm{~m}$ & $\mathrm{~m}$ & $\mathrm{~m}$ & 4 & $\mathrm{~m}$ & $\mathrm{~m}$ & $\mathrm{~m}$ \\
\hline China $^{9}$ & 6 & 612 & $\mathrm{~m}$ & $\mathrm{~m}$ & 3669 & $\mathrm{~m}$ & $m$ & 3 & 816 & $\mathrm{~m}$ & $\mathrm{~m}$ \\
\hline Kolumbien ${ }^{9}$ & 5 & 1000 & $\mathrm{~m}$ & $\mathrm{~m}$ & 5000 & $\mathrm{~m}$ & $\mathrm{~m}$ & 4 & 1200 & $\mathrm{~m}$ & $\mathrm{~m}$ \\
\hline Indien & $\mathrm{m}$ & $\mathrm{m}$ & $\mathrm{m}$ & $\mathrm{m}$ & $\mathrm{m}$ & $\mathrm{m}$ & $\mathrm{m}$ & $\mathrm{m}$ & $\mathrm{m}$ & $\mathrm{m}$ & $\mathrm{m}$ \\
\hline Indonesien & $\mathrm{m}$ & $\mathrm{m}$ & $\mathrm{m}$ & $\mathrm{m}$ & $\mathrm{m}$ & $\mathrm{m}$ & $\mathrm{m}$ & $\mathrm{m}$ & $\mathrm{m}$ & $\mathrm{m}$ & $\mathrm{m}$ \\
\hline Lettland & 6 & 592 & $\mathrm{~m}$ & $\mathrm{~m}$ & 3551 & $\mathrm{~m}$ & $\mathrm{~m}$ & 3 & 794 & $\mathrm{~m}$ & $\mathrm{~m}$ \\
\hline Russische Föd. & $\mathrm{m}$ & $\mathrm{m}$ & $\mathrm{m}$ & $\mathrm{m}$ & $\mathrm{m}$ & $\mathrm{m}$ & $\mathrm{m}$ & $\mathrm{m}$ & $\mathrm{m}$ & $\mathrm{m}$ & $\mathrm{m}$ \\
\hline Saudi-Arabien & $\mathrm{m}$ & $\mathrm{m}$ & $\mathrm{m}$ & $\mathrm{m}$ & $\mathrm{m}$ & $\mathrm{m}$ & $\mathrm{m}$ & $\mathrm{m}$ & $\mathrm{m}$ & $\mathrm{m}$ & $\mathrm{m}$ \\
\hline Südafrika & $\mathrm{m}$ & $\mathrm{m}$ & $\mathrm{m}$ & $\mathrm{m}$ & $\mathrm{m}$ & $\mathrm{m}$ & $\mathrm{m}$ & $\mathrm{m}$ & $\mathrm{m}$ & $\mathrm{m}$ & $\mathrm{m}$ \\
\hline G20-Durchschnitt ${ }^{8}$ & 6 & 811 & m & m & 4488 & m & m & 3 & 939 & m & m \\
\hline
\end{tabular}

Anmerkung: Die Spalten mit Daten zur Unterrichtszeit im Pflichtteil des Sekundarbereichs II, d.h. die Spalten (19) bis (25), sind im Internet verfügbar (s. StatLink unten).

1. Bezieht sich auf Vollzeit-Schulpflicht, ohne Elementarbereich, auch wenn dieser der Schulpflicht unterliegt. 2. Schüler unterliegen bis zum 15. oder 16. Lebensjahr der Vollzeit-Schulpflicht. Für Schüler im allgemeinbildenden Bereich dauert diese bis zum 18. Lebensjahr. 3. Geschätzte Anzahl der Zeitstunden nach Bildungsbereich, da die Unterrichtszeit über mehrere Klassenstufen hinweg flexibel aufgeteilt werden kann. 4. Referenzjahr 2013. 5. Ohne letztes Jahr der Schulpflicht, das entweder Sekundarbereich I oder Sekundarbereich II zugeordnet werden kann. 6. Tatsächliche Unterrichtszeit für Sekundarbereich I und Sekundarbereich II. 7. Die Anzahl der Klassenstufen im Sekundarbereich I beträgt je nach Ausbildungszug 3 oder 4 Jahre. Das vierte Jahr des berufsvorbereitenden Sekundarunterrichts (VMBO) wurde bei der Berechnung nicht berücksichtigt. 8. Brasilien und Schottland sind in den Durchschnittswerten nicht enthalten. 9. Referenzjahr 2012.

Quelle: OECD. Argentinien, China, Indien, Indonesien, Kolumbien, Saudi-Arabien, Südafrika: Statistikinstitut der UNESCO. Lettland: Eurydice. Hinweise s. Anhang 3 unter www.oecd.org/edu/eag.htm. StatLink: http://dx.doi.org/10.1787/888933119549 Erläuterung der Kennzeichnung fehlender Daten s. Hinweise für den Leser. 
Tabelle D1.1 (Forts.)

Unterrichtszeit während der allgemeinen Schulpflicht ${ }^{1}$ (2014)

Nach Bildungsbereich, in öffentlichen Bildungseinrichtungen

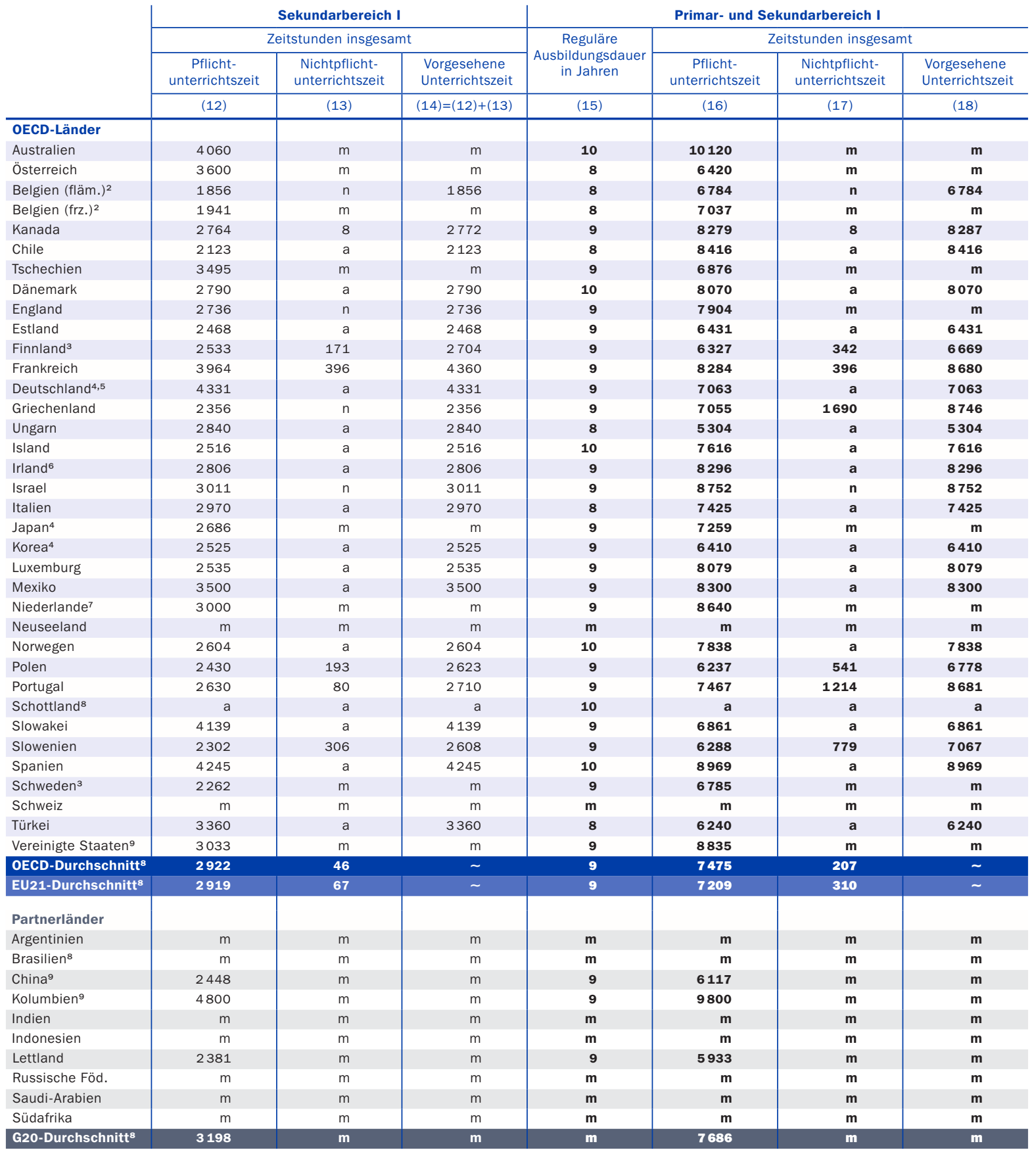

Anmerkung: Die Spalten mit Daten zur Unterrichtszeit im Pflichtteil des Sekundarbereichs II, d.h. die Spalten (19) bis (25), sind im Internet verfügbar (s. StatLink unten).

1. Bezieht sich auf Vollzeit-Schulpflicht, ohne Elementarbereich, auch wenn dieser der Schulpflicht unterliegt. 2. Schüler unterliegen bis zum 15. oder 16. Lebensjahr der Vollzeit-Schulpflicht. Für Schüler im allgemeinbildenden Bereich dauert diese bis zum 18. Lebensjahr. 3. Geschätzte Anzahl der Zeitstunden nach Bildungsbereich, da die Unterrichtszeit über mehrere Klassenstufen hinweg flexibel aufgeteilt werden kann. 4. Referenzjahr 2013. 5. Ohne letztes Jahr der Schulpflicht, das entweder Sekundarbereich I oder Sekundarbereich II zugeordnet werden kann. 6. Tatsächliche Unterrichtszeit für Sekundarbereich I und Sekundarbereich II. 7. Die Anzahl der Klassenstufen im Sekundarbereich I beträgt je nach Ausbildungszug 3 oder 4 Jahre. Das vierte Jahr des berufsvorbereitenden Sekundarunterrichts (VMBO) wurde bei der Berechnung nicht berücksichtigt. 8. Brasilien und Schottland sind in den Durchschnittswerten nicht enthalten. 9. Referenzjahr 2012.

Quelle: OECD. Argentinien, China, Indien, Indonesien, Kolumbien, Saudi-Arabien, Südafrika: Statistikinstitut der UNESCO. Lettland: Eurydice. Hinweise s. Anhang 3 unter www.oecd.org/edu/eag.htm. StatLink: http://dx.doi.org/10.1787/888933119549 Erläuterung der Kennzeichnung fehlender Daten s. Hinweise für den Leser. 
Organisation der allgemeinen Schulpflicht ${ }^{1}$ (2014)

Nach Bildungsbereich, in öffentlichen Bildungseinrichtungen

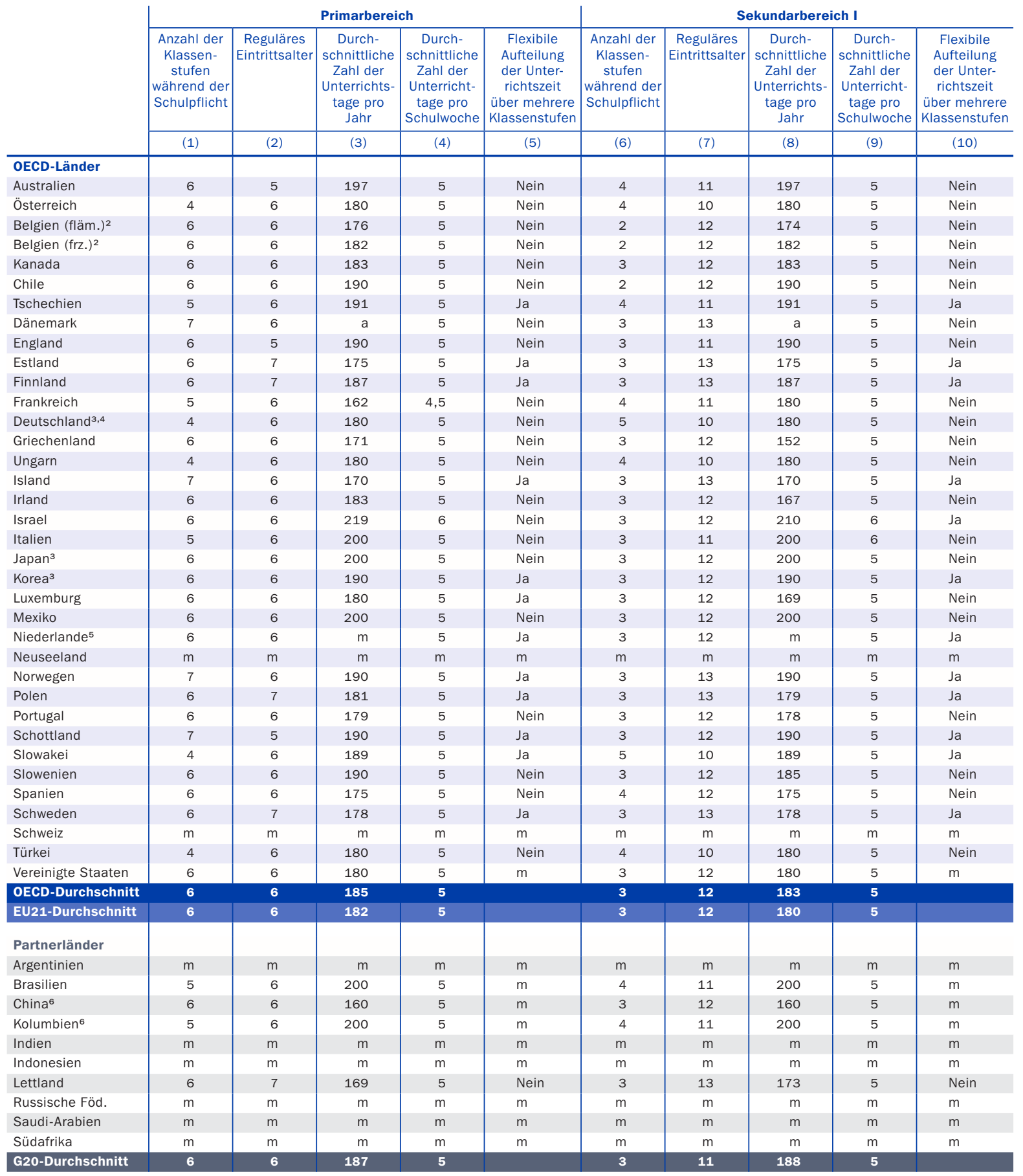

Anmerkung: Die Spalten mit Daten zur Unterrichtszeit im Pflichtteil des Sekundarbereichs II, d. h. die Spalten (11) bis (15), sind im Internet verfügbar (s. StatLink unten).

1. Bezieht sich auf Vollzeit-Schulpflicht, ohne Elementarbereich, auch wenn dieser der Schulpflicht unterliegt. 2. Schüler unterliegen bis zum 15. oder 16. Lebensjahr der Vollzeit-Schulpflicht. Für Schüler im allgemeinbildenden Bereich dauert diese bis zum 18. Lebensjahr. 3. Referenzjahr 2013.

4. Ohne letztes Jahr der Schulpflicht, das entweder Sekundarbereich I oder Sekundarbereich II zugeordnet werden kann. 5. Die Anzahl der Klassenstufen im Sekundarbereich I beträgt je nach Ausbildungszug 3 oder 4 Jahre. Das vierte Jahr des berufsvorbereitenden Sekundarunterrichts (VMBO) wurde bei der Berechnung nicht berücksichtigt. 6. Referenzjahr 2012.

Quelle: OECD. Argentinien, China, Indien, Indonesien, Kolumbien, Saudi-Arabien, Südafrika: Statistikinstitut der UNESCO. Lettland: Eurydice. Hinweise s. Anhang 3 unter www.oecd.org/edu/eag.htm. StatLink: http://dx.doi.org/10.1787/888933119568 Erläuterung der Kennzeichnung fehlender Daten s. Hinweise für den Leser. 
Unterrichtszeit pro Fach im Primarbereich (2014)

Als Prozentsatz der insgesamt vorgesehenen Pflichtunterrichtszeit

\begin{tabular}{|c|c|c|c|c|c|c|c|c|c|c|c|c|c|c|c|c|c|c|}
\hline & 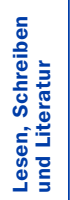 & 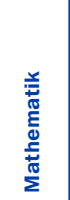 & 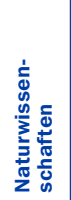 & $\begin{array}{l}\frac{0}{0} \\
\text { E } \\
\frac{y}{\bar{N}} \\
\frac{\pi}{N} \\
\text { D }\end{array}$ & 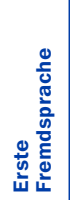 & 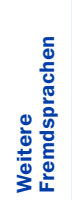 & 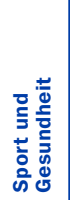 & 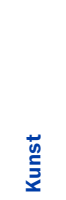 & 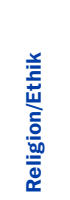 & 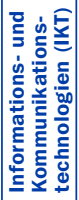 & $\begin{array}{l}\text { 昙 } \\
\text { d } \\
\text { હ }\end{array}$ & 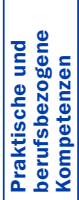 & 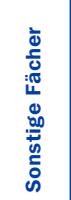 & 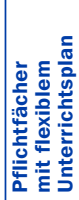 & 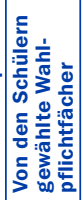 & 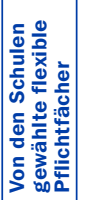 & 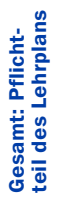 & 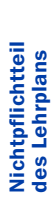 \\
\hline & (1) & (2) & (3) & (4) & (5) & (6) & (7) & (8) & (9) & (10) & (11) & (12) & (13) & (14) & (15) & (16) & (17) & (18) \\
\hline \multicolumn{19}{|l|}{ OECD-Länder } \\
\hline Australien & $x(14)$ & $x(14)$ & $x(14)$ & $x(14)$ & $x(14)$ & $x(14)$ & $x(14)$ & $x(14)$ & $x(14)$ & $x(14)$ & $x(14)$ & $x(14)$ & $x(14)$ & 100 & $x(14)$ & $x(14)$ & 100 & $\mathrm{~m}$ \\
\hline Österreich & 30 & 17 & 13 & $x(3)$ & 2 & $\mathrm{n}$ & 11 & 9 & 9 & $\mathrm{n}$ & $x(3)$ & 6 & 4 & a & $\mathrm{n}$ & a & 100 & $\mathrm{~m}$ \\
\hline Belgien (fläm.) ${ }^{1}$ & 23 & 20 & 18 & $x(3)$ & 4 & $n$ & 7 & 10 & 7 & $\mathrm{n}$ & $\mathrm{n}$ & $\mathrm{n}$ & $\mathrm{n}$ & $\mathrm{n}$ & $n$ & 12 & 100 & $n$ \\
\hline Belgien (frz.) $)^{1}$ & $x(14)$ & $x(14)$ & $x(14)$ & $x(14)$ & 2 & $\mathrm{n}$ & 7 & $x(14)$ & 7 & $\mathrm{n}$ & $x(14)$ & a & $\mathrm{n}$ & 83 & $\mathrm{n}$ & $\mathrm{n}$ & 100 & $\mathrm{~m}$ \\
\hline Kanada & 27 & 18 & 8 & 7 & 2 & $n$ & 10 & 7 & $n$ & $\mathrm{n}$ & $\mathrm{n}$ & $\mathrm{n}$ & 1 & 16 & $n$ & 3 & 100 & $n$ \\
\hline Chile & 20 & 16 & 9 & 9 & 3 & $x(16)$ & 9 & 10 & 5 & $x(16)$ & 3 & $x(16)$ & 2 & $a$ & $\mathrm{n}$ & 15 & 100 & a \\
\hline Tschechien & 30 & 17 & 10 & $x(3)$ & 8 & $\mathrm{n}$ & 8 & 10 & $x(13)$ & 1 & 4 & $x(11)$ & $x(16)$ & a & $x(16)$ & 12 & 100 & $\mathrm{~m}$ \\
\hline Dänemark & 27 & 15 & 6 & 4 & 6 & $\mathrm{n}$ & 8 & 10 & 5 & $\mathrm{n}$ & $\mathrm{n}$ & 6 & 3 & 11 & $n$ & $\mathrm{n}$ & 100 & a \\
\hline England & $x(14)$ & $x(14)$ & $x(14)$ & $x(14)$ & $\mathrm{n}$ & a & $x(14)$ & $x(14)$ & $x(14)$ & $x(14)$ & $x(14)$ & $\mathrm{n}$ & $\mathrm{n}$ & 100 & $n$ & a & 100 & $\mathrm{~m}$ \\
\hline Estland & 23 & 15 & 7 & 5 & 8 & 2 & 11 & 15 & $x(16)$ & $x(16)$ & 3 & a & a & a & a & 12 & 100 & a \\
\hline Finnland & 24 & 16 & 11 & 2 & 6 & $\mathrm{n}$ & 10 & 13 & 5 & a & a & a & $\mathrm{n}$ & 6 & a & 7 & 100 & 5 \\
\hline Frankreich & 37 & 21 & 9 & 5 & 6 & $\mathrm{n}$ & 13 & 9 & $x(17)$ & $x(3)$ & $x(3)$ & $\mathrm{n}$ & $\mathrm{n}$ & $\mathrm{n}$ & $\mathrm{n}$ & $\mathrm{n}$ & 100 & $\mathrm{n}$ \\
\hline Deutschland ${ }^{2}$ & 20 & 16 & 3 & 4 & 6 & $\mathrm{n}$ & 12 & 15 & 8 & $x(11)$ & 1 & $\mathrm{n}$ & 16 & a & $\mathrm{n}$ & a & 100 & a \\
\hline Griechenland & 25 & 13 & 10 & 7 & 8 & 2 & 8 & 10 & 4 & 3 & $\mathrm{n}$ & $\mathrm{n}$ & a & $\mathrm{a}$ & a & 8 & 100 & 36 \\
\hline Ungarn & 33 & 16 & 6 & $n$ & 3 & $\mathrm{n}$ & 18 & 14 & 1 & 1 & 4 & a & $\mathrm{n}$ & a & a & 3 & 100 & a \\
\hline Island & 20 & 16 & 8 & 13 & 6 & $x(5)$ & 9 & 19 & $x(4)$ & 3 & a & $x(8)$ & $x(15)$ & $\mathrm{n}$ & 5 & a & 100 & a \\
\hline Irland $^{3}$ & 20 & 17 & 4 & 8 & $\mathrm{n}$ & a & 4 & 12 & 10 & $x(17)$ & $x(3)$ & $\mathrm{n}$ & 25 & a & a & $\mathrm{m}$ & 100 & a \\
\hline Israel & 23 & 18 & 9 & 8 & 6 & $\mathrm{n}$ & 6 & 5 & 11 & $\mathrm{n}$ & $x(3)$ & 4 & 2 & $\mathrm{n}$ & $\mathrm{n}$ & 7 & 100 & $\mathrm{n}$ \\
\hline Italien & $x(14)$ & $x(14)$ & $x(14)$ & $x(14)$ & 9 & $n$ & $x(14)$ & $x(14)$ & 7 & $n$ & $x(14)$ & a & $\mathrm{n}$ & 84 & a & a & 100 & a \\
\hline$J^{J a p a n}{ }^{2}$ & 24 & 17 & 8 & 8 & 1 & a & 10 & 12 & 3 & a & $\mathrm{n}$ & a & 10 & 7 & $\mathrm{n}$ & $\mathrm{m}$ & 100 & $\mathrm{~m}$ \\
\hline Korea $^{2}$ & 22 & 14 & 9 & 9 & 6 & $\mathrm{n}$ & 7 & 9 & $x(4)$ & $x(13)$ & $x(12)$ & $x(3)$ & 24 & $n$ & $n$ & $\mathrm{n}$ & 100 & a \\
\hline Luxemburg & 26 & 19 & 7 & 2 & $x(1)$ & 18 & 10 & 11 & 7 & a & a & a & a & a & a & a & 100 & a \\
\hline Mexiko & 35 & 27 & 13 & 10 & $\mathrm{~m}$ & a & 5 & 5 & 5 & $\mathrm{n}$ & $\mathrm{n}$ & $\mathrm{n}$ & $\mathrm{n}$ & a & a & a & 100 & a \\
\hline Niederlande & $x(14)$ & $x(14)$ & $x(14)$ & $x(14)$ & $x(14)$ & $\mathrm{n}$ & $x(14)$ & $x(14)$ & $x(14)$ & $x(14)$ & $x(14)$ & $x(14)$ & a & 100 & a & a & 100 & $\mathrm{~m}$ \\
\hline Neuseeland & $\mathrm{m}$ & $\mathrm{m}$ & $\mathrm{m}$ & $\mathrm{m}$ & $\mathrm{m}$ & $\mathrm{m}$ & $\mathrm{m}$ & $\mathrm{m}$ & $\mathrm{m}$ & $\mathrm{m}$ & $\mathrm{m}$ & $\mathrm{m}$ & $\mathrm{m}$ & $\mathrm{m}$ & $\mathrm{m}$ & $\mathrm{m}$ & $\mathbf{m}$ & $\mathrm{m}$ \\
\hline Norwegen & 26 & 17 & 6 & 7 & 7 & $\mathrm{n}$ & 11 & 15 & 8 & a & a & 2 & a & a & $\mathrm{n}$ & 1 & 100 & a \\
\hline Polen ${ }^{4}$ & 18 & 14 & 10 & 5 & 10 & $\mathrm{n}$ & 14 & 7 & $x(18)$ & 3 & 3 & a & 3 & $\mathrm{n}$ & a & 13 & 100 & 9 \\
\hline Portugal & 27 & 27 & 7 & 8 & 3 & $\mathrm{n}$ & 8 & 9 & $x(18)$ & $x(18)$ & 2 & a & 4 & a & $\mathrm{n}$ & 5 & 100 & 23 \\
\hline Schottland ${ }^{5}$ & $x(14)$ & $x(14)$ & $x(14)$ & $x(14)$ & $x(14)$ & $\mathrm{n}$ & $x(14)$ & $x(14)$ & $x(14)$ & $x(14)$ & $x(14)$ & $\mathrm{n}$ & $\mathrm{n}$ & a & a & a & $\mathbf{a}$ & a \\
\hline Slowakei & 27 & 15 & 3 & 3 & 6 & $x(16)$ & 8 & 8 & 4 & 3 & $\mathrm{n}$ & 1 & $x(16)$ & a & $x(16)$ & 21 & 100 & a \\
\hline Slowenien & 23 & 17 & 8 & 7 & 6 & $\mathrm{n}$ & 15 & 16 & $x(4)$ & $x(17)$ & 6 & 2 & 1 & a & $n$ & a & 100 & 12 \\
\hline Spanien & 24 & 16 & 7 & 8 & 10 & $\mathrm{n}$ & 9 & 9 & $x(15)$ & $\mathrm{n}$ & $\mathrm{n}$ & a & $\mathrm{n}$ & a & 7 & 9 & 100 & a \\
\hline Schweden & $\mathrm{m}$ & $\mathrm{m}$ & $\mathrm{m}$ & $\mathrm{m}$ & $\mathrm{m}$ & $\mathrm{m}$ & $\mathrm{m}$ & $\mathrm{m}$ & $\mathrm{m}$ & $\mathrm{m}$ & $\mathrm{m}$ & $\mathrm{m}$ & $\mathrm{m}$ & $\mathrm{m}$ & $\mathrm{m}$ & $\mathrm{m}$ & m & $\mathrm{m}$ \\
\hline Schweiz & $\mathrm{m}$ & $\mathrm{m}$ & $\mathrm{m}$ & $\mathrm{m}$ & $\mathrm{m}$ & $\mathrm{m}$ & $\mathrm{m}$ & $\mathrm{m}$ & $\mathrm{m}$ & $\mathrm{m}$ & $\mathrm{m}$ & $\mathrm{m}$ & $\mathrm{m}$ & $\mathrm{m}$ & $\mathrm{m}$ & $\mathrm{m}$ & $\mathbf{m}$ & $\mathrm{m}$ \\
\hline Türkei & 30 & 17 & 5 & 13 & 5 & $\mathrm{n}$ & 14 & 7 & 2 & $\mathrm{n}$ & $\mathrm{n}$ & 1 & 7 & a & $n$ & a & 100 & a \\
\hline Vereinigte Staaten & $\mathrm{m}$ & $\mathrm{m}$ & $\mathrm{m}$ & $\mathrm{m}$ & $\mathrm{m}$ & $\mathrm{m}$ & $\mathrm{m}$ & $\mathrm{m}$ & $\mathrm{m}$ & $\mathrm{m}$ & $\mathrm{m}$ & $\mathrm{m}$ & $\mathrm{m}$ & $\mathrm{m}$ & $\mathrm{m}$ & $\mathrm{m}$ & m & $\mathrm{m}$ \\
\hline OECD-Durchschnitt ${ }^{5}$ & 22 & 15 & 7 & 6 & 4 & 1 & 8 & 9 & 5 & 1 & 1 & 1 & 3 & 14 & $\mathbf{n}$ & 4 & 100 & 4 \\
\hline EU21-Durchschnitt ${ }^{5}$ & 21 & 14 & 7 & 4 & 5 & 1 & 8 & 9 & 5 & 1 & 1 & 1 & 3 & 15 & $\mathbf{n}$ & 4 & 100 & 5 \\
\hline
\end{tabular}

\begin{tabular}{|c|c|c|c|c|c|c|c|c|c|c|c|c|c|c|c|c|c|c|}
\hline Partnerländer & & & & & & & & & & & & & & & & & & \\
\hline Argentinien & $\mathrm{m}$ & $\mathrm{m}$ & $\mathrm{m}$ & $\mathrm{m}$ & $\mathrm{m}$ & $m$ & $\mathrm{~m}$ & $\mathrm{~m}$ & $\mathrm{~m}$ & $\mathrm{~m}$ & $\mathrm{~m}$ & $\mathrm{~m}$ & $\mathrm{~m}$ & $\mathrm{~m}$ & $\mathrm{~m}$ & $\mathrm{~m}$ & m & $\mathrm{m}$ \\
\hline Brasilien & $\mathrm{m}$ & $\mathrm{m}$ & $\mathrm{m}$ & $\mathrm{m}$ & $\mathrm{m}$ & $\mathrm{n}$ & $\mathrm{m}$ & $\mathrm{m}$ & $\mathrm{m}$ & $\mathrm{m}$ & a & a & $\mathrm{m}$ & $\mathrm{m}$ & $\mathrm{m}$ & $\mathrm{m}$ & m & $\mathrm{m}$ \\
\hline China & $\mathrm{m}$ & $\mathrm{m}$ & $\mathrm{m}$ & $\mathrm{m}$ & $\mathrm{m}$ & $\mathrm{m}$ & $\mathrm{m}$ & $\mathrm{m}$ & $\mathrm{m}$ & $\mathrm{m}$ & $\mathrm{m}$ & $\mathrm{m}$ & $\mathrm{m}$ & $\mathrm{m}$ & $\mathrm{m}$ & $\mathrm{m}$ & m & $\mathrm{m}$ \\
\hline Kolumbien & $\mathrm{m}$ & $\mathrm{m}$ & $\mathrm{m}$ & $\mathrm{m}$ & $\mathrm{m}$ & $\mathrm{m}$ & $\mathrm{m}$ & $\mathrm{m}$ & $\mathrm{m}$ & $\mathrm{m}$ & $\mathrm{m}$ & $\mathrm{m}$ & $\mathrm{m}$ & $\mathrm{m}$ & $\mathrm{m}$ & $\mathrm{m}$ & m & $\mathrm{m}$ \\
\hline Indien & $\mathrm{m}$ & $\mathrm{m}$ & $\mathrm{m}$ & $\mathrm{m}$ & $\mathrm{m}$ & $\mathrm{m}$ & $\mathrm{m}$ & $\mathrm{m}$ & $\mathrm{m}$ & $\mathrm{m}$ & $\mathrm{m}$ & $\mathrm{m}$ & $\mathrm{m}$ & $\mathrm{m}$ & $\mathrm{m}$ & $\mathrm{m}$ & m & $\mathrm{m}$ \\
\hline Indonesien & $\mathrm{m}$ & $\mathrm{m}$ & $\mathrm{m}$ & $\mathrm{m}$ & $\mathrm{m}$ & $\mathrm{m}$ & $\mathrm{m}$ & $\mathrm{m}$ & $\mathrm{m}$ & $\mathrm{m}$ & $\mathrm{m}$ & $\mathrm{m}$ & $\mathrm{m}$ & $\mathrm{m}$ & $\mathrm{m}$ & $\mathrm{m}$ & m & $\mathrm{m}$ \\
\hline Lettland & 21 & 17 & 5 & 6 & 7 & 1 & 8 & 12 & 2 & 1 & a & 4 & 11 & a & a & 6 & 100 & $\mathrm{~m}$ \\
\hline Russische Föd. & $\mathrm{m}$ & $\mathrm{m}$ & $\mathrm{m}$ & $\mathrm{m}$ & $\mathrm{m}$ & $\mathrm{m}$ & $\mathrm{m}$ & $\mathrm{m}$ & $\mathrm{m}$ & $\mathrm{m}$ & $\mathrm{m}$ & $\mathrm{m}$ & $\mathrm{m}$ & $\mathrm{m}$ & $\mathrm{m}$ & $\mathrm{m}$ & m & $\mathrm{m}$ \\
\hline Saudi-Arabien & $\mathrm{m}$ & $\mathrm{m}$ & $\mathrm{m}$ & $\mathrm{m}$ & $\mathrm{m}$ & $\mathrm{m}$ & $\mathrm{m}$ & $\mathrm{m}$ & $\mathrm{m}$ & $\mathrm{m}$ & $\mathrm{m}$ & $\mathrm{m}$ & $\mathrm{m}$ & $\mathrm{m}$ & $\mathrm{m}$ & $\mathrm{m}$ & m & $\mathrm{m}$ \\
\hline Südafrika & $\mathrm{m}$ & $\mathrm{m}$ & $\mathrm{m}$ & $\mathrm{m}$ & $\mathrm{m}$ & $\mathrm{m}$ & $\mathrm{m}$ & $\mathrm{m}$ & $\mathrm{m}$ & $\mathrm{m}$ & $\mathrm{m}$ & $\mathrm{m}$ & $\mathrm{m}$ & $\mathrm{m}$ & $\mathrm{m}$ & $\mathrm{m}$ & m & $\mathrm{m}$ \\
\hline G20-Durchschnitt & m & m & m & m & m & m & m & m & m & m & m & m & m & m & m & m & m & m \\
\hline
\end{tabular}

Anmerkung: Informationen zur Unterrichtszeit pro Fach für die einzelnen Altersjahrgänge sind in Tab. D1.5a bis D1.5I im Internet verfügbar (s. StatLink unten) Die Durchschnitte wurden auf 100 Prozent angepasst und entsprechen nicht genau dem Durchschnitt jeder einzelnen Spalte.

1. Schüler unterliegen bis zum 15. oder 16. Lebensjahr der Vollzeit-Schulpflicht. Für Schüler im allgemeinbildenden Bereich dauert diese bis zum 18. Lebensjahr. 2. Referenzjahr 2013. 3. Die zweite Sprache der Schule (entweder Irisch oder Englisch) ist in „Sonstige Fächer“ enthalten. 4. Ohne die ersten 3 Jahre des Primarbereichs, in denen ein großer Teil der den Pflichtfächern zugeordneten Zeit flexibel ist. 5. Schottland ist in den Durchschnittswerten nicht enthalten. Quelle: OECD. Argentinien, China, Indien, Indonesien, Kolumbien, Saudi-Arabien, Südafrika: Statistikinstitut der UNESCO. Lettland: Eurydice. Hinweise s. Anhang 3 unter www.oecd.org/edu/eag.htm. StatLink: http://dx.doi.org/10.1787/888933119587 Erläuterung der Kennzeichnung fehlender Daten s. Hinweise für den Leser. 
Unterrichtszeit pro Fach im Sekundarbereich I (2014)

Als Prozentsatz der insgesamt vorgesehenen Pflichtunterrichtszeit

\begin{tabular}{|c|c|c|c|c|c|c|c|c|c|c|c|c|c|c|c|c|c|c|}
\hline & 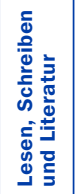 & 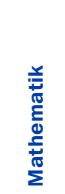 & 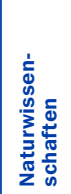 & 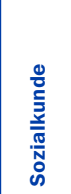 & 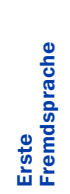 & 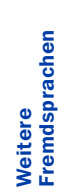 & 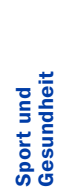 & 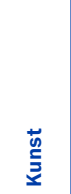 & 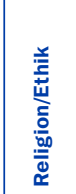 & 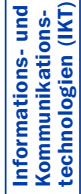 & 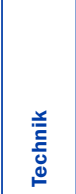 & 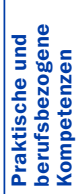 & 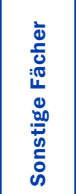 & 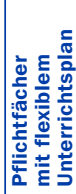 & 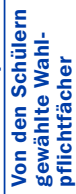 & 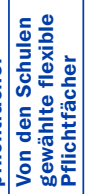 & 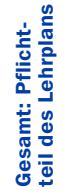 & 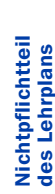 \\
\hline & (1) & (2) & (3) & (4) & (5) & (6) & (7) & (8) & (9) & (10) & (11) & (12) & (13) & (14) & (15) & (16) & (17) & (18) \\
\hline \multicolumn{19}{|l|}{ OECD-Länder } \\
\hline Australien & $x(14)$ & $x(14)$ & $x(14)$ & $x(14)$ & $x(14)$ & $x(14)$ & $x(14)$ & $x(14)$ & $x(14)$ & $x(14)$ & $x(14)$ & $x(14)$ & $x(14)$ & 100 & $x(14)$ & $x(14)$ & 100 & $m$ \\
\hline Österreich & 14 & 14 & 12 & 11 & 12 & $\mathrm{n}$ & 11 & 12 & 7 & $\mathrm{n}$ & $\mathrm{n}$ & 7 & $\mathrm{n}$ & a & 1 & $\mathrm{a}$ & 100 & $\mathrm{~m}$ \\
\hline Belgien (fläm.) $)^{1}$ & 14 & 13 & 5 & 9 & 9 & 6 & 6 & 5 & 6 & $x(15)$ & 6 & $x(15)$ & $x(15)$ & $\mathrm{n}$ & 9 & 9 & 100 & $\mathrm{n}$ \\
\hline Belgien $(\mathrm{frz} .)^{1}$ & 17 & 14 & 9 & 13 & 13 & $\mathrm{n}$ & 9 & 3 & 6 & $\mathrm{~m}$ & 3 & a & $x(15)$ & $\mathrm{n}$ & 13 & $\mathrm{n}$ & 100 & $\mathrm{~m}$ \\
\hline Kanada & 19 & 15 & 10 & 13 & 7 & $\mathrm{n}$ & 10 & 8 & 1 & $\mathrm{n}$ & 3 & 1 & 2 & 4 & 1 & 8 & 100 & $n$ \\
\hline Chile & 16 & 16 & 11 & 11 & 8 & $x(16)$ & 5 & 8 & 5 & $x(16)$ & 3 & $x(16)$ & 3 & a & $\mathrm{n}$ & 14 & 100 & a \\
\hline Tschechien & 12 & 12 & 17 & 9 & 10 & 5 & 8 & 8 & $x(13)$ & 1 & 2 & $x(11)$ & $x(16)$ & a & $x(16)$ & 15 & 100 & $\mathrm{~m}$ \\
\hline Dänemark & 19 & 13 & 17 & 10 & 10 & $x(15)$ & 6 & $x(15)$ & 2 & $x(15)$ & $x(15)$ & 3 & 3 & $\mathrm{n}$ & 12 & 4 & 100 & a \\
\hline England ${ }^{2}$ & 14 & 13 & 12 & 14 & 5 & 4 & 9 & 11 & 4 & 4 & 8 & $n$ & 3 & a & a & a & 100 & $\mathrm{n}$ \\
\hline Estland & 13 & 14 & 21 & 11 & 10 & 10 & 6 & 6 & $x(16)$ & $x(16)$ & 5 & a & a & a & a & 4 & 100 & a \\
\hline Finnland & 12 & 12 & 16 & 8 & 9 & 7 & 9 & 9 & 4 & a & a & a & 6 & 4 & a & 5 & 100 & 7 \\
\hline Frankreich & 15 & 14 & 10 & 11 & 12 & 5 & 12 & 7 & $x(4)$ & $x(11)$ & 6 & $x(15)$ & 3 & $\mathrm{n}$ & 4 & 1 & 100 & 10 \\
\hline Deutschland ${ }^{3}$ & 14 & 13 & 12 & 11 & 19 & $x(5)$ & 9 & 10 & 6 & $x(11)$ & 3 & 2 & 1 & a & $\mathrm{n}$ & a & 100 & a \\
\hline Griechenland & 26 & 11 & 10 & 12 & 6 & 6 & 7 & 6 & 6 & 3 & 2 & 5 & a & a & a & 1 & 100 & $n$ \\
\hline Ungarn & 15 & 13 & 12 & 13 & 12 & $\mathrm{n}$ & 15 & 8 & 2 & 3 & 3 & a & 2 & a & a & 3 & 100 & a \\
\hline Island & 14 & 14 & 8 & 8 & 19 & $x(5)$ & 8 & 8 & $x(4)$ & 2 & a & $x(8)$ & $x(15)$ & $\mathrm{n}$ & 20 & a & 100 & a \\
\hline Irland ${ }^{2}$ & 12 & 12 & 10 & 17 & 10 & $\mathrm{~m}$ & 7 & $\mathrm{~m}$ & 7 & 5 & $\mathrm{~m}$ & $\mathrm{~m}$ & 10 & $\mathrm{~m}$ & $\mathrm{~m}$ & 12 & 100 & a \\
\hline Israel & 17 & 14 & 14 & 15 & 11 & 6 & 5 & $x(16)$ & 9 & $x(3)$ & $x(3)$ & 1 & 4 & 3 & $\mathrm{n}$ & 2 & 100 & $n$ \\
\hline Italien & 33 & 20 & $x(2)$ & $x(1)$ & 10 & 7 & 7 & 13 & 3 & $\mathrm{n}$ & 7 & a & $\mathrm{n}$ & $\mathrm{n}$ & a & a & 100 & a \\
\hline$J^{\prime} a n^{3}$ & 12 & 12 & 12 & 11 & 13 & a & 10 & 7 & 3 & a & 3 & a & 12 & 6 & $\mathrm{n}$ & $\mathrm{m}$ & 100 & $\mathrm{~m}$ \\
\hline Korea $^{3}$ & 13 & 11 & 19 & 15 & 10 & $\mathrm{n}$ & 8 & 8 & $x(4)$ & $x(12)$ & $x(12)$ & $x(3)$ & 9 & $\mathrm{n}$ & $x(16)$ & 6 & 100 & a \\
\hline Luxemburg & 15 & 13 & 8 & 11 & 17 & 13 & 8 & 9 & 7 & a & a & a & a & a & a & $\mathrm{a}$ & 100 & a \\
\hline Mexiko & 14 & 14 & 17 & 12 & 9 & a & 6 & 6 & 8 & $\mathrm{n}$ & 9 & $\mathrm{n}$ & 6 & a & a & $\mathrm{a}$ & 100 & a \\
\hline Niederlande & $x(14)$ & $x(14)$ & $x(14)$ & $x(14)$ & $x(14)$ & $x(14)$ & $x(14)$ & $x(14)$ & $x(14)$ & $x(14)$ & $x(14)$ & $x(14)$ & a & 100 & a & a & 100 & $\mathrm{~m}$ \\
\hline Neuseeland & $\mathrm{m}$ & $\mathrm{m}$ & $\mathrm{m}$ & $\mathrm{m}$ & $\mathrm{m}$ & $\mathrm{m}$ & $\mathrm{m}$ & $\mathrm{m}$ & $\mathrm{m}$ & $\mathrm{m}$ & $\mathrm{m}$ & $\mathrm{m}$ & $\mathrm{m}$ & $\mathrm{m}$ & $\mathrm{m}$ & $\mathrm{m}$ & $\mathbf{m}$ & $\mathrm{m}$ \\
\hline Norwegen & 15 & 12 & 10 & 11 & 9 & 9 & 9 & 9 & 6 & a & $\mathrm{a}$ & 7 & a & a & 4 & $\mathrm{n}$ & 100 & a \\
\hline Polen & 14 & 12 & 12 & 12 & 14 & $x(5)$ & 12 & 4 & $x(18)$ & 2 & 2 & a & 4 & $\mathrm{n}$ & a & 13 & 100 & 8 \\
\hline Portugal & 13 & 13 & 18 & 15 & 9 & 9 & 7 & 6 & $x(18)$ & 2 & $\mathrm{n}$ & a & $\mathrm{n}$ & a & $\mathrm{n}$ & 7 & 100 & 3 \\
\hline Schottland ${ }^{4}$ & $x(14)$ & $x(14)$ & $x(14)$ & $x(14)$ & $x(14)$ & $\mathrm{n}$ & $x(14)$ & $x(14)$ & $x(14)$ & $x(14)$ & $x(14)$ & $\mathrm{n}$ & $\mathrm{n}$ & a & a & a & a & a \\
\hline Slowakei & 16 & 13 & 10 & 10 & 10 & 3 & 7 & 5 & 3 & 1 & $x(16)$ & 1 & $x(16)$ & a & $x(16)$ & 21 & 100 & a \\
\hline Slowenien & 13 & 13 & 17 & 15 & 11 & $x(15)$ & 9 & 8 & $x(4)$ & $x(17)$ & 4 & $\mathrm{n}$ & 2 & a & 7 & $\mathrm{a}$ & 100 & 13 \\
\hline Spanien & 16 & 12 & 8 & 12 & 11 & $\mathrm{n}$ & 7 & 7 & 1 & $x(11)$ & 5 & a & 3 & a & 18 & $\mathrm{n}$ & 100 & a \\
\hline Schweden & $\mathrm{m}$ & $\mathrm{m}$ & $\mathrm{m}$ & $\mathrm{m}$ & $\mathrm{m}$ & $\mathrm{m}$ & $\mathrm{m}$ & $\mathrm{m}$ & $\mathrm{m}$ & $\mathrm{m}$ & $\mathrm{m}$ & $\mathrm{m}$ & $\mathrm{m}$ & $\mathrm{m}$ & $\mathrm{m}$ & $\mathrm{m}$ & m & $\mathrm{m}$ \\
\hline Schweiz & $\mathrm{m}$ & $\mathrm{m}$ & $\mathrm{m}$ & $\mathrm{m}$ & $\mathrm{m}$ & $\mathrm{m}$ & $\mathrm{m}$ & $\mathrm{m}$ & $\mathrm{m}$ & $\mathrm{m}$ & $\mathrm{m}$ & $\mathrm{m}$ & $\mathrm{m}$ & $\mathrm{m}$ & $\mathrm{m}$ & $\mathrm{m}$ & m & $\mathrm{m}$ \\
\hline Türkei & 16 & 14 & 11 & 8 & 10 & $\mathrm{n}$ & 6 & 6 & 6 & 3 & 3 & 1 & $\mathrm{n}$ & a & 17 & a & 100 & a \\
\hline Vereinigte Staaten & $\mathrm{m}$ & $\mathrm{m}$ & $\mathrm{m}$ & $\mathrm{m}$ & $\mathrm{m}$ & $\mathrm{m}$ & $\mathrm{m}$ & $\mathrm{m}$ & $\mathrm{m}$ & $\mathrm{m}$ & $\mathrm{m}$ & $\mathrm{m}$ & $\mathrm{m}$ & $\mathrm{m}$ & $\mathrm{m}$ & $\mathrm{m}$ & m & $\mathrm{m}$ \\
\hline OECD-Durchschnitt ${ }^{4}$ & 14 & 12 & 11 & 10 & 10 & 4 & 7 & 7 & 4 & 1 & 3 & 1 & 3 & 6 & 4 & 4 & 100 & 2 \\
\hline EU21-Durchschnitt ${ }^{4}$ & 14 & 12 & 11 & 11 & 10 & 4 & 8 & 7 & 4 & 2 & 3 & 1 & 2 & 5 & 3 & 4 & 100 & 2 \\
\hline
\end{tabular}

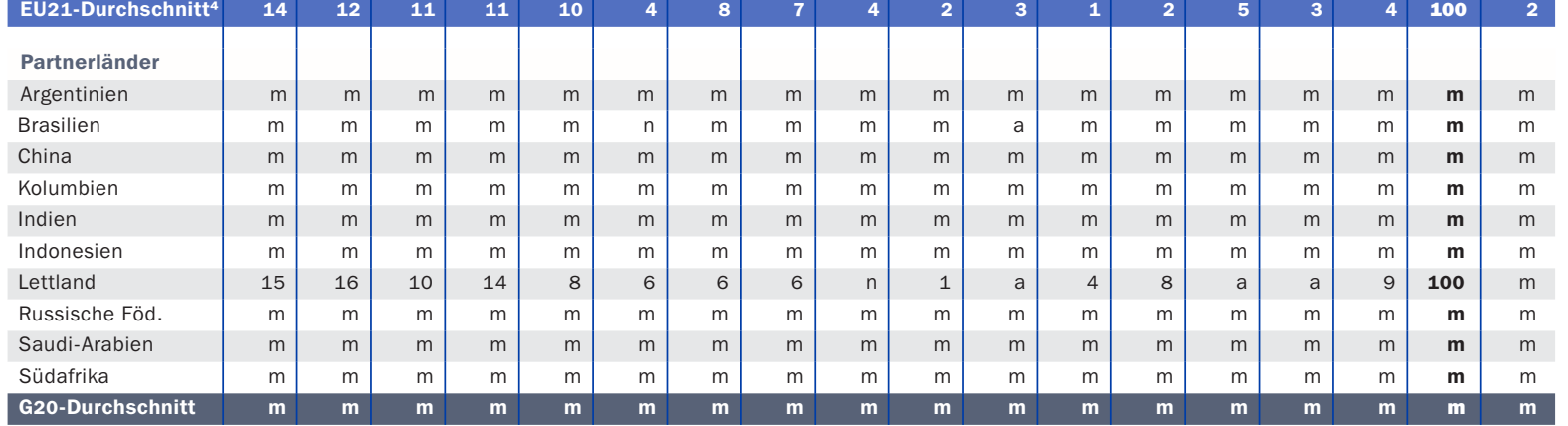

Anmerkung: Informationen zur Unterrichtszeit pro Fach für die einzelnen Altersjahrgänge sind in Tab. D1.5a bis D1.5I im Internet verfügbar (s. StatLink unten) Die Durchschnitte wurden auf 100 Prozent angepasst und entsprechen nicht genau dem Durchschnitt jeder einzelnen Spalte.

1. Schüler unterliegen bis zum 15. oder 16. Lebensjahr der Vollzeit-Schulpflicht. Für Schüler im allgemeinbildenden Bereich dauert diese bis zum 18. Lebensjahr. 2. Tatsächliche Unterrichtszeit. 3. Referenzjahr 2013. 4. Schottland ist in den Durchschnittswerten nicht enthalten.

Quelle: OECD. Argentinien, China, Indien, Indonesien, Kolumbien, Saudi-Arabien, Südafrika: Statistikinstitut der UNESCO. Lettland: Eurydice. Hinweise s. Anhang 3 unter www.oecd.org/edu/eag.htm. StatLink: http://dx.doi.org/10.1787/888933119606

Erläuterung der Kennzeichnung fehlender Daten s. Hinweise für den Leser. 



\section{Wie ist die Schüler-Lehrkräfte-Relation und wie groß sind die Klassen?}

Im Primarbereich beträgt die Klassengröße im Durchschnitt der OECD-Länder mehr als 2r Schüler pro Klasse, in den Partnerländern sind die Klassen in der Regel jedoch größer.

Im Primarbereich sind die Klassen zwischen 2000 und 2012 tendenziell kleiner geworden, insbesondere in den Ländern, die relativ große Klassen hatten wie beispielsweise Korea und die Türkei.

- Im Durchschnitt der OECD-Länder steigt die Zahl der Schüler pro Klasse vom Primar- zum Sekundarbereich I um 2 Schüler an.

Die Arbeitszufriedenheit der Lehrkräfte hängt zwar nur in geringem Maße mit der Klassengröße zusammen, doch wie die internationale OECD-Erhebung zu Lehren und Lernen 2013 (Teaching and Learning International Survey - TALIS) zeigt, nimmt die Zufriedenheit ab, wenn in einer Klasse der Anteil der Schüler mit Verhaltensproblemen 30 Prozent übersteigt.

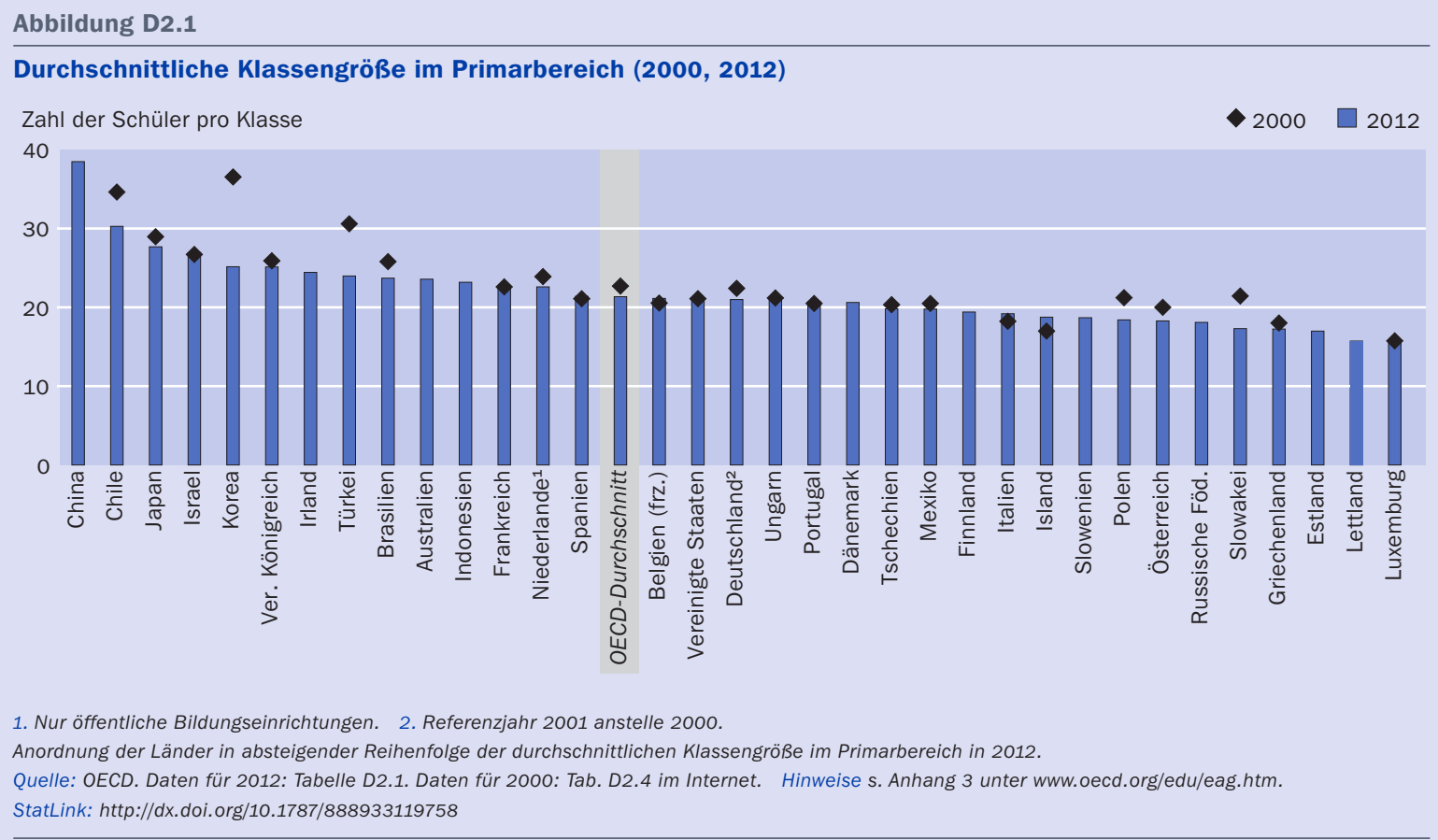

\section{Kontext}

Die Klassengröße und die Schüler-Lehrkräfte-Relation stellen viel diskutierte Aspekte der Ausbildung von Schülern dar. Zusammen mit der Unterrichtszeit der Schüler (s. Indikator Dr), der Arbeitszeit der Lehrer (s. Indikator D4) und der Aufteilung der Zeit der Lehrer zwischen Unterrichten und anderen Pflichten handelt es sich um zwei der bestimmenden Faktoren für die Größe des Lehrkörpers in den einzelnen Ländern. 
Außerdem beeinflussen sie zusammen mit den Gehältern der Lehrkräfte (s. Indikator $\mathrm{D}_{3}$ ) und der Altersverteilung der Lehrkräfte (s. Indikator $\mathrm{D}_{5}$ ) auch die laufenden Ausgaben für Bildung in erheblichem Ausmaß (s. Indikatoren B6 und B7).

Kleinere Klassen werden oft positiv bewertet, denn sie ermöglichen den Lehrern, sich stärker auf die einzelnen Schüler zu konzentrieren, außerdem komme es zu weniger Störungen des Unterrichts, mit denen sich die Lehrkräfte auseinandersetzen müssen. Es gibt zwar einige Belege dafür, dass sich kleinere Klassen bei bestimmten Schülergruppen, z.B. Schülern mit sozioökonomisch ungünstigem Hintergrund, vorteilhaft auswirken (Finn, I998; Krueger, 2002; Piketty und Valdenaire, 2006), insgesamt jedoch sind die Forschungsergebnisse darüber, wie sich die Klassengröße auf die Leistungen der Schüler auswirkt, nicht eindeutig. Nach der internationalen Erhebung der OECD zu Lehren und Lernen (OECD Teaching and Learning International Survey - TALIS) zu urteilen, führen kleinere Klassen nicht notwendigerweise zu größerer Arbeitszufriedenheit (Kasten D2.I). Es gibt jedoch auch Belege für eine mögliche positive Korrelation zwischen kleineren Klassen und innovativeren Unterrichtsformen (Hattie, 2009; OECD, 2014).

Die Schüler-Lehrkräfte-Relation ist ein Hinweis auf die Ressourcenverteilung im Bildungsbereich. Oft ist abzuwägen zwischen einer niedrigeren Schüler-Lehrkräfte-Relation und höheren Gehältern der Lehrkräfte, Investitionen in ihre berufliche Fortbildung, höheren Investitionen in Unterrichtstechnologien oder dem verstärkten Einsatz von Lehrassistenten und anderen Hilfskräften, deren Gehalt oft deutlich unter dem qualifizierter Lehrkräfte liegt. Da immer mehr Kinder mit besonderen Lernbedürfnissen in Regelklassen integriert werden, kann der verstärkte Einsatz von Fachpersonal und Unterstützungsdiensten die für eine Reduzierung der SchülerLehrkräfte-Relation erforderlichen Ressourcen einschränken.

\section{Weitere wichtige Ergebnisse}

Mit Ausnahme von Chile, Island, Mexiko und Norwegen nimmt die Schüler-Lehrkräfte-Relation in allen Ländern mit verfügbaren Daten zwischen dem Primar- und Sekundarbereich I ab, obwohl die Klassengröße zwischen diesen Bildungsbereichen im Allgemeinen steigt.

Im Durchschnitt der OECD-Länder ist die Schüler-Lehrkräfte-Relation im Sekundarbereich in privaten Bildungseinrichtungen etwas günstiger als in öffentlichen Einrichtungen. Dies ist besonders ausgeprägt in Mexiko, wo in öffentlichen Bildungseinrichtungen des Sekundarbereichs fast I5 Schüler mehr auf eine Lehrkraft kommen als in privaten Einrichtungen.

Die Klassengröße unterscheidet sich innerhalb der einzelnen Länder signifikant. Die größten Klassen im Primarbereich finden sich in Chile und China mit 30 und mehr Schülern pro Klasse, dagegen liegt in Estland, Lettland und Luxemburg die Klassengröße im Durchschnitt bei unter 17 Schülern. 


\section{Entwicklungstendenzen}

Zwischen 2000 und 2012 ist die durchschnittliche Klassengröße in Ländern mit verfügbaren Daten für beide Jahre sowohl im Primar-als auch Sekundarbereich I zurückgegangen, und die Unterschiede in der Klassengröße zwischen den einzelnen OECDLändern sind geringer geworden. Im Sekundarbereich I reichte die Klassengröße im Jahr 2000 beispielsweise von I7 Schülern in Island bis zu 38 Schülern in Korea und im Jahr 2012 von 16 Schülern in Estland bis zu 33 Schülern in Korea. In einigen Ländern, die 2000 relativ kleine Klassen hatten, ist die Klassengröße jedoch gestiegen, insbesondere in Dänemark und Island.

\section{Analyse und Interpretationen}

\section{Durchschnittliche Klassengröße im Primar- und Sekundarbereich I}

Im Primarbereich betrug die durchschnittliche Klassengröße in den OECD-Ländern im Jahr 2012 mehr als 2I Schüler pro Klasse. Berücksichtigt man alle Länder mit verfügbaren Daten, so variiert sie jedoch stark und reicht von weniger als I6 Schülern pro Klasse in Lettland und Luxemburg bis zu mehr als 30 Schülern in Chile und China. In nahezu der Hälfte der Länder mit verfügbaren Daten liegt die Klassengröße im Primarbereich bei unter 20 Schülern (Estland, Finnland, Griechenland, Island, Italien, Mexiko, Österreich, Polen, der Russischen Föderation, der Slowakei, Slowenien und Tschechien).

Im Sekundarbereich II (allgemeinbildend) liegt in den OECD-Ländern die durchschnittliche Klassengröße bei fast 24 Schülern. Unter Berücksichtigung aller Länder mit verfügbaren Daten für diesen Bildungsbereich reicht diese Zahl von höchstens 20 Schülern in Estland, Finnland, Island, Lettland, Luxemburg, der Russischen Föderation, der Slowakei, Slowenien und dem Vereinigten Königreich bis zu rund 33 Schülern pro Klasse in Indonesien, Japan und Korea und fast 52 Schülern in China (Tab. D2.I).

Vom Primar- zum Sekundarbereich I steigt die Zahl der Schüler pro Klasse tendenziell an. In China, Indonesien, Korea und Mexiko beträgt der Anstieg der durchschnittlichen Klassengröße mehr als 7 Schüler. Im Vereinigten Königreich und - in geringerem Ausmaß - in Estland und Lettland dagegen nimmt die Zahl der Schüler zwischen diesen beiden Bildungsbereichen ab (Abb. D2.2).

Zwischen 2000 und 2012 ist in den Ländern mit verfügbaren Daten für beide Jahre die durchschnittliche Klassengröße im Primarbereich leicht zurückgegangen (2I Schüler im Jahr 2012 gegenüber 23 Schülern im Jahr 2000). Die Klassengröße ist eher in den Ländern zurückgegangen, in denen auch die Zahl der Schüler zurückgegangen ist. Dies ist jedoch teilweise auch darauf zurückzuführen, dass einige Länder während dieses Zeitraums Reformen im Hinblick auf die Klassengröße umgesetzt haben (s. Indikator B7). Unter den Ländern mit vergleichbaren Daten nahm die Klassengröße jedoch in Ländern wie Korea und der Türkei, die im Jahr 2000 die größten Klassen hatten, deutlich ab (um mehr als 4 Schüler). Die Klassengröße in den Ländern mit den kleinsten Klassen im Jahr 2000 wie Dänemark, Island, Italien und Luxemburg dagegen nahm zu bzw. blieb konstant (Abb. D2.I). Im Sekundarbereich I hat sich der Abstand 


\section{Abbildung D2.2}

Durchschnittliche Klassengröße in Bildungseinrichtungen, nach Bildungsbereich (2012)

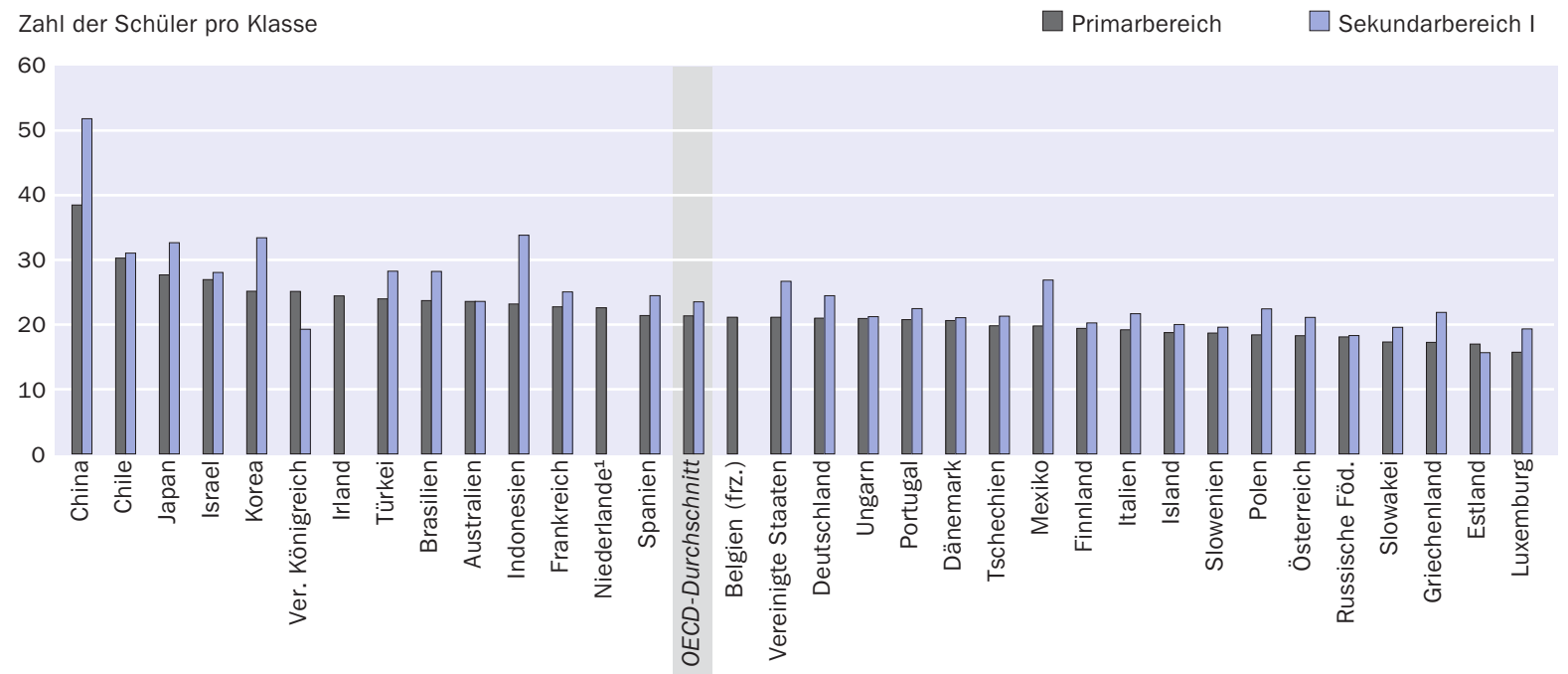

1. Nur öffentliche Bildungseinrichtungen.

Anordnung der Länder in absteigender Reihenfolge der durchschnittlichen Klassengröße im Primarbereich in 2012.

Quelle: OECD. Tabelle D2.1. Hinweise s. Anhang 3 unter www.oecd.org/edu/eag.htm. StatLink: http://dx.doi.org/10.1787/888933119777

zwischen den kleinsten und den größten Klassen von 2000 bis 2012 verringert: In den OECD-Ländern mit vergleichbaren Daten für beide Jahre reichte 2000 die Klassengröße von I7 Schülern (Island) bis zu 38 Schülern (Korea) und im Jahr 2012 von I6 Schülern (Estland) bis zu 33 Schülern (Korea) (Tab. D2.I und Tab. D2.4 im Internet).

Dieser Indikator zur Klassengröße ist auf den Primar- und Sekundarbereich I beschränkt, weil es in den höheren Bildungsbereichen schwierig ist, die Klassengröße zu bestimmen und zu vergleichen, da die Schüler hier je nach Fach häufig unterschiedlich zusammengesetzte Unterrichtsgruppen bilden.

Kasten D2.1

\section{Wie wirkt sich die Klassengröße auf die Arbeitszufriedenheit} der Lehrkräfte aus?

In vielen Ländern ist die ideale Klassengröße für ein effektives Lehren und Lernen Diskussionsthema. Die Klassengröße variiert tendenziell zwischen den Ländern und scheint sich nur in geringem Maße auf die Arbeitszufriedenheit der Lehrkräfte auszuwirken. Die Daten der internationalen Erhebung der OECD zu Lehren und Lernen (OECD Teaching and Learning International Survey - TALIS) aus dem Jahr 2013 weisen darauf hin, dass weniger die Zahl der Schüler als vielmehr die Art der Schüler, die eine Lehrkraft unterrichtet, sich am stärksten auf die Selbstwirksamkeit und Arbeitszufriedenheit der Lehrkräfte auswirkt. Ein Beispiel hierfür findet sich in Abbildung D2.a, wo der minimale Effekt der Klassengröße auf die Arbeitszufriedenheit der Lehrkräfte dem stärkeren Einfluss gegenübergestellt wird, den das Unterrichten von Schülern mit Verhaltensprobleme mit sich bringt. 
Die beiden Schaubilder belegen, dass Lehrkräfte im Sekundarbereich I eine sinkende Arbeitszufriedenheit berichteten, wenn der Anteil der Schüler mit Verhaltensproblemen zunimmt. Die Lehrkräfte gaben an, mit ihrer Arbeit am zufriedensten zu sein, wenn in der Klasse keine Schüler mit Verhaltensproblemen sind, und am wenigsten zufrieden, wenn der Anteil der Schüler mit Verhaltensproblemen in einer Klasse bei über 30 Prozent liegt. Die Daten aus TALIS zeigen, dass dieser negative Zusammenhang in allen teilnehmenden Ländern mit Ausnahme von Island, den Niederlanden und Norwegen statistisch signifikant und in Dänemark, Frankreich, Kroatien, Rumänien, Spanien, Abu Dhabi (Vereinigte Arabische Emirate) und England (Vereinigtes Königreich) besonders stark ist.

Ein vergleichbarer Rückgang der Arbeitszufriedenheit ist nicht zu beobachten, wenn die Klassengröße zunimmt. Wie Abbildung D2.a zeigt, bleibt die Arbeitszufriedenheit bei unterschiedlichen Klassengrößen relativ konstant. Die einzigen Länder, in denen ein signifikanter negativer Zusammenhang zwischen Klassengröße und Arbeitszufriedenheit besteht, sind Estland, Malaysia und England. In allen anderen Ländern ist der Zusammenhang nicht signifikant, die einzige Ausnahme ist Lettland, hier zeigen die Ergebnisse einen positiven Zusammenhang.

Diese Ergebnisse von TALIS 2013 deuten darauf hin, dass der Schwerpunkt vielmehr darauf liegen sollte zu gewährleisten, dass die Lehrkräfte gut darauf vorbereitet sind, unterschiedlich zusammengesetzte und schwierige Klassen zu unterrichten. Dies ist vor allem wichtig, wenn man berücksichtigt, dass im Durchschnitt mehr als 20 Prozent der Lehrkräfte im Sekundarbereich I Fortbildungsbedarf für das Unterrichten von Schülern mit besonderen Lernbedürfnissen angeben und weitere I3 Prozent im Bereich Klassenführung und Schülerverhalten.

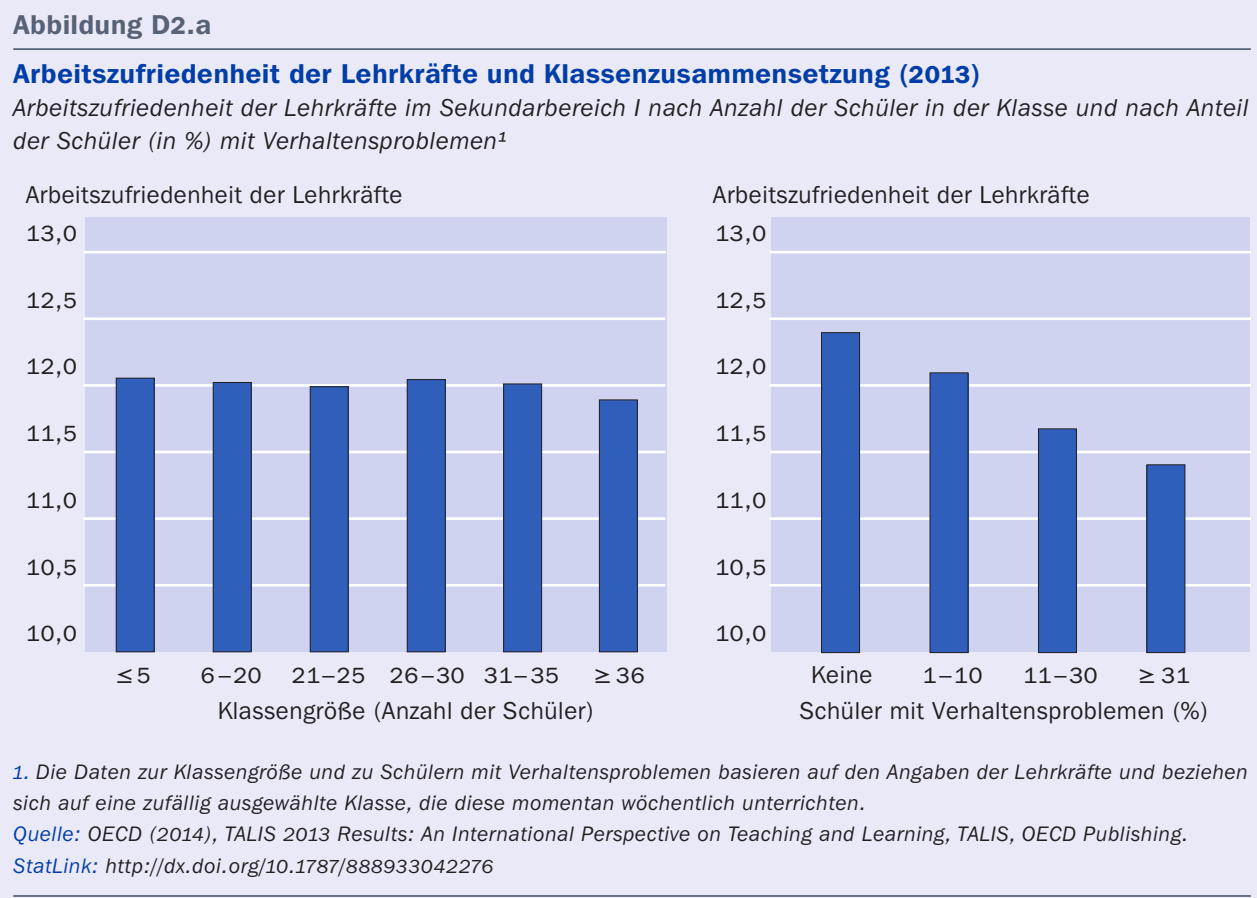




\section{Schüler-Lehrkräfte-Relation}

Die Schüler-Lehrkräfte-Relation ergibt sich aus einer Gegenüberstellung der Zahl der Schüler und der Zahl der Lehrkräfte des gleichen Bildungsbereichs und ähnlicher Bildungseinrichtungen (jeweils gemessen in Vollzeitäquivalenten). Diese Relation berücksichtigt jedoch weder die Unterrichtszeit der Schüler im Verhältnis zur Länge des Arbeitstages einer Lehrkraft noch, wie viel Zeit eine Lehrkraft auf das Unterrichten verwendet. Daher kann sie nicht als Klassengröße interpretiert werden (Kasten D2.2).

Im Durchschnitt der OECD-Länder kommen im Primarbereich auf jede Lehrkraft weniger als I6 Schüler. Die Schüler-Lehrkräfte-Relation reicht von mehr als 28 Schülern pro Lehrkraft in Mexiko und mehr als 22 Schülern in Chile bis zu höchstens II Schülern in Indonesien, Island, Luxemburg, Norwegen, Polen, Saudi-Arabien und Ungarn (Abb. D2.3).

Auch im Sekundarbereich variiert die Schüler-Lehrkräfte-Relation, und zwar stärker: Sie reicht von 30 Schülern pro Lehrkraft (in Vollzeitäquivalenten) in Mexiko bis zu weniger als ro in Belgien, Indonesien, Luxemburg, Österreich und Portugal. Im Durchschnitt der OECD-Länder beträgt die Schüler-Lehrkräfte-Relation im Sekundarbereich rund $\mathrm{I}_{3}$ (Tab. D2.2).

Wie die Unterschiede zwischen den Schüler-Lehrkräfte-Relationen erkennen lassen, kommen im Sekundarbereich weniger Schüler auf eine Lehrkraft (jeweils in Vollzeitäquivalenten) als im Primarbereich. In den meisten Ländern nimmt die Schüler-Lehrkräfte-Relation zwischen dem Primar- und Sekundarbereich I ab, obwohl gleichzeitig die Klassengröße steigt. Dies gilt bis auf vier für alle OECD-Länder: Chile, Island, Luxemburg und Mexiko.

Diese Abnahme der Schüler-Lehrkräfte-Relation spiegelt Unterschiede in der Unterrichtszeit pro Jahr wider, die mit zunehmend höherem Bildungsbereich tendenziell zunimmt (s. Indikator Dr). Sie könnte aber auch auf zeitliche Verzögerungen bei der Anpassung der Zahl der Lehrkräfte an veränderte demografische Gegebenheiten oder auf Unterschiede bei den von Lehrkräften zu unterrichtenden Zeitstunden in den verschiedenen Bildungsbereichen zurückzuführen sein, die mit steigendem Bildungsbereich tendenziell abnehmen, da die Spezialisierung der Lehrer zunimmt. Dieser allgemeine Trend ist zwar über alle Länder hinweg zu beobachten, es gibt jedoch nur uneinheitliche Belege dafür, dass vom pädagogischen Standpunkt her in höheren Bildungsbereichen eine niedrigere Schüler-Lehrkräfte-Relation wünschenswert wäre.

Für den Elementarbereich (s. auch Indikator C2) enthält Tabelle D2.2 Angaben zur Schüler-Lehrkräfte-Relation sowie zur Schüler-Kontaktpersonen-Relation (Lehrkräfte und Hilfslehrkräfte). Einige Länder bauen im Elementarbereich in starkem Maße auf Hilfslehrkräfte. In I2 OECD-Ländern sowie 3 Partnerländern ist die gemeldete zahlenmäßige Schüler-Kontaktpersonen-Relation niedriger als die Schüler-Lehrkräfte-Relation. Jedoch kommt nur in wenigen Ländern eine große Zahl von Hilfslehrkräften zum Einsatz. So ist die Schüler-Kontaktpersonen-Relation in Brasilien, Deutschland, Frankreich, Indonesien, Österreich, den Niederlanden, dem Vereinigten Königreich und den Vereinigten Staaten wesentlich niedriger (um mindestens 2 Schüler) als die SchülerLehrkräfte-Relation. Dieser Unterschied ist in Chile und Israel besonders groß, wo die 

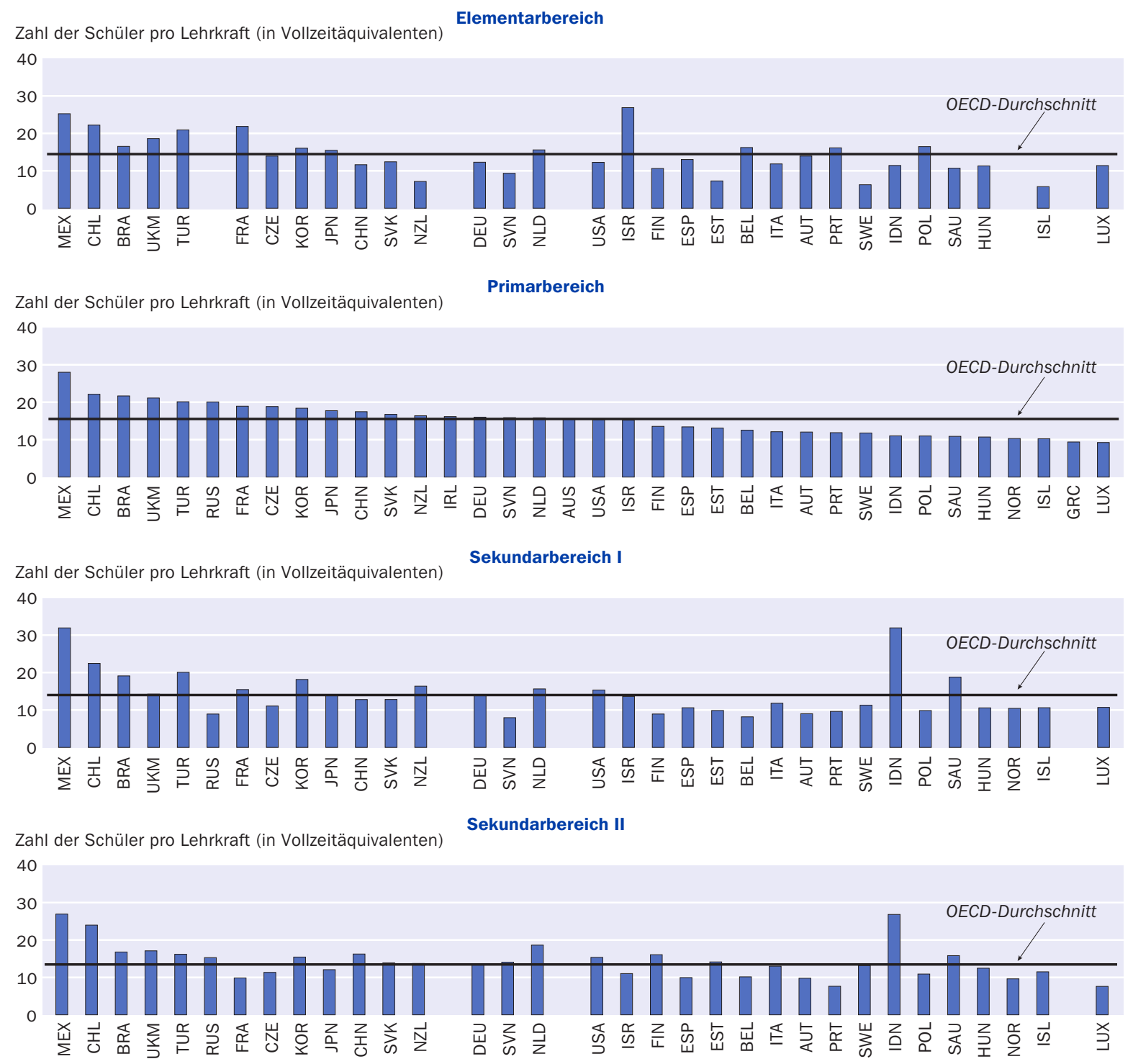

Anordnung der Länder in absteigender Reihenfolge der Schüler-Lehrkräfte-Relation im Primarbereich.

Quelle: OECD. Tabelle D2.2. Hinweise s. Anhang 3 unter www.oecd.org/edu/eag.htm. StatLink: http://dx.doi.org/10.1787/888933119796

Auflistung der verwendeten Ländercodes s. Hinweise für den Leser.

Schüler-Kontaktpersonen-Relation mindestens um Io Schüler niedriger ist als die Schüler-Lehrkräfte-Relation.

Im Tertiärbereich variiert die Studierende-Lehrende-Relation zwischen mindestens 20 Studierenden pro Lehrenden in Belgien, Brasilien, der Russischen Föderation, Saudi-Arabien, Tschechien, der Türkei und dem Vereinigten Königreich und weniger als Io in Norwegen (Tab. D2.2). Allerdings sollten derartige Vergleiche für diesen Bildungsbereich mit Vorsicht vorgenommen werden, da hier immer noch Schwierigkeiten bei der Berechnung von vergleichbaren Vollzeitäquivalenten für Studierende und Lehrende bestehen. In 8 der I4 Länder mit vergleichbaren Daten für den Tertiärbereich ist 
Kasten D2.2

\section{Zusammenhang zwischen Klassengröße und Schüler-Lehrkräfte- Relation}

Die Berechnung der Zahl der Schüler pro Klasse berücksichtigt eine Reihe unterschiedlicher Faktoren: die Schüler-Lehrkräfte-Relation, die Zahl der Klassen oder Schüler, für die eine Lehrkraft verantwortlich ist, die Unterrichtszeit der Schüler im Vergleich zur Länge des Arbeitstags der Lehrkräfte, den Anteil der Zeit, die Lehrkräfte unterrichten, die Zusammenstellung der Klassen sowie die Praxis des Teamunterrichts.

In einer Schule mit 48 Vollzeitschülern und 8 Vollzeitlehrkräften beispielsweise beträgt die Schüler-Lehrkräfte-Relation $6: \mathrm{I}$. Wenn Lehrkräfte schätzungsweise eine 35-Stunden-Woche haben, wovon Io Zeitstunden auf den Unterricht entfallen, und wenn die Unterrichtszeit für jeden Schüler bei 40 Zeitstunden pro Woche liegt, dann lässt sich die durchschnittliche Klassengröße unabhängig von der Klassenzusammenstellung der Schüler wie folgt berechnen:

Geschätzte Klassengröße = 6 Schüler pro Lehrkraft $\times$ (40 Unterrichtszeitstunden pro Schüler : Io Unterrichtszeitstunden pro Lehrkraft) $=24$ Schüler.

Unter Verwendung eines anderen Ansatzes ist die in Tabelle D2.I dargestellte Klassengröße definiert als die Zahl der Schüler in einem gemeinsamen Kurs, basierend auf der höchsten Zahl der gemeinsamen Kurse (normalerweise Pflichtkurse), ohne Unterricht in Kleingruppen. Daher wird die nach der beschriebenen Formel geschätzte Klassengröße der durchschnittlichen Klassengröße in Tabelle D2.I dann ziemlich nahekommen, wenn Unterricht in Kleingruppen weniger häufig vorkommt, wie dies im Primar- und Sekundarbereich I der Fall ist.

Aufgrund dieser Definitionen kann eine ähnliche Schüler-Lehrkräfte-Relation in verschiedenen Ländern zu unterschiedlichen Klassengrößen führen. Im Primarbereich weisen beispielsweise Israel und die Vereinigten Staaten eine ähnliche SchülerLehrkräfte-Relation auf (I5 Schüler pro Lehrkraft - Tab. D2.2), während die durchschnittliche Klassengröße in beiden Ländern sehr unterschiedlich ist ( 27 in Israel und $2 \mathrm{I}$ in den Vereinigten Staaten - Tab. D2.I).

die Studierende-Lehrende-Relation in den stärker berufsorientierten Studiengängen des Tertiärbereichs B niedriger als in den eher theoretisch orientierten Studiengängen des Tertiärbereichs A und weiterführenden forschungsorientierten Studiengängen. Die Türkei ist das einzige Land, das im Tertiärbereich bei den berufsorientierten Studiengängen des Tertiärbereichs B eine signifikant höhere Relation (53:I) als in den theoretisch ausgerichteten Studiengängen des Tertiärbereichs A und den weiterführenden forschungsorientierten Studiengängen aufweist (I6 : I) (Tab. D2.2). 
Die Klassengröße in öffentlichen und privaten Bildungseinrichtungen Für Eltern kann die Klassengröße ein wichtiger Faktor bei der Auswahl der Schule für ihre Kinder sein, daher könnten sich Unterschiede bei der durchschnittlichen Klassengröße zwischen öffentlichen und privaten Bildungseinrichtungen (und auch zwischen unterschiedlichen Arten der privaten Schulen) auf die Schülerzahlen dieser Einrichtungen auswirken.

In den OECD- und Partnerländern mit verfügbaren Daten unterscheidet sich die durchschnittliche Klassengröße zwischen privaten und öffentlichen Bildungseinrichtungen sowohl im Primar- als auch im Sekundarbereich I in der Regel um nicht mehr als 2 Schüler (Tab. D2.I). Es gibt jedoch deutliche Unterschiede zwischen den einzelnen Ländern. So ist beispielsweise in Brasilien, Island, Israel, Lettland, Polen, der Russischen Föderation, Tschechien, der Türkei, dem Vereinigten Königreich und den Vereinigten Staaten im Primarbereich die durchschnittliche Klassengröße in öffentlichen Bildungseinrichtungen um mindestens 4 Schüler pro Klasse größer als in privaten Bildungseinrichtungen. In all diesen Ländern, mit Ausnahme von Brasilien und Israel, ist jedoch der Anteil der privaten Bildungseinrichtungen mit höchstens 5 Prozent der Schüler im Primarbereich relativ klein (s. Tab. Cr.5 im Internet). Dagegen ist die durchschnittliche Klassengröße in privaten Bildungseinrichtungen in Spanien (wo diese von mehr als 30 Prozent der Schüler besucht werden) um mindestens 4 Schüler größer als in öffentlichen Einrichtungen.

Der Vergleich der Klassengröße zwischen öffentlichen und privaten Bildungseinrichtungen ergibt auch für den Sekundarbereich I, wo es mehr private Bildungseinrichtungen gibt, ein uneinheitliches Bild. Die durchschnittliche Klassengröße im Sekundarbereich I ist in 12 OECD-Ländern in privaten Bildungseinrichtungen größer als in öffentlichen Einrichtungen, die Unterschiede sind jedoch tendenziell kleiner als im Primarbereich.

In Ländern mit einem größeren Anteil an privaten Bildungseinrichtungen (sowohl staatlich subventionierten als auch unabhängigen) im Primar- und Sekundarbereich I, d. h. in Ländern, in denen mehr als ıo Prozent der Schüler dieser Bereiche private Bildungseinrichtungen besuchen, wie Argentinien, Australien, Belgien (frz.), Brasilien, Chile, Dänemark, Frankreich, Indonesien, Portugal und Spanien, können große Unterschiede zwischen den Klassengrößen an öffentlichen und privaten Bildungseinrichtungen bestehen. In Spanien, einem der beiden Länder, in denen diese Unterschiede groß sind (ein Unterschied von mindestens 4 Schülern im Primarbereich - und in beiden Bildungsbereichen in Brasilien), haben jedoch private Bildungseinrichtungen tendenziell größere Klassen als öffentliche (Tab. D2.I und Tab. Cr.4). Dies deutet darauf hin, dass in den Ländern, in denen sich ein erheblicher Teil der Schüler und Familien für private Bildungseinrichtungen entscheidet, die Klassengröße kein ausschlaggebender Faktor für diese Entscheidung ist.

Vergleicht man die Schüler-Lehrkräfte-Relation, so ergibt sich ein ähnliches Bild. Im Durchschnitt der Länder mit verfügbaren Daten ist die Schüler-Lehrkräfte-Relation in privaten Bildungseinrichtungen sowohl des Sekundarbereichs I als auch des Sekundarbereichs II etwas niedriger als in öffentlichen Bildungseinrichtungen (Tab. D2.3). Die größten Unterschiede zwischen öffentlichen und privaten Bildungseinrichtungen 
gibt es in Brasilien, Mexiko und der Türkei, wo in öffentlichen Bildungseinrichtungen des Sekundarbereichs I mindestens 7 Schüler mehr auf eine Lehrkraft kommen als in privaten Bildungseinrichtungen. Im Sekundarbereich II ist in Mexiko der Unterschied bei der Schüler-Lehrkräfte-Relation zwischen privaten und öffentlichen Einrichtungen mit mehr als 17 Schülern pro Lehrkraft sogar noch größer als im Sekundarbereich I (I5 Schüler pro Lehrkraft).

In einigen Ländern ist jedoch die Schüler-Lehrkräfte-Relation in öffentlichen Bildungseinrichtungen niedriger als in privaten Bildungseinrichtungen. Der Unterschied ist im Vereinigten Königreich im Sekundarbereich I mit etwa 22 Schülern pro Lehrkraft in privaten Bildungseinrichtungen im Vergleich zu weniger als II Schülern pro Lehrkraft in öffentlichen Bildungseinrichtungen am größten.

\section{Definitionen}

Lehrende Beschäftigte umfasst zwei Kategorien:

- Hilfslehrkräfte und Lehr-|Forschungsassistenten umfassen nicht voll qualifizierte Beschäftigte oder Studierende, die die Lehrkräfte beim Unterrichten der Schüler unterstützen.

Lehrkräfte sind voll qualifiziertes Personal, das direkt mit dem Unterrichten der Schüler befasst ist. Die Kategorie umfasst Lehrkräfte, Förderlehrer und andere Lehrkräfte, die mit Schülern als ganzer Klasse im Klassenzimmer, in kleinen Gruppen in einem Förderraum oder im Einzelunterricht innerhalb oder außerhalb des regulären Unterrichts arbeiten. Diese Kategorie umfasst auch Fachbereichsleiter, deren Aufgaben einen nur geringen Umfang an Unterricht beinhalten, während nicht voll qualifizierte Mitarbeiter, die die Lehrkräfte beim Unterricht unterstützen, wie Hilfslehrkräfte und andere Hilfskräfte, nicht erfasst sind.

\section{Angewandte Methodik}

Die Daten beziehen sich auf das Schul-/Studienjahr 20II/20I2 und beruhen auf der von der OECD im Jahre 2012 durchgeführten UOE-Datenerhebung zur Bildungsstatistik (weitere Einzelheiten s. Anhang 3 unter www.oecd.org/eduleag.htm).

Die Klassengröße wird berechnet, indem die Zahl der Schüler durch die Zahl der Klassen dividiert wird. Um die Vergleichbarkeit zwischen den einzelnen Ländern zu gewährleisten, werden spezielle Förderklassen nicht berücksichtigt. Die Daten beziehen sich ausschließlich auf reguläre Bildungsgänge im Primar- und Sekundarbereich I, Unterricht in Kleingruppen außerhalb des regulären Klassenunterrichts ist nicht erfasst.

Die Schüler-Lehrkräfte-Relation ergibt sich, wenn man (gemessen in Vollzeitäquivalenten) die Zahl der Schüler eines bestimmten Bildungsbereichs durch die Zahl der Lehrkräfte des gleichen Bildungsbereichs und ähnlicher Bildungseinrichtungen dividiert. 
Hinweis zu den Daten aus Israel

Die statistischen Daten für Israel wurden von den zuständigen israelischen Stellen bereitgestellt, die für sie verantwortlich zeichnen. Die Verwendung dieser Daten durch die OECD erfolgt unbeschadet des völkerrechtlichen Status der Golanhöhen, von Ost-Jerusalem und der israelischen Siedlungen im Westjordanland.

\section{Weiterführende Informationen}

Finn, J. (I998), Class Size and Students at Risk: What is Known? What is Next?, US Department of Education, Office of Educational Research and Improvement, National Institute on the Education of At-Risk Students, Washington, DC.

Hattie, J. (2009), Visible Learning: A Synthesis of over 800 Meta-analyses Relating to Achievement, Routledge, London.

Krueger, A. B. (2002), „Economic Considerations and Class Size“, National Bureau of Economic Research Working Paper, No. 8875.

OECD (2014), TALIS 2013 Results: An International Perspective on Teaching and Learning, OECD Publishing, http://dx.doi.org/10.1787/9789264196261-en.

Piketty, T. and M. Valdenaire (2006), L'Impact de la taille des classes sur la réussite scolaire dans les écoles, collèges et lycées français : Estimations à partir du panel primaire 1997 et du panel secondaire 1995, Ministère de l'Éducation nationale, de l'Enseignement supérieur et de la Recherche, Direction de l'évaluation et de la prospective, Paris.

\section{Tabellen Indikator D2}

StatLink: http:/|dx.doi.org/10.1787/888933119682

Tabelle D2.I: Durchschnittliche Klassengröße, nach Art der Bildungseinrichtung und Bildungsbereich (2012)

Tabelle D2.2: Lernende-Lehrende-Relation in Bildungseinrichtungen (2012)

Tabelle D2.3: Schüler-Lehrkräfte-Relation nach Art der Bildungseinrichtung (20I2)

WEB Table D2.4: Average class size, by type of institution and level of education (Durchschnittliche Klassengröße, nach Art der Bildungseinrichtung und Bildungsbereich) (2000) 
Tabelle D2.1

Durchschnittliche Klassengröße, nach Art der Bildungseinrichtung und Bildungsbereich (2012)

Berechnungen basierend auf der Zahl der Schüler und der Zahl der Klassen

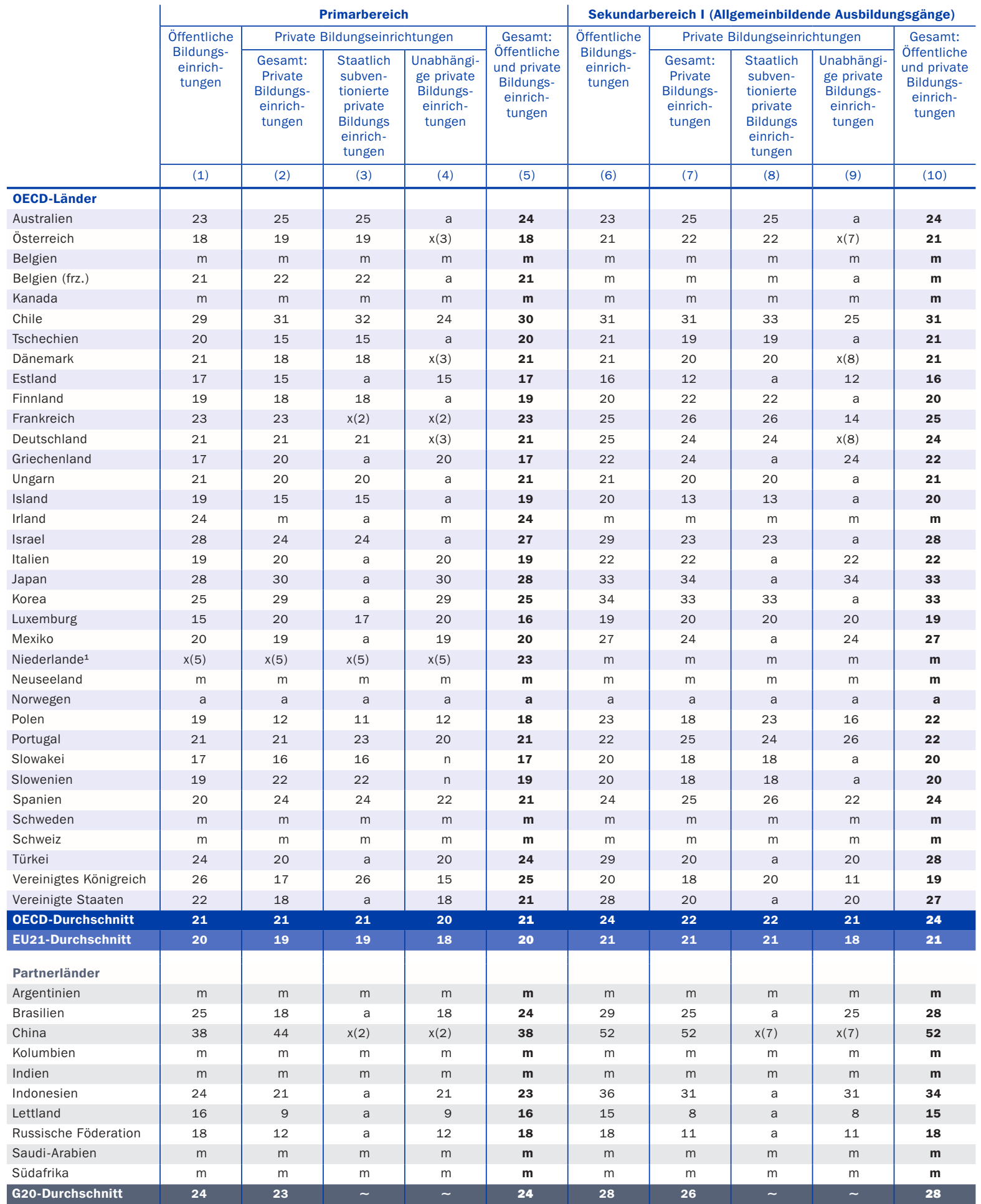

1. Ohne spezielle Förderprogramme und teilweise einschließlich Bildungsgängen auf ISCED-Stufe O.

Quelle: OECD. Argentinien, China, Indien, Indonesien, Kolumbien, Saudi-Arabien und Südafrika: Statistikinstitut der UNESCO. Lettland: Eurostat.

Hinweise s. Anhang 3 unter www.oecd.org/edu/eag.htm. StatLink: http://dx.doi.org/10.1787/888933119701

Erläuterung der Kennzeichnung fehlender Daten s. Hinweise für den Leser. 
Lernende-Lehrende-Relation in Bildungseinrichtungen (2012)

Nach Bildungsbereich (basierend auf Vollzeitäquivalenten)

\begin{tabular}{|c|c|c|c|c|c|c|c|c|c|c|}
\hline & \multicolumn{2}{|c|}{ Elementarbereich } & \multirow{2}{*}{$\begin{array}{l}\text { Primar- } \\
\text { bereich }\end{array}$} & \multicolumn{3}{|c|}{ Sekundarbereich } & \multirow{2}{*}{$\begin{array}{l}\text { Post- } \\
\text { sekundarer, } \\
\text { nicht tertiä- } \\
\text { rer Bereich }\end{array}$} & \multicolumn{3}{|c|}{ Tertiärbereich } \\
\hline & $\begin{array}{c}\text { Relation } \\
\text { Schüler zu } \\
\text { Kontakt- } \\
\text { personen } \\
\text { (Lehrer und } \\
\text { Hilfslehr- } \\
\text { kräfte) }\end{array}$ & $\begin{array}{c}\text { Relation } \\
\text { Schüler zu } \\
\text { Lehrkräften }\end{array}$ & & $\begin{array}{l}\text { Sekundar- } \\
\text { bereich I }\end{array}$ & $\begin{array}{l}\text { Sekundar- } \\
\text { bereich II }\end{array}$ & $\begin{array}{l}\text { Sekundar- } \\
\text { bereich } \\
\text { insgesamt }\end{array}$ & & $\begin{array}{c}\text { Tertiär- } \\
\text { bereich B }\end{array}$ & $\begin{array}{c}\text { Tertiär- } \\
\text { bereich A } \\
\text { und weiter- } \\
\text { führende } \\
\text { forschungs- } \\
\text { orientierte } \\
\text { Studien- } \\
\text { gänge }\end{array}$ & $\begin{array}{c}\text { Tertiär- } \\
\text { bereich } \\
\text { insgesamt }\end{array}$ \\
\hline & (1) & (2) & (3) & (4) & (5) & (6) & (7) & (8) & (9) & (10) \\
\hline \multicolumn{11}{|l|}{ OECD-Länder } \\
\hline Australien ${ }^{1,2}$ & $\mathrm{~m}$ & $\mathrm{~m}$ & 16 & $x(6)$ & $x(6)$ & 12 & $\mathrm{~m}$ & $\mathrm{~m}$ & 14 & $\mathrm{~m}$ \\
\hline Österreich & 10 & 14 & 12 & 9 & 10 & 9 & 10 & $\mathrm{n}$ & 17 & 17 \\
\hline Belgien ${ }^{3}$ & 16 & 16 & 13 & 8 & 10 & 9 & $x(5)$ & $x(10)$ & $x(10)$ & 21 \\
\hline Kanada ${ }^{2,4}$ & $\mathrm{~m}$ & $x(4)$ & $x(4)$ & 16 & 14 & 14 & $\mathrm{~m}$ & $\mathrm{~m}$ & 14 & $\mathrm{~m}$ \\
\hline Chile & 11 & 22 & 22 & 22 & 24 & 23 & a & $\mathrm{m}$ & $\mathrm{m}$ & $\mathrm{m}$ \\
\hline Tschechien & 14 & 14 & 19 & 11 & 11 & 11 & 18 & 17 & 22 & 21 \\
\hline Dänemark & $\mathrm{m}$ & $\mathrm{m}$ & $x(4)$ & 12 & $\mathrm{~m}$ & $\mathrm{~m}$ & $\mathrm{~m}$ & $\mathrm{~m}$ & $\mathrm{~m}$ & $\mathrm{~m}$ \\
\hline Estland & $\mathrm{m}$ & 7 & 13 & 10 & 14 & 12 & $x(5)$ & $\mathrm{m}$ & $\mathrm{m}$ & $\mathrm{m}$ \\
\hline Finnland & $\mathrm{m}$ & 11 & 14 & 9 & 16 & 13 & $x(5)$ & $\mathrm{n}$ & 14 & 14 \\
\hline Frankreich ${ }^{3}$ & 14 & 22 & 19 & 15 & 10 & 13 & $x(8)$ & 17 & 15 & 16 \\
\hline Deutschland & 10 & 12 & 16 & 14 & 14 & 14 & 13 & 14 & 11 & 12 \\
\hline Griechenland & $\mathrm{m}$ & $\mathrm{m}$ & 9 & $\mathrm{~m}$ & $\mathrm{~m}$ & $\mathrm{~m}$ & $\mathrm{~m}$ & $\mathrm{~m}$ & $\mathrm{~m}$ & $\mathrm{~m}$ \\
\hline Ungarn & $\mathrm{m}$ & 11 & 11 & 11 & 12 & 12 & 14 & 21 & 15 & 15 \\
\hline Island & 6 & 6 & 10 & 11 & 11 & 11 & $x(5,10)$ & $x(10)$ & $x(10)$ & 11 \\
\hline Irland ${ }^{2}$ & $\mathrm{~m}$ & $\mathrm{~m}$ & 16 & $x(6)$ & $x(6)$ & 15 & $x(6)$ & $x(10)$ & $x(10)$ & 19 \\
\hline Israel & 13 & 27 & 15 & 14 & 11 & 12 & $\mathrm{~m}$ & $\mathrm{~m}$ & $\mathrm{~m}$ & $\mathrm{~m}$ \\
\hline Italien ${ }^{2}$ & $\mathrm{~m}$ & 12 & 12 & 12 & 13 & 12 & $\mathrm{~m}$ & 10 & 19 & 19 \\
\hline Japan & 15 & 15 & 18 & 14 & 12 & 13 & $x(5,10)$ & $\mathrm{m}$ & $\mathrm{m}$ & $\mathrm{m}$ \\
\hline Korea & 16 & 16 & 18 & 18 & 15 & 17 & a & $\mathrm{m}$ & $\mathrm{m}$ & $\mathrm{m}$ \\
\hline Luxemburg & $\mathrm{m}$ & 11 & 9 & 11 & 8 & 9 & $\mathrm{~m}$ & $\mathrm{~m}$ & $\mathrm{~m}$ & $\mathrm{~m}$ \\
\hline Mexiko & 25 & 25 & 28 & 32 & 27 & 30 & a & 16 & 15 & 15 \\
\hline Niederlande & 14 & 16 & 16 & 16 & 19 & 17 & 21 & 15 & 15 & 15 \\
\hline Neuseeland & $\mathrm{m}$ & 7 & 16 & 16 & 14 & 15 & 22 & 17 & 18 & 18 \\
\hline Norwegen & $\mathrm{m}$ & $\mathrm{m}$ & 10 & 10 & 10 & 10 & $x(5)$ & $x(10)$ & $x(10)$ & 9 \\
\hline Polen & $\mathrm{m}$ & 16 & 11 & 10 & 11 & 10 & 16 & 8 & 15 & 15 \\
\hline Portugal & $\mathrm{m}$ & 16 & 12 & 10 & 8 & 9 & $x(5,10)$ & $x(10)$ & $x(10)$ & 15 \\
\hline Slowakei & 12 & 12 & 17 & 13 & 14 & 13 & 11 & 9 & 14 & 14 \\
\hline Slowenien & 9 & 9 & 16 & 8 & 14 & 11 & $x(5)$ & $x(10)$ & 16 & 18 \\
\hline Spanien & $\mathrm{m}$ & 13 & 13 & 11 & 10 & 10 & a & 10 & 12 & 12 \\
\hline Schweden & 6 & 6 & 12 & 11 & 13 & 12 & 30 & $x(10)$ & 11 & 11 \\
\hline Schweiz & $\mathrm{m}$ & $\mathrm{m}$ & $\mathrm{m}$ & $\mathrm{m}$ & $\mathrm{m}$ & $\mathrm{m}$ & $\mathrm{m}$ & $\mathrm{m}$ & $\mathrm{m}$ & $\mathrm{m}$ \\
\hline Türkei & $\mathrm{m}$ & 21 & 20 & 20 & 16 & 18 & a & 53 & 16 & 20 \\
\hline Ver. Königreich & 12 & 19 & 21 & 14 & 17 & 16 & a & $x(10)$ & $x(10)$ & 20 \\
\hline Vereinigte Staaten & 10 & 12 & 15 & 15 & 15 & 15 & 16 & $x(10)$ & $x(10)$ & 16 \\
\hline OECD-Durchschnitt & 13 & 14 & 15 & 14 & 14 & 13 & 17 & 15 & 15 & 14 \\
\hline EU21-Durchschnitt & 11 & 13 & 14 & 11 & 13 & 12 & 17 & 13 & 15 & 16 \\
\hline \multicolumn{11}{|l|}{ Partnerländer } \\
\hline Argentinien & $\mathrm{m}$ & $\mathrm{m}$ & $\mathrm{m}$ & $\mathrm{m}$ & $\mathrm{m}$ & $\mathrm{m}$ & a & $\mathrm{m}$ & $\mathrm{m}$ & $\mathrm{m}$ \\
\hline Brasilien & 12 & 17 & 22 & 19 & 17 & 18 & a & $x(10)$ & $x(10)$ & 27 \\
\hline China & $\mathrm{m}$ & $\mathrm{m}$ & 17 & 13 & 16 & 14 & $\mathrm{~m}$ & $\mathrm{~m}$ & $\mathrm{~m}$ & $\mathrm{~m}$ \\
\hline Kolumbien & $\mathrm{m}$ & $\mathrm{m}$ & $\mathrm{m}$ & $\mathrm{m}$ & $\mathrm{m}$ & $\mathrm{m}$ & $\mathrm{m}$ & $\mathrm{m}$ & $\mathrm{m}$ & $\mathrm{m}$ \\
\hline Indien & $\mathrm{m}$ & $\mathrm{m}$ & $\mathrm{m}$ & $\mathrm{m}$ & $\mathrm{m}$ & $\mathrm{m}$ & $\mathrm{m}$ & $\mathrm{m}$ & $\mathrm{m}$ & $\mathrm{m}$ \\
\hline Indonesien & $\mathrm{m}$ & 11 & 11 & 8 & 11 & 9 & 17 & 20 & 20 & 20 \\
\hline Lettland & 23 & 26 & 25 & 22 & 23 & 22 & a & $x(10)$ & $x(10)$ & 31 \\
\hline Russische Föd. ${ }^{2}$ & $\mathrm{~m}$ & $\mathrm{~m}$ & 20 & 9 & 15 & 10 & $x(6)$ & 11 & 13 & 12 \\
\hline Saudi-Arabien & $\mathrm{m}$ & 11 & 11 & 10 & 11 & 10 & a & $x(10)$ & $x(10)$ & 21 \\
\hline Südafrika & $\mathrm{m}$ & $\mathrm{m}$ & $\mathrm{m}$ & $\mathrm{m}$ & $\mathrm{m}$ & $\mathrm{m}$ & a & $\mathrm{m}$ & $\mathrm{m}$ & $\mathrm{m}$ \\
\hline -Durchschnitt & 5 & 17 & 19 & 16 & 16 & 15 & & $\sim$ & $\sim$ & $\sim$ \\
\hline
\end{tabular}

1. Im Sekundarbereich II nur allgemeinbildende Bildungsgänge. 2. Nur öffentliche Bildungseinrichtungen (Australien: nur im Tertiärbereich A und in weiterführenden forschungsorientierten Studiengängen; Kanada: nur im Tertiärbereich; Irland: nur im Tertiärbereich; Italien: vom Elementar- bis zum Sekundarbereich; Russische Föderation: nur im Primar- und Sekundarbereich). 3. Ohne unabhängige private Bildungseinrichtungen. 4. Referenzjahr 2011.

Quelle: OECD. Argentinien, China, Indien, Indonesien, Kolumbien, Saudi-Arabien und Südafrika: Statistikinstitut der UNESCO. Lettland: Eurostat. Hinweise s. Anhang 3 unter www.oecd.org/edu/eag.htm. StatLink: http://dx.doi.org/10.1787/888933119720

Erläuterung der Kennzeichnung fehlender Daten s. Hinweise für den Leser. 
Tabelle D2.3

Schüler-Lehrkräfte-Relation nach Art der Bildungseinrichtung (2012)

Nach Bildungsbereich (basierend auf Vollzeitäquivalenten)

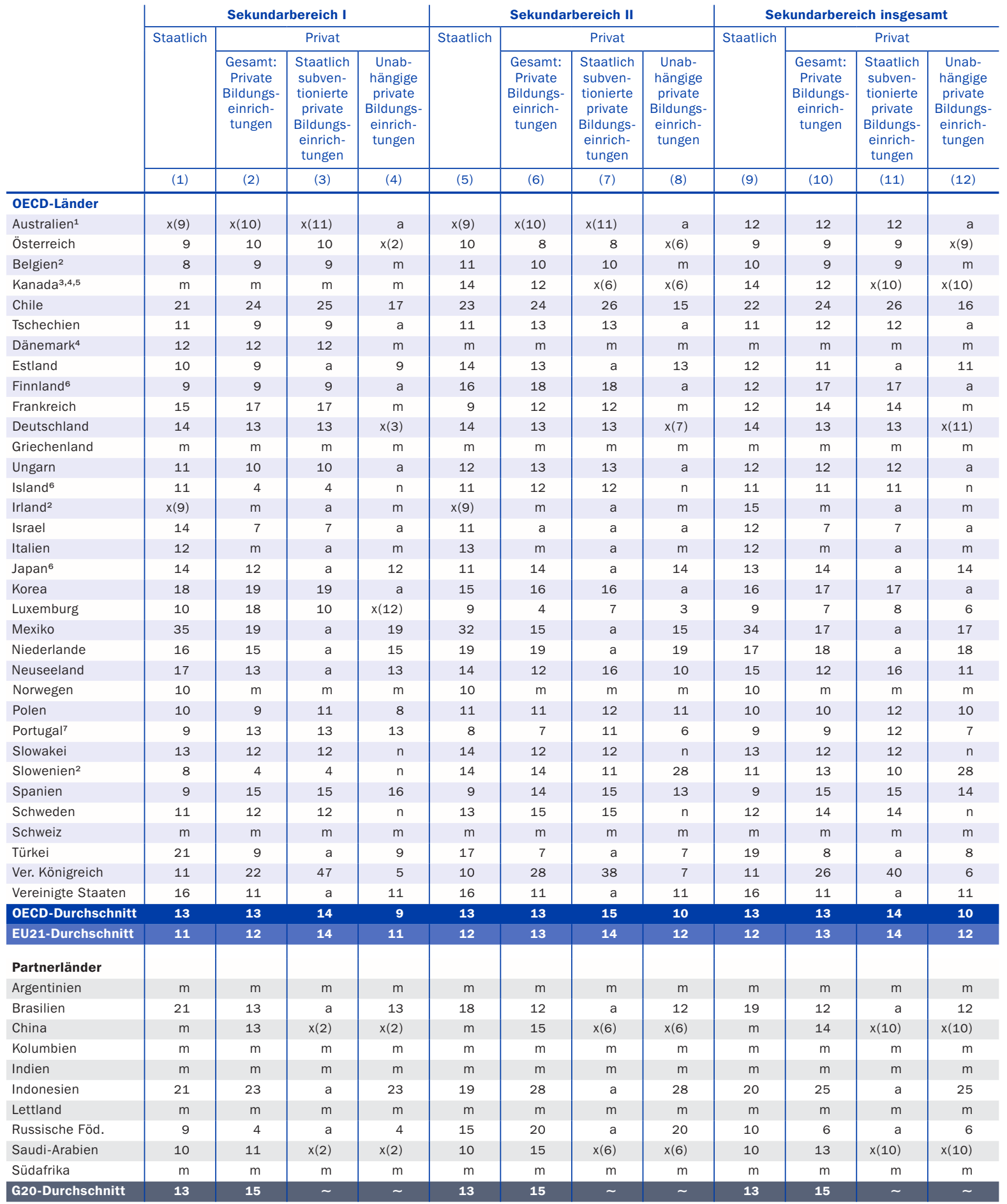

1. Im Sekundarbereich I und II nur allgemeinbildende Bildungsgänge. 2. Sekundarbereich II umfasst auch postsekundaren, nicht tertiären Bereich.

3. Referenzjahr 2011. 4. Sekundarbereich I umfasst auch Primarbereich. 5. Sekundarbereich I umfasst auch Elementarbereich. 6. Sekundarbereich II enthält auch Bildungsgänge des postsekundaren Bereichs. 7. Angaben beziehen sich auf die Zahl der Lehrkräfte im Primar-, Sekundar- und postsekundaren, nicht tertiären Bereich.

Quelle: OECD. Argentinien, China, Indien, Indonesien, Kolumbien, Saudi-Arabien und Südafrika: Statistikinstitut der UNESCO. Lettland: Eurostat. Hinweise s. Anhang 3 unter www.oecd.org/edu/eag.htm). StatLink: http://dx.doi.org/10.1787/888933119739

Erläuterung der Kennzeichnung fehlender Daten s. Hinweise für den Leser. 


\section{Wie hoch sind die Gehälter der Lehrkräfte?}

- Im Durchschnitt der OECD-Länder liegen die Gehälter von Lehrkräften im Elementarbereich bei 80 Prozent der Gehälter von 25 - bis 64 -jährigen ganzjährig Vollzeitbeschäftigten mit einem Abschluss im Tertiärbereich, von Lehrkräften im Primarbereich bei 85 Prozent, im Sekundarbereich I bei 88 Prozent und im Sekundarbereich II bei 92 Prozent dieses Vergleichswerts.

Die gesetzlichen bzw. vertraglich vereinbarten Gehälter von Lehrkräften mit mindestens I5 Jahren Berufserfahrung belaufen sich im Durchschnitt auf 37.350 USDollar im Elementarbereich, 39.024 US-Dollar im Primarbereich, 40.570 US-Dollar im Sekundarbereich I und 42.86I US-Dollar im Sekundarbereich II.

Abbildung D3.1

Gehälter von Lehrkräften im Verhältnis zu den Gehältern von 25- bis 64-jährigen Beschäftigten mit einem Abschluss im Tertiärbereich (2012)

Gehälter von Lehrkräften im Sekundarbereich I an öffentlichen Bildungseinrichtungen

Verhältnis

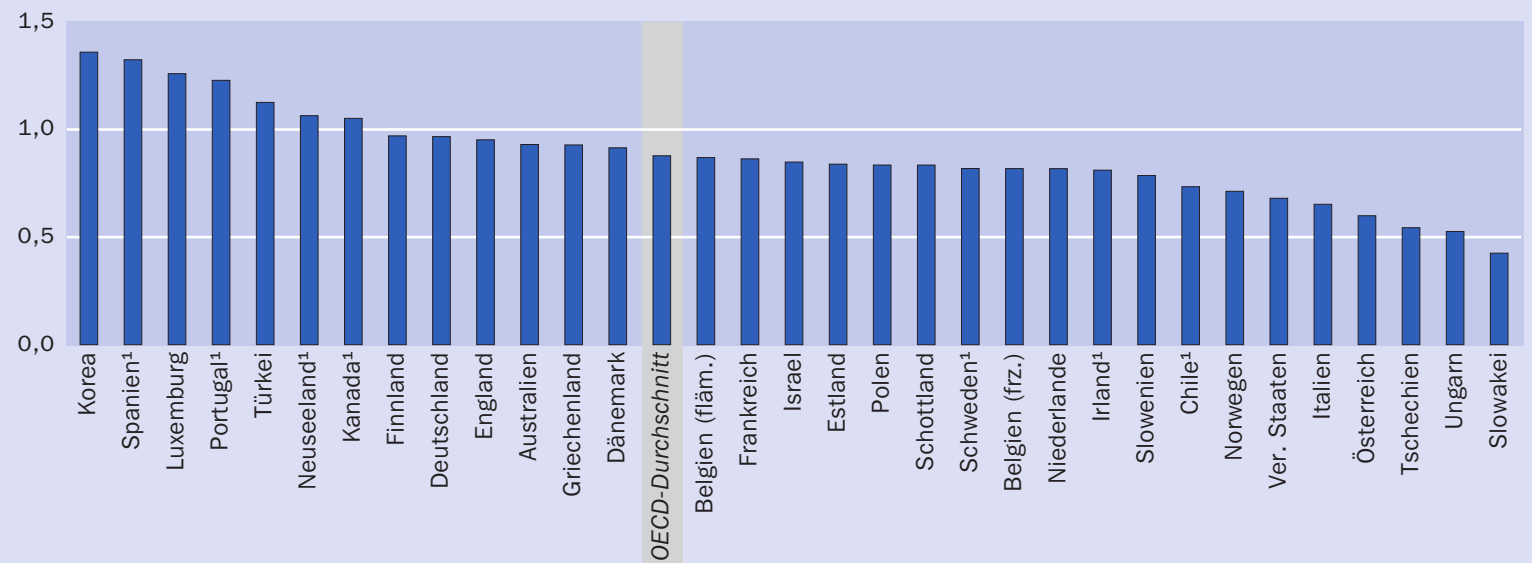

Anmerkung: Die Gehälter der Lehrkräfte beziehen sich entweder auf die tatsächlichen Gehälter von 25- bis 64-jährigen Lehrkräften, einschließlich Bonuszahlungen und Zulagen, oder auf gesetzliche bzw. vertraglich vereinbarte Gehälter nach 15 Jahren Berufserfahrung mit Mindestausbildung. Einzelheiten zur angewandten Methodik s. Tab. D3.2.

1. Referenzjahr 2011.

Anordnung der Länder in absteigender Reihenfolge des Verhältnisses der Gehälter von Lehrkräften zu den Gehältern von ganzjährig vollzeitbeschäftigten 25- bis 64-Jährigen mit einem Abschluss im Tertiärbereich.

Quelle: OECD. Tabelle D3.2. Hinweise s. Anhang 3 unter www.oecd.org/edu/eag.htm. StatLink: http://dx.doi.org/10.1787/888933119929

\section{Kontext}

Die Gehälter der Lehrkräfte sind der größte Einzelposten bei den Kosten der formalen Schulausbildung, und sie wirken sich unmittelbar auf die Attraktivität des Lehrerberufs aus. Sie beeinflussen die Entscheidung, eine Lehrerausbildung aufzunehmen, nach erzieltem Abschluss Lehrkraft zu werden (da die Entscheidungen der Absolventen bei der Berufswahl mit den als Lehrkraft und in anderen Berufen zu erzielenden relativen Einkommen und ihrer im Laufe der Zeit zu erwartenden Steigerung verbunden sind), nach einer Unterbrechung in den Lehrerberuf zurückzukehren und/oder den Lehrerberuf weiterhin auszuüben (da im Allgemeinen mit steigendem Gehalt die 
Neigung zu einem Berufswechsel sinkt) (OECD, 2005). Die stark angewachsenen Staatsschulden aufgrund der staatlichen Reaktionen auf die Finanzkrise Ende 2008 führten zu der nachdrücklichen Forderung an die Politik, die Staatsausgaben zu senken - insbesondere im Bereich der Beschäftigten im öffentlichen Dienst. Da Gehalt und Arbeitsbedingungen wichtige Faktoren sind, wenn es darum geht, kompetente und hoch qualifizierte Lehrer anzuwerben, weiterzubilden und zu halten, sollte die Politik in ihrem Bemühen, sowohl die Qualität des Unterrichts als auch langfristig tragfähige Bildungshaushalte sicherzustellen, die Auswirkungen von Gehaltsveränderungen bei den Lehrkräften sorgsam abwägen (s. Indikatoren B6 und B7).

\section{Weitere wichtige Ergebnisse}

In den meisten OECD-Ländern steigen die Gehälter der Lehrkräfte, je höher der Bildungsbereich ist, in dem sie unterrichten. So liegt beispielsweise das Gehalt einer Lehrkraft im Sekundarbereich II mit I5 Jahren Berufserfahrung in Belgien, Dänemark, Finnland, Indonesien, Polen und der Schweiz (mit II Jahren Berufserfahrung) mindestens 25 Prozent über dem einer Lehrkraft im Elementarbereich mit gleich langer Berufserfahrung.

Die Höchstgehälter (bei Mindestausbildung) sind im Elementar-, Primar- sowie im Sekundarbereich I und II im Durchschnitt um 58, 61, 61 bzw. 62 Prozent höher als die Anfangsgehälter, wobei diese Differenz tendenziell am größten ist, wenn eine Lehrkraft viele Jahre benötigt, um alle Gehaltsstufen zu durchlaufen. In Ländern, in denen die Höchstgehälter erst nach frühestens 30 Jahren erreicht werden, sind sie im Durchschnitt 8o Prozent höher als die Anfangsgehälter.

Die von Lehrkräften mit maximaler Qualifikation in der obersten Gehaltsstufe bezogenen Höchstgehälter belaufen sich im Durchschnitt auf 48.937 US-Dollar pro Jahr im Elementarbereich, 50.984 US-Dollar im Primarbereich, 53.686 USDollar im Sekundarbereich I und 55.IIg US-Dollar im Sekundarbereich II. Jedoch variiert der für eine höhere Qualifikation gewährte Gehaltszuschlag. Lehrkräfte im Primarbereich, die über die maximale Qualifikation verfügen, verdienen beispielsweise in Israel, Mexiko, Polen und Slowenien mindestens 30 Prozent mehr als Lehrkräfte im Primarbereich mit ähnlicher Berufserfahrung, die jedoch nur über die Mindestqualifikation verfügen. In einem Drittel der Länder mit verfügbaren Daten gibt es jedoch überhaupt keinen Unterschied.

In Io der 24 Länder mit verfügbaren Daten sind die durchschnittlichen Jahresgehälter von Lehrkräften im Sekundarbereich II, einschließlich Bonuszahlungen und Zulagen, mindestens Io Prozent höher als die gesetzlichen bzw. vertraglich vereinbarten Gehälter für Lehrkräfte im Sekundarbereich II mit I5 Jahren Berufserfahrung und Mindestausbildung.

\section{Entwicklungstendenzen}

Zwischen 2000 und 2012 war in allen Ländern mit verfügbaren Daten - mit Ausnahme von Frankreich, Griechenland und Japan - ein realer Anstieg der Lehrergehälter zu beobachten. In den meisten Ländern stiegen die Gehälter jedoch ab 2005 langsamer 
als zwischen 2000 und 2005, und auch die Wirtschaftskrise 2008 wirkte sich unmittelbar auf die Gehälter der Lehrkräfte aus, sie wurden entweder eingefroren oder in einigen Ländern gekürzt. Daher sank die Zahl der Länder, in denen die Gehälter real stiegen, zwischen 2008 und 2012 auf weniger als die Hälfte der OECD-Länder.

\section{Analyse und Interpretationen}

\section{Gesetzliche bzw. vertraglich vereinbarte Gehälter von Lehrkräften}

Die Gehälter der Lehrkräfte sind nur eine Komponente der Gesamtvergütung der Lehrkräfte. Diese kann auch Zusatzleistungen wie beispielsweise eine Art Ortszulage für das Unterrichten in abgelegenen Gebieten, Familienzulagen, Fahrpreisermäßigungen im öffentlichen Personennahverkehr sowie Steuerermäßigungen beim Erwerb kultureller Güter enthalten. In den OECD-Ländern gibt es auch große Unterschiede hinsichtlich der Besteuerung und der Sozialversicherungssysteme. Diese Komponenten sollten bei einem Vergleich der gesetzlichen bzw. vertraglich vereinbarten Gehälter zwischen den Ländern immer berücksichtigt werden.

Die Gehälter der Lehrkräfte variieren stark zwischen den einzelnen Ländern. Für Lehrkräfte an Schulen des Sekundarbereichs I mit mindestens I5 Jahren Berufserfahrung reichen sie von weniger als I5.000 US-Dollar in Estland, Indonesien, der Slowakei und Ungarn über mehr als 60.000 US-Dollar in Deutschland, den Niederlanden und der Schweiz (für Lehrkräfte mit mindestens II Jahren Berufserfahrung) bis zu mehr als I00.000 US-Dollar in Luxemburg (Tab. D3.I und Abb. D3.2).

In den meisten Ländern steigen die Gehälter der Lehrkräfte, je höher der Bildungsbereich ist, in dem sie unterrichten. In Belgien, Dänemark, Indonesien, den Niederlanden, Polen, der Slowakei und Ungarn verdienen Lehrkräfte im Sekundarbereich II mit I5 Jahren Berufserfahrung zwischen 20 und 30 Prozent mehr als Lehrkräfte im Elementarbereich mit gleicher Berufserfahrung, in Finnland und der Schweiz (Lehrkräfte mit II Jahren Berufserfahrung) sind es rund 50 Prozent mehr. In Finnland und der Slowakei ist dies hauptsächlich auf den Unterschied zwischen den Gehältern für Lehrkräfte im Elementar- und Primarbereich zurückzuführen. In den Niederlanden ist der größte Unterschied zwischen dem Primar- und Sekundarbereich I zu beobachten, wohingegen in Belgien die Gehälter von Lehrern des Sekundarbereichs II signifikant höher als in den anderen Bildungsbereichen sind. In Dänemark und Ungarn ist der größte Unterschied zwischen den Gehältern im Sekundarbereich II und I zu beobachten, während die Gehälter von Lehrkräften im Sekundarbereich I und im Primarbereich gleich hoch sind. Im Gegensatz hierzu steigen die Gehälter der Lehrkräfte in der Schweiz vom Elementar- bis zum Sekundarbereich II kontinuierlich an. Die Unterschiede zwischen den Gehältern in den einzelnen Bildungsbereichen sollten unter Berücksichtigung der für den Lehrerberuf in dem jeweiligen Bildungsbereich erforderlichen Qualifikationen interpretiert werden (s. Indikator D6).

In Australien, Kanada, Korea und der Türkei besteht zwischen den Gehältern von Lehrkräften mit I5 Jahren Berufserfahrung im Sekundarbereich II und im Elementarbereich 
ein Unterschied von weniger als 5 Prozent; in England, Griechenland, Portugal, Schottland und Slowenien sind die Gehälter für die Lehrkräfte aller Bildungsbereiche gleich. In Estland, Irland und Japan trifft dies auch auf die Gehälter der Lehrkräfte im Primarsowie im Sekundarbereich I und II zu. In Israel besteht zwischen den Gehältern von Lehrkräften an Schulen des Sekundarbereichs II und denen von Lehrkräften an Schulen des Elementarbereichs ein Unterschied von I3 Prozent zugunsten der Lehrkräfte im Elementarbereich. Dies ist hauptsächlich auf die schrittweise Einführung der „Neue Horizonte“ überschriebenen Reform seit 2008 zurückzuführen, die zu einer Steigerung der Gehälter der Lehrkräfte im Elementar-, Primar- und Sekundarbereich I führte. Eine weitere, 2012 eingeleitete Reform soll auch die Gehälter für Lehrkräfte im Sekundarbereich II anheben. In Luxemburg haben Lehrkräfte im Primarbereich mit I5 Jahren Berufserfahrung vor einer 2009 in Kraft getretenen Reform etwa 50 Prozent weniger verdient als Lehrkräfte im Sekundarbereich mit gleicher Berufserfahrung. Inzwischen beträgt der Unterschied zwischen den Gehältern der Lehrkräfte im Primar- und Sekundarbereich jedoch weniger als Io Prozent.

Unterschiede zwischen den Gehältern der Lehrkräfte in den verschiedenen Bildungsbereichen können sowohl die Vorgehensweise von Schulen und Bildungssystemen bei der Anwerbung und dauerhaften Bindung von Lehrkräften in den einzelnen Bildungsbereichen beeinflussen als auch das Ausmaß, in dem Lehrkräfte zwischen den einzelnen Bildungsbereichen wechseln.

\section{Mindest- und Höchstgehälter von Lehrkräften}

Die Bildungssysteme stehen bei der Anwerbung hoch qualifizierter Absolventen als Lehrkräfte großen Herausforderungen gegenüber. Forschungsergebnisse lassen erkennen, dass Gehälter und alternative Beschäftigungsmöglichkeiten einen wesentlichen Einfluss auf die Attraktivität des Lehrerberufs haben (Santiago, 2004). Die Anfangsgehälter von Lehrkräften im Verhältnis zu anderen nicht lehrenden Tätigkeiten und die zu erwartenden Einkommenssteigerungen haben großen Einfluss darauf, ob sich Absolventen für den Lehrerberuf entscheiden. Länder, die das Angebot an Lehrkräften erweitern möchten, insbesondere Länder mit einer alternden Lehrerschaft und/ oder einer wachsenden Bevölkerung im Schulalter, könnten sich überlegen, attraktivere Anfangsgehälter und Karriereaussichten anzubieten. Um jedoch eine gut qualifizierte Lehrerschaft sicherzustellen, sind nicht nur Anstrengungen zur Anwerbung und Auswahl nur der kompetentesten und am höchsten qualifizierten Lehrkräfte erforderlich, sondern man muss sich auch um die Bindung guter Lehrkräfte bemühen.

Im Sekundarbereich I verdienen Lehrkräfte (mit Mindestausbildung) bei Berufseintritt im Durchschnitt 30.735 US-Dollar. Dieses Mindestgehalt variiert zwischen weniger als I5.000 US-Dollar in Brasilien, Estland, Indonesien, Polen, der Slowakei und Ungarn und mehr als 40.000 US-Dollar in Dänemark, Deutschland, Luxemburg und der Schweiz. Für Lehrkräfte (mit maximalen Qualifikationen) in der obersten Gehaltsstufe liegt das Gehalt im Durchschnitt bei 53.686 US-Dollar. Diese oberste Gehaltsstufe variiert von weniger als 20.000 US-Dollar in Estland, Indonesien und der Slowakei bis zu mindestens 75.000 US-Dollar in Korea, Österreich und der Schweiz und mehr als I25.000 US-Dollar in Luxemburg. 


\section{Wie hängen die Gehälter der Lehrkräfte mit den Leistungen der Schüler zusammen?}

Die Ergebnisse der internationalen Schulleistungsstudie PISA 2012 deuten darauf hin, dass leistungsstarke Bildungssysteme tendenziell größeren Wert auf hohe Gehälter für Lehrkräfte legen, insbesondere in Ländern mit generell hohen Einkommen. Von den Ländern und Volkswirtschaften, deren BIP pro Kopf mehr als 20.000 US-Dollar beträgt, u.a. die meisten OECD-Länder, schneiden diejenigen, die den Lehrkräften mehr bezahlen (d. h. höhere Lehrergehälter im Verhältnis zum BIP pro Kopf), tendenziell besser in Mathematik ab. Die Korrelation zwischen diesen beiden Faktoren liegt für 33 Länder und Volkswirtschaften mit hohen Einkommen bei o, 3 o bzw. ohne Katar bei o,40. Dagegen besteht in den Ländern und Volkswirtschaften mit einem BIP pro Kopf von weniger als 20.000 US-Dollar kein Zusammenhang zwischen der Gesamtleistung des Bildungssystems und den Gehältern der Lehrkräfte, was möglicherweise darauf hinweist, dass eine Vielzahl von Ressourcen (die grundlegende Infrastruktur, die Unterrichtsmaterialien, das Verkehrssystem etc.) ebenfalls zu verbessern sind, bis sie ein Niveau erreichen, ab dem weitere materielle Verbesserungen nicht länger den Schülerleistungen zugutekommen, Verbesserungen im Bereich der Humanressourcen (beispielsweise in Form von höheren Lehrergehältern) jedoch schon.

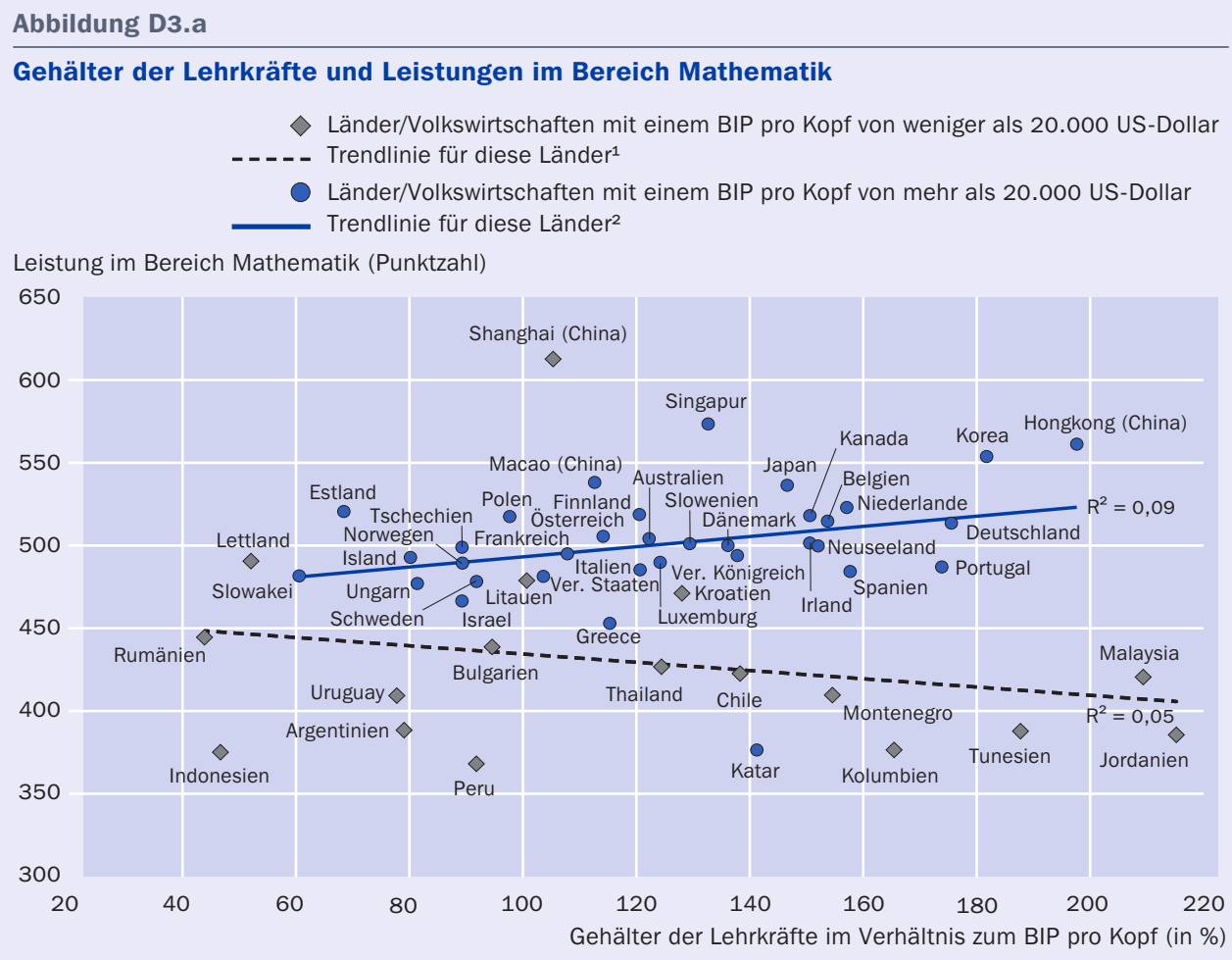

Anmerkung: Die Gehälter der Lehrkräfte im Verhältnis zum BIP pro Kopf beziehen sich auf den gewichteten Durchschnitt von Lehrkräften im Sekundarbereich I und II. Dieser Durchschnitt wird berechnet durch die Gewichtung der Gehälter der Lehrkräfte des Sekundarbereichs I und II aufgrund der entsprechenden Anzahl an 15-jährigen Schülern in dem jeweiligen Bildungsbereich (für Länder/Volkswirtschaften mit verfügbaren Informationen sowohl zum Sekundarbereich I als auch Sekundarbereich II). Die Abbildung zeigt nur Länder/Volkswirtschaften mit verfügbaren Daten

1. Die gestrichelte Linie zeigt einen nicht signifikanter Zusammenhang $(p>0,10)$. 2. Die durchgezogene Linie zeigt einen signifikanter Zusammenhang $(p<0,10)$.

Quelle: OECD (2013), PISA 2012 Results: What Makes Schools Successful? (Volume IV): Resources, Policies and Practices, PISA, OECD Publishing. StatLink: http://dx.doi.org/10.1787/888932957403 
In den meisten Ländern, deren Anfangsgehälter unter dem OECD-Durchschnitt liegen, sind auch die Höchstgehälter niedriger. Im Sekundarbereich I sind hier Frankreich, Japan, Korea und Mexiko die Ausnahme, wo die Anfangsgehälter mindestens 5 Prozent unter dem OECD-Durchschnitt liegen, die Höchstgehälter jedoch deutlich darüber. In Schottland liegen zwar die Anfangsgehälter fast Io Prozent unter dem OECD-Durchschnitt, die Höchstgehälter entsprechen jedoch dem OECD-Durchschnitt. Das Gegenteil trifft in Dänemark und Finnland zu, wo die Anfangsgehälter mindestens Io Prozent über dem OECD-Durchschnitt liegen, während die Höchstgehälter mindestens rund 5 Prozent unter diesem Wert liegen. In Australien und Norwegen liegen die Anfangsgehälter mindestens ıo Prozent über dem OECD-Durchschnitt, die Höchstgehälter hingegen im OECD-Durchschnitt. In Schweden liegen die Anfangsgehälter im OECD-Durchschnitt, die Höchstgehälter jedoch rund 25 Prozent unter dem OECD-Durchschnitt (Abb. D3.2 und Tab. D3.6 im Internet).

Eine Reihe von Ländern hat verhältnismäßig flache Gehaltsstrukturen. So beträgt der Unterschied zwischen dem Anfangsgehalt und dem Höchstgehalt in einigen Ländern weniger als 30 Prozent - in Dänemark (Elementar-, Primar- und Sekundarbereich I),

Abbildung D3.2

Gehälter von Lehrkräften im Sekundarbereich I zu unterschiedlichen Zeitpunkten der beruflichen Laufbahn (2012)

Gesetzliche bzw. vertraglich vereinbarte Jahresgehälter von Lehrkräften an öffentlichen Bildungseinrichtungen, in US-Dollar, kaufkraftbereinigt

Anfangsgehalt (mit Mindestausbildung)

$\triangle$ Gehalt nach 15 Jahren Berufserfahrung (mit Mindestausbildung)

In US-Dollar, kaufkraftbereinigt $\quad$ Höchstgehalt (mit maximaler Ausbildung)

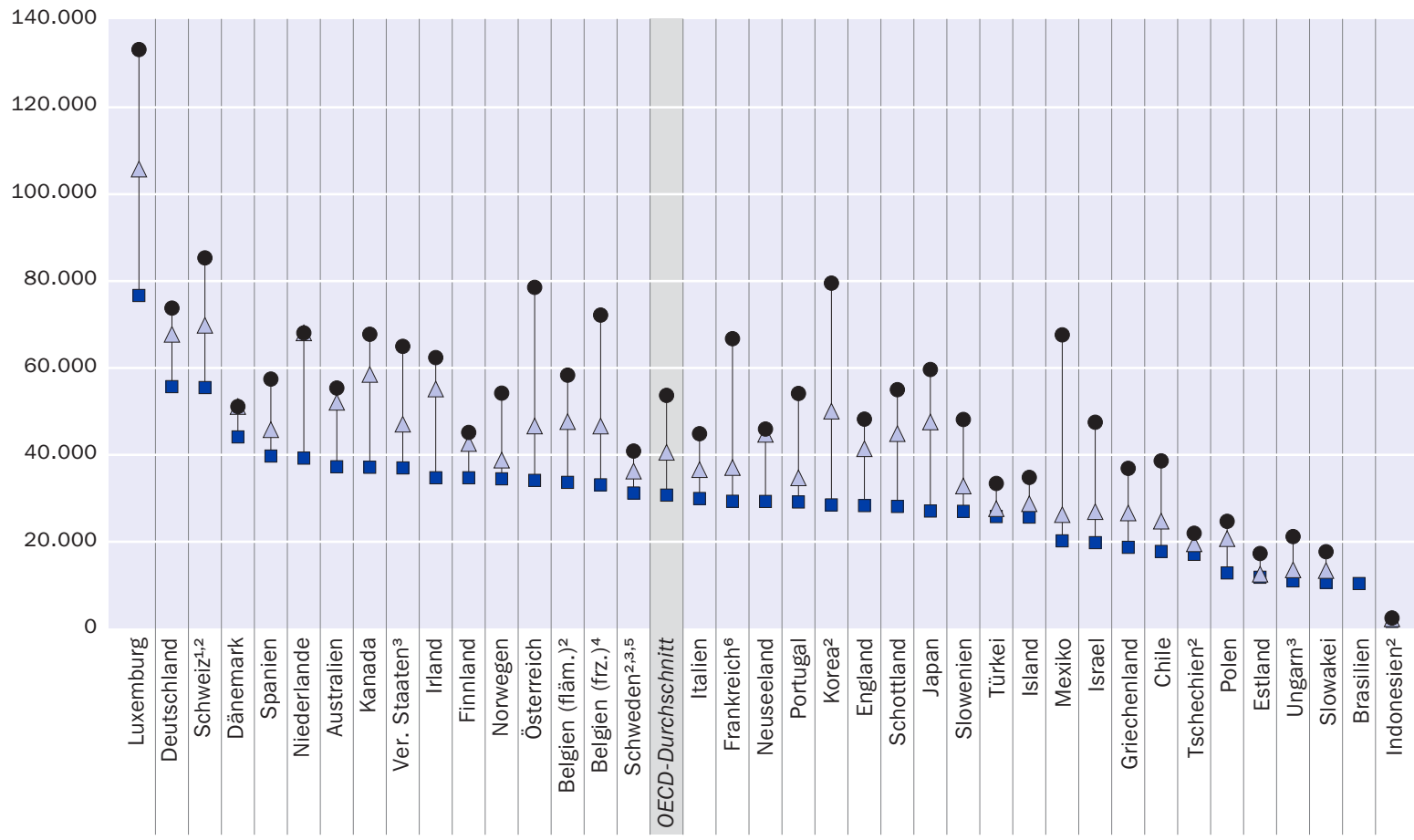

1. Gehälter nach 11 Jahren anstelle 15 Jahren Berufserfahrung. 2. Höchstgehalt bei Mindestausbildung anstelle maximaler Qualifikation. 3. Tatsächliche Grundgehälter. 4. Gehälter von Lehrkräften mit typischer Qualifikation anstelle der Mindestausbildung. $\quad$ 5. Referenzjahr $2011 . \quad 6$. Enthält durchschnittliche Bonuszahlungen für Überstunden. 
in Tschechien, in der Türkei (Sekundarbereich I und II) sowie in Finnland, Norwegen und Schweden (jeweils im Elementarbereich).

Aufgrund geringer finanzieller Anreize kann es in diesen Ländern schwieriger sein, Lehrkräfte zu binden, wenn diese sich der obersten Gehaltsstufe nähern. Komprimierte Gehaltsskalen können jedoch auch Vorteile haben. Es wird oft angeführt, dass für Organisationen mit niedrigeren internen Gehaltsunterschieden ein größeres Vertrauen, ein offenerer Informationsaustausch und mehr Kollegialität unter den Mitarbeitern charakteristisch sind.

Im Gegensatz dazu sind die Gehälter in einigen Ländern in der obersten Gehaltsstufe mindestens doppelt so hoch wie die Anfangsgehälter - in Chile, Israel, Korea und Österreich in allen Bildungsbereichen, in Belgien (frz.) im Elementar-, Primar- und Sekundarbereich I, in Frankreich im Sekundarbereich I und II, in Japan im Primar- und Sekundarbereich, in Polen im Elementar- und Primarbereich und in Ungarn im Sekundarbereich II. In Mexiko sind im Elementar-, Primar- und Sekundarbereich I die Höchstgehälter sogar mehr als dreimal höher als die Anfangsgehälter (Abb. D3.2 und Tab. D3.6 im Internet).

Auch die Gehaltszulage für eine höhere Qualifikation (in der obersten Gehaltsstufe) variiert zwischen den Ländern. Im Sekundarbereich I besteht in Io der 32 Länder, für die Daten für beide Qualifikationsstufen vorliegen, für Lehrkräfte in der obersten Gehaltsstufe kein Unterschied zwischen den Gehältern von Lehrkräften mit Mindestausbildung und Lehrkräften, die über die höchstmögliche Qualifikation verfügen. Lehrkräfte in der obersten Gehaltsstufe, die über die maximale Qualifikation verfügen, verdienen jedoch in Belgien (frz.), Frankreich, Israel, Norwegen und Slowenien mindestens 25 Prozent mehr als Lehrkräfte mit gleicher Berufserfahrung, die aber nur über die Mindestausbildung verfügen. Dieser Gehaltsunterschied reicht bis zu 57 Prozent in Mexiko. Ein ähnliches Bild zeigt sich im Sekundarbereich II (Tab. D3.I und Tab. D3.6 im Internet).

Bei der Analyse der Gehaltsstrukturen von Lehrkräften ist zu berücksichtigen, dass nicht alle Lehrkräfte die Spitze der Gehaltsskala erreichen und nur wenige von ihnen über die maximale Qualifikation verfügen. In Griechenland und Italien beispielsweise befanden sich 2012 weniger als 5 Prozent aller Lehrkräfte in der obersten Gehaltsstufe, und in Frankreich verfügen nur 5 Prozent aller Lehrkräfte im Sekundarbereich I über die maximale Qualifikation.

\section{Berufserfahrung und Gehaltsstufen}

In den Gehaltsskalen sind die Gehälter der Lehrkräfte zu unterschiedlichen Zeitpunkten in ihrer beruflichen Laufbahn festgelegt. Auch eine Entgeltumwandlung, die Mitarbeiter für den Verbleib in einem Unternehmen, einer Organisation bzw. die dauerhafte Zugehörigkeit zu einem bestimmten Berufsstand sowie für die Erfüllung festgesetzter Leistungskriterien belohnt, kann Bestandteil des Gehalts sein. Die OECDDaten über die Gehälter von Lehrkräften beschränken sich auf Angaben zu den gesetzlichen bzw. vertraglich vereinbarten Gehältern an vier Punkten der Gehaltsskala: die Anfangsgehälter, die Gehälter nach Io Jahren Berufserfahrung, nach I5 Jahren Berufserfahrung und die Höchstgehälter. Die in diesem Indikator untersuchten Gehäl- 
ter sind jeweils bezogen auf Lehrkräfte mit der für eine Lehrqualifikation erforderlichen Mindestausbildung. Wie oben erläutert, können weitere Qualifikationen in einigen Ländern zu zusätzlichen Gehaltssteigerungen führen.

In den OECD-Ländern steigen die Gehälter der Lehrkräfte im Verlauf ihres Berufslebens, wie schnell und in welchem Umfang dies jedoch geschieht, ist in den einzelnen Ländern unterschiedlich. Die gesetzlichen bzw. vertraglich vereinbarten Gehälter für Lehrkräfte mit Io und I5 Jahren Berufserfahrung im Sekundarbereich I sind im Durchschnitt um 24 bzw. 35 Prozent höher als die Anfangsgehälter. Außerdem liegen die Gehälter in der obersten Gehaltsstufe, die im Durchschnitt nach 24 Jahren Berufserfahrung erreicht wird, im Durchschnitt 6r Prozent über den Anfangsgehältern. In Israel, Italien, Korea, Spanien und Ungarn erreichen Lehrkräfte im Sekundarbereich I erst nach frühestens 35 Dienstjahren das Höchstgehalt, in Griechenland sogar erst nach 45 Dienstjahren. Im Gegensatz hierzu erreichen Lehrkräfte im Sekundarbereich I in Australien, Dänemark, Estland, Neuseeland und Schottland das Höchstgehalt nach 6 bis 9 Dienstjahren (Tab. D3.I und $\mathrm{D}_{3} \cdot 3$ ).

Während die Gehaltssteigerungen in rund der Hälfte der 3I OECD-Länder mit entsprechenden Daten gleichmäßig verlaufen, sind die Stufen der Gehaltsskala in den restlichen Ländern teilweise unterschiedlich groß.

\section{Gesetzliche bzw. vertraglich vereinbarte Gehälter pro Netto- Unterrichtszeitstunde}

Das durchschnittliche gesetzliche bzw. vertraglich vereinbarte Gehalt je Unterrichtszeitstunde mit I5 Jahren Berufserfahrung liegt im Primarbereich bei 50 US-Dollar, im Sekundarbereich I bei 59 US-Dollar und an allgemeinbildenden Schulen des Sekundarbereichs II bei 68 US-Dollar. Die Gehälter je Unterrichtszeitstunde sind in Chile, Estland, Indonesien, Mexiko (Primar- und Sekundarbereich I), Polen (Primarbereich), der Slowakei, Tschechien (Primarbereich) und Ungarn mit weniger als 30 US-Dollar am niedrigsten. Im Gegensatz dazu betragen die Gehälter je Unterrichtszeitstunde in Belgien, Dänemark, Japan und Korea im Sekundarbereich II sowie in Deutschland und den Niederlanden im Sekundarbereich I und II mehr als go US-Dollar. In Luxemburg betragen sie in allen Bildungsbereichen mehr als I20 US-Dollar (Tab. D3.3).

Da Lehrkräfte im Sekundarbereich weniger Zeitstunden unterrichten müssen als Lehrkräfte im Primarbereich, sind ihre Gehälter je Unterrichtszeitstunde in der Regel höher als in den vorgelagerten Bildungsbereichen, und zwar selbst in Ländern, in denen die gesetzlichen bzw. vertraglich vereinbarten Gehälter ähnlich hoch sind (s. Indikator D4). Im Durchschnitt der OECD-Länder liegt das Gehalt je Unterrichtszeitstunde für eine Lehrkraft im Sekundarbereich II um 32 Prozent über dem einer Lehrkraft im Primarbereich. In Schottland besteht kein Unterschied, während in Dänemark das Gehalt von Lehrkräften im Sekundarbereich II je Unterrichtszeitstunde doppelt so hoch wie das Gehalt von Lehrkräften im Primarbereich ist (Tab. D3·3).

Der Gehaltsunterschied zwischen Lehrkräften im Primar- und Sekundarbereich bleibt bei einem Vergleich der Gehälter pro Arbeitszeitstunde jedoch nicht unbedingt bestehen. So unterscheiden sich beispielsweise in Portugal die Gehälter der Lehrkräfte pro Unterrichtszeitstunde im Primarbereich um 23 Prozent von denen im Sekundarbe- 
reich II, obwohl die gesetzlichen bzw. vertraglich vereinbarten Gehälter und Gesamtarbeitszeiten in beiden Bereichen dieselben sind. Der Unterschied erklärt sich aus der Tatsache, dass Lehrkräfte an Schulen im Primarbereich mehr Zeit mit unterrichtenden Tätigkeiten verbringen als Lehrkräfte an Schulen im Sekundarbereich II (s. Tab. D4.I).

\section{Entwicklungen seit 2000}

Zwischen 2000 und 2012 war in den meisten Ländern mit verfügbaren Daten insgesamt ein realer Anstieg der Lehrergehälter zu beobachten. Bemerkenswerte Ausnahmen sind hier Frankreich, Griechenland und Japan, wo die Gehälter der Lehrkräfte während dieser Zeit real um rund ro Prozent sanken. In Estland, Tschechien und der Türkei (Primar- und Sekundarbereich II) stiegen die Gehälter in diesem Zeitraum um mindestens 50 Prozent (Tab. D3.5).

Zwischen 2005 und 2012 gab es jedoch nur in knapp mehr als der Hälfte der OECDLänder mit verfügbaren Daten einen realen Anstieg der Lehrergehälter, und in den meisten Ländern stiegen die Gehälter ab 2005 weniger als zwischen 2000 und 2005. Ausnahmen sind Belgien (frz., Sekundarbereich), Dänemark (Primar- und Sekundarbereich I), Estland, Israel und Mexiko (Primar- und Sekundarbereich I) sowie Neuseeland, wo der stärkste Anstieg der Gehälter von Lehrkräften nach 2005 erfolgte. In Polen stiegen die Gehälter in allen Bildungsbereichen ebenfalls seit 2005 um mindestens 20 Prozent. Dies ist die Folge eines staatlichen Programms aus dem Jahr 2007, das

Abbildung D3.3

Veränderungen der Gehälter von Lehrkräften im Sekundarbereich I (2000, 2005, 2012)

Index der Veränderung zwischen 2000 und 2012 (2005=100, zu konstanten Preisen), für Lehrkräfte mit 15 Jahren Berufserfahrung (mit Mindestausbildung)

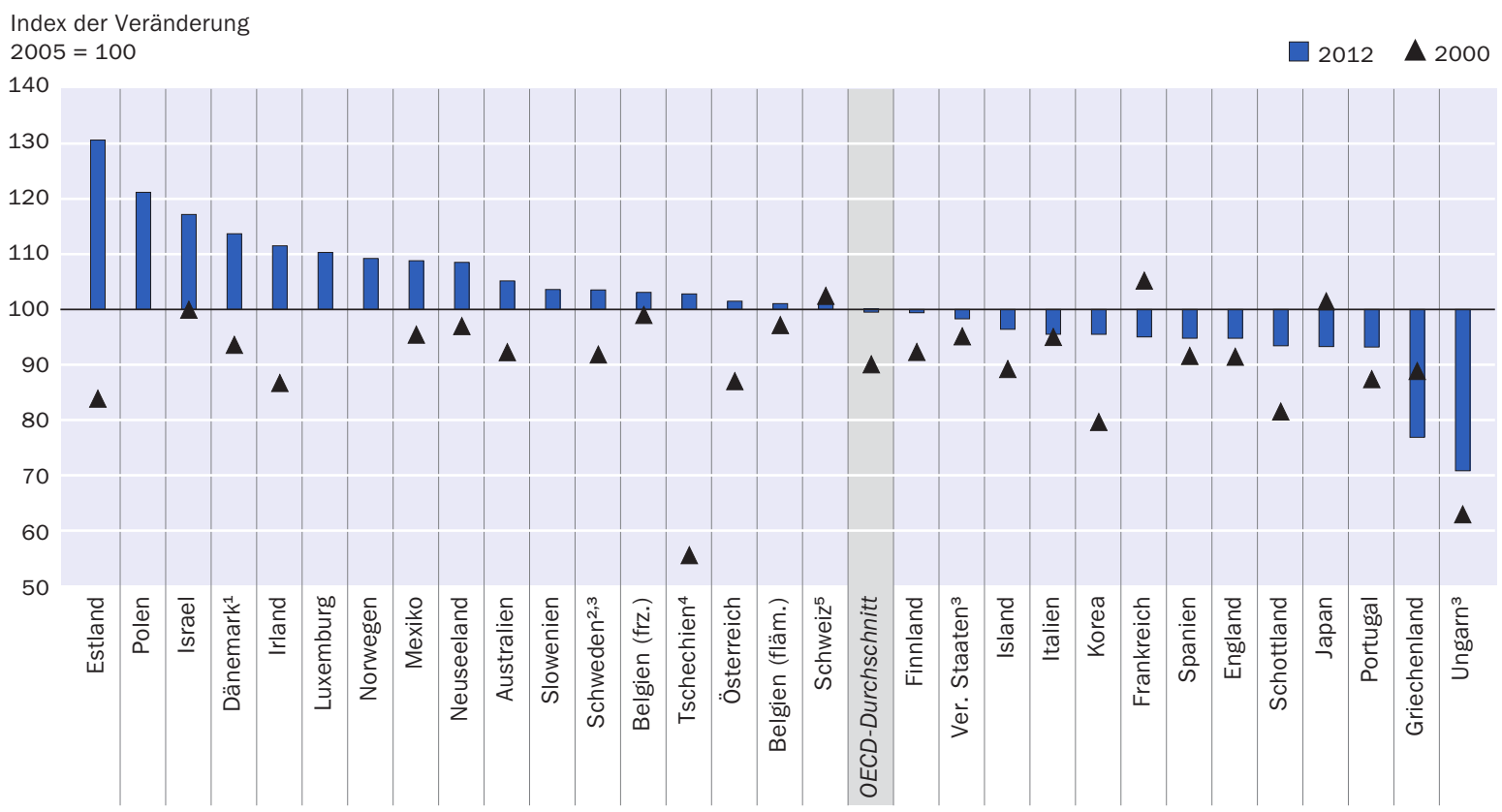

1. Unterbrechung der Zeitreihe im Jahr 2009 aufgrund von Veränderungen in der Methodik. 2. Referenzjahr 2011 anstelle $2012 . \quad 3$. Tatsächliche Grundgehälter. 4. Unterbrechung der Zeitreihe im Jahr 2012 aufgrund von Veränderungen in der Methodik. 5. Gehälter nach 11 Jahren Berufserfahrung.

Anordnung der Länder in absteigender Reihenfolge des Index der Veränderung zwischen 2005 und 2012 der Gehälter von Lehrkräften mit 15 Jahren Berufserfahrung im Sekundarbereich I.

Quelle: OECD. Tabelle D3.5. Hinweise s. Anhang 3 unter www.oecd.org/edu/eag.htm. StatLink: http://dx.doi.org/10.1787/888933119967 
darauf abzielte, die Lehrergehälter zwischen 2008 und 2012 schrittweise anzuheben. Ziel der Reform war es, durch finanzielle Anreizprogramme hoch qualifizierte Lehrer anzuwerben und so die Qualität der Bildung zu verbessern.

In Griechenland und Ungarn dagegen sind die Gehälter seit 2005 um mindestens 20 Prozent gesunken (Abb. D3.3), hauptsächlich jedoch zwischen den Jahren 2008 und 20I2. Dies spiegelt die Auswirkungen der Wirtschaftskrise 2008 auf die Gehälter von Lehrkräften wider - zwischen 2008 und 2012 wurden sie in diesen Ländern entweder eingefroren oder gekürzt (s. Kasten D3.2). Die Zahl der Länder, in denen die Gehälter real stiegen, sank zwischen 2008 und 2012 auf weniger als die Hälfte der OECD-Länder. In England, Estland, Schottland und Spanien sanken die Gehälter zwischen 2008 und 2012 um mindestens 5 Prozent, in Tschechien im gleichen Zeitraum um mindestens Io Prozent.

Obige Analyse der Entwicklungstendenzen bei den Gehältern beruht auf den Gehältern von Lehrkräften mit I5 Jahren Berufserfahrung (eine Näherungsgröße für Lehrkräfte in der Mitte der beruflichen Laufbahn); an bestimmten Punkten der beruflichen Laufbahn als Lehrkraft können die Gehälter jedoch schneller ansteigen als an anderen. Länder, in denen ein Mangel an Lehrkräften herrscht, können beispielsweise die Anfangsgehälter für Lehrkräfte anheben, um durch derartig gezielte Maßnahmen die Attraktivität des Lehrerberufs zu erhöhen (OECD, 2005). In Frankreich beispielsweise wurden die Anfangsgehälter von Lehrkräften 2010 und 201 I angehoben.

Kasten D3.2

\section{Auswirkungen der Wirtschaftskrise}

Die Wirtschafts- und Finanzkrise, die die Weltwirtschaft gegen Ende des Jahres 2008 traf, hatte signifikante Auswirkungen auf die Gehälter von Beamten und Beschäftigten des öffentlichen Dienstes insgesamt. Der Druck, zur Reduzierung der Staatsschulden die staatlichen Ausgaben zu kürzen, führte in immer mehr Ländern zu Einschnitten bei den Gehältern von Lehrkräften und anderen Beschäftigten im öffentlichen Dienst. Im Durchschnitt der OECD-Länder mit verfügbaren Daten gingen die Gehälter von Lehrkräften zwischen 2009 und 2012 in allen Bildungsbereichen zum ersten Mal seit 2000 um rund 5 Prozent zurück.

So wirkte sich die Wirtschaftskrise beispielsweise in England, Estland, Griechenland, Irland, Italien, Portugal, Schottland, Spanien und Ungarn signifikant auf die Gehälter der Lehrkräfte aus. In Estland wurden die Mindestgehälter von Lehrkräften im Jahr 2010 auf das Niveau von 2008 gekürzt und auf diesem Niveau eingefroren. In Griechenland waren die Gehälter von Lehrkräften 20I0, 2011 und 2012 von verschiedenen Kürzungen bei den Zusatzleistungen und Zulagen betroffen. Als Ergebnis sanken die Bruttogehälter zwischen 2009 und 2012 real um rund 25 Prozent. Zusätzlich gingen in Griechenland durch die Einführung einer Solidaritätssteuer auch die Nettogehälter der Lehrkräfte zurück. Diese Steuer erhöhte die steuerliche Belastung der ohnehin schon geringeren Bruttogehälter der Lehrkräfte, darüber hinaus werden die von den Lehrkräften zu entrichtenden Versicherungsbeiträge noch immer anhand der früheren höheren Gehälter berechnet. In Ungarn wurde 
2009 das I3. Monatsgehalt (ein Bonus, der allen Beschäftigten gezahlt wurde) ausgesetzt. Auch wenn allen Beschäftigten des öffentlichen Dienstes, deren Gehalt unter einem bestimmten Einkommensniveau lag, eine Ausgleichszulage gezahlt wurde, war doch das Grundgehalt der Lehrkräfte immer noch stark betroffen. Der weitere Rückgang der Gehälter der Lehrkräfte im Jahr 2012 liegt an der Kürzung von Zusatzvergütungen, z. B. für zusätzliche Unterrichtsstunden. Diese Zusatzvergütungen waren ein wichtiger Bestandteil der Gesamtvergütung der Lehrkräfte, die zusätzlich zum Grundgehalt gezahlt wurden. 2012 sanken diese Zusatzvergütungen im Sekundarbereich I weniger stark als im Sekundarbereich II.

\section{Abbildung D3.b}

Veränderungen der Gehälter von Lehrkräften in den OECD-Ländern (2005-2012)

OECD-Durchschnitt (von Ländern mit verfügbaren Daten für alle Referenzjahre) des Index der Veränderung für Lehrkräfte mit 15 Jahren Berufserfahrung (mit Mindestausbildung) (2005 $=100$, zu konstanten Preisen)

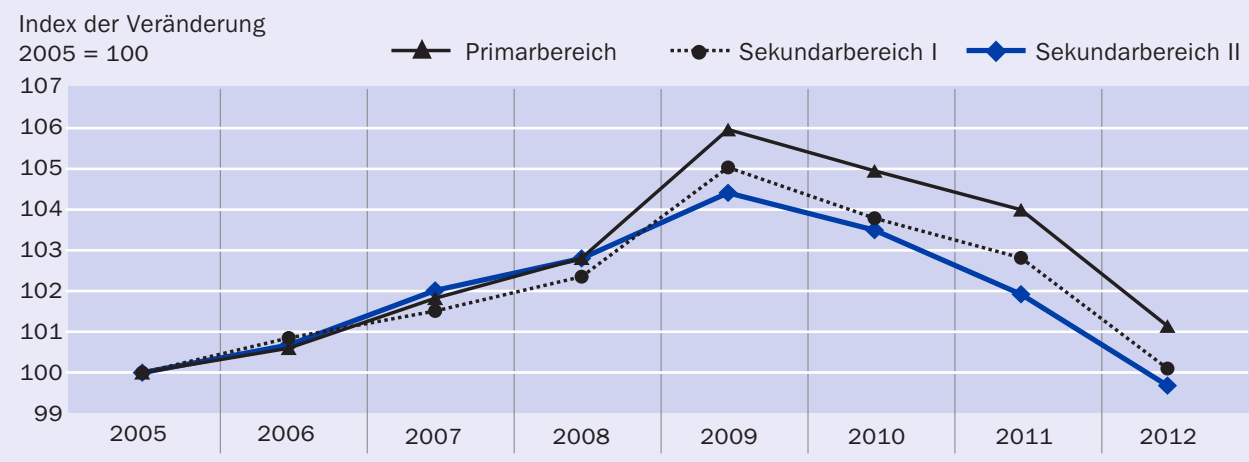

Quelle: OECD. Tabelle D3.5. Hinweise s. Anhang 3 unter www.oecd.org/edu/eag.htm StatLink: $h$ ttp://dx.doi.org/10.1787/888933119986

In Spanien mussten alle Beamten im Juli 20Io Einschnitte bei den Gehältern hinnehmen. Die Höhe dieser Einschnitte war vom Jahresgehalt abhängig, betraf aber sowohl das Grundgehalt als auch die Zulagen. In Irland wurden die Gehälter der Lehrkräfte im Rahmen einer Gehaltsreduzierung für den gesamten öffentlichen Dienst ab dem I. Januar 2oro gesenkt. Darüber hinaus werden Lehrkräfte, die ihre Tätigkeit nach dem I. Januar 20 II aufgenommen haben, nach einer neuen Gehaltsskala bezahlt, die mehr als ıo Prozent niedriger ist als diejenige für Lehrkräfte, die vor diesem Stichtag eingestellt wurden. In Portugal wurden 2oII Gehälter über I.500 Euro als Teil eines Reformpakets mittels einer in einem neuen Gesetz definierten Methode gekürzt. 2012 sanken die Gehälter erneut, da Beamten nur noch I 2 statt wie bisher I4 Monatsgehälter gezahlt wurden.

In England wurden aufgrund der Finanzkrise zwischen 201 I und 2012 die Gehälter von Lehrkräften in allen Bildungsbereichen eingefroren. Im Jahr darauf folgte eine Anhebung für den gesamten öffentlichen Dienst, die jedoch mit I Prozent unterhalb der Inflationsrate blieb. Da die Lehrkräfte einer dreijährigen Gehaltsvereinbarung unterlagen, wurden ihre Gehälter später eingefroren als die Gehälter anderer Beschäftigter im öffentlichen Dienst. Das Scottish Negotiating Committee for Teachers (SNCT) stimmte ebenfalls einem Gehaltsstopp für die Lehrkräfte von April 20II bis März 2013 zu. In Schottland sind Lehrkräfte zwar nicht als Beamte eingestuft, diese Vereinbarung entsprach jedoch dem Einfrieren der Löhne und Gehälter, die Beamte in Schottland hinnehmen mussten. 
In Italien wurden die Lehrergehälter ab $201 \mathrm{I}$ eingefroren. Dieses Einfrieren von Gehältern betraf alle Beamten, einschließlich der Lehrkräfte, und wurde eingeführt als Reaktion auf die internationale Wirtschaftslage und um die von der EU vorgegebenen Haushaltsziele zu erreichen.

Die Wirtschaftskrise könnte sich auch auf das Angebot an Lehrkräften auswirken. Ganz allgemein lässt sich sagen, dass in Zeiten schwacher Konjunktur bei hoher Akademikererwerbslosigkeit und nur niedrigen Akademikergehältern die Arbeit als Lehrkraft für Hochschulabsolventen attraktiver erscheinen könnte als andere Berufe (OECD, 2005).

In den meisten Ländern waren die Steigerungen bzw. Kürzungen der Gehälter der Lehrkräfte im Primar- und Sekundarbereich (I und II) in etwa gleich hoch. In Israel und Luxemburg jedoch stiegen zwischen 2005 und 2012 die Gehälter der Lehrkräfte im Primarbereich deutlich stärker als im Sekundarbereich. In beiden Ländern ist der Unterschied beim Index der Veränderung zwischen den Gehältern von Lehrkräften im Primar- und im Sekundarbereich auf Reformen zurückzuführen, durch die die Gehälter von Lehrkräften im Primarbereich angehoben werden sollten. In Israel war dies hauptsächlich die schrittweise Einführung der „Neue Horizonte“ überschriebenen Reform im Primar- und Sekundarbereich I, die 2008 begann und das Ergebnis einer Vereinbarung zwischen den Bildungsbehörden und der israelischen Lehrergewerkschaft (des Primar- und Sekundarbereichs I) war. Diese Reform verbindet u. a. höhere Gehälter der Lehrkräfte mit längeren Arbeitszeiten (s. Indikator D4). 2012 betraf diese Reform 7I Prozent der vollzeitäquivalenten Lehrkräfte im Elementarbereich, 88 Prozent derjenigen im Primarbereich und 33 Prozent derjenigen im Sekundarbereich I. Im selben Jahr vereinbarte die Regierung mit der Gewerkschaft der Lehrkräfte im Sekundarbereich II ein ähnliches Programm für den Sekundarbereich II. Da diese Reformen noch nicht vollständig umgesetzt sind, ist davon auszugehen, dass auch die Gehälter im Sekundarbereich I und II noch signifikant ansteigen werden.

\section{Die tatsächlichen Durchschnittsgehälter von Lehrkräften}

Die in diesem Indikator von den meisten Ländern angegebenen gesetzlichen bzw. vertraglich vereinbarten Gehälter sind zu unterscheiden sowohl von den tatsächlichen Ausgaben für Gehälter, die von staatlicher Seite zu leisten sind, als auch von den tatsächlichen Durchschnittsgehältern der Lehrkräfte, die auch durch andere Faktoren beeinflusst werden, wie z. B. die Berufserfahrung der Lehrerschaft und die Existenz von Bonuszahlungen und Zulagen im Vergütungssystem.

Bonuszahlungen und Zulagen können eine erhebliche Ergänzung des Grundgehalts darstellen. In der Slowakei erhalten beispielsweise die meisten Lehrkräfte monatliche Bonuszahlungen aufgrund individueller Leistungsbewertungen. Je nach Finanzausstattung der Schule und der Bewertung der einzelnen Lehrkraft kann das durchschnittliche Gehalt der Lehrkräfte in diesem Land einschließlich dieser Bonuszahlungen das Doppelte des Grundgehalts betragen.

Bei einem Vergleich der tatsächlichen Jahresgehälter aller 25- bis 64-jährigen Lehrkräfte mit den gesetzlichen bzw. vertraglich vereinbarten Gehältern bei I5 Jahren Berufser- 


\section{Zusatzvergütungen: Anreizprogramme und Zulagen}

Zusätzlich zu den allgemeinen Gehaltsgruppen kommen im Bildungswesen in zunehmendem Maße Regelungen für Zusatzvergütungen und sonstige Formen der besonderen Anerkennung für Lehrkräfte zum Einsatz. In Verbindung mit dem Anfangsgehalt können solche zusätzlichen Vergütungen die Entscheidung beeinflussen, den Lehrerberuf zu ergreifen bzw. ihn langfristig auszuüben. Während bisher noch keine Daten zur Höhe derartiger Zahlungen erfasst wurden, liegen Angaben zu den möglichen Zusatzvergütungen vor und auf welcher Ebene über ihre Gewährung entschieden wird (s. Tab. $\mathrm{D}_{3} .7 \mathrm{a}, \mathrm{D}_{3} .7 \mathrm{~b}, \mathrm{D}_{3} .7 \mathrm{c}$ und $\mathrm{D}_{3.7} \mathrm{~d}$ im Internet sowie Anhang 3 unter www.oecd.orgleduleag2013).

Zusatzvergütungen werden meistens aufgrund besonderer Aufgaben oder Arbeitsbedingungen gewährt, wie z. B. das Unterrichten an stärker benachteiligten Schulen, insbesondere an Schulen in sehr armen Vierteln, oder an Schulen mit einem hohen Anteil von Schülern, die zu Hause nicht die Unterrichtssprache sprechen. Diese Schulen haben häufig Schwierigkeiten bei der Anwerbung von Lehrkräften, und oft unterrichten an diesen Schulen auch weniger erfahrene Lehrkräfte (OECD, 2005). Die meisten Länder gewähren Zusatzvergütungen für die Übernahme von Managementaufgaben zusätzlich zu Unterrichtsverpflichtungen; rund zwei Drittel der OECD-Länder gewähren diese Zusatzvergütungen, die jährlich gezahlt werden. Rund zwei Drittel der Länder bieten Zusatzvergütungen für das Unterrichten in stärker benachteiligten Gebieten. Die Hälfte der OECD-Länder bieten Zusatzvergütungen für besondere Aktivitäten, wie z. B. Sport- oder Theater-AGs, oder das Unterrichten von Kindern mit besonderen Lernbedürfnissen an Regelschulen.

Auch Zusatzvergütungen für Lehrkräfte aufgrund von Qualifikationen, Ausbildung und Leistung der Lehrkräfte sind in den OECD-Ländern sehr verbreitet. Die häufigsten Zusatzvergütungen sind Vergütungen für eine Erstausbildung und/oder eine Qualifikation, die über die für den Lehrberuf erforderlichen Mindestanforderungen hinausgeht. In rund 8o Prozent der Länder werden derartige Zusatzvergütungen gewährt, wobei es in etwa zwei Drittel der Länder beide Arten der Zusatzvergütung gibt. Außerdem bieten 2I der OECD-Länder mit verfügbaren Daten Zusatzvergütungen für Lehrkräfte mit herausragenden Leistungen. In 17 dieser Länder kann der Schulleiter über ihre Gewährung entscheiden.

In der Hälfte aller OECD-Länder gibt es Zusatzvergütungen aufgrund demografischer Merkmale der Lehrkräfte (Familienstand oder Alter), meistens handelt es sich hierbei um jährliche Zahlungen.

fahrung zeigt sich, dass in Chile, Estland (Primar- und Sekundarbereich), Frankreich (Sekundarbereich II), Island (Sekundarbereich II), Israel (Sekundarbereich), Norwegen (Primar- und Sekundarbereich I), Polen (Elementar-, Primar- und Sekundarbereich I) und Ungarn (Primar- und Sekundarbereich) die durchschnittlichen tatsächlichen Gehälter, einschließlich Bonuszahlungen und Zulagen, mindestens 20 Prozent höher als die gesetzlichen bzw. vertraglich vereinbarten Gehälter für Lehrkräfte mit I5 Jahren 
Berufserfahrung sind. Im Gegensatz dazu sind die durchschnittlichen tatsächlichen Gehälter von 25- bis 64-jährigen Lehrkräften in Belgien (frz., Sekundarbereich II), Griechenland, Luxemburg (Elementar- und Primarbereich), den Niederlanden und Schottland um mindestens 5 Prozent niedriger als die gesetzlichen bzw. vertraglich vereinbarten Gehälter für Lehrkräfte mit I5 Jahren Berufserfahrung (Tab. D3.I und D3.4).

In einigen Ländern variieren die durchschnittlichen tatsächlichen Gehälter von Lehrkräften zwischen den einzelnen Bildungsbereichen stärker als die durchschnittlichen gesetzlichen bzw. vertraglich vereinbarten Gehälter für Lehrkräfte mit I5 Jahren Berufserfahrung. In England, Finnland, Norwegen und Tschechien ist der Unterschied zwischen den durchschnittlichen tatsächlichen Gehältern von Lehrkräften im Sekundarbereich II und den durchschnittlichen tatsächlichen Gehältern von Lehrkräften im Elementarbereich um mindestens ıo Prozentpunkte höher als die Differenz zwischen den jeweiligen gesetzlichen bzw. vertraglich vereinbarten Gehältern. In Frankreich beträgt der Unterschied zwischen den tatsächlichen Gehältern von Lehrkräften im Elementar- und im Sekundarbereich II fast 30 Prozent, der Unterschied der jeweiligen gesetzlichen bzw. vertraglich vereinbarten Gehälter beläuft sich jedoch nur auf Io Prozent. In Israel liegen die gesetzlichen bzw. vertraglich vereinbarten Gehälter von Lehrkräften im Sekundarbereich II um mehr als ıo Prozent unter denen von Lehrkräften des Elementarbereichs, bei den durchschnittlichen tatsächlichen Gehältern ist es jedoch genau umgekehrt: Lehrkräfte des Sekundarbereichs II erhalten im Durchschnitt Io Prozent mehr als Lehrkräfte des Elementarbereichs. In Polen und Norwegen sind die gesetzlichen bzw. vertraglich vereinbarten Gehälter im Elementar- und Primarbereich zwar ähnlich, dennoch unterscheiden sich die durchschnittlichen tatsächlichen Gehälter um rund I5 Prozent. Das Gegenteil trifft auf die Gehälter der Lehrkräfte im Primar- und im Sekundarbereich II in Polen zu - dort sind die tatsächlichen Gehälter zwar ähnlich hoch, die gesetzlichen bzw. vertraglich vereinbarten Gehälter unterscheiden sich jedoch um fast 15 Prozent. Die Bandbreite der Bonuszahlungen in den einzelnen Bildungsbereichen kann diese Unterschiede teilweise erklären (s. Anhang 3 unter www.oecd.orgleduleag.htm).

Kasten D3.4

\section{Tatsächliche Durchschnittsgehälter von Lehrkräften, nach Altersgruppe und Geschlecht}

Im Allgemeinen liegen die tatsächlichen Gehälter von 25- bis 64-jährigen Lehrkräften im Durchschnitt bei 38.253 US-Dollar im Elementarbereich, 4I.300 US-Dollar im Primarbereich, 43.374 US-Dollar im Sekundarbereich I und 47.I65 US-Dollar im Sekundarbereich II. Die Gehaltssteigerungen innerhalb eines Bildungsbereichs ergeben für unterschiedliche Altersgruppen sowie für Männer und Frauen innerhalb der Altersspanne von 25 bis 64 Jahren ein ähnliches Bild.

Die tatsächlichen Gehälter älterer (55- bis 64-jähriger) Lehrkräfte sind im Durchschnitt im Elementarbereich um 3I Prozent, im Primarbereich um 33 Prozent, im Sekundarbereich I um 35 Prozent und im Sekundarbereich II um 38 Prozent höher als die tatsächlichen Gehälter jüngerer (25-bis 34-jähriger) Lehrkräfte. 
Werden die Gehälter der Lehrkräfte im Vergleich zu den Gehältern von 25- bis 64-jährigen ganzjährig Vollzeitbeschäftigten mit einem Abschluss im Tertiärbereich nach Alter aufgeschlüsselt, variiert das Verhältnis je nach Altersgruppe. Die relativen Gehälter der Lehrkräfte sind bei der jüngsten Altersgruppe (25- bis 34-Jährige) höher als bei den älteren Altersgruppen. Dieses Verhältnis ist bei den 25- bis 34-jährigen Lehrkräften mindestens 4 Prozentpunkte (Sekundarbereich II) bis 8 Prozentpunkte (Elementarbereich) höher als das Verhältnis bei den $55^{-}$bis 64 -jährigen Lehrkräften. Dieses höhere Verhältnis bei der jüngsten Altersgruppe im Vergleich zu anderen Altersgruppen ist ein Hinweise auf die Attraktivität des Lehrerberufs. Das könnte ein Beleg dafür sein, dass die Gesamtvergütung für Berufseinsteiger relativ große Zulagen und Zusatzvergütungen enthält. Mit zunehmendem Alter geht dieses Verhältnis jedoch zurück, was darauf hindeutet, dass die Gehälter der Lehrkräfte langsamer steigen als die anderer Berufstätiger und dass die Gehälter anderer, ähnlich ausgebildeter Arbeitskräfte mit fortschreitendem Alter attraktiver werden.

Ein Vergleich der tatsächlichen Gehälter von Lehrerinnen und Lehrern zeigt, dass die Lehrerinnen im Durchschnitt im Elementarbereich etwas mehr und im Primar-, und Sekundarbereich I und II etwas weniger verdienen als ihre männlichen Kollegen. Der Unterschied zwischen den jeweiligen tatsächlichen Gehältern beträgt jedoch weniger als 3 Prozent.

Größere geschlechtsspezifische Unterschiede zeigen sich jedoch, wenn man das Verhältnis zwischen den Gehältern von Lehrkräften und den Gehältern von 25bis 64 -jährigen Beschäftigten mit einem Abschluss im Tertiärbereich betrachtet. Im Durchschnitt über alle Bildungsbereiche hinweg verdienen 25- bis 64 -jährige männliche Lehrkräfte weniger als 85 Prozent des Gehalts eines 25- bis 64 -jährigen ganzjährig vollzeitbeschäftigten Mannes mit einem Abschluss im Tertiärbereich. Weibliche 25 - bis 64 -jährige Lehrkräfte verdienen mehr als 85 Prozent (im Elementarbereich) bis zu I03 Prozent (Sekundarbereich II) dieses Vergleichswertes. Dieses höhere Verhältnis bei den weiblichen Lehrkräfte spiegelt die immer noch bestehenden geschlechtsspezifischen Einkommensunterschiede im Arbeitsmarkt wider, die jedoch nicht für den Lehrerberuf gelten, weshalb dieser Beruf im Vergleich zu anderen für Frauen besonders attraktiv ist (Tab. D3.2 und D3.4).

\section{Die Gehälter von Lehrkräften im Vergleich zu Gehältern von Erwerbstätigen mit einem Abschluss im Tertiärbereich}

Die Neigung junger Menschen, eine Ausbildung zur Lehrkraft aufzunehmen, sowie ausgebildeter Lehrkräfte, die Lehrtätigkeit auch wirklich aufzunehmen bzw. langfristig auszuüben, wird auch dadurch beeinflusst, in welchem Verhältnis die Gehälter der Lehrkräfte zu denen anderer Berufe stehen, die eine ähnlich hohe Qualifikation erfordern, und welche Gehaltssteigerungen zu erwarten sind. In allen OECD-Ländern ist für die Tätigkeit als Lehrkraft ein Abschluss im Tertiärbereich erforderlich (s. Indikator D6 ), daher ist die wahrscheinliche Alternative zu einer Ausbildung zur Lehrkraft ein anderer Studiengang im Tertiärbereich. Um das Gehaltsniveau in verschiedenen Ländern - bei vergleichbaren Ausgangsbedingungen auf dem Arbeitsmarkt - zu interpretieren, werden daher die Gehälter der Lehrkräfte mit denen anderer Berufstätiger 
mit vergleichbarem Bildungsstand verglichen, und zwar mit 25- bis 64-jährigen ganzjährig Vollzeitbeschäftigten mit einem Abschluss im Tertiärbereich.

Die Gehälter von Lehrkräften im Elementarbereich liegen im Durchschnitt bei 8o Prozent der Gehälter von 25- bis 64-jährigen ganzjährig Vollzeitbeschäftigten mit einem Abschluss im Tertiärbereich, im Primarbereich bei 85 Prozent, im Sekundarbereich I bei 88 Prozent und im Sekundarbereich II bei 92 Prozent dieses Vergleichswerts. Im Sekundarbereich II verdienen Lehrkräfte in I2 der 32 Länder mit verfügbaren Daten mindestens ebenso viel wie andere Beschäftigte mit einem Abschluss im Tertiärbereich. Die relativen Gehälter der Lehrkräfte sind in Korea, Luxemburg (Sekundarbereich I und II), Portugal und Spanien am höchsten; dort sind die Gehälter der Lehrkräfte mindestens 20 Prozent höher als die von Beschäftigten mit einem vergleichbaren Abschluss. Die niedrigsten relativen Gehälter für Lehrkräfte im Vergleich zu Gehältern anderer Berufstätiger mit vergleichbarem Bildungsabschluss finden sich in der Slowakei (alle Bildungsbereiche) und in Tschechien und Ungarn im Elementarbereich, wo sich die Gehälter für Lehrkräfte im Durchschnitt auf weniger als 50 Prozent der Gehälter von ganzjährig Vollzeitbeschäftigten mit einem Abschluss im Tertiärbereich belaufen (Tab. D3.2 und Abb. D3.I).

\section{Definitionen}

Die tatsächlichen Gehälter von 25- bis 64-jährigen Lehrkräften beziehen sich auf das durchschnittliche Jahresgehalt, das 25 - bis 64 -jährige vollzeitbeschäftigte Lehrkräfte vor Steuern erhalten. Hierzu gehören tätigkeitsbezogene Zahlungen wie jährliche Bonuszahlungen, ergebnisabhängige Bonuszahlungen, Urlaubsgeld und Lohnfortzahlung im Krankheitsfall. Einkommen aus anderen Quellen, wie staatliche Transferzahlungen, Kapitalerträge und andere nicht direkt mit der beruflichen Tätigkeit in Verbindung stehende Einkommensarten, sind nicht erfasst.

Zulagen zum Grundgehalt sind definiert als jegliche Abweichung beim Gehalt zwischen dem, was eine bestimmte Lehrkraft als Einkommen für die an der Schule geleistete Arbeit tatsächlich bezieht, und dem Betrag, der ausschließlich aufgrund der Erfahrung (d. h. der Anzahl der Berufsjahre als Lehrkraft) gewährt werden würde. Zulagen können dauerhaft oder zeitlich befristet sein und dazu führen, dass eine Lehrkraft in den „außertariflichen Bereich“, in eine andere Gehaltskala oder auf die nächsthöhere Gehaltsstufe derselben Gehaltsskala gelangt.

Die Gehälter von Beschäftigten mit einem Abschluss im Tertiärbereich sind die durchschnittlichen Gehälter von 25- bis 64-jährigen ganzjährig Vollzeitbeschäftigten mit einem Abschluss auf ISCED-Stufe $5 \mathrm{~A} / 5 \mathrm{~B} / 6$. Der Indikator zu den relativen Gehältern ist für das jüngste Jahr berechnet, für das Daten zu den Gehältern vorliegen. Bei Ländern, für die Daten zu den Gehältern von Lehrkräften und von anderen Beschäftigten nicht für dasselbe Jahr vorliegen (z. B. Belgien, Frankreich, Italien, die Niederlande, Norwegen, Schweden und Tschechien), wurde der Indikator mittels der Deflatoren für den privaten Konsum inflationsbereinigt. Die Referenzstatistiken für die Einkommen von Beschäftigten mit einem Abschluss im Tertiärbereich sind in Anhang 3 aufgeführt. 
Gehälter mit 15 Jahren Berufserfahrung beziehen sich auf das reguläre Jahresgehalt einer Vollzeitlehrkraft mit der für eine Lehrerqualifikation erforderlichen Mindestausbildung und ${ }_{5}$ Jahren Berufserfahrung.

Anfangsgehälter beziehen sich auf das durchschnittliche reguläre Bruttojahresgehalt einer Vollzeitlehrkraft am Anfang der Lehrerlaufbahn mit der für eine Lehrerqualifikation erforderlichen Mindestausbildung; Höchstgehälter dagegen beziehen sich auf das maximale Jahresgehalt (an der Spitze der Gehaltsskala) einer Vollzeitlehrkraft mit der maximal in Bezug auf das Gehalt anerkannten Qualifikation.

Gesetzliche bzw. vertraglich vereinbarte Gehälter beziehen sich auf reguläre Gehälter gemäß offiziellen Gehaltsskalen. Die angegebenen Gehälter sind Bruttogehälter (die vom Arbeitgeber für die Arbeit bezahlte Gesamtsumme) abzüglich der Arbeitgeberbeiträge zur Sozial- und Rentenversicherung (entsprechend den gültigen Gehaltsskalen). Die Gehälter werden vor Steuer, d.h. vor Abzug der Einkommensteuer, angegeben. In Tabelle D3.3 wird für das Gehalt pro Nettozeitstunde Kontakt (Unterrichtszeitstunde) das gesetzliche bzw. vertraglich vereinbarte Jahresgehalt einer Lehrkraft durch die Anzahl der jährlichen Netto-Unterrichtszeitstunden (s. Tab. D4.I) geteilt.

\section{Angewandte Methodik}

Die Daten zu den gesetzlichen bzw. vertraglich vereinbarten Gehältern und den Zulagen für Lehrkräfte stammen aus der OECD/INES-Erhebung von 2013 zu Lehrkräften und Lehrplänen. Die Daten beziehen sich auf das Schuljahr 20II/2012 und sind entsprechend den offiziellen Regelungen für öffentliche Einrichtungen angegeben.

Die Angaben zu den Gehältern von Lehrkräften im Sekundarbereich II beziehen sich nur auf Lehrkräfte in allgemeinbildenden Bildungsgängen.

Bei der Berechnung der gesetzlichen bzw. vertraglich vereinbarten Gehälter von Vollzeitlehrkräften im Verhältnis zur Zahl der von ihnen jährlich zu unterrichtenden Zeitstunden wird keine Anpassung der Gehälter an die Zeit, die Lehrkräfte mit verschiedenen anderen unterrichtsbezogenen Aktivitäten verbringen, vorgenommen. Da der Anteil der mit der Erteilung von Unterricht verbrachten Arbeitszeit von Lehrkräften in den OECD-Ländern unterschiedlich hoch ist, ist bei der Interpretation der gesetzlichen bzw. vertraglich vereinbarten Gehälter pro Netto-Unterrichtszeitstunde Vorsicht geboten (s. Indikator D4). Allerdings kann diese Kenngröße zur Schätzung der Kosten für die von Lehrkräften tatsächlich im Klassenzimmer verbrachte Zeit dienen.

Die Bruttogehälter der Lehrkräfte werden mittels KKP für den privaten Konsum aus den „Volkswirtschaftlichen Gesamtrechnungen der OECD“ kaufkraftbereinigt dargestellt. In Ausgaben von Bildung auf einen Blick vor 2012 wurden die Gehälter mittels KKP für das BIP kaufkraftbereinigt dargestellt. Daher ist kein direkter Vergleich der Gehälter der Lehrkräfte in US-Dollar (Tab. D3.I) in dieser Ausgabe von Bildung auf einen Blick mit den in Ausgaben vor 2012 präsentierten möglich. Informationen zu Entwicklungstendenzen bei den Gehältern von Lehrkräften sind in Tabelle D3.5 aufgeführt. In Ergänzung zu Tabelle D3.I, bei der es sich um eine Darstellung der Gehälter von Lehr- 
kräften in US-Dollar, kaufkraftbereinigt mittels KKP, handelt, enthält Anhang 2 eine Tabelle mit den Gehältern von Lehrkräften in Landeswährung. Referenzzeitraum für die Gehälter der Lehrkräfte ist der Zeitraum zwischen dem I. Juli 20II und dem 30. Juni 20I2. Referenzzeitraum für die Kaufkraftparitäten ist 20II/20I2.

Zur Berechnung der Veränderungen der Gehälter von Lehrkräften (Tab. D3.5) erfolgte die Umrechnung der Gehälter auf die Preise von 2005 mittels des Deflators für den privaten Konsum.

Beim Verhältnis der Gehälter von Lehrkräften zu ganzjährig Vollzeitbeschäftigten mit einem Abschluss im Tertiärbereich im Alter von 25 bis 64 Jahren werden bei den Ländern mit verfügbaren Daten für die Berechnung die durchschnittlichen Jahresgehälter von 25- bis 64-jährigen Lehrkräften (einschließlich Bonus- und Zulagenzahlungen) zugrunde gelegt (Tab. D3.4). Für die anderen Länder basiert die Berechnung auf den gesetzlichen bzw. vertraglich vereinbarten Gehältern von Lehrkräften mit 15 Jahren Berufserfahrung (mit Mindestausbildung). Tabelle D3.2 enthält Angaben zu der für das jeweilige Land verwendeten Methodik.

Hinweise zu den für jedes Land verwendeten Definitionen und angewandten Methodiken s. Anhang 3 unter www.oecd.org/edu/eag.htm.

Hinweis zu den Daten aus Israel

Die statistischen Daten für Israel wurden von den zuständigen israelischen Stellen bereitgestellt, die für sie verantwortlich zeichnen. Die Verwendung dieser Daten durch die OECD erfolgt unbeschadet des völkerrechtlichen Status der Golanhöhen, von Ost-Jerusalem und der israelischen Siedlungen im Westjordanland.

\section{Weiterführende Informationen}

OECD (2013), PISA 2013 Results: What Makes Schools Successful? Resources, Policies and Practices, Volume IV, OECD Publishing.

OECD (2012), Bildung auf einen Blick 2012 - OECD-Indikatoren, W. Bertelsmann Verlag, Bielefeld.

OECD (2005), Stärkere Professionalisierung des Lehrerberufs - Wie gute Lehrer gewonnen, gefördert und gehalten werden können, OECD Publishing, http:/|dx.doi.org/10.1787/9789264023673-de.

Santiago, P. (2004), „The Labour Market for Teachers“, in G. Johnes and J. Johnes (eds.), International Handbook on the Economics of Education, Edward Elgar, Cheltenham. 


\section{Tabellen Indikator D3}

StatLink: http://dx.doi.org/10.1787/888933119815

Tabelle D3.I: Gesetzliche bzw. vertraglich vereinbarte Gehälter von Lehrkräften zu unterschiedlichen Zeitpunkten in ihrer beruflichen Laufbahn (2012)

Tabelle D3.2: Gesetzliche bzw. vertraglich vereinbarte Gehälter von Lehrkräften im Verhältnis zu Gehältern von ganzjährig Vollzeitbeschäftigten mit einem Abschluss im Tertiärbereich (2012)

Tabelle D3·3: Vergleich der gesetzlichen bzw. vertraglich vereinbarten Gehälter von Lehrkräften (20I2)

Tabelle D3.4: Durchschnittliche tatsächliche Gehälter von Lehrkräften (2012)

Tabelle D3.5: Entwicklung der Gehälter von Lehrkräften zwischen 2000 und 2012

WEB Table D3.6: Minimum and maximum teachers' statutory salaries (Gesetzliche bzw. vertraglich vereinbarte Mindest- und Höchstgehälter von Lehrkräften) (20I2)

WEB Table D3.7a: Decisions on payments for teachers in public institutions (Entscheidungen über Zahlungen an Lehrkräfte in öffentlichen Bildungseinrichtungen) (2012)

WEB Table D3.7b: Decisions made by school principal on payments for teachers in public institution (Entscheidungen von Schulleitern über Zahlungen an Lehrkräfte in öffentlichen Bildungseinrichtungen) (2012)

WEB Table D3.7c: Decisions made by local or regional authority on payments for teachers in public institutions (Entscheidungen lokaler oder regionaler Behörden über Zahlungen an Lehrkräfte in öffentlichen Bildungseinrichtungen) (20I2)

WEB Table D3.7d: Decisions made by the national authority on payments for teachers in public institutions (Entscheidungen der nationalen Behörde über Zahlungen an Lehrkräfte in öffentlichen Bildungseinrichtungen) (2012) 
Tabelle D3.1

Gesetzliche bzw. vertraglich vereinbarte Gehälter von Lehrkräften zu unterschiedlichen Zeitpunkten der beruflichen Laufbahn (2012)

Jahresgehälter von Lehrkräften an öffentlichen Bildungseinrichtungen, in US-Dollar (kaufkraftbereinigt mittels KKP für den privaten Verbrauch)

\begin{tabular}{|c|c|c|c|c|c|c|c|c|}
\hline & \multicolumn{4}{|c|}{ Elementarbereich } & \multicolumn{4}{|c|}{ Primarbereich } \\
\hline & $\begin{array}{l}\text { Anfangsgehalt/ } \\
\text { Mindest- } \\
\text { ausbildung }\end{array}$ & \begin{tabular}{|l|} 
Gehalt nach 10 \\
Jahren Berufs- \\
erfahrung/Min- \\
destausbildung
\end{tabular} & \begin{tabular}{|l|} 
Gehalt nach 15 \\
Jahren Berufs- \\
erfahrung/Min- \\
destausbildung
\end{tabular} & $\begin{array}{l}\text { Höchstgehalt/ } \\
\text { Mindest- } \\
\text { ausbildung }\end{array}$ & $\begin{array}{l}\text { Anfangsgehalt/ } \\
\text { Mindest- } \\
\text { ausbildung }\end{array}$ & $\begin{array}{l}\text { Gehalt nach } 10 \\
\text { Jahren Berufs- } \\
\text { erfahrung/Min- } \\
\text { destausbildung }\end{array}$ & $\begin{array}{l}\text { Gehalt nach } 15 \\
\text { Jahren Berufs- } \\
\text { erfahrung/Min- } \\
\text { destausbildung }\end{array}$ & $\begin{array}{l}\text { Höchstgehalt/ } \\
\text { Mindest- } \\
\text { ausbildung }\end{array}$ \\
\hline & (1) & (2) & (3) & (4) & (5) & (6) & (7) & (8) \\
\hline \multicolumn{9}{|l|}{ OECD-Länder } \\
\hline Australien & 36768 & 51163 & 50947 & 51320 & 37221 & 51504 & 51289 & 51662 \\
\hline Österreich & 32587 & 38353 & 42994 & 64057 & 32587 & 38353 & 42994 & 64057 \\
\hline Belgien (fläm.) & 33667 & 42283 & 47635 & 58340 & 33667 & 42283 & 47635 & 58340 \\
\hline Belgien (frz.) ${ }^{1}$ & 33109 & 41403 & 46616 & 57042 & 33109 & 41403 & 46616 & 57042 \\
\hline Kanada & 37145 & 55765 & 58495 & 58495 & 37145 & 55765 & 58495 & 58495 \\
\hline Chile & 17770 & 22742 & 24725 & 32656 & 17770 & 22742 & 24725 & 32656 \\
\hline Tschechien & 15807 & 16669 & 17224 & 18728 & 16986 & 18508 & 19363 & 21835 \\
\hline Dänemark & 42230 & 44797 & 46037 & 46037 & 44131 & 49353 & 51122 & 51122 \\
\hline England & 28321 & 41393 & 41393 & 41393 & 28321 & 41393 & 41393 & 41393 \\
\hline Estland & $\mathrm{m}$ & $\mathrm{m}$ & $\mathrm{m}$ & $\mathrm{m}$ & 11828 & 12525 & 12525 & 17288 \\
\hline Finnland $^{2}$ & 27443 & 29638 & 29638 & 29638 & 32148 & 37212 & 39445 & 41811 \\
\hline Frankreich $^{3}$ & 26247 & 31689 & 33994 & 50127 & 26247 & 31689 & 33994 & 50127 \\
\hline Deutschland & $\mathrm{m}$ & $\mathrm{m}$ & $\mathrm{m}$ & $\mathrm{m}$ & 50007 & 59795 & 62195 & 66396 \\
\hline Griechenland & 18718 & 23320 & 26617 & 35503 & 18718 & 23320 & 26617 & 35503 \\
\hline Ungarn 4 & 10627 & 11969 & 12717 & 16771 & 10992 & 12562 & 13520 & 18020 \\
\hline Island & 23763 & 26429 & 26429 & 30240 & 25672 & 28046 & 28742 & 29938 \\
\hline Irland & $\mathrm{m}$ & $\mathrm{m}$ & $\mathrm{m}$ & $\mathrm{m}$ & 33602 & 49233 & 55148 & 62386 \\
\hline Israel & 22215 & 26780 & 29628 & 46539 & 19680 & 26181 & 29413 & 41318 \\
\hline Italien & 27786 & 30567 & 33570 & 40851 & 27786 & 30567 & 33570 & 40851 \\
\hline Japan & $\mathrm{m}$ & $\mathrm{m}$ & $\mathrm{m}$ & $\mathrm{m}$ & 27067 & 40204 & 47561 & 59643 \\
\hline Korea & 28012 & 41700 & 48738 & 79631 & 28591 & 42972 & 50145 & 79631 \\
\hline Luxemburg & 66085 & 87511 & 98788 & 118412 & 66085 & 87511 & 98788 & 118412 \\
\hline Mexiko & 15556 & 15648 & 20296 & 33319 & 15556 & 15648 & 20296 & 33319 \\
\hline Niederlande & 37104 & 45950 & 54865 & 54865 & 37104 & 45950 & 54865 & 54865 \\
\hline Neuseeland & $\mathrm{m}$ & $\mathrm{m}$ & $\mathrm{m}$ & $\mathrm{m}$ & 28961 & 43050 & 43050 & 43050 \\
\hline Norwegen & 33816 & 39235 & 39235 & 39235 & 34484 & 38773 & 38773 & 43318 \\
\hline Polen & 11388 & 14966 & 18160 & 18925 & 11388 & 14966 & 18160 & 18925 \\
\hline Portugal & 29151 & 31928 & 34694 & 48321 & 29151 & 31928 & 34694 & 48321 \\
\hline Schottland & 28124 & 44867 & 44867 & 44867 & 28124 & 44867 & 44867 & 44867 \\
\hline Slowakei & 9513 & 10468 & 10946 & 11806 & 10644 & 12778 & 13365 & 14411 \\
\hline Slowenien & 27006 & 29958 & 32819 & 33819 & 27006 & 29958 & 32819 & 34476 \\
\hline Spanien & 36268 & 39437 & 41862 & 51341 & 36268 & 39437 & 41862 & 51341 \\
\hline Schweden ${ }^{4,5}$ & 30695 & 32785 & 34614 & 36443 & 30695 & 34070 & 35115 & 40709 \\
\hline Schweiz ${ }^{6}$ & 43758 & 54812 & $\mathrm{~m}$ & 67289 & 48904 & 61279 & $\mathrm{~m}$ & 75575 \\
\hline Türkei & 24834 & 25632 & 26653 & 28818 & 24834 & 25632 & 26678 & 28818 \\
\hline Vereinigte Staaten ${ }^{4}$ & 35952 & 46116 & 45300 & 60984 & 36333 & 44995 & 45998 & 58793 \\
\hline OECD-Durchschnitt & 28757 & 35354 & 37350 & 45349 & 29411 & 36846 & 39024 & 46909 \\
\hline EU21-Durchschnitt & 28594 & 34498 & 37502 & 43864 & 29417 & 36072 & 39160 & 45761 \\
\hline \multicolumn{9}{|l|}{ Partnerländer } \\
\hline Argentinien & $\mathrm{m}$ & $\mathrm{m}$ & $\mathrm{m}$ & $\mathrm{m}$ & $\mathrm{m}$ & $\mathrm{m}$ & $\mathrm{m}$ & $\mathrm{m}$ \\
\hline Brasilien & 10375 & $\mathrm{~m}$ & $\mathrm{~m}$ & $\mathrm{~m}$ & 10375 & $\mathrm{~m}$ & $\mathrm{~m}$ & $\mathrm{~m}$ \\
\hline China & $\mathrm{m}$ & $\mathrm{m}$ & $\mathrm{m}$ & $\mathrm{m}$ & $\mathrm{m}$ & $\mathrm{m}$ & $\mathrm{m}$ & $\mathrm{m}$ \\
\hline Kolumbien & $\mathrm{m}$ & $\mathrm{m}$ & $\mathrm{m}$ & $\mathrm{m}$ & $\mathrm{m}$ & $\mathrm{m}$ & $\mathrm{m}$ & $\mathrm{m}$ \\
\hline Indien & $\mathrm{m}$ & $\mathrm{m}$ & $\mathrm{m}$ & $\mathrm{m}$ & $\mathrm{m}$ & $\mathrm{m}$ & $\mathrm{m}$ & $\mathrm{m}$ \\
\hline Indonesien & 1560 & $\mathrm{~m}$ & 1974 & 2249 & 1560 & $\mathrm{~m}$ & 1974 & 2249 \\
\hline Lettland & $\mathrm{m}$ & $\mathrm{m}$ & $\mathrm{m}$ & $\mathrm{m}$ & $\mathrm{m}$ & $\mathrm{m}$ & $\mathrm{m}$ & $\mathrm{m}$ \\
\hline Russische Föd. & $\mathrm{m}$ & $\mathrm{m}$ & $\mathrm{m}$ & $\mathrm{m}$ & $\mathrm{m}$ & $\mathrm{m}$ & $\mathrm{m}$ & $\mathrm{m}$ \\
\hline Saudi-Arabien & $\mathrm{m}$ & $\mathrm{m}$ & $\mathrm{m}$ & $\mathrm{m}$ & $\mathrm{m}$ & $\mathrm{m}$ & $\mathrm{m}$ & $\mathrm{m}$ \\
\hline Südafrika & $\mathrm{m}$ & $\mathrm{m}$ & $\mathrm{m}$ & $\mathrm{m}$ & $\mathrm{m}$ & $\mathrm{m}$ & $\mathrm{m}$ & $\mathrm{m}$ \\
\hline G20-Durchschnitt & m & m & m & $\mathbf{m}$ & m & m & $\mathbf{m}$ & m \\
\hline
\end{tabular}

1. Gehälter von Lehrkräften mit typischer Qualifikation anstelle der Mindestausbildung. Gehälter von Lehrkräften mit Mindestausbildung s. Anhang 3. 2. Enthält für den Elementarbereich nur Kindergartenlehrkräfte. 3. Enthält die durchschnittlichen Zulagen für Überstunden für Lehrkräfte im Sekundarbereich I und II.

4. Tatsächliche Grundgehälter. 5. Referenzjahr 2011. 6. Spalten (2), (6), (10) und (14): Gehälter nach 11 Jahren Berufserfahrung.

Quelle: OECD. Argentinien, China, Indien, Indonesien, Kolumbien, Saudi-Arabien und Südafrika: Statistikinstitut der UNESCO.

Hinweise s. Anhang 3 unter www.oecd.org/edu/eag.htm. StatLink: http://dx.doi.org/10.1787/888933119834

Erläuterung der Kennzeichnung fehlender Daten s. Hinweise für den Leser. 
Tabelle D3.1 (Forts.)

Gesetzliche bzw. vertraglich vereinbarte Gehälter von Lehrkräften zu unterschiedlichen Zeitpunkten der beruflichen Laufbahn (2012)

Jahresgehälter von Lehrkräften an öffentlichen Bildungseinrichtungen, in US-Dollar (kaufkraftbereinigt mittels KKP für den privaten Verbrauch)

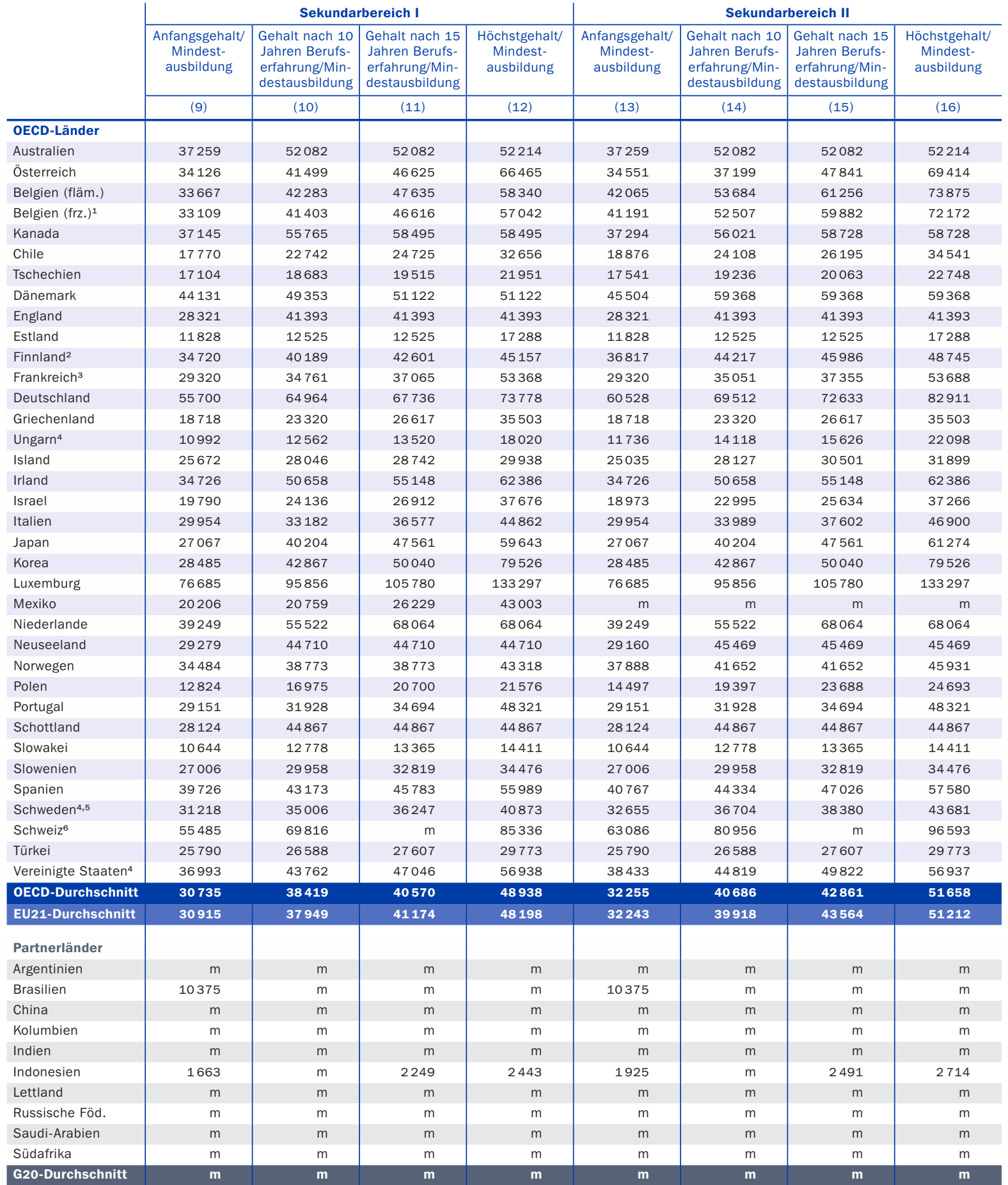

1. Gehälter von Lehrkräften mit typischer Qualifikation anstelle der Mindestausbildung. Gehälter von Lehrkräften mit Mindestausbildung s. Anhang 3. 2. Enthält für den Elementarbereich nur Kindergartenlehrkräfte. 3. Enthält die durchschnittlichen Zulagen für Überstunden für Lehrkräfte im Sekundarbereich I und II.

4. Tatsächliche Grundgehälter. 5. Referenzjahr 2011. 6. Spalten (2), (6), (10) und (14): Gehälter nach 11 Jahren Berufserfahrung.

Quelle: OECD. Argentinien, China, Indien, Indonesien, Kolumbien, Saudi-Arabien und Südafrika: Statistikinstitut der UNESCO.

Hinweise s. Anhang 3 unter www.oecd.org/edu/eag.htm. StatLink: http://dx.doi.org/10.1787/888933119834

Erläuterung der Kennzeichnung fehlender Daten s. Hinweise für den Leser. 
Gesetzliche bzw. vertraglich vereinbarte Gehälter von Lehrkräften im Verhältnis zu Gehältern von ganzjährig Vollzeitbeschäftlgten mit einem Abschluss im Tertiärbereich (2012)

Verhältnis der Gehälter nach Altersgruppe und Geschlecht

\begin{tabular}{|c|c|c|c|c|c|c|}
\hline & \multirow{2}{*}{ Methode $^{1}$} & \multirow{2}{*}{$\begin{array}{l}\text { Referenz- } \\
\text { jahr }\end{array}$} & \multicolumn{4}{|c|}{ 25- bis 64-Jährige } \\
\hline & & & Elementarbereich & Primarbereich & Sekundarbereich I & Sekundarbereich II \\
\hline & (1) & (2) & (3) & (4) & (5) & (6) \\
\hline \multicolumn{7}{|l|}{ OECD-Länder } \\
\hline Australien & Tatsächlich & 2012 & 0,89 & 0,93 & 0,93 & 0,93 \\
\hline Österreich & Gesetzlich bzw. vertraglich vereinbart & 2012 & 0,55 & 0,55 & 0,60 & 0,61 \\
\hline Belgien (fläm.) ${ }^{2}$ & Tatsächlich & 2012 & 0,88 & 0,89 & 0,87 & 1,13 \\
\hline Belgien (frz.) ${ }^{2}$ & Tatsächlich & 2012 & 0,82 & 0,82 & 0,82 & 1,01 \\
\hline Kanada & Gesetzlich bzw. vertraglich vereinbart & 2011 & 1,05 & 1,05 & 1,05 & 1,06 \\
\hline Chile & Tatsächlich & 2011 & 0,73 & 0,73 & 0,73 & 0,77 \\
\hline Tschechien & Tatsächlich & 2012 & 0,46 & 0,54 & 0,54 & 0,58 \\
\hline Dänemark & Tatsächlich & 2012 & 0,83 & 0,92 & 0,92 & 1,06 \\
\hline England $^{3}$ & Tatsächlich & 2012 & 0,86 & 0,86 & 0,95 & 0,95 \\
\hline Estland & Tatsächlich & 2012 & 0,61 & 0,84 & 0,84 & 0,84 \\
\hline Finnland ${ }^{4}$ & Tatsächlich & 2012 & 0,65 & 0,89 & 0,97 & 1,09 \\
\hline Frankreich & Tatsächlich & 2012 & 0,73 & 0,72 & 0,86 & 0,95 \\
\hline Deutschland & Tatsächlich & 2012 & $\mathrm{~m}$ & 0,88 & 0,97 & 1,05 \\
\hline Griechenland & Tatsächlich & 2012 & 0,89 & 0,89 & 0,93 & 0,93 \\
\hline Ungarn & Tatsächlich & 2012 & 0,47 & 0,53 & 0,53 & 0,59 \\
\hline Island & $\mathrm{m}$ & $\mathrm{m}$ & $\mathrm{m}$ & $\mathrm{m}$ & $\mathrm{m}$ & $\mathrm{m}$ \\
\hline Irland & Gesetzlich bzw. vertraglich vereinbart & 2011 & $\mathrm{~m}$ & 0,81 & 0,81 & 0,81 \\
\hline Israel & Tatsächlich & 2012 & 0,80 & 0,87 & 0,85 & 0,88 \\
\hline Italien & Tatsächlich & 2012 & 0,60 & 0,60 & 0,65 & 0,69 \\
\hline Japan & $\mathrm{m}$ & $\mathrm{m}$ & $\mathrm{m}$ & $\mathrm{m}$ & $\mathrm{m}$ & $\mathrm{m}$ \\
\hline Korea & Gesetzlich bzw. vertraglich vereinbart & 2012 & 1,32 & 1,36 & 1,36 & 1,36 \\
\hline Luxemburg & Tatsächlich & 2012 & 1,11 & 1,11 & 1,26 & 1,26 \\
\hline Mexiko & $\mathrm{m}$ & $\mathrm{m}$ & $\mathrm{m}$ & $\mathrm{m}$ & $\mathrm{m}$ & $\mathrm{m}$ \\
\hline Niederlande & Tatsächlich & 2012 & 0,69 & 0,69 & 0,82 & 0,82 \\
\hline Neuseeland & Tatsächlich & 2011 & $\mathrm{~m}$ & 1,04 & 1,06 & 1,09 \\
\hline Norwegen & Tatsächlich & 2012 & 0,63 & 0,71 & 0,71 & 0,76 \\
\hline Polen & Tatsächlich & 2012 & 0,71 & 0,82 & 0,83 & 0,82 \\
\hline Portugal & Gesetzlich bzw. vertraglich vereinbart & 2011 & 1,23 & 1,23 & 1,23 & 1,23 \\
\hline Schottland $d^{3,5}$ & Tatsächlich & 2012 & 0,83 & 0,83 & 0,83 & 0,83 \\
\hline Slowakei & Gesetzlich bzw. vertraglich vereinbart & 2012 & 0,35 & 0,43 & 0,43 & 0,43 \\
\hline Slowenien & Gesetzlich bzw. vertraglich vereinbart & 2012 & 0,79 & 0,79 & 0,79 & 0,79 \\
\hline Spanien & Gesetzlich bzw. vertraglich vereinbart & 2011 & 1,20 & 1,20 & 1,32 & 1,35 \\
\hline Schweden 6 & Tatsächlich & 2011 & 0,75 & 0,82 & 0,82 & 0,87 \\
\hline Schweiz & $\mathrm{m}$ & $\mathrm{m}$ & $\mathrm{m}$ & $\mathrm{m}$ & $\mathrm{m}$ & $\mathrm{m}$ \\
\hline Türkei & Gesetzlich bzw. vertraglich vereinbart & 2012 & 1,09 & 1,09 & 1,13 & 1,13 \\
\hline Vereinigte Staaten & Tatsächlich & 2012 & 0,65 & 0,67 & 0,68 & 0,70 \\
\hline \multicolumn{3}{|l|}{ OECD-Durchschnitt } & 0,80 & 0,85 & 0,88 & 0,92 \\
\hline EU21-Durchschnitt & & & 0,76 & 0,81 & 0,85 & 0,90 \\
\hline \multicolumn{7}{|l|}{ Partnerländer } \\
\hline Argentinien & $\mathrm{m}$ & $\mathrm{m}$ & m & $\mathrm{m}$ & $\mathrm{m}$ & $\mathrm{m}$ \\
\hline Brasilien & $\mathrm{m}$ & $\mathrm{m}$ & $\mathrm{m}$ & $\mathrm{m}$ & $\mathrm{m}$ & $\mathrm{m}$ \\
\hline China & $\mathrm{m}$ & $\mathrm{m}$ & $\mathrm{m}$ & $\mathrm{m}$ & $\mathrm{m}$ & $\mathrm{m}$ \\
\hline Kolumbien & $\mathrm{m}$ & $\mathrm{m}$ & $\mathrm{m}$ & $\mathrm{m}$ & $\mathrm{m}$ & $\mathrm{m}$ \\
\hline Indien & $\mathrm{m}$ & $\mathrm{m}$ & $\mathrm{m}$ & $\mathrm{m}$ & $\mathrm{m}$ & $\mathrm{m}$ \\
\hline Indonesien & $\mathrm{m}$ & $\mathrm{m}$ & $\mathrm{m}$ & $\mathrm{m}$ & $\mathrm{m}$ & $\mathrm{m}$ \\
\hline Lettland & $\mathrm{m}$ & $\mathrm{m}$ & $\mathrm{m}$ & $\mathrm{m}$ & $\mathrm{m}$ & $\mathrm{m}$ \\
\hline Russische Föd. & $\mathrm{m}$ & $\mathrm{m}$ & $\mathrm{m}$ & $\mathrm{m}$ & $\mathrm{m}$ & $\mathrm{m}$ \\
\hline Saudi-Arabien & $\mathrm{m}$ & $\mathrm{m}$ & $\mathrm{m}$ & $\mathrm{m}$ & $\mathrm{m}$ & $\mathrm{m}$ \\
\hline Südafrika & $\mathrm{m}$ & $\mathrm{m}$ & $\mathrm{m}$ & $\mathrm{m}$ & $\mathrm{m}$ & $\mathrm{m}$ \\
\hline G20-Durchschnitt & & & $\mathbf{m}$ & m & $\mathbf{m}$ & $\mathbf{m}$ \\
\hline
\end{tabular}

Anmerkung: Die Spalten mit den Angaben zu den gesetzlich bzw. vertraglich vereinbarten Gehältern von Lehrkräften im Verhältnis zu Gehältern von ganzjährig Vollzeitbeschäftigten mit einem Abschluss im Tertiärbereich, aufgegliedert nach Altersgruppe und Geschlecht, d.h. die Spalten (7) bis (30), sind im Internet verfügbar (s. StatLink unten).

1. Die Angabe „Tatsächlich“ bezieht sich auf das Verhältnis von durchschnittlichen tatsächlichen Gehälter, einschließlich Bonus- und Zulagezahlungen, von 25- bis 64-jährigen Lehrkräften zu Gehältern von 25- bis 64jährigen ganzjährig Vollzeitbeschäftigten mit einem Abschluss im Tertiärbereich. Die Angabe „Gesetzlich bzw. vertraglich vereinbart“ bezieht sich auf das Verhältnis von gesetzlichen bzw. vertraglich vereinbarten Gehältern von Lehrkräften mit 15 Jahren Berufserfahrung und Mindestausbildung (unabhängig vom Alter) zu Gehältern von 25- bis 64-jährigen ganzjährig Vollzeitbeschäftlgten mit einem Abschluss im Tertiärbereich. 2. Daten zu den Gehältern ganzjährig Vollzeitbeschäftigter mit einem Abschluss im Tertiärbereich beziehen sich auf Belgien. 3. Daten zu den Gehältern ganzjährig Vollzeitbeschäftigter mit einem Abschluss im Tertiärbereich beziehen sich auf das Vereinigte Königreich. 4. Enthält für den Elementarbereich nur Kindergartenlehrkräfte. 5. Enthält alle Lehrkräfte, unabhängig von ihrem Alter. 6. Durchschnittliche tatsächliche Gehälter von Lehrkräften, ohne Bonus- und Zulagezahlungen.

Quelle: OECD. Argentinien, China, Indien, Indonesien, Kolumbien, Saudi-Arabien und Südafrika: Statistikinstitut der UNESCO.

Hinweise s. Anhang 3 unter www.oecd.org/edu/eag.htm. StatLink: http://dx.doi.org/10.1787/888933119853

Erläuterung der Kennzeichnung fehlender Daten s. Hinweise für den Leser. 
Vergleich der gesetzlichen bzw. vertraglich vereinbarten Gehälter von Lehrkräften (2012)

Verhältnis zwischen den gesetzlichen bzw. vertraglich vereinbarten Gehältern von Lehrkräften mit Mindestausbildung zu unterschiedlichen

Zeitpunkten der beruflichen Laufbahn und dem Gehalt pro Zeitstunde in US-Dollar (kaufkraftbereinigt mittels KKP für den privaten Verbrauch)

\begin{tabular}{|c|c|c|c|c|c|c|c|c|c|}
\hline & \multicolumn{4}{|c|}{ Verhältnis des Höchstgehalts zum Anfangsgehalt } & \multirow{2}{*}{$\begin{array}{l}\text { Jahre } \\
\text { zwischen } \\
\text { Anfangs- } \\
\text { und Höchst- } \\
\text { gehalt } \\
\text { (Sekundar- } \\
\text { bereich I) }\end{array}$} & \multicolumn{3}{|c|}{$\begin{array}{c}\text { Gehalt je Nettozeitstunde Kontakt } \\
\text { (Unterrichtszeitstunde) nach } 15 \text { Jahren } \\
\text { Berufserfahrung }\end{array}$} & \multirow{2}{*}{$\begin{array}{l}\text { Verhältnis des } \\
\text { Gehalts pro Unter- } \\
\text { richtszeitstunde } \\
\text { von Lehrkräften des } \\
\text { Sekundarbereichs I } \\
\text { zu Lehrkräften des } \\
\text { Primarbereichs } \\
\text { (nach 15 Jahren } \\
\text { Berufserfahrung) }\end{array}$} \\
\hline & $\begin{array}{c}\text { Elementar- } \\
\text { bereich }\end{array}$ & $\begin{array}{l}\text { Primar- } \\
\text { bereich }\end{array}$ & $\begin{array}{c}\text { Sekundar- } \\
\text { bereich I }\end{array}$ & $\begin{array}{l}\text { Sekundar- } \\
\text { bereich II }\end{array}$ & & $\begin{array}{l}\text { Primar- } \\
\text { bereich }\end{array}$ & $\begin{array}{c}\text { Sekundar- } \\
\text { bereich I }\end{array}$ & $\begin{array}{l}\text { Sekundar- } \\
\text { bereich II }\end{array}$ & \\
\hline & (1) & (2) & (3) & (4) & (5) & (6) & (7) & (8) & (9) \\
\hline \multicolumn{10}{|l|}{ OECD-Länder } \\
\hline Australien & 1,40 & 1,39 & 1,40 & 1,40 & 9 & 59 & 64 & 65 & 1,10 \\
\hline Österreich & 1,97 & 1,97 & 1,95 & 2,01 & 34 & 55 & 77 & 81 & 1,47 \\
\hline Belgien (fläm.) & 1,73 & 1,73 & 1,73 & 1,76 & 27 & 64 & 73 & 101 & 1,58 \\
\hline Belgien (frz.) & 1,72 & 1,72 & 1,72 & 1,75 & 27 & 65 & 71 & 100 & 1,54 \\
\hline Kanada & 1,57 & 1,57 & 1,57 & 1,57 & 11 & 73 & 78 & 78 & 1,07 \\
\hline Chile & 1,84 & 1,84 & 1,84 & 1,83 & 30 & 22 & 22 & 24 & 1,06 \\
\hline Tschechien & 1,18 & 1,29 & 1,28 & 1,30 & 27 & 23 & 31 & 34 & 1,45 \\
\hline Dänemark & 1,09 & 1,16 & 1,16 & 1,30 & 8 & 78 & 78 & 161 & 2,07 \\
\hline England & 1,46 & 1,46 & 1,46 & 1,46 & 12 & 61 & 60 & 60 & 0,98 \\
\hline Estland & $\mathrm{m}$ & 1,46 & 1,46 & 1,46 & 7 & 20 & 20 & 22 & 1,09 \\
\hline Finnland $^{1}$ & 1,08 & 1,30 & 1,30 & 1,32 & 20 & 59 & 72 & 84 & 1,43 \\
\hline Frankreich & 1,91 & 1,91 & 1,82 & 1,83 & 29 & 37 & 57 & 58 & 1,57 \\
\hline Deutschland & $\mathrm{m}$ & 1,33 & 1,32 & 1,37 & 28 & 77 & 90 & 101 & 1,31 \\
\hline Griechenland & 1,90 & 1,90 & 1,90 & 1,90 & 45 & 47 & 64 & 64 & 1,37 \\
\hline Ungarn ${ }^{2}$ & 1,58 & 1,64 & 1,64 & 1,88 & 40 & 22 & 22 & 26 & 1,16 \\
\hline Island & 1,27 & 1,17 & 1,17 & 1,27 & 18 & 46 & 46 & 56 & 1,22 \\
\hline Irland & $\mathrm{m}$ & 1,86 & 1,80 & 1,80 & 22 & 60 & 75 & 75 & 1,25 \\
\hline Israel & 2,09 & 2,10 & 1,90 & 1,96 & 36 & 35 & 43 & 46 & 1,31 \\
\hline Italien & 1,47 & 1,47 & 1,50 & 1,57 & 35 & 45 & 59 & 61 & 1,37 \\
\hline Japan & $\mathrm{m}$ & 2,20 & 2,20 & 2,26 & 34 & 65 & 79 & 93 & 1,43 \\
\hline Korea & 2,84 & 2,79 & 2,79 & 2,79 & 37 & 72 & 88 & 91 & 1,26 \\
\hline Luxemburg & 1,79 & 1,79 & 1,74 & 1,74 & 30 & 122 & 143 & 143 & 1,17 \\
\hline Mexiko & 2,14 & 2,14 & 2,13 & $\mathrm{~m}$ & 14 & 25 & 25 & $\mathrm{~m}$ & $\mathrm{~m}$ \\
\hline Niederlande & 1,48 & 1,48 & 1,73 & 1,73 & 14 & 59 & 91 & 91 & 1,54 \\
\hline Neuseeland & $\mathrm{m}$ & 1,49 & 1,53 & 1,56 & 8 & 46 & 53 & 60 & 1,30 \\
\hline Norwegen & 1,16 & 1,26 & 1,26 & 1,21 & 16 & 52 & 58 & 80 & 1,52 \\
\hline Polen & 1,66 & 1,66 & 1,68 & 1,70 & 20 & 29 & 37 & 42 & 1,48 \\
\hline Portugal & 1,66 & 1,66 & 1,66 & 1,66 & 34 & 46 & 56 & 56 & 1,23 \\
\hline Schottland & 1,60 & 1,60 & 1,60 & 1,60 & 6 & 52 & 52 & 52 & 1,00 \\
\hline Slowakei & 1,24 & 1,35 & 1,35 & 1,35 & 32 & 16 & 21 & 22 & 1,35 \\
\hline Slowenien & 1,25 & 1,28 & 1,28 & 1,28 & 13 & 52 & 52 & 58 & 1,10 \\
\hline Spanien & 1,42 & 1,42 & 1,41 & 1,41 & 38 & 48 & 64 & 68 & 1,43 \\
\hline Schweden ${ }^{2,3}$ & 1,19 & 1,33 & 1,31 & 1,34 & a & $\mathrm{m}$ & $\mathrm{m}$ & $\mathrm{m}$ & $\mathrm{m}$ \\
\hline Schweiz & 1,54 & 1,55 & 1,54 & 1,53 & 27 & $\mathrm{~m}$ & $\mathrm{~m}$ & $\mathrm{~m}$ & $\mathrm{~m}$ \\
\hline Türkei & 1,16 & 1,16 & 1,15 & 1,15 & 27 & 37 & 55 & 49 & 1,31 \\
\hline Vereinigte Staaten ${ }^{2}$ & 1,70 & 1,62 & 1,54 & 1,48 & $\mathrm{~m}$ & 41 & 43 & 46 & 1,14 \\
\hline OECD-Durchschnitt & 1,58 & 1,61 & 1,61 & 1,62 & 24 & 50 & 59 & 68 & 1,32 \\
\hline EU21-Durchschnitt & 1,52 & 1,55 & 1,56 & 1,59 & 25 & 52 & 62 & 71 & 1,36 \\
\hline \multicolumn{10}{|l|}{ Partnerländer } \\
\hline Argentinien $^{3}$ & $\mathrm{~m}$ & $\mathrm{~m}$ & $\mathrm{~m}$ & $\mathrm{~m}$ & 25 & $\mathrm{~m}$ & $\mathrm{~m}$ & $\mathrm{~m}$ & $\mathrm{~m}$ \\
\hline Brasilien & $\mathrm{m}$ & $\mathrm{m}$ & $\mathrm{m}$ & $\mathrm{m}$ & $\mathrm{m}$ & $\mathrm{m}$ & $\mathrm{m}$ & $\mathrm{m}$ & $\mathrm{m}$ \\
\hline China & $\mathrm{m}$ & $\mathrm{m}$ & $\mathrm{m}$ & $\mathrm{m}$ & $\mathrm{m}$ & $\mathrm{m}$ & $\mathrm{m}$ & $\mathrm{m}$ & $\mathrm{m}$ \\
\hline Kolumbien & $\mathrm{m}$ & $\mathrm{m}$ & $\mathrm{m}$ & $\mathrm{m}$ & $\mathrm{m}$ & $\mathrm{m}$ & $\mathrm{m}$ & $\mathrm{m}$ & $\mathrm{m}$ \\
\hline Indien & $\mathrm{m}$ & $\mathrm{m}$ & $\mathrm{m}$ & $\mathrm{m}$ & $\mathrm{m}$ & $\mathrm{m}$ & $\mathrm{m}$ & $\mathrm{m}$ & $\mathrm{m}$ \\
\hline Indonesien & 1,44 & 1,44 & 1,47 & 1,41 & 32 & 2 & 3 & 3 & 2,16 \\
\hline Lettland & $\mathrm{m}$ & $\mathrm{m}$ & $\mathrm{m}$ & $\mathrm{m}$ & $\mathrm{m}$ & $\mathrm{m}$ & $\mathrm{m}$ & $m$ & $\mathrm{~m}$ \\
\hline Russische Föd. & $\mathrm{m}$ & $\mathrm{m}$ & $\mathrm{m}$ & $\mathrm{m}$ & $\mathrm{m}$ & $\mathrm{m}$ & $\mathrm{m}$ & $\mathrm{m}$ & $\mathrm{m}$ \\
\hline Saudi-Arabien & $\mathrm{m}$ & $\mathrm{m}$ & $\mathrm{m}$ & $\mathrm{m}$ & $\mathrm{m}$ & $\mathrm{m}$ & $\mathrm{m}$ & $\mathrm{m}$ & $\mathrm{m}$ \\
\hline Südafrika & $\mathrm{m}$ & $\mathrm{m}$ & $\mathrm{m}$ & $\mathrm{m}$ & $\mathrm{m}$ & $\mathrm{m}$ & $\mathrm{m}$ & $\mathrm{m}$ & $\mathrm{m}$ \\
\hline G20-Durchschnitt & $\mathbf{m}$ & $\mathbf{m}$ & $\mathbf{m}$ & $\mathbf{m}$ & m & $\mathbf{m}$ & $\mathbf{m}$ & $\mathbf{m}$ & $\mathbf{m}$ \\
\hline
\end{tabular}

1. Enthält für den Elementarbereich nur Kindergartenlehrkräfte. 2. Tatsächliche Grundgehälter. 3. Referenzjahr 2011.

Quelle: OECD. Argentinien, China, Indien, Indonesien, Kolumbien, Saudi-Arabien und Südafrika: Statistikinstitut der UNESCO.

Hinweise s. Anhang 3 unter www.oecd.org/edu/eag.htm. StatLink: http://dx.doi.org/10.1787/888933119872

Erläuterung der Kennzeichnung fehlender Daten s. Hinweise für den Leser. 


\section{Tabelle D3.4}

Durchschnittliche tatsächliche Gehälter von Lehrkräften (2012)

Durchschnittliche Jahresgehälter (einschließlich Bonus- und Zulagezahlungen) von Lehrkräften an öffentlichen Bildungseinrichtungen, in US-Dollar (kaufkraftbereinigt mittels KKP für den privaten Verbrauch), nach Altersgruppe und Geschlecht

\begin{tabular}{|c|c|c|c|c|}
\hline & \multicolumn{4}{|c|}{ 25- bis 64-Jährige } \\
\hline & Elementarbereich & Primarbereich & Sekundarbereich I & Sekundarbereich II \\
\hline & (1) & (2) & (3) & (4) \\
\hline \multicolumn{5}{|l|}{ OECD-Länder } \\
\hline Australien & 50767 & 52659 & 52928 & 52961 \\
\hline Österreich & $\mathrm{m}$ & $\mathrm{m}$ & $\mathrm{m}$ & $\mathrm{m}$ \\
\hline Belgien (fläm.) & 48998 & 49439 & 48255 & 62528 \\
\hline Belgien (frz.) & 45608 & 45513 & 45418 & 56270 \\
\hline Kanada & $\mathrm{m}$ & $\mathrm{m}$ & $\mathrm{m}$ & $\mathrm{m}$ \\
\hline Chile & 32728 & 32728 & 32728 & 34480 \\
\hline Tschechien & 17411 & 20743 & 20724 & 21985 \\
\hline Dänemark & 50477 & 55330 & 55330 & 64384 \\
\hline England & 43949 & 43949 & 48409 & 48409 \\
\hline Estland & 11456 & 15803 & 15803 & 15803 \\
\hline Finnland $^{1}$ & 31531 & 42910 & 46968 & 52606 \\
\hline Frankreich & 35716 & 35432 & 42217 & 46247 \\
\hline Deutschland & $\mathrm{m}$ & 59598 & 65545 & 71396 \\
\hline Griechenland & 22992 & 22992 & 23941 & 23941 \\
\hline Ungarn & 15031 & 16731 & 16731 & 18716 \\
\hline Island & $\mathrm{m}$ & $\mathrm{m}$ & $\mathrm{m}$ & 38751 \\
\hline Irland & $\mathrm{m}$ & $\mathrm{m}$ & $\mathrm{m}$ & $\mathrm{m}$ \\
\hline Israel & 30544 & 33181 & 32228 & 33386 \\
\hline Italien & 34162 & 34162 & 36947 & 39233 \\
\hline Japan & $\mathrm{m}$ & $\mathrm{m}$ & $\mathrm{m}$ & $\mathrm{m}$ \\
\hline Korea & $\mathrm{m}$ & $\mathrm{m}$ & $\mathrm{m}$ & $\mathrm{m}$ \\
\hline Luxemburg & 92248 & 92248 & 104991 & 104991 \\
\hline Mexiko & $\mathrm{m}$ & $\mathrm{m}$ & $\mathrm{m}$ & $\mathrm{m}$ \\
\hline Niederlande & 49924 & 49924 & 59469 & 59469 \\
\hline Neuseeland ${ }^{2}$ & $\mathrm{~m}$ & 43102 & 43999 & 44897 \\
\hline Norwegen & 40988 & 46722 & 46722 & 49665 \\
\hline Polen & 24317 & 27986 & 28409 & 27769 \\
\hline Portugal & $\mathrm{m}$ & $\mathrm{m}$ & $\mathrm{m}$ & $\mathrm{m}$ \\
\hline Schottland ${ }^{3}$ & 42444 & 42444 & 42444 & 42444 \\
\hline Slowakei & $\mathrm{m}$ & $\mathrm{m}$ & $\mathrm{m}$ & $\mathrm{m}$ \\
\hline Slowenien & $\mathrm{m}$ & $\mathrm{m}$ & $\mathrm{m}$ & $\mathrm{m}$ \\
\hline Spanien & $\mathrm{m}$ & $\mathrm{m}$ & $\mathrm{m}$ & $\mathrm{m}$ \\
\hline Schweden 2,4 & 33036 & 35822 & 35909 & 38347 \\
\hline Schweiz ${ }^{2}$ & $\mathrm{~m}$ & $\mathrm{~m}$ & $\mathrm{~m}$ & 77250 \\
\hline Türkei & $\mathrm{m}$ & $\mathrm{m}$ & $\mathrm{m}$ & $\mathrm{m}$ \\
\hline Vereinigte Staaten & 48985 & 50494 & 51487 & 53198 \\
\hline Durchschnitt & 38253 & 41300 & 43374 & 47165 \\
\hline \multicolumn{5}{|l|}{ Partnerländer } \\
\hline Argentinien & $\mathrm{m}$ & $\mathrm{m}$ & $\mathrm{m}$ & $\mathrm{m}$ \\
\hline Brasilien & $\mathrm{m}$ & $\mathrm{m}$ & $\mathrm{m}$ & $\mathrm{m}$ \\
\hline China & $\mathrm{m}$ & $\mathrm{m}$ & $\mathrm{m}$ & $\mathrm{m}$ \\
\hline Kolumbien & $\mathrm{m}$ & $\mathrm{m}$ & $\mathrm{m}$ & $\mathrm{m}$ \\
\hline Indien & $\mathrm{m}$ & $\mathrm{m}$ & $\mathrm{m}$ & $\mathrm{m}$ \\
\hline Indonesien & $\mathrm{m}$ & $\mathrm{m}$ & $\mathrm{m}$ & $\mathrm{m}$ \\
\hline Lettland & $\mathrm{m}$ & $\mathrm{m}$ & $\mathrm{m}$ & $\mathrm{m}$ \\
\hline Russische Föderation ${ }^{2,5}$ & 18445 & 18445 & 18445 & 18445 \\
\hline Saudi-Arabien & $\mathrm{m}$ & $\mathrm{m}$ & $\mathrm{m}$ & $\mathrm{m}$ \\
\hline Südafrika & $\mathrm{m}$ & $\mathrm{m}$ & $\mathrm{m}$ & $\mathrm{m}$ \\
\hline
\end{tabular}

Anmerkung: Die Spalten mit den Angaben zu den durchschnittlichen tatsächlichen Gehältern der Lehrkräfte, aufgegliedert nach Altersgruppe und Geschlecht, d.h. die Spalten (5) bis (28), sind im Internet verfügbar (s. StatLink unten).

1. Enthält für den Elementarbereich nur Kindergartenlehrkräfte. 2. Referenzjahr 2011. 3. Enthält alle Lehrkräfte, unabhängig von ihrem Alter. 4. Durchschnittliche tatsächliche Gehälter von Lehrkräften, ohne Bonus- und Zulagezahlungen. 5. Durchschnittliche tatsächliche Gehälter von allen Lehrkräften, unabhängig von dem Bildungsbereich, in dem sie unterrichten.

Quelle: OECD. Argentinien, China, Indien, Indonesien, Kolumbien, Saudi-Arabien und Südafrika: Statistikinstitut der UNESCO.

Hinweise s. Anhang 3 unter www.oecd.org/edu/eag.htm. StatLink: http://dx.doi.org/10.1787/888933119891

Erläuterung der Kennzeichnung fehlender Daten s. Hinweise für den Leser. 
Entwicklung der Gehälter von Lehrkräften zwischen 2000 und 2012

Index der Veränderung der gesetzlichen bzw. vertraglich vereinbarten Gehälter von Lehrkräften mit 15 Jahren Berufserfahrung/

Mindestausbildung $(2005=100)$, nach Bildungsbereich (mittels Deflatoren für den privaten Konsum in konstante Preise umgerechnet)

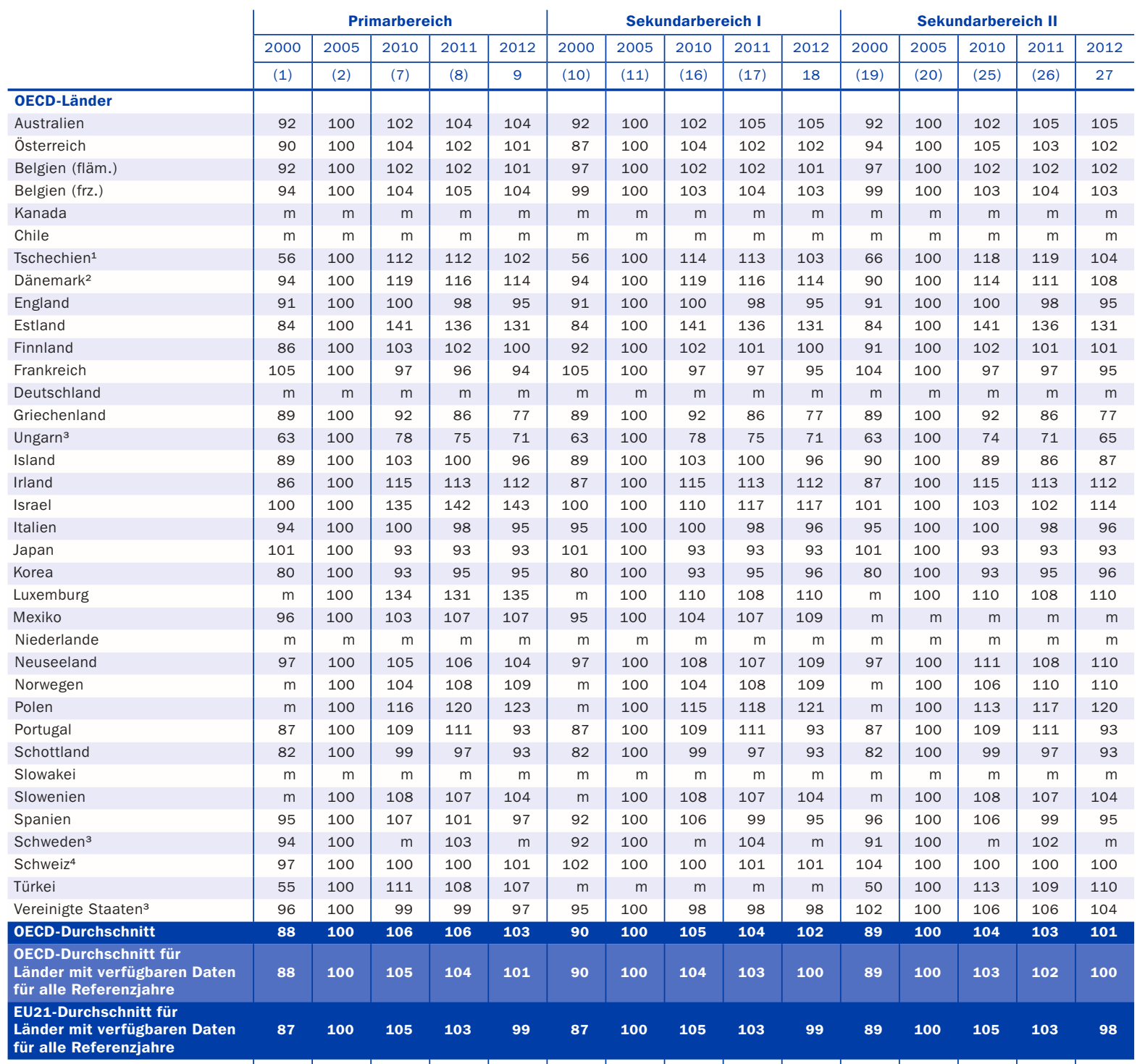

\begin{tabular}{l|c|c|c|c|c|c|c|c|c|c|c|c|c|c|c}
\hline Partnerländer & & & & & & & & & & & & & & \\
Argentinien & $\mathrm{m}$ & $\mathrm{m}$ & $\mathrm{m}$ & $\mathrm{m}$ & $\mathrm{m}$ & $\mathrm{m}$ & $\mathrm{m}$ & $\mathrm{m}$ & $\mathrm{m}$ & $\mathrm{m}$ & $\mathrm{m}$ & $\mathrm{m}$ & $\mathrm{m}$ & $\mathrm{m}$ & $\mathrm{m}$ \\
Brasilien & $\mathrm{m}$ & $\mathrm{m}$ & $\mathrm{m}$ & $\mathrm{m}$ & $\mathrm{m}$ & $\mathrm{m}$ & $\mathrm{m}$ & $\mathrm{m}$ & $\mathrm{m}$ & $\mathrm{m}$ & $\mathrm{m}$ & $\mathrm{m}$ & $\mathrm{m}$ & $\mathrm{m}$ & $\mathrm{m}$ \\
China & $\mathrm{m}$ & $\mathrm{m}$ & $\mathrm{m}$ & $\mathrm{m}$ & $\mathrm{m}$ & $\mathrm{m}$ & $\mathrm{m}$ & $\mathrm{m}$ & $\mathrm{m}$ & $\mathrm{m}$ & $\mathrm{m}$ & $\mathrm{m}$ & $\mathrm{m}$ & $\mathrm{m}$ & $\mathrm{m}$ \\
\hline Kolumbien & $\mathrm{m}$ & $\mathrm{m}$ & $\mathrm{m}$ & $\mathrm{m}$ & $\mathrm{m}$ & $\mathrm{m}$ & $\mathrm{m}$ & $\mathrm{m}$ & $\mathrm{m}$ & $\mathrm{m}$ & $\mathrm{m}$ & $\mathrm{m}$ & $\mathrm{m}$ & $\mathrm{m}$ & $\mathrm{m}$ \\
\hline Indien & $\mathrm{m}$ & $\mathrm{m}$ & $\mathrm{m}$ & $\mathrm{m}$ & $\mathrm{m}$ & $\mathrm{m}$ & $\mathrm{m}$ & $\mathrm{m}$ & $\mathrm{m}$ & $\mathrm{m}$ & $\mathrm{m}$ & $\mathrm{m}$ & $\mathrm{m}$ & $\mathrm{m}$ & $\mathrm{m}$ \\
\hline Indonesien & $\mathrm{m}$ & $\mathrm{m}$ & $\mathrm{m}$ & $\mathrm{m}$ & $\mathrm{m}$ & $\mathrm{m}$ & $\mathrm{m}$ & $\mathrm{m}$ & $\mathrm{m}$ & $\mathrm{m}$ & $\mathrm{m}$ & $\mathrm{m}$ & $\mathrm{m}$ & $\mathrm{m}$ & $\mathrm{m}$ \\
Lettland & $\mathrm{m}$ & $\mathrm{m}$ & $\mathrm{m}$ & $\mathrm{m}$ & $\mathrm{m}$ & $\mathrm{m}$ & $\mathrm{m}$ & $\mathrm{m}$ & $\mathrm{m}$ & $\mathrm{m}$ & $\mathrm{m}$ & $\mathrm{m}$ & $\mathrm{m}$ & $\mathrm{m}$ & $\mathrm{m}$ \\
Russische Föderation & $\mathrm{m}$ & $\mathrm{m}$ & $\mathrm{m}$ & $\mathrm{m}$ & $\mathrm{m}$ & $\mathrm{m}$ & $\mathrm{m}$ & $\mathrm{m}$ & $\mathrm{m}$ & $\mathrm{m}$ & $\mathrm{m}$ & $\mathrm{m}$ & $\mathrm{m}$ & $\mathrm{m}$ & $\mathrm{m}$ \\
Saudi-Arabien & $\mathrm{m}$ & $\mathrm{m}$ & $\mathrm{m}$ & $\mathrm{m}$ & $\mathrm{m}$ & $\mathrm{m}$ & $\mathrm{m}$ & $\mathrm{m}$ & $\mathrm{m}$ & $\mathrm{m}$ & $\mathrm{m}$ & $\mathrm{m}$ & $\mathrm{m}$ & $\mathrm{m}$ & $\mathrm{m}$ \\
\hline Südafrika & $\mathrm{m}$ & $\mathrm{m}$ & $\mathrm{m}$ & $\mathrm{m}$ & $\mathrm{m}$ & $\mathrm{m}$ & $\mathrm{m}$ & $\mathrm{m}$ & $\mathrm{m}$ & $\mathrm{m}$ & $\mathrm{m}$ & $\mathrm{m}$ & $\mathrm{m}$ & $\mathrm{m}$ & $\mathrm{m}$ \\
G20-Durchschnitt & $\mathbf{m}$ & $\mathbf{m}$ & $\mathbf{m}$ & $\mathbf{m}$ & $\mathbf{m}$ & $\mathbf{m}$ & $\mathbf{m}$ & $\mathbf{m}$ & $\mathbf{m}$ & $\mathbf{m}$ & $\mathbf{m}$ & $\mathbf{m}$ & $\mathbf{m}$ & $\mathbf{m}$ & $\mathbf{m}$
\end{tabular}

Anmerkung: Die Spalten mit den Angaben für die Jahre 2006, 2007, 2008 und 2009, d.h. die Spalten (3)-(6), (12)-(15) und (21)-(24), sind im Internet verfügbar (s. StatLink unten)

1. Unterbrechung der Zeitreihe im Jahr 2012 aufgrund von Veränderungen in der Methodik. 2. Unterbrechung der Zeitreihe im Jahr 2009 aufgrund von Veränderungen in der Methodik. 3. Tatsächliche Grundgehälter. 4. Gehälter nach 11 Jahren Berufserfahrung.

Quelle: OECD. Argentinien, China, Indien, Indonesien, Kolumbien, Saudi-Arabien und Südafrika: Statistikinstitut der UNESCO.

Hinweise s. Anhang 3 unter www.oecd.org/edu/eag.htm. StatLink: http://dx.doi.org/10.1787/888933119910

Erläuterung der Kennzeichnung fehlender Daten s. Hinweise für den Leser. 



\section{Indikatior}

\section{Wie viel Zeit unterrichten Lehrkräfte?}

Im Elementarbereich unterrichten Lehrkräfte an öffentlichen Bildungseinrichtungen im Durchschnitt I.oor Zeitstunden im Jahr, im Primarbereich 782 Zeitstunden, im Sekundarbereich I 694 Zeitstunden und im Sekundarbereich II 655 Zeitstunden.

In ungefähr einem Drittel der Länder mit verfügbaren Daten stieg oder sank die Zahl der von den Lehrkräften zu unterrichtenden Zeitstunden zwischen 2000 und 2012 im Primar-, Sekundarbereich I und/oder II um mindestens Io Prozent.

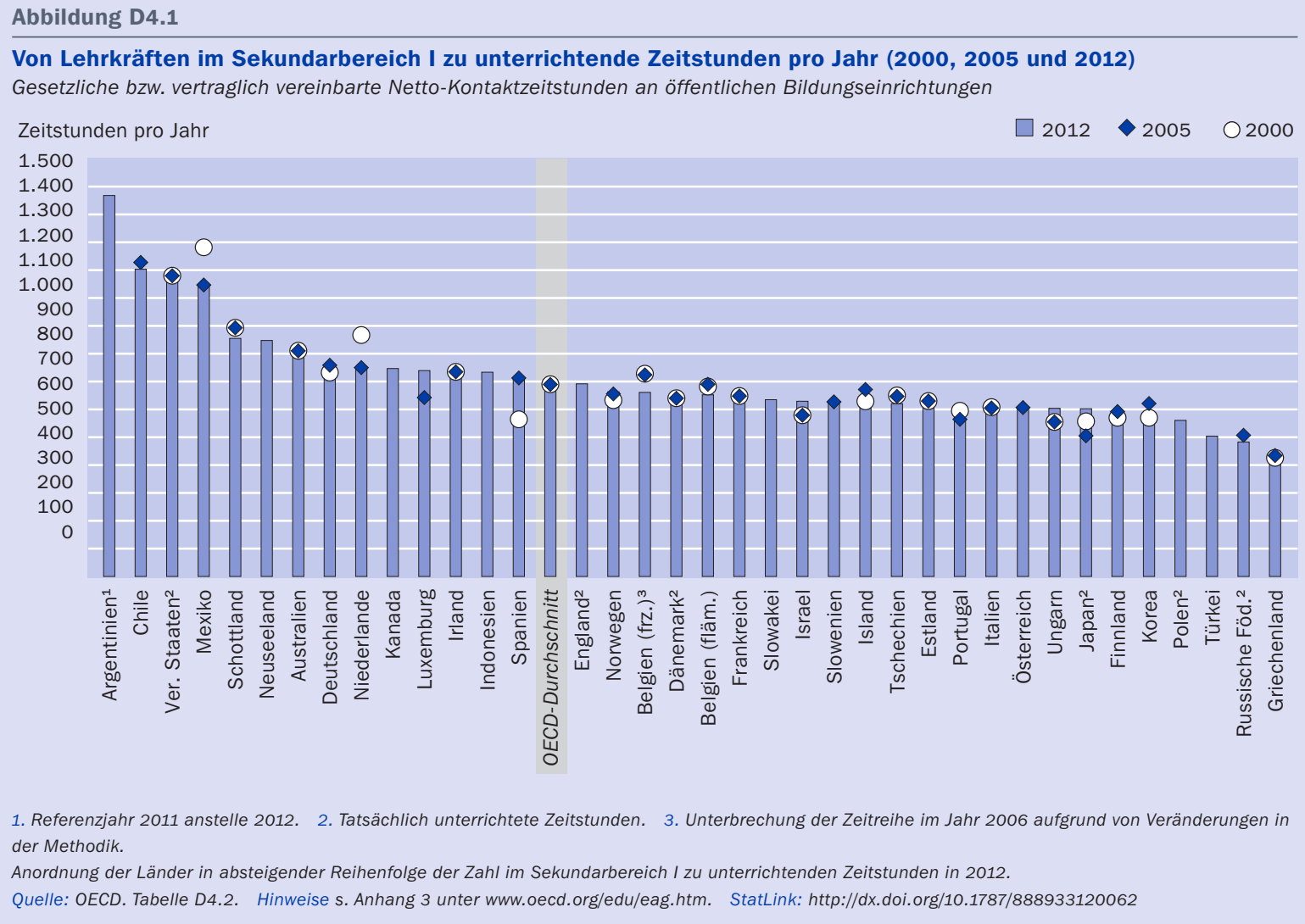

\section{Kontext}

Obwohl die gesetzliche bzw. vertraglich vereinbarte Arbeits- und Unterrichtszeit die tatsächliche Arbeitsbelastung der Lehrkräfte nur zu einem Teil bestimmen, gewähren sie doch einen interessanten Einblick in die unterschiedlichen Anforderungen an Lehrkräfte in den verschiedenen Ländern. Die Unterrichtszeit und das Ausmaß nicht unmittelbar unterrichtsbezogener Aufgaben können auch die Attraktivität des Lehrerberufs beeinflussen. Dieser Indikator zeigt einige weitere wichtige Faktoren auf, die zusammen mit den Gehältern der Lehrkräfte (s. Indikator $\mathrm{D}_{3}$ ) und der durchschnittlichen Klassengröße (s. Indikator D2) die Arbeitsbedingungen der Lehrkräfte bestimmen. 
Der Anteil der gesetzlichen bzw. vertraglich vereinbarten Arbeitszeit, die im Unterricht verbracht wird, gibt Aufschluss darüber, wie viel Zeit für nicht unterrichtende Tätigkeiten wie Unterrichtsvorbereitung, Korrekturen, interne Fortbildung und Besprechungen zur Verfügung steht. Wenn die Unterrichtsverpflichtungen einen großen Teil der gesetzlichen bzw. vertraglich vereinbarten Arbeitszeit ausmachen, kann dies darauf hindeuten, dass weniger (Arbeits-)Zeit für Aufgaben wie Schülerbeurteilungen und Unterrichtsvorbereitung aufgewendet wird.

Zusammen mit Faktoren wie der Klassengröße und der Schüler-Lehrkräfte-Relation (s. Indikator D2), der Unterrichtszeit der Schüler (s. Indikator DI) und den Gehältern der Lehrkräfte (s. Indikator $\mathrm{D}_{3}$ ) beeinflusst die Zeit, die Lehrkräfte unterrichten, auch die von den einzelnen Ländern für Bildung aufzuwendenden Finanzmittel (s. Indikator $\mathrm{B} 7)$.

\section{Weitere wichtige Ergebnisse}

Die durchschnittliche Zahl der von Lehrkräften an öffentlichen Schulen des Elementarbereichs zu unterrichtenden Zeitstunden beträgt 1.001 Stunden pro Jahr, reicht jedoch von 532 Stunden in Mexiko bis zu mehr als I.500 Stunden in Island, Norwegen und Schweden.

Lehrkräfte an öffentlichen Schulen des Primarbereichs unterrichten im Durchschnitt 782 Zeitstunden pro Jahr, dies reicht aber von weniger als 570 Stunden in Griechenland und der Russischen Föderation bis zu mehr als I.000 Stunden in Chile, Indonesien und den Vereinigten Staaten.

Die Zahl der von Lehrkräften an öffentlichen Schulen des Sekundarbereichs I zu unterrichtenden Zeitstunden beträgt im Durchschnitt 694 Stunden pro Jahr, reicht jedoch von 415 Stunden in Griechenland bis zu mehr als I.00o Stunden in Argentinien, Chile, Mexiko und den Vereinigten Staaten.

Im Sekundarbereich II liegt die Zahl der zu unterrichtenden Zeitstunden an öffentlichen Bildungseinrichtungen bei durchschnittlich 655 Stunden im Jahr, sie reicht jedoch von 369 Stunden in Dänemark bis zu mehr als I.000 Stunden in Argentinien, Chile und den Vereinigten Staaten.

Die von Lehrkräften zu unterrichtende Zahl an Zeitstunden ist im Elementarbereich durchschnittlich rund 25 Prozent höher als im Primarbereich; die Zeit, die Lehrkräfte in der Schule arbeiten müssen, bzw. ihre Gesamtarbeitszeit ist in diesen beiden Bildungsbereichen jedoch oft gleich.

Die Vorgaben für die Arbeitszeit der Lehrkräfte unterscheiden sich erheblich in den einzelnen Ländern. In den meisten Ländern ist offiziell festgelegt, wie viele Zeitstunden Lehrkräfte pro Jahr arbeiten müssen. In einigen Ländern wird die Unterrichtszeit nur in Form der Zahl der pro Woche zu gebenden Unterrichtseinheiten festgelegt, und es werden möglicherweise Annahmen getroffen, wie viel Zeit zusätzlich pro Unterrichtseinheit (innerhalb oder außerhalb der Schule) notwendig ist. 


\section{Entwicklungstendenzen}

In rund einem Drittel der Länder mit verfügbaren Daten gab es zwischen 2000 und 2012 im Primar-, Sekundarbereich I und/oder II einen Anstieg bzw. eine Reduzierung der Zahl der von Lehrkräften zu unterrichtenden Zeitstunden um mindestens Io Prozent. In einigen Ländern gab es jedoch außerordentlich große Veränderungen bei den zu unterrichtenden Zeitstunden: In Spanien stieg ihre Zahl im Sekundarbereich um 26 Prozent, während sie in Korea im Primarbereich um fast 20 Prozent sank.

\section{Analyse und Interpretationen}

\section{Zahl der von Lehrkräften zu unterrichtenden Zeitstunden}

In allen Bildungsbereichen gibt es zwischen den einzelnen Ländern Unterschiede hinsichtlich der Zahl an Zeitstunden, die Lehrkräfte an einer öffentlichen Schule durchschnittlich pro Jahr unterrichten müssen.

Im Elementarbereich unterscheidet sich die Zahl der an öffentlichen Bildungseinrichtungen zu unterrichtenden Zeitstunden mehr zwischen den einzelnen Ländern als in allen anderen Bildungsbereichen. Die Zahl der Unterrichtstage reicht von 144 Tagen in Frankreich bis zu 25I Tagen in Indonesien, und die Zahl der von Lehrkräften zu unterrichtenden Zeitstunden reicht von weniger als 700 Stunden in Argentinien, England, Griechenland, Indonesien, Korea und Mexiko bis zu mehr als I.500 Stunden in Island, Norwegen und Schweden. Im Durchschnitt müssen Lehrkräfte in den OECD-Ländern in diesem Bildungsbereich I. oor Stunden im Jahr unterrichten, verteilt auf 40 Wochen oder I9I Unterrichtstage.

Lehrkräfte im Primarbereich müssen im Durchschnitt 782 Zeitstunden pro Jahr unterrichten. In den meisten Ländern mit verfügbaren Daten müssen Lehrkräfte zwischen 3 und 6 Zeitstunden am Tag unterrichten. Ausnahmen sind Chile, Frankreich und die Vereinigten Staaten, wo Lehrkräfte etwas mehr als 6 Zeitstunden am Tag unterrichten. Es bestehen keine einheitlichen Regelungen für die Verteilung der zu unterrichtenden Zeitstunden über das Jahr. So müssen Lehrkräfte in Spanien im Primarbereich beispielsweise 880 Zeitstunden pro Jahr unterrichten, rund Ioo Zeitstunden mehr als im Durchschnitt der OECD-Länder. Diese Stunden sind jedoch auf eine geringere Zahl von Unterrichtstagen verteilt als im OECD-Durchschnitt, da Lehrkräfte in Spanien im Primarbereich durchschnittlich 5 Zeitstunden pro Tag unterrichten gegenüber 4,3 Stunden im OECD-Durchschnitt.

Lehrkräfte im Sekundarbereich I unterrichten durchschnittlich 694 Zeitstunden pro Jahr. Im Sekundarbereich I liegt die zu unterrichtende Zeit zwischen weniger als 600 Zeitstunden in Finnland, Griechenland, Korea, Polen, der Russischen Föderation und der Türkei und mehr als I.00o Zeitstunden in Argentinien, Chile, Mexiko und den Vereinigten Staaten.

Im Durchschnitt ist eine Lehrkraft im Sekundarbereich II (allgemeinbildend) verpflichtet, 655 Zeitstunden pro Jahr zu unterrichten. Nur in sechs Ländern übersteigt die zu 


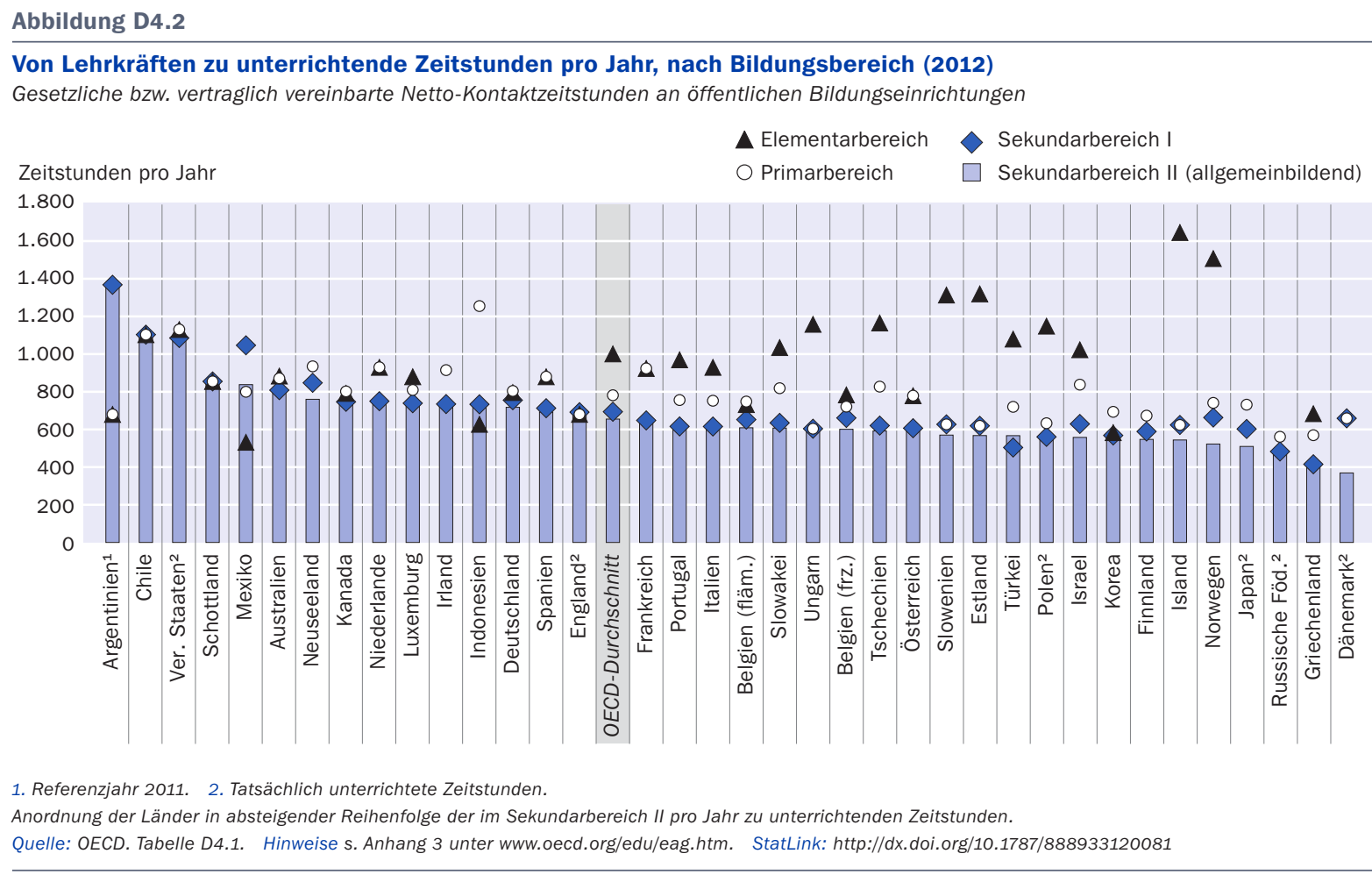

unterrichtende Zeit 800 Zeitstunden: in Argentinien, Australien, Chile, Mexiko, Schottland und den Vereinigten Staaten. In Chile und Schottland jedoch beziehen sich die gemeldeten Zeitstunden auf die maximale Anzahl an Zeitstunden, die eine Lehrkraft gegebenenfalls zu unterrichten hat, und nicht auf die regulär zu unterrichtende Zahl an Zeitstunden. Im Gegensatz hierzu sind die Lehrkräfte in Dänemark, Griechenland und der Russischen Föderation nur zu weniger als 500 Zeitstunden Unterricht im Jahr verpflichtet. Lehrkräfte in Finnland, Griechenland, Japan, Korea, Norwegen, der Russischen Föderation und Slowenien unterrichten im Durchschnitt pro Tag höchstens 3 Zeitstunden, während es in Chile und den Vereinigten Staaten mehr als 5 Zeitstunden und in Argentinien bis zu 8 Zeitstunden sind. Diese Unterschiede könnten teilweise darauf zurückzuführen sein, dass einige Länder Pausen zwischen den Unterrichtseinheiten zur Unterrichtszeit zählen, andere aber nicht (Tab. D4.I und Abb. D4.2).

\section{Unterschiede in der Zahl der zu unterrichtenden Zeitstunden in den verschiedenen Bildungsbereichen}

In den meisten Ländern müssen Lehrkräfte im Sekundarbereich II weniger Zeitstunden unterrichten als im Elementarbereich. Ausnahmen sind Chile und Schottland, wo Lehrkräfte unabhängig vom Bildungsbereich dieselbe Anzahl Zeitstunden unterrichten müssen, sowie Argentinien, England, Indonesien und Mexiko, wo Lehrkräfte im Sekundarbereich II mehr Zeitstunden unterrichten müssen als Lehrkräfte im Elementarbereich (Tab. D4.I und Abb. D4.2).

Der größte Unterschied in der Zahl der zu unterrichtenden Zeitstunden besteht zwischen dem Elementar- und dem Primarbereich. Lehrkräfte müssen im Elementarbereich durchschnittlich fast 25 Prozent mehr Zeit im Klassenzimmer verbringen als Lehrkräfte im Primarbereich. In Estland, Island, Norwegen und Slowenien müssen 
Lehrkräfte im Elementarbereich mindestens doppelt so viel Zeit unterrichten wie Lehrkräfte im Primarbereich. Auch wenn sich die Pflichten der Lehrkräfte in diesen beiden Bildungsbereichen wahrscheinlich voneinander unterscheiden, können sich beträchtliche Unterschiede in den Arbeitsbedingungen zwischen dem Elementarbereich und den anderen Bildungsbereichen auf die Attraktivität des Lehrerberufs im Elementarbereich auswirken.

In Frankreich, Griechenland, Indonesien, Israel, Tschechien und der Türkei ist die Zahl der jährlich zu unterrichtenden Zeitstunden für Lehrkräfte im Primarbereich um mindestens 30 Prozent höher als im Sekundarbereich I. Im Gegensatz dazu beträgt der Unterschied in den Vereinigten Staaten höchstens 5 Prozent, und in Chile, Dänemark, Estland, Island, Schottland, Slowenien und Ungarn besteht überhaupt kein Unterschied. Argentinien, England und Mexiko sind die einzigen Länder, in denen Lehrkräfte im Primarbereich weniger Zeitstunden unterrichten müssen als Lehrkräfte im Sekundarbereich I.

In den meisten Ländern gibt es nur geringe Abweichungen zwischen den im Sekundarbereich I und II zu unterrichtenden Zeitstunden. Jedoch ist in Mexiko und Norwegen die Zahl der jährlich zu unterrichtenden Zeitstunden im Sekundarbereich I mindestens 20 Prozent höher als im Sekundarbereich II, in Dänemark sind es sogar fast 80 Prozent.

\section{Tatsächlich unterrichtete Zeitstunden}

Die in diesem Indikator von den meisten Ländern angegebene gesetzliche bzw. vertraglich vereinbarte Zahl der von Lehrkräften zu unterrichtenden Zeitstunden ist von der Zahl der tatsächlich unterrichteten Zeitstunden zu unterscheiden. Diese umfassen die durchschnittliche Zahl an Zeitstunden pro Jahr, die eine Vollzeitlehrkraft eine Gruppe oder Klasse von Schülern unterrichtet (einschließlich Überstunden). Die Angabe basiert auf Verwaltungsunterlagen, statistischen Datenbanken, repräsentativen Stichprobenerhebungen und sonstigen repräsentativen Quellen.

Nur wenige Länder konnten sowohl die gesetzliche bzw. vertraglich vereinbarte Zahl der von Lehrkräften zu unterrichtenden Zeitstunden als auch die tatsächlich unterrichteten Zeitstunden angeben. Wo Angaben gemacht wurden, deuten die Daten darauf hin, dass sich die Zahl der tatsächlich unterrichteten Zeitstunden manchmal von der gesetzlichen bzw. vertraglich vereinbarten Zahl zu unterrichtender Zeitstunden unterscheiden kann. In Australien beispielsweise arbeiten Lehrkräfte im Sekundarbereich I rund 5 Prozent mehr als vorgeschrieben, während die Zahl der tatsächlich unterrichteten Zeitstunden in Polen bis zu I4 Prozent über der festgelegten Zahl liegt. In Estland dagegen liegt im Sekundarbereich I die Zahl der tatsächlich unterrichteten Zeitstunden 5 Prozent unter der gesetzlichen bzw. vertraglich vereinbarten Zahl zu unterrichtender Zeitstunden (s. Tab. D4.3 und Abb. D4.4 im Internet).

\section{Entwicklungstendenzen der von Lehrkräften zu unterrichtenden Zeitstunden}

In rund der Hälfte der Länder mit verfügbaren Daten hat sich die Zahl der zu unterrichtenden Zeitstunden zwischen 2000 und 2012 in einem oder mehreren Bildungsbereichen um mindestens Io Prozent verändert (Tab. D4.2 und Abb. D4.I). 
Kasten D4.1

\section{Womit verbringen die Lehrkräfte im Sekundarbereich I die Zeit in der Klasse?}

In der internationalen Erhebung der OECD zu Lehren und Lernen (TALIS) von 2013 gaben in den teilnehmenden Ländern und Volkswirtschaften die Lehrkräfte im Sekundarbereich I an, von den drei Arten von Tätigkeiten (lehr- und lernbezogene Tätigkeiten, administrative Tätigkeiten und Tätigkeiten zur Wahrung von Ordnung oder zur Disziplinierung einzelner Schüler oder der ganzen Klasse) den Großteil ihrer Zeit (79 Prozent) im Unterricht mit lehr- und lernbezogenen Tätigkeiten zu verbringen. Dieser Anteil variiert jedoch von Land zu Land zwischen 87 Prozent in Bulgarien und 67 Prozent in Brasilien. Die Wahrung der Ordnung im Klassenzimmer, in der Regel eine große Herausforderung für junge Lehrer, nahm den Angaben zufolge im Durchschnitt aller Länder I3 Prozent der Zeit der Lehrkräfte in Anspruch, wobei auch dieser Anteil von Land zu Land variierte, von 8 Prozent in Polen bis zu 20 Prozent in Brasilien. Die administrativen Aufgaben nahmen für die Lehrkräfte im Vergleich zu den anderen beiden Kategorien den Angaben zufolge am wenigsten Zeit in Anspruch (8 Prozent). Lehrkräfte in Bulgarien und Estland gaben an, 5 Prozent ihrer Zeit im Unterricht mit administrativen Aufgaben zu verbringen, bei den Lehrkräften in Brasilien betrug dieser Anteil I2 Prozent. Die lehr- und lernbezogenen Aufgaben sollten zweifellos den größten Teil der täglich im Unterricht verbrachten Zeit der Lehrkräfte ausmachen. Es ist jedoch nicht klar, ob die anderen beiden Aufgabenbereiche die Qualität des Unterrichts beeinträchtigen oder ob die Lehrkräfte und damit letztlich die Schüler von einer Reduzierung der für administrative Aufgaben und die Wahrung der Ordnung aufgewendeten Zeit im Unterricht zugunsten von mehr Zeit für die lehr- und lernbezogenen Tätigkeiten profitieren würden.

\section{Abbildung D4.a}

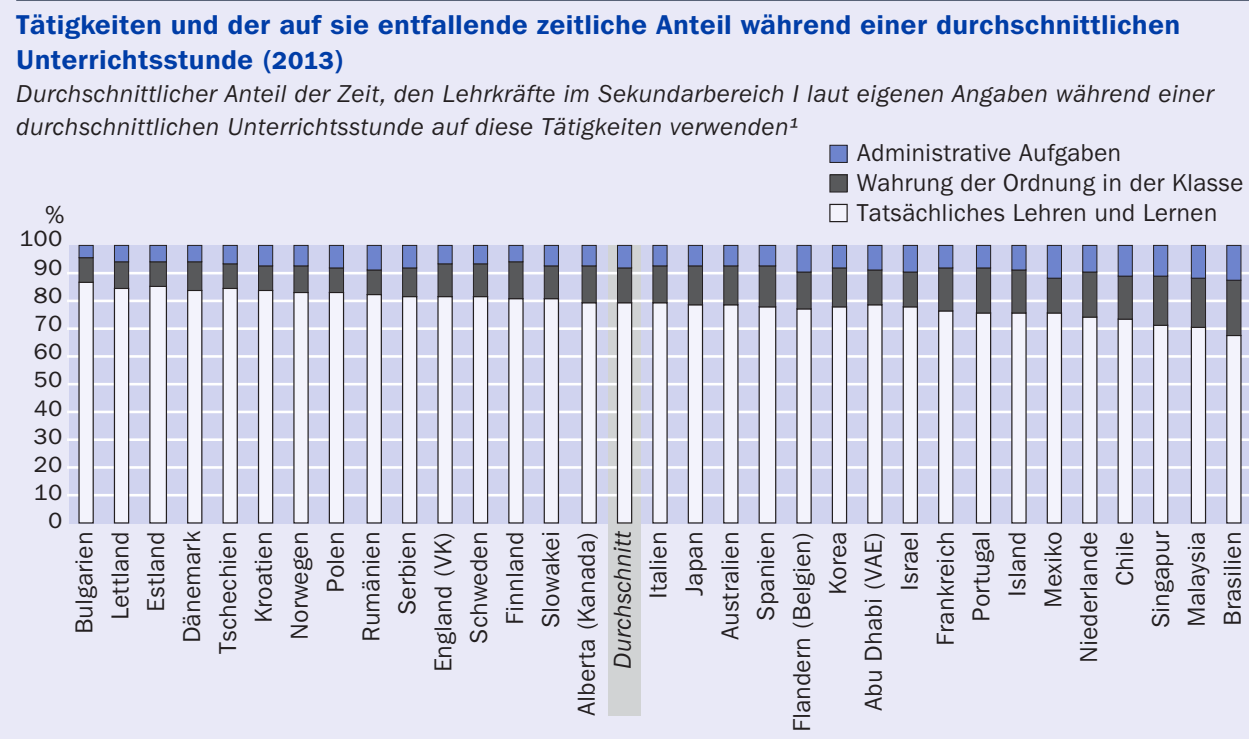

1. Die Daten basieren auf den Angaben der Lehrkräfte und beziehen sich auf eine zufällig ausgewählte Klasse, die diese momentan wöchentlich unterrichten.

Anordnung der Länder in absteigender Reihenfolge des durchschnittlichen Anteils an Zeit, den Lehrkräfte im Sekundarbereich I laut eigenen Angaben auf das tatsächliche Lehren und Lernen verwenden.

Quelle: OECD (2014), TALIS 2013 Results: An International Perspective on Teaching and Learning, TALIS, OECD Publishing. StatLink: http://dx.doi.org/10.1787/888933042124 
In Israel und Japan gab es während dieses Zeitraums eine Steigerung im Primarbereich um I5 Prozent und in der Türkei um I3 Prozent. In Israel war diese Steigerung der Unterrichts- und Arbeitszeit eines der Ergebnisse der Schulreform „Neue Horizonte“, die seit 2008 schrittweise umgesetzt wird. Eine der Hauptmaßnahmen dieser Reform bestand darin, die Arbeitswoche der Lehrkräfte (bei großzügigerer Vergütung) zu verlängern, um Unterricht in Kleingruppen zu ermöglichen. Die Arbeitszeit der Lehrer wurde von 30 auf 36 Zeitstunden pro Woche erhöht und beinhaltet nun in Schulen des Primarbereichs fünf Stunden Unterricht in Kleingruppen. Im Gegenzug stiegen die Gehälter beträchtlich (s. Indikator $\mathrm{D}_{3}$ ).

2012 mussten Lehrkräfte im Sekundarbereich in Spanien 26 Prozent mehr Zeitstunden unterrichten als im Jahr 2000; in Luxemburg mussten Lehrkräfte im Sekundarbereich 2012 I5 Prozent mehr Zeitstunden unterrichten als im Jahr 2005. Zwischen 2000 und 2012 stieg die Zahl der zu unterrichtenden Zeitstunden im Sekundarbereich II auch in Portugal (rund 20 Prozent), Island (I7 Prozent) und der Türkei (I3 Prozent).

Im Gegensatz dazu sank die Netto-Unterrichtszeit zwischen 2000 und 2012 in Korea im Primarbereich um rund 20 Prozent und in Mexiko (im Sekundarbereich I), den Niederlanden (Sekundarbereich I und II) und in Schottland (Primarbereich) um rund Io Prozent. In Schottland war die Reduzierung Teil der Vereinbarung mit den Lehrkräften „Der Lehrerberuf im 2I. Jahrhundert“, durch die 200 I eine 35-Stunden-Arbeitswoche für alle Lehrkräfte sowie eine schrittweise Reduzierung der maximalen Unterrichtszeit auf 22,5 Zeitstunden pro Woche für Lehrkräfte im Primar-, Sekundar- und Sonderschulbereich eingeführt wurde. Selbst nach dieser Reduzierung der Nettokontaktzeit müssen Lehrkräfte dieser Bildungsbereiche in Schottland jedoch immer noch mehr Zeitstunden unterrichten als im Durchschnitt in den OECD-Ländern.

\section{Arbeitszeit der Lehrkräfte}

In den meisten Ländern müssen die Lehrkräfte auf Grundlage offizieller Regelungen eine bestimmte Zahl an Zeitstunden pro Woche arbeiten (unterrichtende und nicht unterrichtende Tätigkeiten), um ein Vollzeitgehalt zu erhalten. Einige Länder legen aber auch fest, wie viel Zeit die Lehrkräfte in der Schule verbringen müssen. Innerhalb dieses Rahmens gibt es jedoch zwischen den einzelnen Ländern Unterschiede hinsichtlich der weiteren Bestimmungen, wie viel Zeit unterrichtend und wie viel Zeit mit anderen Aktivitäten zu verbringen ist (Abb. D4.3).

In mehr als der Hälfte der OECD-Länder wird für einen oder mehrere Bildungsbereiche die Zeit festgelegt, die die Lehrkräfte in der Schule sowohl für Unterricht als auch für nicht unmittelbar unterrichtsbezogene Aktivitäten zur Verfügung stehen müssen. In etwas mehr als der Hälfte dieser Länder unterscheidet sich die Zeit, die Lehrkräfte im Sekundarbereich II und im Elementarbereich in der Schule zur Verfügung stehen müssen, um weniger als Io Prozent. In Israel, Norwegen und Schweden müssen Lehrkräfte im Elementarbereich mindestens 30 Prozent mehr Zeitstunden in der Schule zur Verfügung stehen als Lehrkräfte im Sekundarbereich II (Tab. D4.I).

In Dänemark, Deutschland, Frankreich (Sekundarbereich I und II), Japan (Primar-, Sekundarbereich I und II), den Niederlanden, Österreich (Elementar-, Primar- und Sekundarbereich I) und Tschechien ist die Jahresarbeitszeit der Lehrkräfte, die sie 
Kasten D4.2

\section{Wie viel Zeit verbringen die Lehrkräfte in einer typischen Woche mit den verschiedenen Aufgaben?}

Die Ergebnisse der TALIS-Studie von 2013 legen nahe, dass die Arbeit der Lehrkräfte im Sekundarbereich I eine Vielzahl häufig miteinander konkurrierender Pflichten beinhaltet. Erwartungsgemäß gaben sowohl vollzeit- als auch teilzeitbeschäftigte Lehrkräfte an, den größten Teil ihrer Arbeitszeit mit Unterrichten zu verbringen, nämlich im Gesamtdurchschnitt I 9 Zeitstunden pro Woche, von I5 Zeitstunden in Norwegen bis 27 Zeitstunden in Chile. Die Lehrkräfte in Japan gaben an, nur I 8 Zeitstunden der angegebenen 54 Wochenstunden im Durchschnitt mit Unterrichten zu verbringen, d.h., sie verbringen deutlich mehr Zeit mit anderen Aufgaben als tatsächlich mit Unterricht. Den Angaben zufolge betrug die für die Unterrichtsplanung und -vorbereitung aufgewendete Zeit im Durchschnitt 7 Stunden, von 5 Stunden in Finnland, Israel, Italien, den Niederlanden und Polen bis zu Io Stunden in Kroatien. Die für die Benotung von Schülerleistungen aufgewendete Zeit wurde mit durchschnittlich 5 Stunden angegeben, liegt jedoch in Portugal mit Io Stunden und Singapur mit 9 Stunden annähernd doppelt so hoch.

\section{Abbildung D4.b}

\section{Arbeitszeit der Lehrkräfte (2013)}

Durchschnittliche Anzahl der Zeitstunden, die Lehrkräfte im Sekundarbereich I laut eigenen Angaben während der letzten vollständigen Kalenderwoche auf die folgenden Tätigkeiten verwendet haben ${ }^{1}$

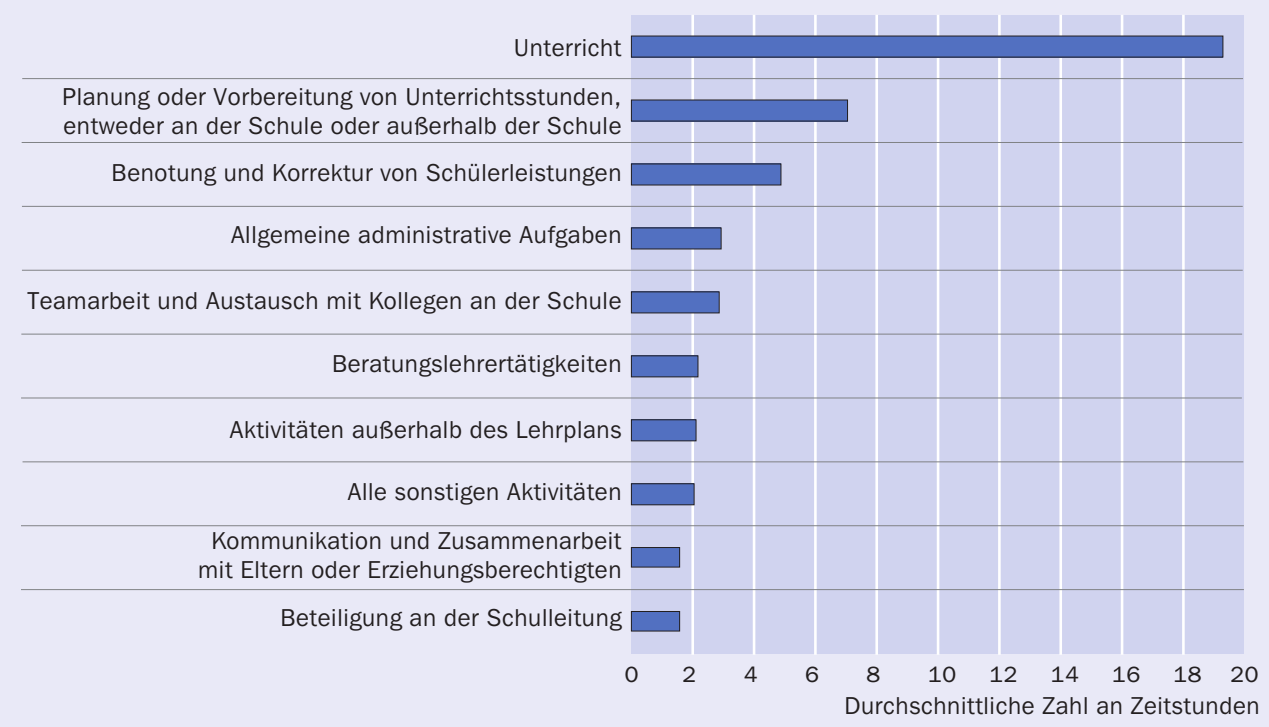

1. Eine „vollständige“ Kalenderwoche ist weder durch Ferien, gesetzliche Feiertage noch Krankheit unterbrochen. Umfasst auch Tätigkeiten, die am Wochenende, am Abend oder sonst außerhalb der Unterrichtszeit wahrgenommen wurden.

Anordnung der Tätigkeiten in absteigender Reihenfolge der durchschnittlichen Anzahl der Zeitstunden, die während der letzten vollständigen Kalenderwoche auf sie verwendet wurden.

Quelle: OECD (2014), TALIS 2013 Results: An International Perspective on Teaching and Learning, TALIS, OECD Publishing. StatLink: http://dx.doi.org/10.1787/888933042029

Auf sonstige Aufgaben wie z. B. Schulleitungstätigkeiten, Elterngespräche und außerlehrplanmäßige Aktivitäten entfallen im Durchschnitt jeweils nur 2 Stunden in der Woche. Lehrkräfte in Korea und Malaysia gaben an, doppelt so viel Zeit (6 Stunden) mit allgemeinen administrativen Tätigkeiten zu verbringen als der Durchschnitt 
der TALIS-Länder. In Japan bilden die außerlehrplanmäßigen Aktivitäten einen wichtigen Bestandteil der Tätigkeit der Lehrkräfte. Hier gaben die Lehrkräfte an, 8 Stunden auf sie zu verwenden, was weit über dem in der TALIS-Studie ermittelten Durchschnitt von 2 Stunden liegt.

Diese Ergebnisse sollen einen Überblick über eine typische Arbeitswoche im Sekundarbereich I in den einzelnen Ländern vermitteln und enthalten deshalb sowohl Angaben von Teilzeitlehrkräften als auch von Vollzeitlehrkräften. Da es zwischen manchen Tätigkeiten Überschneidungen geben kann, sollten diese nicht zu einer Gesamtarbeitszeit aufaddiert werden.

in der Schule oder an einem anderen Ort zu erbringen haben, gesetzlich vorgeschrieben bzw. vertraglich vereinbart, aber es gibt keine festgelegte Aufteilung zwischen der Zeit, die einerseits in der Schule zu verbringen ist und andererseits außerhalb der Schule zu erbringen ist.

In Schweden wird zwar die Gesamtarbeitszeit pro Jahr in Tarifverträgen festgelegt, die Zahl der Wochenarbeitsstunden und die Aufteilung der Arbeitszeit der Lehrer (in Unterricht und nicht unterrichtende Tätigkeiten) wird jedoch von der Schulleitung festgelegt.

Außerdem können sich die Arbeitszeiten und Unterrichtsverpflichtungen von Lehrkräften im Verlauf ihrer beruflichen Laufbahn ändern. Während manche Lehrkräfte am Anfang ihrer Berufstätigkeit als Teil ihrer Einführungsphase möglicherweise weniger Lehrverpflichtungen haben, ermutigen manche Länder ältere Lehrkräfte auch dadurch dazu, im Lehrerberuf zu bleiben, dass sie ihre Pflichten breiter fächern und die Unterrichtszeit verkürzen. In Griechenland beispielsweise reduziert sich die Zahl der zu unterrichtenden Zeitstunden in Abhängigkeit von der Zahl der Dienstjahre einer Lehrkraft. Im Sekundarbereich müssen Lehrkräfte 2I Unterrichtseinheiten pro Woche unterrichten. Nach 6 Jahren sinken die Unterrichtsverpflichtungen auf Ig Unterrichtseinheiten pro Woche und nach I2 Jahren auf I8 Unterrichtseinheiten. Nach 20 Dienstjahren müssen Lehrkräfte I6 Unterrichtseinheiten pro Woche unterrichten, d. h. mehr als 25 Prozent weniger als Lehrkräfte, die am Beginn ihrer Laufbahn stehen. Die verbleibenden Stunden der Pflichtarbeitszeit müssen die Lehrkräfte jedoch in der Schule anwesend sein.

\section{Zeit außerhalb des Unterrichts}

Obwohl die Unterrichtszeit einen erheblichen Anteil der Arbeitsbelastung der Lehrkräfte ausmacht, sollte bei der Untersuchung der Anforderungen an die Lehrkräfte in unterschiedlichen Ländern auch die für die Schülerbenotung, die Unterrichtsvorbereitung, die Korrektur von Schülerarbeiten, Fortbildungen und Lehrerkonferenzen benötigte Zeit berücksichtigt werden. Die für diese Aufgaben außerhalb des Unterrichts zur Verfügung stehende Zeit ist von Land zu Land verschieden, und wenn die Unterrichtsverpflichtungen einen großen Teil der gesetzlichen bzw. vertraglich vereinbarten Arbeitszeit ausmachen, kann dies darauf hindeuten, dass weniger (Arbeits-)Zeit für Aufgaben wie Schülerbeurteilungen und Unterrichtsvorbereitung aufgewendet wird. 
Abbildung D4.3

Auf das Unterrichten entfallende Arbeitszeit der Lehrkräfte (in \%) im Sekundarbereich I (2012)

Netto-Unterrichtszeit als Prozentsatz der gesetzlichen bzw. vertraglich vereinbarten Arbeitszeit und der Arbeitszeit, für die Anwesenheitspflicht an der Schule besteht

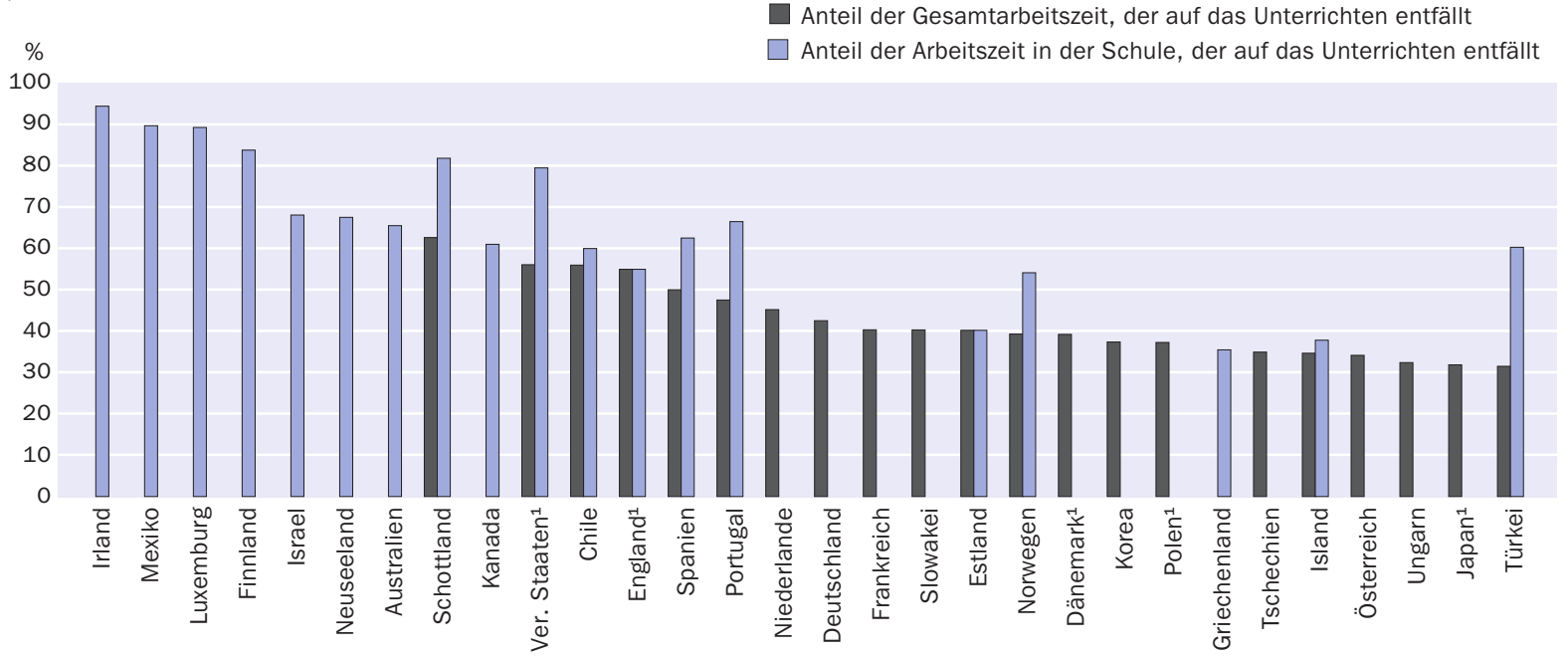

1. Tatsächlich unterrichtete Zeitstunden.

Anordnung der Länder in absteigender Reihenfolge des Anteils der auf das Unterrichten entfallenden Gesamtarbeitszeit von Lehrkräften im Sekundarbereich I (in \%). Quelle: OECD. Tabelle D4.1. Hinweise s. Anhang 3 unter www.oecd.org/edu/eag.htm. StatLink: http://dx.doi.org/10.1787/888933120100

In den 2r Ländern, in denen sowohl Daten zur Zahl der zu unterrichtenden Zeitstunden als auch zur Gesamtarbeitszeit für Lehrkräfte des Sekundarbereichs I zur Verfügung stehen, variiert der Anteil der Arbeitszeit, die Lehrkräfte im Unterricht verbringen, von weniger als 35 Prozent in Island, Japan, Österreich, Tschechien, der Türkei und Ungarn bis zu 63 Prozent in Schottland (Abb. D4.3).

In den I9 Ländern, die sowohl die zu unterrichtenden Zeitstunden als auch die Zahl an Stunden festlegen, die Lehrkräfte im Sekundarbereich I in der Schule anwesend sein müssen, reicht der Prozentsatz der Arbeitszeit, die Lehrkräfte im Unterricht verbringen, von weniger als 40 Prozent in Griechenland und Island bis zu mehr als go Prozent in Irland.

In Belgien (fläm., Sekundarbereich), Belgien (frz.), Italien, Japan (Elementarbereich) und Österreich (Sekundarbereich II) ist nicht offiziell festgelegt, wie viel Zeit für Aktivitäten außerhalb des Unterrichts aufgewendet werden muss. Dies bedeutet allerdings nicht, dass die Lehrkräfte in der Gestaltung anderer Aufgaben völlig frei sind. In Belgien (fläm.) gibt es zwar keine Vorschriften hinsichtlich der für Unterrichtsvorbereitung, Korrektur von Klassenarbeiten, Benotung von Hausaufgaben usw. aufzuwendenden Zeit, es werden jedoch zusätzliche Stunden in der Schule für Aufgaben außerhalb des Unterrichts auf Schulebene festgelegt. In Italien sind bis zu 80 Stunden nicht unterrichtender Tätigkeit in der Schule pro Jahr verpflichtend festgelegt. Von diesen 80 Stunden entfallen bis zu 40 Stunden Pflichtarbeitszeit pro Jahr auf Lehrerkonferenzen, Planungsbesprechungen und Besprechungen mit Eltern, die verbleibenden 40 Stunden auf Klassenkonferenzen. 


\section{Nicht unterrichtende Tätigkeiten, die von Lehrkräften im Sekundar- bereich I wahrzunehmen sind}

Gesetzlich oder aufgrund von Vereinbarungen vorgeschriebene nicht unterrichtende Tätigkeiten im Rahmen der gesetzlich bzw. vertraglich vereinbarten Arbeitszeit in der Schule und/oder Gesamtarbeitszeit

\begin{tabular}{|c|c|c|}
\hline Tätigkeiten der Lehrkräfte & Tätigkeit obligatorisch & Im Ermessen der einzelnen Schulen \\
\hline $\begin{array}{l}\text { Planung oder Vorbereitung } \\
\text { von Unterrichtsstunden }\end{array}$ & $\begin{array}{l}\text { AUS, BFR, BFL, CHL, DNK, ENG, EST, GRC, ISL, } \\
\text { ISR, ITA, NOR, POL, PRT, SCO, SVK¹, ESP, SWE, } \\
\text { TUR, USA }\end{array}$ & $\begin{array}{l}\text { BRA, CZE, HUN, KOR, NLD, NZL, SVK' }{ }^{2}, S V N \text {, } \\
\text { USA }\end{array}$ \\
\hline $\begin{array}{l}\text { Teamarbeit und Austausch } \\
\text { mit den Kollegen }\end{array}$ & $\begin{array}{l}\text { AUS, BFR, CHL, DNK, ENG, EST, FIN, FRA, GRC, } \\
\text { ISR, ITA, LUX, NOR, POL, PRT, SCO, SVK, ESP, } \\
\text { SWE, TUR }\end{array}$ & $\begin{array}{l}\text { BFL, BRA, CZE, HUN, ISL, KOR, NLD, NZL, } \\
\text { SVN, USA }\end{array}$ \\
\hline $\begin{array}{l}\text { Benotung und Korrektur von } \\
\text { Schülerleistungen }\end{array}$ & $\begin{array}{l}\text { AUS, CHL, DNK, ENG, ESP, EST, FRA, GRC, } \\
\text { ISL, ISR, NOR, POL, PRT, SCO, SVK }{ }^{1} \text {, SWE, } \\
\text { TUR, USA }\end{array}$ & $\begin{array}{l}\text { BFL, BRA, CZE, HUN, KOR, NLD, NZL, SVK², } \\
\text { SVN, USA }\end{array}$ \\
\hline Pausenaufsicht & $\begin{array}{l}\text { AUS, CHL, DNK, EST, GRC, ISR, LUX, POL, } \\
\text { SVK, TUR }\end{array}$ & $\begin{array}{l}\text { BFL, BRA, CZE, ENG, HUN, IRL, KOR, NLD, NZL, } \\
\text { SCO, SVN, SWE, USA }\end{array}$ \\
\hline Beratungslehrertätigkeiten & $\begin{array}{l}\text { CHL, DNK, ESP, EST, FRA, GRC, ISR, LUX, PRT, } \\
\text { SVK, SWE, TUR }\end{array}$ & $\begin{array}{l}\text { AUS, BFL, BRA, CZE, HUN, ISL, KOR, NLD, NZL, } \\
\text { SCO, SVN, USA }\end{array}$ \\
\hline $\begin{array}{l}\text { Beteiligung an der Schul- } \\
\text { leitung }\end{array}$ & $\begin{array}{l}\text { CHL, DNK, ESP, EST, FRA, GRC, ISL, ISR, PRT, } \\
\text { SVK, TUR }\end{array}$ & $\begin{array}{l}\text { AUS, BFL, BRA, CZE, HUN, KOR, NLD, NZL, } \\
\text { SCO, SVN, SWE, USA }\end{array}$ \\
\hline $\begin{array}{l}\text { Allgemeine administrative } \\
\text { Aufgaben und Büroarbeiten }\end{array}$ & $\begin{array}{l}\text { AUS, BFR, CHL, DNK, ENG, EST, FRA, GRC, ISL, } \\
\text { ISR, NOR, POL, PRT, SVK }{ }^{1} \text {, SWE, TUR }\end{array}$ & $\begin{array}{l}\text { BFL, BRA, CZE, HUN, KOR, NLD, SCO, SVN, } \\
\text { SVK }{ }^{2} \text {, USA }\end{array}$ \\
\hline $\begin{array}{l}\text { Kommunikation und Zusam- } \\
\text { menarbeit mit Eltern oder } \\
\text { Erziehungsberechtigten }\end{array}$ & $\begin{array}{l}\text { AUS, BFR, CHL, DNK, ENG, ESP, EST, FIN, FRA, } \\
\text { GRC, ISL, ISR, ITA, LUX, NOR, POL, PRT, SVK, } \\
\text { SWE, TUR }\end{array}$ & $\begin{array}{l}\text { BFL, BRA, CZE, HUN, KOR, NLD, NZL, SCO, } \\
\text { SVN, USA }\end{array}$ \\
\hline $\begin{array}{l}\text { Beteiligung an außerlehr- } \\
\text { planmäßigen Aktivitäten }\end{array}$ & CHL, DNK, ESP, EST, ISR, POL, PRT, TUR & $\begin{array}{l}\text { AUS, BFL, BRA, CZE, ENG, GRC, HUN, KOR, } \\
\text { NLD, NZL, SVN, USA }\end{array}$ \\
\hline $\begin{array}{l}\text { Maßnahmen der beruflichen } \\
\text { Fortbildung }\end{array}$ & $\begin{array}{l}\text { BFR, DNK, ENG, EST, FIN, GRC, HUN, ISR, } \\
\text { NOR, POL, PRT, SCO } \text { SVK }^{1}, \text { SWE, TUR }\end{array}$ & $\begin{array}{l}\text { AUS, BFL, BRA, CHL, CZE, ISL, KOR, NLD, NZL, } \\
\mathrm{SCO}^{2}, \mathrm{SVK}^{2}, \mathrm{SVN}, \mathrm{USA}\end{array}$ \\
\hline Sonstiges & CHL, DNK, FIN, FRA, GRC, IRL, PRT, SWE & $\begin{array}{l}\text { BFL, BFR, CZE, EST, HUN, KOR, NLD, NZL, SCO, } \\
\text { SVN, POL, USA }\end{array}$ \\
\hline
\end{tabular}

1. Innerhalb der Gesamtarbeitszeit wahrzunehmen. 2. Innerhalb der in der Schule zu erbringenden Arbeitszeit wahrzunehmen. Quelle: OECD. Tabelle D4.4c im Internet. Hinweise s. Anhang 3 unter www.oecd.org/edu/eag.htm.

StatLink: http://dx.doi.org/10.1787/888933120119

Auflistung der verwendeten Ländercodes s. Hinweise für den Leser.

Nicht unterrichtende Tätigkeiten bilden einen Teil der Arbeitsbelastung und der Arbeitsbedingungen der Lehrkräfte. Die gesetzlichen bzw. aufgrund von Vereinbarungen zwischen den verschiedenen involvierten Akteuren (z. B. Lehrerverbänden, lokalen Behörden, Schulverwaltungsgremien usw.) festgelegten nicht unterrichtenden Tätigkeiten spiegeln nicht notwendigerweise die tatsächliche Beteiligung der Lehrkräfte an nicht unterrichtenden Tätigkeiten wider, bieten jedoch einen Einblick in die Bandbreite und Komplexität des Lehrerberufs.

Die Planung oder Vorbereitung von Unterrichtsstunden, Teamarbeit und Austausch mit den Kollegen sowie Kommunikation und Zusammenarbeit mit Eltern sind die häufigsten nicht unterrichtenden Tätigkeiten, die von Lehrkräften im Sekundarbereich I im Rahmen ihrer gesetzlichen bzw. vertraglich vereinbarten Arbeitszeit in der Schule bzw. Gesamtarbeitszeit wahrgenommen werden müssen. Diese Aufgaben werden in mindestens 20 der 34 Länder mit verfügbaren Daten verlangt. In rund der Hälfte der Länder mit verfügbaren Daten sind auch die Benotung und Korrektur von Schülerleistungen, allgemeine administrative Aufgaben und Büroarbeiten sowie Maßnahmen der beruflichen Fortbildung vorgeschrieben. In rund einem Drittel der Länder müssen Lehrkräfte im Sekundarbereich I ferner in den Pausen Aufsicht führen, Beratungslehrertätigkeiten übernehmen und/oder sich an der Schulleitung beteiligen. Eine Beteiligung der Lehrkräfte im Sekundarbereich I an außerlehrplanmäßigen Aktivitäten nach der Schule ist nur in 8 Ländern vorgeschrieben. In den 
meisten Ländern, in denen die von den Lehrkräften erwarteten nicht unterrichtenden Tätigkeiten aufgeführt werden, wird jedoch die für die einzelnen Aufgaben vorgesehene Zeit nicht festgelegt. In Brasilien, Korea, Neuseeland, den Niederlanden, Slowenien, Tschechien und Ungarn kann jede dieser nicht unterrichtenden Tätigkeiten von den Lehrkräften erwartet werden; die Entscheidung darüber wird jedoch auf Schulebene getroffen.

\section{Definitionen}

Tatsächlich unterrichtete Zeitstunden stehen für die durchschnittliche Zahl an Zeitstunden pro Jahr, die eine Vollzeitlehrkraft eine Gruppe oder Klasse von Schülern unterrichtet, einschließlich aller zusätzlichen Stunden wie Überstunden. Die Daten können aus Verwaltungsunterlagen, statistischen Datenbanken, repräsentativen Stichprobenerhebungen oder anderen repräsentativen Quellen stammen.

Die Zahl der Unterrichtstage wird berechnet als Zahl der Unterrichtswochen multipliziert mit der Anzahl Tage, die eine Lehrkraft pro Woche unterrichtet, abzüglich der Tage, an denen die Schule wegen Ferien geschlossen ist.

Die Zahl der Unterrichtswochen bezieht sich auf die Zahl der Wochen mit Unterricht ohne die Ferienzeiten.

Gesetzliche bzw. vertraglich vereinbarte Unterrichtszeit bzw. die Zahl der von Lehrkräften zu unterrichtenden Zeitstunden wird definiert als die Zahl an geplanten Zeitstunden pro Jahr, die eine Vollzeitlehrkraft auf der Grundlage der offiziellen Vorschriften mit dem Unterrichten einer Gruppe oder Klasse verbringt. Sie wird normalerweise berechnet aus der Zahl der Unterrichtstage pro Jahr multipliziert mit der Anzahl Zeitstunden, die eine Lehrkraft pro Tag unterrichtet (ohne Zeiten, die offiziell als Pausen zwischen einzelnen Unterrichtseinheiten oder Blöcken von Unterrichtseinheiten vorgesehen sind). Einige Länder melden Schätzwerte für die Unterrichtszeit, die auf Erhebungsdaten basieren. Im Primarbereich sind kurze Pausen zwischen den einzelnen Unterrichtseinheiten, während derer die Lehrkraft für die Klasse verantwortlich ist, enthalten.

Arbeitszeit bezieht sich auf die Zahl der gemäß offiziellen Vorschriften von einer Vollzeitlehrkraft zu arbeitenden Zeitstunden. Nicht enthalten sind vergütete Überstunden. Entsprechend den offiziellen Vorschriften in einem bestimmten Land kann sich die Arbeitszeit beziehen auf:

direkt für den Unterricht aufgewendete Zeit und andere lehrplanbezogene Tätigkeiten für die Schüler, wie Haus- und Klassenarbeiten, sowie

Zeit, die in direktem Zusammenhang mit dem Unterricht steht, sowie Stunden, die anderen unterrichtsbezogenen Tätigkeiten gewidmet sind, z. B. Unterrichtsvorbereitung, Beratung der Schüler, Korrekturen von Haus- und Klassenarbeiten, Tätigkeiten zur beruflichen Fortbildung, Besprechungen mit den Eltern, Lehrerkonferenzen und allgemeine schulische Aufgaben. 
Arbeitszeit in der Schule bezieht sich auf die Arbeitszeit, die Lehrkräfte in der Schule arbeiten müssen, und enthält sowohl die Unterrichtszeit als auch Zeit für Tätigkeiten außerhalb des Unterrichts.

\section{Angewandte Methodik}

Die Daten stammen aus der OECD/INES-Erhebung 2013 zu Lehrkräften und Lehrplänen und beziehen sich auf das Schuljahr 20II/I2.

Bei der Interpretation der Unterschiede bei der Zahl der zu unterrichtenden Zeitstunden zwischen den einzelnen Ländern sollte man jedoch berücksichtigen, dass die Nettokontaktzeit, wie sie diesem Indikator zugrunde liegt, nicht unbedingt den Unterrichtsverpflichtungen entspricht. Die Kontaktzeit selbst repräsentiert zwar einen beträchtlichen Bestandteil der Unterrichtsverpflichtungen, aber bei einem Vergleich müssen auch die Vorbereitung der Stunden sowie die erforderliche Nachbereitung (einschließlich der Korrektur der Schülerarbeiten) berücksichtigt werden. Andere wichtige Elemente, wie z. B. die Zahl der unterrichteten Fächer, die Zahl der zu unterrichtenden Schüler und wie viele Jahre eine einzelne Lehrkraft dieselben Schüler unterrichtet, sollten ebenfalls berücksichtigt werden.

Hinweise zu den für jedes Land verwendeten Definitionen und angewandten Methodiken s. Anhang 3 unter www.oecd.org/edu/eag.htm.

Hinweis zu den Daten aus Israel

Die statistischen Daten für Israel wurden von den zuständigen israelischen Stellen bereitgestellt, die für sie verantwortlich zeichnen. Die Verwendung dieser Daten durch die OECD erfolgt unbeschadet des völkerrechtlichen Status der Golanhöhen, von Ost-Jerusalem und der israelischen Siedlungen im Westjordanland.

\section{Weiterführende Informationen}

OECD (2014), Talis 2013 Results: An International Perspective on Teaching and Learning, OECD Publishing, Paris, http://dx.doi.org/10.1787/9789264196261-en.

\section{Tabellen Indikator D4}

StatLink: http://dx.doi.org/10.1787/888933120005

Tabelle D4.I: Aufteilung der Arbeitszeit von Lehrern (2012)

Tabelle D4.2: Zahl der zu unterrichtenden Zeitstunden pro Jahr (2000, 2005, 2010 und 20I2)

WEB Table D4.3: Actual teaching time (Tatsächlich unterrichtete Zeitstunden) (20I2) 
WEB Table D4.4a: Tasks required of teachers according to regulations or agreements, pre-primary education (Von Lehrkräften laut Vorschriften bzw. Vereinbarungen wahrzunehmende Tätigkeiten, Elementarbereich) (20I2)

WEB Table D4.4b: Tasks required of teachers according to regulations or agreements, primary education (Von Lehrkräften laut Vorschriften bzw. Vereinbarungen wahrzunehmende Tätigkeiten, Primarbereich) (2012)

WEB Table D4.4c: Tasks required of teachers according to regulations or agreements, lower secondary education (Von Lehrkräften laut Vorschriften bzw. Vereinbarungen wahrzunehmende Tätigkeiten, Sekundarbereich I) (20I2)

WEB Table D4.4d: Tasks required of teachers according to regulations or agreements, upper secondary education (Von Lehrkräften laut Vorschriften bzw. Vereinbarungen wahrzunehmende Tätigkeiten, Sekundarbereich II) (20I2) 
Aufteilung der Arbeitszeit von Lehrkräften (2012)

Zahl der Unterrichtswochen, Unterrichtstage, Netto-Unterrichtszeitstunden und Gesamtarbeitszeit von Lehrkräften an öffentlichen Bildungseinrichtungen im Verlauf des Schuljahrs

\begin{tabular}{|c|c|c|c|c|c|c|c|c|c|c|c|c|c|c|c|c|c|c|c|c|}
\hline & \multicolumn{4}{|c|}{$\begin{array}{l}\text { Zahl der } \\
\text { Unterrichtswochen }\end{array}$} & \multicolumn{4}{|c|}{ Zahl der Unterrichtstage } & \multicolumn{4}{|c|}{$\begin{array}{l}\text { Netto-Unterrichtszeit- } \\
\text { stunden }\end{array}$} & \multicolumn{4}{|c|}{\begin{tabular}{|c|} 
In der Schule zu \\
erbringende Arbeitszeit \\
(in Zeitstunden)
\end{tabular}} & \multicolumn{4}{|c|}{$\begin{array}{l}\text { Gesetzliche bzw. } \\
\text { vertraglich vereinbarte } \\
\text { Gesamtarbeitszeit } \\
\text { (in Zeitstunden) }\end{array}$} \\
\hline & 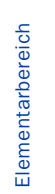 & 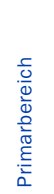 & 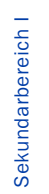 & 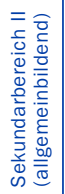 & 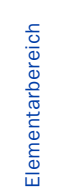 & 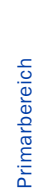 & 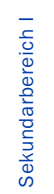 & 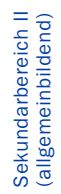 & 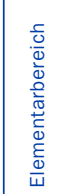 & 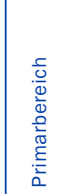 & 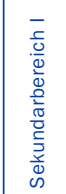 & 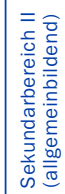 & 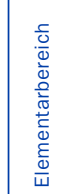 & 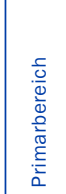 & 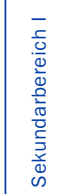 & 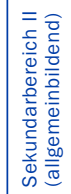 & 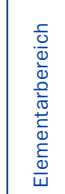 & 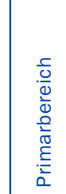 & 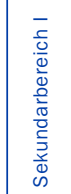 & 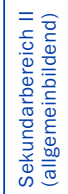 \\
\hline & (1) & (2) & (3) & (4) & (5) & (6) & (7) & $(8)$ & (9) & (10) & (11) & (12) & (13) & (14) & (15) & (16) & (17) & (18) & (19) & (20) \\
\hline \multicolumn{21}{|l|}{ OECD-Länder } \\
\hline Australien ${ }^{1}$ & 40 & 40 & 40 & 40 & 197 & 197 & 197 & 195 & 884 & 871 & 809 & 801 & 1172 & 1211 & 1234 & 1234 & a & a & a & a \\
\hline Österreich ${ }^{1}$ & 38 & 38 & 38 & 38 & 180 & 180 & 180 & 180 & 779 & 779 & 607 & 589 & a & a & a & a & 1776 & 1776 & 1776 & a \\
\hline Belgien (fläm.) ${ }^{1}$ & 37 & 37 & 37 & 37 & 176 & 176 & 174 & 174 & 732 & 748 & 652 & 609 & 915 & 915 & a & a & a & a & a & a \\
\hline Belgien $(\mathrm{frz} .)^{1}$ & 37 & 37 & 37 & 37 & 181 & 181 & 181 & 181 & 784 & 721 & 661 & 601 & $a^{a}$ & a & a & a & a & $a^{a}$ & a & $a^{a}$ \\
\hline Kanada $^{1}$ & 37 & 37 & 37 & 37 & 183 & 183 & 183 & 183 & 792 & 802 & 747 & 751 & 1213 & 1223 & 1224 & 1229 & a & $a^{2}$ & a & d \\
\hline Chile $^{2}$ & 38 & 38 & 38 & 38 & 179 & 179 & 179 & 179 & 1103 & 1103 & 1103 & 1103 & 1839 & 1839 & 1839 & 1839 & 1971 & 1971 & 1971 & 1971 \\
\hline Tschechien $^{1}$ & 39 & 39 & 39 & 39 & 188 & 188 & 188 & 188 & 1166 & 827 & 620 & 592 & a & a & a & a & 1776 & 1776 & 1776 & 1776 \\
\hline Dänemark & a & a & a & a & a & a & 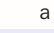 & a & a & 659 & 659 & 369 & a & a & a & a & 1680 & 1680 & 1680 & 1680 \\
\hline England $d^{3}$ & 38 & 38 & 38 & 38 & 189 & 189 & 189 & 189 & 680 & 680 & 692 & 692 & 1259 & 1259 & 1259 & 1259 & 1259 & 1259 & 1259 & 1259 \\
\hline Estland $^{2}$ & 46 & 35 & 35 & 35 & 220 & 172 & 172 & 172 & 1320 & 619 & 619 & 568 & 1610 & 1540 & 1540 & 1540 & 1610 & 1540 & 1540 & 1540 \\
\hline Finnland ${ }^{4}$ & $\mathrm{~m}$ & 38 & 38 & 38 & $\mathrm{~m}$ & 187 & 187 & 187 & $\mathrm{~m}$ & 673 & 589 & 547 & $\mathrm{~m}$ & 787 & 703 & 642 & a & a & a & a \\
\hline Frankreich ${ }^{1}$ & 36 & 36 & 36 & 36 & 144 & 144 & a & a & 924 & 924 & 648 & 648 & 972 & 972 & a & a & 1607 & 1607 & 1607 & 1607 \\
\hline Deutschland $^{1}$ & 40 & 40 & 40 & 40 & 193 & 193 & 193 & 193 & 796 & 804 & 755 & 718 & a & a & a & a & 1776 & 1776 & 1776 & 1776 \\
\hline Griechenl & 35 & 35 & 31 & 31 & 171 & 171 & 152 & 152 & 684 & 569 & 415 & 415 & 1140 & 1140 & 1170 & 1170 & a & a & a & a \\
\hline Ungarn ${ }^{4}$ & 37 & 37 & 37 & 37 & 181 & 183 & 183 & 183 & 1158 & 604 & 604 & 604 & $\mathrm{~m}$ & $\mathrm{~m}$ & $\mathrm{~m}$ & $\mathrm{~m}$ & 1864 & 1864 & 1864 & 1864 \\
\hline Island $^{1}$ & 48 & 37 & 37 & 35 & 227 & 180 & 180 & 170 & 1646 & 624 & 624 & 544 & 1800 & 1650 & 1650 & 1720 & 1800 & 1800 & 1800 & 1800 \\
\hline Irland ${ }^{1}$ & $\mathrm{~m}$ & 37 & 33 & 33 & $\mathrm{~m}$ & 183 & 167 & 167 & $\mathrm{~m}$ & 915 & 735 & 735 & $\mathrm{~m}$ & 1079 & 778 & 778 & a & a & a & a \\
\hline Israel $^{1}$ & 38 & 38 & 37 & 37 & 182 & 182 & 175 & 175 & 1023 & 838 & 629 & 558 & 1023 & 1219 & 924 & 781 & 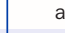 & $a_{-}$ & a & a \\
\hline Italien ${ }^{1}$ & 42 & 39 & 39 & 39 & 186 & 171 & 171 & 171 & 930 & 752 & 616 & 616 & a & a & a & a & a & a & a & d \\
\hline $\mathrm{Japan}^{3}$ & 39 & 40 & 40 & 39 & $\mathrm{~m}$ & 200 & 200 & 196 & $\mathrm{~m}$ & 731 & 602 & 510 & a & a & a & a & a & 1891 & 1891 & 1891 \\
\hline Korea $^{4}$ & 36 & 38 & 38 & 38 & 180 & 190 & 190 & 190 & 583 & 694 & 568 & 549 & a & a & a & a & 1520 & 1520 & 1520 & 1520 \\
\hline Luxembur: & 36 & 36 & 36 & 36 & 176 & 176 & 176 & 176 & 880 & 810 & 739 & 739 & 1060 & 990 & 828 & 828 & a & a & a & a \\
\hline Mexiko ${ }^{1}$ & 42 & 42 & 42 & 36 & 200 & 200 & 200 & 171 & 532 & 800 & 1047 & 838 & 772 & 800 & 1167 & 971 & $a^{a}$ & a & a & a \\
\hline Niederlanc & 40 & 40 & $\mathrm{~m}$ & $\mathrm{~m}$ & 195 & 195 & $\mathrm{~m}$ & $\mathrm{~m}$ & 930 & 930 & 750 & 750 & a & a & a & a & 1659 & 1659 & 1659 & 1659 \\
\hline Neuseelar & $\mathrm{m}$ & 39 & 39 & 38 & $\mathrm{~m}$ & 195 & 193 & 190 & $\mathrm{~m}$ & 935 & 848 & 760 & $\mathrm{~m}$ & 1560 & 1255 & 950 & a & a & a & $a^{a}$ \\
\hline Norwegen ${ }^{1}$ & 45 & 38 & 38 & 38 & 225 & 190 & 190 & 190 & 1508 & 741 & 663 & 523 & 1508 & 1300 & 1225 & 1150 & 1688 & 1688 & 1688 & 1688 \\
\hline Polen ${ }^{3}$ & 45 & 38 & 38 & 37 & 218 & 184 & 182 & 180 & 1149 & 633 & 561 & 558 & $\mathrm{~m}$ & $\mathrm{~m}$ & $\mathrm{~m}$ & $\mathrm{~m}$ & 1816 & 1520 & 1504 & 1488 \\
\hline Portugal $^{2}$ & 42 & 37 & 37 & 37 & 194 & 168 & 168 & 168 & 970 & 756 & 616 & 616 & 1116 & 1027 & 926 & 926 & 1426 & 1296 & 1296 & 1296 \\
\hline Schottland ${ }^{2}$ & 38 & 38 & 38 & 3 & 190 & 190 & 190 & 190 & 855 & 855 & 55 & 855 & 1045 & 1045 & 1045 & 1045 & 1365 & 1365 & 1365 & 1365 \\
\hline Slowake ${ }^{1}$ & 42 & 38 & $3 \varepsilon$ & 3 & 1 & 184 & 184 & 184 & 1035 & 819 & 35 & 607 & $\mathrm{~m}$ & $\mathrm{~m}$ & $\mathrm{~m}$ & $\mathrm{~m}$ & 1575 & 1575 & 1575 & 1575 \\
\hline Slowenien ${ }^{1}$ & 46 & 40 & 40 & 40 & 219 & 190 & 190 & 190 & 1314 & 627 & 627 & 570 & a & a & a & a & $\mathrm{m}$ & $\mathrm{m}$ & $\mathrm{m}$ & $\mathrm{m}$ \\
\hline Spanien $^{1}$ & 37 & 37 & 37 & 36 & 176 & 176 & 176 & 171 & 880 & 880 & 713 & 693 & 1140 & 1140 & 1140 & 1140 & 1425 & 1425 & 1425 & 1425 \\
\hline Schweden ${ }^{1}$ & 47 & a & a & a & 224 & a & a & a & 1792 & $\mathrm{~m}$ & $\mathrm{~m}$ & $\mathrm{~m}$ & 1792 & 1360 & 1360 & 1360 & a & 1767 & 1767 & 1767 \\
\hline Schweiz & $\mathrm{m}$ & $\mathrm{m}$ & $\mathrm{m}$ & $\mathrm{m}$ & $\mathrm{m}$ & $\mathrm{m}$ & $\mathrm{m}$ & $\mathrm{m}$ & $\mathrm{m}$ & $\mathrm{m}$ & $\mathrm{m}$ & $\mathrm{m}$ & $\mathrm{m}$ & $\mathrm{m}$ & $\mathrm{m}$ & $\mathrm{m}$ & $\mathrm{m}$ & $\mathrm{m}$ & $\mathrm{m}$ & $\mathrm{m}$ \\
\hline Türkei $^{1}$ & 38 & 38 & 38 & 38 & 180 & 180 & 180 & 180 & 1080 & 720 & 504 & 567 & 1160 & 980 & 836 & 921 & 1600 & 1600 & 1600 & 1600 \\
\hline Vereinigte St & 36 & 36 & 36 & 36 & 180 & 180 & 180 & 180 & 1131 & 1131 & 1085 & 1076 & 1365 & 1362 & 1366 & 1365 & 1890 & 1922 & 1936 & 1960 \\
\hline OECD-Durchschnitt & 40 & 38 & 38 & 37 & 191 & 183 & 182 & 180 & 1001 & 782 & 694 & 655 & 1258 & 1200 & 1173 & 1142 & 1654 & 1649 & 1649 & 1643 \\
\hline EU21-Durchschnitt & 40 & 38 & 37 & 37 & 190 & 180 & 179 & 179 & 988 & 754 & 653 & 622 & 1205 & 1104 & 1075 & 1069 & 1615 & 1592 & 1591 & 1577 \\
\hline \multicolumn{21}{|l|}{ Part } \\
\hline Arge & 36 & 36 & 36 & 36 & 170 & 170 & 171 & 171 & 680 & 680 & 1368 & 1368 & $\mathrm{~m}$ & $\mathrm{~m}$ & $\mathrm{~m}$ & $\mathrm{~m}$ & $\mathrm{~m}$ & $\mathrm{~m}$ & $\mathrm{~m}$ & $\mathrm{~m}$ \\
\hline Brasilien & 42 & 42 & 42 & 42 & 203 & 203 & 203 & 203 & $\mathrm{~m}$ & $\mathrm{~m}$ & $\mathrm{~m}$ & $\mathrm{~m}$ & 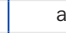 & a & a & a & a & $a_{-}$ & $a^{a}$ & a \\
\hline $\mathrm{Ch}$ & $\mathrm{m}$ & $\mathrm{m}$ & $\mathrm{m}$ & $\mathrm{m}$ & $\mathrm{m}$ & $\mathrm{m}$ & $\mathrm{m}$ & $\mathrm{m}$ & $\mathrm{m}$ & $\mathrm{m}$ & $\mathrm{m}$ & $\mathrm{m}$ & $\mathrm{m}$ & $\mathrm{m}$ & $\mathrm{m}$ & $\mathrm{m}$ & $\mathrm{m}$ & $\mathrm{m}$ & n & $\mathrm{m}$ \\
\hline Kolumbien & $\mathrm{m}$ & $\mathrm{m}$ & $\mathrm{m}$ & $\mathrm{m}$ & $\mathrm{m}$ & $\mathrm{m}$ & $\mathrm{m}$ & $\mathrm{m}$ & $\mathrm{m}$ & $\mathrm{m}$ & $\mathrm{m}$ & $\mathrm{m}$ & $m$ & $\mathrm{~m}$ & $\mathrm{~m}$ & $\mathrm{~m}$ & $\mathrm{~m}$ & & 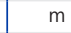 & $\mathrm{m}$ \\
\hline Indien & $\mathrm{m}$ & $\mathrm{m}$ & $\mathrm{m}$ & $\mathrm{m}$ & $\mathrm{m}$ & $\mathrm{m}$ & $\mathrm{m}$ & $\mathrm{m}$ & $\mathrm{m}$ & $\mathrm{m}$ & $\mathrm{m}$ & $\mathrm{m}$ & $\mathrm{m}$ & $\mathrm{m}$ & $\mathrm{m}$ & $\mathrm{m}$ & $\mathrm{m}$ & $\mathrm{m}$ & $\mathrm{m}$ & $\mathrm{m}$ \\
\hline Indones & 44 & 44 & 44 & 44 & 251 & 251 & 163 & 163 & 628 & 1255 & 734 & 734 & $\mathrm{~m}$ & $\mathrm{~m}$ & $\mathrm{~m}$ & $\mathrm{~m}$ & $\mathrm{~m}$ & $\mathrm{~m}$ & $\mathrm{~m}$ & $\mathrm{~m}$ \\
\hline Lettland & $\mathrm{m}$ & $\mathrm{m}$ & $\mathrm{m}$ & $\mathrm{m}$ & $\mathrm{m}$ & $\mathrm{m}$ & $\mathrm{m}$ & $\mathrm{m}$ & $\mathrm{m}$ & $\mathrm{m}$ & $\mathrm{m}$ & $\mathrm{m}$ & $\mathrm{m}$ & $\mathrm{m}$ & $\mathrm{m}$ & $\mathrm{m}$ & $\mathrm{m}$ & $\mathrm{m}$ & $\mathrm{m}$ & $\mathrm{m}$ \\
\hline Rus & $\mathrm{m}$ & 34 & 35 & 35 & $\mathrm{~m}$ & 170 & 210 & 210 & $\mathrm{~m}$ & 561 & 483 & 483 & a & a & a & a & a & 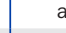 & a & 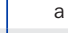 \\
\hline Saudi-Arabien & $m$ & $\mathrm{~m}$ & $\mathrm{~m}$ & $\mathrm{~m}$ & $\mathrm{~m}$ & $\mathrm{~m}$ & $\mathrm{~m}$ & $\mathrm{~m}$ & $\mathrm{~m}$ & $\mathrm{~m}$ & $\mathrm{~m}$ & $\mathrm{~m}$ & $\mathrm{~m}$ & $\mathrm{~m}$ & $\mathrm{~m}$ & $\mathrm{~m}$ & $\mathrm{~m}$ & $\mathrm{~m}$ & $\mathrm{~m}$ & $\mathrm{~m}$ \\
\hline rika & $\mathrm{m}$ & $\mathrm{m}$ & $\mathrm{m}$ & $\mathrm{m}$ & $\mathrm{m}$ & $\mathrm{m}$ & $\mathrm{m}$ & $\mathrm{m}$ & $\mathrm{m}$ & $\mathrm{m}$ & $\mathrm{m}$ & $\mathrm{m}$ & $\mathrm{m}$ & $\mathrm{m}$ & $\mathrm{m}$ & $\mathrm{m}$ & $\mathrm{m}$ & $\mathrm{m}$ & $\mathrm{m}$ & $\mathrm{m}$ \\
\hline G20-Durcl & m & m & $\mathbf{m}$ & m & m & $\mathbf{m}$ & $\mathbf{m}$ & $\mathbf{m}$ & $\mathbf{m}$ & $\mathbf{m}$ & $\mathbf{m}$ & $\mathbf{m}$ & $\mathbf{m}$ & $\mathbf{m}$ & $\mathbf{m}$ & m & $\mathrm{m}$ & m & m & \\
\hline
\end{tabular}

1. In der Regel zu unterrichtende Zeitstunden. 2. Höchstens zu unterrichtende Zeitstunden. 3. Tatsächlich unterrichtete Zeitstunden. 4. Mindestens zu unterrichtende Zeitstunden. 5. Referenzjahr 2011.

Quelle: OECD. Argentinien, China, Indien, Indonesien, Kolumbien, Saudi-Arabien und Südafrika: Statistikinstitut der UNESCO. Hinweise s. Anhang 3 unter www.oecd.org/edu/eag.htm. StatLink: http://dx.doi.org/10.1787/888933120024

Erläuterung der Kennzeichnung fehlender Daten s. Hinweise für den Leser. 
Tabelle D4.2

Zahl der zu unterrichtenden Zeitstunden pro Jahr (2000, 2005, 2010 und 2012)

Gesetzliche bzw. vertraglich vereinbarte Netto-Kontaktzeitstunden an öffentlichen Bildungseinrichtungen, nach Bildungsbereich

\begin{tabular}{|c|c|c|c|c|c|c|c|c|c|c|c|c|}
\hline & \multicolumn{4}{|c|}{ Primarbereich } & \multicolumn{4}{|c|}{ Sekundarbereich I } & \multicolumn{4}{|c|}{ Sekundarbereich II } \\
\hline & 2000 & 2005 & 2010 & 2012 & 2000 & 2005 & 2010 & 2012 & 2000 & 2005 & 2010 & 2012 \\
\hline & (1) & (2) & (7) & (9) & (10) & (11) & (16) & (18) & (19) & (20) & (25) & (27) \\
\hline \multicolumn{13}{|l|}{ OECD-Länder } \\
\hline Australien & 882 & 888 & 868 & 871 & 811 & 810 & 819 & 809 & 803 & 810 & 803 & 801 \\
\hline Österreich & m & 774 & 779 & 779 & $\mathrm{~m}$ & 607 & 607 & 607 & $\mathrm{~m}$ & 589 & 589 & 589 \\
\hline Belgien (fläm.) & 767 & 761 & 761 & 748 & 682 & 690 & 675 & 652 & 638 & 645 & 630 & 609 \\
\hline Belgien (frz.) $)^{1}$ & 804 & 722 & 732 & 721 & 728 & 724 & 671 & 661 & 668 & 664 & 610 & 601 \\
\hline Kanada & $\mathrm{m}$ & $\mathrm{m}$ & 799 & 802 & $\mathrm{~m}$ & $\mathrm{~m}$ & 740 & 747 & $\mathrm{~m}$ & $\mathrm{~m}$ & 744 & 751 \\
\hline Chile & $\mathrm{m}$ & 1128 & 1105 & 1103 & $\mathrm{~m}$ & 1128 & 1105 & 1103 & $\mathrm{~m}$ & 1128 & 1105 & 1103 \\
\hline Tschechien & $\mathrm{m}$ & 813 & 862 & 827 & 650 & 647 & 647 & 620 & 621 & 617 & 617 & 592 \\
\hline Dänemark ${ }^{2}$ & 640 & 640 & 650 & 659 & 640 & 640 & 650 & 659 & $\mathrm{~m}$ & $\mathrm{~m}$ & 377 & 369 \\
\hline England $^{2}$ & $\mathrm{~m}$ & $\mathrm{~m}$ & 684 & 680 & $\mathrm{~m}$ & $\mathrm{~m}$ & 703 & 692 & $\mathrm{~m}$ & $\mathrm{~m}$ & 703 & 692 \\
\hline Estland & 630 & 630 & 630 & 619 & 630 & 630 & 630 & 619 & 578 & 578 & 578 & 568 \\
\hline Finnland & 656 & 677 & 680 & 673 & 570 & 592 & 595 & 589 & 527 & 550 & 553 & 547 \\
\hline Frankreich & 936 & 936 & 936 & 924 & 648 & 648 & 648 & 648 & 648 & 648 & 648 & 648 \\
\hline Deutschland & 783 & 808 & 805 & 804 & 732 & 758 & 756 & 755 & 690 & 714 & 713 & 718 \\
\hline Griechenland & 609 & 604 & 589 & 569 & 426 & 434 & 415 & 415 & 429 & 430 & 415 & 415 \\
\hline Ungarn & 583 & 583 & 604 & 604 & 555 & 555 & 604 & 604 & 555 & 555 & 604 & 604 \\
\hline Island & 629 & 671 & 624 & 624 & 629 & 671 & 624 & 624 & 464 & 560 & 544 & 544 \\
\hline Irland & 915 & 915 & 915 & 915 & 735 & 735 & 735 & 735 & 735 & 735 & 735 & 735 \\
\hline Israel & 731 & 731 & 820 & 838 & 579 & 579 & 598 & 629 & 524 & 524 & 521 & 558 \\
\hline Italien & 744 & 739 & 770 & 752 & 608 & 605 & 630 & 616 & 608 & 605 & 630 & 616 \\
\hline$J a p a n^{2}$ & 635 & 578 & 707 & 731 & 557 & 505 & 602 & 602 & 478 & 429 & 500 & 510 \\
\hline Korea & 865 & 883 & 807 & 694 & 570 & 621 & 627 & 568 & 530 & 605 & 616 & 549 \\
\hline Luxemburg & $\mathrm{m}$ & 774 & 739 & 810 & $\mathrm{~m}$ & 642 & 634 & 739 & $\mathrm{~m}$ & 642 & 634 & 739 \\
\hline Mexiko & 800 & 800 & 800 & 800 & 1182 & 1047 & 1047 & 1047 & $\mathrm{~m}$ & 848 & 843 & 838 \\
\hline Niederlande & 930 & 930 & 930 & 930 & 867 & 750 & 750 & 750 & 867 & 750 & 750 & 750 \\
\hline Neuseeland & $\mathrm{m}$ & $\mathrm{m}$ & 930 & 935 & $\mathrm{~m}$ & $\mathrm{~m}$ & 845 & 848 & $\mathrm{~m}$ & $\mathrm{~m}$ & 760 & 760 \\
\hline Norwegen & 713 & 741 & 741 & 741 & 633 & 656 & 654 & 663 & 505 & 524 & 523 & 523 \\
\hline Polen ${ }^{2}$ & $\mathrm{~m}$ & $\mathrm{~m}$ & 644 & 633 & $\mathrm{~m}$ & $\mathrm{~m}$ & 572 & 561 & $\mathrm{~m}$ & $\mathrm{~m}$ & 571 & 558 \\
\hline Portugal & 815 & 855 & 779 & 756 & 595 & 564 & 634 & 616 & 515 & 513 & 634 & 616 \\
\hline Schottland & 950 & 893 & 855 & 855 & 893 & 893 & 855 & 855 & 893 & 893 & 855 & 855 \\
\hline Slowakei & $\mathrm{m}$ & $\mathrm{m}$ & 841 & 819 & $\mathrm{~m}$ & $\mathrm{~m}$ & 652 & 635 & $\mathrm{~m}$ & $\mathrm{~m}$ & 624 & 607 \\
\hline Slowenien & $\mathrm{m}$ & 627 & 627 & 627 & $\mathrm{~m}$ & 627 & 627 & 627 & $\mathrm{~m}$ & 570 & 570 & 570 \\
\hline Spanien & 880 & 880 & 880 & 880 & 564 & 713 & 713 & 713 & 548 & 693 & 693 & 693 \\
\hline Schweden & $\mathrm{m}$ & $\mathrm{m}$ & $\mathrm{m}$ & $\mathrm{m}$ & $\mathrm{m}$ & $\mathrm{m}$ & $\mathrm{m}$ & $\mathrm{m}$ & $\mathrm{m}$ & $\mathrm{m}$ & $\mathrm{m}$ & $\mathrm{m}$ \\
\hline Schweiz & 884 & $\mathrm{~m}$ & $\mathrm{~m}$ & $\mathrm{~m}$ & 859 & $\mathrm{~m}$ & $\mathrm{~m}$ & $\mathrm{~m}$ & 674 & $\mathrm{~m}$ & $\mathrm{~m}$ & $\mathrm{~m}$ \\
\hline Türkei & 639 & 639 & 621 & 720 & a & a & a & 504 & 504 & 567 & 551 & 567 \\
\hline Vereinigte Staaten ${ }^{2}$ & 1080 & 1080 & 1097 & 1131 & 1080 & 1080 & 1068 & 1085 & 1080 & 1080 & 1051 & 1076 \\
\hline OECD-Durchschnitt & 780 & 783 & 783 & 782 & 697 & 698 & 701 & 694 & 628 & 659 & 656 & 655 \\
\hline $\begin{array}{l}\text { OECD-Durchschnitt für } \\
\text { Länder mit Daten für } 2000, \\
2005,2010 \text { und } 2012\end{array}$ & 776 & 774 & 775 & 773 & 690 & 689 & 694 & 689 & 626 & 639 & 642 & 639 \\
\hline $\begin{array}{l}\text { EU21-Durchschnitt für } \\
\text { Länder mit Daten für 2000, } \\
2005,2010 \text { und } 2012\end{array}$ & 776 & 771 & 768 & 761 & 658 & 661 & 663 & 657 & 635 & 639 & 644 & 638 \\
\hline \multicolumn{13}{|l|}{ Partnerländer } \\
\hline Argentinien ${ }^{3}$ & $\mathrm{~m}$ & $\mathrm{~m}$ & 720 & 680 & $\mathrm{~m}$ & $\mathrm{~m}$ & 1448 & 1368 & $\mathrm{~m}$ & $\mathrm{~m}$ & 1448 & 1368 \\
\hline Brasilien & $\mathrm{m}$ & $\mathrm{m}$ & $\mathrm{m}$ & $\mathrm{m}$ & $\mathrm{m}$ & $\mathrm{m}$ & $\mathrm{m}$ & $\mathrm{m}$ & $\mathrm{m}$ & $\mathrm{m}$ & $\mathrm{m}$ & $\mathrm{m}$ \\
\hline China & $\mathrm{m}$ & $\mathrm{m}$ & $\mathrm{m}$ & $\mathrm{m}$ & $\mathrm{m}$ & $\mathrm{m}$ & $\mathrm{m}$ & $\mathrm{m}$ & $\mathrm{m}$ & $\mathrm{m}$ & $\mathrm{m}$ & $\mathrm{m}$ \\
\hline Kolumbien & $\mathrm{m}$ & $\mathrm{m}$ & $\mathrm{m}$ & $\mathrm{m}$ & $\mathrm{m}$ & $\mathrm{m}$ & $\mathrm{m}$ & $\mathrm{m}$ & $\mathrm{m}$ & $\mathrm{m}$ & $\mathrm{m}$ & $\mathrm{m}$ \\
\hline Indien & $\mathrm{m}$ & $\mathrm{m}$ & $\mathrm{m}$ & $\mathrm{m}$ & $\mathrm{m}$ & $\mathrm{m}$ & $\mathrm{m}$ & $\mathrm{m}$ & $\mathrm{m}$ & $\mathrm{m}$ & $\mathrm{m}$ & $\mathrm{m}$ \\
\hline Indonesien & $\mathrm{m}$ & $\mathrm{m}$ & $\mathrm{m}$ & 1255 & $\mathrm{~m}$ & $\mathrm{~m}$ & $\mathrm{~m}$ & 734 & $\mathrm{~m}$ & $\mathrm{~m}$ & $\mathrm{~m}$ & 734 \\
\hline Lettland & $\mathrm{m}$ & $\mathrm{m}$ & $\mathrm{m}$ & $\mathrm{m}$ & $\mathrm{m}$ & $\mathrm{m}$ & $\mathrm{m}$ & $\mathrm{m}$ & $\mathrm{m}$ & $\mathrm{m}$ & $\mathrm{m}$ & $\mathrm{m}$ \\
\hline Russische Föderation² & $\mathrm{m}$ & 615 & 615 & 561 & $\mathrm{~m}$ & 507 & 507 & 483 & $\mathrm{~m}$ & 507 & 507 & 483 \\
\hline Saudi-Arabien & $\mathrm{m}$ & $\mathrm{m}$ & $\mathrm{m}$ & $\mathrm{m}$ & $\mathrm{m}$ & $\mathrm{m}$ & $\mathrm{m}$ & $\mathrm{m}$ & $\mathrm{m}$ & $\mathrm{m}$ & $\mathrm{m}$ & $\mathrm{m}$ \\
\hline Südafrika & $\mathrm{m}$ & $\mathrm{m}$ & $\mathrm{m}$ & $\mathrm{m}$ & $\mathrm{m}$ & $\mathrm{m}$ & $\mathrm{m}$ & $\mathrm{m}$ & $\mathrm{m}$ & $\mathrm{m}$ & $\mathrm{m}$ & $\mathrm{m}$ \\
\hline G20-Durchschnitt & $\mathbf{m}$ & $\mathbf{m}$ & m & $\mathbf{m}$ & $\mathbf{m}$ & $\mathbf{m}$ & $m$ & $\mathbf{m}$ & $\mathbf{m}$ & $\mathbf{m}$ & $\mathbf{m}$ & $\mathbf{m}$ \\
\hline
\end{tabular}

Anmerkung: Die Spalten mit den Angaben für die Jahre 2006, 2007, 2008, 2009 und 2011, d. h. die Spalten (3)-(6), (8), (12)-(15), (17), (21)-(24) und (26), sind im Internet verfügbar (s. StatLink unten).

1. Unterbrechung der Zeitreihe in 2006 aufgrund von Veränderungen in der Methodik. 2. Tatsächlich unterrichtete Zeitstunden. 3. Referenzjahr 2011 anstelle 2012. Quelle: OECD. Argentinien, China, Indien, Indonesien, Kolumbien, Saudi-Arabien und Südafrika: Statistikinstitut der UNESCO.

Hinweise s. Anhang 3 unter www.oecd.org/edu/eag.htm. StatLink: http://dx.doi.org/10.1787/888933120043

Erläuterung der Kennzeichnung fehlender Daten s. Hinweise für den Leser. 


\section{Indikatior D.5}

\section{Wie ist die Zusammensetzung der Lehrerschaft?}

2012 waren im Durchschnitt der OECD-Länder 36 Prozent der Lehrkräfte im Sekundarbereich mindestens 50 Jahre alt; die Bandbreite reichte von höchstens 25 Prozent in Brasilien, Indonesien, Korea, Luxemburg und Polen bis zu mehr als 6o Prozent in Italien.

Zwischen 2002 und 2012 ist der Anteil der Lehrkräfte im Sekundarbereich, die 50 Jahre und älter sind, im Durchschnitt aller Länder mit vergleichbaren Daten jährlich um I,3 Prozent gestiegen.

Im Durchschnitt der OECD-Länder sind zwei Drittel der Lehrkräfte und wissenschaftlichen Mitarbeiter weiblich, der Anteil der Frauen sinkt jedoch mit jedem höheren Bildungsbereich: von 97 Prozent im Elementarbereich über 82 Prozent im Primarbereich, 67 Prozent im Sekundarbereich I, 57 Prozent im Sekundarbereich II bis auf 42 Prozent im Tertiärbereich.

\section{Abbildung D5.1}

Anteil der Lehrkräfte im Sekundarbereich (in \%), die mindestens 50 Jahre alt sind, und dessen durchschnittlicher jährlicher Anstieg (2002-2012)

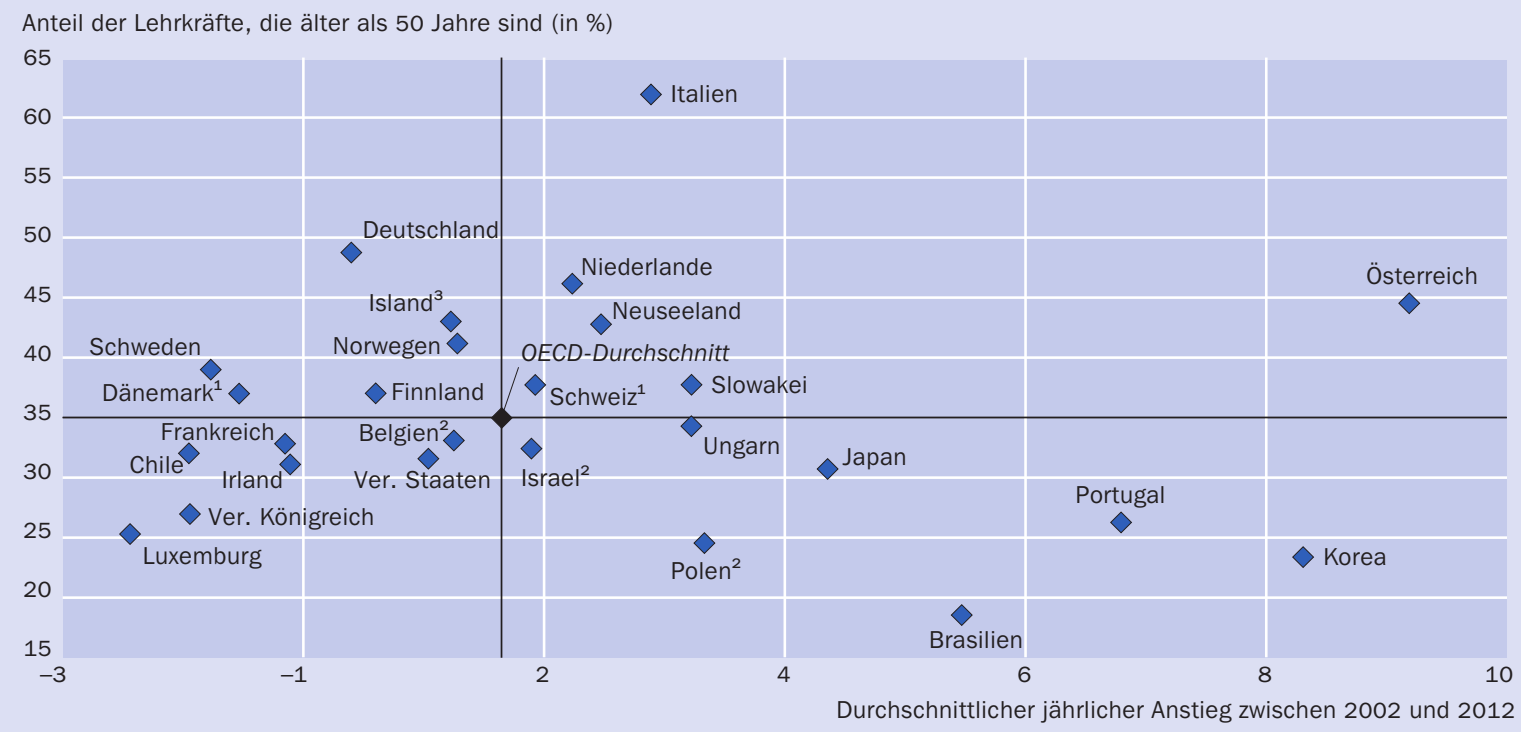

1. Referenzjahr 2003 anstelle 2002. 2. Referenzjahr 2004 anstelle 2002. 3. Referenzjahr 2011 anstelle 2012.

Quelle: OECD. Tabelle D5.2. Hinweise s. Anhang 3 unter www.oecd.org/edu/eag.htm. StatLink: http://dx.doi.org/10.1787/888933120214

\section{Kontext}

Die Nachfrage nach Lehrkräften hängt von einer Reihe unterschiedlicher Faktoren ab, wie z. B. der Altersstruktur der Bevölkerung im Schulalter, der durchschnittlichen Klassengröße, den Unterrichtsverpflichtungen der Lehrkräfte, der vorgeschriebenen Unterrichtszeit für Schüler, dem Einsatz von Lehrassistenten und anderen „,außerhalb 
des Klassenzimmers" tätigen Mitarbeitern in Schulen, den Beteiligungsquoten in den verschiedenen Bildungsbereichen, den Erfolgsquoten in den einzelnen Klassenstufen sowie dem Anfangs- und Endalter der Schulpflicht. Da in mehreren OECD-Ländern ein großer Teil der Lehrkräfte im kommenden Jahrzehnt das Ruhestandsalter erreichen und/oder eine Zunahme der Bevölkerung im Schulalter prognostiziert wird, werden die Regierungen unter Druck stehen, neue Lehrkräfte anzuwerben und auszubilden. In Anbetracht überzeugender Belege, dass die Qualität der Lehrkräfte der wichtigste bestimmende Faktor innerhalb der Schule für die Leistungen der Schüler ist, müssen konzertierte Anstrengungen unternommen werden, die Fähigsten für den Lehrerberuf zu gewinnen und eine qualitativ hochwertige Ausbildung zu bieten (Hiebert and Stigler, I999; OECD 2005).

Die politischen Rahmenbedingungen für Lehrkräfte müssen sicherstellen, dass Lehrkräfte in einer Umgebung tätig sind, die effektive Lehrkräfte ermutigt, weiterhin zu unterrichten. Darüber hinaus erfordern das Ungleichgewicht zwischen den Geschlechtern im Lehrerberuf - im Elementar-, Primar- und Sekundarbereich I unterrichten im Wesentlichen Frauen - sowie die sich daraus ergebenden Auswirkungen auf das Lernen der Schüler genauere Untersuchungen.

\section{Weitere wichtige Ergebnisse}

In fast allen Ländern, mit Ausnahme von Finnland und der Russischen Föderation, sind die meisten Lehrenden im Tertiärbereich Männer.

Im Durchschnitt der OECD-Länder sind 31 Prozent der Lehrkräfte im Primarbereich mindestens 50 Jahre alt. Jedoch sind in sieben OECD- und Partnerländern (Belgien, Brasilien, Irland, Israel, Korea, Luxemburg und dem Vereinigten Königreich) mehr als die Hälfte der Lehrkräfte im Primarbereich jünger als 40 Jahre.

Lehrkräfte im Sekundarbereich I haben im Durchschnitt 16 Jahre Lehrerfahrung (davon fast Io Jahre an ihrer aktuellen Schule), 3 Jahre Berufserfahrung in einem anderen Bildungsberuf und 4 Jahre Berufserfahrung in anderen Beschäftigungen.

\section{Entwicklungstendenzen}

Zwischen 2002 und 2012 ist der Anteil der Lehrkräfte im Sekundarbereich, die 50 Jahre und älter sind, im Durchschnitt aller Länder mit vergleichbaren Daten um 4 Prozentpunkte gestiegen. In Italien, Japan, Korea und Portugal nahm ihr Anteil in diesem Zeitraum um mindestens Io Prozentpunkte zu und in Österreich sogar um 26 Prozentpunkte. In Ländern, in denen die Gefahr besteht, bei einem gleichbleibenden oder wachsenden Anteil der Bevölkerung im Schulalter einen wesentlichen Teil der Lehrkräfte durch ein Ausscheiden aus dem Erwerbsleben zu verlieren, müssen die Regierungen deutlich stärkere Anreize für junge Menschen im Sekundarbereich II und Tertiärbereich schaffen, sich für den Lehrerberuf zu entscheiden. Außerdem müssen die Ausbildungsgänge für Lehrkräfte erweitert und, falls erforderlich, alternative Qualifizierungswege für bereits im Berufsleben stehende Menschen geschaffen werden, die einen Berufswechsel anstreben. Finanzielle Engpässe, insbesondere durch Pensionsverpflichtungen und medizinische Versorgungskosten für Menschen 
im Ruhestand, werden wahrscheinlich zu einem stärkeren Druck auf die Regierungen führen, Bildungsangebote zu reduzieren, die Klassenstärke zu erhöhen, eigenverantwortliches Online-Lernen stärker zu integrieren oder eine Kombination dieser Maßnahmen umzusetzen (Abrams, 20II; Peterson, 20I0).

\section{Analyse und Interpretationen}

\section{Anteil männlicher und weiblicher Lehrkräfte}

Im Durchschnitt der OECD-Länder sind zwei Drittel der Lehrkräfte aller Bildungsbereiche, also vom Elementar- bis zum Tertiärbereich, weiblich. Frauen stellen vom Elementarbereich bis zum Sekundarbereich II die Mehrzahl der Lehrkräfte in den OECDLändern, jedoch sinkt der Anteil der Frauen mit jedem höheren Bildungsbereich. Im Tertiärbereich sind die meisten Lehrenden in den OECD-Ländern Männer. In diesem Bildungsbereich sind im Durchschnitt der OECD-Länder nur 42 Prozent der Lehrenden Frauen. Trotz dieser generellen Verteilung bestehen in jedem Bildungsbereich große Unterschiede zwischen den einzelnen Ländern.

In den OECD-Ländern sind im Durchschnitt 97 Prozent der Lehrkräfte im Elementarbereich und 82 Prozent der Lehrkräfte im Primarbereich Frauen. In allen Ländern mit verfügbaren Daten mit Ausnahme Frankreichs und der Niederlande sind 93 Prozent

Abbildung D5.2

Geschlechterstruktur der Lehrerschaft (2012)

Anteil der weiblichen Lehrkräfte an öffentlichen und privaten Bildungseinrichtungen, nach Bildungsbereich

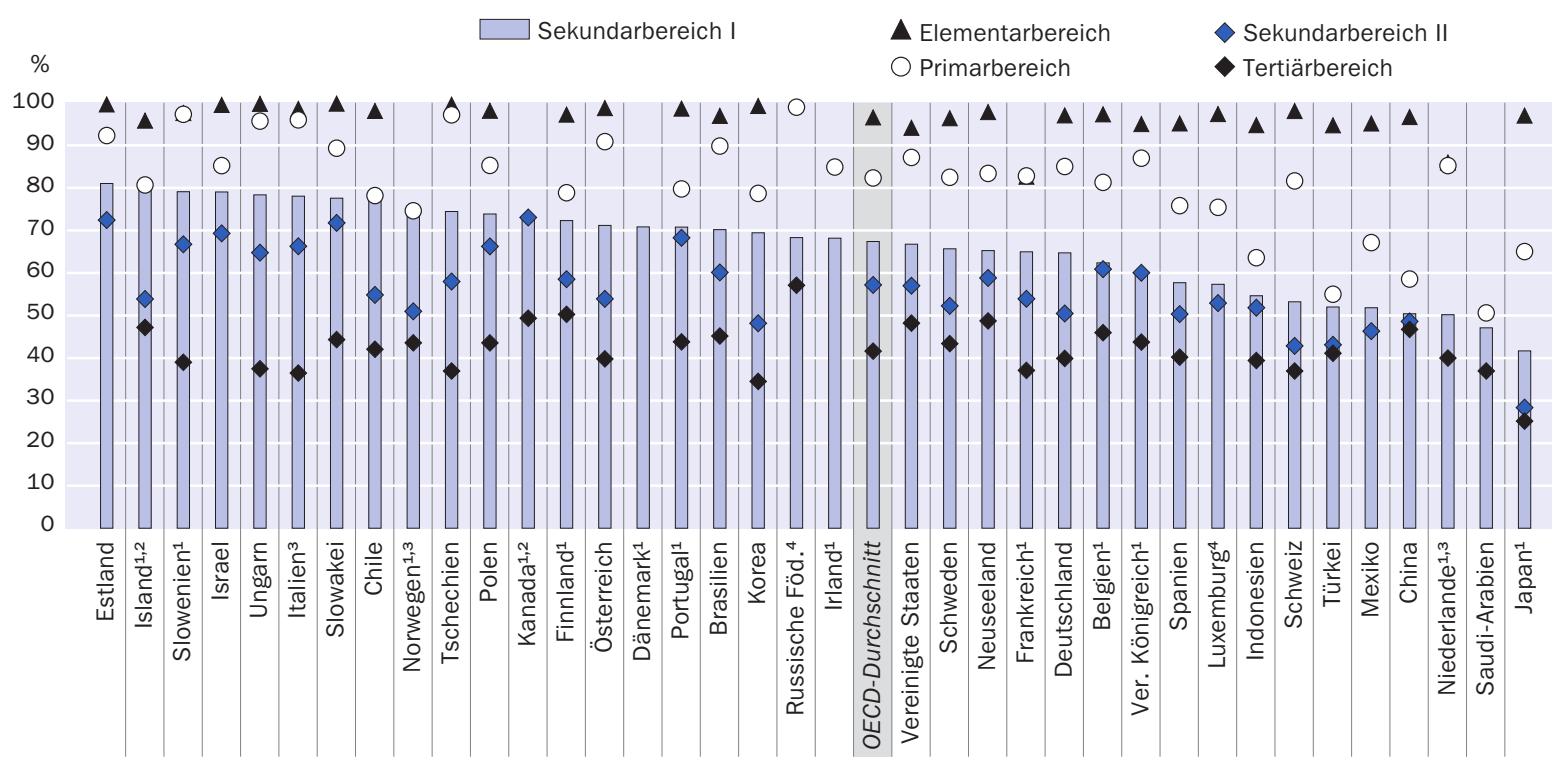

1. Einige Bildungsbereiche sind in anderen Bildungsbereichen enthalten. Einzelheiten s. Erläuterung von "x“ in Hinweise für den Leser. 2. Referenzjahr 2011. 3. Nur öffentliche Bildungseinrichtungen (Italien: Elementar- und Sekundarbereich). 4. Private Bildungseinrichtungen des Sekundarbereichs II umfassen auch private Bildungseinrichtungen des Sekundarbereichs I.

Anordnung der Länder in absteigender Reihenfolge des Anteils von weiblichen Lehrkräften (in \%) im Sekundarbereich I.

Quelle: OECD. Tabelle D5.3. Hinweise s. Anhang 3 unter www.oecd.org/edu/eag.htm. StatLink: http://dx.doi.org/10.1787/888933120233 
der Lehrkräfte im Elementarbereich Frauen, in Frankreich sind es 83 Prozent und in den Niederlanden 86 Prozent. In den 37 Ländern, für die Daten zu den Beschäftigten vorliegen, mit Ausnahme von China, Indonesien, Japan, Kanada, Saudi-Arabien und der Türkei, stellen Frauen mindestens 75 Prozent der Lehrkräfte (Abb. D5.2).

Im Sekundarbereich I ist in den OECD-Ländern zwar die Mehrzahl der Lehrkräfte weiblich (67 Prozent), der Anteil der Männer ist in diesem Bildungsbereich jedoch höher als im Primarbereich. Unter den OECD-Ländern bestehen starke Unterschiede beim Anteil der weiblichen Lehrkräfte, von weniger als der Hälfte der Lehrkräfte in Japan bis zu mehr als 80 Prozent in Estland, Island und der Russischen Föderation. Im Sekundarbereich II sinkt der durchschnittliche Anteil weiblicher Lehrkräfte in den OECD-Ländern auf 57 Prozent und variiert zwischen 28 Prozent in Japan und 73 Prozent in Kanada.

Während im Durchschnitt der OECD-Länder die meisten Lehrenden im Tertiärbereich Männer sind, variiert der Anteil der Frauen erheblich zwischen den einzelnen Ländern, von ungefähr jeder Vierten in Japan bis zu mindestens jeder Zweiten in Finnland und der Russischen Föderation.

\section{Altersstruktur der Lehrerschaft}

Die Altersstruktur der Lehrerschaft wird durch Veränderungen bei den Bevölkerungszahlen und der Altersstruktur der Bevölkerung, die Dauer der Studiengänge im Tertiärbereich sowie die Gehälter und Arbeitsbedingungen der Lehrkräfte beeinflusst. Sinkende Geburtenzahlen führen zu einer geringeren Nachfrage nach neuen Lehrkräften; Studiengänge im Tertiärbereich werden in einigen Ländern später abgeschlossen als in anderen. Während wettbewerbsfähige Gehälter und gute Arbeitsbedingungen in einigen Ländern dazu führen, dass der Lehrerberuf für junge Menschen attraktiv ist, führen diese Faktoren andererseits auch dazu, dass Lehrkräfte ihren Beruf nicht aufgeben und somit die Anzahl der offenen Stellen begrenzt ist (weitere Informationen zum Beschäftigungsstatus der Lehrkräfte s. Kasten D5.2).

Im Durchschnitt der OECD-Länder sind rund 3I Prozent der Lehrkräfte im Primarbereich mindestens 50 Jahre alt, in Deutschland, Italien und Schweden liegt dieser Anteil bei mehr als 40 Prozent. Der Anteil der unter 30-jährigen Lehrkräfte liegt nur in Belgien, Chile, Irland, Korea, Luxemburg und dem Vereinigten Königreich bei mindestens 20 Prozent (Abb. D5.3 im Internet).

Im Sekundarbereich findet sich eine ähnliche Altersstruktur der Lehrerschaft. Im Durchschnitt der OECD-Länder sind 36 Prozent der Lehrkräfte mindestens 50 Jahre alt. In Deutschland, Estland, Island, Italien, Neuseeland, den Niederlanden, Norwegen und Österreich sind mindestens 40 Prozent der Lehrkräfte im Sekundarbereich 50 Jahre und älter. Nur in Brasilien und Indonesien ist die Mehrzahl der Lehrkräfte im Sekundarbereich jünger als 40 Jahre (5I Prozent bzw. 62 Prozent). Der Anteil der Lehrkräfte, die mindestens 50 Jahre alt sind, ist in Estland, Frankreich, Israel, Italien und der Slowakei im Sekundarbereich II mindestens Io Prozentpunkte höher als im Primarbereich (Tab. D5.I und Abb. D5.2). 
Das steigende Durchschnittsalter der Lehrerschaft führt nicht nur dazu, dass Anstrengungen bei der Anwerbung und Ausbildung unternommen werden, um Lehrkräfte zu ersetzen, die in den Ruhestand gehen, es hat auch Auswirkungen auf die öffentlichen Haushalte. In den meisten Schulsystemen besteht ein Zusammenhang zwischen den Gehältern der Lehrkräfte und der Anzahl der Berufsjahre. Ein höherer Anteil älterer Lehrkräfte in der Lehrerschaft erhöht die Kosten der Schulbildung, was zu einer Beschränkung der Mittel führt, die für die Umsetzung anderer Initiativen auf Schulebene zur Verfügung stehen (s. Indikator $\mathrm{D}_{3}$ ).

Trotz eines höheren Anteils an Lehrkräften im Alter von mindestens 50 Jahren im Sekundarbereich im Vergleich zum Primarbereich stellen junge Lehrkräfte einen wesentlichen Teil des Lehrkörpers - im Primar- und Sekundarbereich sind im Durchschnitt der OECD-Länder I3 Prozent bzw. ıo Prozent der Lehrkräfte höchstens 30 Jahre alt. Nur in Deutschland, Estland, Finnland, Island, Italien, Portugal, Schweden, Slowenien, Tschechien und Ungarn sind höchstens ro Prozent der Lehrkräfte im Primar- und

Kasten D5.1

\section{Berufserfahrung der Lehrerschaft}

Die Ergebnisse der TALIS-Erhebung (Teaching and Learning International Survey) der OECD 2013 bieten einen Überblick über die Berufserfahrung der Lehrerschaft. Die Lehrkräfte wurden zu ihrer Berufserfahrung als Lehrkraft an ihrer Schule oder anderswo sowie zu ihrer Berufserfahrung in anderen Bildungstätigkeiten (ohne die Lehrertätigkeit) und in anderen Berufen befragt. Lehrkräfte im Sekundarbereich I verfügen im Durchschnitt über I 6 Jahre Erfahrung im Lehrerberuf (darunter fast Io Jahre an ihrer gegenwärtigen Schule), 3 Jahre Berufserfahrung in anderen Bildungsberufen sowie über 4 Jahre Berufserfahrung in anderen Berufen (s. Abb. D5.a). Ihren Angaben zufolge verfügt die Lehrerschaft in Bulgarien, Estland und Lettland mit mehr als 20 Jahren Berufserfahrung als Lehrkraft und ungefähr I5 Jahren an ihrer gegenwärtigen Schule über die längste Erfahrung in ihrem Beruf. Am anderen Ende des Spektrums liegt Singapur; hier geben die Lehrkräfte im Durchschnitt etwas weniger als Io Jahre Berufserfahrung als Lehrkraft an. Der große Anteil erfahrener Lehrkräfte scheint jedoch interessanterweise nicht mit einer verstärkten Beteiligung an Mentorenprogrammen einherzugehen. Vielmehr beträgt in Bulgarien, Estland und Lettland der Prozentsatz der Lehrkräfte, die nach eigenen Angaben einen Mentor haben oder als Mentoren tätig sind, nicht mehr als ro Prozent; in Singapur geben dagegen fast 40 Prozent der Lehrkräfte an, an einem Mentorenprogramm teilzunehmen.

Die nachfolgende Abbildung zeigt ferner, dass Lehrkräfte in Korea und Japan im Vergleich zu Lehrkräften in den anderen Ländern der TALIS-Erhebung eine kürzere Zeit an ihrer gegenwärtigen Schule tätig sind, was von einer erhöhten Fluktuation von Schule zu Schule in diesen beiden Ländern zeugt. Zwar liegen die Lehrkräfte in Korea und Japan hinsichtlich ihrer gesamten Berufserfahrung als Lehrkräfte über dem TALIS-Durchschnitt; die an ihrer gegenwärtigen Schule verbrachte Zeit liegt jedoch weit unter dem Durchschnitt. Den Angaben zufolge haben sie weniger als ein Drittel ihrer Berufserfahrung als Lehrkräfte an ihrer gegenwärtigen Schule erworben. Sie unterscheiden sich in ihrer Berufserfahrung von Lehrkräften anderer 
Länder auch hinsichtlich der Zeit, die sie in anderen Bildungsberufen oder sonstigen Berufen verbracht haben. Lehrkräfte in Korea und Japan geben an, dass sie nahezu ihre gesamte Berufserfahrung im Lehrerberuf erworben haben, während Lehrkräfte in den anderen Ländern der TALIS-Erhebung den Angaben zufolge im Durchschnitt mehr als 5 Jahre in anderen Bildungsberufen oder sonstigen Berufen tätig waren.

Abbildung D5.a

Berufserfahrung der Lehrkräfte (2013)

Durchschnittliche Berufserfahrung von Lehrkräften im Sekundarbereich I in Jahren

Durchschnittliche Jahre Berufserfahrung als Lehrkraft an der gegenwärtigen Schule

$\square$ Durchschnittliche Jahre Berufserfahrung als Lehrkraft

$\square$ Durchschnittliche Jahre Berufserfahrung in sonstigen Bildungsberufen

$\square$ Durchschnittliche Jahre Berufserfahrung in sonstigen Berufen

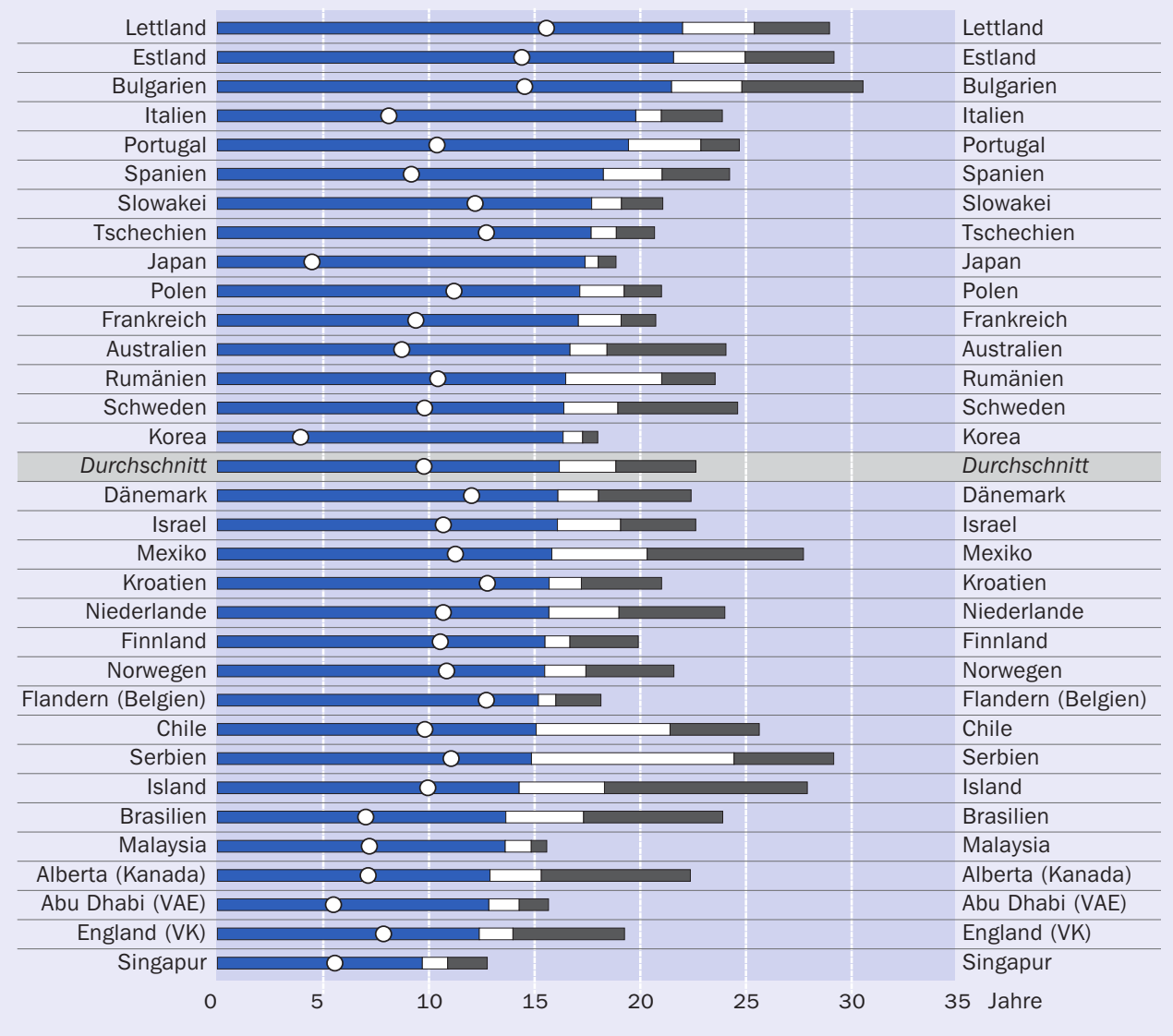

Anordnung der Länder in absteigender Reihenfolge der durchschnittlichen Gesamtanzahl an Jahren Berufserfahrung als Lehrkraft. Quelle: OECD (2014), TALIS 2013 Results: An International Perspective on Teaching and Learning, TALIS, OECD Publishing. StatLink: http://dx.doi.org/10.1787/888933041155

In Anbetracht der Tatsache, dass die Berufserfahrung den Lehrkräften hilft, ihre Kompetenzen zu entwickeln, sind diese Zahlen bedeutsam. Die Festanstellung einer Lehrkraft kann ferner Einfluss auf ihre Bereitschaft haben, innovative Methoden oder Reformen umzusetzen (Goodson, Moore and Hargreaves, 2006). Die Länge der Berufserfahrung kann insbesondere zu Beginn der beruflichen Laufbahn einer Lehrkraft von Bedeutung sein. Einige Studien belegen, dass jedes Jahr mehr an Erfahrung insbesondere in den ersten fünf Berufsjahren als Lehrkraft in Zusammenhang mit besseren Schülerleistungen steht (Rockoff, 2004; Rivkin, Hanushek und Kain, 2005; Harris und Sass, 20II). 


\section{Beschäftigungsstatus der Lehrkräfte}

Den Ergebnissen der TALIS-Erhebung (Teaching and Learning International Survey) zufolge sind im Sekundarbereich I im Durchschnitt aller Länder 83 Prozent der Lehrkräfte (ohne Vertretungslehrkräfte) unbefristet angestellt und 82 Prozent in Vollzeit tätig. Die nachfolgende Abbildung zeigt, dass den Angaben der Lehrkräfte zufolge sie in Malaysia über das höchste Maß an Arbeitsplatzsicherheit verfügen. Fast alle von ihnen geben an, unbefristet beschäftigt zu sein, und nahezu alle, in Vollzeit zu arbeiten.

Da der Beschäftigungsstatus eine wichtige Rolle dabei spielen kann, ob sich Menschen für den Lehrerberuf entscheiden und auch dabei bleiben, sollten Anstrengungen unternommen werden, eine erhöhte Arbeitsplatzsicherheit (durch langfristige oder unbefristete Verträge) und mehr Flexibilität (durch die Möglichkeit der Teilzeitbeschäftigung) zu gewährleisten (OECD, 2006).

\section{Abbildung D5.b}

Vertragliche Grundlage der Beschäftigung als Lehrkraft im Sekundarbereich I (2013)

Anteil der Lehrkräfte im Sekundarbereich I (in \%) mit einem unbefristeten Vertrag

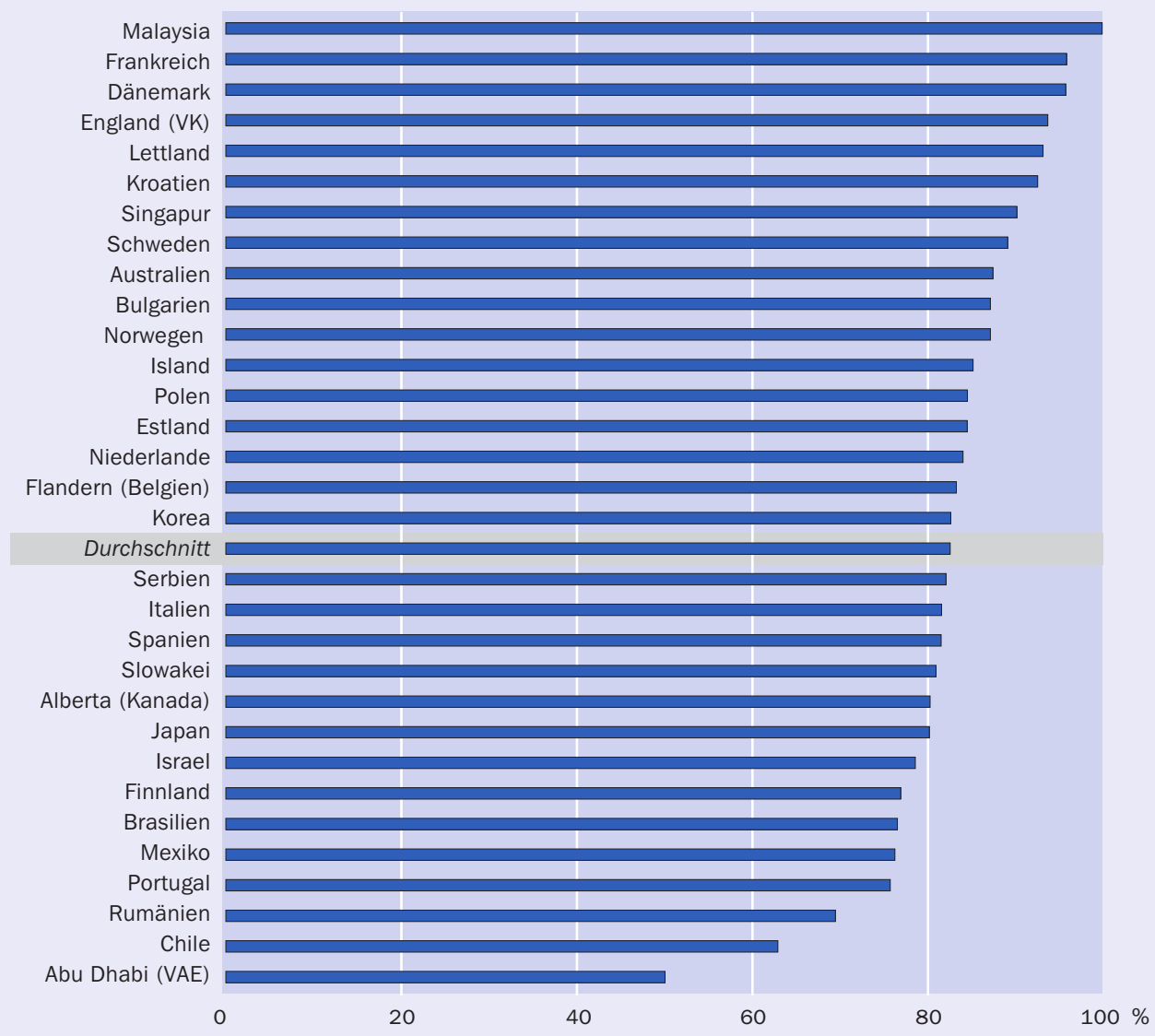

Quelle: OECD (2014), TALIS 2013 Results: An International Perspective on Teaching and Learning, TALIS, OECD Publishing. StatLink: $h$ ttp://dx.doi.org/10.1787/888933120233 
Sekundarbereich jünger als 30 Jahre. Dies lässt sich zum Teil dadurch erklären, dass die Studierenden in diesen Ländern ihre Ausbildung im Tertiärbereich erst relativ spät abschließen (s. Anhang I).

\section{Veränderungen der Altersstruktur der Lehrerschaft zwischen 2002 und 2012}

In den Ländern mit vergleichbaren Trenddaten sowohl für 2002 als auch 2012 ist der durchschnittliche Anteil von Lehrkräften im Sekundarbereich, die 50 Jahre oder älter sind, zwischen 2002 und 2012 jährlich um I, 3 Prozent gestiegen. Der entsprechende Prozentsatz variiert jedoch stark zwischen den einzelnen Ländern. In Brasilien, Japan, Korea und Portugal betrug die jährliche Zunahme im Durchschnitt mehr als 4 Prozent pro Jahr. Am größten war sie in Österreich, wo sie sich auf 9 Prozent pro Jahr belief. Auf der anderen Seite sank in Chile, Dänemark, Luxemburg, Schweden und dem Vereinigten Königreich die durchschnittliche jährliche Zunahme um mindestens I Prozent (Tab. D5.2).

In allen Ländern sollten die Veränderungen bei der Zahl der Lehrkräfte ungefähr den Veränderungen bei der Zahl junger Menschen im Schulalter entsprechen. In Ländern mit einer steigenden Zahl von Schülern im schulpflichtigen Alter in diesem Zeitraum (s. Indikator CI) werden neue Lehrkräfte eingestellt werden müssen, um einen Ausgleich für die hohe Zahl der in den I96oer- und I97oer-Jahren eingestellten Lehrkräfte zu schaffen, die im nächsten Jahrzehnt das Ruhestandsalter erreichen werden. Die Zahl der angebotenen Ausbildungsgänge für den Lehrerberuf wird wohl gesteigert und verstärkt Anreize für Studierende geschaffen werden müssen, den Lehrerberuf zu ergreifen (s. Indikator D6). Im Gegensatz hierzu müssen aufgrund der möglicherweise hohen Kosten, die vom Einzelnen und der Gesellschaft zu tragen sind, wenn beträchtliche Mittel in die Ausbildung von Lehrkräften investiert werden, Länder mit einer abnehmenden Bevölkerung im Schulalter, wie Chile, Deutschland, Japan, Korea, Österreich und Polen, sicherstellen, dass die Qualität der Lehrerausbildung nicht durch eine große Zahl von Anwärtern bzw. Absolventen von Ausbildungsgängen für Lehrkräfte untergraben wird, die keine Anstellung als Lehrkraft finden (OECD, 2006).

\section{Definitionen}

Abschließende Qualifikation (ISCED) bezieht sich auf die Art des Bildungsabschlusses (z. B. auf den ISCED-Stufen $3,5 \mathrm{~B}, 5 \mathrm{~A}$ ), über den eine neue Lehrkraft verfügen muss, um an einer öffentlichen Einrichtung Unterricht im Primar-, Sekundarbereich I und Sekundarbereich II (allgemeinbildende Bildungsgänge) zu erteilen.

\section{Angewandte Methodik}

Die Daten beziehen sich auf das Schuljahr 20II/20I2 und beruhen auf der von der OECD im Jahre 2012 durchgeführten UOE-Datenerhebung zur Bildungsstatistik (weitere Informationen s. Anhang 3 unter www.oecd.org/eduleag.htm). Die Daten zu Lehrkräften aufgegliedert nach Alter für 2002 sind gegebenenfalls 2013 überarbeitet worden, um die Konsistenz mit den Daten von 20II zu gewährleisten. 
Hinweis zu den Daten aus Israel

Die statistischen Daten für Israel wurden von den zuständigen israelischen Stellen bereitgestellt, die für sie verantwortlich zeichnen. Die Verwendung dieser Daten durch die OECD erfolgt unbeschadet des völkerrechtlichen Status der Golanhöhen, von Ost-Jerusalem und der israelischen Siedlungen im Westjordanland.

\section{Weiterführende Informationen}

Abrams, S.E. (20II), „Technology in Moderation“, The Teachers College Record, www. tcrecord.org/content. asp? contentid $=16584$.

Goodson, I., S. Moore and A. Hargreaves (2006), „Teacher nostalgia and the sustainability of reform: The generation and degeneration of teachers' missions, memory and meaning“, Educational Administrative Quarterly, Vol. 42, pp. 42-6I.

Harris, D. N. and T.R. Sass (20II), „Teacher training, teacher quality and student achievement“, Journal of Public Economics, Vol. 95, pp. 798-8I2.

Hanushek, E., S. Machin and L. Woessmann (20II), „The economics of international differences in educational achievement", Handbook of the Economics of Education, Vol. 3, pp. 89-200.

Hiebert, J. and J. Stigler (1999), The Teaching Gap: Best Ideas from the World's Teachers for Improving Education in the Classroom, Free Press, New York.

OECD (2014), TALIS 2013 Results: An International Perspective on Teaching and Learning, TALIS, OECD Publishing, Paris, http:/|dx.doi.org/10.1787/9789264196261-en.

OECD (2006), Stärkere Professionalisierung des Lehrerberufs - Wie gute Lehrer gewonnen, gefördert und gehalten werden können, OECD Publishing, Paris, http:/|dx.doi.org/10.1787| 9789264023673-de.

Peterson, P. (2010), Saving Schools: From Horace Mann to Virtual Learning, Harvard University Press, Cambridge.

Rivkin, S., E. Hanushek and J. Kain (2005), „Teachers, schools, and academic achievement“, Econometrica, Vol. 73/2, pp. 4I7-458.

Rockoff, J.E. (2004), „The impact of individual teachers on students' achievement: Evidence from panel data“, American Economic Review, Vol. 94/2, pp. 247-252. 


\section{Tabellen Indikator D5}

StatLink: http://dx.doi.org/10.1787/888933120138

Tabelle D5.I: Altersstruktur der Lehrerschaft (2012)

Tabelle D5.2: Altersstruktur der Lehrerschaft (2002 und 2012)

Tabelle D5.3: Geschlechterstruktur der Lehrerschaft (2012) 
Altersstruktur der Lehrerschaft (2012)

Alter der Lehrkräfte an öffentlichen und privaten Bildungseinrichtungen (jeweiliger Anteil in \%), nach Bildungsbereich und Altersgruppe, basierend auf Personenzahlen

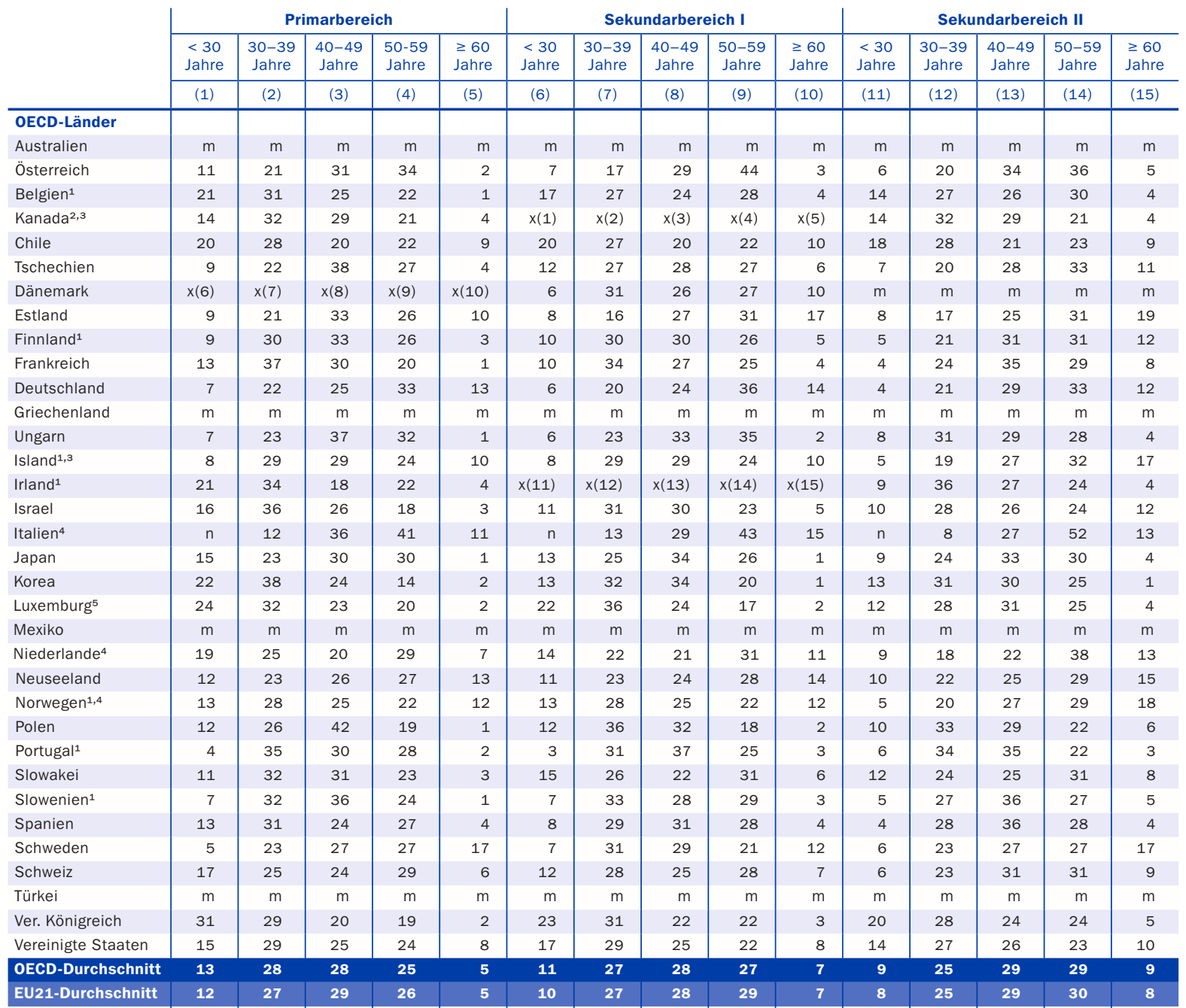

\begin{tabular}{|c|c|c|c|c|c|c|c|c|c|c|c|c|c|c|c|}
\hline EU21-Durchschnitt & 12 & 27 & 29 & 26 & 5 & 10 & 27 & 28 & 29 & 7 & 8 & 25 & 29 & 30 & 8 \\
\hline \multicolumn{16}{|l|}{ Partnerländer } \\
\hline Argentinien & $\mathrm{m}$ & $\mathrm{m}$ & $\mathrm{m}$ & $\mathrm{m}$ & $\mathrm{m}$ & $\mathrm{m}$ & $\mathrm{m}$ & $\mathrm{m}$ & $\mathrm{m}$ & $\mathrm{m}$ & $\mathrm{m}$ & $\mathrm{m}$ & $\mathrm{m}$ & $\mathrm{m}$ & $\mathrm{m}$ \\
\hline Brasilien & 16 & 36 & 33 & 13 & 2 & 17 & 35 & 30 & 15 & 3 & 16 & 34 & 30 & 16 & 3 \\
\hline China & $\mathrm{m}$ & $\mathrm{m}$ & $\mathrm{m}$ & $\mathrm{m}$ & $\mathrm{m}$ & $\mathrm{m}$ & $\mathrm{m}$ & $\mathrm{m}$ & $\mathrm{m}$ & $\mathrm{m}$ & $\mathrm{m}$ & $\mathrm{m}$ & $\mathrm{m}$ & $\mathrm{m}$ & $\mathrm{m}$ \\
\hline Kolumbien & $\mathrm{m}$ & $\mathrm{m}$ & $\mathrm{m}$ & $\mathrm{m}$ & $\mathrm{m}$ & $\mathrm{m}$ & $\mathrm{m}$ & $\mathrm{m}$ & $\mathrm{m}$ & $\mathrm{m}$ & $\mathrm{m}$ & $\mathrm{m}$ & $\mathrm{m}$ & $\mathrm{m}$ & $\mathrm{m}$ \\
\hline Indien & $\mathrm{m}$ & $\mathrm{m}$ & $\mathrm{m}$ & $\mathrm{m}$ & $\mathrm{m}$ & $\mathrm{m}$ & $\mathrm{m}$ & $\mathrm{m}$ & $\mathrm{m}$ & $\mathrm{m}$ & $\mathrm{m}$ & $\mathrm{m}$ & $\mathrm{m}$ & $\mathrm{m}$ & $\mathrm{m}$ \\
\hline Indonesien & 19 & 22 & 41 & 16 & 1 & 34 & 30 & 27 & 8 & 1 & 21 & 37 & 31 & 9 & 1 \\
\hline Lettland & $\mathrm{m}$ & $\mathrm{m}$ & $\mathrm{m}$ & $\mathrm{m}$ & $\mathrm{m}$ & $\mathrm{m}$ & $\mathrm{m}$ & $\mathrm{m}$ & $\mathrm{m}$ & $\mathrm{m}$ & $\mathrm{m}$ & $\mathrm{m}$ & $\mathrm{m}$ & $\mathrm{m}$ & $\mathrm{m}$ \\
\hline Russische Föd. & $\mathrm{m}$ & $\mathrm{m}$ & $\mathrm{m}$ & $\mathrm{m}$ & $\mathrm{m}$ & $\mathrm{m}$ & $\mathrm{m}$ & $\mathrm{m}$ & $\mathrm{m}$ & $\mathrm{m}$ & $\mathrm{m}$ & $\mathrm{m}$ & $\mathrm{m}$ & $\mathrm{m}$ & $\mathrm{m}$ \\
\hline Saudi-Arabien & $\mathrm{m}$ & $\mathrm{m}$ & $\mathrm{m}$ & $\mathrm{m}$ & $\mathrm{m}$ & $\mathrm{m}$ & $\mathrm{m}$ & $\mathrm{m}$ & $\mathrm{m}$ & $\mathrm{m}$ & m & $\mathrm{m}$ & $\mathrm{m}$ & $\mathrm{m}$ & $\mathrm{m}$ \\
\hline Südafrika & $\mathrm{m}$ & $\mathrm{m}$ & $\mathrm{m}$ & $\mathrm{m}$ & $\mathrm{m}$ & $\mathrm{m}$ & $\mathrm{m}$ & $\mathrm{m}$ & $\mathrm{m}$ & $\mathrm{m}$ & $\mathrm{m}$ & $\mathrm{m}$ & $\mathrm{m}$ & $\mathrm{m}$ & $\mathrm{m}$ \\
\hline G20-Durchschnitt & m & m & $\mathbf{m}$ & m & $\mathbf{m}$ & m & m & $\mathbf{m}$ & m & m & $\mathbf{m}$ & $\mathbf{m}$ & m & $\mathbf{m}$ & m \\
\hline
\end{tabular}

1. Sekundarbereich II umfasst postsekundaren, nicht tertiären Bereich (bzw. teilweise postsekundaren, nicht tertiären Bereich in Island und Portugal sowie Sekundarbereich I und postsekundaren, nicht tertiären Bereich in Irland). 2. Primarbereich umfasst Elementarbereich. 3. Referenzjahr 2011. 4. Nur öffentliche Bildungseinrichtungen. 5. Bildungseinrichtungen des Sekundarbereichs II umfassen auch private Bildungseinrichtungen des Sekundarbereichs I. Quelle: OECD. Argentinien, China, Indien, Indonesien, Kolumbien, Saudi-Arabien und Südafrika: Statistikinstitut der UNESCO. Lettland: Eurostat. Hinweise s. Anhang 3 unter www.oecd.org/edu/eag.htm. StatLink: http://dx.doi.org/10.1787/888933120157 Erläuterung der Kennzeichnung fehlender Daten s. Hinweise für den Leser. 
Tabelle D5.2

Altersstruktur der Lehrerschaft (2002 und 2012)

Alter der Lehrkräfte an öffentlichen und privaten Bildungseinrichtungen (jeweiliger Anteil in \%), basierend auf Personenzahlen

\begin{tabular}{|c|c|c|c|c|c|c|c|c|c|c|c|c|c|}
\hline & \multicolumn{5}{|c|}{ Sekundarbereich (2012) } & \multicolumn{5}{|c|}{ Sekundarbereich (2002) } & \multicolumn{3}{|c|}{$\begin{array}{l}\text { Anteil der Lehrkräfte im } \\
\text { Sekundarbereich, die mindestens } \\
50 \text { Jahre alt sind (in \%) }\end{array}$} \\
\hline & $\begin{array}{l}<30 \\
\text { Jahre }\end{array}$ & $\begin{array}{c}\text { 30-39 } \\
\text { Jahre }\end{array}$ & $\begin{array}{l}40-49 \\
\text { Jahre }\end{array}$ & $\begin{array}{c}50-59 \\
\text { Jahre }\end{array}$ & $\begin{array}{l}\geq 60 \\
\text { Jahre }\end{array}$ & $\begin{array}{l}<30 \\
\text { Jahre }\end{array}$ & $\begin{array}{c}\text { 30-39 } \\
\text { Jahre }\end{array}$ & $\begin{array}{c}40-49 \\
\text { Jahre }\end{array}$ & $\begin{array}{c}50-59 \\
\text { Jahre }\end{array}$ & $\begin{array}{l}\geq 60 \\
\text { Jahre }\end{array}$ & 2012 & 2002 & $\begin{array}{c}\text { Durchschnittl. } \\
\text { jährlicher Anstieg } \\
\text { (2002-2012) }\end{array}$ \\
\hline & (1) & (2) & (3) & (4) & (5) & (6) & (7) & (8) & (9) & (10) & (11) & (12) & (13) \\
\hline \multicolumn{14}{|l|}{ OECD-Länder } \\
\hline Australien & $\mathrm{m}$ & $\mathrm{m}$ & $\mathrm{m}$ & $\mathrm{m}$ & $\mathrm{m}$ & $\mathrm{m}$ & $\mathrm{m}$ & $\mathrm{m}$ & $\mathrm{m}$ & $\mathrm{m}$ & $\mathrm{m}$ & $\mathrm{m}$ & $\mathrm{m}$ \\
\hline Österreich & 7 & 18 & 31 & 41 & 4 & 10 & 29 & 43 & 18 & 1 & 45 & 19 & 9,2 \\
\hline Belgien $^{1,2}$ & 15 & 27 & 25 & 29 & 4 & 14 & 23 & 33 & 28 & 3 & 33 & 30 & 0,9 \\
\hline Kanada $^{3}$ & 14 & 32 & 29 & 21 & 4 & $\mathrm{~m}$ & $\mathrm{~m}$ & $\mathrm{~m}$ & $\mathrm{~m}$ & $\mathrm{~m}$ & 26 & $\mathrm{~m}$ & $\mathrm{~m}$ \\
\hline Kolumbien & 19 & 28 & 21 & 23 & 9 & 7 & 23 & 33 & 27 & 10 & 32 & 37 & -1.4 \\
\hline Tschechien & 9 & 23 & 28 & 30 & 9 & $\mathrm{~m}$ & $\mathrm{~m}$ & $\mathrm{~m}$ & $\mathrm{~m}$ & $\mathrm{~m}$ & 39 & $\mathrm{~m}$ & $\mathrm{~m}$ \\
\hline Dänemark ${ }^{4}$ & 6 & 31 & 26 & 27 & 10 & 12 & 24 & 24 & 35 & 6 & 37 & 41 & $-1,0$ \\
\hline Estland & 8 & 17 & 26 & 31 & 18 & $\mathrm{~m}$ & $\mathrm{~m}$ & $\mathrm{~m}$ & $\mathrm{~m}$ & $\mathrm{~m}$ & 49 & $\mathrm{~m}$ & $\mathrm{~m}$ \\
\hline Finnland $^{1}$ & 7 & 25 & 30 & 28 & 9 & 8 & 26 & 30 & 32 & 4 & 37 & 36 & 0,2 \\
\hline Frankreich & 7 & 29 & 31 & 27 & 6 & 13 & 27 & 25 & 34 & 1 & 33 & 35 & $-0,6$ \\
\hline Deutschland & 5 & 21 & 26 & 35 & 13 & 4 & 15 & 33 & 42 & 7 & 49 & 49 & 0,0 \\
\hline Griechenland & $\mathrm{m}$ & $\mathrm{m}$ & $\mathrm{m}$ & $\mathrm{m}$ & $\mathrm{m}$ & $\mathrm{m}$ & $\mathrm{m}$ & $\mathrm{m}$ & $\mathrm{m}$ & $\mathrm{m}$ & $\mathrm{m}$ & $\mathrm{m}$ & $\mathrm{m}$ \\
\hline Ungarn & 7 & 28 & 31 & 31 & 3 & 15 & 26 & 33 & 22 & 3 & 34 & 26 & 2,9 \\
\hline Island ${ }^{1,3}$ & 6 & 23 & 28 & 29 & 14 & 7 & 21 & 32 & 28 & 12 & 43 & 39 & 0,9 \\
\hline Irland ${ }^{1}$ & 9 & 33 & 26 & 26 & 6 & 11 & 26 & 30 & 27 & 6 & 31 & 33 & $-0,5$ \\
\hline$|s r a e|^{2}$ & 10 & 30 & 28 & 23 & 9 & 12 & 30 & 31 & 24 & 4 & 32 & 28 & 1,6 \\
\hline Italien 5 & $n$ & 10 & 28 & 48 & 14 & 1 & 11 & 40 & 44 & 4 & 62 & 48 & 2,6 \\
\hline Japan & 11 & 24 & 34 & 28 & 3 & 11 & 32 & 36 & 19 & 2 & 31 & 21 & 4,1 \\
\hline Korea & 13 & 32 & 32 & 22 & 1 & 17 & 37 & 35 & 10 & 1 & 23 & 11 & 8,2 \\
\hline Luxemburg & 15 & 31 & 28 & 22 & 3 & 8 & 27 & 29 & 29 & 2 & 25 & 31 & $-1,9$ \\
\hline Mexiko & $\mathrm{m}$ & $\mathrm{m}$ & $\mathrm{m}$ & $\mathrm{m}$ & $\mathrm{m}$ & $\mathrm{m}$ & $\mathrm{m}$ & $\mathrm{m}$ & $\mathrm{m}$ & $\mathrm{m}$ & $\mathrm{m}$ & $\mathrm{m}$ & $\mathrm{m}$ \\
\hline Niederlande 5 & 12 & 20 & 22 & 34 & 12 & 9 & 17 & 36 & 35 & 3 & 46 & 38 & 1,9 \\
\hline Neuseeland & 10 & 22 & 25 & 28 & 15 & 14 & 20 & 32 & 28 & 7 & 43 & 35 & 2,2 \\
\hline Norwegen ${ }^{1,5}$ & 9 & 24 & 26 & 26 & 15 & 12 & 23 & 27 & 30 & 7 & 41 & 38 & 0,9 \\
\hline Polen ${ }^{2}$ & 11 & 35 & 30 & 20 & 4 & 22 & 31 & 28 & 16 & 3 & 25 & 18 & 3,1 \\
\hline Portugal $^{1}$ & 5 & 33 & 36 & 24 & 3 & 22 & 37 & 27 & 12 & 2 & 26 & 14 & 6,7 \\
\hline Slowakei & 14 & 25 & 23 & 31 & 7 & 19 & 24 & 29 & 23 & 6 & 38 & 28 & 2,9 \\
\hline Slowenien ${ }^{1}$ & 6 & 30 & 32 & 28 & 4 & $\mathrm{~m}$ & $\mathrm{~m}$ & $\mathrm{~m}$ & $\mathrm{~m}$ & $\mathrm{~m}$ & 32 & $\mathrm{~m}$ & $\mathrm{~m}$ \\
\hline Spanien & 6 & 29 & 33 & 28 & 4 & $\mathrm{~m}$ & $\mathrm{~m}$ & $\mathrm{~m}$ & $\mathrm{~m}$ & $\mathrm{~m}$ & 32 & $\mathrm{~m}$ & $\mathrm{~m}$ \\
\hline Schweden & 7 & 27 & 28 & 24 & 15 & 11 & 20 & 24 & 35 & 9 & 39 & 44 & $-1,2$ \\
\hline Schweiz $z^{4,5}$ & 9 & 26 & 28 & 30 & 8 & 13 & 24 & 31 & 28 & 5 & 38 & 32 & 1,6 \\
\hline Türkei & $\mathrm{m}$ & $\mathrm{m}$ & $\mathrm{m}$ & $\mathrm{m}$ & $\mathrm{m}$ & $\mathrm{m}$ & $\mathrm{m}$ & $\mathrm{m}$ & $\mathrm{m}$ & $\mathrm{m}$ & $\mathrm{m}$ & $\mathrm{m}$ & $\mathrm{m}$ \\
\hline Vereinigtes Königreich & 21 & 29 & 23 & 23 & 4 & 13 & 22 & 33 & 30 & 1 & 27 & 31 & $-1,4$ \\
\hline Vereinigte Staaten & 16 & 28 & 25 & 23 & 9 & 17 & 22 & 32 & 26 & 3 & 32 & 30 & 0,7 \\
\hline OECD-Durchschnitt & 10 & 26 & 28 & 28 & 8 & 12 & 25 & 31 & 27 & 4 & 36 & 32 & $\sim$ \\
\hline $\begin{array}{l}\text { Durchschnitt für Länder } \\
\text { mit verfügbaren Daten } \\
\text { für beide Referenzjahre }\end{array}$ & 10 & 27 & 28 & 27 & 8 & 13 & 25 & 31 & 26 & 4 & 35 & 31 & 1,3 \\
\hline EU21-Durchschnitt & 9 & 26 & 28 & 29 & 8 & 12 & 24 & 31 & 29 & 4 & 37 & 33 & $\sim$ \\
\hline \multicolumn{14}{|l|}{ Partnerländer } \\
\hline Argentinien & $\mathrm{m}$ & $\mathrm{m}$ & $\mathrm{m}$ & $\mathrm{m}$ & $\mathrm{m}$ & $\mathrm{m}$ & $\mathrm{m}$ & $\mathrm{m}$ & $\mathrm{m}$ & $\mathrm{m}$ & $\mathrm{m}$ & $\mathrm{m}$ & $\mathrm{m}$ \\
\hline Brasilien & 17 & 35 & 30 & 16 & 3 & 26 & 35 & 26 & 11 & 2 & 19 & 13 & 5,3 \\
\hline China & $\mathrm{m}$ & $\mathrm{m}$ & $\mathrm{m}$ & $\mathrm{m}$ & $\mathrm{m}$ & $\mathrm{m}$ & $\mathrm{m}$ & $\mathrm{m}$ & $\mathrm{m}$ & $\mathrm{m}$ & $\mathrm{m}$ & $\mathrm{m}$ & $\mathrm{m}$ \\
\hline Kolumbien & $\mathrm{m}$ & $\mathrm{m}$ & $\mathrm{m}$ & $\mathrm{m}$ & $\mathrm{m}$ & $\mathrm{m}$ & $\mathrm{m}$ & $\mathrm{m}$ & $\mathrm{m}$ & $\mathrm{m}$ & $\mathrm{m}$ & $\mathrm{m}$ & $\mathrm{m}$ \\
\hline Indien & $\mathrm{m}$ & $\mathrm{m}$ & $\mathrm{m}$ & $\mathrm{m}$ & $\mathrm{m}$ & $\mathrm{m}$ & $\mathrm{m}$ & $\mathrm{m}$ & $\mathrm{m}$ & $\mathrm{m}$ & $\mathrm{m}$ & $\mathrm{m}$ & $\mathrm{m}$ \\
\hline Indonesien & 29 & 33 & 29 & 8 & 1 & $\mathrm{~m}$ & $\mathrm{~m}$ & $\mathrm{~m}$ & $\mathrm{~m}$ & $\mathrm{~m}$ & 10 & $\mathrm{~m}$ & $\mathrm{~m}$ \\
\hline Lettland & $\mathrm{m}$ & $\mathrm{m}$ & $\mathrm{m}$ & $\mathrm{m}$ & $\mathrm{m}$ & $\mathrm{m}$ & $\mathrm{m}$ & $\mathrm{m}$ & $\mathrm{m}$ & $\mathrm{m}$ & $\mathrm{m}$ & $\mathrm{m}$ & $\mathrm{m}$ \\
\hline Russische Föderation & $\mathrm{m}$ & $\mathrm{m}$ & $\mathrm{m}$ & $\mathrm{m}$ & $\mathrm{m}$ & $\mathrm{m}$ & $\mathrm{m}$ & $\mathrm{m}$ & $\mathrm{m}$ & $\mathrm{m}$ & $\mathrm{m}$ & $\mathrm{m}$ & $\mathrm{m}$ \\
\hline Saudi-Arabien & $\mathrm{m}$ & $\mathrm{m}$ & $\mathrm{m}$ & $\mathrm{m}$ & $\mathrm{m}$ & $\mathrm{m}$ & $\mathrm{m}$ & $\mathrm{m}$ & $\mathrm{m}$ & $\mathrm{m}$ & $\mathrm{m}$ & $\mathrm{m}$ & $\mathrm{m}$ \\
\hline Südafrika & $\mathrm{m}$ & $\mathrm{m}$ & $\mathrm{m}$ & $\mathrm{m}$ & $\mathrm{m}$ & $\mathrm{m}$ & $\mathrm{m}$ & $\mathrm{m}$ & $\mathrm{m}$ & $\mathrm{m}$ & $\mathrm{m}$ & $\mathrm{m}$ & $\mathrm{m}$ \\
\hline G20-Durchschnitt & m & m & m & m & m & m & m & m & m & m & m & m & $\mathbf{m}$ \\
\hline
\end{tabular}

1. Umfasst postsekundaren, nicht tertiären Bereich (teilweise postsekundaren, nicht tertiären Bereich in Island und Portugal). 2. Referenzjahr 2003 anstelle 2002. 3. Referenzjahr 2011 anstelle 2012. 4. Referenzjahr 2004 anstelle 2002. 5. Nur öffentliche Bildungseinrichtungen (Schweiz: nur für 2002).

Quelle: OECD. Argentinien, China, Indien, Indonesien, Kolumbien, Saudi-Arabien und Südafrika: Statistikinstitut der UNESCO. Lettland: Eurostat.

Hinweise s. Anhang 3 unter www.oecd.org/edu/eag.htm. StatLink: http://dx.doi.org/10.1787/888933120176

Erläuterung der Kennzeichnung fehlender Daten s. Hinweise für den Leser. 
Geschlechterstruktur der Lehrerschaft (2012)

Anteil der weiblichen Lehrkräfte an öffentlichen und privaten Bildungseinrichtungen (in \%), nach Bildungsbereich, basierend auf Personenzahlen

\begin{tabular}{|c|c|c|c|c|c|c|c|c|c|c|c|}
\hline & \multirow{2}{*}{$\mid \begin{array}{c}\text { Elementar- } \\
\text { bereich }\end{array}$} & \multirow{2}{*}{$\begin{array}{l}\text { Primar- } \\
\text { bereich }\end{array}$} & \multirow{2}{*}{$\left|\begin{array}{c}\text { Sekundar- } \\
\text { bereich I }\end{array}\right|$} & \multicolumn{3}{|c|}{ Sekundarbereich II } & \multirow{2}{*}{$\begin{array}{c}\text { Postse- } \\
\text { kundarer, } \\
\text { nicht } \\
\text { tertiärer } \\
\text { Bereich }\end{array}$} & \multicolumn{3}{|c|}{ Tertiärbereich } & \multirow{2}{*}{$\begin{array}{c}\text { Alle } \\
\text { Bildungs- } \\
\text { bereiche } \\
\text { zusammen }\end{array}$} \\
\hline & & & & $\begin{array}{c}\text { Allgemein- } \\
\text { bildende } \\
\text { Bildungs- } \\
\text { gänge }\end{array}$ & \begin{tabular}{|c|} 
Berufsvor- \\
bereitende/ \\
Berufs- \\
bildende \\
Bildungs- \\
gänge
\end{tabular} & $\begin{array}{c}\text { Alle } \\
\text { Bildungs- } \\
\text { gänge }\end{array}$ & & $\begin{array}{c}\text { Tertiär- } \\
\text { bereich B }\end{array}$ & \begin{tabular}{|c|} 
Tertiärbe- \\
reich A und \\
weiterfüh- \\
rende for- \\
schungs- \\
orientierte \\
Studien- \\
gänge \\
\end{tabular} & $\begin{array}{c}\text { Tertiär- } \\
\text { bereich } \\
\text { insgesamt }\end{array}$ & \\
\hline & (1) & (2) & (3) & (4) & (5) & (6) & (7) & (8) & (9) & (10) & (11) \\
\hline \multicolumn{12}{|l|}{ OECD-Länder } \\
\hline Australien & $\mathrm{m}$ & $\mathrm{m}$ & $\mathrm{m}$ & $\mathrm{m}$ & $\mathrm{m}$ & $\mathrm{m}$ & $\mathrm{m}$ & $\mathrm{m}$ & 44 & $\mathrm{~m}$ & $\mathrm{~m}$ \\
\hline Österreich & 99 & 91 & 71 & 63 & 50 & 54 & 53 & $x(10)$ & $x(10)$ & 40 & 65 \\
\hline Belgien & 97 & 81 & 62 & 61 & $x(6)$ & 61 & $x(6)$ & $x(10)$ & $x(10)$ & 46 & 70 \\
\hline Kanada $^{1}$ & $x(2)$ & 73 & $x(2)$ & $x(6)$ & $x(6)$ & 73 & $\mathrm{~m}$ & 54 & 43 & 49 & $\mathrm{~m}$ \\
\hline Chile & 98 & 78 & 77 & 57 & 49 & 55 & a & 43 & 42 & 42 & 64 \\
\hline Tschechien & 100 & 97 & 74 & $x(6)$ & $x(6)$ & 58 & 56 & 61 & 34 & 37 & $\mathrm{~m}$ \\
\hline Dänemark & $x(3)$ & $x(3)$ & 71 & $\mathrm{~m}$ & $\mathrm{~m}$ & $\mathrm{~m}$ & $\mathrm{~m}$ & $\mathrm{~m}$ & $\mathrm{~m}$ & $\mathrm{~m}$ & $\mathrm{~m}$ \\
\hline Estland & 100 & 92 & 81 & 78 & 64 & 72 & $x(5)$ & $\mathrm{m}$ & $\mathrm{m}$ & $\mathrm{m}$ & 88 \\
\hline Finnland & 97 & 79 & 72 & 70 & 54 & 59 & $x(6)$ & $\mathrm{n}$ & 50 & 50 & 71 \\
\hline Frankreich & 83 & 83 & 65 & 55 & 51 & 54 & $x(8)$ & 38 & 37 & 37 & 66 \\
\hline Deutschland & 97 & 85 & 65 & 54 & 43 & 50 & 53 & 55 & 37 & 40 & 65 \\
\hline Griechenland & $\mathrm{m}$ & $\mathrm{m}$ & $\mathrm{m}$ & $\mathrm{m}$ & $\mathrm{m}$ & $\mathrm{m}$ & $\mathrm{m}$ & $\mathrm{m}$ & $\mathrm{m}$ & $\mathrm{m}$ & $\mathrm{m}$ \\
\hline Ungarn & 100 & 96 & 78 & 68 & 54 & 65 & 52 & 48 & 36 & 37 & 76 \\
\hline Island ${ }^{1}$ & 96 & 81 & 81 & $x(6)$ & $x(6)$ & 54 & $x(6,10)$ & $x(10)$ & $x(10)$ & 47 & 73 \\
\hline Irland & $\mathrm{m}$ & 85 & $x(6)$ & 69 & 53 & 68 & $x(6)$ & $\mathrm{m}$ & $\mathrm{m}$ & $\mathrm{m}$ & $\mathrm{m}$ \\
\hline Israel & 99 & 85 & 79 & $x(6)$ & $x(6)$ & 69 & $\mathrm{~m}$ & $\mathrm{~m}$ & $\mathrm{~m}$ & $\mathrm{~m}$ & $\mathrm{~m}$ \\
\hline Italien ${ }^{2}$ & 99 & 96 & 78 & 75 & 61 & 66 & $\mathrm{~m}$ & 33 & 36 & 36 & 77 \\
\hline Japan & 97 & 65 & 42 & 28 & 63 & 28 & $x(6,10)$ & 47 & 19 & 25 & 48 \\
\hline Korea & 99 & 79 & 69 & 50 & 43 & 48 & a & 43 & 32 & 35 & 60 \\
\hline Luxemburg ${ }^{3}$ & 97 & 75 & 57 & 62 & 43 & 53 & $\mathrm{~m}$ & $\mathrm{~m}$ & 45 & 45 & $\mathrm{~m}$ \\
\hline Mexiko & 95 & 67 & 52 & 46 & 48 & 46 & a & $\mathrm{m}$ & $\mathrm{m}$ & $\mathrm{m}$ & $\mathrm{m}$ \\
\hline Niederlande $^{2}$ & 86 & 85 & 50 & 50 & 50 & 50 & 51 & 41 & 40 & 40 & 64 \\
\hline Neuseeland & 98 & 83 & 65 & 60 & 54 & 59 & 55 & 49 & 49 & 49 & 70 \\
\hline Norwegen ${ }^{2}$ & $\mathrm{~m}$ & 75 & 75 & $x(6)$ & $x(6)$ & 51 & $x(6)$ & $x(10)$ & $x(10)$ & 44 & 63 \\
\hline Polen & 98 & 85 & 74 & 71 & 62 & 66 & 65 & 69 & 43 & 44 & 74 \\
\hline Portugal & 99 & 80 & 71 & $x(6)$ & $x(6)$ & 68 & $x(6,10)$ & $x(10)$ & $x(10)$ & 44 & 70 \\
\hline Slowakei & 100 & 89 & 78 & 74 & 71 & 72 & 55 & 62 & 44 & 44 & 76 \\
\hline Slowenien & 98 & 97 & 79 & 71 & 64 & 67 & $x(4,5)$ & $x(10)$ & 39 & 39 & 75 \\
\hline Spanien & 95 & 76 & 58 & $x(6)$ & $x(6)$ & 50 & a & 45 & 39 & 40 & 65 \\
\hline Schweden & 96 & 82 & 66 & 50 & 54 & 52 & 51 & $\mathrm{n}$ & 43 & 43 & 74 \\
\hline Schweiz & 98 & 82 & 53 & 45 & 42 & 43 & $\mathrm{~m}$ & 33 & 37 & 37 & 58 \\
\hline Türkei & 95 & 55 & 52 & 44 & 42 & 43 & a & 33 & 42 & 41 & 52 \\
\hline Ver. Königreich & 95 & 87 & 60 & 60 & 60 & 60 & a & $x(10)$ & $x(10)$ & 44 & 68 \\
\hline Vereinigte Staaten & 94 & 87 & 67 & $x(6)$ & $x(6)$ & 57 & 63 & $x(10)$ & $x(10)$ & 48 & 70 \\
\hline OECD-Durchschnitt & 97 & 82 & 67 & 59 & 53 & 57 & 55 & 47 & 40 & 42 & 68 \\
\hline EU21-Durchschnitt & 96 & 86 & 69 & 64 & 56 & 60 & 54 & 50 & 40 & 42 & 71 \\
\hline \multicolumn{12}{|l|}{ Partnerländer } \\
\hline Argentinien & $\mathrm{m}$ & $\mathrm{m}$ & $\mathrm{m}$ & $\mathrm{m}$ & $\mathrm{m}$ & $\mathrm{m}$ & $\mathrm{m}$ & $\mathrm{m}$ & $\mathrm{m}$ & $\mathrm{m}$ & $\mathrm{m}$ \\
\hline Brasilien & 97 & 90 & 70 & 62 & 52 & 60 & a & $x(10)$ & $x(10)$ & 45 & 74 \\
\hline China & 97 & 59 & 50 & 48 & 49 & 49 & $\mathrm{~m}$ & 49 & 28 & 47 & 57 \\
\hline Kolumbien & 93 & 77 & 54 & $x(6)$ & $x(6)$ & 46 & a & $\mathrm{m}$ & $\mathrm{m}$ & $\mathrm{m}$ & 68 \\
\hline Indien & $m$ & $\mathrm{~m}$ & $\mathrm{~m}$ & $m$ & $\mathrm{~m}$ & $\mathrm{~m}$ & $\mathrm{~m}$ & $\mathrm{~m}$ & $\mathrm{~m}$ & $\mathrm{~m}$ & $\mathrm{~m}$ \\
\hline Indonesien & 95 & 64 & 55 & 53 & 49 & 52 & $\mathrm{~m}$ & 39 & $x(10)$ & 39 & 61 \\
\hline Lettland & $\mathrm{m}$ & $\mathrm{m}$ & $\mathrm{m}$ & $\mathrm{m}$ & $\mathrm{m}$ & $\mathrm{m}$ & $\mathrm{m}$ & $\mathrm{m}$ & $\mathrm{m}$ & $\mathrm{m}$ & $\mathrm{m}$ \\
\hline Russische Föd. & 100 & 99 & 84 & $x(6)$ & 68 & 68 & $x(8)$ & 75 & 53 & 57 & 83 \\
\hline Saudi-Arabien & $\mathrm{m}$ & 51 & 52 & $x(6)$ & $x(6)$ & 56 & a & $x(10)$ & $x(10)$ & 37 & 51 \\
\hline Südafrika & $\mathrm{m}$ & $\mathrm{m}$ & $\mathrm{m}$ & $\mathrm{m}$ & $\mathrm{m}$ & $\mathrm{m}$ & $\mathrm{m}$ & $\mathrm{m}$ & $\mathrm{m}$ & $\mathrm{m}$ & $\mathrm{m}$ \\
\hline G20-Durchschnitt & $\mathbf{m}$ & $\mathbf{m}$ & $\mathbf{m}$ & m & m & m & $\mathbf{m}$ & $\mathbf{m}$ & $\mathbf{m}$ & $\mathbf{m}$ & $\mathbf{m}$ \\
\hline
\end{tabular}

1. Referenzjahr 2011. 2. Nur öffentliche Bildungseinrichtungen (Italien: Elementar- bis Sekundarbereich). 3. Bildungseinrichtungen des Sekundarbereichs II umfassen auch private Bildungseinrichtungen des Sekundarbereichs I.

Quelle: OECD. Argentinien, China, Indien, Indonesien, Kolumbien, Saudi-Arabien und Südafrika: Statistikinstitut der UNESCO. Lettland: Eurostat.

Hinweise s. Anhang 3 unter www.oecd.org/edu/eag.htm. StatLink: http://dx.doi.org/10.1787/888933120195

Erläuterung der Kennzeichnung fehlender Daten s. Hinweise für den Leser. 



\section{Welche Anforderungen und Ausbildungs- voraussetzungen gelten für den Lehrerberuf?}

Nur in 4 der 34 OECD-Länder mit verfügbaren Daten ist für Lehrkräfte im Elementarbereich ein Masterabschluss erforderlich, im Sekundarbereich II (allgemeinbildend) dagegen verlangen 22 der 36 Länder mit verfügbaren Daten diesen Abschluss.

In 27 der 36 OECD- und Partnerländer gelten mindestens für einen Bildungsbereich Auswahlkriterien für die Aufnahme und/oder Fortsetzung der Lehrererstausbildung, und in 20 Ländern sind zusätzlich zur Lehrererstausbildung weitere Anforderungen zu erfüllen, bevor man unterrichten darf und/oder vollständig für den Lehrerberuf qualifiziert ist.

\section{Abbildung D6.1}

Auswahl der Lehrkräfte (2013)

Für Lehrkräfte allgemeinbildender Fächer an öffentlichen Bildungseinrichtungen

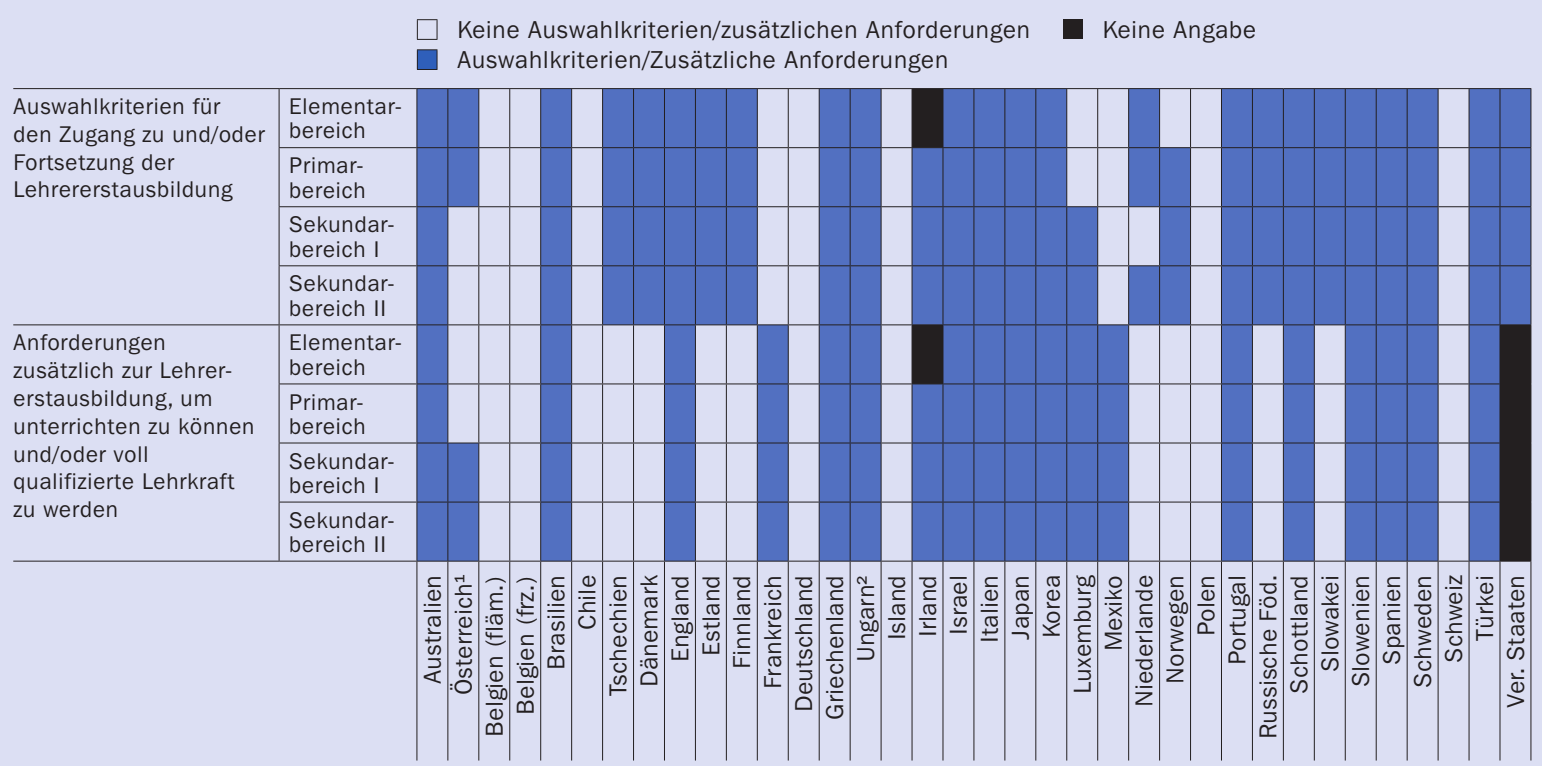

1. Bezieht sich nur auf Lehrkräfte in Allgemein bildenden höheren Schulen, Unterstufe, im Sekundarbereich I. 2. Referenzjahr 2014.

\section{Kontext}

Angesicht der weitreichenden wirtschaftlichen und sozialen Veränderungen der letzten Jahre ist eine hochwertige Schulausbildung wichtiger denn je. Die Länder sind inzwischen nicht nur daran interessiert, eine ausreichende Zahl von Lehrkräften zur Verfügung zu haben, sondern auch daran, die Qualität der Lernangebote für alle zu steigern. Letzteres lässt sich nur erreichen, wenn alle Schüler einen qualitativ hochwertigen Unterricht erhalten. Bei den Bemühungen, die Schulen zu verbessern, spielen die Lehrkräfte eine zentrale Rolle: Eine Steigerung der Effektivität der Schulen 
hängt in starkem Maße davon ab sicherzustellen, dass kompetente und motivierte Personen als Lehrkraft arbeiten möchten und dass sie effektiv in ihrer Arbeit sind (OECD, 2006).

Um die besten Kandidaten für den Lehrerberuf zu gewinnen, müssen die Länder nicht nur eine angemessene Bezahlung bieten, was wiederum Ausdruck der Tatsache ist, dass Lehrkräfte in der Gesellschaft wertgeschätzt werden, sondern auch ein Umfeld garantieren, das Lehrkräften die Autonomie gibt, professionell zu arbeiten und unmittelbar an der Verbesserung der Schulen mitzuwirken.

Des Weiteren sollten angehende Lehrkräfte eine qualitativ hochwertige Erstausbildung erhalten. Die Art der Qualifikationen sowie Dauer und Inhalt der Ausbildung entscheiden, inwieweit die Erstausbildung der Lehrkräfte diese tatsächlich auf ihre zukünftige Rolle vorbereitet. Ganz gleichgültig wie qualitativ hochwertig die Lehrerausbildung ist, kann die Erstausbildung die Lehrkräfte niemals auf alle Anforderungen vorbereiten, die während ihrer Berufslaufbahn auf sie zukommen werden. Angesichts der Veränderungen der demografischen Zusammensetzung der Schülerschaft, der Anzahl der Berufsjahre, die viele Lehrkräfte unterrichten, und der Notwendigkeit, Wissen und Können auf dem neuesten Stand zu halten, kann die Lehrererstausbildung nur als Ausgangspunkt für die kontinuierliche Weiterentwicklung der Lehrkräfte betrachtet werden. Viele Fähigkeiten und Fertigkeiten sowie pädagogisches Geschick lassen sich am besten im Berufsalltag entwickeln, daher sollten Lehrkräfte am Anfang ihrer Berufslaufbahn durch Einführungs- und Mentorenprogramme unterstützt und später durch Anreizprogramme und entsprechende Angebote zur beruflichen Fortbildung angeregt werden (s. Indikator D7).

\section{Weitere wichtige Ergebnisse}

In nahezu der Hälfte der Länder mit verfügbaren Daten ist der Zugang zur Lehrerausbildung, unabhängig vom Bildungsbereich, durch einen Numerus clausus beschränkt.

Die Dauer der Ausbildung von Lehrkräften für den Elementarbereich variiert stärker als die für irgendeinen anderen Bildungsbereich: von 2 Jahren für eine grundlegende Qualifikation in Japan bis zu 5 Jahren in Chile, Frankreich, Island, Italien und Österreich.

Die Ausbildung für Lehrkräfte des Elementar- und Primarbereichs erfolgt normalerweise nach dem einphasigen Modell, bei dem die pädagogische und praktische Ausbildung gleichzeitig mit der fachbezogenen Ausbildung erfolgt, während das zweiphasige Modell, bei dem die pädagogische und praktische Ausbildung nach dem Fachstudium erfolgt, bei der Ausbildung von Lehrkräften für den Sekundarbereich I und II weiter verbreitet ist.

Angehende Lehrkräfte für allgemeinbildende Fächer des Sekundarbereichs müssen in etwa 8 o Prozent der Länder mit verfügbaren Daten ein Unterrichtspraktikum absolvieren und Kurse in Pädagogik/Didaktik, verschiedenen Studienfächern und Erziehungswissenschaft belegen. In etwa zwei Drittel der Länder sind auch Kurse zur Entwicklungspsychologie obligatorisch, und in der Hälfte der Länder wird wissenschaftliches Arbeiten verlangt. 
Absolventen einer Lehrererstausbildung können in etwa 70 Prozent der Länder in allen Bildungsbereichen unmittelbar mit dem Unterrichten beginnen. In 20 Ländern sind die Lehrkräfte für alle Bildungsbereiche ohne weitere Anforderungen voll für den Lehrerberuf qualifiziert.

Formale Einführungsprogramme sind in etwa der Hälfte der Länder mit verfügbaren Daten Pflicht; in den meisten Ländern sind Lehrkräfte aus dem jeweiligen Schulkollegium dafür verantwortlich, Berufsanfänger zu unterstützen.

Alternative Einstiegsmöglichkeiten in den Lehrerberuf gibt es in etwa der Hälfte der Länder mit verfügbaren Daten. Diese werden überwiegend als spezielle Ausbildungsgänge an traditionellen Lehrerausbildungseinrichtungen angeboten.

\section{Analyse und Interpretationen}

\section{Erstausbildung von Lehrkräften}

Die Lehrererstausbildung, zusammen mit anderen Faktoren wie der gesellschaftlichen Anerkennung und dem Status des Lehrerberufs, den Arbeitsbedingungen in der Schule und den Zulassungsbedingungen zur Erstausbildung, wirkt sich in qualitativer wie quantitativer Hinsicht auf das Angebot an angehenden Lehrkräften aus. Darüber hinaus beeinflussen Zulassungsbedingungen grundsätzlich, ob der Lehrerberuf offen für qualifizierte Kandidaten mit unterschiedlichem Hintergrund ist.

\section{Auswahlkriterien für die Aufnahme und Fortsetzung der Lehrererstausbildung}

Die für die Aufnahme einer Lehrererstausbildung erforderlichen Abschlüsse sind in den OECD- und Partnerländern sehr ähnlich. Die Mindestanforderung ist in der Regel der erfolgreiche Abschluss des Sekundarbereichs II. Lediglich in Österreich und der Slowakei können Absolventen des Sekundarbereichs I eine Lehrerausbildung beginnen, jedoch nur für eine Lehrtätigkeit im Elementarbereich (Tab. D6.2c und Tab. D6.2a, D6.2b und D6.2d im Internet).

Dagegen unterscheiden sich die Länder sehr bei den zusätzlich geltenden Zulassungskriterien für die Lehrererstausbildung. In etwa der Hälfte der Länder mit verfügbaren Daten ist der Zugang zu Lehrerausbildungseinrichtungen durch einen Numerus clausus beschränkt. In den meisten Ländern gelten diese Regelungen für die Ausbildung der Lehrkräfte für alle Bildungsbereiche (entweder für den Erstzugang oder zu einem späteren Zeitpunkt der Lehrererstausbildung). In einigen Ländern gelten sie jedoch nur für die Lehrtätigkeit in einem oder mehreren Bildungsbereichen: in Österreich nur für den Elementarbereich, in Dänemark für alle Bildungsbereiche außer dem Sekundarbereich II, in Deutschland und Irland für den Primar- und Sekundarbereich, in Luxemburg für den Zugang zu einem späteren Zeitpunkt der Lehrererstausbildung im Sekundarbereich II und in Spanien für den Elementar- und Primarbereich.

In etwa zwei Drittel der Länder mit verfügbaren Daten gelten zusätzlich zu den erforderlichen Abschlüssen weitere Auswahlkriterien für den Zugang zur Lehrererstausbildung für alle Bildungsbereiche. Am häufigsten ist das Auswahlkriterium der Noten- 
durchschnitt der Kandidaten beim Abschluss des Sekundarbereichs II. Dies gilt in I9 der 32 Länder mit verfügbaren Daten für angehende Lehrkräfte des Sekundarbereichs I. In 9 Ländern basiert die Auswahl für diesen Bildungsbereich auf einem Interview, während 8 Länder eine selektive Zulassungsprüfung haben. In 5 Ländern müssen die Kandidaten einen Standardtest bestehen, um sicherzustellen, dass sie bestimmte Mindestanforderungen erfüllen. In der überwiegenden Zahl der Länder, die Auswahlkriterien einsetzen, werden die Kandidaten anhand einer Kombination verschiedener Kriterien ausgewählt. I8 der 23 Länder, die angaben, für angehende Lehrkräfte des Sekundarbereichs I Auswahlkriterien anzuwenden, nutzen mehr als ein Auswahlkriterium.

Die Auswahlkriterien für die Lehrererstausbildung sind für alle angehenden Lehrkräfte ähnlich, unabhängig vom Bildungsbereich, in dem sie unterrichten werden. Auswahlkriterien für die Fortsetzung der Lehrererstausbildung werden jedoch etwas häufiger bei den angehenden Lehrkräften des Sekundarbereichs II eingesetzt: Für angehende Lehrkräfte im Elementarbereich gelten in 9 der 35 Länder mit verfügbaren Daten derartige Kriterien, für Lehrkräfte an allgemeinbildenden Schulen des Sekundarbereichs II in 12 von 36 Ländern.

\section{Dauer der Lehrererstausbildung}

Die Dauer der Erstausbildung von Lehrkräften für den Elementarbereich variiert stark in den 35 Ländern, für die entsprechende Daten vorliegen: von 2 Jahren für eine grundlegende Qualifikation in Japan bis zu 5 Jahren in Chile, Frankreich, Island, Italien und Österreich. In Ländern mit Daten zur Erstausbildung von Lehrkräften für den Elementar- und Primarbereich ist die Dauer der entsprechenden Ausbildungsgänge in 22 Ländern zwar vergleichbar, in 5 Ländern jedoch verlängert sich die Ausbildungsdauer im Vergleich zum Elementarbereich um ein halbes oder ganzes Jahr und in weiteren 4 Ländern um zwei Jahre. In Deutschland verlängert sich die Ausbildung zwischen beiden Bildungsbereichen um 3,5 Jahre, und nur in Österreich ist die Erstausbildung für Lehrkräfte des Primarbereichs mit 3 Jahren kürzer als für angehende Lehrkräfte des Elementarbereichs mit 5 Jahren (Tab. D6.Ia, D6.Ib, D6.Ic und D6.Id).

Für die Lehrtätigkeit im Sekundarbereich I (allgemeinbildend) variiert die Dauer der Erstausbildung zwischen 3 Jahren in Österreich (für Lehrkräfte der Neuen Mittelschule und der Hauptschule) und Belgien und 6 bis 6,5 Jahren in Deutschland, Italien und Luxemburg. Von den 36 Ländern mit verfügbaren Daten für die Erstausbildung von Lehrkräften sowohl für den Sekundarbereich I als auch den Sekundarbereich II ist die Dauer dieser Bildungsgänge in 25 Ländern vergleichbar, in den übrigen Ländern gibt es jedoch einige Unterschiede. In Chile, Schweden, der Schweiz, der Türkei und Ungarn dauert die Erstausbildung für Lehrkräfte des Sekundarbereichs II ein halbes oder ein ganzes Jahr länger als für diejenigen des Sekundarbereichs I, in Belgien, Dänemark und den Niederlanden I, 5 bis 2 Jahre. Die Dauer der Erstausbildung von Lehrkräften für den Sekundarbereich II (allgemeinbildend) reicht von 4 Jahren in ro der Länder bis zu 6,5 Jahren in Deutschland und Luxemburg (Abb. D6.2).

\section{Struktur der Lehrererstausbildung}

Vereinfacht gesagt gibt es zwei Modelle der Lehrerausbildung: das einphasige und das zweiphasige Modell. Die Ausbildung für angehende Lehrkräfte des Elementarund Primarbereichs erfolgt in den OECD- und Partnerländern normalerweise nach 
dem einphasigen Modell, bei dem die pädagogische und schulpraktische Ausbildung gleichzeitig mit der fachbezogenen Ausbildung erfolgt. Dies gilt in 23 der 35 Länder mit verfügbaren Daten für angehende Lehrkräfte des Elementarbereichs und in 22 der 36 Länder für angehende Lehrkräfte des Primarbereichs. Nur in Brasilien, England und Frankreich folgt die Lehrererstausbildung für den Elementar- und Primarbereich hauptsächlich dem zweiphasigen Modell, d. h., die pädagogische und schulpraktische Ausbildung folgt nach dem Fachstudium. Die Ausbildung von Lehrkräften für den Sekundarbereich I und II ist anders strukturiert. In I3 der 36 Länder mit verfügbaren Daten erfolgt die Ausbildung der Lehrkräfte für den Sekundarbereich I (allgemeinbildend) nach dem zweiphasigen Modell, aber weitere I3 Länder bieten sowohl einphasige als auch zweiphasige Bildungsgänge. Bei der Ausbildung der Lehrkräfte für den Sekundarbereich II (allgemeinbildend) bieten nur Finnland, Griechenland, Japan, Polen, die Russische Föderation und die Slowakei überwiegend einphasige Bildungsgänge. In I6 der 36 Länder mit verfügbaren Daten sind sowohl einphasige als auch zweiphasige Bildungsgänge verfügbar, dagegen erwerben in I3 Ländern die angehenden Lehrkräfte zunächst in einem oder mehreren Fächern einen Abschluss im Tertiärbereich, bevor sie dann Pädagogik in Theorie und Praxis studieren (zweiphasiges Modell) (Tab. D6.ra, D6.rb, D6.Ic und D6.Id).

Von den 12 Ländern mit verfügbaren Daten mit speziellen Anforderungen für Lehrkräfte in berufsbildenden Schulen des Sekundarbereichs II organisiert die Hälfte deren Erstausbildung anders als die der Lehrkräfte für allgemeinbildende Schulen. In Belgien (frz.), den Niederlanden und Österreich erfolgt die pädagogische und schulpraktische Ausbildung der Lehrkräfte für berufsbildende Schulen zeitgleich mit der fachbezogenen Ausbildung (d. h. einphasiges Modell), während die Ausbildung angehender Lehrkräfte allgemeinbildendender Schulen sowohl nach dem einphasigen als auch dem zweiphasigen Modell erfolgt (Tab. D6.Id).

\section{Festlegung des Inhalts der Lehrererstausbildung}

Nahezu überall sind Hochschuleinrichtungen für die Konzeption des Lehrplans der Lehrererstausbildung verantwortlich. In Australien, Chile, Griechenland, Island, Mexiko, Schottland, Tschechien und der Türkei spielen sie auch eine Rolle bei der Festlegung des inhaltlichen Rahmens. In etwa zwei Drittel der Länder mit verfügbaren Daten legen zentrale oder bundesstaatliche Bildungsbehörden den inhaltlichen Rahmen für die Lehrererstausbildung fest, in etwa einem Drittel der Länder sind diese Behörden auch für die Akkreditierung von Bildungsprogrammen zur Lehrererstausbildung zuständig. Im Allgemeinen ist an der Entscheidung über den inhaltlichen Rahmen der Lehrererstausbildung auch ein unabhängiges, von den Bildungsbehörden beauftragtes Institut beteiligt, und zwar überwiegend für die Evaluierung und/oder Akkreditierung von Bildungsprogrammen zur Lehrererstausbildung (in etwa der Hälfte der Länder). In etwa der Hälfte der Länder bieten Lehrerverbände oder -gewerkschaften Rat und Empfehlungen zum Inhalt der Lehrererstausbildung. In weniger als einem Drittel der Länder spielen die Schulen oder Schulaufsichtsbehörden eine Rolle bei der Festlegung des Inhalts der Lehrererstausbildung. Nur in Brasilien, Dänemark, Finnland (für die Organisation des Unterrichtspraktikums), Korea, Norwegen und der Russischen Föderation sind lokale, kommunale, subregionale und/oder regionale Bildungsbehörden an der Entscheidung über die Inhalte der Lehrererstausbildung beteiligt (Tab. D6.4a, D6.4b, D6.4c, D6.4d im Internet). 


\section{Inhalte der Lehrererstausbildung}

In der überwiegenden Mehrzahl der OECD- und Partnerländer müssen angehende Lehrkräfte des Sekundarbereichs I (allgemeinbildend) Kurse in Pädagogik/Didaktik, verschiedenen Studienfächern und Erziehungswissenschaft belegen und ein Unterrichtspraktikum absolvieren. In etwa 80 Prozent der Länder mit verfügbaren Daten sind diese Elemente obligatorisch. In etwa zwei Drittel der Länder mit verfügbaren Daten sind auch Kurse zur Entwicklungspsychologie Pflicht, und in der Hälfte der Länder ist die Fähigkeit zu wissenschaftlichem Arbeiten zu erwerben. In I4 von 32 Ländern entscheiden die Lehrerausbildungseinrichtungen, ob wissenschaftliches Arbeiten Teil der Lehrerausbildung ist oder nicht (Abb. D6.3 und Tab. D6.3c). Bei den angehenden Lehrkräften des Sekundarbereichs II (allgemeinbildend) ist das Bild ähnlich (Tab. D6.3d im Internet).

Die Inhalte der Lehrererstausbildung unterscheiden sich zwischen den Lehrkräften für allgemein- und berufsbildende Schulen und zwischen den verschiedenen Bildungsbereichen mit Ausnahme der fachbezogenen Ausbildungsteile nur in geringem Maße. Für Lehrkräfte für den Elementarbereich ist in 20 der 33 Länder mit verfügbaren Daten eine fachbezogene Ausbildung Pflicht, aber, wie zu erwarten, ist ein Fachstudium für angehende Lehrkräfte des Sekundarbereichs II (allgemeinbildend) weit häufiger Pflicht (in 28 der 34 Länder). Außerdem besuchen in etwa zwei Drittel der Länder angehende Lehrkräfte des Elementarbereichs und in drei Viertel der Länder angehende Lehrkräfte des Primarbereichs separate fachwissenschaftliche Kurse, dies ist jedoch für den Sekundarbereich II nur in einem Drittel der Länder der Fall. In etwa zwei von drei Ländern gibt es gemeinsame fachwissenschaftliche Kurse für alle angehenden Lehrkräfte, unabhängig davon, in welchem Bildungsbereich sie unterrichten werden. Das könnte den Lehrkräften den Wechsel zwischen verschiedenen Bildungsbereichen erleichtern (Tab. D6.3c und Tab. D6.3a, D6.3b und D6.3d im Internet).

Abbildung D6.2

Dauer der Lehrererstausbildung (2013)

Für Lehrkräfte allgemeinbildender Fächer an öffentlichen Bildungseinrichtungen

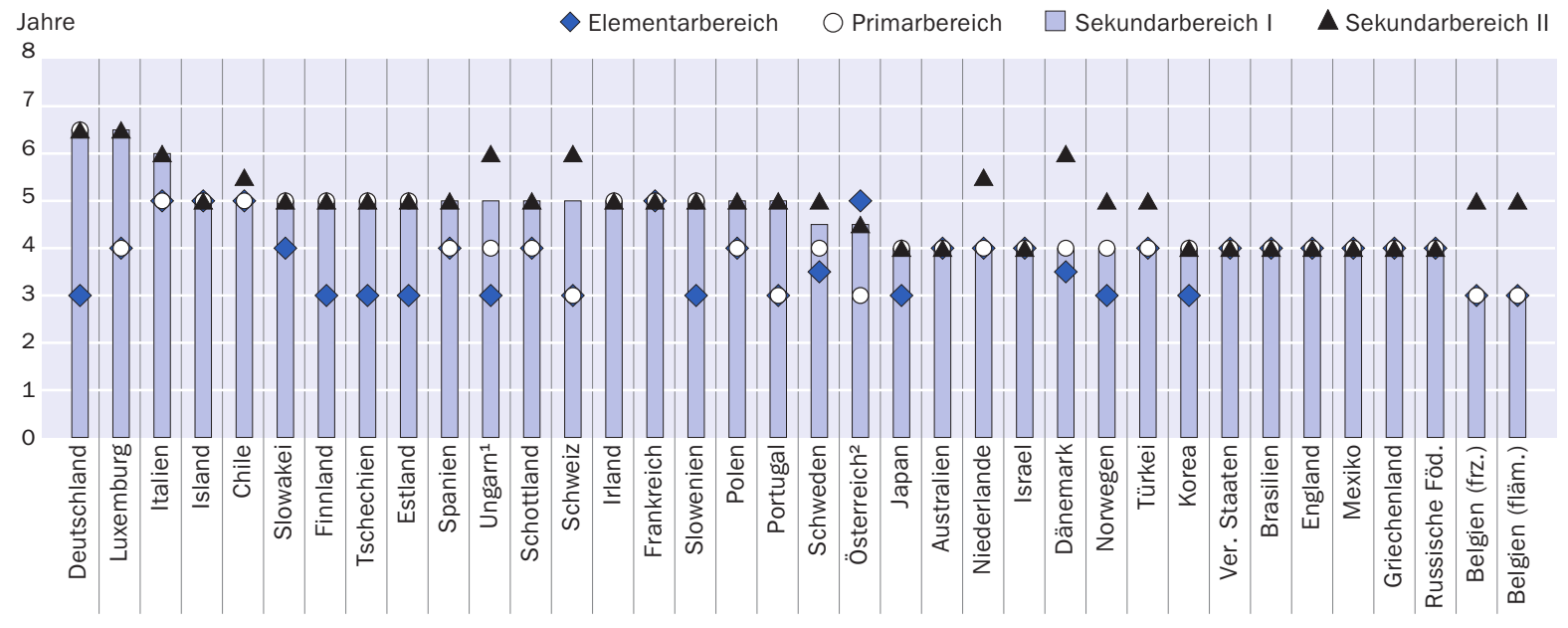

1. Referenzjahr 2014. 2. Bezieht sich nur auf Lehrkräfte in Allgemein bildenden höheren Schulen, Unterstufe. 


\section{Enthält die Lehrerausbildung formale fachliche und pädagogische sowie schulpraktische Ausbildungsteile für einige oder alle zu unterrichtenden Fächer? Fühlen sich die Lehrkräfte gut auf ihre Arbeit vorbereitet?}

Struktur, Inhalt und Schwerpunkte der Lehrererstausbildung variieren zwischen den Ländern erheblich. Dennoch bietet die Lehrerausbildung üblicherweise die Möglichkeit, zusätzlich zur fachlichen und pädagogischen/fachdidaktischen Ausbildung auch schulpraktische Erfahrung zu erwerben. Laut der internationale Erhebung der OECD zu Lehren und Lernen (Teaching and Learning International Survey - TALIS)

Abbildung D6.a

Wie gut sich Lehrkräfte auf das Lehren vorbereitet fühlen (2013)

Anteil der Lehrkräfte des Sekundarbereichs I (in \%), die sich fachlich und fachdidaktisch "sehr gut vorbereitet", "gut vorbereitet“, „begrenzt vorbereitet“ oder und „überhaupt nicht vorbereitet“ für ihre Unterrichtsfächer fühlen und ob dies Teil ihrer formalen Aus- und Fortbildung war

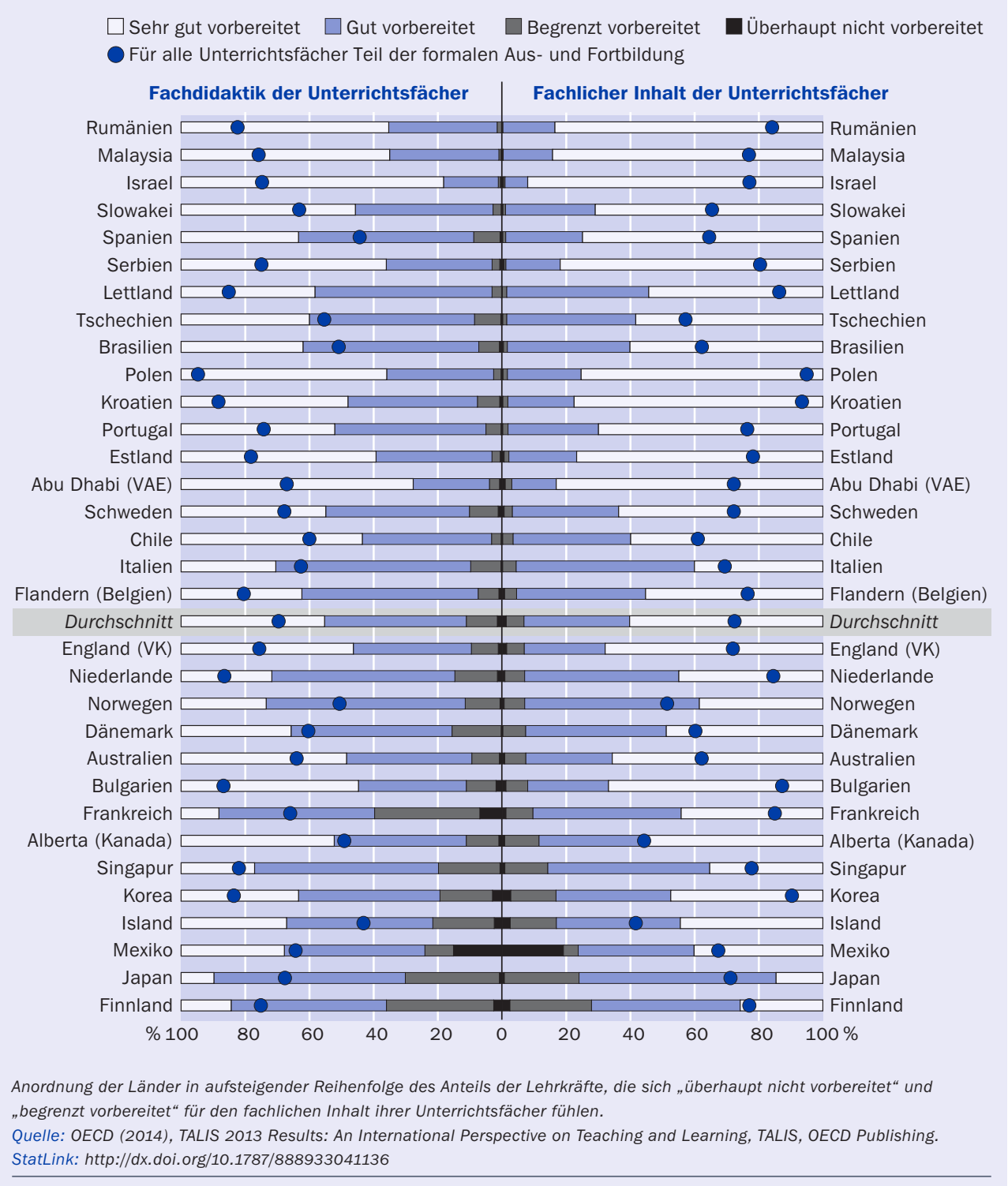


aus dem Jahr 20I3 haben die meisten Lehrkräfte des Sekundarbereichs I für einige oder alle Fächer, die sie unterrichten, eine formale fachliche und pädagogische/ fachdidaktische sowie schulpraktische Ausbildung erhalten. Im Durchschnitt geben 72 Prozent der Lehrkräfte an, für alle Fächer, die sie unterrichten, eine formale Ausbildung, einschließlich fachspezifischer Inhalte, erhalten zu haben. Weitere 23 Prozent der Lehrkräfte gaben an, zumindest für einige der Fächer, die sie unterrichten, vorab fachlich ausgebildet worden zu sein. In Island und Alberta (Kanada) gaben weniger als die Hälfte der Lehrkräfte ( 42 bzw. 44 Prozent) an, ihre formale Ausbildung habe alle Fächer umfasst, die sie unterrichten, was darauf schließen lässt, dass ein Großteil der Lehrkräfte Fächer unterrichtet, für die sie als Teil ihrer formalen Ausbildung möglicherweise nicht speziell vorbereitet wurden. Etwa 70 Prozent der Lehrkräfte des Sekundarbereichs I gaben an, ihre formale Ausbildung habe für alle Fächer, die sie unterrichten, Fachdidaktik umfasst, und 23 Prozent gaben an, dies treffe auf einige der Fächer, die sie unterrichten, zu. Bei den schulpraktischen Bestandteilen ergibt sich ein ähnliches Bild: Im Durchschnitt gaben 67 Prozent der Lehrkräfte an, ihre formale Ausbildung habe für alle Fächer, die sie unterrichten, Unterrichtspraktika enthalten, während 22 Prozent angaben, dies gelte für einige der Fächer, die sie unterrichten.

Im Allgemeinen fühlen sich die Lehrkräfte durch die formale Ausbildung gut auf ihre Arbeit als Lehrkräfte vorbereitet. Im Durchschnitt gaben 93 Prozent der Lehrkräfte an, fachlich gut oder sehr gut auf ihre Unterrichtsfächer vorbereitet zu sein, und 89 Prozent gaben an, fachdidaktisch und praktisch gut oder sehr gut auf ihre Unterrichtsfächer vorbereitet zu sein. Dennoch fällt auf, dass sich etwa jede vierte Lehrkraft in Finnland, Japan und Mexiko nicht oder nur begrenzt fachlich, fachdidaktisch und praktisch auf ihre Unterrichtsfächer vorbereitet fühlt.

In Chile, Frankreich und den Vereinigten Staaten entscheiden allein die Lehrerausbildungseinrichtungen über den Lehrplan an diesen Einrichtungen. Ab dem Studienjahr 2013/20I4 greift jedoch in Frankreich eine Reform, die Pflichtelemente der Lehrererstausbildung festlegt.

In der großen Mehrzahl der OECD- und Partnerländer mit verfügbaren Daten ist ein Unterrichtspraktikum für eine Lehrtätigkeit in allen Bildungsbereichen Pflicht. Die erforderliche Dauer und die Organisation dieses Praktikums variieren jedoch erheblich. Für angehende Lehrkräfte des Sekundarbereichs I (allgemeinbildend) ist das Unterrichtspraktikum in 32 der 36 Länder mit verfügbaren Daten Pflicht. In etwa der Hälfte der 22 Länder mit verfügbaren Daten dauert das Praktikum typischerweise zwischen 70 und 120 Tage. In Japan, Korea, der Russischen Föderation, Spanien und der Türkei dauert das Praktikum jedoch höchstens 40 Tage, in Deutschland dagegen mindestens 282 Tage. Sofern ein Unterrichtspraktikum Pflichtbestandteil der Lehrerausbildung ist, dienen Lehrkräfte aus dem jeweiligen Schulkollegium als Mentoren zur Unterstützung der Lehrkräfte in Ausbildung. In 27 der 35 Länder mit verfügbaren Daten sind auch die Lehrkräfte der Lehrerausbildungseinrichtungen mit eingebunden und in 20 Ländern die Schulleitung. Dagegen ist nur in Mexiko und in den Vereinigten Staaten die örtliche Bildungsbehörde auch für die Unterstützung der Lehrkräfte in Ausbildung zuständig, und nur in Mexiko ist auch die Schulaufsichtsbehörde daran beteiligt (Tab. D6.3c). 
Obligatorischer Inhalt der Lehrererstausbildung (2013)

Für Lehrkräfte allgemeinbildender Fächer an öffentlichen Bildungseinrichtungen des Sekundarbereichs I

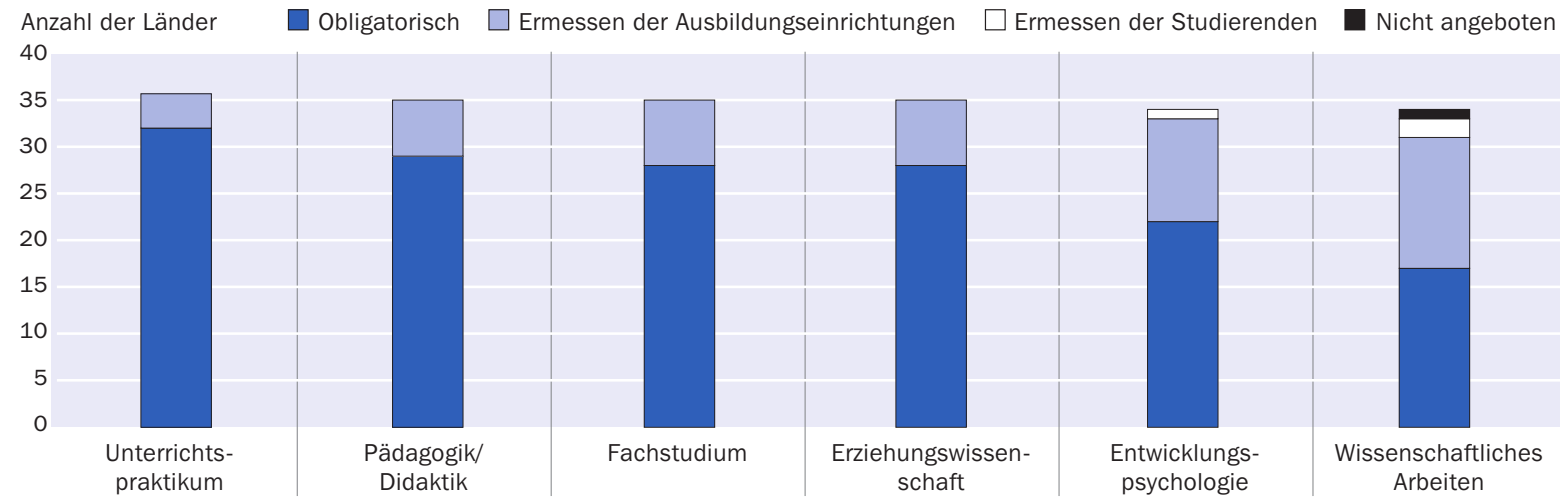

Anordnung der Inhalte in absteigender Reihenfolge der Anzahl der Länder, die diese Bereiche als obligatorisch angaben.

Quelle: OECD. Tabelle D6.3c. Hinweise s. Anhang 3 unter www.oecd.org/edu/eag.htm. StatLink: http://dx.doi.org/10.1787/888933120442

\section{Bildungsstand der Lehrkräfte}

Die Qualifikation, die nach dem erfolgreichen Abschluss der Lehrerausbildung verliehen wird, lässt nicht nur das Niveau des erworbenen Wissens und Könnens der angehenden Lehrkräfte erkennen, sondern kann auch Ausdruck des gesellschaftlichen Status der Lehrkräfte sein (OECD, 2006).

Die abschließende Qualifikation der Ausbildung von Lehrkräften ist in fast allen Ländern, die Daten gemeldet haben, eine Qualifikation im Tertiärbereich. Bei den angehenden Lehrkräften des Elementarbereichs unterscheiden sich jedoch die erworbenen Abschlüsse. In der Slowakei können Lehrkräfte des Elementarbereichs mit einem Abschluss im Sekundarbereich II zu unterrichten beginnen, in Österreich nach Abschluss eines postsekundaren, nicht tertiären Bildungsganges (ISCED-Stufe 4). In 25 der 35 Länder mit verfügbaren Daten kann man in diesem Bildungsbereich nach Erwerb eines Abschlusses im Tertiärbereich A am Ende der Lehrererstausbildung unterrichten, in 6 Ländern erhalten angehende Lehrkräfte einen berufsorientierten Abschluss des Tertiärbereichs B. Dagegen verlangen 35 der 36 Länder mit verfügbaren Daten von zukünftigen Lehrkräften des Sekundarbereichs II (allgemeinbildend) einen Abschluss im Tertiärbereich A (Tab. D6.ra, D6.rb, D6.Ic und D6.Id).

Nur in England, Frankreich, Island und Italien wird von Lehrkräften des Elementarbereichs ein Masterabschluss verlangt, in II der 35 Länder mit verfügbaren Daten ist ein Masterabschluss erforderlich, um im Primarbereich zu unterrichten, und in 17 bzw. 22 Ländern gilt dies für den Sekundarbereich I und II (allgemeinbildend).

Wenn sich die Anforderungen für die Lehrtätigkeit an berufsbildenden Schulen von denjenigen an allgemeinbildenden Schulen unterscheiden, dann meistens dahin gehend, dass die Lehrererstausbildung kürzer ist und ein niedrigerer Abschluss erworben wird. In 8 Ländern ist die Lehrererstausbildung für den Sekundarbereich II an berufsbildendenden Schulen kürzer, in 6 Ländern wird von angehenden Lehrkräften berufsbildender Schulen im Gegensatz zu den allgemeinbildenden Schulen kein Master-, sondern ein Bachelorabschluss verlangt (Tab. D6.Id). 


\section{Gibt es formale Einführungsprogramme für weniger erfahrene Lehrkräfte und nehmen diese auch daran teil?}

Um den Zusammenhang zwischen der Verfügbarkeit von und der Teilnahme an Einführungsprogrammen präzise zu untersuchen, müssen die Teilnahmequoten der Lehrkräfte betrachtet werden, die zu dem Zeitpunkt Zugang zu einem Einführungskurs haben, wenn sie zur Teilnahme berechtigt sind (d.h. zu Beginn ihrer Berufslaufbahn oder wenn sie die Schule wechseln). Leider wurden diese Angaben bei TALIS nicht erhoben. Die nachfolgende Analyse konzentriert sich daher auf Lehrkräfte, die weniger als drei Jahre Berufserfahrung als Lehrkräfte haben und weniger als drei Jahre an ihrer jetzigen Schule unterrichten. Beschränkt man die Stichprobe auf diese weniger erfahrenen Lehrkräfte, begrenzt dies die Zeit, die verstrichen ist, seit sie erstmals zur Teilnahme an einem Einführungskurs berechtigt waren, und erhöht die Chancen, dass sie noch immer an der ersten Schule arbeiten (für die wiederum die Angaben der Schulleiter über die Verfügbarkeit von Einführungsprogrammen vorliegen).

\section{Abbildung D6.b}

\section{Zugang zu und Teilnahme an formalen Einführungsprogrammen für neue Lehrkräfte}

Anteil der Lehrkräfte im Sekundarbereich I (in \%), die weniger als drei Jahre Berufserfahrung an ihrer jetzigen Schule und weniger als drei Jahre Berufserfahrung als Lehrer haben, die an einer Schule arbeiten, deren Schulleiter einen Zugang zu formalen Einführungsprogrammen angab, und Anteil der Lehrkräfte (in \%) mit diesen Merkmalen, die angaben, an einem formalen Einführungsprogramm teilgenommen zu haben ${ }^{1,2}$

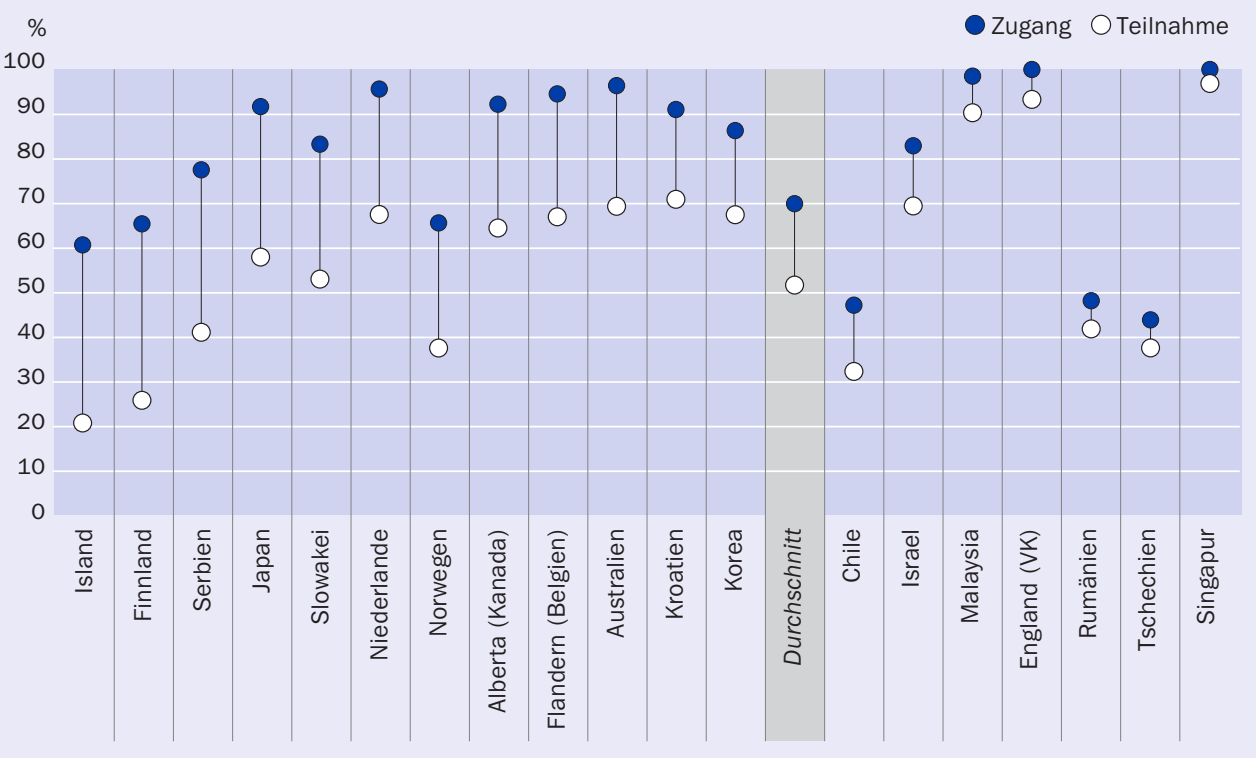

1. Daten zum Zugang zu Einführungsprogrammen stammen aus den Schulleiterfragebögen, Daten zur Teilnahme aus den Lehrerfragebögen. Lehrkräfte wurden nach ihrer Teilnahme an einem Einführungsprogramm während ihrer ersten regulären Anstellung als Lehrer befragt. 2. Die in dieser Abbildung verwendeten Daten beziehen sich ausschließlich auf formale Einführungsprogramme, d.h., die Teilnahme an oder der Zugang zu informellen Einführungsaktivitäten, die nicht Teil eines formalen Einführungsprogramms sind, oder eine allgemeine und/oder administrative Einführung in die Schule sind nicht berücksichtigt. Anordnung der Länder in absteigender Reihenfolge des Unterschieds zwischen Zugang zu und Teilnahme an Einführungsprogrammen. Länder sind in dieser nicht enthalten, wenn der Anteil der Lehrkräfte (in \%), die weniger als drei Jahre Berufserfahrung an ihrer jetzigen Schule und weniger als drei Jahre Berufserfahrung als Lehrer haben, unter 5 Prozent liegt. Quelle: OECD (2014), TALIS 2013 Results: An International Perspective on Teaching and Learning, TALIS, OECD Publishing. StatLink: http://dx.doi.org/10.1787/888933041459 
Laut der TALIS-Studie 2013 arbeiten etwa 70 Prozent der weniger erfahrenen Lehrkräfte im Sekundarbereich I an Schulen, deren Schulleiter angab, dass es Einführungsprogramme gebe, aber nur etwas mehr als die Hälfte dieser Lehrkräfte gab auch an, an einem derartigen Programm teilgenommen zu haben. Das bedeutet, dass einige Lehrkräfte, die Zugang zu Einführungsprogrammen haben, diese möglicherweise nicht nutzen. In Malaysia, Rumänien, Singapur, Tschechien und England (Vereinigtes Königreich) scheinen die Angaben der Lehrkräfte zur Teilnahme an Einführungsprogrammen den Angaben der Schulleiter zur Verfügbarkeit dieser Programme zu entsprechen, was die Vermutung nahelegt, dass die meisten Lehrkräfte die ihnen zur Verfügung stehenden Einführungsprogramme auch nutzen.

\section{Anforderungen für die Aufnahme des Lehrerberufs}

Die Anforderungen für die Aufnahme des Lehrerberufs selbst sind für alle Bildungsbereiche sowie für allgemeinbildende und berufsbildende Schulen nahezu identisch. In 25 der 35 Länder mit verfügbaren Daten können Absolventen der Lehrererstausbildung im Primar- und Sekundarbereich I und II unmittelbar mit dem Unterrichten beginnen, in 24 von 34 Ländern gilt dies für den Elementarbereich. In 20 Ländern sind neue Lehrkräfte in allen Bildungsbereichen ohne weitere Anforderungen voll für den Lehrerberuf qualifiziert (Tab. D6.5c sowie Tab. D6.5a, D6.5b und D6.5d im Internet).

Dagegen müssen Kandidaten für den Lehrerberuf in Brasilien, Frankreich, Korea, Mexiko, Spanien und der Türkei eine selektive Zulassungsprüfung bestehen, bevor sie unterrichten dürfen. In Japan müssen die Kandidaten sowohl eine selektive Zulassungsprüfung bestehen als auch eine Lizenz erwerben, was auch für Griechenland gilt, wo die Kandidaten darüber hinaus noch zusätzlich einen standardisierten Test bestehen müssen. In Luxemburg (Elementar- und Primarbereich) müssen die Kandidaten eine selektive Zulassungsprüfung bestehen und einen standardisierten Test in den drei Landessprachen ablegen. In Australien und Österreich (Allgemein bildende höhere Schule, Unterstufe [Sekundarbereich I] und Oberstufe [Sekundarbereich II]) müssen die Kandidaten eine Lizenz erwerben, damit sie unterrichten dürfen.

In I4 der 35 Länder mit verfügbaren Daten müssen die Kandidaten eine Probezeit bestehen, um voll für den Sekundarbereich I (allgemeinbildend) qualifiziert zu sein. In England, Griechenland, Israel, Schottland und Schweden müssen neue Lehrkräfte eine Lizenz erwerben und eine Probezeit bestehen, um voll qualifiziert zu sein.

\section{Formale Einführungsprogramme}

Mittlerweile wird erkannt, dass die Erfahrungen, die in den ersten Berufsjahren gemacht werden, darüber entscheiden, ob Lehrkräfte den Lehrerberuf dauerhaft ausüben. Gut konzipierte Einführungs- und Unterstützungsprogramme für Berufsanfänger können die Verbleibquote von Lehrkräften verbessern und ganz allgemein die Effektivität und Arbeitszufriedenheit neuer Lehrkräfte verbessern (OECD, 2006).

In etwa der Hälfte der Länder mit verfügbaren Daten sind formale, für alle Bildungsbereiche ähnliche Einführungsprogramme Pflicht. Beispielsweise sind für Lehrkräfte des Sekundarbereichs I in I8 der 33 Länder mit verfügbaren Daten formale Einführungsprogramme Pflicht, in weiteren 8 Ländern liegen derartige Einführungsprogram- 
me im Ermessen der Schulen. In den meisten Ländern, in denen diese Einführungsprogramme obligatorisch sind ( 13 von I8 Ländern), ist der erfolgreiche Abschluss des Einführungsprogramms erforderlich, um sich als Lehrkraft zu qualifizieren. Nur in Estland, Japan, Korea und Mexiko sind Einführungsprogramme Pflicht, ohne an die volle Qualifizierung als Lehrkraft im Sekundarbereich I geknüpft zu sein. Die Dauer der Einführungsprogramme reicht in den 20 Ländern mit verfügbaren Daten von höchstens einem Monat in Griechenland, Korea und Mexiko bis zu 24 Monaten in Ungarn (wobei der Durchschnitt bei Io,5 Monaten liegt) (Tab. D6.5c und Tab. D6.5a, D6.5 b und D6.5d im Internet).

In der Mehrzahl der Länder ( 23 der 25 Länder mit verfügbaren Daten und Einführungsprogrammen für Lehrkräfte im Sekundarbereich I) dienen andere Lehrkräfte derselben Schule als Mentoren, und in 2I der 25 Länder ist auch die Schulleitung dafür verantwortlich, die neuen Lehrkräfte zu unterstützen. Weit seltener sind Außenstehende in die Unterstützung der neuen Lehrkräfte eingebunden: So sind beispielsweise nur in etwa einem Drittel der Länder Beschäftigte der Lehrerausbildungseinrichtungen eingebunden und nur in vier Ländern die Schulaufsichtsbehörde und die örtliche Bildungsbehörde. In etwa der Hälfte der Länder mit Einführungsprogrammen und verfügbaren Daten werden jedoch die Einführungsprogramme in Zusammenarbeit zwischen der jeweiligen Schule und der Lehrerausbildungseinrichtung oder dem zuständigen Ministerium organisiert.

In zwei von drei Ländern müssen diejenigen, die neue Lehrkräfte im Sekundarbereich I unterstützen, nicht speziell dafür ausgebildet sein, in einigen Ländern erhalten sie jedoch eine Form der Aufwandsentschädigung. In 8 der 2I Länder mit Einführungsprogrammen und verfügbaren Daten erhalten sie eine Gehaltszulage, in 3 Ländern erhalten sie einen Zeitausgleich.

\section{Alternative Einstiegsmöglichkeiten in den Lehrerberuf}

Viele Länder bieten Personen mit Berufserfahrung ohne formale Lehrerqualifikation Einstiegsmöglichkeiten in den Lehrerberuf. Diese Möglichkeiten können entweder als Reaktion auf einen Lehrkräftemangel entwickelt werden oder um die Basis möglicher Bewerber zu erweitern.

In rund der Hälfte der Länder mit verfügbaren Daten existieren alternative Einstiegsmöglichkeiten. Nur wenige Länder konnten Angaben zum Anteil der neuen Lehrkräfte, die auf alternativem Weg in den Lehrerberuf eingestiegen sind, machen, aber in Israel (Elementarbereich und Sekundarbereich II) und England (Primar- und Sekundarbereich) waren mindestens Io Prozent der neuen Lehrkräfte Seiteneinsteiger. In Belgien (frz.) machten Seiteneinsteiger im Sekundarbereich I und II I2 bzw. 20 Prozent aller aktiven Lehrkräfte aus (Tab. D6.6a, D6.6b, D6.6c und D6.6d im Internet).

Die meisten Länder mit alternativen Einstiegsmöglichkeiten gaben an, dass Seiteneinsteiger eine gewisse Ausbildung an traditionellen Lehrerausbildungseinrichtungen erhalten, obwohl es unter bestimmten Bedingungen auch oft möglich ist, ohne eine spezielle Ausbildung den Lehrerberuf aufzunehmen. Andere alternative Einstiegsmöglichkeiten sind schulbasierte Kurse oder Fernlehrgänge. In den Niederlanden können 
Seiteneinsteiger unmittelbar nach Bestehen eines Eignungstests mit dem Unterrichten beginnen, innerhalb von zwei Jahren erhalten sie eine maßgeschneiderte Ausbildung und Unterstützung, um die volle Lehrerqualifikation zu erlangen.

\section{Definitionen}

Alternative Einstiegsmöglichkeiten sind Wege, die Personen mit Berufserfahrung außerhalb des Bildungssystems den Zugang zum Lehrerberuf ohne vollständige Lehrerqualifikation ermöglichen. Personen, die den Lehrerberuf über alternative Einstiegsmöglichkeiten aufnehmen, werden als Seiteneinsteiger bezeichnet.

Die selektive Zulassungsprüfung ist eine Prüfung, die von örtlichen, regionalen oder nationalen Behörden zur Auswahl der besten Bewerber für eine begrenzte und festgelegte Anzahl von Plätzen an Lehrerausbildungseinrichtungen und/oder als Lehrkräfte des öffentlichen Bildungssystems organisiert wird.

Bei dem einphasigen Modell der Lehrererstausbildung erfolgt die pädagogische und praktische Ausbildung gleichzeitig mit der fachbezogenen Ausbildung.

Bei dem zweiphasigen Modell der Lehrererstausbildung erfolgt die pädagogische und praktische Ausbildung nach der fachbezogenen Ausbildung. Bei diesem Modell erwerben die Studierenden normalerweise erst einen Abschluss im Tertiärbereich (A oder B) in einem oder mehreren Fächern und beginnen danach die theoretische und praktische pädagogische Ausbildung.

Befähigungsnachweis oder Lizenz bezieht sich auf eine Zertifizierung, Lizenz oder ein ähnliches von einer staatlichen Behörde oder Einrichtung ausgestelltes Dokument, mit dem einer Lehrkraft bescheinigt wird, dass sie qualifiziert ist und die für die Erteilung von Unterricht im öffentlichen Bildungswesen erforderlichen Standards erfüllt. Die für einen Befähigungsnachweis oder eine Lizenz bestehenden Anforderungen gehen über die für den regulären erziehungswissenschaftlichen Bildungsabschluss hinaus.

Ein Einführungsprogramm umfasst strukturierte regelmäßige Aktivitäten, um den Einstieg in den Lehrerberuf beispielsweise durch erfahrene Lehrkräfte, die als Mentor dienen, Gruppenarbeit mit anderen neuen Lehrkräften etc. zu unterstützen. Einführungsprogramme sind von Unterrichtspraktika, die Teil der Lehrererstausbildung sind, zu unterscheiden.

Lehrererstausbildung bezieht sich auf die formale theoretische und praktische Ausbildung, die man abschließen muss, um das Diplom/den Abschluss zu erwerben, das/der für Lehrkräfte an öffentlichen Bildungseinrichtungen erforderlich ist (gilt nicht für alternative Einstiegsmöglichkeiten). Die Lehrererstausbildung umfasst sowohl das Fachstudium eines oder mehrerer Fächer als auch die pädagogische und praktische Ausbildung, selbst wenn diese zweiphasig erfolgt.

Numerus clausus bezieht sich auf eine nur begrenzt verfügbare Anzahl von Studienplätzen für die Lehrererstausbildung. 
Probezeit bezieht sich auf den Beschäftigungsstatus von Lehrern beim Berufseinstieg, die eine Festanstellung unter der Bedingung erhalten, dass sie während eines bestimmten gesetzlichen oder durch Bestimmungen festgelegten Zeitraums zufriedenstellende Leistungen erbringen. Diese Berufserfahrung ist in einigen Ländern Pflicht für die Erlangung der Lizenz/Lehrerlaubnis.

Ein Unterrichtspraktikum bietet Studierenden, die die Erstausbildung als Lehrkraft absolvieren, Unterrichtspraxis unter Anleitung, bei der sie von der Unterrichtserfahrung einer erfahrenen Lehrkraft profitieren können.

\section{Angewandte Methodik}

Die Daten stammen aus der OECD/INES-Erhebung 2013 zur Entwicklung der Kenntnisse und Fähigkeiten von Lehrkräften und beziehen sich auf das Schuljahr 2012/2013.

Hinweise zu den für diesen Indikator in den einzelnen Ländern verwendeten Definitionen und der angewandten Methodik s. Anhang 3 unter www.oecd.org/edu/eag.htm.

\section{Anmerkung zu den Daten aus Israel}

Die statistischen Daten für Israel wurden von den zuständigen israelischen Stellen bereitgestellt, die für sie verantwortlich zeichnen. Die Verwendung dieser Daten durch die OECD erfolgt unbeschadet des völkerrechtlichen Status der Golanhöhen, von Ost-Jerusalem und der israelischen Siedlungen im Westjordanland.

\section{Weiterführende Informationen}

OECD (2006), Stärkere Professionalisierung des Lehrerberufs - Wie gute Lehrer gewonnen, gefördert und gehalten werden können, OECD Publishing, Paris, http:|/dx.doi.org/10.1787| 9789264018044-en.

OECD (2014), TALIS 2013 Results: An International Perspective on Teaching and Learning, OECD Publishing, Paris, http://dx.doi.org/10.1787/9789264196261-en.

\section{Tabellen Indikator D6}

StatLink: http://dx.doi.org/10.1787/888933120252

Tabelle D6.ra: Lehrererstausbildung und Berufseintritt, Elementarbereich (2013)

Tabelle D6.rb: Lehrererstausbildung und Berufseintritt, Primarbereich (2013)

Tabelle D6.Ic: Lehrererstausbildung und Berufseintritt, Sekundarbereich I (2013)

Tabelle D6.Id: Lehrererstausbildung und Berufseintritt, Sekundarbereich II (2013) 
WEB Table D6.2a: Requirements to enter and progress in initial teacher education, pre-primary education (Voraussetzungen für Zugang zu und Fortsetzung der Lehrererstausbildung, Elementarbereich) (2013)

WEB Table D6.2b: Requirements to enter and progress in initial teacher education, primary education (Voraussetzungen für Zugang zu und Fortsetzung der Lehrererstausbildung, Primarbereich) (2013)

Tabelle D6.2c: Voraussetzungen für Zugang zu und Fortsetzung der Lehrererstausbildung, Sekundarbereich I (2013)

WEB Table D6.2d: Requirements to enter and progress in initial teacher education, upper secondary education (Voraussetzungen für Zugang zu und Fortsetzung der Lehrererstausbildung, Sekundarbereich II) (2013)

WEB Table D6.3a: Content of initial teacher education, pre-primary education (Inhalt der Lehrererstausbildung, Elementarbereich) (2013)

WEB Table D6.3b: Content of initial teacher education, primary education (Inhalt der Lehrererstausbildung, Primarbereich) (2013)

Tabelle D6.3c: Inhalt der Lehrererstausbildung, Sekundarbereich I (2013)

WEB Table D6.3d: Content of initial teacher education, upper secondary education (Inhalt der Lehrererstausbildung, Sekundarbereich II) (2013)

WEB Table D6.4a: Role of entities and levels of government in deciding content of initial teacher education programmes, pre-primary education (Zuständigkeit der verschiedenen Einrichtungen und staatlichen Ebenen bei der Festlegung des Inhalts der Lehrererstausbildung, Elementarbereich) (2013)

WEB Table D6.4b: Role of entities and levels of government in deciding content of initial teacher education programmes, primary education (Zuständigkeit der verschiedenen Einrichtungen und staatlichen Ebenen bei der Festlegung des Inhalts der Lehrererstausbildung, Primarbereich) (2013)

WEB Table D6.4c: Role of entities and levels of government in deciding content of initial teacher education programmes, lower secondary education (Zuständigkeit der verschiedenen Einrichtungen und staatlichen Ebenen bei der Festlegung des Inhalts der Lehrererstausbildung, Sekundarbereich I) (2013)

WEB Table D6.4d: Role of entities and levels of government in deciding content of initial teacher education programmes, upper secondary education (Zuständigkeit der verschiedenen Einrichtungen und staatlichen Ebenen bei der Festlegung des Inhalts der Lehrererstausbildung, Sekundarbereich II) (2013)

WEB Table D6.5a: Entry into the teaching profession, pre-primary education (Einstieg in den Lehrerberuf, Elementarbereich) (2013) 
WEB Table D6.5b: Entry into the teaching profession, primary education (Einstieg in den Lehrerberuf, Primarbereich) (2013)

Tabelle D6.5c: Einstieg in den Lehrerberuf, Sekundarbereich I (2013)

WEB Table D6.5d: Entry into the teaching profession, upper secondary education (Einstieg in den Lehrerberuf, Sekundarbereich II) (2013)

WEB Table D6.6a: Alternative pathways into the teaching profession, pre-primary education (Alternative Einstiegsmöglichkeiten in den Lehrerberuf, Elementarbereich) (2013)

WEB Table D6.6b: Alternative pathways into the teaching profession, primary education (Alternative Einstiegsmöglichkeiten in den Lehrerberuf, Primarbereich) (2013)

WEB Table D6.6c: Alternative pathways into the teaching profession, lower secondary education (Alternative Einstiegsmöglichkeiten in den Lehrerberuf, Sekundarbereich I) (2013)

WEB Table D6.6d: Alternative pathways into the teaching profession, upper secondary education (Alternative Einstiegsmöglichkeiten in den Lehrerberuf, Sekundarbereich II) (2013) 
Lehrererstausbildung und Berufseintritt, Elementarbereich (2013)

Öffentliche Bildungseinrichtungen

\begin{tabular}{|c|c|c|c|c|c|c|c|c|c|c|}
\hline & 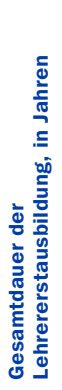 & 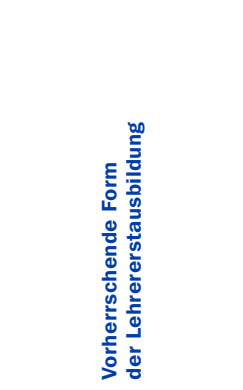 & 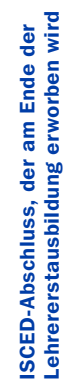 & 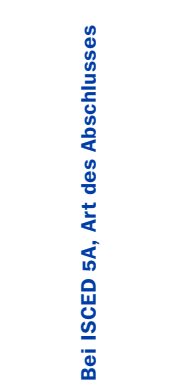 & 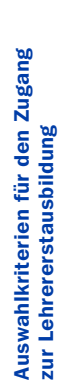 & 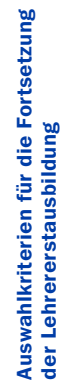 & 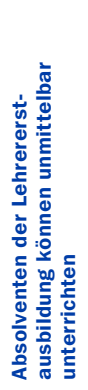 & 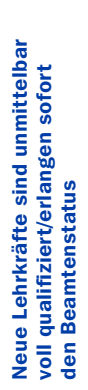 & 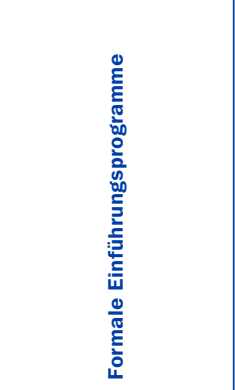 & 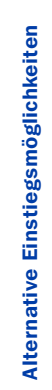 \\
\hline & (1) & (2) & (4) & (5) & (8) & (9) & (10) & (11) & (12) & (13) \\
\hline \multicolumn{11}{|l|}{ OECD-Länder } \\
\hline Australien & 4 & Einphasig & $5 \mathrm{~A}$ & Bachelor & Ja & Nein & Nein & Ja & Ermessen der Schulen & Ja \\
\hline Österreich & 5 & Einphasig & 4 & a & $\mathrm{Ja}$ & a & Ja & Ja & Nicht angeboten & Nein \\
\hline Belgien (fläm.) & 3 & Einphasig & $5 B$ & a & Nein & a & Ja & $\mathrm{Ja}$ & Ermessen der Schulen & Ja \\
\hline Belgien (frz.) & 3 & Einphasig & $5 \mathrm{~B}$ & a & Nein & a & $\mathrm{Ja}$ & Ja & Ermessen der Schulen & Ja \\
\hline Kanada & $\mathrm{m}$ & $\mathrm{m}$ & $\mathrm{m}$ & $\mathrm{m}$ & $\mathrm{m}$ & $\mathrm{m}$ & $\mathrm{m}$ & $\mathrm{m}$ & $\mathrm{m}$ & $\mathrm{m}$ \\
\hline Chile & 5 & Einphasig \& zweiphasig & $5 \mathrm{~A}$ & Bachelor & Nein & Nein & Ja & Ja & Nicht angeboten & Nein \\
\hline Tschechien & 3 & Einphasig & $5 \mathrm{~A}$ & Bachelor & $\mathrm{Ja}$ & Ja & Ja & Ja & Ermessen der Schulen & Nein \\
\hline Dänemark & 3,5 & Einphasig & $5 B$ & a & $\mathrm{Ja}$ & Nein & $\mathrm{Ja}$ & Ja & Ermessen der Schulen & Ja \\
\hline England & 4 & Zweiphasig & $5 \mathrm{~A}$ & Master & $\mathrm{Ja}$ & Nein & $\mathrm{Ja}$ & Nein & Pflicht & $\mathrm{Ja}$ \\
\hline Estland & 3 & Einphasig & $5 \mathrm{~A}$ & Bachelor & $\mathrm{Ja}$ & $\mathrm{Ja}$ & $\mathrm{Ja}$ & $\mathrm{Ja}$ & Pflicht & Nein \\
\hline Finnland & 3 & Einphasig & $5 \mathrm{~A}$ & Bachelor & $\mathrm{Ja}$ & a & $\mathrm{Ja}$ & $\mathrm{Ja}$ & Nicht angeboten & $\mathrm{Ja}$ \\
\hline Frankreich & 5 & Zweiphasig & $5 \mathrm{~A}$ & Master & Nein & Nein & Nein & Nein & Pflicht & Ja \\
\hline Deutschland & 3 & Einphasig \& zweiphasig & $5 \mathrm{~B}$ & a & $\mathrm{m}$ & a & Ja & $\mathrm{Ja}$ & a & Ja \\
\hline Griechenland & 4 & Einphasig & $5 \mathrm{~A}$ & Bachelor & Ja & a & Nein & Nein & Pflicht & Nein \\
\hline Ungarn ${ }^{1}$ & 3 & Einphasig & $5 \mathrm{~A}$ & Bachelor & $\mathrm{Ja}$ & a & $\mathrm{Ja}$ & Nein & Pflicht & $\mathrm{m}$ \\
\hline Island & 5 & Einphasig & $5 \mathrm{~A}$ & Master & Nein & Nein & Ja & Ja & Nicht angeboten & Nein \\
\hline Irland & $\mathrm{m}$ & $\mathrm{m}$ & $\mathrm{m}$ & $\mathrm{m}$ & $\mathrm{m}$ & $\mathrm{m}$ & $\mathrm{m}$ & $\mathrm{m}$ & $\mathrm{m}$ & $\mathrm{m}$ \\
\hline Israel & 4 & Einphasig \& zweiphasig & $5 \mathrm{~A}$ & Bachelor & Ja & $\mathrm{Ja}$ & Ja & Nein & Pflicht & Ja \\
\hline Italien & 5 & Einphasig & $5 \mathrm{~A}$ & Master & Ja & a & Ja & Nein & Pflicht & Nein \\
\hline Japan & 2,4 & Einphasig & $5 \mathrm{~B}, 5 \mathrm{~A}$ & a & Ja & a & Nein & Ja & Pflicht & Ja \\
\hline Korea & $2-4$ & Einphasig \& zweiphasig & $5 B, 5 A$ & a & $\mathrm{Ja}$ & a & Nein & $\mathrm{Ja}$ & Pflicht & Nein \\
\hline Luxemburg & 4 & Einphasig & $5 \mathrm{~A}$ & Bachelor & Nein & a & Nein & Nein & Nicht angeboten & Nein \\
\hline Mexiko & 4 & Einphasig & $5 \mathrm{~A}$ & Bachelor & Nein & Nein & Nein & Ja & Pflicht & Ja \\
\hline Niederlande & 4 & Einphasig & $5 \mathrm{~A}$ & Bachelor & Nein & $\mathrm{Ja}$ & Ja & $\mathrm{Ja}$ & Nicht angeboten & Ja \\
\hline Neuseeland & $\mathrm{m}$ & $\mathrm{m}$ & $\mathrm{m}$ & $\mathrm{m}$ & $\mathrm{m}$ & $\mathrm{m}$ & $\mathrm{m}$ & $\mathrm{m}$ & $\mathrm{m}$ & $\mathrm{m}$ \\
\hline Norwegen & 3 & Einphasig & $5 \mathrm{~A}$ & Bachelor & Nein & a & Ja & Ja & Ermessen der Schulen & $\mathrm{Ja}$ \\
\hline Polen & 5,3 & Einphasig & $5 \mathrm{~A}$ & Master, Bachelor & Nein & Nein & Ja & Ja & Nicht angeboten & $\mathrm{Ja}$ \\
\hline Portugal & 3 & Einphasig \& zweiphasig & $5 \mathrm{~A}$ & Bachelor & $\mathrm{Ja}$ & Nein & Ja & Nein & Nicht angeboten & Nein \\
\hline Schottland & 4 & Einphasig \& zweiphasig & $5 \mathrm{~A}$ & Bachelor & $\mathrm{Ja}$ & $\mathrm{Ja}$ & Ja & Nein & Pflicht & Nein \\
\hline Slowakei & 4 & Einphasig & 3 & a & $\mathrm{Ja}$ & Nein & Ja & Ja & Pflicht & Nein \\
\hline Slowenien & 3 & Einphasig \& zweiphasig & $5 \mathrm{~A}$ & Bachelor & $\mathrm{Ja}$ & $\mathrm{Ja}$ & Ja & Nein & Ermessen der Schulen & Ja \\
\hline Spanien & 4 & Einphasig & $5 \mathrm{~A}$ & Bachelor & $\mathrm{Ja}$ & a & Nein & Nein & Nicht angeboten & Nein \\
\hline Schweden & 3,5 & Einphasig \& zweiphasig & $5 \mathrm{~A}$ & Bachelor & Ja & a & Ja & Nein & Pflicht & Ja \\
\hline Schweiz & 3 & Einphasig & $5 \mathrm{~A}$ & Bachelor & Nein & Nein & $\mathrm{Ja}$ & $\mathrm{Ja}$ & $\mathrm{m}$ & $\mathrm{m}$ \\
\hline Türkei & 4 & Einphasig & $5 \mathrm{~A}$ & Bachelor & $\mathrm{Ja}$ & a & Nein & Nein & Pflicht & Nein \\
\hline $\begin{array}{l}\text { Vereinigte Staaten } \\
\text { Partnerländer }\end{array}$ & 4 & Einphasig \& zweiphasig & $5 \mathrm{~A}$ & Bachelor & $\mathrm{Ja}$ & $\mathrm{Ja}$ & $\mathrm{m}$ & $\mathrm{m}$ & Ermessen der Schulen & Ja \\
\hline Brasilien & 4 & Zweiphasig & $5 \mathrm{~B}$ & a & $\mathrm{Ja}$ & a & Nein & Nein & $\mathrm{m}$ & Nein \\
\hline Russische Föd. & 4 & Einphasig & $5 \mathrm{~B}$ & a & $\mathrm{Ja}$ & $\mathrm{Ja}$ & $\mathrm{Ja}$ & Ja & Nicht angeboten & Ja \\
\hline
\end{tabular}

Anmerkung: Die Spalten mit den Angaben zur Dauer der zweiphasigen Ausbildung, d.h. Spalte (3), sowie Prozentsatz der neuen und Prozentsatz aller Lehrkräfte, welche die Lehrererstausbildung mit der in Spalte (5) angegebenen Qualifikation abgeschlossen haben, d.h. die Spalten (6) und (7), sind im Internet verfügbar (s. StatLink unten). In föderalen Staaten bzw. Ländern mit stark dezentralen Schulsystemen kann es in den einzelnen Bundesstaaten, Provinzen oder Regionen unterschiedliche Vorschriften geben. Weitere Informationen s. Anhang 3.

1. Referenzjahr 2014.

Quelle: OECD. Hinweise s. Anhang 3 unter www.oecd.org/edu/eag.htm. StatLink: http://dx.doi.org/10.1787/888933120271

Erläuterung der Kennzeichnung fehlender Daten s. Hinweise für den Leser. 
Tabelle D6.1b

Lehrererstausbildung und Berufseintritt, Primarbereich (2013)

Öffentliche Bildungseinrichtungen

\begin{tabular}{|c|c|c|c|c|c|c|c|c|c|c|}
\hline & 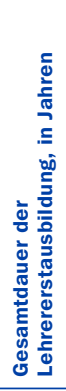 & 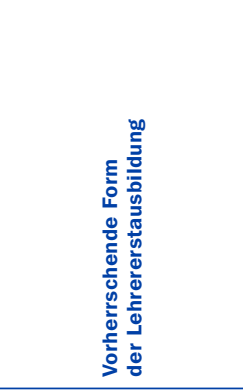 & 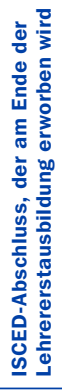 & 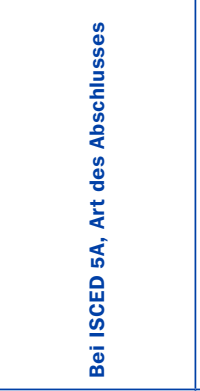 & 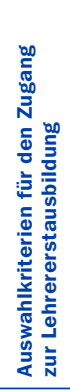 & 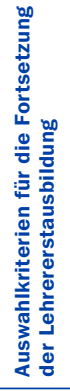 & 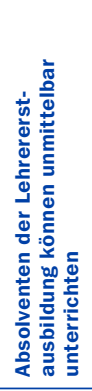 & 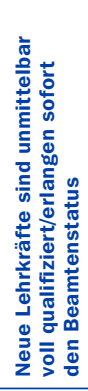 & 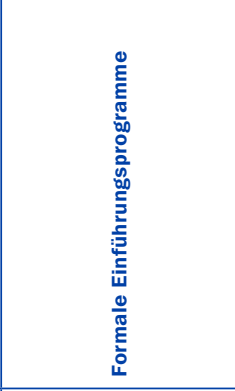 & 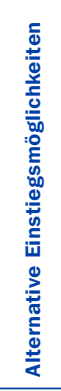 \\
\hline & (1) & (2) & (4) & (5) & (8) & (9) & (10) & (11) & (12) & (13) \\
\hline \multicolumn{11}{|l|}{ OECD-Länder } \\
\hline Australien & 4 & Einphasig \& zweiphasig & $5 \mathrm{~A}$ & Bachelor, Sonstige & Ja & Nein & Nein & Ja & Ermessen der Schulen & $\mathrm{m}$ \\
\hline Österreich & 3 & Einphasig & $5 \mathrm{~A}$ & Bachelor & $\mathrm{Ja}$ & a & Ja & $\mathrm{Ja}$ & Nicht angeboten & Nein \\
\hline Belgien (fläm.) & 3 & Einphasig & $5 B$ & a & Nein & a & Ja & Ja & Ermessen der Schulen & Ja \\
\hline Belgien (frz.) & 3 & Einphasig & $5 B$ & a & Nein & a & Ja & Ja & Ermessen der Schulen & Ja \\
\hline Kanada & $\mathrm{m}$ & $\mathrm{m}$ & $\mathrm{m}$ & $\mathrm{m}$ & $\mathrm{m}$ & $\mathrm{m}$ & $\mathrm{m}$ & $\mathrm{m}$ & $\mathrm{m}$ & $\mathrm{m}$ \\
\hline Chile & 5 & Einphasig \& zweiphasig & $5 \mathrm{~A}$ & Bachelor & Nein & Nein & Ja & $\mathrm{Ja}$ & Nicht angeboten & Nein \\
\hline Tschechien & 5 & Einphasig & $5 \mathrm{~A}$ & Master & Ja & Ja & Ja & Ja & Ermessen der Schulen & Ja \\
\hline Dänemark & 4 & Einphasig & $5 B$ & a & $\mathrm{Ja}$ & Nein & Ja & $\mathrm{Ja}$ & Ermessen der Schulen & $\mathrm{Ja}$ \\
\hline England & 4 & Zweiphasig & $5 \mathrm{~A}$ & Master & $\mathrm{Ja}$ & Nein & Ja & Nein & Pflicht & $\mathrm{Ja}$ \\
\hline Estland & 5 & Einphasig \& zweiphasig & $5 \mathrm{~A}$ & Master & Ja & Ja & Ja & Ja & Pflicht & Nein \\
\hline Finnland & 5 & Einphasig & $5 \mathrm{~A}$ & Master & Ja & a & Ja & Ja & Nicht angeboten & Ja \\
\hline Frankreich & 5 & Zweiphasig & $5 \mathrm{~A}$ & Master & Nein & Nein & Nein & Nein & Pflicht & Ja \\
\hline Deutschland & 6,5 & Zweiphasig & $5 \mathrm{~A}$ & Master & Nein & Nein & Ja & Ja & $m$ & Ja \\
\hline Griechenland & 4 & Einphasig & $5 \mathrm{~A}$ & Bachelor & Ja & a & Nein & Nein & Pflicht & Nein \\
\hline Ungarn $^{1}$ & 4 & Einphasig & $5 \mathrm{~A}$ & Bachelor & Ja & a & Ja & Nein & Pflicht & $m$ \\
\hline Island & 5 & Einphasig & $5 \mathrm{~A}$ & Master & Nein & Nein & Ja & $\mathrm{Ja}$ & Nicht angeboten & Nein \\
\hline Irland & 4,6 & Einphasig \& zweiphasig & $5 \mathrm{~A}$ & Bachelor & $\mathrm{Ja}$ & Ja & Ja & Nein & Pflicht & Nein \\
\hline Israel & 4 & Einphasig \& zweiphasig & $5 \mathrm{~A}$ & Bachelor & Ja & Ja & Ja & Nein & Pflicht & Ja \\
\hline Italien & 5 & Einphasig & $5 \mathrm{~A}$ & Master & Ja & a & Ja & Nein & Pflicht & Nein \\
\hline Japan & 4 & Einphasig & $5 \mathrm{~A}$ & Bachelor & $\mathrm{Ja}$ & a & Nein & Ja & Pflicht & $\mathrm{Ja}$ \\
\hline Korea & 4 & Einphasig & $5 \mathrm{~A}$ & Bachelor & Ja & a & Nein & Ja & Pflicht & Nein \\
\hline Luxemburg & 4 & Einphasig & $5 \mathrm{~A}$ & Bachelor & Nein & a & Nein & Nein & Nicht angeboten & Nein \\
\hline Mexiko & 4 & Einphasig & $5 \mathrm{~A}$ & Bachelor & Nein & Nein & Nein & Ja & Pflicht & $\mathrm{Ja}$ \\
\hline Niederlande & 4 & Einphasig & $5 \mathrm{~A}$ & Bachelor & Nein & Ja & Ja & Ja & Nicht angeboten & Ja \\
\hline Neuseeland & $\mathrm{m}$ & $m$ & $\mathrm{~m}$ & $m$ & $\mathrm{~m}$ & $\mathrm{~m}$ & $\mathrm{~m}$ & $m$ & $m$ & $\mathrm{~m}$ \\
\hline Norwegen & 4 & Einphasig & $5 \mathrm{~A}$ & Bachelor & $\mathrm{Ja}$ & a & Ja & Ja & Ermessen der Schulen & $\mathrm{m}$ \\
\hline Polen & 5,3 & Einphasig & $5 \mathrm{~A}$ & Master, Bachelor & Nein & Nein & $\mathrm{Ja}$ & Ja & Nicht angeboten & $\mathrm{Ja}$ \\
\hline Portugal & 3 & Einphasig \& zweiphasig & $5 \mathrm{~A}$ & Bachelor & Ja & Nein & Ja & Nein & Nicht angeboten & Nein \\
\hline Schottland & 4 & Einphasig \& zweiphasig & $5 \mathrm{~A}$ & Bachelor & $\mathrm{Ja}$ & $\mathrm{Ja}$ & Ja & Nein & Pflicht & Nein \\
\hline Slowakei & 5 & Einphasig & $5 \mathrm{~A}$ & Master & $\mathrm{Ja}$ & Nein & Ja & Ja & Pflicht & Nein \\
\hline Slowenien & 5 & Einphasig \& zweiphasig & $5 \mathrm{~A}$ & Master & $\mathrm{Ja}$ & Ja & Ja & Nein & Ermessen der Schulen & $\mathrm{Ja}$ \\
\hline Spanien & 4 & Einphasig & $5 \mathrm{~A}$ & Bachelor & $\mathrm{Ja}$ & a & Nein & Nein & Nicht angeboten & Nein \\
\hline Schweden & 4 & Einphasig \& zweiphasig & $5 \mathrm{~A}$ & Master & $\mathrm{Ja}$ & a & Ja & Nein & Pflicht & Ja \\
\hline Schweiz & 3 & Einphasig & $5 \mathrm{~A}$ & Bachelor & Nein & Nein & Ja & Ja & $m$ & $\mathrm{~m}$ \\
\hline Türkei & 4 & Einphasig & $5 \mathrm{~A}$ & Bachelor & $\mathrm{Ja}$ & a & Nein & Nein & Pflicht & Nein \\
\hline $\begin{array}{l}\text { Vereinigte Staaten } \\
\text { Partnerländer }\end{array}$ & 4 & Einphasig \& zweiphasig & $5 \mathrm{~A}$ & Bachelor & Ja & $\mathrm{Ja}$ & $\mathrm{m}$ & $\mathrm{m}$ & Ermessen der Schulen & $\mathrm{Ja}$ \\
\hline Brasilien & 4 & Zweiphasig & $5 B$ & a & $\mathrm{Ja}$ & a & Nein & Nein & $m$ & Nein \\
\hline Russische Föd. & 4 & Einphasig & $5 \mathrm{~A}$ & Bachelor & $\mathrm{Ja}$ & $\mathrm{Ja}$ & $\mathrm{Ja}$ & $\mathrm{Ja}$ & Nicht angeboten & $\mathrm{Ja}$ \\
\hline
\end{tabular}

Anmerkung: Die Spalten mit den Angaben zur Dauer der zweiphasigen Ausbildung, d.h. Spalte (3), sowie Prozentsatz der neuen und Prozentsatz aller Lehrkräfte, welche die Lehrererstausbildung mit der in Spalte (5) angegebenen Qualifikation abgeschlossen haben, d.h. die Spalten (6) und (7), sind im Internet verfügbar (s. StatLink unten). In föderalen Staaten bzw. Ländern mit stark dezentralen Schulsystemen kann es in den einzelnen Bundesstaaten, Provinzen oder Regionen unterschiedliche Vorschriften geben. Weitere Informationen s. Anhang 3.

1. Referenzjahr 2014

Quelle: OECD. Hinweise s. Anhang 3 unter www.oecd.org/edu/eag.htm. StatLink: http://dx.doi.org/10.1787/888933120290

Erläuterung der Kennzeichnung fehlender Daten s. Hinweise für den Leser. 
Lehrererstausbildung und Berufseintritt, Sekundarbereich I (2013)

Öffentliche Bildungseinrichtungen

\begin{tabular}{|c|c|c|c|c|c|c|c|c|c|c|c|}
\hline & 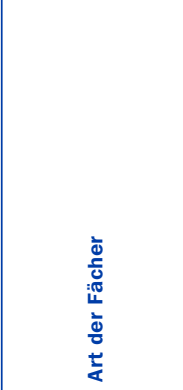 & 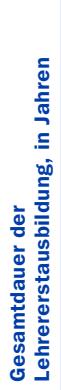 & 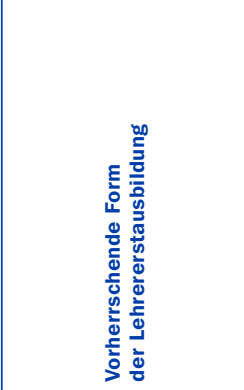 & 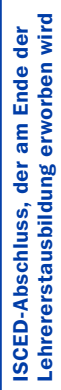 & 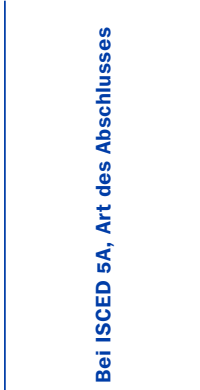 & 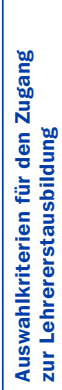 & 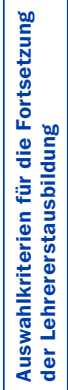 & 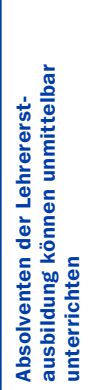 & 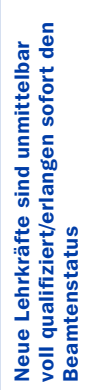 & 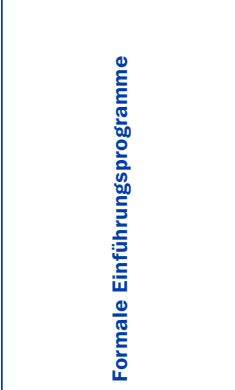 & 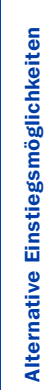 \\
\hline & & (1) & (2) & (4) & (5) & (8) & (9) & (10) & (11) & (12) & (13) \\
\hline \multicolumn{12}{|l|}{ OECD-Länder } \\
\hline Australien & $\begin{array}{l}\text { Allgemeinbildend } \\
\text { Berufsbildend }\end{array}$ & $\begin{array}{l}4 \\
m\end{array}$ & $\begin{array}{l}\text { Einphasig \& zweiphasig } \\
\mathrm{m}\end{array}$ & $\begin{array}{l}5 \mathrm{~A} \\
\mathrm{~m}\end{array}$ & $\begin{array}{l}\text { Bachelor, Sonstige } \\
\mathrm{m}\end{array}$ & $\begin{array}{l}\mathrm{Ja} \\
\mathrm{m}\end{array}$ & $\begin{array}{l}\text { Nein } \\
m\end{array}$ & $\begin{array}{l}\text { Nein } \\
m\end{array}$ & $\begin{array}{l}\mathrm{Ja} \\
\mathrm{m}\end{array}$ & $\begin{array}{l}\text { Ermessen der Schulen } \\
\mathrm{m}\end{array}$ & $\begin{array}{l}m \\
m\end{array}$ \\
\hline Österreich & $\begin{array}{l}\text { Alle }(\mathrm{AHS})^{1} \\
\text { Alle }(\mathrm{NMS}, \mathrm{HS})^{2}\end{array}$ & $\begin{array}{l}4,5 \\
3\end{array}$ & $\begin{array}{l}\text { Einphasig \& zweiphasig } \\
\text { Einphasig }\end{array}$ & $\begin{array}{l}5 \mathrm{~A} \\
5 \mathrm{~A}\end{array}$ & $\begin{array}{l}\text { Master } \\
\text { Bachelor }\end{array}$ & $\begin{array}{l}\text { Nein } \\
\text { Ja }\end{array}$ & $\begin{array}{l}\text { Nein } \\
\mathrm{a}\end{array}$ & $\begin{array}{l}\text { Nein } \\
\text { Ja }\end{array}$ & $\begin{array}{l}\mathrm{Ja} \\
\mathrm{Ja}\end{array}$ & $\begin{array}{l}\text { Pflicht } \\
\text { Nicht angeboten }\end{array}$ & $\begin{array}{l}\text { Nein } \\
\text { Nein }\end{array}$ \\
\hline Belgien (fläm.) & $\begin{array}{l}\text { Allgemeinbildend } \\
\text { Berufsbildend }\end{array}$ & $\begin{array}{l}3 \\
\mathrm{~m}\end{array}$ & $\begin{array}{l}\text { Einphasig } \\
\text { Einphasig \& zweiphasig }\end{array}$ & $\begin{array}{l}5 B \\
m\end{array}$ & $\begin{array}{l}a \\
a\end{array}$ & $\begin{array}{l}\text { Nein } \\
\text { Nein }\end{array}$ & $\begin{array}{l}\text { a } \\
\text { Nein }\end{array}$ & $\begin{array}{l}\mathrm{Ja} \\
\mathrm{Ja}\end{array}$ & $\begin{array}{l}\mathrm{Ja} \\
\mathrm{Ja}\end{array}$ & $\begin{array}{l}\text { Ermessen der Schulen } \\
\text { Ermessen der Schulen }\end{array}$ & $\begin{array}{l}\mathrm{Ja} \\
\mathrm{Ja}\end{array}$ \\
\hline Belgien (frz.) & Alle & 3 & Einphasig & $5 B$ & a & Nein & a & Ja & Ja & Ermessen der Schulen & Ja \\
\hline Kanada & $\mathrm{m}$ & $\mathrm{m}$ & $\mathrm{m}$ & $\mathrm{m}$ & $m$ & $m$ & $m$ & $\mathrm{~m}$ & $\mathrm{~m}$ & $m$ & $m$ \\
\hline Chile & Alle & 5 & Einphasig \& zweiphasig & $5 \mathrm{~A}$ & Bachelor & Nein & Nein & Ja & Ja & Nicht angeboten & Nein \\
\hline Tschechien & Alle & 5 & Einphasig \& zweiphasig & $5 \mathrm{~A}$ & Master & $\mathrm{Ja}$ & $\mathrm{Ja}$ & $\mathrm{Ja}$ & $\mathrm{Ja}$ & Ermessen der Schulen & Ja \\
\hline Dänemark & Alle & 4 & Einphasig & $5 B$ & $a$ & Ja & Nein & $\mathrm{Ja}$ & $\mathrm{Ja}$ & Ermessen der Schulen & Ja \\
\hline England & Alle & 4 & Zweiphasig & $5 \mathrm{~A}$ & Master & $\mathrm{Ja}$ & Nein & Ja & Nein & Pflicht & Ja \\
\hline Estland & Alle & 5 & Zweiphasig & $5 \mathrm{~A}$ & Master & Ja & $\mathrm{Ja}$ & Ja & $\mathrm{Ja}$ & Pflicht & Nein \\
\hline Finnland & Alle & 5 & Einphasig & $5 \mathrm{~A}$ & Master & $\mathrm{Ja}$ & a & Ja & $\mathrm{Ja}$ & Nicht angeboten & Ja \\
\hline Frankreich & Alle & 5 & Zweiphasig & $5 \mathrm{~A}$ & Master & Nein & Nein & Nein & Nein & Pflicht & Ja \\
\hline Deutschland & Alle & 6,5 & Zweiphasig & $5 \mathrm{~A}$ & Master & Nein & Nein & Ja & $\mathrm{Ja}$ & $\mathrm{m}$ & Ja \\
\hline Griechenland & Alle & 4 & Alle & $5 \mathrm{~A}$ & Bachelor & Ja & $a$ & Nein & Nein & Pflicht & Nein \\
\hline Ungarn ${ }^{3}$ & Alle & 5 & Einphasig \& zweiphasig & $5 \mathrm{~A}$ & Master & Ja & $\mathrm{Ja}$ & Ja & Nein & Pflicht & $\mathrm{m}$ \\
\hline Island & Alle & 5 & Einphasig & $5 \mathrm{~A}$ & Master & Nein & Nein & Ja & $\mathrm{Ja}$ & Nicht angeboten & Nein \\
\hline Irland & Alle & 5 & Zweiphasig & $5 \mathrm{~A}$ & Bachelor & $\mathrm{Ja}$ & Nein & Ja & Nein & Pflicht & Nein \\
\hline Israel & Alle & 4 & Einphasig \& zweiphasig & $5 \mathrm{~A}$ & Bachelor & $\mathrm{Ja}$ & $\mathrm{Ja}$ & $\mathrm{Ja}$ & Nein & Pflicht & Ja \\
\hline Italien & Alle & 6 & Zweiphasig & $5 \mathrm{~A}$ & Master & m & $\mathrm{Ja}$ & Ja & Nein & Pflicht & Nein \\
\hline Japan & Alle & 4 & Einphasig & $5 \mathrm{~A}$ & Bachelor & Ja & $a$ & Nein & Ja & Pflicht & Ja \\
\hline Korea & Alle & 4 & Einphasig \& zweiphasig & $5 \mathrm{~A}$ & Bachelor & Ja & $a$ & Nein & $\mathrm{Ja}$ & Pflicht & Nein \\
\hline Luxemburg & $\begin{array}{l}\text { Allgemeinbildend } \\
\text { Berufsbildend }\end{array}$ & $\begin{array}{l}6,5 \\
6,5\end{array}$ & $\begin{array}{l}\text { Zweiphasig } \\
\text { Zweiphasig }\end{array}$ & $\begin{array}{l}5 \mathrm{~A} \\
5 \mathrm{~A}\end{array}$ & $\begin{array}{l}\text { Master } \\
\text { Master }\end{array}$ & $\begin{array}{l}\text { Nein } \\
\text { Nein }\end{array}$ & $\begin{array}{l}\mathrm{Ja} \\
\mathrm{Ja}\end{array}$ & $\begin{array}{l}\mathrm{Ja} \\
\mathrm{Ja}\end{array}$ & $\begin{array}{l}\text { Nein } \\
\text { Nein }\end{array}$ & $\begin{array}{l}\text { Pflicht } \\
\text { Pflicht }\end{array}$ & $\begin{array}{l}\text { Nein } \\
\text { Ja }\end{array}$ \\
\hline Mexiko & $\begin{array}{l}\text { Allgemeinbildend } \\
\text { Berufsbildend }\end{array}$ & $\begin{array}{l}4 \\
\mathrm{~m}\end{array}$ & $\begin{array}{l}\text { Einphasig } \\
\mathrm{m}\end{array}$ & $\begin{array}{l}5 \mathrm{~A} \\
\mathrm{~m}\end{array}$ & $\begin{array}{l}\text { Bachelor } \\
\mathrm{m}\end{array}$ & $\begin{array}{l}\text { Nein } \\
\mathrm{m}\end{array}$ & $\begin{array}{l}\text { Nein } \\
\mathrm{m}\end{array}$ & $\begin{array}{l}\text { Nein } \\
\mathrm{m}\end{array}$ & $\begin{array}{l}\mathrm{Ja} \\
\mathrm{m}\end{array}$ & $\begin{array}{l}\text { Pflicht } \\
\mathrm{m}\end{array}$ & $\begin{array}{l}\text { Nein } \\
\mathrm{m}\end{array}$ \\
\hline Niederlande & Alle & 4 & Einphasig & $5 \mathrm{~A}$ & Bachelor & Nein & Nein & Ja & Ja & Nicht angeboten & Ja \\
\hline Neuseeland & $\mathrm{m}$ & $\mathrm{m}$ & $\mathrm{m}$ & $\mathrm{m}$ & $\mathrm{m}$ & $\mathrm{m}$ & $\mathrm{m}$ & $\mathrm{m}$ & $\mathrm{m}$ & $\mathrm{m}$ & $m$ \\
\hline Norwegen & Alle & 4 & Einphasig \& zweiphasig & $5 \mathrm{~A}$ & Bachelor & Ja & a & Ja & Ja & Ermessen der Schulen & $m$ \\
\hline Polen & Alle & 5 & Einphasig & $5 \mathrm{~A}$ & Master, Bachelor & Nein & Nein & $\mathrm{Ja}$ & Ja & Nicht angeboten & Ja \\
\hline Portugal & Alle & 5 & Einphasig \& zweiphasig & $5 \mathrm{~A}$ & Master & $\mathrm{Ja}$ & Nein & Ja & Nein & Nicht angeboten & Nein \\
\hline Schottland & Alle & 5 & Einphasig \& zweiphasig & $5 \mathrm{~A}$ & Bachelor & Ja & $\mathrm{Ja}$ & Ja & Nein & Pflicht & Nein \\
\hline Slowakei & Alle & 5 & Einphasig & $5 \mathrm{~A}$ & Master & Ja & Nein & $\mathrm{Ja}$ & Ja & Pflicht & Ja \\
\hline Slowenien & Alle & 5 & Einphasig \& zweiphasig & $5 \mathrm{~A}$ & Master & $\mathrm{Ja}$ & $\mathrm{Ja}$ & $\mathrm{Ja}$ & Nein & Ermessen der Schulen & Ja \\
\hline Spanien & Alle & 5 & Zweiphasig & $5 \mathrm{~A}$ & Master & Ja & Nein & Nein & Nein & Nicht angeboten & Nein \\
\hline Schweden & Alle & 4,5 & Alle & $5 \mathrm{~A}$ & Master & Ja & $a$ & Ja & Nein & Pflicht & Ja \\
\hline Schweiz & Alle & 5 & Einphasig \& zweiphasig & $5 \mathrm{~A}$ & Master & Nein & Nein & Ja & Ja & $\mathrm{m}$ & $\mathrm{m}$ \\
\hline Türkei & Alle & 4 & Einphasig & $5 \mathrm{~A}$ & Bachelor & $\mathrm{Ja}$ & $a$ & Nein & Nein & Pflicht & Nein \\
\hline $\begin{array}{l}\text { Ver. Staaten } \\
\text { Partnerländer }\end{array}$ & Alle & 4 & Einphasig \& zweiphasig & $5 \mathrm{~A}$ & Bachelor & $\mathrm{Ja}$ & $\mathrm{Ja}$ & $\mathrm{m}$ & $\mathrm{m}$ & Ermessen der Schulen & $\mathrm{Ja}$ \\
\hline Brasilien & Alle & 4 & Zweiphasig & $5 B$ & a & $\mathrm{Ja}$ & a & Nein & Nein & $\mathrm{m}$ & Nein \\
\hline Russische Föd. & Alle & 4 & Einphasig & $5 \mathrm{~A}$ & Bachelor & $\mathrm{Ja}$ & $\mathrm{Ja}$ & Ja & Ja & Nicht angeboten & Ja \\
\hline
\end{tabular}

Anmerkung: Die Spalten mit den Angaben zur Dauer der zweiphasigen Ausbildung, d.h. Spalte (3), sowie Prozentsatz der neuen und Prozentsatz aller Lehrkräfte, welche die Lehrererstausbildung mit der in Spalte (5) angegebenen Qualifikation abgeschlossen haben, d.h. die Spalten (6) und (7), sind im Internet verfügbar (s. StatLink unten). In föderalen Staaten bzw. Ländern mit stark dezentralen Schulsystemen kann es in den einzelnen Bundesstaaten, Provinzen oder Regionen unterschiedliche Vorschriften geben. Weitere Informationen s. Anhang 3.

1. „(AHS)“ steht für Allgemein bildende höhere Schulen, Unterstufe. 2. „(NMS, HS)“ steht für Neue Mittelschulen und Hauptschulen. 3. Referenzjahr 2014. Quelle: OECD. Hinweise s. Anhang 3 unter www.oecd.org/edu/eag.htm. StatLink: http://dx.doi.org/10.1787/888933120309

Erläuterung der Kennzeichnung fehlender Daten s. Hinweise für den Leser. 
Lehrererstausbildung und Berufseintritt, Sekundarbereich II (2013)

Öffentliche Bildungseinrichtungen

\begin{tabular}{|c|c|c|c|c|c|c|c|c|c|c|c|}
\hline & 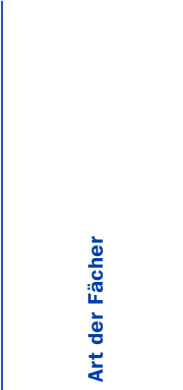 & 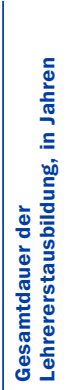 & 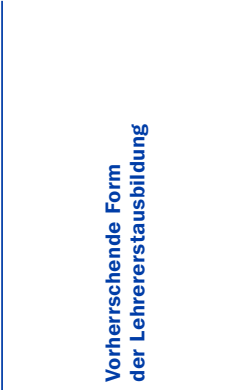 & 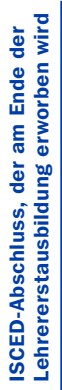 & 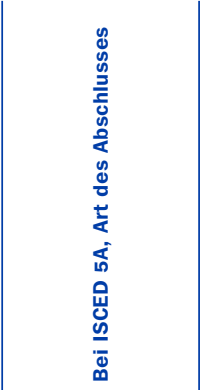 & 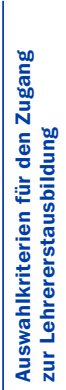 & 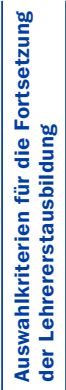 & 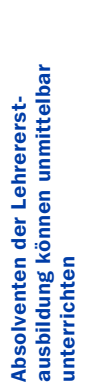 & 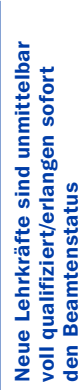 & 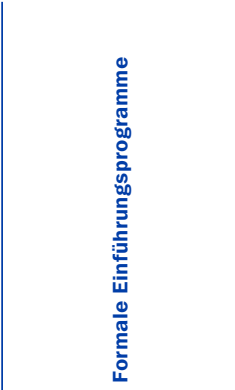 & 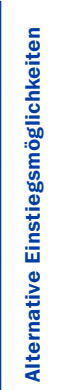 \\
\hline & & (1) & (2) & (4) & (5) & (8) & (9) & (10) & (11) & (12) & $(13)$ \\
\hline \multicolumn{12}{|l|}{ OECD-Länder } \\
\hline Australien & $\begin{array}{l}\text { Allgemeinbildend } \\
\text { Berufsbildend }\end{array}$ & $\begin{array}{l}4 \\
\mathrm{~m}\end{array}$ & $\begin{array}{l}\text { Einphasig \& zweiphasig } \\
\mathrm{m}\end{array}$ & $\begin{array}{l}5 \mathrm{~A} \\
\mathrm{~m}\end{array}$ & $\begin{array}{l}\text { Bachelor, Sonstige } \\
\mathrm{m}\end{array}$ & $\begin{array}{l}\mathrm{Ja} \\
\mathrm{m}\end{array}$ & $\begin{array}{l}\text { Nein } \\
m\end{array}$ & $\begin{array}{l}\text { Nein } \\
m\end{array}$ & $\begin{array}{l}\mathrm{Ja} \\
\mathrm{m}\end{array}$ & $\begin{array}{l}\text { Ermessen der Schulen } \\
\mathrm{m}\end{array}$ & $\begin{array}{l}m \\
m\end{array}$ \\
\hline Österreich & $\begin{array}{l}\text { Allgemeinbildend } \\
\text { Berufsbildend }\end{array}$ & $\begin{array}{l}4,5 \\
4\end{array}$ & $\begin{array}{l}\text { Einphasig \& zweiphasig } \\
\text { Einphasig }\end{array}$ & $\begin{array}{l}5 \mathrm{~A} \\
5 \mathrm{~A}\end{array}$ & $\begin{array}{l}\text { Master } \\
\text { Bachelor }\end{array}$ & $\begin{array}{l}\text { Nein } \\
\text { Ja }\end{array}$ & $\begin{array}{l}\text { Nein } \\
a\end{array}$ & $\begin{array}{l}\text { Nein } \\
\text { Ja }\end{array}$ & $\begin{array}{l}\mathrm{Ja} \\
\mathrm{Ja}\end{array}$ & $\begin{array}{l}\text { Pflicht } \\
\text { Nicht angeboten }\end{array}$ & $\begin{array}{l}\text { Nein } \\
\text { Nein }\end{array}$ \\
\hline Belgien (fläm.) & $\begin{array}{l}\text { Allgemeinbildend } \\
\text { Berufsbildend }\end{array}$ & $\begin{array}{l}5 \\
m\end{array}$ & $\begin{array}{l}\text { Zweiphasig } \\
\text { Einphasig \& zweiphasig }\end{array}$ & $\begin{array}{l}5 \mathrm{~A} \\
\mathrm{~m}\end{array}$ & $\begin{array}{l}\text { Sonstige } \\
\text { a }\end{array}$ & $\begin{array}{l}\text { Nein } \\
\text { Nein }\end{array}$ & $\begin{array}{l}\text { Nein } \\
\text { Nein }\end{array}$ & $\begin{array}{l}\mathrm{Ja} \\
\mathrm{Ja}\end{array}$ & $\begin{array}{l}\mathrm{Ja} \\
\mathrm{Ja}\end{array}$ & $\begin{array}{l}\text { Ermessen der Schulen } \\
\text { Ermessen der Schulen }\end{array}$ & $\begin{array}{l}\mathrm{Ja} \\
\mathrm{Ja}\end{array}$ \\
\hline Belgien (frz.) & $\begin{array}{l}\text { Allgemeinbildend } \\
\text { Berufsbildend }\end{array}$ & $\begin{array}{l}5 \\
3\end{array}$ & $\begin{array}{l}\text { Einphasig \& zweiphasig } \\
\text { Einphasig }\end{array}$ & $\begin{array}{l}5 \mathrm{~A} \\
5 \mathrm{~B}\end{array}$ & $\begin{array}{l}\text { Master } \\
\text { a }\end{array}$ & $\begin{array}{l}\text { Nein } \\
\text { Nein }\end{array}$ & $\begin{array}{l}\text { Nein } \\
\text { Nein }\end{array}$ & $\begin{array}{l}\mathrm{Ja} \\
\mathrm{Ja}\end{array}$ & $\begin{array}{l}\mathrm{Ja} \\
\mathrm{Ja}\end{array}$ & $\begin{array}{l}\text { Ermessen der Schulen } \\
\text { Ermessen der Schulen }\end{array}$ & $\begin{array}{l}\mathrm{Ja} \\
\mathrm{Ja}\end{array}$ \\
\hline Kanada & $\mathrm{m}$ & $m$ & $\mathrm{~m}$ & $\mathrm{~m}$ & $\mathrm{~m}$ & $\mathrm{~m}$ & $\mathrm{~m}$ & $\mathrm{~m}$ & $\mathrm{~m}$ & $m$ & $m$ \\
\hline Chile & Alle & 5,5 & Einphasig \& zweiphasig & $5 \mathrm{~A}$ & Bachelor & Nein & Nein & Ja & Ja & Nicht angeboten & Ja \\
\hline Tschechien & $\begin{array}{l}\text { Allgemeinbildend } \\
\text { Berufsbildend }\end{array}$ & $\begin{array}{l}5 \\
\mathrm{~m}\end{array}$ & $\begin{array}{l}\text { Einphasig \& zweiphasig } \\
\text { Zweiphasig }\end{array}$ & $\begin{array}{l}5 A \\
5 A\end{array}$ & $\begin{array}{l}\text { Master } \\
\text { Bachelor }\end{array}$ & $\begin{array}{l}\mathrm{Ja} \\
\mathrm{Ja}\end{array}$ & $\begin{array}{l}\mathrm{Ja} \\
\mathrm{a}\end{array}$ & $\begin{array}{l}\mathrm{Ja} \\
\mathrm{Ja}\end{array}$ & $\begin{array}{l}\mathrm{Ja} \\
\mathrm{Ja}\end{array}$ & $\begin{array}{l}\text { Ermessen der Schulen } \\
\text { Ermessen der Schulen }\end{array}$ & $\begin{array}{l}\mathrm{Ja} \\
\mathrm{Ja}\end{array}$ \\
\hline Dänemark & $\begin{array}{l}\text { Allgemeinbildend } \\
\text { Berufsbildend }\end{array}$ & $\begin{array}{l}6 \\
\mathrm{~m}\end{array}$ & $\begin{array}{l}\text { Zweiphasig } \\
\text { Zweiphasig }\end{array}$ & $\begin{array}{l}5 \mathrm{~A} \\
5 \mathrm{~B}\end{array}$ & $\begin{array}{l}\text { Master } \\
\text { a }\end{array}$ & $\begin{array}{l}\text { Ja } \\
\text { Nein }\end{array}$ & $\begin{array}{l}\text { Nein } \\
\text { Nein }\end{array}$ & $\begin{array}{l}\mathrm{Ja} \\
\mathrm{Ja}\end{array}$ & $\begin{array}{l}\mathrm{Ja} \\
\mathrm{Ja}\end{array}$ & $\begin{array}{l}\text { Ermessen der Schulen } \\
\text { Ermessen der Schulen }\end{array}$ & $\begin{array}{l}\text { Nein } \\
\text { Nein }\end{array}$ \\
\hline England & Alle & 4 & Zweiphasig & $5 \mathrm{~A}$ & Master & $\mathrm{Ja}$ & Nein & $\mathrm{Ja}$ & Nein & Pflicht & Ja \\
\hline Estland & $\begin{array}{l}\text { Allgemeinbildend } \\
\text { Berufsbildend }\end{array}$ & $\begin{array}{l}5 \\
3\end{array}$ & $\begin{array}{l}\text { Zweiphasig } \\
\text { Zweiphasig }\end{array}$ & $\begin{array}{l}5 \mathrm{~A} \\
5 \mathrm{~A}\end{array}$ & $\begin{array}{l}\text { Master } \\
\text { Bachelor }\end{array}$ & $\mathrm{Ja}$ & $\begin{array}{l}\mathrm{Ja} \\
\mathrm{Ja}\end{array}$ & $\begin{array}{l}\mathrm{Ja} \\
\mathrm{Ja}\end{array}$ & $\begin{array}{l}\mathrm{Ja} \\
\mathrm{Ja}\end{array}$ & $\begin{array}{l}\text { Pflicht } \\
\text { Pflicht }\end{array}$ & $\begin{array}{l}\text { Nein } \\
\text { Nein }\end{array}$ \\
\hline Finnland & $\begin{array}{l}\text { Allgemeinbildend } \\
\text { Berufsbildend }\end{array}$ & $\begin{array}{l}5 \\
4\end{array}$ & $\begin{array}{l}\text { Einphasig } \\
\text { Zweiphasig }\end{array}$ & $\begin{array}{l}5 \mathrm{~A} \\
5 \mathrm{~A}\end{array}$ & $\begin{array}{l}\text { Master } \\
\text { Bachelor }\end{array}$ & $\begin{array}{l}\mathrm{Ja} \\
\mathrm{Ja}\end{array}$ & $\begin{array}{l}\mathrm{a} \\
\mathrm{a}\end{array}$ & $\begin{array}{l}\mathrm{Ja} \\
\mathrm{Ja}\end{array}$ & $\begin{array}{l}\mathrm{Ja} \\
\mathrm{Ja}\end{array}$ & $\begin{array}{l}\text { Nicht angeboten } \\
\text { Nicht angeboten }\end{array}$ & $\begin{array}{l}\mathrm{Ja} \\
\mathrm{m}\end{array}$ \\
\hline Frankreich & Alle & 5 & Zweiphasig & $5 \mathrm{~A}$ & Master & Nein & Nein & Nein & Nein & Pflicht & Ja \\
\hline Deutschland & Alle & 6,5 & Zweiphasig & $5 \mathrm{~A}$ & Master & Nein & Nein & $\mathrm{Ja}$ & Ja & $\mathrm{m}$ & Ja \\
\hline Griechenland & Alle & 4 & Einphasig & $5 \mathrm{~A}$ & Bachelor & Ja & $a$ & Nein & Nein & Pflicht & Ja \\
\hline Ungarn ${ }^{1}$ & Alle & 6 & Einphasig \& zweiphasig & $5 \mathrm{~A}$ & Master & Ja & Ja & $\mathrm{Ja}$ & Nein & Pflicht & $\mathrm{m}$ \\
\hline Island & $\begin{array}{l}\text { Allgemeinbildend } \\
\text { Berufsbildend }\end{array}$ & $\begin{array}{l}5 \\
4\end{array}$ & $\begin{array}{l}\text { Zweiphasig } \\
\text { Zweiphasig }\end{array}$ & $\begin{array}{l}5 \mathrm{~A} \\
5 \mathrm{~A}\end{array}$ & $\begin{array}{l}\text { Master } \\
\text { Master }\end{array}$ & $\begin{array}{l}\text { Nein } \\
\text { Nein }\end{array}$ & $\begin{array}{l}\text { Nein } \\
\text { Nein }\end{array}$ & $\begin{array}{l}\mathrm{Ja} \\
\mathrm{Ja}\end{array}$ & $\begin{array}{l}\mathrm{Ja} \\
\mathrm{Ja}\end{array}$ & $\begin{array}{l}\text { Nicht angeboten } \\
\text { Nicht angeboten }\end{array}$ & $\begin{array}{l}\text { Nein } \\
\text { Nein }\end{array}$ \\
\hline Irland & Alle & 5 & Zweiphasig & $5 \mathrm{~A}$ & Bachelor & $\mathrm{Ja}$ & Nein & $\mathrm{Ja}$ & Nein & Pflicht & Nein \\
\hline Israel & Alle & 4 & Einphasig \& zweiphasig & $5 \mathrm{~A}$ & Bachelor & $\mathrm{Ja}$ & Ja & $\mathrm{Ja}$ & Nein & Pflicht & Ja \\
\hline Italien & Alle & 6 & Zweiphasig & $5 \mathrm{~A}$ & Master & $\mathrm{m}$ & Ja & $\mathrm{Ja}$ & Nein & Pflicht & Nein \\
\hline Japan & Alle & 4 & Einphasig & $5 \mathrm{~A}$ & Bachelor & $\mathrm{Ja}$ & a & Nein & $\mathrm{Ja}$ & Pflicht & $\mathrm{Ja}$ \\
\hline Korea & Alle & 4 & Einphasig \& zweiphasig & $5 \mathrm{~A}$ & Bachelor & Ja & $a$ & Nein & $\mathrm{Ja}$ & Pflicht & Nein \\
\hline Luxemburg & $\begin{array}{l}\text { Allgemeinbildend } \\
\text { Berufsbildend }\end{array}$ & $\begin{array}{l}6,5 \\
6,5\end{array}$ & $\begin{array}{l}\text { Zweiphasig } \\
\text { Zweiphasig }\end{array}$ & $\begin{array}{l}5 \mathrm{~A} \\
5 \mathrm{~A}\end{array}$ & $\begin{array}{l}\text { Master } \\
\text { Master }\end{array}$ & $\begin{array}{l}\text { Nein } \\
\text { Nein }\end{array}$ & $\begin{array}{l}\mathrm{Ja} \\
\mathrm{Ja}\end{array}$ & $\begin{array}{l}\mathrm{Ja} \\
\mathrm{Ja}\end{array}$ & $\begin{array}{l}\text { Nein } \\
\text { Nein }\end{array}$ & $\begin{array}{l}\text { Pflicht } \\
\text { Pflicht }\end{array}$ & $\begin{array}{l}\text { Nein } \\
\text { Ja }\end{array}$ \\
\hline Mexiko & Alle & 4 & a & $5 \mathrm{~A}$ & Bachelor & Nein & Nein & Nein & $\mathrm{Ja}$ & Nicht angeboten & Nein \\
\hline Niederlande & $\begin{array}{l}\text { Allgemeinbildend } \\
\text { Berufsbildend }\end{array}$ & $\begin{array}{l}5,5 \\
4\end{array}$ & $\begin{array}{l}\text { Einphasig \& zweiphasig } \\
\text { Einphasig }\end{array}$ & $\begin{array}{l}5 \mathrm{~A} \\
5 \mathrm{~A}\end{array}$ & $\begin{array}{l}\text { Master } \\
\text { Bachelor }\end{array}$ & $\begin{array}{l}\text { Nein } \\
\text { Nein }\end{array}$ & \begin{tabular}{|l} 
Ja \\
Nein
\end{tabular} & $\begin{array}{l}\mathrm{Ja} \\
\mathrm{Ja}\end{array}$ & $\begin{array}{l}\mathrm{Ja} \\
\mathrm{Ja}\end{array}$ & $\begin{array}{l}\text { Nicht angeboten } \\
\text { Nicht angeboten }\end{array}$ & $\begin{array}{l}\mathrm{Ja} \\
\mathrm{Ja}\end{array}$ \\
\hline Neuseeland & $\mathrm{m}$ & $m$ & $\mathrm{~m}$ & $\mathrm{~m}$ & $\mathrm{~m}$ & $m$ & $m$ & $\mathrm{~m}$ & $\mathrm{~m}$ & $\mathrm{~m}$ & $\mathrm{~m}$ \\
\hline Norwegen & $\begin{array}{l}\text { Allgemeinbildend } \\
\text { Berufsbildend }\end{array}$ & $\begin{array}{l}4-6 \\
3\end{array}$ & $\begin{array}{l}\text { Zweiphasig } \\
\text { Zweiphasig }\end{array}$ & $\begin{array}{l}5 \mathrm{~A} \\
5 \mathrm{~A}\end{array}$ & $\begin{array}{l}\text { Master } \\
\text { Bachelor }\end{array}$ & $\begin{array}{l}\mathrm{Ja} \\
\mathrm{Ja}\end{array}$ & $\begin{array}{l}\text { Nein } \\
\text { Nein }\end{array}$ & $\begin{array}{l}\mathrm{Ja} \\
\mathrm{Ja}\end{array}$ & $\begin{array}{l}\mathrm{Ja} \\
\mathrm{Ja}\end{array}$ & $\begin{array}{l}\text { Ermessen der Schulen } \\
\text { Ermessen der Schulen }\end{array}$ & $\begin{array}{l}m \\
m\end{array}$ \\
\hline Polen & Alle & 5 & Einphasig & $5 \mathrm{~A}$ & Master & Nein & Nein & $\mathrm{Ja}$ & Ja & Nicht angeboten & Ja \\
\hline Portugal & Alle & 5 & Einphasig \& zweiphasig & $5 \mathrm{~A}$ & Master & $\mathrm{Ja}$ & Nein & $\mathrm{Ja}$ & Nein & Nicht angeboten & Nein \\
\hline Schottland & Alle & 5 & Einphasig \& zweiphasig & $5 \mathrm{~A}$ & Bachelor & $\mathrm{Ja}$ & Ja & $\mathrm{Ja}$ & Nein & Pflicht & Nein \\
\hline Slowakei & Alle & 5 & Einphasig & $5 \mathrm{~A}$ & Master & $\mathrm{Ja}$ & Nein & $\mathrm{Ja}$ & $\mathrm{Ja}$ & Pflicht & $\mathrm{Ja}$ \\
\hline Slowenien & Alle & 5 & Einphasig \& zweiphasig & $5 \mathrm{~A}$ & Master & Ja & Ja & $\mathrm{Ja}$ & Nein & Ermessen der Schulen & Ja \\
\hline Spanien & Alle & 5 & Zweiphasig & $5 \mathrm{~A}$ & Master & $\mathrm{Ja}$ & Nein & Nein & Nein & Nicht angeboten & Nein \\
\hline Schweden & $\begin{array}{l}\text { Allgemeinbildend } \\
\text { Berufsbildend }\end{array}$ & $\begin{array}{l}5 \\
1,5\end{array}$ & $\begin{array}{l}\text { Einphasig \& zweiphasig } \\
\text { Einphasig \& zweiphasig }\end{array}$ & $\begin{array}{l}5 \mathrm{~A} \\
5 \mathrm{~B}\end{array}$ & $\begin{array}{l}\text { Master } \\
\text { a }\end{array}$ & $\begin{array}{l}\mathrm{Ja} \\
\mathrm{Ja}\end{array}$ & $\begin{array}{l}a \\
a\end{array}$ & $\begin{array}{l}\mathrm{Ja} \\
\mathrm{Ja}\end{array}$ & $\begin{array}{l}\text { Nein } \\
\text { Nein }\end{array}$ & $\begin{array}{l}\text { Pflicht } \\
\text { Pflicht }\end{array}$ & $\begin{array}{l}\mathrm{Ja} \\
\mathrm{Ja}\end{array}$ \\
\hline Schweiz & $\begin{array}{l}\text { Allgemeinbildend } \\
\text { Berufsbildend }\end{array}$ & $\begin{array}{l}6 \\
\mathrm{~m}\end{array}$ & $\begin{array}{l}\text { Einphasig \& zweiphasig } \\
\mathrm{m}\end{array}$ & $\begin{array}{l}5 \mathrm{~A} \\
5 \mathrm{~A}\end{array}$ & $\begin{array}{l}\text { Master } \\
\text { Master }\end{array}$ & $\begin{array}{l}\text { Nein } \\
\text { Nein }\end{array}$ & $\begin{array}{l}\text { Nein } \\
\text { Nein }\end{array}$ & $\begin{array}{l}\mathrm{Ja} \\
\mathrm{m}\end{array}$ & $\begin{array}{l}\mathrm{Ja} \\
\mathrm{Ja}\end{array}$ & $\begin{array}{l}\mathrm{m} \\
\mathrm{m}\end{array}$ & $\begin{array}{l}m \\
m\end{array}$ \\
\hline Türkei & Alle & 5 & Einphasig \& zweiphasig & $5 \mathrm{~A}$ & Bachelor & Ja & a & Nein & Nein & Pflicht & Nein \\
\hline $\begin{array}{l}\text { Ver. Staaten } \\
\text { Partnerländer }\end{array}$ & Alle & 4 & Einphasig \& zweiphasig & $5 \mathrm{~A}$ & Bachelor & $\mathrm{Ja}$ & Ja & $\mathrm{m}$ & $\mathrm{m}$ & Ermessen der Schulen & Ja \\
\hline $\begin{array}{l}\text { Brasilien } \\
\text { Russische Föd. }\end{array}$ & $\begin{array}{l}\text { Alle } \\
\text { Alle }\end{array}$ & $\begin{array}{l}4 \\
4\end{array}$ & $\begin{array}{l}\text { Zweiphasig } \\
\text { Einphasig }\end{array}$ & $\begin{array}{l}5 B \\
5 A\end{array}$ & $\begin{array}{l}\text { a } \\
\text { Bachelor }\end{array}$ & $\begin{array}{l}\mathrm{Ja} \\
\mathrm{Ja}\end{array}$ & $\begin{array}{l}\mathrm{a} \\
\mathrm{Ja}\end{array}$ & $\begin{array}{l}\text { Nein } \\
\text { Ja }\end{array}$ & $\begin{array}{l}\text { Nein } \\
\text { Ja }\end{array}$ & $\begin{array}{l}\mathrm{m} \\
\text { Nicht angeboten }\end{array}$ & $\begin{array}{l}\text { Nein } \\
\text { Ja }\end{array}$ \\
\hline
\end{tabular}

Anmerkung: Die Spalten mit den Angaben zur Dauer der zweiphasigen Ausbildung, d.h. Spalte (3), sowie Prozentsatz der neuen und Prozentsatz aller Lehrkräfte, welche die Lehrererstausbildung mit der in Spalte (5) angegebenen Qualifikation abgeschlossen haben, d.h. die Spalten (6) und (7), sind im Internet verfügbar (s. StatLink unten). In föderalen Staaten bzw. Ländern mit stark dezentralen Schulsystemen kann es in den einzelnen Bundesstaaten, Provinzen oder Regionen unterschiedliche Vorschriften geben. Weitere Informationen s. Anhang 3.

1. Referenzjahr 2014

Quelle: OECD. Hinweise s. Anhang 3 unter www.oecd.org/edu/eag.htm. StatLink: http://dx.doi.org/10.1787/888933120328

Erläuterung der Kennzeichnung fehlender Daten s. Hinweise für den Leser. 
Voraussetzungen für Zugang zu und Fortsetzung der Lehrererstausbildung, Sekundarbereich I (2013)

Öffentliche Bildungseinrichtungen

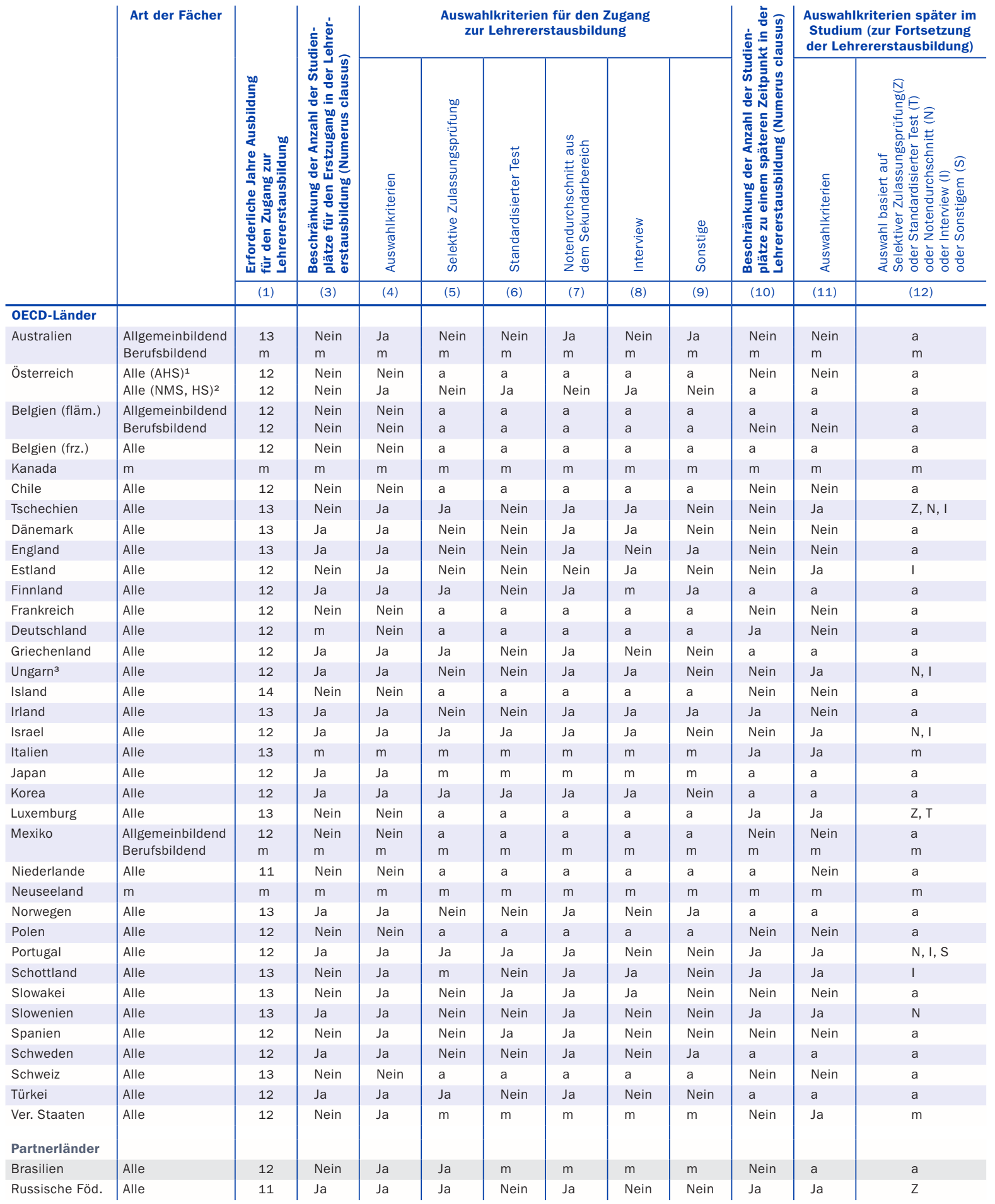

Anmerkung: Die Spalten mit den Angaben zu dem ISCED-Abschluss, der für den Zugang zur Lehrererstausbildung mindestens erforderlich ist, d. h. Spalte (2), und einzelne Spalten mit Angaben zu den Auswahlkriterien zur Fortsetzung der Lehrererstausbildung, d. h. Spalten (13) bis (17), sind im Internet verfügbar (s. StatLink unten). In föderalen Staaten bzw. Ländern mit stark dezentralen Schulsystemen kann es in den einzelnen Bundesstaaten, Provinzen oder Regionen unterschiedliche Vorschriften geben. Weitere Informationen s. Anhang 3.

1. „(AHS)“ steht für Allgemein bildende höhere Schulen, Unterstufe. 2. „(NMS, HS)“ steht für Neue Mittelschulen und Hauptschulen. 3. Referenzjahr 2014. Quelle: OECD. Hinweise s. Anhang 3 unter www.oecd.org/edu/eag.htm. StatLink: http://dx.doi.org/10.1787/888933120347

Erläuterung der Kennzeichnung fehlender Daten s. Hinweise für den Leser. 
Inhalt der Lehrererstausbildung, Sekundarbereich I (2013)

Öffentliche Bildungseinrichtungen

\begin{tabular}{|c|c|c|c|c|c|c|c|}
\hline & \multirow[t]{3}{*}{ Art der Fächer } & \multicolumn{2}{|c|}{ Fachstudium } & \multirow{2}{*}{\begin{tabular}{|c|c|}
$\begin{array}{c}\text { Pädagogik/ } \\
\text { Didaktik }\end{array}$ \\
$\begin{array}{c}\text { Teil der } \\
\text { Lehrererstausbildung }\end{array}$
\end{tabular}} & \multirow{2}{*}{\begin{tabular}{|c|c|}
$\begin{array}{c}\text { Erziehungs- } \\
\text { wissenschaft }\end{array}$ \\
$\begin{array}{c}\text { Teil der } \\
\text { Lehrererstausbildung }\end{array}$
\end{tabular}} & \multirow{2}{*}{\begin{tabular}{|c|}
$\begin{array}{c}\text { Entwicklungs- } \\
\text { psychologie }\end{array}$ \\
Teil der \\
Lehrererstausbildung
\end{tabular}} & \multirow{2}{*}{\begin{tabular}{|c|}
$\begin{array}{c}\text { Wissenschaftliches } \\
\text { Arbeiten }\end{array}$ \\
$\begin{array}{c}\text { Teil der } \\
\text { Lehrererstausbildung }\end{array}$
\end{tabular}} \\
\hline & & \begin{tabular}{|c|} 
Teil der \\
Lehrererstausbildung
\end{tabular} & \begin{tabular}{|c|} 
Spezielle \\
Kurse für \\
angehende \\
Lehrkräfte \\
\end{tabular} & & & & \\
\hline & & (1) & (3) & (4) & (5) & (6) & (7) \\
\hline \multicolumn{8}{|l|}{ OECD-Länder } \\
\hline \multirow[t]{2}{*}{ Australien } & Allgemeinbildend & Pflicht & Nein & Pflicht & Pflicht & Pflicht & $\begin{array}{l}\text { Ermessen der Ausbil- } \\
\text { dungseinrichtungen }\end{array}$ \\
\hline & Berufsbildend & $\mathrm{m}$ & $\mathrm{m}$ & $\mathrm{m}$ & $\mathrm{m}$ & $\mathrm{m}$ & $\mathrm{m}$ \\
\hline Österreich & $\begin{array}{l}\text { Alle (AHS) })^{1,2} \\
\text { Alle (NMS, HS) })^{1,3}\end{array}$ & $\begin{array}{l}\text { Pflicht } \\
\text { Pflicht }\end{array}$ & $\begin{array}{l}\text { Nein } \\
\text { Ja }\end{array}$ & $\begin{array}{l}\text { Pflicht } \\
\text { Pflicht }\end{array}$ & $\begin{array}{l}\text { Pflicht } \\
\text { Pflicht }\end{array}$ & $\begin{array}{l}\text { Pflicht } \\
\text { Pflicht }\end{array}$ & $\begin{array}{l}\text { Pflicht } \\
\text { Pflicht }\end{array}$ \\
\hline \multirow[t]{2}{*}{ Belgien (fläm.) } & Allgemeinbildend & Pflicht & Ja & $\begin{array}{l}\text { Ermessen der Ausbil- } \\
\text { dungseinrichtungen }\end{array}$ & $\begin{array}{l}\text { Ermessen der Ausbil- } \\
\text { dungseinrichtungen }\end{array}$ & $\begin{array}{l}\text { Ermessen der Ausbil- } \\
\text { dungseinrichtungen }\end{array}$ & $\begin{array}{l}\text { Ermessen der Ausbil- } \\
\text { dungseinrichtungen }\end{array}$ \\
\hline & Berufsbildend & $m$ & $\mathrm{~m}$ & $\begin{array}{l}\text { Ermessen der Ausbil- } \\
\text { dungseinrichtungen }\end{array}$ & $\begin{array}{l}\text { Ermessen der Ausbil- } \\
\text { dungseinrichtungen }\end{array}$ & $\begin{array}{l}\text { Ermessen der Ausbil- } \\
\text { dungseinrichtungen }\end{array}$ & $\begin{array}{l}\text { Ermessen der Ausbil- } \\
\text { dungseinrichtungen }\end{array}$ \\
\hline Belgien (frz.) ${ }^{1}$ & Alle & Pflicht & Ja & Pflicht & Pflicht & Pflicht & Pflicht \\
\hline Kanada & $m$ & $\mathrm{~m}$ & $\mathrm{~m}$ & $\mathrm{~m}$ & $\mathrm{~m}$ & $\mathrm{~m}$ & $\mathrm{~m}$ \\
\hline Chile & Alle & $\begin{array}{l}\text { Ermessen der Ausbil- } \\
\text { dungseinrichtungen }\end{array}$ & Nein & $\begin{array}{l}\text { Ermessen der Ausbil- } \\
\text { dungseinrichtungen }\end{array}$ & $\begin{array}{l}\text { Ermessen der Ausbil- } \\
\text { dungseinrichtungen }\end{array}$ & $\begin{array}{l}\text { Ermessen der Ausbil- } \\
\text { dungseinrichtungen }\end{array}$ & $\begin{array}{l}\text { Ermessen der Ausbil- } \\
\text { dungseinrichtungen }\end{array}$ \\
\hline Tschechien & Alle & $\begin{array}{l}\text { Ermessen der Ausbil- } \\
\text { dungseinrichtungen }\end{array}$ & $\mathrm{m}$ & Pflicht & Pflicht & Pflicht & $\begin{array}{l}\text { Ermessen der Ausbil- } \\
\text { dungseinrichtungen }\end{array}$ \\
\hline Dänemark ${ }^{1}$ & Alle & Pflicht & Ja & Pflicht & Pflicht & Pflicht & Nicht angeboten \\
\hline England & Alle & Pflicht & $\mathrm{Ja}$ & Pflicht & $\begin{array}{l}\text { Ermessen der Ausbil- } \\
\text { dungseinrichtungen }\end{array}$ & $\begin{array}{l}\text { Ermessen der Ausbil- } \\
\text { dungseinrichtungen }\end{array}$ & $\begin{array}{l}\text { Ermessen der Ausbil- } \\
\text { dungseinrichtungen }\end{array}$ \\
\hline Estland & Alle & $\begin{array}{l}\text { Ermessen der Ausbil- } \\
\text { dungseinrichtungen }\end{array}$ & Nein & Pflicht & Pflicht & $\begin{array}{l}\text { Ermessen der Ausbil- } \\
\text { dungseinrichtungen }\end{array}$ & Pflicht \\
\hline Finnland & Alle & Pflicht & Nein & Pflicht & Pflicht & $\begin{array}{l}\text { Ermessen der Ausbil- } \\
\text { dungseinrichtungen }\end{array}$ & Pflicht \\
\hline Frankreich & Alle & $\begin{array}{l}\text { Ermessen der Ausbil- } \\
\text { dungseinrichtungen }\end{array}$ & Nein & $\begin{array}{l}\text { Ermessen der Ausbil- } \\
\text { dungseinrichtungen }\end{array}$ & $\begin{array}{l}\text { Ermessen der Ausbil- } \\
\text { dungseinrichtungen }\end{array}$ & $\begin{array}{l}\text { Ermessen der Ausbil- } \\
\text { dungseinrichtungen }\end{array}$ & $\begin{array}{l}\text { Ermessen der Ausbil- } \\
\text { dungseinrichtungen }\end{array}$ \\
\hline Deutschland $^{1}$ & Alle & Pflicht & Nein & Pflicht & Pflicht & Pflicht & $\begin{array}{l}\text { Ermessen der Ausbil- } \\
\text { dungseinrichtungen }\end{array}$ \\
\hline Griechenland & Alle & Pflicht & Ja & Pflicht & Pflicht & $\begin{array}{l}\text { Ermessen der Ausbil- } \\
\text { dungseinrichtungen }\end{array}$ & $\begin{array}{l}\text { Ermessen der Ausbil- } \\
\text { dungseinrichtungen }\end{array}$ \\
\hline Ungarn 1,4 & Alle & Pflicht & Ja & Pflicht & Pflicht & Pflicht & Pflicht \\
\hline Island & Alle & $\begin{array}{l}\text { Ermessen der Ausbil- } \\
\text { dungseinrichtungen }\end{array}$ & $\mathrm{m}$ & $\begin{array}{l}\text { Ermessen der Ausbil- } \\
\text { dungseinrichtungen }\end{array}$ & $\begin{array}{l}\text { Ermessen der Ausbil- } \\
\text { dungseinrichtungen }\end{array}$ & $\begin{array}{l}\text { Ermessen der Ausbil- } \\
\text { dungseinrichtungen }\end{array}$ & $\begin{array}{l}\text { Ermessen der Ausbil- } \\
\text { dungseinrichtungen }\end{array}$ \\
\hline Irland ${ }^{1}$ & Alle & Pflicht & Nein & Pflicht & Pflicht & Pflicht & Pflicht \\
\hline Israel $^{1}$ & Alle & Pflicht & $\mathrm{Ja}$ & Pflicht & Pflicht & Pflicht & Pflicht \\
\hline Italien & Alle & Pflicht & $m$ & $\mathrm{~m}$ & $\mathrm{~m}$ & $m$ & m \\
\hline$J^{\prime a p a n}{ }^{1}$ & Alle & Pflicht & Ja & Pflicht & Pflicht & Pflicht & $\begin{array}{l}\text { Ermessen der } \\
\text { Studierenden }\end{array}$ \\
\hline Korea & Alle & Pflicht & Ja & Pflicht & Pflicht & $\begin{array}{l}\text { Ermessen der Ausbil- } \\
\text { dungseinrichtungen }\end{array}$ & $\begin{array}{l}\text { Ermessen der Ausbil- } \\
\text { dungseinrichtungen }\end{array}$ \\
\hline Luxemburg & Alle & Pflicht & Nein & Pflicht & Pflicht & Pflicht & Pflicht \\
\hline Mexiko $^{1}$ & $\begin{array}{l}\text { Allgemeinbildend } \\
\text { Berufsbildend }\end{array}$ & $\begin{array}{l}\text { Pflicht } \\
\text { Nicht angeboten }\end{array}$ & $\begin{array}{l}\text { Ja } \\
\mathrm{a}\end{array}$ & $\begin{array}{l}\text { Pflicht } \\
\text { Nicht angeboten }\end{array}$ & $\begin{array}{l}\text { Pflicht } \\
\text { Nicht angeboten }\end{array}$ & $\begin{array}{l}\text { Pflicht } \\
\text { Nicht angeboten }\end{array}$ & $\begin{array}{l}\text { Ermessen der } \\
\text { Studierenden } \\
\text { Nicht angeboten }\end{array}$ \\
\hline Niederlande & Alle & $\begin{array}{l}\text { Ermessen der Ausbil- } \\
\text { dungseinrichtungen }\end{array}$ & Ja & $\begin{array}{l}\text { Ermessen der Ausbil- } \\
\text { dungseinrichtungen }\end{array}$ & $\begin{array}{l}\text { Ermessen der Ausbil- } \\
\text { dungseinrichtungen }\end{array}$ & $\begin{array}{l}\text { Ermessen der Ausbil- } \\
\text { dungseinrichtungen }\end{array}$ & $\begin{array}{l}\text { Ermessen der Ausbil- } \\
\text { dungseinrichtungen }\end{array}$ \\
\hline Neuseeland & $m$ & $\mathrm{~m}$ & m & $\mathrm{m}$ & $\mathrm{m}$ & $m$ & $\mathrm{~m}$ \\
\hline Norwegen & Alle & Pflicht & $\mathrm{Ja}$ & Pflicht & Pflicht & Pflicht & Pflicht \\
\hline Polen & Alle & Pflicht & Nein & Pflicht & Pflicht & Pflicht & Pflicht \\
\hline Portugal & Alle & Pflicht & Ja & Pflicht & Pflicht & Pflicht & Pflicht \\
\hline Schottland & Alle & $\mathrm{m}$ & $\mathrm{m}$ & Pflicht & Pflicht & Pflicht & $\mathrm{m}$ \\
\hline Slowakei & Alle & Pflicht & Ja & Pflicht & Pflicht & Pflicht & $\begin{array}{l}\text { Ermessen der Ausbil- } \\
\text { dungseinrichtungen }\end{array}$ \\
\hline Slowenien ${ }^{1}$ & Alle & Pflicht & Ja & Pflicht & Pflicht & Pflicht & Pflicht \\
\hline Spanien $^{1}$ & Alle & Pflicht & Nein & Pflicht & Pflicht & Pflicht & Pflicht \\
\hline Schweden ${ }^{1}$ & Alle & Pflicht & Nein & Pflicht & Pflicht & Pflicht & Pflicht \\
\hline Schweiz & Alle & Pflicht & Nein & Pflicht & Pflicht & $\mathrm{m}$ & Pflicht \\
\hline Türkei & Alle & Pflicht & Ja & Pflicht & Pflicht & Pflicht & Pflicht \\
\hline Ver. Staaten & Alle & $\begin{array}{l}\text { Ermessen der Ausbil- } \\
\text { dungseinrichtungen }\end{array}$ & $\mathrm{m}$ & $\begin{array}{l}\text { Ermessen der Ausbil- } \\
\text { dungseinrichtungen }\end{array}$ & $\begin{array}{l}\text { Ermessen der Ausbil- } \\
\text { dungseinrichtungen }\end{array}$ & $\begin{array}{l}\text { Ermessen der Ausbil- } \\
\text { dungseinrichtungen }\end{array}$ & $\begin{array}{l}\text { Ermessen der Ausbil- } \\
\text { dungseinrichtungen }\end{array}$ \\
\hline \multicolumn{8}{|l|}{ Partnerländer } \\
\hline Brasilien $^{1}$ & Alle & Pflicht & Nein & Pflicht & Pflicht & $\begin{array}{l}\text { Ermessen der } \\
\text { Studierenden }\end{array}$ & $\begin{array}{l}\text { Ermessen der Ausbil- } \\
\text { dungseinrichtungen }\end{array}$ \\
\hline Russische Föd. & Alle & Pflicht & Ja & Pflicht & Pflicht & Pflicht & Pflicht \\
\hline
\end{tabular}

Anmerkung: Die Spalten mit den Angaben zur Mindestanzahl der Studienfächer, d.h. Spalte (2), zu den Anforderungen an die auf der eigenständigen wissenschaftlichen Arbeit der Studierenden basierenden Dissertation, $d . h$. Spalte (8), und ob es gemeinsame fachwissenschaftliche Kurse für alle angehenden Lehrkräfte gibt, $d$. h. Spalte (17), sind im Internet verfügbar (s. StatLink unten). In föderalen Staaten bzw. Ländern mit stark dezentralen Schulsystemen kann es in den einzelnen Bundesstaaten, Provinzen oder Regionen unterschiedliche Vorschriften geben. Weitere Informationen s. Anhang 3.

1. Typische Dauer in Tagen wird basierend auf Angaben in anderen Einheiten geschätzt, z. B. Anzahl der Stunden, Wochen, Jahre oder Leistungspunkte (Credits) in Spalte (10). Hinweise s. Anhang 3. 2. „(AHS)“ steht für Allgemein bildende höhere Schulen, Unterstufe. 3. „(NMS, HS)“ steht für Neue Mittelschulen und Hauptschulen.

4. Referenzjahr 2014

Quelle: OECD. Hinweise s. Anhang 3 unter www.oecd.org/edu/eag.htm. StatLink: http://dx.doi.org/10.1787/888933120366

Erläuterung der Kennzeichnung fehlender Daten s. Hinweise für den Leser. 
Tabelle D6.3c (Forts.)

Inhalt der Lehrererstausbildung, Sekundarbereich I (2013)

Öffentliche Bildungseinrichtungen

\begin{tabular}{|c|c|c|c|c|c|c|c|c|c|}
\hline & \multirow[t]{4}{*}{ Art der Fächer } & \multicolumn{8}{|c|}{ Unterrichtspraktikum } \\
\hline & & \multirow{2}{*}{$\begin{array}{c}\text { Teil } \\
\text { der Lehrer- } \\
\text { erstausbildung }\end{array}$} & \multirow{2}{*}{$\begin{array}{c}\text { Typische } \\
\text { Gesamtdauer, } \\
\text { in Tagen }\end{array}$} & \multicolumn{6}{|c|}{ Hauptverantwortliche für die Unterstützung neuer Lehrkräfte } \\
\hline & & & & $\begin{array}{c}\text { Mentoren aus } \\
\text { dem Lehrer- } \\
\text { kollegium }\end{array}$ & Schulleitung & \begin{tabular}{|c|} 
Schulauf- \\
sichtsbehörde
\end{tabular} & \begin{tabular}{|c|} 
Beschäftigte \\
der Lehrer- \\
ausbildungs- \\
einrichtung
\end{tabular} & $\begin{array}{l}\text { Örtliche } \\
\text { Bildungs- } \\
\text { behörden }\end{array}$ & Sonstige \\
\hline & & (9) & (10) & (11) & (12) & (13) & (14) & (15) & (16) \\
\hline \multicolumn{10}{|l|}{ OECD-Länder } \\
\hline Australien & $\begin{array}{l}\text { Allgemeinbildend } \\
\text { Berufsbildend }\end{array}$ & $\begin{array}{l}\text { Pflicht } \\
\text { m }\end{array}$ & $\begin{array}{l}80 \\
m\end{array}$ & $\begin{array}{l}\mathrm{Ja} \\
\mathrm{m}\end{array}$ & $\begin{array}{l}\mathrm{Ja} \\
\mathrm{m}\end{array}$ & $\begin{array}{l}\mathrm{a} \\
\mathrm{m}\end{array}$ & $\begin{array}{l}\mathrm{Ja} \\
\mathrm{m}\end{array}$ & $\begin{array}{l}\mathrm{a} \\
\mathrm{m}\end{array}$ & $\begin{array}{l}\mathrm{m} \\
\mathrm{m}\end{array}$ \\
\hline Österreich & $\begin{array}{l}\text { Alle }(\mathrm{AHS})^{1,2} \\
\text { Alle }(\mathrm{NMS}, \mathrm{HS})^{1,3}\end{array}$ & $\begin{array}{l}\text { Pflicht } \\
\text { Pflicht }\end{array}$ & $\begin{array}{l}78 \\
113\end{array}$ & $\begin{array}{l}\mathrm{Ja} \\
\mathrm{Ja}\end{array}$ & $\begin{array}{l}\text { Nein } \\
\text { Nein }\end{array}$ & $\begin{array}{l}\text { Nein } \\
\text { Nein }\end{array}$ & $\begin{array}{l}\mathrm{Ja} \\
\mathrm{Ja}\end{array}$ & $\begin{array}{l}\text { Nein } \\
\text { Nein }\end{array}$ & $\begin{array}{l}\mathrm{a} \\
\mathrm{a}\end{array}$ \\
\hline Belgien (fläm.) & $\begin{array}{l}\text { Allgemeinbildend } \\
\text { Berufsbildend }\end{array}$ & $\begin{array}{l}\text { Pflicht } \\
\text { Pflicht }\end{array}$ & $\begin{array}{l}m \\
m\end{array}$ & $\begin{array}{l}\text { Ja } \\
\text { Ja }\end{array}$ & $\begin{array}{l}\mathrm{Ja} \\
\mathrm{Ja}\end{array}$ & $\begin{array}{l}\text { Nein } \\
\text { Nein }\end{array}$ & $\begin{array}{l}\mathrm{Ja} \\
\mathrm{Ja}\end{array}$ & $\begin{array}{l}\text { Nein } \\
\text { Nein }\end{array}$ & $\begin{array}{l}\mathrm{a} \\
\mathrm{a}\end{array}$ \\
\hline Belgien (frz.) $)^{1}$ & Alle & Pflicht & 120 & $\mathrm{Ja}$ & Nein & Nein & $\mathrm{Ja}$ & Nein & a \\
\hline Kanada & $\mathrm{m}$ & $\mathrm{m}$ & $\mathrm{m}$ & $\mathrm{m}$ & $\mathrm{m}$ & $\mathrm{m}$ & $\mathrm{m}$ & $\mathrm{m}$ & $\mathrm{m}$ \\
\hline Chile & Alle & $\begin{array}{l}\text { Ermessen der Ausbil- } \\
\text { dungseinrichtungen }\end{array}$ & $\mathrm{m}$ & $\mathrm{m}$ & $\mathrm{Ja}$ & a & $\mathrm{Ja}$ & Nein & a \\
\hline Tschechien & Alle & $\begin{array}{l}\text { Ermessen der Ausbil- } \\
\text { dungseinrichtungen }\end{array}$ & $\mathrm{m}$ & $\mathrm{Ja}$ & Nein & Nein & Nein & Nein & Nein \\
\hline Dänemark ${ }^{1}$ & Alle & Pflicht & 100 & $\mathrm{Ja}$ & Nein & Nein & $\mathrm{Ja}$ & Nein & Nein \\
\hline England & Alle & Pflicht & 120 & $\mathrm{Ja}$ & Nein & Nein & Ja & Nein & a \\
\hline Estland & Alle & Pflicht & 50 & $\mathrm{Ja}$ & $\mathrm{Ja}$ & a & $\mathrm{Ja}$ & Nein & a \\
\hline Finnland & Alle & Pflicht & $\mathrm{m}$ & Ja & $\mathrm{m}$ & a & $\mathrm{Ja}$ & $\mathrm{m}$ & $\mathrm{m}$ \\
\hline Frankreich & Alle & $\begin{array}{l}\text { Ermessen der Ausbil- } \\
\text { dungseinrichtungen }\end{array}$ & $\mathrm{m}$ & a & a & a & a & a & a \\
\hline Deutschland $^{1}$ & Alle & Pflicht & $282-604$ & Ja & $\mathrm{Ja}$ & Nein & $\mathrm{Ja}$ & Nein & Nein \\
\hline Griechenland & Alle & Pflicht & $\mathrm{m}$ & $\mathrm{Ja}$ & Nein & Nein & $\mathrm{Ja}$ & Nein & Nein \\
\hline Ungarn 1,4 & Alle & Pflicht & $120-140$ & $\mathrm{Ja}$ & $\mathrm{Ja}$ & a & $\mathrm{Ja}$ & Nein & a \\
\hline Island Island & Alle & Pflicht & 105 & $\mathrm{Ja}$ & $\mathrm{Ja}$ & Nein & Nein & Nein & a \\
\hline Irland $^{1}$ & Alle & Pflicht & 100 & $\mathrm{Ja}$ & $\mathrm{Ja}$ & Nein & $\mathrm{Ja}$ & Nein & a \\
\hline$\left.\right|_{\text {srael }} ^{1}$ & Alle & Pflicht & 60 & $\mathrm{Ja}$ & Nein & Nein & $\mathrm{Ja}$ & Nein & Nein \\
\hline Italien & Alle & Pflicht & $\mathrm{m}$ & $\mathrm{Ja}$ & Ja & Nein & $\mathrm{Ja}$ & Nein & $\mathrm{Ja}$ \\
\hline$J^{J a p a n}{ }^{1}$ & Alle & Pflicht & 20 & $\mathrm{Ja}$ & $\mathrm{Ja}$ & a & Nein & Nein & a \\
\hline Korea & Alle & Pflicht & 40 & $\mathrm{Ja}$ & $\mathrm{Ja}$ & Nein & $\mathrm{Ja}$ & Nein & a \\
\hline Luxemburg & Alle & Pflicht & $\mathrm{m}$ & $\mathrm{Ja}$ & $\mathrm{Ja}$ & Nein & $\mathrm{Ja}$ & Nein & a \\
\hline Mexiko $^{1}$ & $\begin{array}{l}\text { Allgemeinbildend } \\
\text { Berufsbildend }\end{array}$ & $\begin{array}{l}\text { Pflicht } \\
\text { Ermessen } \\
\text { der Studierenden }\end{array}$ & $\begin{array}{l}m \\
a\end{array}$ & $\begin{array}{l}\text { Ja } \\
\mathrm{a}\end{array}$ & $\begin{array}{l}\text { Ja } \\
\mathrm{a}\end{array}$ & $\begin{array}{l}\mathrm{Ja} \\
\mathrm{a}\end{array}$ & $\begin{array}{l}\mathrm{Ja} \\
\mathrm{a}\end{array}$ & $\begin{array}{l}\text { Ja } \\
\mathrm{a}\end{array}$ & $\begin{array}{l}\text { Nein } \\
\text { a }\end{array}$ \\
\hline Niederlande & Alle & Pflicht & $\mathrm{m}$ & $\mathrm{Ja}$ & $\mathrm{m}$ & Nein & $\mathrm{Ja}$ & Nein & a \\
\hline Neuseeland & $m$ & $m$ & $\mathrm{~m}$ & $\mathrm{~m}$ & $\mathrm{~m}$ & $\mathrm{~m}$ & $\mathrm{~m}$ & $\mathrm{~m}$ & $\mathrm{~m}$ \\
\hline Norwegen & Alle & Pflicht & 100 & Ja & Nein & Nein & $\mathrm{Ja}$ & Nein & Nein \\
\hline Polen & Alle & Pflicht & $\mathrm{m}$ & $\mathrm{Ja}$ & $\mathrm{Ja}$ & Nein & Nein & Nein & a \\
\hline Portugal & Alle & Pflicht & 160 & Ja & Nein & Nein & Nein & Nein & Nein \\
\hline Schottland & Alle & Pflicht & 90 & $\mathrm{Ja}$ & $\mathrm{Ja}$ & Nein & $\mathrm{Ja}$ & Nein & a \\
\hline Slowakei & Alle & Pflicht & $\mathrm{m}$ & $\mathrm{Ja}$ & $\mathrm{Ja}$ & Nein & Nein & Nein & a \\
\hline Slowenien ${ }^{1}$ & Alle & Pflicht & $50-55$ & $\mathrm{Ja}$ & $\mathrm{Ja}$ & Nein & $\mathrm{Ja}$ & Nein & Nein \\
\hline Spanien ${ }^{1}$ & Alle & Pflicht & 40 & $\mathrm{Ja}$ & Nein & Nein & Nein & Nein & Nein \\
\hline Schweden ${ }^{1}$ & Alle & Pflicht & 100 & Ja & Nein & Nein & $\mathrm{Ja}$ & Nein & Nein \\
\hline Schweiz & Alle & Pflicht & $\mathrm{m}$ & $\mathrm{m}$ & $\mathrm{m}$ & $\mathrm{m}$ & $\mathrm{m}$ & $\mathrm{m}$ & $\mathrm{m}$ \\
\hline Türkei & Alle & Pflicht & 30 & Ja & $\mathrm{Ja}$ & Nein & $\mathrm{Ja}$ & Nein & a \\
\hline $\begin{array}{l}\text { Ver. Staaten } \\
\text { Partnerländer }\end{array}$ & Alle & $\begin{array}{l}\text { Ermessen der Ausbil- } \\
\text { dungseinrichtungen }\end{array}$ & $\mathrm{m}$ & $\mathrm{Ja}$ & $\mathrm{Ja}$ & $\mathrm{m}$ & $\mathrm{Ja}$ & $\mathrm{Ja}$ & $\mathrm{m}$ \\
\hline Brasilien $^{1}$ & Alle & Pflicht & 75 & $\mathrm{Ja}$ & Nein & a & $\mathrm{Ja}$ & Nein & $\mathrm{m}$ \\
\hline Russische Föd. & Alle & Pflicht & 36 & $\mathrm{Ja}$ & $\mathrm{Ja}$ & Nein & $\mathrm{Ja}$ & Nein & a \\
\hline
\end{tabular}

Anmerkung: Die Spalten mit den Angaben zur Mindestanzahl der Studienfächer, d.h. Spalte (2), zu den Anforderungen an die auf der eigenständigen wissenschaftlichen Arbeit der Studierenden basierenden Dissertation, d.h. Spalte (8), und ob es gemeinsame fachwissenschaftliche Kurse für alle angehenden Lehrkräfte gibt, d. h. Spalte (17), sind im Internet verfügbar (s. StatLink unten). In föderalen Staaten bzw. Ländern mit stark dezentralen Schulsystemen kann es in den einzelnen Bundesstaaten, Provinzen oder Regionen unterschiedliche Vorschriften geben. Weitere Informationen s. Anhang 3.

1. Typische Dauer in Tagen wird basierend auf Angaben in anderen Einheiten geschätzt, z. B. Anzahl der Stunden, Wochen, Jahre oder Leistungspunkte (Credits) in Spalte (10). Hinweise s. Anhang 3. 2. „(AHS)“ steht für Allgemein bildende höhere Schulen, Unterstufe. 3. „(NMS, HS)“ steht für Neue Mittelschulen und Hauptschulen.

4. Referenzjahr 2014

Quelle: OECD. Hinweise s. Anhang 3 unter www.oecd.org/edu/eag.htm. StatLink: http://dx.doi.org/10.1787/888933120366

Erläuterung der Kennzeichnung fehlender Daten s. Hinweise für den Leser. 
Einstieg in den Lehrerberuf, Sekundarbereich I (2013)

Öffentliche Bildungseinrichtungen

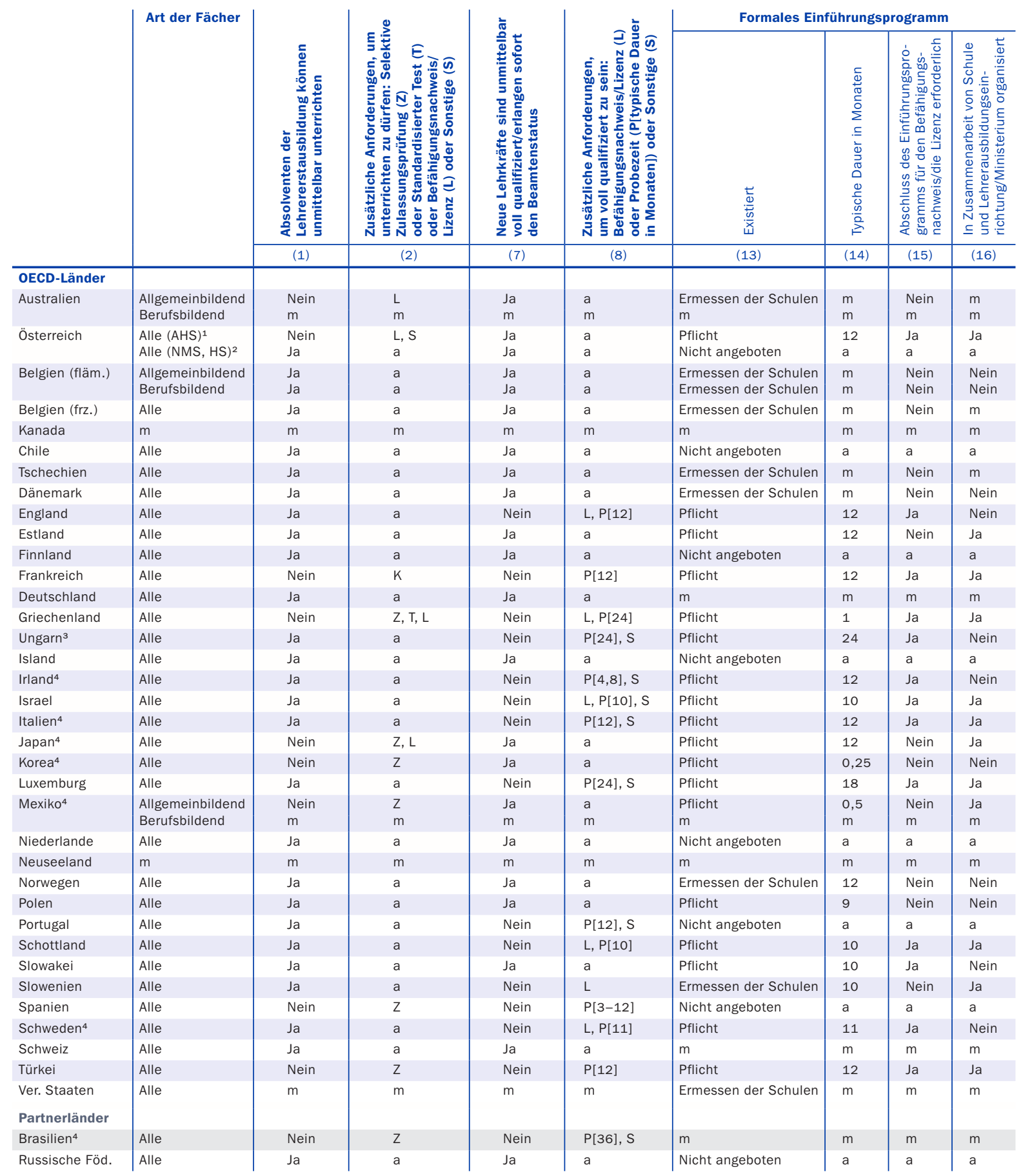

Anmerkung: Die Spalten mit den Angaben zu den zusätzlichen Anforderungen, um unterrichten zu dürfen, d.h. die Spalten (3) bis (6), und voll qualifiziert zu sein, d.h. die Spalten (9) bis (12), den Hauptverantwortlichen für die Unterstützung neuer Lehrkräfte, d.h. die Spalten (17) bis (22), deren erforderliche Ausbildung und Zeitaufwandsentschädigung, d.h. die Spalten (23) und (24), sowie der Prozentsatz der Lehrkräfte, die den Beruf innerhalb der ersten 5 Jahre aufgeben, d.h. Spalte (25), sind im Internet verfügbar (s. StatLink unten). In föderalen Staaten bzw. Ländern mit stark dezentralen Schulsystemen kann es in den einzelnen Bundesstaaten, Provinzen oder Regionen unterschiedliche Vorschriften geben. Weitere Informationen s. Anhang 3.

1. „(AHS)“ steht für Allgemein bildende höhere Schulen, Unterstufe. 2. „(NMS, HS) “ steht für Neue Mittelschulen und Hauptschulen. 3. Referenzjahr 2014.

4. Typische Dauer in Monaten wird basierend auf Angaben in anderen Einheiten geschätzt, z. B. Anzahl der Stunden, Wochen, Jahre oder Leistungspunkte (Credits) in den Spalten (8), (11) und/oder (14). Hinweise s. Anhang 3.

Quelle: OECD. Hinweise s. Anhang 3 unter www.oecd.org/edu/eag.htm. StatLink: http://dx.doi.org/10.1787/888933120385 Erläuterung der Kennzeichnung fehlender Daten s. Hinweise für den Leser. 


\section{Wie umfassend sind die Maßnahmen zur beruflichen Fortbildung für Lehrkräfte?}

In rund drei Viertel der OECD- und Partnerländer mit verfügbaren Daten besteht für Lehrkräfte in allen Bildungsbereichen die Pflicht zur beruflichen Fortbildung. In I7 Ländern wird berufliche Fortbildung von allen Lehrkräften im Sekundarbereich I verlangt, in 8 Ländern ist sie Voraussetzung für eine Beförderung oder Gehaltserhöhung, und in 6 Ländern gibt es keinerlei Verpflichtung zur beruflichen Fortbildung.

In den meisten Ländern werden Entscheidungen über obligatorische und freiwillige Maßnahmen zur beruflichen Fortbildung einzelner Lehrkräfte meistens von den Lehrkräften und der Schulleitung getroffen.

Abbildung D7.1

Berufliche Fortbildungsverpflichtungen für Lehrkräfte (2013)

Für Lehrkräfte allgemeinbildender Fächer an öffentlichen Bildungseinrichtungen im Sekundarbereich I

$\square$ Ja $\square$ Nein

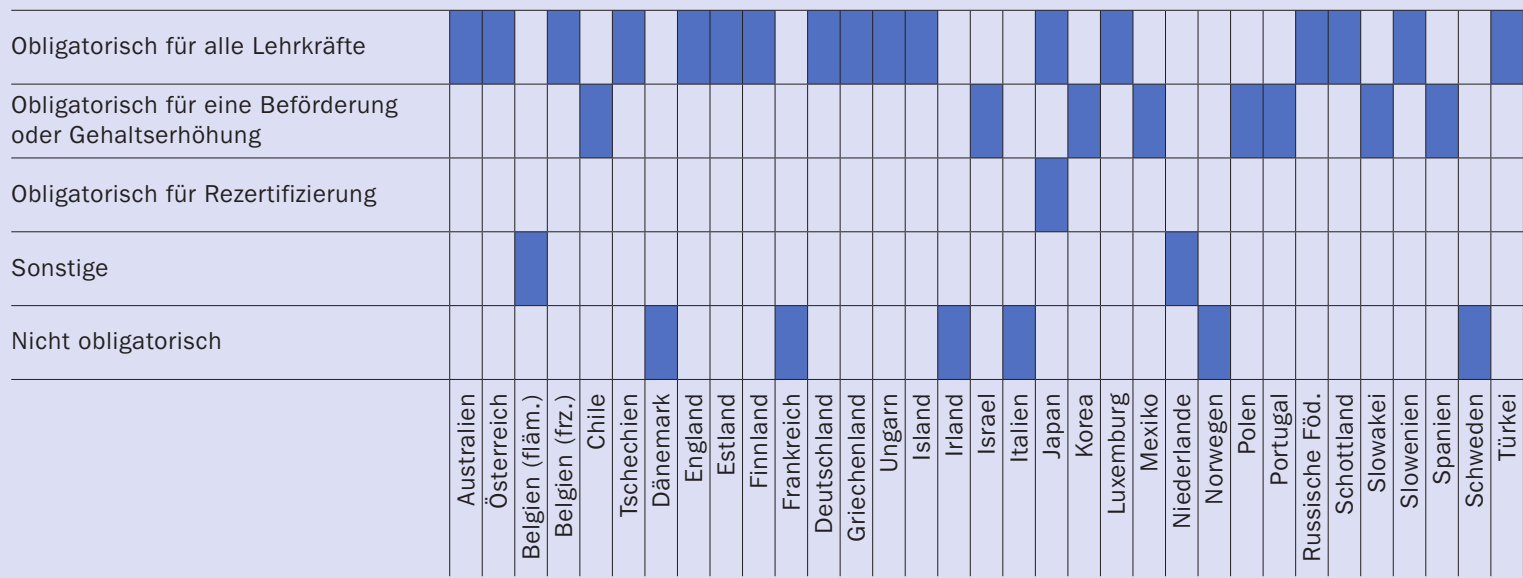

Quelle: OECD. Tabelle D7.1c. Hinweise s. Anhang 3 unter www.oecd.org/edu/eag.htm. StatLink: http://dx.doi.org/10.1787/888933120537

\section{Kontext}

Die Lehrkräfteausbildung wird immer mehr als Prozess des lebenslangen Lernens betrachtet. Während die Erstausbildung der Lehrkräfte die Grundlagen schafft, bietet die kontinuierliche berufliche Fortbildung ein Instrument zur qualitativen Weiterentwicklung der Lehrkräfte und die langfristige Bindung eines effektiven Lehrkörpers. Fortbildungsmaßnahmen ermöglichen es den Lehrkräften, ihr pädagogisches Wissen und Verständnis aufzufrischen, weiterzuentwickeln und zu erweitern und ihre Kompetenzen und Methoden zu verbessern. Sie können neuen Lehrkräften den Einstieg in das Berufsleben erleichtern und Defizite in der Erstausbildung der Lehrkräfte kompensieren. Im Hinblick darauf, dass sich die Anforderungen an die Lehrerschaft im Lauf der Zeit ändern können, ist der Ansatz des lebenslangen Lernens bei der beruflichen Fortbildung von Lehrkräften von entscheidender Bedeutung. Beispielsweise 
verlangen die zunehmende Vielfalt der Lernenden, die verstärkte zunehmende Integration von Schülern mit besonderen Lernbedürfnissen und der wachsende Einsatz von Computer und Internet von den Lehrkräften, dass sie ihre Fähigkeiten ständig auf den neuesten Stand bringen. Im beruflichen Bildungssystem müssen die Lehrkräfte und Ausbilder immer auf der Höhe der sich ändernden Anforderungen eines modernen Arbeitsplatzes sein (OECD, 2006).

In verschiedenen Studien zeigte sich eine Korrelation zwischen der kontinuierlichen Fortbildung der Lehrkräfte und einer signifikanten Steigerung des Lernerfolgs der Schüler (Yoon et al., 2007). Da eine wachsende Zahl der Lehrkräfte auf alternativen Wegen in den Lehrberuf einsteigt - entweder als Seiteneinsteiger, die bereits im Berufsleben stehen, oder als Quereinsteiger, d.h. als Hochschulabsolventen, die zur Besetzung freier Stellen in Fächern mit großem Bedarf auf der Schnellspur in den Lehrberuf einsteigen -, geht an leicht zugänglichen einschlägigen Fortbildungsmöglichkeiten kein Weg mehr vorbei (Clotfelter, Lass and Vigdor, 2007; Mueller, 2012; Headden, 20I4). Untersuchungen zeigen, dass die Tätigkeit erfahrener Lehrkräfte als Mentoren zusätzlich zu formalen Fortbildungsmaßnahmen eine deutliche Verbesserung der Qualität des Unterrichts bewirken kann und somit besonders hilfreich ist für Lehrkräfte, die auf alternativen Wegen in den Lehrberuf eintreten (Rockoff, 2008).

Exzellente Fortbildungsmöglichkeiten haben auch signifikante Auswirkungen auf die Bindung der Lehrkräfte (Allensworth, Ponisciak and Mazzeo, 2009). Da die hohe Fluktuation unter Lehrkräften insbesondere an Schulen, deren Einzugsbereich soziale Randgebiete umfasst, ein ernstes Problem darstellt (Ewing and Smith, 2003; OECD, 2006; Headden, 20I4), sollte der beruflichen Fortbildung eine hohe Priorität beigemessen werden.

\section{Weitere wichtige Ergebnisse}

In den meisten Ländern werden die vorgeschriebenen beruflichen Fortbildungsmaßnahmen im Hinblick auf die jeweiligen Schulentwicklungsschwerpunkte geplant. In 20 Ländern sind Schulentwicklungsschwerpunkte im Sekundarbereich I das ausschließliche Kriterium bzw. eines der Kriterien bei der Planung der Fortbildungsmaßnahmen; in 4 Ländern werden sie nicht im Hinblick darauf geplant.

Die einzelnen Länder verfügen über Strategien zur Finanzierung und zur Förderung obligatorischer beruflicher Fortbildung. In I4 OECD- und Partnerländern werden die Kosten dafür im Sekundarbereich I vollständig vom Staat subventioniert bzw. teilweise aus öffentlichen Mitteln finanziert; in 8 Ländern werden sie teilweise subventioniert.

Den Angaben zufolge stehen den Lehrkräften in allen Ländern neben den obligatorischen Maßnahmen auch freiwillige Maßnahmen der beruflichen Fortbildung offen. Diese Maßnahmen werden jedoch nur in seltenen Fällen vollständig durch öffentliche Mittel finanziert.

Berufliche Fortbildungsmaßnahmen im Sekundarbereich I werden meist von Hochschulen (34 Länder), Einrichtungen zur Erstausbildung der Lehrkräfte (30 Länder), Schulen (3I Länder) und privatwirtschaftlichen Einrichtungen (30 Länder) angeboten. Die nächstfolgenden Anbieter sind öffentliche Stellen für die Fortbildung von 
Lehrkräften und berufsständische Organisationen der Lehrkräfte (je 22 Länder), Lehrergewerkschaften (20 Länder) und lokale Bildungsbehörden (I8 Länder). Nur in 6 Ländern werden solche Maßnahmen von den Schulaufsichtsbehörden angeboten.

Bei der Verbreitung von Informationen zu beruflichen Fortbildungsmaßnahmen spielen Schulleitungen die größte Rolle. In rund zwei Drittel der Länder sind auch zentrale oder bundesstaatliche Bildungsbehörden zuständig für die Verbreitung von Informationen zu beruflichen Fortbildungsmaßnahmen.

\section{Analyse und Interpretationen}

\section{Anforderungen an obligatorische berufliche Fortbildungsmaßnahmen}

Der Ansatz des lebenslangen Lernens in der Lehrkräfteausbildung erfordert Angebote und Anreize zur beruflichen Fortbildung über die gesamte berufliche Laufbahn einer Lehrkraft hinweg. Berufliche Fortbildung kann eine Vielzahl von Maßnahmen umfassen: formale Fortbildungskurse, Seminare, Konferenzen und Workshops, OnlineSchulungen sowie Mentoren- und Supervisionsprogramme. Der Nutzen beruflicher Fortbildung ist jedoch abhängig von der Qualität der Angebote und entsprechenden Möglichkeiten zur Rückmeldung und nachbereitenden Unterstützung.

Die Notwendigkeit beruflicher Fortbildung besteht in allen Bildungsbereichen. In 25 der 33 Länder mit verfügbaren Daten ist berufliche Fortbildung für Lehrkräfte aller Bildungsbereiche obligatorisch. Während I6 dieser 25 Länder angaben, dass Fortbildung für alle Lehrkräfte obligatorisch ist, ist sie in Chile, Israel, Korea, Mexiko (im Elementar- und Primarbereich sowie in allgemeinbildenden Bildungsgängen des Sekundarbereichs I), Polen, Portugal, der Slowakei und Spanien Voraussetzung für eine Beförderung oder Gehaltserhöhungen. In Island sind Fortbildungsmaßnahmen zwar für alle Lehrkräfte des Primar- und Sekundarbereichs I obligatorisch, für Lehrkräfte des Elementar- und Sekundarbereichs sind sie den Angaben zufolge jedoch als Teil einer vertraglichen Verpflichtung im Rahmen einer Gehaltsvereinbarung zwischen Lehrerverbänden und Arbeitgebern ebenfalls obligatorisch. In Japan müssen alle Lehrkräfte im zehnten Berufsjahr und für ihre Rezertifizierung an beruflichen Fortbildungsmaßnahmen teilnehmen. In Belgien (fläm.) und den Niederlanden ist die berufliche Fortbildung unter Lehrkräften zwar weit verbreitet und kann (je nach Schule) durch die Schule oder den Träger vorgeschrieben werden; es gibt jedoch kein Gesetz, das die berufliche Fortbildung für obligatorisch erklärt. In Frankreich, Irland (Primar- und Sekundarbereich), Mexiko (berufsbildende Bildungsgänge des Sekundarbereichs I und Sekundarbereich II) und Österreich (berufsbildende Bildungsgänge des Sekundarbereichs II) gibt es keine Verpflichtung zu beruflicher Fortbildung. In Dänemark, Norwegen und Schweden besteht zwar keine Fortbildungspflicht, aber Bildungsbehörden und Schulträger sind verpflichtet, Maßnahmen zur Fortbildung anzubieten und den Lehrkräften die Teilnahme daran zu ermöglichen. In Italien bezeichnet es das Nationale Lehrerabkommen als unmittelbare Verpflichtung der Schulen und Bildungsbehörden, den Lehrkräften Möglichkeiten der beruflichen Fortbildung anzubieten, und als 
berufliches Anrecht der Lehrkräfte, diese angeboten zu bekommen (Tab. D7.Ic sowie Tab. D7.ra, D7.Ib und D7.Id im Internet).

\section{Mindestdauer der obligatorischen beruflichen Fortbildungsmaßnahmen}

Die Dauer der obligatorischen beruflichen Fortbildungsmaßnahmen unterscheidet sich in den einzelnen Ländern sehr. In manchen Ländern (z. B. Deutschland, England und der Russischen Föderation) ist kein Mindestumfang an beruflicher Fortbildung für Lehrkräfte vorgeschrieben, in anderen dagegen schon. In den Ländern, in denen ein Mindestumfang an jährlicher Fortbildung für alle Lehrkräfte vorgeschrieben ist, reicht dieser von 8 Stunden im Jahr in Luxemburg bis zu I50 Stunden im Jahr in Island (für Lehrkräfte im Primarund Sekundarbereich I). In Estland müssen Lehrkräfte über einen Zeitraum von 5 Jahren mindestens an I6o Stunden beruflicher Fortbildung teilnehmen, in Ungarn mindestens I20 Stunden über einen Zeitraum von 7 Jahren. In Japan müssen alle Lehrkräfte mit zehn Jahren Berufserfahrung an einem Fortbildungsprogramm teilnehmen. Hierzu gehören durchschnittlich I23 Stunden beruflicher Fortbildung für Lehrkräfte des Elementarbereichs und 23I Stunden für Lehrkräfte im Primar- und Sekundarbereich. Darüber hinaus müssen Lehrkräfte in Japan zur Rezertifizierung alle so Jahre an 30 Stunden beruflicher Fortbildung teilnehmen (Tab. D7.Ic sowie Tab. D7.Ia, D7.Ib und D7.Id im Internet).

In Spanien müssen Lehrkräfte als Voraussetzung für eine Beförderung oder Gehaltserhöhungen alle 6 Jahre an 250 bis 300 Stunden beruflicher Fortbildung teilnehmen, während in Mexiko im Elementar- und Primarbereich sowie im Sekundarbereich I für Lehrkräfte 78 Stunden Fortbildung im Jahr vorgeschrieben sind. In Israel müssen Lehrkräfte im Elementar- und Primarbereich sowie im Sekundarbereich I alle drei Jahre zwischen I8o und 2 Io Stunden an beruflicher Fortbildung teilnehmen; im Sekundarbereich II sind es jedes Jahr II2 Stunden. In Korea müssen Lehrkräfte als Voraussetzung für ein höheres Lehrerzertifikat (normalerweise nach 3 bis 4 Jahren Lehrtätigkeit) bzw. um sich als Lehrkraft mit besonderen Kompetenzen (Su-seak Gyo-sa) zu qualifizieren, an 90 Zeitstunden beruflicher Fortbildung teilnehmen, während es in Portugal 25 Zeitstunden alle zwei Jahre sind. In der Slowakei müssen Lehrkräfte als Voraussetzung für eine Gehaltserhöhung ein 300 Stunden entsprechendes Fortbildungsguthaben (credits) ansammeln. Dieses Guthaben ist jedoch nur sieben Jahre nach Abschluss der jeweiligen Fortbildungsmaßnahme gültig. Deshalb müssen sich die Lehrkräfte kontinuierlich fortbilden, um ein Mindestguthaben und damit ihr Gehaltsniveau beizubehalten.

\section{Die Planung der beruflichen Fortbildung}

In den 23 Ländern, in denen eine Pflicht zur beruflichen Fortbildung besteht und Daten über deren Planung zur Verfügung stehen, verlangen ro Länder Pläne für Lehrkräfte und Schulen. In Griechenland, Island, der Russischen Föderation, Tschechien und Ungarn werden nur Pläne für die einzelnen Schulen verlangt, in Estland (Primar- und Sekundarbereich), Schottland und der Türkei nur Pläne für die einzelnen Lehrkräfte. In Deutschland, Estland (Elementarbereich), Finnland, Luxemburg, Österreich und Spanien wird dagegen gar keine Planung verlangt (Tab. D7.2c sowie Tab. D7.2a, D7.2b und D7.2d im Internet).

In 20 der 24 Länder mit verfügbaren Daten werden die obligatorischen beruflichen Fortbildungsmaßnahmen für Lehrkräfte im Sekundarbereich I im Hinblick auf die jeweiligen Schulentwicklungsschwerpunkte geplant. In Japan, der Russischen Föde- 
ration, der Slowakei und Tschechien werden diese Maßnahmen ausschließlich im Hinblick auf die jeweiligen Schulentwicklungsschwerpunkte geplant; in I6 von 20 Ländern ist dies nicht das ausschließliche Kriterium. In Korea, Luxemburg, Mexiko und Spanien werden obligatorische berufliche Fortbildungsmaßnahmen hingegen nicht im Hinblick auf die jeweiligen Schulentwicklungsschwerpunkte geplant.

Von den 32 OECD- und Partnerländern mitverfügbaren Daten werden in 24 Ländern die nicht obligatorischen beruflichen Fortbildungsmaßnahmen für Lehrkräfte im Sekundarbereich I im Hinblick auf die jeweiligen Schulentwicklungsschwerpunkte geplant. In 8 Ländern ist dies nicht der Fall. 22 der 24 Länder gaben an, die Planung dieser Maßnahmen erfolge nicht ausschließlich im Hinblick auf die jeweiligen Schulentwicklungsschwerpunkte. Japan und Tschechien gaben dagegen an, dass dies das ausschließliche Planungskriterium sei. Für Lehrkräfte im Elementar- und Primarbereich sowie im Sekundarbereich II wird von ähnlichen Planungserfordernissen für die berufliche Fortbildung berichtet (Tab. D7.3c sowie Tab. D7.3a, D7.3b und D7.3d im Internet).

\section{Der Inhalt der beruflichen Fortbildungsmaßnahmen}

In 17 der 24 OECD- und Partnerländer mit verfügbaren Daten ist der Inhalt der obligatorischen beruflichen Fortbildungsmaßnahmen im Sekundarbereich I nicht festgelegt. Auch wenn der Inhalt nicht festgelegt ist, müssen diese Maßnahmen jedoch in 6 dieser I7 Länder vorgegebenen Standards genügen. In Belgien (frz.) und England werden diese Standards ausschließlich durch die zentralen Bildungsbehörden festgelegt, während sie in Korea sowohl von den zentralen als auch von den regionalen Bildungsbehörden festgelegt werden. In Griechenland sind die zentralen und regionalen Bildungsbehörden sowie die Schulaufsichtsbehörde und das Institut für Bildungspolitik an der Festlegung der Standards beteiligt. In der Russischen Föderation sind die zentralen und regionalen Bildungsbehörden in Zusammenarbeit mit den Hochschulen und Schulen hierfür zuständig.

Kasten D7.1

\section{In welchen Bereichen besteht laut Angaben der Lehrkräfte ein hoher Fortbildungsbedarf?}

In der internationalen Erhebung der OECD zu Lehren und Lernen (TALIS) aus dem Jahr 2013 nannten die Lehrkräfte das Unterrichten von Kindern mit besonderen Lernbedürfnissen in allen teilnehmenden Ländern am häufigsten als Bereich mit großem Fortbildungsbedarf. Im Durchschnitt geben rund 22 Prozent der Lehrkräfte an, in diesem besonderen Aspekt ihrer Unterrichtstätigkeit Bedarf an Fortbildung zu haben, in Brasilien sogar 6o Prozent und in Mexiko 47 Prozent. Im Durchschnitt stehen an zweiter und dritter Stelle der wichtigsten Bereiche mit Fortbildungsbedarf nach Angaben der Lehrkräfte der Einsatz von Computern und Internet im Unterricht (I9 Prozent der Lehrkräfte) und der Einsatz neuer Technologien am Arbeitsplatz (I8 Prozent der Lehrkräfte). Lehrkräfte in allen Ländern der TALIS-Erhebung nannten dies als wichtige Fortbildungsbereiche, insbesondere in Brasilien (mit 27 Prozent bzw. 37 Prozent), Italien ( 36 Prozent bzw. 32 Prozent) und Malaysia ( 38 Prozent bzw. 3I Prozent). Dies legt nahe, dass sich die Lehrkräfte für schlecht ausgerüstet halten, den bestmöglichen Nutzen aus diesen Technologien für das Lehren und Lernen zu ziehen. 
Auch andere Bereiche werden von einem großen Teil der Lehrkräfte mancher Länder als verbesserungsfähig angegeben: In Japan und Korea geben beispielsweise über 40 Prozent der Lehrkräfte einen Bedarf an beruflicher Fortbildung im Bereich der Ausbildungsberatung für Schüler an. Lehrkräfte in Japan melden einen Bedarf an Fortbildung in den Bereichen Fachwissen und Verständnis im jeweiligen Unterrichtsgegenstand (5I Prozent), fachdidaktische Kenntnisse im jeweiligen Unterrichtsgegenstand (57 Prozent), Schülerverhalten und Klassenführung (43 Prozent), Methoden der Beurteilung von Schülern (40 Prozent) und das Herangehen an individualisiertes Lernen (4o Prozent). In den meisten europäischen Ländern scheint der Unterricht in einem multikulturellen bzw. multilingualen Umfeld kein wichtiges Thema zu sein; anders ist es jedoch in lateinamerikanischen Ländern und in Italien: 46 Prozent der Lehrkräfte in Brasilien, 24 Prozent in Chile, 27 Prozent in Italien und 33 Prozent in Mexiko geben an, Bedarf an Fortbildung in diesem Bereich zu haben.

Abbildung D7.a

Fortbildungsbedarf der Lehrkräfte (2013)

Anteil der Lehrkräfte im Sekundarbereich I (in \%), die einen großen Fortbildungsbedarf in den folgenden

Bereichen nannten

Unterrichten von Schülern mit besonderen Lernbedürfnissen ${ }^{1}$

Einsatz von Computer und Internet im Unterricht

Einsatz neuer Technologien am Arbeitsplatz

Schülerverhalten und Klassenführung

Unterrichten in einem multikulturellen bzw. multilingualen Umfeld

Herangehen an individualisiertes Lernen

Berufsberatung und Beratungslehrertätigkeiten

Methoden der Beurteilung von Schülern

Unterrichten lehrplanübergreifender Kompetenzen

(z. B. Problemlösekompetenz, Lernen lernen)

Herangehen an die Entwicklung berufsübergreifender Kompetenzen für den zukünftigen Beruf oder ein zukünftiges Studium

Fachdidaktische Kompetenz im Unterrichtsfach

Schulleitung und -verwaltung

Fachwissen und Verständnis des jeweiligen Unterrichtsgegenstands

Kenntnis des Lehrplans
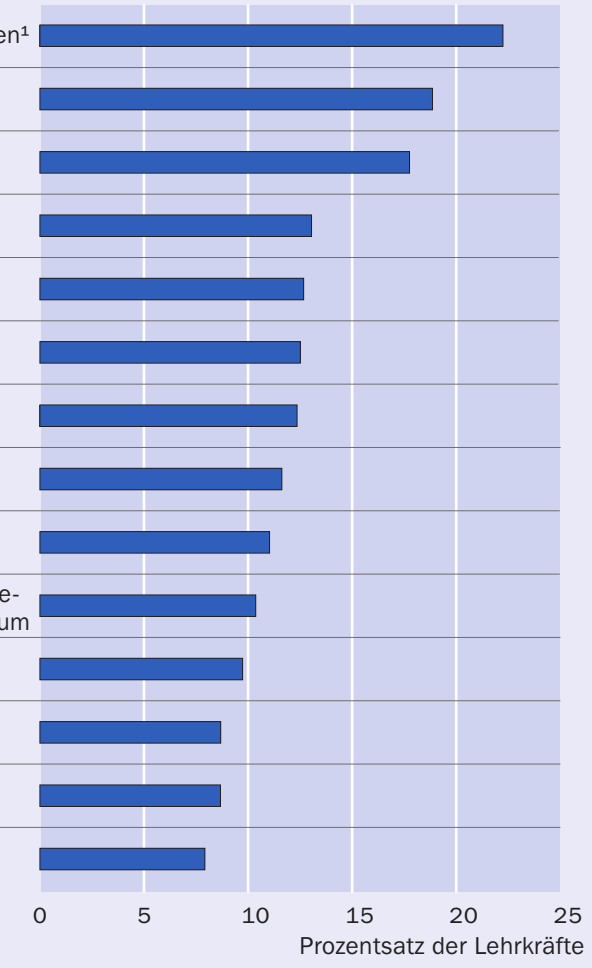

1. „Schüler mit besonderen Lernbedürfnissen“ sind international nicht präzise definiert, üblicherweise fallen darunter Schüler, für die formal spezielle Lernbedürfnisse festgelegt wurden, weil sie geistig, körperlich oder seelisch benachteiligt sind. Oft handelt es sich bei Schülern mit besonderen Lernbedürfnissen um diejenigen, für die zusätzliche öffentliche oder private Mittel (Personal-, Sach- oder Finanzmittel) zur Unterstützung ihrer Bildung bereitgestellt wurden. „Hochbegabte Schüler“ werden gemäß der hier und in anderen Veröffentlichungen der OECD verwendeten Definition nicht als Schüler mit besonderen Bedürfnissen betrachtet. Einige Lehrkräfte betrachten alle Schüler als individuelle Lernende mit ganz eigenen, besonderen Lernbedürfnissen. Zum Zwecke dieser Erhebung ist es wichtig, auf objektivere Weise beurteilen zu können, wer besondere Lernbedürfnisse hat und wer nicht. Daher wird eingangs so großer Wert auf eine formale Festlegung gelegt.

Anordnung der Bereiche in absteigender Reihenfolge des Anteils der Lehrkräfte (in \%), die einen großen Fortbildungsbedarf für den jeweiligen Bereich angaben.

Quelle: OECD (2014), TALIS 2013 Results: An International Perspective on Teaching and Learning, TALIS, OECD Publishing. StatLink: http://dx.doi.org/10.1787/888933041668 
In Israel, Mexiko, Portugal, der Slowakei, Slowenien, Spanien und der Türkei dagegen ist der Inhalt der obligatorischen beruflichen Fortbildungsmaßnahmen vorgegeben. In Mexiko, der Slowakei und Spanien werden die Inhalte der Maßnahmen ausschließlich von den zentralen Bildungsbehörden vorgegeben. In Slowenien wird der Inhalt dagegen von den zentralen Bildungsbehörden in Zusammenarbeit mit den Hochschulen und Schulen festgelegt, während in der Türkei die Vorgaben durch die zentralen und regionalen Bildungsbehörden, die Hochschulen und die Schulaufsichtsbehörde erarbeitet werden. In Portugal wird der Inhalt von den zentralen Bildungsbehörden, den Lehrerverbänden, den Lehrergewerkschaften, den Universitäten und den Schulen gemeinsam festgelegt. In Israel sind hierfür die zentralen Bildungsbehörden, die Schulaufsichtsbehörde, die Lehrerverbände, die Lehrergewerkschaften, die Hochschulen, Schulen und sonstige Anbieter von Bildungsleistungen zuständig. Im Elementar- und Primarbereich sowie im Sekundarbereich II ergibt sich ein ähnliches Bild (s. Tab. D7.2c sowie Tab. D7.2a, D7.2b und D7.2d im Internet).

\section{Entscheidungen über berufliche Fortbildungsmaßnahmen der einzelnen Lehrkräfte}

Bei der Entscheidung über die obligatorischen Maßnahmen zur beruflichen Fortbildung einzelner Lehrkräfte spielen die Lehrkräfte selbst sowie die Schulverwaltungen eine große Rolle. Im Sekundarbereich I gaben zwei Drittel der Länder, in denen eine Pflicht zur beruflichen Fortbildung besteht, an, dass die Lehrkräfte selbst die Maßnahmen vorschlagen, an denen sie teilnehmen wollen, während 7 Länder angaben, dass die Lehrkräfte entscheiden, an welchen Fortbildungsmaßnahmen sie teilnehmen. In Belgien (frz.), Estland, Finnland, Israel, Polen, Slowenien und der Türkei schlagen zwar die Lehrkräfte die Maßnahmen vor, ihre Wahl muss jedoch von der Schulleitung validiert werden. In rund einem Drittel der Länder schlägt die Schulleitung die Maßnahmen vor; nur in Österreich, Portugal, der Russischen Föderation, Tschechien und Ungarn entscheidet die Schulleitung über die erforderlichen Maßnahmen.

In Japan machen die Lehrkräfte und die Schulleitung Vorschläge hinsichtlich der Fortbildungsmaßnahmen; ihre Wahl muss jedoch von den Bildungsbehörden validiert werden. In Korea können die Lehrkräfte bei der Entscheidung über den Inhalt der obligatorischen Fortbildungsmaßnahmen einbezogen werden, indem sie Vorschläge unterbreiten, letztendlich aber entscheiden die Bildungsbehörden über die Fortbildungsmaßnahmen der Lehrkräfte. In Chile schlagen die Schulleitung und die Bildungsbehörden Maßnahmen vor, aber die jeweilige Lehrkraft entscheidet über die Teilnahme. In Spanien verhält es sich ähnlich: Hier werden die Maßnahmen von den regionalen Bildungsbehörden vorgeschlagen, die abschließende Entscheidung liegt jedoch bei der Lehrkraft. In der Türkei werden die Maßnahmen von den Lehrkräften, der Schulaufsichtsbehörde und den lokalen Bildungsbehörden vorgeschlagen, von der Schulleitung validiert, und die letztendliche Entscheidung wird von den regionalen und zentralen Bildungsbehörden gemeinsam getroffen (Abb. D7.2a und Tab. D7.Ic)

Im Elementar- und Primarbereich sowie im Sekundarbereich II ergibt sich ein ähnliches Bild. In Österreich jedoch schlagen zwar im Elementarbereich die Schulleitung und die Schulaufsichtsbehörde obligatorische Fortbildungsmaßnahmen vor, die Entscheidung über die Teilnahme trifft jedoch die Lehrkraft. Im Primar- und Sekundarbereich ist das Gegenteil der Fall: Hier schlagen die Lehrkräfte die Maßnahmen vor, 
Wer entscheidet über die obligatorischen beruflichen Fortbildungsmaßnahmen einzelner Lehrkräfte? (2013)

Für Lehrkräfte allgemeinbildender Fächer an öffentlichen Bildungseinrichtungen, Sekundarbereich I

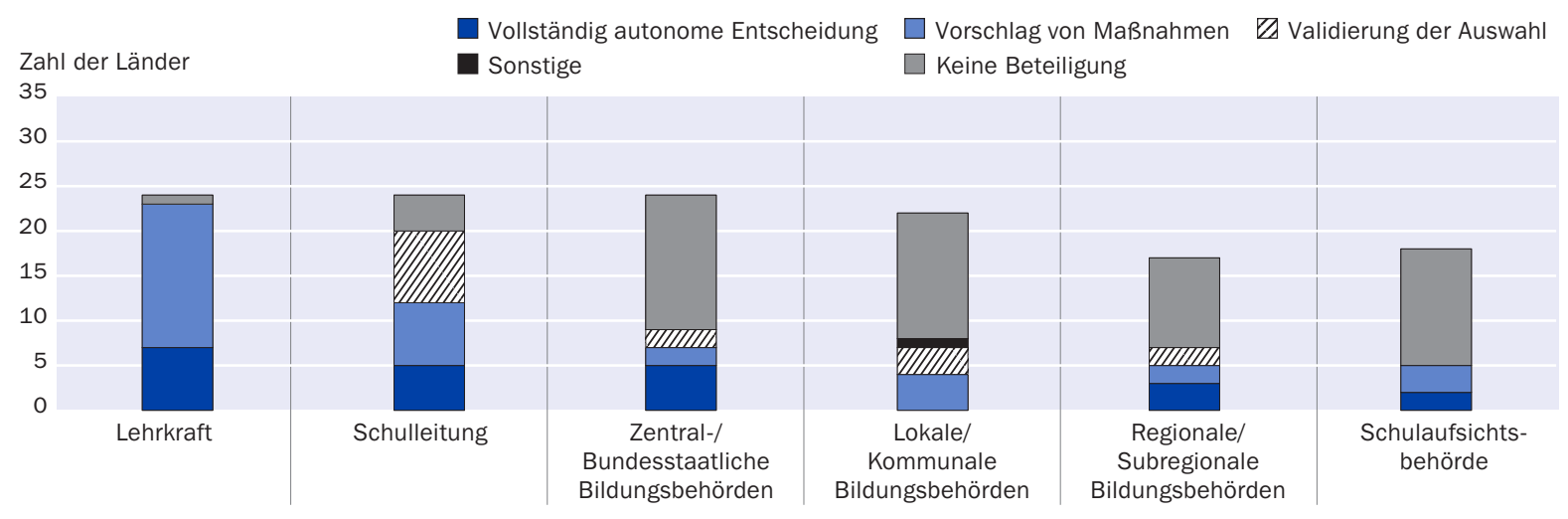

Anordnung der Entscheidungsträger in absteigender Reihenfolge der Zahl an Ländern, die angeben, dass dieser Entscheidungsträger bei der Entscheidung über die obligatorischen beruflichen Fortbildungsmaßnahmen von Lehrkräften eine Rolle spielt.

Quelle: OECD. Tabelle D7.1c. Hinweise s. Anhang 3 unter www.oecd.org/edu/eag.htm. StatLink: http://dx.doi.org/10.1787/888933120556

Abbildung D7.2b

Wer entscheidet über die nicht obligatorischen beruflichen Fortbildungsmaßnahmen einzelner Lehrkräfte? (2013)

Für Lehrkräfte allgemeinbildender Fächer an öffentlichen Bildungseinrichtungen, Sekundarbereich I

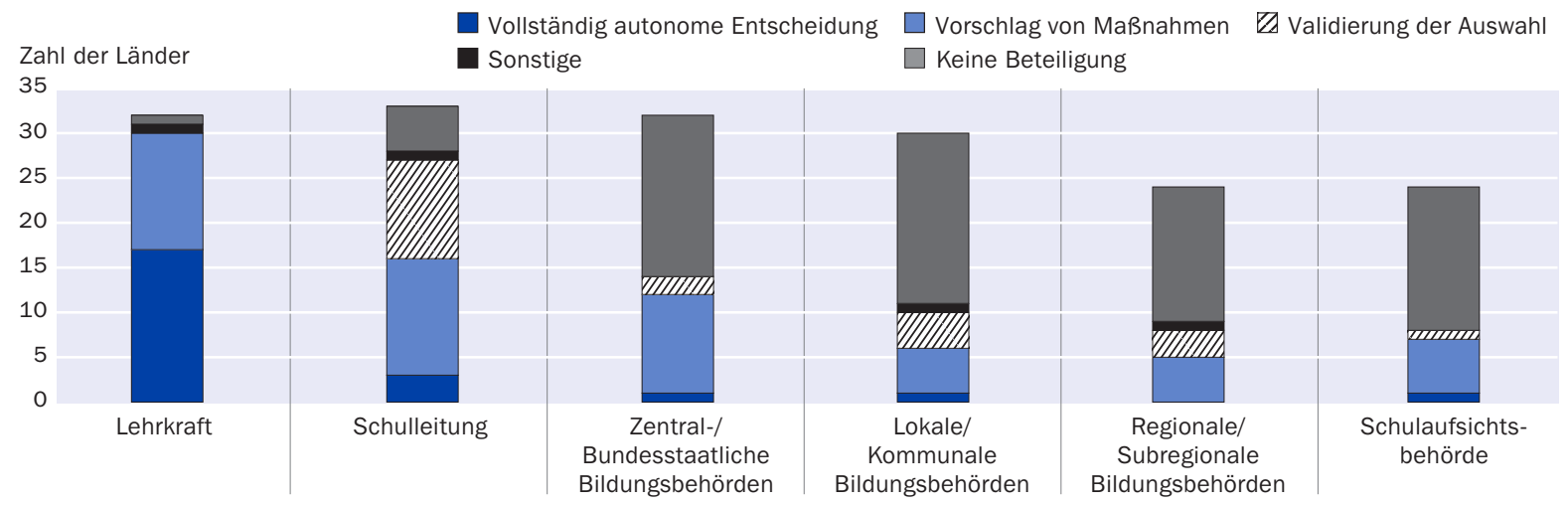

Anordnung der Entscheidungsträger in absteigender Reihenfolge der Zahl an Ländern, die angeben, dass dieser Entscheidungsträger bei der Entscheidung über die nicht obligatorischen beruflichen Fortbildungsmaßnahmen von Lehrkräften eine Rolle spielt.

Quelle: OECD. Tabelle D7.3c. Hinweise s. Anhang 3 unter www.oecd.org/edu/eag.htm. StatLink: http://dx.doi.org/10.1787/888933120575

während die Schulleitung und die Schulaufsichtsbehörde über die Teilnahme entscheiden (Tab. D7.2a, D7.2b und D7.2d im Internet).

In der Hälfte der Länder entscheiden die Lehrkräfte selbst über die Teilnahme an nicht obligatorischen beruflichen Fortbildungsmaßnahmen, in der anderen Hälfte der Länder können sie nur Vorschläge zu solchen Maßnahmen machen. Allerdings müssen in einem Drittel der Länder die Entscheidungen oder Vorschläge der Lehrkräfte von der Schulleitung validiert werden, und in der Hälfte der Länder schlägt die Schulleitung entsprechende Maßnahmen für die Lehrkräfte vor (Abb. D7.2b). In Schweden können Lehrkräfte und Schulleitung informell Einfluss nehmen auf die jeweiligen beruflichen Fortbildungsmaßnahmen, zuständig für die Bereitstellung der beruflichen Fortbildung für die Lehrkräfte sind jedoch die lokalen und regionalen Bildungsbehörden. In Dänemark bestimmt ausschließlich die Schulleitung über die beruflichen Fortbildungsmaßnahmen der Lehrkräfte. 
Nur in 8 Ländern spielt die Schulaufsichtsbehörde eine Rolle bei der Entscheidung über die nicht obligatorischen beruflichen Fortbildungsmaßnahmen. In 6 dieser Länder kann die Schulaufsichtsbehörde Vorschläge zu den Maßnahmen machen, in Österreich entscheidet sie (im Primar- und Sekundarbereich) über diese Maßnahmen, und in Israel validiert sie diese. Ebenso besteht in einem Drittel der Länder mit verfügbaren Daten die Rolle der zentralen, regionalen und lokalen Bildungsbehörden hauptsächlich darin, Maßnahmen vorzuschlagen oder zu validieren. Nur in der Türkei ist die zentrale Bildungsbehörde für die Entscheidung zuständig, an welchen nicht obligatorischen beruflichen Fortbildungsmaßnahmen die Lehrkräfte teilnehmen sollen (Tab. D7.3c sowie Tab. D7.3a, D7.3b und D7.3d im Internet).

\section{Strategien zu Finanzierung und Förderung von beruflicher Fortbildung}

Berufliche Fortbildung kann jeweils von der öffentlichen Hand alleine, von den Arbeitgebern oder von den Einzelnen sowie mit einer Kombination dieser Möglichkeiten finanziert werden. Staatlicherseits können bestimmte Strategien zu Finanzierung und Förderung verfolgt werden, in deren Rahmen berufliche Fortbildungsmaßnahmen vom Staat subventioniert bzw. die Kosten vom Staat mitgetragen werden, um unter den Lehrkräften Anreize zur beruflichen Fortbildung zu schaffen. $\mathrm{Zu}$ diesen Strategien zählt die Bereitstellung von Mitteln zur Deckung der Kosten von Fortbildungsmaßnahmen, zur Kompensation entgangener Einkommen (d. h. die bezahlte Freistellung für die Dauer der Maßnahme) und zur Übernahme der Kosten für Vertretungslehrkräfte.

In allen Ländern, in denen eine Pflicht zur Fortbildung besteht, gibt es Strategien zu deren Finanzierung und Förderung. In rund der Hälfte der Länder mit verfügbaren Daten werden die Kosten der obligatorischen beruflichen Fortbildung vollständig übernommen. In II Ländern werden die Kosten für Lehrkräfte im Elementarbereich vollständig übernommen, in weiteren ro Ländern werden sie teilweise übernommen. In I4 Ländern werden die Kosten für Lehrkräfte im Primarbereich und im Sekundarbereich I vollständig übernommen, in 8 Ländern teilweise. In I2 Ländern werden die Kosten für Lehrkräfte im Sekundarbereich II vollständig übernommen, in 9 Ländern teilweise (Abb. D7.3a sowie Tab. D7.Ia, D7.Ib und D7.Id im Internet).

Im Allgemeinen werden in allen Ländern mit einer Pflicht zur beruflichen Fortbildung die Teilnahmegebühren für obligatorische Lehrgänge zur beruflichen Fortbildung entweder ganz oder teilweise übernommen. Ausnahmen sind hier Chile und Japan (sofern es sich um Maßnahmen zur Rezertifizierung handelt), wo die Kosten der Teilnahme nie übernommen werden. Während entgangene Einkommen (für die Dauer der Fortbildung) und die Kosten für Vertretungslehrkräfte in Deutschland, der Russischen Föderation und Slowenien immer übernommen werden, werden sie in Japan (sofern es sich um Maßnahmen zur Rezertifizierung handelt) und Spanien nie übernommen. Im Gegensatz dazu werden in rund der Hälfte der Länder die Kosten für Vertretungslehrkräfte immer übernommen. In den übrigen Ländern werden die entgangenen Einkommen der Lehrkräfte und die Kosten für Vertretungslehrkräfte entweder oft oder manchmal übernommen. In der Hälfte der Länder wird den Schulen sogar ein separates Budget für die obligatorischen beruflichen Fortbildungsmaßnahmen der Lehrkräfte zugeteilt (Tab. D7.Ic sowie Tab. D7.ra, D7.Ib und D7.Id im Internet). 


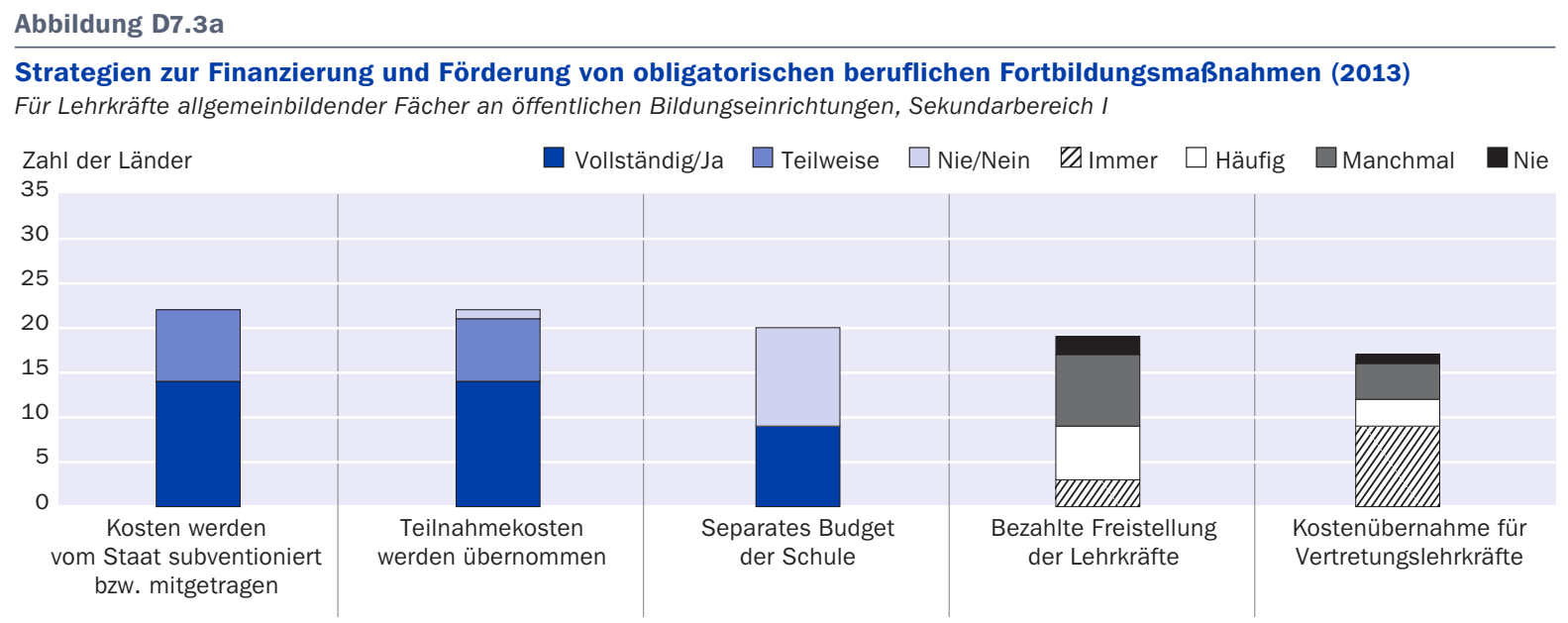

Quelle: OECD. Tabelle7.1c. Hinweise s. Anhang 3 unter www.oecd.org/edu/eag.htm. StatLink: http://dx.doi.org/10.1787/888933120594

Abbildung D7.3b

Strategien zur Finanzierung und Förderung von nicht obligatorischen beruflichen Fortbildungsmaßnahmen (2013)

Für Lehrkräfte allgemeinbildender Fächer an öffentlichen Bildungseinrichtungen, Sekundarbereich I

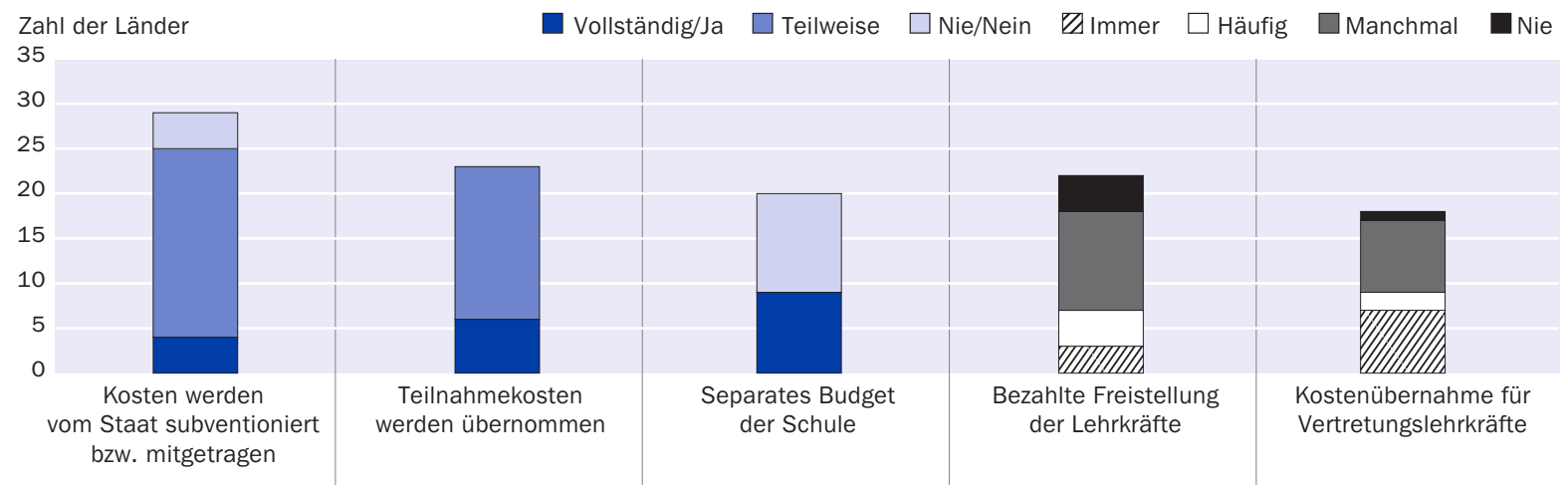

Quelle: OECD. Tabelle D7.3c. Hinweise s. Anhang 3 unter www.oecd.org/edu/eag.htm. StatLink: http://dx.doi.org/10.1787/888933120613

Im Gegensatz dazu werden in den OECD- und Partnerländern mit verfügbaren Daten die Kosten für nicht obligatorische berufliche Fortbildungsmaßnahmen nur selten vollständig übernommen. Für Lehrkräfte im Sekundarbereich I werden die Kosten in Deutschland, Griechenland, Israel und Mexiko vollständig übernommen, in 2I Ländern teilweise übernommen und in Belgien (frz.), Estland, Portugal und der Slowakei nie übernommen. Drei Viertel der Länder mit verfügbaren Daten gaben an, dass die Teilnahmegebühren für diese Maßnahmen teilweise übernommen werden; in den anderen Ländern werden sie vollständig übernommen. Ferner gibt es für Lehrkräfte im Sekundarbereich I manchmal (I Länder), oft (4 Länder) oder immer (3 Länder) bezahlte Freistellungen für die Dauer der Teilnahme an diesen Maßnahmen. In Israel, Japan, Luxemburg und Spanien ist dies jedoch für Lehrkräfte im Sekundarbereich I nie der Fall. In 7 Ländern werden die Kosten für Vertretungslehrkräfte immer übernommen, in Io Ländern oft oder manchmal. In Spanien werden diese Kosten nie übernommen. In 9 Ländern wird den Schulen auch ein separates Budget für nicht obligatorische berufliche Fortbildungsmaßnahmen für Lehrkräfte zugeteilt (Abb. D7.3b und Tab. D7.3c). 
Ähnliche Strategien zu Finanzierung und Förderung gibt es für Lehrkräfte im Elementar- und Primarbereich sowie im Sekundarbereich II (Tab. D7.3a, D7.3b und D7.3 im Internet).

\section{Anbieter von beruflichen Fortbildungsmaßnahmen}

In einer Reihe von Ländern ist der Einsatz öffentlicher Mittel für berufliche Fortbildungsmaßnahmen an die Angebote einiger weniger Organisationen gebunden (Einrichtungen für Lehrerbildung oder Einrichtungen mit einer Spezialisierung auf berufliche Fortbildung). Dies kann besonders in den Ländern, in denen eine Fortbildungspflicht besteht, bedeuten, dass ein geringerer Anreiz zu Innovation und Qualitätsverbesserung besteht. Es ist daher wichtig, eine gewisse Bandbreite an Anbietern beruflicher Fortbildung zu fördern und die Einhaltung von Qualitätsstandards sowie die Verbreitung bewährter Methoden sicherzustellen (OECD, 2006).

Berufliche Fortbildung gibt es in unterschiedlichem institutionellem Rahmen, sie kann schulintern oder durch externe Anbieter wie Fortbildungsinstitute und Universitäten angeboten werden. In allen OECD- und Partnerländern mit Ausnahme von Japan bieten Hochschulen berufliche Fortbildungsmaßnahmen für Lehrkräfte aller Bildungsbereiche an. Mit Ausnahme von Belgien (frz.), Island, Japan, Luxemburg (Elementar- und Primarbereich) und Österreich (Kindergarten [Elementarbereich], Allgemein bildende höhere Schule, Unterstufe [Sekundarbereich I] und Oberstufe [Sekundarbereich II]) werden derartige Maßnahmen in allen Ländern auch von Einrichtungen zur Erstausbildung von Lehrkräften angeboten. In allen Ländern mit Ausnahme von Island, Österreich (Volksschule [Primarbereich], Hauptschule, Neue Mittelschule und Allgemein bildende höhere Schule, Unterstufe [Sekundarbereich I] und Allgemein bildende höhere Schule, Oberstufe [Sekundarbereich II]), der Russischen Föderation und Tschechien spielen auch die Schulen selbst eine wichtige Rolle als Anbieter von beruflichen Fortbildungsmaßnahmen.

Neben diesen verschiedenen Bildungseinrichtungen sind privatwirtschaftliche Einrichtungen die häufigsten Anbieter für berufliche Fortbildungsmaßnahmen: mit Ausnahme von Israel, Japan, Luxemburg (Elementar- und Primarbereich sowie Sekundarbereich II), Österreich, Spanien und Tschechien bieten sie in 4 von 5 Ländern solche Maßnahmen an.

Zwei Drittel der Länder gaben ferner an, dass diese Maßnahmen von einer öffentlichen Stelle für die Fortbildung von Lehrkräften und/oder von berufsständischen Organisationen der Lehrkräfte angeboten werden. In rund der Hälfte der Länder werden diese Maßnahmen auch von Lehrergewerkschaften und lokalen Bildungsbehörden angeboten. Nur in Frankreich, Griechenland, Israel (Elementarbereich), Italien, Luxemburg (Elementar- und Primarbereich), Österreich (berufsbildender Sekundarbereich II), Polen, Schottland und der Türkei werden diese Maßnahmen für Lehrkräfte von der Schulaufsichtsbehörde angeboten (Tab. D7.4a, D7.4b, D7.4c und D7.4d im Internet).

\section{Verbreitung von Informationen über berufliche Fortbildungs- maßnahmen für Lehrkräfte}

In allen Bildungsbereichen spielt die Schulleitung die wichtigste Rolle bei der Verbreitung von Informationen über berufliche Fortbildungsmaßnahmen. Von den 34 OECD- 
Kasten D7.2

\section{Müssen Lehrkräfte die Teilnahme an beruflichen Fortbildungs- maßnahmen selbst bezahlen?}

Verschiedene Arten von beruflichen Fortbildungsmaßnahmen erfordern unterschiedlich hohe Investitionen. Der TALIS-Erhebung von 2013 zufolge gaben mehr als die Hälfte der Lehrkräfte, die an beruflichen Fortbildungsmaßnahmen teilgenommen hatten, an, unabhängig von der Art des Angebots nichts dafür bezahlt zu haben (mit Ausnahme von Qualifizierungsmaßnahmen), und höchstens io Prozent gaben an, die gesamten Kosten selbst getragen zu haben. Angebote zur Qualifizierung sind tendenziell aufwendiger (im Hinblick auf Zeit und Geld) und tendenziell eher außerhalb der Schule organisiert (d. h. an einer Universität oder einer Akademie). Daher ist es nicht überraschend, dass die Übernahme eines Teils der Kosten oder der gesamten Kosten für diese Programme durch die Lehrkräfte wahrscheinlicher ist.

\section{Abbildung D7.b}

Anteil der Kosten von Fortbildungsmaßnahmen, den Lehrkräfte selbst tragen (2013)

Anteil der Lehrkräfte im Sekundarbereich I (in \%), die angaben, an den folgenden Fortbildungsmaßnahmen teilgenommen zu haben und keine Kosten getragen, anteilig Kosten getragen bzw. die gesamten Kosten selbst getragen zu haben ${ }^{1}$

Kurse/Workshops

Mentorenprogramme und/oder Hospitieren bei Kollegen und Coaching als Teil einer formalen Vereinbarung der Schule

Beteiligung an einem speziell der beruflichen Fortbildung gewidmeten Netzwerk für Lehrkräfte

Bildungskonferenzen oder -seminare, auf denen Lehrkräfte und/oder Wissenschaftler ihre Forschungsergebnisse vorstellen und Bildungsthemen diskutieren

Hospitationen an anderen Schulen

Hospitationen in Unternehmen, öffentlichen Einrichtungen oder nicht staatlichen Organisationen

Wissenschaftliches Arbeiten zu einem Thema von beruflichem Interesse (allein oder mit anderen)

Berufsbegleitende Fortbildungskurse in Unternehmen, öffentlichen Einrichtungen oder nicht staatlichen Organisationen

Qualifikationsprogramm (z. B. zu einem akademischen Abschluss führender Studiengang)

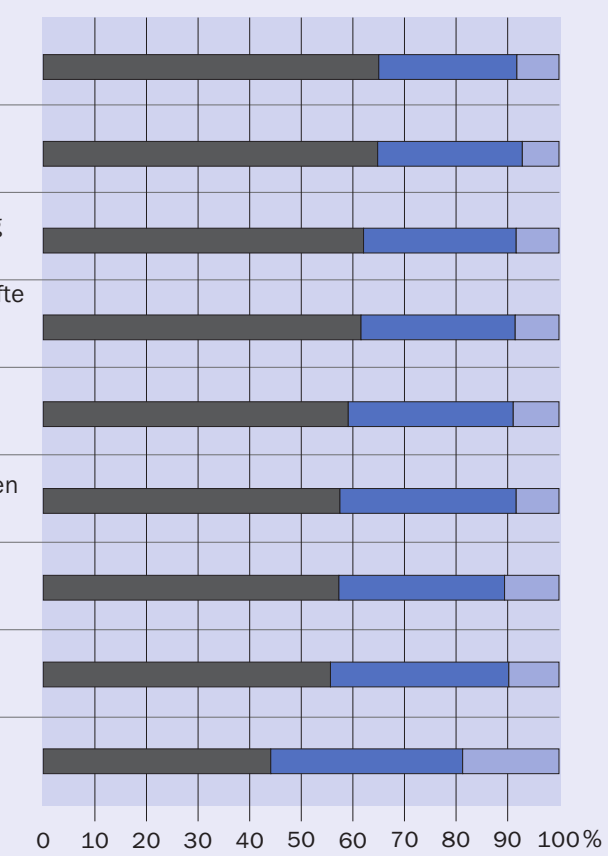

1. Lehrkräfte können gleichzeitig an mehr als einer Fortbildungsmaßnahme teilnehmen. Die Lehrkräfte wurden nicht danach gefragt, wie viel sie für eine einzelne Fortbildung gezahlt haben, sondern danach, welchen Anteil der Kosten sie für Fortbildungsmaßnahmen, an denen sie teilgenommen haben, insgesamt selbst getragen haben. Die in dieser Abbildung angegebenen Prozentsätze sind daher als allgemeines Kostenniveau zu betrachten, das Lehrkräfte, die an jeder der Fortbildungsmaßnahmen teilgenommen haben, laut eigenen Angaben selbst getragen haben.

Anordnung der Fortbildungsmaßnahmen in absteigender Reihenfolge des durchschnittlichen Anteils der Lehrkräfte, die angaben, dafür keine Kosten getragen zu haben.

Quelle: OECD (2014), TALIS 2013 Results: An International Perspective on Teaching and Learning, TALIS, OECD Publishing. StatLink: http://dx.doi.org/10.1787/888933041535 


\section{An welcher Art beruflicher Fortbildungsmaßnahmen nehmen Lehrkräfte teil?}

Die Ergebnisse der TALIS-Studie von 2013 legen nahe, dass Kurse oder Workshops die häufigsten beruflichen Fortbildungsmaßnahmen darstellen, an der Lehrkräfte den eigenen Angaben zufolge teilnahmen: Durchschnittlich gaben 7r Prozent der Lehrkräfte im Sekundarbereich I an, im Erhebungszeitraum an einer solchen Maßnahme teilgenommen zu haben. In praktisch allen teilnehmenden Ländern und Volkswirtschaften wurde die Teilnahme an Kursen oder Workshops am häufigsten genannt. Hier lag die Beteiligungsquote in manchen Ländern bei etwa 8o Prozent, in Malaysia, Mexiko und Singapur sogar bei mehr als go Prozent.

Die nach Kursen und Workshops am häufigsten genannte Maßnahme ist die Teilnahme an Bildungskonferenzen und -seminaren (44 Prozent) und die Beteiligung an einem Netzwerk für Lehrkräfte (37 Prozent). Am seltensten wurden mit 13 Prozent Hospitationen in Unternehmen oder anderen Einrichtungen und berufsbegleitende Fortbildungskurse in diesen Einrichtungen (I4 Prozent) genannt.

Abbildung D7.C

In den letzten 12 Monaten von Lehrkräften wahrgenommene Maßnahmen zur beruflichen Fortbildung, nach Art und Dauer (2013)

Teilnahmequoten und durchschnittliche Anzahl von Tagen für jede Fortbildungsart, an der Lehrkräfte

im Sekundarbereich I laut eigenen Angaben in den 12 Monaten vor der Erhebung teilgenommen haben

\begin{tabular}{|c|c|c|}
\hline & $\begin{array}{c}\text { Anteil der Lehrkräfte (in \%), die in den } \\
12 \text { Monaten vor der Erhebung an den } \\
\text { folgenden Fortbildungsmaßnahmen } \\
\text { teilgenommen haben }\end{array}$ & $\begin{array}{l}\text { Durchschnittliche } \\
\text { Teilnahmedauer } \\
\text { der Teilnehmer, } \\
\text { in Tagen }\end{array}$ \\
\hline Kurse/Workshops & $71 \%$ & 8 \\
\hline $\begin{array}{l}\text { Bildungskonferenzen oder -seminare, auf denen Lehr- } \\
\text { kräfte und/oder Wissenschaftler ihre Forschungs- } \\
\text { ergebnisse vorstellen und Bildungsthemen diskutieren }\end{array}$ & $44 \%$ & 4 \\
\hline Hospitationen an anderen Schulen & $19 \%$ & 3 \\
\hline $\begin{array}{r}\text { Berufsbegleitende Fortbildungskurse } \\
\text { in Unternehmen, öffentlichen Einrichtungen } \\
\text { oder nicht staatlichen Organisationen }\end{array}$ & $14 \%$ & 7 \\
\hline $\begin{array}{l}\text { Hospitationen in Unternehmen, öffentlichen } \\
\text { Einrichtungen oder nicht staatlichen Organisationen }\end{array}$ & $13 \%$ & 3 \\
\hline $\begin{array}{l}\text { Beteiligung an einem speziell der beruflichen } \\
\text { Fortbildung gewidmeten Netzwerk für Lehrkräfte }\end{array}$ & $37 \%$ & \\
\hline $\begin{array}{l}\text { Wissenschaftliches Arbeiten zu einem Thema von } \\
\text { beruflichem Interesse (allein oder mit anderen) }\end{array}$ & $31 \%$ & \\
\hline $\begin{array}{r}\text { Mentorenprogramme und/oder Hospitieren } \\
\text { bei Kollegen und Coaching als Teil einer formalen } \\
\text { Vereinbarung der Schule }\end{array}$ & $29 \%$ & \\
\hline $\begin{array}{l}\text { Qualifikationsprogramm (z.B. zu einem } \\
\text { akademischen Abschluss führender Studiengang) }\end{array}$ & $18 \%$ & \\
\hline
\end{tabular}

Anordnung der Maßnahmen in absteigender Reihenfolge pro Block, basierend auf dem Anteil der Lehrkräfte (in \%), die angaben, in den 12 Monaten vor der Erhebung an Fortbildungsmaßnahmen teilgenommen zu haben.

Quelle: OECD (2014), TALIS 2013 Results: An International Perspective on Teaching and Learning, TALIS, OECD Publishing. StatLink: http://dx.doi.org/10.1787/888933041554 
und Partnerländern gaben nur Finnland und Schweden an, dass die Schulleitung nicht formell für die Weitergabe dieser Art Informationen zuständig ist. In rund zwei Drittel der Länder ist auch die zentral-/bundesstaatliche Bildungsbehörde zuständig für die Verbreitung von Informationen über berufliche Fortbildungsmaßnahmen. Etwas mehr als die Hälfte der Länder gab ferner an, dass die regionalen oder lokalen Bildungsbehörden am Informationsprozess beteiligt sind. In Frankreich, Griechenland, Israel, Italien, Luxemburg (Elementar- und Primarbereich sowie Sekundarbereich I), Österreich (Elementarbereich und berufsbildende Bildungsgänge im Sekundarbereich II), Polen und Schottland gibt auch die Schulaufsichtsbehörde diese Informationen an die Lehrkräfte weiter (Tab. D7.4a, D7.4b, D7.4c und D7.4d im Internet).

\section{Beteiligung an beruflichen Fortbildungsmaßnahmen}

Der Anteil der Lehrkräfte, die an beruflichen Fortbildungsmaßnahmen teilnehmen, unterscheidet sich deutlich von Land zu Land. In den I4 Ländern mit verfügbaren Daten reicht er von Ioo Prozent in Belgien (frz.), Luxemburg, Österreich (Primarbereich, Neue Mittelschule und Hauptschule [Sekundarbereich I]), Schottland und der Türkei (Elementar- und Primarbereich) über mindestens 90 Prozent der Lehrkräfte in Estland (Primar- und Sekundarbereich I, Sekundarbereich II [allgemeinbildend]), Israel (Elementar- und Primarbereich sowie Sekundarbereich I), den Niederlanden und den Vereinigten Staaten (Primar- und Sekundarbereich) bis zu 24 Prozent der Lehrkräfte im Sekundarbereich II in Brasilien (Tab. D7.4a, D7.4b, D7.4c und D7.4d im Internet).

\section{Definitionen}

Unter beruflichen Fortbildungsmaßnahmen werden alle Aktivitäten verstanden, die dazu dienen, die Fähigkeiten und Kenntnisse sowie das Fachwissen und andere Merkmale einer Lehrkraft (bzw. allgemein gesprochen einer Fachkraft) zu entwickeln. Hierbei handelt es sich um formale Maßnahmen, z. B. um Kurse und Workshops, aber auch um die formalisierte Zusammenarbeit zwischen Lehrkräften und die Beteiligung an beruflichen Netzwerken. Berufliche Fortbildungsmaßnahmen beziehen sich also nicht auf die Alltagspraxis der Lehrkräfte, in der sie sich auch beruflich weiterentwickeln.

\section{Angewandte Methodik}

Die Daten stammen aus der OECD/INES-Erhebung: Survey on Developing Teacher's Knowledge and Skills aus dem Jahr 2013 und beziehen sich auf das Schuljahr 2012/2013.

Hinweise zu den für jedes Land verwendeten Definitionen und angewandten Methodiken s. Anhang 3 unter www.oecd.org/eduleag.htm.

Anmerkung zu den Daten aus Israel

Die statistischen Daten für Israel wurden von den zuständigen israelischen Stellen bereitgestellt, die für sie verantwortlich zeichnen. Die Verwendung dieser Daten durch die OECD erfolgt unbeschadet des völkerrechtlichen Status der Golanhöhen, von Ost-Jerusalem und der israelischen Siedlungen im Westjordanland. 


\section{Weiterführende Informationen}

Allensworth, E., S. Ponisciak and C. Mazzeo (2009), The Schools Teachers Leave: Teacher Mobility in Chicago Public Schools, Consortium on Chicago School Research, University of Chicago, Chicago.

Clotfelter, C. T., H. F. Ladd and J. L. Vigdor (2009), „How and why do teacher credentials matter for student achievement?", NBER Working Paper 12828, National Bureau of Economic Research, January 2007, www.nber.org/papers/w12828.

Ewing, R. A. and D. L. Smith (2003), „Retaining quality beginning teachers in the profession“, English Teaching: Practice and Critique, May 2003, Vol. 2, No. I, pp. 15-32, http:/l edlinked.soe.waikato.ac.nz/research/files/etpc/files/2003v2n1art2.pdf.

Headden, S. (2014), Beginners in the Classroom: What the Changing Demographics of Teaching Mean for Schools, Students, and Society, Carnegie Foundation for the Advancement of Teaching, March 20I4, www.carnegiefoundation.org/sites/default/files/beginners_in_ classroom.pdf.

Mueller, C. M. (2012), The Impact of Teacher Certification Programmes on Teacher Efficacy, Job Satisfaction, and Teacher Performance: A Comparison of Traditional and Alternative Certification, http://digitalcommons.wku.edu/diss/28.

OECD (2014), TALIS 2013 Results: An International Perspective on Teaching and Learning, TALIS, OECD Publishing, Paris, http:|/dx.doi.org/10.1787/9789264196261-en.

OECD (2006), Stärkere Professionalisierung des Lehrerberufs - Wie gute Lehrer gewonnen, gefördert und gehalten werden können, OECD Publishing, Paris, http:||dx.doi.org/10.1787| 9789264023673-de.

Rockoff, J. (2008), „Does mentoring reduce turnover and improve skills of new employees? Evidence from teachers in New York City“, NBER Working Paper 13868, National Bureau of Economic Research, March 2008, www.nber.org/papers/w13868.

Yoon, K.S., T. Duncan, S. W.-Y. Lee, B. Scarloss and K. Shapley (2007), „Reviewing the evidence on how teacher professional development affects student achievement", Issues \& Answers Report, REL 2007: No. 033, U.S. Department of Education, Institute of Education Sciences, National Center for Education Evaluation and Regional Assistance, Regional Educational Laboratory Southwest, Washington DC, http:||ies.ed.gov/ ncee/edlabs/regions/southwest/pdf/REL_2007033.pdf. 


\section{Tabellen Indikator D7}

StatLink: http://dx.doi.org/10.1787/888933120461

WEB Table D7.ra: Requirements for teachers' professional development, preprimary education (Berufliche Fortbildungsverpflichtungen für Lehrkräfte im Elementarbereich) (2013)

WEB Table D7.Ib: Requirements for teachers' professional development, primary education (Berufliche Fortbildungsverpflichtungen für Lehrkräfte im Primarbereich) (2013)

Tabelle 7.Ic: Berufliche Fortbildungsverpflichtungen für Lehrkräfte, Sekundarbereich I (2013)

WEB Table D7.Id: Requirements for teachers' professional development, upper secondary education (Berufliche Fortbildungsverpflichtungen für Lehrkräfte im Sekundarbereich II) (2013)

WEB Table D7.2a: Content of compulsory teachers' professional development activities, pre-primary education (Inhalt der obligatorischen beruflichen Fortbildungsmaßnahmen für Lehrkräfte, Elementarbereich) (2013)

WEB Table D7.2b: Content of compulsory teachers' professional development activities, primary education (Inhalt der obligatorischen beruflichen Fortbildungsmaßnahmen für Lehrkräfte, Primarbereich) (2013)

Tabelle D7.2c: Inhalt der obligatorischen beruflichen Fortbildungsmaßnahmen für Lehrkräfte, Sekundarbereich I (2013)

WEB Table D7.2d: Content of compulsory teachers' professional development activities, upper secondary education (Inhalt der obligatorischen beruflichen Fortbildungsmaßnahmen für Lehrkräfte, Sekundarbereich II) (2013)

WEB Table D7.3a: Non-compulsory teachers' professional development, preprimary education (Nicht obligatorische berufliche Fortbildung für Lehrkräfte, Elementarbereich) (2013)

WEB Table D7.3b: Non-compulsory teachers' professional development, primary education (Nicht obligatorische berufliche Fortbildung für Lehrkräfte, Primarbereich) (2013)

Tabelle D7.3c: Nicht obligatorische berufliche Fortbildung für Lehrkräfte, Sekundarbereich I (2013)

WEB Table D7.3d: Non-compulsory teachers' professional development, upper secondary education (Nicht obligatorische berufliche Fortbildung für Lehrkräfte, Sekundarbereich II) (2013) 
WEB Table D7.4a: Dissemination of teachers' professional development activities, pre-primary education (Verbreitung von Informationen zur beruflichen Fortbildung von Lehrkräften, Elementarbereich) (2013)

WEB Table D7.4b: Dissemination of teachers' professional development activities, primary education (Verbreitung von Informationen zur beruflichen Fortbildung für Lehrkräfte, Primarbereich) (2013)

WEB Table D7.4c: Dissemination of teachers' professional development activities, lower secondary education (Verbreitung von Informationen zur beruflichen Fortbildung für Lehrkräfte, Sekundarbereich I) (2013)

WEB Table D7.4d: Dissemination of teachers' professional development activities, upper secondary education (Verbreitung von Informationen zur beruflichen Fortbildung für Lehrkräfte, Sekundarbereich II) (2013) 
Berufliche Fortbildungsverpflichtungen für Lehrkräfte, Sekundarbereich I (2013) In öffentlichen Bildungseinrichtungen

\begin{tabular}{|c|c|c|c|c|c|}
\hline & Art der Fächer & Fortbildungsverpflichtungen & $\begin{array}{l}\text { Jahr der } \\
\text { Fest- } \\
\text { legung }\end{array}$ & $\begin{array}{l}\text { Geogra- } \\
\text { fischer } \\
\text { Geltungs- } \\
\text { bereich }\end{array}$ & $\begin{array}{c}\text { Mindestdauer der } \\
\text { obligatorischen beruflichen } \\
\text { Fortbildungsmaßnahme }\end{array}$ \\
\hline & & (1) & (2) & (3) & $(4)$ \\
\hline \multicolumn{6}{|l|}{ OECD-Länder } \\
\hline Australien & Alle & Obligatorisch für alle Lehrkräfte & $\mathrm{m}$ & $\mathrm{m}$ & $\mathrm{m}$ \\
\hline Österreich & $\begin{array}{l}\text { Alle }(\mathrm{AHS})^{1} \\
\text { Alle }(\mathrm{NMS}, \mathrm{HS})^{2}\end{array}$ & $\begin{array}{l}\text { Obligatorisch für alle Lehrkräfte } \\
\text { Obligatorisch für alle Lehrkräfte }\end{array}$ & $\begin{array}{l}2005 \\
1984\end{array}$ & $\begin{array}{l}\text { Landesweit } \\
\text { Landesweit }\end{array}$ & $\begin{array}{l}\text { a } \\
15 \text { Std. jedes Jahr }\end{array}$ \\
\hline Belgien (fläm.) & Alle & Sonstige & a & a & a \\
\hline Belgien (frz.) ${ }^{3}$ & Alle & Obligatorisch für alle Lehrkräfte & 2002 & Landesweit & 18 Std. jedes Jahr \\
\hline Kanada & $\mathrm{m}$ & $\mathrm{m}$ & m & $\mathrm{m}$ & $\mathrm{m}$ \\
\hline Chile & Alle & Obligatorisch für eine Beförderung oder Gehaltserhöhung & $\mathrm{m}$ & Landesweit & $\mathrm{m}$ \\
\hline Tschechien & Alle & Obligatorisch für alle Lehrkräfte & 2005 & Landesweit & $\mathrm{m}$ \\
\hline Dänemark & Alle & Keine Verpflichtung & a & a & a \\
\hline England & Alle & Obligatorisch für alle Lehrkräfte & 1998 & Landesweit & a \\
\hline Estland & Alle & Obligatorisch für alle Lehrkräfte & 2000 & Landesweit & 160 Std. alle 5 Jahre \\
\hline Finnland $^{3}$ & Alle & Obligatorisch für alle Lehrkräfte & $\mathrm{m}$ & Landesweit & 30 Std. jedes Jahr \\
\hline Frankreich & Alle & Keine Verpflichtung & a & a & a \\
\hline Deutschland & Alle & Obligatorisch für alle Lehrkräfte & $\mathrm{m}$ & Landesweit & a \\
\hline Griechenland & Alle & Obligatorisch für alle Lehrkräfte & 1985 & Landesweit & $\mathrm{m}$ \\
\hline Ungarn & Alle & Obligatorisch für alle Lehrkräfte & 1997 & Landesweit & 120 Std. alle 7 Jahre \\
\hline Island & Alle & Obligatorisch für alle Lehrkräfte & 2008 & Landesweit & 150 Std. jedes Jahr \\
\hline Irland & Alle & Keine Verpflichtung & a & a & a \\
\hline Israel & Alle & Obligatorisch für eine Beförderung oder Gehaltserhöhung & 2008 & Landesweit & 180-210 Std. alle 3 Jahre \\
\hline Italien & Alle & Keine Verpflichtung & a & a & a \\
\hline Japan & Alle & $\begin{array}{l}\text { Obligatorisch für alle Lehrkräfte } \\
\text { Obligatorisch für die Rezertifizierung }\end{array}$ & $\begin{array}{l}2002 \\
2009\end{array}$ & $\begin{array}{l}\text { Landesweit } \\
\text { Landesweit }\end{array}$ & $\begin{array}{l}231 \text { Std. } \\
30 \text { Std. alle } 10 \text { Jahre }\end{array}$ \\
\hline Korea & Alle & Obligatorisch für eine Beförderung oder Gehaltserhöhung & 1972 & Landesweit & 90 Std. \\
\hline Luxemburg & Alle & Obligatorisch für alle Lehrkräfte & 2007 & Landesweit & 8 Std. jedes Jahr \\
\hline Mexiko & $\begin{array}{l}\text { Allgemeinbildend } \\
\text { Berufsbildend }\end{array}$ & $\begin{array}{l}\text { Obligatorisch für eine Beförderung oder Gehaltserhöhung } \\
\text { Keine Verpflichtung }\end{array}$ & $\begin{array}{l}1993 \\
a\end{array}$ & $\begin{array}{l}\text { Landesweit } \\
\text { a }\end{array}$ & $\begin{array}{l}78 \text { Std. jedes Jahr } \\
\text { a }\end{array}$ \\
\hline Niederlande & Alle & Sonstige & a & a & a \\
\hline Neuseeland & Alle & $\mathrm{m}$ & $\mathrm{m}$ & $\mathrm{m}$ & $\mathrm{m}$ \\
\hline Norwegen & Alle & Keine Verpflichtung & a & a & a \\
\hline Polen & Alle & Obligatorisch für eine Beförderung oder Gehaltserhöhung & 1999 & Landesweit & a \\
\hline Portugal & Alle & Obligatorisch für eine Beförderung oder Gehaltserhöhung & 2012 & Landesweit & 25 Std. alle 2 Jahre \\
\hline Schottland & Alle & Obligatorisch für alle Lehrkräfte & 2000 & Landesweit & 35 Std. jedes Jahr \\
\hline Slowakei ${ }^{3}$ & Alle & Obligatorisch für eine Beförderung oder Gehaltserhöhung & 2009 & Landesweit & 300 Std. \\
\hline Slowenien & Alle & Obligatorisch für alle Lehrkräfte & 2004 & Landesweit & $\mathrm{m}$ \\
\hline Spanien $^{3}$ & Alle & Obligatorisch für eine Beförderung oder Gehaltserhöhung & 2011 & Landesweit & 250-300 Std. alle 6 Jahre \\
\hline Schweden & Alle & Keine Verpflichtung & a & a & a \\
\hline Schweiz & Alle & $\mathrm{m}$ & $\mathrm{m}$ & $\mathrm{m}$ & $\mathrm{m}$ \\
\hline Türkei & Alle & Obligatorisch für alle Lehrkräfte & 1960 & Landesweit & 30 Std. jedes Jahr \\
\hline $\begin{array}{l}\text { Vereinigte Staaten } \\
\text { Partnerländer }\end{array}$ & Alle & $\mathrm{m}$ & $\mathrm{m}$ & $\mathrm{m}$ & $\mathrm{m}$ \\
\hline Brasilien & Alle & $\mathrm{m}$ & $\mathrm{m}$ & $\mathrm{m}$ & $\mathrm{m}$ \\
\hline Russische Föd. & Alle & Obligatorisch für alle Lehrkräfte & $\mathrm{m}$ & Landesweit & a \\
\hline
\end{tabular}

Rolle bei der Entscheidung über berufliche Fortbildung

Vollständig autonome Entscheidung (AE)

Vorschlag von Maßnahmen (VM)

Validierung der Auswahl (VA)

Sonstige (S)

Keine Beteiligung $(K B)$

Anmerkung: In föderalen Staaten bzw. Ländern mit stark dezentralen Schulsystemen kann es in den einzelnen Bundesstaaten, Provinzen oder Regionen unterschiedliche Vorschriften geben. Weitere Informationen s. Anhang 3.

1. „(AHS) “ steht für Allgemein bildende höhere Schulen, Unterstufe. 2. „(NMS, HS) “ steht für Neue Mittelschulen und Hauptschulen. 3. Die Mindestdauer in Stunden ist geschätzt aufgrund der Verpflichtungen, d.h. der Zahl an Tagen, Wochen oder Leistungspunkten, in einer anderen Bezugsgröße in Bezug auf Spalte (4). Hinweise s. Anhang 3 unter www.oecd.org/edu/eag.htm.

Quelle: OECD. Hinweise s. Anhang 3 unter www.oecd.org/edu/eag.htm. StatLink: http://dx.doi.org/10.1787/888933120480

Erläuterung der Kennzeichnung fehlender Daten s. Hinweise für den Leser. 
Berufliche Fortbildungsverpflichtungen für Lehrkräfte, Sekundarbereich I (2013)

In öffentlichen Bildungseinrichtungen

\begin{tabular}{|c|c|c|c|c|c|c|c|c|c|c|c|c|}
\hline & \multirow[t]{2}{*}{ Art der Fächer } & \multicolumn{6}{|c|}{$\begin{array}{l}\text { Wer entscheidet über die beruflichen } \\
\text { Fortbildungsmaßnahmen einzelner Lehrkräfte? }\end{array}$} & \multicolumn{5}{|c|}{$\begin{array}{l}\text { Strategien zu Finanzierung und Förderung } \\
\text { von beruflicher Fortbildung }\end{array}$} \\
\hline & & 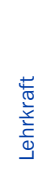 & $\begin{array}{l}\text { on } \\
\frac{1}{3} \\
\frac{+}{0} \\
\overline{\bar{J}} \\
\frac{0}{0} \\
\infty\end{array}$ & 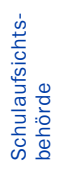 & 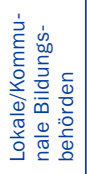 & 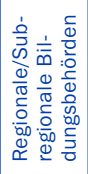 & 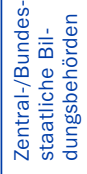 & 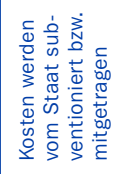 & 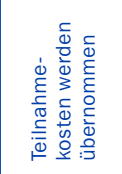 & 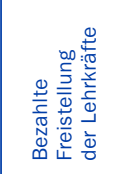 & 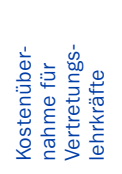 & 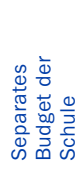 \\
\hline & & (5) & (6) & (7) & (8) & (9) & (10) & (11) & (12) & (13) & (14) & (15) \\
\hline \multicolumn{13}{|l|}{ OECD-Länder } \\
\hline Australien & Alle & $\mathrm{m}$ & $\mathrm{m}$ & a & a & $\mathrm{m}$ & $\mathrm{m}$ & $m$ & $m$ & $m$ & $\mathrm{~m}$ & $\mathrm{~m}$ \\
\hline Österreich & $\begin{array}{l}\text { Alle }(\mathrm{AHS})^{1} \\
\text { Alle }(\mathrm{NMS}, \mathrm{HS})^{2}\end{array}$ & $\begin{array}{l}\text { VM } \\
\text { VM }\end{array}$ & $\begin{array}{l}\mathrm{AE} \\
\mathrm{AE}\end{array}$ & $\begin{array}{l}\mathrm{AE} \\
\mathrm{AE}\end{array}$ & $\begin{array}{l}K B \\
K B\end{array}$ & $\begin{array}{l}\mathrm{a} \\
\mathrm{a}\end{array}$ & $\begin{array}{l}K B \\
K B\end{array}$ & $\begin{array}{l}\text { Vollständig } \\
\text { Vollständig }\end{array}$ & $\begin{array}{l}\text { Vollständig } \\
\text { Vollständig }\end{array}$ & $\begin{array}{l}\text { Häufig } \\
\text { Häufig }\end{array}$ & $\begin{array}{l}\text { Immer } \\
\text { Immer }\end{array}$ & $\begin{array}{l}\text { Nein } \\
\text { Nein }\end{array}$ \\
\hline Belgien (fläm.) & Alle & a & a & a & a & a & a & $a$ & $a$ & $a$ & a & a \\
\hline Belgien (frz.) ${ }^{3}$ & Alle & VM & VA & $\mathrm{KB}$ & $\mathrm{KB}$ & $\mathrm{KB}$ & $\mathrm{KB}$ & Vollständig & Vollständig & Manchmal & $a$ & Nein \\
\hline Kanada & $m$ & $\mathrm{~m}$ & $\mathrm{~m}$ & $\mathrm{~m}$ & $m$ & $\mathrm{~m}$ & $m$ & $m$ & $m$ & $m$ & $\mathrm{~m}$ & $\mathrm{~m}$ \\
\hline Chile & Alle & $\mathrm{AE}$ & VM & a & VM & a & VM & Teilweise & $\mathrm{Nie}$ & Manchmal & $\mathrm{m}$ & Ja \\
\hline Tschechien & Alle & VM & $\mathrm{AE}$ & $\mathrm{KB}$ & $\mathrm{KB}$ & $\mathrm{KB}$ & $\mathrm{KB}$ & Vollständig & Teilweise & Manchmal & Häufig & $\mathrm{Ja}$ \\
\hline Dänemark & Alle & $a$ & a & a & a & $a$ & a & $a$ & $a$ & $a$ & a & a \\
\hline England & Alle & VM & VM & VM & $\mathrm{KB}$ & a & $\mathrm{KB}$ & $a$ & a & a & $a$ & a \\
\hline Estland & Alle & VM & VA & a & VM & a & $\mathrm{KB}$ & Vollständig & Vollständig & Häufig & Häufig & $\mathrm{Ja}$ \\
\hline Finnland $^{3}$ & Alle & VM & VA & a & a & $\mathrm{KB}$ & $\mathrm{KB}$ & Vollständig & Vollständig & $m$ & $m$ & $\mathrm{~m}$ \\
\hline Frankreich & Alle & $a$ & a & a & a & a & a & $a$ & $a$ & $a$ & a & a \\
\hline Deutschland & Alle & $\mathrm{AE}$ & VA & $\mathrm{KB}$ & $\mathrm{KB}$ & $\mathrm{KB}$ & $\mathrm{KB}$ & Vollständig & Vollständig & Immer & Immer & Ja \\
\hline Griechenland & Alle & VM & VM & $\mathrm{AE}$ & $\mathrm{KB}$ & $A E$ & $\mathrm{AE}$ & Vollständig & Vollständig & Häufig & Immer & Nein \\
\hline Ungarn & Alle & VM & $\mathrm{AE}$ & a & VA & $\mathrm{KB}$ & $\mathrm{KB}$ & Teilweise & Teilweise & Manchmal & $a$ & $\mathrm{~m}$ \\
\hline Island & Alle & $\mathrm{AE}$ & VM & a & $\mathrm{KB}$ & a & $\mathrm{KB}$ & Vollständig & Vollständig & Häufig & Immer & $\mathrm{Ja}$ \\
\hline Irland & Alle & $a$ & a & a & a & a & a & $a$ & a & $a$ & a & a \\
\hline Israel & Alle & VM & VA & $\mathrm{KB}$ & S & $\mathrm{KB}$ & $\mathrm{KB}$ & Vollständig & Vollständig & Manchmal & Immer & Nein \\
\hline Italien & Alle & $a$ & a & a & a & a & a & $a$ & $a$ & a & a & a \\
\hline Japan & Alle & $\begin{array}{l}\text { VM } \\
\text { VM }\end{array}$ & $\begin{array}{l}\text { VM } \\
\text { VM }\end{array}$ & $\begin{array}{l}\mathrm{a} \\
\mathrm{a}\end{array}$ & $\begin{array}{l}\text { VA } \\
\text { VA }\end{array}$ & $\begin{array}{l}\text { VA } \\
\text { VA }\end{array}$ & $\begin{array}{l}\text { VA } \\
\text { VA }\end{array}$ & $\begin{array}{l}\text { Teilweise } \\
\text { Teilweise }\end{array}$ & $\begin{array}{l}\text { Teilweise } \\
\text { Nie }\end{array}$ & $\begin{array}{l}\mathrm{Nie} \\
\mathrm{Nie}\end{array}$ & $\begin{array}{l}\text { Manchmal } \\
\mathrm{Nie}\end{array}$ & $\begin{array}{l}\mathrm{Ja} \\
\mathrm{Ja}\end{array}$ \\
\hline Korea & Alle & VM & $\mathrm{KB}$ & $\mathrm{KB}$ & $\mathrm{KB}$ & $\mathrm{AE}$ & $\mathrm{AE}$ & Teilweise & Vollständig & Manchmal & Immer & Nein \\
\hline Luxemburg & Alle & $\mathrm{AE}$ & $\mathrm{KB}$ & $\mathrm{KB}$ & $\mathrm{KB}$ & $\mathrm{KB}$ & VA & Vollständig & Vollständig & Häufig & Immer & Nein \\
\hline Mexiko & $\begin{array}{l}\text { Allgemeinbildend } \\
\text { Berufsbildend }\end{array}$ & $\begin{array}{l}\mathrm{AE} \\
\mathrm{a}\end{array}$ & $\begin{array}{l}\mathrm{KB} \\
\mathrm{a}\end{array}$ & $\begin{array}{l}\mathrm{KB} \\
\mathrm{a}\end{array}$ & $\begin{array}{l}\mathrm{KB} \\
\mathrm{a}\end{array}$ & $\begin{array}{l}\mathrm{KB} \\
\mathrm{a}\end{array}$ & $\begin{array}{l}\mathrm{AE} \\
\mathrm{a}\end{array}$ & $\begin{array}{l}\text { Vollständig } \\
\text { a }\end{array}$ & $\begin{array}{l}\text { Vollständig } \\
\text { a }\end{array}$ & $\begin{array}{l}a \\
a\end{array}$ & $\begin{array}{l}\text { Häufig } \\
\text { a }\end{array}$ & $\begin{array}{l}\text { Nein } \\
a\end{array}$ \\
\hline Niederlande & Alle & $a$ & a & a & a & $\mathrm{a}$ & a & $a$ & $a$ & $a$ & a & a \\
\hline Neuseeland & Alle & $\mathrm{m}$ & $\mathrm{m}$ & $m$ & $\mathrm{~m}$ & $\mathrm{~m}$ & $\mathrm{~m}$ & $m$ & $m$ & $m$ & $m$ & $\mathrm{~m}$ \\
\hline Norwegen & Alle & $a$ & a & a & a & a & a & $a$ & $a$ & a & $a$ & a \\
\hline Polen & Alle & VM & VA & VM & VA & VM & VM & Teilweise & Teilweise & Manchmal & Manchmal & Nein \\
\hline Portugal & Alle & $\mathrm{KB}$ & $\mathrm{AE}$ & $\mathrm{KB}$ & $\mathrm{KB}$ & $\mathrm{KB}$ & $\mathrm{KB}$ & Vollständig & Vollständig & $a$ & $a$ & Nein \\
\hline Schottland & Alle & VM & VM & $\mathrm{KB}$ & VM & a & $\mathrm{KB}$ & $m$ & $m$ & $m$ & $m$ & $\mathrm{~m}$ \\
\hline Slowakei ${ }^{3}$ & Alle & $\mathrm{AE}$ & VM & $\mathrm{KB}$ & $\mathrm{KB}$ & $\mathrm{KB}$ & $\mathrm{KB}$ & Teilweise & Teilweise & Häufig & Manchmal & $\mathrm{Ja}$ \\
\hline Slowenien & Alle & VM & VA & $\mathrm{KB}$ & a & a & $\mathrm{AE}$ & Teilweise & Teilweise & Immer & Immer & $\mathrm{Ja}$ \\
\hline Spanien $^{3}$ & Alle & $\mathrm{AE}$ & $\mathrm{KB}$ & $\mathrm{KB}$ & $\mathrm{KB}$ & VM & $\mathrm{KB}$ & Vollständig & Vollständig & Nie & $\mathrm{Nie}$ & Nein \\
\hline Schweden & Alle & $a$ & a & a & a & a & a & $a$ & $a$ & $a$ & a & a \\
\hline Schweiz & Alle & $\mathrm{m}$ & $\mathrm{m}$ & $\mathrm{m}$ & $\mathrm{m}$ & $\mathrm{m}$ & $\mathrm{m}$ & $m$ & $m$ & $m$ & $\mathrm{~m}$ & $\mathrm{~m}$ \\
\hline Türkei & Alle & VM & VA & VM & VM & $\mathrm{AE}$ & $\mathrm{AE}$ & Vollständig & Vollständig & a & a & Nein \\
\hline $\begin{array}{l}\text { Vereinigte Staaten } \\
\text { Partnerländer }\end{array}$ & Alle & $\mathrm{m}$ & $\mathrm{m}$ & $\mathrm{m}$ & $\mathrm{m}$ & $\mathrm{m}$ & $\mathrm{m}$ & $m$ & $m$ & Manchmal & Manchmal & $\mathrm{m}$ \\
\hline Brasilien & Alle & $\mathrm{m}$ & $\mathrm{m}$ & $\mathrm{m}$ & $\mathrm{m}$ & $\mathrm{m}$ & $\mathrm{m}$ & $\mathrm{m}$ & $\mathrm{m}$ & $m$ & $\mathrm{~m}$ & $\mathrm{~m}$ \\
\hline Russische Föd. & Alle & VM & $\mathrm{AE}$ & $\mathrm{KB}$ & $\mathrm{KB}$ & VA & $\mathrm{KB}$ & Teilweise & Teilweise & Immer & Immer & $\mathrm{Ja}$ \\
\hline
\end{tabular}

Rolle bei der Entscheidung über berufliche Fortbildung

Vollständig autonome Entscheidung (AE)

Vorschlag von Maßnahmen (VM)

Validierung der Auswahl (VA)

Sonstige (S)

Keine Beteiligung (KB)

Anmerkung: In föderalen Staaten bzw. Ländern mit stark dezentralen Schulsystemen kann es in den einzelnen Bundesstaaten, Provinzen oder Regionen unterschiedliche Vorschriften geben. Weitere Informationen s. Anhang 3.

1. „(AHS) “ steht für Allgemein bildende höhere Schulen, Unterstufe. 2. „(NMS, HS)“ steht für Neue Mittelschulen und Hauptschulen. 3. Die Mindestdauer in Stunden ist geschätzt aufgrund der Verpflichtungen, d.h. der Zahl an Tagen, Wochen oder Leistungspunkten, in einer anderen Bezugsgröße in Bezug auf Spalte (4). Hinweise s. Anhang 3 unter www.oecd.org/edu/eag.htm.

Quelle: OECD. Hinweise s. Anhang 3 unter www.oecd.org/edu/eag.htm. StatLink: http://dx.doi.org/10.1787/888933120480

Erläuterung der Kennzeichnung fehlender Daten s. Hinweise für den Leser. 
Inhalt der obligatorischen beruflichen Fortbildungsmaßnahmen für Lehrkräfte, Sekundarbereich I (2013) In öffentlichen Bildungseinrichtungen

\begin{tabular}{|c|c|c|c|c|}
\hline & Art der Fächer & Fortbildungsverpflichtungen & Fortbildungsplanung & $\begin{array}{c}\text { Fortbildungsmaßnahmen } \\
\text { im Hinblick auf die } \\
\text { jeweiligen Schulent- } \\
\text { wicklungsschwerpunkte } \\
\text { geplant }\end{array}$ \\
\hline & & (1) & $(2)$ & (3) \\
\hline \multicolumn{5}{|l|}{ OECD-Länder } \\
\hline Australien & Alle & Obligatorisch für alle Lehrkräfte & $\mathrm{m}$ & $\mathrm{m}$ \\
\hline Österreich & $\begin{array}{l}\text { Alle (AHS) } \\
\text { Alle (NMS, HS) }{ }^{2}\end{array}$ & $\begin{array}{l}\text { Obligatorisch für alle Lehrkräfte } \\
\text { Obligatorisch für alle Lehrkräfte }\end{array}$ & $\begin{array}{l}\text { Keine Planung } \\
\text { Keine Planung }\end{array}$ & $\begin{array}{l}\text { Ja, aber nicht ausschließlich } \\
\text { Ja, aber nicht ausschließlich }\end{array}$ \\
\hline Belgien (fläm.) & Alle & Sonstige & a & a \\
\hline Belgien (frz.) & Alle & Obligatorisch für alle Lehrkräfte & Planung der Schule u. Lehrkraft & Ja, aber nicht ausschließlich \\
\hline Kanada & m & $\mathrm{m}$ & $\mathrm{m}$ & $\mathrm{m}$ \\
\hline Chile & Alle & Obligatorisch für eine Beförderung oder Gehaltserhöhung & $\mathrm{m}$ & Ja, aber nicht ausschließlich \\
\hline Tschechien & Alle & Obligatorisch für alle Lehrkräfte & Planung der Schule & Ja, auschließlich \\
\hline Dänemark & Alle & Keine Verpflichtung & a & $a$ \\
\hline England & Alle & Obligatorisch für alle Lehrkräfte & Planung der Schule u. Lehrkraft & Ja, aber nicht ausschließlich \\
\hline Estland & Alle & Obligatorisch für alle Lehrkräfte & Planung der Lehrkraft & Ja, aber nicht ausschließlich \\
\hline Finnland & Alle & Obligatorisch für alle Lehrkräfte & Keine Planung & $\mathrm{m}$ \\
\hline Frankreich & Alle & Keine Verpflichtung & a & a \\
\hline Deutschland & Alle & Obligatorisch für alle Lehrkräfte & Keine Planung & Ja, aber nicht ausschließlich \\
\hline Griechenland & Alle & Obligatorisch für alle Lehrkräfte & Planung der Schule & Ja, aber nicht ausschließlich \\
\hline Ungarn & Alle & Obligatorisch für alle Lehrkräfte & Planung der Schule & Ja, aber nicht ausschließlich \\
\hline Island & Alle & Obligatorisch für alle Lehrkräfte & Planung der Schule & Ja, aber nicht ausschließlich \\
\hline Irland & Alle & Keine Verpflichtung & a & a \\
\hline Israel & Alle & Obligatorisch für eine Beförderung oder Gehaltserhöhung & Planung der Schule u. Lehrkraft & Ja, aber nicht ausschließlich \\
\hline Italien & Alle & Keine Verpflichtung & a & a \\
\hline Japan & Alle & $\begin{array}{l}\text { Obligatorisch für alle Lehrkräfte } \\
\text { Obligatorisch für die Erneuerung der Lehrerlaubnis }\end{array}$ & $\begin{array}{l}\text { Planung der Schule u. Lehrkraft } \\
\text { Planung der Schule u. Lehrkraft }\end{array}$ & $\begin{array}{l}\text { Ja, auschließlich } \\
\text { Ja, auschließlich }\end{array}$ \\
\hline Korea & Alle & Obligatorisch für eine Beförderung oder Gehaltserhöhung & Planung der Schule u. Lehrkraft & Nein \\
\hline Luxemburg & Alle & Obligatorisch für alle Lehrkräfte & Keine Planung & Nein \\
\hline Mexiko & $\begin{array}{l}\text { Allgemeinbildend } \\
\text { Berufsbildend }\end{array}$ & $\begin{array}{l}\text { Obligatorisch für eine Beförderung oder Gehaltserhöhung } \\
\text { Keine Verpflichtung }\end{array}$ & $\begin{array}{l}\text { Planung der Schule u. Lehrkraft } \\
\text { a }\end{array}$ & $\begin{array}{l}\text { Nein } \\
\text { a }\end{array}$ \\
\hline Niederlande & Alle & Sonstige & a & a \\
\hline Neuseeland & $\mathrm{m}$ & $\mathrm{m}$ & $\mathrm{m}$ & $\mathrm{m}$ \\
\hline Norwegen & Alle & Keine Verpflichtung & a & a \\
\hline Polen & Alle & Obligatorisch für eine Beförderung oder Gehaltserhöhung & Planung der Schule u. Lehrkraft & Ja, aber nicht ausschließlich \\
\hline Portugal & Alle & Obligatorisch für eine Beförderung oder Gehaltserhöhung & Planung der Schule u. Lehrkraft & Ja, aber nicht ausschließlich \\
\hline Schottland & Alle & Obligatorisch für alle Lehrkräfte & Planung der Lehrkraft & Ja, aber nicht ausschließlich \\
\hline Slowakei & Alle & Obligatorisch für eine Beförderung oder Gehaltserhöhung & Planung der Schule u. Lehrkraft & Ja, auschließlich \\
\hline Slowenien & Alle & Obligatorisch für alle Lehrkräfte & Planung der Schule u. Lehrkraft & Ja, aber nicht ausschließlich \\
\hline Spanien & Alle & Obligatorisch für eine Beförderung oder Gehaltserhöhung & Keine Planung & Nein \\
\hline Schweden & Alle & Keine Verpflichtung & a & $a$ \\
\hline Schweiz & Alle & $\mathrm{m}$ & $\mathrm{m}$ & $\mathrm{m}$ \\
\hline Türkei & Alle & Obligatorisch für alle Lehrkräfte & Planung der Lehrkraft & Ja, aber nicht ausschließlich \\
\hline $\begin{array}{l}\text { Ver. Staaten } \\
\text { Partnerländer }\end{array}$ & Alle & $\mathrm{m}$ & $\mathrm{m}$ & Ja, aber nicht ausschließlich \\
\hline Brasilien & Alle & $\mathrm{m}$ & $\mathrm{m}$ & $m$ \\
\hline Russische Föd. & Alle & Obligatorisch für alle Lehrkräfte & Planung der Schule & Ja, auschließlich \\
\hline
\end{tabular}

Anmerkung: Die einzelnen Spalten mit den Angaben, wer die Standards/Themenbereiche für die berufliche Fortbildung festlegt, also Universitäten, Schulen oder sonstige Bildungseinrichtungen, d.h. die Spalten (6) bis (8), Lehrerverbände oder Lehrergewerkschaften, d.h. die Spalten (10) und (11), lokale/kommunale, regionale/subregionale bzw. zentral-/bundesstaatliche Bildungsbehörden, d.h. die Spalten (13) bis (15), Schulaufsichtsbehörde oder Sonstige, d.h. die Spalten (17) und (18), sind im Internet verfügbar (s. StatLink unten). In föderalen Staaten bzw. Ländern mit stark dezentralen Schulsystemen kann es in den einzelnen Bundesstaaten, Provinzen oder Regionen unterschiedliche Vorschriften geben. Weitere Informationen s. Anhang 3.

1. „(AHS) “ steht für Allgemein bildende höhere Schulen, Unterstufe. 2. „(NMS, HS) “ steht für Neue Mittelschulen und Hauptschulen.

Quelle: OECD. Hinweise s. Anhang 3 unter www.oecd.org/edu/eag.htm. StatLink: http://dx.doi.org/10.1787/888933120499

Erläuterung der Kennzeichnung fehlender Daten s. Hinweise für den Leser. 
Tabelle D7.2c (Forts.)

Inhalt der obligatorischen beruflichen Fortbildungsmaßnahmen für Lehrkräfte, Sekundarbereich I (2013) In öffentlichen Bildungseinrichtungen

\begin{tabular}{|c|c|c|c|c|c|c|}
\hline & \multirow[t]{3}{*}{ Art der Fächer } & \multirow[t]{2}{*}{ Inhalt der beruflichen Fortbildungsmaßnahmen spezifiziert } & \multicolumn{4}{|c|}{$\begin{array}{l}\text { Wer legt die Standards und/oder } \\
\text { Themenkomplexe für die beruflichen } \\
\text { Fortbildungsmaßnahmen fest? }\end{array}$} \\
\hline & & & 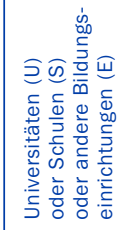 & 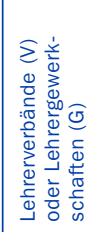 & 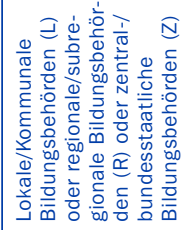 & 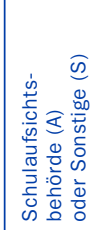 \\
\hline & & (4) & (5) & (9) & $(12)$ & $(16)$ \\
\hline \multicolumn{7}{|l|}{ OECD-Länder } \\
\hline Australien & Alle & $\mathrm{m}$ & $\mathrm{m}$ & $\mathrm{m}$ & $\mathrm{m}$ & $\mathrm{m}$ \\
\hline Österreich & $\begin{array}{l}\text { Alle }(\mathrm{AHS})^{1} \\
\text { Alle }(\mathrm{NMS}, \mathrm{HS})^{2}\end{array}$ & $\begin{array}{l}\text { Inhalt nicht spezifiziert } \\
\text { Inhalt nicht spezifiziert }\end{array}$ & a & a & $\begin{array}{l}\mathrm{a} \\
\mathrm{a}\end{array}$ & a \\
\hline Belgien (fläm.) & Alle & a & a & a & a & a \\
\hline Belgien (frz.) & Alle & Im Einklang mit eingeführten Standards, Inhalt aber nicht spezifiziert & Nein & Nein & Z & Nein \\
\hline Kanada & $\mathrm{m}$ & $\mathrm{m}$ & $\mathrm{m}$ & $\mathrm{m}$ & $\mathrm{m}$ & $\mathrm{m}$ \\
\hline Chile & Alle & Im Einklang mit eingeführten Standards, Inhalt aber nicht spezifiziert & Nein & Nein & Nein & S \\
\hline Tschechien & Alle & Inhalt nicht spezifiziert & a & a & a & a \\
\hline Dänemark & Alle & a & a & a & a & a \\
\hline England & Alle & Im Einklang mit eingeführten Standards, Inhalt aber nicht spezifiziert & Nein & Nein & $z$ & Nein \\
\hline Estland & Alle & Inhalt nicht spezifiziert & a & a & a & a \\
\hline Finnland & Alle & Inhalt nicht spezifiziert & a & a & $a$ & $a$ \\
\hline Frankreich & Alle & $a$ & a & $a$ & a & a \\
\hline Deutschland & Alle & Inhalt nicht spezifiziert & $a$ & a & $a$ & a \\
\hline Griechenland & Alle & Im Einklang mit eingeführten Standards, Inhalt aber nicht spezifiziert & E & Nein & $\mathrm{R}, \mathrm{Z}$ & A \\
\hline Ungarn & Alle & Inhalt nicht spezifiziert & a & a & a & a \\
\hline Island & Alle & Inhalt nicht spezifiziert & a & a & a & a \\
\hline Irland & Alle & a & a & a & a & a \\
\hline Israel & Alle & Berufliche Fortbildung in bestimmten Themenbereichen obligatorisch & $\mathrm{U}, \mathrm{S}, \mathrm{E}$ & V, G & Z & A \\
\hline Italien & Alle & a & a & a & a & a \\
\hline Japan & Alle & $\begin{array}{l}\text { Inhalt nicht spezifiziert } \\
\text { Inhalt nicht spezifiziert }\end{array}$ & a & a & a & a \\
\hline Korea & Alle & Im Einklang mit eingeführten Standards, Inhalt aber nicht spezifiziert & Nein & Nein & R, Z & Nein \\
\hline Luxemburg & Alle & Inhalt nicht spezifiziert & a & a & a & a \\
\hline Mexiko & $\begin{array}{l}\text { Allgemeinbildend } \\
\text { Berufsbildend }\end{array}$ & $\begin{array}{l}\text { Berufliche Fortbildung in bestimmten Themenbereichen obligatorisch } \\
\text { a }\end{array}$ & $\begin{array}{l}\text { Nein } \\
\text { a }\end{array}$ & $\begin{array}{l}\text { Nein } \\
\text { a }\end{array}$ & $\begin{array}{l}Z \\
a\end{array}$ & $\begin{array}{l}\text { Nein } \\
\text { a }\end{array}$ \\
\hline Niederlande & Alle & a & a & a & a & a \\
\hline Neuseeland & $\mathrm{m}$ & $\mathrm{m}$ & $\mathrm{m}$ & $\mathrm{m}$ & $\mathrm{m}$ & $\mathrm{m}$ \\
\hline Norwegen & Alle & a & a & a & a & a \\
\hline Polen & Alle & Inhalt nicht spezifiziert & a & a & a & a \\
\hline Portugal & Alle & Berufliche Fortbildung in bestimmten Themenbereichen obligatorisch & U, S & V, G & Z & Nein \\
\hline Schottland & Alle & Inhalt nicht spezifiziert & a & a & a & a \\
\hline Slowakei & Alle & Berufliche Fortbildung in bestimmten Themenbereichen obligatorisch & Nein & Nein & Z & Nein \\
\hline Slowenien & Alle & Berufliche Fortbildung in bestimmten Themenbereichen obligatorisch & U, S & Nein & Z & Nein \\
\hline Spanien & Alle & Berufliche Fortbildung in bestimmten Themenbereichen obligatorisch & Nein & Nein & Z & Nein \\
\hline Schweden & Alle & a & a & a & a & a \\
\hline Schweiz & Alle & $\mathrm{m}$ & $\mathrm{m}$ & $\mathrm{m}$ & $\mathrm{m}$ & $\mathrm{m}$ \\
\hline Türkei & Alle & Berufliche Fortbildung in bestimmten Themenbereichen obligatorisch & U & Nein & $\mathrm{R}, \mathrm{Z}$ & A \\
\hline $\begin{array}{l}\text { Ver. Staaten } \\
\text { Partnerländer }\end{array}$ & Alle & $\mathrm{m}$ & $\mathrm{m}$ & $\mathrm{m}$ & $\mathrm{m}$ & $\mathrm{m}$ \\
\hline Brasilien & Alle & $\mathrm{m}$ & $m$ & $\mathrm{~m}$ & $\mathrm{~m}$ & $\mathrm{~m}$ \\
\hline Russische Föd. & Alle & Im Einklang mit eingeführten Standards, Inhalt aber nicht spezifiziert & U, S & Nein & $\mathrm{R}, \mathrm{Z}$ & Nein \\
\hline
\end{tabular}

Anmerkung: Die einzelnen Spalten mit den Angaben, wer die Standards/Themenbereiche für die berufliche Fortbildung festlegt, also Universitäten, Schulen oder sonstige Bildungseinrichtungen, d.h. die Spalten (6) bis (8), Lehrerverbände oder Lehrergewerkschaften, d.h. die Spalten (10) und (11), lokale/kommunale, regionale/subregionale bzw. zentral-/bundesstaatliche Bildungsbehörden, d.h. die Spalten (13) bis (15), Schulaufsichtsbehörde oder Sonstige, d.h. die Spalten (17) und (18), sind im Internet verfügbar (s. StatLink unten). In föderalen Staaten bzw. Ländern mit stark dezentralen Schulsystemen kann es in den einzelnen Bundesstaaten, Provinzen oder Regionen unterschiedliche Vorschriften geben. Weitere Informationen s. Anhang 3.

1. „(AHS) “ steht für Allgemein bildende höhere Schulen, Unterstufe. 2. „(NMS, HS)“ steht für Neue Mittelschulen und Hauptschulen.

Quelle: OECD. Hinweise s. Anhang 3 unter www.oecd.org/edu/eag.htm. StatLink: http://dx.doi.org/10.1787/888933120499

Erläuterung der Kennzeichnung fehlender Daten s. Hinweise für den Leser. 


\section{Tabelle D7.3c}

Nicht obligatorische berufliche Fortbildung für Lehrkräfte, Sekundarbereich I (2013)

In öffentlichen Bildungseinrichtungen

\begin{tabular}{|c|c|c|c|c|c|c|c|c|}
\hline & \multirow[t]{3}{*}{ Art der Fächer } & \multicolumn{7}{|c|}{ Wer entscheidet über die obligatorischen beruflichen Fortbildungsmaßnahmen einzelner Lehrkräfte? } \\
\hline & & \multirow{2}{*}{$\begin{array}{l}\text { Lehrkraft } \\
\text { (1) }\end{array}$} & \multirow{2}{*}{$\begin{array}{c}\text { Schulleitung } \\
\text { (2) }\end{array}$} & \multirow{2}{*}{$\begin{array}{l}\text { Schulaufsichts- } \\
\text { behörde }\end{array}$} & \multirow{2}{*}{$\begin{array}{c}\text { Lokale/ } \\
\text { Kommunale } \\
\begin{array}{c}\text { Bildungs- } \\
\text { behörden }\end{array} \\
\text { (4) }\end{array}$} & \multirow{2}{*}{$\begin{array}{c}\text { Regionale/ } \\
\text { Subregionale } \\
\text { Bildungs- } \\
\text { behörden }\end{array}$} & \multirow{2}{*}{$\begin{array}{c}\text { Zentral-/ } \\
\begin{array}{c}\text { Bundesstaat- } \\
\text { liche Bildungs- } \\
\text { behörden }\end{array} \\
\text { (6) }\end{array}$} & \multirow{2}{*}{$\begin{array}{c}\text { Sonstige } \\
\text { (7) }\end{array}$} \\
\hline & & & & & & & & \\
\hline \multicolumn{9}{|l|}{ OECD-Länder } \\
\hline Australien & Alle & $\mathrm{m}$ & $\mathrm{m}$ & a & a & $\mathrm{m}$ & $\mathrm{m}$ & $\mathrm{m}$ \\
\hline Österreich & $\begin{array}{l}\text { Alle }(\mathrm{AHS})^{1} \\
\text { Alle }(\mathrm{NMS}, \mathrm{HS})^{2}\end{array}$ & $\begin{array}{l}\text { VM } \\
\text { VM }\end{array}$ & $\begin{array}{l}A E \\
A E\end{array}$ & $\begin{array}{l}A E \\
A E\end{array}$ & $\begin{array}{l}K B \\
K B\end{array}$ & $\begin{array}{l}\mathrm{a} \\
\mathrm{a}\end{array}$ & $\begin{array}{l}K B \\
K B\end{array}$ & $\begin{array}{l}\mathrm{a} \\
\mathrm{a}\end{array}$ \\
\hline Belgien (fläm.) & Alle & VM & VM & $\mathrm{KB}$ & $\mathrm{KB}$ & $\mathrm{KB}$ & VM & a \\
\hline Belgien (frz.) & Alle & $\mathrm{AE}$ & VA & $\mathrm{KB}$ & KB & $\mathrm{KB}$ & VM & a \\
\hline Kanada & $\mathrm{m}$ & $\mathrm{m}$ & $\mathrm{m}$ & $\mathrm{m}$ & $\mathrm{m}$ & $\mathrm{m}$ & $\mathrm{m}$ & $\mathrm{m}$ \\
\hline Chile & Alle & $\mathrm{AE}$ & VA & a & KB & a & VM & a \\
\hline Tschechien & Alle & VM & $\mathrm{AE}$ & $\mathrm{KB}$ & $\mathrm{KB}$ & $\mathrm{KB}$ & $\mathrm{KB}$ & a \\
\hline Dänemark & Alle & $\mathrm{KB}$ & $\mathrm{AE}$ & a & $\mathrm{KB}$ & KB & KB & a \\
\hline England & Alle & $\mathrm{AE}$ & VM & $\mathrm{KB}$ & $\mathrm{KB}$ & $a$ & $\mathrm{~KB}$ & a \\
\hline Estland & Alle & $\mathrm{AE}$ & VM & a & VM & a & $\mathrm{KB}$ & a \\
\hline Finnland & Alle & VM & VA & a & a & $\mathrm{KB}$ & $\mathrm{KB}$ & a \\
\hline Frankreich & Alle & VM & VA & VM & $\mathrm{KB}$ & $K B$ & VA & VM \\
\hline Deutschland & Alle & $\mathrm{AE}$ & VA & $\mathrm{KB}$ & $\mathrm{KB}$ & $\mathrm{KB}$ & $\mathrm{KB}$ & a \\
\hline Griechenland & Alle & $\mathrm{AE}$ & VM & VM & $\mathrm{KB}$ & VM & VM & a \\
\hline Ungarn & Alle & VM & $\mathrm{KB}$ & $\mathrm{KB}$ & $\mathrm{KB}$ & $\mathrm{KB}$ & $\mathrm{KB}$ & a \\
\hline Island & Alle & VM & VM & a & $\mathrm{KB}$ & a & $\mathrm{KB}$ & a \\
\hline Irland & Alle & VM & VM & $\mathrm{KB}$ & a & a & VM & a \\
\hline Israel & Alle & $\mathrm{AE}$ & VA & VA & $S$ & $S$ & $\mathrm{~KB}$ & a \\
\hline Italien & Alle & $\mathrm{AE}$ & VM & VM & VM & VM & VM & a \\
\hline Japan & Alle & VM & VM & a & VA & VA & VM & a \\
\hline Korea & Alle & $\mathrm{AE}$ & VM & VM & VM & VM & VM & a \\
\hline Luxemburg & Alle & $\mathrm{AE}$ & VM & $K B$ & $\mathrm{~KB}$ & KB & $K B$ & $\mathrm{~KB}$ \\
\hline Mexiko & $\begin{array}{l}\text { Allgemeinbildend } \\
\text { Berufsbildend }\end{array}$ & $\begin{array}{l}\mathrm{AE} \\
\mathrm{a}\end{array}$ & $\begin{array}{l}\mathrm{KB} \\
\mathrm{a}\end{array}$ & $\begin{array}{l}\mathrm{KB} \\
\mathrm{a}\end{array}$ & $\begin{array}{l}\mathrm{KB} \\
\mathrm{a}\end{array}$ & $\begin{array}{l}\text { VM } \\
a\end{array}$ & $\begin{array}{l}\text { VM } \\
\text { a }\end{array}$ & $\begin{array}{l}\mathrm{a} \\
\mathrm{a}\end{array}$ \\
\hline Niederlande & Alle & VM & VM & $\mathrm{KB}$ & KB & $\mathrm{KB}$ & $\mathrm{KB}$ & KB \\
\hline Neuseeland & $m$ & $\mathrm{~m}$ & $\mathrm{~m}$ & $\mathrm{~m}$ & $\mathrm{~m}$ & $\mathrm{~m}$ & $\mathrm{~m}$ & $\mathrm{~m}$ \\
\hline Norwegen & Alle & $\mathrm{m}$ & VA & $\mathrm{m}$ & VA & $\mathrm{m}$ & $\mathrm{m}$ & $a$ \\
\hline Polen & Alle & $\mathrm{AE}$ & VM & VM & VM & VM & VM & a \\
\hline Portugal & Alle & $\mathrm{AE}$ & $\mathrm{KB}$ & $\mathrm{KB}$ & $\mathrm{KB}$ & $\mathrm{KB}$ & $\mathrm{KB}$ & $\mathrm{KB}$ \\
\hline Schottland & Alle & VM & VM & $\mathrm{KB}$ & VM & a & KB & $\mathrm{m}$ \\
\hline Slowakei & Alle & $\mathrm{AE}$ & $\mathrm{KB}$ & $\mathrm{KB}$ & KB & KB & $\mathrm{KB}$ & $\mathrm{KB}$ \\
\hline Slowenien & Alle & $\mathrm{AE}$ & VA & a & a & a & VM & a \\
\hline Spanien & Alle & $\mathrm{AE}$ & $\mathrm{KB}$ & $\mathrm{KB}$ & KB & KB & VA & a \\
\hline Schweden & Alle & $\mathrm{s}$ & $\mathrm{s}$ & $\mathrm{KB}$ & $\mathrm{AE}$ & $\mathrm{KB}$ & $K B$ & a \\
\hline Schweiz & Alle & $\mathrm{m}$ & $\mathrm{m}$ & $\mathrm{m}$ & $\mathrm{m}$ & $\mathrm{m}$ & $\mathrm{m}$ & $\mathrm{m}$ \\
\hline Türkei & Alle & VM & VA & VM & VA & VA & $\mathrm{AE}$ & a \\
\hline $\begin{array}{l}\text { Ver. Staaten } \\
\text { Partnerländer }\end{array}$ & Alle & $\mathrm{m}$ & $\mathrm{m}$ & $\mathrm{m}$ & $\mathrm{m}$ & $\mathrm{m}$ & $\mathrm{m}$ & $\mathrm{m}$ \\
\hline Brasilien & Alle & $\mathrm{AE}$ & VA & a & VA & VA & $\mathrm{KB}$ & $\mathrm{m}$ \\
\hline Russische Föd. & Alle & VM & VA & $K B$ & $\mathrm{~KB}$ & $\mathrm{~KB}$ & $\mathrm{~KB}$ & $a$ \\
\hline
\end{tabular}

Rolle bei der Entscheidung über berufliche Fortbildung

Vollständig autonome Entscheidung ( $A E)$

Vorschlag von Maßnahmen (VM)

Validierung der Auswahl (VA)

Sonstige (S)

Keine Beteiligung $(K B)$

Anmerkung: In föderalen Staaten bzw. Ländern mit stark dezentralen Schulsystemen kann es in den einzelnen Bundesstaaten, Provinzen oder Regionen unterschiedliche Vorschriften geben. Weitere Informationen s. Anhang 3.

1. „(AHS) “ steht für Allgemein bildende höhere Schulen, Unterstufe. 2. „(NMS, HS)“ steht für Neue Mittelschulen und Hauptschulen.

Quelle: OECD. Hinweise s. Anhang 3 unter www.oecd.org/edu/eag.htm. StatLink: http://dx.doi.org/10.1787/888933120518

Erläuterung der Kennzeichnung fehlender Daten s. Hinweise für den Leser. 
Tabelle D7.3c (Forts.)

Nicht obligatorische berufliche Fortbildung für Lehrkräfte, Sekundarbereich I (2013)

In öffentlichen Bildungseinrichtungen

\begin{tabular}{|c|c|c|c|c|c|c|c|}
\hline & \multirow[t]{3}{*}{ Art der Fächer } & \multirow{2}{*}{$\begin{array}{l}\text { Berufliche Fortbildungs- } \\
\text { maßnahmen werden im } \\
\text { Hinblick auf die jeweiligen } \\
\text { Schulentwicklungs- } \\
\text { schwerpunkte geplant }\end{array}$} & \multicolumn{5}{|c|}{ Strategien zur Finanzierung und Förderung von beruflicher Fortbildung } \\
\hline & & & $\begin{array}{c}\text { Kosten werden } \\
\text { vom Staat sub- } \\
\text { ventioniert bzw. } \\
\text { mitgetragen }\end{array}$ & $\begin{array}{c}\text { Teilnahme- } \\
\text { kosten werden } \\
\text { übernommen }\end{array}$ & $\begin{array}{c}\text { Bezahlte } \\
\text { Freistellung der } \\
\text { Lehrkräfte }\end{array}$ & $\begin{array}{l}\text { Kostenübernah- } \\
\text { me für Vertre- } \\
\text { tungslehrkräfte }\end{array}$ & $\begin{array}{c}\text { Separates } \\
\text { Budget der } \\
\text { Schule }\end{array}$ \\
\hline & & (8) & (9) & (10) & (11) & $(12)$ & (13) \\
\hline \multicolumn{8}{|l|}{ OECD-Länder } \\
\hline Australien & Alle & $\mathrm{m}$ & $\mathrm{m}$ & $\mathrm{m}$ & $\mathrm{m}$ & $\mathrm{m}$ & $\mathrm{m}$ \\
\hline Österreich & $\begin{array}{l}\text { Alle }(\mathrm{AHS})^{1} \\
\text { Alle }(\mathrm{NMS}, \mathrm{HS})^{2}\end{array}$ & $\begin{array}{l}\text { Ja, aber nicht ausschließlich } \\
\text { Ja, aber nicht ausschließlich }\end{array}$ & $\begin{array}{l}\text { Teilweise } \\
\text { Teilweise }\end{array}$ & $\begin{array}{l}\text { Teilweise } \\
\text { Teilweise }\end{array}$ & $\begin{array}{l}\text { Häufig } \\
\text { Häufig }\end{array}$ & $\begin{array}{l}\text { Immer } \\
\text { Immer }\end{array}$ & $\begin{array}{l}\text { Nein } \\
\text { Nein }\end{array}$ \\
\hline Belgien (fläm.) & Alle & Ja, aber nicht ausschließlich & Teilweise & Teilweise & Häufig & a & Ja \\
\hline Belgien (frz.) & Alle & Nein & Nie & a & a & a & a \\
\hline Kanada & $\mathrm{m}$ & $\mathrm{m}$ & $\mathrm{m}$ & $\mathrm{m}$ & $\mathrm{m}$ & $\mathrm{m}$ & $\mathrm{m}$ \\
\hline Chile & Alle & Ja, aber nicht ausschließlich & Teilweise & $\mathrm{m}$ & $\mathrm{m}$ & $\mathrm{m}$ & $\mathrm{m}$ \\
\hline Tschechien & Alle & Ja, auschließlich & Teilweise & Teilweise & Manchmal & Häufig & $\mathrm{Ja}$ \\
\hline Dänemark & Alle & Ja, aber nicht ausschließlich & Teilweise & $\mathrm{m}$ & $\mathrm{m}$ & $\mathrm{m}$ & $\mathrm{m}$ \\
\hline England & Alle & Ja, aber nicht ausschließlich & Teilweise & Teilweise & Manchmal & Manchmal & Nein \\
\hline Estland & Alle & Nein & Nie & a & a & a & a \\
\hline Finnland & Alle & $\mathrm{m}$ & $\mathrm{m}$ & $\mathrm{m}$ & $\mathrm{m}$ & $\mathrm{m}$ & $\mathrm{m}$ \\
\hline Frankreich & Alle & Ja, aber nicht ausschließlich & Teilweise & Teilweise & Immer & Manchmal & Nein \\
\hline Deutschland & Alle & Ja, aber nicht ausschließlich & Vollständig & Vollständig & Immer & Immer & Ja \\
\hline Griechenland & Alle & Ja, aber nicht ausschließlich & Vollständig & Vollständig & Manchmal & Manchmal & Nein \\
\hline Ungarn & Alle & Ja, aber nicht ausschließlich & $\mathrm{m}$ & $\mathrm{m}$ & $\mathrm{m}$ & $\mathrm{m}$ & $\mathrm{m}$ \\
\hline Island & Alle & Ja, aber nicht ausschließlich & Teilweise & Vollständig & Manchmal & Immer & $\mathrm{m}$ \\
\hline Irland & Alle & Ja, aber nicht ausschließlich & Teilweise & Teilweise & Häufig & Häufig & Nein \\
\hline Israel & Alle & Ja, aber nicht ausschließlich & Vollständig & Vollständig & Nie & Immer & Ja \\
\hline Italien & Alle & Ja, aber nicht ausschließlich & Teilweise & Vollständig & Manchmal & Manchmal & Ja \\
\hline Japan & Alle & Ja, auschließlich & Teilweise & Teilweise & Nie & $\mathrm{m}$ & $\mathrm{Ja}$ \\
\hline Korea & Alle & Ja, aber nicht ausschließlich & Teilweise & Teilweise & Manchmal & Manchmal & Ja \\
\hline Luxemburg & Alle & Ja, aber nicht ausschließlich & Teilweise & Teilweise & Nie & Immer & Nein \\
\hline Mexiko & $\begin{array}{l}\text { Allgemeinbildend } \\
\text { Berufsbildend }\end{array}$ & $\begin{array}{l}\text { Nein } \\
a\end{array}$ & $\begin{array}{l}\text { Vollständig } \\
\text { a }\end{array}$ & $\begin{array}{l}\text { Vollständig } \\
\text { a }\end{array}$ & $\begin{array}{l}a \\
a\end{array}$ & $\begin{array}{l}\mathrm{a} \\
\mathrm{a}\end{array}$ & $\begin{array}{l}\text { Nein } \\
\text { a }\end{array}$ \\
\hline Niederlande & Alle & $\mathrm{m}$ & Teilweise & Teilweise & Manchmal & Manchmal & Ja \\
\hline Neuseeland & $m$ & $m$ & $\mathrm{~m}$ & $\mathrm{~m}$ & $\mathrm{~m}$ & $\mathrm{~m}$ & $\mathrm{~m}$ \\
\hline Norwegen & Alle & Ja, aber nicht ausschließlich & Teilweise & Teilweise & Häufig & Manchmal & $\mathrm{m}$ \\
\hline Polen & Alle & Nein & Teilweise & Teilweise & Manchmal & Manchmal & Nein \\
\hline Portugal & Alle & Ja, aber nicht ausschließlich & $\mathrm{Nie}$ & a & a & a & a \\
\hline Schottland & Alle & Ja, aber nicht ausschließlich & $\mathrm{m}$ & $\mathrm{m}$ & $\mathrm{m}$ & $\mathrm{m}$ & $\mathrm{m}$ \\
\hline Slowakei & Alle & Nein & $\mathrm{Nie}$ & a & a & a & a \\
\hline Slowenien & Alle & Ja, aber nicht ausschließlich & Teilweise & Teilweise & Immer & Immer & Ja \\
\hline Spanien & Alle & Nein & Teilweise & Teilweise & $\mathrm{Nie}$ & $\mathrm{Nie}$ & Nein \\
\hline Schweden & Alle & Ja, aber nicht ausschließlich & Teilweise & Teilweise & Manchmal & $\mathrm{m}$ & Nein \\
\hline Schweiz & Alle & $\mathrm{m}$ & $\mathrm{m}$ & $\mathrm{m}$ & $\mathrm{m}$ & $\mathrm{m}$ & $\mathrm{m}$ \\
\hline Türkei & Alle & Ja, aber nicht ausschließlich & Teilweise & Teilweise & Manchmal & a & Nein \\
\hline $\begin{array}{l}\text { Ver. Staaten } \\
\text { Partnerländer }\end{array}$ & Alle & Ja, aber nicht ausschließlich & $\mathrm{m}$ & $\mathrm{m}$ & m & $\mathrm{m}$ & $\mathrm{m}$ \\
\hline Brasilien & Alle & Nein & Teilweise & Teilweise & Manchmal & Immer & $\mathrm{m}$ \\
\hline Russische Föd. & Alle & Nein & $\mathrm{m}$ & $\mathrm{m}$ & $\mathrm{m}$ & $\mathrm{m}$ & $\mathrm{m}$ \\
\hline
\end{tabular}

Rolle bei der Entscheidung über berufliche Fortbildung

Vollständig autonome Entscheidung ( $A E)$

Vorschlag von Maßnahmen (VM)

Validierung der Auswahl (VA)

Sonstige (S)

Keine Beteiligung $(K B)$

Anmerkung: In föderalen Staaten bzw. Ländern mit stark dezentralen Schulsystemen kann es in den einzelnen Bundesstaaten, Provinzen oder Regionen unterschiedliche Vorschriften geben. Weitere Informationen s. Anhang 3.

1. „(AHS)“ steht für Allgemein bildende höhere Schulen, Unterstufe. 2. „(NMS, HS) “ steht für Neue Mittelschulen und Hauptschulen.

Quelle: OECD. Hinweise s. Anhang 3 unter www.oecd.org/edu/eag.htm. StatLink: http://dx.doi.org/10.1787/888933120518

Erläuterung der Kennzeichnung fehlender Daten s. Hinweise für den Leser. 



\section{Merkmale der Bildungssysteme}

Alle Tabellen im Anhang I sind im Internet verfügbar unter:

StatLink: http://dx.doi.org/10.1787/888933120632 
Tabelle X1.1a

Abschlussquoten im Sekundarbereich II: Typisches Abschlussalter und Art der Abschlussquote

(Brutto- bzw. Nettoabschlussquote) (2012)

Das typische Abschlussalter bezieht sich auf das Alter der Studierenden zu Beginn des Studienjahres; die Schüler werden im Allgemeinen ein Jahr älter sein, wenn der Abschluss gegen Ende des Schuljahres erfolgt. Bei der Berechnung der Bruttoabschlussquoten wird das typische Abschlussalter verwendet.

\begin{tabular}{|c|c|c|c|c|c|c|c|}
\hline & \multicolumn{7}{|c|}{ Typisches Abschlussalter } \\
\hline & \multirow[t]{2}{*}{ Erstabschluss } & \multicolumn{2}{|c|}{ Ausrichtung des Bildungsgangs } & \multicolumn{4}{|c|}{ Weitere Ausbildung/Arbeitsmarkteintritt } \\
\hline & & Allgemeinbildend & $\begin{array}{l}\text { Berufs- } \\
\text { vorbereitend/ } \\
\text { Berufsbildend }\end{array}$ & ISCED $3 \mathrm{~A}$ & ISCED 3B & ISCED 3C (kurz) ${ }^{1}$ & ${\text { ISCED } 3 C \text { (lang) }^{1}}^{1}$ \\
\hline \multicolumn{8}{|l|}{ OECD-Länder } \\
\hline Australien & 17 & 17 & 17 & 17 & a & 17 & 17 \\
\hline Österreich & $17-18$ & $17-18$ & $17-19$ & $17-18$ & $17-19$ & $14-15$ & $16-17$ \\
\hline Belgien & 18 & 18 & 18 & 18 & a & 18 & 18 \\
\hline Kanada & $17-18$ & $17-18$ & $17-18$ & $17-18$ & a & a & $17-18$ \\
\hline Chile & 17 & 17 & 17 & 17 & a & a & a \\
\hline Tschechien & $18-19$ & $18-19$ & $17-19$ & $18-19$ & $18-19$ & a & $17-18$ \\
\hline Dänemark & $18-19$ & $18-19$ & $20-21$ & $18-19$ & $a$ & 27 & $20-21$ \\
\hline Estland & 19 & 19 & 19 & 19 & 19 & a & 19 \\
\hline Finnland & 19 & 19 & 19 & 19 & a & a & a \\
\hline Frankreich & $17-19$ & $17-18$ & $16-19$ & $17-18$ & $18-20$ & $16-18$ & $18-20$ \\
\hline Deutschland & $19-20$ & $19-20$ & $19-20$ & $19-20$ & $19-20$ & $19-20$ & a \\
\hline Griechenland & 18 & 18 & 18 & 18 & a & 18 & 18 \\
\hline Ungarn & 18 & 18 & $18-19$ & 18 & a & 18 & $18-19$ \\
\hline Island & 19 & 19 & 17 & 19 & 20 & 19 & 19 \\
\hline Irland & $18-19$ & 18 & 19 & 18 & a & 19 & 18 \\
\hline Israel & 17 & 17 & 17 & 17 & a & $a$ & 17 \\
\hline Italien & 19 & 19 & 18 & 19 & 18 & 17 & a \\
\hline Japan & 17 & 17 & 17 & 17 & 17 & 15 & 17 \\
\hline Korea & 18 & 18 & 18 & 18 & a & a & 18 \\
\hline Luxemburg & $17-20$ & $17-18$ & $17-20$ & $17-19$ & $18-20$ & $16-18$ & $17-19$ \\
\hline Mexiko & $17-18$ & $17-18$ & $17-18$ & $17-18$ & a & a & $17-18$ \\
\hline Niederlande & $17-19$ & 17 & 19 & 17 & a & a & 18 \\
\hline Neuseeland & $17-18$ & $17-18$ & $17-18$ & 18 & 17 & 16 & 17 \\
\hline Norwegen & $18-20$ & 18 & $19-20$ & 18 & a & $\mathrm{m}$ & $19-20$ \\
\hline Polen & $18-19$ & 19 & 20 & 19 & a & a & 19 \\
\hline Portugal & 17 & 17 & 18 & $\mathrm{~m}$ & $\mathrm{~m}$ & $\mathrm{~m}$ & $\mathrm{~m}$ \\
\hline Slowakei & $18-19$ & 19 & 19 & $19-20$ & a & 17 & $18-19$ \\
\hline Slowenien & 18 & 18 & $16-18$ & 18 & 18 & 16 & 17 \\
\hline Spanien & 17 & 17 & 17 & 17 & 17 & 17 & 17 \\
\hline Schweden & 18 & 18 & 18 & 18 & 18 & 18 & 18 \\
\hline Schweiz & $18-20$ & $18-20$ & $18-20$ & $18-20$ & $18-20$ & $17-19$ & $18-20$ \\
\hline Türkei & 17 & 17 & 17 & 17 & a & $\mathrm{m}$ & a \\
\hline Vereinigtes Königreich & 16 & 16 & 16 & 18 & 18 & 16 & 16 \\
\hline $\begin{array}{l}\text { Vereinigte Staaten } \\
\text { Partnerländer }\end{array}$ & 17 & 17 & $\mathrm{~m}$ & 17 & $\mathrm{~m}$ & $\mathrm{~m}$ & $\mathrm{~m}$ \\
\hline Argentinien & 17 & 17 & 17 & 17 & a & a & a \\
\hline Brasilien & $17-18$ & $17-18$ & $18-19$ & $17-18$ & $18-19$ & a & a \\
\hline China & 17 & 17 & 17 & 17 & $\mathrm{~m}$ & 17 & 17 \\
\hline Kolumbien & $\mathrm{m}$ & $\mathrm{m}$ & $\mathrm{m}$ & $\mathrm{m}$ & $\mathrm{m}$ & $\mathrm{m}$ & $\mathrm{m}$ \\
\hline Indien & $\mathrm{m}$ & $\mathrm{m}$ & $\mathrm{m}$ & $\mathrm{m}$ & $\mathrm{m}$ & $\mathrm{m}$ & $\mathrm{m}$ \\
\hline Indonesien & 17 & 17 & 17 & 17 & 17 & a & a \\
\hline Lettland & 19 & 19 & 19 & 19 & $\mathrm{n}$ & a & 19 \\
\hline Russische Föderation & 17 & 17 & 17 & 17 & 17 & 16 & 17 \\
\hline Saudi-Arabien & $\mathrm{m}$ & $\mathrm{m}$ & $\mathrm{m}$ & $\mathrm{m}$ & $\mathrm{m}$ & $\mathrm{m}$ & $\mathrm{m}$ \\
\hline Südafrika & $\mathrm{m}$ & $\mathrm{m}$ & $\mathrm{m}$ & $\mathrm{m}$ & $\mathrm{m}$ & $\mathrm{m}$ & $\mathrm{m}$ \\
\hline
\end{tabular}

1. Dauer ISCED 3C: kurz - mindestens 1 Jahr kürzer als ISCED-3A/3B-Bildungsgänge; lang - ähnlich lang wie ISCED-3A/3B-Bildungsgänge.

Quelle: OECD. Argentinien, China, Indien, Indonesien, Kolumbien, Saudi-Arabien und Südafrika: Statistikinstitut der UNESCO. Lettland: Eurostat.

Hinweise s. Anhang 3 unter www.oecd.org/edu/eag.htm. StatLink: http://dx.doi.org/10.1787/888933120651

Erläuterung der Kennzeichnung fehlender Daten s. Hinweise für den Leser. 
Abschlussquoten im Sekundarbereich II: Typisches Abschlussalter und Art der Abschlussquote (Brutto- bzw. Nettoabschlussquote) (2012)

\begin{tabular}{|c|c|c|c|c|c|c|c|}
\hline & \multicolumn{7}{|c|}{ Art der Abschlussquote: Brutto- gegenüber Nettoabschlussquote } \\
\hline & \multirow{2}{*}{$\begin{array}{l}\text { Absolventen mit } \\
\text { Erstabschluss }\end{array}$} & \multicolumn{2}{|c|}{ Ausrichtung des Bildungsgangs } & \multicolumn{4}{|c|}{ Weitere Ausbildung/Arbeitsmarkteintritt } \\
\hline & & Allgemeinbildend & $\begin{array}{l}\text { Berufs- } \\
\text { vorbereitend/ } \\
\text { Berufsbildend }\end{array}$ & ISCED $3 \mathrm{~A}$ & ISCED 3B & ISCED 3 C (kurz) ${ }^{1}$ & ISCED $3 C$ (lang) $^{1}$ \\
\hline \multicolumn{8}{|l|}{ OECD-Länder } \\
\hline Australien & netto & netto & netto & netto & a & $\mathrm{m}$ & netto \\
\hline Österreich & netto & netto & netto & netto & netto & netto & netto \\
\hline Belgien & $\mathrm{m}$ & netto & netto & netto & a & netto & netto \\
\hline Kanada & netto & netto & netto & netto & $a$ & a & netto \\
\hline Chile & netto & netto & netto & netto & a & a & a \\
\hline Tschechien & netto & netto & netto & netto & netto & a & netto \\
\hline Dänemark & netto & netto & netto & netto & a & netto & netto \\
\hline Estland & $\mathrm{m}$ & netto & netto & netto & netto & a & netto \\
\hline Finnland & netto & netto & netto & netto & a & a & a \\
\hline Frankreich & $\mathrm{m}$ & netto & netto & netto & netto & netto & netto \\
\hline Deutschland & brutto & brutto & brutto & brutto & brutto & brutto & a \\
\hline Griechenland & brutto & brutto & brutto & brutto & $a$ & $\mathrm{~m}$ & brutto \\
\hline Ungarn & netto & netto & netto & netto & a & $\mathrm{m}$ & netto \\
\hline Island & netto & netto & netto & netto & netto & netto & netto \\
\hline Irland & netto & netto & netto & netto & $a$ & netto & netto \\
\hline Israel & netto & netto & netto & netto & a & a & netto \\
\hline Italien & brutto & netto & brutto & netto & brutto & brutto & a \\
\hline Japan & brutto & brutto & brutto & brutto & brutto & $\mathrm{m}$ & brutto \\
\hline Korea & brutto & brutto & brutto & brutto & $a$ & a & brutto \\
\hline Luxemburg & netto & netto & netto & netto & netto & netto & netto \\
\hline Mexiko & netto & netto & netto & netto & a & a & netto \\
\hline Niederlande & netto & netto & netto & netto & a & a & netto \\
\hline Neuseeland & netto & netto & $\mathrm{m}$ & netto & $\mathrm{m}$ & netto & $\mathrm{m}$ \\
\hline Norwegen & netto & netto & netto & netto & a & $\mathrm{m}$ & netto \\
\hline Polen & netto & netto & netto & netto & a & a & netto \\
\hline Portugal & $\mathrm{m}$ & netto & netto & $\mathrm{m}$ & $\mathrm{m}$ & $\mathrm{m}$ & $\mathrm{m}$ \\
\hline Slowakei & netto & netto & netto & netto & a & netto & netto \\
\hline Slowenien & brutto & netto & brutto & netto & brutto & netto & brutto \\
\hline Spanien & brutto & brutto & brutto & brutto & brutto & brutto & brutto \\
\hline Schweden & netto & netto & netto & netto & a & a & netto \\
\hline Schweiz & $\mathrm{m}$ & netto & netto & netto & netto & netto & netto \\
\hline Türkei & netto & netto & netto & netto & a & $\mathrm{m}$ & a \\
\hline Vereinigtes Königreich & brutto & $\mathrm{m}$ & $\mathrm{m}$ & $\mathrm{m}$ & $\mathrm{m}$ & brutto & brutto \\
\hline $\begin{array}{l}\text { Vereinigte Staaten } \\
\text { Partneränder }\end{array}$ & netto & $\mathrm{m}$ & $\mathrm{m}$ & $\mathrm{m}$ & $\mathrm{m}$ & $\mathrm{m}$ & $\mathrm{m}$ \\
\hline Argentinien & $\mathrm{m}$ & netto & netto & netto & a & a & a \\
\hline Brasilien & $\mathrm{m}$ & netto & netto & netto & netto & a & a \\
\hline China & brutto & brutto & brutto & brutto & $\mathrm{m}$ & brutto & brutto \\
\hline Kolumbien & $\mathrm{m}$ & $\mathrm{m}$ & $\mathrm{m}$ & $\mathrm{m}$ & $\mathrm{m}$ & $\mathrm{m}$ & $\mathrm{m}$ \\
\hline Indien & $\mathrm{m}$ & $\mathrm{m}$ & $\mathrm{m}$ & $\mathrm{m}$ & $\mathrm{m}$ & $\mathrm{m}$ & $\mathrm{m}$ \\
\hline Indonesien & $\mathrm{m}$ & netto & netto & netto & netto & a & a \\
\hline Lettland & netto & netto & netto & netto & $\mathrm{n}$ & a & netto \\
\hline Russische Föderation & $\mathrm{m}$ & brutto & brutto & brutto & brutto & brutto & brutto \\
\hline Saudi-Arabien & $\mathrm{m}$ & $\mathrm{m}$ & $\mathrm{m}$ & $\mathrm{m}$ & $\mathrm{m}$ & $\mathrm{m}$ & $\mathrm{m}$ \\
\hline Südafrika & $\mathrm{m}$ & $\mathrm{m}$ & $\mathrm{m}$ & $\mathrm{m}$ & $\mathrm{m}$ & $\mathrm{m}$ & $\mathrm{m}$ \\
\hline
\end{tabular}

1. Dauer ISCED 3C: kurz - mindestens 1 Jahr kürzer als ISCED-3A/3B-Bildungsgänge; lang - ähnlich lang wie ISCED-3A/3B-Bildungsgänge. Quelle: OECD. Argentinien, China, Indien, Indonesien, Kolumbien, Saudi-Arabien und Südafrika: Statistikinstitut der UNESCO. Lettland: Eurostat. Hinweise s. Anhang 3 unter www.oecd.org/edu/eag.htm. StatLink: http://dx.doi.org/10.1787/888933120651 Erläuterung der Kennzeichnung fehlender Daten s. Hinweise für den Leser. 
Tabelle X1.1b

Abschlussquoten im postsekundaren, nicht tertiären Bereich: Typisches Abschlussalter und Art der Abschlussquote (Brutto- bzw. Nettoabschlussquote) (2012)

Das typische Abschlussalter bezieht sich auf das Alter der Schüler zu Beginn des Schuljahres; die Schüler werden im Allgemeinen ein Jahr älter sein, wenn der Abschluss gegen Ende des Schuljahres erfolgt. Bei der Berechnung der Bruttoabschlussquoten wird das typische Abschlussalter verwendet.

\begin{tabular}{|c|c|c|c|c|c|c|c|c|}
\hline & \multicolumn{4}{|c|}{ Typisches Abschlussalter } & \multirow{2}{*}{\multicolumn{4}{|c|}{$\begin{array}{c}\begin{array}{c}\text { Art der Abschlussquote: } \\
\text { Brutto- gegenüber Nettoabschlussquote }\end{array} \\
\text { Weitere Ausbildung/Arbeitsmarkteintritt }\end{array}$}} \\
\hline & \multirow[t]{2}{*}{ Erstabschluss } & \multicolumn{3}{|c|}{ Weitere Ausbildung/Arbeitsmarkteintritt } & & & & \\
\hline & & ISCED 4A & ISCED 4B & ISCED 4 C & $\begin{array}{c}\text { Absolventen mit } \\
\text { Erstabschluss }\end{array}$ & ISCED 4A & ISCED 4B & ISCED $4 \mathrm{C}$ \\
\hline OECD-Länder & & & & & & & & \\
\hline Australien & $18-20$ & a & a & $18-20$ & netto & a & a & netto \\
\hline Österreich & $18-19$ & $18-19$ & $19-20$ & $23-24$ & netto & netto & netto & netto \\
\hline Belgien & $19-21$ & 19 & $19-21$ & $19-21$ & $\mathrm{~m}$ & netto & netto & netto \\
\hline Kanada & $\mathrm{m}$ & $\mathrm{m}$ & $\mathrm{m}$ & $30-34$ & $\mathrm{~m}$ & $\mathrm{~m}$ & $\mathrm{~m}$ & $\mathrm{~m}$ \\
\hline Chile & a & a & a & a & a & a & a & a \\
\hline Tschechien & $19-20$ & $19-20$ & a & $19-20$ & netto & netto & a & netto \\
\hline Dänemark & 21 & 21 & a & $\mathrm{a}$ & netto & netto & a & a \\
\hline Estland & 21 & a & 21 & a & $\mathrm{m}$ & a & netto & a \\
\hline Finnland & $35-39$ & $\mathrm{a}$ & a & $35-39$ & netto & a & a & netto \\
\hline Frankreich & $\mathrm{m}$ & $\mathrm{m}$ & $\mathrm{m}$ & $\mathrm{m}$ & $\mathrm{m}$ & brutto & a & brutto \\
\hline Deutschland & 22 & 22 & 22 & a & brutto & brutto & brutto & a \\
\hline Griechenland & 20 & $\mathrm{a}$ & a & 20 & $\mathrm{~m}$ & $\mathrm{a}$ & a & netto \\
\hline Ungarn & $\mathrm{a}$ & $\mathrm{a}$ & a & $19-20$ & netto & a & a & netto \\
\hline Island & a & a & a & 26 & netto & $\mathrm{a}$ & a & netto \\
\hline Irland & 23 & a & a & 23 & netto & a & a & netto \\
\hline Israel & $\mathrm{m}$ & $\mathrm{m}$ & $\mathrm{m}$ & $\mathrm{a}$ & $\mathrm{m}$ & $\mathrm{m}$ & $\mathrm{m}$ & a \\
\hline Italien & 20 & a & a & 20 & brutto & a & a & brutto \\
\hline Japan & 18 & 18 & 18 & 18 & $\mathrm{~m}$ & $\mathrm{~m}$ & $\mathrm{~m}$ & $\mathrm{~m}$ \\
\hline Korea & a & a & a & a & a & a & a & a \\
\hline Luxemburg & $21-25$ & a & a & $21-25$ & netto & a & a & netto \\
\hline Mexiko & a & a & a & a & a & a & a & a \\
\hline Niederlande & 20 & a & a & 20 & netto & a & a & netto \\
\hline Neuseeland & 18 & 18 & 18 & 18 & netto & netto & netto & netto \\
\hline Norwegen & $20-22$ & $20-22$ & a & $21-22$ & netto & netto & a & netto \\
\hline Polen & 21 & a & a & 21 & netto & a & a & netto \\
\hline Portugal & 21 & a & a & a & netto & a & a & a \\
\hline Slowakei & 21 & $21-22$ & a & a & netto & netto & a & a \\
\hline Slowenien & $19-20$ & $19-20$ & $19-20$ & a & netto & netto & netto & a \\
\hline Spanien & a & a & a & a & a & a & a & a \\
\hline Schweden & $19-22$ & $\mathrm{~m}$ & $\mathrm{~m}$ & $19-22$ & $\mathrm{~m}$ & $\mathrm{~m}$ & $\mathrm{~m}$ & netto \\
\hline Schweiz & $21-23$ & $21-23$ & $21-23$ & a & $\mathrm{m}$ & netto & netto & a \\
\hline Türkei & a & a & a & a & a & a & a & a \\
\hline Vereinigtes Königreich & a & a & a & a & a & a & a & a \\
\hline $\begin{array}{l}\text { Vereinigte Staaten } \\
\text { Partnerländer }\end{array}$ & $\mathrm{m}$ & $\mathrm{m}$ & $\mathrm{m}$ & $\mathrm{m}$ & $\mathrm{m}$ & $\mathrm{m}$ & $\mathrm{m}$ & $\mathrm{m}$ \\
\hline Argentinien & a & a & a & a & a & a & a & a \\
\hline Brasilien & a & a & a & a & a & a & a & a \\
\hline Kolumbien & a & $\mathrm{m}$ & $\mathrm{m}$ & $\mathrm{m}$ & $\mathrm{m}$ & $\mathrm{m}$ & netto & $\mathrm{m}$ \\
\hline China & 18 & 18 & 18 & 18 & $\mathrm{~m}$ & brutto & brutto & brutto \\
\hline Indien & $\mathrm{m}$ & $\mathrm{m}$ & $\mathrm{m}$ & $\mathrm{m}$ & $\mathrm{m}$ & $\mathrm{m}$ & $\mathrm{m}$ & $\mathrm{m}$ \\
\hline Indonesien & $\mathrm{m}$ & $\mathrm{m}$ & $\mathrm{m}$ & $\mathrm{m}$ & $\mathrm{m}$ & $\mathrm{m}$ & $\mathrm{m}$ & $\mathrm{m}$ \\
\hline Lettland & a & a & a & a & a & a & a & a \\
\hline Russische Föderation & 18 & a & a & 18 & $\mathrm{~m}$ & a & a & $\mathrm{m}$ \\
\hline Saudi-Arabien & $\mathrm{m}$ & $\mathrm{m}$ & $\mathrm{m}$ & $\mathrm{m}$ & $\mathrm{m}$ & $\mathrm{m}$ & $\mathrm{m}$ & $\mathrm{m}$ \\
\hline Südafrika & $\mathrm{m}$ & $\mathrm{m}$ & $\mathrm{m}$ & $\mathrm{m}$ & $\mathrm{m}$ & $\mathrm{m}$ & $\mathrm{m}$ & $\mathrm{m}$ \\
\hline
\end{tabular}

Quelle: OECD. Argentinien, China, Indien, Indonesien, Kolumbien, Saudi-Arabien und Südafrika: Statistikinstitut der UNESCO. Lettland: Eurostat. 
Abschlussquoten im Tertiärbereich: Typisches Abschlussalter und Art der Abschlussquote

(Brutto- bzw. Nettoabschlussquote) (2012)

Das typische Abschlussalter bezieht sich auf das Alter der Studierenden zu Beginn des Studienjahres; die Studierenden werden im Allgemeinen ein Jahr älter sein, wenn der Abschluss gegen Ende des Studienjahres erfolgt. Bei der Berechnung der Bruttoabschlussquoten wird das typische Abschlussalter verwendet.

\begin{tabular}{|c|c|c|c|c|c|c|c|}
\hline & \multicolumn{7}{|c|}{ Typisches Abschlussalter } \\
\hline & \multirow{2}{*}{$\begin{array}{l}\text { Erstabschluss } \\
\text { Tertiärbereich B }\end{array}$} & \multirow{2}{*}{$\begin{array}{c}\text { Tertiärbereich B } \\
\text { (erster Abschluss) }\end{array}$} & \multirow{2}{*}{$\begin{array}{l}\text { Erstabschluss } \\
\text { Tertiärbereich A }\end{array}$} & \multicolumn{3}{|c|}{ Tertiärbereich A (erster und zweiter Abschluss) } & \multirow{2}{*}{$\begin{array}{l}\text { Weiterführende } \\
\text { forschungs- } \\
\text { orientierte } \\
\text { Studiengänge }\end{array}$} \\
\hline & & & & $\begin{array}{c}3 \text { bis weniger als } \\
5 \text { Jahre }\end{array}$ & 5 bis 6 Jahre & $\begin{array}{l}\text { Länger als } \\
6 \text { Jahre }\end{array}$ & \\
\hline \multicolumn{8}{|l|}{ OECD-Länder } \\
\hline Australien & 21 & 21 & 23 & 23 & 23 & 23 & $\mathrm{~m}$ \\
\hline Österreich & $21-23$ & $21-23$ & $23-25$ & $22-24$ & $24-26$ & a & $27-29$ \\
\hline Belgien & $21-22$ & $21-22$ & 21 & $\mathrm{~m}$ & $\mathrm{~m}$ & $\mathrm{~m}$ & $27-29$ \\
\hline Kanada & $21-24$ & $21-24$ & $22-24$ & 22 & $23-24$ & 25 & $27-29$ \\
\hline Chile & $21-25$ & $21-25$ & $24-26$ & $23-26$ & $24-26$ & $25-26$ & $30-34$ \\
\hline Tschechien & $21-22$ & $21-22$ & $22-24$ & $22-24$ & $25-26$ & a & $30-34$ \\
\hline Dänemark & $23-25$ & $23-25$ & 24 & 24 & 26 & $25-29$ & $30-34$ \\
\hline Estland & 22 & 22 & $22-24$ & 22 & 24 & a & $30-34$ \\
\hline Finnland & $30-34$ & $30-34$ & $25-29$ & 24 & a & a & $30-34$ \\
\hline Frankreich & $19-23$ & $19-23$ & $19-24$ & $19-22$ & $21-24$ & $27-29$ & $26-28$ \\
\hline Deutschland & $21-23$ & $21-23$ & $24-27$ & $24-26$ & $25-27$ & a & $28-29$ \\
\hline Griechenland & $24-25$ & $24-25$ & $23-24$ & $23-24$ & $23-24$ & a & $30-34$ \\
\hline Ungarn & 20 & 20 & $22-24$ & $21-23$ & $23-24$ & a & $30-34$ \\
\hline Island & 25 & 25 & 23 & 23 & 25 & a & 29 \\
\hline Irland & $20-21$ & $20-21$ & 21 & 21 & 23 & 25 & 27 \\
\hline Israel & $\mathrm{m}$ & $\mathrm{m}$ & $26-27$ & $26-27$ & $27-29$ & a & $30-34$ \\
\hline Italien & $22-23$ & $22-23$ & 23 & 23 & 25 & a & $30-34$ \\
\hline Japan & 19 & 19 & $21-23$ & 21 & 23 & a & 26 \\
\hline Korea & 20 & 20 & $22-24$ & $22-26$ & $24-25$ & a & $30-34$ \\
\hline Luxemburg & $20-25$ & $20-25$ & $21-25$ & $21-22$ & $23-24$ & $24-25$ & $26-28$ \\
\hline Mexiko & 20 & 20 & 23 & 23 & $23-26$ & $\mathrm{~m}$ & $24-28$ \\
\hline Niederlande & 27 & 27 & 23 & 23 & a & a & $\mathrm{m}$ \\
\hline Neuseeland & $19-21$ & $19-21$ & $21-23$ & $21-23$ & 23 & 24 & $27-28$ \\
\hline Norwegen & 24 & 24 & $22-27$ & $22-23$ & $24-25$ & $26-27$ & $29-34$ \\
\hline Polen & 22 & 22 & $23-25$ & 23 & 25 & a & $25-29$ \\
\hline Portugal & $35-39$ & $35-39$ & 22 & 22 & $>40$ & a & $>40$ \\
\hline Slowakei & $21-22$ & $21-22$ & $21-22$ & $21-22$ & 23 & a & $26-27$ \\
\hline Slowenien & $23-25$ & $23-25$ & $23-26$ & $23-24$ & $25-26$ & a & 28 \\
\hline Spanien & 19 & 19 & $20-22$ & 20 & 22 & a & $26-28$ \\
\hline Schweden & $21-23$ & $21-23$ & 25 & 25 & 25 & $\mathrm{n}$ & $30-34$ \\
\hline Schweiz & $23-29$ & $23-29$ & $24-26$ & $24-26$ & $25-27$ & $25-27$ & $30-34$ \\
\hline Türkei & 21 & 21 & $22-24$ & $23-24$ & $25-26$ & a & $30-34$ \\
\hline Vereinigtes Königreich & $19-24$ & $19-24$ & $20-25$ & $20-22$ & $22-24$ & $23-25$ & $25-29$ \\
\hline $\begin{array}{l}\text { Vereinigte Staaten } \\
\text { Partnerländer }\end{array}$ & 19 & 19 & 21 & 21 & 23 & 24 & 26 \\
\hline Argentinien & $20-24$ & $20-24$ & $21-24$ & $21-22$ & $22-23$ & $23-24$ & $25-29$ \\
\hline Brasilien & $21-23$ & $21-23$ & $22-24$ & $22-24$ & $\mathrm{~m}$ & $\mathrm{~m}$ & $30-34$ \\
\hline China & 20 & 20 & 21 & 21 & 22 & 22 & 27 \\
\hline Kolumbien & $\mathrm{m}$ & $\mathrm{m}$ & $\mathrm{m}$ & $\mathrm{m}$ & $\mathrm{m}$ & $\mathrm{m}$ & $\mathrm{m}$ \\
\hline Indien & $\mathrm{m}$ & $\mathrm{m}$ & $\mathrm{m}$ & $\mathrm{m}$ & $\mathrm{m}$ & $\mathrm{m}$ & $\mathrm{m}$ \\
\hline Indonesien & 24 & 24 & 22 & 22 & 24 & 26 & 27 \\
\hline Lettland & $21-23$ & $21-23$ & $23-25$ & $22-25$ & a & a & $30-34$ \\
\hline Russische Föderation & 20 & 20 & 22 & 21 & 22 & 23 & $\mathrm{~m}$ \\
\hline Saudi-Arabien & 20 & 20 & 21 & 21 & 21 & 21 & 27 \\
\hline Südafrika & 20 & 20 & 21 & 21 & 22 & 22 & 25 \\
\hline
\end{tabular}

Anmerkung: Wenn Daten zum Tertiärbereich A, aufgegliedert nach der Dauer der Studiengänge, verfügbar waren, ist die Abschlussquote für alle Studiengänge die Summe der Abschlussquoten, aufgegliedert nach der Dauer der Studiengänge.

Quelle: OECD. Argentinien, China, Indien, Indonesien, Kolumbien, Saudi-Arabien und Südafrika: Statistikinstitut der UNESCO. Lettland: Eurostat. Hinweise s. Anhang 3 unter www.oecd.org/edu/eag.htm. StatLink: http://dx.doi.org/10.1787/888933120689 Erläuterung der Kennzeichnung fehlender Daten s. Hinweise für den Leser. 
Tabelle X1.1c (Forts.)

Abschlussquoten im Tertiärbereich: Typisches Abschlussalter und Art der Abschlussquote (Brutto- bzw. Nettoabschlussquote) (2012)

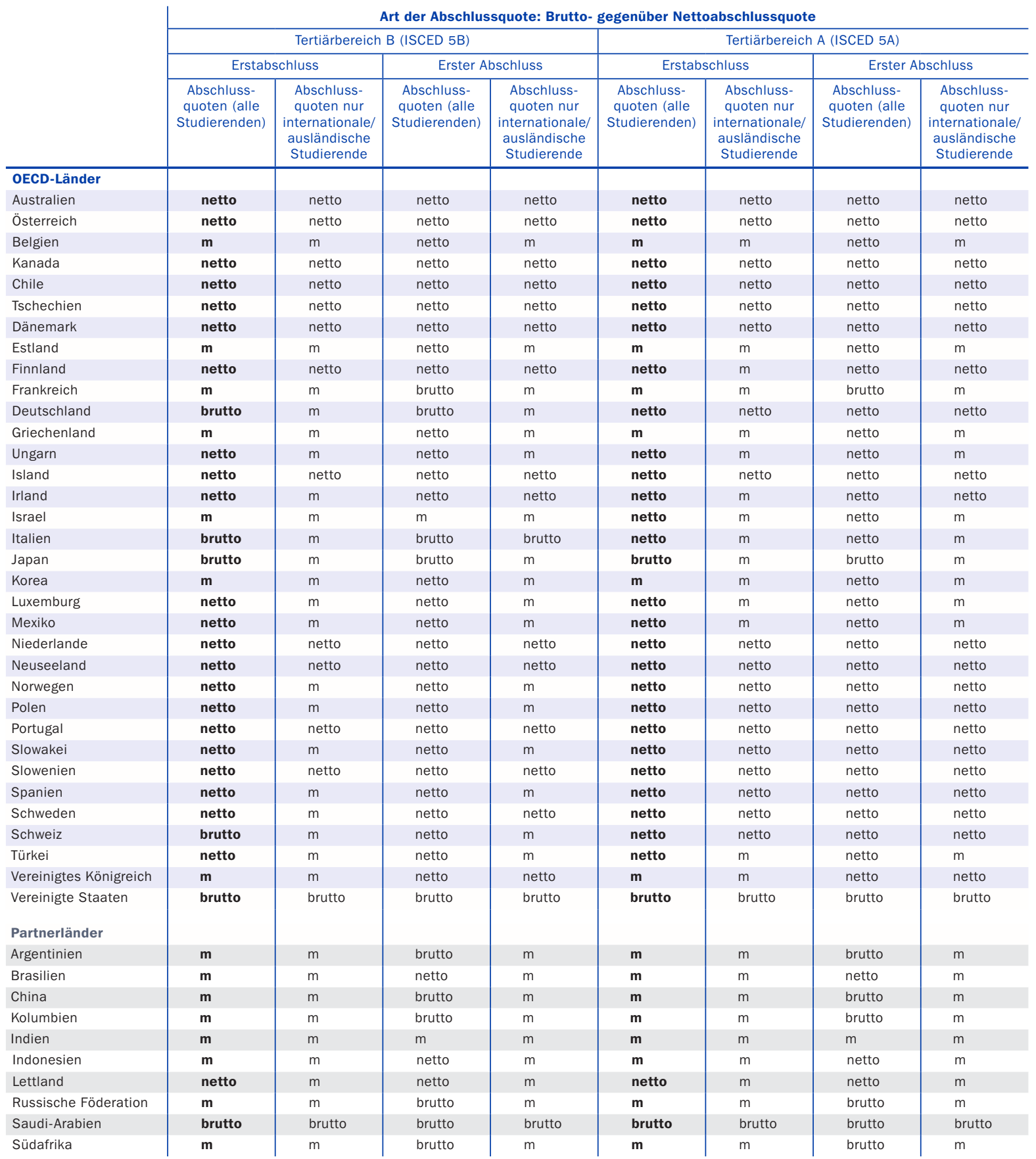

Anmerkung: Wenn Daten zum Tertiärbereich A, aufgegliedert nach der Dauer der Studiengänge, verfügbar waren, ist die Abschlussquote für alle Studiengänge die Summe der Abschlussquoten, aufgegliedert nach der Dauer der Studiengänge.

Quelle: OECD. Argentinien, China, Indien, Indonesien, Kolumbien, Saudi-Arabien und Südafrika: Statistikinstitut der UNESCO. Lettland: Eurostat. Hinweise s. Anhang 3 unter www.oecd.org/edu/eag.htm. StatLink: http://dx.doi.org/10.1787/888933120689 Erläuterung der Kennzeichnung fehlender Daten s. Hinweise für den Leser. 
Studienanfängerquoten: Typisches Eintrittsalter und Art der Studienanfängerquote (Brutto- bzw. Nettoanfängerquote) (2012)

\begin{tabular}{|c|c|c|c|c|c|c|c|c|c|}
\hline & \multirow{2}{*}{\multicolumn{3}{|c|}{ Typisches Eintrittsalter }} & \multirow{2}{*}{\multicolumn{3}{|c|}{$\begin{array}{l}\begin{array}{c}\text { Art der Studienanfängerquote: Brutto- } \\
\text { gegenüber Netto-Studienanfängerquote }\end{array} \\
\text { Alle Studierenden }\end{array}$}} & \multirow{2}{*}{\multicolumn{3}{|c|}{$\begin{array}{c}\begin{array}{c}\text { Art der Studienanfängerquote: Brutto- } \\
\text { gegenüber Netto-Studienanfängerquote }\end{array} \\
\text { Internationale Studierende }\end{array}$}} \\
\hline & & & & & & & & & \\
\hline & ISCED 5A & ISCED 5B & ISCED 6 & ISCED 5A & ISCED 5B & ISCED 6 & ISCED 5A & ISCED 5B & ISCED 6 \\
\hline \multicolumn{10}{|l|}{ OECD-Länder } \\
\hline Australien & 18 & 18 & $22-23$ & netto & $\mathrm{m}$ & netto & netto & $\mathrm{m}$ & netto \\
\hline Österreich & $19-20$ & $20-21$ & $25-26$ & netto & netto & netto & netto & netto & netto \\
\hline Belgien & $18-19$ & $18-19$ & $\mathrm{~m}$ & netto & netto & $\mathrm{m}$ & $\mathrm{m}$ & $\mathrm{m}$ & $\mathrm{m}$ \\
\hline Kanada & $\mathrm{m}$ & $\mathrm{m}$ & $\mathrm{m}$ & $\mathrm{m}$ & $\mathrm{m}$ & $\mathrm{m}$ & $\mathrm{m}$ & $\mathrm{m}$ & $\mathrm{m}$ \\
\hline Chile & 18 & $18-19$ & $26-27$ & netto & netto & netto & netto & netto & netto \\
\hline Tschechien & $19-20$ & $19-20$ & $24-25$ & netto & netto & netto & netto & netto & netto \\
\hline Dänemark & $20-21$ & $20-21$ & $25-27$ & netto & netto & netto & netto & netto & netto \\
\hline Estland & 19 & 19 & 24 & netto & netto & netto & $\mathrm{m}$ & $\mathrm{m}$ & $\mathrm{m}$ \\
\hline Finnland & 19 & a & $26-28$ & netto & a & netto & $\mathrm{m}$ & a & $\mathrm{m}$ \\
\hline Frankreich & 18 & 19 & $23-25$ & netto & $\mathrm{m}$ & netto & $\mathrm{m}$ & $\mathrm{m}$ & $\mathrm{m}$ \\
\hline Deutschland & $19-21$ & $19-21$ & $26-27$ & netto & netto & netto & netto & $\mathrm{m}$ & netto \\
\hline Griechenland & 18 & 18 & 24 & netto & netto & $\mathrm{m}$ & $\mathrm{m}$ & $\mathrm{m}$ & $\mathrm{m}$ \\
\hline Ungarn & 19 & 19 & 25 & netto & netto & netto & $m$ & $m$ & $\mathrm{~m}$ \\
\hline Island & 20 & 20 & 25 & netto & netto & netto & netto & $\mathrm{n}$ & netto \\
\hline Irland & 18 & 18 & $m$ & netto & netto & $\mathrm{m}$ & netto & netto & $\mathrm{m}$ \\
\hline Israel & $22-24$ & 18 & $27-29$ & netto & netto & netto & $\mathrm{m}$ & $\mathrm{m}$ & $\mathrm{m}$ \\
\hline Italien & 19 & 18 & $25-26$ & netto & netto & netto & $\mathrm{m}$ & $\mathrm{m}$ & $\mathrm{m}$ \\
\hline Japan & 18 & 18 & 24 & netto & netto & netto & $\mathrm{m}$ & $\mathrm{m}$ & $\mathrm{m}$ \\
\hline Korea & 18 & 18 & $24-29$ & netto & netto & netto & $\mathrm{m}$ & $\mathrm{m}$ & $\mathrm{m}$ \\
\hline Luxemburg & $\mathrm{m}$ & $\mathrm{m}$ & $\mathrm{m}$ & netto & netto & netto & $\mathrm{m}$ & $\mathrm{m}$ & $\mathrm{m}$ \\
\hline Mexiko & 18 & 18 & 24 & netto & netto & netto & $\mathrm{m}$ & $\mathrm{m}$ & $\mathrm{m}$ \\
\hline Niederlande & $18-19$ & $17-18$ & $22-23$ & netto & netto & netto & netto & netto & netto \\
\hline Neuseeland & 18 & 18 & $23-24$ & netto & netto & netto & netto & netto & netto \\
\hline Norwegen & $19-20$ & 19 & $26-27$ & netto & netto & netto & netto & netto & netto \\
\hline Polen & $19-20$ & $19-20$ & $\mathrm{~m}$ & netto & netto & $\mathrm{m}$ & netto & $\mathrm{m}$ & $\mathrm{m}$ \\
\hline Portugal & 18 & 18 & $22-24$ & netto & netto & netto & netto & netto & netto \\
\hline Slowakei & 19 & 20 & 24 & netto & netto & netto & netto & $\mathrm{m}$ & netto \\
\hline Slowenien & 19 & 19 & $24-26$ & netto & netto & netto & netto & netto & netto \\
\hline Spanien & 18 & $19-20$ & 25 & netto & netto & $\mathrm{m}$ & netto & $\mathrm{m}$ & $\mathrm{m}$ \\
\hline Schweden & 19 & 19 & $25-27$ & netto & netto & netto & netto & netto & netto \\
\hline Schweiz & 21 & 26 & 27 & netto & netto & netto & netto & $\mathrm{m}$ & netto \\
\hline Türkei & $18-19$ & $18-19$ & $26-27$ & netto & netto & netto & $\mathrm{m}$ & $\mathrm{m}$ & $\mathrm{m}$ \\
\hline Vereinigtes Königreich & 18 & 18 & $22-24$ & netto & netto & netto & netto & netto & netto \\
\hline $\begin{array}{l}\text { Vereinigte Staaten } \\
\text { Partnerländer }\end{array}$ & 18 & 18 & 24 & netto & $\mathrm{m}$ & $\mathrm{m}$ & brutto & $\mathrm{m}$ & $\mathrm{m}$ \\
\hline Argentinien & 18 & 18 & 25 & netto & netto & netto & $\mathrm{m}$ & $\mathrm{m}$ & $\mathrm{m}$ \\
\hline Brasilien & $\mathrm{m}$ & $\mathrm{m}$ & $\mathrm{m}$ & $\mathrm{m}$ & $\mathrm{m}$ & $\mathrm{m}$ & $\mathrm{m}$ & $\mathrm{m}$ & $\mathrm{m}$ \\
\hline China & 17 & 17 & 21 & brutto & brutto & brutto & $\mathrm{m}$ & $\mathrm{m}$ & $\mathrm{m}$ \\
\hline Kolumbien & $\mathrm{m}$ & $\mathrm{m}$ & $\mathrm{m}$ & $\mathrm{m}$ & $\mathrm{m}$ & $\mathrm{m}$ & netto & netto & $\mathrm{m}$ \\
\hline Indien & $\mathrm{m}$ & $m$ & $\mathrm{~m}$ & $\mathrm{~m}$ & $\mathrm{~m}$ & $\mathrm{~m}$ & $\mathrm{~m}$ & $\mathrm{~m}$ & $\mathrm{~m}$ \\
\hline Indonesien & 18 & 18 & $25-26$ & netto & netto & netto & $\mathrm{m}$ & $\mathrm{m}$ & $\mathrm{m}$ \\
\hline Lettland & 18 & 18 & 22 & netto & netto & $\mathrm{m}$ & netto & netto & $\mathrm{m}$ \\
\hline Russische Föderation & 18 & 18 & $23-24$ & brutto & brutto & brutto & $\mathrm{m}$ & $\mathrm{m}$ & $\mathrm{m}$ \\
\hline Saudi-Arabien & $18-22$ & 18 & 24 & brutto & brutto & brutto & brutto & brutto & brutto \\
\hline Südafrika & $\mathrm{m}$ & $\mathrm{m}$ & $\mathrm{m}$ & $\mathrm{m}$ & $\mathrm{m}$ & $\mathrm{m}$ & $\mathrm{m}$ & $\mathrm{m}$ & $\mathrm{m}$ \\
\hline
\end{tabular}

Quelle: OECD. Argentinien, China, Indien, Indonesien, Kolumbien, Saudi-Arabien und Südafrika: Statistikinstitut der UNESCO. Lettland: Eurostat. Hinweise s. Anhang 3 unter www.oecd.org/edu/eag.htm. StatLink: http://dx.doi.org/10.1787/888933120708

Erläuterung der Kennzeichnung fehlender Daten s. Hinweise für den Leser. 
Tabelle X1.2a

Für die Berechnung der Finanzindikatoren verwendete Haushalts- und Schuljahre, OECD-Länder

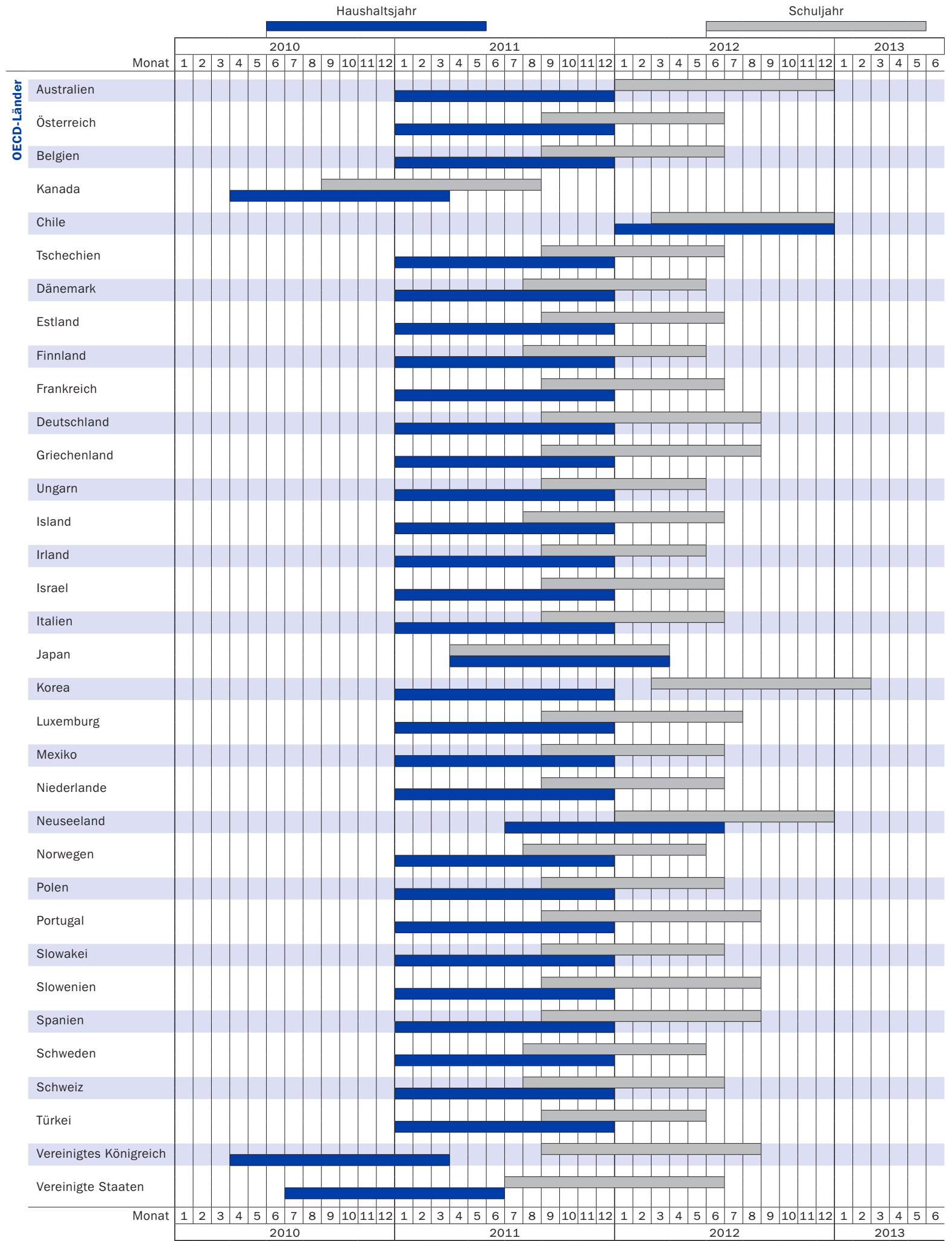

Quelle: OECD. Hinweise s. Anhang 3 unter www.oecd.org/edu/eag.htm. StatLink: http://dx.doi.org/10.1787/888933120727 
Für die Berechnung der Finanzindikatoren verwendete Haushalts- und Schuljahre, Partnerländer

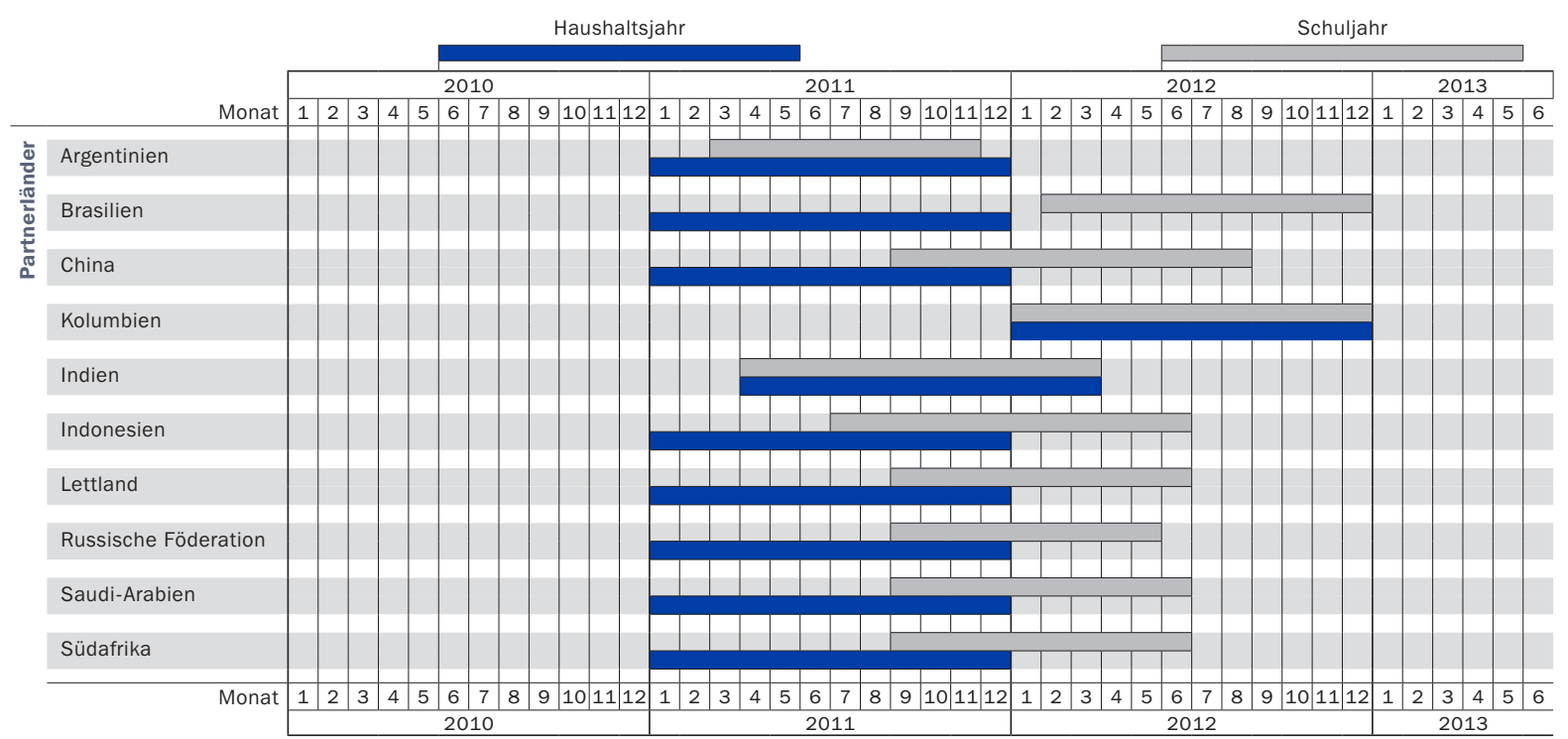

Quelle: OECD. Argentinien, China, Indien, Indonesien, Kolumbien, Saudi-Arabien und Südafrika: Statistikinstitut der UNESCO. Lettland: Eurostat. Hinweise s. Anhang 3 unter www.oecd.org/edu/eag.htm. StatLink: http://dx.doi.org/10.1787/888933120746

Hinweis zu den Daten aus Israel

Die statistischen Daten für Israel wurden von den zuständigen israelischen Stellen bereitgestellt, die für sie verantwortlich zeichnen. Die Verwendung dieser Daten durch die OECD erfolgt unbeschadet des völkerrechtlichen Status der Golanhöhen, von Ost-Jerusalem und der israelischen Siedlungen im Westjordanland. 



\section{Statistische Bezugsdaten}

Alle Tabellen im Anhang 2 sind im Internet verfügbar unter:

StatLink: http://dx.doi.org/10.1787/888933120765 
Tabelle X2.1

Überblick über das wirtschaftliche Umfeld anhand grundlegender Kennzahlen (Referenzzeitraum: Kalenderjahr 2011, zu konstanten Preisen von 2011)

\begin{tabular}{|c|c|c|c|c|}
\hline & $\begin{array}{l}\text { Öffentliche Gesamtausgaben } \\
\text { als Prozentsatz des BIP }\end{array}$ & $\begin{array}{c}\text { BIP pro Kopf } \\
\text { (in US-Dollar, } \\
\text { kaufkraftbereinigt) }\end{array}$ & $\begin{array}{l}\text { BIP-Deflator } \\
(2005=100)\end{array}$ & $\begin{array}{l}\text { BIP-Deflator } \\
(2000=100)\end{array}$ \\
\hline & (1) & (2) & (3) & (4) \\
\hline \multicolumn{5}{|l|}{ OECD-Länder } \\
\hline Australien & 33,5 & 43208 & 125,9 & 150,3 \\
\hline Österreich & 50,8 & 42978 & 111,2 & 120,3 \\
\hline Belgien & 53,5 & 40093 & 112,7 & 125,1 \\
\hline Kanada $^{1}$ & 41,8 & 37480 & 115,0 & 129,4 \\
\hline Chile $^{2}$ & $\mathrm{~m}$ & 21486 & 125,3 & 177,3 \\
\hline Tschechien & 43,2 & 27046 & 105,6 & 118,6 \\
\hline Dänemark & 57,7 & 41843 & 115,1 & 129,1 \\
\hline Estland & 37,7 & 23088 & 132,5 & 170,2 \\
\hline Finnland & 55,3 & 38611 & 111,9 & 117,0 \\
\hline Frankreich & 55,9 & 36391 & 110,7 & 122,0 \\
\hline Deutschland & 45,2 & 40990 & 106,3 & 112,1 \\
\hline Griechenland & $\mathrm{m}$ & 26622 & 115,9 & 135,9 \\
\hline Ungarn & 50,1 & 22413 & 125,0 & 171,5 \\
\hline Island & 47,4 & 38224 & 153,7 & 187,0 \\
\hline Irland & 47,1 & 42943 & 97,4 & 118,3 \\
\hline Israel & 39,6 & 30168 & 112,2 & 119,4 \\
\hline Italien & 49,9 & 33870 & 110,9 & 126,6 \\
\hline Japan & 42,2 & 34967 & 92,4 & 86,0 \\
\hline Korea & 30,2 & 29035 & 114,2 & 131,4 \\
\hline Luxemburg & 42,9 & 88668 & 125,1 & 144,5 \\
\hline Mexiko & 25,5 & 17125 & 137,6 & 192,0 \\
\hline Niederlande & 49,9 & 43150 & 108,0 & 124,3 \\
\hline Neuseeland & 34,2 & 31487 & 119,0 & 133,8 \\
\hline Norwegen $^{3}$ & 58,2 & 46696 & 123,2 & 141,7 \\
\hline Polen & 43,4 & 21753 & 118,1 & 134,0 \\
\hline Portugal & 49,3 & 25672 & 109,3 & 127,1 \\
\hline Slowakei & 38,2 & 25130 & 108,1 & 134,5 \\
\hline Slowenien & 50,8 & 28156 & 114,5 & 148,3 \\
\hline Spanien & 45,9 & 32157 & 110,3 & 135,6 \\
\hline Schweden & 51,5 & 41761 & 112,7 & 120,6 \\
\hline Schweiz & 33,7 & 51582 & 108,0 & 112,1 \\
\hline Türkei & 37,4 & 17781 & 157,1 & 489,7 \\
\hline Vereinigtes Königreich & 49,6 & 33886 & 117,1 & 130,9 \\
\hline Vereinigte Staaten & 37,4 & 49321 & 112,2 & 126,0 \\
\hline \multicolumn{5}{|l|}{ Partnerländer } \\
\hline Argentinien & $\mathrm{m}$ & 10805 & $\mathrm{~m}$ & m \\
\hline Brasilien & 31,6 & 11735 & 151,1 & 239,7 \\
\hline China & $\mathrm{m}$ & 8397 & $\mathrm{~m}$ & $\mathrm{~m}$ \\
\hline Kolumbien & $\mathrm{m}$ & 10303 & $\mathrm{~m}$ & $\mathrm{~m}$ \\
\hline Indien & $\mathrm{m}$ & $\mathrm{m}$ & $\mathrm{m}$ & $\mathrm{m}$ \\
\hline Indonesien & $\mathrm{m}$ & $\mathrm{m}$ & $\mathrm{m}$ & $\mathrm{m}$ \\
\hline Lettland & $\mathrm{m}$ & 19984 & $\mathrm{~m}$ & $\mathrm{~m}$ \\
\hline Russische Föderation & $\mathrm{m}$ & 22502 & 208,0 & 457,4 \\
\hline Saudi-Arabien & $\mathrm{m}$ & $\mathrm{m}$ & $\mathrm{m}$ & $\mathrm{m}$ \\
\hline Südafrika & $\mathrm{m}$ & 10052 & $\mathrm{~m}$ & $\mathrm{~m}$ \\
\hline
\end{tabular}

1. Referenzjahr 2010. 2. Referenzjahr 2012 anstelle 2011. Der BIP-Deflator bezieht sich auf 2001-2012 anstelle $2000-2011$ sowie auf $2006-2012$ anstelle 2005-2011. 3. Für Norwegen wird der BIP-Festlandmarktwert verwendet.

Quelle: OECD. Hinweise s. Anhang 3 unter www.oecd.org/edu/eag.htm. StatLink: http://dx.doi.org/10.1787/888933120784

Erläuterung der Kennzeichnung fehlender Daten s. Hinweise für den Leser. 
Grundlegende statistische Bezugsdaten (Referenzzeitraum: Kalenderjahr 2011, zu konstanten Preisen von 2011) ${ }^{1}$

\begin{tabular}{|c|c|c|c|c|c|c|c|}
\hline & \begin{tabular}{|c} 
Bruttoinlands- \\
produkt \\
(in Mio. Landes- \\
währung)
\end{tabular} & $\begin{array}{c}\text { Bruttoinlands- } \\
\text { produkt } \\
\text { (angepasst an } \\
\text { das Haushalts- } \\
\text { jahr) }\end{array}$ & $\begin{array}{c}\text { Öffentliche } \\
\text { Gesamtausgaben } \\
\text { (in Mio. Landes- } \\
\text { währung) }\end{array}$ & $\begin{array}{l}\text { Gesamtbevölke- } \\
\text { rung in Tausend } \\
\text { (Schätzung } \\
\text { zur Mitte des } \\
\text { Jahres) }\end{array}$ & $\begin{array}{c}\text { Kaufkraft- } \\
\text { paritäten (KKP) } \\
\text { für das BIP } \\
(\text { US-Dollar = 1) }\end{array}$ & \begin{tabular}{|c} 
Kaufkraftparität \\
$($ KKP) für das BIP \\
(Eurozone = 1)
\end{tabular} & $\begin{array}{c}\text { Kaufkraftparität } \\
\text { (KKP) für } \\
\text { den privaten } \\
\text { Verbrauch } \\
\text { (US-Dollar = 1) }\end{array}$ \\
\hline & (1) & (2) & (3) & (4) & (5) & (6) & (7) \\
\hline \multicolumn{8}{|l|}{ OECD-Länder } \\
\hline Australien & 1486071 & & 498406 & 22761 & 1,511 & 1,937 & 1,581 \\
\hline Österreich & 299240 & & 151994 & 8389 & 0,830 & 1,064 & 0,857 \\
\hline Belgien & 369259 & & 197422 & 10978 & 0,839 & 1,076 & 0,906 \\
\hline Kanada ${ }^{4}$ & 1719631 & 1576759 & 658901 & 34483 & 1,220 & 1,564 & 1,300 \\
\hline Chile $^{5}$ & 130526894 & & $\mathrm{~m}$ & 17450 & 348,131 & 446,322 & 370,164 \\
\hline Tschechien & 3823401 & & 1653244 & 10497 & 13,468 & 17,267 & 15,565 \\
\hline Dänemark & 1791773 & & 1034208 & 5569 & 7,689 & 9,858 & 8,571 \\
\hline Estland & 16216 & & 6109 & 1340 & 0,524 & 0,672 & 0,621 \\
\hline Finnland & 188679 & & 104259 & 5387 & 0,907 & 1,163 & 1,002 \\
\hline Frankreich & 2001398 & & 1118728 & 65115 & 0,845 & 1,083 & 0,902 \\
\hline Deutschland & 2609900 & & 1178650 & 81779 & 0,779 & 0,998 & 0,850 \\
\hline Griechenland & 208532 & & 108003 & 11300 & 0,693 & 0,889 & 0,779 \\
\hline Ungarn & 27635435 & & 13834811 & 9972 & 123,650 & 158,526 & 145,007 \\
\hline Island & 1628677 & & 771800 & 319 & 133,563 & 171,235 & 145,921 \\
\hline Irland & 162600 & & 76536 & 4577 & 0,827 & 1,061 & 0,962 \\
\hline Israel & 923900 & & 365561 & 7763 & 3,945 & 5,058 & 4,470 \\
\hline Italien & 1580410 & & 788137 & 60724 & 0,768 & 0,985 & 0,839 \\
\hline$J^{J a p a n}{ }^{6}$ & 478985700 & 477208400 & 199103100 & 127831 & 106,762 & 136,874 & 121,366 \\
\hline Korea & 1235160500 & & 373227400 & 49779 & 854,586 & 1095,623 & 910,471 \\
\hline Luxemburg & 41730 & & 17882 & 519 & 0,906 & 1,162 & 0,994 \\
\hline Mexiko & 14351494 & & 3655757 & 109220 & 7,673 & 9,837 & 8,953 \\
\hline Niederlande & 599047 & & 298715 & 16693 & 0,832 & 1,066 & 0,882 \\
\hline Neuseeland & 206546 & & 70669 & 4415 & 1,486 & 1,905 & 1,607 \\
\hline Norwegen $^{7}$ & 2075197 & & 1207768 & 4953 & 8,973 & 11,503 & 9,806 \\
\hline Polen & 1528127 & & 663757 & 38526 & 1,823 & 2,338 & 1,992 \\
\hline Portugal & 171126 & & 84423 & 10622 & 0,628 & 0,805 & 0,715 \\
\hline Slowakei & 68974 & & 26381 & 5398 & 0,508 & 0,652 & 0,580 \\
\hline Slowenien & 36150 & & 18350 & 2053 & 0,625 & 0,802 & 0,708 \\
\hline Spanien & 1046327 & & 480111 & 46125 & 0,705 & 0,904 & 0,790 \\
\hline Schweden & 3480543 & & 1792006 & 9450 & 8,820 & 11,308 & 9,464 \\
\hline Schweiz & 585102 & & 196889 & 7869 & 1,441 & 1,848 & 1,654 \\
\hline Türkei & 1297713 & & 485001 & 73950 & 0,987 & 1,265 & 1,147 \\
\hline Vereinigtes Königreich & 1536937 & 1484161 & 736445 & 62735 & 0,698 & 0,895 & 0,705 \\
\hline Vereinigte Staaten & 15533800 & 15389925 & 5754000 & 312036 & 1 & 1,282 & 1 \\
\hline Eurozone & & & & & 0,780 & & \\
\hline \multicolumn{8}{|l|}{ Partnerländer } \\
\hline Argentinien & 1842022 & & $\mathrm{~m}$ & 41282 & 4,130 & 5,294 & $\mathrm{~m}$ \\
\hline Brasilien & 4143013 & & 1308035 & 195243 & 1,808 & 2,318 & $\mathrm{~m}$ \\
\hline China & 47310405 & & $\mathrm{~m}$ & 1347350 & 4,182 & 5,361 & $\mathrm{~m}$ \\
\hline Kolumbien & 621615000 & & $\mathrm{~m}$ & 46045 & 1310,367 & 1679,958 & $\mathrm{~m}$ \\
\hline Indien & $\mathrm{m}$ & & $\mathrm{m}$ & 1221156 & 19,786 & 25,367 & $\mathrm{~m}$ \\
\hline Indonesien 5 & $\mathrm{~m}$ & & 1435406700 & $\mathrm{~m}$ & 6737,746 & 8638,135 & $\mathrm{~m}$ \\
\hline Lettland & 14275 & & $\mathrm{~m}$ & 2058 & 0,347 & 0,445 & $\mathrm{~m}$ \\
\hline Russische Föderation & 55799573 & & $\mathrm{~m}$ & 142961 & 17,346 & 22,238 & 17,415 \\
\hline Saudi-Arabien & $\mathrm{m}$ & & $\mathrm{m}$ & $\mathrm{m}$ & $\mathrm{m}$ & $\mathrm{m}$ & $\mathrm{m}$ \\
\hline Südafrika & 2659366 & & $\mathrm{~m}$ & 50587 & 5,230 & 6,705 & $m$ \\
\hline
\end{tabular}

1. Angaben zu BIP, KKP und öffentlichen Gesamtausgaben für Länder in der Eurozone in Euro. 2. BIP in Australien sowie BIP und öffentliche Gesamtausgaben in Neuseeland für das Haushaltsjahr berechnet. 3. Bei Ländern, für die das BIP nicht für denselben Referenzzeitraum wie die Daten zu den Bildungsfinanzen angegeben wurde, wurde das BIP geschätzt als $w_{t-1}\left(B I P_{t-1}\right)+w_{t}\left(B I P_{t}\right)$, mit $w_{t}$ und $w_{t-1}$ als Gewichtung für die entsprechenden Anteile der beiden Referenzzeiträume für das BIP innerhalb des Haushaltsjahres für Bildung. In Kapitel B wurden für Japan, Kanada, das Vereinigte Königreich und die Vereinigten Staaten Anpassungen vorgenommen. 4. Referenzjahr 2010. 5. Referenzjahr 2012. 6. Öffentliche Gesamtausgaben an das Haushaltsjahr angepasst. 7. Für Norwegen wird der BIP-Festlandmarktwert verwendet.

Quelle: OECD. Hinweise s. Anhang 3 unter www.oecd.org/edu/eag.htm. StatLink: http://dx.doi.org/10.1787/888933120803

Erläuterung der Kennzeichnung fehlender Daten s. Hinweise für den Leser. 
Tabelle X2.3

Grundlegende statistische Bezugsdaten (Referenzzeitraum: Kalenderjahr 1995, 2000, 2005, 2008, 2009, 2010)1

\begin{tabular}{|c|c|c|c|c|c|c|}
\hline & \multicolumn{6}{|c|}{$\begin{array}{l}\text { Bruttoinlandsprodukt } \\
\text { (in Mio. Landeswährung, zu jeweiligen Preisen) }\end{array}$} \\
\hline & 1995 & 2000 & 2005 & 2008 & 2009 & 2010 \\
\hline & (1) & (2) & (3) & (4) & (5) & (6) \\
\hline \multicolumn{7}{|l|}{ OECD-Länder } \\
\hline Australien & 529282 & 705562 & 998312 & 1258654 & 1296324 & 1406671 \\
\hline Österreich & 174794 & 208474 & 245243 & 282744 & 276228 & 285165 \\
\hline Belgien & 207927 & 252543 & 303435 & 346375 & 340669 & 355740 \\
\hline Kanada & 810426 & 1076577 & 1373845 & 1603418 & 1528985 & 1624608 \\
\hline Chile $^{2}$ & 29336967 & 42094989 & 82018171 & 96443761 & 111007886 & 121492697 \\
\hline Tschechien & 1533676 & 2269695 & 3116056 & 3848411 & 3758979 & 3790880 \\
\hline Dänemark & 1019545 & 1293963 & 1545257 & 1753152 & 1664790 & 1760051 \\
\hline Estland & 2767 & 6160 & 11182 & 16235 & 13970 & 14371 \\
\hline Finnland & 96064 & 132195 & 157429 & 185670 & 172318 & 178724 \\
\hline Frankreich & 1196181 & 1439603 & 1718047 & 1933195 & 1885763 & 1936720 \\
\hline Deutschland & 1848500 & 2047500 & 2224400 & 2473800 & 2374200 & 2495000 \\
\hline Griechenland & 88742 & 135043 & 193050 & 233198 & 231081 & 222152 \\
\hline Ungarn & 5727829 & 13089047 & 22018283 & 26543305 & 25626480 & 26513032 \\
\hline Island & 454013 & 683747 & 1025740 & 1480346 & 1497934 & 1535932 \\
\hline Irland & 53775 & 105644 & 162897 & 180249 & 162284 & 158097 \\
\hline Israel & 289555 & 506173 & 600011 & 764697 & 809230 & 866231 \\
\hline Italien & 952158 & 1198292 & 1436379 & 1575144 & 1519695 & 1551886 \\
\hline Japan & 501706900 & 509860000 & 503903000 & 501209300 & 471138700 & 482384400 \\
\hline Korea & 409653600 & 603236000 & 865240900 & 1026451800 & 1065036800 & 1173274900 \\
\hline Luxemburg & 15108 & 21998 & 30270 & 37372 & 35575 & 39303 \\
\hline Mexiko & 2013954 & 6020649 & 9220649 & 12153436 & 11893247 & 13029103 \\
\hline Niederlande & 305261 & 417960 & 513407 & 594481 & 573235 & 586789 \\
\hline Neuseeland & 95368 & 118377 & 161645 & 185555 & 189718 & 199113 \\
\hline Norwegen ${ }^{3}$ & 806858 & 1113894 & 1464974 & 1862873 & 1875850 & 1987362 \\
\hline Polen & 337222 & 744378 & 983302 & 1275508 & 1344505 & 1416585 \\
\hline Portugal & 87841 & 127317 & 154269 & 171983 & 168529 & 172860 \\
\hline Slowakei & 19319 & 31177 & 49314 & 66842 & 62794 & 65897 \\
\hline Slowenien & 10357 & 18566 & 28722 & 37244 & 35420 & 35485 \\
\hline Spanien & 446795 & 629907 & 909298 & 1087788 & 1046894 & 1045620 \\
\hline Schweden & 1809575 & 2265447 & 2769375 & 3204320 & 3105790 & 3337531 \\
\hline Schweiz & 383096 & 432405 & 479088 & 567852 & 554372 & 574314 \\
\hline Türkei & 10435 & 166658 & 648932 & 950534 & 952559 & 1098799 \\
\hline Vereinigtes Königreich & 748200 & 987139 & 1276743 & 1462070 & 1417359 & 1485615 \\
\hline Vereinigte Staaten ${ }^{4}$ & 7664000 & 10289700 & 13095400 & 14720300 & 14417900 & 14958300 \\
\hline \multicolumn{7}{|l|}{ Partnerländer } \\
\hline Brasilien & 705641 & 1179482 & 2147240 & 3032204 & 3239404 & 3770085 \\
\hline Russische Föderation & 1427029 & 7298009 & 21609766 & 41276849 & 38807219 & 46308541 \\
\hline
\end{tabular}

1. Angaben zu BIP und öffentlichen Gesamtausgaben für Länder in der Eurozone in Euro. 2. Referenzjahre 1996, 2001, $2006,2009,2010$ und 2011 anstelle 1995, 2000, 2005, 2008, 2009 und 2010. 3. Für Norwegen wird der BIP-Festlandmarktwert verwendet. 4. Die Vereinigten Staaten haben in den vergangenen 6 Monaten ihre gesamte BIP-Serie überarbeitet. Die angegebenen Daten in US-Dollar (aktuelle Fassung) entsprechen nicht denjenigen in Tab. X2.2b in Bildung auf einen Blick 2013.

Quelle: OECD. Hinweise s. Anhang 3 unter www.oecd.org/edu/eag.htm. StatLink: http://dx.doi.org/10.1787/888933120822

Erläuterung der Kennzeichnung fehlender Daten s. Hinweise für den Leser. 
Grundlegende statistische Bezugsdaten (Referenzzeitraum: Kalenderjahr 1995, 2000, 2005, 2008, 2009, 2010)1

\begin{tabular}{|c|c|c|c|c|c|c|}
\hline & \multicolumn{6}{|c|}{$\begin{array}{l}\text { Öffentliche Gesamtausgaben } \\
\text { (in Mio. Landeswährung, zu jeweiligen Preisen) }\end{array}$} \\
\hline & 1995 & 2000 & 2005 & 2008 & 2009 & 2010 \\
\hline & (7) & (8) & (9) & (10) & (11) & (12) \\
\hline \multicolumn{7}{|l|}{ OECD-Länder } \\
\hline Australien & 184270 & 225913 & 309431 & 405784 & 450682 & 473579 \\
\hline Österreich & 98428 & 108287 & 122585 & 139494 & 145333 & 150593 \\
\hline Belgien & 108336 & 123943 & 157399 & 172484 & 183071 & 187026 \\
\hline Kanada & 392886 & 442560 & 539234 & 612322 & 619880 & 638212 \\
\hline Chile $^{2}$ & 6705897 & 10559689 & 15327440 & 23797395 & 24273284 & 27847954 \\
\hline Tschechien & 813015 & 945255 & 1340123 & 1583527 & 1679551 & 1661774 \\
\hline Dänemark & 604404 & 694479 & 815717 & 903263 & 967096 & 1016158 \\
\hline Estland & 1142 & 2225 & 3757 & 6441 & 6259 & 5828 \\
\hline Finnland & 59103 & 63903 & 79262 & 91372 & 96708 & 99707 \\
\hline Frankreich & 650606 & 744119 & 920351 & 1030025 & 1070585 & 1095602 \\
\hline Deutschland & 1014050 & 923360 & 1043450 & 1090460 & 1146270 & 1194130 \\
\hline Griechenland & 40783 & 63693 & 86097 & 117992 & 124669 & 114302 \\
\hline Ungarn & 3197916 & 6251647 & 11032047 & 13070489 & 13179236 & 13252926 \\
\hline Island & $\mathrm{m}$ & 286259 & 433346 & 853725 & 763327 & 791880 \\
\hline Irland & 22093 & 33010 & 55177 & 77009 & 78500 & 103427 \\
\hline Israel & 152248 & 261087 & 296289 & 332256 & 350569 & 367301 \\
\hline Italien & 497257 & 549577 & 688251 & 765537 & 788361 & 782101 \\
\hline Japan & 181284700 & 193917400 & 183640900 & 188561300 & 197216300 & 195879800 \\
\hline Korea & 83399300 & 135324800 & 230062600 & 312548300 & 352323300 & 353006600 \\
\hline Luxemburg & 5996 & 8270 & 12573 & 14624 & 16084 & 17098 \\
\hline Mexiko & 384960 & 1139998 & 1979808 & 2894807 & 3114065 & 3355288 \\
\hline Niederlande & 172305 & 184612 & 229965 & 274781 & 294782 & 301284 \\
\hline Neuseeland & 31743 & $\mathrm{~m}$ & 62645 & 64002 & 64013 & 70450 \\
\hline Norwegen ${ }^{3}$ & 480575 & 626569 & 818805 & 1018107 & 1101034 & 1149163 \\
\hline Polen & 147561 & 294012 & 427147 & 551403 & 599837 & 643465 \\
\hline Portugal & 36787 & 52983 & 71830 & 77055 & 83842 & 88987 \\
\hline Slowakei & 9392 & 16255 & 18730 & 23340 & 26079 & 26329 \\
\hline Slowenien & $\mathrm{m}$ & 8636 & 13011 & 16511 & 17456 & 17894 \\
\hline Spanien & 198730 & 246890 & 349501 & 450948 & 484759 & 485467 \\
\hline Schweden & 1175297 & 1248029 & 1491382 & 1657889 & 1706362 & 1746603 \\
\hline Schweiz & 139873 & 151837 & 176236 & 187914 & 185629 & 189561 \\
\hline Türkei & $\mathrm{m}$ & $\mathrm{m}$ & $\mathrm{m}$ & 345392 & 410658 & 442178 \\
\hline Vereinigtes Königreich & 322956 & 358902 & 553033 & 686738 & 719127 & 738598 \\
\hline Vereinigte Staaten ${ }^{4}$ & 2732629 & 3353547 & 4563353 & 5567081 & 5913918 & 6153839 \\
\hline \multicolumn{7}{|l|}{ Partnerländer } \\
\hline Brasilien & 224283 & 394349 & 670514 & 939831 & 1082430 & 1211373 \\
\hline Russische Föderation & $\mathrm{m}$ & 2016630 & 7380575 & $\mathrm{~m}$ & $\mathrm{~m}$ & $\mathrm{~m}$ \\
\hline
\end{tabular}

1. Angaben zu BIP und öffentlichen Gesamtausgaben für Länder in der Eurozone in Euro. 2. Referenzjahre 1996, 2001, 2006, 2009,2010 und 2011 anstelle 1995, 2000, 2005, 2008, 2009 und 2010. 3. Für Norwegen wird der BIP-Festlandmarktwert verwendet. 4. Die Vereinigten Staaten haben in den vergangenen 6 Monaten ihre gesamte BIP-Serie überarbeitet. Die angegebenen Daten in US-Dollar (aktuelle Fassung) entsprechen nicht denjenigen in Tab. X2.2b in Bildung auf einen Blick 2013.

Quelle: OECD. Hinweise s. Anhang 3 unter www.oecd.org/edu/eag.htm. StatLink: http://dx.doi.org/10.1787/888933120822

Erläuterung der Kennzeichnung fehlender Daten s. Hinweise für den Leser. 
Tabelle X2.3 (Forts. 2)

Grundlegende statistische Bezugsdaten (Referenzzeitraum: Kalenderjahr 1995, 2000, 2005, 2008, 2009, 2010)1

\begin{tabular}{|c|c|c|c|c|c|c|}
\hline & \multicolumn{3}{|c|}{$\begin{array}{l}\text { Bruttoinlandsprodukt } \\
\text { (in Mio. Landeswährung, zu konstanten Preisen von 2011) }\end{array}$} & \multicolumn{3}{|c|}{$\begin{array}{l}\text { Öffentliche Gesamtausgaben } \\
\text { (in Mio. Landeswährung, zu konstanten Preisen von 2011) }\end{array}$} \\
\hline & 2008 & 2009 & 2010 & 2008 & 2009 & 2010 \\
\hline & (13) & (14) & (15) & (16) & (17) & (18) \\
\hline \multicolumn{7}{|l|}{ OECD-Länder } \\
\hline Australien & 1375819 & 1402865 & 1434244 & 443558 & 487722 & 482862 \\
\hline Österreich & 297293 & 285925 & 291003 & 146672 & 150435 & 153676 \\
\hline Belgien & 364791 & 354574 & 362822 & 181655 & 190543 & 190749 \\
\hline Kanada & 1671305 & 1624953 & 1677274 & 638247 & 658787 & 658901 \\
\hline Chile $^{2}$ & 110452877 & 116818603 & 123656889 & 27254129 & 25543871 & 28344020 \\
\hline Tschechien & 3837505 & 3664553 & 3754953 & 1579039 & 1637361 & 1646025 \\
\hline Dänemark & 1853636 & 1748645 & 1772834 & 955034 & 1015808 & 1023538 \\
\hline Estland & 16799 & 14432 & 14801 & 6665 & 6466 & 6002 \\
\hline Finnland & 194283 & 177686 & 183665 & 95611 & 99721 & 102464 \\
\hline Frankreich & 1990948 & 1928281 & 1961536 & 1060796 & 1094723 & 1109640 \\
\hline Deutschland & 2560001 & 2428276 & 2525710 & 1128458 & 1170839 & 1205713 \\
\hline Griechenland & 243803 & 236157 & 224476 & 123358 & 127407 & 115498 \\
\hline Ungarn & 28879245 & 26925469 & 27209655 & 14220756 & 13847282 & 13601143 \\
\hline Island & 1770149 & 1653991 & 1586198 & 1020856 & 842852 & 817795 \\
\hline Irland & 171830 & 160862 & 159143 & 73412 & 77813 & 104111 \\
\hline Israel & 825824 & 836130 & 883492 & 360815 & 363329 & 376084 \\
\hline Italien & 1636078 & 1546188 & 1572878 & 795152 & 802104 & 792681 \\
\hline Japan & 478719139 & 452242239 & 473315676 & 180100216 & 189306336 & 192197301 \\
\hline Korea & 1116963517 & 1120497242 & 1191330100 & 340108565 & 370670089 & 358438920 \\
\hline Luxemburg & 42053 & 39717 & 40949 & 16456 & 17957 & 17814 \\
\hline Mexiko & 13948277 & 13111724 & 13809745 & 3322317 & 3433105 & 3556321 \\
\hline Niederlande & 606723 & 584488 & 593435 & 280440 & 300569 & 304625 \\
\hline Neuseeland & 198840 & 201811 & 202120 & 68584 & 68093 & 71514 \\
\hline Norwegen $^{3}$ & 2022838 & 1989836 & 2023518 & 1105532 & 1167938 & 1170070 \\
\hline Polen & 1384908 & 1407547 & 1462014 & 598697 & 627963 & 664100 \\
\hline Portugal & 175091 & 169991 & 173288 & 78447 & 84569 & 89207 \\
\hline Slowakei & 67467 & 64142 & 66975 & 23558 & 26639 & 26760 \\
\hline Slowenien & 38509 & 35448 & 35895 & 17071 & 17470 & 18101 \\
\hline Spanien & 1089665 & 1047939 & 1045810 & 451726 & 485243 & 485555 \\
\hline Schweden & 3341343 & 3173393 & 3381351 & 1728784 & 1743504 & 1769535 \\
\hline Schweiz & 569329 & 558302 & 576450 & 188403 & 186945 & 190266 \\
\hline Türkei & 1148373 & 1092921 & 1193023 & 417280 & 471170 & 480096 \\
\hline Vereinigtes Königreich & 1576650 & 1495115 & 1520013 & 740556 & 758578 & 755700 \\
\hline Vereinigte Staaten ${ }^{4}$ & 15307038 & 14878116 & 15251973 & 5788980 & 6102689 & 6274656 \\
\hline \multicolumn{7}{|l|}{ Partnerländer } \\
\hline Brasilien & 3762637 & 3750286 & 4121383 & 1166228 & 1253138 & 1324250 \\
\hline Russische Föderation & 55541270 & 51198261 & 53504548 & $\mathrm{~m}$ & $\mathrm{~m}$ & $\mathrm{~m}$ \\
\hline
\end{tabular}

1. Angaben zu BIP und öffentlichen Gesamtausgaben für Länder in der Eurozone in Euro. 2. Referenzjahre 1996, 2001, $2006,2009,2010$ und 2011 anstelle 1995, 2000, 2005, 2008, 2009 und 2010. 3. Für Norwegen wird der BIP-Festlandmarktwert verwendet. 4. Die Vereinigten Staaten haben in den vergangenen 6 Monaten ihre gesamte BIP-Serie überarbeitet. Die angegebenen Daten in US-Dollar (aktuelle Fassung) entsprechen nicht denjenigen in Tab. X2.2b in Bildung auf einen Blick 2013.

Quelle: OECD. Hinweise s. Anhang 3 unter www.oecd.org/edu/eag.htm. StatLink: http://dx.doi.org/10.1787/888933120822

Erläuterung der Kennzeichnung fehlender Daten s. Hinweise für den Leser. 
Gesetzliche bzw. vertraglich vereinbarte Gehälter von Lehrkräften zu unterschiedlichen Zeitpunkten in ihrer beruflichen Laufbahn (2012)

Gesetzliche bzw. vertraglich vereinbarte Jahresgehälter von Lehrkräften an öffentlichen Bildungseinrichtungen, in Landeswährung

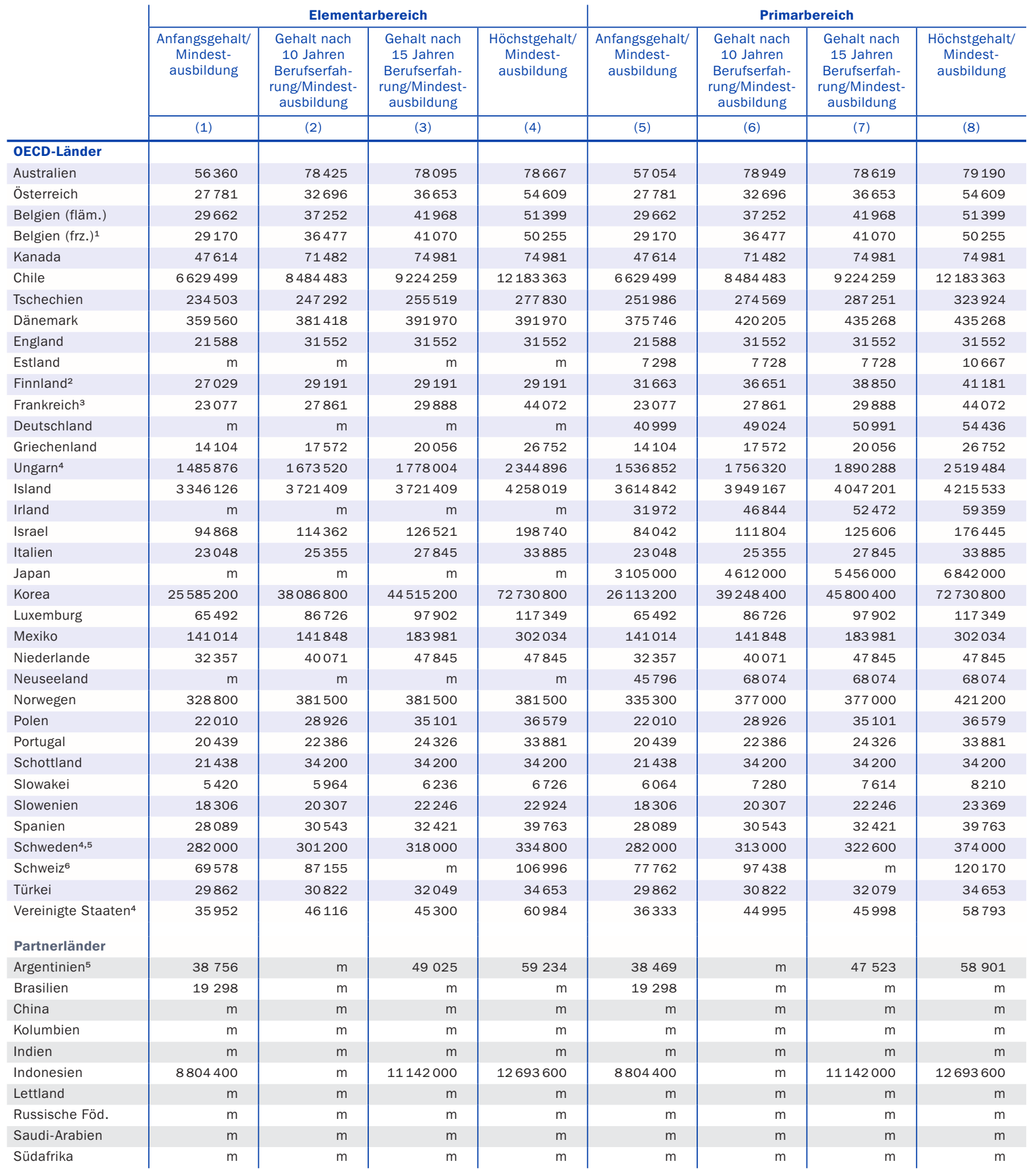

1. Gehälter von Lehrkräften mit den typischen Qualifikationen anstelle der Mindestausbildung. Weitere Hinweise zu den Gehältern von Lehrkräften mit Mindestausbildung s. Anhang 3. 2. Im Elementarbereich nur Kindergartenlehrkräfte. 3. Einschließlich durchschnittlicher Bonuszahlungen für Überstunden für Lehrkräfte im Sekundarbereich I und II. 4. Tatsächliche Grundgehälter. 5. Referenzjahr 2011. 6. Spalten (2), (6), (10) und (14): Gehälter nach 11 Jahren Berufserfahrung.

Quelle: OECD. Argentinien: Statistikinstitut der UNESCO (World Education Indicators Programm). Hinweise s. Anhang 3 unter www.oecd.org/edu/eag.htm. StatLink: http://dx.doi.org/10.1787/888933120860

Erläuterung der Kennzeichnung fehlender Daten s. Hinweise für den Leser. 
Tabelle X2.4a (Forts.)

Gesetzliche bzw. vertraglich vereinbarte Gehälter von Lehrkräften zu unterschiedlichen Zeitpunkten in ihrer beruflichen Laufbahn (2012)

Gesetzliche bzw. vertraglich vereinbarte Jahresgehälter von Lehrkräften an öffentlichen Bildungseinrichtungen, in Landeswährung

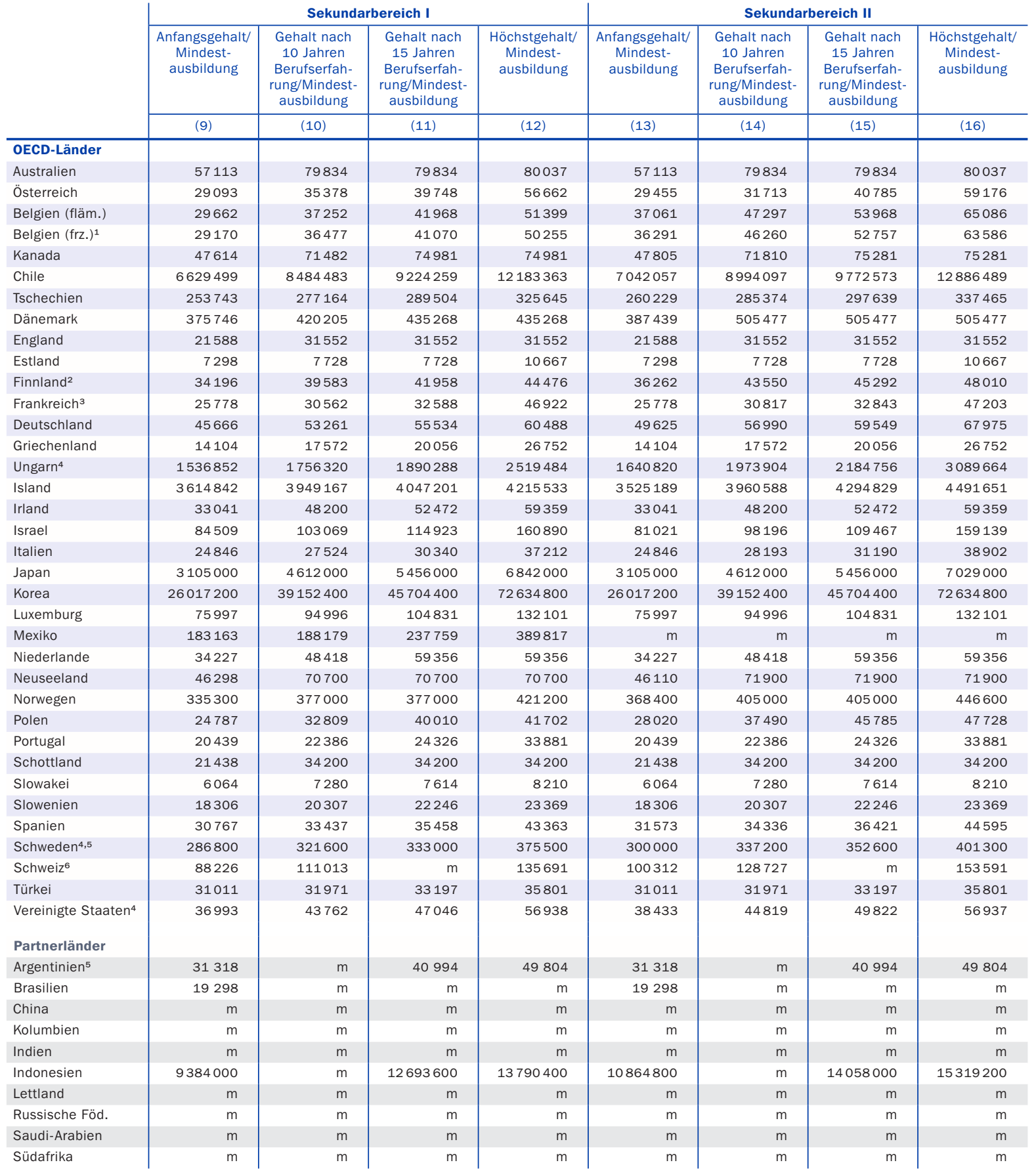

1. Gehälter von Lehrkräften mit den typischen Qualifikationen anstelle der Mindestausbildung. Weitere Hinweise zu den Gehältern von Lehrkräften mit Mindestausbildung s. Anhang 3. 2. Im Elementarbereich nur Kindergartenlehrkräfte. 3. Einschließlich durchschnittlicher Bonuszahlungen für Überstunden für Lehrkräfte im Sekundarbereich I und II. 4. Tatsächliche Grundgehälter. 5. Referenzjahr 2011. 6. Spalten (2), (6), (10) und (14): Gehälter nach 11 Jahren Berufserfahrung.

Quelle: OECD. Argentinien: Statistikinstitut der UNESCO (World Education Indicators Programm). Hinweise s. Anhang 3 unter www.oecd.org/edu/eag.htm. StatLink: http://dx.doi.org/10.1787/888933120860

Erläuterung der Kennzeichnung fehlender Daten s. Hinweise für den Leser. 
Entwicklung der Gehälter von Lehrkräften zwischen 2000 und $2012^{1}$

Gesetzliche bzw. vertraglich vereinbarte Jahresgehälter an öffentlichen Bildungseinrichtungen von Lehrkräften mit 15 Jahren Berufserfahrung/Mindestausbildung, nach Bildungsbereich, in Landeswährung

\begin{tabular}{|c|c|c|c|c|c|c|c|c|c|c|}
\hline & \multicolumn{5}{|c|}{ Primarbereich } & \multicolumn{5}{|c|}{ Sekundarbereich I } \\
\hline & 2000 & 2005 & 2010 & 2011 & 2012 & 2000 & 2005 & 2010 & 2011 & 2012 \\
\hline & (1) & (2) & (7) & (8) & (9) & (10) & (11) & (16) & (17) & (18) \\
\hline \multicolumn{11}{|l|}{ OECD-Länder } \\
\hline Australien & 50995 & 62240 & 73706 & 76732 & 78619 & 51016 & 62384 & 73706 & 77715 & 79834 \\
\hline Österreich & 25826 & 31050 & 35526 & 35889 & 36653 & 26916 & 33635 & 38451 & 38882 & 39748 \\
\hline Belgien (fläm.) & 29579 & 35417 & 40042 & 41094 & 41968 & 31191 & 35417 & 40042 & 41094 & 41968 \\
\hline Belgien (frz.) & 28638 & 33598 & 38875 & 40184 & 41070 & 30482 & 33973 & 38875 & 40184 & 41070 \\
\hline Kanada & $\mathrm{m}$ & $\mathrm{m}$ & 71608 & 73154 & 74981 & $\mathrm{~m}$ & $\mathrm{~m}$ & 71608 & 73154 & 74981 \\
\hline Chile & $\mathrm{m}$ & $\mathrm{m}$ & 8493461 & 8785016 & 9224259 & $\mathrm{~m}$ & $\mathrm{~m}$ & 8493461 & 8785016 & 9224259 \\
\hline Tschechien ${ }^{2}$ & 125501 & 250559 & 310711 & 311793 & 287251 & 125501 & 250559 & 314897 & 314495 & 289504 \\
\hline Dänemark ${ }^{3}$ & 285200 & 332015 & 434802 & 434802 & 435268 & 285200 & 332015 & 434802 & 434802 & 435268 \\
\hline England & 23193 & 27123 & 30842 & 31552 & 31552 & 23193 & 27123 & 30842 & 31552 & 31552 \\
\hline Estland & 3068 & 4379 & 7728 & 7728 & 7728 & 3068 & 4379 & 7728 & 7728 & 7728 \\
\hline Finnland & 26506 & 33171 & 37769 & 38222 & 38850 & 31115 & 36109 & 40791 & 41280 & 41958 \\
\hline Frankreich & 27288 & 28395 & 29674 & 29831 & 29888 & 29456 & 30667 & 32258 & 32537 & 32588 \\
\hline Deutschland & $\mathrm{m}$ & $\mathrm{m}$ & 47647 & 49587 & 50991 & $\mathrm{~m}$ & $\mathrm{~m}$ & 52784 & 54514 & 55534 \\
\hline Griechenland & 16292 & 21237 & 22707 & 21958 & 20056 & 16292 & 21237 & 22707 & 21958 & 20056 \\
\hline Ungarn 4 & 897168 & 1944576 & 1916568 & 1911204 & 1890288 & 897168 & 1944576 & 1916568 & 1911204 & 1890288 \\
\hline Island & 1884000 & 2573556 & 3987224 & 3987224 & 4047201 & 1884000 & 2573556 & 3987224 & 3987224 & 4047201 \\
\hline Irland & 33370 & 46591 & 53620 & 52472 & 52472 & 33729 & 46591 & 53620 & 52472 & 52472 \\
\hline Israel & 68421 & 73496 & 112005 & 121858 & 125606 & 76048 & 82030 & 102514 & 112095 & 114923 \\
\hline Italien & 20849 & 25234 & 27645 & 27845 & 27845 & 22836 & 27487 & 30121 & 30340 & 30340 \\
\hline Japan & 6645000 & 6236000 & 5555000 & 5456000 & 5456000 & 6645000 & 6236000 & 5555000 & 5456000 & 5456000 \\
\hline Korea & 26757000 & 39712000 & 42003257 & 44222400 & 45800400 & 26661000 & 39616000 & 41907257 & 44126400 & 45704400 \\
\hline Luxemburg & $\mathrm{m}$ & 62139 & 93182 & 93182 & 97902 & $\mathrm{~m}$ & 81258 & 99782 & 99782 & 104831 \\
\hline Mexiko & 86748 & 124082 & 163419 & 176627 & 183981 & 109779 & 157816 & 209350 & 224596 & 237759 \\
\hline Niederlande & $\mathrm{m}$ & $\mathrm{m}$ & 44288 & 46108 & 47845 & $\mathrm{~m}$ & $\mathrm{~m}$ & 53984 & 56163 & 59356 \\
\hline Neuseeland & 49450 & 54979 & 65609 & 67413 & 68074 & 49450 & 54979 & 67295 & 68197 & 70700 \\
\hline Norwegen & $\mathrm{m}$ & 302000 & 349000 & 370000 & 377000 & $\mathrm{~m}$ & 302000 & 349000 & 370000 & 377000 \\
\hline Polen & $\mathrm{m}$ & 23328 & 30785 & 32878 & 35101 & $\mathrm{~m}$ & 26935 & 35071 & 37459 & 40010 \\
\hline Portugal & 17180 & 22775 & 27038 & 28069 & 24326 & 17180 & 22775 & 27038 & 28069 & 24326 \\
\hline Schottland & 22743 & 29827 & 33666 & 34200 & 34200 & 22743 & 29827 & 33666 & 34200 & 34200 \\
\hline Slowakei & $\mathrm{m}$ & $\mathrm{m}$ & 7492 & 7518 & 7614 & $\mathrm{~m}$ & $\mathrm{~m}$ & 7492 & 7518 & 7614 \\
\hline Slowenien & $\mathrm{m}$ & 17939 & 22433 & 22646 & 22246 & $\mathrm{~m}$ & 17939 & 22433 & 22646 & 22246 \\
\hline Spanien & 22701 & 28122 & 33889 & 32685 & 32421 & 24528 & 31561 & 37820 & 36124 & 35458 \\
\hline Schweden ${ }^{4}$ & 248300 & 283200 & $\mathrm{~m}$ & 322600 & $\mathrm{~m}$ & 248300 & 290400 & $\mathrm{~m}$ & 333000 & $\mathrm{~m}$ \\
\hline Schweiz ${ }^{5}$ & 85513 & 90483 & 96241 & 96923 & 97438 & 102409 & 103037 & 109537 & 110777 & 111013 \\
\hline Türkei & 2638 & 17166 & 28144 & 29822 & 32079 & a & a & a & a & 33197 \\
\hline $\begin{array}{l}\text { Vereinigte Staaten }{ }^{4} \\
\text { Partnerländer }\end{array}$ & 35323 & 40734 & 45226 & 46130 & 45998 & 35185 & 41090 & 45049 & 45950 & 47046 \\
\hline Argentinien ${ }^{4}$ & $\mathrm{~m}$ & $\mathrm{~m}$ & 34842 & $\mathrm{~m}$ & 47523 & $\mathrm{~m}$ & $\mathrm{~m}$ & 31934 & $m$ & 40994 \\
\hline Brasilien & $\mathrm{m}$ & $\mathrm{m}$ & $\mathrm{m}$ & $\mathrm{m}$ & $\mathrm{m}$ & $\mathrm{m}$ & $\mathrm{m}$ & $\mathrm{m}$ & $\mathrm{m}$ & $\mathrm{m}$ \\
\hline China & $\mathrm{m}$ & $\mathrm{m}$ & $\mathrm{m}$ & $\mathrm{m}$ & $\mathrm{m}$ & $\mathrm{m}$ & $\mathrm{m}$ & $\mathrm{m}$ & $\mathrm{m}$ & $\mathrm{m}$ \\
\hline Kolumbien & $\mathrm{m}$ & $\mathrm{m}$ & $\mathrm{m}$ & $\mathrm{m}$ & $\mathrm{m}$ & $\mathrm{m}$ & $\mathrm{m}$ & $\mathrm{m}$ & $\mathrm{m}$ & $\mathrm{m}$ \\
\hline Indien & $\mathrm{m}$ & $\mathrm{m}$ & $\mathrm{m}$ & $\mathrm{m}$ & $\mathrm{m}$ & $\mathrm{m}$ & $\mathrm{m}$ & $\mathrm{m}$ & $m$ & $\mathrm{~m}$ \\
\hline Indonesien & $\mathrm{m}$ & $\mathrm{m}$ & 11142000 & $\mathrm{~m}$ & 11142000 & $\mathrm{~m}$ & $\mathrm{~m}$ & 12693600 & $\mathrm{~m}$ & 12693600 \\
\hline Lettland & $\mathrm{m}$ & $\mathrm{m}$ & $\mathrm{m}$ & $\mathrm{m}$ & $\mathrm{m}$ & $\mathrm{m}$ & $\mathrm{m}$ & $\mathrm{m}$ & $m$ & $\mathrm{~m}$ \\
\hline Russische Föd. & $\mathrm{m}$ & $\mathrm{m}$ & $\mathrm{m}$ & $\mathrm{m}$ & $\mathrm{m}$ & $\mathrm{m}$ & $\mathrm{m}$ & $\mathrm{m}$ & $\mathrm{m}$ & $\mathrm{m}$ \\
\hline Saudi-Arabien & $\mathrm{m}$ & $\mathrm{m}$ & $\mathrm{m}$ & $\mathrm{m}$ & $\mathrm{m}$ & $\mathrm{m}$ & $\mathrm{m}$ & $\mathrm{m}$ & $\mathrm{m}$ & $\mathrm{m}$ \\
\hline Südafrika & $\mathrm{m}$ & $\mathrm{m}$ & $\mathrm{m}$ & $\mathrm{m}$ & $\mathrm{m}$ & $\mathrm{m}$ & $\mathrm{m}$ & $\mathrm{m}$ & $\mathrm{m}$ & $\mathrm{m}$ \\
\hline
\end{tabular}

Anmerkung: Die Spalten mit den Angaben für die Jahre 2006, 2007, 2008 und 2009, d.h. die Spalten (3)-(6), (12)-(15), (21)-(24), sind im Internet verfügbar (s. StatLink unten).

1. Angaben zu den Gehältern der Lehrkräfte in Ländern der aktuellen Eurozone in Euro. 2. Unterbrechung der Zeitreihe im Jahr 2012 aufgrund von Veränderungen in der Methodik. 3. Unterbrechung der Zeitreihe im Jahr 2009 aufgrund von Veränderungen in der Methodik. 5. Gehälter nach 11 Jahren Berufserfahrung. Quelle: OECD. Argentinien: Statistikinstitut der UNESCO (World Education Indicators Programme). Hinweise s. Anhang 3 unter www.oecd.org/edu/eag.htm. StatLink: $h$ ttp://dx.doi.org/10.1787/888933120879

Erläuterung der Kennzeichnung fehlender Daten s. Hinweise für den Leser. 
Tabelle X2.4b (Forts.)

Entwicklung der Gehälter von Lehrkräften zwischen 2000 und 2012 ${ }^{1}$

Gesetzliche bzw. vertraglich vereinbarte Jahresgehälter an öffentlichen Bildungseinrichtungen von Lehrkräften mit 15 Jahren Berufserfahrung/Mindestausbildung, nach Bildungsbereich, in Landeswährung

\begin{tabular}{|c|c|c|c|c|c|}
\hline & \multicolumn{5}{|c|}{ Sekundarbereich II } \\
\hline & 2000 & 2005 & 2010 & 2011 & 2012 \\
\hline & (19) & (20) & (25) & (26) & (27) \\
\hline \multicolumn{6}{|l|}{ OECD-Länder } \\
\hline Australien & 51016 & 62384 & 73706 & 77715 & 79834 \\
\hline Österreich & 29728 & 34265 & 39535 & 39927 & 40785 \\
\hline Belgien (fläm.) & 39886 & 45301 & 51454 & 52844 & 53968 \\
\hline Belgien (frz.) & 39207 & 43704 & 50108 & 51643 & 52757 \\
\hline Kanada & $\mathrm{m}$ & $\mathrm{m}$ & 71886 & 73440 & 75281 \\
\hline Chile & $\mathrm{m}$ & $\mathrm{m}$ & 9004818 & 9307217 & 9772573 \\
\hline Tschechien ${ }^{2}$ & 152941 & 255125 & 334084 & 335696 & 297639 \\
\hline Dänemark ${ }^{3}$ & 335000 & 404229 & 504046 & 504046 & 505477 \\
\hline England & 23193 & 27123 & 30842 & 31552 & 31552 \\
\hline Estland & 3068 & 4379 & 7728 & 7728 & 7728 \\
\hline Finnland & 32681 & 38263 & 43168 & 43686 & 45292 \\
\hline Frankreich & 29456 & 30895 & 32472 & 32752 & 32843 \\
\hline Deutschland & $\mathrm{m}$ & $\mathrm{m}$ & 57150 & 58930 & 59549 \\
\hline Griechenland & 16292 & 21237 & 22707 & 21958 & 20056 \\
\hline Ungarn 4 & 1128996 & 2432388 & 2262636 & 2260944 & 2184756 \\
\hline Island & 2220000 & 3014000 & 4012000 & 4012000 & 4294829 \\
\hline Irland & 33729 & 46591 & 53620 & 52472 & 52472 \\
\hline Israel & 75097 & 80052 & 93450 & 95590 & 109467 \\
\hline Italien & 23518 & 28259 & 30966 & 31190 & 31190 \\
\hline Japan & 6649000 & 6237000 & 5555000 & 5456000 & 5456000 \\
\hline Korea & 26661000 & 39616000 & 41907257 & 44126400 & 45704400 \\
\hline Luxemburg & $\mathrm{m}$ & 81258 & 99782 & 99782 & 104831 \\
\hline Mexiko & $\mathrm{m}$ & $\mathrm{m}$ & $\mathrm{m}$ & $\mathrm{m}$ & $\mathrm{m}$ \\
\hline Niederlande & $\mathrm{m}$ & $\mathrm{m}$ & 53984 & 56163 & 59356 \\
\hline Neuseeland & 49450 & 54979 & 68980 & 68980 & 71900 \\
\hline Norwegen & $\mathrm{m}$ & 321000 & 376400 & 398000 & 405000 \\
\hline Polen & $\mathrm{m}$ & 31216 & 40120 & 42860 & 45785 \\
\hline Portugal & 17180 & 22775 & 27038 & 28069 & 24326 \\
\hline Schottland & 22743 & 29827 & 33666 & 34200 & 34200 \\
\hline Slowakei & $\mathrm{m}$ & $\mathrm{m}$ & 7498 & 7518 & 7614 \\
\hline Slowenien & $\mathrm{m}$ & 17939 & 22433 & 22646 & 22246 \\
\hline Spanien & 26366 & 32293 & 38613 & 36749 & 36421 \\
\hline Schweden ${ }^{4}$ & 264700 & 313600 & $\mathrm{~m}$ & 352600 & $\mathrm{~m}$ \\
\hline Schweiz ${ }^{5}$ & 121629 & 120602 & 127839 & 128860 & 128727 \\
\hline Türkei & 2441 & 17403 & 28883 & 30483 & 33197 \\
\hline Vereinigte Staaten ${ }^{4}$ & 37838 & 41044 & 48446 & 49414 & 49822 \\
\hline Partnerländer & & & & & \\
\hline Argentinien ${ }^{4}$ & $\mathrm{~m}$ & $\mathrm{~m}$ & 31934 & $\mathrm{~m}$ & 40994 \\
\hline Brasilien & $\mathrm{m}$ & $\mathrm{m}$ & $\mathrm{m}$ & $\mathrm{m}$ & $\mathrm{m}$ \\
\hline China & $\mathrm{m}$ & $\mathrm{m}$ & $\mathrm{m}$ & $\mathrm{m}$ & $\mathrm{m}$ \\
\hline Kolumbien & $\mathrm{m}$ & $\mathrm{m}$ & $\mathrm{m}$ & $\mathrm{m}$ & $\mathrm{m}$ \\
\hline Indien & $\mathrm{m}$ & $\mathrm{m}$ & $\mathrm{m}$ & $\mathrm{m}$ & $\mathrm{m}$ \\
\hline Indonesien & $\mathrm{m}$ & $\mathrm{m}$ & 14058000 & $\mathrm{~m}$ & 14058000 \\
\hline Lettland & $\mathrm{m}$ & $\mathrm{m}$ & $\mathrm{m}$ & $\mathrm{m}$ & $\mathrm{m}$ \\
\hline Russische Föderation & $\mathrm{m}$ & $\mathrm{m}$ & $\mathrm{m}$ & $\mathrm{m}$ & $\mathrm{m}$ \\
\hline Saudi-Arabien & $\mathrm{m}$ & $\mathrm{m}$ & $\mathrm{m}$ & $\mathrm{m}$ & $\mathrm{m}$ \\
\hline Südafrika & $\mathrm{m}$ & $\mathrm{m}$ & $\mathrm{m}$ & $\mathrm{m}$ & $\mathrm{m}$ \\
\hline
\end{tabular}

Anmerkung: Die Spalten mit den Angaben für die Jahre 2006, 2007, 2008 und 2009, d.h. die Spalten (3)-(6), (12)-(15), (21)-(24), sind im Internet verfügbar (s. StatLink unten).

1. Angaben zu den Gehältern der Lehrkräfte in Ländern der aktuellen Eurozone in Euro. 2. Unterbrechung der Zeitreihe im Jahr 2012 aufgrund von Veränderungen in der Methodik. 3. Unterbrechung der Zeitreihe im Jahr 2009 aufgrund von Veränderungen in der Methodik. 5. Gehälter nach 11 Jahren Berufserfahrung. Quelle: OECD. Argentinien: Statistikinstitut der UNESCO (World Education Indicators Programme). Hinweise s. Anhang 3 unter www.oecd.org/edu/eag.htm. 
Statistische Bezugsdaten zur Berechnung der Gehälter von Lehrkräften (2000, 2005-2012)

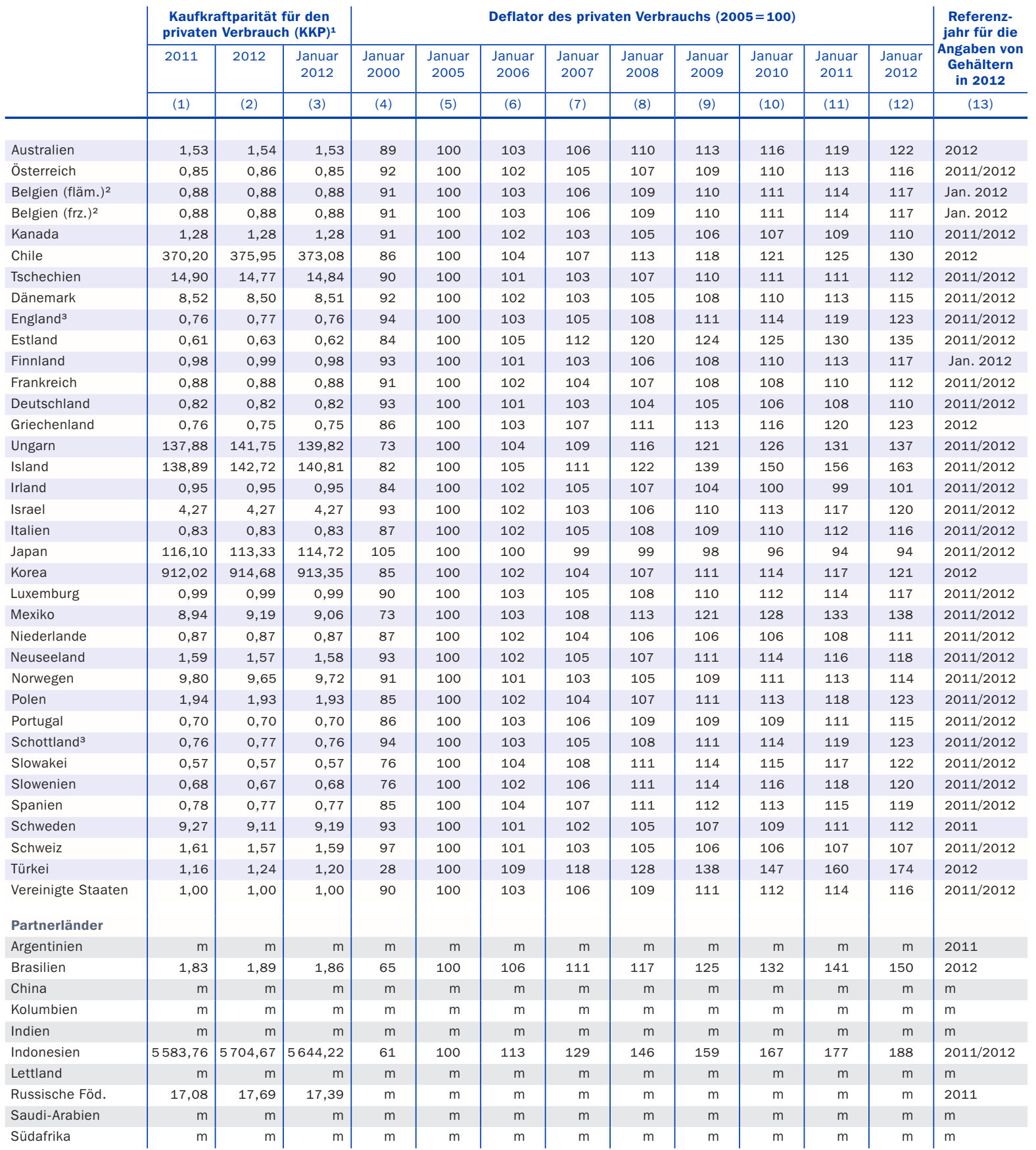

1. Angaben zu KKP und BIP für Länder der aktuellen Eurozone in Euro. 2. Angaben zu KKP und Deflator beziehen sich auf ganz Belgien. 3. Angaben zu KKP und Deflator beziehen sich auf das Vereinigte Königreich.

Quelle: OECD. Argentinien: Statistikinstitut der UNESCO (World Education Indicators Programme). Hinweise s. Anhang 3 unter www.oecd.org/edu/eag.htm. StatLink: $h$ ttp://dx.doi.org/10.1787/888933120898

Erläuterung der Kennzeichnung fehlender Daten s. Hinweise für den Leser. 


\section{Allgemeine Hinweise}

\section{Definitionen}

Das Bruttoinlandsprodukt (BIP) entspricht der Wertschöpfung der von inländischen Herstellern produzierten Waren und Dienstleistungen, einschließlich Handel und Transport, abzüglich des Werts für den Zwischenverbrauch des Käufers plus Importzölle. Das BIP wird in der jeweiligen Landeswährung (in Millionen) angegeben. Für Länder, die diese Informationen für ein Bezugsjahr angeben, das vom Kalenderjahr abweicht (z. B. Australien und Neuseeland), werden Anpassungen durch lineare Gewichtung des jeweiligen BIP zwischen zwei aufeinanderfolgenden nationalen Bezugsjahren entsprechend dem Kalenderjahr vorgenommen.

Der BIP-Deflator wird berechnet durch Division des BIP zu Marktpreisen durch das BIP zu konstanten Preisen. Er liefert einen Hinweis auf das relative Preisniveau in einem Land.

Das BIP pro Kopf ist das Bruttoinlandsprodukt (in US-Dollar, kaufkraftbereinigt) dividiert durch die Bevölkerungszahl.

Die Kaufkraftparitäts-Umrechnungskurse (KKP) sind die Währungsumrechnungskurse, die die Kaufkraft verschiedener Währungen ausgleichen. Dies bedeutet, dass man mit einer bestimmten Geldsumme, wenn sie anhand der KKP-Kurse in die verschiedenen Währungen umgerechnet wird, in allen Ländern den gleichen Waren- und Dienstleistungskorb erwerben kann. Daher werden durch Verwendung der KKP-Währungsumrechnungskurse die Preisniveau-Unterschiede zwischen den Ländern aufgehoben. Werden Ausgaben bezogen auf das BIP für verschiedene Länder mithilfe der KKP in eine einheitliche Währung umgerechnet, werden sie praktisch mit den gleichen internationalen Preisen ausgedrückt, sodass Vergleiche zwischen den Ländern nur die Unterschiede im Volumen der gekauften Waren und Dienstleistungen widerspiegeln.

Die öffentlichen Gesamtausgaben, wie bei der Berechnung der Indikatoren verwendet, entsprechen den nicht rückzahlbaren laufenden Ausgaben und Investitionsausgaben auf allen Ebenen des Staates. Die laufenden Ausgaben umfassen die konsumtiven Ausgaben (z. B. Arbeitsentgelte für Mitarbeiter, Verbrauch von Vorprodukten und -dienstleistungen, Verbrauch von Sachvermögen und Militärausgaben), geleistete Besitzeinkommen, Subventionen und andere geleistete Transferzahlungen (z.B. Sozialversicherungen, Sozialhilfe, Renten und sonstige Wohlfahrtsleistungen). Investitionsausgaben sind Ausgaben zum Erwerb und/oder der Wertsteigerung von Gütern des Anlagevermögens, Grundstücken, immateriellen Vermögensgegenständen, Staatsanleihen und nicht militärischen Sachvermögen und Ausgaben zur Finanzierung von Nettokapitaltransfers.

\section{Quellen}

Die Ausgabe des Jahres 20I4 der National Accounts of OECD Countries: Detailed Tables, Volume II.

Der theoretische Rahmen der OECD National Accounts wird seit vielen Jahren von der UN-Publikation A System of National Accounts vorgegeben, die I968 erschien. Im Jahr 1993 erschien eine überarbeitete Fassung (häufig als SNA93 bezeichnet).

OECD Analytical Database, Januar 2014.

\footnotetext{
Hinweis zu den Daten aus Israel

Die statistischen Daten für Israel wurden von den zuständigen israelischen Stellen bereitgestellt, die für sie verantwortlich zeichnen. Die Verwendung dieser Daten durch die OECD erfolgt unbeschadet des völkerrechtlichen Status der Golanhöhen, von Ost-Jerusalem und der israelischen Siedlungen im Westjordanland.
} 


\section{Quellen, Methoden und technische Hinweise}

Anhang 3 zu Quellen und Methoden liegt nur in elektronischer Form vor. Er kann eingesehen werden unter www.oecd.org/edu/eag.htm.

Anhang 3: Kapitel A www.oecd.org/edu/eag/annex3-ChapterA.pdf

Anhang 3: Kapitel B

www.oecd.org/eduleag/annex3-ChapterB.pdf

Anhang 3: Kapitel C

www.oecd.org/edu/eag/annex3-ChapterC.pdf
Anhang 3: Indikator DI

www.oecd.org/edu/eag/annex3-IndicatorD1.pdf

Anhang 3: Indikatoren $\mathrm{D}_{2}-\mathrm{D}_{5}$

www.oecd.org/edu/eag/annex3-IndicatorD 2-D5.pdf

Anhang 3: Indikator D6

www.oecd.org/edu/eag/annex3-IndicatorD6.pdf

Anhang 3: Indikator D7

www.oecd.org/edu/eag/annex3-IndicatorD7.pdf 



\section{Mitwirkende an dieser Publikation}

Viele Personen haben bei der Erstellung dieser Publikation mitgewirkt. Nachfolgend sind die Namen der Ländervertreter aufgeführt, die an den INES-Sitzungen und den vorbereitenden Arbeiten für die Veröffentlichung dieser Ausgabe von Bildung auf einen Blick 2014-OECD-Indikatoren aktiv mitgewirkt haben.

Die OECD möchte ihnen allen an dieser Stelle für ihren wertvollen Beitrag danken. 


\section{INES-Arbeitsgruppe}

Frau Maria Laura ALONSO (Argentinien)

Herr Julián FALCONE (Argentinien)

Frau Marcela JÁUREGUI (Argentinien)

Frau Stephanie BOWLES (Australien)

Herr Paul CMIEL (Australien)

Herr Stuart FAUNT (Australien)

Frau Cheryl HOPKINS (Australien)

Frau Joanna KORDIS (Australien)

Herr Scott MATHESON (Vorsitzender INES-Arbeits-

gruppe, Australien)

Frau Margaret PEARCE (Australien)

Frau Mary-Anne SAKKARA (Australien)

Herr Mark UNWIN (Australien)

Frau Shelagh WHITTLESTON (Australien)

Herr Philippe DIEU (Belgien)

Frau Isabelle ERAUW (Belgien)

Frau Nathalie JAUNIAUX (Belgien)

Herr Guy STOFFELEN (Belgien)

Herr Raymond VAN DE SIJPE (Belgien)

Frau Ann VAN DRIESSCHE (Belgien)

Herr Daniel Jaime CAPISTRANO DE OLIVEIRA (Brasilien)

Frau Carla D'Lourdes DO NASCIMENTO (Brasilien)

Frau Juliana MARQUES DA SILVA (Brasilien)

Frau Ana Carolina SILVA CIROTTO (Brasilien)

Frau María Paz DONOSO (Chile)

Frau Eliana CHAMIZO (Chile)

Herr Fabian RAMÍREZ (Chile)

Herr Francisco LAGOS MARIN (Chile)

Herr Gabriel Alonso UGARTE VERA (Chile)

Herr David INOSTROZA (Chile)

Frau Stine ALBECK SEITZBERG (Dänemark)

Herr Jens ANDERSEN (Dänemark)

Herr Henrik BANG (Dänemark)

Frau Katja BEHRENS (Dänemark)

Herr Erik CHRISTIANSEN (Dänemark)

Herr Peter Bohnstedt Anan HANSEN (Dänemark)

Herr Leo Elmbirk JENSEN (Dänemark)

Herr Kristian ORNSHOLT (Dänemark)

Herr Signe Tychsen PHILIP (Dänemark)

Herr Jens Brunsborg STORM (Dänemark)

Frau Maria SVANEBORG (Dänemark)

Herr Heinz-Werner FREITAG (Deutschland)

Herr Heinz-Werner HETMEIER (Deutschland)

Frau Christiane KRÜGER-HEMMER (Deutschland)

Herr Marco MUNDELIUS (Deutschland)

Herr Martin A. SCHULZE (Deutschland)

Frau Eveline VON GAESSLER (Deutschland)

Frau Katrin WERY (Deutschland)

Herr Heinrich WIRTZ (Deutschland)

Frau Tiina ANNUS (Estland)

Herr Jan PAKULSKI (Europäische Kommission)

Frau Christine COIN (Eurostat, Europäische Kommission)
Herr Jacques LANNELUC (Eurostat, Europäische

Kommission)

Herr Timo ERTOLA (Finnland)

Herr Ville HEINONEN (Finnland)

Herr Matti KYRÖ (Finnland)

Herr Mika TUONONEN (Finnland)

Herr Cedric AFSA (Frankreich)

Frau Mireille DUBOIS (Frankreich)

Frau Pierrette BRIANT (Frankreich)

Frau Nadine ESQUIEU (Frankreich)

Frau Bénédicte GALTIER (Frankreich)

Frau Stéphanie LEMERLE (Frankreich)

Frau Florence LEFRESNE (Frankreich)

Frau Valérie LIOGIER (Frankreich)

Frau Hélène MICHAUDON (Frankreich)

Frau Pascale POULET-COULIBANDO (Frankreich)

Herr Robert RAKOCEVIC (Frankreich)

Frau Marguerite RUDOLF (Frankreich)

Frau Dimitra FARMAKIOUTOU (Griechenland)

Frau Maria FASSARI (Griechenland)

Herr Konstantinos KAMPANAKIS (Griechenland)

Frau Akrivi NIKOLAKOPOULOU (Griechenland)

Frau Athena PLESSA-PAPADAKI (Griechenland)

Frau Ida KINTAMANI (Indonesien)

Herr Yul Yunazwin NAZARUDDIN (Indonesien)

Frau Siti SOFIA (Indonesien)

Herr Gary Ó DONNCHADHA (Irland)

Herr Diarmuid REIDY (Irland)

Frau Nicola TICKNER (Irland)

Herr Gunnar J. ÁRNASON (Island)

Herr Julius K. BJORNSSON (Island)

Frau Asta URBANCIC (Island)

Frau Sophie ARTSEV (Israel)

Frau Yael ATIYAH (Israel)

Herr Yoav AZULAY (Israel)

Herr Yonatan BAR ON (Israel)

Frau Nava BRENNER (Israel)

Frau Livnat GAVRIELOV (Israel)

Herr Yosef GIDANIAN (Israel)

Herr Pinhas KLEIN (Israel)

Herr Aviel KRENTZLER (Israel)

Herr Daniel LEVI-MAZLOUM (Israel)

Herr Haim PORTNOY (Israel)

Frau Naama STEINBERG (Israel)

Frau Gianna BARBIERI (Italien)

Herr Massimiliano CICCIA (Italien)

Frau Daniela DI ASCENZO (Italien)

Frau Paola DI GIROLAMO (Italien)

Frau Maria Teresa MORANA (Italien)

Frau Claudia PIZZELLA (Italien)

Herr Paolo SESTITO (Italien)

Herr Paolo TURCHETTI (Italien)

Herr Yu KAMEOKA (Japan) 
Herr Koji YANAGISAWA (Japan)

Frau Nami JINDA (Japan)

Herr Takashi MURAO (Japan)

Herr Naoki OYAKE (Japan)

Herr Hiromi SASAI (Japan)

Frau Kumiko TANSHO-HIRABAYASHI (Japan)

Frau Natsue SAITO (Japan)

Frau Hiroe HINO (Japan)

Herr Patric BLOUIN (Kanada)

Frau Shannon DELBRIDGE (Kanada)

Herr Tomasz GLUSZYNSKI (Kanada)

Frau Amanda HODGKINSON (Kanada)

Herr Michael MARTIN (Kanada)

Frau Dallas MORROW (Kanada)

Herr Enzo PIZZOFERRATO (Kanada)

Herr Janusz ZIEMINSKI (Kanada)

Herr Juan Carlos BOLÍVAR (Kolumbien)

Frau Jennifer DIAZ (Kolumbien)

Herr Javier Andrés RUBIO (Kolumbien)

Frau Azucena VALLEJO (Kolumbien)

Frau Elsa Nelly VELASCO (Kolumbien)

Herr Victor Alejandro VENEGAS (Kolumbien)

Herr Andrés VERGARA (Kolumbien)

Herr Hong Bo CHOI (Korea)

Frau Sujin CHOI (Korea)

Frau Jeongwon HWANG (Korea)

Frau Yoon Hee IM (Korea)

Frau Hae Suk LEE (Korea)

Frau Hyun Mi LEE (Korea)

Frau Won Hee NA (Korea)

Frau Hyo Jeong SEO (Korea)

Herr Myung Suk SONG (Korea)

Frau Ennata KIVRINA (Lettland)

Herr Reinis MARKVARTS (Lettland)

Herr Jérôme Levy (Luxemburg)

Frau Charlotte MAHON (Luxemburg)

Frau Elisa MAZZUCATO (Luxemburg)

Herr Claude SCHABER (Luxemburg)

Herr Antonio ÁVILA DÍAZ (Mexiko)

Frau Cynthia CABRERA CARDENAS (Mexiko)

Herr Agustin CASO-RAPHAEL (Mexiko)

Herr René GÓMORA CASTILLO (Mexiko)

Herr Juan Manuel HERNÁNDEZ VÁZQUEZ (Mexiko)

Herr Tomás RAMÍREZ REYNOSO (Mexiko)

Herr Héctor Virgilio ROBLES VASQUEZ (Mexiko)

Frau Annette SANTOS (Mexiko)

Herr Lorenzo VERGARA LÓPEZ (Mexiko)

Frau Julia ARNOLD (Neuseeland)

Herr David SCOTT (Neuseeland)

Frau Danielle ANDARABI (Niederlande )

Frau Linda DE PAEPE (Niederlande)

Herr Hugo ELBERS (Niederlande)

Herr Mark GROEN (Niederlande)

Herr Dick TAKKENBERG (Niederlande)

Frau Pauline THOOLEN (Niederlande)
Frau Anouschka VAN DER MEULEN (Niederlande)

Frau Floor VAN OORT (Niederlande)

Herr Fred WENTINK (Niederlande)

Frau Marie ARNEBERG (Norwegen)

Herr Sadiq Kwesi BOATENG (Norwegen)

Herr Kjetil DIGRE (Norwegen)

Herr Geir NYGÅRD (Norwegen)

Frau Anne Katrine MORTENSEN (Norwegen)

Frau Anne-Marie RUSTAD HOLSETER (Norwegen)

Frau Sabine MARTINSCHITZ (Österreich)

Herr Mark NÉMET (Österreich)

Herr Wolfgang PAULI (Österreich)

Frau Helga POSSET (Österreich)

Frau Natascha RIHA (Österreich)

Frau Barbara ANTOSIEWICZ (Polen)

Frau Renata KORZENIOWSKA-PUCULEK (Polen)

Frau Malgorzata KRZYSZTOFIK (Polen)

Herr Andrzej KURKIEWCZ (Polen)

Herr Slawomir NALECZ (Polen)

Frau Anna NOWOZYNSKA (Polen)

Frau Isabel CORREIA (Portugal)

Frau Janine COSTA (Portugal)

Frau Teresa KOL DE ALVARENGA (Portugal)

Frau Mónica LUENGO (Portugal)

Herr Carlos Alberto MALACA (Portugal)

Frau Sandrine MIRANDA (Portugal)

Frau Rute NUNES (Portugal)

Herr Joao PEREIRA DE MATOS (Portugal)

Herr José RAFAEL (Portugal)

Herr Nuno Miguel RODRIGUES (Portugal)

Herr Joaquim SANTOS (Portugal)

Herr Mark AGRANOVICH (Russische Föderation)

Herr Evgeny BUTKO (Russische Föderation)

Frau Anna FATEEVA (Russische Föderation)

Frau Irina SELIVERSTOVA (Russische Föderation)

Herr Ahmed F. HAYAJNEH (Saudi-Arabien)

Frau Anna ERIKSSON (Schweden)

Herr Andreas FRODELL (Schweden)

Frau Maria GÖTHERSTRÖM (Schweden)

Frau Marie KAHLROTH (Schweden)

Herr Kenny PETERSSON (Schweden)

Frau Eva-Marie LARSSON (Schweden)

Herr Torbjörn LINDQVIST (Schweden)

Herr Kenny PETERSSON (Schweden)

Herr Hans-Åke ÖSTRÖM (Schweden)

Frau Katrin HOLENSTEIN (Schweiz)

Herr Emanuel VON ERLACH (Schweiz)

Herr Stefan C. WOLTER (Schweiz)

Herr Peter BRODNIANSKY (Slowakei)

Frau Alzbeta FERENCICOVA (Slowakei)

Herr Frantisek ZAJICEK (Slowakei)

Frau Andreja BARLE LAKOTA (Slowenien)

Frau Ksenija BREGAR-GOLOBIĆ (Slowenien)

Herr Branimir JABLANOVIĆ (Slowenien)

Frau Helga KOČEVAR (Slowenien) 
Frau Tanja TAŠTANOSKA (Slowenien)

Frau Breda LOŽAR (Slowenien)

Frau Dusa MARJETIC (Slowenien)

Herr Mitja SARDOC (Slowenien)

Frau Tatjana ŠKRBEC (Slowenien)

Frau Irena SVETIN (Slowenien)

Frau Jadranka TUŠ (Slowenien)

Frau Laura ALONSO CARMONA (Spanien)

Herr Eduardo DE LA FUENTE FUENTE (Spanien)

Herr Jesús IBAÑEZ MILLA (Spanien)

Herr Joaquín MARTÍN MUÑOZ (Spanien)

Frau Cristina MONEO OCAÑA (Spanien)

Herr Ismael SANZ LABRADOR (Spanien)

Frau Carmen UREÑA UREÑA (Spanien)

Frau Bheki MPANZA (Südafrika)

Herr Jacques APPELGRYN (Südafrika)

Herr Nyokong MOSIUOA (Südafrika)

Frau Hersheela NARSEE (Südafrika)

Frau Soňa FOřTOVÁ (Tschechien)

Herr Vladimír HULÍK (Tschechien)

Frau Michaela KLENHOVA (Tschechien)

Frau Michaela MARŠÍKOVÁ (Tschechien)
Herr Lubomir MARTINEC (Tschechien)

Frau Hümeyra ALTUNTAŞ (Türkei)

Herr Derhan DOĞAN (Türkei)

Frau Dilek GÜLEÇYÜZ (Türkei)

Frau Nur SALMANOĞLU (Türkei)

Herr Serdar YILMAZ (Türkei)

Herr Said Ould Ahmedou VOFFAL (UNESCO)

Frau Tünde HAGYMÁSY (Ungarn)

Herr Tibor KÖNYVESI (Ungarn)

Herr László LIMBACHER (Ungarn)

Herr Kristián SZÉLL (Ungarn)

Frau Lorna BERTRAND (Vereinigtes Königreich)

Frau Elisabeth BOYLING (Vereinigtes Königreich)

Herr Anthony CLARKE (Vereinigtes Königreich)

Herr Stephen HEWITT (Vereinigtes Königreich)

Frau Emily KNOWLES (Vereinigtes Königreich)

Herr Christopher MORRISS (Vereinigtes Königreich)

Frau Rachel DINKES (Vereinigte Staaten)

Frau Jennifer HARWOOD (Vereinigte Staaten)

Frau Jana KEMP (Vereinigte Staaten)

Frau Ashley ROBERTS (Vereinigte Staaten)

Thomas SNYDER (Vereinigte Staaten)

\section{Netzwerk zu den Arbeltsmarktergebnissen sowle den wirtschaftllchen und sozialen Auswlrkungen des Lernens (LSO)}

Herr Paul CMIEL (Australien)

Frau Shannon MADDEN (Australien)

Herr Scott MATHESON (Australien)

Frau Margaret PEARCE (Australien)

Frau Mary-Anne SAKKARA (Australien)

Frau Isabelle ERAUW (Belgien)

Frau Geneviève HINDRYCKX (Belgien)

Herr Daniel Jaime CAPISTRANO DE OLIVEIRA (Brasilien)

Herr Carlos Augusto DOS SANTOS ALMEIDA (Brasilien)

Frau Juliana MARQUES DA SILVA (Brasilien)

Frau Camila Neves SOUTO (Brasilien)

Frau Mircea BADESCU (CEDEFOP)

Herr Marco SERAFINI (CEDEFOP)

Herr Fabián GREDIG (Chile)

Frau Paulina HUAIQUIMIL (Chile)

Herr David INOSTROZA (Chile)

Herr Fabián RAMIREZ (Chile)

Frau Alexandra RUEDA (Chile)

Herr Gabriel UGARTE (Chile)

Herr Jens ANDERSEN (Dänemark)

Herr Martin A. SCHULZE (Deutschland)

Herr Hans-Werner FREITAG (Deutschland)

Frau Christiane KRÜGER-HEMMER (Deutschland)

Herr Marco MUNDELIUS (Deutschland)

Frau Eveline VON GAESSLER (Deutschland)

Frau Tiina ANNUS (Estland)

Frau Ingrid JAGGO (Estland)

Herr Priit LAANOJA (Estland)
Frau Eve TÕNISSON (Estland)

Frau Aune VALK (Estland)

Frau Katrin REIN (Estland)

Herr Jens FISHER-KOTTENSTEDE (Europäische

Kommission)

Frau Marta BECK-DOMZALSKA (Eurostat, Europäische

Kommission)

Frau Sabine GAGEL (Eurostat, Europäische Kommission)

Frau Irja BLOMQVIST (Finnland)

Frau Aila REPO (Finnland)

Herr Mika WITTING (Finnland)

Herr Cédric AFSA (Frankreich)

Frau Pascale POULET-COULIBANDO (Frankreich)

Herr Vasileios KARAVITIS (Griechenland)

Frau Athena PLESSA-PAPADAKI (Griechenland)

Herr Georgios VAFIAS (Griechenland)

Frau Gillian GOLDEN (Irland)

Frau Nicola TICKNER (Irland)

Frau Âsta M. URBANCIC (Island)

Herr Yosef GIDANIAN (Israel)

Herr David MAAGAN (Israel)

Herr Haim PORTNOY (Israel)

Frau Raffaella CASCIOLI (Italien)

Herr Gaetano PROTO (Italien)

Frau Liana VERZICCO (Italien)

Herr Koji YANAGISAWA (Japan)

Herr Naoki OYAKE (Japan)

Herr Patric BLOUIN (Kanada) 
Herr Patrice DE BROUCKER (Vorsitzender LSO-Netzwerk, Kanada)

Herr Patrick BUSSIERE (Kanada)

Frau Amanda HODGKINSON (Kanada)

Frau Dallas MORROW (Kanada)

Herr Nicolas RAHAL (Kanada)

Frau Jihee CHOI (Korea)

Frau Jeongwon HWANG (Korea)

Frau Eunhye LEE (Korea)

Herr Cheonsoo PARK (Korea)

Frau Young Sun RA (Korea)

Frau Ji Young RYU (Korea)

Herr Jung-seung Thomas YANG (Korea)

Herr Jérôme LEVY (Luxemburg)

Frau Karin MEYER (Luxemburg)

Herr Juan Manuel HERNÁNDEZ VÁZQUEZ (Mexiko)

Herr Héctor ROBLES (Mexiko)

Frau Julia ARNOLD (Neuseeland)

Herr David SCOTT (Neuseeland)

Herr André DE MOOR (Niederlande)

Herr Ted REININGA (Niederlande)

Frau Tanja TRAAG (Niederlande)

Herr Francis VAN DER MOOREN (Niederlande)

Herr Bernard VERLAAN (Niederlande)

Herr Sadiq-Kwesi BOATENG (Norwegen)

Herr Lars NERDRUM (Norwegen)

Herr Geir NYGÅRD (Norwegen)

Herr Anne-Marie RUSTAD HOLSETER (Norwegen)

Herr Andreas GRIMM (Österreich)

Herr Mark Német (Österreich)

Herr Jacek MASLANKOWSKI (Polen)

Frau Anna NOWOZYNSKA (Polen)
Herr Carlos Alberto MALACA (Portugal)

Herr Joaquim SANTOS (Portugal)

Herr Mark AGRANOVICH (Russische Föderation)

Frau Anna FATEEVA (Russische Föderation)

Frau Natalia KOVALEVA (Russische Föderation)

Herr Torbjorn LINDQVIST (Schweden)

Herr Kenny PETERSSON (Schweden)

Herr Russell SCHMIEDER (Schweden)

Frau Wayra CABALLERO LIARDET (Schweiz)

Herr Emanuel VON ERLACH (Schweiz)

Herr Frantisek BLANAR (Slowakei)

Frau Gabriela JAKUBOVÁ (Slowakei)

Frau Helga KOĆEVAR (Slowenien)

Frau Tatjana SKRBEC (Slowenien)

Frau Raquel ÁLVAREZ-ESTEBAN (Spanien)

Frau Carmen UREÑA UREÑA (Spanien)

Frau Sona FORTOVA (Tschechien)

Frau Vendula KAŠPAROVA (Tschechien)

Frau Michaela KLENHOVA (Tschechien)

Frau Jitka KONRADOVA (Tschechien)

Frau Hümeyra ALTUNTAŞ (Türkei)

Herr Cengiz SARAÇOĞLU (Türkei)

Herr Friedrich HUEBLER (UNESCO)

Herr László LIMBACHER (Ungarn)

Herr Kristián SZÉLL (Ungarn)

Frau Eva TOT (Ungarn)

Herr Anthony CLARKE (Vereinigtes Königreich)

Frau Emily KNOWLES (Vereinigtes Königreich)

Herr Stephen LEMAN (Vereinigtes Königreich)

Frau Rachel DINKES (Vereinigte Staaten)

Frau Ashley ROBERTS (Vereinigte Staaten)

Herr Thomas SNYDER (Vereinigte Staaten)

\section{Netzwerk für Informationen zu Bildungsstrukturen, -politiken und -praktiken} auf Systemebene (NESLI)

\author{
Frau Stephanie BOWLES (Australien) \\ Herr Paul CMIEL (Australien) \\ Frau Shannon MADDEN (Australien) \\ Herr Scott MATHESON (Australien) \\ Herr Philippe DIEU (Belgien) \\ Frau Nathalie JAUNIAUX (Belgien) \\ Frau Hélène LENOIR (Belgien) \\ Herr Raymond VAN DE SIJPE (Belgien) \\ Frau Ann VAN DRIESSCHE (Belgien) \\ Herr Daniel Jaime CAPISTRANO DE OLIVEIRA (Brasilien) \\ Frau Juliana MARQUES DA SILVA (Brasilien) \\ Herr Gabriel Alonso UGARTE VERA (Chile) \\ Herr Jorgen Balling RASMUSSEN (Dänemark) \\ Frau Amalie SCHMIDT (Dänemark) \\ Frau Pia BRUGGER (Deutschland) \\ Herr Heinz-Werner HETMEIER (Deutschland) \\ Frau Christiane Krüger-Hemmer (Deutschland) \\ Herr Marco MUNDELIUS (Deutschland)
}

Frau Tiina ANNUS (Estland)

Herr Lene MEJER (Europäische Kommission)

Frau Nathalie BAIDAK (Eurydice)

Frau Arlette DELHAXHE (Eurydice)

Herr Timo KUMPULAINEN (Finnland)

Frau Petra PACKALEN (Finnland)

Herr Matti VÄISÄNEN (Finnland)

Frau Kristiina VOLMARI (Finnland)

Frau Florence LEFRESNE (Frankreich)

Herr Robert RAKOCEVIC (Frankreich)

Frau Dimitra FARMAKIOTOU (Griechenland)

Frau Maria FASSARI (Griechenland)

Frau Eudokia KARDAMITSI (Griechenland)

Herr Georgios MALLIOS (Griechenland)

Herr Stylianos MERKOURIS (Griechenland)

Herr Konstantinos PAPACHRISTOS (Griechenland)

Frau Athena PLESSA-PAPADAKI (Griechenland)

Herr Gary Ó DONNCHADHA (Irland) 
Frau Nicola TICKNER (Irland)

Herr Gunnar J. ÁRNASON (Island)

Frau Asta URBANCIC (Island)

Herr Yoav AZULAY (Israel)

Frau Livnat GAVRIELOV (Israel)

Herr Yosef GIDANIAN (Israel)

Herr Pinhas KLEIN (Israel)

Herr Daniel LEVI-MAZLOUM (Israel)

Herr Haim PORTNOY (Israel)

Frau Libby SHAPIRA (Israel)

Frau Gianna BARBIERI (Italien)

Frau Lucia DE FABRIZIO (Italien)

Frau Kumiko TANSHO-HIRABAYASHI (Japan)

Frau Nami JINDA (Japan)

Frau Shannon DELBRIDGE (Kanada)

Frau Sujin CHOI (Korea)

Herr Jeongwon HWANG (Korea)

Herr Gilles HIRT (Luxemburg)

Herr Jérôme LEVY (Luxemburg)

Frau Ana Maria ACEVES ESTRADA (Mexiko)

Herr Antonio ÁVILA DÍAZ (Mexiko)

Frau Cynthia CABRERA CARDENAS (Mexiko)

Herr Juan Martín SOCA DE IÑIGO (Mexiko)

Frau Kathy LIU (Neuseeland)

Herr Cyril MAKO (Neuseeland)

Frau Linda DE PAEPE (Niederlande)

Herr Dick VAN VLIET (Niederlande)

Herr Kjetil HELGELAND (Norwegen)

Herr Christian KRENTHALLER (Österreich)

Herr Andreas GRIMM (Österreich)

Frau Renata KARNAS (Polen)

Frau Renata KORZENIOWSKA-PUBULEK (Polen)

Frau Anna NOWOŻYŃSKA (Polen)
Herr Joaquim SANTOS (Portugal)

Herr Mark AGRANOVICH (Russische Föderation)

Frau Anna FATEEVA (Russische Föderation)

Frau Camilla THINSZ FJELLSTROM (Schweden)

Frau Helena WINTGREN (Schweden)

Frau Réjane DEPPIERRAZ (Schweiz)

Frau Katrin MÜHLEMANN (Schweiz)

Frau Alzbeta FERENCICOVA (Slowakei)

Frau Andreja BARLE LAKOTA (Slowenien)

Frau Ksenija BREGAR GOLOBIĆ (Slowenien)

Herr Mitja SARDOĆ (Slowenien)

Herr Matija VILFAN (Slowenien)

Herr Antonio DEL SASTRE (Spanien)

Frau Laura ALONSO CARMONA (Spanien)

Herr Joaquin MARTIN (Spanien)

Herr Valentín RAMOS SALVADOR (Spanien)

Herr Ismael SANZ LABRADOR (Spanien)

Frau Noelia VALLE BENITO (Spanien)

Frau Michaela KLENHOVA (Tschechien)

Frau Stanislava RADOTINSKA HVEZDOVA (Tschechien)

Frau Hümeyra ALTUNTAŞ (Türkei)

Frau Dilek GÜLEÇYÜZ (Türkei)

Frau Anna IMRE (Ungarn)

Frau Lorna BERTRAND (Vereinigtes Königreich)

Frau Elisabeth BOYLING (Vereinigtes Königreich)

Herr Anthony CLARKE (Vereinigtes Königreich)

Frau Louise CUTHBERTSON (Vereinigtes Königreich)

Frau Emily KNOWLES (Vereinigtes Königreich)

Herr Christopher MORRISS (Vereinigtes Königreich)

Frau Rachel DINKES (Vereinigte Staaten)

Frau Jana KEMP (Vereinigte Staaten)

Herr Tom SNYDER (Vorsitzender NESLI-Netzwerk, Vereinigte Staaten)

\section{Sonstige Mitwirkende an dieser Publikation}

Herr Samuel E. ABRAMS (NESLI-Berater)

Herr Sam STERN (NESLI-Berater)

Frau Anna BORKOWSKY (LSO-Beraterin)

BRANTRA SPRL (Übersetzung)

Frau Sally Caroline HINCHCLIFFE (Edition)

Frau Marion SCHNEPF (Layout)

Herr Dan SHERMAN (LSO-Berater)

Frau Fung-Kwan TAM (Layout) 


\section{Weiterführende OECD-Publikationen}

Equity, Excellence and Inclusiveness in Education: Policy Lessons from Around the World, International Summit on the Teaching Profession (2014)

http://dx.doi.org/10.1787/9789264214033-en

Teachers for the 21st Century: Using Evaluation to Improve Teaching (2013)

http://dx.doi.org/10.1787/9789264193864-en

PISA 2012 Ergebnisse: Was Schülerinnen und Schüler wissen und können (Band I, überarbeitete Ausgabe, Februar 2014): Schülerleistungen in Lesekompetenz, Mathematik und Naturwissenschaften http://dx.doi.org/10.1787/9789264208858-de

PISA 2012 Results: Excellence through Equity (Volume II): Giving Every Student the Chance to Succeed (2013)

http://dx.doi.org/10.1787/9789264201132-en

PISA 2012 Results: Ready to Learn (Volume III): Students' Engagement, Drive and Self-Beliefs (2013) http://dx.doi.org/10.1787/9789264201170-en

PISA 2012 Results: What Makes Schools Successful (Volume IV): Resources, Policies and Practices (2013)

http://dx.doi.org/10.1787/9789264201156-en

PISA 2012 Results: Creative Problem Solving (Volume V): Students' Skills in Tackling Real-Life Problems (2014)

http://dx.doi.org/10.1787/9789264208070-en

PISA 2012 Results: Students and Money (Volume VI): Financial Literacy Skills for the 21st Century (2014)

http://dx.doi.org/10.1787/9789264208094-en

TALIS 2013 Results: An International Perspective on Teaching and Learning (2014)

http://dx.doi.org/10.1787/9789264196261-en

OECD Skills Outlook 2013: First Results from the Survey of Adult Skills (2013)

http://dx.doi.org/10.1787/9789264204256-en

The Survey of Adult Skills: Reader's Companion (2013)

http://dx.doi.org/10.1787/9789264204027-en

Innovative Learning Environments, Educational Research and Innovation (2013)

http://dx.doi.org/10.1787/9789264203488-en

Synergies for Better Learning: An International Perspective on Evaluation and Assessment (2013)

http:|/dx.doi.org/10.1787/9789264190658-en

Trends Shaping Education 2013 (2013)

http://dx.doi.org/10.1787/trends_edu-2013-en
How's Life? Measuring Well-being (2013)

http://dx.doi.org/10.1787/9789264201392-en

International Migration Outlook 2013 (2013)

http://dx.doi.org/10.1787/migr_outlook-2013-en

Bessere Kompetenzen, bessere Arbeitsplätze, ein besseres Leben: Ein strategisches Konzept für die Kompetenzpolitik (2012)

http:/|dx.doi.org/10.1787/9789264179479-de

Equity and Quality in Education: Supporting Disadvantaged Students and Schools (2012)

http://dx.doi.org/10.1787/9789264130852-en

Gleichstellung der Geschlechter: Zeit zu handeln (2013)

http://dx.doi.org/10.1787/9789264190344-de

Starting Strong III: Eine Qualitäts-Toolbox für die Frühkindliche Bildung, Betreuung und Erziehung (2013)

http://dx.doi.org/10.1787/9789264202184-de

Health at a Glance: OECD Indicators (2011)

http://dx.doi.org/10.1787/health_glance-2011-en

OECD-Studien zur Berufsbildung: Lernen für die Arbeitswelt (2010)

http://dx.doi.org/10.1787/9789264087842-de

OECD Information Technology Outlook 2010 (2010)

http://dx.doi.org/10.1787/it_outlook-2010-en

Improving Health and Social Cohesion through Education (2010)

http://dx.doi.org/10.1787/9789264086319-en

Tertiary Education for the Knowledge Society: Volume 1 and Volume 2 (2008)

http://dx.doi.org/10.1787/9789264046535-en

Starting Strong II: Early Childhood Education and Care (2006)

http:|/dx.doi.org/10.1787/9789264035461-en

Stärkere Professionalisierung des Lehrerberufs: Wie gute Lehrer gewonnen, gefördert und gehalten werden können (2006)

http:|/dx.doi.org/10.1787/9789264023673-de

Die OECD-Publikationen können im OECD-OnlineBookshop eingesehen und erworben werden: www.oecdbookshop.org 


\section{ORGANISATION FÜR WIRTSCHAFTLICHE ZUSAMMENARBEIT UND ENTWICKLUNG}

Die OECD ist ein in seiner Art einzigartiges Forum, in dem die Regierungen von 34 demokratischen Staaten gemeinsam an der Bewältigung von Herausforderungen der Globalisierung im Wirtschafts-, Sozial- und Umweltbereich arbeiten. Die OECD steht auch in vorderster Linie bei den Bemühungen um ein besseres Verständnis der neuen Entwicklungen und durch sie ausgelöster Befürchtungen, indem sie Untersuchungen zu Themen wie Corporate Governance, Informationswirtschaft oder Bevölkerungsalterung durchführt. Die Organisation bietet den Regierungen einen Rahmen, der es ihnen ermöglicht, ihre Politikerfahrungen auszutauschen, nach Lösungsansätzen für gemeinsame Probleme zu suchen, empfehlenswerte Praktiken aufzuzeigen und auf eine Koordinierung nationaler und internationaler Politiken hinzuarbeiten.

Die OECD-Mitgliedstaaten sind: Australien, Belgien, Chile, Dänemark, Deutschland, Estland, Finnland, Frankreich, Griechenland, Irland, Island, Israel, Italien, Japan, Kanada, Korea, Luxemburg, Mexiko, Neuseeland, die Niederlande, Norwegen, Österreich, Polen, Portugal, Schweden, Schweiz, die Slowakische Republik, Slowenien, Spanien, die Tschechische Republik, Türkei, Ungarn, das Vereinigte Königreich und die Vereinigten Staaten. Die Kommission der Europäischen Gemeinschaften nimmt an den Arbeiten der OECD teil.

OECD Publishing sorgt dafür, dass die Ergebnisse der statistischen Analysen und der Untersuchungen der Organisation zu wirtschaftlichen, sozialen und umweltpolitischen Themen sowie die von den Mitgliedstaaten vereinbarten Übereinkommen, Leitlinien und Standards weite Verbreitung finden. 


\title{
Bildungsbericht 2014
}

\author{
Schwerpunkt Inklusion
}

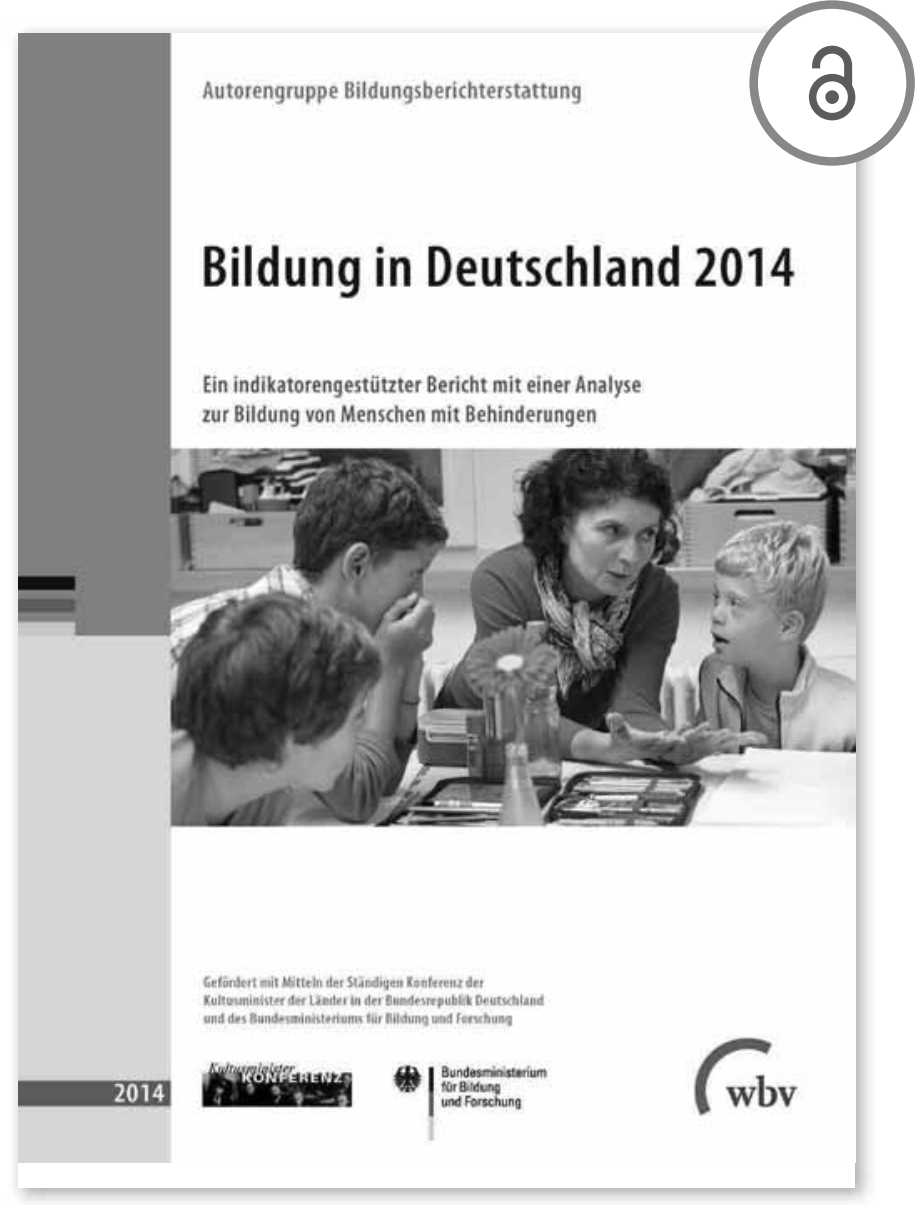

Autorengruppe Bildungsberichterstattung ( $\mathrm{Hg}$.)
In der 5. Auflage von „Bildung in Deutschland“ analysieren die Autoren die Situation von Menschen mit Behinderungen im Bildungssystem.

Der Bericht „Bildung in Deutschland“ erscheint seit 2006 alle zwei Jahre als umfassende und empirisch fundierte Bestandsaufnahme des deutschen Bildungswesens: von der frühkindlichen Bildung, Betreuung und Erziehung über die allgemeinbildende Schule und die non-formalen Lernwelten im Schulalter, die berufliche Ausbildung und Hochschulbildung bis hin zur Weiterbildung im Erwachsenenalter.

\section{„Der Bildungsbericht ist} Ermutigung und Auftrag zugleich ... die Ergebnisse zeigen, dass sich Investitionen in Bildung für die Einzelnen und die Gesellschaft lohnen."

Bundesbildungsministerin, Prof. Dr. Wanka und die Präsidentin der Kultusministerkonferenz, Ministerin Löhrmann in einer gemeinsamen Presseerklärung

\section{Bildung in Deutschland 2014}

Ein indikatorengestützter Bericht mit einer Analyse zur Bildung von Menschen mit Behinderungen

2014, 342 S., $49,90 €(D)$

ISBN 978-3-7639-5417-9

Kostenloser Download:

wbv-open-access.de 


\title{
Schülerleistungen im weltweiten Vergleich
}

\author{
Aktuelle Ausgabe der PISA-Studie
}

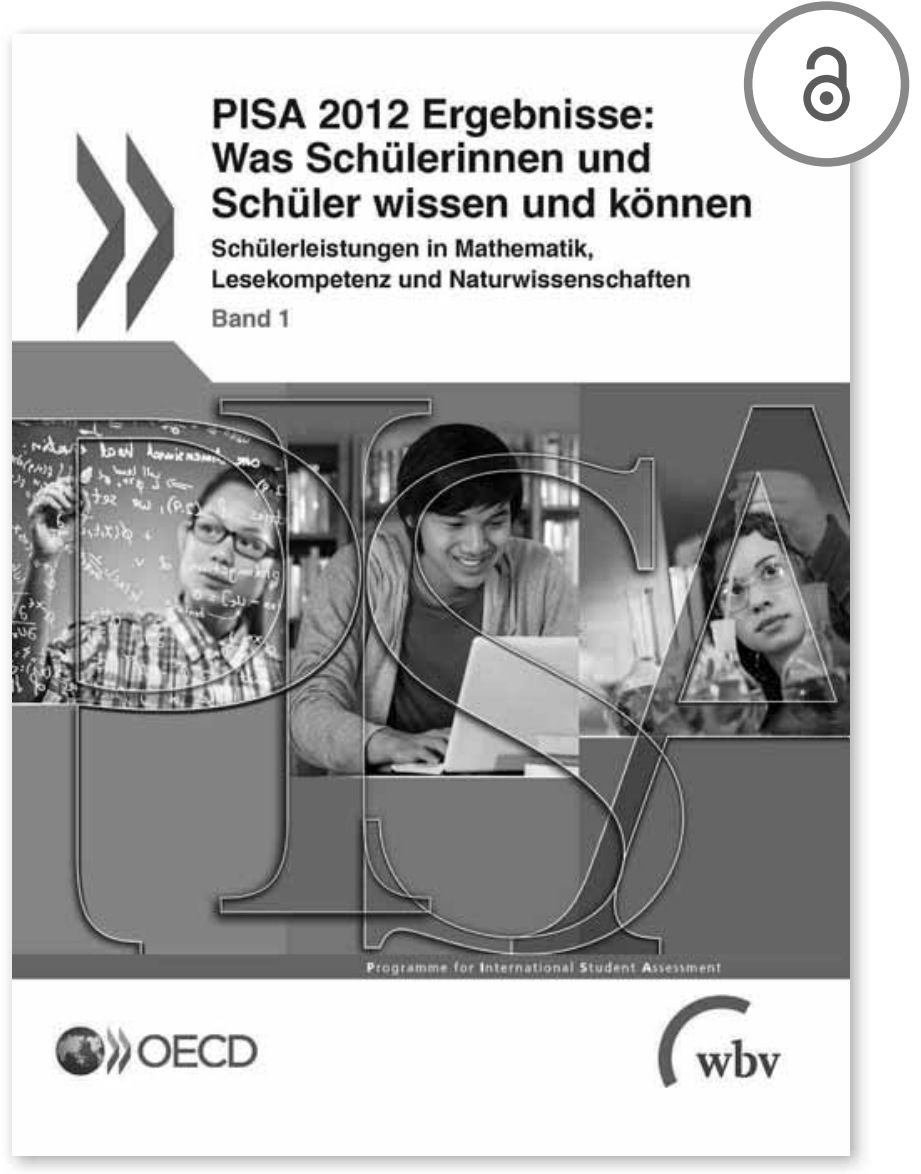

Der Band fasst die Ergebnisse der Schülerinnen und Schüler aus der weltweiten Schulleistungsstudie PISA 2012 zusammen. Der Schwerpunkt liegt auf den Bereichen Mathematik, Naturwissenschaften und Lesekompetenz.

Die PISA-Studie betrachtet bereits zum fünften Mal die Ergebnisse der beteiligten Länder im wirtschaftlichen und sozialen Kontext. Die Studie, die von der Organisation für wirtschaftliche Zusammenarbeit und Entwicklung (OECD) im Dreijahresturnus herausgegeben wird, macht das umfangreiche Datenmaterial aus 64 Ländern mit Hilfe von speziell entwickelten Indikatoren vergleichbar.

PISA 2012 wendet sich an Bildungspolitiker, Wissenschaftler und an Leserinnen und Leser, die einen Überblick über die Leistungsfähigkeit des eigenen Landes im internationalen Vergleich gewinnen möchten.

PISA 2012 Band 2 „Exzellenz durch Chancengerechtigkeit" erscheint im Herbst 2014 in deutscher Sprache. ISBN 978-3-7639-5470-4

OECD (Hg.)

PISA 2012 Ergebnisse:

Was Schülerinnen und Schüler wissen und können

Schülerleistungen in Mathematik, Lesekompetenz und Naturwissenschaften Band 1

2013, 467 S., $69,00 €(D)$

ISBN 978-3-7639-5321-9

Kostenloser Download:

wbv-open-access.de 


\section{Bildung auf einen Blick 2014 OECD-INDIKATOREN}

Bildung auf einen Blick 2014 - OECD-Indikatoren ist die maßgebliche Quelle für präzise und relevante Informationen zum Stand der Bildung weltweit. Bildung auf einen Blick bietet Daten zu den Strukturen, der Finanzierung und der Leistungsfähigkeit der Bildungssysteme der 34 OECD-Länder sowie einer Reihe von Partnerländern.

Mit mehr als 150 Abbildungen, 300 Tabellen und über 100000 Zahlen bietet Bildung auf einen Blick wesentliche Informationen zum Output der Bildungseinrichtungen, den Auswirkungen des Lernens in den einzelnen Ländern, zu den in Bildung investierten Finanz- und Humanressourcen, zu Bildungszugang, Bildungsbeteiligung und Bildungsverlauf sowie zum Lernumfeld und der Organisation der Schulen.

Neue Daten und Informationen in dieser Ausgabe umfassen:

- Neue Indikatoren zu privaten Bildungseinrichtungen, den Voraussetzungen für den Lehrerberuf sowie Maßnahmen zur beruflichen Fortbildung von Lehrkräften und deren Teilnahme daran.

- Daten aus der Erhebung zu den grundlegenden Kompetenzen Erwachsener (OECD Programme for the International Assessment of Adult Competencies - PIAAC) des Jahres $2012 \mathrm{zu}$

Bildungsstand, Beschäftigung, Bildungsmobilität zwischen den Generationen, Einkommen und gesamtgesellschaftlichen Auswirkungen im Zusammenhang mit unterschiedlichen Kompetenzstufen.

- In verschiedenen Indikatoren neueste Daten aus der internationalen Erhebung der OECD zu Lehren und Lernen (TALIS) des Jahres 2013 und der Internationalen Schulleistungsstudie PISA 2012 der OECD.

- Eine Analyse der Auswirkungen der jüngsten Wirtschaftskrise auf das Zusammenspiel von Bildungsstand, Beschäftigung, Einkommen und öffentlichen Haushalten.

- Detailliertere Informationen zu Erfolgsquoten im Sekundarbereich II und den verschiedenen Formen von Studiendarlehen und ihrer Inanspruchnahme.

- Erstmalig Daten aus Kolumbien und Lettland.

Die den Tabellen und Abbildungen dieser Ausgabe zugrunde liegenden Excel-Tabellen können über die jeweils darunter angegebenen StatLinks eingesehen werden. Die Tabellen und Abbildungen sowie die gesamte OECD-Online-Bildungsdatenbank sind über die Website der OECD unter www.oecd.org/edu/eag.htm zugänglich.

Inhalt

Kapitel A: Bildungsergebnisse und Bildungserträge

Kapitel B: Die in Bildung investierten Finanz- und Humanressourcen

Kapitel C: Bildungszugang, Bildungsbeteiligung und Bildungsverlauf

Kapitel D: Das Lernumfeld und die Organisation von Schulen

Diese Studie ist in der OECD iLibrary veröffentlicht, die alle Bücher, periodisch erscheinenden

Publikationen und statistischen Datenbanken der OECD enthält: www.oecd-ilibrary.org.

Für weitere Informationen können Sie sich gerne an oecdilibrary@oecd.org wenden. 